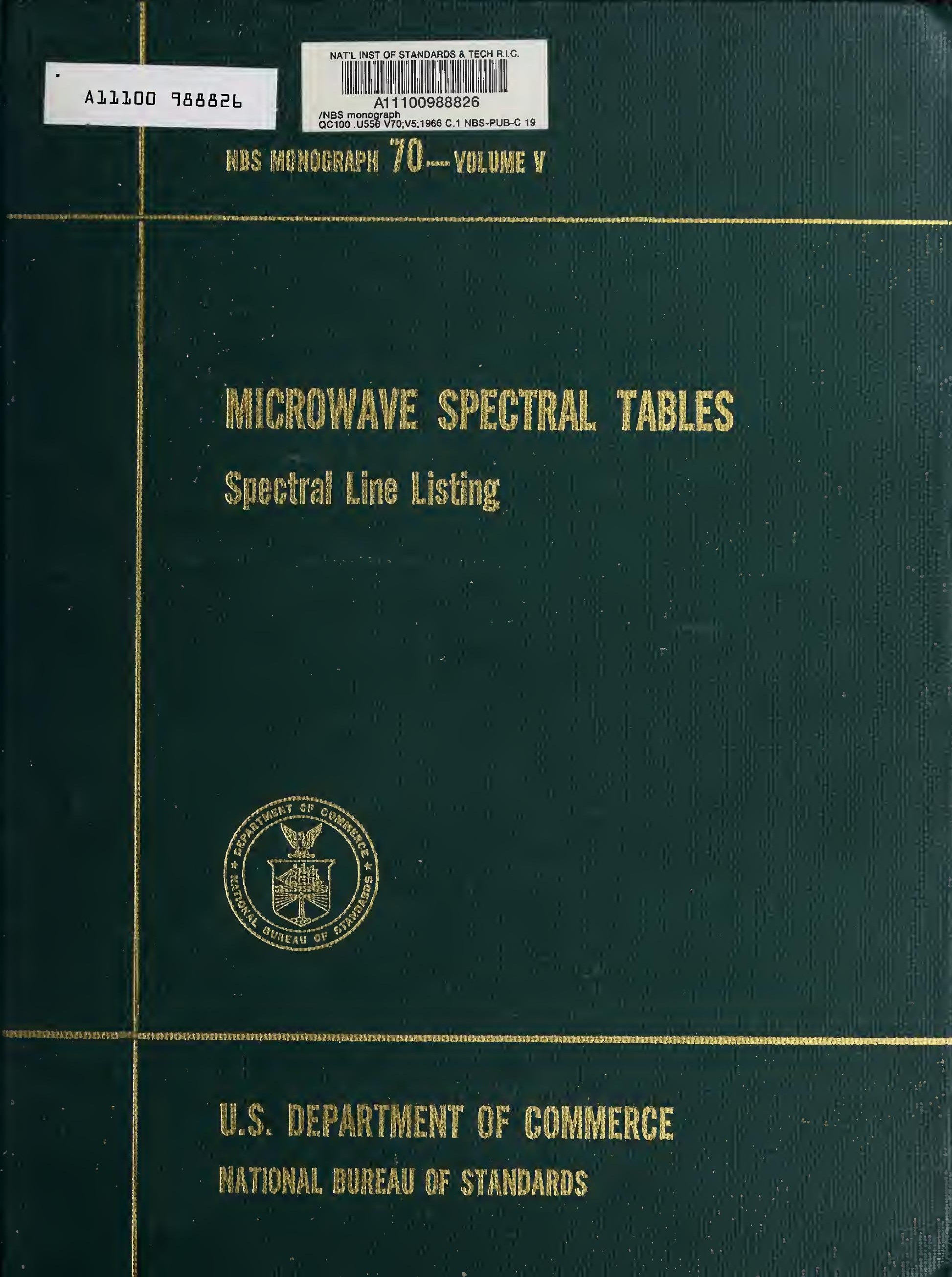





UNITED STATES DEPARTMENT OF COMMERCE

C. R. Smith, Secretary

NATIONAL BUREAU OF STANDARDS A. V. Astin, Director

\section{MICROWAVE SPECTRAL TABLES \\ Volume V. Spectral Line Listing}

Marian S. Cord, Matthew S. Lojko, and Jean D. Petersen

Institute for Basic Standards, National Bureau of Standards, Boulder, Colorado

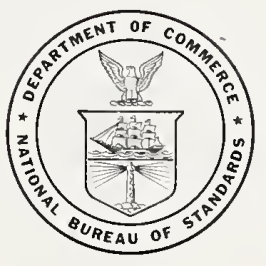

National Bureau of Standards Monograph 70 - Volume V 


\section{Microwave Spectral Tables}

This five-volume NBS Monograph presents a comprehensive compilation of microwave spectra including measured frequencies, assigned molecular species, assigned quantum numbers, and molecular constants determined from these data. The volumes are available by purchase from the Superintendent of Documents, Government Printing Office, Washington, D.C. 20402. Orders from foreign countries should include an additional one-fourth of the price of the publication to cover the postage.

\section{Titles of the volumes}

I. Diatomic Molecules, $\$ 2.00$

II. Line Strengths of Asymmetric Rotors, $\$ 3.00$

III. Polyatomic Molecules With Internal Rotation (In press)

IV. Polyatomic Molecules Without Internal Rotation (In press)

V. Spectral Line Listing, $\$ 4.75$

Library of Congress Catalog Card Number: 63-62235 


\section{Foreword}

The present volume of the Bureau of Standards Spectral Tables will be welcomed by microwave spectroscopists and those who are interested in applying microwave spectroscopy to analytical and other practical purposes. The great accuracy with which microwave lines can be measured, the broad range of frequencies which can be covered, and the sharpness of microwave lines makes this field of spectroscopy in many ways comparable to optical atomic spectroscopy. We need much more practical experience in the utilization of this technique for analytical purposes: but it certainly seems that the accurate measurement of a very few spectral lines should serve to identify with very great certainty the presence of a compound whose lines have been tabulated. However, without tables such as these it was impractical to make the literature search required to find out what substance was causing a given set of frequencies. Now this should be a very easy matter. I certainly look forward to the wide utilization of these tables not only by those who have already been working in this field, but by new workers who will now find it much more convenient to utilize this tool to help solve their own identification and characterization problems.

Naturally no set of tables of this kind can be complete, either with respect to the substances covered or the spectral lines of any given substance, so the fact that an observed line is not listed in these tables is not usually meaningful. However, if the spectrum of a given substance has been partly mapped and listed herein, its presence in a mixture (if its proportion is high enough) should be readily detected if enough of the observed lines are searched for in the present listing. When a line has been tentatively identified, one can then turn to Vols. I, III or IV of this series and look for other known strong lines of the substance to use as corroboration.

\section{E. Bright Wilson, Harvard University.}




\section{Contents}

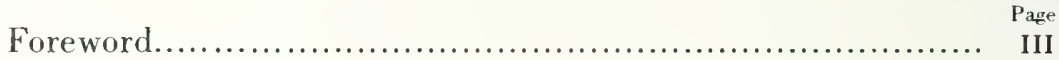

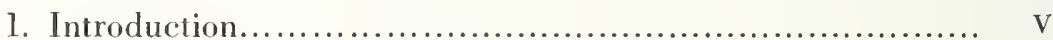

2. Spectral line table...................................... 1

3. Index ................................................... 528 


\title{
Microwave Spectral Tables
}

\section{Spectrall Line listing}

\author{
Marian S. Cord, Matthew S. Lojko, and Jean D. Petersen \\ I his volume is a listing of the spectral lines reported in Volumes I, III, and IV of the Micro- \\ wave Spectral Tables. These lines are listed according to ascending magnitude of frequency \\ and should provide a ready reference.
}

Key words: Microwave spectra, molecular spectra, spectral lines, rotational quantum numbers, diatomic molecules, polyatomic molecules, hyperfine.

\section{Introduction}

Volume $\mathrm{V}$ of Monograph 70 is a listing of the spectral lines reported in Volumes I, III, and IV of the Microwave Spectral Tables. These lines have been automatically sorted and are listed according to ascending magnitude of frequency. For each spectral line the following data are given in order: the formula for the molecular isotopic species; the number of the volume of this series in which the line was originally tabulated $(1,3$, or 4$)$ : the identification number used in that volume for ready reference (in Volume I no identification numbers were used); rotational quantum number, given in the general form $\mathrm{J}^{\prime}, \mathrm{K}_{-1}^{\prime}, \mathrm{K}_{+1}^{\prime} \leftarrow \mathrm{J}, \mathrm{K}_{-1}, \mathrm{~K}_{+1}$ (primes denoting upper state); the vibrational state (ground, excited, or blank, if unknown); the hyperfine quantum numbers; the frequency, and its accuracy (if given in the article from which the line was reported). Volume II contains no spectral lines.

While the material for this volume was prepared as part of the reviewing for the previous ones, most credit for the presentation of the data is due to the effort expended on the programing which was required to accomplish the tremendous job of sorting and tabulating. The authors would like to acknowledge help given in this rregard by Mrs. Judith Stephenson and Miss Carol Nielsen. 



\begin{tabular}{|c|c|c|c|c|c|c|c|c|c|c|}
\hline \multirow{2}{*}{\multicolumn{2}{|c|}{ Isotopic Species }} & \multirow{2}{*}{$\begin{array}{l}\text { Vol.-Id. } \\
\text { Nos. }\end{array}$} & \multirow{2}{*}{$\begin{array}{c}\text { Rotational } \\
\text { Quantum Nos. }\end{array}$} & \multirow{2}{*}{ Vib. State } & \multicolumn{4}{|c|}{ Hyperfine } & \multirow{2}{*}{$\begin{array}{l}\text { Frequency } \\
\mathrm{MH}_{z}\end{array}$} & \multirow{2}{*}{$\begin{array}{l}\text { Acc. } \\
\pm \mathrm{MH}_{2}\end{array}$} \\
\hline & & & & & $F_{1}^{\prime}$ & $\mathrm{F}^{\prime}$ & $F_{1}$ & $\mathrm{~F}$ & & \\
\hline $\mathrm{C}^{12} \mathrm{H}_{3} \mathrm{I}^{127}$ & & 4. 481 & $1,1 \leftarrow 1,1$ & Ground & & $5 / 2$ & & $3 / 2$ & 292.5 & .04 \\
\hline $\mathrm{HC}^{12} \mathrm{HO}^{16}$ & & 4- 381 & $8,3,5 \leftarrow 8,3,6$ & Ground & & & & & 301.10 & .01 \\
\hline $\mathrm{HC}^{12} \mathrm{HO}^{16}$ & 1 & 4. 381 & $3,2,1 \leftarrow 3,2,2$ & Ground & & & & & 355.586 & .005 \\
\hline $\mathrm{C}^{12} \mathrm{H}_{3} \mathrm{I}^{127}$ & & 4- 481 & $2,2 \leftarrow 2,2$ & Ground & & $7 / 2$ & & $9 / 2$ & 375.0 & .3 \\
\hline $\mathrm{C}^{12} \mathrm{H}_{3} \mathrm{I}^{127}$ & & 4- 481 & $3,3 \leftarrow 3,3$ & Ground & & $9 / 2$ & & $11 / 2$ & 444.76 & .10 \\
\hline $\mathrm{HC}^{12} \mathrm{~N}^{14}$ & & 4- 291 & $1 \leftarrow 1$ & Excited & & 1 & & 1 & 448.967 & .010 \\
\hline $\mathrm{HC}^{12} \mathrm{~N}^{14}$ & & 4- 291 & $1 \leftarrow 1$ & Excited & & 2 & & 2 & 448.967 & .010 \\
\hline $\mathrm{C}^{12} \mathrm{H}_{3} \mathrm{I}^{127}$ & & 4- 481 & $4,4 \leftarrow 4,4$ & Ground & & $11 / 2$ & & $13 / 2$ & 481.05 & .10 \\
\hline $\mathrm{HDO}^{16}$ & & 4-1712 & $5,4,1 \leftarrow 5,4,2$ & Ground & 5 & $11 / 2$ & 5 & $9 / 2$ & 486.266 & .002 \\
\hline $\mathrm{HDO}^{16}$ & & 4-1712 & $5,4,1 \leftarrow 5,4,2$ & Ground & 5 & $11 / 2$ & 4 & $9 / 2$ & 486.450 & .002 \\
\hline $\mathrm{HDO}^{16}$ & & 4-1712 & $5,4,1 \leftarrow 5,4,2$ & Ground & 5 & $11 / 2$ & 6 & $13 / 2$ & 486.487 & .002 \\
\hline $\mathrm{HDO}^{16}$ & & 4-1712 & $5,4,1 \leftarrow 5,4,2$ & Ground & & & & & 486.528 & .002 \\
\hline $\mathrm{HDO}^{16}$ & & 4-1712 & $5,4,1 \leftarrow 5,4,2$ & Ground & 5 & $11 / 2$ & 6 & $13 / 2$ & 486.569 & .002 \\
\hline $\mathrm{HDO}^{16}$ & & $4-1712$ & $5,4,1 \leftarrow 5,4,2$ & Ground & 5 & $11 / 2$ & 4 & $9 / 2$ & 486.606 & .002 \\
\hline $\mathrm{C}^{12} \mathrm{~F}_{3}^{19} \mathrm{I}^{127}$ & & 4. 231 & $3,3 \leftarrow 3,3$ & Ground & & $9 / 2$ & & $11 / 2$ & 500.4 & .4 \\
\hline $\mathrm{C}^{12} \mathrm{H}_{3} \mathrm{I}^{127}$ & & 4. 481 & $5,5 \leftarrow 5,5$ & Ground & & $13 / 2$ & & $15 / 2$ & 503.05 & .15 \\
\hline $\mathrm{C}^{12} \mathrm{H}_{3} \mathrm{I}^{127}$ & & 4- 481 & $6,6 \leftarrow 6,6$ & Ground & & $15 / 2$ & & $17 / 2$ & 517.3 & .4 \\
\hline $\mathrm{HC}^{12} \mathrm{HO}^{16}$ & & 4- 381 & $9,3,6 \leftarrow 9,3,7$ & Ground & & & & & 601.07 & .005 \\
\hline $\mathrm{HC}^{12} \mathrm{DO}^{16}$ & & 4- 385 & $3,2,1 \leftarrow 3,2,2$ & Ground & & & & & 644.893 & .005 \\
\hline $\mathrm{HDO}^{16}$ & & 4-1712 & $3,3,0 \leftarrow 3,3,1$ & Ground & 3 & $5 / 2$ & 2 & $3 / 2$ & 824.475 & .002 \\
\hline $\mathrm{HDO}^{16}$ & & $4-1712$ & $3,3,0 \leftarrow 3,3,1$ & Ground & 4 & $9 / 2$ & 4 & $7 / 2$ & 824.507 & .002 \\
\hline $\mathrm{HDO}^{16}$ & & 4-1712 & $3,3,0 \leftarrow 3,3,1$ & Ground & 3 & $5 / 2$ & 4 & $7 / 2$ & 824.524 & .002 \\
\hline $\mathrm{HDO}^{16}$ & & 4-1712 & $3,3,0 \leftarrow 3,3,1$ & Ground & 3 & $7 / 2$ & 3 & $5 / 2$ & 824.548 & .002 \\
\hline $\mathrm{HDO}^{16}$ & & $4-1712$ & $3,3,0 \leftarrow 3,3,1$ & Ground & 3 & $7 / 2$ & 4 & $9 / 2$ & 824.568 & .002 \\
\hline $\mathrm{HDO}^{16}$ & & 4-1712 & $3,3,0 \leftarrow 3,3,1$ & Ground & 2 & $5 / 2$ & 4 & $7 / 2$ & 824.604 & .002 \\
\hline $\mathrm{HDO}^{16}$ & & 4-1712 & $3,3,0 \leftarrow 3,3,1$ & Ground & & & & & 824.670 & .002 \\
\hline $\mathrm{HDO}^{16}$ & & $4-1712$ & $3,3,0 \leftarrow 3,3,1$ & Ground & 2 & $5 / 2$ & 4 & $7 / 2$ & 824.741 & .002 \\
\hline $\mathrm{HDO}^{16}$ & & 4-1712 & $3,3,0 \leftarrow 3,3,1$ & Ground & 3 & $7 / 2$ & 4 & $9 / 2$ & 824.773 & .002 \\
\hline $\mathrm{HDO}^{16}$ & & 4-1712 & $3,3,0 \leftarrow 3,3,1$ & Ground & 3 & $7 / 2$ & 3 & $5 / 2$ & 824.790 & .002 \\
\hline $\mathrm{HDO}^{16}$ & & 4-1712 & $3,3,0 \leftarrow 3,3,1$ & Ground & 3 & $5 / 2$ & 4 & $7 / 2$ & 824.813 & .002 \\
\hline $\mathrm{HDO}^{16}$ & & 4-1712 & $3,3,0 \leftarrow 3,3,1$ & Ground & 4 & $9 / 2$ & 4 & $7 / 2$ & 824.834 & .002 \\
\hline $\mathrm{HDO}^{16}$ & & 4-1712 & $3,3,0 \leftarrow 3,3,1$ & Ground & 3 & $5 / 2$ & 2 & $3 / 2$ & 824.863 & .002 \\
\hline $\mathrm{HC}^{12} \mathrm{HO}^{16}$ & & 4- 381 & $4,2,2 \leftarrow 4,2,3$ & Ground & & & & & 1065.85 & .02 \\
\hline $\mathrm{HC}^{12} \mathrm{~N}^{14}$ & & 4- 291 & $2 \leftarrow 2$ & Excited & & 2 & & 2 & 1346.677 & .005 \\
\hline $\mathrm{HC}^{12} \mathrm{~N}^{14}$ & & 4- 291 & $2 \leftarrow 2$ & Excited & & 1 & & 1 & 1346.796 & .005 \\
\hline $\mathrm{HC}^{12} \mathrm{~N}^{14}$ & & 4- 291 & $2 \leftarrow 2$ & Excited & & 3 & & 3 & 1346.796 & .005 \\
\hline $\mathrm{N}^{14} \mathrm{D}_{3}$ & & 4-1775 & $5,3 \leftarrow 5,3$ & Ground & & & & & 1507.50 & \\
\hline $\mathrm{N}^{14} \mathrm{D}_{3}$ & & 4. 1775 & $5,3 \leftarrow 5,3$ & Ground & & & & & 1509.22 & \\
\hline $\mathrm{N}^{14} \mathrm{D}_{3}$ & & $4-1775$ & $9,7 \leftarrow 9,7$ & Ground & & & & & 1509.65 & \\
\hline $\mathrm{N}^{14} \mathrm{D}_{3}$ & & $4-1775$ & $3,1 \leftarrow 3,1$ & Ground & & & & & 1537.81 & \\
\hline $\mathrm{N}^{14} \mathrm{D}_{3}$ & & 4-1775 & $11,9 \leftarrow 11,9$ & Ground & & & & & 1540.09 & \\
\hline $\mathrm{N}^{14} \mathrm{D}_{3}$ & & 4-1775 & $4,3 \leftarrow 4,3$ & Ground & & & & & l 557.545 & \\
\hline $\mathrm{N}^{14} \mathrm{D}_{3}$ & & 4-1775 & $4,3 \leftarrow 4,3$ & Ground & & & & & 1557.702 & \\
\hline $\mathrm{N}^{14} \mathrm{D}_{3}$ & & 4-1775 & $4,3 \leftarrow 4,3$ & Ground & & & & & 1558.178 & \\
\hline $\mathrm{N}^{14} \mathrm{D}_{3}$ & & 4-1775 & $4,3 \leftarrow 4,3$ & Ground & & & & & 1558.61 & \\
\hline
\end{tabular}




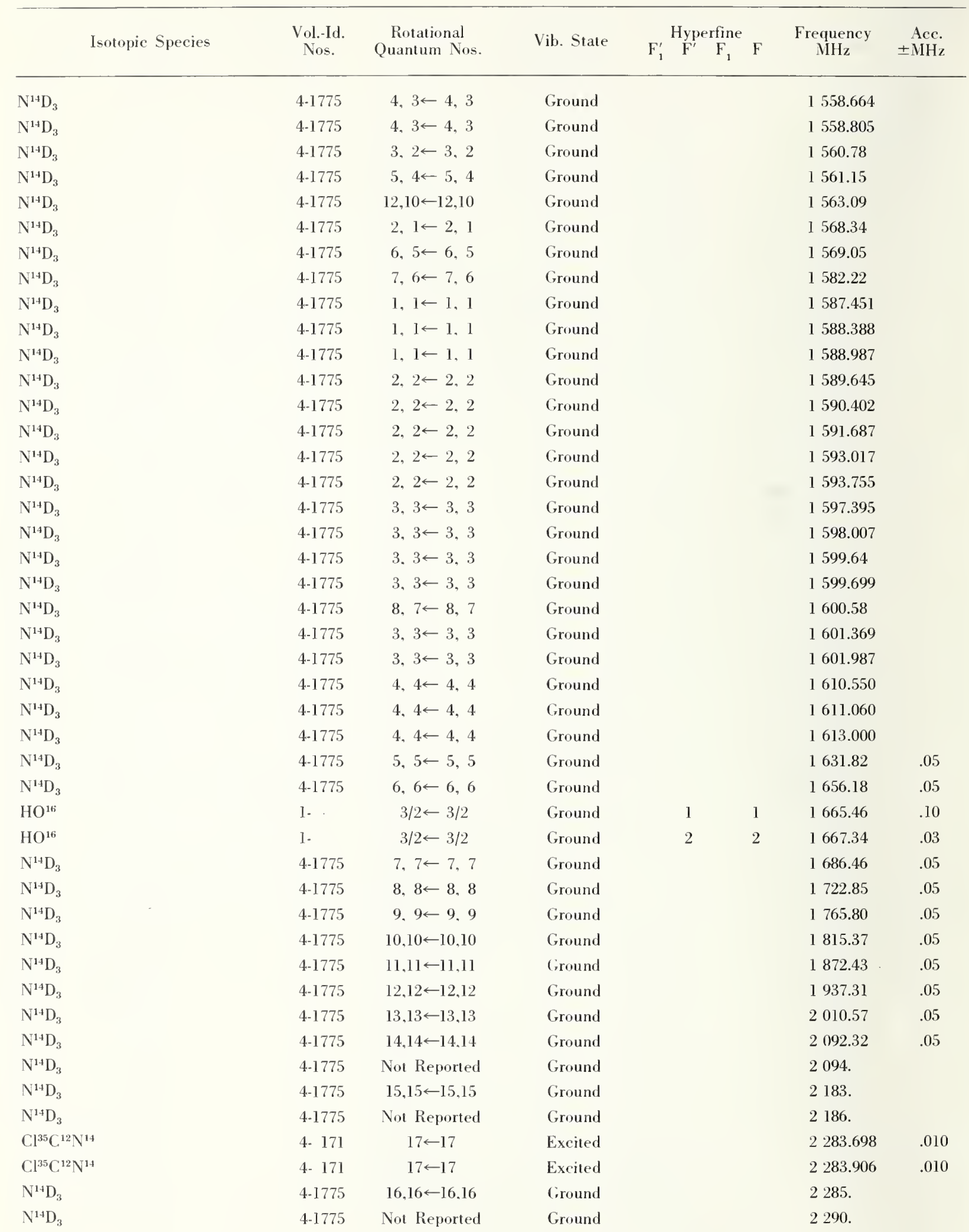




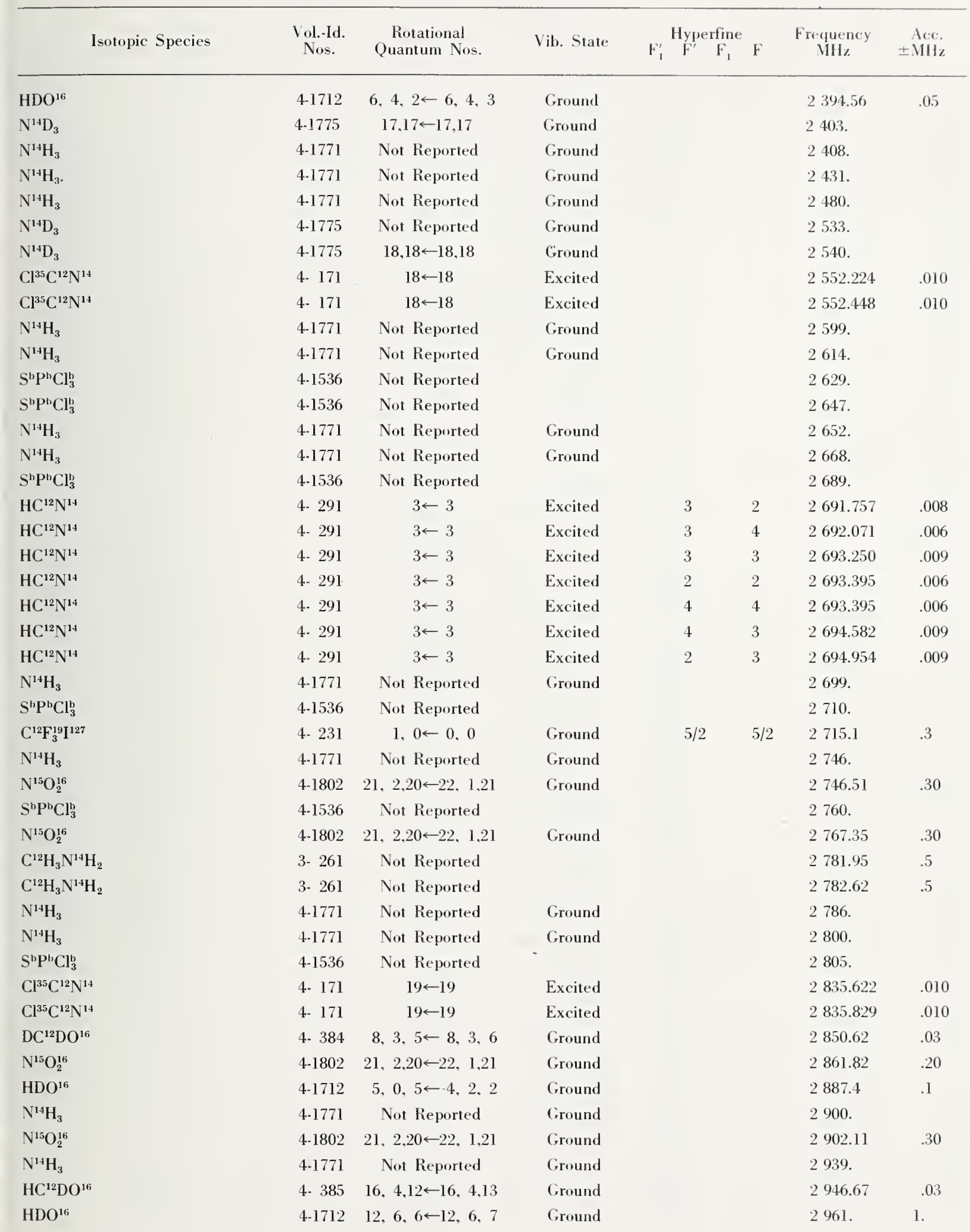




\begin{tabular}{|c|c|c|c|c|c|c|c|}
\hline Isotopic Species & $\begin{array}{l}\text { Vol.-Id. } \\
\text { Nos. }\end{array}$ & $\begin{array}{c}\text { Rotational } \\
\text { Quantum Nos. }\end{array}$ & Vib. State & $\mathrm{F}_{1}^{\prime} \mathrm{F}^{2} \quad \mathrm{~F}_{1}$ & $\mathbf{F}$ & $\begin{array}{l}\text { Frequency } \\
\text { M }\end{array}$ & $\begin{array}{r}\text { Acc. } \\
\pm \mathrm{MHz}\end{array}$ \\
\hline $\mathrm{N}^{14} \mathrm{H}_{3}$ & $4-1771$ & Not Reported & Ground & & & 2978. & \\
\hline $\mathrm{N}^{14} \mathrm{H}_{3}$ & $4-1771$ & Not Reported & Ground & & & 3010. & \\
\hline $\mathrm{C}^{12} \mathrm{H}_{3} \mathrm{~N}^{14} \mathrm{H}_{2}$ & 3- 261 & Not Reported & & & & 3015.17 & .5 \\
\hline $\mathrm{C}^{12} \mathrm{H}_{3} \mathrm{~N}^{14} \mathrm{H}_{2}$ & 3- 261 & Not Reported & & & & 3019.90 & .5 \\
\hline $\mathrm{HDO}^{16}$ & $4-1712$ & $9,5,4 \leftarrow 9,5,5$ & Ground & & & 3044.71 & .10 \\
\hline $\mathrm{DC}^{12} \mathrm{DO}^{16}$ & 4- 384 & $13,4,9 \leftarrow 13,4,10$ & Ground & & & 3079.48 & .03 \\
\hline $\mathrm{C}^{12} \mathrm{~F}_{3}^{19} \mathrm{I}^{127}$ & 4- 231 & $1,0 \leftarrow 0,0$ & Ground & $7 / 2$ & $5 / 2$ & 3162.9 & .25 \\
\hline $\mathrm{N}^{1+} \mathrm{H}_{3}$ & $4-1771$ & Not Reported & Ground & & & 3187. & \\
\hline $\mathrm{HC}^{12} \mathrm{HO}^{16}$ & 4- 381 & $12,3,9 \leftarrow 12,3,10$ & Ground & & & 3225.58 & .01 \\
\hline $\mathrm{N}^{1+} \mathrm{H}_{3}$ & $4-1771$ & Not Reported & Ground & & & 3261. & \\
\hline $\mathrm{HC}^{12} \mathrm{DO}^{16}$ & 4- 385' & $10,3,7 \leftarrow 10,3,8$ & Ground & & & 3283.09 & .03 \\
\hline $\mathrm{HC}^{12} \mathrm{DO}^{16}$ & 4. 385 & $23,5,18 \leftarrow 23,5,19$ & Ground & & & 3330.66 & .04 \\
\hline $\mathrm{C}^{12} \mathrm{~F}_{3}^{19} \mathrm{I}^{127}$ & 4- 231 & $1,0 \leftarrow 0,0$ & Ground & $3 / 2$ & $5 / 2$ & 3362.9 & .4 \\
\hline $\mathrm{C}^{12} \mathrm{H}_{3} \mathrm{~N}^{1+4} \mathrm{H}_{2}$ & $3-261$ & Not Reported & & & & 3389.74 & .5 \\
\hline $\mathrm{C}^{12} \mathrm{~F}_{3}^{19} \mathrm{C}^{12} \mathrm{O}^{16} \mathrm{O}^{16} \mathrm{H} \cdot \mathrm{HC}^{12} \mathrm{O}^{16} \mathrm{O}^{16} \mathrm{H}$ & 3. 661 & $3, \quad, \quad \leftarrow 2, \quad$, & Ground & & & 3462.2 & \\
\hline $\mathrm{N}^{1-4} \mathrm{D}_{2} \mathrm{H}$ & $4-1774$ & Not Reported & Ground & & & 3470. & \\
\hline $\mathrm{C}^{12} \mathrm{H}_{3} \mathrm{~N}^{14} \mathrm{H}_{2}$ & 3. 261 & Not Reported & & & & 3483.67 & .5 \\
\hline $\mathrm{C}^{12} \mathrm{H}_{3} \mathrm{~N}^{14} \mathrm{H}_{2}$ & 3- 261 & Not Reported & & & & 3505.76 & .5 \\
\hline $\mathrm{HC}^{12} \mathrm{HO}^{16}$ & 4- 381 & $20,4,16 \leftarrow 20,4,17$ & Ground & & & 3518.85 & .5 \\
\hline $\mathrm{N}^{15} \mathrm{O}_{2}^{16}$ & $4-1802$ & $7,1,7 \leftarrow 8,0,8$ & Ground & & & 3660.75 & .24 \\
\hline $\mathrm{DC}^{12} \mathrm{DO}^{16}$ & 4. 384 & $4,2,2 \leftarrow 4,2,3$ & Ground & & & 3687.28 & .04 \\
\hline $\mathrm{DC}^{12} \mathrm{~N}^{14}$ & 4. 292 & $4 \leftarrow 4$ & Excited & & & 3722.98 & .02 \\
\hline $\mathrm{N}^{15} \mathrm{O}_{2}^{16}$ & $4-1802$ & $7,1,7 \leftarrow 8,0,8$ & Ground & & & 3759.69 & .01 \\
\hline $\mathrm{C}^{12} \mathrm{H}_{3} \mathrm{~B}^{\mathrm{b}} \mathrm{F}_{2}^{19}$ & 3- 91 & $2, \quad \leftarrow 1, \quad$, & Ground & & & 3773.5 & .1 \\
\hline $\mathrm{C}^{12} \mathrm{H}_{3} \mathrm{~N}^{14} \mathrm{H}_{2}$ & 3- 261 & Not Reported & & & & 3797.95 & .5 \\
\hline $\mathrm{N}^{14} \mathrm{D}_{2} \mathrm{H}$ & 4-1774 & Not Reported & Ground & & & 3865. & \\
\hline $\mathrm{N}^{15} \mathrm{O}_{2}^{16}$ & 4-1802 & $7,1,7 \leftarrow 8,0,8$ & Ground & & & 3900.57 & .10 \\
\hline $\mathrm{C}^{12} \mathrm{H}_{3} \mathrm{~N}^{14} \mathrm{H}_{2}$ & 3. 261 & Not Reported & & & & 3921.96 & .5 \\
\hline $\mathrm{C}^{12} \mathrm{H}_{3} \mathrm{~N}^{14} \mathrm{H}_{2}$ & 3. 261 & Not Reported & & & & 4076.65 & .01 \\
\hline $\mathrm{N}^{15} \mathrm{O}_{2}^{16}$ & $4-1802$ & $7,1,7 \leftarrow 8,0,8$ & Ground & & & 4082.16 & .15 \\
\hline $\mathrm{N}^{1+} \mathrm{D}_{2} \mathrm{H}$ & $4-1774$ & Not Reported & Ground & & & 4086. & \\
\hline $\mathrm{Cl}^{35} \mathrm{C}^{12} \mathrm{~N}^{14}$ & 4- 171 & $23 \leftarrow 23$ & Excited & & & 4117.869 & .020 \\
\hline $\mathrm{Cl}^{35} \mathrm{C}^{12} \mathrm{~N}^{14}$ & 4- 171 & $23 \leftarrow 23$ & Excited & & & 4118.067 & .020 \\
\hline $\mathrm{C}^{12} \mathrm{H}_{3} \mathrm{~N}^{14} \mathrm{H}_{2}$ & 3. 261 & Not Reported & & & & 4129.01 & .5 \\
\hline $\mathrm{C}^{12} \mathrm{H}_{3} \mathrm{~N}^{14} \mathrm{H}_{2}$ & 3- 261 & Not Reported & & & & 4129.84 & .5 \\
\hline $\mathrm{C}^{12} \mathrm{H}_{3} \mathrm{~N}^{14} \mathrm{H}_{2}$ & 3- 261 & Not Reported & & & & 4142.15 & .5 \\
\hline $\mathrm{N}^{14} \mathrm{H}_{3}$ & $4-1771$ & Not Reported & Ground & & & 4161. & \\
\hline $\mathrm{N}^{14} \mathrm{H}_{3}$ & 4-1771 & Not Reported & Ground & & & 4199. & \\
\hline $\mathrm{N}^{14} \mathrm{H}_{3}$ & $4-1771$ & Not Reported & Ground & & & 4216 & \\
\hline $\mathrm{N}^{14} \mathrm{H}_{3}$ & $4-1771$ & Not Reported & Ground & & & 4219. & \\
\hline $\mathrm{N}^{1+4} \mathrm{H}_{3}$ & $4-1771$ & Not Reported & Ground & & & 4241. & \\
\hline $\mathrm{N}^{15} \mathrm{O}_{2}^{* 6}$ & $4-1802$ & $7,1,7 \leftarrow 8,0,8$ & Ground & & & 4243.94 & .02 \\
\hline $\mathrm{N}^{14} \mathrm{H}_{3}$ & $4-1771$ & Not Reported & Ground & & & 4282 & \\
\hline $\mathrm{N}^{15} \mathrm{O}_{2}^{16}$ & 4-1802 & $7,1,7 \leftarrow 8,0,8$ & Ground & & & 4321.59 & .06 \\
\hline $\mathrm{HC}^{12} \mathrm{HO}^{18}$ & 4- 383 & $1,1,0 \leftarrow 1,1,1$ & Ground & & & 4388.85 & .5 \\
\hline
\end{tabular}




\begin{tabular}{|c|c|c|c|c|c|c|c|c|c|}
\hline Isotopic Species & $\begin{array}{l}\text { Vol..Id. } \\
\text { Nos. }\end{array}$ & $\begin{array}{c}\text { Rotational } \\
\text { Quantum Nos. }\end{array}$ & Vib. State & $\mathrm{F}_{1}^{\prime}$ & $\begin{array}{r}\text { Typ } \\
F^{\prime}\end{array}$ & $\underset{F_{1}}{\text { rfine }}$ & $\mathbf{F}$ & $\begin{array}{c}\text { Frequency } \\
\text { MIIz }\end{array}$ & $\begin{aligned} & \text { Acc. } \\
\pm & \text { MHz }\end{aligned}$ \\
\hline $\mathrm{N}^{14} \mathrm{H}_{3}$ & 4-1771 & Not Reported & Ground & & & & & 4407. & \\
\hline $\mathrm{N}^{14} \mathrm{H}_{3}$ & $4-1771$ & Not Reported & Ground & & & & & 4.410 & \\
\hline $\mathrm{C}^{12} \mathrm{H}_{3} \mathrm{~N}^{14} \mathrm{H}_{2}$ & 3- 261 & Not Reported & & & & & & 4480.55 & .5 \\
\hline $\mathrm{HC}^{12} \mathrm{~N}^{14}$ & 4. 291 & $4 \leftarrow 4$ & Excited & & 4 & & 3 & 4.486 .762 & .013 \\
\hline $\mathrm{HC}^{12} \mathrm{~N}^{14}$ & 4- 291 & $4 \leftarrow 4$ & Excited & & 4 & & 5 & 4487.000 & .006 \\
\hline $\mathrm{HC}^{12} \mathrm{~N}^{14}$ & 4- 291 & $4 \leftarrow 4$ & Excited & & 4 & & 4 & 4488.381 & .020 \\
\hline $\mathrm{HC}^{12} \mathrm{~N}^{14}$ & 4- 291 & $4 \leftarrow 4$ & Excited & & 3 & & 3 & 4.488 .522 & .020 \\
\hline $\mathrm{HC}^{12} \mathrm{~N}^{14}$ & 4- 291 & $4 \leftarrow 4$ & Excited & & 5 & & 5 & 4488.522 & .020 \\
\hline $\mathrm{HC}^{12} \mathrm{DO}^{16}$ & 4- 385 & $5,2,3 \leftarrow 5,2,4$ & Ground & & & & & 4.489 .08 & .03 \\
\hline $\mathrm{DC}^{12} \mathrm{DO}^{16}$ & 4- 384 & $19,5,14 \leftarrow 19,5,15$ & Ground & & & & & 4508.39 & .04 \\
\hline $\mathrm{N}^{14} \mathrm{H}_{3}$ & $4 \cdot 1771$ & Not Reported & Ground & & & & & 4511 & \\
\hline $\mathrm{C}^{12} \mathrm{H}_{3} \mathrm{~N}^{14} \mathrm{H}_{2}$ & 3- 261 & Not Reported & & & & & & 4543.00 & .5 \\
\hline $\mathrm{HC}^{13} \mathrm{HO}^{16}$ & 4- 382 & $1,1,0 \leftarrow 1,1,1$ & Ground & & & & & 4593.26 & .5 \\
\hline $\mathrm{C}^{12} \mathrm{H}_{3} \mathrm{~N}^{14} \mathrm{H}_{2}$ & 3. 261 & $8,3, \leftarrow 9,2$, & Ground & & & & & 4660 & \\
\hline $\mathrm{C}^{12} \mathrm{H}_{3} \mathrm{~N}^{14} \mathrm{H}_{2}$ & 3- 261 & Not Reported & & & & & & 4660.42 & .5 \\
\hline $\mathrm{HC}^{12} \mathrm{DO}^{16}$ & 4. 385 & $17,4,13 \leftarrow 17,4,14$ & Ground & & & & & 4713.90 & \\
\hline $\mathrm{N}^{14} \mathrm{H}_{3}$ & $4-1771$ & Not Reported & Ground & & & & & 4. 721 . & \\
\hline $\mathrm{H}_{2} \mathrm{~N}^{14} \mathrm{~N}^{14} \mathrm{H}_{2}$ & 3. 51 & Not Reported & & & & & & 4764.0 & \\
\hline $\mathrm{K}^{39} \mathrm{Br}^{81}$ & $1-$ & $1 \leftarrow 0$ & Excited & $5 / 2$ & 3 & $3 / 2$ & 3 & 4793.140 & \\
\hline $\mathrm{K}^{39} \mathrm{Br}^{81}$ & $1-$ & $1 \leftarrow 0$ & Excited & $1 / 2$ & 2 & $3 / 2$ & 3 & 4794.062 & \\
\hline $\mathrm{K}^{39} \mathrm{Br}^{79}$ & 1 . & $1 \leftarrow 0$ & Excited & $3 / 2$ & 2 & $3 / 2$ & 3 & 4806.153 & \\
\hline $\mathrm{K}^{39} \mathrm{Br}^{79}$ & 1. & $1 \leftarrow 0$ & Excited & $3 / 2$ & 3 & $3 / 2$ & 3 & 4808.247 & \\
\hline $\mathrm{K}^{39} \mathrm{Br}^{79}$ & 1 . & $1 \leftarrow 0$ & Excited & $5 / 2$ & 2 & $3 / 2$ & 3 & 4808.990 & \\
\hline $\mathrm{K}^{39} \mathrm{Br}^{79}$ & $1-$ & $1 \leftarrow 0$ & Excited & $5 / 2$ & 4 & $3 / 2$ & 3 & 4. 809.129 & \\
\hline $\mathrm{K}^{39} \mathrm{Br}^{79}$ & $1-$ & $1 \leftarrow 0$ & Excited & $5 / 2$ & 3 & $3 / 2$ & 3 & 4811.835 & \\
\hline $\mathrm{K}^{39} \mathrm{Br}^{79}$ & $1-$ & $1 \leftarrow 0$ & Excited & $1 / 2$ & 2 & $3 / 2$ & 3 & 4812.622 & \\
\hline $\mathrm{K}^{39} \mathrm{Br}^{81}$ & $1-$ & $1 \leftarrow 0$ & Ground & $3 / 2$ & 2 & $3 / 2$ & 3 & 4815.635 & \\
\hline $\mathrm{K}^{39} \mathrm{Br}^{81}$ & 1 . & $1 \leftarrow 0$ & Ground & $3 / 2$ & 1 & $3 / 2$ & 0 & 4. 815.884 & \\
\hline $\mathrm{K}^{39} \mathrm{Br}^{81}$ & 1 - & $1 \leftarrow 0$ & Ground & $3 / 2$ & 3 & $3 / 2$ & 3 & 4. 817.056 & \\
\hline $\mathrm{K}^{39} \mathrm{Br}^{81}$ & 1 - & $1 \leftarrow 0$ & Ground & $5 / 2$ & 2 & $3 / 2$ & 3 & 4817.909 & \\
\hline $\mathrm{K}^{39} \mathrm{Br}^{81}$ & 1 . & $1 \leftarrow 0$ & Ground & $5 / 2$ & 4 & $3 / 2$ & 3 & 4817.992 & \\
\hline $\mathrm{K}^{39} \mathrm{Br}^{81}$ & $1-$ & $1 \leftarrow 0$ & Ground & $5 / 2$ & 1 & $3 / 2$ & 0 & 4818.143 & \\
\hline $\mathrm{K}^{39} \mathrm{Br}^{81}$ & $1-$ & $1 \leftarrow 0$ & Ground & $5 / 2$ & 3 & $3 / 2$ & 3 & 4819.815 & \\
\hline $\mathrm{K}^{39} \mathrm{Br}^{81}$ & 1 . & $1 \leftarrow 0$ & Ground & $1 / 2$ & 1 & $3 / 2$ & 0 & 4.820 .130 & \\
\hline $\mathrm{K}^{39} \mathrm{Br}^{81}$ & 1 . & $1 \leftarrow 0$ & Ground & $1 / 2$ & 2 & $3 / 2$ & 3 & 4820.613 & \\
\hline $\mathrm{HC}^{12} \mathrm{HO}^{16}$ & 4- 381 & $1,1,0 \leftarrow 1,1,1$ & Ground & & & & & 4829.73 & .01 \\
\hline $\mathrm{K}^{39} \mathrm{Br}^{79}$ & 1 . & $1 \leftarrow 0$ & Excited & $3 / 2$ & 2 & $3 / 2$ & 3 & 4830.463 & \\
\hline $\mathrm{K}^{39} \mathrm{Br}^{79}$ & 1 . & $1 \leftarrow 0$ & Excited & $3 / 2$ & 3 & $3 / 2$ & 3 & 4. 832.362 & \\
\hline $\mathrm{K}^{39} \mathrm{Br}^{79}$ & 1 . & $1 \leftarrow 0$ & Excited & $5 / 2$ & 2 & $3 / 2$ & 3 & 4833.143 & \\
\hline $\mathrm{K}^{39} \mathrm{Br}^{79}$ & 1 - & $1 \leftarrow 0$ & Excited & $5 / 2$ & 4 & $3 / 2$ & 3 & 4. 833.270 & \\
\hline $\mathrm{K}^{39} \mathrm{Br}^{79}$ & 1 . & $1 \leftarrow 0$ & Excited & $5 / 2$ & 3 & $3 / 2$ & 3 & 4835.743 & \\
\hline $\mathrm{K}^{34} \mathrm{Br}^{79}$ & $1-$ & $1 \leftarrow 0$ & Excited & $1 / 2$ & 2 & $3 / 2$ & 3 & 4836.530 & \\
\hline $\mathrm{N}^{1+} \mathrm{H}_{3}$ & 4-1771 & Not Reported & Ground & & & & & 4850 & \\
\hline $\mathrm{K}^{39} \mathrm{Br}^{79}$ & $1-$ & $1 \leftarrow 0$ & Ground & $3 / 2$ & 2 & $3 / 2$ & 3 & 4854.856 & \\
\hline $\mathrm{K}^{39} \mathrm{Br}^{79}$ & 1 . & $1 \leftarrow 0$ & Ground & $3 / 2$ & 3 & $3 / 2$ & 3 & 4856.588 & \\
\hline
\end{tabular}




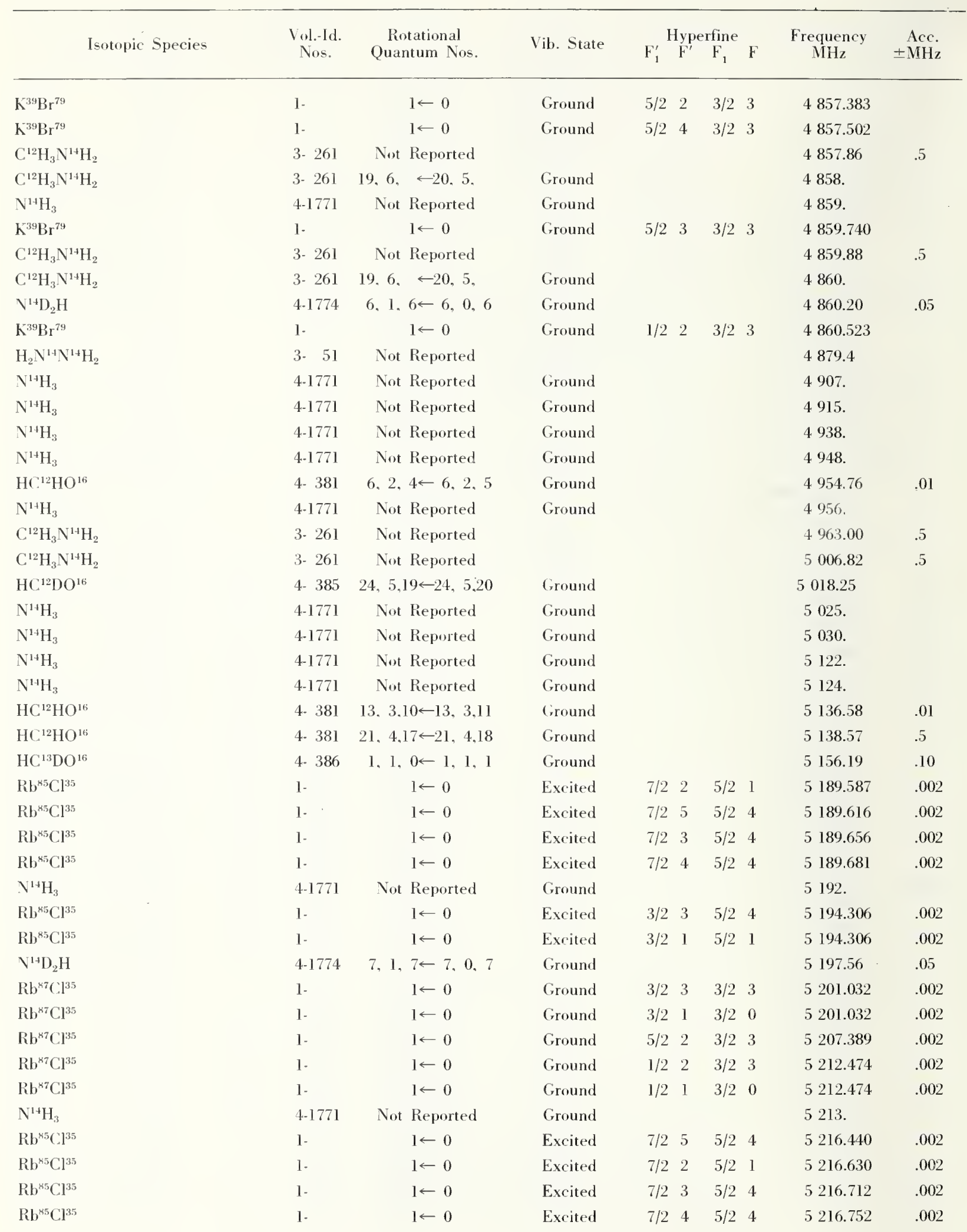




\begin{tabular}{|c|c|c|c|c|c|c|c|c|c|}
\hline Isotopic Species & $\begin{array}{l}\text { Vol.-Id. } \\
\text { Nos. }\end{array}$ & $\begin{array}{l}\text { Rotational } \\
\text { Quantum Nos. }\end{array}$ & Vih. State & $\mathrm{F}_{1}^{\prime}$ & $\begin{array}{l}\text { typer } \\
\mathrm{F}^{\prime}\end{array}$ & $\begin{array}{l}\text { rfine } \\
F_{1}\end{array}$ & $\mathrm{~F}$ & $\begin{array}{c}\text { Froquency } \\
\text { MHz }\end{array}$ & $\begin{aligned} \text { Ace } \\
\pm \\
\pm 11 \mathrm{I}_{\mathrm{z}}\end{aligned}$ \\
\hline $\mathrm{Rb}^{85} \mathrm{Cl}^{35}$ & 1 . & $1 \leftarrow 0$ & Excited & $3 / 2$ & 3 & $5 / 2$ & 4 & 5221.395 & .002 \\
\hline $\mathrm{Rb}^{85} \mathrm{Cl}^{35}$ & 1 . & $1 \leftarrow 0$ & Excited & 32 & 1 & $5 / 2$ & 1 & 5221.395 & .002 \\
\hline $\mathrm{Rb}^{85} \mathrm{Cl}^{35}$ & 1. & $1 \leftarrow 0$ & Excited & $3 / 2$ & 2 & $5 / 2$ & 1 & 5221.421 & .002 \\
\hline $\mathrm{N}^{14} \mathrm{H}_{3}$ & 4-1771 & Not Reported & Ground & & & & & 5230. & \\
\hline $\mathrm{Rb}^{\mathrm{x} 5} \mathrm{Cl}^{35}$ & 1 . & $1 \leftarrow 0$ & Ground & $5 / 2$ & 3 & $5 / 2$ & 4 & 5232.671 & .002 \\
\hline $\mathrm{Rb}^{85} \mathrm{Cl}^{35}$ & $1-$ & $1 \leftarrow 0$ & Ground & $5 / 2$ & 2 & $5 / 2$ & 1 & 5232.750 & .002 \\
\hline $\mathrm{Rb}^{85} \mathrm{Cl}^{35}$ & $1-$ & $1 \leftarrow 0$ & Ground & $5 / 2$ & 4 & $5 / 2$ & 4 & 5232.809 & .002 \\
\hline $\mathrm{Rb}^{85} \mathrm{Cl}^{35}$ & 1 . & $1 \leftarrow 0$ & Ground & $5 / 2$ & 1 & $5 / 2$ & 1 & 5232.889 & .002 \\
\hline $\mathrm{N}^{14} \mathrm{H}_{3}$ & $4-1771$ & Not Reported & Ground & & & & & 5236. & \\
\hline $\mathrm{Rb}^{85} \mathrm{Cl}^{35}$ & $1-$ & $1 \leftarrow 0$ & Ground & $7 / 2$ & 2 & $5 / 2$ & 1 & 5243.745 & .002 \\
\hline $\mathrm{Rb}^{85} \mathrm{Cl}^{35}$ & 1 . & $1 \leftarrow 0$ & Ground & $7 / 2$ & 5 & $5 / 2$ & 4 & 5243.788 & .002 \\
\hline $\mathrm{Rb}^{85} \mathrm{Cl}^{35}$ & $1-$ & $1 \leftarrow 0$ & Ground & $7 / 2$ & 3 & $5 / 2$ & 4 & 5243.855 & .022 \\
\hline $\mathrm{Rb}^{85} \mathrm{Cl}^{35}$ & $1-$ & $1 \leftarrow 0$ & Ground & $7 / 2$ & 4 & $5 / 2$ & 4 & 5243.905 & .002 \\
\hline $\mathrm{Rb}^{87} \mathrm{Cl}^{35}$ & 1 . & $1 \leftarrow 0$ & Ground & $5 / 2$ & 4 & $3 / 2$ & 3 & 5247.332 & .002 \\
\hline $\mathrm{Rb}^{85} \mathrm{Cl}^{35}$ & $1-$ & $1 \leftarrow 0$ & Ground & $3 / 2$ & 3 & $5 / 2$ & 4 & 5248.566 & .002 \\
\hline $\mathrm{Rb}^{85} \mathrm{Cl}^{35}$ & $1-$ & $1 \leftarrow 0$ & Ground & $3 / 2$ & 1 & $5 / 2$ & 1 & 5248.566 & .002 \\
\hline $\mathrm{Rb}^{85} \mathrm{Cl}^{35}$ & 1. & $1 \leftarrow 0$ & Ground & $3 / 2$ & 2 & $5 / 2$ & 1 & 5248.596 & .002 \\
\hline $\mathrm{C}^{12} \mathrm{H}_{3} \mathrm{~N}^{14} \mathrm{H}_{2}$ & 3- 261 & Not Reported & & & & & & 5284.82 & .01 \\
\hline $\mathrm{HC}^{12} \mathrm{DO}^{16}$ & 4- 385 & $1,1,0 \leftarrow 1,1,1$ & Ground & & & & & 5346.64 & .03 \\
\hline $\mathrm{N}^{14} \mathrm{H}_{3}$ & $4-1771$ & Not Reported & Ground & & & & & 5364. & \\
\hline $\mathrm{N}^{14} \mathrm{D}_{2} \mathrm{H}$ & $4-1774$ & $8,1,8 \leftarrow 8,0,8$ & Ground & & & & & 5364.03 & .05 \\
\hline $\mathrm{N}^{14} \mathrm{H}_{3}$ & $4-1771$ & Not Reported & Ground & & & & & 5368. & \\
\hline $\mathrm{H}_{2} \mathrm{~N}^{14} \mathrm{~N}^{14} \mathrm{H}_{2}$ & 3- 51 & Not Reported & & & & & & 5386.0 & \\
\hline $\mathrm{N}^{14} \mathrm{H}_{3}$ & $4-1771$ & Not Reported & Ground & & & & & 5392. & \\
\hline $\mathrm{N}^{14} \mathrm{D}_{2} \mathrm{H}$ & 4-1774 & $7,1,7 \leftarrow 7,0,7$ & Ground & & & & & 5392.07 & .05 \\
\hline $\mathrm{N}^{14} \mathrm{D}_{2} \mathrm{H}$ & 4-1774 & $8,1,8 \leftarrow 8,0,8$ & Ground & & & & & 5414.15 & .05 \\
\hline $\mathrm{N}^{14} \mathrm{H}_{3}$ & 4.1771 & Not Reported & Ground & & & & & 5415 & \\
\hline $\mathrm{DC}^{12} \mathrm{DO}^{16}$ & 4- 384 & $14,4,10 \leftarrow 14,4.11$ & Ground & & & & & 5461.54 & \\
\hline $\mathrm{N}^{14} \mathrm{D}_{2} \mathrm{H}$ & 4.1774 & $9,1,9 \leftarrow 9,0,9$ & Ground & & & & & 5494.98 & .05 \\
\hline $\mathrm{N}^{14} \mathrm{H}_{3}$ & 4-1771 & Not Reported & Ground & & & & & 5495. & \\
\hline $\mathrm{N}^{14} \mathrm{D}_{2} \mathrm{H}$ & $4 \cdot 1774$ & $9,1,9 \leftarrow 9.0 .9$ & Ground & & & & & 5507.75 & .05 \\
\hline $\mathrm{C}^{12} \mathrm{H}_{3} \mathrm{C}^{12} \mathrm{H}_{2} \mathrm{I}^{127}$ & 3. 571 & $1,0,1 \leftarrow 0,0,0$ & Ground & & $5 / 2$ & & $5 / 2$ & 5542.08 & .05 \\
\hline $\mathrm{C}^{12} \mathrm{H}_{3} \mathrm{~N}^{14} \mathrm{H}_{2}$ & 3- 261 & Not Reported & & & & & & 5546.75 & .5 \\
\hline $\mathrm{N}^{14} \mathrm{H}_{3}$ & $4 \cdot 1771$ & Not Reported & Ground & & & & & 5549. & \\
\hline $\mathrm{H}_{2} \mathrm{~N}^{14} \mathrm{~N}^{14} \mathrm{H}_{2}$ & 3- 51 & Not Reported & & & & & & 5562.53 & \\
\hline $\mathrm{H}_{2} \mathrm{~N}^{14} \mathrm{~N}^{14} \mathrm{H}_{2}$ & $3-51$ & Not Reported & & & & & & 5568.98 & \\
\hline $\mathrm{N}^{14} \mathrm{H}_{3}$ & 4-1771 & Not Reported & Ground & & & & & 5574 & \\
\hline $\mathrm{N}^{14} \mathrm{D}_{2} \mathrm{H}$ & $4-1774$ & $6,1,6 \leftarrow 6,0,6$ & Ground & & & & & 5581.08 & .05 \\
\hline $\mathrm{DC}^{12} \mathrm{~N}^{14}$ & 4- 292 & $5 \leftarrow 5$ & Excited & & & & & $5583: 85$ & .02 \\
\hline $\mathrm{C}^{12} \mathrm{H}_{3} \mathrm{~N}^{14} \mathrm{H}_{2}$ & 3- 261 & Not Reported & & & & & & 5602.57 & .5 \\
\hline $\mathrm{N}^{14} \mathrm{D}_{2} \mathrm{H}$ & $4 \cdot 1774$ & $10,1,10 \leftarrow 10,0,10$ & Ground & & & & & 5631.97 & .05 \\
\hline $\mathrm{N}^{14} \mathrm{D}_{2} \mathrm{H}$ & $4-1774$ & $10.1,10 \leftarrow 10,0,10$ & Ground & & & & & 5635.18 & .05 \\
\hline $\mathrm{DC}^{12} \mathrm{DO}^{16}$ & 4- 384 & $9,3,6 \leftarrow 9,3,7$ & Ground & & & & & 5636.98 & \\
\hline $\mathrm{C}^{12} \mathrm{H}_{3} \mathrm{~N}^{14} \mathrm{H}_{2}$ & 3- 261 & Not Reported & & & & & & 5679.92 & .5 \\
\hline $\mathrm{C}^{12} \mathrm{H}_{3} \mathrm{~N}^{14} \mathrm{H}_{2}$ & 3. 261 & Not Reported & & & & & & 5680.84 & .5 \\
\hline
\end{tabular}




\begin{tabular}{|c|c|c|c|c|c|c|c|}
\hline Isotopic Species & $\begin{array}{l}\text { Vol.-Id. } \\
\text { Nos. }\end{array}$ & $\begin{array}{c}\text { Rotational } \\
\text { Quantum Nos. }\end{array}$ & Vib. State & $\begin{array}{c}F_{1}^{\prime} \quad F^{\prime} \quad F_{1}\end{array}$ & $\mathrm{~F}$ & $\begin{array}{c}\text { Frequency } \\
\mathrm{MHz}\end{array}$ & $\begin{array}{r}\text { Acc. } \\
\pm \mathrm{MHz}\end{array}$ \\
\hline $\mathrm{N}^{1+1} \mathrm{H}_{3}$ & $4-1771$ & Not Reported & Ground & & & 5689. & \\
\hline $\mathrm{HC}^{12} \mathrm{DO}^{16}$ & 4. 385 & $11,3,8 \leftarrow 11,3,9$ & Ground & & & 5702.6 & \\
\hline $\mathrm{HDO}^{16}$ & $4-1712$ & $4,3,1 \leftarrow 4,3,2$ & Ground & & & 5702.78 & \\
\hline $\mathrm{N}^{11} \mathrm{H}_{3}$ & $4-1771$ & Not Reported & Ground & & & 5726. & \\
\hline $\mathrm{C}^{12} \mathrm{H}_{3} \mathrm{~N}^{1+} \mathrm{H}_{2}$ & 3- 261 & Not Reported & & & & 5766.68 & .5 \\
\hline $\mathrm{C}^{12} \mathrm{H}_{3} \mathrm{~N}^{14} \mathrm{H}_{2}$ & 3- 261 & $8,3, \leftarrow 9,2$ & Ground & & & 5767. & \\
\hline $\mathrm{N}^{1+} \mathrm{D}_{2} \mathrm{H}$ & 4-1774 & $11,1,11 \leftarrow 11,0,11$ & Ground & & & 5786.44 & .05 \\
\hline $\mathrm{N}^{1+} \mathrm{D}_{2} \mathrm{H}$ & $4-1774$ & $11,1,11 \leftarrow 11,0,11$ & Ground & & & 5787.16 & .05 \\
\hline $\mathrm{C}^{12} \mathrm{H}_{3} \mathrm{C}^{12} \mathrm{H}_{2} \mathrm{I}^{127}$ & 3- 571 & $1,0,1 \leftarrow 0,0,0$ & Ground & $7 / 2$ & $5 / 2$ & 5852.44 & .05 \\
\hline $\mathrm{C}^{12} \mathrm{H}_{3} \mathrm{~N}^{14} \mathrm{H}_{2}$ & 3- 261 & Not Reported & & & & 5876.61 & .5 \\
\hline $\mathrm{N}^{14} \mathrm{D}_{2} \mathrm{H}$ & $4-1774$ & $12,1,12 \leftarrow 12,0,12$ & Ground & & & 5962.30 & .20 \\
\hline $\mathrm{I}^{127} \mathrm{C}^{13} \mathrm{~N}^{14}$ & 4. 512 & $1 \leftarrow 0$ & Ground & $5 / 2$ & $5 / 2$ & 5974.43 & .5 \\
\hline $\mathrm{C}^{12} \mathrm{H}_{3} \mathrm{C}^{12} \mathrm{H}_{2} I^{127}$ & $3 \cdot .571$ & $1,0,1 \leftarrow 0,0,0$ & Ground & $3 / 2$ & $5 / 2$ & 5988.1 & .5 \\
\hline $\mathrm{H}_{2} \mathrm{~N}^{1+} \mathrm{N}^{1+} \mathrm{H}_{2}$ & 3- 51 & Not Reported & & & & 5992. & \\
\hline${ }^{127} \mathrm{C}^{12} \mathrm{~N}^{14}$ & 4- 511 & $\mathrm{l} \leftarrow 0$ & Excited & $5 / 2$ & $5 / 2$ & 6051.36 & .5 \\
\hline $\mathrm{I}^{127} \mathrm{C}^{12} \mathrm{~N}^{14}$ & 4- 511 & $1 \leftarrow 0$ & Ground & $5 / 2$ & $5 / 2$ & 6070.66 & .5 \\
\hline $\mathrm{I}^{127} \mathrm{C}^{12} \mathrm{~N}^{14}$ & 4- 511 & $1 \leftarrow 0$ & Ground & $5 / 2$ & $5 / 2$ & 6071.61 & .5 \\
\hline $\mathrm{DC}^{12} \mathrm{DO}^{16}$ & 4- 384 & $1,1,0 \leftarrow 1,1,1$ & Ground & & & 6096.10 & .02 \\
\hline $\mathrm{N}^{14} \mathrm{D}_{2} \mathrm{H}$ & $4-1774$ & Not Reported & Ground & & & 6105. & \\
\hline$I^{127} C^{12} \mathrm{~N}^{14}$ & 4- 511 & $1 \leftarrow 0$ & Excited & $5 / 2$ & $5 / 2$ & 6106.71 & .5 \\
\hline $\mathrm{H}_{2} \mathrm{~N}^{1+} \mathrm{N}^{1 \cdot 1} \mathrm{H}_{2}$ & 3- 51 & Not Reported & & & & 6144. & \\
\hline $\mathrm{C}^{12} \mathrm{H}_{3} \mathrm{~N}^{1+} \mathrm{H}_{2}$ & 3- 261 & Not Reported & & & & 6153.64 & .5 \\
\hline $\mathrm{N}^{14} \mathrm{D}_{2} \mathrm{H}$ & $4-1774$ & $13,1,13 \leftarrow 13,0,13$ & Ground & & & 6161.86 & .20 \\
\hline $\mathrm{C}^{12} \mathrm{H}_{3} \mathrm{~N}^{1+} \mathrm{H}_{2}$ & 3- 261 & Not Reported & & & & 6172.20 & .5 \\
\hline $\mathrm{C}^{12} \mathrm{H}_{3} \mathrm{~N}^{14} \mathrm{H}_{2}$ & $3 \cdot 261$ & Not Reported & & & & 6246.42 & .5 \\
\hline $\mathrm{C}^{12} \mathrm{H}_{3} \mathrm{~N}^{1+} \mathrm{H}_{2}$ & 3- 261 & Not Reported & & & & 6269.81 & .5 \\
\hline $\mathrm{C}^{12} \mathrm{H}_{3} \mathrm{~N}^{1-4} \mathrm{H}_{2}$ & $3-261$ & $13,3, \leftarrow 12,4$, & Ground & & & 6270. & \\
\hline $\mathrm{C}^{12} \mathrm{H}_{3} \mathrm{~N}^{1+1} \mathrm{H}_{2}$ & 3- 261 & Not Reported & & & & 6349.51 & .5 \\
\hline $\mathrm{C}^{12} \mathrm{H}_{3} \mathrm{~N}^{1+1} \mathrm{H}_{2}$ & $3-261$ & Not Reported & & & & 6350.09 & .5 \\
\hline $\mathrm{N}^{14} \mathrm{D}_{2} \mathrm{H}$ & $4-1774$ & $14,1,14 \leftarrow 14.0,14$ & Ground & & & 6387.23 & .20 \\
\hline $\mathrm{C}^{12} \mathrm{H}_{3} \mathrm{~N}^{14} \mathrm{H}_{2}$ & 3- 261 & $8,3, \leftarrow 9,2$, & Ground & & & 6450. & \\
\hline $\mathrm{C}^{12} \mathrm{H}_{3} \mathrm{~N}^{14} \mathrm{H}_{2}$ & 3- 261 & Not Reported & & & & 6450.42 & .5 \\
\hline $\mathrm{N}^{1+} \mathrm{D}_{2} \mathrm{H}$ & $4-1774$ & $5,1,5 \leftarrow 5,0,5$ & Ground & & & 64461.09 & .05 \\
\hline $\mathrm{N}^{14} \mathrm{H}_{3}$ & 4-1771 & Not Reported & Ground & & & 6463. & \\
\hline $\mathrm{C}^{12} \mathrm{H}_{3} \mathrm{~N}^{14} \mathrm{H}_{2}$ & 3- 261 & Not Reported & & & & 6469.43 & .5 \\
\hline $\mathrm{I}^{127} \mathrm{C}^{13} \mathrm{~N}^{14}$ & 4- 512 & $1 \leftarrow 0$ & Ground & $7 / 2$ & $5 / 2$ & 6480.72 & .5 \\
\hline $\mathrm{C}^{12} \mathrm{H}_{3} \mathrm{~N}^{14} \mathrm{H}_{2}$ & 3- 261 & Not Reported & & & & 6487.99 & .5 \\
\hline $\mathrm{H}_{2} \mathrm{~N}^{14} \mathrm{~N}^{14} \mathrm{H}_{2}$ & 3- 51 & Not Reported & & & & 6498.3 & \\
\hline $\mathrm{C}^{12} \mathrm{H}_{3} \mathrm{~N}^{1+1} \mathrm{H}_{2}$ & 3- 261 & $19,6, \leftarrow 20,5$ & Ground & & & 6500. & \\
\hline $\mathrm{C}^{12} \mathrm{H}_{3} \mathrm{~N}^{1+1} \mathrm{H}_{2}$ & 3- 261 & Not Reported & & & & 6500.42 & .5 \\
\hline${ }^{[27} \mathrm{C}^{12} \mathrm{~N}^{14}$ & 4- 511 & $1 \leftarrow 0$ & Excited & $7 / 2$ & $5 / 2$ & 6559.63 & .5 \\
\hline $\mathrm{H}_{2} \mathrm{~N}^{14} \mathrm{~N}^{1+} \mathrm{H}_{2}$ & 3- 51 & Not Reported & & & & 6575.71 & \\
\hline${ }^{127} \mathrm{C}^{12} \mathrm{~N}^{14}$ & 4- 511 & $1 \leftarrow 0$ & Ground & $7 / 2$ & $5 / 2$ & 6577.06 & .5 \\
\hline $\mathrm{I}^{127} \mathrm{C}^{12} \mathrm{~N}^{14}$ & 4- 511 & $1 \leftarrow 0$ & Ground & $7 / 2$ & $5 / 2$ & 6577.95 & .5 \\
\hline $\mathrm{H}_{2} \mathrm{~N}^{14} \mathrm{~N}^{14} \mathrm{H}_{2}$ & 3- 51 & Not Reported & & & & 6588.6 & \\
\hline
\end{tabular}




\begin{tabular}{|c|c|c|c|c|c|c|c|c|c|}
\hline Isotopic Species & $\begin{array}{l}\text { Vol.-Id. } \\
\text { Nos. }\end{array}$ & $\begin{array}{c}\text { Rotational } \\
\text { Quantum Nos. }\end{array}$ & Vib. State & $F_{1}^{\prime \prime}$ & Hyper & $\begin{array}{c}\text { rfine } \\
F_{1}\end{array}$ & $\mathrm{~F}$ & $\begin{array}{c}\text { Frequency } \\
\mathrm{MHz}\end{array}$ & $\begin{aligned} & \text { Acc. } \\
\pm & \mathrm{MHz}\end{aligned}$ \\
\hline $\mathrm{N}^{14} \mathrm{H}_{3}$ & 4-1771 & Not Reported & Ground & & & & & 6598. & \\
\hline$I^{127} \mathrm{C}^{12} \mathrm{~N}^{14}$ & 4- 511 & $1 \leftarrow 0$ & Excited & & $7 / 2$ & & $5 / 2$ & 6610.24 & .5 \\
\hline $\mathrm{N}^{14} \mathrm{D}_{2} \mathrm{H}$ & 4-1774 & Not Reported & Ground & & & & & 6641. & \\
\hline $\mathrm{C}^{12} \mathrm{H}_{3} \mathrm{~N}^{14} \mathrm{H}_{2}$ & 3- 261 & Not Reported & & & & & & 6655.04 & .01 \\
\hline${ }^{127} \mathrm{C}^{13} \mathrm{~N}^{14}$ & 4. 512 & $1 \leftarrow 0$ & Ground & & $3 / 2$ & & $5 / 2$ & 6703.25 & .5 \\
\hline $\mathrm{HC}^{12} \mathrm{~N}^{14}$ & 4- 291 & $5 \leftarrow 5$ & Excited & & 5 & & 5 & 6731.793 & .011 \\
\hline $\mathrm{HC}^{12} \mathrm{~N}^{14}$ & 4- 291 & $5 \leftarrow 5$ & Excited & & 4 & & 4 & 6731.925 & .009 \\
\hline $\mathrm{HC}^{12} \mathrm{~N}^{14}$ & 4- 291 & $5 \leftarrow 5$ & Excited & & 6 & & 6 & 6731.925 & .009 \\
\hline $\mathrm{C}^{\mathrm{i} 2} \mathrm{H}_{3} \mathrm{~N}^{14} \mathrm{H}_{2}$ & 3- 261 & Not Reported & & & & & & 6748.80 & .5 \\
\hline $\mathrm{HC}^{13} \mathrm{HO}^{16}$ & 4- 382 & $14,3,11 \leftarrow 14,3,12$ & Ground & & & & & 6752.31 & .5 \\
\hline $\mathrm{H}_{2} \mathrm{~N}^{14} \mathrm{~N}^{14} \mathrm{H}_{2}$ & 3. 51 & Not Reported & & & & & & 6759.91 & \\
\hline $\mathrm{I}^{127} \mathrm{C}^{12} \mathrm{~N}^{14}$ & 4- 511 & $1 \leftarrow 0$ & Excited & & $3 / 2$ & & $5 / 2$ & 6782.16 & .5 \\
\hline $\mathrm{I}^{127} \mathrm{C}^{12} \mathrm{~N}^{14}$ & 4- 511 & $1 \leftarrow 0$ & Ground & & $3 / 2$ & & $5 / 2$ & 6799.79 & .5 \\
\hline $\mathrm{I}^{127} \mathrm{C}^{12} \mathrm{~N}^{14}$ & 4. 511 & $1 \leftarrow 0$ & Excited & & $3 / 2$ & & $5 / 2$ & 6830.47 & .5 \\
\hline $\mathrm{C}^{12} \mathrm{H}_{3} \mathrm{~N}^{14} \mathrm{H}_{2}$ & 3- 261 & Not Reported & & & & & & 6837.58 & .5 \\
\hline $\mathrm{C}^{12} \mathrm{H}_{3} \mathrm{~N}^{14} \mathrm{H}_{2}$ & 3- 261 & $8,3, \leftarrow 9,2$, & Ground & & & & & 6867. & \\
\hline $\mathrm{C}^{12} \mathrm{H}_{3} \mathrm{~N}^{14} \mathrm{H}_{2}$ & 3- 261 & Not Reported & & & & & & 6867.17 & .5 \\
\hline $\mathrm{C}^{12} \mathrm{H}_{3} \mathrm{~N}^{14} \mathrm{H}_{2}$ & 3. 261 & Not Reported & Ground & & & & & 6894.81 & .04 \\
\hline $\mathrm{N}^{14} \mathrm{D}_{2} \mathrm{H}$ & 4-1774 & Not Reported & Ground & & & & & 6922. & \\
\hline $\mathrm{C}^{12} \mathrm{H}_{3} \mathrm{~N}^{14} \mathrm{H}_{2}$ & $3 \cdot 261$ & Not Reported & Ground & & & & & 6939.82 & .1 \\
\hline $\mathrm{N}^{14} \mathrm{H}_{3}$ & $4-1771$ & Not Reported & Ground & & & & & 6975. & \\
\hline $\mathrm{F}_{3}^{19} \mathrm{~B}^{\mathrm{h}} \cdot \mathrm{N}^{\mathrm{b}}\left(\mathrm{C}^{12} \mathrm{H}_{3}\right)_{3}$ & $3-801$ & $2, \leftarrow 1$, & & & & & & 6990. & \\
\hline $\mathrm{C}^{12} \mathrm{H}_{3} \mathrm{~N}^{14} \mathrm{H}_{2}$ & 3- 261 & Not Reported & Ground & & & & & 7000.71 & .1 \\
\hline $\mathrm{DC}^{12} \mathrm{~N}^{14}$ & 4- 292 & $3 \leftarrow 3$ & Excited & & & & & 7050.92 & .1 \\
\hline $\mathrm{N}^{14} \mathrm{H}_{3}$ & 4-1771 & Not Reported & Ground & & & & & 7104. & \\
\hline $\mathrm{C}^{12} \mathrm{H}_{3} \mathrm{~N}^{14} \mathrm{H}_{2}$ & 3- 261 & Not Reported & Ground & & & & & 7115.14 & .1 \\
\hline $\mathrm{C}^{12} \mathrm{H}_{3} \mathrm{~N}^{14} \mathrm{H}_{2}$ & 3- 261 & Not Reported & Ground & & & & & 7213.43 & .1 \\
\hline $\mathrm{N}^{14} \mathrm{D}_{2} \mathrm{H}$ & 4-1774 & Not Reported & Ground & & & & & 7238. & \\
\hline $\mathrm{C}^{12} \mathrm{H}_{3} \mathrm{~N}^{14} \mathrm{H}_{2}$ & 3- 261 & Not Reported & Ground & & & & & 7253.64 & .1 \\
\hline $\mathrm{N}^{14} \mathrm{H}_{3}$ & $4-1771$ & $15,6 \leftarrow 15,6$ & Ground & & & & & 7285.80 & .05 \\
\hline $\mathrm{HC}^{12} \mathrm{DO}^{16}$ & 4- 385 & $18,4,14 \leftarrow 18,4,15$ & Ground & & & & & 7322.35 & \\
\hline $\mathrm{HC}^{12} \mathrm{HO}^{16}$ & 4. 381 & $22,4,18 \leftarrow 22,4,19$ & Ground & & & & & 7362.60 & \\
\hline $\mathrm{N}^{14} \mathrm{H}_{3}$ & 4-1771 & $14,4 \leftarrow 14,4$ & Ground & & & & & 7370.05 & .05 \\
\hline $\mathrm{C}^{12} \mathrm{H}_{3} \mathrm{~N}^{14} \mathrm{H}_{2}$ & $3 \cdot 261$ & Not Reported & - & & & & & 7382.93 & .01 \\
\hline $\mathrm{C}^{12} \mathrm{H}_{3} \mathrm{~N}^{14} \mathrm{H}_{2}$ & $3 \cdot 261$ & Not Reported & & & & & & 7383.78 & .01 \\
\hline $\mathrm{H}_{2} \mathrm{~N}^{14} \mathrm{C}^{12} \mathrm{~N}^{14}$ & 4. 361 & $7,1,6 \leftarrow 7,1,7$ & Ground & & & & & 7384.82 & .5 \\
\hline $\mathrm{N}^{14} \mathrm{D}_{2} \mathrm{H}$ & $4-1774$ & Not Reported & Ground & & & & & 7388. & \\
\hline $\mathrm{DC}^{12} \mathrm{~N}^{15}$ & 4. 296 & $6 \leftarrow 6$ & Excited & & & & & 7391.80 & .1 \\
\hline $\mathrm{K}^{39} \mathrm{Cl}^{37}$ & $1-$ & $1 \leftarrow 0$ & Excited & $1 / 2$ & 21 & $3 / 2$ & 0 & 7426.754 & \\
\hline $\mathrm{K}^{39} \mathrm{Cl}^{37}$ & $1-$ & $1 \leftarrow 0$ & Excited & $1 / 2$ & 22 & $3 / 2$ & 3 & 7426.754 & \\
\hline $\mathrm{Cl}^{35} \mathrm{O}_{2}^{16}$ & 4-1381 & $11,2,9 \leftarrow 10,3,8$ & Ground & & $19 / 2$ & & $17 / 2$ & 7438.2 & \\
\hline $\mathrm{H}_{2} \mathrm{~N}^{14} \mathrm{~N}^{14} \mathrm{H}_{2}$ & $3-51$ & Not Reported & & & & & & 7444.9 & \\
\hline $\mathrm{Cl}^{35} \mathrm{O}_{2}^{16}$ & $4-1381$ & $11,3,8 \leftarrow 12,2,11$ & Ground & & $27 / 2$ & & $25 / 2$ & 7449.0 & \\
\hline $\mathrm{Cl}^{35} \mathrm{O}_{2}^{16}$ & 4-1381 & $11,2,9 \leftarrow 10,3,8$ & Ground & & $21 / 2$ & & $19 / 2$ & 7457.1 & \\
\hline $\mathrm{K}^{41} \mathrm{Cl}^{35}$ & $1-$ & $1 \leftarrow 0$ & Excited & $1 / 2$ & 22 & $3 / 2$ & 3 & 7468.107 & \\
\hline
\end{tabular}




\begin{tabular}{|c|c|c|c|c|c|c|c|c|}
\hline Isotopic Species & $\begin{array}{l}\text { Vol.-Id. } \\
\text { Nos. }\end{array}$ & $\begin{array}{c}\text { Rotational } \\
\text { Quantum Nos. }\end{array}$ & Vib. State & $\mathrm{F}_{1}^{\prime} \mathrm{F}^{\prime}$ & $\begin{array}{l}\text { rfine } \\
F_{1}\end{array}$ & $F$ & $\begin{array}{c}\text { Frequency } \\
\mathrm{MHz}^{2}\end{array}$ & $\begin{aligned} & \text { Acc. } \\
\pm & \mathrm{MHz}\end{aligned}$ \\
\hline $\mathrm{K}^{41} \mathrm{Cl}^{35}$ & 1 . & $1 \leftarrow 0$ & Excited & $1 / 2 \quad 1$ & $3 / 2$ & 0 & 7468.107 & \\
\hline $\mathrm{Cl}^{35} \mathrm{O}_{2}^{16}$ & 4-1381 & $11,3,8 \leftarrow 12,2,11$ & Ground & $25 / 2$ & & $23 / 2$ & 7469.2 & \\
\hline $\mathrm{K}^{39} \mathrm{Cl}^{37}$ & $1-$ & $1 \leftarrow 0$ & Ground & $3 / 21$ & $3 / 2$ & 0 & 7469.370 & \\
\hline $\mathrm{K}^{39} \mathrm{Cl}^{37}$ & $1-$ & $1 \leftarrow 0$ & Ground & $3 / 22$ & $3 / 2$ & 3 & 7469.370 & \\
\hline $\mathrm{K}^{39} \mathrm{Cl}^{37}$ & $1-$ & $1 \leftarrow 0$ & Ground & $3 / 2 \quad 3$ & $3 / 2$ & 3 & 7469.370 & \\
\hline $\mathrm{K}^{39} \mathrm{Cl}^{37}$ & 1 & $1 \leftarrow 0$ & Ground & $3 / 20$ & $3 / 2$ & 0 & 7469.370 & \\
\hline $\mathrm{K}^{39} \mathrm{Cl}^{37}$ & $1-$ & $1 \leftarrow 0$ & Ground & $5 / 22$ & $3 / 2$ & 3 & 7470.776 & \\
\hline $\mathrm{K}^{39} \mathrm{Cl}^{37}$ & 1 & $1 \leftarrow 0$ & Ground & $5 / 2 \quad 3$ & $3 / 2$ & 3 & 7470.776 & \\
\hline $\mathrm{K}^{39} \mathrm{Cl}^{37}$ & 1 . & $1 \leftarrow 0$ & Ground & $5 / 24$ & $3 / 2$ & 3 & 7470.776 & \\
\hline $\mathrm{K}^{39} \mathrm{Cl}^{37}$ & $1-$ & $1 \leftarrow 0$ & Ground & $5 / 2 \quad 1$ & $3 / 2$ & 0 & 7470.776 & \\
\hline $\mathrm{K}^{39} \mathrm{Cl}^{37}$ & $1-$ & $1 \leftarrow 0$ & Ground & $1 / 22$ & $3 / 2$ & 3 & 7471.917 & \\
\hline $\mathrm{K}^{39} \mathrm{Cl}^{37}$ & $1-$ & $1 \leftarrow 0$ & Ground & $1 / 2 \quad 1$ & $3 / 2$ & 0 & 7471.917 & \\
\hline $\mathrm{Cl}^{35} \mathrm{O}_{2}^{16}$ & 4.1381 & $11,2,9 \leftarrow 10,3,8$ & Ground & $23 / 2$ & & $21 / 2$ & 7476.2 & \\
\hline $\mathrm{Cl}^{35} \mathrm{O}_{2}^{16}$ & $4 \cdot 1381$ & $11,3,8 \leftarrow 12,2,11$ & Ground & $23 / 2$ & & $21 / 2$ & 7483.6 & \\
\hline $\mathrm{Cl}^{35} \mathrm{O}_{2}^{16}$ & $4 \cdot 1381$ & $11,3,8 \leftarrow 12,2,11$ & Ground & $21 / 2$ & & $19 / 2$ & 7493.8 & \\
\hline $\mathrm{Cl}^{35} \mathrm{O}_{2}^{16}$ & 4-1381 & $11,2,9 \leftarrow 10,3,8$ & Ground & $25 / 2$ & & $23 / 2$ & 7494.9 & \\
\hline $\mathrm{K}^{41} \mathrm{Cl}^{35}$ & $1-$ & $1 \leftarrow 0$ & Ground & $3 / 2 \quad 0$ & $3 / 2$ & 0 & 7510.555 & \\
\hline $\mathrm{K}^{41} \mathrm{Cl}^{35}$ & $1-$ & $1 \leftarrow 0$ & Ground & $3 / 2 \quad 3$ & $3 / 2$ & 3 & 7510.555 & \\
\hline $\mathrm{K}^{41} \mathrm{Cl}^{35}$ & 1 - & $1 \leftarrow 0$ & Ground & $3 / 2 \quad 2$ & $3 / 2$ & 3 & 7510.555 & \\
\hline $\mathrm{K}^{41} \mathrm{Cl}^{35}$ & 1 . & $1 \leftarrow 0$ & Ground & $3 / 2 \quad 1$ & $3 / 2$ & 0 & 7510.555 & \\
\hline $\mathrm{K}^{41} \mathrm{Cl}^{35}$ & $1-$ & $1 \leftarrow 0$ & Ground & $5 / 2 \quad 1$ & $3 / 2$ & 0 & 7512.280 & \\
\hline $\mathrm{K}^{41} \mathrm{Cl}^{35}$ & $1-$ & $1 \leftarrow 0$ & Ground & $5 / 2 \quad 2$ & $3 / 2$ & 3 & 7512.280 & \\
\hline $\mathrm{K}^{41} \mathrm{Cl}^{35}$ & 1 & $1 \leftarrow 0$ & Ground & $5 / 2 \quad 4$ & $3 / 2$ & 3 & 7512.280 & \\
\hline $\mathrm{K}^{41} \mathrm{Cl}^{35}$ & $1-$ & $1 \leftarrow 0$ & Ground & $5 / 23$ & $3 / 2$ & 3 & 7512.280 & \\
\hline $\mathrm{K}^{41} \mathrm{Cl}^{35}$ & $1-$ & $1 \leftarrow 0$ & Ground & $1 / 2 \quad 2$ & $3 / 2$ & 3 & 7513.659 & \\
\hline $\mathrm{K}^{41} \mathrm{Cl}^{35}$ & $1-$ & $1 \leftarrow 0$ & Ground & $1 / 2 \quad 1$ & $3 / 2$ & 0 & 7513.659 & \\
\hline $\mathrm{C}^{12} \mathrm{H}_{3} \mathrm{~N}^{1+4} \mathrm{H}_{2}$ & 3- 261 & Not Reported & & & & & 7515.56 & .5 \\
\hline $\mathrm{K}^{39} \mathrm{Cl}^{35}$ & $1-$ & $1 \leftarrow 0$ & Excited & $3 / 2 \quad 2$ & $3 / 2$ & 3 & 7547.073 & \\
\hline $\mathrm{K}^{39} \mathrm{Cl}^{35}$ & 1 . & $1 \leftarrow 0$ & Excited & $3 / 2 \quad 1$ & $3 / 2$ & 0 & 7547.073 & \\
\hline $\mathrm{K}^{39} \mathrm{Cl}^{35}$ & 1 . & $1 \leftarrow 0$ & Excited & $3 / 2 \quad 3$ & $3 / 2$ & 3 & 7547.073 & \\
\hline $\mathrm{K}^{39} \mathrm{Cl}^{35}$ & 1 & $1 \leftarrow 0$ & Excited & $3 / 2 \quad 3$ & $3 / 2$ & 3 & 7547.136 & \\
\hline $\mathrm{K}^{39} \mathrm{Cl}^{35}$ & 1 - & $1 \leftarrow 0$ & Excited & $3 / 2 \quad 2$ & $3 / 2$ & 3 & 7547.136 & \\
\hline $\mathrm{K}^{39} \mathrm{Cl}^{35}$ & $1-$ & $1 \leftarrow 0$ & Excited & $3 / 2 \quad 1$ & $3 / 2$ & 0 & 7547.136 & \\
\hline $\mathrm{K}^{39} \mathrm{Cl}^{35}$ & 1 - & $1 \leftarrow 0$ & Excited & $1 / 2 \quad 2$ & $3 / 2$ & 3 & 7549.569 & \\
\hline $\mathrm{K}^{39} \mathrm{Cl}^{35}$ & $1-$ & $1 \leftarrow 0$ & Excited & $1 / 2 \quad 1$ & $3 / 2$ & 0 & 7549.569 & \\
\hline $\mathrm{N}^{14} \mathrm{H}_{2} \mathrm{D}$ & $4-1773$ & $5,1,5 \leftarrow 5,0,5$ & Ground & & & & 7562.06 & .05 \\
\hline $\mathrm{Cl}^{35} \mathrm{O}_{2}^{16 i}$ & 4-1381 & $11,2,9 \leftarrow 10,3,8$ & Ground & & & & 7569.1 & \\
\hline $\mathrm{C}^{12} \mathrm{H}_{3} \mathrm{O}^{16} \mathrm{H}$ & 3- 211 & Not Reported & Ground & & & & 7587 & \\
\hline $\mathrm{K}^{39} \mathrm{Cl}^{35}$ & $1-$ & $1 \leftarrow 0$ & Excited & $3 / 2 \quad 3$ & $3 / 2$ & 3 & 7593.830 & \\
\hline $\mathrm{K}^{39} \mathrm{Cl}^{35}$ & $1-$ & $1 \leftarrow 0$ & Excited & $3 / 2 \quad 2$ & $3 / 2$ & 3 & 7593.830 & \\
\hline $\mathrm{K}^{39} \mathrm{Cl}^{35}$ & $1-$ & $1 \leftarrow 0$ & Excited & $3 / 2 \quad 1$ & $3 / 2$ & 0 & 7593.830 & \\
\hline $\mathrm{K}^{39} \mathrm{Cl}^{35}$ & $1-$ & $1 \leftarrow 0$ & Excited & $3 / 2 \quad 2$ & $3 / 2$ & 3 & 7593.868 & \\
\hline $\mathrm{K}^{39} \mathrm{Cl}^{35}$ & $1-$ & $1 \leftarrow 0$ & Excited & $3 / 2 \quad 1$ & $3 / 2$ & 0 & 7593.868 & \\
\hline $\mathrm{K}^{39} \mathrm{Cl}^{35}$ & $1-$ & $1 \leftarrow 0$ & Excited & $3 / 2 \quad 3$ & $3 / 2$ & 3 & 7593.868 & \\
\hline $\mathrm{K}^{399} \mathrm{Cl}^{35}$ & $1-$ & $1 \leftarrow 0$ & Excited & $1 / 2 \quad 1$ & $3 / 2$ & 0 & 7596.347 & \\
\hline
\end{tabular}


Vol.-Id. Rotational Nos. Quantum Nos.
Vib. State
Frepuency Ace $111 \%+\mathrm{HH}_{2}$

\begin{tabular}{|c|c|c|c|c|c|c|c|c|c|}
\hline $\mathrm{K}^{39} \mathrm{Cl}^{35}$ & 1 . & $1 \leftarrow 0$ & Excited & $1 / 2$ & 2 & $3 / 2$ & 3 & 7.596 .347 & \\
\hline $\mathrm{N}^{14} \mathrm{H}_{3}$ & $4-1771$ & $16,8 \leftarrow 16,8$ & Ground & & & & & 7617.90 & .15 \\
\hline $\mathrm{N}^{14} \mathrm{O}_{2}^{16} \mathrm{~F}^{19}$ & 4.1581 & $5,4,1 \leftarrow 5,4,2$ & Ground & & & & & 7623.1 & \\
\hline $\mathrm{Cl}^{35} \mathrm{O}_{2}^{16}$ & $4 \cdot 1381$ & $11,2,9 \longleftarrow 10,3,8$ & Ground & & & & & 7627.3 & \\
\hline $\mathrm{DC}^{12} \mathrm{~N}^{14}$ & 4- 292 & $4 \leftarrow 4$ & Excited & & & & & $76.34,45$ & .1 \\
\hline $\mathrm{K}^{39} \mathrm{Cl}^{35}$ & $1-$ & $1 \leftarrow 0$ & Excited & $3 / 2$ & 3 & $3 / 2$ & 3 & 7640.783 & \\
\hline $\mathrm{K}^{39} \mathrm{Cl}^{35}$ & $1-$ & $1 \leftarrow 0$ & Excited & $3 / 2$ & 2 & $3 / 2$ & 3 & 7640.783 & \\
\hline $\mathrm{K}^{39} \mathrm{Cl}^{35}$ & 1. & $1 \leftarrow 0$ & Excited & $3 / 2$ & 1 & $3 / 2$ & 0 & 7640.783 & \\
\hline $\mathrm{K}^{39} \mathrm{Cl}^{35}$ & $1-$ & $1 \leftarrow 0$ & Excited & $3 / 2$ & 3 & $3 / 2$ & 3 & 7640.795 & \\
\hline $\mathrm{K}^{39} \mathrm{Cl}^{35}$ & 1- & $1 \leftarrow 0$ & Excited & $3 / 2$ & 1 & $3 / 2$ & 0 & 7640.795 & \\
\hline $\mathrm{K}^{39} \mathrm{Cl}^{35}$ & $1-$ & $1 \leftarrow 0$ & Excited & $3 / 2$ & 2 & $3 / 2$ & 3 & 7640.795 & \\
\hline $\mathrm{K}^{39} \mathrm{Cl}^{35}$ & $1-$ & $1 \leftarrow 0$ & Excited & $5 / 2$ & 2 & $3 / 2$ & 3 & 7642.200 & \\
\hline $\mathrm{K}^{39} \mathrm{Cl}^{35}$ & $1-$ & $1 \leftarrow 0$ & Excited & $5 / 2$ & 3 & $3 / 2$ & 3 & 7642.200 & \\
\hline $\mathrm{K}^{39} \mathrm{Cl}^{35}$ & $1-$ & $1 \leftarrow 0$ & Excited & $5 / 2$ & 4 & $3 / 2$ & 3 & 7642.200 & \\
\hline $\mathrm{K}^{39} \mathrm{Cl}^{35}$ & $1-$ & $1 \leftarrow 0$ & Excited & $5 / 2$ & 1 & $3 / 2$ & 0 & 7642.200 & \\
\hline $\mathrm{K}^{39} \mathrm{Cl}^{35}$ & $1-$ & $1 \leftarrow 0$ & Excited & $1 / 2$ & 1 & $3 / 2$ & 0 & 7643.316 & \\
\hline $\mathrm{K}^{39} \mathrm{Cl}^{35}$ & $1-$ & $1 \leftarrow 0$ & Excited & $1 / 2$ & 2 & $3 / 2$ & 3 & 7643.316 & \\
\hline $\mathrm{DC}^{13} \mathrm{~N}^{14}$ & 4- 294 & $6 \leftarrow 6$ & Excited & & & & & 7652.70 & .05 \\
\hline $\mathrm{Cl}^{35} \mathrm{O}_{2}^{16}$ & 4-1381 & $11,2,9 \leftarrow 10,3,8$ & Ground & & $23 / 2$ & & $21 / 2$ & 7660.0 & \\
\hline $\mathrm{Cl}^{35} \mathrm{O}_{2}^{16}$ & $4-1381$ & $11,2,9 \leftarrow 10,3,8$ & Ground & & $21 / 2$ & & $19 / 2$ & 7672.3 & \\
\hline $\mathrm{C}^{12} \mathrm{H}_{3} \mathrm{O}^{16} \mathrm{H}$ & 3- 211 & Not Reported & Ground & & & & & 7680 & \\
\hline $\mathrm{K}^{39} \mathrm{Cl}^{35}$ & $1-$ & $1 \leftarrow 0$ & Ground & $3 / 2$ & 2 & $3 / 2$ & 3 & 7687.942 & \\
\hline $\mathrm{K}^{39} \mathrm{Cl}^{35}$ & $1-$ & $1 \leftarrow 0$ & Ground & $3 / 2$ & 1 & $3 / 2$ & 0 & 7687.942 & \\
\hline $\mathrm{K}^{39} \mathrm{Cl}^{35}$ & 1- & $1 \leftarrow 0$ & Ground & $3 / 2$ & 3 & $3 / 2$ & 3 & 7687.942 & \\
\hline $\mathrm{K}^{39} \mathrm{Cl}^{35}$ & 1. & $1 \leftarrow 0$ & Ground & $3 / 2$ & 0 & $3 / 2$ & 0 & 7687.942 & \\
\hline $\mathrm{K}^{39} \mathrm{Cl}^{35}$ & 1. & $1 \leftarrow 0$ & Cround & $5 / 2$ & 4 & $3 / 2$ & 3 & 7689.356 & \\
\hline $\mathrm{K}^{39} \mathrm{Cl}^{35}$ & $1-$ & $1 \leftarrow 0$ & Ground & $5 / 2$ & 1 & $3 / 2$ & 0 & 7689.356 & \\
\hline $\mathrm{K}^{39} \mathrm{Cl}^{35}$ & 1. & $1 \leftarrow 0$ & Ground & $5 / 2$ & 3 & $3 / 2$ & 3 & 7689.356 & \\
\hline $\mathrm{K}^{39} \mathrm{Cl}^{35}$ & 1. & $1 \leftarrow 0$ & Ground & $5 / 2$ & 2 & $3 / 2$ & 3 & 7689.356 & \\
\hline $\mathrm{K}^{39} \mathrm{Cl}^{35}$ & $1-$ & $1 \leftarrow 0$ & Ground & $1 / 2$ & 1 & $3 / 2$ & 0 & 7690.487 & \\
\hline $\mathrm{K}^{39} \mathrm{Cl}^{35}$ & 1. & $1 \leftarrow 0$ & Ground & $1 / 2$ & 2 & $3 / 2$ & 3 & 7690.487 & \\
\hline $\mathrm{Br}^{81} \mathrm{~F}_{3}^{19}$ & 4. 82 & $1,1,0 \leftarrow 1,0,1$ & Ground & & $3 / 2$ & & $5 / 2$ & 7691.42 & \\
\hline $\mathrm{Br}^{79} \mathrm{~F}_{3}^{19}$ & 4. 81 & $1,1,0 \leftarrow 1,0,1$ & Ground & & $3 / 2$ & & $5 / 2$ & 7691.42 & \\
\hline $\mathrm{C}^{12} \mathrm{H}_{3} \mathrm{~N}^{14} \mathrm{H}_{2}$ & 3- 261 & Not Reported & - Ground & & & & & 7718.11 & .1 \\
\hline $\mathrm{C}^{12} \mathrm{H}_{3} \mathrm{~N}^{14} \mathrm{H}_{2}$ & 3- 261 & Not Reported & Ground & & & & & 7727.74 & .04 \\
\hline $\mathrm{C}^{12} \mathrm{H}_{3} \mathrm{~N}^{14} \mathrm{H}_{2}$ & 3- 261 & Not Reported & Cround & & & & & 7757.18 & .1 \\
\hline $\mathrm{HO}^{16}$ & 1. & $3 / 2,2 \leftarrow 3 / 2,2$ & Ground & & 1 & & 1 & 7760.36 & .15 \\
\hline $\mathrm{Br}^{\times 1} \mathbf{F}_{3}^{19}$ & 4- 82 & $1,1,0 \leftarrow 1,0,1$ & Ground & & $3 / 2$ & & $1 / 2$ & 7792.44 & \\
\hline $\mathrm{Br}^{81} \mathrm{~F}_{3}^{19}$ & 4. 82 & $1,1,0 \leftarrow 1,0,1$ & Ground & & $5 / 2$ & & $3 / 2$ & 7795.73 & \\
\hline $\mathrm{N}^{14} \mathrm{D}_{2} \mathrm{H}$ & $4-1774$ & $6,2,5 \leftarrow 6,1,5$ & Ground & & & & & 7801.38 & .05 \\
\hline $\mathrm{Br}^{79} \mathrm{~F}_{3}^{19}$ & 4. 81 & $1,1,0 \leftarrow 1,0,1$ & Ground & & $3 / 2$ & & $1 / 2$ & 7812.84 & \\
\hline $\mathrm{C}^{12} \mathrm{H}_{3} \mathrm{O}^{16} \mathrm{H}$ & 3. 211 & $12, \quad \leftarrow 11$, & Ground & & & & & 7816. & \\
\hline $\mathrm{DC}^{12} \mathrm{~N}^{14}$ & 4- 292 & $6 \leftarrow 6$ & Excited & & & & & 7816.20 & .02 \\
\hline $\mathrm{Br}^{79} \mathrm{~F}_{3}^{19}$ & 4- 81 & $1,1,0 \leftarrow 1,0,1$ & Ground & & $5 / 2$ & & $3 / 2$ & 7816.22 & \\
\hline $\mathrm{HO}^{16}$ & $1-$ & $3 / 2,2 \leftarrow 3 / 2,2$ & Ground & & 2 & & 2 & 7819.92 & .10 \\
\hline
\end{tabular}




\begin{tabular}{|c|c|c|c|c|c|c|c|}
\hline \multirow{3}{*}{$\frac{\text { Isotopic Species }}{\mathrm{HC}^{12} \mathrm{HO}^{16}}$} & \multirow{3}{*}{$\begin{array}{l}\text { Vol.-Id. } \\
\text { Nos. } \\
\text { 4- } 381\end{array}$} & \multirow{3}{*}{$\begin{array}{c}\begin{array}{c}\text { Rotational } \\
\text { Quantum Nos. }\end{array} \\
31,5,26 \leftarrow 31,5,27\end{array}$} & \multirow{3}{*}{$\begin{array}{c}\text { Vib. State } \\
\text { Ground }\end{array}$} & \multicolumn{2}{|c|}{ Hyperfine } & \multirow{2}{*}{$\begin{array}{c}\text { Frequency } \\
\mathrm{MHz}\end{array}$} & \multirow{2}{*}{$\begin{array}{l}\text { Acc. } \\
\pm \mathrm{MHz}\end{array}$} \\
\hline & & & & $\mathrm{F}_{1}^{\prime} \quad \mathrm{F}^{\prime}$ & $F_{1} \quad F$ & & \\
\hline & & & & & & 7833.20 & \\
\hline $\mathrm{DN}^{14} \mathrm{O}_{3}^{16}$ & 3- $\quad 32$ & $5,4,1 \leftarrow 5,4,2$ & Ground & & & 7833.96 & \\
\hline $\mathrm{Cl}^{35} \mathrm{O}_{2}^{16}$ & 4-1381 & $11,3,8 \leftarrow 12.2,11$ & Ground & & & 7840.4 & \\
\hline $\mathrm{C}^{12} \mathrm{H}_{3} \mathrm{~S}^{32} \mathrm{H}$ & 3- 221 & $5,1,4 \leftarrow 5,1,5$ & Ground & & & 7846.0 & .1 \\
\hline $\mathrm{HC}^{12} \mathrm{HO}^{16}$ & 4- 381 & $14,3,11 \leftarrow-14,3,12$ & Ground & & & 7892.03 & \\
\hline $\mathrm{N}^{14} \mathrm{H}_{3}$ & $4-1771$ & $13,2 \leftarrow-13,2$ & Ground & & & 7894.37 & .05 \\
\hline $\mathrm{C}^{12} \mathrm{H}_{3} \mathrm{~N}^{14} \mathrm{H}_{2}$ & 3- 261 & Not Reported & Ground & & & 7896.89 & .1 \\
\hline $\mathrm{HDC}^{12}: \mathrm{C}^{12} \mathrm{O}^{16}$ & 4- 713 & $21,2,19 \leftarrow 21,2,20$ & Ground & & & 7901.08 & \\
\hline $\mathrm{C}^{12} \mathrm{H}_{3} \mathrm{~N}^{14} \mathrm{H}_{2}$ & 3- 261 & Not Reported & Ground & & & 7911.49 & .04 \\
\hline $\mathrm{Br}^{81} \mathrm{~F}_{3}^{19}$ & 4- 82 & $1,1,0 \leftarrow 1,0,1$ & Ground & $5 / 2$ & $5 / 2$ & 7922.30 & \\
\hline $\mathrm{H}_{2} \mathrm{C}^{12}: \mathrm{C}^{12} \mathrm{O}^{16}$ & 4- 711 & $6,1,5 \leftarrow 6,1,6$ & Ground & & & 7925.18 & \\
\hline $\mathrm{HDS}^{32}$ & 4-1727 & $6,4,2 \leftarrow 6,4,3$ & Ground & & & 7936.74 & .05 \\
\hline $\mathrm{C}^{12} \mathrm{H}_{2}: \mathrm{C}^{12} \mathrm{HBr}^{81}$ & 4- 728 & $1,0,1 \leftarrow 0,0,0$ & Ground & $5 / 2$ & $3 / 2$ & 7960.00 & \\
\hline $\mathrm{Br}^{79} \mathrm{~F}_{3}^{19}$ & 4- 81 & $1,1,0 \leftarrow 1,0,1$ & Ground & $5 / 2$ & $5 / 2$ & 7967.96 & \\
\hline $\mathrm{H}_{2} \mathrm{~N}^{14} \mathrm{~N}^{14} \mathrm{H}_{2}$ & $3-51$ & Not Reported & & & & 7977.76 & \\
\hline $\mathrm{B} \mathbf{r}^{81} \mathrm{~F}_{3}^{19}$ & 4. 82 & $1,1,0 \leftarrow 1,0,1$ & Ground & $1 / 2$ & $3 / 2$ & 7981.36 & \\
\hline $\mathrm{C}^{12} \mathrm{H}_{2}: \mathrm{C}^{12} \mathrm{HBr}^{79}$ & 4- 727 & $1,0,1 \leftarrow 0,0,0$ & Ground & $5 / 2$ & $3 / 2$ & 8001.82 & \\
\hline $\mathrm{HC}^{13} \mathrm{HO}^{16}$ & 4. 382 & $7,2,5 \leftarrow 7,2,6$ & Ground & & & 8012.56 & .5 \\
\hline $\mathrm{Br}^{81} \mathrm{C}^{12} \mathrm{~N}^{14}$ & 4- 142 & $1 \leftarrow 0$ & Excited & $1 / 2$ & $3 / 2$ & 8028.04 & .1 \\
\hline $\mathrm{Br}^{79} \mathbf{F}_{3}^{19}$ & 4- 81 & $1,1,0 \leftarrow 1,0,1$ & Ground & $1 / 2$ & $3 / 2$ & 8039.00 & \\
\hline $\mathrm{Br}^{79} \mathrm{C}^{12} \mathrm{~N}^{14}$ & 4- 141 & $1 \leftarrow 0$ & Excited & $1 / 2$ & $3 / 2$ & 8047.08 & .1 \\
\hline $\mathrm{Br}^{81} \mathrm{C}^{12} \mathrm{~N}^{14}$ & 4- 142 & $1 \leftarrow 0$ & Ground & $1 / 2$ & $3 / 2$ & 8051.48 & .1 \\
\hline $\mathrm{C}^{12} \mathrm{H}_{2}: \mathrm{C}^{12} \mathrm{HBr}^{81}$ & 4- 728 & $1,0,1 \leftarrow 0,0,0$ & Ground & $3 / 2$ & $3 / 2$ & 8058.90 & \\
\hline$\left(\mathrm{C}^{12} \mathrm{H}_{3}\right)_{2} \mathrm{O}^{16}$ & 3- 591 & Not Reported & Ground & & & 8060. & 1. \\
\hline $\mathrm{Br}^{79} \mathrm{C}^{12} \mathrm{~N}^{14}$ & 4- 141 & $1 \leftarrow 0$ & Ground & $1 / 2$ & $3 / 2$ & 8070.45 & .1 \\
\hline$\left(\mathrm{C}^{12} \mathrm{H}_{3}\right)_{2} \mathrm{O}^{16}$ & 3- 591 & Not Reported & Ground & & & 8074. & 1. \\
\hline $\mathrm{C}^{12} \mathrm{~F}_{3}^{19} \mathrm{C}^{12} \mathrm{O}^{16} \mathrm{O}^{16} \mathrm{H} \cdot \mathrm{HC}^{12} \mathrm{O}^{16} \mathrm{O}^{16} \mathrm{H}$ & $3 \cdot 661$ & $7, \quad \leftarrow 6$, & Ground & & & 8079.1 & \\
\hline $\mathrm{F}^{19} \mathrm{HC}^{12} \mathrm{O}^{18}$ & 4. 274 & $4,0,4 \leftarrow 3,1,3$ & Ground & & & 8085.9 & .2 \\
\hline$\left(\mathrm{C}^{13} \mathrm{H}_{3}\right)\left(\mathrm{C}^{12} \mathrm{H}_{3}\right) \mathrm{O}^{16}$ & 3- 594 & $2,0,2 \leftarrow 1,1,1$ & Ground & & & 8086.2 & .2 \\
\hline $\mathrm{Br}^{81} \mathrm{C}^{12} \mathrm{~N}^{14}$ & 4- 142 & $1 \leftarrow 0$ & Excited & 1 & $3 / 2$ & 8090.25 & .1 \\
\hline $\mathrm{T}]^{205} \mathrm{I}^{127}$ & $1-$ & $5 \leftarrow 4$ & Excited & $15 / 2$ & $13 / 2$ & 8097.22 & 0.05 \\
\hline $\mathrm{HN}^{14} \mathrm{O}_{3}^{16}$ & $3-\quad 31$ & $7,6,1 \leftarrow 7,6,2$ & Ground & & & 8097.58 & \\
\hline $\mathrm{Br}^{79} \mathrm{C}^{12} \mathrm{~N}^{14}$ & 4. 141 & $1 \leftarrow 0$ & Excited & $1 / 2$ & $3 / 2$ & 8109.78 & .1 \\
\hline $\mathrm{DO}^{16}$ & $1-$ & $5 / 2,3 \leftarrow 5 / 2,3$ & Ground & $3 / 2$ & $3 / 2$ & 8110.20 & .10 \\
\hline$\left(\mathrm{C}^{12} \mathrm{H}_{3}\right)_{2} \mathrm{O}^{16}$ & 3- 591 & Not Reported & Ground & & & 8114. & 1. \\
\hline $\mathrm{Tl}^{205} \mathrm{I}^{127}$ & $1-$ & $5 \leftarrow 4$ & Excited & $15 / 2$ & $13 / 2$ & 8117.06 & 0.03 \\
\hline $\mathrm{DO}^{16}$ & $1-$ & $5 / 2,3 \leftarrow 5 / 2,3$ & Ground & $5 / 2$ & $5 / 2$ & 8117.69 & .10 \\
\hline $\mathrm{C}^{12} \mathrm{H}_{2}: \mathrm{C}^{12} \mathrm{HBr}^{79}$ & 4- 727 & $1,0,1 \leftarrow 0,0,0$ & Ground & $3 / 2$ & $3 / 2$ & 8119.60 & \\
\hline $\mathrm{DO}^{16}$ & $1-$ & $5 / 2,3 \leftarrow 5 / 2,3$ & Ground & $7 / 2$ & $7 / 2$ & 8127.64 & .15 \\
\hline$T l^{205} I^{127}$ & $1 \cdot$ & $5 \leftarrow 4$ & Ground & $9 / 2$ & $7 / 2$ & 8131.45 & 0.04 \\
\hline $\mathrm{C}^{12} \mathrm{H}_{3} \mathrm{~N}^{14} \mathrm{H}_{2}$ & 3- 261 & Not Reported & Ground & & & 8131.59 & .1 \\
\hline $\mathrm{Tl}^{205} \mathrm{I}^{127}$ & 1 - & $5 \leftarrow 4$ & Ground & $11 / 2$ & $9 / 2$ & 8133.10 & 0.03 \\
\hline $\mathrm{H}_{2} \mathrm{~N}^{14} \mathrm{~N}^{14} \mathrm{H}_{2}$ & 3. 51 & Not Reported & & & & 8134.63 & \\
\hline $\mathrm{HO}^{16}$ & $1-$ & $5 / 2,3 \leftarrow 5 / 2.3$ & Ground & 2 & 2 & 8135.51 & .15 \\
\hline $\mathrm{Tl}^{205} \mathrm{I}^{127}$ & 1 . & $5 \leftarrow 4$ & Ground & $15 / 2$ & $13 / 2$ & 8136.96 & 0.02 \\
\hline
\end{tabular}




\begin{tabular}{|c|c|c|c|c|c|c|c|c|c|}
\hline Isotopic Species & $\begin{array}{l}\text { Vol.-Id. } \\
\text { Nos. }\end{array}$ & $\begin{array}{c}\text { Rotational } \\
\text { Quantum Nos. }\end{array}$ & Vib. State & $\mathrm{F}_{1}^{\prime}$ & $\begin{array}{l}\text { Hyper } \\
F^{\prime}\end{array}$ & $\begin{array}{l}\text { fine } \\
\mathrm{F}_{1}\end{array}$ & $\mathrm{~F}$ & $\begin{array}{c}\text { Frequency } \\
\mathrm{MHz}^{-}\end{array}$ & $\begin{array}{l}\text { Acc. } \\
\pm \text { MHz }\end{array}$ \\
\hline$T \mathbf{l}^{205} \mathrm{I}^{127}$ & $1-$ & $5 \leftarrow 4$ & Ground & & $13 / 2$ & & $11 / 2$ & 8138.66 & 0.03 \\
\hline $\mathrm{C}^{12} \mathrm{H}_{3} \mathrm{C}^{12} \mathrm{O}^{16} \mathrm{C}^{12} \mathrm{~N}^{14}$ & 3- 671 & $2,0,2 \leftarrow 1,1,1$ & Ground & & & & & 8142.5 & .2 \\
\hline $\mathrm{Br}^{81} \mathrm{C}^{12} \mathrm{~N}^{14}$ & 4- 142 & $1 \leftarrow 0$ & Excited & $5 / 2$ & & $3 / 2$ & & 8142.89 & .1 \\
\hline $\mathrm{C}^{12} \mathrm{H}_{3} \mathrm{O}^{16} \mathrm{~N}^{14} \mathrm{O}_{2}^{16}$ & $3 \cdot 181$ & $1,0,1 \leftarrow 0,0,0$ & Ground & & & & & 8145.90 & .2 \\
\hline $\mathrm{H}_{2} \mathrm{~N}^{14} \mathrm{~N}^{14} \mathrm{H}_{2}$ & 3- 51 & Not Reported & & & & & & 8147.09 & \\
\hline $\mathrm{N}^{14} \mathrm{H}_{3}$ & 4-1771 & $15,7 \leftarrow 15,7$ & Ground & & & & & 8152.68 & .10 \\
\hline $\mathrm{Br}^{81} \mathrm{C}^{12} \mathrm{~N}^{14}$ & 4. 142 & $1 \leftarrow 0$ & Ground & $5 / 2$ & $5 / 2$ & $3 / 2$ & $5 / 2$ & 8164.96 & .1 \\
\hline$\left(\mathrm{C}^{12} \mathrm{H}_{3}\right)_{2} \mathrm{O}^{16}$ & 3. 591 & Not Reported & Ground & & & & & 8165. & 5. \\
\hline $\mathrm{Br}^{81} \mathrm{C}^{12} \mathrm{~N}^{14}$ & 4. 142 & $1 \leftarrow 0$ & Ground & $5 / 2$ & $7 / 2$ & $3 / 2$ & $5 / 2$ & 8165.68 & .1 \\
\hline $\mathrm{Br}^{79} \mathrm{C}^{12} \mathrm{~N}^{14}$ & 4- 141 & $1 \leftarrow 0$ & Excited & $5 / 2$ & & $3 / 2$ & & 8183.87 & .1 \\
\hline $\mathrm{HO}^{16}$ & $1-$ & $5 / 2,3 \leftarrow 5 / 2,3$ & Ground & & 3 & & 3 & 8188.94 & .10 \\
\hline $\mathrm{C}^{12}{ }_{*} \mathrm{HDC}^{12} \mathrm{H}_{2} \mathrm{C}^{12}{ }_{*} \mathrm{Cl}_{2}^{35}$ & 4-1065 & $2,0,2 \leftarrow 1,1,1$ & Ground & & & & & 8191.0 & \\
\hline $\mathrm{C}^{12} \mathrm{H}_{3} \mathrm{O}^{16} \mathrm{H}$ & $3 \cdot 211$ & $33,2, \leftarrow 33,1$, & Ground & & & & & 8198. & \\
\hline $\mathrm{C}^{12} \mathrm{H}_{3} \mathrm{~N}^{14} \mathrm{H}_{2}$ & 3- 261 & Not Reported & Ground & & & & & 8201.65 & .04 \\
\hline $\mathrm{Br}^{79} \mathrm{C}^{12} \mathrm{~N}^{14}$ & 4- 141 & $1 \leftarrow 0$ & Ground & $5 / 2$ & $5 / 2$ & $3 / 2$ & $5 / 2$ & 8206.18 & .1 \\
\hline $\mathrm{Br}^{79} \mathrm{C}^{12} \mathrm{~N}^{14}$ & 4- 141 & $1 \leftarrow 0$ & Ground & $5 / 2$ & $7 / 2$ & $3 / 2$ & $5 / 2$ & 8206.92 & .1 \\
\hline $\mathrm{Br}^{79} \mathrm{C}^{12} \mathrm{~N}^{14}$ & 4- 141 & $1 \leftarrow 0$ & Ground & $5 / 2$ & $3 / 2$ & $3 / 2$ & $5 / 2$ & 8207.39 & .1 \\
\hline $\mathrm{Cl}^{35} \mathrm{O}_{2}^{16}$ & 4-1381 & $11,3,8 \leftarrow 12,2,11$ & Ground & & $21 / 2$ & & $19 / 2$ & 8214.3 & \\
\hline $\mathrm{HDSe}^{82}$ & $4-1758$ & $11,6,6 \leftarrow 11,6,5$ & Ground & & & & & 8215.8 & \\
\hline $\mathrm{C}^{12} \mathrm{H}_{3} \mathrm{~N}^{14} \mathrm{H}_{2}$ & $3 \cdot 261$ & Not Reported & Ground & & & & & 8233.22 & .1 \\
\hline $\mathrm{Cl}^{35} \mathrm{O}_{2}^{16}$ & $4-1381$ & $11,3,8 \leftarrow 12,2,11$ & Ground & & $23 / 2$ & & $21 / 2$ & 8235.3 & \\
\hline $\mathrm{HDSe}^{80}$ & $4-1757$ & $11,6,6 \leftarrow 11,6,5$ & Ground & & & & & 8240.6 & \\
\hline $\mathrm{C}^{12} \mathrm{H}_{3} \mathrm{C}^{12} \mathrm{HO}^{16}$ & 3- 471 & $2,0,2 \leftarrow 1,1,1$ & Ground & & & & & 8243.0 & .5 \\
\hline $\mathrm{Br}^{79} \mathrm{C}^{12} \mathrm{~N}^{14}$ & 4- 141 & $1 \leftarrow 0$ & Excited & $5 / 2$ & & $3 / 2$ & & 8245.29 & .1 \\
\hline $\mathrm{C}^{12} * \mathrm{H}_{2} \mathrm{C}^{12} \mathrm{H}_{2} \mathrm{C}^{12} * \mathrm{Cl}_{2}^{35}$ & 4-1061 & $2,0,2 \leftarrow 1,1,1$ & Ground & & & & & 8250.4 & \\
\hline $\mathrm{Cl}^{35} \mathrm{O}_{2}^{16}$ & $4-1381$ & $11,3,8 \leftarrow 12,2,11$ & Ground & & $25 / 2$ & & $23 / 2$ & 8253.7 & \\
\hline $\mathrm{C}^{12} * \mathrm{H}_{2} \mathrm{C}^{12} \mathrm{H}_{2} \mathrm{C}^{12} \mathrm{Cl}^{35} \mathrm{Cl}^{37}$ & 4-1062 & $8,4,4 \leftarrow 8,3,5$ & Ground & & & & & 8259.2 & \\
\hline $\mathrm{HDSe}^{78}$ & $4-1756$ & $11,6,6 \leftarrow 11,6,5$ & Ground & & & & & 8266.6 & \\
\hline $\mathrm{Cl}^{35} \mathrm{O}_{2}^{16}$ & 4-1381 & $11,3,8 \leftarrow 12,2,11$ & Ground & & $27 / 2$ & & $25 / 2$ & 8268.6 & \\
\hline $\mathrm{C}^{12} \mathrm{H}_{3} \mathrm{~N}^{14} \mathrm{H}_{2}$ & 3- 261 & Not Reported & Ground & & & & & 8268.99 & .1 \\
\hline $\mathrm{H}_{2} \mathrm{~N}^{14} \mathrm{~N}^{14} \mathrm{H}_{2}$ & 3- 51 & Not Reported & & & & & & 8270.73 & \\
\hline $\mathrm{H}_{2} \mathrm{~N}^{14} \mathrm{~N}^{14} \mathrm{H}_{2}$ & $3-51$ & Not Reported & & & & & & 8273.57 & \\
\hline $\mathrm{N}^{14} \mathrm{H}_{3}$ & $4-1771$ & Not Reported & Ground & & & & & 8278. & \\
\hline $\mathrm{HDSe}^{77}$ & 4-1755 & $11,6,6 \leftarrow 11,6,5$ & Ground & & & & & 8280.0 & \\
\hline $\mathrm{N}^{14} \mathrm{H}_{3}$ & 4-1771 & Not Reported & Ground & & & & & 8283. & \\
\hline $\mathrm{N}^{14} \mathrm{D}_{2} \mathrm{H}$ & $4-1774$ & $3,1,3 \leftarrow 3,0,3$ & Ground & & & & & 8283.92 & .05 \\
\hline $\mathrm{Br}^{81} \mathrm{C}^{12} \mathrm{~N}^{14}$ & 4- 142 & $1 \leftarrow 0$ & Excited & $3 / 2$ & & $3 / 2$ & & 8286.87 & .1 \\
\hline $\mathrm{HDSe}^{76}$ & 4-1759 & $11,6,6 \leftarrow 11,6,5$ & Ground & & & & & 8293.6 & \\
\hline $\mathrm{C}^{12} * \mathrm{D}_{2} \mathrm{C}^{12} \mathrm{D}_{2} \mathrm{C}^{12} * \mathrm{Cl}_{2}^{35}$ & 4-1063 & $8,4,4 \leftarrow 8,3,5$ & Ground & & & & & 8297,0 & \\
\hline $\mathrm{O}^{16} \mathrm{~F}_{2}^{19}$ & 4-1611 & $5,2,4 \leftarrow 6,1,5$ & Ground & & & & & 8299.51 & .10 \\
\hline $\mathrm{C}^{12} \mathrm{H}_{3} \mathrm{O}^{16} \mathrm{~N}^{14} \mathrm{O}_{2}^{16}$ & 3- 181 & $9,3,7 \leftarrow 9,3,6$ & Ground & & & & & 8300.64 & .1 \\
\hline $\mathrm{Br}^{81} \mathrm{C}^{12} \mathrm{~N}^{14}$ & 4- 142 & $1 \leftarrow 0$ & Ground & $3 / 2$ & $5 / 2$ & $3 / 2$ & $3 / 2$ & 8308.27 & .1 \\
\hline $\mathrm{Br}^{81} \mathrm{C}^{12} \mathrm{~N}^{14}$ & 4- 142 & $1 \leftarrow 0$ & Ground & $3 / 2$ & $3 / 2$ & $3 / 2$ & $3 / 2$ & 8308.89 & .1 \\
\hline $\mathrm{Br}^{81} \mathrm{C}^{12} \mathrm{~N}^{14}$ & 4- 142 & $1 \leftarrow 0$ & Ground & $3 / 2$ & $1 / 2$ & $3 / 2$ & $3 / 2$ & 8309.67 & .1 \\
\hline $\mathrm{Br}^{81} \mathrm{C}^{12} \mathrm{~N}^{14}$ & 4- 142 & $1 \leftarrow 0$ & Excited & $3 / 2$ & & $3 / 2$ & & 8346.07 & .1 \\
\hline
\end{tabular}




\begin{tabular}{|c|c|c|c|c|c|c|c|c|c|}
\hline Isotopic Species & $\begin{array}{l}\text { Vol.-Id. } \\
\text { Nos. }\end{array}$ & $\begin{array}{l}\text { Rotational } \\
\text { Quantum Nos. }\end{array}$ & Vib. State & $\mathrm{F}_{1}^{\prime}$ & $\begin{array}{l}\text { Iyper } \\
\mathrm{F}^{\prime}\end{array}$ & $\begin{array}{l}\text { rfine } \\
\mathrm{F}_{1}\end{array}$ & $\mathrm{~F}$ & $\begin{array}{l}\text { Frequency } \\
\text { } \mathrm{HHz}^{2}\end{array}$ & $\begin{aligned} \text { Acc. } \\
\pm \mathrm{MHz}\end{aligned}$ \\
\hline $\mathrm{Br}^{79} \mathrm{C}^{12} \mathrm{~N}^{14}$ & 4. 141 & $1 \leftarrow 0$ & Excited & $3 / 2$ & & $3 / 2$ & & 8356.48 & .1 \\
\hline $\mathrm{Br}^{79} \mathrm{C}^{12} \mathrm{~N}^{14}$ & 4- 141 & $1 \leftarrow 0$ & Ground & $3 / 2$ & $5 / 2$ & $3 / 2$ & $3 / 2$ & 8377.95 & .1 \\
\hline $\mathrm{Br}^{79} \mathrm{C}^{12} \mathrm{~N}^{14}$ & 4- 141 & $1 \leftarrow 0$ & Ground & $3 / 2$ & $3 / 2$ & $3 / 2$ & $3 / 2$ & 8378.58 & .1 \\
\hline $\mathrm{Br}^{79} \mathrm{C}^{12} \mathrm{~N}^{14}$ & 4- 141 & $1 \leftarrow 0$ & Ground & $3 / 2$ & $1 / 2$ & $3 / 2$ & $3 / 2$ & 8379.38 & .1 \\
\hline $\mathrm{C}^{12} \mathrm{H}_{3} \mathrm{O}^{16} \mathrm{H}$ & 3- 211 & $2, \quad \leftarrow 1$, & Ground & & & & & 8380. & \\
\hline $\mathrm{C}^{12} \mathrm{H}_{3} \mathrm{~N}^{1+1} \mathrm{H}_{2}$ & $3-261$ & $13,3, \leftarrow 12,4$ & Ground & & & & & 8411.94 & .1 \\
\hline $\mathrm{Br}^{79} \mathrm{C}^{12} \mathrm{~N}^{14}$ & 4. 141 & $1 \leftarrow 0$ & Excited & $3 / 2$ & & $3 / 2$ & & 8416.30 & .1 \\
\hline $\mathrm{H}_{2} \mathrm{~N}^{14} \mathrm{~N}^{1+} \mathrm{H}_{2}$ & $3-51$ & Not Reported & & & & & & 8478.7 & \\
\hline $\mathrm{C}^{12} \mathrm{H}_{2}: \mathrm{C}^{12} \mathrm{HC}^{12} \mathrm{~F}^{19}: \mathrm{C}^{12} \mathrm{H}_{2}$ & 3- 911 & $2,1,2 \leftarrow 2,0,2$ & Ground & & & & & 8481.94 & .03 \\
\hline $\mathrm{C}^{12}{ }_{*} \mathrm{H}_{2} \mathrm{C}^{13} \mathrm{H}_{2} \mathrm{C}^{12} * \mathrm{Cl}_{2}^{35}$ & $4-1068$ & $8,5.3 \leftarrow 8,4,4$ & Ground & & & & & 8485.0 & \\
\hline $\mathrm{C}^{12} * \mathrm{H}_{2} \mathrm{C}^{13} \mathrm{H}_{2} \mathrm{C}^{12} * \mathrm{Cl}_{2}^{35}$ & $4-1068$ & $8,4,4 \leftarrow 8,3,5$ & Ground & & & & & 8487.4 & \\
\hline $\mathrm{DC}^{12} \mathrm{DO}^{16}$ & 4- 384 & $5,2,3 \leftarrow 5,2,4$ & Ground & & & & & 8519.10 & \\
\hline $\mathrm{D}_{2} \mathrm{C}^{12}: \mathrm{C}^{12} \mathrm{O}^{16}$ & 4- 712 & $5,1,4 \leftarrow 5,1,5$ & Ground & & & & & 8521.53 & \\
\hline $\mathrm{Br}^{81} \mathrm{Cl}^{37}$ & $1-$ & $1 \leftarrow 0$ & Ground & $1 / 2$ & 2 & $3 / 2$ & 3 & 8525.53 & \\
\hline $\mathrm{HC}^{12} \mathrm{~N}^{14}$ & 4. 291 & $3 \leftarrow 3$ & Excited & & & & & 8557.50 & .1 \\
\hline $\mathrm{Br}^{79} \mathrm{Cl}^{37}$ & 1. & $1 \leftarrow 0$ & Ground & $1 / 2$ & 2 & $3 / 2$ & 3 & 8559.58 & \\
\hline $\mathrm{HC}^{12} \mathrm{O}^{16} \mathrm{O}^{16} \mathrm{C}^{12} \mathrm{H}_{3} \mathrm{E}$ & 3- 502 & $6,2,4 \leftarrow 6,2,5$ & Ground & & & & & 8571.07 & .35 \\
\hline $\mathrm{HC}^{12} \mathrm{O}^{16} \mathrm{O}^{16} \mathrm{C}^{12} \mathrm{H}_{3}-\mathrm{A}$ & 3- 501 & $6,2,4 \leftarrow 6,2,5$ & Ground & & & & & 8577.35 & .35 \\
\hline $\mathrm{HDO}^{16}$ & $4-1712$ & $7,4,3 \leftarrow 7,4,4$ & Ground & & & & & 8577.7 & .1 \\
\hline $\mathrm{C}^{12}{ }_{*} \mathrm{D}_{2} \mathrm{C}^{12} \mathrm{D}_{2} \mathrm{C}^{12} * \mathrm{Cl}_{2}^{35}$ & $4-1063$ & $4,2,3 \leftarrow 4,1,4$ & Ground & & & & & 8605.0 & \\
\hline $\mathrm{O}^{16} \mathrm{~F}_{2}^{19}$ & 4-1611 & $12,2,10 \leftarrow 13,1,13$ & Ground & & & & & 8610.91 & .10 \\
\hline $\mathrm{N}^{\mathrm{h}} \mathrm{O}_{2}^{\mathrm{h}} \mathrm{Cl}^{\mathrm{br}}$ & $4-1463$ & Not Reported & & & & & & 8621.50 & \\
\hline $\mathrm{N}^{\prime \prime} \mathrm{O}_{2}^{\mathrm{b}} \mathrm{Cl}^{\mathrm{b}}$ & $4-1463$ & Not Reported & & & & & & 8622.20 & \\
\hline $\mathrm{t}-\mathrm{C}^{12} * \mathrm{HDC}^{12} \mathrm{H}_{2} \mathrm{C}^{12} * \mathrm{Cl}^{35} \mathrm{Cl}^{37}$ & $4-1067$ & $8,5,3 \leftarrow 8,4,4$ & Ground & & & & & 8625.4 & \\
\hline $\mathrm{C}_{\mathrm{k}}^{12} \mathrm{H}_{13} \mathrm{Br}^{81}$ & $4-1332$ & $6, \leftarrow 5$ & Excited & & & & & 8627.5 & \\
\hline $\mathrm{N}^{14} \mathrm{O}_{2}^{16} \mathrm{Cl}^{37}$ & $4-1462$ & $1,0,1 \leftarrow 0,0,0$ & Ground & & $3 / 2$ & & $3 / 2$ & 8644.60 & \\
\hline $\mathrm{HC}^{12} \mathrm{O}^{16} \mathrm{O}^{16} \mathrm{H}$ & $3-71$ & $32,5,27 \leftarrow 32,5,28$ & & & & & & 8662. & \\
\hline $\mathrm{N}^{14} \mathrm{O}_{2}^{16} \mathrm{Cl}^{37}$ & 4-1462 & $1,0,1 \leftarrow 0,0,0$ & Ground & & $5 / 2$ & & $3 / 2$ & 8663.20 & \\
\hline $\mathrm{Br}^{81} \mathrm{Cl}^{37}$ & $1-$ & $1 \leftarrow 0$ & Ground & $5 / 2$ & 3 & $3 / 2$ & 3 & 8663.40 & \\
\hline $\mathrm{C}^{12} \mathrm{H}_{3} \mathrm{C}^{12} \mathrm{~F}^{19}: \mathrm{C}^{12} \mathrm{H}_{2}$ & $3-721$ & $20,15,5 \leftarrow 20,15,6$ & Ground & & & & & 8668.27 & .1 \\
\hline $\mathrm{C}^{12} \mathrm{H}_{3} \mathrm{C}^{12} \mathrm{~F}^{19}: \mathrm{C}^{12} \mathrm{H}_{2}$ & $3-721$ & $20,15,5 \leftarrow 20.15,6$ & Ground & & & & & 8669.25 & .1 \\
\hline $\mathrm{Br}^{81} \mathrm{Cl}^{37}$ & $1-$ & $1 \leftarrow 0$ & Ground & $5 / 2$ & 2 & $3 / 2$ & 3 & 8671.87 & \\
\hline $\mathrm{DO}^{16}$ & $1-$ & $11 / 2,5 \leftarrow 11 / 2,5$ & Ground & & $13 / 2$ & & $13 / 2$ & 8672.36 & .10 \\
\hline $\mathrm{DO}^{16}$ & $1-$ & $11 / 2,5 \leftarrow 11 / 2,5$ & Ground & & $11 / 2$ & & $11 / 2$ & 8672.36 & .10 \\
\hline $\mathrm{DOO}^{16}$ & 1. & $11 / 2,5 \leftarrow 11 / 2,5$ & Ground & & $9 / 2$ & & $9 / 2$ & 8672.36 & .10 \\
\hline $\mathrm{Br}^{\times 1} \mathrm{Cl}^{37}$ & $1-$ & $1 \leftarrow 0$ & Ground & $5 / 2$ & 4 & $3 / 2$ & 3 & 8676.37 & \\
\hline $\mathrm{N}^{14} \mathrm{O}_{2}^{16} \mathrm{Cl}^{37}$ & 4-1462 & $1,0,1 \leftarrow 0,0,0$ & Ground & & $1 / 2$ & & $3 / 2$ & 8678.10 & \\
\hline $\mathrm{Br}^{81} \mathrm{Cl}^{37}$ & $1-$ & $1 \leftarrow 0$ & Ground & $5 / 2$ & 1 & $3 / 2$ & 0 & 8683.06 & \\
\hline $\mathrm{C}^{12} \mathrm{H}_{3} \mathrm{~N}^{1+4} \mathrm{H}_{2}$ & $3-261$ & Not Reported & Ground & & & & & 8684.29 & .04 \\
\hline $\mathrm{D}_{2} \mathrm{C}^{12}: \mathrm{C}^{12} \mathrm{O}^{16}$ & 4. 712 & $18,2.16 \leftarrow 18,2.17$ & Ground & & & & & 8687.06 & \\
\hline $\mathrm{C}^{12} \mathrm{H}_{3} \mathrm{O}^{16} \mathrm{~N}^{14} \mathrm{O}_{2}^{16}$ & 3- 181 & $6,2,5 \leftarrow 6,2,4$ & Ground & & & & & 8688.00 & .1 \\
\hline $\mathrm{C}_{\mathrm{K}}^{12} \mathrm{H}_{13} \mathrm{Br}^{79}$ & 4-1331 & $6, \leftarrow 5$ & Excited & & & & & 8716.5 & \\
\hline $\mathrm{C}^{12} \mathrm{H}_{3} \mathrm{C}^{12} \mathrm{HO}^{16}$ & 3- 471 & Not Reported & Ground & & & & & 8723.11 & \\
\hline $\mathrm{Br}^{79} \mathrm{Cl}^{37}$ & $1-$ & $1 \leftarrow 0$ & Ground & $5 / 2$ & 3 & $3 / 2$ & 3 & 8725.49 & \\
\hline $\mathrm{Br}^{79} \mathrm{Cl}^{37}$ & 1- & $1 \leftarrow 0$ & Ground & $5 / 2$ & 2 & $3 / 2$ & 3 & 8733.84 & \\
\hline
\end{tabular}




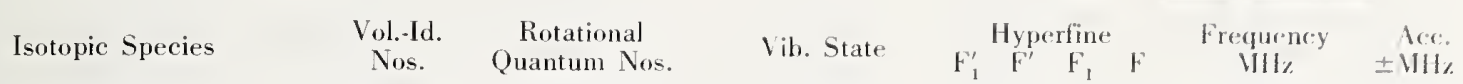

\begin{tabular}{|c|c|c|c|c|c|c|c|c|c|}
\hline $\mathrm{Br}^{79} \mathrm{Cl}^{37}$ & $1-$ & $1 \leftarrow 0$ & Ground & $5 / 2$ & 4 & $3 / 2$ & 3 & 8738.47 & \\
\hline $\mathrm{Br}^{79} \mathrm{Cl}^{37}$ & 1 . & $1 \leftarrow 0$ & Ground & $5 / 2$ & 1 & $3 / 2$ & 0 & 8745.17 & \\
\hline $\mathrm{HDSe}^{\mathrm{k} 2}$ & 4-1758 & $4,3,2 \leftarrow 4,3,1$ & Ground & & & & & 8756.7 & .1 \\
\hline $\mathrm{N}^{14} \mathrm{H}_{3}$ & $4-1771$ & $13,4 \leftarrow 13,4$ & Ground & & & & & 8762.87 & .0 .5 \\
\hline $\mathrm{N}^{14} \mathrm{H}_{3}$ & $4-1771$ & $14,6 \leftarrow 14,6$ & Ground & & & & & 8766.96 & .0 .5 \\
\hline $\mathrm{C}^{12}{ }_{*} \mathrm{HDC}^{12} \mathrm{H}_{2} \mathrm{C}^{12}{ }_{*} \mathrm{Cl}_{2}^{3.5}$ & 4-1065 & $4,1,3 \leftarrow 4,0,4$ & Ground & & & & & 8767.0 & \\
\hline $\mathrm{O}^{16} \mathrm{~F}_{2}^{19}$ & 4-1611 & $34,8,27 \leftarrow 35,7,28$ & Ground & & & & & 8769.86 & .10 \\
\hline HDSe $^{80}$ & $4-1757$ & $4,3,2 \leftarrow 4,3,1$ & Ground & & & & & 8771.05 & .1 \\
\hline $\mathrm{N}^{1+} \mathrm{H}_{3}$ & $4-1771$ & Not Reported & Ground & & & & & 8778. & \\
\hline $\mathrm{O}^{16} \mathrm{~F}_{2}^{19}$ & $4-1611$ & $31,6,25 \leftarrow 30,7,24$ & Ground & & & & & 8779.55 & .10 \\
\hline $\mathrm{O}^{16} \mathrm{~F}_{2}^{19}$ & 4-1611 & $20.5 .15 \leftarrow 21,4,18$ & Ground & & & & & 8782.91 & .10 \\
\hline HDSe $^{78}$ & 4-1756 & $4,3,2 \leftarrow 4,3,1$ & Ground & & & & & 8786.05 & .1 \\
\hline $\mathrm{C}_{6}^{12} \mathrm{H}_{5} \mathrm{~N}^{14} \mathrm{O}_{2}^{16}$ & $3-1041$ & $4,0,4 \leftarrow 3,0,3$ & Ground & & & & & 8793. & 1.5 \\
\hline $\mathrm{HDSe}^{77}$ & $4-1755$ & $4,3,2 \leftarrow 4,3,1$ & Ground & & & & & 8793.95 & .1 \\
\hline $\mathrm{HDSe}^{76}$ & $4-1759$ & $4,3,2 \leftarrow 4,3,1$ & Ground & & & & & 8801.85 & .1 \\
\hline $\mathrm{C}^{12} \mathrm{H}_{3} \mathrm{~N}^{14} \mathrm{H}_{2}$ & 3- 261 & Not Reported & Ground & & & & & 8813.22 & .1 \\
\hline $\mathrm{Br}^{81} F_{3}^{19}$ & 4. 82 & $2,1,1 \leftarrow 2,0,2$ & Ground & & $5 / 2$ & & $5 / 2$ & 8819.04 & \\
\hline $\mathrm{N}^{14} \mathrm{H}_{3}$ & $4-1771$ & $16,9 \leftarrow 16,9$ & Ground & & & & & 8823.90 & .10 \\
\hline $\mathrm{H}_{2} \mathrm{~N}^{1+} \mathrm{N}^{14} \mathrm{H}_{2}$ & 3- 51 & Not Reported & & & & & & 8824.0 & \\
\hline $\mathrm{s}-\left(\mathrm{C}^{12} \mathrm{H}_{2} \mathrm{D}\right)\left(\mathrm{C}^{12} \mathrm{H}_{3}\right) \mathrm{O}^{16}$ & 3- 596 & $5,1,5 \leftarrow 4,2,2$ & Ground & & & & & 8828.6 & .5 \\
\hline $\mathrm{C}^{12}{ }_{*} \mathrm{D}_{2} \mathrm{C}^{12} \mathrm{D}_{2} \mathrm{C}^{12}{ }_{*} \mathrm{Cl}^{35} \mathrm{Cl}^{37}$ & 4-1064 & $2,1,2 \leftarrow 1,0,1$ & Ground & & & & & 8831.3 & \\
\hline $\mathrm{C}^{12}{ }_{*} \mathrm{H}_{2} \mathrm{C}^{12} \mathrm{H}_{2} \mathrm{C}^{2} * \mathrm{Cl}_{2}^{35}$ & 4- 1061 & $9,5,4 \leftarrow 9,4,5$ & Ground & & & & & 8836.8 & \\
\hline $\mathrm{HDO}^{16}$ & $4-1712$ & $10,5,5 \leftarrow 10,5,6$ & Ground & & & & & 8836.95 & .1 \\
\hline $\mathrm{Br}^{81} \mathrm{Cl}^{37}$ & $1-$ & $1 \leftarrow 0$ & Ground & $3 / 2$ & 3 & $3 / 2$ & 3 & 8852.93 & \\
\hline $\mathrm{C}^{12} \mathrm{H}_{3} \mathrm{C}^{12} \mathrm{~F}^{19}: \mathrm{C}^{12} \mathrm{H}_{2}$ & $3-721$ & $4,3,1 \leftarrow 4,3,2$ & Ground & & & & & 8855.45 & .1 \\
\hline $\mathrm{C}^{12}{ }_{*} \mathrm{H}_{2} \mathrm{C}^{12} \mathrm{H}_{2} \mathrm{C}^{12} * \mathrm{Cl}^{35} \mathrm{Cl}^{37}$ & 4-1062 & $5,4,1 \leftarrow 5,3,2$ & Ground & & & & & 8857.4 & \\
\hline $\mathrm{Br}^{81} \mathrm{Cl}^{35}$ & $1-$ & $1 \leftarrow 0$ & Ground & $1 / 2$ & 2 & $3 / 2$ & 3 & 8865.66 & \\
\hline $\mathrm{N}^{14} \mathrm{O}_{2}^{16} \mathrm{Cl}^{35}$ & 4-1461 & $1,0,1 \leftarrow 0,0,0$ & Ground & & $3 / 2$ & & $3 / 2$ & 8876.28 & \\
\hline $\mathrm{C}^{12} \mathrm{H}_{3} \mathrm{~N}^{14} \mathrm{H}_{2}$ & 3- 261 & Not Reported & Ground & & & & & 8884.29 & .1 \\
\hline $\mathrm{HC}^{12} \mathrm{HO}^{16}$ & 4- 381 & $7,2,5 \leftarrow 7,2,6$ & Ground & & & & & 8884.87 & \\
\hline s- $\left(\mathrm{C}^{12} \mathrm{H}_{2} \mathrm{D}\right)\left(\mathrm{C}^{12} \mathrm{H}_{3}\right) \mathrm{O}^{16}$ & 3- 596 & Not Reported & Ground & & & & & 8890. & 5. \\
\hline $\mathrm{C}^{12} \mathrm{H}_{3} \mathrm{C}^{12} \mathrm{~F}^{19}: \mathrm{C}^{12} \mathrm{H}_{2}$ & 3- 721 & $3,3,0 \leftarrow 3,2,1$ & Ground & & & & & 8892.53 & .1 \\
\hline $\mathrm{HC}^{12} \mathrm{~N}^{15}$ & 4- 295 & $6 \leftarrow 6$ & Excited & & & & & 8897.20 & .1 \\
\hline$\left(\mathrm{C}^{12} \mathrm{H}_{3}\right)_{2} \mathrm{O}^{16}$ & 3- 591 & Not Reported & Ground & & & & & 8898. & 5. \\
\hline $\mathrm{Br}^{79} \mathrm{Cl}^{35}$ & $1-$ & $1 \leftarrow 0$ & Ground & $1 / 2$ & 2 & $3 / 2$ & 3 & 8899.50 & \\
\hline $\mathrm{N}^{14} \mathrm{O}_{2}^{16} \mathrm{Cl}^{35}$ & $4-1461$ & $1,0,1 \leftarrow 0,0,0$ & Ground & & $5 / 2$ & & $3 / 2$ & 8899.90 & \\
\hline $\mathrm{N}^{14} \mathrm{H}_{3}$ & $4-1771$ & Not Reported & Ground & & & & & 8903. & \\
\hline $\mathrm{C}^{12} \mathrm{H}_{3} \mathrm{C}^{12} * \mathrm{HO}^{16} \mathrm{C}^{12}{ }_{*} \mathrm{H}_{2}$ & 3- 761 & $9,4,5 \leftarrow 8,5,4$ & Ground & & & & & 8906.22 & .1 \\
\hline $\mathrm{C}^{12} \mathrm{H}_{3} \mathrm{C}^{12} * \mathrm{HO}^{16} \mathrm{C}^{12} * \mathrm{H}_{2}$ & 3- 761 & $9,4,5 \leftarrow 8,5,4$ & Ground & & & & & 8907.53 & .1 \\
\hline $\mathrm{C}^{12}{ }_{*} \mathrm{H}_{2} \mathrm{C}^{12} \mathrm{H}_{2} \mathrm{C}^{12} * \mathrm{Cl}_{2}^{35}$ & $4-1061$ & $4,3,2 \leftarrow 4,2,3$ & Ground & & & & & 8909.3 & \\
\hline$\left(\mathrm{C}^{12} \mathrm{H}_{3}\right)_{2} \mathrm{O}^{16}$ & 3- 591 & Not Reported & Ground & & & & & 8911. & 5. \\
\hline $\mathrm{Br}^{79} \mathrm{~F}_{3}^{19}$ & 4- 81 & $2,1,1 \leftarrow 2,0,2$ & Ground & & $5 / 2$ & & $5 / 2$ & 8911.82 & \\
\hline $\mathrm{N}^{14} \mathrm{O}_{2}^{16} \mathrm{Cl}^{35}$ & $4-1461$ & $1,0,1 \leftarrow 0,0,0$ & Ground & & $1 / 2$ & & $3 / 2$ & 8918.70 & \\
\hline $\mathrm{N}^{1+4} \mathrm{H}_{3}$ & $4-1771$ & Not Reported & Ground & & & & & 8922. & \\
\hline $\mathrm{HC}^{12} \mathrm{DO}^{16}$ & 4- 385 & $6,2,4 \leftarrow 6,2,5$ & Ground & & & & & 8922.59 & \\
\hline
\end{tabular}




\begin{tabular}{|c|c|c|c|c|c|c|c|c|c|}
\hline Isotopic Species & $\begin{array}{l}\text { Vol.-Id. } \\
\text { Nos. }\end{array}$ & $\begin{array}{c}\text { Rotational } \\
\text { Quantum Nos. }\end{array}$ & Vib. State & $\mathrm{F}_{1}^{\prime}{ }^{\mathrm{H}}$ & & $\begin{array}{l}\text { rfine } \\
F_{1}\end{array}$ & $\mathbf{F}$ & $\begin{array}{c}\text { Frequency } \\
\mathrm{MHz}\end{array}$ & $\begin{aligned} & \text { Acc. } \\
\pm & \mathrm{MHz}\end{aligned}$ \\
\hline$\left(\mathrm{C}^{12} \mathrm{D}_{3}\right)_{2} \mathrm{C}^{12} \mathrm{H}_{3} \mathrm{Si} \mathrm{i}^{\mathrm{b}} \mathrm{H}$ & 3- 879 & $1,1,0 \leftarrow 0,0,0$ & Ground & & & & & 8941.09 & .1 \\
\hline $\mathrm{s}-\left(\mathrm{C}^{12} \mathrm{H}_{2} \mathrm{D}\right)\left(\mathrm{C}^{12} \mathrm{H}_{3}\right) \mathrm{O}^{16}$ & 3. 596 & Not Reported & Ground & & & & & 8950. & 5. \\
\hline $\mathrm{C}^{12} \mathrm{H}_{3} \mathrm{~N}^{14} \mathrm{H}_{2}$ & 3- 261 & Not Reported & Ground & & & & & 8950.90 & .1 \\
\hline $\mathrm{Br}^{79} \mathrm{Cl}^{37}$ & 1 . & $1 \leftarrow 0$ & Ground & $3 / 2$ & 3 & $3 / 2$ & 3 & 8951.38 & \\
\hline$\left(\mathrm{C}^{12} \mathrm{H}_{3}\right)_{2} \mathrm{O}^{16}$ & 3- 591 & Not Reported & Ground & & & & & 8955. & 5. \\
\hline $\mathrm{C}^{12}{ }_{*} \mathrm{H}_{2} \mathrm{C}^{12} \mathrm{H}_{2} \mathrm{C}^{12} * \mathrm{Cl}_{2}^{35}$ & $4-1061$ & $4,1,3 \leftarrow 4,0,4$ & Ground & & & & & 8955.2 & \\
\hline $\mathrm{C}^{12}{ }_{*} \mathrm{D}_{2} \mathrm{C}^{12} \mathrm{D}_{2} \mathrm{C}^{12}{ }_{*} \mathrm{Cl}_{2}^{15}$ & $4-1063$ & $5,5,0 \leftarrow 5,4,1$ & Ground & & & & & 8958.4 & \\
\hline $\mathrm{s}-\left(\mathrm{C}^{12} \mathrm{H}_{2} \mathrm{D}\right)\left(\mathrm{C}^{12} \mathrm{H}_{3}\right) \mathrm{O}^{18}$ & 3- 596 & Not Reported & Ground & & & & & 8960. & 5. \\
\hline $\mathrm{Br}^{79} \mathrm{Cl}^{37}$ & $1-$ & $1 \leftarrow 0$ & Ground & $3 / 2$ & 2 & $3 / 2$ & 3 & 8964.19 & \\
\hline $\mathrm{HC}^{12} \mathrm{O}^{16} \mathrm{O}^{16} \mathrm{H}$ & 3. 71 & $16,3,13 \leftarrow 16,3,14$ & & & & & & 8968.50 & \\
\hline $\mathrm{Br}^{81} \mathrm{Cl}^{35}$ & 1. & $1 \leftarrow 0$ & Excited & $5 / 2$ & 4 & $3 / 2$ & 3 & 8972.41 & \\
\hline $\mathrm{Bi}^{209} \mathrm{Cl}_{3}^{35}$ & 4- 71 & $3, \leftarrow 2$, & Ground & & & & & 8982. & 1. \\
\hline$\left(\mathrm{C}^{12} \mathrm{H}_{3}\right)_{2} \mathrm{Si}^{28} \mathrm{D}_{2}$ & 3- 643 & $1,1,0 \leftarrow 1,0,1$ & Ground & & & & & 8993.41 & .05 \\
\hline$\left(\mathrm{C}^{12} \mathrm{H}_{3}\right)_{2} \mathrm{Si}^{28} \mathrm{D}_{2}$ & 3- 643 & $1,1,0 \leftarrow 1,0,1$ & Ground & & & & & 8994.12 & .05 \\
\hline$\left(\mathrm{C}^{12} \mathrm{H}_{3}\right)_{2} \mathrm{Si}^{2{ }^{2}} \mathrm{D}_{2}$ & 3- 643 & $1,1,0 \leftarrow 1,0,1$ & Ground & & & & & 8994.82 & .05 \\
\hline $\mathrm{t}-\mathrm{C}^{12}{ }_{*} \mathrm{HDC}^{12} \mathrm{H}_{2} \mathrm{C}^{12}{ }_{*} \mathrm{Cl}^{35} \mathrm{Cl}^{37}$ & $4-1067$ & $4,4,0 \leftarrow 4,3,1$ & Ground & & & & & 8995.9 & \\
\hline $\mathrm{Br}^{81} \mathrm{Cl}^{35}$ & 1 - & $1 \leftarrow 0$ & Ground & $5 / 2$ & 3 & $3 / 2$ & 3 & 9001.44 & \\
\hline $\mathrm{N}^{\mathrm{h}} \mathrm{O}_{2}^{\mathrm{h}} \mathrm{Cl}^{\mathrm{h}}$ & $4-1463$ & Not Reported & & & & & & 9002.52 & \\
\hline $\mathrm{N}^{\mathrm{b}} \mathrm{O}_{2}^{\mathrm{h}} \mathrm{Cl}^{\mathrm{b}}$ & $4-1463$ & Not Reported & & & & & & 9003.58 & \\
\hline $\mathrm{Br}^{81} \mathrm{Cl}^{35}$ & 1 - & $1 \leftarrow 0$ & Ground & $5 / 2$ & 2 & $3 / 2$ & 3 & 9012.97 & \\
\hline $\mathrm{C}_{6}^{12} \mathrm{H}_{5} \mathrm{~N}^{14} \mathrm{O}_{2}^{16}$ & $3-1041$ & $4,2,3 \leftarrow 3,2,2$ & Ground & & & & & 9013. & 1.5 \\
\hline $\mathrm{N}^{14} \mathrm{H}_{3}$ & $4-1771$ & Not Reported & Ground & & & & & 9014. & \\
\hline $\mathrm{Br}^{81} \mathrm{Cl}^{35}$ & $1-$ & $1 \leftarrow 0$ & Ground & $5 / 2$ & 4 & $3 / 2$ & 3 & 9018.40 & \\
\hline $\mathrm{HC}^{13} \mathrm{~N}^{14}$ & 4- 293 & $6 \leftarrow 6$ & Excited & & & & & 9018.87 & .05 \\
\hline $\mathrm{C}^{12}{ }_{*} \mathrm{H}_{2} \mathrm{C}^{12} \mathrm{H}_{2} \mathrm{C}^{12}{ }_{*} \mathrm{Cl}^{35} \mathrm{Cl}^{37}$ & $4-1062$ & $9,5,4 \leftarrow 9,4,5$ & Ground & & & & & 9025.6 & \\
\hline $\mathrm{Br}^{81} \mathrm{Cl}^{35}$ & 1 . & $1 \leftarrow 0$ & Ground & $5 / 2$ & 1 & $3 / 2$ & 0 & 9026.17 & \\
\hline $\mathrm{N}^{14} \mathrm{H}_{3}$ & $4-1771$ & $12,1 \leftarrow 12,1$ & Ground & & & & & 9032.81 & .025 \\
\hline $\mathrm{N}^{14} \mathrm{H}_{3}$ & $4-1771$ & $12,1 \leftarrow 12,1$ & Ground & & & & & 9033.13 & .025 \\
\hline $\mathrm{Br}^{79} \mathrm{Cl}^{35}$ & $1-$ & $1 \leftarrow 0$ & Excited & $5 / 2$ & 4 & $3 / 2$ & 3 & 9034.14 & \\
\hline $\mathrm{C}^{12} \mathrm{H}_{3} \mathrm{~N}^{14} \mathrm{H}_{2}$ & $3 \cdot 261$ & Not Reported & Ground & & & & & 9057.85 & .04 \\
\hline $\mathrm{Br}^{79} \mathrm{Cl}^{35}$ & $1-$ & $1 \leftarrow 0$ & Ground & $5 / 2$ & 3 & $3 / 2$ & 3 & 9063.77 & \\
\hline $\mathrm{C}^{12}{ }_{*} \mathrm{D}_{2} \mathrm{C}^{12} \mathrm{D}_{2} \mathrm{C}^{12} * \mathrm{Cl}^{35} \mathrm{Cl}^{37}$ & $4-1064$ & $7,3,4 \leftarrow 7,2,5$ & Ground & & & & & 9064.3 & \\
\hline $\mathrm{HC}^{12}: \mathrm{C}^{12} \mathrm{C}^{12} \mathrm{H}: \mathrm{C}^{12} \mathrm{H}_{2}$ & $4-1131$ & $1, \quad, \leftarrow 0$, & Ground & & & & & 9074.72 & .03 \\
\hline $\mathrm{HC}^{12}: \mathrm{C}^{12} \mathrm{C}^{12} \mathrm{H}: \mathrm{C}^{12} \mathrm{H}_{2}$ & 4-1131 & $1, \quad \leftarrow 0, \quad$ & Ground & & & & & 9074.72 & .03 \\
\hline $\mathrm{Br}^{79} \mathrm{Cl}^{35}$ & 1. & $1 \leftarrow 0$ & Ground & $5 / 2$ & 2 & $3 / 2$ & 3 & 9074.91 & \\
\hline $\mathrm{C}^{12}{ }_{*} \mathrm{D}_{2} \mathrm{C}^{12} \mathrm{D}_{2} \mathrm{C}^{12}{ }_{*} \mathrm{Cl}_{2}^{35}$ & $4-1063$ & $8,6,2 \leftarrow 8,5,3$ & Ground & & & & & 9075.4 & \\
\hline $\mathrm{C}^{12} \mathrm{H}_{3} \mathrm{~N}^{14} \mathrm{H}_{2}$ & 3- 261 & Not Reported & Ground & & & & & 9079.39 & .04 \\
\hline $\mathrm{Br}^{79} \mathrm{Cl}^{35}$ & 1 . & $1 \leftarrow 0$ & Ground & $5 / 2$ & 4 & $3 / 2$ & 3 & 9080.73 & \\
\hline $\mathrm{C}_{6}^{12} \mathrm{H}_{5} \mathrm{~N}^{14} \mathrm{O}_{2}^{16}$ & $3-1041$ & $4,3,2 \leftarrow 3,3,1$ & Ground & & & & & 9085. & 2.5 \\
\hline $\mathrm{C}_{6}^{12} \mathrm{H}_{5} \mathrm{~N}^{14} \mathrm{O}_{2}^{16}$ & $3-1041$ & $4,3,1 \leftarrow 3,3,0$ & Ground & & & & & 9085. & 2.5 \\
\hline $\mathrm{Br}^{79} \mathrm{Cl}^{35}$ & $1-$ & $1 \leftarrow 0$ & Ground & $5 / 2$ & 1 & $3 / 2$ & 0 & 9088.61 & \\
\hline $\mathrm{H}_{2} \mathrm{C}^{12}: \mathrm{C}^{12} \mathrm{HF}^{19}$ & 4. 781 & $3,1,2 \leftarrow 3,1,3$ & Ground & & & & & 9111.32 & .05 \\
\hline$\left(\mathrm{C}^{12} \mathrm{H}_{3}\right)_{2} \mathrm{O}^{16}$ & 3- 591 & $2,0,2 \leftarrow 1,1,1$ & Ground & & & & & 9119.7 & .5 \\
\hline $\mathrm{C}^{12} \mathrm{H}_{3} \mathrm{~N}^{14} \mathrm{H}_{2}$ & 3- 261 & Not Reported & Ground & & & & & 9127.61 & .04 \\
\hline $\mathrm{HDSe}^{\mathrm{8} 2}$ & 4-1758 & $2,2,1 \leftarrow 2,2,0$ & Ground & & & & & 9127.75 & .1 \\
\hline
\end{tabular}




\begin{tabular}{|c|c|c|c|c|c|c|c|c|c|}
\hline Isotopic Species & $\begin{array}{l}\text { Vol.-Id. } \\
\text { Nos. }\end{array}$ & $\begin{array}{c}\text { Rotational } \\
\text { Quantum Nos. }\end{array}$ & Vib. State & $F_{i}^{\prime}$ & $\begin{array}{l}\text { Hype } \\
F^{\prime}\end{array}$ & $\begin{array}{c}\text { rfine } \\
F_{1}\end{array}$ & $\mathrm{~F}$ & $\begin{array}{c}\text { Frequency } \\
\mathrm{MHz}\end{array}$ & $\begin{aligned} & \text { Acc. } \\
\pm & \mathrm{MH} \%\end{aligned}$ \\
\hline $\mathrm{C}^{12} \mathrm{H}_{3} \mathrm{~N}^{14} \mathrm{H}_{2}$ & 3- 261 & Not Reported & Ground & & & & & 9128.14 & .04 \\
\hline $\mathrm{HDSe}^{80}$ & $4-1757$ & $2,2,1 \leftarrow 2,2,0$ & Ground & & & & & 9138.55 & \\
\hline $\mathrm{HDSe}^{80}$ & 4-1757 & $2,2,1 \leftarrow 2,2,0$ & Ground & & & & & 9138.55 & .1 \\
\hline $\mathrm{t}-\mathrm{C}^{12}{ }_{*} \mathrm{HDC}^{12} \mathrm{H}_{2} \mathrm{C}^{12}{ }_{*} \mathrm{Cl}^{35} \mathrm{Cl}^{37}$ & 4-1067 & $7,3,4 \leftarrow 7,2,5$ & Ground & & & & & $914 \quad 0$ & \\
\hline $\mathrm{HDSe}^{78}$ & 4-1756 & $2,2,1 \leftarrow 2,2,0$ & Ground & & & & & 9149.6 .5 & .1 \\
\hline$\left(\mathrm{C}^{12} \mathrm{H}_{3}\right)_{2} \mathrm{O}^{16}$ & 3- 591 & Not Reported & Ground & & & & & 9150 & 5. \\
\hline $\mathrm{HDSe}^{77}$ & $4-1755$ & $2,2,1 \leftarrow 2,2,0$ & Ground & & & & & 9155.85 & .1 \\
\hline $\mathrm{HDSe}^{77}$ & 4-1755 & $2,2,1 \leftarrow 2,2,0$ & Ground & & & & & 9155.85 & .1 \\
\hline $\mathrm{HDSe}^{76}$ & $4-1759$ & $2,2,1 \leftarrow 2,2,0$ & Ground & & & & & 9161.50 & .1 \\
\hline $\mathrm{C}^{12} \mathrm{H}_{3} \mathrm{C}^{12}{ }_{*} \mathrm{H}_{2} \mathrm{O}^{16} \mathrm{C}^{12}{ }_{*} \mathrm{C}^{12} \mathrm{H}_{3}$ & 3- 951 & $8,3,6 \leftarrow 8,2,6$ & Ground & & & & & 9168.84 & .2 \\
\hline $\mathrm{Br}^{81} \mathrm{~F}_{3}^{19}$ & 4. 82 & $2,1,1 \leftarrow 2,0,2$ & Ground & & $7 / 2$ & & $7 / 2$ & 9173.13 & \\
\hline $\mathrm{Si}^{28} \mathrm{D}_{3} \mathrm{C}^{12} \mathrm{H}: \mathrm{C}^{12} \mathrm{H}_{2}$ & 3- 612 & $1,0,1 \leftarrow 0,0,0$ & Ground & & & & & 9174.9 & .05 \\
\hline $\mathrm{Si}^{28} \mathrm{D}_{3} \mathrm{C}^{12} \mathrm{H}: \mathrm{C}^{12} \mathrm{H}_{2}$ & 3- 612 & $1,0,1 \leftarrow 0,0,0$ & Ground & & & & & 9177.78 & .05 \\
\hline $\mathrm{H}_{2} \mathrm{C}^{12}: \mathrm{C}^{12} \mathrm{O}^{16}$ & 4. 711 & $27,2,25 \leftarrow-27,2,26$ & Ground & & & & & 9188.20 & \\
\hline $\mathrm{Br}^{81} \mathrm{Cl}^{35}$ & $1-$ & $1 \leftarrow 0$ & Ground & $3 / 2$ & 3 & $3 / 2$ & 3 & 9193.26 & \\
\hline $\mathrm{O}_{3}^{16}$ & $4-1841$ & $20,3,17 \ll-21,2,20$ & Ground & & & & & 9201. & \\
\hline $\mathrm{Br}^{81} \mathrm{Cl}^{35}$ & $1-$ & $1 \leftarrow 0$ & Ground & $3 / 2$ & 2 & $3 / 2$ & 3 & 9209.57 & \\
\hline $\mathrm{Br}^{79} \mathrm{~F}_{3}^{19}$ & 4- 81 & $2,1,1 \leftarrow 2,0,2$ & Ground & & $7 / 2$ & & $7 / 2$ & 9215.06 . & \\
\hline $\mathrm{C}^{12} \mathrm{H}_{3} \mathrm{~N}^{14} \mathrm{H}_{2}$ & 3- 261 & Not Reported & Ground & & & & & 9223.83 & .1 \\
\hline $\mathrm{O}^{\mathrm{h}} \mathrm{O}^{\mathrm{h}} \mathrm{O}^{\mathrm{h}}$ & $4-1847$ & Not Reported & & & & & & 9225.8 & \\
\hline $\mathrm{H}_{2} \mathrm{~N}^{14} \mathrm{~N}^{14} \mathrm{H}_{2}$ & $3-\quad 51$ & Not Reported & & & & & & 9227.5 & \\
\hline $\mathrm{C}^{12} \mathrm{~F}_{3}^{19} \mathrm{C}^{12} \mathrm{O}^{16} \mathrm{O}^{16} \mathrm{H} \cdot \mathrm{HC}^{12} \mathrm{O}^{16} \mathrm{O}^{16} \mathrm{H}$ & 3- 661 & $8, \quad \leftarrow 7$, & Ground & & & & & 9235.2 & \\
\hline $\mathrm{HC}^{12} \mathrm{~N}^{14}$ & 4- 291 & $4 \leftarrow 4$ & Excited & & & & & 9242.20 & .1 \\
\hline $\mathrm{C}^{12}{ }_{*} \mathrm{D}_{2} \mathrm{C}^{12} \mathrm{D}_{2} \mathrm{C}^{12}{ }_{*} \mathrm{Cl}_{2}^{35}$ & $4-1063$ & $6,4,3 \leftarrow 6,3,4$ & Ground & & & & & 9242.3 & \\
\hline $\mathrm{HN}^{14} \mathrm{O}_{3}^{16}$ & 3- 31 & $12,10,2 \leftarrow 12,10,3$ & Ground & & & & & 9245.56 & \\
\hline $\mathrm{C}_{6}^{12} \mathrm{H}_{5} \mathrm{~N}^{14} \mathrm{O}_{2}^{16}$ & $3-1041$ & $4,2,2 \leftarrow 3,2,1$ & Ground & & & & & 9251. & 10. \\
\hline $\mathrm{C}_{*}^{12} \mathrm{H}_{2} \mathrm{C}^{12} \mathrm{H}_{2} \mathrm{C}_{*}^{12} \mathrm{Cl}_{2}^{35}$ & 4-1061 & $8,5,3 \leftarrow 8,4,4$ & Ground & & & & & 9252.1 & \\
\hline $\mathrm{DC}^{12} \mathrm{DO}^{16}$ & 4- 384 & $15,4,11 \leftarrow 15,4,12$ & Ground & & & & & 9259.88 & \\
\hline $\mathrm{N}^{14} \mathrm{~S}^{32} \mathrm{~F}_{3}^{19}$ & 4-1661 & $1,0 \leftarrow 0,0$ & Ground & & 0 & & 1 & 9271.90 & \\
\hline $\mathrm{N}^{14} \mathrm{H}_{3}$ & 4-1771 & $12,2 \leftarrow 12,2$ & Ground & & & & & 9272.10 & .10 \\
\hline $\mathrm{N}^{14} \mathrm{~S}^{32} \mathrm{~F}_{3}^{19}$ & $4-1661$ & $1,0 \leftarrow 0,0$ & Ground & & 2 & & 1 & 9272.42 & \\
\hline $\mathrm{N}^{14} \mathrm{~S}^{32} \mathrm{~F}_{3}^{19}$ & $4-1661$ & $1, \leftarrow 0$ & Ground & & & & & 9272.56 & \\
\hline $\mathrm{N}^{14} S^{32} F_{3}^{19}$ & 4-1661 & $1,0 \leftarrow 0,0$ & Ground & & 1 & & 1 & 9272.79 & \\
\hline $\mathrm{C}^{12}{ }_{*} \mathrm{D}_{2} \mathrm{C}^{12} \mathrm{D}_{2} \mathrm{C}^{12}{ }_{*} \mathrm{Cl}^{35} \mathrm{Cl}^{37}$ & $4-1064$ & $6,4,3 \leftarrow 6,3,4$ & Ground & & & & & 9275.7 & \\
\hline $\mathrm{N}^{14} \mathrm{H}_{3}$ & 4-1771 & $15,8 \leftarrow 15,8$ & Ground & & & & & 9283.65 & .10 \\
\hline $\mathrm{C}^{12} \mathrm{H}_{3} \mathrm{~N}^{14} \mathrm{H}_{2}$ & 3- 261 & Not Reported & Ground & & & & & 9285.77 & .1 \\
\hline $\mathrm{Br}^{79} \mathrm{Cl}^{35}$ & $1-$ & $1 \leftarrow 0$ & Ground & $3 / 2$ & 3 & $3 / 2$ & 3 & 9291.61 & \\
\hline $\mathrm{HC}^{12}: \mathrm{C}^{12} \mathrm{C}^{12} \mathrm{DO}^{16}$ & 4- 921 & $3,1,3 \leftarrow 4,0,4$ & Ground & & & & & 9300.33 & .02 \\
\hline $\mathrm{C}^{12} \mathrm{H}_{3} \mathrm{C}^{12} \mathrm{~F}^{19}: \mathrm{C}^{12} \mathrm{H}_{2}$ & 3- 721 & $27,20,7 \leftarrow 27,20,8$ & Ground & & & & & 9307.38 & .1 \\
\hline $\mathrm{Br}^{79} \mathrm{Cl}^{35}$ & $1-$ & $1 \leftarrow 0$ & Ground & $3 / 2$ & 2 & $3 / 2$ & 3 & 9307.96 & \\
\hline $\mathrm{C}^{12} \mathrm{H}_{3} \mathrm{C}^{12} \mathrm{~F}^{19}: \mathrm{C}^{12} \mathrm{H}_{2}$ & 3- 721 & $27,20,7 \leftarrow 27,20,8$ & Ground & & & & & 9308.35 & .1 \\
\hline $\mathrm{C}^{12} \mathrm{H}_{3} \mathrm{Ge}^{\mathrm{h}} \mathrm{Cl}^{35} \mathrm{Cl}_{2}^{37}$ & 3- 104 & $3,2,2 \leftarrow 2,1,2$ & & & & & & 9315. & 15. \\
\hline$\overline{\mathrm{a}-\mathrm{C}^{12} \mathrm{H}_{2} \mathrm{DS}{ }^{28} \mathrm{HF}_{12}^{19}}$ & $3-204$ & $1,0,1 \leftarrow 0,0,0$ & Ground & & & & & 9334.73 & .2 \\
\hline $\mathrm{s}-\mathrm{Si}^{28} \mathrm{HD}_{2} \mathrm{C}^{12} \mathrm{H}: \mathrm{C}^{12} \mathrm{H}_{2}$ & 3. 622 & $1,1,0 \leftarrow 0,0,0$ & Ground & & & & & 9354.8 & .10 \\
\hline $\mathrm{N}^{\mathrm{h}} \mathrm{O}_{2}^{\mathrm{t}} \mathrm{Cl}^{\mathrm{b}}$ & 4-1463 & Not Reported & & & & & & 9368.20 & \\
\hline
\end{tabular}




\begin{tabular}{|c|c|c|c|c|c|c|c|}
\hline Isotopic Species & $\begin{array}{l}\text { Vol.-Id. } \\
\text { Nos. }\end{array}$ & $\begin{array}{c}\text { Rotational } \\
\text { Quantum Nos. }\end{array}$ & Vib. State & $\mathrm{F}_{1}^{\prime} \mathrm{F}^{\frac{2}{2}} \mathrm{~F}_{1}$ & $F$ & $\begin{array}{c}\text { Frequency } \\
\mathrm{MHz}\end{array}$ & $\begin{aligned} & \text { Acc. } \\
& \pm \mathrm{MHz}\end{aligned}$ \\
\hline$\left(\mathrm{C}^{12} \mathrm{H}_{3}\right)_{3} \mathrm{C}^{12} \mathrm{~F}^{19}$ & 3- 981 & $1,0 \leftarrow 0,0$ & Excited & & & 9408.0 & \\
\hline $\mathrm{HC}^{12} \mathrm{O}^{16} \mathrm{O}^{16} \mathrm{H}$ & 3- 71 & $24,4,20 \longleftarrow 24,4,21$ & & & & 9410 . & \\
\hline $\mathrm{HC}^{12} \mathrm{DO}^{16}$ & 4- 385 & $12,3,9 \leftarrow 12,3,10$ & Ground & & & 9412.51 & \\
\hline$\left(\mathrm{C}^{12} \mathrm{H}_{3}\right)_{3} \mathrm{C}^{12} \mathrm{~F}^{19}$ & 3- 981 & $1,0 \leftarrow 0,0$ & Ground & & & 9417.7 & \\
\hline$\left(\mathrm{C}^{12} \mathrm{H}_{3}\right)_{3} \mathrm{C}^{12} \mathrm{~F}^{19}$ & 3- 981 & $1,0 \leftarrow 0,0$ & Ground & & & 9418.0 & \\
\hline $\mathrm{HC}^{12} \mathrm{~N}^{14}$ & 4- 291 & $6 \leftarrow 6$ & Excited & & & 9423.32 & .02 \\
\hline $\mathrm{C}^{12} \mathrm{H}_{3} \mathrm{C}^{12} * \mathrm{H}_{2} \mathrm{O}^{16} \mathrm{C}^{12} * \mathrm{C}^{12} \mathrm{H}_{3}$ & 3- 951 & $3,2,2 \leftarrow 3,1,2$ & Ground & & & 9423.92 & .2 \\
\hline$\left(\mathrm{C}^{12} \mathrm{H}_{3}\right)_{3} \mathrm{C}^{12} \mathrm{~F}^{19}$ & 3. 981 & $1,0 \leftarrow 0,0$ & Ground & & & 9424.30 & \\
\hline $\mathrm{C}^{12} * \mathrm{D}_{2} \mathrm{C}^{12} \mathrm{D}_{2} \mathrm{C}^{12} * \mathrm{Cl}_{2}^{35}$ & $4-1063$ & $7,3,4 \leftarrow 7,2,5$ & Ground & & & 9425.7 & \\
\hline$\left(\mathrm{C}^{12} \mathrm{H}_{3}\right)_{3} \mathrm{C}^{12} \mathrm{~F}^{19}$ & 3- 981 & $1,0 \leftarrow 0,0$ & Excited & & & 9427.3 & \\
\hline $\mathrm{s}-\mathrm{C}^{12} \mathrm{H}_{2} \mathrm{DSi}^{28} \mathrm{HF}_{2}^{19}$ & 3. 203 & $1,0,1 \leftarrow 0,0,0$ & Ground & & & 9437.10 & .2 \\
\hline$\left(\mathrm{C}^{12} \mathrm{H}_{3}\right)_{3} \mathrm{C}^{12} \mathrm{~F}^{19}$ & 3- 981 & $1,0 \leftarrow 0,0$ & Excited & & & 9441.0 & \\
\hline $\mathrm{C}^{12}{ }_{*} \mathrm{H}_{2} \mathrm{C}^{12} \mathrm{H}_{2} \mathrm{C}^{12} * \mathrm{Cl}_{2}^{35}$ & 4-1061 & $8,4,4 \leftarrow 8,3,5$ & Ground & & & 9447.6 & \\
\hline $\mathrm{HN}^{14} \mathrm{O}_{3}^{16}$ & $3-31$ & $3,3,0 \leftarrow 3,2,1$ & Ground & & & 9447.97 & \\
\hline $\mathrm{C}^{12} * \mathrm{D}_{2} \mathrm{C}^{12} \mathrm{D}_{2} \mathrm{C}^{12} * \mathrm{Cl}_{2}^{35}$ & $4 \cdot 1063$ & $5,5,1 \leftarrow 5,4,2$ & Ground & & & 9448.0 & \\
\hline $\mathrm{C}^{12} \mathrm{H}_{3} \mathrm{~N}^{14} \mathrm{H}_{2}$ & 3- 261 & Not Reported & Ground & & & 9452.63 & .1 \\
\hline $\mathrm{C}^{12} \mathrm{H}_{3} \mathrm{~N}^{14} \mathrm{H}_{2}$ & 3- 261 & Not Repurted & Ground & & & 9453.06 & .1 \\
\hline $\mathrm{C}^{12} \mathrm{H}_{3} \mathrm{Ge}^{\mathrm{b}} \mathrm{Cl}_{2}^{35} \mathrm{Cl}^{37}$ & 3- 105 & $3,2,2 \leftarrow 2,1,2$ & & & & 9455. & 15. \\
\hline $\mathrm{C}^{12} \mathrm{H}_{3} \mathrm{~N}^{14} \mathrm{H}_{2}$ & 3- 261 & Not Reported & Ground & & & 9459.96 & .1 \\
\hline $\mathrm{HDC}^{12}: \mathrm{C}^{12} \mathrm{O}^{16}$ & 4- 713 & $22,2,20 \leftarrow 22,2,21$. & Ground & & & 9462.69 & \\
\hline $\mathrm{N}^{14} \mathrm{H}_{3}$ & 4-1771 & $13,5 \leftarrow 13,5$ & Ground & & & 9476.06 & .10 \\
\hline $\mathrm{C}^{12}{ }_{*} \mathrm{HDC}^{12} \mathrm{H}_{2} \mathrm{C}^{12}{ }_{*} \mathrm{Cl}_{2}^{35}$ & 4-1065 & $7,3,4 \leftarrow 7,2,5$ & Ground & & & 9488.8 & \\
\hline $\mathrm{C}^{12}{ }_{*} \mathrm{H}_{2} \mathrm{C}^{12} \mathrm{H}_{2} \mathrm{C}^{12} * \mathrm{Cl}_{2}^{35}$ & 4-1061 & $7,3,4 \leftarrow 7,2,5$ & Ground & & & 9489.9 & \\
\hline $\mathrm{H}_{2} \mathrm{~N}^{14} \mathrm{C}^{12} \mathrm{~N}^{14}$ & 4- 361 & $8,1,7 \leftarrow 8,1,8$ & Ground & & & 9490.48 & .5 \\
\hline $\mathrm{H}_{2} \mathrm{~N}^{14} \mathrm{C}^{12} \mathrm{~N}^{14}$ & 4- 361 & $8,1,7 \leftarrow 8,1,8$ & Ground & & & 9491.29 & .5 \\
\hline $\mathrm{H}_{2} \mathrm{~N}^{14} \mathrm{C}^{12} \mathrm{~N}^{14}$ & 4- 361 & $8,1,7 \leftarrow 8,1,8$ & Ground & & & 9493.00 & .5 \\
\hline $\mathrm{H}_{2} \mathrm{~N}^{14} \mathrm{C}^{12} \mathrm{~N}^{14}$ & 4- 361 & $8,1,7 \leftarrow 8,1,8$ & Ground & & & 9493.77 & .5 \\
\hline $\mathrm{a}-\mathrm{Si}^{28} \mathrm{HD}_{2} \mathrm{C}^{12} \mathrm{H}: \mathrm{C}^{12} \mathrm{H}_{2}$ & 3- 623 & $1,1,0 \leftarrow 0,0,0$ & Ground & & & 9511.02 & .10 \\
\hline $\mathrm{C}^{13} \mathrm{H}_{3} \mathrm{C}^{12} \mathrm{HO}$ & 3- 476 & $2,0,2 \leftarrow 1,1,1$ & Ground & & & 9513.06 & .2 \\
\hline $\mathrm{c}-\mathrm{C}^{12}{ }_{*} \mathrm{HDCl}^{12} \mathrm{H}_{2} \mathrm{Cl}_{*}{ }^{12} \mathrm{Cl}^{35} \mathrm{Cl}^{37}$ & 4.1066 & $10,5,5 \leftarrow 10,4,6^{-}$ & Ground & & & 9516.9 & \\
\hline $\mathrm{N}^{14} \mathrm{D}_{2} \mathrm{H}$ & $4-1774$ & $4,1,4 \leftarrow 4,0,4$ & Ground & & & 9517.55 & .05 \\
\hline $\mathrm{N}^{14} \mathrm{H}_{3}$ & $4-1771$ & Not Reported & Ground & & & 9521. & \\
\hline $\mathrm{O}^{16} \mathrm{~F}_{2}^{19}$ & $4 \cdot 1611$ & $34,8,26 \leftarrow 35,7,29$ & Ground & & & 9533.43 & .10 \\
\hline $\mathrm{H}_{2} \mathrm{~N}^{14} \mathrm{~N}^{14} \mathrm{H}_{2}$ & $3-\quad 51$ & Not Reported & & & & 9543.51 & \\
\hline $\mathrm{C}^{12}{ }_{*} \mathrm{D}_{2} \mathrm{C}^{12} \mathrm{D}_{2} \mathrm{C}^{12}{ }_{*} \mathrm{Cl}_{2}^{35}$ & 4-1063 & $6,5,2 \leftarrow 6,4,3$ & Ground & & & 9554.8 & \\
\hline $\mathrm{H}_{2} \mathrm{~N}^{14} \mathrm{~N}^{14} \mathrm{H}_{2}$ & 3- 51 & Not Reported & & & & 9555.23 & \\
\hline $\mathrm{C}^{12} * \mathrm{D}_{2} \mathrm{C}^{12} \mathrm{D}_{2} \mathrm{C}^{12} * \mathrm{Cl}^{35} \mathrm{Cl}^{37}$ & 4-1064 & $10,5,5 \leftarrow 10,4,6$ & Ground & & & 9560.8 & \\
\hline $\mathrm{DO}^{16}$ & 1 . & $7 / 2,4 \leftarrow 7 / 2,4$ & Ground & $5 / 2$ & $5 / 2$ & 9578.51 & .15 \\
\hline $\mathrm{C}^{12} \mathrm{H}_{3} \mathrm{~N}^{14} \mathrm{H}_{2}$ & 3- 261 & Not Reported & Ground & & & 9584.09 & .1 \\
\hline $\mathrm{DO}^{16}$ & $1-$ & $7 / 2,4 \leftarrow 7 / 2,4$ & Ground & $7 / 2$ & $7 / 2$ & 9586.03 & .10 \\
\hline $\mathrm{C}^{12}{ }_{*} \mathrm{HDC}^{12} \mathrm{H}_{2} \mathrm{C}^{12} * \mathrm{Cl}_{2}^{35}$ & 4-1065 & $2,1,2 \leftarrow 1,0,1$ & Ground & & & 9592.8 & \\
\hline $\mathrm{C}^{12} \mathrm{H}_{3} \mathrm{Ge}^{\mathrm{b}} \mathrm{Cl}_{3}^{35}$ & 3- 107 & $3, \leftarrow 2$ & & & & 9595. & 15. \\
\hline $\mathrm{DO}^{16}$ & $1-$ & $7 / 2,4 \leftarrow 7 / 2,4$ & Ground & $9 / 2$ & $9 / 2$ & 9595.26 & .10 \\
\hline $\mathrm{C}_{6}^{12} \mathrm{H}_{5} \mathrm{~N}^{14} \dot{\mathrm{O}}_{2}^{16}$ & $3-1041$ & $4,1,3 \leftarrow 3,1,2$ & Ground & & & 9598. & 1.5 \\
\hline $\mathrm{C}^{12}{ }_{*} \mathrm{H}_{2} \mathrm{C}^{12} \mathrm{H}_{2} \mathrm{C}^{12}{ }_{*} \mathrm{Cl}_{2}^{35}$ & 4-1061 & $4,4,0 \leftarrow 4,3,1$ & Ground & & & 9598.3 & \\
\hline
\end{tabular}




\begin{tabular}{|c|c|c|c|c|c|c|c|}
\hline lsotopic Species & $\begin{array}{l}\text { Vol.-Id. } \\
\text { Nos. }\end{array}$ & $\begin{array}{c}\text { Rotational } \\
\text { Quantum Nos. }\end{array}$ & Vib. State & $\begin{array}{l}\text { Hyperfine } \\
F_{1}^{\prime} F^{\prime} \quad F_{1}\end{array}$ & $\mathrm{~F}$ & $\begin{array}{l}\text { lirequency } \\
\text { MHz. }\end{array}$ & $\begin{aligned} & \text { Acec } \\
& \pm \text { MIIz }\end{aligned}$ \\
\hline $\mathrm{N}^{14} \mathrm{H}_{3}$ & 4-1771 & Not Reported & Ground & & & 9636. & \\
\hline $\mathrm{O}^{\mathrm{b}} \mathrm{O}^{\mathrm{h}} \mathrm{O}^{\mathrm{b}}$ & $4-1847$ & Not Reported & & & & 9641.7 & \\
\hline $\mathrm{C}^{12} \mathrm{H}_{3} \mathrm{C}^{12}{ }_{*} \mathrm{H}_{2} \mathrm{O}^{16} \mathrm{C}^{12}{ }_{*} \mathrm{C}^{12} \mathrm{H}_{3}$ & 3. 951 & $23,7,17 \leftarrow 23,6,17$ & Ground & & & 9641.95 & .2 \\
\hline $\mathrm{C}^{12} \mathrm{H}_{3} \mathrm{C}^{12}{ }_{*} \mathrm{H}_{2} \mathrm{O}^{16} \mathrm{C}^{12}{ }_{*} \mathrm{C}^{12} \mathrm{H}_{3}$ & 3. 951 & $23,7,17 \leftarrow 23,6,17$ & Ground & & & 9643.07 & .2 \\
\hline $\mathrm{C}^{12} \mathrm{H}_{3} \mathrm{C}^{12}{ }_{*} \mathrm{H}_{2} \mathrm{O}^{16} \mathrm{C}^{12}{ }_{*} \mathrm{C}^{12} \mathrm{H}_{3}$ & 3. 951 & $23,7,17 \leftarrow 23,6,17$ & Ground & & & 9644.25 & .2 \\
\hline $\mathrm{HC}^{12} \mathrm{O}^{16} \mathrm{O}^{16} \mathrm{C}^{12} \mathrm{H}_{3}-\mathrm{E}$ & 3. 502 & $3,1,2 \leftarrow 3,1,3$ & Ground & & & 9647.10 & .35 \\
\hline $\mathrm{S}^{34} \mathrm{O}_{2}^{16}$ & 4-1833 & $10,2,8 \leftarrow 11,1,11$ & Ground & & & 9650.63 & .02 \\
\hline $\mathrm{HC}^{12} \mathrm{O}^{16} \mathrm{O}^{16} \mathrm{C}^{12} \mathrm{H}_{3}-\mathrm{A}$ & 3- 501 & $3,1,2 \leftarrow 3,1,3$ & Ground & & & 965.3 .41 & .35 \\
\hline $\mathrm{N}^{14} \mathrm{H}_{3}$ & $4-1771$ & $14,3 \leftarrow 14,3$ & Ground & & & 9670.78 & .10 \\
\hline $\mathrm{c}-\mathrm{HDN}^{14} \mathrm{C}^{12} \mathrm{HO}^{16}$ & 3- 152 & $1,1,1 \leftarrow 2,0,2$ & Ground & & & 9689.15 & \\
\hline $\mathrm{H}_{2} \mathrm{~N}^{14} \mathrm{~N}^{14} \mathrm{H}_{2}$ & $3-51$ & Not Reported & & & & 9689.62 & \\
\hline $\mathrm{H}_{2} \mathrm{~N}^{14} \mathrm{~N}^{14} \mathrm{H}_{2}$ & $3-\quad 51$ & Not Reported & & & & 9689.72 & \\
\hline $\mathrm{C}^{12} * \mathrm{D}_{2} \mathrm{C}^{12} \mathrm{D}_{2} \mathrm{C}^{12} * \mathrm{Cl}^{35} \mathrm{Cl}^{37}$ & 4-1064 & $8,6,2 \leftarrow 8,5,3$ & Ground & & & 9689.8 & \\
\hline $\mathrm{H}_{2} \mathrm{~N}^{14} \mathrm{~N}^{14} \mathrm{H}_{2}$ & 3. 51 & Not Reported & & & & 9689.80 & \\
\hline $\mathrm{HC}^{12} \mathrm{O}^{16} \mathrm{O}^{16} \mathrm{H}$ & 3- 71 & $9,2,7 \leftarrow 9,2,8$ & & & & 9696.83 & \\
\hline $\mathrm{H}_{2} \mathrm{~N}^{14} \mathrm{~N}^{14} \mathrm{H}_{2}$ & $3-51$ & Not Reported & & & & 9697.59 & \\
\hline a- $\mathrm{Si}^{28} \mathrm{H}_{2} \mathrm{DC}{ }^{12} \mathrm{H}: \mathrm{C}^{12} \mathrm{H}_{2}$ & 3- 621 & $1,1,0 \leftarrow 0,0,0$ & Ground & & & 9705.16 & .10 \\
\hline $\mathrm{C}^{12} \mathrm{H}_{3} \mathrm{~N}^{14} \mathrm{H}_{2}$ & 3- 261 & $2,0, \leftarrow 1,1$ & Ground & & & 9706.10 & .1 \\
\hline t. $\mathrm{C}^{12} \mathrm{H}_{2} \mathrm{DC}^{12} \mathrm{H}_{2} \mathrm{Cl}^{35}$ & 3- 543 & $1,0,1 \leftarrow 0,0,0$ & Ground & $3 / 2$ & $3 / 2$ & 9726.45 & .05 \\
\hline $\mathrm{Tl}^{205} \mathrm{I}^{127}$ & $1-$ & $6 \leftarrow 5$ & Excited & & & 9734.0 & \\
\hline t- $\mathrm{C}^{12} \mathrm{H}_{2} \mathrm{DC}^{12} \mathrm{H}_{2} \mathrm{Cl}^{35}$ & 3- 543 & $1,0,1 \leftarrow 0,0,0$ & Ground & $5 / 2$ & $3 / 2$ & 9738.77 & .05 \\
\hline $\mathrm{C}^{12}{ }_{*} \mathrm{D}_{2} \mathrm{C}^{12} \mathrm{D}_{2} \mathrm{C}^{12}{ }_{*} \mathrm{Cl}^{35} \mathrm{Cl}^{37}$ & $4-1064$ & $5,5,1 \leftarrow 5,4,2$ & Ground & & & 9743.7 & \\
\hline $\mathrm{t}-\mathrm{C}^{12} \mathrm{H}_{2} \mathrm{DC}^{12} \mathrm{H}_{2} \mathrm{Cl}^{35}$ & 3- 543 & $1,0,1 \leftarrow 0,0,0$ & Ground & $1 / 2$ & $3 / 2$ & 9748.59 & .05 \\
\hline $\mathrm{Tl}^{205} \mathrm{I}^{127}$ & $1-$ & $6 \leftarrow 5$ & Ground & $9 / 2$ & $7 / 2$ & 9755.55 & 0.04 \\
\hline $\mathrm{DC}^{12} \mathrm{O}^{16} \mathrm{O}^{16} \mathrm{C}^{12} \mathrm{H}_{3}-\mathrm{E}$ & 3. 504 & $6,2,4 \leftarrow 6,2,5$ & Ground & & & 9756.44 & .35 \\
\hline $\mathrm{Tl}^{205} \mathrm{I}^{127}$ & $1-$ & $6 \leftarrow 5$ & Ground & $11 / 2$ & $9 / 2$ & 9757.30 & 0.03 \\
\hline $\mathrm{Tl}^{205} \mathrm{I}^{127}$ & $1-$ & $6 \leftarrow 5$ & Ground & $7 / 2$ & $5 / 2$ & 9758.18 & 0.03 \\
\hline $\mathrm{Tl}^{205} \mathrm{I}^{127}$ & $1-$ & $6 \leftarrow 5$ & Ground & $13 / 2$ & $11 / 2$ & 9761.27 & 0.02 \\
\hline $\mathrm{DC}^{12} \mathrm{O}^{16} \mathrm{O}^{16} \mathrm{C}^{12} \mathrm{H}_{3}-\mathrm{A}$ & 3- 503 & $6,2,4 \leftarrow 6,2,5$ & Ground & & & 9762.83 & .35 \\
\hline $\mathrm{Tl}^{205} \mathrm{I}^{127}$ & 1 - & $6 \leftarrow 5$ & Ground & $17 / 2$ & $15 / 2$ & 9763.27 & 0.02 \\
\hline $\mathrm{Tl}^{205} \mathrm{I}^{127}$ & $1-$ & $6 \leftarrow 5$ & Ground & $15 / 2$ & $13 / 2$ & 9764.52 & 0.03 \\
\hline $\mathrm{C}^{12} \mathrm{H}_{3} \mathrm{~N}^{14} \mathrm{H}_{2}$ & 3- 261 & Not Reported & Ground & & & 9779.33 & .04 \\
\hline $\mathrm{C}^{12} \mathrm{H}_{3} \mathrm{C}^{12}{ }_{*} \mathrm{HO}^{16} \mathrm{C}^{12}{ }_{*} \mathrm{H}_{2}$ & 3. 761 & Not Reported & Ground & & & 9797.13 & .1 \\
\hline $\mathrm{C}^{12} \mathrm{H}_{3} \mathrm{C}^{12}{ }_{*} \mathrm{HO}^{16} \mathrm{C}^{12}{ }_{*} \mathrm{H}_{2}$ & 3- 761 & Not Reported & Ground & & & 9798.95 & .1 \\
\hline $\mathrm{C}^{12} \mathrm{H}_{3} \mathrm{C}^{12}{ }_{*} \mathrm{HO}^{16} \mathrm{C}^{12}{ }_{*} \mathrm{H}_{2}$ & 3- 761 & Not Reported & Ground & & & 9799.75 & .1 \\
\hline $\mathrm{Tl}^{203} \mathrm{I}^{127}$ & $1-$ & $6 \leftarrow 5$ & Ground & $15 / 2$ & $13 / 2$ & 9801.20 & 0.05 \\
\hline $\mathrm{C}^{12}{ }_{*} \mathrm{D}_{2} \mathrm{C}^{12} \mathrm{D}_{2} \mathrm{C}^{12}{ }_{*} \mathrm{Cl}^{35} \mathrm{Cl}^{37}$ & $4 \cdot 1064$ & $6,5,2 \leftarrow 6,4,3$ & Ground & & & 9806.0 & \\
\hline $\mathrm{N}^{14} \mathrm{H}_{3}$ & 4-1771 & $14,7 \leftarrow 14.7$ & Ground & & & 9814.30 & .05 \\
\hline $\mathrm{O}^{\mathrm{h}} \mathrm{O}^{\mathrm{b}} \mathrm{O}^{\mathrm{b}}$ & 4-1847 & Not Reported & & & & $9823:$ & \\
\hline $\mathrm{N}^{14} \mathrm{H}_{3}$ & 4-1771 & Not Reported & Ground & & & 9829. & \\
\hline $\mathrm{HC}^{12} \mathrm{O}^{16} \mathrm{O}^{16} \mathrm{H}$ & $3-71$ & $3,1,2 \leftarrow 3,1,3$ & & & & 9831.98 & \\
\hline $\mathrm{C}^{12}{ }_{*} \mathrm{H}_{2} \mathrm{C}^{12} \mathrm{H}_{2} \mathrm{C}^{12}{ }_{*} \mathrm{Cl}_{2}^{35}$ & 4-1061 & $2,1,2 \leftarrow 1,0,1$ & Ground & & & 9833.3 & \\
\hline $\mathrm{C}^{12} \mathrm{Cl}_{3}^{35} \mathrm{~F}^{19}$ & 4- 191 & $2,1 \leftarrow 1,1$ & Ground & & & 9853.68 & .08 \\
\hline $\mathrm{DC}^{12} \mathrm{~N}^{15}$ & 4. 296 & $7 \leftarrow 7$ & Excited & & & 9854.15 & .1 \\
\hline $\mathrm{C}^{12} \mathrm{Cl}_{3}^{35} \mathrm{~F}^{19}$ & 4- 191 & $2,1 \leftarrow 1,1$ & Ground & & & 9855.60 & .20 \\
\hline
\end{tabular}




\begin{tabular}{|c|c|c|c|c|c|c|c|}
\hline Isotopic Species & $\begin{array}{l}\text { Vol.-Id. } \\
\text { Nos. }\end{array}$ & $\begin{array}{c}\text { Rotational } \\
\text { Quantum Nos. }\end{array}$ & Vib. State & $\mathrm{F}_{1}^{\prime} \stackrel{\text { Hyperfin }}{\mathrm{F}^{\prime}} \mathrm{F}_{1}$ & $\mathrm{~F}$ & $\begin{array}{l}\text { Frequency } \\
\mathrm{MHz}\end{array}$ & $\begin{aligned} & \text { Acc. } \\
& \pm \mathrm{MHz}\end{aligned}$ \\
\hline $\mathrm{C}^{12} \mathrm{Cl}_{3}^{35} \mathrm{~F}^{19}$ & 4- 191 & $2,1 \leftarrow 1,1$ & Ground & & & 9859.30 & .04 \\
\hline $\mathrm{C}^{12} \mathrm{Cl}_{3}^{35} \mathrm{~F}^{19}$ & 4- 191 & $2,1 \leftarrow 1,1$ & Ground & & & 9860.60 & .10 \\
\hline $\mathrm{C}^{12} \mathrm{Cl}_{3}^{35} \mathrm{~F}^{19}$ & 4- 191 & $2,1 \leftarrow 1,1$ & Ground & & & 9861.80 & .30 \\
\hline $\mathrm{C}^{12}{ }_{*} \mathrm{H}_{2} \mathrm{C}^{12} \mathrm{H}_{2} \mathrm{C}^{12}{ }_{*} \mathrm{Cl}^{35} \mathrm{Cl}^{37}$ & 4-1062 & $4,2,3 \leftarrow 4,1,4$ & Ground & & & 9861.9 & \\
\hline $\mathrm{C}^{12} \mathrm{Cl}_{3}^{35} \mathrm{~F}^{19}$ & 4- 191 & $2,1 \leftarrow 1,1$ & Ground & & & 9863.96 & .05 \\
\hline $\mathrm{C}^{12} \mathrm{Cl}_{3}^{35} \mathrm{~F}^{19}$ & 4- 191 & $2,1 \leftarrow 1,1$ & Ground & & & 9865.00 & .20 \\
\hline $\mathrm{C}^{12} \mathrm{Cl}_{3}^{35} \mathrm{~F}^{19}$ & 4- 191 & $2,1 \leftarrow 1,1$ & Ground & & & 9866.69 & .11 \\
\hline $\mathrm{C}^{12} \mathrm{Cl}_{3}^{35} \mathrm{~F}^{19}$ & 4- 191 & $2,1 \leftarrow 1,1$ & Ground & & & 9870.50 & .20 \\
\hline $\mathrm{C}^{12} \mathrm{Cl}_{3}^{35} \mathrm{~F}^{19}$ & 4- 191 & $2,1 \leftarrow 1,1$ & Ground & & & 9875.00 & .25 \\
\hline $\mathrm{Tl}^{205} \mathrm{Br}^{81}$ & $1-$ & $4 \leftarrow 3$ & Excited & $9 / 2$ & $7 / 2$ & 9876.60 & 0.15 \\
\hline $\mathrm{Tl}^{205} \mathrm{Br}^{81}$ & $1-$ & $4 \leftarrow 3$ & Excited & $11 / 2$ & $9 / 2$ & 9876.60 & 0.15 \\
\hline $\mathrm{C}^{12} \mathrm{Cl}_{3}^{35} \mathrm{~F}^{19}$ & 4- 191 & $2,1 \leftarrow 1,1$ & Ground & & & 9877.00 & .25 \\
\hline $\mathrm{s}-\mathrm{Si}^{28} \mathrm{H}_{2} \mathrm{DC}^{12} \mathrm{H}: \mathrm{C}^{12} \mathrm{H}_{2}$ & 3- 619 & $1,1,0 \leftarrow 0,0,0$ & Ground & & & 9881.05 & .10 \\
\hline $\mathrm{C}^{12}{ }_{*} \mathrm{H}_{2} \mathrm{C}^{12} \mathrm{H}_{2} \mathrm{C}^{12}{ }_{*} \mathrm{Cl}^{35} \mathrm{Cl}^{37}$ & 4-1062 & $4,4,0 \leftarrow 4,3,1$ & Ground & & & 9899.9 & \\
\hline $\mathrm{Tl}^{205} \mathrm{Br}^{81}$ & $1-$ & $4 \leftarrow 3$ & Excited & $9 / 2$ & $7 / 2$ & 9906.80 & 0.10 \\
\hline $\mathrm{Tl}^{205} \mathrm{Br}^{81}$ & $1-$ & $4 \leftarrow 3$ & Excited & $11 / 2$ & $9 / 2$ & 9906.80 & 0.10 \\
\hline $\mathrm{DO}^{16}$ & 1 - & $11 / 2,6 \leftarrow 11 / 2,6$ & Ground & $9 / 2$ & $9 / 2$ & 9914.39 & .10 \\
\hline $\mathrm{HDC}^{12}: \mathrm{C}^{12} \mathrm{O}^{16}$ & 4- 713 & $6,1,5 \leftarrow 6,1,6$ & Ground & & & 9919.95 & \\
\hline $\mathrm{DO}^{16}$ & $1-$ & $11 / 2,6 \leftarrow 11 / 2,6$ & Ground & $11 / 2$ & $11 / 2$ & 9921.53 & .10 \\
\hline $\mathrm{DO}^{16}$ & 1 - & $11 / 2,6 \leftarrow 11 / 2,6$ & Ground & $13 / 2$ & $13 / 2$ & 9929.88 & .10 \\
\hline $\mathrm{C}^{12} \mathrm{H}_{3} \mathrm{O}^{16} \mathrm{H}$ & 3- 211 & $9,1, \leftarrow 8,2$ & Ground & & & 9936.2 & .1 \\
\hline $\mathrm{Tl}^{205} \mathrm{Br}^{81}$ & $1-$ & $4 \leftarrow 3$ & Excited & $11 / 2$ & $9 / 2$ & 9937.15 & 0.10 \\
\hline $\mathrm{Tl}^{205} \mathrm{Br}^{81}$ & $1-$ & $4 \leftarrow 3$ & Excited & $9 / 2$ & $7 / 2$ & 9937.15 & 0.10 \\
\hline $\mathrm{C}^{12} \mathrm{H}_{3} \mathrm{~N}^{14} \mathrm{H}_{2}$ & 3- 261 & Not Reported & Ground & & & 9938.95 & .04 \\
\hline $\mathrm{DC}^{12} \mathrm{O}^{16} \mathrm{O}^{16} \mathrm{C}^{12} \mathrm{H}_{3}-\mathrm{E}$ & 3- 504 & $3,1,2 \leftarrow 3,1,3$ & Ground & & & 9939.98 & .2 \\
\hline $\mathrm{DC}^{12} \mathrm{O}^{16} \mathrm{O}^{16} \mathrm{C}^{12} \mathrm{H}_{3}-\mathrm{A}$ & 3- 503 & $3,1,2 \leftarrow 3,1,3$ & Ground & & & 9945.74 & .2 \\
\hline $\mathrm{C}^{12} \mathrm{H}_{3} \mathrm{C}^{12} \mathrm{~F}^{19}: \mathrm{C}^{12} \mathrm{H}_{2}$ & 3- 721 & $16,12,4 \leftarrow 16,12,5$ & Ground & & & 9950.12 & .1 \\
\hline $\mathrm{C}^{12} \mathrm{H}_{3} \mathrm{C}^{12} \mathrm{~F}^{19}: \mathrm{C}^{12} \mathrm{H}_{2}$ & 3- 721 & $16,12,4 \leftarrow 16,12,5$ & Ground & & & 9950.92 & .1 \\
\hline $\mathrm{C}^{12} \mathrm{H}_{3} \mathrm{O}^{16} \mathrm{H}$ & 3- 211 & $8, \quad \leftarrow 7$, & Ground & & & 9960. & \\
\hline $\mathrm{C}^{12}{ }_{*} \mathrm{HDC}^{12} \mathrm{H}_{2} \mathrm{C}^{12}{ }_{*} \mathrm{Cl}_{2}^{35}$ & 4-1065 & $5,4,2 \leftarrow 5,3,3$ & Ground & & & 9964.8 & \\
\hline $\mathrm{N}^{14} \mathrm{H}_{3}$ & $4-1771$ & Not Reported & Ground & & & 9967. & \\
\hline $\mathrm{Tl}^{205} \mathrm{Br}^{81}$ & $1-$ & $4 \leftarrow 3$ & Excited & $11 / 2$ & $9 / 2$ & 9967.35 & 0.08 \\
\hline $\mathrm{Tl}^{205} \mathrm{Br}^{81}$ & $1-$ & $4 \leftarrow 3$ & Excited & $9 / 2$ & $7 / 2$ & 9967.35 & 0.08 \\
\hline $\mathrm{C}^{12}{ }_{*} \mathrm{H}_{2} \mathrm{C}^{12} \mathrm{H}_{2} \mathrm{C}^{12}{ }_{*} \mathrm{Cl}_{2}^{35}$ & 4-1061 & $4,2,3 \leftarrow 4,1,4$ & Ground & & & 9967.5 & \\
\hline $\mathrm{N}^{14} \mathrm{O}_{2}^{16} \mathrm{Cl}^{35}$ & $4-1461$ & $6,2,5 \leftarrow 6,2,4$ & Ground & $11 / 2$ & $11 / 2$ & 9973.90 & \\
\hline $\mathrm{N}^{14} \mathrm{O}_{2}^{16} \mathrm{Cl}^{35}$ & 4-1461 & $6,2,5 \leftarrow 6,2,4$ & Ground & $13 / 2$ & $13 / 2$ & 9973.90 & \\
\hline $\mathrm{N}^{14} \mathrm{O}_{2}^{16} \mathrm{Cl}^{35}$ & 4-1461 & $6,2,5 \leftarrow 6,2,4$ & Ground & $9 / 2$ & $9 / 2$ & 9976.40 & \\
\hline $\mathrm{N}^{14} \mathrm{O}_{2}^{16} \mathrm{Cl}^{35}$ & $4-1461$ & $6,2,5 \leftarrow 6,2,4$ & Ground & $15 / 2$ & $15 / 2$ & 9976.40 & \\
\hline $\mathrm{C}^{12} \mathrm{H}_{3} \mathrm{O}^{16} \mathrm{H}$ & 3- 211 & $5,2,3 \leftarrow 4,3,2$ & Ground & & & 9978.6 & .1 \\
\hline $\mathrm{Tl}^{205} \mathrm{Br}^{81}$ & $1-$ & $4 \leftarrow 3$ & Excited & $9 / 2$ & $7 / 2$ & 9998.00 & 0.03 \\
\hline $\mathrm{Tl}^{205} \mathrm{Br}^{81}$ & 1 - & $4 \leftarrow 3$ & Excited & $11 / 2$ & $9 / 2$ & 9998.00 & 0.03 \\
\hline $\mathrm{C}^{12} \mathrm{H}_{3} \mathrm{O}^{16} \mathrm{H}$ & 3- 211 & $4,3, \leftarrow 5,2$, & Ground & & & 10002 . & \\
\hline $\mathrm{T}^{205} \mathrm{Br}^{81}$ & 1. & $4 \leftarrow 3$ & Excited & $9 / 2$ & $7 / 2$ & 10028.30 & 0.03 \\
\hline $\mathrm{Tl}^{205} \mathrm{Br}^{81}$ & $1-$ & $4 \leftarrow 3$ & Excited & $11 / 2$ & $9 / 2$ & 10028.30 & 0.03 \\
\hline $\mathrm{Tl}^{205} \mathrm{Br}^{81}$ & $1-$ & $4 \leftarrow 3$ & Excited & $5 / 2$ & $3 / 2$ & 10031.36 & 0.04 \\
\hline
\end{tabular}




\begin{tabular}{|c|c|c|c|c|c|c|c|}
\hline Isotopic Species & $\begin{array}{l}\text { Vol.-Id. } \\
\text { Nos. }\end{array}$ & $\begin{array}{c}\text { Rotational } \\
\text { Quantum Nos. }\end{array}$ & Vib. State & $\mathrm{F}_{1}^{\prime} \quad \mathrm{F}^{\prime} \quad \mathrm{F}_{1}$ Hyperfine & $\mathrm{F}$ & $\begin{array}{l}\text { Frequency } \\
\mathrm{MHz}_{2}\end{array}$ & $\begin{aligned} & \text { Acc. } \\
\pm & \text { MHz }\end{aligned}$ \\
\hline $\mathrm{Tl}^{205} \mathrm{Br}^{81}$ & 1- & $4 \leftarrow 3$ & Excited & $7 / 2$ & $5 / 2$ & 10031.36 & 0.04 \\
\hline $\mathrm{O}^{16} \mathrm{~F}_{2}^{19}$ & $4-1611$ & $9,2,7 \leftarrow 10,1,10$ & Ground & & & 10057.72 & .10 \\
\hline $\mathrm{C}^{12}{ }_{*} \mathrm{H}_{2} \mathrm{C}^{13} \mathrm{H}_{2} \mathrm{C}^{12} * \mathrm{Cl}_{2}^{35}$ & 4-1068 & $10,6,4 \leftarrow 10,5,5$ & Ground & & & 10058.20 & \\
\hline $\mathrm{C}^{12} \mathrm{H}_{3} \mathrm{O}^{16} \mathrm{H}$ & 3- 211 & $5,2,4 \leftarrow 4,3,1$ & Ground & & & 10058.3 & .1 \\
\hline $\mathrm{Tl}^{205} \mathrm{Br}^{81}$ & $1-$ & $4 \leftarrow 3$ & Excited & $9 / 2$ & $7 / 2$ & 10058.68 & 0.03 \\
\hline $\mathrm{Tl}^{205} \mathrm{Br}^{81}$ & $1-$ & $4 \leftarrow 3$ & Excited & $11 / 2$ & $9 / 2$ & 10058.68 & 0.03 \\
\hline $\mathrm{C}^{12}{ }_{*} \mathrm{H}_{2} \mathrm{C}^{13} \mathrm{H}_{2} \mathrm{C}^{12}{ }_{*} \mathrm{Cl}_{2}^{35}$ & $4-1068$ & $10,5,5 \leftarrow 10,4,6$ & Ground & & & 10060.25 & \\
\hline $\mathrm{Tl}^{205} \mathrm{Br}^{81}$ & 1 - & $4 \leftarrow 3$ & Excited & $5 / 2$ & $3 / 2$ & 10061.70 & 0.03 \\
\hline $\mathrm{Tl}^{205} \mathrm{Br}^{81}$ & 1 . & $4 \leftarrow 3$ & Excited & $7 / 2$ & $5 / 2$ & 10061.70 & 0.03 \\
\hline c- $\mathrm{C}^{12} \mathrm{H}_{3} \mathrm{C}^{12} \mathrm{H}: \mathrm{C}^{12} \mathrm{HF}^{19} \cdot \mathrm{E}$ & 3. 702 & $1,0,1 \leftarrow 0,0,0$ & & & & 10062.98 & .2 \\
\hline c- $\mathrm{C}^{12} \mathrm{H}_{3} \mathrm{C}^{12} \mathrm{H}: \mathrm{C}^{12} \mathrm{HF}^{19}-\mathrm{A}$ & 3. 701 & $1,0,1 \leftarrow 0,0,0$ & & & & 10064.23 & .2 \\
\hline $\mathrm{D}_{2} \mathrm{O}_{2}^{16}$ & 3. 42 & Not Reported & & & & 10068. & 3. \\
\hline $\mathrm{g}-\mathrm{C}^{12} \mathrm{H}_{2} \mathrm{DC}^{12} \mathrm{H}_{2} \mathrm{Cl}^{35}$ & 3. 544 & $1,0,1 \leftarrow 0,0,0$ & Ground & $3 / 2$ & $3 / 2$ & 10072.98 & .05 \\
\hline $\left.\mathrm{g}-\mathrm{C}^{12} \mathrm{H}_{2} \mathrm{DC}^{12} \mathrm{H}_{2} \mathrm{Cl}\right]^{35}$ & 3- 544 & $1,0,1 \leftarrow 0,0,0$ & Ground & $5 / 2$ & $3 / 2$ & 10084.92 & .05 \\
\hline $\mathrm{Tl}^{205} \mathrm{Br}^{81}$ & 1 . & $4 \leftarrow 3$ & Excited & $9 / 2$ & $7 / 2$ & 10089.30 & 0.03 \\
\hline $\mathrm{Tl}^{205} \mathrm{Br}^{81}$ & $1-$ & $4 \leftarrow 3$ & Excited & $11 / 2$ & $9 / 2$ & 10089.30 & 0.03 \\
\hline $\mathrm{Si}^{28} \mathrm{H}_{3} \mathrm{C}^{12} \mathrm{H}: \mathrm{C}^{12} \mathrm{H}_{2}$ & 3. 611 & $1,0,1 \leftarrow 0,0,0$ & Ground & & & 10089.96 & .05 \\
\hline $\mathrm{Si}^{28} \mathrm{H}_{3} \mathrm{C}^{12} \mathrm{H}: \mathrm{C}^{12} \mathrm{H}_{2}$ & 3. 611 & $1,0,1 \leftarrow 0,0,0$ & Ground & & & 10090.73 & .05 \\
\hline $\mathrm{N}^{14} \mathrm{H}_{3}$ & $4-1771$ & Not Reported & Ground & & & 10091. & \\
\hline $\mathrm{Tl}^{205} \mathrm{Br}^{81}$ & $1-$ & $4 \leftarrow 3$ & Excited & $7 / 2$ & $5 / 2$ & 10092.38 & 0.03 \\
\hline $\mathrm{Tl}^{205} \mathrm{Br}^{81}$ & 1. & $4 \leftarrow 3$ & Excited & $5 / 2$ & $3 / 2$ & 10092.38 & 0.03 \\
\hline $\mathrm{g}-\mathrm{C}^{12} \mathrm{H}_{2} \mathrm{DC}^{12} \mathrm{H}_{2} \mathrm{Cl}^{35}$ & 3- 544 & $1,0,1 \leftarrow 0,0,0$ & Ground & $1 / 2$ & $3 / 2$ & 10094.21 & .05 \\
\hline $\mathrm{Si}^{28} \mathrm{H}_{3} \mathrm{C}^{12} \mathrm{H}: \mathrm{C}^{12} \mathrm{H}_{2}$ & 3. 611 & $1,0,1 \leftarrow 0,0,0$ & Ground & & & 10095.99 & .05 \\
\hline $\mathrm{C}^{12} \mathrm{H}_{3} \mathrm{C}^{12}{ }_{*} \mathrm{H}_{2} \mathrm{O}^{16} \mathrm{C}^{12}{ }_{*} \mathrm{C}^{12} \mathrm{H}_{3}$ & 3. 951 & $4,2,2 \leftarrow 4,1,3$ & Ground & & & 10099.17 & .2 \\
\hline $\mathrm{C}^{12} \mathrm{H}_{3} \mathrm{~N}^{14} \mathrm{H}_{2}$ & 3- 261 & Not Reported & Ground & & & 10108.45 & .1 \\
\hline $\mathrm{C}^{12} \mathrm{H}_{3} \mathrm{~N}^{14} \mathrm{H}_{2}$ & 3- 261 & Not Reported & Ground & & & 10109.61 & .1 \\
\hline$\left(\mathrm{C}^{12} \mathrm{H}_{3}\right)_{2} \mathrm{Si}^{28} \mathrm{D}_{2}$ & 3. 643 & $2,1,1 \leftarrow 2,0,2$ & Ground & & & 10112.93 & .05 \\
\hline$\left(\mathrm{C}^{12} \mathrm{H}_{3}\right)_{2} \mathrm{Si}^{28} \mathrm{D}_{2}$ & 3- 643 & $2,1,1 \leftarrow 2,0,2$ & Ground & & & 10113.72 & .05 \\
\hline$\left(\mathrm{C}^{12} \mathrm{H}_{3}\right)_{2} \mathrm{Si}^{28} \mathrm{D}_{2}$ & 3- 643 & $2,1,1 \leftarrow 2,0,2$ & Ground & & & 10114.53 & .05 \\
\hline $\mathrm{Tl}^{205} \mathrm{Br}^{81}$ & 1 . & $4 \leftarrow 3$ & Excited & $11 / 2$ & $9 / 2$ & 10119.78 & 0.03 \\
\hline $\mathrm{Tl}^{205} \mathrm{Br}^{81}$ & 1. & $4 \leftarrow 3$ & Exeited & $9 / 2$ & $7 / 2$ & 10119.78 & 0.03 \\
\hline $\mathrm{Tl}^{205} \mathrm{Br}^{81}$ & 1. & $4 \leftarrow 3$ & Excited & $7 / 2$ & $5 / 2$ & 10122.81 & 0.03 \\
\hline $\mathrm{Tl}^{205} \mathrm{Br}^{81}$ & 1. & $4 \leftarrow 3$ & Excited & $5 / 2$ & $3 / 2$ & 10122.81 & 0.03 \\
\hline $\mathrm{C}^{13} \mathrm{H}_{3} \mathrm{C}^{12} \mathrm{HO}$ & 3. 476 & $3,0,3 \leftarrow 2,1,2$ & Ground & & & 10146.83 & .2 \\
\hline $\mathrm{Tl}^{203} \mathrm{Br}^{81}$ & 1 - & $4 \leftarrow 3$ & Excited & $11 / 2$ & $9 / 2$ & 10147.89 & 0.04 \\
\hline $\mathrm{Tl}^{203} \mathrm{Br}^{81}$ & 1- & $4 \leftarrow 3$ & Excited & $9 / 2$ & $7 / 2$ & 10147.89 & 0.04 \\
\hline $\mathrm{Tl}^{205} \mathrm{Br}^{81}$ & $1-$ & $4 \leftarrow 3$ & Ground & $9 / 2$ & $7 / 2$ & 10150.36 & 0.03 \\
\hline $\mathrm{Tl}^{205} \mathrm{Br}^{81}$ & $1-$ & $4 \leftarrow 3$ & Ground & $11 / 2$ & $9 / 2$ & 10150.36 & 0.03 \\
\hline $\mathrm{Tl}^{205} \mathrm{Br}^{81}$ & $1-$ & $4 \leftarrow 3$ & Ground & $7 / 2$ & $5 / 2$ & 10153.41 & 0.03 \\
\hline $\mathrm{Tl}^{205} \mathrm{Br}^{81}$ & $1-$ & $4 \leftarrow 3$ & Ground & $5 / 2$ & $3 / 2$ & 10153.41 & 0.03 \\
\hline $\mathrm{C}^{12} \mathrm{H}_{3} \mathrm{~N}^{14} \mathrm{H}_{2}$ & 3. 261 & Not Reported & Ground & & & 10178.86 & .1 \\
\hline $\mathrm{Tl}^{203} \mathrm{Br}^{81}$ & $1-$ & $4 \leftarrow 3$ & Ground & $9 / 2$ & $7 / 2$ & 10178.87 & 0.04 \\
\hline $\mathrm{Tl}^{203} \mathrm{Br}^{81}$ & $1-$ & $4 \leftarrow 3$ & Ground & $11 / 2$ & $9 / 2$ & 10178.87 & 0.04 \\
\hline $\mathrm{Tl}^{203} \mathrm{Br}^{81}$ & $1-$ & $4 \leftarrow 3$ & Ground & $7 / 2$ & $5 / 2$ & 10181.86 & 0.06 \\
\hline $\mathrm{Tl}^{203} \mathrm{Br}^{81}$ & 1 - & $4 \leftarrow 3$ & Ground & $5 / 2$ & $3 / 2$ & 10181.86 & 0.06 \\
\hline
\end{tabular}




\begin{tabular}{|c|c|c|c|c|c|c|c|c|c|}
\hline Isotopic Species & $\begin{array}{l}\text { Vol.-Id. } \\
\text { Nos. }\end{array}$ & $\begin{array}{c}\text { Rotational } \\
\text { Quantum Nos. }\end{array}$ & Vib. State & $\mathrm{F}_{1}^{\prime}$ & $\underset{\mathrm{F}^{\prime}}{\text { Hyper }}$ & $\begin{array}{l}\text { rfine } \\
\mathrm{F}_{1}\end{array}$ & $F$ & $\begin{array}{c}\text { Frequency } \\
\mathrm{MHz}\end{array}$ & $\begin{aligned} & \text { Acc. } \\
\pm & \mathrm{MHz}\end{aligned}$ \\
\hline $\mathrm{DO}^{16}$ & 1 . & $9 / 2,5 \leftarrow 9 / 2,5$ & Ground & & $7 / 2$ & & $7 / 2$ & 10191.64 & .10 \\
\hline $\mathrm{DO}^{16}$ & $1-$ & $9 / 2,5 \leftarrow 9 / 2,5$ & Ground & & $9 / 2$ & & $9 / 2$ & 10199.10 & .10 \\
\hline $\mathrm{DC}^{13} \mathrm{~N}^{14}$ & 4- 294 & $7 \leftarrow 7$ & Excited & & & & & 10201.95 & .05 \\
\hline $\mathrm{DO}^{16}$ & 1 & $9 / 2,5 \leftarrow 9 / 2,5$ & Ground & & $11 / 2$ & & $11 / 2$ & 10208.14 & .10 \\
\hline $\mathrm{C}^{12} \mathrm{D}_{3} \mathrm{Si}^{\mathrm{b}} \mathrm{HD}_{2}$ & 3- 331 & $8,1,7 \leftarrow 8,1,8$ & & & & & & 10208.20 & .2 \\
\hline $\mathrm{Tl}^{205} \mathrm{Br}^{79}$ & $1-$ & $4 \leftarrow 3$ & Excited & & $11 / 2$ & & $9 / 2$ & 10208.93 & 0.03 \\
\hline $\mathrm{Tl}^{205} \mathrm{Br}^{79}$ & $1-$ & $4 \leftarrow 3$ & Excited & & $9 / 2$ & & $7 / 2$ & 10208.93 & 0.03 \\
\hline $\mathrm{D}_{2} \mathrm{O}_{2}^{16}$ & $3-\quad 42$ & Not Reported & & & & & & 10209 & 3. \\
\hline $\mathrm{Tl}^{205} \mathrm{Br}^{79}$ & $1-$ & $4 \leftarrow 3$ & Excited & & $5 / 2$ & & $3 / 2$ & 10212.58 & 0.04 \\
\hline $\mathrm{Tl}^{205} \mathrm{Br}^{79}$ & 1. & $4 \leftarrow 3$ & Excited & & $7 / 2$ & & $5 / 2$ & 10212.58 & 0.04 \\
\hline $\mathrm{O}_{3}^{16}$ & 4-1841 & $10,1,9 \leftarrow 9,2,8$ & Ground & & & & & 10226 . & \\
\hline $\mathrm{HDS}^{32}$ & $4-1727$ & $11,6,5 \leftarrow 11,6,6$ & Ground & & & & & 10235.81 & .05 \\
\hline $\mathrm{C}^{12} \mathrm{H}_{3} \mathrm{C}^{12} \mathrm{H}_{2} \mathrm{Cl}^{37}$ & 3- 542 & $1,0,1 \leftarrow 0,0,0$ & Ground & & $3 / 2$ & & $3 / 2$ & 10238.66 & .05 \\
\hline $\mathrm{Tl}^{205} \mathrm{Br}^{79}$ & 1 - & $4 \leftarrow 3$ & Excited & & $11 / 2$ & & $9 / 2$ & 10240.21 & 0.03 \\
\hline $\mathrm{Tl}^{205} \mathrm{Br}^{79}$ & $1-$ & $4 \leftarrow 3$ & Excited & & $9 / 2$ & & $7 / 2$ & 10240.21 & 0.03 \\
\hline $\mathrm{C}^{12} \mathrm{H}_{3} \mathrm{~N}^{14} \mathrm{H}_{2}$ & 3- 261 & Not Reported & Ground & & & & & 10240.48 & .04 \\
\hline $\mathrm{Tl}^{205} \mathrm{Br}^{79}$ & $1-$ & $4 \leftarrow 3$ & Excited & & $5 / 2$ & & $3 / 2$ & 10243.80 & 0.03 \\
\hline $\mathrm{Tl}^{205} \mathrm{Br}^{79}$ & $1-$ & $4 \leftarrow 3$ & Excited & & $7 / 2$ & & $5 / 2$ & 10243.80 & 0.03 \\
\hline $\mathrm{C}^{12} \mathrm{H}_{3} \mathrm{C}^{12} \mathrm{H}_{2} \mathrm{Cl}^{37}$ & 3- 542 & $1,0,1 \leftarrow 0,0,0$ & Ground & & $5 / 2$ & & $3 / 2$ & 10248.08 & .05 \\
\hline $\mathrm{C}^{12} \mathrm{H}_{3} \mathrm{C}^{12} \mathrm{H}_{2} \mathrm{Cl}^{37}$ & 3- 542 & $1,0,1 \leftarrow 0,0,0$ & Ground & & $1 / 2$ & & $3 / 2$ & 10255.97 & .05 \\
\hline $\mathrm{C}^{12} \mathrm{H}_{3} \mathrm{~N}^{14} \mathrm{H}_{2}$ & 3- 261 & $4,2, \leftarrow 5,1$, & Ground & & & & & 10262.41 & .1 \\
\hline $\mathrm{t}-\mathrm{C}^{12} * \mathrm{HDC}^{12} \mathrm{H}_{2} \mathrm{C}^{12} * \mathrm{Cl}^{35} \mathrm{Cl}^{37}$ & 4-1067 & $10,6,4 \leftarrow 10,5,5$ & Ground & & & & & 10270.1 & \\
\hline $\mathrm{Tl}^{205} \mathrm{Br}^{79}$ & 1 - & $4 \leftarrow 3$ & Excited & & $9 / 2$ & & $7 / 2$ & 10271.55 & 0.03 \\
\hline $\mathrm{Tl}^{205} \mathrm{Br}^{79}$ & $1-$ & $4 \leftarrow 3$ & Excited & & $11 / 2$ & & $9 / 2$ & 10271.55 & 0.03 \\
\hline $\mathrm{Tl}^{205} \mathrm{Br}^{79}$ & $1-$ & $4 \leftarrow 3$ & Excited & & $7 / 2$ & & $5 / 2$ & 10275.20 & 0.03 \\
\hline $\mathrm{Tl}^{205} \mathrm{Br}^{79}$ & $1-$ & $4 \leftarrow 3$ & Excited & & $5 / 9$. & & $3 / 2$ & 10275.20 & 0.03 \\
\hline $\mathrm{HDO}^{16}$ & $4 \cdot 1712$ & $2,2,1 \leftarrow 2,2,0$ & Ground & 1 & $3 / 9$ & 2 & $5 / 2$ & 10278.079 & .001 \\
\hline $\mathrm{HDO}^{16}$ & 4-1712 & $2,2,1 \leftarrow 2,2,0$ & Ground & 3 & $5 / 2$ & 3 & $7 / 2$ & 10278.136 & .001 \\
\hline $\mathrm{HDO}^{16}$ & 4-1712 & $2,2,1 \leftarrow 2,2,0$ & Ground & 1 & $1 / 2$ & 1 & $3 / 2$ & 10278.168 & .001 \\
\hline $\mathrm{HDO}^{16}$ & 4-1712 & $2,2,1 \leftarrow 2,2,0$ & Ground & 3 & $5 / 2$ & 1 & $3 / 2$ & 10278.225 & .001 \\
\hline $\mathrm{HDO}^{16}$ & 4-1712 & $2,2,1 \leftarrow 2,2,0$ & Cround & & & & & 10278.245 & .001 \\
\hline $\mathrm{HDO}^{16}$ & 4-1712 & $2,2,1 \leftarrow 2,2,0$ & Excited & 1 & $3 / 2$ & 3 & $5 / 2$ & 10278.264 & .001 \\
\hline $\mathrm{HDO}^{16}$ & 4.1712 & $2,2,1 \leftarrow 2,2,0$ & Ground & 1 & $3 / 2$ & 1 & $1 / 2$ & 10278.323 & .001 \\
\hline $\mathrm{HDO}^{16}$ & 4-1712 & $2,2,1 \leftarrow 2,2,0$ & Ground & 3 & $7 / 2$ & 3 & $5 / 2$ & 10278.355 & .001 \\
\hline $\mathrm{HDO}^{16}$ & $4 \cdot 1712$ & $2,2,1 \leftarrow 2,2,0$ & Ground & 2 & $5 / 2$ & 1 & $3 / 2$ & 10278.412 & .001 \\
\hline $\mathrm{C}^{12} \mathrm{H}_{3} \mathrm{C}^{12} * \mathrm{H}_{2} \mathrm{O}^{16} \mathrm{C}^{12} * \mathrm{C}^{12} \mathrm{H}_{3}$ & 3- 951 & $3,2,1 \leftarrow 3,1,2$ & Ground & & & & & 10281.98 & .2 \\
\hline $\mathrm{N}^{14} \mathrm{H}_{3}$ & $4-1771^{\text {it }}$ & $12,4 \leftarrow 12,4$ & Ground & & & & & 10293.46 & .10 \\
\hline $\mathrm{Tl}^{205} \mathrm{Br}^{79}$ & 1 - & $4 \leftarrow 3$ & Excited & & $9 / 2$ & & $7 / 2$ & 10302.91 & 0.03 \\
\hline $\mathrm{Tl}^{205} \mathrm{Br}^{79}$ & $1-$ & $4 \leftarrow 3$ & Excited & & $11 / 2$ & & $9 / 2$ & 10302.91 & 0.03 \\
\hline $\mathrm{DC}^{12} \mathrm{DO}^{16}$ & 4- 384 & $10,3,7 \leftarrow 10,3,8$ & Ground & & & & & 10304.64 & \\
\hline $\mathrm{Tl}^{205} \mathrm{Br}^{79}$ & $1-$ & $4 \leftarrow 3$ & Excited & & $5 / 2$ & & $3 / 2$ & 10306.50 & 0.03 \\
\hline $\mathrm{Tl}^{205} \mathrm{Br}^{79}$ & $1-$ & $4 \leftarrow 3$ & Excited & & $7 / 2$ & & $5 / 2$ & 10306.50 & 0.03 \\
\hline$\left(\mathrm{C}^{12} \mathrm{H}_{3}\right)_{3} \mathrm{Si}^{28} \mathrm{D}$ & 3- 872 & 1. $\leftarrow 0$ & Ground & & & & & 10319.4 & .10 \\
\hline $\mathrm{Tl}^{203} \mathrm{Br}^{79}$ & $1-$ & $4 \leftarrow 3$ & Excited & & $9 / 2$ & & $7 / 2$ & 10331.16 & 0.04 \\
\hline $\mathrm{Tl}^{203} \mathrm{Br}^{79}$ & $1-$ & $4 \leftarrow 3$ & Excited & & $11 / 2$ & & $9 / 2$ & 10331.16 & 0.04 \\
\hline
\end{tabular}




\begin{tabular}{|c|c|c|c|c|c|c|c|}
\hline \multirow{2}{*}{ Isotopic Species } & \multirow{2}{*}{$\begin{array}{l}\text { Vol.-Id. } \\
\text { Nos. }\end{array}$} & \multirow{2}{*}{$\begin{array}{c}\text { Rotational } \\
\text { Quantum Nos. }\end{array}$} & \multirow{2}{*}{ Vib. State } & \multicolumn{2}{|l|}{ Hyperfine } & \multirow{2}{*}{$\begin{array}{c}\text { Frequency } \\
\text { IIIt }\end{array}$} & \multirow{2}{*}{$\begin{aligned} & \text { lece } \\
\pm & 111 \%\end{aligned}$} \\
\hline & & & & $\mathrm{F}_{1}^{\prime} \quad \mathrm{F}^{\prime} \quad \mathrm{F}_{1}$ & $\mathrm{~F}$ & & \\
\hline $\left.\mathrm{O}_{3}\right)_{2} \mathrm{O}^{16}$ & 3- 592 & $2,0,2 \leftarrow 1,1,1$ & Ground & & & 103.32 .3 & .5 \\
\hline $\mathrm{Br}^{79}$ & 1 . & $4 \leftarrow 3$ & Ground & $9 / 2$ & $7 / 2$ & 10334,35 & 0.03 \\
\hline $\mathrm{Br}^{79}$ & 1 . & $4 \leftarrow 3$ & Ground & $11 / 2$ & $9 / 2$ & 10.334 .35 & 0.03 \\
\hline$!_{2}^{16}$ & 3- 43 & $8, \quad \leftarrow 8$, & & & & 10336 & 3. \\
\hline $3 r^{79}$ & $1-$ & $4 \leftarrow 3$ & Ground & $7 / 2$ & $5 / 2$ & 10337.98 & 0.03 \\
\hline $3 r^{79}$ & $1-$ & $4 \leftarrow 3$ & Ground & $5 / 2$ & $3 / 2$ & 10337.98 & 0.03 \\
\hline $\mathrm{O}_{3}^{16}$ & $3-\quad 31$ & $6,5,1 \leftarrow 6,5,2$ & Ground & & & 10.344 .23 & \\
\hline $\mathrm{Br}^{79}$ & $1-$ & $4 \leftarrow 3$ & Ground & $9 / 2$ & $7 / 2$ & 10362.63 & 0.03 \\
\hline $\mathrm{Br}^{79}$ & 1 . & $4 \leftarrow 3$ & Ground & $11 / 2$ & $9 / 2$ & 10362.63 & 0.03 \\
\hline $\mathrm{Br}^{79}$ & $1-$ & $4 \leftarrow 3$ & Ground & $7 / 2$ & $5 / 2$ & 10366.24 & 0.04 \\
\hline $\mathrm{Br}^{79}$ & 1 - & $4 \leftarrow 3$ & Ground & $5 / 2$ & $3 / 2$ & 10366.24 & 0.04 \\
\hline${ }^{2} \mathrm{HO}^{16}$ & 4- 381 & $23,4,19 \longleftarrow 23,4,20$ & Ground & & & 10366.51 & \\
\hline $9^{17}$ & $4-1714$ & $2,2,0 \leftarrow 2,2,1$ & Ground & & & 10374.56 & \\
\hline $\mathrm{H}_{3} \mathrm{C}^{12} \mathrm{~F}^{19}: \mathrm{C}^{12} \mathrm{H}_{2}$ & 3. 721 & $8,6,2 \leftarrow 8,6,3$ & Ground & & & 10379.75 & .1 \\
\hline $\mathrm{H}_{3} \mathrm{~N}^{14} \mathrm{H}_{2}$ & 3- 261 & Not Reported & Ground & & & 10379.79 & .1 \\
\hline $\mathrm{H}_{3} \mathrm{~N}^{14} \mathrm{H}_{2}$ & 3- 261 & Not Reported & Ground & & & 10381.21 & .1 \\
\hline${ }_{3} \mathrm{C}^{13} \mathrm{H}_{2} \mathrm{Cl}^{35}$ & 3- 546 & $1,0,1 \leftarrow 0,0,0$ & Ground & $3 / 2$ & $3 / 2$ & 10386.51 & .05 \\
\hline $\mathrm{Cl}^{37}$ & $1-$ & $2 \leftarrow 1$ & Excited & $5 / 2$ & $3 / 2$ & 10387.80 & 0.12 \\
\hline $\mathrm{Cl}^{37}$ & $1-$ & $2 \leftarrow 1$ & Excited & $7 / 2$ & $5 / 2$ & 10387.80 & 0.12 \\
\hline${ }_{3}^{19} \mathrm{C}^{12} \mathrm{O}^{16} \mathrm{O}^{16} \mathrm{H} \cdot \mathrm{HC}^{12} \mathrm{O}^{16} \mathrm{O}^{16} \mathrm{H}$ & 3- 661 & $9, \quad \leftarrow 8$, & Ground & & & 10388.5 & \\
\hline 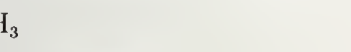 & $4-1771$ & $16,10 \leftarrow 16,10$ & Ground & & & 10397.12 & .10 \\
\hline $\mathrm{H}_{3} \mathrm{C}^{12} \mathrm{D}_{3} \mathrm{Si}^{28} \mathrm{H}_{2}$ & 3. 642 & $1,1,0 \leftarrow 1,0,1$ & Ground & & & 10397.79 & .05 \\
\hline $\mathrm{N}^{15} \mathrm{C}^{12} \mathrm{HO}^{16}$ & 3- 158 & $3,0,3 \leftarrow 2,1,2$ & Ground & & & 10397.83 & \\
\hline $\mathrm{I}_{3} \mathrm{C}^{12} \mathrm{D}_{3} \mathrm{Si}^{2 x} \mathrm{H}_{2}$ & 3- 642 & $1,1,0 \leftarrow 1,0,1$ & Ground & & & 10398.58 & .05 \\
\hline $\mathrm{I}_{3} \mathrm{C}^{13} \mathrm{H}_{2} \mathrm{Cl}^{35}$ & 3- 546 & $1,0,1 \leftarrow 0,0,0$ & Ground & $5 / 2$ & $3 / 2$ & 10398.86 & .05 \\
\hline $\mathrm{I}_{3} \mathrm{C}^{12} \mathrm{~F}^{19}: \mathrm{C}^{12} \mathrm{H}_{2}$ & 3- 721 & $8,6,2 \leftarrow 8,6,3$ & Ground & & & 10399.20 & .1 \\
\hline $\left.\mathrm{D}_{3}\right)_{2} \mathrm{O}^{16}$ & 3. 592 & Not Reported & Ground & & & 10400 & 5. \\
\hline $\mathrm{Cl}^{37}$ & $1-$ & $2 \leftarrow 1$ & Excited & $7 / 2$ & $5 / 2$ & 10403.28 & 0.06 \\
\hline $\mathrm{Cl}^{37}$ & 1 . & $2 \leftarrow 1$ & Excited & $5 / 2$ & $3 / 2$ & 10403.28 & 0.06 \\
\hline $\mathrm{I}_{3} \mathrm{C}^{13} \mathrm{H}_{2} \mathrm{Cl}^{35}$ & 3- 546 & $1,0,1 \leftarrow 0,0,0$ & Ground & $1 / 2$ & $3 / 2$ & 10408.78 & .05 \\
\hline $\mathrm{I}_{3} \mathrm{~S}^{32} \mathrm{C}^{12} \mathrm{D}_{3}$ & $3-606$ & $1,1,0 \leftarrow 1,0,1$ & Ground & & & $10+13.11$ & .05 \\
\hline $\left.\mathrm{D}_{3}\right)_{2} \mathrm{O}^{16}$ & 3. 592 & Not Reported & Ground & & & $10+15$ & 5. \\
\hline${ }^{2} \mathrm{~N}^{14}$ & 4. 292 & $7 \leftarrow 7$ & Excited & & & $10+19.88$ & .03 \\
\hline $\left.\mathrm{D}_{3}\right)_{2} \mathrm{O}^{16}$ & 3. 592 & Not Reported & - Ground & & & 10425 . & 5. \\
\hline $\mathrm{H}_{3} \mathrm{~S}^{32} \mathrm{C}^{12} \mathrm{D}_{3}$ & 3- 606 & $1,1,0 \leftarrow 1,0,1$ & Ground & & & 10425.98 & .05 \\
\hline $\mathrm{H}_{3}$ & $4-1771$ & $13,6 \leftarrow 13,6$ & Ground & & & 10426.76 & .10 \\
\hline $\mathrm{Cl}^{37}$ & $1-$ & $2 \leftarrow 1$ & Ground & $7 / 2$ & $5 / 2$ & $104: 32.38$ & 0.06 \\
\hline $\mathrm{Cl}^{37}$ & 1 - & $2 \leftarrow 1$ & Ground & $5 / 2$ & $3 / 2$ & 10432.38 & 0.06 \\
\hline $\mathrm{I}_{3} \mathrm{~S}^{32} \mathrm{C}^{12} \mathrm{D}_{3}$ & 3- 606 & $1,1,0 \leftarrow 1,0,1$ & Ground & & & 10432.81 & .05 \\
\hline $\mathrm{H}_{3} \mathrm{C}^{12} \mathrm{~F}^{19}: \mathrm{C}^{12} \mathrm{H}_{2}$ & 3- 721 & $12,9,3 \leftarrow 12,9,4$ & Ground & & & 10433.24 & .1 \\
\hline $\mathrm{Cl}^{37}$ & $1-$ & $2 \leftarrow 1$ & Ground & $3 / 2$ & $3 / 2$ & 10434.48 & 0.06 \\
\hline $\mathrm{H}_{2} \mathrm{C}^{12} \mathrm{H}_{2} \mathrm{C}^{12} \mathrm{Cl}_{2}^{35}$ & $4 \cdot 1061$ & $5,3,3 \leftarrow 5,2,4$ & Ground & & & 10441.2 & \\
\hline $\mathrm{H}_{3} \mathrm{~S}^{32} \mathrm{C}^{12} \mathrm{D}_{3}$ & 3. 606 & $1,1,0 \leftarrow 1,0,1$ & Ground & & & $10+41.92$ & .05 \\
\hline $\mathrm{I}_{3} \mathrm{C}^{12} \mathrm{H}_{2} \mathrm{Cl}^{35}$ & 3- 541 & $1,0,1 \leftarrow 0,0,0$ & Ground & $3 / 2$ & $3 / 2$ & 10446.11 & .05 \\
\hline${ }^{3} \mathrm{Cl}^{37}$ & 1 . & $2 \leftarrow 1$ & Ciround & $5 / 2$ & $3 / 2$ & $10+47.98$ & 0.06 \\
\hline
\end{tabular}




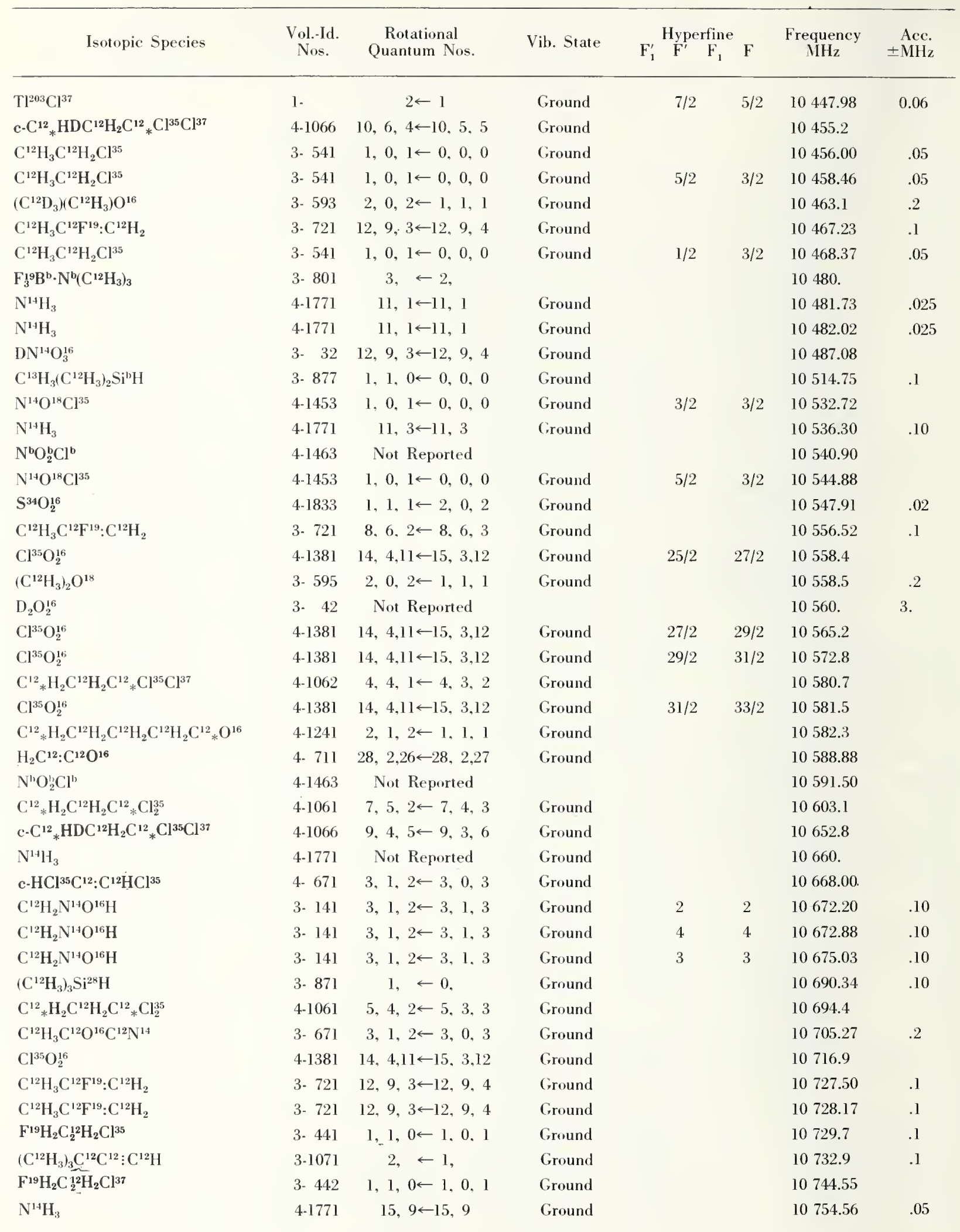




\begin{tabular}{|c|c|c|c|c|c|c|c|c|c|}
\hline Isotopic Species & $\begin{array}{l}\text { Vol.-Id. } \\
\text { Nos. }\end{array}$ & $\begin{array}{c}\text { Rotational } \\
\text { Quantum Nos. }\end{array}$ & Vib. State & $F_{1}^{\prime}$ & Hyper & $\begin{array}{c}\text { rfine } \\
F_{1}\end{array}$ & $\mathrm{~F}$ & $\begin{array}{c}\text { Frequency } \\
\mathrm{MHz}\end{array}$ & $\begin{aligned} & \text { Acc. } \\
\pm & \mathrm{MH} / \mathrm{z}\end{aligned}$ \\
\hline $\mathrm{t}-\mathrm{C}^{12}{ }_{*} \mathrm{HDC}^{12} \mathrm{H}_{2} \mathrm{C}^{12}{ }_{*} \mathrm{Cl}^{35} \mathrm{Cl}^{37}$ & 4-1067 & $9,4,5 \leftarrow 9,3,6$ & Ground & & & & & 10758.8 & \\
\hline $\mathrm{N}^{14} \mathrm{H}_{3}$ & 4.1771 & $11,2 \leftarrow 11,2$ & Ground & & & & & 10759.82 & .05 \\
\hline $\mathrm{HC}^{12}: \mathrm{C}^{12} \mathrm{C}^{12} \mathrm{DO}^{16}$ & 4. 921 & $6,0,6 \leftarrow 5,1,5$ & Ground & & & & & 10763.74 & .02 \\
\hline $\mathrm{Cl}^{35} \mathrm{O}_{2}^{16}$ & 4. 1381 & $28,7,22 \leftarrow 29,6,23$ & Ground & & $53 / 2$ & & $55 / 2$ & 10767.2 & \\
\hline $\mathrm{Cl}^{35} \mathrm{O}_{2}^{16}$ & 4-1381 & $28,7,22 \leftarrow 29,6,23$ & Ground & & $55 / 2$ & & $57 / 2$ & 10768.9 & \\
\hline$C]^{35} \mathrm{O}_{2}^{16}$ & 4-1381 & $28,7,22 \leftarrow 29,6,23$ & Ground & & $57 / 2$ & & $59 / 2$ & 10770.7 & \\
\hline $\mathrm{C}^{12} \mathrm{H}_{3} \mathrm{C}^{12}{ }_{*} \mathrm{H}_{2} \mathrm{O}^{16} \mathrm{C}^{12}{ }_{*} \mathrm{C}^{12} \mathrm{H}_{3}$ & 3- 951 & $5,2,3 \leftarrow 5,1,4$ & Ground & & & & & 10771.40 & .2 \\
\hline $\mathrm{Cl}^{35} \mathrm{O}_{2}^{16}$ & 4-1381 & $28,7,22 \leftarrow 29,6,23$ & Ground & & $59 / 2$ & & $61 / 2$ & 10771.9 & \\
\hline $\mathrm{C}^{12} \mathrm{H}_{3} \mathrm{C}^{12}{ }_{*} \mathrm{HO}^{16} \mathrm{C}^{12}{ }_{*} \mathrm{H}_{2}$ & 3- 761 & Not Reported & Ground & & & & & 10786.85 & .1 \\
\hline $\mathrm{C}^{12} \mathrm{H}_{3} \mathrm{C}^{12} \mathrm{~F}^{19}: \mathrm{C}^{12} \mathrm{H}_{2}$ & 3. 721 & $3,2,1 \leftarrow 3,2,2$ & Ground & & & & & 10790.88 & .1 \\
\hline $\mathrm{HDS}^{34}$ & 4. 1729 & $4,3,1 \leftarrow 4,3,2$ & Ground & & & & & 10802.36 & \\
\hline $\mathrm{DN}^{14} \mathrm{O}_{3}^{16}$ & 3. 32 & $4,3,1 \leftarrow 4,3,2$ & Ground & & & & & 10807.99 & \\
\hline $\mathrm{C}^{12} \mathrm{H}_{3} \mathrm{C}^{12}{ }_{*} \mathrm{HO}^{16} \mathrm{C}^{12}{ }_{*} \mathrm{H}_{2}$ & 3- 761 & Not Reported & Ground & & & & & 10816.43 & .1 \\
\hline $\mathrm{HDS}^{33}$ & $4-1728$ & $4,3,1 \leftarrow 4,3,2$ & Ground & & $5 / 2$ & & $5 / 2$ & 10830.54 & \\
\hline $\mathrm{HDS}^{33}$ & 4-1728 & $4,3,1 \leftarrow 4,3,2$ & Ground & & $11 / 2$ & & $11 / 2$ & 10830.83 & \\
\hline $\mathrm{HDS}^{33}$ & 4. 1728 & $4,3,1 \leftarrow 4,3,2$ & Ground & & $7 / 2$ & & $7 / 2$ & 10831.37 & \\
\hline $\mathrm{HDS}^{33}$ & 4-1728 & $4,3,1 \leftarrow 4,3,2$ & Ground & & $5 / 2$ & & $5 / 2$ & 10831.63 & \\
\hline $\mathrm{HDO}_{2}^{16}$ & $3-\quad 43$ & $3, \quad \leftarrow 3, \quad$, & & & & & & 10836. & 3. \\
\hline $\mathrm{N}^{14} \mathrm{H}_{3}$ & 4-1771 & $12,3 \leftarrow 12,3$ & Ground & & & & & 10836.10 & .05 \\
\hline $\mathrm{Tl}^{205} \mathrm{Cl}^{35}$ & 1. & $2 \leftarrow 1$ & Excited & & $7 / 2$ & & $5 / 2$ & 10841.66 & 0.03 \\
\hline $\mathrm{Tl}^{205} \mathrm{Cl}^{35}$ & 1 . & $2 \leftarrow 1$ & Excited & & $5 / 2$ & & $3 / 2$ & 10841.66 & 0.03 \\
\hline $\mathrm{N}^{14} \mathrm{H}_{2} \mathrm{D}$ & 4-1773 & $6,1,6 \leftarrow 6,0,6$ & Ground & & & & & 10842.62 & .05 \\
\hline $\mathrm{N}^{14} \mathrm{H}_{3}$ & $4-1771$ & Not Reported & Ground & & & & & 10844. & \\
\hline $\mathrm{C}^{12} \mathrm{H}_{3} \mathrm{C}^{12}{ }_{*} \mathrm{HO}^{16} \mathrm{C}^{12}{ }_{*} \mathrm{H}_{2}$ & 3. 761 & $11,5,6 \leftarrow 10,6,5$ & Ground & & & & & 10845.88 & .1 \\
\hline $\mathrm{C}^{12} \mathrm{H}_{3} \mathrm{C}^{12}{ }_{*} \mathrm{HO}^{16} \mathrm{C}^{12}{ }_{*} \mathrm{H}_{2}$ & 3. 761 & $11,5,6 \leftarrow 10,6,5$ & Ground & & & & & 10846.38 & .1 \\
\hline $\mathrm{N}^{14} \mathrm{O}^{16} \mathrm{Cl}^{37}$ & $4-1452$ & $1,0,1 \leftarrow 0,0,0$ & Ground & & $3 / 2$ & & $3 / 2$ & 10849.36 & \\
\hline $\mathrm{N}^{14} \mathrm{O}^{16} \mathrm{Cl}^{37}$ & 4. 1452 & $1,0,1 \leftarrow 0,0,0$ & Ground & & $5 / 2$ & & $3 / 2$ & 10858.96 & \\
\hline $\mathrm{HDS}^{32}$ & $4-1727$ & $4,3,1 \leftarrow 4,3,2$ & Ground & & & & & 10861.07 & .05 \\
\hline $\mathrm{C}^{12}{ }_{*} \mathrm{H}_{2} \mathrm{C}^{12} \mathrm{H}_{2} \mathrm{C}^{12}{ }_{*} \mathrm{Cl}^{35} \mathrm{Cl}^{37}$ & 4-1062 & $5,4,2 \leftarrow 5,3,3$ & Ground & & & & & 10863.7 & \\
\hline $\mathrm{C}^{12}{ }_{*} \mathrm{HDC}^{12} \mathrm{H}_{2} \mathrm{C}^{12}{ }_{*} \mathrm{Cl}_{2}^{35}$ & $4-1065$ & $6,4,3 \leftarrow 6,3,4$ & Ground & & & & & 10863.8 & \\
\hline $\mathrm{N}^{14} \mathrm{O}^{16} \mathrm{Cl}^{37}$ & $4-1452$ & $1,0,1 \leftarrow 0,0,0$ & Ground & & $1 / 2$ & & $3 / 2$ & 10866.65 & \\
\hline $\mathrm{Cl}^{35} \mathrm{O}_{2}^{16}$ & $4-1381$ & $14,4,11 \leftarrow 15,3,12$ & Ground & & $31 / 2$ & & $33 / 2$ & 10868.7 & \\
\hline $\mathrm{Cl}^{35} \mathrm{O}_{2}^{16}$ & $4-1381$ & $14,4,11 \leftarrow 15,3,12$ & Ground & & $29 / 2$ & & $3 \mathrm{H} / 2$ & 10877.8 & \\
\hline $\mathrm{HC}^{12} \mathrm{O}^{16} \mathrm{O}^{16} \mathrm{C}^{12} \mathrm{D}_{3}-\mathrm{A}$ & 3- 507 & $1,0,1 \leftarrow 0,0,0$ & Ground & & & & & 10879.95 & .2 \\
\hline $\mathrm{C}^{12} \mathrm{H}_{3} \mathrm{C}^{12}{ }_{*} \mathrm{H}_{2} \mathrm{O}^{16} \mathrm{C}^{12}{ }_{*} \mathrm{C}^{12} \mathrm{H}_{3}$ & 3. 951 & $4,1,3 \leftarrow 4,0,4$ & Ground & & & & & 10887.01 & .2 \\
\hline $\mathrm{Cl}^{35} \mathrm{O}_{2}^{16}$ & 4-1381 & $14,4,11 \leftarrow 15,3.12$ & Ground & & $27 / 2$ & & $29 / 2$ & 10887.1 & \\
\hline $\mathrm{Tl}^{205} \mathrm{Cl}^{35}$ & $1-$ & $2 \leftarrow 1$ & Excited & & $7 / 2$ & & $5 / 2$ & 10888.80 & 0.03 \\
\hline $\mathrm{Tl}^{205} \mathrm{Cl}^{35}$ & $1-$ & $2 \leftarrow 1$ & Excited & & $5 / 2$ & & $3 / 2$ & 10888.80 & 0.03 \\
\hline $\mathrm{Cl}^{35} \mathrm{O}_{2}^{16}$ & 4-1381 & $14,4,11 \leftarrow 15,3,12$ & Ground & & $25 / 2$ & & $27 / 2$ & 10896.2 & \\
\hline c-HDN ${ }^{15} \mathrm{C}^{12} \mathrm{HO}^{16}$ & 3. 158 & $1,1,1 \leftarrow 2,0,2$ & Ground & & & & & 10897.20 & \\
\hline $\mathrm{t}-\mathrm{C}^{12}{ }_{*} \mathrm{HDC}^{12} \mathrm{H}_{2} \mathrm{C}^{12}{ }_{*} \mathrm{Cl}^{35} \mathrm{Cl}^{37}$ & 4-1067 & $6,4,3 \leftarrow 6,3,4$ & Ground & & & & & 10903.5 & \\
\hline $\mathrm{Tl}^{203} \mathrm{Cl}^{35}$ & 1. & $2 \leftarrow 1$ & Excited & & $7 / 2$ & & $5 / 2$ & 10904.36 & 0.03 \\
\hline $\mathrm{Tl}^{203} \mathrm{Cl}^{35}$ & 1 . & $2 \leftarrow 1$ & Excited & & $5 / 2$ & & $3 / 2$ & 10904.36 & 0.03 \\
\hline $\mathrm{D}_{2} \mathrm{O}^{16}$ & 4-1713 & $3,1,3 \leftarrow 2,2,0$ & Ground & $7 / 2$ & 3 & $5 / 2$ & 2 & 10919.301 & .001 \\
\hline $\mathrm{D}_{2} \mathrm{O}^{16}$ & 4-1713 & $3,1,3 \leftarrow 2,2,0$ & Ground & $9 / 2$ & 5 & $7 / 2$ & 4 & 10919.357 & .001 \\
\hline
\end{tabular}




\begin{tabular}{|c|c|c|c|c|c|c|c|c|c|}
\hline Isotopic Species & $\begin{array}{l}\text { Vol.-ld. } \\
\text { Nos. }\end{array}$ & $\begin{array}{c}\text { Rotational } \\
\text { Quantum Nos. }\end{array}$ & Vib. State & $\mathrm{F}_{1}^{\prime}$ & Hyper & $\begin{array}{l}\text { rfine } \\
\mathrm{F}_{1}\end{array}$ & $F$ & $\begin{array}{c}\text { Frequency } \\
\mathrm{MHz}\end{array}$ & $\begin{aligned} & \text { Acc. } \\
& \pm \mathrm{MHz}\end{aligned}$ \\
\hline $\mathrm{D}_{2} \mathrm{O}^{16}$ & 4-1713 & $3,1,3 \leftarrow 2,2,0$ & Ground & $5 / 2$ & 4 & $3 / 2$ & 3 & 10919.521 & .001 \\
\hline $\mathrm{D}_{2} \mathrm{O}^{16}$ & 4-1713 & $3,1,3 \leftarrow 2,2,0$ & Ground & $9 / 2$ & 3 & $7 / 2$ & 2 & 10919.603 & .001 \\
\hline $\mathrm{N}^{\mathrm{b}} \mathrm{O}_{2}^{\mathrm{b}} \mathrm{Cl}^{\mathrm{b}}$ & $4-1463$ & Not Reported & & & & & & 10931.70 & \\
\hline $\mathrm{Tl}^{205} \mathrm{Cl}^{35}$ & 1 - & $2 \leftarrow 1$ & Ground & & $7 / 2$ & & $5 / 2$ & 10936.48 & 0.02 \\
\hline $\mathrm{Tl}^{205} \mathrm{Cl}^{35}$ & 1 . & $2 \leftarrow 1$ & Ground & & $5 / 2$ & & $3 / 2$ & 10936.48 & 0.02 \\
\hline $\mathrm{Tl}^{205} \mathrm{Cl}^{35}$ & $1-$ & $2 \leftarrow 1$ & Ground & & $3 / 2$ & & $3 / 2$ & 10939.30 & 0.02 \\
\hline $\mathrm{C}^{12} \mathrm{H}_{3} \mathrm{C}^{12} * \mathrm{HO}^{16} \mathrm{C}^{12}{ }_{*} \mathrm{H}_{2}$ & 3- 761 & Not Reported & Ground & & & & & 10939.88 & .1 \\
\hline $\mathrm{D}_{2} \mathrm{O}^{16}$ & 4-1713 & $4,4,1 \leftarrow 5,3,2$ & Ground & & & & & 10947.13 & .05 \\
\hline $\mathrm{Tl}^{203} \mathrm{Cl}^{35}$ & $1-$ & $2 \leftarrow 1$ & Ground & & $7 / 2$ & & $5 / 2$ & 10952.16 & 0.03 \\
\hline $\mathrm{Tl}^{203} \mathrm{Cl}^{35}$ & $1-$ & $2 \leftarrow 1$ & Ground & & $5 / 2$ & & $3 / 2$ & 10952.16 & 0.03 \\
\hline c- $\mathrm{Cl}^{12} \mathrm{HDCl}^{12} \mathrm{H}_{2} \mathrm{Cl}^{12} * \mathrm{Cl}^{35} \mathrm{Cl}^{37}$ & 4-1066 & $6,4,3 \leftarrow 6,3,4$ & Ground & & & & & 10957.8 & \\
\hline $\mathrm{C}^{12} \mathrm{H}_{3} \mathrm{C}^{12}{ }_{*} \mathrm{H}_{2} \mathrm{O}^{16} \mathrm{C}^{12}{ }_{*} \mathrm{C}^{12} \mathrm{H}_{3}$ & 3- 951 & $2,2,0 \leftarrow 2,1,1$ & Ground & & & & & 10967.72 & .2 \\
\hline $\mathrm{Cl}^{35} \mathrm{O}_{2}^{16}$ & $4-1381$ & 28, $7,22 \leftarrow 29,6,23$ & Ground & & & & & 10976.7 & \\
\hline $\mathrm{C}^{12} \mathrm{H}_{3} \mathrm{~S}^{32} \mathrm{H}$ & 3- 221 & $6,1,5 \leftarrow 6,1,6$ & Ground & & & & & 10983.4 & .1 \\
\hline $\mathrm{C}^{12} * \mathrm{H}_{2} \mathrm{C}^{12} \mathrm{H}_{2} \mathrm{C}^{12} * \mathrm{Cl}_{2}^{35}$ & 4-1061 & $6,2,4 \leftarrow 6,1,5$ & Ground & & & & & 11007.3 & \\
\hline $\mathrm{C}^{12} \mathrm{H}_{2} \mathrm{~N}^{14} \mathrm{O}^{16} \mathrm{H}$ & 3- 141 & $1,1,1 \leftarrow 2,0,2$ & Ground & & 1 & & 2 & 11007.38 & .10 \\
\hline $\mathrm{C}^{12} \mathrm{H}_{2} \mathrm{~N}^{14} \mathrm{O}^{16} \mathrm{H}$ & 3- 141 & $1,1,1 \leftarrow 2,0,2$ & Ground & & 2 & & 2 & 11008.88 & .10 \\
\hline $\mathrm{C}^{12} \mathrm{H}_{2} \mathrm{~N}^{14} \mathrm{O}^{16} \mathrm{H}$ & 3- 141 & $1,1,1 \leftarrow 2,0,2$ & Ground & & 1 & & 1 & 11008.88 & .10 \\
\hline $\mathrm{C}^{12} \mathrm{H}_{2} \mathrm{~N}^{14} \mathrm{O}^{16} \mathrm{H}$ & 3- 141 & $1,1,1 \leftarrow 2,0,2$ & Ground & & 2 & & 3 & 11009.65 & .10 \\
\hline $\mathrm{C}^{12} \mathrm{H}_{2} \mathrm{~N}^{14} \mathrm{O}^{16} \mathrm{H}$ & 3- 141 & $1,1,1 \leftarrow 2,0,2$ & Ground & & 0 & & 1 & 11012.32 & .10 \\
\hline $\mathrm{Br}^{79} \mathrm{~F}_{3}^{19}$ & 4- 81 & $3,1,2 \leftarrow 3,0,3$ & Ground & & $7 / 2$ & & $7 / 2$ & 11022.16 & \\
\hline $\mathrm{Br}^{81} \mathrm{~F}_{3}^{19}$ & 4. 82 & $3,1,2 \leftarrow 3,0,3$ & Ground & & $7 / 2$ & & $7 / 2$ & 11033.69 & \\
\hline a- $\mathrm{C}^{12} \mathrm{H}_{2} \mathrm{DS}^{32} \mathrm{C}^{12} \mathrm{H}_{3}$ & 3- 605 & $1,1,0 \leftarrow 1,0,1$ & Ground & & & & & 11044.96 & .05 \\
\hline $\mathrm{C}^{12} \mathrm{H}_{3} \mathrm{O}^{16} \mathrm{H}$ & 3- 211 & Not Reported & Ground & & & & & 11050.5 & .1 \\
\hline $\mathrm{H}_{2} \mathrm{O}_{2}^{16}$ & $3-41$ & Not Reported & & & & & & 11072.4 & .5 \\
\hline $\mathrm{O}_{3}^{16}$ & $4-1841$ & $4,0,4 \leftarrow 3,1,3$ & Ground & & & & & 11073. & \\
\hline $\mathrm{HC}^{12} \mathrm{DO}^{16}$ & 4- 385 & $19,4,15 \leftarrow 19,4,16$ & Ground & & & & & 11074.30 & \\
\hline $\mathrm{C}^{12} \mathrm{H}_{3} \mathrm{C}^{12}{ }_{*} \mathrm{HO}^{16} \mathrm{C}^{12}{ }_{*} \mathrm{H}_{2}$ & 3- 761 & Not Reported & Ground & & & & & 11087.72 & .1 \\
\hline $\mathrm{N}^{14} \mathrm{O}^{16} \mathrm{Cl}^{35}$ & $4-1451$ & $1,0,1 \leftarrow 0,0,0$ & Ground & & $3 / 2$ & & $3 / 2$ & 11104.15 & \\
\hline $\mathrm{D}_{2} \mathrm{O}_{2}^{16}$ & $3-\quad 42$ & Not Reported & & & & & & 11112. & 3. \\
\hline $\mathrm{N}^{14} \mathrm{O}^{16} \mathrm{Cl}^{35}$ & $4-1451$ & $1,0,1 \leftarrow 0,0,0$ & Ground & & $5 / 2$ & & $3 / 2$ & 11116.33 & \\
\hline $\mathrm{N}^{14} \mathrm{O}_{2}^{16} \mathrm{~F}^{19}$ & 4-1581 & $8,6,2 \leftarrow 8,6,3$ & Ground & & & & & 11120.0 & \\
\hline $\mathrm{C}^{12}{ }_{*} \mathrm{H}_{2} \mathrm{C}^{12} \mathrm{H}_{2} \mathrm{C}^{12} * \mathrm{Cl}^{35} \mathrm{Cl}^{37}$ & 4-1062 & $7,5,2 \leftarrow 7,4,3$ & Ground & & & & & 11121.9 & \\
\hline $\mathrm{N}^{14} \mathrm{O}^{16} \mathrm{Cl}^{35}$ & $4-1451$ & $1,0,1 \leftarrow 0,0,0$ & Ground & & $1 / 2$ & & $3 / 2$ & 11126.05 & \\
\hline $\mathrm{N}^{14} \mathrm{H}_{3}$ & $4-1771$ & $12,5 \leftarrow 12,5$ & Ground & & & & & 11132.70 & .05 \\
\hline $\mathrm{Br}^{81} \mathrm{~F}_{3}^{19}$ & 4- 82 & $3,1,2 \leftarrow 3,0,3$ & Ground & & $5 / 2$ & & $5 / 2$ & 11150.02 & \\
\hline $\mathrm{F}^{19} \mathrm{H}_{2} \mathrm{C}_{2}^{12} \mathrm{H}_{2} \mathrm{Cl}^{37}$ & 3- 442 & $2,1,1 \leftarrow 2,0,2$ & Ground & & & & & 11152.15 & \\
\hline $\mathrm{F}^{19} \mathrm{H}_{2} \mathrm{C}_{2}^{12} \mathrm{H}_{2} \mathrm{Cl}^{35}$ & 3- 441 & $2,1,1 \leftarrow 2,0,2$ & Ground & & & & & 11155. & .1 \\
\hline $\mathrm{Br}^{79} \mathrm{~F}_{3}^{19}$ & 4- 81 & $3,1,2 \leftarrow 3,0,3$ & Ground & & $5 / 2$ & & $5 / 2$ & 11162.14 & \\
\hline $\mathrm{C}^{13} \mathrm{H}_{3} \mathrm{C}^{13} \mathrm{HO}^{16}$ & 3- 478 & $3,0,3 \leftarrow 2,1,2$ & Ground & & & & & 11167.75 & .2 \\
\hline $\mathrm{N}^{14} \mathrm{H}_{3}$ & 4-1771 & $14,8 \leftarrow 14,8$ & Ground & & & & & 11177.38 & .05 \\
\hline $\mathrm{Cl}^{35} \mathrm{O}_{2}^{16}$ & 4-1381 & $28,7,22 \leftarrow 29,6,23$ & Ground & & $59 / 2$ & & $61 / 2$ & 11179.3 & \\
\hline $\mathrm{Cl}^{35} \mathrm{O}_{2}^{16}$ & 4-1381 & $28,7,22 \leftarrow 29,6,23$ & Ground & & $57 / 2$ & & $59 / 2$ & 11181.2 & \\
\hline $\mathrm{Cl}^{35} \mathrm{O}_{2}^{16}$ & 4- 1381 & $28,7,22 \leftarrow 29,6,23$ & Ground & & $55 / 2$ & & $57 / 2$ & 11183.0 & \\
\hline $\mathrm{Cl}^{35} \mathrm{O}_{2}^{16}$ & 4-1381 & $28,7,22 \leftarrow 29,6,23$ & Ground & & $53 / 2$ & & $55 / 2$ & 11184.5 & \\
\hline
\end{tabular}




\begin{tabular}{|c|c|c|c|c|c|c|c|}
\hline Isotopic Species & $\begin{array}{l}\text { Vol.-Id. } \\
\text { Nos. }\end{array}$ & $\begin{array}{l}\text { Rotational } \\
\text { Quantum Nos. }\end{array}$ & Vib. State & $F_{1} \stackrel{\text { Hyperfine }}{F^{\prime}} F_{1}$ & $\mathrm{~F}$ & $\begin{array}{c}\text { Frequency } \\
\text { MH } \%\end{array}$ & $\begin{aligned} & \text { Acc. } \\
& \pm \text { MHz }\end{aligned}$ \\
\hline $\mathrm{a}-\left(\mathrm{C}^{12} \mathrm{H}_{2} \mathrm{D}\right)\left(\mathrm{C}^{12} \mathrm{H}_{3}\right) \mathrm{O}^{16}$ & 3- 597 & $2,0,2 \leftarrow 1,1,1$ & Ground & & & 11201.6 & .2 \\
\hline $\mathrm{C}^{12} \mathrm{H}_{3} \mathrm{C}^{12}{ }_{*} \mathrm{H}_{2} \mathrm{O}^{16} \mathrm{C}^{12}{ }_{*} \mathrm{C}^{12} \mathrm{H}_{3}$ & 3. 951 & $19,6,14 \leftarrow 19,5,14$ & Ground & & & 11204.67 & .2 \\
\hline $\mathrm{C}^{12} \mathrm{H}_{3} \mathrm{C}^{12}{ }_{*} \mathrm{H}_{2} \mathrm{O}^{16} \mathrm{C}^{12}{ }_{*} \mathrm{C}^{12} \mathrm{H}_{3}$ & 3- 951 & $19,6,14 \leftarrow 19,5,14$ & Ground & & & 11205.59 & .2 \\
\hline $\mathrm{C}^{12} \mathrm{H}_{3} \mathrm{C}^{12}{ }_{*} \mathrm{H}_{2} \mathrm{O}^{16} \mathrm{C}^{12}{ }_{*} \mathrm{C}^{12} \mathrm{H}_{3}$ & 3. 951 & $19,6,14 \leftarrow 19,5,14$ & Ground & & & 11206.47 & .2 \\
\hline $\mathrm{t}-\mathrm{C}^{12}{ }_{*} \mathrm{HDC}^{12} \mathrm{H}_{2} \mathrm{C}^{12}{ }_{*} \mathrm{Cl}^{35} \mathrm{Cl}^{37}$ & $4-1067$ & $6,5,1 \leftarrow 6,4,2$ & Ground & & & 11206.5 & \\
\hline $\mathrm{C}^{12} \mathrm{H}_{3} \mathrm{C}^{12} \mathrm{~F}^{19}: \mathrm{C}^{12} \mathrm{H}_{2}$ & 3. 721 & $23,17,6 \leftarrow 23,17,7$ & Ground & & & 11235.41 & .1 \\
\hline $\mathrm{HDS}^{34}$ & $4-1729$ & $2,2,0 \leftarrow 2,2,1$ & Ground & & & 11235.45 & \\
\hline $\mathrm{C}^{12}{ }_{*} \mathrm{HDC}^{12} \mathrm{H}_{2} \mathrm{C}^{12}{ }_{*} \mathrm{Cl}_{2}^{35}$ & $4 \cdot 1065$ & $9,4,5 \leftarrow 9,3,6$ & Ground & & & 11236.2 & \\
\hline $\mathrm{C}^{12} \mathrm{H}_{3} \mathrm{C}^{12} \mathrm{~F}^{19}: \mathrm{C}^{12} \mathrm{H}_{2}$ & 3- 721 & $23,17,6 \leftarrow 23,17,7$ & Ground & & & 11236.52 & .1 \\
\hline $\operatorname{HDS}^{33}$ & $4-1728$ & $2,2,0 \leftarrow 2,2,1$ & Ground & $3 / 2$ & $1 / 2$ & 11251.28 & \\
\hline $\mathrm{HDS}^{33}$ & $4-1728$ & $2,2,0 \leftarrow 2,2,1$ & Ground & $5 / 2$ & $7 / 2$ & 11252.85 & \\
\hline HDS $^{33}$ & $4-1728$ & $2,2,0 \leftarrow 2,2,1$ & Ground & $5 / 2$ & $3 / 2$ & 11254.82 & \\
\hline HDS $^{33}$ & 4.1728 & $2,2,0 \leftarrow 2,2,1$ & Ground & $1 / 2$ & $1 / 2$ & 11257.16 & \\
\hline HDS $^{33}$ & $4-1728$ & $2,2,0 \leftarrow 2,2,1$ & Ground & $7 / 2$ & $7 / 2$ & 11258.55 & \\
\hline $\mathrm{HDS}^{33}$ & $4-1728$ & $2,2,0 \leftarrow 2,2,1$ & Ground & $3 / 2$ & $3 / 2$ & 11259.09 & \\
\hline HDS $^{33}$ & $4-1728$ & $2,2,0 \leftarrow 2,2,1$ & Ground & $5 / 2$ & $5 / 2$ & 11260.52 & \\
\hline $\mathrm{HDS}^{33}$ & 4. 1728 & $2,2,0 \leftarrow 2,2,1$ & Ground & $3 / 2$ & $5 / 2$ & 11264.78 & \\
\hline $\mathrm{HDS}^{33}$ & $4-1728$ & $2,2,0 \leftarrow 2,2,1$ & Ground & & & 11264.78 & \\
\hline HDS $^{33}$ & $4-1728$ & $2,2,0 \leftarrow 2,2,1$ & Ground & $7 / 2$ & $5 / 2$ & 11266.35 & \\
\hline $\mathrm{Br}^{81} \mathrm{~F}_{3}^{19}$ & 4- 82 & $3,1,2 \leftarrow 3,0,3$ & Ground & $9 / 2$ & $9 / 2$ & 11282.56 & \\
\hline $\mathrm{HDS}^{32}$ & $4-1727$ & $2,2,0 \leftarrow 2,2,1$ & Ground & & & 11283.83 & .05 \\
\hline $\mathrm{C}^{12} \mathrm{H}_{3} \mathrm{C}^{12} \mathrm{D}_{3} \mathrm{Si}^{28} \mathrm{H}_{2}$ & 3- 642 & $2,1,1 \leftarrow 2,0,2$ & Ground & & & 11309.18 & .05 \\
\hline $\mathrm{C}^{12} \mathrm{H}_{3} \mathrm{C}^{12} \mathrm{D}_{3} \mathrm{Si}^{28} \mathrm{H}_{2}$ & 3- 642 & $2,1,1 \leftarrow 2,0,2$ & Ground & & & 11310.02 & .05 \\
\hline $\mathrm{Br}^{79} \mathrm{~F}_{3}^{19}$ & 4- 81 & $3,1,2 \leftarrow 3,0,3$ & Ground & $9 / 2$ & $9 / 2$ & 11319.44 & \\
\hline $\mathrm{C}^{12} \mathrm{H}_{3} \mathrm{C}^{12}{ }_{*} \mathrm{HO}^{16} \mathrm{C}^{12}{ }_{*} \mathrm{H}_{2}$ & 3- 761 & $1,1,1 \leftarrow 1,0,1$ & Ground & & & 11341.70 & .1 \\
\hline $\mathrm{C}^{12}{ }_{*} \mathrm{H}_{2} \mathrm{C}^{12} \mathrm{H}_{2} \mathrm{C}^{12} \mathrm{H}_{2} \mathrm{C}^{12} \mathrm{H}_{2} \mathrm{C}^{12} \mathrm{O}^{16}$ & 4-1241 & $2,0,2 \leftarrow 1,0,1$ & Ground & & & 11349.1 & \\
\hline $\mathrm{H}_{2} \mathrm{~N}^{14} \mathrm{~N}^{14} \mathrm{H}_{2}$ & 3- 51 & Not Reported & & & & 11351.2 & \\
\hline $\mathrm{H}_{2} \mathrm{~N}^{14} \mathrm{~N}^{14} \mathrm{H}_{2}$ & 3- 51 & $11,3 \leftarrow 12,2$ & Ground & & & 11351.4 & \\
\hline $\mathrm{H}_{2} \mathrm{~N}^{14} \mathrm{~N}^{14} \mathrm{H}_{2}$ & 3- 51 & Not Reported & & & & 11351.56 & \\
\hline c- $\mathrm{C}^{12}{ }_{*} \mathrm{HDC}^{12} \mathrm{H}_{2} \mathrm{C}^{12}{ }_{*} \mathrm{Cl}^{35} \mathrm{Cl}^{37}$ & 4-1066 & $6.5,1 \leftarrow 6,4,2$ & Ground & & & 11361.1 & \\
\hline $\mathrm{H}_{2} \mathrm{~N}^{14} \mathrm{~N}^{14} \mathrm{H}_{2}$ & 3- 51 & $11,3 \leftarrow 12,2$ & Ground & & & 11363.0 & \\
\hline $\mathrm{S}^{33} \mathrm{O}_{2}^{16}$ & 4-1832 & $1,1,1 \leftarrow 2,0,2$ & Ground & $1 / 2$ & $1 / 2$ & 11368.002 & .015 \\
\hline $\mathrm{S}^{33} \mathrm{O}_{2}^{16}$ & 4-1832 & $1,1,1 \leftarrow 2,0,2$ & Ground & $1 / 2$ & $3 / 2$ & 11368.002 & .015 \\
\hline $\mathrm{S}^{33} \mathrm{O}_{2}^{16}$ & 4. 1832 & $1,1,1 \leftarrow 2,0,2$ & Ground & $5 / 2$ & $7 / 2$ & 11373.286 & .015 \\
\hline $\mathrm{S}^{33} \mathrm{O}_{2}^{16}$ & 4-1832 & $1,1,1 \leftarrow 2,0,2$ & Ground & $5 / 2$ & $5 / 2$ & 11373.286 & .015 \\
\hline $\mathrm{S}^{33} \mathrm{O}_{2}^{16}$ & 4-1832 & $1,1,1 \leftarrow 2,0,2$ & Ground & $5 / 2$ & $3 / 2$ & 11373.286 & .015 \\
\hline $\mathrm{S}^{33} \mathrm{O}_{2}^{16}$ & 4-1832 & $1,1,1 \leftarrow 2,0,2$ & Ground & $3 / 2$ & $3 / 2$ & 11379.825 & .015 \\
\hline $\mathrm{S}^{33} \mathrm{O}_{2}^{16}$ & 4-1832 & $1,1,1 \leftarrow 2,0,2$ & Ground & $3 / 2$ & $1 / 2$ & 11379.825 & .015 \\
\hline $\mathrm{S}^{33} \mathrm{O}_{2}^{16}$ & 4-1832 & $1,1,1 \leftarrow 2,0,2$ & Ground & $3 / 2$ & $5 / 2$ & 11379.825 & .015 \\
\hline $\mathrm{H}_{2} \mathrm{~N}^{14} \mathrm{~N}^{14} \mathrm{H}_{2}$ & $3-\quad 51$ & Not Reported & & & & 11388.0 & \\
\hline $\mathrm{H}_{2} \mathrm{~N}^{14} \mathrm{~N}^{14} \mathrm{H}_{2}$ & 3- 51 & Not Reported & & & & 11390.0 & \\
\hline $\mathrm{D}_{2} \mathrm{O}_{2}^{16}$ & 3- 42 & Not Reported & & & & 11391. & 3. \\
\hline $\mathrm{N}^{14} \mathrm{H}_{3}$ & 4-1771 & Not Reported & Ground & & & 11400. & \\
\hline $\mathrm{Br}^{81} \mathrm{~F}_{3}^{19}$ & 4- 82 & $3,1,2 \leftarrow 3,0,3$ & Ground & $3 / 2$ & $3 / 2$ & 11401.82 & \\
\hline $\mathrm{H}_{2} \mathrm{~N}^{14} \mathrm{~N}^{14} \mathrm{H}_{2}$ & 3. 51 & Not Reported & & & & 11406.2 & \\
\hline
\end{tabular}




\begin{tabular}{|c|c|c|c|c|c|c|c|}
\hline Isotopic Species & $\begin{array}{l}\text { Vol.-Id. } \\
\text { Nos. }\end{array}$ & $\begin{array}{c}\text { Rotational } \\
\text { Quantum Nos. }\end{array}$ & Vib. State & $\mathrm{F}_{1}^{\prime} \stackrel{\mathrm{F}^{\prime}}{\stackrel{\text { Hyperfine }}{\mathrm{F}_{1}}}$ & $\mathrm{~F}$ & $\begin{array}{c}\text { Frequency } \\
\mathrm{MHz}\end{array}$ & $\begin{aligned} & \text { Acc. } \\
& \pm \mathrm{MHz}\end{aligned}$ \\
\hline $\mathrm{H}_{2} \mathrm{~N}^{14} \mathrm{~N}^{14} \mathrm{H}_{2}$ & $3-\quad 51$ & Not Reported & & & & 11413.67 & \\
\hline $\mathrm{s}-\mathrm{HC}^{12} \mathrm{O}^{16} \mathrm{O}^{16} \mathrm{C}^{12} \mathrm{H}_{2} \mathrm{D}-\mathrm{A}$ & 3- 505 & $1,0,1 \leftarrow 0,0,0$ & Ground & & & 11419.54 & .2 \\
\hline c- $\mathrm{HDN}^{14} \mathrm{C}^{12} \mathrm{HO}^{16}$ & 3- 152 & $7,1,6 \leftarrow 6,2,5$ & Ground & & & 11423.09 & \\
\hline $\mathrm{DC}^{12} \mathrm{~N}^{14}$ & 4- 292 & $5 \leftarrow 5$ & Excited & & & 11449.55 & .1 \\
\hline $\mathrm{D}_{2} \mathrm{O}_{2}^{16}$ & $3-\quad 42$ & Not Reported & & & & 11460 . & 3. \\
\hline $\mathrm{HC}^{12} \mathrm{O}^{16} \mathrm{O}^{16} \mathrm{C}^{12} \mathrm{D}_{3}-\mathrm{A}$ & 3. 507 & $7,2,5 \leftarrow 7,2,6$ & Ground & & & 11461.77 & .35 \\
\hline $\mathrm{Br}^{79} \mathrm{~F}_{3}^{19}$ & 4- 81 & $3,1,2 \leftarrow 3,0,3$ & Ground & $3 / 2$ & $3 / 2$ & 11462.68 & \\
\hline $\mathrm{C}^{12} \mathrm{H}_{3} \mathrm{C}^{12}{ }_{*} \mathrm{HO}^{16} \mathrm{C}^{12}{ }_{*} \mathrm{H}_{2}$ & 3- 761 & Not Reported & Ground & & & 11466.80 & .1 \\
\hline $\mathrm{C}^{12} \mathrm{D}_{3} \mathrm{C}^{13} \mathrm{O}^{16} \mathrm{C}^{12} \mathrm{~N}^{14}$ & 3. 676 & $1,1,1 \leftarrow 0,0,0$ & Ground & & & 11492.04 & .2 \\
\hline $\mathrm{C}^{12} \mathrm{D}_{3} \mathrm{C}^{12} \mathrm{O}^{16} \mathrm{C}^{12} \mathrm{~N}^{14}$ & 3- 675 & $1,1,1 \leftarrow 0,0,0$ & Ground & & & 11500.72 & .2 \\
\hline $\mathrm{C}^{12} \mathrm{H}_{3} \mathrm{C}^{12}{ }_{*} \mathrm{HO}^{16} \mathrm{C}^{12} * \mathrm{H}_{2}$ & 3- 761 & $4,1,4 \leftarrow 3,2,1$ & Ground & & & 11502.18 & .1 \\
\hline $\mathrm{HC}^{12} \mathrm{O}^{16} \mathrm{O}^{16} \mathrm{H}$ & 3- 71 & $33,5,28 \leftarrow 33,5,29$ & & & & 11512. & \\
\hline $\mathrm{C}^{12}{ }_{*} \mathrm{H}_{2} \mathrm{C}^{12} \mathrm{H}_{2} \mathrm{C}^{12} * \mathrm{Cl}_{2}^{35}$ & 4-1061 & $6,4,3 \leftarrow 6,3,4$ & Ground & & & 11521.0 & \\
\hline $\mathrm{C}^{12} \mathrm{H}_{3} \mathrm{C}^{12} \mathrm{~F}^{19}: \mathrm{C}^{12} \mathrm{H}_{2}$ & 3. 721 & $4,3,1 \leftarrow 4,2,2$ & Ground & & & 11521.81 & .1 \\
\hline $\mathrm{C}^{12} \mathrm{H}_{3} \mathrm{C}^{12} \mathrm{~F}^{19}: \mathrm{C}^{12} \mathrm{H}_{2}$ & 3- 721 & $4,3,1 \leftarrow 4,2,2$ & Ground & & & 11525.52 & .1 \\
\hline $\mathrm{C}^{12} \mathrm{H}_{3} \mathrm{C}^{12}{ }_{*} \mathrm{H}_{2} \mathrm{O}^{16} \mathrm{C}^{12}{ }_{*} \mathrm{C}^{12} \mathrm{H}_{3}$ & 3- 951 & $1,1,1 \leftarrow 0,0,0$ & Ground & & & 11526.30 & .2 \\
\hline c. $\mathrm{C}^{12}{ }_{*} \mathrm{HDC}^{12} \mathrm{H}_{2} \mathrm{C}^{12}{ }_{*} \mathrm{Cl}^{35} \mathrm{Cl}^{37}$ & $4 \cdot 1066$ & $5,1,4 \leftarrow 5,0,5$ & Ground & & & 11529.8 & \\
\hline $\mathrm{C}^{12} \mathrm{H}_{3} \mathrm{C}^{12} \mathrm{~F}^{19}: \mathrm{C}^{12} \mathrm{H}_{2}$ & 3- 721 & $4,3,1 \leftarrow 4,2,2$ & Ground & & & 11542.43 & .1 \\
\hline $\mathrm{C}^{12} \mathrm{H}_{2} \mathrm{~N}^{14} \mathrm{O}^{16} \mathrm{H}$ & 3- 141 & $3,0,3 \leftarrow 2,1,2$ & Ground & 2 & 1 & 11567.22 & .10 \\
\hline $\mathrm{C}^{12} \mathrm{H}_{2} \mathrm{~N}^{14} \mathrm{O}^{16} \mathrm{H}$ & 3- 141 & $3,0,3 \leftarrow 2,1,2$ & Ground & 4 & 3 & 11567.73 & .10 \\
\hline $\mathrm{C}^{12} \mathrm{H}_{2} \mathrm{~N}^{14} \mathrm{O}^{16} \mathrm{H}$ & 3- 141 & $3,0,3 \leftarrow 2,1,2$ & Ground & 3 & 2 & 11569.21 & .10 \\
\hline $\mathrm{O}^{16} \mathrm{O}^{18} \mathrm{O}^{18}$ & $4-1844$ & $2,1,2 \leftarrow 3,0,3$ & Ground & & & 11575.0 & \\
\hline $\mathrm{C}^{12} * \mathrm{H}_{2} \mathrm{C}^{12} \mathrm{H}_{2} \mathrm{C}^{12} * \mathrm{Cl}^{35} \mathrm{Cl}^{37}$ & 4-1062 & $6,4,3 \leftarrow 6,3,4$ & Ground & & & 11601.2 & \\
\hline $\mathrm{Cl}^{35} \mathrm{O}^{16} \mathrm{O}^{18}$ & 4-1383 & $3,0,3 \leftarrow 2,1,2$ & Ground & 1 & 0 & 11633.8 & \\
\hline $\mathrm{C}]^{35} \mathrm{O}^{16} \mathrm{O}^{18}$ & 4-1383 & $3,0,3 \leftarrow 2,1,2$ & Ground & 2 & 1 & 11640.1 & \\
\hline $\mathrm{F}^{19} \mathrm{HCC}^{12} \mathrm{O}^{16}$ & 4- 271 & $2,1,2 \leftarrow 3,0,3$ & & & & 11647.9 & .1 \\
\hline $\mathrm{F}^{19} \mathrm{HC}^{12} \mathrm{O}^{16}$ & 4. 271 & $3,0,3 \leftarrow 2,1,2$ & & & & 11648.01 & .04 \\
\hline $\mathrm{N}^{14} \mathrm{H}_{3}$ & $4-1771$ & $13,7 \leftarrow 13,7$ & Ground & & & 11673.16 & .05 \\
\hline $\mathrm{C}^{35} \mathrm{O}^{16} \mathrm{O}^{18}$ & 4-1383 & $3,0,3 \leftarrow 2,1,2$ & Ground & 3 & 2 & 11677.5 & \\
\hline $\mathrm{DN}^{14} \mathrm{O}_{3}^{16}$ & 3. $\quad 32$ & $8,6,2 \leftarrow 8,6,3$ & Ground & & & 11680.10 & \\
\hline $\mathrm{DC}^{12} \mathrm{~N}^{14}$ & 4. 292 & $4 \leftarrow 4$ & Excited & & & 11680.55 & .1 \\
\hline $\mathrm{HC}^{12} \mathrm{O}^{18} \mathrm{O}^{16} \mathrm{C}^{12} \mathrm{H}_{3} \cdot \mathrm{A}$ & 3. 513 & $1,0,1 \leftarrow 0,0,0$ & Ground & & & 11714.45 & .2 \\
\hline$\left(\mathrm{C}^{12} \mathrm{H}_{3}\right)_{2} \mathrm{~S}^{34}$ & 3. 602 & $1,1,0 \leftarrow 1,0,1$ & Ground & & & 11724.09 & .05 \\
\hline $\mathrm{C}^{12} \mathrm{H}_{3} \mathrm{C}^{12} \mathrm{~F}^{19}: \mathrm{C}^{12} \mathrm{H}_{2}$ & 3- 721 & $3,2,1 \leftarrow 3,1,2$ & Ground & & & 11724.93 & .1 \\
\hline $\mathrm{C}^{12} \mathrm{H}_{3} \mathrm{C}^{12} \mathrm{~F}^{19}: \mathrm{C}^{12} \mathrm{H}_{2}$ & 3- 721 & $3,2,1 \leftarrow 3,1,2$ & Ground & & & 11725.89 & .1 \\
\hline $\mathrm{C}^{12} \mathrm{H}_{3} \mathrm{C}^{12} \mathrm{~F}^{19}: \mathrm{C}^{12} \mathrm{H}_{2}$ & 3. 721 & $30,22,8 \leftarrow 30,22,9$ & Ground & & & 11726.82 & .1 \\
\hline $\mathrm{C}^{12} \mathrm{H}_{3} \mathrm{C}^{12} \mathrm{~F}^{19}: \mathrm{C}^{12} \mathrm{H}_{2}$ & 3- 721 & $30,22,8 \leftarrow 30,22,9$ & Ground & & & 11727.84 & .1 \\
\hline c- $\mathrm{HCl}^{35} \mathrm{C}^{12}: \mathrm{C}^{12} \mathrm{HCl}^{35}$ & 4. 671 & $4,1,3 \leftarrow 4,0,4$ & Ground & & & 11730.06 & \\
\hline $\mathrm{C}_{6}^{12} \mathrm{H}_{5} \mathrm{~F}^{19}$ & $4-1281$ & $3,1,3 \leftarrow 2,1,2$ & Ground & & & 11731.9 & \\
\hline $\mathrm{C}^{35} \mathrm{O}^{16} \mathrm{O}^{18}$ & 4-1383 & $3,0,3 \leftarrow 2,1,2$ & Ground & 4 & 3 & 11736.2 & \\
\hline $\mathrm{D}_{2} \mathrm{~N}^{14} \mathrm{C}^{12} \mathrm{HO}^{16}$ & 3- 154 & $1,1,1 \leftarrow 2,0,2$ & Ground & & & 11747.37 & \\
\hline $\mathrm{C}^{12} \mathrm{H}_{3} \mathrm{C}^{12}{ }_{*} \mathrm{HO}^{16} \mathrm{C}^{12}{ }_{*} \mathrm{H}_{2}$ & 3- 761 & $23,14, \leftarrow 24,13$, & Ground & & & 11747.79 & .1 \\
\hline $\mathrm{C}^{12} \mathrm{H}_{3} \mathrm{C}^{12} * \mathrm{HO}^{16} \mathrm{C}^{12} * \mathrm{H}_{2}$ & 3. 761 & $23,14, \leftarrow 24,13$, & Ground & & & 11748.57 & .1 \\
\hline $\mathrm{C}^{12}{ }_{*} \mathrm{HDC}^{12} \mathrm{H}_{2} \mathrm{C}^{12}{ }_{*} \mathrm{Cl}_{2}^{35}$ & $4-1065$ & $5,5,0 \leftarrow 5,4,1$ & Ground & & & 11752.0 & \\
\hline $\mathrm{HC}^{12} \mathrm{HO}^{16}$ & 4. 381 & $15,3,12 \leftarrow 15,3,13$ & Ground & & & 11753.13 & \\
\hline
\end{tabular}




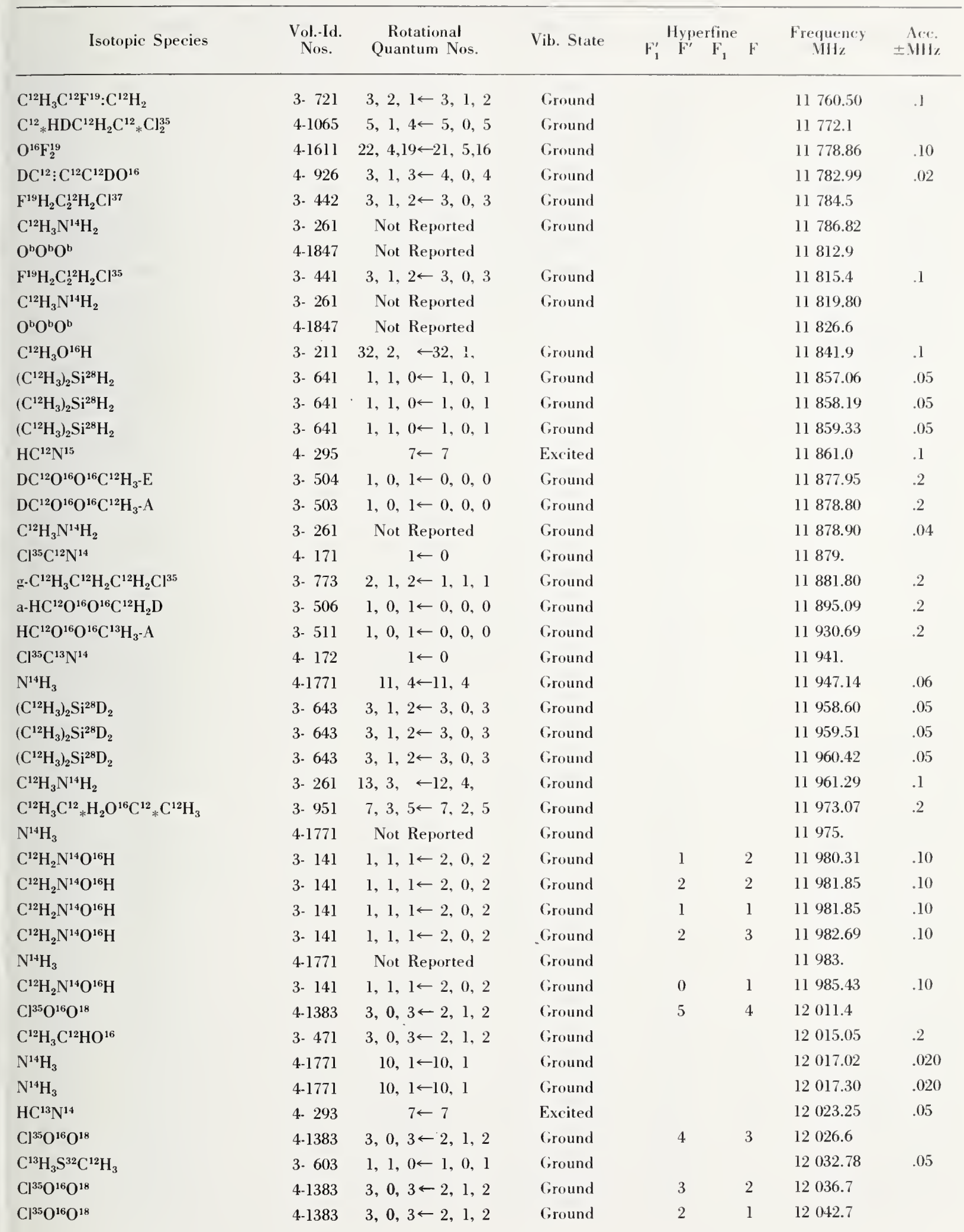




\begin{tabular}{|c|c|c|c|c|c|c|}
\hline Isotopic Species & $\begin{array}{l}\text { Vol.-Id. } \\
\text { Nos. }\end{array}$ & $\begin{array}{c}\text { Rotational } \\
\text { Quantum Nos. }\end{array}$ & Vib. State & $\mathrm{F}_{1}^{\prime} \stackrel{\text { Hyperfine }}{\mathrm{F}^{\prime}} \mathrm{F}_{1} \quad \mathrm{~F}$ & $\begin{array}{c}\text { Frequency } \\
\mathrm{MHz}\end{array}$ & $\begin{array}{r}\text { Acc. } \\
+\mathrm{MHz}\end{array}$ \\
\hline $\mathrm{C}^{12} \mathrm{H}_{3} \mathrm{~N}^{1+} \mathrm{H}_{2}$ & 3- 261 & Not Reported & Ground & & 12061.92 & .1 \\
\hline $\mathrm{C}^{12}{ }_{*} \mathrm{D}_{2} \mathrm{C}^{12} \mathrm{D}_{2} \mathrm{C}^{12}{ }_{*} \mathrm{Cl}_{2}^{35}$ & 4-1063 & $3,0,3 \leftarrow 2,1,2$ & Ground & & 12062.6 & \\
\hline $\mathrm{O}^{\mathrm{b}} \mathrm{O}^{\mathrm{b}} \mathrm{O}^{\mathrm{b}}$ & 4- 1847 & Not Reported & & & 12067.8 & \\
\hline $\mathrm{HC}^{12} \mathrm{O}^{16} \mathrm{O}^{18} \mathrm{C}^{12} \mathrm{H}_{3}-\mathrm{A}$ & 3. 515 & $1,0,1 \leftarrow 0,0,0$ & Ground & & 12068.35 & .2 \\
\hline $\mathrm{C}^{12} \mathrm{H}_{3} \mathrm{C}^{12}{ }_{*} \mathrm{HO}^{16} \mathrm{C}^{12}{ }_{*} \mathrm{H}_{2}$ & 3. 761 & $1,1,0 \leftarrow 1,0,1$ & Ground & & 12072.04 & .1 \\
\hline$\left(\mathrm{C}^{12} \mathrm{H}_{3}\right)_{2} \mathrm{~S}^{32}$ & 3. 601 & $1,1,0 \leftarrow 1,0,1$ & Ground & & 12091.72 & .05 \\
\hline$\left(\mathrm{C}^{12} \mathrm{H}_{3}\right)_{2} \mathrm{~S}^{32}$ & 3- 601 & $1,1,0 \leftarrow 1,0,1$ & Ground & & 12091.96 & .05 \\
\hline$\left(\mathrm{C}^{12} \mathrm{H}_{3}\right)_{2} \mathrm{~S}^{32}$ & 3. 601 & $1,1,0 \leftarrow 1,0,1$ & Ground & & 12092.03 & .05 \\
\hline$\left(\mathrm{C}^{12} \mathrm{H}_{3}\right)_{2} \mathrm{~S}^{32}$ & 3- 601 & $1,1,0 \leftarrow 1,0,1$ & Ground & & 12092.20 & .05 \\
\hline $\mathrm{C}^{12}{ }_{*} \mathrm{D}_{2} \mathrm{C}^{12} \mathrm{D}_{2} \mathrm{C}^{12}{ }_{*} \mathrm{Cl}^{35} \mathrm{Cl}^{37}$ & $4-1064$ & $2,2,1 \leftarrow 1,1,0$ & Ground & & 12096.5 & \\
\hline $\mathrm{C}^{12} \mathrm{H}_{3} \mathrm{~S}^{32} \mathrm{C}^{12} \mathrm{D}_{3}$ & 3- 606 & $2,1,1 \leftarrow 2,0,2$ & Ground & & 12111.96 & .05 \\
\hline $\mathrm{C}^{12} \mathrm{H}_{3} \mathrm{~S}^{32} \mathrm{C}^{12} \mathrm{D}_{3}$ & 3- 606 & $2,1,1 \leftarrow 2,0,2$ & Ground & & 12114.76 & .05 \\
\hline $\mathrm{C}^{12} \mathrm{H}_{3} \mathrm{~S}^{32} \mathrm{C}^{12} \mathrm{D}_{3}$ & 3- 606 & $2,1,1 \leftarrow 2,0,2$ & Ground & & 12122.46 & .05 \\
\hline $\mathrm{C}^{12} \mathrm{H}_{3} \mathrm{~S}^{32} \mathrm{C}^{12} \mathrm{D}_{3}$ & 3- 606 & $2,1,1 \leftarrow 2,0,2$ & Ground & & 12123.88 & .05 \\
\hline $\mathrm{HC}^{13} \mathrm{O}^{16} \mathrm{O}^{16} \mathrm{C}^{12} \mathrm{H}_{3}-\mathrm{E}$ & 3- 509 & $1,0,1 \leftarrow 0,0,0$ & Ground & & 12127.05 & .2 \\
\hline $\mathrm{HC}^{13} \mathrm{O}^{16} \mathrm{O}^{16} \mathrm{C}^{12} \mathrm{H}_{3}-\mathrm{A}$ & 3. 508 & $1,0,1 \leftarrow 0,0,0$ & Ground & & 12127.96 & .2 \\
\hline$\left(\mathrm{C}^{12} \mathrm{H}_{3}\right)_{2} \mathrm{~S}^{32}$ & 3- 601 & $2,1,2 \leftarrow 2,2,1$ & Ground & & 12142.83 & .05 \\
\hline$\left(\mathrm{C}^{12} \mathrm{H}_{3}\right)_{2} \mathrm{~S}^{32}$ & 3- 601 & $2,1,2 \leftarrow 2,2,1$ & Ground & & 12143.37 & .05 \\
\hline$\left(\mathrm{C}^{12} \mathrm{H}_{3}\right)_{2} \mathrm{~S}^{32}$ & 3- 601 & $2,1,2 \leftarrow 2,2,1$ & Ground & & 12143.86 & .05 \\
\hline$\left(\mathrm{C}^{12} \mathrm{H}_{3}\right)_{2} \mathrm{~S}^{32}$ & 3- 601 & $2,1,2 \leftarrow 2,2,1$ & Ground & & 12143.99 & .05 \\
\hline $\mathrm{N}^{14} \mathrm{H}_{3}$ & 4-1771 & Not Reported & Ground & & 12147. & \\
\hline $\mathrm{N}^{14} \mathrm{H}_{3}$ & $4-1771$ & Not Reported & Ground & & 12150. & \\
\hline $\mathrm{N}^{14} \mathrm{H}_{2} \mathrm{D}$ & $4 \cdot 1773$ & $7,1,7 \leftarrow 7,0,7$ & Ground & & 12154.57 & .05 \\
\hline $\mathrm{C}^{12} \mathrm{H}_{3} \mathrm{C}^{12} \mathrm{HO}^{16}$ & $3-471$ & $11,2,9 \longleftarrow 11,2,10$ & Ground & & 12158.31 & .2 \\
\hline $\mathrm{C}^{12} \mathrm{H}_{3} \mathrm{~N}^{14} \mathrm{H}_{2}$ & 3- 261 & $13,3, \leftarrow 12,4$, & Ground & & 12162.44 & .1 \\
\hline $\mathrm{O}^{16} \mathrm{C}^{12} \mathrm{~S}^{32}$ & 4. 521 & $1 \leftarrow 0$ & Ground & & 12162.97 & \\
\hline c. $\mathrm{HDN}^{14} \mathrm{C}^{12} \mathrm{HO}^{16}$ & 3. 152 & $3,0,3 \leftarrow 2,1,2$ & Ground & & 12166.33 & \\
\hline $\mathrm{O}^{\mathrm{b}} \mathrm{O}^{\mathrm{b}} \mathrm{O}^{\mathrm{b}}$ & $4-1847$ & Not Reported & & & 12171.0 & \\
\hline $\mathrm{C}^{12} \mathrm{D}_{3} \mathrm{C}^{13} \mathrm{O}^{16} \mathrm{C}^{12} \mathrm{~N}^{14}$ & 3-. 676 & $2,1,2 \leftarrow 1,1,1$ & Ground & & 12177.98 & .2 \\
\hline $\mathrm{C}^{12} \mathrm{H}_{3} \mathrm{O}^{16} \mathrm{H}$ & 3- 211 & $3,1, \leftarrow 2,0$, & Ground & & 12178.6 & .1 \\
\hline $\mathrm{C}^{12} \mathrm{D}_{3} \mathrm{C}^{12} \mathrm{O}^{16} \mathrm{C}^{12} \mathrm{~N}^{14}$ & 3- 675 & $2,1,2 \leftarrow 1,1,1$ & Ground & & 12192.56 & .2 \\
\hline $\mathrm{C}^{12} \mathrm{D}_{2} \mathrm{C}^{12} \mathrm{D}_{2} \mathrm{C}^{12} \mathrm{Cl}^{35} \mathrm{Cl}^{37}$ & $4-1064$ & $3,1,3 \leftarrow 2,0,2$ & Ground & & 12202.5 & \\
\hline $\mathrm{HC}^{12} \mathrm{O}^{16} \mathrm{O}^{16} \mathrm{C}^{12} \mathrm{H}_{3}-\mathrm{E}$ & 3- 502 & $1,0,1 \leftarrow 0,0,0$ & Ground & & 12218.21 & .2 \\
\hline $\mathrm{HC}^{12} \mathrm{O}^{16} \mathrm{O}^{16} \mathrm{C}^{12} \mathrm{H}_{3}-\mathrm{A}$ & 3- 501 & $1,0,1 \leftarrow 0,0,0$ & Ground & & 12219.29 & .2 \\
\hline $\mathrm{C}^{12} \mathrm{H}_{3} \mathrm{O}^{16} \mathrm{H}$ & 3- 211 & Not Reported & Ground & & 12229.4 & .1 \\
\hline $\mathrm{C}^{12} \mathrm{H}_{3} \mathrm{~N}^{14} \mathrm{H}_{2}$ & 3- 261 & $15,5, \quad \leftarrow 16,4$ & Ground & & 12238.84 & .1 \\
\hline $\mathrm{N}^{14} \mathrm{H}_{3}$ & $4-1771$ & $12,6 \leftarrow 12,6$ & Ground & & 12251.46 & .06 \\
\hline $\mathrm{C}^{12} \mathrm{H}_{3} \mathrm{~N}^{14} \mathrm{H}_{2}$ & 3- 261 & $15,5, \quad \longleftarrow 16,4$ & Ground & & 12258.96 & .1 \\
\hline $\mathrm{C}^{12} \mathrm{H}_{3} \mathrm{~N}^{14} \mathrm{H}_{2}$ & 3- 261 & Not Reported & Ground & & 12271.51 & .1 \\
\hline $\mathrm{s}-\mathrm{C}^{12} \mathrm{H}_{2} \mathrm{DC}^{12} \mathrm{HO}^{16}$ & 3- 473 & $4,1,3 \leftarrow 4,1,4$ & Ground & & 12273.5 & .3 \\
\hline $\mathrm{C}^{12} \mathrm{H}_{3} \mathrm{C}^{12} \mathrm{~F}^{19}: \mathrm{C}^{12} \mathrm{H}_{2}$ & 3- 721 & $5,4,1 \leftarrow 5,3,2$ & Ground & & 12291.71 & .1 \\
\hline $\mathrm{C}^{12} \mathrm{H}_{23} \mathrm{C}^{12} \mathrm{~F}^{19}: \mathrm{C}^{12} \mathrm{H}_{2}$ & 3- 721 & $5,4,1 \leftarrow 5,3,2$ & Ground & & 12301.64 & .1 \\
\hline $\mathrm{C}^{12} \mathrm{H}_{3} \mathrm{~N}^{14} \mathrm{H}_{2}$ & 3- 261 & Not Reported & Ground & & 12306.86 & .1 \\
\hline $\mathrm{N}^{14} \mathrm{H}_{3}$ & $4-1771$ & $17,12 \longleftarrow 17,12$ & Ground & & 12308.40 & .10 \\
\hline $\mathrm{C}^{12} \mathrm{H}_{3} \mathrm{C}^{12} \mathrm{~F}^{19}: \mathrm{C}^{12} \mathrm{H}_{2}$ & 3- 721 & $5,4,1 \leftarrow 5,3,2$ & Ground & & 12311.73 & .1 \\
\hline
\end{tabular}


Vol.-Id. Nos.
Rotational
Quantum Nos.
Vib. State $\begin{aligned} \text { Frequency } & \text { Arce } \\ \text { NHz } & \pm \text { WHz }\end{aligned}$

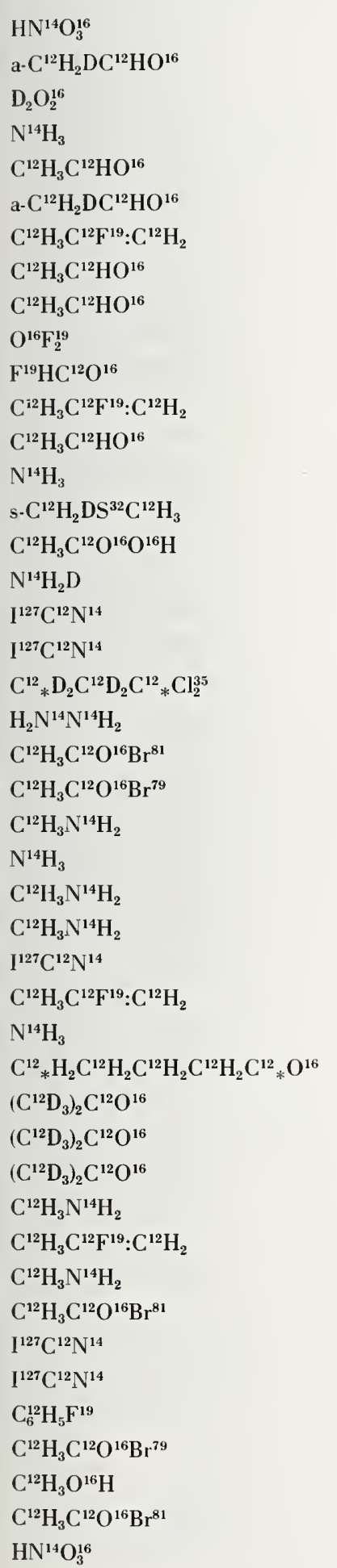

\begin{tabular}{|c|c|c|}
\hline 3. 31 & $11,9,2 \leftarrow-11,9,3$ & Ground \\
\hline 3. 481 & $5,1,4 \leftarrow 5,1,5$ & Ground \\
\hline $3-\quad 42$ & Not Reported & \\
\hline $4-1771$ & $10,2 \leftarrow-10,2$ & Ground \\
\hline 3- 471 & Not Reported & Ground \\
\hline 3- 481 & $5,1,4 \leftarrow 5,1,5$ & Ground \\
\hline 3- 721 & $2,1,1 \leftarrow 2,1,2$ & Ground \\
\hline 3. 471 & Not Reported & Ground \\
\hline 3- 471 & Not Reported & \\
\hline $4-1611$ & $36,7,30 \leftarrow 35,8,27$ & Ground \\
\hline 4- 271 & $4,0,4 \leftarrow 3,1,3$ & \\
\hline 3- 721 & $4,4,0 \leftarrow 4,3,1$ & Ground \\
\hline 3- 471 & Not Reported & \\
\hline $4-1771$ & Not Reported & Ground \\
\hline 3. 604 & $1,1,0 \leftarrow 1,0,1$ & Ground \\
\hline 3. 491 & $3,2,1 \leftarrow 3,1,2$ & Ground \\
\hline $4-1773$ & $10,2,9 \leftarrow 10,1,9$ & Ground \\
\hline 4- 511 & $2 \leftarrow 1$ & Ground \\
\hline 4. 511 & $2 \leftarrow 1$ & Ground \\
\hline $4-1063$ & $3,1,3 \leftarrow 2,0,2$ & Ground \\
\hline
\end{tabular}

3- $51 \quad$ Not Reported

3. $352 \quad 1,1,1 \leftarrow 0,0,0 \quad$ Ground

3- 351

3- 261

4-1771

3- 261

3- 261

4. 511

3. 721

4-1771

4-1241

3. 752

3- 752

3- 752

3. 261

3- 721

3. 261

3- 352

4. 511

4. 511

4. 1281

3. 351

3. 211

3. 352

3. 31
$1,1,1 \leftarrow 0,0,0$

$13,3, \leftarrow 12,4$,

Not Reported

Not Reported

Not Reported

$$
2 \leftarrow 1
$$

$4,4,0 \leftarrow 4,3,1$

$16,11 \leftarrow 16,11$

$2,1,1 \leftarrow 1,1,0$

$1,1,1 \leftarrow 0,0,0$

$1,1,1 \leftarrow 0,0,0$

$1,1,1 \leftarrow 0,0,0$

Not Reported

$4,4,0 \leftarrow 4,3,1$

Not Reported

$1,1,1 \leftarrow 0,0,0$

$$
2 \leftarrow 1
$$$$
2 \leftarrow 1
$$

$3,0,3 \leftarrow 2,0,2$

$1,1,1 \leftarrow 0,0,0$

$5,1, \leftarrow 5,1$,

$1,1,1 \leftarrow 0,0,0$

$5,4,1 \leftarrow 5,4,2$
Ground

Ground

Ground

Ground

Ground

Excited

Ground

Ground

Ground

Ground

Ground

Ground

Ground

Ground

Ground

Ground

Ground

Ground

Ground

Ground

Ground

Ground

Ground
12317.35

12319.72

$12335 . \quad 3$.

$12336.48 \quad .05$

12338.17

$12339.69 \quad 2$

12343.48 . 1

12366.25

12381.40

$12387.79 \quad .10$

$12388.8 \quad .1$

$12389.35 \quad .1$

12391.52

12392.

$12393.28 \quad .05$

$12398.58 \quad .4$

$12399.24 \quad .05$

$\begin{array}{llll}5 / 2 & 3 / 2 & 12400.35 & .5\end{array}$

$\begin{array}{llll}5 / 2 & 3 / 2 & 12401.33 & .5\end{array}$

12403.3

12424.12

$\begin{array}{lllll}3 / 2 & 3 / 2 & 12426.91 & .15\end{array}$

$\begin{array}{llll}3 / 2 & 3 / 2 & 12433.58 & .15\end{array}$

12444.

12444.

$12444.04 \quad .04$

12445.

$\begin{array}{lllll}7 / 2 & 7 / 2 & 12451.36 & .5\end{array}$

$12458.58 \quad .1$

$12461.04 \quad .10$

12465.9

$12479.45 \quad .04$

$12481.21 \quad .04$

$12482.76 \quad .04$

$12482.96 \quad .04$

$12483.38 \quad .1$

$12484.56 \quad .04$

$\begin{array}{llll}5 / 2 & 3 / 2 & 12484.78 & .15\end{array}$

$\begin{array}{llll}7 / 2 & 7 / 2 & 12489.27 & .5\end{array}$

$\begin{array}{lllll}7 / 2 & 7 / 2 & 12489.88 & .5\end{array}$

12492.5

$\begin{array}{llll}5 / 2 & 3 / 2 & 12502.61 & .15\end{array}$

$12511.0 \quad .1$

$\begin{array}{llll}1 / 2 & 3 / 2 & 12531.19 & .15\end{array}$

12540.98 


$\mathrm{C}^{12} \mathrm{H}_{3} \mathrm{C}^{12} \mathrm{~F}^{19}: \mathrm{C}^{12} \mathrm{H}_{2}$
$4 \mathrm{~d}-\mathrm{C}_{6}^{12} \mathrm{H}_{5} \mathrm{C}^{12} \mathrm{~N}^{14}$
$\mathrm{Re}^{185} \mathrm{O}_{3}^{16} \mathrm{Cl}^{37}$
$\mathrm{C}^{\mathrm{1}} \mathrm{H}_{3} \mathrm{C}^{12} \mathrm{O}^{16} \mathrm{Br}^{79}$
$\mathrm{I}^{127} \mathrm{C}^{12} \mathrm{~N}^{14}$
$\mathrm{HC}^{12} \mathrm{~N}^{14}$
$\mathrm{C}^{12}{ }_{*} \mathrm{HDC}^{12} \mathrm{H}_{2} \mathrm{C}^{12}{ }_{*} \mathrm{Cl}_{2}^{35}$
$\mathrm{C}^{12} \mathrm{H}_{3} \mathrm{C}^{12} \mathrm{O}^{18} \mathrm{C}^{12} \mathrm{~N}^{14}$
$\mathrm{C}_{6}^{12} \mathrm{H}_{5} \mathrm{C}^{12} \mathrm{~N}^{15}$
$\mathrm{C}^{12} \mathrm{H}_{3} \mathrm{~N}^{14} \mathrm{H}_{2}$
$\mathrm{C}^{12} \mathrm{H}_{3} \mathrm{C}^{12}{ }_{*} \mathrm{HO}^{16} \mathrm{C}^{12}{ }_{*} \mathrm{H}_{2}$
$\mathrm{C}^{12} \mathrm{H}_{3} \mathrm{C}^{12}{ }_{*} \mathrm{HO}^{16} \mathrm{C}^{12}{ }_{*} \mathrm{H}_{2}$
$\mathrm{C}^{12} \mathrm{H}_{3} \mathrm{C}^{12}{ }_{*} \mathrm{HO}^{16} \mathrm{C}^{12}{ }_{*} \mathrm{H}_{2}$
$\mathrm{C}^{12} \mathrm{H}_{3} \mathrm{O}^{16} \mathrm{~N}^{14} \mathrm{O}_{2}^{16}$
$\mathrm{C}^{12} \mathrm{H}_{3} \mathrm{C}^{12}{ }_{*} \mathrm{HO}^{16} \mathrm{C}^{12}{ }_{*} \mathrm{H}_{2}$
$\mathrm{~N}^{14} \mathrm{H}_{3}$

3. $721 \quad 2,1,1 \leftarrow 2,0,2$

Ground

4-1296

$5,1,5 \leftarrow 4,1,4$

Ground

4. 1472

$3, \leftarrow 2$,

3- 351

$1,1,1 \leftarrow 0,0,0$

4. 511

$$
2 \leftarrow 1
$$

4- 291

$7 \leftarrow 7$

4-1065

$3,0,3 \leftarrow 2,1,2$

Ground

Ground

Excited

Excited

3. 674

$1,1,1 \leftarrow 0,0,0$

Ground

4-1292

$5,1,5 \leftarrow 4,1,4$

Ground

3. 261

$6,1, \leftarrow 5,2$,

Ground

3- 761

$1,0,1 \leftarrow 0,0,0$

3- 761

Not Reported

3- 761

1, $0,1 \leftarrow 0,0,0$

3. 181

$4,1,4 \leftarrow 4,1,3$

3- 761

$1,0,1 \leftarrow 0,0,0$

4. 1771

Not Reported

${ }^{127} \mathrm{C}^{12} \mathrm{~N}^{14}$

$\mathrm{C}^{12} \mathrm{H}_{3} \mathrm{C}^{12}{ }_{*} \mathrm{HO}^{16} \mathrm{C}^{12}{ }_{*} \mathrm{H}_{2}$

$3 \mathrm{~d}-\mathrm{C}_{6}^{12} \mathrm{H}_{5} \mathrm{C}^{12} \mathrm{~N}^{14}$

$\mathrm{D}_{2} \mathrm{~N}^{15} \mathrm{C}^{12} \mathrm{HO}^{16}$

s. $\mathrm{C}^{12} \mathrm{H}_{2} \mathrm{DC}^{12} \mathrm{HO}^{16}$

$\mathrm{F}^{19} \mathrm{H}_{2} \mathrm{C}_{2}^{12} \mathrm{H}_{2} \mathrm{Cl}^{37}$

$\mathrm{C}^{12} \mathrm{H}_{3} \mathrm{C}^{12} \mathrm{HO}^{16}$

$\mathrm{DC}^{12} \mathrm{~N}^{15}$

$\mathrm{N}^{14} \mathrm{H}_{3}$

${ }^{127} \mathrm{C}^{12} \mathrm{~N}^{14}$

s- $\mathrm{C}^{12} \mathrm{H}_{2} \mathrm{DC}^{12} \mathrm{HO}^{16}$

$\mathrm{Si}^{28} \mathrm{H}_{3} \mathrm{C}^{12} \mathrm{H}: \mathrm{C}^{12} \mathrm{H}_{2}$

$\mathrm{Si}^{28} \mathrm{H}_{3} \mathrm{C}^{12} \mathrm{H}: \mathrm{C}^{12} \mathrm{H}_{2}$

$\mathrm{F}^{19} \mathrm{H}_{2} \mathrm{C}_{2}^{12} \mathrm{H}_{2} \mathrm{Cl}^{35}$

$4 \mathrm{C}^{13}-\mathrm{C}_{6}^{12} \mathrm{H}_{5} \mathrm{C}^{12} \mathrm{~N}^{14}$

$\mathrm{I}^{127} \mathrm{C}^{12} \mathrm{~N}^{14}$

$\mathrm{Cl}^{35} \mathrm{O}_{2}^{16}$

$\mathrm{C}^{12} \mathrm{H}_{3} \mathrm{~N}^{14} \mathrm{H}_{2}$

$\mathrm{C}^{12} \mathrm{D}_{3} \mathrm{Si}^{\mathrm{b}} \mathrm{HD}_{2}$

$\mathrm{C}^{12} \mathrm{H}_{3} \mathrm{P}^{31} \mathrm{H}_{2}$

$\mathrm{Si}^{28} \mathrm{D}_{2} \mathrm{~F}_{2}^{19}$

$\mathrm{C}_{6}^{12} \mathrm{H}_{5} \mathrm{C}^{13} \mathrm{~N}^{14}$

$\mathrm{C}^{12} \mathrm{H}_{3} \mathrm{O}^{16} \mathrm{H}$

$\mathrm{H}_{2} \mathrm{~N}^{14} \mathrm{~N}^{14} \mathrm{H}_{2}$

$\mathrm{C}^{12} \mathrm{H}_{3} \mathrm{C}^{12} \mathrm{D}_{3} \mathrm{Si}^{28} \mathrm{H}_{2}$

$\mathrm{C}^{12} \mathrm{H}_{3} \mathrm{C}^{12} \mathrm{D}_{3} \mathrm{Si}^{28} \mathrm{H}_{2}$

$\mathrm{N}^{14} \mathrm{H}_{3}$

2d- $\mathrm{C}_{6}^{12} \mathrm{H}_{5} \mathrm{C}^{12} \mathrm{~N}^{14}$

$\mathrm{O}^{16} \mathrm{~F}_{2}^{19}$
4. $511 \quad 2 \leftarrow 1$

3- $761 \quad 1,0,1 \leftarrow 0,0,0$

4- 1295

$5,1,5 \leftarrow 4,1,4$

3. 161

1, $1,1 \leftarrow 2,0,2$

3- 473

$4,1,3 \leftarrow 4,1,4$

3- 442

3- 471

4. 296

4.1771

4. 511

3. 473

$4,1,3 \leftarrow 4,0,4$

$3,0,3 \leftarrow 2,1.2$

$$
8 \leftarrow 8
$$

$15,10 \leftarrow 15,10$

$$
2 \leftarrow 1
$$

3. 611

Not Reported

3. 611

$7,1,6 \leftarrow 7,1,7$

$7,1,6 \leftarrow 7,1,7$

3. 441

$4,1,3 \leftarrow 4,0,4$

4-1301

4- 511

$5,1,5 \leftarrow 4,1,4$

$$
2 \leftarrow 1
$$

4-1381

3. 261

$13,2,11 \leftarrow 14,1,14$

Not Reported

3- 331

$9,1,8 \leftarrow 9,1,9$

3- 271

$1,1,1 \leftarrow 2,0,2$

4- 1603

4-1293

3- 211

$1,1,0 \leftarrow 1,0,1$

$5,1,5 \leftarrow 4,1,4$

3. 51

Not Reported

3. 642

$3,1,2 \leftarrow 3,0,3$

3- 642

3. 1. $2 \leftarrow 3,0,3$

4-1771

Not Reported

4. 1294

$5,1,5 \leftarrow 4,1,4$

4. 1611

$14,2,13 \leftarrow 13,3,10$
Not Reported
Ground

Ground

Ground

Ground

Ground

Ground

Ground

Ground

Ground

Ground

Ground

Ground

Ground

Ground

Excited

Ground

Excited

Ground

Ground

Ground

Ground

Ground

Ground

Ground

Ground

Ground

Ground

Ground

Ground

Ground

Ground

Ground

Ground
$12545.38 \quad .1$

$12547.0 \quad .2$

12550.

$\begin{array}{llll}1 / 2 & 3 / 2 & 12558.12 & .15\end{array}$

$\begin{array}{llll}7 / 2 & 7 / 2 & 12558.38 & .5\end{array}$

$12562.32 \quad .03$

12569.5

12577.

12586.0

12592.65

12595.01

12596.59

12598.99

12609.40

12614.92

12620 .

$5 / 2 \quad 7 / 2 \quad 12622.19$

12633.52

12648.5

12649.10

12660.45

12665.0

12666.62

12667.25

12674.12

$3 / 2$

$3 / 2$

12699.69

12706.25

12714.59

12715.13

12736.4

12736.6

$3 / 2$

$3 / 2$

12737.22

$29 / 2 \quad 31 / 2$

12742.7

12744.25

12754.31

12756.4

12758.30

12770.9

12770.9

12772.8

12776.79

.05

12777.78

.05

12778 .

12782.1

.2

12782.59 
$\mathrm{N}^{14} \mathrm{H}_{2} \mathrm{D}$

$3 \mathrm{C}^{13} \cdot \mathrm{C}_{6}^{12} \mathrm{H}_{5} \mathrm{C}^{12} \mathrm{~N}^{14}$

$\mathrm{C}^{12} \mathrm{H}_{2} \mathrm{~N}^{14} \mathrm{O}^{16} \mathrm{D}$

$\mathrm{C}^{12} \mathrm{H}_{2} \mathrm{~N}^{14} \mathrm{O}^{16} \mathrm{D}$

$\mathrm{C}^{12} \mathrm{H}_{3} \mathrm{C}^{12}{ }_{*} \mathrm{HO}^{16} \mathrm{C}^{12}{ }_{*} \mathrm{H}_{2}$ $\mathrm{C}^{12} \mathrm{H}_{3} \mathrm{C}^{12}{ }_{*} \mathrm{HO}^{16} \mathrm{C}^{12}{ }_{*} \mathrm{H}_{2}$ g. $\mathrm{C}^{12} \mathrm{H}_{3} \mathrm{C}^{12} \mathrm{H}_{2} \mathrm{C}^{12} \mathrm{H}_{2} \mathrm{Cl}^{35}$

$\mathrm{Cl}^{35} \mathrm{O}_{2}^{16}$

$\mathrm{C}^{12} \mathrm{H}_{3} \mathrm{C}^{12}{ }_{*} \mathrm{HO}^{16} \mathrm{C}^{12}{ }_{*} \mathrm{H}_{2}$ $\mathrm{C}^{12} \mathrm{H}_{3} \mathrm{C}^{12}{ }_{*} \mathrm{HO}^{16} \mathrm{C}^{12}{ }_{*} \mathrm{H}_{2}$ $\mathrm{C}^{12} \mathrm{H}_{3} \mathrm{C}^{12}{ }_{*} \mathrm{HO}^{16} \mathrm{C}^{12}{ }_{*} \mathrm{H}_{2}$ $\mathrm{C}^{12} \mathrm{H}_{3} \mathrm{~N}^{14} \mathrm{H}_{2}$

$\mathrm{C}^{12} \mathrm{H}_{3} \mathrm{C}^{12} \mathrm{O}^{18} \mathrm{C}^{12} \mathrm{~N}^{14}$

$\mathrm{C}^{13} \mathrm{H}_{3} \mathrm{C}^{12} \mathrm{O}^{16} \mathrm{C}^{12} \mathrm{~N}^{14}$

$2 \mathrm{C}^{13}-\mathrm{C}_{6}^{12} \mathrm{H}_{5} \mathrm{C}^{12} \mathrm{~N}^{14}$

$\mathrm{Cl}^{35} \mathrm{O}_{2}^{16}$

$1 \mathrm{C}^{13}-\mathrm{C}_{6}^{12} \mathrm{H}_{5} \mathrm{C}^{12} \mathrm{~N}^{14}$

$\mathrm{C}_{6}^{12} \mathrm{H}_{5} \mathrm{C}^{12} \mathrm{~N}^{14}$

$\mathrm{C}^{12} \mathrm{H}_{3} \mathrm{C}^{12}{ }_{*} \mathrm{HO}^{16} \mathrm{C}^{12}{ }_{*} \mathrm{H}_{2}$

$\mathrm{C}^{12} \mathrm{H}_{3} \mathrm{~N}^{14} \mathrm{H}_{2}$

DO $^{16}$

$\mathrm{DO}^{16}$

$\mathrm{DO}^{16}$

$\mathrm{N}^{14} \mathrm{H}_{3}$

$\mathrm{Cl}^{35} \mathrm{O}_{2}^{16}$

$\mathrm{H}_{2} \mathrm{~N}^{14} \mathrm{~N}^{14} \mathrm{H}_{2}$

$\mathrm{N}^{14} \mathrm{H}_{3}$

${ }^{127} \mathrm{C}^{12} \mathrm{~N}^{14}$

$\mathrm{H}_{2} \mathrm{~N}^{14} \mathrm{~N}^{14} \mathrm{H}_{2}$

${ }^{127} \mathrm{C}^{12} \mathrm{~N}^{14}$

$\mathrm{C}^{13} \mathrm{H}_{3} \mathrm{C}^{12} \mathrm{O}^{16} \mathrm{C}^{12} \mathrm{~N}^{14}$

$\left(\mathrm{C}^{12} \mathrm{H}_{3}\right)_{2} \mathrm{Si}^{28} \mathrm{H}_{2}$

$\mathrm{C}^{12} \mathrm{H}_{3} \mathrm{~B}^{\mathrm{b}} \mathrm{F}_{2}^{19}$

$\left(\mathrm{C}^{12} \mathrm{H}_{3}\right)_{2} \mathrm{Si}^{28} \mathrm{H}_{2}$

$\left(\mathrm{C}^{12} \mathrm{H}_{3}\right)_{2} \mathrm{Si}^{28} \mathrm{H}_{2}$

$\mathrm{C}^{12} \mathrm{H}_{3} \mathrm{C}^{12} \mathrm{O}^{16} \mathrm{O}^{16} \mathrm{H}$

$\mathrm{C}^{12} \mathrm{H}_{3} \mathrm{C}^{12} \mathrm{O}^{16} \mathrm{O}^{16} \mathrm{H}$

${ }^{127} \mathrm{C}^{12} \mathrm{~N}^{14}$

$\mathrm{C}^{12} \mathrm{H}_{2}: \mathrm{C}^{12} \mathrm{HC}^{12} \mathrm{~F}^{19}: \mathrm{C}^{12} \mathrm{H}_{2}$

$\mathrm{I}^{127} \mathrm{C}^{12} \mathrm{~N}^{14}$

$\mathrm{I}^{127} \mathrm{C}^{12} \mathrm{~N}^{14}$

$\mathrm{I}^{127} \mathrm{C}^{12} \mathrm{~N}^{14}$

$\mathrm{C}_{6}^{12} \mathrm{H}_{5} \mathrm{~F}^{19}$

$\mathrm{C}^{12} \mathrm{H}_{3} \mathrm{C}^{12} \mathrm{~F}^{19}: \mathrm{C}^{12} \mathrm{H}_{2}$

$\mathrm{C}^{12} \mathrm{H}_{3} \mathrm{C}^{12} \mathrm{~F}^{19}: \mathrm{C}^{12} \mathrm{H}_{2}$
4-1773 8, $1,8 \leftarrow 8,0,8 \quad$ Ground

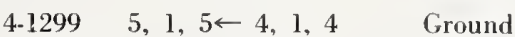

3- $142 \quad 1,1,1 \leftarrow 2,0,2 \quad$ Ground

3- $142 \quad 1,1,1 \leftarrow 2,0,2 \quad$ Ground

3- $761 \quad 13,6,7 \leftarrow 12,7,6 \quad$ Ground

3- $761 \quad 13,6,7 \leftarrow 12,7,6 \quad$ Ground

3- $773 \quad 2,1,1 \leftarrow 1,1,0 \quad$ Ground

4-1381 13, 2,11 $14,1,14 \quad$ Ground

3- $761 \quad 2,1,1 \leftarrow 2,0,2 \quad$ Ground

3- $761 \quad 2,1,1 \leftarrow 2,0,2 \quad$ Ground

3- 761

3. 261

$2,1,1 \leftarrow 2,0,2$

Ground

3- 674

Not Reported

Ground

3. 672

$2,1,2 \leftarrow 1,1,1$

Ground

4-1298

$1,1,1 \leftarrow 0,0,0$

Ground

4-1381

4-1297

$5,1,5 \leftarrow 4,1,4$

Ground

4-1291

$13,2,11 \leftarrow 14,1,14$

Ground

$5,1,5 \leftarrow 4,1,4$

Ground

3. 761

$5,1,5 \leftarrow 4,1,4$

Ground

3. 261

$2,1,1 \leftarrow 2,0,2$

Ground

1 -

Not Reported

Ground

1. $13 / 2,6 \leftarrow 13 / 2,6 \quad$ Ground

1 -

4-1771

$13 / 2,6 \leftarrow 13 / 2,6$

Ground

$11,5 \leftarrow 11,5$

4-1381

$13,2,11 \leftarrow 14,1,14$

3- 51

$$
6,2 \leftarrow 7,1
$$

4. 1771

4. 511

$14,9 \leftarrow 14,9$

3. 51

4. 511

3- 672

$$
2 \leftarrow 1
$$

$6,2 \leftarrow 7,1$

$2 \leftarrow 1$

3. 641

$2,1,2 \leftarrow 1,1,1$

$2,1,1 \leftarrow 2,0,2$

3. 91

$1, \quad \leftarrow 0, \quad$

3. 641

3- 641

$2,1,1 \leftarrow 2,0,2$

$2,1,1 \leftarrow 2,0,2$

3- 491

$3,3,0 \leftarrow 3,2,1$

3- 491

$2,1,1 \leftarrow 2,0,2$

$2 \leftarrow 1$

4- 511

3. 911

4. 511

$1,1,1 \leftarrow 0,0,0$

$2 \leftarrow 1$

4- 511

$2 \leftarrow 1$

4. 511

$2 \leftarrow 1$

4-1281

$3,2,2 \leftarrow 2,2,1$

3- 721

$19,14,5 \leftarrow 19,14,6$

3- 721

$19,14,5 \leftarrow 19,14,6$
Ground

Ground

Ground

Ground

Ground

Ground

Excited

Ground

Ground

Ground

Ground

Ground

Ground

Ground

Ground

Ground

Ground

Ground

Excited

Ground

Ground

Ground
$12784.10 \quad 05$

$12786.1 \quad .2$

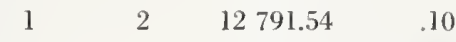

$\begin{array}{llll}2 & 3 & 12793.90 \quad .10\end{array}$

$12801.74 \quad .1$

$12802.48 \quad .1$

$12820.80 \quad .2$

$27 / 2 \quad 29 / 2 \quad 12822.4$

$12825.07 \quad .1$

$12830.22 \quad .1$

$12837.32 \quad .1$

12841.24

$12842.31 \quad .2$

$12858.27 \quad .2$

$12861.7 \quad .3$

$25 / 2 \quad 27 / 2 \quad 12883.5$

$12888.8 \quad .2$

$12897.8 \quad .2$

$12901.27 \quad .1$

$12903.16 \quad .1$

$\begin{array}{llll}13 / 2 & 13 / 2 & 12918.01 & .10\end{array}$

$\begin{array}{llll}11 / 2 & 11 / 2 & 12918.01 & .10\end{array}$

$15 / 2 \quad 15 / 2 \quad 12918.01 \quad 10$

$12923.10 \quad .06$

$23 / 2 \quad 25 / 2 \quad 12929.4$

12946.7

$12951.32 \quad .06$

$\begin{array}{llll}9 / 2 & 7 / 2 & 12956.38 & .5\end{array}$

12958.1

$\begin{array}{llll}7 / 2 & 5 / 2 & 12959.17 & .5\end{array}$

$12960.62 \quad .2$

$12978.49 \quad .05$

$12979.4 \quad .1$

$12979.76 \quad .05$

$12981.03 \quad .05$

12984.48

12989.83

$\begin{array}{llll}7 / 2 & 5 / 2 & 12994.98 & .5\end{array}$

$12995.53 \quad .03$

$\begin{array}{llll}7 / 2 & 5 / 2 & 12996.50 & .5\end{array}$

$\begin{array}{llll}7 / 2 & 5 / 2 & 12996.93 & .5\end{array}$

$\begin{array}{lllll}1 / 2 & 3 / 2 & 13011.34 & .5\end{array}$

13015.7

$13019.59 \quad .1$

$13020.78 \quad .1$ 


\begin{tabular}{|c|c|c|c|c|c|c|c|c|}
\hline Isotopic Species & $\begin{array}{l}\text { Vol.-Id. } \\
\text { Nos. }\end{array}$ & $\begin{array}{c}\text { Rotational } \\
\text { Quantum Nos. }\end{array}$ & Vib. State & $\mathrm{F}_{1}^{\prime}$ & $\underset{\mathrm{F}^{\prime}}{\text { Hyperfine }} \mathrm{F}_{1}$ & $\mathrm{~F}$ & $\begin{array}{c}\text { Frequency } \\
\mathrm{MHz}\end{array}$ & $\begin{aligned} & \text { Acc. } \\
\pm & \mathrm{MHz}\end{aligned}$ \\
\hline${ }^{127} \mathrm{C}^{12} \mathrm{~N}^{14}$ & 4- 511 & $2 \leftarrow 1$ & Excited & & $9 / 2$ & $7 / 2$ & 13021.92 & .5 \\
\hline $\mathrm{HDO}_{2}^{16}$ & 3- 43 & $2, \quad \leftarrow 2$, & & & & & 13032. & 3. \\
\hline $\mathrm{C}^{12} \mathrm{H}_{3} \mathrm{C}^{13} \mathrm{HO}^{16}$ & 3- 477 & $3,0,3 \leftarrow 2,1,2$ & Ground & & & & 13039.14 & .2 \\
\hline $\mathrm{I}^{127} \mathrm{C}^{12} \mathrm{~N}^{14}$ & 4- 511 & $2 \leftarrow 1$ & Ground & & $1 / 2$ & $3 / 2$ & 13048.33 & .5 \\
\hline $\mathrm{C}^{12} \mathrm{H}_{3} \mathrm{~N}^{14} \mathrm{H}_{2}$ & 3- 261 & Not Reported & Ground & & & & 13050.32 & .1 \\
\hline $\mathrm{N}^{14} \mathrm{H}_{3}$ & 4-1771 & Not Reported & Ground & & & & 13065 . & \\
\hline $4 d-\mathrm{C}_{6}^{12} \mathrm{H}_{5} \mathrm{C}^{12} \mathrm{~N}^{14}$ & 4-1296 & $5,0,5 \leftarrow 4,0,4$ & Ground & & & & 13072.4 & .2 \\
\hline $\mathrm{C}^{12} \mathrm{H}_{3} \mathrm{C}^{12} \mathrm{O}^{16} \mathrm{C}^{13} \mathrm{~N}^{14}$ & 3- 673 & $2,1,2 \leftarrow 1,1,1$ & Ground & & & & 13083.99 & .2 \\
\hline $\mathrm{C}^{12} \mathrm{H}_{3} \mathrm{C}^{12} \mathrm{O}^{16} \mathrm{~F}^{19}$ & 3- 391 & $2,1,1 \leftarrow 2,1,2$ & Ground & & & & 13091.42 & .2 \\
\hline $\mathrm{C}_{6}^{12} \mathrm{H}_{5} \mathrm{Cl}^{35}$ & 4.1271 & $5,1,5 \leftarrow 4,1,4$ & Ground & & & & 13112.6 & \\
\hline a- $C^{12} \mathrm{H}_{2} \mathrm{DS}^{32} \mathrm{C}^{12} \mathrm{H}_{3}$ & 3- 605 & $2,1,1 \leftarrow 2,0,2$ & Ground & & & & 13112.72 & .05 \\
\hline $\mathrm{C}_{6}^{12} \mathrm{H}_{5} \mathrm{C}^{12} \mathrm{~N}^{15}$ & 4-1292 & $5,0,5 \leftarrow 4,0,4$ & Ground & & & & 13113.0 & .2 \\
\hline $\mathrm{H}_{2} \mathrm{~N}^{14} \mathrm{~N}^{14} \mathrm{H}_{2}$ & 3. 51 & $6,2 \leftarrow 7,1$ & Ground & & & & 13113.3 & .05 \\
\hline $\mathrm{C}^{12} \mathrm{H}_{2} \mathrm{~N}^{14} \mathrm{O}^{16} \mathrm{H}$ & 3- 141 & $9,2,7 \leftarrow 9,2,8$ & Ground & & 10 & 10 & 13113.34 & .10 \\
\hline $\mathrm{C}^{12} \mathrm{H}_{2} \mathrm{~N}^{14} \mathrm{O}^{16} \mathrm{H}$ & 3- 141 & $9,2,7 \leftarrow 9,2,8$ & Ground & & 8 & 8 & 13113.34 & .10 \\
\hline $\mathrm{C}^{12} \mathrm{H}_{2} \mathrm{~N}^{14} \mathrm{O}^{16} \mathrm{H}$ & 3. 141 & $9,2,7 \leftarrow 9,2,8$ & Ground & & 9 & 9 & 13114.20 & .10 \\
\hline $\mathrm{DC}^{13} \mathrm{~N}^{14}$ & 4- 294 & $8 \leftarrow 8$ & Excited & & & & 13114.35 & .1 \\
\hline $\mathrm{N}^{14} \mathrm{H}_{3}$ & 4-1771 & Not Reported & Ground & & & & 13119. & \\
\hline $\mathrm{N}^{14} \mathrm{H}_{2} \mathrm{D}$ & 4-1773 & $8,1,8 \leftarrow 8,0,8$ & Ground & & & & 13119.94 & .05 \\
\hline $\mathrm{C}^{12} \mathrm{D}_{3} \mathrm{C}^{12} \mathrm{O}^{16} \mathrm{C}^{12} \mathrm{~J}^{14}$ & 3. 675 & $2,0,2 \leftarrow 1,0,1$ & Ground & & & & 13128.25 & .2 \\
\hline $\mathrm{I}^{127} \mathrm{C}^{12} \mathrm{~N}^{14}$ & 4- 511 & $2 \leftarrow 1$ & Ground & & $5 / 2$ & $5 / 2$ & 13129.36 & .5 \\
\hline${ }^{[127} \mathrm{C}^{12} \mathrm{~N}^{14}$ & 4- 511 & $2 \leftarrow 1$ & Ground & & $5 / 2$ & $5 / 2$ & 13129.68 & .5 \\
\hline $\mathrm{c}-\mathrm{HCl}^{35} \mathrm{C}^{12}: \mathrm{C}^{12} \mathrm{HCl}^{35}$ & 4- 671 & $5,1,4 \leftarrow 5,0.5$ & Ground & & & & 13147.17 & \\
\hline $\mathrm{H}_{2} \mathrm{~N}^{14} \mathrm{~N}^{14} \mathrm{H}_{2}$ & 3- 51 & Not Reported & & & & & 13151.3 & \\
\hline $\mathrm{Tl}^{205} \mathrm{~F}^{19}$ & $1-$ & $1 \leftarrow 0$ & Excited & & & & 13155.78 & 0.06 \\
\hline $\mathrm{C}_{6}^{12} \mathrm{H}_{5} \mathrm{~F}^{19}$ & 4-1281 & $34.11,23 \leftarrow 34,11,24$ & Ground & & & & 13156.6 & \\
\hline $\mathrm{C}^{12} \mathrm{H}_{3} \mathrm{C}^{12} \mathrm{O}^{16} \mathrm{C}^{12} \mathrm{~N}^{14}$ & 3- 671 & $2,1,2 \leftarrow 1,1,1$ & Ground & & & & 13165.78 & .2 \\
\hline $\mathrm{C}^{12} \mathrm{H}_{3} \mathrm{C}^{12} \mathrm{O}^{16} \mathrm{C}^{13} \mathrm{~N}^{14}$ & 3- 673 & $1,1,1 \leftarrow 0,0.0$ & Ground & & & & 13170.70 & .2 \\
\hline $\mathrm{C}^{12} * \mathrm{H}_{2} \mathrm{C}^{13} \mathrm{H}_{2} \mathrm{C}^{12} * \mathrm{Cl}_{2}^{35}$ & 4-1068 & $11,5,6 \longleftarrow 11,4,7$ & Ground & & & & 13171. & \\
\hline $\mathrm{C}^{12} * \mathrm{H}_{2} \mathrm{C}^{13} \mathrm{H}_{2} \mathrm{C}^{12} * \mathrm{Cl}_{2}^{35}$ & 4-1068 & $11,7,4 \leftarrow 11,6,5$ & Ground & & & & 13171. & \\
\hline $\mathrm{N}^{14} \mathrm{H}_{3}$ & 4-1771 & Not Reported & Ground & & & & 13175. & \\
\hline $3 \mathrm{~d}-\mathrm{C}_{6}^{12} \mathrm{H}_{5} \mathrm{C}^{12} \mathrm{~N}^{14}$ & 4-1295 & $5,0,5 \leftarrow 4,0,4$ & Ground & & & & 13175.7 & .2 \\
\hline $\mathrm{C}^{12} \mathrm{H}_{3} \mathrm{~N}^{14} \mathrm{H}_{2}$ & 3- 261 & $6,1, \leftarrow 5,2$ & Ground & & & & 13175.80 & \\
\hline $\mathrm{C}^{12} \mathrm{H}_{3} \mathrm{~N}^{14} \mathrm{H}_{2}$ & 3- 261 & $6,1, \leftarrow 5,2$, & Ground & & & & 13176. & \\
\hline $\mathrm{C}^{12} \mathrm{H}_{3} \mathrm{~N}^{14} \mathrm{H}_{2}$ & 3- 261 & $6,1, \leftarrow 5,2$, & Ground & & & & 13177.34 & \\
\hline $\mathrm{C}^{12} \mathrm{H}_{3} \mathrm{C}^{12} \mathrm{O}^{16} \mathrm{C}^{12} \mathrm{~N}^{14}$ & 3- 671 & $1,1,1 \leftarrow 0,0,0$ & Ground & & & & 13188.21 & .2 \\
\hline $\mathrm{H}_{2} \mathrm{~N}^{1+} \mathrm{N}^{1+} \mathrm{H}_{2}$ & $3-\quad 51$ & Not Reported & & & & & 13191.71 & \\
\hline $\mathrm{H}_{2} \mathrm{~N}^{14} \mathrm{~N}^{14} \mathrm{H}_{2}$ & 3. 51 & Not Reported & & & & & 13192.5 & \\
\hline $\mathrm{H}_{2} \mathrm{~N}^{1+4} \mathrm{~N}^{14} \mathrm{H}_{2}$ & $3-\quad 51$ & Not Reported & & & & & 13193.29 & \\
\hline${ }^{127} \mathrm{C}^{12} \mathrm{~N}^{14}$ & 4. 511 & $2 \leftarrow 1$ & Excited & & $5 / 2$ & $5 / 2$ & 13193.32 & .5 \\
\hline $\mathrm{H}_{2} \mathrm{~N}^{14} \mathrm{~N}^{14} \mathrm{H}_{2}$ & $3-\quad 51$ & Not Reported & & & & & 13194.13 & \\
\hline $\mathrm{HC}^{12} \mathrm{O}^{16} \mathrm{O}^{16} \mathrm{C}^{12} \mathrm{D}_{3}-\mathrm{A}$ & 3- 507 & $4,1,3 \leftarrow 4,1,4$ & Ground & & & & 13199.17 & .35 \\
\hline $\mathrm{N}^{14} \mathrm{H}_{3}$ & 4-1771 & Not Reported & Ground & & & & 13210. & \\
\hline $\mathrm{N}^{14} \mathrm{H}_{2} \mathrm{D}$ & 4-1773 & $9,1,9 \leftarrow 9,0,9$ & Ground & & & & 13217.78 & .05 \\
\hline $\mathrm{C}^{12}{ }_{*} \mathrm{H}_{2} \mathrm{C}^{12} \mathrm{H}_{2} \mathrm{C}^{12}{ }_{*} \mathrm{Cl}^{35} \mathrm{Cl}^{37}$ & 4-1062 & $3,1,3 \leftarrow 2,0,2$ & Ground & & & & 13232.1 & \\
\hline
\end{tabular}




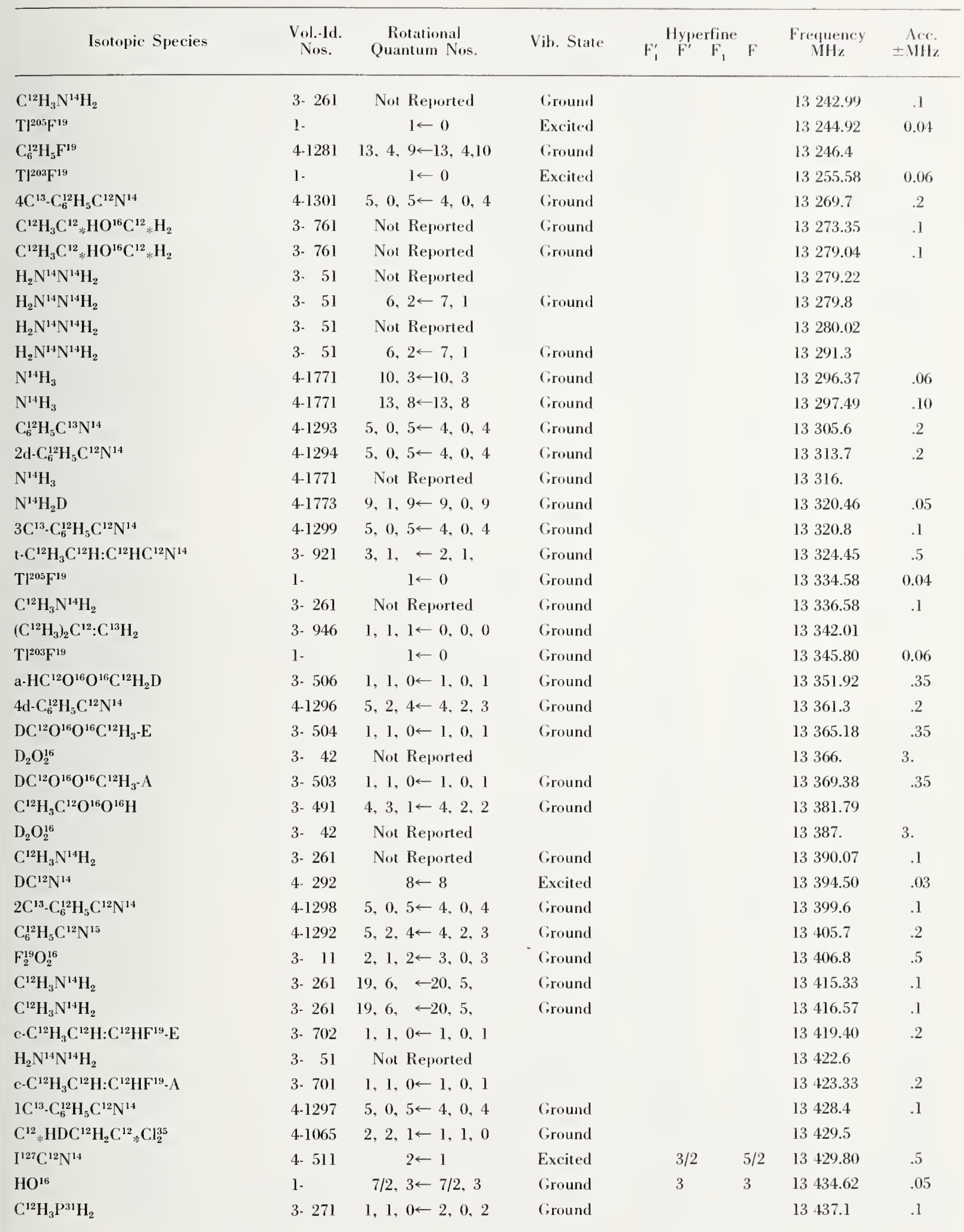




\begin{tabular}{|c|c|c|c|c|c|c|c|}
\hline Isotopic Species & $\begin{array}{l}\text { Vol.-Id. } \\
\text { Nos. }\end{array}$ & $\begin{array}{c}\text { Rotational } \\
\text { Quantum Nos. }\end{array}$ & Vib. State & 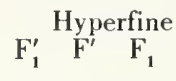 & $\mathbf{F}$ & $\begin{array}{c}\text { Frequency } \\
\mathrm{MHz}\end{array}$ & $\begin{aligned} & \text { Acc. } \\
& \pm \mathrm{MHz}\end{aligned}$ \\
\hline $\mathrm{C}_{6}^{12} \mathrm{H}_{5} \mathrm{C}^{12} \mathrm{~N}^{14}$ & 4-1291 & $5,0,5 \leftarrow 4,0,4$ & Ground & & & 13437.5 & .2 \\
\hline $\mathrm{HO}^{16}$ & 1 & $7 / 2,3 \leftarrow 7 / 2,3$ & Ground & 4 & 4 & 13441.36 & .05 \\
\hline $\mathrm{c} \cdot \mathrm{HCl}^{35} \mathrm{C}^{12}: \mathrm{C}^{12} \mathrm{HCl}^{35}$ & 4. 671 & $4,0,4 \leftarrow 3,1,3$ & Ground & & & 13445.60 & \\
\hline $\mathrm{C}^{12}{ }_{*} \mathrm{H}_{2} \mathrm{C}^{12} \mathrm{H}_{2} \mathrm{C}^{12}{ }_{*} \mathrm{Cl}_{2}^{35}$ & 4-1061 & $3,1,3 \leftarrow 2,0,2$ & Ground & & & 13447.3 & \\
\hline $\mathrm{C}^{12} \mathrm{H}_{3} \mathrm{P}^{31} \mathrm{H}_{2}$ & 3. 271 & $1,1,0 \leftarrow 2,0,2$ & Ground & & & 13451.8 & .1 \\
\hline $\mathrm{C}^{12} \mathrm{H}_{3} \mathrm{~N}^{14} \mathrm{H}_{2}$ & 3- 261 & Not Reported & Ground & & & 13464.76 & .1 \\
\hline $\mathrm{I}^{127} \mathrm{C}^{12} \mathrm{~N}^{14}$ & 4- 511 & $2 \leftarrow 1$ & Ground & $3 / 2$ & $5 / 2$ & 13465.77 & .5 \\
\hline $\mathrm{t} \cdot \mathrm{C}^{12} \mathrm{H}_{3} \mathrm{C}^{12} \mathrm{H}: \mathrm{C}^{12} \mathrm{HC}^{12} \mathrm{~N}^{14}$ & 3- 921 & $3,0, \leftarrow 2,0$, & Ground & & & 13475.89 & .5 \\
\hline $\mathrm{t}-\mathrm{C}^{12} \mathrm{H}_{3} \mathrm{C}^{12} \mathrm{H}: \mathrm{C}^{12} \mathrm{HC}^{12} \mathrm{~N}^{14}$ & 3. 921 & $3,2, \leftarrow 2,2$, & Ground & & & 13477.2 & .5 \\
\hline $\mathrm{N}^{14} \mathrm{H}_{3}$ & 4-1771 & Not Reported & Ground & & & 13488. & \\
\hline $\mathrm{O}^{16} \mathrm{~F}_{2}^{19}$ & 4-1611 & $36,7,29 \longleftarrow 35,8,28$ & Ground & & & 13500.68 & .10 \\
\hline $\mathrm{C}^{12} \mathrm{D}_{2}: \mathrm{C}^{12} \mathrm{DBr}^{81}$ & 4- 726 & $2,1,2 \leftarrow 1,1,1$ & Ground & $1 / 2$ & $1 / 2$ & 13511.6 & \\
\hline${ }^{127} \mathrm{C}^{12} \mathrm{~N}^{14}$ & 4. 511 & $2 \leftarrow 1$ & Excited & $3 / 2$ & $5 / 2$ & 13527.88 & .5 \\
\hline $\mathrm{C}^{12} \mathrm{H}_{3} \mathrm{~N}^{14} \mathrm{H}_{2}$ & 3- 261 & Not Reported & Ground & & & 13528.26 & .04 \\
\hline $\mathrm{C}^{12} \mathrm{D}_{3} \mathrm{C}^{12} \mathrm{O}^{16} \mathrm{~F}^{19}$ & 3- 392 & $10,6,4 \leftarrow 10,6,5$ & Ground & & & 13528.40 & .2 \\
\hline $3 \mathrm{~d}-\mathrm{C}_{6}^{12} \mathrm{H}_{5} \mathrm{C}^{12} \mathrm{~N}^{14}$ & 4-1295 & $5,2,4 \leftarrow 4,2,3$ & Ground & & & 13529.1 & .2 \\
\hline $\mathrm{C}^{12} \mathrm{D}_{3} \mathrm{C}^{12} \mathrm{O}^{16} \mathrm{~F}^{19}$ & 3- 392 & $10,6,4 \leftarrow 10,6,5$ & Ground & & & 13531.55 & .2 \\
\hline $\mathrm{C}_{6}^{12} \mathrm{H}_{5} \mathrm{~F}^{19}$ & 4-1281 & $3,2,1 \leftarrow 2,2,0$ & Ground & & & 13539.0 & \\
\hline $\mathrm{H}_{2} \mathrm{~N}^{14} \mathrm{~N}^{14} \mathrm{H}_{2}$ & 3- 51 & Not Reported & & & & 13542.53 & \\
\hline $\mathrm{H}_{2} \mathrm{~N}^{14} \mathrm{~N}^{14} \mathrm{H}_{2}$ & 3- 51 & Not Reported & & & & 13557.30 & \\
\hline $\mathrm{C}^{12} \mathrm{D}_{2}: \mathrm{C}^{12} \mathrm{DBr}^{81}$ & 4. 726 & $2,1,2 \leftarrow 1,1,1$ & Ground & $3 / 2$ & $1 / 2$ & 13564.3 & \\
\hline $\mathrm{C}^{12} \mathrm{D}_{2}: \mathrm{C}^{12} \mathrm{DBr}^{79}$ & 4- 725 & $2,1,2 \leftarrow 1,1,1$ & Ground & $1 / 2$ & $1 / 2$ & 13572.4 & \\
\hline $\mathrm{O}^{16} \mathrm{~F}_{2}^{19}$ & 4-1611 & $13,2,11 \leftarrow 14,1,14$ & Ground & & & 13575.01 & .01 \\
\hline $\mathrm{O}^{16} \mathrm{~F}_{2}^{19}$ & $4 \cdot 1611$ & $13,2.11 \leftarrow 14,1,14$ & Ground & & & 13575.28 & .01 \\
\hline $\mathrm{O}^{16} \mathrm{~F}_{2}^{19}$ & 4-1611 & $13,2.11 \leftarrow 14,1,4$ & Ground & & & 13575.51 & .01 \\
\hline $4 \mathrm{C}^{13}-\mathrm{C}_{6}^{12} \mathrm{H}_{5} \mathrm{C}^{12} \mathrm{~N}^{14}$ & 4-1301 & $5,2,4 \leftarrow 4,2,3$ & Ground & & & 13578.1 & .1 \\
\hline $\mathrm{DN}^{14} \mathrm{O}_{3}^{16}$ & 3- 32 & $3,2,1 \leftarrow 3,2,2$ & Ground & & & 13579.09 & \\
\hline $\mathrm{C}^{12} \mathrm{D}_{2}: \mathrm{C}^{12} \mathrm{DBr}^{81}$ & 4- 726 & $2,1,2 \leftarrow 1,1,1$ & Ground & $7 / 2$ & $5 / 2$ & 13585.0 & \\
\hline $\mathrm{C}^{12} \mathrm{H}_{3} \mathrm{C}^{12} \mathrm{~F}^{19}: \mathrm{C}^{12} \mathrm{H}_{2}$ & 3- 721 & $7,5,2 \leftarrow 7,5,3$ & Ground & & & 13589.71 & .1 \\
\hline $\mathrm{C}^{12} \mathrm{D}_{2}: \mathrm{C}^{12} \mathrm{DBr}^{81}$ & 4- 726 & Not Reported & Ground & $3 / 2$ & $5 / 2$ & 13592.6 & .1 \\
\hline $\mathrm{C}^{12} \mathrm{D}_{2}: \mathrm{C}^{12} \mathrm{DBr}^{81}$ & 4- 726 & Not Reported & Ground & $1 / 2$ & $3 / 2$ & 13592.6 & .1 \\
\hline $\mathrm{C}^{12} \mathrm{H}_{3} \mathrm{~N}^{14} \mathrm{H}_{2}$ & 3- 261 & Not Reported & Ground & & & 13592.68 & .1 \\
\hline c. $\left.\mathrm{HCl}^{35} \mathrm{C}^{12}: \mathrm{C}^{12} \mathrm{HC}\right]^{35}$ & 4- 671 & $1,1,1 \leftarrow 0,0,0$ & Ground & & & 13600.90 & \\
\hline $\mathrm{C}^{13} \mathrm{H}_{3} \mathrm{C}^{12} \mathrm{H}_{3} \mathrm{C}^{12}: \mathrm{C}^{12} \mathrm{H}_{2}$ & 3- 945 & $1,1,1 \leftarrow 0,0,0$ & Ground & & & 13604.08 & \\
\hline $\mathrm{C}^{12} \mathrm{H}_{3} \mathrm{C}^{12} \mathrm{~F}^{19}: \mathrm{C}^{12} \mathrm{H}_{2}$ & 3- 721 & $7,5,2 \leftarrow 7,5,3$ & Ground & & & 13606.97 & .1 \\
\hline $\mathrm{C}^{12} \mathrm{D}_{2}: \mathrm{C}^{12} \mathrm{DBr}^{81}$ & 4. 726 & $2,1,2 \leftarrow 1,1,1$ & Ground & & & 13609.29 & .05 \\
\hline $\mathrm{N}^{14} \mathrm{H}_{3}$ & 4-1771 & $9,1 \leftarrow 9,1$ & Ground & & & 13612.08 & .04 \\
\hline $\mathrm{N}^{14} \mathrm{H}_{3}$ & 4-1771 & $9,1 \leftarrow 9,1$ & Ground & & & 13612.36 & .04 \\
\hline $\mathrm{C}_{6}^{12} \mathrm{H}_{5} \mathrm{C}^{13} \mathrm{~N}^{14}$ & 4-1293 & $5,2,4 \leftarrow 4,2,3$ & Ground & & & 13617.8 & .2 \\
\hline $\mathrm{N}^{14} \mathrm{H}_{3}$ & $4-1771$ & Not Reported & Ground & & & 13626. & \\
\hline $\mathrm{N}^{14} \mathrm{H}_{2} \mathrm{D}$ & $4-1773$ & $10,1,10 \leftarrow 10,0,10$ & Ground & & & 13626.80 & .05 \\
\hline $\mathrm{D}_{2} \mathrm{O}_{2}^{16}$ & $3-\quad 42$ & Not Reported & & & & 13628. & 3. \\
\hline $\mathrm{t}-\mathrm{C}^{12} \mathrm{H}_{3} \mathrm{C}^{12} \mathrm{H}: \mathrm{C}^{12} \mathrm{HC}^{12} \mathrm{~N}^{14}$ & 3- 921 & $3,1, \leftarrow 2,1$, & Ground & & & 13629.06 & .5 \\
\hline $\mathrm{H}_{2} \mathrm{~N}^{14} \mathrm{~N}^{14} \mathrm{H}_{2}$ & 3- 51 & Not Reported & & & & 13632.40 & \\
\hline $\mathrm{C}^{12} \mathrm{D}_{2}: \mathrm{C}^{12} \mathrm{DBr}^{79}$ & 4- 725 & $2,1,2 \leftarrow 1,1,1$ & Ground & $3 / 2$ & $1 / 2$ & 13635.9 & \\
\hline
\end{tabular}




\begin{tabular}{|c|c|c|c|c|c|c|c|}
\hline Isotopic Species & $\begin{array}{l}\text { Vol.-Id. } \\
\text { Nos. }\end{array}$ & $\begin{array}{c}\text { Rotational } \\
\text { Quantum Nos. }\end{array}$ & Vib. State & $\mathrm{F}_{1}^{\prime} \stackrel{\text { Hyperfine }}{\mathrm{F}^{\prime}} \mathrm{F}_{1}$ & $\mathrm{~F}$ & $\begin{array}{l}\text { Frequency } \\
\mathrm{MHz}\end{array}$ & $\begin{aligned} & \text { Acc. } \\
\pm & \mathrm{MH}\end{aligned}$ \\
\hline $\mathrm{C}^{12} \mathrm{D}_{2}: \mathrm{C}^{12} \mathrm{DBr}^{81}$ & 4. 726 & $2,1,2 \leftarrow 1,1,1$ & Ground & $5 / 2$ & $5 / 2$ & 13638.4 & \\
\hline $\mathrm{C}^{12} \mathrm{H}_{3} \mathrm{As}^{75} \mathrm{~F}_{2}^{19}$ & 3- 81 & $18,14,4 \leftarrow 18,14,5$ & Ground & $37 / 2$ & $37 / 2$ & 13641.15 & .05 \\
\hline $\mathrm{C}^{12} \mathrm{H}_{3} \mathrm{As}^{75} \mathrm{~F}_{2}^{19}$ & 3- 81 & $18,14,4 \leftarrow 18,14,5$ & Ground & $35 / 2$ & $35 / 2$ & 13641.60 & .05 \\
\hline $\mathrm{C}^{12} \mathrm{D}_{2}: \mathrm{C}^{12} \mathrm{DBr}^{81}$ & 4- 726 & $2,1,2 \leftarrow 1,1,1$ & Ground & $3 / 2$ & $3 / 2$ & 13645.4 & \\
\hline $\mathrm{C}^{12} \mathrm{H}_{3} \mathrm{As}^{75} \mathrm{~F}_{2}^{19}$ & 3. 81 & $18,14,4 \leftarrow 18,14,5$ & Ground & $37 / 2$ & $37 / 2$ & 13647.31 & .05 \\
\hline $\mathrm{C}^{12} \mathrm{H}_{3} \mathrm{As}^{75} \mathrm{~F}_{2}^{19}$ & 3. 81 & $18,14,4 \leftarrow 18,14,5$ & Ground & $39 / 2$ & $39 / 2$ & 13647.31 & .05 \\
\hline $\mathrm{C}^{12} \mathrm{D}_{2}: \mathrm{C}^{12} \mathrm{DBr}^{81}$ & 4. 726 & Not Reported & Ground & $3 / 2$ & $3 / 2$ & 13647.7 & .2 \\
\hline $\mathrm{C}^{12} \mathrm{H}_{3} \mathrm{As}^{75} \mathrm{~F}_{2}^{19}$ & $3-81$ & $18,14,4 \leftarrow 18,14,5$ & Ground & $33 / 2$ & $33 / 2$ & 13647.79 & .05 \\
\hline $\mathrm{C}^{12} \mathrm{H}_{3} \mathrm{As}^{75} \mathrm{~F}_{2}^{19}$ & $3-81$ & $18,14,4 \leftarrow 18,14,5$ & Ground & $35 / 2$ & $35 / 2$ & 13647.79 & .05 \\
\hline $\mathrm{C}^{12} \mathrm{H}_{3} \mathrm{As}^{75} \mathrm{~F}_{2}^{19}$ & 3- 81 & $18,15,4 \leftarrow 18,13,5$ & Ground & $37 / 2$ & $37 / 2$ & 13649.58 & .05 \\
\hline $\mathrm{C}^{12} \mathrm{H}_{3} \mathrm{As}^{75} \mathrm{~F}_{2}^{19}$ & 3- 81 & $18.15,4 \leftarrow 18,13,5$ & Ground & $35 / 2$ & $35 / 2$ & 13650.09 & .05 \\
\hline $3 \mathrm{C}^{13}-\mathrm{C}_{6}^{12} \mathrm{H}_{5} \mathrm{C}^{12} \mathrm{~N}^{14}$ & 4-1299 & $5,2,4 \leftarrow 4,2,3$ & Ground & & & 13652.0 & .2 \\
\hline $\mathrm{C}^{12} \mathrm{H}_{3} \mathrm{As}^{75} \mathrm{~F}_{2}^{19}$ & 3- 81 & $18,14,4 \leftarrow 18,14,5$ & Ground & $39 / 2$ & $39 / 2$ & 13653.49 & .05 \\
\hline $\mathrm{C}^{12} \mathrm{H}_{3} \mathrm{As}^{75} \mathrm{~F}_{2}^{19}$ & 3- 81 & $18,14,4 \leftarrow 18,14,5$ & Ground & $33 / 2$ & $33 / 2$ & 13653.97 & .05 \\
\hline $\mathrm{C}^{12} \mathrm{H}_{3} \mathrm{As}^{75} \mathrm{~F}_{2}^{19}$ & 3. 81 & $18,15,4 \leftarrow 18,13,5$ & Ground & $39 / 2$ & $39 / 2$ & 13655.27 & .05 \\
\hline $\mathrm{C}^{12} \mathrm{H}_{3} \mathrm{As}^{75} \mathrm{~F}_{2}^{19}$ & 3. 81 & $18,15,4 \leftarrow 18,13,5$ & Ground & $37 / 2$ & $37 / 2$ & 13655.27 & .05 \\
\hline $\mathrm{C}^{12} \mathrm{H}_{3} \mathrm{As}^{75} \mathrm{~F}_{2}^{19}$ & 3- 81 & $18,15,4 \leftarrow 18,13,5$ & Ground & $35 / 2$ & $35 / 2$ & 13655.68 & .05 \\
\hline $\mathrm{C}^{12} \mathrm{H}_{3} \mathrm{As}^{75} \mathrm{~F}_{2}^{19}$ & 3- 81 & $18,15,4 \leftarrow 18,13,5$ & Ground & $33 / 2$ & $33 / 2$ & 13655.68 & .05 \\
\hline $\mathrm{N}^{14} \mathrm{H}_{3}$ & 4-1771 & Not Reported & Ground & & & 13657. & \\
\hline $\mathrm{C}^{12} \mathrm{H}_{3} \mathrm{As}^{75} \mathrm{~F}_{2}^{19}$ & 3- 81 & $17,13,4 \leftarrow 17,13,5$ & Ground & $35 / 2$ & $35 / 2$ & 13658.73 & .05 \\
\hline $\mathrm{C}^{12} \mathrm{H}_{3} \mathrm{As}^{75} \mathrm{~F}_{2}^{19}$ & 3- 81 & $17,13,4 \leftarrow 17,13,5$ & Ground & $33 / 2$ & $33 / 2$ & 13659.24 & .05 \\
\hline $\mathrm{C}_{6}^{12} \mathrm{H}_{5} \mathrm{Cl}^{35}$ & 4-1271 & $5,0,5 \leftarrow 4.0,4$ & Ground & & & 13660.4 & \\
\hline $\mathrm{C}^{12} \mathrm{D}_{2}: \mathrm{C}^{12} \mathrm{DBr}^{79}$ & 4. 725 & $2,1,2 \leftarrow 1,1,1$ & Ground & $7 / 2$ & $5 / 2$ & 13660.5 & \\
\hline $\mathrm{C}^{12} \mathrm{H}_{3} \mathrm{As}^{75} \mathrm{~F}_{2}^{19}$ & 3- 81 & $18,15,4 \leftarrow 18,13,5$ & Ground & $39 / 2$ & $39 / 2$ & 13660.85 & .05 \\
\hline $\mathrm{C}^{12} \mathrm{H}_{3} \mathrm{As}^{75} \mathrm{~F}_{2}^{19}$ & 3- 81 & $18,15,4 \leftarrow 18,13,5$ & Ground & $33 / 2$ & $33 / 2$ & 13661.24 & .05 \\
\hline $\mathrm{C}^{12} \mathrm{H}_{3} \mathrm{As}^{75} \mathrm{~F}_{2}^{19}$ & 3- 81 & $17,14,4 \leftarrow 17,12,5$ & Ground & $35 / 2$ & $35 / 2$ & 13662.75 & .05 \\
\hline $\mathrm{C}^{12} \mathrm{H}_{3} \mathrm{As}^{75} \mathrm{~F}_{2}^{19}$ & 3- 81 & $17,14,4 \leftarrow 17,12,5$ & Ground & $33 / 2$ & $33 / 2$ & 13663.27 & .05 \\
\hline $\mathrm{C}^{12} \mathrm{H}_{3} \mathrm{As}^{75} \mathrm{~F}_{2}^{19}$ & 3- 81 & $17,13,4 \leftarrow 17,13,5$ & Ground & $35 / 2$ & $35 / 2$ & 13663.71 & .05 \\
\hline $\mathrm{C}^{12} \mathrm{H}_{3} \mathrm{As}^{75} \mathrm{~F}_{2}^{19}$ & 3- 81 & $17,13,4 \leftarrow 17,13,5$ & Ground & $33 / 2$ & $33 / 2$ & 13664.28 & .05 \\
\hline $\mathrm{C}^{12} \mathrm{H}_{3} \mathrm{As}^{75} \mathrm{~F}_{2}^{19}$ & 3- 81 & $17,13,4 \leftarrow 17,13,5$ & Ground & $37 / 2$ & $37 / 2$ & 13665.24 & .05 \\
\hline $\mathrm{C}^{12} \mathrm{H}_{3} \mathrm{As}^{75} \mathrm{~F}_{2}^{19}$ & 3- 81 & $17,13,4 \leftarrow 17,13,5$ & Ground & $31 / 2$ & $31 / 2$ & 13665.81 & .05 \\
\hline $\mathrm{C}^{12} \mathrm{H}_{3} \mathrm{As}^{75} \mathrm{~F}_{2}^{19}$ & 3- 81 & $17,14,4 \leftarrow 17,12,5$ & Ground & $35 / 2$ & $35 / 2$ & 13667.71 & .05 \\
\hline $\mathrm{C}^{12} \mathrm{H}_{3} \mathrm{As}^{75} \mathrm{~F}_{2}^{19}$ & 3. 81 & $17,14,4 \leftarrow 17,12,5$ & Ground & $33 / 2$ & $33 / 2$ & 13668.23 & .05 \\
\hline $\mathrm{C}^{12} \mathrm{H}_{3} \mathrm{As}^{75} \mathrm{~F}_{2}^{19}$ & 3- 81 & $17,14,4 \leftarrow 17,12,5$ & Ground & $37 / 2$ & $37 / 2$ & 13668.90 & .05 \\
\hline $\mathrm{C}^{12} \mathrm{H}_{3} \mathrm{As}^{75} \mathrm{~F}_{2}^{19}$ & 3- 81 & $17,14,4 \leftarrow 17,12,5$ & Ground & $31 / 2$ & $31 / 2$ & 13669.39 & .05 \\
\hline $\mathrm{C}^{12} \mathrm{H}_{3} \mathrm{As}^{75} \mathrm{~F}_{2}^{19}$ & 3- 81 & $17,13,4 \leftarrow 17,13,5$ & Ground & $37 / 2$ & $37 / 2$ & 13670.12 & .05 \\
\hline $\mathrm{C}^{12} \mathrm{H}_{3} \mathrm{As}^{75} \mathrm{~F}_{2}^{19}$ & 3- 81 & $17,13,4 \leftarrow 17,13,5$ & Ground & $31 / 2$ & $31 / 2$ & 13670.61 & .05 \\
\hline $\mathrm{C}^{12} \mathrm{H}_{3} \mathrm{As}^{75} \mathrm{~F}_{2}^{19}$ & 3- 81 & $16,12,4 \leftarrow 16,12,5$ & Ground & $33 / 2$ & $33 / 2$ & 13673.03 & .05 \\
\hline $\mathrm{C}^{12} \mathrm{H}_{3} \mathrm{As}^{75} \mathrm{~F}_{2}^{19}$ & 3- 81 & $17,14,4 \leftarrow 17,12,5$ & Ground & $37 / 2$ & $37 / 2$ & 13673.74 & .05 \\
\hline $\mathrm{C}^{12} \mathrm{H}_{3} \mathrm{As}^{75} \mathrm{~F}_{2}^{19}$ & 3- 81 & $16,12,4 \leftarrow 16,12,5$ & Ground & $31 / 2$ & $31 / 2$ & 13673.74 & .05 \\
\hline $\mathrm{C}^{12} \mathrm{H}_{3} \mathrm{As}^{75} \mathrm{~F}_{2}^{19}$ & 3- 81 & $17,14,4 \leftarrow 17,12,5$ & Ground & $31 / 2$ & $31 / 2$ & 13674.34 & .05 \\
\hline $\mathrm{C}^{12} \mathrm{H}_{3} \mathrm{As}^{75} \mathrm{~F}_{2}^{19}$ & 3- 81 & $16,13,4 \leftarrow 16,11,5$ & Ground & $33 / 2$ & $33 / 2$ & 13674.34 & .05 \\
\hline $\mathrm{C}^{12} \mathrm{H}_{3} \mathrm{As}^{75} \mathrm{~F}_{2}^{19}$ & 3- 81 & $16,13,4 \leftarrow 16,11,5$ & Ground & $31 / 2$ & $31 / 2$ & 13675.04 & .05 \\
\hline $\mathrm{C}^{12} \mathrm{H}_{3} \mathrm{As}^{75} \mathrm{~F}_{2}^{19}$ & 3- 81 & $16,12,4 \leftarrow 16,12,5$ & Ground & $33 / 2$ & $33 / 2$ & 13677.04 & .05 \\
\hline $\mathrm{C}^{12} \mathrm{H}_{3} \mathrm{As}^{75} \mathrm{~F}_{2}^{19}$ & 3- 81 & $16,12,4 \leftarrow 16,12,5$ & Ground & $31 / 2$ & $31 / 2$ & 13677.67 & .05 \\
\hline
\end{tabular}




\begin{tabular}{|c|c|c|c|c|c|c|c|}
\hline Isotopic Species & $\begin{array}{l}\text { Vol.-Id. } \\
\text { Nos. }\end{array}$ & $\begin{array}{c}\text { Rotational } \\
\text { Quantum Nos. }\end{array}$ & Vib. State & $\mathrm{F}_{1}^{\prime} \quad \mathrm{F}^{\prime} \quad \mathrm{F}_{1}$ & e $\mathrm{F}$ & $\begin{array}{l}\text { Frequency } \\
\mathrm{MHz}\end{array}$ & $\begin{array}{r}\text { Acc. } \\
\pm \mathrm{MHz}\end{array}$ \\
\hline $\mathrm{C}^{12} \mathrm{H}_{3} \mathrm{As}^{75} \mathrm{~F}_{2}^{19}$ & 3- 81 & $16,13,4 \leftarrow 16,11,5$ & Ground & $33 / 2$ & $33 / 2$ & 13678.73 & .05 \\
\hline $\mathrm{C}^{12} \mathrm{H}_{3} \mathrm{As}^{75} \mathrm{~F}_{2}^{19}$ & 3- 81 & $16,13,4 \leftarrow 16,11,5$ & Ground & $31 / 2$ & $31 / 2$ & 13679.34 & .05 \\
\hline $\mathrm{C}^{12} \mathrm{H}_{3} \mathrm{As}^{75} \mathrm{~F}_{2}^{19}$ & 3- 81 & $16,12,4 \leftarrow 16,12,5$ & Ground & $35 / 2$ & $35 / 2$ & 13679.95 & .05 \\
\hline $\mathrm{C}^{12} \mathrm{H}_{3} \mathrm{As}^{75} \mathrm{~F}_{2}^{19}$ & 3- 81 & $16.12,4 \leftarrow 16,12,5$ & Ground & $29 / 2$ & $29 / 2$ & 13680.63 & .05 \\
\hline $\mathrm{C}^{12} \mathrm{H}_{3} \mathrm{As}^{75} \mathrm{~F}_{2}^{19}$ & 3. 81 & $16,13,4 \leftarrow 16,11,5$ & Ground & $35 / 2$ & $35 / 2$ & 13681.13 & .05 \\
\hline $\mathrm{C}^{12} \mathrm{H}_{3} \mathrm{As}^{75} \mathrm{~F}_{2}^{19}$ & 3. 81 & $16,13,4 \leftarrow 16,11,5$ & Ground & $29 / 2$ & $29 / 2$ & 13681.72 & .05 \\
\hline $\mathrm{C}^{12} \mathrm{D}_{2}: \mathrm{C}^{12} \mathrm{DBr}^{81}$ & 4. 726 & $2,1,2 \leftarrow 1,1,1$ & Ground & $5 / 2$ & $3 / 2$ & 13683.0 & \\
\hline $\mathrm{C}^{12} \mathrm{H}_{3} \mathrm{As}^{75} \mathrm{~F}_{2}^{19}$ & 3- 81 & $16,12,4 \leftarrow 16,12,5$ & Ground & $35 / 2$ & $35 / 2$ & 13683.88 & .05 \\
\hline $\mathrm{C}^{12} \mathrm{H}_{3} \mathrm{As}^{75} \mathrm{~F}_{2}^{19}$ & 3- 81 & $16,12,4 \leftarrow 16,12,5$ & Ground & $29 / 2$ & $29 / 2$ & 13684.50 & .05 \\
\hline $2 \mathrm{~d}-\mathrm{C}_{6}^{12} \mathrm{H}_{5} \mathrm{C}^{12} \mathrm{~N}^{14}$ & $4-1294$ & $5,2,4 \leftarrow 4,2,3$ & Ground & & & 13684.6 & .2 \\
\hline $\mathrm{C}^{12} \mathrm{H}_{3} \mathrm{As}^{75} \mathrm{~F}_{2}^{19}$ & 3. 81 & $16,13,4 \leftarrow 16,11,5$ & Ground & $35 / 2$ & $35 / 2$ & 13685.30 & .05 \\
\hline $\mathrm{C}^{12} \mathrm{H}_{3} \mathrm{As}^{75} \mathrm{~F}_{2}^{19}$ & 3. 81 & $16.13,4 \leftarrow 16,11,5$ & Ground & $29 / 2$ & $29 / 2$ & 13685.89 & .05 \\
\hline $4 d \cdot \mathrm{C}_{6}^{12} \mathrm{H}_{5} \mathrm{C}^{12} \mathrm{~N}^{14}$ & $4-1296$ & $5,2,3 \leftarrow 4,2,2$ & Ground & & & 13687.7 & .2 \\
\hline $\mathrm{C}^{12} \mathrm{D}_{2}: \mathrm{C}^{12} \mathrm{DBr}^{79}$ & 4- 725 & $2,1,2 \leftarrow 1,1,1$ & Ground & & & 13689.58 & .04 \\
\hline $\mathrm{N}^{14} \mathrm{H}_{3}$ & $4-1771$ & $10,4 \leftarrow 10,4$ & Ground & & & 13700.96 & .06 \\
\hline $\mathrm{C}^{12} \mathrm{H}_{3} \mathrm{C}^{12}{ }_{*} \mathrm{HO}^{16} \mathrm{C}^{12}{ }_{*} \mathrm{H}_{2}$ & 3. 761 & $21,13, \leftarrow 22,12$, & Ground & & & 13715.56 & .1 \\
\hline $\mathrm{C}^{12} \mathrm{H}_{3} \mathrm{C}^{12}{ }_{*} \mathrm{HO}^{16} \mathrm{C}^{12} * \mathrm{H}_{2}$ & 3- 761 & $21,13, \leftarrow 22,12$ & Ground & & & 13716.40 & .1 \\
\hline $\mathrm{N}^{14} \mathrm{H}_{3}$ & $4-1771$ & $12,7 \leftarrow 12,7$ & Ground & & & 13719.51 & .08 \\
\hline $\mathrm{Cl}^{35} \mathrm{O}_{2}^{16}$ & 4-1381 & 13. $2,11 \leftarrow 14,1,14$ & Ground & & & 13720.7 & \\
\hline $\mathrm{C}^{12} \mathrm{H}_{3} \mathrm{Sn}^{129} \mathrm{H}_{3}$ & 3. 347 & $1, \leftarrow 0$ & Ground & & & 13721.1 & \\
\hline $\mathrm{C}^{12} \mathrm{H}_{3} \mathrm{As}^{75} \mathrm{~F}_{2}^{19}$ & 3- 81 & $11,8,4 \leftarrow 11,6,5$ & Ground & $25 / 2$ & $25 / 2$ & 13723.91 & .05 \\
\hline $\mathrm{C}^{12} \mathrm{H}_{3} \mathrm{As}^{75} \mathrm{~F}_{2}^{19}$ & 3- 81 & $11,7,4 \leftarrow 11,7,5$ & Ground & $25 / 2$ & $25 / 2$ & 13723.91 & .05 \\
\hline $\mathrm{C}^{12} \mathrm{D}_{2}: \mathrm{C}^{12} \mathrm{DBr}^{79}$ & 4. 725 & $2,1,2 \leftarrow 1,1,1$ & Ground & $5 / 2$ & $5 / 2$ & 13724.5 & \\
\hline $\mathrm{C}^{12} \mathrm{H}_{3} \mathrm{As}^{75} \mathrm{~F}_{2}^{19}$ & 3- 81 & $10,7,4 \longleftarrow 10,5,5$ & Ground & $23 / 2$ & $23 / 2$ & 13728.97 & .05 \\
\hline $\mathrm{C}^{12} \mathrm{H}_{3} \mathrm{As}^{75} \mathrm{~F}_{2}^{19}$ & 3- 81 & $10,6,4 \leftarrow 10,6,5$ & Ground & $23 / 2$ & $23 / 2$ & 13728.97 & .05 \\
\hline $\mathrm{C}^{12} \mathrm{H}_{3} \mathrm{Sn}^{120} \mathrm{H}_{3}$ & 3- 345 & $1, \leftarrow 0$, & Ground & & & 13729.81 & \\
\hline $\mathrm{C}^{12} \mathrm{H}_{3} \mathrm{As}^{75} \mathrm{~F}_{2}^{19}$ & 3- 81 & $10,6,4 \leftarrow 10,6,5$ & Ground & $17 / 2$ & $17 / 2$ & 13730.97 & .05 \\
\hline $\mathrm{C}^{12} \mathrm{H}_{3} \mathrm{As}^{75} \mathrm{~F}_{2}^{19}$ & 3- 81 & $10,7,4 \leftarrow 10,5,5$ & Ground & $17 / 2$ & $17 / 2$ & 13730.97 & .05 \\
\hline $\mathrm{C}^{12} \mathrm{D}_{2}: \mathrm{C}^{12} \mathrm{DBr}^{79}$ & 4- 725 & $2,1,2 \leftarrow 1,1,1$ & Ground & $3 / 2$ & $3 / 2$ & 13732.7 & \\
\hline $\mathrm{C}^{12} \mathrm{H}_{3} \mathrm{Sn}^{120} \mathrm{H}_{3}$ & 3. 345 & $1, \leftarrow 0$ & Ground & & & 13735.34 & \\
\hline $\mathrm{C}_{6}^{12} \mathrm{H}_{5} \mathrm{C}^{12} \mathrm{~N}^{15}$ & $4-1292$ & $5,2,3 \leftarrow 4,2,2$ & Ground & & & 13736.7 & .2 \\
\hline $\mathrm{C}^{12} \mathrm{H}_{3} \mathrm{Sn}^{122} \mathrm{H}_{3}$ & 3- 346 & $1, \leftarrow 0$ & Ground & & & 13736.90 & \\
\hline $\mathrm{C}^{12} \mathrm{H}_{3} \mathrm{As}^{75} \mathrm{~F}_{2}^{19}$ & 3- 81 & $8,5,4 \leftarrow 8,3,5$ & Ground & $19 / 2$ & $19 / 2$ & 13737.52 & .05 \\
\hline $\mathrm{C}^{12} \mathrm{H}_{3} \mathrm{As}^{75} \mathrm{~F}_{2}^{9}$ & 3. 81 & $8,4,4 \leftarrow 8,4,5$ & Ground & $19 / 2$ & $19 / 2$ & 13737.52 & .05 \\
\hline $\mathrm{C}^{12} \mathrm{H}_{3} \mathrm{Sn}^{120} \mathrm{H}_{3}$ & 3- 345 & $1, \leftarrow 0$ & Ground & & & 13737.98 & \\
\hline $2 \mathrm{C}^{13} \cdot \mathrm{C}_{6}^{12} \mathrm{H}_{5} \mathrm{C}^{12} \mathrm{~N}^{14}$ & $4-1298$ & $5,2,4 \leftarrow 4,2,3$ & Ground & & & 13739.3 & .1 \\
\hline $\mathrm{C}^{12} \mathrm{H}_{3} \mathrm{Sn}^{122} \mathrm{H}_{3}$ & 3. 346 & $1, \leftarrow 0$ & Ground & & & 13740.01 & \\
\hline $\mathrm{C}^{12} \mathrm{H}_{3} \mathrm{As}^{75} \mathrm{~F}_{2}^{19}$ & 3. 81 & $8,4,4 \leftarrow 8,4,5$ & Ground & $13 / 2$ & $13 / 2$ & 13741.32 & .05 \\
\hline $\mathrm{C}^{12} \mathrm{H}_{3} \mathrm{As}^{75} \mathrm{~F}_{2}^{19}$ & 3- 81 & $8,5,4 \leftarrow 8,3,5$ & Ground & $13 / 2$ & $13 / 2$ & 13741.32 & .05 \\
\hline $\mathrm{C}^{12} \mathrm{H}_{3} \mathrm{As}^{75} \mathrm{~F}_{2}^{19}$ & 3- 81 & $7,3,4 \leftarrow 7,3,5$ & Ground & $17 / 2$ & $17 / 2$ & 13741.67 & .05 \\
\hline $\mathrm{C}^{12} \mathrm{H}_{3} \mathrm{As}^{75} \mathrm{~F}_{2}^{19}$ & 3. 81 & $7,4,4 \leftarrow 7,2,5$ & Ground & $17 / 2$ & $17 / 2$ & 13741.67 & .05 \\
\hline $\mathrm{C}^{12} \mathrm{H}_{3} \mathrm{Sn}^{124} \mathrm{H}_{3}$ & 3- 347 & $1, \leftarrow 0$ & Ground & & & 13742.56 & \\
\hline $\mathrm{C}_{6}^{12} \mathrm{H}_{5} \mathrm{~F}^{19}$ & $4-1281$ & $31,10,21 \leftarrow 31,10,22$ & Ground & & & 13746.6 & \\
\hline $\mathrm{C}^{12} \mathrm{H}_{3} \mathrm{As}^{75} \mathrm{~F}_{2}^{19}$ & 3- 81 & $7,3,4 \leftarrow 7,3,5$ & Ground & $11 / 2$ & $11 / 2$ & 13747.12 & .05 \\
\hline $\mathrm{C}^{12} \mathrm{H}_{3} \mathrm{As}^{75} \mathrm{~F}_{2}^{19}$ & 3- 81 & $7,4,4 \leftarrow 7,2,5$ & Ground & $11 / 2$ & $11 / 2$ & 13747.12 & .05 \\
\hline
\end{tabular}




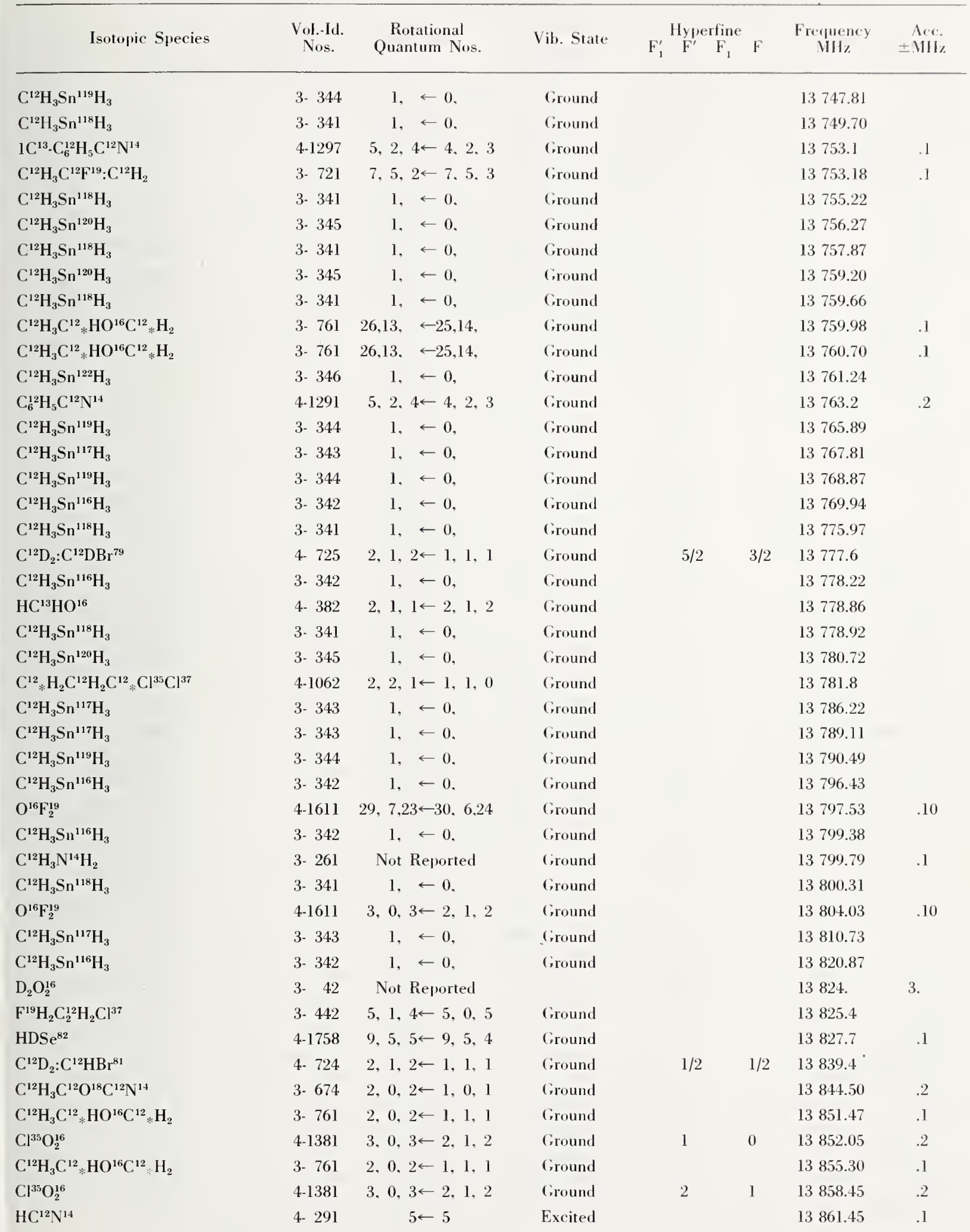




\begin{tabular}{|c|c|c|c|c|c|c|c|}
\hline Isotopic Species & $\begin{array}{l}\text { Vol.-Id. } \\
\text { Nos. }\end{array}$ & $\begin{array}{c}\text { Rotational } \\
\text { Quantum Nos. }\end{array}$ & Vib. State & 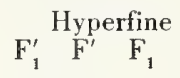 & $\mathbf{F}$ & $\begin{array}{l}\text { Frequency } \\
\mathrm{MHz}\end{array}$ & $\begin{aligned} & \text { Acc. } \\
& \pm \mathrm{MHz}\end{aligned}$ \\
\hline $\mathrm{HDSe}^{80}$ & $4-1757$ & $9,5,5 \leftarrow 9,5,4$ & Ground & & & 13862.65 & .1 \\
\hline $\mathrm{C}^{12} \mathrm{D}_{2}: \mathrm{C}^{12} \mathrm{DBr}^{81}$ & 4- 726 & $2,0,2 \leftarrow 1,0,1$ & Ground & $3 / 2$ & $3 / 2$ & 13863.9 & \\
\hline $\mathrm{S}^{32}{ }_{*} \mathrm{C}^{12} \mathrm{H}: \mathrm{C}^{13} \mathrm{HC}^{12} \mathrm{H}: \mathrm{C}^{12}{ }_{*} \mathrm{H}$ & $4-1168$ & $12,6,6 \leftarrow 12,6,7$ & Ground & & & 13882.7 & .05 \\
\hline $\mathrm{C}^{12} \mathrm{H}_{3} \mathrm{C}^{12}{ }_{*} \mathrm{HO}^{16} \mathrm{C}^{12}{ }_{*} \mathrm{H}_{2}$ & 3- 761 & $2,0,2 \leftarrow 1,1,1$ & Ground & & & 13891.15 & .1 \\
\hline $\mathrm{C}^{12} \mathrm{D}_{2}: \mathrm{C}^{12} \mathrm{HBr}^{81}$ & 4- 724 & $2,1,2 \leftarrow 1,1,1$ & Ground & $3 / 2$ & $1 / 2$ & 13892.1 & \\
\hline $\mathrm{Cl}^{15} \mathrm{O}_{2}^{16}$ & $4-1381$ & $3,0,3 \leftarrow 2,1,2$ & Ground & 3 & 2 & 13894.5 & .2 \\
\hline $\mathrm{C}^{12} \mathrm{H}_{3} \mathrm{~N}^{14} \mathrm{H}_{2}$ & 3- 261 & Not Reported & Ground & & & 13897.60 & .1 \\
\hline $\mathrm{HDSe}^{78}$ & $4-1756$ & $9,5,5 \leftarrow 9,5,4$ & Ground & & & 13899.3 & .1 \\
\hline $\mathrm{C}^{12}{ }_{*} \mathrm{H}_{2} \mathrm{C}^{12} \mathrm{H}_{2} \mathrm{C}^{12}{ }_{*} \mathrm{Cl}_{2}^{35}$ & $4-1061$ & $2,2,1 \leftarrow 1,1,0$ & Ground & & & 13899.3 & \\
\hline $\mathrm{C}^{12} \mathrm{D}_{2}: \mathrm{C}^{12} \mathrm{HBr}^{79}$ & 4- 723 & $2,1,2 \leftarrow 1,1,1$ & Ground & $1 / 2$ & $1 / 2$ & 13901.6 & \\
\hline $\mathrm{C}^{12} \mathrm{D}_{2}: \mathrm{C}^{12} \mathrm{HBr}^{81}$ & 4- 724 & $2,1,2 \leftarrow 1,1,1$ & Ground & $7 / 2$ & $5 / 2$ & 13910.5 & \\
\hline $\mathrm{C}^{12} \mathrm{D}_{2}: \mathrm{C}^{12} \mathrm{DBr}^{\mathrm{b}}$ & 4- 732 & Not Reported & Ground & & & 13911.7 & .2 \\
\hline $\mathrm{HDSe}^{77}$ & $4-1755$ & $9,5,5 \leftarrow 9,5,4$ & Ground & & & 13918.3 & .1 \\
\hline $\mathrm{HC}^{12} \mathrm{O}^{16} \mathrm{O}^{16} \mathrm{C}^{12} \mathrm{D}_{3}-\mathrm{A}$ & 3- 507 & $2,1,1 \leftarrow 2,0,2$ & Ground & & & 13918.67 & .2 \\
\hline $\mathrm{C}^{12} \mathrm{D}_{2}: \mathrm{C}^{12} \mathrm{DBr}^{79}$ & 4- 725 & Not Reported & Ground & $3 / 2$ & $3 / 2$ & 13922.7 & .1 \\
\hline $\mathrm{N}^{14} \mathrm{H}_{3}$ & 4-1771 & Not Reported & Ground & & & 13923. & \\
\hline $\mathrm{N}^{14} \mathrm{D}_{2} \mathrm{H}$ & $4-1774$ & $9,3,7 \leftarrow 9,2,7$ & Ground & & & 13923.95 & .05 \\
\hline $3 \mathrm{~d}-\mathrm{C}_{6}^{12} \mathrm{H}_{5} \mathrm{C}^{12} \mathrm{~N}^{14}$ & $4-1295$ & $5,2,3 \leftarrow 4,2,2$ & Ground & & & 13929.0 & .2 \\
\hline $\mathrm{C}^{12} \mathrm{H}_{3} \mathrm{~N}^{14} \mathrm{H}_{2}$ & 3- 261 & Not Reported & Ground & & & 13932.46 & .04 \\
\hline $\mathrm{C}^{12} \mathrm{D}_{2}: \mathrm{C}^{12} \mathrm{DBr}^{81}$ & 4- 726 & $2,0,2 \leftarrow 1,0,1$ & Ground & $5 / 2$ & $3 / 2$ & 13933.4 & \\
\hline $\mathrm{C}^{12} \mathrm{D}_{2}: \mathrm{C}^{12} \mathrm{DBr}^{81}$ & 4- 726 & $2,0,2 \leftarrow 1,0,1$ & Ground & $7 / 2$ & $5 / 2$ & 13933.4 & \\
\hline$\left(\mathrm{C}^{12} \mathrm{H}_{3}\right)_{2} \mathrm{~S}^{34}$ & 3- 602 & $2,1,1 \leftarrow 2,0,2$ & Ground & & & 13933.60 & .05 \\
\hline $\mathrm{C}^{12} \mathrm{D}_{2}: \mathrm{C}^{12} \mathrm{HBr}^{81}$ & 4- 724 & $2,1,2 \leftarrow 1,1,1$ & Ground & & & 13936.08 & .06 \\
\hline $\mathrm{HDSe}^{76}$ & $4-1759$ & $9,5,5 \leftarrow 9,5,4$ & Ground & & & 13937.8 & .1 \\
\hline $\mathrm{C}^{12} \mathrm{D}_{2}: \mathrm{C}^{12} \mathrm{DBr}^{81}$ & 4- 726 & Not Reported & Ground & $1 / 2$ & $1 / 2$ & 13938.8 & .1 \\
\hline $\mathrm{C}^{12} \mathrm{D}_{2}: \mathrm{C}^{12} \mathrm{DBr}^{81}$ & 4- 726 & $2,0,2 \leftarrow 1,0,1$ & Ground & & & 13942.31 & .06 \\
\hline $\mathrm{C}^{12} \mathrm{H}_{3} \mathrm{C}^{12} \mathrm{~F}^{19}: \mathrm{C}^{12} \mathrm{H}_{2}$ & 3- 721 & $1,0,1 \leftarrow 0,0,0$ & Ground & & & 13948.05 & .1 \\
\hline $\mathrm{F}^{19} \mathrm{H}_{2} \mathrm{C}_{2}^{12} \mathrm{H}_{2} \mathrm{Cl}^{35}$ & 3- 441 & $5,1,4 \leftarrow 5,0,5$ & Ground & & & 13952.1 & .1 \\
\hline $\mathrm{Cl}^{35} \mathrm{O}_{2}^{16}$ & 4-1381 & $3,0,3 \leftarrow 2,1,2$ & Ground & 4 & 3 & 13953.6 & .2 \\
\hline $\mathrm{C}^{13} \mathrm{H}_{3} \mathrm{C}^{12} \mathrm{O}^{16} \mathrm{C}^{12} \mathrm{~N}^{14}$ & 3- 672 & $2,0,2 \leftarrow 1,0,1$ & Ground & & & 13959.01 & .2 \\
\hline $\mathrm{C}^{12} \mathrm{D}_{2}: \mathrm{C}^{12} \mathrm{HBr}^{79}$ & 4- 723 & $2,1,2 \leftarrow 1,1,1$ & Ground & $3 / 2$ & $1 / 2$ & 13963.9 & \\
\hline $\mathrm{C}^{12} \mathrm{D}_{2}: \mathrm{C}^{12} \mathrm{HBr}^{81}$ & 4- 724 & $2,1,2 \leftarrow 1,1,1$ & Ground & $5 / 2$ & $5 / 2$ & 13963.9 & \\
\hline $\mathrm{C}^{12} \mathrm{H}_{3} \mathrm{C}^{12} \mathrm{~F}^{19}: \mathrm{C}^{12} \mathrm{H}_{2}$ & 3- 721 & $1,0,1 \leftarrow 0,0,0$ & Ground & & & 13968.65 & .1 \\
\hline $\mathrm{C}^{12} \mathrm{D}_{2}: \mathrm{C}^{12} \mathrm{HBr}^{81}$ & 4- 724 & Not Reported & Ground & $5 / 2$ & $5 / 2$ & 13969.6 & .1 \\
\hline $\mathrm{C}_{6}^{12} \mathrm{H}_{5} \mathrm{C}^{13} \mathrm{~N}^{14}$ & $4-1293$ & $5,2,3 \leftarrow 4,2,2$ & Ground & & & 13970.7 & .2 \\
\hline $\mathrm{C}^{12} \mathrm{D}_{2}: \mathrm{C}^{12} \mathrm{HBr}^{81}$ & 4- 724 & $2,1,2 \leftarrow 1,1,1$ & Ground & $3 / 2$ & $3 / 2$ & 13973.7 & \\
\hline $\mathrm{N}^{14} \mathrm{H}_{3}$ & $4-1771$ & $9,2 \leftarrow 9,2$ & Ground & & & 13974.54 & .08 \\
\hline $\mathrm{C}^{12} \mathrm{H}_{2} \mathrm{~N}^{14} \mathrm{O}^{16} \mathrm{D}$ & 3- 142 & $1,1,1 \leftarrow 2,0,2$ & Ground & 1 & 2 & 13986.09 & .10 \\
\hline $\mathrm{C}^{12} \mathrm{D}_{2}: \mathrm{C}^{12} \mathrm{HBr}^{79}$ & 4- 723 & $2,1,2 \leftarrow 1,1,1$ & Ground & $7 / 2$ & $5 / 2$ & 13986.4 & \\
\hline $\mathrm{C}^{12} \mathrm{H}_{2} \mathrm{~N}^{14} \mathrm{O}^{16} \mathrm{D}$ & 3- 142 & $1,1,1 \leftarrow 2,0,2$ & Ground & 2 & 3 & 13988.28 & .10 \\
\hline $\mathrm{H}_{2} \mathrm{~N}^{14} \mathrm{~N}^{14} \mathrm{H}_{2}$ & 3- 51 & Not Reported & & & & 13988.41 & \\
\hline $\mathrm{C}^{12} \mathrm{H}_{2} \mathrm{~N}^{14} \mathrm{O}^{16} \mathrm{D}$ & 3- 142 & $1,1,1 \leftarrow 2,0,2$ & Ground & 0 & 1 & 13990.74 & .10 \\
\hline $\mathrm{C}^{12} \mathrm{D}_{2}: \mathrm{C}^{12} \mathrm{DBr}^{\mathrm{b}}$ & 4- 732 & Not Reported & Ground & & & 14004.9 & .1 \\
\hline $\mathrm{C}_{6}^{12} \mathrm{H}_{5} \mathrm{Cl}^{35}$ & $4-1271$ & $5,2,4 \leftarrow 4,2,3$ & Ground & & & 14005.4 & \\
\hline $\mathrm{C}^{12} \mathrm{D}_{2}: \mathrm{C}^{12} \mathrm{HBr}^{81}$ & 4- 724 & $2,1,2 \leftarrow 1,1,1$ & Ground & $5 / 2$ & $3 / 2$ & 14007.2 & \\
\hline
\end{tabular}




\begin{tabular}{|c|c|c|c|c|c|c|c|}
\hline Isotopic Species & $\begin{array}{l}\text { Vol.-Id. } \\
\text { Nos. }\end{array}$ & $\begin{array}{c}\text { Rotational } \\
\text { Quantum Nos. }\end{array}$ & Vib. State & 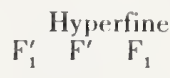 & $\mathrm{F}$ & $\begin{array}{c}\text { Frequency } \\
\mathrm{MHz}\end{array}$ & $\begin{aligned} & \text { Acc. } \\
\pm & \mathrm{MHz}\end{aligned}$ \\
\hline $\mathrm{C}_{6}^{12} \mathrm{H}_{5} \mathrm{Cl}^{35}$ & 4-1271 & $5,2,4 \leftarrow 4,2,3$ & Ground & & & 14008.3 & \\
\hline $\mathrm{C}^{12} \mathrm{D}_{2}: \mathrm{C}^{12} \mathrm{DBr}^{79}$ & 4. 725 & $2,0,2 \leftarrow 1,0,1$ & Ground & $7 / 2$ & $5 / 2$ & 14015.6 & \\
\hline $\mathrm{C}^{12} \mathrm{D}_{2}: \mathrm{C}^{12} \mathrm{DBr}^{79}$ & 4. 725 & $2,0,2 \leftarrow 1,0,1$ & Ground & $5 / 2$ & $3 / 2$ & $14 \cdot 015.6$ & \\
\hline $\mathrm{C}^{12} \mathrm{D}_{2}: \mathrm{C}^{12} \mathrm{HBr}^{79}$ & 4- 723 & $2,1,2 \leftarrow 1,1,1$ & Ground & & & 14.015 .74 & .05 \\
\hline $\mathrm{C}^{12} \mathrm{D}_{2}: \mathrm{C}^{12} \mathrm{DBr}^{79}$ & 4. 725 & Not Reported & Ground & $1 / 2$ & $1 / 2$ & 14021.0 & .1 \\
\hline $\mathrm{C}^{12} \mathrm{D}_{2}: \mathrm{C}^{12} \mathrm{DBr}^{79}$ & 4. 725 & $2,0,2 \leftarrow 1,0,1$ & Ground & & & 14022.12 & .05 \\
\hline $\mathrm{C}^{12} \mathrm{H}_{3} \mathrm{C}^{12}{ }_{*} \mathrm{HO}^{16} \mathrm{C}^{12}{ }_{*} \mathrm{H}_{2}$ & 3- 761 & $3,1,2 \leftarrow 3,0,3$ & Ground & & & 14025.86 & .1 \\
\hline $3 \mathrm{C}^{13} \cdot \mathrm{C}_{6}^{12} \mathrm{H}_{5} \mathrm{C}^{12} \mathrm{~N}^{14}$ & 4-1299 & $5,2,3 \leftarrow 4,2,2$ & Ground & & & 14026.5 & .1 \\
\hline $\mathrm{C}^{12} \mathrm{H}_{3} \mathrm{C}^{12}{ }_{*} \mathrm{HO}^{16} \mathrm{C}^{12}{ }_{*} \mathrm{H}_{2}$ & 3- 761 & $3,1,2 \leftarrow 3,0,3$ & Ground & & & 14030.68 & .1 \\
\hline $\mathrm{C}^{12} \mathrm{D}_{2}: \mathrm{C}^{12} \mathrm{DBr}^{81}$ & 4. 726 & $2,0,2 \leftarrow 1,0,1$ & Ground & $5 / 2$ & $5 / 2$ & 14031.4 & \\
\hline c. $\mathrm{C}^{12} \mathrm{HD}: \mathrm{C}^{12} \mathrm{DBr}^{81}$ & 4- 746 & $2,1,2 \leftarrow 1,1,1$ & Ground & $1 / 2$ & $1 / 2$ & 14033.0 & .1 \\
\hline $\mathrm{C}^{12} \mathrm{H}_{3} \mathrm{~N}^{14} \mathrm{H}_{2}$ & 3- 261 & Not Reported & Ground & & & 14033.54 & .04 \\
\hline $\mathrm{s} \cdot \mathrm{C}^{12} \mathrm{H}_{2} \mathrm{DS}^{32} \mathrm{C}^{12} \mathrm{H}_{3}$ & 3- 604 & $2,0,2 \leftarrow 1,1,1$ & Ground & & & 14035.40 & .05 \\
\hline $\mathrm{C}_{6}^{12} \mathrm{H}_{5} \mathrm{~F}^{19}$ & 4-1281 & $16,5,11 \leftarrow 16,5,12$ & Ground & & & 14036.9 & \\
\hline $\mathrm{C}^{12} \mathrm{H}_{3} \mathrm{~N}^{14} \mathrm{H}_{2}$ & 3. 261 & Not Reported & Ground & & & 14044.39 & .04 \\
\hline $\mathrm{C}^{12} \mathrm{H}_{3} \mathrm{C}^{12}{ }_{*} \mathrm{HO}^{16} \mathrm{C}^{12}{ }_{*} \mathrm{H}_{2}$ & 3- 761 & $3,1,2 \leftarrow 3,0,3$ & Ground & & & 14047.52 & .1 \\
\hline $\mathrm{C}^{12} \mathrm{D}_{2}: \mathrm{C}^{12} \mathrm{HBr}^{79}$ & 4- 723 & $2,1,2 \leftarrow 1,1,1$ & Ground & $5 / 2$ & $5 / 2$ & 14050.6 & \\
\hline $\mathrm{C}^{12} \mathrm{H}_{3} \mathrm{C}^{12}{ }_{*} \mathrm{HO}^{16} \mathrm{C}^{12}{ }_{*} \mathrm{H}_{2}$ & 3. 761 & Not Reported & Ground & & & 14053.63 & .1 \\
\hline $\mathrm{C}^{12} \mathrm{D}_{2}: \mathrm{C}^{12} \mathrm{HBr}^{79}$ & 4- 723 & $2,1,2 \leftarrow 1,1,1$ & Ground & $3 / 2$ & $3 / 2$ & 14057.3 & \\
\hline $\mathrm{H}_{2} \mathrm{~N}^{14} \mathrm{~N}^{14} \mathrm{H}_{2}$ & 3- 51 & Not Reported & & & & 14065.4 & \\
\hline $\mathrm{N}^{14} \mathrm{H}_{3}$ & 4.1771 & Not Reported & Ground & & & 14067 & \\
\hline $\mathrm{N}^{14} \mathrm{H}_{2} \mathrm{D}$ & $4-1773$ & $11,1,11 \leftarrow 11,0,11$ & Ground & & & 14069.73 & .05 \\
\hline $\mathrm{C}^{12} \mathrm{H}_{3} \mathrm{C}^{12} \mathrm{O}^{16} \mathrm{C}^{13} \mathrm{~N}^{14}$ & 3- 673 & $2,0,2 \leftarrow 1,0,1$ & Ground & & & 14076.57 & $.2^{\circ}$ \\
\hline $\mathrm{C}^{12} \mathrm{D}_{2}\left(\mathrm{C}^{12} \mathrm{~N}^{14}\right)_{2}$ & 4. 903 & $1,1,0 \leftarrow 1,0,1$ & Ground & & & 14077.66 & \\
\hline $\mathrm{C}^{12} \mathrm{D}_{3} \mathrm{Ge}^{74} \mathrm{H}_{3}$ & 3- 296 & $1,0 \leftarrow 0,0$ & Ground & & & 14077.80 & .10 \\
\hline $\mathrm{C}^{12} \mathrm{H}_{3} \mathrm{C}^{12}{ }_{*} \mathrm{HO}^{16} \mathrm{C}^{12}{ }_{*} \mathrm{H}_{2}$ & 3- 761 & $3,1,2 \leftarrow 3,0,3$ & Ground & & & 14084.31 & .1 \\
\hline $\mathrm{C}^{12} \mathrm{H}_{3} \mathrm{O}^{16} \mathrm{H}$ & 3- 211 & Not Reported & Ground & & & 14084.8 & .1 \\
\hline c- $\mathrm{C}^{12} \mathrm{HD}: \mathrm{C}^{12} \mathrm{DBr}^{81}$ & 4. 746 & $2,1,2 \leftarrow 1,1,1$ & Ground & $3 / 2$ & $1 / 2$ & 14085.6 & .1 \\
\hline $\mathrm{C}^{12} \mathrm{H}_{3} \mathrm{C}^{12}{ }_{*} \mathrm{HO}^{16} \mathrm{C}^{12}{ }_{*} \mathrm{H}_{2}$ & 3- 761 & $3,1,2 \leftarrow 3,0,3$ & Ground & & & 14087.32 & .1 \\
\hline $\mathrm{C}^{13} \mathrm{H}_{3} \mathrm{~S}^{32} \mathrm{C}^{12} \mathrm{H}_{3}$ & 3- 603 & $2,1,1 \leftarrow 2,0,2$ & Ground & & & 14090.96 & .05 \\
\hline c- $\mathrm{C}^{12} \mathrm{HD}: \mathrm{C}^{12} \mathrm{DBr}^{79}$ & 4- 744 & $2,1,2 \leftarrow 1,1,1$ & Ground & $1 / 2$ & $1 / 2$ & 14093.1 & .2 \\
\hline $\mathrm{C}^{12} \mathrm{HD}: \mathrm{C}^{12} \mathrm{DBr}^{\mathrm{b}}$ & 4. 749 & Not Reported & & & & 14095.4 & .2 \\
\hline $\mathrm{C}^{12} \mathrm{H}_{3} \mathrm{~N}^{14} \mathrm{H}_{2}$ & 3. 261 & Not Reported & Ground & & & 14098.16 & .1 \\
\hline $4 \mathrm{~d}-\mathrm{C}_{6}^{12} \mathrm{H}_{5} \mathrm{C}^{12} \mathrm{~N}^{14}$ & $4-1296$ & $5,1,4 \leftarrow 4,1,3$ & Ground & & & 14101.6 & .2 \\
\hline $\mathrm{N}^{14} \mathrm{H}_{3}$ & $4-1771$ & Not Reported & Ground & & & 14102 & \\
\hline $\mathrm{C}^{12} \mathrm{D}_{2}: \mathrm{C}^{12} \mathrm{HBr}^{79}$ & 4- 723 & $2,1,2 \leftarrow 1,1,1$ & Ground & $5 / 2$ & $3 / 2$ & 14.102 .4 & \\
\hline $\mathrm{N}^{14} \mathrm{H}_{2} \mathrm{D}$ & $4-1773$ & $6,1,6 \leftarrow 6,0,6$ & Ground & & & 14104.32 & .05 \\
\hline $2 \mathrm{~d} \cdot \mathrm{C}_{6}^{12} \mathrm{H}_{5} \mathrm{C}^{12} \mathrm{~N}^{14}$ & 4-1294 & $5,2,3 \leftarrow 4,2,2$ & Ground & & & 14104.5 & .2 \\
\hline $\mathrm{C}^{12} \mathrm{D}_{3} \mathrm{Ge}^{74} \mathrm{H}_{3}$ & 3- 296 & $1,0 \leftarrow 0,0$ & Ground & & & 14105.9 & .10 \\
\hline $\mathrm{c}-\mathrm{C}^{12} \mathrm{HD}: \mathrm{C}^{12} \mathrm{DBr}^{81}$ & 4- 746 & $2,1,2 \leftarrow 1,1,1$ & Ground & $7 / 2$ & $5 / 2$ & 14107.3 & .1 \\
\hline $\mathrm{C}^{12} \mathrm{H}_{3} \mathrm{~N}^{14} \mathrm{H}_{2}$ & 3- 261 & Not Reported & Ground & & & 14115.35 & .1 \\
\hline $1 \mathrm{C}^{13}-\mathrm{C}_{6}^{12} \mathrm{H}_{5} \mathrm{C}^{12} \mathrm{~N}^{14}$ & 4- 1297 & $5,2,3 \leftarrow 4,2,2$ & Ground & & & 14120.6 & .2 \\
\hline $\mathrm{Cl}^{35} \mathrm{O}_{2}^{16}$ & 4-1381 & $3,0,3 \leftarrow 2,1,2$ & Ground & & & 14121.9 & \\
\hline $2 \mathrm{C}^{13}-\mathrm{C}_{6}^{12} \mathrm{H}_{5} \mathrm{C}^{12} \mathrm{~N}^{14}$ & 4-1298 & $5,2,3 \leftarrow 4,2,2$ & Ground & & & 14124.8 & .1 \\
\hline $\mathrm{C}_{6}^{12} \mathrm{H}_{5} \mathrm{~F}^{19}$ & $4-1281$ & $3,1,2 \leftarrow 2,1,1$ & Ground & & & 14125.8 & \\
\hline
\end{tabular}




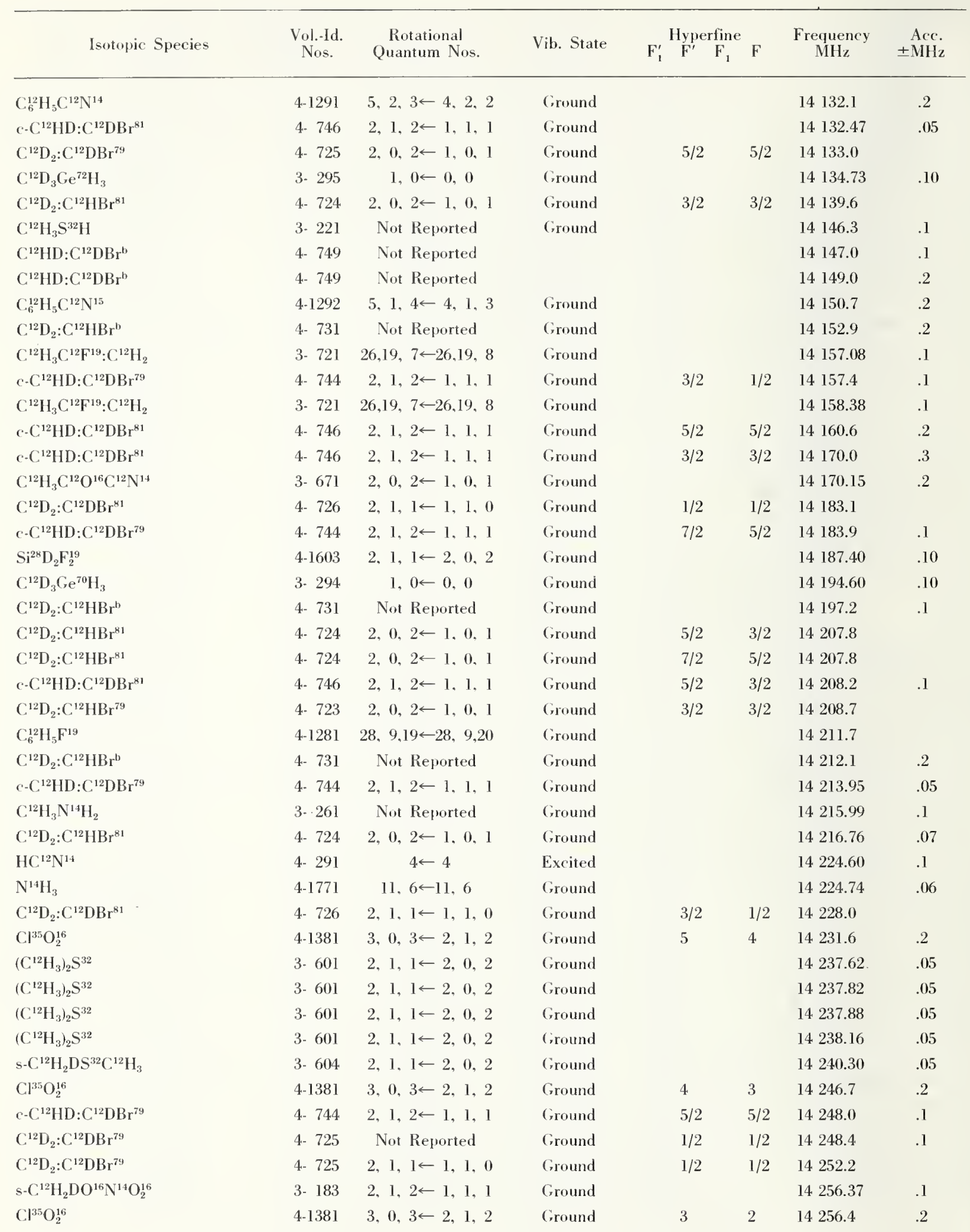




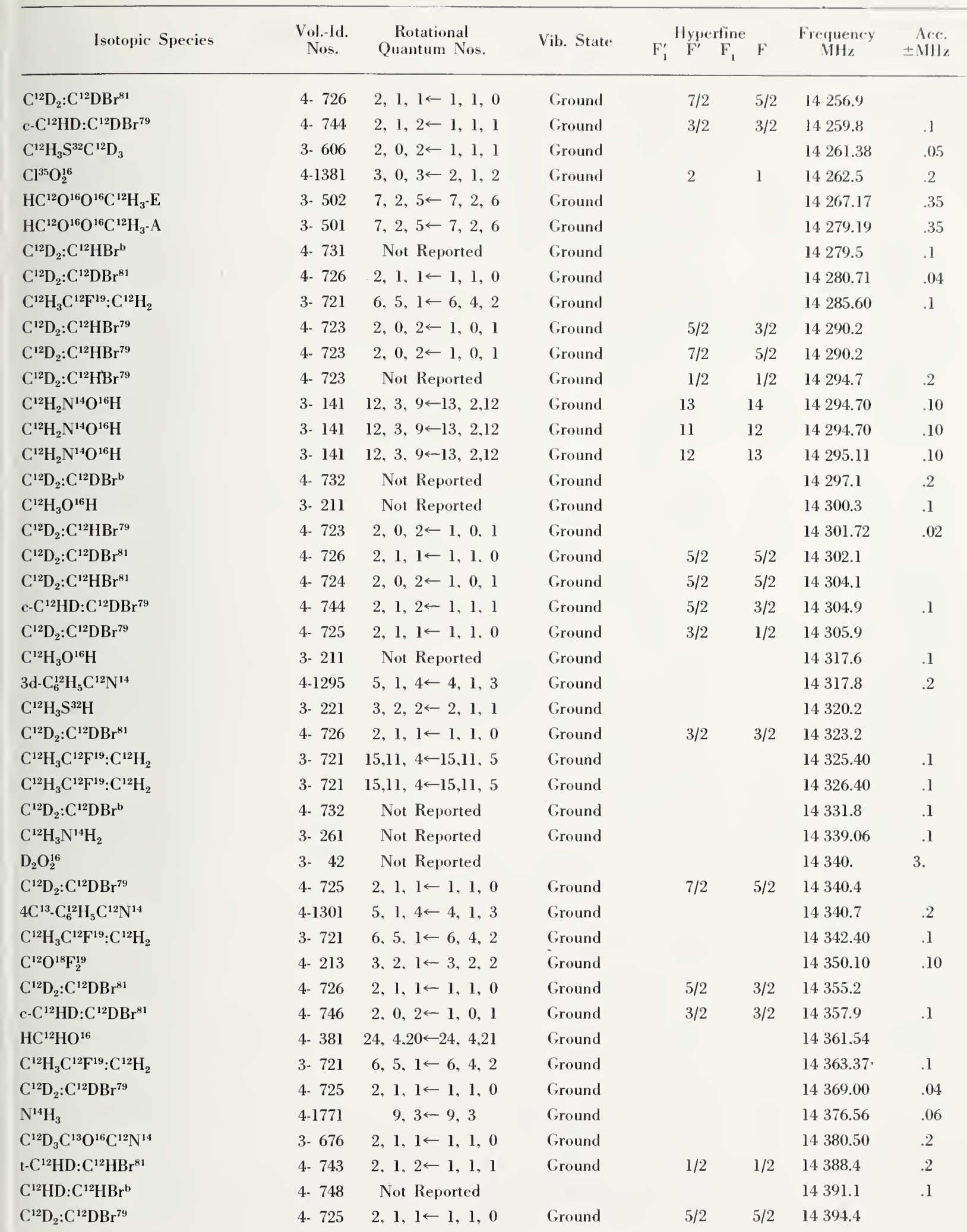




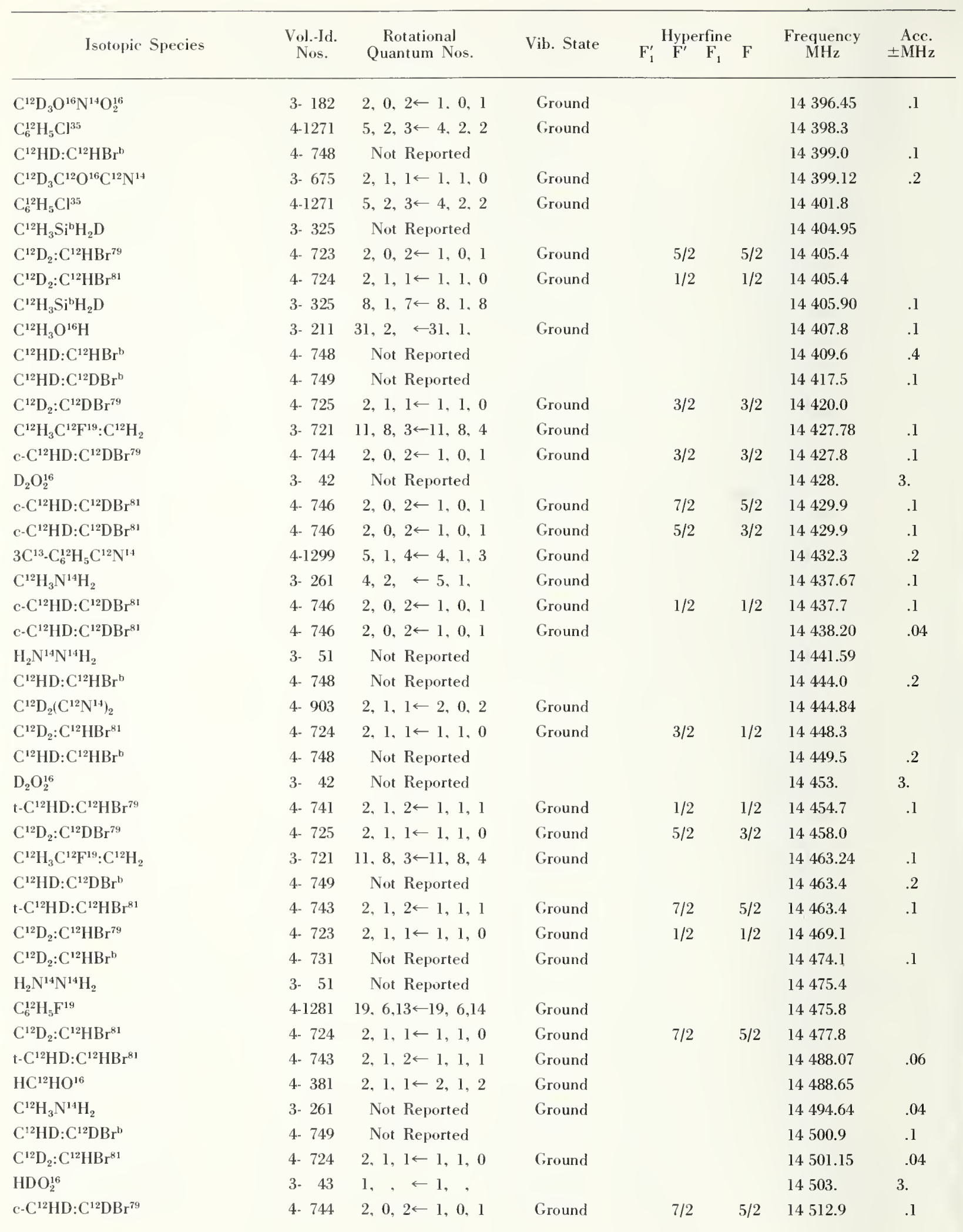




\begin{tabular}{|c|c|c|c|c|c|c|c|}
\hline Isotopic Species & $\begin{array}{l}\text { Vol.-Id. } \\
\text { Nos. }\end{array}$ & $\begin{array}{c}\text { Rotational } \\
\text { Quantum Nos. }\end{array}$ & Vib. State & $\mathrm{F}_{1}^{\prime} \mathrm{F}^{\frac{\text { Hyperfin }}{\prime}} \mathrm{F}_{1}$ & F & $\begin{array}{c}\text { Frenueney } \\
\text { HHI }\end{array}$ & $\begin{aligned} & \text { Aces } \\
\pm & \text { MII\% }\end{aligned}$ \\
\hline c. $\mathrm{C}^{12} \mathrm{HD}: \mathrm{C}^{12} \mathrm{DBr}^{79}$ & 4- 744 & $2,0,2 \leftarrow 1,0,1$ & Ground & $5 / 2$ & $3 / 2$ & 14.512 .9 & .1 \\
\hline$\left(\mathrm{C}^{12} \mathrm{H}_{3}\right)_{2} \mathrm{~S}^{32}$ & 3- 601 & $10,5,5 \leftarrow 9,6,4$ & Ground & & & 14515.57 & .05 \\
\hline $\mathrm{C}_{6}^{12} \mathrm{H}_{5} \mathrm{~F}^{19}$ & 4-1281 & $25,8,17 \longleftarrow 25,8,18$ & Ground & & & 14516.3 & \\
\hline$\left(\mathrm{C}^{12} \mathrm{H}_{3}\right)_{2} \mathrm{~S}^{32}$ & 3- 601 & $10,5,5 \leftarrow 9,6,4$ & Ground & & & 14517.27 & .0 .5 \\
\hline $\mathrm{t}-\mathrm{C}^{12} \mathrm{HD}: \mathrm{C}^{12} \mathrm{HBr}^{79}$ & 4- 741 & $2,1,2 \leftarrow 1,1,1$ & Ground & $3 / 2$ & $1 / 2$ & 14517.5 & .2 \\
\hline $\mathrm{t}-\mathrm{C}^{12} \mathrm{HD}: \mathrm{C}^{12} \mathrm{HBr}^{81}$ & 4- 743 & $2,1,2 \leftarrow 1,1,1$ & Ground & $5 / 2$ & $5 / 2$ & 14517.5 & .2 \\
\hline $\mathrm{C}^{12} \mathrm{HD}: \mathrm{C}^{12} \mathrm{DBr}^{\mathrm{b}}$ & 4- 749 & Not Reported & & & & 14517.7 & .2 \\
\hline$\left(\mathrm{C}^{12} \mathrm{H}_{3}\right)_{2} \mathrm{~S}^{32}$ & 3. 601 & $10,5,5 \leftarrow 9,6,4$ & Ground & & & 14518.96 & .05 \\
\hline $\mathrm{C}^{12} \mathrm{D}_{2}: \mathrm{C}^{12} \mathrm{HBr}^{81}$ & 4- 724 & $2,1,1 \leftarrow 1,1,0$ & Ground & $5 / 2$ & $5 / 2$ & 14521.2 & \\
\hline $\mathrm{t}-\mathrm{C}^{12} \mathrm{HD}: \mathrm{C}^{12} \mathrm{DBr}^{81}$ & 4- 747 & $2,1,2 \leftarrow 1,1,1$ & Ground & $1 / 2$ & $1 / 2$ & 14.523 .2 & .1 \\
\hline c. $\mathrm{C}^{12} \mathrm{HD}: \mathrm{C}^{12} \mathrm{DBr}^{79}$ & 4- 744 & $2,0,2 \leftarrow 1,0,1$ & Ground & $1 / 2$ & $1 / 2$ & 14523.2 & .1 \\
\hline c. $\mathrm{C}^{12} \mathrm{HD}: \mathrm{C}^{12} \mathrm{DBr}^{79}$ & 4- 744 & $2,0,2 \leftarrow 1,0,1$ & Ground & & & 14523.38 & .04 \\
\hline $\mathrm{C}^{12} \mathrm{D}_{2}: \mathrm{C}^{12} \mathrm{HBr}^{79}$ & 4- 723 & $2,1,1 \leftarrow 1,1,0$ & Ground & $3 / 2$ & $1 / 2$ & 14525.5 & \\
\hline $\mathrm{t}-\mathrm{C}^{12} \mathrm{HD}: \mathrm{C}^{12} \mathrm{HBr}^{81}$ & 4. 743 & $2,1,2 \leftarrow 1,1,1$ & Ground & $3 / 2$ & $3 / 2$ & 14525.7 & .2 \\
\hline $\mathrm{C}^{12} \mathrm{HD}: \mathrm{C}^{12} \mathrm{HBr}^{b}$ & 4- 748 & Not Reported & & & & 14526.9 & .2 \\
\hline $2 \mathrm{C}^{13}-\mathrm{C}_{6}^{12} \mathrm{H}_{5} \mathrm{C}^{12} \mathrm{~N}^{14}$ & 4-1298 & $5,1,4 \leftarrow 4,1,3$ & Ground & & & 14. 529.1 & .2 \\
\hline c. $\mathrm{C}^{12} \mathrm{HD}: \mathrm{C}^{12} \mathrm{DBr}^{81}$ & 4- 746 & $2,0,2 \leftarrow 1,0,1$ & Ground & $5 / 2$ & $5 / 2$ & 14529.6 & .1 \\
\hline $\mathrm{HN}^{14} \mathrm{O}_{3}^{16}$ & $3-\quad 31$ & $4,3,1 \leftarrow 4,3,2$ & Ground & & & 14. 534.25 & \\
\hline$c-\mathrm{C}^{12} \mathrm{HD}: \mathrm{C}^{12} \mathrm{DBr}^{81}$ & 4- 746 & $2,0,2 \leftarrow 1,0,1$ & Ground & $3 / 2$ & $1 / 2$ & 14.538 .7 & .1 \\
\hline $\mathrm{t}-\mathrm{C}^{12} \mathrm{HD}: \mathrm{C}^{12} \mathrm{HBr}^{79}$ & 4- 741 & $2,1,2 \leftarrow 1,1,1$ & Ground & $7 / 2$ & $5 / 2$ & 14541.2 & .1 \\
\hline $\mathrm{C}^{12} \mathrm{HD}: \mathrm{C}^{12} \mathrm{DBr}^{\mathrm{b}}$ & 4- 749 & Not Reported & & & & 14541.2 & .1 \\
\hline $\mathrm{C}^{12} \mathrm{D}_{2}: \mathrm{C}^{12} \mathrm{HBr}^{81}$ & 4- 724 & $2,1,1 \leftarrow 1,1,0$ & Ground & $3 / 2$ & $3 / 2$ & 14543.8 & \\
\hline $\mathrm{C}_{6}^{12} \mathrm{H}_{5} \mathrm{C}^{12} \mathrm{~N}^{14}$ & 4-1291 & $5,1,4 \leftarrow 4,1,3$ & Ground & & & 14545.3 & .2 \\
\hline $\mathrm{C}^{12} \mathrm{HD}: \mathrm{C}^{12} \mathrm{DBr}^{\mathrm{b}}$ & 4- 749 & Not Reported & & & & 14548.2 & .2 \\
\hline $\mathrm{C}^{12} \mathrm{H}_{3} \mathrm{~S}^{32} \mathrm{H}$ & 3. 221 & Not Reported & Ground & & & 14548.4 & .1 \\
\hline $\mathrm{Cl}^{35} \mathrm{O}_{2}^{16}$ & $4-1381$ & $13,2,11 \leftarrow 14,1,14$ & Ground & $23 / 2$ & $25 / 2$ & 14549.5 & \\
\hline $\mathrm{C}^{12} \mathrm{D}_{2}: \mathrm{C}^{12} \mathrm{HBr}^{\mathrm{b}}$ & 4- 731 & Not Reported & Ground & & & 14.552 .1 & .1 \\
\hline $\mathrm{H}_{2} \mathrm{~N}^{14} \mathrm{~N}^{14} \mathrm{H}_{2}$ & $3-51$ & Not Reported & & & & 14556.31 & \\
\hline $\mathrm{C}^{12} \mathrm{D}_{2}: \mathrm{C}^{12} \mathrm{HBr}^{79}$ & 4- 723 & $2,1,1 \leftarrow 1,1,0$ & Ground & $7 / 2$ & $5 / 2$ & 14560.8 & \\
\hline $\mathrm{t} \cdot \mathrm{C}^{12} \mathrm{HD}: \mathrm{C}^{12} \mathrm{HBr}^{81}$ & 4- 743 & $2,1,2 \leftarrow 1,1,1$ & Ground & $5 / 2$ & $3 / 2$ & 14562.7 & .1 \\
\hline $\mathrm{N}^{14} \mathrm{H}_{3}$ & 4-1771 & Not Reported & Ground & & & 14566. & \\
\hline $\mathrm{a}-\mathrm{C}^{12} \mathrm{H}_{2} \mathrm{DO}^{16} \mathrm{~N}^{14} \mathrm{O}_{2}^{16}$ & 3- 184 & $2,1,2 \leftarrow 1,1,1$ & Ground & & & 14567.27 & .1 \\
\hline $\mathrm{H}_{2} \mathrm{~N}^{14} \mathrm{~N}^{14} \mathrm{H}_{2}$ & 3. 51 & Not Reported & & & & 14570.8 & \\
\hline $\mathrm{t}-\mathrm{C}^{12} \mathrm{HD}: \mathrm{C}^{12} \mathrm{HBr}^{79}$ & 4- 741 & $2,1,2 \leftarrow 1,1,1$ & Ground & & & 14571.50 & .05 \\
\hline $\mathrm{C}^{12} \mathrm{D}_{2}: \mathrm{C}^{12} \mathrm{HBr}^{81}$ & 4- 724 & $2,1,1 \leftarrow 1,1,0$ & Ground & $5 / 2$ & $3 / 2$ & 14574.2 & \\
\hline $\mathrm{t}-\mathrm{C}^{12} \mathrm{HD}: \mathrm{C}^{12} \mathrm{DBr}^{81}$ & 4- 747 & $2,1,2 \leftarrow 1,1,1$ & Ground & $3 / 2$ & $1 / 2$ & 14576.0 & .1 \\
\hline $\mathrm{C}^{12} \mathrm{H}_{3} \mathrm{C}^{12} \mathrm{O}^{16} \mathrm{O}^{16} \mathrm{H}$ & 3. 491 & $9,6,3 \leftarrow 9,6,4$ & Ground & & & 14577.35 & \\
\hline $\mathrm{F}_{2}^{19} \mathrm{O}_{2}^{18}$ & $3-\quad 13$ & $1,1,0 \leftarrow 1,0,1$ & Ground & & & 14579.88 & .1 \\
\hline $\mathrm{C}^{12} \mathrm{HD}: \mathrm{C}^{12} \mathrm{DBr}^{\mathrm{b}}$ & 4- 749 & Not Reported & & & & $14580.3^{\circ}$ & .2 \\
\hline $\mathrm{C}^{12} \mathrm{D}_{2}: \mathrm{C}^{12} \mathrm{HBr}^{79}$ & 4- 723 & $2,1,1 \leftarrow 1,1,0$ & Ground & & & 14.587 .84 & .04 \\
\hline $\mathrm{C}^{12} \mathrm{HD}: \mathrm{C}^{12} \mathrm{DBr}^{\mathrm{b}}$ & 4- 749 & Not Reported & & & & 14588.75 & .05 \\
\hline $\mathrm{HC}^{13} \mathrm{HO}^{16}$ & 4- 382 & $16,3,13 \leftarrow 16,3,14$ & Ground & & & 14592.44 & \\
\hline t- $\mathrm{C}^{12} \mathrm{HD}: \mathrm{C}^{12} \mathrm{DBr}^{81}$ & 4- 747 & $2,1,2 \leftarrow 1,1,1$ & Ground & $7 / 2$ & $5 / 2$ & 14596.2 & .1 \\
\hline $\mathrm{F}^{19} \mathrm{HC}^{12} \mathrm{O}^{18}$ & 4- 274 & $2,1,2 \leftarrow 3,0,3$ & Ground & & & 14601.9 & .2 \\
\hline $\mathrm{t}-\mathrm{C}^{12} \mathrm{HD}: \mathrm{C}^{12} \mathrm{HBr}^{79}$ & 4- 741 & $2,1,2 \leftarrow 1,1,1$ & Ground & $5 / 2$ & $5 / 2$ & 14605.5 & .2 \\
\hline
\end{tabular}




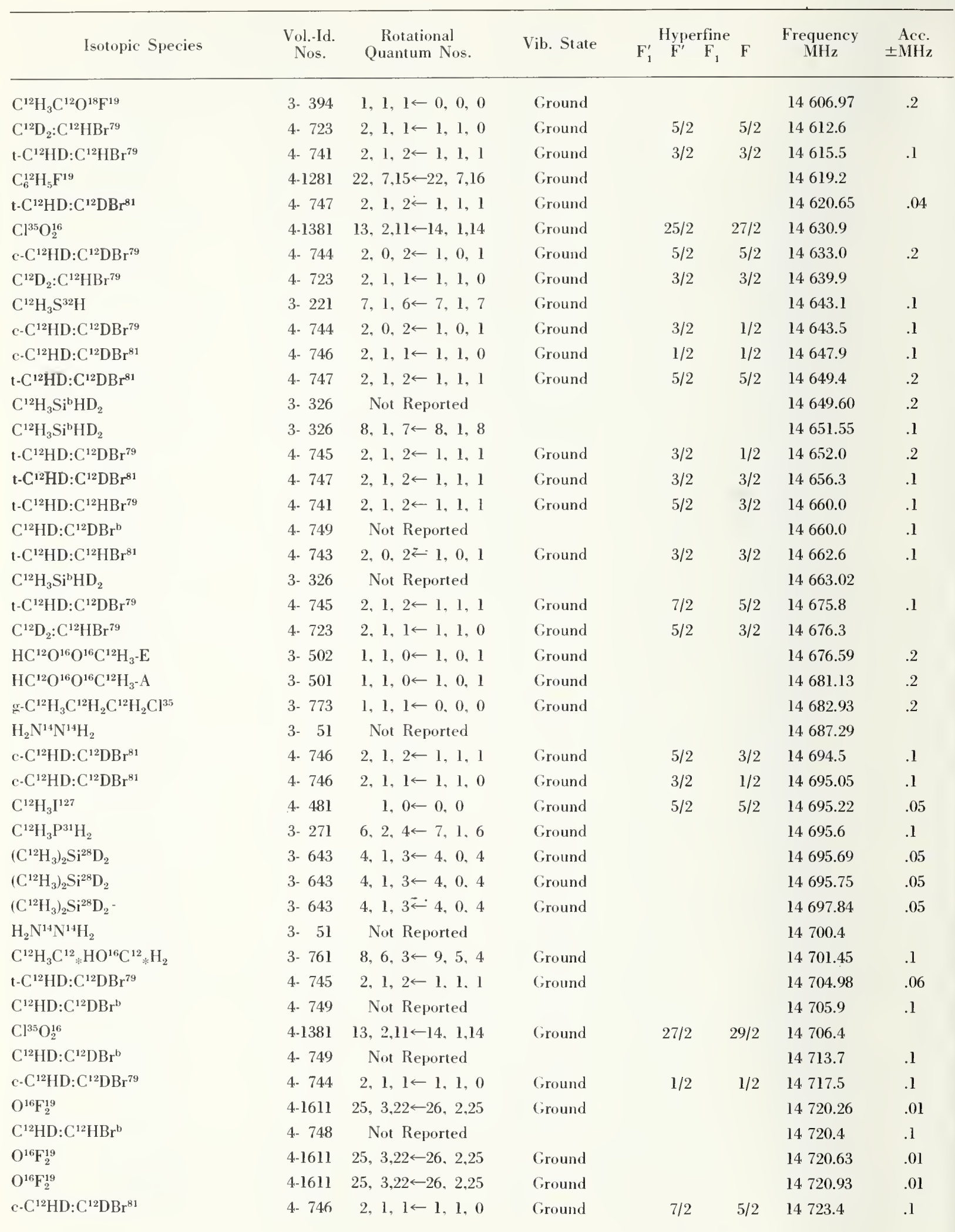




\begin{tabular}{|c|c|c|c|c|c|c|c|c|}
\hline Isotopic Species & $\begin{array}{l}\text { Vol.-Id. } \\
\text { Nos. }\end{array}$ & $\begin{array}{c}\text { Rotational } \\
\text { Quantum Nos. }\end{array}$ & Vib. State & $F_{1}^{\prime}$ & $\begin{array}{l}\text { Hyperfine } \\
\mathrm{F}^{\prime} \quad \mathrm{F}_{1}\end{array}$ & $F$ & $\begin{array}{c}\text { Frequency } \\
\text { Mll\% }\end{array}$ & $\begin{aligned} & \text { Acr: } \\
\pm & \mathrm{HHz}\end{aligned}$ \\
\hline $\mathrm{HC}^{12} \mathrm{HO}^{16}$ & 4- 381 & $8,2,6 \leftarrow 8,2,7$ & Ground & & & & 14726.74 & \\
\hline $\mathrm{C}^{12} \mathrm{HD}: \mathrm{C}^{12} \mathrm{DBr}^{\mathrm{b}}$ & 4- 749 & Not Reported & & & & & 14.732 .4 & .1 \\
\hline t- $\mathrm{C}^{12} \mathrm{HD}: \mathrm{C}^{12} \mathrm{HBr}^{81}$ & 4- 743 & $2,0,2 \leftarrow 1,0,1$ & Cround & & $5 / 2$ & $3 / 2$ & 14732.4 & .1 \\
\hline $\mathrm{t} \cdot \mathrm{C}^{12} \mathrm{HD}: \mathrm{C}^{12} \mathrm{HBr}^{81}$ & 4- 743 & $2,0,2 \leftarrow 1,0,1$ & Cround & & $7 / 2$ & $5 / 2$ & 14732.4 & .1 \\
\hline $\mathrm{C}^{12} \mathrm{H}_{3} \mathrm{C}^{12} \mathrm{~F}^{19}: \mathrm{C}^{12} \mathrm{H}_{2}$ & $3-721$ & $11,8,3 \leftarrow 11,8,4$ & Ground & & & & 14. 732.60 & .1 \\
\hline $\mathrm{C}_{6}^{12} \mathrm{H}_{5} \mathrm{O}^{16} \mathrm{H}$ & $3-1051$ & $4,0,4 \leftarrow 3,1,3$ & Ground & & & & 14733.1 & \\
\hline $\mathrm{C}^{12} \mathrm{H}_{3} \mathrm{C}^{12} \mathrm{~F}^{19}: \mathrm{C}^{12} \mathrm{H}_{2}$ & 3- 721 & $11,8,3 \leftarrow 11,8,4$ & Cround & & & & 14733.20 & .1 \\
\hline $\mathrm{C}^{12} \mathrm{H}_{3} \mathrm{C}^{12}{ }_{*} \mathrm{HO}^{16} \mathrm{C}^{12}{ }_{*} \mathrm{H}_{2}$ & 3- 761 & Not Reported & Ground & & & & 14739.48 & .1 \\
\hline t. $\mathrm{C}^{12} \mathrm{HD}: \mathrm{C}^{12} \mathrm{DBr}^{79}$ & 4- 745 & $2,1,2 \leftarrow 1,1,1$ & Ground & & $5 / 2$ & $5 / 2$ & 14740.0 & .2 \\
\hline $\mathrm{t}-\mathrm{C}^{12} \mathrm{HD}: \mathrm{C}^{12} \mathrm{HBr}^{81}$ & 4- 743 & $2,0,2 \leftarrow 1,0,1$ & Ground & & & & 14741.07 & .05 \\
\hline$c-\mathrm{C}^{12} \mathrm{HD}: \mathrm{C}^{12} \mathrm{DBr}^{81}$ & 4- 746 & $2,1,1 \leftarrow 1,1,0$ & Ground & & & & 14747.95 & .04 \\
\hline $\mathrm{t}-\mathrm{C}^{12} \mathrm{HD}: \mathrm{C}^{12} \mathrm{DBr}^{79}$ & 4. 745 & $2,1,2 \leftarrow 1,1,1$ & Ground & & $3 / 2$ & $3 / 2$ & 14748.1 & .2 \\
\hline $\mathrm{C}^{12} \mathrm{HD}: \mathrm{C}^{12} \mathrm{HBr}^{\mathrm{b}}$ & 4- 748 & Not Reported & & & & & 14754.7 & .1 \\
\hline $\mathrm{C}^{12} \mathrm{H}_{3} \mathrm{C}^{12}{ }_{*} \mathrm{HO}^{16} \mathrm{C}^{12}{ }_{*} \mathrm{H}_{2}$ & 3- 761 & Not Reported & Ground & & & & 14756.47 & .1 \\
\hline$c-\mathrm{C}^{12} \mathrm{H}_{3} \mathrm{C}^{12} \mathrm{H}: \mathrm{C}^{12} \mathrm{HF}^{19}-\mathrm{E}$ & 3- 702 & $2,1,1 \leftarrow 2,0,2$ & & & & & 14759.00 & .2 \\
\hline $\mathrm{C}^{12} \mathrm{H}_{3} \mathrm{C}^{12} * \mathrm{HO}^{16} \mathrm{C}^{12}{ }_{*} \mathrm{H}_{2}$ & 3- 761 & $15,7, \leftarrow 14,8$, & Ground & & & & 14760.68 & .1 \\
\hline $\mathrm{C}^{12} \mathrm{H}_{3} \mathrm{C}^{12} \mathrm{H}: \mathrm{C}^{12} \mathrm{HF}^{19}$ & 3- 711 & $2,1,2 \leftarrow 1,1,1$ & Ground & & & & 14761. & \\
\hline $\mathrm{C}^{12} \mathrm{H}_{3} \mathrm{C}^{12}{ }_{*} \mathrm{HO}^{16} \mathrm{C}^{12}{ }_{*} \mathrm{H}_{2}$ & 3- 761 & $15,7, \leftarrow 14,8$, & Ground & & & & 14761.60 & .1 \\
\hline $\mathrm{C}^{12} \mathrm{HD}: \mathrm{C}^{12} \mathrm{DBr}^{\mathrm{b}}$ & 4- 749 & Not Reported & & & & & 14761.8 & .2 \\
\hline $\mathrm{C}^{12} \mathrm{H}_{3} \mathrm{~S}^{32} \mathrm{H}$ & 3- 221 & $1,1, \leftarrow 2,0$, & Ground & & & & 14764.5 & .1 \\
\hline$c-\mathrm{C}^{12} \mathrm{H}_{3} \mathrm{C}^{12} \mathrm{H}: \mathrm{C}^{12} \mathrm{HF}^{19}-\mathrm{A}$ & 3- 701 & $2,1,1 \leftarrow 2,0,2$ & & & & & 14765.85 & .2 \\
\hline $\mathrm{Cl}^{35} \mathrm{O}_{2}^{16}$ & $4-1381$ & $13,2,11 \leftarrow 14,1,14$ & Ground & & $29 / 2$ & $31 / 2$ & 14770.3 & \\
\hline c. $\mathrm{C}^{12} \mathrm{HD}: \mathrm{C}^{12} \mathrm{DBr}^{81}$ & 4- 746 & $2,1,1 \leftarrow 1,1,0$ & Ground & & $5 / 2$ & $5 / 2$ & 14771.0 & .1 \\
\hline $\mathrm{C}^{12} \mathrm{H}_{3} \mathrm{~N}^{14} \mathrm{H}_{2}$ & 3- 261 & Not Reported & Ground & & & & 14771.22 & .1 \\
\hline $\mathrm{C}^{12} \mathrm{H}_{3} \mathrm{C}^{12} \mathrm{HO}^{18}$ & 3- 479 & $5,1,4 \leftarrow 5,1,5$ & Ground & & & & 14772.90 & .3 \\
\hline $\mathrm{HC}^{12} \mathrm{O}^{16} \mathrm{O}^{18} \mathrm{H}$ & 3- 77 & $4,1,4 \leftarrow 4,1,3$ & Ground & & & & 14773.56 & .1 \\
\hline$c-\mathrm{C}^{12} \mathrm{HD}: \mathrm{C}^{12} \mathrm{DBr}^{79}$ & 4- 744 & $2,1,1 \leftarrow 1,1,0$ & Ground & & $3 / 2$ & $1 / 2$ & 14774.0 & .2 \\
\hline $\mathrm{C}^{12} \mathrm{HD}: \mathrm{C}^{12} \mathrm{DBr}^{\mathrm{b}}$ & 4- 749 & Not Reported & & & & & 14777.5 & .2 \\
\hline $\mathrm{C}^{12} \mathrm{HD}: \mathrm{C}^{12} \mathrm{DBr}^{\mathrm{b}}$ & 4- 749 & Not Reported & & & & & 14781.3 & .2 \\
\hline $\mathrm{C}^{12} \mathrm{Cl}_{3}^{35} \mathrm{~F}^{19}$ & 4- 191 & $3,2 \leftarrow 2,2$ & Ground & & & & 14784.75 & .10 \\
\hline $\mathrm{C}^{12} \mathrm{H}_{3} \mathrm{C}^{12} \mathrm{H}: \mathrm{C}^{12} \mathrm{HF}^{19}$ & 3- 711 & $2,1,2 \leftarrow 1,1,1$ & Ground & & & & 14789.20 & \\
\hline $\mathrm{C}^{12} \mathrm{H}_{2} \mathrm{Cl}^{37} \mathrm{C}^{12} \mathrm{~N}^{14}$ & 4- 652 & $12,1,11 \leftarrow 11,2,10$ & Ground & & & & 14789.70 & .2 \\
\hline $\mathrm{C}^{12} \mathrm{H}_{3} \mathrm{C}^{12} \mathrm{H}: \mathrm{C}^{12} \mathrm{HF}^{19}$ & 3- 711 & $2,1,2 \leftarrow 1,1,1$ & Ground & & & & 14789.91 & .1 \\
\hline $\mathrm{C}^{12} \mathrm{Cl}_{3}^{35} \mathrm{~F}^{19}$ & 4- 191 & $3,1 \leftarrow 2,1$ & Ground & & & & 14790.46 & .08 \\
\hline c. $\mathrm{C}^{12} \mathrm{HD}: \mathrm{C}^{12} \mathrm{DBr}^{81}$ & 4- 746 & $2,1,1 \leftarrow 1,1,0$ & Cround & & $3 / 2$ & $3 / 2$ & 14790.6 & .1 \\
\hline$\left(\mathrm{C}^{12} \mathrm{H}_{3}\right)_{2} \mathrm{Si}^{28} \mathrm{H}_{2}$ & 3- 641 & $3,1,2 \leftarrow 3,0,3$ & Ground & & & & 14792.71 & .05 \\
\hline $\mathrm{C}^{12} \mathrm{Cl}_{3}^{35} \mathrm{~F}^{19}$ & 4- 191 & $3,1 \leftarrow 2,1$ & Ground & & & & 14792.80 & .06 \\
\hline $\mathrm{t}-\mathrm{C}^{12} \mathrm{HD}: \mathrm{C}^{12} \mathrm{DBr}^{79}$ & 4- 745 & $2,1,2 \leftarrow 1,1,1$ & Ground & & $5 / 2$ & $3 / 2$ & 14793.1 & .1 \\
\hline $\mathrm{C}^{12} \mathrm{Cl}_{3}^{35} \mathrm{~F}^{19}$ & 4- 191 & $3,1 \leftarrow 2,1$ & Ground & & & & 14793.92 & .08 \\
\hline$\left(\mathrm{C}^{12} \mathrm{H}_{3}\right)_{2} \mathrm{Si}^{28} \mathrm{H}_{2}$ & 3- 641 & $3,1,2 \leftarrow 3,0,3$ & Ground & & & & 14794.11 & .05 \\
\hline $\mathrm{C}^{12} \mathrm{Cl}_{3}^{35} \mathrm{~F}^{19}$ & 4- 191 & $3,2 \leftarrow 2,2$ & Ground & & & & 14.794 .66 & .08 \\
\hline $\mathrm{C}^{12} \mathrm{Cl}_{3}^{35} \mathrm{~F}^{19}$ & 4- 191 & $3,1 \leftarrow 2,1$ & Ground & & & & 14795.26 & .08 \\
\hline$\left(\mathrm{C}^{12} \mathrm{H}_{3}\right)_{2} \mathrm{Si}^{28} \mathrm{H}_{2}$ & 3- 641 & $3,1,2 \leftarrow 3,0,3$ & Ground & & & & 14795.50 & .05 \\
\hline $\mathrm{C}^{12} \mathrm{Cl}_{3}^{35} \mathrm{~F}^{19}$ & 4. 191 & $3,2 \leftarrow 2,2$ & Ground & & & & 14796.25 & .10 \\
\hline $\mathrm{C}^{12} \mathrm{Cl}_{3}^{35} \mathrm{~F}^{19}$ & 4- 191 & $3,2 \leftarrow 2,2$ & Ground & & & & 14797.12 & .10 \\
\hline
\end{tabular}




\begin{tabular}{|c|c|c|c|c|c|c|c|}
\hline Isotopic Species & $\begin{array}{l}\text { Vol.-Id. } \\
\text { Nos. }\end{array}$ & $\begin{array}{c}\text { Rotational } \\
\text { Quantum Nos. }\end{array}$ & Vib. State & 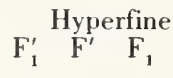 & $\mathrm{F}$ & $\begin{array}{l}\text { Frequency } \\
\mathrm{MHz}\end{array}$ & $\begin{array}{r}\text { Acc. } \\
\pm \mathrm{MHz}\end{array}$ \\
\hline $\mathrm{C}^{12} \mathrm{HD}: \mathrm{C}^{12} \mathrm{DBr}^{b}$ & 4- 749 & Not Reported & & & & 14798.1 & .1 \\
\hline $\mathrm{C}^{12} \mathrm{Cl}_{3}^{35} \mathrm{~F}^{19}$ & 4- 191 & $3,1 \leftarrow 2,1$ & Ground & & & 14799.50 & .30 \\
\hline $\mathrm{C}^{12} \cdot \mathrm{H}_{2}: \mathrm{C}^{12} \mathrm{HC}^{12} \mathrm{~F}^{19}: \mathrm{C}^{12} \mathrm{H}_{2}$ & 3- 911 & $4,1.3 \leftarrow 4,0,4$ & Ground & & & 14799.7 & .2 \\
\hline $\mathrm{C}^{13} \mathrm{H}_{2}: \mathrm{C}^{13} \mathrm{HBr}^{81}$ & 4- 734 & $2,1,2 \leftarrow 1,1,1$ & Ground & $1 / 2$ & $1 / 2$ & 14802.5 & .1 \\
\hline $\mathrm{C}^{12} \mathrm{Cl}_{3}^{35} \mathrm{~F}^{19}$ & 4- 191 & $3,2 \leftarrow 2,2$ & Ground & & & 14803.40 & .30 \\
\hline $\mathrm{C}^{12} \mathrm{HD}: \mathrm{C}^{12} \mathrm{DBr}^{\mathrm{b}}$ & 4- 749 & Not Reported & & & & 14804.8 & .2 \\
\hline c- $\mathrm{C}^{12} \mathrm{HD}: \mathrm{C}^{12} \mathrm{DBr}^{79}$ & 4- 744 & $2,1,1 \leftarrow 1,1,0$ & Ground & $7 / 2$ & $5 / 2$ & 14807.8 & .1 \\
\hline $\mathrm{C}^{12} \mathrm{H}_{3} \mathrm{C}^{12} \mathrm{O}^{16} \mathrm{Cl}^{35}$ & 3- 361 & $4,2,2 \leftarrow 4,1,3$ & Ground & & & 14810.8 & .2 \\
\hline $\mathrm{C}_{6}^{12} \mathrm{H}_{5} \mathrm{Cl}^{35}$ & $4-1271$ & $5,1,4 \leftarrow 4,1,3$ & Ground & & & 14811.6 & \\
\hline $\mathrm{C}^{12} \mathrm{H}_{3} \mathrm{C}^{12} \mathrm{O}^{16} \mathrm{Cl}^{35}$ & 3- 361 & $4,2,2 \leftarrow 4,1,3$ & Ground & & & 14814.2 & .2 \\
\hline $\mathrm{C}^{12} \mathrm{HD}: \mathrm{C}^{12} \mathrm{DBr}^{\mathrm{b}}$ & 4- 749 & Not Reported & & & & 14814.3 & .2 \\
\hline $\mathrm{C}^{12} \mathrm{HD}: \mathrm{C}^{12} \mathrm{DBr}^{\mathrm{b}}$ & 4- 749 & Not Reported & & & & 14816.0 & .1 \\
\hline $\mathrm{t}-\mathrm{C}^{12} \mathrm{HD}: \mathrm{C}^{12} \mathrm{HBr}^{79}$ & 4- 741 & $2,0,2 \leftarrow 1,0,1$ & Ground & $7 / 2$ & $5 / 2$ & 14816.1 & .1 \\
\hline${ }^{t-} \mathrm{C}^{12} \mathrm{HD}: \mathrm{C}^{12} \mathrm{HBr}^{79}$ & 4- 741 & $2,0,2 \leftarrow 1,0,1$ & Ground & $5 / 2$ & $3 / 2$ & 14816.1 & .1 \\
\hline $\mathrm{C}^{12} \mathrm{H}_{3} \mathrm{C}^{12} \mathrm{O}^{16} \mathrm{Cl}^{35}$ & 3- 361 & $4,2,2 \leftarrow 4,1,3$ & Ground & & & 14817.2 & .2 \\
\hline $\mathrm{N}^{14} \mathrm{H}_{3}$ & $4-1771$ & $10,5 \leftarrow 10,5$ & Ground & & & 14822.70 & .06 \\
\hline${ }^{c}-\mathrm{C}^{12} \mathrm{HD}: \mathrm{C}^{12} \mathrm{DBr}^{81}$ & 4. 746 & $2,1,1 \leftarrow 1,1,0$ & Ground & $5 / 2$ & $3 / 2$ & 14824.1 & .1 \\
\hline $\mathrm{t}-\mathrm{C}^{12} \mathrm{HD}: \mathrm{C}^{12} \mathrm{HBr}^{79}$ & 4- 741 & $2,0,2 \leftarrow 1,0,1$ & Ground & $1 / 2$ & $1 / 2$ & 14825.9 & .1 \\
\hline $\mathrm{t} \cdot \mathrm{C}^{12} \mathrm{HD}: \mathrm{C}^{12} \mathrm{HBr}^{79}$ & 4-. 741 & $2,0,2 \leftarrow 1,0,1$ & Ground & & & 14826.14 & .06 \\
\hline $\mathrm{a}-\mathrm{C}^{12} \mathrm{HD}_{2} \mathrm{C}^{12} \mathrm{HO}^{16}$ & 3- 482 & $5,1,4 \leftarrow 5,1,5$ & Ground & & & 14827.5 & .3 \\
\hline $\mathrm{H}_{2} \mathrm{O}_{2}^{16}$ & 3- 41 & Not Reported & & & & 14829.5 & .2 \\
\hline $\mathrm{t}-\mathrm{C}^{12} \mathrm{HD}: \mathrm{C}^{12} \mathrm{HBr}^{81}$ & 4- 743 & $2,0,2 \leftarrow 1,0,1$ & Ground & $5 / 2$ & $5 / 2$ & 14831.0 & .1 \\
\hline c- $\mathrm{C}^{12} \mathrm{HD}: \mathrm{C}^{12} \mathrm{DBr}^{79}$ & 4- 744 & $2,1,1 \leftarrow 1,1,0$ & Ground & & & 14837.07 & .04 \\
\hline $\mathrm{a}-\mathrm{C}^{12} \mathrm{HD}_{2} \mathrm{C}^{12} \mathrm{HO}^{16}$ & 3- 482 & $5,1,4 \leftarrow 5,1,5$ & Ground & & & 14839.05 & .3 \\
\hline $\mathrm{t}-\mathrm{C}^{12} \mathrm{HD}: \mathrm{C}^{12} \mathrm{HBr}^{81}$ & 4. 743 & $2,0,2 \leftarrow 1,0,1$ & Ground & $3 / 2$ & $1 / 2$ & 14839.6 & .1 \\
\hline $\mathrm{C}_{6}^{12} \mathrm{H}_{5} \mathrm{O}^{16} \mathrm{H}$ & $3-1051$ & $4,0,4 \leftarrow 3,1,3$ & Ground & & & 14844.9 & \\
\hline $\mathrm{C}^{12} \mathrm{HD}: \mathrm{C}^{12} \mathrm{HBr}^{\mathrm{b}}$ & 4- 748 & Not Reported & & & & 14849.3 & .1 \\
\hline $\mathrm{Cl}^{35} \mathrm{O}^{16} \mathrm{O}^{18}$ & $4-1383$ & $7,1,6 \leftarrow 6,2,5$, & Ground & 5 & 4 & 14855.6 & \\
\hline $\mathrm{D}_{2} \mathrm{O}_{2}^{16}$ & $3, \quad 42$ & Not Reported & & & & 14861. & 3. \\
\hline c- $\mathrm{C}^{12} \mathrm{HD}: \mathrm{C}^{12} \mathrm{DBr}^{79}$ & 4- 744 & $2,1,1 \leftarrow 1,1,0$ & Ground & $5 / 2$ & $5 / 2$ & 14864.6 & .1 \\
\hline $\mathrm{C}^{12} \mathrm{H}_{3} \mathrm{~S}^{32} \mathrm{H}$ & 3- 221 & Not Reported & Ground & & & 14865.1 & .1 \\
\hline $\mathrm{O}_{3}^{16}$ & $4-1841$ & $23,4,20 \leftarrow 24,3,21$ & Ground & & & 14866. & \\
\hline $\mathrm{C}^{\mathrm{b}} \mathrm{H}_{2}: \mathrm{C}^{\mathrm{b}} \mathrm{HBr}^{79}$ & 4. 753 & Not Reported & Ground & $1 / 2$ & $1 / 2$ & 14871.1 & \\
\hline $\mathrm{HC}^{12} \mathrm{DO}^{16}$ & 4. 385 & $13,3,10 \leftarrow 13,3,11$ & Ground & & & 14873.02 & \\
\hline $\mathrm{C}^{\mathrm{b}} \mathrm{H}_{2}: \mathrm{C}^{\mathrm{b}} \mathrm{HBr}^{8 \mathrm{I}}$ & 4. 754 & Not Reported & Ground & $7 / 2$ & $5 / 2$ & 14875.4 & \\
\hline $\mathrm{Cl}^{35} \mathrm{O}^{16} \mathrm{O}^{18}$ & $4-1383$ & $7,1,6 \leftarrow 6,2,5$ & Ground & 6 & 5 & 14881.2 & \\
\hline $\mathrm{C}^{12} \mathrm{H}_{3} \mathrm{~S}^{32} \mathrm{H}$ & 3- 221 & Not Reported & Ground & & & 14888.0 & .1 \\
\hline c- $\mathrm{C}^{12} \mathrm{HD}: \mathrm{C}^{12} \mathrm{DBr}^{79}$ & 4- 744 & $2,1,1 \leftarrow 1,1,0$ & Ground & $3 / 2$ & $3 / 2$ & 14888.1 & .1 \\
\hline $\mathrm{S}^{32}{ }_{*} \mathrm{C}^{12} \mathrm{H}: \mathrm{C}^{13} \mathrm{HC}^{12} \mathrm{H}: \mathrm{C}^{12}{ }_{*} \mathrm{H}$ & $4-1168$ & $2,1,2 \leftarrow 1,1,1$ & Ground & & & 14891.3 & .05 \\
\hline${ }^{1-}-\mathrm{C}^{12} \mathrm{HD}: \mathrm{C}^{12} \mathrm{HBr}^{81}$ & 4. 743 & $2,1,1 \leftarrow 1,1,0$ & Ground & $1 / 2$ & $1 / 2$ & 14897.3 & .1 \\
\hline $\mathrm{C}^{13} \mathrm{H}_{2}: \mathrm{C}^{13} \mathrm{HBr}^{81}$ & 4. 734 & $2,1,2 \leftarrow 1,1,1$ & Ground & & & 14900.24 & .05 \\
\hline $\mathrm{H}_{2} \mathrm{~N}^{1+} \mathrm{N}^{14} \mathrm{H}_{2}$ & 3- 51 & Not Reported & & & & 14900.5 & \\
\hline c. $\mathrm{C}^{12} \mathrm{HD}: \mathrm{C}^{12} \mathrm{HBr}^{81}$ & 4- 742 & $2,1,2 \leftarrow 1,1,1$ & Ground & $1 / 2$ & $1 / 2$ & 14909.1 & .2 \\
\hline $\mathrm{C}^{12} \mathrm{H}_{3} \mathrm{C}^{12} \mathrm{D}_{3} \mathrm{Si}^{28} \mathrm{H}_{2}$ & 3- 642 & $4,1,3 \leftarrow 4,0,4$ & Ground & & & 14909.62 & .05 \\
\hline $\mathrm{Cl}^{35} \mathrm{O}^{16} \mathrm{O}^{18}$ & $4-1383$ & $7,1,6 \leftarrow 6,2,5$ & Ground & 7 & 6 & 14910.0 & \\
\hline
\end{tabular}




\begin{tabular}{|c|c|c|c|c|c|c|c|}
\hline Isotopic Species & $\begin{array}{l}\text { Vol.-Id. } \\
\text { Nos. }\end{array}$ & $\begin{array}{c}\text { Rotational } \\
\text { Quantum Nos. }\end{array}$ & Vib. State & $\mathrm{F}_{1}^{\prime} \stackrel{\text { Hyperfine }}{\mathrm{F}^{\prime}} \mathrm{F}_{1}$ & $\mathbf{F}$ & $\begin{array}{c}\text { Frequency } \\
\text { MHz }\end{array}$ & $\begin{aligned} & \text { Acc. } \\
\pm & \mathrm{MHz}\end{aligned}$ \\
\hline $\mathrm{C}^{12} \mathrm{H}_{3} \mathrm{~N}^{14} \mathrm{H}_{2}$ & 3-261 & Not Reported & Ground & & & 14910.71 & .04 \\
\hline $\mathrm{C}^{12} \mathrm{H}_{3} \mathrm{C}^{12} \mathrm{D}_{3} \mathrm{Si}^{28} \mathrm{H}_{2}$ & 3- 642 & $4,1,3 \leftarrow 4,0,4$ & Ground & & & 14910.75 & .05 \\
\hline $\mathrm{s}-\mathrm{HC}^{12} \mathrm{O}^{16} \mathrm{O}^{16} \mathrm{C}^{12} \mathrm{H}_{2} \mathrm{D}-\mathrm{A}$ & 3- 505 & $1,1,0 \leftarrow 1,0,1$ & Ground & & & 14. 916.50 & .35 \\
\hline $\mathrm{C}^{12} \mathrm{HD}: \mathrm{C}^{12} \mathrm{DBr}^{\mathrm{b}}$ & 4- 749 & Not Reported & & & & 14918.6 & .1 \\
\hline $\mathrm{HC}^{12} \mathrm{O}^{18} \mathrm{O}^{16} \mathrm{H}$ & 3- 76 & $4,1,4 \leftarrow 4,1,3$ & Ground & & & 14.919 .20 & .1 \\
\hline $\mathrm{F}^{19} \mathrm{HC}^{13} \mathrm{O}^{16}$ & 4- 273 & $4,0,4 \leftarrow 3,1,3$ & & & & 14919.9 & .2 \\
\hline$c-\mathrm{C}^{12} \mathrm{HD}: \mathrm{C}^{12} \mathrm{DBr}^{79}$ & 4. 744 & $2,1,1 \leftarrow 1,1,0$ & Ground & $5 / 2$ & $3 / 2$ & 14.928 .0 & .1 \\
\hline $\mathrm{C}^{\mathrm{b}} \mathrm{H}: \mathrm{C}^{\mathrm{b}} \mathrm{HBr}^{\mathrm{b}}$ & 4. 752 & Not Reported & Ground & $5 / 2$ & $5 / 2$ & 14.928 .9 & \\
\hline $\mathrm{N}^{14} \mathrm{O}_{2}^{16}$ & 4-1801 & $7,1,7 \leftarrow 8,0,8$ & Ground & & & 14929.90 & \\
\hline $\mathrm{t} \cdot \mathrm{C}^{12} \mathrm{HD}: \mathrm{C}^{12} \mathrm{HBr}^{79}$ & 4- 741 & $2,0,2 \leftarrow 1,0,1$ & Ground & $5 / 2$ & $5 / 2$ & 14934.1 & .1 \\
\hline $\mathrm{C}^{b} \mathrm{H}_{2}: \mathrm{C}^{b} \mathrm{HBr}^{79}$ & 4- 753 & Not Reported & Ground & $3 / 2$ & $1 / 2$ & 14.934 .5 & \\
\hline $\mathrm{C}^{\mathrm{b}} \mathrm{H}_{2}: \mathrm{C}^{\mathrm{b}} \mathrm{HBr}^{81}$ & 4- 754 & Not Reported & Ground & $3 / 2$ & $3 / 2$ & 14936.7 & \\
\hline $\mathrm{C}^{12} \mathrm{HD}: \mathrm{C}^{12} \mathrm{HBr}^{\mathrm{b}}$ & 4. 748 & Not Reported & & & & 14937.0 & .2 \\
\hline $\mathrm{Cl}^{35} \mathrm{O}^{16} \mathrm{O}^{18}$ & $4 \cdot 1383$ & $7,1,6 \leftarrow 6,2,5$ & Ground & 8 & 7 & 14939.1 & \\
\hline $\mathrm{C}^{\mathrm{b}} \mathrm{H}_{2}: \mathrm{C}^{\mathrm{b}} \mathrm{HBr}^{\mathrm{b}}$ & 4. 752 & Not Reported & Ground & & & 14941.3 & \\
\hline t- $\mathrm{C}^{12} \mathrm{HD}: \mathrm{C}^{12} \mathrm{HBr}^{81}$ & 4- 743 & $2,1,1 \leftarrow 1,1,0$ & Ground & $3 / 2$ & $1 / 2$ & 14942.5 & .2 \\
\hline $\mathrm{C}^{12} \mathrm{H}_{3} \mathrm{~S}^{32} \mathrm{C}^{12} \mathrm{D}_{3}$ & 3- 606 & $3,1,2 \leftarrow 3,0,3$ & Ground & & & 14943.65 & .05 \\
\hline $\mathrm{C}^{12} \mathrm{H}_{3} \mathrm{C}^{12} \mathrm{H}: \mathrm{C}^{12} \mathrm{HF}^{19}$ & 3- 711 & $2,1,2 \leftarrow 1,1,1$ & Ground & & & 14944.2 & \\
\hline t- $\mathrm{C}^{12} \mathrm{HD}: \mathrm{C}^{12} \mathrm{HBr}^{81}$ & 4- 743 & $2,0,2 \leftarrow 1,0,1$ & Ground & $3 / 2$ & $1 / 2$ & 14944.5 & .1 \\
\hline $\mathrm{C}^{12} \mathrm{HCl}^{37} \mathrm{~F}_{2}^{19}$ & 4- 252 & $1,1,0 \leftarrow 0,0,0$ & Ground & $1 / 2$ & $3 / 2$ & 14945.25 & \\
\hline $\mathrm{C}^{12} \mathrm{H}_{3} \mathrm{~S}^{32} \mathrm{C}^{12} \mathrm{D}_{3}$ & 3- 606 & $3,1,2 \leftarrow 3,0,3$ & Ground & & & 14949.04 & .05 \\
\hline $\mathrm{C}^{12} \mathrm{HCl}^{37} \mathrm{~F}_{2}^{19}$ & 4. 252 & $1,1,0 \leftarrow 0,0,0$ & Ground & $5 / 2$ & $3 / 2$ & 14949.85 & \\
\hline $\mathrm{C}^{12} \mathrm{HCl}^{37} \mathrm{~F}_{2}^{19}$ & 4- 252 & $1,1,0 \leftarrow 0,0,0$ & Ground & & & 14950.94 & .03 \\
\hline $\mathrm{C}^{12} \mathrm{H}_{3} \mathrm{~S}^{32} \mathrm{C}^{12} \mathrm{D}_{3}$ & 3- 606 & $3,1,2 \leftarrow 3,0,3$ & Ground & & & 14.954 .42 & .05 \\
\hline $\mathrm{C}^{12} \mathrm{HCl}^{37} \mathrm{~F}_{2}^{19}$ & 4- 252 & $1,1,0 \leftarrow 0,0,0$ & Ground & $3 / 2$ & $3 / 2$ & 14.955 .67 & \\
\hline $\mathrm{C}^{12}{ }_{*} \mathrm{H}_{2} \mathrm{C}^{13} \mathrm{H}_{2} \mathrm{C}^{12}{ }_{*} \mathrm{Cl}_{2}^{35}$ & 4-1068 & $9,5,5 \leftarrow 9,4,6$ & Ground & & & 14958. & \\
\hline $\mathrm{C}^{12}{ }_{*} \mathrm{H}_{2} \mathrm{C}^{13} \mathrm{H}_{2} \mathrm{C}^{12} \mathrm{Cl}_{2}^{35}$ & 4-1068 & $9,6,4 \leftarrow 9,5,5$ & Ground & & & 14. 958 & \\
\hline $\mathrm{C}^{b} \mathrm{H}_{2}: \mathrm{C}^{\mathrm{b}} \mathrm{HBr}^{79}$ & 4- 753 & Not Reported & Ground & $7 / 2$ & $5 / 2$ & 14. 958.2 & \\
\hline $\mathrm{N}^{14} \mathrm{O}_{2}^{16}$ & 4-1801 & $7,1,7 \leftarrow 8,0,8$ & Ground & & & 14.961 .00 & \\
\hline $\mathrm{C}^{12} \mathrm{H}_{3} \mathrm{~N}^{14} \mathrm{H}_{2}$ & 3- 261 & Not Reported & Ground & & & 14.961 .12 & \\
\hline c- $\mathrm{C}^{12} \mathrm{HD}: \mathrm{C}^{12} \mathrm{HBr}^{81}$ & 4- 742 & $2,1,2 \leftarrow 1,1,1$ & Ground & $3 / 2$ & $1 / 2$ & 14.962 .1 & .1 \\
\hline $\mathrm{C}^{12} \mathrm{HD}: \mathrm{C}^{12} \mathrm{HBr}^{\mathrm{b}}$ & 4- 748 & Not Reported & & & & 14. 964.2 & .1 \\
\hline $\mathrm{C}^{12} \mathrm{HD}: \mathrm{C}^{12} \mathrm{HBr}^{\mathrm{b}}$ & 4- 748 & Not Reported & & & & 14.966 .6 & .1 \\
\hline $\mathrm{c}-\mathrm{HCl}^{35} \mathrm{C}^{12}: \mathrm{C}^{12} \mathrm{HCl}^{35}$ & 4- 671 & $6,1,5 \leftarrow 6,0,6$ & Ground & & & 14.968 .41 & \\
\hline $\mathrm{t}-\mathrm{C}^{12} \mathrm{HD}: \mathrm{C}^{12} \mathrm{HBr}^{81}$ & 4- 743 & $2,1,1 \leftarrow 1,1,0$ & Ground & $7 / 2$ & $5 / 2$ & 14. 971.4 & .1 \\
\hline $\mathrm{C}^{\mathrm{b}} \mathrm{H}_{2}: \mathrm{C}^{\mathrm{b}} \mathrm{HBr}^{81}$ & 4- 754 & Not Reported & Ground & $5 / 2$ & $3 / 2$ & 14.974 .3 & \\
\hline $\mathrm{C}^{12} \mathrm{HD}: \mathrm{C}^{12} \mathrm{HBr}^{\mathrm{b}}$ & 4- 748 & Not Reported & & & & 14.976 .1 & .1 \\
\hline$c \cdot \mathrm{C}^{12} \mathrm{HD}: \mathrm{C}^{12} \mathrm{HBr}^{81}$ & 4- 742 & $2,1,2 \leftarrow 1,1,1$ & Ground & $7 / 2$ & $5 / 2$ & 14979.9 & .1 \\
\hline $\mathrm{C}^{12} \mathrm{HD}: \mathrm{C}^{12} \mathrm{DBr}^{\mathrm{b}}$ & 4- 749 & Not Reported & & & & 14. 980.1 & .1 \\
\hline $\mathrm{C}^{13} \mathrm{H}_{2}: \mathrm{C}^{12} \mathrm{HBr}^{81}$ & 4- 736 & Not Reported & Cround & $1 / 2$ & $1 / 2$ & 14980.8 & \\
\hline $\mathrm{C}^{12} \mathrm{HD}: \mathrm{C}^{12} \mathrm{DBr}^{\mathrm{b}}$ & 4- 749 & Not Reported & & & & 14983.7 & .1 \\
\hline $\mathrm{C}^{13} \mathrm{H}_{2}: \mathrm{C}^{13} \mathrm{HBr}^{79}$ & 4- 733 & $2,1,2 \leftarrow 1,1,1$ & Ground & & & 14988.18 & .05 \\
\hline $\mathrm{C}^{12} \mathrm{H}_{3} \mathrm{P}^{31} \mathrm{H}_{2}$ & 3- 271 & $6,2,4 \leftarrow 7,1,6$ & Cround & & & 14991.7 & .1 \\
\hline $\mathrm{t}-\mathrm{C}^{12} \mathrm{HD}: \mathrm{C}^{12} \mathrm{HBr}^{81}$ & 4- 743 & $2,1,1 \leftarrow 1,1,0$ & Ground & & & 14.995 .68 & .04 \\
\hline $\mathrm{C}^{12} \mathrm{HD}: \mathrm{C}^{12} \mathrm{HBr}^{\mathrm{b}}$ & 4- 748 & Not Reported & & & & 14996.1 & .1 \\
\hline
\end{tabular}




\begin{tabular}{|c|c|c|c|c|c|c|c|}
\hline Isotopic Species & $\begin{array}{l}\text { Vol.-Id. } \\
\text { Nos. }\end{array}$ & $\begin{array}{c}\text { Rotational } \\
\text { Quantum Nos. }\end{array}$ & Vib. State & $\mathrm{F}_{1}^{\prime} \stackrel{\text { Hyperfine }}{\mathrm{F}^{\prime} \quad \mathrm{F}_{1}}$ & e $F$ & $\begin{array}{l}\text { Frequency } \\
\mathrm{MHz}\end{array}$ & $\begin{array}{r}\text { Acc. } \\
\pm \mathrm{MHz}\end{array}$ \\
\hline $\mathrm{t}-\mathrm{C}^{12} \mathrm{HD}: \mathrm{C}^{12} \mathrm{DBr}^{81}$ & 4- 747 & $2,0,2 \leftarrow 1,0,1$ & Ground & $7 / 2$ & $5 / 2$ & 14996.9 & .1 \\
\hline $\mathrm{t}-\mathrm{C}^{12} \mathrm{HD}: \mathrm{C}^{12} \mathrm{DBr}^{81}$ & 4- 747 & $2,0,2 \leftarrow 1,0,1$ & Ground & $5 / 2$ & $3 / 2$ & 14996.9 & .1 \\
\hline $\mathrm{t}-\mathrm{C}^{12} \mathrm{HD}: \mathrm{C}^{12} \mathrm{DBr}^{79}$ & 4. 745 & $2,0,2 \leftarrow 1,0,1$ & Ground & $3 / 2$ & $3 / 2$ & 15001.35 & .05 \\
\hline $\mathrm{C}^{12} \mathrm{H}_{3} \mathrm{~S}^{32} \mathrm{C}^{12} \mathrm{D}_{3}$ & 3- 606 & $3,1,2 \leftarrow 3,0,3$ & Ground & & & 15001.68 & .05 \\
\hline $\mathrm{Cl}^{37} \mathrm{O}_{2}^{16}$ & 4-1382 & $11,2,9 \leftarrow 10,3,8$ & Ground & $19 / 2$ & $17 / 2$ & 15002.8 & \\
\hline $\mathrm{N}^{14} \mathrm{H}_{3}$ & $4-1771$ & Not Reported & Ground & & & 15004 & \\
\hline c. $\mathrm{C}^{12} \mathrm{HD}: \mathrm{C}^{12} \mathrm{HBr}^{81}$ & 4. 742 & $2,1,2 \leftarrow 1,1,1$ & Ground & & & 15004.18 & .06 \\
\hline $\mathrm{C}^{12} \mathrm{HD}: \mathrm{C}^{12} \mathrm{DBr} \mathrm{r}^{\mathrm{b}}$ & 4. 749 & Not Reported & & & & 15004.8 & .1 \\
\hline $\mathrm{t}-\mathrm{C}^{12} \mathrm{HD}: \mathrm{C}^{12} \mathrm{DBr}^{81}$ & 4. 747 & $2,0,2 \leftarrow 1,0,1$ & Ground & & & 15005.28 & .07 \\
\hline $\mathrm{C}^{12} \mathrm{H}_{3} \mathrm{C}^{12} \mathrm{O}^{16} \mathrm{~F}^{19}$ & 3- 391 & $1.0,1 \leftarrow 0,0,0$ & Ground & & & 15007.91 & .2 \\
\hline $\mathrm{C}^{12} \mathrm{D}_{2}\left(\mathrm{C}^{12} \mathrm{~N}^{14}\right)_{2}$ & 4- 903 & $3,1,2 \leftarrow 3,0,3$ & Ground & & & 15008.56 & \\
\hline $\mathrm{C}^{12} \mathrm{HD}: \mathrm{C}^{12} \mathrm{DBr}^{\mathrm{b}}$ & 4. 749 & Not Reported & & & & 15016.9 & .1 \\
\hline $\mathrm{t}-\mathrm{C}^{12} \mathrm{HD}: \mathrm{C}^{12} \mathrm{HBr}^{81}$ & 4. 743 & $2,1,1 \leftarrow 1,1,0$ & Ground & $5 / 2$ & $5 / 2$ & 15017.7 & .1 \\
\hline $4 \mathrm{~d}-\mathrm{C}_{6}^{12} \mathrm{H}_{5} \mathrm{C}^{12} \mathrm{~N}^{14}$ & 4-1296 & $6,1,6 \leftarrow 5,1,5$ & Ground & & & 15017.9 & .2 \\
\hline $\mathrm{Cl}^{37} \mathrm{O}_{2}^{16}$ & 4-1382 & $11,2,9 \leftarrow 10,3,8$ & Ground & $21 / 2$ & $19 / 2$ & 15019.1 & \\
\hline $\mathrm{C}^{13} \mathrm{H}_{2}: \mathrm{C}^{13} \mathrm{HBr}^{79}$ & 4- 733 & Not Reported & Ground & $5 / 2$ & $5 / 2$ & 15022.1 & \\
\hline $\mathrm{C}^{12} \mathrm{H}_{3} \mathrm{O}^{16} \mathrm{~N}^{14} \mathrm{O}_{2}^{16}$ & 3- 181 & $2,1,2 \leftarrow 1,1,1$ & Ground & & & 15022.38 & .1 \\
\hline $\mathrm{N}^{14} \mathrm{O}_{2}^{16}$ & 4-1801 & $7,1,7 \leftarrow 8,0,8$ & Ground & & & 15025.37 & \\
\hline $\mathrm{C}^{12} \mathrm{HD}: \mathrm{C}^{12} \mathrm{HBr}^{\mathrm{b}}$ & 4- 748 & Not Reported & & & & 15028.5 & .1 \\
\hline $\mathrm{C}^{12} \mathrm{H}_{3} \mathrm{C}^{12} \mathrm{H}: \mathrm{C}^{12} \mathrm{HF}^{19}$ & 3. 711 & $2,0,2 \leftarrow 1,0,1$ & Ground & & & 15029.68 & \\
\hline $\mathrm{C}^{12} \mathrm{H}_{3} \mathrm{O}^{16} \mathrm{~N}^{14} \mathrm{O}_{2}^{16}$ & 3. 181 & $2,1,2 \leftarrow 1,1,1$ & Ground & & & 15031.69 & .1 \\
\hline $\mathrm{C}^{13} \mathrm{H}_{2}: \mathrm{C}^{12} \mathrm{HBr}^{81}$ & 4. 736 & Not Reported & Ground & $3 / 2$ & $1 / 2$ & 15031.8 & \\
\hline $\mathrm{S}^{32}{ }_{*} \mathrm{HC}^{13}: \mathrm{C}^{12} \mathrm{HC}^{12} \mathrm{H}: \mathrm{C}^{12}{ }_{*} \mathrm{H}$ & $4-1167$ & $2,1,2 \leftarrow 1,1,1$ & Ground & & & 15032.8 & .05 \\
\hline c- $\mathrm{C}^{12} \mathrm{HD}: \mathrm{C}^{12} \mathrm{HBr}^{81}$ & 4- 742 & $2,1,2 \leftarrow 1,1,1$ & Ground & $5 / 2$ & $5 / 2$ & 15033.5 & .1 \\
\hline $\mathrm{C}^{13} \mathrm{H}_{2}: \mathrm{C}^{13} \mathrm{HBr}^{79}$ & 4- 733 & Not Reported & Ground & $3 / 2$ & $3 / 2$ & 15033.6 & .2 \\
\hline $\mathrm{CJ}^{35} \mathrm{O}^{16} \mathrm{O}^{18}$ & 4-1383 & $7,1,6 \leftarrow 6,2,5$ & Ground & 9 & 8 & 15035. & \\
\hline $\mathrm{Cl}^{37} \mathrm{O}_{2}^{16}$ & 4-1382 & $11,2,9 \leftarrow 10,3,8$ & Ground & $23 / 2$ & $21 / 2$ & 15035.1 & \\
\hline $\mathrm{C}^{12} \mathrm{H}_{2} \mathrm{Cl}^{37} \mathrm{C}^{12} \mathrm{~N}^{14}$ & 4- 652 & $6,0,6 \leftarrow 5,1,5$ & Ground & & & 15038.34 & .2 \\
\hline$\left(\mathrm{C}^{12} \mathrm{H}_{3}\right)_{2} \mathrm{C}^{12} \mathrm{O}^{16}$ & 3- 751 & $1,1,1 \leftarrow 0,0,0$ & Ground & & & 15038.47 & .04 \\
\hline $\mathrm{t} \cdot \mathrm{C}^{12} \mathrm{HD}: \mathrm{C}^{12} \mathrm{HBr}^{81}$ & 4- 743 & $2,1,1 \leftarrow 1,1,0$ & Ground & $3 / 2$ & $3 / 2$ & 15038.6 & .1 \\
\hline $\mathrm{C}^{12} \mathrm{H}_{3} \mathrm{O}^{16} \mathrm{~N}^{14} \mathrm{O}_{2}^{16}$ & 3- 181 & $2,1,2 \leftarrow 1,1,1$ & Ground & & & 15039.95 & .1 \\
\hline $\mathrm{C}^{12} \mathrm{HD}: \mathrm{C}^{12} \mathrm{HBr}^{\mathrm{b}}$ & 4- 748 & Not Reported & & & & 15045.0 & .2 \\
\hline $\mathrm{C}^{12} \mathrm{HD}: \mathrm{C}^{12} \mathrm{DBr}^{\mathrm{b}}$ & 4. 749 & Not Reported & & & & 15045.1 & .3 \\
\hline $\mathrm{C}^{12} \mathrm{H}_{3} \mathrm{~N}^{14} \mathrm{H}_{2}$ & 3- 261 & Not Reported & Ground & & & 15047.43 & .1 \\
\hline $\mathrm{Cl}^{37} \mathrm{O}_{2}^{16}$ & 4-1382 & $11,2,9 \leftarrow 10,3,8$ & Ground & $25 / 2$ & $23 / 2$ & 15051.1 & \\
\hline $\mathrm{C}^{13} \mathrm{H}_{2}: \mathrm{C}^{12} \mathrm{HBr}^{81}$ & 4- 736 & Not Reported & Ground & $7 / 2$ & $5 / 2$ & 15053.2 & \\
\hline $\mathrm{C}^{12} \mathrm{HD}: \mathrm{C}^{12} \mathrm{DBr}^{\mathrm{b}}$ & 4- 749 & Not Reported & & & & 15055.2 & .1 \\
\hline $\mathrm{t}-\mathrm{C}^{12} \mathrm{HD}: \mathrm{C}^{12} \mathrm{HBr}^{79}$ & 4- 741 & $2,1,1 \leftarrow 1,1,0$ & Ground & $7 / 2$ & $5 / 2$ & 15055.3 & 1. \\
\hline $\mathrm{H}_{2} \mathrm{~N}^{14} \mathrm{~N}^{14} \mathrm{H}_{2}$ & 3. 51 & $1,1 \leftarrow 2,0$ & Ground & 2 & 3 & 15058.60 & .05 \\
\hline $\mathrm{Cl}^{35} \mathrm{O}^{16} \mathrm{O}^{18}$ & 4-1383 & $7,1,6 \leftarrow 6,2,5$ & Ground & 8 & 7 & 15059.2 & \\
\hline $\mathrm{H}_{2} \mathrm{~N}^{14} \mathrm{~N}^{14} \mathrm{H}_{2}$ & $3-51$ & $1,1 \leftarrow 2,0$ & Ground & 1 & 2 & 15059.51 & .05 \\
\hline $\mathrm{H}_{2} \mathrm{~N}^{14} \mathrm{~N}^{14} \mathrm{H}_{2}$ & $3-\quad 51$ & $1,1 \leftarrow 2,0$ & Ground & 2 & 3 & 15060.23 & .05 \\
\hline$c-\mathrm{C}^{12} \mathrm{HD}: \mathrm{C}^{12} \mathrm{HBr}^{79}$ & 4. 739 & $2,1,2 \leftarrow 1,1,1$ & Ground & $7 / 2$ & $5 / 2$ & 15060.3 & .1 \\
\hline $\mathrm{C}^{12} \mathrm{HD}: \mathrm{C}^{12} \mathrm{DBr}^{\mathrm{b}}$ & 4- 749 & Not Reported & & & & 15060.4 & .1 \\
\hline $\mathrm{H}_{2} \mathrm{~N}^{14} \mathrm{~N}^{14} \mathrm{H}_{2}$ & $3-51$ & $1,1 \leftarrow 2,0$ & Ground & 3 & 4 & 15061.12 & .05 \\
\hline
\end{tabular}




\begin{tabular}{|c|c|c|c|c|c|c|c|}
\hline Isotopic Species & $\begin{array}{l}\text { Vol.-Id. } \\
\text { Nos. }\end{array}$ & $\begin{array}{c}\text { Rotational } \\
\text { Quantum Nos. }\end{array}$ & Vib. State & $\begin{array}{c}\mathrm{F}_{1}^{\prime} \mathrm{F}^{\prime} \quad \mathrm{F}_{1}\end{array}$ & $\mathrm{~F}$ & $\begin{array}{c}\text { Frequency } \\
\mathrm{MH}_{z}\end{array}$ & $\begin{aligned} \text { Acc. } \\
\pm \mathrm{MHz}\end{aligned}$ \\
\hline $\mathrm{a}-\mathrm{HC}^{12} \mathrm{O}^{16} \mathrm{O}^{16} \mathrm{C}^{12} \mathrm{H}_{2} \Gamma$ & 3- 506 & $2,1,1 \leftarrow 2,0,2$ & Ground & & & 15061.90 & .2 \\
\hline $\mathrm{H}_{2} \mathrm{~N}^{14} \mathrm{~N}^{14} \mathrm{H}_{2}$ & $3-51$ & $1,1 \leftarrow 2,0$ & Ground & 1 & 2 & 15061.94 & .05 \\
\hline $\mathrm{H}_{2} \mathrm{~N}^{14} \mathrm{~N}^{14} \mathrm{H}_{2}$ & 3- 51 & $1,1 \leftarrow 2,0$ & Ground & 1 & 1 & 15062.65 & .05 \\
\hline $\mathrm{a}-\mathrm{HC}^{12} \mathrm{O}^{16} \mathrm{O}^{16} \mathrm{C}^{12} \mathrm{H}_{2} \mathrm{D}$ & 3- 506 & $2,1,1 \leftarrow 2,0,2$ & Ground & & & 15063.28 & .2 \\
\hline $\mathrm{H}_{2} \mathrm{~N}^{14} \mathrm{~N}^{14} \mathrm{H}_{2}$ & 3- 51 & $1,1 \leftarrow 2,0$ & Ground & 1 & 0 & 15063.45 & .05 \\
\hline $\mathrm{C}_{6}^{12} \mathrm{H}_{5} \mathrm{C}^{12} \mathrm{~N}^{15}$ & $4-1292$ & $6,1,6 \leftarrow 5,1,5$ & Ground & & & 15064.0 & .2 \\
\hline $\mathrm{H}_{2} \mathrm{~N}^{14} \mathrm{~N}^{14} \mathrm{H}_{2}$ & 3- 51 & $1,1 \leftarrow 2,0$ & Ground & 2 & 3 & 15064.36 & .05 \\
\hline$\left(\mathrm{C}^{12} \mathrm{H}_{3}\right)_{2} \mathrm{C}^{12} \mathrm{O}^{16}$ & 3- 751 & $1,1,1 \leftarrow 0,0,0$ & Ground & & & 15064.91 & .04 \\
\hline $\mathrm{H}_{2} \mathrm{~N}^{14} \mathrm{~N}^{14} \mathrm{H}_{2}$ & 3- 51 & $1,1 \leftarrow 2,0$ & Ground & 1 & 2 & 15065.06 & .05 \\
\hline $\mathrm{H}_{2} \mathrm{~N}^{14} \mathrm{~N}^{14} \mathrm{H}_{2}$ & 3- 51 & $1,1 \leftarrow 2,0$ & Ground & 2 & 3 & 15066.02 & .05 \\
\hline $\mathrm{H}_{2} \mathrm{~N}^{14} \mathrm{~N}^{14} \mathrm{H}_{2}$ & $3-\quad 51$ & $1,1 \leftarrow 2,0$ & Ground & 3 & 4 & 15066.95 & .05 \\
\hline $\mathrm{H}_{2} \mathrm{~N}^{14} \mathrm{~N}^{14} \mathrm{H}_{2}$ & $3-\quad 51$ & $1,1 \leftarrow 2,0$ & Ground & 1 & 2 & 15067.55 & .05 \\
\hline $\mathrm{D}_{2} \mathrm{O}_{2}^{16}$ & 3- 42 & Not Reported & & & & 15068. & 3. \\
\hline $\mathrm{H}_{2} \mathrm{~N}^{14} \mathrm{~N}^{14} \mathrm{H}_{2}$ & $3-51$ & $1,1 \leftarrow 2,0$ & Ground & 1 & 1 & 15068.17 & .05 \\
\hline $\mathrm{H}_{2} \mathrm{~N}^{14} \mathrm{~N}^{14} \mathrm{H}_{2}$ & 3- 51 & $1,1 \leftarrow 2,0$ & Ground & 1 & 0 & 15069.35 & .05 \\
\hline $\mathrm{t}-\mathrm{C}^{12} \mathrm{HD}: \mathrm{C}^{12} \mathrm{HBr}^{81}$ & 4- 743 & $2,1,1 \leftarrow 1,1,0$ & Ground & $5 / 2$ & $3 / 2$ & 15070.4 & .1 \\
\hline $\mathrm{C}^{12} \mathrm{HD}: \mathrm{C}^{12} \mathrm{DBr} \mathrm{r}^{\mathrm{b}}$ & 4- 749 & Not Reported & & & & 15070.7 & .1 \\
\hline$\left(\mathrm{C}^{12} \mathrm{H}_{3}\right)_{2} \mathrm{C}^{12} \mathrm{O}^{16}$ & 3- 751 & $1,1,1 \leftarrow 0,0,0$ & Ground & & & 15074.05 & .04 \\
\hline c- $\mathrm{C}^{12} \mathrm{HD}: \mathrm{C}^{12} \mathrm{HBr}^{81}$ & 4. 742 & $2,1,2 \leftarrow 1,1,1$ & Ground & $5 / 2$ & $3 / 2$ & 15076.3 & .1 \\
\hline $\mathrm{C}^{13} \mathrm{H}_{2}: \mathrm{C}^{13} \mathrm{HBr}^{79}$ & 4- 733 & Not Reported & Ground & $5 / 2$ & $3 / 2$ & 15076.7 & \\
\hline $\mathrm{C}^{13} \mathrm{H}_{2}: \mathrm{C}^{12} \mathrm{HBr}^{81}$ & 4- 736 & $2,1,2 \leftarrow 1,1,1$ & Ground & & & 15077.69 & .05 \\
\hline $\mathrm{Cl}^{35} \mathrm{O}^{16} \mathrm{O}^{18}$ & 4-1383 & $7,1,6 \leftarrow 6,2,5$ & Ground & 7 & 6 & 15078.4 & \\
\hline $\mathrm{DC}^{12} \mathrm{DO}^{16}$ & 4- 384 & $16,4,12 \longleftarrow 16,4,13$ & Ground & & & 15080.34 & \\
\hline $\mathrm{t}-\mathrm{C}^{12} \mathrm{HD}: \mathrm{C}^{12} \mathrm{HBr}^{79}$ & 4. 741 & $2,1,1 \leftarrow 1,1,0$ & Ground & & & 15083.70 & .07 \\
\hline $\mathrm{t}-\mathrm{C}^{12} \mathrm{HD}: \mathrm{C}^{12} \mathrm{DBr}^{79}$ & 4- 745 & $2,0,2 \leftarrow 1,0,1$ & Ground & $5 / 2$ & $3 / 2$ & 15084.1 & .1 \\
\hline $\mathrm{t}-\mathrm{C}^{12} \mathrm{HD}: \mathrm{C}^{12} \mathrm{DBr}^{79}$ & 4- 745 & $2,0,2 \leftarrow 1,0,1$ & Ground & $7 / 2$ & $5 / 2$ & 15084.1 & .1 \\
\hline $\mathrm{C}^{12} \mathrm{HC}^{35} \mathrm{~F}_{2}^{19}$ & 4- 251 & $1,1,0 \leftarrow 0,0,0$ & Ground & $1 / 2$ & $3 / 2$ & 15088.57 & \\
\hline$c-\mathrm{C}^{12} \mathrm{HD}: \mathrm{C}^{12} \mathrm{HBr}^{79}$ & 4- 739 & $2,1,2 \leftarrow 1,1,1$ & Ground & & & 15089.11 & .06 \\
\hline $\mathrm{C}^{12} \mathrm{H}_{3} \mathrm{~S}^{32} \mathrm{H}$ & 3- 221 & Not Reported & Ground & & & 15089.3 & .1 \\
\hline $\mathrm{H}_{2} \mathrm{~N}^{14} \mathrm{~N}^{14} \mathrm{H}_{2}$ & 3- 51 & $1,1 \leftarrow 2,0$ & Ground & & & 15091.2 & \\
\hline $\mathrm{Cl}^{35} \mathrm{O}^{16} \mathrm{O}^{18}$ & 4-1383 & $7,1,6 \leftarrow 6,2,5$ & Ground & 6 & 5 & 15093.6 & \\
\hline $\mathrm{t}-\mathrm{C}^{12} \mathrm{HD}: \mathrm{C}^{12} \mathrm{DBr}^{79}$ & 4- 745 & $2,0,2 \leftarrow 1,0,1$ & Ground & & & 15094.31 & .05 \\
\hline $\mathrm{C}^{12} \mathrm{HC}^{35} \mathrm{~F}_{2}^{19}$ & 4- 251 & $1,1,0 \leftarrow 0,0,0$ & Ground & $5 / 2$ & $3 / 2$ & 15094.42 & \\
\hline $\mathrm{C}^{12} \mathrm{H}_{3} \mathrm{~N}^{14} \mathrm{H}_{2}$ & 3- 261 & Not Reported & Ground & & & 15094.56 & .1 \\
\hline $\mathrm{t}-\mathrm{C}^{12} \mathrm{HD}: \mathrm{C}^{12} \mathrm{DBr}^{81}$ & 4- 747 & $2,0,2 \leftarrow 1,0,1$ & Ground & $5 / 2$ & $5 / 2$ & 15094.8 & .2 \\
\hline $\mathrm{C}^{12} \mathrm{HCl}^{35} \mathrm{~F}_{2}^{19}$ & 4- 251 & $1,1,0 \leftarrow 0,0,0$ & Ground & & & 15095.94 & .02 \\
\hline$\left(\mathrm{C}^{12} \mathrm{H}_{3}\right)_{2} \mathrm{C}^{12} \mathrm{O}^{16}$ & 3- 751 & $1,1,1 \leftarrow 0,0,0$ & Ground & & & 15096.36 & .04 \\
\hline $\mathrm{C}^{12} \mathrm{H}_{3} \mathrm{C}^{12} \mathrm{~F}^{19}: \mathrm{C}^{12} \mathrm{H}_{2}$ & 3. 721 & $1,1,1 \leftarrow 0,0,0$ & Ground & & & 15096.93 & .1 \\
\hline $\mathrm{H}_{2} \mathrm{~N}^{14} \mathrm{~N}^{14} \mathrm{H}_{2}$ & 3- 51 & Not Reported & & & & 15 099.30, & \\
\hline $\mathrm{H}_{2} \mathrm{~N}^{14} \mathrm{~N}^{14} \mathrm{H}_{2}$ & 3- 51 & Not Reported & & & & 15099.86 & \\
\hline $\mathrm{C}^{\mathrm{b}} \mathrm{H}_{2}: \mathrm{C}^{\mathrm{b}} \mathrm{HBr}^{81}$ & 4- 754 & $2,0,2 \leftarrow 1,0,1$ & Ground & $3 / 2$ & $3 / 2$ & 15100.1 & .2 \\
\hline $\mathrm{H}_{2} \mathrm{~N}^{14} \mathrm{~N}^{14} \mathrm{H}_{2}$ & $3-51$ & Not Reported & & & & 15100.72 & \\
\hline $\mathrm{C}^{12} \mathrm{H}_{3} \mathrm{I}^{127}$ & 4- 481 & $1,0 \leftarrow 0,0$ & Ground & $7 / 2$ & $5 / 2$ & 15100.74 & .05 \\
\hline $\mathrm{H}_{2} \mathrm{~N}^{14} \mathrm{~N}^{14} \mathrm{H}_{2}$ & 3. 51 & Not Reported & & & & 15101.32 & \\
\hline $\mathrm{C}^{12} \mathrm{HCl}^{35} \mathrm{~F}_{2}^{19}$ & 4- 251 & $1,1,0 \leftarrow 0,0,0$ & Ground & $3 / 2$ & $3 / 2$ & 15101.91 & \\
\hline
\end{tabular}




\begin{tabular}{|c|c|c|c|c|c|c|c|}
\hline Isotopic Species & $\begin{array}{l}\text { Vol.-Id. } \\
\text { Nos. }\end{array}$ & $\begin{array}{c}\text { Rotational } \\
\text { Quantum Nos. }\end{array}$ & Vib. State & $\mathrm{F}_{1}^{\prime} \stackrel{\mathrm{F}^{\prime}}{\text { Hyperfin }} \mathrm{F}_{1}$ & $F$ & $\begin{array}{c}\text { Frequency } \\
\mathrm{MHz}\end{array}$ & $\begin{aligned} & \text { Acc. } \\
\pm & \mathrm{MHz}\end{aligned}$ \\
\hline $\mathrm{C}^{12} \mathrm{H}_{3} \mathrm{~S}^{32} \mathrm{H}$ & 3- 221 & Not Reported & Ground & & & 15102.2 & .1 \\
\hline $\mathrm{H}_{2} \mathrm{~N}^{14} \mathrm{~N}^{14} \mathrm{H}_{2}$ & 3- 51 & $1,1 \leftarrow 2,0$ & Ground & & & 15102.4 & \\
\hline t- $\mathrm{C}^{12} \mathrm{HD}: \mathrm{C}^{12} \mathrm{DBr}^{81}$ & 4. 747 & $2,0,2 \leftarrow 1,0,1$ & Ground & $3 / 2$ & $1 / 2$ & 15103.1 & .1 \\
\hline $\mathrm{H}_{2} \mathrm{~N}^{14} \mathrm{~N}^{14} \mathrm{H}_{2}$ & 3- 51 & Not Reported & & & & 15103.40 & \\
\hline $\mathrm{C}^{12} \mathrm{H}_{3} \mathrm{~S}^{32} \mathrm{H}$ & 3- 221 & Not Reported & Ground & & & 15103.5 & .1 \\
\hline $\mathrm{H}_{2} \mathrm{~N}^{14} \mathrm{~N}^{14} \mathrm{H}_{2}$ & 3- 51 & Not Reported & & & & 15104.37 & \\
\hline $\mathrm{C}^{12} \mathrm{H}_{2} \mathrm{~N}^{14} \mathrm{O}^{16} \mathrm{H}$ & 3. 141 & $16,3,13 \leftarrow 16,3,14$ & Ground & 17 & 17 & 15105.64 & .10 \\
\hline $\mathrm{C}^{12} \mathrm{H}_{2} \mathrm{~N}^{14} \mathrm{O}^{16} \mathrm{H}$ & 3- 141 & $16,3,13 \leftarrow 16,3,14$ & Ground & 15 & 15 & 15105.64 & .10 \\
\hline $\mathrm{C}^{12} \mathrm{H}_{2} \mathrm{~N}^{14} \mathrm{O}^{16} \mathrm{H}$ & 3- 141 & $16,3,13 \leftarrow 16,3,14$ & Ground & 16 & 16 & 15106.03 & .10 \\
\hline $\mathrm{C}^{12} \mathrm{H}_{3} \mathrm{~N}^{14} \mathrm{H}_{2}$ & 3- 261 & Not Reported & Ground & & & 15109.45 & .1 \\
\hline $\mathrm{H}_{2} \mathrm{~N}^{14} \mathrm{~N}^{14} \mathrm{H}_{2}$ & 3- 51 & $1,1 \leftarrow 2,0$ & Ground & & & 15109.6 & .05 \\
\hline $\mathrm{t}-\mathrm{C}^{12} \mathrm{HD}: \mathrm{C}^{12} \mathrm{HBr}^{79}$ & 4. 741 & $2,1,1 \leftarrow 1,1,0$ & Ground & $5 / 2$ & $5 / 2$ & 15110.0 & .2 \\
\hline $\mathrm{C}^{13} \mathrm{H}_{2}: \mathrm{C}^{12} \mathrm{HBr}^{79}$ & 4. 735 & $2,1,2 \leftarrow 1,1,1$ & Ground & $3 / 2$ & $1 / 2$ & 15111.0 & \\
\hline $\mathrm{C}^{\mathrm{b}} \mathrm{H}_{2}: \mathrm{C}^{\mathrm{b}} \mathrm{HBr}^{81}$ & 4- 754 & Not Reported & Ground & $3 / 2$ & $3 / 2$ & 15114.1 & \\
\hline $\mathrm{C}^{37} \mathrm{O}_{2}^{16}$ & 4-1382 & $11,2,9 \leftarrow 10,3,8$ & Ground & & & 15114.1 & \\
\hline $\mathrm{C}^{12} \mathrm{H}_{3} \mathrm{C}^{12} \mathrm{H}: \mathrm{C}^{12} \mathrm{HF}^{19}$ & 3- 711 & $2,1,1 \leftarrow 1,1,0$ & Ground & & & 15115.1 & \\
\hline $\mathrm{C}^{\mathrm{b}} \mathrm{H}_{2}: \mathrm{C}^{\mathrm{b}} \mathrm{HBr}^{\mathrm{b}}$ & 4. 752 & Not Reported & Ground & & & 15118.4 & \\
\hline $\mathrm{C}^{12} \mathrm{H}_{3} \mathrm{~S}^{32} \mathrm{H}$ & 3- 221 & Not Reported & Ground & & & 15123.2 & .1 \\
\hline $\mathrm{c}-\mathrm{C}^{12} \mathrm{HD}: \mathrm{C}^{12} \mathrm{HBr}^{79}$ & 4- 739 & $2,1,2 \leftarrow 1,1,1$ & Ground & $5 / 2$ & $5 / 2$ & 15124.7 & .1 \\
\hline $\mathrm{c}-\mathrm{C}^{12} \mathrm{HD}: \mathrm{C}^{12} \mathrm{HBr}^{79}$ & 4- 739 & $2,1,2 \leftarrow 1,1,1$ & Ground & $3 / 2$ & $3 / 2$ & 15130.7 & .1 \\
\hline $\mathrm{C}^{37} \mathrm{O}_{2}^{16}$ & $4-1382$ & $3,0,3 \leftarrow 2,1,2$ & Ground & 1 & 0 & 15131.8 & .2 \\
\hline $\mathrm{N}^{14} \mathrm{H}_{3}$ & $4-1771$ & Not Reported & Ground & & & 15132. & \\
\hline $3 \mathrm{~d}-\mathrm{C}_{6}^{12} \mathrm{H}_{5} \mathrm{C}^{12} \mathrm{~N}^{14}$ & $4-1295$ & $6,1,6 \leftarrow 5,1,5$ & Ground & & & 15132.1 & .2 \\
\hline $\mathrm{C}^{\mathrm{b}} \mathrm{H}_{2}: \mathrm{C}^{\mathrm{b}} \mathrm{HBr}^{79}$ & 4. 753 & Not Reported & Ground & $7 / 2$ & $5 / 2$ & 15135.0 & \\
\hline $\mathrm{t}-\mathrm{C}^{12} \mathrm{HD}: \mathrm{C}^{12} \mathrm{HBr}^{79}$ & 4. 741 & $2,1,1 \leftarrow 1,1,0$ & Ground & $3 / 2$ & $3 / 2$ & 15135.2 & .2 \\
\hline $\mathrm{C}^{12} \mathrm{D}_{3} \mathrm{Si}^{28} \mathrm{DF}_{2}^{19}$ & 3- 199 & $2,1,2 \leftarrow 1,1,1$ & Ground & & & 15135.65 & .1 \\
\hline $\mathrm{N}^{14} \mathrm{O}_{2}^{16}$ & 4-1801 & $7,1,7 \leftarrow 8,0,8$ & Ground & & & 15136.42 & \\
\hline $\mathrm{Cl}^{37} \mathrm{O}_{2}^{16}$ & $4-1382$ & $3,0,3 \leftarrow 2,1,2$ & Ground & 2 & 1 & 15136.9 & .2 \\
\hline $\mathrm{C}^{12} \mathrm{H}_{2}: \mathrm{C}^{12} \mathrm{DBr}^{81}$ & 4- . 722 & $2,1,2 \leftarrow 1,1,1$ & Ground & $1 / 2$ & $1 / 2$ & 15139.1 & \\
\hline $\mathrm{C}^{12} \mathrm{H}_{3} \mathrm{~N}^{14} \mathrm{H}_{2}$ & 3- 261 & Not Reported & Ground & & & 15141.72 & .1 \\
\hline $\mathrm{C}^{13} \mathrm{O}^{16} \mathrm{~F}_{2}^{19}$ & 4- 212 & $12,11,1 \leftarrow 12,11,2$ & Ground & & & 15143.78 & .10 \\
\hline $\mathrm{HC}^{12}: \mathrm{C}^{12} \mathrm{C}^{12} \mathrm{HO}^{16}$ & 4- 911 & $4,1,4 \leftarrow 5,0,5$ & Ground & & & 15146.06 & .02 \\
\hline $\mathrm{C}^{12} \mathrm{H}_{3} \mathrm{~N}^{14} \mathrm{H}_{2}$ & 3- 261 & Not Reported & Ground & & & 15146.16 & .04 \\
\hline $\mathrm{C}^{\mathrm{b}} \mathrm{H}_{2}: \mathrm{C}^{\mathrm{b}} \mathrm{HBr}^{81}$ & 4- 754 & Not Reported & Ground & $5 / 2$ & $3 / 2$ & 15151.6 & \\
\hline $\mathrm{c}-\mathrm{C}^{12} \mathrm{HF}^{19}: \mathrm{C}^{12} \mathrm{HCl}^{37}$ & 4- 642 & $3,1,2 \leftarrow 3,0,3$ & Ground & $9 / 2$ & $9 / 2$ & 15154.71 & \\
\hline $\mathrm{C}^{13} \mathrm{H}_{2}: \mathrm{C}^{13} \mathrm{HBr}^{81}$ & 4- 734 & $2,0,2 \leftarrow 1,0,1$ & Excited & $7 / 2$ & $5 / 2$ & 15155.3 & \\
\hline $\mathrm{c}-\mathrm{C}^{12} \mathrm{HF}^{19}: \mathrm{C}^{12} \mathrm{HCl}^{37}$ & 4. 642 & $3,1,2 \leftarrow 3,0,3$ & Ground & $5 / 2$ & $5 / 2$ & 15157.89 & \\
\hline $\mathrm{c}-\mathrm{C}^{12} \mathrm{HF}^{19}: \mathrm{C}^{12} \mathrm{HCl}^{37}$ & 4. 642 & $3,1,2 \leftarrow 3,0,3$ & Ground & $7 / 2$ & $7 / 2$ & 15160.37 & \\
\hline $\mathrm{Cl}^{37} \mathrm{O}_{2}^{16}$ & $4-1382$ & $11,2,9 \leftarrow 10,3,8$ & Ground & $25 / 2$ & $23 / 2$ & 15161.9 & \\
\hline $\mathrm{C}^{13} \mathrm{H}_{2}: \mathrm{C}^{12} \mathrm{HBr}^{79}$ & 4- 735 & $2,1,2 \leftarrow 1,1,1$ & Ground & & & 15164.38 & .05 \\
\hline $\mathrm{C}^{12} \mathrm{H}_{3} \mathrm{~S}^{32} \mathrm{H}$ & 3- 221 & Not Reported & Ground & & & 15165.1 & .1 \\
\hline $\mathrm{Cl}^{37} \mathrm{O}_{2}^{16}$ & 4-1382 & $3,0,3 \leftarrow 2,1,2$ & Ground & 3 & 2 & 15166.8 & .2 \\
\hline $\mathrm{C}^{\mathrm{b}} \mathrm{H}_{2}: \mathrm{C}^{\mathrm{b}} \mathrm{HBr}^{\mathrm{b}}$ & 4- 752 & Not Reported & Ground & $7 / 2$ & $5 / 2$ & 15169.7 & \\
\hline t- $\mathrm{C}^{12} \mathrm{HD}: \mathrm{C}^{12} \mathrm{HBr}^{79}$ & 4- 741 & $2,1,1 \leftarrow 1,1,0$ & Ground & $5 / 2$ & $3 / 2$ & 15173.7 & .1 \\
\hline $\mathrm{C}^{12} \mathrm{HD}: \mathrm{C}^{12} \mathrm{DBr}^{\mathrm{b}}$ & 4. 749 & Not Reported & & & & 15173.7 & .2 \\
\hline
\end{tabular}




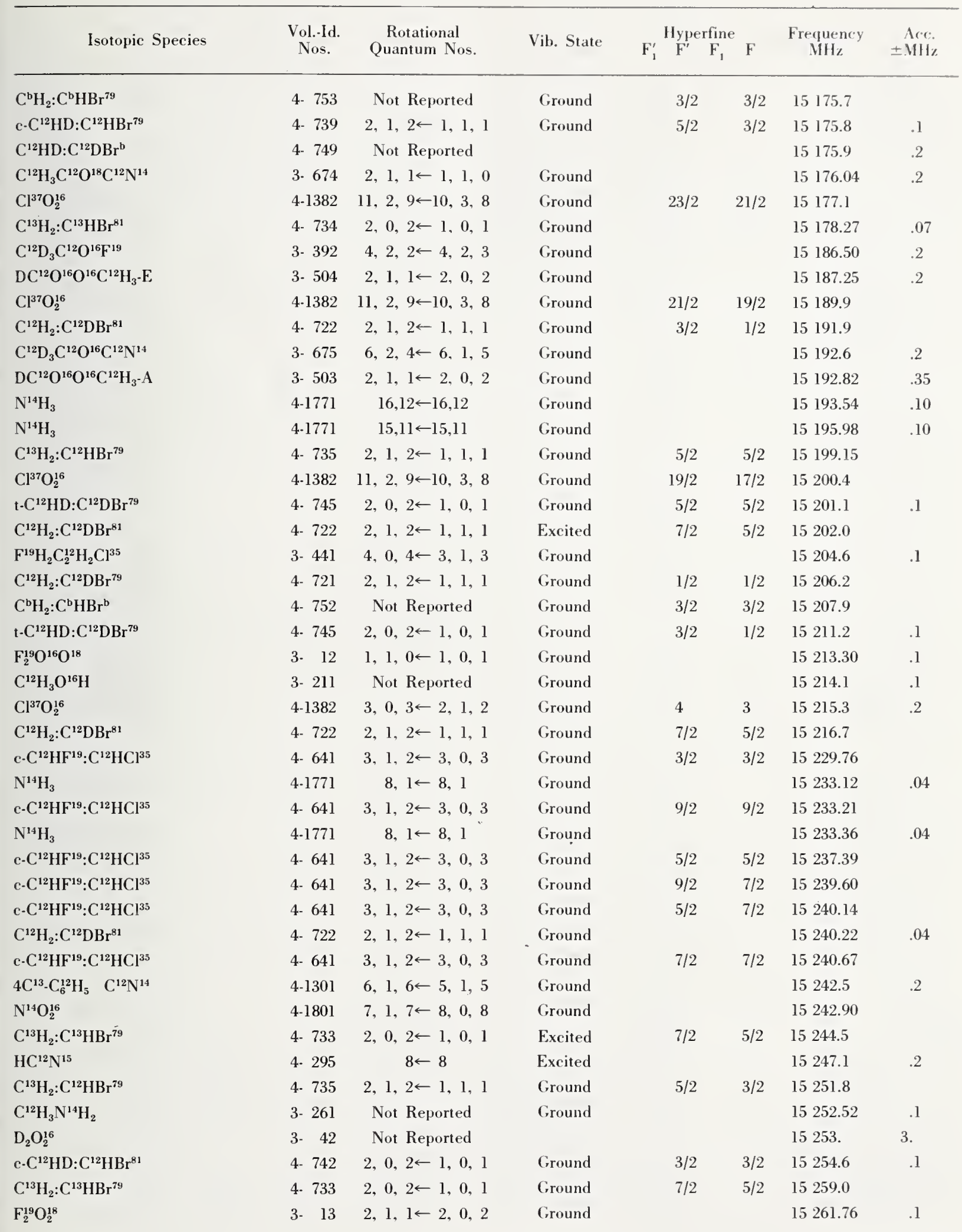




\begin{tabular}{|c|c|c|c|c|c|c|c|}
\hline Isotopic Species & $\begin{array}{l}\text { Vol.-Id. } \\
\text { Nos. }\end{array}$ & $\begin{array}{c}\text { Rotational } \\
\text { Quantum Nos. }\end{array}$ & Vib. State & $\mathrm{F}_{1}^{\prime} \stackrel{\text { Hyperfine }}{\mathrm{F}^{\prime}} \mathrm{F}_{1}$ & $\mathrm{~F}$ & $\begin{array}{c}\text { Frequency } \\
\mathrm{MHz}\end{array}$ & $\begin{aligned} & \text { Acc. } \\
& \pm \mathrm{MHz}\end{aligned}$ \\
\hline $\mathrm{C}^{12} \mathrm{H}_{2} \mathrm{~N}^{14} \mathrm{O}^{16} \mathrm{H}$ & 3- 141 & $9,2,7 \leftarrow 10,1,10$ & Ground & 10 & 11 & 15265.32 & .10 \\
\hline $\mathrm{C}^{12} \mathrm{H}_{2} \mathrm{~N}^{14} \mathrm{O}^{16} \mathrm{H}$ & 3. 141 & $9,2,7 \leftarrow 10,1,10$ & Ground & 8 & 9 & 15265.32 & .10 \\
\hline $\mathrm{C}^{12} \mathrm{H}_{2} \mathrm{~N}^{14} \mathrm{O}^{16} \mathrm{H}$ & 3- 141 & $9,2,7 \leftarrow 10,1,10$ & Ground & 9 & 10 & 15267.31 & .10 \\
\hline $\mathrm{C}^{\mathrm{b}} \mathrm{H}_{2}: \mathrm{C}^{\mathrm{b}} \mathrm{HBr}^{81}$ & 4. 754 & Not Reported & Ground & $5 / 2$ & $5 / 2$ & 15268.1 & \\
\hline $\mathrm{N}^{14} \mathrm{H}_{3}$ & $4-1771$ & $14,10 \leftarrow 14,10$ & Ground & & & 15268.24 & .06 \\
\hline $\mathrm{C}^{13} \mathrm{H}_{3} \mathrm{C}^{12} \mathrm{O}^{16} \mathrm{C}^{12} \mathrm{~N}^{14}$ & 3- 672 & $2,1,1 \leftarrow 1,1,0$ & Ground & & & 15268.39 & .2 \\
\hline $\mathrm{C}^{13} \mathrm{H}_{2}: \mathrm{C}^{13} \mathrm{HBr}^{79}$ & 4- 733 & $2,0,2 \leftarrow 1,0,1$ & Ground & & & 15269.00 & .11 \\
\hline $\mathrm{C}^{12} \mathrm{H}_{2}: \mathrm{C}^{12} \mathrm{DBr}^{81}$ & 4. 722 & $2,1,2 \leftarrow 1,1,1$ & Ground & $5 / 2$ & $5 / 2$ & 15269.3 & \\
\hline $\mathrm{C}^{12} \mathrm{H}_{2}: \mathrm{C}^{12} \mathrm{DBr}^{79}$ & 4- 721 & $2,1,2 \leftarrow 1,1,1$ & Ground & $3 / 2$ & $1 / 2$ & 15270.1 & \\
\hline $\mathrm{C}^{12} \mathrm{H}_{3} \mathrm{C}^{12} \mathrm{H}: \mathrm{C}^{12} \mathrm{HF}^{19}$ & 3- 711 & $2,1,1 \leftarrow 1,1,0$ & Ground & & & 15271.35 & .1 \\
\hline $\mathrm{C}^{12} \mathrm{H}_{3} \mathrm{C}^{12} \mathrm{H}: \mathrm{C}^{12} \mathrm{HF}^{19}$ & 3- 711 & $2,1,1 \leftarrow 1,1,0$ & Ground & & & 15272.05 & \\
\hline $\mathrm{C}^{12} \mathrm{H}_{3} \mathrm{I}^{127}$ & 4- 481 & $1,0 \leftarrow 0,0$ & Ground & $3 / 2$ & $5 / 2$ & 15275.87 & .05 \\
\hline $\mathrm{C}^{13} \mathrm{H}_{2}: \mathrm{C}^{12} \mathrm{HBr}^{81}$ & 4- 736 & Not Reported & Ground & $3 / 2$ & $3 / 2$ & 15276.4 & \\
\hline $\mathrm{C}^{12} \mathrm{H}_{2}: \mathrm{C}^{12} \mathrm{DBr}^{81}$ & 4. 722 & $2,1,2 \leftarrow 1,1,1$ & Ground & $3 / 2$ & $3 / 2$ & 15278.1 & \\
\hline $\mathrm{s}-\mathrm{C}^{12} \mathrm{H}_{2} \mathrm{DO}^{16} \mathrm{~N}^{14} \mathrm{O}_{2}^{16}$ & 3- 183 & $2,0,2 \leftarrow 1,0,1$ & Ground & & & 15280.53 & .1 \\
\hline $\mathrm{C}^{12} \mathrm{H}_{2}: \mathrm{C}^{12} \mathrm{DBr}^{79}$ & 4- 721 & $2,1,2 \leftarrow 1,1,1$ & Excited & $7 / 2$ & $5 / 2$ & 15281.1 & \\
\hline $\mathrm{C}_{6}^{12} \mathrm{H}_{5} \mathrm{C}^{13} \mathrm{~N}^{14}$ & $4-1293$ & $6,1,6 \leftarrow 5,1,5$ & Ground & & & 15283.5 & .2 \\
\hline $2 \mathrm{~d}-\mathrm{C}_{6}^{12} \mathrm{H}_{5} \mathrm{C}^{12} \mathrm{~N}^{14}$ & $4-1294$ & $6,1,6 \leftarrow 5,1,5$ & Ground & & & 15290.0 & .2 \\
\hline $\mathrm{C}^{12} \mathrm{H}_{2}: \mathrm{C}^{12} \mathrm{DBr}^{79}$ & 4. 721 & $2,1,2 \leftarrow 1,1,1$ & Ground & $7 / 2$ & $5 / 2$ & 15298.0 & \\
\hline $\mathrm{C}^{12} \mathrm{H}_{3} \mathrm{C}^{12} \mathrm{H}: \mathrm{C}^{12} \mathrm{HF}^{19}$ & 3- 711 & $2,1,1 \leftarrow 1,1,0$ & Ground & & & 15298.7 & \\
\hline $3 \mathrm{C}^{13}-\mathrm{C}_{6}^{12} \mathrm{H}_{5} \mathrm{C}^{12} \mathrm{~N}^{14}$ & 4-1299 & $6,1,6 \leftarrow 5,1,5$ & Ground & & & 15299.3 & .2 \\
\hline $\mathrm{t} \cdot \mathrm{C}^{12} \mathrm{HD}: \mathrm{C}^{12} \mathrm{DBr}^{81}$ & 4. 747 & $2,1,1 \leftarrow 1,1,0$ & Ground & $1 / 2$ & $1 / 2$ & 15300.8 & .1 \\
\hline $\mathrm{C}^{12} \mathrm{H}_{3} \mathrm{O}^{16} \mathrm{H}$ & 3- 211 & Not Reported & Ground & & & 15303.4 & .1 \\
\hline $\mathrm{C}^{12} \mathrm{HD}: \mathrm{C}^{12} \mathrm{DBr}{ }^{b}$ & 4. 749 & Not Reported & & & & 15305.0 & .1 \\
\hline $\mathrm{C}^{12} \mathrm{HD}: \mathrm{C}^{12} \mathrm{HBr}^{\mathrm{b}}$ & 4- 748 & Not Reported & & & & 15309.4 & .1 \\
\hline $\mathrm{C}^{12} \mathrm{H}_{2}: \mathrm{C}^{12} \mathrm{DBr}^{81}$ & 4- 722 & $2,1,2 \leftarrow 1,1,1$ & Ground & $5 / 2$ & $3 / 2$ & 15315.7 & \\
\hline $\mathrm{F}_{2}^{19} \mathrm{O}^{16} \mathrm{O}^{18}$ & 3- 12 & $1,1,0 \leftarrow 1,0,1$ & Ground & & & 15319.85 & .1 \\
\hline c. $\mathrm{C}^{12} \mathrm{HD}: \mathrm{C}^{12} \mathrm{HBr}^{81}$ & 4- 742 & $2,0,2 \leftarrow 1,0,1$ & Ground & $5 / 2$ & $3 / 2$ & 15322.6 & .1 \\
\hline $\mathrm{c}-\mathrm{C}^{12} \mathrm{HD}: \mathrm{C}^{12} \mathrm{HBr}^{81}$ & 4. 742 & $2,0,2 \leftarrow 1,0,1$ & Ground & $7 / 2$ & $5 / 2$ & 15322.6 & .1 \\
\hline $\mathrm{C}^{12} \mathrm{HD}: \mathrm{C}^{12} \mathrm{DBr}^{\mathrm{b}}$ & 4. 749 & Not Reported & & & & 15322.7 & .1 \\
\hline $\mathrm{C}^{12} \mathrm{H}_{2}: \mathrm{C}^{12} \mathrm{DBr}^{79}$ & 4- 721 & $2,1,2 \leftarrow 1,1,1$ & Ground & & & 15326.89 & .04 \\
\hline c- $\mathrm{C}^{12} \mathrm{HD}: \mathrm{C}^{12} \mathrm{HBr}^{79}$ & 4- 739 & $2,0,2 \leftarrow 1,0,1$ & Ground & $3 / 2$ & $3 / 2$ & 15328.8 & .1 \\
\hline $\mathrm{C}^{12} \mathrm{D}_{3} \mathrm{C}^{12} \mathrm{O}^{16} \mathrm{O}^{16} \mathrm{H}$ & 3- 492 & $1,1,1 \leftarrow 0,0,0$ & & & & 15329.70 & .4 \\
\hline c. $\mathrm{C}^{12} \mathrm{HD}: \mathrm{C}^{12} \mathrm{HBr}^{81}$ & 4. 742 & $2,0,2 \leftarrow 1,0,1$ & Ground & & & 15330.96 & .05 \\
\hline $\mathrm{C}^{\mathrm{b}} \mathrm{H}_{2}: \mathrm{C}^{\mathrm{b}} \mathrm{HBr}^{\mathrm{b}}$ & 4. 752 & Not Reported & Excited & $7 / 2$ & $5 / 2$ & 15331.6 & \\
\hline $\mathrm{C}^{12} \mathrm{H}_{3} \mathrm{~S}^{32} \mathrm{H}$ & 3- 221 & Not Reported & Ground & & & 15335.9 & .1 \\
\hline $\mathrm{C}^{12} \mathrm{H}_{3} \mathrm{~S}^{32} \mathrm{H}$ & 3- 221 & $3,2,1 \leftarrow 2,1,2$ & Ground & & & 15339.0 & \\
\hline $\mathrm{N}^{14} \mathrm{O}_{2}^{16}$ & $4-1801$ & $7,1,7 \leftarrow 8,0,8$ & Ground & & & 15342.75 & \\
\hline $\mathrm{t}-\mathrm{C}^{12} \mathrm{HD}: \mathrm{C}^{12} \mathrm{DBr}^{81}$ & 4- 747 & $2,1,1 \leftarrow 1,1,0$ & Ground & $3 / 2$ & $1 / 2$ & 15345.5 & .1 \\
\hline $\mathrm{C}^{\mathrm{b}} \mathrm{H}_{2}: \mathrm{C}^{\mathrm{b}} \mathrm{HBr}^{\mathrm{b}}$. & 4- 752 & Not Reported & Ground & $7 / 2$ & $5 / 2$ & 15345.8 & \\
\hline $\mathrm{C}^{13} \mathrm{H}_{2}: \mathrm{C}^{12} \mathrm{HBr}^{79}$ & 4- 735 & Not Reported & Ground & $3 / 2$ & $3 / 2$ & 15351.0 & \\
\hline $\mathrm{C}^{13} \mathrm{I}_{2}: \mathrm{C}^{12} \mathrm{HBr}^{81}$ & 4- 736 & $2,0,2 \leftarrow 1,0,1$ & Ground & & & 15354.34 & .06 \\
\hline $\mathrm{C}^{12} \mathrm{H}_{3} \mathrm{~N}^{14} \mathrm{H}_{2}$ & $3-261$ & Not Reported & Ground & & & 15357.69 & .04 \\
\hline $\mathrm{C}^{13} \mathrm{H}_{2}: \mathrm{C}^{13} \mathrm{HBr}^{81}$ & 4. 734 & $2,1,1 \leftarrow 1,1,0$ & Ground & $1 / 2$ & $1 / 2$ & 15361.5 & \\
\hline $\mathrm{C}^{12} \mathrm{H}_{2}: \mathrm{C}^{12} \mathrm{DBr}^{79}$ & 4- 721 & $2,1,2 \leftarrow 1,1,1$ & Ground & $5 / 2$ & $5 / 2$ & 15361.9 & \\
\hline
\end{tabular}




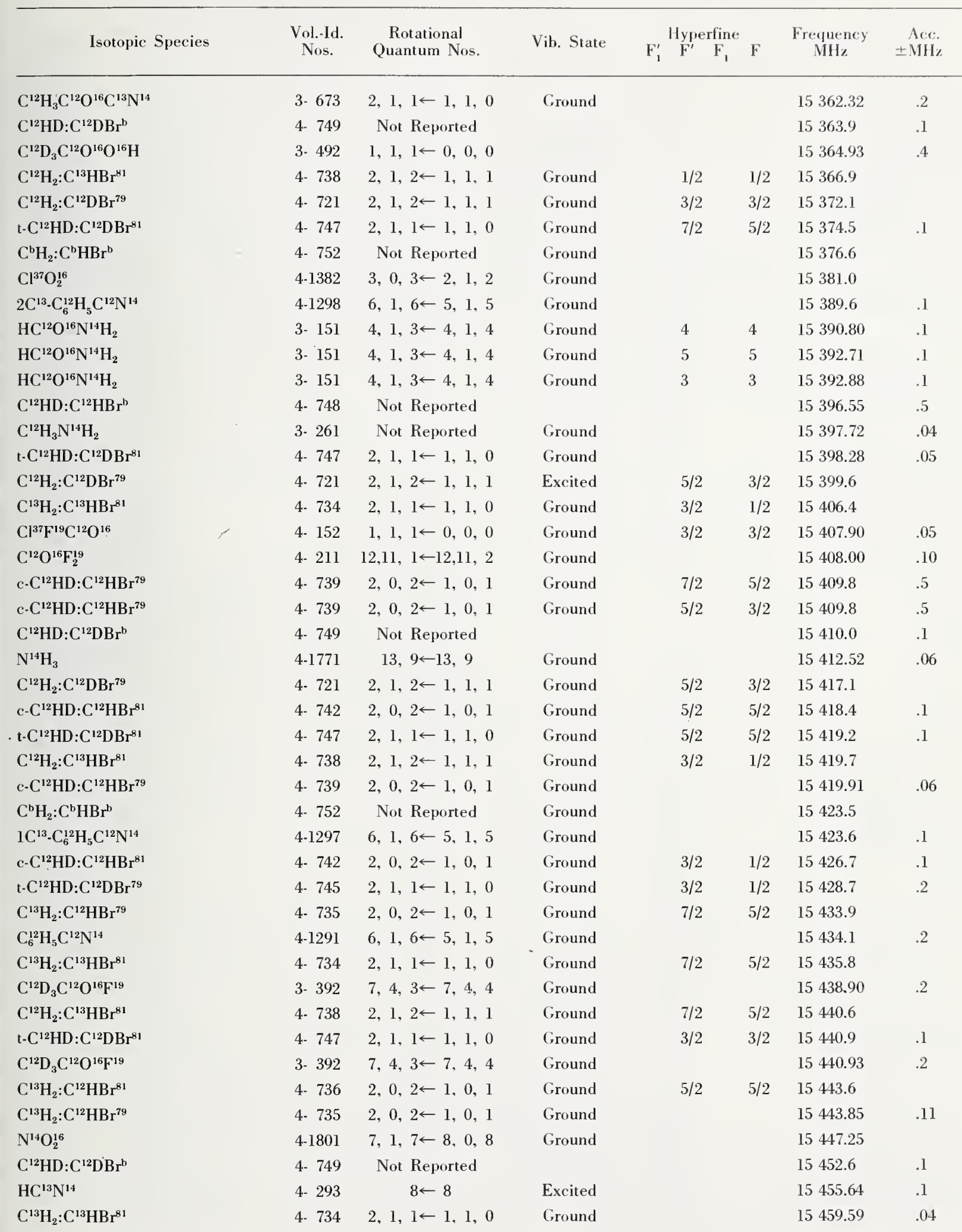




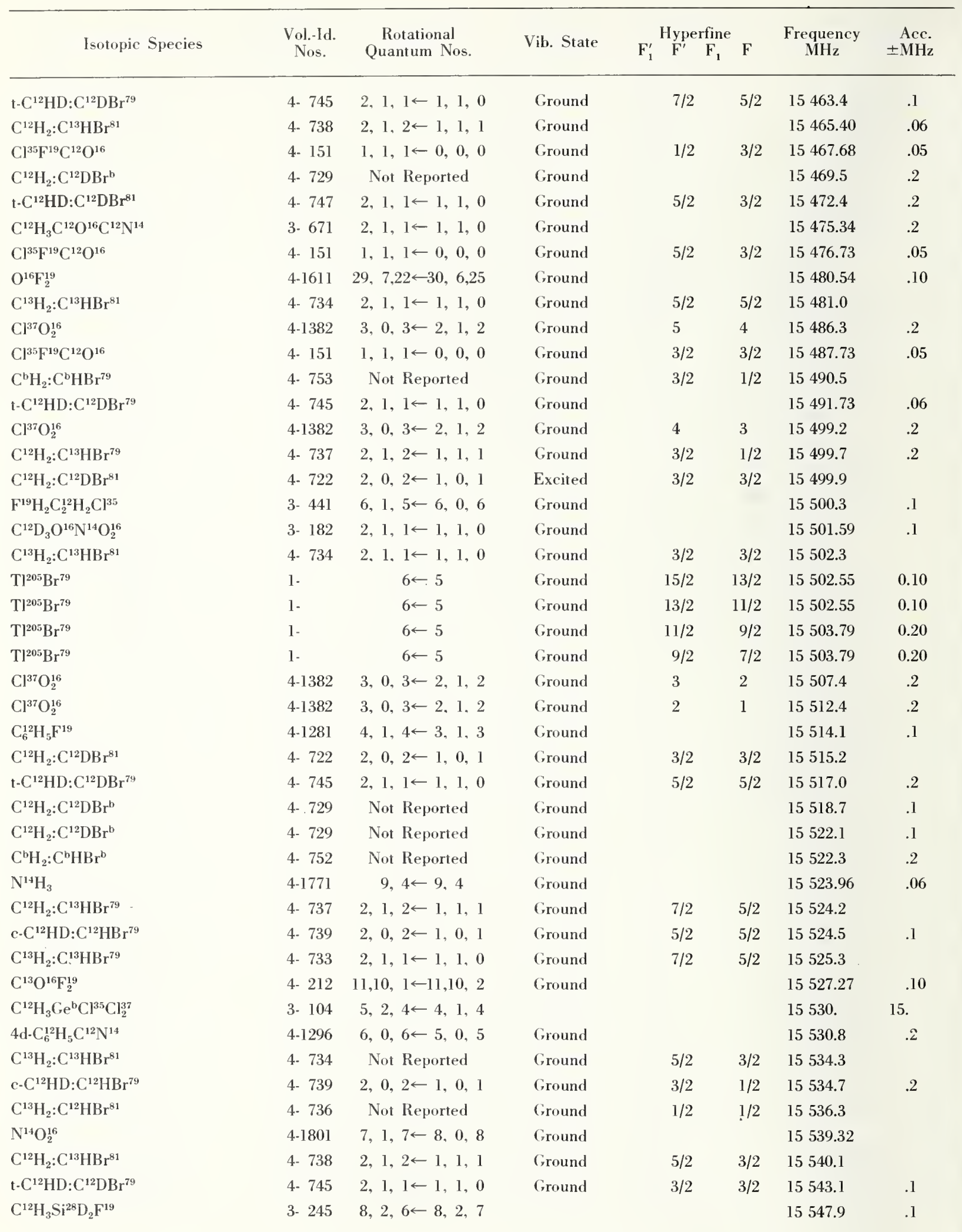




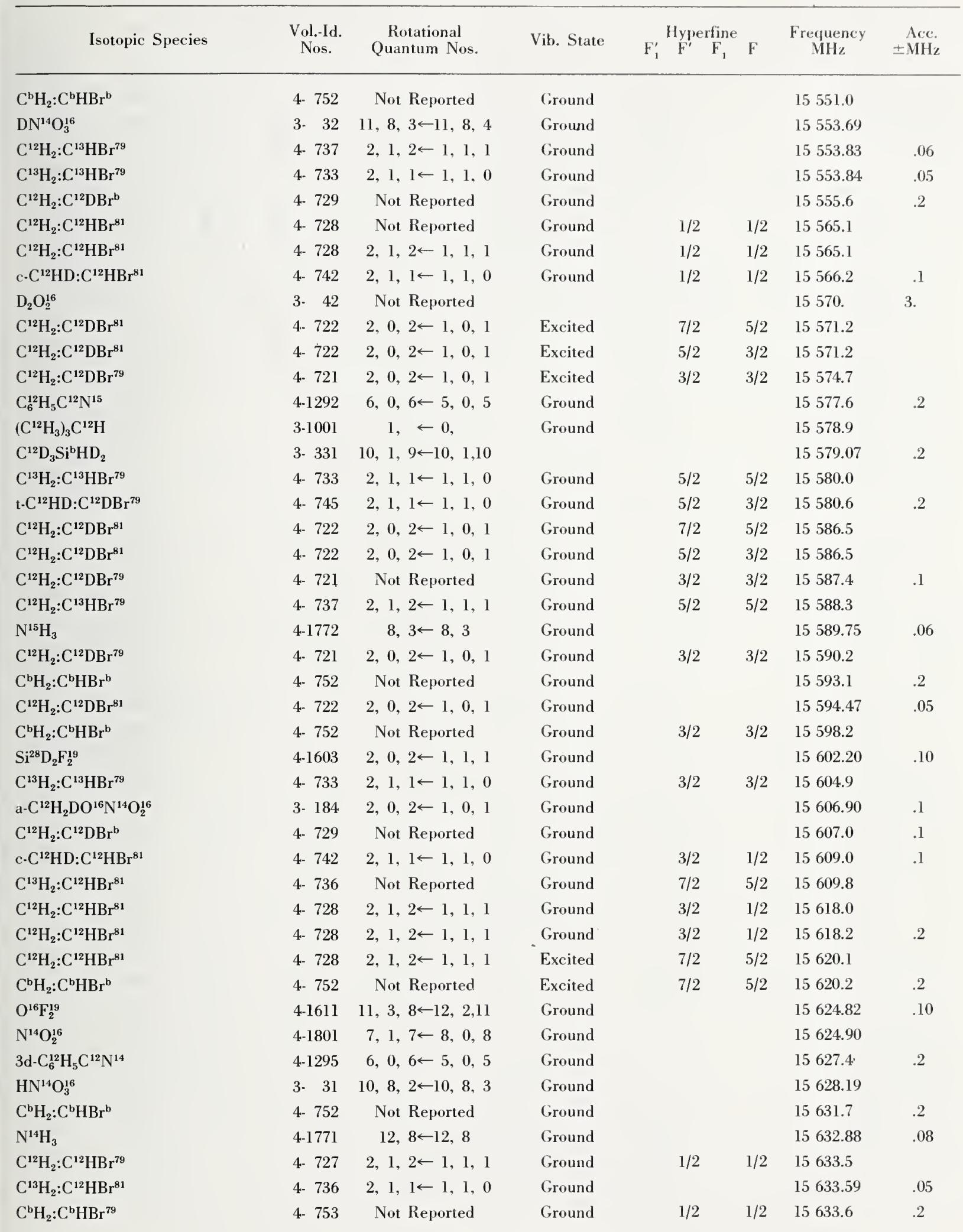




\begin{tabular}{|c|c|c|c|c|c|c|c|}
\hline Isotopic Species & $\begin{array}{l}\text { Vol.-Id. } \\
\text { Nos. }\end{array}$ & $\begin{array}{c}\text { Rotational } \\
\text { Quantum Nos. }\end{array}$ & Vib. State & $\mathrm{F}_{1}^{\prime} \mathrm{F}^{\text {Hyperfine }} \quad \mathrm{F}_{1}$ & $\mathrm{~F}$ & $\begin{array}{c}\text { Frequency } \\
\mathrm{MHz}\end{array}$ & $\begin{aligned} & \text { Acc. } \\
\pm & \mathrm{MHz}\end{aligned}$ \\
\hline $\mathrm{C}^{12} \mathrm{H}_{2}: \mathrm{C}^{12} \mathrm{HBr}^{81}$ & 4- 728 & $2,1,2 \leftarrow 1,1,1$ & Ground & $7 / 2$ & $5 / 2$ & 15638.2 & \\
\hline $\mathrm{C}^{\mathrm{b}} \mathrm{H}_{2}: \mathrm{C}^{\mathrm{b}} \mathrm{HBr}^{81}$ & 4- 754 & Not Reported & Ground & $7 / 2$ & $5 / 2$ & 15638.4 & \\
\hline$c-\mathrm{C}^{12} \mathrm{HD}: \mathrm{C}^{12} \mathrm{HBr}^{81}$ & 4- 742 & $2,1,1 \leftarrow 1,1,0$ & Ground & $7 / 2$ & $5 / 2$ & 15638.7 & .1 \\
\hline $\mathrm{N}^{14} \mathrm{H}_{3}$ & 4-1771 & $8,2 \leftarrow 8,2$ & Ground & & & 15639.84 & .06 \\
\hline $\mathrm{C}^{12} \mathrm{H}_{2}: \mathrm{C}^{13} \mathrm{HBr}^{79}$ & 4- 737 & Not Reported & Ground & $7 / 2$ & $5 / 2$ & 15643.4 & \\
\hline $\mathrm{C}^{13} \mathrm{H}_{2}: \mathrm{C}^{13} \mathrm{HBr}^{79}$ & 4- 733 & $2,1,1 \leftarrow 1,1,0$ & Ground & $7 / 2$ & $5 / 2$ & 15643.4 & \\
\hline $\mathrm{N}^{14} \mathrm{O}_{2}^{16}$ & 4-1801 & $7,1,7 \leftarrow 8,0,8$ & Ground & & & 15653.98 & \\
\hline $\mathrm{C}^{13} \mathrm{H}_{2}: \mathrm{C}^{12} \mathrm{HBr}^{81}$ & 4. 736 & Not Reported & Ground & $5 / 2$ & $5 / 2$ & 15654.8 & \\
\hline $\mathrm{C}^{12} \mathrm{H}_{2}: \mathrm{C}^{12} \mathrm{DBr}^{79}$ & 4- 721 & $2,0,2 \leftarrow 1,0,1$ & Excited & $5 / 2$ & $3 / 2$ & 15659.9 & \\
\hline $\mathrm{C}^{12} \mathrm{H}_{2}: \mathrm{C}^{12} \mathrm{DBr}^{79}$ & 4. 721 & $2,0,2 \leftarrow 1,0,1$ & Excited & $7 / 2$ & $5 / 2$ & 15659.9 & \\
\hline c- $\mathrm{C}^{12} \mathrm{HD}: \mathrm{C}^{12} \mathrm{HBr}^{81}$ & 4. 742 & $2,1,1 \leftarrow 1,1,0$ & Ground & & & 15661.85 & .04 \\
\hline $\mathrm{C}^{\mathrm{b}} \mathrm{H}_{2}: \mathrm{C}^{\mathrm{b}} \mathrm{HBr}^{79}$ & 4- 753 & Not Reported & Ground & $3 / 2$ & $1 / 2$ & 15663.4 & \\
\hline $\mathrm{C}^{12} \mathrm{H}_{2}: \mathrm{C}^{12} \mathrm{HBr}^{81}$ & 4- 728 & $2,1,2 \leftarrow 1,1,1$ & Ground & & & 15663.84 & .04 \\
\hline $\mathrm{C}^{12}{ }_{*} \mathrm{D}_{2} \mathrm{C}^{12} \mathrm{D}_{2} \mathrm{C}^{12}{ }_{*} \mathrm{Cl}^{35} \mathrm{Cl}^{37}$ & 4-1064 & $4,1.4 \leftarrow 3,0,3$ & Ground & & & 15665.6 & \\
\hline $\mathrm{C}^{12} \mathrm{H}_{2}: \mathrm{C}^{12} \mathrm{DBr}^{79}$ & 4- 721 & $2,0,2 \leftarrow 1,0,1$ & Ground & $7 / 2$ & $5 / 2$ & 15675.3 & \\
\hline $\mathrm{C}^{12} \mathrm{H}_{2}: \mathrm{C}^{12} \mathrm{DBr}^{79}$ & 4- 721 & $2,0,2 \leftarrow 1,0,1$ & Ground & $5 / 2$ & $3 / 2$ & 15675.3 & \\
\hline $\mathrm{C}^{12} \mathrm{O}^{18} \mathrm{~F}_{2}^{19}$ & 4- 213 & $2,1,2 \leftarrow 2,1,1$ & Ground & & & 15675.67 & .10 \\
\hline $\mathrm{C}^{\mathrm{b}} \mathrm{H}_{2}: \mathrm{C}^{\mathrm{b}} \mathrm{HBr}^{8 \mathrm{I}}$ & 4- 754 & Not Reported & Ground & $3 / 2$ & $3 / 2$ & 15676.1 & \\
\hline c. $\mathrm{C}^{12} \mathrm{HD}: \mathrm{C}^{12} \mathrm{HBr}^{81}$ & 4. 742 & 2. $1.1 \leftarrow 1,1,0$ & Ground & $5 / 2$ & $5 / 2$ & 15681.5 & .2 \\
\hline $\mathrm{C}^{12} \mathrm{H}_{3} \mathrm{C}^{12}{ }_{*} \mathrm{HO}^{16} \mathrm{C}^{12}{ }_{*} \mathrm{H}_{2}$ & 3- 761 & $19,12, \quad \leftarrow 20,11$ & Ground & & & 15681.55 & .1 \\
\hline $\mathrm{C}^{12} \mathrm{H}_{3} \mathrm{C}^{12}{ }_{*} \mathrm{HO}^{16} \mathrm{C}^{12}{ }_{*} \mathrm{H}_{2}$ & 3- 761 & $19,12, \quad \leftarrow 20,11$ & Ground & & & 15682.39 & .1 \\
\hline $\mathrm{C}^{12} \mathrm{H}_{2}: \mathrm{C}^{13} \mathrm{HBr}^{81}$ & 4- 738 & $2,0,2 \leftarrow 1,0,1$ & Ground & $3 / 2$ & $3 / 2$ & 15682.9 & \\
\hline $\mathrm{D}_{2} \mathrm{O}_{2}^{16}$ & 3- 42 & Not Reported & & & & 15684 & 3. \\
\hline $\mathrm{C}^{12} \mathrm{H}_{2}: \mathrm{C}^{12} \mathrm{DBr}^{79}$ & 4- 721 & $2,0,2 \leftarrow 1,0,1$ & Ground & & & 15685.14 & .06 \\
\hline $\mathrm{C}^{\mathrm{b}} \mathrm{H}_{2}: \mathrm{C}^{\mathrm{b}} \mathrm{HBr}^{\mathrm{b}}$ & 4. 752 & Not Reported & Ground & & & 15686.2 & .2 \\
\hline $\mathrm{C}^{12} \mathrm{H}_{2}: \mathrm{C}^{12} \mathrm{DBr}^{79}$ & 4. 721 & $2,0,2 \leftarrow 1,0,1$ & Ground & $1 / 2$ & $1 / 2$ & 15686.8 & \\
\hline $\mathrm{C}^{12} \mathrm{H}_{2}: \mathrm{C}^{12} \mathrm{DBr}^{81}$ & 4- 722 & $2,0,2 \leftarrow 1,0,1$ & Ground & $5 / 2$ & $5 / 2$ & 15686.8 & \\
\hline $\mathrm{C}_{6}^{12} \mathrm{H}_{5} \mathrm{Cl}^{35}$ & 4-1271 & $6,1,6 \leftarrow 5,1,5$ & Ground & & & 15689.2 & \\
\hline $\mathrm{C}^{12} \mathrm{H}_{2}: \mathrm{C}^{12} \mathrm{HBr}^{81}$ & 4: 728 & Not Repurted & Ground & $5 / 2$ & $5 / 2$ & 15691.3 & .1 \\
\hline $\mathrm{C}^{12} \mathrm{H}_{2}: \mathrm{C}^{12} \mathrm{HBr}^{81}$ & 4- 728 & $2,1,2 \leftarrow 1,1,1$ & Ground & $5 / 2$ & $5 / 2$ & 15691.3 & \\
\hline c- $\mathrm{C}^{12} \mathrm{HD}: \mathrm{C}^{12} \mathrm{HBr}^{79}$ & 4- 739 & $2,1,1 \leftarrow 1,1,0$ & Ground & $3 / 2$ & $1 / 2$ & 15691.5 & .1 \\
\hline $\mathrm{C}^{12} \mathrm{H}_{2}: \mathrm{C}^{12} \mathrm{HBr}^{81}$ & 4- 728 & $2,1,2 \leftarrow 1,1,1$ & Ground & $5 / 2$ & $5 / 2$ & 15691.7 & \\
\hline $\mathrm{C}^{\mathrm{b}} \mathrm{H}_{2}: \mathrm{C}^{\mathrm{b}} \mathrm{HBr}^{79}$ & 4. 753 & Not Reported & Ground & $3 / 2$ & $1 / 2$ & 15696.8 & .2 \\
\hline $\mathrm{C}^{12} \mathrm{H}_{2}: \mathrm{C}^{12} \mathrm{HBr}^{79}$ & 4. 727 & $2,1,2 \leftarrow 1,1,1$ & Ground & $3 / 2$ & $1 / 2$ & 15696.9 & \\
\hline $\mathrm{C}^{13} \mathrm{H}_{2}: \mathrm{C}^{12} \mathrm{HBr}^{79}$ & 4- 735 & $2,1,1 \leftarrow 1,1,0$ & Ground & $7 / 2$ & $5 / 2$ & 15698.2 & \\
\hline $\mathrm{C}^{12} \mathrm{H}_{2}: \mathrm{C}^{12} \mathrm{HBr}^{81}$ & 4- 728 & $2,1,2 \leftarrow 1,1,1$ & Ground & $3 / 2$ & $3 / 2$ & 15699.5 & \\
\hline $\mathrm{C}^{12} \mathrm{H}_{2}: \mathrm{C}^{12} \mathrm{HBr}^{79}$ & 4. 727 & $2,1,2 \leftarrow 1,1,1$ & Excited & $7 / 2$ & $5 / 2$ & 15702.1 & \\
\hline $\mathrm{c}-\mathrm{C}^{12} \mathrm{HD}: \mathrm{C}^{12} \mathrm{HBr}^{81}$ & 4. 742 & $2,1,1 \leftarrow 1,1,0$ & Ground & $3 / 2$ & $3 / 2$ & 15704.5 & .1 \\
\hline $\mathrm{C}^{b} \mathrm{H}_{2}: \mathrm{C}^{\mathrm{b}} \mathrm{HBr}^{81}$ & 4- 754 & Not Reported & Ground & $5 / 2$ & $3 / 2$ & 15707.9 & \\
\hline $\mathrm{C}^{12} \mathrm{HD}: \mathrm{C}^{12} \mathrm{HBr}^{\mathrm{b}}$ & 4- 748 & Not Reported & & & & 15716.5 & .1 \\
\hline $\mathrm{C}^{12} \mathrm{H}_{2}: \mathrm{C}^{12} \mathrm{HBr}^{79}$ & 4- 727 & $2,1,2 \leftarrow 1,1,1$ & Ground & $7 / 2$ & $5 / 2$ & 15720.8 & \\
\hline $\mathrm{C}^{12} \mathrm{HD}: \mathrm{C}^{12} \mathrm{HBr}^{\mathrm{b}}$ & 4- 748 & Not Reported & & & & 15720.9 & .2 \\
\hline $\mathrm{C}^{12} \mathrm{HD}: \mathrm{C}^{12} \mathrm{HBr}^{\mathrm{b}}$ & 4- 748 & Not Reported & & & & 15723.9 & .2 \\
\hline $\mathrm{C}^{12} \mathrm{H}_{3} \mathrm{C}^{12}{ }_{*} \mathrm{HO}^{16} \mathrm{C}^{12}{ }_{*} \mathrm{H}_{2}$ & 3- 761 & $28,14, \quad \leftarrow 27,15$ & Ground & & & 15725.83 & .1 \\
\hline
\end{tabular}




\begin{tabular}{|c|c|c|c|c|c|c|c|c|}
\hline Isotopic Species & $\begin{array}{l}\text { Vol.-Id. } \\
\text { Nos. }\end{array}$ & $\begin{array}{c}\text { Rotational } \\
\text { Quantum Nos. }\end{array}$ & Vib. State & $\mathrm{F}_{1}^{\prime}$ & $\begin{array}{l}\text { Hyperfine } \\
\mathrm{F}^{\prime} \quad \mathrm{F}_{1}\end{array}$ & $\mathrm{~F}$ & $\begin{array}{c}\text { Frequency } \\
\text { MHz }\end{array}$ & $\begin{aligned} & \text { Arc. } \\
&+\mathrm{NH}_{2}\end{aligned}$ \\
\hline $\mathrm{C}^{12} \mathrm{H}_{3} \mathrm{C}^{12}{ }_{*} \mathrm{HO}^{16} \mathrm{C}^{12}{ }_{*} \mathrm{H}_{2}$ & 3- 761 & $28,14, \leftarrow 27,15$, & Ground & & & & 15725.98 & .1 \\
\hline $\mathrm{C}^{12} \mathrm{H}_{3} \mathrm{C}^{12}{ }_{*} \mathrm{HO}^{16} \mathrm{C}^{12}{ }_{*} \mathrm{H}_{2}$ & 3. 761 & $28,14, \leftarrow 27,15$, & Ground & & & & 15726.58 & .1 \\
\hline $\mathrm{C}^{13} \mathrm{H}_{2}: \mathrm{C}^{12} \mathrm{HBr}^{79}$ & 4- 735 & $2,1,1 \leftarrow 1,1,0$ & Ground & & & & 15726.64 & .05 \\
\hline c. $\mathrm{C}^{12} \mathrm{HD}: \mathrm{C}^{12} \mathrm{HBr}^{79}$ & 4- 739 & $2,1,1 \leftarrow 1,1,0$ & Ground & & $7 / 2$ & $5 / 2$ & 15726.9 & .1 \\
\hline $\mathrm{C}^{12} \mathrm{H}_{3} \mathrm{C}^{12} \mathrm{~F}^{19}: \mathrm{C}^{12} \mathrm{H}_{2}$ & 3- 721 & $2,2,1 \leftarrow 2,1,2$ & Ground & & & & 15727.42 & .1 \\
\hline $\mathrm{C}^{12} \mathrm{H}_{3} \mathrm{C}^{12}{ }_{*} \mathrm{HO}^{16} \mathrm{C}^{12}{ }_{*} \mathrm{H}_{2}$ & 3. 761 & Not Reported & Ground & & & & 15731.38 & .1 \\
\hline$c-\mathrm{C}^{12} \mathrm{HD}: \mathrm{C}^{12} \mathrm{HBr}^{81}$ & 4- 742 & $2,1,1 \leftarrow 1,1,0$ & Ground & & $5 / 2$ & $3 / 2$ & 15734.7 & .1 \\
\hline $\mathrm{C}^{12} \mathrm{H}_{2}: \mathrm{C}^{12} \mathrm{HBr}^{81}$ & 4- 728 & $2,1,2 \leftarrow 1,1,1$ & Ground & & $5 / 2$ & $3 / 2$ & 15737.2 & \\
\hline $\mathrm{C}^{\mathrm{b}} \mathrm{H}_{2}: \mathrm{C}^{\mathrm{b}} \mathrm{HBr}^{81}$ & 4- 754 & Not Reported & Ground & & $5 / 2$ & $3 / 2$ & 15737.3 & \\
\hline $\mathrm{C}^{12} \mathrm{H}_{3} \mathrm{C}^{12}{ }_{*} \mathrm{HO}^{16} \mathrm{C}^{12}{ }_{*} \mathrm{H}_{2}$ & $3-761$ & $4,1,3 \leftarrow 4,0,4$ & Ground & & & & 15738.20 & $.1 \%$ \\
\hline $\mathrm{C}^{12} \mathrm{H}_{3} \mathrm{C}^{12}{ }_{*} \mathrm{HO}^{16} \mathrm{C}^{12}{ }_{*} \mathrm{H}_{2}$ & $3-761$ & $4,1,3 \leftarrow 4,0,4$ & Ground & & & & 15741.10 & .1 \\
\hline $\mathrm{C}^{12} \mathrm{H}_{3} \mathrm{C}^{12}{ }_{*} \mathrm{HO}^{16} \mathrm{C}^{12}{ }_{*} \mathrm{H}_{2}$ & 3- 761 & $4,1,3 \leftarrow 4,0,4$ & Ground & & & & 15742.20 & .1 \\
\hline $\mathrm{C}^{12} \mathrm{H}_{2}: \mathrm{C}^{12} \mathrm{HBr}^{79}$ & 4- 727 & $2,1,2 \leftarrow 1,1,1$ & Ground & & & & 15750.57 & .04 \\
\hline $\mathrm{C}^{12} \mathrm{O}^{16} \mathrm{~F}_{2}^{19}$ & 4- 211 & $11,10,1 \leftarrow 11,10,2$ & Ground & & & & 15752.33 & .10 \\
\hline $\mathrm{Cl}^{35} \mathrm{~F}^{19} \mathrm{C}^{12} \mathrm{O}^{16}$ & 4- 151 & $9,3,6 \leftarrow 9,3,7$ & Ground & & & & 15753.04 & .05 \\
\hline $\mathrm{C}^{12} \mathrm{H}_{2}: \mathrm{C}^{13} \mathrm{HBr}^{81}$ & 4- 738 & $2,0,2 \leftarrow 1,0,1$ & Ground & & $7 / 2$ & $5 / 2$ & 15753.2 & \\
\hline c- $\mathrm{C}^{12} \mathrm{HD}: \mathrm{C}^{12} \mathrm{HBr}^{79}$ & 4- 739 & $2,1,1 \leftarrow 1,1,0$ & Ground & & & & 15754.71 & .05 \\
\hline $\mathrm{C}^{12} \mathrm{H}_{3} \mathrm{Ge}^{\mathrm{b}} \mathrm{Cl}_{2}^{35} \mathrm{Cl}^{37}$ & 3- 105 & $5,2,4 \leftarrow 4,1,4$ & & & & & 15755. & 15. \\
\hline $\mathrm{C}^{12} \mathrm{H}_{3} \mathrm{C}^{12}{ }_{*} \mathrm{HO}^{16} \mathrm{C}^{12}{ }_{*} \mathrm{H}_{2}$ & 3- 761 & Not Reported & Ground & & & & 15756.36 & .1 \\
\hline $4 \mathrm{C}^{13}-\mathrm{C}_{6}^{12} \mathrm{H}_{5} \mathrm{C}^{12} \mathrm{~N}^{14}$ & 4-1301 & $6,0,6 \leftarrow 5,0,5$ & Ground & & & & 15758.6 & .1 \\
\hline $\mathrm{C}^{\mathrm{b}} \mathrm{H}_{2}: \mathrm{C}^{\mathrm{b}} \mathrm{HBr}^{79}$ & 4- 753 & Not Reported & Ground & & $3 / 2$ & $3 / 2$ & 15759.5 & \\
\hline $\mathrm{C}^{12} \mathrm{H}_{2}: \mathrm{C}^{13} \mathrm{HBr}^{81}$ & 4- 738 & $2,0,2 \leftarrow 1,0,1$ & Ground & & & & 15761.79 & .06 \\
\hline $\mathrm{O}^{16} \mathrm{~F}_{2}^{19}$ & 4-1611 & $8,2,6 \leftarrow 9,1,9$ & Ground & & & & 15771.44 & .10 \\
\hline $\mathrm{N}^{14} \mathrm{H}_{3}$ & 4-1771 & Not Reported & Ground & & & & 15772. & \\
\hline $\mathrm{C}^{12}{ }_{*} \mathrm{H}_{2} \mathrm{C}^{12} \mathrm{H}_{2} \mathrm{C}^{12} \mathrm{H}_{2} \mathrm{C}^{12} \mathrm{H}_{2} \mathrm{C}^{12} \mathrm{O}^{16}$ & $4-1241$ & $3,1,3 \leftarrow 2,1,2$ & Ground & & & & 15773.9 & \\
\hline $\mathrm{C}^{12} \mathrm{H}_{3} \mathrm{C}^{12}{ }_{*} \mathrm{HO}^{16} \mathrm{C}^{12}{ }_{*} \mathrm{H}_{2}$ & 3. 761 & $4,1,3 \leftarrow 4,0,4$ & Ground & & & & 15775.13 & .1 \\
\hline $\mathrm{C}^{13} \mathrm{H}_{2}: \mathrm{C}^{12} \mathrm{HBr}^{79}$ & 4. 735 & $2,1,1 \leftarrow 1,1,0$ & Ground & & $3 / 2$ & $3 / 2$ & 15777.7 & \\
\hline $\mathrm{C}^{12} \mathrm{H}_{3} \mathrm{C}^{12}{ }_{*} \mathrm{HO}^{16} \mathrm{C}^{12}{ }_{*} \mathrm{H}_{2}$ & $3 \cdot 761$ & $4,1,3 \leftarrow 4,0,4$ & Ground & & & & 15777.87 & .1 \\
\hline$c \cdot \mathrm{C}^{12} \mathrm{HD}: \mathrm{C}^{12} \mathrm{HBr}^{79}$ & 4- 739 & $2,1,1 \leftarrow 1,1,0$ & Ground & & $5 / 2$ & $5 / 2$ & 15778.1 & .1 \\
\hline $\mathrm{C}^{12} \mathrm{D}_{2}\left(\mathrm{C}^{12} \mathrm{~N}^{14}\right)_{2}$ & 4- 903 & $4,1,3 \leftarrow 4,0,4$ & Ground & & & & 15784.72 & \\
\hline $\mathrm{C}^{12} \mathrm{H}_{2}: \mathrm{C}^{12} \mathrm{HBr}^{79}$ & 4- 727 & $2,1,2 \leftarrow 1,1,1$ & Ground & & $5 / 2$ & $5 / 2$ & 15784.8 & \\
\hline $2 \mathrm{~d}-\mathrm{C}_{6}^{12} \mathrm{H}_{5} \mathrm{C}^{12} \mathrm{~N}^{14}$ & 4-1294 & $6,0,6 \leftarrow 5,0,5$ & Ground & & & & 15786.3 & .2 \\
\hline $\mathrm{C}^{12} \mathrm{H}_{2}: \mathrm{C}^{12} \mathrm{HBr}^{79}$ & 4- 727 & $2,1,2 \leftarrow 1,1,1$ & Ground & & $3 / 2$ & $3 / 2$ & 15794.2 & \\
\hline $\mathrm{C}^{\mathrm{b}} \mathrm{H}_{2}: \mathrm{C}^{\mathrm{b}} \mathrm{HBr}^{\mathrm{b}}$ & 4- 752 & Not Reported & Ground & & $3 / 2$ & $3 / 2$ & 15794.3 & \\
\hline $\mathrm{C}^{12} \mathrm{H}_{2} \mathrm{Cl}^{35} \mathrm{C}^{12} \mathrm{~N}^{14}$ & 4- 651 & $6,0,6 \leftarrow 5,1,5$ & Ground & & & & 15794.54 & .2 \\
\hline $\mathrm{C}^{12} \mathrm{H}_{2}: \mathrm{C}^{12} \mathrm{DBr}^{79}$ & 4- 721 & $2,0,2 \leftarrow 1,0,1$ & Ground & & $5 / 2$ & $5 / 2$ & 15795.4 & \\
\hline $\mathrm{C}_{6}^{12} \mathrm{H}_{5} \mathrm{C}^{13} \mathrm{~N}^{14}$ & $4-1293$ & $6,0,6 \leftarrow 5,0,5$ & Ground & & & & 15799.9 & .2 \\
\hline $\mathrm{C}^{12} \mathrm{H}_{3} \mathrm{C}^{12} \mathrm{O}^{16} \mathrm{~F}^{19}$ & 3. 391 & Not Reported & Ground & & & & 15802.28 & .2 \\
\hline c- $\mathrm{C}^{12} \mathrm{HD}: \mathrm{C}^{12} \mathrm{HBr}^{79}$ & 4- 739 & $2,1,1 \leftarrow 1,1,0$ & Ground & & $3 / 2$ & $3 / 2$ & 15805.95 & .1 \\
\hline $3 \mathrm{C}^{13}-\mathrm{C}_{6}^{12} \mathrm{H}_{5} \mathrm{C}^{12} \mathrm{~N}^{14}$ & 4-1299 & $6,0,6 \leftarrow 5,0,5$ & Ground & & & & 15809.9 & .1 \\
\hline $\mathrm{C}^{13} \mathrm{H}_{2}: \mathrm{C}^{12} \mathrm{HBr}^{79}$ & 4- 735 & $2,1,1 \leftarrow 1,1,0$ & Ground & & $5 / 2$ & $3 / 2$ & 15815.7 & \\
\hline $\mathrm{F}_{2}^{19} \mathrm{O}_{2}^{16}$ & $3-\quad 11$ & $1,1,0 \leftarrow 1,0,1$ & Excited & & & & 15817.85 & .1 \\
\hline $\mathrm{C}^{\mathrm{b}} \mathrm{H}_{2}: \mathrm{C}^{\mathrm{b}} \mathrm{HBr}^{\mathrm{b}}$ & 4- 752 & Not Reported & Ground & & & & 15827.9 & \\
\hline $\mathrm{DC}^{12} \mathrm{~N}^{15}$ & 4. 296 & $9 \leftarrow 9$ & Excited & & & & 15830.90 & .1 \\
\hline
\end{tabular}




\begin{tabular}{|c|c|c|c|c|c|c|c|c|}
\hline Isotopic Species & $\begin{array}{l}\text { Vol.-Id. } \\
\text { Nos. }\end{array}$ & $\begin{array}{c}\text { Rotational } \\
\text { Quantum Nos. }\end{array}$ & Vib. State & $\mathrm{F}_{1}^{\prime}$ & $\begin{array}{l}\text { Hyperfine } \\
\mathrm{F}^{\prime} \quad \mathrm{F}_{1}\end{array}$ & $F$ & $\begin{array}{c}\text { Frequency } \\
\mathrm{MHz}^{2}\end{array}$ & $\begin{aligned} & \text { Acc. } \\
& \pm \mathrm{MHz}\end{aligned}$ \\
\hline $\mathrm{DN}^{14} \mathrm{O}_{3}^{16}$ & 3- 32 & $2,1,1 \leftarrow 2,1,2$ & Ground & & & & 15832.83 & \\
\hline $\mathrm{C}^{12} \mathrm{H}_{2}: \mathrm{C}^{12} \mathrm{HBr}^{79}$ & 4. 727 & $2,1,2 \leftarrow 1,1,1$ & Ground & & $5 / 2$ & $3 / 2$ & 15839.2 & \\
\hline $\mathrm{C}^{12} \mathrm{H}_{2}: \mathrm{C}^{12} \mathrm{HBr}^{79}$ & 4- 727 & $2,1,2 \leftarrow 1,1,1$ & Ground & & $5 / 2$ & $3 / 2$ & 15839.3 & \\
\hline $\mathrm{C}^{12} \mathrm{H}_{3} \mathrm{~N}^{14} \mathrm{H}_{2}$ & 3- 261 & Not Reported & Ground & & & & 15842.14 & .04 \\
\hline c- $\mathrm{C}^{12} \mathrm{HD}: \mathrm{C}^{12} \mathrm{HBr}^{79}$ & 4- 739 & 2,$1 ; 1 \leftarrow 1,1,0$ & Ground & & $5 / 2$ & $3 / 2$ & 15842.4 & .2 \\
\hline $\mathrm{C}^{12} \mathrm{H}_{2}: \mathrm{C}^{13} \mathrm{HBr}^{79}$ & 4. 737 & $2,0,2 \leftarrow 1,0,1$ & Ground & & $7 / 2$ & $5 / 2$ & 15843.4 & \\
\hline $\mathrm{Cl}^{37} \mathrm{~F}^{19} \mathrm{C}^{12} \mathrm{O}^{16}$ & 4. 152 & $2,1,2 \leftarrow 1,1,1$ & Ground & & $7 / 2$ & $5 / 2$ & 15848.84 & .05 \\
\hline $\mathrm{C}^{\mathrm{b}} \mathrm{H}_{2}: \mathrm{C}^{\mathrm{b}} \mathrm{HBr}^{81}$ & 4. 754 & Not Reported & Ground & & $5 / 2$ & $5 / 2$ & 15852.1 & \\
\hline $\mathrm{C}^{12} \mathrm{H}_{2}: \mathrm{C}^{13} \mathrm{HBr}^{79}$ & 4- 737 & $2,0,2 \leftarrow 1,0,1$ & Ground & & & & 15853.47 & .11 \\
\hline $\mathrm{C}^{12} \mathrm{H}_{2}: \mathrm{C}^{12} \mathrm{DBr}^{81}$ & 4. 722 & $2,1,1 \leftarrow 1,1,0$ & Ground & & $1 / 2$ & $1 / 2$ & 15857.3 & \\
\hline $\mathrm{Cl}^{37} \mathrm{~F}^{19} \mathrm{C}^{12} \mathrm{O}^{16}$ & 4. 152 & $2,1,2 \leftarrow 1,1,1$ & Ground & & $1 / 2$ & $1 / 2$ & 15859.84 & .05 \\
\hline $\mathrm{C}^{12}{ }_{*} \mathrm{D}_{2} \mathrm{C}^{12} \mathrm{D}_{2} \mathrm{C}^{12} * \mathrm{Cl}_{2}^{35}$ & 4-1063 & $4,0,4 \leftarrow 3,1,3$ & Ground & & & & 15860.2 & \\
\hline $\mathrm{C}^{12}{ }_{*} \mathrm{D}_{2} \mathrm{C}^{12} \mathrm{D}_{2} \mathrm{C}^{12}{ }_{*} \mathrm{Cl}_{2}^{35}$ & 4-1063 & $3,2,2 \leftarrow 2,1,1$ & Ground & & & & 15869.4 & \\
\hline $\mathrm{C}^{12} \mathrm{H}_{3} \mathrm{C}^{12} \mathrm{O}^{16} \mathrm{C}^{12} \mathrm{~N}^{14}$ & 3- 671 & $3,0,3 \leftarrow 2,1,2$ & Ground & & & & 15871.37 & .2 \\
\hline $\mathrm{C}^{12} \mathrm{H}_{2}: \mathrm{C}^{12} \mathrm{HBr}^{81}$ & 4. 728 & $2,0,2 \leftarrow 1,0,1$ & Ground & & $3 / 2$ & $3 / 2$ & 15879.6 & \\
\hline $\mathrm{C}^{12} \mathrm{H}_{2}: \mathrm{C}^{12} \mathrm{HBr}^{81}$ & 4- 728 & $2,0,2 \leftarrow 1,0,1$ & Ground & & $3 / 2$ & $3 / 2$ & 15879.7 & \\
\hline $\mathrm{C}^{13} \mathrm{O}^{16} \mathrm{~F}_{2}^{19}$ & 4- 212 & $10,9,1 \leftarrow 10,9,2$ & Ground & & & & 15881.70 & .10 \\
\hline $\mathrm{HC}^{12} \mathrm{O}^{16} \mathrm{O}^{18} \mathrm{C}^{12} \mathrm{H}_{3}$ E & 3- 516 & $2,1,1 \leftarrow 2,0,2$ & Ground & & & & 15881.96 & .35 \\
\hline $\mathrm{C}^{12} \mathrm{D}_{3} \mathrm{Si}^{30} \mathrm{DF}_{2}^{19}$ & 3- 202 & $2,0,2 \leftarrow 1,0,1$ & Ground & & & & 15885.81 & .2 \\
\hline $\mathrm{C}^{12} \mathrm{H}_{3} \mathrm{C}^{12} \mathrm{O}^{16} \mathrm{~F}^{19}$ & 3- 391 & Not Reported & Ground & & & & 15886.51 & .2 \\
\hline $\mathrm{HC}^{12} \mathrm{O}^{16} \mathrm{O}^{18} \mathrm{C}^{12} \mathrm{H}_{3}-\mathrm{A}$ & 3- 515 & $2,1,1 \leftarrow 2,0,2$ & Ground & & & & 15887.28 & .35 \\
\hline $\mathrm{D}_{2} \mathrm{O}_{2}^{16}$ & 3- 42 & Not Reported & & & & & 15890. & 3. \\
\hline $\mathrm{F}_{2}^{19} \mathrm{O}^{16} \mathrm{O}^{18}$ & $3-\quad 12$ & $2,1,1 \leftarrow 2,0,2$ & Ground & & & & 15892.15 & .1 \\
\hline $\mathrm{H}_{2} \mathrm{~N}^{14} \mathrm{~N}^{14} \mathrm{H}_{2}$ & 3- 51 & Not Reported & & & & & 15892.15 & \\
\hline $\mathrm{C}^{12} \mathrm{D}_{3} \mathrm{Si}^{29} \mathrm{DF}_{2}^{19}$ & 3- 201 & $2,0,2 \leftarrow 1,0,1$ & Ground & & & & 15894.60 & .2 \\
\hline $\mathrm{C}^{12} \mathrm{H}_{3} \mathrm{Ge}^{74} \mathrm{D}_{3}$ & 3- 293 & $1,0 \leftarrow 0,0$ & Ground & & & & 15900.15 & .10 \\
\hline $2 \mathrm{C}^{13} \cdot \mathrm{C}_{6}^{12} \mathrm{H}_{5} \mathrm{C}^{12} \mathrm{~N}^{14}$ & 4-1298 & $6,0,6 \leftarrow 5,0,5$ & Ground & & & & 15900.6 & .2 \\
\hline $\mathrm{C}^{12} \mathrm{D}_{3} \mathrm{Si}^{28} \mathrm{DF}_{2}^{19}$ & 3- 199 & $2,0,2 \leftarrow 1,0,1$ & Ground & & & & 15903.16 & .1 \\
\hline $\mathrm{C}^{12} \mathrm{H}_{2}: \mathrm{C}^{12} \mathrm{DBr}^{81}$ & 4- 722 & $2,1,1 \leftarrow 1,1,0$ & Ground & & $3 / 2$ & $1 / 2$ & 15904.5 & \\
\hline $\mathrm{F}_{2}^{19} \mathrm{O}_{2}^{16}$ & 3. 11 & $1,1,0 \leftarrow 1,0,1$ & Ground & & & & 15906.04 & .1 \\
\hline $\mathrm{HC}^{12} \mathrm{DO}^{16}$ & 4- 385 & $7,2,5 \leftarrow 7,2,6$ & Ground & & & & 15907.38 & \\
\hline $\mathrm{C}^{12} \mathrm{H}_{3} \mathrm{~N}^{14} \mathrm{H}_{2}$ & 3- 261 & $8,3, \leftarrow 9,2$ & Ground & & & & 15907.61 & .1 \\
\hline $\mathrm{N}^{15} \mathrm{H}_{3}$ & 4-1772 & $9,5 \leftarrow 9,5$ & Ground & & & & 15908.53 & .10 \\
\hline $\mathrm{C}^{12} \mathrm{HD}\left(\mathrm{C}^{12} \mathrm{~N}^{14}\right)_{2}$ & 4. 902 & $1,1,0 \leftarrow 1,0,1$ & Ground & & & & 15916.73 & \\
\hline $\mathrm{C}^{12} \mathrm{H}_{2}: \mathrm{C}^{12} \mathrm{DBr}^{81}$ & 4- 722 & $2,1,1 \leftarrow 1,1,0$ & Excited & & $7 / 2$ & $5 / 2$ & 15920.2 & \\
\hline $\mathrm{H}_{2} \mathrm{~N}^{14} \mathrm{~N}^{14} \mathrm{H}_{2}$ & 3- 51 & Not Reported & & & & & 15921.66 & \\
\hline $\mathrm{C}^{12} \mathrm{H}_{2}: \mathrm{C}^{12} \mathrm{DBr}^{81}$ & 4- 722 & $2,1,1 \leftarrow 1,1,0$ & Ground & & $7 / 2$ & $5 / 2$ & 15932.7 & \\
\hline $\mathrm{N}^{14} \mathrm{H}_{3}$ & 4-1771 & $11,7 \leftarrow 11,7$ & Ground & & & & 15933.32 & .06 \\
\hline $\mathrm{C}^{12} \mathrm{H}_{2}: \mathrm{C}^{12} \mathrm{HBr}^{81}$ & 4. 728 & $2,0,2 \leftarrow 1,0,1$ & Excited & & $7 / 2$ & $5 / 2$ & 15934.2 & \\
\hline $\mathrm{C}^{12} \mathrm{H}_{2}: \mathrm{C}^{12} \mathrm{HBr}^{81}$ & 4. 728 & $2,0,2 \leftarrow 1,0,1$ & Excited & & $5 / 2$ & $3 / 2$ & 15934.2 & \\
\hline $\mathrm{C}^{12} \mathrm{H}_{2}: \mathrm{C}^{12} \mathrm{HBr}^{81}$ & 4- 728 & $2,0,2 \leftarrow 1,0,1$ & Excited & & $7 / 2$ & $5 / 2$ & 15934.3 & \\
\hline $\mathrm{C}^{12} \mathrm{H}_{3} \mathrm{C}^{12} \mathrm{O}^{16} \mathrm{~F}^{19}$ & 3- 391 & Not Reported & Ground & & & & 15938.33 & .2 \\
\hline $1 \mathrm{C}^{13}-\mathrm{C}_{6}^{12} \mathrm{H}_{5} \mathrm{C}^{12} \mathrm{~N}^{14}$ & 4-1297 & $6,0,6 \leftarrow 5,0,5$ & Ground & & & & 15941.3 & .1 \\
\hline $\mathrm{C}^{12} \mathrm{H}_{3} \mathrm{Ge}^{72} \mathrm{D}_{3}$ & 3. 292 & $1,0 \leftarrow 0,0$ & Ground & & & & 15942.15 & .10 \\
\hline $\mathrm{C}^{12} \mathrm{H}_{2}: \mathrm{C}^{12} \mathrm{HBr}^{81}$ & 4. 728 & $2,0,2 \leftarrow 1,0,1$ & Ground & & $5 / 2$ & $3 / 2$ & 15949.5 & \\
\hline
\end{tabular}




\begin{tabular}{|c|c|c|c|c|c|c|c|c|}
\hline Isotopic Species & $\begin{array}{l}\text { Vol.-Id. } \\
\text { Nos. }\end{array}$ & $\begin{array}{c}\text { Rotational } \\
\text { Quantum Nos. }\end{array}$ & Vib. State & $F_{1}^{\prime}$ & $\begin{array}{l}\text { Hyperfine } \\
F^{\prime} F_{1}\end{array}$ & $\mathrm{~F}$ & $\begin{array}{l}\text { Frequency } \\
\qquad \mathrm{MHz}^{-}\end{array}$ & $\begin{aligned} & \text { Acc. } \\
\pm & \mathrm{MHz}_{2}\end{aligned}$ \\
\hline $\mathrm{C}^{12} \mathrm{H}_{2}: \mathrm{C}^{12} \mathrm{HBr}^{81}$ & 4- 728 & $2,0,2 \leftarrow 1,0,1$ & Ground & & $7 / 2$ & $5 / 2$ & 15949.5 & \\
\hline $\mathrm{C}^{\mathrm{b}} \mathrm{H}_{2}: \mathrm{C}^{\mathrm{b}} \mathrm{HBr}^{\mathrm{b}}$ & 4- 752 & Not Reported & Ground & & $7 / 2$ & $5 / 2$ & 15949.5 & \\
\hline $\mathrm{C}_{6}^{12} \mathrm{H}_{5} \mathrm{C}^{12} \mathrm{~N}^{14}$ & 4-1291 & $6,0,6 \leftarrow 5,0,5$ & Ground & & & & 15951.9 & .2 \\
\hline $\mathrm{C}^{\mathrm{b}} \mathrm{H}_{2}: \mathrm{C}^{\mathrm{b}} \mathrm{HBr}^{79}$ & 4- 753 & Not Reported & Ground & & $3 / 2$ & $3 / 2$ & 15955.0 & \\
\hline $\mathrm{C}^{12} \mathrm{H}_{2}: \mathrm{C}^{12} \mathrm{HBr}^{79}$ & 4- 727 & $2,0,2 \leftarrow 1,0,1$ & Ground & & $3 / 2$ & $3 / 2$ & 15955.1 & \\
\hline $\mathrm{C}^{12} \mathrm{H}_{2}: \mathrm{C}^{12} \mathrm{DBr}^{81}$ & 4- 722 & $2,1,1 \leftarrow 1,1,0$ & Ground & & & & 15957.28 & .04 \\
\hline $\mathrm{C}^{12} \mathrm{H}_{2}: \mathrm{C}^{12} \mathrm{HBr}^{81}$ & 4- 728 & $2,0,2 \leftarrow 1,0,1$ & Ground & & & & 15958.13 & .06 \\
\hline $\mathrm{C}^{12} \mathrm{H}_{2}: \mathrm{C}^{13} \mathrm{HBr}^{81}$ & 4- 738 & $2,1,1 \leftarrow 1,1,0$ & Ground & & $1 / 2$ & $1 / 2$ & 15962.1 & \\
\hline $\mathrm{C}^{12} \mathrm{H}_{2}: \mathrm{C}^{12} \mathrm{HBr}^{81}$ & 4- 728 & Not Reported & Ground & & $1 / 2$ & $1 / 2$ & 15962.9 & .2 \\
\hline $\mathrm{C}^{12} \mathrm{H}_{3} \mathrm{C}^{12} \mathrm{HO}^{16}$ & 3- 471 & $5,1,4 \leftarrow 5,1,5$ & Ground & & & & 15968.60 & .2 \\
\hline $\mathrm{C}^{b} \mathrm{H}_{2}: \mathrm{C}^{b} \mathrm{HBr}^{\mathrm{b}}$ & 4- 752 & Not Reported & Ground & & & & 15978.2 & \\
\hline $\mathrm{C}^{12} \mathrm{H}_{2}: \mathrm{C}^{12} \mathrm{DBr}^{81}$ & 4- 722 & $2,1,1 \leftarrow 1,1,0$ & Ground & & $5 / 2$ & $5 / 2$ & 15980.4 & \\
\hline $\mathrm{C}^{12} \mathrm{H}_{3} \mathrm{C}^{12} \mathrm{H}: \mathrm{C}^{12}: \mathrm{C}^{12} \mathrm{H}_{2}$ & 3- 931 & $2,1,2 \leftarrow 1,1,1$ & Ground & & & & 15985.82 & .03 \\
\hline $\mathrm{C}^{12} \mathrm{H}_{3} \mathrm{Ge}^{70} \mathrm{D}_{3}$ & 3- 291 & $1,0 \leftarrow 0,0$ & Ground & & & & 15985.97 & .10 \\
\hline $\mathrm{C}^{12} \mathrm{H}_{3} \mathrm{C}^{12} \mathrm{H}: \mathrm{C}^{12}: \mathrm{C}^{12} \mathrm{H}_{2}$ & 3- 931 & $2,1,2 \leftarrow 1,1,1$ & Ground & & & & 15987.84 & .03 \\
\hline $\mathrm{C}^{12} \mathrm{H}_{3} \mathrm{C}^{12} \mathrm{HO}^{16}$ & 3- 471 & $5,1,4 \leftarrow 5,1,5$ & Ground & & & & 15988.80 & .3 \\
\hline $\mathrm{C}^{12} \mathrm{H}_{2}: \mathrm{C}^{12} \mathrm{DBr}^{79}$ & 4- 721 & $2,1,1 \leftarrow 1,1,0$ & Ground & & $3 / 2$ & $1 / 2$ & 15989.0 & \\
\hline $\mathrm{C}^{12} \mathrm{H}_{3} \mathrm{Ge}^{\mathrm{b}} \mathrm{Cl}_{3}^{35}$ & 3- 107 & $5, \leftarrow 4$ & & & & & 15995. & 15. \\
\hline $\mathrm{C}^{12} \mathrm{H}_{3} \mathrm{~N}^{14} \mathrm{H}_{2}$ & 3. 261 & Not Reported & Ground & & & & 15999.68 & .1 \\
\hline $\mathrm{C}^{12} \mathrm{H}_{2}: \mathrm{C}^{12} \mathrm{DBr}^{81}$ & 4- 722 & $2,1,1 \leftarrow 1,1,0$ & Ground & & $3 / 2$ & $3 / 2$ & 15999.8 & \\
\hline $4 d-C_{6}^{12} \mathrm{H}_{5} \mathrm{C}^{12} \mathrm{~N}^{14}$ & 4-1296 & $6,2,5 \leftarrow 5,2,4$ & Ground & & & & 16002.2 & .2 \\
\hline $\mathrm{N}^{14} \mathrm{O}_{2}^{16}$ & 4-1801 & $39,3,37 \leftarrow 40,2,38$ & Ground & & & & 16008.35 & \\
\hline $\mathrm{C}^{\mathrm{b}} \mathrm{H}_{2}: \mathrm{C}^{\mathrm{b}} \mathrm{HBr}^{\mathrm{b}}$ & 4- 752 & Not Reported & Ground & & $3 / 2$ & $1 / 2$ & 16008.7 & \\
\hline $\mathrm{C}^{12} \mathrm{H}_{2}: \mathrm{C}^{12} \mathrm{DBr}^{79}$ & 4- 721 & $2,1,1 \leftarrow 1,1,0$ & Excited & & $7 / 2$ & $5 / 2$ & 16010.1 & \\
\hline $\mathrm{N}^{14} \mathrm{O}_{2}^{16}$ & 4-1801 & $39,3,37 \leftarrow 40,2,38$ & Ground & & & & 16014.05 & \\
\hline $\mathrm{F}_{2}^{19} \mathrm{O}_{2}^{16}$ & 3- 11 & $1,1,0 \leftarrow 1,0,1$ & Ground & & & & 16016.74 & .1 \\
\hline $\mathrm{N}^{14} \mathrm{O}_{2}^{16}$ & 4-1801 & $39,3,37 \leftarrow 40,2,38$ & Ground & & & & 16019.90 & \\
\hline $\mathrm{C}^{12} \mathrm{H}_{2}: \mathrm{C}^{12} \mathrm{DBr}^{79}$ & 4- 721 & $2,1,1 \leftarrow 1,1,0$ & Ground & & $7 / 2$ & $5 / 2$ & 16022.7 & \\
\hline $\mathrm{C}^{b} \mathrm{H}_{2}: \mathrm{C}^{b} \mathrm{HBr}^{\mathrm{b}}$ & 4- 752 & Not Reported & Excited & & $7 / 2$ & $5 / 2$ & 16023.0 & \\
\hline $\mathrm{C}^{12} \mathrm{H}_{2}: \mathrm{C}^{12} \mathrm{HBr}^{79}$ & 4- 727 & $2,0,2 \leftarrow 1,0,1$ & Excited & & $7 / 2$ & $5 / 2$ & 16023.0 & \\
\hline $\mathrm{C}^{12} \mathrm{H}_{2}: \mathrm{C}^{12} \mathrm{HBr}^{79}$ & 4- 727 & $2,0,2 \leftarrow 1,0,1$ & Excited & & $5 / 2$ & $3 / 2$ & 16023.0 & \\
\hline $\mathrm{N}^{14} \mathrm{O}_{2}^{16}$ & 4-1801 & $39,3,37 \leftarrow 40,2,38$ & Ground & & & & 16023.65 & \\
\hline $\mathrm{DC}^{12} \mathrm{O}^{16} \mathrm{O}^{16} \mathrm{C}^{12} \mathrm{H}_{3}-\mathrm{E}$ & 3- 504 & $7,2,5 \leftarrow 7,2,6$ & Ground & & & & 16024.25 & .35 \\
\hline$D^{12} \mathrm{~N}^{14}$ & 4- 292 & $6 \leftarrow 6$ & Excited & & & & 16025.35 & .1 \\
\hline $\mathrm{N}^{14} \mathrm{O}_{2}^{16}$ & 4-1801 & $39,3,37 \leftarrow 40,2,38$ & Ground & & & & 16025.95 & \\
\hline $\mathrm{N}^{14} \mathrm{O}_{2}^{16}$ & 4-1801 & $39,3,37 \leftarrow 40,2,38$ & Ground & & & & 16031.85 & \\
\hline $\mathrm{H}_{2} \mathrm{O}_{2}^{16}$ & $3-41$ & Not Reported & & & & & 16032. & 2. \\
\hline $\mathrm{C}^{12} \mathrm{H}_{2}: \mathrm{C}^{12} \mathrm{DBr}^{81}$ & 4- 722 & $2,1,1 \leftarrow 1,1,0$ & Ground & & $5 / 2$ & $3 / 2$ & 16033.4 & \\
\hline $\mathrm{DC}^{12} \mathrm{O}^{16} \mathrm{O}^{16} \mathrm{C}^{12} \mathrm{H}_{3}-\mathrm{A}$ & 3. 503 & $7,2,5 \leftarrow 7,2,6$ & Ground & & & & $16035: 33$ & .35 \\
\hline $\mathrm{HC}^{12} \mathrm{O}^{16} \mathrm{O}^{16} \mathrm{C}^{12} \mathrm{H}_{3}-\mathrm{E}$ & 3. 502 & $4,1,3 \leftarrow 4,1,4$ & Ground & & & & 16037.23 & .35 \\
\hline $\mathrm{C}^{b} \mathrm{H}_{2}: \mathrm{C}^{\mathrm{b}} \mathrm{HBr}^{\mathrm{b}}$ & 4- 752 & Not Reported & Ground & & $7 / 2$ & $5 / 2$ & 16037.5 & \\
\hline $\mathrm{HC}^{12} \mathrm{DO}^{16}$ & 4- 385 & $2,1,1 \leftarrow 2,1,2$ & Ground & & & & 16038.06 & \\
\hline $\mathrm{C}^{12} \mathrm{H}_{2}: \mathrm{C}^{12} \mathrm{HBr}^{79}$ & 4- 727 & $2,0,2 \leftarrow 1,0,1$ & Ground & & $7 / 2$ & $5 / 2$ & 16038.6 & \\
\hline $\mathrm{C}^{12} \mathrm{H}_{2}: \mathrm{C}^{12} \mathrm{HBr}^{79}$ & 4- 727 & $2,0,2 \leftarrow 1,0,1$ & Ground & & $5 / 2$ & $3 / 2$ & 16038.6 & \\
\hline $\mathrm{C}^{12} \mathrm{H}_{2}: \mathrm{C}^{12} \mathrm{HBr}^{79}$ & 4- 727 & $2,0,2 \leftarrow 1,0.1$ & Ground & & $7 / 2$ & $5 / 2$ & 16038.7 & \\
\hline
\end{tabular}




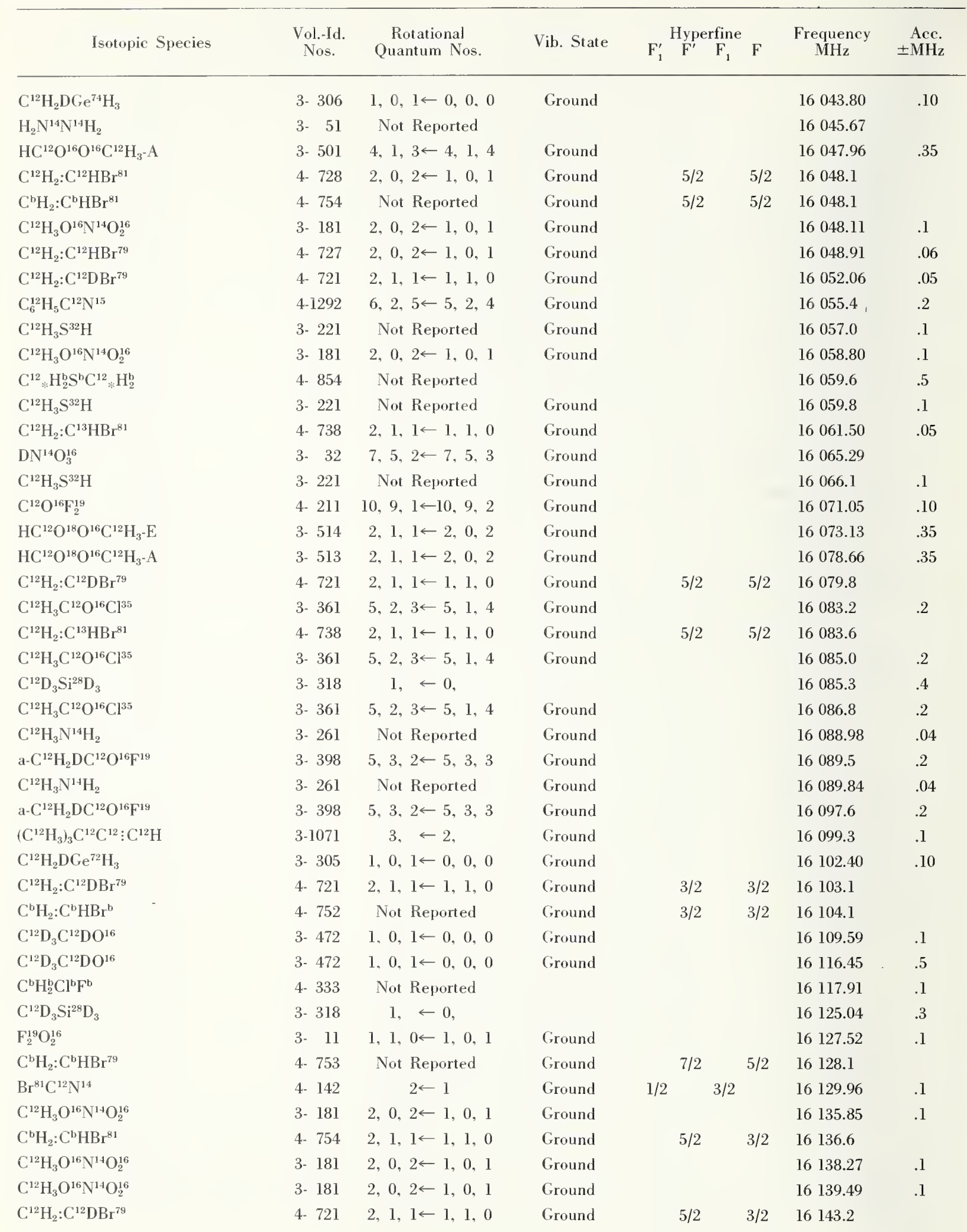




\begin{tabular}{|c|c|c|c|c|c|c|c|c|c|}
\hline Isotopic Species & $\begin{array}{l}\text { Vol.-Id. } \\
\text { Nos. }\end{array}$ & $\begin{array}{c}\text { Rotational } \\
\text { Quantum Nos. }\end{array}$ & Vib. State & $F_{1}^{\prime}$ & $\begin{array}{l}\text { Hypex } \\
\mathrm{F}^{\prime}\end{array}$ & $\begin{array}{c}\text { rfine } \\
F_{1}\end{array}$ & $\mathrm{~F}$ & $\begin{array}{l}\text { Frequenry } \\
\mathrm{MHz}_{z}\end{array}$ & $\begin{aligned} & \text { Arce. } \\
& \pm \text { MHL }\end{aligned}$ \\
\hline $\mathrm{HC}^{12} \mathrm{~N}^{14}$ & 4- 291 & $8 \leftarrow 8$ & Excited & & & & & 16148.55 & .05 \\
\hline $\mathrm{C}^{12} \mathrm{H}_{2}: \mathrm{C}^{12} \mathrm{HC}^{12} \mathrm{~F}^{19}: \mathrm{C}^{12} \mathrm{H}_{2}$ & 3. 911 & $5,2,3 \leftarrow 5,1,4$ & Ground & & & & & 16148.9 & .2 \\
\hline $\mathrm{Tl}^{205} \mathrm{I}^{127}$ & $1-$ & $10 \leftarrow 9$ & Excited & & & & & 16152.0 & \\
\hline $\mathrm{C}^{12} \mathrm{H}_{2}: \mathrm{C}^{12} \mathrm{HBr}^{79}$ & 4- 727 & $2,0,2 \leftarrow 1,0,1$ & Ground & & $5 / 2$ & & $3 / 2$ & 16156.4 & \\
\hline $\mathrm{C}^{12} \mathrm{H}_{2}: \mathrm{C}^{12} \mathrm{HBr}^{79}$ & 4. 727 & $2,0,2 \leftarrow 1,0,1$ & Ground & & $5 / 2$ & & $5 / 2$ & 16156.5 & .2 \\
\hline $\mathrm{C}^{12} \mathrm{H}_{2}: \mathrm{C}^{13} \mathrm{HBr}^{79}$ & 4- 737 & $2,1,1 \leftarrow 1,1,0$ & Ground & & & & & 16156.52 & .09 \\
\hline $\mathrm{S}^{32}{ }_{*} \mathrm{C}^{12} \mathrm{H}: \mathrm{C}^{13} \mathrm{HC}^{12} \mathrm{H}: \mathrm{C}^{12}{ }_{*} \mathrm{H}$ & $4-1168$ & $2,0,2 \leftarrow 1,0,1$ & Ground & & & & & 16157.7 & .05 \\
\hline $\mathrm{C}^{12} \mathrm{D}_{3} \mathrm{Si}^{28} \mathrm{D}_{3}$ & 3- 318 & $1, \leftarrow 0$ & & & & & & 16158.06 & .2 \\
\hline $\mathrm{C}^{12} \mathrm{H}_{2}: \mathrm{C}^{12} \mathrm{HBr}^{81}$ & 4- 728 & $2,1,1 \leftarrow 1,1,0$ & Ground & & $1 / 2$ & & $1 / 2$ & 16158.4 & \\
\hline $\mathrm{C}_{*}^{12} \mathrm{H}_{2}^{\mathrm{b}} \mathrm{S}^{\mathrm{b}} \mathrm{C}^{12}{ }_{*} \mathrm{H}_{2}^{\mathrm{b}}$ & 4- 854 & Not Reported & & & & & & 16161.8 & .5 \\
\hline $\mathrm{O}_{3}^{16}$ & 4-1841 & $27,3,25 \leftarrow 26,4,22$ & Ground & & & & & 16163. & \\
\hline $\mathrm{C}^{12} \mathrm{H}_{2} \mathrm{DGe}^{70} \mathrm{H}_{3}$ & 3- 304 & $1,0,1 \leftarrow 0,0,0$ & Ground & & & & & 16163.70 & .10 \\
\hline $\mathrm{C}^{\mathrm{b}} \mathrm{H}_{2}^{\mathrm{b}} \mathrm{Cl}^{\mathrm{b}} \mathrm{F}^{\mathrm{b}}$ & 4- 333 & Not Reported & & & & & & 16166.58 & .1 \\
\hline $\mathrm{c}-\mathrm{HDC}^{12}{ }_{*} \mathrm{O}^{16} \mathrm{C}^{12}{ }_{*} \mathrm{DH}$ & 4- 845 & $2,2,0 \leftarrow 2,1,1$ & Ground & & & & & 16168.15 & .05 \\
\hline $\mathrm{C}_{6}^{12} \mathrm{H}_{5} \mathrm{~F}^{19}$ & 4-1281 & $4,0,4 \leftarrow 3,0,3$ & Ground & & & & & 16172.3 & .1 \\
\hline $\mathrm{Br}^{79} \mathrm{C}^{12} \mathrm{~N}^{14}$ & 4- 141 & $2 \leftarrow 1$ & Ground & $1 / 2$ & $3 / 2$ & $3 / 2$ & $3 / 2$ & 16172.30 & .1 \\
\hline $\mathrm{Br}^{79} \mathrm{C}^{12} \mathrm{~N}^{14}$ & 4- 141 & $2 \leftarrow 1$ & Ground & $1 / 2$ & $3 / 2$ & $3 / 2$ & $5 / 2$ & 16172.90 & .1 \\
\hline $\mathrm{Br}^{79} \mathrm{C}^{12} \mathrm{~N}^{14}$ & 4- 141 & $2 \leftarrow 1$ & Ground & $1 / 2$ & $3 / 2$ & $3 / 2$ & $1 / 2$ & 16173.40 & .1 \\
\hline $\mathrm{C}^{12} \mathrm{H}_{2} \mathrm{DC}^{12} \vdots \mathrm{C}^{12} \mathrm{H}$ & 4-1047 & $1,0,1 \leftarrow 0,0,0$ & Ground & & & & & 16181.12 & .1 \\
\hline$T]^{205} I^{127}$ & $1-$ & $10 \leftarrow 9$ & Excited & & & & & 16191.4 & \\
\hline $3 \mathrm{~d}-\mathrm{C}_{6}^{12} \mathrm{H}_{5} \mathrm{C}^{12} \mathrm{~N}^{14}$ & 4-1295 & $6,2,5 \leftarrow 5,2,4$ & Ground & & & & & 16196.3 & .2 \\
\hline $\mathrm{C}^{12} \mathrm{H}_{3} \mathrm{~N}^{14} \mathrm{O}_{2}^{16}$ & 3- 171 & Not Reported & Ground & & & & & 16199.43 & \\
\hline $\mathrm{C}^{12} \mathrm{H}_{2}: \mathrm{C}^{12} \mathrm{HBr}^{81}$ & 4- 728 & $2,1,1 \leftarrow 1,1,0$ & Ground & & $3 / 2$ & & $1 / 2$ & 16203.7 & \\
\hline $\mathrm{C}^{12} \mathrm{H}_{2}: \mathrm{C}^{12} \mathrm{HBr}^{81}$ & 4- 728 & $2,1,1 \leftarrow 1,1,0$ & Ground & & $3 / 2$ & & $1 / 2$ & 16203.8 & \\
\hline $\mathrm{C}^{12} \mathrm{H}_{3} \mathrm{C}^{12} \mathrm{O}^{16} \mathrm{~F}^{19}$ & 3- 391 & Not Reported & Ground & & & & & 16205.5 & .2 \\
\hline $\mathrm{DC}^{12}: \mathrm{C}^{12} \mathrm{C}^{12} \mathrm{DO}^{16}$ & 4- 926 & $7,0,7 \leftarrow 6,1,6$ & Ground & & & & & 16206.27 & .02 \\
\hline $\mathrm{C}^{13} \mathrm{O}^{16} \mathrm{~F}_{2}^{19}$ & 4- 212 & $9,8,1 \leftarrow 9,8,2$ & Ground & & & & & 16206.91 & .10 \\
\hline $\mathrm{C}^{12} \mathrm{H}_{2}: \mathrm{C}^{13} \mathrm{HBr}^{79}$ & 4- 737 & Not Reported & Ground & & $5 / 2$ & & $5 / 2$ & 16208.3 & \\
\hline $\mathrm{C}^{12} \mathrm{D}_{3} \mathrm{C}^{12} \mathrm{HO}^{16}$ & 3- 474 & $6,1,5 \leftarrow 6,1,6$ & Ground & & & & & 16208.84 & .5 \\
\hline $\mathrm{C}_{6}^{12} \mathrm{H}_{5} \mathrm{Cl}^{35}$ & $4-1271$ & $6,0,6 \leftarrow 5,0,5$ & Ground & & & & & 16210.3 & \\
\hline $\mathrm{HN}^{14} \mathrm{O}_{3}^{16}$ & 3- 31 & $3,2,1 \leftarrow 3,2,2$ & Ground & & & & & 16215.59 & \\
\hline $\mathrm{Cl}^{35} \mathrm{~F}^{19} \mathrm{C}^{12} \mathrm{O}^{16}$ & 4- 151 & $2,1,2 \leftarrow 1,1,1$ & Ground & & $5 / 2$ & & $3 / 2$ & 16218.39 & .05 \\
\hline $\mathrm{C}^{12} \mathrm{H}_{2}: \mathrm{C}^{12} \mathrm{HBr}^{81}$ & 4- 728 & $2,1,1 \leftarrow 1,1,0$ & Excited & & $7 / 2$ & & $5 / 2$ & 16219.8 & \\
\hline $\mathrm{C}^{12} \mathrm{H}_{2}: \mathrm{C}^{12} \mathrm{HBr}^{\mathrm{b}}$ & 4- 751 & Not Reported & & & & & & 16224.3 & .1 \\
\hline $\mathrm{C}^{12} \mathrm{D}_{3} \mathrm{C}^{12} \mathrm{HO}^{16}$ & 3. 474 & $6,1,5 \leftarrow 6,1,6$ & Ground & & & & & 16224.33 & .3 \\
\hline $\mathrm{Br}^{81} \mathrm{C}^{12} \mathrm{~N}^{14}$ & 4- 142 & $2 \leftarrow 1$ & Excited & $3 / 2$ & & $3 / 2$ & & 16227.73 & .1 \\
\hline $\mathrm{C}^{12} \mathrm{H}_{3} \mathrm{~N}^{14} \mathrm{H}_{2}$ & 3- 261 & Not Reported & Ground & & & & & 16228.00 & \\
\hline a- $\mathrm{C}^{12} \mathrm{H}_{2} \mathrm{DS}^{32} \mathrm{C}^{12} \mathrm{H}_{3}$ & 3- 605 & $2,0,2 \leftarrow 1,1,1$ & Ground & & & & & 16228.21 & .05 \\
\hline$T I^{205} I^{127}$ & $1-$ & $10 \leftarrow 9$ & Excited & & $15 / 2$ & & $13 / 2$ & 16228.26 & 0.10 \\
\hline $\mathrm{Tl}^{205} \mathrm{I}^{127}$ & $1-$ & $10 \leftarrow 9$ & Excited & & $17 / 2$ & & $15 / 2$ & 16228.26 & 0.10 \\
\hline $\mathrm{Tl}^{205} \mathrm{I}^{127}$ & $1-$ & $10 \leftarrow 9$ & Excited & & $19 / 2$ & & $17 / 2$ & 16228.26 & 0.10 \\
\hline $\mathrm{Tl}^{205} \mathrm{I}^{127}$ & 1. & $10 \leftarrow 9$ & Excited & & $25 / 2$ & & $23 / 2$ & 16230.50 & 0.10 \\
\hline$\left.T\right|^{205} I^{127}$ & 1 - & $10 \leftarrow 9$ & Excited & & $23 / 2$ & & $21 / 2$ & 16230.50 & 0.10 \\
\hline$T l^{205} I^{127}$ & $1-$ & $10 \leftarrow 9$ & Excited & & $21 / 2$ & & $19 / 2$ & 16230.50 & 0.10 \\
\hline $\mathrm{C}^{12} \mathrm{H}_{2}: \mathrm{C}^{12} \mathrm{HBr}^{81}$ & 4- 728 & $2,1,1 \leftarrow 1,1,0$ & Ground & & $7 / 2$ & & $5 / 2$ & 16232.7 & \\
\hline
\end{tabular}




\begin{tabular}{|c|c|c|c|c|c|c|c|c|c|}
\hline Isotopic Species & $\begin{array}{l}\text { Vol.-Id. } \\
\text { Nos. }\end{array}$ & $\begin{array}{c}\text { Rotational } \\
\text { Quantum Nos. }\end{array}$ & Vib. State & $\mathrm{F}_{1}^{\prime}{ }^{\mathrm{H}}$ & $\begin{array}{c}\text { Hyper } \\
\mathrm{F}^{\prime}\end{array}$ & $\begin{array}{c}\text { rfine } \\
F_{1}\end{array}$ & $\mathrm{~F}$ & $\begin{array}{c}\text { Frequency } \\
\mathrm{MHz}\end{array}$ & $\begin{array}{r}\text { Acc. } \\
\pm \mathrm{MHz}\end{array}$ \\
\hline $\mathrm{C}^{12} \mathrm{H}_{2}: \mathrm{C}^{12} \mathrm{HBr}^{81}$ & 4- 728 & Not Reported & Ground & & $7 / 2$ & & $5 / 2$ & 16232.9 & \\
\hline $\mathrm{C}^{12} \mathrm{H}_{2}: \mathrm{C}^{12} \mathrm{HBr}^{79}$ & 4- 727 & $2,1,1 \leftarrow 1,1,0$ & Ground & & $1 / 2$ & & $1 / 2$ & 16233.5 & \\
\hline $\mathrm{Cl}^{35} \mathrm{~F}^{19} \mathrm{C}^{12} \mathrm{O}^{16}$ & 4. 151 & $2,1,2 \leftarrow 1,1,1$ & Ground & & $7 / 2$ & & $5 / 2$ & 16237.11 & .05 \\
\hline $\mathrm{F}_{2}^{19} \mathrm{O}_{2}^{16}$ & 3- 11 & $1,1,0 \leftarrow 1,0,1$ & Ground & & & & & 16239.55 & .1 \\
\hline $\mathrm{C}^{12} \mathrm{H}_{3} \mathrm{~N}^{14} \mathrm{H}_{2}$ & 3- 261 & Not Reported & Ground & & & & & 16240.64 & .1 \\
\hline $\mathrm{C}^{12} \mathrm{H}_{3} \mathrm{C}^{12} \mathrm{O}^{16} \mathrm{~F}^{19}$ & 3- 391 & Not Reported & Ground & & & & & 16243.4 & .2 \\
\hline $\mathrm{Cl}^{35} \mathrm{~F}^{19} \mathrm{C}^{12} \mathrm{O}^{16}$ & 4- 151 & $2,1,2 \leftarrow 1,1,1$ & Ground & & $3 / 2$ & & $1 / 2$ & 16243.64 & .05 \\
\hline$\left(\mathrm{C}^{12} \mathrm{H}_{3}\right)_{2} \mathrm{~S}^{32}$ & 3- 601 & $2,0,2 \leftarrow 1,1,1$ & Ground & & & & & 16246.12 & .05 \\
\hline$\left(\mathrm{C}^{12} \mathrm{H}_{3}\right)_{2} \mathrm{~S}^{32}$ & 3- 601 & $2,0,2 \leftarrow 1,1,1$ & Ground & & & & & 16246.27 & .05 \\
\hline$\left(\mathrm{C}^{12} \mathrm{H}_{3}\right)_{2} \mathrm{~S}^{32}$ & 3- 601 & $2,0,2 \leftarrow 1,1,1$ & Ground & & & & & 16246.28 & .05 \\
\hline$\left(\mathrm{C}^{12} \mathrm{H}_{3}\right)_{2} \mathrm{~S}^{32}$ & 3. 601 & $2,0,2 \leftarrow 1,1,1$ & Ground & & & & & 16246.45 & .05 \\
\hline $\mathrm{C}^{12} \mathrm{H}_{2}: \mathrm{C}^{13} \mathrm{HBr}^{79}$ & 4- 737 & Not Reported & Ground & & $5 / 2$ & & $3 / 2$ & 16247.0 & \\
\hline $\mathrm{Cl}^{35} \mathrm{~F}^{19} \mathrm{C}^{12} \mathrm{O}^{16}$ & 4- 151 & $2,1,2 \leftarrow 1,1,1$ & Ground & & $1 / 2$ & & $1 / 2$ & 16251.05 & .05 \\
\hline $\mathrm{C}^{12} \mathrm{H}_{2}: \mathrm{C}^{12} \mathrm{HBr}^{81}$ & 4- 728 & $2,1,1 \leftarrow 1,1,0$ & Ground & & & & & 16256.67 & .04 \\
\hline $\mathrm{C}^{12} \mathrm{H}_{3} \mathrm{C}^{12} \mathrm{H}: \mathrm{C}^{12}: \mathrm{C}^{12} \mathrm{H}_{2}$ & 3- 931 & $2,0,2 \leftarrow 1,0,1$ & Ground & & & & & 16256.76 & .03 \\
\hline $\mathrm{C}^{12} \mathrm{H}_{3} \mathrm{C}^{12} \mathrm{H}: \mathrm{C}^{12}: \mathrm{C}^{12} \mathrm{H}_{2}$ & 3. 931 & $2,0,2 \leftarrow 1,0,1$ & Ground & & & & & 16256.93 & .03 \\
\hline $\mathrm{HC}^{12} \mathrm{O}^{16} \mathrm{O}^{16} \mathrm{C}^{13} \mathrm{H}_{3}-\mathrm{E}$ & 3- 512 & 2. $1,1 \leftarrow 2,0,2$ & Ground & & & & & 16260.44 & .35 \\
\hline $\mathrm{HC}^{12} \mathrm{O}^{16} \mathrm{O}^{16} \mathrm{C}^{13} \mathrm{H}_{3}-\mathrm{A}$ & 3- 511 & $2,1,1 \leftarrow 2,0,2$ & Ground & & & & & 16266.40 & .35 \\
\hline $\mathrm{Tl}^{205} \mathrm{I}^{127}$ & $1-$ & $10 \leftarrow 9$ & Ground & & $19 / 2$ & & $17 / 2$ & 16268.26 & 0.10 \\
\hline $\mathrm{Tl}^{205} \mathrm{I}^{127}$ & $1-$ & $10 \leftarrow 9$ & Ground & & $17 / 2$ & & $15 / 2$ & 16268.26 & 0.10 \\
\hline $\mathrm{Tl}^{205} \mathrm{I}^{127}$ & $1-$ & $10 \leftarrow 9$ & Ground & & $15 / 2$ & & $13 / 2$ & 16268.26 & 0.10 \\
\hline $\mathrm{C}^{12} \mathrm{HD}\left(\mathrm{C}^{12} \mathrm{~N}^{14}\right)_{2}$ & 4. 902 & $2,1,1 \leftarrow 2,0,2$ & Ground & & & & & 16268.84 & \\
\hline $\mathrm{Tl}^{205} \mathrm{I}^{127}$ & $1-$ & $10 \leftarrow 9$ & Ground & & $25 / 2$ & & $23 / 2$ & 16270.38 & 0.10 \\
\hline $\mathrm{Tl}^{205} \mathrm{I}^{127}$ & $1-$ & $10 \leftarrow 9$ & Ground & & $23 / 2$ & & $21 / 2$ & 16270.38 & 0.10 \\
\hline $\mathrm{Tl}^{205} \mathrm{I}^{127}$ & $1-$ & $10 \leftarrow 9$ & Ground & & $21 / 2$ & & $19 / 2$ & 16270.38 & 0.10 \\
\hline $\mathrm{HC}^{12} \mathrm{O}^{16} \mathrm{O}^{16} \mathrm{C}^{12} \mathrm{D}_{3}-\mathrm{A}$ & 3. 507 & $3,1,2 \leftarrow 3,0,3$ & Ground & & & & & 16270.80 & .2 \\
\hline $\mathrm{Br}^{81} \mathrm{C}^{12} \mathrm{~N}^{14}$ & 4. 142 & $2 \leftarrow 1$ & Ground & $3 / 2$ & $5 / 2$ & $3 / 2$ & $5 / 2$ & 16273.00 & .1 \\
\hline $\mathrm{C}^{12} \mathrm{H}_{3} \mathrm{C}^{12} \mathrm{O}^{16} \mathrm{~F}^{19}$ & 3- 391 & Not Reported & Ground & & & & & 16273.5 & .2 \\
\hline $\mathrm{Br}^{81} \mathrm{C}^{12} \mathrm{~N}^{14}$ & 4- 142 & $2 \leftarrow 1$ & Ground & $3 / 2$ & $5 / 2$ & $3 / 2$ & $3 / 2$ & 16273.62 & .1 \\
\hline $\mathrm{Br}^{81} \mathrm{C}^{12} \mathrm{~N}^{14}$ & 4. 142 & $2 \leftarrow 1$ & Ground & $3 / 2$ & $3 / 2$ & $3 / 2$ & $1 / 2$ & 16274.38 & .1 \\
\hline $\mathrm{S}^{32}{ }_{*} \mathrm{HC}^{13}: \mathrm{C}^{12} \mathrm{HC}^{12} \mathrm{H}: \mathrm{C}^{12}{ }_{*} \mathrm{H}$ & $4-1167$ & $2,0,2 \leftarrow 1,0,1$ & Ground & & & & & 16275.2 & .05 \\
\hline $\mathrm{HC}^{13} \mathrm{O}^{16} \mathrm{O}^{16} \mathrm{C}^{12} \mathrm{H}_{3}-\mathrm{E}$ & 3- 509 & $2,1,1 \leftarrow 2,0,2$ & Ground & & & & & 16276.50 & .35 \\
\hline $\mathrm{C}^{12} \mathrm{H}_{2}: \mathrm{C}^{12} \mathrm{HBr}^{81}$ & 4. 728 & $2,1,1 \leftarrow 1,1,0$ & Ground & & $5 / 2$ & & $5 / 2$ & 16278.3 & \\
\hline $\mathrm{C}^{12} \mathrm{H}_{2}: \mathrm{C}^{12} \mathrm{HBr}^{81}$ & 4- 728 & Not Reported & Ground & & $5 / 2$ & & $5 / 2$ & 16278.4 & \\
\hline $\mathrm{HC}^{13} \mathrm{O}^{16} \mathrm{O}^{16} \mathrm{C}^{12} \mathrm{H}_{3}-\mathrm{A}$ & 3- 508 & $2,1,1 \leftarrow 2,0,2$ & Ground & & & & & 16282.62 & .35 \\
\hline $\mathrm{C}^{12} \mathrm{H}_{3} \mathrm{C}^{12} \mathrm{O}^{16} \mathrm{~F}^{19}$ & 3- 391 & Not Reported & Ground & & & & & 16285.8 & .2 \\
\hline $\mathrm{H}_{2} \mathrm{~N}^{14} \mathrm{~N}^{14} \mathrm{H}_{2}$ & 3. 51 & Not Reported & & & & & & 16286.4 & \\
\hline $\mathrm{C}^{b} \mathrm{H}_{2}: \mathrm{C}^{b} \mathrm{HBr}^{79}$ & 4- 753 & Not Reported & Ground & & $3 / 2$ & & $1 / 2$ & 16287.6 & \\
\hline $\mathrm{C}^{12} \mathrm{H}_{2}: \mathrm{C}^{12} \mathrm{HBr}^{79}$ & 4. 727 & $2,1,1 \leftarrow 1,1,0$ & Ground & & $3 / 2$ & & $1 / 2$ & 16287.6 & \\
\hline $\mathrm{C}^{b} \mathrm{H}_{2}^{b} \mathrm{CI}^{\mathrm{b}} \mathrm{F}^{\mathrm{b}}$ & 4- 333 & Not Reported & & & & & & 16296.9 & 1. \\
\hline $\mathrm{Br}^{79} \mathrm{C}^{12} \mathrm{~N}^{14}$ & 4- 14.1 & $2 \leftarrow 1$ & Excited & $3 / 2$ & & $3 / 2$ & & 16299.07 & .1 \\
\hline $\mathrm{C}^{12} \mathrm{H}_{2}: \mathrm{C}^{12} \mathrm{HBr}^{81}$ & 4- 728 & $2,1,1 \leftarrow 1,1,0$ & Ground & & $3 / 2$ & & $3 / 2$ & 16299.2 & \\
\hline $\mathrm{C}^{b} \mathrm{H}_{2}: \mathrm{C}^{b} \mathrm{HBr}^{81}$ & 4- 754 & Not Reported & Ground & & $3 / 2$ & & $3 / 2$ & 16299.4 & .2 \\
\hline $\mathrm{C}_{6}^{12} \mathrm{H}_{5} \mathrm{C}^{13} \mathrm{~N}^{14}$ & $4-1293$ & $6,2,5 \leftarrow 5,2,4$ & Ground & & & & & 16307.4 & .2 \\
\hline $\mathrm{C}^{12} \mathrm{H}_{2}: \mathrm{C}^{12} \mathrm{HBr}^{79}$ & 4. 727 & $2,1,1 \leftarrow 1,1,0$ & Excited & & $7 / 2$ & & $5 / 2$ & 16309.1 & \\
\hline
\end{tabular}


Vib. State

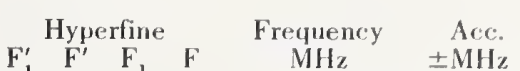

\begin{tabular}{|c|c|c|c|c|c|c|c|c|c|}
\hline $\mathrm{H}_{2} \mathrm{~N}^{14} \mathrm{~N}^{14} \mathrm{H}_{2}$ & 3. 51 & Not Reported & & & & & & 16313.92 & \\
\hline $\mathrm{C}^{12} \mathrm{H}_{3} \mathrm{C}^{12} \mathrm{O}^{16} \mathrm{~F}^{19}$ & 3- 391 & Not Reported & Ground & & & & & 16314.8 & .2 \\
\hline $\mathrm{N}^{14} \mathrm{H}_{3}$ & $4-1771$ & $10,6 \leftarrow 10,6$ & Ground & & & & & 16319.38 & .04 \\
\hline $\mathrm{C}^{12} \mathrm{H}_{2}: \mathrm{C}^{12} \mathrm{HBr}^{79}$ & 4. 727 & $2,1,1 \leftarrow 1,1,0$ & Ground & & $7 / 2$ & & $5 / 2$ & 16322.1 & \\
\hline $\mathrm{C}^{\mathrm{b}} \mathrm{H}_{2}: \mathrm{C}^{\mathrm{b}} \mathrm{HBr}^{79}$ & 4- 753 & Not Reported & Ground & & $7 / 2$ & & $5 / 2$ & 16322.1 & \\
\hline $\mathrm{F}_{2}^{19} \mathrm{O}_{2}^{18}$ & 3- 13 & $3,1,2 \leftarrow 3,0,3$ & Ground & & & & & 16327.46 & .1 \\
\hline $\mathrm{Br}^{81} \mathrm{C}^{12} \mathrm{~N}^{14}$ & 4- 142 & $2 \leftarrow 1$ & Excited & $7 / 2$ & & $5 / 2$ & & 16329.72 & .1 \\
\hline $\mathrm{Br}^{81} \mathrm{C}^{12} \mathrm{~N}^{14}$ & 4. 142 & $2 \leftarrow 1$ & Excited & $5 / 2$ & & $3 / 2$ & & 16329.72 & .1 \\
\hline $\mathrm{C}^{b} \mathrm{H}_{2}: \mathrm{C}^{b} \mathrm{HBr}^{81}$ & 4- 754 & Not Reported & Ground & & $5 / 2$ & & $3 / 2$ & 16331.4 & \\
\hline $\mathrm{C}^{12} \mathrm{H}_{2}: \mathrm{C}^{12} \mathrm{HBr}^{81}$ & 4- 728 & $2,1,1 \leftarrow 1,1,0$ & Ground & & $5 / 2$ & & $3 / 2$ & 16331.4 & \\
\hline $\mathrm{Si}^{28} \mathrm{H}_{3} \mathrm{C}^{12} \mathrm{H}: \mathrm{C}^{12} \mathrm{H}_{2}$ & 3- 611 & $8,1,7 \leftarrow 8,1,8$ & Ground & & & & & 16338.77 & .05 \\
\hline $\mathrm{Si}^{28} \mathrm{H}_{3} \mathrm{C}^{12} \mathrm{H}: \mathrm{C}^{12} \mathrm{H}_{2}$ & 3. 611 & $8,1,7 \leftarrow 8,1,8$ & Ground & & & & & 16339.47 & .05 \\
\hline $\mathrm{C}^{12} \mathrm{H}_{3} \mathrm{Ce}^{74} \mathrm{HD}_{2}$ & 3- 303 & $1,0,1 \leftarrow 0,0,0$ & Ground & & & & & 16341.2 & .10 \\
\hline $\mathrm{C}^{12} \mathrm{H}_{3} \mathrm{~N}^{14} \mathrm{O}_{2}^{16}$ & 3- 171 & Not Reported & Ground & & & & & 16342 . & 5. \\
\hline $\mathrm{D}_{2} \mathrm{O}_{2}^{16}$ & 3. 42 & Not Reported & & & & & & 16344 . & 3. \\
\hline $\mathrm{Br}^{79} \mathrm{C}^{12} \mathrm{~N}^{14}$ & 4. 141 & $2 \leftarrow 1$ & Ground & $3 / 2$ & $5 / 2$ & $3 / 2$ & $5 / 2$ & 16345.38 & .1 \\
\hline $3 \mathrm{C}^{13}-\mathrm{C}_{6}^{12} \mathrm{H}_{5} \mathrm{C}^{12} \mathrm{~N}^{14}$ & 4-1299 & $6,2,5 \leftarrow 5,2,4$ & Ground & & & & & 16346.0 & .2 \\
\hline $\mathrm{Br}^{79} \mathrm{C}^{12} \mathrm{~N}^{14}$ & 4- 141 & $2 \leftarrow 1$ & Ground & $3 / 2$ & $3 / 2$ & $3 / 2$ & $3 / 2$ & 16346.17 & .1 \\
\hline $\mathrm{C}^{12} \mathrm{H}_{2} \mathrm{Cl}^{35} \mathrm{C}^{12} \mathrm{~N}^{14}$ & 4- 651 & $9,2,7 \leftarrow 10,1,10$ & Ground & & & & & 16347.33 & .2 \\
\hline $\mathrm{C}^{12} \mathrm{H}_{2}: \mathrm{C}^{12} \mathrm{HBr}^{79}$ & 4. 727 & $2,1,1 \leftarrow 1,1,0$ & Ground & & & & & 16350.85 & .04 \\
\hline $\mathrm{F}_{2}^{19} \mathrm{O}_{2}^{16}$ & $3-11$ & $1,1,0 \leftarrow 1,0,1$ & Ground & & & & & 16353. & .5 \\
\hline $\mathrm{C}^{12} \mathrm{O}^{16} \mathrm{~F}_{2}^{19}$ & 4- 211 & $9,8,1 \leftarrow 9,8,2$ & Ground & & & & & 16363.41 & .10 \\
\hline $\mathrm{C}^{12} \mathrm{H}_{3} \mathrm{~N}^{14} \mathrm{H}_{2}$ & 3- 261 & Not Reported & Ground & & & & & 16373.56 & \\
\hline $\mathrm{Br}^{81} \mathrm{C}^{12} \mathrm{~N}^{14}$ & 4- 142 & $2 \leftarrow 1$ & Ground & $5 / 2$ & & $3 / 2$ & & 16375.43 & .1 \\
\hline $\mathrm{Br}^{81} \mathrm{C}^{12} \mathrm{~N}^{14}$ & 4- 142 & $2 \leftarrow 1$ & Ground & $7 / 2$ & & $5 / 2$ & & 16375.43 & .1 \\
\hline $\mathrm{C}^{12} \mathrm{H}_{2}: \mathrm{C}^{12} \mathrm{HBr}^{79}$ & 4- 727 & $2,1,1 \leftarrow 1,1,0$ & Ground & & $5 / 2$ & & $5 / 2$ & 16376.7 & \\
\hline $\mathrm{C}^{\mathrm{b}} \mathrm{H}_{2}: \mathrm{C}^{\mathrm{b}} \mathrm{HBr}^{79}$ & 4- 753 & Not Reported & Ground & & $5 / 2$ & & $5 / 2$ & 16376.8 & \\
\hline $\mathrm{H}_{2} \mathrm{~N}^{14} \mathrm{~N}^{14} \mathrm{H}_{2}$ & $3-51$ & Not Reported & & & & & & 16376.94 & \\
\hline $\mathrm{a}-\mathrm{C}^{12} \mathrm{H}_{2} \mathrm{DC}^{12} \mathrm{H}: \mathrm{C}^{12} \mathrm{H}_{2}$ & 3- 742 & $1,0,1 \leftarrow 0,0,0$ & Ground & & & & & 16377.15 & .15 \\
\hline $2 \mathrm{~d} \cdot \mathrm{C}_{6}^{12} \mathrm{H}_{5} \mathrm{C}^{12} \mathrm{~N}^{14}$ & $4-1294$ & $6,2,5 \leftarrow 5,2,4$ & Ground & & & & & 16381.1 & .2 \\
\hline $\mathrm{HDO}_{2}^{16}$ & $3-\quad 43$ & $9, \quad, \leftarrow 9, \quad$, & & & & & & 16382 . & 3. \\
\hline $\mathrm{HC}^{12} \mathrm{O}^{16} \mathrm{O}^{16} \mathrm{H}$ & $3-71$ & $4,1,3 \leftarrow 4,1,4$ & & & & & & 16382.2 & \\
\hline $\mathrm{Br}^{81} \mathrm{C}^{12} \mathrm{~N}^{14}$ & 4- 142 & $2 \leftarrow 1$ & Ground & $1 / 2$ & & $1 / 2$ & & 16387.20 & .1 \\
\hline $\mathrm{C}^{12} \mathrm{H}_{3} \mathrm{Ge}^{72} \mathrm{HD}_{2}$ & 3- 302 & $1,0,1 \leftarrow 0,0,0$ & Ground & & & & & 16388.2 & .10 \\
\hline $\mathrm{DC}^{13} \mathrm{~N}^{14}$ & 4- 294 & $9 \leftarrow 9$ & Excited & & & & & 16389.63 & .1 \\
\hline $\mathrm{C}^{12} \mathrm{H}_{3} \mathrm{O}^{16} \mathrm{H}$ & 3- 211 & $14,, \leftarrow-13$, & Ground & & & & & 16395 . & \\
\hline $\mathrm{C}^{12} \mathrm{H}_{3} \mathrm{O}^{16} \mathrm{H}$ & 3- 211 & Not Reported & Ground & & & & & 16395.8 & 5. \\
\hline $\mathrm{C}^{12} \mathrm{H}_{3} \mathrm{C}^{12} \mathrm{H}_{2} \mathrm{O}^{16} \mathrm{H}$ & 3- 581 & $5,1,4 \leftarrow 5,1,5$ & Ground & & & & & 16399.85 & .01 \\
\hline $\mathrm{C}^{12} \mathrm{H}_{2}: \mathrm{C}^{12} \mathrm{HBr}^{79}$ & 4- 727 & $2,1,1 \leftarrow 1,1,0$ & Ground & & $3 / 2$ & & $3 / 2$ & 16401.8 & \\
\hline $\mathrm{C}^{\mathrm{b}} \mathrm{H}_{2}: \mathrm{C}^{\mathrm{b}} \mathrm{HBr}^{\mathrm{b}}$ & 4- 752 & Not Reported & Ground & & $3 / 2$ & & $3 / 2$ & 16401.8 & \\
\hline $\mathrm{C}^{12} \mathrm{D}_{3} \mathrm{C}^{12} \mathrm{HO}^{16}$ & 3- 474 & $1,0,1 \leftarrow 0,0,0$ & Ground & & & & & 16407.00 & .2 \\
\hline $\mathrm{C}^{12} \mathrm{H}_{3} \mathrm{~N}^{14} \mathrm{O}_{2}^{16}$ & 3- 171 & Not Reported & Ground & & & & & 16407.48 & \\
\hline $\mathrm{C}^{12} \mathrm{H}_{3} \mathrm{~N}^{14} \mathrm{H}_{2}$ & 3- 261 & Not Reported & Ground & & & & & 16410.63 & .04 \\
\hline $\mathrm{C}^{12} \mathrm{H}_{3} \mathrm{~N}^{14} \mathrm{O}_{2}^{16}$ & 3- 171 & Not Reported & Cround & & & & & 16414.84 & \\
\hline $\mathrm{Br}^{81} \mathrm{C}^{12} \mathrm{~N}^{14}$ & 4- 142 & $2 \leftarrow 1$ & Ground & $3 / 2$ & & $5 / 2$ & & 16417.0 & .1 \\
\hline
\end{tabular}




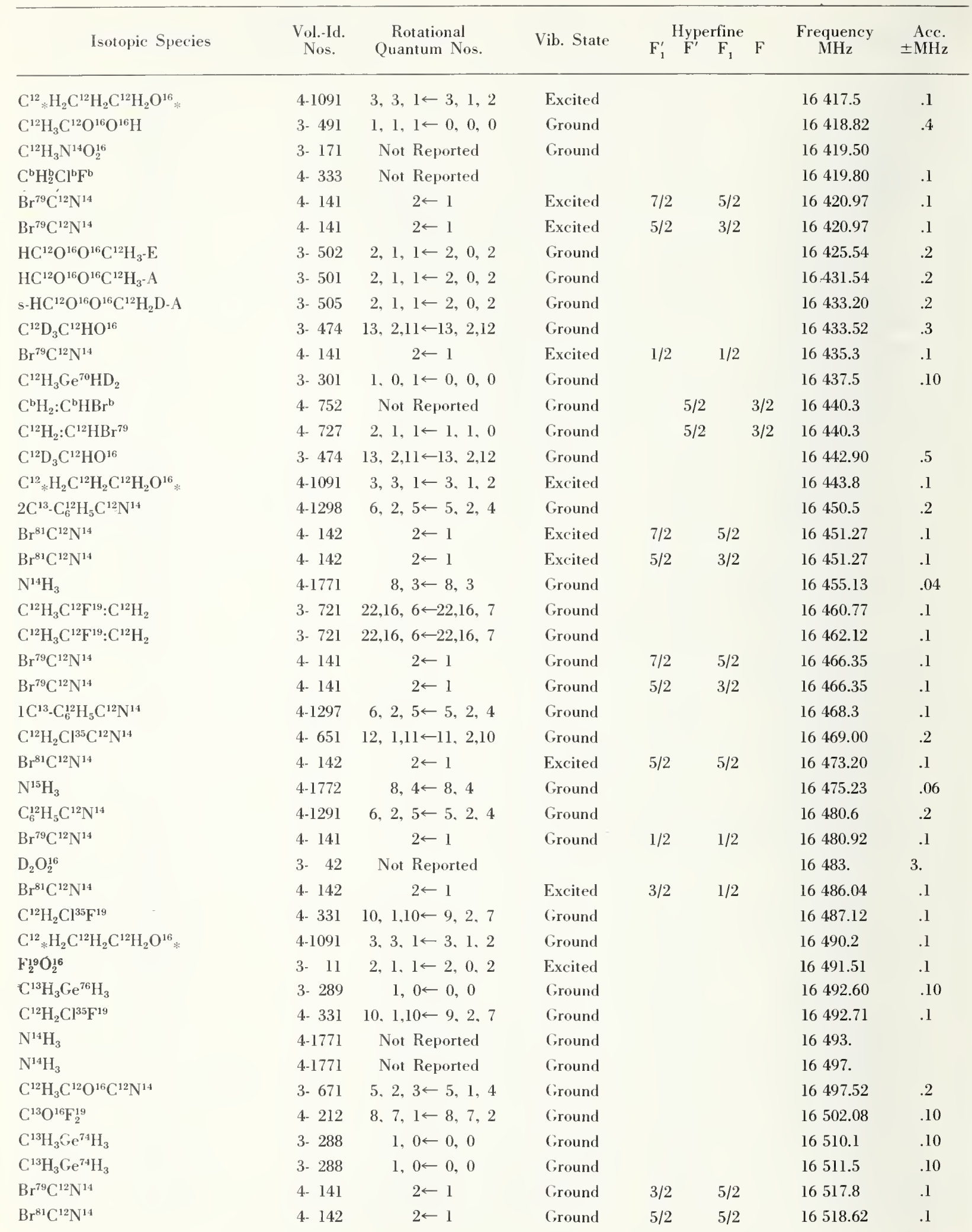


Vol.-Id. Rotational Quantum Nos.
Vib. State
Frequency Ace. $\mathrm{MH}_{z} \pm \mathrm{VH}$

\begin{tabular}{|c|c|c|c|c|c|c|c|}
\hline $\mathrm{Cl}^{35} \mathrm{O}_{2}^{16}$ & $4-1381$ & $14,2,13 \leftarrow 13,3,10$ & Ground & $31 / 2$ & $29 / 2$ & 16522.4 & \\
\hline $\mathrm{C}^{12} \mathrm{H}_{3} \mathrm{As}^{75} \mathrm{~F}_{2}^{19}$ & 3- 81 & $28,23,5 \leftarrow 28,23,6$ & Ground & $55 / 2$ & $55 / 2$ & 16524.58 & .05 \\
\hline $\mathrm{C}^{12} \mathrm{H}_{3} \mathrm{As}^{75} \mathrm{~F}_{2}^{19}$ & 3- 81 & $28,23,5 \leftarrow 28,23,6$ & Ground & $57 / 2$ & $57 / 2$ & 16524.58 & .05 \\
\hline $\mathrm{Si}^{28} \mathrm{D}_{2} \mathrm{~F}_{2}^{19}$ & $4-1603$ & $3,1,2 \leftarrow 3,0,3$ & Ground & & & 16.525 .65 & .10 \\
\hline $\mathrm{DC}^{13}: \mathrm{C}^{12} \mathrm{C}^{12} \mathrm{HO}^{16}$ & 4. 917 & $2,1,2 \leftarrow 1,1,1$ & Ground & & & 16527.51 & .02 \\
\hline $\mathrm{C}^{12} \mathrm{H}_{3} \mathrm{~N}^{14} \mathrm{O}_{2}^{16}$ & 3- 171 & Not Reported & Ground & & & 16527.51 & \\
\hline $\mathrm{a} \cdot \mathrm{C}^{12} \mathrm{H}_{2} \mathrm{DSi}^{28} \mathrm{HF}_{2}^{19}$ & 3- 204 & $2,1,2 \leftarrow 1,1,1$ & Ground & & & 16528.39 & .2 \\
\hline $\mathrm{C}^{12} \mathrm{H}_{3} \mathrm{As}^{75} \mathrm{~F}_{2}^{19}$ & 3- 81 & $28,23,5 \leftarrow 28,23,6$ & Ground & $59 / 2$ & $59 / 2$ & 16529.17 & .05 \\
\hline $\mathrm{C}^{12} \mathrm{H}_{3} \mathrm{As}^{75} \mathrm{~F}_{2}^{19}$ & 3- 81 & $28,23,5 \leftarrow 28,23,6$ & Ground & $53 / 2$ & $53 / 2$ & 16529.17 & .05 \\
\hline $\mathrm{C}^{12} \mathrm{H}_{3} \mathrm{C}^{12} \mathrm{H}: \mathrm{C}^{12}: \mathrm{C}^{12} \mathrm{H}_{2}$ & 3- 931 & $2,1,1 \leftarrow 1,1,0$ & Ground & & & 16529.90 & .03 \\
\hline $\mathrm{Br}^{81} \mathrm{C}^{12} \mathrm{~N}^{14}$ & 4: 142 & $2 \leftarrow 1$ & Ground & $3 / 2$ & $1 / 2$ & 16531.31 & .1 \\
\hline $\mathrm{C}^{12} \mathrm{O}^{18} \mathrm{~F}_{2}^{19}$ & 4. 213 & $1,0,1 \leftarrow 0,0,0$ & Ground & & & 16531.91 & .10 \\
\hline $\mathrm{C}^{12} \mathrm{H}_{3} \mathrm{C}^{12} \mathrm{H}: \mathrm{C}^{12}: \mathrm{C}^{12} \mathrm{H}_{2}$ & 3- 931 & $2,1,1 \leftarrow 1,1,0$ & Ground & & & 16532.29 & .03 \\
\hline $\mathrm{C}^{12} \mathrm{H}_{3} \mathrm{C}^{12} \mathrm{O}^{16} \mathrm{O}^{16} \mathrm{H}$ & 3- 491 & $5,4,1 \leftarrow 5,3,2$ & Ground & & & 16539.43 & .4 \\
\hline $\mathrm{C}^{12} \mathrm{H}_{3} \mathrm{C}^{12} \mathrm{HO}^{16}$ & 3. 471 & Not Reported & & & & 16541.75 & \\
\hline $\mathrm{Cl}^{35} \mathrm{O}_{2}^{16}$ & $4-1381$ & $14,2,13 \leftarrow 13,3,10$ & Ground & $29 / 2$ & $27 / 2$ & 16542.1 & \\
\hline $\mathrm{Br}^{79} \mathrm{C}^{12} \mathrm{~N}^{14}$ & 4- 141 & $2 \leftarrow 1$ & Excited & $5 / 2$ & $3 / 2$ & 16542.45 & .1 \\
\hline $\mathrm{Br}^{79} \mathrm{C}^{12} \mathrm{~N}^{14}$ & 4- 141 & $2 \leftarrow 1$ & Excited & $7 / 2$ & $5 / 2$ & 16542.45 & .1 \\
\hline $4 \mathrm{~d}-\mathrm{C}_{6}^{12} \mathrm{H}_{5} \mathrm{C}^{12} \mathrm{~N}^{14}$ & $4-1296$ & $6,2,4 \leftarrow 5,2,3$ & Ground & & & 16550.2 & .2 \\
\hline $\mathrm{C}^{13} \mathrm{H}_{3} \mathrm{Ge}^{74} \mathrm{H}_{3}$ & 3- 288 & $1,0 \leftarrow 0,0$ & Ground & & & 16550.20 & .10 \\
\hline $\mathrm{C}^{12} \mathrm{H}_{3} \mathrm{C}^{12} \mathrm{HO}^{16}$ & 3- 471 & Not Reported & & & & 16551.01 & \\
\hline $\mathrm{C}^{12} \mathrm{H}_{3} \mathrm{As}^{75} \mathrm{~F}_{2}^{19}$ & 3. 81 & $28,24,5 \leftarrow 28,22,6$ & Ground & $55 / 2$ & $55 / 2$ & 16551.39 & .05 \\
\hline $\mathrm{C}^{12} \mathrm{H}_{3} \mathrm{As}^{75} \mathrm{~F}_{2}^{19}$ & 3- 81 & $28,24,5 \leftarrow 28,22,6$ & Ground & $57 / 2$ & $57 / 2$ & 16551.39 & .05 \\
\hline $\mathrm{C}^{12} \mathrm{H}_{3} \mathrm{As}^{75} \mathrm{~F}_{2}^{19}$ & 3. 81 & $28,24,5 \leftarrow 28,22,6$ & Ground & $53 / 2$ & $53 / 2$ & 16555.31 & .05 \\
\hline $\mathrm{C}^{12} \mathrm{H}_{3} \mathrm{As}^{75} \mathrm{~F}_{2}^{19}$ & $3-81$ & $28,24,5 \leftarrow 28,22,6$ & Ground & $59 / 2$ & $59 / 2$ & 16555.31 & .05 \\
\hline $\mathrm{C}^{12} \mathrm{H}_{3} \mathrm{O}^{16} \mathrm{H}$ & 3- 211 & Not Reported & Ground & & & 16556. & 5. \\
\hline $\mathrm{Br}^{79} \mathrm{C}^{12} \mathrm{~N}^{14}$ & 4- 141 & $2 \leftarrow 1$ & Excited & $1 / 2$ & $1 / 2$ & 16556.67 & .1 \\
\hline $\mathrm{s}-\mathrm{C}^{12} \mathrm{H}_{2} \mathrm{DO}{ }^{16} \mathrm{~N}^{14} \mathrm{O}_{2}^{16}$ & 3- 183 & $2,1,1 \leftarrow 1,1,0$ & Ground & & & 16558.08 & .1 \\
\hline $\mathrm{C}^{12} \mathrm{H}_{3} A \mathrm{~s}^{75} \mathrm{~F}_{2}^{19}$ & 3- 81 & $27,22,5 \leftarrow 27,22,6$ & Ground & $53 / 2$ & $53 / 2$ & 16558.95 & .05 \\
\hline $\mathrm{C}^{12} \mathrm{H}_{3} \mathrm{As}^{75} \mathrm{~F}_{2}^{19}$ & 3- 81 & $27,22,5 \leftarrow 27,22,6$ & Ground & $55 / 2$ & $55 / 2$ & 16558.95 & .05 \\
\hline $\mathrm{C}^{12} \mathrm{H}_{3} \mathrm{~N}^{14} \mathrm{O}_{2}^{16}$ & 3- 171 & Not Reported & Ground & & & 16561.51 & \\
\hline $\mathrm{C}^{12} \mathrm{H}_{3} \mathrm{As}^{75} \mathrm{~F}_{2}^{19}$ & 3- 81 & $27,22,5 \leftarrow 27,22,6$ & Ground & $57 / 2$ & $57 / 2$ & 16563.55 & .05 \\
\hline $\mathrm{C}^{12} \mathrm{H}_{3} \mathrm{As}^{75} \mathrm{~F}_{2}^{19}$ & 3- 81 & $27,22,5 \leftarrow 27,22,6$ & Ground & $51 / 2$ & $51 / 2$ & 16563.55 & .05 \\
\hline $\mathrm{C}^{12} \mathrm{H}_{3} \mathrm{As}^{75} \mathrm{~F}_{2}^{19}$ & 3- 81 & $27,22,5 \leftarrow 27,22,6$ & Ground & $53 / 2$ & $53 / 2$ & 16565.86 & .05 \\
\hline $\mathrm{C}^{12} \mathrm{H}_{3} \mathrm{As}^{75} \mathrm{~F}_{2}^{19}$ & 3- 81 & $27,22,5 \leftarrow 27,22,6$ & Ground & $55 / 2$ & $55 / 2$ & 16565.86 & .05 \\
\hline $\mathrm{Cl}^{35} \mathrm{O}_{2}^{16}$ & $4-1381$ & $14,2,13 \leftarrow 13,3,10$ & Ground & $27 / 2$ & $25 / 2$ & 16566.7 & \\
\hline $\mathrm{C}^{12} \mathrm{H}_{3} \mathrm{As}^{75} \mathrm{~F}_{2}^{19}$ & 3- 81 & $27,22,5 \leftarrow 27,22,6$ & Ground & $57 / 2$ & $57 / 2$ & 16570.36 & .05 \\
\hline $\mathrm{C}^{12} \mathrm{H}_{3} \mathrm{As}^{75} \mathrm{~F}_{2}^{19}$ & 3. 81 & $27,22,5 \leftarrow 27,22.6$ & Ground & $51 / 2$ & $51 / 2$ & 16570.36 & .05 \\
\hline $\mathrm{C}^{12} \mathrm{H}_{3} \mathrm{As}^{75} \mathrm{~F}_{2}^{19}$ & 3- 81 & $27,23,5 \leftarrow 27,21,6$ & Ground & $55 / 2$ & $55 / 2$ & 16574,40 & .05 \\
\hline $\mathrm{C}^{12} \mathrm{H}_{3} \mathrm{As}^{75} \mathrm{~F}_{2}^{19}$ & 3- 81 & $27,23,5 \leftarrow 27.21,6$ & Ground & $53 / 2$ & $53 / 2$ & 16574.40 & .05 \\
\hline $\mathrm{F}_{2}^{19} \mathrm{O}_{2}^{16}$ & 3- 11 & $2,1,1 \leftarrow 2,0,2$ & Ground & & & 16577.38 & .1 \\
\hline $\mathrm{C}^{12} \mathrm{H}_{3} \mathrm{As}^{75} \mathrm{~F}_{2}^{19}$ & 3- 81 & $27,23,5 \leftarrow 27,21,6$ & Ground & $55 / 2$ & $55 / 2$ & 16577.85 & .05 \\
\hline $\mathrm{C}^{12} \mathrm{H}_{3} \mathrm{As}^{75} \mathrm{~F}_{2}^{19}$ & 3- 81 & $27,23,5 \leftarrow 27,21.6$ & Ground & $53 / 2$ & $53 / 2$ & 16577.85 & .05 \\
\hline $\mathrm{C}^{12} \mathrm{H}_{3} \mathrm{As}^{75} \mathrm{~F}_{2}^{19}$ & 3- 81 & $27,23,5 \leftarrow 27.21,6$ & Ground & $57 / 2$ & $57 / 2$ & 16578.40 & .05 \\
\hline $\mathrm{C}^{12} \mathrm{H}_{3} \mathrm{As}^{75} \mathrm{~F}_{2}^{19}$ & 3- 81 & $27,23,5 \leftarrow 27,21,6$ & Ground & $51 / 2$ & $51 / 2$ & 16578.40 & .05 \\
\hline
\end{tabular}




\begin{tabular}{|c|c|c|c|c|c|c|c|}
\hline \multirow{3}{*}{$\begin{aligned} \text { Isotopic Species } \\
\mathrm{C}^{12} \mathrm{H}_{3} A s^{75} \mathrm{~F}_{2}^{19}\end{aligned}$} & \multirow{3}{*}{$\begin{array}{l}\text { Vol.-Id. } \\
\text { Nos. } \\
\text { 3- } 81\end{array}$} & \multirow{3}{*}{$\begin{array}{c}\begin{array}{c}\text { Rotational } \\
\text { Quantum Nos. }\end{array} \\
27,23,5 \leftarrow 27,21,6\end{array}$} & \multirow{3}{*}{$\begin{array}{c}\text { Vib. State } \\
\text { Ground }\end{array}$} & \multicolumn{2}{|c|}{ Hyperfine } & \multirow{3}{*}{$\begin{array}{c}\begin{array}{c}\text { Frequency } \\
\mathrm{MHz}\end{array} \\
16581.88\end{array}$} & \multirow{3}{*}{$\begin{array}{r}\text { Acc. } \\
\pm \mathrm{MHz} \\
.05\end{array}$} \\
\hline & & & & $\mathrm{F}_{1}^{\prime} \quad \mathrm{F}^{\prime}$ & $F_{1} \quad F$ & & \\
\hline & & & & $57 / 2$ & $57 / 2$ & & \\
\hline $\mathrm{C}^{12} \mathrm{H}_{3} \mathrm{As}^{75} \mathrm{~F}_{2}^{19}$ & 3- 81 & $27,23,5 \leftarrow 27,21,6$ & Ground & $51 / 2$ & $51 / 2$ & 16581.88 & .05 \\
\hline $\mathrm{C}^{12} \mathrm{H}_{3} \mathrm{As}^{75} \mathrm{~F}_{2}^{19}$ & $3-\quad 81$ & $26,21,5 \leftarrow 26,21,6$ & Ground & $51 / 2$ & $51 / 2$ & 16589.19 & .05 \\
\hline $\mathrm{C}^{12} \mathrm{H}_{3} A s^{75} \mathrm{~F}_{2}^{19}$ & $3-81$ & $26,21,5 \leftarrow 26,21,6$ & Ground & $53 / 2$ & $53 / 2$ & 16589.19 & .05 \\
\hline $\mathrm{Cl}^{35} \mathrm{O}_{2}^{16}$ & 4-1381 & $14,2,13 \leftarrow 13,3,10$ & Ground & $25 / 2$ & $23 / 2$ & 16592.7 & \\
\hline $\mathrm{Br}^{79} \mathrm{C}^{12} \mathrm{~N}^{14}$ & 4- 141 & $2 \leftarrow 1$ & Excited & $5 / 2$ & $5 / 2$ & 16593.38 & .1 \\
\hline $\mathrm{C}^{12} \mathrm{H}_{3} \mathrm{As}^{75} \mathrm{~F}_{2}^{19}$ & 3. 81 & $26,21,5 \leftarrow 26,21,6$ & Ground & $49 / 2$ & $49 / 2$ & 16593.72 & .05 \\
\hline $\mathrm{C}^{12} \mathrm{H}_{3} \mathrm{As}^{75} \mathrm{~F}_{2}^{19}$ & $3-81$ & $26,21,5 \leftarrow 26,21,6$ & Ground & $55 / 2$ & $55 / 2$ & 16593.72 & .05 \\
\hline $\mathrm{C}^{12} \mathrm{H}_{3} \mathrm{As}^{75} \mathrm{~F}_{2}^{19}$ & $3-81$ & $26,21,5 \leftarrow 26,21,6$ & Ground & $51 / 2$ & $51 / 2$ & 16595.32 & .05 \\
\hline $\mathrm{C}^{12} \mathrm{H}_{3} A \mathrm{~s}^{75} \mathrm{~F}_{2}^{19}$ & 3. 81 & $26,21,5 \leftarrow 26,21,6$ & Ground & $53 / 2$ & $53 / 2$ & 16595.32 & .05 \\
\hline $\mathrm{C}^{12} \mathrm{H}_{3} A \mathrm{~s}^{75} \mathrm{~F}_{2}^{19}$ & $3-81$ & $26,22,5 \leftarrow 26,20,6$ & Ground & $51 / 2$ & $51 / 2$ & 16598.89 & .05 \\
\hline $\mathrm{C}^{12} \mathrm{H}_{3} \mathrm{As}^{75} \mathrm{~F}_{2}^{19}$ & 3- 81 & $26,22,5 \leftarrow 26,20,6$ & Ground & $53 / 2$ & $53 / 2$ & 16598.89 & .05 \\
\hline $\mathrm{C}^{12} \mathrm{H}_{3} \mathrm{As}^{75} \mathrm{~F}_{2}^{19}$ & $3-\quad 81$ & $26,21,5 \leftarrow 26,21,6$ & Ground & $49 / 2$ & $49 / 2$ & 16599.81 & .05 \\
\hline $\mathrm{C}^{12} \mathrm{H}_{3} \mathrm{As}^{75} \mathrm{~F}_{2}^{19}$ & $3-81$ & $26,21,5 \leftarrow 26,21,6$ & Ground & $55 / 2$ & $55 / 2$ & 16599.81 & .05 \\
\hline $\mathrm{C}^{12} \mathrm{H}_{3} \mathrm{As}{ }^{75} \mathrm{~F}_{2}^{19}$ & 3- 81 & $26,22,5 \leftarrow 26,20,6$ & Ground & $51 / 2$ & $51 / 2$ & 16602.22 & .05 \\
\hline $\mathrm{C}^{12} \mathrm{H}_{3} \mathrm{As}^{75} \mathrm{~F}_{2}^{19}$ & $3-81$ & $26,22,5 \leftarrow-26,20,6$ & Ground & $53 / 2$ & $53 / 2$ & 16602.22 & .05 \\
\hline $\mathrm{C}^{12} \mathrm{H}_{3} \mathrm{As}^{75} \mathrm{~F}_{2}^{19}$ & $3-81$ & $26,22,5 \leftarrow 26,20,6$ & Ground & $55 / 2$ & $55 / 2$ & 16602.97 & .05 \\
\hline $\mathrm{C}^{12} \mathrm{H}_{3} \mathrm{As}^{75} \mathrm{~F}_{2}^{19}$ & 3. 81 & $26,22,5 \leftarrow 26,20,6$ & Ground & $49 / 2$ & $49 / 2$ & 16602.97 & .05 \\
\hline $\mathrm{Br}^{81} \mathrm{C}^{12} \mathrm{~N}^{14}$ & 4- 142 & $2 \leftarrow 1$ & Excited & $3 / 2$ & $1 / 2$ & 16605.92 & .1 \\
\hline $\mathrm{C}^{12} \mathrm{H}_{3} \mathrm{As}^{75} \mathrm{~F}_{2}^{19}$ & $3-81$ & $26,22,5 \leftarrow 26,20,6$ & Ground & $55 / 2$ & $55 / 2$ & 16606.36 & .05 \\
\hline $\mathrm{C}^{12} \mathrm{H}_{3} \mathrm{As}^{75} \mathrm{~F}_{2}^{19}$ & $3-81$ & $26,22,5 \leftarrow 26,20,6$ & Ground & $49 / 2$ & $49 / 2$ & 16606.36 & .05 \\
\hline $\mathrm{Br}^{79} \mathrm{C}^{12} \mathrm{~N}^{14}$ & 4. 141 & $2 \leftarrow 1$ & Excited & $3 / 2$ & $1 / 2$ & 16608.6 & .1 \\
\hline $\mathrm{C}_{6}^{12} \mathrm{H}_{5} \mathrm{C}^{12} \mathrm{~N}^{15}$ & 4-1292 & $6,2,4 \leftarrow 5,2,3$ & Ground & & & 16609.9 & .2 \\
\hline $\mathrm{C}^{13} \mathrm{H}_{3} \mathrm{Ge}^{72} \mathrm{H}_{3}$ & 3- 287 & $1,0 \leftarrow 0,0$ & Ground & & & 16610.80 & .10 \\
\hline $\mathrm{D}_{2} \mathrm{O}_{2}^{16}$ & 3. 42 & Not Reported & & & & 16613. & 3. \\
\hline $\mathrm{C}^{12} \mathrm{H}_{3} \mathrm{As}^{75} \mathrm{~F}_{2}^{19}$ & $3-81$ & $25,20,5 \leftarrow 25,20,6$ & Ground & $51 / 2$ & $51 / 2$ & 16615.68 & .05 \\
\hline $\mathrm{C}^{12} \mathrm{H}_{3} \mathrm{As}^{75} \mathrm{~F}_{2}^{19}$ & $3-81$ & $25,20,5 \leftarrow 25,20,6$ & Ground & $49 / 2$ & $49 / 2$ & 16615.92 & .05 \\
\hline $\mathrm{C}_{6}^{12} \mathrm{H}_{5} \mathrm{C}^{12} \mathrm{~N}^{14}$ & 4-1291 & $6,5,2 \leftarrow 5,5,1$ & Ground & & & 16616.4 & .2 \\
\hline $\mathrm{C}_{6}^{12} \mathrm{H}_{5} \mathrm{C}^{12} \mathrm{~N}^{14}$ & 4-1291 & $6,5,1 \leftarrow 5,5,0$ & Ground & & & 16616.4 & .2 \\
\hline $\mathrm{C}^{12} \mathrm{H}_{3} \mathrm{As}^{75} \mathrm{~F}_{2}^{19}$ & $3-81$ & $25,20,5 \leftarrow 25,20,6$ & Ground & $53 / 2$ & $53 / 2$ & 16620.20 & .05 \\
\hline $\mathrm{C}^{12} \mathrm{H}_{3} \mathrm{As}^{75} \mathrm{~F}_{2}^{19}$ & 3- 81 & $25,20,5 \leftarrow 25,20,6$ & Ground & $47 / 2$ & $47 / 2$ & 16620.45 & .05 \\
\hline $\mathrm{C}^{12} \mathrm{H}_{3} \mathrm{As} \mathrm{s}^{75} \mathrm{~F}_{2}^{19}$ & $3-\quad 81$ & $25,20,5 \leftarrow 25,20,6$ & Ground & $51 / 2$ & $51 / 2$ & 16620.96 & .05 \\
\hline $\mathrm{C}^{12} \mathrm{H}_{3} \mathrm{As}^{75} \mathrm{~F}_{2}^{19}$ & 3- 81 & $25,20,5 \leftarrow 25,20,6$ & Ground & $49 / 2$ & $49 / 2$ & 16621.21 & .05 \\
\hline $\mathrm{C}^{12} \mathrm{H}_{3} \mathrm{As}^{75} \mathrm{~F}_{2}^{19}$ & $3-81$ & $25,21,5 \leftarrow 25,19,6$ & Ground & $51 / 2$ & $51 / 2$ & 16621.38 & .05 \\
\hline $\mathrm{C}^{12} \mathrm{H}_{3} \mathrm{As}{ }^{75} \mathrm{~F}_{2}^{19}$ & $3-81$ & $25,21,5 \leftarrow 25,19,6$ & Ground & $49 / 2$ & $49 / 2$ & 16621.61 & .05 \\
\hline $\mathrm{C}^{12}{ }_{*} \mathrm{H}_{2} \mathrm{C}^{12} \mathrm{H}_{2} \mathrm{C}^{12} \mathrm{H}_{2} \mathrm{C}^{12} \mathrm{H}_{2} \mathrm{C}^{12} * \mathrm{O}^{16}$ & 4-1241 & $3,0,3 \leftarrow 2,0,2$ & Ground & & & 16621.8 & \\
\hline $\mathrm{C}^{12} \mathrm{H}_{3} A s^{75} \mathrm{~F}_{2}^{19}$ & 3. 81 & $25,21,5 \leftarrow 25,19,6$ & Ground & $51 / 2$ & $51 / 2$ & 16624.54 & .05 \\
\hline $\mathrm{C}^{12} \mathrm{H}_{3} \mathrm{As}^{75} \mathrm{~F}_{2}^{19}$ & 3. 81 & $25,21,5 \leftarrow 25,19,6$ & Ground & $49 / 2$ & $49 / 2$ & 16624.78 & .05 \\
\hline $\mathrm{C}^{12} \mathrm{H}_{3} \mathrm{As}^{75} \mathrm{~F}_{2}^{19}$ & $3-81$ & $25,21,5 \leftarrow 25,19,6$ & Ground & $53 / 2$ & $53 / 2$ & 16625.44 & .05 \\
\hline $\mathrm{C}^{12} \mathrm{H}_{3} \mathrm{As}^{75} \mathrm{~F}_{2}^{19}$ & $3-81$ & $25,20,5 \leftarrow 25,20,6$ & Ground & $53 / 2$ & $53 / 2$ & 16625.44 & .05 \\
\hline $\mathrm{C}^{12} \mathrm{H}_{3} \mathrm{As}^{75} \mathrm{~F}_{2}^{19}$ & $3-81$ & $25,21,5 \leftarrow 25,19,6$ & Ground & $47 / 2$ & $47 / 2$ & 16625.75 & .05 \\
\hline $\mathrm{C}^{12} \mathrm{H}_{3} A \mathrm{~s}^{75} \mathrm{~F}_{2}^{19}$ & 3- 81 & $25,20,5 \leftarrow 25,20,6$ & Ground & $47 / 2$ & $47 / 2$ & 16625.75 & .05 \\
\hline $\mathrm{C}^{12} \mathrm{O}^{16} \mathrm{~F}_{2}^{19}$ & 4- 211 & $8,7,1 \leftarrow 8,7,2$ & Ground & & & 16628.49 & .10 \\
\hline $\mathrm{C}^{12} \mathrm{H}_{3} \mathrm{As}^{75} \mathrm{~F}_{2}^{19}$ & 3. 81 & $25,21,5 \leftarrow 25,19,6$ & Ground & $53 / 2$ & $53 / 2$ & 16628.81 & .05 \\
\hline $\mathrm{C}^{12} \mathrm{H}_{3} \mathrm{As}^{75} \mathrm{~F}_{2}^{19}$ & 3- 81 & $25,21,5 \leftarrow 25,19,6$ & Ground & $47 / 2$ & $47 / 2$ & 16629.05 & .05 \\
\hline
\end{tabular}




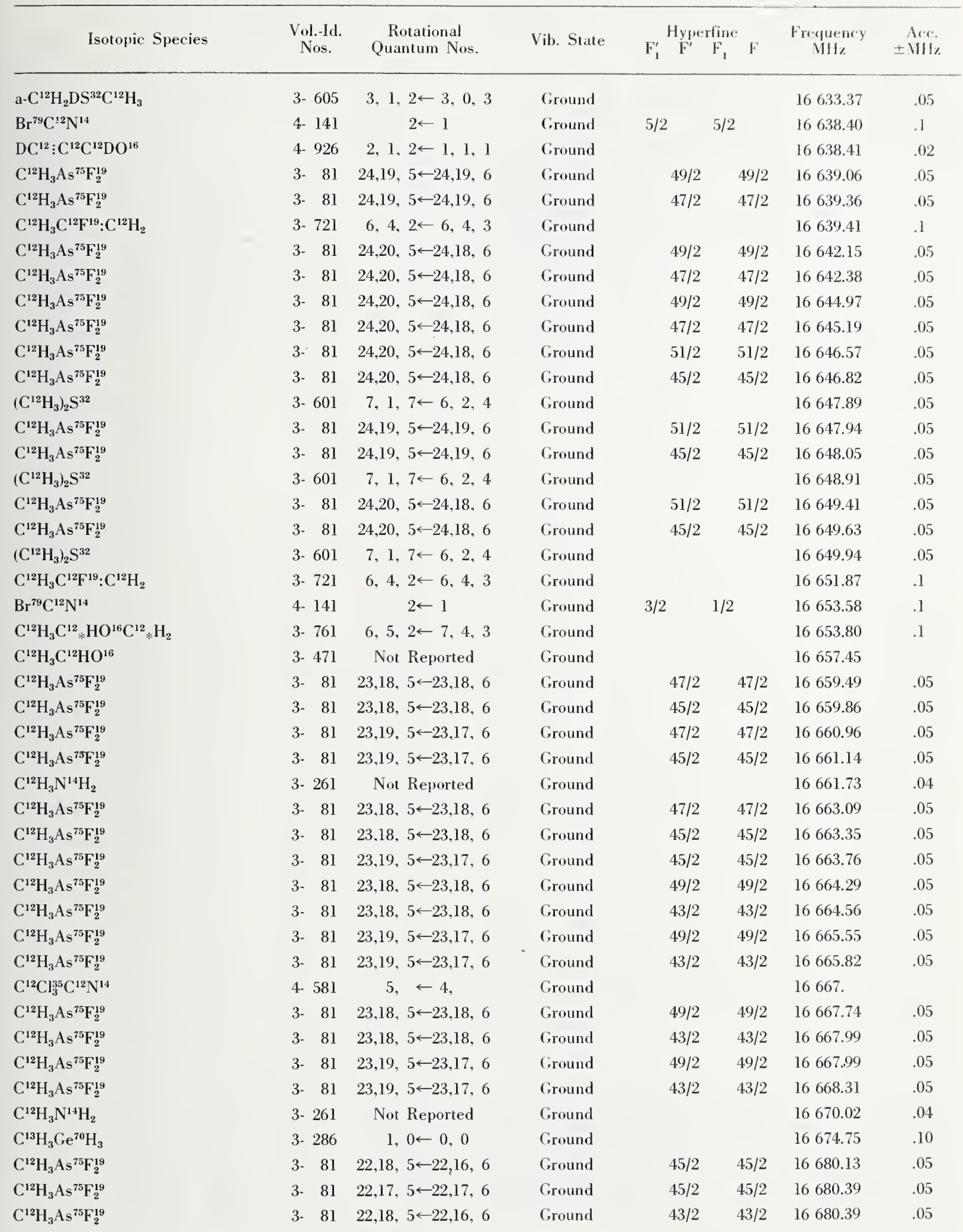




\begin{tabular}{|c|c|c|c|c|c|c|c|}
\hline \multirow{2}{*}{ Isotopic Species } & \multirow{2}{*}{$\begin{array}{l}\text { Vol.-Id. } \\
\text { Nos. }\end{array}$} & \multirow{2}{*}{$\begin{array}{c}\text { Rotational } \\
\text { Quantum Nos. }\end{array}$} & \multirow{2}{*}{ Vib. State } & \multicolumn{2}{|c|}{ Hyperfine } & \multirow{2}{*}{$\begin{array}{l}\text { Frequency } \\
\mathrm{MHz}\end{array}$} & \multirow{2}{*}{$\begin{aligned} & \text { Acc. } \\
\pm & \mathrm{MHz}\end{aligned}$} \\
\hline & & & & $\mathrm{F}_{1}^{\prime} \quad \mathrm{F}^{\prime}$ & $F_{1} \quad F$ & & \\
\hline $\mathrm{C}^{12} \mathrm{H}_{3} \mathrm{As}^{75} \mathrm{~F}_{2}^{19}$ & 3- 81 & $22,17,5 \leftarrow 22,17,6$ & Ground & $43 / 2$ & $43 / 2$ & 16680.63 & .05 \\
\hline $\mathrm{C}^{12} \mathrm{H}_{3} \mathrm{~N}^{14} \mathrm{H}_{2}$ & 3. 261 & $15,5, \leftarrow 16,4$, & Ground & & & 16681.80 & .1 \\
\hline $\mathrm{C}^{12} \mathrm{H}_{3} \mathrm{C}^{12} \mathrm{HO}^{16}$ & 3. 471 & $12,2,10 \leftarrow 12,2,11$ & Ground & & & 16682.08 & .2 \\
\hline $\mathrm{C}^{12} \mathrm{H}_{3} \mathrm{As}^{75} \mathrm{~F}_{2}^{19}$ & 3- 81 & $22,17,5 \leftarrow 22,17,6$ & Ground & $47 / 2$ & $47 / 2$ & 16682.54 & .05 \\
\hline $\mathrm{C}^{12} \mathrm{H}_{3} \mathrm{As}^{75} \mathrm{~F}_{2}^{19}$ & 3- 81 & $22,18,5 \leftarrow 22,16,6$ & Ground & $47 / 2$ & $47 / 2$ & 16682.54 & .05 \\
\hline $\mathrm{C}^{12} \mathrm{H}_{3} \mathrm{As}^{75} \mathrm{~F}_{2}^{19}$ & 3- 81 & $22,18,5 \leftarrow 22,16,6$ & Ground & $41 / 2$ & $41 / 2$ & 16682.87 & .05 \\
\hline $\mathrm{C}^{12} \mathrm{H}_{3} \mathrm{As}^{75} \mathrm{~F}_{2}^{19}$ & 3. 81 & $22,17,5 \leftarrow 22,17,6$ & Ground & $41 / 2$ & $41 / 2$ & 16682.87 & .05 \\
\hline $\mathrm{C}^{12} \mathrm{H}_{3} \mathrm{As}^{75} \mathrm{~F}_{2}^{19}$ & 3- 81 & $22,18,5 \leftarrow 22,16,6$ & Ground & $47 / 2$ & $47 / 2$ & 16684.93 & .05 \\
\hline $\mathrm{C}^{12} \mathrm{H}_{3} \mathrm{As}^{75} \mathrm{~F}_{2}^{19}$ & 3. 81 & $22,17,5 \leftarrow 22,17,6$ & Ground & $47 / 2$ & $47 / 2$ & 16685.19 & .05 \\
\hline $\mathrm{C}^{12} \mathrm{H}_{3} \mathrm{As}^{75} \mathrm{~F}_{2}^{19}$ & 3- 81 & $22,18,5 \leftarrow 22,16,6$ & Ground & $41 / 2$ & $41 / 2$ & 16685.19 & .05 \\
\hline $\mathrm{C}^{12} \mathrm{H}_{3} \mathrm{As}^{75} \mathrm{~F}_{2}^{19}$ & 3- 81 & $22,17.5 \leftarrow 22,17,6$ & Ground & $41 / 2$ & $41 / 2$ & 16685.46 & .05 \\
\hline $\mathrm{C}^{12} \mathrm{H}_{3} \mathrm{~N}^{14} \mathrm{O}_{2}^{16}$ & 3- 171 & Not Reported & Ground & & & 16689. & 5. \\
\hline $\mathrm{Si}^{28} \mathrm{D}_{2} \mathrm{~F}_{2}^{19}$ & $4-1603$ & $3,1,2 \leftarrow 3,0,3$ & Excited & & & 16689.30 & .10 \\
\hline $\mathrm{F}_{2}^{19} \mathrm{O}_{2}^{16}$ & 3. 11 & $2,2,1 \leftarrow 3,1,2$ & Ground & & & 16690.0 & .5 \\
\hline $\mathrm{C}_{6}^{12} \mathrm{H}_{5} \mathrm{C}^{12} \mathrm{~N}^{14}$ & 4-1291 & $6,3,3 \leftarrow 5,3,2$ & Ground & & & 16694.3 & .2 \\
\hline $\mathrm{H}_{2} \mathrm{~N}^{14} \mathrm{~N}^{14} \mathrm{H}_{2}$ & 3- 51 & Not Reported & & & & 16698.20 & \\
\hline $\mathrm{F}_{2}^{19} \mathrm{O}_{2}^{16}$ & 3- 11 & $2,1,1 \leftarrow 2,0,2$ & Ground & & & 16700.24 & .1 \\
\hline $\mathrm{HN}^{14} \mathrm{O}_{3}^{16}$ & 3- 31 & $3,2,1 \leftarrow 3,1,2$ & Ground & & & 16700.74 & \\
\hline $\mathrm{P}^{31} \mathrm{O}^{16} \mathrm{~F}_{2}^{19} \mathrm{Cl}^{35}$ & $4-1391$ & $18,5,13 \leftarrow 18,4,14$ & Ground & $33 / 2$ & $33 / 2$ & 16704.418 & \\
\hline $\mathrm{P}^{331} \mathrm{O}^{16} \mathrm{~F}_{2}^{19} \mathrm{Cl}^{35}$ & $4-1391$ & $18,5,13 \leftarrow 18,4,14$ & Ground & $39 / 2$ & $39 / 2$ & 16704.418 & \\
\hline c- $\mathrm{C}^{12} \mathrm{HF}^{19}: \mathrm{C}^{12} \mathrm{HCl}^{37}$ & 4- 642 & $4,1,3 \leftarrow 4,0,4$ & Ground & $5 / 2$ & $5 / 2$ & 16705.23 & \\
\hline $\mathrm{P}^{31} \mathrm{O}^{16} \mathrm{~F}_{2}^{19} \mathrm{Cl}^{35}$ & 4-1391 & $18,5,13 \leftarrow 18,4,14$ & Ground & $37 / 2$ & $37 / 2$ & 16705.627 & \\
\hline $\mathrm{P}^{31} \mathrm{O}^{16} \mathrm{~F}_{2}^{19} \mathrm{Cl}^{35}$ & $4-1391$ & $18,5,13 \leftarrow 18,4,14$ & Ground & $35 / 2$ & $35 / 2$ & 16705.627 & \\
\hline $\mathrm{C}^{12} \mathrm{H}_{3} \mathrm{~A} \mathrm{~s}^{75} \mathrm{~F}_{2}^{19}$ & 3- 81 & $20,16,5 \leftarrow 20,14,6$ & Ground & $41 / 2$ & $41 / 2$ & 16705.82 & .05 \\
\hline $\mathrm{C}^{12} \mathrm{H}_{3} \mathrm{As}^{75} \mathrm{~F}_{2}^{19}$ & 3- 81 & $20,16,5 \leftarrow 20,14,6$ & Ground & $39 / 2$ & $39 / 2$ & 16706.22 & .05 \\
\hline $\mathrm{C}^{12} \mathrm{H}_{3} \mathrm{As}{ }^{75} \mathrm{~F}_{2}^{19}$ & 3- 81 & $20.15,5 \leftarrow 20,15,6$ & Ground & $41 / 2$ & $41 / 2$ & 16707.06 & .05 \\
\hline c- $\mathrm{C}^{12} \mathrm{HF}^{19}: \mathrm{C}^{12} \mathrm{HCl}^{37}$ & 4- 642 & $4,1,3 \leftarrow 4,0,4$ & Ground & $11 / 2$ & $11 / 2$ & 16707.20 & \\
\hline $\mathrm{C}^{12} \mathrm{H}_{3} \mathrm{As}^{75} \mathrm{~F}_{2}^{19}$ & 3- 81 & $20,15,5 \leftarrow 20,15,6$ & Ground & $39 / 2$ & $39 / 2$ & 16707.45 & .05 \\
\hline $\mathrm{C}^{12} \mathrm{H}_{3} \mathrm{As}^{75} \mathrm{~F}_{2}^{19}$ & 3- .81 & $20,16,5 \leftarrow 20,14,6$ & Ground & $41 / 2$ & $41 / 2$ & 16708.04 & .05 \\
\hline $\mathrm{C}^{12} \mathrm{H}_{3} \mathrm{As}^{75} \mathrm{~F}_{2}^{19}$ & 3- 81 & $20,16,5 \leftarrow 20,14,6$ & Ground & $39 / 2$ & $39 / 2$ & 16708.44 & .05 \\
\hline $\mathrm{C}^{12} \mathrm{H}_{3} \mathrm{As}^{75} \mathrm{~F}_{2}^{19}$ & 3- 81 & $20,15,5 \leftarrow 20,15,6$ & Ground & $41 / 2$ & $41 / 2$ & 16708.90 & .05 \\
\hline $\mathrm{C}^{12} \mathrm{H}_{3} \mathrm{As}^{75} \mathrm{~F}_{2}^{19}$ & 3- 81 & $20,15,5 \leftarrow 20,15,6$ & Ground & $39 / 2$ & $39 / 2$ & 16709.30 & .05 \\
\hline c. $\mathrm{C}^{12} \mathrm{HF}^{19}: \mathrm{C}^{12} \mathrm{HCl}^{37}$ & 4- 642 & $4,1,3 \leftarrow 4,0,4$ & Ground & $7 / 2$ & $7 / 2$ & 16710.90 & \\
\hline $\mathrm{C}^{12} \mathrm{H}_{3} \mathrm{As}^{75} \mathrm{~F}_{2}^{19}$ & 3- 81 & $20,16,5 \leftarrow 20,14,6$ & Ground & $43 / 2$ & $43 / 2$ & 16711.15 & .05 \\
\hline $\mathrm{C}^{12} \mathrm{H}_{3} \mathrm{As}^{75} \mathrm{~F}_{2}^{19}$ & 3- 81 & $20,16,5 \leftarrow 20,14,6$ & Ground & $37 / 2$ & $37 / 2$ & 16711.55 & .05 \\
\hline $\mathrm{C}^{12} \mathrm{H}_{3} \mathrm{~A} \mathrm{~s}^{75} \mathrm{~F}_{2}^{19}$ & 3- 81 & $20,15,5 \leftarrow 20,15,6$ & Ground & $43 / 2$ & $43 / 2$ & 16712.50 & .05 \\
\hline $\mathrm{C}^{12} \mathrm{H}_{3} \mathrm{As}^{75} \mathrm{~F}_{2}^{19}$ & 3- 81 & $20,15,5 \leftarrow 20,15,6$ & Ground & $37 / 2$ & $37 / 2$ & 16712.76 & .05 \\
\hline c. $\mathrm{C}^{12} \mathrm{HF}^{19}: \mathrm{C}^{12} \mathrm{HCl}^{37}$ & 4- 642 & $4,1,3 \leftarrow 4,0,4$ & Ground & $9 / 2$ & $9 / 2$ & 16712.87 & \\
\hline $\mathrm{Br}^{79} \mathrm{C}^{12} \mathrm{~N}^{14}$ & 4- 141 & $2 \leftarrow 1$ & Excited & $5 / 2$ & $5 / 2$ & 16712.9 & .1 \\
\hline $\mathrm{C}^{12} \mathrm{H}_{3} \mathrm{As}^{75} \mathrm{~F}_{2}^{19}$ & $3-\quad 81$ & $20,16,5 \leftarrow 20,14,6$ & Ground & $43 / 2$ & $43 / 2$ & 16713.39 & .05 \\
\hline $\mathrm{C}^{12} \mathrm{H}_{3} \mathrm{As}^{75} \mathrm{~F}_{2}^{19}$ & 3- 81 & $20,16,5 \leftarrow 20,14,6$ & Ground & $37 / 2$ & $37 / 2$ & 16713.73 & .05 \\
\hline $\mathrm{C}^{12} \mathrm{H}_{3} \mathrm{As}^{75} \mathrm{~F}_{2}^{19}$ & 3- 81 & $20,15,5 \leftarrow 20,15,6$ & Ground & $43 / 2$ & $43 / 2$ & 16714.30 & .05 \\
\hline $\mathrm{C}^{12} \mathrm{H}_{3} \mathrm{As}^{75} \mathrm{~F}_{2}^{19}$ & 3- 81 & $20,15,5 \leftarrow 20,15,6$ & Ground & $37 / 2$ & $37 / 2$ & 16714.65 & .05 \\
\hline $\mathrm{C}^{12} \mathrm{H}_{3} \mathrm{As}^{75} \mathrm{~F}_{2}^{19}$ & 3- 81 & $19,15,5 \leftarrow 19,13,6$ & Ground & $39 / 2$ & $39 / 2$ & 16717.31 & .05 \\
\hline $\mathrm{C}^{12} \mathrm{H}_{3} \mathrm{As}^{75} \mathrm{~F}_{2}^{19}$ & 3- 81 & $19,15,5 \leftarrow 19,13,6$ & Cround & $37 / 2$ & $37 / 2$ & 16717.75 & .05 \\
\hline
\end{tabular}




\begin{tabular}{|c|c|c|c|c|c|c|c|}
\hline Isotopic Species & $\begin{array}{l}\text { Vol.-Id. } \\
\text { Nos. }\end{array}$ & $\begin{array}{c}\text { Rotational } \\
\text { Quantum Nos. }\end{array}$ & Vib. State & $\mathrm{F}_{1}^{\prime} \mathrm{F}^{\text {Hyper }}$ & $\underset{\mathrm{F}}{\mathrm{rfine}} \mathrm{F}$ & $\begin{array}{c}\text { Frequency } \\
\mathrm{MHz}_{z}\end{array}$ & $\begin{aligned} & \text { Acr. } \\
\pm & \mathrm{MHz}\end{aligned}$ \\
\hline $\mathrm{C}^{12} \mathrm{H}_{3} \mathrm{As}^{75} \mathrm{~F}_{2}^{19}$ & 3- 81 & $19,14,5 \leftarrow 19,14,6$ & Ground & $39 / 2$ & $39 / 2$ & 16719.06 & .05 \\
\hline $\mathrm{C}^{12} \mathrm{H}_{3} \mathrm{As}^{75} \mathrm{~F}_{2}^{19}$ & 3- 81 & $19,14,5 \leftarrow 19,14,6$ & Ground & $37 / 2$ & $37 / 2$ & 16719.53 & .05 \\
\hline $\mathrm{C}^{12} \mathrm{H}_{3} \mathrm{As}^{75} \mathrm{~F}_{2}^{19}$ & $3-\quad 81$ & $19,15,5 \leftarrow 19,13,6$ & Ground & $39 / 2$ & $39 / 2$ & 16719.53 & .05 \\
\hline $\mathrm{C}^{12} \mathrm{H}_{3} \mathrm{As}^{75} \mathrm{~F}_{2}^{19}$ & 3- 81 & $19,15,5 \leftarrow 19,13,6$ & Ground & $37 / 2$ & $37 / 2$ & 16719.98 & .05 \\
\hline $\mathrm{C}^{12} \mathrm{H}_{3} \mathrm{As}^{75} \mathrm{~F}_{2}^{19}$ & $3-81$ & $19,14,5 \leftarrow 19,14,6$ & Ground & $39 / 2$ & $39 / 2$ & 16720.59 & .05 \\
\hline $\mathrm{C}^{12} \mathrm{H}_{3} \mathrm{As}^{75} \mathrm{~F}_{2}^{19}$ & $3-\quad 81$ & $19,14,5 \leftarrow 19,14,6$ & Ground & $37 / 2$ & $37 / 2$ & 16721.05 & .05 \\
\hline $\mathrm{C}^{12} \mathrm{H}_{3} \mathrm{C}^{12}{ }_{*} \mathrm{HO}^{16} \mathrm{C}^{12}{ }_{*} \mathrm{H}_{2}$ & 3. 761 & $17,8, \leftarrow 16,9$ & Ground & & & 16721.31 & .1 \\
\hline $\mathrm{C}^{12} \mathrm{H}_{3} \mathrm{~N}^{14} \mathrm{O}_{2}^{16}$ & 3. 171 & Not Reported & Ground & & & 16721.81 & \\
\hline $\mathrm{C}^{12} \mathrm{H}_{3} \mathrm{C}^{12}{ }_{*} \mathrm{HO}^{16} \mathrm{C}^{12}{ }_{*} \mathrm{H}_{2}$ & 3- 761 & $17,8, \leftarrow 16,9$ & Ground & & & 16722.23 & .1 \\
\hline $\mathrm{C}^{12} \mathrm{H}_{3} \mathrm{As}^{75} \mathrm{~F}_{2}^{19}$ & $3-81$ & $19,15,5 \leftarrow 19,13,6$ & Ground & $41 / 2$ & $41 / 2$ & 16723.04 & .05 \\
\hline $\mathrm{C}^{12} \mathrm{H}_{3} \mathrm{As}^{75} \mathrm{~F}_{2}^{19}$ & $3-81$ & $19,15,5 \leftarrow 19,13,6$ & Ground & $35 / 2$ & $35 / 2$ & 16723.52 & .05 \\
\hline $\mathrm{C}^{12} \mathrm{H}_{3} \mathrm{As}^{75} \mathrm{~F}_{2}^{19^{\prime}}$ & $3-\quad 81$ & $19,14,5 \leftarrow 19,14,6$ & Ground & $41 / 2$ & $41 / 2$ & 16724.80 & .05 \\
\hline $\mathrm{C}^{12} \mathrm{H}_{3} \mathrm{As}^{75} \mathrm{~F}_{2}^{19}$ & 3- 81 & $19,15,5 \leftarrow 19,13,6$ & Ground & $41 / 2$ & $41 / 2$ & 16725.24 & .05 \\
\hline $\mathrm{C}^{12} \mathrm{H}_{3} \mathrm{As}^{75} \mathrm{~F}_{2}^{19}$ & 3- 81 & $19,14,5 \leftarrow 19,14,6$ & Ground & $35 / 2$ & $35 / 2$ & 16725.24 & .05 \\
\hline $\mathrm{C}^{12} \mathrm{H}_{3} \mathrm{As}^{75} \mathrm{~F}_{2}^{19}$ & 3- 81 & $19,15,5 \leftarrow 19,13,6$ & Ground & $35 / 2$ & $35 / 2$ & 16725.70 & .05 \\
\hline $\mathrm{C}^{12} \mathrm{H}_{3} \mathrm{As}^{75} \mathrm{~F}_{2}^{19}$ & $3-\quad 81$ & $19,14,5 \leftarrow 19,14,6$ & Ground & $41 / 2$ & $41 / 2$ & 16726.29 & .05 \\
\hline $\mathrm{C}^{12} \mathrm{H}_{3} \mathrm{As}^{75} \mathrm{~F}_{2}^{19}$ & 3- 81 & $19,14,5 \leftarrow 19,14,6$ & Ground & $35 / 2$ & $35 / 2$ & 16726.71 & .05 \\
\hline $\mathrm{C}^{12} \mathrm{H}_{3} \mathrm{As}^{75} \mathrm{~F}_{2}^{19}$ & 3- 81 & $18,13,5 \leftarrow 18,13,6$ & Ground & $37 / 2$ & $37 / 2$ & 16727.30 & .05 \\
\hline $\mathrm{C}^{12} \mathrm{H}_{3} \mathrm{As}^{75} \mathrm{~F}_{2}^{19}$ & 3- 81 & $18,14,5 \leftarrow 18,12,6$ & Ground & $37 / 2$ & $37 / 2$ & 16727.30 & .05 \\
\hline $\mathrm{C}^{12} \mathrm{H}_{3} \mathrm{As}^{75} \mathrm{~F}_{2}^{19}$ & $3-81$ & $18,13,5 \leftarrow 18,13,6$ & Ground & $35 / 2$ & $35 / 2$ & 16727.80 & .05 \\
\hline $\mathrm{C}^{12} \mathrm{H}_{3} \mathrm{As}^{75} \mathrm{~F}_{2}^{19}$ & 3- 81 & $18,14,5 \leftarrow 18,12,6$ & Ground & $35 / 2$ & $35 / 2$ & 16727.80 & .05 \\
\hline $\mathrm{Br}^{79} \mathrm{C}^{12} \mathrm{~N}^{14}$ & 4- 141 & $2 \leftarrow 1$ & Excited & $3 / 2$ & $1 / 2$ & 16727.97 & .1 \\
\hline $\mathrm{C}^{12} \mathrm{H}_{3} \mathrm{As}^{75} \mathrm{~F}_{2}^{19}$ & 3- 81 & $18,14,5 \leftarrow 18,12,6$ & Ground & $37 / 2$ & $37 / 2$ & 16730.71 & .05 \\
\hline $\mathrm{C}^{12} \mathrm{H}_{3} \mathrm{As}^{75} \mathrm{~F}_{2}^{19}$ & 3. 81 & $18,13,5 \leftarrow 18,13,6$ & Ground & $37 / 2$ & $37 / 2$ & $16730.7 \cdot 1$ & .05 \\
\hline $\mathrm{C}^{12} \mathrm{H}_{3} \mathrm{As}^{75} \mathrm{~F}_{2}^{19}$ & 3- 81 & $18,13,5 \leftarrow 18,13,6$ & Ground & $35 / 2$ & $35 / 2$ & 16731.22 & .05 \\
\hline $\mathrm{C}^{12} \mathrm{H}_{3} \mathrm{As}^{75} \mathrm{~F}_{2}^{19}$ & 3- 81 & $18,14,5 \leftarrow 18,12,6$ & Ground & $35 / 2$ & $35 / 2$ & 16731.22 & .05 \\
\hline $\mathrm{C}^{12} \mathrm{H}_{3} \mathrm{As}^{75} \mathrm{~F}_{2}^{19}$ & 3- 81 & $18,14,5 \leftarrow 18,12,6$ & Ground & $39 / 2$ & $39 / 2$ & 16733.47 & .05 \\
\hline $\mathrm{C}^{12} \mathrm{H}_{3} \mathrm{As}^{75} \mathrm{~F}_{2}^{19}$ & $3-\quad 81$ & $18,13,5 \leftarrow 18,13,6$ & Ground & $39 / 2$ & $39 / 2$ & 16733.47 & .05 \\
\hline $\mathrm{C}^{12} \mathrm{H}_{3} \mathrm{As}^{75} \mathrm{~F}_{2}^{19}$ & 3- 81 & $18,14,5 \leftarrow 18,12,6$ & Ground & $33 / 2$ & $33 / 2$ & 16733.96 & .05 \\
\hline $\mathrm{C}^{12} \mathrm{H}_{3} \mathrm{As}^{75} \mathrm{~F}_{2}^{19}$ & 3- 81 & $18,13,5 \leftarrow 18,13,6$ & Ground & $33 / 2$ & $33 / 2$ & 16733.96 & .05 \\
\hline $\mathrm{C}^{12} \mathrm{H}_{3} \mathrm{As}^{75} \mathrm{~F}_{2}^{19}$ & 3. 81 & $18,13,5 \leftarrow 18,13,6$ & Ground & $39 / 2$ & $39 / 2$ & 16736.85 & .05 \\
\hline $\mathrm{C}^{12} \mathrm{H}_{3} \mathrm{As}^{75} \mathrm{~F}_{2}^{19}$ & 3- 81 & $18,14,5 \leftarrow 18,12,6$ & Ground & $39 / 2$ & $39 / 2$ & 16736.85 & .05 \\
\hline $\mathrm{C}^{12} \mathrm{H}_{3} \mathrm{As}^{75} \mathrm{~F}_{2}^{19}$ & 3- 81 & $18,14,5 \leftarrow 18,12,6$ & Ground & $33 / 2$ & $33 / 2$ & 16737.38 & .05 \\
\hline $\mathrm{C}^{12} \mathrm{H}_{3} \mathrm{As}^{75} \mathrm{~F}_{2}^{19}$ & $3-\quad 81$ & $18,13,5 \leftarrow 18,13,6$ & Ground & $33 / 2$ & $33 / 2$ & 16737.38 & .05 \\
\hline $\mathrm{C}^{12} \mathrm{H}_{3} \mathrm{As}^{75} \mathrm{~F}_{2}^{19}$ & 3- 81 & $17,12,5 \leftarrow 17,12,6$ & Ground & $35 / 2$ & $35 / 2$ & 16738.29 & .05 \\
\hline $\mathrm{C}^{12} \mathrm{H}_{3} \mathrm{As}^{75} \mathrm{~F}_{2}^{19}$ & 3- 81 & $17,13,5 \leftarrow 17,11,6$ & Ground & $35 / 2$ & $35 / 2$ & 16738.29 & .05 \\
\hline $\mathrm{C}^{12} \mathrm{H}_{3} \mathrm{As}^{75} \mathrm{~F}_{2}^{19}$ & 3- 81 & $17,13,5 \leftarrow 17,11,6$ & Ground & $33 / 2$ & $33 / 2$ & 16738.84 & .05 \\
\hline $\mathrm{C}^{12} \mathrm{H}_{3} \mathrm{As}^{75} \mathrm{~F}_{2}^{19}$ & $3-\quad 81$ & $17,12,5 \leftarrow 17,12,6$ & Ground & $33 / 2$ & $33 / 2$ & 16738.84 & .05 \\
\hline $\mathrm{DC}^{12} \mathrm{~N}^{14}$ & 4- 292 & $9 \leftarrow 9$ & Excited & & & 16739.42 & .03 \\
\hline $\mathrm{C}^{12} \mathrm{H}_{3} \mathrm{As}^{75} \mathrm{~F}_{2}^{19}$ & $3-\quad 81$ & $17,13,5 \leftarrow 17,11,6$ & Ground & $35 / 2$ & $35 / 2$ & 16739.50 & .05 \\
\hline $\mathrm{C}^{12} \mathrm{H}_{3} \mathrm{As}^{75} \mathrm{~F}_{2}^{19}$ & 3- 81 & $17,12,5 \leftarrow 17,12,6$ & Ground & $35 / 2$ & $35 / 2$ & 16739.50 & .05 \\
\hline $\mathrm{C}^{12} \mathrm{H}_{3} \mathrm{As}^{75} \mathrm{~F}_{2}^{19}$ & 3- 81 & $17,13,5 \leftarrow 17,11,6$ & Ground & $33 / 2$ & $33 / 2$ & 16740.00 & .05 \\
\hline $\mathrm{C}^{12} \mathrm{H}_{3} \mathrm{As}^{75} \mathrm{~F}_{2}^{19}$ & $3-\quad 81$ & $17,12,5 \leftarrow 17,12,6$ & Ground & $33 / 2$ & $33 / 2$ & 16740.00 & .05 \\
\hline $\mathrm{C}^{12} \mathrm{H}_{3} \mathrm{C}^{12} \mathrm{O}^{16} \mathrm{O}^{16} \mathrm{H}$ & 3- 491 & $1,1,1 \leftarrow 0,0,0$ & Ground & & & 16741.72 & .4 \\
\hline $\mathrm{C}^{12} * \mathrm{H}_{2} \mathrm{~S}^{32} \mathrm{C}^{12} \mathrm{H}_{2}$ & 4- 851 & $3,1,3 \leftarrow 3,1,2$ & Ground & & & 16742.4 & .2 \\
\hline
\end{tabular}




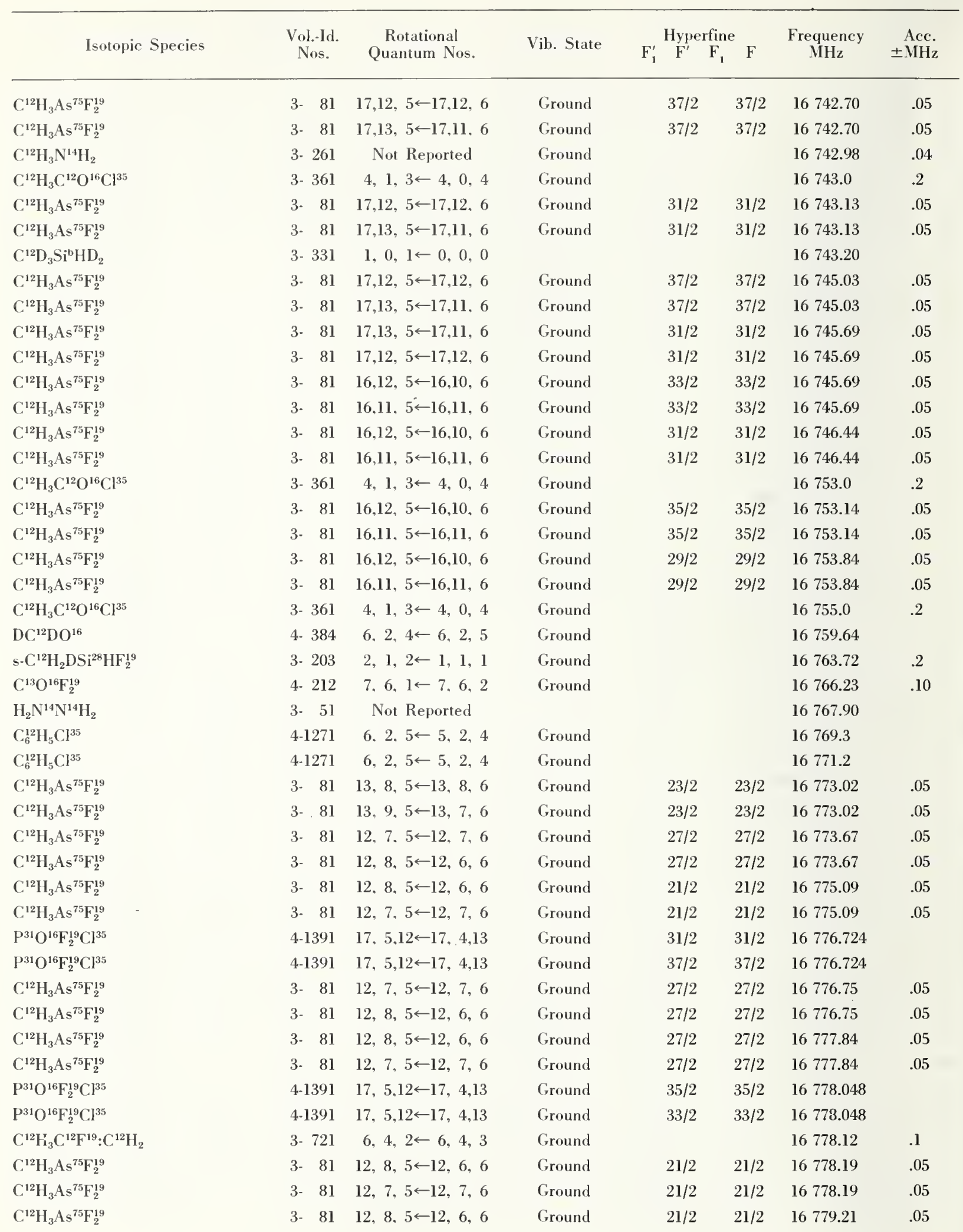




\begin{tabular}{|c|c|c|c|c|c|c|c|}
\hline \multirow{3}{*}{$\frac{\text { Isotopic Species }}{\mathrm{C}^{12} \mathrm{H}_{3} \mathrm{As}^{75} \mathrm{~F}_{2}^{19}}$} & \multirow{3}{*}{$\begin{array}{l}\text { Vol.-Id. } \\
\text { Nos. } \\
\text { 3- } 81\end{array}$} & \multirow{3}{*}{$\begin{array}{c}\text { Rotational } \\
\text { Quantum Nos. } \\
12,7,5 \leftarrow 12,7,6\end{array}$} & \multirow{3}{*}{$\begin{array}{c}\text { Vib. State } \\
\text { Ground }\end{array}$} & \multicolumn{2}{|c|}{ Hyperfine } & \multirow{2}{*}{$\begin{array}{l}\text { Frequeney } \\
\mathrm{MH}_{z}\end{array}$} & \multirow{2}{*}{$\begin{aligned} & \text { Acc. } \\
\pm & \mathrm{MHz}\end{aligned}$} \\
\hline & & & & $F_{1}^{\prime} \quad F^{\prime} \quad F_{1}$ & $\mathbf{F}$ & & \\
\hline & & & & $21 / 2$ & $21 / 2$ & 16779.21 & .05 \\
\hline $\mathrm{C}^{12} \mathrm{H}_{3} \mathrm{As}^{75} \mathrm{~F}_{2}^{19}$ & 3. 81 & $11,7,5 \leftarrow 11,5,6$ & Ground & $25 / 2$ & $25 / 2$ & 16781.11 & .05 \\
\hline $\mathrm{C}^{12} \mathrm{H}_{3} \mathrm{As}^{75} \mathrm{~F}_{2}^{19}$ & 3- 81 & $11,6,5 \leftarrow 11,6,6$ & Ground & $25 / 2$ & $25 / 2$ & 16781.11 & .05 \\
\hline $\mathrm{C}^{12} \mathrm{H}_{3} \mathrm{As}^{75} \mathrm{~F}_{2}^{19}$ & 3. 81 & $11,7,5 \leftarrow 11,5,6$ & Ground & $19 / 2$ & $19 / 2$ & 16782.95 & .05 \\
\hline $\mathrm{C}^{12} \mathrm{H}_{3} \mathrm{As}^{75} \mathrm{~F}_{2}^{19}$ & 3. 81 & $11,6,5 \leftarrow 11,6,6$ & Ground & $19 / 2$ & $19 / 2$ & 16782.95 & .05 \\
\hline $\mathrm{C}^{12} \mathrm{D}_{3} \mathrm{Si}^{\mathrm{b}} \mathrm{HD}_{2}$ & 3- 331 & $1,0,1 \leftarrow 0,0,0$ & & & & 16783.88 & .2 \\
\hline $\mathrm{C}^{12} \mathrm{H}_{3} \mathrm{As}^{75} \mathrm{~F}_{2}^{19}$ & 3- 81 & $10,6,5 \leftarrow 10,4,6$ & Ground & $23 / 2$ & $23 / 2$ & 16785.12 & .05 \\
\hline $\mathrm{C}^{12} \mathrm{H}_{3} \mathrm{As}^{75} \mathrm{~F}_{2}^{19}$ & 3- 81 & $10,5,5 \leftarrow 10,5,6$ & Ground & $23 / 2$ & $23 / 2$ & 16785.12 & .05 \\
\hline $\mathrm{C}^{12} \mathrm{H}_{3} \mathrm{C}^{12}{ }_{*} \mathrm{HO}^{16} \mathrm{C}^{12}{ }_{*} \mathrm{H}_{2}$ & 3- 761 & $6,2,5 \leftarrow 5,3,2$ & Ground & & & 16786.62 & .1 \\
\hline $\mathrm{C}^{12} \mathrm{H}_{3} \mathrm{C}^{12}{ }_{*} \mathrm{HO}^{16} \mathrm{C}^{12}{ }_{*} \mathrm{H}_{2}$ & 3. 761 & $6,2,5 \leftarrow 5,3,2$ & Ground & & & 16786.96 & .1 \\
\hline $\mathrm{C}^{12} \mathrm{H}_{3} \mathrm{As}^{75} \mathrm{~F}_{2}^{19}$ & 3. 81 & $10,6,5 \leftarrow 10,4,6$ & Ground & $17 / 2$ & $17 / 2$ & 16787.50 & .05 \\
\hline $\mathrm{C}^{12} \mathrm{H}_{3} \mathrm{As}^{75} \mathrm{~F}_{2}^{19}$ & 3- 81 & $10,5,5 \leftarrow 10,5,6$ & Ground & $17 / 2$ & $17 / 2$ & 16787.50 & .05 \\
\hline $\mathrm{C}^{12} \mathrm{H}_{3} \mathrm{As}^{75} \mathrm{~F}_{2}^{19}$ & $3-81$ & $9,5,5 \leftarrow 9,3,6$ & Ground & $21 / 2$ & $21 / 2$ & 16788.91 & .05 \\
\hline $\mathrm{C}^{12} \mathrm{H}_{3} \mathrm{As}^{75} \mathrm{~F}_{2}^{19}$ & $3-81$ & $9,4,5 \leftarrow 9,4,6$ & Ground & $21 / 2$ & $21 / 2$ & 16788.91 & .05 \\
\hline $\mathrm{C}^{12} \mathrm{D}_{2}\left(\mathrm{C}^{12} \mathrm{~N}^{14}\right)_{2}$ & 4- 903 & $5,1,4 \leftarrow 5,0,5$ & Ground & & & 16791.92 & \\
\hline $\mathrm{C}^{12} \mathrm{H}_{3} \mathrm{As}^{75} \mathrm{~F}_{2}^{19}$ & 3. 81 & $9,5,5 \leftarrow 9,3,6$ & Ground & $15 / 2$ & $15 / 2$ & 16792.16 & .05 \\
\hline $\mathrm{C}^{12} \mathrm{H}_{3} \mathrm{As}^{75} \mathrm{~F}_{2}^{19}$ & 3- 81 & $9,4,5 \leftarrow 9,4,6$ & Ground & $15 / 2$ & $15 / 2$ & 16792.16 & .05 \\
\hline $\mathrm{C}^{12} \mathrm{H}_{3} \mathrm{~S}^{32} \mathrm{H}$ & 3. 221 & Not Reported & Ground & & & 16796.4 & .1 \\
\hline $\mathrm{DC}^{13}: \mathrm{C}^{12} \mathrm{C}^{12} \mathrm{HO}^{16}$ & 4. 917 & $2,0,2 \leftarrow 1,0,1$ & Ground & & & 16796.64 & .02 \\
\hline $\mathrm{C}^{12} \mathrm{H}_{3} \mathrm{As}^{75} \mathrm{~F}_{2}^{19}$ & 3. 81 & $7,2,5 \leftarrow 7,2,6$ & Ground & $17 / 2$ & $17 / 2$ & 16797.27 & .05 \\
\hline $\mathrm{C}^{12} \mathrm{H}_{3} A \mathrm{~s}^{75} \mathrm{~F}_{2}^{19}$ & 3- 81 & $7,3,5 \leftarrow 7,1,6$ & Ground & $17 / 2$ & $17 / 2$ & 16797.27 & .05 \\
\hline $\mathrm{N}^{14} \mathrm{H}_{3}$ & 4-1771 & $9,5 \leftarrow 9,5$ & Ground & & & 16798.22 & .04 \\
\hline $\mathrm{D}_{2} \mathrm{O}_{2}^{16}$ & $3-\quad 42$ & Not Reported & & & & 16803. & 3. \\
\hline $\mathrm{C}^{12} \mathrm{H}_{3} \mathrm{As}^{75} \mathrm{~F}_{2}^{19}$ & 3- 81 & $7,3,5 \leftarrow 7,1,6$ & Ground & $11 / 2$ & $11 / 2$ & 16803.68 & .05 \\
\hline $\mathrm{C}^{12} \mathrm{H}_{3} \mathrm{As}^{75} \mathrm{~F}_{2}^{19}$ & $3-81$ & $7,2,5 \leftarrow 7,2,6$ & Ground & $11 / 2$ & $11 / 2$ & 16803.68 & .05 \\
\hline $\mathrm{C}^{12} \mathrm{H}_{3} \mathrm{~N}^{14} \mathrm{O}_{2}^{16}$ & 3- 171 & Not Reported & Ground & & & 16807. & 5. \\
\hline $\mathrm{C}^{12} \mathrm{HD}\left(\mathrm{C}^{12} \mathrm{~N}^{14}\right)_{2}$ & 4- 902 & $3,1,2 \leftarrow 3,0,3$ & Ground & & & 16807.95 & \\
\hline $\mathrm{F}_{2}^{19} \mathrm{O}_{2}^{16}$ & 3. $\quad 11$ & $2,1,1 \leftarrow 2,0,2$ & Ground & & & 16822.03 & .1 \\
\hline $\mathrm{C}^{12} \mathrm{H}_{3} \mathrm{~N}^{14} \mathrm{O}_{2}^{16}$ & 3- 171 & Not Reported & Ground & & & 16823. & 5. \\
\hline $\mathrm{C}^{12}{ }_{*} \mathrm{H}_{2} \mathrm{C}^{12} \mathrm{H}_{2} \mathrm{C}^{12}{ }_{*} \mathrm{CI}^{35} \mathrm{CI}^{37}$ & $4-1062$ & $4,1,4 \leftarrow 3,0,3$ & Ground & & & 16826.1 & \\
\hline $\mathrm{s}-\mathrm{C}^{12} \mathrm{H}_{2} \mathrm{DC}^{12} \mathrm{H}: \mathrm{C}^{12} \mathrm{H}_{2}$ & 3- 743 & $1,0,1 \leftarrow 0,0,0$ & Ground & & & 16832.90 & .15 \\
\hline $\mathrm{P}^{31} \mathrm{O}^{16} \mathrm{~F}_{2}^{19} \mathrm{Cl}^{35}$ & 4-1391 & $16,5,11 \leftarrow 16,4,12$ & Ground & $29 / 2$ & $29 / 2$ & 16833.360 & \\
\hline $\mathrm{P}^{31} \mathrm{O}^{16} \mathrm{~F}_{2}^{19} \mathrm{Cl}^{35}$ & 4-1391 & $18,5,14 \leftarrow 18,4,15$ & Ground & $33 / 2$ & $33 / 2$ & 16833.536 & \\
\hline $\mathrm{P}^{31} \mathrm{O}^{16} \mathrm{~F}_{2}^{19} \mathrm{Cl}^{35}$ & 4-1391 & $18,5,14 \leftarrow 18,4,15$ & Ground & $39 / 2$ & $39 / 2$ & 16833.536 & \\
\hline $\mathrm{P}^{31} \mathrm{O}^{16} \mathrm{~F}_{2}^{19} \mathrm{Cl}^{35}$ & 4-1391 & $18,5,14 \leftarrow 18,4,15$ & Ground & $35 / 2$ & $35 / 2$ & 16834.744 & \\
\hline $\mathrm{P}^{31} \mathrm{O}^{16} \mathrm{~F}_{2}^{19} \mathrm{Cl}^{35}$ & 4-1391 & $18,5,14 \leftarrow 18,4,15$ & Ground & $37 / 2$ & $37 / 2$ & 16834.835 & \\
\hline $\mathrm{P}^{31} \mathrm{O}^{16} \mathrm{~F}_{2}^{19} \mathrm{Cl}^{35}$ & 4-1391 & $16,5,11 \leftarrow 16,4,12$ & Ground & $31 / 2$ & $31 / 2$ & 16834.835 & \\
\hline $\mathrm{P}^{31} \mathrm{O}^{16} \mathrm{~F}_{2}^{19} \mathrm{Cl}^{35}$ & 4-1391 & $16,5,11 \leftarrow 16,4,12$ & Ground & $33 / 2$ & $33 / 2$ & 16834.975 & \\
\hline $\mathrm{N}^{14} \mathrm{H}_{3}$ & 4-1771 & $7,1 \leftarrow 7,1$ & Ground & & & 16840.95 & .04 \\
\hline $\mathrm{N}^{14} \mathrm{H}_{3}$ & $4-1771$ & $7,1 \leftarrow 7,1$ & Ground & & & 16841.16 & .04 \\
\hline $4 \mathrm{C}^{13} \cdot \mathrm{C}_{6}^{12} \mathrm{H}_{5} \mathrm{C}^{12} \mathrm{~N}^{14}$ & $4-1301$ & $6,2,4 \leftarrow 5,2,3$ & Ground & & & 16843.6 & .2 \\
\hline $3 d-\mathrm{C}_{6}^{12} \mathrm{H}_{5} \mathrm{C}^{12} \mathrm{~N}^{14}$ & 4-1295 & $6,2,4 \leftarrow 5,2,3$ & Ground & & & 16859.0 & .2 \\
\hline c. $\mathrm{C}^{12} \mathrm{HF}^{19}: \mathrm{C}^{12} \mathrm{HCI}^{35}$ & 4- 641 & $4,1,3 \leftarrow 4,0,4$ & Ground & $5 / 2$ & $5 / 2$ & 16860.48 & \\
\hline $\mathrm{P}^{31} \mathrm{O}^{16} \mathrm{~F}_{2}^{19} \mathrm{Cl}^{35}$ & 4-1391 & $17,5,13 \leftarrow 17,4,14$ & Ground & $37 / 2$ & $37 / 2$ & 16860.600 & \\
\hline $\mathrm{P}^{31} \mathrm{O}^{16} \mathrm{~F}_{2}^{19} \mathrm{Cl}^{35}$ & 4-1391 & $17,5,13 \leftarrow 17,4,14$ & Ground & $31 / 2$ & $31 / 2$ & 16860.600 & \\
\hline
\end{tabular}




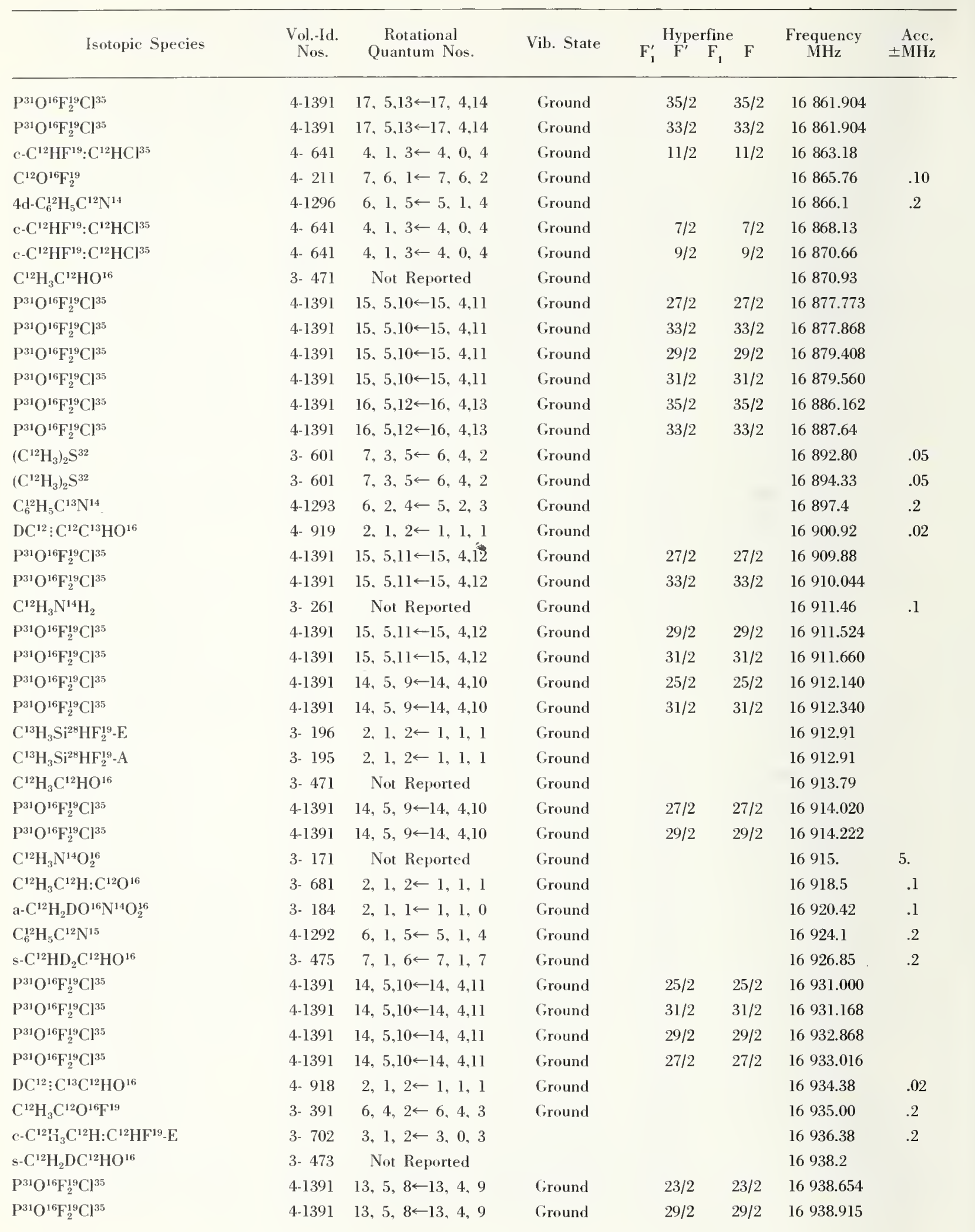




\begin{tabular}{|c|c|c|c|c|c|c|c|}
\hline Isotopic Species & $\begin{array}{c}\text { Vol.-Id. } \\
\text { Nos. }\end{array}$ & $\begin{array}{c}\text { Rotational } \\
\text { Quantum Nos. }\end{array}$ & Vib. State & $\mathrm{F}_{1}^{\prime} \mathrm{F}^{\prime} \quad \mathrm{F}_{1}$ & $\mathrm{~F}$ & $\begin{array}{l}\text { Frequency } \\
\text { MHz. }\end{array}$ & $\begin{aligned} & \text { Acce. } \\
& \pm . \mathrm{MH}_{\mathrm{z}}\end{aligned}$ \\
\hline $\mathrm{P}^{31} \mathrm{O}^{16} \mathrm{~F}_{2}^{19} \mathrm{Cl}^{35}$ & 4-1391 & $13,5,8 \leftarrow 13,4,9$ & Ground & $25 / 2$ & $25 / 2$ & 16940.860 & \\
\hline $\mathrm{P}^{31} \mathrm{O}^{16} \mathrm{~F}_{2}^{19} \mathrm{C}^{35}$ & 4-1391 & $13,5,8 \leftarrow 13,4,9$ & Ground & $27 / 2$ & $27 / 2$ & 16941.040 & \\
\hline $\mathrm{C}^{12} \mathrm{H}_{3} \mathrm{O}^{16} \mathrm{H}$ & 3- 211 & $30,2, \leftarrow 30,1$, & Ground & & & 16941.6 & .1 \\
\hline $\mathrm{F}_{2}^{19} \mathrm{O}_{2}^{16}$ & $3-\quad 11$ & $2,1,1 \leftarrow 2,0,2$ & Ground & & & 16944.86 & .1 \\
\hline c- $\mathrm{C}^{12} \mathrm{H}_{3} \mathrm{C}^{12} \mathrm{H}: \mathrm{C}^{12} \mathrm{HF}^{19}-\mathrm{A}$ & 3- 701 & $3,1,2 \leftarrow 3,0,3$ & & & & 16945.20 & .2 \\
\hline $\mathrm{C}_{6}^{12} \mathrm{H}_{5} \mathrm{O}^{16} \mathrm{H}$ & $3-1051$ & $11,4,7 \leftarrow 11,3,8$ & Ground & & & 16945.3 & \\
\hline $\mathrm{C}^{12} \mathrm{H}_{3} \mathrm{~N}^{14} \mathrm{H}_{2}$ & 3- 261 & $17,4, \leftarrow 16,5$, & Ground & & & 16947.65 & .1 \\
\hline $\mathrm{C}^{12} \mathrm{H}_{3} \mathrm{~N}^{14} \mathrm{O}_{2}^{16}$ & 3- 171 & Not Reported & Ground & & & 16948. & 5. \\
\hline $\mathrm{P}^{31} \mathrm{O}^{16} \mathrm{~F}_{2}^{19} \mathrm{Cl}^{35}$ & 4-1391 & $13,5,9 \longleftarrow 13,4,10$ & Ground & $23 / 2$ & $23 / 2$ & 16949.266 & \\
\hline $\mathrm{P}^{31} \mathrm{O}^{16} \mathrm{~F}_{2}^{19} \mathrm{Cl}^{35}$ & 4-1391 & $13,5,9 \leftarrow 13,4,10$ & Ground & $29 / 2$ & $29 / 2$ & 16949.451 & \\
\hline $\mathrm{F}_{2}^{19} \mathrm{O}^{16} \mathrm{O}^{18}$ & 3- 12 & $3,1,2 \leftarrow 3,0,3$ & Ground & & & 16950.37 & .1 \\
\hline $\mathrm{P}^{31} \mathrm{O}^{16} \mathrm{~F}_{2}^{19} \mathrm{Cl}^{35}$ & 4-1391 & $13,5,9 \leftarrow 13,4,10$ & Ground & $25 / 2$ & $25 / 2$ & 16951.413 & \\
\hline $\mathrm{P}^{31} \mathrm{O}^{16} \mathrm{~F}_{2}^{19} \mathrm{Cl} l^{35}$ & 4-1391 & $13,5,9 \leftarrow 13,4,10$ & Ground & $27 / 2$ & $27 / 2$ & 16951.602 & \\
\hline $\mathrm{C}^{12} \mathrm{H}_{3} \mathrm{Si}^{28} \mathrm{DF}_{2}^{19}-\mathrm{A}$ & 3- 197 & Not Reported & Ground & & & 16952.9 & \\
\hline $\mathrm{s}-\mathrm{C}^{12} \mathrm{HD}_{2} \mathrm{C}^{12} \mathrm{HO}^{16}$ & 3- 475 & $1,0,1 \leftarrow 0,0,0$ & Ground & & & 16953.90 & .2 \\
\hline $\mathrm{C}_{6}^{12} \mathrm{H}_{5} \mathrm{Cl}^{35}$ & 4-1271 & $6,3,4 \leftarrow 5,3,3$ & Ground & & & 16954.9 & \\
\hline $\mathrm{C}^{12} \mathrm{H}_{3} \mathrm{C}^{12} \mathrm{H}: \mathrm{C}^{12} \mathrm{O}^{16}$ & 3- 681 & $2,1,2 \leftarrow 1,1,1$ & Ground & & & 16955.5 & .1 \\
\hline $\mathrm{P}^{31} \mathrm{O}^{16} \mathrm{~F}_{2}^{19} \mathrm{Cl}^{35}$ & 4-1391 & $12,5,7 \leftarrow 12,4,8$ & Ground & $27 / 2$ & $27 / 2$ & 16959.161 & \\
\hline $\mathrm{P}^{31} \mathrm{O}^{16} \mathrm{~F}_{2}^{19} \mathrm{Cl}^{35}$ & 4-1391 & $12,5,7 \leftarrow 12,4,8$ & Ground & $21 / 2$ & $21 / 2$ & 16959.161 & \\
\hline $\mathrm{C}_{6}^{12} \mathrm{H}_{5} \mathrm{Cl}^{35}$ & 4-1271 & $6,3,4 \leftarrow 5,3,3$ & Ground & & & 16959.3 & \\
\hline $\mathrm{HC}^{12} \mathrm{O}^{16} \mathrm{~N}^{14} \mathrm{H}_{2}$ & 3- 151 & $6,2,5 \leftarrow 7,1,6$ & Ground & 5 & 6 & 16960.96 & .1 \\
\hline $\mathrm{HC}^{12} \mathrm{O}^{16} \mathrm{~N}^{14} \mathrm{H}_{2}$ & 3- 151 & $6,2,5 \leftarrow 7,1,6$ & Ground & 6 & 7 & 16960.96 & .1 \\
\hline $\mathrm{HC}^{12} \mathrm{O}^{16} \mathrm{~N}^{14} \mathrm{H}_{2}$ & 3- 151 & $6,2,5 \leftarrow 7,1,6$ & Ground & 7 & 8 & 16960.96 & .1 \\
\hline $\mathrm{P}^{31} \mathrm{O}^{16} \mathrm{~F}_{2}^{19} \mathrm{Cl}^{35}$ & 4-1391 & $12,5,7 \leftarrow 12,4,8$ & Ground & $23 / 2$ & $23 / 2$ & 16961.692 & \\
\hline $\mathrm{P}^{31} \mathrm{O}^{16} \mathrm{~F}_{2}^{19} \mathrm{Cl}^{35}$ & 4-1391 & $12,5,7 \leftarrow 12,4,8$ & Ground & $25 / 2$ & $25 / 2$ & 16961.692 & \\
\hline $\mathrm{P}^{31} \mathrm{O}^{16} \mathrm{~F}_{2}^{19} \mathrm{Cl} \mathrm{l}^{35}$ & 4-1391 & $12,5,8 \leftarrow 12,4,9$ & Ground & $21 / 2$ & $21 / 2$ & 16964.803 & \\
\hline $\mathrm{P}^{31} \mathrm{O}^{16} \mathrm{~F}_{2}^{19} \mathrm{Cl}^{35}$ & 4-1391 & $12,5,8 \leftarrow 12,4,9$ & Ground & $27 / 2$ & $27 / 2$ & 16964.803 & \\
\hline $\mathrm{P}^{31} \mathrm{O}^{16} \mathrm{~F}_{2}^{19} \mathrm{Cl}^{35}$ & 4-1391 & $12,5,8 \leftarrow 12,4,9$ & Ground & $25 / 2$ & $25 / 2$ & 16967.329 & \\
\hline $\mathrm{P}^{31} \mathrm{O}^{16} \mathrm{~F}_{2}^{19} \mathrm{Cl}^{35}$ & 4-1391 & $12,5,8 \leftarrow 12,4,9$ & Ground & $23 / 2$ & $23 / 2$ & 16967.329 & \\
\hline $3 \mathrm{C}^{13}-\mathrm{C}_{6}^{12} \mathrm{H}_{5} \mathrm{C}^{12} \mathrm{~N}^{14}$ & $4-1299$ & $6,2,4 \leftarrow 5,2,3$ & Ground & & & 16970.1 & .1 \\
\hline $\mathrm{S}^{32} \mathrm{O}^{16} \mathrm{~F}_{2}^{19}$ & 4-1621 & $1,1,0 \leftarrow 0,0,0$ & Ground & & & 16971.79 & .1 \\
\hline $\mathrm{C}^{12} \mathrm{H}_{3} \mathrm{C}^{12} \mathrm{O}^{16} \mathrm{~F}^{19}$ & 3- 391 & $6,4,2 \leftarrow 6,4,3$ & Ground & & & 16972.60 & .2 \\
\hline $\mathrm{P}^{31} \mathrm{O}^{16} \mathrm{~F}_{2}^{19} \mathrm{Cl}^{35}$ & 4-1391 & $11,5,6 \leftarrow 11,4,7$ & Ground & $19 / 2$ & $19 / 2$ & 16974.173 & \\
\hline $\mathrm{P}^{31} \mathrm{O}^{16} \mathrm{~F}_{2}^{19} \mathrm{Cl}^{35}$ & 4-1391 & $11,5,6 \leftarrow 11,4,7$ & Ground & $25 / 2$ & $25 / 2$ & 16974.578 & \\
\hline $\mathrm{C}^{12} \mathrm{H}_{3} \mathrm{C}^{12} \mathrm{H}_{2} \mathrm{I}^{127}$ & 3- 571 & $3,1,3 \leftarrow 2,1,2$ & Ground & $5 / 2$ & $3 / 2$ & 16976.8 & \\
\hline $\mathrm{P}^{31} \mathrm{O}^{16} \mathrm{~F}_{2}^{19} \mathrm{Cl}^{35}$ & 4-1391 & $11,5,6 \leftarrow 11,4,7$ & Ground & $21 / 2$ & $21 / 2$ & 16977.300 & \\
\hline $\mathrm{P}^{31} \mathrm{O}^{16} \mathrm{~F}_{2}^{19} \mathrm{Cl}^{35}$ & 4-1391 & $11,5,6 \leftarrow 11,4,7$ & Ground & $23 / 2$ & $23 / 2$ & 16977.300 & \\
\hline $\mathrm{P}^{31} \mathrm{O}^{16} \mathrm{~F}_{2}^{19} \mathrm{Cl}^{35}$ & 4-1391 & $11,5,7 \leftarrow 11,4,8$ & Ground & $23 / 2$ & $23 / 2$ & 16977.300 & \\
\hline $\mathrm{P}^{31} \mathrm{O}^{16} \mathrm{~F}_{2}^{19} \mathrm{Cl}^{35}$ & 4-1391 & $11,5,7 \leftarrow 11,4,8$ & Ground & $21 / 2$ & $21 / 2$ & $16977.3 \theta 0$ & \\
\hline $\mathrm{P}^{31} \mathrm{O}^{16} \mathrm{~F}_{2}^{19} \mathrm{Cl}^{35}$ & 4-1391 & $11,5,7 \leftarrow 11,4,8$ & Cround & $25 / 2$ & $25 / 2$ & 16980.100 & \\
\hline $\mathrm{P}^{31} \mathrm{O}^{16} \mathrm{~F}_{2}^{19} \mathrm{Cl}^{35}$ & 4-1391 & $11,5,7 \leftarrow 11,4,8$ & Ground & $19 / 2$ & $19 / 2$ & 16980.100 & \\
\hline $\mathrm{S}^{32} \mathrm{O}^{16} \mathrm{~F}_{2}^{19}$ & 4-1621 & $6,4,2 \leftarrow 6,4,3$ & Ground & & & 16980.58 & .1 \\
\hline $\mathrm{H}_{2} \mathrm{C}^{12}: \mathrm{C}^{12} \mathrm{O}^{16}$ & 4- 711 & $9,1,8 \leftarrow 9,1,9$ & Ground & & & 16980.97 & \\
\hline $\mathrm{C}^{12} \mathrm{H}_{3} \mathrm{C}^{12} \mathrm{~F}^{19}: \mathrm{C}^{12} \mathrm{H}_{2}$ & 3- 721 & $5,5,0 \leftarrow 5,4,1$ & Ground & & & 16984.60 & .1 \\
\hline $\mathrm{P}^{31} \mathrm{O}^{16} \mathrm{~F}_{2}^{19} \mathrm{Cl}^{35}$ & 4-1391 & $10,5,5 \leftarrow 10,4,6$ & Ground & $17 / 2$ & $17 / 2$ & 16985.587 & \\
\hline
\end{tabular}




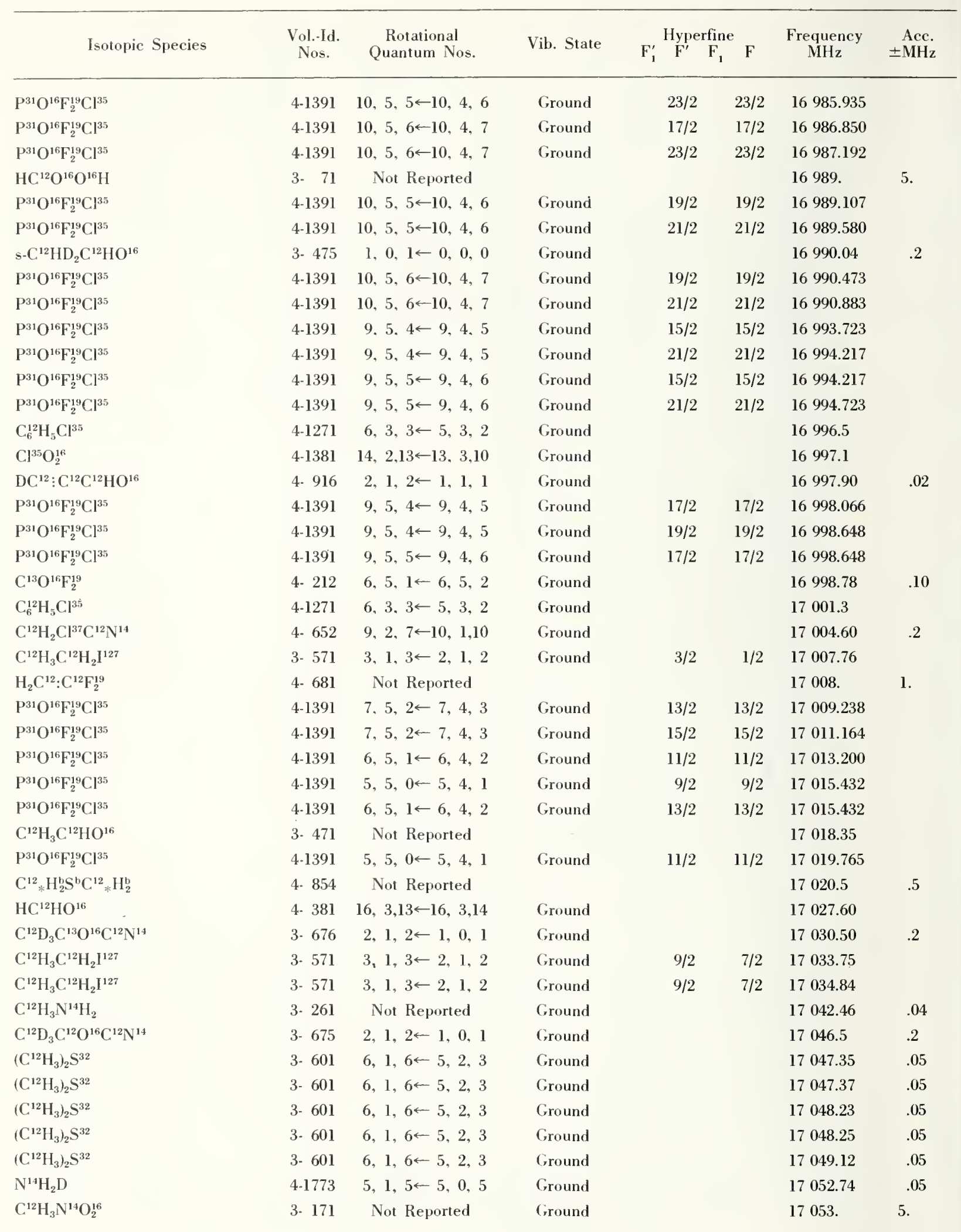




\begin{tabular}{|c|c|c|c|c|c|c|c|c|}
\hline Isotopic Species & $\begin{array}{l}\text { Vol.-Id. } \\
\text { Nos. }\end{array}$ & $\begin{array}{c}\text { Rotational } \\
\text { Quantum Nos. }\end{array}$ & Vib. State & $\mathrm{F}_{1}^{\prime}$ & $\begin{array}{c}\text { Hyperfine } \\
\mathrm{F}^{\prime} \quad \mathrm{F}_{1}\end{array}$ & F & $\begin{array}{c}\text { Frequency } \\
\text { MH\% }\end{array}$ & $\begin{aligned} & \text { Ares } \\
& \pm \text { MII }\end{aligned}$ \\
\hline $\mathrm{s}-\mathrm{C}^{12} \mathrm{HD}_{2} \mathrm{C}^{12} \mathrm{HO}^{16}$ & 3- 475 & $1,0,1 \leftarrow 0,0,0$ & Ground & & & & 17056.65 & .3 \\
\hline $\mathrm{C}_{6}^{12} \mathrm{H}_{5} \mathrm{O}^{16} \mathrm{H}$ & 3-1051 & $11,4,7 \leftarrow 11,3,8$ & Ground & & & & 17056.8 & \\
\hline $\mathrm{DC}^{13}: \mathrm{C}^{12} \mathrm{C}^{12} \mathrm{HO}^{16}$ & 4- 917 & $2,1,1 \leftarrow 1,1,0$ & Ground & & & & 17068.70 & .02 \\
\hline $\mathrm{C}^{12} \mathrm{H}_{3} \mathrm{C}^{12} \mathrm{H}_{2} \mathrm{I}^{127}$ & 3- 571 & $3,0,3 \leftarrow 2,0,2$ & Ground & & $9 / 2$ & $9 / 2$ & 17070.40 & .0 .5 \\
\hline $\mathrm{H}_{2} \mathrm{~N}^{14} \mathrm{~N}^{14} \mathrm{H}_{2}$ & $3-51$ & Not Reported & & & & & 17071.6 & \\
\hline $\mathrm{H}_{2} \mathrm{~N}^{14} \mathrm{~N}^{14} \mathrm{H}_{2}$ & $3-51$ & $3,0 \leftarrow 2,1$ & Ground & & 4 & 4 & 17072.48 & .05 \\
\hline $\mathrm{H}_{2} \mathrm{~N}^{14} \mathrm{~N}^{14} \mathrm{H}_{2}$ & $3-\quad 51$ & $3,0 \leftarrow 2,1$ & Ground & & 4 & 3 & 17073.08 & .0 .5 \\
\hline $\mathrm{H}_{2} \mathrm{~N}^{14} \mathrm{~N}^{14} \mathrm{H}_{2}$ & 3. 51 & $3,0 \leftarrow 2,1$ & Ground & & 5 & 4 & 17073.60 & .05 \\
\hline$\left(\mathrm{C}^{12} \mathrm{H}_{3}\right)_{2} \mathrm{~S}^{32}$ & 3- 601 & $5,2,3 \leftarrow 4,3,2$ & Ground & & & & 17073.67 & .05 \\
\hline $\mathrm{H}_{2} \mathrm{~N}^{14} \mathrm{~N}^{14} \mathrm{H}_{2}$ & 3- 51 & $3,0 \leftarrow 2,1$ & Ground & & 3 & 2 & 17074.14 & .05 \\
\hline $\mathrm{H}_{2} \mathrm{~N}^{14} \mathrm{~N}^{14} \mathrm{H}_{2}$ & $3-51$ & $3,0 \leftarrow 2,1$ & Ground & & 1 & 1 & 17074.48 & .05 \\
\hline $\mathrm{C}^{12} \mathrm{O}^{16} \mathrm{~F}_{2}^{19}$ & 4- 211 & $6,5,1 \leftarrow 6,5,2$ & Ground & & & & 17074.52 & .10 \\
\hline$\left(\mathrm{C}^{12} \mathrm{H}_{3}\right)_{2} \mathrm{~S}^{32}$ & 3- 601 & $5,2,3 \leftarrow 4,3,2$ & Ground & & & & 17074.70 & .05 \\
\hline $\mathrm{H}_{2} \mathrm{~N}^{14} \mathrm{~N}^{14} \mathrm{H}_{2}$ & $3-\quad 51$ & $3,0 \leftarrow 2,1$ & Ground & & 3 & 3 & 17075.10 & .05 \\
\hline $2 \mathrm{~d} \cdot \mathrm{C}_{6}^{12} \mathrm{H}_{5} \mathrm{C}^{12} \mathrm{~N}^{14}$ & 4-1294 & $6,2,4 \leftarrow 5,2,3$ & Ground & & & & 17075.4 & .2 \\
\hline$\left(\mathrm{C}^{12} \mathrm{H}_{3}\right)_{2} \mathrm{~S}^{32}$ & 3- 601 & $5,2,3 \leftarrow 4,3,2$ & Ground & & & & 17075.45 & .05 \\
\hline $\mathrm{N}^{\mathrm{b}} \mathrm{O}_{2}^{\mathrm{b}} \mathrm{Cl}^{\mathrm{b}}$ & $4-1463$ & Not Reported & & & & & 17075.74 & \\
\hline $\mathrm{H}_{2} \mathrm{~N}^{14} \mathrm{~N}^{14} \mathrm{H}_{2}$ & $3-\quad 51$ & $3,0 \leftarrow 2,1$ & Ground & & 3 & 2 & 17075.84 & .05 \\
\hline$\left(\mathrm{C}^{12} \mathrm{H}_{3}\right)_{2} \mathrm{~S}^{32}$ & 3- 601 & $5,2,3 \leftarrow 4,3,2$ & Ground & & & & 17075.97 & .05 \\
\hline $\mathrm{N}^{\mathrm{b}} \mathrm{O}_{2}^{\mathrm{b}} \mathrm{Cl}{ }^{\mathrm{b}}$ & 4-1463 & Not Reported & & & & & 17077.00 & \\
\hline $\mathrm{H}_{2} \mathrm{~N}^{14} \mathrm{~N}^{14} \mathrm{H}_{2}$ & 3. 51 & Not Reported & & & & & 17077.2 & \\
\hline $\mathrm{H}_{2} \mathrm{~N}^{14} \mathrm{~N}^{14} \mathrm{H}_{2}$ & 3- 51 & $3,0 \leftarrow 2,1$ & Ground & & 4 & 4 & 17078.11 & .05 \\
\hline $\mathrm{H}_{2} \mathrm{~N}^{14} \mathrm{~N}^{14} \mathrm{H}_{2}$ & $3-\quad 51$ & $3,0 \leftarrow 2,1$ & Ground & & 4 & 3 & 17078.78 & .05 \\
\hline $\mathrm{H}_{2} \mathrm{~N}^{14} \mathrm{~N}^{14} \mathrm{H}_{2}$ & $3-\quad 51$ & $3,0 \leftarrow 2,1$ & Ground & & 5 & 4 & 17079.35 & .05 \\
\hline $\mathrm{H}_{2} \mathrm{~N}^{14} \mathrm{~N}^{14} \mathrm{H}_{2}$ & $3-\quad 51$ & $3,0 \leftarrow 2,1$ & Ground & & 3 & 2 & 17079.81 & .05 \\
\hline $\mathrm{H}_{2} \mathrm{~N}^{14} \mathrm{~N}^{14} \mathrm{H}_{2}$ & 3- 51 & $3,0 \leftarrow 2,1$ & Ground & & 1 & 1 & 17080.10 & .05 \\
\hline $\mathrm{H}_{2} \mathrm{~N}^{14} \mathrm{~N}^{14} \mathrm{H}_{2}$ & $3-51$ & $3,0 \leftarrow 2,1$ & Ground & & 3 & 3 & 17080.85 & .05 \\
\hline $1 \mathrm{C}^{13}-\mathrm{C}_{6}^{12} \mathrm{H}_{5} \mathrm{C}^{12} \mathrm{~N}^{14}$ & 4-1297 & $6,2,4 \leftarrow 5,2,3$ & Ground & & & & 17081.3 & .2 \\
\hline $\mathrm{H}_{2} \mathrm{~N}^{14} \mathrm{~N}^{14} \mathrm{H}_{2}$ & 3- 51 & $3,0 \leftarrow 2,1$ & Ground & & 3 & 2 & 17081.33 & .05 \\
\hline $\mathrm{Na}^{23} \mathrm{Br}^{79}$ & $1-$ & $2 \leftarrow 1$ & Excited & & $3 / 2$ & $1 / 2$ & 17082.5 & .8 \\
\hline $\mathrm{Na}^{23} \mathrm{Br}^{79}$ & $1-$ & $2 \leftarrow 1$ & Excited & & $5 / 2$ & $5 / 2$ & 17082.5 & .8 \\
\hline $\mathrm{H}_{2} \mathrm{~N}^{14} \mathrm{~N}^{14} \mathrm{H}_{2}$ & $3-\quad 51$ & $3,0 \leftarrow 2,1$ & Ground & & & & 17086.3 & .05 \\
\hline $\mathrm{F}_{2}^{19} \mathrm{O}^{16} \mathrm{O}^{18}$ & $3-\quad 12$ & $3,1,2 \leftarrow 3,0,3$ & Ground & & & & 17089.0 & .5 \\
\hline $2 \mathrm{C}^{13}-\mathrm{C}_{6}^{12} \mathrm{H}_{5} \mathrm{C}^{12} \mathrm{~N}^{14}$ & 4-1298 & $6,2,4 \leftarrow 5,2,3$ & Ground & & & & 17090.5 & .1 \\
\hline $\mathrm{C}^{12} \mathrm{H}_{3} \mathrm{C}^{12} \mathrm{O}^{16} \mathrm{Br}^{81}$ & 3. 352 & $2,1,2 \leftarrow 1,0,1$ & Ground & & $3 / 2$ & $3 / 2$ & 17090.78 & .15 \\
\hline $\mathrm{H}_{2} \mathrm{~N}^{14} \mathrm{~N}^{14} \mathrm{H}_{2}$ & $3-\quad 51$ & Not Reported & & & & & 17092.35 & \\
\hline $\mathrm{t}-\mathrm{HDC}^{12} * \mathrm{O}^{16} \mathrm{C}^{12}{ }_{*} \mathrm{HD}$ & 4- 844 & $2,2,0 \leftarrow 2,1,1$ & Ground & & & & 17092.43 & .05 \\
\hline $\mathrm{H}_{2} \mathrm{~N}^{14} \mathrm{~N}^{14} \mathrm{H}_{2}$ & 3- 51 & $3,0 \leftarrow 2,1$ & Ground & & & & 17092.7 & \\
\hline $\mathrm{C}_{6}^{12} \mathrm{H}_{5} \mathrm{C}^{12} \mathrm{~N}^{14}$ & 4-1291 & $6,2,4 \leftarrow 5,2,3$ & Ground & & & & 17095.8 & .2 \\
\hline $\mathrm{C}^{12} \mathrm{H}_{3} \mathrm{C}^{12} \mathrm{H}_{2} \mathrm{I}^{127}$ & 3. 571 & $3,1,3 \leftarrow 2,1,2$ & Ground & & $11 / 2$ & $9 / 2$ & 17096.08 & \\
\hline $\mathrm{N}^{15} \mathrm{H}_{3}$ & 4-1772 & $7,3 \leftarrow 7,3$ & Ground & & & & 17097.38 & .06 \\
\hline $\mathrm{H}_{2} \mathrm{~N}^{14} \mathrm{~N}^{14} \mathrm{H}_{2}$ & 3- 51 & Not Reported & & & & & 17103.84 & \\
\hline $\mathrm{H}_{2} \mathrm{~N}^{14} \mathrm{~N}^{14} \mathrm{H}_{2}$ & 3- 51 & $3,0 \leftarrow 2,1$ & Ground & & & & 17104.1 & \\
\hline $\mathrm{H}_{2} \mathrm{~N}^{14} \mathrm{~N}^{14} \mathrm{H}_{2}$ & 3- 51 & Not Reported & & & & & 17105.42 & \\
\hline $\mathrm{C}^{12} \mathrm{H}_{3} \mathrm{~N}^{14} \mathrm{H}_{2}$ & $3-261$ & Not Reported & Ground & & & & 17108.99 & .04 \\
\hline
\end{tabular}




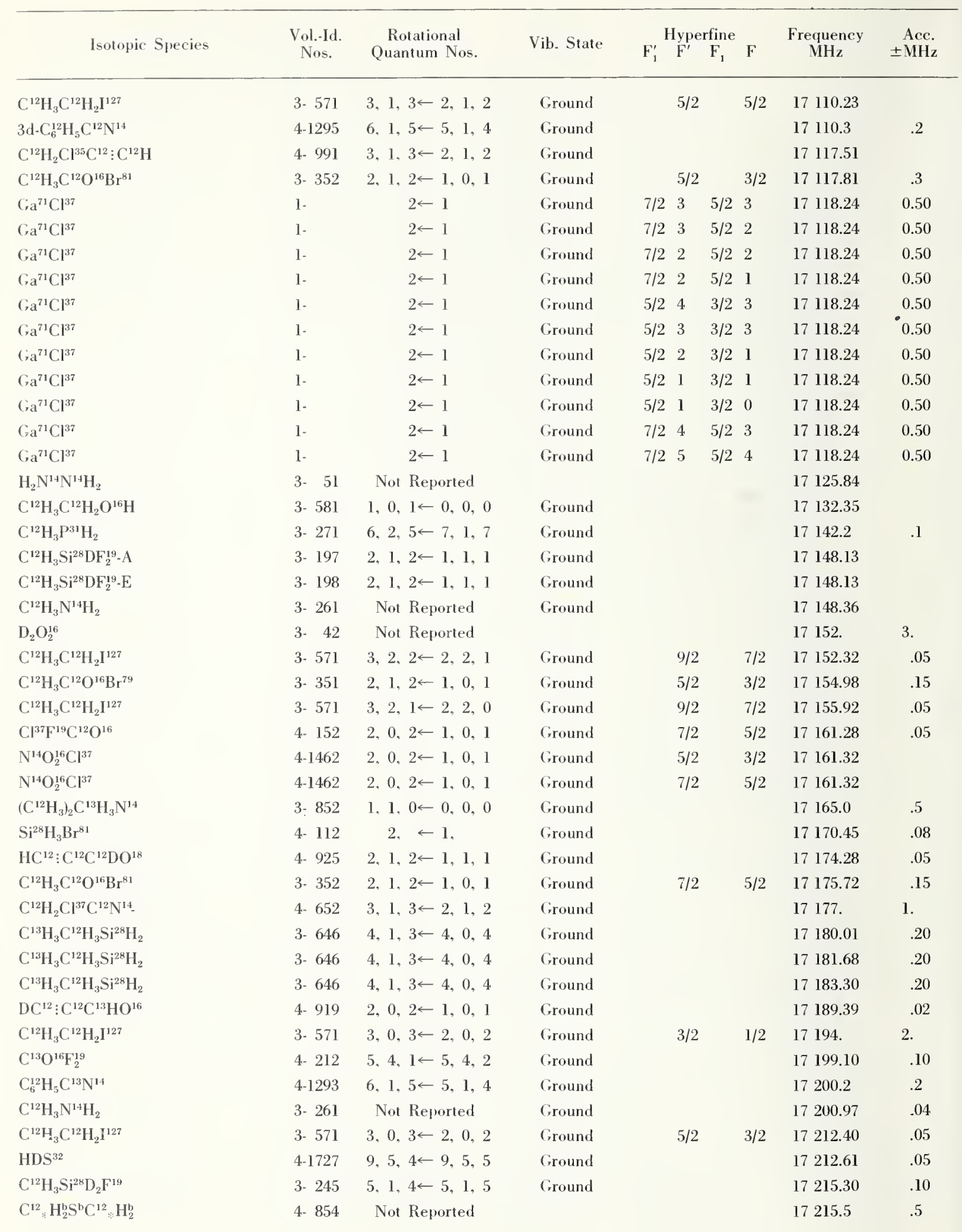




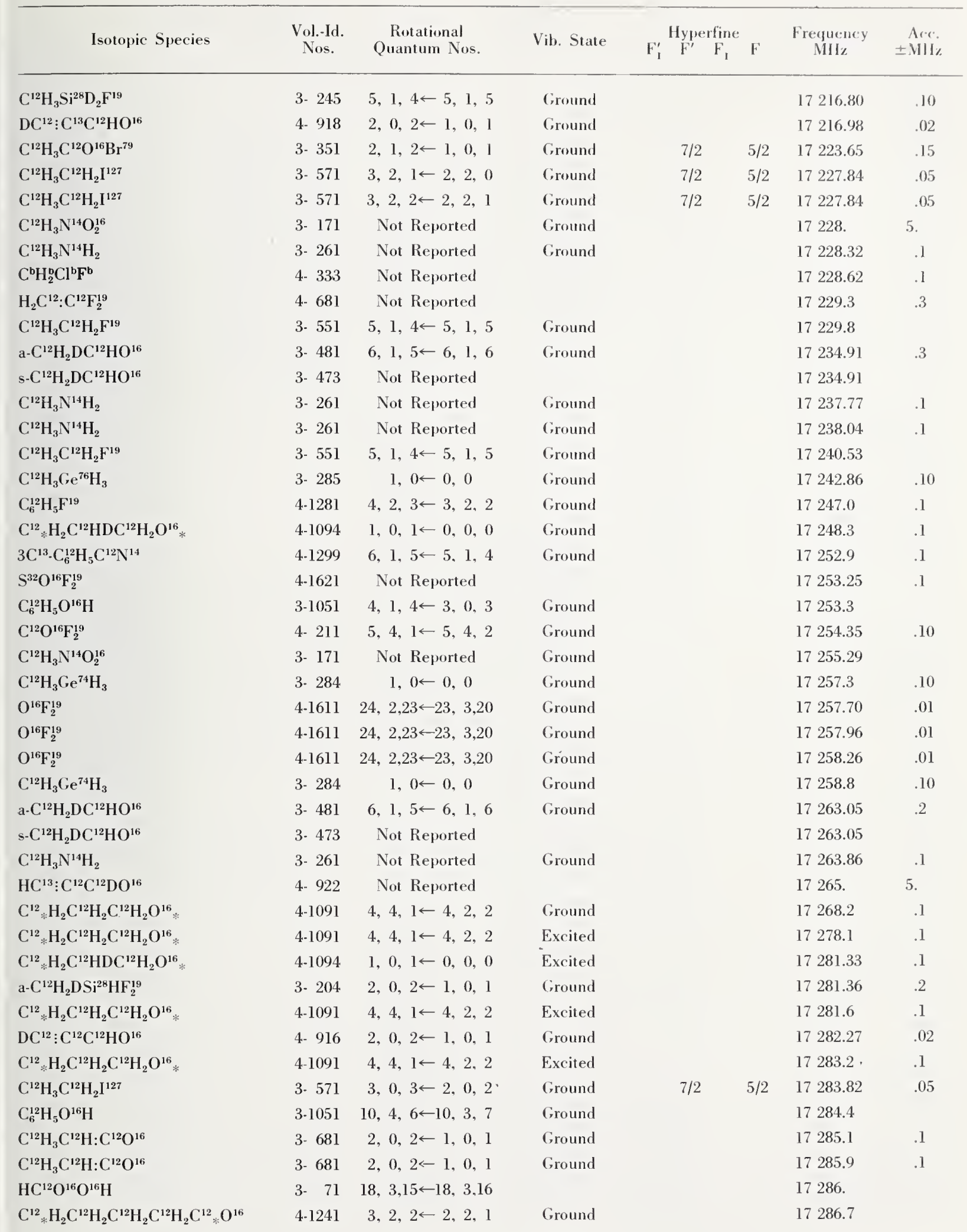




\begin{tabular}{|c|c|c|c|c|c|c|c|c|c|}
\hline Isotopic Species & $\begin{array}{l}\text { Vol.-Id. } \\
\text { Nos. }\end{array}$ & $\begin{array}{c}\text { Rotational } \\
\text { Quantum Nos. }\end{array}$ & Vib. State & $\mathrm{F}_{1}^{\prime}$ & $\begin{array}{l}\text { Нype } \\
\mathrm{F}^{\prime}\end{array}$ & rfine & $F$ & $\begin{array}{c}\text { Frequency } \\
\mathrm{MHz}\end{array}$ & $\begin{aligned} & \text { Acc. } \\
\pm & \mathrm{MHz}\end{aligned}$ \\
\hline $\mathrm{Si}^{28} \mathrm{H}_{3} \mathrm{Br}^{79}$ & 4- 111 & $2, \leftarrow 1$, & Ground & & & & & 17287.30 & .08 \\
\hline $\mathrm{Ga}^{69} \mathrm{Cl}^{37}$ & 1 . & $2 \leftarrow 1$ & Ground & $7 / 2$ & 3 & $5 / 2$ & 3 & 17289.15 & 0.50 \\
\hline $\mathrm{Cra}^{69} \mathrm{Cl}^{37}$ & 1 . & $2 \leftarrow 1$ & Ground & $7 / 2$ & 4 & $5 / 2$ & 3 & 17289.15 & 0.50 \\
\hline $\mathrm{Ga}^{69} \mathrm{Cl}^{37}$ & $1-$ & $2 \leftarrow 1$ & Ground & $7 / 2$ & 5 & $5 / 2$ & 4 & 17289.15 & 0.50 \\
\hline $\mathrm{Ga}^{69} \mathrm{Cl}^{37}$ & 1 - & $2 \leftarrow 1$ & Ground & $5 / 2$ & 4 & $3 / 2$ & 3 & 17289.15 & 0.50 \\
\hline $\mathrm{Ga}^{69} \mathrm{Cl}^{37}$ & 1. & $2 \leftarrow 1$ & Ground & $7 / 2$ & 2 & $5 / 2$ & 1 & 17289.15 & 0.50 \\
\hline $\mathrm{Ga}^{69} \mathrm{Cl}^{37}$ & 1 - & $2 \leftarrow 1$ & Ground & $7 / 2$ & 2 & $5 / 2$ & 2 & 17289.15 & 0.50 \\
\hline $\mathrm{Ga}^{69} \mathrm{Cl}^{37}$ & 1 . & $2 \leftarrow 1$ & Ground & $7 / 2$ & 3 & $5 / 2$ & 2 & 17289.15 & 0.50 \\
\hline $\mathrm{Ca}^{69} \mathrm{Cl}^{37}$ & $1-$ & $2 \leftarrow 1$ & Ground & $5 / 2$ & 3 & $3 / 2$ & 3 & 17289.15 & 0.50 \\
\hline $\mathrm{Ga}^{69} \mathrm{Cl}^{37}$ & $1-$ & $2 \leftarrow 1$ & Ground & $5 / 2$ & 1 & $3 / 2$ & 0 & 17289.15 & 0.50 \\
\hline $\mathrm{Ca}^{69} \mathrm{Cl}^{37}$ & 1 . & $2 \leftarrow 1$ & Ground & $5 / 2$ & 1 & $3 / 2$ & 1 & 17289.15 & 0.50 \\
\hline $\mathrm{Ca}^{69} \mathrm{Cl}^{37}$ & $1-$ & $2 \leftarrow 1$ & Ground & $5 / 2$ & 2 & $3 / 2$ & 1 & 17289.15 & 0.50 \\
\hline $\mathrm{N}^{14} \mathrm{H}_{3}$ & $4-1771$ & $7,2 \leftarrow 7,2$ & Ground & & & & & 17291.54 & .04 \\
\hline $\mathrm{C}^{12} \mathrm{H}_{3} \mathrm{Ge}^{74} \mathrm{H}_{3}$ & 3- 284 & $1,0 \leftarrow 0,0$ & Ground & & & & & 17299.43 & .10 \\
\hline $\mathrm{C}^{12} \mathrm{H}_{3} \mathrm{~N}^{14} \mathrm{H}_{2}$ & 3- 261 & Not Reported & Ground & & & & & 17302.03 & .04 \\
\hline $\mathrm{S}^{32} \mathrm{O}^{16} \mathrm{~F}_{2}^{19}$ & 4-1621 & $5,3,2 \leftarrow 5,3,3$ & Ground & & & & & 17304.89 & .1 \\
\hline $2 \mathrm{~d} \cdot \mathrm{C}_{6}^{12} \mathrm{H}_{5} \mathrm{C}^{12} \mathrm{~N}^{14}$ & 4-1294 & $6,1,5 \leftarrow 5,1,4$ & Ground & & & & & 17313.0 & .2 \\
\hline $\mathrm{a} \cdot \mathrm{C}^{12} \mathrm{HD}_{2} \mathrm{C}^{12} \mathrm{O}^{16} \mathrm{~F}^{19}$ & 3. 396 & $4,2,2 \leftarrow 4,2,3$ & Ground & & & & & 17319.30 & .2 \\
\hline $\mathrm{C}^{12} \mathrm{H}_{3} \mathrm{~S}^{32} \mathrm{H}$ & 3. 221 & Not Reported & Ground & & & & & 17320.4 & .1 \\
\hline $\mathrm{HC}^{13}: \mathrm{C}^{12} \mathrm{C}^{12} \mathrm{DO}^{16}$ & 4. 922 & Not Reported & & & & & & 17325 & 5. \\
\hline $\mathrm{Cl}^{35} \mathrm{O}_{2}^{16}$ & 4-1381 & $21,4,17 \leftarrow 20,5,16$ & Ground & & $39 / 2$ & & $37 / 2$ & 17325.0 & \\
\hline $\mathrm{H}_{2} \mathrm{~N}^{14} \mathrm{~N}^{14} \mathrm{H}_{2}$ & 3. 51 & Not Reported & & & & & & 17326.69 & \\
\hline $\mathrm{s}-\mathrm{C}^{12} \mathrm{H}_{2} \mathrm{DS}^{32} \mathrm{C}^{12} \mathrm{H}_{3}$ & 3- 604 & $3,1,2 \leftarrow 3,0,3$ & Ground & & & & & 17327.39 & .05 \\
\hline $\mathrm{C}^{12} \mathrm{H}_{3} \mathrm{Ge}^{73} \mathrm{H}_{3}$ & 3- 283 & $1,0 \leftarrow 0,0$ & Ground & & $7 / 2$ & & $9 / 2$ & 17328.4 & .10 \\
\hline $\mathrm{C}^{12} \mathrm{H}_{3} \mathrm{Ge}^{73} \mathrm{H}_{3}$ & 3- 283 & $1,0 \leftarrow 0,0$ & Ground & & $11 / 2$ & & $9 / 2$ & 17328.4 & .10 \\
\hline $\mathrm{C}^{12} \mathrm{H}_{3} \mathrm{Ce}^{73} \mathrm{H}_{3}$ & 3. 283 & $1,0 \leftarrow 0,0$ & Ground & & $9 / 2$ & & $9 / 2$ & 17328.9 & .10 \\
\hline $\mathrm{Cl}^{135} \mathrm{O}_{2}^{16}$ & 4-1381 & $21,4,17 \leftarrow 20,5,16$ & Ground & & $41 / 2$ & & $39 / 2$ & 17331.6 & \\
\hline $\mathrm{C}^{\mathrm{b}} \mathrm{H}_{2}^{\mathrm{b}} \mathrm{Cl}^{\mathrm{b}} \mathrm{F}^{\mathrm{b}}$ & 4- 333 & Not Reported & & & & & & 17331.76 & .1 \\
\hline $\mathrm{H}_{2} \mathrm{~N}^{14} \mathrm{~N}^{14} \mathrm{H}_{2}$ & $3-51$ & Not Reported & & & & & & 17332.72 & \\
\hline $\mathrm{Cl}^{35} \mathrm{O}_{2}^{16}$ & 4-1381 & $21,4,17 \leftarrow 20,5,16$ & Ground & & $43 / 2$ & & $41 / 2$ & 17338.2 & \\
\hline $\mathrm{C}^{12} \mathrm{H}_{3} \mathrm{C}^{12} \mathrm{H}_{2} \mathbf{I}^{127}$ & 3. 571 & $3,0,3 \leftarrow 2,0,2$ & Ground & & $11 / 2$ & & $9 / 2$ & 17342.28 & .05 \\
\hline $\mathrm{Cl}^{35} \mathrm{O}_{2}^{16}$ & 4-1381 & $21,4,17 \leftarrow 20,5,16$ & Ground & & $45 / 2$ & & $43 / 2$ & 17344.7 & \\
\hline $\mathrm{C}^{12} \mathrm{H}_{3} \mathrm{~N}^{14} \mathrm{H}_{2}$ & 3. 261 & Not Reported & Ground & & & & & 17345.10 & .1 \\
\hline $\mathrm{C}^{12} \mathrm{H}_{3} \mathrm{~N}^{14} \mathrm{H}_{2}$ & 3- 261 & Not Reported & Ground & & & & & 17345.70 & .1 \\
\hline $\mathrm{C}^{12} \mathrm{H}_{3} \mathrm{~N}^{14} \mathrm{O}_{2}^{16}$ & 3- 171 & Not Reported & Ground & & & & & 17346.40 & \\
\hline$\left(\mathrm{C}^{12} \mathrm{D}_{3}\right)_{2} \mathrm{C}^{12} \mathrm{H}_{3} \mathrm{Si} \mathrm{i}^{\mathrm{b}} \mathrm{H}$ & 3. 879 & $2,1,1 \leftarrow 1,0,1$ & Ground & & & & & 17346.60 & .2 \\
\hline $\mathrm{DN}^{14} \mathrm{O}_{3}^{16}$ & 3- 32 & $1,0,1 \leftarrow 0,0,0$ & Ground & & 0 & & 1 & 17347.27 & \\
\hline $\mathrm{DN}^{14} \mathrm{O}_{3}^{16}$ & 3- 32 & $1,0,1 \leftarrow 0,0,0$ & Ground & & 2 & & 1 & 17347.64 & \\
\hline $\mathrm{DN}^{14} \mathrm{O}_{3}^{16}$ & $3-\quad 32$ & $1,0,1 \leftarrow 0,0,0$ & Ground & & 1 & & 1 & 17347.89 & \\
\hline$\left(\mathrm{C}^{12} \mathrm{H}_{3}\right)_{2} \mathrm{Si}^{30} \mathrm{H}_{2}$ & 3- 645 & $4,1,3 \leftarrow 4,0,4$ & Ground & & & & & 17353.41 & .20 \\
\hline$\left(\mathrm{C}^{12} \mathrm{H}_{3}\right)_{2} \mathrm{Si}^{30} \mathrm{H}_{2}$ & 3- 645 & $4,1,3 \leftarrow 4,0,4$ & Ground & & & & & 17354.68 & .20 \\
\hline $\mathrm{O}^{16} \mathrm{~F}_{2}^{19}$ & 4-1611 & $7,1,6 \leftarrow 6,2,5$ & Ground & & & & & 17354.71 & .10 \\
\hline $\mathrm{C}^{12} \mathrm{H}_{3} \mathrm{C}^{12} \mathrm{H}_{2} \mathrm{I}^{127}$ & 3- 571 & $3,0,3 \leftarrow 2,0,2$ & Ground & & $9 / 2$ & & $7 / 2$ & 17354.96 & .05 \\
\hline$\left(\mathrm{C}^{12} \mathrm{H}_{3}\right)_{2} \mathrm{Si}^{30} \mathrm{H}_{2}$ & 3- 645 & $4,1,3 \leftarrow 4,0,4$ & Ground & & & & & 17356.26 & .20 \\
\hline $\mathrm{DC}^{12}: \mathrm{C}^{12} \mathrm{C}^{12} \mathrm{DO}^{16}$ & 4. 926 & $2,1,1 \leftarrow 1,1,0$ & Ground & & & & & 17357.40 & .02 \\
\hline
\end{tabular}


Vib. State

$F_{1}^{\prime} \underset{F^{\prime}}{\operatorname{Hyperfine}} \underset{F_{1}}{\operatorname{Fon}} \mathrm{F}$

Frequency
$\mathrm{MH}_{2}$
$\mathrm{Acce}$

$\begin{array}{lcclc}\text { 3- } 879 & 2,1,1 \leftarrow 1,0,1 & \text { Ground } & 17358.67 & .2 \\ 3-282 & 1,0 \leftarrow 0,0 & \text { Ground } & 17358.78 & .10 \\ \text { 3- } 261 & \text { Not Reported } & \text { Ground } & 17360.58 & .1 \\ \text { 3- } 261 & \text { Not Reported } & \text { Ground } & 17361.10 & .1 \\ \text { 3- } 482 & 1,0,1 \leftarrow 0,0,0 & \text { Ground } & 17363.35 & .2 \\ \text { 3- } 171 & \text { Not Reported } & \text { Ground } & 17365 . & 5 . \\ \text { 4- } 922 & 2,1,2 \leftarrow 1,1,1 & \text { Ground } & 17365.03 & .02 \\ 3-1051 & 4,1,4 \leftarrow 3,0,3 & \text { Ground } & 17365.1 & \\ \text { 4- } 212 & 4,3,1 \leftarrow 4,3,2 & \text { Ground } & 17366.77 & .10 \\ \text { 4-1298 } & 6,1,5 \leftarrow 5,1,4 & \text { Ground } & 17367.4 & .1 \\ \text { 3- } 879 & 2,1,1 \leftarrow 1,0,1 & \text { Ground } & 17374.08 & .1 \\ 3-851 & 1, \leftarrow 0, & \text { Ground } & 17375.0 & .3 \\ \text { 4-1297 } & 6,1,5 \leftarrow 5,1,4 & \text { Ground } & 17376.0 & .1 \\ 3-193 & 2,1,2 \leftarrow 1,1,1 & \text { Ground } & 17378.12 & \\ 3-193 & 2,1,2 \leftarrow 1,1,1 & \text { Ground } & 17378.12 & \\ \text { 4-1771 } & 8,4 \leftarrow 8,4 & \text { Ground } & 17378.14 & .04\end{array}$

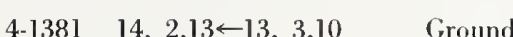

$25 / 2 \quad 23 / 2 \quad 17379.6$

3-851 $1, \leftarrow 0, \quad$ Ground

3- $571 \quad 3,0,3 \leftarrow 2,0,2 \quad$ Ground

3- $482 \quad 1,0,1 \leftarrow 0,0,0 \quad$ Cround

3. $191 \quad 2,1,2 \leftarrow 1,1,1 \quad$ Ground

3. $1922,1,2 \leftarrow 1,1,1 \quad$ Ground

3. $851 \quad 1, \leftarrow 0, \quad$ Ground

4-1291 6, 1, $5 \leftarrow 5,1,4 \quad$ Ground

4-1774 $6,2,5 \leftarrow 6,1,5 \quad$ Ground

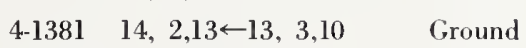

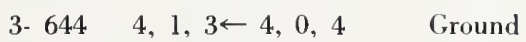

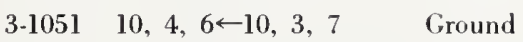

3- $6444,1,3 \leftarrow 4,0,4 \quad$ Ground

3. $6444,1,3 \leftarrow 4,0,4 \quad$ Ground

3- $851 \quad 1, \leftarrow 0, \quad$ Ground

4- $2114,3,1 \leftarrow 4,3,2 \quad$ Ground

3- $851 \quad 1, \leftarrow 0, \quad$ Ground

3- 744 $1,0,1 \leftarrow 0,0,0 \quad$ Ground

4- $351 \quad 34,8,27 \leftarrow 33,9,24 \quad$ - Ground

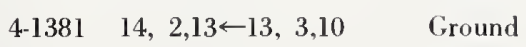

4. $901 \quad 6,0,6 \leftarrow 5,1,5 \quad$ Ground

3- 191 Not Reported Ground

4- 333

Not Reported

3. 731

$2,1,2 \leftarrow 1,1,1$

Ground

4-1271

$6,2,4 \leftarrow 5,2,3$

Ground

3- 281

$1,0 \leftarrow 0,0$

Ground

3- 851

$1, \leftarrow 0$,

Ground

4-1271

$6,2,4 \leftarrow 5,2,3$

Ground

$17380.8 \quad .3$

$\begin{array}{llll}3 / 2 & 3 / 2 & 17382.34 & .05\end{array}$

$17387.12 \quad .3$

17387.22

17387.22

$17387.9 \quad .3$

$17389.9 \quad .2$

$17392.56 \quad .05$

$27 / 2 \quad 25 / 2 \quad 17393.8$

$17394.96 \quad .20$

17396.2

$17396.51 \quad .20$

$17398.06 \quad .20$

17401 . $\quad 1$.

$17404.77 \quad .10$

$17407.45 \quad .10$

$17411.29 \quad .03$

$17411.86 \quad .10$

$29 / 2 \quad 27 / 2 \quad 17413.2$

17414.02

17416.0

$17416.50 \quad .1$

17419.8 .2

17421.0

$17421.36 \quad .10$

$17421.41 \quad .10$

17423.0

17428.89 


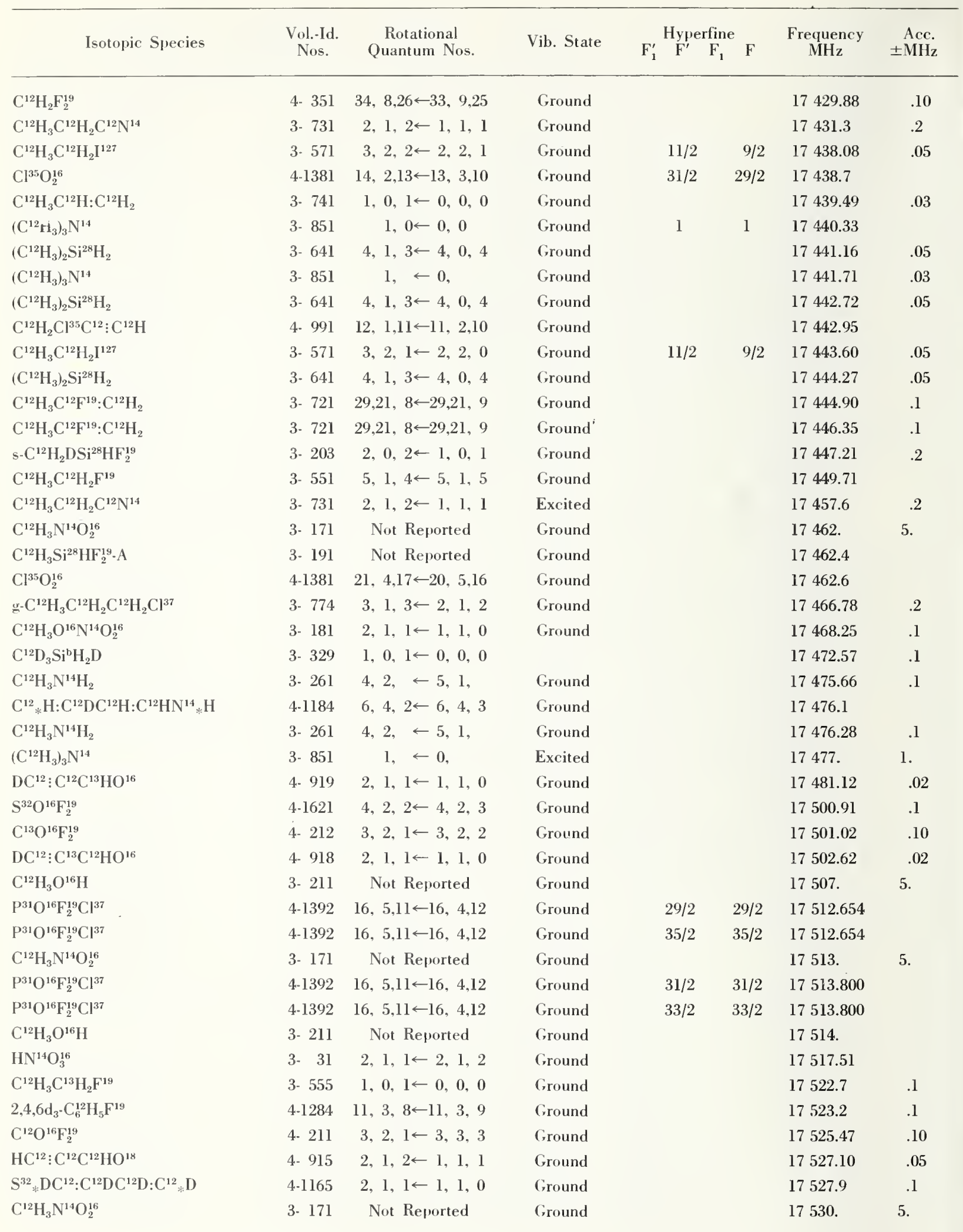




\begin{tabular}{|c|c|c|c|c|c|c|c|c|c|}
\hline \multirow{3}{*}{$\frac{\text { Isotopic Species }}{\mathrm{C}^{12} \mathrm{H}_{3} \mathrm{C}^{12} \mathrm{H}_{2} \mathrm{~F}^{19}}$} & \multirow{3}{*}{$\begin{array}{c}\begin{array}{c}\text { Vol.-Id. } \\
\text { Nos. }\end{array} \\
\text { 3. } 551\end{array}$} & \multirow{3}{*}{$\begin{array}{c}\begin{array}{c}\text { Rotational } \\
\text { Quantum Nos. }\end{array} \\
1,0,1 \leftarrow 0,0,0\end{array}$} & \multirow{3}{*}{$\begin{array}{c}\text { Vib. State } \\
\text { Ground }\end{array}$} & \multicolumn{4}{|c|}{ Hyperfine } & \multirow{2}{*}{$\begin{array}{c}\text { Frequens:y } \\
\text { MHIz }\end{array}$} & \multirow{2}{*}{$\begin{array}{l}\text { Are. } \\
\pm \text { Mll\% }\end{array}$} \\
\hline & & & & $F_{1}^{\prime}$ & $F^{\prime}$ & $\mathbf{F}_{1}$ & $\mathrm{~F}$ & & \\
\hline & & & & & & & & 17530.5 & \\
\hline $\mathrm{F}_{2}^{19} \mathrm{O}_{2}^{16}$ & $3-11$ & $3,1,2 \leftarrow 3,0,3$ & Excited & & & & & 17540.88 & .1 \\
\hline $\mathrm{HC}^{13}: \mathrm{C}^{12} \mathrm{C}^{12} \mathrm{DO}^{16}$ & 4- 922 & Not Reported & & & & & & 1754.5. & 5. \\
\hline $\mathrm{C}^{12} \mathrm{HD}\left(\mathrm{C}^{12} \mathrm{~N}^{14}\right)_{2}$ & 4- 902 & $4,1,3 \leftarrow 4,0,4$ & Ground & & & & & 17545.41 & \\
\hline $\mathrm{C}^{12} \mathrm{H}_{3} \mathrm{O}^{16} \mathrm{~N}^{14} \mathrm{O}_{2}^{16}$ & 3- 181 & $2,1,1 \leftarrow 1,1,0$ & Ground & & & & & 17548.41 & .1 \\
\hline $\mathrm{N}^{15} \mathrm{H}_{3}$ & 4-1772 & $9,6 \leftarrow 9,6$ & Ground & & & & & 17548.42 & .08 \\
\hline $\mathrm{P}^{31} \mathrm{O}^{16} \mathrm{~F}_{2}^{19} \mathrm{Cl}^{37}$ & 4-1392 & $15,5,10 \leftarrow 15,4,11$ & Ground & & $33 / 2$ & & $33 / 2$ & 17549.551 & \\
\hline $\mathrm{P}^{31} \mathrm{O}^{16} \mathrm{~F}_{2}^{19} \mathrm{Cl}^{37}$ & $4 \cdot 1392$ & $15,5,10 \leftarrow 15,4,11$ & Ground & & $27 / 2$ & & $27 / 2$ & 17549.551 & \\
\hline $\mathrm{C}^{12} \mathrm{H}_{3} \mathrm{C}^{12} \mathrm{H}_{2} \mathrm{~F}^{19}$ & 3- 551 & $1,0,1 \leftarrow 0,0,0$ & Ground & & & & & 17549.69 & \\
\hline $\mathrm{C}^{12} \mathrm{H}_{3} \mathrm{C}^{12} \mathrm{H}_{2} \mathrm{I}^{127}$ & 3. 571 & $3,1,2 \leftarrow 2,1,1$ & Ground & & $7 / 2$ & & $5 / 2$ & 17549.70 & \\
\hline $\mathrm{C}^{12} \mathrm{H}_{2} \mathrm{Cl}^{35} \mathrm{C}^{12} \mathrm{~N}^{14}$ & 4. 651 & $3,1,3 \leftarrow 2,1,2$ & Ground & & & & & 17550. & 1. \\
\hline $\mathrm{P}^{31} \mathrm{O}^{16} \mathrm{~F}_{2}^{19} \mathrm{Cl}^{37}$ & 4-1392 & $16,5,12 \leftarrow 16,4,13$ & Ground & & $35 / 2$ & & $35 / 2$ & 17551.220 & \\
\hline $\mathrm{P}^{31} \mathrm{O}^{16} \mathrm{~F}_{2}^{19} \mathrm{Cl}^{37}$ & 4.1392 & $15,5,10 \leftarrow 15,4,11$ & Ground & & $29 / 2$ & & $29 / 2$ & 17551.220 & \\
\hline $\mathrm{P}^{31} \mathrm{O}^{16} \mathrm{~F}_{2}^{19} \mathrm{Cl}^{37}$ & 4-1392 & $15,5,10 \leftarrow 15,4,11$ & Ground & & $31 / 2$ & & $31 / 2$ & 17551.220 & \\
\hline $\mathrm{P}^{31} \mathrm{O}^{16} \mathrm{~F}_{2}^{19} \mathrm{Cl}^{37}$ & 4-1392 & $16,5,12 \leftarrow 16,4,13$ & Ground & & $29 / 2$ & & $29 / 2$ & 17551.220 & \\
\hline $\mathrm{P}^{31} \mathrm{O}^{16} \mathrm{~F}_{2}^{19} \mathrm{Cl}^{37}$ & 4-1392 & $16,5,12 \leftarrow 16,4,13$ & Ground & & $33 / 2$ & & $33 / 2$ & 17552.406 & \\
\hline $\mathrm{P}^{31} \mathrm{O}^{16} \mathrm{~F}_{2}^{19} \mathrm{Cl}^{37}$ & 4-1392 & $16,5,12 \leftarrow 16,4,13$ & Ground & & $31 / 2$ & & $31 / 2$ & 17552.406 & \\
\hline $\mathrm{C}^{12} \mathrm{H}_{3} \mathrm{O}^{16} \mathrm{~N}^{14} \mathrm{Q}_{2}^{16}$ & 3. 181 & $2,1,1 \leftarrow 1,1,0$ & Ground & & & & & 17555.17 & .1 \\
\hline $\mathrm{C}^{12} \mathrm{H}_{2} \mathrm{Cl}^{35} \mathrm{C}^{12}: \mathrm{C}^{12} \mathrm{H}$ & 4. 991 & $3,0,3 \leftarrow 2,0,2$ & Ground & & & & & 17559.47 & \\
\hline $\mathrm{C}^{12} \mathrm{H}_{3} \mathrm{O}^{16} \mathrm{~N}^{14} \mathrm{O}_{2}^{16}$ & 3. 181 & $2,1,1 \leftarrow 1,1,0$ & Ground & & & & & 17560.84 & .1 \\
\hline $\mathrm{HC}^{12}: \mathrm{C}^{12} \mathrm{C}^{12} \mathrm{DO}^{18}$ & 4- 925 & $2,0,2 \leftarrow 1,0,1$ & Ground & & & & & 17561.76 & .05 \\
\hline $\mathrm{C}^{12} \mathrm{H}_{3} \mathrm{C}^{12} \mathrm{H}_{2} \mathrm{~F}^{19}$ & 3- 551 & $1,0,1 \leftarrow 0,0,0$ & Ground & & & & & 17564.66 & \\
\hline $\mathrm{N}^{14} \mathrm{O}_{2}^{16} \mathrm{~F}^{19}$ & 4-1581 & $1,0,1 \leftarrow 0,0,0$ & Ground & & & & & 17566.2 & \\
\hline $\mathrm{C}^{13} \mathrm{H}_{3} \mathrm{~S}^{32} \mathrm{C}^{12} \mathrm{H}_{3}$ & 3- 603 & $3,1,2 \leftarrow 3,0,3$ & Ground & & & & & 17569.40 & .05 \\
\hline $\mathrm{DC}^{12}: \mathrm{C}^{12} \mathrm{C}^{12} \mathrm{HO}^{16}$ & 4- 916 & $2,1,1 \leftarrow 1,1,0$ & Ground & & & & & 17569.69 & .02 \\
\hline $\mathrm{C}^{12} \mathrm{H}_{3} \mathrm{Si}^{28} \mathrm{H}_{2} \mathrm{~F}^{19}$ & 3- 2411 & Not Reported & & & & & & 17571.94 & 1 \\
\hline $\mathrm{P}^{31} \mathrm{O}^{16} \mathrm{~F}_{2}^{19} \mathrm{Cl}^{37}$ & 4-1392 & $15,5,11 \leftarrow 15,4,12$ & Ground & & $33 / 2$ & & $33 / 2$ & 17572.927 & \\
\hline $\mathrm{P}^{31} \mathrm{O}^{16} \mathrm{~F}_{2}^{19} \mathrm{Cl}^{37}$ & $4 \cdot 1392$ & $15,5,11 \leftarrow 15,4,12$ & Ground & & $27 / 2$ & & $27 / 2$ & 17572.927 & \\
\hline $\mathrm{Ga}^{71} \mathrm{Cl}^{35}$ & $1-$ & $2 \leftarrow 1$ & Excited & $7 / 2$ & 2 & $5 / 2$ & 2 & 17573.70 & 0.50 \\
\hline $\mathrm{Ga}^{71} \mathrm{Cl}^{35}$ & 1 . & $2 \leftarrow 1$ & Excited & $7 / 2$ & 3 & $5 / 2$ & 2 & 17573.70 & 0.50 \\
\hline $\mathrm{Ga}^{71} \mathrm{Cl}^{35}$ & $1-$ & $2 \leftarrow 1$ & Excited & $7 / 2$ & 3 & $5 / 2$ & 3 & 17573.70 & 0.50 \\
\hline $\mathrm{Ga}^{71} \mathrm{Cl}^{35}$ & 1 . & $2 \leftarrow 1$ & Excited & $7 / 2$ & 4 & $5 / 2$ & 3 & 17573.70 & 0.50 \\
\hline $\mathrm{Ga}^{71} \mathrm{Cl}^{35}$ & 1 . & $2 \leftarrow 1$ & Excited & $7 / 2$ & 5 & $5 / 2$ & 4 & 17573.70 & 0.50 \\
\hline $\mathrm{Ga}^{71} \mathrm{Cl}^{35}$ & 1 . & $2 \leftarrow 1$ & Excited & $5 / 2$ & 4 & $3 / 2$ & 3 & 17573.70 & 0.50 \\
\hline $\mathrm{Ga}^{71} \mathrm{Cl}^{35}$ & $1-$ & $2 \leftarrow 1$ & Excited & $7 / 2$ & 2 & $5 / 2$ & 1 & 17573.70 & 0.50 \\
\hline $\mathrm{Ga}^{71} \mathrm{Cl}^{35}$ & $1-$ & $2 \leftarrow 1$ & Excited & $5 / 2$ & 1 & $3 / 2$ & 0 & 17573.70 & 0.50 \\
\hline $\mathrm{Ga}^{71} \mathrm{Cl}^{35}$ & $1 \cdot$ & $2 \leftarrow 1$ & Excited & $5 / 2$ & 1 & $3 / 2$ & 1 & 17573.70 & 0.50 \\
\hline $\mathrm{Ga}^{71} \mathrm{Cl}^{35}$ & 1 . & $2 \leftarrow 1$ & Excited & $5 / 2$ & 2 & $3 / 2$ & 1 & 17573.70 & 0.50 \\
\hline $\mathrm{Ga}^{71} \mathrm{Cl}^{35}$ & 1 . & $2 \leftarrow 1$ & Excited & $5 / 2$ & 3 & $3 / 2$ & 3 & 17573.70 & 0.50 \\
\hline $\mathrm{C}^{12} \mathrm{H}_{3} \mathrm{Si}^{28} \mathrm{H}_{2} \mathrm{~F}^{19}$ & 3- 241 & Not Reported & & & & & & 17573.95 & .1 \\
\hline $\mathrm{P}^{31} \mathrm{O}^{16} \mathrm{~F}_{2}^{19} \mathrm{Cl}^{37}$ & 4-1392 & $15,5,11 \leftarrow 15,4,12$ & Ground & & $31 / 2$ & & $31 / 2$ & 17574.270 & \\
\hline $\mathrm{P}^{31} \mathrm{O}^{16} \mathrm{~F}_{2}^{19} \mathrm{Cl}^{37}$ & 4-1392 & $15,5,11 \leftarrow 15,4,12$ & Ground & & $29 / 2$ & & $29 / 2$ & 17574.270 & \\
\hline $\mathrm{C}^{12} \mathrm{H}_{3} \mathrm{C}^{12} \mathrm{H}_{2} \mathrm{I}^{127}$ & 3- 571 & $3,1,2 \leftarrow 2,1,1$ & Ground & & $9 / 2$ & & $7 / 2$ & 17574.5 & \\
\hline $\mathrm{C}^{12} \mathrm{H}_{3} \mathrm{C}^{12} \mathrm{H}_{2} \mathrm{I}^{127}$ & 3- 571 & $3,1,2 \leftarrow 2,1,1$ & Ground & & $9 / 2$ & & $7 / 2$ & 17575.24 & \\
\hline $\mathrm{C}^{12} \mathrm{H}_{3} \mathrm{C}^{12} \mathrm{O}^{16} \mathrm{C}^{12} \mathrm{~N}^{14}$ & 3- 671 & $6,2,4 \leftarrow 6,1,5$ & Ground & & & & & 17576.96 & .2 \\
\hline
\end{tabular}




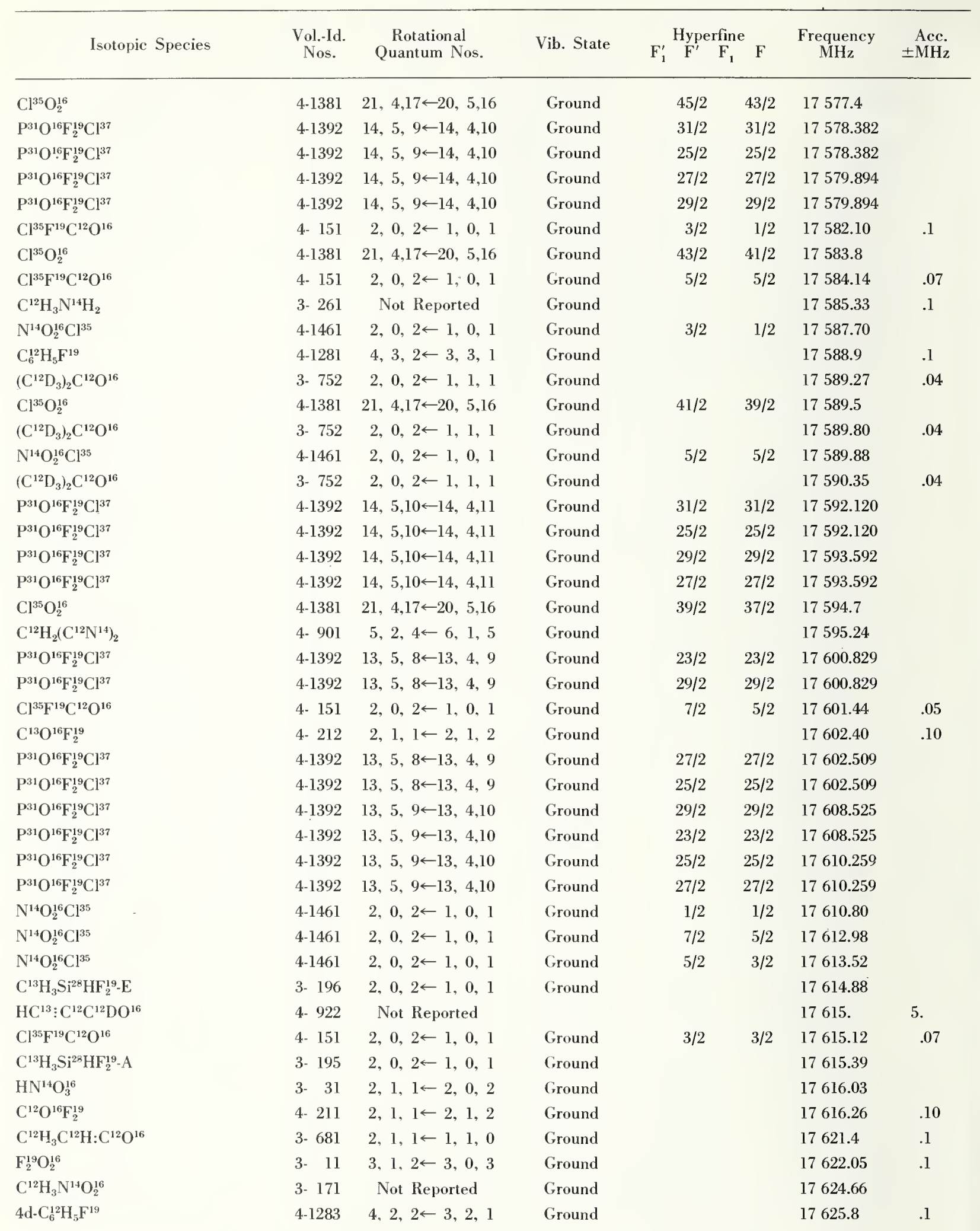




\begin{tabular}{|c|c|c|c|c|c|c|c|c|c|}
\hline Isotopic Species & $\begin{array}{l}\text { Vol.-Id. } \\
\text { Nos. }\end{array}$ & $\begin{array}{c}\text { Rotational } \\
\text { Quantum Nos. }\end{array}$ & Vib. State & $\mathbf{F}_{1}^{\prime \prime}$ & $\begin{array}{l}\text { Hyper } \\
\mathrm{F}^{\prime}\end{array}$ & $\begin{array}{l}\text { Ifine } \\
F_{1}\end{array}$ & $\mathrm{~F}$ & $\begin{array}{c}\text { Frequency } \\
\mathrm{MHz}^{-}\end{array}$ & $\begin{aligned} & \text { Acce } \\
\pm & \mathrm{MH} \%\end{aligned}$ \\
\hline $\mathrm{C}^{13} \mathrm{O}^{16} \mathrm{~F}_{2}^{19}$ & 4. 212 & $1,0,1 \leftarrow 0,0,0$ & Ground & & & & & 17627.05 & .10 \\
\hline $\mathrm{N}^{14} \mathrm{O}_{2}^{16} \mathrm{Cl}^{35}$ & $4-1461$ & Not Reported & & & & & & 17627.90 & \\
\hline $\mathrm{N}^{14} \mathrm{O}_{2}^{16} \mathrm{Cl}^{35}$ & $4-1461$ & $2,0,2 \leftarrow 1,0,1$ & Ground & & $3 / 2$ & & $3 / 2$ & 17629.90 & \\
\hline $\mathrm{C}^{12} \mathrm{O}^{16} \mathrm{~F}_{2}^{19}$ & 4. 211 & $1,0,1 \leftarrow 0,0,0$ & Ground & & & & & 17633.95 & .10 \\
\hline $\mathrm{HC}^{13}: \mathrm{C}^{12} \mathrm{C}^{12} \cdot \mathrm{DO}^{16}$ & 4- 922 & Not Reported & & & & & & 17637. & 5. \\
\hline $\mathrm{C}^{12} \mathrm{H}_{3} \mathrm{C}^{12} \mathrm{H}_{2} \mathrm{I}^{127}$ & 3- 571 & $3,1,2 \leftarrow 2,1,1$ & Ground & & $11 / 2$ & & $9 / 2$ & 17643.66 & \\
\hline $\mathrm{C}^{12} \mathrm{H}_{3} \mathrm{~N}^{14} \mathrm{O}_{2}^{16}$ & 3- 171 & Not Reported & Ground & & & & & 17645.77 & \\
\hline $\mathrm{C}^{12} \mathrm{H}_{3} \mathrm{C}^{12}{ }_{*} \mathrm{HO}^{16} \mathrm{C}^{12}{ }_{*} \mathrm{H}_{2}$ & 3. 761 & $17,11, \leftarrow 18,10$ & Ground & & & & & 17645.83 & .1 \\
\hline $\mathrm{C}^{12} \mathrm{H}_{3} \mathrm{C}^{12}{ }_{*} \mathrm{HO}^{16} \mathrm{C}^{12}{ }_{*} \mathrm{H}_{2}$ & 3- 761 & $17,11, \leftarrow 18,10$ & Ground & & & & & 17646.35 & .1 \\
\hline $\mathrm{C}^{12} \mathrm{H}_{3} \mathrm{C}^{12}{ }_{*} \mathrm{HO}^{16} \mathrm{C}^{12}{ }_{*} \mathrm{H}_{2}$ & 3. 761 & $17,11, \leftarrow 18,10$ & Ground & & & & & 17646.86 & .1 \\
\hline $\mathrm{C}^{12} \mathrm{H}_{3} \mathrm{Si}^{28} \mathrm{HF}_{2}^{19}-\mathrm{A}$ & 3- 191 & Not Reported & Ground & & & & & 17647.2 & \\
\hline $\mathrm{C}^{12} \mathrm{H}_{2} \mathrm{Cl}^{37} \mathrm{~F}^{19}$ & 4- 332 & $17,1,17 \leftarrow 16,2,14$ & Ground & & & & & 17648.07 & .1 \\
\hline $\mathrm{C}^{12} \mathrm{D}_{3} \mathrm{C}^{12} \mathrm{O}^{16} \mathrm{~F}^{19}$ & 3- 392 & $12,7,5 \leftarrow 12,7,6$ & Ground & & & & & 17650.87 & .2 \\
\hline $\mathrm{Ca}^{69} \mathrm{Cl}^{35}$ & 1 . & $2 \leftarrow 1$ & Excited & $5 / 2$ & 2 & $3 / 2$ & 1 & 17650.97 & 0.50 \\
\hline $\mathrm{Ca}^{69} \mathrm{Cl}^{35}$ & 1 . & $2 \leftarrow 1$ & Excited & $5 / 2$ & 1 & $3 / 2$ & 0 & 17650.97 & 0.50 \\
\hline $\mathrm{Ca}^{{ }^{69}} \mathrm{Cl}^{35}$ & 1. & $2 \leftarrow 1$ & Excited & $5 / 2$ & 1 & $3 / 2$ & 1 & 17650.97 & 0.50 \\
\hline $\mathrm{Ga}^{69} \mathrm{Cl}^{35}$ & 1 . & $2 \leftarrow 1$ & Excited & $5 / 2$ & 3 & $3 / 2$ & 3 & 17650.97 & 0.50 \\
\hline $\mathrm{Ga}^{69} \mathrm{Cl}^{35}$ & 1 . & $2 \leftarrow 1$ & Excited & $7 / 2$ & 2 & $5 / 2$ & 1 & 17650.97 & 0.50 \\
\hline $\mathrm{Ga}^{69} \mathrm{Cl}^{35}$ & 1 . & $2 \leftarrow 1$ & Excited & $5 / 2$ & 4 & $3 / 2$ & 3 & 17650.97 & 0.50 \\
\hline $\mathrm{Ca}^{69} \mathrm{Cl}^{35}$ & 1 - & $2 \leftarrow 1$ & Excited & $7 / 2$ & 5 & $5 / 2$ & 4 & 17650.97 & 0.50 \\
\hline $\mathrm{Ca}^{69} \mathrm{Cl}^{35}$ & 1 - & $2 \leftarrow 1$ & Excited & $7 / 2$ & 3 & $5 / 2$ & 3 & 17650.97 & 0.50 \\
\hline $\mathrm{Ga}^{69} \mathrm{Cl}^{35}$ & $1-$ & $2 \leftarrow 1$ & Excited & $7 / 2$ & 4 & $5 / 2$ & 3 & 17650.97 & 0.50 \\
\hline $\mathrm{Ca}^{69} \mathrm{Cl}^{35}$ & 1 . & $2 \leftarrow 1$ & Excited & $7 / 2$ & 2 & $5 / 2$ & 2 & 17650.97 & 0.50 \\
\hline $\mathrm{Ga}^{69} \mathrm{Cl}^{35}$ & $1-$ & $2 \leftarrow 1$ & Excited & $7 / 2$ & 3 & $5 / 2$ & 2 & 17650.97 & 0.50 \\
\hline $\mathrm{C}^{12} \mathrm{H}_{2} \mathrm{Cl}^{37} \mathrm{~F}^{19}$ & 4- 332 & $17,1,17 \leftarrow 16,2,14$ & Ground & & & & & 17652.92 & .1 \\
\hline $\mathrm{N}^{14} \mathrm{O}_{2}^{16} \mathrm{Cl}^{35}$ & $4-1461$ & $2,0,2 \leftarrow 1,0,1$ & Ground & & $1 / 2$ & & $3 / 2$ & 17653.20 & \\
\hline $\mathrm{S}^{32} \mathrm{O}^{16} \mathrm{~F}_{2}^{19}$ & $4-1621$ & Not Reported & & & & & & 17653.47 & .1 \\
\hline $\mathrm{C}^{12} \mathrm{D}_{3} \mathrm{C}^{12} \mathrm{O}^{16} \mathrm{~F}^{19}$ & 3- 392 & $12,7,5 \leftarrow 12,7,6$ & Ground & & & & & 17655.53 & .2 \\
\hline $\mathrm{C}^{12} \mathrm{H}_{3} \mathrm{C}^{12} \mathrm{H}: \mathrm{C}^{12} \mathrm{O}^{16}$ & 3. 681 & $2,1,1 \leftarrow 1,1,0$ & Ground & & & & & 17659.9 & .1 \\
\hline $\mathrm{C}^{12} \mathrm{H}_{3} \mathrm{~N}^{14} \mathrm{H}_{2}$ & 3. 261 & Not Reported & Ground & & & & & 17660.45 & .1 \\
\hline $\mathrm{P}^{31} \mathrm{O}^{16} \mathrm{~F}_{2}^{19} \mathrm{C}^{37}$ & 4- 1392 & $7,5,2 \leftarrow 7,4,3$ & Ground & & $13 / 2$ & & $13 / 2$ & 17661.152 & \\
\hline $\mathrm{P}^{31} \mathrm{O}^{16} \mathrm{~F}_{2}^{19} \mathrm{Cl}^{37}$ & 4-1392 & $7,5,2 \leftarrow 7,4,3$ & Ground & & $15 / 2$ & & $15 / 2$ & 17662.260 & \\
\hline $\mathrm{C}^{12} \mathrm{H}_{3} \mathrm{C}^{12} \mathrm{H}_{2} 1^{127}$ & 3. 571 & $3,1,2 \leftarrow 2,1,1$ & Ground & & $3 / 2$ & & $3 / 2$ & 17662.8 & \\
\hline $\mathrm{P}^{31} \mathrm{O}^{16} \mathrm{~F}_{2}^{19} \mathrm{Cl}^{37}$ & 4-1392 & $6,5,1 \leftarrow 6,4,2$ & Ground & & $11 / 2$ & & $11 / 2$ & 17664.240 & \\
\hline $\mathrm{P}^{31} \mathrm{O}^{16} \mathrm{~F}_{2}^{19} \mathrm{Cl}^{37}$ & 4-1392 & $6,5,1 \leftarrow 6,4,2$ & Ground & & $13 / 2$ & & $13 / 2$ & 17666.026 & \\
\hline $\mathrm{P}^{31} \mathrm{O}^{16} \mathrm{~F}_{2}^{19} \mathrm{Cl}^{37}$ & 4-1392 & $5,5,0 \leftarrow 5,4,1$ & Ground & & $9 / 2$ & & $9 / 2$ & 17666.660 & \\
\hline $\mathrm{Ga}^{71} \mathrm{Cl}^{35}$ & $1-$ & $2 \leftarrow 1$ & Excited & $5 / 2$ & 1 & $3 / 2$ & 1 & 17666.88 & 0.50 \\
\hline $\mathrm{Ga}^{71} \mathrm{Cl}^{35}$ & 1. & $2 \leftarrow 1$ & Excited & $5 / 2$ & 1 & $3 / 2$ & 0 & 17666.88 & 0.50 \\
\hline $\mathrm{Ga}^{71} \mathrm{Cl}^{35}$ & 1 - & $2 \leftarrow 1$ & Excited & $7 / 2$ & 4 & $5 / 2$ & 3 & 17666.88 & 0.50 \\
\hline $\mathrm{Ga}^{71} \mathrm{Cl}^{35}$ & 1 . & $2 \leftarrow 1$ & Excited & $7 / 2$ & 3 & $5 / 2$ & 2 & 17666.88 & 0.50 \\
\hline $\mathrm{Ga}^{71} \mathrm{Cl}^{35}$ & 1 . & $2 \leftarrow 1$ & Excited & $7 / 2$ & 3 & $5 / 2$ & 3 & 17666.88 & 0.50 \\
\hline $\mathrm{Ga}^{71} \mathrm{Cl}^{35}$ & 1 . & $2 \leftarrow 1$ & Excited & $7 / 2$ & 2 & $5 / 2$ & 2 & 17666.88 & 0.50 \\
\hline $\mathrm{Ga}^{71} \mathrm{Cl}^{35}$ & 1 . & $2 \leftarrow 1$ & Excited & $7 / 2$ & 2 & $5 / 2$ & 1 & 17666.88 & 0.50 \\
\hline $\mathrm{Ga}^{71} \mathrm{Cl}^{35}$ & 1 . & $2 \leftarrow 1$ & Excited & $7 / 2$ & 5 & $5 / 2$ & 4 & 17666.88 & 0.50 \\
\hline $\mathrm{Ga}^{71} \mathrm{Cl}^{35}$ & 1. & $2 \leftarrow 1$ & Excited & $5 / 2$ & 4 & $3 / 2$ & 3 & 17666.88 & 0.50 \\
\hline
\end{tabular}




\begin{tabular}{|c|c|c|c|c|c|c|c|c|c|}
\hline Isotopic Species & $\begin{array}{l}\text { Vol.-Id. } \\
\text { Nos. }\end{array}$ & $\begin{array}{c}\text { Rotational } \\
\text { Quantum Nos. }\end{array}$ & Vib. State & $\mathrm{F}_{1}^{\prime}$ & Hype & $\begin{array}{c}\mathrm{F}_{1} \\
\mathrm{rfine}\end{array}$ & $\mathrm{F}$ & $\begin{array}{c}\text { Frequency } \\
\mathrm{MHz}^{2}\end{array}$ & $\begin{array}{r}\text { Acc. } \\
\pm \mathrm{MHz}\end{array}$ \\
\hline $\mathrm{Ga}^{71} \mathrm{Cl}^{35}$ & $1-$ & $2 \leftarrow 1$ & Excited & $5 / 2$ & 2 & $3 / 2$ & 1 & 17666.88 & 0.50 \\
\hline $\mathrm{Ga}^{71} \mathrm{Cl}^{35}$ & $1-$ & $2 \leftarrow 1$ & Excited & $5 / 2$ & 3 & $3 / 2$ & 3 & 17666.88 & 0.50 \\
\hline $\mathrm{C}^{12} \mathrm{H}_{3} \mathrm{C}^{12} \mathrm{~F}^{19}: \mathrm{C}^{12} \mathrm{H}_{2}$ & 3- 721 & $7,6,1 \leftarrow 7,5,2$ & Ground & & & & & 17668.70 & .1 \\
\hline $\mathrm{P}^{31} \mathrm{O}^{16} \mathrm{~F}_{2}^{19} \mathrm{Cl}^{37}$ & 4-1392 & $5,5,0 \leftarrow 5,4,1$ & Ground & & $11 / 2$ & & $11 / 2$ & 17669.590 & \\
\hline $\mathrm{C}^{12} \mathrm{H}_{2}\left(\mathrm{C}^{12} \mathrm{~N}^{14}\right)_{2}$ & 4- 901 & Not Reported & Ground & & & & & 17670.5 & .1 \\
\hline $\mathrm{D}_{2} \mathrm{C}^{12}: \mathrm{C}^{12} \mathrm{O}^{16}$ & 4- 712 & $1,0,1 \leftarrow 0,0,0$ & Ground & & & & & 17673.61 & \\
\hline $\mathrm{C}^{12} \mathrm{H}_{3} \mathrm{C}^{12} \mathrm{H}_{2} \mathrm{I}^{127}$ & 3- 571 & $3,1,2 \leftarrow 2,1,1$ & Ground & & $1 / 2$ & & $1 / 2$ & 17676.2 & \\
\hline $\mathrm{C}_{6}^{12} \mathrm{H}_{5} \mathrm{~F}^{19}$ & 4-1281 & $4,3,1 \leftarrow 3,3,0$ & Ground & & & & & 17676.6 & .1 \\
\hline $\mathrm{C}^{12} \mathrm{H}_{3} \mathrm{Si}^{28} \mathrm{DF}_{2}^{19} \cdot \mathrm{E}$ & 3- 198 & $2,0,2 \leftarrow 1,0,1$ & Ground & & & & & 17683.49 & \\
\hline $\mathrm{C}^{12} \mathrm{H}_{3} \mathrm{Si}^{28} \mathrm{DF}_{2}^{19}-\mathrm{A}$ & 3- 197 & $2,0,2 \leftarrow 1,0,1$ & Ground & & & & & 17684.10 & \\
\hline $\mathrm{HC}^{13}: \mathrm{C}^{12} \mathrm{C}^{12} \mathrm{DO}^{16}$ & 4. 922 & Not Reported & & & & & & 17685. & 5. \\
\hline $\mathrm{C}^{12} \mathrm{H}_{3} \mathrm{C}^{12} * \mathrm{HO}^{16} \mathrm{C}^{12} * \mathrm{H}_{2}$ & 3- 761 & $30,15, \quad \leftarrow 29,16$ & Ground & & & & & 17692.15 & .1 \\
\hline $\mathrm{C}^{12} \mathrm{H}_{3} \mathrm{C}^{12} * \mathrm{HO}^{16} \mathrm{C}^{12} * \mathrm{H}_{2}$ & 3. 761 & $30,15, \quad \leftarrow 29,16$ & Ground & & & & & 17692.55 & .1 \\
\hline $\mathrm{D}_{2} \mathrm{C}^{12}: \mathrm{C}^{12} \mathrm{O}^{16}$ & 4- 712 & $1,0,1 \leftarrow 0,0,0$ & Excited & & & & & 17692.59 & \\
\hline $\mathrm{C}^{12} \mathrm{H}_{3} \mathrm{C}^{12} * \mathrm{HO}^{16} \mathrm{C}^{12}{ }_{*} \mathrm{H}_{2}$ & 3- 761 & $30,15, \quad \leftarrow 29,16$ & Ground & & & & & 17692.97 & .1 \\
\hline $\mathrm{D}_{2} \mathrm{C}^{12}: \mathrm{C}^{12} \mathrm{O}^{16}$ & 4- 712 & $1,0,1 \leftarrow 0,0,0$ & Excited & & & & & 17695.00 & \\
\hline$\left(\mathrm{C}^{12} \mathrm{H}_{3}\right)_{2} \mathrm{~S}^{34}$ & 3- 602 & $3,1,2 \leftarrow 3,0,3$ & Ground & & & & & 17697.30 & .05 \\
\hline $\mathrm{C}_{6}^{12} \mathrm{H}_{5} \mathrm{Cl}^{35}$ & $4 \cdot 1271$ & $6,1,5 \leftarrow 5,1,4$ & Ground & & & & & 17705.8 & \\
\hline $\mathrm{C}^{12}{ }_{*} \mathrm{H}_{2} \mathrm{~S}^{32} \mathrm{C}^{12}{ }_{*} \mathrm{H}_{2}$ & 4- 851 & $11,4,8 \leftarrow 11,4,7$ & Ground & & & & & 17716.8 & .2 \\
\hline $\mathrm{C}^{12} \mathrm{H}_{3} \mathrm{Si}^{28} \mathrm{HF}_{2}^{19}-\mathrm{A}$ & 3- 191 & Not Reported & Ground & & & & & 17717.1 & \\
\hline $\mathrm{C}^{12} \mathrm{D}_{2} \mathrm{HC}^{12} \mathrm{HDF}^{19}$ & 3- 563 & $6,1,6 \leftarrow 5,2,3$ & Ground & & & & & 17717.2 & .1 \\
\hline $\mathrm{C}^{12} \mathrm{H}_{3} \mathrm{Si}^{28} \mathrm{HF}_{2}^{19}-\mathrm{A}$ & 3- 191 & Not Reported & Ground & & & & & 17719.3 & \\
\hline $\mathrm{C}^{12} \mathrm{H}_{3} \mathrm{C}^{12} \mathrm{~F}^{19}: \mathrm{C}^{12} \mathrm{H}_{2}$ & 3- 721 & $8,6,2 \leftarrow 8,5,3$ & Ground & & & & & 17723.34 & .1 \\
\hline $\mathrm{C}_{6}^{12} \mathrm{H}_{5} \mathrm{~F}^{19}$ & 4-1281 & Not Reported & & & & & & 17724. & 5. \\
\hline $\mathrm{D}_{2} \mathrm{C}^{12}: \mathrm{C}^{12} \mathrm{O}^{16}$ & 4- 712 & $1,0,1 \leftarrow 0,0,0$ & Excited & & & & & 17.727 .13 & \\
\hline $\mathrm{C}^{12} \mathrm{H}_{3} \mathrm{C}^{12} \mathrm{~F}^{19}: \mathrm{C}^{12} \mathrm{H}_{2}$ & 3- 721 & $8,6,2 \leftarrow 8,5,3$ & Ground & & & & & 17727.50 & .1 \\
\hline $\mathrm{C}^{12}{ }_{*} \mathrm{H}: \mathrm{C}^{12} \mathrm{HO}^{18} \mathrm{C}^{12} \mathrm{H}: \mathrm{C}^{12}{ }_{*} \mathrm{H}$ & 4.1152 & $4,4,1 \leftarrow 4,2,2$ & Ground & & & & & 17729.3 & .2 \\
\hline $\mathrm{S}^{32}{ }_{*} \mathrm{HC}^{12}: \mathrm{C}^{12} \mathrm{DC}^{12} \mathrm{D}: \mathrm{C}^{12}{ }_{*} \mathrm{H}$ & 4-1164 & $2,1,1 \leftarrow 1,1,0$ & Ground & & & & & 17729.6 & .1 \\
\hline $\mathrm{S}^{32}{ }_{*} \mathrm{HC}^{12}: \mathrm{C}^{12} \mathrm{DC}^{12} \mathrm{D}: \mathrm{C}^{12}{ }_{*} \mathrm{H}$ & $4 \cdot 1164$ & $11,5,7 \leftarrow 11,5,6$ & Ground & & & & & 17731.0 & .1 \\
\hline $\mathrm{HC}^{12}: \mathrm{C}^{12} \mathrm{C}^{12} \mathrm{H}: \mathrm{C}^{12} \mathrm{H}_{2}$ & $4-1131$ & $2,1,2 \leftarrow 1,1,1$ & Ground & & & & & 17734.50 & \\
\hline $\mathrm{C}^{12} \mathrm{H}_{3} \mathrm{C}^{12} \mathrm{~F}^{19}: \mathrm{C}^{12} \mathrm{H}_{2}$ & 3. 721 & $8,6,2 \leftarrow 8,5,3$ & Ground & & & & & 17734.82 & .1 \\
\hline $\mathrm{c}-\mathrm{HDC}^{12}: \mathrm{C}^{12} \mathrm{DF}^{19}$ & 4. 789 & $1,0,1 \leftarrow 0,0,0$ & Ground & & & & & 17743.8 & .1 \\
\hline $\mathrm{Ga}^{69} \mathrm{Cl}^{35}$ & $1-$ & $2 \leftarrow 1$ & Excited & $7 / 2$ & 3 & $5 / 2$ & 2 & 17743.96 & 0.50 \\
\hline $\mathrm{Ga}^{69} \mathrm{Cl}^{35}$ & $1 \cdot$ & $2 \leftarrow 1$ & Excited & $7 / 2$ & 3 & $5 / 2$ & 3 & 17743.96 & 0.50 \\
\hline $\mathrm{Ga}^{69} \mathrm{Cl}^{35}$ & $1-$ & $2 \leftarrow 1$ & Excited & $7 / 2$ & 4 & $5 / 2$ & 3 & 17743.96 & 0.50 \\
\hline $\mathrm{Ga}^{69} \mathrm{Cl}^{35}$ & $1-$ & $2 \leftarrow 1$ & Excited & $7 / 2$ & 5 & $5 / 2$ & 4 & 17743.96 & 0.50 \\
\hline $\mathrm{Ga}^{69} \mathrm{Cl}^{35}$ & $1-$ & $2 \leftarrow 1$ & Excited & $7 / 2$ & 2 & $5 / 2$ & 1 & 17743.96 & 0.50 \\
\hline $\mathrm{Ga}^{69} \mathrm{Cl}^{35}$ & $1-$ & $2 \leftarrow 1$ & Excited & $7 / 2$ & 2 & $5 / 2$ & 2 & 17743.96 & 0.50 \\
\hline $\mathrm{Ga}^{69} \mathrm{Cl}^{35}$ & $1-$ & $2 \leftarrow 1$ & Excited & $5 / 2$ & 4 & $3 / 2$ & 3 & 17743.96 & 0.50 \\
\hline $\mathrm{Ga}^{69} \mathrm{Cl}^{35}$ & $1-$ & $2 \leftarrow 1$ & Excited & $5 / 2$ & 2 & $3 / 2$ & 1 & 17743.96 & 0.50 \\
\hline $\mathrm{Ga}^{69} \mathrm{Cl}^{35}$ & $1-$ & $2 \leftarrow 1$ & Excited & $5 / 2$ & 3 & $3 / 2$ & 3 & 17743.96 & 0.50 \\
\hline $\mathrm{Ga}^{69} \mathrm{Cl}^{35}$ & $1-$ & $2 \leftarrow 1$ & Excited & $5 / 2$ & 1 & $3 / 2$ & 0 & 17743.96 & 0.50 \\
\hline $\mathrm{Ga}^{69} \mathrm{Cl}^{35}$ & 1 . & $2 \leftarrow 1$ & Excited & $5 / 2$ & 1 & $3 / 2$ & 1 & 17743.96 & 0.50 \\
\hline $\mathrm{C}^{12} \mathrm{H}_{2} \mathrm{~N}^{14} \mathrm{O}^{16} \mathrm{H}$ & 3- 141 & $5,2,4 \leftarrow 6,1,5$ & Ground & & 5 & & 6 & 17744.62 & .10 \\
\hline $\mathrm{C}^{12} \mathrm{H}_{3} \mathrm{C}^{12} \mathrm{O}^{16} \mathrm{~F}^{19}$ & 3- 391 & $10,7,3 \leftarrow-10,7,4$ & Ground & & & & & 17745.20 & .2 \\
\hline
\end{tabular}




\begin{tabular}{|c|c|c|c|c|c|c|c|c|c|}
\hline Isotopic Species & $\begin{array}{l}\text { Vol.-Id. } \\
\text { Nos. }\end{array}$ & $\begin{array}{c}\text { Rotational } \\
\text { Quantum Nos. }\end{array}$ & Vib. State & $F_{1}^{\prime}$ & $\begin{array}{l}\text { Hyy, } \\
\mathrm{F}^{\prime}\end{array}$ & rfine & F & $\begin{array}{l}\text { Frequenry } \\
\text { MIIz }\end{array}$ & $\begin{aligned} \text { Ares. } \\
\pm \mathrm{MH} \%\end{aligned}$ \\
\hline $\mathrm{C}^{12} \mathrm{H}_{2} \mathrm{~N}^{14} \mathrm{O}^{16} \mathrm{H}$ & 3- 141 & $5,2,4 \leftarrow 6,1,5$ & Ground & & 6 & & 7 & 17745.95 & .10 \\
\hline $\mathrm{C}^{12} \mathrm{H}_{2} \mathrm{~N}^{14} \mathrm{O}^{16} \mathrm{H}$ & 3- 141 & $5,2,4 \leftarrow 6,1,5$ & Ground & & 4 & & 5 & 17745.95 & .10 \\
\hline $\mathrm{HC}^{13}: \mathrm{C}^{12} \mathrm{C}^{12} \mathrm{HO}^{16}$ & 4. 912 & $2,1,2 \leftarrow 1,1,1$ & Ground & & & & & 17748.96 & .02 \\
\hline $\mathrm{C}_{6}^{12} \mathrm{H}_{5} \mathrm{O}^{16} \mathrm{H}$ & 3-1051 & $12,4,8 \leftarrow 12,3,9$ & Ground & & & & & 17752.3 & \\
\hline $\mathrm{Ga}^{71} \mathrm{Cl}^{35}$ & 1 - & $2 \leftarrow 1$ & Ground & $7 / 2$ & 2 & $5 / 2$ & 1 & 17759.09 & 0.50 \\
\hline $\mathrm{Ga}^{71} \mathrm{Cl}^{35}$ & $1-$ & $2 \leftarrow 1$ & Ground & $7 / 2$ & 3 & $5 / 2$ & 3 & 17759.09 & 0.50 \\
\hline $\mathrm{Ga}^{71} \mathrm{Cl}^{35}$ & $1-$ & $2 \leftarrow 1$ & Ground & $7 / 2$ & 2 & $5 / 2$ & 2 & 17759.09 & 0.50 \\
\hline $\mathrm{Ga}^{71} \mathrm{Cl}^{35}$ & 1 . & $2 \leftarrow 1$ & Ground & $7 / 2$ & 3 & $5 / 2$ & 2 & 17759.09 & 0.50 \\
\hline $\mathrm{Ga}^{71} \mathrm{Cl}^{35}$ & $1-$ & $2 \leftarrow 1$ & Ground & $5 / 2$ & 1 & $3 / 2$ & 0 & 17759.09 & 0.50 \\
\hline $\mathrm{Ga}^{71} \mathrm{Cl}^{35}$ & 1 . & $2 \leftarrow 1$ & Ground & $7 / 2$ & 5 & $5 / 2$ & 4 & 17759.09 & 0.50 \\
\hline $\mathrm{Ga}^{71} \mathrm{Cl}^{35}$ & $1 \cdot$ & $2 \leftarrow 1$ & Ground & $5 / 2$ & 1 & $3 / 2$ & 1 & 17759.09 & 0.50 \\
\hline $\mathrm{Ga}^{71} \mathrm{Cl}^{35}$ & $1-$ & $2 \leftarrow 1$ & Ground & $5 / 2$ & 2 & $3 / 2$ & 1 & 17759.09 & 0.50 \\
\hline $\mathrm{Ga}^{71} \mathrm{Cl}^{35}$ & $1-$ & $2 \leftarrow 1$ & Ground & $5 / 2$ & 3 & $3 / 2$ & 3 & 17759.09 & 0.50 \\
\hline $\mathrm{Ga}^{71} \mathrm{Cl}^{35}$ & $1-$ & $2 \leftarrow 1$ & Ground & $5 / 2$ & 4 & $3 / 2$ & 3 & 17759.09 & 0.50 \\
\hline $\mathrm{Ga}^{71} \mathrm{Cl}^{35}$ & $1-$ & $2 \leftarrow 1$ & Ground & $7 / 2$ & 4 & $5 / 2$ & 3 & 17759.09 & 0.50 \\
\hline $\mathrm{F}_{2}^{19} \mathrm{O}_{2}^{16}$ & 3. 11 & $3,1,2 \leftarrow 3,0,3$ & Ground & & & & & 17764.15 & .1 \\
\hline $\mathrm{C}_{6}^{12} \mathrm{H}_{5} \mathrm{~N}^{14} \mathrm{O}_{2}^{16}$ & $3 \cdot 1041$ & $8,2,7 \leftarrow 7,2,6$ & Ground & & & & & 17765. & 2. \\
\hline${ }^{\mathrm{t}}-\mathrm{C}^{12} \mathrm{H}_{3} \mathrm{C}^{12} \mathrm{H}: \mathrm{C}^{12} \mathrm{HC}^{12} \mathrm{~N}^{14}$ & 3- 921 & $4,1, \leftarrow 3,1$, & Ground & & & & & 17765.04 & .5 \\
\hline $\mathrm{C}^{12} \mathrm{D}_{3} \mathrm{O}^{16} \mathrm{H}$ & 3- 214 & Not Reported & Ground & & & & & 17775.1 & .5 \\
\hline $\mathrm{s}-\mathrm{C}^{12} \mathrm{H}_{2} \mathrm{DC}^{12} \mathrm{HO}^{16}$ & 3- 473 & Not Reported & & & & & & 17777.2 & \\
\hline $\mathrm{C}^{12} \mathrm{H}_{2}: \mathrm{C}^{12} \mathrm{HC}^{12} \mathrm{~F}^{19}: \mathrm{C}^{12} \mathrm{H}_{2}$ & 3- 911 & $6,2,4 \leftarrow 6,1,5$ & Ground & & & & & 17778.5 & .2 \\
\hline $\mathrm{C}^{\mathrm{b}} \mathrm{H}_{2}^{\mathrm{b}} \mathrm{Cl}^{\mathrm{b}} \mathrm{F}^{\mathrm{b}}$ & 4- 333 & Not Reported & & & & & & 17782.62 & .1 \\
\hline $\mathrm{C}^{\mathrm{b}} \mathrm{H}_{2}^{\mathrm{b}} \mathrm{Cl}^{\mathrm{b}} \mathrm{F}^{\mathrm{b}}$ & 4- 333 & Not Reported & & & & & & 17783.68 & .1 \\
\hline $\mathrm{C}^{12} \mathrm{H}_{2} \mathrm{~N}^{14} \mathrm{O}^{16} \mathrm{H}$ & 3- 141 & $4,1,3 \leftarrow 4,1,4$ & Ground & & 3 & & 3 & 17784.10 & .10 \\
\hline $\mathrm{C}^{12} \mathrm{H}_{2} \mathrm{~N}^{14} \mathrm{O}^{16} \mathrm{H}$ & 3- 141 & $4,1,3 \leftarrow 4,1,4$ & Ground & & 5 & & 5 & 17784.10 & .10 \\
\hline $\mathrm{C}^{12} \mathrm{H}_{2} \mathrm{~N}^{14} \mathrm{O}^{16} \mathrm{H}$ & 3- 141 & $4,1,3 \leftarrow 4,1,4$ & Ground & & 4 & & 4 & 17786.54 & .10 \\
\hline $\mathrm{H}_{2} \mathrm{~N}^{14} \mathrm{~N}^{14} \mathrm{H}_{2}$ & 3. 51 & Not Reported & & & & & & 17797.71 & \\
\hline $\mathrm{C}^{12} \mathrm{O}^{16} \mathrm{~F}_{2}^{19}$ & 4- 211 & $2,2,1 \leftarrow 2,0,2$ & Ground & & & & & 17798.14 & .10 \\
\hline $\mathrm{S}^{32} \mathrm{O}^{16} \mathrm{~F}_{2}^{19}$ & 4-1621 & Not Reported & & & & & & 17798.42 & .1 \\
\hline $\mathrm{C}^{13} \mathrm{O}^{16} \mathrm{~F}_{2}^{19}$ & 4- 212 & $2,2,1 \leftarrow 2,0,2$ & Ground & & & & & 17805.26 & .10 \\
\hline $\mathrm{Tl}^{205} \mathrm{I}^{127}$ & $1-$ & $11 \leftarrow 10$ & Excited & & & & & 17809.2 & \\
\hline${ }^{a}-\mathrm{C}^{12} \mathrm{H}_{3} \mathrm{C}^{12} \mathrm{H}_{2} \mathrm{C}^{12} \mathrm{H}_{2} \mathrm{Cl}^{35}$ & 3- 773 & $3,1,3 \leftarrow 2,1,2$ & Ground & & & & & 17810.83 & .2 \\
\hline $\mathrm{C}^{12} \mathrm{H}_{3} \mathrm{Si}^{28} \mathrm{HF}_{2}^{19}-\mathrm{A}$ & 3- 191 & Not Reported & Ground & & & & & 17817.1 & \\
\hline $\mathrm{C}^{12} \mathrm{H}_{3} \mathrm{C}^{12} \mathrm{D}_{3} \mathrm{Si}^{28} \mathrm{H}_{2}$ & 3- 642 & $5,1,4 \leftarrow 5,0,5$ & Ground & & & & & 17823.41 & .05 \\
\hline $\mathrm{C}^{12} \mathrm{H}_{3} \mathrm{C}^{12} \mathrm{D}_{3} \mathrm{Si}^{28} \mathrm{H}_{2}$ & 3- 642 & $5,1,4 \leftarrow 5,0,5$ & Ground & & & & & 17824.74 & .05 \\
\hline $\mathrm{Tl}^{203} \mathrm{I}^{127}$ & 1 - & $11 \leftarrow 10$ & Excited & & & & & 17831.8 & \\
\hline $\mathrm{HC}^{12}: \mathrm{C}^{12} \mathrm{C}^{12} \mathrm{HO}^{18}$ & 4- 915 & $2,0,2 \leftarrow 1,0,1$ & Ground & & & & & 17833.28 & .05 \\
\hline $\mathrm{C}^{12}{ }_{*} \mathrm{H}: \mathrm{C}^{12} \mathrm{HC}^{12} \mathrm{H}: \mathrm{C}^{12} \mathrm{HN}^{14}{ }_{*} \mathrm{D}$ & 4-1182 & $6,4,2 \leftarrow 6,4,3$ & Ground & & & & & 17834.1 & \\
\hline $\mathrm{Ga}^{69} \mathrm{Cl}^{35}$ & $1-$ & $2 \leftarrow 1$ & Excited & $5 / 2$ & 2 & $3 / 2$ & 1 & 17837.00 & 0.50 \\
\hline $\mathrm{Ga}^{69} \mathrm{Cl}^{35}$ & 1 . & $2 \leftarrow 1$ & Excited & $5 / 2$ & 1 & $3 / 2$ & 0 & 17837.00 & 0.50 \\
\hline $\mathrm{Ga}^{69} \mathrm{Cl}^{35}$ & $1-$ & $2 \leftarrow 1$ & Excited & $5 / 2$ & 1 & $3 / 2$ & 1 & 17837.00 & 0.50 \\
\hline $\mathrm{Ga}^{69} \mathrm{Cl}^{35}$ & 1 - & $2 \leftarrow 1$ & Excited & $5 / 2$ & 3 & $3 / 2$ & 3 & 17837.00 & 0.50 \\
\hline $\mathrm{Ga}^{69} \mathrm{Cl}^{35}$ & $1-$ & $2 \leftarrow 1$ & Excited & $5 / 2$ & 4 & $3 / 2$ & 3 & 17837.00 & 0.50 \\
\hline $\mathrm{Ga}^{69} \mathrm{Cl}^{35}$ & $1-$ & $2 \leftarrow 1$ & Excited & $7 / 2$ & 2 & $5 / 2$ & 1 & 17837.00 & 0.50 \\
\hline $\mathrm{Ga}^{69} \mathrm{Cl}^{35}$ & $1-$ & $2 \leftarrow 1$ & Excited & $7 / 2$ & 2 & $5 / 2$ & 2 & 17837.00 & 0.50 \\
\hline
\end{tabular}




\begin{tabular}{|c|c|c|c|c|c|c|c|c|c|}
\hline Isotopic Species & $\begin{array}{l}\text { Vol.-Id. } \\
\text { Nos. }\end{array}$ & $\begin{array}{c}\text { Rotational } \\
\text { Quantum Nos. }\end{array}$ & Vib. State & $\mathrm{F}_{1}^{\prime}$ & $\begin{array}{l}\text { Hyper } \\
F^{\prime}\end{array}$ & $\begin{array}{l}\text { rfine } \\
F_{1}\end{array}$ & $\mathbf{F}$ & $\begin{array}{l}\text { Frequency } \\
\qquad \mathrm{MHz}\end{array}$ & $\begin{array}{r}\text { Acc. } \\
\pm \mathrm{MHz}\end{array}$ \\
\hline $\mathrm{Ga}^{69} \mathrm{Cl}^{35}$ & $1-$ & $2 \leftarrow 1$ & Excited & $7 / 2$ & 3 & $5 / 2$ & 2 & 17837.00 & 0.50 \\
\hline $\mathrm{Ga}^{69} \mathrm{Cl}^{35}$ & $1-$ & $2 \leftarrow 1$ & Excited & $7 / 2$ & 3 & $5 / 2$ & 3 & 17837.00 & 0.50 \\
\hline $\mathrm{Ca}^{69} \mathrm{Cl}^{35}$ & $1-$ & $2 \leftarrow 1$ & Excited & $7 / 2$ & 4 & $5 / 2$ & 3 & 17837.00 & 0.50 \\
\hline $\mathrm{Ga}^{69} \mathrm{Cl}^{35}$ & $1-$ & $2 \leftarrow 1$ & Excited & $7 / 2$ & 5 & $5 / 2$ & 4 & 17837.00 & 0.50 \\
\hline $\mathrm{HC}^{12}: \mathrm{C}^{12} \mathrm{C}^{13} \mathrm{DO}^{16}$ & 4. 924 & $2,1,2 \leftarrow 1,1,1$ & Ground & & & & & 17839.00 & .02 \\
\hline $\mathrm{C}^{12} \mathrm{D}_{3} \mathrm{O}^{16} \mathrm{H}$ & 3- 214 & Not Reported & Ground & & & & & 17839.1 & .5 \\
\hline $\mathrm{C}^{12} \mathrm{H}_{3} \mathrm{C}^{12} \mathrm{O}^{16} \mathrm{~F}^{19}$ & 3- 391 & $10,7,3 \leftarrow 10,7,4$ & Ground & & & & & 17839.23 & .2 \\
\hline $\mathrm{HC}^{12}: \mathrm{C}^{13} \mathrm{C}^{12} \mathrm{DO}^{16}$ & 4- 923 & $2,1,2 \leftarrow 1,1.1$ & Ground & & & & & 17842.78 & .02 \\
\hline $\mathrm{H}_{2} \mathrm{C}^{12}: \mathrm{C}^{12} \mathrm{~F}_{2}^{19}$ & 4- 681 & Not Reported & & & & & & 17843.8 & .3 \\
\hline $\mathrm{C}^{12}{ }_{*} \mathrm{D}: \mathrm{C}^{12} \mathrm{HC}^{12} \mathrm{H}: \mathrm{C}^{12} \mathrm{HN}^{14}{ }_{*} \mathrm{H}$ & $4-1183$ & $7,7,0 \leftarrow 7,6,1$ & Ground & & & & & 17845.0 & \\
\hline $\mathrm{DC}^{12}: \mathrm{C}^{12} \mathrm{C}^{12} \mathrm{HO}^{16}$ & 4- 916 & $4,1,4 \leftarrow 5,0,5$ & Ground & & & & & 17845.34 & .02 \\
\hline $\mathrm{C}^{12} \mathrm{H}_{3} \mathrm{~N}^{14} \mathrm{H}_{2}$ & 3- 261 & Not Reported & Ground & & & & & 17849.46 & .04 \\
\hline $\mathrm{T}]^{205} \mathbf{I}^{127}$ & $1-$ & $11 \leftarrow 10$ & Excited & & & & & 17852.8 & \\
\hline $\mathrm{N}^{15} \mathrm{H}_{3}$ & $4-1772$ & $8,5 \leftarrow 8,5$ & Ground & & & & & 17855.57 & .08 \\
\hline $\mathrm{Na}^{23} \mathrm{Br}^{79}$ & $1-$ & $2 \leftarrow 1$ & Excited & & $5 / 2$ & & $3 / 2$ & 17856.57 & .10 \\
\hline $\mathrm{Na}^{23} \mathrm{Br}^{79}$ & 1 - & $2 \leftarrow 1$ & Excited & & $7 / 2$ & & $5 / 2$ & 17856.57 & .10 \\
\hline $\mathrm{S}^{32}{ }_{*} \mathrm{HC}^{13}: \mathrm{C}^{12} \mathrm{HC}^{12} \mathrm{H}: \mathrm{C}^{12}{ }_{*} \mathrm{H}$ & $4-1167$ & $12,6,6 \leftarrow 12,6,7$ & Ground & & & & & 17858.5 & .05 \\
\hline $\mathrm{C}^{13}{ }_{*} \mathrm{H}: \mathrm{C}^{12} \mathrm{HO}^{16} \mathrm{C}^{12} \mathrm{H}: \mathrm{C}^{12}{ }_{*} \mathrm{H}$ & $4-1157$ & $10,8,2 \leftarrow 10,8,3$ & Ground & & & & & 17863.7 & .1 \\
\hline $\mathrm{C}^{12} \mathrm{H}_{3} \mathrm{~N}^{14} \mathrm{O}_{2}^{16}$ & 3- 171 & Not Reported & Ground & & & & & 17864. & 5. \\
\hline $\mathrm{C}_{6}^{12} \mathrm{H}_{5} \mathrm{O}^{16} \mathrm{H}$ & 3-1051 & $12,4,8 \leftarrow 12,3,9$ & Ground & & & & & 17864.0 & \\
\hline $\mathrm{H}_{2} \mathrm{~N}^{14} \mathrm{~N}^{14} \mathrm{H}_{2}$ & 3- 51 & Not Reported & & & & & & 17865.95 & \\
\hline $\mathrm{Na}^{23} \mathrm{Br}^{81}$ & 1 . & $2 \leftarrow 1$ & Excited & & $7 / 2$ & & $5 / 2$ & 17868.49 & .10 \\
\hline $\mathrm{Na}^{23} \mathrm{Br}^{81}$ & 1 - & $2 \leftarrow 1$ & Excited & & $5 / 2$ & & $3 / 2$ & 17868.49 & .10 \\
\hline $\mathrm{s}-\mathrm{C}^{12} \mathrm{H}_{2} \mathrm{DC}^{12} \mathrm{HO}^{16}$ & 3- 473 & Not Reported & & & & & & 17868.8 & \\
\hline$c-\mathrm{HF}^{19} \mathrm{C}^{12}: \mathrm{C}^{12} \mathrm{HF}^{19}$ & 4- 691 & $2,1,1 \leftarrow 2,0,2$ & Ground & & & & & 17870.03 & .05 \\
\hline $\mathrm{C}^{13} \mathrm{H}_{3} \mathrm{O}^{16} \mathrm{H}$ & 3. 213 & $31,2, \leftarrow 31,1$, & Ground & & & & & 17870.5 & .1 \\
\hline $\mathrm{C}^{12} \mathrm{H}_{3} \mathrm{~N}^{14} \mathrm{H}_{2}$ & 3- 261 & Not Reported & Ground & & & & & 17874.52 & .1 \\
\hline$\left(\mathrm{C}^{12} \mathrm{H}_{3}\right)_{2} \mathrm{~S}^{32}$ & 3. 601 & $3,1,2 \leftarrow 3,0,3$ & Ground & & & & & 17874.98 & .05 \\
\hline$\left(\mathrm{C}^{12} \mathrm{H}_{3}\right)_{2} \mathrm{~S}^{32}$ & 3- 601 & $3,1,2 \leftarrow 3,0,3$ & Ground & & & & & 17875.28 & .05 \\
\hline$\left(\mathrm{C}^{12} \mathrm{H}_{3}\right)_{2} \mathrm{~S}^{32}$ & 3- 601 & $3,1,2 \leftarrow 3,0,3$ & Ground & & & & & 17875.29 & .05 \\
\hline$\left(\mathrm{C}^{12} \mathrm{H}_{3}\right)_{2} \mathrm{~S}^{32}$ & 3- 601 & $3,1,2 \leftarrow 3,0,3$ & Ground & & & & & 17875.58 & .05 \\
\hline$\left(\mathrm{C}^{12} \mathrm{H}_{3}\right)_{2} \mathrm{~S}^{32}$ & 3- 601 & $3,1,2 \leftarrow 3,0,3$ & Ground & & & & & 17875.61 & .05 \\
\hline $\mathrm{T}^{203} \mathrm{I}^{127}$ & $1-$ & $11 \leftarrow 10$ & Excited & & & & & 17875.8 & \\
\hline $\mathrm{C}^{12} \mathrm{H}_{3} \mathrm{~N}^{14} \mathrm{H}_{2}$ & 3. 261 & Not Reported & Ground & & & & & 17887.20 & .1 \\
\hline $\mathrm{C}^{12} \mathrm{O}^{16} \mathrm{~F}_{2}^{19}$ & 4- 211 & $3,3,1 \leftarrow 3,1,2$ & Ground & & & & & 17890.51 & .10 \\
\hline $\mathrm{C}^{12} \mathrm{H}_{3} \mathrm{C}^{12} \mathrm{H}_{2} \mathrm{C}^{12} \mathrm{~N}^{14}$ & 3. 731 & $2,0,2 \leftarrow 1,0,1$ & Ground & & & & & 17891.0 & .2 \\
\hline $\mathrm{H}_{2} \mathrm{C}^{12}: \mathrm{C}^{12} \mathrm{~F}_{2}^{19}$ & 4- 681 & Not Reported & & & & & & 17892.1 & .3 \\
\hline $\mathrm{Tl}^{205} \mathrm{I}^{127}$ & $1-$ & $11 \leftarrow 10$ & Ground & & & & & 17896.0 & \\
\hline $\mathrm{C}^{12} \mathrm{H}_{3} \mathrm{C}^{12} \mathrm{H}_{2} \mathrm{C}^{12} \mathrm{~N}^{14}$ & 3- 731 & $2,0,2 \leftarrow 1,0,1$ & Ground & & & & & 17896.9 & .2 \\
\hline $\mathrm{D}_{2} \mathrm{~N}^{14} \mathrm{C}^{12} \mathrm{~N}^{14}$ & 4- 363 & $1,0,1 \leftarrow 0,0,0$ & Ground & & & & & 17899.7 & .1 \\
\hline $\mathrm{F}_{2}^{19} \mathrm{O}_{2}^{16}$ & 3- 11 & $3,1,2 \leftarrow 3,0,3$ & Ground & & & & & 17903.30 & .1 \\
\hline $\mathrm{C}^{12} \mathrm{H}_{3} \mathrm{~N}^{14} \mathrm{O}_{2}^{16}$ & 3. 171 & Not Reported & Ground & & & & & 17904.86 & \\
\hline $\mathrm{D}_{2} \mathrm{~N}^{14} \mathrm{C}^{12} \mathrm{~N}^{14}$ & 4- 363 & $1,0,1 \leftarrow 0,0,0$ & Excited & & & & & 17905.2 & .2 \\
\hline $\mathrm{Ca}^{69} \mathrm{Cl}^{35}$ & $1-$ & $2 \leftarrow 1$ & Ground & $3 / 2$ & 1 & $1 / 2$ & 1 & 17906.92 & 0.20 \\
\hline $\mathrm{Cra}^{69} \mathrm{Cl}^{35}$ & $1-$ & $2 \leftarrow 1$ & Cround & $5 / 2$ & 4 & $5 / 2$ & 4 & 17906.92 & 0.20 \\
\hline
\end{tabular}




\begin{tabular}{|c|c|c|c|c|c|c|c|c|c|}
\hline Isotopic Species & $\begin{array}{l}\text { Vol.-Id. } \\
\text { Nos. }\end{array}$ & $\begin{array}{c}\text { Rotational } \\
\text { Quantum Nos. }\end{array}$ & Vib. State & $\mathrm{F}_{1}^{\prime 11}$ & yper| & $\underset{F_{1}}{\text { fine }}$ & $\mathrm{F}$ & $\begin{array}{c}\text { Frerpency } \\
\mathrm{MHz}^{-}\end{array}$ & $\begin{array}{l}\text { Acce } \\
\pm \mathrm{MH} \%\end{array}$ \\
\hline $\mathrm{Ga}^{69} \mathrm{Cl}^{35}$ & 1. & $2 \leftarrow 1$ & Ground & $5 / 2$ & 4 & $5 / 2$ & 3 & 17906.92 & 0.20 \\
\hline $\mathrm{Ga}^{69} \mathrm{Cl}^{35}$ & $1-$ & $2 \leftarrow 1$ & Ground & $5 / 2$ & 3 & $5 / 2$ & 4 & 17906.92 & 0.20 \\
\hline $\mathrm{Ga}^{69} \mathrm{Cl}^{35}$ & $1-$ & $2 \leftarrow 1$ & Ground & $5 / 2$ & 3 & $5 / 2$ & 3 & 17906.92 & 0.20 \\
\hline $\mathrm{Ga}^{69} \mathrm{Cl}^{35}$ & $1-$ & $2 \leftarrow 1$ & Ground & $5 / 2$ & 3 & $5 / 2$ & 2 & 17906.92 & 0.20 \\
\hline $\mathrm{Ga}^{69} \mathrm{Cl}^{35}$ & $1-$ & $2 \leftarrow 1$ & Ground & $5 / 2$ & 2 & $5 / 2$ & 3 & 17906.92 & 0.20 \\
\hline $\mathrm{Ga}^{69} \mathrm{Cl}^{35}$ & $1-$ & $2 \leftarrow 1$ & Ground & $5 / 2$ & 2 & $5 / 2$ & 2 & 17906.92 & 0.20 \\
\hline $\mathrm{Ga}^{69} \mathrm{Cl}^{35}$ & 1. & $2 \leftarrow 1$ & Ground & $5 / 2$ & 2 & $5 / 2$ & 1 & 17906.92 & 0.20 \\
\hline $\mathrm{Ga}^{69} \mathrm{Cl}^{35}$ & 1 . & $2 \leftarrow 1$ & Ground & $5 / 2$ & 1 & $5 / 2$ & 2 & 17906.92 & 0.20 \\
\hline $\mathrm{Ga}^{69} \mathrm{Cl}^{35}$ & 1. & $2 \leftarrow 1$ & Ground & $3 / 2$ & 3 & $1 / 2$ & 2 & 17906.92 & 0.20 \\
\hline $\mathrm{Ga}^{69} \mathrm{Cl}^{35}$ & $1-$ & $2 \leftarrow 1$ & Ground & $3 / 2$ & 2 & $1 / 2$ & 1 & 17906.92 & 0.20 \\
\hline $\mathrm{Ga}^{69} \mathrm{Cl}^{35}$ & 1. & $2 \leftarrow 1$ & Ground & $3 / 2$ & 2 & $1 / 2$ & 2 & 17906.92 & 0.20 \\
\hline $\mathrm{C}^{13} \mathrm{O}^{16} \mathrm{~F}_{2}^{19}$ & 4. 212 & $3,3,1 \leftarrow 3,1,2$ & Ground & & & & & 17908.80 & .10 \\
\hline $\mathrm{C}^{12} \mathrm{H}_{3} \mathrm{O}^{16} \mathrm{H}$ & 3- 211 & Not Reported & Ground & & & & & 17911.1 & .1 \\
\hline $\mathrm{C}^{12} \mathrm{H}_{3} \mathrm{~N}^{14} \mathrm{H}_{2}$ & $3-261$ & Not Reported & Ground & & & & & 17913.74 & .04 \\
\hline $\mathrm{C}^{13} \mathrm{H}_{3} \mathrm{C}^{12} \mathrm{O}^{16} \mathrm{~F}^{19}$ & 3- 393 & $12,8,4 \leftarrow 12,8,5$ & Ground & & & & & 17915.80 & .2 \\
\hline $\mathrm{C}^{12} \mathrm{D}_{3} \mathrm{O}^{16} \mathrm{H}$ & 3- 214 & Not Reported & Ground & & & & & 17918.9 & .5 \\
\hline$T l^{203} I^{127}$ & $1-$ & $11 \leftarrow 10$ & Excited & & & & & 17919.2 & \\
\hline $\mathrm{C}^{12} \mathrm{H}_{3} \mathrm{C}^{12} \mathrm{H}_{2} \mathrm{C}^{12} \mathrm{~N}^{14}$ & 3- 731 & $2,0,2 \leftarrow 1,0,1$ & Excited & & & & & 17920.3 & .2 \\
\hline $4 d-C_{6}^{12} H_{5} F^{19}$ & 4-1283 & $4,1,3 \leftarrow 3,1,2$ & Ground & & & & & 17920.4 & .1 \\
\hline $\mathrm{HC}^{12}: \mathrm{C}^{12} \mathrm{C}^{12} \mathrm{DO}^{16}$ & 4- 921 & $2,1,2 \leftarrow 1,1,1$ & Ground & & & & & 17928.23 & .02 \\
\hline $\mathrm{Ga}^{69} \mathrm{Cl}^{35}$ & $1-$ & $2 \leftarrow 1$ & Ground & $1 / 2$ & 1 & $1 / 2$ & 1 & 17928.55 & 0.20 \\
\hline $\mathrm{Ga}^{69} \mathrm{Cl}^{35}$ & 1 - & $2 \leftarrow 1$ & Ground & $7 / 2$ & 4 & $5 / 2$ & 4 & 17928.55 & 0.20 \\
\hline $\mathrm{Ga}^{69} \mathrm{Cl}^{35}$ & 1 . & $2 \leftarrow 1$ & Ground & $5 / 2$ & 3 & $3 / 2$ & 2 & 17928.55 & 0.20 \\
\hline $\mathrm{Ga}^{69} \mathrm{Cl}^{35}$ & $1-$ & $2 \leftarrow 1$ & Ground & $5 / 2$ & 2 & $3 / 2$ & 2 & 17928.55 & 0.20 \\
\hline $\mathrm{Ga}^{69} \mathrm{Cl}^{35}$ & 1 - & $2 \leftarrow 1$ & Ground & $1 / 2$ & 1 & $1 / 2$ & 2 & 17928.55 & 0.20 \\
\hline $\mathrm{Ga}^{69} \mathrm{Cl}^{35}$ & $1-$ & $2 \leftarrow 1$ & Ground & $1 / 2$ & 2 & $1 / 2$ & 1 & 17928.55 & 0.20 \\
\hline $\mathrm{Ga}^{69} \mathrm{Cl}^{35}$ & $1-$ & $2 \leftarrow 1$ & Ground & $1 / 2$ & 2 & $1 / 2$ & 2 & 17928.55 & 0.20 \\
\hline $\mathrm{Ga}^{69} \mathrm{Cl}^{35}$ & 1. & $2 \leftarrow 1$ & Ground & $7 / 2$ & 3 & $5 / 2$ & 2 & 17930.57 & 0.20 \\
\hline $\mathrm{Ga}^{69} \mathrm{Cl}^{35}$ & 1 . & $2 \leftarrow 1$ & Ground & $7 / 2$ & 2 & $5 / 2$ & 2 & 17930.57 & 0.20 \\
\hline $\mathrm{Ga}^{69} \mathrm{Cl}^{25}$ & 1. & $2 \leftarrow 1$ & Ground & $7 / 2$ & 2 & $5 / 2$ & 1 & 17930.57 & 0.20 \\
\hline $\mathrm{Ga}^{69} \mathrm{Cl}^{35}$ & $1-$ & $2 \leftarrow 1$ & Ground & $5 / 2$ & 4 & $3 / 2$ & 3 & 17930.57 & 0.20 \\
\hline $\mathrm{Ga}^{69} \mathrm{Cl}^{35}$ & 1 - & $2 \leftarrow 1$ & Ground & $5 / 2$ & 3 & $3 / 2$ & 3 & 17930.57 & 0.20 \\
\hline $\mathrm{Ga}^{69} \mathrm{Cl}^{35}$ & 1 - & $2 \leftarrow 1$ & Ground & $5 / 2$ & 2 & $3 / 2$ & 1 & 17930.57 & 0.20 \\
\hline $\mathrm{Ga}^{69} \mathrm{Cl}^{35}$ & 1 . & $2 \leftarrow 1$ & Ground & $5 / 2$ & 1 & $3 / 2$ & 1 & 17930.57 & 0.20 \\
\hline $\mathrm{Ga}^{69} \mathrm{Cl}^{35}$ & $1-$ & $2 \leftarrow 1$ & Ground & $5 / 2$ & 1 & $3 / 2$ & 0 & 17930.57 & 0.20 \\
\hline $\mathrm{Ga}^{69} \mathrm{Cl}^{35}$ & 1 . & $2 \leftarrow 1$ & Ground & $7 / 2$ & 3 & $5 / 2$ & 3 & 17930.57 & 0.20 \\
\hline $\mathrm{Ga}^{69} \mathrm{Cl}^{35}$ & 1 . & $2 \leftarrow 1$ & Ground & $7 / 2$ & 4 & $5 / 2$ & 3 & 17930.57 & 0.20 \\
\hline $\mathrm{Ga}^{69} \mathrm{Cl}^{35}$ & $1-$ & $2 \leftarrow 1$ & Ground & $7 / 2$ & 5 & $5 / 2$ & 4 & 17930.57 & 0.20 \\
\hline $\mathrm{Ga}^{69} \mathrm{Cl}^{35}$ & 1 - & $2 \leftarrow 1$ & Ground & $3 / 2$ & 1 & $3 / 2$ & 2 & 17942.92 & 0.40 \\
\hline $\mathrm{Ga}^{69} \mathrm{Cl}^{35}$ & $1-$ & $2 \leftarrow 1$ & Ground & $3 / 2$ & 2 & $3 / 2$ & 2 & 17942.92 & 0.40 \\
\hline $\mathrm{Ga}^{69} \mathrm{Cl}^{35}$ & $1-$ & $2 \leftarrow 1$ & Ground & $3 / 2$ & 3 & $3 / 2$ & 2 & 17942.92 & 0.40 \\
\hline $\mathrm{N}^{15} \mathrm{H}_{3}$ & 4-1772 & $6,2 \leftarrow 6,2$ & Ground & & & & & 17943.45 & .10 \\
\hline $\mathrm{Bi}^{209} \mathrm{Cl}_{3}^{35}$ & 4. 71 & $6, \leftarrow 5$, & Ground & & & & & 17944. & 1. \\
\hline $\mathrm{Ga}^{69} \mathrm{Cl}^{35}$ & $1-$ & $2 \leftarrow 1$ & Ground & $3 / 2$ & 1 & $3 / 2$ & 1 & 17946.83 & 0.30 \\
\hline $\mathrm{Ga}^{69} \mathrm{Cl}^{35}$ & 1 . & $2 \leftarrow 1$ & Ground & $3 / 2$ & 1 & $3 / 2$ & 0 & 17946.83 & 0.30 \\
\hline
\end{tabular}




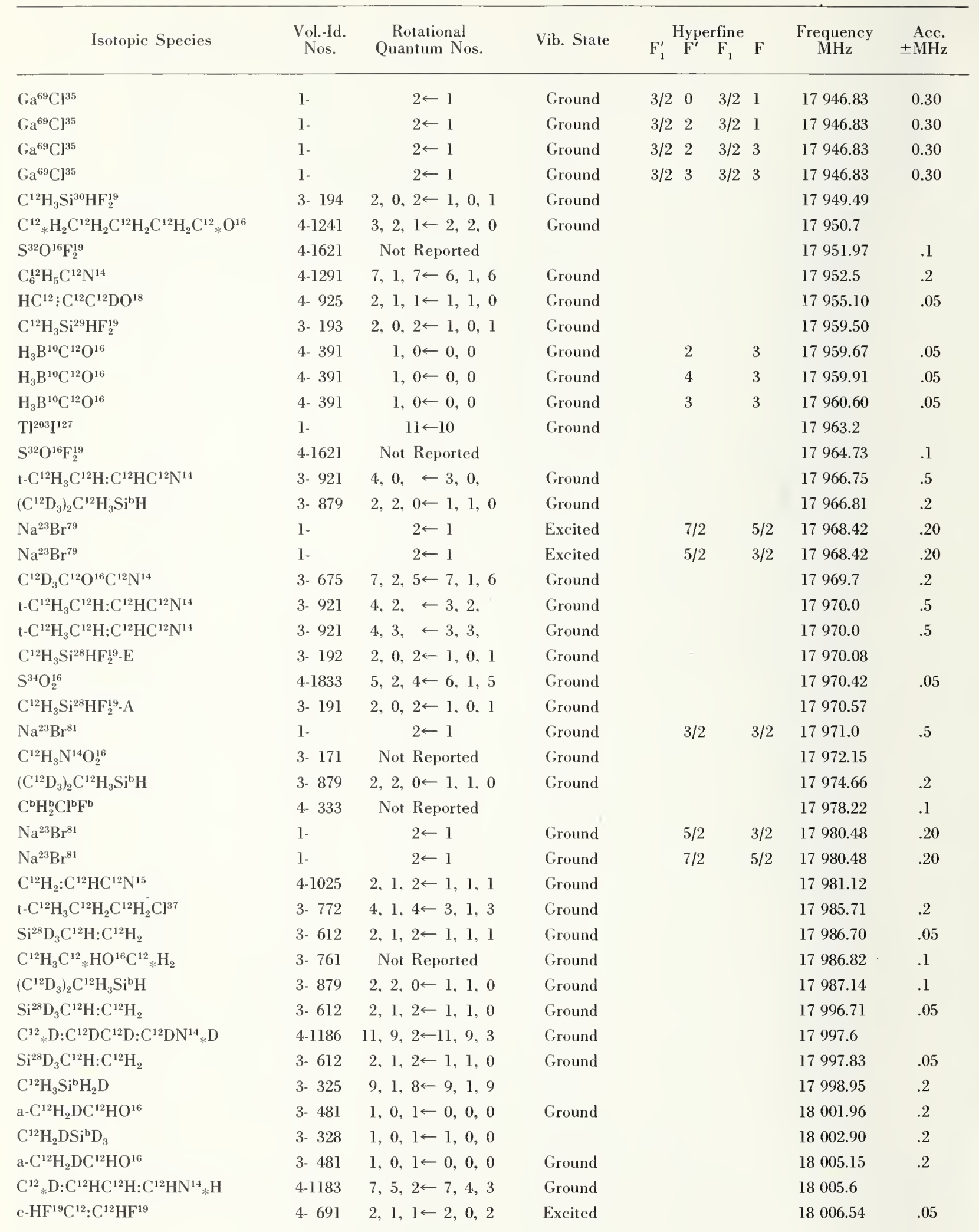




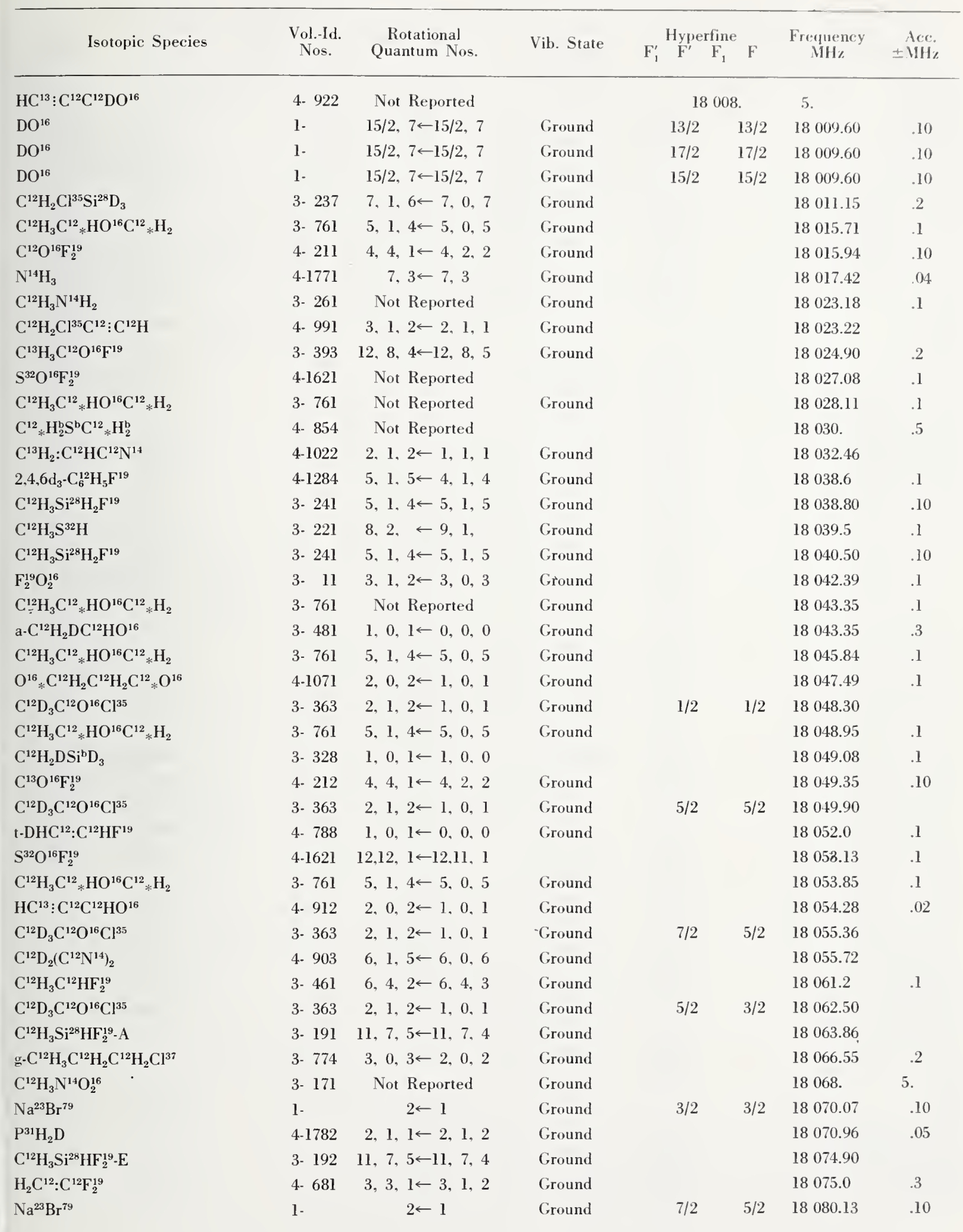




\begin{tabular}{|c|c|c|c|c|c|c|c|}
\hline Isotopic Species & $\begin{array}{l}\text { Vol.-Id. } \\
\text { Nos. }\end{array}$ & $\begin{array}{c}\text { Rotational } \\
\text { Quantum Nos. }\end{array}$ & Vib. State & $\mathrm{F}_{1}^{\prime} \quad \stackrel{\mathrm{F}^{\prime}}{\mathrm{F}_{1}}$ & $\mathrm{~F}$ & $\begin{array}{l}\text { Frequency } \\
\mathrm{MHz}\end{array}$ & $\begin{aligned} & \text { Acc. } \\
& \pm \mathrm{MHz}\end{aligned}$ \\
\hline $\mathrm{Na}^{23} \mathrm{Br}^{79}$ & 1 . & $2 \leftarrow 1$ & Ground & $5 / 2$ & $3 / 2$ & 18080.13 & .10 \\
\hline $\mathrm{C}^{12} \mathrm{D}_{3} \mathrm{O}^{16} \mathrm{H}$ & 3- 214 & Not Reported & Ground & & & 18081.2 & .5 \\
\hline $\mathrm{C}^{12} \mathrm{D}_{3} \mathrm{Si}^{29} \mathrm{H}_{3}$ & 3- 324 & $1, \leftarrow 0$, & & & & 18081.65 & .3 \\
\hline $\mathrm{H}_{2} \mathrm{~N}^{14} \mathrm{~N}^{14} \mathrm{H}_{2}$ & 3- 51 & Not Reported & & & & 18086.02 & \\
\hline $\mathrm{C}^{12} \mathrm{H}_{2}\left(\mathrm{C}^{12} \mathrm{~N}^{14}\right)\left(\mathrm{C}^{12} \mathrm{~N}^{15}\right)$ & 4. 904 & $1,1,0 \leftarrow 1,0,1$ & Ground & & & 18088.67 & \\
\hline$\left(\mathrm{C}^{12} \mathrm{H}_{3}\right)_{3} \mathrm{C}^{12} \mathrm{Cl}^{35}$ & 3. 971 & $3,2 \leftarrow 2,2$ & Ground & $5 / 2$ & $5 / 2$ & 18094.42 & .15 \\
\hline$\left(\mathrm{C}^{12} \mathrm{H}_{3}\right)_{3} \mathrm{C}^{12} \mathrm{Cl}^{35}$ & 3. 971 & $3,2 \leftarrow 2,2$ & Ground & $7 / 2$ & $5 / 2$ & 18094.42 & .15 \\
\hline$\left(\mathrm{C}^{12} \mathrm{H}_{3}\right)_{3} \mathrm{C}^{12} \mathrm{Cl}^{35}$ & 3- 971 & $3,1 \leftarrow 2,1$ & Ground & $7 / 2$ & $7 / 2$ & 18095.24 & .1 \\
\hline $\mathrm{O}^{16} \mathrm{~F}_{2}^{19}$ & 4-1611 & $18,3.16 \leftarrow 17,4,13$ & Ground & & & 18095.67 & .10 \\
\hline $\mathrm{Na}^{23} \mathrm{Br}^{79}$ & $1-$ & $2 \leftarrow 1$ & Ground & $3 / 2$ & $1 / 2$ & 18095.95 & .15 \\
\hline $\mathrm{Na}^{23} \mathrm{Br}^{79}$ & 1 - & $2 \leftarrow 1$ & Ground & $5 / 2$ & $5 / 2$ & 18095.95 & .15 \\
\hline $\mathrm{C}^{12} \mathrm{D}_{3} \mathrm{O}^{16} \mathrm{H}$ & 3- 214 & Not Reported & Ground & & & 18097.0 & .5 \\
\hline $\mathrm{C}^{12} \mathrm{H}_{2}: \mathrm{C}^{12} \mathrm{DC}^{12} \mathrm{~N}^{14}$ & $4-1026$ & $2,1,2 \leftarrow 1,1,1$ & Ground & 2 & 1 & 18098.69 & \\
\hline $\mathrm{C}^{12} \mathrm{H}_{2}: \mathrm{C}^{12} \mathrm{DC}^{12} \mathrm{~N}^{14}$ & $4-1026$ & $2,1,2 \leftarrow 1,1,1$ & Ground & 2 & 2 & 18099.18 & \\
\hline $\mathrm{C}^{12} \mathrm{H}_{2}: \mathrm{C}^{12} \mathrm{DC}^{12} \mathrm{~N}^{14}$ & $4-1026$ & $2,1,2 \leftarrow 1,1,1$ & Ground & 3 & 2 & 18099.85 & \\
\hline $\mathrm{HC}^{13}: \mathrm{C}^{12} \mathrm{C}^{12} \mathrm{DO}^{16}$ & 4- 922 & Not Reported & & & & 18100. & 5. \\
\hline $\mathrm{C}^{12} \mathrm{H}_{2}: \mathrm{C}^{12} \mathrm{DC}^{12} \mathrm{~N}^{14}$ & $4-1026$ & $2,1,2 \leftarrow 1,1,1$ & Ground & 1 & 0 & 18100.97 & \\
\hline $\mathrm{C}^{12} \mathrm{H}_{3} \mathrm{~N}^{14} \mathrm{O}_{2}^{16}$ & 3- 171 & Not Reported & Ground & & & 18102. & 5. \\
\hline$\left(\mathrm{C}^{12} \mathrm{H}_{3}\right)_{3} \mathrm{C}^{12} \mathrm{Cl}^{35}$ & 3. 971 & $3,0 \leftarrow 2,0$ & Ground & $5 / 2$ & $3 / 2$ & 18102.76 & .1 \\
\hline$\left(\mathrm{C}^{12} \mathrm{H}_{3}\right)_{3} \mathrm{C}^{12} \mathrm{Cl}^{35}$ & 3. 971 & $3,0 \leftarrow 2,0$ & Ground & $3 / 2$ & $1 / 2$ & 18102.76 & .1 \\
\hline$\left(\mathrm{C}^{12} \mathrm{H}_{3}\right)_{3} \mathrm{C}^{12} \mathrm{Cl}^{35}$ & 3- 971 & $3,1 \leftarrow 2,1$ & Ground & $5 / 2$ & $3 / 2$ & 18103.84 & .15 \\
\hline$\left(\mathrm{C}^{12} \mathrm{H}_{3}\right)_{3} \mathrm{C}^{12} \mathrm{Cl}^{35}$ & 3- 971 & $3,1 \leftarrow 2,1$ & Ground & $7 / 2$ & $5 / 2$ & 18103.84 & .15 \\
\hline $\mathrm{C}^{12} \mathrm{H}_{3} \mathrm{C}^{13} \mathrm{H}_{2} \mathrm{~F}^{19}$ & 3- 555 & $5,1,4 \leftarrow 5,1,5$ & Ground & & & 18103.9 & .1 \\
\hline $\mathrm{C}^{12} \mathrm{H}_{3} \mathrm{C}^{12}{ }_{*} \mathrm{HO}^{16} \mathrm{C}^{12}{ }_{*} \mathrm{H}_{2}$ & 3- 761 & $5,1,4 \leftarrow 5,0,5$ & Ground & & & 18104.06 & .1 \\
\hline$\left(\mathrm{C}^{12} \mathrm{H}_{3}\right)_{3} \mathrm{C}^{12} \mathrm{Cl}^{35}$ & 3- 971 & $3,2 \leftarrow 2,2$ & Ground & $5 / 2$ & $3 / 2$ & 18106.19 & .1 \\
\hline$\left(\mathrm{C}^{12} \mathrm{H}_{3}\right)_{3} \mathrm{C}^{12} \mathrm{Cl}^{35}$ & 3. 971 & $3,2 \leftarrow 2,2$ & Ground & $3 / 2$ & $3 / 2$ & 18106.19 & .1 \\
\hline$\left(\mathrm{C}^{12} \mathrm{H}_{3}\right)_{3} \mathrm{C}^{12} \mathrm{Cl}^{35}$ & 3. 971 & $3, \leftarrow 2$ & Ground & & & 18106.35 & .10 \\
\hline$\left(\mathrm{C}^{12} \mathrm{H}_{3}\right)_{3} \mathrm{C}^{12} \mathrm{Cl}^{35}$ & 3. 971 & $3,0 \leftarrow 2,0$ & Ground & $9 / 2$ & $7 / 2$ & 18107.19 & .15 \\
\hline$\left(\mathrm{C}^{12} \mathrm{H}_{3}\right)_{3} \mathrm{C}^{12} \mathrm{Cl}^{35}$ & 3- 971 & $3,0 \leftarrow 2,0$ & Ground & $7 / 2$ & $5 / 2$ & 18107.19 & .15 \\
\hline$\left(\mathrm{C}^{12} \mathrm{H}_{3}\right)_{3} \mathrm{C}^{12} \mathrm{Cl}^{35}$ & 3. 971 & $3,1 \leftarrow 2,1$ & Ground & $3 / 2$ & $1 / 2$ & 18108.06 & .15 \\
\hline$\left(\mathrm{C}^{12} \mathrm{H}_{3}\right)_{3} \mathrm{C}^{12} \mathrm{Cl}^{35}$ & 3. 971 & $3,1 \leftarrow 2,1$ & Ground & $9 / 2$ & $7 / 2$ & 18108.06 & .15 \\
\hline $\mathrm{S}^{32}{ }_{*} \mathrm{HC}^{12}: \mathrm{C}^{12} \mathrm{DC}^{12} \mathrm{D}: \mathrm{C}^{12}{ }_{*} \mathrm{H}$ & $4-1164$ & $4,1,4 \leftarrow 4,1,3$ & Ground & & & 18109.1 & .1 \\
\hline$\left(\mathrm{C}^{12} \mathrm{H}_{3}\right)_{3} \mathrm{C}^{12} \mathrm{C}^{35}$ & 3- 971 & $3,1 \leftarrow 2,1$ & Ground & $5 / 2$ & $5 / 2$ & 18109.66 & .1 \\
\hline$\left(\mathrm{C}^{12} \mathrm{H}_{3}\right)_{3} \mathrm{C}^{12} \mathrm{Cl}^{35}$ & 3. 971 & $3,2 \leftarrow 2,2$ & Ground & $9 / 2$ & $7 / 2$ & 18111.15 & .15 \\
\hline$\left(\mathrm{C}^{12} \mathrm{H}_{3}\right)_{3} \mathrm{C}^{12} \mathrm{C}^{35}$ & 3. 971 & $3,2 \leftarrow 2,2$ & Ground & $7 / 2$ & $7 / 2$ & 18111.15 & .15 \\
\hline $\mathrm{C}^{12} \mathrm{H}_{3} \mathrm{~N}^{14} \mathrm{O}_{2}^{16}$ & 3. 171 & Not Reported & Ground & & & 18112. & 5. \\
\hline$\left(\mathrm{C}^{12} \mathrm{H}_{3}\right)_{3} \mathrm{C}^{12} \mathrm{Cl}^{35}$ & 3. 971 & $3,1 \leftarrow 2,1$ & Ground & $3 / 2$ & $3 / 2$ & 18116.23 & .1 \\
\hline $\mathrm{H}_{2} \mathrm{~N}^{14} \mathrm{~N}^{14} \mathrm{H}_{2}$ & 3- 51 & Not Reported & & & & 18118.9 & \\
\hline$\left(\mathrm{C}^{12} \mathrm{H}_{3}\right)_{3} \mathrm{C}^{12} \mathrm{Cl}^{35}$ & 3. 971 & $3,2 \leftarrow 2,2$ & Ground & $3 / 2$ & $1 / 2$ & 18122.08 & .1 \\
\hline $\mathrm{N}^{14} \mathrm{H}_{3}$ & $4-1771$ & $12,9 \leftarrow 12,9$ & Ground & & & 18127.32 & .04 \\
\hline $\mathrm{K}^{39} \boldsymbol{I}^{127}$ & $1-$ & $5 \leftarrow 4$ & Excited & & & 18129.61 & 0.20 \\
\hline $\mathrm{C}^{12} \mathrm{H}_{3} \mathrm{~N}^{14} \mathrm{O}_{2}^{16}$ & 3. 171 & Not Reported & Ground & & & 18136. & 5. \\
\hline $\mathrm{HC}^{13}: \mathrm{C}^{12} \mathrm{C}^{12} \mathrm{DO}^{16}$ & 4. 922 & $2,1,1 \leftarrow 1,1,0$ & Ground & & & 18140.43 & .02 \\
\hline $\mathrm{C}^{12} \mathrm{H}_{3} \mathrm{P}^{31} \mathrm{H}_{2}$ & 3- 271 & $6,2,5 \leftarrow 7,1,7$ & Ground & & & 18141.1 & .1 \\
\hline $\mathrm{C}_{6}^{12} \mathrm{H}_{5} \mathrm{~N}^{14} \mathrm{O}_{2}^{16}$ & $3-1041$ & $8,7,2 \leftarrow 7,7,1$ & Ground & & & 18142. & 4. \\
\hline
\end{tabular}




\begin{tabular}{|c|c|c|c|c|c|c|}
\hline Isotopic Species & $\begin{array}{l}\text { Vol.-Id. } \\
\text { Nos. }\end{array}$ & $\begin{array}{c}\text { Rotational } \\
\text { Quantum Nos. }\end{array}$ & Vib. State & \begin{tabular}{c}
\multicolumn{3}{c}{ Hyperfine } \\
$\mathbf{F}_{1}^{\prime} \stackrel{F^{\prime}}{F_{1}} \quad \mathbf{F}$
\end{tabular} & $\begin{array}{c}\text { Frequency } \\
\mathrm{MHz}\end{array}$ & $\begin{aligned} & \text { Acc. } \\
\pm & \mathrm{MHz}\end{aligned}$ \\
\hline $\mathrm{C}_{6}^{12} \mathrm{H}_{5} \mathrm{~N}^{14} \mathrm{O}_{2}^{16}$ & $3-1041$ & $8,7,3 \leftarrow 7,7,2$ & Ground & & 18142. & 4. \\
\hline $\mathrm{HC}^{13}: \mathrm{C}^{12} \mathrm{C}^{12} \mathrm{DO}^{16}$ & 4- 922 & Not Reported & & & 18142. & 5. \\
\hline $\mathrm{HC}^{12}: \mathrm{C}^{12} \mathrm{C}^{12} \mathrm{HO}^{18}$ & 4. 915 & $2,1,1 \leftarrow 1,1,0$ & Ground & & 18142.95 & .05 \\
\hline $\mathrm{C}^{12}{ }_{*} \mathrm{D}: \mathrm{C}^{12} \mathrm{DC}^{12} \mathrm{D}: \mathrm{C}^{12} \mathrm{DN}^{14}{ }_{*} \mathrm{D}$ & 4-1186 & $10,8,2 \leftarrow 10,8,3$ & Ground & & 18143.6 & \\
\hline $3 \mathrm{~d}-\mathrm{C}_{6}^{12} \mathrm{H}_{5} \mathrm{~F}^{19}$ & 4-1282 & $4,2,2 \leftarrow 3,2,1$ & Ground & & 18144.5 & .1 \\
\hline $\mathrm{HC}^{12}: \mathrm{C}^{12} \mathrm{C}^{12} \mathrm{H}: \mathrm{C}^{12} \mathrm{H}_{2}$ & 4-1131 & $2,0,2 \leftarrow 1,0,1$ & Ground & & 18146.52 & \\
\hline $\mathrm{C}^{12} \mathrm{H}_{3} \mathrm{Si}^{28} \mathrm{HF}_{2}^{19}-\mathrm{A}$ & 3. 191 & Not Reported & Ground & & 18147.8 & \\
\hline $\mathrm{C}^{12} \mathrm{D}_{3} \mathrm{Si}^{28} \mathrm{H}_{3}$ & 3- 323 & $1, \leftarrow 0$ & & & 18150.0 & .3 \\
\hline $\mathrm{C}^{12} \mathrm{H}_{3} \mathrm{Si}^{28} \mathrm{HF}_{2}^{19}-\mathrm{A}$ & 3- 191 & Not Reported & Ground & & 18150.2 & \\
\hline $\mathrm{C}_{6}^{12} \mathrm{H}_{5} \mathrm{~N}^{14} \mathrm{O}_{2}^{16}$ & 3-1041 & $8,6,2 \leftarrow 7,6,1$ & Ground & & 18160. & 5. \\
\hline $\mathrm{C}_{6}^{12} \mathrm{H}_{5} \mathrm{~N}^{14} \mathrm{O}_{2}^{16}$ & $3-1041$ & $8,6,3 \leftarrow 7,6,2$ & Ground & & 18160. & 5. \\
\hline $\mathrm{C}^{12} \mathrm{H}_{3} \mathrm{O}^{16} \mathrm{H}$ & 3- 211 & Not Reported & Ground & & 18161.4 & 5. \\
\hline $\mathrm{N}^{14} \mathrm{H}_{3}$ & 4-1771 & $11,8 \leftarrow 11,8$ & Ground & & 18162.54 & .04 \\
\hline $\mathrm{C}^{12} \mathrm{H}_{3} \mathrm{~N}^{14} \mathrm{O}_{2}^{16}$ & 3- 171 & Not Reported & Ground & & 18172. & 5. \\
\hline $\mathrm{t}-\mathrm{C}^{12} \mathrm{H}_{3} \mathrm{C}^{12} \mathrm{H}: \mathrm{C}^{12} \mathrm{HC}^{12} \mathrm{~N}^{14}$ & 3- 921 & $4,1, \leftarrow 3,1$ & Ground & & 18172.15 & .5 \\
\hline $\mathrm{C}^{12} \mathrm{O}^{16} \mathrm{~F}_{2}^{19}$ & 4- 211 & $5,5,1 \leftarrow 5,3,2$ & Ground & & 18176.22 & .10 \\
\hline $\mathrm{N}^{14} \mathrm{H}_{3}$ & 4-1771 & $13,10 \leftarrow 13,10$ & Ground & & 18177.99 & .06 \\
\hline $\mathrm{F}_{2}^{19} \mathrm{O}_{2}^{16}$ & $3-\quad 11$ & $3,1,2 \leftarrow 3,0,3$ & Ground & & 18182.24 & .1 \\
\hline $\mathrm{C}^{12} * \mathrm{DN}^{14} \mathrm{C}^{12} \mathrm{DC}^{12} \mathrm{H}: \mathrm{C}^{12} \mathrm{DN}^{14} *$ & 4-1142 & $11,8,3 \leftarrow 11,7,4$ & Ground & & 18182.3 & \\
\hline $\mathrm{Si}^{28} \mathrm{H}_{3} \mathrm{~N}^{14} \mathrm{C}^{12} \mathrm{~S}^{32}$ & 4- 491 & $6, \leftarrow 5$ & Ground & & 18192.17 & \\
\hline $\mathrm{C}^{12} \mathrm{D}_{3} \mathrm{Si}^{28} \mathrm{H}_{3}$ & 3- 323 & $1, \leftarrow 0$ & & & 18192.81 & .2 \\
\hline $\mathrm{F}^{19} \mathrm{DC}^{12} \mathrm{O}^{16}$ & 4- 272 & $4,1,3 \leftarrow 4,1,4$ & & & 18193.7 & .1 \\
\hline $\mathrm{HC}^{12}: \mathrm{C}^{12} \mathrm{C}^{12} \mathrm{~N}^{14}$ & 4- 881 & $2 \leftarrow 1$ & Ground & & 18196.6 & \\
\hline$\left(\mathrm{C}^{12} \mathrm{H}_{3}\right)_{2} \mathrm{~S}^{32}$ & 3- 601 & $14,2,13 \leftarrow 13,3,10$ & Ground & & 18199.20 & .05 \\
\hline $\mathrm{C}_{6}^{12} \mathrm{H}_{5} \mathrm{~N}^{14} \mathrm{O}_{2}^{16}$ & 3-104l & $8,5,4 \leftarrow 7,5,3$ & Ground & & 18200. & 4. \\
\hline$\left(\mathrm{C}^{12} \mathrm{H}_{3}\right)_{2} \mathrm{~S}^{32}$ & 3- 601 & $14,2,13 \leftarrow 13,3,10$ & Ground & & 18201.03 & .05 \\
\hline $\mathrm{C}^{12}{ }_{*} \mathrm{D}: \mathrm{C}^{12} \mathrm{DC}^{12} \mathrm{D}: \mathrm{C}^{12} \mathrm{DN}^{14}{ }_{*} \mathrm{H}$ & 4-1185 & $7,7,1 \leftarrow 7,6,2$ & Ground & & 18202.2 & \\
\hline$\left(\mathrm{C}^{12} \mathrm{H}_{3}\right)_{2} \mathrm{~S}^{32}$ & 3- 601 & $14,2,13 \leftarrow 13,3,10$ & Ground & & 18202.86 & .05 \\
\hline $\mathrm{C}^{12}{ }_{*} \mathrm{H}: \mathrm{C}^{12} \mathrm{DO}^{16} \mathrm{C}^{12} \mathrm{D}: \mathrm{C}^{12}{ }_{*} \mathrm{H}$ & $4-1156$ & $10,8,2 \leftarrow 10,7,3$ & Ground & & 18205.2 & \\
\hline $\mathrm{C}^{12}{ }_{*} \mathrm{D}: \mathrm{C}^{12} \mathrm{HC}^{12} \mathrm{H}: \mathrm{C}^{12} \mathrm{HN}^{14}{ }_{*} \mathrm{H}$ & 4-1183 & $5,5,1 \leftarrow 5,4,2$ & Ground & & 18208.1 & \\
\hline $\mathrm{S}^{32} \mathrm{O}^{16} \mathrm{~F}_{2}^{19}$ & 4-1621 & Not Reported & & & 18208.41 & .1 \\
\hline$K^{39} I^{127}$ & 1 - & $5 \leftarrow 4$ & Ground & & 18209.77 & 0.10 \\
\hline $\mathrm{C}^{12} \mathrm{H}_{2}: \mathrm{C}^{12} \mathrm{HC}^{12} \mathrm{HO}^{16}$ & 3- 691 & $2,1,1 \leftarrow 1,1,0$ & Ground & & 18211.08 & \\
\hline $\mathrm{DC}^{12} \mathrm{O}^{16} \mathrm{O}^{16} \mathrm{C}^{12} \mathrm{H}_{3}-\mathrm{E}$ & 3- 504 & $3,1,2 \leftarrow 3,0,3$ & Ground & & 18212.03 & .2 \\
\hline $\mathrm{C}^{12}{ }_{*} \mathrm{H}: \mathrm{C}^{12} \mathrm{HO}^{16} \mathrm{C}^{12} \mathrm{H}: \mathrm{C}^{12}{ }_{*} \mathrm{D}$ & 4-1155 & $11,8,3 \leftarrow 11,8,4$ & Ground & & 18213.4 & \\
\hline $\mathrm{HC}^{13}: \mathrm{C}^{12} \mathrm{C}^{12} \mathrm{DO}^{16}$ & 4- 922 & Not Reported & & & 18215. & 5. \\
\hline $\mathrm{DC}^{12} \mathrm{O}^{16} \mathrm{O}^{16} \mathrm{C}^{12} \mathrm{H}_{3^{-}} \mathrm{A}$ & 3- 503 & $3,1,2 \leftarrow 3,0,3$ & Ground & & 18219.75 & .2 \\
\hline $\mathrm{C}^{12} \mathrm{H}_{3} \mathrm{O}^{16} \mathrm{H}$ & 3- 211 & Not Reported & Ground & & 18222 & \\
\hline $\mathrm{HC}^{12}: \mathrm{C}^{12} \mathrm{C}^{13} \mathrm{HO}^{16}$ & 4- 914 & $2,1,2 \leftarrow 1,1,1$ & Ground & & $18226.2 \dot{0}$ & .02 \\
\hline $\mathrm{C}^{12} \mathrm{D}_{3} \mathrm{O}^{16} \mathrm{H}$ & 3- 214 & Not Reported & Ground & & 18227.3 & .5 \\
\hline $\mathrm{C}^{\mathrm{b}} \mathrm{H}_{2}^{\mathrm{b}} \mathrm{Cl}^{\mathrm{b}} \mathrm{F}^{\mathrm{b}}$ & 4- 333 & Not Reported & & & 18229.29 & .1 \\
\hline $\mathrm{C}^{13} \mathrm{O}^{16} \mathrm{~F}_{2}^{19}$ & 4- 212 & $5,5,1 \leftarrow 5,3,2$ & Ground & & 18229.66 & .10 \\
\hline $\mathrm{S}^{32} \mathrm{O}^{16} \mathrm{~F}_{2}^{19}$ & 4-1621 & Not Reported & & & 18232.98 & .1 \\
\hline $\mathrm{s}-\mathrm{C}^{12} \mathrm{HD}_{2} \mathrm{C}^{12} \mathrm{O}^{16} \mathrm{~F}^{19}$ & 3- 395 & $7,4,3 \leftarrow 7,4,4$ & Ground & & 18233.5 & .2 \\
\hline $\mathrm{C}^{12} \mathrm{H}_{3} \mathrm{~N}^{14} \mathrm{O}_{2}^{16}$ & 3- 171 & Not Reported & Ground & & 18239. & 5. \\
\hline
\end{tabular}




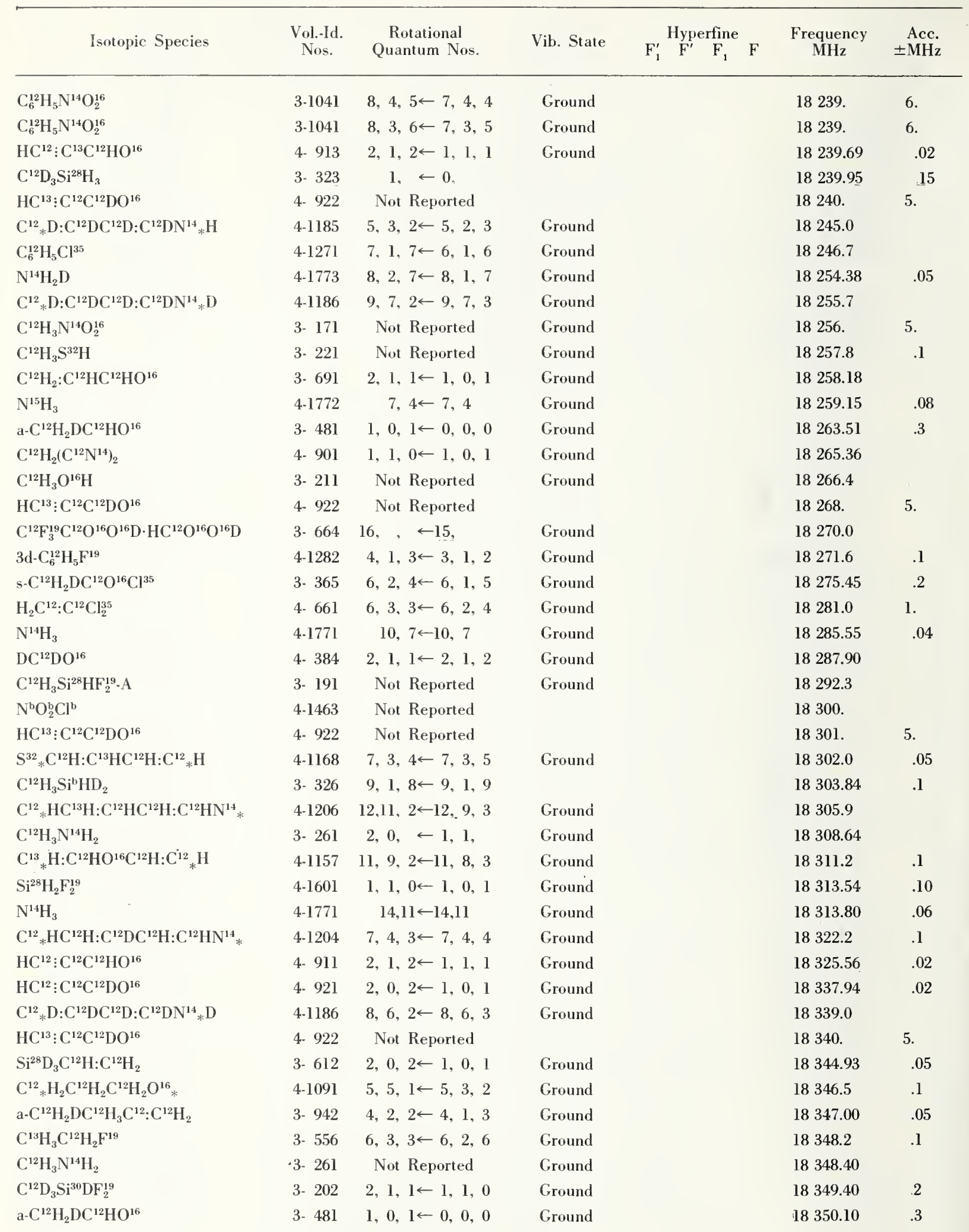




\begin{tabular}{|c|c|c|c|c|c|c|c|c|}
\hline Isotopic Species & $\begin{array}{c}\text { Vol.-Id. } \\
\text { Nos. }\end{array}$ & $\begin{array}{c}\text { Rotational } \\
\text { Quantum Nos. }\end{array}$ & Vib. State & $\mathrm{F}_{1}^{\prime}$ & $\begin{array}{l}\text { Hyperfine } \\
\mathrm{F}^{\prime} \\
\mathrm{F}_{1}\end{array}$ & $\mathrm{~F}$ & $\begin{array}{c}\text { Frequency } \\
\mathrm{MHz}\end{array}$ & $\begin{aligned} & \text { Acc. } \\
\pm & \mathrm{MHz}\end{aligned}$ \\
\hline $\mathrm{Si}^{28} \mathrm{D}_{3} \mathrm{C}^{12} \mathrm{H}: \mathrm{C}^{12} \mathrm{H}_{2}$ & 3. 612 & $2,0,2 \leftarrow 1,0,1$ & Ground & & & & 18350.34 & .05 \\
\hline $\mathrm{C}^{12} \mathrm{~F}_{3}^{19} \mathrm{C}^{12} \mathrm{O}^{16} \mathrm{O}^{16} \mathrm{H} \cdot \mathrm{HC}^{12} \mathrm{O}^{16} \mathrm{O}^{16} \mathrm{D}$ & 3- 663 & $16, \quad \leftarrow 15$ & Ground & & & & 18351.7 & \\
\hline $\mathrm{HN}^{15} \mathrm{O}_{3}^{16}$ & $3-\quad 33$ & $1,0,1 \leftarrow 0,0,0$ & Ground & & & & 18357.05 & \\
\hline$\left(\mathrm{C}^{12} \mathrm{H}_{3}\right)_{2} \mathrm{C}^{12}: \mathrm{C}^{12} \mathrm{H}_{2}$ & 3- 941 & $5,5,1 \leftarrow 5,4,2$ & Ground & & & & 18358.45 & .05 \\
\hline $\mathrm{HN}^{14} \mathrm{O}_{3}^{16}$ & $3-31$ & $1,0,1 \leftarrow 0,0,0$ & Ground & & 0 & 1 & 18360.06 & \\
\hline $\mathrm{HN}^{14} \mathrm{O}_{3}^{16}$ & $3-31$ & $1,0,1 \leftarrow 0,0,0$ & Ground & & 2 & 1 & 18360.48 & \\
\hline $\mathrm{HN}^{14} \mathrm{O}_{3}^{16}$ & $3-\quad 31$ & $1,0,1 \leftarrow 0,0,0$ & Ground & & 1 & 1 & 18360.78 & \\
\hline $\mathrm{HC}^{13}: \mathrm{C}^{12} \mathrm{C}^{12} \mathrm{HO}^{16}$ & 4. 912 & $2,1,1 \leftarrow 1,1,0$ & Ground & & & & 18363.05 & .02 \\
\hline $\mathrm{C}^{12} \mathrm{D}_{3} \mathrm{Si}^{29} \mathrm{DF}_{2}^{19}$ & 3- 201 & $2,1,1 \leftarrow 1,1,0$ & Ground & & & & 18367.14 & .2 \\
\hline $\mathrm{H}_{2} \mathrm{C}^{12}: \mathrm{C}^{12} \mathrm{Cl}^{35} \mathrm{Cl}^{37}$ & 4. 662 & $9,3,6 \leftarrow 9,2,7$ & Ground & & & & 18367.5 & .5 \\
\hline $\mathrm{C}^{12} \mathrm{H}_{3} \mathrm{C}^{12} \mathrm{HO}^{18}$ & 3- 479 & $1,0,1 \leftarrow 0,0,0$ & Ground & & & & 18367.75 & .5 \\
\hline $\mathrm{C}^{12} \mathrm{H}_{3} \mathrm{C}^{12} \mathrm{H}_{2} \mathrm{O}^{16} \mathrm{H}$ & 3- 581 & $9,3,7 \leftarrow 8,4,4$ & Ground & & & & 18367.8 & .1 \\
\hline $\mathrm{C}_{6}^{12} \mathrm{H}_{5} \mathrm{~F}^{19}$ & $4-1281$ & Not Reported & & & & & 18370. & 5. \\
\hline $\mathrm{C}^{12} \mathrm{H}_{3} \mathrm{C}^{12} \mathrm{HO}^{18}$ & 3- 479 & $1,0,1 \leftarrow 0,0,0$ & Ground & & & & 18370.23 & .5 \\
\hline$\left(\mathrm{C}^{12} \mathrm{D}_{3}\right)_{2} \mathrm{C}^{12} \mathrm{H}_{3} \mathrm{Si}^{\mathrm{b}} \mathrm{H}$ & 3- 879 & $2,2,1 \leftarrow 1,1,1$ & Ground & & & & 18372.55 & .2 \\
\hline $\mathrm{C}^{12} \mathrm{O}^{16} \mathrm{~F}_{2}^{19}$ & 4. 211 & $6,6,1 \leftarrow 6,4,2$ & Ground & & & & 18373.76 & .10 \\
\hline $\mathrm{C}^{12} \mathrm{H}_{2} \mathrm{Cl}_{2}^{35}$ & 4- 341 & $7,0,7 \leftarrow 6,1,6$ & Ground & & & & 18375. & 5. \\
\hline $\mathrm{P}^{31} \mathrm{O}^{16} \mathrm{~F}_{3}^{19}$ & 4-1671 & $2, \leftarrow 1$ & Ground & & & & 18377.03 & .05 \\
\hline $\mathrm{C}^{12} \mathrm{H}_{3} \mathrm{C}^{12} \mathrm{H}_{2} \mathrm{C}^{12} \mathrm{~N}^{14}$ & $3 \cdot 731$ & $2,1,1 \leftarrow 1,1,0$ & Ground & & & & 18377.5 & .2 \\
\hline $\mathrm{t} \cdot \mathrm{Si}^{28} \mathrm{H}_{3} \mathrm{C}^{12} \mathrm{H}: \mathrm{C}^{12} \mathrm{HD}$ & 3- 618 & $2,1.2 \leftarrow 1,1,1$ & Ground & & & & 18377.57 & .10 \\
\hline$\left(\mathrm{C}^{12} \mathrm{D}_{3}\right)_{2} \mathrm{C}^{12} \mathrm{H}_{3} \mathrm{Si}^{\mathrm{b}} \mathrm{H}$ & 3. 879 & $2,2,1 \leftarrow 1,1,1$ & Ground & & & & 18378.75 & .2 \\
\hline $\mathrm{C}^{\mathrm{b}} \mathrm{H}_{2}^{\mathrm{b}} \mathrm{Cl}^{\mathrm{b}} \mathrm{F}^{\mathrm{b}}$ & 4. 333 & Not Reported & & & & & 18381.82 & .1 \\
\hline $\mathrm{C}^{12} \mathrm{H}_{3} \mathrm{C}^{12} \mathrm{O}^{18} \mathrm{~F}^{19}$ & 3- 394 & $6,4,2 \leftarrow 6,4,3$ & Ground & & & & 18382.46 & .2 \\
\hline $\mathrm{C}^{\mathrm{b}} \mathrm{H}_{2}^{\mathrm{b}} \mathrm{Cl}^{\mathrm{b}} \mathrm{F}^{\mathrm{b}}$ & 4- 333 & Not Reported & & & & & 18382.50 & .1 \\
\hline $\mathrm{C}^{12} \mathrm{D}_{3} \mathrm{Si}^{28} \mathrm{DF}_{2}^{19}$ & 3- 199 & $2,1,1 \leftarrow 1,1,0$ & Ground & & & & 18385.27 & .1 \\
\hline $\mathrm{t}-\mathrm{C}^{12} \mathrm{H}_{3} \mathrm{C}^{12} \mathrm{H}_{2} \mathrm{C}^{12} \mathrm{H}_{2} \mathrm{Cl}^{35}$ & 3- 771 & 4. $1,4 \leftarrow 3,1,3$ & Ground & & & & 18389.10 & .2 \\
\hline$\left(\mathrm{C}^{12} \mathrm{D}_{3}\right)_{2} \mathrm{C}^{12} \mathrm{H}_{3} \mathrm{Si}^{\mathrm{b}} \mathrm{H}$ & 3. 879 & $2,2,1 \leftarrow 1,1,1$ & Ground & & & & 18390.30 & .1 \\
\hline $\mathrm{N}^{14} \mathrm{H}_{3}$ & 4-1771 & $6,1 \leftarrow 6,1$ & Ground & & & & 18391.46 & .04 \\
\hline $\mathrm{N}^{14} \mathrm{H}_{3}$ & 4-1771 & $6,1 \leftarrow 6,1$ & Ground & & & & 18391.65 & .04 \\
\hline $\mathrm{C}^{12} \mathrm{D}_{3} \mathrm{O}^{16} \mathrm{H}$ & 3- 214 & Not Reported & Ground & & & & 18395.6 & .5 \\
\hline $\mathrm{C}^{12} \mathrm{H}_{3} \mathrm{~S}^{32} \mathrm{H}$ & 3. 221 & Not Reported & Ground & & & & 18396.0 & .1 \\
\hline $\mathrm{C}^{12} \mathrm{~F}_{3}^{19} \mathrm{C}^{12} \mathrm{O}^{16} \mathrm{O}^{16} \mathrm{D} \cdot \mathrm{HC}^{12} \mathrm{O}^{16} \mathrm{O}^{16} \mathrm{H}$ & 3. 662 & $16, \quad \leftarrow 15$ & Ground & & & & 18397.0 & \\
\hline $\mathrm{C}^{12} \mathrm{H}_{3} \mathrm{C}^{12} \mathrm{H}_{2} \mathrm{C}^{12} \mathrm{~N}^{14}$ & 3- 731 & $2,1,1 \leftarrow 1,1,0$ & Excited & & & & 18398.0 & .2 \\
\hline $\mathrm{t} \cdot \mathrm{C}^{12} \mathrm{H}_{3} \mathrm{C}^{12} \mathrm{H}_{2} \mathrm{C}^{12} \mathrm{H}_{2} \mathrm{Cl}^{37}$ & 3- 772 & $4,1,3 \leftarrow 3,1,2$ & Ground & & & & 18398.68 & .2 \\
\hline $\mathrm{HC}^{13}: \mathrm{C}^{12} \mathrm{C}^{12} \mathrm{DO}^{16}$ & 4- 922 & Not Reported & & & & & 18400. & 5. \\
\hline $\mathrm{S}^{32} \mathrm{O}^{16} \mathrm{~F}_{2}^{19}$ & 4-1621 & Not Reported & & & & & 18401.14 & .1 \\
\hline $\mathrm{s}-\mathrm{C}^{12} \mathrm{H}_{2} \mathrm{DC}^{12} \mathrm{HO}^{16}$ & 3- 473 & $5,1,4 \leftarrow 5,1.5$ & Ground & & & & 18402.40 & .3 \\
\hline $\mathrm{C}^{12} \mathrm{H}_{3} \mathrm{Si}^{28} \mathrm{HF}_{2}^{19}-\mathrm{A}$ & 3. 191 & Not Reported & Ground & & & & 18403.1 & \\
\hline $\mathrm{C}^{12} \mathrm{H}_{2}: \mathrm{C}^{13} \mathrm{HC}^{12} \mathrm{~N}^{14}$ & 4-1023 & $2,1,2 \leftarrow 1,1,1$ & Ground & & & & 18405.33 & \\
\hline $\mathrm{C}^{12} \mathrm{H}_{2}\left(\mathrm{C}^{12} \mathrm{~N}^{14}\right)\left(\mathrm{C}^{12} \mathrm{~N}^{15}\right)$ & 4- 904 & $2,1,1 \leftarrow 2,0,2$ & Ground & & & & 18405.56 & \\
\hline $\mathrm{C}_{6}^{12} \mathrm{H}_{5} \mathrm{C}^{12} \mathrm{~N}^{14}$ & 4-1291 & $7,0.7 \leftarrow 6,0.6$ & Ground & & & & 18410.0 & .2 \\
\hline $\mathrm{C}^{12} \mathrm{H}_{2}: \mathrm{C}^{12} \mathrm{HC}^{12} \mathrm{~N}^{15}$ & $4 \cdot 1025$ & $2,0,2 \leftarrow 1,0,1$ & Ground & & & & 18410.18 & \\
\hline $2,4,6 d_{3}-C_{6}^{12} H_{5} F^{19}$ & $4 \cdot 1284$ & $5,0,5 \leftarrow 4,0,4$ & Ground & & & & 18413.5 & .1 \\
\hline $\mathrm{C}^{12} \mathrm{H}_{3} \mathrm{C}^{12} \mathrm{O}^{18} \mathrm{C}^{12} \mathrm{~N}^{14}$ & 3- 674 & $2,1,2 \leftarrow 1,0,1$ & Ground & & & & 18414.00 & .2 \\
\hline $\mathrm{C}^{12} \mathrm{H}_{3} \mathrm{C}^{12} \mathrm{O}^{18} \mathrm{~F}^{19}$ & 3- 394 & $6,4,2 \leftarrow 6,4,3$ & Ground & & & & 18414.95 & .2 \\
\hline
\end{tabular}




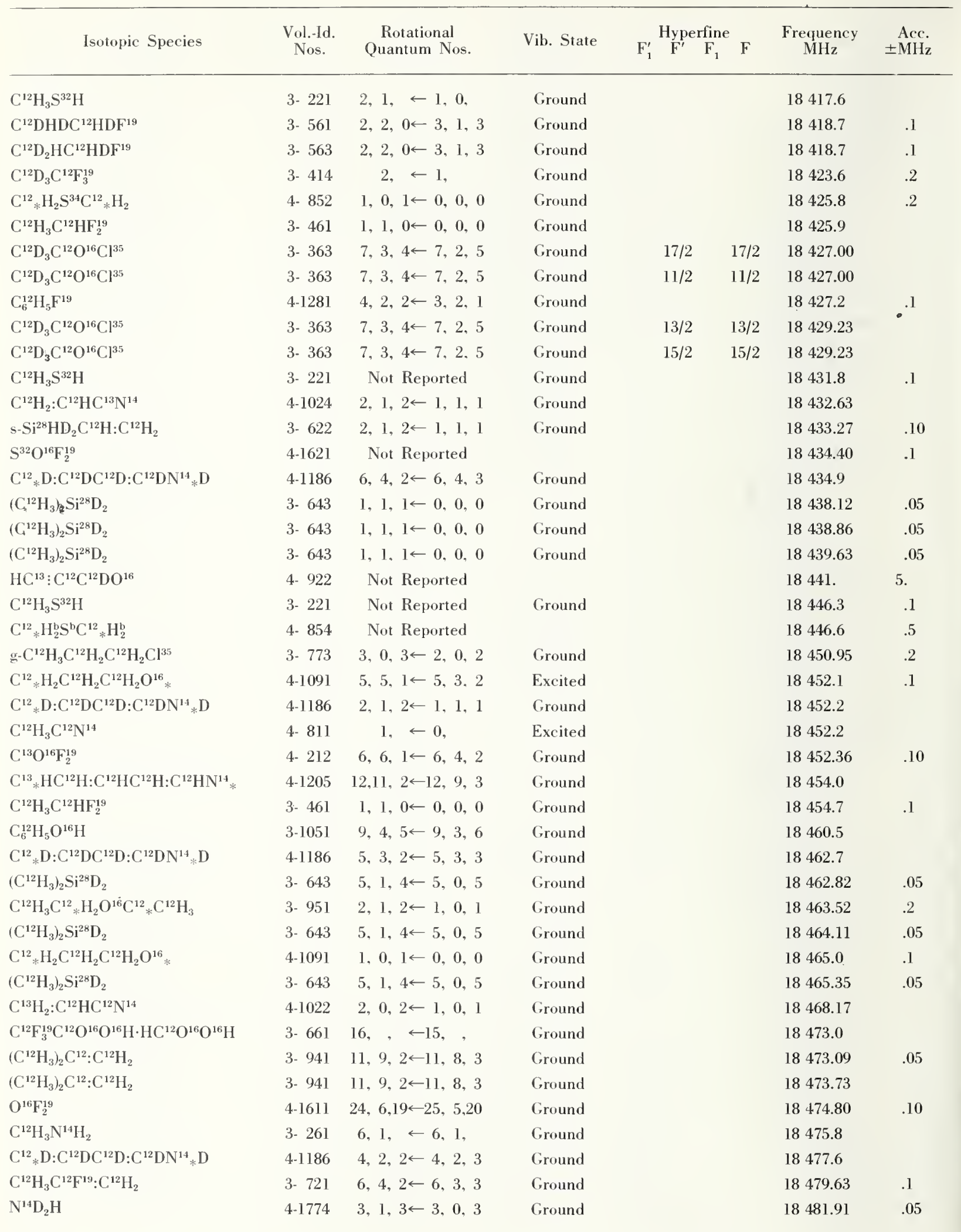




\begin{tabular}{|c|c|c|c|c|c|c|c|c|}
\hline Isotopic Species & $\begin{array}{l}\text { Vol.-Id. } \\
\text { Nos. }\end{array}$ & $\begin{array}{c}\text { Rotational } \\
\text { Quantum Nos. }\end{array}$ & Vib. State & $\mathrm{F}_{1}^{\prime}$ & $\begin{array}{l}\text { Hyperfine } \\
\mathbf{F}^{\prime} \quad \mathrm{F}_{1}\end{array}$ & $\mathrm{~F}$ & $\begin{array}{c}\text { Frequency } \\
\text { MHz }\end{array}$ & $\begin{aligned} & \text { Acc. } \\
\pm & \mathrm{MHz}\end{aligned}$ \\
\hline $\mathrm{C}^{12} \mathrm{H}_{3} \mathrm{~N}^{14} \mathrm{H}_{2}$ & 3- 261 & $6,1, \leftarrow 6,1$, & Ground & & & & 18482.4 & \\
\hline $\mathrm{C}^{12}{ }^{1} \mathrm{D}: \mathrm{C}^{12} \mathrm{DC}^{12} \mathrm{D}: \mathrm{C}^{12} \mathrm{DN}^{14}{ }_{*} \mathrm{D}$ & 4-1186 & $3,1,2 \leftarrow 3,1,3$ & Ground & & & & 18484.5 & \\
\hline $\mathrm{C}^{12} \mathrm{H}_{3} \mathrm{~N}^{14} \mathrm{H}_{2}$ & 3. 261 & Not Reported & & & & & 18486. & \\
\hline $\mathrm{C}^{12}{ }_{*} \mathrm{H}: \mathrm{C}^{12} \mathrm{HO}^{16} \mathrm{C}^{12} \mathrm{D}: \mathrm{C}^{12}{ }_{*} \mathrm{H}$ & 4-1154 & $5,5,1 \leftarrow 5,4,2$ & Ground & & & & 18489.2 & \\
\hline $\mathrm{C}^{12}{ }_{*} \mathrm{D}: \mathrm{C}^{12} \mathrm{DC}^{12} \mathrm{D}: \mathrm{C}^{12} \mathrm{DN}^{14}{ }_{*} \mathrm{D}$ & 4-1186 & $3,2,2 \leftarrow 3,0,3$ & Ground & & & & 18489.3 & \\
\hline $\mathrm{C}^{12}{ }_{*} \mathrm{H}_{2}^{\mathrm{b}} \mathrm{S}^{\mathrm{b}} \mathrm{C}^{12}{ }_{*} \mathrm{H}_{2}^{\mathrm{b}}$ & 4- 854 & Not Reported & & & & & 18489.7 & .5 \\
\hline $\mathrm{C}^{12}{ }_{*} \mathrm{H}_{2} \mathrm{C}^{12} \mathrm{H}_{2} \mathrm{C}^{12} \mathrm{H}_{2} \mathrm{O}^{16} *$ & 4-1091 & $5,5,1 \leftarrow 5,3,2$ & Excited & & & & 18490.0 & .1 \\
\hline $\mathrm{C}^{12}{ }^{12} \mathrm{D}: \mathrm{C}^{12} \mathrm{DC}^{12} \mathrm{D}: \mathrm{C}^{12} \mathrm{DN}^{14} * \mathrm{D}$ & 4-1186 & $4,3,2 \leftarrow 4,1,3$ & Ground & & & & 18491.8 & \\
\hline $\mathrm{C}^{12} \mathrm{H}_{3} \mathrm{~S}^{32} \mathrm{H}$ & 3. 221 & Not Reported & Ground & & & & 18494.1 & .1 \\
\hline $\mathrm{C}^{12}{ }_{*} \mathrm{D}: \mathrm{C}^{12} \mathrm{DC}^{12} \mathrm{D}: \mathrm{C}^{12} \mathrm{DN}^{14}{ }_{*} \mathrm{D}$ & 4-1186 & $5,4,2 \leftarrow 5,2,3$ & Ground & & & & 18497.3 & \\
\hline $\mathrm{C}^{12}{ }_{*} \mathrm{H}_{2} \mathrm{C}^{12} \mathrm{H}_{2} \mathrm{C}^{12} \mathrm{H}_{2} \mathrm{O}^{16} *$ & 4-1091 & $1,0,1 \leftarrow 0,0,0$ & Excited & & & & 18498. & \\
\hline $\mathrm{C}^{12} \mathrm{HD}\left(\mathrm{C}^{12} \mathrm{~N}^{14}\right)_{2}$ & 4- 902 & $5,1,4 \leftarrow 5,0,5$ & Ground & & & & 18498.82 & \\
\hline $\mathrm{N}^{14} \mathrm{H}_{3}$ & 4-1771 & $9,6 \leftarrow 9,6$ & Ground & & & & 184.99 .28 & .04 \\
\hline $\mathrm{C}^{12} \mathrm{H}_{3} \mathrm{~S}^{32} \mathrm{H}$ & 3- 221 & Not Reported & Ground & & & & 18499.7 & .1 \\
\hline $\mathrm{s}-\mathrm{C}^{12} \mathrm{H}_{2} \mathrm{DC}^{12} \mathrm{HO}^{16}$ & 3. 473 & $1,0,1 \leftarrow 0,0,0$ & Ground & & & & 18501.87 & .1 \\
\hline $\mathrm{s}-\mathrm{C}^{12} \mathrm{H}_{2} \mathrm{DC}^{12} \mathrm{HO}^{16}$ & 3- 473 & $1,0,1 \leftarrow 0,0,0$ & Ground & & & & 18504.36 & .1 \\
\hline $\mathrm{D}_{2} \mathrm{~N}^{15} \mathrm{C}^{12} \mathrm{HO}^{16}$ & $3-161$ & $1,0,1 \leftarrow 0,0,0$ & Ground & & & & 18505.25 & \\
\hline $\mathrm{C}^{12} \mathrm{H}_{3} \mathrm{C}^{12} \mathrm{~N}^{14}$ & 4- 811 & $1, \leftarrow 0$, & Excited & & & & 18506.9 & \\
\hline $\mathrm{C}^{12}{ }_{*} \mathrm{D}: \mathrm{C}^{12} \mathrm{DC}^{12} \mathrm{D}: \mathrm{C}^{12} \mathrm{DN}^{14}{ }_{*} \mathrm{D}$ & 4-1186 & $6,5,2 \leftarrow 6,3,3$ & Ground & & & & 18507.2 & \\
\hline $\mathrm{C}^{12} \mathrm{HDCl}^{35} \mathrm{Si}^{28} \mathrm{H}_{3}$ & 3- 236 & $5,1,4 \leftarrow 5,0,5$ & Ground & & & & 18508.34 & .2 \\
\hline $\mathrm{C}^{12} \mathrm{H}_{3} \mathrm{~S}^{32} \mathrm{H}$ & 3- 221 & Not Reported & Ground & & & & 18509.7 & .1 \\
\hline $\mathrm{C}^{12} \mathrm{H}_{2}: \mathrm{C}^{12} \mathrm{HC}^{12} \mathrm{~N}^{14}$ & 4-1021 & $2,1,2 \leftarrow 1,1,1$ & Ground & & 2 & 1 & 18512.14 & \\
\hline $\mathrm{C}^{12} \mathrm{H}_{2}: \mathrm{C}^{12} \mathrm{HC}^{12} \mathrm{~N}^{14}$ & 4-1021 & $2,1,2 \leftarrow 1,1,1$ & Ground & & 2 & 2 & 18512.68 & \\
\hline $\mathrm{C}^{12} \mathrm{H}_{2}: \mathrm{C}^{12} \mathrm{HC}^{12} \mathrm{~N}^{14}$ & 4-1021 & $2,1,2 \leftarrow 1,1,1$ & Ground & & 3 & 2 & 18513.31 & \\
\hline $\mathrm{C}^{12} \mathrm{H}_{2}: \mathrm{C}^{12} \mathrm{HC}^{12} \mathrm{~N}^{14}$ & $4-1021$ & $2,1,2 \leftarrow 1,1,1$ & Ground & & 1 & 0 & 18514.43 & \\
\hline $\mathrm{S}^{32}{ }_{*} \mathrm{HC}^{12}: \mathrm{C}^{12} \mathrm{DC}^{12} \mathrm{H}: \mathrm{C}^{12}{ }_{*} \mathrm{H}$ & 4-1163 & $2,1,1 \leftarrow 1,1,0$ & Ground & & & & 18519.8 & .1 \\
\hline $\mathrm{C}^{12}{ }_{*} \mathrm{D}: \mathrm{C}^{12} \mathrm{DC}^{12} \mathrm{D}: \mathrm{C}^{12} \mathrm{DN}^{14}{ }_{*} \mathrm{D}$ & 4-1186 & $2,0,2 \leftarrow 1,0,1$ & Ground & & & & 18520.4 & \\
\hline $\mathrm{N}^{14} \mathrm{~S}^{34} \mathrm{~F}_{3}^{19}$ & 4-1663 & $2, \leftarrow 1$, & Ground & & & & 18521.34 & \\
\hline $\mathrm{C}^{12}{ }_{*} \mathrm{D}: \mathrm{C}^{12} \mathrm{DC}^{12} \mathrm{D}: \mathrm{C}^{12} \mathrm{DN}^{14}{ }_{*} \mathrm{D}$ & 4-1186 & $7,6,2 \leftarrow 7,4,3$ & Ground & & & & 18523.1 & \\
\hline $\mathrm{HC}^{13}: \mathrm{C}^{12} \mathrm{C}^{12} \mathrm{DO}^{16}$ & 4. 922 & Not Reported & & & & & 18530. & 5. \\
\hline $\mathrm{N}^{14} \mathrm{H}_{3}$ & 4-1771 & $15,12 \leftarrow 15,12$ & Ground & & & & 18535.16 & .08 \\
\hline $\mathrm{C}^{13} \mathrm{H}_{3}\left(\mathrm{C}^{12} \mathrm{H}_{3}\right)_{2} \mathrm{C}^{12} \mathrm{~F}^{19}$ & 3- 982 & $2,1,1 \leftarrow 1,0,1$ & Ground & & & & 18536. & \\
\hline $\mathrm{C}^{12}{ }_{*} \mathrm{H}: \mathrm{C}^{12} \mathrm{HC}^{12} \mathrm{H}: \mathrm{C}^{12} \mathrm{HN}^{14}{ }_{*} \mathrm{H}$ & 4-1181 & $10,10,1 \leftarrow 10,8,2$ & Ground & & & & 18537.8 & \\
\hline $\mathrm{N}^{14} \mathrm{~S}^{32} \mathrm{~F}_{3}^{19}$ & 4-1661 & $2, \leftarrow 1$, & Ground & & & & 18545.10 & \\
\hline $\mathrm{t} \cdot \mathrm{DHC}^{12}: \mathrm{C}^{12} \mathrm{DF}^{19}$ & 4. 791 & $1,0,1 \leftarrow 0,0,0$ & Ground & & & & 18547.0 & .1 \\
\hline $\mathrm{C}^{12}{ }_{*} \mathrm{D}: \mathrm{C}^{12} \mathrm{DC}^{12} \mathrm{D}: \mathrm{C}^{12} \mathrm{DN}^{14}{ }_{*} \mathrm{D}$ & 4-1186 & $8,7,2 \leftarrow 8,5,3$ & Ground & & & & 18548.1 & \\
\hline $\mathrm{HC}^{12}: \mathrm{C}^{12} \mathrm{C}^{13} \mathrm{HO}^{16}$ & 4. 914 & $2,0,2 \leftarrow 1,0,1$ & Ground & & & & 18556.16 & .02 \\
\hline $\mathrm{HC}^{13}: \mathrm{C}^{12} \mathrm{C}^{12} \mathrm{DO}^{16}$ & 4. 922 & Not Reported & & & & & 18559. & 5. \\
\hline $\mathrm{HC}^{12}: \mathrm{C}^{13} \mathrm{C}^{12} \mathrm{HO}^{16}$ & 4- 913 & $2,0,2 \leftarrow 1,0,1$ & Ground & & & & 18561.73 & .02 \\
\hline $\mathrm{C}^{12} \mathrm{H}_{3} \mathrm{~N}^{14} \mathrm{H}_{2}$ & 3- 261 & Not Reported & Ground & & & & 18562.40 & .1 \\
\hline $\mathrm{a}-\mathrm{Si}^{28} \mathrm{HD}_{2} \mathrm{C}^{12} \mathrm{H}: \mathrm{C}^{12} \mathrm{H}_{2}$ & 3. 623 & $2,1,2 \leftarrow 1,1,1$ & Ground & & & & 18563.63 & .10 \\
\hline $\mathrm{HC}^{12}: \mathrm{C}^{12} \mathrm{C}^{12} \mathrm{H}: \mathrm{C}^{12} \mathrm{H}_{2}$ & 4-1131 & $2,1,1 \leftarrow 1,1,0$ & Ground & & & & 18564.74 & \\
\hline $\mathrm{Si}^{28} \mathrm{H}_{2} \mathrm{~F}_{2}^{19}$ & 4-1601 & $1,1,0 \leftarrow 1,0,1$ & Excited & & & & 18569.32 & .10 \\
\hline $\mathrm{S}^{32} \mathrm{O}^{16} \mathrm{~F}_{2}^{19}$ & $4 \cdot 1621$ & Not Reported & & & & & 18569.62 & .1 \\
\hline $\mathrm{S}^{32}{ }_{*} \mathrm{HC}^{12}: \mathrm{C}^{12} \mathrm{DC}^{12} \mathrm{H}: \mathrm{C}^{12}{ }_{*} \mathrm{H}$ & 4-1163 & $9,4,6 \leftarrow 9,4,5$ & Ground & & & & 18569.8 & .1 \\
\hline
\end{tabular}




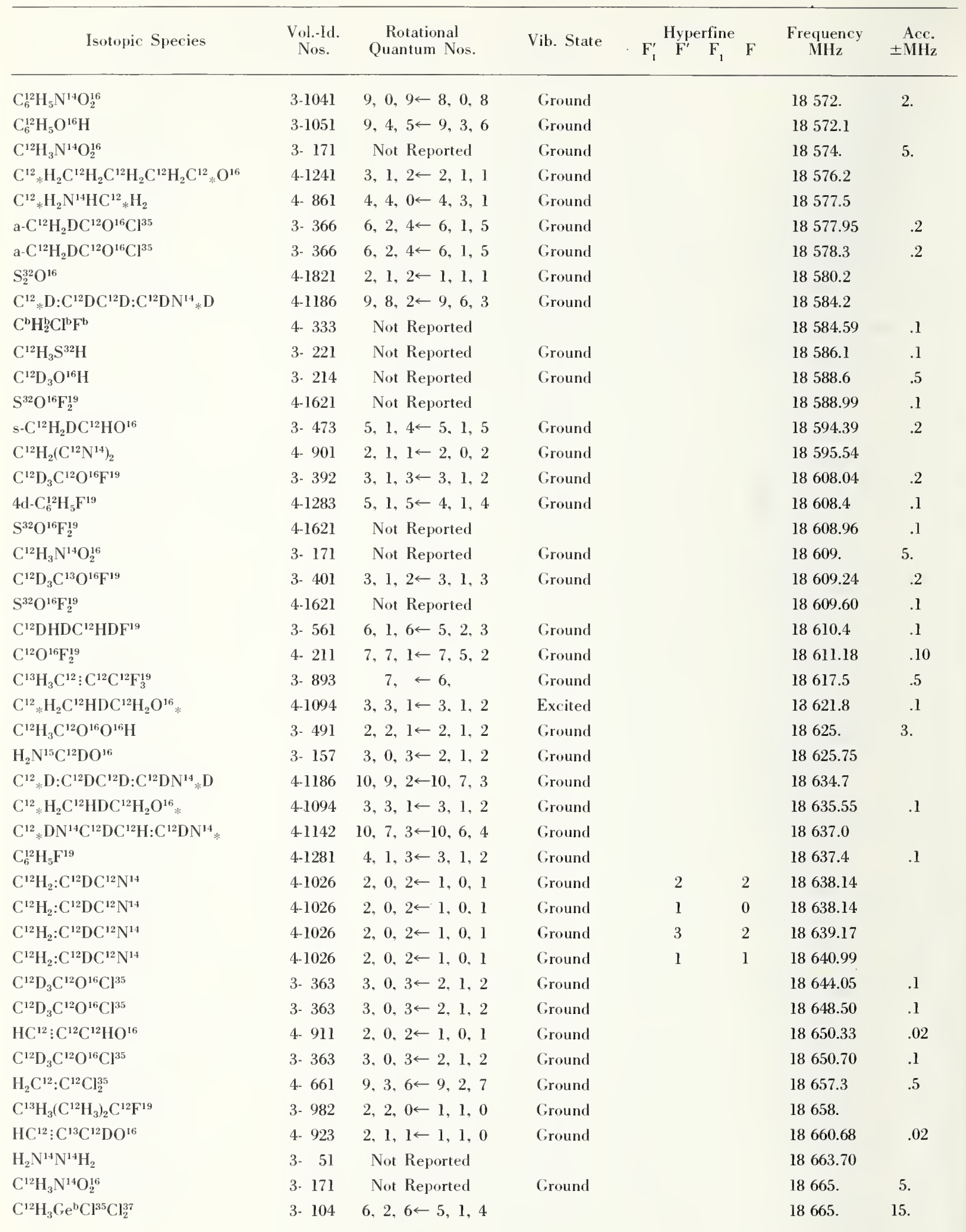




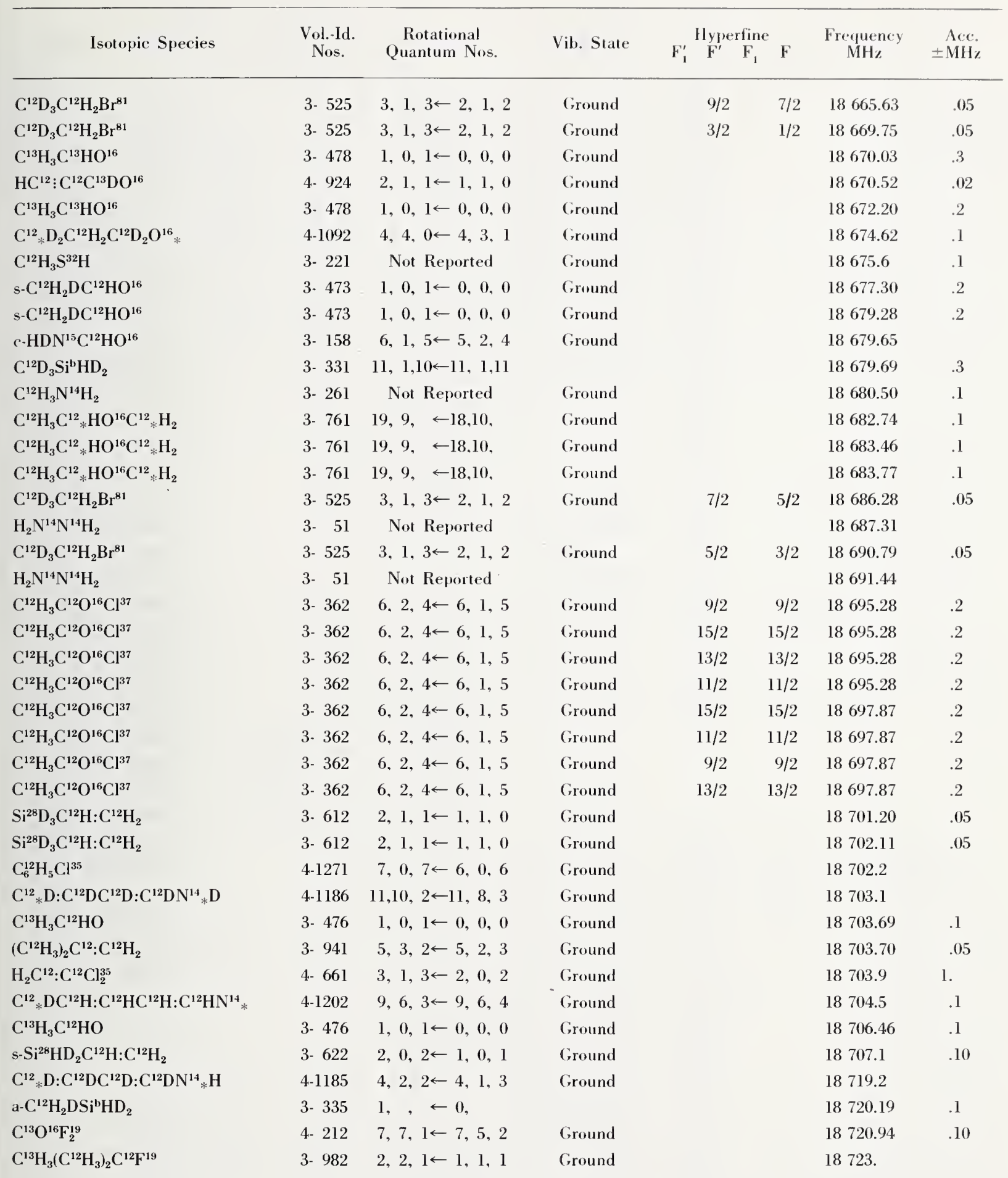




\begin{tabular}{|c|c|c|c|c|c|c|c|c|c|}
\hline Isotopic Species & $\begin{array}{l}\text { Vol.-Id. } \\
\text { Nos. }\end{array}$ & $\begin{array}{c}\text { Rotational } \\
\text { Quantum Nos. }\end{array}$ & Vib. State & $\mathrm{F}_{1}^{\prime}$ & $\begin{array}{l}\text { Hype } \\
\mathrm{F}^{\prime}\end{array}$ & $\mathrm{F}_{1}$ & $F$ & $\begin{array}{c}\text { Frequency } \\
\mathrm{MHz}\end{array}$ & $\begin{aligned} & \text { Acc. } \\
& \pm \mathrm{MHz}\end{aligned}$ \\
\hline $\mathrm{Si}^{28} \mathrm{D}_{3} \mathrm{C}^{12} \mathrm{H}: \mathrm{C}^{12} \mathrm{H}_{2}$ & 3- 612 & $2,1,1 \leftarrow 1,1,0$ & Ground & & & & & 18724.23 & .05 \\
\hline $\mathrm{C}^{12} \mathrm{D}_{3} \mathrm{C}^{12} \mathrm{O}^{16} \mathrm{Cl}^{35}$ & 3- 363 & $6,3,3 \leftarrow 6, \cdot 2,4$ & Ground & & $15 / 2$ & & $15 / 2$ & 18724.40 & \\
\hline $\mathrm{C}^{12} \mathrm{D}_{3} \mathrm{C}^{12} \mathrm{O}^{16} \mathrm{Cl}^{35}$ & 3- 363 & $6,3,3 \leftarrow 6,2,4$ & Ground & & $9 / 2$ & & $9 / 2$ & 18724.40 & \\
\hline $\mathrm{C}^{12} \mathrm{D}_{3} \mathrm{C}^{12} \mathrm{O}^{16} \mathrm{Cl}^{35}$ & 3- 363 & $6,3,3 \leftarrow 6,2,4$ & Ground & & $11 / 2$ & & $11 / 2$ & 18725.55 & \\
\hline $\mathrm{C}^{12} \mathrm{D}_{3} \mathrm{C}^{12} \mathrm{O}^{16} \mathrm{Cl}^{35}$ & 3- 363 & $6,3,3 \leftarrow 6,2,4$ & Ground & & $13 / 2$ & & $13 / 2$ & 18725.55 & \\
\hline $\mathrm{C}^{12} \mathrm{D}_{3} \mathrm{C}^{12} \mathrm{O}^{16} \mathrm{Cl}^{37}$ & 3- 364 & $7,3,4 \leftarrow 7,2,5$ & Ground & & $17 / 2$ & & $17 / 2$ & 18730.03 & \\
\hline $\mathrm{C}^{12} \mathrm{D}_{3} \mathrm{C}^{12} \mathrm{O}^{16} \mathrm{Cl}^{37}$ & 3- 364 & $7,3,4 \leftarrow 7,2,5$ & Ground & & $11 / 2$ & & $11 / 2$ & 18730.03 & \\
\hline $\mathrm{C}^{12}{ }_{*} \mathrm{H}: \mathrm{C}^{12} \mathrm{HC}^{12} \mathrm{H}: \mathrm{C}^{12} \mathrm{HN}^{14}{ }_{*} \mathrm{D}$ & 4-1182 & $4,4,1 \leftarrow 4,2,2$ & Ground & & & & & 18730.5 & \\
\hline $\mathrm{C}^{12} \mathrm{D}_{3} \mathrm{C}^{12} \mathrm{O}^{16} \mathrm{Cl}^{37}$ & 3- 364 & $7,3,4 \leftarrow 7,2,5$ & Ground & & $15 / 2$ & & $15 / 2$ & 18732.27 & \\
\hline $\mathrm{C}^{12} \mathrm{D}_{3} \mathrm{C}^{12} \mathrm{O}^{16} \mathrm{Cl}^{37}$ & 3- 364 & $7,3,4 \leftarrow 7,2,5$ & Ground & & $13 / 2$ & & $13 / 2$ & 18732.27 & \\
\hline $\mathrm{D}_{2} \mathrm{C}^{12}: \mathrm{C}^{12} \mathrm{O}^{16}$ & 4- 712 & $22,2,20 \leftarrow 22,2,21$ & Ground & & & & & 18737.62 & \\
\hline $\mathrm{c}-\mathrm{HDC}^{12} * \mathrm{O}^{16} \mathrm{C}^{12}{ }_{*} \mathrm{DH}$ & 4- 845 & $2,1,1 \leftarrow 2,0,2$ & Ground & & & & & 18741.20 & .05 \\
\hline $3 d-C_{6}^{12} H_{5} F^{19}$ & 4-1282 & $5,1,5 \leftarrow 4,1,4$ & Ground & & & & & 18745.2 & .1 \\
\hline$\left(\mathrm{C}^{12} \mathrm{H}_{3}\right)_{2} \mathrm{C}^{12}: \mathrm{C}^{12} \mathrm{H}_{2}$ & $3 \cdot 941$ & $9,8,1 \leftarrow 9,7,2$ & Ground & & & & & 18747.34 & .05 \\
\hline$\left(\mathrm{C}^{12} \mathrm{H}_{3}\right)_{2} \mathrm{C}^{12}: \mathrm{C}^{12} \mathrm{H}_{2}$ & 3- 941 & $9,8,1 \leftarrow 9,7,2$ & Ground & & & & & 18748.06 & \\
\hline $\mathrm{C}^{12}{ }_{*} \mathrm{HC}^{12} \mathrm{D}: \mathrm{C}^{12} \mathrm{HC}^{12} \mathrm{H}: \mathrm{C}^{12} \mathrm{HN}^{14} *$ & $4-1203$ & $9,6,3 \leftarrow 9,6,4$ & Ground & & & & & 18751.5 & .1 \\
\hline $\mathrm{HC}^{12}: \mathrm{C}^{12} \mathrm{C}^{12} \mathrm{DO}^{16}$ & 4- 921 & $2,1,1 \leftarrow 1,1,0$ & Ground & & & & & 18753.58 & .02 \\
\hline $\mathrm{s}-\mathrm{C}^{12} \mathrm{H}_{2} \mathrm{DC}^{12} \mathrm{O}^{16} \mathrm{Cl}^{35}$ & 3. 365 & $3,0,3 \leftarrow 2,1,2$ & Ground & & & & & 18758.5 & .2 \\
\hline $\mathrm{s}-\mathrm{C}^{12} \mathrm{H}_{2} \mathrm{DC}^{12} \mathrm{O}^{16} \mathrm{Cl}^{35}$ & 3. 365 & $3,0,3 \leftarrow 2,1,2$ & Ground & & & & & 18759.0 & .2 \\
\hline $\mathrm{C}^{12}{ }_{*} \mathrm{HC}^{12} \mathrm{H}: \mathrm{C}^{12} \mathrm{HC}^{12} \mathrm{H}: \mathrm{C}^{12} \mathrm{HN}^{14} *$ & 4-1201 & $12,9,3 \leftarrow 12,9,4$ & Ground & & & & & 18760.9 & \\
\hline $\mathrm{C}^{13} \mathrm{H}_{3} \mathrm{C}^{12} \mathrm{O}^{16} \mathrm{C}^{12} \mathrm{~N}^{14}$ & $3-672$ & $2,1,2 \leftarrow 1,0,1$ & Ground & & & & & 18761.11 & .2 \\
\hline $\mathrm{C}^{12} \mathrm{H}_{3} \mathrm{Si}^{28} \mathrm{HF}_{2}^{19} \cdot \mathrm{A}$ & 3. 191 & Not Reported & Ground & & & & & 18761.6 & \\
\hline $\mathrm{t}-\mathrm{Si}^{28} \mathrm{H}_{3} \mathrm{C}^{12} \mathrm{H}: \mathrm{C}^{12} \mathrm{HD}$ & 3- 618 & $2,0,2 \leftarrow 1,0,1$ & Ground & & & & & 18766.27 & .10 \\
\hline $\mathrm{O}^{16} \mathrm{O}^{18} \mathrm{O}^{16}$ & 4-1843 & $4,0,4 \leftarrow 3,1,3$ & Ground & & & & & 18768. & \\
\hline $\mathrm{In}^{115} \mathrm{Cl}^{37}$ & $1-$ & $3 \leftarrow 2$ & Ground & $15 / 2$ & 6 & $13 / 2$ & 5 & 18768.93 & 0.20 \\
\hline $\operatorname{In}^{115} \mathrm{Cl}^{37}$ & $1-$ & $3 \leftarrow 2$ & Ground & $15 / 2$ & 9 & $13 / 2$ & 8 & 18768.93 & 0.20 \\
\hline $\operatorname{In}^{115} \mathrm{Cl}^{37}$ & $1-$ & $3 \leftarrow 2$ & Ground & $15 / 2$ & 8 & $13 / 2$ & 7 & 18768.93 & 0.20 \\
\hline $\ln ^{115} \mathrm{Cl}^{37}$ & $1-$ & $3 \leftarrow 2$ & Ground & $15 / 2$ & 7 & $13 / 2$ & 6 & 18768.93 & 0.20 \\
\hline $\mathrm{a}-\mathrm{C}^{12} \mathrm{H}_{2} \mathrm{DSi}^{\mathrm{b}} \mathrm{HD}_{2}$ & 3- 335 & $1, \quad \leftarrow 0, \quad$ & & & & & & 18769.49 & .1 \\
\hline $\mathrm{HC}^{12} \mathrm{O}^{18} \mathrm{O}^{16} \mathrm{C}^{12} \mathrm{H}_{3}-\mathrm{E}$ & 3- 514 & $3,1,2 \leftarrow 3,0,3$ & Ground & & & & & 18770.0 & .35 \\
\hline $\mathrm{C}^{12} \mathrm{H}_{2} \mathrm{~N}^{14} \mathrm{O}^{16} \mathrm{H}$ & 3- 141 & $10,2,8 \leftarrow 10,2,9$ & Cround & & 11 & & 11 & 18770.96 & .10 \\
\hline $\mathrm{C}^{12} \mathrm{H}_{2} \mathrm{~N}^{14} \mathrm{O}^{16} \mathrm{H}$ & 3- 141 & $10,2,8 \leftarrow 10,2,9$ & Ground & & 9 & & 9 & 18770.96 & .10 \\
\hline $\mathrm{C}^{12} \mathrm{H}_{2} \mathrm{~N}^{14} \mathrm{O}^{16} \mathrm{H}$ & 3. 141 & $10,2,8 \leftarrow 10,2,9$ & Ground & & 10 & & 10 & 18771.93 & .10 \\
\hline $\mathrm{C}^{12} \mathrm{H}_{3} \mathrm{C}^{12} \mathrm{H}_{2} \mathrm{O}^{16} \mathrm{H}$ & 3. 581 & $7,3,5 \leftarrow 8,2,6$ & Ground & & & & & 18772.5 & .1 \\
\hline $\mathrm{C}^{12} \mathrm{D}_{3} \mathrm{C}^{12} \mathrm{H}_{2} \mathrm{Br}^{79}$ & 3. 523 & $3,1,3 \leftarrow 2,1,2$ & Ground & & $9 / 2$ & & $7 / 2$ & 18777.32 & .05 \\
\hline $\mathrm{HC}^{12} \mathrm{O}^{18} \mathrm{O}^{16} \mathrm{C}^{12} \mathrm{H}_{3}-\mathrm{A}$ & 3. 513 & $3,1,2 \leftarrow 3,0,3$ & Ground & & & & & 18777.42 & .2 \\
\hline $\mathrm{C}^{12} \mathrm{H}_{3} \mathrm{~S}^{32} \mathrm{H}$ & $3 \cdot 221$ & Not Reported & Ground & & & & & 18778.6 & .1 \\
\hline c- $\mathrm{C}^{12} \mathrm{HF}^{19}: \mathrm{C}^{12} \mathrm{HCl}^{37}$ & 4. 642 & $5,1,4 \leftarrow 5,0,5$ & Ground & & $7 / 2$ & & $7 / 2$ & 18780.34 & \\
\hline $\mathrm{H}_{2} \mathrm{~N}^{14} \mathrm{~N}^{14} \mathrm{H}_{2}$ & $3-51$ & Not Reported & & & & & & 18781.43 & \\
\hline c. $\mathrm{C}^{12} \mathrm{HF}^{19}: \mathrm{C}^{12} \mathrm{HCl}^{37}$ & 4- 642 & $5,1,4 \leftarrow 5,0,5$ & Ground & & $13 / 2$ & & $13 / 2$ & 18781.91 & \\
\hline $\mathrm{C}^{12} \mathrm{D}_{3} \mathrm{C}^{12} \mathrm{H}_{2} \mathrm{Br}^{79}$ & 3- 523 & $3,1,3 \leftarrow 2,1,2$ & Ground & & $3 / 2$ & & $1 / 2$ & 18782.26 & .05 \\
\hline $\mathrm{N}^{15} \mathrm{H}_{3}$ & $4-1772$ & $6,3 \leftarrow 6,3$ & Ground & & & & & 18788.25 & .06 \\
\hline $\mathrm{C}^{12}{ }_{*} \mathrm{H}: \mathrm{C}^{12} \mathrm{HO}^{18} \mathrm{C}^{12} \mathrm{H}: \mathrm{C}^{12}{ }_{*} \mathrm{H}$ & 4-1152 & $7,5,2 \leftarrow 7,5,3$ & Ground & & & & & 18790.4 & .1 \\
\hline
\end{tabular}




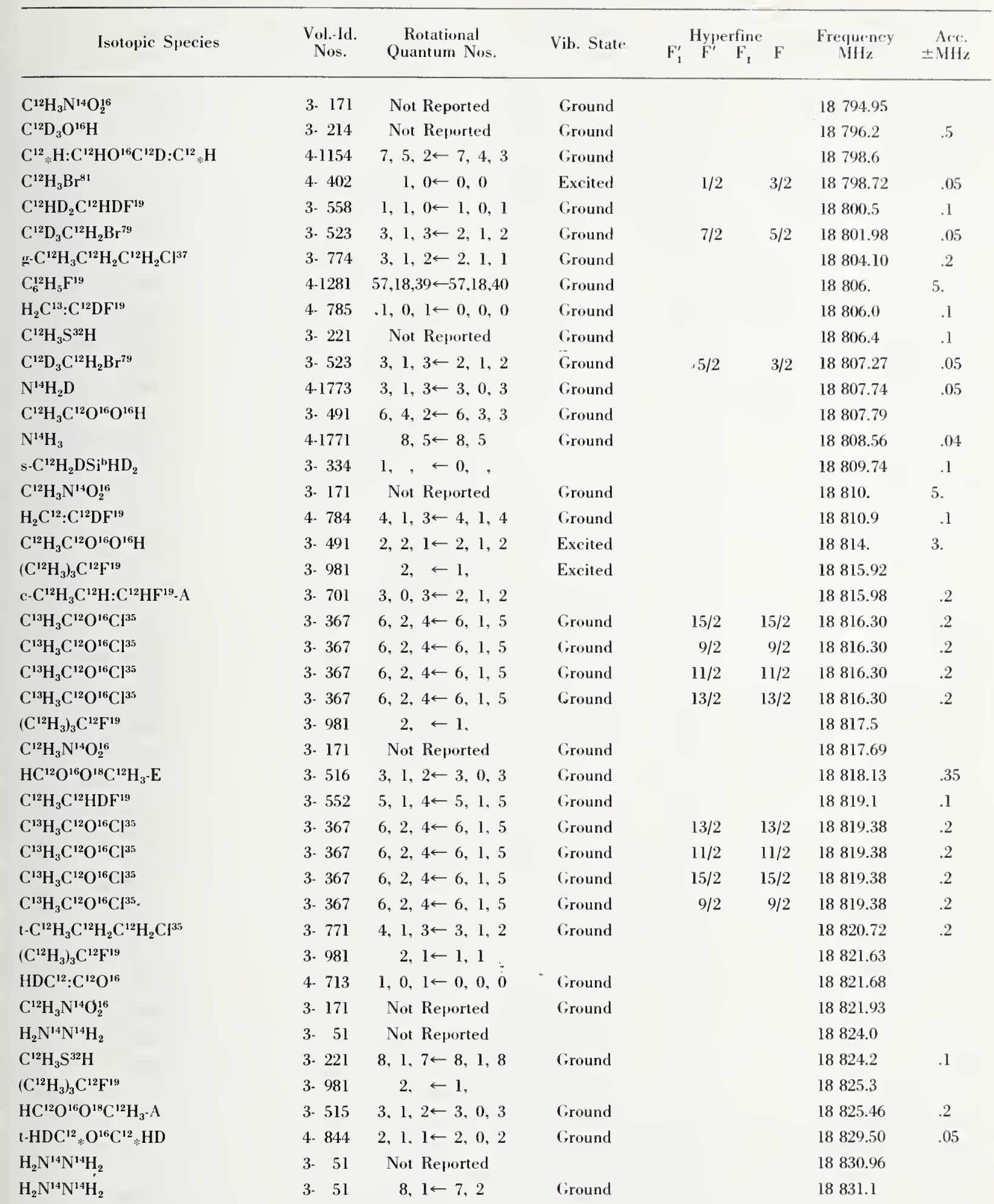




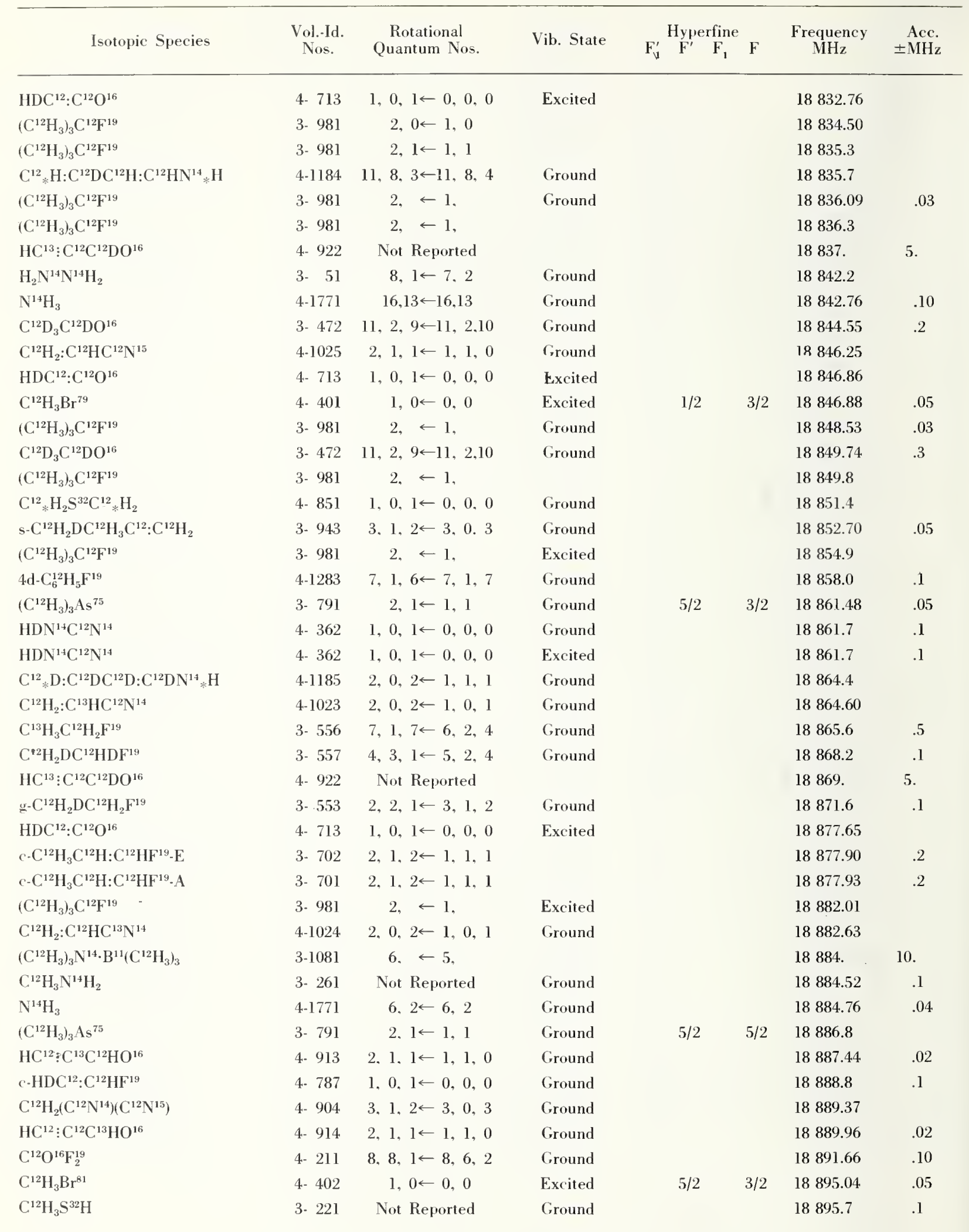




\begin{tabular}{|c|c|c|c|c|c|c|c|}
\hline Isotopic Species & $\begin{array}{l}\text { Vol.-Id. } \\
\text { Nos. }\end{array}$ & $\begin{array}{c}\text { Rotational } \\
\text { Quantum Nos. }\end{array}$ & Vib. State & $F_{1}^{\prime} \quad \begin{array}{l}\text { Hyperfine } \\
F^{\prime} \quad F_{1}\end{array}$ & $\mathrm{~F}$ & $\begin{array}{l}\text { Frecquency } \\
\qquad \mathrm{HHz}_{\mathrm{z}}\end{array}$ & $\begin{aligned} & \text { Acc. } \\
& \pm \mathrm{NH}\end{aligned}$ \\
\hline s- $-\mathrm{HC}^{12} \mathrm{O}^{16} \mathrm{O}^{16} \mathrm{C}^{12} \mathrm{H}_{2} \mathrm{D}-\mathrm{A}$ & 3. 505 & $3,1,2 \leftarrow 3,0,3$ & Ground & & & 18896.82 & .2 \\
\hline$\left(\mathrm{C}^{12} \mathrm{D}_{3}\right)_{2} \mathrm{O}^{16}$ & 3- 592 & $1,1,0 \leftarrow 1,0,1$ & Ground & & & 18898.3 & .2 \\
\hline $\mathrm{C}^{12} \mathrm{H}_{3} \mathrm{C}^{12} \mathrm{~F}^{19}: \mathrm{C}^{12} \mathrm{H}_{2}$ & 3. 721 & $10,7,3 \leftarrow 10,7,4$ & Ground & & & 18900.32 & .1 \\
\hline $\mathrm{C}^{12} \mathrm{H}_{3} \mathrm{C}^{12} \mathrm{~F}^{19}: \mathrm{C}^{12} \mathrm{H}_{2}$ & 3- 721 & $10,7,3 \leftarrow 10,7,4$ & Ground & & & 18900.98 & .1 \\
\hline $\mathrm{D}_{2} \mathrm{~N}^{14} \mathrm{C}^{12} \mathrm{HO}^{16}$ & 3- 154 & $1,0,1 \leftarrow 0,0,0$ & Ground & & & 18904.01 & .1 \\
\hline$\left(\mathrm{C}^{12} \mathrm{H}_{3}\right)_{3} \mathrm{As}^{75}$ & 3- 791 & $2,0 \leftarrow 1,0$ & Ground & $5 / 2$ & $3 / 2$ & 18904.22 & .05 \\
\hline$\left(\mathrm{C}^{12} \mathrm{H}_{3}\right)_{3} \mathrm{As}{ }^{75}$ & 3. 791 & $2,0 \leftarrow 1,0$ & Ground & $7 / 2$ & $5 / 2$ & 18904.22 & .05 \\
\hline $\mathrm{C}^{13} \mathrm{H}_{3} \mathrm{C}^{12} \mathrm{H}_{3} \mathrm{C}^{12}: \mathrm{C}^{12} \mathrm{H}_{2}$ & 3. 945 & $4,2,2 \leftarrow 4,1,3$ & Ground & & & 18905.09 & \\
\hline $\mathrm{H}_{2} \mathrm{C}^{12}: \mathrm{C}^{12} \mathrm{~F}_{2}^{19}$ & 4. 681 & Not Reported & & & & 18907.5 & .3 \\
\hline $\mathrm{C}^{12} \mathrm{H}_{3} \mathrm{Ce}^{\mathrm{b}} \mathrm{Cl}_{2}^{35} \mathrm{C}^{37}$ & 3. 105 & $6,2,6 \leftarrow 5,1,4$ & & & & 18910. & 15. \\
\hline $\mathrm{C}^{13} \mathrm{H}_{2}: \mathrm{C}^{12} \mathrm{HC}^{12} \mathrm{~N}^{14}$ & $4-1022$ & $2,1,1 \leftarrow 1,1,0$ & Ground & & & 18911.15 & \\
\hline$\left(\mathrm{C}^{12} \mathrm{H}_{3}\right)_{3} \mathrm{As}^{75}$ & 3. 791 & $2,1 \leftarrow 1,1$ & Ground & $7 / 2$ & $5 / 2$ & 18912.15 & .05 \\
\hline$\left(\mathrm{C}^{12} \mathrm{D}_{3}\right)_{2} \mathrm{O}^{16}$ & 3. 592 & $1,1,0 \leftarrow 1,0,1$ & Ground & & & 18912.8 & .2 \\
\hline $\mathrm{O}^{16} \mathrm{O}^{18} \mathrm{O}^{16}$ & $4-1843$ & $25,3,23 \leftarrow-24,4,20$ & Ground & & & 18916. & \\
\hline $\mathrm{C}^{12} \mathrm{H}_{2} \mathrm{Cl}^{35} \mathrm{~F}^{19}$ & 4- 331 & $17,2,15 \leftarrow 16,3,14$ & Ground & & & 18916.70 & .1 \\
\hline $\mathrm{C}_{6}^{12} \mathrm{H}_{5} \mathrm{O}^{16} \mathrm{H}$ & $3-1051$ & $5,0,5 \leftarrow 4,1,4$ & Ground & & & 18919.46 & \\
\hline $\mathrm{C}^{12} \mathrm{D}_{3} \mathrm{O}^{16} \mathrm{H}$ & $3 \cdot 214$ & Not Reported & Ground & & & 18923.7 & .5 \\
\hline$\left(\mathrm{C}^{12} \mathrm{H}_{3}\right)_{3} \mathrm{As}^{75}$ & 3. 791 & $2,1 \leftarrow 1,1$ & Ground & $3 / 2$ & $1 / 2$ & 18925.3 & \\
\hline $\mathrm{C}^{12} \mathrm{H}_{3} \mathrm{~N}^{14} \mathrm{H}_{2}$ & 3- 261 & Not Reported & Ground & & & 18928.16 & \\
\hline $\mathrm{D}_{2} \mathrm{~N}^{14} \mathrm{C}^{12} \mathrm{HO}^{16}$ & 3. 154 & $1,0,1 \leftarrow 0,0,0$ & Excited & & & 18929.5 & \\
\hline $\mathrm{C}^{12} \mathrm{H}_{3} \mathrm{~N}^{14} \mathrm{O}_{2}^{16}$ & 3. 171 & Not Reported & Ground & & & 18938. & 5. \\
\hline $\mathrm{H}_{2} \mathrm{~N}^{14} \mathrm{~N}^{14} \mathrm{H}_{2}$ & 3. 51 & Not Reported & & & & 18940.14 & \\
\hline $\mathrm{C}^{12} \mathrm{H}_{3} \mathrm{Br}^{81}$ & 4- 402 & $1,0 \leftarrow 0,0$ & Ground & $1 / 2$ & $3 / 2$ & 18943.38 & .05 \\
\hline $\mathrm{HC}^{12} \mathrm{O}^{16} \mathrm{~N}^{14} \mathrm{H}_{2}$ & 3- 151 & $1,1,1 \leftarrow 2,0,2$ & Ground & 1 & 2 & 18956.28 & .1 \\
\hline $\mathrm{HC}^{12} \mathrm{O}^{16} \mathrm{~N}^{14} \mathrm{H}_{2}$ & 3- 151 & $1,1,1 \leftarrow 2,0,2$ & Ground & 2 & 3 & 18956.28 & .1 \\
\hline $\mathrm{HC}^{12} \mathrm{O}^{16} \mathrm{~N}^{14} \mathrm{H}_{2}$ & 3- 151 & $1,1,1 \leftarrow 2,0,2$ & Ground & 0 & 1 & 18956.28 & .1 \\
\hline $\mathrm{Cl}^{137} \mathrm{~F}^{19} \mathrm{C}^{12} \mathrm{O}^{16}$ & 4- 152 & $2,1,1 \leftarrow 1,1,0$ & Ground & $7 / 2$ & $5 / 2$ & 18959.00 & .07 \\
\hline $\mathrm{C}^{12} \mathrm{H}_{2} \mathrm{Cl}^{35} \mathrm{~F}^{19}$ & 4. 331 & $17,1,17 \leftarrow 16,2,14$ & Ground & & & 18961.29 & .1 \\
\hline $\mathrm{C}^{12} \mathrm{H}_{3} \mathrm{Br}^{79}$ & 4- 401 & $1,0 \leftarrow 0,0$ & Excited & $5 / 2$ & $3 / 2$ & 18962.19 & .05 \\
\hline $\mathrm{C}^{12} \mathrm{D}_{3} \mathrm{C}^{12} \mathrm{DO}^{16}$ & 3- 472 & Not Reported & & & & 18963.78 & \\
\hline $\mathrm{t}-\mathrm{HDN}{ }^{15} \mathrm{C}^{12} \mathrm{HO}^{16}$ & 3- 159 & $4,0,4 \leftarrow 3,1,3$ & Ground & & & 18964.62 & \\
\hline $\mathrm{C}^{12} \mathrm{H}_{2}: \mathrm{C}^{12} \mathrm{HC}^{12} \mathrm{~N}^{14}$ & $4-1021$ & $2,0,2 \leftarrow 1,0,1$ & Ground & 2 & 2 & 18965.48 & \\
\hline $\mathrm{C}^{12} \mathrm{H}_{2}: \mathrm{C}^{12} \mathrm{HC}^{12} \mathrm{~N}^{14}$ & $4-1021$ & $2,0,2 \leftarrow 1,0,1$ & Ground & 1 & 0 & 18965.48 & \\
\hline $\mathrm{C}^{12} \mathrm{H}_{2}: \mathrm{C}^{12} \mathrm{HC}^{12} \mathrm{~N}^{14}$ & 4-1021 & $2,0,2 \leftarrow 1,0,1$ & Ground & 3 & 2 & 18966.61 & \\
\hline $\mathrm{C}^{12} \mathrm{H}_{2} \mathrm{Cl}^{35} \mathrm{~F}^{19}$ & 4- 331 & $17,1,17 \leftarrow 16,2,14$ & Ground & & & 18967.52 & .1 \\
\hline $\mathrm{C}^{12} * \mathrm{DN}^{14} \mathrm{C}^{12} \mathrm{DC}^{12} \mathrm{H}: \mathrm{C}^{12} \mathrm{DN}^{14} *$ & $4-1142$ & $9,6,4 \leftarrow 9,5,4$ & Ground & & & 18968.0 & \\
\hline $\mathrm{C}^{12} \mathrm{H}_{2}: \mathrm{C}^{12} \mathrm{HC}^{12} \mathrm{~N}^{14}$ & $4-1021$ & $2,0,2 \leftarrow 1,0,1$ & Ground & 1 & 1 & 18968.41 & \\
\hline $\mathrm{HN}^{14} \mathrm{O}_{3}^{16}$ & 3- 31 & $9,7,2 \leftarrow 9,7,3$ & Ground & & & 18969.56 & \\
\hline $\mathrm{C}^{12} \mathrm{H}_{2} \mathrm{~F}_{2}^{19}$ & 4- 351 & $43,12,31 \leftarrow 44,11,34$ & Ground & & & 18972.43 & .10 \\
\hline $\mathrm{C}^{12} \mathrm{H}_{2} \mathrm{~F}_{2}^{19}$ & 4- 351 & $43,12,32 \leftarrow 44,11,33$ & Ground & & & 18972.43 & .10 \\
\hline $\mathrm{C}^{12} \mathrm{H}_{3} \mathrm{C}^{12} * \mathrm{HO}^{16} \mathrm{C}^{12} * \mathrm{H}_{2}$ & 3- 761 & $4,1,3 \leftarrow 3,2,2$ & Ground & & & 18972.75 & .1 \\
\hline $\mathrm{C}^{12} \mathrm{H}_{3} \mathrm{C}^{12}{ }_{*} \mathrm{HO}^{16} \mathrm{C}^{12}{ }_{*} \mathrm{H}_{2}$ & 3. 761 & $4,1,3 \leftarrow 3,2,2$ & Ground & & & 18973.03 & .1 \\
\hline $\mathrm{C}^{12} \mathrm{H}_{2}: \mathrm{C}^{12} \mathrm{HC}^{12} \mathrm{~F}^{19}: \mathrm{C}^{12} \mathrm{H}_{2}$ & 3- 911 & $2,1,2 \leftarrow 1,0,1$ & Ground & & & 18973.87 & .03 \\
\hline $\mathrm{C}^{12}{ }_{*} \mathrm{D}: \mathrm{C}^{12} \mathrm{DC}^{12} \mathrm{D}: \mathrm{C}^{12} \mathrm{DN}^{14}{ }_{*} \mathrm{H}$ & $4 \cdot 1185$ & $9,9,0 \leftarrow 9,8,1$ & Ground & & & 18975.3 & \\
\hline $\mathrm{HC}^{12}: \mathrm{C}^{12} \mathrm{C}^{12} \mathrm{HO}^{16}$ & 4. 911 & $2,1,1 \leftarrow 1,1,0$ & Ground & & & 18978.78 & .02 \\
\hline
\end{tabular}




\begin{tabular}{|c|c|c|c|c|c|c|c|c|}
\hline Isotopic Species & $\begin{array}{l}\text { Vol.-Id. } \\
\text { Nos. }\end{array}$ & $\begin{array}{c}\text { Rotational } \\
\text { Quantum Nos. }\end{array}$ & Vib. State & $F_{1}^{\prime}$ & $\begin{array}{c}\text { Hyperfin } \\
\mathrm{F}^{\prime} \quad \mathrm{F}_{1}\end{array}$ & e F & $\begin{array}{c}\text { Frequency } \\
\mathrm{MHz}\end{array}$ & $\begin{array}{r}\text { Acc. } \\
\pm \mathrm{MHz}\end{array}$ \\
\hline $\mathrm{s}-\mathrm{Si}^{28} \mathrm{HD}_{2} \mathrm{C}^{12} \mathrm{H}: \mathrm{C}^{12} \mathrm{H}_{2}$ & 3- 622 & $2,1,1 \leftarrow 1,1,0$ & Ground & & & & 18986.14 & .10 \\
\hline $\mathrm{C}^{12}{ }_{*} \mathrm{D}: \mathrm{C}^{12} \mathrm{DC}^{12} \mathrm{D}: \mathrm{C}^{12} \mathrm{DN}^{14}{ }_{*} \mathrm{H}$ & 4-1185 & $3,1,2 \leftarrow 3,0,3$ & Ground & & & & 18989.6 & \\
\hline $\mathrm{s}-\mathrm{C}^{12} \mathrm{H}_{2} \mathrm{DC}^{12} \mathrm{HO}^{16}$ & 3. 473 & Not Reported & & & & & 18991.57 & \\
\hline $\mathrm{C}^{12} \mathrm{H}_{3} \mathrm{~S}^{32} \mathrm{H}$ & 3- 221 & Not Reported & Ground & & & & 18991.8 & .1 \\
\hline $\mathrm{C}^{12} \mathrm{H}_{3} \mathrm{Br}^{79}$ & 4- 401 & $1,0 \leftarrow 0,0$ & Ground & & $1 / 2$ & $3 / 2$ & 18992.47 & .05 \\
\hline $\mathrm{C}^{12} \mathrm{D}_{3} \mathrm{C}^{12} \mathrm{H}_{2} \mathrm{Br}^{81}$ & 3. 525 & $3,0,3 \leftarrow 2,0,2$ & Ground & & $7 / 2$ & $5 / 2$ & 18993.67 & .05 \\
\hline $\mathrm{C}^{12} \mathrm{H}_{2} \mathrm{~N}^{14} \mathrm{O}^{16} \mathrm{H}$ & 3- 141 & $8,2,6 \leftarrow 9,1,9$ & Ground & & 7 & 8 & 18993.86 & .10 \\
\hline $\mathrm{C}^{12} \mathrm{H}_{2} \mathrm{~N}^{14} \mathrm{O}^{16} \mathrm{H}$ & 3- 141 & $8,2,6 \leftarrow 9,1,9$ & Ground & & 9 & 10 & 18993.86 & .10 \\
\hline $\mathrm{C}^{12} \mathrm{D}_{3} \mathrm{C}^{12} \mathrm{H}_{2} \mathrm{Br}^{81}$ & 3. 525 & $3,0,3 \leftarrow 2,0,2$ & Ground & & $9 / 2$ & $7 / 2$ & 18994.08 & .05 \\
\hline $\mathrm{C}^{12} \mathrm{H}_{3} \mathrm{C}^{13}: \mathrm{C}^{12} \mathrm{C}^{12} \mathrm{~F}_{3}^{19}$ & 3- 894 & $7, \leftarrow 6$, & Ground & & & & 18995.0 & .5 \\
\hline $\mathrm{C}^{12} \mathrm{H}_{2} \mathrm{~N}^{14} \mathrm{O}^{16} \mathrm{H}$ & 3- 141 & $8,2,6 \leftarrow 9,1,9$ & Ground & & 8 & 9 & 18995.60 & .10 \\
\hline $\mathrm{HC}^{13}: \mathrm{C}^{12} \mathrm{C}^{12} \mathrm{DO}^{16}$ & 4- 922 & Not Reported & & & & & 19001. & 5. \\
\hline $\mathrm{t}-\mathrm{C}^{12} \mathrm{H}_{2} \mathrm{DC}^{12} \mathrm{H}_{2} \mathrm{Cl}^{35}$ & 3. 543 & $2,1,2 \leftarrow 1,1,1$ & Ground & & $5 / 2$ & $3 / 2$ & 19002.3 & .05 \\
\hline $\mathrm{a}-\mathrm{C}^{12} \mathrm{D}_{2} \mathrm{H}\left(\mathrm{C}^{12} \mathrm{H}_{3}\right)_{2} \mathrm{Si}^{\mathrm{b}} \mathrm{D}$ & 3- 884 & $2,1,1 \leftarrow 1,0,1$ & Ground & & & & 19002.95 & .10 \\
\hline $\mathrm{S}^{34}{ }_{*} \mathrm{HC}^{12}: \mathrm{C}^{12} \mathrm{HC}^{12} \mathrm{H}: \mathrm{C}^{12}{ }_{*} \mathrm{H}$ & 4-1166 & $2,1,1 \leftarrow 1,1,0$ & Ground & & & & 19003.9 & 3. \\
\hline $\mathrm{DN}^{14} \mathrm{O}_{3}^{16}$ & 3- 32 & $1,1,1 \leftarrow 0,0,0$ & Ground & & 1 & 1 & 19005.40 & \\
\hline $\mathrm{DN}^{14} \mathrm{O}_{3}^{16}$ & $3-\quad 32$ & $1,1,1 \leftarrow 0,0,0$ & Ground & & 2 & 1 & 19005.61 & \\
\hline $\mathrm{t}-\mathrm{C}^{12} \mathrm{H}_{2} \mathrm{DC}^{12} \mathrm{H}_{2} \mathrm{Cl}^{35}$ & 3. 543 & $2,1,2 \leftarrow 1,1,1$ & Ground & & $5 / 2$ & $5 / 2$ & 19005.8 & .05 \\
\hline $\mathrm{DN}^{14} \mathrm{O}_{3}^{16}$ & 3- 32 & $1,1,1 \leftarrow 0,0,0$ & Ground & & 0 & 1 & 19005.89 & \\
\hline $\mathrm{C}^{12} \mathrm{H}_{3} \mathrm{C}^{12} \mathrm{H}_{2} \mathrm{O}^{16} \mathrm{H}$ & 3. 581 & $6,2,4 \leftarrow 5,3,3$ & Ground & & & & 19006.19 & .01 \\
\hline $\mathrm{S}^{34}{ }_{*} \mathrm{HC}^{12}: \mathrm{C}^{12} \mathrm{HC}^{12} \mathrm{H}: \mathrm{C}^{12}{ }_{*} \mathrm{H}$ & $4-1166$ & $2,1,1 \leftarrow 1,1,0$ & Ground & & & & 19006.4 & .05 \\
\hline $\mathrm{t}-\mathrm{C}^{12} \mathrm{H}_{2} \mathrm{DC}^{12} \mathrm{H}_{2} \mathrm{Cl}^{35}$ & 3- 543 & $2,1,2 \leftarrow 1,1,1$ & Ground & & $3 / 2$ & $3 / 2$ & 19008.6 & .05 \\
\hline $\mathrm{O}^{16} \mathrm{~F}_{2}^{19}$ & 4-1611 & $15,4,11 \leftarrow 16,3,14$ & Ground & & & & 19009.18 & .10 \\
\hline $\mathrm{C}^{12}{ }_{*} \mathrm{H}: \mathrm{C}^{12} \mathrm{HO}^{16} \mathrm{C}^{12} \mathrm{H}: \mathrm{C}^{12}{ }_{*} \mathrm{H}$ & 4-1151 & $8,8,1 \leftarrow 8,6,2$ & Ground & & & & 19011.46 & \\
\hline $\mathrm{S}^{32}{ }_{*} \mathrm{HC}^{12}: \mathrm{C}^{12} \mathrm{DC}^{12} \mathrm{H}: \mathrm{C}^{12}{ }_{*} \mathrm{H}$ & 4-1163 & $4,1,4 \leftarrow 4,1,3$ & Ground & & & & 19012.5 & .1 \\
\hline $\mathrm{c}-\mathrm{Si}^{28} \mathrm{H}_{3} \mathrm{C}^{12} \mathrm{H}: \mathrm{C}^{12} \mathrm{HD}$ & 3- 617 & $2,1,2 \leftarrow 1,1,1$ & Ground & & & & 19013.32 & .10 \\
\hline $\mathrm{C}^{12} \mathrm{H}_{3} \mathrm{~N}^{14} \mathrm{H}_{2}$ & 3- 261 & Not Reported & Ground & & & & 19013.55 & .04 \\
\hline $\mathrm{C}^{12} \mathrm{D}_{3} \mathrm{C}^{12} \mathrm{H}_{2} \mathrm{Br}^{81}$ & 3- 525 & $3,0,3 \leftarrow 2,0,2$ & Ground & & $3 / 2$ & $1 / 2$ & 19013.66 & .05 \\
\hline $\mathrm{t}-\mathrm{C}^{12} \mathrm{H}_{2} \mathrm{DC}^{12} \mathrm{H}_{2} \mathrm{Cl}^{35}$ & 3- 543 & $2,1,2 \leftarrow 1,1,1$ & Ground & & $7 / 2$ & $5 / 2$ & 19014.6 & .05 \\
\hline $\mathrm{C}^{12} \mathrm{D}_{3} \mathrm{C}^{12} \mathrm{H}_{2} \mathrm{Br}^{81}$ & 3- 525 & $3,0,3 \leftarrow 2,0,2$ & Ground & & $5 / 2$ & $3 / 2$ & 19014.75 & .05 \\
\hline $\mathrm{a}^{-} \mathrm{Si}^{28} \mathrm{HD}_{2} \mathrm{C}^{12} \mathrm{H}: \mathrm{C}^{12} \mathrm{H}_{2}$ & 3- 623 & $2,0,2 \leftarrow 1,0,1$ & Ground & & & & 19015.05 & .10 \\
\hline $\mathrm{C}^{12} \mathrm{H}_{3} \mathrm{Br}^{81}$ & 4- 402 & $1,0 \leftarrow 0,0$ & Excited & & $3 / 2$ & $3 / 2$ & 19015.66 & .05 \\
\hline $\mathrm{t}-\mathrm{C}^{12} \mathrm{H}_{2} \mathrm{DC}^{12} \mathrm{H}_{2} \mathrm{Cl}^{35}$ & 3- 543 & $2,1,2 \leftarrow 1,1,1$ & Ground & & $1 / 2$ & $1 / 2$ & 19023.9 & .05 \\
\hline $\mathrm{HC}^{12} \mathrm{O}^{16} \mathrm{O}^{16} \mathrm{C}^{13} \mathrm{H}_{3}-\mathrm{E}$ & 3- 512 & $3,1,2 \leftarrow 3,0,3$ & Ground & & & & 19024.13 & .2 \\
\hline $\mathrm{C}^{12} \mathrm{H}_{3} \mathrm{~N}^{14} \mathrm{O}_{2}^{16}$ & 3- 171 & Not Reported & Ground & & & & 19025 . & 5. \\
\hline $\mathrm{C}^{12} \mathrm{H}_{3} \mathrm{~S}^{32} \mathrm{H}$ & 3- 221 & Not Reported & Ground & & & & 19027.1 & .1 \\
\hline $\mathrm{H}_{2} \mathrm{~N}^{15} \mathrm{C}^{12} \mathrm{DO}^{16}$ & 3- 157 & $4,2,3 \leftarrow 5,1,4$ & Ground & & & & 19029.94 & \\
\hline $\mathrm{C}_{6}^{12} \mathrm{H}_{5} \mathrm{O}^{16} \mathrm{H}$ & 3-1051 & $5,0,5 \leftarrow 4,1,4$ & Ground & & & & 19031.50 & \\
\hline $\mathrm{HC}^{12} \mathrm{O}^{16} \mathrm{O}^{16} \mathrm{C}^{13} \mathrm{H}_{3}-\mathrm{A}$ & 3. 511 & $3,1,2 \leftarrow 3,0,3$ & Ground & & & & 19032.18 & .2 \\
\hline $\mathrm{C}^{12}{ }_{*} \mathrm{DHC}^{12} \mathrm{H}: \mathrm{C}^{12}{ }_{*} \mathrm{H}$ & 4-1034 & $2,1,1 \leftarrow 2,1,2$ & Ground & & & & 19034.3 & \\
\hline $\mathrm{C}^{12} \mathrm{H}_{2} \mathrm{Cl}^{35} \mathrm{Si}^{28} \mathrm{D}_{3}$ & 3- 237 & $8,1,7 \leftarrow 8,0,8$ & Ground & & & & 19034.52 & .2 \\
\hline
\end{tabular}




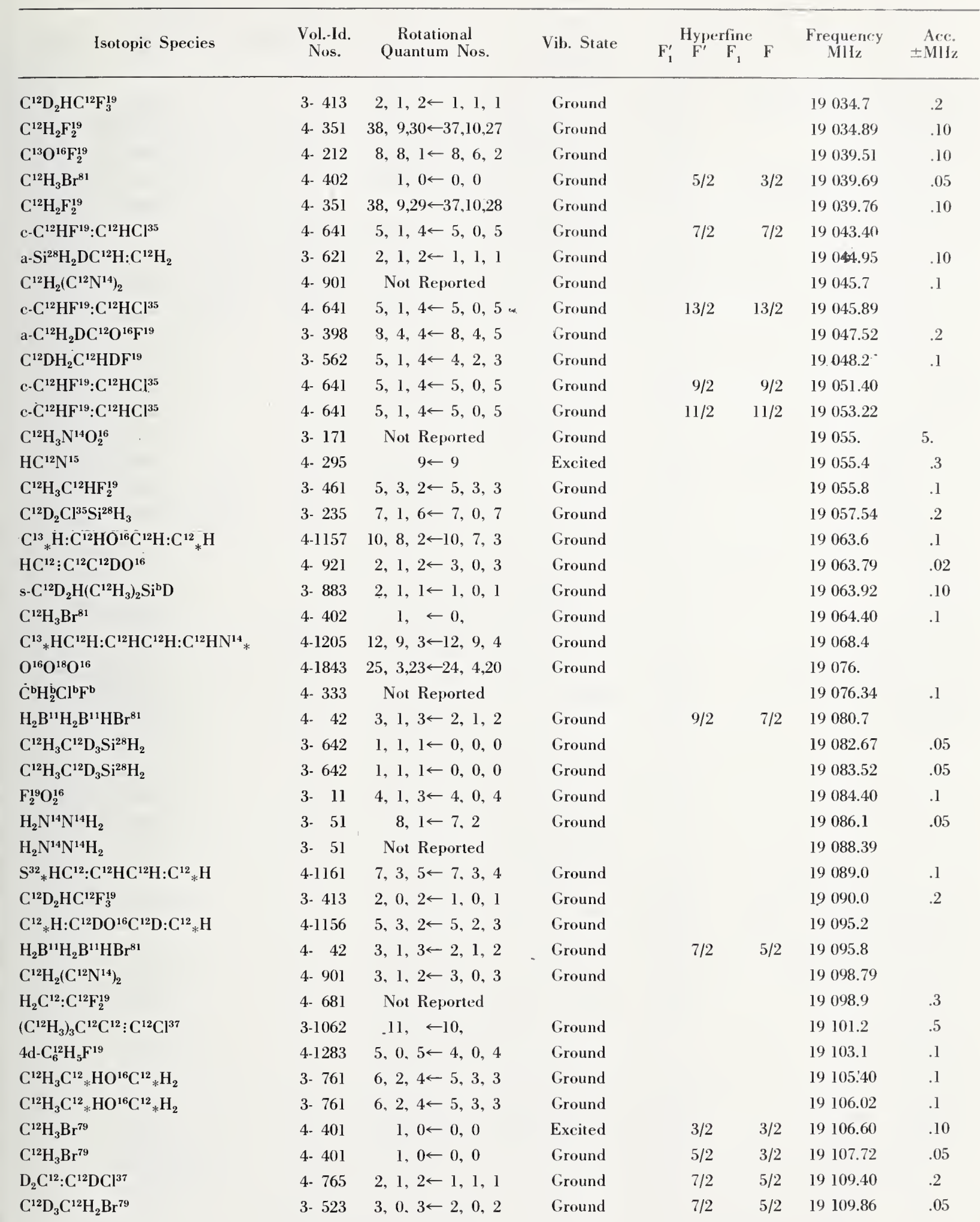




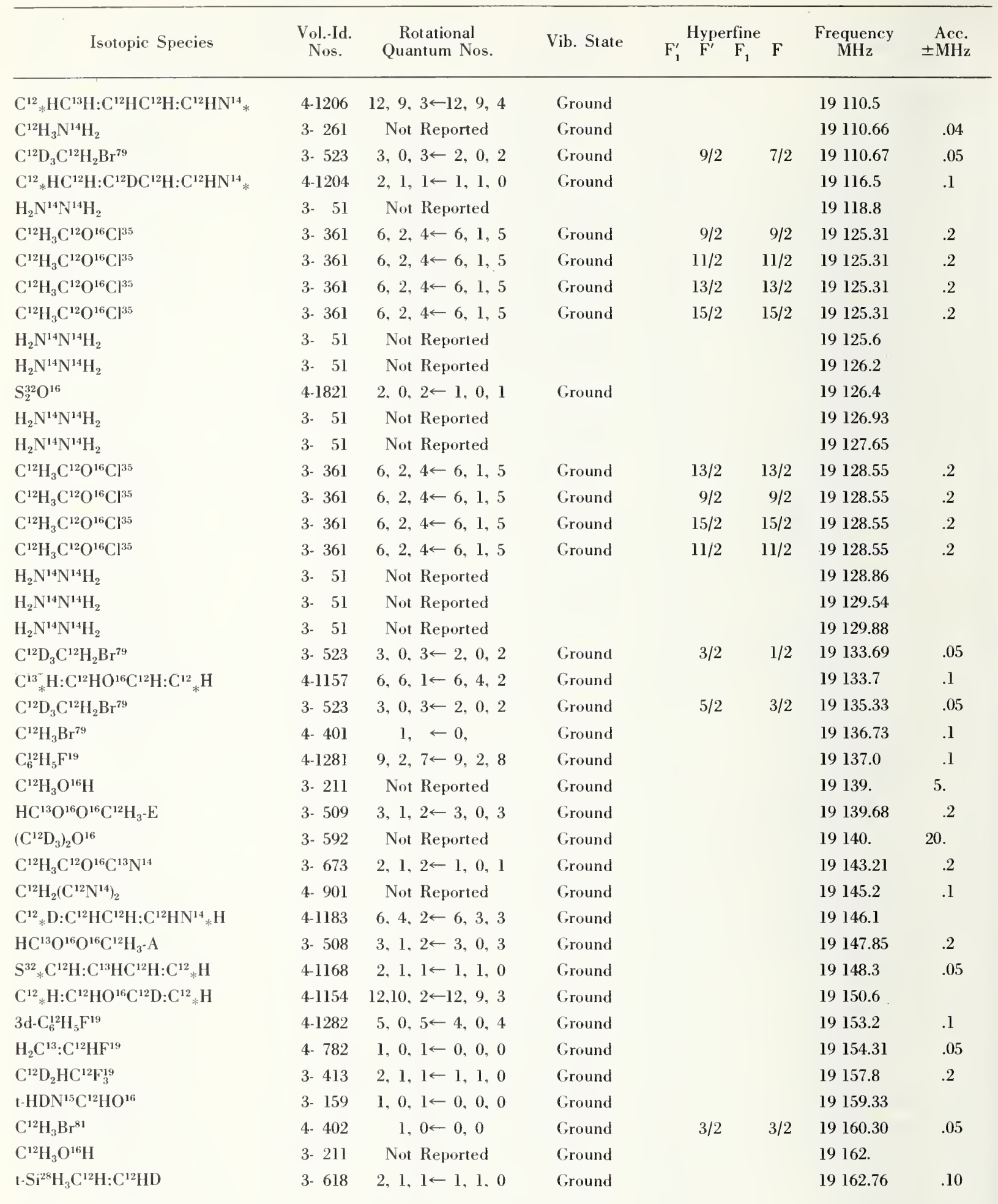




\begin{tabular}{|c|c|c|c|c|c|c|c|}
\hline Isotopic Species & $\begin{array}{l}\text { Vol.-Id. } \\
\text { Nos. }\end{array}$ & $\begin{array}{c}\text { Rotational } \\
\text { Quantum Nos. }\end{array}$ & Vib. State & $\mathrm{F}_{1}^{\prime} \stackrel{\text { Hyperfi }}{\mathrm{F}^{\prime}} \mathrm{F}$ & $\mathrm{F}$ & $\begin{array}{c}\text { Frequency } \\
\mathrm{MHz}^{-}\end{array}$ & $\begin{aligned} & \text { Acce. } \\
\pm & \mathrm{MH} \%\end{aligned}$ \\
\hline $\mathrm{Si}^{28} \mathrm{H}_{3} \mathrm{C}^{12} \mathrm{H}: \mathrm{C}^{13} \mathrm{H}_{2}$ & 3. 624 & $2,1,2 \leftarrow 1,1,1$ & Ground & & & 19162.94 & .10 \\
\hline $\mathrm{HC}^{13}: \mathrm{C}^{12} \mathrm{C}^{12} \mathrm{DO}^{16}$ & 4- 922 & Not Reported & & & & 19164. & 5. \\
\hline $\mathrm{HC}^{12}{ }_{*}: \mathrm{C}^{12} \mathrm{HO}^{16} \mathrm{C}^{12} \mathrm{O}^{16} \mathrm{O}^{16}{ }_{*}$ & 4. 931 & $3,1,3 \leftarrow 2,1,2$ & Ground & & & 19169.62 & .10 \\
\hline $\mathrm{C}^{12} \mathrm{H}_{3} \mathrm{~S}^{32} \mathrm{H}$ & 3- 221 & Not Reported & Ground & & & 19173.0 & .1 \\
\hline $\mathrm{C}^{12} \mathrm{H}_{3} \mathrm{C}^{12}: \mathrm{C}^{12} \mathrm{C}^{12} \mathrm{~F}_{3}^{19}$ & 3- 891 & $7, \leftarrow 6$, & Ground & & & 19176.2 & .1 \\
\hline $\mathrm{C}_{6}^{12} \mathrm{H}_{5} \mathrm{C}^{12} \mathrm{~N}^{14}$ & $4-1291$ & $7,2,6 \leftarrow 6,2,5$ & Ground & & & 19179.5 & \\
\hline $\mathrm{H}_{2} \mathrm{~B}^{11} \mathrm{H}_{2} \mathrm{~B}^{11} \mathrm{HBr}^{79}$ & 4. 41 & $3,1,3 \leftarrow 2,1,2$ & Ground & $9 / 2$ & $7 / 2$ & 19182.0 & \\
\hline $\mathrm{C}^{12}{ }_{*} \mathrm{HC}^{12} \mathrm{H}: \mathrm{C}^{12} \mathrm{DC}^{12} \mathrm{H}: \mathrm{C}^{12} \mathrm{HN}^{14} *$ & 4-1204 & $6,3,3 \leftarrow 6,3,4$ & Ground & & & 19186.0 & .1 \\
\hline $\mathrm{C}^{12}{ }_{*} \mathrm{D}: \mathrm{C}^{12} \mathrm{DC}^{12} \mathrm{D}: \mathrm{C}^{12} \mathrm{DN}^{14}{ }_{*} \mathrm{H}$ & 4-1185 & $3,2,2 \leftarrow 3,1,3$ & Ground & & & 19189.4 & \\
\hline $\mathrm{C}^{12} \mathrm{H}_{3} \mathrm{Ge}^{\mathrm{b}} \mathrm{Cl}_{3}^{35}$ & 3- 107 & $6, \leftarrow 5$, & & & & 19190. & 15. \\
\hline $\left.\mathrm{H}_{2}^{\mathrm{b}} \mathrm{C}^{\mathrm{b}}: \mathrm{C}^{\mathrm{b}} \mathrm{H}^{\mathrm{b}} \mathrm{C}\right]^{\mathrm{b}}$ & 4- 772 & Not Reported & Ground & & & 19190.48 & \\
\hline $\mathrm{C}^{12} \mathrm{H}_{3}^{*} \mathrm{~S}^{32} \mathrm{C}^{12} \mathrm{D}_{3}$ & 3- 606 & $4,1,3 \leftarrow 4,0,4$ & Ground & & & 19190.49 & .05 \\
\hline $\mathrm{C}^{12} \mathrm{H}_{2}: \mathrm{C}^{12} \mathrm{DC}^{12} \mathrm{~N}^{14}$ & $4-1026$ & $2,1,1 \leftarrow 1,1,0$ & Ground & 2 & 1 & 19190.57 & \\
\hline $\mathrm{C}^{12} \mathrm{D}_{2}\left(\mathrm{C}^{12} \mathrm{~N}^{14}\right)_{2}$ & 4- 903 & $1,1,1 \leftarrow 0,0,0$ & Ground & & & 19191.00 & \\
\hline $\mathrm{C}^{12} \mathrm{H}_{2}: \mathrm{C}^{12} \mathrm{DC}^{12} \mathrm{~N}^{14}$ & 4-1026 & $2,1,1 \leftarrow 1,1,0$ & Ground & 3 & 2 & 19191.72 & \\
\hline $\mathrm{C}^{12} \mathrm{H}_{2}: \mathrm{C}^{12} \mathrm{DC}^{12} \mathrm{~N}^{14}$ & $4-1026$ & $2,1,1 \leftarrow 1,1,0$ & Ground & 1 & 0 & 19192.98 & \\
\hline $\mathrm{C}^{12}{ }_{*} \mathrm{DN}^{14} \mathrm{C}^{12} \mathrm{DC}^{12} \mathrm{H}: \mathrm{C}^{12} \mathrm{DN}^{14} *$ & $4-1142$ & $8,5,3 \leftarrow 8,4,4$ & Ground & & & 19193.3 & \\
\hline $\mathrm{C}^{12} \mathrm{H}_{3} \mathrm{C}^{12} \mathrm{O}^{16} \mathrm{C}^{12} \mathrm{~N}^{14}$ & 3- 671 & $2,1,2 \leftarrow 1,0,1$ & Ground & & & 19193.60 & .2 \\
\hline $\mathrm{H}_{2} \mathrm{~B}^{11} \mathrm{H}_{2} \mathrm{~B}^{11} \mathrm{HBr}^{79}$ & 4- 41 & $3,1,3 \leftarrow 2,1,2$ & Ground & $7 / 2$ & $5 / 2$ & 19200.6 & \\
\hline $\mathrm{HC}^{13}: \mathrm{C}^{12} \mathrm{C}^{12} \mathrm{DO}^{16}$ & 4- 922 & Not Reported & & & & 19202. & 5. \\
\hline $\mathrm{N}^{\mathrm{b}} \mathrm{O}_{2}^{\mathrm{b}} \mathrm{Cl}^{\mathrm{b}}$ & 4-1463 & Not Reported & & & & 19202.52 & \\
\hline $\mathrm{N}^{\mathrm{b}} \mathrm{O}_{2}^{\mathrm{b}} \mathrm{Cl}^{\mathrm{b}}$ & 4-1463 & Not Reported & & & & 19203.68 & \\
\hline $\mathrm{C}^{12} \mathrm{H}_{3} \mathrm{~S}^{32} \mathrm{C}^{12} \mathrm{D}_{3}$ & 3- 606 & $4,1,3 \leftarrow 4,0,4$ & Ground & & & 19204.21 & .05 \\
\hline $\mathrm{C}^{12} \mathrm{H}_{3} \mathrm{~S}^{32} \mathrm{C}^{12} \mathrm{D}_{3}$ & 3- 606 & $4,1,3 \leftarrow 4,0,4$ & Ground & & & 19206.75 & .05 \\
\hline $\mathrm{s}-\mathrm{Si}^{28} \mathrm{H}_{2} \mathrm{DC}{ }^{12} \mathrm{H}: \mathrm{C}^{12} \mathrm{H}_{2}$ & 3- 619 & $2,1,2 \leftarrow 1,1,1$ & Ground & & & 19213.72 & .10 \\
\hline $\mathrm{C}^{12} \mathrm{H}_{3} \mathrm{C}^{12}: \mathrm{C}^{12} \mathrm{C}^{12} \mathrm{~F}_{3}^{19}$ & 3- 891 & $7, \leftarrow 6$ & Excited & & & 19214.8 & .1 \\
\hline $\mathrm{N}^{14} \mathrm{H}_{3}$ & 4-1771 & $7,4 \leftarrow 7,4$ & Ground & & & 19218.36 & .04 \\
\hline $\mathrm{C}^{12} \mathrm{O}^{16} \mathrm{~F}_{2}^{19}$ & 4- 211 & $9,9,1 \leftarrow 9,7,2$ & Ground & & & 19218.49 & .10 \\
\hline g. $\mathrm{C}^{12} \mathrm{H}_{3} \mathrm{C}^{12} \mathrm{H}_{2} \mathrm{C}^{12} \mathrm{H}_{2} \mathrm{Cl}^{35}$ & 3- 773 & $3,1,2 \leftarrow 2,1,1$ & Ground & & & 19218.84 & .2 \\
\hline $\mathrm{C}_{6}^{12} \mathrm{H}_{5} \mathrm{~F}^{19}$ & 4-1281 & $5,1,5 \leftarrow 4,1,4$ & Ground & & & 19219.8 & .1 \\
\hline $\mathrm{C}^{12} \mathrm{H}_{3} \mathrm{C}^{12} \mathrm{HO}^{16}$ & 3- 471 & $1,0,1 \leftarrow 0,0,0$ & Ground & & & 19225.7 & .2 \\
\hline $\mathrm{C}^{12} \mathrm{H}_{2} \mathrm{~N}^{14} \mathrm{O}^{16} \mathrm{H}$ & 3- 141 & $10,2,8 \leftarrow 10,2,9$ & Ground & 9 & 9 & 19226.21 & .10 \\
\hline $\mathrm{C}^{12} \mathrm{H}_{2} \mathrm{~N}^{14} \mathrm{O}^{16} \mathrm{H}$ & 3- 141 & $10,2,8 \leftarrow 10,2,9$ & Ground & 11 & 11 & 19226.21 & .10 \\
\hline $\mathrm{C}^{12} \mathrm{H}_{2} \mathrm{~N}^{14} \mathrm{O}^{16} \mathrm{H}$ & 3- 141 & $10,2,8 \leftarrow 10,2,9$ & Ground & 10 & 10 & 19227.17 & .10 \\
\hline $\mathrm{C}^{12} \mathrm{H}_{3} \mathrm{C}^{13} \mathrm{HO}^{16}$ & 3- 477 & $1,0,1 \leftarrow 0,0,0$ & Ground & & & 19229.94 & .2 \\
\hline$\left(\mathrm{C}^{12} \mathrm{H}_{3} \mathrm{C}^{12} \mathrm{H}_{2}\right)_{2} \mathrm{O}^{16}$ & 3-1011 & Not Reported & & & & 19230 . & \\
\hline $\mathrm{HC}^{13}: \mathrm{C}^{12} \mathrm{C}^{12} \mathrm{DO}^{16}$ & 4- 922 & Not Reported & & & & 19230 . & 5. \\
\hline $\mathrm{C}^{12} \mathrm{H}_{2} \mathrm{Cl}^{37} \mathrm{~F}^{19}$ & 4- 332 & $5,0,5 \leftarrow 4,1,4$ & Ground & & & 19232.16 & .1 \\
\hline $\mathrm{C}^{12} \mathrm{H}_{3} \mathrm{C}^{13} \mathrm{HO}^{16}$ & 3- 477 & $1,0,1 \leftarrow 0,0,0$ & Ground & & & 19232.43 & .3 \\
\hline $\mathrm{C}^{12} \mathrm{H}_{3} \mathrm{~N}^{14} \mathrm{O}_{2}^{16}$ & 3- 171 & Not Reported & Ground & & & 19233. & 5. \\
\hline $\mathrm{C}_{6}^{12} \mathrm{H}_{5} \mathrm{~F}^{19}$ & $4 \cdot 1281$ & Not Reported & & & & 19238. & 5. \\
\hline $\mathrm{C}^{12}{ }_{*} \mathrm{D}: \mathrm{C}^{12} \mathrm{HC}^{12} \mathrm{H}: \mathrm{C}^{12} \mathrm{HN}^{14}{ }_{*} \mathrm{H}$ & 4-1183 & $12,10,2 \leftarrow 12,9,3$ & Ground & & & 19245.1 & \\
\hline $\mathrm{C}^{13}{ }_{*} \mathrm{H}: \mathrm{C}^{12} \mathrm{HO}^{16} \mathrm{C}^{12} \mathrm{H}: \mathrm{C}^{12}{ }_{*} \mathrm{H}$ & $4-1157$ & $9,7,2 \leftarrow 9,7,3$ & Ground & & & 19248.2 & .1 \\
\hline $\mathrm{C}^{12}{ }_{*} \mathrm{H}_{2} \mathrm{~N}^{14} \mathrm{DC}^{12}{ }_{*} \mathrm{H}_{2}$ & 4- 862 & $13,12,1 \leftarrow 13,12,2$ & Ground & & & 19250. & 10. \\
\hline $\mathrm{C}^{12} \mathrm{H}_{3} \mathrm{O}^{16} \mathrm{H}$ & 3- 211 & Not Reported & Ground & & & 19252. & \\
\hline
\end{tabular}




\begin{tabular}{|c|c|c|c|c|c|c|c|c|}
\hline Isotopic Species & $\begin{array}{l}\text { Vol.-Id. } \\
\text { Nos. }\end{array}$ & $\begin{array}{c}\text { Rotational } \\
\text { Quantum Nos. }\end{array}$ & Vib. State & $\mathrm{F}_{1}^{\prime}$ & $\begin{array}{c}\text { Hyperfine } \\
\mathbf{F}^{\prime} \quad \mathrm{F}_{1}\end{array}$ & $\mathrm{~F}$ & $\begin{array}{c}\text { Frequency } \\
\mathrm{MHz}\end{array}$ & $\begin{aligned} & \text { Acc. } \\
\pm & \mathrm{MHz}\end{aligned}$ \\
\hline $\mathrm{C}^{12} \mathrm{H}_{3} \mathrm{Br}^{79}$ & 4. 401 & $1,0 \leftarrow 0,0$ & Ground & & $i 3 / 2$ & $3 / 2$ & 19252.11 & .05 \\
\hline $\mathrm{Si}^{28} \mathrm{H}_{3} \mathrm{C}^{12} \mathrm{D}: \mathrm{C}^{12} \mathrm{H}_{2}$ & 3- 616 & $2,1,2 \leftarrow 1,1,1$ & Ground & & & & $19 \underline{252.34}$ & .10 \\
\hline $\mathrm{C}^{12} \mathrm{H}_{3} \mathrm{C}^{12}: \mathrm{C}^{12} \mathrm{C}^{12} \mathrm{~F}_{3}^{19}$ & 3- 891 & $7, \leftarrow 6$ & Excited & & & & 19252.4 & .1 \\
\hline $\mathrm{c}-\mathrm{HDC}^{12}{ }_{*} \mathrm{O}^{16} \mathrm{C}^{12}{ }_{*} \mathrm{DH}$ & 4. 845 & $3,2,1 \leftarrow 3,1,2$ & Ground & & & & 19253.07 & .05 \\
\hline $\mathrm{C}^{12} \mathrm{H}_{3} \mathrm{C}^{12} \mathrm{~F}^{19}: \mathrm{C}^{12} \mathrm{H}_{2}$ & 3- 721 & $14,10,4 \leftarrow 14,10,5$ & Ground & & & & 19253.42 & .1 \\
\hline $\mathrm{F}_{2}^{19} \mathrm{O}_{2}^{16}$ & 3- $\quad 11$ & $4,1,3 \leftarrow 4,0,4$ & Ground & & & & 19253.5 & .5 \\
\hline $\mathrm{t}-\mathrm{DHC} \mathrm{C}^{12}: \mathrm{C}^{12} \mathrm{HF}^{19}$ & 4- 788 & $5,1,4 \leftarrow 5,1,5$ & Ground & & & & 19253.7 & .1 \\
\hline $\mathrm{H}_{2} \mathrm{C}^{12}: \mathrm{C}^{12} \mathrm{~F}_{2}^{19}$ & 4. 681 & Not Reported & & & & & 19254 & 1. \\
\hline $\mathrm{C}^{12} \mathrm{H}_{3} \mathrm{C}^{12} \mathrm{~F}^{19}: \mathrm{C}^{12} \mathrm{H}_{2}$ & 3- 721 & $14,10,4 \leftarrow 14,10,5$ & Ground & & & & 19254.38 & .1 \\
\hline $\mathrm{C}^{12}{ }_{*} \mathrm{H}: \mathrm{C}^{12} \mathrm{DC}^{12} \mathrm{H}: \mathrm{C}^{12} \mathrm{HN}^{14}{ }_{*} \mathrm{H}$ & $4-1184$ & $5,3,2 \leftarrow 5,3,3$ & Ground & & & & 19256. & \\
\hline $\mathrm{C}^{12} \mathrm{H}_{3} \mathrm{C}^{12} \mathrm{HO}^{16}$ & 3- 471 & $1,0,1 \leftarrow 0,0,0$ & Ground & & & & 19262.3 & .3 \\
\hline $\mathrm{O}^{16} \mathrm{O}^{16} \mathrm{O}^{18}$ & $4-1842$ & $2,1,2 \leftarrow 3,0,3$ & Ground & & & & 19263.1 & \\
\hline $\mathrm{C}^{12} \mathrm{H}_{3} \mathrm{C}^{12} \mathrm{HO}^{16}$ & 3- 471 & $1,0,1 \leftarrow 0,0,0$ & Ground & & & & 19265.3 & .2 \\
\hline $\mathrm{C}^{12} \mathrm{H}_{3} \mathrm{C}^{12} \mathrm{HO}^{16}$ & 3- 471 & $1,0,1 \leftarrow 0,0,0$ & Ground & & & & 19268.27 & .2 \\
\hline $\mathrm{O}^{18} \mathrm{O}^{16} \mathrm{O}^{18}$ & 4-1846 & $20,3,17 \leftarrow 21,2,20$ & Ground & & & & 19270.1 & \\
\hline $\mathrm{HN}^{14} \mathrm{O}_{3}^{16}$ & $3-\quad 31$ & $1,1,1 \leftarrow 0,0,0$ & Ground & & 1 & 1 & 19271.45 & \\
\hline $\mathrm{HN}^{14} \mathrm{O}_{3}^{16}$ & $3-\quad 31$ & $1,1,1 \leftarrow 0,0,0$ & Ground & & 2 & 1 & 19271.69 & \\
\hline $\mathrm{HN}^{14} \mathrm{O}_{3}^{16}$ & $3-\quad 31$ & $1,1,1 \leftarrow 0,0,0$ & Ground & & 0 & 1 & 19272.06 & \\
\hline $\mathrm{HN}^{15} \mathrm{O}_{3}^{16}$ & $3-\quad 33$ & $1,1,1 \leftarrow 0,0,0$ & Ground & & & & 19272.44 & \\
\hline $\mathrm{C}^{12} \mathrm{H}_{3} \mathrm{~S}^{32} \mathrm{H}$ & 3- 221 & Not Reported & Ground & & & & 19273.6 & .1 \\
\hline $\mathrm{C}^{\mathrm{b}} \mathrm{H}_{2}^{\mathrm{b}} \mathrm{Cl}^{\mathrm{b}} \mathrm{F}^{\mathrm{b}}$ & 4. 333 & Not Reported & & & & & 19273.78 & .1 \\
\hline $\mathrm{H}_{2} \mathrm{~B}^{11} \mathrm{H}_{2} \mathrm{~B}^{10} \mathrm{HBr}^{81}$ & 4. 46 & $3,1,3 \leftarrow 2,1,2$ & Ground & & $9 / 2$ & $7 / 2$ & 19281 & \\
\hline $\mathrm{HC}^{13}: \mathrm{C}^{12} \mathrm{C}^{12} \mathrm{DO}^{16}$ & 4- 922 & Not Reported & & & & & 19282 . & 5. \\
\hline $4 \mathrm{~d}-\mathrm{C}_{6}^{12} \mathrm{H}_{5} \mathrm{~F}^{19}$ & $4-1283$ & $12,3,9 \leftarrow 12,3,10$ & Ground & & & & 19285.1 & .1 \\
\hline $\mathrm{C}^{12} \mathrm{H}_{3} \mathrm{C}^{12}: \mathrm{C}^{12} \mathrm{C}^{12} \mathrm{~F}_{3}^{19}$ & 3. 891 & $7, \leftarrow 6$ & Excited & & & & 19291.0 & .1 \\
\hline $\mathrm{C}^{12}{ }_{*} \mathrm{D}: \mathrm{C}^{12} \mathrm{DC}^{12} \mathrm{D}: \mathrm{C}^{12} \mathrm{DN}^{14}{ }_{*} \mathrm{H}$ & $4-1185$ & $4,3,2 \leftarrow 4,2,3$ & Ground & & & & 19294.1 & \\
\hline $\mathrm{C}^{12} \mathrm{D}_{3} \mathrm{O}^{16} \mathrm{H}$ & 3. 214 & Not Reported & Ground & & & & 19294.5 & .5 \\
\hline $\mathrm{H}_{3} \mathrm{C}^{12} \mathrm{C}^{12}: \mathrm{C}^{12} \mathrm{C}^{12}: \mathrm{C}^{12} \mathrm{D}$ & 4.1192 & $5,3 \leftarrow 4,3$ & Ground & & & & 19296.08 & .1 \\
\hline $\mathrm{H}_{3} \mathrm{C}^{12} \mathrm{C}^{12}: \mathrm{C}^{12} \mathrm{C}^{12}: \mathrm{C}^{12} \mathrm{D}$ & 4-1192 & $5,2 \leftarrow 4,2$ & Ground & & & & 19296.98 & .1 \\
\hline $\mathrm{H}_{2} \mathrm{~B}^{11} \mathrm{H}_{2} \mathrm{~B}^{10} \mathrm{HBr}^{81}$ & 4- 46 & $3,1,3 \leftarrow 2,1,2$ & Ground & & $7 / 2$ & $5 / 2$ & 19297. & \\
\hline $\mathrm{H}_{3} \mathrm{C}^{12} \mathrm{C}^{12}: \mathrm{C}^{12} \mathrm{C}^{12}: \mathrm{C}^{12} \mathrm{D}$ & $4-1192$ & $5,1 \leftarrow 4,1$ & Ground & & & & 19297.52 & .1 \\
\hline $\mathrm{H}_{3} \mathrm{C}^{12} \mathrm{C}^{12}: \mathrm{C}^{12} \mathrm{C}^{12}: \mathrm{C}^{12} \mathrm{D}$ & 4-1192 & $5,0 \leftarrow 4,0$ & Ground & & & & 19297.70 & .1 \\
\hline $\mathrm{C}^{12} \mathrm{D}_{3} \mathrm{C}^{12} \mathrm{O}^{16} \mathrm{C}^{12} \mathrm{~N}^{i 4}$ & 3. 675 & $3,0,3 \leftarrow 2,0,2$ & Ground & & & & 19297.8 & .2 \\
\hline $\left.\mathrm{C}^{12} \mathrm{HCl}_{2}^{35} \mathrm{Cl}\right]^{37}$ & 4. 262 & $3,2,1 \leftarrow 2,1,1$ & Ground & & & & 19298.31 & .21 \\
\hline $\mathrm{HC}^{12} \mathrm{O}^{16} \mathrm{O}^{16} \mathrm{C}^{12} \mathrm{H}_{3}-\mathrm{E}$ & 3- 502 & $3,1,2 \leftarrow 3,0,3$ & Ground & & & & 19298.88 & .2 \\
\hline $\mathrm{HC}^{12} \mathrm{O}^{16} \mathrm{O}^{16} \mathrm{C}^{12} \mathrm{H}_{3}-\mathrm{A}$ & 3- 501 & $3,1,2 \leftarrow 3,0,3$ & Ground & & & & 19307.57 & .2 \\
\hline $\mathrm{HC}^{13} \mathrm{~N}^{14}$ & 4. 293 & $9 \leftarrow 9$ & Excited & & & & 19315.70 & .1 \\
\hline $\mathrm{C}^{\mathrm{b}} \mathrm{H}_{2}^{\mathrm{b}} \mathrm{Cl}^{\mathrm{b}} \mathrm{F}^{\mathrm{b}}$ & 4- 333 & Not Reported & & & & & 19316.96 & .1 \\
\hline $\mathrm{C}^{12} \mathrm{H}_{2}\left(\mathrm{C}^{12} \mathrm{~N}^{14}\right)_{2}$ & 4- 901 & Not Reported & Ground & & & & 19318.3 & .1 \\
\hline $\mathrm{C}^{12} \mathrm{H}_{3} \mathrm{C}^{12} \mathrm{~F}^{19}: \mathrm{C}^{12} \mathrm{H}_{2}$ & 3- 721 & $9,7,2 \leftarrow 9,6,3$ & Ground & & & & 19318.79 & .1 \\
\hline $\mathrm{C}^{12} \mathrm{H}_{3} \mathrm{C}^{12} \mathrm{~F}^{19}: \mathrm{C}^{12} \mathrm{H}_{2}$ & 3. 721 & $9,7,2 \leftarrow 9,6,3$ & Ground & & & & 19319.22 & .1 \\
\hline $\mathrm{C}^{12} \mathrm{D}_{3} \mathrm{C}^{12} \mathrm{H}_{2} \mathrm{Br}^{81}$ & 3. 525 & $3,1,2 \leftarrow 2,1,1$ & Ground & & $3 / 2$ & $1 / 2$ & 19320.66 & .05 \\
\hline $\mathrm{Si}^{30} \mathrm{H}_{3} \mathrm{C}^{12} \mathrm{H}: \mathrm{C}^{12} \mathrm{H}_{2}$ & 3. 614 & $2,1,2 \leftarrow 1,1,1$ & Ground & & & & 19320.91 & .10 \\
\hline $\mathrm{D}_{2} \mathrm{O}_{2}^{16}$ & 3- $\quad 42$ & Not Reported & & & & & 19322. & 3. \\
\hline
\end{tabular}




\begin{tabular}{|c|c|c|c|c|c|c|c|}
\hline Isotopic Species & $\begin{array}{l}\text { Vol.-Id. } \\
\text { Nos. }\end{array}$ & $\begin{array}{c}\text { Rotational } \\
\text { Quantum Nos. }\end{array}$ & Vib. State & $\mathrm{F}_{1}^{\prime} \quad \stackrel{\text { Hyperfine }}{\mathrm{F}^{\prime}} \quad \mathrm{F}_{1}$ & $\mathrm{~F}$ & $\begin{array}{c}\text { Frequency } \\
\mathrm{MHz}\end{array}$ & $\begin{aligned} & \text { Acc. } \\
& \pm \mathrm{MHz}\end{aligned}$ \\
\hline $\mathrm{C}^{12} \mathrm{D}_{3} \mathrm{C}^{12} \mathrm{H}_{2} \mathrm{Br}^{81}$ & 3. 525 & $3,1,2 \leftarrow 2,1,1$ & Ground & $9 / 2$ & $7 / 2$ & 19322.63 & .05 \\
\hline $\mathrm{C}^{12} \mathrm{H}_{2}\left(\mathrm{C}^{12} \mathrm{~N}^{14}\right)_{2}$ & 4- 901 & Not Reported & Ground & & & 19324.2 & .1 \\
\hline $\mathrm{C}^{12} \mathrm{H}_{3} \mathrm{~S}^{32} \mathrm{C}^{12} \mathrm{D}_{3}$ & 3. 606 & $4,1,3 \leftarrow 4,0,4$ & Ground & & & 19327.03 & .05 \\
\hline $\mathrm{C}^{12} \mathrm{H}_{3} \mathrm{~S}^{32} \mathrm{C}^{12} \mathrm{D}_{3}$ & 3. 606 & $4,1,3 \leftarrow 4,0,4$ & Ground & & & 19327.31 & .05 \\
\hline $\mathrm{C}^{12} \mathrm{H}_{3} \mathrm{C}^{12}: \mathrm{C}^{12} \mathrm{C}^{12} \mathrm{~F}_{3}^{19}$ & 3. 891 & $7, \leftarrow 6$, & Excited & & & 19328. & 2. \\
\hline $\mathrm{H}_{3} \mathrm{C}^{12} \mathrm{C}^{12}: \mathrm{C}^{12} \mathrm{C}^{12}: \mathrm{C}^{12} \mathrm{D}$ & $4-1192$ & $5,1 \leftarrow 4,1$ & Excited & & & 19328.94 & .1 \\
\hline $\mathrm{C}^{12} \mathrm{H}_{2}: \mathrm{C}^{13} \mathrm{HC}^{12} \mathrm{~N}^{14}$ & 4-1023 & $2,1,1 \leftarrow 1,1,0$ & Ground & & & 19331.98 & \\
\hline c- $\mathrm{C}^{12} \mathrm{HF}^{19}: \mathrm{C}^{12} \mathrm{HCl}^{37}$ & 4- 642 & $1,1,1 \leftarrow 0,0,0$ & Ground & $3 / 2$ & $3 / 2$ & 19333.62 & \\
\hline $\mathrm{C}^{12} \mathrm{H}_{3} \mathrm{~S}^{32} \mathrm{H}$ & 3. 221 & Not Reported & Ground & & & 19334.0 & .1 \\
\hline$c-\mathrm{C}^{12} \mathrm{HF}^{19}: \mathrm{C}^{12} \mathrm{HCl}^{37}$ & 4. 642 & $1,1,1 \leftarrow 0,0,0$ & Ground & $5 / 2$ & $3 / 2$ & 19335.66 & \\
\hline $\mathrm{H}_{3} \mathrm{C}^{12} \mathrm{C}^{12}: \mathrm{C}^{12} \mathrm{C}^{12}: \mathrm{C}^{12} \mathrm{D}$ & $4-1192$ & $5,3 \leftarrow 4,3$ & Excited & & & 19335.80 & .1 \\
\hline $\mathrm{C}^{12}{ }_{*} \mathrm{DN}^{14} \mathrm{C}^{12} \mathrm{DC}^{12} \mathrm{H}: \mathrm{C}^{12} \mathrm{DN}^{14}{ }_{*}$ & $4-1142$ & $7,4,3 \leftarrow 7,3,4$ & Ground & & & 19336.6 & \\
\hline $\mathrm{H}_{3} \mathrm{C}^{12} \mathrm{C}^{12}: \mathrm{C}^{12} \mathrm{C}^{12}: \mathrm{C}^{12} \mathrm{D}$ & 4-1192 & $5,4 \leftarrow 4,4$ & Excited & & & 19337.14 & .1 \\
\hline $\mathrm{H}_{3} \mathrm{C}^{12} \mathrm{C}^{12}: \mathrm{C}^{12} \mathrm{C}^{12}: \mathrm{C}^{12} \mathrm{D}$ & $4-1192$ & $5,2 \leftarrow 4,2$ & Excited & & & 19337.14 & .1 \\
\hline$c-\mathrm{C}^{12} \mathrm{HF}^{19}: \mathrm{C}^{12} \mathrm{HC}^{37}$ & 4. 642 & $1,1,1 \leftarrow 0,0,0$ & Ground & $1 / 2$ & $3 / 2$ & 19337.18 & \\
\hline $\mathrm{H}_{3} \mathrm{C}^{12} \mathrm{C}^{12}: \mathrm{C}^{12} \mathrm{C}^{12}: \mathrm{C}^{12} \mathrm{D}$ & 4-1192 & $5,3 \leftarrow 4,3$ & Excité & & & 19338.02 & .1 \\
\hline $\mathrm{H}_{3} \mathrm{C}^{12} \mathrm{C}^{12}: \mathrm{C}^{12} \mathrm{C}^{12}: \mathrm{C}^{12} \mathrm{D}$ & 4-1192 & $5,1 \leftarrow 4,1$ & Excited & & & 19338.02 & .1 \\
\hline $\mathrm{H}_{3} \mathrm{C}^{12} \mathrm{C}^{12}: \mathrm{C}^{12} \mathrm{C}^{12}: \mathrm{C}^{12} \mathrm{D}$ & 4-1192 & $5,2 \leftarrow 4,2$ & Excited & & & 19338.58 & .1 \\
\hline $\mathrm{H}_{3} \mathrm{C}^{12} \mathrm{C}^{12}: \mathrm{C}^{12} \mathrm{C}^{12}: \mathrm{C}^{12} \mathrm{D}$ & 4-1192 & $5,0 \leftarrow 4,0$ & Excited & & & 19338.58 & .1 \\
\hline $\mathrm{C}^{12} \mathrm{D}_{3} \mathrm{C}^{12} \mathrm{H}_{2} \mathrm{Br}^{81}$ & 3- 525 & $3,1,2 \leftarrow 2,1,1$ & Ground & $5 / 2$ & $3 / 2$ & 19338.73 & .05 \\
\hline $\mathrm{C}^{12} \mathrm{H}_{2}: \mathrm{C}^{12} \mathrm{HC}^{13} \mathrm{~N}^{14}$ & 4-1024 & $2,1,1 \leftarrow 1,1,0$ & Ground & & & 19340.26 & \\
\hline $\mathrm{H}_{2} \mathrm{~N}^{14} \mathrm{~N}^{14} \mathrm{H}_{2}$ & 3. 51 & $8,1 \leftarrow 7,2$ & Ground & & & 19341.1 & \\
\hline $\mathrm{HC}^{13}: \mathrm{C}^{12} \mathrm{C}^{12} \mathrm{DO}^{16}$ & 4- 922 & Not Reported & & & & 19342. & 5. \\
\hline $\mathrm{C}^{12} \mathrm{H}_{3} \mathrm{C}^{12} \mathrm{H}_{2} \mathrm{O}^{16} \mathrm{H}$ & 3. 581 & $4,2,3 \leftarrow 5,1,4$ & Ground & & & 19343.9 & .1 \\
\hline $\mathrm{DC}^{12} \mathrm{~N}^{15}$ & 4. 296 & $10 \leftarrow 10$ & Excited & & & 19344.30 & .1 \\
\hline $\mathrm{C}^{12} \mathrm{D}_{3} \mathrm{C}^{12} \mathrm{H}_{2} \mathrm{Br}^{81}$ & 3- 525 & $3,1,2 \leftarrow 2,1,1$ & Ground & $7 / 2$ & $5 / 2$ & 19344.35 & .05 \\
\hline $\mathrm{H}_{3} \mathrm{C}^{12} \mathrm{C}^{12}: \mathrm{C}^{12} \mathrm{C}^{12}: \mathrm{C}^{12} \mathrm{D}$ & $4-1192$ & $5,1 \leftarrow 4,1$ & Excited & & & 19348.50 & .1 \\
\hline $\mathrm{a}-\mathrm{C}^{12} \mathrm{H}_{2} \mathrm{DC}^{12} \mathrm{O}^{16} \mathrm{Cl}^{35}$ & 3- 366 & $2,1,2 \leftarrow 1,0,1$ & Ground & & & 19352.5 & .2 \\
\hline $\mathrm{H}_{2} \mathrm{~N}^{14} \mathrm{~N}^{14} \mathrm{H}_{2}$ & $3-51$ & $8,1 \leftarrow 7,2$ & Ground & & & 19352.5 & \\
\hline $\mathrm{H}_{2} \mathrm{~N}^{14} \mathrm{~N}^{14} \mathrm{H}_{2}$ & 3- 51 & Not Reported & & & & 19352.65 & \\
\hline $\mathrm{g} \cdot \mathrm{C}^{12} \mathrm{H}_{3} \mathrm{C}^{12} \mathrm{H}_{2} \mathrm{C}^{12} \mathrm{H}_{2} \mathrm{Cl}^{37}$ & 3- 774 & $8,1,7 \leftarrow 8,0,8$ & Ground & & & 19352.82 & .2 \\
\hline $\mathrm{H}_{2} \mathrm{~N}^{14} \mathrm{~N}^{14} \mathrm{H}_{2}$ & 3- 51 & Not Reported & & & & 19353.0 & \\
\hline $\mathrm{H}_{2} \mathrm{C}^{12}: \mathrm{C}^{13} \mathrm{DF}^{19}$ & 4- 786 & $1,0,1 \leftarrow 0,0,0$ & Ground & & & 19358.0 & .1 \\
\hline $\mathrm{C}^{12}{ }_{*} \mathrm{D}: \mathrm{C}^{12} \mathrm{DC}^{12} \mathrm{D}: \mathrm{C}^{12} \mathrm{DN}^{14}{ }^{*} \mathrm{H}$ & 4-1185 & $2,1,2 \leftarrow 1,0,1$ & Ground & & & 19361.5 & \\
\hline $\mathrm{C}^{12} \mathrm{H}_{3} \mathrm{C}^{12} \mathrm{~F}^{19}: \mathrm{C}^{12} \mathrm{H}_{2}$ & 3. 721 & $5,3,2 \leftarrow 5,3,3$ & Ground & & & 19369.15 & .1 \\
\hline $\mathrm{C}^{12} \mathrm{H}_{3} \mathrm{~N}^{14} \mathrm{O}_{2}^{16}$ & 3. 171 & Not Reported & Ground & & & 19370. & 5. \\
\hline $\mathrm{S}^{32}{ }_{*} \mathrm{DC}^{12}: \mathrm{C}^{12} \mathrm{HC}^{12} \mathrm{H}: \mathrm{C}^{12}{ }_{*} \mathrm{H}$ & 4-1162 & $2,1,1 \leftarrow 1,1,0$ & Ground & & & 19372.4 & .1 \\
\hline $\mathrm{HC}^{13}: \mathrm{C}^{12} \mathrm{C}^{12} \mathrm{DO}^{16}$ & 4. 922 & Not Reported & & & & 19380. & 5. \\
\hline $\mathrm{H}_{2} \mathrm{~B}^{11} \mathrm{H}_{2} \mathrm{~B}^{10} \mathrm{HBr}^{79}$ & 4- 45 & $3,1,3 \leftarrow 2,1,2$ & Ground & $9 / 2$ & $7 / 2$ & 19380.6 & \\
\hline $\mathrm{C}_{6}^{12} \mathrm{H}_{5} \mathrm{C}^{12} \mathrm{~N}^{14}$ & 4-1291 & $7,6,2 \leftarrow 6,6,1$ & Ground & & & 19383.5 & \\
\hline $\mathrm{C}_{6}^{12} \mathrm{H}_{5} \mathrm{C}^{12} \mathrm{~N}^{14}$ & 4.1291 & $7,6,1 \leftarrow 6,6,0$ & Ground & & & 19383.5 & \\
\hline $\mathrm{N}^{15} \mathrm{H}_{3}$ & 4-1772 & $5,2 \leftarrow 5,2$ & Ground & & & 19387.53 & .06 \\
\hline
\end{tabular}




\begin{tabular}{|c|c|c|c|c|c|c|c|c|}
\hline Isotopic Species & $\begin{array}{l}\text { Vol.-Id. } \\
\text { Nos. }\end{array}$ & $\begin{array}{c}\text { Rotational } \\
\text { Quantum Nos. }\end{array}$ & Vib. State & $\mathbf{F}_{1}^{\prime}$ & $\begin{array}{c}\text { Hyperfine } \\
\mathrm{F}^{\prime} \quad \mathrm{F}_{1}\end{array}$ & $\mathbf{F}$ & $\begin{array}{c}\text { Frequency } \\
\mathrm{MH}_{z}\end{array}$ & $\begin{aligned} & \text { Acc. } \\
& \pm \mathrm{MHz}\end{aligned}$ \\
\hline $\mathrm{H}_{2} \mathrm{C}^{12}: \mathrm{C}^{12} \mathrm{DF}^{19}$ & 4- 784 & $1,0,1 \leftarrow 0,0,0$ & Ground & & & & 19388.1 & .1 \\
\hline $\mathrm{C}^{12} \mathrm{H}_{3} \mathrm{O}^{16} \mathrm{H}$ & 3- 211 & $29,2, \leftarrow 29,1$, & Ground & & & & 19390.18 & .1 \\
\hline $\mathrm{C}^{12} \mathrm{H}_{2}\left(\mathrm{C}^{12} \mathrm{~N}^{14}\right)_{2}$ & 4. 901 & Not Reported & Ground & & & & 19397.7 & .1 \\
\hline $\mathrm{C}_{6}^{12} \mathrm{H}_{5} \mathrm{C}^{12} \mathrm{~N}^{14}$ & 4-1291 & $7,5,3 \leftarrow 6,5,2$ & Ground & & & & 19398.1 & \\
\hline $\mathrm{C}_{6}^{12} \mathrm{H}_{5} \mathrm{C}^{12} \mathrm{~N}^{14}$ & 4-1291 & $7,5,2 \leftarrow 6,5,1$ & Ground & & & & 19398.1 & \\
\hline $\mathrm{H}_{2} \mathrm{~B}^{11} \mathrm{H}_{2} \mathrm{~B}^{10} \mathrm{HBr}^{79}$ & 4- 45 & $3,1,3 \leftarrow 2,1,2$ & Ground & & $7 / 2$ & $5 / 2$ & 19398.8 & \\
\hline $\mathrm{C}^{\mathrm{b}} \mathrm{H}_{2}^{\mathrm{b}} \mathrm{Cl}^{\mathrm{b}} \mathrm{F}^{\mathrm{b}}$ & 4- 333 & Not Reported & & & & & 19400.74 & .1 \\
\hline $\mathrm{HC}^{12} \mathrm{~N}^{14}$ & 4- 291 & $6 \leftarrow 6$ & Excited & & & & 19402.20 & .1 \\
\hline $\mathrm{C}^{12}{ }_{*} \mathrm{HC}^{12} \mathrm{H}: \mathrm{C}^{12} \mathrm{HC}^{12} \mathrm{H}: \mathrm{C}^{12} \mathrm{HN}^{14} *$ & $4 \cdot 1201$ & $11,8,3 \leftarrow-11,8,4$ & Ground & & & & 19405.4 & \\
\hline $\mathrm{a}-\mathrm{Si}^{28} \mathrm{H}_{2} \mathrm{DC}^{12} \mathrm{H}: \mathrm{C}^{12} \mathrm{H}_{2}$ & 3- 621 & $2,0,2 \leftarrow 1,0,1$ & Ground & & & & 19406.68 & .10 \\
\hline $\mathrm{C}^{13} \mathrm{O}^{16} \mathrm{~F}_{2}^{19}$ & 4- 212 & $9,9,1 \leftarrow 9,7,2$ & Ground & & & & 19411.99 & .10 \\
\hline $\mathrm{a} \cdot \mathrm{C}^{12} \mathrm{HD}_{2} \mathrm{C}^{12} \mathrm{O}^{16} \mathrm{~F}^{19}$ & 3- 396 & $7,4,3 \leftarrow 7,4,4$ & Ground & & & & 19412.00 & .2 \\
\hline $\mathrm{H}_{2} \mathrm{~B}^{11} \mathrm{H}_{2} \mathrm{~B}^{11} \mathrm{HBr}^{81}$ & 4- $\quad 42$ & $3,2,2 \leftarrow 2,2,1$ & Ground & & $9 / 2$ & $7 / 2$ & 19412.5 & \\
\hline $\mathrm{H}_{2} \mathrm{~B}^{11} \mathrm{H}_{2} \mathrm{~B}^{11} \mathrm{HBr}^{81}$ & 4- $\quad 42$ & $3,2,1 \leftarrow 2,2,0$ & Ground & & $9 / 2$ & $7 / 2$ & 19412.5 & \\
\hline $\mathrm{a}-\mathrm{C}^{12} \mathrm{HD}_{2} \mathrm{C}^{12} \mathrm{O}^{16} \mathrm{~F}^{19}$ & 3- 396 & $7,4,3 \leftarrow 7,4,4$ & Ground & & & & 19413.95 & .2 \\
\hline $\mathrm{P}^{31} \mathrm{HD}_{2}$ & $4-1783$ & $3,2,2 \leftarrow 3,1,2$ & Ground & & & & 19415.19 & .05 \\
\hline $\mathrm{F}_{2}^{19} \mathrm{O}_{2}^{16}$ & 3- 11 & $4,1,3 \leftarrow 4,0,4$ & Ground & & & & 19418.45 & .1 \\
\hline $\mathrm{H}_{2} \mathrm{~B}^{11} \mathrm{H}_{2} \mathrm{~B}^{11} \mathrm{HBr}^{81}$ & 4- $\quad 42$ & $3,0,3 \leftarrow 2,0,2$ & Ground & & $9 / 2$ & $7 / 2$ & 19419.1 & \\
\hline $\mathrm{H}_{2} \mathrm{~B}^{11} \mathrm{H}_{2} \mathrm{~B}^{11} \mathrm{HBr}^{81}$ & 4- 42 & $3,0,3 \leftarrow 2,0,2$ & Ground & & $7 / 2$ & $5 / 2$ & 19419.1 & \\
\hline $\mathrm{C}^{12} \mathrm{H}_{3} \mathrm{~N}^{14} \mathrm{O}_{2}^{16}$ & 3- 171 & Not Reported & Ground & & & & 19420. & 5. \\
\hline $\mathrm{C}^{12} * \mathrm{DN}^{14} \mathrm{C}^{12} \mathrm{DC}^{12} \mathrm{H}: \mathrm{C}^{12} \mathrm{DN}^{14} *$ & 4-1142 & $6,3,3 \leftarrow 6,2,4$ & Ground & & & & 19422.6 & \\
\hline $\mathrm{C}_{6}^{12} \mathrm{H}_{5} \mathrm{C}^{12} \mathrm{~N}^{14}$ & $4 \cdot 1291$ & $7,4,3 \leftarrow 6,4,2$ & Ground & & & & 19426.0 & \\
\hline $\mathrm{C}_{6}^{12} \mathrm{H}_{5} \mathrm{C}^{12} \mathrm{~N}^{14}$ & 4-1291 & $7,4,4 \leftarrow 6,4,3$ & Ground & & & & 19426.0 & \\
\hline $\mathrm{C}^{12} \mathrm{H}_{2}: \mathrm{C}^{12} \mathrm{HC}^{12} \mathrm{~N}^{14}$ & 4-1021 & $2,1,1 \leftarrow 1,1,0$ & Ground & & 2 & 1 & 19426.67 & \\
\hline $\mathrm{C}^{12} \mathrm{H}_{2}: \mathrm{C}^{12} \mathrm{HC}^{12} \mathrm{~N}^{14}$ & 4-1021 & $2,1,1 \leftarrow 1,1,0$ & Ground & & 3 & 2 & 19427.80 & \\
\hline $\mathrm{C}^{12} \mathrm{H}_{2}: \mathrm{C}^{12} \mathrm{HC}^{12} \mathrm{~N}^{14}$ & $4 \cdot 1021$ & $2,1,1 \leftarrow 1,1,0$ & Ground & & 1 & 0 & 19429.06 & \\
\hline $\mathrm{C}_{6}^{12} \mathrm{H}_{5} \mathrm{~F}^{19}$ & 4-1281 & $35,11,24 \leftarrow 35,11,25$ & Ground & & & & 19432.8 & \\
\hline $\mathrm{S}^{32}{ }_{*} \mathrm{DC}^{12}: \mathrm{C}^{12} \mathrm{DC}^{12} \mathrm{D}: \mathrm{C}^{12}{ }_{*} \mathrm{D}$ & 4-1165 & 3. $1,3 \leftarrow 2,1,2$ & Ground & & & & 19433.8 & .1 \\
\hline $\mathrm{H}_{2} \mathrm{~B}^{11} \mathrm{H}_{2} \mathrm{~B}^{11} \mathrm{HBr}^{81}$ & 4- . 42 & $3,0,3 \leftarrow 2,0,2$ & Ground & & $5 / 2$ & $3 / 2$ & 19434.4 & \\
\hline $\mathrm{H}_{2} \mathrm{~B}^{11} \mathrm{H}_{2} \mathrm{~B}^{11} \mathrm{HBr}^{81}$ & 4- 42 & $3,0,3 \leftarrow 2,0,2$ & Ground & & $3 / 2$ & $1 / 2$ & 19434.4 & \\
\hline $\mathrm{C}^{12} \mathrm{D}_{3} \mathrm{C}^{12} \mathrm{H}_{2} \mathrm{Br}^{79}$ & 3- 523 & $3,1,2 \leftarrow 2,1,1$ & Ground & & $3 / 2$ & $1 / 2$ & 19439.72 & .05 \\
\hline$\left(\mathrm{C}^{12} \mathrm{H}_{3} \mathrm{C}^{12} \mathrm{H}_{2}\right)_{2} \mathrm{O}^{16}$ & $3-1011$ & Not Reported & & & & & 19440. & \\
\hline $3 \mathrm{~d}-\mathrm{C}_{6}^{12} \mathrm{H}_{5} \mathrm{~F}^{19}$ & 4-1282 & $9,2,7 \leftarrow 9,2,8$ & Ground & & & & 19440.8 & .1 \\
\hline $\mathrm{C}^{12} \mathrm{D}_{3} \mathrm{C}^{12} \mathrm{H}_{2} \mathrm{Br}^{79}$ & 3- 523 & $3,1,2 \leftarrow 2,1,1$ & Ground & & $9 / 2$ & $7 / 2$ & 19441.68 & .05 \\
\hline $\mathrm{C}^{12} * \mathrm{DN}^{14} \mathrm{C}^{12} \mathrm{DC}^{12} \mathrm{H}: \mathrm{C}^{12} \mathrm{DN}^{14} *$ & $4-1142$ & $8,6,3 \leftarrow 8,5,4$ & Ground & & & & 19443.3 & \\
\hline g- $\mathrm{C}^{12} \mathrm{H}_{2} \mathrm{DC}^{12} \mathrm{H}_{2} \mathrm{~F}^{19}$ & 3. 553 & $5,1,4 \leftarrow 4,2,3$ & Ground & & & & 19443.8 & .1 \\
\hline $\mathrm{C}^{\mathrm{b}} \mathrm{H}_{2}^{\mathrm{b}} \mathrm{Cl}^{\mathrm{b}} \mathrm{F}^{\mathrm{b}}$ & 4- 333 & Not Reported & & & & & 19447.26 & .1 \\
\hline $\mathrm{C}^{12}{ }^{\mathrm{D}} \mathrm{N}^{14} \mathrm{C}^{12} \mathrm{DC}^{12} \mathrm{H}: \mathrm{C}^{12} \mathrm{DN}^{14} *$ & $4-1142$ & $9,7,3 \leftarrow 9,6,4$ & Ground & & & & 19448.4 & \\
\hline $\mathrm{C}_{6}^{12} \mathrm{H}_{5} \mathrm{C}^{12} \mathrm{~N}^{14}$ & $4-1291$ & $7,3,5 \leftarrow 6,3,4$ & Ground & & & & 19449.2 & \\
\hline $\mathrm{C}^{12}{ }_{*} \mathrm{DN}^{14} \mathrm{C}^{12} \mathrm{DC}^{12} \mathrm{H}: \mathrm{C}^{12} \mathrm{DN}^{14} *$ & 4-1142 & $7,5,3 \leftarrow 7,4,4$ & Ground & & & & 19454.0 & \\
\hline$c-\mathrm{C}^{12} \mathrm{HF}^{19}: \mathrm{C}^{12} \mathrm{HCl}^{35}$ & 4- 641 & $1,1,1 \leftarrow 0,0,0$ & Ground & & $3 / 2$ & $3 / 2$ & 19456.39 & \\
\hline c- $\mathrm{C}^{12} \mathrm{HF}^{19}: \mathrm{C}^{12} \mathrm{HCl}^{35}$ & 4. 641 & $1,1,1 \leftarrow 0,0,0$ & Ground & & $5 / 2$ & $3 / 2$ & 19459.04 & \\
\hline $\mathrm{S}^{32}{ }_{*} \mathrm{HC}^{13}: \mathrm{C}^{12} \mathrm{HC}^{12} \mathrm{H}: \mathrm{C}^{12}{ }_{*} \mathrm{H}$ & $4 \cdot 1167$ & $2,1,1 \leftarrow 1,0,1$ & Ground & & & & 19459.8 & .05 \\
\hline
\end{tabular}




\begin{tabular}{|c|c|c|c|c|c|c|c|c|c|}
\hline Isotopic Species & $\begin{array}{l}\text { Vol.-Id. } \\
\text { Nos. }\end{array}$ & $\begin{array}{c}\text { Rotational } \\
\text { Quantum Nos. }\end{array}$ & Vib. State & $F_{1}^{\prime}$ & Fyp' & $\underset{F_{1}}{\text { rfine }}$ & $\mathrm{F}$ & $\begin{array}{l}\text { Frequency } \\
\mathrm{MHl}^{2}\end{array}$ & $\begin{aligned} & \text { Acc. } \\
\pm & \mathrm{MH}_{\mathrm{z}}\end{aligned}$ \\
\hline $\mathrm{C}^{12} \mathrm{D}_{3} \mathrm{C}^{12} \mathrm{H}_{2} \mathrm{Br}^{79}$ & 3. 523 & $3,1,2 \leftarrow 2,1,1$ & Ground & & $5 / 2$ & & $3 / 2$ & 19460.56 & .05 \\
\hline$c-\mathrm{C}^{12} \mathrm{HF}^{19}: \mathrm{C}^{12} \mathrm{HCl}^{35}$ & 4- 641 & $1,1,1 \leftarrow 0,0,0$ & Ground & & $1 / 2$ & & $3 / 2$ & 19461.25 & \\
\hline $\mathrm{C}^{12} \mathrm{H}_{2}\left(\mathrm{C}^{12} \mathrm{~N}^{14}\right)_{2}$ & 4- 901 & Not Reported & Ground & & & & & 19466.3 & .1 \\
\hline $\mathrm{a}-\mathrm{C}^{12} \mathrm{HD}_{2} \mathrm{C}^{12} \mathrm{O}^{16} \mathrm{~F}^{19}$ & 3- 396 & $10,6,4 \leftarrow 10,6,5$ & Ground & & & & & 19467.27 & .2 \\
\hline $\mathrm{C}^{12} \mathrm{D}_{3} \mathrm{C}^{12} \mathrm{H}_{2} \mathrm{Br}^{79}$ & 3. 523 & $3,1,2 \leftarrow 2,1,1$ & Ground & & $7 / 2$ & & $5 / 2$ & 19467.83 & .05 \\
\hline $\mathrm{C}^{12} \mathrm{H}_{3} \mathrm{~N}^{14} \mathrm{O}_{2}^{16}$ & 3- 171 & Not Reported & Ground & & & & & 19468.86 & \\
\hline $\mathrm{H}_{2} \mathrm{~B}^{11} \mathrm{H}_{2} \mathrm{~B}^{11} \mathrm{HBr}^{81}$ & 4- 42 & $3,2,2 \leftarrow 2,2,1$ & Ground & & $7 / 2$ & & $5 / 2$ & 19470.1 & \\
\hline $\mathrm{C}^{12}{ }_{*} \mathrm{DN}^{14} \mathrm{C}^{12} \mathrm{DC}^{12} \mathrm{H}: \mathrm{C}^{12} \mathrm{DN}^{14} *$ & 4-1142 & $5,2,3 \leftarrow 5,1,4$ & Ground & & & & & 19470.3 & \\
\hline $\mathrm{C}^{12}{ }_{*} \mathrm{DN}^{14} \mathrm{C}^{12} \mathrm{DC}^{12} \mathrm{H}: \mathrm{C}^{12} \mathrm{DN}^{14} *$ & 4-1142 & $6,4,3 \leftarrow 6,3,4$ & Ground & & & & & 19470.3 & \\
\hline a- $\mathrm{C}^{12} \mathrm{D}_{2} \mathrm{H}\left(\mathrm{C}^{12} \mathrm{H}_{3}\right)_{2} \mathrm{Si}^{\mathrm{b}} \mathrm{D}$ & 3- 884 & $2,2,0 \leftarrow 1,1,0$ & Ground & & & & & 19470.41 & .10 \\
\hline a- $\mathrm{C}^{12} \mathrm{HD}_{2} \mathrm{C}^{12} \mathrm{O}^{16} \mathrm{~F}^{19}$ & 3- 396 & $10,6,4 \leftarrow 10,6,5$ & Ground & & & & & 19471.22 & .2 \\
\hline $\mathrm{H}_{2} \mathrm{~B}^{11} \mathrm{H}_{2} \mathrm{~B}^{11} \mathrm{HBr}^{81}$ & 4. 42 & $3,2,1 \leftarrow 2,2,0$ & Ground & & $7 / 2$ & & $5 / 2$ & 19475.9 & \\
\hline a- $\mathrm{Si}^{28} \mathrm{HD}_{2} \mathrm{C}^{12} \mathrm{H}: \mathrm{C}^{12} \mathrm{H}_{2}$ & 3. 623 & $2,1,1 \leftarrow 1,1,0$ & Ground & & & & & 19480.67 & .10 \\
\hline $\mathrm{C}^{12}{ }_{*} \mathrm{DN}^{14} \mathrm{C}^{12} \mathrm{DC}^{12} \mathrm{H}: \mathrm{C}^{12} \mathrm{DN}^{14} *$ & $4-1142$ & $10,8,3 \leftarrow 10,7,4$ & Ground & & & & & 19480.9 & \\
\hline $\mathrm{D}_{2} \mathrm{C}^{12}: \mathrm{C}^{12} \mathrm{DCl}^{35}$ & 4- 763 & $2,1,2 \leftarrow 1,1,1$ & Ground & & & & & 19485.95 & \\
\hline $\mathrm{In}^{115} \mathrm{Cl}^{35}$ & $1-$ & $3 \leftarrow 2$ & Excited & $15 / 2$ & 9 & $13 / 2$ & 8 & 19486.10 & 0.20 \\
\hline $\operatorname{In}^{115} \mathrm{Cl}^{35}$ & $1-$ & $3 \leftarrow 2$ & Excited & $15 / 2$ & 6 & $13 / 2$ & 5 & 19486.10 & 0.20 \\
\hline $\mathrm{In}^{115} \mathrm{Cl}^{35}$ & $1-$ & $3 \leftarrow 2$ & Excited & $15 / 2$ & 8 & $13 / 2$ & 7 & 19486.10 & 0.20 \\
\hline $\operatorname{In}^{115} \mathrm{Cl}^{35}$ & $1-$ & $3 \leftarrow 2$ & Excited & $15 / 2$ & 7 & $13 / 2$ & 6 & 19486.10 & 0.20 \\
\hline $\mathrm{C}^{12} \mathrm{H}_{3} \mathrm{~N}^{14} \mathrm{O}_{2}^{16}$ & 3- 171 & Not Reported & Ground & & & & & 19486.13 & \\
\hline $\mathrm{C}^{12} \mathrm{DN}^{14} \mathrm{C}^{12} \mathrm{DC}^{12} \mathrm{H}: \mathrm{C}^{12} \mathrm{DN}^{14} *$ & $4-1142$ & $5,3,3 \leftarrow 5,2,4$ & Ground & & & & & 19487.1 & \\
\hline $\mathrm{a}-\mathrm{C}^{12} \mathrm{H}_{2} \mathrm{DC}^{12} \mathrm{O}^{16} \mathrm{~F}^{19}$ & 3- 398 & $4,2,2 \leftarrow 4,2,3$ & Ground & & & & & 19487.98 & .2 \\
\hline $\mathrm{H}_{2} \mathrm{~N}^{14} \mathrm{~N}^{14} \mathrm{H}_{2}$ & 3- 51 & Not Reported & & & & & & 19.488 .29 & \\
\hline $\mathrm{S}^{32}{ }_{*} \mathrm{HC}^{12}: \mathrm{C}^{12} \mathrm{HC}^{12} \mathrm{H}: \mathrm{C}^{12}{ }_{*} \mathrm{H}$ & 4-1161 & $2,1,1 \leftarrow 1,1,0$ & Ground & & & & & 19490.2 & .1 \\
\hline $\mathrm{C}^{12} \mathrm{HDCl}^{35} \mathrm{Si}^{28} \mathrm{H}_{3}$ & 3- 236 & $6,1,5 \leftarrow 6,0,6$ & Ground & & & & & 19490.20 & .2 \\
\hline a- $\mathrm{C}^{12} \mathrm{H}_{2} \mathrm{DC}^{12} \mathrm{O}^{16} \mathrm{~F}^{19}$ & 3- 398 & $4,2,2 \leftarrow 4,2,3$ & Ground & & & & & 19490.73 & .2 \\
\hline $\operatorname{In}^{115} \mathrm{Cl}^{35}$ & 1 - & $3 \leftarrow 2$ & Excited & $9 / 2$ & 3 & $9 / 2$ & 4 & 19491.88 & 0.20 \\
\hline $\operatorname{In}^{115} \mathrm{Cl}^{35}$ & $1-$ & $3 \leftarrow 2$ & Excited & $3 / 2$ & 0 & $5 / 2$ & 1 & 19491.88 & 0.20 \\
\hline $\operatorname{In}^{115} \mathrm{Cl}^{35}$ & $1-$ & $3 \leftarrow 2$ & Excited & $9 / 2$ & 6 & $9 / 2$ & 6 & 19491.88 & 0.20 \\
\hline $\mathrm{In}^{115} \mathrm{Cl}^{35}$ & 1 - & $3 \leftarrow 2$ & Excited & $9 / 2$ & 5 & $9 / 2$ & 5 & 19491.88 & 0.20 \\
\hline $\mathrm{In}^{115} \mathrm{Cl} \mathrm{l}^{35}$ & 1 - & $3 \leftarrow 2$ & Excited & $9 / 2$ & 4 & $9 / 2$ & 4 & 19491.88 & 0.20 \\
\hline $\operatorname{In}^{115} \mathrm{Cl}^{35}$ & $1-$ & $3 \leftarrow 2$ & Excited & $3 / 2$ & 1 & $5 / 2$ & 2 & 19491.88 & 0.20 \\
\hline $\operatorname{In}^{115} \mathrm{Cl}^{35}$ & $1-$ & $3 \leftarrow 2$ & Excited & $3 / 2$ & 3 & $5 / 2$ & 4 & 19491.88 & 0.20 \\
\hline $\mathrm{In}^{115} \mathrm{Cl}^{35}$ & ]- & $3 \leftarrow 2$ & Excited & $3 / 2$ & 2 & $5 / 2$ & 3 & 19491.88 & 0.20 \\
\hline $\operatorname{In}^{115} \mathrm{Cl}^{35}$ & $1-$ & $3 \leftarrow 2$ & Excited & $13 / 2$ & 7 & $11 / 2$ & 6 & 19491.88 & 0.20 \\
\hline $\mathrm{C}^{12} \mathrm{HCl}_{2}^{35} \mathrm{Cl}^{37}$ & 4- 262 & $3,3,0 \leftarrow 2,2,0$ & Ground & & & & & 19492.81 & .17 \\
\hline $\mathrm{C}^{12}{ }_{*} \mathrm{DN}^{14} \mathrm{C}^{12} \mathrm{DC}^{12} \mathrm{H}: \mathrm{C}^{12} \mathrm{DN}^{14} *$ & 4-1142 & $4,1,3 \leftarrow 4,0,4$ & Ground & & & & & 19495.3 & \\
\hline $\mathrm{C}^{12}{ }_{*} \mathrm{DN}^{14} \mathrm{C}^{12} \mathrm{DC}^{12} \mathrm{H}: \mathrm{C}^{12} \mathrm{DN}^{14}{ }_{*}$ & 4-1142 & $4,2,3 \leftarrow 4,1,4$ & Ground & & & & & 19495.3 & \\
\hline $\mathrm{C}^{12}{ }_{*} \mathrm{DN}^{14} \mathrm{C}^{12} \mathrm{DC}^{12} \mathrm{H}: \mathrm{C}^{12} \mathrm{DN}^{14}{ }_{*}$ & 4-1142 & $3,0,3 \leftarrow 2,1,2$ & Ground & & & & & 19495.3 & \\
\hline $\mathrm{C}^{12} \mathrm{D}_{3} \mathrm{C}^{12} \mathrm{O}^{16} \mathrm{O}^{16} \mathrm{H}$ & 3- 492 & $6,4,2 \leftarrow 6,3,3$ & Ground & & & & & 19495.85 & \\
\hline $\operatorname{In}^{115} \mathrm{Cl}^{35}$ & 1 - & $3 \leftarrow 2$ & Excited & $13 / 2$ & 8 & $11 / 2$ & 7 & 19496.29 & 0.20 \\
\hline $\left.\operatorname{In}^{115} \mathrm{Cl}\right]^{35}$ & $1-$ & $3 \leftarrow 2$ & Excited & $13 / 2$ & 6 & $11 / 2$ & 5 & 19496.29 & 0.20 \\
\hline $\mathrm{In}^{115} \mathrm{Cl}^{35}$ & 1 - & $3 \leftarrow 2$ & Excited & $13 / 2$ & 5 & $11 / 2$ & 4 & 19496.29 & 0.20 \\
\hline
\end{tabular}




\begin{tabular}{|c|c|c|c|c|c|c|c|c|c|}
\hline Isotopic Species & $\begin{array}{l}\text { Vol.-Id. } \\
\text { Nos. }\end{array}$ & $\begin{array}{c}\text { Rotational } \\
\text { Quantum Nos. }\end{array}$ & Vib. State & $\mathrm{F}_{1}^{\prime}$ & Hype & $\underset{F_{1}}{\operatorname{erfine}}$ & $F$ & $\begin{array}{c}\text { Frequency } \\
\mathrm{MHz}\end{array}$ & $\begin{aligned} & \text { Acc. } \\
& \pm \mathrm{MHz}\end{aligned}$ \\
\hline $\mathrm{D}_{2} \mathrm{C}^{12}: \mathrm{C}^{12} \mathrm{DCl}^{35}$ & 4- 763 & $2,1,2 \leftarrow 1,1,1$ & Ground & & $7 / 2$ & & $5 / 2$ & 19500.15 & .2 \\
\hline $\mathrm{C}^{12}{ }_{*} \mathrm{D}: \mathrm{C}^{12} \mathrm{DC}^{12} \mathrm{D}: \mathrm{C}^{12} \mathrm{DN}^{14}{ }_{*} \mathrm{H}$ & 4-1185 & $5,4,2 \leftarrow 5,3,3$ & Ground & & & & & 19501.5 & \\
\hline $\mathrm{H}_{2} \mathrm{~N}^{14} \mathrm{~N}^{14} \mathrm{H}_{2}$ & $3-\quad 51$ & Not Reported & & & & & & 19502.92 & \\
\hline $\mathrm{C}^{12} \mathrm{H}_{3} \mathrm{~N}^{14} \mathrm{O}_{2}^{16}$ & 3- 171 & Not Reported & Ground & & & & & 19509.18 & \\
\hline $\mathrm{C}^{12} \mathrm{H}_{3} \mathrm{~S}^{32} \mathrm{H}$ & 3- 221 & Not Reported & Ground & & & & & 19510.4 & .1 \\
\hline $\mathrm{C}^{12}{ }_{*} \mathrm{DN}^{14} \mathrm{C}^{12} \mathrm{DC}^{12} \mathrm{H}: \mathrm{C}^{12} \mathrm{DN}^{14}{ }_{*}$ & $4-1142$ & $3,1,3 \leftarrow 2,0,2$ & Ground & & & & & 19510.6 & \\
\hline $\mathrm{H}_{2} \mathrm{~B}^{11} \mathrm{H}_{2} \mathrm{~B}^{11} \mathrm{HBr}^{79}$ & 4- 41 & $3,2,2 \leftarrow 2,2,1$ & Ground & & $9 / 2$ & & $7 / 2$ & 19511.0 & \\
\hline $\mathrm{C}_{6}^{12} \mathrm{H}_{5} \mathrm{Cl}^{35}$ & $4-1271$ & $7,2,6 \leftarrow 6,2,5$ & Ground & & & & & 19513.4 & \\
\hline $\mathrm{C}^{12} \mathrm{D}_{3} \mathrm{C}^{13}: \mathrm{C}^{12} \mathrm{C}^{12} \mathrm{~F}_{3}^{19}$ & 3- 895 & $8, \leftarrow 7$, & Ground & & & & & 19516.0 & .5 \\
\hline $\mathrm{c}-\mathrm{Si}^{28} \mathrm{H}_{3} \mathrm{C}^{12} \mathrm{H}: \mathrm{C}^{12} \mathrm{HD}$ & 3- 617 & $2,0,2 \leftarrow 1,0,1$ & Ground & & & & & 19517.07 & .10 \\
\hline $\mathrm{H}_{2} \mathrm{~B}^{11} \mathrm{H}_{2} \mathrm{~B}^{11} \mathrm{HBr}^{79}$ & 4- $\quad 41$ & $3,2,1 \leftarrow 2,2,0$ & Ground & & $9 / 2$ & & $7 / 2$ & 19517.5 & \\
\hline $\mathrm{Si}^{29} \mathrm{H}_{3} \mathrm{C}^{12} \mathrm{H}: \mathrm{C}^{12} \mathrm{H}_{2}$ & 3- 613 & $2,1,2 \leftarrow 1,1,1$ & Ground & & & & & 19523.22 & .10 \\
\hline $\mathrm{C}^{12}{ }_{*} \mathrm{HC}^{12} \mathrm{D}: \mathrm{C}^{12} \mathrm{HC}^{12} \mathrm{H}: \mathrm{C}^{12} \mathrm{HN}^{14} *$ & $4-1203$ & $2,1,1 \leftarrow 1,1,0$ & Ground & & & & & 19523.6 & .1 \\
\hline $\mathrm{H}_{2} \mathrm{~B}^{11} \mathrm{H}_{2} \mathrm{~B}^{11} \mathrm{HBr}^{79}$ & 4- 41 & $3,0,3 \leftarrow 2,0,2$ & Ground & & $9 / 2$ & & $7 / 2$ & 19524.7 & \\
\hline $\mathrm{H}_{2} \mathrm{~B}^{11} \mathrm{H}_{2} \mathrm{~B}^{11} \mathrm{HBr}^{79}$ & 4. 41 & $3,0,3 \leftarrow 2,0,2$ & Ground & & $7 / 2$ & & $5 / 2$ & 19524.7 & \\
\hline $\mathrm{In}^{115} \mathrm{Cl}^{35}$ & 1 - & $3 \leftarrow 2$ & Ground & $9 / 2$ & 6 & $7 / 2$ & 5 & 19526.26 & 0.20 \\
\hline $\operatorname{In}^{115} \mathrm{Cl}^{35}$ & $1-$ & $3 \leftarrow 2$ & Ground & $9 / 2$ & 5 & $7 / 2$ & 4 & 19526.26 & 0.20 \\
\hline $\operatorname{In}^{115} \mathrm{Cl}^{35}$ & $1-$ & $3 \leftarrow 2$ & Ground & $9 / 2$ & 4 & $7 / 2$ & 3 & $19 \dot{ } 527.77$ & 0.20 \\
\hline $\operatorname{In}^{115} \mathrm{Cl}^{35}$ & $1-$ & $3 \leftarrow 2$ & Ground & $9 / 2$ & 3 & $7 / 2$ & 2 & 19527.77 & 0.20 \\
\hline $\mathrm{C}_{6}^{12} \mathrm{H}_{5} \mathrm{C}^{12} \mathrm{~N}^{14}$ & 4-1291 & $7,3,4 \leftarrow 6,3,3$ & Ground & & & & & 19534.8 & \\
\hline $\mathrm{C}_{6}^{12} \mathrm{H}_{5} \mathrm{~F}^{19}$ & 4-1281 & $17,5,12 \leftarrow 17,5,13$ & Ground & & & & & 19535.1 & \\
\hline $\mathrm{C}^{12}{ }_{*} \mathrm{DC}^{12} \mathrm{H}: \mathrm{C}^{12} \mathrm{HC}^{12} \mathrm{H}: \mathrm{C}^{12} \mathrm{HN}^{14} *$ & 4-1202 & $2,1,1 \leftarrow 1,1,0$ & Ground & & & & & 19537.4 & .1 \\
\hline $\mathrm{C}^{12} \mathrm{H}_{3} \mathrm{C}^{12} \mathrm{O}^{16} \mathrm{C}^{13} \mathrm{~N}^{14}$ & 3- 673 & $3,1,3 \leftarrow 2,1,2$ & Ground & & & & & 19537.93 & .2 \\
\hline $\operatorname{In}^{115} \mathrm{Cl}^{35}$ & $1-$ & $3 \leftarrow 2$ & Ground & $5 / 2$ & 2 & $5 / 2$ & 2 & 19539.67 & 0.20 \\
\hline $\operatorname{In}^{115} \mathrm{Cl}^{35}$ & $1-$ & $3 \leftarrow 2$ & Ground & $5 / 2$ & 1 & $5 / 2$ & 1 & 19539.67 & 0.20 \\
\hline $\operatorname{In}^{115} \mathrm{Cl}^{35}$ & $1-$ & $3 \leftarrow 2$ & Ground & $5 / 2$ & 3 & $5 / 2$ & 3 & 19539.67 & 0.20 \\
\hline $\operatorname{In}^{115} \mathrm{Cl}^{35}$ & $1-$ & $3 \leftarrow 2$ & Ground & $5 / 2$ & 4 & $5 / 2$ & 4 & 19539.67 & 0.20 \\
\hline $\mathrm{C}^{12}{ }_{*} \mathrm{H}: \mathrm{C}^{12} \mathrm{HC}^{12} \mathrm{H}: \mathrm{C}^{12} \mathrm{HN}^{14}{ }_{*} \mathrm{D}$ & $4-1182$ & $5,3,2 \leftarrow 5,3,3$ & Ground & & & & & 19540.4 & \\
\hline $\mathrm{H}_{2} \mathrm{~B}^{11} \mathrm{H}_{2} \mathrm{~B}^{11} \mathrm{HBr}^{79}$ & 4- - 41 & $3,0,3 \leftarrow 2,0,2$ & Ground & & $3 / 2$ & & $1 / 2$ & 19543.2 & \\
\hline $\mathrm{H}_{2} \mathrm{~B}^{11} \mathrm{H}_{2} \mathrm{~B}^{11} \mathrm{HBr}^{79}$ & 4. 41 & $3,0,3 \leftarrow 2,0,2$ & Ground & & $5 / 2$ & & $3 / 2$ & 19543.2 & \\
\hline $\mathrm{C}^{13} \mathrm{H}_{3} \mathrm{~N}^{14} \mathrm{C}^{12}$ & 4- 832 & $1,0 \leftarrow 0,0$ & Ground & & & & & 19543.4 & .3 \\
\hline $\mathrm{s}-\mathrm{C}^{12} \mathrm{D}_{2} \mathrm{H}\left(\mathrm{C}^{12} \mathrm{H}_{3}\right)_{2} \mathrm{Si}^{\mathrm{b}} \mathrm{D}$ & 3. 883 & $2,2,0 \leftarrow 1,1,0$ & Ground & & & & & 19544.30 & .10 \\
\hline $\mathrm{C}^{12} \mathrm{H}_{2}\left(\mathrm{C}^{12} \mathrm{~N}^{14}\right)\left(\mathrm{C}^{12} \mathrm{~N}^{15}\right)$ & 4- 904 & $4,1,3 \leftarrow 4,0,4$ & Ground & & & & & 19548.66 & \\
\hline $\mathrm{C}^{13}{ }_{*} \mathrm{HC}^{12} \mathrm{H}: \mathrm{C}^{12} \mathrm{HC}^{12} \mathrm{H}: \mathrm{C}^{12} \mathrm{HN}^{14} *$ & 4-1205 & $11,8,3 \leftarrow 11,8,4$ & Ground & & & & & 19549.9 & \\
\hline $\mathrm{C}^{12}{ }^{1} \mathrm{DN}^{14} \mathrm{C}^{12} \mathrm{DC}^{12} \mathrm{H}: \mathrm{C}^{12} \mathrm{DN}^{14} *$ & 4-1142 & $11,9,3 \leftarrow 11,8,4$ & Ground & & & & & 19557.3 & \\
\hline $\mathrm{H}_{2} \mathrm{~N}^{14} \mathrm{~N}^{14} \mathrm{H}_{2}$ & 3- 51 & Not Reported & & & & & & 19559.0 & \\
\hline $\mathrm{s} \cdot \mathrm{C}^{12} \mathrm{H}_{2} \mathrm{DSi}^{\mathrm{b}} \mathrm{H}_{2} \mathrm{D}$ & 3- 332 & $1, \quad \leftarrow 0$, & & & & & & 19559.2 & \\
\hline $\mathrm{C}^{12} \mathrm{H}_{3} \mathrm{~N}^{14} \mathrm{O}_{2}^{16}$ & 3- 171 & Not Reported & Ground & & & & & 19560.95 & \\
\hline $\mathrm{H}_{2} \mathrm{~N}^{14} \mathrm{~N}^{14} \mathrm{H}_{2}$ & 3- 51 & Not Reported & & & & & & 19561.4 & \\
\hline $\operatorname{In}^{115} \mathrm{Cl}^{35}$ & $1-$ & $3 \leftarrow 2$ & Ground & $11 / 2$ & 7 & $9 / 2$ & 6 & 19563.97 & 0.20 \\
\hline $\mathrm{In}^{115} \mathrm{Cl}^{35}$ & $1-$ & $3 \leftarrow 2$ & Ground & $11 / 2$ & 6 & $9 / 2$ & 5 & 19563.97 & 0.20 \\
\hline $\operatorname{In}^{115} \mathrm{Cl}^{35}$ & $1-$ & $3 \leftarrow 2$ & Ground & $11 / 2$ & 5 & $9 / 2$ & 4 & 19563.97 & 0.20 \\
\hline $\operatorname{In}^{115} \mathrm{Cl}^{35}$ & $1-$ & $3 \leftarrow 2$ & Ground & $11 / 2$ & 4 & $9 / 2$ & 3 & 19563.97 & 0.20 \\
\hline $\operatorname{In}^{115} \mathrm{Cl}^{35}$ & $1-$ & $3 \leftarrow 2$ & Ground & $11 / 2$ & 4 & $11 / 2$ & 4 & 19563.97 & 0.20 \\
\hline $\operatorname{In}^{115} \mathrm{Cl}^{35}$ & $1-$ & $3 \leftarrow 2$ & Ground & $11 / 2$ & 6 & $11 / 2$ & 6 & 19563.97 & 0.20 \\
\hline
\end{tabular}




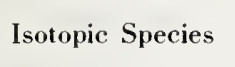

$$
\begin{array}{cc}
\text { Vol.-Id. } & \text { Rotational } \\
\text { Nos. } & \text { Quantum Nos. }
\end{array}
$$

Vib. State

Frequency Ace.

\begin{tabular}{|c|c|c|c|c|c|c|c|c|c|}
\hline $\mathrm{In}^{115} \mathrm{Cl}^{35}$ & $1-$ & $3 \leftarrow 2$ & Ground & $11 / 2$ & 5 & $11 / 2$ & 5 & 19563.97 & 0.20 \\
\hline $\operatorname{In}^{115} \mathrm{Cl}^{35}$ & 1 - & $3 \leftarrow 2$ & Ground & $11 / 2$ & 7 & $11 / 2$ & 7 & 19563.97 & 0.20 \\
\hline $\mathrm{In}^{115} \mathrm{Cl} \mathrm{I}^{35}$ & $1-$ & $3 \leftarrow 2$ & Ground & $11 / 2$ & 4 & $9 / 2$ & 3 & 19565.84 & 0.20 \\
\hline $\operatorname{In}^{115} \mathrm{Cl}^{35}$ & l- & $3 \leftarrow 2$ & Ground & $11 / 2$ & 7 & $9 / 2$ & 6 & 19565.84 & 0.20 \\
\hline $\operatorname{In}^{115} \mathrm{Cl}^{35}$ & 1 - & $3 \leftarrow 2$ & Ground & $11 / 2$ & 6 & $9 / 2$ & 5 & 19565.84 & 0.20 \\
\hline $\operatorname{In}^{115} \mathrm{Cl}^{35}$ & 1 - & $3 \leftarrow 2$ & Ground & $11 / 2$ & 5 & $9 / 2$ & 4 & 19565.84 & 0.20 \\
\hline $\operatorname{In}^{115} \mathrm{Cl}^{35}$ & $1-$ & $3 \leftarrow 2$ & Ground & $11 / 2$ & 5 & $11 / 2$ & 5 & 19565.84 & 0.20 \\
\hline $\operatorname{In}^{115} \mathrm{Cl}^{35}$ & $1-$ & $3 \leftarrow 2$ & Ground & $11 / 2$ & 6 & $11 / 2$ & 6 & 19565.84 & 0.20 \\
\hline $\operatorname{In}^{115} \mathrm{Cl}^{35}$ & $1-$ & $3 \leftarrow 2$ & Ground & $11 / 2$ & 7 & $11 / 2$ & 7 & 19565.84 & 0.20 \\
\hline $\operatorname{In}^{115} \mathrm{Cl}^{35}$ & $1-$ & $3 \leftarrow 2$ & Ground & $11 / 2$ & 4 & $11 / 2$ & 4 & 19565.84 & 0.20 \\
\hline $\mathrm{C}^{12} \mathrm{H}_{3} \mathrm{~S}^{32} \mathrm{H}$ & 3- 221 & Not Reported & Ground & & & & & 19568.3 & .1 \\
\hline $\mathrm{In}^{115} \mathrm{Cl}^{35}$ & 1 - & $3 \leftarrow 2$ & Ground & $7 / 2$ & 5 & $7 / 2$ & 5 & 19570.25 & 0.20 \\
\hline $\operatorname{In}^{115} \mathrm{Cl}^{35}$ & $1-$ & $3 \leftarrow 2$ & Ground & $7 / 2$ & 3 & $7 / 2$ & 3 & 19570.25 & 0.20 \\
\hline $\operatorname{In}^{115} \mathrm{Cl}^{35}$ & 1 - & $3 \leftarrow 2$ & Ground & $7 / 2$ & 2 & $7 / 2$ & 2 & 19570.25 & 0.20 \\
\hline $\operatorname{In}^{115} \mathrm{Cl}^{35}$ & $1-$ & $3 \leftarrow 2$ & Ground & $7 / 2$ & 4 & $7 / 2$ & 4 & 19570.25 & 0.20 \\
\hline $\mathrm{C}^{12}{ }_{*} \mathrm{H}: \mathrm{C}^{12} \mathrm{HO}^{16} \mathrm{C}^{12} \mathrm{H}: \mathrm{C}^{12}{ }_{*} \mathrm{D}$ & 4.-1155 & $5,3,2 \leftarrow 5,3,3$ & Ground & & & & & 19572.5 & \\
\hline $\mathrm{C}^{12} \mathrm{D}_{3} \mathrm{Si}^{28} \mathrm{H}_{2} \mathrm{~F}^{19}$ & 3. 244 & $6,1,5 \leftarrow 6,1,6$ & Ground & & & & & 19573.03 & .10 \\
\hline $\mathrm{C}^{12}{ }_{*} \mathrm{HC}^{13} \mathrm{H}: \mathrm{C}^{12} \mathrm{HC}^{12} \mathrm{H} \mathrm{C}^{12} \mathrm{HN}^{14}{ }_{*}$ & 4-1206 & $11,8,3 \leftarrow 11,8,4$ & Ground & & & & & 19573.1 & \\
\hline $\mathrm{C}^{12} \mathrm{H}_{3} \mathrm{~N}^{14} \mathrm{O}_{2}^{16}$ & 3- 171 & Not Reported & Ground & & & & & 19576. & 5. \\
\hline $\operatorname{In}^{115} \mathrm{Cl}^{35}$ & $1-$ & $3 \leftarrow 2$ & Ground & $15 / 2$ & 8 & $13 / 2$ & 7 & 19578.36 & 0.20 \\
\hline $\operatorname{In}^{115} \mathrm{Cl}^{35}$ & 1- & $3 \leftarrow 2$ & Ground & $15 / 2$ & 9 & $13 / 2$ & 8 & 19578.36 & 0.20 \\
\hline $\operatorname{In}^{115} \mathrm{Cl}^{35}$ & $1-$ & $3 \leftarrow 2$ & Ground & $15 / 2$ & 7 & $13 / 2$ & 6 & 19578.36 & 0.20 \\
\hline $\operatorname{In}^{115} \mathrm{Cl}^{35}$ & 1 - & $3 \leftarrow 2$ & Ground & $15 / 2$ & 6 & $13 / 2$ & 5 & 19578.36 & 0.20 \\
\hline $\mathrm{F}_{2}^{19} \mathrm{O}_{2}^{16}$ & 3- 11 & $4,1,3 \leftarrow 4,0,4$ & Ground & & & & & 19581.70 & .1 \\
\hline $\mathrm{F}_{2}^{19} \mathrm{~N}^{14} \mathrm{~N}^{14} \mathrm{~F}_{2}^{19}$ & 3- 21 & $2,2,0 \leftarrow 1,1,0$ & Ground & & & & & 19582.6 & .3 \\
\hline $\operatorname{In}^{115} \mathrm{Cl}^{35}$ & $1-$ & $3 \leftarrow 2$ & Ground & $3 / 2$ & 0 & $5 / 2$ & 1 & 19584.56 & 0.20 \\
\hline $\mathrm{In}^{115} \mathrm{Cl}^{35}$ & $1-$ & $3 \leftarrow 2$ & Ground & $9 / 2$ & 6 & $9 / 2$ & 6 & 19584.56 & 0.20 \\
\hline $\mathrm{In}^{115} \mathrm{Cl}^{35}$ & 1 . & $3 \leftarrow 2$ & Ground & $9 / 2$ & 5 & $9 / 2$ & 5 & 19584.56 & 0.20 \\
\hline $\operatorname{In}^{115} \mathrm{Cl}^{35}$ & $1-$ & $3 \leftarrow 2$ & Ground & $9 / 2$ & 4 & $9 / 2$ & 4 & 19584.56 & 0.20 \\
\hline $\operatorname{In}^{115} \mathrm{Cl}^{35}$ & $1-$ & $3 \leftarrow 2$ & Ground & $9 / 2$ & 3 & $9 / 2$ & 3 & 19584.56 & 0.20 \\
\hline $\mathrm{In}^{115} \mathrm{Cl}^{35}$ & $1-$ & $3 \leftarrow 2$ & Ground & $3 / 2$ & 1 & $5 / 2$ & 2 & 19584.56 & 0.20 \\
\hline $\mathrm{In}^{115} \mathrm{Cl}^{35}$ & $1-$ & $3 \leftarrow 2$ & Ground & $3 / 2$ & 3 & $5 / 2$ & 4 & 19584.56 & 0.20 \\
\hline $\operatorname{In}^{115} \mathrm{Cl}^{35}$ & $1-$ & $3 \leftarrow 2$ & Ground & $3 / 2$ & 2 & $5 / 2$ & 3 & 19584.56 & 0.20 \\
\hline $\operatorname{In}^{115} \mathrm{Cl}^{35}$ & $1-$ & $3 \leftarrow 2$ & Ground & $13 / 2$ & 7 & $11 / 2$ & 6 & 19584.56 & 0.20 \\
\hline $\mathrm{H}_{2} \mathrm{~B}^{11} \mathrm{H}_{2} \mathrm{~B}^{11} \mathrm{HBr}^{79}$ & 4- 41 & $3,2,2 \leftarrow 2,2,1$ & Ground & & $7 / 2$ & & $5 / 2$ & 19586.1 & \\
\hline $\mathrm{In}^{115} \mathrm{Cl}^{35}$ & $1-$ & $3 \leftarrow 2$ & Ground & $13 / 2$ & 5 & $11 / 2$ & 4 & 19589.08 & 0.20 \\
\hline $\operatorname{In}^{115} \mathrm{Cl}^{35}$ & $1-$ & $3 \leftarrow 2$ & Ground & $13 / 2$ & 8 & $11 / 2$ & 7 & 19589.08 & 0.20 \\
\hline $\operatorname{In}^{115} \mathrm{Cl}^{35}$ & $1-$ & $3 \leftarrow 2$ & Ground & $13 / 2$ & 6 & $11 / 2$ & 5 & 19589.08 & 0.20 \\
\hline $\mathrm{H}_{2} \mathrm{~B}^{11} \mathrm{H}_{2} \mathrm{~B}^{11} \mathrm{HBr}^{79}$ & 4- 41 & $3,2,1 \leftarrow 2,2,0$ & Ground & & $7 / 2$ & & $5 / 2$ & 19589.8 & \\
\hline$\left(\mathrm{C}^{12} \mathrm{H}_{3} \mathrm{C}^{12} \mathrm{H}_{2}\right)_{2} \mathrm{O}^{16}$ & $3-1011$ & Not Reported & & & & & & 19590. & \\
\hline $\mathrm{Si}^{28} \mathrm{H}_{3} \mathrm{C}^{12} \mathrm{H}: \mathrm{C}^{13} \mathrm{H}_{2}$ & 3- 624 & $2,0,2 \leftarrow 1,0,1$ & Ground & & & & & 19590.25 & .10 \\
\hline $\mathrm{HC}^{12} \mathrm{HO}^{16}$ & 4- 381 & $25,4,21 \leftarrow 25,4,22$ & Ground & & & & & 19595.23 & \\
\hline $\mathrm{C}^{12} \mathrm{O}^{16} \mathrm{~F}_{2}^{19}$ & 4- 211 & $10,10,1 \leftarrow 10,8,2$ & Ground & & & & & 19595.29 & .10 \\
\hline $\mathrm{C}^{12} \mathrm{H}_{3} \mathrm{C}^{12}{ }_{*} \mathrm{HO}^{16} \mathrm{C}^{12}{ }_{*} \mathrm{H}_{2}$ & 3- 761 & $8,3,6 \leftarrow 7,4,3$ & Ground & & & & & 19598.51 & .1 \\
\hline $\mathrm{C}^{12} \mathrm{D}_{2}\left(\mathrm{C}^{12} \mathrm{~N}^{14}\right)_{2}$ & 4- 903 & $7,1,6 \leftarrow 7,0,7$ & Ground & & & & & 19601.55 & \\
\hline
\end{tabular}




\begin{tabular}{|c|c|c|c|c|c|c|c|c|c|}
\hline Isotopic Species & $\begin{array}{l}\text { Vol.-Id. } \\
\text { Nos. }\end{array}$ & $\begin{array}{c}\text { Rotational } \\
\text { Quantum Nos. }\end{array}$ & Vib. State & $F_{1}^{\prime}$ & $\begin{array}{l}\text { Hype } \\
\mathrm{F}^{\prime}\end{array}$ & $\begin{array}{l}\text { rfine } \\
F_{1}\end{array}$ & $\mathbf{F}$ & $\begin{array}{c}\text { Frequency } \\
\mathrm{MHz}\end{array}$ & $\begin{aligned} & \text { Acc. } \\
& \pm \mathrm{MHz}\end{aligned}$ \\
\hline $\mathrm{C}^{12} \mathrm{H}_{3} \mathrm{C}^{12} * \mathrm{HO}^{16} \mathrm{C}^{12} * \mathrm{H}_{2}$ & 3- 761 & Not Reported & Ground & & & & & 19602.38 & .1 \\
\hline $\mathrm{O}^{16}{ }_{*} \mathrm{C}^{12} \mathrm{H}_{2} \mathrm{C}^{12} \mathrm{H}_{2} \mathrm{C}^{12}{ }_{*} \mathrm{O}^{16}$ & $4-1071$ & $2,1,1 \leftarrow 1,1,0$ & Ground & & & & & 19602.54 & .1 \\
\hline$\left(\mathrm{C}^{12} \mathrm{D}_{3}\right)_{2} \mathrm{O}^{16}$ & 3- 592 & $2,1,1 \leftarrow 2,0,2$ & Ground & & & & & 19603.2 & .2 \\
\hline $\mathrm{C}^{12} \mathrm{H}_{3} \mathrm{C}^{12}{ }_{*} \mathrm{HO}^{16} \mathrm{C}^{12}{ }_{*} \mathrm{H}_{2}$ & 3- 761 & $8,3,6 \leftarrow 7,4,3$ & Ground & & & & & 19603.72 & .1 \\
\hline $\mathrm{t}-\mathrm{HDN}^{14} \mathrm{C}^{12} \mathrm{HO}^{16}$ & 3. 153 & $1,0,1 \leftarrow 0,0,0$ & Ground & & & & & 19606.11 & .1 \\
\hline$\left(\mathrm{C}^{12} \mathrm{D}_{3}\right)_{2} \mathrm{O}^{16}$ & 3- 592 & Not Reported & Ground & & & & & 19607.1 & .2 \\
\hline a- $\mathrm{C}^{12} \mathrm{H}_{2} \mathrm{DSi}^{\mathrm{b}} \mathrm{H}_{2} \mathrm{D}$ & 3- 333 & $1, \quad \leftarrow 0, \quad$, & & & & & & 19607.85 & \\
\hline $\mathrm{C}^{12} \mathrm{H}_{3} \mathrm{C}^{12}{ }_{*} \mathrm{HO}^{16} \mathrm{C}^{12}{ }_{*} \mathrm{H}_{2}$ & 3- 761 & $15,10, \leftarrow 16,9$ & Ground & & & & & 19608.29 & .1 \\
\hline $\mathrm{C}^{12} \mathrm{H}_{3} \mathrm{C}^{12}{ }_{*} \mathrm{HO}^{16} \mathrm{C}^{12}{ }_{*} \mathrm{H}_{2}$ & 3- 761 & $15,10, \leftarrow 16,9$ & Ground & & & & & 19608.64 & $\because 1$ \\
\hline $\mathrm{C}^{12} \mathrm{H}_{3} \mathrm{C}^{12}{ }_{*} \mathrm{HO}^{16} \mathrm{C}^{12}{ }_{*} \mathrm{H}_{2}$ & 3- 761 & $15,10, \leftarrow 16,9$ & Ground & & & & & 19609.28 & .1 \\
\hline $\mathrm{Si}^{28} \mathrm{H}_{3} \mathrm{C}^{13} \mathrm{H}: \mathrm{C}^{12} \mathrm{H}_{2}$ & 3- 615 & $2,1,2 \leftarrow 1,1,1$ & Ground & & & & & 19611.24 & .10 \\
\hline $\mathrm{H}_{2} \mathrm{~B}^{11} \mathrm{H}_{2} \mathrm{~B}^{10} \mathrm{HBr}^{81}$ & 4- 46 & $3,0,3 \leftarrow 2,0,2$ & Ground & & $9 / 2$ & & $7 / 2$ & 19611.7 & \\
\hline $\mathrm{H}_{2} \mathrm{~B}^{11} \mathrm{H}_{2} \mathrm{~B}^{10} \mathrm{HBr}^{81}$ & 4. 46 & $3,0,3 \leftarrow 2,0,2$ & Ground & & $7 / 2$ & & $5 / 2$ & 19611.7 & \\
\hline$\left(\mathrm{C}^{12} \mathrm{H}_{3}\right)_{3} \mathrm{C}^{12} \mathrm{C}^{12}: \mathrm{C}^{12} \mathrm{Cl}^{35}$ & $3-1061$ & $11, \leftarrow 10$ & Ground & & & & & 19617.1 & .5 \\
\hline $\mathrm{C}^{12} \mathrm{H}_{3} \mathrm{~N}^{14} \mathrm{O}_{2}^{16}$ & 3- 171 & Not Reported & Ground & & & & & 19619.86 & \\
\hline $\operatorname{In}^{115} \mathrm{Cl}^{35}$ & $1-$ & $3 \leftarrow 2$ & Ground & $5 / 2$ & 1 & $7 / 2$ & 2 & 19621.36 & 0.20 \\
\hline $\operatorname{In}^{115} \mathrm{Cl}^{35}$ & $1-$ & $3 \leftarrow 2$ & Ground & $5 / 2$ & 2 & $7 / 2$ & 3 & 19621.36 & 0.20 \\
\hline $\mathrm{In}^{115} \mathrm{Cl}^{35}$ & $1-$ & $3 \leftarrow 2$ & Ground & $5 / 2$ & 3 & $7 / 2$ & 4 & 19621.36 & 0.20 \\
\hline $\operatorname{In}^{115} \mathrm{Cl}^{35}$ & 1 - & $3 \leftarrow 2$ & Ground & $5 / 2$ & 4 & $7 / 2$ & 5 & 19621.36 & 0.20 \\
\hline $\mathrm{t}-\mathrm{HDN}{ }^{14} \mathrm{C}^{12} \mathrm{HO}^{16}$ & 3- 153 & $1,0,1 \leftarrow 0,0,0$ & Excited & & & & & 19621.6 & \\
\hline $\mathrm{C}^{12} \mathrm{~F}_{3}^{19} \mathrm{C}^{12} \mathrm{O}^{16} \mathrm{O}^{16} \mathrm{H} \cdot \mathrm{HC}^{12} \mathrm{O}^{16} \mathrm{O}^{16} \mathrm{H}$ & 3- 661 & $17, \quad \leftarrow 16$, & Ground & & & & & 19621.8 & \\
\hline$\overline{\mathrm{C}}^{\mathrm{b}} \mathrm{H}_{2}^{\mathrm{b}} \mathrm{Cl}^{\mathrm{b}} \mathrm{F}^{\mathrm{b}}$ & 4- 333 & Not Reported & & & & & & 19624.74 & .1 \\
\hline $\mathrm{In}^{115} \mathrm{Cl}^{35}$ & $1-$ & $3 \leftarrow 2$ & Ground & $7 / 2$ & 4 & $9 / 2$ & 5 & 19628.75 & 0.20 \\
\hline $\mathrm{In}^{115} \mathrm{Cl}^{35}$ & $1-$ & $3 \leftarrow 2$ & Ground & $7 / 2$ & 2 & $9 / 2$ & 3 & 19628.75 & 0.20 \\
\hline $\ln ^{115} \mathrm{Cl}^{35}$ & 1 - & $3 \leftarrow 2$ & Ground & $7 / 2$ & 5 & $9 / 2$ & 6 & 19628.75 & 0.20 \\
\hline $\mathrm{In}^{115} \mathrm{Cl}^{35}$ & $1-$ & $3 \leftarrow 2$ & Ground & $7 / 2$ & 3 & $9 / 2$ & 4 & 19628.75 & 0.20 \\
\hline $\mathrm{C}^{12}{ }_{*} \mathrm{HC}^{12} \mathrm{D}: \mathrm{C}^{12} \mathrm{HC}^{12} \mathrm{H}: \mathrm{C}^{12} \mathrm{HN}^{14} *$ & $4-1203$ & $7,4,3 \leftarrow 7,4,4$ & Ground & & & & & 19628.8 & .1 \\
\hline $\mathrm{C}^{12} \mathrm{H}_{3} \mathrm{C}^{12} \mathrm{H}_{2} \mathrm{O}^{16} \mathrm{H}$ & 3- 581 & $3,1,2 \leftarrow 2,2,1$ & Ground & & & & & 19629.0 & .1 \\
\hline $\mathrm{C}^{12} \mathrm{D}_{3} \mathrm{C}^{12}: \mathrm{C}^{12} \mathrm{C}^{13} \mathrm{~F}_{3}^{19}$ & 3- 896 & $8, \leftarrow 7$, & Ground & & & & & 19631.0 & .5 \\
\hline $\mathrm{C}^{12}{ }_{*} \mathrm{DC}^{12} \mathrm{H}: \mathrm{C}^{12} \mathrm{HC}^{12} \mathrm{H}: \mathrm{C}^{12} \mathrm{HN}^{14}{ }_{*}$ & $4-1202$ & $7,4,3 \leftarrow 7,4,4$ & Ground & & & & & 19631.7 & .1 \\
\hline $\mathrm{Br}^{81} \mathrm{~F}_{3}^{19}$ & 4. 82 & $2,1,2 \leftarrow 1,0,1$ & Ground & & $7 / 2$ & & $5 / 2$ & 19633.95 & \\
\hline$\left(\mathrm{C}^{12} \mathrm{H}_{3}\right)_{2} \mathrm{C}^{12}: \mathrm{C}^{12} \mathrm{HD}$ & 3- 944 & $3,1,2 \leftarrow 3,0,3$ & Ground & & & & & 19639.41 & \\
\hline $\mathrm{C}^{\mathrm{b}} \mathrm{H}_{2}^{\mathrm{b}} \mathrm{Cl}^{\mathrm{b}} \mathrm{F}^{\mathrm{b}}$ & 4- 333 & Not Reported & & & & & & 19640.67 & .1 \\
\hline $\mathrm{C}^{12} \mathrm{HCl}_{2}^{35} \mathrm{Cl}^{37}$ & 4. 262 & $3,3,1 \leftarrow 2,2,1$ & Ground & & & & & 19643.13 & .01 \\
\hline g- $\mathrm{C}^{12} \mathrm{H}_{2} \mathrm{DC}^{12} \mathrm{H}_{2} \mathrm{Cl}^{35}$ & 3. 544 & $2,1,2 \leftarrow 1,1,1$ & Ground & & $5 / 2$ & & $3 / 2$ & 19643.6 & .05 \\
\hline${ }_{\mathrm{g}-} \mathrm{C}^{12} \mathrm{H}_{2} \mathrm{DC}^{12} \mathrm{H}_{2} \mathrm{Cl}^{35}$ & 3- 544 & $2,1,2 \leftarrow 1,1,1$ & Ground & & $5 / 2$ & & $5 / 2$ & 19646.4 & .05 \\
\hline $\mathrm{HC}^{13}: \mathrm{C}^{12} \mathrm{C}^{12} \mathrm{DO}^{16}$ & 4. 922 & Not Reported & & & & & & 19647. & 5. \\
\hline $\mathrm{C}^{12} * \mathrm{H}_{2} \mathrm{C}^{12} \mathrm{D}: \mathrm{C}^{12} * \mathrm{D}$ & 4-1033 & $11,8,3 \leftarrow 11,8,4$ & Ground & & & & & 19647.9 & \\
\hline$\left(\mathrm{C}^{12} \mathrm{D}_{3}\right)_{2} \mathrm{O}^{16}$ & 3. 592 & Not Reported & Ground & & & & & 19650. & 20. \\
\hline $\mathrm{g}-\mathrm{C}^{12} \mathrm{H}_{2} \mathrm{DC}^{12} \mathrm{H}_{2} \mathrm{Cl}^{35}$ & 3. 544 & $2,1,2 \leftarrow 1,1,1$ & Ground & & $3 / 2$ & & $3 / 2$ & 19650.0 & .05 \\
\hline g. $\mathrm{C}^{12} \mathrm{H}_{2} \mathrm{DC}^{12} \mathrm{H}_{2} \mathrm{Cl}^{35}$ & 3- 544 & $2,1,2 \leftarrow 1,1,1$ & Ground & & $7 / 2$ & & $5 / 2$ & 19655.4 & .05 \\
\hline $\mathrm{C}^{12} \mathrm{H}_{3} \mathrm{C}^{12} \mathrm{HDF}^{19}$ & 3. 552 & $2,2,0 \leftarrow 3,1,3$ & Ground & & & & & 19657.6 & .1 \\
\hline $\mathrm{C}^{12} * \mathrm{H}_{2} \mathrm{C}^{12} \mathrm{H}: \mathrm{C}^{12} \mathrm{HC}^{12} \mathrm{H}: \mathrm{C}^{12} * \mathrm{H}$ & $4-1231$ & $7,5,2 \leftarrow 7,4,3$ & Ground & & & & & 19658.9 & .1 \\
\hline $\mathrm{C}^{12} \mathrm{H}_{3} \mathrm{C}^{12}{ }_{*} \mathrm{HO}^{16} \mathrm{C}^{12}{ }_{*} \mathrm{H}_{2}$ & 3. 761 & $32,16, \leftarrow 31,17$ & Ground & & & & & 19658.93 & .1 \\
\hline $\mathrm{C}^{12} \mathrm{H}_{3} \mathrm{C}^{12}{ }_{*} \mathrm{HO}^{16} \mathrm{C}^{12}{ }_{*} \mathrm{H}_{2}$ & 3. 761 & $32,16, \leftarrow 31,17$, & Ground & & & & & 19659.50 & .1 \\
\hline
\end{tabular}




\begin{tabular}{|c|c|c|c|c|c|c|c|}
\hline Isotopic Species & $\begin{array}{l}\text { Vol.-Id. } \\
\text { Nos. }\end{array}$ & $\begin{array}{c}\text { Rotational } \\
\text { Quantum Nos. }\end{array}$ & Vib. State & $\mathrm{F}_{1}^{\prime} \quad \mathrm{F}^{\prime} \quad \mathrm{F}_{1}$ & $\mathrm{~F}$ & $\begin{array}{c}\text { Frequency } \\
\text { MHz }\end{array}$ & $\begin{aligned} & \text { Acce. } \\
\pm & \mathrm{MHz}\end{aligned}$ \\
\hline $\mathrm{C}^{12} \mathrm{H}_{3} \mathrm{C}^{12} \mathrm{D}_{2} \mathrm{Cl}^{35}$ & 3. 547 & $2,1,2 \leftarrow 1,1,1$ & Ground & $5 / 2$ & $3 / 2$ & 19659.54 & .05 \\
\hline $\mathrm{C}^{12} \mathrm{H}_{3} \mathrm{C}^{12}{ }_{*} \mathrm{HO}^{16} \mathrm{C}^{12}{ }_{*} \mathrm{H}_{2}$ & 3. 761 & $32,16, \leftarrow 31,17$, & Ground & & & 19659.80 & .1 \\
\hline $\mathrm{C}^{12} \mathrm{H}_{3} \mathrm{C}^{12} \mathrm{O}^{16} \mathrm{C}^{12} \mathrm{~N}^{14}$ & 3- 671 & $3,1,3 \leftarrow 2,1,2$ & Ground & & & 19659.98 & .2 \\
\hline $\mathrm{C}^{12} \mathrm{H}_{3} \mathrm{C}^{12}{ }_{*} \mathrm{HO}^{16} \mathrm{C}^{12}{ }_{*} \mathrm{H}_{2}$ & 3- 761 & Not Reported & Ground & & & 19660.31 & .1 \\
\hline $\mathrm{H}_{2} \mathrm{C}^{12}: \mathrm{C}^{12} \mathrm{~F}_{2}^{19}$ & 4- 681 & Not Reported & & & & 19660.9 & .3 \\
\hline $\mathrm{C}^{13} \mathrm{H}_{3} \mathrm{C}^{12} \mathrm{H}_{2} \mathrm{~F}^{19}$ & 3- 556 & $3,2,1 \leftarrow 4,1,4$ & Ground & & & 19663.2 & .1 \\
\hline $\mathrm{C}^{12} \mathrm{H}_{3} \mathrm{C}^{12} \mathrm{D}_{2} \mathrm{Cl}^{35}$ & 3. 547 & $2,1,2 \leftarrow 1,1,1$ & Ground & $5 / 2$ & $5 / 2$ & 19663.44 & .05 \\
\hline $\mathrm{C}^{12} \mathrm{H}_{3} \mathrm{C}^{12} \mathrm{D}_{3} \mathrm{Si}^{28} \mathrm{H}_{2}$ & 3- 642 & $3,0,3 \leftarrow 2,1,2$ & Ground & & & 19663.69 & .05 \\
\hline g- $\mathrm{C}^{12} \mathrm{H}_{2} \mathrm{DC}^{12} \mathrm{H}_{2} \mathrm{Cl}^{35}$ & 3- 544 & $2,1,2 \leftarrow 1,1,1$ & Ground & $1 / 2$ & $1 / 2$ & 19664.2 & .05 \\
\hline $\mathrm{C}^{12} \mathrm{H}_{3} \mathrm{C}^{12} \mathrm{D}_{3} \mathrm{Si}^{28} \mathrm{H}_{2}$ & 3- 642 & $3,0,3 \leftarrow 2,1,2$ & Ground & & & 19664.24 & .05 \\
\hline $\mathrm{C}^{12} \mathrm{H}_{3} \mathrm{C}^{12} \mathrm{D}_{2} \mathrm{Cl}^{35}$ & 3- 547 & $2,1,2 \leftarrow 1,1,1$ & Ground & $3 / 2$ & $3 / 2$ & 19665.87 & .05 \\
\hline $\mathrm{C}^{12} \mathrm{H}_{3} \mathrm{C}^{12} * \mathrm{H}_{2} \mathrm{O}^{16} \mathrm{C}^{12} * \mathrm{C}^{12} \mathrm{H}_{3}$ & 3. 951 & $8,2,6 \leftarrow 8,1,7$ & Ground & & & 19666.15 & .2 \\
\hline $\mathrm{C}^{12}{ }_{*} \mathrm{H}: \mathrm{C}^{12} \mathrm{HO}^{16} \mathrm{C}^{12} \mathrm{D}: \mathrm{C}^{12}{ }_{*} \mathrm{H}$ & $4-1154$ & $10,9,1 \leftarrow 10,8,2$ & Ground & & & 19666.2 & \\
\hline $\mathrm{C}^{12} \mathrm{D}_{3} \mathrm{C}^{12}: \mathrm{C}^{12} \mathrm{C}^{12} \mathrm{~F}_{3}^{19}$ & 3- 892 & $8, \leftarrow 7$, & Ground & & & 19666.3 & .1 \\
\hline $\mathrm{C}^{12} \mathrm{H}_{3} \mathrm{C}^{12}{ }_{*} \mathrm{H}_{2} \mathrm{O}^{16} \mathrm{C}^{12}{ }_{*} \mathrm{C}^{12} \mathrm{H}_{3}$ & 3. 951 & $8,2,6 \leftarrow 8,1,7$ & Ground & & & 19667.05 & .2 \\
\hline $\mathrm{C}^{12} \mathrm{D}_{3} \mathrm{C}^{12} \mathrm{O}^{16} \mathrm{Cl}^{37}$ & 3- 364 & $8,3,5 \leftarrow 8,2,6$ & Ground & $17 / 2$ & $17 / 2$ & 19667.25 & \\
\hline $\mathrm{C}^{12} \mathrm{D}_{3} \mathrm{C}^{12} \mathrm{O}^{16} \mathrm{Cl}^{37}$ & 3- 364 & $8,3,5 \leftarrow 8,2,6$ & Ground & $13 / 2$ & $13 / 2$ & 19667.25 & \\
\hline $\mathrm{C}^{12} \mathrm{D}_{3} \mathrm{C}^{12} \mathrm{O}^{16} \mathrm{Cl}^{37}$ & 3. 364 & $8,3,5 \leftarrow 8,2,6$ & Ground & $19 / 2$ & $19 / 2$ & 19667.25 & \\
\hline $\mathrm{C}^{12} \mathrm{D}_{3} \mathrm{C}^{12} \mathrm{O}^{16} \mathrm{Cl}^{37}$ & $3-364$ & $8,3,5 \leftarrow 8,2,6$ & Ground & $15 / 2$ & $15 / 2$ & 19667.25 & \\
\hline $\mathrm{Br}^{79} \mathrm{~F}_{3}^{19}$ & 4.- 81 & $2,1,2 \leftarrow 1,0,1$ & Ground & $7 / 2$ & $5 / 2$ & 19667.92 & \\
\hline $\mathrm{C}^{12} \mathrm{H}_{3} \mathrm{C}^{12} * \mathrm{H}_{2} \mathrm{O}^{16} \mathrm{C}^{12} * \mathrm{C}^{12} \mathrm{H}_{3}$ & 3- 951 & $8,2,6 \leftarrow 8,1,7$ & Ground & & & 19667.94 & .2 \\
\hline $\mathrm{C}^{12} \mathrm{H}_{3} \mathrm{C}^{12} \mathrm{D}_{2} \mathrm{Cl}^{35}$ & 3. 547 & $2,1,2 \leftarrow 1,1,1$ & Ground & & & 19669.02 & .05 \\
\hline$\left(\mathrm{C}^{12} \mathrm{H}_{3}\right)_{2} \mathrm{C}^{12}: \mathrm{C}^{12} \mathrm{H}_{2}$ & 3. 941 & $4,2,2 \leftarrow 4,1,3$ & Ground & & & 19669.25 & .05 \\
\hline $\mathrm{C}^{12} \mathrm{H}_{3} \mathrm{C}^{12} \mathrm{HDC}^{12} \mathrm{H}_{3}$ & 3- 784 & $2,1,1 \leftarrow 2,0,2$ & Ground & & & 19670.78 & .06 \\
\hline $\mathrm{C}^{12} \mathrm{H}_{3} \mathrm{C}^{12} \mathrm{D}_{2} \mathrm{Cl}^{35}$ & 3- 547 & $2,1,2 \leftarrow 1,1,1$ & Ground & $7 / 2$ & $5 / 2$ & 19672.38 & .05 \\
\hline $\mathrm{H}_{2} \mathrm{~N}^{14} \mathrm{~N}^{14} \mathrm{H}_{2}$ & 3- 51 & Not Reported & & & & 19672.93 & \\
\hline $\mathrm{C}_{6}^{12} \mathrm{H}_{5} \mathrm{~F}^{19}$ & $4-1281$ & $5,0,5 \leftarrow 4,0,4$ & Ground & & & 19678.2 & .1 \\
\hline $\mathrm{C}^{12}{ }_{*} \mathrm{H}: \mathrm{C}^{12} \mathrm{HC}^{12} \mathrm{H}: \mathrm{C}^{12} \mathrm{HN}^{14}{ }_{*} \mathrm{D}$ & 4-1182 & $11,8,3 \leftarrow 11,8,4$ & Ground & & & 19681.4 & \\
\hline $\mathrm{C}^{12} \mathrm{H}_{3} \mathrm{C}^{12} \mathrm{D}_{2} \mathrm{Cl}^{35}$ & 3- 547 & $2,1,2 \leftarrow 1,1,1$ & Ground & $1 / 2$ & $1 / 2$ & 19681.83 & .05 \\
\hline $\mathrm{S}_{2}^{32} \mathrm{O}^{16}$ & 4-1821 & $2,1,1 \leftarrow 1,1,0$ & Ground & & & 19684.3 & \\
\hline $\mathrm{C}^{b} \mathrm{H}_{2}^{\mathrm{b}} \mathrm{Cl}^{\mathrm{b}} \mathrm{F}^{\mathrm{b}}$ & 4. 333 & Not Reported & & & & 19687.12 & .1 \\
\hline $\mathrm{C}^{12} \mathrm{HD}\left(\mathrm{C}^{12} \mathrm{~N}^{14}\right)_{2}$ & 4- 902 & $6,1,5 \leftarrow 6,0,6$ & Ground & & & 19688.76 & \\
\hline $\mathrm{C}^{12} \mathrm{H}_{3} \mathrm{Si}^{28} \mathrm{H}_{2} \mathrm{~F}^{19}$ & 3- 241 & $9,2,7 \leftarrow 9,2,8$ & Ground & & & 19693.37 & .10 \\
\hline $\mathrm{C}^{12}{ }_{*} \mathrm{DN}^{14} \mathrm{C}^{12} \mathrm{DC}^{12} \mathrm{H}: \mathrm{C}^{12} \mathrm{DN}^{14} *$ & $4-1142$ & $12,10,3 \leftarrow 12,9,4$ & Ground & & & 19693.7 & \\
\hline $\mathrm{C}^{12} \mathrm{H}_{3} \mathrm{Si}^{28} \mathrm{H}_{2} \mathrm{~F}^{19}$ & 3. 241 & $9,2,7 \leftarrow 9,2,8$ & Ground & & & 19694.15 & .10 \\
\hline $\mathrm{HC}^{12} \mathrm{O}^{16} \mathrm{O}^{16} \mathrm{C}^{12} \mathrm{D}_{3^{-}} \mathrm{A}$ & 3. 507 & $5,1,4 \leftarrow 5,1,5$ & Ground & & & 19697.49 & .35 \\
\hline $\mathrm{C}^{12} \mathrm{H}_{3} \mathrm{~N}^{14} \mathrm{C}^{12} \mathrm{~S}^{34}$ & 3- 425 & $4, \quad \leftarrow 3$, & Ground & & & 19700. & \\
\hline $\mathrm{N}^{15} \mathrm{H}_{3}$ & $4-1772$ & $8,6 \leftarrow 8,6$ & Ground & & & 19701.99 & .06 \\
\hline $\mathrm{C}^{12} \mathrm{H}_{3} \mathrm{As}^{75} \mathrm{~F}_{2}^{19}$ & 3- 81 & $26,21,6 \leftarrow 26,19,7$ & Ground & $53 / 2$ & $53 / 2$ & 19702.69 & .05 \\
\hline $\mathrm{C}^{12} \mathrm{H}_{3} \mathrm{As}^{75} \mathrm{~F}_{2}^{19}$ & 3- 81 & $26,20,6 \leftarrow 26,20,7$ & Ground & $53 / 2$ & $53 / 2$ & 19702.69 & .05 \\
\hline $\mathrm{C}^{12} \mathrm{H}_{3} \mathrm{~S}^{32} \mathrm{H}$ & 3- 221 & Not Reported & Ground & & & 19702.9 & .1 \\
\hline $\mathrm{C}^{12} \mathrm{H}_{3} \mathrm{As}^{75} \mathrm{~F}_{2}^{19}$ & 3- 81 & $26,20,6 \leftarrow 26,20,7$ & Ground & $53 / 2$ & $53 / 2$ & 19703.62 & .05 \\
\hline $\mathrm{C}^{12} \mathrm{H}_{3} \mathrm{As}^{75} \mathrm{~F}_{2}^{19}$ & 3- 81 & $26,20,6 \leftarrow 26,20,7$ & Ground & $51 / 2$ & $51 / 2$ & 19703.62 & .05 \\
\hline $\mathrm{C}^{12} \mathrm{H}_{3} \mathrm{As}^{75} \mathrm{~F}_{2}^{19}$ & 3. 81 & $26,21,6 \leftarrow 26,19,7$ & Ground & $53 / 2$ & $53 / 2$ & 19703.62 & .05 \\
\hline $\mathrm{C}^{12} \mathrm{H}_{3} \mathrm{As}^{75} \mathrm{~F}_{2}^{19}$ & 3. 81 & $26,21,6 \leftarrow 26,19,7$ & Ground & $51 / 2$ & $51 / 2$ & 19703.62 & .05 \\
\hline
\end{tabular}




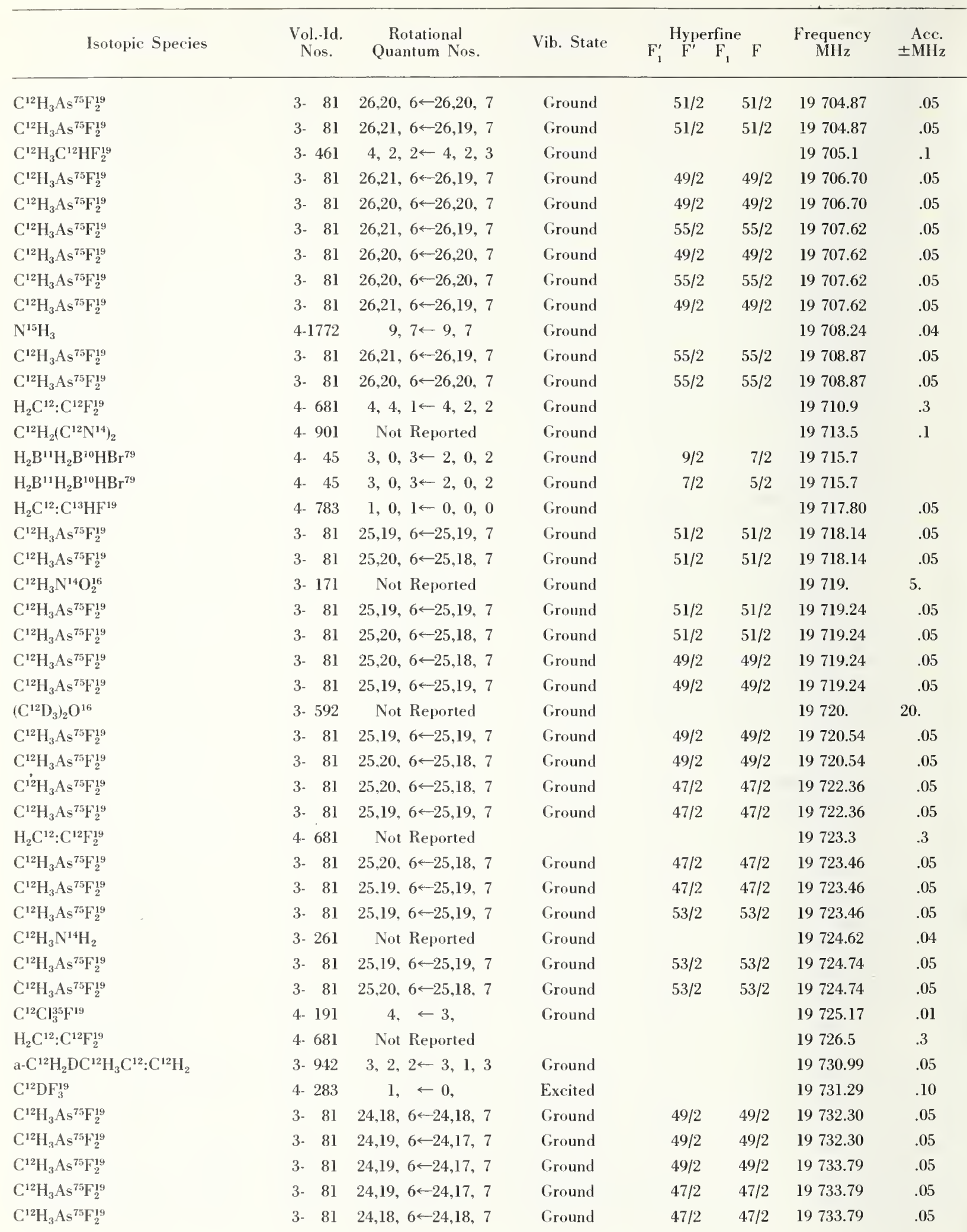




\begin{tabular}{|c|c|c|c|c|c|c|c|}
\hline Isotopic Species & $\begin{array}{l}\text { Vol.-Id. } \\
\text { Nos. }\end{array}$ & $\begin{array}{c}\text { Rotational } \\
\text { Quantum Nos. }\end{array}$ & Vib. State & $\mathrm{F}_{1}^{\prime} \stackrel{\text { Hyperfin }}{\mathrm{F}^{\prime} \quad \mathrm{F}_{1}}$ & $\mathrm{~F}$ & $\begin{array}{l}\text { Frequency } \\
\text { MHz }\end{array}$ & $\begin{aligned} & \text { Acc. } \\
\pm & \mathrm{MHz}\end{aligned}$ \\
\hline $\mathrm{C}^{12} \mathrm{H}_{3} \mathrm{As}^{75} \mathrm{~F}_{2}^{19}$ & 3- 81 & $24,18,6 \leftarrow 24,18,7$ & Ground & $49 / 2$ & $49 / 2$ & 19733.79 & .05 \\
\hline $\mathrm{C}^{12} \mathrm{H}_{3} \mathrm{As}^{75} \mathrm{~F}_{2}^{19}$ & 3- 81 & $24,18,6 \leftarrow 24,18,7$ & Ground & $47 / 2$ & $47 / 2$ & 19734.90 & .05 \\
\hline $\mathrm{C}^{12} \mathrm{H}_{3} \mathrm{As}^{75} \mathrm{~F}_{2}^{19}$ & 3- 81 & $24,19,6 \leftarrow 24,17,7$ & Ground & $47 / 2$ & $47 / 2$ & 19734.90 & .05 \\
\hline$\left(\mathrm{C}^{12} \mathrm{H}_{3}\right)_{2} \mathrm{C}^{12}: \mathrm{C}^{12} \mathrm{H}_{2}$ & 3- 941 & $7,7,0 \leftarrow 7,6,1$ & Ground & & & 19736.70 & .05 \\
\hline $\mathrm{C}^{12} \mathrm{H}_{3} \mathrm{As}^{75} \mathrm{~F}_{2}^{19}$ & 3- 81 & $24,18,6 \leftarrow 24,18,7$ & Ground & $45 / 2$ & $45 / 2$ & 19736.79 & .05 \\
\hline $\mathrm{C}^{12} \mathrm{H}_{3} \mathrm{As}^{75} \mathrm{~F}_{2}^{19}$ & 3- 81 & $24,19,6 \leftarrow 24,17,7$ & Ground & $45 / 2$ & $45 / 2$ & 19736.79 & .05 \\
\hline $\mathrm{a}-\mathrm{C}^{12} \mathrm{H}_{2} \mathrm{D}\left(\mathrm{C}^{12} \mathrm{H}_{3}\right)_{2} \mathrm{Si}^{\mathrm{b}} \mathrm{D}$ & 3- 882 & $2,1,1 \leftarrow 1,0,1$ & Ground & & & 19736.85 & .10 \\
\hline$\left(\mathrm{C}^{12} \mathrm{H}_{3}\right)_{2} \mathrm{C}^{12}: \mathrm{C}^{12} \mathrm{H}_{2}$ & 3- 94.1 & $7,7,0 \leftarrow 7,6,1$ & Ground & & & 19737.40 & \\
\hline $\mathrm{Si}^{28} \mathrm{H}_{3} \mathrm{C}^{12} \mathrm{H}: \mathrm{C}^{12} \mathrm{H}_{2}$ & 3- 611 & $2,1,2 \leftarrow 1,1,1$ & Ground & & & 19737.64 & .05 \\
\hline $\mathrm{C}^{12} \mathrm{H}_{3} \mathrm{As}^{75} \mathrm{~F}_{2}^{19}$ & 3- 81 & $24,18,6 \leftarrow 24,18,7$ & Ground & $45 / 2$ & $45 / 2$ & 19738.29 & .05 \\
\hline $\mathrm{C}^{12} \mathrm{H}_{3} \mathrm{As}^{75} \mathrm{~F}_{2}^{19}$ & 3- 81 & $24,18,6 \leftarrow 24,18,7$ & Ground & $51 / 2$ & $51 / 2$ & 19738.29 & .05 \\
\hline $\mathrm{C}^{12} \mathrm{H}_{3} \mathrm{As}^{75} \mathrm{~F}_{2}^{19}$ & 3- 81 & $24,19,6 \leftarrow 24,17,7$ & Ground & $51 / 2$ & $51 / 2$ & 19738.29 & .05 \\
\hline $\mathrm{C}^{12} \mathrm{H}_{3} \mathrm{As}^{75} \mathrm{~F}_{2}^{19}$ & 3- 81 & $24,19,6 \leftarrow 24,17,7$ & Ground & $45 / 2$ & $45 / 2$ & 19738.29 & .05 \\
\hline $\mathrm{Si}^{28} \mathrm{H}_{3} \mathrm{C}^{12} \mathrm{H}: \mathrm{C}^{12} \mathrm{H}_{2}$ & 3- 611 & $2,1,2 \leftarrow 1,1,1$ & Ground & & & 19738.6 & .05 \\
\hline $\mathrm{H}_{2} \mathrm{C}^{12}: \mathrm{C}^{12} \mathrm{HF}^{19}$ & 4- 781 & $1,0,1 \leftarrow 0,0,0$ & Excited & & & 19738.83 & .05 \\
\hline $\mathrm{Br}^{81} \mathrm{~F}_{3}^{19}$ & 4- 82 & $2,1,2 \leftarrow 1,0,1$ & Ground & $5 / 2$ & $3 / 2$ & 19739.27 & \\
\hline $\mathrm{C}^{12} \mathrm{H}_{3} \mathrm{As}^{75} \mathrm{~F}_{2}^{19}$ & 3- 81 & $24,18,6 \leftarrow 24,18,7$ & Ground & $51 / 2$ & $51 / 2$ & 19739.39 & .05 \\
\hline $\mathrm{C}^{12} \mathrm{H}_{3} \mathrm{As}^{75} \mathrm{~F}_{2}^{19}$ & 3- 81 & $24,19,6 \leftarrow 24,17,7$ & Ground & $51 / 2$ & $51 / 2$ & 19739.39 & .05 \\
\hline$\left(\mathrm{C}^{12} \mathrm{H}_{3}\right)_{3} \mathrm{C}^{12} \mathrm{C}^{12}: \mathrm{C}^{13} \mathrm{D}$ & $3-1075$ & $4, \leftarrow 3$, & Ground & & & 19740.3 & .1 \\
\hline $\mathrm{t}-\mathrm{HDC}^{12}{ }_{*} \mathrm{O}^{16} \mathrm{C}^{12}{ }_{*} \mathrm{HD}$ & 4- 844 & $3,2,1 \leftarrow 3,1,2$ & Ground & & & 19742.81 & .05 \\
\hline $\mathrm{HC}^{12} \mathrm{O}^{16} \mathrm{O}^{16} \mathrm{C}^{12} \mathrm{D}_{3^{-}} \mathrm{A}$ & 3- 507 & $4,1,3 \leftarrow 4,0,4$ & Ground & & & 19744.04 & .2 \\
\hline $\mathrm{D}_{2} \mathrm{C}^{12}: \mathrm{C}^{12} \mathrm{DCl}^{37}$ & 4- 765 & $2,0,2 \leftarrow 1,0,1$ & Ground & $7 / 2$ & $5 / 2$ & 19744.98 & .2 \\
\hline $\mathrm{C}^{12} \mathrm{H}_{3} \mathrm{As}^{75} \mathrm{~F}_{2}^{19}$ & 3- 81 & $23,18,6 \leftarrow 23,16,7$ & Ground & $47 / 2$ & $47 / 2$ & 19745.16 & .05 \\
\hline $\mathrm{C}^{12} \mathrm{H}_{3} \mathrm{As}^{75} \mathrm{~F}_{2}^{19}$ & 3- 81 & $23,17,6 \leftarrow 23,17,7$ & Ground & $47 / 2$ & $47 / 2$ & 19745.16 & .05 \\
\hline $\mathrm{C}^{12} \mathrm{H}_{3} \mathrm{As}^{75} \mathrm{~F}_{2}^{19}$ & 3- 81 & $23,18,6 \leftarrow 23,16,7$ & Ground & $47 / 2$ & $47 / 2$ & 19746.89 & .05 \\
\hline $\mathrm{C}^{12} \mathrm{H}_{3} \mathrm{As}^{75} \mathrm{~F}_{2}^{19}$ & 3- 81 & $23,17,6 \leftarrow 23,17,7$ & Ground & $47 / 2$ & $47 / 2$ & 19746.89 & .05 \\
\hline $\mathrm{C}^{12} \mathrm{H}_{3} \mathrm{As}^{75} \mathrm{~F}_{2}^{19}$ & 3- 81 & $23,18,6 \leftarrow 23,16,7$ & Ground & $45 / 2$ & $45 / 2$ & 19746.89 & .05 \\
\hline $\mathrm{C}^{12} \mathrm{H}_{3} \mathrm{As}^{75} \mathrm{~F}_{2}^{19}$ & 3- 81 & $23,17,6 \leftarrow 23,17,7$ & Ground & $45 / 2$ & $45 / 2$ & 19746.89 & .05 \\
\hline $\mathrm{H}_{2} \mathrm{C}^{12}: \mathrm{C}^{12} \mathrm{Cl}_{2}^{35}$ & 4- 661 & $5,3,2 \leftarrow 5,2,3$ & Ground & & & 19747.0 & 1. \\
\hline $\mathrm{C}^{12} \mathrm{H}_{3} \mathrm{As}^{75} \mathrm{~F}_{2}^{19}$ & 3- 81 & $23,18,6 \leftarrow 23,16,7$ & Ground & $45 / 2$ & $45 / 2$ & 19747.82 & .05 \\
\hline $\mathrm{C}^{12} \mathrm{H}_{3} \mathrm{As}^{75} \mathrm{~F}_{2}^{19}$ & 3- 81 & $23,17,6 \leftarrow 23,17,7$ & Cround & $45 / 2$ & $45 / 2$ & 19747.82 & .05 \\
\hline $\mathrm{S}^{32}{ }_{*} \mathrm{HC}^{12}: \mathrm{C}^{12} \mathrm{DC}^{12} \mathrm{H}: \mathrm{C}^{12}{ }_{*} \mathrm{H}$ & $4-1163$ & $11,5,7 \leftarrow 11,5,6$ & Ground & & & 19749.1 & .1 \\
\hline $\mathrm{C}^{12} \mathrm{H}_{3} \mathrm{As}^{75} \mathrm{~F}_{2}^{19}$ & 3- 81 & $23,17,6 \leftarrow 23,17,7$ & Ground & $43 / 2$ & $43 / 2$ & 19749.81 & .05 \\
\hline $\mathrm{C}^{12} \mathrm{H}_{3} \mathrm{As}^{75} \mathrm{~F}_{2}^{19}$ & 3- 81 & $23,18,6 \leftarrow 23,16,7$ & Ground & $43 / 2$ & $43 / 2$ & 19749.81 & .05 \\
\hline $\mathrm{C}^{12} \mathrm{H}_{3} \mathrm{As}^{75} \mathrm{~F}_{2}^{19}$ & 3- 81 & $23,17,6 \leftarrow 23,17,7$ & Ground & $43 / 2$ & $43 / 2$ & 19751.49 & .05 \\
\hline $\mathrm{C}^{12} \mathrm{H}_{3} \mathrm{As}^{75} \mathrm{~F}_{2}^{19}$ & 3. 81 & $23,17,6 \leftarrow 23,17,7$ & Ground & $49 / 2$ & $49 / 2$ & 19751.49 & .05 \\
\hline $\mathrm{C}^{12} \mathrm{H}_{3} \mathrm{As}^{75} \mathrm{~F}_{2}^{19}$ & 3- 81 & $23,18,6 \leftarrow 23,16,7$ & Ground & $43 / 2$ & $43 / 2$ & 19751.49 & .05 \\
\hline $\mathrm{C}^{12} \mathrm{H}_{3} \mathrm{As}^{75} \mathrm{~F}_{2}^{19}$ & 3- 81 & $23,18,6 \leftarrow 23,16,7$ & Ground & $49 / 2$ & $49 / 2$ & 19751.49 & .05 \\
\hline $\mathrm{Si}^{30} \mathrm{H}_{3} \mathrm{C}^{12} \mathrm{H}: \mathrm{C}^{12} \mathrm{H}_{2}$ & 3- 614 & $2,0,2 \leftarrow 1,0,1$ & Ground & & & 19751.60 & .10 \\
\hline $\mathrm{C}^{12} \mathrm{H}_{3} \mathrm{As}^{75} \mathrm{~F}_{2}^{19}$ & 3- 81 & $23,18,6 \leftarrow 23,16,7$ & Ground & $49 / 2$ & $49 / 2$ & 19752.44 & .05 \\
\hline $\mathrm{C}^{12} \mathrm{H}_{3} \mathrm{As}^{75} \mathrm{~F}_{2}^{19}$ & 3- 81 & $23,17,6 \leftarrow 23,17,7$ & Ground & $49 / 2$ & $49 / 2$ & 19752.44 & .05 \\
\hline $\mathrm{s}-\mathrm{Si}^{28} \mathrm{H}_{2} \mathrm{DC}^{12} \mathrm{H}: \mathrm{C}^{12} \mathrm{H}_{2}$ & 3. 619 & $2,0,2 \leftarrow 1,0,1$ & Ground & & & 19752.92 & .10 \\
\hline $\mathrm{C}^{12} \mathrm{H}_{3} \mathrm{C}^{12}: \mathrm{C}^{12} \mathrm{C}^{12} \mathrm{H}_{2} \mathrm{Cl}^{35}$ & 3- 901 & $7,1,7 \leftarrow 6,1,6$ & Ground & & & 19753.23 & .05 \\
\hline $\mathrm{H}_{2} \mathrm{C}^{12}: \mathrm{C}^{12} \mathrm{HF}^{19}$ & 4- 781 & $1,0,1 \leftarrow 0,0,0$ & Ground & & & 19755.01 & .05 \\
\hline $\mathrm{C}^{12} \mathrm{H}_{3} \mathrm{As}^{75} \mathrm{~F}_{2}^{19}$ & 3- 81 & $22,17,6 \leftrightarrow 22,15,7$ & Ground & $45 / 2$ & $45 / 2$ & 19756.43 & .05 \\
\hline
\end{tabular}




\begin{tabular}{|c|c|c|c|c|c|c|c|}
\hline Isotopic Species & $\begin{array}{l}\text { Vol.-Id. } \\
\text { Nos. }\end{array}$ & $\begin{array}{c}\text { Rotational } \\
\text { Quantum Nos. }\end{array}$ & Vib. State & \begin{tabular}{c}
\multicolumn{3}{c}{ Hyperfin } \\
$\mathrm{F}_{1}^{\prime} \quad \mathrm{F}^{\prime} \quad \mathrm{F}_{1}$
\end{tabular} & $\mathrm{~F}$ & $\begin{array}{l}\text { Frequency } \\
\mathrm{MHz}\end{array}$ & $\begin{aligned} & \text { Acc. } \\
\pm & \mathrm{MHz}\end{aligned}$ \\
\hline $\mathrm{C}^{12} \mathrm{H}_{3} \mathrm{As}^{75} \mathrm{~F}_{2}^{19}$ & 3- 81 & $22,16,6 \leftarrow 22,16,7$ & Ground & $45 / 2$ & $45 / 2$ & 19756.43 & .05 \\
\hline $\mathrm{N}^{14} \mathrm{H}_{3}$ & $4-1771$ & $6,3 \leftarrow 6,3$ & Ground & & $\sigma$ & 19757.40 & .04 \\
\hline $\mathrm{C}^{12} \mathrm{H}_{3} \mathrm{As}^{75} \mathrm{~F}_{2}^{19}$ & 3- 81 & $22,16,6 \leftarrow 22,16,7$ & Ground & $43 / 2$ & $43 / 2$ & 19758.40 & .05 \\
\hline $\mathrm{C}^{12} \mathrm{H}_{3} \mathrm{As}^{75} \mathrm{~F}_{2}^{19}$ & 3- 81 & $22,16,6 \leftarrow 22,16,7$ & Ground & $45 / 2$ & $45 / 2$ & 19758.40 & .05 \\
\hline $\mathrm{C}^{12} \mathrm{H}_{3} \mathrm{As}^{75} \mathrm{~F}_{2}^{19}$ & 3- 81 & $22,17,6 \leftarrow 22,15,7$ & Ground & $43 / 2$ & $43 / 2$ & 19758.40 & .05 \\
\hline $\mathrm{C}^{12} \mathrm{H}_{3} \mathrm{As}^{75} \mathrm{~F}_{2}^{19}$ & 3- 81 & $22,17,6 \leftarrow 22,15,7$ & Ground & $45 / 2$ & $45 / 2$ & 19758.40 & .05 \\
\hline $\mathrm{H}_{2} \mathrm{~B}^{11} \mathrm{H}_{2} \mathrm{~B}^{11} \mathrm{HBr}^{81}$ & 4. 42 & $3,1,2 \leftarrow 2,1,1$ & Ground & $9 / 2$ & $7 / 2$ & 19759.0 & \\
\hline $\mathrm{C}^{12} \mathrm{H}_{3} \mathrm{As}^{75} \mathrm{~F}_{2}^{19}$ & 3. 81 & $22,16,6 \leftarrow 22,16,7$ & Ground & $43 / 2$ & $43 / 2$ & 19759.34 & .05 \\
\hline $\mathrm{C}^{12} \mathrm{H}_{3} \mathrm{As}^{75} \mathrm{~F}_{2}^{19}$ & 3- 81 & $22,17,6 \leftarrow 22,15,7$ & Ground & $43 / 2$ & $43 / 2$ & 19759.34 & .05 \\
\hline $\mathrm{C}^{12} \mathrm{H}_{3} \mathrm{As}^{75} \mathrm{~F}_{2}^{19}$ & 3- 81 & $22,16,6 \leftarrow 22,16,7$ & Ground & $41 / 2$ & $41 / 2$ & 19761.35 & .05 \\
\hline $\mathrm{C}^{12} \mathrm{H}_{3} \mathrm{As}^{75} \mathrm{~F}_{2}^{19}$ & 3- 81 & $22,17,6 \leftarrow 22,15,7$ & Ground & $41 / 2$ & $41 / 2$ & 19761.35 & .05 \\
\hline $\mathrm{C}^{12} \mathrm{H}_{3} \mathrm{As}^{75} \mathrm{~F}_{2}^{19}$ & 3- 81 & $22,16,6 \leftarrow 22,16,7$ & Ground & $41 / 2$ & $41 / 2$ & 19763.34 & .05 \\
\hline $\mathrm{C}^{12} \mathrm{H}_{3} \mathrm{As}^{75} \mathrm{~F}_{2}^{19}$ & 3- 81 & $22,17,6 \leftarrow 22,15,7$ & Ground & $41 / 2$ & $41 / 2$ & 19763.34 & .05 \\
\hline $\mathrm{C}^{12} \mathrm{H}_{3} \mathrm{As}^{75} \mathrm{~F}_{2}^{19}$ & 3- 81 & $22,16,6 \leftarrow 22,16,7$ & Ground & $47 / 2$ & $47 / 2$ & 19763.34 & .05 \\
\hline $\mathrm{C}^{12} \mathrm{H}_{3} \mathrm{As}^{75} \mathrm{~F}_{2}^{19}$ & 3- 81 & $22,17,6 \leftarrow 22,15,7$ & Ground & $47 / 2$ & $47 / 2$ & 19763.34 & .05 \\
\hline $\mathrm{C}^{12} \mathrm{H}_{3} \mathrm{As}^{75} \mathrm{~F}_{2}^{19}$ & 3- 81 & $22,17,6 \leftarrow 22,15,7$ & Ground & $47 / 2$ & $47 / 2$ & 19764.30 & .05 \\
\hline $\mathrm{C}^{12} \mathrm{H}_{3} \mathrm{As}^{75} \mathrm{~F}_{2}^{19}$ & 3- 81 & $22,16,6 \leftarrow 22,16,7$ & Ground & $47 / 2$ & $47 / 2$ & 19764.30 & .05 \\
\hline $\mathrm{C}^{13} \mathrm{H}_{3} \mathrm{C}^{12} \mathrm{H}_{3} \mathrm{C}^{12}: \mathrm{C}^{12} \mathrm{H}_{2}$ & 3. 945 & $3,1,2 \leftarrow 3,0,3$ & Ground & & & 19764.88 & \\
\hline $\mathrm{C}^{12}{ }_{*} \mathrm{H}: \mathrm{C}^{12} \mathrm{HO}^{16} \mathrm{C}^{12} \mathrm{H}: \mathrm{C}^{12}{ }_{*} \mathrm{H}$ & $4-1151$ & $12,10,2 \leftarrow 12,10,3$ & Ground & & & 19767.98 & \\
\hline $\mathrm{C}^{12} \mathrm{H}_{3} \mathrm{As}^{75} \mathrm{~F}_{2}^{19}$ & 3- 81 & $21,15,6 \leftarrow 21,15,7$ & Ground & $43 / 2$ & $43 / 2$ & 19768.51 & .05 \\
\hline $\mathrm{C}^{12} \mathrm{H}_{3} \mathrm{As}^{75} \mathrm{~F}_{2}^{19}$ & 3. 81 & $21,16,6 \leftarrow 21,14,7$ & Ground & $43 / 2$ & $43 / 2$ & 19768.51 & .05 \\
\hline $\mathrm{C}^{12} \mathrm{H}_{3} \mathrm{As}^{75} \mathrm{~F}_{2}^{19}$ & 3. 81 & $21,16,6 \leftarrow 21,14,7$ & Ground & $41 / 2$ & $41 / 2$ & 19768.95 & .05 \\
\hline $\mathrm{C}^{12} \mathrm{H}_{3} \mathrm{As}^{75} \mathrm{~F}_{2}^{19}$ & 3. 81 & $21,15,6 \leftarrow-21.15,7$ & Ground & $41 / 2$ & $41 / 2$ & 19768.95 & .05 \\
\hline $\mathrm{C}^{13} \mathrm{H}_{3} \mathrm{C}^{12} \mathrm{H}_{2} \mathrm{C}^{135}$ & 3- 545 & $2,1,2 \leftarrow 1,1,1$ & Ground & $5 / 2$ & $3 / 2$ & 19772.27 & .05 \\
\hline $\mathrm{C}^{12} \mathrm{H}_{3} \mathrm{As}^{75} \mathrm{~F}_{2}^{19}$ & 3- 81 & $21,15,6 \leftarrow 21,15,7$ & Ground & $45 / 2$ & $45 / 2$ & 19773.93 & .05 \\
\hline $\mathrm{C}^{12} \mathrm{H}_{3} \mathrm{As}^{75} \mathrm{~F}_{2}^{19}$ & 3- 81 & $21,16,6 \leftarrow 21,14,7$ & Ground & $45 / 2$ & $45 / 2$ & 19773.93 & .05 \\
\hline $\mathrm{C}^{12} \mathrm{H}_{3} \mathrm{As}^{75} \mathrm{~F}_{2}^{19}$ & 3- 81 & $21,16,6 \leftarrow 21,14,7$ & Ground & $39 / 2$ & $39 / 2$ & 19774.22 & .05 \\
\hline $\mathrm{C}^{12} \mathrm{H}_{3} \mathrm{As}^{75} \mathrm{~F}_{2}^{19}$ & 3. 81 & $21,15,6 \leftarrow 21,15,7$ & Ground & $39 / 2$ & $39 / 2$ & 19774.22 & .05 \\
\hline $\mathrm{H}_{2} \mathrm{~B}^{11} \mathrm{H}_{2} \mathrm{~B}^{11} \mathrm{HBr}^{81}$ & 4. 42 & $3,1,2 \leftarrow 2,1,1$ & Ground & $7 / 2$ & $5 / 2$ & 19774.5 & \\
\hline $\mathrm{C}^{13} \mathrm{H}_{3} \mathrm{C}^{12} \mathrm{H}_{2} \mathrm{C}^{35}$ & 3- 545 & $2,1,2 \leftarrow 1,1,1$ & Ground & $5 / 2$ & $5 / 2$ & 19775.61 & .05 \\
\hline $\mathrm{a}-\mathrm{Si}^{28} \mathrm{H}_{2} \mathrm{DC} \mathrm{C}^{12} \mathrm{H}: \mathrm{C}^{12} \mathrm{H}_{2}$ & 3- 621 & $2,1,1 \leftarrow 1,1,0$ & Ground & & & 19775.85 & .10 \\
\hline $\mathrm{C}^{12} \mathrm{H}_{3} \mathrm{~N}^{14} \mathrm{H}_{2}$ & 3. 261 & $4,2, \leftarrow 5,1$, & Ground & & & 19776.01 & .1 \\
\hline $\mathrm{C}^{12} \mathrm{H}_{3} \mathrm{As}^{75} \mathrm{~F}_{2}^{19}$ & 3- 81 & $20,14,6 \leftarrow 20,14,7$ & Ground & $41 / 2$ & $41 / 2$ & 19777.80 & .05 \\
\hline $\mathrm{C}^{12} \mathrm{H}_{3} \mathrm{As}^{75} \mathrm{~F}_{2}^{19}$ & 3. 81 & $20,15,6 \leftarrow 20,13,7$ & Ground & $41 / 2$ & $41 / 2$ & 19777.80 & .05 \\
\hline $\mathrm{C}^{12} \mathrm{H}_{3} \mathrm{~N}^{14} \mathrm{H}_{2}$ & 3- 261 & $4,2, \leftarrow 5,1$, & Ground & & & 19777.85 & .1 \\
\hline $\mathrm{C}^{12}{ }_{*} \mathrm{D}: \mathrm{C}^{12} \mathrm{DC}^{12} \mathrm{D}: \mathrm{C}^{12} \mathrm{DN}^{14}{ }_{*} \mathrm{H}$ & 4-1185 & $12,11,1 \leftarrow 12,10,2$ & Ground & & & 19778.1 & \\
\hline $\mathrm{C}^{12} \mathrm{H}_{3} \mathrm{As}^{75} \mathrm{~F}_{2}^{19}$ & 3- 81 & $20,15,6 \leftarrow 20,13,7$ & Ground & $39 / 2$ & $39 / 2$ & 19778.22 & .05 \\
\hline $\mathrm{C}^{12} \mathrm{H}_{3} \mathrm{As}^{75} \mathrm{~F}_{2}^{19}$ & 3- 81 & $20,14,6 \leftarrow 20,14,7$ & Ground & $39 / 2$ & $39 / 2$ & 19778.22 & .05 \\
\hline $\mathrm{C}^{13} \mathrm{H}_{3} \mathrm{C}^{12} \mathrm{H}_{2} \mathrm{Cl}^{35}$ & 3- 545 & $2,1,2 \leftarrow 1,1,1$ & Ground & $3 / 2$ & $3 / 2$ & 19778.66 & .05 \\
\hline $\mathrm{C}^{12} \mathrm{H}_{3} \mathrm{As}^{75} \mathrm{~F}_{2}^{19}$ & 3- 81 & $20,15,6 \leftarrow 20,13,7$ & Ground & $43 / 2$ & $43 / 2$ & 19783.53 & .05 \\
\hline $\mathrm{C}^{12} \mathrm{H}_{3} \mathrm{As}^{75} \mathrm{~F}_{2}^{19}$ & 3- 81 & $20,14,6 \leftarrow 20,14,7$ & Ground & $43 / 2$ & $43 / 2$ & 19783.53 & .05 \\
\hline $\mathrm{C}^{12} \mathrm{H}_{3} \mathrm{As}^{75} \mathrm{~F}_{2}^{19}$ & 3. 81 & $20,14,6 \leftarrow 20,14,7$ & Ground & $37 / 2$ & $37 / 2$ & 19783.93 & .05 \\
\hline $\mathrm{C}^{12} \mathrm{H}_{3} \mathrm{As}^{75} \mathrm{~F}_{2}^{19}$ & 3- 81 & $20,15,6 \leftarrow 20,13,7$ & Ground & $37 / 2$ & $37 / 2$ & 19783.93 & .05 \\
\hline
\end{tabular}




\begin{tabular}{|c|c|c|c|c|c|c|c|c|}
\hline Isotopic Species & $\begin{array}{l}\text { Vol.-Id. } \\
\text { Nos. }\end{array}$ & $\begin{array}{c}\text { Rotational } \\
\text { Quantum Nos. }\end{array}$ & Vib. State & $F_{1}^{\prime \prime}$ & $\begin{array}{c}\text { Hyperfin } \\
\mathrm{F}^{\prime}\end{array}$ & $\mathrm{F}$ & $\begin{array}{l}\text { Frequency } \\
\text { MHz }\end{array}$ & $\begin{aligned} & \text { Ace. } \\
\pm & \mathrm{MHz}\end{aligned}$ \\
\hline $\mathrm{C}^{12}{ }_{*} \mathrm{H}_{2} \mathrm{C}^{12} \mathrm{H}: \mathrm{C}^{12}{ }_{*} \mathrm{H}$ & 4-1031 & $12,7,5 \leftarrow 12,7,6$ & Ground & & & & 19784.3 & \\
\hline $\mathrm{C}^{13} \mathrm{H}_{3} \mathrm{C}^{12} \mathrm{H}_{2} \mathrm{Cl}^{35}$ & 3- 54.5 & $2,1,2 \leftarrow 1,1,1$ & Ground & & $7 / 2$ & $5 / 2$ & 19784.42 & .05 \\
\hline $\mathrm{C}^{12} \mathrm{H}_{2}\left(\mathrm{C}^{12} \mathrm{~N}^{14}\right)_{2}$ & 4. 901 & $4,1,3 \leftarrow 4,0,4$ & Ground & & & & 19785.23 & \\
\hline $\mathrm{s}-\mathrm{C}^{12} \mathrm{H}_{2} \mathrm{D}\left(\mathrm{C}^{12} \mathrm{H}_{3}\right)_{2} \mathrm{Si}^{\mathrm{b}} \mathrm{D}$ & 3. 881 & $2,1,1 \leftarrow 1,0,1$ & Ground & & & & 19787.30 & .10 \\
\hline $\mathrm{C}^{12} \mathrm{D}_{3} \mathrm{Si}^{28} \mathrm{H}_{2} \mathrm{~F}^{19}$ & 3- 244 & $10,2,8 \leftarrow 10,2,9$ & Ground & & & & 19793.05 & .10 \\
\hline $\mathrm{C}^{13} \mathrm{H}_{3} \mathrm{C}^{12} \mathrm{H}_{2} \mathrm{Cl}^{35}$ & 3- 545 & $2,1,2 \leftarrow 1,1,1$ & Ground & & $1 / 2$ & $1 / 2$ & 19793.4 & .05 \\
\hline $\mathrm{N}^{15} \mathrm{H}_{3}$ & $4-1772$ & $7,5 \leftarrow 7,5$ & Ground & & & & 19793.45 & .06 \\
\hline $\mathrm{Br}^{79} \mathrm{~F}_{3}^{19}$ & 4- 81 & $2,1,2 \leftarrow 1,0,1$ & Ground & & $5 / 2$ & $3 / 2$ & 19793.83 & \\
\hline $\mathrm{C}^{12} \mathrm{H}_{3} \mathrm{~N}^{14} \mathrm{O}_{2}^{16}$ & 3- 171 & Not Reported & Ground & & & & 19794. & 5. \\
\hline $\mathrm{C}_{6}^{12} \mathrm{H}_{5} \mathrm{Cl}^{35}$ & $4-1271$ & $7,3,5 \leftarrow 6,3,4$ & Ground & & & & 19797.9 & \\
\hline $\mathrm{C}^{13} \mathrm{DF}_{3}^{19}$ & 4- 284 & $1, \leftarrow 0$, & Ground & & & & 19798.67 & .10 \\
\hline $\mathrm{C}^{12} \mathrm{H}_{3} \mathrm{As}^{75} \mathrm{~F}_{2}^{19}$ & $3-81$ & $17,12,6 \leftarrow 17,10,7$ & Ground & & $35 / 2$ & $35 / 2$ & 19799.25 & .05 \\
\hline $\mathrm{C}^{12} \mathrm{H}_{3} \mathrm{As}^{75} \mathrm{~F}_{2}^{19}$ & $3-81$ & $17,11,6 \leftarrow 17,11,7$ & Ground & & $35 / 2$ & $35 / 2$ & 19799.25 & .05 \\
\hline $\mathrm{C}_{6}^{12} \mathrm{H}_{5} \mathrm{Cl}^{35}$ & 4-1271 & $7,3,5 \leftarrow 6,3,4$ & Ground & & & & 19800.7 & \\
\hline $\mathrm{C}^{12} \mathrm{DF}_{3}^{19}$ & 4- 283 & $1, \leftarrow 0$ & Excited & & & & 19800.96 & .10 \\
\hline $\mathrm{C}^{12} \mathrm{HCl}_{3}^{35}$ & 4- 261 & $3,2 \leftarrow 2,2$ & Ground & & & & 19801.23 & \\
\hline $\mathrm{Si}^{28} \mathrm{H}_{3} \mathrm{C}^{12} \mathrm{D}: \mathrm{C}^{12} \mathrm{H}_{2}$ & 3- 616 & $2,0,2 \leftarrow 1,0,1$ & Ground & & & & 19801.56 & .10 \\
\hline g- $\mathrm{C}^{12} \mathrm{H}_{3} \mathrm{C}^{12} \mathrm{H}_{2} \mathrm{C}^{12} \mathrm{H}_{2} \mathrm{Cl}^{35}$ & 3- 773 & $8,1,7 \leftarrow 8,0,8$ & Ground & & & & 19801.74 & .2 \\
\hline $\mathrm{C}^{12} \mathrm{HCl}_{3}^{35}$ & 4- 261 & $3,2 \leftarrow 2,2$ & Ground & & & & 19802.67 & .14 \\
\hline $\mathrm{C}^{12} \mathrm{HCl}_{3}^{35}$ & 4- 261 & $3,2 \leftarrow 2,2$ & Ground & & & & 19803.70 & .16 \\
\hline $\mathrm{C}^{12} \mathrm{HCl}_{3}^{35}$ & 4- 261 & $3,2 \leftarrow 2,2$ & Ground & & & & 19804.43 & .16 \\
\hline $\mathrm{C}^{12} \mathrm{H}_{3} \mathrm{As}^{75} \mathrm{~F}_{2}^{19}$ & 3- 81 & $16,10,6 \leftarrow 16,10,7$ & Ground & & $33 / 2$ & $33 / 2$ & 19804.60 & .05 \\
\hline $\mathrm{C}^{12} \mathrm{H}_{3} \mathrm{As}^{75} \mathrm{~F}_{2}^{19}$ & $3-81$ & $16,11,6 \leftarrow 16,9,7$ & Ground & & $33 / 2$ & $33 / 2$ & 19804.60 & .05 \\
\hline $\mathrm{H}_{2} \mathrm{~N}^{14} \mathrm{~N}^{14} \mathrm{H}_{2}$ & 3- 51 & Not Reported & & & & & 19804.8 & \\
\hline $\mathrm{C}^{12} \mathrm{H}_{3} \mathrm{As}^{75} \mathrm{~F}_{2}^{19}$ & $3-81$ & $16,10,6 \leftarrow 16,10,7$ & Ground & & $31 / 2$ & $31 / 2$ & 19805.38 & .05 \\
\hline $\mathrm{C}^{12} \mathrm{H}_{3} \mathrm{As}^{75} \mathrm{~F}_{2}^{19}$ & $3-81$ & $16,11,6 \leftarrow 16,9,7$ & Ground & & $31 / 2$ & $31 / 2$ & 19805.38 & .05 \\
\hline $\mathrm{C}^{12} \mathrm{HCl}_{3}^{35}$ & 4- 261 & Not Reported & Ground & & & & 19805.57 & .14 \\
\hline $\mathrm{H}_{2} \mathrm{~N}^{14} \mathrm{~N}^{14} \mathrm{H}_{2}$ & $3-\quad 51$ & Not Reported & & & & & 19806.06 & \\
\hline $\mathrm{C}^{12} \mathrm{HCl}_{3}^{35}$ & 4- 261 & Not Reported & Ground & & & & 19806.21 & \\
\hline $\mathrm{C}^{12} \mathrm{H}_{3} \mathrm{As}^{75} \mathrm{~F}_{2}^{19}$ & $3-\quad 81$ & $17,12,6 \leftarrow 17,10,7$ & Ground & & $37 / 2$ & $37 / 2$ & 19806.78 & .05 \\
\hline $\mathrm{C}^{12} \mathrm{H}_{3} \mathrm{As}^{75} \mathrm{~F}_{2}^{19}$ & $3-81$ & $17,11,6 \leftarrow 17,11,7$ & Ground & & $37 / 2$ & $37 / 2$ & 19806.78 & .05 \\
\hline $\mathrm{C}^{12}{ }_{*} \mathrm{H}: \mathrm{C}^{12} \mathrm{HC}^{12} \mathrm{H}: \mathrm{C}^{12} \mathrm{HN}^{14}{ }_{*} \mathrm{H}$ & $4-1181$ & $11,11,1 \leftarrow 11,9,2$ & Ground & & & & 19806.8 & \\
\hline $\mathrm{C}^{12} \mathrm{H}_{3} \mathrm{As}^{75} \mathrm{~F}_{2}^{19}$ & 3- 81 & $17,11,6 \leftarrow 17,11,7$ & Ground & & $31 / 2$ & $31 / 2$ & 19807.40 & .05 \\
\hline $\mathrm{C}^{12} \mathrm{H}_{3} \mathrm{As}^{75} \mathrm{~F}_{2}^{19}$ & 3- 81 & $17,12,6 \leftarrow 17,10,7$ & Ground & & $31 / 2$ & $31 / 2$ & 19807.40 & .05 \\
\hline $\mathrm{C}^{12} \mathrm{HCl}_{3}^{35}$ & 4- 261 & $3,1 \leftarrow 2,1$ & Ground & & & & 19808.28 & .12 \\
\hline $\mathrm{a}-\mathrm{C}^{12} \mathrm{D}_{2} \mathrm{H}\left(\mathrm{C}^{12} \mathrm{H}_{3}\right)_{2} \mathrm{Si}^{\mathrm{b}} \mathrm{D}$ & 3- 884 & $2,2,1 \leftarrow 1,1,1$ & Ground & & & & 19808.32 & .10 \\
\hline $\mathrm{c}-\mathrm{HF}^{19} \mathrm{C}^{12}: \mathrm{C}^{13} \mathrm{HF}^{19}$ & 4- 692 & $3,1,2 \leftarrow 3,0,3$ & Ground & & & & 19808.46 & .05 \\
\hline $\mathrm{C}^{12} \mathrm{H}_{3} \mathrm{As}^{75} \mathrm{~F}_{2}^{19}$ & 3- 81 & $15,9,6 \leftarrow 15,9,7$ & Ground & & $31 / 2$ & $31 / 2$ & 19809.09 & .05 \\
\hline $\mathrm{C}^{12} \mathrm{H}_{3} \mathrm{As}^{75} \mathrm{~F}_{2}^{19}$ & $3-81$ & $15,10,6 \leftarrow 15,8,7$ & Ground & & $31 / 2$ & $31 / 2$ & 19809.09 & .05 \\
\hline $\mathrm{C}^{12} \mathrm{H}_{3} \mathrm{As}^{75} \mathrm{~F}_{2}^{19}$ & $3-81$ & $15,10,6 \leftarrow 15,8,7$ & Ground & & $29 / 2$ & $29 / 2$ & 19809.94 & .05 \\
\hline $\mathrm{C}^{12} \mathrm{H}_{3} \mathrm{As}^{75} \mathrm{~F}_{2}^{19}$ & $3-\quad 81$ & $15,9,6 \leftarrow 15,9,7$ & Ground & & $29 / 2$ & $29 / 2$ & 19809.94 & .05 \\
\hline $\mathrm{C}^{12} \mathrm{DF}_{3}^{19}$ & 4- 283 & $1, \leftarrow 0$ & Excited & & & & 19810.30 & .10 \\
\hline $\mathrm{C}^{12} \mathrm{HCl}_{3}^{35}$ & 4- 261 & $3,2 \leftarrow 2,2$ & Ground & & & & 19810.57 & .05 \\
\hline $\mathrm{N}^{15} \mathrm{H}_{3}$ & 4-1772 & $10,8 \leftarrow 10,8$ & Ground & & & & 19810.86 & .06 \\
\hline $\mathrm{C}^{12} \mathrm{DF}_{3}^{19}$ & 4- 283 & $1, \leftarrow 0$ & Excited & & & & 19811.26 & .10 \\
\hline
\end{tabular}




\begin{tabular}{|c|c|c|c|c|c|c|c|}
\hline Isotopic Species & $\begin{array}{l}\text { Vol.-Id. } \\
\text { Nos. }\end{array}$ & $\begin{array}{c}\text { Rotational } \\
\text { Quantum Nos. }\end{array}$ & Vib. State & $\mathrm{F}_{1}^{\prime} \mathrm{F}^{\prime} \quad \mathbf{F}_{1}$ & e $F$ & $\begin{array}{c}\text { Frequency } \\
\mathrm{MHz}^{-}\end{array}$ & $\begin{aligned} & \text { Acc. } \\
& \pm \mathrm{MHz}\end{aligned}$ \\
\hline $\mathrm{C}^{12} \mathrm{H}_{3} \mathrm{As}^{75} \mathrm{~F}_{2}^{19}$ & $3-81$ & $16,10,6 \leftarrow 16,10,7$ & Ground & $35 / 2$ & $35 / 2$ & 19812.87 & .05 \\
\hline $\mathrm{C}^{12} \mathrm{H}_{3} \mathrm{As}^{75} \mathrm{~F}_{2}^{19}$ & $3-81$ & $16,11,6 \leftarrow 16,9,7$ & Ground & $35 / 2$ & $35 / 2$ & 19812.87 & .05 \\
\hline $\mathrm{C}^{12} \mathrm{HCl}_{3}^{35}$ & 4- 261 & $3, \leftarrow 2$, & Ground & & & 19812.92 & .10 \\
\hline $\mathrm{C}^{12} \mathrm{H}_{3} \mathrm{C}^{12} \mathrm{HF}_{2}^{19}$ & 3- 461 & $12,9,3 \leftarrow 12,9,4$ & Ground & & & 19813.4 & \\
\hline $\mathrm{C}^{12} \mathrm{H}_{3} \mathrm{As}^{75} \mathrm{~F}_{2}^{19}$ & $3-81$ & $16,11,6 \leftarrow 16,9,7$ & Ground & $29 / 2$ & $29 / 2$ & 19813.68 & .05 \\
\hline $\mathrm{C}^{12} \mathrm{H}_{3} \mathrm{As}^{75} \mathrm{~F}_{2}^{19}$ & $3-\quad 81$ & $16,10,6 \leftarrow 16,10,7$ & Ground & $29 / 2$ & $29 / 2$ & 19813.68 & .05 \\
\hline $\mathrm{C}^{12} \mathrm{HCl}_{3}^{35}$ & 4- 261 & $3, \leftarrow 2$, & Ground & & & 19814.95 & .10 \\
\hline $\mathrm{C}^{12} \mathrm{HCl}_{3}^{35}$ & 4- 261 & $3, \leftarrow 2$, & Ground & & & 19816.76 & .14 \\
\hline $\mathrm{C}^{12} \mathrm{HCl}_{3}^{35}$ & 4- 261 & $3, \leftarrow 2$, & Ground & & & 19817.66 & .13 \\
\hline $\mathrm{C}^{12} \mathrm{H}_{3} \mathrm{C}^{12} \mathrm{HF}_{2}^{19}$ & 3- 461 & $12,9.3 \leftarrow 12,9,4$ & Ground & & & 19818.0 & \\
\hline $\mathrm{C}^{12} \mathrm{H}_{3} \mathrm{As}^{75} \mathrm{~F}_{2}^{19}$ & 3- 81 & $15,10,6 \leftarrow 15,8,7$ & Ground & $33 / 2$ & $33 / 2$ & 19818.39 & .05 \\
\hline $\mathrm{C}^{12} \mathrm{H}_{3} \mathrm{As}^{75} \mathrm{~F}_{2}^{19}$ & $3-81$ & $15,9,6 \leftarrow 15,9,7$ & Ground & $33 / 2$ & $33 / 2$ & 19818.39 & .05 \\
\hline $\mathrm{C}^{12} \mathrm{HCl}_{3}^{35}$ & 4- 261 & $3, \leftarrow 2$, & Ground & & & 19818.73 & .17 \\
\hline $\mathrm{C}^{12} \mathrm{H}_{2} \mathrm{DC}^{12} \mathrm{~F}_{3}^{19}$ & 3. 412 & $2,1,2 \leftarrow 1,1,1$ & Ground & & & 19818.74 & .2 \\
\hline $\mathrm{C}^{12} \mathrm{H}_{3} \mathrm{As}^{75} \mathrm{~F}_{2}^{19}$ & 3. 81 & $15,10,6 \leftarrow 15,8,7$ & Ground & $27 / 2$ & $27 / 2$ & 19819.38 & .05 \\
\hline $\mathrm{C}^{12} \mathrm{H}_{3} \mathrm{As}^{75} \mathrm{~F}_{2}^{19}$ & 3. 81 & $15,9,6 \leftarrow 15,9,7$ & Ground & $27 / 2$ & $27 / 2$ & 19819.38 & .05 \\
\hline $\mathrm{C}^{12} \mathrm{HCl}_{3}^{35}$ & 4- 261 & $3, \leftarrow 2$, & Ground & & & 19819.65 & .17 \\
\hline $\mathrm{C}^{12} \mathrm{HCl}_{3}^{35}$ & 4- 261 & $3,2 \leftarrow 2,2$ & Ground & & & 19821.00 & .10 \\
\hline $\mathrm{C}^{12} \mathrm{HCl}_{3}^{35}$ & 4- 261 & $3,2 \leftarrow 2,2$ & Ground & & & 19822.19 & .12 \\
\hline $\mathrm{C}^{12} \mathrm{HCl}_{3}^{35}$ & 4- 261 & $3,2 \leftarrow 2,2$ & Ground & & & 19823.08 & .17 \\
\hline $\mathrm{C}^{12} \mathrm{H}_{3} \mathrm{As}^{75} \mathrm{~F}_{2}^{19}$ & $3-81$ & $14,8,6 \leftarrow 14,8,7$ & Ground & $31 / 2$ & $31 / 2$ & 19823.39 & .05 \\
\hline $\mathrm{C}^{12} \mathrm{H}_{3} \mathrm{As}^{75} \mathrm{~F}_{2}^{19}$ & $3-81$ & $14,9,6 \leftarrow 14,7,7$ & Ground & $31 / 2$ & $31 / 2$ & 19823.39 & .05 \\
\hline $\mathrm{C}^{12} \mathrm{DF}_{3}^{19}$ & 4- 283 & $1, \leftarrow 0$, & Excited & & & 19823.40 & .10 \\
\hline $\mathrm{C}^{12} \mathrm{H}_{3} \mathrm{As}^{75} \mathrm{~F}_{2}^{19}$ & $3-81$ & $14,8,6 \leftarrow 14,8,7$ & Ground & $25 / 2$ & $25 / 2$ & 19824.47 & .05 \\
\hline $\mathrm{C}^{12} \mathrm{H}_{3} \mathrm{As}^{75} \mathrm{~F}_{2}^{19}$ & 3- 81 & $14,9,6 \leftarrow 14,7,7$ & Ground & $25 / 2$ & $25 / 2$ & 19824.47 & .05 \\
\hline $\mathrm{Si}^{28} \mathrm{H}_{2} \mathrm{~F}_{2}^{19}$ & 4-1601 & $2,1,1 \leftarrow 2,0,2$ & Ground & & & 19824.84 & .10 \\
\hline $\mathrm{C}^{12} \mathrm{H}_{3} \mathrm{C}^{12} \mathrm{O}^{16} \mathrm{C}^{13} \mathrm{~N}^{14}$ & 3- 673 & $7,2,5 \leftarrow 7,1,6$ & Ground & & & 19824.98 & .2 \\
\hline $\mathrm{C}^{12} \mathrm{H}_{3} \mathrm{As}^{75} \mathrm{~F}_{2}^{19}$ & $3-81$ & $13,7,6 \leftarrow 13,7,7$ & Ground & $29 / 2$ & $29 / 2$ & 19827.98 & .05 \\
\hline $\mathrm{C}^{12} \mathrm{H}_{3} \mathrm{As}^{75} \mathrm{~F}_{2}^{19}$ & $3-81$ & $13,8,6 \leftarrow 13,6,7$ & Ground & $29 / 2$ & $29 / 2$ & 19827.98 & .05 \\
\hline $\mathrm{C}^{12} \mathrm{H}_{3} \mathrm{~N}^{14} \mathrm{O}_{2}^{16}$ & 3- 171 & Not Reported & Cround & & & 19828. & 5. \\
\hline $\mathrm{C}^{12} \mathrm{H}_{3} \mathrm{C}^{12} \mathrm{O}^{16} \mathrm{C}^{13} \mathrm{~N}^{14}$ & 3. 673 & $7,2,5 \leftarrow 7,1,6$ & Ground & & & 19828.54 & .2 \\
\hline $\mathrm{C}^{12}{ }_{*} \mathrm{HC}^{12} \mathrm{D}: \mathrm{C}^{12} \mathrm{HC}^{12} \mathrm{H}: \mathrm{C}^{12} \mathrm{HN}^{14}{ }_{*}$ & 4-1203 & $6,3,3 \leftarrow 6,3.4$ & Ground & & & 19828.8 & .1 \\
\hline $\mathrm{C}^{12} \mathrm{H}_{3} \mathrm{As}^{75} \mathrm{~F}_{2}^{19}$ & 3- 81 & $13,8,6 \leftarrow 13,6,7$ & Ground & $23 / 2$ & $23 / 2$ & 19829.30 & .05 \\
\hline $\mathrm{C}^{12} \mathrm{H}_{3} A \mathrm{~s}^{75} \mathrm{~F}_{2}^{19}$ & 3- 81 & $13,7,6 \leftarrow 13,7,7$ & Ground & $23 / 2$ & $23 / 2$ & 19829.30 & .05 \\
\hline $\mathrm{C}^{12} \mathrm{H}_{3} \mathrm{As}^{75} \mathrm{~F}_{2}^{19}$ & 3- 81 & $12,6,6 \leftarrow 12,6,7$ & Ground & $27 / 2$ & $27 / 2$ & 19832.22 & .05 \\
\hline $\mathrm{C}^{12} \mathrm{H}_{3} \mathrm{As}^{75} \mathrm{~F}_{2}^{19}$ & 3. 81 & $12,7,6 \leftarrow 12,5,7$ & Ground & $27 / 2$ & $27 / 2$ & 19832.22 & .05 \\
\hline $\mathrm{C}^{12} \mathrm{H}_{3} \mathrm{As}^{75} \mathrm{~F}_{2}^{19}$ & 3- 81 & $12,7,6 \leftarrow 12,5,7$ & Ground & $21 / 2$ & $21 / 2$ & 19833.84 & .05 \\
\hline $\mathrm{C}^{12} \mathrm{H}_{3} \mathrm{As}^{75} \mathrm{~F}_{2}^{19}$ & 3- 81 & $12,6,6 \leftarrow 12,6,7$ & Ground & $21 / 2$ & $21 / 2$ & 19833.84 & .05 \\
\hline $\mathrm{C}^{12} \mathrm{H}_{3} \mathrm{As}^{75} \mathrm{~F}_{2}^{19}$ & 3- 81 & $11,6,6 \leftarrow 11,4,7$ & Ground & $19 / 2$ & $19 / 2$ & 19834.67 & .05 \\
\hline $\mathrm{C}^{12} \mathrm{H}_{3} \mathrm{As}^{75} \mathrm{~F}_{2}^{19}$ & $3-81$ & $11,5,6 \leftarrow 11,5,7$ & Ground & $19 / 2$ & $19 / 2$ & 19834.67 & .05 \\
\hline $\mathrm{C}^{12} \mathrm{H}_{3} \mathrm{As}^{75} \mathrm{~F}_{2}^{19}$ & 3- 81 & $11,6,6 \leftarrow 11,4,7$ & Ground & $25 / 2$ & $25 / 2$ & 19836.16 & .05 \\
\hline $\mathrm{C}^{12} \mathrm{H}_{3} \mathrm{As}^{75} \mathrm{~F}_{2}^{19}$ & 3- 81 & $11,5,6 \leftarrow 11,5,7$ & Ground & $25 / 2$ & $25 / 2$ & 19836.16 & .05 \\
\hline $\mathrm{C}^{12} \mathrm{D}_{3} \mathrm{C}^{12} \mathrm{O}^{16} \mathrm{Cl}^{35}$ & 3- 363 & $8,3,5 \leftarrow 8,2,6$ & Ground & $19 / 2$ & $19 / 2$ & 19836.38 & \\
\hline $\mathrm{C}^{12} \mathrm{D}_{3} \mathrm{C}^{12} \mathrm{O}^{16} \mathrm{Cl}^{35}$ & 3- 363 & $8,3,5 \leftarrow 8,2,6$ & Ground & $13 / 2$ & $13 / 2$ & 19836.38 & \\
\hline $\mathrm{C}^{12} \mathrm{D}_{3} \mathrm{C}^{12} \mathrm{O}^{16} \mathrm{Cl}^{35}$ & 3- 363 & $8,3,5 \leftarrow 8,2,6$ & Ground & $17 / 2$ & $17 / 2$ & 19837.06 & \\
\hline
\end{tabular}




\begin{tabular}{|c|c|c|c|c|c|c|c|c|}
\hline Isotopic Species & $\begin{array}{l}\text { Vol.-Id. } \\
\text { Nos. }\end{array}$ & $\begin{array}{c}\text { Rotational } \\
\text { Quantum Nos. }\end{array}$ & Vib. State & $F_{1}^{\prime \prime}$ & $\begin{array}{l}\text { Hyperfine } \\
\mathbf{F}^{\prime} \quad F_{1}\end{array}$ & F & $\begin{array}{l}\text { Frequency } \\
\text { MHz }\end{array}$ & $\begin{aligned} & \text { Acc. } \\
& \pm \mathrm{MH}\end{aligned}$ \\
\hline $\mathrm{C}^{12} \mathrm{D}_{3} \mathrm{C}^{12} \mathrm{O}^{16} \mathrm{Cl}^{35}$ & 3- 363 & $8,3,5 \leftarrow 8,2,6$ & Fround & & $15 / 2$ & $15 / 2$ & 19837.06 & \\
\hline $\mathrm{C}^{12} \mathrm{H}_{3} \mathrm{As}^{75} \mathrm{~F}_{2}^{19}$ & 3. 81 & $11,5,6 \leftarrow 11,5,7$ & Ground & & $19 / 2$ & $19 / 2$ & 19838.21 & .05 \\
\hline $\mathrm{C}^{12} \mathrm{H}_{3} \mathrm{As}^{75} \mathrm{~F}_{2}^{19}$ & $3-81$ & $11,6,6 \leftarrow-11,4,7$ & Ground & & $19 / 2$ & $19 / 2$ & 19838.21 & .05 \\
\hline $\mathrm{N}^{14} \mathrm{H}_{3}$ & 4-1771 & $5,1 \leftarrow 5,1$ & Ground & & & & 19838.26 & .02 \\
\hline $\mathrm{N}^{14} \mathrm{H}_{3}$ & 4-1771 & $5,1 \leftarrow 5,1$ & Ground & & & & 19838.41 & .02 \\
\hline $\mathrm{C}^{12} \mathrm{H}_{3} \mathrm{As}^{75} \mathrm{~F}_{2}^{19}$ & $3-81$ & $10,4,6 \leftarrow 10,4,7$ & Ground & & $17 / 2$ & $17 / 2$ & 19839.13 & .05 \\
\hline $\mathrm{C}^{12} \mathrm{H}_{3} \mathrm{As}^{75} \mathrm{~F}_{2}^{19}$ & 3. 81 & $11,5,6 \leftarrow 11,5,7$ & Ground & & $19 / 2$ & $19 / 2$ & 19839.13 & .05 \\
\hline $\mathrm{C}^{12} \mathrm{H}_{3} \mathrm{As}^{75} \mathrm{~F}_{2}^{19}$ & 3- 81 & $10,5,6 \leftarrow 10,3,7$ & Ground & & $17 / 2$ & $17 / 2$ & 19839.13 & .05 \\
\hline $\mathrm{C}^{12} \mathrm{H}_{3} \mathrm{As}^{75} \mathrm{~F}_{2}^{19}$ & 3- 81 & $11,6,6 \leftarrow 11,4,7$ & Ground & & $19 / 2$ & $19 / 2$ & 19839.13 & .05 \\
\hline $\mathrm{C}^{12} \mathrm{H}_{3} \mathrm{As}^{75} \mathrm{~F}_{2}^{19}$ & 3- 81 & $10,4,6 \leftarrow 10,4,7$ & Ground & & $23 / 2$ & $23 / 2$ & 19839.97 & .05 \\
\hline $\mathrm{C}^{12} \mathrm{H}_{3} \mathrm{As}^{75} \mathrm{~F}_{2}^{19}$ & 3- 81 & $10,5,6 \leftarrow 10,3,7$ & Ground & & $23 / 2$ & $23 / 2$ & 19839.97 & .05 \\
\hline $\mathrm{C}^{12} \mathrm{DF}_{3}^{19}$ & 4. 283 & $1, \leftarrow 0$, & Ground & & & & 19842.21 & .10 \\
\hline $\mathrm{C}^{12} \mathrm{H}_{3} \mathrm{As}^{75} \mathrm{~F}_{2}^{19}$ & 3- 81 & $10,4,6 \leftarrow 10,4,7$ & Ground & & $17 / 2$ & $17 / 2$ & 19842.75 & .05 \\
\hline $\mathrm{C}^{12} \mathrm{H}_{3} \mathrm{As}^{75} \mathrm{~F}_{2}^{19}$ & 3- 81 & $10,5,6 \leftarrow 10,3,7$ & Ground & & $17 / 2$ & $17 / 2$ & 19842.75 & .05 \\
\hline $\mathrm{C}^{13} \mathrm{O}^{16} \mathrm{~F}_{2}^{19}$ & 4- 212 & $10,10,1 \leftarrow 10,8,2$ & Cround & & & & 19843.06 & .10 \\
\hline $\mathrm{C}^{12}{ }_{*} \mathrm{DC}^{12} \mathrm{H}: \mathrm{C}^{12} \mathrm{HC}^{12} \mathrm{H}: \mathrm{C}^{12} \mathrm{HN}^{14}{ }_{*}$ & 4-1202 & $6,3,3 \leftarrow 6,3,4$ & Ground & & & & 19843.5 & .1 \\
\hline $\mathrm{C}^{12} \mathrm{H}_{3} \mathrm{As}^{75} \mathrm{~F}_{2}^{19}$ & 3- 81 & $10,5,6 \leftarrow 10,3,7$ & Ground & & $17 / 2$ & $17 / 2$ & 19843.71 & .05 \\
\hline $\mathrm{C}^{12} \mathrm{H}_{3} \mathrm{As}^{75} \mathrm{~F}_{2}^{19}$ & 3. 81 & $10,4,6 \leftarrow 10,4,7$ & Ground & & $17 / 2$ & $17 / 2$ & 19843.71 & .05 \\
\hline $\mathrm{C}^{12} \mathrm{D}_{3} \mathrm{O}^{16} \mathrm{H}$ & 3- 214 & Not Reported & Ground & & & & 19844.8 & .5 \\
\hline $\mathrm{C}^{12} \mathrm{DF}_{3}^{19}$ & 4- 283 & $1, \leftarrow 0$, & Excited & & & & 19846.16 & .10 \\
\hline $\mathrm{C}^{12} \mathrm{H}_{2} \mathrm{DC}^{12} \mathrm{~F}_{3}^{19}$ & 3- 412 & $2,0,2 \leftarrow 1,0,1$ & Ground & & & & 19846.45 & .2 \\
\hline$c-\mathrm{HDN}^{15} \mathrm{C}^{12} \mathrm{HO}^{16}$ & 3- 158 & $1,0,1 \leftarrow 0,0,0$ & Ground & & & & 19846.70 & \\
\hline $\mathrm{C}^{12} \mathrm{H}_{2}\left(\mathrm{C}^{12} \mathrm{~N}^{14}\right)_{2}$ & 4. 901 & Not Reported & Ground & & & & 19847.4 & .1 \\
\hline $\mathrm{C}^{12}{ }_{*} \mathrm{D}: \mathrm{C}^{12} \mathrm{DC}^{12} \mathrm{D}: \mathrm{C}^{12} \mathrm{DN}^{14}{ }_{*} \mathrm{H}$ & 4-1185 & $6,5,2 \leftarrow 6,4,3$ & Ground & & & & 19848.7 & \\
\hline $\mathrm{C}^{12} \mathrm{DF}_{3}^{19}$ & 4- 283 & $1, \leftarrow 0$ & Fxcited & & & & 19850.13 & .10 \\
\hline $\mathrm{C}^{12} \mathrm{DF}_{3}^{19}$ & 4- 283 & $1, \leftarrow 0$ & Excited & & & & 19851.33 & .10 \\
\hline $\mathrm{C}^{12}{ }_{*} \mathrm{H}: \mathrm{C}^{12} \mathrm{DO}^{16} \mathrm{C}^{12} \mathrm{D}: \mathrm{C}^{12}{ }_{*} \mathrm{H}$ & 4-1156 & $5,5,1 \leftarrow 5,4,2$ & Ground & & & & 19851.7 & \\
\hline $\mathrm{Si}^{28} \mathrm{H}_{3} \mathrm{C}^{12} \mathrm{H}: \mathrm{C}^{12} \mathrm{H}_{2}$ & 3- 611 & $2,1,2 \leftarrow 1,1,1$ & Ground & & & & 19853.9 & .05 \\
\hline $\mathrm{D}_{2} \mathrm{O}_{2}^{16}$ & $3-42$ & Not Reported & & & & & 19854. & 3. \\
\hline $\mathrm{C}^{12} \mathrm{DF}_{3}^{19}$ & 4- 283 & $1, \leftarrow 0$ & Excited & & & & 19854.13 & .10 \\
\hline $\mathrm{C}^{12}{ }_{*} \mathrm{H}_{2} \mathrm{~N}^{14} \mathrm{DC}^{12}{ }_{*} \mathrm{H}_{2}$ & 4- 862 & $12,11,1 \leftarrow 12,11,2$ & Ground & & & & 19860. & 10. \\
\hline $\mathrm{C}^{12} \mathrm{H}_{2}\left(\mathrm{C}^{12} \mathrm{~N}^{14}\right)_{2}$ & 4- 901 & Not Reported & Ground & & & & 19862.9 & .1 \\
\hline $\mathrm{C}^{12}{ }_{*} \mathrm{DN}^{14} \mathrm{C}^{12} \mathrm{DC}^{12} \mathrm{H}: \mathrm{C}^{12} \mathrm{DN}^{14} *$ & $4-1142$ & $2,2,1 \leftarrow 1,1,0$ & Ground & & & & 19863.7 & \\
\hline $\mathrm{H}_{2} \mathrm{~B}^{11} \mathrm{H}_{2} \mathrm{~B}^{11} \mathrm{HBr}^{79}$ & 4- 41 & $3,1,2 \leftarrow 2,1,1$ & Ground & & $9 / 2$ & $7 / 2$ & 19867.6 & \\
\hline $\mathrm{C}^{\mathrm{b}} \mathrm{H}_{2}^{\mathrm{b}} \mathrm{Cl}^{\mathrm{b}} \mathrm{F}^{\mathrm{b}}$ & 4. 333 & Not Reported & $\cdot$ & & & & 19868.76 & .1 \\
\hline $\mathrm{H}_{2} \mathrm{~N}^{14} \mathrm{~N}^{14} \mathrm{H}_{2}$ & 3- 51 & Not Reported & & & & & 19874.46 & \\
\hline $\mathrm{H}_{2} \mathrm{~N}^{14} \mathrm{~N}^{14} \mathrm{H}_{2}$ & 3- 51 & Not Reported & & & & & 19875.04 & \\
\hline $\mathrm{C}^{12} \mathrm{H}_{2} \mathrm{DC}^{12} \mathrm{~F}_{3}^{19}$ & 3- 412 & $2,1,1 \leftarrow 1,1,0$ & Ground & & & & 19876.68 & .2 \\
\hline $\mathrm{HC}^{13}: \mathrm{C}^{12} \mathrm{C}^{12} \mathrm{DO}^{16}$ & 4. 922 & Not Reported & & & & & 19878. & 5. \\
\hline $\mathrm{H}_{2} \mathrm{~B}^{11} \mathrm{H}_{2} \mathrm{~B}^{11} \mathrm{HBr}^{79}$ & 4- 41 & $3,1,2 \leftarrow 2,1,1$ & Ground & & $7 / 2$ & $5 / 2$ & 19885.8 & \\
\hline $\mathrm{s}-\mathrm{C}^{12} \mathrm{D}_{2} \mathrm{H}\left(\mathrm{C}^{12} \mathrm{H}_{3}\right)_{2} \mathrm{Si}^{\mathrm{b}} \mathrm{D}$ & 3- 883 & $2,2,1 \leftarrow 1,1,1$ & Ground & & & & 19892.55 & .10 \\
\hline $\mathrm{C}_{6}^{12} \mathrm{H}_{5} \mathrm{Cl}^{35}$ & 4-1271 & $7,3,4 \leftarrow 6,3,3$ & Ground & & & & 19893.5 & \\
\hline $\mathrm{C}_{6}^{12} \mathrm{H}_{5} \mathrm{Cl}^{35}$ & 4-1271 & $7,3,4 \leftarrow 6,3,3$ & Ground & & & & 19895.8 & \\
\hline $\mathrm{C}^{13}{ }_{*} \mathrm{HC}^{12} \mathrm{H}: \mathrm{C}^{12} \mathrm{HC}^{12} \mathrm{H}: \mathrm{C}^{12} \mathrm{HN}^{14}{ }_{*}$ & 4-1205 & $10,7,3 \leftarrow 10,7,4$ & Ground & & & & 19898.3 & \\
\hline $\mathrm{C}^{12} \mathrm{HD}_{2} \mathrm{C}^{12} \mathrm{HDF}^{19}$ & 3- 558 & $2,1,1 \leftarrow 2,0,2$ & Ground & & & & 19898.9 & .1 \\
\hline
\end{tabular}




\begin{tabular}{|c|c|c|c|c|c|c|c|}
\hline Isotopic Species & $\begin{array}{l}\text { Vol.-Id. } \\
\text { Nos. }\end{array}$ & $\begin{array}{c}\text { Rotational } \\
\text { Quantum Nos. }\end{array}$ & Vib. State & $\mathrm{F}_{1}^{\prime} \stackrel{\text { Hyperfin }}{\mathrm{F}^{\prime}} \quad \mathrm{F}_{1}$ & $\mathrm{~F}$ & $\begin{array}{c}\text { Frequency } \\
\mathrm{MHz}\end{array}$ & $\begin{aligned} & \text { Acc. } \\
\pm & \mathrm{MHz}\end{aligned}$ \\
\hline $\mathrm{C}^{12} \mathrm{H}_{2}\left(\mathrm{C}^{12} \mathrm{~N}^{14}\right)_{2}$ & 4- 901 & Not Reported & Ground & & & 19902.9 & .1 \\
\hline $\mathrm{C}^{12} \mathrm{D}_{3} \mathrm{O}^{16} \mathrm{H}$ & 3- 214 & Not Reported & Ground & & & 19905.8 & .5 \\
\hline $\mathrm{C}^{12} \mathrm{H}_{3} \mathrm{~S}^{32} \mathrm{H}$ & 3- 221 & Not Reported & Ground & & & 19912.2 & .1 \\
\hline $\mathrm{C}^{12}{ }_{*} \mathrm{H}_{2} \mathrm{C}^{12} \mathrm{H}: \mathrm{C}^{12} \mathrm{HC}^{12} \mathrm{H}: \mathrm{C}^{12}{ }_{*} \mathrm{H}$ & 4-1231 & $6,4,2 \leftarrow 6,3,3$ & Ground & & & 19914.7 & .1 \\
\hline $\mathrm{C}^{12} \mathrm{H}_{2} \mathrm{Cl}^{37} \mathrm{~F}^{19}$ & 4- 332 & $20,2,19 \leftarrow 19,3,16$ & Ground & & & 19917.48 & .1 \\
\hline $\mathrm{F}_{2}^{19} \mathrm{~N}^{14} \mathrm{~N}^{14} \mathrm{~F}_{2}^{19}$ & $3-\quad 21$ & $2,2,1 \leftarrow 1,1,1$ & Ground & & & 19917.9 & .2 \\
\hline $\mathrm{C}^{12} \mathrm{H}_{2} \mathrm{Cl}^{37} \mathrm{~F}^{19}$ & 4- 332 & $20,2,19 \leftarrow 19,3,16$ & Ground & & & 19919.07 & .1 \\
\hline $\mathrm{C}^{12} \mathrm{H}_{3} \mathrm{~N}^{14} \mathrm{H}_{2}$ & 3- 261 & Not Reported & Ground & & & 19919.56 & .04 \\
\hline $\mathrm{t}-\mathrm{C}^{12} \mathrm{H}_{2} \mathrm{DC}^{12} \mathrm{H}_{2} \mathrm{Cl}^{35}$ & 3- 543 & $2,1,1 \leftarrow 1,1,0$ & Ground & $5 / 2$ & $3 / 2$ & 19923.90 & .05 \\
\hline $\mathrm{S}^{32}{ }_{*} \mathrm{DC}^{12}: \mathrm{C}^{12} \mathrm{DC}^{12} \mathrm{D}: \mathrm{C}^{12}{ }_{*} \mathrm{D}$ & 4-1165 & $3,0,3 \leftarrow 2,0,2$ & Ground & & & 19925.3 & .1 \\
\hline $\mathrm{t}-\mathrm{C}^{12} \mathrm{H}_{2} \mathrm{DC}^{12} \mathrm{H}_{2} \mathrm{Cl}^{35}$ & 3- 543 & $2,1,1 \leftarrow 1,1,0$ & Ground & $3 / 2$ & $3 / 2$ & 19926.35 & .05 \\
\hline $\mathrm{C}^{12} \mathrm{H}_{3} \mathrm{C}^{12} \mathrm{O}^{16} \mathrm{Cl}^{35}$ & 3- 361 & $3,0,3 \leftarrow 2,1,2$ & Ground & $7 / 2$ & $5 / 2$ & 19926.80 & .2 \\
\hline $\mathrm{C}^{12} \mathrm{H}_{3} \mathrm{C}^{12} \mathrm{O}^{16} \mathrm{Cl}^{35}$ & 3- 361 & $3,0,3 \leftarrow 2,1,2$ & Ground & $5 / 2$ & $3 / 2$ & 19928.25 & .2 \\
\hline $\mathrm{C}^{12} \mathrm{H}_{3} \mathrm{~N}^{14} \mathrm{C}^{12} \mathrm{~S}^{34}$ & 3- 425 & $4, \quad \leftarrow 3$, & & & & 19929. & \\
\hline $\mathrm{C}^{12} \mathrm{H}_{3} \mathrm{C}^{12} \mathrm{O}^{16} \mathrm{Cl}^{35}$ & 3- 361 & $3,0,3 \leftarrow 2,1,2$ & Ground & $5 / 2$ & $5 / 2$ & 19932.10 & .2 \\
\hline $\mathrm{t}-\mathrm{C}^{12} \mathrm{H}_{2} \mathrm{DC}^{12} \mathrm{H}_{2} \mathrm{Cl}^{35}$ & 3- 543 & $2,1,1 \leftarrow 1,1,0$ & Ground & $5 / 2$ & $5 / 2$ & 19932.95 & .05 \\
\hline $\mathrm{C}^{12} \mathrm{H}_{3} \mathrm{~N}^{14} \mathrm{H}_{2}$ & 3- 261 & Not Reported & Ground & & & 19933.82 & .1 \\
\hline $\mathrm{C}^{12} \mathrm{H}_{3} \mathrm{C}^{12} \mathrm{O}^{16} \mathrm{Cl}^{35}$ & 3- 361 & $3,0,3 \leftarrow 2,1,2$ & Ground & $9 / 2$ & $7 / 2$ & 19934.00 & .2 \\
\hline $\mathrm{C}^{12} \mathrm{H}_{3} \mathrm{C}^{12} \mathrm{O}^{16} \mathrm{C}^{12} \mathrm{~N}^{14}$ & 3- 671 & $7,2,5 \leftarrow 7,1,6$ & Ground & & & 19935.72 & .2 \\
\hline $\mathrm{C}^{12} \mathrm{H}_{3} \mathrm{C}^{12} \mathrm{O}^{16} \mathrm{Cl}^{35}$ & 3- 361 & $3,0,3 \leftarrow 2,1,2$ & Ground & $3 / 2$ & $1 / 2$ & 19936.00 & .2 \\
\hline $\mathrm{t}-\mathrm{C}^{12} \mathrm{H}_{2} \mathrm{DC}^{12} \mathrm{H}_{2} \mathrm{Cl}^{35}$ & 3- 543 & $2,1,1 \leftarrow 1,1,0$ & Ground & $7 / 2$ & $5 / 2$ & 19936.20 & .05 \\
\hline $\mathrm{C}^{12} \mathrm{H}_{3} \mathrm{C}^{12} \mathrm{O}^{16} \mathrm{C}^{12} \mathrm{~N}^{14}$ & 3- 671 & $7,2,5 \leftarrow 7,1,6$ & Ground & & & 19939.43 & .2 \\
\hline $\mathrm{C}^{12}{ }_{*} \mathrm{H}: \mathrm{C}^{12} \mathrm{HO}^{16} \mathrm{C}^{12} \mathrm{H}: \mathrm{C}^{12}{ }_{*} \mathrm{D}$ & 4-1155 & $4,4,1 \leftarrow 4,2,2$ & Ground & & & 19939.7 & \\
\hline $\mathrm{Si}^{30} \mathrm{D}_{2} \mathrm{~F}_{2}^{19}$ & 4-1605 & $4,1,3 \leftarrow 4,0,4$ & Ground & & & 19940.69 & .10 \\
\hline $\mathrm{C}^{12} \mathrm{H}_{3} \mathrm{C}^{12} \mathrm{O}^{16} \mathrm{Cl}^{35}$ & 3- 361 & $3,0,3 \leftarrow 2,1,2$ & Ground & $3 / 2$ & $3 / 2$ & 19941.80 & .2 \\
\hline $\mathrm{t}-\mathrm{C}^{12} \mathrm{H}_{2} \mathrm{DC}^{12} \mathrm{H}_{2} \mathrm{Cl}^{35}$ & 3- 543 & $2,1,1 \leftarrow 1,1,0$ & Ground & $3 / 2$ & $1 / 2$ & 19942.45 & .05 \\
\hline $\mathrm{C}^{12} * \mathrm{H}: \mathrm{C}^{12} \mathrm{HO}^{16} \mathrm{C}^{12} \mathrm{D}: \mathrm{C}^{12}{ }_{*} \mathrm{H}$ & 4-1154 & $6,4,2 \leftarrow 6,3,3$ & Ground & & & 19942.6 & \\
\hline $\mathrm{H}_{2} \mathrm{~B}^{11} \mathrm{H}_{2} \mathrm{~B}^{10} \mathrm{HBr}^{81}$ & 4- 46 & $3,1,2 \leftarrow 2,1,1$ & Ground & $9 / 2$ & $7 / 2$ & 19942.8 & \\
\hline$\left(\mathrm{C}^{12} \mathrm{H}_{3}\right)_{2} \mathrm{C}^{12}: \mathrm{C}^{12} \mathrm{HD}$ & 3- 944 & $3,1,2 \leftarrow 3,1,3$ & Ground & & & 19944.54 & \\
\hline $\mathrm{H}_{2} \mathrm{~N}^{14} \mathrm{~N}^{14} \mathrm{H}_{2}$ & $3-\quad 51$ & Not Reported & & & & 19945.6 & \\
\hline t- $\mathrm{C}^{12} \mathrm{H}_{2} \mathrm{DC}^{12} \mathrm{H}_{2} \mathrm{Cl}^{35}$ & 3- 543 & $2,1,1 \leftarrow 1,1,0$ & Ground & $1 / 2$ & $1 / 2$ & 19945.95 & .05 \\
\hline$\left(\mathrm{C}^{12} \mathrm{H}_{3}\right)_{2} \mathrm{C}^{12}: \mathrm{C}^{13} \mathrm{H}_{2}$ & 3- 946 & $4,2,2 \leftarrow 4,1,3$ & Ground & & & 19947.74 & \\
\hline $\mathrm{C}^{12}{ }_{*} \mathrm{HC}^{12} \mathrm{H}: \mathrm{C}^{12} \mathrm{DC}^{12} \mathrm{H}: \mathrm{C}^{12} \mathrm{HN}^{14} *$ & 4-1204 & $3,1,3 \leftarrow 2,1,2$ & Ground & & & 19950.7 & .1 \\
\hline $\mathrm{C}_{6}^{12} \mathrm{H}_{5} \mathrm{~F}^{19}$ & 4-1281 & $7,1,6 \leftarrow 7,1,7$ & Ground & & & 19953.0 & .1 \\
\hline $\mathrm{HC}^{13}: \mathrm{C}^{12} \mathrm{C}^{12} \mathrm{DO}^{16}$ & 4. 922 & Not Reported & & & & 19955. & 5. \\
\hline $\mathrm{Si}^{29} \mathrm{D}_{2} \mathrm{~F}_{2}^{19}$ & $4-1604$ & $4,1,3 \leftarrow 4,0,4$ & Ground & & & 19955.10 & .10 \\
\hline $\mathrm{H}_{2} \mathrm{~B}^{11} \mathrm{H}_{2} \mathrm{~B}^{10} \mathrm{HBr}^{81}$ & 4- 46 & $3,1,2 \leftarrow 2,1,1$ & Ground & $7 / 2$ & $5 / 2$ & 19958.6 & \\
\hline $\mathrm{C}^{12} \mathrm{HCl}^{35}: \mathrm{C}^{12} \mathrm{~F}_{2}^{19}$ & 4- 611 & $3,1,3 \leftarrow 2,0,2$ & Ground & $5 / 2$ & $3 / 2$ & 19961.4 & .5 \\
\hline $\mathrm{s}-\mathrm{C}^{12} \mathrm{H}_{2} \mathrm{D}\left(\mathrm{C}^{12} \mathrm{H}_{3}\right)_{2} \mathrm{Si}^{\mathrm{b}} \mathrm{D}$ & 3- 881 & $2,2,0 \leftarrow 1,1,0$ & Ground & & & 19962.62 & .10 \\
\hline $\mathrm{Si}^{29} \mathrm{H}_{3} \mathrm{C}^{12} \mathrm{H}: \mathrm{C}^{12} \mathrm{H}_{2}$ & 3- 613 & $2,0,2 \leftarrow 1,0,1$ & Cround & & & 19962.92 & .10 \\
\hline $\mathrm{C}^{12} \mathrm{HCl}^{35}: \mathrm{C}^{12} \mathrm{~F}_{2}^{19}$ & 4- 611 & $3,1,3 \leftarrow 2,0,2$ & Ground & $9 / 2$ & $7 / 2$ & 19964.0 & .5 \\
\hline $\mathrm{C}^{12} \mathrm{HCl}^{35}: \mathrm{C}^{12} \mathrm{~F}_{2}^{19}$ & 4- 611 & $3,1,3 \leftarrow 2,0,2$ & Ground & $7 / 2$ & $5 / 2$ & 19965.3 & .5 \\
\hline $\mathrm{C}^{12} \mathrm{H}_{3} \mathrm{C}^{12} \mathrm{O}^{16} \mathrm{Br}^{81}$ & 3- 352 & $7,1,6 \leftarrow 7,0,7$ & Ground & $11 / 2$ & $11 / 2$ & 19966.22 & .15 \\
\hline $\mathrm{C}^{12} \mathrm{H}_{3} \mathrm{O}^{16} \mathrm{H}$ & 3- 211 & $2,1, \leftarrow 3,0$, & Ground & & & 19967. & \\
\hline $\mathrm{C}^{12} \mathrm{H}_{3} \mathrm{C}^{12} \mathrm{O}^{16} \mathrm{Br}^{81}$ & 3- 352 & $7,1,6 \leftarrow 7,0,7$ & Ground & $11 / 2$ & $11 / 2$ & 19969.09 & .15 \\
\hline
\end{tabular}




\begin{tabular}{|c|c|c|c|c|c|c|c|}
\hline Isotopic Species & $\begin{array}{c}\text { Vol.-Id. } \\
\text { Nos. }\end{array}$ & $\begin{array}{c}\text { Rotational } \\
\text { Quantum Nos. }\end{array}$ & Vil. State & $F_{1}^{\prime} \stackrel{\text { Hyperfin }}{F^{\prime}} \quad F_{1}$ & $F$ & $\begin{array}{c}\text { Frecguency } \\
\text { MHz }\end{array}$ & $\begin{aligned} & \text { A } \bullet \% . \\
\pm & \mathrm{MHz}\end{aligned}$ \\
\hline $\mathrm{C}^{12} \mathrm{H}_{3} \mathrm{C}^{12} \mathrm{O}^{16} \mathrm{Br}^{81}$ & 3. 352 & $7,1,6 \leftarrow 7,0,7$ & Ground & $17 / 2$ & $17 / 2$ & 19969.09 & .15 \\
\hline $\mathrm{C}^{12} \mathrm{HCl}^{35}: \mathrm{C}^{12} \mathrm{~F}_{2}^{19}$ & 4- 611 & $3,1,3 \leftarrow 2,0,2$ & Ground & $5 / 2$ & $5 / 2$ & 19970.6 & .5 \\
\hline $\mathrm{C}_{6}^{12} \mathrm{H}_{5} \mathrm{C}^{12} \mathrm{~N}^{15}$ & 4-1292 & $8,1,8 \leftarrow 7,1,7$ & Ground & & & 19970.6 & .2 \\
\hline $\mathrm{C}^{12} \mathrm{H}_{3} \mathrm{C}^{12} \mathrm{O}^{16} \mathrm{Br}^{81}$ & 3- 352 & $7,1,6 \leftarrow 7,0,7$ & Ground & $17 / 2$ & $17 / 2$ & 19971.96 & .15 \\
\hline $\mathrm{Si}^{28} \mathrm{D}_{2} \mathrm{~F}_{2}^{19}$ & $4-1603$ & $4,1,3 \leftarrow 4,0,4$ & Ground & & & 19972.85 & .10 \\
\hline $\mathrm{C}^{12} \mathrm{H}_{3} \mathrm{C}^{12} \mathrm{H}_{2} \mathrm{Cl}^{37}$ & 3- 542 & $2,1,2 \leftarrow 1,1,1$ & Ground & $5 / 2$ & $3 / 2$ & 19973.43 & .05 \\
\hline $\mathrm{C}^{12} \mathrm{H}_{3} \mathrm{C}^{12} \mathrm{H}_{2} \mathrm{Cl}^{37}$ & 3- 542 & $2,1,2 \leftarrow 1,1,1$ & Ground & $5 / 2$ & $5 / 2$ & 19976.16 & .05 \\
\hline $\mathrm{C}^{12} \mathrm{H}_{3} \mathrm{C}^{12} \mathrm{~F}^{19}: \mathrm{C}^{12} \mathrm{H}_{2}$ & 3. 721 & $5,3,2 \leftarrow 5,2,3$ & Ground & & & 19977.08 & .1 \\
\hline $\mathrm{C}^{12} \mathrm{H}_{3} \mathrm{C}^{12} \mathrm{~F}^{19}: \mathrm{C}^{12} \mathrm{H}_{2}$ & 3- 721 & $4,4,1 \leftarrow 4,3,2$ & Ground & & & 19977.08 & .1 \\
\hline $\mathrm{c}-\mathrm{HCl}^{35} \mathrm{C}^{12}: \mathrm{C}^{12} \mathrm{HCl}^{35}$ & 4. 671 & $8,1,7 \leftarrow 8,0,8$ & Ground & & & 19977.83 & \\
\hline $\mathrm{C}^{12} \mathrm{H}_{3} \mathrm{C}^{12} \mathrm{H}_{2} \mathrm{Cl}^{37}$ & 3- 542 & $2,1,2 \leftarrow 1,1,1$ & Ground & $3 / 2$ & $3 / 2$ & 19978.51 & .05 \\
\hline $\mathrm{C}^{12} \mathrm{H}_{3} \mathrm{C}^{12} \mathrm{O}^{16} \mathrm{Br}^{81}$ & 3- 352 & $7,1,6 \leftarrow 7,0,7$ & Ground & $13 / 2$ & $13 / 2$ & 19978.80 & .15 \\
\hline $\mathrm{H}_{2} \mathrm{~N}^{14} \mathrm{C}^{12} \mathrm{~N}^{14}$ & 4. 361 & $1,0, \leftarrow 0,0$, & Excited & & & 19980.0 & .2 \\
\hline $\mathrm{C}^{12} \mathrm{H}_{3} \mathrm{C}^{12} \mathrm{O}^{16} \mathrm{Br}^{81}$ & 3- 352 & $7,1,6 \leftarrow 7,0,7$ & Ground & $13 / 2$ & $13 / 2$ & 19981.44 & .15 \\
\hline $\mathrm{C}^{12} \mathrm{H}_{3} \mathrm{C}^{12} \mathrm{O}^{16} \mathrm{Br}^{81}$ & 3- 352 & $7,1,6 \leftarrow 7,0,7$ & Ground & $15 / 2$ & $15 / 2$ & 19981.44 & .15 \\
\hline $\mathrm{C}^{12} \mathrm{H}_{3} \mathrm{C}^{12} \mathrm{H}_{2} \mathrm{Cl}^{37}$ & 3- 542 & $2,1,2 \leftarrow 1,1,1$ & Ground & $7 / 2$ & $5 / 2$ & 19983.22 & .05 \\
\hline $\mathrm{C}^{12} \mathrm{H}_{3} \mathrm{C}^{12} \mathrm{O}^{16} \mathrm{Br}^{81}$ & 3- 352 & $7,1,6 \leftarrow 7,0,7$ & Ground & $15 / 2$ & $15 / 2$ & 19984.18 & .15 \\
\hline $\mathrm{C}^{12}{ }_{*} \mathrm{H}_{2} \mathrm{C}^{12} \mathrm{H}_{2} \mathrm{C}^{12}{ }_{*} \mathrm{HC}^{12} \mathrm{~N}^{14}$ & 4-1171 & $3,1,3 \leftarrow 2,1,2$ & Ground & & & 19984.59 & .05 \\
\hline $\mathrm{N}^{15} \mathrm{H}_{3}$ & 4-1772 & $6,4 \leftarrow 6,4$ & Ground & & & 19984.75 & .06 \\
\hline $\mathrm{a}-\mathrm{C}^{12} \mathrm{H}_{2} \mathrm{DC}^{12} \mathrm{O}^{16} \mathrm{Cl}^{35}$ & 3- 366 & $7,3,4 \leftarrow 7,2,5$ & Ground & & & 19987.2 & .2 \\
\hline $\mathrm{a} \cdot \mathrm{C}^{12} \mathrm{H}_{2} \mathrm{DC}^{12} \mathrm{O}^{16} \mathrm{Cl}^{35}$ & 3- 366 & $7,3,4 \leftarrow 7,2,5$ & Ground & & & 19988.0 & .2 \\
\hline $\mathrm{C}^{12} \mathrm{H}_{3} \mathrm{C}^{12} \mathrm{H}_{2} \mathrm{Cl}^{37}$ & 3- 542 & $2,1,2 \leftarrow 1,1,1$ & Ground & $1 / 2$ & $1 / 2$ & 19990.44 & .05 \\
\hline $\mathrm{C}^{12}{ }_{*} \mathrm{HC}^{12} \mathrm{D}: \mathrm{C}^{12} \mathrm{HC}^{12} \mathrm{H}: \mathrm{C}^{12} \mathrm{HN}^{14}{ }_{*}$ & $4-1203$ & $3,1,3 \leftarrow 2,1,2$ & Ground & & & 19993.5 & .1 \\
\hline $\mathrm{C}^{12} \mathrm{H}_{3} \mathrm{Si}^{\mathrm{b}} \mathrm{HD}_{2}$ & 3- 326 & $1,0,1 \leftarrow 0,0,0$ & & & & 19995.56 & .1 \\
\hline $\mathrm{H}_{2} \mathrm{~N}^{14} \mathrm{C}^{12} \mathrm{~N}^{14}$ & 4- 361 & $1,0, \leftarrow 0,0$, & Ground & & & 19995.8 & .2 \\
\hline $\mathrm{C}^{12} \mathrm{H}_{3} \mathrm{C}^{12} \mathrm{O}^{16} \mathrm{Br}^{81}$ & 3- 352 & $4,1,4 \leftarrow 3,1,3$ & Ground & $11 / 2$ & $9 / 2$ & 19999.26 & .15 \\
\hline $\mathrm{C}^{12} \mathrm{~F}_{3}^{19} \mathrm{Cl}^{35}$ & 4- 161 & $3,2 \leftarrow 2,2$ & Ground & $5 / 2$ & $5 / 2$ & 19999.66 & \\
\hline $\mathrm{C}^{12} \mathrm{~F}_{3}^{19} \mathrm{Cl}^{35}$ & 4- 161 & $3,2 \leftarrow 2,2$ & Ground & $7 / 2$ & $5 / 2$ & 19999.66 & \\
\hline $\mathrm{C}^{12} \mathrm{H}_{3} \mathrm{~S}^{32} \mathrm{H}$ & 3- 221 & Not Reported & Ground & & & 19999.9 & .1 \\
\hline$\left(\mathrm{C}^{12} \mathrm{D}_{3}\right)_{3} \mathrm{C}^{12} \mathrm{Cl}^{37}$ & 3- 977 & $4, \leftarrow 3,5$ & Ground & & & 20001.5 & 3. \\
\hline $\mathrm{C}^{12} \mathrm{H}_{3} \mathrm{C}^{12} \mathrm{O}^{16} \mathrm{Br}^{81}$ & 3- 352 & $4,1,4 \leftarrow 3,1,3$ & Ground & $5 / 2$ & $3 / 2$ & 20003.13 & .15 \\
\hline $\mathrm{C}^{12} \mathrm{H}_{2} \mathrm{Cl}^{35} \mathrm{Si}^{28} \mathrm{D}_{3}$ & 3- 237 & $9,1,8 \leftarrow 9,0,9$ & Ground & & & 20003.13 & .2 \\
\hline $\mathrm{t}-\mathrm{DHC} \mathrm{C}^{12}: \mathrm{C}^{12} \mathrm{DF}^{19}$ & 4- 791 & $4,1,3 \leftarrow 4,1,4$ & Ground & & & 20004.8 & .1 \\
\hline $\mathrm{C}^{12} \mathrm{H}_{3} \mathrm{C}^{12} \mathrm{O}^{16} \mathrm{Br}^{81}$ & 3- 352 & $4,1,4 \leftarrow 3,1,3$ & Ground & $9 / 2$ & $7 / 2$ & 20007.96 & .15 \\
\hline $\mathrm{C}^{13} \mathrm{H}_{3}\left(\mathrm{C}^{12} \mathrm{H}_{3}\right)_{2} \mathrm{C}^{12} \mathrm{C}^{12} \vdots \mathrm{C}^{12} \mathrm{D}$ & $3-1078$ & $4,1,4 \leftarrow 3,1,3$ & Ground & & & 20009.0 & .1 \\
\hline $\mathrm{N}^{15} \mathrm{H}_{3}$ & 4-1772 & $11,9 \leftarrow 11,9$ & Ground & & & 20010.05 & .08 \\
\hline $\mathrm{C}^{12} \mathrm{~F}_{3}^{19} \mathrm{Cl}^{35}$ & 4- 161 & $3,1 \leftarrow 2,1$ & Ground & $7 / 2$ & $5 / 2$ & 20010.84 & \\
\hline $\mathrm{C}^{12} \mathrm{~F}_{3}^{19} \mathrm{Cl}^{35}$ & 4- 161 & $3,1 \leftarrow 2,1$ & Ground & $5 / 2$ & $3 / 2$ & 20010.84 & \\
\hline $\mathrm{C}^{12} \mathrm{H}_{2} \mathrm{Cl}^{37} \mathrm{~F}^{19}$ & 4- 332 & $18,1,18 \leftarrow 17,2,15$ & Ground & & & $20011.2 \dot{2}$ & .1 \\
\hline $\mathrm{C}^{12} \mathrm{H}_{3} \mathrm{C}^{12} \mathrm{O}^{16} \mathrm{Br}^{81}$ & 3- 352 & $4,1,4 \leftarrow 3,1,3$ & Ground & $7 / 2$ & $5 / 2$ & 20012.11 & .15 \\
\hline $\mathrm{C}^{12} \mathrm{~F}_{3}^{19} \mathrm{Cl}^{35}$ & 4. 161 & $3,2 \leftarrow 2,2$ & Ground & $3 / 2$ & $3 / 2$ & 20013.68 & \\
\hline $\mathrm{C}^{12} \mathrm{~F}_{3}^{19} \mathrm{Cl}^{35}$ & 4- 161 & $3,2 \leftarrow 2,2$ & Ground & $5 / 2$ & $3 / 2$ & 20013.68 & \\
\hline $\mathrm{C}^{12} \mathrm{~F}_{3}^{19} \mathrm{Cl}^{35}$ & 4. 161 & $3,1 \leftarrow 2,1$ & Ground & $3 / 2$ & $1 / 2$ & 20015.77 & \\
\hline $\mathrm{C}^{12} \mathrm{~F}_{3}^{19} \mathrm{Cl}^{35}$ & 4- 161 & $3,1 \leftarrow 2,1$ & Ground & $9 / 2$ & $7 / 2$ & 20015.77 & \\
\hline $\mathrm{C}^{12} \mathrm{H}_{2} \mathrm{Cl}^{37} \mathrm{~F}^{19}$ & 4- 332 & $18,1,18 \leftarrow 17,2,15$ & Ground & & & 20016.47 & .1 \\
\hline
\end{tabular}




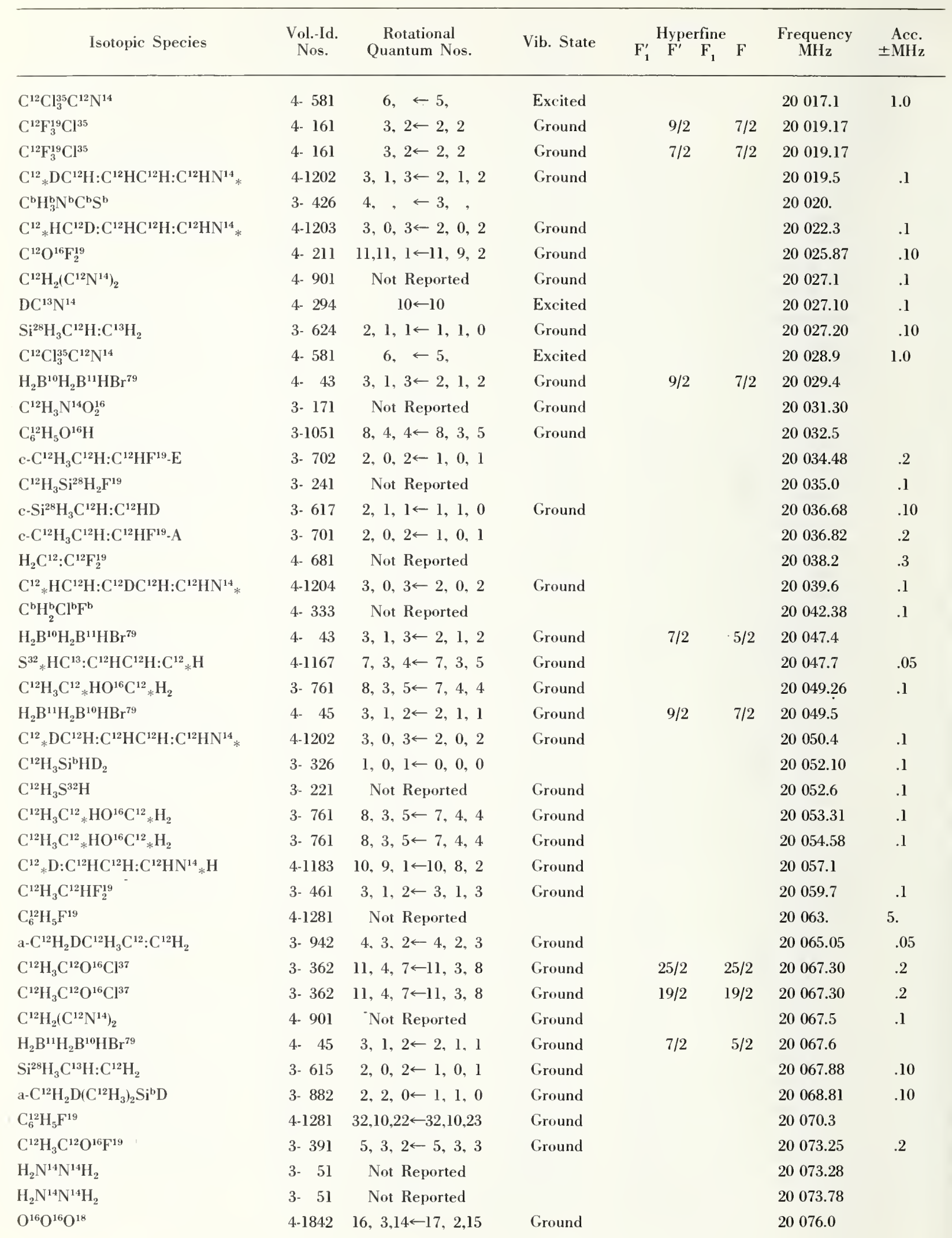




\begin{tabular}{|c|c|c|c|c|c|c|c|}
\hline Isotopic Species & $\begin{array}{l}\text { Vol.-Id. } \\
\text { Nos. }\end{array}$ & $\begin{array}{c}\text { Rotational } \\
\text { Quantum Nos. }\end{array}$ & Vib. Statc & $\mathrm{F}_{1}^{\prime} \mathrm{F}^{\text {Hyperfine }} \quad \mathrm{F}_{1}$ & $\mathbf{F}$ & $\begin{array}{c}\text { Frequency } \\
\mathrm{MHz}^{2}\end{array}$ & $\begin{array}{r}\text { Acc. } \\
\pm \mathrm{MHz}\end{array}$ \\
\hline $\mathrm{C}^{12} \mathrm{H}_{3} \mathrm{~N}^{14} \mathrm{H}_{2}$ & $3-261$ & Not Reported & Ground & & & 20076.00 & .04 \\
\hline $\mathrm{Cl}^{35} \mathrm{~F}_{3}^{19}$ & 4-1371 & $5,1,4 \leftarrow 5,0,5$ & Ground & $7 / 2$ & $7 / 2$ & 20078.22 & .15 \\
\hline $\mathrm{C}^{12} \mathrm{H}_{3} \mathrm{~N}^{14} \mathrm{O}_{2}^{16}$ & 3- 171 & Not Reported & Ground & & & 20084.41 & \\
\hline $\mathrm{C}^{12}{ }_{*} \mathrm{H}_{2} \mathrm{C}^{12} \mathrm{H}: \mathrm{C}^{12} \mathrm{HC}^{12} \mathrm{H}: \mathrm{C}^{12}{ }_{*} \mathrm{H}$ & 4-1231 & $5,3,2 \leftarrow 5,2,3$ & Ground & & & 20085.22 & .1 \\
\hline $\mathrm{Si}^{28} \mathrm{H}_{2} \mathrm{~F}_{2}^{19}$ & 4-1601 & $2,1,1 \leftarrow 2,0,2$. & Excited & & & 20091.49 & .10 \\
\hline $\mathrm{C}^{12} \mathrm{H}_{2}\left(\mathrm{C}^{12} \mathrm{~N}^{14}\right)_{2}$ & 4- 901 & Not Reported & Ground & & & 20093.5 & .1 \\
\hline $\mathrm{C}^{12} \mathrm{H}_{3} \mathrm{C}^{12} \mathrm{O}^{16} \mathrm{~F}^{19}$ & 3- 391 & $5,3,2 \leftarrow 5,3,3$ & Ground & & & 20094.58 & .2 \\
\hline $\mathrm{C}^{12} \mathrm{H}_{3} \mathrm{C}^{12} \mathrm{O}^{16} \mathrm{~F}^{19}$ & 3- 391 & Not Reported & Ground & & & 20095.87 & .2 \\
\hline $\mathrm{C}_{6}^{12} \mathrm{H}_{5} \mathrm{C}^{12} \mathrm{~N}^{14}$ & 4-1291 & $7,2,5 \leftarrow 6,2,4$ & Ground & & & 20096.3 & \\
\hline $\mathrm{HC}^{13}: \mathrm{C}^{12} \mathrm{C}^{12} \mathrm{DO}^{16}$ & 4- 922 & Not Reported & & & & 20098. & 5. \\
\hline $\mathrm{C}^{12} \mathrm{H}_{3} \mathrm{C}^{13} \mathrm{O}^{16} \mathrm{~F}^{19}$ & 3- 399 & $5,3,2 \leftarrow 5,3,3$ & Ground & & & 20099.10 & .2 \\
\hline $\mathrm{C}^{12} \mathrm{H}_{3} \mathrm{C}^{13} \mathrm{O}^{16} \mathrm{~F}^{19}$ & 3- 399 & $5,3,2 \leftarrow 5,3,3$ & Ground & & & 20099.20 & .2 \\
\hline $\mathrm{C}^{12} \mathrm{H}_{3} \mathrm{C}^{12}: \mathrm{C}^{12} \mathrm{C}^{12} \mathrm{H}_{2} \mathrm{Cl}^{35}$ & 3. 901 & $7,0,7 \leftarrow 6,0,6$ & Ground & & & 20100 & \\
\hline$c-\mathrm{HF}^{19} \mathrm{C}^{12}: \mathrm{C}^{12} \mathrm{HF}^{19}$ & 4- 691 & $3,1,2 \leftarrow 3,0,3$ & Ground & & & 20101.45 & .05 \\
\hline $\mathrm{t}-\mathrm{HDN}^{14} \mathrm{C}^{12} \mathrm{HO}^{16}$ & 3- 153 & $5,1,4 \leftarrow 5,1,5$ & Ground & 5 & 5 & 20103.88 & .1 \\
\hline $\mathrm{C}^{12} \mathrm{H}_{3} \mathrm{~N}^{14} \mathrm{C}^{12}$ & 4- 831 & $1,0 \leftarrow 0,0$ & Ground & & & 20105.76 & .1 \\
\hline $\mathrm{t}-\mathrm{HDN} \mathrm{N}^{14} \mathrm{C}^{12} \mathrm{HO}^{16}$ & 3- 153 & $5,1,4 \leftarrow 5,1.5$ & Ground & 6 & 6 & 20105.84 & .1 \\
\hline $\mathrm{t}-\mathrm{HDN}^{14} \mathrm{C}^{12} \mathrm{HO}^{16}$ & 3- 153 & $5,1,4 \leftarrow 5,1,5$ & Ground & 4 & 4 & 20105.84 & .1 \\
\hline $\mathrm{C}^{13} \mathrm{H}_{3}\left(\mathrm{C}^{12} \mathrm{H}_{3}\right)_{2} \mathrm{C}^{12} \mathrm{C}^{12}: \mathrm{C}^{12} \mathrm{D}$ & $3-1078$ & $4,1,3 \leftarrow 3,1,2$ & Ground & & & 20112.4 & .1 \\
\hline $\mathrm{s}-\mathrm{C}^{12} \mathrm{H}_{2} \mathrm{D}\left(\mathrm{C}^{12} \mathrm{H}_{3}\right)_{2} \mathrm{Si}{ }^{\mathrm{b}} \mathrm{D}$ & 3- 881 & $2,2,1 \leftarrow 1,1,1$ & Ground & & & 20116.38 & .10 \\
\hline $\mathrm{C}^{12}{ }_{*} \mathrm{HC}^{12} \mathrm{D}: \mathrm{C}^{12} \mathrm{HC}^{12} \mathrm{H}: \mathrm{C}^{12} \mathrm{HN}^{14} *$ & 4-1203 & $9,7,3 \leftarrow 9,5,4$ & Ground & & & 20116.7 & .1 \\
\hline $\mathrm{C}^{12}{ }_{*} \mathrm{D}: \mathrm{C}^{12} \mathrm{DC}^{12} \mathrm{D}: \mathrm{C}^{12} \mathrm{DN}^{14}{ }_{*} \mathrm{H}$ & 4-1185 & $8,8,1 \leftarrow 8,7,2$ & Ground & & & 20117.5 & \\
\hline c- $\mathrm{C}^{12} \mathrm{H}_{3} \mathrm{C}^{12} \mathrm{H}: \mathrm{C}^{12} \mathrm{HF}^{19}-\mathrm{E}$ & 3- 702 & $4,1,3 \leftarrow 4,0,4$ & & & & 20123.76 & .2 \\
\hline $\mathrm{C}^{12} \mathrm{HCl}^{35}: \mathrm{C}^{12} \mathrm{~F}_{2}^{19}$ & 4- 611 & $9,1,8 \leftarrow 8,2,7$ & Ground & & & 20128.1 & .1 \\
\hline $\mathrm{H}_{2} \mathrm{~N}^{15} \mathrm{C}^{12} \mathrm{HO}^{16}$ & 3- 156 & $1,1,1 \leftarrow 2,0,2$ & Ground & & & 20131.44 & \\
\hline $\mathrm{N}^{15} \mathrm{H}_{3}$ & $4-1772$ & $4,1 \leftarrow 4,1$ & Ground & & & 20131.53 & .12 \\
\hline$\left(\mathrm{C}^{12} \mathrm{H}_{3}\right)_{3} \mathrm{C}^{12} \mathrm{C}^{13} \vdots \mathrm{C}^{12} \mathrm{D}$ & $3-1076$ & $4, \leftarrow 3$, & Ground & & & 20134.6 & .1 \\
\hline $\mathrm{C}^{12} \mathrm{H}_{2}\left(\mathrm{C}^{12} \mathrm{~N}^{14}\right)_{2}$ & 4- 901 & Not Reported & Ground & & & 20135.7 & .1 \\
\hline $\mathrm{C}^{12} \mathrm{H}_{3} \mathrm{C}^{12}: \mathrm{C}^{12} \mathrm{C}^{12} \mathrm{H}_{2} \mathrm{Cl}^{35}$ & 3- 901 & $7,3,5 \leftarrow 6,3,4$ & Ground & & & 20136.7 & .15 \\
\hline $\mathrm{C}^{12} \mathrm{H}_{3} \mathrm{C}^{12} \vdots \mathrm{C}^{12} \mathrm{C}^{12} \mathrm{H}_{2} \mathrm{Cl}^{35}$ & 3- 901 & $7,3,4 \leftarrow 6,3,3$ & Ground & & & 20136.7 & .15 \\
\hline c- $\mathrm{C}^{12} \mathrm{H}_{3} \mathrm{C}^{12} \mathrm{H}: \mathrm{C}^{12} \mathrm{HF}^{19}-\mathrm{A}$ & 3. 701 & $4,1,3 \leftarrow 4,0,4$ & & & & 20136.88 & .2 \\
\hline $\mathrm{C}^{12} \mathrm{H}_{3} \mathrm{C}^{12}: \mathrm{C}^{12} \mathrm{C}^{12} \mathrm{H}_{2} \mathrm{Cl}^{35}$ & 3. 901 & $7,4,4 \leftarrow 6,4,3$ & Ground & & & 20137.8 & .15 \\
\hline $\mathrm{C}^{12} \mathrm{H}_{3} \mathrm{C}^{12}: \mathrm{C}^{12} \mathrm{C}^{12} \mathrm{H}_{2} \mathrm{Cl}^{35}$ & 3. 901 & $7,4,3 \leftarrow 6,4,2$ & Ground & & & 20137.8 & .15 \\
\hline $\mathrm{C}^{12} \mathrm{H}_{3} \mathrm{~S}^{32} \mathrm{H}$ & 3- 221 & Not Reported & Ground & & & 20138.6 & .1 \\
\hline $\mathrm{C}^{12} \mathrm{H}_{3} \mathrm{C}^{12} \mathrm{O}^{16} \mathrm{Br}^{79}$ & 3- 351 & $4,1,4 \leftarrow 3,1,3$ & Ground & $11 / 2$ & $9 / 2$ & 20139.43 & .15 \\
\hline $\mathrm{C}^{12} \mathrm{H}_{3} \mathrm{~N}^{14} \mathrm{C}^{12} \mathrm{~S}^{32}$ & 3- 421 & $4,1,4 \leftarrow 3,1,3$ & Ground & & & 20140. & \\
\hline $\mathrm{HC}^{13}: \mathrm{C}^{12} \mathrm{C}^{12} \mathrm{DO}^{16}$ & 4. 922 & Not Reported & & & & 20142 & 5. \\
\hline $\mathrm{C}^{12} \mathrm{H}_{3} \mathrm{C}^{12} \mathrm{O}^{16} \mathrm{Cl}^{37}$ & 3- 362 & $2,1,2 \leftarrow 1,0,1$ & Ground & & & 20142.4 & .2 \\
\hline $\mathrm{C}^{12} \mathrm{H}_{2}\left(\mathrm{C}^{12} \mathrm{~N}^{14}\right)_{2}$ & 4- 901 & Not Reported & Ground & & & 20142.8 & .1 \\
\hline $\mathrm{C}^{\mathrm{b}} \mathrm{H}_{2}^{\mathrm{b}} \mathrm{Cl}^{\mathrm{b}} \mathrm{F}^{\mathrm{b}}$ & 4- 333 & Not Reported & & & & 20143.55 & 1. \\
\hline $\mathrm{C}^{12} \mathrm{H}_{3} \mathrm{C}^{12} \mathrm{O}^{16} \mathrm{Br}^{79}$ & 3- 351 & $4,1,4 \leftarrow 3,1,3$ & Ground & $5 / 2$ & $3 / 2$ & 20143.77 & .15 \\
\hline $\mathrm{C}_{6}^{12} \mathrm{H}_{5} \mathrm{O}^{16} \mathrm{H}$ & $3-1051$ & $8,4,4 \leftarrow 8,3,5$ & Ground & & & 20145.3 & \\
\hline $\mathrm{C}^{12} \mathrm{H}_{3} \mathrm{C}^{12} \mathrm{O}^{16} \mathrm{Cl}^{37}$ & 3- 362 & $2,1,2 \leftarrow 1,0,1$ & Ground & & & 20149.3 & .2 \\
\hline $\mathrm{C}^{12} \mathrm{H}_{3} \mathrm{C}^{12} \mathrm{O}^{16} \mathrm{Br}^{79}$ & 3- 351 & $4,1,4 \leftarrow 3,1,3$ & Ground & $9 / 2$ & $7 / 2$ & 20150.49 & .15 \\
\hline $\mathrm{C}^{12} \mathrm{H}_{3} \mathrm{C}^{12} \mathrm{O}^{16} \mathrm{Br}^{79}$ & 3- 351 & $4,1,4 \leftarrow 3,1,3$ & Ground & $7 / 2$ & $5 / 2$ & 20154.92 & .15 \\
\hline
\end{tabular}




\begin{tabular}{|c|c|c|c|c|c|c|c|}
\hline \multirow{2}{*}{ Isotopic Species } & \multirow{2}{*}{$\begin{array}{l}\text { Vol.-Id. } \\
\text { Nos. }\end{array}$} & \multirow{2}{*}{$\begin{array}{c}\text { Rotational } \\
\text { Quantum Nos. }\end{array}$} & \multirow{2}{*}{ Vib. State } & \multicolumn{2}{|c|}{ Hyperfine } & \multirow{2}{*}{$\begin{array}{l}\text { Frequency } \\
\mathrm{MHz}\end{array}$} & \multirow{2}{*}{$\begin{aligned} & \text { Acc. } \\
\pm & \mathrm{MHz}\end{aligned}$} \\
\hline & & & & $\begin{array}{lll}F_{1}^{\prime} & F^{\prime} & F_{1}\end{array}$ & $\mathrm{~F}$ & & \\
\hline $\mathrm{N}^{14} \mathrm{O}_{2}^{16} \mathrm{~F}^{19}$ & 4-1581 & $6,4,3 \leftarrow 6,4,2$ & Ground & & & 20155.1 & \\
\hline $\mathrm{Si}^{28} \mathrm{D}_{2} \mathrm{~F}_{2}^{19}$ & $4-1603$ & $4,1,3 \leftarrow 4,0,4$ & Excited & & & 20155.80 & .10 \\
\hline $\mathrm{C}^{12}{ }_{*} \mathrm{DC}^{12} \mathrm{H}: \mathrm{C}^{12} \mathrm{HC}^{12} \mathrm{H}: \mathrm{C}^{12} \mathrm{HN}^{14} *$ & 4-1202 & $9,7,3 \leftarrow 9,5,4$ & Ground & & & 20160.8 & .1 \\
\hline $\mathrm{D}_{2} \mathrm{C}^{12}: \mathrm{C}^{12} \mathrm{DCl}^{35}$ & 4- 763 & $2,0,2 \leftarrow 1,0,1$ & Ground & $7 / 2$ & $5 / 2$ & 20161.10 & .2 \\
\hline $\mathrm{C}^{12} \mathrm{H}_{3} \mathrm{O}^{16} \mathrm{H}$ & 3- 211 & Not Reported & Ground & & & 20171.07 & .1 \\
\hline $\mathrm{C}^{12} \mathrm{H}_{3} \mathrm{C}^{12} \mathrm{O}^{16} \mathrm{Br}^{79}$ & 3- 351 & $7,1,6 \leftarrow 7,0,7$ & Ground & $11 / 2$ & $11 / 2$ & 20171.49 & .15 \\
\hline $\mathrm{C}^{12} \mathrm{D}_{3} \mathrm{C}^{12} \mathrm{O}^{16} \mathrm{Cl}^{35}$ & 3- 363 & $5,3,2 \leftarrow 5,2,3$ & Ground & $7 / 2$ & $7 / 2$ & 20171.82 & \\
\hline $\mathrm{C}^{12} \mathrm{D}_{3} \mathrm{C}^{12} \mathrm{O}^{16} \mathrm{Cl}^{35}$ & 3- 363 & $5,3,2 \leftarrow 5,2,3$ & Ground & $13 / 2$ & $13 / 2$ & 20173.96 & \\
\hline $\mathrm{C}^{12} \mathrm{H}_{3} \mathrm{C}^{12} \mathrm{O}^{16} \mathrm{Br}^{79}$ & 3. 351 & $7,1,6 \leftarrow 7,0,7$ & Ground & $17 / 2$ & $17 / 2$ & 20174.67 & .15 \\
\hline $\mathrm{C}^{12} \mathrm{H}_{3} \mathrm{C}^{12} \mathrm{O}^{16} \mathrm{Br}^{79}$ & 3- 351 & $7,1,6 \leftarrow 7,0,7$ & Ground & $11 / 2$ & $11 / 2$ & 20174.67 & .15 \\
\hline $\mathrm{Si}^{28} \mathrm{H}_{3} \mathrm{C}^{12} \mathrm{H}: \mathrm{C}^{12} \mathrm{H}_{2}$ & 3- 611 & $2,0,2 \leftarrow 1,0,1$ & Ground & & & 20174.75 & .05 \\
\hline$\left(\mathrm{C}^{12} \mathrm{H}_{3}\right)_{2} \mathrm{C}^{12}: \mathrm{C}^{13} \mathrm{H}_{2}$ & 3. 946 & $3,1,2 \leftarrow 3,0,3$ & Ground & & & 20174.97 & \\
\hline $2.4,6 \mathrm{~d}_{3}-\mathrm{C}_{6}^{12} \mathrm{H}_{5} \mathrm{~F}^{19}$ & 4-1284 & $5,2,4 \leftarrow 4,2,3$ & Ground & & & 20175.5 & .1 \\
\hline $\mathrm{Si}^{28} \mathrm{H}_{3} \mathrm{C}^{12} \mathrm{H}: \mathrm{C}^{12} \mathrm{H}_{2}$ & 3- 611 & $2,0,2 \leftarrow 1,0,1$ & Ground & & & 20176.20 & .05 \\
\hline g- $\mathrm{C}^{12} \mathrm{H}_{3} \mathrm{C}^{12} \mathrm{H}_{2} \mathrm{C}^{12} \mathrm{H}_{2} \mathrm{Cl}^{37}$ & 3. 774 & $2,1,2 \leftarrow 1,0,1$ & Ground & & & 20177.44 & .2 \\
\hline $\mathrm{C}^{12} \mathrm{H}_{3} \mathrm{C}^{12} \mathrm{O}^{16} \mathrm{Br}^{79}$ & 3- 351 & $7,1,6 \leftarrow 7,0,7$ & Ground & $17 / 2$ & $17 / 2$ & 20177.63 & .15 \\
\hline $\mathrm{C}^{12} \mathrm{D}_{3} \mathrm{C}^{12} \mathrm{O}^{16} \mathrm{Cl}^{35}$ & 3- 363 & $5,3,2 \leftarrow 5,2,3$ & Ground & $9 / 2$ & $9 / 2$ & 20179.30 & \\
\hline $\mathrm{C}^{12} \mathrm{H}_{2}\left(\mathrm{C}^{12} \mathrm{~N}^{14}\right)_{2}$ & 4- 901 & Not Reported & Ground & & & 20179.7 & .1 \\
\hline$H C^{12} N^{14}$ & 4- 291 & $9 \leftarrow 9$ & Excited & & & 20181.40 & .05 \\
\hline $\mathrm{C}^{12} \mathrm{D}_{3} \mathrm{C}^{12} \mathrm{O}^{16} \mathrm{Cl}^{35}$ & 3- 363 & $5,3,2 \leftarrow 5,2,3$ & Ground & $11 / 2$ & $11 / 2$ & 20181.40 & \\
\hline $\mathrm{C}^{12} \mathrm{D}_{3} \mathrm{O}^{16} \mathrm{~N}^{14} \mathrm{O}_{2}^{16}$ & 3. 182 & $3,1,3 \leftarrow 2,1,2$ & Ground & & & 20181.61 & .1 \\
\hline $\mathrm{C}^{12} \mathrm{H}_{2}\left(\mathrm{C}^{12} \mathrm{~N}^{14}\right)_{2}$ & 4- 901 & Not Reported & Ground & & & 20183.1 & .1 \\
\hline $\mathrm{C}^{12} \mathrm{D}_{3} \mathrm{C}^{12} \mathrm{O}^{16} \mathrm{Cl}^{35}$ & 3- 363 & $5,3,2 \leftarrow 5,2,3$ & Ground & & & 20183.80 & .1 \\
\hline $\mathrm{C}^{12} \mathrm{H}_{3} \mathrm{C}^{12} \mathrm{O}^{16} \mathrm{Br}^{79}$ & 3. 351 & $7,1,6 \leftarrow 7,0,7$ & Ground & $13 / 2$ & $13 / 2$ & 29186.19 & .15 \\
\hline $\mathrm{Si}^{28} \mathrm{H}_{3} \mathrm{C}^{12} \mathrm{H}: \mathrm{C}^{12} \mathrm{H}_{2}$ & 3- 611 & $2,0,2 \leftarrow 1,0,1$ & Ground & & & 20186.62 & .05 \\
\hline $\mathrm{C}^{12}{ }_{*} \mathrm{H}_{2} \mathrm{C}^{12} \mathrm{H}: \mathrm{C}^{12} \mathrm{HC}^{12} \mathrm{H}: \mathrm{C}^{12}{ }_{*} \mathrm{H}$ & 4-1231 & $4,2,2 \leftarrow 4,1,3$ & Ground & & & 20187.1 & .1 \\
\hline $\mathrm{C}^{12} \mathrm{H}_{3} \mathrm{~N}^{14} \mathrm{O}_{2}^{16}$ & 3. 171 & Not Reported & Ground & & & 20188. & 5. \\
\hline $\mathrm{C}^{12} \mathrm{H}_{3} \mathrm{C}^{12} \mathrm{O}^{16} \mathrm{Br}^{79}$ & 3-. 351 & $7,1,6 \leftarrow 7,0,7$ & Ground & $15 / 2$ & $15 / 2$ & 20189.13 & .15 \\
\hline $\mathrm{C}^{12} \mathrm{H}_{3} \mathrm{C}^{12} \mathrm{O}^{16} \mathrm{Br}^{79}$ & 3- 351 & $7,1,6 \leftarrow 7,0,7$ & Ground & $13 / 2$ & $13 / 2$ & 20189.13 & .15 \\
\hline $\mathrm{C}^{12} \mathrm{H}_{3} \mathrm{C}^{12} \mathrm{O}^{16} \mathrm{Br}^{79}$ & 3- 351 & $7,1,6 \leftarrow 7,0,7$ & Ground & $15 / 2$ & $15 / 2$ & 20192.05 & .15 \\
\hline $\mathrm{Si}^{30} \mathrm{H}_{3} \mathrm{C}^{12} \mathrm{H}: \mathrm{C}^{12} \mathrm{H}_{2}$ & 3. 614 & $2,1,1 \leftarrow 1,1,0$ & Ground & & & 20192.25 & .10 \\
\hline $\mathrm{C}_{6}^{12} \mathrm{H}_{5} \mathrm{C}^{12} \mathrm{~N}^{14}$ & 4-1291 & $7,1,6 \leftarrow 6,1,5$ & Ground & & & 20193.7 & \\
\hline $\mathrm{C}^{12}{ }_{*} \mathrm{D}: \mathrm{C}^{12} \mathrm{HC}^{12} \mathrm{H}: \mathrm{C}^{12} \mathrm{HN}^{14}{ }_{*} \mathrm{H}$ & $4 \cdot 1183$ & $5,3,2 \leftarrow 5,2,3$ & Ground & & & 20194. & \\
\hline $\mathrm{C}^{12}{ }_{*} \mathrm{HC}^{13} \mathrm{H}: \mathrm{C}^{12} \mathrm{HC}^{12} \mathrm{H}: \mathrm{C}^{12} \mathrm{HN}^{14} *$ & 4-1206 & $2,1,1 \leftarrow 1,1,0$ & Ground & & & 20194.4 & \\
\hline $\mathrm{C}^{12} \mathrm{H}_{3} \mathrm{C}^{12}{ }_{*} \mathrm{H}_{2} \mathrm{O}^{16} \mathrm{C}^{12}{ }_{*} \mathrm{C}^{12} \mathrm{H}_{3}$ & 3- 951 & $11,4,7 \leftarrow 11,3,8$ & Ground & & & 20201.05 & .2 \\
\hline $\mathrm{C}^{13} \mathrm{HC}^{12} \mathrm{H}: \mathrm{C}^{12} \mathrm{HC}^{12} \mathrm{H}: \mathrm{C}^{12} \mathrm{HN}^{14} *$ & $4 \cdot 1205$ & $2,1,1 \leftarrow 1,1,0$ & Ground & & & 20205.5 & \\
\hline $\mathrm{H}_{2} \mathrm{C}^{12}: \mathrm{C}^{12} \mathrm{O}^{16}$ & 4. 711 & $1,0,1 \leftarrow 0,0,0$ & Ground & & & 20209.20 & \\
\hline $\mathrm{C}^{12} \mathrm{H}_{3} \mathrm{C}^{12} \mathrm{O}^{16} \mathrm{O}^{16} \mathrm{H}$ & 3- 491 & $8,5,3 \leftarrow 8,5,4$ & Ground & & & 20209.32 & \\
\hline $\mathrm{C}^{12} \mathrm{HC}^{12} \mathrm{H}: \mathrm{C}^{12} \mathrm{HC}^{12} \mathrm{H}: \mathrm{C}^{12} \mathrm{HN}^{14} *$ & $4-1201$ & $9,6,3 \leftarrow 9,6,4$ & Ground & & & 20211.25 & \\
\hline $\mathrm{C}^{12} \mathrm{H}_{2}: \mathrm{C}^{12} \mathrm{~F}^{19} \mathrm{Cl}^{35}$ & 4. 631 & $3,0,3 \leftarrow 2,1,2$ & Ground & & & 20214.29 & \\
\hline $\mathrm{C}^{12} \mathrm{H}_{3} \mathrm{~N}^{14} \mathrm{C}^{12} \mathrm{~S}^{32}$ & 3- 421 & $4, \quad \leftarrow 3$, & Ground & & & 20216 & \\
\hline $\mathrm{S}^{32} \mathrm{O}_{2}^{16} \mathrm{~F}_{2}^{19}$ & $4-1631$ & $2,1,1 \leftarrow 1,0,1$ & Excited & & & 20218.15 & .10 \\
\hline $\mathrm{C}_{6}^{12} \mathrm{H}_{5} \mathrm{~F}^{19}$ & $4-1281$ & $54,17,37 \leftarrow 54,17,38$ & Ground & & & 20219. & 5. \\
\hline$\left(\mathrm{C}^{12} \mathrm{H}_{3}\right)_{3} \mathrm{C}^{12} \mathrm{Br}^{81}$ & 3. 962 & $5,4 \leftarrow 4,4$ & Ground & $7 / 2$ & $5 / 2$ & 20219.7 & .5 \\
\hline $\mathrm{H}_{2} \mathrm{C}^{12}: \mathrm{C}^{12} \mathrm{O}^{16}$ & 4- 711 & $1,0,1 \leftarrow 0,0,0$ & Excited & & & 20219.92 & \\
\hline
\end{tabular}




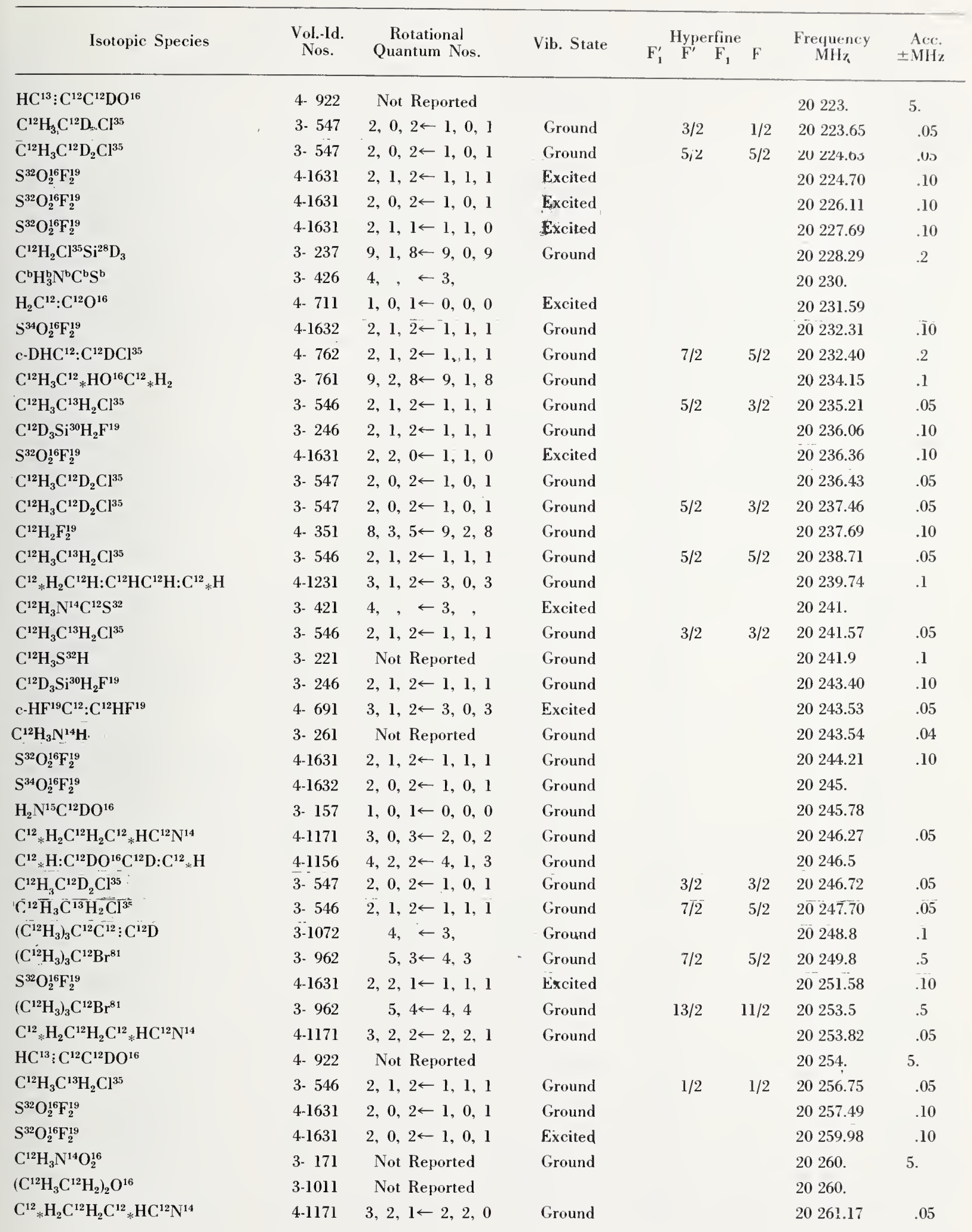




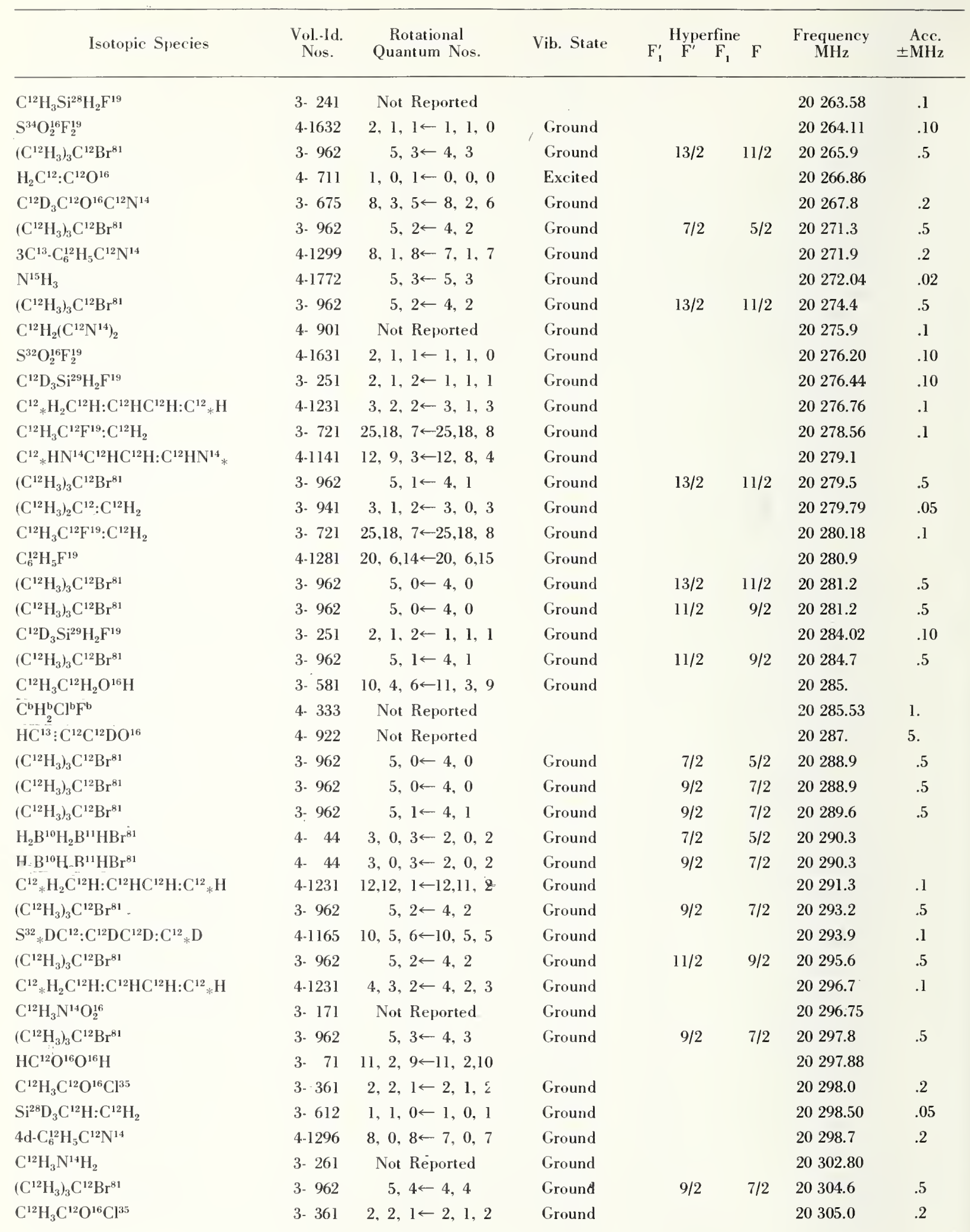




\begin{tabular}{|c|c|c|c|c|c|c|c|}
\hline Isotopic Species & $\begin{array}{l}\text { Vol.-ld. } \\
\text { Nos. }\end{array}$ & $\begin{array}{c}\text { Rotational } \\
\text { Quantum Nos. }\end{array}$ & Vib. State & $\mathrm{F}_{1}^{\prime} \mathrm{F}^{\text {Hyperfine }} \mathrm{F}_{1}$ & $\mathrm{~F}$ & $\begin{array}{c}\text { Frerpuency } \\
\mathrm{NlHz}^{2}\end{array}$ & $\begin{aligned} & \text { Acc. } \\
\pm & \mathrm{HHH}\end{aligned}$ \\
\hline $\mathrm{C}^{12}{ }_{*} \mathrm{D}: \mathrm{C}^{12} \mathrm{HC}^{12} \mathrm{H}: \mathrm{C}^{12} \mathrm{HN}^{14}{ }_{*} \mathrm{H}$ & 4-1183 & $6,6,1 \leftarrow 6,5,2$ & Ground & & & 20310.1 & \\
\hline $\mathrm{s}-\mathrm{Si}^{28} \mathrm{H}_{2} \mathrm{DC}^{12} \mathrm{H}: \mathrm{C}^{12} \mathrm{H}_{2}$ & 3- 619 & $2,1,1 \leftarrow 1,1,0$ & Ground & & & 20.310 .72 & .10 \\
\hline $\mathrm{C}^{13} \mathrm{H}_{3} \mathrm{C}^{12} \mathrm{H}_{2} \mathrm{Cl}^{35}$ & 3- 545 & $2,0,2 \leftarrow 1,0,1$ & Ground & $5 / 2$ & $3 / 2$ & 20313.27 & .05 \\
\hline$\left(\mathrm{C}^{12} \mathrm{H}_{3}\right)_{3} \mathrm{C}^{12} \mathrm{Br}^{81}$ & 3- 962 & $5,3 \leftarrow 4,3$ & Ground & $11 / 2$ & $9 / 2$ & 20313.8 & .5 \\
\hline $\mathrm{C}^{13} \mathrm{H}_{3} \mathrm{C}^{12} \mathrm{H}_{2} \mathrm{Cl}^{35}$ & 3- 545 & $2,0,2 \leftarrow 1,0,1$ & Ground & $7 / 2$ & $5 / 2$ & 20315.02 & .05 \\
\hline $\mathrm{C}^{12} \mathrm{H}_{3} \mathrm{C}^{12} \mathrm{HF}_{2}^{19}$ & 3- 461 & $3,2,2 \leftarrow 3,0,3$ & Ground & & & 20317.9 & .1 \\
\hline $\mathrm{C}^{12} \mathrm{D}_{3} \mathrm{Si}^{28} \mathrm{H}_{2} \mathrm{~F}^{19}$ & 3- 244 & $2,1,2 \leftarrow 1,1,1$ & Ground & & & 20319.39 & .10 \\
\hline$\left(\mathrm{C}^{12} \mathrm{H}_{3} \mathrm{C}^{12} \mathrm{H}_{2}\right)_{2} \mathrm{O}^{16}$ & $3-1011$ & Not Reported & & & & 20320 . & \\
\hline $\mathrm{DC}^{12}: \mathrm{C}^{12} \mathrm{Cl}^{37}$ & 4- 604 & $2 \leftarrow 1$ & Ground & $3 / 2$ & $1 / 2$ & 20321.12 & .1 \\
\hline $\mathrm{S}^{32}{ }_{*} \mathrm{HC}^{13}: \mathrm{C}^{12} \mathrm{HC}^{12} \mathrm{H}: \mathrm{C}^{12}{ }_{*} \mathrm{H}$ & $4-1167$ & $4,1,3 \leftarrow 4,1,4$ & Ground & & & 20321.3 & .05 \\
\hline $\mathrm{C}^{13} \mathrm{H}_{3} \mathrm{C}^{12} \mathrm{H}_{2} \mathrm{Cl}^{35}$ & 3. 545 & $2,0,2 \leftarrow 1,0,1$ & Ground & $3 / 2$ & $3 / 2$ & 20322.10 & .05 \\
\hline $\mathrm{DC}^{12}: \mathrm{C}^{12} \mathrm{Cl}^{37}$ & 4- 604 & $2 \leftarrow 1$ & Ground & $5 / 2$ & $5 / 2$ & 20322.50 & .1 \\
\hline $\mathrm{C}^{12} \mathrm{H}_{3} \mathrm{~N}^{14} \mathrm{H}_{2}$ & 3- 261 & Not Reported & Ground & & & 20325.82 & .1 \\
\hline $\mathrm{C}^{12} \mathrm{D}_{3} \mathrm{Si}^{28} \mathrm{H}_{2} \mathrm{~F}^{19}$ & 3- 244 & $2,1,2 \leftarrow 1,1,1$ & Ground & & & 20326.70 & .10 \\
\hline $\mathrm{C}^{12} \mathrm{H}_{3} \mathrm{C}^{12} \mathrm{O}^{16} \mathrm{Cl}^{35}$ & 3- 361 & $2,1,2 \leftarrow 1,0,1$ & Ground & $3 / 2$ & $1 / 2$ & 20327.30 & .2 \\
\hline $\mathrm{C}^{12} \mathrm{H}_{3} \mathrm{C}^{12}{ }_{*} \mathrm{H}_{2} \mathrm{O}^{16} \mathrm{C}^{12}{ }_{*} \mathrm{C}^{12} \mathrm{H}_{3}$ & 3- 951 & $3,0,3 \leftarrow 2,1,2$ & Ground & & & 20327.53 & .2 \\
\hline $\mathrm{C}^{12}{ }_{*} \mathrm{H}: \mathrm{C}^{12} \mathrm{HO}^{18} \mathrm{C}^{12} \mathrm{H}: \mathrm{C}^{12}{ }_{*} \mathrm{H}$ & 4-1152 & $6,4,2 \leftarrow 6,4,3$ & Ground & & & 20328.7 & .1 \\
\hline $\mathrm{C}^{13} \mathrm{H}_{3} \mathrm{O}^{16} \mathrm{H}$ & 3- 213 & $30,2, \quad \leftarrow 30,1$ & Ground & & & 20329.32 & .1 \\
\hline $\mathrm{C}^{12} \mathrm{H}_{2} \mathrm{~N}^{14} \mathrm{O}^{16} \mathrm{H}$ & 3- 141 & $5,2,4 \leftarrow 6,1,5$ & Ground & 5 & 6 & 20332.08 & .10 \\
\hline $\mathrm{C}^{12} \mathrm{H}_{3} \mathrm{C}^{12} \mathrm{O}^{16} \mathrm{Cl}^{35}$ & 3. 361 & $2,1,2 \leftarrow 1,0,1$ & Ground & $1 / 2$ & $1 / 2$ & 20332.60 & .2 \\
\hline a- $C^{12} \mathrm{H}_{2} \mathrm{D}\left(\mathrm{C}^{12} \mathrm{H}_{3}\right)_{2} \mathrm{Si}{ }^{\mathrm{b}} \mathrm{D}$ & 3- 882 & $2,2,1 \leftarrow 1,1,1$ & Ground & & & 20333.25 & .10 \\
\hline $\mathrm{C}^{12} \mathrm{H}_{2} \mathrm{~N}^{14} \mathrm{O}^{16} \mathrm{H}$ & $3 \cdot 141$ & $5,2,4 \leftarrow 6,1,5$ & Ground & 4 & 5 & 20333.55 & .10 \\
\hline $\mathrm{C}^{12} \mathrm{H}_{2} \mathrm{~N}^{14} \mathrm{O}^{16} \mathrm{H}$ & $3 \cdot 141$ & $5,2,4 \leftarrow 6,1,5$ & Ground & 6 & 7 & 20333.55 & .10 \\
\hline s. $\mathrm{C}^{12} \mathrm{H}_{2} \mathrm{DC}^{12} \mathrm{H}_{3} \mathrm{C}^{12}: \mathrm{C}^{12} \mathrm{H}_{2}$ & 3. 943 & $3,2,2 \leftarrow 3,1,3$ & Ground & & & 20334.26 & .05 \\
\hline $\mathrm{C}^{12} \mathrm{H}_{3} \mathrm{C}^{12} \mathrm{O}^{16} \mathrm{Cl}^{35}$ & 3- 361 & $2,1,2 \leftarrow 1,0,1$ & Ground & $5 / 2$ & $5 / 2$ & 20334.80 & .2 \\
\hline $\mathrm{S}^{32} \mathrm{O}_{2}^{16}$ & 4-1831 & $12,3,9 \leftarrow 13,2,12$ & Ground & & & 20335.47 & .1 \\
\hline $\mathrm{C}^{12}{ }_{*} \mathrm{H}_{2} \mathrm{C}^{12} \mathrm{H}: \mathrm{C}^{12} \mathrm{HC}^{12} \mathrm{H}: \mathrm{C}^{12}{ }_{*} \mathrm{H}$ & 4-1231 & $5,4,2 \leftarrow 5,3,3$ & Ground & & & 20336.7 & .1 \\
\hline $\mathrm{DC}^{12}: \mathrm{C}^{12} \mathrm{Cl}^{37}$ & 4- 604 & $2 \leftarrow 1$ & Ground & $1 / 2$ & $1 / 2$ & 20336.84 & .1 \\
\hline $\mathrm{C}^{13} \mathrm{O}^{16} \mathrm{~F}_{2}^{19}$ & 4- 212 & $11,11,1 \leftarrow 11,9,2$ & Ground & & & 20337.14 & .10 \\
\hline $\mathrm{DC}^{12}: \mathrm{C}^{12} \mathrm{Cl}^{37}$ & 4- 604 & $2 \leftarrow 1$ & Ground & $7 / 2$ & $5 / 2$ & 20338.29 & .1 \\
\hline $\mathrm{DC}^{12}: \mathrm{C}^{12} \mathrm{Cl}^{37}$ & 4- 604 & $2 \leftarrow 1$ & Ground & $5 / 2$ & $3 / 2$ & 20338.29 & .1 \\
\hline$\left(\mathrm{C}^{12} \mathrm{H}_{3}\right)_{3} \mathrm{C}^{12} \mathrm{Br}^{81}$ & 3- 962 & $5,4 \leftarrow 4,4$ & Ground & $11 / 2$ & $9 / 2$ & 20339.4 & .5 \\
\hline $\mathrm{C}^{12} \mathrm{H}_{3} \mathrm{C}^{12} \mathrm{O}^{16} \mathrm{Cl}^{35}$ & 3- 361 & $2,1,2 \leftarrow 1,0,1$ & Ground & $7 / 2$ & $5 / 2$ & 20340.25 & .2 \\
\hline$\left(\mathrm{C}^{12} \mathrm{H}_{3}\right)_{2} \mathrm{C}^{12}: \mathrm{C}^{13} \mathrm{H}_{2}$ & 3. 946 & $3,2,2 \leftarrow 3,1,3$ & Ground & & & 20340.93 & \\
\hline c- $-\mathrm{HDN}^{14} \mathrm{C}^{12} \mathrm{HO}^{16}$ & 3- 152 & $1,0,1 \leftarrow 0,0,0$ & - Excited & & & 20341.2 & \\
\hline $\mathrm{c}-\mathrm{HDN} \mathrm{N}^{14} \mathrm{C}^{12} \mathrm{HO}^{16}$ & 3- 152 & $1,0,1 \leftarrow 0,0,0$ & Ground & & & 20344.25 & .1 \\
\hline $\mathrm{H}_{2} \mathrm{C}^{12}: \mathrm{C}^{12} \mathrm{~F}_{2}^{19}$ & 4- 681 & Not Reported & & & & 20345.0 & .3 \\
\hline $\mathrm{C}^{12} \mathrm{H}_{3} \mathrm{O}^{16} \mathrm{H}$ & 3- 211 & Not Reported & Ground & & & 20346.83 & .1 \\
\hline $\mathrm{C}^{12} \mathrm{H}_{3} \mathrm{C}^{12} \mathrm{O}^{16} \mathrm{Cl}^{35}$ & 3- 361 & $2,1,2 \leftarrow 1,0,1$ & Ground & $5 / 2$ & $3 / 2$ & 20349.25 & .2 \\
\hline $\mathrm{C}^{12} \mathrm{D}_{2}: \mathrm{C}^{12} \mathrm{DBr}^{81}$ & 4- 726 & $3,1,3 \leftarrow 2,1,2$ & Ground & $3 / 2$ & $3 / 2$ & $20349 . \dot{3}$ & \\
\hline $\mathrm{DC}^{12}: \mathrm{C}^{12} \mathrm{Cl}^{37}$ & 4- 604 & $2 \leftarrow 1$ & Ground & $3 / 2$ & $3 / 2$ & 20349.48 & .1 \\
\hline $\mathrm{C}^{12} \mathrm{D}_{2} \mathrm{HC}^{12}: \mathrm{C}^{12} \mathrm{C}^{12} \mathrm{~F}_{3}^{19}$ & 3- 897 & $8, \quad ; \leftarrow 7$, & Ground & & & 20349.5 & .5 \\
\hline $\mathrm{C}^{12} \mathrm{H}_{3} \mathrm{~N}^{14} \mathrm{C}^{12} \mathrm{~S}^{32}$ & 3. 421 & $4, \quad \leftarrow 3, \quad$, & Excited & & & 20350 & \\
\hline $\mathrm{C}_{6}^{12} \mathrm{H}_{5} \mathrm{O}^{16} \mathrm{H}$ & $3-1051$ & $5,1,5 \leftarrow 4,0,4$ & Ground & & & 20353.2 & \\
\hline $\mathrm{C}^{12} \mathrm{H}_{3} \mathrm{C}^{12} \mathrm{O}^{16} \mathrm{Cl}^{35}$ & 3- 361 & $2,1,2 \leftarrow 1,0,1$ & Ground & $3 / 2$ & $3 / 2$ & 20353.25 & .2 \\
\hline
\end{tabular}




\begin{tabular}{|c|c|c|c|c|c|c|c|}
\hline Isotopic Species & $\begin{array}{l}\text { Vol.-Id. } \\
\text { Nos. }\end{array}$ & $\begin{array}{c}\text { Rotational } \\
\text { Quantum Nos. }\end{array}$ & Vib. State & $\mathbf{F}_{1}^{\prime} \mathbf{F}^{\prime} \quad \mathbf{F}_{1}$ & $\mathbf{F}$ & $\begin{array}{c}\text { Frequency } \\
\mathrm{MHz}\end{array}$ & $\begin{array}{c}\text { Acc. } \\
\pm \mathrm{MHz}\end{array}$ \\
\hline $\mathrm{C}^{12} \mathrm{H}_{3} \mathrm{C}^{12} \mathrm{HDF}^{19}$ & 3- 552 & $6,1,6 \leftarrow 5,2,3$ & Ground & & & 20353.4 & .1 \\
\hline $\mathrm{H}_{3} \mathrm{C}^{12} \mathrm{C}^{12}: \mathrm{C}^{12} \mathrm{C}^{12}: \mathrm{C}^{12} \mathrm{H}$ & 4-1191 & $5,4 \leftarrow 4,4$ & Ground & & & 20354.18 & .1 \\
\hline $\mathrm{H}_{3} \mathrm{C}^{12} \mathrm{C}^{12}: \mathrm{C}^{12} \mathrm{C}^{12}: \mathrm{C}^{12} \mathrm{H}$ & $4-1191$ & $5,3 \leftarrow 4,3$ & Ground & & & 20355.55 & .1 \\
\hline $\mathrm{C}^{12} \mathrm{D}_{3} \mathrm{C}^{12} \mathrm{O}^{16} \mathrm{~F}^{19}$ & 3. 392 & $9,5,4 \leftarrow 9,5,5$ & Ground & & & 20356.01 & .2 \\
\hline $\mathrm{a} \cdot \mathrm{C}^{12} \mathrm{HD}_{2} \mathrm{C}^{12} \mathrm{O}^{16} \mathrm{~F}^{19}$ & 3- 396 & $3,1,2 \leftarrow 3,1,3$ & Ground & & & 20356.22 & .2 \\
\hline $\mathrm{H}_{3} \mathrm{C}^{12} \mathrm{C}^{12}: \mathrm{C}^{12} \mathrm{C}^{12}: \mathrm{C}^{12} \mathrm{H}$ & 4-1191 & $5,2 \leftarrow 4,2$ & Ground & & & 20356.56 & .1 \\
\hline $\mathrm{H}_{3} \mathrm{C}^{12} \mathrm{C}^{12}: \mathrm{C}^{12} \mathrm{C}^{12}: \mathrm{C}^{12} \mathrm{H}$ & 4-1191 & $5,0 \leftarrow 4,0$ & Ground & & & 20357.38 & .1 \\
\hline $\mathrm{H}_{3} \mathrm{C}^{12} \mathrm{C}^{12}: \mathrm{C}^{12} \mathrm{C}^{12}: \mathrm{C}^{12} \mathrm{H}$ & 4.1191 & $5,1 \leftarrow 4,1$ & Ground & & & 20357.38 & .1 \\
\hline $\mathrm{C}^{12} \mathrm{H}_{3} \mathrm{C}^{12} \mathrm{O}^{16} \mathrm{O}^{16} \mathrm{H}$ & 3- 491 & $7,5,2 \leftarrow 7,4,3$ & Ground & & & 20357.84 & \\
\hline $\mathrm{C}^{12} \mathrm{D}_{3} \mathrm{C}^{12} \mathrm{O}^{16} \mathrm{~F}^{19}$ & 3- 392 & $9,5,4 \leftarrow 9,5,5$ & Ground & & & 20359.26 & .2 \\
\hline $\mathrm{a}-\mathrm{C}^{12} \mathrm{HD}_{2} \mathrm{C}^{12} \mathrm{O}^{16} \mathrm{~F}^{19}$ & 3- 396 & $3,1,2 \leftarrow 3,1,3$ & Ground & & & 20359.45 & .2 \\
\hline$\left(\mathrm{C}^{12} \mathrm{H}_{3}\right)_{3} \mathrm{C}^{12} \mathrm{Br}^{79}$ & 3- 961 & $5,4 \leftarrow 4,4$ & Ground & $7 / 2$ & $5 / 2$ & 20365.3 & .5 \\
\hline $\mathrm{H}_{2}^{\mathrm{b}} \mathrm{C}^{\mathrm{b}}: \mathrm{C}^{\mathrm{b}} \mathrm{H}^{\mathrm{b}} \mathrm{Cl}^{\mathrm{b}}$ & 4- 772 & Not Reported & Ground & & & 20368.40 & \\
\hline $\mathrm{C}^{12} \mathrm{H}_{3} \mathrm{Si}^{28} \mathrm{HF}_{2}^{19}-\mathrm{A}$ & 3- 191 & $10,6,5 \leftarrow 10,6,4$ & Ground & & & 20369.85 & \\
\hline $\mathrm{Si}^{28} \mathrm{H}_{3} \mathrm{C}^{12} \mathrm{D}: \mathrm{C}^{12} \mathrm{H}_{2}$ & 3- 616 & $2,1,1 \leftarrow 1,1,0$ & Ground & & & 20370.22 & .10 \\
\hline $\mathrm{N}^{14} \mathrm{H}_{3}$ & 4-1771 & $5,2 \leftarrow 5,2$ & Ground & & & 20371.46 & .02 \\
\hline $\mathrm{C}^{12} \mathrm{H}_{3} \mathrm{C}^{12} \mathrm{H}_{2} \mathrm{Cl}^{35}$ & 3- 541 & $2,1,2 \leftarrow 1,1,1$ & Ground & $5 / 2$ & $3 / 2$ & 20371.50 & .05 \\
\hline $\mathrm{C}^{12}{ }_{*} \mathrm{HC}^{12} \mathrm{D}: \mathrm{C}^{12} \mathrm{HC}^{12} \mathrm{H}: \mathrm{C}^{12} \mathrm{HN}^{14} *$ & 4-1203 & $10,8,3 \leftarrow 10,6,4$ & Ground & & & 20372.0 & .1 \\
\hline $\mathrm{C}^{12}{ }_{*} \mathrm{D}: \mathrm{C}^{12} \mathrm{DC}^{12} \mathrm{D}: \mathrm{C}^{12} \mathrm{DN}^{14}{ }_{*} \mathrm{H}$ & 4-1185 & $7,6,2 \leftarrow 7,5,3$ & Ground & & & 20372.6 & \\
\hline $\mathrm{C}^{12}{ }_{*} \mathrm{HC}^{12} \mathrm{H}: \mathrm{C}^{12} \mathrm{HC}^{12} \mathrm{H}: \mathrm{C}^{12} \mathrm{HN}^{14}{ }_{*}$ & $4-1201$ & $2,1,1 \leftarrow 1,1,0$ & Ground & & & 20374.2 & \\
\hline $\mathrm{C}^{12} \mathrm{H}_{3} \mathrm{C}^{12} \mathrm{H}_{2} \mathrm{Cl}^{35}$ & 3. 541 & $2,1,2 \leftarrow 1,1,1$ & Ground & $5 / 2$ & $5 / 2$ & 20374.88 & .05 \\
\hline $\mathrm{H}_{2}^{\mathrm{b}} \mathrm{C}^{\mathrm{b}}: \mathrm{C}^{\mathrm{b}} \mathrm{H}^{\mathrm{b}} \mathrm{Cl}^{\mathrm{b}}$ & 4- 772 & Not Reported & Ground & & & 20375.00 & \\
\hline $\mathrm{C}^{12} \mathrm{H}_{3} \mathrm{Si}^{28} \mathrm{HF}_{2}^{19} \cdot \mathrm{E}$ & 3- 192 & $10,6,5 \leftarrow 10,6,4$ & Ground & & & 20377.40 & \\
\hline $\mathrm{C}^{12} \mathrm{H}_{3} \mathrm{C}^{12} \mathrm{H}_{2} \mathrm{Cl}^{35}$ & 3- 541 & $2,1,2 \leftarrow 1,1,1$ & Ground & $3 / 2$ & $3 / 2$ & 20377.89 & .05 \\
\hline $\mathrm{C}^{12} \mathrm{H}_{3} \mathrm{C}^{12} \mathrm{H}_{2} \mathrm{Cl}^{35}$ & 3- 541 & $2,1,2 \leftarrow 1,1,1$ & Ground & & & 20380.58 & .05 \\
\hline $\mathrm{C}^{12} \mathrm{D}_{2}: \mathrm{C}^{12} \mathrm{DBr}^{81}$ & 4. 726 & $3,1.3 \leftarrow 2,1,2$ & Excited & $9 / 2$ & $7 / 2$ & 20381.3 & \\
\hline $\mathrm{C}^{12} \mathrm{H}_{3} \mathrm{~S}^{32} \mathrm{H}$ & 3- 221 & Not Reported & Ground & & & 20383.2 & .1 \\
\hline $\mathrm{C}^{12} \mathrm{H}_{3} \mathrm{C}^{12} \mathrm{H}_{2} \mathrm{Cl}^{35}$ & 3. 541 & $2,1,2 \leftarrow 1,1,1$ & Ground & $7 / 2$ & $5 / 2$ & 20383.79 & .05 \\
\hline $3 \mathrm{~d}-\mathrm{C}_{6}^{12} \mathrm{H}_{5} \mathrm{C}^{12} \mathrm{~N}^{14}$ & 4-1295 & $8,0,8 \leftarrow 7,0,7$ & Ground & & & 20383.8 & .2 \\
\hline $\mathrm{C}^{12} \mathrm{H}_{3} \mathrm{~N}^{14} \mathrm{O}_{2}^{16}$ & 3- 171 & Not Reported & Ground & & & 20385. & \\
\hline $\mathrm{C}^{\mathrm{b}} \mathrm{H}_{3}^{\mathrm{b}} \mathrm{C}^{\mathrm{b}} \mathrm{H}_{2}^{\mathrm{b}} \mathrm{Cl}^{35}$ & 3- 548 & Not Reported & & & & 20387.36 & .05 \\
\hline $\mathrm{C}^{12} \mathrm{D}_{2}: \mathrm{C}^{12} \mathrm{DBr}^{81}$ & 4- 726 & $3,1,3 \leftarrow 2,1,2$ & Ground & $5 / 2$ & $5 / 2$ & 20388.7 & \\
\hline${ }_{25}-\mathrm{C}^{12} \mathrm{H}_{3} \mathrm{C}^{12} \mathrm{H}_{2} \mathrm{C}^{12} \mathrm{H}_{2} \mathrm{Cl}^{35}$ & 3- 773 & $2,1,2 \leftarrow 1,0,1$ & Ground & & & 20388.94 & .2 \\
\hline $2 \mathrm{C}^{13}-\mathrm{C}_{6}^{12} \mathrm{H}_{5} \mathrm{C}^{12} \mathrm{~N}^{14}$ & 4-1298 & $8,1,8 \leftarrow 7,1,7$ & Ground & & & 20389.0 & .2 \\
\hline $\mathrm{C}^{12}{ }_{*} \mathrm{H}: \mathrm{C}^{12} \mathrm{HO}^{18} \mathrm{C}^{12} \mathrm{H}: \mathrm{C}^{12}{ }_{*} \mathrm{H}$ & 4-1152 & $5,5,1 \leftarrow 5,3,2$ & Ground & & & 20390.3 & .1 \\
\hline $\mathrm{H}_{3} \mathrm{C}^{12} \mathrm{C}^{12}: \mathrm{C}^{12} \mathrm{C}^{12}: \mathrm{C}^{12} \mathrm{H}$ & 4-1191 & $5,1 \leftarrow 4,1$ & Excited: & & & 20390.87 & .1 \\
\hline $\mathrm{C}^{12} \mathrm{D}_{3} \mathrm{C}^{13} \mathrm{O}^{16} \mathrm{~F}^{19}$ & 3- 401 & $9,5,4 \leftarrow 9,5,5$ & Ground & & & 20391.43 & .2 \\
\hline $\mathrm{C}^{12} \mathrm{H}_{2}: \mathrm{C}^{12} \mathrm{~F}^{19} \mathrm{Cl}^{35}$ & 4- 631 & $6,2,4 \leftarrow 6,1,5$ & Ground & & & 20391.51 & \\
\hline $\mathrm{C}^{12} \mathrm{D}_{3} \mathrm{C}^{13} \mathrm{O}^{16} \mathrm{~F}^{19}$ & 3- 401 & $9,5,4 \leftarrow 9,5,5$ & Ground & & & 20391.54 & .2 \\
\hline $\mathrm{C}^{12} \mathrm{H}_{3} \mathrm{C}^{12} \mathrm{H}_{2} \mathrm{Cl}^{35}$ & 3- 541 & $2,1,2 \leftarrow 1,1,1$ & Ground & $1 / 2$ & $1 / 2$ & 20392.86 & .05 \\
\hline $\mathrm{DN}^{14} \mathrm{C}^{12} \mathrm{O}^{16}$ & 4. 303 & $1, \quad \leftarrow 0, \quad$ & Ground & & & 20394.7 & \\
\hline $\mathrm{C}^{12} \mathrm{H}_{2}\left(\mathrm{C}^{12} \mathrm{~N}^{14}\right)\left(\mathrm{C}^{12} \mathrm{~N}^{15}\right)$ & 4- 904 & $5,1,4 \leftarrow 5,0,5$ & Ground & & & 20394.99 & \\
\hline $\mathrm{DN}^{14} \mathrm{O}_{3}^{16}$ & 3- 32 & $6,4,2 \leftarrow 6,4,3$ & Ground & & & 20396.03 & \\
\hline $\mathrm{C}^{12} \mathrm{H}_{2}\left(\mathrm{C}^{12} \mathrm{~N}^{14}\right)_{2}$ & 4- 901 & Not Reported & Ground & & & 20396.8 & .1 \\
\hline $\mathrm{H}_{2} \mathrm{~B}^{10} \mathrm{H}_{2} \mathrm{~B}^{11} \mathrm{HBr}^{79}$ & $4-43$ & $3,0,3 \leftarrow 2,0,2$ & Ground & $9 / 2$ & $7 / 2$ & 20396.9 & \\
\hline
\end{tabular}




\section{$\mathrm{H}_{2} \mathrm{~B}^{10} \mathrm{H}_{2} \mathrm{~B}^{11} \mathrm{HBr}^{79}$}

$\mathrm{C}^{12} \mathrm{D}_{2} \mathrm{Cl}^{35} \mathrm{Si}^{28} \mathrm{H}_{3}$

$\mathrm{H}_{3} \mathrm{C}^{12} \mathrm{C}^{12}: \mathrm{C}^{12} \mathrm{C}^{12}: \mathrm{C}^{12} \mathrm{H}$

$\mathrm{H}_{3} \mathrm{C}^{12} \mathrm{C}^{12}: \mathrm{C}^{12} \mathrm{C}^{12}: \mathrm{G}^{12} \mathrm{H}$

$\mathrm{C}^{12} \mathrm{D}_{2}: \mathrm{C}^{12} \mathrm{DBr}^{81}$

$\mathrm{H}_{3} \mathrm{C}^{12} \mathrm{C}^{12}: \mathrm{C}^{12} \mathrm{C}^{12}: \mathrm{C}^{12} \mathrm{H}$

$\mathrm{H}_{3} \mathrm{C}^{12} \mathrm{C}^{12}: \mathrm{C}^{12} \mathrm{C}^{12}: \mathrm{C}^{12} \mathrm{H}$

$\left(\mathrm{C}^{12} \mathrm{H}_{3}\right)_{3} \mathrm{C}^{12} \mathrm{Br}^{79}$

$\mathrm{H}_{3} \mathrm{C}^{12} \mathrm{C}^{12}: \mathrm{C}^{12} \mathrm{C}^{12}: \mathrm{C}^{12} \mathrm{H}$

$\mathrm{H}_{3} \mathrm{C}^{12} \mathrm{C}^{12}: \mathrm{C}^{12} \mathrm{C}^{12}: \mathrm{C}^{12} \mathrm{H}$

$\mathrm{C}^{12} \mathrm{D}_{2}: \mathrm{C}^{12} \mathrm{DBr}^{81}$

$\mathrm{C}^{12} \mathrm{H}_{3} \mathrm{~N}^{14} \mathrm{O}_{2}^{16}$

$\mathrm{C}^{12} \mathrm{D}_{2}: \mathrm{C}^{12} \mathrm{DBr}^{81}$

$\mathrm{C}^{12}{ }_{*} \mathrm{H}_{2} \mathrm{C}^{12} \mathrm{H}: \mathrm{C}^{12} \mathrm{HC}^{12} \mathrm{H}: \mathrm{C}^{12}{ }_{*} \mathrm{H}$

$\left(\mathrm{C}^{12} \mathrm{H}_{3}\right)_{3} \mathrm{C}^{12} \mathrm{Br}^{79}$

$\mathrm{Si}^{28} \mathrm{H}_{3} \mathrm{C}^{12} \mathrm{H}: \mathrm{C}^{12} \mathrm{H}_{2}$

$\mathrm{Si}^{28} \mathrm{H}_{3} \mathrm{C}^{12} \mathrm{H}: \mathrm{C}^{12} \mathrm{H}_{2}$

$\mathrm{C}^{12}{ }_{*} \mathrm{H}_{2} \mathrm{~N}^{14} \mathrm{DC}^{12}{ }_{*} \mathrm{H}_{2}$

$\mathrm{C}^{12} \mathrm{D}_{2}: \mathrm{C}^{12} \mathrm{DBr}^{81}$

$\mathrm{H}_{2}^{\mathrm{b}} \mathrm{C}^{\mathrm{b}}: \mathrm{C}^{\mathrm{b}} \mathrm{H}^{\mathrm{b}} \mathrm{Cl}^{\mathrm{b}}$

$\mathrm{H}_{3} \mathrm{C}^{12} \mathrm{C}^{12}: \mathrm{C}^{12} \mathrm{C}^{12}: \mathrm{C}^{12} \mathrm{H}$

$\mathrm{Si}^{29} \mathrm{H}_{3} \mathrm{C}^{12} \mathrm{H}: \mathrm{C}^{12} \mathrm{H}_{2}$

$\mathrm{C}^{\mathbf{b}} \mathrm{H}_{3}^{\mathrm{b}} \mathrm{N}^{\mathbf{b}} \mathrm{C}^{\mathbf{b}} \mathrm{S}^{\mathrm{b}}$

$\mathrm{H}_{2} \mathrm{~N}^{14} \mathrm{~N}^{14} \mathrm{H}_{2}$

$\mathrm{S}^{32}{ }_{*} \mathrm{HC}^{12}: \mathrm{C}^{12} \mathrm{DC}^{12} \mathrm{D}: \mathrm{C}^{12}{ }_{*} \mathrm{H}$

$\left(\mathrm{C}^{12} \mathrm{D}_{3}\right)_{3} \mathrm{C}^{12} \mathrm{Cl}^{35}$

$\mathrm{HC}^{13}: \mathrm{C}^{12} \mathrm{C}^{12} \mathrm{DO}^{16}$

$\left(\mathrm{C}^{12} \mathrm{H}_{3}\right)_{3} \mathrm{C}^{12} \mathrm{Br}^{79}$

$\mathrm{C}^{13}{ }_{*} \mathrm{H}: \mathrm{C}^{12} \mathrm{HO}^{16} \mathrm{C}^{12} \mathrm{H}: \mathrm{C}^{12}{ }_{*} \mathrm{H}$

$\mathrm{C}^{12} \mathrm{D}_{2}: \mathrm{C}^{12} \mathrm{DBr}^{81}$

$\mathrm{C}^{12} \mathrm{D}_{2}: \mathrm{C}^{12} \mathrm{DBr}^{81}$

$\left(\mathrm{C}^{12} \mathrm{H}_{3}\right)_{3} \mathrm{C}^{12} \mathrm{Br}^{79}$

$\left(\mathrm{C}^{12} \mathrm{H}_{3}\right)_{2} \mathrm{C}^{12}: \mathrm{C}^{13} \mathrm{H}_{2}$

$\mathrm{C}^{12}{ }_{*} \mathrm{HC}^{12} \mathrm{H}: \mathrm{C}^{12} \mathrm{HC}^{12} \mathrm{H}: \mathrm{C}^{12} \mathrm{HN}^{14}{ }^{4}$ $\left(\mathrm{C}^{12} \mathrm{H}_{3}\right)_{3} \mathrm{C}^{12} \mathrm{Br}^{79}$

$\mathrm{H}_{2} \mathrm{~N}^{14} \mathrm{C}^{12} \mathrm{DO}^{16}$

$\mathrm{HC}^{12} \mathrm{O}^{16} \mathrm{O}^{16} \mathrm{C}^{12} \mathrm{D}_{3}-\mathrm{A}$

$\left(\mathrm{C}^{12} \mathrm{H}_{3}\right)_{3} \mathrm{C}^{12} \mathrm{Br}^{79}$

$\mathrm{C}^{12} \mathrm{H}_{2} \mathrm{DSi}^{\mathrm{b}} \mathrm{H}_{3}$

${ }^{1 C^{13}} \cdot \mathrm{C}_{6}^{12} \mathrm{H}_{5} \mathrm{C}^{12} \mathrm{~N}^{14}$

$\mathrm{C}^{12}{ }_{*} \mathrm{DC}^{12} \mathrm{H}: \mathrm{C}^{12} \mathrm{HC}^{12} \mathrm{H}: \mathrm{C}^{12} \mathrm{HN}^{14}$ * $\left(\mathrm{C}^{12} \mathrm{H}_{3}\right)_{3} \mathrm{C}^{12} \mathrm{Br}^{79}$

$\left(\mathrm{C}^{12} \mathrm{H}_{3}\right)_{3} \mathrm{C}^{12} \mathrm{Br}^{79}$

$\left(\mathrm{C}^{12} \mathrm{H}_{3}\right)_{3} \mathrm{C}^{12} \mathrm{Br}^{79}$

$\mathrm{C}^{12} \mathrm{H}_{3} \mathrm{~N}^{14} \mathrm{C}^{12} \mathrm{~S}^{32}$

\begin{tabular}{|c|c|c|}
\hline 4- 43 & $3,0,3 \leftarrow 2,0,2$ & Ground \\
\hline 3- 235 & $8,1,7 \leftarrow 8,0,8$ & Ground \\
\hline $4 \cdot 1191$ & $5,2 \leftarrow 4,2$ & Excited \\
\hline $4-1191$ & $5,4 \leftarrow 4,4$ & Excited \\
\hline 4- 726 & $3,1,3 \leftarrow 2,1,2$ & Ground \\
\hline $4-1191$ & $5,3 \leftarrow 4,3$ & Excite \\
\hline 4-1191 & $5,1 \leftarrow 4,1$ & Excite \\
\hline 3- 961 & $5,3 \leftarrow 4,3$ & Groun \\
\hline 4-1191 & $5,2 \leftarrow 4,2$ & Excite \\
\hline 4-1191 & $5,0 \leftarrow 4,0$ & Excite \\
\hline 4- 726 & $3,1,3 \leftarrow 2,1,2$ & Groun \\
\hline 3- 171 & Not Reported & Ground \\
\hline 4. 726 & $3,1,3 \leftarrow 2,1,2$ & Excite \\
\hline 4-1231 & $6,5,2 \leftarrow 6,4,3$ & Groun \\
\hline 3. 961 & $5,4 \leftarrow 4,4$ & Groun \\
\hline 3. 611 & $9,1,8 \leftarrow 9,1,9$ & Groun \\
\hline 3- 611 & $9,1,8 \leftarrow 9,1,9$ & Grour \\
\hline 4. 862 & $11,10,1 \leftarrow 11,10,2$ & Grour \\
\hline 4. 726 & $3,1,3 \leftarrow 2,1,2$ & Groun \\
\hline 4- 772 & Not Reported & Grour \\
\hline $4-1191$ & $5,1 \leftarrow 4,1$ & Excit \\
\hline 3. 613 & $2,1,1 \leftarrow 1,1,0$ & Grour \\
\hline 3. 426 & $4, \quad \leftarrow 3$, & \\
\hline
\end{tabular}

3. $51 \quad$ Not Reported

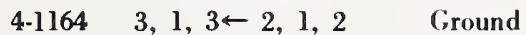

3- 976

$4, \leftarrow 3$,

4. 922

Not Reported

3- 961

$5,3 \leftarrow 4,3$

Ground

4-1157

4. 726

$8,6,2 \leftarrow 8,6,3$

Ground

4. 726

$3,1,3 \leftarrow 2,1,2$

Ground

$3,1,3 \leftarrow 2,1,2$

Ground

$5,2 \leftarrow 4,2$

3- 946

$4,3,2 \leftarrow 4,2,3$

Ground

Ground

4-1201

3- 961

3- 155

3- 507

3- 961

$8,5,3 \leftarrow 8,5,4$

Ground

$$
5,2 \leftarrow 4,2
$$

Ground

$3,0,3 \leftarrow 2,1,2 \quad$ Ground

$2,1,2 \leftarrow 1,1,1$

$5,1 \leftarrow 4,1$

3- 327

$1,0,1 \leftarrow 0,0,0$

4. 1297

4-1202

3- 961

$8,1,8 \leftarrow 7,1,7$

Ground

Ground

Ground

Ground

Ground

3. 961

, $8,3 \leftarrow 10,6,4$

$5,0 \leftarrow 4,0$

3. 961

$5,0 \leftarrow 4,0$

$5, \leftarrow 4$,

Ground

Ground

3. 421
$4, \quad \leftarrow 3$,

\begin{tabular}{|c|c|c|}
\hline \multirow{4}{*}{\multicolumn{2}{|c|}{$7 / 2$}} & 20396.9 \\
\hline & & 20397.79 \\
\hline & & 20399.69 \\
\hline & & 20399.69 \\
\hline
\end{tabular}

$9 / 2 \quad 7 / 2 \quad 20400.5$

$20400.64 \quad$.1

$20400.64 \quad .1$

$\begin{array}{lllll}7 / 2 & 5 / 2 & 20400.9 & .5\end{array}$

$20401.24 \quad .1$

$20401.24 \quad .1$

$3 / 2 \quad 1 / 2 \quad 20401.7$

20405 . 5 .

$7 / 2 \quad 5 / 2 \quad 20405.6$

$20406.4 \quad .1$

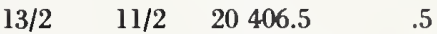

$20408.43 \quad .05$

$20409.38 \quad .05$

20410 . 10.

$20411.14 \quad .05$

20411.65

$20411.95 \quad .1$

$20412.81 \quad .10$

20413.

20414.9

$20415.8 \quad .1$

$20417.9 \quad 3$.

20420 . 5 .

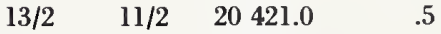

$20423.6 \quad .1$

$7 / 2 \quad 5 / 2 \quad 20424.6$

$5 / 2 \quad 3 / 2 \quad 20426.4$

$7 / 2 \quad 5 / 2 \quad 20427.3$

20429.62

20430.0

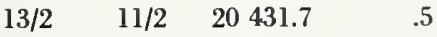

20435.77

$20435.80 \quad .2$

$13 / 2 \quad 11 / 2 \quad 20437.6 \quad .5$

20437.6

$20439.0 \quad$.1

$20439.5 \quad .1$

$11 / 2 \quad 9 / 2 \quad 20439.6 \quad .5$

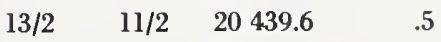

$20441.9 \quad .3$

20443. 


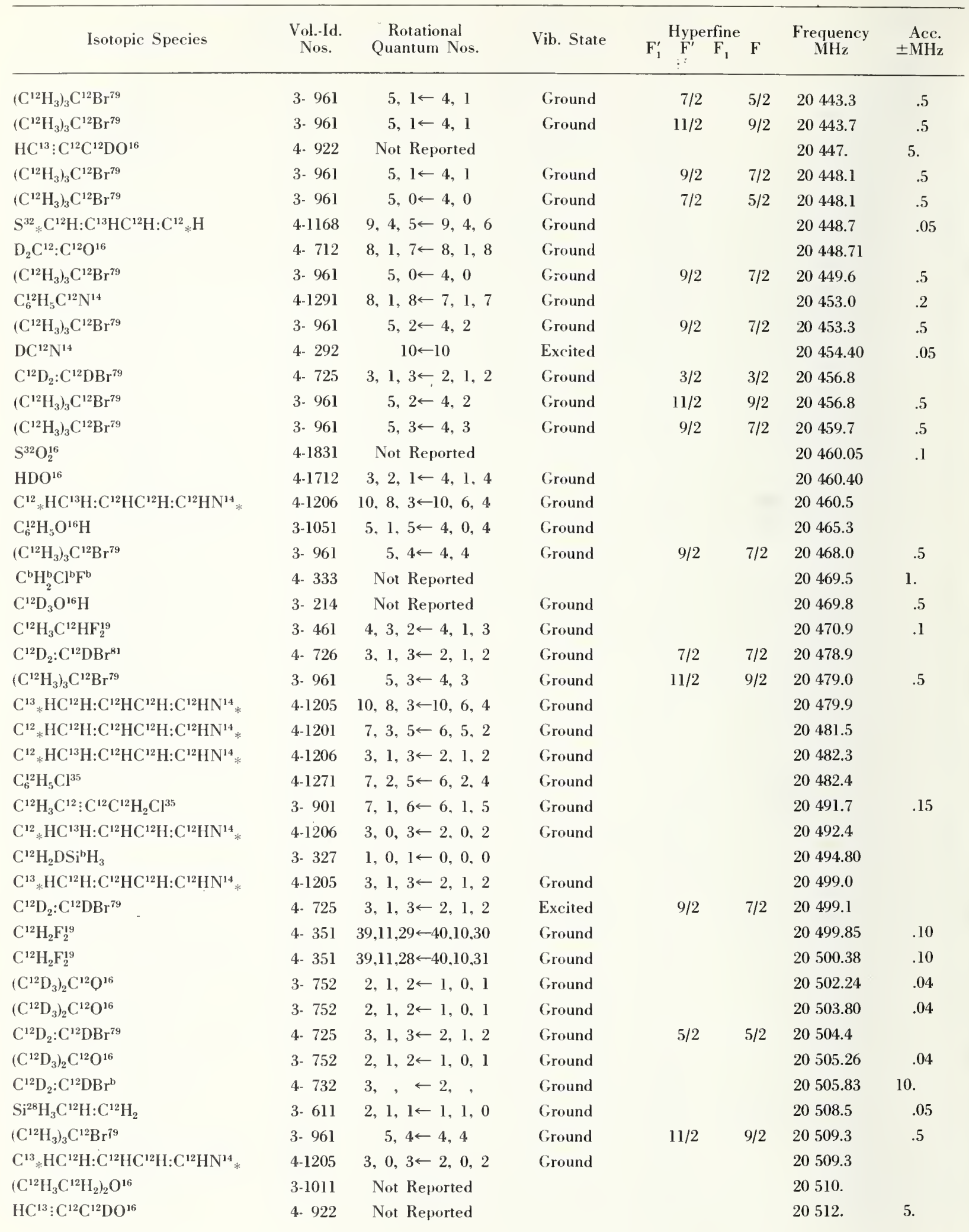




\begin{tabular}{|c|c|c|c|c|c|c|c|}
\hline Isotopic Species & $\begin{array}{c}\text { Vol,-Id. } \\
\text { Nos. }\end{array}$ & $\begin{array}{c}\text { Rotational } \\
\text { Quantum Nos. }\end{array}$ & Vib. State & $\mathrm{F}_{1}^{\prime} \stackrel{\text { Hyperfine }}{\mathrm{F}^{\prime}} \mathrm{F}_{1}$ & $\mathrm{~F}$ & $\begin{array}{c}\text { Frerjuency } \\
\text { MHz }\end{array}$ & $\begin{aligned} & \text { Acc. } \\
\pm & \mathrm{MH} \%\end{aligned}$ \\
\hline$\left(\mathrm{C}^{13} \mathrm{H}_{3}\right)_{2} \mathrm{C}^{12} \mathrm{H}_{3} \mathrm{Si}^{\mathrm{b}} \mathrm{H}$ & 3- 878 & $2,1,1 \leftarrow 1,0,1$ & Ground & & & 20512.02 & .1 \\
\hline $\mathrm{C}^{12} \mathrm{H}_{3} \mathrm{C}^{12} \mathrm{H}_{2} \mathrm{O}^{16} \mathrm{H}$ & 3. 581 & $10,3,7 \leftarrow 11,1,10$ & Ground & & & 20513.18 & .01 \\
\hline $\mathrm{S}^{32}{ }_{*} \mathrm{DC}^{12}: \mathrm{C}^{12} \mathrm{HC}^{12} \mathrm{H}: \mathrm{C}^{12}{ }_{*} \mathrm{H}$ & 4-1162 & $10,5,6 \leftarrow 10,5,5$ & Ground & & & 20514.0 & .1 \\
\hline $\mathrm{C}^{12} \mathrm{O}^{16} \mathrm{~F}_{2}^{19}$ & 4. 211 & $12,12,1 \leftarrow 12,10,2$ & Ground & & & 20514.14 & .10 \\
\hline $\mathrm{C}_{6}^{12} \mathrm{H}_{5} \mathrm{~F}^{19}$ & 4-1281 & $29,9,20 \leftarrow 29,9,21$ & Ground & & & 20514.5 & \\
\hline $\mathrm{C}^{12} \mathrm{D}_{2}: \mathrm{C}^{12} \mathrm{DBr}^{79}$ & 4. 725 & $3,1,3 \leftarrow 2,1,2$ & Ground & $9 / 2$ & $7 / 2$ & 20518.4 & \\
\hline 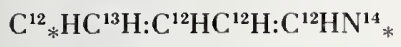 & $4 \cdot 1206$ & $11,9,3 \leftarrow 11,7,4$ & Ground & & & 20518.9 & \\
\hline $\mathrm{C}^{12}{ }_{*} \mathrm{H}: \mathrm{C}^{12} \mathrm{DC}^{12} \mathrm{H}: \mathrm{C}^{12} \mathrm{HN}^{14}{ }_{*} \mathrm{H}$ & $4-1184$ & $4,2,2 \leftarrow 4,2,3$ & Ground & & & 20519.1 & \\
\hline $\mathrm{C}^{12} \mathrm{D}_{2}: \mathrm{C}^{12} \mathrm{DBr}^{79}$ & 4- 725 & $3,1,3 \leftarrow 2,1,2$ & Ground & $3 / 2$ & $1 / 2$ & 20519.9 & \\
\hline $\mathrm{C}^{12}{ }_{*} \mathrm{H}_{2} \mathrm{C}^{12} \mathrm{H}_{2} \mathrm{C}^{12}{ }_{*} \mathrm{HC}^{12} \mathrm{~N}^{14}$ & 4-1171 & $3,1,2 \leftarrow 2,1,1$ & Ground & & & 20521.10 & .05 \\
\hline $\mathrm{t}-\mathrm{HDC}^{12}: \mathrm{C}^{12} \mathrm{DCl}^{37}$ & 4. 764 & $2,1,2 \leftarrow 1,1,1$ & Ground & $7 / 2$ & $5 / 2$ & 20523.55 & .2 \\
\hline $\mathrm{C}^{12} \mathrm{H}_{2}\left(\mathrm{C}^{12} \mathrm{~N}^{14}\right)_{2}$ & 4- 901 & Not Reported & Ground & & & 20524.9 & .1 \\
\hline $\mathrm{C}^{12} \mathrm{D}_{2}: \mathrm{C}^{12} \mathrm{DBr}^{79}$ & 4- 725 & $3,1,3 \leftarrow 2,1,2$ & Excited & $7 / 2$ & $5 / 2$ & 20528.1 & \\
\hline $\mathrm{HDC}^{12}: \mathrm{C}^{12} \mathrm{~F}_{2}^{19}$ & 4- 682 & $5,3,2 \leftarrow 5,3,3$ & Ground & & & 20529.2 & .3 \\
\hline $\mathrm{C}^{12} \mathrm{D}_{2}: \mathrm{C}^{12} \mathrm{DBr}^{79}$ & 4. 725 & $3,1,3 \leftarrow 2,1,2$ & Excited & $5 / 2$ & $3 / 2$ & 20530.2 & \\
\hline $\mathrm{C}^{12} \mathrm{D}_{2}: \mathrm{C}^{12} \mathrm{DBr}^{79}$ & 4. 725 & $3,1,3 \leftarrow 2,1,2$ & Ground & & & 20531.11 & .04 \\
\hline $\mathrm{C}^{12} \mathrm{H}_{2}\left(\mathrm{C}^{12} \mathrm{~N}^{14}\right)_{2}$ & 4- 901 & Not Reported & Ground & & & 20532.9 & .1 \\
\hline $\mathrm{C}^{12} \mathrm{D}_{2}: \mathrm{C}^{12} \mathrm{DBr}^{\mathrm{b}}$ & 4- 732 & $3, \quad \leftarrow 2, \quad$, & Ground & & & 20535.86 & 10. \\
\hline $\mathrm{Si}^{28} \mathrm{H}_{3} \mathrm{C}^{13} \mathrm{H}: \mathrm{C}^{12} \mathrm{H}_{2}$ & 3- 615 & $2,1,1 \leftarrow 1,1,0$ & Ground & & & 20536.54 & .10 \\
\hline $\mathrm{C}^{12} \mathrm{D}_{2}: \mathrm{C}^{12} \mathrm{DBr}^{\mathrm{b}}$ & 4- 732 & $3, \quad \leftarrow 2, \quad$, & Ground & & & 20536.65 & 10. \\
\hline g- $\mathrm{C}^{12} \mathrm{H}_{2} \mathrm{DC}^{12} \mathrm{H}_{2} \mathrm{~F}^{19}$ & 3- 553 & $5,3,2 \leftarrow 6,2,5$ & Ground & & & 20540.9 & .1 \\
\hline $\mathrm{C}^{12} \mathrm{H}_{3} \mathrm{C}^{12} \mathrm{O}^{16} \mathrm{Br}^{81}$ & 3- 352 & $9 ; 2,7 \leftarrow 9,1,8$ & Ground & & & 20541.46 & \\
\hline $\mathrm{C}^{12}{ }_{*} \mathrm{H}: \mathrm{C}^{12} \mathrm{HO}^{16} \mathrm{C}^{12} \mathrm{D}: \mathrm{C}^{12}{ }_{*} \mathrm{H}$ & $4 \cdot 1154$ & $6,6,1 \leftarrow 6,5,2$ & Ground & & & 20541.8 & \\
\hline $\mathrm{C}^{12} \mathrm{H}_{3} \mathrm{C}^{12} \mathrm{O}^{16} \mathrm{Br}^{81}$ & 3. 352 & $9,2,7 \leftarrow 9,1,8$ & Ground & & & 20543.00 & \\
\hline $\mathrm{C}^{13}{ }_{*} \mathrm{HC}^{12} \mathrm{H}: \mathrm{C}^{12} \mathrm{HC}^{12} \mathrm{H}: \mathrm{C}^{12} \mathrm{HN}^{14}{ }_{*}$ & 4-1205 & $11,9,3 \leftarrow 11,7,4$ & Ground & & & 20543.3 & \\
\hline $\mathrm{HC}^{12} \mathrm{O}^{16} \mathrm{O}^{16} \mathrm{H}$ & 3. 71 & $1,1,1 \leftarrow 2,0,2$ & & & & 20543.96 & \\
\hline $\mathrm{C}^{12} \mathrm{H}_{3} \mathrm{C}^{12}{ }_{*} \mathrm{HO}^{16} \mathrm{C}^{12}{ }_{*} \mathrm{H}_{2}$ & 3. 761 & Not Reported & Ground & & & 20545.78 & .1 \\
\hline $\mathrm{C}^{12} \mathrm{H}_{3} \mathrm{~N}^{14} \mathrm{H}_{2}$ & 3. 261 & $13,3, \leftarrow 12,4$, & Ground & & & 20547.17 & .04 \\
\hline $\mathrm{C}^{12} \mathrm{H}_{3} \mathrm{~S}^{32} \mathrm{C}^{12} \mathrm{D}_{3}$ & 3. 606 & $1,1,1 \leftarrow 0,0,0$ & Ground & & & 20547.20 & .05 \\
\hline $\mathrm{C}^{12} \mathrm{D}_{2}: \mathrm{C}^{12} \mathrm{DBr}^{79}$ & 4- 725 & $3,1,3 \leftarrow 2,1,2$ & Ground & $7 / 2$ & $5 / 2$ & 20547.4 & \\
\hline $\mathrm{C}^{12} \mathrm{H}_{3} \mathrm{~S}^{32} \mathrm{C}^{12} \mathrm{D}_{3}$ & 3. 606 & $1,1,1 \leftarrow 0,0,0$ & Ground & & & 20547.90 & .05 \\
\hline $\mathrm{C}^{12} \mathrm{D}_{2}: \mathrm{C}^{12} \mathrm{DBr}^{79}$ & 4- 725 & $3,1,3 \leftarrow 2,1,2$ & Ground & $5 / 2$ & $3 / 2$ & 20549.4 & \\
\hline $\mathrm{C}^{12} \mathrm{H}_{3} \mathrm{~S}^{32} \mathrm{C}^{12} \mathrm{D}_{3}$ & 3- 606 & $1,1,1 \leftarrow 0,0,0$ & Ground & & & 20553.47 & .05 \\
\hline $\mathrm{C}^{12} \mathrm{D}_{2}: \mathrm{C}^{12} \mathrm{DBr}^{\mathrm{b}}$ & 4. 732 & $3, . \leftarrow 2, \quad$, & Ground & & & 20554. & 5. \\
\hline $\mathrm{C}^{12} \mathrm{D}_{2}: \mathrm{C}^{12} \mathrm{DBr}^{\mathrm{b}}$ & 4. 732 & $3, \quad . \quad \leftarrow 2$, & - Ground & & & 20554.03 & 10. \\
\hline $\mathrm{C}_{6}^{12} \mathrm{H}_{5} \mathrm{Cl}^{35}$ & 4-1271 & $7,1,6 \leftarrow 6,1,5$ & Ground & & & 20554.7 & \\
\hline $\mathrm{C}^{12} \mathrm{D}_{2}: \mathrm{C}^{12} \mathrm{DBr}^{\mathrm{b}}$ & 4- 732 & $3, \quad \leftarrow 2, \quad$, & Ground & & & 20556. & 5. \\
\hline $\mathrm{C}^{12} \mathrm{H}_{3} \mathrm{C}^{12}{ }_{*} \mathrm{H}_{2} \mathrm{O}^{16} \mathrm{C}^{12}{ }_{*} \mathrm{C}^{12} \mathrm{H}_{3}$ & 3. 951 & $10.4 .6 \leftarrow 10,3,7$ & Ground & & & 20556.93 & .2 \\
\hline $\mathrm{C}^{12} \mathrm{H}_{3} \mathrm{C}^{12} \mathrm{D}_{2} \mathrm{Br}^{81}$ & 3- 526 & $3,1,3 \leftarrow 2,1,2$ & Ground & $9 / 2$ & $7 / 2$ & 20560.17 & .05 \\
\hline $\mathrm{H}_{2}^{\mathrm{b}} \mathrm{C}^{\mathrm{b}}: \mathrm{C}^{\mathrm{b}} \mathrm{H}^{\mathrm{b}} \mathrm{Cl}^{\mathrm{b}}$ & 4. 772 & Not Reported & Ground & & & 20560.75 & \\
\hline $\mathrm{C}^{12} \mathrm{H}_{3} \mathrm{C}^{12} \mathrm{D}_{2} \mathrm{Br}^{81}$ & 3- 526 & $3,1,3 \leftarrow 2,1,2$ & Ground & $3 / 2$ & $1 / 2$ & 20563.36 & .05 \\
\hline $\mathrm{C}^{12} \mathrm{H}_{2} \mathrm{~N}^{14} \mathrm{O}^{16} \mathrm{D}$ & 3- 142 & $1,0,1 \leftarrow 0,0,0$ & & 2 & 1 & 20566.08 & .10 \\
\hline $\mathrm{C}^{12} \mathrm{H}_{2} \mathrm{~N}^{14} \mathrm{O}^{16} \mathrm{D}$ & 3- 142 & $1,0,1 \leftarrow 0,0,0$ & & 1 & 1 & 20566.97 & .10 \\
\hline
\end{tabular}




\begin{tabular}{|c|c|c|c|c|c|c|c|}
\hline Isotopic Species & $\begin{array}{l}\text { Vol.-Id. } \\
\text { Nos. }\end{array}$ & $\begin{array}{c}\text { Rotational } \\
\text { Quantum Nos. }\end{array}$ & Vib. State & $\mathrm{F}_{1}^{\prime} \quad \mathrm{F}^{\prime} \quad \mathrm{F}_{1}$ & $F$ & $\begin{array}{l}\text { Frequency } \\
\quad \mathrm{MHz}\end{array}$ & $\begin{aligned} & \text { Acc. } \\
\pm & \mathrm{MHz}\end{aligned}$ \\
\hline$\left(\mathrm{C}^{12} \mathrm{H}_{3} \mathrm{C}^{12} \mathrm{H}_{2}\right)_{2} \mathrm{O}^{16}$ & $3-1011$ & Not Reported & & & & 20570. & \\
\hline $\mathrm{C}^{12} \mathrm{H}_{2} \mathrm{~F}_{2}^{19}$ & 4- 351 & $42,10,33 \leftarrow 41,11,30$ & Ground & & & 20570.63 & .10 \\
\hline $\mathrm{C}^{12} \mathrm{H}_{2} \mathrm{~F}_{2}^{19}$ & 4- 351 & $42,10,32 \leftarrow 41,11,31$ & Ground & & & 20571.99 & .10 \\
\hline $2 \mathrm{~d}-\mathrm{C}_{6}^{12} \mathrm{H}_{5} \mathrm{C}^{12} \mathrm{~N}^{14}$ & $4-1294$ & $8,0,8 \leftarrow 7,0,7$ & Ground & & & 20582.0 & .2 \\
\hline $\mathrm{C}^{12} \mathrm{H}_{3} \mathrm{C}^{12} \mathrm{D}_{2} \mathrm{Br}^{81}$ & 3. 526 & $3,1,3 \leftarrow 2,1,2$ & Ground & $7 / 2$ & $5 / 2$ & 20582.64 & .05 \\
\hline $4 \mathrm{C}^{13}-\mathrm{C}_{6}^{12} \mathrm{H}_{5} \mathrm{C}^{12} \mathrm{~N}^{14}$ & $4-1301$ & $8,0,8 \leftarrow 7,0,7$ & Ground & & & 20585.1 & .2 \\
\hline $\mathrm{C}^{12} \mathrm{H}_{3} \mathrm{C}^{12} \mathrm{D}_{2} \mathrm{Br}^{81}$ & 3- 526 & $3,1,3 \leftarrow 2,1,2$ & Ground & $5 / 2$ & $3 / 2$ & 20586.21 & .05 \\
\hline$\left(\mathrm{C}^{12} \mathrm{H}_{3}\right)_{2} \mathrm{~S}^{32}$ & 3. 601 & $6,4,3 \leftarrow 7,3,4$ & Ground & & & 20590.99 & .05 \\
\hline$\left(\mathrm{C}^{12} \mathrm{H}_{3}\right)_{3} \mathrm{Si}^{30} \mathrm{D}$ & 3- 876 & $2, \leftarrow 1$, & Ground & & & 20592.50 & .20 \\
\hline$\left(\mathrm{C}^{12} \mathrm{H}_{3}\right)_{2} \mathrm{~S}^{32}$ & 3- 601 & $6,4,3 \leftarrow 7,3,4$ & Ground & & & 20592.70 & .05 \\
\hline $\mathrm{C}^{12} \mathrm{D}_{2} \mathrm{Cl}^{35} \mathrm{Si}^{-28} \mathrm{H}_{3}$ & 3- 235 & $8,1,7 \leftarrow 8,0,8$ & Ground & & & 20593.01 & .2 \\
\hline$\left(\mathrm{C}^{12} \mathrm{H}_{3}\right)_{2} \mathrm{~S}^{32}$ & 3. 601 & $6,4,3 \leftarrow 7,3,4$ & Ground & & & 20593.52 & .05 \\
\hline $\mathrm{C}^{12}{ }_{*} \mathrm{HC}^{12} \mathrm{H}: \mathrm{C}^{12} \mathrm{HC}^{12} \mathrm{H}: \mathrm{C}^{12} \mathrm{HN}^{14} *$ & $4-1201$ & $4,1,3 \leftarrow 3,3,0$ & Ground & & & 20594.0 & \\
\hline$\left(\mathrm{C}^{12} \mathrm{H}_{3}\right)_{2} \mathrm{~S}^{32}$ & 3. 601 & $6,4,3 \leftarrow 7,3,4$ & Ground & & & 20595.36 & .05 \\
\hline $\mathrm{S}^{33} \mathrm{O}_{2}^{16}$ & $4-1832$ & $5,2,4 \leftarrow 6,1,5$ & Ground & $7 / 2$ & $9 / 2$ & 20602.07 & \\
\hline $\mathrm{C}^{12} \mathrm{H}_{2}\left(\mathrm{C}^{12} \mathrm{~N}^{14}\right)_{2}$ & 4- 901 & Not Reported & Ground & & & 20602.8 & .1 \\
\hline $\mathrm{S}^{33} \mathrm{O}_{2}^{16}$ & $4-1832$ & $5,2,4 \leftarrow 6,1,5$ & Ground & $13 / 2$ & $15 / 2$ & 20603.55 & \\
\hline $\mathrm{S}^{33} \mathrm{O}_{2}^{16}$ & $4-1832$ & $5,2,4 \leftarrow 6,1,5$ & Ground & $9 / 2$ & $11 / 2$ & 20608.13 & \\
\hline $\mathrm{N}^{14} \mathrm{D}_{2} \mathrm{H}$ & $4-1774$ & $8,3,6 \leftarrow 8,2,6$ & Ground & & & 20608.77 & .05 \\
\hline $\mathrm{C}^{12}{ }_{*} \mathrm{D}_{2} \mathrm{C}^{12} \mathrm{H}_{2} \mathrm{C}^{12} \mathrm{D}_{2} \mathrm{O}^{16} *$ & $4-1092$ & $3,2,2 \leftarrow 3,1,3$ & Excited & & & 20610.72 & .1 \\
\hline $\mathrm{C}^{12} \mathrm{D}_{2}: \mathrm{C}^{12} \mathrm{DBr}^{79}$ & 4. 725 & $3,1,3 \leftarrow 2,1,2$ & Ground & $7 / 2$ & $7 / 2$ & 20611.4 & \\
\hline$\left(\mathrm{C}^{12} \mathrm{H}_{3}\right)_{3} \mathrm{Si}^{29} \mathrm{D}$ & 3. 874 & $2, \leftarrow 1$ & Ground & & & 20615.49 & .20 \\
\hline a- $\mathrm{C}^{12} \mathrm{H}_{2} \mathrm{DC}^{12} \mathrm{H}_{2} \mathrm{C}^{12} \mathrm{H}_{3}$ & 3- 786 & $2,1,1 \leftarrow 2,0,2$ & Ground & & & 20616.12 & .06 \\
\hline $4 d-C_{6}^{12} H_{5} F^{19}$ & $4-1283$ & $5,2,4 \leftarrow 4,2,3$ & Ground & & & 20616.2 & .1 \\
\hline $\mathrm{C}^{12} \mathrm{D}_{3} \mathrm{~S}^{32} \mathrm{H}$ & 3- 224 & $1,0,1 \leftarrow 0,0,0$ & Ground & & & 20619.0 & \\
\hline $\mathrm{C}^{12} \mathrm{H}_{2} \mathrm{Cl}^{35} \mathrm{~F}^{19}$ & 4. 331 & $5,0,5 \leftarrow 4,1,4$ & Ground & & & 20619.17 & .1 \\
\hline $\mathrm{C}^{12} \mathrm{H}_{2} \mathrm{Cl}^{35} \mathrm{~F}^{19}$ & 4- 331 & $5,0,5 \leftarrow 4,1,4$ & Ground & & & 20620.26 & .1 \\
\hline $\mathrm{C}^{12} \mathrm{H}_{2} \mathrm{Cl}^{35} \mathrm{~F}^{19}$ & 4- 331 & $5,0,5 \leftarrow 4,1,4$ & Ground & & & 20621.30 & .1 \\
\hline $\mathrm{C}^{\mathrm{b}} \mathrm{HF}_{3}^{\mathrm{b}}$ & 4. 285 & $1, \leftarrow 0$ & & & & 20621.38 & .10 \\
\hline $\mathrm{Si}^{28} \mathrm{H}_{3} \mathrm{C}^{12} \mathrm{H}: \mathrm{C}^{12} \mathrm{H}_{2}$ & 3- 611 & $2,1,1 \leftarrow 1,1,0$ & Ground & & & 20621.8 & .05 \\
\hline $\mathrm{C}^{12} \mathrm{H}_{3} \mathrm{C}^{12} \mathrm{O}^{16} \mathrm{Br}^{79}$ & 3- 351 & $9,2,7 \leftarrow 9,1,8$ & Ground & & & 20621.91 & \\
\hline $\mathrm{C}^{12} \mathrm{H}_{3} \mathrm{C}^{12} \mathrm{O}^{16} \mathrm{Br}^{79}$ & 3- 351 & $9,2,7 \leftarrow 9,1,8$ & Ground & & & 20623.67 & \\
\hline $\mathrm{C}^{12}{ }_{*} \mathrm{H}: \mathrm{C}^{12} \mathrm{HO}^{16} \mathrm{C}^{12}{ }^{12} \mathrm{H}: \mathrm{C}^{12} * \mathrm{H}$ & $4-1151$ & $9,9,1 \leftarrow 9,7,2$ & Ground & & & 20624.34 & \\
\hline $\mathrm{C}^{12} \mathrm{D}_{3} \mathrm{~S}^{32} \mathrm{H}$ & 3- 224 & $1,0,1 \leftarrow 0,0,0$ & Ground & & & 20627.6 & \\
\hline $\mathrm{C}^{12} \mathrm{H}_{3} \mathrm{C}^{12} \mathrm{H}_{2} \mathrm{~F}^{19}$ & 3- 551 & Not Reported & & & & 20636.57 & \\
\hline $\mathrm{C}^{12}{ }_{*} \mathrm{HC}^{13} \mathrm{H}: \mathrm{C}^{12} \mathrm{HC}^{12} \mathrm{H}: \mathrm{C}^{12} \mathrm{HN}^{14}{ }_{*}$ & $4-1206$ & $12,10,3 \leftarrow 12,8,4$ & Ground & & & 20636.8 & \\
\hline $\mathrm{C}_{6}^{12} \mathrm{H}_{5} \mathrm{C}^{13} \mathrm{~N}^{14}$ & $4-1293$ & $8,0,8 \leftarrow 7,0,7$ & Ground & & & 20637.2 & .2 \\
\hline $3 \mathrm{C}^{13}-\mathrm{C}_{6}^{12} \mathrm{H}_{5} \mathrm{C}^{12} \mathrm{~N}^{14}$ & $4-1299$ & $8,0,8 \leftarrow 7,0,7$ & Ground & & & 20637.5 & .1 \\
\hline $\mathrm{C}^{12}{ }_{*} \mathrm{H}: \mathrm{C}^{12} \mathrm{HO}^{16} \mathrm{C}^{12} \mathrm{H}: \mathrm{C}^{12}{ }_{*} \mathrm{H}$ & $4-1151$ & $11,9,2 \leftarrow 11,9,3$ & Ground & & & 20637.71 & \\
\hline$\left(\mathrm{C}^{12} \mathrm{H}_{3}\right)_{3} \mathrm{Si}^{28} \mathrm{D}$ & 3- 872 & $2, \leftarrow 1$ & Ground & & & 20638.87 & .10 \\
\hline $\mathrm{C}^{12} \mathrm{H}_{3} \mathrm{C}^{12} \mathrm{H}_{2} \mathrm{~F}^{19}$ & 3- 551 & Not Reported & & & & 20642.17 & \\
\hline $\mathrm{C}^{12} \mathrm{D}_{3} \mathrm{O}^{16} \mathrm{H}$ & 3- 214 & Not Reported & Ground & & & 20642.5 & .5 \\
\hline $\mathrm{C}^{13} \mathrm{H}_{2} \mathrm{C}^{35} \mathrm{Si}^{28} \mathrm{H}_{3}$ & 3- 233 & $6,0,6 \leftarrow 5,1,5$ & Ground & $9 / 2$ & $7 / 2$ & 20643.52 & .05 \\
\hline
\end{tabular}




\begin{tabular}{|c|c|c|c|c|c|c|c|c|}
\hline Isotopic Species & $\begin{array}{l}\text { Vol.-Id. } \\
\text { Nos. }\end{array}$ & $\begin{array}{c}\text { Rotational } \\
\text { Quantum Nos. }\end{array}$ & Vib. State & $\mathrm{F}_{1}^{\prime}$ & $\begin{array}{l}\text { Hyperfine } \\
\mathrm{F}^{\prime} \quad \mathrm{F}_{1}\end{array}$ & $F$ & $\begin{array}{c}\text { Frequency } \\
\mathrm{WHz}\end{array}$ & $\begin{aligned} & \text { Acc. } \\
\pm & \mathrm{MHz}\end{aligned}$ \\
\hline $\mathrm{Cl}^{37} \mathrm{O}_{2}^{16}$ & 4-1382 & $14,2,13 \leftarrow 13,3,10$ & Ground & & $31 / 2$ & $29 / 2$ & 20643.6 & \\
\hline $\mathrm{C}^{13} \mathrm{HF}_{3}^{19}$ & 4- 282 & $1, \leftarrow 0$ & Ground & & & & 20643.93 & .10 \\
\hline $\mathrm{C}^{13} \mathrm{H}_{2} \mathrm{Cl}^{35} \mathrm{Si}^{28} \mathrm{H}_{3}$ & 3- 233 & $6,0,6 \leftarrow 5,1,5$ & Ground & & $15 / 2$ & $13 / 2$ & 20644.81 & .05 \\
\hline $\mathrm{C}^{12} \mathrm{H}_{3} \mathrm{C}^{12}{ }_{*} \mathrm{HO}^{16} \mathrm{C}^{12}{ }_{*} \mathrm{H}_{2}$ & 3. 761 & $21,10, \leftarrow 20,11$ & Ground & & & & 20644.92 & .1 \\
\hline $\mathrm{C}^{12} \mathrm{H}_{3} \mathrm{C}^{12}{ }_{*} \mathrm{HO}^{16} \mathrm{C}^{12}{ }_{*} \mathrm{H}_{2}$ & 3- 761 & $21,10, \leftarrow 20,11$ & Ground & & & & 20645.46 & .1 \\
\hline $\mathrm{C}^{12} \mathrm{H}_{3} \mathrm{C}^{12}{ }_{*} \mathrm{HO}^{16} \mathrm{C}^{12}{ }_{*} \mathrm{H}_{2}$ & 3- 761 & $21,10, \leftarrow 20,11$ & Ground & & & & 20645.91 & .1 \\
\hline $\mathrm{C}^{13} \mathrm{H}_{3} \mathrm{C}^{12} \mathrm{H}_{3} \mathrm{Si}^{28} \mathrm{H}_{2}$ & 3. 646 & $5,1,4 \leftarrow 5,0,5$ & Ground & & & & 20646.21 & .20 \\
\hline $\mathrm{C}^{12} \mathrm{H}_{3} \mathrm{~S}^{32} \mathrm{H}$ & 3- 221 & Not Reported & Ground & & & & 20646.4 & .1 \\
\hline $\mathrm{Si}^{28} \mathrm{H}_{3} \mathrm{C}^{12} \mathrm{H}: \mathrm{C}^{12} \mathrm{H}_{2}$ & 3- 611 & $2,1,1 \leftarrow 1,1,0$ & Ground & & & & 20646.43 & .05 \\
\hline $\mathrm{C}^{13} \mathrm{H}_{2} \mathrm{Cl}^{35} \mathrm{Si}^{28} \mathrm{H}_{3}$ & 3. 233 & $6,0,6 \leftarrow 5,1,5$ & Ground & & $11 / 2$ & $9 / 2$ & 20646.97 & .05 \\
\hline $\mathrm{C}^{13} \mathrm{H}_{3} \mathrm{C}^{12} \mathrm{H}_{3} \mathrm{Si}^{28} \mathrm{H}_{2}$ & 3. 646 & $5,1,4 \leftarrow 5,0,5$ & Ground & & & & .20647 .95 & .20 \\
\hline $\mathrm{C}^{13} \mathrm{H}_{2} \mathrm{Cl}^{35} \mathrm{Si}^{28} \mathrm{H}_{3}$ & 3- 233 & $6,0,6 \leftarrow 5,1,5$ & Ground & & $13 / 2$ & $11 / 2$ & $20 \cdot 648.29$ & .05 \\
\hline $\mathrm{C}^{12}{ }_{*} \mathrm{HC}^{12} \mathrm{H}: \mathrm{C}^{12} \mathrm{HC}^{12} \mathrm{H}: \mathrm{C}^{12} \mathrm{HN}^{14} *$ & 4-1201 & $6,3,3 \leftarrow 6,3,4$ & Ground & & & & 20648.5 & \\
\hline $\mathrm{HC}^{13} \mathrm{HO}^{16}$ & 4- 382 & $17,3,14 \leftarrow 17,3,15$ & Ground & & & & 20649.30 & \\
\hline $\mathrm{C}^{13} \mathrm{H}_{3} \mathrm{C}^{12} \mathrm{H}_{3} \mathrm{Si}^{28} \mathrm{H}_{2}$ & 3- 646 & $5,1,4 \leftarrow 5,0,5$ & Ground & & & & 20649.83 & .20 \\
\hline $\mathrm{C}^{12} \mathrm{HF}_{3}^{19}$ & 4- 281 & $1, \leftarrow 0$, & Excited & & & & 20650.59 & .10 \\
\hline $\mathrm{C}^{12} \mathrm{H}_{3} \mathrm{C}^{12} \mathrm{HO}^{16}$ & 3- 471 & Not Reported & & & & & 20650.80 & \\
\hline $\mathrm{S}^{32} * \mathrm{DC}^{12}: \mathrm{C}^{12} \mathrm{DC}^{12} \mathrm{D}: \mathrm{C}^{12}{ }_{*} \mathrm{D}$ & 4-1165 & $7,3,5 \leftarrow 7,3,4$ & Ground & & & & 20651.9 & .1 \\
\hline $\mathrm{C}^{12} \mathrm{HF}_{3}^{19}$ & 4. 281 & $1, \leftarrow 0$ & Excited & & & & 20658.67 & .10 \\
\hline $\mathrm{Cl}^{37} \mathrm{O}_{2}^{16}$ & 4-1382 & $14,2,13 \leftarrow 13,3,10$ & Ground & & $29 / 2$ & $27 / 2$ & 20661.4 & \\
\hline $\mathrm{C}^{12} \mathrm{H}_{3} \mathrm{C}^{12} \mathrm{HF}_{2}^{19}$ & 3- 461 & $12,9,3 \leftarrow 12,9,4$ & Ground & & & & 20662.0 & \\
\hline $\mathrm{C}_{6}^{12} \mathrm{H}_{5} \mathrm{~F}^{19}$ & $4-1281$ & $23,7,16 \leftarrow 23,7,17$ & Ground & & & & 20662.1 & \\
\hline $\mathrm{Na}^{23} \mathrm{I}^{127}$ & $1-$ & $3 \leftarrow 2$ & Excited & & $7 / 2$ & $5 / 2$ & 20663.68 & .2 \\
\hline $\mathrm{H}_{2} \mathrm{~N}^{15} \mathrm{C}^{12} \mathrm{HO}^{16}$ & 3- 156 & $1,0,1 \leftarrow 0,0,0$ & Ground & & & & 20664.33 & \\
\hline $\mathrm{C}^{12}{ }_{*} \mathrm{HC}^{12} \mathrm{H}: \mathrm{C}^{12} \mathrm{HC}^{12} \mathrm{H}: \mathrm{C}^{12} \mathrm{HN}^{14} *$ & 4-1201 & $8,6,3 \leftarrow 8,4,4$ & Ground & & & & 20666.8 & \\
\hline $\mathrm{C}^{12} \mathrm{HF}_{3}^{19}$ & 4- 281 & $1, \leftarrow 0$ & Excited & & & & 20667.26 & .10 \\
\hline $\mathrm{C}^{12} \mathrm{H}_{2}\left(\mathrm{C}^{12} \mathrm{~N}^{14}\right)_{2}$ & 4- 901 & $5,1,4 \leftarrow 5,0,5$ & Ground & & & & 20667.93 & \\
\hline$g \cdot \mathrm{C}^{12} \mathrm{H}_{2} \mathrm{DC}^{12} \mathrm{H}_{2} \mathrm{Cl}^{35}$ & 3. 544 & $2,1,1 \leftarrow 1,1,0$ & Ground & & $5 / 2$ & $3 / 2$ & 20668.28 & .05 \\
\hline $\mathrm{C}^{13}{ }_{*} \mathrm{HC}^{12} \mathrm{H}: \mathrm{C}^{12} \mathrm{HC}^{12} \mathrm{H}: \mathrm{C}^{12} \mathrm{HN}^{14} *$ & 4-1205 & $12,10,3 \leftarrow 12,8,4$ & Ground & & & & 20669.9 & \\
\hline g- $\mathrm{C}^{12} \mathrm{H}_{2} \mathrm{DC}^{12} \mathrm{H}_{2} \mathrm{Cl}^{35}$ & 3- 544 & $2,1,1 \leftarrow 1,1,0$ & Ground & & $3 / 2$ & $-3 / 2$ & 20670,34 & .05 \\
\hline $\mathrm{Si}^{28} \mathrm{D}_{3} \mathrm{C}^{12} \mathrm{H}: \mathrm{C}^{12} \mathrm{H}_{2}$ & 3- 612 & $2,1,1 \leftarrow 2,0,2$ & Ground & & & & 20672.34 & .05 \\
\hline $\mathrm{C}^{12} \mathrm{H}_{3} \mathrm{C}^{12} \mathrm{HO}^{18}$ & 3- 479 & $6,1,5 \leftarrow 6,1,6$ & Ground & & & & 20674.05 & .2 \\
\hline $\mathrm{Na}^{23} \mathrm{I}^{127}$ & 1 . & $3 \leftarrow 2$ & Excited & & $11 / 2$ & $9 / 2$ & 20674.43 & .2 \\
\hline $\mathrm{C}^{12} \mathrm{D}_{3} \mathrm{~S}^{32} \mathrm{H}$ & 3- 224 & $1,0,1 \leftarrow 0,0,0$ & Ground & & & & 20674.8 & \\
\hline $\mathrm{C}^{12} \mathrm{H}_{3} \mathrm{C}^{12} \mathrm{~F}_{3}^{19}$ & 3- 411 & $2, \leftarrow 1$, & Excited & & & & 20675.2 & \\
\hline $\mathrm{Na}^{23} \mathrm{I}^{127}$ & 1 . & $3 \leftarrow 2$ & Excited & & $9 / 2$ & $7 / 2$ & 20676.96 & .2 \\
\hline $\mathrm{Na}^{23} I^{127}$ & $1-$ & $3 \leftarrow 2$ & Excited & & $7 / 2$ & $7 / 2$ & 20676.96 & .2 \\
\hline g. $\mathrm{C}^{12} \mathrm{H}_{2} \mathrm{DC}^{12} \mathrm{H}_{2} \mathrm{Cl}^{35}$ & 3- 544 & $2,1,1 \leftarrow 1,1,0$ & Ground & & $5 / 2$ & $5 / 2$ & 20677.17 & .05 \\
\hline $\mathrm{C}^{12} \mathrm{HF}_{3}^{19}$ & 4- 281 & $1, \leftarrow 0$ & Excited & & & & 20677.36 & .10 \\
\hline $\mathrm{C}^{12} \mathrm{H}_{3} \mathrm{C}^{12} \mathrm{~F}_{3}^{19}$ & 3. 411 & $2, \leftarrow 1$, & Exciled & & & & 20678.2 & \\
\hline $\mathrm{C}^{12}{ }_{*} \mathrm{HC}^{12} \mathrm{H}: \mathrm{C}^{12} \mathrm{HC}^{12} \mathrm{H}: \mathrm{C}^{12} \mathrm{HN}^{14}{ }_{*}$ & 4-1201 & $9,7,3 \leftarrow 9,5,4$ & Ground & & & & 20678.5 & \\
\hline $\mathrm{C}^{12} \mathrm{D}_{3} \mathrm{~S}^{32} \mathrm{H}$ & 3- 224 & $1,0,1 \leftarrow 0,0,0$ & Ground & & & & 20678.9 & \\
\hline $\mathrm{g}-\mathrm{C}^{12} \mathrm{H}_{2} \mathrm{DC}^{12} \mathrm{H}_{2} \mathrm{Cl}^{35}$ & 3. 544 & $2,1,1 \leftarrow 1,1,0$ & Ground & & $7 / 2$ & $5 / 2$ & 20680.09 & .05 \\
\hline $\mathrm{C}^{12} \mathrm{H}_{3} \mathrm{C}^{12} \mathrm{D}_{2} \mathrm{Br}^{79}$ & 3- 524 & $3,1,3 \leftarrow 2,1,2$ & Ground & & $9 / 2$ & $7 / 2$ & 20680.26 & .05 \\
\hline
\end{tabular}




\begin{tabular}{|c|c|c|c|c|c|c|c|}
\hline \multirow{2}{*}{ Isotopic Species } & \multirow{2}{*}{$\begin{array}{l}\text { Vol.-Id. } \\
\text { Nos. }\end{array}$} & \multirow{2}{*}{$\begin{array}{c}\text { Rotational } \\
\text { Quantum Nos. }\end{array}$} & \multirow{2}{*}{ Vib. State } & \multicolumn{2}{|c|}{ Hyperfine } & \multirow{2}{*}{$\begin{array}{l}\text { Frequency } \\
\quad \mathrm{MHz}\end{array}$} & \multirow{2}{*}{$\begin{aligned} & \text { Acc. } \\
\pm & \mathrm{MHz}\end{aligned}$} \\
\hline & & & & $\begin{array}{lll}F_{1}^{\prime} & F^{\prime} & F_{1}\end{array}$ & $\mathrm{~F}$ & & \\
\hline $\mathrm{O}^{\mathrm{b}} \mathrm{O}^{\mathrm{b}} \mathrm{O}^{\mathrm{b}}$ & $4-1847$ & Not Reported & & & & 20680.7 & \\
\hline $\mathrm{Cl}^{37} \mathrm{O}_{2}^{16}$ & 4-1382 & $14,2,13 \leftarrow 13,3,10$ & Ground & $27 / 2$ & $25 / 2$ & 20682.2 & \\
\hline $\mathrm{N}^{15} \mathrm{H}_{3}$ & 4. 1772 & $4,2 \leftarrow 4,2$ & Ground & & & 20682.87 & .02 \\
\hline $\mathrm{C}^{12} \mathrm{H}_{3} \mathrm{C}^{12} \mathrm{D}_{2} \mathrm{Br}^{79}$ & 3- 524 & $3,1,3 \leftarrow 2,1,2$ & Ground & $3 / 2$ & $1 / 2$ & 20684.07 & .05 \\
\hline g. $\mathrm{C}^{12} \mathrm{H}_{2} \mathrm{DC}^{12} \mathrm{H}_{2} \mathrm{Cl}^{35}$ & 3- 544 & $2,1,1 \leftarrow 1,1,0$ & Ground & $3 / 2$ & $1 / 2$ & 20686.34 & .05 \\
\hline $\mathrm{Cl}^{35} \mathrm{O}_{2}^{16}$ & $4 \cdot 1381$ & $7,1,6 \leftarrow 6,2,5$ & Ground & & & 20688.0 & .2 \\
\hline g- $\mathrm{C}^{12} \mathrm{H}_{2} \mathrm{DC}^{12} \mathrm{H}_{2} \mathrm{Cl}^{35}$ & 3- 544 & $2,1,1 \leftarrow 1,1,0$ & Ground & $1 / 2$ & $1 / 2$ & 20689.31 & .05 \\
\hline $\mathrm{C}^{13} \mathrm{H}_{3} \mathrm{C}^{12} \mathrm{H}_{2} \mathrm{Br}^{81}$ & 3. 531 & $3,1,3 \leftarrow 2,1,2$ & Ground & $9 / 2$ & $7 / 2$ & 20689.88 & .05 \\
\hline$\left(\mathrm{C}^{13} \mathrm{H}_{3}\right)_{2} \mathrm{C}^{12} \mathrm{H}_{3} \mathrm{Si}^{\mathrm{b}} \mathrm{H}$ & 3- 878 & $2,2,0 \leftarrow 1,1,0$ & Ground & & & 20690.03 & .1 \\
\hline $\mathrm{C}^{12} \mathrm{H}_{2}\left(\mathrm{C}^{12} \mathrm{~N}^{14}\right)_{2}$ & 4- 901 & Not Reported & Ground & & & 20691 & .1 \\
\hline $\mathrm{C}^{12}{ }_{\lrcorner} \mathrm{HC}^{12} \mathrm{H}: \mathrm{C}^{12} \mathrm{HC}^{12} \mathrm{H}: \mathrm{C}^{12} \mathrm{HN}^{14} *$ & $4 \cdot 1201$ & $5,2,3 \leftarrow 5,2,4$ & Ground & & & 20691.0 & \\
\hline $\mathrm{C}^{13} \mathrm{H}_{3} \mathrm{C}^{12} \mathrm{H}_{2} \mathrm{Br}^{81}$ & 3- 531 & $3,1,3 \leftarrow 2,1,2$ & Ground & $3 / 2$ & $1 / 2$ & 20693.57 & .05 \\
\hline $\mathrm{C}^{12} \mathrm{H}_{3} \mathrm{C}^{12} \mathrm{~F}_{3}^{19}$ & $3 \cdot 411$ & $2, \leftarrow 1$ & Excited & & & 20694.8 & \\
\hline$\left(\mathrm{C}^{12} \mathrm{D}_{3}\right)_{2} \mathrm{O}^{16}$ & 3- 592 & $3,1,2 \leftarrow 3,0,3$ & Ground & & & 20695.5 & .5 \\
\hline $\mathrm{C}^{12} \mathrm{HF}_{3}^{19}$ & 4- 281 & $1, \leftarrow 0$, & Ground & & & 20697.73 & .10 \\
\hline $\mathrm{S}^{34} \mathrm{O}_{2}^{16}$ & 4-1833 & $8,2,6 \leftarrow 9,1,9$ & Ground & & & 20699.30 & .02 \\
\hline $\mathrm{C}^{12} * \mathrm{H}_{2} \mathrm{C}^{12} \mathrm{D}: \mathrm{C}^{12} * \mathrm{H}$ & 4-1032 & $8,5,3 \leftarrow 8,5,4$ & Ground & & & $20700 . \downarrow$ & \\
\hline $\mathrm{C}^{12} \mathrm{H}_{3} \mathrm{C}^{12} \mathrm{HO}^{16}$ & 3- 471 & Not Reported & & & & 20701.5 & \\
\hline $\mathrm{C}^{12}{ }_{*} \mathrm{HN}^{14} \mathrm{C}^{12} \mathrm{HC}^{12} \mathrm{H}: \mathrm{C}^{12} \mathrm{HN}^{14}{ }_{*}$ & 4-1141 & $11,8,3 \leftarrow 11,7,4$ & Ground & & & 20703.6 & \\
\hline $\mathrm{C}^{\mathrm{b}} * \mathrm{H}_{2}^{\mathrm{b}} \mathrm{N}^{\mathrm{b}} \mathrm{H}^{\mathrm{b}} \mathrm{C}_{*}^{\mathrm{b}} \mathrm{H}_{2}^{\mathrm{b}}$ & 4- 863 & Not Reported & & & & 20703.8 & .5 \\
\hline $\mathrm{Cl}^{37} \mathrm{O}_{2}^{16}$ & 4-1382 & $14,2,13 \leftarrow 13,3,10$ & Ground & $25 / 2$ & $23 / 2$ & 20705.5 & \\
\hline $\mathrm{C}^{12} \mathrm{HF}_{3}^{19}$ & 4- 281 & $1, \leftarrow 0$ & Excited & & & 20705.82 & .10 \\
\hline $\mathrm{C}^{12} \mathrm{H}_{2}\left(\mathrm{C}^{12} \mathrm{~N}^{14}\right)_{2}$ & 4. 901 & Not Reported & Ground & & & 20706.8 & .1 \\
\hline $\mathrm{C}^{12} \mathrm{H}_{3} \mathrm{C}^{12} \mathrm{D}_{2} \mathrm{Br}^{79}$ & 3. 524 & $3,1,3 \leftarrow 2,1,2$ & Ground & $7 / 2$ & $5 / 2$ & 20707.16 & .05 \\
\hline $\mathrm{C}^{12} \mathrm{H}_{3} \mathrm{C}^{12} \mathrm{~F}_{3}^{19}$ & 3- 411 & Not Reported & & & & 20707.4 & \\
\hline $\mathrm{C}^{12} \mathrm{H}_{3} \mathrm{C}^{12} \mathrm{~F}_{3}^{19}$ & 3- 411 & $2, \leftarrow 1$ & Excited & & & 20708.18 & \\
\hline $\mathrm{C}^{12} * \mathrm{HC}^{12} \mathrm{H}: \mathrm{C}^{12} \mathrm{HC}^{12} \mathrm{H}: \mathrm{C}^{12} \mathrm{HN}^{14} *$ & 4-1201 & $3,1,3 \leftarrow 2,1,2$ & Ground & & & 20709.0 & \\
\hline $\mathrm{C}^{12} \mathrm{H}_{3} \mathrm{C}^{12} \mathrm{~F}_{3}^{19}$ & 3- 411 & $2, \leftarrow 1$ & Excited & & & 20709.7 & \\
\hline $\mathrm{C}^{13} \mathrm{H}_{3} \mathrm{C}^{12} \mathrm{H}_{2} \mathrm{Br}^{81}$ & 3- 531 & $3,1,3 \leftarrow 2,1,2$ & Ground & $7 / 2$ & $5 / 2$ & 20711.40 & .05 \\
\hline $\mathrm{C}^{12} \mathrm{H}_{3} \mathrm{C}^{12} \mathrm{D}_{2} \mathrm{Br}^{79}$ & 3. 524 & $3,1,3 \leftarrow 2,1,2$ & Ground & $5 / 2$ & $3 / 2$ & 20711.43 & .05 \\
\hline $\mathrm{Cl}^{35} \mathrm{O}_{2}^{16}$ & 4-1381 & $7,1,6 \leftarrow 6,2,5$ & Ground & & & 20713.3 & .2 \\
\hline $\mathrm{C}^{12} \mathrm{HF}_{3}^{19}$ & 4- 281 & $1, \leftarrow 0$ & Excited & & & 20713.54 & .10 \\
\hline $\mathrm{C}^{13} \mathrm{H}_{3} \mathrm{C}^{12} \mathrm{H}_{2} \mathrm{Br}^{81}$ & 3- 531 & $3,1,3 \leftarrow 2,1,2$ & Ground & $5 / 2$ & $3 / 2$ & 20715.41 & .05 \\
\hline $\mathrm{HC}^{13}: \mathrm{C}^{12} \mathrm{C}^{12} \mathrm{DO}^{16}$ & 4. 922 & Not Reported & & & & 20716. & 5. \\
\hline $\mathrm{N}^{14} \mathrm{H}_{3}$ & $4-1771$ & $8,6 \leftarrow 8,6$ & Ground & & & 20719.21 & .02 \\
\hline$\left(\mathrm{C}^{12} \mathrm{H}_{3} \mathrm{C}^{12} \mathrm{H}_{2}\right)_{2} \mathrm{O}^{16}$ & 3-1011 & Not Reported & & & & 20720 . & \\
\hline $\mathrm{C}^{12} \mathrm{HF}_{3}^{19}$ & 4- 281 & $1, \leftarrow 0$ & Excited & & & 20720.99 & .10 \\
\hline $\mathrm{C}^{12} \mathrm{HC}^{12} \mathrm{H}: \mathrm{C}^{12} \mathrm{HC}^{12} \mathrm{H}: \mathrm{C}^{12} \mathrm{HN}^{14} *$ & $4-1201$ & $3,0,3 \leftarrow 2,0,2$ & Ground & & & 20722.5 & \\
\hline
\end{tabular}




\begin{tabular}{|c|c|c|c|c|c|c|c|}
\hline Isotopic Species & $\begin{array}{l}\text { Vol.-Id. } \\
\text { Nos. }\end{array}$ & $\begin{array}{c}\text { Rotational } \\
\text { Quantum Nos. }\end{array}$ & Vib. State & $\mathrm{F}_{1}^{\prime} \mathrm{F}^{\prime} \mathrm{F}$ & $\mathrm{F}$ & $\begin{array}{c}\text { Frequency } \\
\text { MHz }\end{array}$ & $\begin{aligned} & \text { Arce. } \\
\pm & \text { Mllz }\end{aligned}$ \\
\hline $\mathrm{e}^{12} \mathrm{H}_{3} \mathrm{C}^{12} \mathrm{~F}_{3}^{19}$ & 3. 411 & $2, \leftarrow 1$ & Excited & & & 20725.0 & \\
\hline $\mathrm{C}_{6}^{12} \mathrm{H}_{5} \mathrm{~F}^{19}$ & $4-1281$ & $26,8,18 \leftarrow 26,8,19$ & Ground & & & 20725.5 & \\
\hline $\mathrm{C}^{12} \mathrm{H}_{2}\left(\mathrm{C}^{12} \mathrm{~N}^{14}\right)_{2}$ & 4- 901 & Not Reported & Ground & & & 20726. & .1 \\
\hline $\mathrm{D}_{2} \mathrm{O}_{2}^{16}$ & $3-\quad 42$ & Not Reported & & & & 20728. & 3. \\
\hline $\mathrm{DC}^{12}: \mathrm{C}^{12} \mathrm{Cl}^{35}$ & 4. 603 & $2 \leftarrow 1$ & Ground & $3 / 2$ & $1 / 2$ & 20728.03 & .1 \\
\hline $\mathrm{C}^{12}{ }_{*} \mathrm{H}_{2} \mathrm{C}^{13} \mathrm{H}_{2} \mathrm{C}^{12} \mathrm{Cl}_{2}^{35}$ & 4-1068 & $5,5,1 \leftarrow 4,0,4$ & Ground & & & 20728.54 & \\
\hline $\mathrm{DC}^{12}: \mathrm{C}^{12} \mathrm{Cl}^{35}$ & 4. 603 & $2 \leftarrow 1$ & Ground & $5 / 2$ & $5 / 2$ & 20729.79 & .1 \\
\hline $\mathrm{C}^{12} \mathrm{D}_{3} \mathrm{~S}^{32} \mathrm{H}$ & 3- 224 & $1,0,1 \leftarrow 0,0,0$ & Ground & & & 20732.0 & \\
\hline $\mathrm{C}^{12} \mathrm{D}_{3} \mathrm{~S}^{32} \mathrm{H}$ & 3- 224 & $1,0,1 \leftarrow 0,0,0$ & Ground & & & 20732.8 & \\
\hline $\mathrm{C}^{12}{ }_{*} \mathrm{H}: \mathrm{C}^{12} \mathrm{HC}^{12} \mathrm{H}: \mathrm{C}^{12} \mathrm{HN}^{14}{ }_{*} \mathrm{D}$ & 4-1182 & $4,2,2 \leftarrow 4,2,3$ & Ground & & & 20735. & \\
\hline $\mathrm{N}^{14} \mathrm{H}_{3}$ & $4 \cdot 1771$ & $9,7 \leftarrow 9,7$ & Ground & & & 20735.44 & .02 \\
\hline $\mathrm{HC}^{13} \mathrm{HO}^{16}$ & 4. 382 & $9,2,7 \leftarrow 9,2,8$ & Ground & & & 20736.30 & \\
\hline $\mathrm{C}^{12} \mathrm{H}_{2}\left(\mathrm{C}^{12} \mathrm{~N}^{14}\right)_{2}$ & 4. 901 & Not Reported & Ground & & & 20738. & .1 \\
\hline $\mathrm{Na}^{23} \mathrm{I}^{127}$ & 1 . & $3 \leftarrow 2$ & Excited & $9 / 2$ & $9 / 2$ & 20738.98 & .20 \\
\hline$\left(\mathrm{C}^{12} \mathrm{H}_{3} \mathrm{C}^{12} \mathrm{H}_{2}\right)_{2} \mathrm{O}^{16}$ & 3-1011 & Not Reported & & & & 20740 . & \\
\hline $\mathrm{C}^{12} \mathrm{H}_{3} \mathrm{C}^{12} \mathrm{~F}_{3}^{19}$ & 3. 411 & $2, \leftarrow 1$, & Ground & & & 20740.53 & .1 \\
\hline $\mathrm{Cl}^{35} \mathrm{O}_{2}^{16}$ & $4 \cdot 1381$ & $7,1,6 \leftarrow 6,2,5$ & Ground & & & 20741.8 & .2 \\
\hline $\mathrm{DC}^{12} \vdots \mathrm{C}^{12} \mathrm{Cl}^{35}$ & 4- 603 & $2 \leftarrow 1$ & Ground & $3 / 2$ & $5 / 2$ & 20744.00 & .1 \\
\hline $\mathrm{P}^{31} \mathrm{O}^{16} \mathrm{~F}_{2}^{19} \mathrm{Cl}^{35}$ & $4 \cdot 1391$ & $14,6,8 \leftarrow 14,5,9$ & Ground & $31 / 2$ & $31 / 2$ & 20744.17 & \\
\hline $\mathrm{P}^{31} \mathrm{O}^{16} \mathrm{~F}_{2}^{19} \mathrm{Cl}^{35}$ & $4-1391$ & $14,6,9 \leftarrow 14,5,10$ & Ground & $31 / 2$ & $31 / 2$ & 20744.17 & \\
\hline $\mathrm{P}^{31} \mathrm{O}^{16} \mathrm{~F}_{2}^{19} \mathrm{Cl}^{35}$ & 4-1391 & $14,6,9 \leftarrow 14,5,10$ & Ground & $25 / 2$ & $25 / 2$ & 20744.17 & \\
\hline $\mathrm{P}^{31} \mathrm{O}^{16} \mathrm{~F}_{2}^{19} \mathrm{Cl}^{35}$ & 4-1391 & $14,6,8 \leftarrow 14,5,9$ & Ground & $25 / 2$ & $25 / 2$ & 20744.17 & \\
\hline $\mathrm{C}^{12} \mathrm{~F}_{3}^{19} \mathrm{Br}^{81}$ & 4- 222 & $5,3 \leftarrow 4,3$ & Ground & $7 / 2$ & $5 / 2$ & 20744.2 & \\
\hline $\mathrm{P}^{31} \mathrm{O}^{16} \mathrm{~F}_{2}^{19} \mathrm{Cl}^{35}$ & 4-1391 & $14,6,8 \leftarrow 14,5,9$ & Ground & $29 / 2$ & $29 / 2$ & 20746.36 & \\
\hline $\mathrm{P}^{31} \mathrm{O}^{16} \mathrm{~F}_{2}^{19} \mathrm{Cl}^{35}$ & $4 \cdot 1391$ & $14,6,8 \leftarrow 14,5,9$ & Ground & $27 / 2$ & $27 / 2$ & 20746.36 & \\
\hline $\left.\mathrm{P}^{31} \mathrm{O}^{16} \mathrm{~F}_{2}^{19} \mathrm{Cl}\right]^{35}$ & 4-1391 & $14,6,9 \leftarrow 14,5,10$ & Ground & $27 / 2$ & $27 / 2$ & 20746.36 & \\
\hline $\left.\mathrm{P}^{31} \mathrm{O}^{16} \mathrm{~F}_{2}^{19} \mathrm{C}\right]^{35}$ & 4-1391 & $14,6,9 \leftarrow 14,5,10$ & Ground & $29 / 2$ & $29 / 2$ & 20746.36 & \\
\hline $\mathrm{a}-\mathrm{C}^{12} \mathrm{HD}_{2} \mathrm{C}^{12} \mathrm{HO}^{16}$ & 3- 482 & $6,1,5 \leftarrow 6,1,6$ & Ground & & & 20746.48 & .2 \\
\hline $\mathrm{DC}^{12}: \mathrm{C}^{12} \mathrm{Cl}^{35}$ & 4- 603 & $2 \leftarrow 1$ & Ground & $1 / 2$ & $1 / 2$ & 20748.02 & .1 \\
\hline $\mathrm{C}^{12} \mathrm{~F}_{3}^{19} \mathrm{Br}^{81}$ & 4. 222 & $5,4 \leftarrow 4,4$ & Ground & $13 / 2$ & $11 / 2$ & 20749.6 & \\
\hline $\mathrm{DC}^{12}: \mathrm{C}^{12} \mathrm{Cl}^{35}$ & 4- 603 & $2 \leftarrow 1$ & Ground & $7 / 2$ & $5 / 2$ & 20749.76 & .1 \\
\hline $\mathrm{DC}^{12}: \mathrm{C}^{12} \mathrm{Cl}^{35}$ & 4- 603 & $2 \leftarrow 1$ & Ground & $5 / 2$ & $3 / 2$ & 20749.76 & .1 \\
\hline $2 \mathrm{C}^{13} \cdot \mathrm{C}_{6}^{12} \mathrm{H}_{5} \mathrm{C}^{12} \mathrm{~N}^{14}$ & $4 \cdot 1298$ & $8,0,8 \leftarrow 7,0,7$ & Ground & & & 20750.9 & .2 \\
\hline $\mathrm{t} \cdot \mathrm{HDN}^{14} \mathrm{C}^{12} \mathrm{HO}^{16}$ & 3. 153 & $4,0,4 \leftarrow 3,1,3$ & Ground & & & 20751.45 & \\
\hline $\mathrm{s}-\mathrm{C}^{12} \mathrm{H}_{2} \mathrm{DC}^{12} \mathrm{H}_{3} \mathrm{C}^{12}: \mathrm{C}^{12} \mathrm{H}_{2}$ & 3- 943 & $2,0,2 \leftarrow 1,1,1$ & - Ground & & & 20752.87 & .05 \\
\hline $\mathrm{H}_{2} \mathrm{C}^{12}: \mathrm{C}^{12} \mathrm{O}^{16}$ & 4. 711 & $10,1,9 \longleftarrow 10,1,10$ & Ground & & & 20753.90 & \\
\hline $\mathrm{P}^{31} \mathrm{H}_{2} \mathrm{D}$ & 4-1782 & Not Reported & Ground & & & 20754.57 & .05 \\
\hline $\mathrm{P}^{31} \mathrm{O}^{16} \mathrm{~F}_{2}^{19} \mathrm{Cl}^{35}$ & 4-1391 & $13,6,8 \leftarrow 13,5,9$ & Ground & $29 / 2$ & $29 / 2$ & 20755.88 & \\
\hline $\mathrm{P}^{31} \mathrm{O}^{16} \mathrm{~F}_{2}^{19} \mathrm{Cl}^{35}$ & 4-1391 & $13,6,7 \leftarrow 13,5,8$ & Ground & $29 / 2$ & $29 / 2$ & 20755.88 & \\
\hline $\mathrm{P}^{31} \mathrm{O}^{16} \mathrm{~F}_{2}^{19} \mathrm{Cl}^{35}$ & 4-1391 & $13,6,7 \leftarrow 13,5,8$ & Ground & $23 / 2$ & $23 / 2$ & 20755.88 & \\
\hline $\mathrm{P}^{31} \mathrm{O}^{16} \mathrm{~F}_{2}^{19} \mathrm{Cl}^{35}$ & 4.1391 & $13,6,8 \leftarrow 13,5,9$ & Ground & $23 / 2$ & $23 / 2$ & 20755.88 & \\
\hline $\mathrm{C}^{12} \mathrm{H}_{3} \mathrm{C}^{12} \mathrm{~F}_{3}^{19}$ & 3- -411 & $2, \leftarrow 1$ & Excited & & & 20757.4 & \\
\hline $\mathrm{C}^{12} \mathrm{H}_{2} \mathrm{Cl}^{35} \mathrm{Si}^{28} \mathrm{H}_{3}$ & 3- 231 & $5,1,4 \leftarrow 5,0,5$ & Ground & $7 / 2$ & $7 / 2$ & 20757.70 & .2 \\
\hline $\mathrm{P}^{31} \mathrm{O}^{16} \mathrm{~F}_{2}^{19} \mathrm{Cl}^{35}$ & 4-1391 & $13,6,8 \leftarrow 13,5,9$ & Ground & $25 / 2$ & $25 / 2$ & 20758.31 & \\
\hline $\mathrm{P}^{31} \mathrm{O}^{16} \mathrm{~F}_{0}^{19} \mathrm{Cl}^{35}$ & 4-1391 & $13,6,7 \leftarrow 13,5,8$ & Ground & $27 / 2$ & $27 / 2$ & 20758.31 & \\
\hline
\end{tabular}




\begin{tabular}{|c|c|c|c|c|c|c|c|}
\hline Isotopic Species & $\begin{array}{l}\text { Vol.-Id. } \\
\text { Nos. }\end{array}$ & $\begin{array}{c}\text { Rotational } \\
\text { Quantum Nos. }\end{array}$ & Vib. State & $\mathrm{F}_{1}^{\prime} \stackrel{\mathrm{F}^{\prime}}{\text { Hyperfine }} \mathrm{F}_{1}$ & $\mathrm{e} F$ & $\begin{array}{c}\text { Frequency } \\
\mathrm{MHz}\end{array}$ & $\begin{aligned} & \text { Acc. } \\
& \pm \mathrm{MHz}\end{aligned}$ \\
\hline $\mathrm{P}^{31} \mathrm{O}^{16} \mathrm{~F}_{2}^{19} \mathrm{Cl}^{35}$ & 4-1391 & $13,6,8 \leftarrow 13,5,9$ & Ground & $27 / 2$ & $27 / 2$ & 20758.31 & \\
\hline $\left.\mathrm{P}^{31} \mathrm{O}^{16} \mathrm{~F}_{2}^{19} \mathrm{C}\right]^{35}$ & 4-1391 & $13,6,7 \leftarrow 13,5,8$ & Ground & $25 / 2$ & $25 / 2$ & 20758.31 & \\
\hline $\mathrm{C}^{12} \mathrm{H}_{2} \mathrm{Cl}^{35} \mathrm{Si}^{28} \mathrm{H}_{3}$ & 3- 231 & $5,1,4 \leftarrow 5,0,5$ & Ground & $13 / 2$ & $13 / 2$ & 20759.47 & .2 \\
\hline $\mathrm{a}-\mathrm{C}^{12} \mathrm{HD}_{2} \mathrm{C}^{12} \mathrm{HO}^{16}$ & 3- 482 & $6,1,5 \leftarrow 6,1,6$ & Ground & & & 20761.20 & .2 \\
\hline $\mathrm{C}^{12} \mathrm{H}_{2} \mathrm{Cl}^{35} \mathrm{Si}^{28} \mathrm{H}_{3}$ & 3- 231 & $5,1,4 \leftarrow 5,0,5$ & Ground & & & 20761.87 & .2 \\
\hline $\mathrm{C}^{12} \mathrm{H}_{2} \mathrm{Cl}^{35} \mathrm{Si}^{28} \mathrm{H}_{3}$ & 3- 231 & $5,1,4 \leftarrow 5,0,5$ & Ground & $9 / 2$ & $9 / 2$ & 20763.92 & .2 \\
\hline $\mathrm{DC}^{12}: \mathrm{C}^{12} \mathrm{Cl}^{35}$ & 4- 603 & $2 \leftarrow 1$ & Ground & $3 / 2$ & $3 / 2$ & 20763.96 & .1 \\
\hline $\mathrm{C}^{12} \mathrm{~F}_{3}^{19} \mathrm{Br}^{81}$ & 4- 222 & $5,3 \leftarrow 4,3$ & Ground & $13 / 2$ & $11 / 2$ & 20764.2 & \\
\hline $\mathrm{Na}^{23} \mathbf{I}^{127}$ & $1-$ & $3 \leftarrow 2$ & Excited & $5 / 2$ & $3 / 2$ & 20764.43 & .40 \\
\hline $\mathrm{P}^{31} \mathrm{O}^{16} \mathrm{~F}_{2}^{19} \mathrm{Cl}^{35}$ & 4-1391 & $12,6,6 \leftarrow-12,5,7$ & Ground & $27 / 2$ & $27 / 2$ & 20765.28 & \\
\hline $\mathrm{P}^{31} \mathrm{O}^{16} \mathrm{~F}_{2}^{19} \mathrm{Cl}^{35}$ & 4.1391 & $12,6,7 \leftarrow 12,5,8$ & Ground & $21 / 2$ & $21 / 2$ & $20765.2^{8}$ & \\
\hline $\mathrm{P}^{31} \mathrm{O}^{16} \mathrm{~F}_{2}^{19} \mathrm{Cl}^{35}$ & $4 \cdot 1391$ & $12,6,7 \leftarrow 12,5,8$ & Ground & $27 / 2$ & $27 / 2$ & 20765.23 & \\
\hline $\mathrm{P}^{31} \mathrm{O}^{16} \mathrm{~F}_{2}^{19} \mathrm{Cl}^{35}$ & 4-1391 & $12,6,6 \leftarrow 12,5,7$ & Ground & $21 / 2$ & $21 / 2$ & 20765.28 & \\
\hline $\mathrm{C}^{12} \mathrm{H}_{2} \mathrm{Cl}^{35} \mathrm{Si}^{28} \mathrm{H}_{3}$ & 3- 231 & $5,1,4 \leftarrow 5,0,5$ & Ground & $11 / 2$ & $11 / 2$ & 20765.66 & .2 \\
\hline $\mathrm{C}^{12} \mathrm{HDHC}^{12} \mathrm{HDF}^{19}$ & 3- 559 & $1,1,0 \leftarrow 1,0,1$ & Ground & & & 20766.0 & .1 \\
\hline $\mathrm{H}_{2} \mathrm{~B}^{10} \mathrm{H}_{2} \mathrm{~B}^{11} \mathrm{HBr}^{79}$ & 4. 43 & $3,1,2 \leftarrow 2,1,1$ & Ground & $9 / 2$ & $7 / 2$ & 20766.4 & \\
\hline$\left(\mathrm{C}^{12} \mathrm{H}_{3}\right)_{2} \mathrm{C}^{12}: \mathrm{C}^{12} \mathrm{H}_{2}$ & 3. 941 & $6,6,1 \leftarrow 6,5,2$ & Ground & & & 20766.70 & .05 \\
\hline$\left(\mathrm{C}^{12} \mathrm{H}_{3}\right)_{2} \mathrm{C}^{12}: \mathrm{C}^{12} \mathrm{H}_{2}$ & 3- 941 & $6,6,1 \leftarrow 6,5,2$ & Ground & & & 20767.19 & \\
\hline$\left(\mathrm{C}^{12} \mathrm{H}_{3}\right)_{2} \mathrm{C}^{12}: \mathrm{C}^{12} \mathrm{H}_{2}$ & 3- 941 & $6,6,1 \leftarrow 6,5,2$ & Ground & & & 20767.23 & \\
\hline$\left(\mathrm{C}^{12} \mathrm{H}_{3}\right)_{2} \mathrm{C}^{12}: \mathrm{C}^{12} \mathrm{H}_{2}$ & 3- 941 & $3,2,2 \leftarrow 3,1,3$ & Ground & & & 20767.71 & .05 \\
\hline$\left(\mathrm{C}^{12} \mathrm{H}_{3}\right)_{2} \mathrm{~S}^{32}$ & 3. 601 & $6,2,5 \leftarrow 5,3,2$ & Ground & & & 20768.25 & .05 \\
\hline$\left(\mathrm{C}^{12} \mathrm{H}_{3}\right)_{2} \mathrm{~S}^{32}$ & 3. 601 & $6,2,5 \leftarrow 5,3,2$ & Ground & & & 20768.31 & .05 \\
\hline $\mathrm{P}^{31} \mathrm{O}^{16} \mathrm{~F}_{2}^{19} \mathrm{Cl}^{35}$ & 4-1391 & $12,6,7 \leftarrow 12,5,8$ & Ground & $23 / 2$ & $23 / 2$ & 20768.50 & \\
\hline $\mathrm{P}^{31} \mathrm{O}^{16} \mathrm{~F}_{2}^{19} \mathrm{Cl}^{35}$ & 4-1391 & $12,6,7 \leftarrow 12,5,8$ & Ground & $25 / 2$ & $25 / 2$ & 20768.50 & \\
\hline $\mathrm{P}^{31} \mathrm{O}^{16} \mathrm{~F}_{2}^{19} \mathrm{Cl}^{35}$ & 4-1391 & $12,6,6 \leftarrow 12,5,7$ & Ground & $25 / 2$ & $25 / 2$ & 20768.50 & \\
\hline $\mathrm{P}^{31} \mathrm{O}^{16} \mathrm{~F}_{2}^{19} \mathrm{Cl}^{35}$ & 4-1391 & $12,6,6 \leftarrow 12,5,7$ & Ground & $23 / 2$ & $23 / 2$ & 20768.50 & \\
\hline $\mathrm{C}^{13} \mathrm{H}_{3} \mathrm{C}^{12} \mathrm{O}^{16} \mathrm{~F}^{19}$ & 3. 393 & $4,2,2 \leftarrow 4,2,3$ & Ground & & & 20768.85 & .2 \\
\hline$\left(\mathrm{C}^{12} \mathrm{H}_{3}\right)_{2} \mathrm{~S}^{32}$ & 3- 601 & $6,2,5 \leftarrow 5,3,2$ & Ground & & & 20769.17 & .05 \\
\hline$\cdot\left(\mathrm{C}^{12} \mathrm{H}_{3}\right)_{2} \mathrm{~S}^{32}$ & 3. 601 & $6,2,5 \leftarrow 5,3,2$ & Ground & & & 20769.23 & .05 \\
\hline$\left(\mathrm{C}^{12} \mathrm{H}_{3}\right)_{2} \mathrm{~S}^{32}$ & 3- 601 & $6,2,5 \leftarrow 5,3,2$ & Ground & & & 20770.09 & .05 \\
\hline$\left(\mathrm{C}^{12} \mathrm{H}_{3}\right)_{2} \mathrm{~S}^{32}$ & 3- 601 & $6,2,5 \leftarrow 5,3,2$ & Ground & & & 20770.10 & .05 \\
\hline$\left(\mathrm{C}^{12} \mathrm{H}_{3}\right)_{2} \mathrm{~S}^{32}$ & 3. 601 & $6,2,5 \leftarrow 5,3,2$ & Ground & & & 20770.21 & .05 \\
\hline $\mathrm{Cl}^{35} \mathrm{O}_{2}^{16}$ & 4-1381 & $7,1,6 \leftarrow 6,2,5$ & Ground & & & 20770.6 & .2 \\
\hline $\mathrm{C}^{12} \mathrm{~F}_{3}^{19} \mathrm{Br}^{81}$ & 4- 222 & $5,2 \leftarrow 4,2$ & Ground & $7 / 2$ & $5 / 2$ & 20770.7 & \\
\hline $\mathrm{C}^{12} \mathrm{H}_{3} \mathrm{C}^{13} \mathrm{H}_{2} \mathrm{Cl}^{35}$ & 3- 546 & $2,0,2 \leftarrow 1,0,1$ & Ground & $3 / 2$ & $1 / 2$ & 20771.41 & .05 \\
\hline $\mathrm{C}^{12} \mathrm{H}_{3} \mathrm{C}^{12} \mathrm{O}^{18} \mathrm{~F}^{19}$ & 3- 394 & $5,3,2 \leftarrow 5,3,3$ & Ground & & & 20772.09 & .2 \\
\hline $\mathrm{Br}^{81} \mathrm{~F}^{19}$ & 1 . & $1 \leftarrow 0$ & Excited & $1 / 2$ & $3 / 2$ & 20772.3 & \\
\hline $\mathrm{C}^{12} \mathrm{H}_{3} \mathrm{C}^{13} \mathrm{H}_{2} \mathrm{Cl}^{35}$ & 3. 546 & $2,0,2 \leftarrow 1,0,1$ & Ground & $5 / 2$ & $5 / 2$ & 20772.35 & .05 \\
\hline $\mathrm{P}^{31} \mathrm{O}^{16} \mathrm{~F}_{2}^{19} \mathrm{Cl}^{35}$ & 4-1391 & $11,6,5 \leftarrow 11,5,6$ & Ground & $19 / 2$ & $19 / 2$ & 20772.50 & \\
\hline $\mathrm{P}^{31} \mathrm{O}^{16} \mathrm{~F}_{2}^{19} \mathrm{Cl}^{35}$ & 4-1391 & $11,6,6 \leftarrow 11,5,7$ & Ground & $19 / 2$ & $19 / 2$ & 20772.50 & \\
\hline $\mathrm{P}^{31} \mathrm{O}^{16} \mathrm{~F}_{2}^{19} \mathrm{Cl}^{35}$ & 4-1391 & $11,6,5 \leftarrow 11,5,6$ & Ground & $25 / 2$ & $25 / 2$ & 20772.87 & \\
\hline $\mathrm{P}^{31} \mathrm{O}^{16} \mathrm{~F}_{2}^{19} \mathrm{Cl}^{35}$ & 4-1391 & $11,6,6 \leftarrow 11,5,7$ & Ground & $25 / 2$ & $25 / 2$ & 20772.87 & \\
\hline $\mathrm{C}^{12} \mathrm{D}_{3} \mathrm{C}^{12} \mathrm{O}^{16} \mathrm{O}^{16} \mathrm{H}$ & 3- 492 & $7,4,3 \leftarrow 7,3,4$ & Ground & & & 20773.23 & \\
\hline $\mathrm{C}^{12} \mathrm{~F}_{3}^{19} \mathrm{Br}^{81}$ & 4- 222 & $5,2 \leftarrow 4,2$ & Ground & $13 / 2$ & $11 / 2$ & 20774.3 & \\
\hline $\mathrm{P}^{31} \mathrm{O}^{16} \mathrm{~F}_{2}^{19} \mathrm{Cl}^{35}$ & 4-1391 & $11,6,5 \leftarrow 11,5,6$ & Ground & $21 / 2$ & $21 / 2$ & 20776.10 & \\
\hline
\end{tabular}




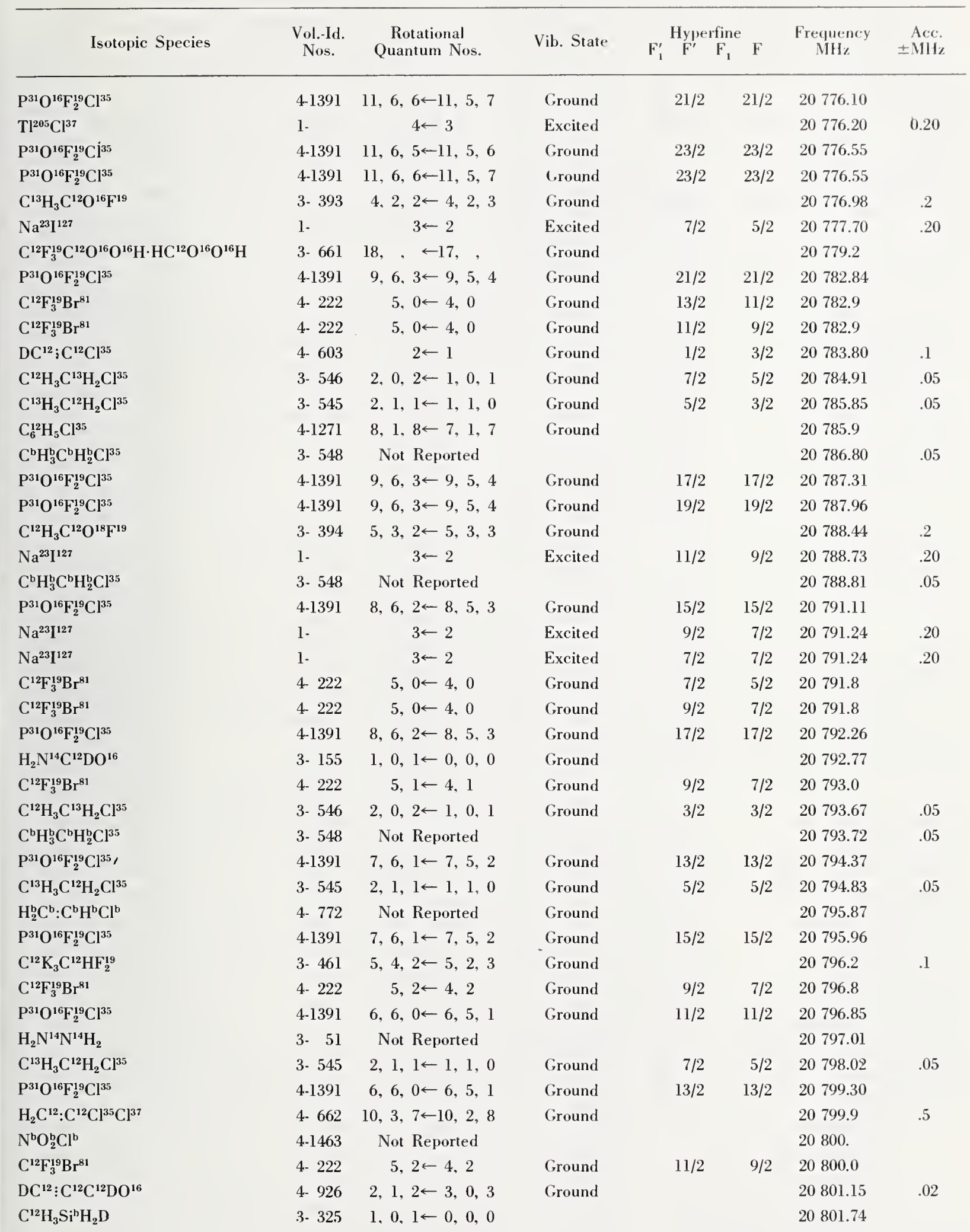




\begin{tabular}{|c|c|c|c|c|c|c|c|}
\hline Isotopic Species & $\begin{array}{l}\text { Vol.-Id. } \\
\text { Nos. }\end{array}$ & $\begin{array}{c}\text { Rotational } \\
\text { Quantum Nos. }\end{array}$ & Vib. State & 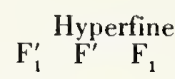 & $\mathbf{F}$ & $\begin{array}{l}\text { Frequency } \\
\qquad \mathrm{MHz}\end{array}$ & $\begin{aligned} & \text { Acc. } \\
\pm & \mathrm{MHz}\end{aligned}$ \\
\hline $\mathrm{H}_{2} \mathrm{C}^{12}: \mathrm{C}^{12} \mathrm{Cl}^{35} \mathrm{Cl}^{37}$ & 4- 662 & $10,3,7 \leftarrow 10,2,8$ & Ground & & & 20801.9 & .5 \\
\hline $\mathrm{C}^{12} \mathrm{~F}_{3}^{19} \mathrm{Br}^{81}$ & 4. 222 & $5,3 \leftarrow 4,3$ & Ground & $9 / 2$ & $7 / 2$ & 20803.0 & \\
\hline $\mathrm{Na}^{23} \mathrm{I}^{127}$ & 1 - & $3 \leftarrow 2$ & Excited & $5 / 2$ & $5 / 2$ & 20803.00 & .20 \\
\hline $\mathrm{O}^{16}{ }_{*} \mathrm{C}^{12} \mathrm{H}_{2} \mathrm{O}^{16} \mathrm{C}^{12} \mathrm{H}_{2} \mathrm{O}^{16} \mathrm{C}^{13}{ }_{*} \mathrm{H}_{2}$ & 4-1102 & 2. $1, \leftarrow \leftarrow 1,1$ & Ground & & & 20804. & \\
\hline $\mathrm{C}^{13} \mathrm{H}_{3} \mathrm{C}^{12} \mathrm{H}_{2} \mathrm{Cl}^{35}$ & 3- 545 & $2,1,1 \leftarrow 1,1,0$ & Ground & $3 / 2$ & $1 / 2$ & 20804.15 & .05 \\
\hline $\mathrm{H}_{2} \mathrm{C}^{12}: \mathrm{C}^{12} \mathrm{Cl}^{15} \mathrm{Cl}^{37}$ & 4. 662 & $10,3,7 \leftarrow 10,2,8$ & Ground & & & 20804.2 & .5 \\
\hline $\mathrm{N}^{14} \mathrm{H}_{3}$ & $4-1771$ & $7,5 \leftarrow 7,5$ & Ground & & & 20804.83 & .02 \\
\hline $\mathrm{HC}^{13}: \mathrm{C}^{12} \mathrm{C}^{12} \mathrm{DO}^{16}$ & 4- 922 & Not Reported & & & & 20805. & 5. \\
\hline $\mathrm{Tl}^{203} \mathrm{Cl}^{37}$ & $1-$ & $4 \leftarrow 3$ & Excited & & & 20806.64 & 0.30 \\
\hline $\mathrm{C}^{12} \mathrm{H}_{2} \mathrm{DC}^{12} \mathrm{HDF}^{19}$ & 3- 557 & $1,1,0 \leftarrow 1,0,1$ & Ground & & & 20806.9 & .1 \\
\hline $\mathrm{C}^{13} \mathrm{H}_{3} \mathrm{C}^{12} \mathrm{H}_{2} \mathrm{Cl}^{35}$ & 3- 545 & $2,1,1 \leftarrow 1,1,0$ & Ground & $1 / 2$ & $1 / 2$ & 20807.44 & .05 \\
\hline $\mathrm{C}^{13} \mathrm{H}_{3} \mathrm{C}^{12} \mathrm{H}_{2} \mathrm{Br}^{79}$ & 3- 528 & $3,1,3 \leftarrow 2,1,2$ & Ground & $9 / 2$ & $7 / 2$ & 20809.94 & .05 \\
\hline a- $\mathrm{C}^{12} \mathrm{H}_{2} \mathrm{DS} \mathrm{i}^{28} \mathrm{HF}_{2}^{19}$ & 3- 204 & $2,1,1 \leftarrow 1,1,0$ & Ground & & & 20810.02 & 2. \\
\hline $\mathrm{C}^{12} \mathrm{~F}_{3}^{19} \mathrm{Br}^{81}$ & 4- 222 & $5,4 \leftarrow 4,4$ & Ground & $9 / 2$ & $7 / 2$ & 20811.2 & \\
\hline $\mathrm{C}^{13} \mathrm{H}_{3} \mathrm{C}^{12} \mathrm{H}_{2} \mathrm{Br}^{79}$ & 3- 528 & $3,1,3 \leftarrow 2,1,2$ & Ground & $3 / 2$ & $1 / 2$ & 20814.35 & .05 \\
\hline $1 \mathrm{C}^{13}-\mathrm{C}_{6}^{12} \mathrm{H}_{5} \mathrm{C}^{12} \mathrm{~N}^{14}$ & $4-1297$ & $8,0,8 \leftarrow 7,0,7$ & Ground & & & 20814.5 & .1 \\
\hline $\mathrm{P}^{31} \mathrm{H}_{2} \mathrm{D}$ & $4-1782$ & $4,1,4 \leftarrow 4,0,4$ & Ground & & & 20815.38 & .05 \\
\hline $\mathrm{HC}^{13}: \mathrm{C}^{12} \mathrm{C}^{12} \mathrm{DO}^{16}$ & 4. 922 & Not Reported & & & & 20819. & 5. \\
\hline $\mathrm{C}^{12} \mathrm{D}_{2}: \mathrm{C}^{12} \mathrm{DBr}^{81}$ & 4. 726 & $3,2,2 \leftarrow 2,2,1$ & Ground & $3 / 2$ & $1 / 2$ & 20819.6 & \\
\hline $\left.\mathrm{C}^{12} \mathrm{H}_{3} \mathrm{C}^{12} \mathrm{D}_{2} \mathrm{C}\right]^{35}$ & 3. 547 & $2,1,1 \leftarrow 1,1,0$ & Ground & $5 / 2$ & $3 / 2$ & 20820.49 & .05 \\
\hline$\left(\mathrm{C}^{12} \mathrm{H}_{3}\right)_{2} \mathrm{C}^{12} \mathrm{O}^{16}$ & 3. 751 & $2,0,2 \leftarrow 1,1,1$ & Ground & & & 20820.89 & .04 \\
\hline $\mathrm{Cl}^{35} \mathrm{O}_{2}^{16}$ & 4-1381 & $7,1,6 \leftarrow 6,2,5$ & Ground & & & 20821.7 & \\
\hline $\mathrm{C}^{12} \mathrm{~F}_{3}^{19} \mathrm{Br}^{81}$ & 4. 222 & $5,3 \leftarrow 4,3$ & Ground & $11 / 2$ & $9 / 2$ & 20822.2 & \\
\hline $\mathrm{C}^{12} \mathrm{H}_{2}: \mathrm{C}^{12} \mathrm{~F}^{19} \mathrm{Cl}$ & 4. 632 & $2,1,2 \leftarrow 1,0,1$ & Ground & & & 20822.8 & \\
\hline $\mathrm{C}^{12} \mathrm{H}_{3} \mathrm{C}^{12} \mathrm{D}_{2} \mathrm{Cl}^{35}$ & 3. 547 & $2,1,1 \leftarrow 1,1,0$ & Ground & $3 / 2$ & $3 / 2$ & 20823.26 & .05 \\
\hline $\mathrm{C}^{12} \mathrm{D}_{2}: \mathrm{C}^{12} \mathrm{DBr}^{81}$ & 4- 726 & $3,2,1 \leftarrow 2,2,0$ & Ground & $3 / 2$ & $1 / 2$ & 20827.4 & \\
\hline $\mathrm{C}_{6}^{12} \mathrm{H}_{5} \mathrm{C}^{12} \mathrm{~N}^{14}$ & $4-1291$ & $8,0,8 \leftarrow 7,0,7$ & Ground & & & 20828.3 & .2 \\
\hline $\mathrm{C}^{12} \mathrm{D}_{2}: \mathrm{C}^{12} \mathrm{DBr}^{81}$ & 4. 726 & $3,0,3 \leftarrow 2,0,2$ & Ground & $3 / 2$ & $3 / 2$ & 20828.5 & \\
\hline $\mathrm{Br}^{79} \mathrm{~F}^{19}$ & 1. & $1 \leftarrow 0$ & Excited & $1 / 2$ & $3 / 2$ & 20828.9 & \\
\hline $\mathrm{C}^{12} \mathrm{H}_{3} \mathrm{C}^{12} \mathrm{D}_{2} \mathrm{Cl}^{35}$ & 3. 547 & $2,1,1 \leftarrow 1,1,0$ & Ground & $5 / 2$ & $5 / 2$ & 20829.38 & .05 \\
\hline $\mathrm{C}^{12} \mathrm{H}_{3} \mathrm{C}^{12} \mathrm{D}_{2} \mathrm{Cl}^{35}$ & 3- 547 & $2,1,1 \leftarrow 1,1,0$ & Ground & & & 20830.34 & .05 \\
\hline $\mathrm{C}^{12} \mathrm{H}_{3} \mathrm{~N}^{14} \mathrm{H}_{2}$ & 3- 261 & $13,3, \leftarrow 12,4$, & Ground & & & 20831.28 & .04 \\
\hline $\mathrm{C}^{12} \mathrm{H}_{3} \mathrm{C}^{12} \mathrm{D}_{2} \mathrm{Cl}^{35}$ & 3. 547 & $2,1,1 \leftarrow 1,1,0$ & Ground & $7 / 2$ & $5 / 2$ & 20833.26 & .05 \\
\hline $\mathrm{D}_{2} \mathrm{C}^{12}: \mathrm{C}^{12} \mathrm{DCl}^{35}$ & 4- 763 & $2,1,1 \leftarrow 1,1,0$ & Ground & & & 20833.55 & \\
\hline $\mathrm{C}^{13} \mathrm{H}_{3} \mathrm{C}^{12} \mathrm{H}_{2} \mathrm{Br}^{79}$ & 3. 528 & $3,1,3 \leftarrow 2,1,2$. & Ground & $7 / 2$ & $5 / 2$ & 20835.57 & .05 \\
\hline $\mathrm{c}-\mathrm{DHC}^{12}: \mathrm{C}^{12} \mathrm{DCl}^{35}$ & 4. 762 & $2,0,2 \leftarrow 1,0,1$ & Ground & $7 / 2$ & $5 / 2$ & 20837.33 & .2 \\
\hline$\left(\mathrm{C}^{12} \mathrm{H}_{3}\right)_{3} \mathrm{C}^{12} \mathrm{C}^{12}: \mathrm{C}^{12} \mathrm{C}^{37}$ & $3-1062$ & $12, \leftarrow 11$ & Ground & & & 20837.7 & .5 \\
\hline $\mathrm{C}^{12}{ }_{*} \mathrm{HC}^{12} \mathrm{D}: \mathrm{C}^{12} \mathrm{HC}^{12} \mathrm{H}: \mathrm{C}^{12} \mathrm{HN}^{14} *$ & 4-1203 & $11,9,3 \leftarrow 11,7,4$ & Ground & & & 20838.4 & .1 \\
\hline $\mathrm{C}^{12} \mathrm{H}_{3} \mathrm{C}^{12} \mathrm{D}_{2} \mathrm{Cl}^{35}$ & 3- 547 & $2,1,1 \leftarrow 1,1,0$ & Ground & $3 / 2$ & $1 / 2$ & 20839.28 & .05 \\
\hline $\mathrm{C}^{13} \mathrm{H}_{3} \mathrm{C}^{12} \mathrm{H}_{2} \mathrm{Br}^{79}$ & 3. 528 & $3,1,3 \leftarrow 2,1,2$ & Ground & $5 / 2$ & $3 / 2$ & 20840.44 & .05 \\
\hline $\mathrm{C}^{12} \mathrm{H}_{3} \mathrm{C}^{12} \mathrm{D}_{2} \mathrm{Cl}^{35}$ & 3. 547 & $2,1,1 \leftarrow 1,1,0$ & Ground & $1 / 2$ & $1 / 2$ & 20843.07 & .05 \\
\hline
\end{tabular}


Vol.-Id. Rotational Nos.
Quantum Nos.
Vib. State
$\mathrm{B}_{5}^{11} \mathrm{D}_{9}$

$\mathrm{D}_{2} \mathrm{C}^{12}: \mathrm{C}^{12} \mathrm{DCl}^{35}$

$\left(\mathrm{C}^{13} \mathrm{H}_{3}\right)_{2} \mathrm{C}^{12} \mathrm{H}_{3} \mathrm{Si}{ }^{11} \mathrm{H}$

$\mathrm{N}^{14} \mathrm{H}_{3}$

$\mathrm{C}^{12} \mathrm{~F}_{3}^{19} \mathrm{Br}^{81}$

$\mathrm{C}^{12}{ }_{*} \mathrm{H}_{2} \mathrm{C}^{13} \mathrm{H}_{2} \mathrm{C}^{12}{ }_{*} \mathrm{Cl}_{2}^{35}$

$\mathrm{Na}^{23} \mathrm{I}^{127}$

$\mathrm{C}^{12} \mathrm{H}_{2}\left(\mathrm{C}^{12} \mathrm{~N}^{14}\right)_{2}$

$\mathrm{HDC}^{12}: \mathrm{C}^{12} \mathrm{O}^{16}$

$\mathrm{Cl}^{35} \mathrm{O}_{2}^{16}$

$2,4,6 \mathrm{~d}_{3}-\mathrm{C}_{6}^{12} \mathrm{H}_{5} \mathrm{~F}^{19}$

$\mathrm{C}^{13} \mathrm{H}_{3}\left(\mathrm{C}^{12} \mathrm{H}_{3}\right)_{2} \mathrm{Si}^{1} \mathrm{H}$

$\mathrm{O}^{16} \mathrm{O}^{18} \mathrm{O}^{18}$

$\mathrm{HC}^{13}: \mathrm{C}^{12} \mathrm{C}^{12} \mathrm{DO}^{16}$

$\mathrm{Tl}^{205} \mathrm{Cl}^{37}$

$\mathrm{C}^{12}{ }_{*} \mathrm{H}_{2} \mathrm{C}^{12} \mathrm{H}_{2} \mathrm{C}^{12} \mathrm{H}_{2} \mathrm{C}^{12} \mathrm{H}_{2} \mathrm{C}^{12}{ }_{*} \mathrm{O}^{16}$

$\mathrm{C}^{12} \mathrm{D}_{2}: \mathrm{C}^{12} \mathrm{HBr}^{81}$

$\mathrm{C}^{12} \mathrm{HF}_{3}^{19}$

$\mathrm{C}^{12} \mathrm{H}_{3} \mathrm{C}^{12} \mathrm{D}_{2} \mathrm{Cl}^{35}$

$\mathrm{C}^{12} \mathrm{D}_{3} \mathrm{C}^{12} \mathrm{O}^{16} \mathrm{C}^{12} \mathrm{~N}^{14}$

$\left(\mathrm{C}^{12} \mathrm{H}_{3}\right)_{3} \mathrm{C}^{12} \mathrm{C}^{12}: \mathrm{C}^{13} \mathrm{H}$

$\mathrm{C}^{12} \mathrm{DHDC}^{12} \mathrm{HDF}^{19}$

$\mathrm{C}^{12} \mathrm{H}_{3} \mathrm{C}^{12} \mathrm{D}_{2} \mathrm{Cl}^{35}$

$\mathrm{C}^{12} \mathrm{H}_{3} \mathrm{C}^{12} \mathrm{D}_{2} \mathrm{Cl}^{35}$

$\mathrm{C}^{12} \mathrm{D}_{2}: \mathrm{C}^{12} \mathrm{HBr}^{81}$

$\mathrm{C}^{12} \mathrm{H}_{3} \mathrm{C}^{12} \mathrm{D}_{2} \mathrm{Cl}^{35}$

$\mathrm{Na}^{23} \mathrm{I}^{127}$

$\left(\mathrm{C}^{12} \mathrm{H}_{3} \mathrm{C}^{12} \mathrm{H}_{2}\right)_{2} \mathrm{O}^{16}$

$\mathrm{Cl}^{35} \mathrm{O}_{2}^{16}$

$\mathrm{S}^{32} \mathrm{O}^{16} \mathrm{~F}_{2}^{19}$

$\mathrm{C}^{12} \mathrm{H}_{3} \mathrm{C}^{12} \mathrm{D}_{2} \mathrm{Cl}^{35}$

$\mathrm{C}_{6}^{12} \mathrm{H}_{5} \mathrm{~F}^{19}$

$\mathrm{C}^{\mathrm{b}} \mathrm{H}_{3}^{\mathrm{b}} \mathrm{C}^{\mathrm{h}} \mathrm{H}_{2}^{\mathrm{b}} \mathrm{Cl}^{35}$

$\mathrm{C}^{12} \mathrm{D}_{2}: \mathrm{C}^{12} \mathrm{DBr}^{\mathrm{b}}$

$\mathrm{C}^{12}{ }_{*} \mathrm{H}: \mathrm{C}^{12} \mathrm{DO}^{16} \mathrm{C}^{12} \mathrm{D}: \mathrm{C}^{12}{ }_{*} \mathrm{H}$

$\mathrm{C}^{\mathrm{b}} \mathrm{H}_{3}^{\mathrm{b}} \mathrm{C}^{\mathrm{b}} \mathrm{H}_{2}^{\mathrm{b}} \mathrm{Cl}^{35}$

$\mathrm{C}^{12} \mathrm{H}_{3} \mathrm{C}^{12}{ }_{*} \mathrm{H}_{2} \mathrm{O}^{16} \mathrm{C}^{12}{ }_{*} \mathrm{C}^{12} \mathrm{H}_{3}$

$\mathrm{C}^{12} \mathrm{D}_{2}: \mathrm{C}^{12} \mathrm{DBr}^{81}$

$\mathrm{C}^{12} \mathrm{D}_{2}: \mathrm{C}^{12} \mathrm{DBr}^{81}$

$\mathrm{C}^{12} \mathrm{H}_{3} \mathrm{C}^{12}{ }_{*} \mathrm{H}_{2} \mathrm{O}^{16} \mathrm{C}^{12}{ }_{*} \mathrm{C}^{12} \mathrm{H}_{3}$

$\mathrm{C}^{13} \mathrm{H}_{3} \mathrm{C}^{12} \mathrm{H}_{3} \mathrm{C}^{12}: \mathrm{C}^{12} \mathrm{H}_{2}$

$\mathrm{C}^{12} \mathrm{D}_{2}: \mathrm{C}^{12} \mathrm{HBr}^{81}$

$\mathrm{C}^{12} \mathrm{H}_{3} \mathrm{C}^{12}{ }_{*} \mathrm{H}_{2} \mathrm{O}^{16} \mathrm{C}^{12}{ }_{*} \mathrm{C}^{12} \mathrm{H}_{3}$

$\mathrm{C}^{12} \mathrm{H}_{3} \mathrm{C}^{12} \mathrm{H}_{2} \mathrm{Cl}^{35}$

$\mathrm{C}^{12} \mathrm{H}_{3} \mathrm{C}^{12} \mathrm{H}_{2} \mathrm{Cl}^{35}$
4. $61 \quad 2, \leftarrow 1$

4. 763

$2,1,1 \leftarrow 1,1,0$

3. 878

$2,2,1 \leftarrow 1,1,1$

$10,8 \leftarrow 10,8$

$5,4 \leftarrow 4,4$

4.- 222

4-1068

1 .

$4,2,3 \leftarrow 3,1,2$

$3 \leftarrow 2$

4- $901 \quad$ Not Reported

4. 713

$27,2,25 \leftarrow 27,2,26$

4-1381

$7,1,6 \leftarrow 6,2,5$

4-1284

$5,3,3 \leftarrow 4,3,2$

3- 877

$2,1,1 \leftarrow 1,0,1$

4-1844

$21,2,20 \leftarrow 20,3,17$

4. 922

Not Reported

1 .

4-1241

4. 724

$$
4 \leftarrow 3
$$

$4,1,4 \leftarrow 3,1,3$

4. 724

$3,1,3 \leftarrow 2,1,2$

4- 281

$1, \leftarrow 0$,

3- 547

3- 675

$3,1,2 \leftarrow 3,0,3$

$9,3,6 \leftarrow 9,2,7$

$4, \leftarrow 3$,

3. 561

$6,1,5 \leftarrow 6,1,6$

3. 547

$3,1,2 \leftarrow 3,0,3$

3. 547

4. 724

$3,1,2 \leftarrow 3,0,3$

$3,1,3 \leftarrow 2,1,2$

3- 547

1 -

$3,1,2 \leftarrow 3,0,3$

$$
3 \leftarrow 2
$$

3-1011 Not Reported

4-1381

4-1621

$7,1,6 \leftarrow 6,2,5$

$14,11,3 \leftarrow 14,11,4$

3. 547

$3,1,2 \leftarrow 3,0,3$

4-1281

Not Reported

3- 548 Not Reported

4. 732

$3, \quad \leftarrow 2, \quad$

4-1156

$2,0,2 \leftarrow 1,1,1$

3- 548

Not Reported

3. $951 \quad 17,6,12 \leftarrow 17,5,12$

4. 726

$3,2,2 \leftarrow 2,2,1$

4. 726

$3,2,2 \leftarrow 2,2,1$

3. 951

$17,6,12 \leftarrow 17,5,12$

3- 945

$4,3,2 \leftarrow 4,2,3$

4- 724

$3,1,3 \leftarrow 2,1,2$

3. 951

$17,6,12 \leftarrow 17,5,12$

3- 541

$2,0,2 \leftarrow 1,0,1$

3. 541
Ground

Ground

Ground

Ground

Ground

Ground

Ground

Ground

Ground

Excited

Ground

Ground

Ground

Ground

Ground

Ground

Ground

Excited

Excited

Ground

Ground

Ground

Ground

Ground

Ground

Ground

Ground

Excited

Ground

Ground

Ground

Ground

Ground

Ground

Ground

Ground

Ground

Ground

Ground

Ground
Frequency Acc. $\mathrm{MHz}_{\mathrm{z}} \pm \mathrm{MHz}$
$\mathrm{F}_{1}^{\prime} \stackrel{\text { Hyperfine }}{\mathrm{F}^{\prime}} \mathrm{F}_{1} \mathrm{~F}$

20845.4

$5 / 2 \quad 20847.59$

20848.06

20852.51

02

$11 / 2 \quad 9 / 2 \quad 20852.8$

20853.91

$\begin{array}{llll}9 / 2 & 9 / 2 & 20854.59 & .20\end{array}$

20855.5

20855.93

20857.2

20859.0

$20860.02 \quad .1$

20861.2

20862.

5.

20864.11

0.20

20868.2

$9 / 2 \quad 7 / 2 \quad 20871.4$

$20872.78 \quad .10$

$3 / 2 \quad 3 / 2 \quad 20872.9 \quad .05$

$20873.53 \quad .2$

20874.9

20875.3

$\begin{array}{llll}9 / 2 & 9 / 2 & 20 & 875.6\end{array}$

$20877.60 \quad .05$

$5 / 2 \quad 5 / 2 \quad 20878.4$

$5 / 2 \quad 5 / 2 \quad 20878.7 \quad .05$

$\begin{array}{llll}5 / 2 & 3 / 2 & 20879.61 & .20\end{array}$

20880

$20881.2 \quad .2$

$20881.41 \quad .1$

$\begin{array}{llll}7 / 2 & 7 / 2 & 20 & 881.6\end{array}$

20882 . 5.

$20884.9 \quad .05$

20885.5210.

20886.6

$20888.2 \quad .05$

$20888.81 \quad .2$

$7 / 2 \quad 7 / 2 \quad 20888.9$

$9 / 2 \quad 7 / 2 \quad 20888.9$

$20889.68 \quad .2$

20889.82

$9 / 2 \quad 7 / 2 \quad 20890.5$

$20890.57 \quad .2$

$\begin{array}{llll}3 / 2 & 1 / 2 & 20891.45 & .05\end{array}$

$5 / 2 \quad 5 / 2 \quad 20892.41 \quad .05$ 


\begin{tabular}{|c|c|c|c|c|c|c|c|}
\hline \multirow{2}{*}{ Isotopic Species } & \multirow{2}{*}{$\begin{array}{l}\text { Vol.-Id. } \\
\text { Nos. }\end{array}$} & \multirow{2}{*}{$\begin{array}{c}\text { Rotational } \\
\text { Quantum Nos. }\end{array}$} & \multirow{2}{*}{ Vib. State } & \multicolumn{2}{|c|}{ Hyperfine } & \multirow{2}{*}{$\begin{array}{l}\text { Frequency } \\
\quad \mathrm{MHz}\end{array}$} & \multirow{2}{*}{$\begin{aligned} & \text { Acc. } \\
& \pm \mathrm{MHz}\end{aligned}$} \\
\hline & & & & $F_{1} \quad F^{2} \quad F_{1}$ & $\mathbf{F}$ & & \\
\hline $\mathrm{Na}^{23} \mathrm{~J}^{127}$ & 1 . & $3 \leftarrow 2$ & Excited & $7 / 2$ & $5 / 2$ & 20892.92 & .20 \\
\hline $\mathrm{C}^{12}{ }_{*} \mathrm{H}_{2} \mathrm{C}^{12} \mathrm{H}_{2} \mathrm{C}^{12} \mathrm{H}_{2} \mathrm{C}^{12} \mathrm{H}_{2} \mathrm{C}^{12}{ }_{*} \mathrm{O}^{16}$ & 4-1241 & $19,6,13 \leftarrow 19,6,14$ & Ground & & & 20893. & 5. \\
\hline $\mathrm{C}^{12} \mathrm{H}_{3} \mathrm{C}^{12} \mathrm{O}^{16} \mathrm{C}^{12} \mathrm{~N}^{14}$ & 3- 671 & $3,0,3 \leftarrow 2,0,2$ & Ground & & & 20894.60 & .2 \\
\hline $\mathrm{C}^{12} \mathrm{H}_{3} \mathrm{C}^{12} \mathrm{O}^{16} \mathrm{C}^{12} \mathrm{~N}^{14}$ & 3- 671 & $3,0,3 \leftarrow 2,0,2$ & Ground & & & 20895.08 & .2 \\
\hline $\mathrm{Tl}^{203} \mathrm{Cl}^{37}$ & 1 . & $4 \leftarrow 3$ & Ground & & & 20895.33 & 0.10 \\
\hline $\mathrm{C}^{12} \mathrm{H}_{3} \mathrm{O}^{16} \mathrm{H}$ & 3- 211 & Not Reported & Ground & & & 20898. & 5. \\
\hline $\mathrm{C}^{12} \mathrm{D}_{2}: \mathrm{C}^{12} \mathrm{DBr}^{81}$ & 4. 726 & $3,2,1 \leftarrow 2,2,0$ & Ground & $7 / 2$ & $7 / 2$ & 20898.6 & \\
\hline $\mathrm{C}^{12} \mathrm{D}_{2}: \mathrm{C}^{12} \mathrm{DBr}^{81}$ & 4- 726 & $3,2,1 \leftarrow 2,2,0$ & Ground & $9 / 2$ & $7 / 2$ & 20898.6 & \\
\hline $\mathrm{C}^{12} \mathrm{D}_{3} \mathrm{C}^{12} \mathrm{O}^{16} \mathrm{~F}^{19}$ & 3- 392 & Not Reported & Ground & & & 20898.95 & .2 \\
\hline $\mathrm{O}^{16}{ }^{16} \mathrm{C}^{12} \mathrm{H}_{2} \mathrm{O}^{16} \mathrm{C}^{12} \mathrm{H}_{2} \mathrm{O}^{16} \mathrm{C}^{13} * \mathrm{H}_{2}$ & 4-1102 & $2,0, \leftarrow 1,0$, & Ground & & & 20900 . & \\
\hline $\mathrm{Cl}^{35} \mathrm{O}_{2}^{16}$ & 4-1381 & $7,1,6 \leftarrow 6,2,5$ & Ground & & & 20900.6 & .2 \\
\hline $\mathrm{C}^{12} \mathrm{D}_{2}: \mathrm{C}^{12} \mathrm{HBr}^{81}$ & 4- 724 & $3,1,3 \leftarrow 2,1,2$ & Ground & & . & 20900.84 & .04 \\
\hline $\mathrm{C}^{12} \mathrm{D}_{2}: \mathrm{C}^{12} \mathrm{DBr}^{81}$ & 4- 726 & $3,0,3 \leftarrow 2,0,2$ & Ground & $7 / 2$ & $5 / 2$ & 20901.4 & \\
\hline $\mathrm{C}^{12} \mathrm{D}_{2}: \mathrm{C}^{12} \mathrm{DBr}^{81}$ & 4. 726 & $3,0,3 \leftarrow 2,0,2$ & Ground & $9 / 2$ & $7 / 2$ & 20901.4 & \\
\hline $\mathrm{Na}^{23} \mathrm{I}^{127}$ & $1-$ & $3 \leftarrow 2$ & Excited & $11 / 2$ & $9 / 2$ & 20903.62 & .20 \\
\hline $\mathrm{C}^{12} \mathrm{H}_{3} \mathrm{C}^{12} \mathrm{H}_{2} \mathrm{Cl}^{35}$ & 3- 541 & $2,0,2 \leftarrow 1,0,1$ & Ground & & & 20903.77 & .05 \\
\hline $\mathrm{C}^{12} \mathrm{H}_{3} \mathrm{C}^{12} \mathrm{H}_{2} \mathrm{Cl}^{35}$ & 3- 541 & $2,0,2 \leftarrow 1,0,1$ & Ground & $5 / 2$ & $3 / 2$ & 20904.87 & .05 \\
\hline $\mathrm{C}^{12} \mathrm{H}_{3} \mathrm{C}^{12} \mathrm{H}_{2} \mathrm{Cl}^{35}$ & 3- 541 & $2,0,2 \leftarrow 1,0,1$ & Ground & $7 / 2$ & $5 / 2$ & 20904.87 & .05 \\
\hline $\mathrm{Na}^{23} \mathrm{I}^{127}$ & 1 . & $3 \leftarrow 2$ & Excited & $7 / 2$ & $7 / 2$ & 20906.05 & .20 \\
\hline $\mathrm{Na}^{23} \mathrm{I}^{127}$ & $1-$ & $3 \leftarrow 2$ & Excited & $9 / 2$ & $7 / 2$ & 20906.05 & .20 \\
\hline $\mathrm{C}^{12} \mathrm{D}_{2}: \mathrm{C}^{12} \mathrm{DBr}^{81}$ & 4- 726 & $3,0,3 \leftarrow 2,0,2$ & Ground & & & 20906.26 & .2 \\
\hline $\mathrm{C}^{12} \mathrm{H}_{3} \mathrm{Si}^{\mathrm{h}} \mathrm{H}_{2} \mathrm{D}$ & 3- 325 & $1,0,1 \leftarrow 0,0,0$ & & & & 20906.36 & .1 \\
\hline $\mathrm{C}^{12} \mathrm{H}_{2}: \mathrm{C}^{12} \mathrm{HC}^{12} \mathrm{~F}^{19}: \mathrm{C}^{12} \mathrm{H}_{2}$ & 3- 911 & $7,2,5 \leftarrow 7,1,6$ & Ground & & & 20907.7 & .2 \\
\hline $\mathrm{C}^{12} \mathrm{H}_{3} \mathrm{O}^{16} \mathrm{H}$ & 3- 211 & Not Reported & Ground & & & 20908.87 & .1 \\
\hline $\mathrm{C}^{12}{ }_{*} \mathrm{H}: \mathrm{C}^{12} \mathrm{HC}^{12} \mathrm{H}: \mathrm{C}^{12} \mathrm{HN}^{14}{ }_{*} \mathrm{H}$ & 4-1181 & $12,10,2 \leftarrow 12,10,3$ & Ground & & & 20909.7 & \\
\hline $\mathrm{O}^{16} \mathrm{~F}_{2}^{19}$ & 4-1611 & $27,5,23 \leftarrow 26,6,20$ & Ground & & & 20910.24 & .10 \\
\hline $\mathrm{C}^{12} \mathrm{D}_{2}: \mathrm{C}^{12} \mathrm{DBr}^{\mathrm{b}}$ & 4- 732 & $3, \quad \leftarrow 2$, & Ground & & & 20911.19 & 10. \\
\hline $\mathrm{C}^{12} \mathrm{H}_{3} \mathrm{~N}^{14} \mathrm{H}_{2}$ & 3- 261 & Not Reported & Ground & & & 20911.74 & .1 \\
\hline $\mathrm{C}^{12} \mathrm{H}_{3} \mathrm{C}^{12} \mathrm{H}_{2} \mathrm{Cl}^{35}$ & 3. 541 & $2,0,2 \leftarrow 1,0,1$ & Ground & $3 / 2$ & $3 / 2$ & 20913.69 & .05 \\
\hline $\mathrm{C}^{12} \mathrm{D}_{2}: \mathrm{C}^{12} \mathrm{HBr}^{81}$ & 4- 724 & $3,1,3 \leftarrow 2,1,2$ & Ground & $7 / 2$ & $5 / 2$ & 20914.3 & \\
\hline $\mathrm{Cl}^{35} \mathrm{O}_{2}^{16}$ & 4-1381 & $7,1,6 \leftarrow 6,2,5$ & Ground & & & 20915.9 & .2 \\
\hline $\mathrm{C}^{12} \mathrm{D}_{2}: \mathrm{C}^{12} \mathrm{HBr}^{81}$ & 4. 724 & $3,1,3 \leftarrow 2,1,2$ & Ground & $5 / 2$ & $3 / 2$ & 20916.1 & \\
\hline $\mathrm{C}^{12} \mathrm{D}_{2}: \mathrm{C}^{12} \mathrm{DBr}^{81}$ & 4. 726 & $3,2,2 \leftarrow 2,2,1$ & Ground & $5 / 2$ & $3 / 2$ & 20917.0 & \\
\hline $\mathrm{C}^{12} \mathrm{D}_{2}: \mathrm{C}^{12} \mathrm{DBr}^{81}$ & 4- 726 & $3,2,2 \leftarrow 2,2,1$ & Ground & $3 / 2$ & $3 / 2$ & 20917.0 & \\
\hline $\mathrm{C}^{12} \mathrm{D}_{2}: \mathrm{C}^{12} \mathrm{DBr}^{81}$ & 4- 726 & $3,2,2 \leftarrow 2,2,1$ & Ground & & & 20917.00 & .06 \\
\hline $\mathrm{Na}^{23} \mathrm{I}^{127}$ & 1 . & $3 \leftarrow 2$ & Excited & $5 / 2$ & $5 / 2$ & 20917.89 & .20 \\
\hline $\mathrm{C}^{12}{ }_{*} \mathrm{H}_{2} \mathrm{~N}^{14} \mathrm{DC}^{12}{ }_{*} \mathrm{H}_{2}$ & 4- 862 & $10,9,1 \leftarrow-10,9,2$ & Ground & & & 20918.5 & .5 \\
\hline $\mathrm{t}-\mathrm{HDC}^{12}: \mathrm{C}^{12} \mathrm{DCl}^{35}$ & 4. 761 & $2,1,2 \leftarrow 1,1,1$ & Ground & & & 20924.41 & \\
\hline $\mathrm{C}^{12} \mathrm{D}_{2}: \mathrm{C}^{12} \mathrm{DBr}^{79}$ & 4- 725 & $3,2,2 \leftarrow 2,2,1$ & Ground & $3 / 2$ & $1 / 2$ & 20925.7 & \\
\hline $\mathrm{C}^{12} \mathrm{D}_{2}: \mathrm{C}^{12} \mathrm{DBr}^{81}$ & 4- 726 & $3,0,3 \leftarrow 2,0,2$ & Ground & $3 / 2$ & $1 / 2$ & 20925.7 & \\
\hline $\mathrm{C}^{12} \mathrm{D}_{2}: \mathrm{C}^{12} \mathrm{DBr}^{81}$ & 4. 726 & $3,0,3 \leftarrow 2,0,2$ & Ground & $5 / 2$ & $3 / 2$ & 20925.7 & \\
\hline $\mathrm{C}^{12} \mathrm{D}_{2}: \mathrm{C}^{12} \mathrm{DBr}^{81}$ & 4- 726 & $3,2,1 \leftarrow 2,2,0$ & Ground & & & 20926.71 & .06 \\
\hline $\mathrm{C}^{12} \mathrm{D}_{2}: \mathrm{C}^{12} \mathrm{DBr}^{81}$ & 4. 726 & $3,2,1 \leftarrow 2,2,0$ & Ground & $3 / 2$ & $3 / 2$ & 20927.0 & \\
\hline $\mathrm{C}^{12} \mathrm{D}_{2}: \mathrm{C}^{12} \mathrm{DBr}^{81}$ & 4- 726 & $3,2,1 \leftarrow 2,2,0$ & Ground & $5 / 2$ & $3 / 2$ & 20927.0 & \\
\hline $\mathrm{Br}^{81} \mathrm{~F}^{19}$ & 1 . & $1 \leftarrow 0$ & Ground & $1 / 2$ & $3 / 2$ & 20928.4 & \\
\hline
\end{tabular}




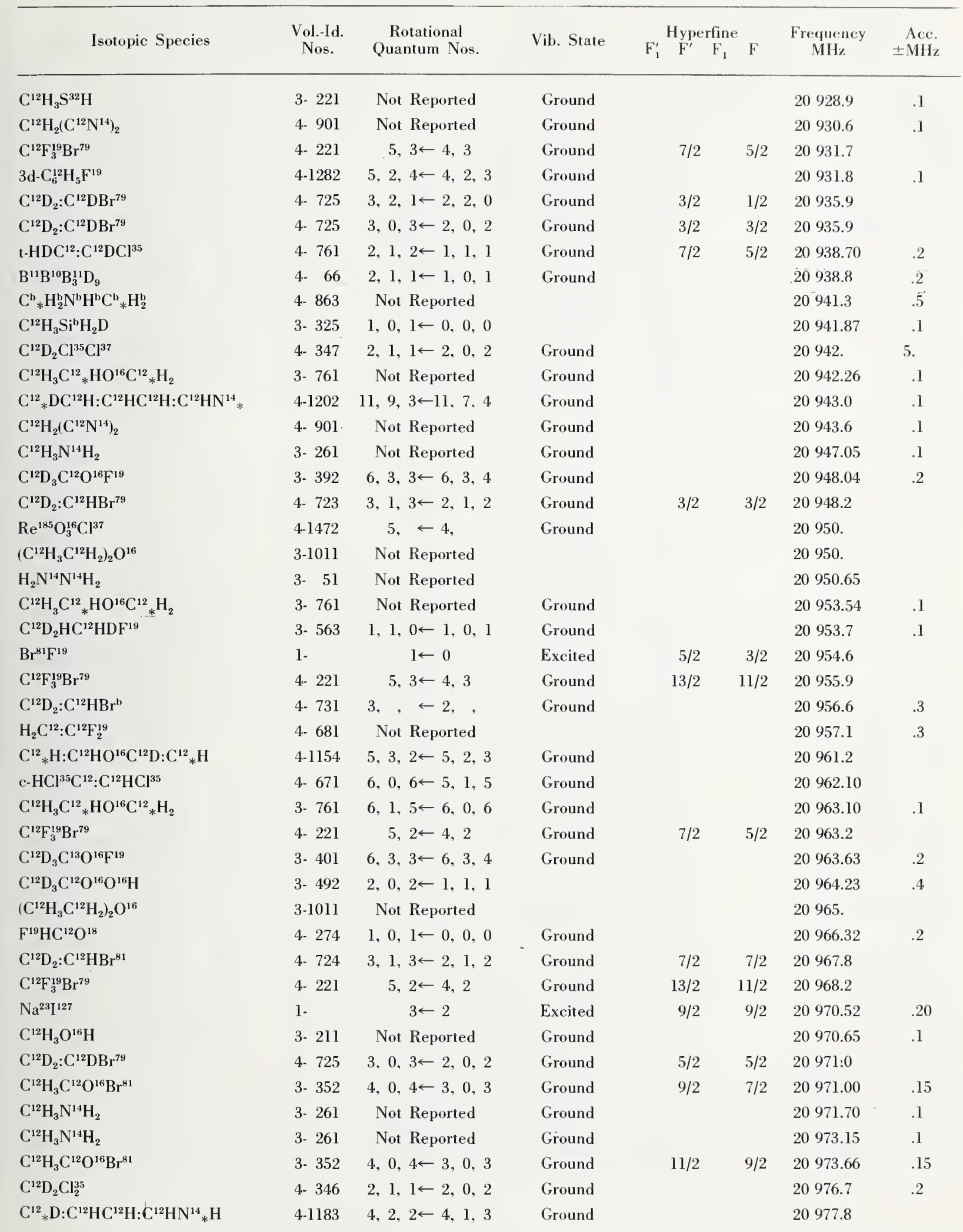




\begin{tabular}{|c|c|c|c|c|c|c|c|}
\hline \multirow{2}{*}{ Isotopic Species } & \multirow{2}{*}{$\begin{array}{l}\text { Vol.-Id. } \\
\text { Nos. }\end{array}$} & \multirow{2}{*}{$\begin{array}{c}\text { Rotational } \\
\text { Quantum Nos. }\end{array}$} & \multirow{2}{*}{ Vib. State } & \multicolumn{2}{|c|}{ Hyperfine } & \multirow{2}{*}{$\begin{array}{l}\text { Frequency } \\
\mathrm{MHz}\end{array}$} & \multirow{2}{*}{$\begin{aligned} & \text { Acc. } \\
& \pm \mathrm{MHz}\end{aligned}$} \\
\hline & & & & $\begin{array}{lll}F_{1}^{\prime} & F^{\prime} & F_{1}\end{array}$ & $\mathbf{F}$ & & \\
\hline $\mathrm{C}^{12} \mathrm{~F}_{3}^{19} \mathrm{Br}^{79}$ & 4- 221 & $5,0 \leftarrow 4,0$ & Ground & $13 / 2$ & $11 / 2$ & 20978.2 & \\
\hline $\mathrm{C}^{12} \mathrm{~F}_{3}^{19} \mathrm{Br}^{79}$ & 4- 221 & $5,0 \leftarrow 4,0$ & Ground & $11 / 2$ & $9 / 2$ & 20978.2 & \\
\hline $\mathrm{HC}^{13}: \mathrm{C}^{12} \mathrm{C}^{12} \mathrm{DO}^{16}$ & 4- 922 & Not Reported & & & & 20979. & 5. \\
\hline $\mathrm{Cl}^{37} \mathrm{~F}_{3}^{19}$ & $4-1372$ & $5,1,4 \leftarrow 5,0,5$ & Ground & $7 / 2$ & $7 / 2$ & 20981.36 & .15 \\
\hline $\mathrm{C}^{12} \mathrm{H}_{3} \mathrm{C}^{12} \mathrm{O}^{16} \mathrm{Br}^{81}$ & 3. 352 & $4,0,4 \leftarrow 3,0,3$ & Ground & $7 / 2$ & $5 / 2$ & 20982.43 & .15 \\
\hline $\mathrm{C}^{12} \mathrm{H}_{3} \mathrm{C}^{12} \mathrm{O}^{16} \mathrm{Br}^{81}$ & 3- 352 & $4,0,4 \leftarrow 3,0,3$ & Ground & $5 / 2$ & $3 / 2$ & 20984.47 & .15 \\
\hline $\mathrm{s}-\mathrm{C}^{12} \mathrm{H}_{2} \mathrm{DSi}^{28} \mathrm{HF}_{2}^{19}$ & 3- 203 & $2,1,1 \leftarrow 1,1,0$ & Ground & & & 20985.49 & 2. \\
\hline $\mathrm{Br}^{79} \mathrm{~F}^{19}$ & 1 - & $1 \leftarrow 0$ & Ground & $1 / 2$ & $3 / 2$ & 20985.5 & \\
\hline $\mathrm{C}^{12} \mathrm{D}_{2}: \mathrm{C}^{12} \mathrm{DBr}^{81}$ & 4- 726 & $3,2,2 \leftarrow 2,2,1$ & Ground & $7 / 2$ & $5 / 2$ & 20987.0 & \\
\hline $\mathrm{C}^{12} \mathrm{D}_{2}: \mathrm{C}^{12} \mathrm{DBr}^{81}$ & 4- 726 & $3,2,2 \leftarrow 2,2,1$ & Ground & $5 / 2$ & $5 / 2$ & 20987.0 & \\
\hline $\mathrm{C}^{12} \mathrm{~F}_{3}^{19} \mathrm{Br}^{79}$ & 4- 221 & $5,0 \leftarrow 4,0$ & Ground & $9 / 2$ & $7 / 2$ & 20988.5 & \\
\hline $\mathrm{C}^{12} \mathrm{~F}_{3}^{19} \mathrm{Br}^{79}$ & 4- 221 & $5,0 \leftarrow 4,0$ & Ground & $7 / 2$ & $5 / 2$ & 20988.5 & \\
\hline $\mathrm{C}^{12} \mathrm{H}_{3} \mathrm{O}^{16} \mathrm{H}$ & 3- 211 & Not Reported & Ground & & & 20989. & 5. \\
\hline $\mathrm{DC}^{12} \mathrm{O}^{16} \mathrm{O}^{16} \mathrm{H}$ & 3. 73 & $4,1,4 \leftarrow 4,1,3$ & Ground & & & 20989.6 & .3 \\
\hline $\mathrm{D}_{2} \mathrm{O}_{2}^{16}$ & 3. 42 & Not Reported & & & & 20990. & 3. \\
\hline $\mathrm{C}^{12} \mathrm{~F}_{3}^{19} \mathrm{Br}^{79}$ & 4- 221 & $5,1 \leftarrow 4,1$ & Ground & $9 / 2$ & $7 / 2$ & 20990.1 & \\
\hline $\mathrm{C}^{12} \mathrm{D}_{2}: \mathrm{C}^{12} \mathrm{HBr}^{79}$ & 4- 723 & $3,1,3 \leftarrow 2,1,2$ & Excited & $9 / 2$ & $7 / 2$ & 20990.4 & \\
\hline $\mathrm{Cl}^{35} \mathrm{~F}_{3}^{19}$ & $4-1371$ & $5,1,4 \leftarrow 5,0,5$ & Ground & $13 / 2$ & $13 / 2$ & 20990.64 & .15 \\
\hline $\mathrm{C}^{12} \mathrm{D}_{3} \mathrm{C}^{12} \mathrm{O}^{16} \mathrm{O}^{16} \mathrm{H}$ & 3- 492 & $2,0,2 \leftarrow 1,1,1$ & & & & 20992.55 & .4 \\
\hline $\mathrm{C}^{12} \mathrm{H}_{2} \mathrm{~N}^{14} \mathrm{O}^{16} \mathrm{H}$ & 3- 141 & $17,3,14 \leftarrow 17,3,15$ & Ground & 16 & 16 & 20993.06 & .10 \\
\hline $\mathrm{C}^{12} \mathrm{H}_{2} \mathrm{~N}^{14} \mathrm{O}^{16} \mathrm{H}$ & 3. 141 & $17,3,14 \leftarrow 17,3,15$ & Ground & 18 & 18 & 20993.06 & .10 \\
\hline $\mathrm{C}^{12} \mathrm{H}_{2} \mathrm{~N}^{14} \mathrm{O}^{16} \mathrm{H}$ & 3- 141 & $17,3,14 \leftarrow 17,3,15$ & Ground & 17 & 17 & 20993.56 & .10 \\
\hline $\mathrm{N}^{14} \mathrm{H}_{3}$ & 4-1771 & $6,4 \leftarrow 6,4$ & Ground & & & 20994.61 & .02 \\
\hline $\mathrm{C}^{12} \mathrm{~F}_{3}^{19} \mathrm{Br}^{79}$ & 4- 221 & $5,2 \leftarrow 4,2$ & Ground & $9 / 2$ & $7 / 2$ & 20994.7 & \\
\hline $\mathrm{C}^{12} \mathrm{D}_{2}: \mathrm{C}^{12} \mathrm{HBr}^{79}$ & 4- 723 & $3,1,3 \leftarrow 2,1,2$ & Ground & $5 / 2$ & $5 / 2$ & 20995.2 & \\
\hline $\mathrm{C}^{12} \mathrm{DHDC}^{12} \mathrm{HDF}^{19}$ & 3- 561 & $1,1,0 \leftarrow 1,0,1$ & Ground & & & 20995.7 & .1 \\
\hline $\mathrm{C}^{12} \mathrm{H}_{3} \mathrm{C}^{12}{ }_{*} \mathrm{HO}^{16} \mathrm{C}^{12}{ }_{*} \mathrm{H}_{2}$ & 3. 761 & $6,1,5 \leftarrow 6,0,6$ & Ground & & & 20995.83 & .1 \\
\hline $\mathrm{C}^{12} \mathrm{H}_{3} \mathrm{C}^{12} \mathrm{H}_{2} \mathrm{Cl}^{37}$ & 3- 542 & $2,1,1 \leftarrow 1,1,0$ & Ground & $5 / 2$ & $3 / 2$ & 20996.90 & .05 \\
\hline $\mathrm{C}^{12} \mathrm{D}_{2}: \mathrm{C}^{12} \mathrm{DBr}^{81}$ & 4. 726 & $3,2,1 \leftarrow 2,2,0$ & Ground & $7 / 2$ & $5 / 2$ & 20997.1 & \\
\hline $\mathrm{C}^{12} \mathrm{D}_{2}: \mathrm{C}^{12} \mathrm{DBr}^{81}$ & 4- 726 & $3,2,1 \leftarrow 2,2,0$ & Ground & $5 / 2$ & $5 / 2$ & 20997.1 & \\
\hline $\mathrm{C}^{12} \mathrm{H}_{3} \mathrm{C}^{12} \mathrm{H}_{2} \mathrm{Cl}^{37}$ & 3- 542 & $2,1,1 \leftarrow 1,1,0$ & Ground & $3 / 2$ & $3 / 2$ & 20998.48 & .05 \\
\hline $\mathrm{C}^{12} \mathrm{~F}_{3}^{19} \mathrm{Br}^{79}$ & 4. 221 & $5,2 \leftarrow 4,2$ & Ground & $11 / 2$ & $9 / 2$ & 20998.8 & \\
\hline$\left(\mathrm{C}^{12} \mathrm{H}_{3} \mathrm{C}^{12} \mathrm{H}_{2}\right)_{2} \mathrm{O}^{16}$ & $3-1011$ & Not Reported & & & & 21000 & \\
\hline $\mathrm{C}^{12} \mathrm{~F}_{3}^{19} \mathrm{Br}^{79}$ & 4- 221 & $5,3 \leftarrow 4,3$ & Ground & $9 / 2$ & $7 / 2$ & 21001.9 & \\
\hline $\mathrm{C}^{12} \mathrm{H}_{3} \mathrm{C}^{12} \mathrm{D}_{2} \mathrm{Br}^{81}$ & 3. 526 & $3,0,3 \leftarrow 2,0,2$ & Ground & $9 / 2$ & $7 / 2$ & 21002.59 & .05 \\
\hline $\mathrm{C}^{12} \mathrm{H}_{3} \mathrm{C}^{12} \mathrm{H}_{2} \mathrm{CI}^{37}$ & 3. 542 & $2,1,1 \leftarrow 1,1,0$ & Ground & $5 / 2$ & $5 / 2$ & 21003.51 & .05 \\
\hline $\mathrm{HC}^{13}: \mathrm{C}^{12} \mathrm{C}^{12} \mathrm{DO}^{16}$ & 4. 922 & Not Reported & & & & 21005. & 5. \\
\hline $\mathrm{C}^{12} \mathrm{H}_{3} \mathrm{C}^{12} \mathrm{D}_{2} \mathrm{Br}^{81}$ & 3- 526 & $3,0,3 \leftarrow 2,0,2$ & Ground & $7 / 2$ & $5 / 2$ & 21005.19 & .05 \\
\hline $\mathrm{C}^{12} \mathrm{H}_{3} \mathrm{C}^{12} \mathrm{H}_{2} \mathrm{Cl}^{37}$ & 3- 542 & $2,1,1 \leftarrow 1,1,0$ & Ground & $7 / 2$ & $5 / 2$ & 21006.28 & .05 \\
\hline $\mathrm{C}^{12}{ }_{*} \mathrm{H}: \mathrm{C}^{12} \mathrm{DO}^{16} \mathrm{C}^{12} \mathrm{D}: \mathrm{C}^{12}{ }_{*} \mathrm{H}$ & 4-1156 & $3,1,2 \leftarrow 3,0,3$ & Ground & & & 21006.7 & \\
\hline $\mathrm{Na}^{23} \mathrm{I}^{127}$ & 1 . & $3 \leftarrow 2$ & Excited & $7 / 2$ & $5 / 2$ & 21008.40 & .20 \\
\hline $\mathrm{C}^{12} \mathrm{D}_{2}: \mathrm{C}^{12} \mathrm{DBr}^{79}$ & 4. 725 & $3,2,2 \leftarrow 2,2,1$ & Ground & $9 / 2$ & $7 / 2$ & 21009.4 & \\
\hline $\mathrm{C}^{12} \mathrm{D}_{2}: \mathrm{C}^{12} \mathrm{DBr}^{79}$ & 4. 725 & $3,2,2 \leftarrow 2,2,1$ & Ground & $7 / 2$ & $7 / 2$ & 21009.4 & \\
\hline
\end{tabular}




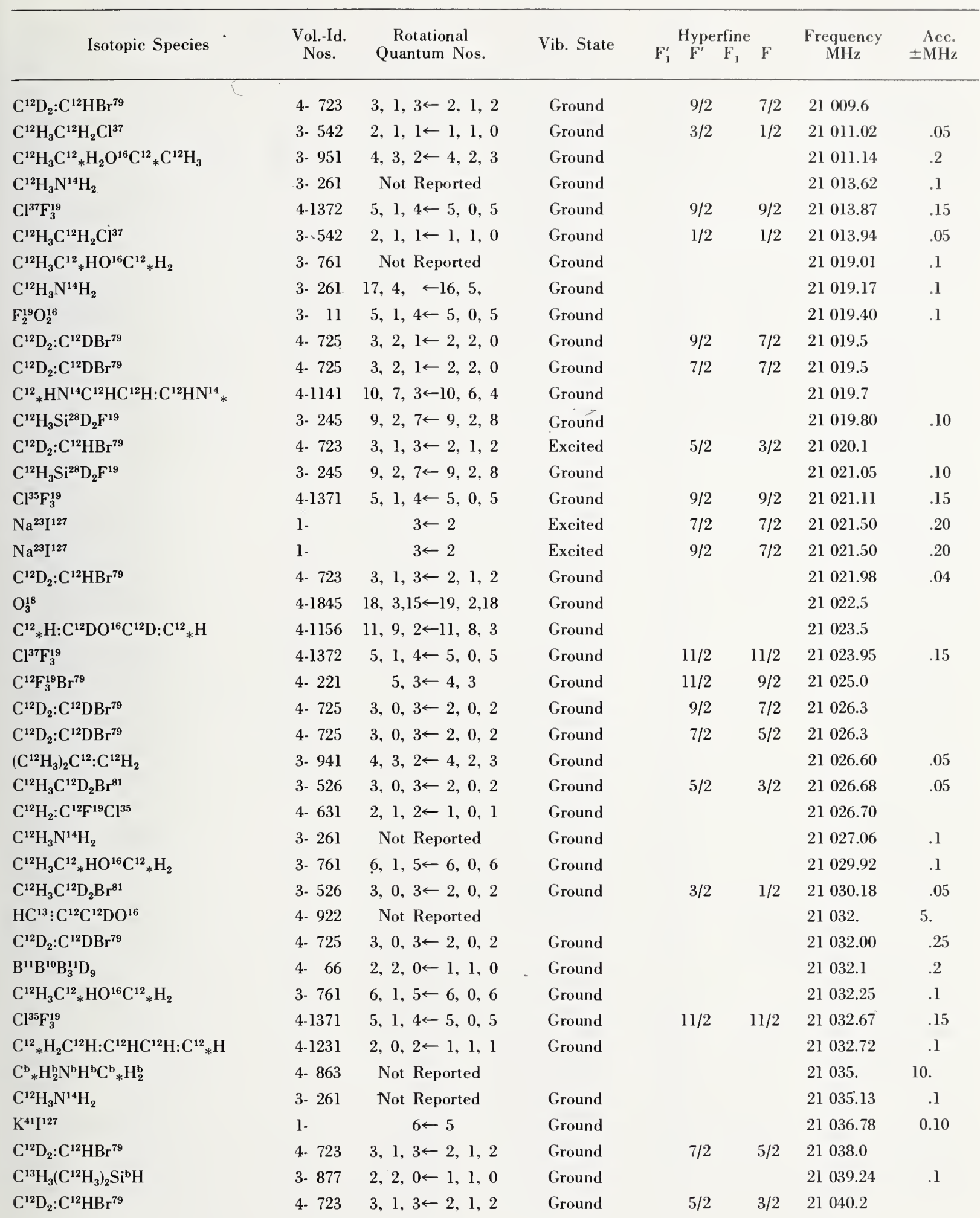




\begin{tabular}{|c|c|c|c|c|c|c|c|}
\hline Isotopic Species & $\begin{array}{l}\text { Vol.-Id. } \\
\text { Nos. }\end{array}$ & $\begin{array}{c}\text { Rotational } \\
\text { Quantum Nos. }\end{array}$ & Vib. State & \begin{tabular}{cc}
\multicolumn{2}{r}{ Hyperfine } \\
$F_{1}^{\prime} \quad F^{\prime} \quad F_{1}$
\end{tabular} & $\mathrm{~F}$ & $\begin{array}{l}\text { Frequency } \\
\text { MHz }\end{array}$ & $\begin{aligned} & \text { Acc. } \\
\pm & \mathrm{MHz}\end{aligned}$ \\
\hline $\mathrm{C}^{12} \mathrm{D}_{2}: \mathrm{C}^{12} \mathrm{DBr}^{79}$ & 4- 725 & $3,2,2 \leftarrow 2,2,1$ & Ground & & & 21043.02 & .07 \\
\hline $\mathrm{C}^{12} \mathrm{D}_{2}: \mathrm{C}^{12} \mathrm{DBr}^{79}$ & 4- 725 & $3,2,2 \leftarrow 2,2,1$ & Ground & $3 / 2$ & $3 / 2$ & 21043.2 & \\
\hline $\mathrm{C}^{12} \mathrm{D}_{2}: \mathrm{C}^{12} \mathrm{DBr}^{79}$ & 4- 725 & $3,2,2 \leftarrow 2,2,1$ & Ground & $5 / 2$ & $3 / 2$ & 21043.2 & \\
\hline $\mathrm{Br}^{79} \mathrm{~F}^{19}$ & $1-$ & $1 \leftarrow 0$ & Excited & $5 / 2$ & $3 / 2$ & 21045.6 & \\
\hline $\mathrm{C}^{12} \mathrm{H}_{2}: \mathrm{C}^{12} \mathrm{HC}^{12} \mathrm{~F}^{19}: \mathrm{C}^{12} \mathrm{H}_{2}$ & 3- 911 & $2,2,1 \leftarrow 2,1,2$ & Ground & & & 21051.13 & .03 \\
\hline $\mathrm{C}^{12} \mathrm{H}_{3} \mathrm{~N}^{14} \mathrm{H}_{2}$ & 3. 261 & $17,4, \leftarrow 16,5$, & Ground & & & 21051.62 & .1 \\
\hline $\mathrm{B}_{4}^{11} \mathrm{~B}^{10} \mathrm{D}_{9}$ & 4- 62 & $2, \leftarrow 1$ & Ground & & & 21051.8 & .2 \\
\hline $\mathrm{C}^{12} \mathrm{D}_{2}: \mathrm{C}^{12} \mathrm{DBr}^{79}$ & 4. 725 & $3,2,1 \leftarrow 2,2,0$ & Ground & & & 21053.15 & .06 \\
\hline $\mathrm{C}^{\mathrm{b}} \mathrm{H}_{2}^{\mathrm{b}} \mathrm{Cl}^{\mathrm{b}} \mathrm{F}^{\mathrm{b}}$ & 4- 333 & Not Reported & & & & 21053.4 & 1. \\
\hline $\mathrm{C}^{12} \mathrm{D}_{2}: \mathrm{C}^{12} \mathrm{DBr}^{79}$ & 4- 725 & $3,2,1 \leftarrow 2,2,0$ & Ground & $3 / 2$ & $3 / 2$ & 21053.5 & \\
\hline $\mathrm{C}^{12} \mathrm{D}_{2}: \mathrm{C}^{12} \mathrm{DBr}^{79}$ & 4- 725 & $3,2,1 \leftarrow 2,2,0$ & Ground & $5 / 2$ & $3 / 2$ & 21053.5 & \\
\hline $\mathrm{C}^{12} \mathrm{H}_{2}\left(\mathrm{C}^{12} \mathrm{~N}^{14}\right)_{2}$ & 4- 901 & Not Reported & Ground & & & 21055.0 & .1 \\
\hline $\mathrm{C}^{12} \mathrm{D}_{2}: \mathrm{C}^{12} \mathrm{DBr}^{79}$ & 4- 725 & $3,0,3 \leftarrow 2,0,2$ & Ground & $5 / 2$ & $3 / 2$ & 21055.4 & \\
\hline $\mathrm{C}^{12} \mathrm{D}_{2}: \mathrm{C}^{12} \mathrm{DBr}^{79}$ & 4- 725 & $3,0,3 \leftarrow 2,0,2$ & Ground & $3 / 2$ & $1 / 2$ & 21055.4 & \\
\hline $\mathrm{HDC}^{12}: \mathrm{C}^{12} \mathrm{~F}_{2}^{19}$ & 4- 682 & $3,3,1 \leftarrow 3,1,2$ & Ground & & & 21056.0 & .3 \\
\hline $\mathrm{C}^{12} \mathrm{H}_{3} \mathrm{~S}^{32} \mathrm{H}$ & 3- 221 & Not Reported & Ground & & & 21057.4 & .1 \\
\hline $\mathrm{C}^{12} \mathrm{H}_{3} \mathrm{C}^{12}{ }_{*} \mathrm{HO}^{16} \mathrm{C}^{12}{ }_{*} \mathrm{H}_{2}$ & 3- 761 & Not Reported & Ground & & & 21060.27 & .1 \\
\hline $\mathrm{C}^{\mathrm{b}}{ }_{*} \mathrm{H}_{2}^{\mathrm{b}} \mathrm{N}^{\mathrm{b}} \mathrm{H}^{\mathrm{b}} \mathrm{C}^{\mathrm{b}}{ }_{*} \mathrm{H}_{2}^{\mathrm{b}}$ & 4- 863 & Not Reported & & & & 21068. & 10. \\
\hline$\left(\mathrm{C}^{12} \mathrm{H}_{3}\right)_{2} \mathrm{Si}^{28} \mathrm{H}_{2}$ & 3- 641 & $5,1,4 \leftarrow 5,0,5$ & Ground & & & 21068.32 & .05 \\
\hline$\left(\mathrm{C}^{12} \mathrm{H}_{3}\right)_{2} \mathrm{Si}^{28} \mathrm{H}_{2}$ & 3. 641 & $5,1,4 \leftarrow 5,0,5$ & Ground & & & 21070.13 & .05 \\
\hline $\mathrm{N}^{14} \mathrm{H}_{3}$ & $4-1771$ & $11,9 \leftarrow 11,9$ & Ground & & & 21070.70 & .02 \\
\hline$\left(\mathrm{C}^{12} \mathrm{H}_{3}\right)_{2} \mathrm{Si}^{28} \mathrm{H}_{2}$ & 3- 641 & $5,1,4 \leftarrow 5,0,5$ & Ground & & & 21071.97 & .05 \\
\hline $\mathrm{C}^{12} \mathrm{H}_{2}\left(\mathrm{C}^{12} \mathrm{~N}^{14}\right)_{2}$ & 4- 901 & Not Reported & Ground & & & 21080.9 & .1 \\
\hline $\mathrm{C}^{13} \mathrm{H}_{3} \mathrm{C}^{12} \mathrm{H}_{2} \mathrm{Br}^{81}$ & 3- 531 & $3,0,3 \leftarrow 2,0,2$ & Ground & $9 / 2$ & $7 / 2$ & 21083.35 & .05 \\
\hline $\mathrm{C}^{12} \mathrm{H}_{2} \mathrm{Cl}^{35} \mathrm{~F}^{19}$ & 4- 331 & $18,1,18 \leftarrow 17,2,15$ & Ground & & & 21084.05 & .1 \\
\hline $\mathrm{D}_{2} \mathrm{C}^{12}: \mathrm{C}^{12} \mathrm{~F}_{2}^{19}$ & 4- 683 & $4,2,2 \leftarrow 4,2,3$ & Ground & & & 21084.9 & .3 \\
\hline $\mathrm{O}^{16} \mathrm{O}^{16} \mathrm{O}^{18}$ & $4-1842$ & $19,3,16 \leftarrow 20,2,19$ & Ground & & & 21086.0 & \\
\hline$\left(\mathrm{C}^{12} \mathrm{H}_{3}\right)_{2} \mathrm{Si}^{29} \mathrm{H}_{2}$ & 3. 644 & $5,1,4 \leftarrow 5,0,5$ & Ground & & & 21086.34 & .20 \\
\hline $\mathrm{C}^{12} \mathrm{HD}\left(\mathrm{C}^{12} \mathrm{~N}^{14}\right)_{2}$ & 4- 902 & $1,1,1 \leftarrow 0,0,0$ & Ground & & & 21086.78 & \\
\hline$\left(\mathrm{C}^{12} \mathrm{H}_{3}\right)_{2} \mathrm{Si}^{29} \mathrm{H}_{2}$ & 3. 644 & $5,1,4 \leftarrow 5,0,5$ & Ground & & & 21088.16 & .20 \\
\hline$\left(\mathrm{C}^{12} \mathrm{H}_{3}\right)_{2} \mathrm{Si}^{29} \mathrm{H}_{2}$ & 3- 644 & $5,1,4 \leftarrow 5,0,5$ & Ground & & & 21089.93 & .20 \\
\hline $\mathrm{C}^{12} \mathrm{H}_{2} \mathrm{Cl}^{35} \mathrm{~F}^{19}$ & 4- 331 & $18,1,18 \leftarrow 17,2,15$ & Ground & & & 21090.31 & .1 \\
\hline $\mathrm{C}^{12} * \mathrm{HO}^{16} \mathrm{C}^{12} \mathrm{HC}^{12} \mathrm{H}_{2} \mathrm{C}^{12} \mathrm{H}_{2} \mathrm{C}^{12} * \mathrm{H}_{2}$ & $4-1251$ & $3,1,3 \leftarrow 2,1,2$ & Ground & & & 21094. & 5. \\
\hline $\mathrm{O}^{16}{ }_{*} \mathrm{C}^{12} \mathrm{H}_{2} \mathrm{O}^{16} \mathrm{C}^{12} \mathrm{H}_{2} \mathrm{O}^{16} \mathrm{C}^{12}{ }_{*} \mathrm{H}_{2}$ & $4-1101$ & $2, \leftarrow 1$, & Ground & & & 21094.3 & \\
\hline $\mathrm{C}^{12} \mathrm{D}_{2}: \mathrm{C}^{12} \mathrm{HBr}^{79}$ & 4- 723 & $3,1,3 \leftarrow 2,1,2$ & Ground & $7 / 2$ & $7 / 2$ & 21102.2 & \\
\hline $\mathrm{C}^{12}{ }_{*} \mathrm{D}: \mathrm{C}^{12} \mathrm{DC}^{12} \mathrm{D}: \mathrm{C}^{12} \mathrm{DN}^{14}{ }_{*} \mathrm{H}$ & 4-1185 & $8,7,2 \leftarrow 8,6,3$ & Ground & & & 21104.3 & \\
\hline $\mathrm{C}^{13} \mathrm{H}_{3} \mathrm{C}^{12} \mathrm{H}_{2} \mathrm{Br}^{81}$ & 3- 531 & $3,0,3 \leftarrow 2,0,2$ & Ground & $5 / 2$ & $3 / 2$ & 21104.47 & .05 \\
\hline $\mathrm{HC}^{13}: \mathrm{C}^{12} \mathrm{C}^{12} \mathrm{DO}^{16}$ & 4- 922 & Not Reported & & & & 21105. & 5. \\
\hline$\left(\mathrm{C}^{12} \mathrm{H}_{3}\right)_{2} \mathrm{Si}^{30} \mathrm{H}_{2}$ & 3- 645 & $5,1,4 \leftarrow 5,0,5$ & Ground & & & 21106.76 & .20 \\
\hline $\mathrm{H}_{2} \mathrm{~N}^{14} \mathrm{~N}^{14} \mathrm{H}_{2}$ & 3. 51 & Not Reported & & & & 21107.10 & \\
\hline$\left(\mathrm{C}^{12} \mathrm{H}_{3}\right)_{2} \mathrm{Si}^{30} \mathrm{H}_{2}$ & 3- 645 & $5,1,4 \leftarrow 5,0,5$ & Ground & & & 21108.42 & .20 \\
\hline $\mathrm{Na}^{231_{1}{ }^{127}}$ & $1-$ & $3 \leftarrow 2$ & Ground & $3 / 2$ & $1 / 2$ & 21108.64 & .20 \\
\hline$\left(\mathrm{C}^{12} \mathrm{H}_{3}\right)_{2} \mathrm{Si}^{30} \mathrm{H}_{2}$ & 3- 645 & $5,1,4 \leftarrow 5,0,5$ & Ground & & & 21110.22 & .20 \\
\hline
\end{tabular}




\begin{tabular}{|c|c|c|c|c|c|c|c|}
\hline Isotopic Species & $\begin{array}{l}\text { Vol.-Id. } \\
\text { Nos. }\end{array}$ & $\begin{array}{c}\text { Rotational } \\
\text { Quantum Nos. }\end{array}$ & Vib. State & $F_{1}^{\prime} F^{\prime}$ & F & $\begin{array}{c}\text { Frequency } \\
\mathrm{MH}_{z}\end{array}$ & $\begin{aligned} & \text { Acc. } \\
\pm & \mathrm{MHz}\end{aligned}$ \\
\hline $\mathrm{H}_{2} \mathrm{~N}^{14} \mathrm{~N}^{14} \mathrm{H}_{2}$ & $3-\quad 51$ & Not Reported & & & & 21110.25 & \\
\hline $\mathrm{Br}^{81} \mathrm{~F}^{19}$ & $1-$ & $1 \leftarrow 0$ & Ground & $5 / 2$ & $3 / 2$ & 21110.4 & \\
\hline $\mathrm{C}^{12} \mathrm{D}_{2}: \mathrm{C}^{12} \mathrm{DBr}^{\mathrm{b}}$ & 4- 732 & $3, \quad, \quad \leftarrow 2, \quad$, & Ground & & & 21110.9 & .1 \\
\hline $\mathrm{Na}^{23} I^{127}$ & $1-$ & $3 \leftarrow 2$ & Ground & $5 / 2$ & $3 / 2$ & 21111.67 & .20 \\
\hline $\mathrm{C}^{12} \mathrm{H}_{3} \mathrm{C}^{12}{ }_{*} \mathrm{HO}^{16} \mathrm{C}^{12}{ }_{*} \mathrm{H}_{2}$ & 3- 761 & $6,1,5 \leftarrow 6,0,6$ & Ground & & & 21115.40 & .1 \\
\hline $\mathrm{B}^{11} \mathrm{~B}^{10} \mathrm{~B}_{3}^{11} \mathrm{D}_{9}$ & 4- 66 & $2,2,1 \leftarrow 1,1,1$ & Ground & & & 21117.2 & .2 \\
\hline $\mathrm{Cl}^{37} \mathrm{O}_{2}^{16}$ & 4-1382 & $14,2,13 \leftarrow 13,3,10$ & Ground & & & 21119.5 & \\
\hline $\mathrm{C}^{12} \mathrm{D}_{3} \mathrm{C}^{12} \mathrm{O}^{16} \mathrm{Cl}^{37}$ & 3- 364 & $7,2,5 \leftarrow 7,1,6$ & Ground & $17 / 2$ & $17 / 2$ & 21123.0 & \\
\hline $\mathrm{C}^{12} \mathrm{D}_{3} \mathrm{C}^{12} \mathrm{O}^{16} \mathrm{Cl}^{37}$ & 3- 364 & $7,2,5 \leftarrow 7,1,6$ & Ground & $11 / 2$ & $11 / 2$ & 21123.0 & \\
\hline $\mathrm{C}^{12} \mathrm{D}_{3} \mathrm{C}^{12} \mathrm{O}^{16} \mathrm{Cl}^{37}$ & 3- 364 & $7,2,5 \leftarrow 7,1,6$ & Ground & $13 / 2$ & $13 / 2$ & 21123.0 & \\
\hline $\mathrm{C}^{12} \mathrm{D}_{3} \mathrm{C}^{12} \mathrm{O}^{16} \mathrm{Cl}^{37}$ & 3- 364 & $7,2,5 \leftarrow 7,1,6$ & Ground & $15 / 2$ & $15 / 2$ & 21123.0 & \\
\hline $\mathrm{Na}^{23} \mathrm{I}^{127}$ & $1-$ & $3 \leftarrow 2$ & Ground & $7 / 2$ & $5 / 2$ & 21124.58 & .20 \\
\hline $\mathrm{C}^{12} \mathrm{D}_{2}: \mathrm{C}^{12} \mathrm{DBr}^{79}$ & 4- 725 & $3,2,2 \leftarrow 2,2,1$ & Ground & $7 / 2$ & $5 / 2$ & 21126.9 & \\
\hline $\mathrm{C}^{12} \mathrm{D}_{2}: \mathrm{C}^{12} \mathrm{DBr}^{79}$ & 4- 725 & $3,2,2 \leftarrow 2,2,1$ & Ground & $5 / 2$ & $5 / 2$ & 21126.9 & \\
\hline $\mathrm{H}_{2} \mathrm{~N}^{14} \mathrm{~N}^{14} \mathrm{H}_{2}$ & $3-51$ & Not Reported & & & & 21127.0 & \\
\hline $4 d-\mathrm{C}_{6}^{12} \mathrm{H}_{5} \mathrm{~F}^{19}$ & $4-1283$ & $5,4,2 \leftarrow 4,4,1$ & Ground & & & 21128.5 & .1 \\
\hline $\mathrm{C}^{12} \mathrm{H}_{3} \mathrm{C}^{12} \mathrm{D}_{2} \mathrm{Br}^{79}$ & 3- 524 & $3,0,3 \leftarrow 2,0,2$ & Ground & $9 / 2$ & $7 / 2$ & 21128.81 & .05 \\
\hline $\mathrm{C}^{12} \mathrm{H}_{3} \mathrm{~S}^{32} \mathrm{H}$ & 3- 221 & Not Reported & Ground & & & 21131.1 & .1 \\
\hline $\mathrm{C}^{12} \mathrm{H}_{3} \mathrm{C}^{12} \mathrm{D}_{2} \mathrm{Br}^{79}$ & $3-524$ & $3,0,3 \leftarrow 2,0,2$ & Ground & $7 / 2$ & $5 / 2$ & 21132.01 & .05 \\
\hline$c-\mathrm{C}^{12} \mathrm{HD}: \mathrm{C}^{12} \mathrm{DBr}^{81}$ & 4- 746 & $3,1,3 \leftarrow 2,1,2$ & Ground & $3 / 2$ & $3 / 2$ & 21134.2 & .2 \\
\hline $\mathrm{N}^{14} \mathrm{H}_{3}$ & $4-1771$ & $4,1 \leftarrow 4,1$ & Ground & & & 21134.29 & .02 \\
\hline $4 d-\mathrm{C}_{6}^{12} \mathrm{H}_{5} \mathrm{~F}^{19}$ & $4-1283$ & $5,4,1 \leftarrow 4,4,0$ & Ground & & & 21134.6 & .1 \\
\hline $\mathrm{C}^{12} \mathrm{D}_{3} \mathrm{Si}^{30} \mathrm{H}_{2} \mathrm{~F}^{19}$ & 3- 246 & $2,0,2 \leftarrow 1,0,1$ & Ground & & & 21134.95 & .10 \\
\hline $\mathrm{Na}^{23} \mathrm{I}^{127}$ & 1 - & $3 \leftarrow 2$ & Ground & $11 / 2$ & $9 / 2$ & 21135.35 & .20 \\
\hline $\mathrm{C}^{12} \mathrm{HD}\left(\mathrm{C}^{12} \mathrm{~N}^{14}\right)_{2}$ & 4- 902 & $7,1,6 \leftarrow 7,0,7$ & Cround & & & 21135.78 & \\
\hline $\mathrm{C}^{12} \mathrm{D}_{2}: \mathrm{C}^{12} \mathrm{DBr}^{79}$ & 4- 725 & $3,2,1 \leftarrow 2,2,0$ & Ground & $7 / 2$ & $5 / 2$ & 21137.0 & \\
\hline $\mathrm{C}^{12} \mathrm{D}_{2}: \mathrm{C}^{12} \mathrm{DBr}^{79}$ & 4. 725 & $3,2,1 \leftarrow 2,2,0$ & Ground & $5 / 2$ & $5 / 2$ & 21137.0 & \\
\hline $\mathrm{Na}^{23} \mathrm{I}^{127}$ & $1-$ & $3 \leftarrow 2$ & Ground & $7 / 2$ & $7 / 2$ & 21137.49 & .20 \\
\hline $\mathrm{Na}^{23} \mathrm{I}^{127}$ & $1-$ & $3 \leftarrow 2$ & Ground & $9 / 2$ & $7 / 2$ & 21137.49 & .20 \\
\hline $\mathrm{O}^{\mathrm{h}} \mathrm{O}^{\mathrm{h}} \mathrm{O}^{\mathrm{b}}$ & $4-1847$ & Not Reported & & & & 21141.0 & \\
\hline $\mathrm{Na}^{23} \mathrm{I}^{127}$ & $1-$ & $3 \leftarrow 2$ & Ground & $3 / 2$ & $3 / 2$ & 21141.93 & .20 \\
\hline $\mathrm{C}^{12} \mathrm{D}_{2}: \mathrm{C}^{12} \mathrm{DBr}^{79}$ & 4- 725 & $3,0,3 \leftarrow 2,0,2$ & Ground & $7 / 2$ & $7 / 2$ & 21143.3 & \\
\hline $\mathrm{HC}^{13}: \mathrm{C}^{12} \mathrm{C}^{12} \mathrm{DO}^{16}$ & 4- 922 & Not Reported & & & & 21144. & 5. \\
\hline $\mathrm{B}_{2}^{10} \mathrm{~B}_{3}^{11} \mathrm{D}_{9}$ & 4- 63 & $2,1,1 \leftarrow 1,0,1$ & Ground & & & 21146. & 1.0 \\
\hline $\mathrm{C}^{12} \mathrm{D}_{3} \mathrm{Si}^{30} \mathrm{H}_{2} \mathrm{~F}^{19}$ & 3- 246 & $2,0,2 \leftarrow 1,0,1$ & Ground & & & 21148.76 & .10 \\
\hline$T l^{205} I^{127}$ & $1-$ & $13 \leftarrow 12$ & Ground & $25 / 2$ & $23 / 2$ & 21148.78 & 0.05 \\
\hline$T l^{205} \mathrm{I}^{127}$ & $1-$ & $13 \leftarrow 12$ & Ground & $21 / 2$ & $19 / 2$ & 21148.78 & 0.05 \\
\hline$T l^{205} \mathrm{I}^{127}$ & 1 - & $13 \leftarrow 12$ & Ground & $23 / 2$ & $21 / 2$ & 21148.78 & 0.05 \\
\hline $\mathrm{Na}^{23} \mathrm{I}^{127}$ & $1-$ & $3 \leftarrow 2$ & Ground & $5 / 2$ & $5 / 2$ & 21148.85 & .20 \\
\hline $\mathrm{Tl}^{205} \mathrm{l}^{127}$ & $1-$ & $13 \leftarrow 12$ & Ground & $29 / 2$ & $27 / 2$ & 21149.81 & 0.10 \\
\hline $\mathrm{Tl}^{205} \mathrm{I}^{127}$ & $1-$ & $13 \leftarrow 12$ & Ground & $27 / 2$ & $25 / 2$ & $21 \quad 149.81$ & 0.10 \\
\hline$T l^{205} \mathrm{I}^{127}$ & 1 - & $13 \leftarrow 12$ & Ground & $31 / 2$ & $29 / 2$ & 21149.81 & 0.10 \\
\hline $\mathrm{C}^{13} \mathrm{H}_{3} \mathrm{Si}^{28} \mathrm{H}_{3}$ & 3- 312 & $1, \leftarrow 0$, & & & & 21150.7 & \\
\hline
\end{tabular}




\begin{tabular}{|c|c|c|c|c|c|c|c|}
\hline Isotopic Species & $\begin{array}{l}\text { Vol.-Id. } \\
\text { Nos. }\end{array}$ & $\begin{array}{c}\text { Rotational } \\
\text { Quantum Nos. }\end{array}$ & Vib. State & $F_{1} \quad \begin{array}{c}\text { Hyperfine } \\
F^{\prime} \quad F_{1}\end{array}$ & $\mathrm{~F}$ & $\begin{array}{c}\text { Frequency } \\
\mathrm{MHz}\end{array}$ & $\begin{aligned} & \text { Acc. } \\
\pm & \mathrm{MHz}\end{aligned}$ \\
\hline c- $\mathrm{C}^{12} \mathrm{HD}: \mathrm{C}^{12} \mathrm{DBr}^{81}$ & 4- 746 & $3,1,3 \leftarrow 2,1,2$ & Excited & $5 / 2$ & $5 / 2$ & 21153.1 & .2 \\
\hline $\mathrm{H}_{2} \mathrm{~N}^{14} \mathrm{~N}^{14} \mathrm{H}_{2}$ & 3- 51 & $13,2 \leftarrow 12,3$ & Ground & & & 21153.6 & \\
\hline $\mathrm{C}_{6}^{12} \mathrm{H}_{5} \mathrm{Cl}^{35}$ & $4-1271$ & $8,0,8 \leftarrow 7,0,7$ & Ground & & & 21157.0 & \\
\hline $\mathrm{C}^{12} \mathrm{H}_{3} \mathrm{C}^{12} \mathrm{D}_{2} \mathrm{Br}^{79}$ & 3. 524 & $3,0,3 \leftarrow 2,0,2$ & Ground & $5 / 2$ & $3 / 2$ & 21157.81 & .05 \\
\hline $\mathrm{HC}^{13}: \mathrm{C}^{12} \mathrm{C}^{12} \mathrm{DO}^{16}$ & 4- 922 & Not Reported & & & & 21158. & 5. \\
\hline $\mathrm{c}-\mathrm{HCl}^{35} \mathrm{C}^{12}: \mathrm{C}^{12} \mathrm{HCl}^{37}$ & 4- 672 & $8,1,7 \leftarrow 8,0,8$ & Ground & & & 21161.6 & 1. \\
\hline $\mathrm{C}^{12} \mathrm{H}_{3} \mathrm{C}^{12} \mathrm{D}_{2} \mathrm{Br}^{79}$ & 3. 524 & $3,0,3 \leftarrow 2,0,2$ & Ground & $3 / 2$ & $1 / 2$ & 21162.20 & .05 \\
\hline $\mathrm{c}-\mathrm{C}^{12} \mathrm{HD}: \mathrm{C}^{12} \mathrm{DBr}^{81}$ & 4. 746 & $3,1,3 \leftarrow 2,1,2$ & Excited & $9 / 2$ & $7 / 2$ & 21164.7 & .1 \\
\hline $\mathrm{HC}^{13}: \mathrm{C}^{12} \mathrm{C}^{12} \mathrm{DO}^{16}$ & 4. 922 & Not Reported & & & & 21165. & 5. \\
\hline $4 \mathrm{~d}-\mathrm{C}_{6}^{12} \mathrm{H}_{5} \mathrm{~F}^{19}$ & $4-1283$ & $5,3,3 \leftarrow 4,3,2$ & Ground & & & 21165.0 & .1 \\
\hline $\mathrm{C}^{12} \mathrm{D}_{3} \mathrm{Si}^{29} \mathrm{H}_{2} \mathrm{~F}^{19}$ & 3- 251 & $2,0,2 \leftarrow 1,0,1$ & Ground & & & 21165.26 & .10 \\
\hline $\mathrm{H}_{2} \mathrm{~N}^{14} \mathrm{~N}^{14} \mathrm{H}_{2}$ & 3- 51 & $13,2 \leftarrow 12,3$ & Ground & & & 21165.4 & \\
\hline $\mathrm{C}^{12} \mathrm{H}_{3} \mathrm{C}^{13} \mathrm{H}_{2} \mathrm{Br}^{81}$ & 3- 529 & $3,1,3 \leftarrow 2,1,2$ & Ground & $9 / 2$ & $7 / 2$ & 21166.97 & .05 \\
\hline $\mathrm{C}^{12} \mathrm{H}_{3} \mathrm{C}^{13} \mathrm{H}_{2} \mathrm{Br}^{81}$ & 3- 529 & $3,1,3 \leftarrow 2,1,2$ & Ground & $3 / 2$ & $1 / 2$ & $21 \cdot 170.52$ & .05 \\
\hline $\mathrm{s}-\mathrm{C}^{12} \mathrm{HD}_{2} \mathrm{C}^{12} \mathrm{HO}^{16}$ & 3. 475 & $9,1,8 \leftarrow 9,1,9$ & Ground & & & 21170.68 & .2 \\
\hline 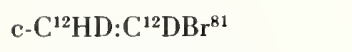 & 4- 746 & $3,1,3 \leftarrow 2,1,2$ & Ground & $5 / 2$ & $5 / 2$ & 21174.6 & .2 \\
\hline$\left(\mathrm{C}^{12} \mathrm{H}_{3} \mathrm{C}^{12} \mathrm{H}_{2}\right)_{2} \mathrm{O}^{16}$ & 3-1011 & Not Reported & & & & 21175. & \\
\hline $\mathrm{C}^{12} \mathrm{D}_{3} \mathrm{Si}^{29} \mathrm{H}_{2} \mathrm{~F}^{19}$ & 3. 251 & $2,0,2 \leftarrow 1,0,1$ & Ground & & & 21179.40 & .10 \\
\hline $\mathrm{Br}^{81} \mathrm{~F}^{19}$ & 1 - & $1 \leftarrow 0$ & Excited & $3 / 2$ & $3 / 2$ & 21181.7 & \\
\hline $\mathrm{K}^{39} \mathbf{I}^{127}$ & 1 . & $6 \leftarrow 5$ & Excited & & & 21184.73 & 0.10 \\
\hline $\mathrm{c}-\mathrm{C}^{12} \mathrm{HD}: \mathrm{C}^{12} \mathrm{DBr}^{81}$ & 4- 746 & $3,1,3 \leftarrow 2,1,2$ & Ground & $9 / 2$ & $7 / 2$ & 21185.9 & .1 \\
\hline $\mathrm{C}^{12} \mathrm{H}_{2}\left(\mathrm{C}^{12} \mathrm{~N}^{14}\right)_{2}$ & 4. 901 & Not Reported & Ground & & & 21186.9 & .1 \\
\hline $\mathrm{C}^{12} \mathrm{H}_{3} \mathrm{C}^{13} \mathrm{H}_{2} \mathrm{Br}^{81}$ & 3- 529 & $3,1,3 \leftarrow 2,1,2$ & Ground & $7 / 2$ & $5 / 2$ & 21188.89 & .05 \\
\hline c- $\mathrm{C}^{12} \mathrm{HD}: \mathrm{C}^{12} \mathrm{DBr}^{81}$ & 4. 746 & $3,1,3 \leftarrow 2,1,2$ & Excited & $7 / 2$ & $5 / 2$ & 21189.5 & .1 \\
\hline $\mathrm{C}^{12} \mathrm{H}_{3} \mathrm{~N}^{14} \mathrm{O}_{2}^{16}$ & 3- 171 & Not Reported & Ground & & & 21190. & 5. \\
\hline $\mathrm{HC}^{12} \mathrm{O}^{16} \mathrm{~N}^{14} \mathrm{H}_{2}$ & 3. 151 & $1,0,1 \leftarrow 0,0,0$ & Excited & & & 21190.7 & \\
\hline c.- $\mathrm{C}^{12} \mathrm{HD}: \mathrm{C}^{12} \mathrm{DBr}^{81}$ & 4- 746 & $3,1,3 \leftarrow 2,1,2$ & Excited & $5 / 2$ & $3 / 2$ & 21191.0 & .2 \\
\hline $\mathrm{C}^{12} \mathrm{H}_{3} \mathrm{C}^{13} \mathrm{H}_{2} \mathrm{Br}^{81}$ & 3- 529 & $3,1,3 \leftarrow 2,1,2$ & Ground & $5 / 2$ & $3 / 2$ & 21192.78 & .05 \\
\hline $\mathrm{C}^{12} \mathrm{HD}: \mathrm{C}^{12} \mathrm{DBr}^{\mathrm{b}}$ & 4- 749 & Not Reported & & & & 21194.0 & .2 \\
\hline c- $\mathrm{C}^{12} \mathrm{HD}: \mathrm{C}^{12} \mathrm{DBr}^{81}$ & 4- 746 & $3,1,3 \leftarrow 2,1,2$ & Ground & & & 21196.72 & .05 \\
\hline $\mathrm{C}^{12} \mathrm{D}_{3} \mathrm{Si}^{28} \mathrm{H}_{2} \mathrm{~F}^{19}$ & 3- 244 & $2,0,2 \leftarrow 1,0,1$ & Ground & & & 21197.28 & .10 \\
\hline $\mathrm{C}^{12} \mathrm{HD}: \mathrm{C}^{12} \mathrm{DBr}^{\mathrm{b}}$ & 4- 749 & Not Reported & & & & 21197.5 & .1 \\
\hline $\mathrm{C}^{13} \mathrm{H}_{3}\left(\mathrm{C}^{12} \mathrm{H}_{3}\right)_{2} \mathrm{Si}^{\mathrm{b}} \mathrm{H}$ & 3- 877 & $2,2,1 \leftarrow 1,1,1$ & Ground & & & 21199.01 & .1 \\
\hline $\mathrm{C}^{12} \mathrm{HD}: \mathrm{C}^{12} \mathrm{DBr}^{\mathrm{b}}$ & 4. 749 & Not Reported & & & & 21202.2 & .1 \\
\hline $\mathrm{N}^{15} \mathrm{H}_{3}$ & $4-1772$ & $3,1 \leftarrow 3,1$ & Ground & & & 21202.30 & .02 \\
\hline $\mathrm{Br}^{79} \mathrm{~F}^{19}$ & 1 - & $1 \leftarrow 0$ & Ground & $5 / 2$ & $3 / 2$ & 21202.6 & \\
\hline $\mathrm{C}^{13} \mathrm{H}_{3}\left(\mathrm{C}^{12} \mathrm{H}_{3}\right)_{2} \mathrm{C}^{12} \mathrm{C}^{12}: \mathrm{C}^{12} \mathrm{H}$ & 3-1077 & $4,1,4 \leftarrow 3,1,3$ & Ground & & & 21204.4 & .1 \\
\hline $\mathrm{HC}^{12} \mathrm{O}^{16} \mathrm{~N}^{14} \mathrm{H}_{2}$ & 3- 151 & $1,0,1 \leftarrow 0,0,0$ & Ground & 0 & 1 & 21206.56 & .1 \\
\hline $\mathrm{HC}^{12} \mathrm{O}^{16} \mathrm{~N}^{14} \mathrm{H}_{2}$ & 3- 151 & $1,0,1 \leftarrow 0,0,0$ & Ground & 2 & 1 & 21207.43 & .1 \\
\hline
\end{tabular}




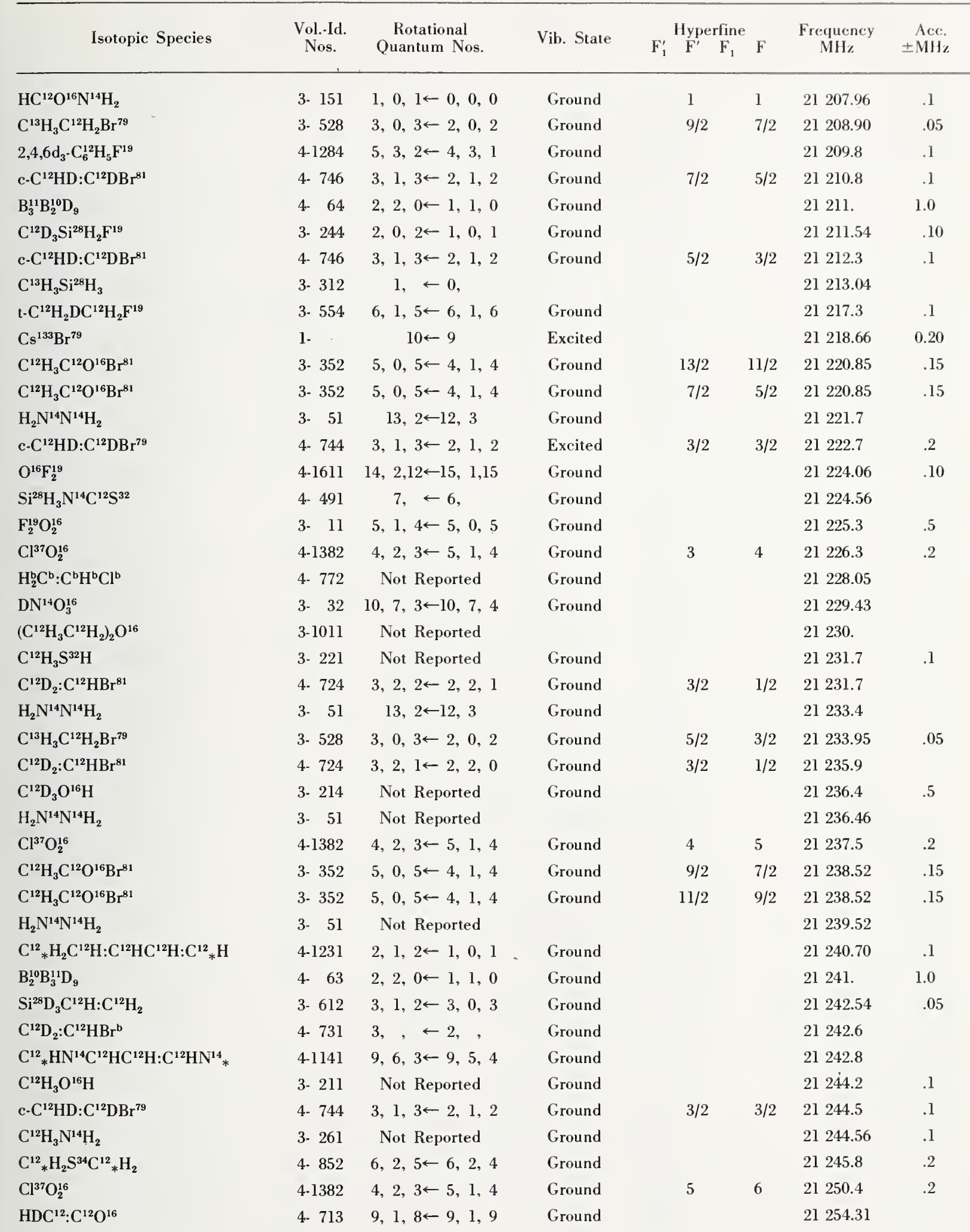




\begin{tabular}{|c|c|c|c|c|c|c|c|}
\hline Isotopic Species & $\begin{array}{l}\text { Vol.-Id. } \\
\text { Nos. }\end{array}$ & $\begin{array}{c}\text { Rotational } \\
\text { Quantum Nos. }\end{array}$ & Vib. State & $\mathrm{F}_{1}^{\prime} \quad \mathrm{F}^{\prime} \quad \mathrm{F}_{1}$ & $\mathbf{F}$ & $\begin{array}{l}\text { Frequency } \\
\qquad \mathrm{MHz}^{-}\end{array}$ & $\begin{array}{r}\text { Acc. } \\
\pm \mathrm{MHz}\end{array}$ \\
\hline $\mathrm{Cs}^{133} \mathrm{Br}^{81}$ & $1-$ & $10 \leftarrow 9$ & Ground & & & 21254.44 & 0.10 \\
\hline $\mathrm{S}^{32}{ }_{*} \mathrm{HC}^{12}: \mathrm{C}^{12} \mathrm{DC}^{12} \mathrm{H}: \mathrm{C}^{12}{ }_{*} \mathrm{H}$ & 4-1163 & $3,1,3 \leftarrow 2,1,2$ & Ground & & & 21254.5 & .1 \\
\hline $\mathrm{a} \cdot \mathrm{C}^{12} \mathrm{H}_{2} \mathrm{DC}^{12} \mathrm{H}_{3} \mathrm{C}^{12}: \mathrm{C}^{12} \mathrm{H}_{2}$ & 3. 942 & $2,0,2 \leftarrow 1,1,1$ & Ground & & & 21256.85 & .05 \\
\hline $\left.\mathrm{t}-\mathrm{HDC}^{12}: \mathrm{C}^{12} \mathrm{DC}\right]^{37}$ & 4- 764 & $2,0,2 \leftarrow 1,0,1$ & Ground & $7 / 2$ & $5 / 2$ & 21257.18 & .2 \\
\hline $\mathrm{C}^{12} \mathrm{D}_{2}: \mathrm{C}^{12} \mathrm{HBr}^{\mathrm{b}}$ & 4- 731 & $3, \quad \leftarrow 2$, & Ground & & & 21258.5 & \\
\hline $\mathrm{C}^{12} \mathrm{H}_{2}\left(\mathrm{C}^{12} \mathrm{~N}^{14}\right)_{2}$ & 4- 901 & Not Reported & Ground & & & 21260.9 & .1 \\
\hline $\mathrm{S}^{32} \mathrm{P}^{31} \mathrm{~F}_{3}^{19}$ & $4-1691$ & $4, \leftarrow 3$, & Ground & & & 21260.95 & .05 \\
\hline $\mathrm{C}^{12}{ }_{*} \mathrm{H}: \mathrm{C}^{12} \mathrm{DC}^{12} \mathrm{H}: \mathrm{C}^{12} \mathrm{HN}^{14}{ }_{*} \mathrm{H}$ & $4-1184$ & $2,1,2 \leftarrow 1,1,1$ & Ground & & & 21262.1 & \\
\hline 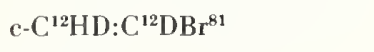 & 4- 746 & $3,1,3 \leftarrow 2,1,2$ & Ground & $7 / 2$ & $7 / 2$ & 21264.0 & .2 \\
\hline $\mathrm{C}^{37} \mathrm{O}_{2}^{16}$ & $4-1382$ & $4,2,3 \leftarrow 5,1,4$ & Ground & 6 & 7 & 21264.3 & .2 \\
\hline $\mathrm{C}^{12}{ }_{*} \mathrm{H}: \mathrm{C}^{12} \mathrm{HC}^{12} \mathrm{H}: \mathrm{C}^{12} \mathrm{HN}^{14}{ }_{*} \mathrm{H}$ & $4-1181$ & $12,12,1 \leftarrow 12,10,2$ & Ground & & & 21269.9 & \\
\hline $\mathrm{C}^{12} \mathrm{H}_{2}\left(\mathrm{C}^{12} \mathrm{~N}^{14}\right)_{2}$ & 4- 901 & Not Reported & Ground & & & 21271. & .1 \\
\hline c- $\mathrm{C}^{12} \mathrm{HD}: \mathrm{C}^{12} \mathrm{DBr}^{79}$ & 4- 744 & $3,1,3 \leftarrow 2,1,2$ & Excited & $5 / 2$ & $5 / 2$ & 21271.4 & .2 \\
\hline $\mathrm{C}^{13} \mathrm{H}_{3} \mathrm{C}^{12}: \mathrm{C}^{12} \mathrm{C}^{12} \mathrm{~F}_{3}^{19}$ & 3- 893 & $8, \leftarrow 7$ & Ground & & & 21278.0 & .5 \\
\hline $\mathrm{K}^{39} \mathrm{I}^{127}$ & 1 - & $6 \leftarrow 5$ & Excited & & & 21279.07 & 0.10 \\
\hline $\mathrm{C}_{*}^{\mathrm{b}} \mathrm{H}_{2}^{\mathrm{b}} \mathrm{N}^{\mathrm{b}} \mathrm{H}^{\mathrm{b}} \mathrm{C}^{\mathrm{b}}{ }_{*} \mathrm{H}_{2}^{\mathrm{b}}$ & 4- 863 & Not Reported & & & & 21279.8 & .5 \\
\hline $\mathrm{C}^{12} \mathrm{D}_{2}: \mathrm{C}^{12} \mathrm{HBr}^{\mathrm{b}}$ & 4. 731 & $3, \quad \leftarrow 2$, & Ground & & & 21284.4 & .2 \\
\hline c- $\mathrm{C}^{12} \mathrm{HD}: \mathrm{C}^{12} \mathrm{DBr}^{79}$ & 4- 744 & $3,1,3 \leftarrow 2,1,2$ & Excited & $9 / 2$ & $7 / 2$ & 21285.1 & .1 \\
\hline $\mathrm{N}^{14} \mathrm{H}_{3}$ & $4-1771$ & $5,3 \leftarrow 5,3$ & Ground & & & 21285.27 & .02 \\
\hline $\mathrm{C}^{12} \mathrm{D}_{2}: \mathrm{C}^{12} \mathrm{DBr}^{\mathrm{b}}$ & 4- 732 & $3, \quad \leftarrow 2, \quad$, & Ground & & & 21285.4 & .2 \\
\hline $\mathrm{C}^{12} \mathrm{D}_{2}: \mathrm{C}^{12} \mathrm{HBr}^{\mathrm{b}}$ & 4- 731 & $3, \quad \leftarrow 2, \quad$ & Ground & & & 21285.9 & \\
\hline $\mathrm{C}^{12} \mathrm{H}_{3} \mathrm{C}^{13} \mathrm{H}_{2} \mathrm{Br}^{79}$ & 3. 527 & $3,1,3 \leftarrow 2,1,2$ & Ground & $9 / 2$ & $7 / 2$ & 21289.31 & .05 \\
\hline $\mathrm{HC}^{12} \mathrm{O}^{16} \mathrm{O}^{18} \mathrm{H}$ & 3- 77 & $1,0,1 \leftarrow 0,0,0$ & Ground & & & 21289.64 & .1 \\
\hline $\mathrm{C}^{12} \mathrm{D}_{3} \mathrm{C}^{12} \mathrm{HO}^{16}$ & 3- 474 & $14,2,12 \leftarrow 14,2,13$ & Ground & & & 21292.13 & .3 \\
\hline $\mathrm{S}^{32}{ }_{*} \mathrm{HC}^{12}: \mathrm{C}^{12} \mathrm{DC}^{12} \mathrm{D}: \mathrm{C}^{12}{ }_{*} \mathrm{H}$ & 4-1164 & $3,0,3 \leftarrow 2,0,2$ & Ground & & & 21292.2 & .1 \\
\hline $\mathrm{Cs}^{133} \mathrm{Br}^{79}$ & 1. & $10 \leftarrow 9$ & Excited & & & 21292.40 & 0.20 \\
\hline $\mathrm{c}-\mathrm{C}^{12} \mathrm{HD}: \mathrm{C}^{12} \mathrm{DBr}^{79}$ & 4- 744 & $3,1,3 \leftarrow 2,1,2$ & Ground & $5 / 2$ & $5 / 2$ & 21292.8 & .1 \\
\hline $\mathrm{C}^{12} \mathrm{D}_{3} \mathrm{Si}^{28} \mathrm{DF}_{2}^{19}$ & 3- 199 & $2,1,1 \leftarrow 1,0,1$ & Ground & & & 21292.84 & .1 \\
\hline $\mathrm{C}^{12} \mathrm{H}_{3} \mathrm{C}^{13} \mathrm{H}_{2} \mathrm{Br}^{79}$ & 3- 527 & $3,1,3 \leftarrow 2,1,2$ & Ground & & & 21293.52 & $.05^{\prime}$ \\
\hline $\mathrm{DC}^{12} \mathrm{O}^{16} \mathrm{O}^{16} \mathrm{D}$ & 3- 74 & $1,0,1 \leftarrow 0,0,0$ & Ground & & & 21293.9 & .3 \\
\hline $\mathrm{C}^{12} \mathrm{H}_{3} \mathrm{~N}^{14} \mathrm{H}_{2}$ & 3- 261 & Not Reported & Ground & & & 21297.12 & .04 \\
\hline $\mathrm{C}^{b} \mathrm{H}_{2}^{\mathrm{b}} \mathrm{Cl}^{\mathrm{b}} \mathrm{F}^{\mathrm{b}}$ & 4- 333 & Not Reported & & & & 21298.60 & .1 \\
\hline $\mathrm{C}^{12} \mathrm{D}_{2}: \mathrm{C}^{12} \mathrm{HBr}^{81}$ & 4. 724 & $3,2,2 \leftarrow 2,2,1$ & Ground & $9 / 2$ & $7 / 2$ & 21299.6 & \\
\hline $\mathrm{C}^{12} \mathrm{D}_{2}: \mathrm{C}^{12} \mathrm{HBr}^{81}$ & 4. 724 & $3,2,2 \leftarrow 2,2,1$ & Ground & $7 / 2$ & $7 / 2$ & 21299.6 & \\
\hline $\mathrm{S}^{32}{ }_{*} \mathrm{HC}^{12}: \mathrm{C}^{12} \mathrm{DC}^{12} \mathrm{D}: \mathrm{C}^{12}{ }_{*} \mathrm{H}$ & $4-1164$ & $6,2,5 \leftarrow 6,2,4$ & Ground & & & 21299.7 & .1 \\
\hline $\mathrm{N}^{\mathrm{b}} \mathrm{O}_{2}^{\mathrm{b}} \mathrm{Cl}^{\mathrm{b}}$ & $4-1463$ & Not Reported & & & & 21300. & \\
\hline $\mathrm{C}^{12} \mathrm{D}_{2}: \mathrm{C}^{12} \mathrm{HBr}^{\mathrm{b}}$ & 4- 731 & $3, \quad \leftarrow 2$, & Ground & & & 21300.0 & .05 \\
\hline $\mathrm{HC}^{12} \mathrm{O}^{18} \mathrm{O}^{16} \mathrm{H}$ & 3. 76 & $1,0,1 \leftarrow 0,0,0$ & Ground & & & 21301.67 & .1 \\
\hline $\mathrm{C}^{12}{ }_{*} \mathrm{D}: \mathrm{C}^{12} \mathrm{HC}^{12} \mathrm{H}: \mathrm{C}^{12} \mathrm{HN}^{14}{ }_{*} \mathrm{H}$ & $4-1183$ & $2,0,2 \leftarrow 1,1,1$ & Ground & & & 21302.6 & \\
\hline $\mathrm{C}^{12} \mathrm{D}_{3} \mathrm{C}^{12} \mathrm{HO}^{16}$ & 3. 474 & $14,2,12 \leftarrow 14,2,13$ & Ground & & & 21303.65 & .4 \\
\hline $\mathrm{C}^{12} \mathrm{D}_{2}: \mathrm{C}^{12} \mathrm{HBr}^{81}$ & 4. 724 & $3,2,1 \leftarrow 2,2,0$ & Ground & $9 / 2$ & $7 / 2$ & 21304.8 & \\
\hline $\mathrm{C}^{12} \mathrm{D}_{2}: \mathrm{C}^{12} \mathrm{HBr}^{81}$ & 4. 724 & $3,2,1 \leftarrow 2,2,0$ & Ground & $7 / 2$ & $7 / 2$ & 21304.8 & \\
\hline $\mathrm{C}^{12} \mathrm{D}_{3} \mathrm{Cl}^{37}$ & 4. 425 & $1,0 \leftarrow 0,0$ & Ground & $3 / 2$ & $3 / 2$ & 21305.15 & .08 \\
\hline
\end{tabular}


Vib. State $\mathrm{F}_{1}^{\prime} \stackrel{\text { Hyperfine }}{\mathrm{F}^{\prime}} \underset{\mathrm{F}_{1}}{\mathrm{~F}} \mathrm{~F}$

c- $\mathrm{C}^{12} \mathrm{HD}: \mathrm{C}^{12} \mathrm{DBr}^{79}$

$\left(\mathrm{C}^{12} \mathrm{H}_{3} \mathrm{C}^{12} \mathrm{H}_{2}\right)_{2} \mathrm{O}^{16}$

c- $\mathrm{C}^{12} \mathrm{HD}: \mathrm{C}^{12} \mathrm{DBr}^{79}$

$\mathrm{C}^{12} \mathrm{H}_{3} \mathrm{C}^{13} \mathrm{H}_{2} \mathrm{Br}^{79}$

$\mathrm{C}^{12} \mathrm{D}_{2}: \mathrm{C}^{12} \mathrm{HBr}^{81}$

$\mathrm{C}^{12} \mathrm{D}_{2}: \mathrm{C}^{12} \mathrm{HBr}^{81}$

$\mathrm{C}^{12} \mathrm{HD}: \mathrm{C}^{12} \mathrm{DBr}^{\mathrm{b}}$

c- $\mathrm{C}^{12} \mathrm{HD}: \mathrm{C}^{12} \mathrm{DBr}^{79}$

$\mathrm{Br}^{79} \mathrm{~F}^{19}$

$\mathrm{C}^{12} \mathrm{D}_{3} \mathrm{Cl}^{37}$

$\mathrm{C}^{12} \mathrm{D}_{2}: \mathrm{C}^{12} \mathrm{HBr}^{81}$

$\left(\mathrm{C}^{12} \mathrm{H}_{3}\right)_{2} \mathrm{C}^{12}: \mathrm{C}^{12} \mathrm{HD}$

$\mathrm{C}^{12} \mathrm{H}_{3} \mathrm{C}^{13} \mathrm{H}_{2} \mathrm{Br}^{79}$

$\mathrm{C}^{13} \mathrm{H}_{3}\left(\mathrm{C}^{12} \mathrm{H}_{3}\right)_{2} \mathrm{C}^{12} \mathrm{C}^{12}: \mathrm{C}^{12} \mathrm{H}$

$\mathrm{C}^{12} \mathrm{D}_{2}: \mathrm{C}^{12} \mathrm{DBr}^{\mathrm{b}}$

$\mathrm{C}^{12} \mathrm{H}_{3} \mathrm{C}^{12} \mathrm{~F}^{19}: \mathrm{C}^{12} \mathrm{H}_{2}$

$\left(\mathrm{C}^{12} \mathrm{H}_{3}\right)_{3} \mathrm{Si}^{30} \mathrm{H}$

$\mathrm{HN}^{15} \mathrm{C}^{12} \mathrm{O}^{16}$

$\mathrm{C}^{12} \mathrm{D}_{2}: \mathrm{C}^{12} \mathrm{HBr}^{81}$

$\mathrm{C}^{12} \mathrm{D}_{2}: \mathrm{C}^{12} \mathrm{HBr}^{81}$

$\mathrm{C}^{12} \mathrm{D}_{2}: \mathrm{C}^{12} \mathrm{HBr}^{81}$

$\left(\mathrm{C}^{12} \mathrm{H}_{3}\right)_{3} \mathrm{C}^{12} \mathrm{C}^{13}: \mathrm{C}^{12} \mathrm{H}$

$\mathrm{B}_{2}^{10} \mathrm{~B}_{3}^{11} \mathrm{D}_{9}$

$\mathrm{C}^{12} \mathrm{H}_{2} \mathrm{Cl}^{35} \mathrm{Si}^{28} \mathrm{D}_{3}$

$\mathrm{C}^{12} \mathrm{D}_{3} \mathrm{Cl}^{37}$

$\mathrm{C}^{12} \mathrm{H}_{3} \mathrm{C}^{13} \mathrm{H}_{2} \mathrm{Cl}^{35}$

$\mathrm{C}^{12} \mathrm{D}_{2}: \mathrm{C}^{12} \mathrm{HBr}^{81}$

$\mathrm{C}^{12} \mathrm{D}_{2}: \mathrm{C}^{12} \mathrm{HBr}^{81}$

$\mathrm{C}^{12} \mathrm{D}_{2}: \mathrm{C}^{12} \mathrm{HBr}^{81}$

$\mathrm{C}^{12} \mathrm{D}_{2}: \mathrm{C}^{12} \mathrm{DBr}^{\mathrm{b}}$

$\mathrm{C}^{12} \mathrm{H}_{3} \mathrm{C}^{13} \mathrm{H}_{2} \mathrm{Cl}^{35}$

c- ${ }^{12} \mathrm{HD}: \mathrm{C}^{12} \mathrm{DBr}^{79}$

$\mathrm{Br}^{81} \mathrm{~F}^{19}$

c- $\mathrm{C}^{12} \mathrm{HD}: \mathrm{C}^{12} \mathrm{DBr}^{79}$

$\left(\mathrm{C}^{12} \mathrm{H}_{3}\right)_{2} \mathrm{Si}^{30} \mathrm{H}_{2}$

$\mathrm{C}^{12} \mathrm{D}_{2}: \mathrm{C}^{12} \mathrm{HBr}^{81}$

$\mathrm{C}^{12} \mathrm{D}_{2}: \mathrm{C}^{12} \mathrm{HBr}^{81}$

$\left(\mathrm{C}^{12} \mathrm{H}_{3}\right)_{2} \mathrm{Si}^{30} \mathrm{H}_{2}$

$\left(\mathrm{C}^{12} \mathrm{H}_{3} \mathrm{C}^{12} \mathrm{H}_{2}\right)_{2} \mathrm{O}^{16}$

$\mathrm{C}^{\mathrm{b}}{ }_{*} \mathrm{H}_{2}^{\mathrm{b}} \mathrm{N}^{\mathrm{b}} \mathrm{H}^{\mathrm{b}} \mathrm{C}^{\mathrm{b}}{ }_{*} \mathrm{H}_{2}^{\mathrm{b}}$

$\left(\mathrm{C}^{12} \mathrm{H}_{3}\right)_{2} \mathrm{Si}^{30} \mathrm{H}_{2}$

$\mathrm{C}^{12} \mathrm{H}_{3} \mathrm{C}^{13} \mathrm{H}_{2} \mathrm{Cl}^{35}$

$\mathrm{C}^{12} \mathrm{D}_{2}: \mathrm{C}^{12} \mathrm{HBr}^{\mathrm{b}}$
4- $744 \quad 3,1,3 \leftarrow 2,1,2 \quad$ Ground

3-1011 Not Reported

4- $744 \quad 3,1,3 \leftarrow 2,1,2$

Excited

3. 527

$3,1,3 \leftarrow 2,1,2$

Ground

4- 724

$3,0,3 \leftarrow 2,0,2$

Ground

4- 724

$3,0,3 \leftarrow 2,0,2$

4- 749

Not Reported

4- 744

$3,1,3 \leftarrow 2,1,2$

1 .

$1 \leftarrow 0$

4- 425

$1,0 \leftarrow 0,0$

4- 724

$3,0,3 \leftarrow 2,0,2$

3. 944

$2,0,2 \leftarrow 1,1,1$

3- 527

$3,1,3 \leftarrow 2,1,2$

3-1077

$4,1,3 \leftarrow 3,1,2$

4- 732

$3, \quad, \leftarrow 2, \quad$,

3- 721

$4,2,2 \leftarrow 4,2,3$

3- 875

$2, \leftarrow 1$,

4- 302

$1, \quad \leftarrow 0, \quad$

4- 724

$3,2,2 \leftarrow 2,2,1$

4. 724

$3,2,2 \leftarrow 2,2,1$

4- 724

$3,2,2 \leftarrow 2,2,1$

3-1074

$4, \leftarrow 3$,

4- 63

$2,2,1 \leftarrow 1,1,1$

3- 237

10,1

$, 9 \leftarrow 10,0,10$

4- 425

$1,0 \leftarrow 0,0$

3- 546

$2,1,1 \leftarrow 1,1,0$

4- 724

$3,2,1 \leftarrow 2,2,0$

4- 724

4. 724

$3,2,1 \leftarrow 2,2,0$

4. 732

$3,2,1 \leftarrow 2,2,0$

3- 546

$3, \quad \leftarrow 2$,

4- 744

$2,1,1 \leftarrow 1,1,0$

1 -

$3,1,3 \leftarrow 2,1,2$

$$
1 \leftarrow 0
$$

4- 744

$3,1,3 \leftarrow 2,1,2$

3- 645

$1,1,1 \leftarrow 0,0,0$

4- 724

$3,0,3 \leftarrow 2,0,2$

4- 724

3- 645

$3,0,3 \leftarrow 2,0,2$

3-1011

$1,1,1 \leftarrow 0,0,0$

Not Reported

4- $863 \quad$ Not Reported

3- 645

$1,1,1 \leftarrow 0,0,0$

3. 546

$2,1,1 \leftarrow 1,1,0$

4- 731
Ground

Ground

Excited

Ground

Ground

Ground

Ground

Ground

Ground

Ground

Ground

Ground

Ground

Ground

Ground

Ground

Ground

Ground

Ground

Ground

Ground

Ground

Ground

Ground

Ground

Ground

Ground

Ground

Ground

Ground

Ground

Ground

Ground

Ground
Ground
$7 / 2$

2] 306.5

21310.

$\begin{array}{lllll}7 / 2 & 5 / 2 & 21 & 314.8 & .2\end{array}$

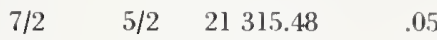

$9 / 2 \quad 7 / 2 \quad 21315.8$

$7 / 2 \quad 5 / 2 \quad 21315.8$

21318.1

21319.36

$3 / 2 \quad 3 / 2 \quad 21319.4$

$5 / 2 \quad 3 / 2 \quad 21319.79$

21319.8

21319.80

$5 / 2 \quad 3 / 2 \quad 21320.07$

21320.8

21321.8

21323.23

21323.35

21323.5

21 326.95

$3 / 2 \quad 3 / 2 \quad 21327.2$

$5 / 2 \quad 3 / 2 \quad 21327.2$

21327.2

21329.

21330.46

$1 / 2 \quad 3 / 2$

21331.51

21331.72

21332.29

$3 / 2 \quad 3 / 2 \quad 21332.5$

$5 / 2 \quad 3 / 2$

21332.5

21333.0

$3 / 2 \quad 3 / 2$

21334.11

$7 / 2 \quad 5 / 2 \quad 21336.2$

$3 / 2 \quad 3 / 2 \quad 21337.5$

$5 / 2 \quad 3 / 2$

21337.9

21 337.99

$5 / 2$

$3 / 2$

$3 / 2$

21339.0

21339.0

21339.18

21340.

21340.

10.

21340.20

$5 / 2$

$5 / 2$

21340.42

21 343.8
.20

.20

1

.05

.2

.05

.08

.3

.05

.1

.2

.20

.06

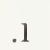

1.0

.2

.07

.2

.05

.1

.20

.05

.1 


\begin{tabular}{|c|c|c|c|c|c|c|c|}
\hline Isotopic Species & $\begin{array}{l}\text { Vol.-Id. } \\
\text { Nos. }\end{array}$ & $\begin{array}{c}\text { Rotational } \\
\text { Quantum Nos. }\end{array}$ & Vib. State & \begin{tabular}{cc}
\multicolumn{2}{c}{ Hyperfine } \\
$\mathrm{F}_{1}^{\prime} \quad \mathrm{F}^{\prime} \quad \mathrm{F}_{1}$
\end{tabular} & $\mathbf{F}$ & $\begin{array}{c}\text { Frequency } \\
\mathrm{MHz}\end{array}$ & $\begin{array}{r}\text { Acc. } \\
\pm \mathrm{MHz}\end{array}$ \\
\hline $\mathrm{C}^{12} \mathrm{H}_{3} \mathrm{C}^{13} \mathrm{H}_{2} \mathrm{Cl}^{35}$ & 3- 546 & $2,1,1 \leftarrow 1,1,0$ & Ground & $7 / 2$ & $5 / 2$ & 21344.00 & .05 \\
\hline $\mathrm{C}^{\mathrm{b}}{ }_{*} \mathrm{H}_{2}^{\mathrm{b}} \mathrm{N}^{\mathrm{b}} \mathrm{H}^{\mathrm{b}} \mathrm{C}^{\mathrm{b}}{ }_{*} \mathrm{H}_{2}^{\mathrm{b}}$ & 4. 863 & Not Reported & & & & 21345. & 10. \\
\hline $\mathrm{C}^{12} \mathrm{D}_{2}: \mathrm{C}^{12} \mathrm{DBr}^{\mathrm{b}}$ & 4- 732 & $3, \quad \leftarrow 2, \quad$, & Ground & & & 21345.8 & .1 \\
\hline $\mathrm{C}^{12} \mathrm{H}_{3} \mathrm{C}^{12}{ }_{*} \mathrm{HO}^{16} \mathrm{C}^{12}{ }_{*} \mathrm{H}_{2}$ & 3- 761 & Not Reported & Ground & & & 21346.97 & .1 \\
\hline $\mathrm{C}^{12} \mathrm{D}_{3} \mathrm{O}^{16} \mathrm{~N}^{14} \mathrm{O}_{2}^{16}$ & 3- 182 & $3,0,3 \leftarrow 2,0,2$ & Ground & & & 21347.74 & .1 \\
\hline $\mathrm{C}^{12} \mathrm{HD}: \mathrm{C}^{12} \mathrm{DBr}^{\mathrm{b}}$ & 4. 749 & Not Reported & & & & 21347.8 & .2 \\
\hline $\mathrm{C}^{12} \mathrm{H}_{3} \mathrm{C}^{13} \mathrm{H}_{2} \mathrm{Cl}^{35}$ & 3- 546 & $2,1,1 \leftarrow 1,1,0$ & Ground & $3 / 2$ & $1 / 2$ & 21349.93 & .05 \\
\hline$\left(\mathrm{C}^{12} \mathrm{H}_{3}\right)_{3} \mathrm{Si}^{29} \mathrm{H}$ & 3- 873 & $2, \leftarrow 1$, & Ground & & & 21351.36 & .20 \\
\hline $\mathrm{C}^{12} \mathrm{H}_{3} \mathrm{C}^{13} \mathrm{H}_{2} \mathrm{Cl}^{35}$ & 3- 546 & $2,1,1 \leftarrow 1,1,0$ & Ground & $1 / 2$ & $1 / 2$ & 21353.66 & .05 \\
\hline $\mathrm{C}^{\mathrm{b}}{ }_{*} \mathrm{H}_{2}^{\mathrm{b}} \mathrm{N}^{\mathrm{b}} \mathrm{H}^{\mathrm{b}} \mathrm{C}^{\mathrm{b}}{ }_{*} \mathrm{H}_{2}^{\mathrm{b}}$ & 4- 863 & Not Reported & & & & 21355. & 10. \\
\hline $\mathrm{C}^{12}{ }_{*} \mathrm{H}: \mathrm{C}^{12} \mathrm{DO}^{16} \mathrm{C}^{12} \mathrm{D}: \mathrm{C}^{12}{ }_{*} \mathrm{H}$ & $4-1156$ & $12,9,3 \leftarrow 12,8,4$ & Ground & & & 21360.1 & \\
\hline $\mathrm{DC}^{12} \mathrm{~N}^{14}$ & 4- 292 & $7 \leftarrow 7$ & Excited & & & 21360.15 & .1 \\
\hline $\mathrm{C}^{12}{ }_{*} \mathrm{H}_{2} \mathrm{~N}^{14} \mathrm{HC}^{12}{ }_{*} \mathrm{H}_{2}$ & 4. 861 & $4,3,1 \leftarrow 4,2,2$ & Ground & & & 21360.6 & \\
\hline $\mathrm{N}^{14} \mathrm{O}^{16} \mathrm{Cl}^{37}$ & $4-1452$ & $2,1,2 \leftarrow 1,1,1$ & Ground & $5 / 2$ & $3 / 2$ & 21362.64 & .30 \\
\hline $\mathrm{C}^{12} \mathrm{D}_{2}: \mathrm{C}^{12} \mathrm{DBr}^{81}$ & 4- 726 & $3,1,2 \leftarrow 2,1,1$ & Ground & $3 / 2$ & $3 / 2$ & 21362.8 & \\
\hline $\mathrm{N}^{14} \mathrm{O}^{16} \mathrm{Cl}^{37}$ & $4-1452$ & $2,1,2 \leftarrow 1,1,1$ & Ground & $3 / 2$ & $3 / 2$ & 21364.7 & .6 \\
\hline $\mathrm{C}^{13} \mathrm{H}_{3} \mathrm{Si}^{28} \mathrm{HF}_{2}^{19}-\mathrm{E}$ & 3- 196 & $2,1,1 \leftarrow 1,1,0$ & Ground & & & 21365.37 & \\
\hline $\mathrm{C}^{13} \mathrm{H}_{3} \mathrm{Si}^{28} \mathrm{HF}_{2}^{19}-\mathrm{A}$ & 3- 195 & $2,1,1 \leftarrow 1,1,0$ & Ground & & & 21365.37 & \\
\hline $\mathrm{C}^{13}{ }_{*} \mathrm{H}: \mathrm{C}^{12} \mathrm{HO}^{16} \mathrm{C}^{12} \mathrm{H} \mathrm{C}^{12}{ }_{*} \mathrm{H}^{-}$ & $4-1157$ & $7,5,2 \leftarrow 7,5,3$ & Ground & & & 21366.1 & .1 \\
\hline $\mathrm{Cs}^{133} \mathrm{Br}^{79}$ & $1-$ & $10 \leftarrow 9$ & Excited & & & 21366.36 & 0.20 \\
\hline $\mathrm{N}^{14} \mathrm{O}^{16} \mathrm{Cl}^{37}$ & $4-1452$ & $2,1,2 \leftarrow 1,1,1$ & Ground & $5 / 2$ & $5 / 2$ & 21367.47 & .20 \\
\hline $\mathrm{C}^{12}{ }_{*} \mathrm{H}: \mathrm{C}^{12} \mathrm{HC}^{12} \mathrm{H}: \mathrm{C}^{12} \mathrm{HN}^{14}{ }_{*} \mathrm{H}$ & $4-1181$ & $11,9,2 \leftarrow 11,9,3$ & Ground & & & 21368.2 & \\
\hline $\mathrm{C}^{12} \mathrm{D}_{2} \mathrm{Cl}^{35} \mathrm{Cl}^{37}$ & 4- 347 & $3,1,2 \leftarrow 3,0,3$ & Ground & & & 21370. & 5. \\
\hline $\mathrm{C}^{12} \mathrm{H}_{2}\left(\mathrm{C}^{12} \mathrm{~N}^{14}\right)_{2}$ & 4- 901 & Not Reported & Ground & & & 21371.5 & .1 \\
\hline $\mathrm{N}^{14} \mathrm{O}^{16} \mathrm{Cl}^{37}$ & $4-1452$ & $2,1,2 \leftarrow 1,1,1$ & Ground & $7 / 2$ & $5 / 2$ & 21371.53 & .15 \\
\hline $\mathrm{K}^{39} \mathrm{I}^{127}$ & 1 - & $6 \leftarrow 5$ & Excited & & & 21373.63 & 0.10 \\
\hline c- $-\mathrm{C}^{12} \mathrm{H}_{3} \mathrm{C}^{12} \mathrm{H}: \mathrm{C}^{12} \mathrm{HF}^{19}-\mathrm{E}$ & 3- 702 & $2,1,1 \leftarrow 1,1,0$ & & & & 21373.90 & .2 \\
\hline $\mathrm{C}^{12} \mathrm{H}_{3} \mathrm{C}^{12} \mathrm{H}_{2} \mathrm{Cl}^{35}$ & 3- 541 . & $2,1,1 \leftarrow 1,1,0$ & Ground & $5 / 2$ & $3 / 2$ & 21376.08 & .1 \\
\hline $\mathrm{C}^{12}{ }_{*} \mathrm{H}: \mathrm{C}^{12} \mathrm{HO}^{16} \mathrm{C}^{12} \mathrm{H}: \mathrm{C}^{12}{ }_{*} \mathrm{H}$ & $4-1151$ & $10,8,2 \leftarrow 10,8,3$ & Ground & & & 21377.91 & \\
\hline $\mathrm{C}^{12} \mathrm{H}_{3} \mathrm{C}^{12} \mathrm{H}_{2} \mathrm{Cl}^{35}$ & 3. 541 & $2,1,1 \leftarrow 1,1,0$ & Ground & $3 / 2$ & $3 / 2$ & 21378.65 & .1 \\
\hline c- $\mathrm{C}^{12} \mathrm{H}_{3} \mathrm{C}^{12} \mathrm{H}: \mathrm{C}^{12} \mathrm{HF}^{19}{ }_{-\mathrm{A}}$ & 3. 701 & $2,1,1 \leftarrow 1,1,0$ & & & & 21378.87 & .2 \\
\hline $\mathrm{C}^{13} \mathrm{H}_{3} \mathrm{C}^{12} \mathrm{H}_{3} \mathrm{Si}^{28} \mathrm{H}_{2}$ & 3. 646 & $1,1,1 \leftarrow 0,0,0$ & Ground & & & 21379.40 & .20 \\
\hline $\mathrm{C}^{\mathrm{b}}{ }_{*} \mathrm{H}_{2}^{\mathrm{b}} \mathrm{N}^{\mathrm{b}} \mathrm{H}^{\mathrm{b}} \mathrm{C}^{\mathrm{b}}{ }_{*} \mathrm{H}_{2}^{\mathrm{b}}$ & 4. 863 & Not Reported & & & & 21380. & 10. \\
\hline$\left(\mathrm{C}^{12} \mathrm{H}_{3}\right)_{3} \mathrm{Si}^{28} \mathrm{H}$ & 3- 871 & $2, \leftarrow 1$, & Ground & & & 21380.58 & .10 \\
\hline $\mathrm{C}^{13} \mathrm{H}_{3} \mathrm{C}^{12} \mathrm{H}_{3} \mathrm{Si}^{28} \mathrm{H}_{2}$ & 3. 646 & $1,1,1 \leftarrow 0,0,0$ & Ground & & & 21380.70 & .20 \\
\hline $\mathrm{C}^{13} \mathrm{H}_{3} \mathrm{C}^{12} \mathrm{H}_{3} \mathrm{Si}^{28} \mathrm{H}_{2}$ & 3- 646 & $1,1,1 \leftarrow 0,0,0$ & Ground & & & 21382.00 & .20 \\
\hline $\mathrm{C}^{12} \mathrm{H}_{3} \mathrm{C}^{12} \mathrm{H}_{2} \mathrm{Cl}^{35}$ & 3. 541 & $2,1,1 \leftarrow 1,1,0$ & Ground & $5 / 2$ & $5 / 2$ & 21385.02 & .1 \\
\hline $\mathrm{C}^{12}{ }_{*} \mathrm{H}_{2} \mathrm{~N}^{14} \mathrm{DC}^{12}{ }_{*} \mathrm{H}_{2}$ & 4- 862 & $9,8,1 \leftarrow 9,8,2$ & Ground & & & 21385.1 & .5 \\
\hline $\mathrm{C}^{12} \mathrm{H}_{3} \mathrm{C}^{12} \mathrm{H}_{2} \mathrm{Cl}^{35}$ & 3- 541 & $2,1,1 \leftarrow 1,1,0$ & Ground & $7 / 2$ & $5 / 2$ & 21388.49 & .1 \\
\hline $\mathrm{C}_{6}^{12} \mathrm{H}_{5} \mathrm{~F}^{19}$ & $4-1281$ & $5,2,4 \leftarrow 4,2,3$ & Ground & & & 21389.2 & .1 \\
\hline 4d- $\mathrm{C}_{6}^{12} \mathrm{H}_{5} \mathrm{~F}^{19}$ & $4-1283$ & $5,3,2 \leftarrow 4,3,1$ & Ground & & & 21391.0 & .1 \\
\hline $\mathrm{N}^{14} \mathrm{H}_{3}$ & $4-1771$ & $12,10 \leftarrow 12,10$ & Ground & & & 21391.55 & .05 \\
\hline $\mathrm{C}^{12}{ }_{*} \mathrm{HN}^{14} \mathrm{C}^{12} \mathrm{HC}^{12} \mathrm{H}: \mathrm{C}^{12} \mathrm{HN}^{14}{ }_{*}$ & $4-1141$ & $8,5,3 \leftarrow 8,4,4$ & Ground & & & 21391.6 & \\
\hline $\mathrm{C}^{12} \mathrm{H}_{3} \mathrm{C}^{12} \mathrm{H}_{2} \mathrm{Cl}^{35}$ & 3- 541 & $2,1,1 \leftarrow 1,1,0$ & Ground & $3 / 2$ & $1 / 2$ & 21394.83 & .1 \\
\hline $\mathrm{C}^{12} \mathrm{D}_{2}: \mathrm{C}^{12} \mathrm{HBr}^{81}$ & 4- 724 & $3,2,2 \leftarrow 2,2,1$ & Ground & $7 / 2$ & $5 / 2$ & 21395.1 & \\
\hline
\end{tabular}




\begin{tabular}{|c|c|c|c|c|c|c|c|}
\hline \multirow{2}{*}{ Isotopic Species } & \multirow{2}{*}{$\begin{array}{l}\text { Vol.-Id. } \\
\text { Nos. }\end{array}$} & \multirow{2}{*}{$\begin{array}{c}\text { Rotational } \\
\text { Quantum Nos. }\end{array}$} & \multirow{2}{*}{ Vib. State } & \multicolumn{2}{|c|}{ Hyperfine } & \multirow{2}{*}{$\begin{array}{l}\text { Frequency } \\
\qquad \mathrm{MHz}_{2}\end{array}$} & \multirow{2}{*}{$\begin{aligned} & \text { Acc. } \\
\pm & \mathrm{MHz}\end{aligned}$} \\
\hline & & & & $\begin{array}{lll}F_{1}^{\prime} & F^{\prime} & F_{1}\end{array}$ & $\mathbf{F}$ & & \\
\hline $\mathrm{C}^{12} \mathrm{D}_{2}: \mathrm{C}^{12} \mathrm{HBr}^{81}$ & 4- 724 & $3,2,2 \leftarrow 2,2,1$ & Ground & $5 / 2$ & $5 / 2$ & 21395.1 & \\
\hline $\mathrm{C}^{12} \mathrm{D}_{2}: \mathrm{C}^{12} \mathrm{DBr}^{81}$ & 4. 726 & $3,1,2 \leftarrow 2,1,1$ & Excited & $3 / 2$ & $1 / 2$ & 21395.6 & \\
\hline $\mathrm{C}^{12} \mathrm{D}_{2}: \mathrm{C}^{12} \mathrm{DBr}^{81}$ & 4- 726 & $3,1,2 \leftarrow 2,1,1$ & Excited & $9 / 2$ & $7 / 2$ & 21395.6 & \\
\hline $\mathrm{C}^{12} \mathrm{H}_{3} \mathrm{C}^{12} \mathrm{H}_{2} \mathrm{Cl}^{35}$ & 3- 541 & $2,1,1 \leftarrow 1,1,0$ & Ground & $1 / 2$ & $1 / 2$ & 21398.18 & .1 \\
\hline $\mathrm{C}^{12} \mathrm{H}_{3} \mathrm{C}^{12} \mathrm{HF}_{2}^{19}$ & 3- 461 & $6,5,2 \leftarrow 6,3,3$ & Ground & & & 21399.2 & .1 \\
\hline $\mathrm{C}^{12}{ }_{*} \mathrm{HC}^{12} \mathrm{H}: \mathrm{C}^{12} \mathrm{HC}^{12} \mathrm{H}: \mathrm{C}^{12} \mathrm{HN}^{14}{ }_{*}$ & 4-1201 & $7,2,5 \leftarrow 6,4,2$ & Ground & & & 21399.5 & \\
\hline $\operatorname{Re}^{b} \mathrm{O}_{3}^{16} \mathrm{~F}^{19}$ & 4-1594 & $3, \leftarrow 2$, & Ground & & & 21400 . & 50. \\
\hline $\mathrm{C}^{b}{ }_{*} \mathrm{H}_{2}^{\mathrm{b}} \mathrm{N}^{\mathrm{b}} \mathrm{H}^{\mathrm{b}} \mathrm{C}^{\mathrm{b}}{ }_{*} \mathrm{H}_{2}^{\mathrm{b}}$ & 4- 863 & Not Reported & & & & 21400 . & 10. \\
\hline$c-C^{12} \mathrm{HD}: \mathrm{C}^{12} \mathrm{DBr}^{79}$ & 4. 744 & $3,1,3 \leftarrow 2,1,2$ & Ground & $7 / 2$ & $7 / 2$ & 21400.0 & .2 \\
\hline$\left(\mathrm{C}^{12} \mathrm{H}_{3}\right)_{3} \mathrm{C}^{12} \mathrm{C}^{12}: \mathrm{C}^{12} \mathrm{Cl}^{35}$ & 3-1061 & $12, \leftarrow 11$, & Ground & & & 21400.5 & .5 \\
\hline $\mathrm{C}^{12} \mathrm{H}_{2}\left(\mathrm{C}^{12} \mathrm{~N}^{14}\right)_{2}$ & 4- 901 & Not Reported & Ground & & & 21400.6 & .1 \\
\hline $\mathrm{C}^{12} \mathrm{D}_{2}: \mathrm{C}^{12} \mathrm{DBr}^{81}$ & 4- 726 & $3,1,2 \leftarrow 2,1,1$ & Ground & $5 / 2$ & $5 / 2$ & 21400.7 & \\
\hline $\mathrm{S}^{32} \mathrm{~F}_{5}^{19} \mathrm{Cl}$ & 4-1422 & $6, \leftarrow 5$, & Ground & & & 21401. & .5 \\
\hline $\mathrm{C}^{12} \mathrm{D}_{2}: \mathrm{C}^{12} \mathrm{HBr}^{81}$ & 4- 724 & $3,2,1 \leftarrow 2,2,0$ & Ground & $5 / 2$ & $5 / 2$ & 21401.1 & \\
\hline $\mathrm{C}^{12} \mathrm{D}_{2}: \mathrm{C}^{12} \mathrm{HBr}^{81}$ & 4. 724 & $3,2,1 \leftarrow 2,2,0$ & Ground & $7 / 2$ & $5 / 2$ & 21401.1 & \\
\hline $\mathrm{C}^{13} \mathrm{H}_{3} \mathrm{C}^{12} \mathrm{O}^{16} \mathrm{~F}^{19}$ & 3- 393 & $8,5,3 \leftarrow 8,5,4$ & Ground & & & 21405.82 & .2 \\
\hline $\mathrm{C}^{12} \mathrm{D}_{2}: \mathrm{C}^{12} \mathrm{DBr}^{81}$ & 4- 726 & $3,1,2 \leftarrow 2,1,1$ & Ground & $9 / 2$ & $7 / 2$ & 21408.5 & \\
\hline $\mathrm{C}^{12} \mathrm{D}: \mathrm{C}^{12} \mathrm{DBr}^{81}$ & 4- 726 & $3,1,2 \leftarrow 2,1,1$ & Ground & $3 / 2$ & $1 / 2$ & 21408.5 & \\
\hline $\mathrm{C}^{12} \mathrm{H}_{3} \mathrm{Si}^{28} \mathrm{DF}_{2}^{19} \cdot \mathrm{E}$ & 3- 198 & $2,1,1 \leftarrow 1,1,0$ & Ground & & & 21409.56 & \\
\hline $\mathrm{C}^{12} \mathrm{H}_{3} \mathrm{Si}^{28} \mathrm{DF}_{2}^{19} \cdot \mathrm{A}$ & 3- 197 & $2,1,1 \leftarrow 1,1,0$ & Ground & & & 21409.56 & \\
\hline $\mathrm{C}^{12}{ }_{*} \mathrm{H}_{2}^{\mathrm{b}} \mathrm{S}^{\mathrm{b}} \mathrm{C}^{12}{ }_{*} \mathrm{H}_{2}^{\mathrm{b}}$ & 4- 854 & Not Reported & & & & 21411.4 & .2 \\
\hline$\left(\mathrm{C}^{12} \mathrm{H}_{3}\right)_{3} \mathrm{C}^{12} \mathrm{C}^{12} \mathrm{~N}^{15}$ & $3-1022$ & $4,3 \leftarrow 3,3$ & Ground & & & 21414.8 & .2 \\
\hline$\left(\mathrm{C}^{12} \mathrm{H}_{3}\right)_{3} \mathrm{C}^{12} \mathrm{C}^{12} \mathrm{~N}^{15}$ & 3-1022 & $4,1 \leftarrow 3,1$ & Ground & & & 21414.8 & .2 \\
\hline$\left(\mathrm{C}^{12} \mathrm{H}_{3}\right)_{3} \mathrm{C}^{12} \mathrm{C}^{12} \mathrm{~N}^{15}$ & $3-1022$ & $4,2 \leftarrow 3,2$ & Ground & & & 21414.8 & .2 \\
\hline $\mathrm{C}^{12}{ }_{*} \mathrm{H}: \mathrm{C}^{12} \mathrm{HC}^{12} \mathrm{H}: \mathrm{C}^{12} \mathrm{HN}^{14}{ }_{*} \mathrm{D}$ & 4-1182 & $2,1,2 \leftarrow 1,1,1$ & Ground & & & 21416.3 & \\
\hline $\mathrm{C}^{12} \mathrm{D}_{2}: \mathrm{C}^{12} \mathrm{DBr}^{81}$ & 4- 726 & $3,1,2 \leftarrow 2,1,1$ & Excited & $7 / 2$ & $5 / 2$ & 21419.7 & \\
\hline $\mathrm{C}^{12} \mathrm{D}_{2}: \mathrm{C}^{12} \mathrm{DBr}^{81}$ & 4. 726 & $3,1,2 \leftarrow 2,1,1$ & Excited & $5 / 2$ & $3 / 2$ & 21419.7 & \\
\hline $\mathrm{C}^{12} \mathrm{D}_{2}: \mathrm{C}^{12} \mathrm{DBr}^{81}$ & 4. 726 & $3,1,2 \leftarrow 2,1,1$ & Ground & & & 21420.24 & .05 \\
\hline $\mathrm{C}^{12} \mathrm{D}_{2}: \mathrm{C}^{12} \mathrm{HBr}^{79}$ & 4. 723 & $3,2,2 \leftarrow 2,2,1$ & Ground & $9 / 2$ & $7 / 2$ & 21420.3 & \\
\hline $\mathrm{C}^{12} \mathrm{D}_{2}: \mathrm{C}^{12} \mathrm{HBr}^{79}$ & 4- 723 & $3,2,2 \leftarrow 2,2,1$ & Ground & $7 / 2$ & $7 / 2$ & 21420.3 & \\
\hline $\mathrm{C}^{12} \mathrm{H}_{2} \mathrm{~F}_{2}^{19}$ & 4- 351 & Not Reported & Ground & & & 21423.20 & .10 \\
\hline $\mathrm{C}^{12} \mathrm{H}_{3} \mathrm{C}^{12} \mathrm{H}_{2} \mathrm{Br}^{81}$ & 3- 522 & $3,1,3 \leftarrow 2,1,2$ & Ground & $9 / 2$ & $7 / 2$ & 21424.66 & .05 \\
\hline $\mathrm{F}_{2}^{19} \mathrm{O}_{2}^{16}$ & 3- 11 & $5,1,4 \leftarrow 5,0,5$. & Ground & & & 21424.8 & .5 \\
\hline $\mathrm{C}^{12} \mathrm{D}_{2} \mathrm{Cl}_{2}^{35}$ & 4. 346 & $3,1,2 \leftarrow 3,0,3$ & Ground & & & 21425 . & 5. \\
\hline $\mathrm{C}^{12} \mathrm{D}_{2}: \mathrm{C}^{12} \mathrm{HBr}^{79}$ & 4- 723 & $3,2,1 \leftarrow 2,2,0$ & Ground & $9 / 2$ & $7 / 2$ & 21425.0 & \\
\hline $\mathrm{C}^{12} \mathrm{D}_{2}: \mathrm{C}^{12} \mathrm{HBr}^{79}$ & 4. 723 & $3,2,1 \leftarrow 2,2,0$ & Ground & $7 / 2$ & $7 / 2$ & 21425.0 & \\
\hline $\mathrm{As}^{75} \mathrm{Cl}_{3}^{35}$ & 4- 11 & $5, \leftarrow 4$ & Excited & & & 21426. & 10. \\
\hline $\mathrm{s} \cdot \mathrm{HC} \mathrm{C}^{12} \mathrm{O}^{16} \mathrm{O}^{16} \mathrm{C}^{12} \mathrm{H}_{2} \mathrm{D}-\mathrm{A}$ & 3- 505 & $2,1,2 \leftarrow 1,1,1$ & Ground & & & 21427.79 & .2 \\
\hline $\mathrm{C}^{12}{ }_{*} \mathrm{H}: \mathrm{C}^{12} \mathrm{HC}^{12} \mathrm{H}: \mathrm{C}^{12} \mathrm{HN}^{14}{ }_{*} \mathrm{D}$ & 4. 1182 & $3,1,2 \leftarrow 3,1,3$ & Ground & & & 21427.8 & \\
\hline $\mathrm{H}_{2}^{\mathrm{b}} \mathrm{C}^{\mathrm{b}}: \mathrm{C}^{\mathrm{b}} \mathrm{H}^{\mathrm{b}} \mathrm{Cl}^{\mathrm{b}}$ & 4- 772 & Not Reported & Ground & & & 21428 . & \\
\hline $\mathrm{C}^{12} \mathrm{H}_{3} \mathrm{C}^{12} \mathrm{H}_{2} \mathrm{Br}^{81}$ & 3- 522 & $3,1,3 \leftarrow 2,1,2$ & Ground & $3 / 2$ & $1 / 2$ & 21428.29 & .05 \\
\hline $\mathrm{H}_{2} \mathrm{C}^{12}: \mathrm{C}^{12} \mathrm{Cl}_{2}^{\mathrm{b}}$ & 4. 663 & Not Reported & Ground & & & 21428.5 & 1. \\
\hline $\mathrm{C}^{12}{ }_{*} \mathrm{H}_{2} \mathrm{C}^{12} \mathrm{D}: \mathrm{C}^{12}{ }_{*} \mathrm{D}$ & 4-1033 & $3,2,1 \leftarrow 3,2,2$ & Ground & & & 21429.0 & \\
\hline $\mathrm{C}^{12} \mathrm{H}_{2} \mathrm{Cl}^{35} \mathrm{~F}^{19}$ & 4- 331 & $22,1,22 \leftarrow 21,2,19$ & Ground & & & 21429.80 & .1 \\
\hline $\mathrm{C}^{12} \mathrm{H}_{2}\left(\mathrm{C}^{12} \mathrm{~N}^{14}\right)_{2}$ & 4. 901 & Not Reported & Ground & & & 21431.9 & .1 \\
\hline
\end{tabular}




\begin{tabular}{|c|c|c|c|c|c|c|c|}
\hline \multirow{2}{*}{ Isotopic Species } & \multirow{2}{*}{$\begin{array}{l}\text { Vol.-Id. } \\
\text { Nos. }\end{array}$} & \multirow{2}{*}{$\begin{array}{c}\text { Rotational } \\
\text { Quantum Nos. }\end{array}$} & \multirow{2}{*}{ Vib. State } & \multicolumn{2}{|l|}{ Hyperfine } & \multirow{2}{*}{$\begin{array}{c}\text { Frequency } \\
\mathrm{NHz}\end{array}$} & \multirow{2}{*}{$\begin{aligned} & \text { Acc. } \\
& \pm \mathrm{MHz}\end{aligned}$} \\
\hline & & & & $\begin{array}{lll}\mathrm{F}_{1}^{\prime} & \mathrm{F}^{\prime} & \mathrm{F}_{1}\end{array}$ & $\mathrm{~F}$ & & \\
\hline $\mathrm{C}^{12} \mathrm{D}_{2}: \mathrm{C}^{12} \mathrm{DBr}^{81}$ & 4. 726 & $3,1,2 \leftarrow 2,1,1$ & Ground & $7 / 2$ & $5 / 2$ & 21432.6 & \\
\hline $\mathrm{C}^{12} \mathrm{D}_{2}: \mathrm{C}^{12} \mathrm{DBr}^{81}$ & 4. 726 & $3,1,2 \leftarrow 2,1,1$ & Ground & $5 / 2$ & $3 / 2$ & 21432.6 & \\
\hline $\mathrm{C}^{12} \mathrm{H}_{3} \mathrm{C}^{12} \mathrm{H}_{2} \mathrm{Cl}^{35}$ & 3- 541 & $2,1,1 \leftarrow 1,1,0$ & Ground & $5 / 2$ & $3 / 2$ & 21433.79 & .05 \\
\hline $\mathrm{HC}^{13} \vdots \mathrm{C}^{12} \mathrm{C}^{12} \mathrm{DO}^{16}$ & 4. 922 & Not Reported & & & & 21434. & 5. \\
\hline $\mathrm{C}^{12} \mathrm{H}_{3} \mathrm{C}^{12} \mathrm{H}_{2} \mathrm{Br}^{81}$ & 3- 522 & $3,1,3 \leftarrow 2,1,2$ & Ground & & & 21434.1 & \\
\hline $\mathrm{C}^{\mathrm{b}}{ }_{*} \mathrm{H}_{2}^{\mathrm{b}} \mathrm{N}^{\mathrm{b}} \mathrm{H}^{\mathrm{b}} \mathrm{C}^{\mathrm{b}}{ }_{*} \mathrm{H}_{2}^{\mathrm{b}}$ & 4. 863 & Dot Reported & & & & 21435 . & 10. \\
\hline $\mathrm{C}^{12} \mathrm{H}_{3} \mathrm{C}^{12} \mathrm{H}_{2} \mathrm{Cl}^{35}$ & 3- 541 & $2,1,1 \leftarrow 1,1,0$ & Ground & $3 / 2$ & $3 / 2$ & 21436.27 & .05 \\
\hline $\mathrm{C}^{12} \mathrm{D}_{2}: \mathrm{C}^{12} \mathrm{DBr}^{\mathrm{b}}$ & 4- 732 & $3, \quad \leftarrow 2, \quad$, & Ground & & & 21437.0 & .1 \\
\hline $\mathrm{C}^{12} \mathrm{H}_{2} \mathrm{Cl}^{35} \mathrm{~F}^{19}$ & 4- 331 & $22,1,22 \leftarrow 21,2,19$ & Ground & & & 21437.05 & .1 \\
\hline $\mathrm{Cs}^{133} \mathrm{Br}^{79}$ & $1-$ & $10 \leftarrow 9$ & Excited & & & 21440.65 & 0.20 \\
\hline $\mathrm{C}^{12} \mathrm{D}_{2}: \mathrm{C}^{12} \mathrm{HBr}^{79}$ & 4- 723 & $3,0,3 \leftarrow 2,0,2$ & Ground & $7 / 2$ & $5 / 2$ & 21440.9 & \\
\hline $\mathrm{C}^{12} \mathrm{D}_{2}: \mathrm{C}^{12} \mathrm{HBr}^{79}$ & 4. 723 & $3,0,3 \leftarrow 2,0,2$ & Ground & $9 / 2$ & $7 / 2$ & 21440.9 & \\
\hline $2,4,6 \mathrm{~d}_{3}-\mathrm{C}_{6}^{12} \mathrm{H}_{5} \mathrm{~F}^{19}$ & 4.1284 & $6,1,6 \leftarrow 5,1,5$ & Ground & & & 21441.2 & .1 \\
\hline $\mathrm{C}^{12} \mathrm{H}_{3} \mathrm{C}^{12}{ }_{*} \mathrm{H}_{2} \mathrm{O}^{16} \mathrm{C}^{12} * \mathrm{C}^{12} \mathrm{H}_{3}$ & 3- 951 & $2,1,1 \leftarrow 1,0,1$ & Ground & & & 21441.30 & .2 \\
\hline $\mathrm{C}^{12} \mathrm{H}_{3} \mathrm{C}^{12} \mathrm{H}_{2} \mathrm{Cl}^{35}$ & 3- 541 & $2,1,1 \leftarrow 1,1,0$ & Ground & $5 / 2$ & $5 / 2$ & 21442.73 & .05 \\
\hline $\mathrm{C}^{12} \mathrm{H}_{2}\left(\mathrm{C}^{12} \mathrm{~N}^{14}\right)\left(\mathrm{C}^{12} \mathrm{~N}^{15}\right)$ & 4- 904 & $6,1,5 \leftarrow 6,0,6$ & Ground & & & 21443.07 & \\
\hline $\mathrm{C}^{12} \mathrm{H}_{3} \mathrm{C}^{12} \mathrm{H}_{2} \mathrm{Cl}^{35}$ & $3-541$ & $2,1,1 \leftarrow 1,1,0$ & Ground & & & 21443.38 & .05 \\
\hline $\mathrm{C}^{12}{ }_{*} \mathrm{D}: \mathrm{C}^{12} \mathrm{HC}^{12} \mathrm{H}: \mathrm{C}^{12} \mathrm{HN}^{14}{ }_{*} \mathrm{H}$ & 4-1183 & $3,1,2 \leftarrow 3,0,3$ & Ground & & & 21444.6 & \\
\hline $\mathrm{C}^{12} \mathrm{H}_{3} \mathrm{C}^{12} \mathrm{HDC}^{12} \mathrm{H}_{3}$ & 3. 784 & $3,1,2 \leftarrow 3,0,3$ & Ground & & & 21445.48 & .06 \\
\hline $\mathrm{C}^{12}{ }_{*} \mathrm{HO}^{16} \mathrm{C}^{12} \mathrm{HC}^{12} \mathrm{H}_{2} \mathrm{C}^{12} \mathrm{H}_{2} \mathrm{C}^{12}{ }_{*} \mathrm{H}_{2}$ & 4.1251 & $3,0,3 \leftarrow 2,0,2$ & Ground & & & 21446. & 5. \\
\hline$\left(\mathrm{C}^{12} \mathrm{H}_{3}\right)_{3} \mathrm{C}^{12} \mathrm{C}^{12}: \mathrm{C}^{12} \mathrm{H}$ & $3-1071$ & $4,1 \leftarrow 3,1$ & Ground & & & 21446.0 & .1 \\
\hline $\mathrm{C}^{12} \mathrm{D}_{2}: \mathrm{C}^{12} \mathrm{HBr}^{79}$ & 4- 723 & $3,0,3 \leftarrow 2,0,2$ & Ground & & & 21446.15 & .2 \\
\hline $\mathrm{C}^{12} \mathrm{H}_{3} \mathrm{C}^{12} \mathrm{H}_{2} \mathrm{Cl}^{35}$ & 3- 541 & $2,1,1 \leftarrow 1,1,0$ & Ground & $7 / 2$ & $5 / 2$ & 21446.21 & .05 \\
\hline $\mathrm{C}^{12} \mathrm{H}_{3} \mathrm{C}^{12} \mathrm{H}_{2} \mathrm{Br}^{81}$ & 3. 522 & $3,1,3 \leftarrow 2,1,2$ & Ground & $7 / 2$ & $5 / 2$ & 21446.41 & .05 \\
\hline $\left.\mathrm{c}-\mathrm{DHC}^{12}: \mathrm{C}^{12} \mathrm{DCl}\right]^{35}$ & 4- 762 & $2,1,1 \leftarrow 1,1,0$ & Ground & & & 21446.65 & \\
\hline$\left(\mathrm{C}^{12} \mathrm{H}_{3}\right)_{2} \mathrm{C}^{12}: \mathrm{C}^{12} \mathrm{H}_{2}$ & 3- 941 & $12,10,2 \leftarrow 12,9,3$ & Ground & & & 21449.36 & .05 \\
\hline$\left(\mathrm{C}^{12} \mathrm{H}_{3} \mathrm{C}^{12} \mathrm{H}_{2}\right)_{2} \mathrm{O}^{16}$ & 3-1011 & Not Reported & & & & 21450 & \\
\hline $\mathrm{C}^{12} \mathrm{HCl}^{35}: \mathrm{C}^{12} \mathrm{~F}_{2}^{19}$ & 4- 611 & $13,2,11 \leftarrow 12,3,10$ & Ground & & & 21450. & .1 \\
\hline$\left(\mathrm{C}^{12} \mathrm{H}_{3}\right)_{2} \mathrm{C}^{12}: \mathrm{C}^{12} \mathrm{H}_{2}$ & 3- 941 & $12,10,2 \leftarrow 12,9,3$ & Ground & & & 21450.11 & \\
\hline$\left(\mathrm{C}^{12} \mathrm{H}_{3}\right)_{2} \mathrm{C}^{12}: \mathrm{C}^{12} \mathrm{H}_{2}$ & 3. 941 & $12,10,2 \leftarrow 12,9,3$ & Ground & & & 21450.14 & \\
\hline $\mathrm{C}^{12} \mathrm{H} \mathrm{C}^{12} \mathrm{H} \mathrm{Br}^{81}$ & 3- 522 & $3,1,3 \leftarrow 2,1,2$ & Ground & $5 / 2$ & $3 / 2$ & 21450.32 & .05 \\
\hline $\mathrm{C}^{12} \mathrm{H}_{3} \mathrm{C}^{12} \mathrm{O}^{16} \mathrm{Br}^{79}$ & 3- 351 & $5,0,5 \leftarrow 4,1,4$ & Ground & $7 / 2$ & $5 / 2$ & 21450.87 & .15 \\
\hline $\mathrm{C}^{12} \mathrm{H}_{3} \mathrm{C}^{12} \mathrm{O}^{16} \mathrm{Br}^{79}$ & 3- 351 & $5,0,5 \leftarrow 4,1,4$ & Ground & $13 / 2$ & $11 / 2$ & 21450.87 & .15 \\
\hline $\mathrm{C}^{12} \mathrm{D}_{2}: \mathrm{C}^{12} \mathrm{DBr}^{\mathrm{b}}$ & 4- 732 & $3, \quad \leftarrow 2, \quad$, & Ground & & & 21450.9 & .1 \\
\hline $\mathrm{C}^{12} \mathrm{H}_{3} \mathrm{C}^{12} \mathrm{H}_{2} \mathrm{Cl}^{35}$ & 3- 541 & $2,1,1 \leftarrow 1,1,0$ & Ground & $3 / 2$ & $1 / 2$ & 21452.27 & .05 \\
\hline $\mathrm{C}^{12} \mathrm{D}_{2}: \mathrm{C}^{12} \mathrm{HBr}^{79}$ & 4- 723 & $3,2,2 \leftarrow 2,2,1$ & Ground & & & 21453.22 & .06 \\
\hline$\left(\mathrm{C}^{12} \mathrm{H}_{3}\right)_{3} \mathrm{C}^{12} \mathrm{C}^{12} \vdots \mathrm{C}^{12} \mathrm{H}$ & $3-1071$ & $4, \leftarrow 3$, & Ground & & & 21453.5 & .1 \\
\hline $\mathrm{C}^{12} \mathrm{D}_{2}: \mathrm{C}^{12} \mathrm{HBr}^{79}$ & 4- 723 & $3,2,2 \leftarrow 2,2,1$ & Ground & $3 / 2$ & $3 / 2$ & 21453.6 & \\
\hline $\mathrm{C}^{12} \mathrm{D}_{2}: \mathrm{C}^{12} \mathrm{HBr}^{79}$ & 4. 723 & $3,2,2 \leftarrow 2,2,1$ & Ground & $5 / 2$ & $3 / 2$ & 21453.6 & \\
\hline $\mathrm{C}^{12} \mathrm{H}_{3} \mathrm{C}^{12} \mathrm{D}_{2} \mathrm{Br}^{81}$ & 3- 526 & $3,1,2 \leftarrow 2,1,1$ & Ground & $3 / 2$ & $1 / 2$ & 21454.68 & .05 \\
\hline $\left.\mathrm{C}^{12} \mathrm{H}_{3} \mathrm{C}^{12} \mathrm{H}_{2} \mathrm{C}\right]^{35}$ & 3- 541 & $2,1,1 \leftarrow 1,1,0$ & Ground & $1 / 2$ & $1 / 2$ & 21455.62 & .05 \\
\hline $\mathrm{C}^{12} \mathrm{D}_{2}\left(\mathrm{C}^{12} \mathrm{~N}^{14}\right)_{2}$ & 4- 903 & $8,1,7 \leftarrow 8,0,8$ & Ground & & & 21456.12 & \\
\hline$\left(\mathrm{C}^{12} \mathrm{H}_{3}\right)_{3} \mathrm{C}^{12} \mathrm{C}^{12}: \mathrm{C}^{12} \mathrm{H}$ & $3-1071$ & $4, \leftarrow 3$ & Ground & & & 21456.4 & .1 \\
\hline $\mathrm{C}^{12} \mathrm{D}_{2}: \mathrm{C}^{12} \mathrm{HBr}^{79}$ & 4- 723 & $3,2,1 \leftarrow 2,2,0$ & Ground & & & 21458.14 & .06 \\
\hline
\end{tabular}


Vib. State

$F_{1}^{\prime} \quad F^{\prime} \quad F_{1} \quad F$

Frequency Acc.

\begin{tabular}{|c|c|c|c|c|c|c|c|}
\hline $\mathrm{C}^{12} \mathrm{D}_{2}: \mathrm{C}^{12} \mathrm{HBr}^{79}$ & 4. 723 & $3,2,1 \leftarrow 2,2,0$ & Ground & $5 / 2$ & $3 / 2$ & 21458.9 & \\
\hline $\mathrm{C}^{12} \mathrm{D}_{2}: \mathrm{C}^{12} \mathrm{HBr}^{79}$ & 4- 723 & $3,2,1 \leftarrow 2,2,0$ & Ground & $3 / 2$ & $3 / 2$ & 21458.9 & \\
\hline $\mathrm{C}^{12} \mathrm{H}_{3} \mathrm{C}^{12} \mathrm{D}_{2} \mathrm{Br}^{81}$ & 3- 526 & $3,1,2 \leftarrow 2,1,1$ & Ground & $9 / 2$ & $7 / 2$ & 21459.19 & .05 \\
\hline $\mathrm{HC}^{13}: \mathrm{C}^{12} \mathrm{C}^{12} \mathrm{DO}^{16}$ & 4- 922 & Not Reported & & & & 21461. & 5. \\
\hline$c-\mathrm{DHC}^{12}: \mathrm{C}^{12} \mathrm{DCl}^{35}$ & 4- 762 & $2,1,1 \leftarrow 1,1,0$ & Ground & $7 / 2$ & $5 / 2$ & 21461.10 & .2 \\
\hline $\mathrm{H}_{2} \mathrm{C}^{12}: \mathrm{C}^{12} \mathrm{Cl}_{2}^{\mathrm{b}}$ & 4- 663 & Not Reported & Ground & & & 21461.5 & 1. \\
\hline $\mathrm{C}^{13} \mathrm{H}_{3} \mathrm{C}^{12} \mathrm{O}^{16} \mathrm{~F}^{19}$ & 3- 393 & $8,5,3 \leftarrow 8,5,4$ & Ground & & & 21462.35 & .2 \\
\hline $\mathrm{C}^{12} \mathrm{H}_{3} \mathrm{C}^{12} \mathrm{O}^{16} \mathrm{O}^{16} \mathrm{H}$ & 3. 491 & $4,2,2 \leftarrow 4,1,3$ & Ground & & & 21463.58 & \\
\hline$\left(\mathrm{C}^{12} \mathrm{H}_{3}\right)_{3} \mathrm{C}^{12} \mathrm{C}^{12} \vdots \mathrm{C}^{12} \mathrm{H}$ & $3-1071$ & $4, \leftarrow 3$, & Ground & & & 21465.5 & .1 \\
\hline $\mathrm{C}^{12} \mathrm{D}_{2}: \mathrm{C}^{12} \mathrm{HBr}^{79}$ & 4- 723 & $3,0,3 \leftarrow 2,0,2$ & Ground & $3 / 2$ & $1 / 2$ & 21468.6 & \\
\hline $\mathrm{C}^{12} \mathrm{D}_{2}: \mathrm{C}^{12} \mathrm{HBr}^{79}$ & 4- 723 & $3,0,3 \leftarrow 2,0,2$ & Ground & $5 / 2$ & $3 / 2$ & 21468.6 & \\
\hline $\mathrm{Cl}^{37} \mathrm{O}_{2}^{16}$ & $4-1382$ & $4,2,3 \leftarrow 5,1,4$ & Ground & & & 21468.6 & \\
\hline $\mathrm{C}^{12} \mathrm{H}_{3} \mathrm{C}^{12} \mathrm{O}^{16} \mathrm{Br}^{79}$ & 3- 351 & $5,0,5 \leftarrow 4,1,4$ & Ground & $11 / 2$ & $9 / 2$ & 21471.39 & .15 \\
\hline $\mathrm{C}^{12} \mathrm{H}_{3} \mathrm{C}^{12} \mathrm{O}^{16} \mathrm{Br}^{79}$ & 3- 351 & $5,0,5 \leftarrow 4,1,4$ & Ground & $9 / 2$ & $7 / 2$ & 21471.39 & .15 \\
\hline $\mathrm{As}^{75} \mathrm{Cl}_{3}^{35}$ & 4. $\quad 11$ & $5, \leftarrow 4$, & Ground & & & 21472. & 10. \\
\hline $\mathrm{C}^{12}{ }_{*} \mathrm{H}_{2} \mathrm{~N}^{14} \mathrm{HC}^{12}{ }_{*} \mathrm{H}_{2}$ & 4. 861 & $5,4,1 \leftarrow 5,3,2$ & Ground & & & 21474.0 & \\
\hline $\mathrm{Br}^{79} \mathrm{~F}^{19}$ & $1-$ & $1 \leftarrow 0$ & Ground & $3 / 2$ & $3 / 2$ & 21475.4 & \\
\hline $\mathrm{C}^{12}{ }_{*} \mathrm{H}: \mathrm{C}^{12} \mathrm{HO}^{18} \mathrm{C}^{12} \mathrm{H}: \mathrm{C}^{12}{ }_{*} \mathrm{H}$ & $4-1152$ & $5,3,2 \leftarrow 5,3,3$ & Ground & & & 21475.8 & .1 \\
\hline $\mathrm{Cs}^{133} \mathrm{~F}^{19}$ & $1-$ & $2 \leftarrow 1$ & Excited & & & 21477.5 & 1.0 \\
\hline $\mathrm{C}^{12} \mathrm{H}_{3} \mathrm{~N}^{14} \mathrm{H}_{2}$ & 3- 261 & Not Reported & Ground & & & 21477.62 & .1 \\
\hline $\mathrm{C}^{12} \mathrm{D}_{2}: \mathrm{C}^{12} \mathrm{DBr}^{79}$ & 4- 725 & $3,1,2 \leftarrow 2,1,1$ & Ground & $3 / 2$ & $3 / 2$ & 21477.7 & \\
\hline $\mathrm{C}^{13} \mathrm{H}_{3} \mathrm{C}^{12} \mathrm{H}_{2} \mathrm{Br}^{81}$ & 3- 531 & $3,1,2 \leftarrow 2,1,1$ & Ground & $9 / 2$ & $7 / 2$ & 21477.98 & .05 \\
\hline $\mathrm{C}^{12} \mathrm{D}_{2}: \mathrm{C}^{12} \mathrm{DBr}^{\mathrm{b}}$ & 4- 732 & $3, \quad \leftarrow 2, \quad$, & Ground & & & 21479.8 & .1 \\
\hline $\mathrm{C}^{12} \mathrm{H}_{3} \mathrm{C}^{12} \mathrm{D}_{2} \mathrm{Br}^{81}$ & 3- 526 & $3,1,2 \leftarrow 2,1,1$ & Ground & $5 / 2$ & $3 / 2$ & 21481.07 & .05 \\
\hline $\mathrm{C}^{12} \mathrm{H}_{3} \mathrm{C}^{12} \mathrm{~F}^{19}: \mathrm{C}^{12} \mathrm{H}_{2}$ & 3. 721 & $4,2,4 \leftarrow 4,1,3$ & Ground & & & 21481.14 & .1 \\
\hline $\mathrm{C}^{12} \mathrm{H}_{3} \mathrm{C}^{12} \mathrm{O}^{16} \mathrm{C}^{12} \mathrm{~N}^{14}$ & 3- 671 & $3,2,2 \leftarrow 2,2,1$ & Ground & & & 21481.42 & .2 \\
\hline $\mathrm{C}^{12} \mathrm{H}_{3} \mathrm{C}^{12} \mathrm{D}_{2} \mathrm{Br}^{81}$ & 3- 526 & $3,1,2 \leftarrow 2,1,1$ & Ground & $7 / 2$ & $5 / 2$ & 21481.74 & .05 \\
\hline $\mathrm{H}_{2} \mathrm{C}^{12}: \mathrm{C}^{12} \mathrm{Cl}_{2}^{\mathrm{b}}$ & 4- 663 & Not Reported & Ground & & & 21483.0 & 1.5 \\
\hline $\mathrm{C}^{12} \mathrm{D}_{2}: \mathrm{C}^{12} \mathrm{DBr}^{81}$ & 4- 726 & $3,1,2 \leftarrow 2,1,1$ & Ground & $7 / 2$ & $7 / 2$ & 21483.7 & \\
\hline $\mathrm{H}_{2} \mathrm{C}^{12}: \mathrm{C}^{12} \mathrm{~F}_{2}^{19}$ & 4- 681 & Not Reported & & & & 21484.0 & .3 \\
\hline $\mathrm{C}^{12} \mathrm{D}_{3} \mathrm{C}^{12} \mathrm{O}^{16} \mathrm{C}^{12} \mathrm{~N}^{14}$ & 3- 675 & $3,1,2 \leftarrow 2,1,1$ & Ground & & & 21484.8 & .3 \\
\hline $\mathrm{C}^{12}{ }_{*} \mathrm{HN}^{14} \mathrm{C}^{12} \mathrm{HC}^{12} \mathrm{H}: \mathrm{C}^{12} \mathrm{HN}^{14} *$ & 4-1141 & $7,4,3 \leftarrow 7,3,4$ & Ground & & & 21486.3 & \\
\hline$\left(\mathrm{C}^{12} \mathrm{H}_{3}\right)_{3} \mathrm{C}^{12} \mathrm{C}^{12}: \mathrm{C}^{12} \mathrm{H}$ & 3-1071 & $4, \leftarrow 3$ & Excited & & & 21486.4 & .1 \\
\hline$\left(\mathrm{C}^{12} \mathrm{H}_{3}\right)_{2} \mathrm{Si}^{29} \mathrm{H}_{2}$ & 3- 644 & $1,1,1 \leftarrow 0,0,0$ & Ground & & & 21489.88 & .20 \\
\hline $\mathrm{H}_{2} \mathrm{C}^{12}: \mathrm{C}^{12} \mathrm{Cl}_{2}^{35}$ & 4- 661 & $10,3,7 \leftarrow 10,2,8$ & Ground & & & 21490.1 & .5 \\
\hline$\left(\mathrm{C}^{12} \mathrm{H}_{3}\right)_{2} \mathrm{Si}^{29} \mathrm{H}_{2}$ & 3- 644 & $1,1,1 \leftarrow 0,0,0$ & Ground & & & 21491.07 & .20 \\
\hline $\mathrm{H}_{2} \mathrm{C}^{12}: \mathrm{C}^{12} \mathrm{Cl}_{2}^{35}$ & 4- 661 & $10,3,7 \leftarrow 10,2,8$ & Ground & & & 21492.3 & .5 \\
\hline$\left(\mathrm{C}^{12} \mathrm{H}_{3}\right)_{2} \mathrm{Si}^{29} \mathrm{H}_{2}$ & 3- 644 & $1,1,1 \leftarrow 0,0,0$ & Ground & & & 21492.33 & .20 \\
\hline $\mathrm{C}^{13} \mathrm{H}_{3} \mathrm{C}^{12} \mathrm{H}_{2} \mathrm{Br}^{81}$ & 3- 531 & $3,1,2 \leftarrow 2,1,1$ & Ground & $5 / 2$ & $3 / 2$ & 21494.67 & .05 \\
\hline $\mathrm{H}_{2} \mathrm{C}^{12}: \mathrm{C}^{12} \mathrm{Cl}_{2}^{35}$ & 4. 661 & $10,3,7 \leftarrow 10,2,8$ & Ground & & & 21494.8 & .5 \\
\hline
\end{tabular}




\begin{tabular}{|c|c|c|c|c|c|c|c|}
\hline \multirow{2}{*}{ Isotopic Species } & \multirow{2}{*}{$\begin{array}{l}\text { Vol.-Id. } \\
\text { Nos. }\end{array}$} & \multirow{2}{*}{$\begin{array}{c}\text { Rotational } \\
\text { Quantum Nos. }\end{array}$} & \multirow{2}{*}{ Vib. State } & \multicolumn{2}{|c|}{ Hyperfine } & \multirow{2}{*}{$\begin{array}{l}\text { Frequency } \\
\mathrm{MHz}\end{array}$} & \multirow{2}{*}{$\begin{array}{r}\text { Acc. } \\
\pm \mathrm{MHz}\end{array}$} \\
\hline & & & & $\begin{array}{lll}F_{1}^{\prime} & F^{\prime} & F_{1}\end{array}$ & $\mathrm{~F}$ & & \\
\hline $\mathrm{C}^{12} \mathrm{H}_{3} \mathrm{C}^{12} \mathrm{HF}_{2}^{19}$ & 3- 461 & $6,5,2 \leftarrow 6,3,3$ & Ground & & & 21496.7 & \\
\hline $\mathrm{C}^{12} \mathrm{H}_{3} \mathrm{C}^{12} \mathrm{H}_{2} \mathrm{~F}^{19}$ & 3- 551 & Not Reported & & & & 21498.03 & \\
\hline $\mathrm{C}^{12} \mathrm{H}_{3} \mathrm{C}^{12} \mathrm{HF}_{2}^{19}$ & 3. 461 & $6,5,2 \leftarrow 6,3,3$ & Ground & & & 21498.2 & \\
\hline$\left(\mathrm{C}^{12} \mathrm{H}_{3}\right)_{3} \mathrm{C}^{12} \mathrm{C}^{12}: \mathrm{C}^{12} \mathrm{H}$ & $3-1071$ & $4,1 \leftarrow 3,1$ & Excited & & & 21499.7 & .1 \\
\hline $\mathrm{C}^{12} \mathrm{H}_{3} \mathrm{~N}^{14} \mathrm{O}_{2}^{16}$ & 3. 171 & Not Reported & Ground & & & 21500. & 5. \\
\hline $\mathrm{C}^{12} \mathrm{H}_{3} \mathrm{C}^{12} \mathrm{H}_{2} \mathrm{O}^{16} \mathrm{H}$ & 3- 581 & $6,2,5 \leftarrow 5,3,2$ & Ground & & & 21501. & \\
\hline $\mathrm{C}^{13} \mathrm{H}_{3} \mathrm{C}^{12} \mathrm{H}_{2} \mathrm{Br}^{81}$ & 3. 531 & $3,1,2 \leftarrow 2,1,1$ & Ground & $7 / 2$ & $5 / 2$ & 21501.20 & .05 \\
\hline $\mathrm{C}^{12} \mathrm{H}_{2}\left(\mathrm{C}^{12} \mathrm{~N}^{14}\right)_{2}$ & 4. 901 & Not Reported & Ground & & & 21508.8 & .1 \\
\hline $\mathrm{Cl}^{37} \mathrm{O}_{2}^{16}$ & $4-1382$ & $14,2,13 \leftarrow 13,3,10$ & Ground & $25 / 2$ & $23 / 2$ & 21509.9 & \\
\hline $\mathrm{C}^{12} \mathrm{H}_{2} \mathrm{Cl}^{37} \mathrm{Si}^{28} \mathrm{H}_{3}$ & 3. 232 & $6,1,5 \leftarrow 6,0,6$ & Ground & & & 21511.17 & .2 \\
\hline $\mathrm{C}^{12} \mathrm{D}_{2}: \mathrm{C}^{12} \mathrm{DBr}^{\mathrm{b}}$ & 4. 732 & $3, \quad, \leftarrow 2$, & Ground & & & 21512.2 & .1 \\
\hline $\mathrm{Cs}^{133} \mathrm{Br}^{79}$ & 1 . & $10 \leftarrow 9$ & Excited & & & 21514.48 & 0.20 \\
\hline $\mathrm{C}^{12} \mathrm{D}_{\mathrm{2}}: \mathrm{C}^{12} \mathrm{DBr}^{79}$ & 4. 725 & $3,1,2 \leftarrow 2,1,1$ & Excited & $5 / 2$ & $5 / 2$ & 21516.3 & \\
\hline $\mathrm{t}-\mathrm{HDN}{ }^{14} \mathrm{C}^{12} \mathrm{HO}^{16}$ & 3. 153 & $1,1,1 \leftarrow 2,0,2$ & Ground & & & 21516.74 & \\
\hline$\left(\mathrm{C}^{12} \mathrm{H}_{3}\right)_{2} \mathrm{C}^{12}: \mathrm{C}^{12} \mathrm{H}_{2}$ & 3- 941 & $5,4,2 \leftarrow 5,3,3$ & Ground & & & 21519.40 & .05 \\
\hline $\mathrm{C}^{12} \mathrm{D}_{3} \mathrm{O}^{16} \mathrm{H}$ & 3. 214 & Not Reported & Ground & & & 21519.5 & .5 \\
\hline $\mathrm{C}^{12} \mathrm{H}_{3} \mathrm{~S}^{32} \mathrm{H}$ & 3. 221 & Not Reported & Ground & & & 21519.9 & .1 \\
\hline $\mathrm{C}^{12} \mathrm{D}_{2}: \mathrm{C}^{12} \mathrm{DBr}^{\mathrm{b}}$ & 4- 732 & $3, \quad \leftarrow 2,$, & Ground & & & 21521.8 & .2 \\
\hline $\mathrm{Cl}^{37} \mathrm{O}_{2}^{16}$ & $4-1382$ & $14,2,13 \leftarrow 13,3,10$ & Ground & $27 / 2$ & $25 / 2$ & 21522.6 & \\
\hline $\mathrm{C}^{12} \mathrm{H}_{3} \mathrm{C}^{12} \mathrm{H}_{2} \mathrm{~F}^{19}$ & 3- 551 & $7,1,7 \leftarrow 6,2,4$ & Ground & & & 21523.36 & \\
\hline $\mathrm{C}^{12} \mathrm{H}_{3} \mathrm{C}^{12} \mathrm{O}^{16} \mathrm{Br}^{81}$ & 3. 352 & $3,1,3 \leftarrow 2,0,2$ & Ground & $7 / 2$ & $5 / 2$ & 21524.02 & .15 \\
\hline $\mathrm{C}^{12} \mathrm{D}_{2}: \mathrm{C}^{12} \mathrm{DBr}^{79}$ & 4. 725 & $3,1,2 \leftarrow 2,1,1$ & Excited & $3 / 2$ & $1 / 2$ & 21525.5 & \\
\hline $\mathrm{C}^{12} \mathrm{D}_{2}: \mathrm{C}^{12} \mathrm{DBr}^{79}$ & 4- 725 & $3,1,2 \leftarrow 2,1,1$ & Excited & $9 / 2$ & $7 / 2$ & 21525.5 & \\
\hline $\mathrm{H}_{2} \mathrm{~N}^{14} \mathrm{~N}^{14} \mathrm{H}_{2}$ & 3- 51 & Not Reported & & & & 21527.14 & \\
\hline $\mathrm{C}^{12} \mathrm{D}_{2}: \mathrm{C}^{12} \mathrm{DBr}^{79}$ & 4. 725 & $3,1,2 \leftarrow 2,1,1$ & Ground & $5 / 2$ & $5 / 2$ & 21529.3 & \\
\hline $\mathrm{Cl}^{35} \mathrm{~F}^{19} \mathrm{C}^{12} \mathrm{O}^{16}$ & 4. 151 & $6,2,4 \leftarrow 6,1,5$ & Ground & & & 21533.58 & .05 \\
\hline $\mathrm{C}^{12} \mathrm{D}_{2}: \mathrm{C}^{12} \mathrm{HBr}^{79}$ & 4- 723 & $3,2,2 \leftarrow 2,2,1$ & Ground & $5 / 2$ & $5 / 2$ & 21535.5 & \\
\hline $\mathrm{C}^{12} \mathrm{D}_{2}: \mathrm{C}^{12} \mathrm{HBr}^{79}$ & 4. 723 & $3,2,2 \leftarrow 2,2,1$ & Ground & $7 / 2$ & $5 / 2$ & 21535.5 & \\
\hline $\mathrm{C}^{12} \mathrm{D}_{2}: \mathrm{C}^{12} \mathrm{DBr}^{79}$ & 4. 725 & $3,1,2 \leftarrow 2,1,1$ & Ground & $3 / 2$ & $1 / 2$ & 21538.4 & \\
\hline $\mathrm{C}^{12} \mathrm{D}_{2}: \mathrm{C}^{12} \mathrm{DBr}^{79}$ & 4- 725 & $3,1,2 \leftarrow 2,1,1$ & Ground & $9 / 2$ & $7 / 2$ & 21538.4 & \\
\hline $\mathrm{C}^{12}{ }_{*} \mathrm{HN}^{14} \mathrm{C}^{12} \mathrm{HC}^{12} \mathrm{H}: \mathrm{C}^{12} \mathrm{HN}^{14}{ }_{*}$ & $4-1141$ & $8,6,3 \leftarrow 8,5,4$ & Ground & & & 21539. & \\
\hline $\mathrm{Cl}^{37} \mathrm{O}_{2}^{16}$ & $4-1382$ & $14,2,13 \leftarrow 13,3,10$ & Ground & $29 / 2$ & $27 / 2$ & 21539.8 & \\
\hline $\mathrm{C}^{12} \mathrm{D}_{2}: \mathrm{C}^{12} \mathrm{HBr}^{79}$ & 4- 723 & $3,2,1 \leftarrow 2,2,0$ & Ground & $5 / 2$ & $5 / 2$ & 21540.9 & \\
\hline $\mathrm{C}^{12} \mathrm{D}_{2}: \mathrm{C}^{12} \mathrm{HBr}^{79}$ & 4. 723 & $3,2,1 \leftarrow 2,2,0$ & Ground & $7 / 2$ & $5 / 2$ & 21540.9 & \\
\hline $\mathrm{t} \cdot \mathrm{C}^{12} \mathrm{H}_{2} \mathrm{DC}^{12} \mathrm{H}_{2} \mathrm{~F}^{19}$ & 3. 554 & $6,3,4 \leftarrow 7,2,5$ & Ground & & & 21542.8 & .1 \\
\hline $\mathrm{C}^{12} \mathrm{D}_{2}: \mathrm{C}^{12} \mathrm{DBr}^{\mathrm{b}}$ & 4. 732 & $3, \quad \leftarrow 2, \quad$, & Ground & & & 21542.9 & .1 \\
\hline $\mathrm{C}^{12}{ }_{*} \mathrm{HN}^{14} \mathrm{C}^{12} \mathrm{HC}^{12} \mathrm{H}: \mathrm{C}^{12} \mathrm{HN}^{14}{ }_{*}$ & $4-1141$ & $6,3,3 \leftarrow 6,2,4$ & Ground & & & 21543. & \\
\hline $\mathrm{C}^{12}{ }_{*} \mathrm{H}_{2} \mathrm{C}^{12} \mathrm{H}: \mathrm{C}^{12}{ }_{*} \mathrm{H}$ & 4-1031 & $5,3,2 \leftarrow 5,3,3$ & Ground & & & 21544.2 & \\
\hline $\mathrm{C}^{12} \mathrm{H}_{3} \mathrm{C}^{12} \mathrm{H}_{2} \mathrm{Br}^{79}$ & 3- 521 & $3,1,3 \leftarrow 2,1,2$ & Ground & $9 / 2$ & $7 / 2$ & 21545.67 & .05 \\
\hline $\mathrm{C}_{6}^{12} \mathrm{H}_{5} \mathrm{O}^{16} \mathrm{H}$ & $3 \cdot 1051$ & $7,4,3 \leftarrow 7,3,4$ & Ground & & & 21546.5 & \\
\hline $\mathrm{S}^{32}{ }_{*} \mathrm{HC}^{12}: \mathrm{C}^{12} \mathrm{HC}^{12} \mathrm{H}: \mathrm{C}^{12}{ }_{*} \mathrm{H}$ & $4-1161$ & $9,4,6 \leftarrow 9,4,5$ & Ground & & & 21547.5 & .1 \\
\hline $\mathrm{C}^{12} \mathrm{H}_{3} \mathrm{C}^{12} \mathrm{H}_{2} \mathrm{~F}^{19}$ & 3. 551 & Not Reported & & & & 21547.94 & \\
\hline $\mathrm{HC}^{13}: \mathrm{C}^{12} \mathrm{C}^{12} \mathrm{DO}^{16}$ & 4- 922 & Not Reported & & & & 21548. & 5. \\
\hline $\mathrm{C}^{12} \mathrm{D}_{2}: \mathrm{C}^{12} \mathrm{DBr}^{79}$ & 4- 725 & $3,1,2 \leftarrow 2,1,1$ & Ground & & & 21548.27 & .05 \\
\hline
\end{tabular}


Vol.-Id. Nos.
Rotational Quantum Nos.

Vib. State

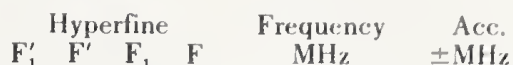

\begin{tabular}{|c|c|c|c|c|c|c|c|}
\hline $\mathrm{C}^{12} \mathrm{H}_{3} \mathrm{C}^{12} \mathrm{H}_{2} \mathrm{Br}^{79}$ & 3- 521 & $3,1,3 \leftarrow 2,1,2$ & Ground & $3 / 2$ & $1 / 2$ & 21.550 .04 & .05 \\
\hline $\mathrm{C}^{12} \mathrm{H}_{3} \mathrm{O}^{16} \mathrm{H}$ & 3- 211 & Not Reported & Ground & & & 21550.31 & .1 \\
\hline $\mathrm{C}_{6}^{12} \mathrm{H}_{5} \mathrm{~F}^{19}$ & $4-1281$ & Not Reported & & & & 21551. & 5. \\
\hline $\mathrm{HDO}_{2}^{16}$ & 3. 43 & $21, \quad, \quad \leftarrow 21$, & & & & 21553. & 3. \\
\hline $\mathrm{C}^{12} \mathrm{D}_{2}: \mathrm{C}^{12} \mathrm{DBr}^{79}$ & 4. 725 & $3,1,2 \leftarrow 2,1,1$ & Excited & $5 / 2$ & $3 / 2$ & 21554.1 & \\
\hline $\mathrm{C}^{12} \mathrm{D}_{2}: \mathrm{C}^{12} \mathrm{DBr}^{79}$ & 4- 725 & $3,1,2 \leftarrow 2,1,1$ & Excited & $7 / 2$ & $5 / 2$ & 21554.1 & \\
\hline $\mathrm{C}^{12}{ }_{*} \mathrm{HN}^{14} \mathrm{C}^{12} \mathrm{HC}^{12} \mathrm{H}: \mathrm{C}^{12} \mathrm{HN}^{14}{ }_{*}$ & $4-1141$ & $7,5,3 \leftarrow 7,4,4$ & Ground & & & 21554.9 & \\
\hline $\mathrm{C}^{12} \mathrm{H}_{3} \mathrm{~S}^{32} \mathrm{H}$ & 3- 221 & Not Reported & Ground & & & 21555.6 & .1 \\
\hline $\mathrm{C}^{12} \mathrm{H}_{3} \mathrm{C}^{12} \mathrm{O}^{16} \mathrm{Br}^{81}$ & 3. 352 & $3,1,3 \leftarrow 2,0,2$ & Ground & $9 / 2$ & $7 / 2$ & 21557.11 & .15 \\
\hline $\mathrm{C}^{12} \mathrm{H}_{3} \mathrm{C}^{12} \mathrm{H}_{2} \mathrm{Br}^{79}$ & 3- 521 & $3,1,3 \leftarrow 2,1,2$ & Ground & & & 21557.2 & \\
\hline $\mathrm{C}^{12}{ }_{*} \mathrm{H}: \mathrm{C}^{12} \mathrm{HO}^{16} \mathrm{C}^{12} \mathrm{D}: \mathrm{C}^{12}{ }_{*} \mathrm{H}$ & $4-1154$ & $8,8,0 \leftarrow 8,7,1$ & Ground & & & 21557.6 & \\
\hline$\left(\mathrm{C}^{12} \mathrm{H}_{3} \mathrm{C}^{12} \mathrm{H}_{2}\right)_{2} \mathrm{O}^{16}$ & $3-1011$ & Not Reported & & & & 21560. & \\
\hline c- $\mathrm{C}^{12} \mathrm{HD}: \mathrm{C}^{12} \mathrm{DBr}^{81}$ & 4- 746 & $3,2,2 \leftarrow 2,2,1$ & Ground & $3 / 2$ & $1 / 2$ & 21560.0 & .1 \\
\hline $\mathrm{H}_{2} \mathrm{C}^{12}: \mathrm{C}^{12} \mathrm{Cl}_{2}^{\mathrm{b}}$ & 4. 663 & Not Reported & Ground & & & 21560.3 & 1. \\
\hline $\mathrm{Cl}^{37} \mathrm{O}_{2}^{16}$ & $4-1382$ & $14,2,13 \leftarrow 13,3,10$ & Ground & $31 / 2$ & $29 / 2$ & 21561.8 & \\
\hline $\mathrm{H}_{2} \mathrm{C}^{12}: \mathrm{C}^{12} \mathrm{CI}_{2}^{\mathrm{b}}$ & 4. 663 & Not Reported & Ground & & & 21562.5 & 1. \\
\hline $\mathrm{C}^{12} \mathrm{H}_{3} \mathrm{C}^{12} \mathrm{O}^{16} \mathrm{Br}^{81}$ & 3. 352 & $3,1,3 \leftarrow 2,0,2$ & Ground & $5 / 2$ & $3 / 2$ & 21562.60 & .15 \\
\hline $\mathrm{K}^{39} \mathrm{I}^{127}$ & $1-$ & $6 \leftarrow 5$ & Excited & & & 21563.91 & 0.10 \\
\hline $\mathrm{H}_{2} \mathrm{C}^{12}: \mathrm{C}^{12} \mathrm{Cl}_{2}^{\mathrm{b}}$ & 4- 663 & Not Reported & Ground & & & 21564. & 1. \\
\hline $\mathrm{C}^{12}{ }_{*} \mathrm{HN}^{14} \mathrm{C}^{12} \mathrm{HC}^{12} \mathrm{H}: \mathrm{C}^{12} \mathrm{HN}^{14}{ }_{*}$ & $4-1141$ & $11,9,3 \leftarrow 11,8,4$ & Ground & & & 21564. & \\
\hline $\mathrm{a}-\mathrm{C}^{12} \mathrm{H}_{2} \mathrm{DC}^{12} \mathrm{O}^{16} \mathrm{Cl}^{35}$ & 3- 366 & $8,3,5 \leftarrow 8,2,6$ & Ground & & & 21565.5 & .2 \\
\hline$c-\mathrm{C}^{12} \mathrm{HD}: \mathrm{C}^{12} \mathrm{DBr}^{81}$ & 4. 746 & $3,2,1 \leftarrow 2,2,0$ & Ground & $3 / 2$ & $1 / 2$ & 21567.2 & .1 \\
\hline $\mathrm{C}^{12} \mathrm{D}_{2}: \mathrm{C}^{12} \mathrm{DBr}^{79}$ & 4- 725 & $3,1,2 \leftarrow 2,1,1$ & Ground & $5 / 2$ & $3 / 2$ & 21567.2 & \\
\hline $\mathrm{C}^{12} \mathrm{D}_{2}: \mathrm{C}^{12} \mathrm{DBr}^{79}$ & 4. 725 & $3,1,2 \leftarrow 2,1,1$ & Ground & $7 / 2$ & $5 / 2$ & 21567.2 & \\
\hline $\mathrm{C}^{12} \mathrm{~F}_{3}^{19} \mathrm{C}^{12}: \mathrm{C}^{12} \mathrm{D}$ & 4- 874 & $4, \leftarrow 3$ & Ground & & & 21568.2 & .3 \\
\hline $\mathrm{C}^{12} \mathrm{H}_{3} \mathrm{C}^{12}{ }_{*} \mathrm{HO}^{16} \mathrm{C}^{12}{ }_{*} \mathrm{H}_{2}$ & 3- 761 & $13,9, \leftarrow 14,8$ & Ground & & & 21568.32 & .1 \\
\hline $\mathrm{C}^{12}{ }_{*} \mathrm{H}_{2} \mathrm{C}^{12} \mathrm{H}_{2} \mathrm{C}^{12} \mathrm{H}_{2} \mathrm{C}^{12} \mathrm{H}_{2} \mathrm{C}^{12}{ }_{*} \mathrm{O}^{16}$ & $4-1241$ & $4,0,4 \leftarrow 3,0,3$ & Ground & & & 21568.5 & \\
\hline $\mathrm{C}^{12} \mathrm{H}_{3} \mathrm{C}^{12}{ }_{*} \mathrm{HO}^{16} \mathrm{C}^{12}{ }_{*} \mathrm{H}_{2}$ & 3- 761 & $13,9, \leftarrow 14,8$ & Ground & & & 21569.20 & .1 \\
\hline $\mathrm{C}^{12} \mathrm{H}_{3} \mathrm{C}^{12} \mathrm{H}_{2} \mathrm{Br}^{79}$ & 3. 521 & $3,1,3 \leftarrow 2,1,2$ & Ground & $7 / 2$ & $5 / 2$ & 21571.56 & .05 \\
\hline $\mathrm{C}^{12} \mathrm{D}_{2}: \mathrm{C}^{12} \mathrm{DBr}^{\mathrm{b}}$ & 4- 732 & Not Reported & Ground & & & 21571.6 & .1 \\
\hline c- $\mathrm{C}^{12} \mathrm{HD}: \mathrm{C}^{12} \mathrm{DBr}^{81}$ & 4- 746 & $3,0,3 \leftarrow 2,0,2$ & Ground & $3 / 2$ & $3 / 2$ & 21571.8 & .2 \\
\hline $\mathrm{C}^{12}{ }_{*} \mathrm{HN}^{14} \mathrm{C}^{12} \mathrm{HC}^{12} \mathrm{H}: \mathrm{C}^{12} \mathrm{HN}^{14}{ }_{*}$ & $4-1141$ & $6,4,3 \leftarrow 6,3,4$ & Ground & & & 21571.8 & $\Rightarrow$ \\
\hline $\mathrm{C}^{12} \mathrm{H}_{3} \mathrm{C}^{12} \mathrm{H}_{2} \mathrm{O}^{16} \mathrm{H}$ & 3- 581 & Not Reported & & & & 21572.00 & .01 \\
\hline $\mathrm{H}_{2} \mathrm{C}^{12}: \mathrm{C}^{12} \mathrm{~F}_{2}^{19}$ & 4- 681 & Not Reported & & & & 21572.6 & .3 \\
\hline $\mathrm{C}^{12}{ }_{*} \mathrm{HN}^{14} \mathrm{C}^{12} \mathrm{HC}^{12} \mathrm{H}: \mathrm{C}^{12} \mathrm{HN}^{14}{ }_{*}$ & $4-1141$ & $5,2,3 \leftarrow 5,1,4$ & Ground & & & 21575.9 & \\
\hline $\mathrm{C}^{12} \mathrm{HCl}^{35}: \mathrm{C}^{12} \mathrm{~F}_{2}^{19}$ & 4- 611 & $9,2,7 \leftarrow 9,1,8$ & Ground & $21 / 2$ & $21 / 2$ & 21576.1 & .1 \\
\hline $\mathrm{C}^{12} \mathrm{HCl}^{35}: \mathrm{C}^{12} \mathrm{~F}_{2}^{19}$ & 4- 611 & $9,2,7 \leftarrow 9,1,8$ & Ground & $15 / 2$ & $15 / 2$ & 21576.1 & .1 \\
\hline $\mathrm{C}^{12} \mathrm{H}_{3} \mathrm{C}^{12} \mathrm{H}_{2} \mathrm{Br}^{79}$ & 3. 521 & $3,1,3 \leftarrow 2,1,2$ & Ground & $5 / 2$ & $3 / 2$ & 21576.45 & .05 \\
\hline $\mathrm{C}^{12} \mathrm{HCl}^{35}: \mathrm{C}^{12} \mathrm{~F}_{2}^{19}$ & 4. 611 & $9,2,7 \leftarrow 9,1,8$ & Ground & $17 / 2$ & $17 / 2$ & 21577.0 & .1 \\
\hline $\mathrm{C}^{12} \mathrm{HCl}^{35}: \mathrm{C}^{12} \mathrm{~F}_{2}^{19}$ & 4. 611 & $9,2,7 \leftarrow 9,1,8$ & Ground & $19 / 2$ & $19 / 2$ & 21577.0 & .1 \\
\hline $\mathrm{C}^{12} \mathrm{HD}: \mathrm{C}^{12} \mathrm{DBr}^{\mathrm{b}}$ & 4- 749 & Not Reported & & & & 21581.3 & .2 \\
\hline $\mathrm{C}^{13} \mathrm{H}_{3} \mathrm{C}^{12} \mathrm{H}_{3} \mathrm{C}^{12}: \mathrm{C}^{12} \mathrm{H}_{2}$ & 3- 945 & $2,0,2 \leftarrow 1,1,1$ & Ground & & & 21582.34 & \\
\hline $\mathrm{C}^{12} \mathrm{H}_{3} \mathrm{C}^{12} \mathrm{D}_{2} \mathrm{Br}^{79}$ & 3. 524 & $3,1,2 \leftarrow 2,1,1$ & Ground & $3 / 2$ & $1 / 2$ & 21584.83 & .05 \\
\hline $\mathrm{C}^{12}{ }_{*} \mathrm{HN}^{14} \mathrm{C}^{12} \mathrm{HC}^{12} \mathrm{H}: \mathrm{C}^{12} \mathrm{HN}^{14}{ }_{*}$ & $4-1141$ & $3,0,3 \leftarrow 2,1,2$ & Ground & & & 21586.9 & \\
\hline
\end{tabular}




\begin{tabular}{|c|c|c|c|c|c|c|c|c|}
\hline Isotopic Species & $\begin{array}{l}\text { Vol.-Id. } \\
\text { Nos. }\end{array}$ & $\begin{array}{c}\text { Rotational } \\
\text { Quantum Nos. }\end{array}$ & Vib. State & $\mathrm{F}_{1}^{\prime}$ & $\begin{array}{l}\text { Hyperfine } \\
\mathrm{F}^{\prime} \quad \mathrm{F}_{1}\end{array}$ & $\mathrm{~F}$ & $\begin{array}{c}\text { Frequency } \\
\mathrm{MHz}\end{array}$ & $\begin{aligned} & \text { Acc. } \\
& \pm \mathrm{MHz}\end{aligned}$ \\
\hline $\mathrm{D}_{2} \mathrm{C}^{12}: \mathrm{C}^{12} \mathrm{~F}_{2}^{19}$ & 4- 683 & $3,3,1 \leftarrow 3,1,2$ & Ground & & & & 21587.7 & .3 \\
\hline $\mathrm{Cs}^{133} \mathrm{Br}^{79}$ & $1-$ & $10 \leftarrow 9$ & Ground & & & & 21588.57 & 0.10 \\
\hline $3 \mathrm{~d}-\mathrm{C}_{6}^{12} \mathrm{H}_{5} \mathrm{~F}^{19}$ & 4-1282 & $5,4,2 \leftarrow 4,4,1$ & Ground & & & & 21588.9 & .1 \\
\hline $\mathrm{C}^{12} \mathrm{H}_{3} \mathrm{C}^{13} \mathrm{H}_{2} \mathrm{Br}^{81}$ & 3- 529 & $3,0,3 \leftarrow 2,0,2$ & Ground & & $9 / 2$ & $7 / 2$ & 21590.10 & .05 \\
\hline $\mathrm{C}^{12} \mathrm{H}_{3} \mathrm{C}^{12} \mathrm{D}_{2} \mathrm{Br}^{79}$ & 3- 524 & $3,1,2 \leftarrow 2,1,1$ & Ground & & $9 / 2$ & $7 / 2$ & 21590.35 & .05 \\
\hline $\mathrm{C}^{12} \mathrm{H}_{3} \mathrm{C}^{12} \mathrm{O}^{16} \mathrm{Br}^{79}$ & 3- 351 & $3,1,3 \leftarrow 2,0,2$ & Ground & & $7 / 2$ & $5 / 2$ & 21592.05 & .15 \\
\hline $\mathrm{C}^{12} \mathrm{H}_{3} \mathrm{C}^{12} \mathrm{O}^{16} \mathrm{Br}^{81}$ & 3- 352 & $3,1,3 \leftarrow 2,0,2$ & Ground & & $3 / 2$ & $1 / 2$ & 21595.04 & .15 \\
\hline $\mathrm{C}^{12} \mathrm{HD}: \mathrm{C}^{12} \mathrm{DBr}^{\mathrm{b}}$ & 4- 749 & Not Reported & & & & & 21595.6 & .1 \\
\hline $\mathrm{C}^{12} \mathrm{H}_{33} \mathrm{C}^{12} \mathrm{HO}^{16}$ & 3- 474 & $7,1,6-7,1,7$ & Ground & & & & 21596.15 & .4 \\
\hline $\mathrm{C}^{12} \mathrm{H}_{2} \mathrm{Cl}^{37} \mathrm{~F}^{19}$ & 4- 332 & $19,1,19 \leftarrow 18,2,16$ & Ground & & & & 21596.35 & .1 \\
\hline $\mathrm{C}^{12} \mathrm{HD}: \mathrm{C}^{12} \mathrm{DBr}^{\mathrm{b}}$ & 4- 749 & Not Reported & & & & & 21596.9 & .1 \\
\hline $\mathrm{N}^{15} \mathrm{H}_{3}$ & $4-1772$ & $5,4 \leftarrow 5,4$ & Ground & & & & 21597.86 & .02 \\
\hline $\mathrm{C}^{12}{ }_{*} \mathrm{HN}^{14} \mathrm{C}^{12} \mathrm{HC}^{12} \mathrm{H}: \mathrm{C}^{12} \mathrm{HN}^{14}{ }_{*}$ & $4-1141$ & $3,1,3 \leftarrow 2,0,2$ & Ground & & & & 21598.5 & \\
\hline $\mathrm{C}^{12} \mathrm{H}_{2} \mathrm{Cl}^{37} \mathrm{~F}^{19}$ & 4- 332 & $19,1,19 \leftarrow 18,2,16$ & Ground & & & & 21600.0 & 1.0 \\
\hline $\mathrm{c}-\mathrm{C}^{12} \mathrm{HD}: \mathrm{C}^{12} \mathrm{DBr}^{81}$ & 4- 746 & $3,0,3 \leftarrow 2,0,2$ & Ground & & $5 / 2$ & $5 / 2$ & 21600.5 & .1 \\
\hline $\mathrm{H}_{2} \mathrm{C}^{12}: \mathrm{C}^{12} \mathrm{Cl}_{2}^{\mathrm{b}}$ & 4. 663 & Not Reported & Ground & & & & 21601.5 & 1.5 \\
\hline $3 \mathrm{~d}-\mathrm{C}_{6}^{12} \mathrm{H}_{5} \mathrm{~F}^{19}$ & $4-1282$ & $5,4,1 \leftarrow 4,4,0$ & Ground & & & & 21601.5 & .1 \\
\hline $\mathrm{C}^{12} \mathrm{H}_{2} \mathrm{Cl}^{37} \mathrm{~F}^{19}$ & 4. 332 & $22,1,22 \leftarrow 21,2,19$ & Ground & & & & 21603.23 & .1 \\
\hline $\mathrm{C}^{12} \mathrm{H}_{2} \mathrm{Cl}^{35} \mathrm{Si}^{28} \mathrm{D}_{3}$ & 3- 237 & $10,1,9 \leftarrow 10,0,10$ & Ground & & & & 21604.26 & .2 \\
\hline $\mathrm{C}^{12} \mathrm{H}_{3} \mathrm{C}^{12} \mathrm{D}_{3} \mathrm{Si}^{28} \mathrm{H}_{2}$ & 3- 642 & $6,1,5 \leftarrow 6,0,6$ & Ground & & & & 21604.75 & .05 \\
\hline $\mathrm{C}^{13} \mathrm{H}_{3} \mathrm{C}^{12} \mathrm{H}_{2}^{\prime} \mathrm{Br}^{79}$ & 3- 528 & $3,1,2 \leftarrow 2,1,1$ & Ground & & $3 / 2$ & $1 / 2$ & 21605.90 & .05 \\
\hline $\mathrm{N}^{14} \mathrm{O}^{16} \mathrm{Br}^{81}$ & 4- 122 & $3,1,3 \leftarrow 2,1,2$ & Ground & & $5 / 2$ & $5 / 2$ & 21606.22 & .25 \\
\hline $\mathrm{C}^{12} \mathrm{H}_{3} \mathrm{C}^{12} \mathrm{D}_{3} \mathrm{Si}^{28} \mathrm{H}_{2}$ & 3- 642 & $6,1,5 \leftarrow 6,0,6$ & Ground & & & & 21606.33 & .05 \\
\hline $\mathrm{C}^{13} \mathrm{H}_{3} \mathrm{C}^{12} \mathrm{H}_{2} \mathrm{Br}^{79}$ & 3- 528 & $3,1,2 \leftarrow 2,1,1$ & Ground & & $9 / 2$ & $7 / 2$ & 21606.77 & .05 \\
\hline $\mathrm{C}_{6}^{12} \mathrm{H}_{5} \mathrm{~F}^{19}$ & $4-1281$ & $51,16,35 \leftarrow 51,16,36$ & Ground & & & & 21608. & 5. \\
\hline $\mathrm{C}^{12} \mathrm{D}_{2}: \mathrm{C}^{12} \mathrm{DBr}^{79}$ & 4- 725 & $3,1,2 \leftarrow 2,1,1$ & Excited & & $7 / 2$ & $7 / 2$ & 21608.0 & \\
\hline $\mathrm{N}^{14} \mathrm{O}^{16} \mathrm{Br}^{81}$ & 4- 122 & $3,1,3 \leftarrow 2,1,2$ & Ground & & $3 / 2$ & $1 / 2$ & 21608.49 & .25 \\
\hline $\mathrm{C}^{12} \mathrm{H}_{2} \mathrm{Cl}^{37} \mathrm{~F}^{19}$ & 4- 332 & $22,1,22 \leftarrow 21,2,19$ & Ground & & & & 21608.55 & .1 \\
\hline $\mathrm{N}^{14} \mathrm{O}^{16} \mathrm{Br}^{81}$ & 4- 122 & $3,1,3 \leftarrow 2,1,2$ & Ground & & $9 / 2$ & $7 / 2$ & 21609.91 & .25 \\
\hline $\mathrm{C}^{12} \mathrm{H}_{3} \mathrm{C}^{13} \mathrm{H}_{2} \mathrm{Br}^{81}$ & 3- 529 & $3,0,3 \leftarrow 2,0,2$ & Ground & & $5 / 2$ & $3 / 2$ & 21612.01 & .05 \\
\hline $\mathrm{N}^{14} \mathrm{O}_{2}^{16} \mathrm{~F}^{19}$ & 4-1581 & $2,2,1 \leftarrow 2,0,2$ & Ground & & & & 21613.7 & \\
\hline $\mathrm{C}^{12} \mathrm{H}_{3} \mathrm{~N}^{14} \mathrm{H}_{2}$ & 3- 261 & Not Reported & Ground & & & & 21614.33 & .1 \\
\hline $3 \mathrm{~d}-\mathrm{C}_{6}^{12} \mathrm{H}_{5} \mathrm{~F}^{19}$ & 4-1282 & $5,3,3 \leftarrow 4,3,2$ & Ground & & & & 21614.6 & .1 \\
\hline $\mathrm{C}^{12} \mathrm{H}_{3} \mathrm{C}^{12} \mathrm{D}_{2} \mathrm{Br}^{79}$ & 3. 524 & $3,1,2 \leftarrow 2,1,1$ & Ground & & $5 / 2$ & $3 / 2$ & 21616.46 & .05 \\
\hline $\mathrm{C}^{12} \mathrm{D}_{3} \mathrm{C}^{12} \mathrm{HO}^{16}$ & 3- 474 & $7,1,6 \leftarrow 7,1,7$ & Ground & & & & 21616.82 & .2 \\
\hline $\mathrm{S}^{32}{ }_{*} \mathrm{DC}^{12}: \mathrm{C}^{12} \mathrm{HC}^{12} \mathrm{H}: \mathrm{C}^{12}{ }_{*} \mathrm{H}$ & 4-1162 & $3,1,3 \leftarrow 2,1,2$ & Ground & & & & 21617.0 & .1 \\
\hline $\mathrm{Cs}^{133} \mathrm{~F}^{19}$ & 1. & $2 \leftarrow 1$ & Excited & & & & 21617.09 & .60 \\
\hline $\mathrm{C}^{12} \mathrm{H}_{3} \mathrm{C}^{12} \mathrm{D}_{2} \mathrm{Br}^{79}$ & 3. 524 & $3,1,2 \leftarrow 2,1,1$ & Ground & & $7 / 2$ & $5 / 2$ & 21617.29 & .05 \\
\hline
\end{tabular}


Vol.-Id. Rotational

Quantum Nos.
Vib. State
$\mathrm{Rb}^{85} \mathrm{I}^{127}$

$\mathrm{HC}^{13}: \mathrm{C}^{12} \mathrm{C}^{12} \mathrm{DO}^{16}$

$\mathrm{F}_{2}^{19} \mathrm{O}_{2}^{16}$

$\mathrm{C}^{12} \mathrm{D}_{2}: \mathrm{C}^{12} \mathrm{DBr}^{79}$

$\mathrm{C}^{12} \mathrm{H}_{3} \mathrm{C}^{12}{ }_{*} \mathrm{HO}^{16} \mathrm{C}^{12}{ }_{*} \mathrm{H}_{2}$

$\mathrm{C}^{12} \mathrm{H}_{3} \mathrm{C}^{12}{ }_{*} \mathrm{HO}^{16} \mathrm{C}^{12}{ }_{*} \mathrm{H}_{2}$

$\mathrm{C}^{13} \mathrm{H}_{3} \mathrm{C}^{12} \mathrm{H}_{2} \mathrm{Br}^{39}$

$\mathrm{C}^{\mathrm{b}} \mathrm{H}_{2}^{\mathrm{b}} \mathrm{Cl}^{\mathrm{b}} \mathrm{F}^{\mathrm{b}}$

$\mathrm{N}^{14} \mathrm{O}^{16} \mathrm{Br}^{81}$

$\mathrm{N}^{14} \mathrm{O}^{16} \mathrm{Br}^{81}$

$\mathrm{C}^{12} \mathrm{HD}_{2} \mathrm{C}^{12} \mathrm{HDF}^{19}$

$\mathrm{C}^{12}{ }_{*} \mathrm{HN}^{14} \mathrm{C}^{12} \mathrm{HC}^{12} \mathrm{H}: \mathrm{C}^{12} \mathrm{HN}^{14}{ }^{4}$

$\mathrm{C}^{12} \mathrm{H}_{2} \mathrm{Cl}^{35} \mathrm{Si}^{28} \mathrm{H}_{3}$

c- $\mathrm{C}^{12} \mathrm{HD}: \mathrm{C}^{12} \mathrm{DBr}^{81}$

c- $\mathrm{C}^{12} \mathrm{HD}: \mathrm{C}^{12} \mathrm{DBr}^{81}$

$\mathrm{C}^{12} \mathrm{H}_{3} \mathrm{C}^{12} \mathrm{O}^{16} \mathrm{Br}^{79}$

$2,4,6 \mathrm{~d}_{3}-\mathrm{C}_{6}^{12} \mathrm{H}_{5} \mathrm{~F}^{19}$

$\mathrm{C}^{12} \mathrm{H}_{2} \mathrm{Cl}^{35} \mathrm{Si}^{28} \mathrm{H}_{3}$

$\mathrm{C}^{13} \mathrm{H}_{3} \mathrm{C}^{12} \mathrm{H}_{2} \mathrm{Br}^{79}$

$\mathrm{C}^{12} \mathrm{H}_{2} \mathrm{Cl}^{35} \mathrm{Si}^{28} \mathrm{H}_{3}$

$\mathrm{C}^{12} \mathrm{H}_{2} \mathrm{Cl}^{35} \mathrm{Si}^{28} \mathrm{H}_{3}$

$\mathrm{N}^{15} \mathrm{H}_{3}$

$\mathrm{C}^{12} \mathrm{H}_{3} \mathrm{C}^{12} \mathrm{O}^{16} \mathrm{Br}^{79}$

c- $\mathrm{C}^{12} \mathrm{HD}: \mathrm{C}^{12} \mathrm{DBr}^{81}$

c- $\mathrm{C}^{12} \mathrm{HD}: \mathrm{C}^{12} \mathrm{DBr}^{81}$

$\mathrm{C}^{12} \mathrm{H}_{2} \mathrm{Cl}^{35} \mathrm{Si}^{28} \mathrm{H}_{3}$

$\mathrm{C}^{12} \mathrm{H}_{3} \mathrm{C}^{12} \mathrm{HO}^{16}$

$\mathrm{HC}^{13}: \mathrm{C}^{12} \mathrm{C}^{12} \mathrm{DO}^{16}$

$\mathrm{C}^{12}{ }_{*} \mathrm{H}_{2} \mathrm{C}^{12} \mathrm{H}_{2} \mathrm{C}^{12} \mathrm{HCl}^{37}$

$\mathrm{C}^{12}{ }_{*} \mathrm{H}_{2} \mathrm{C}^{12} \mathrm{H}_{2} \mathrm{C}^{12} * \mathrm{HCl}^{37}$

c-C ${ }^{12} \mathrm{HD}: \mathrm{C}^{12} \mathrm{DBr}^{81}$

c-C ${ }^{12} \mathrm{HD}: \mathrm{C}^{12} \mathrm{DBr}^{81}$

$\mathrm{C}^{12}{ }_{*} \mathrm{H}_{2} \mathrm{C}^{12} \mathrm{H}_{2} \mathrm{C}^{12}{ }_{*} \mathrm{HCl}^{37}$

$\mathrm{C}^{12}{ }_{*} \mathrm{H}_{2} \mathrm{C}^{12} \mathrm{H}_{2} \mathrm{C}^{12}{ }_{*} \mathrm{HCl}^{37}$

$2,4,6 \mathrm{~d}_{3}-\mathrm{C}_{6}^{12} \mathrm{H}_{5} \mathrm{~F}^{19}$

$\mathrm{HC}^{12} \mathrm{O}^{16} \mathrm{O}^{16} \mathrm{C}^{12} \mathrm{D}_{3}-\mathrm{A}$

t- $\mathrm{C}^{12} \mathrm{HD}: \mathrm{C}^{12} \mathrm{HBr}^{81}$

$\left(\mathrm{C}^{12} \mathrm{H}_{3}\right)_{2} \mathrm{Si}^{28} \mathrm{H}_{2}$

$\mathrm{HC}^{13}: \mathrm{C}^{12} \mathrm{C}^{12} \mathrm{DO}^{16}$

$\left(\mathrm{C}^{12} \mathrm{H}_{3}\right)_{2} \mathrm{Si}^{28} \mathrm{H}_{2}$

$\mathrm{C}^{12} \mathrm{H}_{3} \mathrm{C}^{12} \mathrm{HO}^{16}$

c- $\mathrm{C}^{12} \mathrm{HD}: \mathrm{C}^{12} \mathrm{DBr}^{81}$

$\left(\mathrm{C}^{12} \mathrm{H}_{3}\right)_{2} \mathrm{Si}^{28} \mathrm{H}_{2}$
$1-$

4. 922

$11 \leftarrow 10$

3- 11

Not Reported

4. 725

$5,1,4 \leftarrow 5,0,5$

$3,1,2 \leftarrow 2,1$,
$34,17, \leftarrow 33,18$,

3- $761 \quad 34,17, \leftarrow 33,18$,

3- 528

$3,1,2 \leftarrow 2,1,1$

4- 333

Not Reported

4. 122

$3,1,3 \leftarrow 2,1,2$

4- 122

$3,1,3 \leftarrow 2,1,2$

3. 558

$3,1,2 \leftarrow 3,0,3$

4-1141 12,10, $3 \leftarrow 12,9,4$

3- $231 \quad 6,1,5 \leftarrow 6,0,6$

4. 746

$3,2,2 \leftarrow 2,2,1$

4- 746

$3,2,2 \leftarrow 2,2,1$

3. 351

$3,1,3 \leftarrow 2,0,2$

4-1284

3- 231

3. 528

$5,1,4 \leftarrow 4,1,3$

3. 231

$6,1,5 \leftarrow 6,0,6$

$3,1,2 \leftarrow 2,1,1$

$6,1,5 \leftarrow 6,0,6$

3. 231

4- 1772

$6,1,5 \leftarrow 6,0,6$

3. 351

$4,3 \leftarrow 4,3$

4- 746

$3,1,3 \leftarrow 2,0,2$

$3,2,1 \leftarrow 2,2,0$

4- 746

$3,2,1 \leftarrow 2,2,0$

3- 231

$6,1,5 \leftarrow 6,0,6$

3- 471

4. 922

Not Reported

4-1082

Not Reported

4-1082

4- 746

4.- 746

4- 1082

4- 1082

4-1284

3- 507

4. 743

$3,1,3 \leftarrow 2,1,2$

Ground

$3,1,3 \leftarrow 2,1,2$

Ground

Ground

$3,0,3 \leftarrow 2,0,2$

Ground

Ground

Ground

$6,0,6 \leftarrow 5,0,5$

Ground

3- 641

$2,0,2 \leftarrow 1,0,1$

$3,1,3 \leftarrow 2,1,2$

Excited

Ground

4- 922

$1,1,1 \leftarrow 0,0,0$

3- 641

Not Reported

3. 471

$1,1,1 \leftarrow 0,0,0$

4- 746

Not Reported

3. 641

$3,0,3 \leftarrow 2,0,2$

$1,1,1 \leftarrow 0,0,0$

Ground

Ground

Ground
Ground

$7 / 2$

$\begin{array}{lll}21625.78 & .1 \\ 21626.39 & .1\end{array}$

$5 / 2$

$5 / 2$

$7 / 2 \quad 5 / 2$

21626.46

21626.6

21628.84

21630.32

21630.4

21631.

$9 / 2 \quad 9 / 2 \quad 21631.36$

$9 / 2 \quad 7 / 2 \quad 21631.4$

$7 / 2 \quad 7 / 2 \quad 21631.4$

$9 / 2 \quad 7 / 2$

21631.72

21631.8

$15 / 2 \quad 15 / 2 \quad 21632.81$

$7 / 2 \quad 5 / 2 \quad 21634.34$

21634.98

$11 / 2$

$11 / 2$

21637.41

21637.91

$5 / 2 \quad 3 / 2 \quad 21638.05$

$9 / 2 \quad 7 / 2 \quad 21638.5$

$7 / 2$

$13 / 2$

$7 / 2$

$13 / 2$

21638.5

21638.88

21640.36

21642 .

$7 / 2$

$5 / 2$

21644.8
$5 / 2$

$7 / 2$

$9 / 2$

$9 / 2$

$3 / 2$

$3 / 2$

$5 / 2$

$7 / 2$

$7 / 2$

$1 / 2$

21 644.8

21647.4

21647.4

21647.5

21647.5

21648.5

21648.80

$3 / 2$

$3 / 2$

21648.9

21 649.82

21650 .

21651.08

21651.27

21651.91

21652.35

.04

.05 


\begin{tabular}{|c|c|c|c|c|c|c|c|}
\hline Isotopic Species & $\begin{array}{l}\text { Vol.-Id. } \\
\text { Nos. }\end{array}$ & $\begin{array}{c}\text { Rotational } \\
\text { Quantum Nos. }\end{array}$ & Vib. State & 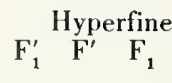 & $\mathrm{F}$ & $\begin{array}{c}\text { Frequency } \\
\mathrm{MHz}\end{array}$ & $\begin{array}{r}\text { Acc. } \\
\pm \mathrm{MHz}\end{array}$ \\
\hline $\mathrm{C}^{12} \mathrm{HD}: \mathrm{C}^{12} \mathrm{HBr}^{\mathrm{b}}$ & 4- 748 & Not Reported & & & & 21657.0 & 2. \\
\hline $\mathrm{C}_{6}^{12} \mathrm{H}_{5} \mathrm{O}^{16} \mathrm{H}$ & 3-1051 & $7,4,3 \leftarrow 7,3,4$ & Ground & & & 21658.1 & \\
\hline $\mathrm{Ce}^{74} \mathrm{HCl}_{3}^{35}$ & 4-1493 & $5, \leftarrow 4$, & Ground & & & 21659.15 & .07 \\
\hline$K^{39} \mathbf{I}^{127}$ & $1-$ & $6 \leftarrow 5$ & Excited & & & 21659.38 & 0.10 \\
\hline $\mathrm{c}-\mathrm{C}^{12} \mathrm{HD}: \mathrm{C}^{12} \mathrm{DBr}^{81}$ & 4- 746 & $3,2,2 \leftarrow 2,2,1$ & Ground & & & 21660.16 & .04 \\
\hline $\mathrm{e}-\mathrm{C}^{12} \mathrm{HD}: \mathrm{C}^{12} \mathrm{DBr}^{81}$ & 4. 746 & $3,2,2 \leftarrow 2,2,1$ & Ground & $3 / 2$ & $3 / 2$ & 21660.2 & .1 \\
\hline$c-\mathrm{C}^{12} \mathrm{HD}: \mathrm{C}^{12} \mathrm{DBr}^{81}$ & 4. 746 & $3,2,2 \leftarrow 2,2,1$ & Ground & $5 / 2$ & $3 / 2$ & 21660.2 & .1 \\
\hline $\mathrm{C}^{12} \mathrm{H}_{3} \mathrm{Si}^{28} \mathrm{DF}_{2}^{19}-\mathrm{A}$ & 3. 197 & Not Reported & Ground & & & 21661.4 & \\
\hline $\mathrm{H}_{2} \mathrm{~N}^{14} \mathrm{~N}^{14} \mathrm{H}_{2}$ & 3- 51 & Not Reported & & & & 21661.71 & \\
\hline $\mathrm{C}^{12} \mathrm{HD}: \mathrm{C}^{12} \mathrm{HBr}^{\mathrm{b}}$ & 4- 748 & Not Reported & & & & 21662.0 & .2 \\
\hline$\left(\mathrm{e}^{74} \mathrm{HCl}_{3}^{35}\right.$ & 4-1493 & $5, \leftarrow 4$ & Excited & & & 21662.45 & .07 \\
\hline $\mathrm{HC}^{12} \mathrm{O}^{16} \mathrm{O}^{16} \mathrm{C}^{12} \mathrm{H}_{3}-\mathrm{E}$ & 3- 502 & $8,2,6 \leftarrow 8,2,7$ & Ground & & & 21663.10 & .35 \\
\hline $\mathrm{D}_{2} \mathrm{C}^{12} \approx \mathrm{O}^{16} \mathrm{C}^{12} * \mathrm{D}_{2}$ & 4- 843 & $4,2,2 \leftarrow 4,1,3$ & Ground & & & 21664. & \\
\hline c- $\mathrm{C}^{12} \mathrm{HD}: \mathrm{C}^{12} \mathrm{DBr}^{81}$ & 4. 746 & $3,2,1 \leftarrow 2,2,0$ & Ground & & & 21667.30 & .04 \\
\hline c-C $\mathrm{C}^{12} \mathrm{HD}: \mathrm{C}^{12} \mathrm{DBr}^{81}$ & 4- 746 & $3,2,1 \leftarrow 2,2,0$ & Ground & $5 / 2$ & $3 / 2$ & 21667.5 & .1 \\
\hline 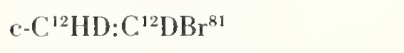 & 4- 746 & $3,2,1 \leftarrow 2,2,0$ & Ground & $3 / 2$ & $3 / 2$ & 21667.5 & .1 \\
\hline $\mathrm{N}^{15} \mathrm{H}_{3}$ & 4-1772 & $6,5 \leftarrow 6,5$ & Ground & & & 21667.93 & .02 \\
\hline$c-\mathrm{C}^{12} \mathrm{HD}: \mathrm{C}^{12} \mathrm{DBr}^{79}$ & 4- 744 & $3,2,2 \leftarrow 2,2,1$ & Ground & $3 / 2$ & $1 / 2$ & 21668.2 & .2 \\
\hline $\mathrm{C}^{12} \mathrm{D}_{3} \mathrm{Cl}^{3.5}$ & 4- 424 & $1,0 \leftarrow 0,0$ & Ground & $3 / 2$ & $3 / 2$ & 21668.88 & .08 \\
\hline $\mathrm{C}^{12} \mathrm{~F}_{3}^{19} \mathrm{C}^{12} \mathrm{O}^{16} \mathrm{O}^{16} \mathrm{D} \cdot \mathrm{HC}^{12} \mathrm{O}^{16} \mathrm{O}^{16} \mathrm{D}$ & 3- 664 & $19, \quad \leftarrow 18$, & Ground & & & 21669.7 & \\
\hline $\mathrm{t}-\mathrm{C}^{12} \mathrm{HD}: \mathrm{C}^{12} \mathrm{HBr}^{81}$ & 4- 743 & $3,1,3 \leftarrow 2,1,2$ & Ground & $3 / 2$ & $3 / 2$ & 21670.2 & .2 \\
\hline $\mathrm{c}-\mathrm{C}^{12} \mathrm{HD}: \mathrm{C}^{12} \mathrm{DBr}^{81}$ & 4- 746 & $3,0,3 \leftarrow 2,0,2$ & Ground & $5 / 2$ & $3 / 2$ & 21671.5 & .1 \\
\hline$c-C^{12} \mathrm{HD}: \mathrm{C}^{12} \mathrm{DBr}^{81}$ & 4- 746 & $3,0,3 \leftarrow 2,0,2$ & Ground & $3 / 2$ & $1 / 2$ & 21671.5 & .1 \\
\hline $\mathrm{C}^{12} \mathrm{HD}: \mathrm{C}^{12} \mathrm{DBr}^{\mathrm{b}}$ & 4- 749 & Not Reported & & & & 21673.9 & .1 \\
\hline c. $\mathrm{C}^{12} \mathrm{HD}: \mathrm{C}^{12} \mathrm{DBr}^{79}$ & 4- 744 & $3,2,1 \leftarrow 2,2,0$ & Ground & $3 / 2$ & $1 / 2$ & 21675.6 & .1 \\
\hline $\mathrm{HN}^{14} \mathrm{O}_{3}^{16}$ & 3- $\quad 31$ & $3,3,1 \leftarrow 3,2,2$ & Ground & & & 21676.16 & \\
\hline $\mathrm{C}^{12} \mathrm{H}_{3} \mathrm{C}^{12} \mathrm{O}^{16} \mathrm{Br}^{79}$ & 3- 351 & $3,1,3 \leftarrow 2,0,2$ & Ground & $3 / 2$ & $1 / 2$ & 21677.89 & .15 \\
\hline $\mathrm{HC}^{13} \vdots \mathrm{C}^{12} \mathrm{C}^{12} \mathrm{DO}^{16}$ & 4. 922 & Not Reported & & & & 21678. & 5. \\
\hline $\mathrm{HC}^{12} \mathrm{O}^{16} \mathrm{O}^{16} \mathrm{C}^{12} \mathrm{H}_{3}-\mathrm{A}$ & 3- 501 & $8,2,6 \leftarrow 8,2,7$ & Ground & & & 21680.87 & .35 \\
\hline $\mathrm{C}^{12} \mathrm{H}_{2}\left(\mathrm{C}^{12} \mathrm{~N}^{14}\right)_{2}$ & 4- 901 & Not Reported & Ground & & & 21682.7 & .1 \\
\hline $\mathrm{C}^{12} \mathrm{H}: \mathrm{C}^{12} \mathrm{DO}^{16} \mathrm{C}^{32} \mathrm{D}: \mathrm{C}^{12}{ }_{*} \mathrm{H}$ & $4-1156$ & $9,8,1 \leftarrow 9,7,2$ & Ground & & & 21683.1 & \\
\hline c- $\mathrm{C}^{12} \mathrm{HD}: \mathrm{C}^{12} \mathrm{DBr}^{79}$ & 4- 744 & $3,0,3 \leftarrow 2,0,2$ & Ground & $3 / 2$ & $3 / 2$ & 21683.5 & .2 \\
\hline $\mathrm{O}^{16} \mathrm{O}^{18} \mathrm{O}^{18}$ & $4-1844$ & $10,1,9 \leftarrow 9,2,8$ & Ground & & & 21684.0 & \\
\hline $\mathrm{C}^{12}{ }_{*} \mathrm{H}: \mathrm{C}^{12} \mathrm{HO}^{\mathrm{r} 6} \mathrm{C}^{12} \mathrm{H}: \mathrm{C}^{12}{ }_{*} \mathrm{D}$ & $4-1155$ & $10,7,3 \leftarrow 10,7,4$ & Ground & & & 21685.3 & \\
\hline $\mathrm{C}^{12} \mathrm{D}_{3} \mathrm{Cl}^{35}$ & 4- 424 & $1,0 \leftarrow 0,0$ & Ground & $5 / 2$ & $3 / 2$ & 21687.46 & .08 \\
\hline $\mathrm{H}_{2} \mathrm{C}^{12}: \mathrm{C}^{12} \mathrm{~F}_{2}^{19}$ & 4- 681 & Not Reported & & & & 21689.0 & .3 \\
\hline $\mathrm{t}-\mathrm{C}^{12} \mathrm{HD}: \mathrm{C}^{12} \mathrm{HBr}^{81}$ & 4- 743 & $3,1,3 \leftarrow 2,1,2$ & Excited & $5 / 2$ & $5 / 2$ & 21689.6 & .1 \\
\hline $\mathrm{H}_{2}^{\mathrm{b}} \mathrm{C}_{*}^{\mathrm{h}} \mathrm{O}^{16} \mathrm{C}_{*}^{\mathrm{b}} \mathrm{H}_{2}^{\mathrm{b}}$ & 4- 846 & Not Reported & Excited & & & 21692. & 2. \\
\hline$\left(; \mathrm{e}^{72} \mathrm{HCl}_{3}^{35}\right.$ & 4-1492 & $5, \leftarrow 4$ & Ground & & & 21693.05 & .07 \\
\hline $\mathrm{C}^{12} \mathrm{HD}: \mathrm{C}^{12} \mathrm{HBr}^{\mathrm{b}}$ & 4- 748 & Not Reported & & & & 21693.5 & .5 \\
\hline $\mathrm{s}-\mathrm{C}^{12} \mathrm{H}_{2} \mathrm{DSi}^{28} \mathrm{H}_{2} \mathrm{~F}^{19}$ & 3- 247 & $10,2,8 \leftarrow 10,2,9$ & Ground & & & 21694.80 & .10 \\
\hline $\mathrm{s}-\mathrm{C}^{12} \mathrm{H}_{2} \mathrm{DC}^{12} \mathrm{O}^{16} \mathrm{Cl}^{35}$ & 3- 365 & $5,1,4 \leftarrow 5,0,5$ & Cround & & & 21695.4 & .2 \\
\hline Cie $\mathrm{e}^{72} \mathrm{HCl}_{3}^{35}$ & 4-1492 & $5, \leftarrow 4$ & Excited & & & 21696.76 & .07 \\
\hline $\mathrm{C}^{12} \mathrm{D}_{2}: \mathrm{C}^{12} \mathrm{HBr}^{\mathrm{b}}$ & 4- 731 & $3, \quad \leftarrow 2, \quad$ & Ground & & & 21696.8 & .1 \\
\hline $\mathrm{s}-\mathrm{C}^{12} \mathrm{H}_{2} \mathrm{DC}^{12} \mathrm{O}^{16} \mathrm{Cl}^{3.5}$ & 3- 365 & $5,1,4 \leftarrow 5,0,5$ & Ground & & & 21697.58 & .2 \\
\hline
\end{tabular}




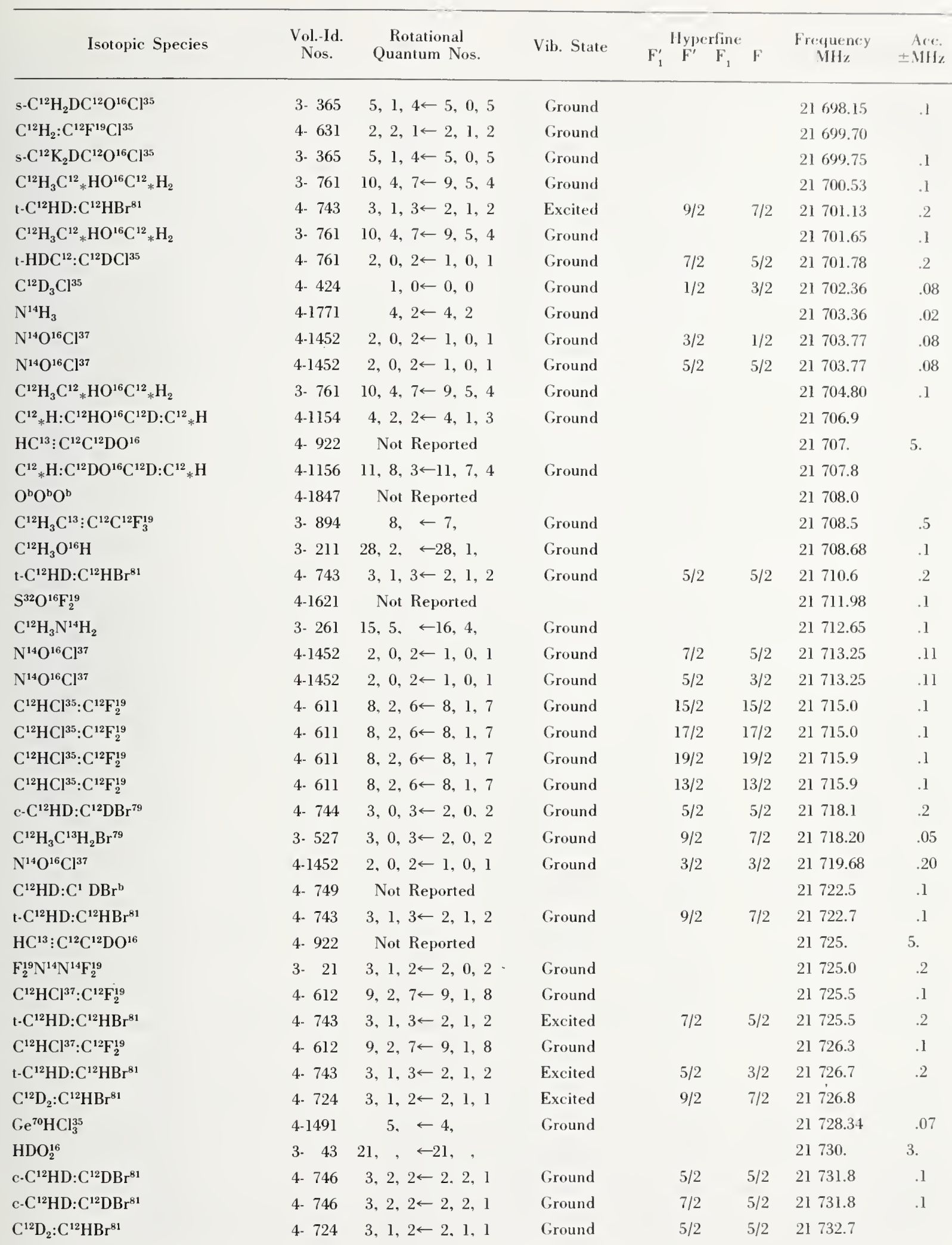




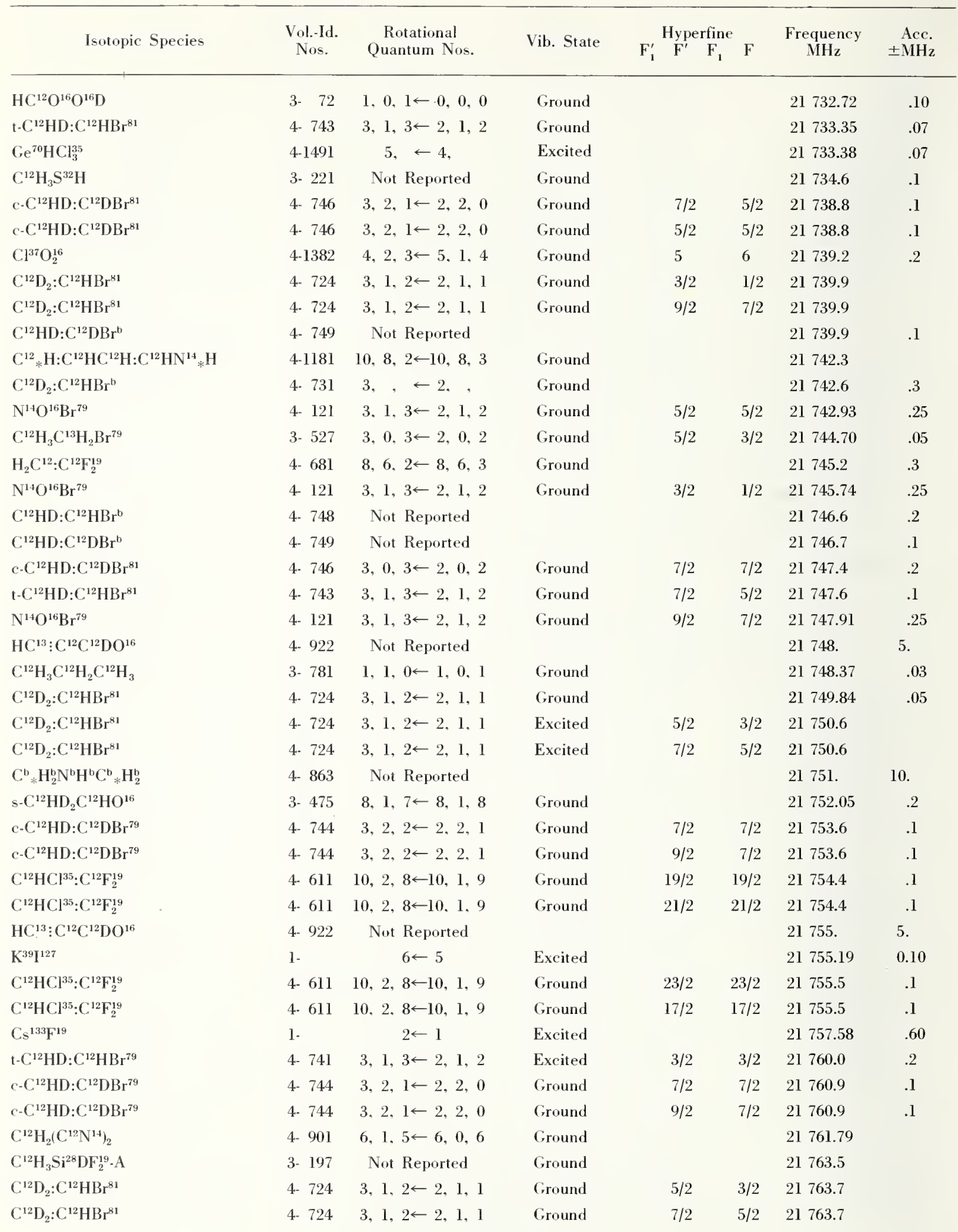




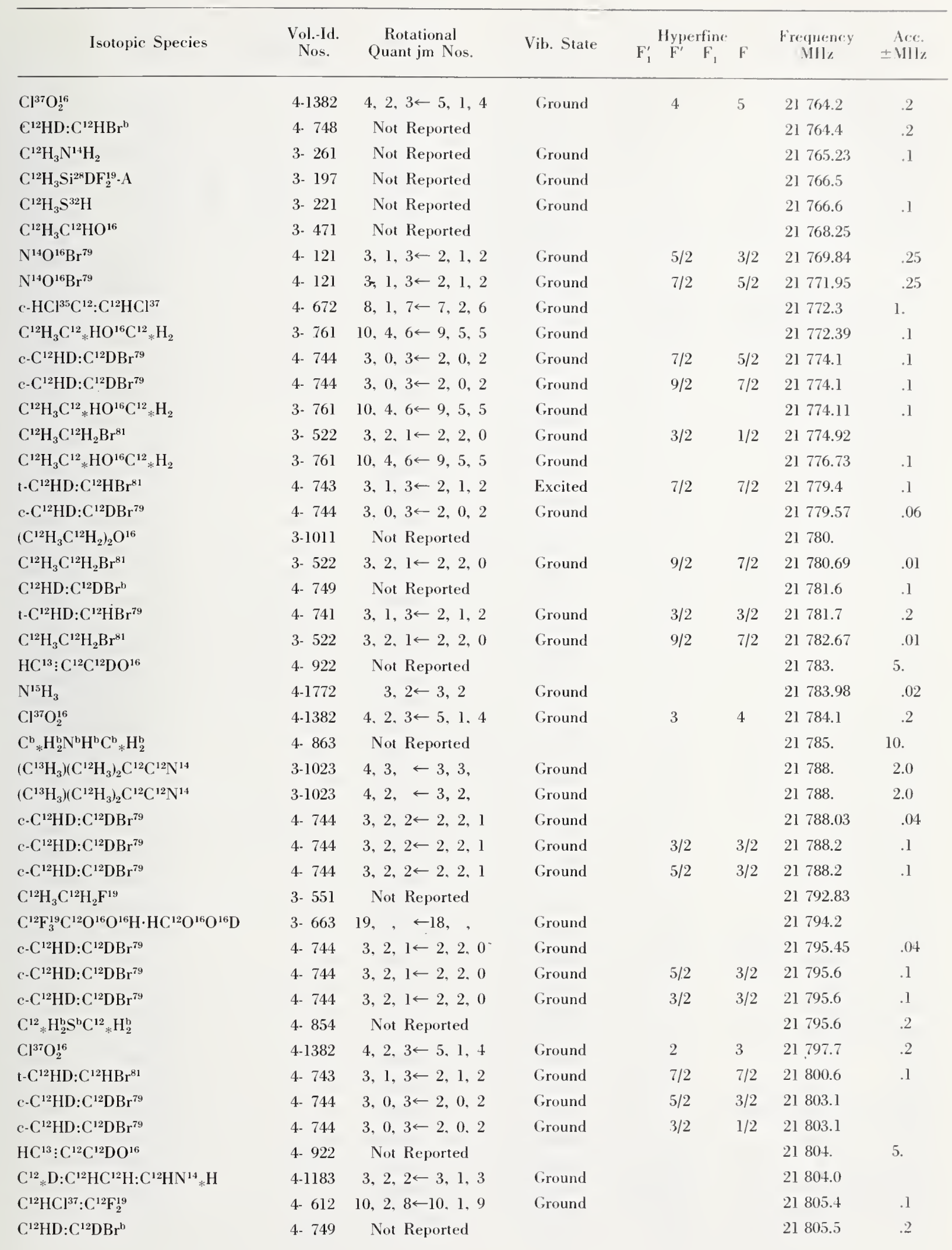


Vib. State

$\mathrm{F}_{1}^{\prime} \stackrel{\mathrm{F}^{\prime}}{\mathrm{F}_{1}} \mathrm{~F}$

Frequency Acc. $\mathrm{MHz}^{\circ} \pm \mathrm{MHz}$
$\mathrm{C}^{12}{ }_{*} \mathrm{H}_{2} \mathrm{~N}^{14} \mathrm{DC}^{12}{ }_{*} \mathrm{H}_{2}$

$\mathrm{HC}^{13}: \mathrm{C}^{12} \mathrm{C}^{12} \mathrm{DO}^{16}$

$\mathrm{C}^{12} \mathrm{D}_{2}: \mathrm{C}^{12} \mathrm{HBr}^{81}$

$\mathrm{t}-\mathrm{C}^{12} \mathrm{HD}: \mathrm{C}^{12} \mathrm{HBr}^{79}$

$\mathrm{C}^{12} \mathrm{D}_{2}: \mathrm{C}^{12} \mathrm{HBr}^{79}$

$\mathrm{HC}^{13}: \mathrm{C}^{12} \mathrm{C}^{12} \mathrm{DO}^{16}$

$\mathrm{N}^{14} \mathrm{H}_{3}$

$\mathrm{C}^{12} \mathrm{D}_{3} \mathrm{C}^{12} \mathrm{DO}^{16}$

$\mathrm{C}^{12}{ }_{*} \mathrm{D}: \mathrm{C}^{12} \mathrm{HC}^{12} \mathrm{H}: \mathrm{C}^{12} \mathrm{HN}^{14}{ }_{*} \mathrm{H}$

$\mathrm{t}-\mathrm{C}^{12} \mathrm{HD}: \mathrm{C}^{12} \mathrm{HBr}^{79}$

$\mathrm{C}^{12}{ }_{*} \mathrm{H}: \mathrm{C}^{12} \mathrm{DC}^{12} \mathrm{H}: \mathrm{C}^{12} \mathrm{HN}^{14}{ }_{*} \mathrm{H}$

$\mathrm{C}^{12} \mathrm{H}_{3} \mathrm{C}^{12} \mathrm{H}_{2} \mathrm{Br}^{81}$

$\mathrm{C}^{12} \mathrm{H}_{3} \mathrm{C}^{12} \mathrm{H}_{2} \mathrm{~F}^{19}$

$\mathrm{H}_{2}^{\mathrm{b}} \mathrm{C}^{\mathrm{b}}: \mathrm{C}^{\mathrm{b}} \mathrm{H}^{\mathrm{b}} \mathrm{Cl}^{\mathrm{b}}$

i- $\mathrm{C}^{12} \mathrm{HD}: \mathrm{C}^{12} \mathrm{HBr}^{79}$

$\mathrm{C}^{12} \mathrm{H}_{2} \mathrm{Cl}^{35} \mathrm{~F}^{19}$

$\mathrm{C}^{12} \mathrm{H}_{2} \mathrm{~N}^{14} \mathrm{O}^{16} \mathrm{D}$

$\mathrm{C}^{12} \mathrm{H}_{2} \mathrm{~N}^{14} \mathrm{O}^{16} \mathrm{D}$

$\mathrm{N}^{14} \mathrm{O}^{16} \mathrm{Br}^{81}$

$\mathrm{N}^{14} \mathrm{O}^{16} \mathrm{Br}^{81}$

$\mathrm{N}^{14} \mathrm{O}^{16} \mathrm{Br}^{81}$

$\mathrm{N}^{14} \mathrm{O}^{16} \mathrm{Br}^{81}$

$\mathrm{N}^{14} \mathrm{O}^{16} \mathrm{Br}^{81}$

$\mathrm{N}^{14} \mathrm{O}^{16} \mathrm{Br}^{81}$

$\mathrm{C}^{12} \mathrm{H}_{2} \mathrm{~N}^{14} \mathrm{O}^{16} \mathrm{D}$

$\mathrm{C}^{12} \mathrm{H}_{2} \mathrm{Cl}^{35} \mathrm{~F}^{19}$

$\mathrm{C}^{12} \mathrm{H}_{3} \mathrm{C}^{12} \mathrm{H}_{2} \mathrm{Br}^{81}$

$\mathrm{DN}^{14} \mathrm{C}^{13} \mathrm{~S}^{32}$

$\mathrm{C}^{12} \mathrm{H}_{3} \mathrm{C}^{12} \mathrm{H}_{2} \mathrm{Br}^{81}$

$\mathrm{C}^{12} \mathrm{H}_{3} \mathrm{C}^{12} \mathrm{H}_{2} \mathrm{Br}^{81}$

a- $\mathrm{C}^{12} \mathrm{H}_{2} \mathrm{DC}^{12} \mathrm{O}^{16} \mathrm{Cl}^{35}$

$\mathrm{DN}^{14} \mathrm{C}^{12} \mathrm{~S}^{32}$

$\mathrm{C}^{12} \mathrm{H}_{3} \mathrm{~N}^{14} \mathrm{H}_{2}$

$\mathrm{C}^{12} \mathrm{~F}_{3}^{19} \mathrm{C}^{12} \mathrm{O}^{16} \mathrm{O}^{16} \mathrm{D} \cdot \mathrm{HC}^{12} \mathrm{O}^{16} \mathrm{O}^{16} \mathrm{H}$

t- $\mathrm{C}^{12} \mathrm{HD}: \mathrm{C}^{12} \mathrm{HBr}^{79}$

$\mathrm{C}^{12} \mathrm{HD}: \mathrm{C}^{12} \mathrm{DBr}^{\mathrm{b}}$

a- $\mathrm{C}^{12} \mathrm{H}_{2} \mathrm{DC}^{12} \mathrm{O}^{16} \mathrm{Cl}^{35}$

$\mathrm{C}_{6}^{12} \mathrm{H}_{5} \mathrm{~F}^{19}$

$\mathrm{N}^{15} \mathrm{H}_{3}$

$\mathrm{C}^{12}{ }_{*} \mathrm{HC}^{12} \mathrm{H}: \mathrm{C}^{12} \mathrm{DC}^{12} \mathrm{H}: \mathrm{C}^{12} \mathrm{HN}^{14}{ }_{*}$

$\mathrm{C}_{6}^{12} \mathrm{H}_{5} \mathrm{~F}^{19}$

$\mathrm{H}_{2}^{\mathrm{b}} \mathrm{C}^{\mathrm{b}}: \mathrm{C}^{\mathrm{b}} \mathrm{H}^{\mathrm{b}} \mathrm{Cl}^{\mathrm{b}}$

$\left(\mathrm{C}^{12} \mathrm{H}_{3}\right)_{3} \mathrm{C}^{12} \mathrm{C}^{13} \mathrm{~N}^{14}$

$\left(\mathrm{C}^{13} \mathrm{H}_{3}\right)\left(\mathrm{C}^{12} \mathrm{H}_{3}\right)_{2} \mathrm{C}^{12} \mathrm{C}^{12} \mathrm{~N}^{14}$
4- $862 \quad 8,7,1 \leftarrow 8,7,2 \quad$ Ground

4- $922 \quad$ Not Reported

4- 724

$3,1,2 \leftarrow 2,1,1$

Ground

4- 741

$3,1,3 \leftarrow 2,1,2$

4- 723

$3,1,2 \leftarrow 2,1,1$

Excited

Ground

4- 922

Not Reported

4-1771

3- 472

$14,11 \leftarrow 14,11$

Ground

Not Reported

4-1183

$8,8,0 \leftarrow 8,7,1$

Ground

4. 741

$3,1,3 \leftarrow 2,1,2$

Excited

4-1184

3. 522

$3,2,2 \leftarrow 3,0,3$

Ground

$3,2,2 \leftarrow 2,2,1$

Ground

Not Reported

4. 772

Not Reported

Ground

4- 741

$3,1,3 \leftarrow 2,1,2$

Ground

4- 331

3- 142

$15,2,14 \leftarrow 14,3,11$

Ground

Ground

3- 142

$1,2,9 \leftarrow 11,2,10$

4. 122

$1,2,9 \leftarrow 11,2,10$

Ground

Ground

4. 122

4- 122

$3,2,1 \leftarrow 2,2,0$

$3,2,2 \leftarrow 2,2,1$

Ground

Ground

4. 122

$3,2,1 \leftarrow 2,2,0$

$3,2,1 \leftarrow 2,2,0$

Ground

4- 122

$3,2,2 \leftarrow 2,2,1$

Ground

4. 122

3- 142

$3,2,2 \leftarrow 2,2,1$

4. 331

3- 522

4. 314

$11,2,9 \leftarrow 11,2,10$

$15,2,14 \leftarrow 14,3,11$

$3,2,1 \leftarrow 2,2,0$

Not Reported

3- 522

3- 522

3. 366

4- 312

3- 261

3- 662

4- 741

4- 749

3- 366

$3,0,3 \leftarrow 2,0,2$

$3,0,3 \leftarrow 2,0,2$

$5,3,2 \leftarrow 5,2,3$

$2,1,2 \leftarrow 1,1,1$

Not Reported

$19, \quad \leftarrow 18$, ,

$3,1,3 \leftarrow 2,1,2$

Not Reported

4-1281

4-1772

$5,3,2 \leftarrow 5,2,3$

$12,3,9 \leftarrow 12,3,10$

$7,6 \leftarrow 7,6$

4-1204

4-1281

$9,7,3 \leftarrow 9,5,4$

$12,3,10 \leftarrow 12,3,11$

4. 772

3-1024

3-1023
Not Reported

$4,2 \leftarrow 3,2$

$4,1, \leftarrow 3,1$,
Ground

Ground

Ground

Ground

Ground

Ground

Ground

Ground

Ground

Ground

Ground

Ground

Ground

Ground

Ground

Ground

Ground

Ground

Ground

Ground
21805.9

.5

21807.

5.

$7 / 2 \quad 7 / 2 \quad 21807.1$

$5 / 2 \quad 5 / 2 \quad 21808.6$

$3 / 2 \quad 3 / 2 \quad 21816.4$

21817.

5.

21818.1

21819.28

21822.2

$\begin{array}{lll}9 / 2 & 7 / 2 & 21822.8\end{array}$

21825 .

$9 / 2 \quad 7 / 2 \quad 21828.23$

21828.32

21829.

$5 / 2 \quad 5 / 2 \quad 21829.7$

21834.20

.2

.1

$\begin{array}{llll}10 & & 21834.20 & .1 \\ 10 & 21834.41 & .10\end{array}$

$12 \quad 12 \quad 21834.41$

.10

$\begin{array}{llll}5 / 2 & 7 / 2 & 21835.19 & .25\end{array}$

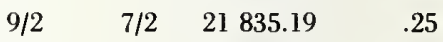

$\begin{array}{llll}7 / 2 & 7 / 2 & 21835.19 & .25\end{array}$

$\begin{array}{lllll}9 / 2 & 7 / 2 & 21835.19 & .25\end{array}$

$\begin{array}{llll}5 / 2 & 7 / 2 & 21835.19 & .25\end{array}$

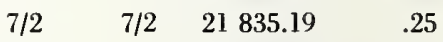

$11 \quad 11 \quad 21835.32$

.10

.1

$9 / 2 \quad 7 / 2 \quad 21837.10$

21839.

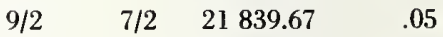

$7 / 2 \quad 5 / 2 \quad 21839.67 \quad .05$

$21840.5 \quad .2$

$21841.04 \quad .5$

21842.31

.04

21842.7

$9 / 2$

$7 / 2$

21844.3

21844.7

21844.75

21846.3

21846.41

21847.6

21848.

5.0

21849.

21850.

10.0

21850.

10.0 


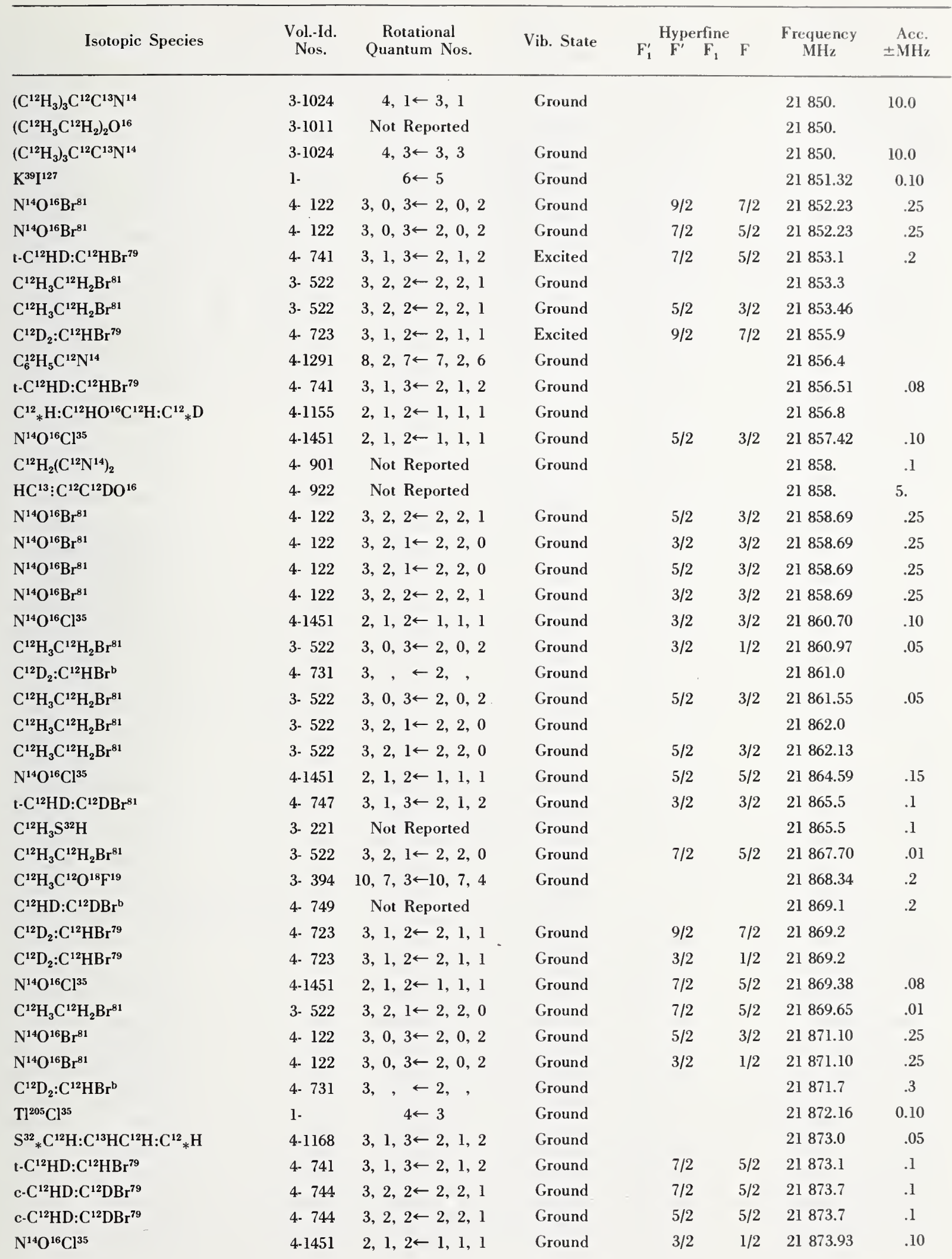




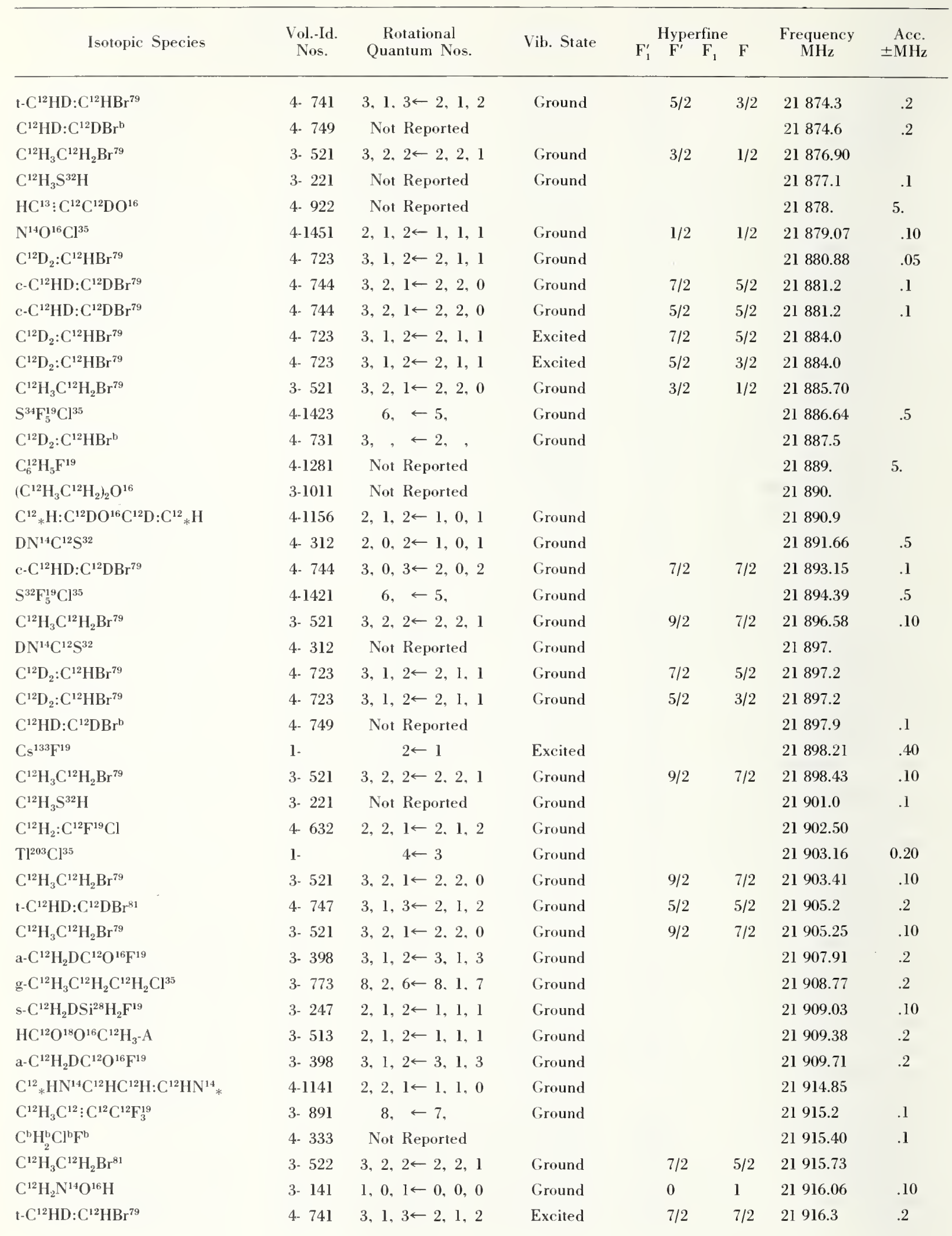


Vib. State

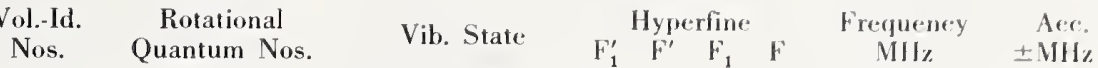

Frequeney

Aer:

$\mathrm{N}^{14} \mathrm{O}^{16} \mathrm{Br}^{81}$

$\mathrm{N}^{14} \mathrm{O}^{16} \mathrm{Br}^{81}$

$\mathrm{N}^{14} \mathrm{O}^{16} \mathrm{Br}^{81}$

$\mathrm{N}^{14} \mathrm{O}^{16} \mathrm{Br}^{81}$

$\mathrm{N}^{14} \mathrm{O}^{16} \mathrm{Br}^{81}$

$\mathrm{N}^{14} \mathrm{O}^{16} \mathrm{Br}^{81}$

t- $\mathrm{C}^{12} \mathrm{HD}: \mathrm{C}^{12} \mathrm{DBr}^{81}$

$\mathrm{C}^{12} \mathrm{H}_{2} \mathrm{~N}^{14} \mathrm{O}^{16} \mathrm{H}$

$\mathrm{C}^{12} \mathrm{H}_{2} \mathrm{~N}^{14} \mathrm{O}^{16} \mathrm{H}$

$\mathrm{H}_{2} \mathrm{C}^{12}: \mathrm{C}^{12} \mathrm{HCl}^{37}$

$\mathrm{C}^{12} \mathrm{D}_{3} \mathrm{C}^{12} \mathrm{DO}^{16}$

$\mathrm{HC}^{13}: \mathrm{C}^{12} \mathrm{C}^{12} \mathrm{DO}^{16}$

$\mathrm{C}^{12} \mathrm{H}_{3} \mathrm{Si}^{28} \mathrm{H}_{2} \mathrm{~F}^{19}$

$\mathrm{C}^{12} \mathrm{H}_{3} \mathrm{C}^{12} \mathrm{H}_{2} \mathrm{Br}^{81}$

$\mathrm{S}^{32} \mathrm{O}^{16} \mathrm{~F}_{2}^{19}$

$\mathrm{C}^{12} \mathrm{H}_{3} \mathrm{Si}^{28} \mathrm{H}_{2} \mathrm{~F}^{19}$

$\mathrm{C}^{12} \mathrm{D}_{3} \mathrm{C}^{12} \mathrm{DO}^{16}$

$\mathrm{C}^{12} \mathrm{HD}: \mathrm{C}^{12} \mathrm{DBr}^{\mathrm{b}}$

t-C $\mathrm{C}^{12} \mathrm{HD}: \mathrm{C}^{12} \mathrm{DBr}^{81}$

$\mathrm{C}^{12} \mathrm{H}_{3} \mathrm{~N}^{14} \mathrm{H}_{2}$

$\mathrm{H}_{2} \mathrm{C}^{12}: \mathrm{C}^{12} \mathrm{HCl}^{37}$

$\mathrm{C}^{12} \mathrm{HCl}^{37}: \mathrm{C}^{12} \mathrm{~F}_{2}^{19}$

$\mathrm{C}^{12} \mathrm{H}_{3} \mathrm{~N}^{14} \mathrm{H}_{2}$

$\mathrm{C}^{12} \mathrm{HCl}^{37}: \mathrm{C}^{12} \mathrm{~F}_{2}^{19}$

$\mathrm{C}_{6}^{12} \mathrm{H}_{5} \mathrm{C}^{12}: \mathrm{C}^{12} \mathrm{H}$

$\mathrm{C}_{6}^{12} \mathrm{H}_{5} \mathrm{C}^{12}: \mathrm{C}^{12} \mathrm{H}$

$\mathrm{H}_{2} \mathrm{~N}^{15} \mathrm{C}^{12} \mathrm{HO}^{16}$

$\mathrm{C}^{12} \mathrm{H}_{2} \mathrm{~F}_{2}^{19}$

$\mathrm{C}^{12} \mathrm{H}_{2} \mathrm{~F}_{2}^{19}$

t-C ${ }^{12} \mathrm{HD}: \mathrm{C}^{12} \mathrm{HBr}^{79}$

$\mathrm{C}^{12} \mathrm{H}_{2} \mathrm{~N}^{14} \mathrm{O}^{16} \mathrm{H}$

$\mathrm{C}^{12} \mathrm{~F}_{3}^{19} \mathrm{C}^{12} \mathrm{O}^{16} \mathrm{O}^{16} \mathrm{H} \cdot \mathrm{HC}^{12} \mathrm{O}^{16} \mathrm{O}^{16} \mathrm{H}$

$\mathrm{K}_{2} \mathrm{C}^{12}: \mathrm{C}^{12} \mathrm{HCl}^{37}$

$\mathrm{C}^{12} \mathrm{H}_{2} \mathrm{~N}^{14} \mathrm{O}^{16} \mathrm{H}$

$\mathrm{C}^{12} \mathrm{H}_{2} \mathrm{~N}^{14} \mathrm{O}^{16} \mathrm{H}$

t- $\mathrm{C}^{12} \mathrm{HD}: \mathrm{C}^{12} \mathrm{DBr}^{81}$

a- $\mathrm{C}^{12} \mathrm{H}_{2} \mathrm{DS}^{32} \mathrm{C}^{12} \mathrm{H}_{3}$

t-C ${ }^{12} \mathrm{HD}: \mathrm{C}^{12} \mathrm{DBr}^{81}$

$\left(\mathrm{C}^{12} \mathrm{H}_{3}\right)_{2} \mathrm{C}^{12}: \mathrm{C}^{13} \mathrm{H}_{2}$

$\mathrm{C}^{12} \mathrm{H}_{3} \mathrm{~S}^{32} \mathrm{H}$

$\mathrm{C}^{\mathrm{b}}{ }_{*} \mathrm{H}_{2}^{\mathrm{b}} \mathrm{N}^{\mathrm{b}} \mathrm{H}^{\mathrm{b}} \mathrm{C}^{\mathrm{b}}{ }_{*} \mathrm{H}_{2}^{\mathrm{b}}$

$\mathrm{C}_{6}^{12} \mathrm{H}_{5} \mathrm{C}^{12}: \mathrm{C}^{12} \mathrm{H}$

$\mathrm{C}_{6}^{12} \mathrm{H}_{5} \mathrm{C}^{12}: \mathrm{C}^{12} \mathrm{H}$

s- $\mathrm{C}^{12} \mathrm{H}_{2} \mathrm{DS}^{32} \mathrm{C}^{12} \mathrm{H}_{3}$

$\mathrm{C}^{12} \mathrm{D}_{2} \mathrm{Cl}^{35} \mathrm{Cl}^{37}$
4- $122 \quad 3,2,2 \leftarrow 2,2,1$

4. $122 \quad 3,2,1 \leftarrow 2,2,0$

Ground

4- 122

$3,2,2 \leftarrow 2,2,1$

4- 122

$3,2,2 \leftarrow 2,2,1$

4- 122

$3,2,1 \leftarrow 2,2,0$

4. 122

$3,2,1 \leftarrow 2,2,0$

4- 747

$3,1,3 \leftarrow 2,1,2$

3- 141

$1,0,1 \leftarrow 0,0,0$

3- 141

$1,0,1 \leftarrow 0,0,0$

4- 767

$2,1,2 \leftarrow 1,1,1$

3- 472

$6,1,5 \leftarrow 6,1,6$

4. 922

Not Reported

3- 241

Not Reported

3- $522 \quad 3,2,1 \leftarrow 2,2,0$

4-1621

$13,10,3 \leftarrow 13,10,4$

3. 241

Not Reported

3- 472

$6,1,5 \leftarrow 6,1,6$

4. 749

Not Reported

4- 747

$3,1,3 \leftarrow 2,1,2$

3- 261

$6,1, \leftarrow 5,2$,

4- 767

$2,1,2 \leftarrow 1,1,1$

4- 612

$8,2,6 \leftarrow 8,1,7$

3- 261

$6,1, \leftarrow 5,2$,

4- 612

$8,2,6 \leftarrow 8,1,7$

3-1091

$8,7,1 \leftarrow 7,7,0$

3-1091

$8,7,2 \leftarrow 7,7,1$

3- 156

$7,1,6 \leftarrow 6,2,5$

4- 351

$46,11,36 \leftarrow 45,12,33$

4. 351

$46,11,35 \leftarrow 45,12,34$

4. 741

$3,1,3 \leftarrow 2,1,2$

3- 141

$1,0,1 \leftarrow 0,0,0$

3. 661

19, $\leftarrow 18$, ,

4- 767

$2,1,2 \leftarrow 1,1,1$.

3- 141

$1,0,1 \leftarrow 0,0,0$

3- 141

$1,0,1 \leftarrow 0,0,0$

4. 747

$3,1,3 \leftarrow 2,1,2$

3- 605

$4,1,3 \leftarrow 4,0,4$

4. 747

$3,1,3 \leftarrow 2,1,2$

3- 946

$2,0,2 \leftarrow 1,1,1$

3- 221

Not Reported

4. 863

Not Reported

3-1091

$8,6,3 \leftarrow 7,6,2$

3-1091

$8,6,2 \leftarrow 7,6,1$

3- 604

$4,1,3 \leftarrow 4,0,4$

4. 347

$4,1,3 \leftarrow 4,0,4$
Ground

Ground

Ground

Ground

Ground

Ground

Ground

Ground

Ground

Ground

Ground

Ground

Ground

Ground

Ground

Ground

Ground

Ground

Ground

Ground

Ground

Ground

Ground

Ground

Ground

Ground

Ground

Ground

Ground

Ground

Ground

Ground

Ground

Ground

Ground

Ground

Ground

Ground

Ground $\begin{array}{llll}5 / 2 & 5 / 2 & 21916.77 & .25\end{array}$

$\begin{array}{llll}7 / 2 & 5 / 2 & 21916.77 & .25\end{array}$

$\begin{array}{llll}7 / 2 & 5 / 2 & 21916.77 & .25\end{array}$

$\begin{array}{llll}3 / 2 & 5 / 2 & 21916.77 & .25\end{array}$

$\begin{array}{llll}5 / 2 & 5 / 2 & 219] 6.77 & .25\end{array}$

$\begin{array}{llll}3 / 2 & 5 / 2 & 21916.77 & .25\end{array}$

$9 / 2 \quad 7 / 2 \quad 21917.0 \quad$.

$\begin{array}{llll}2 & \mathrm{I} & 21917.40 & .10\end{array}$

$\begin{array}{llll}1 & \text { l } & 21918.33 & .10\end{array}$

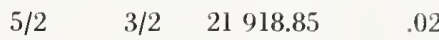

$21919.74 \quad .3$

21921.5.

$21923.25 \quad$.1

$7 / 2 \quad 5 / 2 \quad 21924.14$

$21924.71 \quad$.1

21924.75 .1

$21926.40 \quad .2$

$21926.8 \quad .2$

$21927.64 \quad .04$

$21930.00 \quad 1$

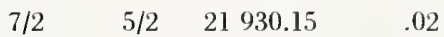

$21931.0 \quad$.1

$21931.48 \quad .1$

$21932.0 \quad .1$

$21933.8 \quad .5$

$21933.8 \quad .5$

21933.95

$21934.33 \quad .10$

$21934.33 \quad .10$

$\begin{array}{llll}7 / 2 & 7 / 2 & 21937.15 & .05\end{array}$

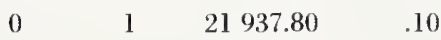

21938.5

$\begin{array}{llll}1 / 2 & 1 / 2 & 21938.65 & .02\end{array}$

$\begin{array}{lllll}2 & 1 & 21939.17 & .10\end{array}$

$\begin{array}{llll}1 & 1 & 21940.06 & .10\end{array}$

$7 / 2 \quad 5 / 2 \quad 21941.1 \quad$.1

$21942.79 \quad .05$

$5 / 2 \quad 3 / 2 \quad 21943.0 \quad .1$

21943.47

$21943.5 \quad .1$

$21945.5 \quad$.5

$21945.9 \quad$.5

$21945.9 \quad 5$

$21947.29 \quad .05$

$21948 . \quad 5$. 
Vib. State $\mathrm{F}_{1}^{\prime} \stackrel{\text { Hyperfine }}{\mathrm{F}^{\prime}} \underset{\mathrm{F}_{1}}{\mathrm{~F}} \mathrm{~F}$

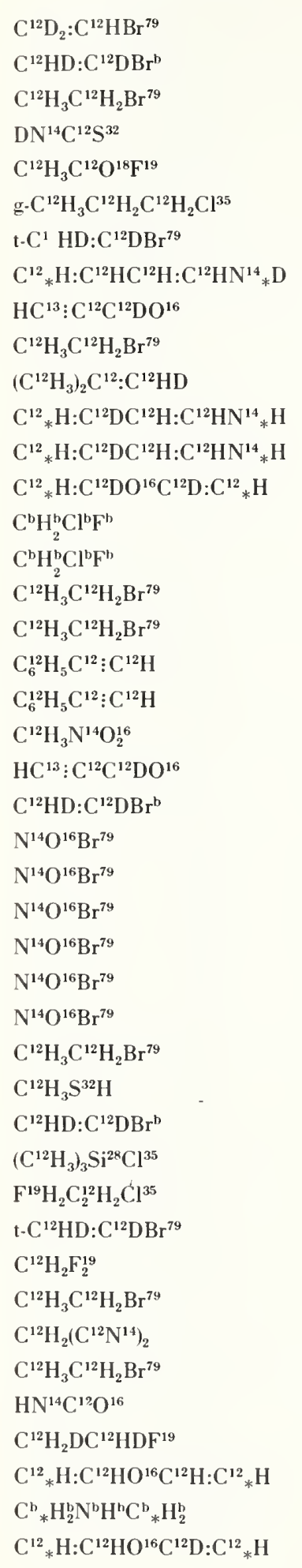

$\begin{array}{lcc}\text { 4- } 723 & 3,1,2 \leftarrow 2,1,1 & \text { Ground } \\ \text { 4- } 749 & \text { Not Reported } & \\ \text { 3- } 521 & 3,2,2 \leftarrow 2,2,1 & \text { Ground } \\ \text { 4- } 312 & 2,1,1 \leftarrow 1,1,0 & \text { Ground } \\ \text { 3- } 394 & 10,7,3 \leftarrow 10,7,4 & \text { Ground } \\ \text { 3- } 773 & 9,2,7 \leftarrow 9,1,8 & \text { Ground } \\ \text { 4- } 745 & 3,1,3 \leftarrow 2,1,2 & \text { Excited } \\ \text { 4-1182 } & 3,2,2 \leftarrow 3,0,3 & \text { Ground }\end{array}$

4- $922 \quad$ Not Reported

3- $521 \quad 3,2,1 \leftarrow 2,2,0$

3. 944

$2,1,2 \leftarrow 1,0,1$

4-1184

$2,0,2 \leftarrow 1,0,1$

4-1184

4-1156

4- 333

Not Reported

4- 333

$4,3,2 \leftarrow 4,2,3$

Not Reported

3. 521

Not Reported

3- 521

$3,0,3 \leftarrow 2,0,2$

3-1091

$3,0,3 \leftarrow 2,0,2$

$8,5,3 \leftarrow 7,5,2$

3-1091

$8,5,4 \leftarrow 7,5,3$

3- 171

Not Reported

4. 922

4- 749

Not Reported

4- 121

Not Reported

4- 121

$3,2,1 \leftarrow 2,2,0$

4- 121

4- 121

$3,2,1 \leftarrow 2,2,0$

$3,2,2 \leftarrow 2,2,1$

$3,2,2 \leftarrow 2,2,1$

4. 121

$3,2,2 \leftarrow 2,2,1$

4. 121

$3,2,1 \leftarrow 2,2,0$

3. 521

3. 221

$3,0,3 \leftarrow 2,0,2$

$9,2, \leftarrow 10,1$,

4. 749

Not Reported

3- 821

3- 441

4. 745

$5, \leftarrow 4$,

$5,0,5 \leftarrow 4,1,4$

$3,1,3 \leftarrow 2,1,2$

4- 351

$9,1,9 \leftarrow 8,2,6$

3. 521

4. 901

$3,2,2 \leftarrow 2,2,1$

3. 521

Not Reported

4- 301

$3,2,2 \leftarrow 2,2,1$

$1,0,1 \leftarrow 0,0,0$

3. 557

$2,1,1 \leftarrow 2,0,2$

4.1151

4. 863

$9,7,2 \leftarrow 9,7,3$

4-1154
Not Reported

$2,0,2 \leftarrow 1,1,1$
Ground

Ground

Ground

Ground

Ground

Ground

Ground

Ground

Ground

Ground

Ground

Ground

Ground

Ground

Ground

Ground

Ground

Ground

Ground

Ground

Ground

Ground

Ground

Ground

Ground

Ground

Ground

Ground

$\begin{array}{llll}7 / 2 & 7 / 2 & 21949.4 & \\ & & 21950.6 & .2 \\ 9 / 2 & 7 / 2 & 21951.20 & \\ & & 21951.82 & .5 \\ & & 21952.95 & .2 \\ & & 21953.55 & .2 \\ 3 / 2 & 3 / 2 & 21955.7 & .2 \\ & & 21957.1 & \\ & & 21958 . & 5 .\end{array}$

$9 / 2 \quad 7 / 2 \quad 21959.77$

21961.51

21964.5

21965.

21965.1

21965.24

21966.23

$9 / 2 \quad 7 / 2 \quad 21966.25$

$7 / 2 \quad 5 / 2 \quad 21966.25$

21966.7

21966.7

21970.

21970.

5.

21971.3

.2

$\begin{array}{lllll}9 / 2 & 7 / 2 & 21 & 972.29 & .25\end{array}$

$\begin{array}{llll}5 / 2 & 7 / 2 & 21972.29 & .25\end{array}$

$\begin{array}{lllll}9 / 2 & 7 / 2 & 21 & 972.29 & .25\end{array}$

$5 / 2 \quad 7 / 2 \quad 21972.29 \quad .25$

$7 / 2 \quad 7 / 2 \quad 21972.29 \quad .25$

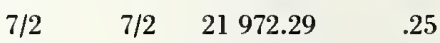

21972.6

21973.2

21973.7

$21974.00 \quad .3$

$21979.4 \quad .1$

$3 / 2$

$3 / 2$

21979.8

21980.68

21981.1

21981.2

$5 / 2$

$3 / 2$

21981.20

21981.7

21984.1

21984.30

21985.

10.
Acc. $\mathrm{MHz}$ 


\begin{tabular}{|c|c|c|c|c|c|c|c|}
\hline Isotopic Species & $\begin{array}{l}\text { Vol.-Id. } \\
\text { Nos. }\end{array}$ & $\begin{array}{c}\text { Rotational } \\
\text { Quantum Nos. }\end{array}$ & Vib. State & \begin{tabular}{c}
\multicolumn{2}{c}{ Hyperfine } \\
$\mathrm{F}_{1}^{\prime} \quad \mathrm{F}^{\prime} \quad \mathrm{F}_{1}$
\end{tabular} & $\mathrm{~F}$ & $\begin{array}{l}\text { Frequency } \\
\mathrm{MHz}\end{array}$ & $\begin{aligned} & \text { Acc. } \\
& \mathrm{MHz}\end{aligned}$ \\
\hline $\mathrm{C}^{12} \mathrm{H}_{3} \mathrm{Si}^{\mathrm{b}} \mathrm{H}_{2} \mathrm{D}$ & 3. 325 & $10,1,9 \leftarrow 10,1,10$ & & & & 21986.66 & \\
\hline $\mathrm{HC}^{13}: \mathrm{C}^{12} \mathrm{C}^{12} \mathrm{DO}^{16}$ & 4. 922 & I ot Reported & & & & 21987. & 5. \\
\hline g. $\mathrm{C}^{12} \mathrm{H}_{3} \mathrm{C}^{12} \mathrm{H}_{2} \mathrm{C}^{12} \mathrm{H}_{2} \mathrm{Cl}^{37}$ & 3. 774 & $9,2,7 \leftarrow 9,1,8$ & Ground & & & 21987.43 & .2 \\
\hline $\mathrm{C}^{12} \mathrm{H}_{2}: \mathrm{C}^{12} \mathrm{DBr}^{\mathrm{b}}$ & 4- 729 & $3, \quad, \quad \leftarrow 2, \quad$, & Ground & & & 21989.0 & \\
\hline $\mathrm{C}^{12} \mathrm{H}_{3} \mathrm{C}^{12} \mathrm{H}_{2} \mathrm{Br}^{79}$ & 3. 521 & $3,2,1 \leftarrow 2,2,0$ & Ground & & & 21989.7 & \\
\hline $\mathrm{C}^{12} \mathrm{H}_{3} \mathrm{C}^{12} \mathrm{H}_{2} \mathrm{Br}^{79}$ & 3- 521 & $3,2,1 \leftarrow 2,2,0$ & Ground & $5 / 2$ & $3 / 2$ & 21990.15 & \\
\hline $\mathrm{C}^{\mathrm{b}}{ }_{*} \mathrm{H}_{2}^{\mathrm{b}} \mathrm{N}^{\mathrm{b}} \mathrm{H}^{\mathrm{b}} \mathrm{C}^{\mathrm{b}}{ }_{*} \mathrm{H}_{2}^{\mathrm{b}}$ & 4- 863 & Not Reported & & & & 21991.0 & .5 \\
\hline $\mathrm{C}^{12} \mathrm{H}_{3} \mathrm{C}^{12} \mathrm{H}_{2} \mathrm{Br}^{79}$ & 3. 521 & $3,0,3 \leftarrow 2,0,2$ & Ground & $3 / 2$ & $1 / 2$ & 21991.60 & .05 \\
\hline $\mathrm{C}^{12} \mathrm{H}_{3} \mathrm{C}^{12} \mathrm{H}_{2} \mathrm{Br}^{79}$ & 3- 521 & $3,0,3 \leftarrow 2,0,2$ & Ground & $5 / 2$ & $3 / 2$ & 21992.44 & .05 \\
\hline $\mathrm{HN}^{14} \mathrm{C}^{12} \mathrm{O}^{16}$ & 4- 301 & $1,0,1 \leftarrow 0,0,0$ & Excited & & & 21993.0 & .02 \\
\hline $\mathrm{N}^{14} \mathrm{O}^{16} \mathrm{Br}^{79}$ & 4. 121 & $3,0,3 \leftarrow 2,0,2$ & Ground & $9 / 2$ & $7 / 2$ & 21993.86 & .25 \\
\hline $\mathrm{N}^{14} \mathrm{O}^{16} \mathrm{Br}^{79}$ & 4- ' 121 & $3,0,3 \leftarrow 2,0,2$ & Ground & $7 / 2$ & $5 / 2$ & 21993.86 & .25 \\
\hline 1- $\mathrm{C}^{12} \mathrm{HD}: \mathrm{C}^{12} \mathrm{DBr}^{81}$ & 4- 747 & $3,1,3 \leftarrow 2,1,2$ & Ground & $7 / 2$ & $7 / 2$ & 21994.6 & .1 \\
\hline g- $\mathrm{C}^{12} \mathrm{H}_{3} \mathrm{C}^{12} \mathrm{H}_{2} \mathrm{C}^{12} \mathrm{H}_{2} \mathrm{Cl}^{37}$ & 3. 774 & $8,2,6 \leftarrow 8,1,7$ & Ground & & & 21996.93 & .2 \\
\hline $\mathrm{C}_{6}^{12} \mathrm{H}_{5} \mathrm{~F}^{19}$ & $4-1281$ & $5,4,2 \leftarrow 4,4,1$ & Ground & & & 21997.3 & .1 \\
\hline $\mathrm{HC}^{13}: \mathrm{C}^{12} \mathrm{C}^{12} \mathrm{DO}^{16}$ & 4- 922 & Not Reported & & & & 21998. & 5. \\
\hline$\left(\mathrm{C}^{12} \mathrm{H}_{3}\right)_{3} \mathrm{C}^{12} \mathrm{C}^{12} \mathrm{~N}^{14}$ & $3-1021$ & $4,3 \leftarrow 3,3$ & Ground & & & 21999.8 & .2 \\
\hline$\left(\mathrm{C}^{12} \mathrm{H}_{3}\right)_{3} \mathrm{C}^{12} \mathrm{C}^{12} \mathrm{~N}^{14}$ & 3-1021 & $4,1 \leftarrow 3,1$ & Ground & & & 21999.8 & .2 \\
\hline$\left(\mathrm{C}^{12} \mathrm{H}_{3}\right)_{3} \mathrm{C}^{12} \mathrm{C}^{12} \mathrm{~N}^{14}$ & $3-1021$ & $4,2 \leftarrow 3,2$ & Ground & & & 21999.8 & .2 \\
\hline $\mathrm{N}^{\mathrm{b}} \mathrm{O}_{2}^{\mathrm{b}} \mathrm{Cl}$ & $4-1463$ & Not Reported & & & & 22000. & \\
\hline $\mathrm{C}^{12} \mathrm{H}_{3} \mathrm{C}^{12} \mathrm{H}_{2} \mathrm{Br}^{79}$ & 3- 521 & $3,2,2 \leftarrow 2,2,1$ & Ground & $7 / 2$ & $5 / 2$ & 22001.05 & .10 \\
\hline $\mathrm{N}^{14} \mathrm{O}^{16} \mathrm{Br}^{79}$ & 4- 121 & $3,2,1 \leftarrow 2,2,0$ & Ground & $5 / 2$ & $3 / 2$ & 22001.07 & .25 \\
\hline $\mathrm{N}^{14} \mathrm{O}^{16} \mathrm{Br}^{79}$ & 4- 121 & $3,2,2 \leftarrow 2,2,1$ & Ground & $3 / 2$ & $3 / 2$ & 22001.07 & .25 \\
\hline $\mathrm{N}^{14} \mathrm{O}^{16} \mathrm{Br}^{79}$ & 4- 121 & $3,2,2 \leftarrow^{\circ} 2,2,1$ & Ground & $5 / 2$ & $3 / 2$ & 22001.07 & .25 \\
\hline $\mathrm{N}^{14} \mathrm{O}^{16} \mathrm{Br}^{79}$ & 4- 121 & $3,2,1 \leftarrow 2,2,0$ & Ground & $3 / 2$ & $3 / 2$ & 22001.07 & .25 \\
\hline $\mathrm{C}^{12} \mathrm{HD}_{2} \mathrm{C}^{12} \mathrm{HDF}^{19}$ & 3- 558 & $6,1,5 \leftarrow 6,1,6$ & Ground & & & 22001.9 & .1 \\
\hline $\mathrm{C}^{12} \mathrm{H}_{3} \mathrm{C}^{12} \mathrm{H}_{2} \mathrm{Br}^{79}$ & 3. 521 & $3,2,2 \leftarrow 2,2,1$ & Ground & $7 / 2$ & $5 / 2$ & 22002.99 & .01 \\
\hline $\mathrm{C}_{6}^{12} \mathrm{H}_{5} \mathrm{C}^{12}: \mathrm{C}^{12} \mathrm{H}$ & 3-1091 & $8,4,5 \leftarrow 7,4,4$ & Ground & & & 22003.4 & .5 \\
\hline $\mathrm{t}-\mathrm{C}^{12} \mathrm{HD}: \mathrm{C}^{12} \mathrm{DBr}^{79}$ & 4- 745 & $3,1,3 \leftarrow 2,1,2$ & Excited & $5 / 2$ & $5 / 2$ & 22003.4 & .2 \\
\hline $\mathrm{C}_{6}^{12} \mathrm{H}_{5} \mathrm{~F}^{19}$ & $4-1281$ & $5,4,1 \leftarrow 4,4,0$ & Ground & & & 22006.1 & .1 \\
\hline $\mathrm{C}^{12} \mathrm{HD}: \mathrm{C}^{12} \mathrm{DBr}^{\mathrm{b}}$ & 4. 749 & Not Reported & & & & 22007.2 & .2 \\
\hline $\mathrm{C}^{12} \mathrm{H}_{3} \mathrm{C}^{12} \mathrm{H}_{2} \mathrm{Br}^{79}$ & 3. 521 & $3,2,1 \leftarrow 2,2,0$ & Ground & $7 / 2$ & $5 / 2$ & 22007.57 & .10 \\
\hline $\mathrm{C}_{6}^{12} \mathrm{H}_{5} \mathrm{C}^{12}: \mathrm{C}^{12} \mathrm{H}$ & 3-1091 & $8,4,4 \leftarrow 7,4,3$ & Ground & & & 22009.5 & .5 \\
\hline $\mathrm{C}^{12} \mathrm{H}_{3} \mathrm{C}^{12} \mathrm{H}_{2} \mathrm{Br}^{79}$ & 3. 521 & $3,2,1 \leftarrow 2,2,0$ & Ground & $7 / 2$ & $5 / 2$ & 22009.50 & .10 \\
\hline $\mathrm{t}-\mathrm{HDC}^{12}: \mathrm{C}^{12} \mathrm{DCC}^{37}$ & 4- 764 & $2,1,1 \leftarrow 1,1,0$ & Ground & & & 22009.90 & \\
\hline $\mathrm{C}^{12}{ }_{*} \mathrm{H}: \mathrm{C}^{12} \mathrm{DC}^{12} \mathrm{H}: \mathrm{C}^{12} \mathrm{HN}^{14}{ }_{*} \mathrm{H}$ & $4-1184$ & $10,7,3 \leftarrow 10,7,4$ & Ground & & & 22010.1 & \\
\hline $\mathrm{C}^{12} \mathrm{H}_{2}: \mathrm{C}^{12} \mathrm{DBr}^{\mathrm{b}}$ & 4- 729 & $3, \quad \leftarrow 2, \quad$, & Ground & & & 22010.5 & \\
\hline $\mathrm{DC}^{12} \mathrm{O}^{16} \mathrm{O}^{16} \mathrm{H}$ & 3- 73 & $1,0,1 \leftarrow 0,0,0$ & Ground & & & 22011.3 & .3 \\
\hline$\left(\mathrm{C}^{12} \mathrm{H}_{3} \mathrm{C}^{12} \mathrm{H}_{2}\right)_{2} \mathrm{O}^{16}$ & 3-1011 & Not Reported & & & & 22015 & \\
\hline $\mathrm{t}-\mathrm{C}^{12} \mathrm{HD}: \mathrm{C}^{12} \mathrm{HBr}^{81}$ & 4- 743 & $3,2,2 \leftarrow 2,2,1$ & Ground & $3 / 2$ & $1 / 2$ & 22015.5 & .1 \\
\hline $\mathrm{C}^{12} \mathrm{H}_{3} \mathrm{C}^{13} \mathrm{H}_{2} \mathrm{Br}^{81}$ & 3. 529 & $3,1,2 \leftarrow 2,1,1$ & Ground & $3 / 2$ & $1 / 2$ & 22016.12 & .05 \\
\hline $\mathrm{N}^{14} \mathrm{O}^{16} \mathrm{Br}^{79}$ & 4. 121 & $3,0,3 \leftarrow 2,0,2$ & Ground & $5 / 2$ & $3 / 2$ & 22016.97 & .25 \\
\hline $\mathrm{N}^{14} \mathrm{O}^{16} \mathrm{Br}^{79}$ & 4- 121 & $3,0,3 \leftarrow 2,0,2$ & Ground & $3 / 2$ & $1 / 2$ & 22016.97 & .25 \\
\hline t. $\mathrm{C}^{12} \mathrm{HD}: \mathrm{C}^{12} \mathrm{DBr}^{79}$ & 4- 745 & $3,1,3 \leftarrow 2,1,2$ & Excited & $9 / 2$ & $7 / 2$ & 22017.3 & .1 \\
\hline
\end{tabular}




\begin{tabular}{|c|c|c|c|c|c|c|c|}
\hline Isotopic Species & $\begin{array}{l}\text { Vol.-Id. } \\
\text { Nos. }\end{array}$ & $\begin{array}{c}\text { Rotational } \\
\text { Quantum Nos. }\end{array}$ & Vib. State & 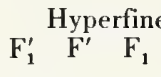 & $\mathrm{e} F$ & $\begin{array}{l}\text { Frequency } \\
\text { MHz }\end{array}$ & $\begin{aligned} \text { Acc. } \\
\pm \mathrm{MHz}\end{aligned}$ \\
\hline $\mathrm{HN}^{14} \mathrm{C}^{12} \mathrm{O}^{16}$ & 4- 301 & $1,0,1 \leftarrow 0,0,0$ & Excited & & & 22017.3 & .02 \\
\hline $\mathrm{C}^{12} \mathrm{H}_{3} \mathrm{C}^{13} \mathrm{H}_{2} \mathrm{Br}^{81}$ & 3- 529 & $3,1,2 \leftarrow 2,1,1$ & Ground & $9 / 2$ & $7 / 2$ & 22017.62 & .05 \\
\hline $\mathrm{t}-\mathrm{C}^{12} \mathrm{HD}: \mathrm{C}^{12} \mathrm{HBr}^{81}$ & 4. 743 & $3,2,1 \leftarrow 2,2,0$ & Ground & $3 / 2$ & $1 / 2$ & 22018.5 & .1 \\
\hline $4 \mathrm{~d} \cdot \mathrm{C}_{6}^{12} \mathrm{H}_{5} \mathrm{~F}^{19}$ & $4-1283$ & $10,2,8 \leftarrow 10,2,9$ & Ground & & & 22018.5 & .1 \\
\hline $\mathrm{Si}^{28} \mathrm{D}_{3} \mathrm{C}^{12} \mathrm{H}: \mathrm{C}^{12} \mathrm{H}_{2}$ & 3. 612 & $4,1,3 \leftarrow 4,0,4$ & Ground & & & 22020.31 & .05 \\
\hline $\mathrm{C}^{12} \mathrm{H}_{2} \mathrm{~N}^{14} \mathrm{O}^{16} \mathrm{H}$ & 3- 141 & $10,3,8 \leftarrow 11,2,9$ & Ground & 10 & 11 & 22021.47 & .10 \\
\hline $\mathrm{t}-\mathrm{HDC}^{12}: \mathrm{C}^{12} \mathrm{DCl}^{37}$ & 4- 764 & $2,1,1 \leftarrow 1,1,0$ & Ground & $7 / 2$ & $5 / 2$ & 22021.70 & .2 \\
\hline $\mathrm{C}^{12} \mathrm{H}_{2} \mathrm{~N}^{14} \mathrm{O}^{16} \mathrm{H}$ & 3. 141 & $10,3,8 \leftarrow 11,2,9$ & Ground & 11 & 12 & 22022.37 & .10 \\
\hline $\mathrm{C}^{12} \mathrm{H}_{2} \mathrm{~N}^{14} \mathrm{O}^{16} \mathrm{H}$ & 3- 141 & $10,3,8 \leftarrow 11,2,9$ & Ground & 9 & 10 & 22022.37 & .10 \\
\hline $\mathrm{C}_{6}^{12} \mathrm{H}_{5} \mathrm{C}^{12}: \mathrm{C}^{12} \mathrm{H}$ & $3-1091$ & $8,3,6 \leftarrow 7,3,5$ & Ground & & & 22023.6 & .5 \\
\hline $\mathrm{C}^{12} \mathrm{H}_{3} \mathrm{C}^{12} \mathrm{D}_{2} \mathrm{Br}^{81}$ & 3- 526 & $5,1,4 \leftarrow 5,0,5$ & Ground & $11 / 2$ & $11 / 2$ & 22024.46 & .05 \\
\hline $\mathrm{C}^{\mathrm{b}}{ }_{*} \mathrm{H}_{2}^{\mathrm{b}} \mathrm{N}^{\mathrm{b}} \mathrm{H}^{\mathrm{b}} \mathrm{C}^{\mathrm{b}}{ }_{*} \mathrm{H}_{2}^{\mathrm{b}}$ & 4. 863 & Not Reported & & & & 22025. & 10. \\
\hline $\mathrm{t}-\mathrm{C}^{12} \mathrm{HD}: \mathrm{C}^{12} \mathrm{DBr}^{79}$ & 4. 745 & $3,1,3 \leftarrow 2,1,2$ & Ground & $5 / 2$ & $5 / 2$ & 22027.3 & .1 \\
\hline $\mathrm{C}^{12} \mathrm{D}_{3} \mathrm{C}^{12} \mathrm{O}^{16} \mathrm{Cl}^{35}$ & 3. 363 & $7,2,5 \leftarrow 7,1,6$ & Ground & $11 / 2$ & $11 / 2$ & 22027.80 & \\
\hline $\mathrm{C}^{12} \mathrm{D}_{3} \mathrm{C}^{12} \mathrm{O}^{16} \mathrm{Cl}^{35}$ & 3. 363 & $7,2,5 \leftarrow 7,1,6$ & Ground & $17 / 2$ & $17 / 2$ & 22027.80 & \\
\hline $\mathrm{C}_{6}^{12} \mathrm{H}_{5} \mathrm{~F}^{19}$ & $4-1281$ & $5,3,3 \leftarrow 4,3,2$ & Ground & & & 22028.8 & .1 \\
\hline $\mathrm{C}^{12} \mathrm{D}_{3} \mathrm{C}^{12} \mathrm{O}^{16} \mathrm{Cl}^{35}$ & 3- 363 & $7,2,5 \leftarrow 7,1,6$ & Ground & $13 / 2$ & $13 / 2$ & 22028.93 & \\
\hline $\mathrm{C}^{12} \mathrm{D}_{3} \mathrm{C}^{12} \mathrm{O}^{16} \mathrm{Cl}^{35}$ & 3- 363 & $7,2,5 \leftarrow 7,1,6$ & Ground & $15 / 2$ & $15 / 2$ & 22028.93 & \\
\hline $\mathrm{C}^{12} \mathrm{DHDC}^{12} \mathrm{HDF}^{19}$ & 3. 561 & $2,1,1 \leftarrow 2,0,2$ & Ground & & & 22029.5 & .1 \\
\hline $\mathrm{C}^{12} \mathrm{D}_{2} \mathrm{Cl}_{2}^{35}$ & 4. 346 & $4,1,3 \leftarrow 4,0,4$ & Ground & & & 22030. & 5. \\
\hline t. $\mathrm{C}^{12} \mathrm{HD}: \mathrm{C}^{12} \mathrm{HBr}^{81}$ & 4- 743 & $3,0,3 \leftarrow 2,0,2$ & Ground & $3 / 2$ & $3 / 2$ & 22030.2 & .2 \\
\hline $\mathrm{S}^{32} \mathrm{O}^{16} \mathrm{~F}_{2}^{19}$ & $4-1621$ & Not Reported & & & & 22030.52 & .1 \\
\hline $\mathrm{C}^{12} \mathrm{H}_{3} \mathrm{C}^{12} \mathrm{D}_{2} \mathrm{Br}^{81}$ & 3- 526 & $5,1,4 \leftarrow 5,0,5$ & Ground & $9 / 2$ & $9 / 2$ & 22030.70 & .05 \\
\hline $\mathrm{S}^{32}{ }_{*} \mathrm{HC}^{13}: \mathrm{C}^{12} \mathrm{HC}^{12} \mathrm{H}: \mathrm{C}^{12}{ }_{*} \mathrm{H}$ & $4-1167$ & $3,1,3 \leftarrow 2,1,2$ & Ground & & & 22031.6 & .05 \\
\hline $\mathrm{C}^{12}{ }_{*} \mathrm{D}: \mathrm{C}^{12} \mathrm{HC}^{12} \mathrm{H}: \mathrm{C}^{12} \mathrm{HN}^{14}{ }_{*} \mathrm{H}$ & $4-1183$ & $2,1,2 \leftarrow 1,0,1$ & Ground & & & 22033.1 & \\
\hline $\mathrm{S}^{32} \mathrm{O}^{16} \mathrm{~F}_{2}^{19}$ & $4 \cdot 1621$ & Not Reported & & & & 22034.25 & .1 \\
\hline $\mathrm{S}^{32}{ }_{*} \mathrm{DC}^{12}: \mathrm{C}^{12} \mathrm{HC}^{12} \mathrm{H}: \mathrm{C}^{12}{ }_{*} \mathrm{H}$ & $4-1162$ & $7,3,5 \leftarrow 7,3,4$ & Ground & & & 22034.3 & .1 \\
\hline $\mathrm{C}^{12} \mathrm{H}_{3} \mathrm{C}^{12} \mathrm{D}_{2} \mathrm{Br}^{79}$ & 3- 524 & $5,1,4 \leftarrow 5,0,5$ & Ground & $11 / 2$ & $11 / 2$ & 22035.23 & .05 \\
\hline $\mathrm{C}^{12} \mathrm{H}_{3} \mathrm{C}^{13} \mathrm{H}_{2} \mathrm{Br}^{81}$ & 3. 529 & $3,1,2 \leftarrow 2,1,1$ & Ground & $5 / 2$ & $3 / 2$ & 22035.68 & .05 \\
\hline $\mathrm{C}^{12}{ }_{*} \mathrm{H}_{2} \mathrm{C}^{12} \mathrm{H}_{2} \mathrm{C}^{12}{ }_{*} \mathrm{HCl}^{37}$ & $4-1082$ & $3,0,3 \leftarrow 2,0,2$ & Ground & $9 / 2$ & $7 / 2$ & 22036.2 & .1 \\
\hline $\mathrm{C}^{12}{ }_{*} \mathrm{H}_{2} \mathrm{C}^{12} \mathrm{H}_{2} \mathrm{C}^{12}{ }_{*} \mathrm{HCl}^{37}$ & $4-1082$ & $3,0,3 \leftarrow 2,0,2$ & Ground & $7 / 2$ & $5 / 2$ & 22036.2 & .1 \\
\hline $\mathrm{C}^{12}{ }_{*} \mathrm{H}: \mathrm{C}^{12} \mathrm{HC}^{12} \mathrm{H}: \mathrm{C}^{12} \mathrm{HN}^{14}{ }^{14} \mathrm{H}$ & $4-1181$ & $9,7,2 \leftarrow 9,7,3$ & Ground & & & 22037.0 & \\
\hline $\mathrm{C}^{12} \mathrm{H}_{2}\left(\mathrm{C}^{12} \mathrm{~N}^{14}\right)_{2}$ & 4- 901 & Not Reported & Ground & & & 22037.0 & .1 \\
\hline $\mathrm{Cs}^{133} \mathrm{~F}^{19}$ & 1- & $2 \leftarrow 1$ & Ground & & & 22038.51 & .20 \\
\hline$\left(\mathrm{C}^{12} \mathrm{H}_{3}\right)_{3} \mathrm{~N}^{14} \cdot \mathrm{B}^{11}\left(\mathrm{C}^{12} \mathrm{H}_{3}\right)_{3}$ & 3-1081 & $7, \leftarrow 6$, & & & & 22039. & 10. \\
\hline $\mathrm{HC}^{12} \mathrm{O}^{16} \mathrm{O}^{16} \mathrm{C}^{12} \mathrm{D}_{3^{-}} \mathrm{A}$ & 3- 507 & $1,1,1 \leftarrow 0,0,0$ & Ground & & & 22039.23 & .35 \\
\hline $\mathrm{O}^{16} \mathrm{~F}_{2}^{19}$ & $4-1611$ & $24,6,18 \leftarrow 25,5,21$ & Ground & & & 22039.31 & .10 \\
\hline $\mathrm{C}^{12} \mathrm{H}_{3} \mathrm{~N}^{14} \mathrm{O}_{2}^{16}$ & 3- 171 & Not Reported & Ground & & & 22040 & \\
\hline $\mathrm{C}^{12} \mathrm{H}_{3} \mathrm{C}^{13} \mathrm{H}_{2} \mathrm{Br}^{81}$ & 3- 529 & $3,1,2 \leftarrow 2,1,1$ & Ground & $7 / 2$ & $5 / 2$ & 22040.21 & .05 \\
\hline
\end{tabular}




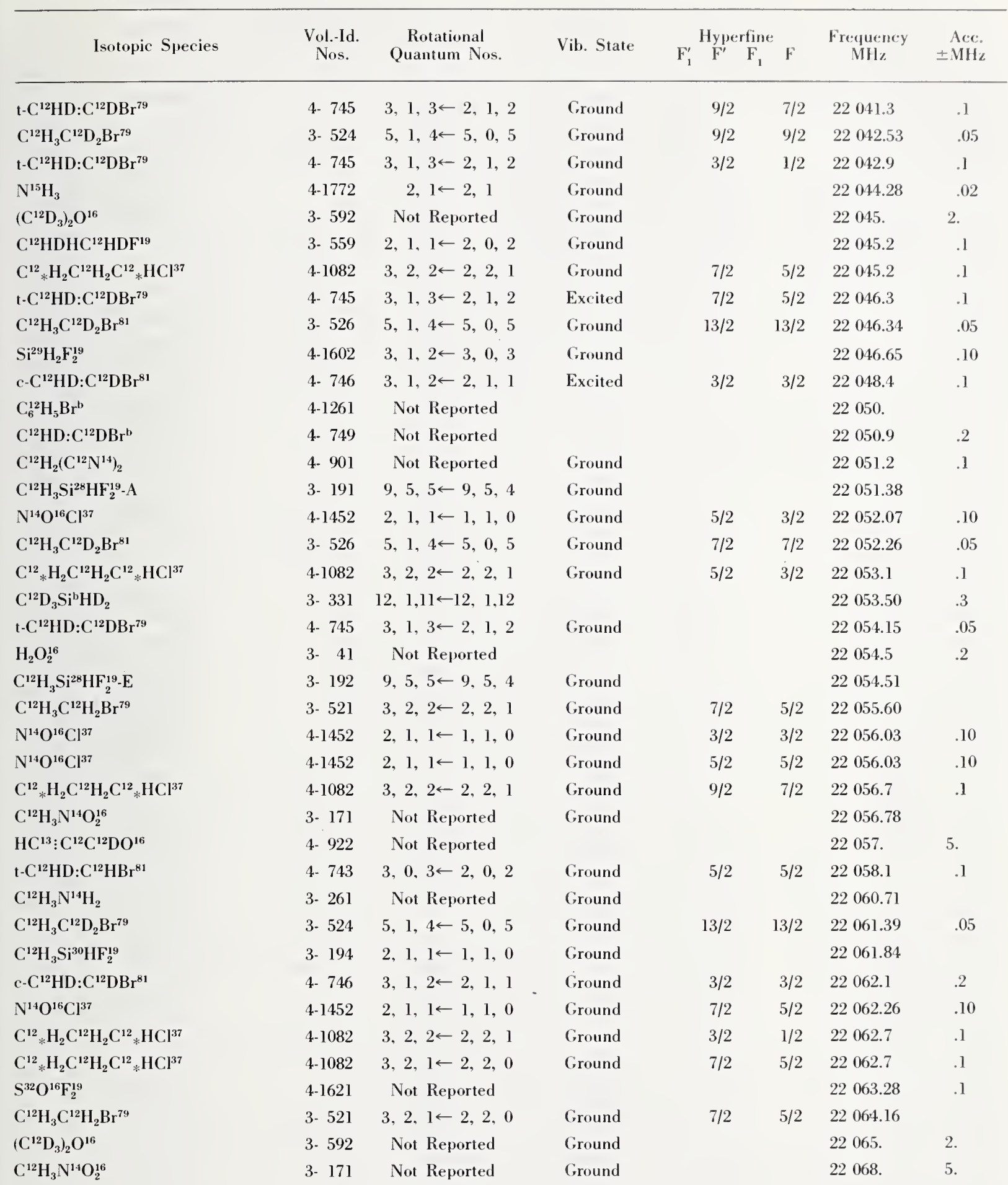




\begin{tabular}{|c|c|c|c|c|c|c|c|}
\hline Isotopic Species & $\begin{array}{l}\text { Vol.-Id. } \\
\text { Nos. }\end{array}$ & $\begin{array}{c}\text { Rotational } \\
\text { Quantum Nos. }\end{array}$ & Vib. State & $\mathrm{F}_{1}^{\prime} \quad \begin{array}{l}\text { Hyperfine } \\
\mathrm{F}^{\prime} \quad \mathrm{F}_{1}\end{array}$ & $\mathrm{~F}$ & $\begin{array}{l}\text { Frequency } \\
\mathrm{MHz}\end{array}$ & $\begin{array}{r}\text { Acc. } \\
\pm \mathrm{MHz}\end{array}$ \\
\hline $\mathrm{C}^{12}{ }_{*} \mathrm{D}: \mathrm{C}^{12} \mathrm{DC}^{12} \mathrm{D}: \mathrm{C}^{12} \mathrm{DN}^{14}{ }_{*} \mathrm{H}$ & 4-1185 & $9,8,2 \leftarrow 9,7,3$ & Ground & & & 22068.0 & \\
\hline $\mathrm{N}^{14} \mathrm{O}^{16} \mathrm{Cl}^{37}$ & $4-1452$ & $2,1,1 \leftarrow 1,1,0$ & Ground & $3 / 2$ & $1 / 2$ & 22068.11 & .18 \\
\hline $\mathrm{C}^{12} \mathrm{H}_{2} \mathrm{C}^{12} \mathrm{D}_{2} \mathrm{Br}^{79}$ & 3. 524 & $5,1,4 \leftarrow 5,0,5$ & Ground & $7 / 2$ & $7 / 2$ & 22068.60 & .05 \\
\hline $\mathrm{C}^{13}{ }_{*} \mathrm{H}: \overline{\mathrm{C}}^{12} \mathrm{HO}^{16} \mathrm{C}^{12} \mathrm{H}: \mathrm{C}^{12}{ }_{*} \mathrm{H}$ & $4-1157$ & $6,4,2 \leftarrow 6,4,3$ & Ground & & & 22069.0 & .1 \\
\hline $\mathrm{a}-\mathrm{C}^{12} \mathrm{H}_{2} \mathrm{DS}^{32} \mathrm{C}^{12} \mathrm{H}_{3}$ & 3- 605 & $1,1,1 \leftarrow 0,0,0$ & Ground & & & 22069.05 & .05 \\
\hline $\mathrm{C}^{12}{ }_{*} \mathrm{H}_{2} \mathrm{C}^{12} \mathrm{H}_{2} \mathrm{C}^{12}{ }_{*} \mathrm{HCl}^{37}$ & $4-1082$ & $3,2,1 \leftarrow 2,2,0$ & Ground & $5 / 2$ & $3 / 2$ & 22069.5 & .1 \\
\hline $\mathrm{N}^{14} \mathrm{O}^{16} \mathrm{Br}^{79}$ & 4- 121 & $3,2,1 \leftarrow 2,2,0$ & Ground & $5 / 2$ & $5 / 2$ & 22069.77 & .25 \\
\hline $\mathrm{N}^{14} \mathrm{O}^{16} \mathrm{Br}^{79}$ & 4- 121 & $3,2,2 \leftarrow 2,2,1$ & Ground & $5 / 2$ & $5 / 2$ & 22069.77 & .25 \\
\hline $\mathrm{N}^{14} \mathrm{O}^{16} \mathrm{Br}^{79}$ & 4. 121 & $3,2,2 \leftarrow 2,2,1$ & Ground & $7 / 2$ & $5 / 2$ & 22069.77 & .25 \\
\hline $\mathrm{N}^{14} \mathrm{O}^{16} \mathrm{Br}^{79}$ & 4- 121 & $3,2,1 \leftarrow 2,2,0$ & Ground & $7 / 2$ & $5 / 2$ & 22069.77 & .25 \\
\hline $\mathrm{N}^{14} \mathrm{O}^{16} \mathrm{Br}^{79}$ & 4- 121 & $3,2,2 \leftarrow 2,2,1$ & Ground & $3 / 2$ & $5 / 2$ & 22069.77 & .25 \\
\hline $\mathrm{N}^{14} \mathrm{O}^{16} \mathrm{Br}^{79}$ & 4. 121 & $3,2,1 \leftarrow 2,2,0$ & Ground & $3 / 2$ & $5 / 2$ & 22069.77 & .25 \\
\hline $\mathrm{C}^{12}{ }_{*} \mathrm{HO}^{16} \mathrm{C}^{12} \mathrm{HC}^{12} \mathrm{H}_{2} \mathrm{C}^{12} \mathrm{H}_{2} \mathrm{C}^{12}{ }_{*} \mathrm{H}_{2}$ & $4-1251$ & $11,8,4 \leftarrow 11,7,4$ & Ground & & & 22070 & 5. \\
\hline $\mathrm{N}^{14} \mathrm{O}^{16} \mathrm{Cl}^{37}$ & $4-1452$ & $2,1,1 \leftarrow 1,1,0$ & Ground & $1 / 2$ & $1 / 2$ & 22071.33 & .16 \\
\hline t- $\mathrm{C}^{12} \mathrm{HD}: \mathrm{C}^{12} \mathrm{DBr}^{79}$ & 4- 745 & $3,1,3 \leftarrow 2,1,2$ & Ground & $7 / 2$ & $5 / 2$ & 22071.4 & .1 \\
\hline$\left(\mathrm{C}^{12} \mathrm{D}_{3}\right)_{2} \mathrm{O}^{16}$ & 3- 592 & $4,1,3 \leftarrow 4,0,4$ & Excited & & & 22072.2 & .2 \\
\hline $\mathrm{t}-\mathrm{C}^{12} \mathrm{HD}: \mathrm{C}^{12} \mathrm{DBr}^{79}$ & 4- 745 & $3,1,3 \leftarrow 2,1,2$ & Ground & $5 / 2$ & $3 / 2$ & 22072.5 & .1 \\
\hline $\mathrm{C}^{12} * \mathrm{H}_{2} \mathrm{C}^{12} \mathrm{H}_{2} \mathrm{C}^{12} * \mathrm{HCl}^{37}$ & $4-1082$ & $3,2,1 \leftarrow 2,2,0$ & Ground & $9 / 2$ & $7 / 2$ & 22072.7 & .1 \\
\hline $\mathrm{C}^{12} \mathrm{D}_{2} \mathrm{HC}^{12} \mathrm{HDF}^{19}$ & 3. 563 & $2,1,1 \leftarrow 2,0,2$ & Ground & & & 22076.1 & .1 \\
\hline $\mathrm{C}^{12} \mathrm{HD}: \mathrm{C}^{12} \mathrm{DBr}^{\mathrm{b}}$ & 4- 749 & Not Reported & & & & 22080.3 & .2 \\
\hline $\mathrm{C}^{\mathrm{b}}{ }_{*} \mathrm{H}_{2}^{\mathrm{b}} \mathrm{N}^{\mathrm{b}} \mathrm{H}^{\mathrm{b}} \mathrm{C}^{\mathrm{b}}{ }_{*} \mathrm{H}_{2}^{\mathrm{b}}$ & 4- 863 & Not Reportcd & & & & 22080.9 & .5 \\
\hline$\left(\mathrm{C}^{12} \mathrm{D}_{3}\right)_{2} \mathrm{O}^{16}$ & 3. 592 & $4,1,3 \leftarrow 4,0,4$ & Excited & & & 22081.4 & .2 \\
\hline $\mathrm{C}^{12} \mathrm{H}_{3} \mathrm{~N}^{14} \mathrm{H}_{2}$ & $3 \cdot 261$ & Not Reported & Ground & & & 22082.37 & \\
\hline $\mathrm{C}^{12} \mathrm{H}_{3} \mathrm{C}^{12} \mathrm{O}^{16} \mathrm{O}^{16} \mathrm{H}$ & 3. 491 & $6,5,1 \leftarrow 6,4,2$ & Ground & & & 22082.56 & .4 \\
\hline $\mathrm{C}^{12} \mathrm{HD}: \mathrm{C}^{12} \mathrm{DBr}^{\mathrm{b}}$ & 4- 749 & Not Reported & & & & 22082.7 & .1 \\
\hline $\mathrm{t} \cdot \mathrm{C}^{12} \mathrm{HD}: \mathrm{C}^{12} \mathrm{HBr}^{81}$ & 4. 743 & $3,2,2 \leftarrow 2,2,1$ & Ground & $7 / 2$ & $7 / 2$ & 22085.5 & .1 \\
\hline $\mathrm{t} \cdot \mathrm{C}^{12} \mathrm{HD}: \mathrm{C}^{12} \mathrm{HBr}^{81}$ & 4- 743 & $3,2,2 \leftarrow 2,2,1$ & Ground & $9 / 2$ & $7 / 2$ & 22085.5 & .1 \\
\hline $\mathrm{c}-\mathrm{C}^{12} \mathrm{HD}: \mathrm{C}^{12} \mathrm{DBr}^{81}$ & 4. 746 & $3,1,2 \leftarrow 2,1,1$ & Excited & $5 / 2$ & $5 / 2$ & 22086.4 & .2 \\
\hline $\mathrm{H}_{2}^{\mathrm{b}} \mathrm{C}^{\mathrm{b}}: \mathrm{C}^{\mathrm{b}} \mathrm{H}^{\mathrm{b}} \mathrm{Cl}^{\mathrm{b}}$ & 4- 772 & Not Reported & Ground & & & 22086.55 & \\
\hline $\mathrm{N}^{14} \mathrm{O}^{16} \mathrm{Br}^{81}$ & 4- 122 & $3,1,2 \leftarrow 2,1,1$ & Ground & $9 / 2$ & $7 / 2$ & 22086.65 & .25 \\
\hline $\mathrm{C}^{12} \mathrm{H}_{3} \mathrm{C}^{12} \mathrm{HO}^{16}$ & 3- 471 & Not Reported & & & & 22087.00 & \\
\hline t. $\mathrm{C}^{12} \mathrm{HD}: \mathrm{C}^{12} \mathrm{HBr}^{81}$ & 4- 743 & $3,2,1 \leftarrow 2,2,0$ & Ground & $7 / 2$ & $7 / 2$ & 22088.7 & .1 \\
\hline $\mathrm{t}-\mathrm{C}^{12} \mathrm{HD}: \mathrm{C}^{12} \mathrm{HBr}^{81}$ & 4. 743 & $3,2,1 \leftarrow 2,2,0$ & Ground & $9 / 2$ & $7 / 2$ & 22088.7 & .1 \\
\hline $\mathrm{C}^{12} \mathrm{H}_{3} \mathrm{Si}^{29} \mathrm{HF}_{2}^{19}$ & 3. 193 & $2,1,1 \leftarrow 1,1,0$ & Ground & & & 22089.10 & \\
\hline $\mathrm{C}^{12} \mathrm{HDCl}^{35} \mathrm{Si}^{28} \mathrm{H}_{3}$ & 3- 236 & $8,1,7 \leftarrow 8,0,8$ & Ground & & & 22089.27 & .2 \\
\hline $\mathrm{N}^{14} \mathrm{O}^{16} \mathrm{Br}^{81}$ & 4. 122 & $3,1,2 \leftarrow 2,1,1$ & Ground & $3 / 2$ & $1 / 2$ & 22089.42 & .25 \\
\hline $\mathrm{C}^{12} \mathrm{H}_{2} \mathrm{Cl}^{35} \mathrm{Si}^{28} \mathrm{D}_{3}$ & 3. 237 & $4,1,4 \leftarrow 3,1,3$ & Ground & & & 22091.50 & .2 \\
\hline $\mathrm{H}_{2}^{\mathrm{b}} \mathrm{C}^{\mathrm{b}}: \mathrm{C}^{\mathrm{b}} \mathrm{H}^{\mathrm{b}} \mathrm{Cl}^{\mathrm{b}}$ & 4. 772 & Not Reported & Ground & & & 22092.50 & \\
\hline $\mathrm{c}-\mathrm{C}^{12} \mathrm{HD}: \mathrm{C}^{12} \mathrm{DBr}^{81}$ & 4. 746 & $3,1,2 \leftarrow 2,1,1$ & Excited & $9 / 2$ & $7 / 2$ & 22094.9 & .1 \\
\hline $\mathrm{C}^{12} \mathrm{H}_{3} \mathrm{O}^{16} \mathrm{H}$ & 3- 211 & Not Reported & Ground & & & 22095. & 5. \\
\hline $\mathrm{H}_{2}^{\mathrm{b}} \mathrm{C}^{\mathrm{b}}{ }_{*} \mathrm{O}^{16} \mathrm{C}^{\mathrm{b}}{ }_{*} \mathrm{H}_{2}^{\mathrm{b}}$ & 4. 846 & Not Reported & Excited & & & 22097. & 5. \\
\hline $\mathrm{C}^{12}{ }_{*} \mathrm{D}_{2} \mathrm{C}^{12} \mathrm{H}_{2} \mathrm{C}^{12} \mathrm{D}_{2} \mathrm{O}^{16}{ }_{*}$ & $4 \cdot 1092$ & $4,3,2 \leftarrow 4,2,3$ & Excited & & & 22097.3 & .1 \\
\hline $\mathrm{DC}^{12} \mathrm{O}^{16} \mathrm{O}^{16} \mathrm{C}^{12} \mathrm{H}_{3}-\mathrm{A}$ & 3- 503 & $2,1,2 \leftarrow 1,1,1$ & Ground & & & 22097.89 & .2 \\
\hline
\end{tabular}




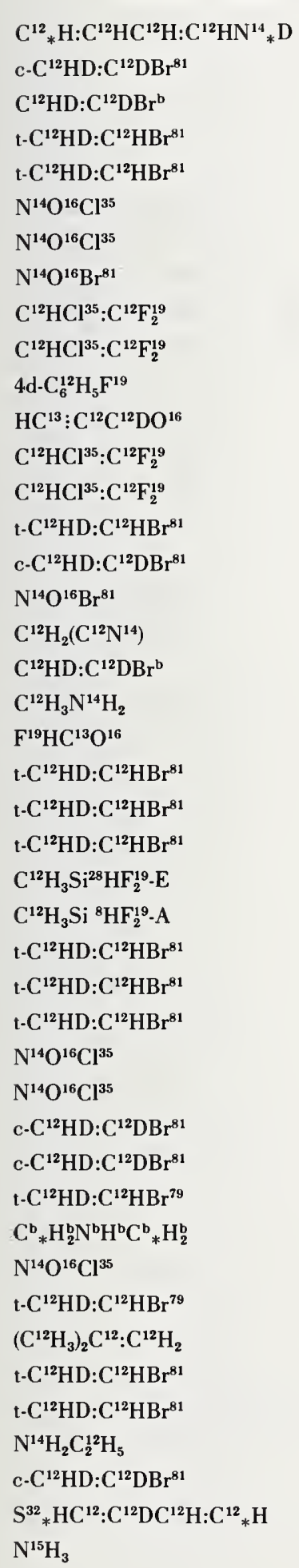

\begin{tabular}{|c|c|}
\hline 4-1182 & $2,0,2 \leftarrow 1,0, \ldots 1$ \\
\hline 4. 746 & $3,1,2 \leftarrow 2,1,1$ \\
\hline 4. 749 & Not Reported \\
\hline 4- 743 & $3,0,3 \leftarrow 2,0,2$ \\
\hline 4- 743 & $3,0,3 \leftarrow 2,0,2$ \\
\hline $4-1451$ & $2,0,2 \leftarrow 1,0,1$ \\
\hline $4-1451$ & $2,0,2 \leftarrow 1,0,1$ \\
\hline 4. 122 & $3,1,2 \leftarrow 2,1,1$ \\
\hline 4. 611 & $7,2,5 \leftarrow 7,1,6$ \\
\hline 4. 611 & $7,2,5 \leftarrow 7,1,6$ \\
\hline 4-1283 & $5,1,4 \leftarrow 4,1,3$ \\
\hline 4. 922 & Not Reported \\
\hline 4- 611 & $7,2,5 \leftarrow 7,1,6$ \\
\hline 4- 611 & $7,2,5 \leftarrow 7,1,6$ \\
\hline 4. 743 & $3,0,3 \leftarrow 2,0,2$ \\
\hline 4. 746 & $3,1,2 \leftarrow 2,1,1$ \\
\hline 4- 122 & $3,1,2 \leftarrow 2,1,1$ \\
\hline 4- 901 & Not Reported \\
\hline 4. 749 & Not Reported \\
\hline 3- 261 & Not Reported \\
\hline 4- 273 & $1,0,1 \leftarrow 0,0,0$ \\
\hline 4. 743 & $3,2,2 \leftarrow 2,2,1$ \\
\hline 4. 743 & $3,2,2 \leftarrow 2,2,1$ \\
\hline 4. 743 & $3,2,2 \leftarrow 2,2,1$ \\
\hline 3- 192 & $2,1,1 \leftarrow 1,1,0$ \\
\hline 3. 191 & $2,1,1 \leftarrow 1,1,0$ \\
\hline 4. 743 & $3,2,1 \leftarrow 2,2,0$ \\
\hline 4- 743 & $3,2,1 \leftarrow 2,2,0$ \\
\hline 4. 743 & $3,2,1 \leftarrow 2,2,0$ \\
\hline $4-1451$ & $2,0,2 \leftarrow 1,0,1$ \\
\hline $4-1451$ & $2,0,2 \leftarrow 1,0,1$ \\
\hline 4- 746 & $3,1,2 \leftarrow 2,1,1$ \\
\hline 4. 746 & $3,1,2 \leftarrow 2,1,1$ \\
\hline 4. 741 & $3,2,2 \leftarrow 2,2,1$ \\
\hline 4. 863 & Not Reported \\
\hline $4-1451$ & $2,0,2 \leftarrow 1,0,1$ \\
\hline 4- 741 & $3,2,1 \leftarrow 2,2,0$ \\
\hline 3. 941 & $2,0,2 \leftarrow 1,1,1$ \\
\hline 4. 743 & $3,0,3 \leftarrow 2,0,2$ \\
\hline 4. 743 & $3,0,3 \leftarrow 2,0,2$ \\
\hline 3. 631 & Not Reported \\
\hline 4- 746 & $3,1,2 \leftarrow 2,1,1$ \\
\hline $4-1163$ & $3,0,3 \leftarrow 2,0,2$ \\
\hline $4-1772$ & $8,7 \leftarrow 8,7$ \\
\hline
\end{tabular}

22099.9

$\begin{array}{rrll}5 / 2 & 5 / 2 & 22100.75 & .1 \\ & & 22103.9 & .2 \\ 7 / 2 & 5 / 2 & 22104.1 & .2 \\ 9 / 2 & 7 / 2 & 22104.1 & .2 \\ 5 / 2 & 5 / 2 & 22106.31 & .20 \\ 3 / 2 & 1 / 2 & 22106.31 & .20 \\ 7 / 2 & 5 / 2 & 22106.69 & .25 \\ 17 / 2 & 17 / 2 & 22107.3 & .1 \\ 11 / 2 & 11 / 2 & 22107.3 & .1 \\ & & 22107.4 & .1 \\ & & 22108 . & 5 .\end{array}$

$\begin{array}{lllll}13 / 2 & 13 / 2 & 22108.6 & .1\end{array}$

$15 / 2 \quad 15 / 2 \quad 22108.6 \quad .1$

$22108.79 \quad .06$

$\begin{array}{lllll}9 / 2 & 7 / 2 & 22 & 109.5 & .1\end{array}$

$\begin{array}{llll}5 / 2 & 3 / 2 & 22 & 110.25\end{array}$

$22110.5 \quad .1$

$22112.3 \quad .1$

$22112.46 \quad .1$

$22112.5 \quad .1$

$22113.79 \quad .06$

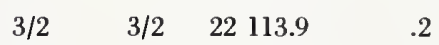

$\begin{array}{llll}5 / 2 & 3 / 2 & 22113.9 & .2\end{array}$

22116.80 22116.80 $22117.13 \quad .06$

$\begin{array}{lllll}5 / 2 & 3 / 2 & 22 & 117.2 & .2\end{array}$

$\begin{array}{lllll}3 / 2 & 3 / 2 & 22 & 117.2 & .2\end{array}$

$\begin{array}{llll}7 / 2 & 5 / 2 & 22118.93 & .07\end{array}$

$\begin{array}{lllll}5 / 2 & 3 / 2 & 22 & 118.93 & .07\end{array}$

$\begin{array}{lllll}7 / 2 & 5 / 2 & 22 & 120.0 & .1\end{array}$

$22120.00 \quad .06$

$\begin{array}{llll}3 / 2 & 1 / 2 & 22 & 124.0\end{array}$
$22125 . \quad 10$.

$\begin{array}{llll}3 / 2 & 3 / 2 & 22 & 126.81\end{array}$

$\begin{array}{llll}3 / 2 & 1 / 2 & 22127.6 & .1\end{array}$

$22128.05 \quad .05$

$\begin{array}{llll}5 / 2 & 3 / 2 & 22128.3 & .2\end{array}$

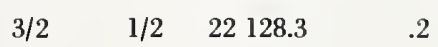

$22130.04 \quad .2$

$\begin{array}{lllll}7 / 2 & 5 / 2 & 22 & 134.4 & .1\end{array}$
$22134.5 \quad .1$ $\begin{array}{ll}22 & 134.89 \quad .02\end{array}$ 


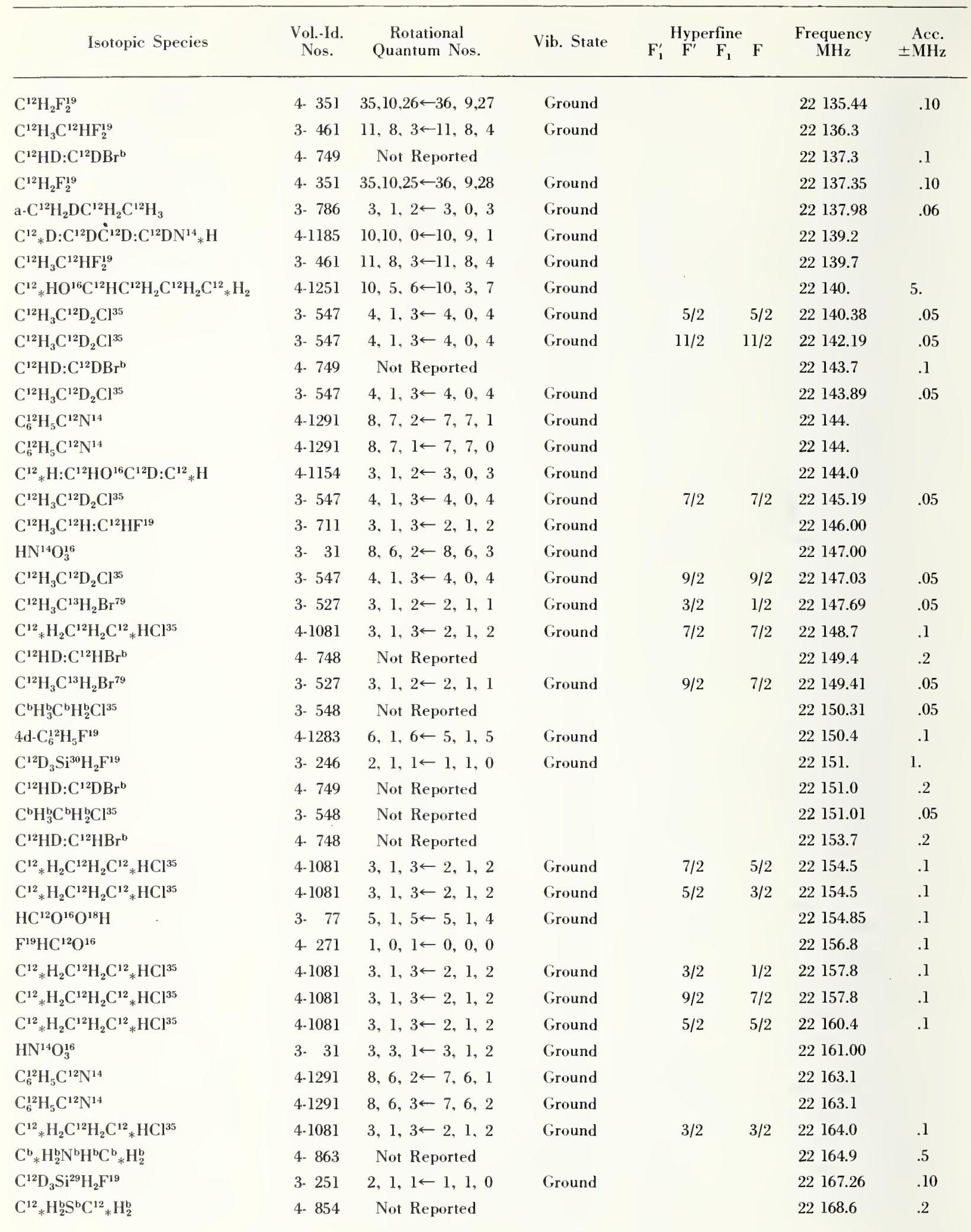




\begin{tabular}{|c|c|c|c|c|c|c|c|}
\hline $\mathrm{HC}^{13}: \mathrm{C}^{12} \mathrm{C}^{12} \mathrm{DO}^{16}$ & 4. 922 & Not Reported & & & & 22169. & 5. \\
\hline $\mathrm{C}^{12} \mathrm{H}_{3} \mathrm{C}^{13} \mathrm{H}_{2} \mathrm{Br}^{79}$ & 3. 527 & $3,1,2 \leftarrow 2,1,1$ & Ground & $5 / 2$ & $3 / 2$ & 22170.88 & .05 \\
\hline $\mathrm{C}^{12} \mathrm{D}_{3} \mathrm{Si}^{30} \mathrm{H}_{2} \mathrm{~F}^{19}$ & 3. 246 & $2,1,1 \leftarrow 1,1,0$ & Ground & & & 22173.46 & .10 \\
\hline $\mathrm{C}^{12} \mathrm{H}_{2}\left(\mathrm{C}^{12} \mathrm{~N}^{14}\right)_{2}$ & 4. 901 & Not Reported & Ground & & & 22173.6 & .1 \\
\hline $\mathrm{C}^{12} \mathrm{D}_{3} \mathrm{O}^{16} \mathrm{H}$ & 3- 214 & Not Reported & Ground & & & 22174.1 & .5 \\
\hline 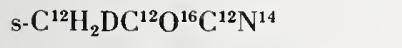 & 3- 677 & $3,1,2 \leftarrow 2,1,1$ & Ground & & & 22174.5 & .2 \\
\hline $\mathrm{C}^{12} \mathrm{H}_{3} \mathrm{C}^{13} \mathrm{H}_{2} \mathrm{Br}^{79}$ & 3- 527 & $3,1,2 \leftarrow 2,1,1$ & Ground & $7 / 2$ & $5 / 2$ & 22176.84 & .05 \\
\hline $\mathrm{C}^{12}{ }^{12} \mathrm{H}: \mathrm{C}^{12} \mathrm{DC}^{12} \mathrm{H}: \mathrm{C}^{12} \mathrm{HN}^{14}{ }_{*} \mathrm{H}$ & $4-1184$ & $4,3,2 \leftarrow 4,1,3$ & Ground & & & 22179. & \\
\hline c- $-\mathrm{HCl}^{35} \mathrm{C}^{-12}: \mathrm{C}^{12} \mathrm{HCl}^{37}$ & 4- 672 & $10,2,8 \leftarrow 10,1,9$ & Ground & & & 22181.0 & 1. \\
\hline $\mathrm{C}^{12}{ }_{*} \mathrm{H}_{2} \mathrm{~N}^{14} \mathrm{DC}^{12}{ }_{*} \mathrm{H}_{2}$ & 4- 862 & $7,6,1 \leftarrow 7,6,2$ & Ground & & & 22181.1 & .5 \\
\hline $\mathrm{D}_{2} \mathrm{C}^{12}: \mathrm{C}^{12} \mathrm{O}^{16}$ & 4. 712 & $23,2,21 \leftarrow 23,2,22$ & Ground & & & 22181.36 & \\
\hline c. $\mathrm{C}^{12} \mathrm{HD}: \mathrm{C}^{12} \mathrm{DBr}^{81}$ & 4- 746 & $3,1,2 \leftarrow 2,1,1$ & Ground & $7 / 2$ & $7 / 2$ & 22181.8 & .1 \\
\hline $\mathrm{c}-\mathrm{HCl}^{35} \mathrm{C}^{12}: \ddot{\mathrm{C}}^{12} \mathrm{HCl}^{37}$ & 4- 672 & $10,2,8 \leftarrow 10,1,9$ & Ground & & & 22183.1 & 1. \\
\hline $\mathrm{C}^{12} \mathrm{H}_{3} \mathrm{C}^{12} \mathrm{H}: \mathrm{C}^{12} \mathrm{HF}^{19}$ & 3- 711 & $3,1,3 \leftarrow 2,1,2$ & Ground & & & 22183.49 & \\
\hline $\mathrm{C}^{12} \mathrm{D}_{3} \mathrm{Si}^{28} \mathrm{H}_{2} \mathrm{~F}^{19}$ & 3- 244 & $2,1,1 \leftarrow 1,1,0$ & Ground & & & 22183.99 & .10 \\
\hline $\mathrm{C}^{12} \mathrm{H}_{3} \mathrm{C}^{12} \mathrm{H}: \mathrm{C}^{12} \mathrm{HF}^{19}$ & 3- 711 & $3,1,3 \leftarrow 2,1,2$ & Ground & & & 22184.00 & .1 \\
\hline $\mathrm{t}-\mathrm{C}^{12} \mathrm{HD}: \mathrm{C}^{12} \mathrm{HBB}^{81}$ & 4- 743 & $3,2,2 \leftarrow 2,2,1$ & Ground & $5 / 2$ & $5 / 2$ & 22184.2 & .2 \\
\hline $\mathrm{t}-\mathrm{C}^{12} \mathrm{HD}: \mathrm{C}^{12} \mathrm{HBr}^{81}$ & 4- 743 & $3,2,2 \leftarrow 2,2,1$ & Ground & $7 / 2$ & $5 / 2$ & 22184.2 & .2 \\
\hline c- $\mathrm{C}^{12} \mathrm{HD}: \mathrm{C}^{12} \mathrm{DBr}^{79}$ & 4- 744 & $3,1,2 \leftarrow 2,1,1$ & Ground & $3 / 2$ & $3 / 2$ & 22184.2 & .1 \\
\hline HDSe $^{82}$ & $4-1758$ & $7,4,4 \leftarrow 7,4,3$ & Ground & & & 22184.4 & \\
\hline $\mathrm{C}_{6}^{12} \mathrm{H}_{5} \mathrm{C}^{12} \mathrm{~N}^{14}$ & 4-1291 & $8,5,4 \leftarrow 7,5,3$ & Ground & & & 22184.7 & \\
\hline $\mathrm{C}_{6}^{12} \mathrm{H}_{5} \mathrm{C}^{12} \mathrm{~N}^{14}$ & $4-1291$ & $8,5,3 \leftarrow 7,5,2$ & Ground & & & 22184.7 & \\
\hline $\mathrm{t}-\mathrm{C}^{12} \mathrm{HD}: \mathrm{C}^{12} \mathrm{HBr}^{81}$ & 4- 743 & $3,2,1 \leftarrow 2,2,0$ & Ground & $5 / 2$ & $5 / 2$ & 22187.6 & .2 \\
\hline $\mathrm{t}-\mathrm{C}^{12} \mathrm{HD}: \mathrm{C}^{12} \mathrm{HBr}^{81}$ & 4. 743 & $3,2,1 \leftarrow 2,2,0$ & Ground & $7 / 2$ & $5 / 2$ & 22187.6 & .2 \\
\hline $\mathrm{C}^{12} \mathrm{HD}: \mathrm{C}^{12} \mathrm{DBr}^{\mathrm{b}}$ & 4- 749 & Not Reported & & & & 22187.7 & .1 \\
\hline $\mathrm{C}^{12} \mathrm{D}_{3} \mathrm{Si}^{29} \mathrm{H}_{2} \mathrm{~F}^{19}$ & 3. 251 & $2,1,1 \leftarrow 1,1,0$ & Ground & & & 22189.69 & .10 \\
\hline $\mathrm{HC}^{13}: \mathrm{C}^{12} \mathrm{C}^{12} \mathrm{DO}^{16}$ & 4- 922 & Not Reported & & & & 22191. & 5. \\
\hline $\mathrm{C}^{\mathrm{b}}{ }_{*} \mathrm{H}_{2}^{\mathrm{b}} \mathrm{N}^{\mathrm{b}} \mathrm{H}^{\mathrm{b}} \mathrm{C}^{\mathrm{b}}{ }_{*} \mathrm{H}_{2}^{\mathrm{b}}$ & 4. 863 & Not Reported & & & & 22195.3 & .5 \\
\hline g. $\mathrm{C}^{12} \mathrm{H}_{3} \mathrm{C}^{12} \mathrm{H}_{2} \mathrm{C}^{12} \mathrm{H}_{2} \mathrm{Cl}^{35}$ & 3- 773 & $7,2,5 \leftarrow 7,1,6$ & Ground & & & 22198.83 & .2 \\
\hline $\mathrm{H}_{2} \mathrm{C}^{13}: \mathrm{C}^{12} \mathrm{HCl}^{35}$ & 4- 769 & $2,0,2 \leftarrow 1,0,1$ & Ground & $7 / 2$ & $5 / 2$ & 22199.21 & .10 \\
\hline $\mathrm{H}_{2} \mathrm{C}^{13}: \mathrm{C}^{12} \mathrm{HCl}^{35}$ & 4. 769 & $2,0,2 \leftarrow 1,0,1$ & Ground & $5 / 2$ & $3 / 2$ & 22199.21 & .10 \\
\hline $\mathrm{S}^{32}{ }_{*} \mathrm{HC}^{12}: \mathrm{C}^{12} \mathrm{HC}^{12} \mathrm{H}: \mathrm{C}^{12}{ }_{*} \mathrm{H}$ & $4-1161$ & $3,1,3 \leftarrow 2,1,2$ & Ground & & & 22202.3 & .1 \\
\hline $\mathrm{t}-\mathrm{C}^{12} \mathrm{HD}: \mathrm{C}^{12} \mathrm{HBr}^{81}$ & 4. 743 & $3,0,3 \leftarrow 2,0,2$ & Ground & $7 / 2$ & $7 / 2$ & 22202.7 & .1 \\
\hline $\mathrm{HC}^{13}: \mathrm{C}^{12} \mathrm{C}^{12} \mathrm{DO}^{16}$ & 4- 922 & Not Reported & & & & 22203. & 5. \\
\hline $\mathrm{C}^{12} \mathrm{H}_{2} \mathrm{~F}_{2}^{19}$ & 4. 351 & $3,0,3 \leftarrow 2,1,2$ & Ground & & & 22204.18 & .10 \\
\hline $\mathrm{H}_{2} \mathrm{C}^{12}: \mathrm{C}^{13} \mathrm{HCl}^{35}$ & 4- 768 & $2,1,2 \leftarrow 1,1,1$ & Ground & $5 / 2$ & $3 / 2$ & 22204.76 & .10 \\
\hline $\mathrm{O}^{16} \mathrm{O}^{18} \mathrm{O}^{16}$ & $4-1843$ & $14,2,12 \leftarrow 15,1,15$ & Ground & & & 22205.4 & \\
\hline $\mathrm{C}^{12} \mathrm{HD}: \mathrm{C}^{12} \mathrm{DBr}^{\mathrm{b}}$ & 4- 749 & Not Reported & & & & 22205.5 & .1 \\
\hline $\mathrm{t}-\mathrm{C}^{12} \mathrm{H}_{3} \mathrm{C}^{12} \mathrm{H}: \mathrm{C}^{12} \mathrm{HC}^{12} \mathrm{~N}^{14}$ & 3- 921 & $5,1, \leftarrow 4,1$, & Ground & & & 22205.78 & .5 \\
\hline $\mathrm{C}^{12}{ }_{*} \mathrm{H}_{2} \mathrm{C}^{12} \mathrm{H}_{2} \mathrm{C}^{12} \mathrm{H}_{2} \mathrm{C}^{12} \mathrm{H}_{2} \mathrm{C}^{12}{ }_{*} \mathrm{O}^{16}$ & $4-1241$ & $22,7,15 \leftarrow 22,7,16$ & Ground & & & 22206. & 5. \\
\hline $\mathrm{C}^{12} \mathrm{D}_{3} \mathrm{Si}^{28} \mathrm{H}_{2} \mathrm{~F}^{19}$ & 3. 244 & $2,1,1 \leftarrow 1,1,0$ & Ground & & & 22206.50 & .10 \\
\hline $\mathrm{C}^{12} \mathrm{HD}: \mathrm{C}^{12} \mathrm{DBr}^{\mathrm{b}}$ & 4- 749 & Not Reported & & & & 22207.7 & .1 \\
\hline $\mathrm{t}-\mathrm{C}^{12} \mathrm{HD}: \mathrm{C}^{12} \mathrm{HBr}^{79}$ & 4- 741 & $3,2,2 \leftarrow 2,2,1$ & Ground & $9 / 2$ & $7 / 2$ & 22208.0 & .1 \\
\hline
\end{tabular}




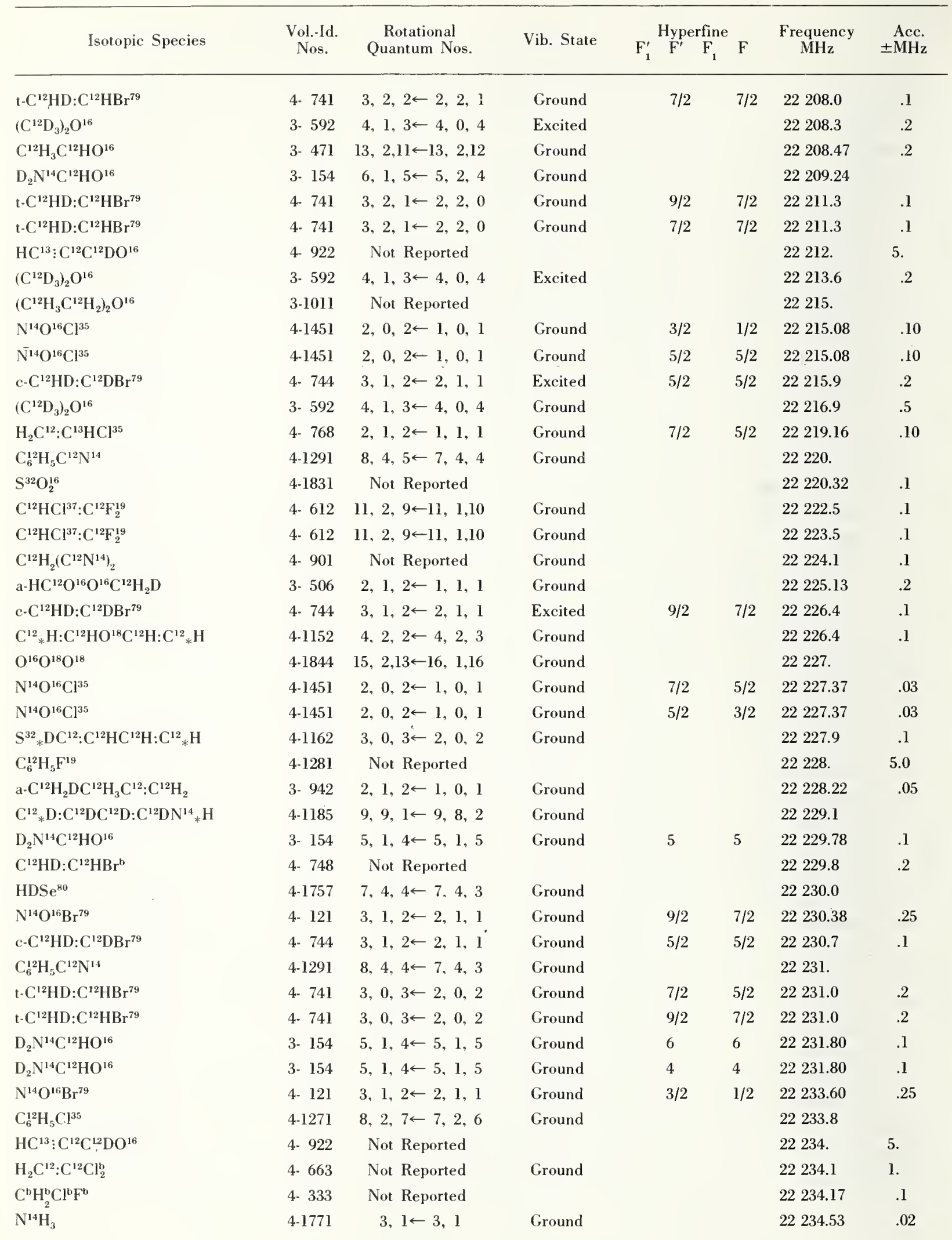




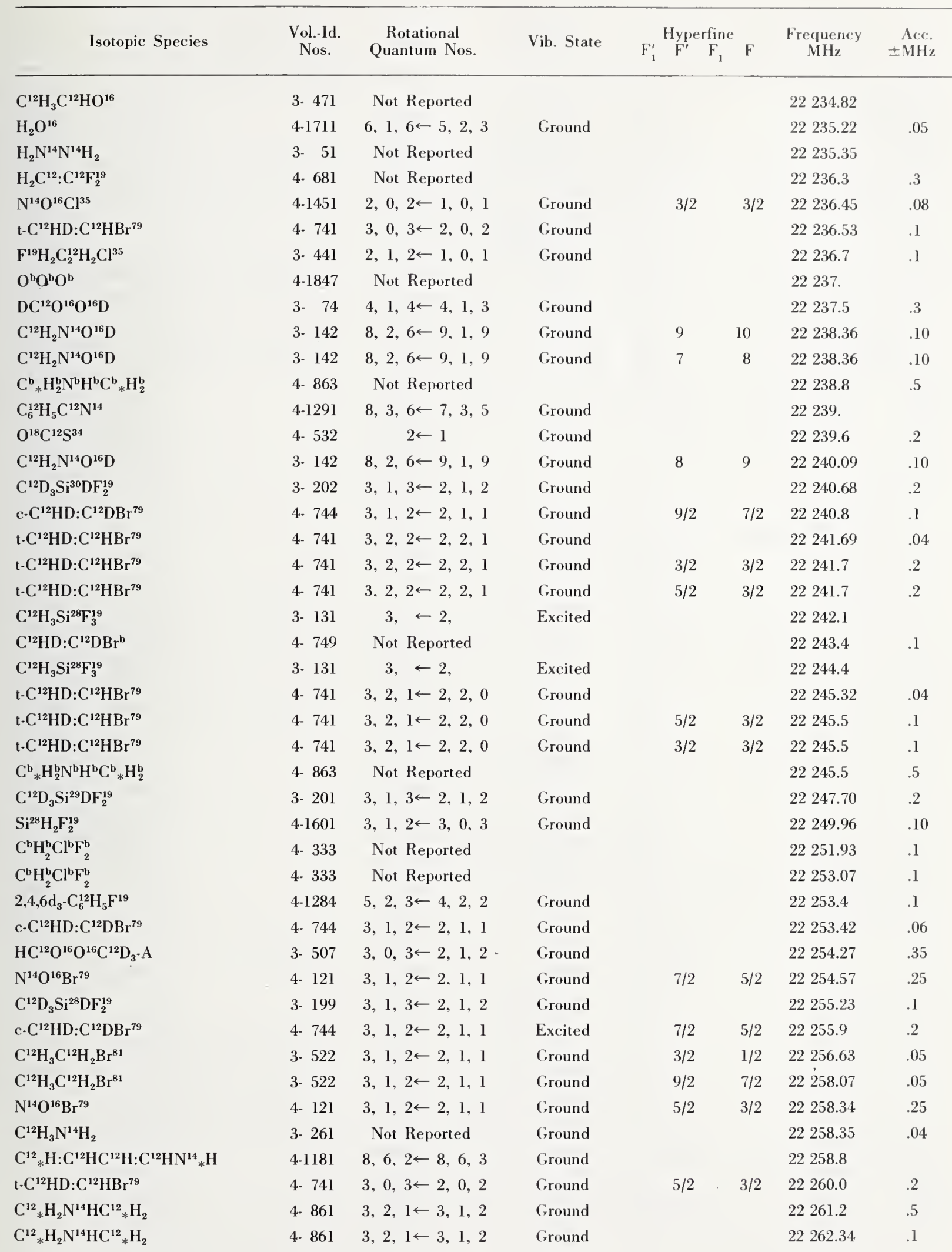




\begin{tabular}{|c|c|c|c|c|c|c|c|}
\hline Isotopic Species & $\begin{array}{l}\text { Vol.-Id. } \\
\text { Nos. }\end{array}$ & $\begin{array}{c}\text { Rotational } \\
\text { Quantum Nos. }\end{array}$ & Vib. State & $\mathrm{F}_{1}^{\prime} \quad \stackrel{\text { Hyperfine }}{\mathrm{F}^{\prime}} \quad \mathrm{F}_{1}$ & e $F$ & $\begin{array}{c}\text { Frequency } \\
\mathrm{MHz}\end{array}$ & $\begin{aligned} & \text { Acc. } \\
& \pm \mathrm{MHz}\end{aligned}$ \\
\hline $\mathrm{HC}^{13}: \mathrm{C}^{12} \mathrm{C}^{12} \mathrm{DO}^{16}$ & 4. 922 & Not Reported & & & & 22266 . & 5. \\
\hline $\mathrm{C}^{12} \mathrm{H}_{3} \mathrm{Si}^{28} \mathrm{~F}_{3}^{19}$ & 3- 131 & $3, \leftarrow 2$, & Excited & & & 22267.48 & \\
\hline $\mathrm{C}^{12} \mathrm{H}_{3} \mathrm{~S}^{32} \mathrm{H}$ & 3. 221 & Not Reported & Ground & & & 22269.4 & .1 \\
\hline$c-\mathrm{C}^{12} \mathrm{HD}: \mathrm{C}^{12} \mathrm{DBr}^{79}$ & 4- 744 & $3,1,2 \leftarrow 2,1,1$ & Ground & $7 / 2$ & $5 / 2$ & 22270.55 & 1 \\
\hline $\mathrm{C}^{12} \mathrm{D}_{3} \mathrm{C}^{13} \mathrm{O}^{16} \mathrm{~F}^{19}$ & 3- 401 & $2,1,2 \leftarrow 1,1,1$ & Ground & & & 22270.72 & .2 \\
\hline $\mathrm{C}^{12} \mathrm{H}_{3} \mathrm{~N}^{14} \mathrm{O}_{2}^{16}$ & 3- 171 & Not Reported & Ground & & 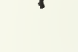 & 22271.57 & \\
\hline $\mathrm{H}_{2} \mathrm{C}^{12}: \mathrm{C}^{12} \mathrm{~F}_{2}^{19}$ & 4- 681 & Not Reported & & & & 22273.4 & .3 \\
\hline $\mathrm{HC}^{12}: \mathrm{C}^{12} \mathrm{Cl}^{37}$ & 4- 602 & $2 \leftarrow 1$ & Ground & $3 / 2$ & $1 / 2$ & 22273.90 & .1 \\
\hline $\mathrm{HC}^{12}: \mathrm{C}^{12} \mathrm{C}^{37}$ & 4- 602 & $2 \leftarrow 1$ & Ground & $5 / 2$ & $5 / 2$ & 22275.10 & .1 \\
\hline $\mathrm{C}^{12} \mathrm{D}_{3} \mathrm{C}^{12} \mathrm{O}^{16} \mathrm{~F}^{19}$ & 3. 392 & $2,1,2 \leftarrow 1,1,1$ & Ground & & & 22275.12 & .2 \\
\hline $\mathrm{C}^{12} \mathrm{H}_{3} \mathrm{C}^{12} \mathrm{H}_{2} \mathrm{Br}^{81}$ & 3. 522 & $3,1,2 \leftarrow 2,1,1$ & Ground & $5 / 2$ & $3 / 2$ & 22275.75 & .05 \\
\hline $\mathrm{a}-\mathrm{C}^{12} \mathrm{H}_{2} \mathrm{DC} \mathrm{C}^{12} \mathrm{O}^{16} \mathrm{C}^{12} \mathrm{~N}^{14}$ & 3- 679 & $8,3.5 \leftarrow 8,2,6$ & Ground & & & 22276.07 & \\
\hline $\mathrm{HDSe}^{78}$ & $4-1756$ & $7,4,4 \leftarrow 7,4,3$ & Ground & & & 22277.6 & \\
\hline $\mathrm{K}^{39} \mathrm{Cl}^{37}$ & 1. & $3 \leftarrow 2$ & Excited & & & 22278.0 & 3.0 \\
\hline $\mathrm{C}^{12} \mathrm{H}_{3} \mathrm{Si}^{28} \mathrm{~F}_{3}^{19}$ & 3- 131 & $3, \leftarrow 2$, & Excited & & & 22278.47 & \\
\hline $\mathrm{C}^{12} \mathrm{H}_{3} \mathrm{~B}^{\mathrm{b}} \mathrm{F}_{2}^{19}$ & 3- 91 & $2, \quad \leftarrow 1$, & Ground & & & 22280.6 & .1 \\
\hline $\mathrm{C}^{12} \mathrm{H}_{3} \mathrm{C}^{12} \mathrm{H}_{2} \mathrm{Br}^{81}$ & 3- 522 & $3,1,2 \leftarrow 2,1,1$ & Ground & $7 / 2$ & $5 / 2$ & 22280.80 & .05 \\
\hline $\mathrm{C}^{12}{ }_{*} \mathrm{H}: \mathrm{C}^{12} \mathrm{HC}^{12} \mathrm{H}: \mathrm{C}^{12} \mathrm{HN}^{14}{ }_{*} \mathrm{D}$ & $4-1182$ & $4,3,2 \leftarrow 4,1,3$ & Ground & & & 22281.6 & \\
\hline $3 \mathrm{~d}-\mathrm{C}_{6}^{12} \mathrm{H}_{5} \mathrm{~F}^{19}$ & 4-1282 & $6,1,6 \leftarrow 5,1,5$ & Ground & & & 22286.5 & .1 \\
\hline $\mathrm{C}^{13} \mathrm{H}_{2}: \mathrm{C}^{13} \mathrm{HBr}^{81}$ & 4- 734 & $3,1,3 \leftarrow 2,1,2$ & Ground & $3 / 2$ & $3 / 2$ & 22286.9 & \\
\hline $\mathrm{C}^{\mathrm{b}}{ }_{*} \mathrm{H}_{2}^{\mathrm{b}} \mathrm{N}^{\mathrm{b}} \mathrm{H}^{\mathrm{b}} \mathrm{C}^{\mathrm{b}}{ }_{*} \mathrm{H}_{2}^{\mathrm{b}}$ & 4- 863 & Not Reported & & & & 22288.8 & .5 \\
\hline $\mathrm{HC}^{12}: \mathrm{C}^{12} \mathrm{Cl}^{37}$ & 4. 602 & $2 \leftarrow 1$ & Ground & $1 / 2$ & $1 / 2$ & 22289.55 & .1 \\
\hline $\mathrm{C}^{12} \mathrm{H}_{2}\left(\mathrm{C}^{12} \mathrm{~N}^{14}\right)_{2}$ & 4- 901 & Not Reported & Ground & & & 22290.3 & .1 \\
\hline $\mathrm{HC}^{12}: \mathrm{C}^{12} \mathrm{Cl}^{37}$ & 4- 602 & $2 \leftarrow 1$ & Ground & $5 / 2$ & $3 / 2$ & 22290.85 & .1 \\
\hline $\mathrm{HC}^{12}: \mathrm{C}^{12} \mathrm{Cl}^{37}$ & 4- 602 & $2 \leftarrow 1$ & Ground & $7 / 2$ & $5 / 2$ & 22290.85 & .1 \\
\hline $\mathrm{C}^{12}{ }_{*} \mathrm{D}_{2} \mathrm{C}^{12} \mathrm{H}_{2} \mathrm{C}^{12} \mathrm{D}_{2} \mathrm{O}^{16}{ }_{*}$ & 4-1092 & $4,3,2 \leftarrow 4,2,3$ & Ground & & & 22291.15 & .1 \\
\hline $\mathrm{C}^{12} \mathrm{H}_{2}\left(\mathrm{C}^{12} \mathrm{~N}^{14}\right)_{2}$ & 4. 901 & Not Reported & Ground & & & 22293.8 & .1 \\
\hline $\mathrm{C}^{12} \mathrm{H}_{3} \mathrm{Si}^{28} \mathrm{~F}_{3}^{19}$ & 3- 131 & $3, \leftarrow 2$, & Ground & & & 22293.87 & .1 \\
\hline $\mathrm{C}^{12} \mathrm{H}_{3} \mathrm{Si}^{28} \mathrm{~F}_{3}^{19}$ & 3. 131 & $3, \leftarrow 2$, & Excited & & & 22296.97 & \\
\hline $\mathrm{C}^{12} \mathrm{D}_{3} \mathrm{C}^{12} \mathrm{O}^{16} \mathrm{C}^{12} \mathrm{~N}^{14}$ & 3- 675 & $4,0,4 \leftarrow 3,1,3$ & Ground & & & 22297.6 & .2 \\
\hline $\mathrm{t}-\mathrm{HDN}{ }^{15} \mathrm{C}^{12} \mathrm{HO}^{16}$ & 3. 159 & $1,1,1 \leftarrow 2,0,2$ & Ground & & & 22298.92 & \\
\hline $\mathrm{C}^{12} \mathrm{H}_{3} \mathrm{C}^{13} \mathrm{H}_{2} \mathrm{C}^{12} \mathrm{H}_{3}$ & 3- 783 & $2,1,1 \leftarrow 2,0,2$ & Ground & & & 22299.03 & .06 \\
\hline $\mathrm{C}^{12} \mathrm{~F}_{3}^{19} \mathrm{C}^{12}: \mathrm{C}^{13} \mathrm{H}$ & 4- 873 & $4, \leftarrow 3$, & Ground & & & 22301.0 & .3 \\
\hline $\mathrm{HC}^{12}: \mathrm{C}^{12} \mathrm{Cl}^{32}$ & 4- 602 & $2 \leftarrow 1$ & Ground & $3 / 2$ & $3 / 2$ & 22302.10 & .1 \\
\hline $\mathrm{HDSe}^{77}$ & $4-1755$ & $7,4,4 \leftarrow 7,4,3$ & Ground & & & 22302.3 & \\
\hline $\mathrm{H}_{2}^{\mathrm{b}} \mathrm{C}^{\mathrm{b}} * \mathrm{O}^{16} \mathrm{C}^{\mathrm{b}} * \mathrm{H}_{2}^{\mathrm{b}}$ & 4- 846 & Not Reported & Excited & & & 22303. & 5. \\
\hline $\mathrm{HC}^{13}: \mathrm{C}^{12} \mathrm{C}^{12} \mathrm{DO}^{16}$ & 4. 922 & Not Reported & & & & 22304. & 5. \\
\hline $\mathrm{C}^{12} \mathrm{HCl}^{35}: \mathrm{C}^{12} \mathrm{~F}_{2}^{19}$ & 4- 611 & $11,2,9 \leftarrow 11,1,10$ & Ground & $21 / 2$ & $21 / 2$ & 22304.1 & .1 \\
\hline $\mathrm{C}^{12} \mathrm{HCl}^{35}: \mathrm{C}^{12} \mathrm{~F}_{2}^{19}$ & 4. 611 & $11,2,9 \leftarrow 11,1,10$ & Ground & $23 / 2$ & $23 / 2$ & 22304.1 & .1 \\
\hline $\mathrm{C}^{12} \mathrm{HCl}^{35}: \mathrm{C}^{12} \mathrm{~F}_{2}^{19}$ & 4. 611 & $11,2,9 \leftarrow 11,1,10$ & Ground & $19 / 2$ & $19 / 2$ & 22305.3 & .1 \\
\hline $\mathrm{C}^{12} \mathrm{HCl}^{35}: \mathrm{C}^{12} \mathrm{~F}_{2}^{19}$ & 4. 611 & $11,2,9 \leftarrow 11,1,10$ & Ground & $25 / 2$ & $25 / 2$ & 22305.3 & .1 \\
\hline $\mathrm{C}^{12}{ }_{*} \mathrm{D}_{2} \mathrm{C}^{12} \mathrm{H}_{2} \mathrm{C}^{12} \mathrm{D}_{2} \mathrm{O}^{16}{ }_{*}$ & $4-1092$ & $6,3,3 \leftarrow 6,2,4$ & Ground & & & 22306.55 & .1 \\
\hline $\mathrm{HC}^{12} \mathrm{O}^{16} \mathrm{O}^{16} \mathrm{C}^{13} \mathrm{H}_{3} \cdot \mathrm{A}$ & 3. 511 & $2,1,2 \leftarrow 1,1,1$ & Ground & & & 22307.45 & .2 \\
\hline $\mathrm{HDO}^{16}$ & $4-1712$ & $5,3,2 \leftarrow 5,3,3$ & Ground & & & 22307.67 & .05 \\
\hline $\mathrm{C}^{12} \mathrm{H}_{3} \mathrm{C}^{12} \mathrm{H}: \mathrm{C}^{12} \mathrm{HF}^{19}$ & 3- 711 & $3,1,3 \leftarrow 2,1,2$ & Ground & & & 22308.50 & \\
\hline
\end{tabular}


Vib. State

Frequency Acc.

\begin{tabular}{|c|c|c|c|c|c|c|c|}
\hline $\mathrm{HC}^{13}: \mathrm{C}^{12} \mathrm{C}^{12} \mathrm{DO}^{16}$ & 4. 922 & Not Reported & & & & 22309 . & 5. \\
\hline $\mathrm{H}_{2} \mathrm{C}^{12}: \mathrm{C}^{12} \mathrm{Cl}_{2}^{\mathrm{b}}$ & 4- 663 & Not Reported & Ground & & & 22311.8 & 1.5 \\
\hline $\mathrm{HC}^{13}: \mathrm{C}^{12} \mathrm{C}^{12} \mathrm{DO}^{16}$ & 4- 922 & Not Reported & & & & 22313. & 5. \\
\hline $\mathrm{C}^{\mathrm{b}} \mathrm{H}_{2}: \mathrm{C}^{\mathrm{b}} \mathrm{HBr}^{\mathrm{b}}$ & 4- 752 & Not Reported & Excited & $9 / 2$ & $7 / 2$ & 22313.4 & \\
\hline $\mathrm{C}^{12} \mathrm{H}_{3} \mathrm{C}^{12} \mathrm{HO}^{16}$ & 3- 471 & Not Reported & & & & 22313.79 & \\
\hline $\mathrm{H}_{2} \mathrm{C}^{12}: \mathrm{C}^{12} \mathrm{Cl}_{2}^{35}$ & 4. 661 & $5,2,4 \leftarrow 5,1,5$ & Ground & & & 22314 . & 1. \\
\hline $\mathrm{DN}_{3}^{14}$ & $4-1702$ & $1,0,1 \leftarrow 0,0,0$ & Ground & & & 22316.1 & \\
\hline $\mathrm{H}_{2} \mathrm{C}^{12}: \mathrm{C}^{12} \mathrm{Cl}_{2}^{35}$ & 4- 661 & $5,2,4 \leftarrow 5,1,5$ & Ground & & & 22318. & 1. \\
\hline$\left(\mathrm{C}^{12} \mathrm{H}_{3}\right)_{2} \mathrm{C}^{12}: \mathrm{C}^{12} \mathrm{H}_{2}$ & 3- 941 & $6,5,2 \leftarrow 6,4,3$ & Ground & & & 22320.86 & .05 \\
\hline $\mathrm{C}_{6}^{12} \mathrm{H}_{5} \mathrm{~F}^{19}$ & $4 \cdot 1281$ & $5,3,2 \leftarrow 4,3,1$ & Ground & & & 22322.1 & .1 \\
\hline $\mathrm{C}^{12} \mathrm{H}_{3} \mathrm{Si}^{28} \mathrm{~F}_{3}^{19}$ & 3. 131 & $3, \leftarrow 2$, & Excited & & & 22323.32 & \\
\hline $\mathrm{C}^{12} \mathrm{H}_{3} \mathrm{C}^{12} \mathrm{O}^{16} \mathrm{O}^{16} \mathrm{H}$ & 3- 491 & Not Reported & & & & 22324 . & 3. \\
\hline $\mathrm{t}-\mathrm{C}^{12} \mathrm{HD}: \mathrm{C}^{12} \mathrm{HBr}^{79}$ & 4- 741 & $3,2,2 \leftarrow 2,2,1$ & Ground & $7 / 2$ & $5 / 2$ & 22325.8 & .1 \\
\hline $\mathrm{t}-\mathrm{C}^{12} \mathrm{HD}: \mathrm{C}^{12} \mathrm{HBr}^{79}$ & 4- 741 & $3,2,2 \leftarrow 2,2,1$ & Ground & $5 / 2$ & $5 / 2$ & 22325.8 & .1 \\
\hline g- $\mathrm{C}^{12} \mathrm{H}_{3} \mathrm{C}^{12} \mathrm{H}_{2} \mathrm{C}^{12} \mathrm{H}_{2} \mathrm{Cl}^{37}$ & 3- 774 & $7,2,5 \leftarrow 7,1,6$ & Ground & & & 22326.14 & .2 \\
\hline $\mathrm{HC}^{12} \mathrm{O}^{16} \mathrm{O}^{16} \mathrm{H}$ & $3-71$ & $27,4,23 \leftarrow 27,4,24$ & & & & 22326.42 & \\
\hline $\mathrm{C}^{12} \mathrm{H}_{3} \mathrm{C}^{12} \mathrm{HO}^{16}$ & 3. 471 & $6,1,5 \leftarrow 6,1,6$ & Ground & & & 22326.56 & .3 \\
\hline $\mathrm{C}^{b} \mathrm{H}_{2}: \mathrm{C}^{\mathrm{b}} \mathrm{HBr}^{\mathrm{b}}$ & 4- 752 & Not Reported & Ground & $5 / 2$ & $5 / 2$ & 22326.9 & \\
\hline $\mathrm{C}^{12} \mathrm{H}_{2}\left(\mathrm{C}^{12} \mathrm{~N}^{14}\right)_{2}$ & 4- 901 & Not Reported & Ground & & & 22327.0 & .1 \\
\hline c- $\mathrm{C}^{12} \mathrm{HD}: \mathrm{C}^{12} \mathrm{DBr}^{79}$ & 4- 744 & $3,1,2 \leftarrow 2,1,1$ & Ground & $7 / 2$ & $7 / 2$ & 22327.4 & .2 \\
\hline $\mathrm{HDSe}^{76}$ & 4-1759 & $7,4,4 \leftarrow 7,4,3$ & Ground & & & 22327.7 & \\
\hline $\mathrm{t}-\mathrm{C}^{12} \mathrm{HD}: \mathrm{C}^{12} \mathrm{HBr}^{79}$ & 4- 741 & $3,2,1 \leftarrow 2,2,0$ & Ground & $5 / 2$ & $5 / 2$ & 22329.6 & .1 \\
\hline $\mathrm{t}-\mathrm{C}^{12} \mathrm{HD}: \mathrm{C}^{12} \mathrm{HBr}^{79}$ & 4- 741 & $3,2,1 \leftarrow 2,2,0$ & Ground & $7 / 2$ & $5 / 2$ & 22329.6 & .1 \\
\hline $\mathrm{C}^{12} \mathrm{H}_{3} \mathrm{~S}^{32} \mathrm{H}$ & 3- 221 & Not Reported & Ground & & & 22329.8 & .1 \\
\hline $\mathrm{HC}^{13}: \mathrm{C}^{12} \mathrm{C}^{12} \mathrm{DO}^{16}$ & 4- 922 & Not Reported & & & & 22331. & 5. \\
\hline $\mathrm{C}^{12} \mathrm{H}_{3} \mathrm{~N}^{14} \mathrm{O}_{2}^{16}$ & 3- 171 & Not Reported & Ground & & & 22332. & 5. \\
\hline $\mathrm{C}^{\mathrm{b}} \mathrm{H}_{2}: \mathrm{C}^{\mathrm{b}} \mathrm{HBr}^{\mathrm{b}}$ & 4- 752 & Not Reported & Ground & $9 / 2$ & $7 / 2$ & 22338.5 & \\
\hline g. $\mathrm{C}^{12} \mathrm{H}_{3} \mathrm{C}^{12} \mathrm{H}_{2} \mathrm{C}^{12} \mathrm{H}_{2} \mathrm{Cl}^{37}$ & 3. 774 & $10,2,8 \leftarrow 10,1,9$ & Ground & & & 22339.23 & .2 \\
\hline $\mathrm{H}_{2}^{\mathrm{b}} \mathrm{C}^{\mathrm{b}}{ }_{*} \mathrm{O}^{16} \mathrm{C}^{\mathrm{b}}{ }_{*} \mathrm{H}_{2}^{\mathrm{b}}$ & 4- 846 & Not Reported & Excited & & & 22340 . & 5. \\
\hline $\mathrm{C}^{12} \mathrm{H}_{3} \mathrm{O}^{16} \mathrm{~N}^{14} \mathrm{O}_{2}^{16}$ & 3- 181 & $3,1,3 \leftarrow 2,1,2$ & Ground & & & 22340.04 & .1 \\
\hline $\mathrm{C}^{12} \mathrm{H}_{3} \mathrm{C}^{12} \mathrm{O}^{16} \mathrm{Cl}^{35}$ & 3. 361 & $7,3,4 \leftarrow 7,2,5$ & Ground & 11 & 11 & 22344.40 & .2 \\
\hline $\operatorname{In}^{115} \mathrm{Br}^{79}$ & $1-$ & $7 \leftarrow 6$ & Ground & $21 / 212$ & $19 / 211$ & 22345.07 & 0.20 \\
\hline $\mathrm{C}^{12} \mathrm{H}_{3} \mathrm{C}^{12} \mathrm{O}^{16} \mathrm{Cl}^{35}$ & 3- 361 & $7,3,4 \leftarrow 7,2,5$ & Ground & 11 & 11 & 22345.20 & .2 \\
\hline $\mathrm{C}^{12} \mathrm{H}_{3} \mathrm{C}^{12} \mathrm{O}^{16} \mathrm{Cl}^{35}$ & 3. 361 & $7,3,4 \leftarrow 7,2,5$ & Ground & 17 & 17 & 22345.20 & .2 \\
\hline $\mathrm{C}^{12} \mathrm{H}_{3} \mathrm{C}^{12} \mathrm{O}^{16} \mathrm{Cl}^{35}$ & 3- 361 & $7,3,4 \leftarrow 7,2,5$ & Ground & 17 & 17 & 22346.02 & .2 \\
\hline $\mathrm{C}^{12} \mathrm{H}_{3} \mathrm{C}^{12} \mathrm{HO}^{16}$ & 3- 471 & $6,1,5 \leftarrow 6,1,6$ & Ground & & & 22346.18 & .2 \\
\hline $\mathrm{C}^{12} \mathrm{H}_{3} \mathrm{C}^{12} \mathrm{O}^{16} \mathrm{Cl}^{35}$ & $3 \cdot 361$ & $7,3,4 \leftarrow 7,2,5$ & Ground & 13 & 13 & 22347.65 & .2 \\
\hline $\mathrm{C}^{12} \mathrm{H}_{3} \mathrm{C}^{12} \mathrm{~F}^{19}: \mathrm{C}^{12} \mathrm{H}_{2}$ & 3- 721 & $8,7,1 \leftarrow 8,6,2$ & Ground & & & 22347.90 & .1 \\
\hline $\mathrm{C}^{12} \mathrm{H}_{3} \mathrm{C}^{12} \mathrm{O}^{16} \mathrm{Cl}^{35}$ & 3. 361 & $7,3,4 \leftarrow 7,2,5$ & Ground & 15 & 15 & 22348.40 & .2 \\
\hline $\mathrm{C}^{12} \mathrm{H}_{3} \mathrm{C}^{12} \mathrm{O}^{16} \mathrm{Cl}^{35}$ & 3- 361 & $7,3,4 \leftarrow 7,2,5$ & Ground & 13 & 13 & 22348.40 & .2 \\
\hline $\mathrm{C}^{12} \mathrm{H}_{3} \mathrm{C}^{12} \mathrm{~F}^{19}: \mathrm{C}^{12} \mathrm{H}_{2}$ & 3- 721 & $8,7,1 \leftarrow 8,6,2$ & Ground & & & 22348.72 & .1 \\
\hline $\mathrm{t}-\mathrm{C}^{12} \mathrm{HD}: \mathrm{C}^{12} \mathrm{HBr}^{79}$ & 4. 741 & $3,0,3 \leftarrow 2,0,2$ & Ground & $7 / 2$ & $7 / 2$ & 22349.0 & .2 \\
\hline $\mathrm{C}^{13} \mathrm{H}_{2}: \mathrm{C}^{13} \mathrm{HBr}^{81}$ & 4- 734 & $3,1,3 \leftarrow 2,1,2$ & Ground & & & 22349.17 & .04 \\
\hline $\mathrm{C}^{12} \mathrm{H}_{3} \mathrm{C}^{12} \mathrm{O}^{16} \mathrm{Cl}^{35}$ & 3- 361 & $7,3,4 \leftarrow 7,2,5$ & Ground & 15 & 15 & 22349.23 & .2 \\
\hline $\mathrm{H}_{2} \mathrm{C}^{12}: \mathrm{C}^{12} \mathrm{Cl}^{35} \mathrm{Cl}^{37}$ & 4- 662 & $4,1,4 \leftarrow 3,0,3$ & Ground & & & 22351.3 & .5 \\
\hline
\end{tabular}




\begin{tabular}{|c|c|c|c|c|c|c|c|}
\hline \multirow{2}{*}{ Isotopic Species } & \multirow{2}{*}{$\begin{array}{l}\text { Vol.-Id. } \\
\text { Nos. }\end{array}$} & \multirow{2}{*}{$\begin{array}{c}\text { Rotational } \\
\text { Quantum Nos. }\end{array}$} & \multirow{2}{*}{ Vib. State } & \multicolumn{2}{|c|}{ Hyperfine } & \multirow{2}{*}{$\begin{array}{c}\text { Frequency } \\
\mathrm{MHz}\end{array}$} & \multirow{2}{*}{$\begin{aligned} & \text { Acc. } \\
\pm & \mathrm{MHz}\end{aligned}$} \\
\hline & & & & $\begin{array}{lll}\mathrm{F}_{1}^{\prime} & \mathrm{F}^{\prime} & \mathrm{F}_{1}\end{array}$ & $\mathbf{F}$ & & \\
\hline $\mathrm{a}-\mathrm{C}^{12} \mathrm{HD}_{2} \mathrm{C}^{12} \mathrm{O}^{16} \mathrm{C}^{12} \mathrm{~N}^{14}$ & 3- 678 & $8,2,6 \leftarrow 8,1,7$ & Ground & & & 22351.7 & .2 \\
\hline $\mathrm{C}^{12} \mathrm{H}_{3} \mathrm{Si}^{\mathrm{b}} \mathrm{HD}_{2}$ & 3- 326 & $10,1,9 \leftarrow 10,1,10$ & & & & 22353.73 & .2 \\
\hline $\mathrm{N}^{14} \mathrm{H}_{3}$ & 4-1771 & $14,12 \leftarrow 14,12$ & Ground & & & 22355 . & .02 \\
\hline $\mathrm{H}_{2} \mathrm{C}^{12}: \mathrm{C}^{12} \mathrm{HCl}^{35}$ & 4- 766 & $2,1,2 \leftarrow 1,1,1$ & Ground & $5 / 2$ & $3 / 2$ & 22355.06 & .02 \\
\hline $\mathrm{C}^{12} \mathrm{H}_{3} \mathrm{C}^{12} \mathrm{O}^{16} \mathrm{O}^{16} \mathrm{H}$ & 3- 491 & Not Reported & & & & 22356. & 3. \\
\hline $\mathrm{C}^{12} \mathrm{H}_{2}\left(\mathrm{C}^{12} \mathrm{~N}^{14}\right)_{2}$ & 4. 901 & Not Reported & Ground & & & 22356.5 & .1 \\
\hline $\mathrm{C}^{12}{ }_{*} \mathrm{H}_{2}^{\mathrm{b}} \mathrm{S}^{\mathrm{b}} \mathrm{C}^{12}{ }_{*} \mathrm{H}_{2}^{\mathrm{b}}$ & 4- 854 & Not Reported & & & & 22358.2 & .2 \\
\hline $\mathrm{a}-\mathrm{C}^{12} \mathrm{HD}_{2} \mathrm{C}^{12} \mathrm{O}^{16} \mathrm{C}^{12} \mathrm{~N}^{14}$ & 3. 678 & $8,3,5 \leftarrow 8,2,6$ & Ground & & & 22358.8 & .2 \\
\hline $\mathrm{HC}^{13} \vdots \mathrm{C}^{12} \mathrm{C}^{12} \mathrm{DO}^{16}$ & 4- 922 & Not Reported & & & & 22359. & 5. \\
\hline $\mathrm{H}_{2} \mathrm{C}^{12}: \mathrm{C}^{12} \mathrm{HCl}^{35}$ & 4. 766 & $2,1,2 \leftarrow 1,1,1$ & Ground & $3 / 2$ & $3 / 2$ & 22360.71 & .02 \\
\hline $\mathrm{H}_{2} \mathrm{C}^{12}: \mathrm{C}^{12} \mathrm{HCl}^{35}$ & 4. 766 & $2,1,2 \leftarrow 1,1,1$ & Ground & $5 / 2$ & $5 / 2$ & 22361.47 & .02 \\
\hline $\mathrm{C}^{12} \mathrm{HCl}^{37}: \mathrm{C}^{12} \mathrm{~F}_{2}^{19}$ & 4- 612 & $7,2,5 \leftarrow 7,1,6$ & Ground & & & 22361.6 & .3 \\
\hline $\mathrm{C}^{12} \mathrm{HCl}^{37}: \mathrm{C}^{12} \mathrm{~F}_{12}^{19}$ & 4- 612 & $7,2,5 \leftarrow 7,1,6$ & Ground & & & 22362.7 & .3 \\
\hline $\mathrm{C}^{\mathrm{b}} \mathrm{H}_{2}: \mathrm{C}^{\mathrm{b}} \mathrm{HBr}^{\mathrm{b}}$ & 4- 752 & Not Reported & Ground & $7 / 2$ & $5 / 2$ & 22363.0 & \\
\hline $\mathrm{C}^{\mathrm{b}} \mathrm{H}_{2}: \mathrm{C}^{\mathrm{b}} \mathrm{HBr}^{\mathrm{b}}$ & 4- 752 & Not Reported & Ground & $5 / 2$ & $3 / 2$ & 22364.4 & \\
\hline $\mathrm{C}^{\mathrm{b}}{ }_{*} \mathrm{H}_{2}^{\mathrm{b}} \mathrm{N}^{\mathrm{b}} \mathrm{H}^{\mathrm{b}} \mathrm{C}^{\mathrm{b}}{ }_{*} \mathrm{H}_{2}^{\mathrm{b}}$ & 4- 863 & Not Reported & & & & 22365.1 & .5 \\
\hline $\mathrm{C}^{12} \mathrm{H}_{3} \mathrm{O}^{16} \mathrm{~N}^{14} \mathrm{O}_{2}^{16}$ & 3- 181 & $3,1,3 \leftarrow 2,1,2$ & Ground & & & 22365.79 & .1 \\
\hline $\mathrm{H}_{2} \mathrm{C}^{12}: \mathrm{C}^{12} \mathrm{HCl}^{35}$ & 4- 766 & $2,1,2 \leftarrow 1,1,1$ & Ground & $7 / 2$ & $5 / 2$ & 22369.38 & .02 \\
\hline $\mathrm{C}^{12} \mathrm{H}_{3} \mathrm{~N}^{14} \mathrm{H}_{2}$ & 3- 261 & Not Reported & Ground & & & 22369.95 & \\
\hline $\mathrm{C}^{13} \mathrm{H}_{3} \mathrm{C}^{12} \mathrm{O}^{16} \mathrm{Cl}^{35}$ & 3. 367 & $6,3,3 \leftarrow 6,2,4$ & Ground & $15 / 2$ & $15 / 2$ & 22371.19 & .2 \\
\hline $\mathrm{C}^{13} \mathrm{H}_{3} \mathrm{C}^{12} \mathrm{O}^{16} \mathrm{Cl}^{35}$ & 3- 367 & $6,3,3 \leftarrow 6,2,4$ & Ground & $9 / 2$ & $9 / 2$ & 22371.19 & .2 \\
\hline $\mathrm{C}^{12} \mathrm{H}_{3} \mathrm{~N}^{14} \mathrm{O}_{2}^{16}$ & 3- 171 & Not Reported & Ground & & & 22372.15 & \\
\hline $\mathrm{HC}^{12} \mathrm{O}^{18} \mathrm{O}^{16} \mathrm{H}$ & 3- 76 & $5,1,5 \leftarrow 5,1,4$ & Ground & & & 22372.49 & .1 \\
\hline $\mathrm{C}^{13} \mathrm{H} \mathrm{C}^{12} \mathrm{O}^{16} \mathrm{Cl}^{35}$ & 3- 367 & $6,3,3 \leftarrow 6,2,4$ & Ground & $11 / 2$ & $11 / 2$ & 22376.50 & .2 \\
\hline $\mathrm{C}^{13} \mathrm{H}_{3} \mathrm{C}^{12} \mathrm{O}^{16} \mathrm{Cl}^{35}$ & 3- 367 & $6,3,3 \leftarrow 6,2,4$ & Ground & $13 / 2$ & $13 / 2$ & 22376.50 & .2 \\
\hline $4 d-\mathrm{C}_{6}^{12} \mathrm{H}_{5} \mathrm{~F}^{19}$ & 4-1283 & $5,2,3 \leftarrow 4,2,2$ & Ground & & & 22378.0 & .1 \\
\hline $\mathrm{O}^{16} \mathrm{~F}_{2}^{19}$ & 4-1611 & $19,5,15 \leftarrow 20,4,16$ & Ground & & & 22378.53 & .10 \\
\hline $\mathrm{H}_{2} \mathrm{C}^{12}: \mathrm{C}^{12} \mathrm{HCl}^{35}$ & 4. 766 & $2,1,2 \leftarrow 1,1,1$ & Ground & $1 / 2$ & $1 / 2$ & 22380.11 & .02 \\
\hline $\mathrm{C}^{12} \mathrm{H}_{2}\left(\mathrm{C}^{12} \mathrm{~N}^{14}\right)_{2}$ & 4- 901 & Not Reported & Ground & & & 22380.5 & .1 \\
\hline $\mathrm{C}^{12} \mathrm{H}_{3} \mathrm{~N}^{14} \mathrm{H}_{2}$ & 3- 261 & Not Reported & Ground & & & 22381.96 & \\
\hline $\mathrm{C}^{12} \mathrm{H}_{2}\left(\mathrm{C}^{12} \mathrm{~N}^{14}\right)_{2}$ & 4- 901 & Not Reported & Ground & & & 22383.9 & .1 \\
\hline $\mathrm{H}_{2} \mathrm{C}^{12}: \mathrm{C}^{12} \mathrm{~F}_{2}^{19}$ & 4- 681 & Not Reported & & & & 22386.2 & .3 \\
\hline $\mathrm{C}^{12} \mathrm{H}_{3} \mathrm{C}^{12} \mathrm{H}_{2} \mathrm{Br}^{79}$ & 3- 521 & $3,1,2 \leftarrow 2,1,1$ & Ground & $3 / 2$ & $1 / 2$ & 22386.74 & .05 \\
\hline $\mathrm{C}^{12} \mathrm{H}_{3} \mathrm{C}^{12} \mathrm{H}_{2} \mathrm{Br}^{79}$ & 3- 521 & $3,1,2 \leftarrow 2,1,1$ & Ground & $9 / 2$ & $7 / 2$ & 22388.13 & .05 \\
\hline $\mathrm{C}^{12} \mathrm{H}_{2}\left(\mathrm{C}^{12} \mathrm{~N}^{14}\right)_{2}$ & 4. 901 & Not Reported & Ground & & & 22389.9 & .1 \\
\hline $2,4,6 d_{3}-C_{6}^{12} H_{5} F^{19}$ & 4-1284 & $12,3,9 \leftarrow 12,3,10$ & Ground & & & 22391.7 & .1 \\
\hline $\mathrm{C}^{12} \mathrm{H}_{3} \mathrm{~N}^{14} \mathrm{O}_{2}^{16}$ & 3- 171 & Not Reported & Ground & & & 22393.96 & \\
\hline $\mathrm{H}_{2} \mathrm{C}^{12}: \mathrm{C}^{12} \mathrm{~F}_{2}^{19}$ & 4. 681 & Not Reported & & & & 22394.8 & .3 \\
\hline $\mathrm{C}^{12} \mathrm{H}_{2} \mathrm{Cl}^{35} \mathrm{~F}^{19}$ & 4- 331 & $19,1,19 \leftarrow 18,2,16$ & Ground & & & 22395.57 & .1 \\
\hline $\mathrm{C}^{12} \mathrm{D}_{2} \mathrm{Cl}^{35} \mathrm{Si}^{28} \mathrm{H}_{3}$ & 3- 235 & $9,1,8 \leftarrow 9,0,9$ & Ground & & & 22399.13 & .2 \\
\hline$\left(\mathrm{C}^{12} \mathrm{H}_{3}\right)_{2} \mathrm{Si}^{28} \mathrm{H}_{2}$ & 3- 641 & $3,0,3 \leftarrow 2,1,2$ & Ground & & & 22402.03 & .05 \\
\hline $\mathrm{C}^{12} \mathrm{H}_{2} \mathrm{Cl}^{35} \mathrm{~F}^{19}$ & 4- 331 & $19,1,19 \leftarrow 18,2,16$ & Ground & & & 22402.23 & .1 \\
\hline$\left(\mathrm{C}^{12} \mathrm{H}_{3}\right)_{2} \mathrm{Si}^{28} \mathrm{H}_{2}$ & 3- 641 & $3,0,3 \leftarrow 2,1,2$ & Ground & & & 22402.90 & .05 \\
\hline$\left(\mathrm{C}^{12} \mathrm{H}_{3}\right)_{2} \mathrm{Si}^{28} \mathrm{H}_{2}$ & 3- 641 & $3,0,3 \leftarrow 2,1,2$ & Ground & & & 22403.80 & .05 \\
\hline g- $\mathrm{C}^{12} \mathrm{H}_{3} \mathrm{C}^{12} \mathrm{H}_{2} \mathrm{C}^{12} \mathrm{H}_{2} \mathrm{Cl}^{35}$ & 3- 773 & $10,2,8 \leftarrow 10,1,9$ & Ground & & & 22404.11 & .2 \\
\hline
\end{tabular}




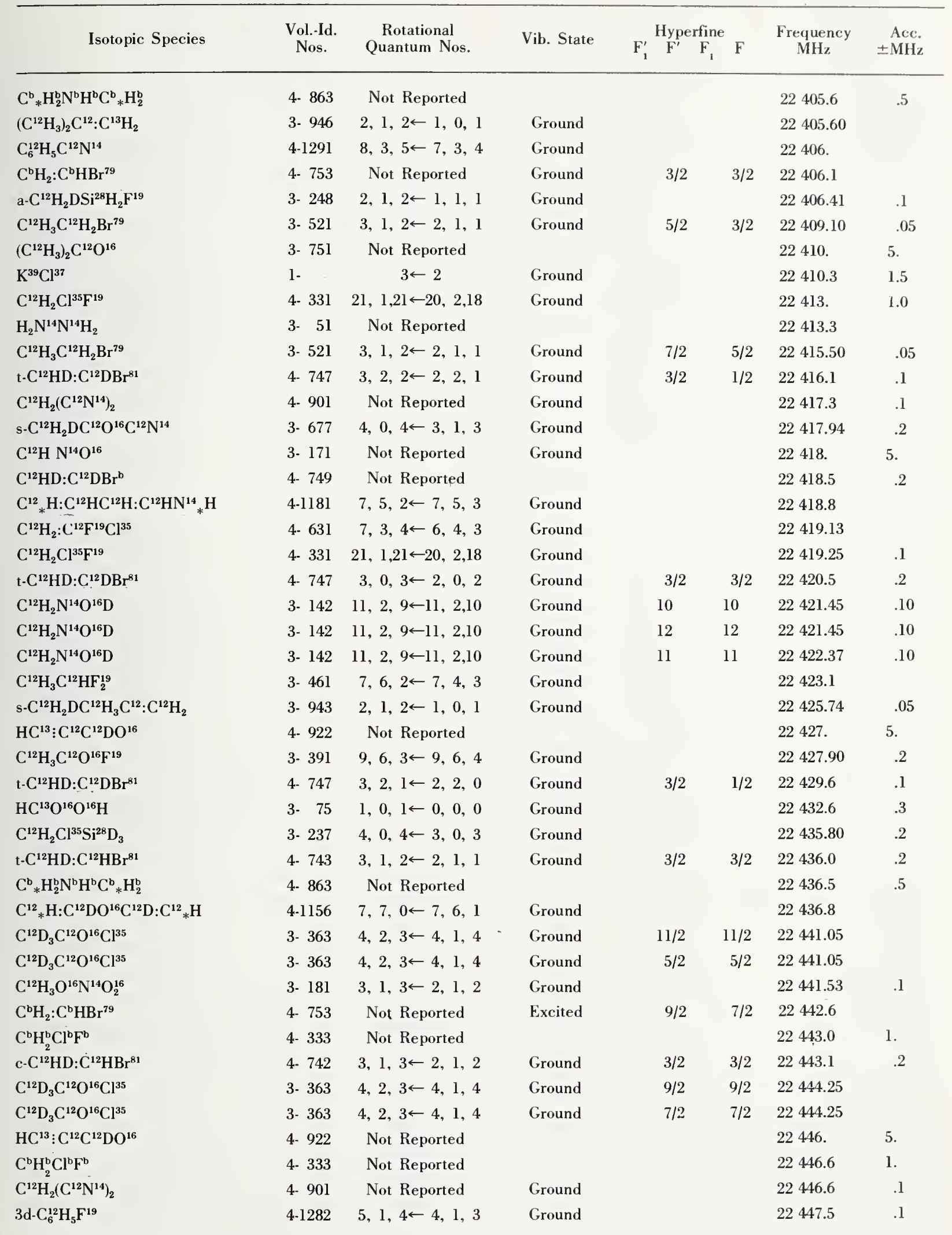




\begin{tabular}{|c|c|c|c|c|c|c|c|}
\hline Isotopic Species & $\begin{array}{l}\text { Vol.-Id. } \\
\text { Nos. }\end{array}$ & $\begin{array}{c}\text { Rotational } \\
\text { Quantum Nos. }\end{array}$ & Vib. State & \begin{tabular}{ccc} 
& \multicolumn{2}{c}{ Hyperfine } \\
$F_{1}^{\prime}$ & $F^{\prime}$ & $F_{1}$
\end{tabular} & $F$ & $\begin{array}{c}\text { Frequency } \\
\mathrm{MHz}\end{array}$ & $\begin{aligned} & \text { Acc. } \\
\pm & \mathrm{MHz}\end{aligned}$ \\
\hline $\mathrm{t}-\mathrm{C}^{12} \mathrm{HD}: \mathrm{C}^{12} \mathrm{DBr}^{81}$ & 4- 747 & $3,0,3 \leftarrow 2,0,2$ & Ground & $5 / 2$ & $5 / 2$ & 22449.4 & .1 \\
\hline $\mathrm{HC}^{13}: \mathrm{C}^{12} \mathrm{C}^{12} \mathrm{DO}^{16}$ & 4- 922 & Not Reported & & & & 22451. & 5. \\
\hline $\mathrm{C}^{12}{ }_{*} \mathrm{H}_{2} \mathrm{C}^{12} \mathrm{H}_{2} \mathrm{C}^{12}{ }_{*} \mathrm{HCl}^{37}$ & 4-1082 & $3,1,2 \leftarrow 2,1,1$ & Ground & $5 / 2$ & $3 / 2$ & 22453.2 & .1 \\
\hline $\mathrm{C}^{12}{ }_{*} \mathrm{H}_{2} \mathrm{C}^{12} \mathrm{H}_{2} \mathrm{C}^{12}{ }_{*} \mathrm{HCl}^{37}$ & 4-1082 & $3,1,2 \leftarrow 2,1,1$ & Ground & $7 / 2$ & $5 / 2$ & 22453.2 & .1 \\
\hline $\mathrm{C}^{\mathrm{b}} \mathrm{H}_{2}: \mathrm{C}^{\mathrm{b}} \mathrm{HBr}^{\mathrm{b}}$ & 4- 752 & Not Reported : & Ground & $5 / 2$ & $5 / 2$ & 22454.0 & \\
\hline $\mathrm{a} \cdot \mathrm{C}^{12} \mathrm{HD}_{2} \mathrm{C}^{12} \mathrm{O}^{16} \mathrm{C}^{12} \mathrm{~N}^{14}$ & 3- 678 & $9,3,6 \leftarrow 9,2,7$ & Ground & & & 22454.2 & .2 \\
\hline $\mathrm{C}^{12} \mathrm{HD}: \mathrm{C}^{12} \mathrm{DBr}^{\mathrm{b}}$ & 4- 749 & Not Reported & & & & 22455.1 & .2 \\
\hline $\mathrm{C}^{12}{ }_{*} \mathrm{H}_{2} \mathrm{C}^{12} \mathrm{H}_{2} \mathrm{C}^{12}{ }_{*} \mathrm{HCl}^{37}$ & $4-1082$ & $3,1,2 \leftarrow 2,1,1$ & Ground & $3 / 2$ & $1 / 2$ & 22456.0 & .1 \\
\hline $\mathrm{C}^{12}{ }_{*} \mathrm{H}_{2} \mathrm{C}^{12} \mathrm{H}_{2} \mathrm{C}^{12}{ }_{*} \mathrm{HCl}^{37}$ & $4 \cdot 1082$ & $3,1,2 \leftarrow 2,1,1$ & Ground & $9 / 2$ & $7 / 2$ & 22456.0 & .1 \\
\hline t. $-\mathrm{C}^{12} \mathrm{H}_{3} \mathrm{C}^{12} \mathrm{H}: \mathrm{C}^{12} \mathrm{HC}^{12} \mathrm{~N}^{14}$ & 3- 921 & $5,0, \leftarrow 4,0$, & Ground & & & 22456.90 & .5 \\
\hline $\mathrm{C}^{12}{ }_{*} \mathrm{H}_{2} \mathrm{C}^{12} \mathrm{H}_{2} \mathrm{C}^{12} * \mathrm{HCl}^{37}$ & 4-1082 & $3,1,2 \leftarrow 2,1,1$ & Ground & $5 / 2$ & $5 / 2$ & 22457.7 & .1 \\
\hline $\mathrm{HC}^{13}: \mathrm{C}^{12} \mathrm{C}^{12} \mathrm{DO}^{16}$ & 4- 922 & Not Reported & & & & 22458. & 5. \\
\hline $\mathrm{C}^{12}{ }_{*} \mathrm{H}: \mathrm{C}^{12} \mathrm{HO}^{16} \mathrm{C}^{12} \mathrm{H}: \mathrm{C}^{12}{ }_{*} \mathrm{H}$ & $4-1151$ & $8,6,2 \leftarrow 8,6,3$ & Ground & & & 22458.99 & \\
\hline $4 d-C_{6}^{12} \mathrm{H}_{5} \mathrm{~F}^{19}$ & $4-1283$ & $6,0,6 \leftarrow 5,0,5$ & Ground & & & 22461.6 & .1 \\
\hline $\mathrm{HC}^{13}: \mathrm{C}^{12} \mathrm{C}^{12} \mathrm{DO}^{16}$ & 4. 922 & Not Reported & & & & 22463. & 5. \\
\hline $\mathrm{C}^{12} \mathrm{H}_{3} \mathrm{C}^{12} \mathrm{H}_{2} \mathrm{~F}^{19}$ & 3. 551 & Not Reported & & & & 22463.5 & \\
\hline $\mathrm{t}-\mathrm{C}^{12} \mathrm{H}_{3} \mathrm{C}^{12} \mathrm{H}: \mathrm{C}^{12} \mathrm{HC}^{12} \mathrm{~N}^{14}$ & 3. 921 & $5,4, \leftarrow 4,4$, & Ground & & & 22463.68 & .5 \\
\hline $\mathrm{t}-\mathrm{C}^{12} \mathrm{H}_{3} \mathrm{C}^{12} \mathrm{H}: \mathrm{C}^{12} \mathrm{HC}^{12} \mathrm{~N}^{14}$ & 3. 921 & $5,3, \leftarrow 4,3$, & Ground & & & 22463.68 & .5 \\
\hline $\mathrm{C}^{12} \mathrm{H}_{3} \mathrm{C}^{12} \mathrm{HO}^{16}$ & 3- 471 & Not Reported & & & & 22464.77 & \\
\hline $\mathrm{C}^{12} \mathrm{H}_{3} \mathrm{~N}^{14} \mathrm{O}_{2}^{16}$ & 3- 171 & Not Reported & Ground & & & 22465. & \\
\hline $\mathrm{C}_{6}^{12} \mathrm{H}_{5} \mathrm{~F}^{19}$ & $4-1281$ & $7,2,6 \leftarrow 7,0,7$ & Ground & & & 22465.2 & .1 \\
\hline $\mathrm{t}-\mathrm{C}^{12} \mathrm{HD}: \mathrm{C}^{12} \mathrm{HBr}^{81}$ & 4- 743 & $3,1,2 \leftarrow 2,1,1$ & Excited & $9 / 2$ & $7 / 2$ & 22466.4 & .1 \\
\hline $\mathrm{HC}^{13}: \mathrm{C}^{12} \mathrm{C}^{12} \mathrm{DO}^{16}$ & 4. 922 & Not Reported & & & & 22467. & 5. \\
\hline $\mathrm{C}^{\mathrm{b}} \mathrm{H}_{2}: \mathrm{C}^{\mathrm{b}} \mathrm{HBr}^{\mathrm{b}}$ & 4- 752 & Not Reported & Ground & $9 / 2$ & $7 / 2$ & 22468.1 & \\
\hline $\mathrm{C}^{12}{ }_{*} \mathrm{H}_{2}^{\mathrm{b}} \mathrm{S}^{\mathrm{b}} \mathrm{C}^{12}{ }_{*} \mathrm{H}_{2}^{\mathrm{b}}$ & 4- 854 & Not Reported & & & & 22468.6 & .2 \\
\hline $\mathrm{C}^{12} \mathrm{HD}: \mathrm{C}^{12} \mathrm{HBr}^{\mathrm{b}}$ & 4- 748 & Not Reported & & & & 22470.5 & .2 \\
\hline $\mathrm{C}^{12} \mathrm{D}_{3} \mathrm{C}^{12} \mathrm{O}^{16} \mathrm{Cl}^{37}$ & 3. 364 & $9,3,6 \leftarrow 9,2,7$ & Ground & $17 / 2$ & $17 / 2$ & 22470.92 & \\
\hline $\mathrm{C}^{12} \mathrm{D}_{3} \mathrm{C}^{12} \mathrm{O}^{16} \mathrm{Cl}^{37}$ & 3. 364 & $9,3,6 \leftarrow 9,2,7$ & Ground & $19 / 2$ & $19 / 2$ & 22470.92 & \\
\hline $\mathrm{C}^{12} \mathrm{D}_{3} \mathrm{C}^{12} \mathrm{O}^{16} \mathrm{Cl}^{37}$ & 3- 364 & $9,3,6 \leftarrow 9,2,7$ & Ground & $21 / 2$ & $21 / 2$ & 22470.92 & \\
\hline $\mathrm{C}^{12} \mathrm{D}_{3} \mathrm{C}^{12} \mathrm{O}^{16} \mathrm{Cl}^{37}$ & 3- 364 & $9,3,6 \leftarrow 9,2,7$ & Ground & $15 / 2$ & $15 / 2$ & 22470.92 & \\
\hline $\mathrm{HC}^{12} \mathrm{O}^{16} \mathrm{O}^{16} \mathrm{H}$ & 3- 71 & $1,0,1 \leftarrow 0,0,0$ & & & & 22471.22 & .1 \\
\hline $\mathrm{N}^{14} \mathrm{O}^{16} \mathrm{Cl}^{35}$ & $4-1451$ & $2,1,1 \leftarrow 1,1,0$ & Excited & $5 / 2$ & $3 / 2$ & 22471.6 & .3 \\
\hline $\mathrm{C}^{\mathrm{b}} \mathrm{H}_{2}: \mathrm{C}^{\mathrm{b}} \mathrm{HBr}^{\mathrm{b}}$ & 4- 752 & Not Reported & Excited & $7 / 2$ & $5 / 2$ & 22471.7 & \\
\hline $\mathrm{t}-\mathrm{C}^{12} \mathrm{HD}: \mathrm{C}^{12} \mathrm{HBr}^{81}$ & 4- 743 & $3,1,2 \leftarrow 2,1,1$ & Ground & $5 / 2$ & $5 / 2$ & 22473.4 & .1 \\
\hline $\mathrm{C}^{12} \mathrm{HD}: \mathrm{C}^{12} \mathrm{DBr}^{\mathrm{b}}$ & 4- 749 & Not Reported & & & & 22473.4 & .1 \\
\hline $\mathrm{C}^{12} \mathrm{H}_{3} \mathrm{C}^{12} \mathrm{H}_{2} \mathrm{O}^{16} \mathrm{H}$ & 3- 581 & $10,4,7 \leftarrow 11,3,8$ & Ground & & & 22474.13 & .01 \\
\hline $\mathrm{C}^{12} \mathrm{HD}: \mathrm{C}^{12} \mathrm{DBr}^{\mathrm{b}}$ & 4- 749 & Not Reported & & & & 22474.4 & .1 \\
\hline $\mathrm{H}_{2} \mathrm{C}^{12}: \mathrm{C}^{12} \mathrm{HCl}^{37}$ & 4. 767 & $2,0,2 \leftarrow 1,0,1$ & Ground & $5 / 2$ & $5 / 2$ & 22474.53 & .02 \\
\hline $\mathrm{N}^{14} \mathrm{O}^{16} \mathrm{Cl}^{35}$ & $4-1451$ & $2,1,1 \leftarrow 1,1,0$ & Excited & $3 / 2$ & $3 / 2$ & 22476.2 & .3 \\
\hline $\mathrm{N}^{14} \mathrm{O}^{16} \mathrm{Cl}^{35}$ & 4-1451 & $2,1,1 \leftarrow 1,1,0$ & Excited & $5 / 2$ & $5 / 2$ & 22476.2 & .3 \\
\hline $\mathrm{C}^{12} \mathrm{H}_{2} \mathrm{Cl}^{35} \mathrm{Si}^{28} \mathrm{H}_{3}$ & 3- 231 & $7,1,6 \leftarrow 7,0,7$ & Ground & & & 22477.10 & .2 \\
\hline $\mathrm{C}^{12}{ }_{*} \mathrm{H}: \mathrm{C}^{12} \mathrm{HO}^{16} \mathrm{C}^{12} \mathrm{D}: \mathrm{C}^{12}{ }_{*} \mathrm{H}$ & 4-1154 & $3,2,2 \leftarrow 3,1,3$ & Ground & & & 22477.6 & \\
\hline $\mathrm{C}^{12} \mathrm{H}_{2}\left(\mathrm{C}^{12} \mathrm{~N}^{14}\right)_{2}$ & 4- 901 & Not Reported & Ground & & & 22477.9 & .1 \\
\hline $\mathrm{C}^{12} \mathrm{H}_{3} \mathrm{~N}^{14} \mathrm{O}_{2}^{16}$ & 3. 171 & Not Reported & Ground & & & 22478. & 5. \\
\hline $\mathrm{C}^{13} \mathrm{H}_{2}: \mathrm{C}^{13} \mathrm{HBr}^{79}$ & 4- 733 & $3,1,3 \leftarrow 2,1,2$ & Ground & & & 22480.64 & .04 \\
\hline
\end{tabular}


Vib. State

$F_{1}^{\prime} \mathbf{F}^{\prime} F_{1} \quad F$

Frequency MII\% t- $\mathrm{C}^{12} \mathrm{H}_{3} \mathrm{C}^{12} \mathrm{H}_{2} \mathrm{C}^{12} \mathrm{H}_{2} \mathrm{Cl}^{37}$

$\mathrm{C}^{12} \mathrm{HD}: \mathrm{C}^{12} \mathrm{DBr}^{\mathrm{b}}$

t-C ${ }^{12} \mathrm{HD}: \mathrm{C}^{12} \mathrm{HBr}^{8 \mathrm{t}}$

$\mathrm{C}^{12} \mathrm{HD}: \mathrm{C}^{12} \mathrm{DBr}^{\mathrm{b}}$

$\mathrm{S}^{32} \mathrm{O}_{2}^{16}$

t-HDC ${ }^{12}: \mathrm{C}^{12} \mathrm{DCl}^{35}$

$\mathrm{N}^{14} \mathrm{O}^{16} \mathrm{Cl}^{35}$

$\mathrm{N}^{14} \mathrm{O}^{16} \mathrm{Cl}^{35}$

t- $\overline{\mathrm{C}^{12}} \mathrm{HD}: \mathrm{C}^{12} \mathrm{DBr}^{81}$

t- $\mathrm{C}^{12} \mathrm{HD}: \mathrm{C}^{12} \mathrm{DB} \mathrm{r}^{81}$

$\mathrm{H}_{2} \mathrm{C}^{12}: \mathrm{C}^{12} \mathrm{HCl}^{37}$

$\mathrm{H}_{2} \mathrm{C}^{12}: \mathrm{C}^{12} \mathrm{HCl}^{37}$

$\mathrm{C}^{\mathrm{b}}{ }_{*} \mathrm{H}_{2}^{\mathrm{b}} \mathrm{N}^{\mathrm{b}} \mathrm{H}^{\mathrm{b}} \mathrm{C}^{\mathrm{b}}{ }_{*} \mathrm{H}_{2}^{\mathrm{b}}$

$\mathrm{C}^{12} \mathrm{H}_{3} \mathrm{~N}^{14} \mathrm{O}_{2}^{16}$

$\left(\mathrm{C}^{12} \mathrm{H}_{3} \mathrm{C}^{12} \mathrm{H}_{2}\right)_{2} \mathrm{O}^{16}$

$\mathrm{t}-\mathrm{C}^{12} \mathrm{HD}: \mathrm{C}^{12} \mathrm{HBr}^{81}$

$\mathrm{C}^{13} \mathrm{H}_{3} \mathrm{C}^{12} \mathrm{O}^{16} \mathrm{Cl}^{35}$

$\mathrm{C}^{13} \mathrm{H}_{3} \mathrm{C}^{12} \mathrm{O}^{16} \mathrm{Cl}^{35}$

t-C $\mathrm{C}^{12} \mathrm{HD}: \mathrm{C}^{12} \mathrm{HBr}^{81}$

$\mathrm{C}^{13} \mathrm{H}_{3} \mathrm{C}^{12} \mathrm{O}^{16} \mathrm{Cl}^{35}$

$\mathrm{C}^{13} \mathrm{H}_{3} \mathrm{C}^{12} \mathrm{O}^{16} \mathrm{Cl}^{35}$

$\mathrm{H}_{2} \mathrm{C}^{12}: \mathrm{C}^{12} \mathrm{HCl}^{37}$

$\mathrm{C}^{13} \mathrm{H}_{3} \mathrm{C}^{12} \mathrm{O}^{16} \mathrm{Cl}^{35}$

$\mathrm{C}^{13} \mathrm{H}_{3} \mathrm{C}^{12} \mathrm{O}^{16} \mathrm{Cl}^{35}$

t-C ${ }^{12} \mathrm{HD}: \mathrm{C}^{12} \mathrm{DBr}^{81}$

t- $\mathrm{C}^{12} \mathrm{HD}: \mathrm{C}^{12} \mathrm{DBr}^{81}$

c- $\mathrm{C}^{12} \mathrm{HD}: \mathrm{C}^{12} \mathrm{HBr}^{81}$

$\mathrm{C}^{13} \mathrm{H}_{3} \mathrm{C}^{12} \mathrm{O}^{16} \mathrm{Cl}^{35}$

$\mathrm{C}^{13} \mathrm{H}_{3} \mathrm{C}^{12} \mathrm{O}^{16} \mathrm{C}^{35}$

c- $\mathrm{C}^{12} \mathrm{HD}: \mathrm{C}^{12} \mathrm{HBr}^{81}$

$\mathrm{C}^{12} \mathrm{H}_{3} \mathrm{C}^{12} \mathrm{~F}^{19}: \mathrm{C}^{12} \mathrm{H}_{2}$

$\mathrm{C}^{\mathrm{b}} \mathrm{H}_{2}: \mathrm{C}^{\mathrm{b}} \mathrm{HBr}^{\mathrm{b}}$

t-HDC ${ }^{12}: \mathrm{C}^{12} \mathrm{DCl}^{35}$

$\mathrm{C}^{12} \mathrm{H}_{3} \mathrm{C}^{12} \mathrm{~F}^{19}: \mathrm{C}^{12} \mathrm{H}_{2}$

$\mathrm{C}^{12}{ }_{*} \mathrm{H}: \mathrm{C}^{12} \mathrm{HO}^{16} \mathrm{C}^{12} \mathrm{H}: \mathrm{C}^{12}{ }_{*} \mathrm{D}$

$\mathrm{C}^{12} \mathrm{H}_{3} \mathrm{Si}^{28} \mathrm{D}_{2} \mathrm{~F}^{19}$

$\mathrm{C}^{\mathrm{b}} \mathrm{H}_{2}: \mathrm{C}^{\mathrm{b}} \mathrm{HBr}^{\mathrm{b}}$

$\mathrm{t}-\mathrm{C}^{12} \mathrm{HD}: \mathrm{C}^{12} \mathrm{DBr}^{81}$

$\mathrm{t}-\mathrm{C}^{12} \mathrm{HD}: \mathrm{C}^{12} \mathrm{DBr}^{81}$

t- $\mathrm{C}^{12} \mathrm{HD}: \mathrm{C}^{12} \mathrm{DBr}^{81}$

$\left(\mathrm{C}^{12} \mathrm{H}_{3}\right)_{2} \mathrm{C}^{12} \mathrm{O}^{16}$

c. $\mathrm{C}^{12} \mathrm{HD}: \mathrm{C}^{12} \mathrm{HBr}^{81}$

$\mathrm{C}^{12} \mathrm{H}_{3} \mathrm{C}^{12} \mathrm{O}^{16} \mathrm{~F}^{19}$

$\mathrm{t}-\mathrm{C}^{12} \mathrm{HD}: \mathrm{C}^{12} \mathrm{HBr}^{81}$

$\mathrm{C}^{12} \mathrm{HD}: \mathrm{C}^{12} \mathrm{DBr}^{\mathrm{b}}$
3. $7725,1,5 \leftarrow 4,1,4 \quad$ Ground

4- 749 Not Reported

4. $743 \quad 3,1,2 \leftarrow 2,1,1$

4- 749 Not Reported

4-1831 24, 4,20ऍ23, 5,19

4- $761 \quad 2,1,1 \leftarrow 1,1,0$

4-1451 2, 1, $1 \leftarrow 1,1,0$

4.1451 2, $1,1 \leftarrow 1,1,0$

4- $747 \quad 3,2,2 \leftarrow 2,2,1$

4- $747 \quad 3,2,2 \leftarrow 2,2,1$

4. $767 \quad 2,0,2 \leftarrow 1,0,1$

4. 767

$2,0,2 \leftarrow 1,0,1$

4. 863

Not Reported

3- 171

3-1011

Not Reported

4. 743

Not Reported

3- 367

$3,1,2 \leftarrow 2,1,1$

3- 367

$8,3,5 \leftarrow 8,2,6$

4. 743

$8,3,5 \leftarrow 8,2,6$

3- 367

$3,1,2 \leftarrow 2,1,1$

3- 367

$8,3,5 \leftarrow 8,2,6$

4. 767

$8,3,5 \leftarrow 8,2,6$

3- 367

$2,0,2 \leftarrow 1,0,1$

3. 367

$8,3,5 \leftarrow 8,2,6$

4- 747

$8,3,5 \leftarrow 8,2,6$

4- 747

$3,0,3 \leftarrow 2,0,2$

4- 742

$3,0,3 \leftarrow 2,0,2$

3- 367

$3,1,3 \leftarrow 2,1,2$

3. 367

$8,3,5 \leftarrow 8,2,6$

4- 742

$8,3,5 \leftarrow 8,2,6$

3- 721

$3,1,3 \leftarrow 2,1,2$

4- 752

$10,8,2 \leftarrow 10,7,3$

4- 761

Not Reported

3- 721

$2,1,1 \leftarrow 1,1,0$

4-1155

$10,8,2 \leftarrow 10,7,3$

Ground

Ground

Ground

Excited

Excited:

Ground

Ground

Ground

Ground

Ground

Excited

Ground

Ground

Ground

Ground

Ground

Ground

Ground

Ground

Ground

Ground

Ground

Ground

Ground

Ground

Ground

Ground

Ground

Ground

3. 245

$3,2,2 \leftarrow 3,0,3$

Ground

Ground

4. 752

$2,1,2 \leftarrow 1,1,1$

4. 747

Not Reported

Ground

Ground

4. 747

$3,0,3 \leftarrow 2,0,2$

4. 747

$3,2,1 \leftarrow 2,2,0$

Ground

Ground

3- 751

$3,2,1 \leftarrow 2,2,0$

4- 742

Not Reported

3. 391

$3,1,3 \leftarrow 2,1,2$

Ground

4- 743

$9,6,3 \leftarrow 9,6,4$

Ground

4. 749

Ground

Not Reported
$22480.92 \quad .2$

$22481.4 \quad .1$

$\begin{array}{lllll}9 / 2 & 7 / 2 & 22 & 481.5 & .1\end{array}$

$22482.4 \quad .1$

$22482.51 \quad .1$

22483.25

$\begin{array}{lllll}3 / 2 & 1 / 2 & 22483.7 & .3\end{array}$

$\begin{array}{lllll}7 / 2 & 5 / 2 & 22 & 483.7 & 3\end{array}$

$\begin{array}{lllll}9 / 2 & 7 / 2 & 22 & 485.7 & .1\end{array}$

$\begin{array}{llll}7 / 2 & 7 / 2 & 22485.7 & .1\end{array}$

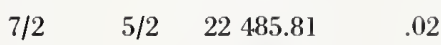

$\begin{array}{llll}5 / 2 & 3 / 2 & 22485.81 & .02\end{array}$

$22486.1 \quad .5$

22489 . 5 .

22490.

$\begin{array}{llll}7 / 2 & 5 / 2 & 22490.9 & .2\end{array}$

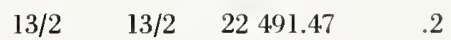

$19 / 2 \quad 19 / 2 \quad 22491.47 \quad .2$

$22491.90 \quad .06$

$\begin{array}{llll}17 / 2 & 17 / 2 & 22492.59 & .2\end{array}$

$15 / 2 \quad 15 / 2 \quad 22492.59 \quad .2$

$\begin{array}{llll}3 / 2 & 3 / 2 & 22493.89 & .02\end{array}$

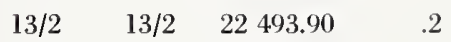

$19 / 2 \quad 19 / 2 \quad 22493.90 \quad .2$

$\begin{array}{lllll}7 / 2 & 5 / 2 & 22 & 494.2 & .1\end{array}$

$\begin{array}{lllll}9 / 2 & 7 / 2 & 22 & 494.2 & .1\end{array}$

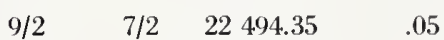

$15 / 2 \quad 15 / 2 \quad 22495.00 \quad .2$

$17 / 2 \quad 17 / 2 \quad 22495.00 \quad .2$

$\begin{array}{lllll}3 / 2 & 1 / 2 & 22 & 496.1 & .1\end{array}$

22496.34

$7 / 2 \quad 5 / 2 \quad 22497.0$

$\begin{array}{llll}7 / 2 & 5 / 2 & 22497.05 & .2\end{array}$

$22497.12 \quad .1$

22497.9

$22498.71 \quad .10$

$5 / 2 \quad 3 / 2 \quad 22498.8$

$22498.94 \quad .04$

$\begin{array}{lllll}9 / 2 & 7 / 2 & 22 & 499.25 & .1\end{array}$

$\begin{array}{lllll}7 / 2 & 7 / 2 & 22 & 499.25 & .1\end{array}$

22500 . $\quad 5$.

$22504.70 \quad .05$

$22505.64 \quad .2$

$\begin{array}{llll}7 / 2 & 5 / 2 & 22505.85 & .05\end{array}$

$22506.0 \quad .1$ 


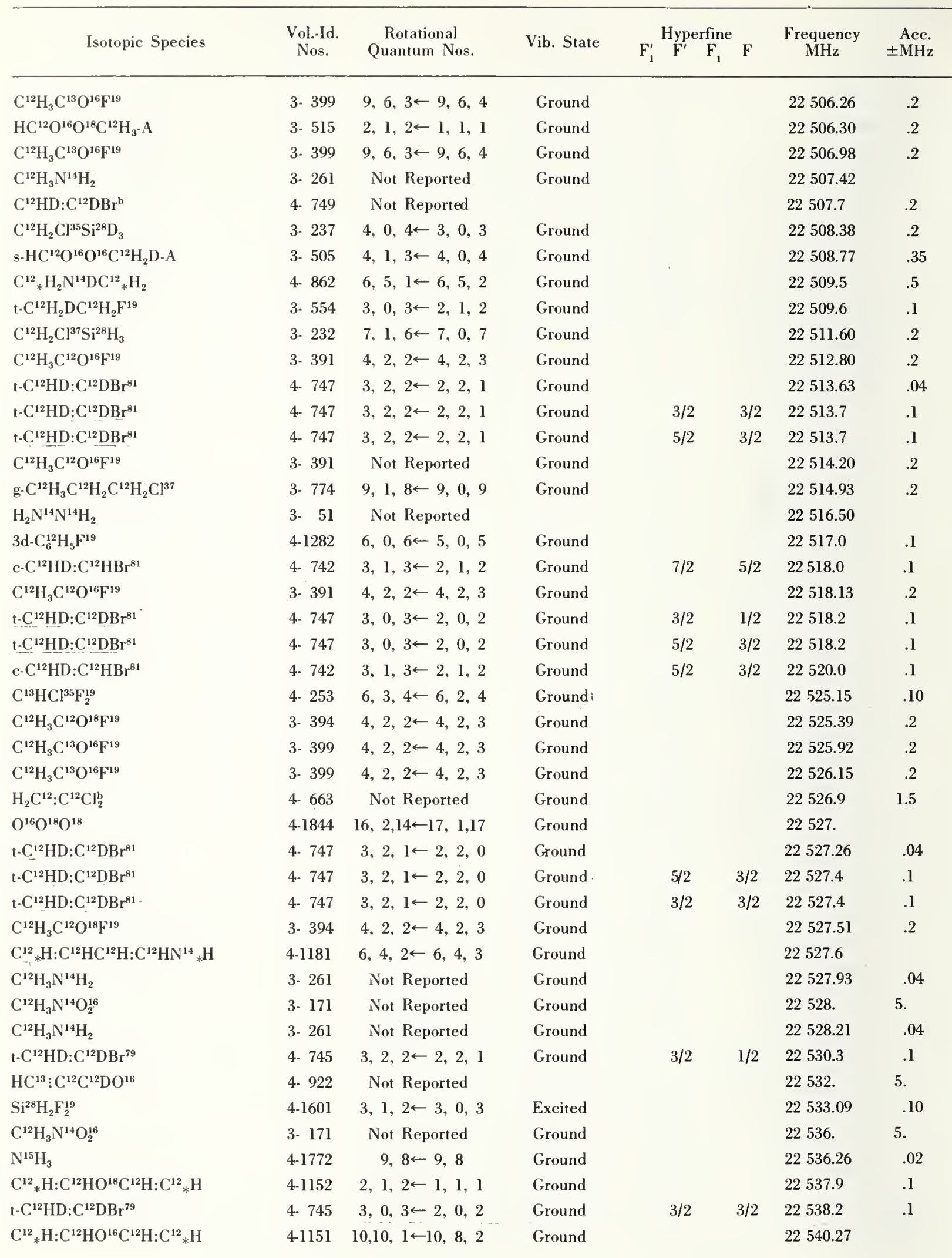




\begin{tabular}{|c|c|c|c|c|c|c|c|}
\hline $\mathrm{C}^{12} \mathrm{H}_{3} \mathrm{C}^{12} \mathrm{H}: \mathrm{C}^{12} \mathrm{HF}^{19}$ & 3. 711 & $3,0,3 \leftarrow 2,0,2$ & Ground & & & 22541.90 & \\
\hline $\mathrm{C}^{12} \mathrm{H}_{3} \mathrm{C}^{12} \mathrm{O}^{16} \mathrm{O}^{16} \mathrm{H}$ & 3. 491 & Not Reported & & & & 22542. & 3. \\
\hline $\mathrm{t}-\mathrm{C}^{12} \mathrm{HD}: \mathrm{C}^{12} \mathrm{DBr}^{79}$ & 4. 745 & $3,2,1 \leftarrow 2,2,0$ & Ground & $3 / 2$ & $1 / 2$ & 22544.4 & .1 \\
\hline $\mathrm{s}-\mathrm{C}^{12} \mathrm{H}_{2} \mathrm{DC}^{12} \mathrm{O}^{16} \mathrm{Cl}^{35}$ & 3- 365 & $7,3,4 \leftarrow 7,2,5$ & Ground & & & 22544.60 & .1 \\
\hline $\mathrm{C}^{12} \mathrm{HCl}^{35} \mathrm{~F}_{2}^{19}$ & 4- 251 & $6,3,4 \leftarrow 6,2,4$ & Ground & $9 / 2$ & $9 / 2$ & 22545.9 & .05 \\
\hline $\mathrm{C}^{12} \mathrm{H}_{3} \mathrm{C}^{12} \mathrm{H} \mathrm{C}^{12} \mathrm{HF}^{19}$ & 3- 711 & $3,2,2 \leftarrow 2,2,1$ & Ground & & & 22546.07 & \\
\hline $\mathrm{Cl}^{37} \mathrm{~F}^{19} \mathrm{C}^{12} \mathrm{O}^{16}$ & 4. 152 & $2,1,2 \leftarrow 1,0,1$ & Ground & $7 / 2$ & $5 / 2$ & 22546.22 & .05 \\
\hline $\mathrm{s}-\mathrm{C}^{12} \mathrm{H}_{2} \mathrm{DC}^{12} \mathrm{O}^{16} \mathrm{Cl}^{35}$ & 3- 365 & $7,3,4 \leftarrow 7,2,5$ & Ground & & & 22546.25 & .2 \\
\hline $\mathrm{C}^{13}{ }_{*} \mathrm{H}: \mathrm{C}^{12} \mathrm{HO}^{16} \mathrm{C}^{12} \mathrm{H}: \mathrm{C}^{12}{ }_{*} \mathrm{H}$ & $4-1157$ & $5,3,2 \leftarrow 5,3,3$ & Ground & & & 22547.1 & .1 \\
\hline $\mathrm{s}-\mathrm{C}^{12} \mathrm{H}_{2} \mathrm{DC}^{12} \mathrm{O}^{16} \mathrm{Cl}^{35}$ & 3. 365 & $7,3,4 \leftarrow 7,2,5$ & Ground & & & 22547.90 & .1 \\
\hline $\mathrm{C}^{12} \mathrm{H}_{3} \mathrm{C}^{12} \mathrm{H}: \mathrm{C}^{12} \mathrm{HF}^{19}$ & 3. 711 & $3,2,1 \leftarrow 2,2,0$ & Ground & & & 22548.08 & .1 \\
\hline $\mathrm{C}^{12} \mathrm{H}_{3} \mathrm{C}^{12} \mathrm{H}: \mathrm{C}^{12} \mathrm{HF}^{19}$ & 3- 711 & $3,2,2 \leftarrow 2,2,1$ & Ground & & & 22548.10 & .1 \\
\hline $\mathrm{S}^{32}{ }_{*} \mathrm{HC}^{12}: \mathrm{C}^{12} \mathrm{DC}^{12} \mathrm{H}: \mathrm{C}^{12}{ }_{*} \mathrm{H}$ & 4-1163 & $6,2,5 \leftarrow 6,2,4$ & Ground & & & 22549.0 & .1 \\
\hline $\mathrm{C}^{12} \mathrm{H}_{3} \mathrm{C}^{12} \mathrm{H}: \mathrm{C}^{12} \mathrm{HF}^{19}$ & 3- 711 & $3,2,1 \leftarrow 2,2,0$ & Ground & & & 22550.06 & \\
\hline $\mathrm{C}^{12} \mathrm{D}_{3} \mathrm{O}^{16} \mathrm{H}$ & 3. 214 & Not Reported & Ground & & & 22550.3 & .5 \\
\hline $\mathrm{C}^{12} \mathrm{HCl}^{35} \mathrm{~F}_{2}^{19}$ & 4- 251 & $6,3,4 \leftarrow 6,2,4$ & Ground & & & 22550.41 & .03 \\
\hline 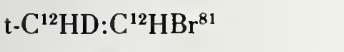 & 4- 743 & $3,1,2 \leftarrow 2,1,1$ & Ground & $7 / 2$ & $7 / 2$ & 22551.7 & .1 \\
\hline $\mathrm{C}^{12} \mathrm{HCl}^{35} \mathrm{~F}_{2}^{19}$ & 4- 251 & $6,3,4 \leftarrow 6,2,4$ & Ground & $11 / 2$ & $11 / 2$ & 22552.9 & .05 \\
\hline $\mathrm{C}^{13} \mathrm{H}_{2}: \mathrm{C}^{12} \mathrm{HBr}^{81}$ & 4. 736 & Not Reported & Ground & $3 / 2$ & $3 / 2$ & 22553.6 & \\
\hline $\mathrm{C}^{12} \mathrm{H}_{2} \mathrm{Cl}^{15} \mathrm{C}^{12} \mathrm{~N}^{14}$ & 4- 651 & $7,0,7 \leftarrow 6,1,6$ & Ground & & & 22554.00 & .2 \\
\hline $\mathrm{C}^{12} \mathrm{HCl}^{35} \mathrm{~F}_{2}^{19}$ & 4. 251 & $6,3,4 \leftarrow 6,2,4$ & Ground & $13 / 2$ & $13 / 2$ & 22554.5 & .05 \\
\hline $\mathrm{C}^{12} \mathrm{H}_{3} \mathrm{C}^{12} \mathrm{O}^{16} \mathrm{~F}^{19}$ & 3- 391 & Not Reported & Ground & & & 22556.28 & .2 \\
\hline $\mathrm{t} \cdot \mathrm{C}^{12} \mathrm{HD}: \mathrm{C}^{12} \mathrm{HBr}^{79}$ & 4. 741 & $3,1,2 \leftarrow 2,1,1$ & Ground & $3 / 2$ & $3 / 2$ & 22556.8 & .1 \\
\hline $\mathrm{c}-\mathrm{C}^{12} \mathrm{HD}: \mathrm{C}^{12} \mathrm{HBr}^{79}$ & 4. 739 & $3,1,3 \leftarrow 2,1,2$ & Ground & $3 / 2$ & $3 / 2$ & 22558.8 & .1 \\
\hline$\left(\mathrm{C}^{12} \mathrm{H}_{3}\right)_{2} \mathrm{C}^{12} \mathrm{O}^{16}$ & 3- 751 & Not Reported & & & & 22560. & 5. \\
\hline $\mathrm{C}_{6}^{12} \mathrm{H}_{5} \mathrm{Cl}^{35}$ & $4-1271$ & $8,6,3 \leftarrow 7,6,2$ & Ground & & & 22560. & 5.0 \\
\hline $\mathrm{C}_{6}^{12} \mathrm{H}_{5} \mathrm{Cl}^{35}$ & $4-1271$ & $8,6,2 \leftarrow 7,6,1$ & Ground & & & 22560. & 5.0 \\
\hline $\mathrm{C}^{12} \mathrm{H}_{3} \mathrm{~S}^{32} \mathrm{H}$ & 3- 221 & Not Reported & Ground & & & 22560.2 & .1 \\
\hline $\mathrm{C}^{13} \mathrm{H}_{2}: \mathrm{C}^{13} \mathrm{HBr}^{79}$ & 4- 733 & $3,1,3 \leftarrow 2,1,2$ & Ground & $7 / 2$ & $7 / 2$ & 22561.0 & \\
\hline $\mathrm{C}^{12} \mathrm{H}_{3} \mathrm{C}^{12} \mathrm{O}^{16} \mathrm{Br}^{81}$ & 3- 352 & $10,2,8 \leftarrow 10,1,9$ & Ground & $17 / 2$ & $17 / 2$ & 22561.01 & .15 \\
\hline $\mathrm{C}^{12} \mathrm{H}_{3} \mathrm{C}^{12} \mathrm{O}^{16} \mathrm{Br}^{81}$ & 3. 352 & $10,2,8 \leftarrow 10,1,9$ & Ground & $23 / 2$ & $23 / 2$ & 22561.63 & .15 \\
\hline $\mathrm{C}^{12} \mathrm{HCl}^{37}: \mathrm{C}^{12} \mathrm{~F}_{2}^{19}$ & 4- 612 & $7,0,7 \leftarrow 6,1,6$ & Ground & & & 22562.0 & .1 \\
\hline $\mathrm{C}^{12}{ }_{*} \mathrm{H}_{2} \mathrm{C}^{12} \mathrm{H}_{2} \mathrm{C}^{12}{ }_{*} \mathrm{HCl}^{35}$ & $4-1081$ & $3,0,3 \leftarrow 2,0,2$ & Ground & $5 / 2$ & $3 / 2$ & 22562.3 & .1 \\
\hline $\mathrm{C}^{12}{ }_{*} \mathrm{H}_{2} \mathrm{C}^{12} \mathrm{H}_{2} \mathrm{C}^{12}{ }_{*} \mathrm{HCl}^{35}$ & $4-1081$ & $3,0,3 \leftarrow 2,0,2$ & Ground & $3 / 2$ & $1 / 2$ & 22562.3 & .1 \\
\hline $\mathrm{C}^{12} \mathrm{H}_{3} \mathrm{C}^{12} \mathrm{~F}^{19}: \mathrm{C}^{12} \mathrm{H}_{2}$ & 3. 721 & $3,1,2 \leftarrow 3,0,3$ & Ground & & & 22562.48 & .1 \\
\hline $\mathrm{C}^{12} \mathrm{H}_{3} \mathrm{C}^{12} \mathrm{O}^{16} \mathrm{Br}^{81}$ & 3. 352 & $10,2,8 \leftarrow 10,1,9$ & Ground & $17 / 2$ & $17 / 2$ & 22563.55 & .15 \\
\hline $\mathrm{N}^{14} \mathrm{H}_{2} \mathrm{C}_{2}^{12} \mathrm{H}_{5}$ & 3. 631 & Not Reported & Ground & & & 22564.05 & .2 \\
\hline $\mathrm{C}^{12} \mathrm{H}_{3} \mathrm{C}^{12} \mathrm{O}^{16} \mathrm{Br}^{81}$ & 3- 352 & $10,2,8 \leftarrow 10,1,9$ & Ground & $23 / 2$ & $23 / 2$ & 22564.33 & \\
\hline $\mathrm{C}^{12} \mathrm{H}_{3} \mathrm{C}^{12} \mathrm{O}^{16} \mathrm{Br}^{81}$ & 3- 352 & $10,2,8 \leftarrow 10,1,9$ & Ground & $19 / 2$ & $19 / 2$ & 22564.33 & \\
\hline $\mathrm{C}^{\mathrm{b}} \mathrm{H}_{2}^{\mathrm{b}} \mathrm{Cl}^{\mathrm{b}} \mathrm{F}^{\mathrm{b}}$ & 4- 333 & Not Reported & & & & 22564.64 & .1 \\
\hline $\mathrm{C}^{12} \mathrm{H}_{3} \mathrm{C}^{12} \mathrm{O}^{16} \mathrm{Br}^{81}$ & 3- 352 & $10,2,8 \leftarrow-10,1,9$ & Ground & $21 / 2$ & $21 / 2$ & 22564.77 & .15 \\
\hline $\mathrm{C}^{12}{ }_{*} \mathrm{H}_{2} \mathrm{C}^{12} \mathrm{H}_{2} \mathrm{C}^{12}{ }_{*} \mathrm{HCl}^{35}$ & 4-1081 & $3,0,3 \leftarrow 2,0,2$ & Ground & $9 / 2$ & $7 / 2$ & 22565.9 & .1 \\
\hline $\mathrm{C}^{12}{ }_{*} \mathrm{H}_{2} \mathrm{C}^{12} \mathrm{H}_{2} \mathrm{C}^{12}{ }_{*} \mathrm{HCl}^{35}$ & $4-1081$ & $3,0,3 \leftarrow 2,0,2$ & Ground & $7 / 2$ & $5 / 2$ & 22565.9 & .1 \\
\hline $\mathrm{C}^{12} \mathrm{H}_{3} \mathrm{C}^{12} \mathrm{O}^{16} \mathrm{Br}^{81}$ & 3- 352 & $10,2,8 \leftarrow 10,1,9$ & Ground & $19 / 2$ & $19 / 2$ & 22566.91 & .15 \\
\hline
\end{tabular}




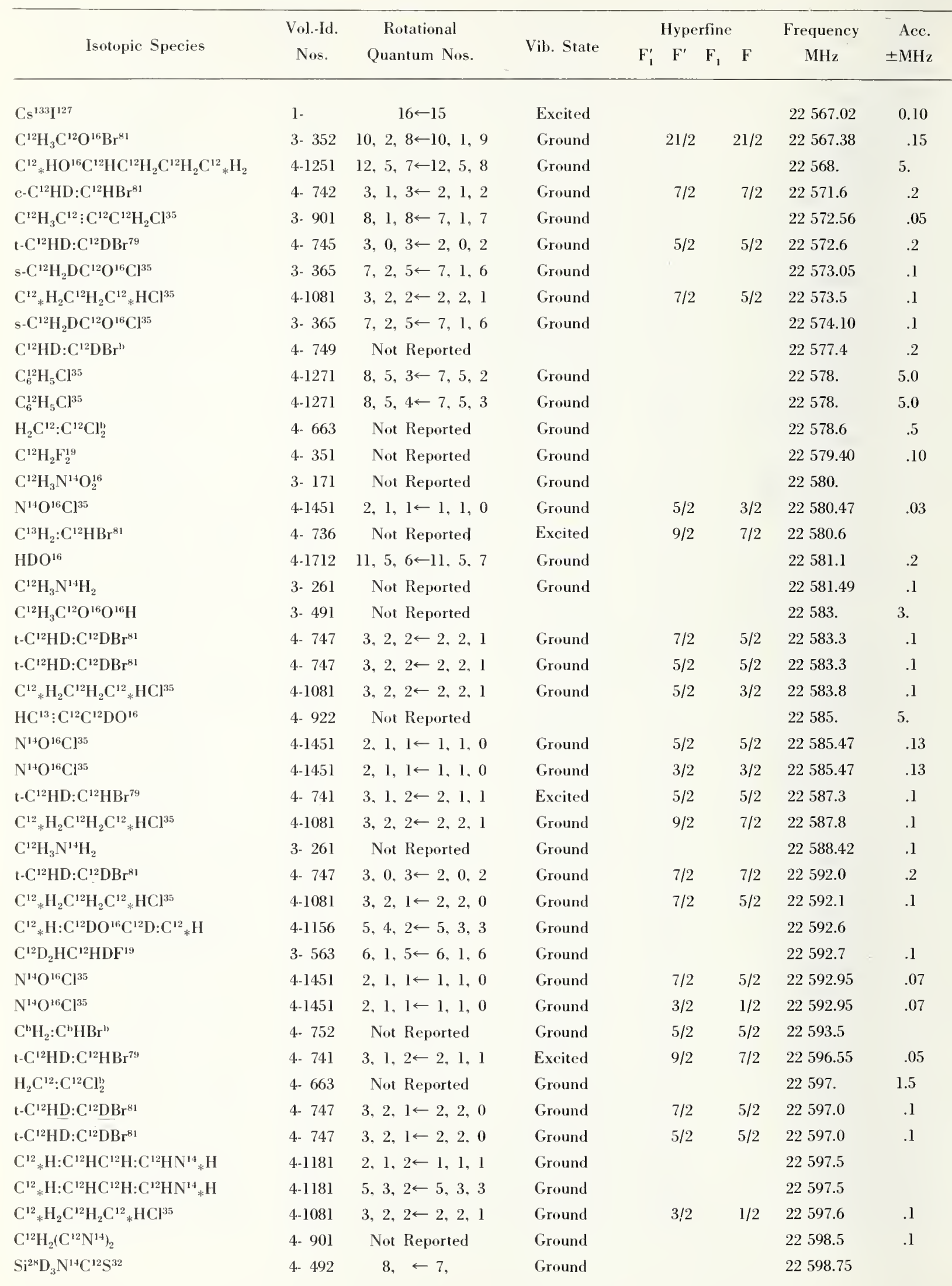




\begin{tabular}{|c|c|c|c|c|c|c|c|}
\hline Isotopic Species & $\begin{array}{l}\text { Vol.-Id. } \\
\text { Nos. }\end{array}$ & $\begin{array}{c}\text { Rotational } \\
\text { Quantum Nos. }\end{array}$ & Vib. State & $\mathrm{F}_{1}^{\prime} \mathrm{F}^{\text {Hyperfine }} \mathrm{F}_{1}$ & $\mathrm{~F}$ & $\begin{array}{l}\text { Frequency } \\
\qquad \mathrm{IHz}\end{array}$ & $\begin{aligned} & \text { Acc. } \\
= & \mathrm{MH} \mathrm{Hz}\end{aligned}$ \\
\hline $\mathrm{N}^{14} \mathrm{O}^{16} \mathrm{Cl}^{35}$ & $4-1451$ & $2,1,1 \leftarrow 1,1,0$ & Ground & $1 / 2$ & $1 / 2$ & 22601.72 & .14 \\
\hline $\mathrm{C}^{12} \mathrm{HD}: \mathrm{C}^{12} \mathrm{DBr}^{\mathrm{b}}$ & 4. 749 & Not Reported & & & & 22602.05 & .1 \\
\hline $\mathrm{t}-\mathrm{C}^{12} \mathrm{HD}: \mathrm{C}^{12} \mathrm{HBr}^{79}$ & 4- 741 & $3,1,2 \leftarrow 2,1,1$ & Ground & $5 / 2$ & $5 / 2$ & 22602.16 & .05 \\
\hline $\mathrm{C}^{12} * \mathrm{H}_{2} \mathrm{C}^{12} \mathrm{H}_{2} \mathrm{C}^{12} * \mathrm{HCl}^{35}$ & 4-1081 & $3,2,1 \leftarrow 2,2,0$ & Ground & $5 / 2$ & $3 / 2$ & 22602.4 & .1 \\
\hline $\mathrm{N}^{14} \mathrm{H}_{2} \mathrm{C}_{2}^{12} \mathrm{H}_{5}$ & 3- 631 & Not Reported & Ground & & & 22603.51 & .2 \\
\hline $\mathrm{C}^{\mathrm{b}} \mathrm{H}_{2}: \mathrm{C}^{\mathrm{b}} \mathrm{HBr}^{\mathrm{b}}$ & 4- 752 & Not Reported & Ground & $9 / 2$ & $7 / 2$ & 22605.45 & \\
\hline c. $\mathrm{C}^{12} \mathrm{HD}: \mathrm{C}^{12} \mathrm{HBr}^{79}$ & 4. 739 & $3,1,3 \leftarrow 2,1,2$ & Ground & $5 / 2$ & $5 / 2$ & 22605.8 & .2 \\
\hline $\mathrm{C}^{12} \mathrm{HD}: \mathrm{C}^{12} \mathrm{DBr}^{\mathrm{b}}$ & 4. 749 & Not Reported & & & & 22606.4 & .1 \\
\hline $\mathrm{C}^{12} \mathrm{H}_{3} \mathrm{C}^{12} \mathrm{O}^{16} \mathrm{Br}^{81}$ & 3- 352 & $4,1,3 \leftarrow 3,1,2$ & Ground & $11 / 2$ & $9 / 2$ & 22606.54 & .15 \\
\hline $\mathrm{C}^{12}{ }_{*} \mathrm{H}_{2} \mathrm{C}^{12} \mathrm{H}_{2} \mathrm{C}^{12}{ }_{*} \mathrm{HCl}^{35}$ & 4-1081 & $3,2,1 \leftarrow 2,2,0$ & Ground & $9 / 2$ & $7 / 2$ & 22606.6 & .1 \\
\hline $\mathrm{C}^{12} \mathrm{HD}: \mathrm{C}^{12} \mathrm{HBr}^{\mathrm{b}}$ & 4- 748 & Not Reported & & & & 22607.45 & .05 \\
\hline $\mathrm{C}^{12} \mathrm{H}_{3} \mathrm{C}^{12} * \mathrm{HO}^{16} \mathrm{C}^{12}{ }_{*} \mathrm{H}_{2}$ & 3. 761 & $23,11, \leftarrow 22,12$, & Ground & & & 22607.49 & .1 \\
\hline $\mathrm{C}^{12} \mathrm{H}_{3} \mathrm{C}^{12}{ }_{*} \mathrm{HO}^{16} \mathrm{C}^{12}{ }_{*} \mathrm{H}_{2}$ & 3- 761 & $23,11, \quad \longleftarrow 22,12$, & Ground & & & 22607.74 & .1 \\
\hline $\mathrm{C}^{12} \mathrm{H}_{3} \mathrm{C}^{12}{ }_{*} \mathrm{HO}^{16} \mathrm{C}^{12} * \mathrm{H}_{2}$ & 3- 761 & $23,11, \quad \longleftarrow 22,12$, & Ground & & & 22608.43 & .1 \\
\hline $\mathrm{t}-\mathrm{C}^{12} \mathrm{HD}: \mathrm{C}^{12} \mathrm{HBr}^{79}$ & 4. 741 & $3,1,2 \leftarrow 2.1,1$ & Ground & $3 / 2$ & $1 / 2$ & 22610.8 & .2 \\
\hline $\mathrm{t}-\mathrm{C}^{12} \mathrm{HD}: \mathrm{C}^{12} \mathrm{HBr}^{79}$ & 4- 741 & $3,1,2 \leftarrow 2,1,1$ & Ground & $9 / 2$ & $7 / 2$ & 22611.8 & .1 \\
\hline $\mathrm{C}^{12} \mathrm{HD}: \mathrm{C}^{12} \mathrm{DBr}^{\mathrm{b}}$ & 4- 749 & Not Reported & & & & 22611.8 & .1 \\
\hline $\mathrm{t} \cdot \mathrm{C}^{12} \mathrm{HD}: \mathrm{C}^{12} \mathrm{DBr}^{79}$ & 4- 745 & $3,1,2 \leftarrow 2,1,1$ & Ground & $7 / 2$ & $7 / 2$ & 22613.1 & .1 \\
\hline $\mathrm{t}-\mathrm{C}^{12} \mathrm{HD}: \mathrm{C}^{12} \mathrm{DBr}^{79}$ & 4- 745 & $3,1,2 \leftarrow 2,1,1$ & Ground & $9 / 2$ & $7 / 2$ & 22613.1 & .1 \\
\hline $\mathrm{C}^{12} \mathrm{DHDC}^{12} \mathrm{HDF}^{19}$ & 3- 561 & $5,1,4 \leftarrow 4,2,3$ & Ground & & & 22613.8 & .1 \\
\hline $\mathrm{C}^{12} \mathrm{H}_{3} \mathrm{C}^{12} \mathrm{O}^{16} \mathrm{Br}^{81}$ & 3- 352 & $4,1,3 \leftarrow 3,1,2$ & Ground & $5 / 2$ & $3 / 2$ & 22614.59 & .15 \\
\hline $\mathrm{C}^{13} \mathrm{H}_{2}: \mathrm{C}^{12} \mathrm{HBr}^{81}$ & 4- 736 & $3,1.3 \leftarrow 2,1,2$ & Ground & & & 22615.89 & .04 \\
\hline $\mathrm{C}^{12} \mathrm{H}_{3} \mathrm{C}^{12} \mathrm{O}^{16} \mathrm{O}^{16} \mathrm{H}$ & 3- 491 & Not Reported & & & & 22616. & 3. \\
\hline $\mathrm{C}^{12} \mathrm{H}_{2}\left(\mathrm{C}^{12} \mathrm{~N}^{14}\right)_{2}$ & 4- 901 & Not Reported & Ground & & & 22616. & .1 \\
\hline $\mathrm{C}^{12} \mathrm{H}_{2} \mathrm{C}^{12} \mathrm{H}_{2} \mathrm{C}^{12} \mathrm{HCl}^{35}$ & $4-1081$ & $3,2,1 \leftarrow 2,2,0$ & Ground & $3 / 2$ & $1 / 2$ & 22616.5 & .1 \\
\hline $\mathrm{C}^{12} \mathrm{H}_{3} \mathrm{C}^{12} \mathrm{O}^{16} \mathrm{Br}^{81}$ & 3- 352 & $4,1,3 \leftarrow 3,1,2$ & Ground & $9 / 2$ & $7 / 2$ & 22616.98 & .15 \\
\hline $\mathrm{C}^{12} * \mathrm{H}: \mathrm{C}^{12} \mathrm{HO}^{16} \mathrm{C}^{12} \mathrm{H}: \mathrm{C}^{12}{ }_{*} \mathrm{D}$ & 4-1155 & $2,0,2 \leftarrow 1,0,1$ & Ground & & & 22617.5 & \\
\hline $\mathrm{s}-\mathrm{C}^{12} \mathrm{H}_{2} \mathrm{DC}^{12} \mathrm{O}^{16} \mathrm{C}^{12} \mathrm{~N}^{14}$ & 3- 677 & $8,2,6 \leftarrow 8,1,7$ & Ground & & & 22617.57 & .2 \\
\hline $\mathrm{N}^{14} \mathrm{H}_{2} \mathrm{C}_{2}^{12} \mathrm{H}_{5}$ & 3. 631 & Not Reported & Ground & & & 22618.89 & .2 \\
\hline $\mathrm{C}^{12} \mathrm{H}_{3} \mathrm{~N}^{14} \mathrm{O}_{2}^{16}$ & 3- 171 & Not Reported & Ground & & & 22620 . & \\
\hline $\mathrm{C}^{12} \mathrm{D}_{3} \mathrm{Si}^{29} \mathrm{DF}_{2}^{19}$ & 3. 201 & $3,0,3 \leftarrow 2,0,2$ & Ground & & & 22620.04 & .2 \\
\hline $\mathrm{C}^{12} \mathrm{HD}: \mathrm{C}^{12} \mathrm{DB}^{\mathrm{b}}$ & 4- 749 & Not Reported & & & & 22620.1 & .2 \\
\hline $\mathrm{c} \cdot \mathrm{C}^{12} \mathrm{HD}: \mathrm{C}^{12} \mathrm{HBr}^{79}$ & 4. 739 & $3,1,3 \leftarrow 2,1,2$ & Ground & $9 / 2$ & $7 / 2$ & 22620.2 & .1 \\
\hline $\mathrm{C}^{12} \mathrm{H}_{3} \mathrm{C}^{12} \mathrm{O}^{16} \mathrm{Br}^{81}$ & 3- 352 & $4,1,3 \leftarrow 3,1,2$ & Ground & $7 / 2$ & $5 / 2$ & 22623.21 & .15 \\
\hline $\mathrm{t}-\mathrm{C}^{12} \mathrm{HD}: \mathrm{C}^{12} \mathrm{HBr}^{79}$ & 4. 741 & $3,1,2 \leftarrow 2,1,1$ & Ground & & & 22624.10 & .04 \\
\hline $\mathrm{N}^{15} \mathrm{H}_{3}$ & 4-1772 & $1,1 \leftarrow 1,1$ & Ground & & & 22624.96 & .02 \\
\hline $\mathrm{N}^{14} \mathrm{H}_{2} \mathrm{C}_{2}^{12} \mathrm{H}_{5}$ & 3- 631 & Not Reported & Ground & & & 22625.17 & .2 \\
\hline $\mathrm{t}-\mathrm{C}^{12} \mathrm{HD}: \mathrm{C}^{12} \mathrm{HBr}^{79}$ & 4- 741 & $3,1,2 \leftarrow 2,1,1$ & Excited & $7 / 2$ & $5 / 2$ & 22625.9 & .2 \\
\hline $\mathrm{t}-\mathrm{C}^{12} \mathrm{HD}: \mathrm{C}^{12} \mathrm{DBr}^{79}$ & 4- 745 & $3,0,3 \leftarrow 2,0,2$ & Ground & $7 / 2$ & $5 / 2$ & 22626.5 & .1 \\
\hline $\mathrm{t}-\mathrm{C}^{12} \mathrm{HD}: \mathrm{C}^{12} \mathrm{DBr}^{79}$ & 4- 745 & $3,0,3 \leftarrow 2,0,2$ & Ground & $9 / 2$ & $7 / 2$ & 22626.5 & .1 \\
\hline $\mathrm{t}-\mathrm{C}^{12} \mathrm{HD}: \mathrm{C}^{12} \mathrm{DBr}^{79}$ & 4- 745 & $3,2,1 \leftarrow 2,2,0$ & Ground & $9 / 2$ & $7 / 2$ & 22627.7 & .1 \\
\hline $\mathrm{t} \cdot \mathrm{C}^{12} \mathrm{HD}: \mathrm{C}^{12} \mathrm{DBr}^{79}$ & 4- 745 & $3,2,1 \leftarrow 2,2,0$ & Ground & $7 / 2$ & $7 / 2$ & 22627.7 & .1 \\
\hline
\end{tabular}




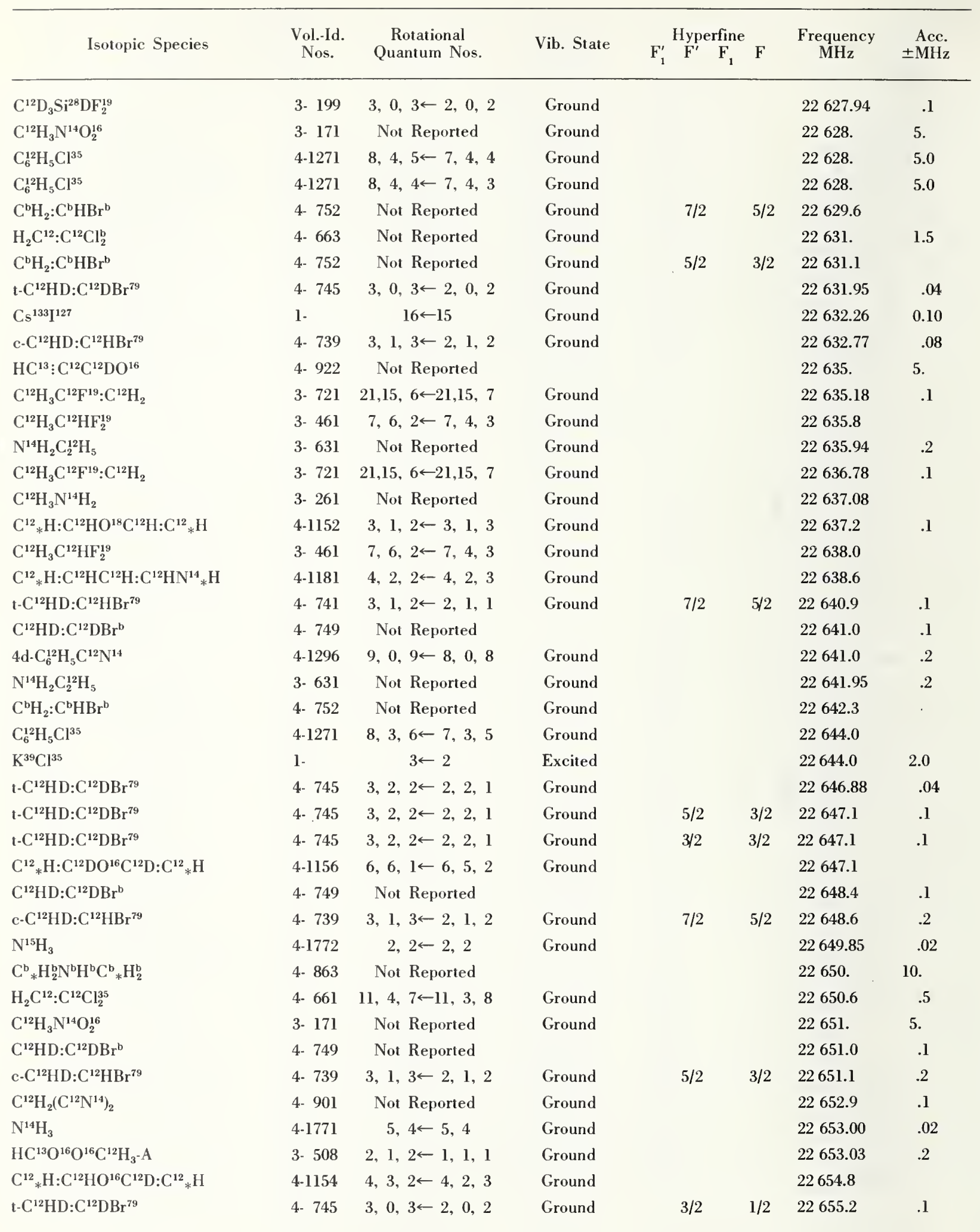




\begin{tabular}{|c|c|c|c|c|c|c|c|c|}
\hline Isotopic Species & $\begin{array}{l}\text { Vol.-Id. } \\
\text { Nos. }\end{array}$ & $\begin{array}{c}\text { Rotational } \\
\text { Quantum Nos. }\end{array}$ & Vib. State & $F_{1}^{\prime}$ & $\begin{array}{c}\text { Hyperfine } \\
\mathrm{F}^{\prime} \quad \mathrm{F}_{1}\end{array}$ & e $F$ & $\begin{array}{l}\text { Frequency } \\
\qquad \mathrm{MHz}^{-}\end{array}$ & $\begin{array}{r}\text { Acc. } \\
\pm \mathrm{MHz}\end{array}$ \\
\hline $\mathrm{t}-\mathrm{C}^{12} \mathrm{HD}: \mathrm{C}^{12} \mathrm{DBr}^{79}$ & 4- 745 & $3,0,3 \leftarrow 2,0,2$ & Ground & & $5 / 2$ & $3 / 2$ & 22655.2 & .1 \\
\hline $\mathrm{C}^{12}{ }_{*} \mathrm{H}: \mathrm{C}^{12} \mathrm{HC}^{12} \mathrm{H}: \mathrm{C}^{12} \mathrm{HN}^{14}{ }_{*} \mathrm{H}$ & $4-1181$ & $3,1,2 \leftarrow 3,1,3$ & Ground & & & & 22657.5 & \\
\hline $\mathrm{C}^{12} \mathrm{HD}_{2} \mathrm{Cl}^{37}$ & 4- 432 & $1,0,1 \leftarrow 0,0,0$ & Ground & & & & 22659.29 & \\
\hline $\mathrm{t}-\mathrm{C}^{12} \mathrm{HD}: \mathrm{C}^{12} \mathrm{DBr}^{79}$ & 4- 745 & $3,2,1 \leftarrow 2,2,0$ & Ground & & & & 22661.15 & .04 \\
\hline $\mathrm{t}-\mathrm{C}^{12} \mathrm{HD}: \mathrm{C}^{12} \mathrm{DBr}^{79}$ & 4- 745 & $3,2,1 \leftarrow 2,2,0$ & Ground & & $3 / 2$ & $3 / 2$ & 22661.3 & .1 \\
\hline $\mathrm{t}-\mathrm{C}^{12} \mathrm{HD}: \mathrm{C}^{12} \mathrm{DBr}^{79}$ & 4- 745 & $3,2,1 \leftarrow 2,2,0$ & Ground & & $5 / 2$ & $3 / 2$ & 22661.3 & .1 \\
\hline $\mathrm{C}^{12} \mathrm{H}_{3} \mathrm{~S}^{32} \mathrm{H}$ & 3. 221 & Not Reported & Ground & & & & 22661.4 & .1 \\
\hline $\mathrm{C}^{12} \mathrm{H}_{2}\left(\mathrm{C}^{12} \mathrm{~N}^{14}\right)_{2}$ & 4- 901 & Not Reported & Ground & & & & 22663. & .1 \\
\hline $3 d \cdot \mathrm{C}_{6}^{12} \mathrm{H}_{5} \mathrm{~F}^{19}$ & 4-1282 & $12,3,9 \leftarrow 12,3,10$ & Ground & & & & 22663.2 & .1 \\
\hline $\mathrm{C}^{13} \mathrm{H}_{3} \mathrm{C}^{12} \mathrm{H}_{3} \mathrm{C}^{12}: \mathrm{C}^{12} \mathrm{H}_{2}$ & 3- 945 & $2,1,2 \leftarrow 1,0,1$ & Ground & & & & 22663.50 & \\
\hline $\mathrm{N}^{14} \mathrm{H}_{2} \mathrm{C}_{2}^{12} \mathrm{H}_{5}$ & 3- 631 & Not Reported & Ground & & & & 22668.35 & .2 \\
\hline $\mathrm{C}^{12}{ }_{*} \mathrm{H}: \mathrm{C}^{12} \mathrm{HC}^{12} \mathrm{H}: \mathrm{C}^{12} \mathrm{HN}^{14}{ }_{*} \mathrm{H}$ & 4-1181 & $3,2,2 \leftarrow 3,0,3$ & Ground & & & & 22670.9 & \\
\hline $\mathrm{C}^{\mathrm{b}} \mathrm{H}_{2}: \mathrm{C}^{\mathrm{b}} \mathrm{HBr}^{79}$ & 4- 753 & Not Reported & Ground & & $3 / 2$ & $3 / 2$ & 22671.5 & \\
\hline $\mathrm{C}^{12}{ }_{*} \mathrm{H}_{2} \mathrm{~N}^{14} \mathrm{HC}^{12}{ }_{*} \mathrm{H}_{2}$ & 4. 861 & $5,5,1 \leftarrow 5,4,1$ & Ground & & & & 22671.9 & .5 \\
\hline $\mathrm{C}^{13} \mathrm{H}_{3} \mathrm{O}^{16} \mathrm{H}$ & 3- 213 & $29,2, \leftarrow 29,1$, & Ground & & & & 22672.90 & .1 \\
\hline $\mathrm{C}^{12} \mathrm{H}_{3} \mathrm{C}^{13} \mathrm{H}_{2} \mathrm{~F}^{19}$ & 3- 555 & $7,1,7 \leftarrow 6,2,4$ & Ground & & & & 22673.8 & .1 \\
\hline $\mathrm{C}^{12} \mathrm{HD}_{2} \mathrm{Cl}^{37}$ & 4- 432 & $1,0,1 \leftarrow 0,0,0$ & Ground & & & & 22673.80 & \\
\hline $\mathrm{C}^{13} \mathrm{H}_{2}: \mathrm{C}^{13} \mathrm{HBr}^{81}$ & 4- 734 & $3,2,1 \leftarrow 2,2,0$ & Ground & & $3 / 2$ & $1 / 2$ & 22676.4 & \\
\hline $\mathrm{C}^{12}{ }_{*} \mathrm{H}: \mathrm{C}^{12} \mathrm{HC}^{12} \mathrm{H}: \mathrm{C}^{12} \mathrm{HN}^{14}{ }_{*} \mathrm{H}$ & $4-1181$ & $4,3,2 \leftarrow 4,1,3$ & Ground & & & & 22679.6 & \\
\hline $\mathrm{C}^{\mathbf{b}}{ }_{*} \mathrm{H}_{2}^{\mathbf{b}} \mathrm{N}^{\mathbf{b}} \mathrm{H}^{\mathbf{b}} \mathrm{C}^{\mathbf{b}}{ }_{*} \mathrm{H}_{2}^{\mathbf{b}}$ & 4- 863 & Not Reported & & & & & 22680 . & 10. \\
\hline $\mathrm{C}^{12} \mathrm{H}_{3} \mathrm{~S}^{32} \mathrm{C}^{12} \mathrm{~N}^{14}$ & 3- 431 & $4, \quad \leftarrow 3$, & Excited & & & & 22680. & 10. \\
\hline $\mathrm{C}^{12} \mathrm{HCl}^{35}: \mathrm{C}^{12} \mathrm{~F}^{19}$ & 4- 611 & $6,2,4 \leftarrow 6,1,5$ & Ground & & $15 / 2$ & $15 / 2$ & 22680.8 & .1 \\
\hline $\mathrm{C}^{12} \mathrm{HCl}^{35}: \mathrm{C}^{12} \mathrm{~F}_{2}^{19}$ & 4- 611 & $6,2,4 \leftarrow 6,1,5$ & Ground & & $9 / 2$ & $9 / 2$ & 22680.8 & .1 \\
\hline $\mathrm{t}-\mathrm{C}^{12} \mathrm{HD}: \mathrm{C}^{12} \mathrm{HBr}^{79}$ & 4- 741 & $3,1,2 \leftarrow 2,1,1$ & Excited & & $7 / 2$ & $7 / 2$ & 22680.9 & .1 \\
\hline $\mathrm{C}^{12} \mathrm{H}_{3} \mathrm{C}^{12} \mathrm{O}^{16} \mathrm{O}^{16} \mathrm{H}$ & 3- 491 & Not Reported & & & & & 22681. & 3. \\
\hline $\mathrm{C}^{12} \mathrm{H}_{2} \mathrm{Cl}^{35} \mathrm{Si}^{28} \mathrm{H}_{3}$ & 3- 231 & $7,1,6 \leftarrow 7,0,7$ & Ground & & $11 / 2$ & $11 / 2$ & 22681.16 & .2 \\
\hline $\mathrm{C}^{12} \mathrm{H}_{2} \mathrm{Cl}^{35} \mathrm{Si}^{28} \mathrm{H}_{3}$ & 3- 231 & $7,1,6 \leftarrow 7,0,7$ & Ground & & $17 / 2$ & $17 / 2$ & 22682.47 & .2 \\
\hline $\mathrm{C}^{12} \mathrm{HCl}^{35}: \mathrm{C}^{12} \mathrm{~F}_{2}^{19}$ & 4- 611 & $6,2,4 \leftarrow 6,1,5$ & Ground & & $13 / 2$ & $13 / 2$ & 22682.6 & .1 \\
\hline $\mathrm{C}^{12} \mathrm{HCl}^{35}: \mathrm{C}^{12} \mathrm{~F}_{2}^{19}$ & 4- 611 & $6,2,4 \leftarrow 6,1,5$ & Ground & & $11 / 2$ & $11 / 2$ & 22682.6 & .1 \\
\hline $\mathrm{C}^{13} \mathrm{H}_{2}: \mathrm{C}^{12} \mathrm{HBr}^{81}$ & 4- 736 & $3,1,3 \leftarrow 2,1,2$ & Ground & & $7 / 2$ & $7 / 2$ & 22683.0 & \\
\hline $\mathrm{C}^{12} \mathrm{H}_{2} \mathrm{Cl}^{35} \mathrm{Si}^{28} \mathrm{H}_{3}$ & 3- 231 & $7,1,6 \leftarrow 7,0,7$ & Ground & & & & 22684.78 & .2 \\
\hline $\mathrm{C}^{12} \mathrm{HD}_{2} \mathrm{Cl}^{37}$ & 4- 432 & $1,0,1 \leftarrow 0,0,0$ & Ground & & & & 22685.60 & \\
\hline $\mathrm{C}^{12} \mathrm{D}_{2} \mathrm{Cl}^{35} \mathrm{Cl}^{37}$ & 4- 347 & $5,1,4 \leftarrow 5,0,5$ & Ground & & & & 22687. & 5. \\
\hline $\mathrm{C}^{12} \mathrm{H}_{2} \mathrm{Cl}^{35} \mathrm{Si}^{28} \mathrm{H}_{3}$ & 3- 231 & $7,1,6 \leftarrow 7,0,7$ & Ground & & $13 / 2$ & $13 / 2$ & 22687.29 & .2 \\
\hline $\mathrm{S}^{32} \mathrm{O}^{16} \mathrm{~F}_{2}^{19}$ & 4-1621 & $14,14,1 \leftarrow 14,13,1$ & & & & & 22687.47 & .1 \\
\hline $\mathrm{HC}^{13}: \mathrm{C}^{12} \mathrm{C}^{12} \mathrm{DO}^{16}$ & 4- 922 & Not Reported & & & & & 22688. & 5. \\
\hline $\mathrm{N}^{14} \mathrm{H}_{3}$ & $4-1771$ & $4,3 \leftarrow 4,3$ & Ground & & & & 22688.29 & .02 \\
\hline $\mathrm{C}^{12} \mathrm{HD}: \mathrm{C}^{12} \mathrm{DBr}^{\mathrm{b}}$ & 4. 749 & Not Reported & & & & & 22688.4 & .1 \\
\hline $\mathrm{C}^{12} \mathrm{HD}: \mathrm{C}^{12} \mathrm{HBr}^{\mathrm{b}}$ & 4- 748 & Not Reported & & & & & 22688.5 & .1 \\
\hline $\mathrm{C}^{12} \mathrm{H}_{2} \mathrm{Cl}^{35} \mathrm{Si}^{28} \mathrm{H}_{3}$ & 3- 231 & $7,1,6 \leftarrow 7,0,7$ & Ground & & $15 / 2$ & $15 / 2$ & 22688.51 & .2 \\
\hline $\mathrm{C}_{6}^{12} \mathrm{H}_{5} \mathrm{O}^{16} \mathrm{H}$ & $3-1051$ & $6,4,2 \leftarrow 6,3,3$ & Ground & & & & 22689.5 & \\
\hline $\mathrm{C}^{12} \mathrm{H}_{3} \mathrm{C}^{12} \mathrm{H}_{2} \mathrm{I}^{127}$ & 3- 571 & $4,1,4 \leftarrow 3,1,3$ & Ground & & $7 / 2$ & $5 / 2$ & 22690.03 & \\
\hline $\mathrm{C}^{12}{ }_{*} \mathrm{H}: \mathrm{C}^{12} \mathrm{HC}^{12} \mathrm{H}: \mathrm{C}^{12} \mathrm{HN}^{14}{ }_{*} \mathrm{H}$ & $4-1181$ & $5,4,2 \leftarrow 5,2,3$ & Ground & & & & 22694.1 & \\
\hline $\mathrm{H}_{2}^{\mathrm{b}} \mathrm{C}_{*}^{\mathrm{b}} \mathrm{O}^{16} \mathrm{C}^{\mathbf{b}}{ }_{*} \mathrm{H}_{2}^{\mathrm{b}}$ & 4- 846 & Not Reported & Excited & & & & 22695 & 5. \\
\hline
\end{tabular}




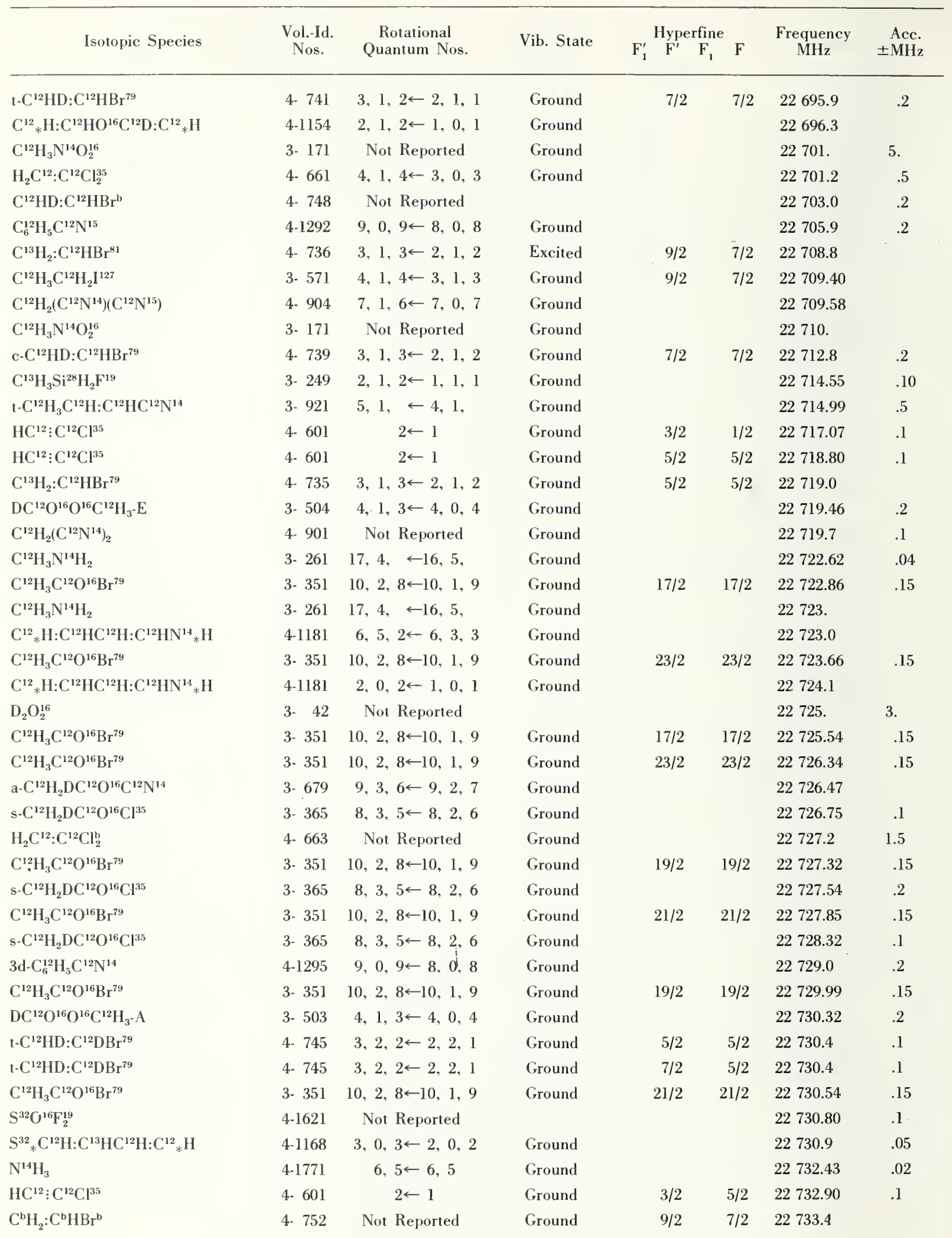




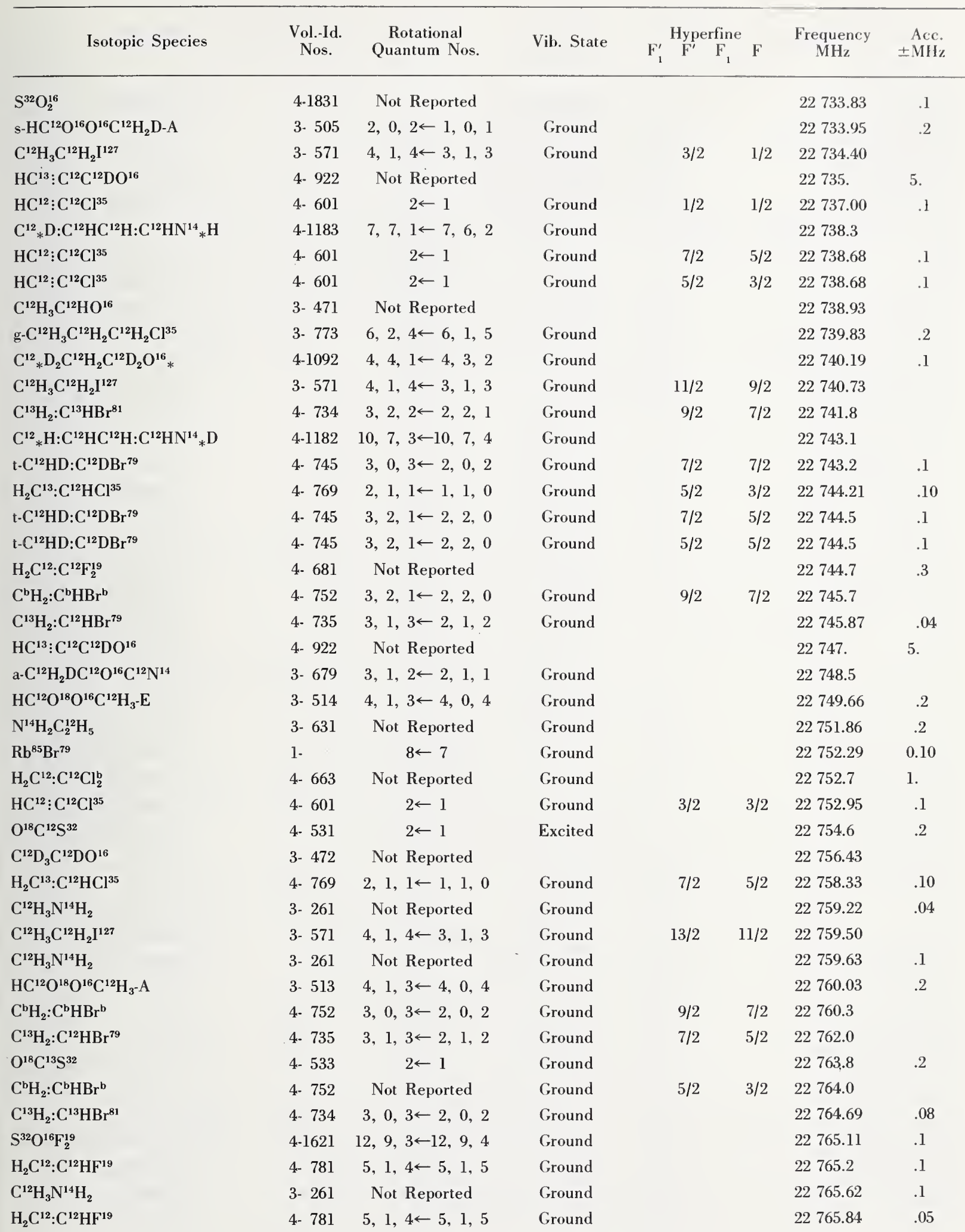




\begin{tabular}{|c|c|c|c|c|c|c|c|c|}
\hline \multirow{2}{*}{ Isotopic Species } & \multirow{2}{*}{$\begin{array}{l}\text { Vol.-Id. } \\
\text { Nos. }\end{array}$} & \multirow{2}{*}{$\begin{array}{c}\text { Rotational } \\
\text { Quantum Nos. }\end{array}$} & \multirow{2}{*}{ Vib. State } & \multicolumn{3}{|c|}{ Hyperfine } & \multirow{2}{*}{$\begin{array}{c}\text { Frequency } \\
\mathrm{MHz}\end{array}$} & \multirow{2}{*}{$\begin{array}{r}\text { Acc. } \\
\pm \mathrm{MHz}\end{array}$} \\
\hline & & & & $\mathrm{F}_{1}^{\prime}$ & $F^{\prime} \quad F_{1}$ & $\mathbf{F}$ & & \\
\hline $\mathrm{H}_{2} \mathrm{~N}^{14} \mathrm{~N}^{14} \mathrm{H}_{2}$ & $3-51$ & Not Reported & & & & & 22766.98 & \\
\hline $\mathrm{C}^{12}{ }_{*} \mathrm{H}: \mathrm{C}^{12} \mathrm{HC}^{12} \mathrm{H}: \mathrm{C}^{12} \mathrm{HN}^{14}{ }_{*} \mathrm{H}$ & $4-1181$ & $7,6,2 \leftarrow 7,4,3$ & Ground & & & & 22769.1 & \\
\hline $\mathrm{C}^{12} \mathrm{H}_{3} \mathrm{C}^{12} \mathrm{H}_{2} \mathrm{C}^{12} \mathrm{H}_{3}$ & 3- 781 & $2,1,1 \leftarrow 2,0,2$ & Ground & & & & 22769.74 & .03 \\
\hline $\mathrm{C}^{13} \mathrm{H}_{2}: \mathrm{C}^{13} \mathrm{HBr}^{81}$ & 4. 734 & $3,2,2 \leftarrow 2,2,1$ & Ground & & & & 22770.11 & .06 \\
\hline $\mathrm{C}^{13} \mathrm{H}_{2}: \mathrm{C}^{13} \mathrm{HBr}^{81}$ & 4- 734 & $3,2,2 \leftarrow 2,2,1$ & Ground & & $5 / 2$ & $3 / 2$ & 22770.4 & \\
\hline $\mathrm{C}^{12}{ }_{*} \mathrm{H}: \mathrm{C}^{12} \mathrm{HO}^{16} \mathrm{C}^{13} \mathrm{H}: \mathrm{C}^{12}{ }_{*} \mathrm{H}$ & 4-1153 & $8,6,2 \leftarrow 8,6,3$ & Ground & & & & 22770.4 & .1 \\
\hline $\mathrm{Tl}^{205} \mathrm{Br}^{81}$ & $1-$ & $9 \leftarrow 8$ & Excited & & & & 22771.22 & 0.20 \\
\hline $\mathrm{HC}^{12}: \mathrm{C}^{12} \mathrm{Cl}^{35}$ & 4- 601 & $2 \leftarrow i$ & Ground & & $1 / 2$ & $3 / 2$ & 22772.82 & .1 \\
\hline $\mathrm{C}^{13} \mathrm{H}_{2}: \mathrm{C}^{13} \mathrm{HBr}^{81}$ & 4- 734 & $3,2,1 \leftarrow 2,2,0$ & Ground & & & & 22774.41 & .05 \\
\hline $\mathrm{C}^{\mathrm{b}} \mathrm{H}_{2}: \mathrm{C}^{\mathrm{b}} \mathrm{HBr}^{\mathrm{b}}$ & 4- 752 & $3,2,1 \leftarrow 2,2,0$ & Ground & & $5 / 2$ & $3 / 2$ & 22774.7 & \\
\hline $\mathrm{C}^{12}{ }_{*} \mathrm{HO}^{16} \mathrm{C}^{12} \mathrm{HC}^{12} \mathrm{H}_{2} \mathrm{C}^{12} \mathrm{H}_{2} \mathrm{C}^{12}{ }_{*} \mathrm{H}_{2}$ & $4-1251$ & $11,6,6 \leftarrow 11,4,7$ & Ground & & & & 22775 . & 5. \\
\hline $\mathrm{g}-\mathrm{C}^{12} \mathrm{H}_{2} \mathrm{DC}^{12} \mathrm{H}_{2} \mathrm{~F}^{19}$ & 3- 553 & $6,1,5 \leftarrow 6,1,6$ & Ground & & & & 22776.2 & .1 \\
\hline $\mathrm{C}^{12} \mathrm{H}_{2}: \mathrm{C}^{12} \mathrm{DBr}^{\mathrm{b}}$ & 4- 729 & $3, \quad \leftarrow 2$, & Ground & & & & 22779. & 5. \\
\hline $\mathrm{H}_{2} \mathrm{~N}^{14} \mathrm{~N}^{14} \mathrm{H}_{2}$ & 3- 51 & Not Reported & & & & & 22779.30 & \\
\hline $\mathrm{a}-\mathrm{C}^{12} \mathrm{H}_{2} \mathrm{DC}^{12} \mathrm{O}^{16} \mathrm{Cl}^{35}$ & 3. 366 & $5,1,4 \leftarrow 5,0,5$ & Ground & & & & 22782.10 & .1 \\
\hline $\mathrm{C}^{12}{ }_{*} \mathrm{H}: \mathrm{C}^{12} \mathrm{HO}^{16} \mathrm{C}^{13} \mathrm{H}: \mathrm{C}^{12}{ }_{*} \mathrm{H}$ & $4-1153$ & $8,6,2 \leftarrow 8,5,3$ & Ground & & & & 22782.7 & .1 \\
\hline $\mathrm{H}_{2} \mathrm{C}^{12}: \mathrm{C}^{12} \mathrm{Cl}_{2}^{\mathrm{b}}$ & 4- 663 & Not Reported & Ground & & & & 22782.8 & 1. \\
\hline $\mathrm{C}^{\mathrm{b}} \mathrm{H}_{2}: \mathrm{C}^{\mathrm{b}} \mathrm{HBr}^{\mathrm{b}}$ & 4- 752 & $3,0,3 \leftarrow 2,0,2$ & Ground & & $5 / 2$ & $3 / 2$ & 22783.1 & \\
\hline a- $\mathrm{C}^{12} \mathrm{H}_{2} \mathrm{DC}^{12} \mathrm{O}^{16} \mathrm{Cl}^{35}$ & 3- 366 & $5,1,4 \leftarrow 5,0,5$ & Ground & & & & 22784.10 & .2 \\
\hline $\mathrm{C}^{12} \mathrm{H}_{3} \mathrm{C}^{12} \mathrm{H}: \mathrm{C}^{12} \mathrm{HF}^{19}$ & 3- 711 & $3,1,2 \leftarrow 2,1,1$ & Ground & & & & 22784.40 & \\
\hline $\mathrm{C}^{12}{ }_{*} \mathrm{D}: \mathrm{C}^{12} \mathrm{HC}^{12} \mathrm{H}: \mathrm{C}^{12} \mathrm{HN}^{14}{ }_{*} \mathrm{H}$ & 4-1183 & $12,9,3 \leftarrow 12,8,4$ & Ground & & & & 22784.7 & \\
\hline $\mathrm{K}^{39} \mathrm{Cl}^{35}$ & 1 . & $3 \leftarrow 2$ & Excited & & & & 22785.2 & 1.0 \\
\hline $\mathrm{Cl}^{35} \mathrm{~F}^{19} \mathrm{C}^{12} \mathrm{O}^{16}$ & 4- 151 & $2,1,2 \leftarrow 1,0,1$ & Ground & & $5 / 2$ & $3 / 2$ & 22785.82 & .05 \\
\hline $\mathrm{a}-\mathrm{C}^{12} \mathrm{H}_{2} \mathrm{DC}^{12} \mathrm{O}^{16} \mathrm{Cl}^{35}$ & 3- 366 & $5,1,4 \leftarrow 5,0,5$ & Ground & & & & 22786.10 & .1 \\
\hline $\mathrm{C}^{12} \mathrm{H}_{2}\left(\mathrm{C}^{12} \mathrm{~N}^{14}\right)_{2}$ & 4- 901 & Not Reported & Ground & & & & 22786.4 & .1 \\
\hline$\left(\mathrm{C}^{12} \mathrm{H}_{3}\right)_{3} \mathrm{C}^{12} \mathrm{~N}^{14} \mathrm{C}^{13}$ & $3-1031$ & $4, \leftarrow 3$, & Ground & & & & 22786.5 & \\
\hline $\mathrm{C}^{12} \mathrm{H}_{3} \mathrm{C}^{12} \mathrm{O}^{16} \mathrm{Br}^{79}$ & 3- 351 & $4,1,3 \leftarrow 3,1,2$ & Ground & & $11 / 2$ & $9 / 2$ & 22786.79 & .15 \\
\hline $\mathrm{C}^{12} \mathrm{H}_{3} \mathrm{C}^{12} \mathrm{O}^{16} \mathrm{Br}^{79}$ & 3- 351 & $4,1,3 \leftarrow 3,1,2$ & Ground & & $11 / 2$ & $9 / 2$ & 22787.47 & .15 \\
\hline$F_{2}^{19} N^{14} N^{14} F_{2}^{19}$ & 3- 21 & $11,5,6 \leftarrow 11,4,8$ & Ground & & & & 22788.3 & .3 \\
\hline $\mathrm{C}^{13} \mathrm{H}_{3} \mathrm{C}^{12} \mathrm{H}_{2} \mathrm{C}^{12} \mathrm{H}_{3}$ & 3. 782 & $2,1,1 \leftarrow 2,0,2$ & Ground & & & & 22788.80 & .06 \\
\hline $\mathrm{C}^{b} \mathrm{H}_{2}: \mathrm{C}^{\mathrm{b}} \mathrm{HBr}^{79}$ & 4. 753 & $3,2,2 \leftarrow 2,2,1$ & Ground & & $3 / 2$ & $1 / 2$ & 22789.2 & \\
\hline $\mathrm{N}^{15} \mathrm{H}_{3}$ & 4-1772 & $3,3 \leftarrow 3,3$ & Ground & & & & 22789.41 & .02 \\
\hline $\mathrm{N}^{14} \mathrm{H}_{2} \mathrm{C}_{2}^{12} \mathrm{H}_{5}$ & 3- 631 & Not Reported & Ground & & & & 22789.47 & .2 \\
\hline $\mathrm{C}^{12}{ }_{*} \mathrm{H}_{2} \mathrm{~N}^{14} \mathrm{DC}^{12}{ }_{*} \mathrm{H}_{2}$ & 4. 862 & $5,4,1 \leftarrow 5,4,2$ & Ground & & & & 22792.3 & .5 \\
\hline$\left(\mathrm{C}^{12} \mathrm{H}_{3}\right)_{2} \mathrm{C}^{12} \mathrm{O}^{16}$ & 3- 751 & $2,0,2 \leftarrow 1,1,1$ & Ground & & & & 22793.22 & .04 \\
\hline $\mathrm{C}^{\mathrm{b}} \mathrm{H}_{2}: \mathrm{C}^{\mathrm{b}} \mathrm{HBr}^{\mathrm{b}}$ & 4. 752 & $3,2,1 \leftarrow 2,2,0$ & Ground & & $3 / 2$ & $1 / 2$ & 22793.5 & \\
\hline $\mathrm{C}^{12} \mathrm{H}_{2}: \mathrm{C}^{12} \mathrm{DBr}^{81}$ & 4- 722 & $3,1,3 \leftarrow 2,1,2$ & Ground & & $3 / 2$ & $3 / 2$ & 22793.6 & \\
\hline$\left(\mathrm{C}^{12} \mathrm{H}_{3}\right)_{2} \mathrm{C}^{12} \mathrm{O}^{16}$ & 3. 751 & $2,0,2 \leftarrow 1,1,1$ & Ground & & & & 22794.24 & .04 \\
\hline $\mathrm{C}^{12} \mathrm{H}_{3} \mathrm{C}^{12} \mathrm{O}^{16} \mathrm{Br}^{79}$ & 3- 351 & $4,1,3 \leftarrow 3,1,2$ & Ground & & $5 / 2$ & $3 / 2$ & 22794.65 & \\
\hline $\mathrm{C}^{12} \mathrm{H}_{3} \mathrm{C}^{12} \mathrm{O}^{16} \mathrm{Br}^{79}$ & 3. 351 & $4,1,3 \leftarrow 3,1,2$ & Ground & & $9 / 2$ & $7 / 2$ & 22797.44 & .15 \\
\hline $\mathrm{C}^{12} \mathrm{H}_{3} \mathrm{C}^{12} \mathrm{O}^{16} \mathrm{Br}^{79}$ & 3. 351 & $4,1,3 \leftarrow 3,1,2$ & Ground & & $9 / 2$ & $7 / 2$ & 22797.96 & .15 \\
\hline $\mathrm{C}^{12} \mathrm{H}_{3} \mathrm{C}^{12} \mathrm{O}^{16} \mathrm{Cl}^{35}$ & 3. 361 & $3,2,2 \leftarrow 3,1,3$ & Ground & & & & 22800.0 & .2 \\
\hline$\left(\mathrm{C}^{12} \mathrm{H}_{3}\right)_{2} \mathrm{C}^{12} \mathrm{O}^{16}$ & 3- 751 & $2,0,2 \leftarrow 1,1,1$ & Ground & & & & 22800.37 & .04 \\
\hline $\mathrm{C}_{6}^{12} \mathrm{H}_{5} \mathrm{O}^{16} \mathrm{H}$ & $3-1051$ & $6,4,2 \leftarrow 6,3,3$ & Ground & & & & 22800.6 & \\
\hline
\end{tabular}




\begin{tabular}{|c|c|c|c|c|c|c|c|c|}
\hline Isotopic Species & $\begin{array}{l}\text { Vol.-Id. } \\
\text { Nos. }\end{array}$ & $\begin{array}{c}\text { Rotational } \\
\text { Quantum Nos. }\end{array}$ & Vib. State & $F_{1}^{\prime}$ & $\begin{array}{l}\text { Hyperfine } \\
\mathrm{F}^{\prime} \mathrm{F}_{1}\end{array}$ & $\mathbf{F}$ & $\begin{array}{c}\text { Frequency } \\
\mathrm{MHz}\end{array}$ & $\begin{aligned} & \text { Acc. } \\
\pm & \mathrm{MHz}\end{aligned}$ \\
\hline $\mathrm{S}^{32}{ }_{*} \mathrm{HC}^{13}: \mathrm{C}^{12} \mathrm{HC}^{12} \mathrm{H}: \mathrm{C}^{12}{ }_{*} \mathrm{H}$ & 4-1167 & $3,0,3 \leftarrow 2,0,2$ & Ground & & & & 22802.8 & .05 \\
\hline $\mathrm{C}^{12} \mathrm{H}_{3} \mathrm{C}^{12} \mathrm{O}^{16} \mathrm{Br}^{79}$ & 3- 351 & $4,1,3 \leftarrow 3,1,2$ & Ground & & $7 / 2$ & $5 / 2$ & 22803.90 & .15 \\
\hline $\mathrm{C}^{12} \mathrm{H}_{3} \mathrm{C}^{12} \mathrm{O}^{16} \mathrm{Cl}^{35}$ & 3- 361 & $3,2,2 \leftarrow 3,1,3$ & Ground & & & & 22804.3 & .2 \\
\hline $\mathrm{C}^{12} \mathrm{D}_{2} \mathrm{Cl}_{2}^{35}$ & 4- 346 & $5,1,4 \leftarrow 5,0,5$ & Ground & & & & 22805. & 5. \\
\hline $\mathrm{C}^{12} \mathrm{H}_{3} \mathrm{C}^{12} \mathrm{O}^{16} \mathrm{Br}^{79}$ & 3- 351 & $4,1,3 \leftarrow 3,1,2$ & Ground & & $7 / 2$ & $5 / 2$ & 22805.15 & .15 \\
\hline $\mathrm{H}_{2} \mathrm{C}^{12}: \mathrm{C}^{13} \mathrm{HCl}^{35}$ & 4- 768 & $2,0,2 \leftarrow 1,0,1$ & Ground & & $7 / 2$ & $5 / 2$ & 22805.33 & .10 \\
\hline $\mathrm{H}_{2} \mathrm{C}^{12}: \mathrm{C}^{13} \mathrm{HCl}^{35}$ & 4. 768 & $2,0,2 \leftarrow 1,0,1$ & Ground & & $5 / 2$ & $3 / 2$ & 22805.33 & .10 \\
\hline $\mathrm{F}_{2}^{19} \mathrm{~N}^{14} \mathrm{~N}^{14} \mathrm{~F}_{2}^{19}$ & $3-\quad 21$ & $10,5,5 \leftarrow 10,4,7$ & Ground & & & & 22805.9 & .3 \\
\hline $\mathrm{C}^{12} \mathrm{D}_{3} \mathrm{C}^{12} \mathrm{DO}^{16}$ & 3- 472 & $3,0,3 \leftarrow 2,1,2$ & Ground & & & & 22808.47 & .2 \\
\hline $\mathrm{C}^{12} \mathrm{H}_{2}\left(\mathrm{C}^{12} \mathrm{~N}^{14}\right)_{2}$ & 4- 901 & Not Reported & Ground & & & & 22809.1 & .1 \\
\hline $\mathrm{C}^{12}{ }_{*} \mathrm{H}: \mathrm{C}^{12} \mathrm{HO}^{16} \mathrm{C}^{12} \mathrm{H}: \mathrm{C}^{12}{ }_{*} \mathrm{H}$ & 4-1151 & $7,5,2 \leftarrow 7,5,3$ & Ground & & & & 22810.92 & \\
\hline $\mathrm{N}^{14} \mathrm{H}_{2} \mathrm{C}_{2}^{12} \mathrm{H}_{5}$ & 3- 631 & Not Reported & Ground & & & & 22815.64 & .2 \\
\hline $\mathrm{C}^{12} \mathrm{H}_{2}: \mathrm{C}^{12} \mathrm{DBr}^{81}$ & 4- 722 & $3,1,3 \leftarrow 2,1,2$ & Excited & & $9 / 2$ & $7 / 2$ & 22818.3 & \\
\hline $\mathrm{C}^{12} \mathrm{H}_{3} \mathrm{~N}^{14} \mathrm{H}_{2}$ & 3. 261 & Not Reported & Ground & & & & 22818.83 & \\
\hline $\mathrm{O}^{18} \mathrm{C}^{12} \mathrm{~S}^{32}$ & 4. 531 & $2 \leftarrow 1$ & Ground & & & & 22819.30 & \\
\hline $\mathrm{C}^{12} \mathrm{H}_{2} \mathrm{Cl}^{35} \mathrm{C}^{12}: \mathrm{C}^{12} \mathrm{H}$ & 4- 991 & $4,1,4 \leftarrow 3,1,3$ & Ground & & & & 22819.59 & \\
\hline $\mathrm{C}^{12} \mathrm{H}_{3} \mathrm{~N}^{14} \mathrm{O}_{2}^{16}$ & 3. 171 & Not Reported & Ground & & & & 22820 . & 5. \\
\hline $\mathrm{C}^{12} \mathrm{H}_{3} \mathrm{C}^{12} \mathrm{H}_{2} \mathrm{O}^{16} \mathrm{H}$ & 3- 581 & Not Reported & & & & & 22820. & \\
\hline $\mathrm{P}^{31} \mathrm{H}_{2} \mathrm{D}$ & $4-1782$ & Not Reported & Ground & & & & 22821.90 & .05 \\
\hline $\mathrm{C}^{12} \mathrm{H}_{3} \mathrm{C}^{12} \mathrm{HF}_{2}^{19}$ & 3- 461 & $11,8,3 \leftarrow 11,8,4$ & Ground & & & & 22822.2 & \\
\hline $\mathrm{C}^{13} \mathrm{H}_{2}: \mathrm{C}^{12} \mathrm{HBr}^{79}$ & 4- 735 & $3,1,3 \leftarrow 2,1,2$ & Ground & & $7 / 2$ & $7 / 2$ & 22826.2 & \\
\hline $\mathrm{C}^{12} \mathrm{H}_{3} \mathrm{C}^{12} \mathrm{O}^{16} \mathrm{O}^{16} \mathrm{H}$ & 3- 491 & Not Reported & & & & & 22827. & 3. \\
\hline $\mathrm{C}^{12} \mathrm{H}_{3} \mathrm{~S}^{32} \mathrm{H}$ & 3. 221 & Not Reported & Ground & & & & 22827.3 & .1 \\
\hline $\mathrm{HC}^{12} \mathrm{O}^{16} \mathrm{O}^{16} \mathrm{C}^{12} \mathrm{H} \cdot \mathrm{A}$ & 3- 501 & $2,1,2 \leftarrow 1,1,1$ & Ground & & & & 22827.91 & .2 \\
\hline $\mathrm{C}_{6}^{12} \mathrm{H}_{5} \mathrm{Cl}^{35}$ & 4-1271 & $8,3,5 \leftarrow 7,3,4$ & Ground & & & & 22829.2 & \\
\hline $\mathrm{C}^{12} \mathrm{H}_{3} \mathrm{~N}^{14} \mathrm{O}_{2}^{16}$ & 3. 171 & Not Reported & Ground & & & & 22830. & \\
\hline $\mathrm{C}^{\mathrm{b}}{ }_{*} \mathrm{H}_{2}^{\mathrm{b}} \mathrm{N}^{\mathrm{b}} \mathrm{H}^{\mathrm{b}} \mathrm{C}^{\mathrm{b}}{ }_{*} \mathrm{H}_{2}^{\mathrm{b}}$ & 4- 863 & Not Reported & & & & & 22830 . & 10. \\
\hline $\mathrm{a}-\mathrm{C}^{12} \mathrm{HD}_{2} \mathrm{C}^{12} \mathrm{O}^{16} \mathrm{C}^{12} \mathrm{~N}^{14}$ & 3. 678 & $6,1,5 \leftarrow 6,0,6$ & Ground & & & & 22833. & 1. \\
\hline $\mathrm{C}^{12} \mathrm{H}_{2}: \mathrm{C}^{12} \mathrm{DBr}^{81}$ & 4- 722 & $3,1,3 \leftarrow 2,1,2$ & Ground & & $5 / 2$ & $5 / 2$ & 22834.1 & \\
\hline $\mathrm{T} 1^{203} \mathrm{Br}^{81}$ & $1-$ & $9 \leftarrow 8$ & Excited & & & & 22834.13 & 0.20 \\
\hline $\mathrm{N}^{14} \mathrm{H}_{3}$ & $4-1771$ & $3,2 \leftarrow 3,2$ & Ground & & & & 22834.17 & .02 \\
\hline $\mathrm{C}^{12} \mathrm{HD}: \mathrm{C}^{12} \mathrm{DBr}^{\mathrm{b}}$ & 4- 749 & Not Reported & & & & & 22834.2 & .2 \\
\hline $\mathrm{C}^{12}{ }_{*} \mathrm{HC}^{12} \mathrm{H}: \mathrm{C}^{12} \mathrm{HC}^{12} \mathrm{H}: \mathrm{C}^{12} \mathrm{HN}^{14}{ }_{*}$ & 4-1201 & $18,14,4 \leftarrow 18,14,5$ & Ground & & & & 22834.8 & .1 \\
\hline $\mathrm{C}^{13}{ }_{*} \mathrm{H}: \mathrm{C}^{12} \mathrm{HO}^{16} \mathrm{C}^{12} \mathrm{H}: \mathrm{C}^{12}{ }_{*} \mathrm{H}$ & $4-1157$ & $4,2,2 \leftarrow 4,2,3$ & Ground & & & & 22836.55 & .1 \\
\hline $\mathrm{C}^{12} \mathrm{D}_{3} \mathrm{C}^{12} \mathrm{DO}^{16}$ & 3- 472 & $3,0,3 \leftarrow 2,1,2$ & Ground & & & & 22837.22 & .4 \\
\hline $\mathrm{H}_{2} \mathrm{~N}^{14} \mathrm{~N}^{14} \mathrm{H}_{2}$ & 3- 51 & Not Reported & & & & & 22839.43 & \\
\hline $\mathrm{T}]^{205} \mathrm{Br}^{81}$ & $1-$ & $9 \leftarrow 8$ & Ground & & & & 22839.75 & 0.10 \\
\hline $\mathrm{C}^{12} \mathrm{~F}_{3}^{19} \mathrm{C}^{13}: \mathrm{C}^{12} \mathrm{H}$ & 4- 872 & $4, \leftarrow 3$, & Ground & & & & 22839.9 & .3 \\
\hline $\mathrm{H}_{2} \mathrm{~N}^{14} \mathrm{~N}^{14} \mathrm{H}_{2}$ & 3- 51 & Not Reported & & & & & 22839.91 & \\
\hline $\mathrm{C}^{13} \mathrm{H}_{2}: \mathrm{C}^{13} \mathrm{HBr}^{81}$ & 4- 734 & $3,2,2 \leftarrow 2,2,1$ & Ground & & $7 / 2$ & $5 / 2$ & 22840.3 & \\
\hline $\mathrm{C}^{12}{ }_{*} \mathrm{H}: \mathrm{C}^{12} \mathrm{HC}^{12} \mathrm{H}: \mathrm{C}^{12} \mathrm{HN}^{14}{ }_{*} \mathrm{H}$ & $4-1181$ & $8,7,2 \leftarrow 8,5,3$ & Ground & & & & 22840.5 & \\
\hline $\mathrm{C}^{12} \mathrm{DH}_{2} \mathrm{C}^{12} \mathrm{HDF}^{19}$ & 3- 562 & $6,1,5 \leftarrow 6,1,6$ & Ground & & & & 22841.0 & .1 \\
\hline $\mathrm{HC}^{13}: \mathrm{C}^{12} \mathrm{C}^{12} \mathrm{DO}^{16}$ & 4- 922 & Not Reported & & & & & 22842. & 5. \\
\hline $\mathrm{C}^{12} \mathrm{H}_{2}: \mathrm{C}^{12} \mathrm{DBr}^{81}$ & 4- 722 & $3,1,3 \leftarrow 2,1,2$ & Excited & & $7 / 2$ & $5 / 2$ & 22843.4 & \\
\hline
\end{tabular}




\begin{tabular}{|c|c|c|c|c|c|c|c|}
\hline \multirow{2}{*}{ Isotopic Species } & \multirow{2}{*}{$\begin{array}{l}\text { Vol.-Id. } \\
\text { Nos. }\end{array}$} & \multirow{2}{*}{$\begin{array}{c}\text { Rotational } \\
\text { Quantum Nos. }\end{array}$} & \multirow{2}{*}{ Vib. State } & \multicolumn{2}{|c|}{ Hyperfine } & \multirow{2}{*}{$\begin{array}{c}\text { Frequency } \\
\mathrm{MHz}\end{array}$} & \multirow{2}{*}{$\begin{aligned} & \text { Acc. } \\
\pm & \mathrm{MHz}\end{aligned}$} \\
\hline & & & & $\begin{array}{lll}F_{1}^{\prime} & F^{\prime} & F_{1}\end{array}$ & $\mathrm{~F}$ & & \\
\hline $\mathrm{C}^{b} \mathrm{H}_{2}: \mathrm{C}^{b} \mathrm{HBr}^{\mathrm{b}}$ & 4. 752 & $3,2,1 \leftarrow 2,2,0$ & Ground & $7 / 2$ & $5 / 2$ & 22844.7 & \\
\hline $\mathrm{C}^{12} \mathrm{H}_{2} \mathrm{Cl}^{35} \mathrm{Si}^{28} \mathrm{D}_{2}$ & 3- 237 & $11,1,10 \leftarrow 11,0,11$ & Ground & & & 22844.72 & .2 \\
\hline $\mathrm{C}^{12} \mathrm{H}_{2}: \mathrm{C}^{12} \mathrm{DBr}^{81}$ & 4. 722 & $3,1,3 \leftarrow 2,1,2$ & Ground & $9 / 2$ & $7 / 2$ & 22845.1 & \\
\hline $\mathrm{C}^{12} \mathrm{H}_{3} \mathrm{C}^{12} \mathrm{O}^{16} \mathrm{Cl}^{37}$ & 3. 362 & $7,3,4 \leftarrow 7,2,5$ & Ground & $11 / 2$ & $11 / 2$ & 22846.60 & .2 \\
\hline $\mathrm{C}^{12} \mathrm{H}_{3} \mathrm{C}^{12} \mathrm{O}^{16} \mathrm{Cl}^{37}$ & 3- 362 & $7,3,4 \leftarrow 7,2,5$ & Ground & $17 / 2$ & $17 / 2$ & 22847.27 & .2 \\
\hline $\mathrm{C}^{12} \mathrm{H}_{3} \mathrm{C}^{12} \mathrm{O}^{10} \mathrm{Cl}^{37}$ & 3. 362 & $7,3,4 \leftarrow 7,2,5$ & Ground & $11 / 2$ & $11 / 2$ & 22847.27 & .2 \\
\hline $\mathrm{C}^{12} \mathrm{H}_{3} \mathrm{C}^{12} \mathrm{O}^{16} \mathrm{Cl}^{37}$ & 3- 362 & $7,3,4 \leftarrow 7,2,5$ & Ground & $17 / 2$ & $17 / 2$ & 22848.00 & .2 \\
\hline $\mathrm{O}^{18} \mathrm{C}^{12} \mathrm{~S}^{32}$ & 4- 531 & $2 \leftarrow 1$ & Excited & & & 22848.70 & .1 \\
\hline $\mathrm{C}^{12} \mathrm{H}_{3} \mathrm{C}^{12} \mathrm{O}^{16} \mathrm{Cl}^{37}$ & 3- 362 & $7,3,4 \leftarrow 7,2,5$ & Ground & $13 / 2$ & $13 / 2$ & 22849.41 & .2 \\
\hline $\mathrm{C}^{12} \mathrm{H}_{3} \mathrm{C}^{12} \mathrm{O}^{16} \mathrm{Cl}^{37}$ & 3- 362 & $7,3,4 \leftarrow 7,2,5$ & Ground & $15 / 2$ & $15 / 2$ & 22850.10 & .2 \\
\hline $\mathrm{C}^{12} \mathrm{H}_{3} \mathrm{C}^{12} \mathrm{O}^{16} \mathrm{Cl}^{37}$ & 3- 362 & $7,3,4 \leftarrow 7,2,5$ & Ground & $13 / 2$ & $13 / 2$ & 22850.10 & .2 \\
\hline $\mathrm{C}^{12} \mathrm{H}_{3} \mathrm{C}^{12} \mathrm{O}^{16} \mathrm{Cl}^{37}$ & 3. 362 & $7,3,4 \leftarrow 7,2,5$ & Ground & $15 / 2$ & $15 / 2$ & 22850.83 & .2 \\
\hline $\mathrm{C}^{12} \mathrm{H}_{2}: \mathrm{C}^{12} \mathrm{~F}^{19} \mathrm{Cl}$ & 4- 632 & $9,4,5 \leftarrow 8,5,4$ & Ground & & & 22852.40 & \\
\hline $\mathrm{C}^{12} \mathrm{H}_{2}\left(\mathrm{C}^{12} \mathrm{~N}^{14}\right)_{2}$ & 4- 901 & Not Reported & Ground & & & 22852.9 & .1 \\
\hline $\mathrm{C}_{6}^{12} \mathrm{H}_{5} \mathrm{O}^{16} \mathrm{H}$ & $3 \cdot 1051$ & $6,0,6 \leftarrow 5,1,5$ & Ground & & & 22854.87 & \\
\hline $\mathrm{C}^{12} \mathrm{H}_{2}: \mathrm{C}^{12} \mathrm{DBr}^{81}$ & 4- 722 & $3,1,3 \leftarrow 2,1,2$ & Ground & & & 22855.91 & .05 \\
\hline $\mathrm{HC}^{13}: \mathrm{C}^{12} \mathrm{C}^{12} \mathrm{DO}^{16}$ & 4- 922 & Not Reported & & & & 22856. & 5. \\
\hline $\mathrm{C}^{12}{ }_{*} \mathrm{H}_{2}^{\mathrm{b}} \mathrm{S}^{\mathrm{b}} \mathrm{C}^{12}{ }_{*} \mathrm{H}_{2}^{\mathrm{b}}$ & 4- 854 & Not Reported & & & & 22857.0 & .2 \\
\hline $\mathrm{H}_{2} \mathrm{C}^{12}: \mathrm{C}^{12} \mathrm{Cl}^{35} \mathrm{Cl}^{37}$ & 4- 662 & $11,4,7 \leftarrow 11,3,8$ & Ground & & & 22858.7 & .5 \\
\hline $\mathrm{C}_{6}^{12} \mathrm{H}_{5} \mathrm{~F}^{19}$ & $4-1281$ & $6,1,6 \leftarrow 5,1,5$ & Ground & & & 22863.3 & .1 \\
\hline $\mathrm{C}^{12} \mathrm{HD}\left(\mathrm{C}^{12} \mathrm{~N}^{14}\right)_{2}$ & 4. 902 & $8,1,7 \leftarrow 8,0,8$ & Ground & & & 22864.92 & \\
\hline $\mathrm{F}_{2}^{19} \mathrm{~N}^{14} \mathrm{~N}^{14} \mathrm{~F}_{2}^{19}$ & 3- 21 & $12,5,7 \leftarrow 12,4,9$ & Ground & & & 22865.6 & .3 \\
\hline $\mathrm{O}_{3}^{18}$ & 4-1845 & $17,1,17 \leftarrow 16,2,14$ & Ground & & & 22866. & \\
\hline $\mathrm{C}^{12} \mathrm{H}_{3} \mathrm{C}^{12} \mathrm{~F}^{19}: \mathrm{C}^{12} \mathrm{H}_{2}$ & 3. 721 & $9,6,3 \leftarrow 9,6,4$ & Ground & & & 22866.67 & .1 \\
\hline $\mathrm{F}_{2}^{19} \mathrm{~N}^{14} \mathrm{~N}^{14} \mathrm{~F}_{2}^{19}$ & 3- 21 & $9,5,4 \leftarrow 9,4,6$ & Ground & & & 22866.9 & .3 \\
\hline $\mathrm{C}^{12} \mathrm{H}_{3} \mathrm{C}^{12} \mathrm{~F}^{19}: \mathrm{C}^{12} \mathrm{H}_{2}$ & 3. 721 & $9,6,3 \leftarrow 9,6,4$ & Ground & & & 22867.00 & .1 \\
\hline $\mathrm{C}^{13}{ }_{*} \mathrm{H}: \mathrm{C}^{12} \mathrm{HO}^{16} \mathrm{C}^{12} \mathrm{H}: \mathrm{C}^{12}{ }_{*} \mathrm{H}$ & 4-1157 & $2,1,2 \leftarrow 1,1,1$ & Ground & & & 22868.1 & .1 \\
\hline $\mathrm{c} \cdot \mathrm{HCl}^{35} \mathrm{C}^{12}: \mathrm{C}^{12} \mathrm{HCl}^{37}$ & 4- 672 & $6,0,6 \leftarrow 5,1,5$ & Ground & & & 22869.4 & .5 \\
\hline $\mathrm{H}_{2}^{\mathrm{b}} \mathrm{C}^{\mathrm{b}}: \mathrm{C}^{\mathrm{b}} \mathrm{H}^{\mathrm{b}} \mathrm{Cl}^{\mathrm{b}}$ & 4. 772 & Not Reported & Ground & & & 22870 & \\
\hline $\mathrm{C}^{12} \mathrm{H}_{2}: \mathrm{C}^{12} \mathrm{DBr}^{81}$ & 4. 722 & $3,1,3 \leftarrow 2,1,2$ & Ground & $7 / 2$ & $5 / 2$ & 22870.2 & \\
\hline $\mathrm{O}^{18} \mathrm{C}^{12} \mathrm{~S}^{32}$ & 4- 531 & $2 \leftarrow 1$ & Excited & & & 22871.28 & .1 \\
\hline $\mathrm{C}^{12} \mathrm{H}_{2}: \mathrm{C}^{12} \mathrm{DBr}^{81}$ & 4. 722 & $3,1,3 \leftarrow 2,1,2$ & Ground & $5 / 2$ & $3 / 2$ & 22871.5 & \\
\hline $\mathrm{C}^{\mathrm{b}} \mathrm{H}_{2}: \mathrm{C}^{\mathrm{b}} \mathrm{HBr}^{79}$ & 4. 753 & $3,2,2 \leftarrow 2,2,1$ & Ground & $9 / 2$ & $7 / 2$ & 22872.8 & \\
\hline $\mathrm{c} \cdot \mathrm{HCl}^{35} \mathrm{C}^{12}: \mathrm{C}^{12} \mathrm{HCl}^{37}$ & 4- 672 & $6,0,6 \leftarrow 5,1,5$ & Ground & & & 22873.9 & .5 \\
\hline $\mathrm{H}_{2} \mathrm{C}^{12}: \mathrm{C}^{12} \mathrm{Cl}_{2}^{\mathrm{b}}$ & 4. 663 & Not Reported & Ground & & & 22874.0 & 1. \\
\hline $\mathrm{HN}^{14} \mathrm{C}^{12} \mathrm{~S}^{34}$ & 4- 316 & $2,1,2 \leftarrow 1,1,1$ & Ground & & & $22874.59^{\circ}$ & .5 \\
\hline $\mathrm{C}^{\mathrm{b}} \mathrm{H}_{2}: \mathrm{C}^{\mathrm{b}} \mathrm{HBr}^{\mathrm{b}}$ & 4. 752 & $3 ; 2,1 \leftarrow 2,2,0$ & Ground & $9 / 2$ & $7 / 2$ & 22877.1 & \\
\hline $\mathrm{C}_{6}^{12} \mathrm{H}_{5} \mathrm{~N}^{14} \mathrm{O}_{2}^{16}$ & 3-1041 & $10,4,7 \leftarrow 9,4,6$ & Ground & & & 22883. & 3. \\
\hline g. $\mathrm{C}^{12} \mathrm{H}_{3} \mathrm{C}^{12} \mathrm{H}_{2} \mathrm{Cl}^{12} \mathrm{H}_{2} \mathrm{Cl}^{37}$ & 3- 774 & $6,2,4 \leftarrow 6,1,5$ & Ground & & & 22883.98 & .2 \\
\hline $\mathrm{C}^{12} \mathrm{H}_{2} \mathrm{Cl}^{35} \mathrm{~F}^{19}$ & 4. 331 & $20,1,20 \leftarrow 19,2,17$ & Ground & & & 22889.15 & .1 \\
\hline $\mathrm{C}^{12} \mathrm{H}_{3} \mathrm{C}^{12} \mathrm{H}_{2} \mathrm{O}^{16} \mathrm{H}$ & 3- 581 & $6,1,5 \leftarrow 6,1,6$ & Ground & & & 22890.95 & .01 \\
\hline $\mathrm{C}^{\mathrm{b}} \mathrm{H}_{2}^{\mathrm{b}} \mathrm{Cl}^{\mathrm{b}} \mathrm{F}^{\mathrm{b}}$ & 4- 333 & Not Reported & & & & 22892.11 & .1 \\
\hline $\mathrm{C}^{12} \mathrm{D}_{2} \mathrm{HC}^{12}: \mathrm{C}^{12} \mathrm{C}^{12} \mathrm{~F}^{19}$ & 3- 897 & $9, \quad, 1 \leftarrow 8$, & Ground & & & 22893.5 & .1 \\
\hline $\mathrm{C}^{13} \mathrm{H}_{2}: \mathrm{C}^{13} \mathrm{HBr}^{79}$ & 4- 733 & $3,0,3 \leftarrow 2,0,2$ & Ground & $9 / 2$ & $7 / 2$ & 22894.8 & \\
\hline $\mathrm{C}^{12} \mathrm{H}_{2} \mathrm{Cl}^{35} \mathrm{~F}^{19}$ & 4- 331 & $20,1,20 \leftarrow 19,2,17$ & Ground & & & 22895.76 & .1 \\
\hline
\end{tabular}


Vol.-Id. Rotational

Nos. Quantum Nos.
Vib. State

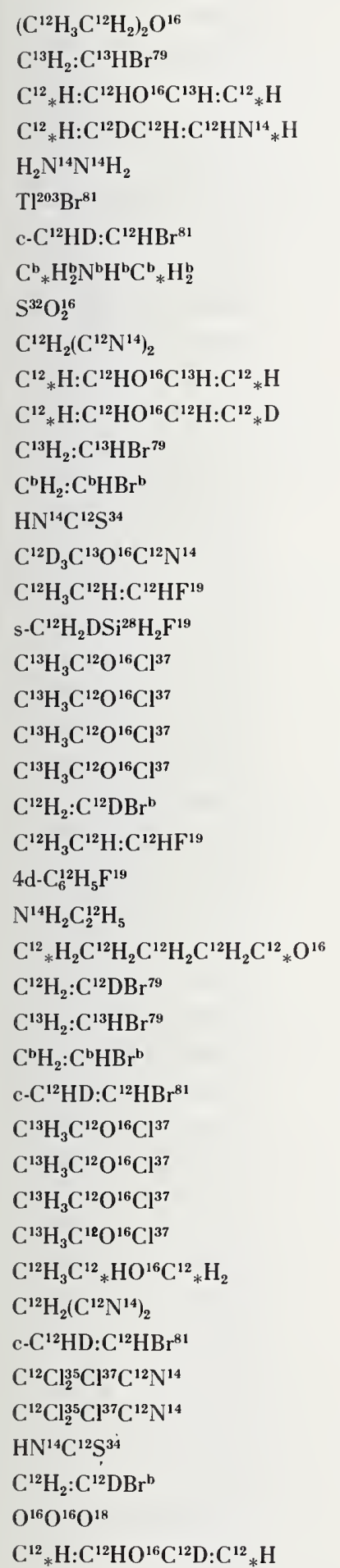

3-1011 Not Reported

4. 733

$3,0,3 \leftarrow 2,0,2$

4-1153

$7,5,2 \leftarrow 7,5,3$

Ground

4-1184

$5,5,1 \leftarrow 5,3,2$

Ground

3. 51

Not Reported

1 -

4- $742 \quad 3,2,2 \leftarrow 2,2,1$

4- 863

Not Reported

4-1831

Not Reported

4- 901

Not Reported

4-1153

$7,5,2 \leftarrow 7,4,3$

4-1155

$4,3,2 \leftarrow 4,1,3$

4- 733

$3,2,2 \leftarrow 2,2,1$

4. 752

$3,2,2 \leftarrow 2,2,1$

4. 316

$2,0,2 \leftarrow 1,0,1$

3. 676

$10,3,7 \lll 10,2,8$

3. 711

$3,1,2 \leftarrow 2,1,1$

3- 247

$2,0,2 \leftarrow 1,0,1$

3- 368

$7,2,5 \leftarrow 7,1,6$

3- 368

$7,2,5 \leftarrow 7,1,6$

3. 368

$7,2,5 \leftarrow 7,1,6$

3- 368

$7,2,5 \leftarrow 7,1,6$

4. 729

$3, \quad \leftarrow 2, \quad$

3. 711

$3,1,2 \leftarrow 2,1,1$

4-1283

$8,1,7 \leftarrow 8,1,8$

3- 631

Not Reported

4-1241

$4,2,3 \leftarrow 3,2,2$

4- 721

$3,1,3 \leftarrow 2,1,2$

4- 733

$3,2,1 \leftarrow 2,2,0$

4- 752

$3,2,1 \leftarrow 2,2,0$

4- 742

$3,2,1 \leftarrow 2,2,0$

3- 368

$7,2,5 \leftarrow 7,1,6$

3- 368

$7,2,5 \leftarrow 7,1,6$

3- 368

3. 368

$7,2,5 \leftarrow 7,1,6$

$7,2,5 \leftarrow 7,1,6$

3- 761

$8,2,7 \leftarrow 8,1,7$

4- 901

Not Reported

4- 742

$3,0,3 \leftarrow 2,0,2$

4. 582

$7,0,7 \leftarrow 6,0,6$

4. 582

$7,1,7 \leftarrow 6,1,6$

4- 316

Not Reported

4- 729

$3, \quad \leftarrow 2$,

4-184h

$23,2,22 \leftarrow 22,3,19$

4-1154
$7,7,1 \leftarrow 7,6,2$
Ground

Ground

Ground

Ground

Ground

Ground

Ground

Ground

Ground

Ground

Ground

Ground

Ground

Ground

Ground

Ground

Ground

Ground

Ground

Ground

Ground

Ground

Ground

Ground

Ground

Ground

Ground

Ground

Ground

Ground

Ground

Ground

Ground

Ground

Ground

Ground

Ground

Ground
22900.

22900.18

.08

22900.8

22901.1

22902.87

$22903.48 \quad 0.10$

$3 / 2 \quad 1 / 2 \quad 22903.9$

$22904.4 \quad .5$

$22904.95 \quad$. 1

22905.0 . .

22906.5 . 1

22906.5

22906.58

.05

$5 / 2 \quad 3 / 2 \quad 22906.7$

$22906.79 \quad .5$

$22907.56 \quad .2$

22907.60

$22907.78 \quad .10$

$\begin{array}{llll}11 / 2 & 11 / 2 & 22908.0 & .2\end{array}$

$\begin{array}{llll}17 / 2 & 17 / 2 & 22908.0 & .2\end{array}$

$15 / 2 \quad 15 / 2 \quad 22908.0 \quad .2$

$13 / 2 \quad 13 / 2 \quad 22908.0 \quad .2$

22908.0

$22908.10 \quad .1$

$22908.8 \quad .1$

$22909.23 \quad .2$

22910.0

$3 / 2 \quad 3 / 2 \quad 22910.9$

$22911.06 \quad .05$

$5 / 2 \quad 3 / 2 \quad 22911.3$

$\begin{array}{llll}3 / 2 & 1 / 2 & 22911.7 & .2\end{array}$

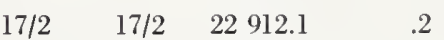

$11 / 2 \quad 11 / 2 \quad 22912.1 \quad .2$

$\begin{array}{llll}15 / 2 & 15 / 2 & 22912.1 & .2\end{array}$

$13 / 2 \quad 13 / 2 \quad 22912.1 \quad .2$

$22912.6 \quad$.1

$22913.4 \quad$.1

$\begin{array}{llll}3 / 2 & 3 / 2 & 22913.8 & .1\end{array}$

22914.

22914.

22915.

22917.9

.2

22918.

22918.6 


\begin{tabular}{|c|c|c|c|c|c|c|c|}
\hline Isotopic Species & $\begin{array}{l}\text { Vol.-Id. } \\
\text { Nos. }\end{array}$ & $\begin{array}{c}\text { Rotational } \\
\text { Quantum Nos. }\end{array}$ & Vib. State & $\mathrm{F}_{1}^{\prime} \stackrel{\text { Hyperfine }}{\stackrel{\text { F }}{\mathrm{F}^{\prime}} \quad \mathrm{F}_{1}}$ & $\mathrm{~F}$ & $\begin{array}{l}\text { Frequency } \\
\mathrm{MHz}\end{array}$ & $\begin{array}{r}\text { Acc. } \\
\pm \mathrm{MHz}\end{array}$ \\
\hline $\mathrm{C}^{12} \mathrm{H}_{2}\left(\mathrm{C}^{12} \mathrm{~N}^{14}\right)_{2}$ & 4- 901 & Not Reported & Ground & & & 22918.7 & .1 \\
\hline $\mathrm{C}^{12} \mathrm{H}_{3} \mathrm{Si}^{28} \mathrm{HDF}^{19}$ & 3. 252 & $2,1,2 \leftarrow 1,1,1$ & Ground & & & 22919.05 & .10 \\
\hline $\mathrm{C}^{\mathrm{b}} \mathrm{H}_{2}^{\mathrm{b}} \mathrm{Cl}^{\mathrm{b}} \mathrm{F}^{\mathrm{b}}$ & 4- 333 & Not Reported & & & & 22919.28 & .1 \\
\hline $\mathrm{C}^{12} \mathrm{H}_{2}\left(\mathrm{C}^{12} \mathrm{~N}^{14}\right)_{2}$ & 4. 901 & Not Reported & Ground & & & 22921.2 & .1 \\
\hline $\mathrm{C}^{12} \mathrm{H}_{2} \mathrm{C}^{35} \mathrm{C}^{12}: \mathrm{C}^{12} \mathrm{H}$ & 4- 991 & $4,1,3 \leftarrow 4,0,4$ & Ground & & & 22921.58 & \\
\hline $\mathrm{C}^{12} \mathrm{H}_{2}: \mathrm{C}^{12} \mathrm{DBr}^{81}$ & 4- 722 & $3,1,3 \leftarrow 2,1,2$ & Ground & $7 / 2$ & $7 / 2$ & 22923.4 & \\
\hline $\mathrm{C}^{\mathrm{b}} \mathrm{H}_{2}: \mathrm{C}^{\mathrm{b}} \mathrm{HBr}^{\mathrm{b}}$ & 4. 752 & $3,0,3 \leftarrow 2,0,2$ & Ground & $5 / 2$ & $3 / 2$ & 22923.4 & \\
\hline $\mathrm{N}^{14} \mathrm{H}_{3}$ & 4-1771 & $7,6 \leftarrow 7,6$ & Ground & & & 22924.94 & .02 \\
\hline $\mathrm{K}^{39} \mathrm{Cl}^{35}$ & 1 . & $3 \leftarrow 2$ & Excited & & & 22925.4 & 0.5 \\
\hline $\mathrm{HDO}_{2}^{16}$ & 3- 43 & $10, \quad \leftarrow 10$, & & & & 22928. & 3. \\
\hline $\mathrm{S}^{32} \mathrm{O}_{2}^{16}$ & 4-1831 & Not Reported & & & & 22928.45 & .1 \\
\hline $\mathrm{H}_{2} \mathrm{C}^{12}: \mathrm{C}^{12} \mathrm{HCl}^{35}$ & 4. 766 & $2,0,2 \leftarrow 1,0,1$ & Ground & $3 / 2$ & $1 / 2$ & 22931.02 & .02 \\
\hline $\mathrm{C}^{12} \mathrm{H}_{2}: \mathrm{C}^{12} \mathrm{DBr}^{79}$ & 4- 721 & $3,1,3 \leftarrow 2,1,2$ & Excited & $5 / 2$ & $5 / 2$ & 22932.0 & \\
\hline $\mathrm{H}_{2} \mathrm{C}^{12}: \mathrm{C}^{12} \mathrm{HCl}^{35}$ & 4- 766 & $2,0,2 \leftarrow 1,0,1$ & Ground & $5 / 2$ & $5 / 2$ & 22932.24 & .02 \\
\hline $\mathrm{C}^{12} \mathrm{D}_{3} \mathrm{C}^{12} \mathrm{O}^{16} \mathrm{C}^{12} \mathrm{~N}^{14}$ & 3. 675 & $10,3,7 \leftarrow 10,2,8$ & Ground & & & 22933.80 & .2 \\
\hline $\mathrm{C}_{6}^{12} \mathrm{H}_{5} \mathrm{C}^{12} \mathrm{~N}^{14}$ & 4-1291 & $8,1,7 \leftarrow 7,1,6$ & Ground & & & 22936. & \\
\hline $\mathrm{C}^{13} \mathrm{H}_{2}: \mathrm{C}^{12} \mathrm{HBr}^{81}$ & 4- 736 & $3,2,2 \leftarrow 2,2,1$ & Ground & $3 / 2$ & $1 / 2$ & 22936.5 & \\
\hline $\mathrm{C}^{12}{ }_{*} \mathrm{H}: \mathrm{C}^{12} \mathrm{HO}^{18} \mathrm{C}^{12} \mathrm{H} \mathrm{C}^{12}{ }^{12} \mathrm{H}$ & $4-1152$ & $3,2,2 \leftarrow 3,0,3$ & Ground & & & 22936.8 & .1 \\
\hline $\mathrm{C}_{6}^{12} \mathrm{H}_{5} \mathrm{C}^{12} \mathrm{~N}^{14}$ & 4-1291 & $9,1,9 \leftarrow 8,1,8$ & Ground & & & 22937.9 & \\
\hline $\mathrm{s}-\mathrm{C}^{12} \mathrm{DH}_{2} \mathrm{C}^{12} \mathrm{H}_{2} \mathrm{C}^{12} \mathrm{H}_{3}$ & 3. 785 & $2,1,1 \leftarrow 2,0,2$ & Ground & & & 22938.16 & .06 \\
\hline$\left(\mathrm{C}^{12} \mathrm{H}_{3}\right)_{2} \mathrm{C}^{12} \mathrm{O}^{16}$ & 3- 751 & Not Reported & & & & 22940. & 5. \\
\hline $\mathrm{C}_{6}^{12} \mathrm{H}_{5} \mathrm{~F}^{19}$ & $4-1281$ & $5,1,4 \leftarrow 4,1,3$ & Ground & & & 22941.0 & .1 \\
\hline$c-\mathrm{C}^{12} \mathrm{HD}: \mathrm{C}^{12} \mathrm{HBr}^{81}$ & 4- 742 & $3,0,3 \leftarrow 2,0,2$ & Ground & $5 / 2$ & $5 / 2$ & 22941.4 & .1 \\
\hline $\mathrm{C}^{12} \mathrm{H}_{2}: \mathrm{C}^{12} \mathrm{DBr}^{\mathrm{b}}$ & 4. 729 & $3, \quad \leftarrow 2, \quad$, & Ground & & & 22942.0 & \\
\hline $\mathrm{C}^{12} \mathrm{H}_{3} \mathrm{C}^{12} \mathrm{O}^{16} \mathrm{O}^{16} \mathrm{H}$ & 3- 491 & Not Reported & & & & 22943. & 3. \\
\hline $\mathrm{C}_{6}^{12} \mathrm{H}_{5} \mathrm{C}^{12} \mathrm{~N}^{14}$ & 4-1291 & $8,1,7 \leftarrow 7,1,6$ & Ground & & & 22943.7 & \\
\hline $\mathrm{C}_{6}^{12} \mathrm{H}_{5} \mathrm{~F}^{19}$ & 4-1281 & $48,15,33 \leftarrow 48,15,34$ & Ground & & & 22943.9 & \\
\hline $\mathrm{C}^{12}{ }_{*} \mathrm{H}: \mathrm{C}^{12} \mathrm{HC}^{12} \mathrm{H}: \mathrm{C}^{12} \mathrm{HN}^{14}{ }_{*} \mathrm{H}$ & 4-1181 & $9,8,2 \leftarrow 9,6,3$ & Ground & & & 22944.6 & \\
\hline $\mathrm{C}^{12} \mathrm{H}_{3} \mathrm{C}^{12} \mathrm{O}^{16} \mathrm{C}^{13} \mathrm{~N}^{14}$ & 3. 673 & $3,1,2 \leftarrow 2,1,1$ & Ground & & & 22945.22 & .2 \\
\hline $\mathrm{C}^{12} \mathrm{H}_{2}: \mathrm{C}^{12} \mathrm{DBr}^{79}$ & 4. 721 & $3,1,3 \leftarrow 2,1,2$ & Excited & $9 / 2$ & $7 / 2$ & 22945.5 & \\
\hline $\mathrm{C}^{12} \mathrm{H}_{3} \mathrm{C}^{12} \mathrm{O}^{16} \mathrm{C}^{13} \mathrm{~N}^{14}$ & 3- 673 & $3,1,2 \leftarrow 2,1,1$ & Ground & & & 22946.19 & .2 \\
\hline $\mathrm{HN}^{14} \mathrm{C}^{12} \mathrm{~S}^{34}$ & 4. 316 & $2,1,1 \leftarrow 1,1,0$ & Ground & & & 22946.47 & .5 \\
\hline $\mathrm{H}_{2} \mathrm{C}^{12}: \mathrm{C}^{12} \mathrm{HCl}^{35}$ & 4. 766 & $2,0,2 \leftarrow 1,0,1$ & Ground & $7 / 2$ & $5 / 2$ & 22946.55 & .02 \\
\hline $\mathrm{H}_{2} \mathrm{C}^{12}: \mathrm{C}^{12} \mathrm{HCl}^{35}$ & 4- 766 & $2,0,2 \leftarrow 1,0,1$ & Ground & $5 / 2$ & $3 / 2$ & 22946.55 & .02 \\
\hline $\mathrm{C}^{12} \mathrm{H}_{3} \mathrm{C}^{12} \mathrm{H}: \mathrm{C}^{12} \mathrm{HF}^{19}$ & 3- 711 & $3,1,2 \leftarrow 2,1,1$ & Ground & & & 22947.90 & \\
\hline $\mathrm{C}^{12} \mathrm{HCl}^{37}: \mathrm{C}^{12} \mathrm{~F}_{2}^{19}$ & 4. 612 & $6,2,4 \leftarrow 6,1,5$ & Ground & & & 22948.4 & .3 \\
\hline $\mathrm{C}^{12} \mathrm{HCl}^{37}: \mathrm{C}^{12} \mathrm{~F}_{2}^{19}$ & 4. 612 & $6,2,4 \leftarrow 6,1,5$ & Ground & & & 22949.6 & .3 \\
\hline $2 \mathrm{~d} \cdot \mathrm{C}_{6}^{12} \mathrm{H}_{5} \mathrm{C}^{12} \mathrm{~N}^{14}$ & $4-1294$ & $9,0,9 \leftarrow 8,0,8$ & Ground & & & 22949.7 & .2 \\
\hline $\mathrm{C}^{12} \mathrm{H}_{2}\left(\mathrm{C}^{12} \mathrm{~N}^{14}\right)_{2}$ & 4. 901 & Not Reported & Ground & & & 22950.2 & .1 \\
\hline $\mathrm{H}_{2} \mathrm{C}^{12}: \mathrm{C}^{12} \mathrm{HCl}^{35}$ & 4. 766 & $2,0,2 \leftarrow 1,0,1$ & Ground & $3 / 2$ & $3 / 2$ & 22956.74 & .02 \\
\hline $\mathrm{H}_{2} \mathrm{C}^{12}: \mathrm{C}^{12} \mathrm{Cl}_{2}^{\mathrm{b}}$ & 4- 663 & Not Reported & Ground & & & 22958.7 & 1. \\
\hline $\mathrm{C}^{12} \mathrm{H}_{2}: \mathrm{C}^{12} \mathrm{DBr}^{79}$ & 4. 721 & $3,1,3 \leftarrow 2,1,2$ & Ground & $5 / 2$ & $5 / 2$ & 22959.2 & \\
\hline $\mathrm{C}^{12} \mathrm{H}_{3} \mathrm{C}^{12}: \mathrm{C}^{12} \mathrm{C}^{12} \mathrm{H}_{7} \mathrm{Cl}^{35}$ & 3- 901 & $8,0,8 \leftarrow 7,0,7$ & Ground & & & 22960.93 & .05 \\
\hline $\mathrm{a} \cdot \mathrm{C}^{12} \mathrm{H}_{2} \mathrm{DC}^{12} \mathrm{HO}^{16}$ & 3- 481 & $7,1,6 \leftarrow 7,1,7$ & Ground & & & 22964.06 & .2 \\
\hline $\mathrm{C}^{12} \mathrm{H}_{2} \mathrm{C}^{35} \mathrm{Si}^{28} \mathrm{D}_{3}$ & 3- 237 & $4,1,3 \leftarrow 3,1,2$ & Ground & & & 22964.29 & .2 \\
\hline
\end{tabular}




\begin{tabular}{|c|c|c|c|c|c|c|c|c|}
\hline Isotopic Species & $\begin{array}{l}\text { Vol.-Id. } \\
\text { Nos. }\end{array}$ & $\begin{array}{c}\text { Rotational } \\
\text { Quantum Nos. }\end{array}$ & Vib. State & $F_{1}^{\prime}$ & $\begin{array}{l}\text { Hyperfint } \\
\mathrm{F}^{\prime} \quad \mathrm{F}_{1}\end{array}$ & $\mathrm{~F}$ & $\begin{array}{l}\text { Frequency } \\
\mathrm{MHz}^{2}\end{array}$ & $\begin{aligned} & \text { Acc. } \\
\pm & \mathrm{MHz}\end{aligned}$ \\
\hline $\mathrm{HC}^{12} \mathrm{HO}^{16}$ & 4. 381 & $9,2,7 \leftarrow 9,2,8$ & Ground & & & & 22965.71 & \\
\hline $\mathrm{C}^{12}{ }_{*} \mathrm{H}: \mathrm{C}^{12} \mathrm{DO}^{16} \mathrm{C}^{12} \mathrm{D}: \mathrm{C}^{12}{ }_{*} \mathrm{H}$ & 4-1156 & $10,7,3 \leftarrow 10,6,4$ & Ground & & & & 22966.5 & \\
\hline $\mathrm{C}_{6}^{12} \mathrm{H}_{5} \mathrm{O}^{16} \mathrm{H}$ & $3-1051$ & $6,0,6 \leftarrow 5,1,5$ & Ground & & & & 22967.07 & \\
\hline $\mathrm{C}^{12}{ }_{*} \mathrm{D}: \mathrm{C}^{12} \mathrm{HC}^{12} \mathrm{H}: \mathrm{C}^{12} \mathrm{HN}^{14}{ }_{*} \mathrm{H}$ & 4-1183 & $6,5,2 \leftarrow 6,4,3$ & Ground & & & & 22967.7 & \\
\hline $\mathrm{C}^{12} \mathrm{H}_{3} \mathrm{C}^{12} \mathrm{O}^{16} \mathrm{O}^{16} \mathrm{H}$ & 3- 491 & Not Reported & & & & & 22968. & 3. \\
\hline $\mathrm{C}^{12} \mathrm{H}_{3} \mathrm{C}^{12} \mathrm{H}_{2} \mathrm{I}^{127}$ & $3-571$ & $4,3,2 \leftarrow 3,3,1$ & Ground & & $11 / 2$ & $9 / 2$ & 22968.75 & .05 \\
\hline $\mathrm{C}^{12} \mathrm{H}_{3} \mathrm{C}^{12} \mathrm{H}_{2} \mathrm{I}^{127}$ & 3- 571 & $4,3,1 \leftarrow 3,3,0$ & Ground & & $11 / 2$ & $9 / 2$ & 22968.75 & .05 \\
\hline $\mathrm{C}^{12} \mathrm{HD}: \mathrm{C}^{12} \mathrm{HBr}^{b}$ & 4- 748 & Not Reported & & & & & 22969.0 & .2 \\
\hline $\mathrm{HC}^{13}: \mathrm{C}^{12} \mathrm{C}^{12} \mathrm{DO}^{16}$ & 4. 922 & Not Reported & & & & & 22972. & 5. \\
\hline $\mathrm{C}_{6}^{12} \mathrm{H}_{5} \mathrm{~N}^{14} \mathrm{O}_{2}^{16}$ & $3-1041$ & $10,4,6 \leftarrow 9,4,5$ & Ground & & & & 22972. & 3. \\
\hline c. $\mathrm{C}^{12} \mathrm{HD}: \mathrm{C}^{12} \mathrm{HBr}^{81}$ & 4. 742 & $3,2,2 \leftarrow 2,2,1$ & Ground & & $7 / 2$ & $7 / 2$ & 22972.5 & .2 \\
\hline$c-\mathrm{C}^{12} \mathrm{HD}: \mathrm{C}^{12} \mathrm{HBr}^{81}$ & 4- 742 & $3,2,2 \leftarrow 2,2,1$ & Ground & & $9 / 2$ & $7 / 2$ & 22972.5 & .2 \\
\hline $\mathrm{C}^{12} \mathrm{H}_{2}: \mathrm{C}^{12} \mathrm{DBr}^{79}$ & 4. 721 & $3,1,3 \leftarrow 2,1,2$ & Ground & & $9 / 2$ & $7 / 2$ & 22972.8 & \\
\hline $\mathrm{C}^{12} \mathrm{H}_{2}: \mathrm{C}^{12} \mathrm{DBr}^{79}$ & 4. 721 & $3,1,3 \leftarrow 2,1,2$ & Ground & & $3 / 2$ & $1 / 2$ & 22974.0 & \\
\hline $\mathrm{N}^{14} \mathrm{H}_{2} \mathrm{C}_{2}^{12} \mathrm{H}_{5}$ & 3- 631 & Not Reported & Ground & & & & 22975.73 & .2 \\
\hline $\mathrm{C}^{12}{ }_{*} \mathrm{H}_{2} \mathrm{C}^{12} \mathrm{H}_{2} \mathrm{C}^{12} \mathrm{H}_{2} \mathrm{O}^{16} *$ & 4.-1091 & $9,7,2 \leftarrow 9,7,3$ & Ground & & & & 22976. & \\
\hline $\mathrm{C}^{12}{ }_{*} \mathrm{H}_{2} \mathrm{~S}^{32} \mathrm{C}^{12}{ }_{*} \mathrm{H}_{2}$ & 4- 851 & $6,2,5 \leftarrow 6,2,4$ & Ground & & & & 22976.4 & .2 \\
\hline$\left(\mathrm{C}^{12} \mathrm{H}_{3}\right)_{2} \mathrm{C}^{12}: \mathrm{C}^{12} \mathrm{H}_{2}$ & 3- 941 & $10,7,3 \leftarrow 10,6,4$ & Ground & & & & 22976.59 & .05 \\
\hline $\mathrm{s}-\mathrm{C}^{12} \mathrm{H}_{2} \mathrm{DC}^{12} \mathrm{HO}^{16}$ & 3- 473 & Not Reported & & & & & 22978. & \\
\hline $\mathrm{C}^{12} \mathrm{H}_{3} \mathrm{C}^{12} \mathrm{H}_{2} \mathrm{I}^{127}$ & 3- 571 & $4,3,2 \leftarrow 3,3,1$ & Ground & & $9 / 2$ & $7 / 2$ & 22978.44 & .05 \\
\hline $\mathrm{C}^{12} \mathrm{H}_{3} \mathrm{C}^{12} \mathrm{H}_{2} \mathrm{I}^{127}$ & 3- 571 & $4,3,1 \leftarrow 3,3,0$ & Ground & & $9 / 2$ & $7 / 2$ & 22978.44 & .05 \\
\hline c. $\mathrm{C}^{12} \mathrm{HD}: \mathrm{C}^{12} \mathrm{HBr}^{81}$ & 4- 742 & $3,2,1 \leftarrow 2,2,0$ & Ground & & $7 / 2$ & $7 / 2$ & 22979.5 & .2 \\
\hline c- $\mathrm{C}^{12} \mathrm{HD}: \mathrm{C}^{12} \mathrm{HBr}^{81}$ & 4- 742 & $3,2,1 \leftarrow 2,2,0$ & Ground & & $9 / 2$ & $7 / 2$ & 22979.5 & .2 \\
\hline $\mathrm{C}^{12}{ }_{*} \mathrm{H}: \mathrm{C}^{12} \mathrm{HC}^{12} \mathrm{H}: \mathrm{C}^{12} \mathrm{HN}^{14}{ }_{*} \mathrm{D}$ & 4-1182 & $5,4,2 \leftarrow 5,2,3$ & Ground & & & & 22979.6 & \\
\hline $\mathrm{C}^{12} \mathrm{H}_{2}\left(\mathrm{C}^{12} \mathrm{~N}^{14}\right)_{2}$ & 4- 901 & Not Reported & Ground & & & & 22980.3 & .1 \\
\hline $\mathrm{C}^{12} \mathrm{H}_{3} \mathrm{~N}^{14} \mathrm{H}_{2}$ & 3- 261 & Not Reported & Ground & & & & 22980.95 & .1 \\
\hline$\left(\mathrm{C}^{12} \mathrm{H}_{3}\right)_{2} \mathrm{C}^{12}: \mathrm{C}^{12} \mathrm{H}_{2}$ & 3- $\dot{9} 41$ & $2,1,2 \leftarrow 1,0,1$ & Ground & & & & 22981.28 & .05 \\
\hline $\mathrm{C}^{12} \mathrm{H}_{3} \mathrm{~N}^{14} \mathrm{H}_{2}$ & 3- 261 & Not Reported & Ground & & & & 22981.60 & .1 \\
\hline $\mathrm{C}^{\mathrm{b}}{ }_{*} \mathrm{H}_{2}^{\mathrm{b}} \mathrm{N}^{\mathrm{b}} \mathrm{H}^{\mathrm{b}} \mathrm{C}^{\mathrm{b}}{ }_{*} \mathrm{H}_{2}^{\mathrm{b}}$ & 4- 863 & Not Reported & & & & & 22982.2 & .5 \\
\hline $\mathrm{t}-\mathrm{C}^{12} \mathrm{H}_{3} \mathrm{C}^{12} \mathrm{H}_{2} \mathrm{C}^{12} \mathrm{H}_{2} \mathrm{Cl}^{35}$ & 3- 771 & $5,1,5 \leftarrow 4,1,4$ & Ground & & & & 22985.16 & .2 \\
\hline $\mathrm{C}^{12} \mathrm{H}_{2}: \mathrm{C}^{12} \mathrm{DBr}^{79}$ & 4- 721 & $3,1,3 \leftarrow 2,1,2$ & Ground & & & & 22985.73 & .04 \\
\hline $\mathrm{H}_{2} \mathrm{C}^{12}: \mathrm{C}^{12} \mathrm{HCl}^{37}$ & 4- 767 & $2,0,2 \leftarrow 1,0,1$ & Ground & & & & 22986.0 & \\
\hline c- $\mathrm{C}^{12} \mathrm{HD}: \mathrm{C}^{12} \mathrm{HBr}^{81}$ & 4. 742 & $3,0,3 \leftarrow 2,0,2$ & Ground & & $7 / 2$ & $5 / 2$ & 22986.35 & .1 \\
\hline$c-\mathrm{C}^{12} \mathrm{HD}: \mathrm{C}^{12} \mathrm{HBr}^{81}$ & 4- 742 & $3,0,3 \leftarrow 2,0,2$. & Ground & & $9 / 2$ & $7 / 2$ & 22986.35 & .1 \\
\hline $\mathrm{C}^{12} \mathrm{H}_{3} \mathrm{C}^{12} \mathrm{HO}^{16}$ & 3- 471 & Not Reported & & & & & 22986.53 & \\
\hline $\mathrm{C}^{13}{ }_{*} \mathrm{H}: \mathrm{C}^{12} \mathrm{HO}^{16} \mathrm{C}^{12} \mathrm{H}: \mathrm{C}^{12}{ }_{*} \mathrm{H}$ & $4-1157$ & $3,1,2 \leftarrow 3,1,3$ & Ground & & & & 22986.7 & .1 \\
\hline $\mathrm{C}^{12}{ }_{*} \mathrm{H}: \mathrm{C}^{12} \mathrm{HO}^{16} \mathrm{C}^{13} \mathrm{H}: \mathrm{C}^{12}{ }_{*} \mathrm{H}$ & 4-1153 & $6,4,2 \leftarrow 6,4,3$ & Ground & & & & 22989.3 & .1 \\
\hline $\mathrm{C}^{13} \mathrm{H}_{2}: \mathrm{C}^{13} \mathrm{HBr}^{79}$ & 4- 733 & Not Reported & Ground & & $7 / 2$ & $5 / 2$ & 22990.5 & \\
\hline c. $\mathrm{C}^{12} \mathrm{HD}: \mathrm{C}^{12} \mathrm{HBr}^{81}$ & 4. 742 & $3,0,3 \leftarrow 2,0,2$ & Ground & & & & $229 \dot{90} .63$ & .04 \\
\hline $\mathrm{C}^{12}{ }_{*} \mathrm{H}: \mathrm{C}^{12} \mathrm{HO}^{16} \mathrm{C}^{13} \mathrm{H}: \mathrm{C}^{12}{ }_{*} \mathrm{H}$ & $4 \cdot 1153$ & $6,4,2 \leftarrow 6,3,3$ & Ground & & & & 22991.5 & .1 \\
\hline $\mathrm{C}^{12} \mathrm{Cl}_{2}^{35} \mathrm{Cl}^{37} \mathrm{C}^{12} \mathrm{~N}^{14}$ & 4- 582 & $7,2,6 \leftarrow 6,2,5$ & Ground & & & & 22992. & \\
\hline $\mathrm{C}^{12} \mathrm{Cl}_{2}^{35} \mathrm{Cl}^{37} \mathrm{C}^{12} \mathrm{~N}^{14}$ & 4- 582 & $7,1,6 \leftarrow 6,1,5$ & Ground & & & & 22992. & \\
\hline $\mathrm{C}^{12} \mathrm{H}_{2} \mathrm{~N}^{14} \mathrm{O}^{16} \mathrm{H}$ & 3- 141 & $8,2,6 \leftarrow 9,1,9$ & Ground & & 9 & 10 & 22992.67 & .10 \\
\hline $\mathrm{C}^{12} \mathrm{H}_{2} \mathrm{~N}^{14} \mathrm{O}^{16} \mathrm{H}$ & 3- 141 & $8,2,6 \leftarrow 9,1,9$ & Ground & & 7 & 8 & 22992.67 & .10 \\
\hline
\end{tabular}




\begin{tabular}{|c|c|c|c|c|c|c|c|}
\hline Isotopic Species & $\begin{array}{c}\text { Vol.-Id. } \\
\text { Nos. }\end{array}$ & $\begin{array}{c}\text { Rotational } \\
\text { Quantum Nos. }\end{array}$ & Vib. State & 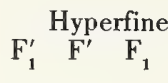 & $\mathrm{F}$ & $\begin{array}{c}\text { Frequency } \\
\mathrm{MHz}\end{array}$ & $\begin{aligned} & \text { Acc. } \\
\pm & \mathrm{MHz}\end{aligned}$ \\
\hline $\mathrm{C}^{12} \mathrm{H}_{2} \mathrm{~N}^{14} \mathrm{O}^{16} \mathrm{H}$ & 3- 141 & $8,2,6 \leftarrow 9,1,9$ & Ground & 8 & 9 & 22994.40 & .10 \\
\hline $\mathrm{C}^{\mathrm{b}} \mathrm{H}_{2}: \mathrm{C}^{\mathrm{b}} \mathrm{HBr}^{\mathrm{b}}$ & 4- 752 & $3,2,1 \leftarrow 2, \dot{2}, 0$ & Ground & $7 / 2$ & $5 / 2$ & 22995.1 & \\
\hline $\mathrm{C}^{12}{ }_{*} \mathrm{H}_{2} \mathrm{C}^{12} \mathrm{H}_{2} \mathrm{C}^{12}{ }_{*} \mathrm{HCl}^{35}$ & 4-1081 & $3,1,2 \leftarrow 2,1,1$ & Ground & $7 / 2$ & $7 / 2$ & 22996.5 & .1 \\
\hline $\mathrm{C}_{8}^{12} \mathrm{H}_{13} \mathrm{Br}^{81}$ & $4-1332$ & $16, \quad \leftarrow 15$ & Excited. & & & 22997. & \\
\hline $\mathrm{C}^{12}{ }_{*} \mathrm{H}: \mathrm{C}^{12} \mathrm{HO}^{16} \mathrm{C}^{12} \mathrm{D}: \mathrm{C}^{12}{ }_{*} \mathrm{H}$ & $4-1154$ & $5,4,2 \leftarrow 5,3,3$ & Ground & & & 22998.2 & \\
\hline $\mathrm{t}-\mathrm{C}^{12} \mathrm{H}_{3} \mathrm{C}^{12} \mathrm{H}_{2} \mathrm{C}^{12} \mathrm{H}_{2} \mathrm{Cl}^{37}$ & 3- 772 & $5,1,4 \leftarrow 4,1,3$ & Ground & & & 22998.38 & .2 \\
\hline $\mathrm{C}^{12} \mathrm{H}_{3} \mathrm{C}^{12}: \mathrm{C}^{12} \mathrm{C}^{12} \mathrm{H}_{2} \mathrm{Cl}^{35}$ & 3- 901 & $8,2,7 \leftarrow 7,2,6$ & Ground & & & 22999.59 & .05 \\
\hline c- $\mathrm{C}^{12} \mathrm{HD}: \mathrm{C}^{12} \mathrm{HBr}^{81}$ & 4- 742 & $3,2,2 \leftarrow 2,2,1$ & Ground & $5 / 2$ & $3 / 2$ & 22999.8 & .2 \\
\hline $\mathrm{c}-\mathrm{C}^{12} \mathrm{HD}: \mathrm{C}^{12} \mathrm{HBr}^{81}$ & 4- 742 & $3,2,2 \leftarrow 2,2,1$ & Ground & $3 / 2$ & $3 / 2$ & 22999.8 & .2 \\
\hline $\mathrm{c}-\mathrm{C}^{12} \mathrm{HD}: \mathrm{C}^{12} \mathrm{HBr}^{81}$ & 4- 742 & $3,2,2 \leftarrow 2,2,1$ & Ground & & & 22999.86 & .07 \\
\hline $\mathrm{a}-\mathrm{C}^{12} \mathrm{H}_{2} \mathrm{DC}^{12} \mathrm{HO}^{16}$ & 3. 481 & $7,1,6 \leftarrow 7,1,7$ & Ground & & & 23000.94 & .2 \\
\hline $\mathrm{C}^{12} \mathrm{H}_{2}: \mathrm{C}^{12} \mathrm{DBr}^{79}$ & 4. 721 & $3,1,3 \leftarrow 2,1,2$ & Ground & $7 / 2$ & $5 / 2$ & 23002.5 & \\
\hline $\mathrm{C}^{12}{ }_{*} \mathrm{H}_{2} \mathrm{C}^{12} \mathrm{H}_{2} \mathrm{C}^{12}{ }_{*} \mathrm{HCl}^{35}$ & $4-1081$ & $3,1,2 \leftarrow 2,1,1$ & Ground & $7 / 2$ & $5 / 2$ & 23003.1 & 1 \\
\hline $\mathrm{C}^{12}{ }_{*} \mathrm{H}_{2} \mathrm{C}^{12} \mathrm{H}_{2} \mathrm{C}^{12}{ }_{*} \mathrm{HCl}^{35}$ & $4-1081$ & $3,1,2 \leftarrow 2,1,1$ & Ground & $5 / 2$ & $3 / 2$ & 23003.1 & .1 \\
\hline $\mathrm{C}^{12} \mathrm{H}_{3} \mathrm{~N}^{14} \mathrm{O}_{2}^{16}$ & 3. 171 & Not Reported & Ground & & & 23004 & 5. \\
\hline $\mathrm{N}^{14} \mathrm{H}_{3}$ & 4-1771 & $15,13 \leftarrow 15,13$ & Ground & & & 23004 & .02 \\
\hline $\mathrm{C}^{12} \mathrm{H}_{2}: \mathrm{C}^{12} \mathrm{DBr}^{79}$ & 4. 721 & $3,1,3 \leftarrow 2,1,2$ & Ground & $5 / 2$ & $3 / 2$ & 23004.1 & \\
\hline $\mathrm{HDC}^{12}: \mathrm{C}^{12} \mathrm{~F}^{19}$ & 4- 682 & $4,2,2 \leftarrow 4,2,3$ & Ground & & & 23004.8 & .3 \\
\hline $\mathrm{C}^{13} \mathrm{H}_{2}: \mathrm{C}^{12} \mathrm{HBr}^{81}$ & 4- 736 & $3,2,2 \leftarrow 2,2,1$ & Ground & $9 / 2$ & $7 / 2$ & 23005.9 & \\
\hline $\mathrm{C}^{12}{ }_{*} \mathrm{H}_{2} \mathrm{C}^{12} \mathrm{H}_{2} \mathrm{C}^{12}{ }_{*} \mathrm{HCl}^{35}$ & 4-1081 & $3,1,2 \leftarrow 2,1,1$ & Ground & $9 / 2$ & $7 / 2$ & 23007.0 & .1 \\
\hline $\mathrm{C}^{12}{ }_{*} \mathrm{H}_{2} \mathrm{C}^{12} \mathrm{H}_{2} \mathrm{C}^{12}{ }_{*} \mathrm{HCl}^{35}$ & $4-1081$ & $3,1,2 \leftarrow 2,1,1$ & Ground & $3 / 2$ & $1 / 2$ & 23007.0 & .1 \\
\hline c- $\mathrm{C}^{12} \mathrm{HD}: \mathrm{C}^{12} \mathrm{HBr}^{81}$ & 4- 742 & $3,2,1 \leftarrow 2,2,0$ & Ground & & & 23007.09 & .08 \\
\hline$c-\mathrm{C}^{12} \mathrm{HD}: \mathrm{C}^{12} \mathrm{HBr}^{81}$ & 4- 742 & $3,2,1 \leftarrow 2,2,0$ & Ground & $5 / 2$ & $3 / 2$ & 23007.4 & .2 \\
\hline $\mathrm{c}-\mathrm{C}^{12} \mathrm{HD}: \mathrm{C}^{12} \mathrm{HBr}^{81}$ & 4. 742 & $3,2,1 \leftarrow 2,2,0$ & Ground & $3 / 2$ & $3 / 2$ & 23007.4 & .2 \\
\hline c- $\mathrm{C}^{12} \mathrm{HD}: \mathrm{C}^{12} \mathrm{HBr}^{81}$ & 4- 742 & $3,0,3 \leftarrow 2,0,2$ & Ground & $5 / 2$ & $3 / 2$ & 23009.4 & .1 \\
\hline $\mathrm{c}-\mathrm{C}^{12} \mathrm{HD}: \mathrm{C}^{12} \mathrm{HBr}^{81}$ & 4. 742 & $3,0,3 \leftarrow 2,0,2$ & Ground & $3 / 2$ & $1 / 2$ & 23009.4 & .1 \\
\hline $\mathrm{C}^{12}{ }_{*} \mathrm{H}_{2} \mathrm{C}^{12} \mathrm{H}_{2} \mathrm{C}^{12}{ }_{*} \mathrm{HCl}^{35}$ & $4-1081$ & $3,1,2 \leftarrow 2,1,1$ & Ground & $5 / 2$ & $5 / 2$ & 23009.4 & .1 \\
\hline $\mathrm{C}^{\mathrm{b}} \mathrm{H}_{2}: \mathrm{C}^{\mathrm{b}} \mathrm{HBr}^{\mathrm{b}}$ & 4- 752 & $3,2,1 \leftarrow 2,2,0$ & Ground & $9 / 2$ & $7 / 2$ & 23009.8 & \\
\hline $\mathrm{C}^{12} \mathrm{HD}: \mathrm{C}^{12} \mathrm{HBr}^{\mathrm{b}}$ & 4- 748 & Not Reported & & & & 23011.5 & .3 \\
\hline $\bar{C}^{13} \mathrm{H}_{2}: \mathrm{C}^{13} \mathrm{HBr}^{79}$ & 4- 733 & $3,0,3 \leftarrow 2,0,2$ & Ground & $9 / 2$ & $7 / 2$ & 23012.2 & \\
\hline $\mathrm{C}^{12} \mathrm{H}_{3} \mathrm{C}^{12} \mathrm{D}_{2} \mathrm{Br}^{81}$ & 3- 526 & $6,1,5 \leftarrow 6,0,6$ & Ground & $13 / 2$ & $13 / 2$ & 23012.88 & .05 \\
\hline $3 \mathrm{C}^{13}-\mathrm{C}_{6}^{12} \mathrm{H}_{5} \mathrm{C}^{12} \mathrm{~N}^{14}$ & $4-1299$ & $9,0,9 \leftarrow 8,0,8$ & Ground & & & 23013.9 & .2 \\
\hline $\mathrm{C}^{12} \mathrm{H}_{3} \mathrm{C}^{12}: \mathrm{C}^{12} \mathrm{C}^{12} \mathrm{H}_{2} \mathrm{Cl}^{35}$ & 3- 901 & $8,3,6 \leftarrow 7,3,5$ & Ground & & & 23014.4 & .15 \\
\hline $\mathrm{C}^{12} \mathrm{H}_{3} \mathrm{C}^{12}: \mathrm{C}^{12} \mathrm{C}^{12} \mathrm{H}_{2} \mathrm{Cl}^{35}$ & 3- 901 & $8,4,5 \leftarrow 7,4,4$ & Ground & & & 23014.4 & .15 \\
\hline $\mathrm{C}^{12} \mathrm{H}_{3} \mathrm{C}^{12}: \mathrm{C}^{12} \mathrm{C}^{12} \mathrm{H}_{2} \mathrm{Cl}^{35}$ & 3- 901 & $8,3,5 \leftarrow 7,3,4$ & Ground & & & 23014.4 & .15 \\
\hline $\mathrm{C}^{12} \mathrm{H}_{3} \mathrm{C}^{12}: \mathrm{C}^{12} \mathrm{C}^{12} \mathrm{H}_{2} \mathrm{Cl}^{35}$ & 3. 901 & $8,4,4 \leftarrow 7,4,3$ & Ground & & & 23014.4 & .15 \\
\hline $\mathrm{C}^{12} \mathrm{H}_{3} \mathrm{~N}^{14} \mathrm{O}_{2}^{16}$ & 3- 171 & Not Reported & Ground & & & 23015 & \\
\hline $\mathrm{C}^{12}{ }_{*} \mathrm{H}_{2} \mathrm{C}^{12} \mathrm{H}_{2} \mathrm{C}^{12}{ }_{*} \mathrm{HCl}^{35}$ & 4-1081 & $3,1,2 \leftarrow 2,1,1$ & Ground & $3 / 2$ & $3 / 2$ & 23015.6 & .1 \\
\hline $\mathrm{C}_{6}^{12} \mathrm{H}_{5} \mathrm{C}^{13} \mathrm{~N}^{14}$ & $4-1293$ & $9,0,9 \leftarrow 8,0,8$ & Ground & & & 23015.9 & .2 \\
\hline $\mathrm{C}^{12}{ }_{*} \mathrm{D}_{2} \mathrm{~S}^{32} \mathrm{C}^{12}{ }_{*} \mathrm{D}_{2}$ & 4- 853 & $6,2,5 \leftarrow 6,2,4$ & Ground & & & 23016.3 & .2 \\
\hline $\mathrm{C}^{12} \mathrm{H}_{3} \mathrm{C}^{12} \mathrm{D}_{2} \mathrm{Br}^{81}$ & 3- 526 & $6,1,5 \leftarrow 6,0,6$ & Ground & $11 / 2$ & $11 / 2$ & 23017.24 & .05 \\
\hline $\mathrm{c}-\mathrm{C}^{12} \mathrm{HD}: \mathrm{C}^{12} \mathrm{HBr}^{79}$ & 4. 739 & $3,2,2 \leftarrow 2,2,1$ & Ground & $3 / 2$ & $1 / 2$ & 23019.1 & .2 \\
\hline $\mathrm{C}^{12} \mathrm{H}_{3} \mathrm{~N}^{14} \mathrm{O}_{2}^{16}$ & 3- 171 & Not Reported & Ground & & & 23021 & 5. \\
\hline
\end{tabular}




\begin{tabular}{|c|c|c|c|c|c|c|c|}
\hline Isotopic Species & $\begin{array}{l}\text { Vol.-Id. } \\
\text { Nos. }\end{array}$ & $\begin{array}{c}\text { Rotational } \\
\text { Quantum Nos. }\end{array}$ & Vib. State & $F_{1} \begin{array}{l}\text { Hyperfine } \\
F^{\prime} \quad F_{1}\end{array}$ & $\mathrm{~F}$ & $\begin{array}{l}\text { Frequency } \\
\quad \mathrm{MHz}\end{array}$ & $\begin{aligned} & \text { Acc. } \\
\pm & \mathrm{MHz}\end{aligned}$ \\
\hline $\mathrm{C}^{12} \mathrm{HCl}^{37}: \mathrm{C}^{12} \mathrm{~F}_{2}^{19}$ & 4. 612 & $12,2,10 \leftarrow 12,1,11$ & Ground & & & 23022.5 & .1 \\
\hline t- $\mathrm{C}^{12} \mathrm{HD}: \mathrm{C}^{12} \mathrm{DBr}^{81}$ & 4. 747 & $3,1,2 \leftarrow 2,1,1$ & Excited & $3 / 2$ & $3 / 2$ & 23022.7 & .2 \\
\hline $\mathrm{C}^{12} \mathrm{~F}_{3}^{19} \mathrm{C}^{12}: \mathrm{C}^{12} \mathrm{H}$ & 4. 871 & $4, \leftarrow 3$, & Ground & & & 23023.4 & .3 \\
\hline $\mathrm{C}^{12} \mathrm{HCl}^{37}: \mathrm{C}^{12} \mathrm{~F}_{2}^{19}$ & 4. 612 & $12,2,10 \leftarrow 12,1,11$ & Ground & & & 23023.5 & .1 \\
\hline $\mathrm{C}^{13} \mathrm{H}_{2}: \mathrm{C}^{12} \mathrm{HBr}^{8 !}$ & 4. 736 & Not Reported & Ground & $9 / 2$ & $7 / 2$ & 23023.5 & \\
\hline $\mathrm{C}^{12}{ }^{12} \mathrm{H}: \mathrm{C}^{12} \mathrm{HO}^{16} \mathrm{C}^{13} \mathrm{H}: \mathrm{C}^{12}{ }_{*} \mathrm{H}$ & $4-1153$ & $2,0,2 \leftarrow 1,1,1$ & Ground & & & 23024.7 & .1 \\
\hline $\mathrm{C}^{12}{ }_{*} \mathrm{H}_{2} \mathrm{~N}^{14} \mathrm{HC}^{12}{ }_{*} \mathrm{H}_{2}$ & 4. 861 & $6,5,1 \leftarrow 6,4,2$ & Ground & & & 23025.3 & \\
\hline c. $\mathrm{C}^{12} \mathrm{HD}: \mathrm{C}^{12} \mathrm{HBr}^{79}$ & 4. 739 & $3,2,1 \leftarrow 2,2,0$ & Ground & $3 / 2$ & $1 / 2$ & 23026.1 & .2 \\
\hline $3 d-C_{6}^{12} H_{5} F^{18}$ & $4 \cdot 1282$ & $5,2,3 \leftarrow 4,2,2$ & Ground & & & 23026.5 & .1 \\
\hline $\mathrm{C}^{12}{ }_{*} \mathrm{H}: \mathrm{C}^{12} \mathrm{HO}^{16} \mathrm{C}^{13} \mathrm{H}: \mathrm{C}^{12}{ }_{*} \mathrm{H}$ & $4-1153$ & $2,1,2 \leftarrow 1,1,1$ & Ground & & & 23027.0 & .1 \\
\hline $\mathrm{C}^{12} \mathrm{HD}: \mathrm{C}^{12} \mathrm{DBr}^{\mathrm{b}}$ & 4. 749 & Not Reported & & & & 23027.2 & .3 \\
\hline $\mathrm{C}^{12}{ }_{*} \mathrm{HO}^{16} \mathrm{C}^{12} \mathrm{HC}^{12} \mathrm{HC}^{12} \mathrm{HC}^{12}{ }_{*} \mathrm{H}$ & $4 \cdot 1251$ & $11,7,4 \leftarrow 11,6,6$ & Ground & & & 23028. & 5. \\
\hline $\mathrm{C}^{13} \mathrm{H}_{2}: \mathrm{C}^{12} \mathrm{HBr}^{81}$ & 4. 736 & $3,0,3 \leftarrow 2,0,2$ & Ground & & & 23028.10 & .08 \\
\hline $\mathrm{C}^{12}{ }_{*} \mathrm{H}_{2} \mathrm{~N}^{14} \mathrm{DC}^{12}{ }_{*} \mathrm{H}_{2}$ & 4. 862 & $4,3,1 \leftarrow 4,3,2$ & Ground & & & 23028.2 & .5 \\
\hline $\mathrm{C}^{12} \mathrm{H}_{3} \mathrm{C}^{12} \mathrm{~F}^{18}: \mathrm{C}^{12} \mathrm{H}_{2}$ & 3- 721 & $5,5,1 \leftarrow 5,4,2$ & Ground & & & 23028.32 & .1 \\
\hline c- $\mathrm{C}^{12} \mathrm{HD}: \mathrm{C}^{12} \mathrm{HBr}^{79}$ & 4. 739 & $3,0,3 \leftarrow 2,0,2$ & Ground & $3 / 2$ & $3 / 2$ & 23031.6 & .1 \\
\hline $\mathrm{C}^{12} \mathrm{H}_{3} \mathrm{C}^{12} \mathrm{D}_{2} \mathrm{Br}^{81}$ & 3. 526 & $6,1,5 \leftarrow 6,0,6$ & Ground & $15 / 2$ & $15 / 2$ & 23032.66 & .05 \\
\hline $\mathrm{C}^{12} \mathrm{H}_{3} \mathrm{O}^{16} \mathrm{H}$ & 3. 211 & Not Reported & Ground & & & 23033. & 5. \\
\hline $\mathrm{N}^{14} \mathrm{H}_{2} \mathrm{C}_{2}^{12} \mathrm{H}_{5}$ & 3. 631 & Not Reported & Ground & & & 23033.75 & .2 \\
\hline $\mathrm{C}^{13} \mathrm{H}_{2}: \mathrm{C}^{12} \mathrm{HBr}^{81}$ & 4736 & $3,2,2 \leftarrow 2,2,1$ & Ground & & & 23034.05 & .05 \\
\hline $\mathrm{C}^{b} \mathrm{H}_{2}: \mathrm{C}^{b} \mathrm{HBr}^{\mathrm{b}}$ & 4- 752 & $3,2,2 \leftarrow 2,2,1$ & Ground & $5 / 2$ & $3 / 2$ & 23034.1 & \\
\hline $\mathrm{S}^{32} \mathrm{O}_{2}^{16}$ & $4 \cdot 1831$ & Not Reported & & & & 23034.83 & .1 \\
\hline $\mathrm{C}^{b}{ }_{*} \mathrm{H}_{2}^{b} \mathrm{~N}^{b} \mathrm{H}^{b} \mathrm{C}^{b}{ }_{*} \mathrm{H}_{2}^{\mathrm{b}}$ & 4. 863 & Not Reported & & & & 23035.0 & .5 \\
\hline $\mathrm{C}^{12} \mathrm{HD}_{2} \mathrm{Cl}^{35}$ & 4. 431 & $1,0,1 \leftarrow 0,0,0$ & Ground & & & 23035.00 & \\
\hline $\mathrm{C}^{12} \mathrm{H}_{3} \mathrm{C}^{12} \mathrm{D}_{2} \mathrm{Br}^{81}$ & 3. 526 & $6,1,5 \leftarrow 6,0,6$ & Ground & $9 / 2$ & $9 / 2$ & 23036.91 & .05 \\
\hline $\mathrm{C}^{12} \mathrm{H}_{3} \mathrm{C}^{12} \mathrm{D}_{2} \mathrm{Br}^{78}$ & 3- 524 & $6,1,5 \leftarrow 6,0,6$ & Ground & $13 / 2$ & $13 / 2$ & 23036.91 & .05 \\
\hline $\mathrm{HC}^{12}{ }_{*}: \mathrm{C}^{12} \mathrm{HO}^{16} \mathrm{C}^{12} \mathrm{O}^{16} \mathrm{O}^{16}{ }_{*}$ & 4. 931 & $3,1,2 \leftarrow 2,1,1$ & Ground & & & 23037.67 & .10 \\
\hline $\mathrm{C}^{13} \mathrm{H}_{2}: \mathrm{C}^{12} \mathrm{HBr}^{81}$ & 4- 736 & $3,2,1 \leftarrow 2,2,0$ & Ground & & & 23038.04 & .06 \\
\hline $\mathrm{C}^{\mathrm{b}} \mathrm{H}_{2}: \mathrm{C}^{\mathrm{b}} \mathrm{HBr}^{\mathrm{b}}$ & 4. 752 & $3,2,1 \leftarrow 2,2,0$ & Ground & $5 / 2$ & $3 / 2$ & 23038.4 & \\
\hline $\mathrm{t}-\mathrm{C}^{12} \mathrm{HD}: \mathrm{C}^{12} \mathrm{DBr}^{81}$ & 4. 747 & $3,1,2 \leftarrow 2,1,1$ & Ground & $3 / 2$ & $3 / 2$ & 23038.7 & .1 \\
\hline $\mathrm{C}^{12} \mathrm{H}_{3} \mathrm{C}^{12} \mathrm{~F}^{19}: \mathrm{C}^{12} \mathrm{H}_{2}$ & 3- 721 & $11,8,3 \leftarrow 11,7,4$ & Ground & & & 23039.75 & .1 \\
\hline $\mathrm{C}^{12} \mathrm{H}_{3} \mathrm{C}^{12} \mathrm{D}_{2} \mathrm{Br}^{79}$ & 3. 524 & $6,1,5 \leftarrow 6,0,6$ & Ground & $11 / 2$ & $11 / 2$ & 23041.97 & .05 \\
\hline $\mathrm{C}^{12} \mathrm{H}_{3} \mathrm{C}^{12} \mathrm{O}^{16} \mathrm{O}^{16} \mathrm{H}$ & 3- 491 & Not Reported & & & & 23042. & 3. \\
\hline $\mathrm{C}^{12} \mathrm{H}_{3} \mathrm{C}^{12} \mathrm{H}_{2} \mathrm{I}^{127}$ & 3- 571 & $4,2,3 \leftarrow 3,2,2$ & Ground & $9 / 2$ & $7 / 2$ & 23042.24 & .05 \\
\hline $\mathrm{T}^{205} \mathrm{Br}^{7 \theta}$ & $1-$ & $9 \leftarrow 8$ & Excited & & & 23042.54 & 0.10 \\
\hline $\mathrm{C}^{12} \mathrm{H}_{3} \mathrm{C}^{12}: \mathrm{C}^{12} \mathrm{C}^{12} \mathrm{H}_{2} \mathrm{Cl}^{35}$ & 3- 901 & $8,2,6 \leftarrow 7,2,5$ & Ground & & & 23042.71 & .05 \\
\hline $\mathrm{H}_{2} \mathrm{C}^{12}: \mathrm{C}^{12} \mathrm{HCl}^{37}$ & 4. 767 & $2,1,1 \leftarrow 1,1,0$ & Ground & $5 / 2$ & $3 / 2$ & 23043.39 & .02 \\
\hline $\mathrm{S}^{32}{ }_{*} \mathrm{HC}^{12}: \mathrm{C}^{12} \mathrm{HC}^{12} \mathrm{H}: \mathrm{C}^{12}{ }_{*} \mathrm{H}$ & $4-1161$ & $3,0,3 \leftarrow 2,0,2$ & Ground & & & 23043.8 & .1 \\
\hline $\mathrm{HN}_{2}^{14} \mathrm{~N}^{15}$ & 4-1703 & $1,0,1 \leftarrow 0,0,0$ & Ground & 0 & 1 & 23044.40 & .05 \\
\hline a- $\mathrm{C}^{12} \mathrm{H}_{2} \mathrm{DC}^{12} \mathrm{O}^{16} \mathrm{C}^{12} \mathrm{~N}^{14}$ & 3. 679 & $7,3,4 \leftarrow 7,2,5$ & Ground & & & 23044.93 & \\
\hline
\end{tabular}




\begin{tabular}{|c|c|c|c|c|c|c|c|}
\hline Isotopic Species & $\begin{array}{l}\text { Vol.-Id. } \\
\text { Nos. }\end{array}$ & $\begin{array}{c}\text { Rotational } \\
\text { Quantum Nos. }\end{array}$ & Vib. State & $\mathrm{F}_{1}^{\prime} \stackrel{\mathrm{F}^{\prime}}{\text { Hyperfin }} \mathrm{F}_{1}$ & $\mathrm{~F}$ & $\begin{array}{l}\text { Frequency } \\
\mathrm{MHz}\end{array}$ & $\begin{array}{r}\text { Acc. } \\
\pm \mathrm{MHz}\end{array}$ \\
\hline $\mathrm{N}^{14} \mathrm{H}_{2} \mathrm{C}_{2}^{12} \mathrm{H}_{5}$ & 3. 631 & Not Reported & Ground & & & 23045.44 & .2 \\
\hline $\mathrm{C}^{13} \mathrm{H}_{3} \mathrm{C}^{12} \mathrm{O}^{16} \mathrm{~F}^{19}$ & 3- 393 & $3,1,2 \leftarrow 3,1,3$ & Ground & & & 23045.70 & .2 \\
\hline $\mathrm{C}^{12}{ }_{*} \mathrm{H}: \mathrm{C}^{12} \mathrm{HO}^{16} \mathrm{C}^{13} \mathrm{H}: \mathrm{C}^{12}{ }_{*} \mathrm{H}$ & $4-1153$ & $5,3,2 \leftarrow 5,2,3$ & Ground & & & 23046.0 & .1 \\
\hline $\mathrm{N}^{15} \mathrm{H}_{3}$ & $4-1772$ & $4,4 \leftarrow 4,4$ & Ground & & & 23046.10 & .02 \\
\hline $\mathrm{HN}_{2}^{14} \mathrm{~N}^{15}$ & $4-1703$ & $1,0,1 \leftarrow 0,0,0$ & Ground & 2 & 1 & 23046.55 & .05 \\
\hline $\mathrm{H}_{2} \mathrm{C}^{12}: \mathrm{C}^{12} \mathrm{HCl}^{37}$ & 4. 767 & $2,1,1 \leftarrow 1,1,0$ & Ground & $3 / 2$ & $3 / 2$ & 23047.00 & .02 \\
\hline $\mathrm{C}^{\mathrm{b}} \mathrm{H}_{2}: \mathrm{C}^{\mathrm{b}} \mathrm{HBr}^{\mathrm{b}}$ & 4- 752 & $3,0,3 \leftarrow 2,0,2$ & Ground & $5 / 2$ & $3 / 2$ & 23047.4 & \\
\hline $\mathrm{HN}_{2}^{14} \mathrm{~N}^{15}$ & $4-1703$ & $1,0,1 \leftarrow 0,0,0$ & Ground & 1 & 1 & 23048.03 & .05 \\
\hline $\mathrm{HN}_{2}^{14} \mathrm{~N}^{15}$ & $4-1703$ & $1,0,1 \leftarrow 0,0,0$ & Ground & & & 23048.2 & \\
\hline $\mathrm{C}^{12} \mathrm{H}_{3} \mathrm{C}^{12} \mathrm{~F}^{19}: \mathrm{C}^{12} \mathrm{H}_{2}$ & 3- 721 & $11,8,3 \leftarrow 11,7,4$ & Ground & & & 23048.95 & .1 \\
\hline $\mathrm{C}^{12} \mathrm{HD}: \mathrm{C}^{12} \mathrm{HBr}^{\mathrm{b}}$ & 4- 748 & Not Reported & & & & 23049.0 & .2 \\
\hline $\mathrm{H}_{2} \mathrm{C}^{12}: \mathrm{C}^{12} \mathrm{HCl}^{37}$ & 4. 767 & $2,1,1 \leftarrow 1,1,0$ & Ground & $5 / 2$ & $5 / 2$ & 23049.57 & .02 \\
\hline $\mathrm{C}^{12} \mathrm{H}_{3} \mathrm{C}^{12} \mathrm{H}_{2} \mathrm{I}^{127}$ & 3. 571 & $4,2,3 \leftarrow 3,2,2$ & Ground & $11 / 2$ & $9 / 2$ & 23050.34 & .05 \\
\hline $\mathrm{C}^{12} \mathrm{H}_{3} \mathrm{C}^{12} \mathrm{H}_{2} \mathrm{I}^{127}$ & 3- 571 & $4,2,2 \leftarrow 3,2,1$ & Ground & $9 / 2$ & $7 / 2$ & 23050.34 & .05 \\
\hline $\mathrm{C}^{13} \mathrm{H}_{3} \mathrm{C}^{12} \mathrm{O}^{16} \mathrm{~F}^{19}$ & 3. 393 & $3,1,2 \leftarrow 3,1,3$ & Ground & & & 23050.60 & .2 \\
\hline $\mathrm{C}^{\mathrm{b}} \mathrm{H}_{2}: \mathrm{C}^{\mathrm{b}} \mathrm{HBr}^{79}$ & 4. 753 & $3,2,2 \leftarrow 2,2,1$ & Ground & $3 / 2$ & $1 / 2$ & 23052.2 & \\
\hline $\mathrm{HC}^{13}: \mathrm{C}^{12} \mathrm{C}^{12} \mathrm{DO}^{16}$ & 4. 922 & Not Reported & & & & 23053. & 5. \\
\hline $\mathrm{C}^{12} \mathrm{~F}_{3}^{19} \mathrm{C}^{12} \vdots \mathrm{C}^{12} \mathrm{H}$ & 4. 871 & $4,1 \leftarrow 3,1$ & Excited & & & 23053.5 & .3 \\
\hline $\mathrm{C}^{12} \mathrm{HD}_{2} \mathrm{Cl}^{35}$ & 4. 431 & $1,0,1 \leftarrow 0,0,0$ & Ground & & & 23053.62 & \\
\hline $\mathrm{H}_{2} \mathrm{C}^{12}: \mathrm{C}^{12} \mathrm{HCl}^{37}$ & 4. 767 & $2,1,1 \leftarrow 1,1,0$ & Ground & $7 / 2$ & $5 / 2$ & 23054.65 & .02 \\
\hline $\mathrm{N}^{15} \mathrm{H}_{3}$ & 4-1772 & $10,9 \leftarrow 10,9$ & Ground & & & 23054.97 & .02 \\
\hline $\mathrm{C}^{12} \mathrm{Cl}_{2}^{35} \mathrm{Cl}^{37} \mathrm{C}^{12} \mathrm{~N}^{14}$ & 4. 582 & $7,3,5 \leftarrow 6,3,4$ & Ground & & & 23055. & \\
\hline $\mathrm{C}^{12}{ }_{*} \mathrm{H}: \mathrm{C}^{12} \mathrm{HO}^{16} \mathrm{C}^{12} \mathrm{H}: \mathrm{C}^{12}{ }_{*} \mathrm{H}$ & $4-1151$ & $6,4,2 \leftarrow 6,4,3$ & Ground & & & 23055.80 & \\
\hline $\mathrm{t}-\mathrm{C}^{12} \mathrm{H}_{2} \mathrm{DC}^{12} \mathrm{H}_{2} \mathrm{~F}^{19}$ & 3. 554 & $3,2,1 \leftarrow 4,1,4$ & Ground & & & 23055.7 & .1 \\
\hline $\mathrm{C}^{12} \mathrm{HD}: \mathrm{C}^{12} \mathrm{DBr}^{\mathrm{b}}$ & 4. 749 & Not Reported & & & & 23057.6 & .2 \\
\hline $\mathrm{H}_{2} \mathrm{C}^{12}: \mathrm{C}^{12} \mathrm{HCl}^{37}$ & 4. 767 & $2,1,1 \leftarrow 1,1,0$ & Ground & $3 / 2$ & $1 / 2$ & 23058.19 & .02 \\
\hline $\mathrm{C}^{12} \mathrm{H}_{3} \mathrm{C}^{12} \mathrm{H}_{2} \mathbf{I}^{127}$ & 3- 571 & $4,2,2 \leftarrow 3,2,1$ & Ground & $11 / 2$ & $9 / 2$ & 23059.77 & .05 \\
\hline $\mathrm{C}^{12} \mathrm{H}_{3} \mathrm{C}^{12} \mathrm{D}_{2} \mathrm{Br}^{79}$ & 3. 524 & $6,1,5 \leftarrow 6,0,6$ & Ground & $15 / 2$ & $15 / 2$ & 23060.18 & .05 \\
\hline $\mathrm{Cs}^{133} \mathrm{Br}^{81}$ & $1-$ & $11 \leftarrow 10$ & Excited & & & 23061.38 & 0.20 \\
\hline $\mathrm{H}_{2} \mathrm{C}^{12}: \mathrm{C}^{12} \mathrm{HCl}^{37}$ & 4. 767 & $2,1,1 \leftarrow 1,1,0$ & Ground & $1 / 2$ & $1 / 2$ & 23063.29 & .02 \\
\hline $\mathrm{C}^{12} \mathrm{D}_{3} \mathrm{C}^{12} \mathrm{HDC}^{12} \mathrm{~N}^{14}$ & 3- 733 & $3,1,3 \leftarrow 2,1,2$ & Ground & & & 23064.59 & .1 \\
\hline $\mathrm{c} \cdot \mathrm{C}^{12} \mathrm{HD} \cdot \mathrm{C}^{12} \mathrm{HBr}^{79}$ & 4. 739 & $3,0,3 \leftarrow 2,0,2$ & Ground & $5 / 2$ & $5 / 2$ & 23064.9 & .2 \\
\hline $\mathrm{C}^{12} \mathrm{H}_{3} \mathrm{C}^{12} \mathrm{D}_{2} \mathrm{Br}^{79}$ & 3. 524 & $6,1,5 \leftarrow 6,0,6$ & Ground & $9 / 2$ & $9 / 2$ & 23065.47 & .05 \\
\hline $\mathrm{C}^{12} \mathrm{O}^{16} \mathrm{Cl}^{35} \mathrm{Cl}^{37}$ & 4- 182 & $5,2,4 \leftarrow 5,1,5$ & Ground & & & 23066.28 & .1 \\
\hline $\mathrm{C}^{12} \mathrm{H}_{3} \mathrm{C}^{13} \mathrm{O}^{16} \mathrm{Cl}^{35}$ & 3. 369 & $8,3,5 \leftarrow 8,2,6$ & Ground & $19 / 2$ & $19 / 2$ & 23066.35 & .2 \\
\hline $\mathrm{C}^{12} \mathrm{H}_{3} \mathrm{C}^{13} \mathrm{O}^{16} \mathrm{Cl}^{35}$ & 3- 369 & $8,3,5 \leftarrow 8,2,6$ & Ground & $13 / 2$ & $13 / 2$ & 23066.35 & .2 \\
\hline $\mathrm{C}^{12} \mathrm{H}_{2}: \mathrm{C}^{12} \mathrm{DBr}^{79}$ & 4- 721 & $3,1,3 \leftarrow 2,1,2$ & Ground & $7 / 2$ & $7 / 2$ & 23066.5 & \\
\hline $\mathrm{K}^{39} \mathrm{Cl}^{35}$ & $1-$ & $3 \leftarrow 2$ & Ground & & & 23067.5 & 0.5 \\
\hline $\mathrm{C}^{12} \mathrm{H}_{3} \mathrm{C}^{13} \mathrm{O}^{16} \mathrm{Cl}^{35}$ & 3. 369 & $8,3,5 \leftarrow 8,2,6$ & Ground & $17 / 2$ & $17 / 2$ & 23067.67 & .2 \\
\hline $\mathrm{C}^{12} \mathrm{H}_{3} \mathrm{C}^{13} \mathrm{O}^{16} \mathrm{Cl}^{35}$ & 3- 369 & $8,3,5 \leftarrow 8,2,6$ & Ground & $15 / 2$ & $15 / 2$ & 23067.67 & .2 \\
\hline $\mathrm{C}^{12} \mathrm{~F}_{3}^{19} \mathrm{C}^{12}: \mathrm{C}^{12} \mathrm{H}$ & 4- 871 & $4, \leftarrow 3$, & Excited & & & 23067.7 & .3 \\
\hline $\mathrm{t} \cdot \mathrm{C}^{12} \mathrm{HD}: \mathrm{C}^{12} \mathrm{DBr}^{81}$ & 4. 747 & $3,1,2 \leftarrow 2,1,1$ & Excited & $9 / 2$ & $7 / 2$ & 23068.2 & .2 \\
\hline
\end{tabular}


Vib. State $\mathrm{F}_{1}^{\prime} \stackrel{\text { Hyperfine }}{\mathrm{F}^{\prime}} \underset{\mathrm{F}}{\mathrm{F}}$

Frequency $\begin{array}{ll} & \text { Acc. } \\ \mathrm{MHz} & \pm \mathrm{MHz}\end{array}$

\begin{tabular}{|c|c|c|c|c|c|c|c|}
\hline c- $\mathrm{C}^{12} \mathrm{HD}: \mathrm{C}^{12} \mathrm{HBr}^{81}$ & 4- 742 & $3,2,2 \leftarrow 2,2,1$ & Ground & $5 / 2$ & $5 / 2$ & 23068.4 & .1 \\
\hline c- $\mathrm{C}^{12} \mathrm{HD}: \mathrm{C}^{12} \mathrm{HBr}^{81}$ & 4- 742 & $3,2,2 \leftarrow 2,2,1$ & Ground & $7 / 2$ & $5 / 2$ & 23068.4 & .1 \\
\hline $\mathrm{C}^{12} \mathrm{HD}_{2} \mathrm{Cl}^{35}$ & 4. 431 & $1,0,1 \leftarrow 0,0,0$ & Ground & & & 23068.51 & \\
\hline $\mathrm{C}^{12} \mathrm{H}_{3} \mathrm{C}^{13} \mathrm{O}^{16} \mathrm{Cl}^{35}$ & 3- 369 & $8,3,5 \leftarrow 8,2,6$ & Ground & $19 / 2$ & $19 / 2$ & 23068.63 & .2 \\
\hline $\mathrm{C}^{12} \mathrm{H}_{3} \mathrm{C}^{13} \mathrm{O}^{16} \mathrm{Cl}^{35}$ & 3. 369 & $8,3,5 \leftarrow 8,2,6$ & Ground & $13 / 2$ & $13 / 2$ & 23068.63 & .2 \\
\hline $\mathrm{C}^{12} \mathrm{H}_{3} \mathrm{C}^{13} \mathrm{O}^{16} \mathrm{Cl}^{35}$ & 3. 369 & $8,3,5 \leftarrow 8,2,6$ & Ground & $15 / 2$ & $15 / 2$ & 23069.90 & .2 \\
\hline $\mathrm{C}^{12} \mathrm{H}_{3} \mathrm{C}^{13} \mathrm{O}^{16} \mathrm{Cl}^{35}$ & 3. 369 & $8,3,5 \leftarrow 8,2,6$ & Ground & $17 / 2$ & $17 / 2$ & 23069.90 & .2 \\
\hline$c-H F^{19} \mathrm{C}^{12}: \mathrm{C}^{13} \mathrm{HF}^{19}$ & 4- 692 & $4,1,3 \leftarrow 4,0,4$ & Ground & & & 23070.58 & .05 \\
\hline $\mathrm{C}^{12} \mathrm{H}_{3} \mathrm{~N}^{14} \mathrm{H}_{2}$ & 3. 261 . & Not Reported & Ground & & & 23071.58 & \\
\hline $\mathrm{C}^{12} \mathrm{H} \mathrm{C}^{12} \mathrm{~F}^{19}: \mathrm{C}^{12} \mathrm{H}$ & 3- 721 & $11,8,3 \leftarrow 11,7,4$ & Ground & & & 23072.82 & .1 \\
\hline $\mathrm{C}^{12} \mathrm{H}_{3} \mathrm{C}^{12} \mathrm{O}^{16} \mathrm{Cl}^{35}$ & 3- 361 & $8,3,5 \leftarrow 8,2,6$ & Ground & 19 & 19 & 23073.27 & .2 \\
\hline $\mathrm{C}^{12} \mathrm{H}_{3} \mathrm{C}^{12} \mathrm{O}^{16} \mathrm{Cl}^{35}$ & 3. 361 & $8,3,5 \leftarrow 8,2,6$ & Ground & 13 & 13 & 23073.27 & .2 \\
\hline$\left(\mathrm{C}^{12} \mathrm{H}_{3}\right)_{2} \mathrm{~S}^{34}$ & 3- 602 & $1,1,1 \leftarrow 0,0,0$ & Ground & & & 23073.35 & .05 \\
\hline $\mathrm{C}^{12} \mathrm{H}_{3} \mathrm{~S}^{32} \mathrm{H}$ & 3- 221 & Not Reported & Ground & & & 23073.8 & .1 \\
\hline $\mathrm{C}^{12} \mathrm{H}_{2}: \mathrm{C}^{12} \mathrm{HC}^{12} \mathrm{~F}^{19}: \mathrm{C}^{12} \mathrm{H}_{2}$ & 3- 911 & $3,2,2 \leftarrow 3,1,3$ & Ground & & & 23074.5 & .2 \\
\hline $\mathrm{C}^{12} \mathrm{H}_{3} \mathrm{C}^{12} \mathrm{O}^{16} \mathrm{Cl}^{35}$ & 3. 361 & $8,3,5 \leftarrow 8,2,6$ & Ground & 15 & 15 & 23074.50 & .2 \\
\hline $\mathrm{C}^{12} \mathrm{H}_{3} \mathrm{C}^{12} \mathrm{O}^{16} \mathrm{Cl}^{35}$ & 3- 361 & $8,3,5 \leftarrow 8,2,6$ & Ground & 17 & 17 & 23074.50 & .2 \\
\hline c- $\mathrm{C}^{12} \mathrm{HD}: \mathrm{C}^{12} \mathrm{HBr}^{81}$ & 4. 742 & $3,2,1 \leftarrow 2,2,0$ & Ground & $7 / 2$ & $5 / 2$ & 23075.4 & .1 \\
\hline$c-\mathrm{C}^{12} \mathrm{HD}: \mathrm{C}^{12} \mathrm{HBr}^{81}$ & 4. 742 & $3,2,1 \leftarrow 2,2,0$ & Ground & $5 / 2$ & $5 / 2$ & 23075.4 & .1 \\
\hline $\mathrm{C}^{12} \mathrm{H}_{3} \mathrm{C}^{12} \mathrm{O}^{16} \mathrm{C}^{35}$ & 3. 361 & $8,3,5 \leftarrow 8,2,6$ & Ground & 13 & 13 & 23075.56 & .2 \\
\hline $\mathrm{C}^{12} \mathrm{H}_{3} \mathrm{C}^{12} \mathrm{O}^{16} \mathrm{Cl}^{35}$ & 3- 361 & $8,3,5 \leftarrow 8,2,6$ & Ground & 19 & 19 & 23075.56 & .2 \\
\hline $\mathrm{t} \cdot \mathrm{C}^{12} \mathrm{HD}: \mathrm{C}^{12} \overline{\mathrm{DBr}}{ }^{81}$ & 4. 747 & $3,1,2 \leftarrow 2,1,1$ & Ground & $5 / 2$ & $5 / 2$ & 23076.5 & .2 \\
\hline $\mathrm{C}^{12} \mathrm{H}_{3} \mathrm{C}^{12} \mathrm{O}^{16} \mathrm{Cl}^{35}$ & 3- 361 & $8,3,5 \leftarrow 8,2,6$ & Ground & $17 / 2$ & $17 / 2$ & 23076.80 & .2 \\
\hline $\mathrm{C}^{12} \mathrm{H}_{3} \mathrm{C}^{12} \mathrm{O}^{16} \mathrm{Cl}^{35}$ & 3- 361 & $8,3,5 \leftarrow 8,2,6$ & Ground & $15 / 2$ & $15 / 2$ & 23076.80 & .2 \\
\hline $\mathrm{C}^{12}{ }_{*} \mathrm{H}: \mathrm{C}^{12} \mathrm{HO}^{16} \mathrm{C}^{13} \mathrm{H}: \mathrm{C}^{12}{ }_{*} \mathrm{H}$ & 4-1153 & $4,2,2 \leftarrow 4,2,3$ & Ground & & & 23077.5 & .1 \\
\hline $\mathrm{C}^{12}{ }_{*} \mathrm{H}: \mathrm{C}^{12} \mathrm{HO}^{16} \mathrm{C}^{13} \mathrm{H}: \mathrm{C}^{12}{ }_{*} \mathrm{H}$ & 4-1153 & $4,2,2 \leftarrow 4,1,3$ & Ground & & & 23077.5 & .1 \\
\hline $\mathrm{C}^{\mathrm{i} 2} \mathrm{H}_{3} \mathrm{~S}^{32} \mathrm{H}$ & 3- 221 & Not Reported & Ground & & & 23078.2 & .1 \\
\hline $\mathrm{Si}^{28} \mathrm{HD}_{2} \mathrm{~N}^{14} \mathrm{C}^{12} \mathrm{~S}^{32}$ & 4- 498 & $8,1, \leftarrow 7,1$, & Ground & & & 23078.48 & .1 \\
\hline$\left(\mathrm{C}^{12} \mathrm{H}_{3} \mathrm{C}^{12} \mathrm{H}_{2}\right)_{2} \mathrm{O}^{16}$ & $3-1011$ & Not Reported & & & & 23080 & \\
\hline $\mathrm{HC}^{12} \mathrm{O}^{16} \mathrm{~N}^{14} \mathrm{H}_{2}$ & 3- 151 & $5,1,4 \leftarrow 5,1,5$ & Ground & 5 & 5 & 23080.06 & .1 \\
\hline $\mathrm{a}-\mathrm{C}^{12} \mathrm{H}_{2} \mathrm{DO}^{16} \mathrm{~N}^{14} \mathrm{O}_{2}^{16}$ & 3- 184 & $3,0,3 \leftarrow 2,0,2$ & Ground & & & 23080.34 & .1 \\
\hline $\mathrm{C}^{12} \mathrm{H}_{3} \mathrm{C}^{12} \mathrm{H}_{2} \mathrm{O}^{16} \mathrm{H}$ & 3- 581 & Not Reported & & & & 23081. & \\
\hline $\mathrm{C}^{12}{ }_{*} \mathrm{D}: \mathrm{C}^{12} \mathrm{DC}^{12} \mathrm{D}: \mathrm{C}^{12} \mathrm{DN}^{14}{ }_{*} \mathrm{H}$ & $4-1185$ & $11,8,3 \leftarrow 11,7,4$ & Ground & & & 23081.1 & \\
\hline $\mathrm{HC}^{12} \mathrm{O}^{16} \mathrm{~N}^{14} \mathrm{H}_{2}$ & 3- 151 & $5,1,4 \leftarrow 5,1,5^{-}$ & Ground & 4 & 4 & 23081.86 & .1 \\
\hline $\mathrm{c}-\mathrm{C}^{12} \mathrm{HD}: \mathrm{C}^{12} \mathrm{HBr}^{81}$ & 4. 742 & $3,0,3 \leftarrow 2,0,2$ & Ground & $9 / 2$ & $7 / 2$ & 23082.2 & 1. \\
\hline $\mathrm{c}-\mathrm{C}^{12} \mathrm{HD}: \mathrm{C}^{12} \mathrm{HBr}^{81}$ & 4- 742 & $3,0,3 \leftarrow 2,0,2$ & Ground & $7 / 2$ & $7 / 2$ & 23082.2 & 1. \\
\hline $\mathrm{HC}^{12} \mathrm{O}^{16} \mathrm{~N}^{14} \mathrm{H}_{2}$ & 3. 151 & $5,1,4 \leftarrow 5,1,5$ & Ground & 6 & 6 & 23082.26 & .1 \\
\hline $\mathrm{C}^{12} \mathrm{~F}_{3}^{19} \mathrm{C}^{12}: \mathrm{C}^{12} \mathrm{H}$ & 4- 871 & $4,1 \leftarrow 3,1$ & Excited & & & $23,082.4$ & .3 \\
\hline $\mathrm{C}^{\mathrm{b}} \mathrm{H}_{2}: \mathrm{C}^{\mathrm{b}} \mathrm{HBr}^{\mathrm{b}}$ & 4- 752 & Not Reported & Ground & & & 23082.8 & .2 \\
\hline $\mathrm{C}^{12} \mathrm{H}_{3} \mathrm{C}^{12} \mathrm{H}_{2} \mathrm{I}^{127}$ & 3- 571 & $4,2,3 \leftarrow 3,2,2$ & Ground & $7 / 2$ & $5 / 2$ & 23083.38 & .05 \\
\hline $\mathrm{HC}^{12} \mathrm{O}^{16} \mathrm{O}^{16} \mathrm{C}^{12} \mathrm{D}_{3}-\mathrm{A}$ & 3- 507 & $2,1,1 \leftarrow 1,1,0$ & Ground & & & 23083.86 & .2 \\
\hline $\mathrm{C}^{12}{ }_{*} \mathrm{H}: \mathrm{C}^{12} \mathrm{HO}^{18} \mathrm{C}^{12} \mathrm{H}: \mathrm{C}^{12}{ }_{*} \mathrm{H}$ & 4-1152 & $2,0,2 \leftarrow 1,0,1$ & Ground & & & 23083.9 & .1 \\
\hline $\mathrm{C}^{12} \mathrm{H}_{2}\left(\mathrm{C}^{12} \mathrm{~N}^{14}\right)_{2}$ & 4- 901 & $7,1,6 \leftarrow 7,0,7$ & Ground & & & 23084.25 & \\
\hline $\mathrm{t}-\mathrm{C}^{12} \mathrm{H} \mathrm{D}: \mathrm{C}^{12} \mathrm{DB} \mathrm{r}^{81}$ & 4. 747 & $3,1,2 \leftarrow 2,1,1$ & Ground & $9 / 2$ & $7 / 2$ & 23084.3 & .1 \\
\hline $\mathrm{Si}^{28} \mathrm{HD}_{2} \mathrm{~N}^{14} \mathrm{C}^{12} \mathrm{~S}^{32}$ & 4. 498 & $8,7, \leftarrow 7,7$, & Ground & & & 23084.74 & .1 \\
\hline
\end{tabular}




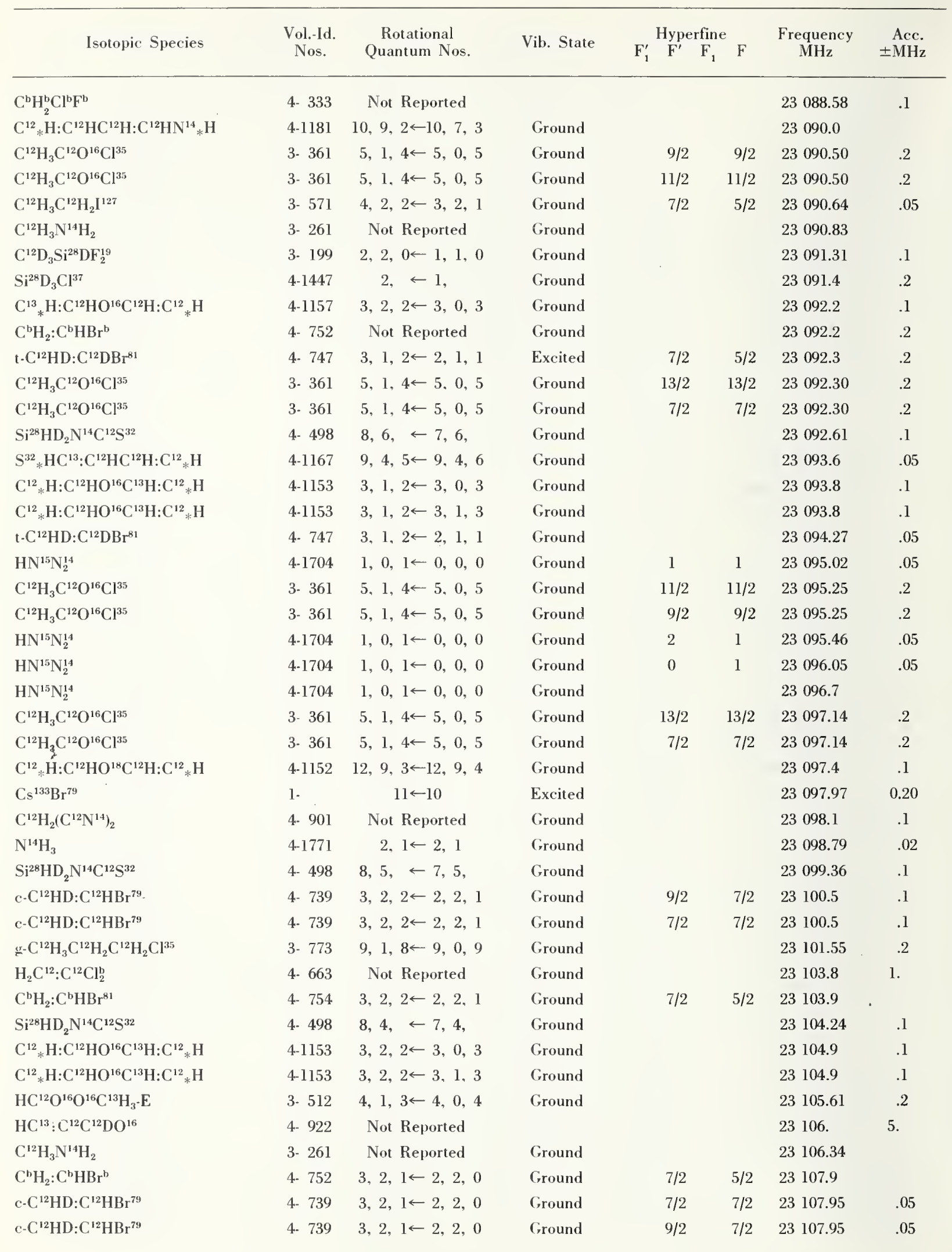


Vib. State

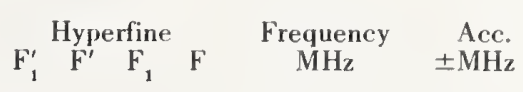

\begin{tabular}{|c|c|c|c|c|c|c|c|}
\hline $\mathrm{Si}^{28} \mathrm{HD}_{2} \mathrm{~N}^{14} \mathrm{C}^{12} \mathrm{~S}^{32}$ & 4- 498 & $8,3, \leftarrow 7,3$, & Ground & & & 23108.25 & .1 \\
\hline${ }^{t}-C^{12} \mathrm{HD}: \mathrm{C}^{12} \mathrm{DBr}^{81}$ & 4. 747 & $3,1,2 \leftarrow 2,1,1$ & Ground & $7 / 2$ & $5 / 2$ & 23108.25 & .1 \\
\hline $\mathrm{F}_{2}^{19} \mathrm{~N}^{14} \mathrm{~N}^{14} \mathrm{~F}_{2}^{19}$ & $3-21$ & $13,5,8 \leftarrow 13,4,10$ & Ground & & & 23110.0 & .3 \\
\hline $\mathrm{C}^{12}{ }_{*} \mathrm{H}: \mathrm{C}^{12} \mathrm{HO}^{16} \mathrm{C}^{13} \mathrm{H}: \mathrm{C}^{12}{ }_{*} \mathrm{H}$ & 4-1153 & $4,3,2 \leftarrow 4,1,3$ & Ground & & & 23110.9 & .1 \\
\hline $\mathrm{C}^{12}{ }_{*} \mathrm{H}: \mathrm{C}^{12} \mathrm{HO}^{16} \mathrm{C}^{13} \mathrm{H}: \mathrm{C}^{12}{ }_{*} \mathrm{H}$ & 4-1153 & $4,3,2 \leftarrow 4,2,3$ & Ground & & & 23110.9 & .1 \\
\hline $\mathrm{C}_{6}^{12} \mathrm{H}_{5} \mathrm{C}^{12} \mathrm{~N}^{14}$ & 4-1291 & $8,2,6 \leftarrow 7,2,5$ & Ground & & & 23111.1 & \\
\hline $\mathrm{C}^{12} \mathrm{~F}_{3}^{19} \mathrm{C}^{12}: \mathrm{C}^{12} \mathrm{H}$ & 4- 871 & $4, \leftarrow 3$, & Excited & & & 23111.2 & .3 \\
\hline $\mathrm{Si}^{28} \mathrm{HD}_{2} \mathrm{~N}^{14} \mathrm{C}^{12} \mathrm{~S}^{32}$ & 4- 498 & $8,2, \leftarrow 7,2$, & Ground & & & 23111.59 & .1 \\
\hline $\mathrm{C}^{12} \mathrm{Cl}_{2}^{35} \mathrm{Cl}^{37} \mathrm{C}^{12} \mathrm{~N}^{14}$ & 4- 582 & $7, \quad \leftarrow 6$, & Ground & & & 23111.9 & 1.0 \\
\hline $\mathrm{C}^{12} \mathrm{H}_{3} \mathrm{C}^{12} \mathrm{O}^{16} \mathrm{C}^{12} \mathrm{~N}^{14}$ & 3- 671 & $3,1,2 \leftarrow 2,1,1$ & Ground & & & 23112.13 & .2 \\
\hline $\mathrm{Tl}^{205} \mathrm{Br}^{79}$ & $1-$ & $9 \leftarrow 8$ & Excited & & & 23112.80 & 0.10 \\
\hline $\mathrm{C}^{12} \mathrm{H}_{2}\left(\mathrm{C}^{12} \mathrm{~N}^{14}\right)_{2}$ & 4. 901 & Not Reported & Ground & & & 23113.3 & .1 \\
\hline $\mathrm{C}^{\mathrm{b}} \mathrm{H}_{2}: \mathrm{C}^{\mathrm{b}} \mathrm{HBr}^{\mathrm{b}}$ & 4- 752 & Not Reported & Ground & & & 23113.8 & .2 \\
\hline $\mathrm{D}_{2} \mathrm{C}^{12}: \mathrm{C}^{12} \mathrm{~F}_{2}^{19}$ & 4. 683 & $3,1,2 \leftarrow 3,1,3$ & Ground & & & 23114.4 & .3 \\
\hline $\mathrm{C}^{12}{ }_{*} \mathrm{H}: \mathrm{C}^{12} \mathrm{HO}^{18} \mathrm{C}^{12} \mathrm{H}: \mathrm{C}^{12}{ }_{*} \mathrm{H}$ & 4-1152 & $4,3,2 \leftarrow 4,1,3$ & Ground & & & 23115.1 & .1 \\
\hline $\mathrm{C}^{12} \mathrm{H}_{3} \mathrm{C}^{12} \mathrm{H}_{2} \mathrm{I}^{127}$ & 3- 571 & $4,3,1 \leftarrow 3,3,0$ & Ground & $7 / 2$ & $5 / 2$ & 23116.56 & .05 \\
\hline $\mathrm{C}^{12} \mathrm{H}_{3} \mathrm{C}^{12} \mathrm{H}_{2} \mathrm{I}^{127}$ & 3. 571 & $4,3,2 \leftarrow 3,3,1$ & Ground & $7 / 2$ & $5 / 2$ & 23116.56 & .05 \\
\hline $\mathrm{HC}^{12} \mathrm{O}^{16} \mathrm{O}^{16} \mathrm{C}^{13} \mathrm{H}_{3}-\mathrm{A}$ & 3- 511 & $4,1,3 \leftarrow 4,0,4$ & Ground & & & 23116.71 & .2 \\
\hline c- $\mathrm{C}^{12} \mathrm{HD}: \mathrm{C}^{12} \mathrm{HBr}^{79}$ & 4. 739 & $3,0,3 \leftarrow 2,0,2$ & Ground & $7 / 2$ & $5 / 2$ & 23118.8 & .1 \\
\hline c- $\mathrm{C}^{12} \mathrm{HD}: \mathrm{C}^{12} \mathrm{HBr}^{79}$ & 4- 739 & $3,0,3 \leftarrow 2,0,2$ & Ground & $9 / 2$ & $7 / 2$ & 23118.8 & .1 \\
\hline $\mathrm{C}^{12} \mathrm{H}_{3} \mathrm{~N}^{14} \mathrm{H}_{2}$ & 3- 261 & Not Reported & Ground & & & 23119.06 & .04 \\
\hline $\mathrm{H}_{2} \mathrm{~N}^{14} \mathrm{~N}^{14} \mathrm{H}_{2}$ & 3-. 51 & Not Reported & & & & 23119.2 & \\
\hline $\mathrm{C}^{12} \mathrm{H}_{3} \mathrm{C}^{12} \mathrm{O}^{16} \mathrm{Cl}^{37}$ & 3- 362 & $8,3,5 \leftarrow 8,2,6$ & Ground & $19 / 2$ & $19 / 2$ & 23120.90 & .2 \\
\hline $\mathrm{C}^{12} \mathrm{H}_{3} \mathrm{C}^{12} \mathrm{O}^{16} \mathrm{Cl}^{37}$ & 3- 362 & $8,3,5 \leftarrow 8,2,6$ & Ground & $13 / 2$ & $13 / 2$ & 23120.90 & .2 \\
\hline $\mathrm{C}^{12} \mathrm{H}_{3} \mathrm{C}^{12} \mathrm{O}^{16} \mathrm{Cl}^{37}$ & 3- 362 & $8,3,5 \leftarrow 8,2,6$ & Ground & $15 / 2$ & $15 / 2$ & 23120.90 & .2 \\
\hline $\mathrm{C}^{12} \mathrm{H}_{3} \mathrm{C}^{12} \mathrm{O}^{16} \mathrm{Cl}^{37}$ & 3. 362 & $8,3,5 \leftarrow 8,2,6$ & Ground & $17 / 2$ & $17 / 2$ & 23120.90 & .2 \\
\hline $\mathrm{C}^{12} \mathrm{H}_{3} \mathrm{O}^{16} \mathrm{H}$ & 3- 211 & Not Reported & Ground & & & 23121.20 & .1 \\
\hline $\mathrm{C}^{12} \mathrm{H}_{3} \mathrm{C}^{12} \mathrm{O}^{16} \mathrm{Cl}^{37}$ & 3- 362 & $8,3,5 \leftarrow 8,2,6$ & Ground & $13 / 2$ & $13 / 2$ & 23122.25 & .2 \\
\hline $\mathrm{C}^{12} \mathrm{H}_{3} \mathrm{C}^{12} \mathrm{O}^{16} \mathrm{Cl}^{37}$ & 3- 362 & $8,3,5 \leftarrow 8,2,6$ & Ground & $19 / 2$ & $19 / 2$ & 23122.25 & .2 \\
\hline $\mathrm{C}^{12} \mathrm{H}_{3} \mathrm{C}^{12} \mathrm{O}^{16} \mathrm{Cl}^{37}$ & 3- 362 & $8,3,5 \leftarrow 8,2,6$ & Ground & $15 / 2$ & $15 / 2$ & 23122.25 & .2 \\
\hline $\mathrm{C}^{12} \mathrm{H}_{3} \mathrm{C}^{12} \mathrm{O}^{16} \mathrm{Cl}^{37}$ & 3- 362 & $8,3,5 \leftarrow 8,2,6$ & Ground & $17 / 2$ & $17 / 2$ & 23122.25 & .2 \\
\hline $\mathrm{c}-\mathrm{C}^{12} \mathrm{HD}: \mathrm{C}^{12} \mathrm{HBr}^{79}$ & 4- 739 & $3,0,3 \leftarrow 2,0,2$ & Ground & & & 23123.76 & .06 \\
\hline $\mathrm{C}^{12}{ }_{*} \mathrm{H}_{2} \mathrm{C}^{12} \mathrm{D}: \mathrm{C}^{12}{ }_{*} \mathrm{D}$ & 4-1033 & $7,5,2 \leftarrow 7,5,3$ & Ground & & & 23124.0 & \\
\hline $\mathrm{HC}^{13}: \mathrm{C}^{12} \mathrm{C}_{1}^{12} \mathrm{DO}^{16}$ & 4. 922 & Not Reported & & & & 23126. & 5. \\
\hline $\mathrm{C}^{12} \mathrm{Cl}_{2}^{35} \mathrm{Cl}^{37} \mathrm{C}^{12} \mathrm{~N}^{14}$ & 4- 582 & $7, \quad \leftarrow 6, \quad$, & Excited & & & 23127.3 & 1.0 \\
\hline $\mathrm{C}^{12} \mathrm{H}_{3} \mathrm{Si}^{28} \mathrm{HF}_{2}^{19}-\mathrm{A}$ & 3- 191 & $8,4,5 \leftarrow 8,4,4$ & Ground & & & 23128.45 & \\
\hline $\mathrm{HDO}_{2}^{16}$ & 3- 43 & $20, \quad \leftarrow 20, \quad$, & & & & 23130. & 3. \\
\hline $\mathrm{H}_{2} \mathrm{~N}^{14} \mathrm{~N}^{14} \mathrm{H}_{2}$ & 3- 51 & Not Reported & & & & 23130.70 & \\
\hline $\mathrm{H}_{2} \mathrm{~N}^{14} \mathrm{~N}^{14} \mathrm{H}_{2}$ & 3. 51 & Not Reported & & & & 23131.19 & \\
\hline $\mathrm{C}^{13} \mathrm{H}_{2}: \mathrm{C}^{13} \mathrm{HBr}^{\beta 1}$ & 4- 734 & $3,1,2 \leftarrow 2,1,1$ & Ground & $3 / 2$ & $3 / 2$ & 23131.6 & \\
\hline c- $\mathrm{C}^{12} \mathrm{HD}: \mathrm{C}^{12} \mathrm{HBr}^{79}$ & 4- 739 & $3,2,2 \leftarrow 2,2,1$ & Ground & & & 23133.36 & .06 \\
\hline $\mathrm{c}-\mathrm{C}^{12} \mathrm{HD}: \mathrm{C}^{12} \mathrm{HBr}^{79}$ & 4- 739 & $3,2,2 \leftarrow 2,2,1$ & Ground & $3 / 2$ & $3 / 2$ & 23133.6 & .2 \\
\hline $\mathrm{c}-\mathrm{C}^{12} \mathrm{HD}: \mathrm{C}^{12} \mathrm{HBr}^{79}$ & 4- 739 & $3,2,2 \leftarrow 2,2,1$ & Ground & $5 / 2$ & $3 / 2$ & 23133.6 & .2 \\
\hline $\mathrm{H}_{2} \mathrm{C}^{12}{ }_{*} \mathrm{O}^{16} \mathrm{C}^{12}{ }_{*} \mathrm{H}_{2}$ & 4- 841 & $3,3,0 \leftarrow 3,2,1$ & Ground & & & 23134.21 & .03 \\
\hline $\mathrm{C}_{6}^{12} \mathrm{H}_{5} \mathrm{~F}^{19}$ & $4-1281$ & $6,0,6 \leftarrow 5,0,5$ & Ground & & & 23134.6 & .1 \\
\hline
\end{tabular}




\begin{tabular}{|c|c|c|c|c|c|c|c|}
\hline \multirow{2}{*}{ Isotopic Species } & \multirow{2}{*}{$\begin{array}{l}\text { Vol.-Id. } \\
\text { Nos. }\end{array}$} & \multirow{2}{*}{$\begin{array}{c}\text { Rotational } \\
\text { Quantum Nos. }\end{array}$} & \multirow{2}{*}{ Vib. State } & \multicolumn{2}{|c|}{ Hyperfine } & \multirow{2}{*}{$\begin{array}{c}\text { Frequency } \\
\mathrm{MHz}\end{array}$} & \multirow{2}{*}{$\begin{aligned} & \text { Acc. } \\
& \pm \mathrm{MHz}\end{aligned}$} \\
\hline & & & & $\begin{array}{lll}F_{1}^{\prime} & F^{\prime} & F_{1}\end{array}$ & $\mathrm{~F}$ & & \\
\hline $\mathrm{C}^{13} \mathrm{H}_{2}: \mathrm{C}^{12} \mathrm{HBr}^{79}$ & 4- 735 & $3,2,2 \leftarrow 2,2,1$ & Ground & $9 / 2$ & $7 / 2$ & 23135.1 & \\
\hline$g-\mathrm{C}^{12} \mathrm{H}_{3} \mathrm{C}^{12} \mathrm{H}_{2} \mathrm{C}^{12} \mathrm{H}_{2} \mathrm{Cl}^{37}$ & 3. 774 & $11,2,9 \leftarrow 11,1,10$ & Ground & & & 23137.29 & .2 \\
\hline $\mathrm{C}^{12} \mathrm{H}_{3} \mathrm{C}^{12} \mathrm{O}^{16} \mathrm{O}^{16} \mathrm{H}$ & 3. 491 & $2,0,2 \leftarrow 1,1,1$ & Excited & & & 23138. & 3. \\
\hline $\mathrm{C}^{12} \mathrm{Cl}^{35} \mathrm{Cl}^{37} \mathrm{C}^{12} \mathrm{~N}^{14}$ & 4- 582 & $7,4,3 \leftarrow 6,4,2$ & Ground & & & 23138. & \\
\hline $\mathrm{C}^{12} \mathrm{C}_{2}^{35} \mathrm{Cl}^{37} \mathrm{C}^{12} \mathrm{~N}^{14}$ & 4- 582 & $7,3,4 \leftarrow 6,3,3$ & Ground & & & 23138. & \\
\hline $\mathrm{F}_{2}^{19} \mathrm{O}_{2}^{18}$ & 3- 13 & $1,1,1 \leftarrow 0,0,0$ & Ground & & & $23 \overline{138.5}$ & .5 \\
\hline $\mathrm{C}^{b} \mathrm{H}_{2}: \mathrm{C}^{b} \mathrm{HBr}^{\mathrm{b}}$ & 4- 752 & $3,2,1 \leftarrow 2,2,0$ & Ground & $9 / 2$ & $7 / 2$ & 23139.35 & \\
\hline $2 \mathrm{C}^{13}-\mathrm{C}_{6}^{12} \mathrm{H}_{5} \mathrm{C}^{12} \mathrm{~N}^{14}$ & 4-1298 & $9,0,9 \leftarrow 8,0,8$ & Ground & & & 23140.0 & .1 \\
\hline $\mathrm{Cs}^{133} \mathrm{Br}^{81}$ & $1-$ & $11 \leftarrow 10$ & Excited & & & 23140.61 & 0.20 \\
\hline c-C ${ }^{12} \mathrm{HD}: \mathrm{C}^{12} \mathrm{HBr}^{79}$ & 4- 739 & $3,2,1 \leftarrow 2,2,0$ & Ground & & & 23140.72 & .06 \\
\hline c- $\mathrm{C}^{12} \mathrm{HD}: \mathrm{C}^{12} \mathrm{HBr}^{79}$ & 4- 739 & $3,2,1 \leftarrow 2,2,0$ & Ground & $3 / 2$ & $3 / 2$ & 23140.9 & .1 \\
\hline c- $\mathrm{C}^{12} \mathrm{HD}: \mathrm{C}^{12} \mathrm{HBr}^{79}$ & 4- 739 & $3,2,1 \leftarrow 2,2,0$ & Ground & $5 / 2$ & $3 / 2$ & 23140.9 & .1 \\
\hline 3 d $\cdot \mathrm{C}_{6}^{12} \mathrm{H}_{5} \mathrm{~F}^{19}$ & $4-1282$ & $8,3,6 \leftarrow 8,1,7$ & Ground & & & 23141.2 & .1 \\
\hline $\mathrm{C}^{12}{ }_{*} \mathrm{H}: \mathrm{C}^{12} \mathrm{HO}^{16} \mathrm{C}^{13} \mathrm{H}: \mathrm{C}^{12}{ }_{*} \mathrm{H}$ & 4-1153 & $2,0,2 \leftarrow 1,0,1$ & Ground & & & 23141.9 & .1 \\
\hline $\mathrm{C}^{12}{ }_{*} \mathrm{H}: \mathrm{C}^{12} \mathrm{HO}^{16} \mathrm{C}^{13} \mathrm{H}: \mathrm{C}^{12}{ }_{*} \mathrm{H}$ & 4-1153 & $2,1,2 \leftarrow 1,0,1$ & Ground & & & 23144.2 & .1 \\
\hline $\mathrm{C}^{12}{ }_{*} \mathrm{H}: \mathrm{C}^{12} \mathrm{HO}^{16} \mathrm{C}^{13} \mathrm{H}: \mathrm{C}^{12}{ }_{*} \mathrm{H}$ & $4-1153$ & $6,5,2 \leftarrow 6,4,3$ & Ground & & & 23144.2 & .2 \\
\hline $\mathrm{C}^{12} \mathrm{H}_{3} \mathrm{C}^{12} \mathrm{HDF}^{19}$ & 3- 552 & $1,1,0 \leftarrow 1,0,1$ & Ground & & & 23144.5 & .1 \\
\hline $\mathrm{C}^{12} \mathrm{HD}: \mathrm{C}^{12} \mathrm{DBr}^{\mathrm{b}}$ & 4. 749 & Not Reported & & & & 23145.9 & .2 \\
\hline c- $\mathrm{C}^{12} \mathrm{HD}: \mathrm{C}^{12} \mathrm{HBr}^{79}$ & 4- 739 & $3,0,3 \leftarrow 2,0,2$ & Ground & $5 / 2$ & $3 / 2$ & 23146.2 & .2 \\
\hline c- $\mathrm{C}^{12} \mathrm{HD}: \mathrm{C}^{12} \mathrm{HBr}^{79}$ & 4. 739 & $3,0,3 \leftarrow 2,0,2$ & Ground & $3 / 2$ & $1 / 2$ & 23146.2 & .2 \\
\hline $\mathrm{C}^{12}{ }_{*} \mathrm{H}: \mathrm{C}^{12} \mathrm{HO}^{16} \mathrm{C}^{13} \mathrm{H}: \mathrm{C}^{12}{ }_{*} \mathrm{H}$ & 4-1153 & $6,5,2 \leftarrow 6,3,3$ & Ground & & & 23146.5 & .1 \\
\hline $\mathrm{Si}^{28} \mathrm{HD}_{2} \mathrm{~N}^{14} \mathrm{C}^{12} \mathrm{~S}^{32}$ & 4- 498 & $8,1, \leftarrow 7,1$, & Ground & & & 23147.76 & .1 \\
\hline $\mathrm{Si}^{30} \mathrm{D}_{3} \mathrm{Cl}^{35}$ & $4-1446$ & $2, \leftarrow 1$ & Ground & & & 23147.9 & .3 \\
\hline $\mathrm{C}^{12} \mathrm{H}_{3} \mathrm{C}^{12} \mathrm{H}_{2} \mathrm{O}^{16} \mathrm{H}$ & 3- 581 & Not Reported & & & & 23148. & \\
\hline $\mathrm{S}^{32}{ }_{*} \mathrm{DC}^{12}: \mathrm{C}^{12} \mathrm{DC}^{12} \mathrm{D}: \mathrm{C}^{12}{ }_{*} \mathrm{D}$ & 4-1165 & $3,2,2 \leftarrow 2,2,1$ & Ground & & & 23149.6 & .1 \\
\hline $\mathrm{H}_{3} \mathrm{C}^{12} \mathrm{C}^{12}: \mathrm{C}^{12} \mathrm{C}^{12}: \mathrm{C}^{12} \mathrm{D}$ & 4-1192 & $6,5 \leftarrow 5,5$ & Ground & & & 23151.67 & .1 \\
\hline $\mathrm{C}^{13}{ }_{*} \mathrm{H}: \mathrm{C}^{12} \mathrm{HO}^{16} \mathrm{C}^{12} \mathrm{H}: \mathrm{C}^{12}{ }_{*} \mathrm{H}$ & $4-1157$ & $4,3,2 \leftarrow 4,1,3$ & Ground & & & 23152.8 & .1 \\
\hline $\mathrm{C}^{12} \mathrm{~F}_{3}^{19} \mathrm{C}^{12}: \mathrm{C}^{12} \mathrm{H}$ & 4- 871 & $4, \leftarrow 3$, & Excited & & & 23153.0 & .3 \\
\hline $\mathrm{t}-\mathrm{C}^{12} \mathrm{HD}: \mathrm{C}^{12} \mathrm{DBr}^{81}$ & 4- 747 & $3,1,2 \leftarrow 2,1,1$ & Ground & $7 / 2$ & $7 / 2$ & 23153.0 & .1 \\
\hline $\mathrm{H}_{3} \mathrm{C}^{12} \mathrm{C}^{12}: \mathrm{C}^{12} \mathrm{C}^{12}: \mathrm{C}^{12} \mathrm{D}$ & 4-1192 & $6,4 \leftarrow 5,4$ & Ground & & & 23153.71 & .1 \\
\hline $\mathrm{H}_{2} \mathrm{C}^{12}: \mathrm{C}^{12} \mathrm{Cl}_{2}^{\mathrm{b}}$ & 4- 663 & Not Reported & Ground & & & 23153.9 & 1. \\
\hline $\mathrm{C}^{\mathrm{b}} \mathrm{H}_{2}^{\mathrm{b}} \mathrm{Cl}^{\mathrm{b}} \mathrm{F}^{\mathrm{b}}$ & 4- 333 & Not Reported & & & & 23154.47 & .1 \\
\hline $\mathrm{H}_{3} \mathrm{C}^{12} \mathrm{C}^{12}: \mathrm{C}^{12} \mathrm{C}^{12}: \mathrm{C}^{12} \mathrm{D}$ & 4-1192 & $6,3 \leftarrow 5,3$ & Ground & & & 23155.25 & .1 \\
\hline $\mathrm{C}^{13} \mathrm{D}_{3} \mathrm{C}^{12}: \mathrm{C}^{12} \mathrm{Cl}^{35}$ & 4- 981 & $6,0 \leftarrow 5,0$ & Ground & $11 / 2$ & $9 / 2$ & 23155.79 & .04 \\
\hline $\mathrm{C}^{13} \mathrm{D}_{3} \mathrm{C}^{12}: \mathrm{C}^{12} \mathrm{Cl}^{35}$ & 4- 981 & $6,0 \leftarrow 5,0$ & Ground & $9 / 2$ & $7 / 2$ & 23155.79 & .04 \\
\hline $\mathrm{H}_{3} \mathrm{C}^{12} \mathrm{C}^{12}: \mathrm{C}^{12} \mathrm{C}^{12}: \mathrm{C}^{12} \mathrm{D}$ & 4-1192 & $6,2 \leftarrow 5,2$ & Ground & & & 23156.34 & .1 \\
\hline $\mathrm{C}^{13} \mathrm{D}_{3} \mathrm{C}^{12}: \mathrm{C}^{12} \mathrm{Cl}^{35}$ & 4- 981 & $6.0 \leftarrow 5,0$ & Ground & $13 / 2$ & $11 / 2$ & 23155.71 & .04 \\
\hline $\mathrm{C}^{13} \mathrm{D}_{3} \mathrm{C}^{12}: \mathrm{C}^{12} \mathrm{Cl}^{35}$ & 4- 981 & $6,0 \leftarrow 5,0$ & Ground & $15 / 2$ & $13 / 2$ & 23156.71 & .04 \\
\hline $\mathrm{H}_{3} \mathrm{C}^{12} \mathrm{C}^{12}: \mathrm{C}^{12} \mathrm{C}^{12}: \mathrm{C}^{12} \mathrm{D}$ & 4-1192 & $6,1 \leftarrow 5,1$ & Ground & & & 23156.99 & .1 \\
\hline $\mathrm{C}^{\mathrm{b}} \mathrm{H}_{2}: \mathrm{C}^{\mathrm{b}} \mathrm{HBr}^{\mathrm{b}}$ & 4- 752 & $3,0,3 \leftarrow 2,0,2$ & Ground & $9 / 2$ & $7 / 2$ & 23157.0 & \\
\hline $\mathrm{H}_{3} \mathrm{C}^{12} \mathrm{C}^{12}: \mathrm{C}^{12} \mathrm{C}^{12} \vdots \mathrm{C}^{12} \mathrm{D}$ & 4-1192 & $6,0 \leftarrow 5,0$ & Ground & & & 23157.21 & .1 \\
\hline $\mathrm{C}^{\mathrm{b}} \mathrm{H}_{2}^{\mathrm{b}} \mathrm{Cl}^{\mathrm{b}} \mathrm{F}^{\mathrm{b}}$ & 4- 333 & Not Reported & & & & 23158.02 & .1 \\
\hline $\mathrm{C}^{12} \mathrm{H}_{3} \mathrm{C}^{12} \mathrm{H}_{2} \mathrm{I}^{127}$ & 3- 571 & $4,2,3 \leftarrow 3,2,2$ & Ground & $13 / 2$ & $11 / 2$ & 23158.50 & .05 \\
\hline $\mathrm{C}^{13} \mathrm{H}_{2}: \mathrm{C}^{13} \mathrm{HBr}^{81}$ & 4- 734 & $3,1,2 \leftarrow 2,1,1$ & Excited & $9 / 2$ & $7 / 2$ & 23159.1 & \\
\hline $\mathrm{C}^{12} \mathrm{H}_{2}\left(\mathrm{C}^{12} \mathrm{~N}^{14}\right)_{2}$ & 4- 901 & Not Reported & Ground & & & 23162. & .1 \\
\hline
\end{tabular}


Vib. State $\mathrm{F}_{1}^{\prime} \stackrel{\text { Hyperfine }}{\mathrm{F}^{\prime}} \underset{\mathrm{F}}{\mathrm{F}} \mathrm{F}$
$\mathrm{C}^{13} \mathrm{H}_{2}: \mathrm{C}^{12} \mathrm{HBr}^{79}$

$\left(\mathrm{C}^{12} \mathrm{D}_{3}\right)\left(\mathrm{C}^{12} \mathrm{H}_{3}\right) \mathrm{O}^{16}$

$\mathrm{S}^{32} \mathrm{O}^{16} \mathrm{~F}_{2}^{19}$

$\mathrm{C}^{13} \mathrm{H}_{2}: \mathrm{C}^{12} \mathrm{HBr}^{79}$

$\mathrm{C}^{12} \mathrm{H}_{3} \mathrm{C}^{12} \mathrm{H}_{2} \mathrm{I}^{127}$

I- $\mathrm{C}^{12} \mathrm{HD}: \mathrm{C}^{12} \mathrm{DBr}^{79}$

$\mathrm{HN}^{14} \mathrm{C}^{12} \mathrm{~S}^{33}$

$\mathrm{HN}^{14} \mathrm{C}^{12} \mathrm{~S}^{33}$

$\mathrm{C}^{\mathrm{b}} \mathrm{H}_{2}: \mathrm{C}^{\mathrm{b}} \mathrm{HBr}^{\mathrm{b}}$

$\mathrm{C}^{13} \mathrm{H}_{2}: \mathrm{C}^{12} \mathrm{HBr}^{79}$

$\mathrm{C}^{12} \mathrm{H}_{3} \mathrm{C}^{12} \mathrm{O}^{16} \mathrm{Cl}^{37}$

$\mathrm{C}^{12} \mathrm{H}_{3} \mathrm{C}^{12} \mathrm{O}^{16} \mathrm{Cl}^{37}$

$\mathrm{C}^{12} \mathrm{H}_{3} \mathrm{C}^{12} \mathrm{O}^{16} \mathrm{Cl}^{37}$

$\mathrm{C}^{12} \mathrm{H}_{3} \mathrm{C}^{12} \mathrm{O}^{16} \mathrm{Cl}^{37}$

$\mathrm{C}^{12} \mathrm{H}_{2}: \mathrm{C}^{13} \mathrm{HBr}^{81}$

$\mathrm{HN}^{14} \mathrm{C}^{12} \mathrm{~S}^{33}$

$\mathrm{HN}^{14} \mathrm{C}^{12} \mathrm{~S}^{33}$

$\mathrm{HN}^{14} \mathrm{C}^{12} \mathrm{~S}^{33}$

$\mathrm{HC}^{12} \mathrm{O}^{16} \mathrm{O}^{18} \mathrm{C}^{12} \mathrm{H}_{3} \cdot \mathrm{E}$

$\mathrm{C}^{12} \mathrm{H}_{3} \mathrm{C}^{12} \mathrm{O}^{18} \mathrm{C}^{12} \mathrm{~N}^{14}$

$\left(\mathrm{C}^{12} \mathrm{D}_{3}\right)\left(\mathrm{C}^{12} \mathrm{H}_{3}\right) \mathrm{O}^{16}$

$\mathrm{Tl}^{203} \mathrm{Br}^{79}$

$\mathrm{C}^{12} \mathrm{H}_{3} \mathrm{C}^{12} \mathrm{O}^{16} \mathrm{Cl}^{37}$

$\mathrm{C}^{12} \mathrm{H}_{3} \mathrm{C}^{12} \mathrm{O}^{16} \mathrm{Cl}^{37}$

$\mathrm{C}^{12} \mathrm{H}_{3} \mathrm{C}^{12} \mathrm{O}^{16} \mathrm{Cl}^{37}$

$\mathrm{C}^{12} \mathrm{H}_{3} \mathrm{C}^{12} \mathrm{O}^{16} \mathrm{Cl}^{37}$

$\mathrm{C}^{13} \mathrm{H}_{2}: \mathrm{C}^{13} \mathrm{HBr}^{81}$

$\mathrm{C}^{12}{ }_{*} \mathrm{H}: \mathrm{C}^{12} \mathrm{HO}^{16} \mathrm{C}^{13} \mathrm{H}: \mathrm{C}^{12}{ }_{*} \mathrm{H}$

$\mathrm{Cs}^{133} \mathrm{Br}^{79}$

$\mathrm{C}^{12} \mathrm{H}_{3} \mathrm{C}^{12} \mathrm{O}^{16} \mathrm{O}^{16} \mathrm{H}$

$\mathrm{HC}^{13}: \mathrm{C}^{12} \mathrm{C}^{12} \mathrm{DO}^{16}$

$\mathrm{HN}^{14} \mathrm{C}^{12} \mathrm{~S}^{33}$

$\mathrm{H}_{2} \mathrm{C}^{12}: \mathrm{C}^{12} \mathrm{~F}_{2}^{19}$

$\mathrm{Tl}^{205} \mathrm{Br}^{79}$

$\mathrm{C}^{\mathrm{b}} \mathrm{H}_{2}: \mathrm{C}^{\mathrm{b}} \mathrm{HBr}^{\mathrm{b}}$

$\mathrm{C}^{12}{ }_{*} \mathrm{H}: \mathrm{C}^{12} \mathrm{HO}^{16} \mathrm{C}^{13} \mathrm{H}: \mathrm{C}^{12}{ }_{*} \mathrm{H}$

$\left(\mathrm{C}^{12} \mathrm{H}_{3}\right)_{3} \mathrm{C}^{12} \mathrm{C}^{12}: \mathrm{C}^{12} \mathrm{Cl}^{35}$

$\mathrm{Ge}^{76} \mathrm{H}_{3} \mathrm{Br}^{81}$

$\mathrm{HC}^{13}: \mathrm{C}^{12} \mathrm{C}^{12} \mathrm{DO}^{16}$

$\mathrm{C}^{12} \mathrm{D}_{3} \mathrm{O}^{16} \mathrm{~N}^{14} \mathrm{O}_{2}^{16}$

$\mathrm{HC}^{12} \mathrm{O}^{16} \mathrm{O}^{18} \mathrm{C}^{12} \mathrm{H}_{3} \cdot \mathrm{A}$

$\mathrm{C}^{12} \mathrm{H}_{2}: \mathrm{C}^{13} \mathrm{HBr}^{81}$

$\mathrm{C}^{13} \mathrm{H}_{2}: \mathrm{C}^{13} \mathrm{HBr}^{81}$

$\mathrm{C}^{\mathrm{b}} \mathrm{H}_{2}: \mathrm{C}^{\mathrm{b}} \mathrm{HBr}^{\mathrm{b}}$

$\mathrm{C}^{12} \mathrm{H}_{2} \mathrm{~F}_{2}^{19}$

\section{735}

$3,0,3 \leftarrow 2,0,2$

Ground

3. 593

$1,1,0 \leftarrow 1,0,1$

Ground

4-1621

Not Reported

4. 735

$3,2,2 \leftarrow 2,2,1$

3. 571

4. 745

$4,2,2 \leftarrow 3,2,1$

4. 315

$3,1,2 \leftarrow 2,1,1$

4- 315

4. 752

$2,0,2 \leftarrow 1,0,1$

$2,0,2 \leftarrow 1,0,1$

4. 735

Not Reported

$3,2,1 \leftarrow 2,2,0$

3. 362

3- 362

3. 362

$7,2,5 \leftarrow 7,1,6$

$7,2,5 \leftarrow 7,1,6$

$7,2,5 \leftarrow 7,1,6$

3- 362

$7,2,5 \leftarrow 7,1,6$

4- 738

$3,1,3 \leftarrow 2,1,2$

4- 315

4. 315

$2,0,2 \leftarrow 1,0,1$

$2,0,2 \leftarrow 1,0,1$

4- 315

$2,0,2 \leftarrow 1,0,1$

3- 516

$4,1,3 \leftarrow 4,0,4$

3- 674

3- 593

1 -

3. 362

$4,0,4 \leftarrow 3,1,3$

$1,1,0 \leftarrow 1,0,1$

$$
9 \leftarrow 8
$$

3. 362

$7,2,5 \leftarrow 7,1,6$

3. 362

3- 362

4- 734

4-1153

1 .

3- 491

4- 922

4- 315

4- 681

1 -

4. 752

$7,2,5 \leftarrow 7,1,6$

$7,2,5 \leftarrow 7,1,6$

$7,2,5 \leftarrow 7,1,6$

$3,1,2 \leftarrow 2,1,1$

$7,6,2 \leftarrow 7,5,3$

$$
11 \leftarrow 10
$$

Ground

Ground

Ground

Ground

Ground

Ground

Ground

Ground

Ground

Ground

Ground

Ground

Ground

Ground

Ground

Ground

Ground

Excited

Excited

Ground

Ground

Ground

Ground

Ground

Ground

Excited

Not Reported

Not Reported

$2,0,2 \leftarrow 1,0,1$

Ground

Not Reported

$$
9 \leftarrow 8
$$

Excited

Not Reported

4-1153

$7,6,2 \leftarrow 7,4,3$

Excited

Ground

3-1061

$$
13, \leftarrow 12 \text {, }
$$

$5, \leftarrow 4$,

4- 108

4- 922

Not Reported

3- 182

$3,1,2 \leftarrow 2,1,1$

3- 515

$4,1,3 \leftarrow 4,0,4$

4. 738

$3,1,3 \leftarrow 2,1,2$

4. 734

$3,1,2 \leftarrow 2,1,1$

4. 752

Not Reported

4- 351

$50,12,39 \longleftarrow 49,13,36$
Frequency

$\begin{array}{ll}\mathrm{MHz}_{\mathrm{z}} & \pm \mathrm{MHz}\end{array}$
Acc. 


\begin{tabular}{|c|c|c|c|c|c|c|c|}
\hline Isotopic Species & $\begin{array}{l}\text { Vol.-Id. } \\
\text { Nos. }\end{array}$ & $\begin{array}{c}\text { Rotational } \\
\text { Quantum Nos. }\end{array}$ & Vib. State & $\mathrm{F}_{1}^{\prime} \mathrm{F}^{\prime} \mathrm{F}$ & ${ }_{1}^{n e} F$ & $\begin{array}{c}\text { Frequency } \\
\mathrm{MHz}\end{array}$ & $\begin{aligned} \text { Acc. } \\
\pm \mathrm{MHz}\end{aligned}$ \\
\hline $\mathrm{C}^{12} \mathrm{H}_{2} \mathrm{~F}_{2}^{19}$ & 4- 351 & $50,12,38 \leftarrow 49,13,37$ & Ground & & & 23188.45 & .10 \\
\hline$\left(\mathrm{C}^{12} \mathrm{H}_{3}\right)_{3} \mathrm{P}^{31}$ & 3- 861 & $2,1 \leftarrow 1,1$ & Excited & & & 23188.65 & .03 \\
\hline $\mathrm{C}^{12} \mathrm{H}_{2}\left(\mathrm{C}^{12} \mathrm{~N}^{14}\right)\left(\mathrm{C}^{12} \mathrm{~N}^{15}\right)$ & 4. 904 & $1,1,1 \leftarrow 0,0,0$ & Ground & & & 23189.52 & \\
\hline $\mathrm{HC}^{13}: \mathrm{C}^{12} \mathrm{C}^{12} \mathrm{DO}^{16}$ & 4. 922 & Not Reported & & & & 23190. & 5. \\
\hline $\mathrm{C}^{12} \mathrm{H}_{3} \mathrm{C}^{12} \mathrm{O}^{18} \mathrm{C}^{12} \mathrm{~N}^{14}$ & 3. 674 & $8,3,5 \leftarrow 8,2,6$ & Ground & & & 23191.46 & .2 \\
\hline $\mathrm{C}^{13} \mathrm{H}_{3} \mathrm{~S}^{32} \mathrm{C}^{12} \mathrm{H}_{3}$ & 3- 603 & $1,1,1 \leftarrow 0,0,0$ & Ground & & & 23192.10 & .05 \\
\hline $\mathrm{a}-\mathrm{C}^{12} \mathrm{HD}_{2} \mathrm{C}^{12} \mathrm{O}^{16} \mathrm{~F}^{19}$ & 3. 396 & $2,1,2 \leftarrow 1,1,1$ & Ground & & & 23193.80 & .2 \\
\hline $\mathrm{H}_{3} \mathrm{C}^{12} \mathrm{C}^{12}: \mathrm{C}^{12} \mathrm{C}^{12} \vdots \mathrm{C}^{12} \mathrm{D}$ & 4-1192 & $6,1 \leftarrow 5,1$ & Excited & & & 23194.67 & .1 \\
\hline $\mathrm{N}^{14} \mathrm{H}_{2} \mathrm{C}_{2}^{12} \mathrm{H}_{5}$ & 3- 631 & Not Reported & Ground & & & 23196.14 & .2 \\
\hline $\mathrm{s}-\mathrm{C}^{12} \mathrm{H}_{2} \mathrm{DS}^{32} \mathrm{C}^{12} \mathrm{H}_{3}$ & 3. 604 & $1,1,1 \leftarrow 0,0,0$ & Ground & & & 23196.66 & .05 \\
\hline $\mathrm{C}^{12} \mathrm{H}_{2}: \mathrm{C}^{13} \mathrm{HBr}^{81}$ & 4- 738 & $3,1,3 \leftarrow 2,1,2$ & Ground & & & 23196.72 & .04 \\
\hline $\mathrm{C}^{13} \mathrm{H}_{2}: \mathrm{C}^{13} \mathrm{HBr}^{81}$ & 4. 734 & $3,1,2 \leftarrow 2,1,1$ & Ground & $5 / 2$ & $3 / 2$ & 23198.2 & .3 \\
\hline $\mathrm{O}^{16} \mathrm{C}^{12} \mathrm{~S}^{36}$ & 4- 525 & $2 \leftarrow 1$ & Ground & & & 23198.66 & \\
\hline $\mathrm{C}^{\mathrm{b}} \mathrm{H}_{2}: \mathrm{C}^{\mathrm{b}} \mathrm{HBr}^{\mathrm{b}}$ & 4- 752 & Not Reported & Ground & $7 / 2$ & $5 / 2$ & 23201.6 & \\
\hline $\mathrm{C}^{12} \mathrm{D}_{3} \mathrm{C}^{12}: \mathrm{C}^{12} \mathrm{Cl}^{37}$ & 4. 974 & $6,5 \leftarrow 5,5$ & Ground & $13 / 2$ & $11 / 2$ & 23202.09 & .04 \\
\hline $\mathrm{H}_{3} \mathrm{C}^{12} \mathrm{C}^{12}: \mathrm{C}^{12} \mathrm{C}^{12}: \mathrm{C}^{12} \mathrm{D}$ & 4-1192 & $6,3 \leftarrow 5,3$ & Excited & & & 23202.96 & .1 \\
\hline $\mathrm{HC}^{12} \mathrm{O}^{16} \mathrm{O}^{16} \mathrm{H}$ & 3. 71 & $19,3,16 \leftarrow 19,3,17$ & 1 & & & 23203.41 & \\
\hline $\mathrm{C}^{12}{ }_{*} \mathrm{H}_{2}^{\mathrm{b}} \mathrm{S}^{\mathrm{b}} \mathrm{C}^{12}{ }_{*} \mathrm{H}_{2}^{\mathrm{b}}$ & 4- 854 & Not Reported & & & & 23203.6 & .2 \\
\hline $\mathrm{H}_{2} \mathrm{C}^{12}: \mathrm{C}^{12} \mathrm{Cl}^{35} \mathrm{Cl}^{37}$ & 4. 662 & $12,4,8 \leftarrow 12,3,9$ & Ground & & & 23203.8 & .5 \\
\hline $\mathrm{H}_{3} \mathrm{C}^{12} \mathrm{C}^{12}: \mathrm{C}^{12} \mathrm{C}^{12}: \mathrm{C}^{12} \mathrm{D}$ & 4-1192 & $6,4 \leftarrow 5,4$ & Excited. & & & 23204.48 & .1 \\
\hline $\mathrm{H}_{3} \mathrm{C}^{12} \mathrm{C}^{12}: \mathrm{C}^{12} \mathrm{C}^{12}: \mathrm{C}^{12} \mathrm{D}$ & 4-1192 & $6,2 \leftarrow 5,2$ & Excited & & & 23204.48 & .1 \\
\hline $\mathrm{H}_{3} \mathrm{C}^{12} \mathrm{C}^{12}: \mathrm{C}^{12} \mathrm{C}^{12}: \mathrm{C}^{12} \mathrm{D}$ & 4-1192 & $6,3 \leftarrow 5,3$ & Excited & & & 23205.54 & .1 \\
\hline $\mathrm{H}_{3} \mathrm{C}^{12} \mathrm{C}^{12}: \mathrm{C}^{12} \mathrm{C}^{12}: \mathrm{C}^{12} \mathrm{D}$ & 4-1192 & $6,1 \leftarrow 5,1$ & Excited & & & 23205.54 & .1 \\
\hline $\mathrm{C}^{12} \mathrm{D}_{3} \mathrm{C}^{12}: \mathrm{C}^{12} \mathrm{Cl}^{37}$ & 4- 974 & $6,4 \leftarrow 5,4$ & Ground & $13 / 2$ & $11 / 2$ & 23296.22 & .04 \\
\hline $\mathrm{H}_{3} \mathrm{C}^{12} \mathrm{C}^{12}: \mathrm{C}^{12} \mathrm{C}^{12}: \mathrm{C}^{12} \mathrm{D}$ & 4-1192 & $6,2 \leftarrow 5,2$ & Excited & & & 23206.23 & .1 \\
\hline $\mathrm{H}_{3} \mathrm{C}^{12} \mathrm{C}^{12}: \mathrm{C}^{12} \mathrm{C}^{12}: \mathrm{C}^{12} \mathrm{D}$ & 4-1192 & $6,0 \leftarrow 5,0$ & Excited & & & 23206.23 & .1 \\
\hline $\mathrm{D}_{2} \mathrm{O}_{2}^{16}$ & $3-\quad 42$ & Not Reported & & & & 23207. & 3. \\
\hline $\mathrm{C}^{13}{ }_{*} \mathrm{H}: \mathrm{C}^{12} \mathrm{HO}^{16} \mathrm{C}^{12} \mathrm{H}: \mathrm{C}^{12}{ }_{*} \mathrm{H}$ & 4-1157 & $2,0,2 \leftarrow 1,0,1$ & Ground & & & 23207.2 & .1 \\
\hline $\mathrm{DC}^{12} \mathrm{~N}^{15}$ & 4- 296 & $11 \leftarrow 11$ & Excited & & & 23207.45 & .2 \\
\hline $\mathrm{H}_{2} \mathrm{C}^{12}: \mathrm{C}^{12} \mathrm{~F}_{2}^{19}$ & 4. 681 & Not Reported & & & & 23208.1 & .3 \\
\hline $\mathrm{C}^{12} \mathrm{D}_{3} \mathrm{C}^{12}: \mathrm{C}^{12} \mathrm{Cl}^{37}$ & 4- 974 & $6,4 \leftarrow 5,4$ & Ground & $11 / 2$ & $9 / 2$ & 23208.34 & .04 \\
\hline $\mathrm{C}^{12} \mathrm{D}_{3} \mathrm{C}^{12}: \mathrm{C}^{12} \mathrm{Cl}^{37}$ & 4. 974 & $6,3 \leftarrow 5,3$ & Ground & $13 / 2$ & $11 / 2$ & 23209.48 & .04 \\
\hline $\mathrm{C}^{12} \mathrm{H}_{2}\left(\mathrm{C}^{12} \mathrm{~N}^{14}\right)_{2}$ & 4- 901 & Not Reported & Ground & & & 23210 . & .1 \\
\hline $\mathrm{C}^{12} \mathrm{D}_{3} \mathrm{C}^{12}: \mathrm{C}^{12} \mathrm{Cl}^{37}$ & 4. 974 & $6,3 \leftarrow 5,3$ & Ground & $11 / 2$ & $9 / 2$ & 23210.33 & .04 \\
\hline $\mathrm{C}^{12} \mathrm{H}_{2}: \mathrm{C}^{13} \mathrm{HBr}^{81}$ & 4- 738 & $3,1,3 \leftarrow 2,1,2$ & Ground & $7 / 2$ & $5 / 2$ & 23210.6 & \\
\hline $\mathrm{C}^{\mathrm{b}} \mathrm{H}_{2}: \mathrm{C}^{\mathrm{b}} \mathrm{HBr}^{\mathrm{b}}$ & 4. 752 & Not Reported & Ground & $5 / 2$ & $3 / 2$ & 23212.1 & \\
\hline $1 \mathrm{C}^{13} \cdot \mathrm{C}_{6}^{12} \mathrm{H}_{5} \mathrm{C}^{12} \mathrm{~N}^{14}$ & 4-1297 & $9,0,9 \leftarrow 8,0,8$ & Ground & & & 23212.6 & .1 \\
\hline $\mathrm{C}^{12}{ }_{*} \mathrm{H}: \mathrm{C}^{12} \mathrm{HO}^{16} \mathrm{C}^{12} \mathrm{H}: \mathrm{C}^{12}{ }_{*} \mathrm{H}$ & 4-1151 & $5,3,2 \leftarrow 5,3,3$ & Ground & & & 23213.45 & \\
\hline $\mathrm{t}-\mathrm{C}^{12} \mathrm{HD}: \mathrm{C}^{12} \mathrm{DBr}^{79}$ & 4. 745 & $3,1,2 \leftarrow 2,1,1$ & Ground & $5 / 2$ & $5 / 2$ & 23213.5 & .1 \\
\hline $\mathrm{C}^{12} \mathrm{D}_{3} \mathrm{C}^{12}: \mathrm{C}^{12} \mathrm{Cl}^{37}$ & 4. 974 & $6,0 \leftarrow 5,0$ & Ground & $13 / 2$ & $11 / 2$ & 23213.64 & .04 \\
\hline $\mathrm{C}^{12} \mathrm{D}_{3} \mathrm{C}^{12}: \mathrm{C}^{12} \mathrm{Cl}^{37}$ & 4. 974 & $6,0 \leftarrow 5,0$ & Ground & $15 / 2$ & $13 / 2$ & 23213.64 & .04 \\
\hline $\mathrm{C}^{12}{ }_{*} \mathrm{D}_{2} \mathrm{~S}^{32} \mathrm{C}^{12}{ }_{*} \mathrm{D}_{2}$ & 4- 853 & $4,1,4 \leftarrow 4,1,3$ & Ground & & & 23214.3 & .2 \\
\hline $\mathrm{C}^{12} \mathrm{H}_{3} \mathrm{C}^{12} \mathrm{H}_{2} \mathrm{I}^{127}$ & 3- 571 & $4,3,1 \leftarrow 3,3,0$ & Ground & $13 / 2$ & $11 / 2$ & 23214.30 & .05 \\
\hline
\end{tabular}




\begin{tabular}{|c|c|c|c|c|c|c|c|}
\hline Isotopic Species & $\begin{array}{l}\text { Vol.-Id. } \\
\text { Nos. }\end{array}$ & $\begin{array}{c}\text { Rotational } \\
\text { Quantum Nos. }\end{array}$ & Vib. State & $\mathrm{F}_{1}^{\prime} \mathrm{F}^{\prime}$ & $\underset{F_{1}}{\mathrm{rfine}} \mathrm{F}$ & $\begin{array}{l}\text { Frequency } \\
\mathrm{MHz}\end{array}$ & $\begin{aligned} & \text { Acc. } \\
\pm & \mathrm{MHz}\end{aligned}$ \\
\hline $\mathrm{C}^{12} \mathrm{H}_{3} \mathrm{C}^{12} \mathrm{H}_{2} \mathrm{I}^{127}$ & 3- 571 & $4,3,2 \leftarrow 3,3,1$ & Ground & $13 / 2$ & $11 / 2$ & 23214.30 & .05 \\
\hline $\mathrm{C}^{12} \mathrm{D}_{3} \mathrm{C}^{12}: \mathrm{C}^{12} \mathrm{Cl}^{37}$ & 4- 974 & $6,3 \leftarrow 5,3$ & Ground & $9 / 2$ & $7 / 2$ & 23214.38 & .04 \\
\hline $\mathrm{C}^{12}{ }_{*} \mathrm{H}_{2}^{\mathrm{b}} \mathrm{S}^{\mathrm{b}} \mathrm{C}^{12}{ }_{*} \mathrm{H}_{2}^{\mathrm{b}}$ & 4. 854 & Not Reported & & & & 23215.2 & .2 \\
\hline $\mathrm{c}-\mathrm{C}^{12} \mathrm{HD}: \mathrm{C}^{12} \mathrm{HBr}^{79}$ & 4. 739 & $3,2,2 \leftarrow 2,2,1$ & Ground & $5 / 2$ & $5 / 2$ & 23215.2 & .2 \\
\hline$c-\mathrm{C}^{12} \mathrm{HD}: \mathrm{C}^{12} \mathrm{HBr}^{79}$ & 4. 739 & $3,2,2 \leftarrow 2,2,1$ & Ground & $7 / 2$ & $5 / 2$ & 23215.2 & .2 \\
\hline $\mathrm{H}_{2} \mathrm{C}^{12}: \mathrm{C}^{12} \mathrm{~F}_{2}^{19}$ & 4- 681 & Not Reported & & & & 23215.3 & .3 \\
\hline $\mathrm{C}^{12} \mathrm{D}_{3} \mathrm{C}^{12}: \mathrm{C}^{12} \mathrm{Cl}^{37}$ & 4- 974 & $6,4 \leftarrow 5,4$ & Ground & $9 / 2$ & $7 / 2$ & 23215.53 & .04 \\
\hline $\mathrm{S}^{32} \mathrm{O}^{16} \mathrm{~F}_{2}^{19}$ & $4 \cdot 1621$ & $2,1,2 \leftarrow 1,1,1$ & Ground & & & 23216.06 & .1 \\
\hline $\mathrm{C}^{12} \mathrm{D}_{3} \mathrm{C}^{12}: \mathrm{C}^{12} \mathrm{Cl}^{37}$ & 4- 974 & $6,5 \leftarrow 5,5$ & Ground & $9 / 2$ & $7 / 2$ & 23217.02 & .04 \\
\hline $\mathrm{C}^{12}{ }_{*} \mathrm{H}_{2} \mathrm{~N}^{14} \mathrm{DC}^{12}{ }_{*} \mathrm{H}_{2}$ & 4- 862 & $3,2,1 \leftarrow 3,2,2$ & Ground & & & 23217.1 & .5 \\
\hline $\mathrm{H}_{3} \mathrm{C}^{12} \mathrm{C}^{12}: \mathrm{C}^{12} \mathrm{C}^{12}: \mathrm{C}^{12} \mathrm{D}$ & 4-1192 & $6,1 \leftarrow 5,1$ & Excited & & & 23218.17 & .1 \\
\hline $\mathrm{C}^{12} \mathrm{O}^{16} \mathrm{Cl}_{2}^{35}$ & 4. 181 & $4,3,1 \leftarrow 4,2,2$ & Ground & & & 23218.36 & .1 \\
\hline $\mathrm{HC}^{13}: \mathrm{C}^{12} \mathrm{C}^{12} \mathrm{DO}^{16}$ & 4- 922 & Not Reported & & & & 23219. & 5. \\
\hline $\mathrm{C}^{12} \mathrm{HD}: \mathrm{C}^{12} \mathrm{DBr}^{\mathrm{b}}$ & 4. 749 & Not Reported & & & & 23219.1 & .3 \\
\hline $\mathrm{C}^{12} \mathrm{H}_{3} \mathrm{~N}^{14} \mathrm{H}_{2}$ & 3- 261 & Not Reported & Ground & & & 23219.21 & .1 \\
\hline $\mathrm{Cs}^{133} \mathrm{Br}^{81}$ & $1-$ & $11 \leftarrow 10$ & Excited & & & 23220.22 & 0.20 \\
\hline $\mathrm{t} \cdot \mathrm{C}^{12} \mathrm{HD}: \mathrm{C}^{12} \mathrm{DBr}^{79}$ & 4- 745 & $3,1,2 \leftarrow 2,1,1$ & Ground & $3 / 2$ & $1 / 2$ & 23221.3 & .1 \\
\hline $\mathrm{t}-\mathrm{C}^{12} \mathrm{HD}: \mathrm{C}^{12} \mathrm{DBr}^{79}$ & 4- 745 & $3,1,2 \leftarrow 2,1,1$ & Ground & $9 / 2$ & $7 / 2$ & 23222.6 & .1 \\
\hline c- $\mathrm{C}^{12} \mathrm{HD}: \mathrm{C}^{12} \mathrm{HBr}^{79}$ & 4. 739 & $3,2,1 \leftarrow 2,2,0$ & Ground & $5 / 2$ & $5 / 2$ & 23222.6 & .2 \\
\hline $\mathrm{c}-\mathrm{C}^{12} \mathrm{HD}: \mathrm{C}^{12} \mathrm{HBr}^{79}$ & 4- 739 & $3,2,1 \leftarrow 2,2,0$ & Ground & $7 / 2$ & $5 / 2$ & 23222.6 & .2 \\
\hline $\mathrm{C}^{\mathrm{b}}{ }_{*} \mathrm{H}_{2}^{\mathrm{b}} \mathrm{N}^{\mathrm{b}} \mathrm{H}^{\mathrm{b}} \mathrm{C}^{\mathrm{b}}{ }_{*} \mathrm{H}_{2}^{\mathrm{b}}$ & 4. 863 & Not Reported & & & & 23223.7 & .5 \\
\hline $\mathrm{C}^{12} \mathrm{H}_{3} \mathrm{P}^{31} \mathrm{H}_{2}$ & 3- 271 & $1,0,1 \leftarrow 0,0,0$ & Ground & & & 23224.6 & .1 \\
\hline $\mathrm{C}^{12} \mathrm{H}_{2}\left(\mathrm{C}^{12} \mathrm{~N}^{14}\right)_{2}$ & 4. 901 & Not Reported & Ground & & & 23224.7 & .1 \\
\hline$\left(\mathrm{C}^{12} \mathrm{H}_{3}\right)_{3} \mathrm{P}^{31}$ & 3- 861 & $2, \leftarrow 1$, & Ground & & & 23225.87 & \\
\hline$\left(\mathrm{C}^{12} \mathrm{H}_{3}\right)_{3} \mathrm{P}^{31}$ & 3- 861 & $2,1 \leftarrow 1,1$ & Excited & & & 23225.87 & .03 \\
\hline $\mathrm{C}_{6}^{12} \mathrm{H}_{5} \mathrm{C}^{12} \mathrm{~N}^{14}$ & $4-1291$ & $9,0,9 \leftarrow 8,0, \overrightarrow{8}$ & Ground & & & 23227.8 & .2 \\
\hline $\mathrm{C}^{12}{ }_{*} \mathrm{H}: \mathrm{C}^{12} \mathrm{HO}^{16} \mathrm{C}^{13} \mathrm{H}: \mathrm{C}^{12}{ }_{*} \mathrm{H}$ & 4-1153 & $8,7,2 \leftarrow 8,6,3$ & Ground & & & 23228.5 & .1 \\
\hline $\mathrm{C}^{13}{ }_{*} \mathrm{H}: \mathrm{C}^{12} \mathrm{HO}^{16} \mathrm{C}^{12} \mathrm{H}: \mathrm{C}^{12}{ }_{*} \mathrm{H}$ & 4.-1157 & $2,1,2 \leftarrow 1,0,1$ & Ground & & & 23228.5 & .1 \\
\hline $\mathrm{In}^{115} \mathrm{Br}^{79}$ & $1-$ & $7 \leftarrow 6$ & Excited & $19 / 211$ & $19 / 211$ & 23228.68 & 0.20 \\
\hline $\operatorname{In}^{115} \mathrm{Br}^{79}$ & 1 . & $7 \leftarrow 6$ & Excited & $19 / 210$ & $19 / 210$ & 23228.68 & 0.20 \\
\hline $\mathrm{H}_{2} \mathrm{~N}^{14} \mathrm{~N}^{14} \mathrm{H}_{2}$ & 3- 51 & Not Reported & & & & 23230.27 & \\
\hline $\mathrm{C}^{12} \mathrm{H}_{3} \mathrm{~S}^{32} \mathrm{H}$ & 3- 221 & Not Reported & Ground & & & 23230.3 & .1 \\
\hline $\mathrm{C}_{8}^{12} \mathrm{H}_{13} \mathrm{Br}^{79}$ & 4-1331 & $16, \leftarrow 15$, & Excited & & & 23231 . & \\
\hline $\mathrm{N}^{14} \mathrm{H}_{3}$ & $4-1771$ & $8,7 \leftarrow 8,7$ & Ground & & & 23232.24 & .02 \\
\hline $\mathrm{C}^{13} \mathrm{H}_{3} \mathrm{C}^{12} \mathrm{H}_{2} \mathrm{~F}^{19}$ & 3- 556 & $6,1,5 \leftarrow 6,1,6$ & Ground & & & 23233.1 & .1 \\
\hline$c-\mathrm{C}^{12} \mathrm{HD}: \mathrm{C}^{12} \mathrm{HBr}^{79}$ & 4. 739 & 3,$0 ; 3 \leftarrow 2,0,2$ & Ground & $7 / 2$ & $7 / 2$ & 23233.3 & .1 \\
\hline $\mathrm{t} \cdot \mathrm{C}^{12} \mathrm{HD}: \mathrm{C}^{12} \mathrm{DBr}^{79}$ & 4. 745 & $3,1,2 \leftarrow 2,1,1$ & Ground & & & 23234.53 & .04 \\
\hline $\mathrm{t}-\mathrm{C}^{12} \mathrm{HD}: \mathrm{C}^{12} \mathrm{DBr}^{79}$ & 4. 745 & $3,1,2 \leftarrow 2,1,1$ & Excited & $7 / 2$ & $5 / 2$ & 23235.6 & .1 \\
\hline $\mathrm{C}^{b} \mathrm{H}_{2}: \mathrm{C}^{b} \mathrm{HBr}^{b}$ & 4- 752 & Not Reported & Excited & $7 / 2$ & $7 / 2$ & 23235.7 & .2 \\
\hline$\left(\mathrm{C}^{12} \mathrm{H}_{3}\right)_{3} \mathrm{P}^{31}$ & 3- 861 & $2, \leftarrow 1$, & Ground & & & 23239.54 & \\
\hline $\mathrm{H}_{2} \mathrm{C}^{12}: \mathrm{C}^{12} \mathrm{Cl}_{2}^{\mathrm{b}}$ & 4. 663 & Not Reported & Ground & & & 23240.0 & 1.5 \\
\hline $\mathrm{C}^{12}{ }_{*} \mathrm{H}: \mathrm{C}^{12} \mathrm{HO}^{16} \mathrm{C}^{13} \mathrm{H}: \mathrm{C}^{12}{ }_{*} \mathrm{H}$ & 4.1153 & $8,7,2 \leftarrow 8,5,3$ & Ground & & & 23240.7 & .1 \\
\hline $\mathrm{g}-\mathrm{C}^{12} \mathrm{H}_{3} \mathrm{C}^{12} \mathrm{H}_{2} \mathrm{C}^{12} \mathrm{H}_{2} \mathrm{Cl}^{37}$ & 3. 774 & $4,1,4 \leftarrow 3,1,3$ & Ground & & & 23242.41 & .2 \\
\hline $\mathrm{C}^{12} \mathrm{D}_{3} \mathrm{C}^{12} \mathrm{O}^{16} \mathrm{Cl}^{35}$ & 3. 363 & $9,3,6 \leftarrow 9,2,7$ & Ground & $21 / 2$ & $21 / 2$ & 23242.90 & \\
\hline $\mathrm{C}^{12} \mathrm{D}_{3} \mathrm{C}^{12} \mathrm{O}^{16} \mathrm{Cl}^{35}$ & 3- 363 & $9,3,6 \leftarrow 9,2,7$ & Ground & $15 / 2$ & $15 / 2$ & 23242.90 & \\
\hline
\end{tabular}




\begin{tabular}{|c|c|c|c|c|c|c|c|c|}
\hline \multirow{2}{*}{ Isotopic Species } & \multirow{2}{*}{$\begin{array}{l}\text { Vol.-Id. } \\
\text { Nos. }\end{array}$} & \multirow{2}{*}{$\begin{array}{c}\text { Rotational } \\
\text { Quantum Nos. }\end{array}$} & \multirow{2}{*}{ Vib. State } & \multicolumn{3}{|c|}{ Hyperfine } & \multirow{2}{*}{$\begin{array}{l}\text { Frequency } \\
\mathrm{MHz}^{-}\end{array}$} & \multirow{2}{*}{$\begin{aligned} & \text { Acc. } \\
& \pm \mathrm{MHz}\end{aligned}$} \\
\hline & & & & $\begin{array}{ll}F_{1}^{\prime} & F^{\prime}\end{array}$ & & $\mathbf{F}$ & & \\
\hline $\mathrm{C}^{12} \mathrm{D}_{3} \mathrm{C}^{12} \mathrm{O}^{16} \mathrm{Cl}^{35}$ & 3- 363 & $9,3,6 \leftarrow 9,2,7$ & Ground & $17 / 2$ & & $17 / 2$ & 23242.90 & \\
\hline $\mathrm{C}^{12} \mathrm{D}_{3} \mathrm{C}^{12} \mathrm{O}^{16} \mathrm{Cl}^{35}$ & 3- 363 & $9,3,6 \leftarrow 9,2,7$ & Ground & $19 / 2$ & & $19 / 2$ & 23242.90 & \\
\hline $\mathrm{HC}^{13}: \mathrm{C}^{12} \mathrm{C}^{12} \mathrm{DO}^{16}$ & 4. 922 & Not Reported & & & & & 23245 . & 5. \\
\hline $\mathrm{Tl}^{203} \mathrm{Br}^{79}$ & 1. & $9 \leftarrow 8$ & Excited & & & & 23246.83 & 0.20 \\
\hline $\mathrm{C}^{13} \mathrm{H}_{2}: \mathrm{C}^{12} \mathrm{HBr}^{79}$ & 4. 735 & $3,2,2 \leftarrow 2,2,1$ & Ground & $7 / 2$ & & $5 / 2$ & 23247.3 & \\
\hline $\mathrm{C}^{12} \mathrm{H}_{2}\left(\mathrm{C}^{12} \mathrm{~N}^{14}\right)_{2}$ & 4. 901 & Not Reported & Ground & & & & 23248.5 & .1 \\
\hline $\mathrm{HDSe}^{80}$ & 4-1757 & $12,6,7 \leftarrow 12,6,6$ & Ground & & & & 23249.8 & \\
\hline $\mathrm{C}^{12} \mathrm{H}_{3} \mathrm{~N}^{14} \mathrm{O}_{2}^{16}$ & 3- 171 & Not Reported & Ground & & & & 23250 . & \\
\hline$\left(\mathrm{C}^{12} \mathrm{H}_{3} \mathrm{C}^{12} \mathrm{H}_{2}\right)_{2} \mathrm{O}^{16}$ & $3 \cdot 1011$ & Not Reported & & & & & 23250 & \\
\hline $\mathrm{C}^{\mathrm{b}}{ }_{*} \mathrm{H}_{2}^{\mathrm{b}} \mathrm{N}^{\mathrm{b}} \mathrm{H}^{\mathrm{b}} \mathrm{C}^{\mathrm{b}}{ }_{*} \mathrm{H}_{2}^{\mathrm{b}}$ & 4- 863 & Not Reported & & & & & 23250 & 10. \\
\hline $\mathrm{C}^{12} \mathrm{H}_{3} \mathrm{P}^{31} \mathrm{H}_{2}$ & 3. 271 & $1,0,1 \leftarrow 0,0,0$ & Ground & & & & 23250.0 & .1 \\
\hline $\mathrm{t}-\mathrm{C}^{12} \mathrm{HD}: \mathrm{C}^{12} \mathrm{DBr}^{79}$ & 4- 745 & $3,1,2 \leftarrow 2,1,1$ & Ground & $7 / 2$ & & $5 / 2$ & 23251.2 & .1 \\
\hline $\mathrm{HDO}_{2}^{16}$ & $3-\quad 43$ & $20, \quad \leftarrow 20$, & & & & & 23252 . & 3. \\
\hline $\mathrm{C}^{\mathrm{b}} \mathrm{H}_{2}: \mathrm{C}^{\mathrm{b}} \mathrm{HBr}^{\mathrm{b}}$ & 4- 752 & $3,2,1 \leftarrow 2,2,0$ & Ground & $7 / 2$ & & $5 / 2$ & 23252.2 & \\
\hline $\mathrm{Tl}^{205} \mathrm{Br}^{79}$ & $1-$ & $9 \leftarrow 8$ & Ground & & & & 23254.06 & 0.05 \\
\hline $\mathrm{C}^{\mathrm{b}} \mathrm{H}_{2}: \mathrm{C}^{\mathrm{b}} \mathrm{HBr}^{\mathrm{b}}$ & 4. 752 & Not Reported & Ground & & & & 23254.8 & \\
\hline $\mathrm{C}^{12}{ }_{*} \mathrm{H}_{2} \mathrm{C}^{12} \mathrm{H}_{2} \mathrm{C}^{12} \mathrm{H}_{2} \mathrm{C}^{12} \mathrm{H}_{2} \mathrm{C}^{12}{ }_{*} \mathrm{O}^{16}$ & 4-1241 & $25,8,17 \leftarrow 25,8,18$ & Ground & & & & 23256. & 5. \\
\hline $\mathrm{C}^{12} \mathrm{H}_{2}: \mathrm{C}^{13} \mathrm{HBr}^{79}$ & 4. 737 & $3,1,3 \leftarrow 2,1,2$ & Ground & $3 / 2$ & & $3 / 2$ & 23256.4 & \\
\hline $\mathrm{C}^{12} \mathrm{H}_{3} \mathrm{~S}^{32} \mathrm{H}$ & 3- 221 & $5,0,5 \leftarrow 4,1,4$ & Ground & & & & 23256.9 & .1 \\
\hline $\mathrm{Cs}^{133} \mathrm{Br}^{79}$ & 1 - & $11 \leftarrow 10$ & Excited & & & & 23259.19 & 0.20 \\
\hline $\mathrm{C}^{12}{ }_{*} \mathrm{H}: \mathrm{C}^{12} \mathrm{HO}^{16} \mathrm{C}^{12} \mathrm{H}: \mathrm{C}^{12}{ }_{*} \mathrm{H}$ & 4-1151 & $2,1,2 \leftarrow 1,1,1$ & Ground & & & & 23259.30 & \\
\hline $\mathrm{C}^{12} \mathrm{H}_{3} \mathrm{~N}^{14} \mathrm{O}_{2}^{16}$ & 3- 171 & Not Reported & Ground & & & & 23260 & \\
\hline $\mathrm{C}^{12} \mathrm{H}_{3} \mathrm{C}^{12} \mathrm{O}^{16} \mathrm{Cl}^{35}$ & 3. 361 & $6,3,3 \leftarrow 6,2,4$ & Ground & $9 / 2$ & & $9 / 2$ & 23260.30 & .2 \\
\hline $\mathrm{Cl}^{37} \mathrm{C}^{13} \mathrm{~N}^{14}$ & 4. 174 & $2 \leftarrow 1$ & Ground & $7 / 2 \quad 9 / 2$ & $5 / 2$ & $7 / 2$ & 23260.31 & \\
\hline $\mathrm{C}^{12} \mathrm{O}^{16} \mathrm{Cl}^{35} \mathrm{Cl}^{37}$ & 4- 182 & $4,1,4 \leftarrow 3,0,3$ & Ground & & & & 23261.0 & .3 \\
\hline $\mathrm{C}^{12} \mathrm{H}_{3} \mathrm{C}^{12} \mathrm{O}^{16} \mathrm{Cl}^{35}$ & 3- 361 & $6,3,3 \leftarrow 6,2,4$ & Ground & $15 / 2$ & & $15 / 2$ & 23261.50 & .2 \\
\hline $\mathrm{C}^{13} \mathrm{H}_{2}: \mathrm{C}^{13} \mathrm{HBr}^{79}$ & 4- 733 & $3,1,2 \leftarrow 2,1,1$ & Ground & $3 / 2$ & & $3 / 2$ & 23261.8 & \\
\hline $\mathrm{H}_{2} \mathrm{C}^{12}: \mathrm{C}^{12} \mathrm{Cl}_{2}^{\mathrm{b}}$ & 4. 663 & Not Reported & Ground & & & & 23262.7 & 1.5 \\
\hline$\left(\mathrm{C}^{12} \mathrm{H}_{3}\right)_{3} \mathrm{P}^{31}$ & 3. 861 & $2,1 \leftarrow 1,1$ & Excited & & & & 23262.8 & \\
\hline $\mathrm{In}^{115} \mathrm{Br}^{79}$ & $1-$ & $7 \leftarrow 6$ & Excited & $19 / 211$ & $17 / 2$ & 10 & 23263.76 & 0.20 \\
\hline $\mathrm{In}^{115} \mathrm{Br}^{79}$ & $1-$ & $7 \leftarrow 6$ & Excited & $21 / 2 \quad 9$ & $19 / 2$ & 8 & 23263.76 & 0.20 \\
\hline $\operatorname{In}^{115} \mathrm{Br}^{79}$ & 1 - & $7 \leftarrow 6$ & Excited & $17 / 2 \quad 8$ & $15 / 2$ & 7 & 23263.76 & 0.20 \\
\hline $\operatorname{In}^{115} \mathrm{Br}^{79}$ & $1-$ & $7 \leftarrow 6$ & Excited & $19 / 210$ & $17 / 2$ & 9 & 23263.76 & 0.20 \\
\hline $\operatorname{In}^{115} \mathrm{Br}^{79}$ & $1-$ & $7 \leftarrow 6$ & Excited & $15 / 29$ & $17 / 2$ & 8 & 23263.76 & 0.20 \\
\hline $\operatorname{In}^{115} \mathrm{Br}^{79}$ & 1 . & $7 \leftarrow 6$ & Excited & $17 / 29$ & $15 / 2$ & 9 & 23263.76 & 0.20 \\
\hline $\mathrm{In}^{115} \mathrm{Br}^{79}$ & $1-$ & $7 \leftarrow 6$ & Excited & $23 / 212$ & $21 / 2$ & 11 & 23263.76 & 0.20 \\
\hline $\mathrm{In}^{115} \mathrm{Br}^{79}$ & $1-$ & $7 \leftarrow 6$ & Excited & $23 / 213$ & $21 / 2$ & 12 & 23263.76 & 0.20 \\
\hline $\operatorname{In}^{115} \mathrm{Br}^{79}$ & 1 - & $7 \leftarrow 6$ & Excited & $23 / 211$ & $21 / 2$ & 10 & 23263.76 & 0.20 \\
\hline $\operatorname{In}^{115} \mathrm{Br}^{79}$ & 1 - & $7 \leftarrow 6$ & Excited & $23 / 210$ & $21 / 2$ & 9 & 23263.76 & 0.20 \\
\hline $\operatorname{In}^{115} \mathrm{Br}^{79}$ & $1-$ & $7 \leftarrow 6$ & Excited & $21 / 210$ & $19 / 2$ & 9 & 23263.76 & 0.20 \\
\hline $\operatorname{In}^{115} \mathrm{Br}^{79}$ & $1-$ & $7 \leftarrow 6$ & Excited & $21 / 211$ & $19 / 2$ & 10 & 23263.76 & 0.20 \\
\hline $\mathrm{In}^{115} \mathrm{Br}^{79}$ & 1 . & $7 \leftarrow 6$ & Excited & $21 / 212$ & $19 / 2$ & 11 & 23263.76 & 0.20 \\
\hline $\mathrm{C}^{12} \mathrm{H}_{2}: \mathrm{C}^{13} \mathrm{HBr}^{81}$ & 4- 738 & $3,1,3 \leftarrow 2,1,2$ & Ground & $7 / 2$ & & $7 / 2$ & 23264.0 & \\
\hline $\mathrm{N}^{14} \mathrm{H}_{2} \mathrm{C}_{2}^{12} \mathrm{H}_{5}$ & 3- 631 & Not Reported & Ground & & & & 23264.16 & .2 \\
\hline
\end{tabular}




\begin{tabular}{|c|c|c|c|c|c|c|c|c|c|}
\hline Isotopic Species & $\begin{array}{l}\text { Vol.-Id. } \\
\text { Nos. }\end{array}$ & $\begin{array}{c}\text { Rotational } \\
\text { Quantum Nos. }\end{array}$ & Vib. State & $\mathrm{F}_{1}^{\prime}$ & $\begin{array}{l}\text { Hype } \\
\mathrm{F}^{\prime}\end{array}$ & $\begin{array}{c}\text { erfine } \\
\mathrm{F}_{1}\end{array}$ & $F$ & $\begin{array}{c}\text { Frequency } \\
\mathrm{MHz}\end{array}$ & $\begin{aligned} & \text { Acc. } \\
\pm & \mathrm{MHz}\end{aligned}$ \\
\hline$\left(\mathrm{C}^{12} \mathrm{H}_{3}\right)_{3} \mathrm{P}^{31}$ & 3. 861 & $2, \leftarrow 1$, & Ground & & & & & 23264.86 & .03 \\
\hline $\mathrm{P}^{\mathrm{b}}\left(\mathrm{C}^{12} \mathrm{~N}^{14}\right)_{3}$ & 4-1111 & $5, \leftarrow 4$, & Ground & & & & & 23265 . & \\
\hline $\mathrm{C}^{12} \mathrm{H}_{3} \mathrm{C}^{12} \mathrm{O}^{16} \mathrm{Cl}^{35}$ & 3- 361 & $6,3,3 \leftarrow 6,2,4$ & Ground & & $11 / 2$ & & $11 / 2$ & 23265.75 & .2 \\
\hline $\mathrm{C}^{12} \mathrm{H}_{3} \mathrm{C}^{12} \mathrm{O}^{16} \mathrm{Cl}^{35}$ & $3-361$ & $6,3,3 \leftarrow 6,2,4$ & Ground & & $13 / 2$ & & $13 / 2$ & 23267.00 & .2 \\
\hline $\mathrm{H}_{2} \mathrm{C}^{12}: \mathrm{C}^{12} \mathrm{~F}_{2}^{19}$ & 4. 681 & Not Reported & & & & & & 23270 . & 1. \\
\hline $\mathrm{C}^{12} \mathrm{H}_{3} \mathrm{C}^{12} \mathrm{O}^{16} \mathrm{C}^{13} \mathrm{~N}^{14}$ & 3- 673 & $4,0,4 \leftarrow 3,1,3$ & Ground & & & & & 23270.4 & .2 \\
\hline $\mathrm{C}^{12} \mathrm{HCl}^{35}: \mathrm{C}^{12} \mathrm{~F}_{2}^{19}$ & 4- 611 & $12,2,10 \leftarrow 12,1,11$ & Ground & & $25 / 2$ & & $25 / 2$ & 23270.9 & .1 \\
\hline $\mathrm{C}^{12} \mathrm{HCl}^{35}: \mathrm{C}^{12} \mathrm{~F}_{2}^{19}$ & 4. 611 & $12,2,10 \leftarrow 12,1,11$ & Ground & & $23 / 2$ & & $23 / 2$ & 23270.9 & .1 \\
\hline$\left(\mathrm{C}^{12} \mathrm{H}_{3}\right)_{3} \mathrm{P}^{31}$ & 3- 861 & $2, \leftarrow 1$ & Excited & & & & & 23271.20 & \\
\hline $\mathrm{C}^{12} \mathrm{HCl}^{35}: \mathrm{C}^{12} \mathrm{~F}_{2}^{19}$ & 4. 611 & $12,2,10 \leftarrow 12,1,11$ & Ground & & $21 / 2$ & & $21 / 2$ & 23272.4 & .1 \\
\hline $\mathrm{C}^{12} \mathrm{HCl}^{35}: \mathrm{C}^{12} \mathrm{~F}_{2}^{19}$ & 4. 611 & $12,2,10 \leftarrow 12,1,11$ & Ground & & $27 / 2$ & & $27 / 2$ & 23272.4 & .1 \\
\hline $\mathrm{C}^{13} \mathrm{H}_{2}: \mathrm{C}^{12} \mathrm{HBr}^{79}$ & 4- 735 & $3,0,2 \leftarrow 2,0,1$ & Ground & & $7 / 2$ & & $7 / 2$ & 23274.0 & \\
\hline$\left(\mathrm{C}^{12} \mathrm{H}_{3}\right)_{2} \mathrm{O}^{16}$ & 3- 591 & Not Reported & Ground & & & & & 23275 . & 20. \\
\hline $\mathrm{HC}^{13}: \mathrm{C}^{12} \mathrm{C}^{12} \mathrm{DO}^{16}$ & 4. 922 & Not Reported & & & & & & 23276. & 5. \\
\hline $\mathrm{C}^{12}{ }_{*} \mathrm{D}: \mathrm{C}^{12} \mathrm{DC}^{12} \mathrm{D}: \mathrm{C}^{12} \mathrm{DN}^{14}{ }_{*} \mathrm{H}$ & 4-1185 & $10,9,2 \leftarrow 10,8,3$ & Ground & & & & & 23277.8 & \\
\hline $\mathrm{H}_{2} \mathrm{C}^{12}{ }_{*} \mathrm{O}^{16} \mathrm{C}^{13}{ }_{*} \mathrm{H}_{2}$ & 4- 842 & $3,2,1 \leftarrow 3,1,2$ & Ground & & & & & 23278.5 & .3 \\
\hline $\mathrm{C}^{12} \mathrm{H}_{3} \mathrm{P}^{31} \mathrm{H}_{2}$ & 3- 271 & $1,0,1 \leftarrow 0,0,0$ & Ground & & & & & 23279.0 & .1 \\
\hline $\operatorname{In}^{115} \mathrm{Br}^{79}$ & 1- & $7 \leftarrow 6$ & Excited & $13 / 2$ & 6 & $13 / 2$ & 6 & 23279.09 & 0.20 \\
\hline $\mathrm{In}^{115} \mathrm{Br}^{79}$ & $1-$ & $7 \leftarrow 6$ & Excited & $5 / 2$ & 4 & $5 / 2$ & 4 & 23279.09 & 0.20 \\
\hline $\mathrm{In}^{115} \mathrm{Br}^{79}$ & $1-$ & $7 \leftarrow 6$ & Excited & $13 / 2$ & 5 & $13 / 2$ & 5 & 23279.09 & 0.20 \\
\hline $\mathrm{In}^{115} \mathrm{Br}^{79}$ & $1-$ & $7 \leftarrow 6$ & Excited & $19 / 2$ & 9 & $17 / 2$ & 8 & 23279.09 & 0.20 \\
\hline $\mathrm{C}^{\mathrm{b}}{ }_{*} \mathrm{H}_{2}^{\mathrm{b}} \mathrm{N}^{\mathrm{b}} \mathrm{H}^{\mathrm{b}} \mathrm{C}^{\mathrm{b}}{ }_{*} \mathrm{H}_{2}^{\mathrm{b}}$ & 4- 863 & Not Reported & & & & & & 23280 . & 10. \\
\hline $\mathrm{C}^{13}{ }_{*} \mathrm{H}: \mathrm{C}^{12} \mathrm{HO}^{16} \mathrm{C}^{12} \mathrm{H}: \mathrm{C}^{12}{ }_{*} \mathrm{H}$ & 4-1157 & $5,4,2 \leftarrow 5,2,3$ & Ground & & & & & 23280.0 & .1 \\
\hline $\mathrm{s}-\mathrm{C}^{12} \mathrm{H}_{2} \mathrm{DC}^{12} \mathrm{O}^{16} \mathrm{~F}^{19}$ & 3- 397 & $7,4,3 \leftarrow 7,4,4$ & Ground & & & & & 23281 & 5. \\
\hline $\mathrm{In}^{115} \mathrm{Br}^{79}$ & $1-$ & $7 \leftarrow 6$ & Excited & $13 / 2$ & 7 & $17 / 2$ & 7 & 23282.61 & 0.20 \\
\hline $\mathrm{In}^{115} \mathrm{Br}^{79}$ & $1-$ & $7 \leftarrow 6$ & Excited & $13 / 2$ & 4 & $13 / 2$ & 4 & 23282.61 & 0.20 \\
\hline $\operatorname{In}^{115} \mathrm{Br}^{79}$ & $1-$ & $7 \leftarrow 6$ & Excited & $13 / 2$ & 3 & $13 / 2$ & 3 & 23282.61 & 0.20 \\
\hline $\mathrm{In}^{115} \mathrm{Br}^{79}$ & $1-$ & $7 \leftarrow 6$ & Excited & $7 / 2$ & 5 & $7 / 2$ & 5 & 23282.61 & 0.20 \\
\hline $\operatorname{In}^{115} \mathrm{Br}^{79}$ & $1-$ & $7 \leftarrow 6$ & Excited & $11 / 2$ & 4 & $11 / 2$ & 4 & 23282.61 & 0.20 \\
\hline $\mathrm{In}^{115} \mathrm{Br}^{79}$ & 1 - & $7 \leftarrow 6$ & Excited & $11 / 2$ & 7 & $11 / 2$ & 7 & 23282.61 & 0.20 \\
\hline $\mathrm{HC}^{12} \mathrm{~N}^{15}$ & 4- 295 & $10 \leftarrow 10$ & Excited & & & & & 23284.1 & .3 \\
\hline $\mathrm{C}^{12} \mathrm{H}_{2}\left(\mathrm{C}^{12} \mathrm{~N}^{14}\right)_{2}$ & 4. 901 & Not Reported & Ground & & & & & 23284.2 & .1 \\
\hline $\operatorname{In}^{115} \mathrm{Br}^{79}$ & $1-$ & $7 \leftarrow 6$ & Excited & $11 / 2$ & 5 & $11 / 2$ & 5 & 23285.37 & 0.20 \\
\hline $\mathrm{In}^{115} \mathrm{Br}^{79}$ & 1 . & $7 \leftarrow 6$ & Excited & $11 / 2$ & 6 & $11 / 2$ & 6 & 23285.37 & 0.20 \\
\hline $\mathrm{In}^{115} \mathrm{Br}^{79}$ & $1-$ & $7 \leftarrow 6$ & Excited & $9 / 2$ & 4 & $9 / 2$ & 4 & 23287.37 & 0.20 \\
\hline $\operatorname{In}^{115} \mathrm{Br}^{79}$ & $1-$ & $7 \leftarrow 6$ & Excited & $9 / 2$ & 5 & $9 / 2$ & 5 & 23287.37 & 0.20 \\
\hline $\mathrm{In}^{115} \mathrm{Br}^{79}$ & $1-$ & $7 \leftarrow 6$ & Excited & $7 / 2$ & 3 & $7 / 2$ & 3 & 23287.37 & 0.20 \\
\hline $\operatorname{In}^{115} \mathrm{Br}^{79}$ & $1-$ & $7 \leftarrow 6$ & Excited & $7 / 2$ & 4 & $7 / 2$ & 4 & 23287.37 & 0.20 \\
\hline $\mathrm{t}-\mathrm{C}^{12} \mathrm{HD}: \mathrm{C}^{12} \mathrm{DBr}^{79}$ & 4. 745 & $3,1,2 \leftarrow 2,1,1$ & Excited & & $7 / 2$ & & $7 / 2$ & 23288.8 & .2 \\
\hline $\mathrm{C}^{12}{ }_{*} \mathrm{H}: \mathrm{C}^{12} \mathrm{HC}^{12} \mathrm{H}: \mathrm{C}^{12} \mathrm{HN}^{14}{ }_{*} \mathrm{H}$ & 4-1181 & $11,10,2 \leftarrow 11,8,3$ & Ground & & & & & 23289.0 & \\
\hline $\mathrm{C}^{\mathrm{b}} \mathrm{H}_{2}: \mathrm{C}^{\mathrm{b}} \mathrm{HBr}^{\mathrm{b}}$ & 4- 752 & Not Reported & Ground & & & & & 23289.2 & \\
\hline $\mathrm{C}^{12} \mathrm{H}_{3} \mathrm{~N}^{14} \mathrm{O}_{2}^{16}$ & 3- 171 & Not Reported & Ground & & & & & 23293.91 & \\
\hline $\mathrm{C}^{12} \mathrm{H}_{2}: \mathrm{C}^{12} \mathrm{HC}^{12} \mathrm{~F}^{19}: \mathrm{C}^{12} \mathrm{H}_{2}$ & 3- 911 & $8,3,5 \leftarrow 8,2,6$ & Ground & & & & & 23294.78 & .03 \\
\hline $\mathrm{C}^{12} \mathrm{H}_{3} \mathrm{C}^{13} \mathrm{H}_{2} \mathrm{~F}^{19}$ & 3. 555 & $2,2,1 \leftarrow 3,1,2$ & Ground & & & & & 23295.7 & .1 \\
\hline$\left(\mathrm{C}^{12} \mathrm{H}_{3}\right)_{3} \mathrm{P}^{31}$ & 3- 861 & $2, \leftarrow 1$ & Excited & & & & & 23295.71 & \\
\hline
\end{tabular}




\begin{tabular}{|c|c|c|c|c|c|c|c|c|}
\hline Isotopic Species & $\begin{array}{l}\text { Vol.-Id. } \\
\text { Nos. }\end{array}$ & $\begin{array}{c}\text { Rotational } \\
\text { Quantum Nos. }\end{array}$ & Vib. State & & $\begin{array}{l}\text { yperfine } \\
\mathrm{F}^{\prime} \quad \mathrm{F}_{1}\end{array}$ & $\mathbf{F}$ & $\begin{array}{c}\text { Frequency } \\
\mathrm{MHz}\end{array}$ & $\begin{aligned} & \text { Acc. } \\
\pm & \mathrm{MHz}\end{aligned}$ \\
\hline $\mathrm{C}^{12} \mathrm{H}_{2}: \mathrm{C}^{12} \mathrm{DBr}^{81}$ & 4. 722 & $3,2,2 \leftarrow 2,2,1$ & Ground & & $3 / 2$ & $1 / 2$ & 23297.2 & \\
\hline $\mathrm{C}^{12} \mathrm{H}_{3} \mathrm{Si}^{30} \mathrm{H}_{2} \mathrm{~F}^{19}$ & 3. 243 & $2,1,2 \leftarrow 1,1,1$ & Ground & & & & 23298.30 & .10 \\
\hline $\mathrm{C}^{13} \mathrm{H}_{2}: \mathrm{C}^{13} \mathrm{HBr}^{79}$ & 4. 733 & $3,1,2 \leftarrow 2,1,1$ & Excited & & $9 / 2$ & $7 / 2$ & 23298.5 & \\
\hline $\mathrm{C}^{12}{ }_{*} \mathrm{H}: \mathrm{C}^{12} \mathrm{HO}^{16} \mathrm{C}^{13} \mathrm{H}_{2} \mathrm{C}^{12}{ }_{*} \mathrm{H}$ & $4 \cdot 1153$ & $9,8,2 \leftarrow 9,7,3$ & Ground & & & & 23299.4 & .1 \\
\hline $\mathrm{Cs}^{133} \mathrm{Br}^{81}$ & $1 \cdot$ & $11 \leftarrow 10$ & Excited & & & & 23299.79 & 0.20 \\
\hline $\mathrm{C}^{12} \mathrm{H}_{3} \mathrm{~N}^{14} \mathrm{H}_{2}$ & 3. 261 & Not Reported & Ground & & & & 23300.79 & .1 \\
\hline $\mathrm{HC}^{12} \mathrm{O}^{18} \mathrm{O}^{16} \mathrm{C}^{12} \mathrm{H}_{3}-\mathrm{E}$ & 3- 514 & $2,0,2 \leftarrow 1,0,1$ & Ground & & & & 23301.71 & .2 \\
\hline $\mathrm{C}^{12} \mathrm{H}_{2}: \mathrm{C}^{13} \mathrm{HBr}^{79}$ & 4- 737 & $3,1,3 \leftarrow 2,1,2$ & Ground & & $5 / 2$ & $5 / 2$ & 23302.9 & \\
\hline $\mathrm{HC}^{12} \mathrm{O}^{18} \mathrm{O}^{16} \mathrm{C}^{12} \mathrm{H}_{3}-\mathrm{A}$ & 3. 513 & $2,0,2 \leftarrow 1,0,1$ & Ground & & & & 23303.55 & .2 \\
\hline $\mathrm{H}_{2} \mathrm{C}^{12}: \mathrm{C}^{12} \mathrm{Cl}_{2}^{35}$ & 4. 661 & $10,4,6 \leftarrow 10,3,7$ & Ground & & & & 23303.7 & .5 \\
\hline $\mathrm{t} \cdot \mathrm{C}^{12} \mathrm{HD}: \mathrm{C}^{12} \mathrm{DBr}^{79}$ & 4. 745 & $3,1,2 \leftarrow 2,1,1$ & Ground & & $7 / 2$ & $7 / 2$ & 23304.8 & .1 \\
\hline $\mathrm{C}^{12}{ }_{*} \mathrm{H}: \mathrm{C}^{12} \mathrm{HO}^{16} \mathrm{C}^{12} \mathrm{H}: \mathrm{C}^{12}{ }_{*} \mathrm{H}$ & $4-1151$ & $4,2,2 \leftarrow 4,2,3$ & Ground & & & & 23305.88 & \\
\hline $\mathrm{C}^{12} \mathrm{H}_{2}: \mathrm{C}^{12} \mathrm{DBr}^{81}$ & 4. 722 & $3,0,3 \leftarrow 2,0,2$ & Ground & & $3 / 2$ & $3 / 2$ & 23306.7 & \\
\hline $\mathrm{C}^{12} \mathrm{H}_{2}: \mathrm{C}^{12} \mathrm{DBr}^{81}$ & 4. 722 & $3,2,1 \leftarrow 2,2,0$ & Ground & & $3 / 2$ & $1 / 2$ & 23306.7 & \\
\hline $\mathrm{C}^{13} \mathrm{H}_{2}: \mathrm{C}^{13} \mathrm{HBr}^{79}$ & 4- 733 & $3,1,2 \leftarrow 2,1,1$ & Ground & & $5 / 2$ & $5 / 2$ & 23307.2 & \\
\hline $\mathrm{In}^{115} \mathrm{Br}^{79}$ & 1 . & $7 \leftarrow 6$ & Ground & $19 / 21$ & $\begin{array}{ll}10 & 19 / 2\end{array}$ & & 23308.30 & 0.20 \\
\hline $\mathrm{In}^{115} \mathrm{Br}^{79}$ & $1-$ & $7 \leftarrow 6$ & Ground & $19 / 21$ & $11 \quad 19 / 2$ & & 23308.30 & 0.20 \\
\hline $\mathrm{C}_{6}^{12} \mathrm{H}_{5} \mathrm{Cl}^{35}$ & $4-1271$ & $9,1,9 \leftarrow 8,1,8$ & Ground & & & & 23308.6 & \\
\hline $\mathrm{C}^{12} \mathrm{H}_{3} \mathrm{~N}^{14} \mathrm{H}_{2}$ & 3- 261 & Not Reported & Ground & & & & 23311.31 & .1 \\
\hline $\mathrm{C}^{12} \mathrm{H}_{2} \mathrm{Cl}_{2}^{35}$ & 4. 341 & $8,2,7 \leftarrow 9,1,8$ & Ground & & & & 23312. & 5. \\
\hline $\mathrm{C}^{12} \mathrm{D}_{3} \mathrm{O}^{16} \mathrm{H}$ & 3- 214 & Not Reported & Ground & & & & 23313.9 & .5 \\
\hline $\mathrm{F}_{2}^{19} \mathrm{O}_{2}^{16}$ & 3. 11 & $4,0,4 \leftarrow 3,1,3$ & Ground & & & & 23314.70 & .1 \\
\hline $\mathrm{C}^{12} \mathrm{H}_{3} \mathrm{P}^{31} \mathrm{H}_{2}$ & 3. 271 & $1,0,1 \leftarrow 0,0,0$ & Ground & & & & 23314.8 & .1 \\
\hline $\mathrm{H}_{2} \mathrm{C}^{12}: \mathrm{C}^{12} \mathrm{Cl}_{2}^{\mathrm{b}}$ & 4. 663 & Not Reported & Ground & & & & 23315.1 & .5 \\
\hline $\mathrm{C}^{12} \mathrm{H}_{3} \mathrm{~N}^{14} \mathrm{H}_{2}$ & 3. 261 & Not Reported & Ground & & & & 23315.55 & .1 \\
\hline $\mathrm{S}^{32} \mathrm{O}^{16} \mathrm{~F}_{2}^{19}$ & 4-1621 & Not Reported & & & & & 23315.91 & .1 \\
\hline $\mathrm{C}^{\mathrm{b}} \mathrm{H}_{2}: \mathrm{C}^{\mathrm{b}} \mathrm{HBr}^{\mathrm{b}}$ & 4- 752 & Not Reported & Ground & & $9 / 2$ & $7 / 2$ & 23316.6 & \\
\hline $\mathrm{C}^{12} \mathrm{H}_{3} \mathrm{C}^{12} \mathrm{O}^{16} \mathrm{O}^{16} \mathrm{H}$ & 3- 491 & Not Reported & & & & & 23317. & 3. \\
\hline $\mathrm{Tl}^{203} \mathrm{Br}^{79}$ & $1-$ & $9 \leftarrow 8$ & Ground & & & & 23317.65 & 0.10 \\
\hline $\mathrm{C}^{12} \mathrm{H}_{2}: \mathrm{C}^{12} \mathrm{DBr}^{\mathrm{b}}$ & 4. 729 & $3, \quad \leftarrow 2, \quad$, & Ground & & & & 23318.0 & .1 \\
\hline $\mathrm{C}^{12} \mathrm{H}_{2}\left(\mathrm{C}^{12} \mathrm{~N}^{14}\right)_{2}$ & 4. 901 & Not Reported & Ground & & & & 23318.2 & .1 \\
\hline $\mathrm{C}^{13} \mathrm{HCl}^{35} \mathrm{~F}_{2}^{19}$ & 4. 253 & $3,2,1 \leftarrow 3,1,3$ & Ground & & & & 23318.61 & .15 \\
\hline g. $\mathrm{C}^{12} \mathrm{H}_{3} \mathrm{C}^{12} \mathrm{H}_{2} \mathrm{C}^{12} \mathrm{H}_{2} \mathrm{Cl}^{35}$ & 3. 773 & $11,2,9 \leftarrow 11,1,10$ & Ground & & & & 23319.44 & .2 \\
\hline $\mathrm{a}-\mathrm{C}^{12} \mathrm{HD}_{2} \mathrm{C}^{12} \mathrm{O}^{16} \mathrm{C}^{12} \mathrm{~N}^{14}$ & 3. 678 & $7,3,4 \leftarrow 7,2,5$ & Ground & & & & 23321.5 & .2 \\
\hline $\mathrm{C}^{12} \mathrm{HDHC}^{12} \mathrm{HDF}^{19}$ & 3- 559 & $6,1,6 \leftarrow 5,2,3$ & Ground & & & & 23322.7 & .1 \\
\hline $\mathrm{H}_{2} \mathrm{C}^{12}: \mathrm{C}^{12} \mathrm{~F}_{2}^{19}$ & 4- 681 & Not Reported & & & & & 23323.0 & .3 \\
\hline $\mathrm{C}^{12}{ }_{*} \mathrm{H}: \mathrm{C}^{12} \mathrm{HO}^{16} \mathrm{C}^{13} \mathrm{H}: \mathrm{C}^{12}{ }_{*} \mathrm{H}$ & $4-1153$ & $9,8,2 \leftarrow 9,6,3$ & Ground & & & & 23323.8 & .1 \\
\hline $\mathrm{C}^{12} \mathrm{H}_{3} \mathrm{P}^{31} \mathrm{H}_{2}$ & 3- 271 & $1,0,1 \leftarrow 0,0,0$ & Ground & & & & 23324.2 & .1 \\
\hline $\mathrm{H}_{2} \mathrm{C}^{12}: \mathrm{C}^{12} \mathrm{Cl}_{2}^{\mathrm{b}}$ & 4. 663 & Not Reported & Ground & & & & 23326.2 & 1.5 \\
\hline $\mathrm{C}^{13} \mathrm{H}_{2}: \mathrm{C}^{13} \mathrm{HBr}^{79}$ & 4- 733 & $3,1,2 \leftarrow 2,1,1$ & Excited & & $7 / 2$ & $5 / 2$ & 23327.6 & \\
\hline $\mathrm{C}^{13} \mathrm{H}_{2}: \mathrm{C}^{13} \mathrm{HBr}^{79}$ & 4- 733 & $3,1,2 \leftarrow 2,1,1$ & Ground & & & & 23328.91 & .06 \\
\hline $\mathrm{In}^{115} \mathrm{Br}^{79}$ & 1 . & $7 \leftarrow 6$ & Ground & $13 / 2$ & $\begin{array}{ll}5 & 11 / 2\end{array}$ & 4 & 23328.97 & 0.20 \\
\hline $\mathrm{In}^{115} \mathrm{Br}^{79}$ & 1 - & $7 \leftarrow 6$ & Ground & $11 / 2$ & $9 / 2$ & 3 & 23328.97 & 0.20 \\
\hline $\mathrm{In}^{115} \mathrm{Br}^{79}$ & $1 \cdot$ & $7 \leftarrow 6$ & Ground & $11 / 2$ & $9 / 2$ & 6 & 23328.97 & 0.20 \\
\hline $\mathrm{C}^{12} \mathrm{H}_{2}: \mathrm{C}^{13} \mathrm{HBr}^{79}$ & 4- 737 & $3,1,3 \leftarrow 2,1,2$ & Ground & & & & 23330.08 & .05 \\
\hline
\end{tabular}




\begin{tabular}{|c|c|c|c|c|c|c|c|c|c|}
\hline \multirow{2}{*}{ Isotopic Species } & \multirow{2}{*}{$\begin{array}{l}\text { Vol.-Id. } \\
\text { Nos. }\end{array}$} & \multirow{2}{*}{$\begin{array}{c}\text { Rotational } \\
\text { Quantum Nos. }\end{array}$} & \multirow{2}{*}{ Vib. State } & \multicolumn{4}{|c|}{ Hyperfine } & \multirow{2}{*}{$\begin{array}{c}\text { Frequency } \\
\mathrm{MHz}\end{array}$} & \multirow{2}{*}{$\begin{aligned} & \text { Acc. } \\
\pm & \mathrm{MHz}\end{aligned}$} \\
\hline & & & & $F_{1}^{\prime}$ & $F^{\prime}$ & $F_{1}$ & $\mathbf{F}$ & & \\
\hline $\mathrm{C}^{12} \mathrm{H}_{3} \mathrm{~N}^{14} \mathrm{O}_{2}^{16}$ & 3. 171 & Not Reported & Ground & & & & & 23330.30 & \\
\hline $\operatorname{In}^{115} \mathrm{Br}^{79}$ & $1-$ & $7 \leftarrow 6$ & Ground & $9 / 2$ & 3 & $7 / 2$ & 2 & 23331.51 & 0.20 \\
\hline In $^{115} \mathrm{Br}^{79}$ & $1-$ & $7 \leftarrow 6$ & Ground & $9 / 2$ & 6 & $7 / 2$ & 5 & 23331.51 & 0.20 \\
\hline $\operatorname{In}^{115} \mathrm{Br}^{79}$ & $1-$ & $7 \leftarrow 6$ & Ground & $7 / 2$ & 2 & $5 / 2$ & 1 & 23331.51 & 0.20 \\
\hline $\operatorname{In}^{115} \mathrm{Br}^{79}$ & 1 - & $7 \leftarrow 6$ & Ground & $7 / 2$ & 5 & $5 / 2$ & 4 & 23331.51 & 0.20 \\
\hline $\mathrm{S}^{32}{ }_{*} \mathrm{DC}^{12}: \mathrm{C}^{12} \mathrm{DC}^{12} \mathrm{D}: \mathrm{C}^{12}{ }_{*} \mathrm{D}$ & $4-1165$ & $6,2,5 \leftarrow 6,2,4$ & Ground & & & & & 23332.0 & .1 \\
\hline $\operatorname{In}^{115} \mathrm{Br}^{79}$ & $1-$ & $7 \leftarrow 6$ & Ground & $15 / 2$ & 6 & $13 / 2$ & 5 & 23334.50 & 0.20 \\
\hline $\operatorname{In}^{115} \mathrm{Br}^{79}$ & 1. & $7 \leftarrow 6$ & Ground & $13 / 2$ & 7 & $11 / 2$ & 6 & 23334.50 & 0.20 \\
\hline $\operatorname{In}^{115} \mathrm{Br}^{79}$ & $1-$ & $7 \leftarrow 6$ & Ground & $13 / 2$ & 8 & $11 / 2$ & 7 & 23334.50 & 0.20 \\
\hline $\operatorname{In}^{115} \mathrm{Br}^{79}$ & 1 . & $7 \leftarrow 6$ & Ground & $7 / 2$ & 4 & $5 / 2$ & 3 & 23334.50 & 0.20 \\
\hline $\operatorname{In}^{115} \mathrm{Br}^{79}$ & 1 . & $7 \leftarrow 6$ & Ground & $7 / 2$ & 3 & $5 / 2$ & 2 & 23334.50 & 0.20 \\
\hline $\mathrm{In}^{115} \mathrm{Br}^{79}$ & $1-$ & $7 \leftarrow 6$ & Ground & $11 / 2$ & 6 & $9 / 2$ & 5 & 23334.50 & 0.20 \\
\hline $\mathrm{In}^{115} \mathrm{Br}^{79}$ & 1 - & $7 \leftarrow 6$ & Ground & $13 / 2$ & 6 & $11 / 2$ & 5 & 23334.50 & 0.20 \\
\hline $\operatorname{In}^{115} \mathrm{Br}^{79}$ & 1 - & $7 \leftarrow 6$ & Ground & $5 / 2$ & 4 & $3 / 2$ & 3 & 23334.50 & 0.20 \\
\hline $\operatorname{In}^{115} \mathrm{Br}^{79}$ & $1-$ & $7 \leftarrow 6$ & Ground & $9 / 2$ & 4 & $7 / 2$ & 3 & 23334.50 & 0.20 \\
\hline $\operatorname{In}^{115} \mathrm{Br}^{79}$ & 1- & $7 \leftarrow 6$ & Ground & $9 / 2$ & 5 & $7 / 2$ & 4 & 23334.50 & 0.20 \\
\hline $\mathrm{In}^{115} \mathrm{Br}^{79}$ & 1 . & $7 \leftarrow 6$ & Ground & $11 / 2$ & 5 & $9 / 2$ & 4 & 23334.50 & 0.20 \\
\hline $\operatorname{In}^{115} \mathrm{Br}^{79}$ & $1-$ & $7 \leftarrow 6$ & Ground & $9 / 2$ & 4 & $7 / 2$ & 3 & 23335.55 & 0.20 \\
\hline $\mathrm{In}^{115} \mathrm{Br}^{79}$ & $1-$ & $7 \leftarrow 6$ & Ground & $15 / 2$ & 6 & $13 / 2$ & 5 & 23335.55 & 0.20 \\
\hline $\operatorname{In}^{115} \mathrm{Br}^{79}$ & 1 . & $7 \leftarrow 6$ & Ground & $9 / 2$ & 5 & $7 / 2$ & 4 & 23335.55 & 0.20 \\
\hline $\mathrm{In}^{115} \mathrm{Br}^{79}$ & $1-$ & $7 \leftarrow 6$ & Ground & $11 / 2$ & 5 & $9 / 2$ & 4 & 23335.55 & 0.20 \\
\hline $\mathrm{In}^{115} \mathrm{Br}^{79}$ & $1-$ & $7 \leftarrow 6$ & Ground & $5 / 2$ & 4 & $3 / 2$ & 3 & 23335.55 & 0.20 \\
\hline $\mathrm{In}^{115} \mathrm{Br}^{79}$ & $1-$ & $7 \leftarrow 6$ & Ground & $7 / 2$ & 3 & $5 / 2$ & 2 & 23335.55 & 0.20 \\
\hline $\operatorname{In}^{115} \mathrm{Br}^{79}$ & 1 - & $7 \leftarrow 6$ & Ground & $7 / 2$ & 4 & $5 / 2$ & 3 & 23335.55 & 0.20 \\
\hline $\operatorname{In}^{115} \mathrm{Br}^{79}$ & $1-$ & $7 \leftarrow 6$ & Ground & $13 / 2$ & 6 & $11 / 2$ & 5 & 23335.55 & 0.20 \\
\hline $\operatorname{In}^{115} \mathrm{Br}^{79}$ & 1 . & $7 \leftarrow 6$ & Ground & $11 / 2$ & 6 & $9 / 2$ & 5 & 23335.55 & 0.20 \\
\hline $\mathrm{In}^{115} \mathrm{Br}^{79}$ & $1-$ & $7 \leftarrow 6$ & Ground & $13 / 2$ & 8 & $11 / 2$ & 7 & 23335.55 & 0.20 \\
\hline $\operatorname{In}^{115} \mathrm{Br}^{79}$ & $1-$ & $7 \leftarrow 6$ & Ground & $13 / 2$ & 7 & $11 / 2$ & 6 & 23335.55 & 0.20 \\
\hline $\mathrm{s}-\mathrm{C}^{12} \mathrm{HD}_{2} \mathrm{C}^{12} \mathrm{O}^{16} \mathrm{~F}^{19}$ & 3- 395 & $2,1,2 \leftarrow 1,1,1$ & Ground & & & & & 23336.00 & .2 \\
\hline$c \cdot \mathrm{HF}^{19} \mathrm{C}^{12}: \mathrm{C}^{12} \mathrm{HF}^{19}$ & 4- 691 & $4,1,3 \leftarrow 4,0,4$ & Ground & & & & & 23336.67 & .05 \\
\hline $\mathrm{C}^{12} \mathrm{H}_{2}: \mathrm{C}^{12} \mathrm{DBr}^{\mathrm{b}}$ & 4- 729 & $3, \quad \leftarrow 2$, & Ground & & & & & 23337.8 & .1 \\
\hline$\left(\mathrm{C}^{12} \mathrm{H}_{3}\right)_{2} \mathrm{C}^{12} \mathrm{O}^{16}$ & 3- 751 & Not Reported & & & & & & 23339. & 5. \\
\hline $\mathrm{HC}^{13}: \mathrm{C}^{12} \mathrm{C}^{12} \mathrm{DO}^{16}$ & 4- 922 & Not Reported & & & & & & 23339 . & 5. \\
\hline $\mathrm{C}_{6}^{12} \mathrm{H}_{5} \mathrm{Cl}^{35}$ & 4-1271 & $8,1,7 \leftarrow 7,1,6-$ & Ground & & & & & 23339 . & 5.0 \\
\hline $\mathrm{C}^{12} \mathrm{H}_{2}: \mathrm{C}^{12} \mathrm{DBr}^{\mathrm{b}}$ & 4- 729 & $3, \quad \leftarrow 2$, & Ground & & & & & 23339.0 & \\
\hline $\mathrm{In}^{115} \mathrm{Br}^{79}$ & 1 - & $7 \leftarrow 6$ & Ground & $15 / 2$ & 7 & $17 / 2$ & 8 & 23339.12 & 0.20 \\
\hline $\operatorname{In}^{115} \mathrm{Br}^{79}$ & $1-$ & $7 \leftarrow 6$ & Ground & $15 / 2$ & 7 & $13 / 2$ & 6 & 23339.12 & 0.20 \\
\hline $\mathrm{In}^{115} \mathrm{Br}^{79}$ & $1-$ & $7 \leftarrow 6$ & Ground & $5 / 2$ & 1 & $3 / 2$ & 0 & 23339.12 & 0.20 \\
\hline $\operatorname{In}^{115} \mathrm{Br}^{79}$ & 1 - & $7 \leftarrow 6$ & Ground & $5 / 2$ & 3 & $3 / 2$ & 2 & 23339.12 & 0.20 \\
\hline $\operatorname{In}^{115} \mathrm{Br}^{79}$ & $1-$ & $7 \leftarrow 6$ & Ground & $5 / 2$ & 2 & $3 / 2$ & 1 & 23339.12 & 0.20 \\
\hline $\operatorname{In}^{115} \mathrm{Br}^{79}$ & $1-$ & $7 \leftarrow 6$ & Ground & $17 / 2$ & 9 & $15 / 2$ & 8 & 23339.12 & 0.20 \\
\hline $\operatorname{In}^{115} \mathrm{Br}^{79}$ & $1-$ & $7 \leftarrow 6$ & Ground & $17 / 21$ & 10 & $15 / 2$ & 9 & 23339.12 & 0.20 \\
\hline $\operatorname{In}^{115} \mathrm{Br}^{79}$ & $1-$ & $7 \leftarrow 6$ & Ground & $19 / 2$ & 9 & $13 / 2$ & 8 & 23339.12 & 0.20 \\
\hline $\mathrm{In}^{115} \mathrm{Br}^{79}$ & 1 . & $7 \leftarrow 6$ & Ground & $15 / 2$ & 8 & $17 / 2$ & 7 & 23339.12 & 0.20 \\
\hline $\operatorname{In}^{115} \mathrm{Br}^{79}$ & $1-$ & $7 \leftarrow 6$ & Ground & $19 / 2$ & 8 & $13 / 2$ & 7 & 23339.12 & 0.20 \\
\hline
\end{tabular}




\begin{tabular}{|c|c|c|c|c|c|c|c|c|}
\hline Isotopic Species & $\begin{array}{l}\text { Vol.-Id. } \\
\text { Nos. }\end{array}$ & $\begin{array}{c}\text { Rotational } \\
\text { Quantum Nos. }\end{array}$ & Vib. State & $\mathrm{F}_{1}^{\prime} \mathrm{F}^{\prime}$ & $\underset{F_{1}}{\text { erfine }}$ & $\mathbf{F}$ & $\begin{array}{c}\text { Frequency } \\
\mathrm{MHz}\end{array}$ & $\begin{aligned} & \text { Acc. } \\
\pm & \mathrm{MHz}\end{aligned}$ \\
\hline $\mathrm{C}^{12} \mathrm{H}_{3} \mathrm{~S}^{32} \mathrm{H}$ & 3- 221 & $2,1, \leftarrow 3,0$, & Ground & & & & 23339.2 & .1 \\
\hline $\mathrm{C}^{\mathrm{b}}{ }_{*} \mathrm{H}_{2}^{\mathrm{b}} \mathrm{N}^{\mathrm{b}} \mathrm{H}^{\mathrm{b}} \mathrm{C}^{\mathrm{b}}{ }_{*} \mathrm{H}_{2}^{\mathrm{b}}$ & 4- 863 & Not Reported & & & & & 23340 . & 10. \\
\hline $\mathrm{Cs}^{133} \mathrm{Br}^{79}$ & $1-$ & $11 \leftarrow 10$ & Excited & & & & 23340.26 & 0.20 \\
\hline $\mathrm{C}^{12} \mathrm{H}_{3} \mathrm{~N}^{14} \mathrm{H}_{2}$ & 3- 261 & $4,2, \leftarrow 5,1$, & Ground & & & & 23340.67 & .04 \\
\hline $\operatorname{In}^{115} \mathrm{Br}^{79}$ & $1-$ & $7 \leftarrow 6$ & Ground & $15 / 27$ & $17 / 2$ & 8 & 23341.01 & 0.20 \\
\hline $\operatorname{In}^{115} \mathrm{Br}^{79}$ & 1 - & $7 \leftarrow 6$ & Ground & $17 / 29$ & $15 / 2$ & 8 & 23341.01 & 0.20 \\
\hline $\operatorname{In}^{115} \mathrm{Br}^{79}$ & $1-$ & $7 \leftarrow 6$ & Ground & $5 / 22$ & $3 / 2$ & 1 & 23341.01 & 0.20 \\
\hline $\operatorname{In}^{115} \mathrm{Br}^{79}$ & 1 - & $7 \leftarrow 6$ & Ground & $17 / 210$ & $15 / 2$ & 9 & 23341.01 & 0.20 \\
\hline $\operatorname{In}^{115} \mathrm{Br}^{79}$ & $1-$ & $7 \leftarrow 6$ & Ground & $5 / 2 \quad 1$ & $3 / 2$ & 0 & 23341.01 & 0.20 \\
\hline $\operatorname{In}^{115} \mathrm{Br}^{79}$ & $1-$ & $7 \leftarrow 6$ & Ground & $19 / 28$ & $13 / 2$ & 7 & 23341.01 & 0.20 \\
\hline $\operatorname{In}^{115} \mathrm{Br}^{79}$ & 1 - & $7 \leftarrow 6$ & Ground & $19 / 29$ & $13 / 2$ & 8 & 23341.01 & 0.20 \\
\hline $\operatorname{In}^{115} \mathrm{Br}^{79}$ & 1 . & $7 \leftarrow 6$ & Ground & $5 / 2 \quad 3$ & $3 / 2$ & 2 & 23341.01 & 0.20 \\
\hline $\operatorname{In}^{115} \mathrm{Br}^{79}$ & $1-$ & $7 \leftarrow 6$ & Ground & $15 / 27$ & $13 / 2$ & 6 & 23341.01 & 0.20 \\
\hline $\operatorname{In}^{115} \mathrm{Br}^{79}$ & $1-$ & $7 \leftarrow 6$ & Ground & $15 / 28$ & $17 / 2$ & 7 & 23341.01 & 0.20 \\
\hline $\mathrm{C}^{12} \mathrm{H}_{3} \mathrm{~N}^{14} \mathrm{H}_{2}$ & 3. 261 & $4,2, \leftarrow 5,1$, & Ground & & & & 23341.31 & .1 \\
\hline $\mathrm{H}_{2}^{\mathrm{b}} \mathrm{C}^{\mathrm{b}} \mathrm{O}^{16} \mathrm{C}^{\mathrm{b}} * \mathrm{H}_{2}^{\mathrm{b}}$ & 4. 846 & Not Reported & Excited & & & & 23341.4 & .3 \\
\hline $\mathrm{C}^{12} \mathrm{H}_{3} \mathrm{Si}^{29} \mathrm{H}_{2} \mathrm{~F}^{19}$ & 3- 242 & $2,1,2 \leftarrow 1,1,1$ & Ground & & & & 23342.66 & .10 \\
\hline $\operatorname{In}^{115} \mathrm{Br}^{79}$ & 1 - & $7 \leftarrow 6$ & Ground & $17 / 29$ & $15 / 2$ & 8 & 23343.33 & 0.20 \\
\hline $\operatorname{In}^{115} \mathrm{Br}^{79}$ & $1-$ & $7 \leftarrow 6$ & Ground & $17 / 29$ & $15 / 2$ & 9 & 23343.33 & 0.20 \\
\hline $\operatorname{In}^{115} \mathrm{Br}^{79}$ & 1 - & $7 \leftarrow 6$ & Ground & $21 / 212$ & $19 / 21$ & 11 & 23343.33 & 0.20 \\
\hline $\operatorname{In}^{115} \mathrm{Br}^{79}$ & $1-$ & $7 \leftarrow 6$ & Ground & $23 / 210$ & $21 / 2$ & 9 & 23343.33 & 0.20 \\
\hline $\operatorname{In}^{115} \mathrm{Br}^{79}$ & $1-$ & $7 \leftarrow 6$ & Ground & $23 / 211$ & $21 / 21$ & 10 & 23343.33 & 0.20 \\
\hline $\mathrm{In}^{115} \mathrm{Br}^{79}$ & 1 - & $7 \leftarrow 6$ & Ground & $23 / 213$ & $21 / 2$ & 12 & 23343.33 & 0.20 \\
\hline $\operatorname{In}^{115} \mathrm{Br}^{79}$ & $1-$ & $7 \leftarrow 6$ & Ground & $15 / 29$ & $17 / 2$ & 8 & 23343.33 & 0.20 \\
\hline $\operatorname{In}^{115} \mathrm{Br}^{79}$ & 1 - & $7 \leftarrow 6$ & Ground & $21 / 210$ & $19 / 2$ & 9 & 23343.33 & 0.20 \\
\hline $\mathrm{In}^{115} \mathrm{Br}^{79}$ & 1 - & $7 \leftarrow 6$ & Ground & $21 / 29$ & $19 / 2$ & 8 & 23343.33 & 0.20 \\
\hline $\operatorname{In}^{115} \mathrm{Br}^{79}$ & $1-$ & $7 \leftarrow 6$ & Ground & $19 / 210$ & $17 / 2$ & 9 & 23343.33 & 0.20 \\
\hline $\operatorname{In}^{115} \mathrm{Br}^{79}$ & $1-$ & $7 \leftarrow 6$ & Ground & $19 / 211$ & $17 / 21$ & 10 & 23343.33 & 0.20 \\
\hline $\operatorname{In}^{115} \mathrm{Br}^{79}$ & 1 - & $7 \leftarrow 6$ & Ground & $21 / 211$ & $19 / 21$ & 10 & 23343.33 & 0.20 \\
\hline $\mathrm{In}^{115} \mathrm{Br}^{79}$ & 1 - & $7 \leftarrow 6$ & Ground & $23 / 212$ & $21 / 21$ & 11 & 23343.33 & 0.20 \\
\hline $\mathrm{Ga}^{71} \mathrm{I}^{127}$ & 1 - & $7 \leftarrow 6$ & Excited & $19 / 29$ & $17 / 2$ & 8 & 23344.45 & 0.30 \\
\hline $\mathrm{Ga}^{71} \mathrm{I}^{127}$ & 1 - & $7 \leftarrow 6$ & Excited & $19 / 28$ & $17 / 2$ & 7 & 23344.45 & 0.30 \\
\hline $\mathrm{Ga}^{71} \mathrm{I}^{127}$ & 1 . & $7 \leftarrow 6$ & Excited & $17 / 29$ & $15 / 2$ & 8 & 23344.45 & 0.30 \\
\hline $\mathrm{Ga}^{71} \mathrm{I}^{127}$ & 1 - & $7 \leftarrow 6$ & Excited & $13 / 28$ & $15 / 2$ & 7 & 23344.45 & 0.30 \\
\hline $\mathrm{Ga}^{71} \mathrm{I}^{127}$ & 1 . & $7 \leftarrow 6$ & Excited & $19 / 211$ & $17 / 2$ & 10 & 23344.45 & 0.30 \\
\hline $\mathrm{Ga}^{71} \mathrm{I}^{127}$ & $1-$ & $7 \leftarrow 6$ & Excited & $19 / 210$ & $17 / 2$ & 9 & 23344.45 & 0.30 \\
\hline $\mathrm{Ga}^{71} I^{127}$ & 1 - & $7 \leftarrow 6$ & Excited & $15 / 29$ & $13 / 2$ & 8 & 23344.45 & 0.30 \\
\hline $\mathrm{Ga}^{71} I^{127}$ & 1 - & $7 \leftarrow 6$ & Excited & $17 / 27$ & $11 / 2$ & 6 & 23344.45 & 0.30 \\
\hline $\mathrm{In}^{115} \mathrm{Br}^{79}$ & l- & $7 \leftarrow 6$ & Ground & $23 / 211$ & $21 / 21$ & 10 & 23345.07 & 0.20 \\
\hline $\operatorname{In}^{115} \mathrm{Br}^{79}$ & $1-$ & $7 \leftarrow 6$ & Ground & $23 / 212$ & $21 / 21$ & & 23345.07 & 0.20 \\
\hline $\operatorname{In}^{115} \mathrm{Er}^{79}$ & 1 - & $7 \leftarrow 6$ & Ground & $15 / 29$ & $17 / 2$ & 8 & 23345.07 & 0.20 \\
\hline $\operatorname{In}^{115} \mathrm{Br}^{79}$ & $1-$ & $7 \leftarrow 6$ & Ground & $21 / 211$ & $19 / 21$ & & 23345.07 & 0.20 \\
\hline $\operatorname{In}^{115} \mathrm{Br}^{79}$ & $1-$ & $7 \leftarrow 6$ & Ground & $23 / 213$ & $21 / 21$ & & 23345.07 & 0.20 \\
\hline $\mathrm{In}^{115} \mathrm{Br}^{79}$ & $1-$ & $7 \leftarrow 6$ & Ground & $21 / 210$ & $19 / 2$ & 9 & 23345.07 & 0.20 \\
\hline $\operatorname{In}^{115} \mathrm{Br}^{79}$ & 1 - & $7 \leftarrow 6$ & Ground & $17 / 29$ & $15 / 2$ & 9 & 23345.07 & 0.20 \\
\hline
\end{tabular}




\begin{tabular}{|c|c|c|c|c|c|c|c|c|}
\hline Isotopic Species & $\begin{array}{l}\text { Vol.-Id. } \\
\text { Nos. }\end{array}$ & $\begin{array}{c}\text { Rotational } \\
\text { Quantum Nos. }\end{array}$ & Vib. State & & $\begin{array}{l}\text { perfine } \\
\mathrm{F}_{1}\end{array}$ & $\mathrm{~F}$ & $\begin{array}{c}\text { Frequency } \\
\mathrm{MHz}\end{array}$ & $\begin{aligned} & \text { Acc. } \\
\pm & \mathrm{MHz}\end{aligned}$ \\
\hline $\mathrm{In}^{115} \mathrm{Br}^{79}$ & 1 . & $7 \leftarrow 6$ & Ground & $21 / 29$ & $19 / 2$ & 8 & 23345.07 & 0.20 \\
\hline $\mathrm{In}^{115} \mathrm{Br}^{79}$ & $1-$ & $7 \leftarrow 6$ & Ground & $19 / 210$ & $17 / 2$ & 9 & 23345.07 & 0.20 \\
\hline $\operatorname{In}^{115} \mathrm{Br}^{79}$ & 1 - & $7 \leftarrow 6$ & Ground & $23 / 210$ & $21 / 2$ & 9 & 23345.07 & 0.20 \\
\hline $\operatorname{In}^{115} \mathrm{Br}^{79}$ & 1 - & $7 \leftarrow 6$ & Ground & $19 / 211$ & $17 / 2$ & 10 & 23345.07 & 0.20 \\
\hline $\mathrm{In}^{115} \mathrm{Br}^{79}$ & $1-$ & $7 \leftarrow 6$ & Ground & $17 / 29$ & $15 / 2$ & 8 & 23345.07 & 0.20 \\
\hline $\mathrm{C}^{\mathrm{b}} \mathrm{H}_{2}: \mathrm{C}^{\mathrm{b}} \mathrm{HBr}^{\mathrm{b}}$ & 4- 752 & Not Reported & Ground & & 12 & $5 / 2$ & 23345.6 & \\
\hline $\mathrm{C}^{12} \mathrm{H}_{2}: \mathrm{C}^{12} \mathrm{DBr}^{81}$ & 4- 722 & $3,2,2 \leftarrow 2,2,1$ & Excited & & 12 & $7 / 2$ & 23345.6 & \\
\hline $\mathrm{C}^{12} \mathrm{H}_{2}: \mathrm{C}^{12} \mathrm{DBr}^{81}$ & 4- 722 & $3,2,2 \leftarrow 2,2,1$ & Excited & & 12 & $7 / 2$ & 23345.6 & \\
\hline $\mathrm{C}^{12}{ }_{*} \mathrm{H}_{2} \mathrm{C}^{12} \mathrm{H}_{2} \mathrm{C}^{12} \mathrm{H}_{2} \mathrm{C}^{12} \mathrm{H}_{2} \mathrm{C}^{12}{ }_{*} \mathrm{O}^{16}$ & $4-1241$ & $4,3,2 \leftarrow 3,3,1$ & Ground & & & & 23346.0 & \\
\hline $\operatorname{In}^{115} \mathrm{Br}^{79}$ & $1-$ & $7 \leftarrow 6$ & Ground & $21 / 212$ & $19 / 2$ & & 23346.51 & 0.20 \\
\hline $\mathrm{In}^{115} \mathrm{Br}^{79}$ & $1-$ & $7 \leftarrow 6$ & Ground & $23 / 210$ & $21 / 2$ & 9 & 23346.51 & 0.20 \\
\hline $\mathrm{In}^{115} \mathrm{Br}^{79}$ & 1 . & $7 \leftarrow 6$ & Ground & $23 / 211$ & $21 / 2$ & & 23346.51 & 0.20 \\
\hline $\mathrm{In}^{115} \mathrm{Br}^{79}$ & $1-$ & $7 \leftarrow 6$ & Ground & $23 / 212$ & $21 / 2$ & & 23346.51 & 0.20 \\
\hline $\mathrm{In}^{115} \mathrm{Br}^{79}$ & $1-$ & $7 \leftarrow 6$ & Ground & $15 / 29$ & $17 / 2$ & 8 & 23346.51 & 0.20 \\
\hline $\mathrm{In}^{115} \mathrm{Br}^{79}$ & 1 . & $7 \leftarrow 6$ & Ground & $17 / 2 \quad 9$ & $15 / 2$ & 9 & 23346.51 & 0.20 \\
\hline $\mathrm{In}^{115} \mathrm{Br}^{79}$ & $1-$ & $7 \leftarrow 6$ & Ground & $17 / 28$ & $15 / 2$ & 7 & 23346.51 & 0.20 \\
\hline $\mathrm{In}^{115} \mathrm{Br}^{79}$ & $1-$ & $7 \leftarrow 6$ & Ground & $19 / 210$ & $17 / 2$ & 9 & 23346.51 & 0.20 \\
\hline $\mathrm{In}^{115} \mathrm{Br}^{79}$ & $1-$ & $7 \leftarrow 6$ & Ground & $21 / 211$ & $19 / 2$ & 10 & 23346.51 & 0.20 \\
\hline $\mathrm{In}^{15} \mathrm{Br}^{79}$ & $1-$ & $7 \leftarrow 6$ & Ground & $21 / 210$ & $19 / 2$ & 9 & 23346.51 & 0.20 \\
\hline $\mathrm{In}^{115} \mathrm{Br}^{79}$ & 1 . & $7 \leftarrow 6$ & Ground & $19 / 211$ & $17 / 2$ & 10 & 23346.51 & 0.20 \\
\hline $\mathrm{In}^{115} \mathrm{Br}^{79}$ & $1-$ & $7 \leftarrow 6$ & Ground & $21 / 2 \quad 9$ & $19 / 2$ & 8 & 23346.51 & 0.20 \\
\hline $\mathrm{In}^{115} \mathrm{Br}^{79}$ & 1 . & $7 \leftarrow 6$ & Ground & $23 / 213$ & $21 / 2$ & 12 & 23346.51 & 0.20 \\
\hline $\mathrm{C}^{12} \mathrm{H}_{3} \mathrm{O}^{16} \mathrm{H}$ & 3. 211 & Not Reported & Ground & & & & 23347.53 & .1 \\
\hline $\mathrm{C}^{12} \mathrm{H}_{2}: \mathrm{C}^{13} \mathrm{HBr}^{79}$ & 4- 737 & $3,1,3 \leftarrow 2,1,2$ & Ground & & 12 & $5 / 2$ & 23347.8 & .3 \\
\hline $\mathrm{C}^{12} \mathrm{H}_{2}\left(\mathrm{C}^{12} \mathrm{~N}^{14}\right)_{2}$ & 4. 901 & Not Reported & Ground & & & & 23349.5 & .1 \\
\hline $\mathrm{H}_{2} \mathrm{C}^{12}: \mathrm{C}^{12} \mathrm{Cl}_{2}^{\mathrm{b}}$ & 4- 663 & Not Reported & Ground & & & & 23350.2 & 1.5 \\
\hline $\mathrm{C}^{12}{ }_{*} \mathrm{H}: \mathrm{C}^{12} \mathrm{HO}^{16} \mathrm{C}^{12} \mathrm{H}: \mathrm{C}^{12}{ }_{*} \mathrm{H}$ & $4-1151$ & $3,1,2 \leftarrow 3,1,3$ & Ground & & & & 23352.47 & \\
\hline $\mathrm{C}^{12} \mathrm{Cl}_{3}^{35} \mathrm{C}^{12} \mathrm{~N}^{14}$ & 4- 581 & $7, \leftarrow 6$, & Excited & & & & 23353.2 & 1.0 \\
\hline$\left(\mathrm{C}^{12} \mathrm{H}_{3}\right)_{2} \mathrm{~S}^{32}$ & 3. 601 & $4,1,3 \leftarrow 4,0,4$ & Ground & & & & 23353.25 & .05 \\
\hline$\left(\mathrm{C}^{12} \mathrm{H}_{3}\right)_{2} \mathrm{~S}^{32}$ & 3- 601 & $4,1,3 \leftarrow 4,0,4$ & Ground & & & & 23353.31 & .05 \\
\hline $\operatorname{In}^{115} \mathrm{Br}^{79}$ & $1-$ & $7 \leftarrow 6$ & Ground & $15 / 28$ & $15 / 2$ & 8 & 23353.40 & 0.20 \\
\hline $\mathrm{In}^{115} \mathrm{Br}^{79}$ & l- & $7 \leftarrow 6$ & Ground & $15 / 2 \quad 6$ & $15 / 2$ & 6 & 23353.40 & 0.20 \\
\hline $\mathrm{In}^{115} \mathrm{Br}^{79}$ & $1-$ & $7 \leftarrow 6$ & Ground & $13 / 28$ & $13 / 2$ & 8 & 23353.40 & 0.20 \\
\hline $\mathrm{In}^{115} \mathrm{Br}^{79}$ & $1-$ & $7 \leftarrow 6$ & Ground & $13 / 27$ & $13 / 2$ & 7 & 23353.40 & 0.20 \\
\hline$\left(\mathrm{C}^{12} \mathrm{H}_{3}\right)_{2} \mathrm{~S}^{32}$ & 3. 601 & $4,1,3 \leftarrow 4,0,4$ & Ground & & & & 23353.64 & .05 \\
\hline$\left(\mathrm{C}^{12} \mathrm{H}_{3}\right)_{2} \mathrm{~S}^{32}$ & 3. 601 & $4,1,3 \leftarrow 4,0,4$ & Ground & & & & 23353.66 & .05 \\
\hline$\left(\mathrm{C}^{12} \mathrm{H}_{3}\right)_{2} \mathrm{~S}^{32}$ & 3- 601 & $4,1,3 \leftarrow 4,0,4$ & Ground & & & & 23354.03 & .05 \\
\hline $\mathrm{C}^{12} \mathrm{H}_{2}: \mathrm{C}^{12} \mathrm{DBr}^{\mathrm{b}}$ & 4. 729 & $3, \quad \leftarrow 2, \quad$, & Ground & & & & 23354.9 & .2 \\
\hline $\mathrm{C}^{12}{ }_{*} \mathrm{H}_{2} \mathrm{~N}^{14} \mathrm{DC}^{12}{ }_{*} \mathrm{H}_{2}$ & 4- 862 & $2,1,1 \leftarrow 2,1,2$ & Ground & & & & 23356.3 & .5 \\
\hline $\mathrm{C}^{12} \mathrm{HCl}^{35}: \mathrm{C}^{12} \mathrm{~F}_{2}^{19}$ & 4. 611 & $5,2,3 \leftarrow 5,1,4$ & Ground & & 12 & $7 / 2$ & 23357.1 & .1 \\
\hline $\mathrm{C}^{12} \mathrm{H}_{2}: \mathrm{C}^{12} \mathrm{DBB}^{81}$ & 4- 722 & $3,0,3 \leftarrow 2,0,2$ & Excited & & 12 & $7 / 2$ & 23358.4 & \\
\hline $\mathrm{C}^{12} \mathrm{H}_{2}: \mathrm{C}^{12} \mathrm{DBBr}^{81}$ & 4- 722 & $3,0,3 \leftarrow 2,0,2$ & Excited & & 12 & $5 / 2$ & 23358.4 & \\
\hline $\operatorname{In}^{115} \mathrm{Br}^{79}$ & $1-$ & $7 \leftarrow 6$ & Ground & $13 / 26$ & $13 / 2$ & 6 & 23358.74 & 0.20 \\
\hline $\mathrm{In}^{115} \mathrm{Br}^{79}$ & $1-$ & $7 \leftarrow 6$ & Ground & $13 / 2 \quad 5$ & $13 / 2$ & 5 & 23358.74 & 0.20 \\
\hline
\end{tabular}




\begin{tabular}{|c|c|c|c|c|c|c|c|c|c|}
\hline Isotopic Species & $\begin{array}{l}\text { Vol.-Id. } \\
\text { Nos. }\end{array}$ & $\begin{array}{c}\text { Rotational } \\
\text { Quantum Nos. }\end{array}$ & Vib. State & $\mathrm{F}_{1}^{\prime}$ & $\begin{array}{l}\text { Hyper } \\
\mathrm{F}^{\prime}\end{array}$ & $\begin{array}{l}\text { rfine } \\
\mathrm{F}_{1}\end{array}$ & F & $\begin{array}{c}\text { Frequency } \\
\mathrm{MHz}\end{array}$ & $\begin{aligned} & \text { Acc. } \\
\pm & \mathrm{MHz}\end{aligned}$ \\
\hline $\mathrm{In}^{115} \mathrm{Br}^{79}$ & $1-$ & $7 \leftarrow 6$ & Ground & $5 / 2$ & 4 & $5 / 2$ & 4 & 23358.74 & 0.20 \\
\hline $\operatorname{In}^{115} \mathrm{Br}^{79}$ & $1-$ & $7 \leftarrow 6$ & Ground & $19 / 2$ & 9 & $17 / 2$ & 8 & 23358.74 & 0.20 \\
\hline $\mathrm{C}^{12}{ }_{*} \mathrm{H}_{2} \mathrm{~N}^{14} \mathrm{DC}^{12}{ }_{*} \mathrm{H}_{2}$ & 4. 862 & $2,1,1 \leftarrow 2,1,2$ & Ground & & & & & 23359.5 & .5 \\
\hline $\mathrm{C}^{12} \mathrm{O}^{16} \mathrm{Cl}_{2}^{35}$ & 4- 181 & $5,2,4 \leftarrow 5,1,5$ & Ground & $13 / 2$ & 5 & $13 / 2$ & 5 & 23359.62 & .1 \\
\hline $\mathrm{C}^{12} \mathrm{H}_{2} \mathrm{~N}^{14} \mathrm{O}^{16} \mathrm{D}$ & 3- 142 & $5,1,4 \leftarrow 5,1,5$ & Ground & & 4 & & 4 & 23360.03 & .10 \\
\hline $\mathrm{C}^{12} \mathrm{H}_{2} \mathrm{~N}^{14} \mathrm{O}^{16} \mathrm{D}$ & $3 \cdot 142$ & $5,1,4 \leftarrow 5,1,5$ & Ground & & 6 & & 6 & 23360.03 & .10 \\
\hline $\mathrm{H}_{2} \mathrm{C}^{12}: \mathrm{C}^{12} \mathrm{~F}_{2}^{19}$ & 4- 681 & Not Reported & & & & & & 23360.4 & .3 \\
\hline $\mathrm{C}^{12} \mathrm{HCl}^{35}: \mathrm{C}^{12} \mathrm{~F}_{2}^{19}$ & 4. 611 & $5,2,3 \leftarrow 5,1,4$ & Ground & & $9 / 2$ & & $9 / 2$ & 23360.5 & .1 \\
\hline $\mathrm{In}^{115} \mathrm{Br}^{79}$ & $1-$ & $7 \leftarrow 6$ & Ground & $13 / 2$ & 7 & $17 / 2$ & 7 & 23361.35 & 0.20 \\
\hline $\mathrm{In}^{115} \mathrm{Br}^{79}$ & $1-$ & $7 \leftarrow 6$ & Ground & $13 / 2$ & 4 & $13 / 2$ & 4 & 23361.35 & 0.20 \\
\hline $\mathrm{In}^{115} \mathrm{Br}^{79}$ & $1-$ & $7 \leftarrow 6$ & Ground & $13 / 2$ & 3 & $13 / 2$ & 3 & 23361.35 & 0.20 \\
\hline $\mathrm{In}^{115} \mathrm{Br}^{79}$ & $1-$ & $7 \leftarrow 6$ & Ground & $11 / 2$ & 7 & $11 / 2$ & 7 & 23361.35 & 0.20 \\
\hline $\mathrm{In}^{115} \mathrm{Br}^{79}$ & $1-$ & $7 \leftarrow 6$ & Ground & $7 / 2$ & 5 & $7 / 2$ & 5 & 23361.35 & 0.20 \\
\hline $\mathrm{In}^{115} \mathrm{Br}^{79}$ & 1 . & $7 \leftarrow 6$ & Ground & $11 / 2$ & 4 & $11 / 2$ & 4 & 23361.35 & 0.20 \\
\hline $\mathrm{C}^{12} \mathrm{H}_{2} \mathrm{~N}^{14} \mathrm{O}^{16} \mathrm{D}$ & 3. 142 & $5,1,4 \leftarrow 5,1,5$ & Ground & & 5 & & 5 & 23362.43 & .10 \\
\hline $\mathrm{In}^{115} \mathrm{Br}^{79}$ & $1-$ & $7 \leftarrow 6$ & Ground & $13 / 2$ & 4 & $13 / 2$ & 4 & 23362.70 & c. 20 \\
\hline $\mathrm{In}^{115} \mathrm{Br}^{79}$ & $1-$ & $7 \leftarrow 6$ & Ground & $13 / 2$ & 7 & $17 / 2$ & 7 & 23362.70 & 0.20 \\
\hline $\operatorname{In}^{115} \mathrm{Br}^{79}$ & 1 - & $7 \leftarrow 6$ & Ground & $13 / 2$ & 31 & $13 / 2$ & 3 & 23362.70 & 0.20 \\
\hline $\mathrm{In}^{115} \mathrm{Br}^{79}$ & $1-$ & $7 \leftarrow 6$ & Ground & $11 / 2$ & 7 & $11 / 2$ & 7 & 23362.70 & 0.20 \\
\hline $\mathrm{In}^{115} \mathrm{Br}^{79}$ & $1-$ & $7 \leftarrow 6$ & Ground & $7 / 2$ & 5 & $7 / 2$ & 5 & 23362.70 & 0.20 \\
\hline $\mathrm{In}^{115} \mathrm{Br}^{79}$ & $1-$ & $7 \leftarrow 6$ & Ground & $11 / 2$ & 4 & $11 / 2$ & 4 & 23362.70 & 0.20 \\
\hline $\mathrm{C}^{12} \mathrm{H}_{3} \mathrm{C}^{12} \mathrm{HO}^{16}$ & 3- 471 & Not Reported & & & & & & 23364.79 & \\
\hline $\mathrm{C}^{12} \mathrm{O}^{16} \mathrm{Cl}_{2}^{35}$ & 4- 181 & $5,2,4 \leftarrow 5,1,5$ & Ground & $13 / 2$ & 7 & $13 / 2$ & 7 & 23364.80 & .1 \\
\hline $\mathrm{C}^{12} \mathrm{O}^{16} \mathrm{Cl}_{2}^{35}$ & 4- 181 & $5,2,4 \leftarrow 5,1,5$ & Ground & 9/2 & 6 & $9 / 2$ & 6 & 23364.80 & .1 \\
\hline $\mathrm{C}^{12} \mathrm{O}^{16} \mathrm{Cl}_{2}^{35}$ & 4- 181 & $5,2,4 \leftarrow 5,1,5$ & Ground & $9 / 2$ & 4 & $9 / 2$ & 4 & 23364.80 & .1 \\
\hline $\mathrm{C}^{12} \mathrm{O}^{16} \mathrm{Cl}_{2}^{35}$ & 4- 181 & $5,2,4 \leftarrow 5,1,5$ & Ground & $9 / 2$ & 3 & $9 / 2$ & 3 & 23364.80 & .1 \\
\hline $\mathrm{C}^{12}{ }_{*} \mathrm{HO}^{16} \mathrm{C}^{12} \mathrm{HC}^{12} \mathrm{H}_{2} \mathrm{C}^{12} \mathrm{H}_{2} \mathrm{C}^{12}{ }_{*} \mathrm{H}_{2}$ & $4-1251$ & $3,2,2 \leftarrow 2,2,1$ & Ground & & & & & 23365. & 5. \\
\hline $\mathrm{C}^{12} \mathrm{HCl}^{35}: \mathrm{C}^{12} \mathrm{~F}_{2}^{19}$ & 4. 611 & $4,1,4 \leftarrow 3,0,3$ & Ground & & $5 / 2$ & & $3 / 2$ & 23365.2 & .1 \\
\hline $\mathrm{C}^{12} \mathrm{HCl}^{35}: \mathrm{C}^{12} \mathrm{~F}_{2}^{19}$ & 4- 611 & $4,1,4 \leftarrow 3,0,3$ & Ground & & $7 / 2$ & & $5 / 2$ & 23365.2 & .1 \\
\hline $\mathrm{In}^{115} \mathrm{Br}^{79}$ & $1-$ & $7 \leftarrow 6$ & Ground & $11 / 2$ & 61 & $11 / 2$ & 6 & 23365.60 & 0.20 \\
\hline $\operatorname{In}^{115} \mathrm{Br}^{79}$ & $1-$ & $7 \leftarrow 6$ & Ground & $11 / 2$ & 51 & $11 / 2$ & 5 & 23365.60 & 0.20 \\
\hline $\mathrm{C}^{12} \mathrm{HCl}^{35}: \mathrm{C}^{12} \mathrm{~F}_{2}^{19}$ & 4. 611 & $4,1,4 \leftarrow 3,0,3$ & Ground & & $9 / 2$ & & $7 / 2$ & 23366.8 & .1 \\
\hline $\mathrm{C}^{12} \mathrm{HCl}^{35}: \mathrm{C}^{12} \mathrm{~F}_{2}^{19}$ & 4- 611 & $4,1,4 \leftarrow 3,0,3$ & Ground & & $11 / 2$ & & $9 / 2$ & 23366.8 & .1 \\
\hline $\operatorname{In}^{115} \mathrm{Br}^{79}$ & $1-$ & $7 \leftarrow 6$ & Ground & $9 / 2$ & 4 & $9 / 2$ & 4 & 23367.97 & 0.20 \\
\hline $\operatorname{In}^{115} \mathrm{Br}^{79}$ & 1. & $7 \leftarrow 6$ & Ground & $9 / 2$ & 5 & $9 / 2$ & 5 & 23367.97 & 0.20 \\
\hline $\operatorname{In}^{115} \mathrm{Br}^{79}$ & 1- & $7 \leftarrow 6$ & Ground & $7 / 2$ & 4 & $7 / 2$ & 4. & 23367.97 & 0.20 \\
\hline $\operatorname{In}^{115} \mathrm{Br}^{79}$ & $1-$ & $7 \leftarrow 6$ & Ground & $7 / 2$ & 3 & $7 / 2$ & 3 & 23367.97 & 0.20 \\
\hline $\mathrm{C}^{12} \mathrm{H}_{2}: \mathrm{C}^{12} \mathrm{DBr}^{81}$ & 4- 722 & $3,2,2 \leftarrow 2,2,1$ & Ground & & $9 / 2$ & & $7 / 2$ & 23368.2 & \\
\hline $\mathrm{C}^{12} \mathrm{H}_{2}: \mathrm{C}^{12} \mathrm{DBr}^{81}$ & 4- 722 & $3,2,2 \leftarrow 2,2,1$ & Ground & & $7 / 2$ & & $7 / 2$ & 23368.2 & \\
\hline $\mathrm{C}^{12} \mathrm{O}^{16} \mathrm{Cl}_{2}^{35}$ & 4. 181 & $5,2,4 \leftarrow 5,1,5$ & Ground & $11 / 2$ & 51 & $11 / 2$ & 5 & 23369.93 & .1 \\
\hline $\mathrm{C}^{12} \mathrm{H}_{3} \mathrm{Si}^{28} \mathrm{H}_{2} \mathrm{~F}^{19}$ & 3- 241 & $2,1,2 \leftarrow 1,1,1$ & Ground & & & & & 23370.40 & .10 \\
\hline $\mathrm{Cl}^{37} \mathrm{C}^{12} \mathrm{~N}^{14}$ & 4- 173 & $2 \leftarrow 1$ & Ground & $3 / 2$ & $5 / 2$ & $1 / 2$ & $3 / 2$ & 23372.72 & \\
\hline $\mathrm{C}^{12} \mathrm{H}_{2}: \mathrm{C}^{12} \mathrm{HBr}^{\mathrm{b}}$ & 4- 751 & $3, \quad \leftarrow 2, \quad$, & Ground & & & & & 23374.4 & .1 \\
\hline $\mathrm{HDO}^{17}$ & $4-1714$ & $3, \quad \leftarrow 2, \quad$, & Ground & & & & & 23374.4 & .05 \\
\hline $\mathrm{C}^{13} \mathrm{H}_{2}: \mathrm{C}^{12} \mathrm{HBr}^{81}$ & 4- 736 & $3,1,2 \leftarrow 2,1,1$ & Excited & & $3 / 2$ & & $3 / 2$ & 23374.7 & .2 \\
\hline
\end{tabular}




\begin{tabular}{|c|c|c|c|c|c|c|c|c|c|}
\hline Isotopic Species & $\begin{array}{l}\text { Vol.-Id. } \\
\text { Nos. }\end{array}$ & $\begin{array}{c}\text { Rotational } \\
\text { Quantum Nos. }\end{array}$ & Vib. State & $\mathrm{F}_{1}^{\prime}$ & $\begin{array}{l}\text { Hyper } \\
\mathrm{F}^{\prime}\end{array}$ & $\mathrm{rfine}_{1}$ & F & $\begin{array}{l}\text { Frequency } \\
\qquad \mathrm{MHz}\end{array}$ & $\begin{aligned} & \text { Acc. } \\
\pm & \mathrm{MHz}\end{aligned}$ \\
\hline $\mathrm{N}^{\mathrm{b}} \mathrm{O}_{2}^{\mathrm{b}} \mathrm{Cl}^{\mathrm{b}}$ & 4-1463 & Not Reported & & & & & & 23376. & \\
\hline $\mathrm{HC}^{13} \mathrm{O}^{16} \mathrm{O}^{16} \mathrm{C}^{12} \mathrm{H}_{3}-\mathrm{E}$ & 3- 509 & $4,1,3 \leftarrow 4,0,4$ & Ground & & & & & 23376.87 & .2 \\
\hline $\mathrm{C}^{12} \mathrm{H}_{2}: \mathrm{C}^{12} \mathrm{DBr}^{81}$ & 4. 722 & $3,2,1 \leftarrow 2,2,0$ & Ground & & $9 / 2$ & & $7 / 2$ & 23377.6 & \\
\hline $\mathrm{C}^{12} \mathrm{H}_{2}: \mathrm{C}^{12} \mathrm{DBr}^{81}$ & 4- 722 & $3,2,1 \leftarrow 2,2,0$ & Ground & & $7 / 2$ & & $7 / 2$ & 23377.6 & \\
\hline $\mathrm{C}^{12} \mathrm{H}_{2}\left(\mathrm{C}^{12} \mathrm{~N}^{14}\right)_{2}$ & 4. 901 & Not Reported & Ground & & & & & 23379. & .1 \\
\hline $\mathrm{Cs}^{133} \mathrm{Br}^{81}$ & 1 . & $11 \leftarrow 10$ & Ground & & & & & 23379.53 & 0.10 \\
\hline $\mathrm{H}_{2} \mathrm{C}^{12}: \mathrm{C}^{12} \mathrm{Cl}_{2}^{\mathrm{b}}$ & 4. 663 & Not Reported & Ground & & & & & 23380.3 & 1. \\
\hline $\mathrm{C}^{12} \mathrm{H}_{2}: \mathrm{C}^{12} \mathrm{DBr}^{81}$ & 4- 722 & $3,0,3 \leftarrow 2,0,2$ & Ground & & $9 / 2$ & & $7 / 2$ & 23381.4 & \\
\hline $\mathrm{C}^{12} \mathrm{H}_{2}: \mathrm{C}^{12} \mathrm{DBr}^{81}$ & 4. 722 & $3,0,3 \leftarrow 2,0,2$ & Ground & & $7 / 2$ & & $5 / 2$ & 23381.4 & \\
\hline $\mathrm{C}^{13} \mathrm{H}_{2}: \mathrm{C}^{13} \mathrm{HBr}^{79}$ & 4- 733 & $3,1,2 \leftarrow 2,1,1$ & Excited & & $7 / 2$ & & $7 / 2$ & 23382.6 & .2 \\
\hline $\mathrm{C}^{12} \mathrm{D}_{3} \mathrm{C}^{12} \mathrm{O}^{16} \mathrm{C}^{37}$ & 3- 364 & $3,1,3 \leftarrow 2,0,2$ & Ground & & $9 / 2$ & & $7 / 2$ & 23382.73 & \\
\hline $\mathrm{C}^{12} \mathrm{H}_{3} \mathrm{Si}^{28} \mathrm{H}_{2} \mathrm{~F}^{19}$ & 3. 241 & Not Reported & & & & & & 23383.04 & .1 \\
\hline $\mathrm{C}_{6}^{12} \mathrm{H}_{5} \mathrm{O}^{16} \mathrm{H}$ & $3-1051$ & $5,4,1 \leftarrow 5,3,2$ & Ground & & & & & 23383.7 & \\
\hline $\mathrm{C}^{12}{ }_{*} \mathrm{H}: \mathrm{C}^{12} \mathrm{HO}^{16} \mathrm{C}^{12} \mathrm{H}: \mathrm{C}^{12}{ }_{*} \mathrm{H}$ & $4-1151$ & $3,2,2 \leftarrow 3,0,3$ & Ground & & & & & 23384.46 & \\
\hline $\mathrm{C}^{12} \mathrm{H}_{2}: \mathrm{C}^{12} \mathrm{DBr}^{81}$ & 4. 722 & $3,0,3 \leftarrow 2,0,2$ & Ground & & & & & 23386.18 & .2 \\
\hline $2,4,6 \mathrm{~d}_{3}-\mathrm{C}_{6}^{12} \mathrm{H}_{5} \mathrm{~F}^{19}$ & $4-1284$ & $10,2,8 \leftarrow 10,2,9$ & Ground & & & & & 23386.2 & .1 \\
\hline $\mathrm{C}^{12} \mathrm{D}_{3} \mathrm{C}^{12} \mathrm{O}^{16} \mathrm{Cl}^{37}$ & 3- 364 & $3,1,3 \leftarrow 2,0,2$ & Ground & & $7 / 2$ & & $5 / 2$ & 23386.40 & \\
\hline $\mathrm{H}_{2} \mathrm{C}^{12}: \mathrm{C}^{12} \mathrm{Cl}_{2}^{\mathrm{b}}$ & 4. 663 & Not Reported & Ground & & & & & 23386.5 & 1.5 \\
\hline $\mathrm{C}^{12} \mathrm{H}_{2}: \mathrm{C}^{12} \mathrm{DBr}^{81}$ & 4- 722 & $3,2,1 \leftarrow 2,2,0$ & Excited & & $3 / 2$ & & $3 / 2$ & 23386.6 & \\
\hline $\mathrm{C}^{12} \mathrm{H}_{2}: \mathrm{C}^{12} \mathrm{DBr}^{81}$ & 4- 722 & $3,2,1 \leftarrow 2,2,0$ & Excited & & $5 / 2$ & & $3 / 2$ & 23386.6 & \\
\hline $\mathrm{HN}^{14} \mathrm{C}^{12} \mathrm{~S}^{32}$ & 4. 311 & $2,1,2 \leftarrow 1,1,0$ & Ground & & & & & 23387. & \\
\hline $\mathrm{HC}^{13} \mathrm{O}^{16} \mathrm{O}^{16} \mathrm{C}^{12} \mathrm{H}_{3}-\mathrm{A}$ & 3- 508 & $4,1,3 \leftarrow 4,0,4$ & Ground & & & & & 23388.31 & .2 \\
\hline $\mathrm{C}^{12} \mathrm{D}_{3} \mathrm{C}^{12} \mathrm{O}^{16} \mathrm{Cl}^{37}$ & 3. 364 & $3,1,3 \leftarrow 2,0,2$ & Ground & & $3 / 2$ & & $3 / 2$ & 23388.60 & \\
\hline $\mathrm{HN}^{14} \mathrm{C}^{13} \mathrm{~S}^{32}$ & 4- 313 & Not Reported & Ground & & & & & 23389. & \\
\hline $\mathrm{Cl}^{37} \mathrm{C}^{12} \mathrm{~N}^{14}$ & 4. 173 & $2 \leftarrow 1$ & Ground & $1 / 2$ & & $1 / 2$ & & 23389.00 & \\
\hline $\mathrm{C}^{12} \mathrm{H}_{2}: \mathrm{C}^{12} \mathrm{DBr}^{\mathrm{b}}$ & 4. 729 & $3, \quad \leftarrow 2, \quad$, & Ground & & & & & 23389.3 & .1 \\
\hline $\mathrm{C}^{12} \mathrm{H}_{3} \mathrm{Si}^{28} \mathrm{H}_{2} \mathrm{~F}^{19}$ & 3- 241 & $2,1,2 \leftarrow 1,1,1$ & Ground & & & & & 23389.50 & .10 \\
\hline $\mathrm{Cl}^{37} \mathrm{C}^{12} \mathrm{~N}^{14}$ & 4- 173 & $2 \leftarrow 1$ & Ground & $5 / 2$ & $5 / 2$ & $3 / 2 \quad 3$ & $3 / 2$ & 23389.61 & \\
\hline $\mathrm{S}^{32} \mathrm{O}^{16} \mathrm{~F}_{2}^{19}$ & $4-1621$ & Not Reported & & & & & & 23389.66 & .1 \\
\hline $\mathrm{Cl}^{37} \mathrm{C}^{12} \mathrm{~N}^{14}$ & 4. 173 & $2 \leftarrow 1$ & Ground & $7 / 2$ & $9 / 2$ & $5 / 27$ & $7 / 2$ & 23390.53 & \\
\hline $\mathrm{Cl}^{37} \mathrm{C}^{12} \mathrm{~N}^{14}$ & 4- 173 & $2 \leftarrow 1$ & Ground & $7 / 2$ & $5 / 2$ & $5 / 23$ & $3 / 2$ & 23390.53 & \\
\hline $\mathrm{C}_{6}^{12} \mathrm{H}_{5} \mathrm{Cl}^{35}$ & 4-1271 & $8,3,5 \leftarrow 7,3,4$ & Ground & & $15 / 2$ & & $13 / 2$ & 23390.7 & .1 \\
\hline $\mathrm{C}_{6}^{12} \mathrm{H}_{5} \mathrm{Cl}^{35}$ & $4-1271$ & $8,3,5 \leftarrow 7,3,4$ & Ground & & $17 / 2$ & & $15 / 2$ & 23390.7 & .1 \\
\hline $\mathrm{H}_{2} \mathrm{C}^{12}: \mathrm{C}^{13} \mathrm{HCl}^{35}$ & 4- 768 & $2,1,1 \leftarrow 1,1,0$ & Ground & & $5 / 2$ & & $3 / 2$ & 23392.21 & .10 \\
\hline $\mathrm{C}_{6}^{12} \mathrm{H}_{5} \mathrm{Cl}^{35}$ & $4-1271$ & $8,3,5 \leftarrow 7,3,4$ & Ground & & $19 / 2$ & & $17 / 2$ & 23392.6 & .1 \\
\hline $\mathrm{C}_{6}^{12} \mathrm{H}_{5} \mathrm{Cl}^{35}$ & $4-1271$ & $8,3,5 \leftarrow 7,3,4$ & Ground & & $13 / 2$ & & $1 / 2$ & 23392.6 & .1 \\
\hline $\mathrm{HC}^{13}: \mathrm{C}^{12} \mathrm{C}^{12} \mathrm{DO}^{16}$ & 4. 922 & Not Reported & & & & & & 23393. & 5. \\
\hline $\mathrm{C}^{13} \mathrm{H}_{2}: \mathrm{C}^{12} \mathrm{HBr}^{81}$ & 4. 736 & Not Reported & Ground & & $3 / 2$ & & $3 / 2$ & 23393.4 & \\
\hline $\mathrm{C}_{6}^{12} \mathrm{H}_{5} \mathrm{~F}^{19}$ & $4-1281$ & $5,2,3 \leftarrow 4,2,2$ & Ground & & & & & 23393.8 & .1 \\
\hline $\mathrm{C}^{12} \mathrm{H}_{3} \mathrm{P}^{31} \mathrm{H}_{2}$ & 3- 271 & $1,0,1 \leftarrow 0,0,0$ & Ground & & & & & 23394.8 & .1 \\
\hline $\mathrm{C}^{\mathrm{b}}{ }_{*} \mathrm{H}_{2}^{\mathrm{b}} \mathrm{N}^{\mathrm{b}} \mathrm{H}^{\mathrm{b}} \mathrm{C}^{\mathrm{b}}{ }_{*} \mathrm{H}_{2}^{\mathrm{b}}$ & 4. 863 & Not Reported & & & & & & 23395. & 10. \\
\hline $\mathrm{C}^{12} \mathrm{H}_{3} \mathrm{P}^{31} \mathrm{H}_{2}$ & 3- 271 & $1,0,1 \leftarrow 0,0,0$ & Ground & & & & & 23395.9 & .1 \\
\hline $\mathrm{C}^{12} \mathrm{H}_{2}: \mathrm{C}^{12} \mathrm{DBr}^{81}$ & 4. 722 & $3,2,2 \leftarrow 2,2,1$ & Ground & & $3 / 2$ & & $3 / 2$ & 23396.9 & \\
\hline $\mathrm{C}^{12} \mathrm{H}_{2}: \mathrm{C}^{12} \mathrm{DBr}^{81}$ & 4. 722 & $3,2,2 \leftarrow 2,2,1$ & Ground & & $5 / 2$ & & $3 / 2$ & 23396.9 & \\
\hline $\mathrm{C}^{12} \mathrm{H}_{2}: \mathrm{C}^{12} \mathrm{DBr}^{81}$ & 4. 722 & $3,2,2 \leftarrow 2,2,1$ & Ground & & & & & 23397.06 & .06 \\
\hline
\end{tabular}




\begin{tabular}{|c|c|c|c|c|c|c|c|c|}
\hline Isotopic Species & $\begin{array}{l}\text { Vol.-Id. } \\
\text { Nos. }\end{array}$ & $\begin{array}{c}\text { Rotational } \\
\text { Quantum Nos. }\end{array}$ & Vib. State & $F_{1}^{\prime}{ }^{H}$ & $\begin{array}{l}\text { Hyperfine } \\
\mathrm{F}^{\prime} \quad \mathrm{F}_{1}\end{array}$ & $\mathrm{~F}$ & $\begin{array}{c}\text { Frequency } \\
\mathrm{MHz}\end{array}$ & $\begin{array}{r}\text { Acc. } \\
\pm \mathrm{MHz}\end{array}$ \\
\hline $\mathrm{C}^{12} \mathrm{H}_{2} \mathrm{Cl}^{35} \mathrm{C}^{12}: \mathrm{C}^{12} \mathrm{H}$ & 4. 991 & $4,0,4 \leftarrow 3,0,3$ & Ground & & & & 23397.48 & \\
\hline $\mathrm{H}_{2} \mathrm{C}^{12}: \mathrm{C}^{12} \mathrm{Cl}_{2}^{\mathrm{b}}$ & 4. 663 & Not Reported & Ground & & & & 23400.0 & 1.5 \\
\hline $\mathrm{s} \cdot \mathrm{C}^{12} \mathrm{HD}_{2} \mathrm{C}^{12} \mathrm{O}^{16} \mathrm{~F}^{19}$ & 3- 395 & $6,3,3 \leftarrow 6,3,4$ & Ground & & & & 23400.00 & .2 \\
\hline $\mathrm{C}^{13} \mathrm{H}_{2}: \mathrm{C}^{13} \mathrm{HBr}^{79}$ & 4. 733 & Not Reported & Ground & & $7 / 2$ & $7 / 2$ & 23400.4 & .2 \\
\hline $\mathrm{C}^{12} \mathrm{H}_{3} \mathrm{C}^{12} \mathrm{O}^{18} \mathrm{C}^{12} \mathrm{~N}^{14}$ & 3. 674 & $9,3,6 \leftarrow 9,2,7$ & Ground & & & & 23401.52 & .2 \\
\hline $\mathrm{Cl}^{37} \mathrm{C}^{12} \mathrm{~N}^{14}$ & 4- 173 & $2 \leftarrow 1$ & Ground & $3 / 2$ & $5 / 2 \quad 3 / 2$ & $5 / 2$ & 23402.47 & \\
\hline $\mathrm{C}^{12}{ }_{*} \mathrm{H}: \mathrm{C}^{12} \mathrm{HO}^{16} \mathrm{C}^{12} \mathrm{H}: \mathrm{C}^{12}{ }_{*} \mathrm{H}$ & 4-1151 & $4,3,2 \leftarrow 4,1,3$ & Ground & & & & 23402.53 & \\
\hline $\mathrm{Si}^{29} \mathrm{D}_{3} \mathrm{Cl}^{35}$ & $4-1445$ & $2, \leftarrow 1$, & Ground & & & & 23402.6 & .3 \\
\hline $\mathrm{C}^{12} \mathrm{H}_{3} \mathrm{C}^{12} \mathrm{O}^{18} \mathrm{C}^{12} \mathrm{~N}^{14}$ & 3- 674 & $9,3,6 \leftarrow 9,2,7$ & Ground & & & & 23403.71 & .2 \\
\hline $\mathrm{C}^{12} \mathrm{H}_{3} \mathrm{C}^{12} \mathrm{O}^{16} \mathrm{O}^{16} \mathrm{H}$ & 3- 491 & Not Reported & & & & & 23405. & 3. \\
\hline $\mathrm{C}^{12} \mathrm{H}_{2}: \mathrm{C}^{12} \mathrm{DBr}^{81}$ & 4- 722 & $3,2,1 \leftarrow 2,2,0$ & Ground & & & & 23406.34 & .3 \\
\hline $\mathrm{H}_{2} \mathrm{C}^{12}: \mathrm{C}^{13} \mathrm{HCl}^{35}$ & 4- 768 & $2,1,1 \leftarrow 1,1,0$ & Ground & & $7 / 2$ & $5 / 2$ & 23406.72 & .10 \\
\hline $\mathrm{C}^{12} \mathrm{H}_{2}\left(\mathrm{C}^{12} \mathrm{~N}^{14}\right)_{2}$ & 4. 901 & Not Reported & Ground & & & & 23406.8 & .1 \\
\hline $\mathrm{C}^{12} \mathrm{H}_{2}: \mathrm{C}^{12} \mathrm{DBr}^{81}$ & 4. 722 & $3,0,3 \leftarrow 2,0,2$ & Ground & & $3 / 2$ & $1 / 2$ & 23407.5 & \\
\hline $\mathrm{C}^{12} \mathrm{H}_{2}: \mathrm{C}^{12} \mathrm{DBr}^{81}$ & 4- 722 & $3,0,3 \leftarrow 2,0,2$ & Ground & & $5 / 2$ & $3 / 2$ & 23407.5 & \\
\hline $\mathrm{C}^{\mathrm{b}} \mathrm{H}_{2}^{\mathrm{b}} \mathrm{Cl}^{\mathrm{b}} \mathrm{F}^{\mathrm{b}}$ & 4- 333 & Not Reported & & & & & 23408.54 & .1 \\
\hline $\mathrm{C}^{12} \mathrm{H}_{2}: \mathrm{C}^{12} \mathrm{DBr}^{81}$ & 4- 722 & $3,2,1 \leftarrow 2,2,0$ & Ground & & $3 / 2$ & $3 / 2$ & 23409.0 & \\
\hline $\mathrm{C}^{12} \mathrm{H}_{2}: \mathrm{C}^{12} \mathrm{DBr}^{81}$ & 4- 722 & $3,2,1 \leftarrow 2,2,0$ & Ground & & $5 / 2$ & $3 / 2$ & 23409.0 & \\
\hline $\mathrm{C}^{12} \mathrm{H}_{3} \mathrm{~N}^{14} \mathrm{H}_{2}$ & 3. 261 & $15,5, \leftarrow 16,4$ & Ground & & & & 23409.16 & .1 \\
\hline $\mathrm{S}^{32} \mathrm{O}^{16} \mathrm{~F}_{2}^{19}$ & 4-1621 & $11,8,3 \leftarrow 11,8,4$ & Ground & & & & 23409.65 & .1 \\
\hline $\mathrm{C}^{12} \mathrm{H}_{2}: \mathrm{C}^{13} \mathrm{HBr}^{79}$ & 4- 737 & $3,1,3 \leftarrow 2,1,2$ & Ground & & $7 / 2$ & $7 / 2$ & 23410.1 & \\
\hline $\mathrm{C}^{12} \mathrm{H}_{3} \mathrm{C}^{12} \mathrm{~F}^{19}: \mathrm{C}^{12} \mathrm{H}_{2}$ & 3- 721 & $10,7,3 \leftarrow 10,6,4$ & Ground & & & & 23411.49 & .1 \\
\hline $\mathrm{H}_{2}^{\mathrm{b}} \mathrm{C}_{*}^{\mathrm{b}} \mathrm{O}^{16} \mathrm{C}^{\mathrm{b}}{ }_{*} \mathrm{H}_{2}^{\mathrm{b}}$ & 4- 846 & Not Reported & Excited & & & & 23412.0 & $: 3$ \\
\hline $\mathrm{C}^{\mathrm{b}}{ }_{*} \mathrm{H}_{2}^{\mathrm{b}} \mathrm{N}^{\mathrm{b}} \mathrm{H}^{\mathrm{b}} \mathrm{C}^{\mathrm{b}}{ }_{*} \mathrm{H}_{2}^{\mathrm{b}}$ & 4. 863 & Not Reported & & & & & 23412.9 & .5 \\
\hline $\mathrm{C}^{12} \mathrm{H}_{2}: \mathrm{C}^{12} \mathrm{DBr}^{79}$ & 4- 721 & $3,2,2 \leftarrow 2,2,1$ & Ground & & $3 / 2$ & $1 / 2$ & 23413.7 & \\
\hline $\mathrm{S}^{32} \mathrm{O}_{2}^{16}$ & $4-1831$ & $5,2,4 \leftarrow 6,1,5$ & Ground & & & & 23414.33 & .03 \\
\hline $\mathrm{C}^{12} \mathrm{H}_{3} \mathrm{C}^{12} \mathrm{H}_{2} \mathrm{I}^{127}$ & 3- 571 & $4,1,3 \leftarrow 3,1,2$ & Ground & & $9 / 2$ & $7 / 2$ & 23414.58 & \\
\hline $\mathrm{C}^{12} \mathrm{H}_{2}\left(\mathrm{C}^{12} \mathrm{~N}^{14}\right)_{2}$ & 4- 901 & Not Reported & Ground & & & & 23414.8 & .1 \\
\hline $\mathrm{C}^{12} \mathrm{H}_{3} \mathrm{O}^{16} \mathrm{H}$ & 3- 211 & Not Reported & Ground & & & & 23415. & 5. \\
\hline $\mathrm{C}^{12} \mathrm{H}_{3} \mathrm{C}^{12} \mathrm{~F}^{19}: \mathrm{C}^{12} \mathrm{H}_{2}$ & 3. 721 & $10,7,3 \leftarrow 10,6,4$ & Ground & & & & 23415.40 & .1 \\
\hline $\mathrm{C}^{12} \mathrm{H}_{3} \mathrm{C}^{12}: \mathrm{C}^{12} \mathrm{C}^{12} \mathrm{H}_{2} \mathrm{Cl}^{35}$ & 3- 901 & $8,1,7 \leftarrow 7,1,6$ & Ground & & & & 23416.04 & .05 \\
\hline $\mathrm{C}^{12} \mathrm{HCl}^{37} \mathrm{~F}_{2}^{19}$ & 4- 252 & $3,2,1 \leftarrow 3,1,3$ & Ground & & & & 23417.65 & .10 \\
\hline $\mathrm{H}_{2} \mathrm{C}^{12}: \mathrm{C}^{12} \mathrm{Cl}_{2}^{\mathrm{b}}$ & 4- 663 & Not Reported & Ground & & & & 23418.5 & 1.5 \\
\hline $\mathrm{C}^{12} \mathrm{H}_{2}\left(\mathrm{C}^{12} \mathrm{~N}^{14}\right)_{2}$ & 4- 901 & Not Reported & Ground & & & & 23420.5 & .1 \\
\hline $\mathrm{C}^{13} \mathrm{H}_{2}: \mathrm{C}^{12} \mathrm{HBr}^{81}$ & 4. 736 & $3,1,2 \leftarrow 2,1,1$ & Excited & & $9 / 2$ & $7 / 2$ & 23420.7 & \\
\hline $\mathrm{O}^{\mathrm{b}} \mathrm{O}^{\mathrm{b}} \mathrm{O}^{\mathrm{b}}$ & $4-1847$ & Not Reported & & & & & 23421. & \\
\hline${ }^{c}-\mathrm{C}^{12} \mathrm{HD}: \mathrm{C}^{12} \mathrm{HBr}^{81}$ & 4. 742 & $3,1,2 \leftarrow 2,1,1$ & Excited & & $3 / 2$ & $3 / 2$ & 23421.1 & .1 \\
\hline $\mathrm{Ga}^{71} \mathrm{I}^{127}$ & 1. & $7 \leftarrow 6$ & Ground & $19 / 21$ & $11 \quad 17 / 21$ & & 23421.95 & 0.20 \\
\hline $\mathrm{Ga}^{71} \mathrm{I}^{127}$ & 1 - & $7 \leftarrow 6$ & Ground & $19 / 2$ & $\begin{array}{ll}8 & 17 / 2\end{array}$ & 7 & 23421.95 & 0.20 \\
\hline $\mathrm{Ga}^{71} I^{127}$ & $1-$ & $7 \leftarrow 6$ & Ground & $17 / 2$ & $\begin{array}{ll}9 & 15 / 2\end{array}$ & 8 & 23421.95 & 0.20 \\
\hline $\mathrm{Ga}^{71} \mathrm{I}^{127}$ & 1 . & $7 \leftarrow 6$ & Ground & $13 / 2$ & $\begin{array}{ll}8 & 15 / 2\end{array}$ & 7 & 23421.95 & 0.20 \\
\hline $\mathrm{Ga}^{71} I^{127}$ & 1 - & $7 \leftarrow 6$ & Ground & $15 / 2$ & $\begin{array}{ll}9 & 13 / 2\end{array}$ & 8 & 23421.95 & 0.20 \\
\hline $\mathrm{Ga}^{71} \mathrm{I}^{127}$ & 1. & $7 \leftarrow 6$ & Ground & $19 / 2$ & $\begin{array}{ll}9 & 17 / 2\end{array}$ & 8 & 23421.95 & 0.20 \\
\hline $\mathrm{Ga}^{71} \mathrm{I}^{127}$ & 1 - & $7 \leftarrow 6$ & Ground & $19 / 210$ & $10 \quad 17 / 2$ & 9 & 23421.95 & 0.20 \\
\hline $\mathrm{Ga}^{71} \mathrm{I}^{127}$ & 1 . & $7 \leftarrow 6$ & Ground & $17 / 2$ & $7 \quad 11 / 2$ & 6 & 23421.95 & 0.20 \\
\hline
\end{tabular}




\begin{tabular}{|c|c|c|c|c|c|c|c|c|}
\hline Isotopic Species & $\begin{array}{l}\text { Vol..Id. } \\
\text { Nos. }\end{array}$ & $\begin{array}{c}\text { Rotational } \\
\text { Quantum Nos. }\end{array}$ & Vib. State & $\mathrm{F}_{1}^{\prime}$ & $\begin{array}{c}\text { Hyperfine } \\
F^{\prime} \quad F_{1}\end{array}$ & $\mathbf{F}$ & $\begin{array}{c}\text { Frequency } \\
\mathrm{MHz}\end{array}$ & $\begin{aligned} & \text { Acc. } \\
\pm & \mathrm{MHz}\end{aligned}$ \\
\hline $\mathrm{N}^{15} \mathrm{H}_{3}$ & $4-1772$ & $5,5 \leftarrow 5,5$ & Ground & & & & 23421.99 & .02 \\
\hline $\mathrm{C}^{12} \mathrm{H}_{3} \mathrm{C}^{12} \mathrm{O}^{16} \mathrm{O}^{16} \mathrm{H}$ & 3- 491 & Not Reported & & & & & 23422 . & 3. \\
\hline $\mathrm{C}^{12} \mathrm{H}_{2}: \mathrm{C}^{12} \mathrm{DBr}^{79}$ & 4. 721 & $3,2,1 \leftarrow 2,2,0$ & Ground & & $3 / 2$ & $1 / 2$ & 23422.25 & \\
\hline $\mathrm{HN}^{14} \mathrm{C}^{12} \mathrm{~S}^{32}$ & 4- 311 & $2,1,2 \leftarrow 1,1,1$ & Ground & & & & 23424.5 & \\
\hline $\mathrm{C}^{12} \mathrm{H}_{3} \mathrm{~N}^{14} \mathrm{H}_{2}$ & 3- 261 & Not Reported & Ground & & & & 23424.70 & .1 \\
\hline $\mathrm{O}^{16} \mathrm{O}^{18} \mathrm{O}^{16}$ & 4-1843 & $16,2,14 \leftarrow 17,1,17$ & Ground & & & & 23425 . & \\
\hline $\mathrm{Rb}^{85} \mathrm{I}^{127}$ & $1-$ & $12 \leftarrow 11$ & Excited & & & & 23425.51 & 0.10 \\
\hline $\mathrm{C}^{12} \mathrm{H}_{3} \mathrm{C}^{12} \mathrm{O}^{16} \mathrm{O}^{16} \mathrm{H}$ & 3. 491 & Not Reported & & & & & 23426 . & 3. \\
\hline $\mathrm{C}^{12} \mathrm{H}_{2}: \mathrm{C}^{12} \mathrm{DBr}^{79}$ & 4- 721 & $3,0,3 \leftarrow 2,0,2$ & Ground & & $3 / 2$ & $3 / 2$ & 23426.2 & \\
\hline $\mathrm{C}^{\mathrm{b}} \mathrm{H}_{2}: \mathrm{C}^{\mathrm{b}} \mathrm{HBr}^{\mathrm{b}}$ & 4- 752 & Not Reported & Ground & & $5 / 2$ & $5 / 2$ & 23426.7 & .2 \\
\hline $\mathrm{HC}^{13}: \mathrm{C}^{12} \mathrm{C}^{12} \mathrm{DO}^{16}$ & 4. 922 & Not Reported & & & & & 23427 . & 5. \\
\hline $\mathrm{C}^{12} \mathrm{H}_{3} \mathrm{C}^{12} \mathrm{H}_{2} \mathrm{C}^{12} \mathrm{~N}^{14}$ & 3. 731 & $1,1,0 \leftarrow 1,0,1$ & Ground & & & & 23428.1 & .2 \\
\hline $\mathrm{H}_{2} \mathrm{C}^{12}: \mathrm{C}^{12} \mathrm{Cl}_{2}^{35}$ & 4. 661 & $12,4,8 \leftarrow 12,3,9$ & Ground & & & & 23428.5 & .5 \\
\hline $\mathrm{C}^{12} \mathrm{H}_{3} \mathrm{C}^{12} \mathrm{H}_{2} \mathrm{O}^{16} \mathrm{H}$ & 3. 581 & Not Reported & & & & & 23428.83 & .01 \\
\hline $\mathrm{C}^{12} \mathrm{H}_{3} \mathrm{C}^{12} \mathrm{O}^{16} \mathrm{O}^{16} \mathrm{H}$ & 3- 491 & Not Reported & & & & & 23429 . & 3. \\
\hline $\mathrm{C}^{12} \mathrm{H}_{2} \mathrm{Cl}^{35} \mathrm{C}^{12}: \mathrm{C}^{12} \mathrm{H}$ & 4. 991 & $4,2,3 \leftarrow 3,2,2$ & Ground & & & & 23429.2 & \\
\hline $\mathrm{C}^{12} \mathrm{H}_{3} \mathrm{~N}^{14} \mathrm{H}_{2}$ & 3. 261 & $15,5, \leftarrow 16,4$, & Ground & & & & 23429.42 & .1 \\
\hline $\mathrm{C}^{12} \mathrm{D}_{2} \mathrm{Cl}^{35} \mathrm{Si}^{28} \mathrm{H}_{3}$ & 3- 235 & $4,1,4 \leftarrow 3,1,3$ & Ground & & & & 23429.48 & .2 \\
\hline $\mathrm{C}^{12} \mathrm{HCl}^{35} \mathrm{~F}_{2}^{19}$ & 4- 251 & $3,2,1 \leftarrow 3,1,3$ & Ground & & & & 23429.85 & .03 \\
\hline $\mathrm{C}^{12} \mathrm{H}_{2}: \mathrm{C}^{12} \mathrm{HBr}^{81}$ & 4. 728 & $3,1,3 \leftarrow 2,1,2$ & Ground & & $3 / 2$ & $3 / 2$ & 23430.8 & \\
\hline $\mathrm{C}^{12} \mathrm{H}_{2}: \mathrm{C}^{12} \mathrm{HBr}^{81}$ & 4. 728 & $3,1,3 \leftarrow 2,1,2$ & Ground & & $3 / 2$ & $3 / 2$ & 23431.00 & \\
\hline $\mathrm{C}^{12} \mathrm{H}_{2}\left(\mathrm{C}^{12} \mathrm{~N}^{14}\right)_{2}$ & 4. 901 & Not Reported & Ground & & & & 23432 . & .1 \\
\hline $\mathrm{H}_{2}^{\mathrm{b}} \mathrm{C}^{\mathrm{b}}{ }_{*} \mathrm{O}^{16} \mathrm{C}^{\mathrm{b}}{ }_{*} \mathrm{H}_{2}^{\mathrm{b}}$ & 4. 846 & Not Reported & Excited & & & & 23432.6 & .3 \\
\hline $\mathrm{C}^{12} \mathrm{H}_{3} \mathrm{~N}^{14} \mathrm{H}_{2}$ & 3- 261 & Not Reported & Ground & & & & 23432.84 & .1 \\
\hline $\mathrm{F}_{2}^{19} \mathrm{O}_{2}^{16}$ & 3. 11 & $6,1,5 \leftarrow 6,0,6$ & Excited & & & & 23433.29 & .1 \\
\hline $\mathrm{C}^{12} \mathrm{HCl}^{35}: \mathrm{C}^{12} \mathrm{~F}_{2}^{19}$ & 4. 611 & $7,0,7 \leftarrow 6,1,6$ & Ground & & & & 23434.2 & .1 \\
\hline $\mathrm{H}_{2} \mathrm{C}^{12}: \mathrm{C}^{12} \mathrm{~F}_{2}^{19}$ & 4. 681 & $7,5,2 \leftarrow 7,5,3$ & Ground & & & & 23435.7 & .3 \\
\hline $\mathrm{F}_{2}^{19} \mathrm{O}_{2}^{16}$ & 3- 11 & $4,0,4 \leftarrow 3,1,3$ & Excited & & & & 23436.63 & .1 \\
\hline$c-\mathrm{C}^{12} \mathrm{HD}: \mathrm{C}^{12} \mathrm{HBr}^{81}$ & 4. 742 & $3,1,2 \leftarrow 2,1,1$ & Ground & & $3 / 2$ & $3 / 2$ & 23437.1 & .1 \\
\hline $\mathrm{C}^{12} \mathrm{H}_{3} \mathrm{C}^{12} \mathrm{H}_{2} \mathrm{I}^{127}$ & 3- 571 & $4,1,3 \leftarrow 3,1,2$ & Ground & & $11 / 2$ & $9 / 2$ & 23438.13 & \\
\hline g. $\mathrm{C}^{12} \mathrm{H}_{3} \mathrm{C}^{12} \mathrm{H}_{2} \mathrm{C}^{12} \mathrm{H}_{2} \mathrm{Cl}^{35}$ & 3. 773 & $5,2,3 \leftarrow 5,1,4$ & Ground & & & & 23438.25 & .2 \\
\hline $\mathrm{C}^{13} \mathrm{H}_{2}: \mathrm{C}^{12} \mathrm{HBr}^{81}$ & 4- 736 & $3,1,2 \leftarrow 2,1,1$ & Ground & & $9 / 2$ & $7 / 2$ & 23438.4 & \\
\hline $\mathrm{C}^{12}{ }_{*} \mathrm{H}: \mathrm{C}^{12} \mathrm{HO}^{16} \mathrm{C}^{12} \mathrm{H}: \mathrm{C}^{12}{ }_{*} \mathrm{H}$ & 4-1151 & $5,4,2 \leftarrow 5,2,3$ & Ground & & & & 23440.06 & \\
\hline $\mathrm{F}_{2}^{19} \mathrm{O}_{2}^{16}$ & 3- 11 & $4,0,4 \leftarrow 3,1,3$ & Ground & & & & 23443.76 & .1 \\
\hline$S^{32} O^{16} F_{2}^{19}$ & 4-1621 & Not Reported & & & & & 23444.36 & .1 \\
\hline $\mathrm{C}^{12} \mathrm{H}_{3} \mathrm{O}^{16} \mathrm{H}$ & 3- 211 & Not Reported & Ground & & & & 23444.82 & .1 \\
\hline $\mathrm{HC}^{13}: \mathrm{C}^{12} \mathrm{C}^{12} \mathrm{DO}^{16}$ & 4- 922 & Not Reported & & & & & 23448 . & 5. \\
\hline $\mathrm{C}^{13} \mathrm{H}_{2}: \mathrm{C}^{12} \mathrm{HBr}^{81}$ & 4- 736 & $3,1,2 \leftarrow 2,1,1$ & Ground & & & & 23448.69 & .08 \\
\hline $\mathrm{C}^{12} \mathrm{H}_{3} \mathrm{~N}^{14} \mathrm{H}_{2}$ & 3- 261 & $6,1, \leftarrow 5,2$, & Ground & & & & 23449.39 & 1 \\
\hline $\mathrm{C}_{8}^{12} \mathrm{H}_{13} \mathrm{Cl}^{37}$ & $4-1342$ & $11, \leftarrow 10$ & Ground & & & & 23449.6 & \\
\hline $\mathrm{C}^{12} \mathrm{H}_{3} \mathrm{~N}^{14} \mathrm{H}_{2}$ & 3. 261 & $6,1, \leftarrow 5,2$, & Ground & & & & 23449.65 & .1 \\
\hline $\mathrm{C}^{12} \mathrm{O}^{16} \mathrm{Cl}^{35} \mathrm{Cl}^{37}$ & 4- 182 & $4,3,1 \leftarrow 4,2,2$ & Ground & & & & 23449.9 & .3 \\
\hline $\mathrm{C}^{12} \mathrm{H}_{3} \mathrm{O}^{16} \mathrm{H}$ & 3- 211 & Not Reported & Ground & & & & 23450 & 5. \\
\hline $\mathrm{C}^{12} \mathrm{DH}_{2} \mathrm{C}^{12} \mathrm{HDF}^{19}$ & 3- 562 & $1,1,0 \leftarrow 1,0,1$ & Ground & & & & 23450.0 & .1 \\
\hline $\mathrm{C}^{12} \mathrm{H}_{3} \mathrm{~N}^{14} \mathrm{H}_{2}$ & $3 \cdot 261$ & $6,1, \leftarrow 5,2$, & Ground & & & & 23450.17 & .1 \\
\hline
\end{tabular}




\begin{tabular}{|c|c|c|c|c|c|c|c|}
\hline Isotopic Species & $\begin{array}{l}\text { Vol.-Id. } \\
\text { Nos. }\end{array}$ & $\begin{array}{c}\text { Rotational } \\
\text { Quantum Nos. }\end{array}$ & Vib. State & $\mathrm{F}_{1}^{\prime} \stackrel{\text { Hyperfine }}{\mathrm{F}^{\prime}} \mathrm{F}_{1}$ & $\mathrm{~F}$ & $\begin{array}{c}\text { Frequency } \\
\mathrm{MHz}\end{array}$ & $\begin{aligned} & \text { Acc. } \\
\pm & \mathrm{MHz}\end{aligned}$ \\
\hline $\mathrm{C}^{\mathrm{b}} \mathrm{H}_{2}^{\mathrm{b}} \mathrm{Cl}^{\mathrm{b}} \mathrm{F}^{\mathrm{b}}$ & 4- 333 & Not Reported & & & & 23450.31 & .1 \\
\hline $\mathrm{C}^{12} \mathrm{D}_{2} \mathrm{HC}^{12} \mathrm{HDF}^{19}$ & 3- 563 & $5,1,4 \leftarrow 4,2,3$ & Ground & & & 23451.0 & .1 \\
\hline $\mathrm{a}-\mathrm{C}^{12} \mathrm{H}_{2} \mathrm{DC}^{12} \mathrm{O}^{16} \mathrm{C}^{12} \mathrm{~N}^{14}$ & 3- 679 & $4,0,4 \leftarrow 3,1,3$ & Ground & & & 23451.09 & \\
\hline $\mathrm{C}^{\mathrm{b}} \mathrm{H}_{2}^{\mathrm{b}} \mathrm{Cl}^{\mathrm{b}} \mathrm{F}^{\mathrm{b}}$ & 4. 333 & Not Reported & & & & 23452.00 & .1 \\
\hline $\mathrm{C}^{12}{ }_{*} \mathrm{H}: \mathrm{C}^{12} \mathrm{HO}^{16} \mathrm{C}^{12} \mathrm{H}: \mathrm{C}^{12}{ }_{*} \mathrm{H}$ & 4-1151 & $2,0,2 \leftarrow 1,0,1$ & Ground & & & 23453.13 & \\
\hline $\mathrm{O}^{16} \mathrm{C}^{12} \mathrm{~S}^{35}$ & 4. 524 & $2 \leftarrow 1$ & Ground & $3 / 2$ & $3 / 2$ & 23453.323 & .011 \\
\hline $\mathrm{H}_{2}^{\mathrm{b}} \mathrm{C}^{\mathrm{b}}{ }^{\mathrm{O}} \mathrm{O}^{16} \mathrm{C}^{\mathrm{b}} \mathrm{H}_{2}^{\mathrm{b}}$ & 4- 846 & Not Reported & Excited & & & 23454.6 & .3 \\
\hline $\mathrm{HC}^{13}: \mathrm{C}^{12} \mathrm{C}^{12} \mathrm{DO}^{16}$ & 4- 922 & Not Reported & & & & 23455 . & 5. \\
\hline $\mathrm{C}^{12} \mathrm{H}_{2}: \mathrm{C}^{12} \mathrm{HBr}^{81}$ & 4- 728 & $3,1,3 \leftarrow 2,1,2$ & Excited & $9 / 2$ & $7 / 2$ & 23455.00 & \\
\hline $\mathrm{C}^{12} \mathrm{H}_{2}: \mathrm{C}^{12} \mathrm{HBr}^{81}$ & 4. 728 & $3,1,3 \leftarrow 2,1,2$ & Excited & $9 / 2$ & $7 / 2$ & 23455.5 & \\
\hline $\mathrm{C}^{12} \mathrm{H}_{2}\left(\mathrm{C}^{12} \mathrm{~N}^{14}\right)_{2}$ & 4. 901 & Not Reported & Ground & & & 23456. & .1 \\
\hline $\mathrm{O}^{16} \mathrm{C}^{12} \mathrm{~S}^{35}$ & 4- 524 & $2 \leftarrow 1$ & Ground & $7 / 2$ & $5 / 2$ & 23456.963 & .011 \\
\hline $\mathrm{O}^{16} \mathrm{C}^{12} \mathrm{~S}^{35}$ & 4. 524 & $2 \leftarrow 1$ & Ground & $5 / 2$ & $3 / 2$ & 23456.963 & .011 \\
\hline $\mathrm{As}^{75} \mathrm{~F}_{3}^{19}$ & 4. 21 & $2,0 \leftarrow 1,0$ & Ground & $3 / 2$ & $1 / 2$ & 23457. & \\
\hline $\mathrm{C}^{12} \mathrm{H}_{3} \mathrm{O}^{16} \mathrm{H}$ & 3- 211 & Not Reported & Ground & & & 23457 . & 5. \\
\hline $\mathrm{HN}^{14} \mathrm{C}^{12} \mathrm{~S}^{32}$ & 4. 311 & $2,0,2 \leftarrow 1,0,1$ & Ground & & & 23458. & \\
\hline $\mathrm{C}^{12} \mathrm{H}_{3} \mathrm{~N}^{14} \mathrm{O}_{2}^{16}$ & 3- 171 & Not Reported & Ground & & & 23458.88 & \\
\hline $\mathrm{S}^{32} \mathrm{O}^{16} \mathrm{~F}_{2}^{19}$ & 4-1621 & $2,0,2 \leftarrow 1,0,1$ & Ground & & & 23459.49 & .1 \\
\hline $\mathrm{C}^{12}{ }_{*} \mathrm{H}_{2} \mathrm{C}^{12} \mathrm{H}_{2} \mathrm{C}^{12} \mathrm{H}_{2} \mathrm{O}^{16} *$ & 4-1091 & $8,6,2 \leftarrow 8,6,3$ & Excited & & & 23460 . & \\
\hline $\mathrm{C}^{12} \mathrm{H}_{2} \mathrm{Cl}^{35} \mathrm{C}^{12}: \mathrm{C}^{12} \mathrm{H}$ & 4- 991 & $4,2,2 \leftarrow 3,2,1$ & Ground & & & 23460.52 & \\
\hline $\mathrm{As}^{75} \mathrm{~F}_{3}^{19}$ & 4- 21 & $2,0 \leftarrow 1,0$ & Ground & $5 / 2$ & $5 / 2$ & 23461.905 & .01 \\
\hline $\mathrm{O}^{16} \mathrm{C}^{12} \mathrm{~S}^{35}$ & 4. 524 & $2 \leftarrow 1$ & Ground & $3 / 2$ & $1 / 2$ & 23462.343 & .011 \\
\hline $\mathrm{O}^{16} \mathrm{C}^{12} \mathrm{~S}^{35}$ & 4. 524 & $2 \leftarrow 1$ & Ground & $5 / 2$ & $5 / 2$ & 23462.343 & .011 \\
\hline $\mathrm{C}^{13} \mathrm{H}_{2}: \mathrm{C}^{12} \mathrm{HBr}^{81}$ & 4- 736 & $3,1,2 \leftarrow 2,1,1$ & Ground & $7 / 2$ & $5 / 2$ & 23462.6 & \\
\hline $\mathrm{C}^{12} \mathrm{H}_{2}: \mathrm{C}^{12} \mathrm{DBr}^{\mathrm{b}}$ & 4.- 729 & $3, \quad \leftarrow 2$, & Ground & & & 23462.9 & .2 \\
\hline $\mathrm{C}^{12} \mathrm{H}_{2}\left(\mathrm{C}^{12} \mathrm{~N}^{14}\right)_{2}$ & 4- 901 & Not Reported & Ground & & & 23463.6 & .1 \\
\hline $\mathrm{HN}^{14} \mathrm{C}^{12} \mathrm{~S}^{32}$ & 4- 311 & $2, \quad \leftarrow 1$, & Ground & & & 23464 . & \\
\hline c- $\mathrm{C}^{12} \mathrm{HD}: \mathrm{C}^{12} \mathrm{HBr}^{81}$ & 4- 742 & $3,1,2 \leftarrow 2,1,1$ & Excited & $9 / 2$ & $7 / 2$ & 23464.6 & .2 \\
\hline $\mathrm{C}^{12} \mathrm{H}_{3} \mathrm{C}^{12} \mathrm{~F}^{19}: \mathrm{C}^{12} \mathrm{H}_{2}$ & 3- 721 & $3,2,2 \leftarrow 3,1,3$ & Ground & & & 23465.32 & .1 \\
\hline $\mathrm{C}^{12} \mathrm{H}_{2} \mathrm{Cl}^{37} \mathrm{Si}^{28} \mathrm{H}_{3}$ & 3- 232 & $4,1,4 \leftarrow 3,1,3$ & Ground & & & 23466.80 & .2 \\
\hline $\mathrm{C}^{12} \mathrm{H}_{3} \mathrm{C}^{12} \mathrm{H}_{2} \mathrm{I}^{127}$ & 3. 571 & $4,1,3 \leftarrow 3,1,2$ & Ground & $13 / 2$ & $11 / 2$ & 23467.01 & \\
\hline $\mathrm{a}-\mathrm{C}^{12} \mathrm{H}_{2} \mathrm{DSi}^{28} \mathrm{H}_{2} \mathrm{~F}^{19}$ & 3- 248 & $2,0,2 \leftarrow 1,0,1$ & Ground & & & 23467.05 & .1 \\
\hline $\mathrm{Ge}^{76} \mathrm{H}_{3} \mathrm{Br}^{79}$ & 4- 107 & $5, \leftarrow 4$, & Ground & & & 23468.0 & 1. \\
\hline $\mathrm{C}^{12} \mathrm{H}_{2}: \mathrm{C}^{12} \mathrm{DBr}^{81}$ & 4- 722 & $3,2,2 \leftarrow 2,2,1$ & Ground & $5 / 2$ & $5 / 2$ & 23468.6 & \\
\hline $\mathrm{C}^{12} \mathrm{H}_{2}: \mathrm{C}^{12} \mathrm{DBr}^{81}$ & 4- 722 & $3,2,2 \leftarrow 2,2,1$ & Ground & $7 / 2$ & $5 / 2$ & 23468.6 & \\
\hline $\mathrm{HO}^{18}$ & $1-$ & $9 / 2,4 \leftarrow 9 / 2,4$ & Ground & 4 & 4 & $23 \overleftarrow{469.5}$ & .5 \\
\hline $\mathrm{C}_{*}^{12} \mathrm{H}_{2} \mathrm{C}^{12} \mathrm{H}_{2} \mathrm{C}^{12} \mathrm{H}_{2} \mathrm{C}^{12} \mathrm{H}_{2} \mathrm{C}^{12}{ }_{*} \mathrm{O}^{16}$ & $4-124.1$ & $4,3,1 \leftarrow 3,3,0$ & Ground & & & 23469.59 & \\
\hline $\mathrm{C}^{12} \mathrm{H}_{3} \mathrm{~N}^{14} \mathrm{O}_{2}^{16}$ & 3- 171 & Not Reported & Ground & & & 23470 . & \\
\hline $\mathrm{C}^{12} \mathrm{H}_{3} \mathrm{P}^{31} \mathrm{H}_{2}$ & 3. 271 & $1,0,1 \leftarrow 0,0,0$ & Ground & & & 23470.3 & .1 \\
\hline $\mathrm{C}^{12} \mathrm{H}_{2}: \mathrm{C}^{12} \mathrm{HBr}^{81}$ & 4- 728 & $3,1,3 \leftarrow 2,1,2$ & Ground & $5 / 2$ & $5 / 2$ & 23470.9 & \\
\hline $\mathrm{C}^{12} \mathrm{H}_{2}: \mathrm{C}^{12} \mathrm{HBr}^{81}$ & 4. 728 & $3,1,3 \leftarrow 2,1,2$ & Ground & $5 / 2$ & $5 / 2$ & 23470.9 & \\
\hline $\mathrm{C}^{12} \mathrm{H}_{3} \mathrm{C}^{12} \mathrm{O}^{16} \mathrm{~F}^{19}$ & 3. 391 & Not Reported & Ground & & & 23470.99 & .2 \\
\hline $\mathrm{C}^{12} \mathrm{H}_{3} \mathrm{C}^{12} \mathrm{O}^{16} \mathrm{O}^{16} \mathrm{H}$ & 3. 491 & Not Reported & & & & 23471. & 3. \\
\hline $\mathrm{As}^{75} \mathrm{~F}_{3}^{19}$ & 4- 21 & $2,1 \leftarrow 1,1$ & Ground & $5 / 2$ & $3 / 2$ & 23471.334 & .01 \\
\hline $\mathrm{C}^{12} \mathrm{H}_{3} \mathrm{C}^{12} \mathrm{~F}^{19}: \mathrm{C}^{12} \mathrm{H}_{2}$ & 3- 721 & $3,2,2 \leftarrow 3,1,3$ & Ground & & & 23472.10 & .1 \\
\hline
\end{tabular}




\begin{tabular}{|c|c|c|c|c|c|c|c|c|}
\hline Isotopic Species & $\begin{array}{l}\text { Vol.-Id. } \\
\text { Nos. }\end{array}$ & $\begin{array}{c}\text { Rotational } \\
\text { Quantum Nos. }\end{array}$ & Vib. State & $\mathrm{F}_{1}^{\prime}$ & $\begin{array}{l}\text { Hyperfine } \\
\mathrm{F}^{\prime} \quad \mathrm{F}_{1}\end{array}$ & $\mathbf{F}$ & $\begin{array}{c}\text { Frequency } \\
\mathrm{MHz}\end{array}$ & $\begin{aligned} & \text { Acc. } \\
\pm & \mathrm{MHz}\end{aligned}$ \\
\hline$c-\mathrm{C}^{12} \mathrm{HD}: \mathrm{C}^{12} \mathrm{HBr}^{81}$ & 4. 742 & $3,1,2 \leftarrow 2,1,1$ & Ground & & $5 / 2$ & $5 / 2$ & 23473.3 & .2 \\
\hline $\mathrm{Ge}^{74} \mathrm{H}_{3} \mathrm{Br}^{81}$ & 4- 106 & $5, \leftarrow 4$, & Ground & & & & 23474.75 & 1. \\
\hline $\mathrm{C}^{12} \mathrm{H}_{3} \mathrm{C}^{12} \mathrm{H}_{2} \mathrm{I}^{127}$ & 3. 571 & $4,1,3 \leftarrow 3,1,2$ & Ground & & $5 / 2$ & $3 / 2$ & 23474.88 & \\
\hline $\mathrm{HN}^{14} \mathrm{C}^{12} \mathrm{~S}^{32}$ & 4- 311 & $2,0, \leftarrow 1,0$, & Excited & & & & 23475 . & .5 \\
\hline$\left(\mathrm{C}^{12} \mathrm{H}_{3}\right)_{3} \mathrm{C}^{12} \mathrm{~N}^{14} \mathrm{C}^{12}$ & 3-1032 & $4, \leftarrow 3$ & Ground & & & & 23475.4 & \\
\hline $\mathrm{C}^{12} \mathrm{H}_{2}: \mathrm{C}^{12} \mathrm{DBr}^{81}$ & 4- 722 & $3,2,1 \leftarrow 2,2,0$ & Ground & & $5 / 2$ & $5 / 2$ & 23478.2 & \\
\hline $\mathrm{C}^{12} \mathrm{H}_{2}: \mathrm{C}^{12} \mathrm{DBr}^{81}$ & 4. 722 & $3,2,1 \leftarrow 2,2,0$ & Ground & & $7 / 2$ & $5 / 2$ & 23478.2 & \\
\hline $\mathrm{HO}^{18}$ & $1-$ & $9 / 2,4 \leftarrow 9 / 2,4$ & Ground & & 5 & 5 & 23479.1 & .5 \\
\hline $\mathrm{C}^{12} \mathrm{H}_{3} \mathrm{C}^{12} \mathrm{O}^{16} \mathrm{C}^{12} \mathrm{~N}^{14}$ & 3- 671 & $4,0,4 \leftarrow 3,1,3$ & Ground & & & & 23479.26 & .2 \\
\hline $\mathrm{C}^{12} \mathrm{H}_{2}: \mathrm{C}^{12} \mathrm{HBr}^{81}$ & 4- 728 & $3,1,3 \leftarrow 2,1,2$ & Excited & & $7 / 2$ & $5 / 2$ & 23480.00 & \\
\hline c- $\mathrm{C}^{12} \mathrm{HD}: \mathrm{C}^{12} \mathrm{HBr}^{81}$ & 4- 742 & $3,1,2 \leftarrow 2,1,1$ & Ground & & $9 / 2$ & $7 / 2$ & 23480.75 & .1 \\
\hline $\mathrm{C}^{12} \mathrm{H}_{2}: \mathrm{C}^{12} \mathrm{HBr}^{\mathrm{b}}$ & 4. 751 & $3, \quad, \leftarrow 2$, & Ground & & & & 23481.6 & .2 \\
\hline $\mathrm{HDO}^{17}$ & 4-1714 & $3, \quad, \quad \leftarrow 2, \quad$, & Ground & & & & 23481.6 & .05 \\
\hline $\mathrm{C}^{12}{ }_{*} \mathrm{H}: \mathrm{C}^{12} \mathrm{HO}^{16} \mathrm{C}^{12} \mathrm{D}: \mathrm{C}^{12}{ }_{*} \mathrm{H}$ & $4-1154$ & $11,10,1 \leftarrow 11,9,2$ & Ground & & & & 23481.7 & \\
\hline $\mathrm{C}^{12} \mathrm{H}_{2}: \mathrm{C}^{12} \mathrm{DBr}^{81}$ & 4- 722 & $3,0,3 \leftarrow 2,0,2$ & Ground & & $7 / 2$ & $7 / 2$ & 23481.7 & \\
\hline $\mathrm{As}^{75} \mathrm{~F}_{3}^{19}$ & 4- 21 & $2,0 \leftarrow 1,0$ & Excited & & $5 / 2$ & $5 / 2$ & 23482. & \\
\hline $\mathrm{C}^{12} \mathrm{H}_{2}: \mathrm{C}^{12} \mathrm{HBr}^{81}$ & 4- 728 & $3,1,3 \leftarrow 2,1,2$ & Ground & & $9 / 2$ & $7 / 2$ & 23482.5 & \\
\hline $\mathrm{C}^{\mathrm{b}} \mathrm{H}_{2}: \mathrm{C}^{b} \mathrm{HBr}^{\mathrm{b}}$ & 4- 752 & Not Reported & Ground & & $9 / 2$ & $7 / 2$ & 23482.6 & \\
\hline $\mathrm{C}^{12} \mathrm{H}_{3} \mathrm{~N}^{14} \mathrm{O}_{2}^{16}$ & 3. 171 & Not Reported & Ground & & & & 23483. & 5. \\
\hline $\mathrm{C}^{12} \mathrm{H}_{2}: \mathrm{C}^{12} \mathrm{HBr}^{81}$ & 4- 728 & $3,1,3 \leftarrow 2,1,2$ & Ground & & $3 / 2$ & $1 / 2$ & 23483.90 & \\
\hline $\mathrm{c} \cdot \mathrm{HF}^{19} \mathrm{C}^{12}: \mathrm{C}^{12} \mathrm{HF}^{19}$ & 4- 691 & $4,1,3 \leftarrow 4,0,4$ & Excited & & & & 23485.96 & .05 \\
\hline $\mathrm{C}^{12} \mathrm{H}_{3} \mathrm{C}^{12} \mathrm{O}^{16} \mathrm{~F}^{19}$ & 3- 391 & Not Reported & Ground & & & & 23487.11 & .2 \\
\hline $\mathrm{C}^{12} \mathrm{H}_{3} \mathrm{C}^{12} \mathrm{O}^{16} \mathrm{C}^{13} \mathrm{~N}^{14}$ & 3- 673 & $8,2,6 \leftarrow 8,1,7$ & Ground & & & & 23487.74 & .2 \\
\hline c. $\mathrm{C}^{12} \mathrm{HD}: \mathrm{C}^{12} \mathrm{HBr}^{81}$ & 4- 742 & $3,1,2 \leftarrow 2,1,1$ & Excited & & $7 / 2$ & $5 / 2$ & 23488.3 & .2 \\
\hline $\mathrm{F}_{2}^{19} \mathrm{O}_{2}^{16}$ & 3. 11 & $6,1,5 \leftarrow 6,0,6$ & Ground & & & & 23488.36 & .1 \\
\hline $\mathrm{C}^{12}{ }_{*} \mathrm{H}_{2} \mathrm{C}^{12} \mathrm{HDCC}^{12} \mathrm{H} \mathrm{O}^{16}{ }_{*}$ & $4-1094$ & $3,1,2 \leftarrow 3,1,3$ & Ground & & & & 23488.5 & .1 \\
\hline$\left(\mathrm{C}^{12} \mathrm{H}_{3}\right)_{2} \mathrm{C}^{12}: \mathrm{C}^{12} \mathrm{H}_{2}$ & 3- 941 & $7,6,2 \leftarrow 7,5,3$ & Ground & & & & 23490.64 & .05 \\
\hline c- $\mathrm{C}^{12} \mathrm{HD}: \mathrm{C}^{12} \mathrm{HBr}^{81}$ & 4- 742 & $3,1,2 \leftarrow 2,1,1$ & Ground & & & & 23490.67 & .07 \\
\hline $\mathrm{C}^{12} \mathrm{H}_{2}: \mathrm{C}^{12} \mathrm{HC}^{12} \mathrm{~F}^{19}: \mathrm{C}^{12} \mathrm{H}_{2}$ & 3. 911 & $8,3,5 \leftarrow 8,2,6$ & Ground & & & & 23491.24 & .03 \\
\hline $\mathrm{As}^{75} \mathrm{~F}_{3}^{19}$ & 4. 21 & $2,1 \leftarrow 1,1$ & Ground & & $3 / 2$ & $3 / 2$ & 23492.423 & .01 \\
\hline $\mathrm{C}^{12} \mathrm{H}_{3} \mathrm{C}^{12} \mathrm{O}^{16} \mathrm{C}^{13} \mathrm{~N}^{14}$ & 3- 673 & $8,2,6 \leftarrow 8,1,7$ & Ground & & & & 23492.79 & .2 \\
\hline $\mathrm{C}^{12} \mathrm{H}_{2}: \mathrm{C}^{12} \mathrm{DBr}^{79}$ & 4- 721 & $3,0,3 \leftarrow 2,0,2$ & Excited & & $9 / 2$ & $7 / 2$ & 23493.0 & \\
\hline $\mathrm{C}^{12} \mathrm{H}_{2}: \mathrm{C}^{12} \mathrm{DBr}^{79}$ & 4. 721 & $3,0,3 \leftarrow 2,0,2$ & Excited & & $7 / 2$ & $5 / 2$ & 23493.0 & \\
\hline $\mathrm{C}^{12} \mathrm{H}_{2}: \mathrm{C}^{12} \mathrm{HBr}^{81}$ & 4- 728 & $3,1,3 \leftarrow 2,1,2$ & Ground & & & & 23493.15 & .04 \\
\hline $\mathrm{C}^{12}{ }_{*} \mathrm{H}: \mathrm{C}^{12} \mathrm{HO}^{18} \mathrm{C}^{12} \mathrm{H}: \mathrm{C}^{12}{ }_{*} \mathrm{H}$ & $4-1152$ & $5,4,2 \leftarrow 5,2,3$ & Ground & & & & 23494.4 & .1 \\
\hline $\mathrm{C}^{12} \mathrm{H}_{3} \mathrm{~S}^{32} \mathrm{H}$ & 3. 221 & Not Reported & Ground & & & & 23494.4 & .1 \\
\hline $\mathrm{C}_{6}^{12} \mathrm{H}_{5} \mathrm{O}^{16} \mathrm{H}$ & 3-1051 & $5,4,1 \leftarrow 5,3,2$ & Ground & & & & 23494.8 & \\
\hline $\mathrm{C}^{12} \mathrm{H}_{2}: \mathrm{C}^{12} \mathrm{DBr}^{79}$ & 4- 721 & $3,2,2 \leftarrow 2,2,1$ & Ground & & $9 / 2$ & $7 / 2$ & 23498.6 & \\
\hline $\mathrm{C}^{12} \mathrm{H}_{2}: \mathrm{C}^{12} \mathrm{DBr}^{79}$ & 4- 721 & $3,2,2 \leftarrow 2,2,1$ & Ground & & $7 / 2$ & $7 / 2$ & 23498.6 & \\
\hline $\mathrm{C}^{12} \mathrm{H}_{2}\left(\mathrm{C}^{12} \mathrm{~N}^{14}\right)_{2}$ & 4. 901 & $1,1,1 \leftarrow 0,0,0$ & Ground & & & & 23498.82 & \\
\hline $\mathrm{C}^{12} \mathrm{H}_{3} \mathrm{~N}^{14} \mathrm{O}_{2}^{16}$ & 3- 171 & Not Reported & Ground & & & & 23499. & 5. \\
\hline $\mathrm{HC}^{13}: \mathrm{C}^{12} \mathrm{C}^{12} \mathrm{DO}^{16}$ & 4. 922 & Not Reported & & & & & 23499. & 5. \\
\hline $\mathrm{HN}^{14} \mathrm{C}^{12} \mathrm{~S}^{32}$ & 4. 311 & $2,1,1 \leftarrow 1,1,0$ & Ground & & & & 23499.5 & \\
\hline $\mathrm{As}^{75} \mathrm{~F}_{3}^{19}$ & 4- 21 & $2,1 \leftarrow 1,1$ & Ground & & $5 / 2$ & $5 / 2$ & 23500.834 & .01 \\
\hline $\mathrm{C}^{13} \mathrm{H}_{2} \mathrm{~F}_{2}^{19}$ & 4. 352 & $3,0,3 \leftarrow 2,1,2$ & Ground & & & & 23501.2 & .4 \\
\hline
\end{tabular}




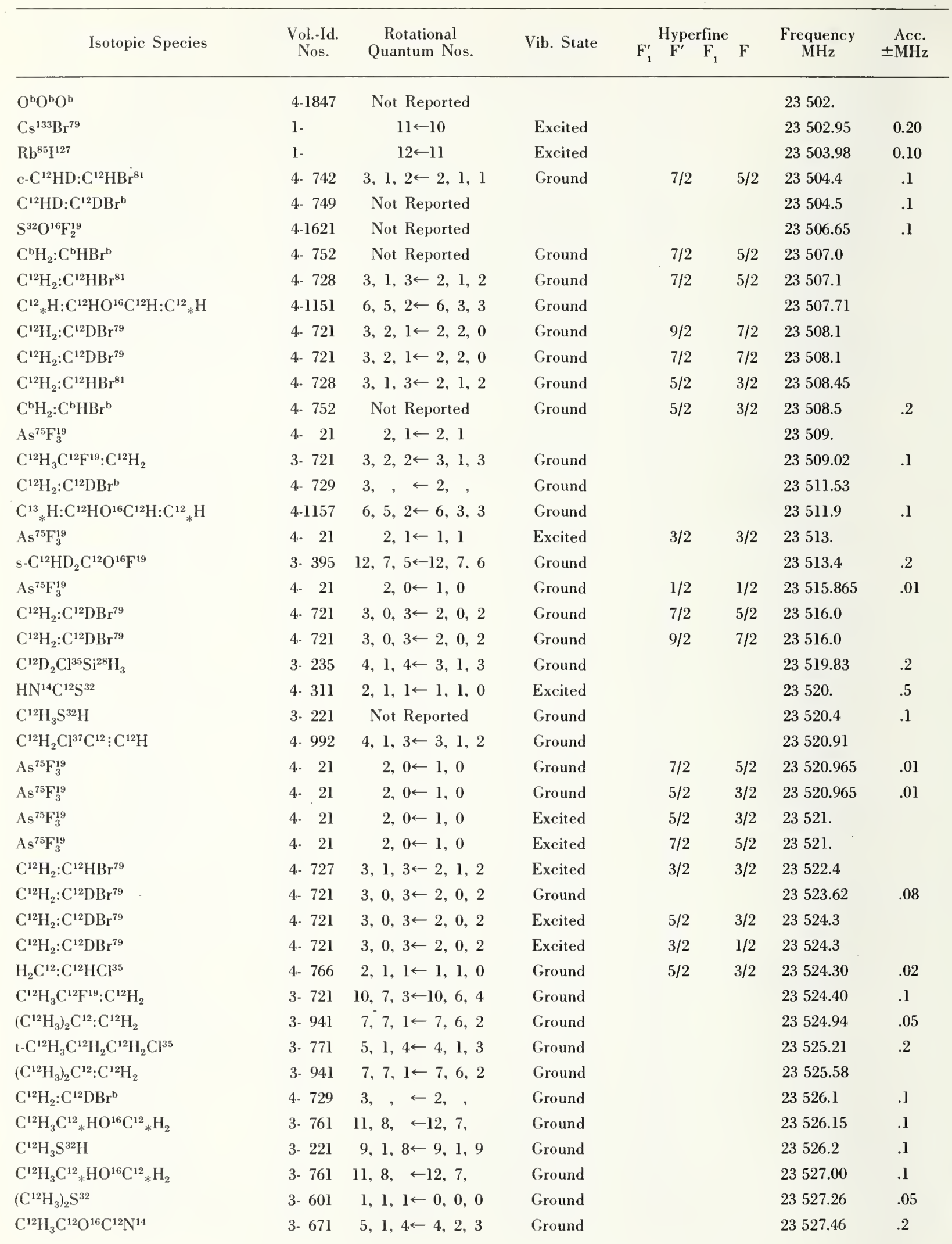


$\left(\mathrm{C}^{12} \mathrm{H}_{3}\right)_{2} \mathrm{~S}^{32}$

$\left(\mathrm{C}^{12} \mathrm{H}_{3}\right)_{2} \mathrm{~S}^{32}$

$\left(\mathrm{C}^{12} \mathrm{H}_{3}\right)_{2} \mathrm{~S}^{32}$

$\mathrm{H}_{2} \mathrm{C}^{12}: \mathrm{C}^{12} \mathrm{HCl}^{35}$

$\mathrm{HC}^{13}: \mathrm{C}^{12} \mathrm{C}^{12} \mathrm{DO}{ }^{16}$

$\mathrm{C}^{12} \mathrm{H}_{3} \mathrm{C}^{12} \mathrm{O}^{16} \mathrm{C}^{12} \mathrm{~N}^{14}$

$\mathrm{C}^{12} \mathrm{H}_{3} \mathrm{Si}^{28} \mathrm{D}_{2} \mathrm{~F}^{19}$

$\mathrm{As}^{75} \mathrm{~F}_{3}^{19}$

$\mathrm{H}, \mathrm{C}^{12}: \mathrm{C}^{12} \mathrm{Cl}_{2}^{35}$

$\mathrm{As}^{75} \mathrm{~F}_{3}^{19}$

$\mathrm{C}^{12} \mathrm{H}_{3} \mathrm{Si}^{28} \mathrm{H}_{2} \mathrm{~F}^{19}$

$\mathrm{C}^{12} \mathrm{H}_{2}: \mathrm{C}^{12} \mathrm{HBr}^{81}$

$\mathrm{H}_{2} \mathrm{C}^{12}: \mathrm{C}^{12} \mathrm{HCl}^{35}$

$\mathrm{C}^{12} \mathrm{H}_{2}: \mathrm{C}^{12} \mathrm{DBr}^{79}$

$\mathrm{C}^{12} \mathrm{H}_{2}: \mathrm{C}^{12} \mathrm{DBr}^{79}$

$\mathrm{C}^{12} \mathrm{H}_{2}: \mathrm{C}^{12} \mathrm{DBr}^{79}$

$\mathrm{O}^{17} \mathrm{C}^{12} \mathrm{~S}^{32}$.

$\mathrm{O}^{17} \mathrm{C}^{12} \mathrm{~S}^{32}$

$\mathrm{O}^{17} \mathrm{C}^{12} \mathrm{~S}^{32}$

$\mathrm{O}^{17} \mathrm{C}^{12} \mathrm{~S}^{32}$

$\mathrm{O}^{17} \mathrm{C}^{12} \mathrm{~S}^{32}$

$\mathrm{O}^{17} \mathrm{C}^{12} \mathrm{~S}^{32}$

$\mathrm{O}^{17} \mathrm{C}^{12} \mathrm{~S}^{32}$

$\mathrm{C}^{12} \mathrm{H}_{3} \mathrm{Si}^{28} \mathrm{D}_{2} \mathrm{~F}^{19}$

$\mathrm{C}^{13} \mathrm{H}_{3} \mathrm{C}^{12} \mathrm{O}^{16} \mathrm{C}^{12} \mathrm{~N}^{14}$

$\mathrm{HN}^{14} \mathrm{C}^{12} \mathrm{~S}^{32}$

$\mathrm{H}_{2} \mathrm{C}^{12}: \mathrm{C}^{12} \mathrm{HCl}^{35}$

$\mathrm{H}_{2} \mathrm{C}^{12}: \mathrm{C}^{12} \mathrm{Cl}_{2}^{\mathrm{b}}$

$\mathrm{C}^{12} \mathrm{H}_{3} \mathrm{C}^{12} \mathrm{O}^{16} \mathrm{O}^{16} \mathrm{H}$

$\mathrm{C}^{13} \mathrm{H}_{3} \mathrm{C}^{12} \mathrm{O}^{16} \mathrm{C}^{12} \mathrm{~N}^{14}$

$\mathrm{C}^{13} \mathrm{H}_{2} \mathrm{Cl}^{35} \mathrm{Si}^{28} \mathrm{H}_{3}$

$\mathrm{C}^{12} \mathrm{H}_{2}: \mathrm{C}^{12} \mathrm{DBr}^{79}$

$\mathrm{C}^{12} \mathrm{H}_{2}: \mathrm{C}^{12} \mathrm{DBr}^{79}$

$\mathrm{C}^{12} \mathrm{H}_{2}: \mathrm{C}^{12} \mathrm{DBr}^{79}$

$\mathrm{As}^{75} \mathrm{~F}_{3}^{19}$

$\mathrm{As}^{75} \mathrm{~F}_{3}^{19}$

$\mathrm{H}_{2} \mathrm{C}^{12}: \mathrm{C}^{12} \mathrm{HCl}^{35}$

$\mathrm{C}^{13} \mathrm{H}_{2} \mathrm{Cl}^{35} \mathrm{Si}^{28} \mathrm{H}_{3}$

\section{$\mathrm{As}^{75} \mathrm{~F}_{3}^{19}$}

$\mathrm{C}^{13} \mathrm{H}_{2} \mathrm{Cl}^{35} \mathrm{Si}^{28} \mathrm{H}_{3}$

$\mathrm{C}^{12} \mathrm{H}_{2}: \mathrm{C}^{13} \mathrm{HBr}^{81}$

$\mathrm{C}^{12} \mathrm{H}_{2}: \mathrm{C}^{12} \mathrm{DBr}^{79}$

$\mathrm{C}^{12} \mathrm{H}_{2}: \mathrm{C}^{12} \mathrm{DBr}^{79}$

c. $\mathrm{C}^{12} \mathrm{HD}: \mathrm{C}^{12} \mathrm{HBr}^{81}$

$\mathrm{C}^{12} \mathrm{H}_{2}$ : $\mathrm{C}^{12} \mathrm{DBr}^{\mathrm{b}}$

$\begin{array}{lll}\text { 3- } 601 & 1,1,1 \leftarrow 0,0,0 & \text { Ground } \\ \text { 3- } 601 & 1,1,1 \leftarrow 0,0,0 & \text { Ground } \\ \text { 3- } 601 & 1,1,1 \leftarrow 0,0,0 & \text { Ground } \\ \text { 4- } 766 & 2,1,1 \leftarrow 1,1,0 & \text { Ground }\end{array}$

4. 922

Not Reported

3. 671

$5,1,4 \leftarrow 4,2,3$

Ground

3- 245

$2,0,2 \leftarrow 1,0,1$

4. 21

$2,1 \leftarrow 1,1$

4. 661

$4,3,2 \leftarrow 4,2.3$

4. 21

$2,1 \leftarrow 1,1$

3. 241

$2,1,2 \leftarrow 1,1,1$

4. 728

$3,1,3 \leftarrow 2,1,2$

4- 766

$2,1,1 \leftarrow 1,1,0$

4- 721

$3,2,2 \leftarrow 2,2,1$

4- 721

$3,2,2 \leftarrow 2,2,1$

4- 721

4. 529

4. 529

$3,2,2 \leftarrow 2,2,1$

$2 \leftarrow 1$

4. 529

$2 \leftarrow 1$

4- 529

$2 \leftarrow 1$

4. 529

4. 529

4. 529

3. 245

3. 672

4. 311

4- 766

4- 663

3- 491

3- 672

3. 233

4. 721

4- 721

4- 721

4- 21

4- 21

4. 766

3. 233

4- 21

3- 233

4. 738

4- 721

4- 721

4. 742

4. 729

$$
2 \leftarrow 1
$$$$
2 \leftarrow 1
$$$$
2 \leftarrow 1
$$$$
2 \leftarrow 1
$$

$2,0,2 \leftarrow 1,0,1$

$8,2,6 \leftarrow 8,1,7$

$2,1,1 \leftarrow 1,1,1$

$2,1,1 \leftarrow 1,1,0$

Not Reported

$3,1,2 \leftarrow 3,0,3$

$8,2,6 \leftarrow 8,1,7$

$8,1,7 \leftarrow 8,0,8$

$3,2,1 \leftarrow 2,2,0$

$3,2,1 \leftarrow 2,2,0$

$$
2,0 \leftarrow 1,0
$$

$2,0 \leftarrow 1,0$

$2,1,1 \leftarrow 1,1,0$

$8,1,7 \leftarrow 8,0,8$

$$
2,1 \leftarrow 1,1
$$

$8,1,7 \leftarrow 8,0,8$

$3,2,2 \leftarrow 2,2,1$

$3,0,3 \leftarrow 2,0,2$

$3,0,3 \leftarrow 2,0,2$

$3,1,2 \leftarrow 2,1,1$

$3, \quad \leftarrow 2$, ,
$3,2,1 \leftarrow 2,2,0$
Ground

Ground

Ground

Excited

Ground

Excited

Ground

Ground

Ground

Ground

Ground

Ground

Ground

Ground

Ground

Ground

Ground

Ground

Ground

Ground

Ground

Ground

Ground

Ground

Ground

Ground

Ground

Ground

Excited

Excited

Ground

Ground

Ground

Ground

Ground

Ground

Ground

Ground
Ground
$23527.50 \quad .05$

$23527.60 \quad .05$

$23527.73 \quad .05$

$\begin{array}{llll}3 / 2 & 3 / 2 & 23528.86 & .02\end{array}$

23529 . $\quad 5$.

$23529.29 \quad .2$

$23530.00 \quad .10$

$\begin{array}{llll}7 / 2 & 5 / 2 & 23530.318 & .01\end{array}$

$23530.7 \quad 1$.

$7 / 2 \quad 5 / 2 \quad 23531$.

$23531.00 \quad .10$

$7 / 2 \quad 7 / 2 \quad 23531.40$

$\begin{array}{llll}5 / 2 & 5 / 2 & 23532.19 & .02\end{array}$

$23532.93 \quad .06$

$5 / 2 \quad 3 / 2 \quad 23533.0$

$3 / 2 \quad 3 / 2 \quad 23533.0$

$\begin{array}{lllll}5 / 2 & 3 / 2 & 23534.101 & .014\end{array}$

$\begin{array}{lllll}7 / 2 & 7 / 2 & 23 & 534.164 & .012\end{array}$

$\begin{array}{llll}1 / 2 & 3 / 2 & 23534.308 & .012\end{array}$

$9 / 2 \quad 7 / 2 \quad 23534.422$

$7 / 2 \quad 5 / 2 \quad 23534.422$

$\begin{array}{lllll}3 / 2 & 3 / 2 & 23534.481 & .014\end{array}$

$\begin{array}{llll}5 / 2 & 5 / 2 & 23534.481 & .014\end{array}$

$23536.25 \quad .10$

$23536.65 \quad .2$

23537.

$\begin{array}{llll}7 / 2 & 5 / 2 & 23538.58 & .02\end{array}$

$23539.4 \quad .5$

23540.87

$23541.99 \quad .2$

$13 / 2 \quad 13 / 2 \quad 23542.4 \quad .1$

$23542.70 \quad .06$

$5 / 2 \quad 3 / 2 \quad 23542.9$

$3 / 2 \quad 3 / 2 \quad 23542.9$

$5 / 2 \quad 3 / 2 \quad 23543$.

$7 / 2 \quad 5 / 2 \quad 23543$.

$\begin{array}{llll}3 / 2 & 1 / 2 & 23543.09 & .02\end{array}$

$19 / 2 \quad 19 / 2 \quad 23543.7 \quad .1$

$\begin{array}{llll}3 / 2 & 1 / 2 & 23545.596 \quad .015\end{array}$

$23546.17 \quad .2$

$3 / 2 \quad 1 / 2 \quad 23546.5$

$5 / 2 \quad 3 / 2 \quad 23546.8$

$3 / 2 \quad 1 / 2 \quad 23546.8$

$7 / 2 \quad 7 / 2 \quad 23547.7$

23547.9 


\begin{tabular}{|c|c|c|c|c|c|c|c|}
\hline Isotopic Species & $\begin{array}{l}\text { Vol.-Id. } \\
\text { Nos. }\end{array}$ & $\begin{array}{c}\text { Rotational } \\
\text { Quantum Nos. }\end{array}$ & Vib. State & $\mathrm{F}_{1}^{\prime} \stackrel{\mathrm{F}^{\prime}}{\text { Hyperfine }} \mathrm{F}_{1}$ & $\mathbf{F}$ & $\begin{array}{c}\text { Frequency } \\
\mathrm{MHz}\end{array}$ & $\begin{aligned} & \text { Acc. } \\
& \pm \mathrm{MHz}\end{aligned}$ \\
\hline $\mathrm{H}_{2} \mathrm{C}^{12}: \mathrm{C}^{12} \mathrm{HCl}^{35}$ & 4- 766 & $2,1,1 \leftarrow 1,1,0$ & Ground & $1 / 2$ & $1 / 2$ & 23549.45 & .02 \\
\hline $\mathrm{c}-\mathrm{C}^{12} \mathrm{HD}: \mathrm{C}^{12} \mathrm{HBr}^{79}$ & 4- 739 & $3,1,2 \leftarrow 2,1,1$ & Excited & $3 / 2$ & $3 / 2$ & 23549.5 & .1 \\
\hline $\mathrm{C}^{13} \mathrm{H}_{2} \mathrm{Cl}^{35} \mathrm{Si}^{28} \mathrm{H}_{3}$ & 3- 233 & $8,1,7 \leftarrow 8,0,8$ & Ground & $17 / 2$ & $17 / 2$ & 23549.7 & .1 \\
\hline $\mathrm{C}^{12} \mathrm{H}_{2}: \mathrm{C}^{12} \mathrm{HBr}^{79}$ & 4- 727 & $3,1,3 \leftarrow 2,1,2$ & Ground & $3 / 2$ & $3 / 2$ & 23549.8 & .2 \\
\hline $\mathrm{Si}^{30} \mathrm{H}_{3} \mathrm{~N}^{14} \mathrm{C}^{12} \mathrm{~S}^{32}$ & 4- 495 & $8, \leftarrow 7$, & Ground & & & 23550.43 & \\
\hline $\mathrm{HC}^{12} \mathrm{O}^{16} \mathrm{O}^{16} \mathrm{C}^{12} \mathrm{H}_{3}-\mathrm{E}$ & 3- 502 & $4,1,3 \leftarrow 4,0,4$ & Ground & & & 23550.84 & .2 \\
\hline $\mathrm{C}^{12}{ }_{*} \mathrm{H}_{2} \mathrm{C}^{12} \mathrm{H}_{2} \mathrm{C}^{12} \mathrm{H}_{2} \mathrm{C}^{12} \mathrm{H}_{2} \mathrm{C}^{12}{ }_{*} \mathrm{O}^{16}$ & 4-1241 & $14,4,10 \leftarrow 14,4,11$ & Ground & & & 23551. & 5. \\
\hline $\mathrm{O}^{\mathrm{b}} \mathrm{O}^{\mathrm{b}} \mathrm{O}^{\mathrm{b}}$ & $4-1847$ & Not Reported & & & & 23552. & \\
\hline $\mathrm{As}^{75} \mathrm{~F}_{3}^{19}$ & 4. 21 & $2,1 \leftarrow 1,1$ & Excited & $7 / 2$ & $5 / 2$ & 23553. & \\
\hline $\mathrm{C}^{12} \mathrm{H}_{3} \mathrm{C}^{12} \mathrm{HO}^{16}$ & 3- 471 & Not Reported & & & & 23553.26 & \\
\hline $\mathrm{C}^{12}{ }_{*} \mathrm{H}: \mathrm{C}^{12} \mathrm{HC}^{12} \mathrm{H}: \mathrm{C}^{12} \mathrm{HN}^{14}{ }_{*} \mathrm{H}$ & 4-1181 & $12,11,2 \leftarrow 12,9,3$ & Ground & & & 23553.9 & \\
\hline $\mathrm{C}_{6}^{12} \mathrm{H}_{5} \mathrm{Cl}^{35}$ & 4-1271 & $8,2,6 \leftarrow 7,2,5$ & Ground & & & 23554.7 & \\
\hline $\mathrm{C}^{12} \mathrm{H}_{3} \mathrm{C}^{12} \mathrm{H}_{2} \mathrm{O}^{16} \mathrm{H}$ & 3- 581 & Not Reported & & & & 23555 . & \\
\hline $\mathrm{C}^{12} \mathrm{H}_{3} \mathrm{Si}^{28} \mathrm{D}_{2} \mathrm{~F}^{19}$ & 3- 245 & $2,0,2 \leftarrow 1,0,1$ & Ground & & & 23556.56 & .10 \\
\hline $\mathrm{H}_{2} \mathrm{C}^{12}: \mathrm{C}^{12} \mathrm{Cl}_{2}^{\mathrm{b}}$ & 4- 663 & Not Reported & Ground & & & 23558.5 & 1.5 \\
\hline $\mathrm{C}^{12} \mathrm{H}_{2}: \mathrm{C}^{13} \mathrm{HBr}^{81}$ & 4- 738 & $3,0,3 \leftarrow 2,0,2$ & Ground & $3 / 2$ & $3 / 2$ & 23558.9 & \\
\hline $\mathrm{C}^{12}{ }_{*} \mathrm{H}_{2}^{\mathrm{b}} \mathrm{S}^{\mathrm{b}} \mathrm{C}^{12}{ }_{*} \mathrm{H}_{2}^{\mathrm{b}}$ & 4- 854 & Not Reported & & & & 23560.0 & 10. \\
\hline $\mathrm{C}^{12} \mathrm{H}_{2}: \mathrm{C}^{12} \mathrm{HBr}^{81}$ & 4- 728 & $3,1,3 \leftarrow 2,1,2$ & Ground & $7 / 2$ & $7 / 2$ & 23560.3 & \\
\hline $\mathrm{C}^{12} \mathrm{H}_{2}: \mathrm{C}^{12} \mathrm{HBr}^{81}$ & 4- 728 & $3,1,3 \leftarrow 2,1,2$ & Ground & $7 / 2$ & $7 / 2$ & 23560.4 & \\
\hline $\mathrm{H}_{2}^{\mathrm{b}} \mathrm{C}^{\mathrm{b}}{ }_{*} \mathrm{O}^{16} \mathrm{C}^{\mathrm{b}}{ }_{*} \mathrm{H}_{2}^{\mathrm{b}}$ & 4. 846 & Not Reported & Excited & & & 23561.1 & .3 \\
\hline $\mathrm{D}_{2} \mathrm{C}^{12}: \mathrm{C}^{12} \mathbf{F}_{2}^{19}$ & 4- 683 & $2,1,2 \leftarrow 1,1,1$ & Ground & & & 23561.7 & .3 \\
\hline $\mathrm{HC}^{12} \mathrm{O}^{16} \mathrm{O}^{16} \mathrm{C}^{12} \mathrm{H}_{3}-\mathrm{A}$ & 3- 501 & $4,1,3 \leftarrow 4,0,4$ & Ground & & & 23562.38 & .2 \\
\hline $\mathrm{C}^{12} \mathrm{H}_{2}\left(\mathrm{C}^{12} \mathrm{~N}^{14}\right)_{2}$ & 4. 901 & Not Reported & Ground & & & 23563.2 & .1 \\
\hline $\mathrm{As}^{75} \mathrm{~F}_{3}^{19}$ & 4- 21 & $2,0 \leftarrow 1,0$ & Ground & $3 / 2$ & $3 / 2$ & 23563.222 & .01 \\
\hline $\mathrm{F}_{2}^{19} \mathrm{O}_{2}^{16}$ & 3- 11 & $4,0,4 \leftarrow 3,1,3$ & Ground & & & 23563.25 & .1 \\
\hline $\mathrm{c} \cdot \mathrm{C}^{12} \mathrm{HD}: \mathrm{C}^{12} \mathrm{HBr}^{79}$ & 4. 739 & $3,1,2 \leftarrow 2,1,1$ & Ground & $3 / 2$ & $3 / 2$ & 23565.7 & .2 \\
\hline $\mathrm{C}^{12}{ }_{*} \mathrm{H}: \mathrm{C}^{12} \mathrm{HO}^{16} \mathrm{C}^{12} \mathrm{D}: \mathrm{C}^{12}{ }_{*} \mathrm{H}$ & $4-1154$ & $6,5,2 \leftarrow 6,4,3$ & Ground & & & 23565.7 & \\
\hline $\mathrm{C}^{12} \mathrm{H}_{3} \mathrm{~S}^{32} \mathrm{H}$ & 3- 221 & Not Reported & Ground & & & 23566.6 & .1 \\
\hline $\mathrm{C}^{13} \mathrm{H}_{2}: \mathrm{C}^{12} \mathrm{HBr}^{79}$ & 4- 735 & $3,1,2 \leftarrow 2,1,1$ & Ground & $5 / 2$ & $5 / 2$ & 23566.7 & \\
\hline $\mathrm{a}-\mathrm{C}^{12} \mathrm{H}_{2} \mathrm{DC}^{12} \mathrm{O}^{16} \mathrm{C}^{12} \mathrm{~N}^{14}$ & 3- 679 & $8,2,6 \leftarrow 8,1,7$ & Ground & & & 23568.45 & \\
\hline $\mathrm{C}^{12} \mathrm{H}_{2}: \mathrm{C}^{12} \mathrm{HBr}^{79}$ & 4- 727 & $3,1,3 \leftarrow 2,1,2$ & Excited & $5 / 2$ & $5 / 2$ & 23570.4 & \\
\hline $\mathrm{a}-\mathrm{C}^{12} \mathrm{H}_{2} \mathrm{DC}^{12} \mathrm{O}^{16} \mathrm{C}^{12} \mathrm{~N}^{14}$ & 3- 679 & $8,2,6 \leftarrow 8,1,7$ & Ground & & & 23570.53 & \\
\hline $\mathrm{D}_{2} \mathrm{O}_{2}^{16}$ & $3-\quad 42$ & Not Reported & & & & 23571. & 3. \\
\hline $\mathrm{Si}^{28} \mathrm{H}_{3} \mathrm{~N}^{14} \mathrm{C}^{12} \mathrm{~S}^{34}$ & 4- 496 & $8, \leftarrow 7$, & Ground & & & 23573.42 & \\
\hline $\mathrm{C}^{12} \mathrm{H}_{3} \mathrm{C}^{12} \mathrm{O}^{16} \mathrm{O}^{16} \mathrm{H}$ & 3. 491 & Not Reported & & & & 23574. & 3. \\
\hline $\mathrm{As}^{75} \mathrm{~F}_{3}^{19}$ & 4- $\quad 21$ & $2,1 \leftarrow 1,1$ & Fround & $1 / 2$ & $1 / 2$ & 23575. & \\
\hline $\mathrm{C}^{\mathrm{b}} \mathrm{H}_{2}: \mathrm{C}^{\mathrm{b}} \mathrm{HBr}^{\mathrm{b}}$ & 4- 752 & Not Reported & Ground & $9 / 2$ & $7 / 2$ & 23576.1 & \\
\hline $\mathrm{C}^{12} \mathrm{H}_{2}\left(\mathrm{C}^{12} \mathrm{~N}^{14}\right)_{2}$ & 4. 901 & Not Reported & Ground & & & 23577.0 & .1 \\
\hline $\mathrm{C}^{12} \mathrm{H}_{3} \mathrm{C}^{12} \mathrm{HO}^{16}$ & 3- 471 & Not Reported & & & & 23577.38 & \\
\hline $\mathrm{C}^{12} \mathrm{HD}: \mathrm{C}^{12} \mathrm{HBr}^{\mathrm{b}}$ & 4- 748 & Not Reported & & & & 23581.5 & .3 \\
\hline g- $-\mathrm{C}^{12} \mathrm{H}_{3} \mathrm{C}^{12} \mathrm{H}_{2} \mathrm{C}^{12} \mathrm{H}_{2} \mathrm{Cl}^{37}$ & 3- 774 & $5,2,3 \leftarrow 5,1,4$ & Ground & & & 23581.92 & .2 \\
\hline $\mathrm{C}^{12} \mathrm{H}_{3} \mathrm{Si}^{28} \mathrm{DF}_{2}^{19}-\mathrm{A}$ & 3- 197 & $12,7,6 \leftarrow 12,7,5$ & Ground & & & 23583.7 & \\
\hline $\mathrm{Cs}^{133} \mathrm{Br}^{79}$ & 1 . & $11 \leftarrow 10$ & Excited & & & 23583.87 & 0.20 \\
\hline $\mathrm{As}^{75} \mathrm{~F}_{3}^{19}$ & 4- 21 & $2,0 \leftarrow 1,0$ & Excited & $3 / 2$ & $3 / 2$ & 23584. & \\
\hline
\end{tabular}


Vol.-Id. Rotational Nos. Quantum Nos.
Vib. State

\section{$\mathrm{C}_{6}^{12} \mathrm{H}_{5} \mathrm{Cl}^{35}$}

$\mathrm{C}^{12} \mathrm{H}_{2}: \mathrm{C}^{12} \mathrm{HBr}^{79}$

$\mathrm{C}^{12} \mathrm{H}_{2}: \mathrm{C}^{12} \mathrm{HBr}^{79}$

$\mathrm{C}^{12} \mathrm{H}_{2}: \mathrm{C}^{12} \mathrm{HBr}^{\mathrm{b}}$

$\mathrm{HDO}^{17}$

$\mathrm{HC}^{13}: \mathrm{C}^{12} \mathrm{C}^{12} \mathrm{DO}^{16}$

$\mathrm{C}^{12} \mathrm{H}_{2}: \mathrm{C}^{13} \mathrm{HBr}^{81}$

$\mathrm{C}^{13} \mathrm{H}_{2}: \mathrm{C}^{12} \mathrm{HBr}^{79}$

$\mathrm{C}^{12} \mathrm{H}_{3} \mathrm{C}^{12} \mathrm{~F}^{19}: \mathrm{C}^{12} \mathrm{H}_{2}$

$\mathrm{C}^{12} \mathrm{H}_{3} \mathrm{C}^{12} \mathrm{~F}^{19}: \mathrm{C}^{12} \mathrm{H}_{2}$

$\mathrm{C}^{12} \mathrm{H}_{3} \mathrm{Si}^{28} \mathrm{DF}_{2}^{19}-\mathrm{E}$

$\mathrm{C}^{12} \mathrm{D}_{2} \mathrm{Cl}^{35} \mathrm{Cl}^{37}$

$\mathrm{C}^{12} \mathrm{H}_{2}\left(\mathrm{C}^{12} \mathrm{~N}^{14}\right)_{2}$

$\mathrm{DC}^{12} \mathrm{O}^{16} \mathrm{O}^{16} \mathrm{C}^{12} \mathrm{H}_{3}-\mathrm{E}$

a- $\mathrm{C}^{12} \mathrm{H}_{2} \mathrm{DC}^{12} \mathrm{O}^{16} \mathrm{C}^{12} \mathrm{~N}^{14}$

$\mathrm{DC}^{12} \mathrm{O}^{16} \mathrm{O}^{16} \mathrm{C}^{12} \mathrm{H}_{3}-\mathrm{A}$

$\mathrm{C}^{12} \mathrm{H}_{3} \mathrm{C}^{12}{ }_{*} \mathrm{HO}^{16} \mathrm{C}^{12}{ }_{*} \mathrm{H}_{2}$

c.- ${ }^{12} \mathrm{HD}: \mathrm{C}^{12} \mathrm{HBr}^{79}$

$\mathrm{C}^{12} \mathrm{H}_{3} \mathrm{C}^{12}{ }_{*} \mathrm{HO}^{16} \mathrm{C}^{12}{ }_{*} \mathrm{H}_{2}$

$\mathrm{C}^{12} \mathrm{H}_{3} \mathrm{~N}^{14} \mathrm{O}_{2}^{16}$

$\mathrm{C}^{12} \mathrm{H}_{3} \mathrm{C}^{12}{ }_{*} \mathrm{HO}^{16} \mathrm{C}^{12}{ }_{*} \mathrm{H}_{2}$

$\mathrm{As}^{75} \mathrm{~F}_{3}^{19}$

$\mathrm{C}^{12} \mathrm{H}_{2}: \mathrm{C}^{12} \mathrm{HBr}^{79}$

$\mathrm{C}_{6}^{12} \mathrm{H}_{5} \mathrm{O}^{16} \mathrm{H}$

$\mathrm{C}^{12} \mathrm{H}_{2}\left(\mathrm{C}^{12} \mathrm{~N}^{14}\right)_{2}$

c- $\mathrm{C}^{12} \mathrm{HD}: \mathrm{C}^{12} \mathrm{HBr}^{79}$

$\mathrm{S}^{32} \mathrm{O}^{16} \mathrm{~F}_{2}^{19}$

$\mathrm{C}^{12}{ }_{*} \mathrm{H}: \mathrm{C}^{12} \mathrm{DO}^{16} \mathrm{C}^{12} \mathrm{D}: \mathrm{C}^{12}{ }_{*} \mathrm{H}$

$\mathrm{C}^{\mathrm{b}} \mathrm{H}_{2}^{\mathrm{b}} \mathrm{Cl}^{\mathrm{b}} \mathrm{F}^{\mathrm{b}}$

$\mathrm{HC}^{13} \mathrm{~N}^{14}$

$\left(\mathrm{C}^{12} \mathrm{H}_{3}\right)_{2} \mathrm{C}^{12} \mathrm{O}^{16}$

$\mathrm{C}^{13} \mathrm{H}_{2}: \mathrm{C}^{12} \mathrm{HBr}^{79}$

$\mathrm{C}^{12} \mathrm{H}_{3} \mathrm{C}^{12} \mathrm{H}_{2} \mathrm{O}^{16} \mathrm{H}$

$\mathrm{C}^{12} \mathrm{H}_{3} \mathrm{C}^{12} \mathrm{O}^{18} \mathrm{C}^{12} \mathrm{~N}^{14}$

$\mathrm{C}^{12} \mathrm{H}_{3} \mathrm{~N}^{14} \mathrm{H}_{2}$ c. $\mathrm{C}^{12} \mathrm{HD}: \mathrm{C}^{12} \mathrm{HBr}^{79}$

$\mathrm{H}_{2} \mathrm{C}^{12}{ }_{*} \mathrm{O}^{16} \mathrm{C}^{12}{ }_{*} \mathrm{H}_{2}$ $\mathrm{S}^{32} \mathrm{O}^{16} \mathrm{~F}_{2}^{19}$

$\mathrm{C}^{12} \mathrm{H}_{2}: \mathrm{C}^{12} \mathrm{HBr}^{79}$

$\mathrm{C}^{12} \mathrm{H}_{2}: \mathrm{C}^{12} \mathrm{DBr}^{\mathrm{b}}$

$\mathrm{C}^{\mathrm{b}}{ }_{*} \mathrm{H}_{2}^{\mathrm{b}} \mathrm{N}^{\mathrm{b}} \mathrm{H}^{\mathrm{b}} \mathrm{C}^{\mathrm{b}}{ }_{*} \mathrm{H}_{2}^{\mathrm{b}}$

$\mathrm{C}^{12} \mathrm{H}_{3} \mathrm{C}^{12} \mathrm{O}^{18} \mathrm{C}^{12} \mathrm{~N}^{14}$

$\mathrm{HC}^{13}: \mathrm{C}^{12} \mathrm{C}^{12} \mathrm{DO}^{16}$

$\mathrm{C}^{12} \mathrm{H}_{2}: \mathrm{C}^{12} \mathrm{HBr}^{79}$
4-1271 $9,0,9 \leftarrow 8,0,8$

Ground

4. $727 \quad 3,1,3 \leftarrow 2,1,2$

4. 727

$3,1,3 \leftarrow 2,1,2$

4- 751

$3, \quad \leftarrow 2, \quad$,

Excited

4-1714

$3, \quad \leftarrow 2, \quad$,

4. 922

Not Reported

4- 738

$3,0,3 \leftarrow 2,0,2$

4- 735

$3,1,2 \leftarrow 2,1,1$

Ground

3. 721

$2,0,2 \leftarrow 1,1,1$

Ground

3. 721

$2,0,2 \leftarrow 1,1,1$

Ground

3- 198

$12,7,6 \leftarrow 12,7,5$

Ground

4. 347

$6,1,5 \leftarrow 6,0,6$

Ground

4. 901

Not Reported

3- 504

$2,0,2 \leftarrow 1,0,1$

Ground

3. 679

$3,1,3 \leftarrow 2,0,2$

Ground

Ground

3. 503

$2,0,2 \leftarrow 1,0,1$

Ground

3. 761

$36,18, \leftarrow 35,19$,

4. 739

$3,1,2 \leftarrow 2,1,1$

3- 761

$36,18, \leftarrow 35,19$

3- 171 Not Reported

3- $76136,18, \leftarrow 35,19$,

4- 21

$2,1 \leftarrow 1,1$

4. 727

$3,1,3 \leftarrow 2,1,2$

3-1051

$6,1,6 \leftarrow 5,0,5$

4- 901

Not Reported

4. 739

$3,1,2 \leftarrow 2,1,1$

4-1621

4-1156

Not Reported

4. 333

$6,5,2 \leftarrow 6,4,3$

Not Reported

4. 293

$$
10 \leftarrow 10
$$

3- 751

Not Reported

4- 735

3. 581

$3,1,2 \leftarrow 2,1,1$

Not Reported

3. 674

$8,2,6 \leftarrow 8,1,7$

3- 261

Not Reported

4- 739

$3,1,2 \leftarrow 2 ; 1,1$

4- 841

$3,2,1 \leftarrow 3,1,2$

4-1621

Not Reported

4- 727

$3,1,3 \leftarrow 2,1,2$

4. 729

$3, \quad \leftarrow 2, \quad$

4- 863

Not Reported

3- 674

$8,2,6 \leftarrow 8,1,7$

4. 922

Not Reported

4. 727
Ground

Ground

Excited

Ground

Ground

Ground

Excited

Ground

Ground

Ground

Excited

Ground

Excited

Ground

Ground

Ground

Ground

Ground

Ground

Ground

Ground

Ground
Frequency
MHIz
Ace.
MII\%

\section{$\mathrm{F}_{1}^{\prime} \mathrm{F}^{\prime} \mathrm{F}_{1} \mathrm{~F}$}

23584.

5.0

9/2 7/2 23584.4

$9 / 2 \quad 7 / 2 \quad 23585.4$

23585.6

23585.6

23587.

$5 / 2 \quad 5 / 2 \quad 23587.1$

23588.28

23589.01

23589.65

23589.7

23590.

23591.

23591.48

23591.75

23593.08

23593.09

$5 / 2 \quad 5 / 2$

23593.4

23593.50

23594.

23594.05

$1 / 2 \quad 1 / 2 \quad 23595$.

$5 / 2 \quad 5 / 2 \quad 23597.55$

23598.90

23601.5

$9 / 2 \quad 7 / 2 \quad 23601.7$

23601.78

23602.5

23602.58

23602.60

23603.

$7 / 2 \quad 5 / 2 \quad 23604.9$

23605.

23607.22

23608.52

$5 / 2 \quad 5 / 2$

23609.6

23610.38

23611.04

$9 / 2$

$7 / 2$

23611.6

23611.7

23612.9

23612.92

23613.

$3 / 2 \quad 1 / 2 \quad 23613.0$ 


\begin{tabular}{|c|c|c|c|c|c|c|c|}
\hline Isotopic Species & $\begin{array}{l}\text { Vol.-Id. } \\
\text { Nos. }\end{array}$ & $\begin{array}{c}\text { Rotational } \\
\text { Quantum Nos. }\end{array}$ & Vib. State & $\mathrm{F}_{1}^{\prime} \stackrel{\mathrm{F}^{\prime}}{\mathrm{F}_{1}}$ & $\mathrm{~F}$ & $\begin{array}{c}\text { Frequency } \\
\mathrm{MHz}\end{array}$ & $\begin{array}{r}\text { Acc. } \\
\pm \mathrm{MHz}\end{array}$ \\
\hline $\mathrm{C}^{12} \mathrm{H}_{2}: \mathrm{C}^{12} \mathrm{HBr}^{79}$ & 4- 727 & $3,1,3 \leftarrow 2,1,2$ & Excited & $5 / 2$ & $3 / 2$ & 23615.6 & \\
\hline $\mathrm{C}^{12} \mathrm{H}_{2}: \mathrm{C}^{13} \mathrm{HBr}^{81}$ & 4- 738 & $3,2,2 \leftarrow 2,2,1$ & Ground & $9 / 2$ & $7 / 2$ & 23617.0 & \\
\hline $\mathrm{C}^{12} \mathrm{H}_{3} \mathrm{~S}^{32} \mathrm{H}$ & 3- 221 & Not Reported & Ground & & & 23617.3 & .1 \\
\hline $\mathrm{c}-\mathrm{C}^{12} \mathrm{HD}: \mathrm{C}^{12} \mathrm{HBr}^{79}$ & 4. 739 & $3,1,2 \leftarrow 2,1,1$ & Ground & $9 / 2$ & $7 / 2$ & 23617.9 & .2 \\
\hline $\mathrm{H}_{2} \mathrm{C}^{12}: \mathrm{C}^{12} \mathrm{Cl}_{2}^{\mathrm{b}}$ & 4- 663 & Not Reported & Ground & & & 23618.6 & 1.5 \\
\hline $\mathrm{C}^{12} \mathrm{H}_{2}: \mathrm{C}^{12} \mathrm{DBr}^{79}$ & 4- 721 & $3,2,2 \leftarrow 2,2,1$ & Ground & $7 / 2$ & $5 / 2$ & 23618.7 & \\
\hline $\mathrm{C}^{12} \mathrm{H}_{2}: \mathrm{C}^{12} \mathrm{DBr}^{79}$ & 4- 721 & $3,2,2 \leftarrow 2,2,1$ & Ground & $5 / 2$ & $5 / 2$ & 23618.7 & \\
\hline $\mathrm{C}^{12} \mathrm{H}_{2} \mathrm{DC}^{12} \mathrm{HDF}^{19}$ & 3- 557 & $6,1,5 \leftarrow 6,1,6$ & Ground & & & 23618.7 & .1 \\
\hline $\mathrm{C}^{12}{ }_{*} \mathrm{H}: \mathrm{C}^{12} \mathrm{HO}^{16} \mathrm{C}^{12} \mathrm{H}: \mathrm{C}^{12}{ }_{*} \mathrm{H}$ & $4-1151$ & $7,6,2 \leftarrow 7,4,3$ & Ground & & & 23619.06 & \\
\hline $\mathrm{F}_{2}^{19} \mathrm{~N}^{14} \mathrm{~N}^{14} \mathrm{~F}_{2}^{19}$ & $3-21$ & $14,5,9 \leftarrow 14,4,11$ & Ground & & & 23620.1 & .3 \\
\hline $\mathrm{c}-\mathrm{HCl}^{35} \mathrm{C}^{12}: \mathrm{C}^{12} \mathrm{HCl}^{37}$ & 4- 672 & $11,2,9 \leftarrow 11,1,10$ & Ground & & & 23620.5 & 1. \\
\hline $\mathrm{C}^{12} \mathrm{H}_{3} \mathrm{C}^{12} \mathrm{~F}^{19}: \mathrm{C}^{12} \mathrm{H}_{2}$ & 3- 721 & $2,0,2 \leftarrow 1,1,1$ & Ground & & & 23621.03 & .1 \\
\hline $\mathrm{C}^{\mathrm{b}} \mathrm{H}_{2}: \mathrm{C}^{\mathrm{b}} \mathrm{HBr}^{\mathrm{b}}$ & 4. 752 & $3,2,1 \leftarrow 2,2,0$ & Ground & $9 / 2$ & $7 / 2$ & 23622.1 & \\
\hline $\mathrm{As}^{75} \mathrm{~F}_{3}^{19}$ & 4. 21 & $2,0 \leftarrow 1,0$ & Ground & $1 / 2$ & $3 / 2$ & 23622.2 & \\
\hline $\mathrm{C}^{12} \mathrm{H}_{3} \mathrm{C}^{12} \mathrm{O}^{16} \mathrm{O}^{16} \mathrm{H}$ & 3- 491 & Not Reported & & & & 23623 & 3. \\
\hline $\mathrm{C}^{12} \mathrm{H}_{2}: \mathrm{C}^{12} \mathrm{HBr}^{79}$ & 4. 727 & $3,1,3 \leftarrow 2,1,2$ & Ground & & & 23624.28 & .04 \\
\hline $\mathrm{C}^{12} \mathrm{H}_{2}: \mathrm{C}^{12} \mathrm{DBr}^{\mathrm{b}}$ & 4. 729 & $3, \quad \leftarrow 2$, & Ground & & & 23624.43 & \\
\hline $\mathrm{S}^{32} \mathrm{O}^{16} \mathrm{~F}_{2}^{19}$ & 4-1621 & Not Reported & & & & 23625.64 & .1 \\
\hline $\mathrm{a}-\mathrm{C}^{12} \mathrm{H}_{2} \mathrm{DSi}^{28} \mathrm{H}_{2} \mathrm{~F}^{19}$ & 3- 248 & $6,1,5 \leftarrow 6,1,6$ & Ground & & & 23626.60 & .1 \\
\hline$\left(\mathrm{C}^{12} \mathrm{H}_{3}\right)_{3} \mathrm{C}^{12} \mathrm{Cl}^{37}$ & 3- 972 & $4, \leftarrow 3$, & Ground & & & 23627.3 & .3 \\
\hline $\mathrm{C}^{12} \mathrm{H}_{2}: \mathrm{C}^{12} \mathrm{DBr}^{79}$ & 4. 721 & $3,2,1 \leftarrow 2,2,0$ & Ground & $5 / 2$ & $5 / 2$ & 23628.5 & \\
\hline $\mathrm{C}^{12} \mathrm{H}_{2}: \mathrm{C}^{12} \mathrm{DBr}^{79}$ & 4- 721 & $3,2,1 \leftarrow 2,2,0$ & Ground & $7 / 2$ & $5 / 2$ & 23628.5 & \\
\hline c- $\mathrm{C}^{12} \mathrm{HD}: \mathrm{C}^{12} \mathrm{HBr}^{79}$ & 4- 739 & $3,1,2 \leftarrow 2,1,1$ & Excited & $7 / 2$ & $5 / 2$ & 23629.8 & .2 \\
\hline$c-\mathrm{C}^{12} \mathrm{HD}: \mathrm{C}^{12} \mathrm{HBr}^{79}$ & 4- 739 & $3,1,2 \leftarrow 2,1,1$ & Ground & & & 23629.80 & .06 \\
\hline $\mathrm{Si}^{28} \mathrm{H}_{2} \mathrm{DN}^{14} \mathrm{C}^{12} \mathrm{~S}^{32}$ & 4- 497 & $8,1, \leftarrow 7,1$, & Ground & & & 23630.62 & .1 \\
\hline $\mathrm{C}^{12}{ }_{*} \mathrm{H}_{2} \mathrm{~N}^{14} \mathrm{HC}^{12}{ }_{*} \mathrm{H}_{2}$ & 4. 861 & $2,1,1 \leftarrow 2,0,2$ & Ground & & & 23632.9 & .5 \\
\hline $\mathrm{Si}^{28} \mathrm{H}_{2} \mathrm{DN}^{14} \mathrm{C}^{12} \mathrm{~S}^{32}$ & 4- 497 & $8,7, \leftarrow 7,7$, & Ground & & & 23633.38 & .1 \\
\hline $\mathrm{C}^{\mathrm{b}} \mathrm{H}_{2}: \mathrm{C}^{\mathrm{b}} \mathrm{HBr}^{\mathrm{b}}$ & 4. 752 & $3,0,3 \leftarrow 2,0,2$ & Ground & $9 / 2$ & $7 / 2$ & 23634.0 & \\
\hline $\mathrm{C}^{12}{ }_{*} \mathrm{H}_{2} \mathrm{~N}^{14} \mathrm{HC}^{12}{ }_{*} \mathrm{H}_{2}$ & 4- 861 & $2,1,1 \leftarrow 2,0,2$ & Ground & & & 23634.41 & .1 \\
\hline $\mathrm{Cl}^{16} \mathrm{C}^{12} \mathrm{~N}^{14}$ & 4- 175 & $2 \leftarrow 1$ & Ground & & & 23635 . & \\
\hline $\mathrm{C}^{12} \mathrm{D}_{3} \mathrm{C}^{13}: \mathrm{C}^{12} \mathrm{Cl}^{35}$ & 4- 979 & $6,0 \leftarrow 5,0$ & Ground & $13 / 2$ & $11 / 2$ & 23635.45 & .04 \\
\hline $\mathrm{C}^{12} \mathrm{D}_{3} \mathrm{C}^{13}: \mathrm{C}^{12} \mathrm{Cl}^{35}$ & 4- 979 & $6,0 \leftarrow 5,0$ & Ground & $15 / 2$ & $13 / 2$ & 23635.45 & .04 \\
\hline $\mathrm{C}^{12} \mathrm{O}^{16} \mathrm{Cl}_{2}^{35}$ & 4. 181 & $4,1,4 \leftarrow 3,0,3$ & Ground & & & 23637.1 & .3 \\
\hline $\mathrm{C}^{12} \mathrm{H}_{2}: \mathrm{C}^{12} \mathrm{DBr}^{\mathrm{b}}$ & 4- 729 & $3, \quad \leftarrow 2$, & Ground & & & 23637.19 & \\
\hline $\mathrm{C}^{12} \mathrm{H}_{2}\left(\mathrm{C}^{12} \mathrm{~N}^{14}\right)_{2}$ & 4- 901 & Not Reported & Ground & & & 23638. & .1 \\
\hline $\mathrm{C}^{12}{ }_{*} \mathrm{H}_{2} \mathrm{~N}^{14} \mathrm{DC}^{12}{ }_{*} \mathrm{H}_{2}$ & 4- 862 & $2,2,1 \leftarrow 2,0,2$ & Ground & & & 23638.6 & .5 \\
\hline $\mathrm{C}^{12} \mathrm{H}_{2}: \mathrm{C}^{13} \mathrm{HBr}^{81}$ & 4. 738 & $3,0,3 \leftarrow 2,0,2$ & Ground & & & 23638.68 & .10 \\
\hline $\mathrm{C}^{12} \mathrm{H}_{2}: \mathrm{C}^{12} \mathrm{HBr}^{79}$ & 4- 727 & $3,1,3 \leftarrow 2,1,2$ & Ground & $7 / 2$ & $5 / 2$ & 23640.65 & \\
\hline $\mathrm{C}^{12} \mathrm{H}_{2}: \mathrm{C}^{12} \mathrm{HBr}^{79}$ & 4. 727 & $3,1,3 \leftarrow 2,1,2$ & Ground & $7 / 2$ & $5 / 2$ & 23640.7 & \\
\hline $\mathrm{C}^{12} \mathrm{HD}: \mathrm{C}^{12} \mathrm{HBr}^{\mathrm{b}}$ & 4. 748 & Not Reported & & & & 23640.8 & .2 \\
\hline $\mathrm{C}_{6}^{12} \mathrm{H}_{5} \mathrm{~F}^{19}$ & 4-1281 & Not Reported & & & & 23642 & 5. \\
\hline $\mathrm{Si}^{28} \mathrm{H}_{2} \mathrm{DN}^{14} \mathrm{C}^{12} \mathrm{~S}^{32}$ & 4- 497 & $8,6, \leftarrow 7,6$, & Ground & & & 23642.29 & .1 \\
\hline $\mathrm{C}^{12} \mathrm{H}_{2}: \mathrm{C}^{12} \mathrm{HBr}^{79}$ & 4. 727 & $3,1,3 \leftarrow 2,1,2$ & Ground & $5 / 2$ & $3 / 2$ & 23642.50 & \\
\hline $\mathrm{H}_{2} \mathrm{C}^{12}: \mathrm{C}^{12} \mathrm{Cl}_{2}^{\mathrm{b}}$ & 4- 663 & Not Reported & Ground & & & 23643.3 & 1. \\
\hline
\end{tabular}




\begin{tabular}{|c|c|c|c|c|c|c|c|}
\hline $\mathrm{C}^{12}{ }_{*} \mathrm{H}_{2} \mathrm{~N}^{14} \mathrm{DC}^{12}{ }_{*} \mathrm{H}_{2}$ & 4. 862 & $2,2,1 \leftarrow 2,0,2$ & Ground & & & 23643.6 & .5 \\
\hline $\mathrm{a} \cdot \mathrm{HC}^{12} \mathrm{O}^{16} \mathrm{O}^{16} \mathrm{C}^{12} \mathrm{H}_{2} \mathrm{D}$ & 3- 506 & $2,0,2 \leftarrow 1,0,1$ & Ground & & & 23644.75 & .2 \\
\hline $\mathrm{C}^{12} \mathrm{D}_{2}\left(\mathrm{C}^{12} \mathrm{~N}^{14}\right)_{2}$ & 4. 903 & $9,1,8 \leftarrow 9,0,9$ & Ground & & & 23645.34 & \\
\hline $\mathrm{C}^{12} \mathrm{H}_{2}: \mathrm{C}^{13} \mathrm{HBr}^{81}$ & 4. 738 & $3,2,2 \leftarrow 2,2,1$ & Ground & & & 23645.38 & .06 \\
\hline c. $\mathrm{C}^{12} \mathrm{HD}: \mathrm{C}^{12} \mathrm{HBr}^{79}$ & 4.- 739 & $3,1,2 \leftarrow 2,1,1$ & Ground & $7 / 2$ & $5 / 2$ & 23646.3 & .1 \\
\hline $\mathrm{C}^{12} \mathrm{H}_{2}: \mathrm{C}^{12} \mathrm{HBr}^{\mathrm{b}}$ & 4- 751 & $3, \quad \leftarrow 2, \quad \leftarrow$, & Ground & & & 23646.3 & .2 \\
\hline $\mathrm{HDO}^{17}$ & $4-1714$ & $3, \quad \leftarrow 2, \quad$, & Ground & & & 23646.3 & .05 \\
\hline $\mathrm{O}^{16} \mathrm{C}^{13} \mathrm{~S}^{34}$ & 4- 527 & $2 \leftarrow 1$ & Ground & & & 23646.92 & \\
\hline $\mathrm{H}_{2} \mathrm{C}^{12}: \mathrm{C}^{12} \mathrm{~F}_{2}^{19}$ & 4. 681 & Not Reported & & & & 23647.1 & .3 \\
\hline $\mathrm{C}^{12} \mathrm{DHDC}^{12} \mathrm{HDF}^{19}$ & 3. 561 & $3,1,2 \leftarrow 3,0,3$ & Ground & & & 23647.6 & .1 \\
\hline $\mathrm{C}^{12} \mathrm{H}_{3} \mathrm{C}^{12} \mathrm{O}^{16} \mathrm{O}^{16} \mathrm{H}$ & 3. 491 & $2,1,2 \leftarrow 1,1,1$ & Ground & & & 23648. & 3. \\
\hline $\mathrm{Si}^{28} \mathrm{H}_{2} \mathrm{DN}^{14} \mathrm{C}^{12} \mathrm{~S}^{32}$ & 4. 497 & $8,5, \leftarrow 7,5$ & Ground & & & 23649.25 & .1 \\
\hline $\mathrm{C}^{12} \mathrm{H}_{2}: \mathrm{C}^{13} \mathrm{HBr}^{81}$ & 4. 738 & $3,2,1 \leftarrow 2,2,0$ & Ground & $5 / 2$ & $3 / 2$ & 23650.7 & \\
\hline $\mathrm{C}^{12} \mathrm{H}_{2}: \mathrm{C}^{13} \mathrm{HBr}^{81}$ & 4- 738 & $3,2,1 \leftarrow 2,2,0$ & Ground & & & 23650.76 & .06 \\
\hline $\mathrm{C}^{12} \mathrm{H}_{3} \mathrm{~N}^{14} \mathrm{O}_{2}^{16}$ & 3. 171 & Not Reported & Ground & & & 23652.02 & \\
\hline $\mathrm{S}^{32}{ }_{*} \mathrm{HC}^{12}: \mathrm{C}^{12} \mathrm{HC}^{12} \mathrm{H}: \mathrm{C}^{12}{ }_{*} \mathrm{H}$ & $4-1161$ & $11,5,7 \leftarrow 11,5,6$ & Ground & & & 23652.9 & .1 \\
\hline $\mathrm{Si}^{28} \mathrm{H}_{2} \mathrm{DN}^{14} \mathrm{C}^{12} \mathrm{~S}^{32}$ & 4. 497 & $8,4, \leftarrow 7,4$, & Ground & & & 23655.15 & .1 \\
\hline $\mathrm{HC}^{13}: \mathrm{C}^{12} \mathrm{C}^{12} \mathrm{DO}^{16}$ & 4- 922 & Not Reported & & & & 23656. & 5. \\
\hline $\mathrm{N}^{14} \mathrm{H}_{3}$ & 4-1771 & $9,8 \leftarrow 9,8$ & Ground & & & 23657.48 & .02 \\
\hline $\mathrm{C}^{13} \mathrm{H}_{2}: \mathrm{C}^{12} \mathrm{HBr}^{79}$ & 4. 735 & $3,1,2 \leftarrow 2,1,1$ & Ground & $7 / 2$ & $7 / 2$ & 23658.3 & \\
\hline $\mathrm{Si}^{28} \mathrm{H}_{2} \mathrm{DN}^{14} \mathrm{C}^{12} \mathrm{~S}^{32}$ & 4. 497 & $8,3, \leftarrow 7,3$, & Ground & & & 23659.41 & .1 \\
\hline $\mathrm{H}_{2} \mathrm{C}^{12}: \mathrm{C}^{12} \mathrm{Cl}_{2}^{\mathrm{b}}$ & 4. 663 & Not Reported & Ground & & & 23660.0 & 1.5 \\
\hline $\mathrm{C}^{12} \mathrm{H}_{3} \mathrm{~N}^{14} \mathrm{O}_{2}^{16}$ & 3. 171 & Not Reported & Ground & & & 23661. & 5. \\
\hline$\left(\mathrm{C}^{12} \mathrm{H}_{3}\right)_{2} \mathrm{C}^{12} \mathrm{O}^{16}$ & 3. 751 & Not Reported & & & & 23661. & 5. \\
\hline $\mathrm{O}^{16} \mathrm{C}^{12} \mathrm{~S}^{34}$ & 4. 523 & $2 \leftarrow 1$ & Ground & & & 23661. & \\
\hline $\mathrm{C}^{12} \mathrm{D}_{3} \mathrm{C}^{12} \mathrm{O}^{16} \mathrm{Cl}^{35}$ & 3- 363 & $3,1,3 \leftarrow 2,0,2$ & Ground & $3 / 2$ & $1 / 2$ & 23662.10 & \\
\hline $\mathrm{Si}^{28} \mathrm{H}_{2} \mathrm{DN}^{14} \mathrm{C}^{12} \mathrm{~S}^{32}$ & 4. 497 & $8,2, \leftarrow 7,2$, & Ground & & & 23662.43 & .1 \\
\hline $\mathrm{Cs}^{133} \mathrm{Br}^{79}$ & 1 . & $11 \leftarrow 10$ & Excited & & & 23665.60 & 0.20 \\
\hline $\mathrm{C}^{\mathrm{b}}{ }_{*} \mathrm{H}_{2}^{\mathrm{b}} \mathrm{N}^{\mathrm{b}} \mathrm{H}^{\mathrm{b}} \mathrm{C}^{\mathrm{b}}{ }_{*} \mathrm{H}_{2}^{\mathrm{b}}$ & 4. 863 & Not Reported & & & & 23665.7 & .5 \\
\hline $\mathrm{C}^{12} \mathrm{D}_{3} \mathrm{C}^{12} \mathrm{O}^{16} \mathrm{Cl}^{35}$ & 3- 363 & $3,1,3 \leftarrow 2,0,2$ & Ground & $5 / 2$ & $3 / 2$ & 23666.35 & \\
\hline $\mathrm{C}^{12} \mathrm{D}_{3} \mathrm{C}^{12} \mathrm{O}^{16} \mathrm{Cl}^{35}$ & 3- 363 & $3,1,3 \leftarrow 2,0,2$ & Ground & $9 / 2$ & $7 / 2$ & 23667.22 & \\
\hline $\mathrm{C}^{12} \mathrm{H}_{2}\left(\mathrm{C}^{12} \mathrm{~N}^{14}\right)_{2}$ & 4. 901 & Not Reported & Ground & & & 23667.9 & .1 \\
\hline $\mathrm{C}^{12} \mathrm{H}_{3} \mathrm{~N}^{14} \mathrm{O}_{2}^{16}$ & 3. 171 & Not Reported & Ground & & & 23668.03 & \\
\hline $\mathrm{C}^{12} \mathrm{H}_{3} \mathrm{C}^{12}{ }_{*} \mathrm{HO}^{16} \mathrm{C}^{12}{ }_{*} \mathrm{H}_{2}$ & 3- 761 & $12,5,8 \leftarrow 11,6,5$ & Ground & & & 23668.22 & .1 \\
\hline $\mathrm{HC}^{13}: \mathrm{C}^{12} \mathrm{C}^{12} \mathrm{DO}^{16}$ & 4. 922 & Not Reported & & & & 23670. & 5. \\
\hline $\mathrm{C}^{12} \mathrm{H}_{3} \mathrm{C}^{12}{ }_{*} \mathrm{HO}^{16} \mathrm{C}^{12}{ }_{*} \mathrm{H}_{2}$ & 3- 761 & $12,5,8 \leftarrow 11,6,5$ & Ground & & & 23670.17 & .1 \\
\hline $\mathrm{Si}^{28} \mathrm{D}_{3} \mathrm{Cl}^{35}$ & $4-1444$ & $2, \leftarrow 1$, & Ground & & & 23670.8 & .2 \\
\hline $\mathrm{C}^{12} \mathrm{D}_{3} \mathrm{C}^{12} \mathrm{O}^{16} \mathrm{Cl}^{35}$ & 3. 363 & $3,1,3 \leftarrow 2,0,2$ & Ground & $7 / 2$ & $5 / 2$ & 23671.50 & \\
\hline $\mathrm{C}^{12} \mathrm{H}_{3} \mathrm{C}^{12}{ }_{*} \mathrm{HO}^{16} \mathrm{C}^{12}{ }_{*} \mathrm{H}_{2}$ & 3- 761 & $12,5,8 \leftarrow 11,6,5$ & Ground & & & 23672.94 & .1 \\
\hline $\mathrm{N}^{14} \mathrm{O}^{16} \mathrm{O}^{18}$ & 4. 1803 & $7,1,7 \leftarrow 8,0,8$ & Ground & & & 23674.33 & \\
\hline $\mathrm{C}^{12} \mathrm{D}_{3} \mathrm{C}^{12} \mathrm{O}^{16} \mathrm{Cl}^{35}$ & 3- 363 & $3,1,3 \leftarrow 2,0,2$ & Ground & $3 / 2$ & $3 / 2$ & 23674.50 & \\
\hline $\mathrm{C}^{12} \mathrm{H}_{2} \mathrm{Cl}^{35} \mathrm{Si}^{28} \mathrm{H}_{3}$ & 3. 231 & $8,1,7 \leftarrow 8,0,8$ & Ground & & & 23674.57 & .2 \\
\hline $\mathrm{C}^{12} \mathrm{H}_{3} \mathrm{C}^{12}{ }_{*} \mathrm{HO}^{16} \mathrm{C}^{12}{ }_{*} \mathrm{H}_{2}$ & 3- 761 & $12,5,7 \leftarrow 11,6,6$ & Ground & & & 23679.29 & .1 \\
\hline $\mathrm{C}^{12} \mathrm{H}_{3} \mathrm{~N}^{14} \mathrm{O}_{2}^{16}$ & 3- 171 & Not Reported & Ground & & & 23680. & \\
\hline $\mathrm{C}^{12} \mathrm{H}_{3} \mathrm{C}^{12}{ }_{*} \mathrm{HO}^{16} \mathrm{C}^{12}{ }_{*} \mathrm{H}_{2}$ & 3. 761 & $12,5,7 \leftarrow 11,6,6$ & Ground & & & 23680.51 & .1 \\
\hline
\end{tabular}




\begin{tabular}{|c|c|c|c|c|c|c|c|c|c|}
\hline \multirow{3}{*}{$\frac{\text { Isotopic Species }}{\mathrm{C}^{12} \mathrm{H}_{3} \mathrm{~N}^{14} \mathrm{H}_{2}}$} & \multirow{3}{*}{$\begin{array}{c}\text { Vol.-Id. } \\
\text { Nos. } \\
\text { 3- } 261\end{array}$} & \multirow{3}{*}{$\begin{array}{c}\begin{array}{c}\text { Rotational } \\
\text { Quantum Nos. }\end{array} \\
11,4, \quad \leftarrow 12,3,\end{array}$} & \multirow{3}{*}{$\begin{array}{c}\text { Vib. State } \\
\text { Ground }\end{array}$} & \multicolumn{4}{|c|}{ Hyperfine } & \multirow{2}{*}{$\begin{array}{c}\text { Frequency } \\
\mathrm{MHz}\end{array}$} & \multirow{2}{*}{$\begin{array}{r}\text { Acc. } \\
\pm \mathrm{MHz}\end{array}$} \\
\hline & & & & $\mathrm{F}_{1}^{\prime}$ & $F^{\prime}$ & $\mathrm{F}_{1}$ & $\mathrm{~F}$ & & \\
\hline & & & & & & & & 23683.17 & .1 \\
\hline $\mathrm{C}^{12} \mathrm{H}_{3} \mathrm{C}^{12}{ }_{*} \mathrm{HO}^{16} \mathrm{C}^{12}{ }_{*} \mathrm{H}_{2}$ & 3- 761 & $12,5,7 \leftarrow 11,6,6$ & Ground & & & & & 23683.96 & .1 \\
\hline $\mathrm{C}^{12} \mathrm{D}_{3} \mathrm{C}^{12} \mathrm{HDC}^{12} \mathrm{~N}^{14}$ & 3- 733 & $3,0,3 \leftarrow 2,0,2$ & Ground & & & & & 23684.68 & .1 \\
\hline $\mathrm{C}_{6}^{12} \mathrm{H}_{5} \mathrm{Br}^{\mathrm{b}}$ & 4-1261 & Not Reported & & & & & & 23690 . & 5. \\
\hline $\mathrm{C}^{12} \mathrm{H}_{2} \mathrm{Cl}^{37} \mathrm{Si}^{28} \mathrm{H}_{3}$ & 3. 232 & $8,1,7 \leftarrow 8,0,8$ & Ground & & & & & 23692.14 & .2 \\
\hline $\mathrm{D}_{2} \mathrm{O}_{2}^{16}$ & 3. 42 & Not Reported & & & & & & 23694 . & 3. \\
\hline $\mathrm{N}^{14} \mathrm{H}_{3}$ & 4-1771 & $1,1 \leftarrow 1,1$ & Ground & & & & & 23694.49 & .02 \\
\hline c- $\mathrm{C}^{12} \mathrm{HD}: \mathrm{C}^{12} \mathrm{HBr}^{79}$ & 4- 739 & $3,1,2 \leftarrow 2,1,1$ & Ground & & $7 / 2$ & & $7 / 2$ & 23697.6 & .1 \\
\hline $\mathrm{C}^{\mathrm{b}} \mathrm{H}_{2}: \mathrm{C}^{\mathrm{b}} \mathrm{HBr}^{\mathrm{b}}$ & 4- 752 & Not Reported & Ground & & & & & 23698.3 & .2 \\
\hline $\mathrm{Si}^{28} \mathrm{H}_{2} \mathrm{DN} \mathrm{N}^{14} \mathrm{C}^{12} \mathrm{~S}^{32}$ & 4- 497 & $8,1, \leftarrow 7,1$, & Ground & & & & & 23698.48 & .1 \\
\hline $\mathrm{Ga}^{69} \mathrm{I}^{127}$ & $1-$ & $7 \leftarrow 6$ & Excited & $19 / 2$ & & $17 / 2$ & 10 & 23698.78 & 0.30 \\
\hline$\left(; a^{69}\right]^{127}$ & 1. & $7 \leftarrow 6$ & Excited & $13 / 2$ & 8 & $15 / 2$ & 7 & 23698.78 & 0.30 \\
\hline$C^{699} I^{127}$ & 1. & $7 \leftarrow 6$ & Excited & $19 / 2$ & 8 & $17 / 2$ & 7 & 23698.78 & 0.30 \\
\hline$C^{699} I^{127}$ & 1. & $7 \leftarrow 6$ & Excited & $17 / 2$ & 9 & $15 / 2$ & 8 & 23698.78 & 0.30 \\
\hline$\left(; a^{69} \mathrm{I}^{127}\right.$ & 1 - & $7 \leftarrow 6$ & Excited & $19 / 2$ & & $17 / 2$ & 9 & 23698.78 & 0.30 \\
\hline ( $: \mathrm{a}^{69} \mathrm{I}^{127}$ & 1. & $7 \leftarrow 6$ & Excited & $19 / 2$ & 9 & $17 / 2$ & 8 & 23698.78 & 0.30 \\
\hline C. $\mathrm{a}^{69} \mathrm{I}^{127}$ & 1. & $7 \leftarrow 6$ & Excited & $15 / 2$ & 9 & $13 / 2$ & 8 & 23698.78 & 0.30 \\
\hline$\left(\mathrm{a}^{69} \mathrm{I}^{127}\right.$ & 1 . & $7 \leftarrow 6$ & Excited & $17 / 2$ & 7 & $11 / 2$ & 6 & 23698.78 & 0.30 \\
\hline $\mathrm{C}^{12} \mathrm{H}_{3} \mathrm{~N}^{14} \mathrm{O}_{2}^{16}$ & 3- 171 & Not Reported & Ground & & & & & 23700.01 & \\
\hline $\mathrm{N}^{14} \mathrm{O}^{16} \mathrm{O}^{18}$ & 4-1803 & $7,1,7 \leftarrow 8,0,8$ & Ground & & & & & 23701.45 & \\
\hline $\mathrm{S}^{32}{ }_{*} \mathrm{HC}^{12}: \mathrm{C}^{12} \mathrm{DC}^{12} \mathrm{D}: \mathrm{C}^{12}{ }_{*} \mathrm{H}$ & 4-1164 & $3,2,2 \leftarrow 2,2,1$ & Ground & & & & & 23701.5 & .1 \\
\hline $\mathrm{C}^{12} \mathrm{H}_{3} \mathrm{C}^{12} \mathrm{O}^{16} \mathrm{O}^{16} \mathrm{H}$ & 3- 491 & Not Reported & & & & & & 23703 . & 3. \\
\hline $\mathrm{C}^{\mathrm{b}} \mathrm{H}_{2}^{\mathrm{b}} \mathrm{Cl}^{\mathrm{b}} \mathrm{F}^{\mathrm{b}}$ & 4. 333 & Not Reported & & & & & & 23703. & 1. \\
\hline $\mathrm{C}^{12} \mathrm{HCl}^{37} \mathrm{~F}_{2}^{19}$ & 4. 252 & $6,3,4 \leftarrow 6,2,4$ & Ground & & $9 / 2$ & & $9 / 2$ & 23704.6 & .05 \\
\hline $\mathrm{C}^{12} \mathrm{H}_{2}: \mathrm{C}^{12} \mathrm{HBr}^{79}$ & 4. 727 & $3,1,3 \leftarrow 2,1,2$ & Ground & & $7 / 2$ & & $7 / 2$ & 23704.8 & \\
\hline $\mathrm{C}^{12} \mathrm{H}_{2}: \mathrm{C}^{12} \mathrm{HBr}^{79}$ & 4- 727 & $3,1,3 \leftarrow 2,1,2$ & Ground & & $7 / 2$ & & $7 / 2$ & 23704.9 & \\
\hline $\mathrm{C}^{12} \mathrm{HCl}^{37} \mathrm{~F}_{2}^{19}$ & 4. 252 & $6,3,4 \leftarrow 6,2,4$ & Ground & & $15 / 2$ & & $15 / 2$ & 23705.8 & .05 \\
\hline $\mathrm{C}^{12} \mathrm{H}_{3} \mathrm{~N}^{14} \mathrm{O}_{2}^{16}$ & 3- 171 & Not Reported & Ground & & & & & 23706. & 5. \\
\hline $\mathrm{C}^{12} \mathrm{H}_{3} \mathrm{O}^{16} \mathrm{~N}^{14} \mathrm{O}_{2}^{16}$ & 3- 181 & $3,0,3 \leftarrow 2,0,2$ & Ground & & & & & 23706.45 & .1 \\
\hline $\mathrm{C}^{12} \mathrm{HCl}^{37} \mathrm{~F}_{2}^{19}$ & 4. 252 & $6,3,4 \leftarrow 6,2,4$ & Ground & & & & & 23708.20 & .02 \\
\hline $\mathrm{C}^{12} \mathrm{H}_{2}: \mathrm{C}^{12} \mathrm{HC}^{12} \mathrm{~F}^{19}: \mathrm{C}^{12} \mathrm{H}_{2}$ & 3- 911 & $8,3,5 \leftarrow 8,2,6$ & Ground & & & & & 23709.41 & .03 \\
\hline $\mathrm{C}^{12} \mathrm{HCl}^{37} \mathrm{~F}_{2}^{19}$ & 4- 252 & $6,3,4 \leftarrow 6,2,4$ & Ground & & $11 / 2$ & & $11 / 2$ & 23710.0 & .05 \\
\hline $\mathrm{C}_{6}^{12} \mathrm{H}_{5} \mathrm{O}^{16} \mathrm{H}$ & $3-1051$ & $6,1,6 \leftarrow 5,0,5$ & Ground & & & & & 23710.65 & \\
\hline $\mathrm{C}^{12} \mathrm{H}_{3} \mathrm{C}^{12} \mathrm{H}_{2} \mathrm{C}^{12} \mathrm{~N}^{14}$ & 3- 731 & $5,0,5 \leftarrow 4,1,4$ & Ground & & & & & 23710.80 & .1 \\
\hline $\mathrm{C}^{\mathrm{b}} \mathrm{H}_{2}^{\mathrm{b}} \mathrm{Cl}^{\mathrm{b}} \mathrm{F}^{\mathrm{b}}$ & 4- 333 & Not Reported & & & & & & 23711.04 & .1 \\
\hline $\mathrm{C}^{12} \mathrm{H}_{3} \mathrm{C}^{12} \mathrm{O}^{16} \mathrm{C}^{12} \mathrm{~N}^{14}$ & 3- 671 & $8,2,6 \leftarrow 8,1,7$ & Ground & & & & & 23711.10 & .2 \\
\hline $\mathrm{C}^{12} \mathrm{HCl}^{37} \mathrm{~F}_{2}^{19}$ & 4- 252 & $6,3,4 \leftarrow 6,2,4$ & Ground & & $13 / 2$ & & $13 / 2$ & 23711.4 & .05 \\
\hline $\mathrm{C}^{12} \mathrm{H}_{3} \mathrm{C}^{12} \mathrm{O}^{16} \mathrm{O}^{16} \mathrm{H}$ & 3- 491 & $2,1,2 \leftarrow 1,1,1$ & Excited & & & & & 23713. & 3. \\
\hline $\mathrm{C}^{12} \mathrm{H}_{2}: \mathrm{C}^{13} \mathrm{HBr}^{81}$ & 4. 738 & $3,2,2 \leftarrow 2,2,1$ & Ground & & $7 / 2$ & & $5 / 2$ & 23716.1 & \\
\hline $\mathrm{C}^{12} \mathrm{H}_{3} \mathrm{C}^{12} \mathrm{O}^{16} \mathrm{C}^{12} \mathrm{~N}^{14}$ & 3- 671 & $8,2,6 \leftarrow 8,1,7$ & Ground & & & & & 23716.83 & .2 \\
\hline $\mathrm{C}^{12} \mathrm{H}_{3} \mathrm{C}^{12} \mathrm{O}^{16} \mathrm{O}^{16} \mathrm{H}$ & 3- 491 & Not Reported & & & & & & 23717. & 3. \\
\hline $\mathrm{C}^{12}{ }_{*} \mathrm{HO}^{16} \mathrm{C}^{12} \mathrm{HC}^{12} \mathrm{H}_{2} \mathrm{C}^{12} \mathrm{H}_{2} \mathrm{C}^{12}{ }_{*} \mathrm{H}_{2}$ & 4-1251 & $10,8,3 \leftarrow 10,7,3$ & Ground & & & & & 23717 . & 5. \\
\hline $\mathrm{C}^{12} \mathrm{D}_{3} \mathrm{C}^{13} \mathrm{O}^{16} \mathrm{~F}^{19}$ & 3. 401 & $2,0,2 \leftarrow 1,1,1$ & Ground & & & & & 23717.18 & .2 \\
\hline $\mathrm{C}^{12} \mathrm{D}_{3} \mathrm{C}^{12} \mathrm{HDC}^{12} \mathrm{~N}^{14}$ & 3. 733 & $3,2,2 \leftarrow 2,2,1$ & Ground & & & & & 23719.06 & .1 \\
\hline $\mathrm{HC}^{13}: \mathrm{C}^{12} \mathrm{C}^{12} \mathrm{DO}^{16}$ & 4- 922 & Not Reported & & & & & & 23720. & 5. \\
\hline
\end{tabular}




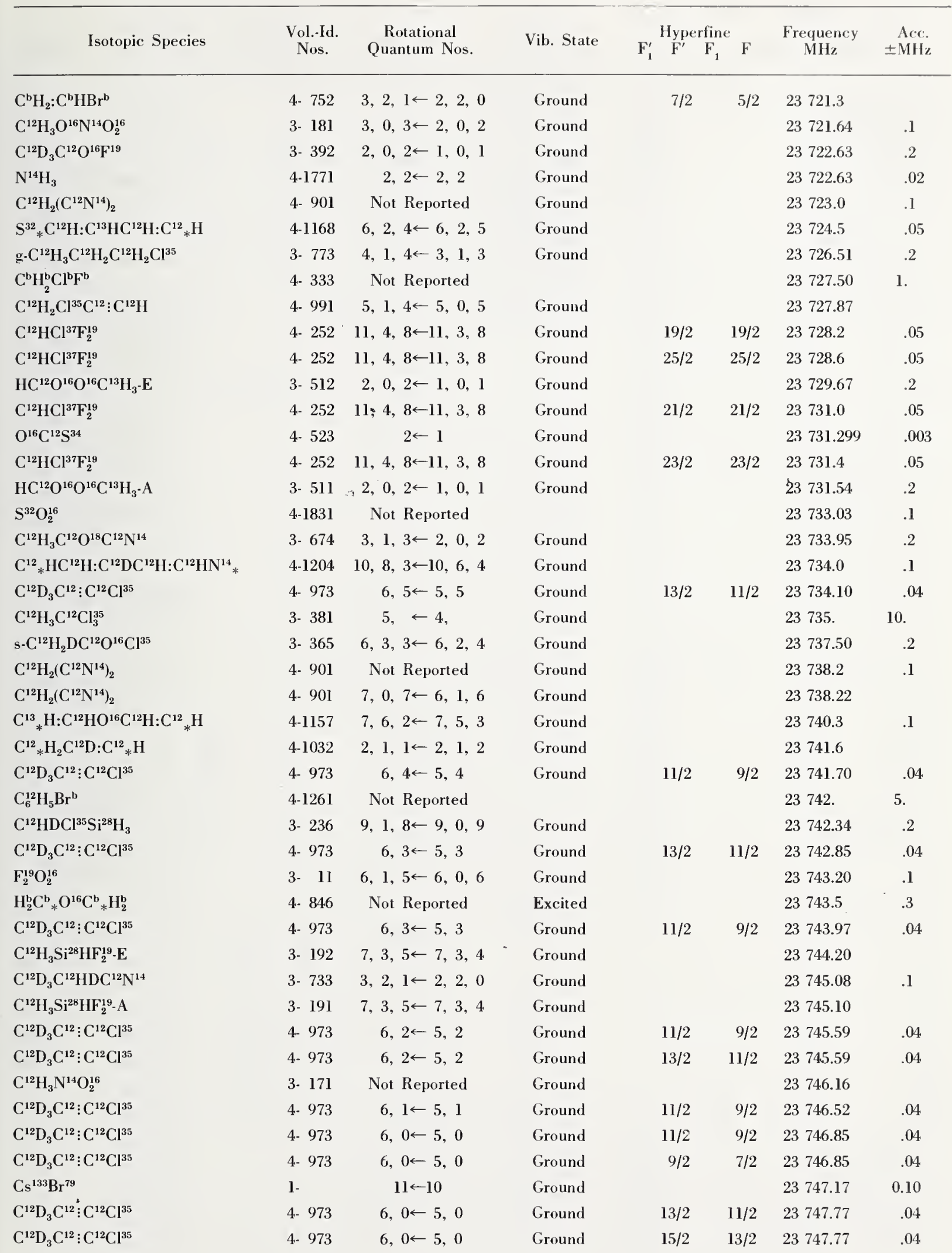




\begin{tabular}{|c|c|c|c|c|c|c|c|c|c|}
\hline Isotopic Species & $\begin{array}{l}\text { Vol.-Id. } \\
\text { Nos. }\end{array}$ & $\begin{array}{c}\text { Rotational } \\
\text { Quantum Nos. }\end{array}$ & Vib. State & $\mathrm{F}_{1}^{\prime}$ & $\begin{array}{l}\text { Hype } \\
\mathrm{F}^{\prime}\end{array}$ & $\mathrm{F}_{1}$ & $\mathrm{~F}$ & $\begin{array}{c}\text { Frequency } \\
\mathrm{MHz}^{2}\end{array}$ & $\begin{aligned} & \text { Acc. } \\
& \pm \mathrm{MHz}\end{aligned}$ \\
\hline$\left(\mathrm{C}^{12} \mathrm{H}_{3}\right)_{2} \mathrm{C}^{12} \mathrm{O}^{16}$ & 3- 751 & Not Reported & & & & & & 23749. & 5. \\
\hline $\mathrm{C}^{12} \mathrm{D}_{3} \mathrm{C}^{12}: \mathrm{C}^{12} \mathrm{Cl}^{35}$ & 4- 973 & $6,3 \leftarrow 5,3$ & Ground & & $9 / 2$ & & $7 / 2$ & 23749.07 & .04 \\
\hline $\mathrm{C}^{\mathrm{b}} \mathrm{H}_{2}: \mathrm{C}^{\mathrm{b}} \mathrm{HBr}^{79}$ & 4- 753 & $3,2,2 \leftarrow 2,2,1$ & Ground & & $9 / 2$ & & $7 / 2$ & 23749.5 & \\
\hline $\mathrm{C}^{12} \mathrm{D}_{3} \mathrm{O}^{16} \mathrm{H}$ & 3- 214 & Not Reported & Ground & & & & & 23750.0 & .5 \\
\hline $\mathrm{C}^{12} \mathrm{D}_{3} \mathrm{C}^{12}: \mathrm{C}^{12} \mathrm{Cl}^{35}$ & 4- 973 & $6,4 \leftarrow 5,4$ & Ground & & $9 / 2$ & & $7 / 2$ & 23750.78 & .04 \\
\hline $\mathrm{C}^{12} \mathrm{D}_{3} \mathrm{C}^{12}: \mathrm{C}^{12} \mathrm{Cl}^{35}$ & 4. 973 & $6,5 \leftarrow 5,5$ & Ground & & $9 / 2$ & & $7 / 2$ & 23753.03 & .04 \\
\hline $\mathrm{C}^{12} \mathrm{H}_{3} \mathrm{~N}^{14} \mathrm{O}_{2}^{16}$ & 3- 171 & Not Reported & Ground & & & & & 23754. & 5. \\
\hline $\mathrm{C}^{\mathrm{b}} \mathrm{H}_{2}: \mathrm{C}^{\mathrm{b}} \mathrm{HBr}^{\mathrm{b}}$ & 4- 752 & $3,2,1 \leftarrow 2,2,0$ & Ground & & $9 / 2$ & & $7 / 2$ & 23754.6 & \\
\hline $\mathrm{H}_{2} \mathrm{C}^{12}: \mathrm{C}^{12} \mathrm{Cl}_{2}^{\mathrm{b}}$ & 4- 663 & Not Reported & Ground & & & & & 23754.6 & 1.5 \\
\hline $\mathrm{Ge}^{74} \mathrm{H}_{3} \mathrm{Br}^{79}$ & 4- 105 & $5, \leftarrow 4$, & Ground & & & & & 23758.99 & 1. \\
\hline $\mathrm{Cl}^{35} \mathrm{C}^{12} \mathrm{~N}^{14}$ & 4- 171 & $2 \leftarrow 1$ & Ground & & & & & 23759. & \\
\hline $\mathrm{Cl}^{35} \mathrm{C}^{13} \mathrm{~N}^{14}$ & 4- 172 & $2 \leftarrow 1$ & Ground & $7 / 2$ & $9 / 2$ & $5 / 2$ & $7 / 2$ & 23760.98 & \\
\hline $\mathrm{C}^{12} \mathrm{D}_{2} \mathrm{Cl}_{2}^{35}$ & 4- 346 & $6,1,5 \leftarrow 6,0,6$ & Ground & & & & & 23761. & 5. \\
\hline $\mathrm{N}^{14} \mathrm{O}^{16} \mathrm{O}^{18}$ & 4-1803 & $7,1,7 \leftarrow 8,0,8$ & Ground & & & & & 23765.13 & \\
\hline $\mathrm{HC}^{13}: \mathrm{C}^{12} \mathrm{C}^{12} \mathrm{DO}^{16}$ & 4. 922 & Not Reported & & & & & & 23767. & 5. \\
\hline $\mathrm{C}^{12} \mathrm{H}_{3} \mathrm{C}^{12} \mathrm{H}_{2} \mathrm{O}^{16} \mathrm{H}$ & 3- 581 & $9,1,8 \leftarrow 8,3,5$ & Ground & & & & & 23769. & \\
\hline $\mathrm{C}^{12} \mathrm{H}_{2}\left(\mathrm{C}^{12} \mathrm{~N}^{14}\right)_{2}$ & 4- 901 & Not Reported & Ground & & & & & 23769.5 & .1 \\
\hline $\mathrm{H}_{2} \mathrm{C}^{12}: \mathrm{C}^{12} \mathrm{~F}_{2}^{19}$ & 4- 681 & Not Reported & & & & & & 23770.5 & .3 \\
\hline $\mathrm{C}^{\mathrm{b}} \mathrm{H}_{2}: \mathrm{C}^{\mathrm{b}} \mathrm{HBr}^{\mathrm{b}}$ & 4- 752 & $3,0,3 \leftarrow 2,0,2$ & Ground & & $9 / 2$ & & $7 / 2$ & 23770.8 & \\
\hline $\mathrm{H}_{2} \mathrm{~N}^{14} \mathrm{~N}^{14} \mathrm{H}_{2}$ & 3- 51 & Not Reported & & & & & & 23771.02 & \\
\hline $\mathrm{C}^{12} \mathrm{H}_{2}: \mathrm{C}^{12} \mathrm{DBr}^{\mathrm{b}}$ & 4. 729 & $3, \quad \leftarrow 2$, & Ground & & & & & 23772.6 & .2 \\
\hline $\mathrm{C}^{12} \mathrm{H}_{3} \mathrm{~S}^{32} \mathrm{H}$ & 3- 221 & Not Reported & Ground & & & & & 23773.8 & .1 \\
\hline $\mathrm{HC}^{13}: \mathrm{C}^{12} \mathrm{C}^{12} \mathrm{DO}^{16}$ & 4- 922 & Not Reported & & & & & & 23775 . & 5. \\
\hline $\mathrm{C}_{6}^{12} \mathrm{H}_{5} \mathrm{Cl}^{35}$ & 4- 1271 & Not Reported & Ground & & & & & 23775.4 & .1 \\
\hline $\mathrm{C}_{6}^{12} \mathrm{H}_{5} \mathrm{Cl}^{35}$ & 4-1271 & $9,1,9 \leftarrow 8,1,8$ & Ground & & $21 / 2$ & & $19 / 2$ & 23775.6 & .1 \\
\hline $\mathrm{C}_{6}^{12} \mathrm{H}_{5} \mathrm{Cl}^{35}$ & 4- 1271 & $9,1,9 \leftarrow 8,1,8$ & Ground & & $17 / 2$ & & $15 / 2$ & 23775.6 & .1 \\
\hline $\mathrm{C}_{6}^{12} \mathrm{H}_{5} \mathrm{Cl}^{35}$ & 4-1271 & $9,1,9 \leftarrow 8,1,8$ & Ground & & $19 / 2$ & & $17 / 2$ & 23775.6 & .1 \\
\hline $\mathrm{C}_{6}^{12} \mathrm{H}_{5} \mathrm{Cl}^{35}$ & 4-1271 & $9,1,9 \leftarrow 8,1,8$ & Ground & & $15 / 2$ & & $13 / 2$ & 23775.6 & .1 \\
\hline $\mathrm{C}^{12} \mathrm{H}_{2} \mathrm{Cl}^{35} \mathrm{Si}^{29} \mathrm{H}_{3}$ & 3- 234 & $8,1,7 \leftarrow 8,0,8$ & Ground & & $19 / 2$ & & $19 / 2$ & 23776.2 & .1 \\
\hline $\mathrm{C}^{12} \mathrm{H}_{2}: \mathrm{C}^{13} \mathrm{HBr}^{79}$ & 4- 737 & $3,0,3 \leftarrow 2,0,2$ & Ground & & & & & 23776.36 & .09 \\
\hline $\mathrm{N}^{14} \mathrm{H}_{3}$ & 4-1771 & $16,14 \leftarrow 16,14$ & Ground & & & & & 23777.4 & .1 \\
\hline$\left(\mathrm{C}^{12} \mathrm{H}_{3}\right)_{2} \mathrm{C}^{12} \mathrm{O}^{16}$ & 3. 751 & Not Reported & & & & & & 23778 . & 5. \\
\hline $\mathrm{Ga}^{69} \mathrm{I}^{127}$ & $1-$ & $7 \leftarrow 6$ & Excited & $19 / 21$ & & $17 / 21$ & 10 & 23778.29 & 0.20 \\
\hline $\mathrm{Ga}^{69} \mathrm{I}^{127}$ & 1 - & $7 \leftarrow 6$ & Excited & $19 / 21$ & & $17 / 2$ & 9 & 23778.29 & 0.20 \\
\hline $\mathrm{Ga}^{69} \mathrm{I}^{127}$ & $1-$ & $7 \leftarrow 6$ & Excited & $19 / 2$ & 9 & $17 / 2$ & 8 & 23778.29 & 0.20 \\
\hline $\mathrm{Ga}^{69} \mathrm{I}^{127}$ & $1-$ & $7 \leftarrow 6$ & Excited & $19 / 2$ & 8 & $17 / 2$ & 7 & 23778.29 & 0.20 \\
\hline $\mathrm{Ga}^{69} \mathrm{~T}^{127}$ & 1. & $7 \leftarrow 6$ & Excited & $17 / 2$ & 9 & $15 / 2$ & 8 & 23778.29 & 0.20 \\
\hline $\mathrm{Ga}^{69} \mathrm{I}^{127}$ & 1 - & $7 \leftarrow 6$ & Excited & $13 / 2$ & 8 & $15 / 2$ & 7 & 23778.29 & 0.20 \\
\hline $\mathrm{Ga}^{69} \mathrm{I}^{127}$ & 1 - & $7 \leftarrow 6$ & Excited & $15 / 2$ & 9 & $13 / 2$ & 8 & 23778.29 & 0.20 \\
\hline $\mathrm{Ga}^{69} \mathrm{I}^{127}$ & 1 - & $7 \leftarrow 6$ & Excited & $17 / 2$ & 7 & $11 / 2$ & 6 & 23778.29 & 0.20 \\
\hline $\mathrm{C}^{12} \mathrm{H}_{2} \mathrm{Cl}^{35} \mathrm{Si}^{29} \mathrm{H}_{3}$ & $3-234$ & $8,1,7 \leftarrow 8,0,8$ & Ground & & & & & 23779.57 & .2 \\
\hline $\mathrm{Ge}^{72} \mathrm{H}_{3} \mathrm{Br}^{81}$ & 4- 104 & $5, \leftarrow 4$, & Ground & & & & & 23780.11 & 1. \\
\hline $\mathrm{C}^{12} \mathrm{H}_{2}\left(\mathrm{C}^{12} \mathrm{~N}^{14}\right)_{2}$ & 4- 901 & Not Reported & Ground & & & & & 23780.5 & .1 \\
\hline $\mathrm{C}^{12}{ }_{*} \mathrm{HC}^{12} \mathrm{H}: \mathrm{C}^{12} \mathrm{HC}^{12} \mathrm{H}: \mathrm{C}^{12} \mathrm{HN}^{14} *$ & $4-1201$ & $16,14,3 \leftarrow 16,12,4$ & Ground & & & & & 23781.4 & .1 \\
\hline $\mathrm{C}^{12} \mathrm{H}_{3} \mathrm{~N}^{14} \mathrm{O}_{2}^{16}$ & 3- 171 & Not Reported & Ground & & & & & 23782. & 5. \\
\hline
\end{tabular}


Vol.-Id. Rotational

Nos. Quantum Nos.

Vib. State $F_{1}^{\prime} \stackrel{F^{\prime}}{\text { Hyperfine }} F_{1} \quad F$

Frequency

$\mathrm{C}^{12} \mathrm{H}_{2} \mathrm{Cl}^{35} \mathrm{Si}^{29} \mathrm{H}_{3}$

$\mathrm{C}^{12} \mathrm{H}_{2}: \mathrm{C}^{13} \mathrm{HBr}^{79}$

$\mathrm{C}^{12}{ }_{*} \mathrm{H}_{2} \mathrm{~N}^{14} \mathrm{DC}^{12}{ }_{*} \mathrm{H}_{2}$

$\mathrm{S}^{32} \mathrm{O}^{16} \mathrm{~F}_{2}^{19}$

$\mathrm{C}^{12}{ }_{*} \mathrm{H}_{2} \mathrm{~N}^{14} \mathrm{DC}^{12}{ }_{*} \mathrm{H}_{2}$

$\mathrm{C}^{12} \mathrm{H}_{2}: \mathrm{C}^{13} \mathrm{HBr}^{79}$

$\mathrm{H}_{2}^{\mathrm{b}} \mathrm{C}^{\mathrm{b}}{ }_{*} \mathrm{O}^{16} \mathrm{C}^{\mathrm{b}}{ }_{*} \mathrm{H}_{2}^{\mathrm{b}}$

$\mathrm{C}^{\mathrm{b}} \mathrm{H}_{2}: \mathrm{C}^{\mathrm{b}} \mathrm{HBr}^{\mathrm{b}}$

$\mathrm{C}^{12}{ }_{*} \mathrm{H}: \mathrm{C}^{12} \mathrm{HO}^{16} \mathrm{C}^{12} \mathrm{H}: \mathrm{C}^{12}{ }_{*} \mathrm{D}$

$\mathrm{C}^{12}{ }_{*} \mathrm{H}: \mathrm{C}^{12} \mathrm{HO}^{16} \mathrm{C}^{12} \mathrm{H}: \mathrm{C}^{12}{ }_{*} \mathrm{H}$

$\left(\mathrm{C}^{12} \mathrm{H}_{3}\right)_{2} \mathrm{C}^{12} \mathrm{O}^{16}$

$\mathrm{C}^{13} \mathrm{H}_{3} \mathrm{Si}^{28} \mathrm{H}_{2} \mathrm{~F}^{19}$

$\mathrm{C}^{12} \mathrm{H}_{3} \mathrm{C}^{12} \mathrm{~F}^{19}: \mathrm{C}^{12} \mathrm{H}_{2}$

$\mathrm{C}^{12} \mathrm{H}_{3} \mathrm{C}^{12} \cdot \mathrm{D}_{2} \mathrm{Cl}^{35}$

$\mathrm{C}^{12} \mathrm{H}_{3} \mathrm{C}^{12} \mathrm{D}_{2} \mathrm{Cl}^{35}$

$\mathrm{H}_{2} \mathrm{C}^{12}: \mathrm{C}^{12} \mathrm{Cl}^{35} \mathrm{Cl}^{37}$

$\mathrm{C}^{12} \mathrm{H}_{2}: \mathrm{C}^{12} \mathrm{DBr}^{\mathrm{b}}$

$\mathrm{C}^{12} \mathrm{H}_{3} \mathrm{~N}^{14} \mathrm{O}_{2}^{16}$

$\mathrm{C}^{12} \mathrm{H}_{3} \mathrm{C}^{12} \mathrm{D}_{2} \mathrm{Cl}^{35}$

$\mathrm{C}^{12} \mathrm{H}_{3} \mathrm{C}^{12}{ }_{*} \mathrm{H}_{2} \mathrm{O}^{16} \mathrm{C}^{12}{ }_{*} \mathrm{C}^{12} \mathrm{H}_{3}$

$\mathrm{C}^{12} \mathrm{H}_{3} \mathrm{C}^{12} \mathrm{D}_{2} \mathrm{C}^{35}$

$\mathrm{C}^{\mathrm{b}} \mathrm{H}_{2}: \mathrm{C}^{\mathrm{b}} \mathrm{HBr}^{\mathrm{b}}$

$\mathrm{C}^{12} \mathrm{H}_{3} \mathrm{C}^{12} \mathrm{D}_{2} \mathrm{Cl}^{35}$

$\mathrm{C}^{12} \mathrm{H}_{3} \mathrm{~S}^{32} \mathrm{H}$

$\mathrm{C}^{12} \mathrm{H}_{2}\left(\mathrm{C}^{12} \mathrm{~N}^{14}\right)_{2}$

$\mathrm{HO}^{16}$

$\mathrm{C}^{12} \mathrm{H}_{3} \mathrm{C}^{12} \mathrm{O}^{16} \mathrm{O}^{16} \mathrm{H}$

$\mathrm{HC}^{13}: \mathrm{C}^{12} \mathrm{C}^{12} \mathrm{DO}^{16}$

$\mathrm{C}^{12} \mathrm{H}_{3} \mathrm{C}^{12} \mathrm{O}^{16} \mathrm{O}^{16} \mathrm{H}$

$\mathrm{HN}_{3}^{14}$

$\mathrm{HN}^{14} \mathrm{~N}^{15} \mathrm{~N}^{14}$

$\mathrm{C}_{6}^{12} \mathrm{H}_{5} \mathrm{O}^{16} \mathrm{H}$

$\mathrm{H}_{2} \mathrm{C}^{12}: \mathrm{C}^{12} \mathrm{~F}_{2}^{19}$

$\mathrm{S}^{32} \mathrm{O}^{16} \mathrm{~F}_{2}^{19}$

$\mathrm{C}^{12} \mathrm{H}_{2}: \mathrm{C}^{12} \mathrm{HC}^{12} \mathrm{~F}^{19}: \mathrm{C}^{12} \mathrm{H}_{2}$

$\mathrm{HN}_{3}^{14}$

$\mathrm{HN}_{3}^{14}$

$\mathrm{HN}_{3}^{14}$

$\mathrm{HN}_{3}^{14}$

$\mathrm{HN}_{3}^{14}$

$\mathrm{HN}_{3}^{14}$

$\mathrm{H}_{2}^{\mathrm{b}} \mathrm{C}^{\mathrm{b}}{ }_{*} \mathrm{O}^{16} \mathrm{C}^{\mathrm{b}}{ }_{*} \mathrm{H}_{2}^{\mathrm{b}}$

$\mathrm{HO}^{16}$

$\mathrm{C}^{12} \mathrm{H}_{2}: \mathrm{C}^{12} \mathrm{DBr}^{\mathrm{b}}$

$\mathrm{C}^{12} \mathrm{H}_{3} \mathrm{C}^{12} \mathrm{O}^{16} \mathrm{O}^{16} \mathrm{H}$
3- $234 \quad 8,1,7 \leftarrow 8,0,8 \quad$ Ground

4. $7373,2,2 \leftarrow 2,2,1$

4. $862 \quad 3,3,1 \leftarrow 3,1,2$

4-1621 Not Reported

4- $862 \quad 3,3,1 \leftarrow 3,1,2$

4. $737 \quad 3,2,1 \leftarrow 2,2,0$

4- $846 \quad$ Not Reported

4- $7523,2,1 \leftarrow 2,2,0$

$4-1155 \quad 5,4,2 \leftarrow 5,2,3$

4-1151

$8,7,2 \leftarrow 8,5,3$

3. 751

Not Reported

3. $249 \quad 2,0,2 \leftarrow 1,0,1$

3- 721

$2,1,2 \leftarrow 1,1,1$

3- 547

$5,1,4 \leftarrow 5,0,5$

3. 547

$5,1,4 \leftarrow 5,0,5$

4. $66210,4,6 \leftarrow 10,3,7$

4. 729

$3, \quad \leftarrow 2, \quad$

3- 171

Not Reported

3- 547

$5,1,4 \leftarrow 5,0,5$

3. 951

$8,4,4 \leftarrow 8,3,5$

3. 547

$5,1,4 \leftarrow 5,0,5$

4- 752

$3,0,2 \leftarrow 2,0,2$

3. 547

$5,1,4 \leftarrow 5,0,5$

3- $22112,1, \leftarrow 11,2$,

4. $901 \quad$ Not Reported

1 -

3. $491 \quad$ Not Reported

4. 922 Not Reported

3- 491 Not Reported

4-1701 $1,0,1 \leftarrow 0,0,0$

4-1705

$1,0,1 \leftarrow 0,0,0$

3-1051

$5,4,2 \leftarrow 5,3,3$

4. 681

Not Reported

4-1621 Not Reported

3. 911

4-1701

$8,3,5 \leftarrow 8,2,6$

4-1701

$1,0,1 \leftarrow 0,0,0$

4-1701

$1,0,1 \leftarrow 0,0,0$

4-1701

$1,0,1 \leftarrow 0,0,0$

4-1701

$1,0,1 \leftarrow 0,0,0$

4-1701

$1,0,1 \leftarrow 0,0,0$

4. 846

$1,0,1 \leftarrow 0,0,0$

1 -

4- 729

Not Reported

$9 / 2,4 \leftarrow 9 / 2,4$

3- 491
Ground

Ground

Ground

Ground

Excited

Ground

Ground

Ground

Ground

Ground

Ground

Ground

Ground

Ground

Ground

Ground

Ground

Ground

Ground

Ground

Ground

Ground

Ground

Excited

Ground

Ground

Ground

Ground

Ground

Ground

Excited

Ground

Ground
$17 / 2$

$17 / 2$

23782.8

23783.36

23784.8

23787.68

23787.8

23788.66

23788.8

$5 / 2 \quad 3 / 2 \quad 23788.9$

23790.0

23790.73

23793.

23794.44

23795.23

$7 / 2$

$7 / 2$

$13 / 2$

$13 / 2$

23795.5

23796.68

23796.8

23797.3

23798.

23798.30

23798.49

$9 / 2$

$5 / 2$

$11 / 2$

$9 / 2$

$3 / 2$

$11 / 2$

23799.7

23799.7

23800.9

23801.8

23803.5

23806.5

23809.

23812 .

23813.

23813.28

23814.

23814.0

23814.4 .

23814.64

23814.66

23815.19

23815.56

23815.7

23816.56

$\begin{array}{lll}23 & 81 & .87\end{array}$

23817.17

23818.0

23818.18

23818.8

23819.
5.

.10

.1

.05

.05

.5

.2

5.

.05

.2

.05

.2

.05

.1

.5

3.

5.

3.

.05

.3

.1

.03

.05

.05

.05

.05

.05

.3

.05

.1

3. 


\begin{tabular}{|c|c|c|c|c|c|c|c|c|c|}
\hline Isotopic Species & $\begin{array}{l}\text { Vol.-Id. } \\
\text { Nos. }\end{array}$ & $\begin{array}{c}\text { Rotational } \\
\text { Quantum Nos. }\end{array}$ & Vib. State & $\mathrm{F}_{1}^{\prime}$ & $\begin{array}{l}\text { Hype } \\
\mathrm{F}^{\prime}\end{array}$ & $\mathrm{F}_{1}$ & $\mathrm{~F}$ & $\begin{array}{c}\text { Frequency } \\
\mathrm{MHz}\end{array}$ & $\begin{aligned} & \text { Acc. } \\
\pm & \mathrm{MHz}\end{aligned}$ \\
\hline $\mathrm{C}^{12}{ }_{*} \mathrm{HC}^{12} \mathrm{H}: \mathrm{C}^{12} \mathrm{HC}^{12} \mathrm{H}: \mathrm{C}^{12} \mathrm{HN}^{14} *$ & $4-1201$ & $17,13,4 \leftarrow 17,13,5$ & Ground & & & & & 23820.8 & .1 \\
\hline $\mathrm{C}^{12} \mathrm{H}_{3} \mathrm{C}^{12} \mathrm{~F}^{19}: \mathrm{C}^{12} \mathrm{H}_{2}$ & 3- 721 & $2,1,2 \leftarrow 1,1,1$ & Ground & & & & & 23822.91 & .1 \\
\hline $\mathrm{C}^{12} \mathrm{H}_{2}\left(\mathrm{C}^{12} \mathrm{~N}^{14}\right)_{2}$ & 4. 901 & Not Reported & Ground & & & & & 23825.5 & .1 \\
\hline$c-\mathrm{HDC}^{12}: \mathrm{C}^{12} \mathrm{DF}^{19}$ & 4- 789 & $5,1,4 \leftarrow 5,1,5$ & Ground & & & & & 23826.7 & .1 \\
\hline $\mathrm{HO}^{16}$ & $1-$ & $9 / 2,4 \leftarrow 9 / 2,4$ & Ground & & 5 & & 5 & 23826.90 & .05 \\
\hline$\left(\mathrm{C}^{12} \mathrm{H}_{3}\right)_{2} \mathrm{C}^{12} \mathrm{O}^{16}$ & 3. 751 & Not Reported & & & & & & 23827. & 5. \\
\hline $\mathrm{S}^{32}{ }_{*} \mathrm{HC}^{12}: \mathrm{C}^{12} \mathrm{DC}^{12} \mathrm{D}: \mathrm{C}^{12}{ }_{*} \mathrm{H}$ & 4-1164 & $8,3,6 \leftarrow 8,3,5$ & Ground & & & & & 23827.0 & .1 \\
\hline $\mathrm{C}^{12} \mathrm{H}_{3} \mathrm{O}^{16} \mathrm{~N}^{14} \mathrm{O}_{2}^{16}$ & 3- 181 & $3,0,3 \leftarrow 2,0,2$ & Ground & & & & & 23829.45 & .1 \\
\hline $\mathrm{C}^{12} \mathrm{H}_{2} \mathrm{Cl}^{35} \mathrm{C}^{12} \mathrm{~N}^{14}$ & 4- 651 & $4,1,3 \leftarrow 4,0,4$ & Ground & & & & & 23829.80 & .2 \\
\hline $\mathrm{C}^{12} \mathrm{D}_{3} \mathrm{I}^{127}$ & 4. 482 & $2,0 \leftarrow 1,0$ & Ground & & $7 / 2$ & & $7 / 2$ & 23831.16 & .08 \\
\hline $\mathrm{C}^{12} \mathrm{H}_{3} \mathrm{O}^{16} \mathrm{~N}^{14} \mathrm{O}_{2}^{16}$ & 3- 181 & $3,0,3 \leftarrow 2,0,2$ & Ground & & & & & 23834.15 & .1 \\
\hline $\mathrm{C}^{12} \mathrm{H}_{2} \mathrm{DC}^{12} \mathrm{HDF}^{19}$ & 3- 557 & $3,1,2 \leftarrow 3,0,3$ & Ground & & & & & 23837.4 & .1 \\
\hline $\mathrm{C}^{12} \mathrm{H}_{3} \mathrm{O}^{16} \mathrm{~N}^{14} \mathrm{O}_{2}^{16}$ & 3- 181 & $3,0,3 \leftarrow 2,0,2$ & Ground & & & & & 2.3837 .4 .3 & .1 \\
\hline $\mathrm{HO}^{16}$ & 1. & $9 / 2,4 \leftarrow 9 / 2,4$ & Ground & & 5 & & 4 & 23837.8 & .3 \\
\hline $\mathrm{O}^{\mathrm{b}} \mathrm{O}^{\mathrm{b}} \mathrm{O}^{\mathrm{b}}$ & 4-1847 & Not Reported & & & & & & 23838. & \\
\hline $\mathrm{Cs}^{133} \mathrm{I}^{127}$ & $1-$ & $17 \leftarrow 16$ & Excited & & & & & 23838.47 & 0.10 \\
\hline$\left(\mathrm{C}^{12} \mathrm{H}_{3}\right)_{2} \mathrm{C}^{12} \mathrm{O}^{16}$ & 3- 751 & Not Reported & & & & & & 23839. & 5. \\
\hline $\mathrm{C}_{6}^{12} \mathrm{H}_{5} \mathrm{~F}^{19}$ & $4-1281$ & $10,2,8 \leftarrow 10,2,9$ & Ground & & & & & 23839.2 & .1 \\
\hline $\mathrm{H}_{2}^{\mathrm{b}} \mathrm{C}^{\mathrm{b}} \mathrm{O}^{16} \mathrm{C}^{\mathrm{b}} * \mathrm{H}_{2}^{\mathrm{b}}$ & 4. 846 & Not Reported & Excited & & & & & 23839.3 & .3 \\
\hline $\mathrm{C}^{12} \mathrm{H}_{3} \mathrm{O}^{16} \mathrm{~N}^{14} \mathrm{O}_{2}^{16}$ & 3- 181 & $3,0,3 \leftarrow 2,0,2$ & Ground & & & & & 23839.80 & .1 \\
\hline $\mathrm{C}^{12} \mathrm{D}_{2} \mathrm{HC}^{12} \mathrm{HDF}^{19}$ & 3- 563 & $3,1,2 \leftarrow 3,0,3$ & Ground & & & & & 23840.0 & .1 \\
\hline $\mathrm{C}^{13} \mathrm{H}_{3} \mathrm{C}^{12} \mathrm{O}^{16} \mathrm{Cl}^{35}$ & 3- 367 & $7,2,5 \leftarrow 7,1,6$ & Ground & & $13 / 2$ & & $13 / 2$ & 23841.25 & .2 \\
\hline $\mathrm{C}^{13} \mathrm{H}_{3} \mathrm{C}^{12} \mathrm{O}^{16} \mathrm{Cl}^{35}$ & 3- 367 & $7,2,5 \leftarrow 7,1,6$ & Ground & & $15 / 2$ & & $15 / 2$ & 23841.25 & .2 \\
\hline $\mathrm{C}^{12} \mathrm{H}_{2}: \overline{\mathrm{C}}^{12} \mathrm{HB}_{\overline{\mathrm{B}}}^{\overline{8}} \overline{\mathrm{i}}$ & 4- 728 & $3, \overline{2}, \overline{2} \leftarrow 2,2,1$ & Ground & & $\overline{3} / 2$ & & $\overline{1} / 2$ & $233 \overrightarrow{4} 1.6$ & .2 \\
\hline $\mathrm{O}^{16} \mathrm{~F}_{2}^{19}$ & $4-1611$ & $7,2,5 \leftarrow 8,1,8$ & Ground & & & & & 23842.38 & .10 \\
\hline $\mathrm{C}^{13} \mathrm{H}_{3} \mathrm{C}^{12} \mathrm{O}^{16} \mathrm{Cl}^{35}$ & 3- 367 & $7,2,5 \leftarrow 7,1,6$ & Ground & & $17 / 2$ & & $17 / 2$ & 23842.59 & .2 \\
\hline $\mathrm{C}^{13} \mathrm{H}_{3} \mathrm{C}^{12} \mathrm{O}^{16} \mathrm{Cl}^{35}$ & 3- 367 & $7,2,5 \leftarrow 7,1,6$ & Ground & & $11 / 2$ & & $11 / 2$ & 23842.59 & .2 \\
\hline $\mathrm{HC}^{13}: \mathrm{C}^{12} \mathrm{C}^{12} \mathrm{DO}^{16}$ & 4. 922 & Not Reported & & & & & & 23843. & 5. \\
\hline $\mathrm{C}^{12} \mathrm{H}_{2}: \mathrm{C}^{12} \mathrm{DBr}^{\mathrm{b}}$ & 4- 729 & $3, \quad \leftarrow 2$, & Ground & & & & & 23843.8 & .1 \\
\hline $\mathrm{C}^{13} \mathrm{H}_{3} \mathrm{C}^{12} \mathrm{O}^{16} \mathrm{Cl}^{35}$ & 3- 367 & $7,2,5 \leftarrow 7,1,6$ & Ground & & $15 / 2$ & & $15 / 2$ & 23846.17 & .2 \\
\hline $\mathrm{C}^{13} \mathrm{H}_{3} \mathrm{C}^{12} \mathrm{O}^{16} \mathrm{Cl}^{35}$ & 3- 367 & $7,2,5 \leftarrow 7,1,6$ & Ground & & $13 / 2$ & & $13 / 2$ & 23846.17 & .2 \\
\hline $\mathrm{C}^{12} \mathrm{H}_{2}: \mathrm{C}^{12} \mathrm{HBr}^{81}$ & 4- 728 & $3,2,1 \leftarrow 2,2,0$ & Ground & & $3 / 2$ & & $1 / 2$ & 23846.9 & \\
\hline $\mathrm{C}^{13} \mathrm{H}_{3} \mathrm{C}^{12} \mathrm{O}^{16} \mathrm{Cl}^{35}$ & 3- 367 & $7,2,5 \leftarrow 7,1,6$ & Ground & & $17 / 2$ & & $17 / 2$ & 23847.47 & .2 \\
\hline $\mathrm{C}^{13} \mathrm{H}_{3} \mathrm{C}^{12} \mathrm{O}^{16} \mathrm{Cl}^{35}$ & 3- 367 & $7,2,5 \leftarrow 7,1,6$ & Ground & & $11 / 2$ & & $11 / 2$ & 23847.47 & .2 \\
\hline $\mathrm{F}_{2}^{19} \mathrm{O}^{16} \mathrm{O}^{18}$ & 3- 12 & $1,1,1 \leftarrow 0,0,0$ & Ground & & & & & 23850.65 & .1 \\
\hline $\mathrm{Ga}^{69} \mathrm{I}^{127}$ & $1-$ & $7 \leftarrow 6$ & Ground & $11 / 2$ & 7 & $9 / 2$ & 6 & 23851.47 & 0.20 \\
\hline $\mathrm{Ga}^{69} \mathrm{I}^{127}$ & $1-$ & $7 \leftarrow 6$ & Ground & $13 / 2$ & 7 & $15 / 2$ & 6 & 23851.47 & 0.20 \\
\hline $\mathrm{Ga}^{69} \mathrm{I}^{127}$ & 1 . & $7 \leftarrow 6$ & Ground & $13 / 2$ & 6 & $11 / 2$ & 5 & 23851.47 & 0.20 \\
\hline $\mathrm{Ga}^{69} \mathrm{I}^{127}$ & $1-$ & $7 \leftarrow 6$ & Ground & $11 / 2$ & 4 & $9 / 2$ & 3 & 23851.47 & 0.20 \\
\hline $\mathrm{Ga}^{69} \mathrm{I}^{127}$ & $1-$ & $7 \leftarrow 6$ & Ground & $9 / 2$ & 4 & $7 / 2$ & 3 & 23851.47 & 0.20 \\
\hline $\mathrm{Ga}^{69} \mathrm{I}^{127}$ & 1 - & $7 \leftarrow 6$ & Ground & $17 / 2$ & 8 & $11 / 2$ & 7 & 23853.25 & 0.20 \\
\hline $\mathrm{Ga}^{69} \mathrm{I}^{127}$ & 1 - & $7 \leftarrow 6$ & Ground & $9 / 2$ & 3 & $7 / 2$ & 2 & 23853.25 & 0.20 \\
\hline$G a^{69} I^{127}$ & $1-$ & $7 \leftarrow 6$ & Ground & $13 / 2$ & 5 & $11 / 2$ & 4 & 23853.25 & 0.20 \\
\hline $\mathrm{Ga}^{69} \mathrm{I}^{127}$ & $1-$ & $7 \leftarrow 6$ & Ground & $9 / 2$ & 6 & $7 / 2$ & 5 & 23853.25 & 0.20 \\
\hline
\end{tabular}




\begin{tabular}{|c|c|c|c|c|c|c|c|c|c|}
\hline Isotopic Species & $\begin{array}{l}\text { Vol.-Id. } \\
\text { Nos. }\end{array}$ & $\begin{array}{c}\text { Rotational } \\
\text { Quantum Nos. }\end{array}$ & Vib. State & $\mathrm{F}_{1}^{\prime}$ & $\begin{array}{l}\text { Hype } \\
\mathrm{F}^{\prime}\end{array}$ & $\mathrm{F}_{1}$ & $F$ & $\begin{array}{c}\text { Frequency } \\
\qquad \mathrm{Hz}^{2}\end{array}$ & $\begin{aligned} & \text { Acc. } \\
& \pm \mathrm{MHz}\end{aligned}$ \\
\hline $\mathrm{Ga}^{69} \mathrm{I}^{127}$ & $1-$ & $7 \leftarrow 6$ & Ground & $9 / 2$ & 5 & $7 / 2$ & 4 & 23853.25 & 0.20 \\
\hline $\mathrm{C}^{12} \mathrm{H}_{2}: \mathrm{C}^{12} \mathrm{HC}^{12} \mathrm{~F}^{19}: \mathrm{C}^{12} \mathrm{H}_{2}$ & 3- 911 & $7,3,4 \leftarrow 7,2,5$ & Ground & & & & & 23853.8 & .2 \\
\hline $\mathrm{C}^{12} \mathrm{H}_{3} \mathrm{O}^{16} \mathrm{H}$ & $3-211$ & $27,2, \leftarrow 27,1$ & Ground & & & & & 23854.25 & .1 \\
\hline $\mathrm{C}^{12} \mathrm{H}_{2}: \mathrm{C}^{12} \mathrm{HBr}^{81}$ & 4- 728 & $3,0,3 \leftarrow 2,0,2$ & Ground & & $3 / 2$ & & $3 / 2$ & 23854.6 & \\
\hline $\mathrm{S}^{32} \mathrm{O}^{16} \mathrm{~F}_{2}^{19}$ & $4-1621$ & Not Reported & & & & & & 23855.24 & .1 \\
\hline $\mathrm{Ga}^{69} \mathrm{I}^{127}$ & $1-$ & $7 \leftarrow 6$ & Ground & $15 / 2$ & 6 & $13 / 2$ & 5 & 23855.66 & 0.20 \\
\hline $\mathrm{Ga}^{69} \mathrm{I}^{127}$ & $1-$ & $7 \leftarrow 6$ & Ground & $15 / 2$ & 7 & $13 / 2$ & 6 & 23855.66 & 0.20 \\
\hline $\mathrm{Ga}^{69} \Gamma^{127}$ & 1 . & $7 \leftarrow 6$ & Ground & $15 / 2$ & 8 & $13 / 2$ & 7 & 23855.66 & 0.20 \\
\hline $\mathrm{C}^{12} \mathrm{H}_{2}\left(\mathrm{C}^{12} \mathrm{~N}^{14}\right)_{2}$ & 4. 901 & Not Reported & Ground & & & & & 23856.2 & .1 \\
\hline $\mathrm{Ga}^{69} \mathrm{I}^{127}$ & $1-$ & $7 \leftarrow 6$ & Ground & $17 / 2$ & 7 & $11 / 2$ & 6 & 23857.29 & 0.20 \\
\hline $\mathrm{Ga}^{69} \mathrm{I}^{127}$ & $1-$ & $7 \leftarrow 6$ & Ground & $15 / 2$ & 9 & $13 / 2$ & 8 & 23857.29 & 0.20 \\
\hline $\mathrm{Ga}^{69} \mathrm{I}^{127}$ & 1 . & $7 \leftarrow 6$ & Ground & $19 / 2$ & 9 & $17 / 2$ & 8 & 23857.29 & 0.20 \\
\hline $\mathrm{Ga}^{69} \mathbf{I}^{127}$ & 1 - & $7 \leftarrow 6$ & Ground & $19 / 2$ & 8 & $17 / 2$ & 7 & 23857.29 & 0.20 \\
\hline $\mathrm{Ga}^{69} \mathrm{I}^{127}$ & $1-$ & $7 \leftarrow 6$ & Ground & $17 / 2$ & 9 & $15 / 2$ & 8 & 23857.29 & 0.20 \\
\hline $\mathrm{Ga}^{69} \mathrm{I}^{127}$ & $1-$ & $7 \leftarrow 6$ & Ground & $13 / 2$ & 8 & $15 / 2$ & 7 & 23857.29 & 0.20 \\
\hline $\mathrm{Ga}^{69} \mathrm{I}^{127}$ & 1 - & $7 \leftarrow 6$ & Ground & $19 / 2$ & 11 & $17 / 2$ & 10 & 23857.29 & 0.20 \\
\hline $\mathrm{Ga}^{69} \mathrm{I}^{127}$ & $1-$ & $7 \leftarrow 6$ & Ground & $19 / 2$ & 10 & $17 / 2$ & 9 & 23857.29 & 0.20 \\
\hline $\mathrm{C}^{12} \mathrm{D}_{3} \mathrm{Si}^{28} \mathrm{DF}_{2}^{19}$ & 3- 199 & $2,2,1 \leftarrow 1,1,1$ & Ground & & & & & 23858.82 & .1 \\
\hline $\mathrm{C}^{12} \mathrm{H}_{2}: \mathrm{C}^{12} \mathrm{DBr}^{\mathrm{b}}$ & 4- 729 & $3, \quad \leftarrow 2$, & Ground & & & & & 23860.89 & \\
\hline $\mathrm{O}_{3}^{16}$ & $4-1841$ & $18,3,15 \leftarrow 19,2,18$ & Ground & & & & & 23861. & \\
\hline $\mathrm{C}^{12} \mathrm{H}_{3} \mathrm{O}^{16} \mathrm{H}$ & 3- 211 & Not Reported & Ground & & & & & 23861. & 5. \\
\hline $\mathrm{C}^{12} \mathrm{D}_{3} \mathrm{C}^{12} \mathrm{O}^{16} \mathrm{~F}^{19}$ & 3- 392 & Not Reported & Ground & & & & & 23861.4 & .2 \\
\hline $\mathrm{C}^{12} \mathrm{H}_{3} \mathrm{~N}^{14} \mathrm{H}_{2}$ & 3. 261 & $11,4, \quad \leftarrow 12,3$, & Ground & & & & & 23861.40 & .04 \\
\hline $\mathrm{C}^{35} \mathrm{C}^{12} \mathrm{~N}^{14}$ & 4. 171 & $2 \leftarrow 1$ & Ground & $3 / 2$ & & $1 / 2$ & & 23862.57 & \\
\hline $\mathrm{C}^{12} \mathrm{H}_{2} \mathrm{~F}_{2}^{19}$ & 4- 351 & $31,9,23 \leftarrow-32,8,24$ & Ground & & & & & 23864.92 & .10 \\
\hline $\mathrm{C}^{12} \mathrm{H}_{3} \mathrm{Si}^{28} \mathrm{D}_{2} \mathrm{~F}^{19}$ & 3. 245 & $6,1,5 \leftarrow 6,1,6$ & Ground & & & & & 23865.70 & .10 \\
\hline $\mathrm{C}_{6}^{12} \mathrm{H}_{5} \mathrm{Cl}^{35}$ & $4-1271$ & $8,1,7 \leftarrow 7,1,6$ & Ground & & $13 / 2$ & & $11 / 2$ & 23866.4 & .1 \\
\hline $\mathrm{C}_{6}^{12} \mathrm{H}_{5} \mathrm{Cl}^{35}$ & $4-1271$ & $8,1,7 \leftarrow 7,1,6$ & Ground & & $15 / 2$ & & $13 / 2$ & 23866.4 & .1 \\
\hline $\mathrm{C}_{6}^{12} \mathrm{H}_{5} \mathrm{Cl}^{35}$ & 4-1271 & $8,1,7 \leftarrow 7,1,6$ & Ground & & $19 / 2$ & & $17 / 2$ & 23866.8 & .1 \\
\hline $\mathrm{C}_{6}^{12} \mathrm{H}_{5} \mathrm{Cl}^{35}$ & 4-1271 & $8,1,7 \leftarrow 7,1,6$ & Ground & & $17 / 2$ & & $15 / 2$ & 23866.8 & .1 \\
\hline $\mathrm{C}^{12}{ }_{*} \mathrm{D}: \mathrm{C}^{12} \mathrm{HC}^{12} \mathrm{H}: \mathrm{C}^{12} \mathrm{HN}^{14}{ }_{*} \mathrm{H}$ & 4-1183 & $7,6,2 \leftarrow 7,5,3$ & Ground & & & & & 23867.2 & \\
\hline $\mathrm{C}_{6}^{12} \mathrm{H}_{5} \mathrm{O}^{16} \mathrm{H}$ & $3-1051$ & $6,4,3 \leftarrow 6,3,4$ & Ground & & & & & 23867.2 & \\
\hline $\mathrm{C}^{12} \mathrm{H}_{2}: \mathrm{C}^{13} \mathrm{HBr}^{79}$ & 4- 737 & $3,2,2 \leftarrow 2,2,1$ & Ground & & $7 / 2$ & & $5 / 2$ & 23868.0 & \\
\hline $\mathrm{C}^{12} \mathrm{H}_{3} \mathrm{Si}^{28} \mathrm{D}_{2} \mathrm{~F}^{19}$ & 3- 245 & $6,1,5 \leftarrow 6,1,6$ & Ground & & & & & 23868.02 & .10 \\
\hline $\mathrm{C}^{12} \mathrm{D}_{3} \mathrm{C}^{12} \mathrm{H}_{2} \mathrm{Br}^{81}$ & 3- 525 & $6,1,5 \leftarrow 6,0,6$ & Ground & & $13 / 2$ & & $13 / 2$ & 23868.13 & .05 \\
\hline $\mathrm{HC}^{13}: \mathrm{C}^{12} \mathrm{C}^{12} \mathrm{DO}^{16}$ & 4. 922 & Not Reported & & & & & & 23870. & 5. \\
\hline $\mathrm{N}^{14} \mathrm{H}_{3}$ & $4-1771$ & $3,3 \leftarrow 3,3$ & Ground & & & & & 23870.129 & \\
\hline $\mathrm{N}^{14} \mathrm{H}_{3}$ & $4-17 \overline{7} 1$ & $3,3 \leftarrow 3,3$ & Ground & & & & & 23870.130 & \\
\hline $\mathrm{N}^{14} \mathrm{H}_{3}$ & $4-1771$ & $3,3 \leftarrow 3,3$ & Ground & & & & & 23870.131 & \\
\hline $\mathrm{C}^{12} \mathrm{H}_{2} \mathrm{~F}_{2}^{19}$ & 4- 351 & $31,9,22 \leftarrow-32,8,25$ & Ground & & & & & 23871.82 & .10 \\
\hline $\mathrm{S}^{32} \mathrm{O}^{16} \mathrm{~F}_{2}^{19}$ & 4-1621 & Not Reported & & & & & & 23872.54 & .1 \\
\hline $\mathrm{C}^{\mathrm{b}} \mathrm{H}_{2}: \mathrm{C}^{\mathrm{b}} \mathrm{HBr}^{\mathrm{b}}$ & 4- 752 & $3,2,1 \leftarrow 2,2,0$ & Ground & & $7 / 2$ & & $5 / 2$ & 23873.3 & \\
\hline
\end{tabular}




\begin{tabular}{|c|c|c|c|c|c|c|c|c|c|}
\hline Isotopic Species & $\begin{array}{l}\text { Vol.-Id. } \\
\text { Nos. }\end{array}$ & $\begin{array}{c}\text { Rotational } \\
\text { Quantum Nos. }\end{array}$ & Vib. State & $\mathrm{F}_{1}^{\prime}$ & $\begin{array}{l}\text { Hyper } \\
\mathrm{F}^{\prime}\end{array}$ & $\mathrm{F}_{1}$ & $\mathrm{~F}$ & $\begin{array}{c}\text { Frequency } \\
\mathrm{MHz}\end{array}$ & $\begin{aligned} \text { Acc. } \\
\pm \mathrm{MHz}\end{aligned}$ \\
\hline $\mathrm{C}^{12} \mathrm{D}_{3} \mathrm{C}^{12} \mathrm{H}_{2} \mathrm{Br}^{81}$ & 3- 525 & $6,1,5 \leftarrow 6,0,6$ & Ground & & $11 / 2$ & & $11 / 2$ & 23873.61 & .05 \\
\hline $\mathrm{C}^{12} \mathrm{H}_{3} \mathrm{~N}^{14} \mathrm{H}_{2}$ & 3. 261 & Not Reported & Ground & & & & & 23873.61 & .04 \\
\hline $\mathrm{C}^{12} \mathrm{H}_{2}: \mathrm{C}^{12} \mathrm{DBr}^{81}$ & 4- 722 & $3,1,2 \leftarrow 2,1,1$ & Ground & & $3 / 2$ & & $3 / 2$ & 23875.3 & \\
\hline $\mathrm{C}^{12} \mathrm{H}_{2}: \mathrm{C}^{12} \mathrm{HC}^{12} \mathrm{~F}^{19}: \mathrm{C}^{12} \mathrm{H}_{2}$ & 3. 911 & $9,3,6 \leftarrow 9,2,7$ & Ground & & & & & 23879.11 & .03 \\
\hline $\mathrm{S}^{32} \mathrm{O}^{16} \mathrm{~F}_{2}^{19}$ & $4-1621$ & $10,7,3 \leftarrow 10,7,4$ & Ground & & & & & 23879.57 & .1 \\
\hline $\mathrm{Cl}^{35} \mathrm{~F}^{19} \mathrm{C}^{12} \mathrm{O}^{16}$ & 4- 151 & $10,3,7 \leftarrow 10,3,8$ & Ground & & & & & 23880.16 & .05 \\
\hline $\mathrm{O}^{16} \mathrm{C}^{13} \mathrm{Se}^{80}$ & 4- 551 & $3 \leftarrow 2$ & Ground & & & & & 23880.18 & .03 \\
\hline $\mathrm{HC}^{13}: \mathrm{C}^{12} \mathrm{C}^{12} \mathrm{DO}^{16}$ & 4. 922 & Not Reported & & & & & & 23881. & 5. \\
\hline $\mathrm{C}^{12} \mathrm{D}_{3} \mathrm{C}^{12} \mathrm{H}_{2} \mathrm{Br}^{79}$ & 3- 523 & $6,1,5 \leftarrow 6,0,6$ & Ground & & $13 / 2$ & & $13 / 2$ & 23881.79 & .05 \\
\hline $\mathrm{Cl}^{35} \mathrm{C}^{13} \mathrm{~N}^{14}$ & 4- 172 & $2 \leftarrow 1$ & Ground & & & & & 23883. & \\
\hline $\mathrm{C}^{12} \mathrm{H}_{2}: \mathrm{C}^{12} \mathrm{HBr}^{81}$ & 4- 728 & $3,0,3 \leftarrow 2,0,2$ & Ground & & $5 / 2$ & & $5 / 2$ & 23883.1 & \\
\hline $\mathrm{Cl}^{35} \mathrm{C}^{12} \mathrm{~N}^{14}$ & 4- 171 & $2 \leftarrow 1$ & Ground & $1 / 2$ & & $1 / 2$ & & 23883.30 & \\
\hline $\mathrm{C}^{b} \mathrm{H}_{2}^{b} \mathrm{Cl}^{b} \mathrm{~F}^{\mathrm{b}}$ & 4- 333 & Not Reported & & & & & & 23883.90 & .1 \\
\hline $\mathrm{N}^{14} \mathrm{O}^{16} \mathrm{O}^{18}$ & $4 \cdot 1803$ & $7,1,7 \leftarrow 8,0,8$ & Ground & & & & & 23883.98 & \\
\hline $\mathrm{C} 1^{35} \mathrm{C}^{12} \mathrm{~N}^{14}$ & 4- 171 & $2 \leftarrow 1$ & Ground & $7 / 2$ & $5 / 2$ & $5 / 2$ & $3 / 2$ & 23885.16 & \\
\hline $\mathrm{Cl}^{35} \mathrm{C}^{12} \mathrm{~N}^{14}$ & 4. 171 & $2 \leftarrow 1$ & Ground & $7 / 2$ & $9 / 2$ & $5 / 2$ & $7 / 2$ & 23885.16 & \\
\hline $\mathrm{O}^{16} \mathrm{C}^{12} \mathrm{Se}^{82}$ & 4. 548 & $3 \leftarrow 2$ & Excited & & & & & 23885.76 & .03 \\
\hline $\mathrm{C}^{12} \mathrm{D}_{3} \mathrm{C}^{12} \mathrm{H}_{2} \mathrm{Br}^{79}$ & 3. 523 & $6,1,5 \leftarrow 6,0,6$ & Ground & & $11 / 2$ & & $11 / 2$ & 23888.35 & .05 \\
\hline $\mathrm{C}^{12} \mathrm{D}_{3} \mathrm{C}^{13} \mathrm{O}^{16} \mathrm{C}^{12} \mathrm{~N}^{14}$ & 3- 676 & $5,3,2 \leftarrow 5,2,3$ & Ground & & & & & 23888.35 & .2 \\
\hline $\mathrm{C}^{12} \mathrm{H}_{2}: \mathrm{C}^{12} \mathrm{HBr}^{81}$ & 4. 728 & $3,2,2 \leftarrow 2,2,1$ & Excited & & $9 / 2$ & & $7 / 2$ & 23888.4 & \\
\hline $\mathrm{C}^{12} \mathrm{H}_{2}: \mathrm{C}^{12} \mathrm{HBr}^{81}$ & 4. 728 & $3,2,2 \leftarrow 2,2,1$ & Excited & & $7 / 2$ & & $7 / 2$ & 23888.4 & \\
\hline $\mathrm{C}^{12}{ }_{*} \mathrm{H}_{2} \mathrm{C}^{12} \mathrm{H}_{2} \mathrm{C}^{12} \mathrm{H}_{2} \mathrm{O}^{16} *$ & 4-1091 & $8,6,2 \leftarrow 8,6,3$ & Ground & & & & & 23890. & \\
\hline $\mathrm{C}^{12} \mathrm{D}_{3} \mathrm{C}^{12} \mathrm{H}_{2} \mathrm{Br}^{81}$ & 3. 525 & $6,1,5 \leftarrow 6,0,6$ & Ground & & $15 / 2$ & & $15 / 2$ & 23890.79 & .05 \\
\hline $\mathrm{C}^{12} \mathrm{H}_{2}: \mathrm{C}^{12} \mathrm{HBr}^{81}$ & 4- 728 & $3,2,1 \leftarrow 2,2,0$ & Excited & & $9 / 2$ & & $7 / 2$ & 23893.5 & \\
\hline $\mathrm{C}^{12} \mathrm{H}_{2}: \mathrm{C}^{12} \mathrm{HBr}^{81}$ & 4. 728 & $3,2,1 \leftarrow 2,2,0$ & Excited & & $7 / 2$ & & $7 / 2$ & 23893.5 & \\
\hline $\mathrm{C}^{12} \mathrm{D}_{3} \mathrm{I}^{127}$ & 4. 482 & $2,1 \leftarrow 1,1$ & Ground & & $7 / 2$ & & $5 / 2$ & 23893.51 & .08 \\
\hline $\mathrm{Si}^{29} \mathrm{H}_{3} \mathrm{~N}^{14} \mathrm{C}^{12} \mathrm{~S}^{32}$ & 4- 494 & $8, \leftarrow 7$, & Ground & & & & & 23894.22 & \\
\hline $\mathrm{C}^{12} \mathrm{H}_{3} \mathrm{~N}^{14} \mathrm{O}_{2}^{16}$ & 3. 171 & Not Reported & Ground & & & & & 23896. & 5. \\
\hline $\mathrm{C}^{12} \mathrm{D}_{3} \mathrm{C}^{12} \mathrm{H}_{2} \mathrm{Br}^{81}$ & 3- 525 & $6,1,5 \leftarrow 6,0,6$ & Ground & & $9 / 2$ & & $9 / 2$ & 23896.07 & .05 \\
\hline $\mathrm{C}^{12} \mathrm{H}_{2}: \mathrm{C}^{12} \mathrm{~F}^{19} \mathrm{Cl}^{35}$ & 4- 631 & $7,3,4 \leftarrow 7,2,5$ & Ground & & & & & 23896.29 & \\
\hline $\mathrm{H}_{2} \mathrm{C}^{12}: \mathrm{C}^{12} \mathrm{Cl}_{2}^{\mathrm{b}}$ & 4. 663 & Not Reported & Ground & & & & & 23896.5 & 1.5 \\
\hline $\mathrm{C}^{12} \mathrm{D}_{3} \mathrm{C}^{12} \mathrm{O}^{16} \mathrm{C}^{12} \mathrm{~N}^{14}$ & 3- 675 & $5,3,2 \leftarrow 5,2,3$ & Ground & & & & & 23897.3 & .2 \\
\hline a- $\mathrm{C}^{12} \mathrm{HD}_{2} \mathrm{C}^{12} \mathrm{O}^{16} \mathrm{C}^{12} \mathrm{~N}^{14}$ & 3- 678 & $10,3,7 \leftarrow 10,2,8$ & Ground & & & & & 23897.77 & .2 \\
\hline $\mathrm{HC}^{13}: \mathrm{C}^{12} \mathrm{C}^{12} \mathrm{DO}^{16}$ & 4. 922 & Not Reported & & & & & & 23898. & 5. \\
\hline $\mathrm{C}^{13}{ }_{*} \mathrm{H}: \mathrm{C}^{12} \mathrm{HO}^{16} \mathrm{C}^{12} \mathrm{H}: \mathrm{C}^{12}{ }_{*} \mathrm{H}$ & $4-1157$ & $7,6,2 \leftarrow 7,4,3$ & Ground & & & & & 23898.3 & .1 \\
\hline $\mathrm{Cl}^{35} \mathrm{C}^{12} \mathrm{~N}^{14}$ & 4. 171 & $2 \leftarrow 1$ & Ground & $3 / 2$ & $3 / 2$ & $3 / 2$ & $3 / 2$ & 23899.59 & \\
\hline $\mathrm{C}^{35} \mathrm{C}^{12} \mathrm{~N}^{14}$ & 4. 171 & $2 \leftarrow 1$ & Ground & $3 / 2$ & $5 / 2$ & $3 / 2$ & $3 / 2$ & 23899.59 & \\
\hline $\mathrm{C}^{35} \mathrm{C}^{12} \mathrm{~N}^{14}$ & 4- 171 & $2 \leftarrow 1$ & Ground & $3 / 2$ & $1 / 2$ & $3 / 2$ & $3 / 2$ & 23899.59 & \\
\hline $\mathrm{C}^{12}{ }_{*} \mathrm{HO}^{16} \mathrm{C}^{12} \mathrm{HC}^{12} \mathrm{H}_{2} \mathrm{C}^{12} \mathrm{H}_{2} \mathrm{C}^{12}{ }_{*} \mathrm{H}_{2}$ & 4.1251 & $11,8,3 \leftarrow 11,7,5$ & Ground & & & & & 23900. & 5. \\
\hline $\mathrm{Cl}^{35} \mathrm{C}^{12} \mathrm{~N}^{14}$ & 4. 171 & $2 \leftarrow 1$ & Ground & $3 / 2$ & $3 / 2$ & $3 / 2$ & $5 / 2$ & 23900.20 & \\
\hline $\mathrm{Cl}^{35} \mathrm{C}^{12} \mathrm{~N}^{14}$ & 4- 171 & $2 \leftarrow 1$ & Ground & $3 / 2$ & $5 / 2$ & $3 / 2$ & $5 / 2$ & 23900.20 & \\
\hline
\end{tabular}




\begin{tabular}{|c|c|c|c|c|c|c|c|}
\hline \multirow{3}{*}{$\frac{\text { Isotopic Species }}{\mathrm{C}^{12} \mathrm{H}_{2}: \mathrm{C}^{12} \mathrm{DBr}^{81}}$} & \multirow{3}{*}{$\begin{array}{c}\begin{array}{c}\text { Vol.-Id. } \\
\text { Nos. }\end{array} \\
\text { 4- } 722\end{array}$} & \multirow{3}{*}{$\begin{array}{c}\begin{array}{c}\text { Rotational } \\
\text { Quantum Nos. }\end{array} \\
3,1,2 \leftarrow 2,1,1\end{array}$} & \multirow{2}{*}{ Vib. State } & \multicolumn{2}{|c|}{ Hyperfine } & \multirow{2}{*}{$\begin{array}{c}\text { Frequency } \\
\mathrm{MHz}\end{array}$} & \multirow{2}{*}{$\begin{array}{r}\text { Acc. } \\
\pm \mathrm{MHz}\end{array}$} \\
\hline & & & & $\mathrm{F}_{1}^{\prime} \quad \mathrm{F}^{\prime}$ & $F_{I} \quad F$ & & \\
\hline & & & Excited & $9 / 2$ & $7 / 2$ & 23904.1 & \\
\hline $\mathrm{C}^{12} \mathrm{H}_{2}: \mathrm{C}^{12} \mathrm{DBr}^{81}$ & 4- 722 & $3,1,2 \leftarrow 2,1,1$ & Excited & $3 / 2$ & $1 / 2$ & 23904.1 & \\
\hline $\mathrm{C}^{12} \mathrm{H}_{2}: \mathrm{C}^{12} \mathrm{HC}^{12} \mathrm{~F}^{19}: \mathrm{C}^{12} \mathrm{H}_{2}$ & 3- 911 & $4,0,4 \leftarrow 3,1,3$ & Excited & & & 23904.63 & .03 \\
\hline $\mathrm{C}^{12} \mathrm{H}_{2}: \mathrm{C}^{12} \mathrm{HBr}^{81}$ & 4- 728 & $3,0,3 \leftarrow 2,0,2$ & Excited & $9 / 2$ & $7 / 2$ & 23905.9 & .3 \\
\hline $\mathrm{DO}^{16}$ & $1-$ & $17 / 2,8 \leftarrow 17 / 2,8$ & Ground & $19 / 2$ & $19 / 2$ & 23907.12 & .10 \\
\hline $\mathrm{DO}^{16}$ & $1-$ & $17 / 2,8 \leftarrow 17 / 2,8$ & Ground & $17 / 2$ & $17 / 2$ & 23907.12 & .10 \\
\hline $\mathrm{DO}^{16}$ & $1-$ & $17 / 2,8 \leftarrow 17 / 2,8$ & Ground & $15 / 2$ & $15 / 2$ & 23907.12 & .10 \\
\hline $\operatorname{Cs}^{133} \mathrm{I}^{127}$ & $1-$ & $17 \leftarrow 16$ & Excited & & & 23907.70 & 0.10 \\
\hline $\mathrm{C}^{\mathrm{b}} \mathrm{H}_{2}^{\mathrm{b}} \mathrm{N}^{\mathrm{b}} \mathrm{H}^{\mathrm{b}} \mathrm{C}^{\mathrm{b}}{ }_{*} \mathrm{H}_{2}^{\mathrm{b}}$ & 4- 863 & Not Reported & & & & 23908. & 10. \\
\hline $\mathrm{C}^{12} \mathrm{D}_{3} \mathrm{C}^{12} \mathrm{H}_{2} \mathrm{Br}^{79}$ & 3- 523 & $6,1,5 \leftarrow 6,0,6$ & Ground & $15 / 2$ & $15 / 2$ & 23909.10 & .05 \\
\hline a- $\mathrm{C}^{12} \mathrm{HD} \mathrm{C}^{12} \mathrm{O}^{16} \mathrm{C}^{12} \mathrm{~N}^{14}$ & 3- 678 & $10,3,7 \leftarrow 10,2,8$ & Ground & & & 23911.19 & .2 \\
\hline $\mathrm{C}^{12} \mathrm{H}_{2}: \mathrm{C}^{12} \mathrm{HBr}^{81}$ & 4- 728 & $3,2,2 \leftarrow 2,2,1$ & Ground & $7 / 2$ & $7 / 2$ & 23911.6 & \\
\hline $\mathrm{C}^{12} \mathrm{H}_{2}: \mathrm{C}^{12} \mathrm{HBr}^{81}$ & 4- 728 & $3,2,2 \leftarrow 2,2,1$ & Ground & $9 / 2$ & $7 / 2$ & 23911.6 & \\
\hline $\mathrm{C}^{12} \mathrm{H}_{2}: \mathrm{C}^{12} \mathrm{DBr}^{81}$ & 4- 722 & $3,1,2 \leftarrow 2,1,1$ & Ground & $5 / 2$ & $5 / 2$ & 23914.3 & \\
\hline $\mathrm{C}^{12} \mathrm{H}_{3} \mathrm{C}^{12} \mathrm{H}_{2} \mathrm{C}^{12} \mathrm{~N}^{14}$ & 3- 731 & $2,1,1 \leftarrow 2,0,2$ & Ground & & & 23915.0 & .2 \\
\hline $\mathrm{C}^{12} \mathrm{D}_{3} \mathrm{C}^{12} \mathrm{H}_{2} \mathrm{Br}^{79}$ & 3- 523 & $6,1,5 \leftarrow 6,0,6$ & Ground & $9 / 2$ & $9 / 2$ & 23915.29 & .05 \\
\hline $\mathrm{C}^{\mathrm{b}} \mathrm{H}_{2}: \mathrm{C}^{\mathrm{b}} \mathrm{HBr}^{\mathrm{b}}$ & 4- 752 & $3,2,1 \leftarrow 2,2,0$ & Ground & $9 / 2$ & $7 / 2$ & 23916.4 & \\
\hline $\mathrm{C}^{12} \mathrm{H}_{2}: \mathrm{C}^{12} \mathrm{HBr}^{81}$ & 4- 728 & $3,2,1 \leftarrow 2,2,0$ & Ground & $9 / 2$ & $7 / 2$ & 23916.6 & \\
\hline $\mathrm{C}^{12} \mathrm{H}_{2}: \mathrm{C}^{12} \mathrm{HBr}^{81}$ & 4- 728 & $3,2,1 \leftarrow 2,2,0$ & Ground & $7 / 2$ & $7 / 2$ & 23916.6 & \\
\hline $\mathrm{C}^{12} \mathrm{H}_{2}: \mathrm{C}^{12} \mathrm{DBr}^{\mathrm{b}}$ & 4- 729 & $3, \quad \leftarrow 2$, & Ground & & & 23917.74 & \\
\hline $\mathrm{Cl}^{35} \mathrm{C}^{12} \mathrm{~N}^{14}$ & 4- 171 & $2 \leftarrow 1$ & Excited & $5 / 2$ & $3 / 2$ & 23917.9 & \\
\hline $\mathrm{C}^{12} \mathrm{H}_{2} \mathrm{Cl}^{35} \mathrm{Si}^{28} \mathrm{H}_{3}$ & 3- 231 & $8,1,7 \leftarrow 8,0,8$ & Ground & $13 / 2$ & $13 / 2$ & 23920.73 & .2 \\
\hline $\mathrm{Cl}^{35} \mathrm{C}^{12} \mathrm{~N}^{14}$ & 4- 171 & $2 \leftarrow 1$ & Ground & $1 / 2$ & $3 / 2$ & 23920.91 & \\
\hline $\mathrm{C}^{12} \mathrm{H}_{2} \mathrm{Cl}^{35} \mathrm{Si}^{28} \mathrm{H}_{3}$ & 3- 231 & $8,1,7 \leftarrow 8,0,8$ & Ground & $19 / 2$ & $19 / 2$ & 23921.78 & .2 \\
\hline $\mathrm{C}^{12} \mathrm{H}_{2}: \mathrm{C}^{12} \mathrm{HBr}^{81}$ & 4- 728 & $3,2,1 \leftarrow 2,2,0$ & Excited & $5 / 2$ & $3 / 2$ & 23922.1 & \\
\hline $\mathrm{C}^{12} \mathrm{H}_{2}: \mathrm{C}^{12} \mathrm{HBr}^{81}$ & 4. 728 & $3,2,1 \leftarrow 2,2,0$ & Excited & $3 / 2$ & $3 / 2$ & 23922.1 & \\
\hline $\mathrm{N}^{15} \mathrm{H}_{3}$ & 4-1772 & $6,6 \leftarrow 6,6$ & Ground & & & 23922.32 & .02 \\
\hline $\mathrm{C}^{12} \mathrm{H}_{2}: \mathrm{C}^{12} \mathrm{DBr}^{81}$ & 4- 722 & $3,1,2 \leftarrow 2,1,1$ & Ground & $3 / 2$ & $1 / 2$ & 23922.9 & \\
\hline $\mathrm{C}^{12} \mathrm{H}_{2}: \mathrm{C}^{12} \mathrm{DBr}^{81}$ & 4- 722 & $3,1,2 \leftarrow 2,1,1$ & Ground & $9 / 2$ & $7 / 2$ & 23922.9 & \\
\hline $\mathrm{C}^{\mathrm{b}}{ }_{*} \mathrm{H}_{2}^{\mathrm{b}} \mathrm{N}^{\mathrm{b}} \mathrm{H}^{\mathrm{b}} \mathrm{C}^{\mathrm{b}}{ }_{*} \mathrm{H}_{2}^{\mathrm{b}}$ & 4. 863 & Not Reported & & & & 23923. & 10. \\
\hline $\mathrm{HC}^{12} \mathrm{O}^{16} \mathrm{O}^{16} \mathrm{C}^{12} \mathrm{H}_{3}-\mathrm{E}$ & 3- 502 & $5,1,4 \leftarrow 5,1,5$ & Ground & & & 23923.07 & .35 \\
\hline $\mathrm{C}^{12} \mathrm{H}_{2}: \mathrm{C}^{12} \mathrm{DBr}^{\mathrm{b}}$ & 4- 729 & $3, \quad \leftarrow 2, \quad$, & Ground & & & 23924.35 & \\
\hline $\mathrm{C}^{12} \mathrm{H}_{2} \mathrm{Cl}^{35} \mathrm{Si}^{28} \mathrm{H}_{3}$ & 3- 231 & $8,1,7 \leftarrow 8,0,8$ & Ground & & & 23924.41 & .2 \\
\hline $\mathrm{C}_{6}^{12} \mathrm{H}_{5} \mathrm{O}^{16} \mathrm{H}$ & $3-1051$ & $5,4,2 \leftarrow 5,3,3$ & Ground & & & 23925.5 & \\
\hline $\mathrm{C}^{12} \mathrm{H}_{2}\left(\mathrm{C}^{12} \mathrm{~N}^{14}\right)_{2}$ & 4- 901 & Not Reported & Ground & & & 23925.5 & .1 \\
\hline $\mathrm{Cl}^{35} \mathrm{C}^{12} \mathrm{~N}^{14}$ & 4- 171 & $2 \leftarrow 1$ & Excited & $3 / 2$ & $3 / 2$ & 23925.5 & \\
\hline $\mathrm{C}^{12} \mathrm{H}_{2} \mathrm{Cl}^{35} \mathrm{Si}^{28} \mathrm{H}_{3}$ & 3- 231 & $8,1,7 \leftarrow 8,0,8$ & Ground & $15 / 2$ & $15 / 2$ & 23926.95 & .2 \\
\hline $\mathrm{C}^{12} \mathrm{H}_{2} \mathrm{Cl}^{35} \mathrm{Si}^{28} \mathrm{H}_{3}$ & 3- 231 & $8,1,7 \leftarrow 8,0,8$ & Ground & $17 / 2$ & $17 / 2$ & $23927: 90$ & .2 \\
\hline $\mathrm{Cl}^{35} \mathrm{C}^{12} \mathrm{~N}^{14}$ & 4- 171 & $2 \leftarrow 1$ & Excited & $5 / 2$ & $5 / 2$ & 23928.7 & \\
\hline $\mathrm{C}^{12} \mathrm{H}_{2}: \mathrm{C}^{12} \mathrm{HBr}^{81}$ & 4- 728 & $3,0,3 \leftarrow 2,0,2$ & Ground & $9 / 2$ & $7 / 2$ & 23928.9 & \\
\hline $\mathrm{C}^{12} \mathrm{H}_{2}: \mathrm{C}^{12} \mathrm{HBr}^{81}$ & 4- 728 & $3,0,3 \leftarrow 2,0,2$ & Ground & $7 / 2$ & $5 / 2$ & 23928.9 & \\
\hline $\mathrm{C}^{12} \mathrm{H}_{2}: \mathrm{C}^{12} \mathrm{DBr}^{81}$ & 4- 722 & $3,1,2 \leftarrow 2,1,1$ & Excited & $7 / 2$ & $5 / 2$ & 23929.0 & \\
\hline
\end{tabular}




\begin{tabular}{|c|c|c|c|c|c|c|c|c|c|}
\hline Isotopic Species & $\begin{array}{l}\text { Vol.-Id. } \\
\text { Nos. }\end{array}$ & $\begin{array}{c}\text { Rotational } \\
\text { Quantum Nos. }\end{array}$ & Vib. State & $\mathrm{F}_{1}^{\prime}$ & $\begin{array}{l}\text { Typer } \\
\mathrm{F}^{\prime}\end{array}$ & $\begin{array}{c}\text { rfine } \\
F_{1}\end{array}$ & $\mathrm{~F}$ & $\begin{array}{c}\text { Frequency } \\
\mathrm{MHz}^{2}\end{array}$ & $\begin{aligned} & \text { Acc. } \\
\pm & \mathrm{MHz}\end{aligned}$ \\
\hline $\mathrm{C}^{12} \mathrm{H}_{2}: \mathrm{C}^{12} \mathrm{DBr}^{81}$ & 4- 722 & $3,1,2 \leftarrow 2,1,1$ & Excited & & $5 / 2$ & & $3 / 2$ & 23929.0 & \\
\hline $\mathrm{HC}^{13}: \mathrm{C}^{12} \mathrm{C}^{12} \mathrm{DO}^{16}$ & 4- 922 & Not Reported & & & & & & 23930 . & 5. \\
\hline $\mathrm{C}^{12} \mathrm{H}_{2}: \mathrm{C}^{12} \mathrm{HBr}^{81}$ & 4. 728 & $3,0,3 \leftarrow 2,0,2$ & Ground & & & & & 23933.31 & .07 \\
\hline $\mathrm{C}^{12} \mathrm{H}_{2}: \mathrm{C}^{12} \mathrm{DBr}^{81}$ & 4- 722 & $3,1,2 \leftarrow 2,1,1$ & Ground & & & & & 23933.48 & .08 \\
\hline$\left(\mathrm{C}^{12} \mathrm{H}_{3}\right)_{2} \mathrm{C}^{12} \mathrm{O}^{16}$ & 3- 751 & Not Reported & & & & & & 23934. & 5. \\
\hline $\mathrm{C}^{12}{ }_{*} \mathrm{H}: \mathrm{C}^{12} \mathrm{HO}^{16} \mathrm{C}^{12} \mathrm{D}: \mathrm{C}^{12}{ }_{*} \mathrm{H}$ & 4.1154 & $12,9,3 \leftarrow 12,8,4$ & Ground & & & & & 23934.4 & \\
\hline $\mathrm{C}^{12} \mathrm{H}_{2}: \mathrm{C}^{12} \mathrm{HBr}^{79}$ & 4. 727 & $3,2,2 \leftarrow 2,2,1$ & Excited & & $3 / 2$ & & $1 / 2$ & 23935.0 & \\
\hline $\mathrm{C}^{13} \mathrm{H}_{3} \mathrm{C}^{12}: \mathrm{C}^{12} \mathrm{C}^{12} \mathrm{~F}_{3}^{19}$ & 3- 893 & $9, \leftarrow 8$ & Ground & & & & & 23937.0 & .5 \\
\hline $\mathrm{C}^{12} \mathrm{H}_{2}: \mathrm{C}^{12} \mathrm{DBr}^{\mathrm{b}}$ & 4- 729 & $3, \quad \leftarrow 2, \quad$, & Ground & & & & & 23937.1 & \\
\hline $\mathrm{C}^{12} \mathrm{H}_{2} \mathrm{Cl}^{37} \mathrm{~F}^{19}$ & 4- 332 & $11,1,10 \leftarrow 10,2,9$ & Ground & & & & & 23937.44 & .1 \\
\hline $\mathrm{Cl}^{15} \mathrm{C}^{12} \mathrm{~N}^{14}$ & 4- 171 & $2 \leftarrow 1$ & Excited & $7 / 2$ & & $5 / 2$ & & 23938.6 & \\
\hline $\mathrm{C}^{12} \mathrm{H}_{2} \mathrm{~N}^{14} \mathrm{O}^{16} \mathrm{D}$ & 3- 142 & $5,1,4 \leftarrow 5,1,5$ & Ground & & 4 & & 4 & 23938.78 & .10 \\
\hline $\mathrm{C}^{12} \mathrm{H}_{2} \mathrm{~N}^{14} \mathrm{O}^{16} \mathrm{D}$ & 3. 142 & $5,1,4 \leftarrow 5,1,5$ & Ground & & 6 & & 6 & 23938.78 & .10 \\
\hline $\mathrm{C}^{12} \mathrm{H}_{3} \mathrm{~N}^{14} \mathrm{O}_{2}^{16}$ & 3- 171 & Not Reported & Ground & & & & & 23939. & 5. \\
\hline $\mathrm{HC}^{12} \mathrm{O}^{16} \mathrm{O}^{16} \mathrm{C}^{12} \mathrm{H}_{3}-\mathrm{A}$ & 3. 501 & $5,1,4 \leftarrow 5,1,5$ & Ground & & & & & 23939.81 & .35 \\
\hline $\mathrm{C}^{12} \mathrm{H}_{2}: \mathrm{C}^{12} \mathrm{HBr}^{81}$ & 4. 728 & $3,2,2 \leftarrow 2,2,1$ & Ground & & $3 / 2$ & & $3 / 2$ & 23940.0 & \\
\hline $\mathrm{C}^{12} \mathrm{H}_{2}: \mathrm{C}^{12} \mathrm{HBr}^{81}$ & 4. 728 & $3,2,2 \leftarrow 2,2,1$ & Ground & & $5 / 2$ & & $3 / 2$ & 23940.0 & \\
\hline $\mathrm{C}^{12} \mathrm{D}_{3} \mathrm{I}^{127}$ & 4- 482 & $2,1 \leftarrow 1,1$ & Ground & & $5 / 2$ & & $5 / 2$ & 23940.01 & .08 \\
\hline $\mathrm{C}^{12} \mathrm{H}_{2}: \mathrm{C}^{12} \mathrm{HBr}^{81}$ & 4- 728 & $3,2,2 \leftarrow 2,2,1$ & Ground & & & & & 23940.06 & .05 \\
\hline $\mathrm{C}^{\mathrm{b}} \mathrm{H}_{2}: \mathrm{C}^{\mathrm{b}} \mathrm{HBr}^{\mathrm{b}}$ & 4- 752 & $3,2,2 \leftarrow 2,2,1$ & Ground & & $5 / 2$ & & $3 / 2$ & 23940.2 & \\
\hline $\mathrm{C}_{6}^{12} \mathrm{H}_{5} \mathrm{~F}^{19}$ & 4-1281 & Not Reported & & & & & & 23941. & 5. \\
\hline $\mathrm{C}^{12} \mathrm{H}_{2} \mathrm{~N}^{14} \mathrm{O}^{16} \mathrm{D}$ & 3- 142 & $5,1,4 \leftarrow 5,1,5$ & Ground & & 5 & & 5 & 23941.21 & .10 \\
\hline $\mathrm{C}^{12} \mathrm{H}_{2}: \mathrm{C}^{12} \mathrm{DBr}^{\mathrm{b}}$ & 4- 729 & $3, \quad \leftarrow 2, \quad$ & Ground & & & & & 23942.9 & \\
\hline $\mathrm{Cl}^{35} \mathrm{C}^{12} \mathrm{~N}^{14}$ & 4. 171 & $2 \leftarrow 1$ & Excited & $3 / 2$ & & $1 / 2$ & & 23944.4 & \\
\hline $\mathrm{C}^{12} \mathrm{H}_{2}: \mathrm{C}^{12} \mathrm{HBr}^{81}$ & 4- .728 & $3,2,1 \leftarrow 2,2,0$ & Ground & & & & & 23944.87 & .05 \\
\hline $\mathrm{C}^{\mathrm{b}} \mathrm{H}_{2}: \mathrm{C}^{\mathrm{b}} \mathrm{HBr}^{\mathrm{b}}$ & 4- 752 & $3,2,1 \leftarrow 2,2,0$ & Ground & & $5 / 2$ & & $3 / 2$ & 23945.0 & \\
\hline $\mathrm{C}^{12} \mathrm{H}_{2}: \mathrm{C}^{12} \mathrm{HBr}^{81}$ & 4- 728 & $3,2,1 \leftarrow 2,2,0$ & Ground & & $3 / 2$ & & $3 / 2$ & 23945.1 & \\
\hline $\mathrm{C}^{12} \mathrm{H}_{2}: \mathrm{C}^{12} \mathrm{HBr}^{81}$ & 4. 728 & $3,2,1 \leftarrow 2,2,0$ & Ground & & $5 / 2$ & & $3 / 2$ & 23945.1 & \\
\hline $\mathrm{C}^{12} \mathrm{H}_{3} \mathrm{C}^{12}{ }_{*} \mathrm{HO}^{16} \mathrm{C}^{12}{ }_{*} \mathrm{H}_{2}$ & 3- 761 & Not Reported & Ground & & & & & 23946.91 & .1 \\
\hline $\mathrm{O}^{16} \mathrm{C}^{12} \mathrm{~S}^{33}$ & 4. 522 & $2 \leftarrow 1$ & Excited & & $7 / 2$ & & $5 / 2$ & 23947.4 & \\
\hline $\mathrm{O}^{16} \mathrm{C}^{12} \mathrm{~S}^{33}$ & 4. 522 & $2 \leftarrow 1$ & Excited & & $1 / 2$ & & $1 / 2$ & 23947.4 & \\
\hline $\mathrm{O}^{16} \mathrm{C}^{12} \mathrm{~S}^{33}$ & 4- 522 & $2 \leftarrow 1$ & Excited & & $5 / 2$ & & $3 / 2$ & 23947.4 & \\
\hline $\mathrm{C}^{12} \mathrm{H}_{2}\left(\mathrm{C}^{12} \mathrm{~N}^{14}\right)_{2}$ & 4- 901 & Not Reported & Ground & & & & & 23947.6 & .1 \\
\hline $\mathrm{C}^{12} \mathrm{H}_{2}: \mathrm{C}^{12} \mathrm{DBr}^{81}$ & 4- 722 & $3,1,2 \leftarrow 2,1,1$ & Ground & & $7 / 2$ & & $5 / 2$ & 23947.8 & \\
\hline $\mathrm{C}^{12} \mathrm{H}_{2}: \mathrm{C}^{12} \mathrm{DBr}^{81}$ & 4- 722 & $3,1,2 \leftarrow 2,1,1$ & Ground & & $5 / 2$ & & $3 / 2$ & 23947.8 & \\
\hline $\mathrm{HC}^{13}: \mathrm{C}^{12} \mathrm{C}^{12} \mathrm{DO}^{16}$ & 4- 922 & Not Reported & & & & & & 23948. & 5. \\
\hline $\mathrm{Cl}^{35} \mathrm{C}^{12} \mathrm{~N}^{14}$ & 4- 171 & $2 \leftarrow 1$ & Excited & $5 / 2$ & & $3 / 2$ & & 23948.2 & \\
\hline $\mathrm{C}^{12} \mathrm{H}_{2}: \mathrm{C}^{12} \mathrm{HC}^{12} \mathrm{~F}^{19}: \mathrm{C}^{12} \mathrm{H}_{2}$ & 3- 911 & $8,3,5 \leftarrow 8,2,6$ & Ground & & & & & 23948.98 & .03 \\
\hline $2,4,6 \mathrm{~d}_{3}-\mathrm{C}_{6}^{12} \mathrm{H}_{5} \mathrm{~F}^{19}$ & 4-1284 & $6,2,5 \leftarrow 5,2,4$ & Ground & & & & & 23950.9 & .1 \\
\hline $\mathrm{F}_{2}^{19} \mathrm{O}^{16} \mathrm{O}^{18}$ & 3- 12 & $4,0,4 \leftarrow 3,1,3$ & Ground & & & & & 23951.57 & .1 \\
\hline $\mathrm{C}^{12} \mathrm{H}_{3} \mathrm{C}^{12}{ }_{*} \mathrm{HO}^{16} \mathrm{C}^{12}{ }_{*} \mathrm{H}_{2}$ & 3. 761 & Not Reported & Ground & & & & & 23951.99 & .1 \\
\hline $\mathrm{C}^{\mathrm{b}} \mathrm{H}_{2}: \mathrm{C}^{\mathrm{b}} \mathrm{HBr}^{\mathrm{b}}$ & 4- 752 & $3,0,3 \leftarrow 2,0,2$ & Ground & & $5 / 2$ & & $3 / 2$ & 23952.7 & \\
\hline $\mathrm{C}^{12} \mathrm{H}_{2}: \mathrm{C}^{12} \mathrm{HBr}^{81}$ & 4- 728 & $3,0,3 \leftarrow 2,0,2$ & Ground & & $5 / 2$ & & $3 / 2$ & 23952.7 & \\
\hline $\mathrm{C}^{12} \mathrm{H}_{2}: \mathrm{C}^{12} \mathrm{HBr}^{81}$ & 4- 728 & $3,0,3 \leftarrow 2,0,2$ & Ground & & $3 / 2$ & & $1 / 2$ & 23952.7 & \\
\hline $\mathrm{C}^{13} \mathrm{H}_{2} \mathrm{Cl}^{35} \mathrm{Si}^{28} \mathrm{H}_{3}$ & 3- 233 & $4,1,4 \leftarrow 3,1,3$ & Ground & $5 / 2$ & $7 / 2$ & $3 / 2$ & $5 / 2$ & 23953.1 & .1 \\
\hline
\end{tabular}




\begin{tabular}{|c|c|c|c|c|c|c|c|c|}
\hline \multirow{3}{*}{$\begin{array}{r}\text { Isotopic Species } \\
\mathrm{C}^{13} \mathrm{H}_{2} \mathrm{Cl}^{35} \mathrm{Si}^{28} \mathrm{H}_{3}\end{array}$} & \multirow{3}{*}{$\begin{array}{c}\text { Vol.-Id. } \\
\text { Nos. } \\
\text { 3- } 233\end{array}$} & \multirow{3}{*}{$\begin{array}{c}\begin{array}{c}\text { Rotational } \\
\text { Quantum Nos. }\end{array} \\
4,1,4 \leftarrow 3,1,3\end{array}$} & \multirow{3}{*}{$\begin{array}{l}\text { Vib. State } \\
\text { Ground }\end{array}$} & \multicolumn{3}{|c|}{ Hyperfine } & \multirow{2}{*}{$\begin{array}{c}\text { Frequency } \\
\mathrm{MHz}_{z}\end{array}$} & \multirow{2}{*}{$\begin{aligned} & \text { Acc. } \\
\pm & \mathrm{MHz}\end{aligned}$} \\
\hline & & & & $\mathrm{F}_{1}^{\prime} \quad \mathrm{F}^{\prime}$ & & $\mathbf{F}$ & & \\
\hline & & & & & & & 23953.63 & .2 \\
\hline $\mathrm{C}^{13} \mathrm{H}_{2} \mathrm{Cl}^{35} \mathrm{Si}^{28} \mathrm{H}_{3}$ & 3- 233 & $4,1,4 \leftarrow 3,1,3$ & Ground & $9 / 211 / 2$ & $7 / 2$ & $9 / 2$ & 23953.9 & .1 \\
\hline $\mathrm{Cl}^{35} \mathrm{C}^{12} \mathrm{~N}^{14}$ & 4. 171 & $2 \leftarrow 1$ & Excited & $3 / 2$ & $3 / 2$ & & 23954.5 & \\
\hline $\mathrm{Cl}^{35} \mathrm{C}^{12} \mathrm{~N}^{14}$ & 4- 171 & $2 \leftarrow 1$ & Excited & $1 / 2$ & $1 / 2$ & & 23954.5 & \\
\hline $\mathrm{C}^{12} \mathrm{H}_{2} \mathrm{Cl}^{37} \mathrm{Si}^{28} \mathrm{H}_{3}$ & 3. 232 & $4,0,4 \leftarrow 3,0,3$ & Ground & & & & 23955.17 & .2 \\
\hline $\mathrm{C}^{12} \mathrm{H}_{3} \mathrm{C}^{12}{ }_{*} \mathrm{HO}^{16} \mathrm{C}^{12}{ }_{*} \mathrm{H}_{2}$ & 3- 761 & $1,1,1 \leftarrow 0,0,0$ & Ground & & & & 23955.64 & .1 \\
\hline $\mathrm{Cl}^{37} \mathrm{~F}_{3}^{19}$ & 4-1372 & $2,1,2 \leftarrow 1,0,1$ & Ground & $5 / 2$ & & $5 / 2$ & 23957.65 & .15 \\
\hline $\mathrm{C}^{12} \mathrm{H}_{2}: \mathrm{C}^{12} \mathrm{DBr}^{\mathrm{b}}$ & 4- 729 & $3, \quad \leftarrow 2, \quad$ & Ground & & & & 23957.7 & .1 \\
\hline $\mathrm{C}^{12}{ }_{*} \mathrm{H}_{2}^{\mathrm{b}} \mathrm{S}^{\mathrm{b}} \mathrm{C}^{12}{ }_{*} \mathrm{H}_{2}^{\mathrm{b}}$ & 4- 854 & Not Reported & & & & & 23958.1 & .2 \\
\hline $\mathrm{S}^{32} \mathrm{O}^{16} \mathrm{~F}_{2}^{19}$ & $4-1621$ & Not Reported & & & & & 23958.29 & .1 \\
\hline $\mathrm{Cl}^{35} \mathrm{C}^{12} \mathrm{~N}^{14}$ & 4- 171 & $2 \leftarrow 1$ & Excited & $5 / 2$ & $5 / 2$ & & 23958.4 & \\
\hline $\mathrm{C}^{12} \mathrm{H}_{2}: \mathrm{C}^{12} \mathrm{HBr}^{79}$ & 4- 727 & $3,2,2 \leftarrow 2,2,1$ & Ground & $3 / 2$ & & $1 / 2$ & 23958.5 & \\
\hline $\mathrm{C}^{12} \mathrm{H}_{2}: \mathrm{C}^{12} \mathrm{HC}^{12} \mathrm{~F}^{19}: \mathrm{C}^{12} \mathrm{H}_{2}$ & 3. 911 & $4,0,4 \leftarrow 3,1,3$ & Ground & & & & 23959.42 & .03 \\
\hline $\mathrm{C}^{12} \mathrm{H}_{3} \mathrm{C}^{12}{ }_{*} \mathrm{HO}^{16} \mathrm{C}^{12}{ }_{*} \mathrm{H}_{2}$ & 3- 761 & $1,1,1 \leftarrow 0,0,0$ & Ground & & & & 23960.29 & .1 \\
\hline $\mathrm{H}_{2}^{\mathrm{b}} \mathrm{C}^{\mathrm{b}}: \mathrm{C}^{\mathrm{b}} \mathrm{H}^{\mathrm{b}} \mathrm{Cl}^{\mathrm{b}}$ & 4- 772 & Not Reported & Ground & & & & 23961. & \\
\hline $\mathrm{C}^{12} \mathrm{H}_{3} \mathrm{C}^{13} \mathrm{H}_{2} \mathrm{C}^{12} \mathrm{H}_{3}$ & 3- 783 & $3,1,2 \leftarrow 3,0,3$ & Ground & & & & 23961.76 & .06 \\
\hline $\mathrm{C}^{12} \mathrm{H}_{2}: \mathrm{C}^{12} \mathrm{HC}^{12} \mathrm{~F}^{19}: \mathrm{C}^{12} \mathrm{H}_{2}$ & 3. 911 & $4,0,4 \leftarrow 3,1,3$ & Excited & & & & 23962.2 & .2 \\
\hline $\mathrm{C}^{12} \mathrm{H}_{2}: \mathrm{C}^{12} \mathrm{HBr}^{79}$ & 4- 727 & $3,2,1 \leftarrow 2,2,0$ & Ground & $3 / 2$ & & $1 / 2$ & 23963.6 & \\
\hline $\mathrm{C}^{12} \mathrm{H}_{2}\left(\mathrm{C}^{12} \mathrm{~N}^{14}\right)_{2}$ & 4- 901 & Not Reported & Ground & & & & 23964. & .1 \\
\hline $\mathrm{O}^{16} \mathrm{C}^{12} \mathrm{Se}^{82}$ & 4- 548 & $3 \leftarrow 2$ & Ground & & & & 23964.33 & \\
\hline $\mathrm{Cl}^{37} \mathrm{~F}_{3}^{19}$ & 4-1372 & $2,1,2 \leftarrow 1,0,1$ & Ground & $3 / 2$ & & $1 / 2$ & 23965.23 & .15 \\
\hline $\mathrm{C}^{12} \mathrm{H}_{3} \mathrm{C}^{12} \mathrm{O}^{16} \mathrm{O}^{16} \mathrm{H}$ & 3- 491 & Not Reported & & & & & 23966. & 3. \\
\hline $\mathrm{Mn}^{55} \mathrm{O}_{2}^{16} \mathrm{O}^{18} \mathrm{~F}^{19}$ & $4-1562$ & $3,1,3 \leftarrow 2,1,2$ & Ground & $11 / 2$ & & $9 / 2$ & 23966.310 & .040 \\
\hline $\mathrm{Mn}^{55} \mathrm{O}_{2}^{16} \mathrm{O}^{18} \mathrm{~F}^{19}$ & $4-1562$ & $3,1,3 \leftarrow 2,1,2$ & Ground & $9 / 2$ & & $7 / 2$ & 23967.106 & .040 \\
\hline $\mathrm{Mn}^{55} \mathrm{O}_{2}^{16} \mathrm{O}^{18} \mathrm{~F}^{19}$ & 4-1562 & $3,1,3 \leftarrow 2,1,2$ & Ground & $7 / 2$ & & $7 / 2$ & 23967.106 & .040 \\
\hline $\mathrm{Mn}^{55} \mathrm{O}_{2}^{16} \mathrm{O}^{18} \mathrm{~F}^{19}$ & 4-1562 & $3,1,3 \leftarrow 2,1,2$ & Ground & $5 / 2$ & & $3 / 2$ & 23967.106 & .040 \\
\hline $\mathrm{Mn}^{55} \mathrm{O}_{2}^{16} \mathrm{O}^{18} \mathrm{~F}^{19}$ & $4-1562$ & $3,1,3 \leftarrow 2,1,2$ & Ground & $7 / 2$ & & $5 / 2$ & 23967.106 & .040 \\
\hline $\mathrm{C}^{12} \mathrm{D}_{3} \mathrm{~N}^{14} \mathrm{D}_{2}$ & 3- 262 & $4,1,3 \leftarrow 3,2,1$ & Ground & & & & 23967.46 & \\
\hline $\mathrm{HC}^{13}: \mathrm{C}^{12} \mathrm{C}^{12} \mathrm{DO}^{16}$ & 4- 922 & Not Reported & & & & & 23968. & 5. \\
\hline $\mathrm{Cl}^{35} \mathrm{C}^{12} \mathrm{~N}^{14}$ & 4- 171 & $2 \leftarrow 1$ & Excited & $7 / 2$ & $5 / 2$ & & 23968.6 & \\
\hline $\mathrm{C}^{12} \mathrm{H}_{3} \mathrm{C}^{12} \mathrm{HDC}^{12} \mathrm{H}_{3}$ & 3- 784 & $4,1,3 \leftarrow 4,0,4$ & Ground & & & & 23971.76 & .06 \\
\hline $\mathrm{Cl}^{37} \mathrm{~F}_{3}^{19}$ & 4-1372 & $2,1,2 \leftarrow 1,0,1$ & Ground & $5 / 2$ & & $3 / 2$ & 23973.87 & .15 \\
\hline $\mathrm{C}^{12} \mathrm{H}_{2} \mathrm{Cl}^{15} \mathrm{C}^{12} \mathrm{~N}^{14}$ & 4- 651 & $4,0,4 \leftarrow 3,0,3$ & Ground & & & & 23974. & 1. \\
\hline $\mathrm{Cl}^{35} \mathrm{C}^{12} \mathrm{~N}^{14}$ & 4- 171 & $2 \leftarrow 1$ & Excited & $3 / 2$ & $1 / 2$ & & 23974.4 & \\
\hline $\mathrm{C}^{12} \mathrm{H}_{2}: \mathrm{C}^{12} \mathrm{HBr}^{79}$ & 4. 727 & $3,0,3 \leftarrow 2,0,2$ & Ground & $3 / 2$ & & $3 / 2$ & 23975.0 & \\
\hline $\mathrm{C}^{12} \mathrm{H}_{3} \mathrm{C}^{12}{ }_{*} \mathrm{HO}^{16} \mathrm{C}^{12}{ }_{*} \mathrm{H}_{2}$ & 3. 761 & $1,1,1 \leftarrow 0,0,0$ & Ground & & & & 23975.20 & .1 \\
\hline $\mathrm{C}^{12} \mathrm{H}_{3} \mathrm{C}^{12} \mathrm{~F}^{19}: \mathrm{C}^{12} \mathrm{H}_{2}$ & 3- 721 & $4,3,2 \leftarrow 4,2,3$ & Ground & & & & 23975.38 & .1 \\
\hline $\mathrm{C}^{12}{ }_{*} \mathrm{H}: \mathrm{C}^{12} \mathrm{HO}^{18} \mathrm{C}^{12} \mathrm{H}: \mathrm{C}^{12}{ }_{*} \mathrm{H}$ & $4-1152$ & $6,6,1 \leftarrow 6,4,2$ & Ground & & & & $23976.1^{\prime}$ & .1 \\
\hline $\mathrm{S}^{32}{ }_{*} \mathrm{DC}^{12}: \mathrm{C}^{12} \mathrm{HC}^{12} \mathrm{H}: \mathrm{C}^{12}{ }_{*} \mathrm{H}$ & $4-1162$ & $12,6,7 \leftarrow 12,6,6$ & Ground & & & & 23976.1 & .1 \\
\hline $\mathrm{s}-\mathrm{C}^{12} \mathrm{H}_{2} \mathrm{DC}^{12} \mathrm{O}^{16} \mathrm{C}^{12} \mathrm{~N}^{14}$ & 3- 677 & $3,1,3 \leftarrow 2,0,2$ & Ground & & & & 23976.34 & .2 \\
\hline $\mathrm{C}_{6}^{12} \mathrm{H}_{5} \mathrm{~F}^{19}$ & $4-1281$ & $15,4,11 \leftarrow 15,4,12$ & Ground & & & & 23976.8 & \\
\hline $\mathrm{Cs}^{133} \coprod^{127}$ & 1 - & $17 \leftarrow 16$ & Excited & & & & 23976.96 & 0.10 \\
\hline $\mathrm{C}^{12} \mathrm{H}_{3} \mathrm{C}^{12} \mathrm{H}: \mathrm{C}^{12}: \mathrm{C}^{12} \mathrm{H}_{2}$ & 3- 931 & $3,1,3 \leftarrow 2,1,2$ & Ground & & & & 23977.46 & .03 \\
\hline $\mathrm{C}^{12} \mathrm{H}_{3} \mathrm{C}^{12} \mathrm{H}: \mathrm{C}^{12}: \mathrm{C}^{12} \mathrm{H}_{2}$ & 3- 931 & $3,1,3 \leftarrow 2,1,2$ & Ground & & & & 23977.89 & .03 \\
\hline $\mathrm{C}_{6}^{12} \mathrm{H}_{5} \mathrm{O}^{16} \mathrm{H}$ & $3-1051$ & $6,4,3 \leftarrow 6,3,4$ & Ground & & & & 23978.6 & \\
\hline
\end{tabular}




\begin{tabular}{|c|c|c|c|c|c|c|c|}
\hline Isotopic Species & $\begin{array}{l}\text { Vol.-Id. } \\
\text { Nos. }\end{array}$ & $\begin{array}{c}\text { Rotational } \\
\text { Quantum Nos. }\end{array}$ & Vib. State & $\mathrm{F}_{1}^{\prime} \mathrm{F}^{\prime}$ Hyper & $\mathrm{F}_{1} \mathrm{~F}$ & $\begin{array}{c}\text { Frequency } \\
\mathrm{MHz}\end{array}$ & $\begin{aligned} & \text { Acc. } \\
& \pm \mathrm{MHz}\end{aligned}$ \\
\hline $\mathrm{HC}^{13}: \mathrm{C}^{12} \mathrm{C}^{12} \mathrm{DO}^{16}$ & 4- 922 & Not Reported & & & & 23980. & 5. \\
\hline $\mathrm{C}^{12}{ }_{*} \mathrm{H}_{2} \mathrm{~N}^{14} \mathrm{DC}^{12}{ }_{*} \mathrm{H}_{2}$ & 4- 862 & $4,4,1 \leftarrow 4,2,2$ & Ground & & & 23983.1 & .5 \\
\hline $\mathrm{C}^{12} \mathrm{H}_{3} \mathrm{C}^{12} \mathrm{~F}^{19}: \mathrm{C}^{12} \mathrm{H}_{2}$ & 3- 721 & $4,3,2 \leftarrow 4,2,3$ & Ground & & & 23983.98 & .1 \\
\hline $3 \mathrm{~d}-\mathrm{C}_{6}^{12} \mathrm{H}_{5} \mathrm{~F}^{19}$ & $4-1282$ & $10,2,8 \leftarrow 10,2,9$ & Ground & & & 23984.4 & .1 \\
\hline $\mathrm{Cl}^{35} \mathrm{C}^{12} \mathrm{~N}^{14}$ & 4. 171 & $2 \leftarrow 1$ & Excited & $1 / 2$ & $1 / 2$ & 23984.6 & \\
\hline $\mathrm{C}^{12} \mathrm{H}_{2}\left(\mathrm{C}^{12} \mathrm{~N}^{14}\right)_{2}$ & 4- 901 & Not Reported & Ground & & & 23985. & .1 \\
\hline $\mathrm{C}_{6}^{12} \mathrm{H}_{5} \mathrm{~N}^{14} \mathrm{O}_{2}^{16}$ & 3-1041 & $10,2,8 \leftarrow 9,2,7$ & Ground & & & 23985. & 3. \\
\hline $\mathrm{C}^{12} \mathrm{H}_{2} \mathrm{~N}^{14} \mathrm{DC}^{12}{ }_{*} \mathrm{H}_{2}$ & 4- 862 & $4,4,1 \leftarrow 4,2,2$ & Ground & & & 23985.1 & .5 \\
\hline $\mathrm{HC}^{12} \mathrm{O}^{16} \mathrm{O}^{18} \mathrm{C}^{12} \mathrm{H}_{3}-\mathrm{E}$ & 3- 516 & $2,0,2 \leftarrow 1,0,1$ & Ground & & & 23985.67 & .2 \\
\hline $\mathrm{F}_{2}^{19} \mathrm{O}_{2}^{16}$ & 3- 11 & $6,1,5 \leftarrow 6,0,6$ & Ground & & & 23986.65 & .1 \\
\hline $\mathrm{Cl}^{37} \mathrm{~F}_{3}^{19}$ & 4-1372 & $2,1,2 \leftarrow 1,0,1$ & Ground & $7 / 2$ & $5 / 2$ & 23986.75 & .15 \\
\hline $\mathrm{HC}^{12} \mathrm{O}^{16} \mathrm{O}^{18} \mathrm{C}^{12} \mathrm{H}_{3}-\mathrm{A}$ & 3. 515 & $2,0,2 \leftarrow 1,0,1$ & Ground & & & 23987.49 & .2 \\
\hline $\mathrm{C}^{12} \mathrm{H}_{2}: \mathrm{C}^{12} \mathrm{DBr}^{79}$ & 4- 721 & $3,1,2 \leftarrow 2,1,1$ & Excited & $3 / 2$ & $3 / 2$ & 23987.6 & \\
\hline $\mathrm{HC}^{13}: \mathrm{C}^{12} \mathrm{C}^{12} \mathrm{DO}^{16}$ & 4- 922 & Not Reported & & & & 23989. & 5. \\
\hline $\mathrm{C}^{12} \mathrm{H}_{3} \mathrm{~S}^{32} \mathrm{H}$ & 3- 221 & Not Reported & Ground & & & 23989.0 & .1 \\
\hline $\mathrm{C}^{12} \mathrm{H}_{3} \mathrm{C}^{13} \mathrm{O}^{16} \mathrm{Cl}^{35}$ & 3- 369 & $7,2,5 \leftarrow 7,1,6$ & Ground & $15 / 2$ & $15 / 2$ & 23989.95 & .2 \\
\hline $\mathrm{C}^{12} \mathrm{H}_{3} \mathrm{C}^{13} \mathrm{O}^{16} \mathrm{Cl}^{35}$ & 3- 369 & $7,2,5 \leftarrow 7,1,6$ & Ground & $13 / 2$ & $13 / 2$ & 23989.95 & .2 \\
\hline $\mathrm{C}^{12} \mathrm{H}_{3} \mathrm{C}^{13} \mathrm{O}^{16} \mathrm{Cl}^{35}$ & 3. 369 & $7,2,5 \leftarrow 7,1,6$ & Ground & $17 / 2$ & $17 / 2$ & 23991.05 & .2 \\
\hline $\mathrm{C}^{12} \mathrm{H}_{3} \mathrm{C}^{13} \mathrm{O}^{16} \mathrm{Cl}^{35}$ & 3- 369 & $7,2,5 \leftarrow 7,1,6$ & Ground & $11 / 2$ & $11 / 2$ & 23991.05 & .2 \\
\hline $\mathrm{C}^{12} \mathrm{D}_{2} \mathrm{Cl}^{35} \mathrm{Si}^{28} \mathrm{H}_{3}$ & 3- 235 & $4,0,4 \leftarrow 3,0,3$ & Ground & & & 23992.05 & .2 \\
\hline $\mathrm{C}^{12} \mathrm{H}_{2}: \mathrm{C}^{12} \mathrm{HBr}^{81}$ & 4- 728 & $3,2,1 \leftarrow 2,2,0$ & Excited & $7 / 2$ & $5 / 2$ & 23992.4 & \\
\hline $\mathrm{C}^{12} \mathrm{H}_{2}: \mathrm{C}^{12} \mathrm{HBr}^{81}$ & 4- 728 & $3,2,1 \leftarrow 2,2,0$ & Excited & $5 / 2$ & $5 / 2$ & 23992.4 & \\
\hline $\mathrm{N}^{14} \mathrm{O}^{16} \mathrm{O}^{18}$ & 4-1803 & $7,1,7 \leftarrow 8,0,8$ & Ground & & & 23992.66 & \\
\hline $\mathrm{Cl}^{37} \mathrm{~F}_{3}^{19}$ & 4.1372 & $2,1,2 \leftarrow 1,0,1$ & Ground & $3 / 2$ & $3 / 2$ & 23994.55 & .15 \\
\hline$C]^{37} \mathbf{F}_{3}^{19}$ & $4-1372$ & $2,1,2 \leftarrow 1,0,1$ & Ground & $1 / 2$ & $1 / 2$ & 23994.55 & .15 \\
\hline $\mathrm{H}_{2} \mathrm{C}^{12}: \mathrm{C}^{12} \mathrm{~F}_{2}^{19}$ & 4. 681 & Not Reported & & & & 23994.7 & .3 \\
\hline$\left(\mathrm{C}^{12} \mathrm{H}_{3}\right)_{2} \mathrm{C}^{12}: \mathrm{C}^{12} \mathrm{H}_{2}$ & 3- 941 & $8,8,0 \leftarrow 8,7,1$ & Ground & & & 23994.84 & .05 \\
\hline $\mathrm{C}^{12} \mathrm{H}_{3} \mathrm{C}^{13} \mathrm{O}^{16} \mathrm{Cl}^{35}$ & $3-369$ & $7,2,5 \leftarrow 7,1,6$ & Ground & $15 / 2$ & $15 / 2$ & 23995.15 & .2 \\
\hline $\mathrm{C}^{12} \mathrm{H}_{3} \mathrm{C}^{13} \mathrm{O}^{16} \mathrm{Cl}^{135}$ & 3- 369 & $7,2,5 \leftarrow 7,1,6$ & Ground & $13 / 2$ & $13 / 2$ & 23995.15 & .2 \\
\hline $\mathrm{C}^{12} \mathrm{H}_{2}: \mathrm{C}^{12} \mathrm{DBr}^{81}$ & 4- 722 & $3,1,2 \leftarrow 2,1,1$ & Ground & $7 / 2$ & $7 / 2$ & 23995.3 & \\
\hline$\left(\mathrm{C}^{12} \mathrm{H}_{3}\right)_{2} \mathrm{C}^{12}: \mathrm{C}_{1}^{12} \mathrm{H}_{2}$ & $3 \cdot 941$ & $8,8,0 \leftarrow 8,7,1$ & Ground & & & 23995.50 & \\
\hline $\mathrm{O}^{16} \mathrm{C}^{12} \mathrm{Se}^{82}$ & 4- 548 & $3 \leftarrow 2$ & Excited & & & 23996.26 & .03 \\
\hline $\mathrm{C}^{12} \mathrm{H}_{3} \mathrm{C}^{13} \mathrm{O}^{16} \mathrm{Cl}^{35}$ & 3- 369 & $7,2,5 \leftarrow 7,1,6$ & Ground & $17 / 2$ & $17 / 2$ & 23996.28 & .2 \\
\hline $\mathrm{C}^{12} \mathrm{H}_{3} \mathrm{C}^{13} \mathrm{O}^{16} \mathrm{Cl}^{35}$ & 3- 369 & $7,2,5 \leftarrow 7,1,6$ & Ground & $11 / 2$ & $11 / 2$ & 23996.28 & .2 \\
\hline $\mathrm{C}^{12} \mathrm{H}_{3} \mathrm{C}^{12} \mathrm{HF}_{2}^{19}$ & 3- 461 & $8,7,2 \leftarrow 8,5,3$ & Ground & & & 23996.4 & \\
\hline $\mathrm{a} \cdot \mathrm{C}^{12} \mathrm{H}_{2} \mathrm{DC}^{12} \mathrm{O}^{16} \mathrm{~F}^{19}$ & 3- 398 & $7,4,3 \leftarrow 7,4,4$ & Ground & & & 23998.35 & .2 \\
\hline $\mathrm{C}^{12} \mathrm{H}_{3} \mathrm{~B}^{\mathrm{b}} \mathrm{F}_{2}^{19}$ & 3- 91 & $2, \quad \leftarrow 1$, & Ground & & & 23999.7 & .1 \\
\hline $\mathrm{C}_{8}^{12} \mathrm{H}_{13} \mathrm{Cl}^{35}$ & $4-1341$ & $11, \leftarrow 10$ & Ground & & & 23999.8 & \\
\hline $\mathrm{C}^{12}{ }_{*} \mathrm{D}: \mathrm{C}^{12} \mathrm{HC}^{12} \mathrm{H}: \mathrm{C}^{12} \mathrm{HN}^{14}{ }_{*} \mathrm{H}$ & $4-1183$ & $11,10,1 \leftarrow 11,9,2$ & Ground & & & 24001.9 & \\
\hline $\mathrm{C}^{12} \mathrm{H}_{2} \mathrm{Cl}^{35} \mathrm{C}^{12} \mathrm{~N}^{14}$ & 4- 651 & $4,2,3 \leftarrow 3,2,2$ & Ground & & & 24002 & 1. \\
\hline $\mathrm{C}^{12} \mathrm{H}_{2}\left(\mathrm{C}^{12} \mathrm{~N}^{14}\right)_{2}$ & 4. 901 & Not Reported & Ground & & & 24003.2 & .1 \\
\hline $\mathrm{C}^{12} \mathrm{H}_{2}: \mathrm{C}^{12} \mathrm{DBr}^{79}$ & 4- 721 & $3,1,2 \leftarrow 2,1,1$ & Ground & $3 / 2$ & $3 / 2$ & 24005.7 & \\
\hline${ }_{2}^{5-} \mathrm{C}^{12} \mathrm{H} \mathrm{C}^{12} \mathrm{H} \mathrm{C}^{12} \mathrm{H} \mathrm{Cl}^{37}$ & 3- 774 & $4,0,4 \leftarrow 3,0,3$ & Ground & & & 24.007 .67 & .2 \\
\hline $\mathrm{C}^{12} \mathrm{H}_{2}: \mathrm{C}^{12} \mathrm{HC}^{12} \mathrm{~F}^{19}: \mathrm{C}^{12} \mathrm{H}_{2}$ & 3- 911 & $4,0,4 \leftarrow 3,1,3$ & Ground & & & 24.007 .74 & .03 \\
\hline $\mathrm{C}^{12} \mathrm{H}_{2}: \mathrm{C}^{12} \mathrm{HBr}^{79}$ & 4- 727 & $3,0,3 \leftarrow 2,0,2$ & Cround & $5 / 2$ & $5 / 2$ & 24009.30 & \\
\hline
\end{tabular}




\begin{tabular}{|c|c|c|c|c|c|c|c|}
\hline \multirow{2}{*}{ Isotopic Species } & \multirow{2}{*}{$\begin{array}{l}\text { Vol.-Id. } \\
\text { Nos. }\end{array}$} & \multirow{2}{*}{$\begin{array}{c}\text { Rotational } \\
\text { Quantum Nos. }\end{array}$} & \multirow{2}{*}{ Vib. State } & \multicolumn{2}{|c|}{ Hyperfine } & \multirow{2}{*}{$\begin{array}{l}\text { Frequency } \\
\text { Mliz }\end{array}$} & \multirow{2}{*}{$\begin{aligned} & \text { Acce } \\
\pm & \text { MHLz }\end{aligned}$} \\
\hline & & & & $F_{1}^{\prime} \quad F^{\prime} \quad F_{1}$ & $\mathrm{~F}$ & & \\
\hline a- $C^{12} \mathrm{H}_{2} \mathrm{DC}^{12} \mathrm{O}^{16} \mathrm{~F}^{19}$ & 3- 398 & $7,4,3 \leftarrow 7,4,4$ & Ground & & & 24010.20 & .2 \\
\hline $\mathrm{C}^{12} \mathrm{H}_{2}: \mathrm{C}^{12} \mathrm{HBr}^{81}$ & 4- 728 & $3,2,2 \leftarrow 2,2,1$ & Ground & $5 / 2$ & $5 / 2$ & 24010.3 & \\
\hline $\mathrm{C}^{12} \mathrm{H}_{2}: \mathrm{C}^{12} \mathrm{HBr}^{\mathrm{B} 1}$ & 4- 728 & $3,2,2 \leftarrow 2,2,1$ & Ground & $7 / 2$ & $5 / 2$ & 24010.3 & \\
\hline $\mathrm{C}^{\mathrm{b}} \mathrm{H}_{2}: \mathrm{C}^{\mathrm{h}} \mathrm{HBr}^{\mathrm{h}}$ & 4- 752 & $3,2,2 \leftarrow 2,2,1$ & Ground & $7 / 2$ & $5 / 2$ & 24010.3 & \\
\hline $\mathrm{C}^{12} \mathrm{H}_{3} \mathrm{C}^{12} \mathrm{~F}^{19}: \mathrm{C}^{12} \mathrm{H}_{2}$ & 3- 721 & $4,3,2 \leftarrow 4,2,3$ & Ground & & & 24010.42 & .1 \\
\hline $\mathrm{C}^{12} \mathrm{H}_{2} \mathrm{Cl}^{35} \mathrm{C}^{12} \mathrm{~N}^{14}$ & 4- 651 & $4,3,2 \leftarrow 3,3,1$ & Ground & & & 24011. & 1. \\
\hline $\mathrm{C}^{12} \mathrm{H}_{2} \mathrm{Cl}^{35} \mathrm{C}^{12} \mathrm{~N}^{14}$ & 4. 651 & $4,3,1 \leftarrow 3,3,0$ & Ground & & & 24011 & 1. \\
\hline $\mathrm{DC}^{12} \mathrm{O}^{16} \mathrm{O}^{16} \mathrm{C}^{12} \mathrm{H}_{3}-\mathrm{E}$ & 3. 504 & $8,2,6 \leftarrow 8,2,7$ & Ground & & & 24011.56 & .35 \\
\hline $\mathrm{O}^{16} \mathrm{C}^{12} \mathrm{~S}^{33}$ & 4- 522 & $2 \leftarrow 1$ & Ground & $3 / 2$ & $1 / 2$ & 24012.33 & .02 \\
\hline$\left(\mathrm{C}^{12} \mathrm{H}_{3}\right)_{2} \mathrm{Si}^{24} \mathrm{D}_{2}$ & 3- 643 & $3,0,3 \leftarrow 2,1,2$ & Ground & & & 24012.43 & .05 \\
\hline$\left(\mathrm{C}^{12} \mathrm{H}_{3}\right)_{2} \mathrm{Si}^{28} \mathrm{D}_{2}$ & 3- 643 & $3,0,3 \leftarrow 2,1,2$ & Ground & & & 24012.92 & .05 \\
\hline $\mathrm{O}^{16} \mathrm{C}^{12} \mathrm{~S}^{33}$ & 4- 522 & $2 \leftarrow 1$ & Ground & $5 / 2$ & $5 / 2$ & 24.012 .94 & .02 \\
\hline$\left(\mathrm{C}^{12} \mathrm{H}_{3}\right)_{2} \mathrm{Si}^{28} \mathrm{D}_{2}$ & 3- 643 & $3,0,3 \leftarrow 2,1,2$ & Ground & & & 24013.39 & .05 \\
\hline $\mathrm{C}^{12} \mathrm{H}_{3} \mathrm{C}^{12} \mathrm{O}^{16} \mathrm{Cl}^{37}$ & 3- 362 & $6,3,3 \leftarrow 6,2,4$ & Ground & $9 / 2$ & $9 / 2$ & 24014.90 & .2 \\
\hline $\mathrm{a} \cdot \mathrm{C}^{12} \mathrm{H}_{2} \mathrm{DC}^{12} \mathrm{O}^{16} \mathrm{C}^{12} \mathrm{~N}^{14}$ & 3. 679 & $6,1,5 \leftarrow 6,0,6$ & Ground & & & 24014.94 & \\
\hline $\mathrm{O}^{16} \mathrm{C}^{12} \mathrm{Se}^{\mathrm{A2}}$ & 4. 548 & $3 \leftarrow 2$ & Excited & & & 24014.97 & .03 \\
\hline $\mathrm{C}^{12} \mathrm{H}_{2}: \mathrm{C}^{12} \mathrm{HBr}^{81}$ & 4- 728 & $3,2,1 \leftarrow 2,2,0$ & Ground & $5 / 2$ & $5 / 2$ & 24015.1 & \\
\hline $\mathrm{C}^{12} \mathrm{H}_{2}: \mathrm{C}^{12} \mathrm{HBr}^{81}$ & 4. 728 & $3,2,1 \leftarrow 2,2,0$ & Ground & $7 / 2$ & $5 / 2$ & 24015.1 & \\
\hline $\mathrm{a}-\mathrm{C}^{12} \mathrm{H}_{2} \mathrm{DC}^{12} \mathrm{O}^{16} \mathrm{Cl}^{35}$ & 3- 366 & $7,2,5 \leftarrow 7,1,6$ & Ground & & & 24015.28 & .2 \\
\hline $\mathrm{C}^{\mathrm{b}} \mathrm{H}_{2}: \mathrm{C}^{\mathrm{b}} \mathrm{HBr}^{\mathrm{b}}$ & 4- 752 & $3,2,1 \leftarrow 2,2,0$ & Ground & $7 / 2$ & $5 / 2$ & 24015.3 & \\
\hline $\mathrm{C}^{12} \mathrm{H}_{3} \mathrm{C}^{12} \mathrm{O}^{16} \mathrm{Cl}^{37}$ & 3- 362 & $6,3,3 \leftarrow 6,2,4$ & Ground & $15 / 2$ & $15 / 2$ & 24015.90 & .2 \\
\hline $\mathrm{C}^{12} \mathrm{H}_{3} \mathrm{~N}^{14} \mathrm{O}_{2}^{16}$ & 3. 171 & Not Reported & Ground & & & 24017 & 5. \\
\hline $\mathrm{C}^{12} \mathrm{H}_{3} \mathrm{C}^{12} \mathrm{O}^{16} \mathrm{~F}^{19}$ & 3- 391 & Not Reported & Ground & & & 24017.14 & .2 \\
\hline $\mathrm{O}^{16} \mathrm{C}^{12} \mathrm{~S}^{33}$ & 4- 522 & $2 \leftarrow 1$ & Ground & $3 / 2$ & $5 / 2$ & 24018.13 & .02 \\
\hline $\mathrm{C}^{12} \mathrm{H}_{3} \mathrm{~N}^{14} \mathrm{H}_{2}$ & 3. 261 & Not Reported & Ground & & & 24019.01 & .1 \\
\hline $\mathrm{C}^{12} \mathrm{H}_{3} \mathrm{C}^{12} \mathrm{O}^{16} \mathrm{Cl}^{37}$ & 3- 362 & $6,3,3 \leftarrow 6,2,4$ & Ground & $11 / 2$ & $11 / 2$ & 24019.20 & .2 \\
\hline $\mathrm{O}^{16} \mathrm{C}^{12} \mathrm{~S}^{33}$ & 4. 522 & $2 \leftarrow 1$ & Ground & $1 / 2$ & $1 / 2$ & 24019.59 & .02 \\
\hline $\mathrm{C}^{12} \mathrm{H}_{3} \mathrm{C}^{12} \mathrm{O}^{16} \mathrm{Cl}^{37}$ & 3- 362 & $6,3,3 \leftarrow 6,2,4$ & Ground & $13 / 2$ & $13 / 2$ & 24020.20 & .2 \\
\hline $\mathrm{O}^{16} \mathrm{C}^{12} \mathrm{~S}^{33}$ & 4. 522 & $2 \leftarrow 1$ & Ground & $7 / 2$ & $5 / 2$ & 24020.23 & .02 \\
\hline $\mathrm{O}^{16} \mathrm{C}^{12} \mathrm{~S}^{33}$ & 4- 522 & $2 \leftarrow 1$ & Ground & $5 / 2$ & $3 / 2$ & 24020.23 & .02 \\
\hline $\mathrm{H}_{2} \mathrm{C}^{12}: \mathrm{C}^{12} \mathrm{~F}_{2}^{19}$ & 4- 681 & Not Reported & & & & 24020.5 & .3 \\
\hline $\mathrm{C}^{12} \mathrm{H}_{2} \mathrm{Cl}^{35} \mathrm{~F}^{19}$ & 4- 331 & $9,1,9 \leftarrow 8,2,6$ & Ground & & & 24020.97 & .1 \\
\hline $\mathrm{S}^{32} \mathrm{C}^{12} \mathrm{Se}^{42}$ & 4. 561 & $6 \leftarrow 5$ & Ground & & & 24021 & 4. \\
\hline $\mathrm{C}^{12} \mathrm{H}_{2} \mathrm{Cl}^{35} \mathrm{~F}^{19}$ & 4- 331 & $9,1,9 \leftarrow 8,2,6$ & Ground & & & 24021.75 & .1 \\
\hline $\mathrm{C}^{12} \mathrm{H}_{2}: \mathrm{C}^{12} \mathrm{HBr}^{79}$ & 4- 727 & $3,2,1 \leftarrow 2,2,0$ & Excited & $7 / 2$ & $7 / 2$ & 24024.05 & \\
\hline $\mathrm{C}^{12} \mathrm{H}_{2}: \mathrm{C}^{12} \mathrm{HBr}^{79}$ & 4. 727 & $3,2,1 \leftarrow 2,2,0$ & Excited & $9 / 2$ & $7 / 2$ & 24024.05 & \\
\hline $\mathrm{s} \cdot \mathrm{C}^{12} \mathrm{H}_{2} \mathrm{DSi}^{28} \mathrm{H}_{2} \mathrm{~F}^{19}$ & 3- 247 & $2,1,1 \leftarrow 1,1,0$ & Ground & & & 24024.70 & .10 \\
\hline $\mathrm{O}^{16} \mathrm{C}^{12} \mathrm{~S}^{33}$ & 4- 522 & $2 \leftarrow 1$ & Ground & $3 / 2$ & $3 / 2$ & 24025.42 & .02 \\
\hline $\mathrm{O}^{16} \mathrm{C}^{12} \mathrm{Se}^{\mathrm{k0}}$ & 4- 547 & $3 \leftarrow 2$ & Excited & & & 24026.39 & .03 \\
\hline $\mathrm{DC}^{13} \mathrm{~N}^{14}$ & 4- 294 & $11 \leftarrow 11$ & Excited & & & 24026.60 & .1 \\
\hline $\mathrm{C}^{12} \mathrm{H}_{2} \mathrm{Cl}^{35} \mathrm{~F}^{19}$ & 4. 331 & $9,1,9 \leftarrow 8,2,6$ & Ground & & & 24026.92 & .1 \\
\hline $\mathrm{C}^{12} \mathrm{H}_{2}: \mathrm{C}^{12} \mathrm{HBr}^{81}$ & 4. 728 & $3,0,3 \leftarrow 2,0,2$ & Ground & $7 / 2$ & $7 / 2$ & 24027.15 & \\
\hline $\mathrm{C}^{12} \mathrm{H}_{2} \mathrm{Cl}^{35} \mathrm{~F}^{19}$ & 4- 331 & $9,1,9 \leftarrow 8,2,6$ & Ground & & & 24.027 .57 & .1 \\
\hline $\mathrm{DC}^{12} \mathrm{O}^{16} \mathrm{O}^{16} \mathrm{C}^{12} \mathrm{H}_{3}-\mathrm{A}$ & 3- 503 & $8,2,6 \leftarrow 8,2,7$ & Ground & & & 24027.98 & .35 \\
\hline $\mathrm{HC}^{13}: \mathrm{C}^{12} \mathrm{C}^{12} \mathrm{DO}^{16}$ & 4. 922 & Not Reported & & & & 24028 & 5. \\
\hline
\end{tabular}




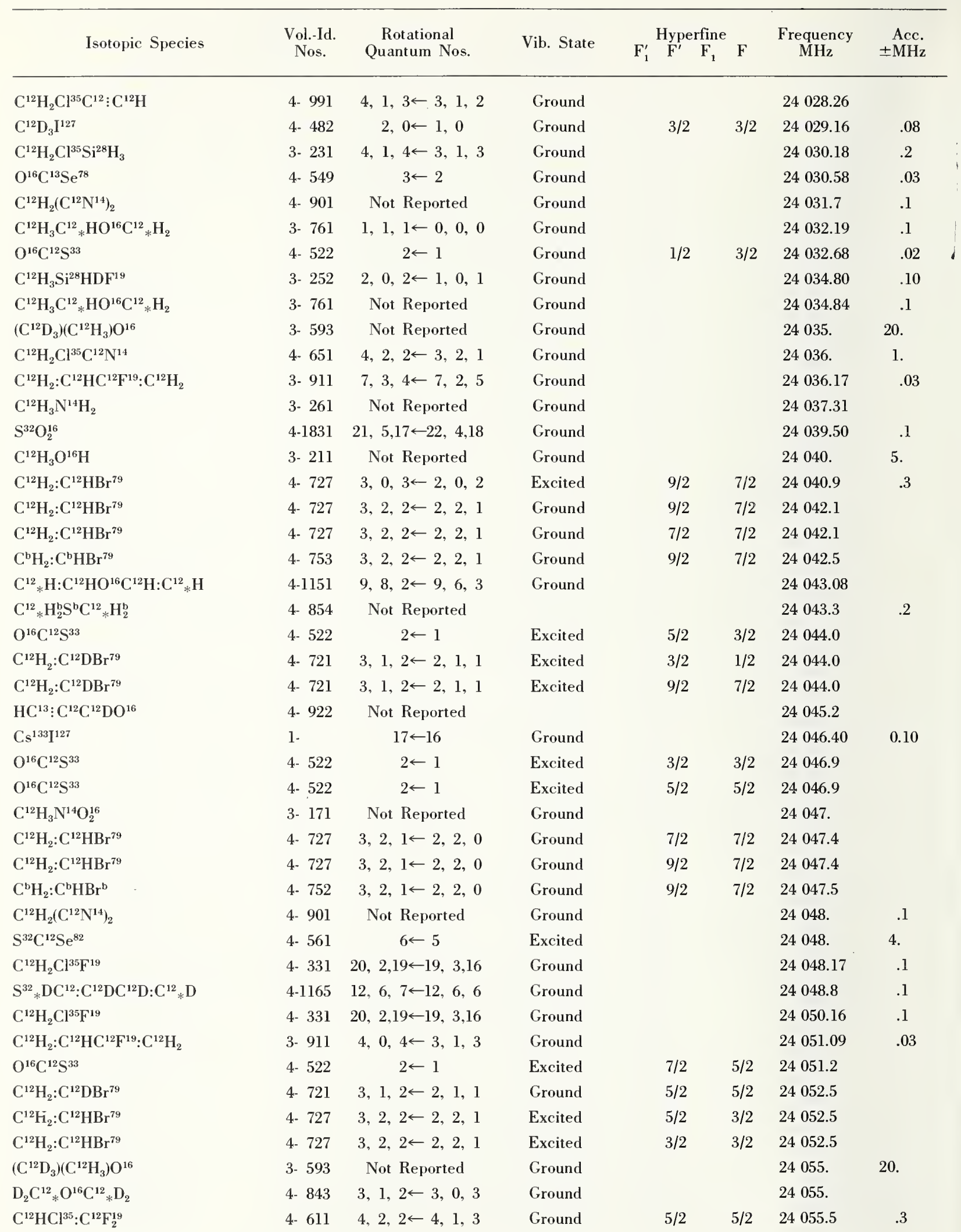


Vib. State

$\mathrm{F}_{1}^{\prime} \stackrel{\mathrm{F}^{\prime}}{\mathrm{F}_{1}} \quad \mathrm{~F}$

Frequency $\mathrm{MH}_{z}$
Acc. $\pm \mathrm{MH} z$

\begin{tabular}{|c|c|c|c|c|c|c|c|}
\hline $\mathrm{C}^{12} \mathrm{HCl}^{35}: \mathrm{C}^{12} \mathrm{~F}_{2}^{19}$ & 4. 611 & $4,2,2 \leftarrow 4,1,3$ & Ground & $11 / 2$ & $11 / 2$ & $24 \quad 057.1$ & .3 \\
\hline $\mathrm{C}^{12} \mathrm{HCl}^{35}: \mathrm{C}^{12} \mathrm{~F}_{2}^{19}$ & 4. 611 & $4,2,2 \leftarrow 4,1,3$ & Ground & $7 / 2$ & $7 / 2$ & 24059.8 & .3 \\
\hline $\mathrm{Cl}^{37} \mathrm{~F}_{3}^{19}$ & $4-1372$ & $5,2,3 \leftarrow 5,1,4$ & Ground & $13 / 2$ & $13 / 2$ & 24. 060.00 & .15 \\
\hline $\mathrm{C}^{12} \mathrm{H}_{2}: \mathrm{C}^{13} \mathrm{HBr}^{81}$ & 4- 738 & $3,1,2 \leftarrow 2,1,1$ & Excited & $9 / 2$ & $7 / 2$ & 24060.5 & \\
\hline $\mathrm{C}^{12} \mathrm{H}_{3} \mathrm{Si}^{28} \mathrm{HF}_{2}^{19}-\mathrm{A}$ & 3. 191 & Not Reported & Ground & & & 24.060 .7 & \\
\hline $\mathrm{C}^{12} \mathrm{HCl}^{35}: \mathrm{C}^{12} \mathrm{~F}_{2}^{19}$ & 4- 611 & $4,2,2 \leftarrow 4,1,3$ & Ground & $9 / 2$ & $9 / 2$ & $24,061.3$ & .3 \\
\hline $\mathrm{Cl}^{37} \mathrm{~F}_{3}^{19}$ & 4-1372 & $5,2,3 \leftarrow 5,1,4$ & Ground & $11 / 2$ & $11 / 2$ & 24. 062.09 & .15 \\
\hline $\mathrm{C}^{12} \mathrm{H}_{2}: \mathrm{C}^{12} \mathrm{DBr}^{79}$ & 4. 721 & $3,1,2 \leftarrow 2,1,1$ & Ground & $3 / 2$ & $1 / 2$ & 24062.2 & \\
\hline $\mathrm{C}^{12} \mathrm{H}_{2}: \mathrm{C}^{12} \mathrm{DBr}^{79}$ & 4- 721 & $3,1,2 \leftarrow 2,1,1$ & Ground & $9 / 2$ & $7 / 2$ & 24062.8 & \\
\hline $\mathrm{C}^{12} \mathrm{H}_{2}: \mathrm{C}^{12} \mathrm{HBr}^{79}$ & 4- 727 & $3,0,3 \leftarrow 2,0,2$ & Ground & $9 / 2$ & $7 / 2$ & 24063.7 & \\
\hline $\mathrm{Cl}^{35} \mathrm{~F}_{3}^{19}$ & $4-1371$ & $2,1,2 \leftarrow 1,0,1$ & Ground & $5 / 2$ & $5 / 2$ & 24063.80 & .15 \\
\hline $\mathrm{C}^{12} \mathrm{H}_{2}: \mathrm{C}^{12} \mathrm{HBr}^{79}$ & 4- 727 & $3,0,3 \leftarrow 2,0,2$ & Ground & $7 / 2$ & $5 / 2$ & 24064.00 & \\
\hline $\mathrm{C}^{12} \mathrm{H}_{2}: \mathrm{C}^{12} \mathrm{HBr}^{79}$ & 4- 727 & $3,0,3 \leftarrow 2,0,2$ & Ground & $9 / 2$ & $7 / 2$ & 24064.00 & \\
\hline $\mathrm{C}^{12} \mathrm{H}_{3} \mathrm{Si}^{28} \mathrm{HF}_{2}^{19}-\mathrm{A}$ & 3- 191 & Not Reported & Ground & & & 24064.1 & \\
\hline $\mathrm{Ge}^{72} \mathrm{H}_{3} \mathrm{Br}^{79}$ & 4- 103 & $5, \leftarrow 4$, & Ground & & & 24064.35 & 1. \\
\hline $\mathrm{N}^{14} \mathrm{O}^{16} \mathrm{O}^{18}$ & 4-1803 & $7,1,7 \leftarrow 8,0,8$ & Ground & & & 24065.1 & \\
\hline $\mathrm{C}^{12} \mathrm{D}_{3} \mathrm{C}^{13} \mathrm{O}^{16} \mathrm{C}^{12} \mathrm{~N}^{14}$ & $3 \cdot 676$ & $4,1,4 \leftarrow 3,1,3$ & Ground & & & 24065.46 & .2 \\
\hline $\mathrm{C}^{12} \mathrm{HDHC}^{12} \mathrm{HDF}^{19}$ & 3- 559 & $3,1,2 \leftarrow 3,0,3$ & Ground & & & 24066.1 & .1 \\
\hline $\mathrm{C}^{12} \mathrm{H}_{3} \mathrm{~S}^{32} \mathrm{H}$ & 3- 221 & Not Reported & Ground & & & 24067.5 & .1 \\
\hline $\mathrm{HC}^{12} \mathrm{HO}^{16}$ & 4. 381 & $17,3,14 \leftarrow 17,3,15$ & Ground & & & 24068.31 & \\
\hline $\mathrm{C}^{12} \mathrm{H}_{2}: \mathrm{C}^{12} \mathrm{HBr}^{79}$ & 4- 727 & $3,0,3 \leftarrow 2,0,2$ & Excited & $5 / 2$ & $3 / 2$ & 24069.10 & \\
\hline $\mathrm{C}^{12} \mathrm{H}_{2}: \mathrm{C}^{12} \mathrm{HBr}^{79}$ & 4. 727 & $3,0,3 \leftarrow 2,0,2$ & Excited & $3 / 2$ & $1 / 2$ & 24069.10 & \\
\hline $\mathrm{C}^{12} \mathrm{H}_{2}: \mathrm{C}^{12} \mathrm{HBr}^{79}$ & 4- 727 & $3,0,3 \leftarrow 2,0,2$ & Ground & & & 24.069 .18 & .08 \\
\hline $\mathrm{O}^{16} \mathrm{C}^{12} \mathrm{~S}^{33}$ & 4- 522 & $2 \leftarrow 1$ & Excited & $5 / 2$ & $3 / 2$ & 24069.2 & \\
\hline $\mathrm{C}^{12} \mathrm{H}_{2}: \mathrm{C}^{13} \mathrm{HBr}^{81}$ & 4- 738 & $3,1,2 \leftarrow 2,1,1$ & Ground & $5 / 2$ & $5 / 2$ & 24071.9 & \\
\hline $\mathrm{O}^{16} \mathrm{C}^{12} \mathrm{~S}^{33}$ & 4- 522 & $2 \leftarrow 1$ & Excited & $5 / 2$ & $5 / 2$ & 24072.0 & \\
\hline $\mathrm{O}^{16} \mathrm{C}^{12} \mathrm{~S}^{33}$ & 4- 522 & $2 \leftarrow 1$ & Excited & $3 / 2$ & $3 / 2$ & 24072.0 & \\
\hline $\mathrm{C}_{6}^{12} \mathrm{H}_{5} \mathrm{~F}^{19}$ & $4-1281$ & $8,1,7 \leftarrow 8,1,8$ & Ground & & & 24072.3 & .1 \\
\hline $\mathrm{C}^{12} \mathrm{H}_{3} \mathrm{C}^{12} \mathrm{O}^{16} \mathrm{~F}^{19}$ & 3- 391 & $3,1,2 \leftarrow 3,1,3$ & Ground & & & 24072.41 & .2 \\
\hline $\mathrm{C}^{12} \mathrm{H}_{2}: \mathrm{C}^{12} \mathrm{HC}^{12} \mathrm{~F}^{19}: \mathrm{C}^{12} \mathrm{H}_{2}$ & 3- 911 & $9,3,6 \leftarrow 9,2,7$ & Ground & & & 24072.85 & .03 \\
\hline $\mathrm{Cl}^{35} \mathrm{~F}_{3}^{19}$ & $4-1371$ & $2,1,2 \leftarrow 1,0,1$ & Ground & $3 / 2$ & $1 / 2$ & 24073.44 & .15 \\
\hline $\mathrm{C}^{12} \mathrm{H}_{2}: \mathrm{C}^{12} \mathrm{DBr}^{79}$ & 4- 721 & $3,1,2 \leftarrow 2,1,1$ & Excited & $7 / 2$ & $5 / 2$ & 24.073 .7 & \\
\hline $\mathrm{C}^{12} \mathrm{H}_{2}: \mathrm{C}^{12} \mathrm{DBr}^{79}$ & 4- 721 & $3,1,2 \leftarrow 2,1,1$ & Excited & $5 / 2$ & $3 / 2$ & 24.073 .7 & \\
\hline$\left(\mathrm{C}^{12} \mathrm{D}_{3}\right)\left(\mathrm{C}^{12} \mathrm{H}_{3}\right) \mathrm{O}^{16}$ & 3- 593 & Not Reported & Ground & & & 24075 & 20. \\
\hline $\mathrm{S}^{32} \mathrm{C}^{12} \mathrm{Se}^{82}$ & 4- 561 & $6 \leftarrow 5$ & Excited & & & 24075 . & 4. \\
\hline $\mathrm{C}^{12} \mathrm{H}_{2}: \mathrm{C}^{12} \mathrm{DBr}^{79}$ & 4- 721 & $3,1,2 \leftarrow 2,1,1$ & Ground & & & 24.075 .33 & .05 \\
\hline $\mathrm{O}^{16} \mathrm{C}^{12} \mathrm{~S}^{33}$ & 4. 522 & $2 \leftarrow 1$ & Excited & $7 / 2$ & $5 / 2$ & 24075.7 & \\
\hline $\mathrm{C}^{12} \mathrm{H}_{2}: \mathrm{C}^{12} \mathrm{HBr}^{79}$ & 4- 727 & $3,2,2 \leftarrow 2,2,1$ & Ground & $3 / 2$ & $3 / 2$ & $\begin{array}{llllll}24 & 076.1\end{array}$ & \\
\hline $\mathrm{C}^{12} \mathrm{H}_{2}: \mathrm{C}^{12} \mathrm{HBr}^{79}$ & 4- 727 & $3,2,2 \leftarrow 2,2,1$ & Ground & $5 / 2$ & $3 / 2$ & 24076.1 & \\
\hline $\mathrm{C}^{12} \mathrm{H}_{2}: \mathrm{C}^{12} \mathrm{HBr}^{79}$ & 4- 727 & $3,2,2 \leftarrow 2,2,1$ & Ground & & & 24.076 .44 & .05 \\
\hline $\mathrm{C}^{12} \mathrm{H}_{2}: \mathrm{C}^{12} \mathrm{HBr}^{79}$ & 4- 727 & $3,2,2 \leftarrow 2,2,1$ & Ground & $5 / 2$ & $3 / 2$ & 24076.7 & \\
\hline $\mathrm{a}-\mathrm{C}^{12} \mathrm{H}_{2} \mathrm{DSi}^{28} \mathrm{HF}_{2}^{19}$ & 3- 204 & $3,1,3 \leftarrow 2,1,2$ & Ground & & & 24.078 .27 & 2. \\
\hline$\left(\mathrm{C}^{12} \mathrm{D}_{3}\right)\left(\mathrm{C}^{12} \mathrm{H}_{3}\right) \mathrm{O}^{16}$ & 3- 593 & $2,1,1 \leftarrow 2,0,2$ & Ground & & & 24078.7 & .2 \\
\hline $\mathrm{C}^{12} \mathrm{H}_{3} \mathrm{~N}^{14} \mathrm{H}_{2}$ & 3- 261 & Not Reported & Ground & & & 24078.75 & .1 \\
\hline $\mathrm{P}^{31} \mathrm{HD}_{2}$ & 4-1783 & $5,3,3 \leftarrow 5,2,3$ & Ground & & & 24079.48 & .05 \\
\hline
\end{tabular}




\begin{tabular}{|c|c|c|c|c|c|c|c|}
\hline \multirow{2}{*}{ Isotopic Species } & \multirow{2}{*}{$\begin{array}{l}\text { Vol.-Id. } \\
\text { Nos. }\end{array}$} & \multirow{2}{*}{$\begin{array}{c}\text { Rotational } \\
\text { Quantum Nos. }\end{array}$} & \multirow{2}{*}{ Vib. State } & \multicolumn{2}{|c|}{ Hyperfine } & \multirow{2}{*}{$\begin{array}{c}\text { Frequency } \\
\mathrm{MHz}\end{array}$} & \multirow{2}{*}{$\begin{aligned} & \text { Acc. } \\
& \pm \mathrm{MHz}\end{aligned}$} \\
\hline & & & & $\begin{array}{lll}F_{1}^{\prime} & F^{\prime} & F_{1}\end{array}$ & $\mathrm{~F}$ & & \\
\hline $\mathrm{C}^{12} \mathrm{H}_{3} \mathrm{C}^{12} \mathrm{O}^{16} \mathrm{~F}^{19}$ & 3. 391 & $3,1,2 \leftarrow 3,1,3$ & Ground & & & 24079.83 & .2 \\
\hline $\mathrm{C}^{12} \mathrm{H}_{2}: \mathrm{C}^{13} \mathrm{HBr}^{81}$ & 4- 738 & $3,1,3 \leftarrow 2,1,1$ & Ground & $9 / 2$ & $7 / 2$ & 24080.2 & \\
\hline $\mathrm{C}^{12} \mathrm{H}_{3} \mathrm{O}^{16} \mathrm{H}$ & 3- 211 & Not Reported & Ground & & & 24081 & 5. \\
\hline $\mathrm{C}^{1 \dot{2}} \mathrm{H}_{2}: \mathrm{C}^{12} \mathrm{HBr}^{79}$ & 4. 727 & $3,2,1 \leftarrow 2,2,0$ & Ground & & & 24081.22 & .05 \\
\hline $\mathrm{C}^{12} \mathrm{D}_{3} \mathrm{I}^{127}$ & 4- 482 & $2,1 \leftarrow 1,1$ & Ground & $3 / 2$ & $5 / 2$ & 24.081 .25 & .08 \\
\hline $\mathrm{C}^{12} \mathrm{H}_{2}: \mathrm{C}^{12} \mathrm{HBr}^{79}$ & 4. 727 & $3,2,1 \leftarrow 2,2,0$ & Ground & $5 / 2$ & $3 / 2$ & 24081.3 & \\
\hline $\mathrm{C}^{12} \mathrm{H}_{2}: \mathrm{C}^{12} \mathrm{HBr}^{79}$ & 4- 727 & $3,2,1 \leftarrow 2,2,0$ & Ground & $3 / 2$ & $3 / 2$ & 24081.3 & \\
\hline $\mathrm{C}^{12} \mathrm{H}_{3} \mathrm{C}^{13} \mathrm{O}^{16} \mathrm{~F}^{19}$ & 3- 399 & $3,1,2 \leftarrow 3,1,3$ & Ground & & & 24082.77 & .2 \\
\hline $\mathrm{C}^{12} \mathrm{H}_{3} \mathrm{C}^{13} \mathrm{O}^{16} \mathrm{~F}^{19}$ & 3. 399 & $3,1,2 \leftarrow 3,1,3$ & Ground & & & 24.082 .84 & .2 \\
\hline $\mathrm{a} \cdot \mathrm{C}^{12} \mathrm{H}_{2} \mathrm{DSi}^{28} \mathrm{HF}_{2}^{19}$ & 3- 204 & $3,1,3 \leftarrow 2,1,2$ & Ground & & & 24083.22 & 2. \\
\hline $\mathrm{S}^{32} \mathrm{O}_{2}^{16}$ & 4-1831 & $8,2,6 \leftarrow 9,1,9$ & Ground & & & 24083.39 & .1 \\
\hline $\mathrm{Cl}^{35} \mathrm{~F}_{3}^{19}$ & 4-1371 & $2,1,2 \leftarrow 1,0,1$ & Ground & $5 / 2$ & $3 / 2$ & 24084.00 & .15 \\
\hline $\mathrm{C}^{b} \mathrm{H}_{2}: \mathrm{C}^{b} \mathrm{HBr}^{b}$ & 4. 752 & Not Reported & Excited & $7 / 2$ & $5 / 2$ & 24085.5 & \\
\hline $\mathrm{C}^{12} \mathrm{H}_{3} \mathrm{C}^{12} \mathrm{O}^{16} \mathrm{Cl}^{35}$ & 3- 361 & $7,2,5 \leftarrow 7,1,6$ & Ground & $15 / 2$ & $15 / 2$ & 24086.30 & .2 \\
\hline $\mathrm{C}^{12} \mathrm{H}_{3} \mathrm{C}^{12} \mathrm{O}^{16} \mathrm{Cl}^{35}$ & 3. 361 & $7,2,5 \leftarrow 7,1,6$ & Ground & $13 / 2$ & $13 / 2$ & 24086.30 & .2 \\
\hline $\mathrm{C}^{12} \mathrm{H}_{3} \mathrm{Si}^{28} \mathrm{HF}_{2}^{19}-\mathrm{A}$ & 3- 191 & Not Reported & Ground & & & 24086.7 & \\
\hline $\mathrm{C}^{12} \mathrm{H}_{3} \mathrm{C}^{12} \mathrm{O}^{16} \mathrm{Cl}^{35}$ & 3- 361 & $7,2,5 \leftarrow 7,1,6$ & Ground & 11 & 11 & 24087.55 & .2 \\
\hline $\mathrm{C}^{12} \mathrm{H}_{3} \mathrm{C}^{12} \mathrm{O}^{16} \mathrm{Cl}^{35}$ & 3. 361 & $7,2,5 \leftarrow 7,1,6$ & Ground & $17 / 2$ & $17 / 2$ & 24. 087.55 & .2 \\
\hline $\mathrm{HC}^{13}: \mathrm{C}^{12} \mathrm{C}^{12} \mathrm{DO}^{16}$ & 4. 922 & Not Reported & & & & 24089. & 5. \\
\hline $\mathrm{C}^{12}{ }_{*} \mathrm{H}_{2} \mathrm{C}^{12} \mathrm{H}_{2} \mathrm{C}^{12} \mathrm{H}_{2} \mathrm{C}^{12} \mathrm{H}_{2} \mathrm{C}^{12}{ } \mathrm{O}^{16}$ & $4-1241$ & $28,9,19 \leftarrow 28,9,20$ & Ground & & & 24089. & 5. \\
\hline $\mathrm{C}^{12} \mathrm{H}_{2}: \mathrm{C}^{12} \mathrm{HC}^{12} \mathrm{~F}^{19}: \mathrm{C}^{12} \mathrm{H}_{2}$ & 3- 911 & $4,0,4 \leftarrow 3,1,3$ & Ground & & & 24089.49 & .03 \\
\hline $\mathrm{C}^{12}{ }_{*} \mathrm{H}_{2} \mathrm{C}^{12} \mathrm{H}: \mathrm{C}^{12}{ }_{*} \mathrm{H}$ & $4 \cdot 1031$ & $2,1,1 \leftarrow 2,1,2$ & Ground & & & 24089.6 & \\
\hline$c-\mathrm{HCl}^{35} \mathrm{C}^{12}: \mathrm{C}^{12} \mathrm{HCl}^{35}$ & 4- 671 & $6,2,4 \leftarrow 6,1,5$ & Ground & & & 24090.1 & \\
\hline $\mathrm{C}^{12} \mathrm{HD}_{2} \mathrm{C}^{12} \mathrm{HDF}^{19}$ & 3. 558 & $4,1,3 \leftarrow 4,0,4$ & Ground & & & 24090.2 & .1 \\
\hline $\mathrm{C}^{12} \mathrm{H}_{2}: \mathrm{C}^{13} \mathrm{HBr}^{81}$ & 4. 738 & $3,1,2 \leftarrow 2,1,1$ & Ground & & & 24090.58 & .06 \\
\hline$c-\mathrm{HF}^{19} \mathrm{C}^{12}: \mathrm{C}^{12} \mathrm{HF}^{19}$ & 4. 691 & $4,3,2 \leftarrow 5,2,3$ & Ground & & & 24090.66 & .05 \\
\hline $\mathrm{C}^{12} \mathrm{H}_{3} \mathrm{C}^{12} \mathrm{O}^{16} \mathrm{Cl}^{35}$ & 3- 361 & $7,2,5 \leftarrow 7,1,6$ & Ground & 13 & 13 & 24091.40 & .2 \\
\hline $\mathrm{C}^{12} \mathrm{H}_{3} \mathrm{C}^{12} \mathrm{O}^{16} \mathrm{Cl}^{35}$ & $3-361$ & $7,2,5 \leftarrow 7,1,6$ & Ground & 15 & 15 & 24091.40 & .2 \\
\hline $\mathrm{O}^{16} \mathrm{C}^{12} \mathrm{~S}^{33}$ & 4- 522 & $2 \leftarrow 1$ & Excited & $7 / 2$ & $5 / 2$ & 24092.4 & \\
\hline $\mathrm{O}^{16} \mathrm{C}^{12} \mathrm{~S}^{33}$ & 4- 522 & $2 \leftarrow 1$ & Excited & $1 / 2$ & $1 / 2$ & 24092.4 & \\
\hline $\mathrm{O}^{16} \mathrm{C}^{12} \mathrm{~S}^{33}$ & 4- 522 & $2 \leftarrow 1$ & Excited & $5 / 2$ & $3 / 2$ & 24092.4 & \\
\hline $\mathrm{C}^{12} \mathrm{H}_{2}: \mathrm{C}^{12} \mathrm{HBr}^{79}$ & 4- 727 & $3,0,3 \leftarrow 2,0,2$ & Ground & $3 / 2$ & $1 / 2$ & 24092.4 & \\
\hline $\mathrm{C}^{12} \mathrm{H}_{2}: \mathrm{C}^{12} \mathrm{HBr}^{79}$ & 4- 727 & $3,0,3 \leftarrow 2,0,2$ & Ground & $5 / 2$ & $3 / 2$ & 24092.4 & \\
\hline $\mathrm{C}^{12} \mathrm{H}_{2}: \mathrm{C}^{12} \mathrm{HBr}^{79}$ & 4- 727 & $3,0,3 \leftarrow 2,0,2$ & Ground & $5 / 2$ & $3 / 2$ & 24092.5 & \\
\hline $\mathrm{C}^{12} \mathrm{H}_{2}: \mathrm{C}^{12} \mathrm{DBr}^{79}$ & 4- 721 & $3,1,2 \leftarrow 2,1,1$ & Ground & $5 / 2$ & $3 / 2$ & 24092.5 & \\
\hline $\mathrm{C}^{12} \mathrm{H}_{2}: \mathrm{C}^{12} \mathrm{DBr}^{79}$ & 4- 721 & $3,1,2 \leftarrow 2,1,1$ & Ground & $7 / 2$ & $5 / 2$ & 24. 092.5 & \\
\hline $\mathrm{C}^{12} \mathrm{H}_{3} \mathrm{Si}^{28} \mathrm{HF}_{2}^{19} \cdot \mathrm{A}$ & 3- 191 & Not Reported & Ground & & & 24092.5 & \\
\hline $\mathrm{C}^{12} \mathrm{H}_{3} \mathrm{C}^{12} \mathrm{O}^{16} \mathrm{Cl}^{35}$ & 3- 361 & $7,2,5 \leftarrow 7,1,6$ & Ground & 17 & 17 & 24092.65 & .2 \\
\hline $\mathrm{C}^{12} \mathrm{H}_{3} \mathrm{C}^{12} \mathrm{O}^{16} \mathrm{Cl}^{35}$ & 3- 361 & $7,2,5 \leftarrow 7,1,6$ & Ground & 11 & 11 & 24092.65 & .2 \\
\hline $\mathrm{C}^{12} \mathrm{H}_{2}\left(\mathrm{C}^{12} \mathrm{~N}^{14}\right)_{2}$ & 4. 901 & $4,2,3 \leftarrow 5,1,4$ & Ground & & & 24093.24 & \\
\hline $\mathrm{C}^{12} \mathrm{D}_{3} \mathrm{C}^{12} \mathrm{O}^{16} \mathrm{C}^{12} \mathrm{~N}^{14}$ & 3- 675 & $4,1,4 \leftarrow 3,1,3$ & Ground & & & 24.093 .70 & .2 \\
\hline $\mathrm{C}_{6}^{12} \mathrm{H}_{5} \mathrm{O}^{16} \mathrm{H}$ & $3 \cdot 1051$ & $7,4,4 \leftarrow 7,3,5$ & Ground & & & 24095.4 & \\
\hline $\mathrm{C}^{12} \mathrm{D}_{2} \mathrm{Cl}^{35} \mathrm{Si}^{28} \mathrm{H}_{3}$ & 3- 235 & $4,0,4 \leftarrow 3,0,3$ & Ground & & & 24095.95 & .2 \\
\hline $\mathrm{C}^{12} \mathrm{H}_{2}: \mathrm{C}^{12} \mathrm{HC}^{12} \mathrm{~F}^{19}: \mathrm{C}^{12} \mathrm{H}_{2}$ & 3- 911 & $8,3,5 \leftarrow 8,2,6$ & Excited & & & 24.096 .12 & .03 \\
\hline $\mathrm{C}^{12} \mathrm{D}_{3} \mathrm{I}^{127}$ & 4- 482 & $2,1 \leftarrow 1,1$ & Ground & $7 / 2$ & $7 / 2$ & 24097.49 & .08 \\
\hline
\end{tabular}




\begin{tabular}{|c|c|c|c|c|c|c|c|c|c|}
\hline Isotopic Species & $\begin{array}{l}\text { Vol.-Id. } \\
\text { Nos. }\end{array}$ & $\begin{array}{c}\text { Rotational } \\
\text { Quantum Nos. }\end{array}$ & Vib. State & $F_{1}^{\prime}$ & Hype & $\begin{array}{c}\text { erfine } \\
\mathrm{F}_{1}\end{array}$ & $F$ & $\begin{array}{c}\text { Frequency } \\
\mathrm{MHz}^{2}\end{array}$ & $\begin{aligned} & \text { Acc. } \\
\pm & \mathrm{MHz}\end{aligned}$ \\
\hline $\mathrm{C}^{12} \mathrm{H}_{3} \mathrm{C}^{12} \mathrm{HF}_{2}^{19}$ & 3. 461 & $10,7,3 \leftarrow 10,7,4$ & Ground & & & & & 24099.1 & \\
\hline $\mathrm{C}^{12} \mathrm{H}_{2} \mathrm{Cl}^{35} \mathrm{Cl}^{37}$ & 4- 342 & $8,0,8 \leftarrow 7,1,7$ & Ground & & & & & 24. 100 . & 5. \\
\hline $\mathrm{Cl}^{35} \mathrm{~F}_{3}^{19}$ & $4-1371$ & $2,1,2 \leftarrow 1,0,1$ & Ground & & $7 / 2$ & & $5 / 2$ & 24100.42 & .15 \\
\hline $\mathrm{C}^{12} \mathrm{H}_{2}^{\mathrm{b}} \mathrm{S}^{\mathrm{b}} \mathrm{C}^{12} \mathrm{H}_{2}^{\mathrm{b}}$ & 4- 854 & Not Reported & & & & & & 24.101 .4 & .2 \\
\hline $\mathrm{Ge}^{70} \mathrm{H}_{3} \mathrm{Br}^{81}$ & 4- 102 & $5, \leftarrow 4$, & Ground & & & & & 24101.61 & 1. \\
\hline $\mathrm{C}^{12} \mathrm{H}_{3} \mathrm{C}^{12} \mathrm{HF}_{2}^{19}$ & 3. 461 & $10,7,3 \leftarrow 10,7,4$ & Ground & & & & & 24101.7 & \\
\hline$\left(\mathrm{C}^{12} \mathrm{H}_{3}\right)_{2} \mathrm{C}^{12} \mathrm{O}^{16}$ & 3. 751 & Not Reported & & & & & & 24102. & 5. \\
\hline $\mathrm{C}^{12} \mathrm{H}_{2}: \mathrm{C}^{13} \mathrm{HBr}^{81}$ & 4. 738 & $3,1,2 \leftarrow 2,1,1$ & Ground & & $5 / 2$ & & $3 / 2$ & 24102.5 & .5 \\
\hline $\mathrm{C}^{12} \mathrm{H}_{2}: \mathrm{C}^{12} \mathrm{DBr}^{\mathrm{b}}$ & 4. 729 & $3, \quad \leftarrow 2, \quad$, & Ground & & & & & 24103. & 5. \\
\hline $\mathrm{C}^{12} \mathrm{H}_{2}: \mathrm{C}^{12} \mathrm{DBr}^{\mathrm{b}}$ & 4- 729 & $3, \quad \leftarrow 2, \quad$, & Ground & & & & & 24103.39 & \\
\hline $\mathrm{C}^{\mathrm{b}} \mathrm{H}_{2}: \mathrm{C}^{\mathrm{b}} \mathrm{HBr}^{\mathrm{b}}$ & 4. 752 & Not Reported & Ground & & $7 / 2$ & & $5 / 2$ & 24104.5 & \\
\hline $\mathrm{C}^{12}{ }_{*} \mathrm{H}_{2}^{\mathrm{b}} \mathrm{S}^{\mathrm{b}} \mathrm{C}^{12}{ }_{*} \mathrm{H}_{2}^{\mathrm{b}}$ & 4- 854 & Not Reported & & & & & & 24. 105.0 & 10. \\
\hline $\mathrm{C}^{b} \mathrm{H}_{2}^{\mathrm{b}} \mathrm{Cl}^{\mathrm{b}} \mathrm{F}^{\mathrm{b}}$ & 4. 333 & Not Reported & & & & & & 24105.38 & .1 \\
\hline $\mathrm{O}^{16} \mathrm{C}^{12} \mathrm{Se}^{80}$ & 4. 547 & $3 \leftarrow 2$ & Ground & & & & & 24105.85 & \\
\hline $\mathrm{C}^{13} \mathrm{H}_{3} \mathrm{C}^{12} \mathrm{O}^{16} \mathrm{C}^{12} \mathrm{~N}^{14}$ & 3- 672 & $9,3,6 \leftarrow 9,2,7$ & Ground & & & & & 24109.5 & .2 \\
\hline $\mathrm{Cl}^{35} \mathrm{~F}_{3}^{19}$ & $4-1371$ & $2,1,2 \leftarrow 1,0,1$ & Ground & & $3 / 2$ & & $3 / 2$ & 24.110 .32 & .15 \\
\hline $\mathrm{Cl}^{35} \mathrm{~F}_{3}^{19}$ & $4-1371$ & $2,1,2 \leftarrow 1,0,1$ & Ground & & $1 / 2$ & & $1 / 2$ & 24110.32 & .15 \\
\hline $\mathrm{Cl}^{37} \mathrm{~F}_{3}^{19}$ & 4-1372 & $6,2,4 \leftarrow 6,1,5$ & Ground & & $15 / 2$ & & $15 / 2$ & 24111.82 & .15 \\
\hline $\mathrm{N}^{\mathrm{b}} \mathrm{O}_{2}^{\mathrm{b}} \mathrm{Cl}^{\mathrm{b}}$ & 4-1463 & Not Reported & & & & & & 24113. & \\
\hline $\mathrm{HC}^{13} \mathrm{O}^{16} \mathrm{O}^{16} \mathrm{C}^{12} \mathrm{H}_{3}-\mathrm{E}$ & 3. 509 & $2,0,2 \leftarrow 1,0,1$ & Ground & & & & & 24114.02 & .2 \\
\hline $\mathrm{Ga}^{71} \mathrm{Br}^{81}$ & 1. & $5 \leftarrow 4$ & Ground & $13 / 2$ & 8 & $11 / 2$ & 7 & 24114.08 & 0.20 \\
\hline $\mathrm{Ga}^{71} \mathrm{Br}^{81}$ & $1-$ & $5 \leftarrow 4$ & Ground & $13 / 2$ & 7 & $11 / 2$ & 6 & 24114.08 & 0.20 \\
\hline $\mathrm{Ga}^{71} \mathrm{Br}^{81}$ & $1 \cdot$ & $5 \leftarrow 4$ & Ground & $13 / 2$ & 6 & $11 / 2$ & 5 & 24114.08 & 0.20 \\
\hline $\mathrm{Ga}^{71} \mathrm{Br}^{81}$ & $1-$ & $5 \leftarrow 4$ & Ground & $13 / 2$ & 5 & $11 / 2$ & 4 & 24114.08 & 0.20 \\
\hline $\mathrm{Ga}^{71} \mathrm{Br}^{81}$ & 1 - & $5 \leftarrow 4$ & Ground & $11 / 2$ & 7 & $9 / 2$ & 6 & 24114.08 & 0.20 \\
\hline $\mathrm{Ga}^{71} \mathrm{Br}^{81}$ & $1-$ & $5 \leftarrow 4$ & Ground & $11 / 2$ & 6 & $9 / 2$ & 5 & 24114.08 & 0.20 \\
\hline $\mathrm{Ga}^{71} \mathrm{Br}^{81}$ & $1-$ & $5 \leftarrow 4$ & Ground & $9 / 2$ & 6 & $7 / 2$ & 5 & 24114.08 & 0.20 \\
\hline $\mathrm{Ga}^{71} \mathrm{Br}^{81}$ & 1 - & $5 \leftarrow 4$ & Ground & $11 / 2$ & 5 & $9 / 2$ & 4 & 24114.08 & 0.20 \\
\hline $\mathrm{Ga}^{71} \mathrm{Br}^{81}$ & 1 - & $5 \leftarrow 4$ & Ground & $11 / 2$ & 4 & $9 / 2$ & 3 & 24114.08 & 0.20 \\
\hline $\mathrm{Ga}^{71} \mathrm{Br}^{81}$ & $1-$ & $5 \leftarrow 4$ & Ground & $9 / 2$ & 5 & $7 / 2$ & 4 & 24114.08 & 0.20 \\
\hline $\mathrm{Ga}^{71} \mathrm{Br}^{81}$ & $1-$ & $5 \leftarrow 4$ & Ground & $9 / 2$ & 4 & $7 / 2$ & 3 & 24114.08 & 0.20 \\
\hline $\mathrm{Ga}^{71} \mathrm{Br}^{81}$ & $1-$ & $5 \leftarrow 4$ & Ground & $9 / 2$ & 3 & $7 / 2$ & 2 & 24114.08 & 0.20 \\
\hline $\mathrm{Ga}^{71} \mathrm{Br}^{81}$ & 1 - & $5 \leftarrow 4$ & Ground & $7 / 2$ & 2 & $5 / 2$ & 1 & 24114.08 & 0.20 \\
\hline $\mathrm{Ga}^{71} \mathrm{Br}^{81}$ & $1-$ & $5 \leftarrow 4$ & Ground & $7 / 2$ & 4 & $5 / 2$ & 3 & 24114.08 & 0.20 \\
\hline $\mathrm{Ga}^{71} \mathrm{Br}^{81}$ & 1. & $5 \leftarrow 4$ & Ground & $7 / 2$ & 3 & $5 / 2$ & 2 & 24114.08 & 0.20 \\
\hline$\left(\mathrm{C}^{12} \mathrm{D}_{3}\right)\left(\mathrm{C}^{12} \mathrm{H}_{3}\right) \mathrm{O}^{16}$ & 3- 593 & Not Reported & Ground & & & & & 24115 & 20. \\
\hline $\mathrm{HC}^{13} \mathrm{O}^{16} \mathrm{O}^{16} \mathrm{C}^{12} \mathrm{H}_{3}-\mathrm{A}$ & 3. 508 & $2,0,2 \leftarrow 1,0,1$ & Ground & & & & & 24115.85 & .2 \\
\hline $\mathrm{C}^{12} \mathrm{H}_{3} \mathrm{C}^{12} \mathrm{~F}^{19}: \mathrm{C}^{12} \mathrm{H}_{2}$ & 3- 721 & $17,12,5 \leftarrow 17,12,6$ & Ground & & & & & 24117.22 & .1 \\
\hline $\mathrm{Cl}^{37} \mathrm{~F}_{3}^{19}$ & $4 \cdot 1372$ & $6,2,4 \leftarrow 6,1,5$ & Ground & & $9 / 2$ & & $9 / 2$ & 24117.35 & .15 \\
\hline $\mathrm{Cl}^{37} \mathrm{~F}_{3}^{19}$ & $4 \cdot 1372$ & $6,2,4 \leftarrow 6,1,5$ & Ground & & $13 / 2$ & & $13 / 2$ & 24118.20 & .15 \\
\hline $\mathrm{C}^{12} \mathrm{H}_{3} \mathrm{C}^{12} \mathrm{~F}^{19}: \mathrm{C}^{12} \mathrm{H}_{2}$ & 3- 721 & $17,12,5 \leftarrow 17,12,6$ & Ground & & & & & 24118.48 & .1 \\
\hline $\mathrm{H}_{2} \mathrm{~N}^{14} \mathrm{~N}^{14} \mathrm{H}_{2}$ & $3-\quad 51$ & Not Reported & & & & & & 24120.0 & \\
\hline $\mathrm{C}^{12} \mathrm{H}_{2}\left(\mathrm{C}^{12} \mathrm{~N}^{14}\right)_{2}$ & 4- 901 & Not Reported & Ground & & & & & 24120.8 & .1 \\
\hline$\left(\mathrm{C}^{12} \mathrm{D}_{3}\right)\left(\mathrm{C}^{12} \mathrm{H}_{3}\right) \mathrm{O}^{16}$ & 3- 593 & Not Reported & Ground & & & & & 24125 & 20. \\
\hline $\mathrm{C}^{12} \mathrm{D}_{3} \mathrm{~N}^{14} \mathrm{D}_{2}$ & 3- 262 & $4,1,3 \leftarrow 3,2,1$ & Ground & & & & & 24125.48 & \\
\hline
\end{tabular}




\begin{tabular}{|c|c|c|c|c|c|c|c|c|c|}
\hline \multirow{2}{*}{ Isotopic Species } & \multirow{2}{*}{$\begin{array}{l}\text { Vol.-Id. } \\
\text { Nos. }\end{array}$} & \multirow{2}{*}{$\begin{array}{c}\text { Rotational } \\
\text { Quantum Nos. }\end{array}$} & \multirow{2}{*}{ Vib. State } & \multicolumn{4}{|c|}{ Hyperfine } & \multirow{2}{*}{$\begin{array}{c}\text { Frequency } \\
\mathrm{MHz}\end{array}$} & \multirow{2}{*}{$\begin{aligned} & \text { Acc. } \\
& \pm \mathrm{MHz}\end{aligned}$} \\
\hline & & & & $\mathrm{F}_{1}^{\prime}$ & & $\mathrm{F}_{1}$ & $\mathrm{~F}$ & & \\
\hline $\mathrm{C}^{12} \mathrm{H}_{2}\left(\mathrm{C}^{12} \mathrm{~N}^{14}\right)_{2}$ & 4- 901 & Not Reported & Ground & & & & & 24126.4 & .1 \\
\hline $\mathrm{C}^{\mathrm{b}} \mathrm{H}_{2}: \mathrm{C}^{\mathrm{b}} \mathrm{HBr}^{\mathrm{b}}$ & 4- 752 & Not Reported & Excited & & $7 / 2$ & & $7 / 2$ & 24127.0 & .2 \\
\hline $\mathrm{H}_{2} \mathrm{C}^{12}: \mathrm{C}^{12} \mathrm{Cl}^{35} \mathrm{Cl}^{37}$ & 4- 662 & $5,0,5 \leftarrow 4,1,4$ & Ground & & & & & 24131.4 & 1. \\
\hline $\mathrm{C}^{12} \mathrm{H}_{3} \mathrm{C}^{12} \mathrm{O}^{16} \mathrm{O}^{16} \mathrm{H}$ & 3- 491 & Not Reported & & & & & & 24132. & 3. \\
\hline $\mathrm{C}^{12} \mathrm{H}_{3} \mathrm{C}^{12} \mathrm{O}^{18} \mathrm{C}^{12} \mathrm{~N}^{14}$ & 3- 674 & $7,3,4 \leftarrow 7,2,5$ & Ground & & & & & 24132.67 & .2 \\
\hline $\mathrm{C}^{12} \mathrm{O}^{16} \mathrm{Cl}^{35} \mathrm{Cl}^{37}$ & 4- 182 & $7,2,5 \leftarrow 6,3,4$ & Ground & & & & & 24132.7 & .3 \\
\hline $\mathrm{C}^{12} \mathrm{H}_{2}: \mathrm{C}^{12} \mathrm{HBr}^{79}$ & 4- 727 & $3,2,2 \leftarrow 2,2,1$ & Excited & & $5 / 2$ & & $5 / 2$ & 24136.9 & \\
\hline $\mathrm{C}^{12} \mathrm{H}_{2}: \mathrm{C}^{12} \mathrm{HBr}^{79}$ & 4- 727 & $3,2,2 \leftarrow 2,2,1$ & Excited & & $7 / 2$ & & $5 / 2$ & 24136.9 & \\
\hline $\mathrm{HC}^{13}: \mathrm{C}^{12} \mathrm{C}^{12} \mathrm{DO}^{16}$ & 4- 922 & Not Reported & & & & & & 24138. & 5. \\
\hline $\mathrm{O}^{16} \mathrm{C}^{12} \mathrm{Se}^{80}$ & 4- 547 & $3 \leftarrow 2$ & Excited & & & & & 24138.05 & .03 \\
\hline $\mathrm{C}^{12} \mathrm{H}_{3} \mathrm{C}^{12} \mathrm{O}^{16} \mathrm{~F}^{19}$ & 3- 391 & Not Reported & Ground & & & & & 24138.78 & .2 \\
\hline $\mathrm{C}^{12} \mathrm{H}_{2}\left(\mathrm{C}^{12} \mathrm{~N}^{14}\right)_{2}$ & 4- 901 & Not Reported & Ground & & & & & 24138.8 & .1 \\
\hline $\mathrm{C}^{12} \mathrm{DHCl}^{35} \mathrm{Cl}^{37}$ & 4- 345 & $1,1,0 \leftarrow 1,0,1$ & Ground & & & & & 24139. & 5. \\
\hline $\mathrm{O}^{16} \mathrm{O}^{18} \mathrm{O}^{18}$ & 4-1844 & $14,2,12 \leftarrow 15,1,15$ & Ground & & & & & 24139. & \\
\hline $\mathrm{C}^{12} \mathrm{H}_{2}: \mathrm{C}^{12} \mathrm{DBr}^{\mathrm{b}}$ & 4- 729 & $3, \quad \leftarrow 2$, & Ground & & & & & 24139.0 & \\
\hline $\mathrm{N}^{14} \mathrm{H}_{3}$ & 4-1771 & $4,4 \leftarrow 4,4$ & Ground & & & & & 24139.41 & .02 \\
\hline $\mathrm{c}-\mathrm{HCl}^{35} \mathrm{C}^{12}: \mathrm{C}^{12} \mathrm{HCl}^{35}$ & 4- 671 & $11,2,9 \leftarrow 11,1,10$ & Ground & & & & & 24139.42 & \\
\hline $\mathrm{C}^{12} \mathrm{H}_{3} \mathrm{~N}^{14} \mathrm{O}_{2}^{16}$ & 3- 171 & Not Reported & Ground & & & & & 24140. & 5. \\
\hline $\operatorname{In}^{115} I^{127}$ & $1-$ & $11 \leftarrow 10$ & Excited & & & & & 24140.91 & 0.20 \\
\hline$\left(\mathrm{C}^{12} \mathrm{H}_{3}\right)_{3} \mathrm{C}^{12} \mathrm{Cl}^{35}$ & 3- 971 & $4, \leftarrow 3$ & Ground & & & & & 24141.5 & .10 \\
\hline $\mathrm{C}^{12} \mathrm{H}_{2}: \mathrm{C}^{12} \mathrm{HBr}^{79}$ & 4- 727 & $3,2,1 \leftarrow 2,2,0$ & Excited & & $7 / 2$ & & $5 / 2$ & 24142.1 & \\
\hline $\mathrm{C}^{12} \mathrm{H}_{2}: \mathrm{C}^{12} \mathrm{HBr}^{79}$ & 4- 727 & $3,2,1 \leftarrow 2,2,0$ & Excited & & $5 / 2$ & & $5 / 2$ & 24142.1 & \\
\hline $\mathrm{C}^{13} \mathrm{H}_{3} \mathrm{C}^{12} \mathrm{H}_{3} \mathrm{Si}^{28} \mathrm{H}_{2}$ & 3- 646 & $6,1,5 \leftarrow 6,0,6$ & Ground & & & & & 24142.60 & .20 \\
\hline $\mathrm{C}^{13} \mathrm{H}_{3} \mathrm{~N}^{14} \mathrm{C}^{12} \mathrm{~S}^{32}$ & 3- 422 & $5, \quad \leftarrow 4, \quad$ & Ground & & & & & 24143. & \\
\hline $\operatorname{In}^{115} I^{127}$ & 1. & $11 \leftarrow 10$ & Excited & & & & & 24143.30 & 0.20 \\
\hline $\mathrm{C}^{12} \mathrm{H}_{2}: \mathrm{C}^{12} \mathrm{DBr}^{\mathrm{b}}$ & 4- 729 & $3, \quad \leftarrow 2, \quad$, & Ground & & & & & 24146.7 & \\
\hline $\mathrm{H}_{2} \mathrm{C}^{12}: \mathrm{C}^{12} \mathrm{~F}_{2}^{19}$ & 4- 681 & Not Reported & & & & & & $24 \quad 149.3$ & .3 \\
\hline $\mathrm{C}^{12} \mathrm{H}_{2}: \mathrm{C}^{12} \mathrm{DBr}^{79}$ & 4- 721 & $3,1,2 \leftarrow 2,1,1$ & Ground & & $7 / 2$ & & $7 / 2$ & 24149.4 & \\
\hline $\mathrm{C}^{13} \mathrm{H}_{3} \mathrm{C}^{12} \mathrm{O}^{16} \mathrm{C}^{12} \mathrm{~N}^{14}$ & 3- 672 & $3,1,3 \leftarrow 2,0,2$ & Ground & & & & & 24150.7 & .2 \\
\hline $\mathrm{C}^{\mathrm{b}} \mathrm{H}_{2}: \mathrm{C}^{\mathrm{b}} \mathrm{HBr}^{\mathrm{b}}$ & 4- 752 & Not Reported & Ground & & $7 / 2$ & & $7 / 2$ & 24150.9 & \\
\hline $\mathrm{D}_{2} \mathrm{O}_{2}^{16}$ & $3-\quad 42$ & Not Reported & & & & & & 24152 & 3. \\
\hline $\mathrm{C}^{12} \mathrm{DH}_{2} \mathrm{C}^{12} \mathrm{HDF}^{19}$ & 3. 562 & $2,2,0 \leftarrow 3,1,3$ & Ground & & & & & 24152.3 & .1 \\
\hline $\mathrm{O}^{16} \mathrm{C}^{12} \mathrm{Se}^{79}$ & 4- 546 & $3 \leftarrow 2$ & Ground & & $7 / 2$ & & $7 / 2$ & $24 \quad 153.204$ & \\
\hline $\mathrm{C}_{6}^{12} \mathrm{H}_{5} \mathrm{Cl}^{35}$ & 4-1271 & $8,2,6 \leftarrow 7,2,5$ & Ground & & $15 / 2$ & & $13 / 2$ & 24156.1 & .1 \\
\hline $\mathrm{C}_{6}^{12} \mathrm{H}_{5} \mathrm{Cl}^{35}$ & 4-1271 & $8,2,6 \leftarrow 7,2,5$ & Ground & & $17 / 2$ & & $15 / 2$ & 24156.1 & .1 \\
\hline $\mathrm{C}_{6}^{12} \mathrm{H}_{5} \mathrm{Cl}^{35}$ & 4-1271 & $8,2,6 \leftarrow 7,2,5$ & Ground & & $13 / 2$ & & $11 / 2$ & 24156.9 & .1 \\
\hline $\mathrm{C}_{6}^{12} \mathrm{H}_{5} \mathrm{Cl}^{35}$ & 4-1271 & $8,2,6 \leftarrow 7,2,5$ & Ground & & $19 / 2$ & & $17 / 2$ & 24156.9 & .1 \\
\hline $\mathrm{O}^{16} \mathrm{C}^{12} \mathrm{Se}^{80}$ & 4- 547 & $3 \leftarrow 2$ & Excited & & & & & 24156.93 & .03 \\
\hline $\mathrm{O}^{16} \mathrm{C}^{12} \mathrm{Se}^{79}$ & 4. 546 & $3 \leftarrow 2$ & Ground & & $1 / 2$ & & $3 / 2$ & 24158.9 & \\
\hline $\mathrm{O}^{16} \mathrm{C}^{12} \mathrm{Se}^{79}$ & 4- 546 & $3 \leftarrow 2$ & Ground & & $11 / 2$ & & $9 / 2$ & 24. 158.9 & \\
\hline $\mathrm{C}^{13}{ }_{*} \mathrm{H}: \mathrm{C}^{12} \mathrm{HO}^{16} \mathrm{C}^{12} \mathrm{H}: \mathrm{C}^{12}{ }_{*} \mathrm{H}$ & $4-1157$ & $8,7,2 \leftarrow 8,6,3$ & Ground & & & & & 24159.2 & .1 \\
\hline $\mathrm{C}^{12} \mathrm{O}^{16} \mathrm{Cl}_{2}^{35}$ & 4- 181 & $3,3,0 \leftarrow 3,2,1$ & Ground & $3 / 2$ & 2 & $3 / 2$ & 1 & 24.159 .62 & .1 \\
\hline $\mathrm{C}^{12} \mathrm{H}_{2}: \mathrm{C}^{12} \mathrm{HBr}^{79}$ & 4- 727 & $3,2,2 \leftarrow 2,2,1$ & Ground & & $5 / 2$ & & $5 / 2$ & 24160.0 & \\
\hline $\mathrm{C}^{12} \mathrm{H}_{2}: \mathrm{C}^{12} \mathrm{HBr}^{79}$ & 4- 727 & $3,2,2 \leftarrow 2,2, \mathbf{1}$ & Ground & & $7 / 2$ & & $5 / 2$ & 24160.0 & \\
\hline $\mathrm{C}^{12} \mathrm{H}_{2}: \mathrm{C}^{12} \mathrm{HBr}^{79}$ & 4- 727 & $3,2,2 \leftarrow 2,2,1$ & Ground & & $7 / 2$ & & $5 / 2$ & 24160.8 & .2 \\
\hline
\end{tabular}




\begin{tabular}{|c|c|c|c|c|c|c|c|c|c|}
\hline Isotopic Species & $\begin{array}{l}\text { Vol.-Id. } \\
\text { Nos. }\end{array}$ & $\begin{array}{c}\text { Rotational } \\
\text { Quantum Nos. }\end{array}$ & Vib. State & $\mathrm{F}_{1}^{\prime}$ & $\begin{array}{l}\text { Hyper } \\
\mathrm{F}^{\prime}\end{array}$ & $\begin{array}{l}\text { rfine } \\
F_{1}\end{array}$ & $\mathrm{~F}$ & $\begin{array}{c}\text { Frequency } \\
\mathrm{MHz}\end{array}$ & $\begin{aligned} & \text { Acc. } \\
\pm & \mathrm{Mll}\end{aligned}$ \\
\hline $\mathrm{C}^{13} \mathrm{H}_{3} \mathrm{C}^{12} \mathrm{O}^{16} \mathrm{C}^{12} \mathrm{~N}^{14}$ & 3- 672 & $8,3,5 \leftarrow 8,2,6$ & Ground & & & & & 24161.20 & .2 \\
\hline $\mathrm{C}^{12} \mathrm{O}^{16} \mathrm{Cl}_{2}^{35}$ & 4- 181 & $3,3,0 \leftarrow 3,2,1$ & Ground & $3 / 2$ & 3 & $3 / 2$ & 3 & 24.161 .42 & .1 \\
\hline $\mathrm{C}^{12} \mathrm{H}_{2}: \mathrm{C}^{12} \mathrm{HBr}^{79}$ & 4. 727 & $3,2,1 \leftarrow 2,2,0$ & Ground & & $5 / 2$ & & $5 / 2$ & 24165.2 & \\
\hline $\mathrm{C}^{12} \mathrm{H}_{2}: \mathrm{C}^{12} \mathrm{HBr}^{79}$ & 4- 727 & $3,2,1 \leftarrow 2,2,0$ & Ground & & $7 / 2$ & & $5 / 2$ & 24165.2 & \\
\hline $\mathrm{C}^{\mathrm{b}} \mathrm{H}_{2}: \mathrm{C}^{\mathrm{b}} \mathrm{HBr}^{\mathrm{b}}$ & 4- 752 & $3,2,1 \leftarrow 2,2,0$ & Ground & & $7 / 2$ & & $5 / 2$ & 24165.6 & \\
\hline $\mathrm{C}^{12} \mathrm{O}^{16} \mathrm{Cl}_{2}^{35}$ & 4. 181 & $3,3,0 \leftarrow 3,2,1$ & Ground & $9 / 2$ & 6 & $9 / 2$ & 6 & $24 \cdot 165.82$ & .1 \\
\hline $\mathrm{C}^{12} \mathrm{O}^{16} \mathrm{Cl}_{2}^{35}$ & 4. 181 & $3,3,0 \leftarrow^{\cdot} 3,2,1$ & Ground & $5 / 2$ & 3 & $3 / 2$ & 2 & 24165.82 & .1 \\
\hline $\mathrm{HC}^{13}: \mathrm{C}^{12} \mathrm{C}^{12} \mathrm{DO}^{16}$ & 4. 922 & Not Reported & & & & & & 24166. & 5. \\
\hline $\mathrm{C}^{12} \mathrm{O}^{16} \mathrm{Cl}_{2}^{35}$ & 4. 181 & $3,3,0 \leftarrow 3,2,1$ & Ground & $3 / 2$ & 1 & $3 / 2$ & 2 & 24166.92 & .1 \\
\hline g- $\mathrm{C}^{12} \mathrm{H}_{3} \mathrm{C}^{12} \mathrm{H}_{2} \mathrm{C}^{12} \mathrm{H}_{2} \mathrm{Cl}^{37}$ & 3- 774 & $4,2,3 \leftarrow 3,2,2$ & Ground & & & & & 24168.19 & .2 \\
\hline$\left(\mathrm{C}^{12} \mathrm{D}_{3}\right)_{2} \mathrm{O}^{16}$ & 3- 592 & Not Reported & Ground & & & & & 24170 & 20. \\
\hline $\mathrm{O}^{16} \mathrm{C}^{12} \mathrm{Se}^{79}$ & 4- 546 & $3 \leftarrow 2$ & Ground & & $13 / 2$ & & $11 / 2$ & 24.170 .194 & \\
\hline $\mathrm{C}^{12} \mathrm{H}_{3} \mathrm{C}^{12} \mathrm{O}^{16} \mathrm{Br}^{81}$ & 3- 352 & $8,1,7 \leftarrow 8,0,8$ & Ground & & $13 / 2$ & & $13 / 2$ & 24170.70 & .15 \\
\hline $\mathrm{C}^{12} \mathrm{DHCl}_{2}^{35}$ & 4. 344 & $1,1,0 \leftarrow 1,0,1$ & Ground & & & & & 24171 & 2. \\
\hline $\mathrm{N}^{14} \mathrm{O}^{16} \mathrm{O}^{18}$ & 4-1803 & $7,1,7 \leftarrow 8,0,8$ & Ground & & & & & 24171.7 & \\
\hline $\mathrm{C}^{12} \mathrm{O}^{16} \mathrm{Cl}_{2}^{35}$ & 4. 181 & $3,3,0 \leftarrow 3,2,1$ & Ground & $9 / 2$ & 4 & $9 / 2$ & 4 & 24. 171.70 & .1 \\
\hline $\mathrm{O}^{16} \mathrm{C}^{14} \mathrm{~S}^{32}$ & 4- 528 & $2 \leftarrow 1$ & Ground & & & & & 24.173 .0 & 1.0 \\
\hline $\mathrm{C}^{12} \mathrm{H}_{3} \mathrm{C}^{12} \mathrm{O}^{16} \mathrm{Br}^{81}$ & 3- 352 & $8,1,7 \leftarrow 8,0,8$ & Ground & & $19 / 2$ & & $19 / 2$ & 24173.27 & .15 \\
\hline $\mathrm{O}^{16} \mathrm{C}^{12} \mathrm{Se}^{78}$ & 4. 545 & $3 \leftarrow 2$ & Excited & & & & & 24.174 .30 & .03 \\
\hline $\mathrm{C}^{12} \mathrm{H}_{3} \mathrm{C}^{12} \mathrm{O}^{16} \mathrm{Br}^{81}$ & 3- 352 & $8,1,7 \leftarrow 8,0,8$ & Ground & & $13 / 2$ & & $13 / 2$ & 24.174 .40 & .15 \\
\hline $\mathrm{C}^{13}{ }_{*} \mathrm{H}: \mathrm{C}^{12} \mathrm{HO}^{16} \mathrm{C}^{12} \mathrm{H}: \mathrm{C}^{12}{ }_{*} \mathrm{H}$ & 4-1157 & $10,10,1 \leftarrow 10,9,2$ & Ground & & & & & 24174.7 & .1 \\
\hline $\mathrm{C}^{12}{ }_{*} \mathrm{H}_{2}^{\mathrm{b}} \mathrm{S}^{\mathrm{b}} \mathrm{C}^{12}{ }_{*} \mathrm{H}_{2}^{\mathrm{b}}$ & 4- 854 & Not Reported & & & & & & 24175.0 & 10. \\
\hline $\mathrm{O}^{16} \mathrm{C}^{13} \mathrm{~S}^{32}$ & 4- 526 & $2 \leftarrow 1$ & Excited & & & & & 24.176 .07 & 1 \\
\hline $\mathrm{C}^{12} \mathrm{H}_{3} \mathrm{C}^{12} \mathrm{O}^{16} \mathrm{Br}^{81}$ & 3- 352 & $8,1,7 \leftarrow 8,0,8$ & Ground & & $19 / 2$ & & $19 / 2$ & 24176.97 & .15 \\
\hline $\mathrm{C}^{12} \mathrm{O}^{16} \mathrm{Cl}_{2}^{35}$ & 4- 181 & $3,3,0 \leftarrow 3,2,1$ & Ground & $5 / 2$ & 3 & $5 / 2$ & 3 & 24.178 .75 & .1 \\
\hline $\mathrm{C}^{12} \mathrm{O}^{16} \mathrm{Cl}_{2}^{35}$ & 4- 181 & $3,3,0 \leftarrow 3,2,1$ & Ground & $7 / 2$ & 4 & $5 / 2$ & 3 & 24.178 .75 & .1 \\
\hline $\mathrm{C}^{12} \mathrm{H}_{2} \mathrm{Cl}^{35} \mathrm{Si}^{29} \mathrm{H}_{3}$ & 3- 234 & $4,0,4 \leftarrow 3,0,3$ & Ground & & & & & 24179.0 & .1 \\
\hline $\mathrm{C}^{12} \mathrm{H}_{2} \mathrm{Cl}^{35} \mathrm{Si}^{29} \mathrm{H}_{3}$ & 3- 234 & $4,0,4 \leftarrow 3,0,3$ & Ground & & & & & 24179.60 & .2 \\
\hline $\mathrm{C}^{13} \mathrm{H}_{3} \mathrm{C}^{12} \mathrm{O}^{16} \mathrm{Cl}^{35}$ & 3- 367 & $5,3,2 \leftarrow 5,2,3$ & Ground & & $7 / 2$ & & $7 / 2$ & 24179.60 & .2 \\
\hline $\mathrm{O}^{16} \mathrm{C}^{12} \mathrm{~S}^{32}$ & 4. 521 & $2 \leftarrow 1$ & Excited & & & & & 24179.62 & \\
\hline $\mathrm{C}^{12} \mathrm{O}^{16} \mathrm{Cl}_{2}^{35}$ & 4. 181 & $3,3,0 \leftarrow 3,2,1$ & Ground & $3 / 2$ & 2 & $5 / 2$ & 3 & 24179.92 & .1 \\
\hline$\left(\mathrm{C}^{12} \mathrm{D}_{3}\right)_{2} \mathrm{O}^{16}$ & 3- 592 & Not Reported & Ground & & & & & 24180 & 20. \\
\hline $\mathrm{O}^{16} \mathrm{C}^{12} \mathrm{~S}^{32}$ & 4- 521 & $2 \leftarrow 1$ & Excited & & & & & 24180.47 & .2 \\
\hline $\mathrm{C}^{12} \mathrm{O}^{16} \mathrm{Cl}_{2}^{35}$ & 4. 181 & $3,3,0 \leftarrow 3,2,1$ & Ground & $7 / 2$ & 5 & $7 / 2$ & 5 & 24180.63 & .1 \\
\hline $\mathrm{C}^{12} \mathrm{O}^{16} \mathrm{Cl}_{2}^{35}$ & 4- 181 & $3,3,0 \leftarrow 3,2,1$ & Ground & $7 / 2$ & 2 & $7 / 2$ & 2 & 24181.28 & .1 \\
\hline $\mathrm{C}^{12} \mathrm{H}_{2}: \mathrm{C}^{12} \mathrm{HBr}^{79}$ & 4. 727 & $3,0,3 \leftarrow 2,0,2$ & Ground & & $7 / 2$ & & $7 / 2$ & 24181.45 & \\
\hline $\mathrm{C}^{\mathrm{b}} \mathrm{H}_{2}: \mathrm{C}^{\mathrm{b}} \mathrm{HBr}^{\mathrm{b}}$ & 4. 752 & $3,0,3 \leftarrow 2,0,2$ & Ground & & $7 / 2$ & & $7 / 2$ & 24181.5 & .2 \\
\hline $\mathrm{Mn}^{55} \mathrm{O}_{2}^{16} \mathrm{O}^{18} \mathrm{~F}^{19}$ & $4-1562$ & $3,0,3 \leftarrow 2,0,2$ & Ground & & $1 / 2$ & & $1 / 2$ & 24181.70 & .150 \\
\hline $\mathrm{Mn}^{55} \mathrm{O}_{2}^{16} \mathrm{O}^{18} \mathrm{~F}^{19}$ & $4-1562$ & $3,0,3 \leftarrow 2,0,2$ & Ground & & $3 / 2$ & & $1 / 2$ & 24181.70 & .150 \\
\hline $\mathrm{C}^{13} \mathrm{H}_{3} \mathrm{C}^{12} \mathrm{O}^{16} \mathrm{Cl}^{35}$ & 3- 367 & $5,3,2 \leftarrow 5,2,3$ & Ground & & $13 / 2$ & & $13 / 2$ & 24181.90 & .2 \\
\hline $\mathrm{C}^{12}{ }_{*} \mathrm{H}_{2}^{\mathrm{b}} \mathrm{S}^{\mathrm{b}} \mathrm{C}^{12}{ }_{*} \mathrm{H}_{2}^{\mathrm{b}}$ & 4. 854 & Not Reported & & & & & & 24183.0 & .2 \\
\hline $\mathrm{Mn}^{55} \mathrm{O}_{2}^{16} \mathrm{O}^{18} \mathrm{~F}^{19}$ & $4-1562$ & $3,2,2 \leftarrow 2,2,1$ & Ground & & $11 / 2$ & & $9 / 2$ & 24.183 .70 & .05 \\
\hline $\mathrm{Mn}^{55} \mathrm{O}_{2}^{16} \mathrm{O}^{18} \mathrm{~F}^{19}$ & 4-1562 & $3,2,2 \leftarrow 2,2,1$ & Ground & & $7 / 2$ & & $9 / 2$ & 24.183 .70 & .05 \\
\hline $\mathrm{Mn}^{55} \mathrm{O}_{2}^{16} \mathrm{O}^{18} \mathrm{~F}^{19}$ & 4-1562 & $3,2,2 \leftarrow 2,2,1$ & Ground & & $3 / 2$ & & $3 / 2$ & 24183.70 & .05 \\
\hline $\mathrm{Mn}^{55} \mathrm{O}_{2}^{16} \mathrm{O}^{18} \mathrm{~F}^{19}$ & $4-1562$ & $3,2,2 \leftarrow 2,2,1$ & Ground & & $9 / 2$ & & $9 / 2$ & 24.183 .70 & .05 \\
\hline
\end{tabular}




\begin{tabular}{|c|c|c|c|c|c|c|c|c|c|}
\hline \multirow{2}{*}{ Isotopic Species } & \multirow{2}{*}{$\begin{array}{l}\text { Vol.-Id. } \\
\text { Nos. }\end{array}$} & \multirow{2}{*}{$\begin{array}{c}\text { Rotational } \\
\text { Quantum Nos. }\end{array}$} & \multirow{2}{*}{ Vib. State } & \multicolumn{4}{|c|}{ Hyperfine } & \multirow{2}{*}{$\begin{array}{c}\text { Frequency } \\
\mathrm{MHz}\end{array}$} & \multirow{2}{*}{$\begin{array}{r}\text { Acc. } \\
\pm \mathrm{MHz}\end{array}$} \\
\hline & & & & $\mathrm{F}_{1}$ & $\mathrm{~F}^{\prime}$ & $\mathrm{F}_{1}$ & $\mathbf{F}$ & & \\
\hline $\mathrm{Mn}^{55} \mathrm{O}_{2}^{16} \mathrm{O}^{18} \mathrm{~F}^{19}$ & 4-1562 & $3,2,2 \leftarrow 2,2,1$ & Ground & & $5 / 2$ & & $3 / 2$ & 24.183 .70 & .05 \\
\hline $\mathrm{Mn}^{55} \mathrm{O}_{2}^{16} \mathrm{O}^{18} \mathrm{~F}^{19}$ & 4-1562 & $3,2,2 \leftarrow 2,2,1$ & Ground & & $1 / 2$ & & $3 / 2$ & 24183.70 & .05 \\
\hline $\mathrm{O}^{16} \mathrm{C}^{12} \mathrm{Se}^{80}$ & 4- 547 & $3 \leftarrow 2$ & Excited & & & & & 24183.97 & \\
\hline $\mathrm{C}^{12} \mathrm{H}_{3} \mathrm{C}^{12} \mathrm{O}^{16} \mathrm{Br}^{81}$ & 3- 352 & $8,1,7 \leftarrow 8,0,8$ & Ground & & $15 / 2$ & & $15 / 2$ & 24.184 .13 & .15 \\
\hline $\mathrm{C}^{12}{ }_{*} \mathrm{D}: \mathrm{C}^{12} \mathrm{HC}^{12} \mathrm{H}: \mathrm{C}^{12} \mathrm{HN}^{14}{ }_{*} \mathrm{H}$ & 4-1183 & $11,8,3 \leftarrow 11,7,4$ & Ground & & & & & 24184.2 & \\
\hline$\left(\mathrm{C}^{12} \mathrm{D}_{3}\right)_{2} \mathrm{O}^{16}$ & 3- 592 & Not Reported & Ground & & & & & 24185. & 20. \\
\hline $\mathrm{C}^{12} \mathrm{H}_{3} \mathrm{C}^{12} \mathrm{O}^{16} \mathrm{Br}^{81}$ & 3- 352 & $8,1,7 \leftarrow 8,0,8$ & Ground & & $17 / 2$ & & $17 / 2$ & 24186.53 & .15 \\
\hline $\mathrm{C}^{12} \mathrm{O}^{16} \mathrm{Cl}_{2}^{35}$ & 4. 181 & $3,3,0 \leftarrow 3,2,1$ & Ground & $7 / 2$ & 4 & $7 / 2$ & 4 & 24186.65 & .1 \\
\hline $\mathrm{Mn}^{55} \mathrm{O}_{2}^{16} \mathrm{O}^{18} \mathrm{~F}^{19}$ & 4-1562 & $3,2,2 \leftarrow 2,2,1$ & Ground & & $7 / 2$ & & $7 / 2$ & 24. 186.85 & .1 \\
\hline $\mathrm{Mn}^{55} \mathrm{O}_{2}^{16} \mathrm{O}^{18} \mathrm{~F}^{19}$ & $4-1562$ & $3,2,2 \leftarrow 2,2,1$ & Ground & & $9 / 2$ & & $7 / 2$ & 24186.85 & .1 \\
\hline $\mathrm{Mn}^{55} \mathrm{O}_{2}^{16} \mathrm{O}^{18} \mathrm{~F}^{19}$ & $4-1562$ & $3,2,2 \leftarrow 2,2,1$ & Ground & & $5 / 2$ & & $7 / 2$ & 24186.85 & .1 \\
\hline $\mathrm{C}^{12} \mathrm{H}_{3} \mathrm{C}^{12} \mathrm{~F}^{19}: \mathrm{C}^{12} \mathrm{H}_{2}$ & 3- 721 & $12,9,3 \leftarrow 12,8,4$ & Ground & & & & & 24187.55 & .1 \\
\hline $\mathrm{C}^{12} \mathrm{H}_{3} \mathrm{C}^{12} \mathrm{O}^{16} \mathrm{Br}^{81}$ & 3- 352 & $8,1,7 \leftarrow 8,0,8$ & Ground & & $15 / 2$ & & $15 / 2$ & 24187.65 & .15 \\
\hline $\mathrm{C}^{12} \mathrm{H}_{3} \mathrm{C}^{12} \mathrm{~F}^{19}: \mathrm{C}^{12} \mathrm{H}_{2}$ & $3 \cdot 721$ & $12,9,3 \leftarrow 12,8,4$ & Ground & & & & & 24188.04 & .1 \\
\hline $\mathrm{C}^{13} \mathrm{H}_{3} \mathrm{C}^{12} \mathrm{O}^{16} \mathrm{Cl}^{35}$ & 3- 367 & $5,3,2 \leftarrow 5,2,3$ & Ground & & $9 / 2$ & & $9 / 2$ & 24188.08 & .2 \\
\hline $\mathrm{O}^{16} \mathrm{C}^{12} \mathrm{Se}^{80}$ & 4- 547 & $3 \leftarrow 2$ & Excited & & & & & 24188.18 & \\
\hline $\mathrm{C}_{6}^{12} \mathrm{H}_{5} \mathrm{~F}^{19}$ & 4-1281 & $45,14,31 \leftarrow 45,14,32$ & Ground & & & & & 24.189 .7 & \\
\hline $\mathrm{C}^{12}{ }_{*} \mathrm{H}_{2}^{\mathrm{b}} \mathrm{S}^{\mathrm{b}} \mathrm{C}^{12}{ }_{*} \mathrm{H}_{2}^{\mathrm{b}}$ & 4- 854 & Not Reported & & & & & & 24190.0 & 10. \\
\hline $\mathrm{C}^{13} \mathrm{H}_{3} \mathrm{C}^{12} \mathrm{O}^{16} \mathrm{Cl}^{35}$ & 3- 367 & $5,3,2 \leftarrow 5,2,3$ & Ground & & $11 / 2$ & & $11 / 2$ & 24190.08 & .2 \\
\hline $\mathrm{C}^{12} \mathrm{H}_{3} \mathrm{C}^{12} \mathrm{O}^{16} \mathrm{Br}^{81}$ & 3- 352 & $8,1,7 \leftarrow 8,0,8$ & Ground & & $17 / 2$ & & $17 / 2$ & 24190.15 & .15 \\
\hline $\mathrm{O}^{16} \mathrm{C}^{12} \mathrm{Se}^{79}$ & 4- 546 & $3 \leftarrow 2$ & Ground & & $9 / 2$ & & $7 / 2$ & 24. 190.787 & \\
\hline $\mathrm{C}^{12} \mathrm{H}_{2}\left(\mathrm{C}^{12} \mathrm{~N}^{14}\right)_{2}$ & 4- 901 & Not Reported & Ground & & & & & 24191.0 & .1 \\
\hline $\mathrm{C}^{12}{ }_{*} \mathrm{H}_{2}^{\mathrm{b}} \mathrm{S}^{\mathrm{b}} \mathrm{C}^{12}{ }_{*} \mathrm{H}_{2}^{\mathrm{b}}$ & 4- 854 & Not Reported & & & & & & 24192.0 & 10. \\
\hline $\mathrm{s}-\mathrm{C}^{12} \mathrm{H}_{2} \mathrm{DCC}^{12} \mathrm{O}^{16} \mathrm{~F}^{19}$ & 3- 397 & $2,1,2 \leftarrow 1,1,1$ & Ground & & & & & 24196.65 & .2 \\
\hline $\mathrm{C}^{12}{ }_{*} \mathrm{H}: \mathrm{C}^{12} \mathrm{HO}^{18} \mathrm{C}^{12} \mathrm{H}: \mathrm{C}^{12}{ }_{*} \mathrm{H}$ & 4-1152 & $6,5,2 \leftarrow 6,3,3$ & Ground & & & & & 24196.7 & .1 \\
\hline $\mathrm{g} \cdot \mathrm{C}^{12} \mathrm{H}_{3} \mathrm{C}^{12} \mathrm{H}_{2} \mathrm{C}^{12} \mathrm{H}_{2} \mathrm{Cl}^{35}$ & 3. 773 & $4,2,2 \leftarrow 4,1,3$ & Ground & & & & & 24.196 .71 & .2 \\
\hline $\mathrm{O}^{16} \mathrm{C}^{14} \mathrm{~S}^{32}$ & 4. 528 & $2 \leftarrow 1$ & Excited & & & & & 24. 197.0 & 1.0 \\
\hline $\mathrm{C}^{12} \mathrm{H}_{2}\left(\mathrm{C}^{12} \mathrm{~N}^{14}\right)_{2}$ & 4- 901 & Not Reported & Ground & & & & & 24200.0 & .1 \\
\hline $\mathrm{C}^{12} \mathrm{H}_{2}: \mathrm{C}^{13} \mathrm{HBr}^{79}$ & 4- 737 & $3,1,2 \leftarrow 2,1,1$ & Excited & & $9 / 2$ & & $7 / 2$ & 24201.6 & \\
\hline $\mathrm{C}^{12} \mathrm{H}_{3} \mathrm{C}^{12} \mathrm{D}_{2} \mathrm{Br}^{81}$ & 3- 526 & $7,1,6 \leftarrow 7,0,7$ & Ground & & $15 / 2$ & & $15 / 2$ & 24201.97 & .05 \\
\hline $\mathrm{S}^{32} \mathrm{C}^{12} \mathrm{Se}^{80}$ & 4- 562 & $6 \leftarrow 5$ & Ground & & & & & 24203. & 4. \\
\hline $\mathrm{C}^{12} \mathrm{D}_{3} \Gamma^{127}$ & 4. 482 & $2,0 \leftarrow 1,0$ & Ground & & $9 / 2$ & & $7 / 2$ & 24203.19 & .08 \\
\hline $\mathrm{D}_{2} \mathrm{O}_{2}^{16}$ & 3- 42 & Not Reported & & & & & & 24204 & 3. \\
\hline $\mathrm{Si}^{30} \mathrm{D}_{3} \mathrm{~F}^{19}$ & 4-1556 & $1, \leftarrow 0$, & Ground & & & & & 24204.5 & .2 \\
\hline $\mathrm{O}^{16} \mathrm{C}^{12} \mathrm{Se}^{79}$ & 4- 546 & $3 \leftarrow 2$ & Ground & & $3 / 2$ & & $3 / 2$ & 24204.692 & \\
\hline $\mathrm{N}^{14} \mathrm{H}_{3}$ & $4-1771$ & $10,9 \leftarrow 10,9$ & Ground & & & & & 24.205 .29 & .02 \\
\hline $\mathrm{C}^{12} \mathrm{H}_{3} \mathrm{C}^{12} \mathrm{O}^{16} \mathrm{C}^{12} \mathrm{~N}^{14}$ & 3- 671 & $6,1,5 \leftarrow 6,0,6$ & Ground & & & & & 24205.33 & .2 \\
\hline $\mathrm{S}^{32} \mathrm{O}^{16} \mathrm{~F}_{2}^{19}$ & 4-1621 & $9,6,3 \leftarrow 9,6,4$ & Ground & & & & & 24205.50 & .1 \\
\hline $\mathrm{C}^{12} \mathrm{H}_{3} \mathrm{C}^{12} \mathrm{D}_{2} \mathrm{Br}^{81}$ & 3- 526 & $7,1,6 \leftarrow 7,0,7$ & Ground & & $13 / 2$ & & $13 / 2$ & 24205.84 & .05 \\
\hline $\mathrm{C}_{6}^{12} \mathrm{H}_{5} \mathrm{O}^{16} \mathrm{H}$ & $3-1051$ & $7,4,4 \leftarrow 7,3,5$ & Ground & & & & & 24206.8 & \\
\hline $\operatorname{In}^{115} \mathrm{I}^{127}$ & $1-$ & $11 \leftarrow 10$ & Excited & & & & & 24206.89 & 0.20 \\
\hline $\mathrm{C}^{12} \mathrm{H}_{2}\left(\mathrm{C}^{12} \mathrm{~N}^{14}\right)_{2}$ & 4- 901 & Not Reported & Ground & & & & & 24207.6 & .1 \\
\hline $\mathrm{C}^{12} \mathrm{H}_{3} \mathrm{C}^{12} \mathrm{O}^{16} \mathrm{O}^{16} \mathrm{H}$ & 3- 491 & Not Reported & & & & . & & 24208 & 3. \\
\hline
\end{tabular}




\begin{tabular}{|c|c|c|c|c|c|c|c|c|}
\hline Isotopic Species & $\begin{array}{l}\text { Vol.-ld. } \\
\text { Nos. }\end{array}$ & $\begin{array}{c}\text { Rotational } \\
\text { Quantum Nos. }\end{array}$ & Vib. State & $\mathrm{F}_{1}^{\prime}$ & $\begin{array}{c}\text { Hyperfin } \\
\mathbf{F}^{\prime} \quad \mathbf{F}_{1}\end{array}$ & $\mathrm{~F}$ & $\begin{array}{c}\text { Frequency } \\
\mathrm{MH}_{z}\end{array}$ & $\begin{aligned} & \text { Acc. } \\
& \pm \mathrm{MH}\end{aligned}$ \\
\hline $\operatorname{In}^{115} I^{127}$ & $1-$ & $11 \leftarrow 10$ & Excited & & & & 24209.36 & 0.20 \\
\hline $\operatorname{In}^{115} I^{127}$ & $1-$ & $11 \leftarrow 10$ & Excited & & & & 24.210 .68 & 0.20 \\
\hline $\mathrm{C}^{b} \mathrm{H}_{2}: \mathrm{C}^{b} \mathrm{HBr}^{b}$ & 4- 752 & Not Reported & Ground & & $5 / 2$ & $5 / 2$ & 24211.3 & \\
\hline $\mathrm{C}^{12} \mathrm{H}_{3} \mathrm{C}^{12} \mathrm{O}^{16} \mathrm{C}^{12} \mathrm{~N}^{14}$ & 3. 671 & $6,1,5 \leftarrow 6,0,6$ & Ground & & & & 24211.49 & .2 \\
\hline $\operatorname{In}^{115} I^{127}$ & 1 - & $11 \leftarrow 10$ & Excited & & & & 24211.78 & 0.20 \\
\hline $\mathrm{C}^{12}{ }_{*} \mathrm{D}: \mathrm{C}^{12} \mathrm{DC}^{12} \mathrm{D}: \mathrm{C}^{12} \mathrm{DN}^{14}{ }_{*} \mathrm{H}$ & $4-1185$ & $10,7,3 \leftarrow 10,6,4$ & Ground & & & & 24213.0 & \\
\hline $\mathrm{C}^{12} \mathrm{H}_{2}\left(\mathrm{C}^{12} \mathrm{~N}^{14}\right)\left(\mathrm{C}^{12} \mathrm{~N}^{15}\right)$ & 4. 904 & $8,1,7 \leftarrow 8,0,8$ & Ground & & & & 24213.27 & \\
\hline $\operatorname{In}^{115} I^{127}$ & $1-$ & $11 \leftarrow 10$ & Excited & & & & 24213.78 & 0.20 \\
\hline $\mathrm{S}^{32} \mathrm{C}^{12} \mathrm{Se}^{80}$ & 4- 562 & $6 \leftarrow 5$ & Excited & & & & 24214 & 4. \\
\hline$\left(\mathrm{C}^{12} \mathrm{D}_{3}\right)_{2} \mathrm{O}^{16}$ & 3. 592 & $5,1,4 \leftarrow 5,0,5$ & Ground & & & & 24219.8 & .5 \\
\hline $\mathrm{C}^{12} \mathrm{H}_{3} \mathrm{C}^{12} \mathrm{D}_{2} \mathrm{Br}^{81}$ & 3- 526 & $7,1,6 \leftarrow 7,0,7$ & Ground & & $17 / 2$ & $17 / 2$ & 24220.70 & .05 \\
\hline $\mathrm{C}^{12}{ }_{*} \mathrm{HO}^{16} \mathrm{C}^{12} \mathrm{HC}^{12} \mathrm{H}_{2} \mathrm{C}^{12} \mathrm{H}_{2} \mathrm{C}^{12}{ }_{*} \mathrm{H}_{2}$ & 4-1251 & $10,8,2 \leftarrow 10,7,4$ & Ground & & & & 24221 & 5. \\
\hline $\mathrm{C}^{\mathrm{b}} \mathrm{H}_{2}: \mathrm{C}^{\mathrm{b}} \mathrm{HBr}^{\mathrm{b}}$ & 4- 752 & Not Reported & Ground & & $9 / 2$ & $7 / 2$ & 24221.0 & \\
\hline $\mathrm{Si}^{28} \mathrm{H}_{3} \mathrm{~N}^{14} \mathrm{C}^{12} \mathrm{~S}^{32}$ & 4- 491 & $8,7 \leftarrow 7,7$ & Ground & & & & 24223.56 & .1 \\
\hline $\mathrm{O}^{16} \mathrm{C}^{14} \mathrm{~S}^{32}$ & 4- 528 & $2 \leftarrow 1$ & Excited & & & & 24224.0 & 1.0 \\
\hline $\mathrm{F}_{2}^{19} \mathrm{O}_{2}^{16}$ & 3- 11 & $6,1,5 \leftarrow 6,0,6$ & Ground & & & & 24224.09 & .1 \\
\hline $\mathrm{C}^{12} \mathrm{H}_{3} \mathrm{C}^{12} \mathrm{D}_{2} \mathrm{Br}^{81}$ & 3- 526 & $7,1,6 \leftarrow 7,0,7$ & Ground & & $11 / 2$ & $11 / 2$ & 24.224 .11 & .05 \\
\hline $\mathrm{HC}^{13}: \mathrm{C}^{12} \mathrm{C}^{12} \mathrm{DO}^{16}$ & 4- 922 & Not Reported & & & & & 24226 . & 5. \\
\hline $\mathrm{DN}^{14} \mathrm{O}_{3}^{16}$ & 3. $\quad 32$ & $5,3,2 \leftarrow 5,3,3$ & Ground & & & & 24229.63 & \\
\hline $\mathrm{S}^{32} \mathrm{C}^{12} \mathrm{Se}^{80}$ & 4- 562 & $6 \leftarrow 5$ & Excited & & & & 24230 . & 4. \\
\hline $\mathrm{C}^{12}{ }_{*} \mathrm{H}_{2}^{\mathrm{b}} \mathrm{S}^{\mathrm{b}} \mathrm{C}^{12}{ }_{*} \mathrm{H}_{2}^{\mathrm{b}}$ & 4- 854 & Not Reported & & & & & 24230.0 & 10. \\
\hline $\mathrm{C}^{12} \mathrm{D}_{3} \mathrm{~N}^{14} \mathrm{D}_{2}$ & 3. 262 & $4,1,3 \leftarrow 3,2,1$ & Ground & & & & 24230.29 & \\
\hline $\mathrm{C}^{b} \mathrm{H}_{2}: \mathrm{C}^{b} \mathrm{HBr}^{b}$ & 4- 752 & $3,1,2 \leftarrow 2,1,1$ & Excited & & $7 / 2$ & $5 / 2$ & 24230.8 & \\
\hline $\mathrm{HC}^{13}: \mathrm{C}^{12} \mathrm{C}^{12} \mathrm{DO}^{16}$ & 4- 922 & Not Reported & & & & & 24232 & 5. \\
\hline $\mathrm{Si}^{28} \mathrm{H}_{3} \mathrm{~N}^{14} \mathrm{C}^{12} \mathrm{~S}^{32}$ & 4- 491 & $8,6 \leftarrow 7,6$ & Ground & & & & 24232.05 & .1 \\
\hline $\mathrm{C}^{12} \mathrm{D}_{3} \mathrm{I}^{127}$ & 4- 482 & $2,1 \leftarrow 1,1$ & Ground & & $5 / 2$ & $3 / 2$ & 24232.16 & .08 \\
\hline $\mathrm{C}^{12} \mathrm{H}_{2}: \mathrm{C}^{13} \mathrm{HBr}^{79}$ & 4. 737 & $3,1,2 \leftarrow 2,1,1$ & Ground & & & & 24233.53 & .06 \\
\hline $\mathrm{Cl}_{2}^{\mathrm{b}} \mathrm{O}^{16}$ & 4-1484 & $1,1,1 \leftarrow 2,0,2$ & Ground & & & & 24233.95 & \\
\hline $\mathrm{O}^{16} \mathrm{C}^{12} \mathrm{Se}^{79}$ & 4. 546 & $3 \leftarrow 2$ & Ground & & $7 / 2$ & $5 / 2$ & 24.234 .329 & \\
\hline $\mathrm{C}^{12} \mathrm{D}_{3} \mathrm{C}^{12} \mathrm{O}^{16} \mathrm{Cl}^{35}$ & 3- 363 & $10,4,6 \leftarrow 10,3,7$ & Ground & & $17 / 2$ & $17 / 2$ & 24235.00 & \\
\hline $\mathrm{C}^{12} \mathrm{D}_{3} \mathrm{C}^{12} \mathrm{O}^{16} \mathrm{Cl}^{35}$ & 3- 363 & $10,4,6 \leftarrow 10,3,7$ & Ground & & $23 / 2$ & $23 / 2$ & 24235.00 & \\
\hline $\mathrm{C}^{12} \mathrm{D}_{3} \mathrm{I}^{127}$ & 4- 482 & $2,0 \leftarrow 1,0$ & Ground & & $7 / 2$ & $5 / 2$ & 24235.67 & .08 \\
\hline $\mathrm{C}^{12} \mathrm{H}_{3} \mathrm{Si}^{28} \mathrm{HF}_{2}^{19}-\mathrm{A}$ & 3. 191 & Not Reported & Ground & & & & 24236.3 & \\
\hline $\mathrm{C}^{12} \mathrm{D}_{3} \mathrm{C}^{12} \mathrm{O}^{16} \mathrm{Cl}^{35}$ & 3. 363 & $10,4,6 \leftarrow 10,3,7-$ & Ground & & $21 / 2$ & $21 / 2$ & 24236.35 & \\
\hline $\mathrm{C}^{12} \mathrm{D}_{3} \mathrm{C}^{12} \mathrm{O}^{16} \mathrm{Cl}^{35}$ & 3- 363 & $10,4,6 \leftarrow 10,3,7$ & Ground & & $19 / 2$ & $19 / 2$ & 24236.35 & \\
\hline $\mathrm{C}^{12} \mathrm{D}_{3} \mathrm{~N}^{14} \mathrm{D}_{2}$ & 3- 262 & $4,1,3 \leftarrow 3,2,1$ & Ground & & & & 24236.48 & \\
\hline $\mathrm{C}^{12}{ }_{*} \mathrm{H}_{2} \mathrm{~N}^{14} \mathrm{DC}^{12}{ }_{*} \mathrm{H}_{2}$ & 4- 862 & $5,5,1 \leftarrow 5,3,2$ & Ground & & & & 24237.5 & .5 \\
\hline $\mathrm{C}^{12} \mathrm{H}_{3} \mathrm{Si}^{28} \mathrm{HF}_{2}^{19}-\mathrm{A}$ & 3- 191 & Not Reported & Ground & & & & 24238.2 & \\
\hline $\mathrm{C}^{12}{ }_{*} \mathrm{H}_{2} \mathrm{~N}^{14} \mathrm{DC}^{12}{ }_{*} \mathrm{H}_{2}$ & 4- 862 & $5,5,1 \leftarrow 5,3,2$ & Ground & & & & $24 \dot{2} 39.1$ & .5 \\
\hline $\mathrm{Si}^{28} \mathrm{H}_{3} \mathrm{~N}^{14} \mathrm{C}^{12} \mathrm{~S}^{32}$ & 4. 491 & $8,5 \leftarrow 7,5$ & Ground & & & & 24239.39 & .1 \\
\hline $\mathrm{C}^{12}{ }_{*} \mathrm{H}_{2} \mathrm{C}^{12} \mathrm{H}_{2} \mathrm{C}^{12} \mathrm{H}_{2} \mathrm{O}^{16} *$ & $4-1091$ & $7,5,2 \leftarrow 7,5,3$ & Excited & & & & 24240 & \\
\hline $\mathrm{C}^{12} \mathrm{H}_{2}\left(\mathrm{C}^{12} \mathrm{~N}^{14}\right)_{2}$ & 4- 901 & Not Reported & Ground & & & & 24240.8 & .1 \\
\hline
\end{tabular}




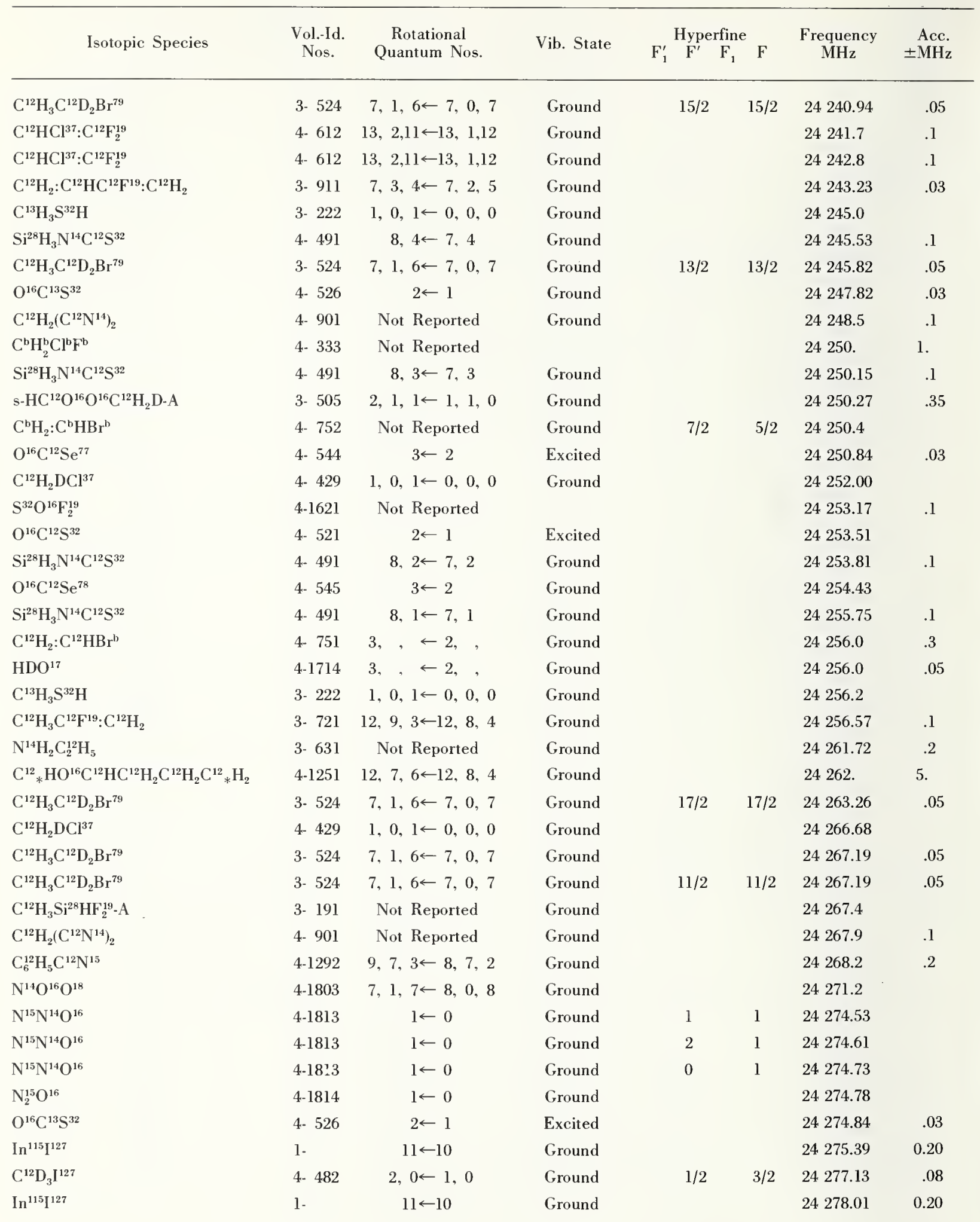


Vib. State

$\mathrm{C}^{12} \mathrm{H}_{2} \mathrm{DCl}^{37}$

$\mathrm{S}^{32} \mathrm{O}^{16} \mathrm{~F}_{2}^{19}$

$\mathrm{C}^{12} \mathrm{H}_{3} \mathrm{~B}^{\mathrm{h}} \mathrm{F}_{2}^{19}$

In $\left.^{115}\right]^{127}$

$\mathrm{C}^{12} \mathrm{D}_{3} \mathrm{I}^{127}$

$\left.\operatorname{In}^{115}\right]^{127}$

$\mathrm{C}^{12} \mathrm{H}_{2}: \mathrm{C}^{12} \mathrm{HBr}^{\text {b }}$

$\mathrm{HDO}^{17}$

$\mathrm{C}^{12}{ }_{*} \mathrm{H}: \mathrm{C}^{12} \mathrm{HC}^{12} \mathrm{H}: \mathrm{C}^{12} \mathrm{HN}^{14}{ }_{*} \mathrm{D}$

$\operatorname{In}^{115}\left[^{127}\right.$

$\mathrm{C}^{12} \mathrm{H}_{3} \mathrm{Si}^{28} \mathrm{HF}_{2}^{19}-\mathrm{A}$

a- ${ }^{12} \mathrm{H}_{2} \mathrm{DC}^{12} \mathrm{H}_{2} \mathrm{C}^{12} \mathrm{H}_{3}$

$\mathrm{C}^{12} \mathrm{H}_{2}: \mathrm{C}^{12} \mathrm{HC}^{12} \mathrm{~F}^{19}: \mathrm{C}^{12} \mathrm{H}_{2}$

$\mathrm{C}^{12} \mathrm{H}_{3} \mathrm{C}^{12} \mathrm{~F}^{19}: \mathrm{C}^{12} \mathrm{H}_{2}$

$\mathrm{H}_{2} \mathrm{~N}^{14} \mathrm{~N}^{14} \mathrm{H}_{2}$

$\mathrm{C}^{12} \mathrm{H}_{3} \mathrm{~N}^{14} \mathrm{O}_{2}^{16}$

$\mathrm{H}_{2} \mathrm{~N}^{14} \mathrm{~N}^{14} \mathrm{H}_{2}$

$\mathrm{O}^{16} \mathrm{C}^{12} \mathrm{Se}^{78}$

$\mathrm{C}^{12} \mathrm{H}_{3} \mathrm{C}^{12} \mathrm{H}_{2} \mathrm{O}^{16} \mathrm{H}$

$\mathrm{C}^{\mathrm{b}} \mathrm{H}_{2}: \mathrm{C}^{\mathrm{h}} \mathrm{HBr}^{\mathrm{h}}$

$\mathrm{O}^{16} \mathrm{C}^{12} \mathrm{~S}^{32}$

$\mathrm{C}^{\mathrm{b}}{ }_{*} \mathrm{H}_{2}^{\mathrm{b}} \mathrm{N}^{\mathrm{b}} \mathrm{H}^{\mathrm{b}} \mathrm{C}^{\mathrm{b}}{ }_{*} \mathrm{H}_{2}^{\mathrm{b}}$

$\mathrm{Re}^{\mathrm{h}} \mathrm{O}_{3}^{16} \mathrm{Cl}^{37}$

$\mathrm{N}^{14} \mathrm{H}_{2} \mathrm{C}_{2}^{12} \mathrm{H}_{5}$

$\mathrm{Mn}^{55} \mathrm{O}_{2}^{16} \mathrm{O}^{18} \mathrm{~F}^{19}$

$\mathrm{Mn}^{55} \mathrm{O}_{2}^{16} \mathrm{O}^{18} \mathrm{~F}^{19}$

$\mathrm{Mn}^{55} \mathrm{O}_{2}^{16} \mathrm{O}^{18} \mathrm{~F}^{19}$

$\mathrm{Mn}^{55} \mathrm{O}_{2}^{16} \mathrm{O}^{18} \mathrm{~F}^{19}$

$\mathrm{Mn}^{55} \mathrm{O}_{2}^{16} \mathrm{O}^{18} \mathrm{~F}^{19}$

$\mathrm{Mn}^{55} \mathrm{O}_{2}^{16} \mathrm{O}^{18} \mathrm{~F}^{19}$

$\mathrm{H}_{2} \mathrm{C}^{12}: \mathrm{C}^{12} \mathrm{~F}_{2}^{19}$

$\mathrm{C}^{12} \mathrm{H}_{3} \mathrm{Si}^{28} \mathrm{HF}_{2}^{19}-\mathrm{A}$

$\mathrm{Ga}^{69} \mathrm{Br}^{81}$

$\mathrm{Ga}^{69} \mathrm{Br}^{81}$

$\mathrm{Ga}^{69} \mathrm{Br}^{81}$

$\mathrm{Ga}^{69} \mathrm{Br}^{81}$

$\mathrm{Ga}^{69} \mathrm{Br}^{81}$

$\mathrm{Ga}^{69} \mathrm{Br}^{81}$

$\mathrm{Ga}^{69} \mathrm{Br}^{81}$

$\mathrm{Ga}^{69} \mathrm{Br}^{81}$

$\mathrm{Ga}^{69} \mathrm{Br}^{81}$

$\mathrm{Ga}^{69} \mathrm{Br}^{\mathrm{H1}}$

$\mathrm{Ca}^{69} \mathrm{Br}^{81}$

$\mathrm{Ga}^{69} \mathrm{Br}^{81}$
4. $429,1,0,1 \leftarrow 0,0,0$

Ground

4-1621 Not Reported

3. $912, \quad \leftarrow 1$, ,

Ground

1 -

$11 \leftarrow 10$

4- 482

$2,1 \leftarrow 1,1$

1 -

$11 \leftarrow 10$

4- 751

$3, \quad \leftarrow 2$,

4-1714

$3, \quad \leftarrow 2$,

4-1182

$6,5,2 \leftarrow 6,3,3$

1 -

$11 \leftarrow 10$

3- 191

Not Reported

3. 786

$4,1,3 \leftarrow 4,0,4$

3. 911

$9,3,6 \leftarrow 9,2,7$

3- 721

$12,9,3 \leftarrow 12,8,4$

3. 51

Not Reported

3. 171

Not Reported

3. 51

Not Reported

4. 545

$$
3 \leftarrow 2
$$

3- 581

Not Reported

4- 752

Not Reported

4. 521

$2 \leftarrow 1$

4. 863

Not Reported

4-1476

$6, \leftarrow 5$,

3. 631

Not Reported

4-1562

$3,2,1 \leftarrow 2,2,0$

4-1562

$3,2,1 \leftarrow 2,2,0$

4-1562

$3,2,1 \leftarrow 2,2,0$

4-1562

$3,2,1 \leftarrow 2,2,0$

4-1562

$3,2,1 \leftarrow 2,2,0$

4-1562

$3,2,1 \leftarrow 2,2,0$

4- 681

Not Reported

3- 191

Not Reported

1 -

$1-$

$5 \leftarrow 4$

$5 \leftarrow 4$

1 -

1 -

$5 \leftarrow 4$

$5 \leftarrow 4$

$5 \leftarrow 4$

$5 \leftarrow 4$

$5 \leftarrow 4$

$5 \leftarrow 4$

$5 \leftarrow 4$

$5 \leftarrow 4$

$5 \leftarrow 4$

$5 \leftarrow 4$
Ground

Ground

Ground

Ground

Ground

Ground

Ground

Ground

Ground

Ground

Ground

Ground

Excited

Excited

Excited

$7 / 2$

$7 / 2$

Ground

Ground

Ground

Ground

Ground

Ground

Ground

Ground

Excited

Excited

Excited

Excited

Excited

Excited

Excited

Excited

Excited

Excited

Excited

Excited
24278.33

24278.55 . I

24278.8 .I

24. $279.23 \quad 0.20$

$\begin{array}{llll}9 / 2 & 7 / 2 & 24279.89 & .08\end{array}$

$24280.42 \quad 0.20$

24. $280.5 \quad$.1

$24.280 .5 \quad .05$

24281.6

24282.48

0.20

24282.8

$24.283 .11 \quad .06$

$24284.40 \quad .03$

24. 285.62

24. 285.79

24. 286.

5.

24. 286.23

24. 286.82

.03

24. 288.71

.01

24289.2

24289.97

24. 290.

10.

24290.

$24291.18 \quad .2$

$\begin{array}{llll}1 / 2 & 3 / 2 & 24292.35 & .08\end{array}$

$\begin{array}{llll}3 / 2 & 3 / 2 & 24292.35 & .08\end{array}$

$\begin{array}{llll}9 / 2 & 9 / 2 & 24.292 .35 & .08\end{array}$

$11 / 2 \quad 9 / 2 \quad 24292.35 \quad .08$

$\begin{array}{llll}7 / 2 & 9 / 2 & 24292.35 & .08\end{array}$

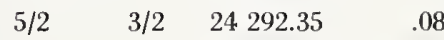

$24293.6 \quad .3$

24. 293.7

$\begin{array}{llllll}13 / 2 & 7 & 11 / 2 & 6 & 24294.26 & 0.20\end{array}$

$\begin{array}{llllll}11 / 2 & 5 & 9 / 2 & 4 & 24.294 .26 & 0.20\end{array}$

$\begin{array}{llllll}11 / 2 & 4 & 9 / 2 & 3 & 24294.26 & 0.20\end{array}$

$\begin{array}{llllll}9 / 2 & 6 & 7 / 2 & 5 & 24294.26 & 0.20\end{array}$

$\begin{array}{llllll}13 / 2 & 6 & 11 / 2 & 5 & 24.294 .26 & 0.20\end{array}$

$\begin{array}{llllll}11 / 2 & 6 & 9 / 2 & 5 & 24.294 .26 & 0.20\end{array}$

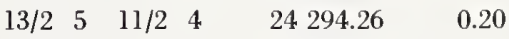

$\begin{array}{llllll}11 / 2 & 7 & 9 / 2 & 6 & 24294.26 & 0.20\end{array}$

$\begin{array}{llllll}7 / 2 & 3 & 5 / 2 & 2 & 24294.26 & 0.20\end{array}$

$\begin{array}{llllll}7 / 2 & 4 & 5 / 2 & 3 & 24294.26 & 0.20\end{array}$

$\begin{array}{llllll}7 / 2 & 2 & 5 / 2 & 1 & 24294.26 & 0.20\end{array}$

$\begin{array}{llllll}9 / 2 & 5 & 7 / 2 & 4 & 24294.26 & 0.20\end{array}$ 


\begin{tabular}{|c|c|c|c|c|c|c|c|c|}
\hline \multirow{2}{*}{ Isotopic Species } & \multirow{2}{*}{$\begin{array}{l}\text { Vol.-Id. } \\
\text { Nos. }\end{array}$} & \multirow{2}{*}{$\begin{array}{c}\text { Rotational } \\
\text { Quantum Nos. }\end{array}$} & \multirow{2}{*}{ Vib. State } & \multicolumn{3}{|c|}{ Hyperfine } & \multirow{2}{*}{$\begin{array}{c}\text { Frequency } \\
\qquad \mathrm{MHz}\end{array}$} & \multirow{2}{*}{$\begin{aligned} & \text { Acc. } \\
& \pm \mathrm{MHz}\end{aligned}$} \\
\hline & & & & $\mathrm{F}_{1}^{\prime}$ & $\mathrm{F}^{\prime}$ & $F_{1} \quad F$ & & \\
\hline $\mathrm{Ga}^{69} \mathrm{Br}^{81}$ & $1-$ & $5 \leftarrow 4$ & Excited & $13 / 2$ & 8 & $11 / 27$ & 24294.26 & 0.20 \\
\hline $\mathrm{Ga}^{69} \mathrm{Br}^{81}$ & $1-$ & $5 \leftarrow 4$ & Excited & $9 / 2$ & 3 & $7 / 2 \quad 2$ & 24294.26 & 0.20 \\
\hline $\mathrm{Ga}^{69} \mathrm{Br}^{81}$ & $1-$ & $5 \leftarrow 4$ & Excited & $9 / 2$ & 4 & $7 / 2 \quad 3$ & 24294.26 & 0.20 \\
\hline $\mathrm{C}^{12} \mathrm{H}_{3} \mathrm{C}^{12} \mathrm{H}_{2} \mathrm{O}^{16} \mathrm{H}$ & 3- 581 & Not Reported & & & & & 24295 . & \\
\hline $\mathrm{Mn}^{55} \mathrm{O}_{2}^{16} \mathrm{O}^{18} \mathrm{~F}^{19}$ & 4-1562 & $3,2,1 \leftarrow 2,2,0$ & Ground & & $7 / 2$ & $7 / 2$ & 24295.45 & .1 \\
\hline $\mathrm{Mn}^{55} \mathrm{O}_{2}^{16} \mathrm{O}^{18} \mathrm{~F}^{19}$ & 4-1562 & $3,2,1 \leftarrow 2,2,0$ & Ground & & $9 / 2$ & $7 / 2$ & 24295.45 & .1 \\
\hline $\mathrm{Mn}^{55} \mathrm{O}_{2}^{16} \mathrm{O}^{18} \mathrm{~F}^{19}$ & 4-1562 & $3,2,1 \leftarrow 2,2,0$ & Ground & & $5 / 2$ & $7 / 2$ & 24.295 .45 & .1 \\
\hline $\mathrm{HC}^{12} \mathrm{O}^{16} \mathrm{O}^{16} \mathrm{C}^{12} \mathrm{H}_{3}-\mathrm{E}$ & 3. 502 & $2,0,2 \leftarrow 1,0,1$ & Ground & & & & 24296.60 & .2 \\
\hline $\mathrm{C}^{12} \mathrm{H}_{2} \mathrm{~F}_{2}^{19}$ & 4. 351 & $54,13,42 \leftarrow 53,14,39$ & Ground & & & & 24. 297.52 & .10 \\
\hline $\mathrm{C}^{12} \mathrm{H}_{2} \mathrm{~F}_{2}^{19}$ & 4- 351 & $54,13,41 \leftarrow 53,14,40$ & Ground & & & & 24297.52 & .10 \\
\hline $\mathrm{C}^{12} \mathrm{H}_{3} \mathrm{C}^{12} \mathrm{O}^{16} \mathrm{O}^{16} \mathrm{H}$ & 3- 491 & Not Reported & & & & & 24298 & 3. \\
\hline $\mathrm{C}^{12} \mathrm{H}_{2}\left(\mathrm{C}^{12} \mathrm{~N}^{14}\right)_{2}$ & 4- 901 & Not Reported & Ground & & & & 24298.2 & .1 \\
\hline $\mathrm{HC}^{12} \mathrm{O}^{16} \mathrm{O}^{16} \mathrm{C}^{12} \mathrm{H}_{3^{-}} \mathrm{A}$ & 3- 501 & $2,0,2 \leftarrow 1,0,1$ & Ground & & & & 24298.40 & .2 \\
\hline $\mathrm{C}_{6}^{12} \mathrm{H}_{5} \mathrm{~F}^{19}$ & $4-1281$ & $8,3,6 \leftarrow 8,1,7$ & Ground & & & & 24300.5 & .1 \\
\hline $\mathrm{O}^{16} \mathrm{C}^{13} \mathrm{~S}^{32}$ & 4- 526 & $2 \leftarrow 1$ & Excited & & & & 24300.58 & .03 \\
\hline $\mathrm{C}^{12} \mathrm{H}_{2}: \mathrm{C}^{12} \mathrm{HC}^{12} \mathrm{~F}^{19}: \mathrm{C}^{12} \mathrm{H}_{2}$ & 3. 911 & $3,1,3 \leftarrow 2,0,2$ & Ground & & & & 24301.42 & .03 \\
\hline $\mathrm{HC}^{13}: \mathrm{C}^{12} \mathrm{C}^{12} \mathrm{DO}^{16}$ & 4- 922 & Not Reported & & & & & 24302 . & 5. \\
\hline $\mathrm{Si}^{28} \mathrm{D}_{2} \mathrm{~F}_{2}^{19}$ & 4-1603 & $4,1,3 \leftarrow 3,2,2$ & Ground & & & & 24302.40 & .10 \\
\hline $\mathrm{C}^{12} \mathrm{H}_{3} \mathrm{~S}^{32} \mathrm{D}$ & 3- 223 & $1,0,1 \leftarrow 0,0,0$ & Ground & & & & 24302.9 & \\
\hline $\mathrm{C}^{12} \mathrm{D}_{2}\left(\mathrm{C}^{12} \mathrm{~N}^{14}\right)_{2}$ & 4- 903 & $2,1,2 \leftarrow 1,0,1$ & Ground & & & & 24304.47 & \\
\hline $\mathrm{C}^{b} \mathrm{H}_{2}: \mathrm{C}^{b} \mathrm{HBr}^{b}$ & 4- 752 & Not Reported & Ground & & $7 / 2$ & $7 / 2$ & 24305.7 & \\
\hline $\mathrm{O}^{16} \mathrm{C}^{12} \mathrm{Se}^{78}$ & 4- 545 & $3 \leftarrow 2$ & Excited & & & & 24305.95 & .03 \\
\hline $\mathrm{C}^{13} \mathrm{H}_{3} \mathrm{~S}^{32} \mathrm{H}$ & 3- 222 & $1,0,1 \leftarrow 0,0,0$ & Ground & & & & 24306.2 & \\
\hline $\mathrm{C}^{12} \mathrm{H}_{2}: \mathrm{C}^{12} \mathrm{HBr}^{81}$ & 4- 728 & $3,1,2 \leftarrow 2,1,1$ & Excited & & $3 / 2$ & $3 / 2$ & 24307.8 & \\
\hline $\mathrm{Cl}^{35} \mathrm{~F}_{3}^{19}$ & 4-1371 & $5,2,3 \leftarrow 5,1,4$ & Ground & & $7 / 2$ & $7 / 2$ & 24308.65 & .15 \\
\hline $\mathrm{Cl}^{35} \mathrm{~F}_{3}^{19}$ & 4. 1371 & $5,2,3 \leftarrow 5,1,4$ & Ground & & $13 / 2$ & $13 / 2$ & 24309.12 & .15 \\
\hline$\left(\mathrm{C}^{12} \mathrm{H}_{3}\right)_{2} \mathrm{O}^{16}$ & 3- 591 & Not Reported & Ground & & & & 24310 . & 20. \\
\hline $\mathrm{Cl}^{35} \mathrm{~F}_{3}^{19}$ & 4-1371 & $5,2,3 \leftarrow 5,1,4$ & Ground & & $9 / 2$ & $9 / 2$ & 24310.05 & .15 \\
\hline $\mathrm{Cl}^{35} \mathrm{~F}_{3}^{19}$ & $4 \cdot 1371$ & $5,2,3 \leftarrow 5,1,4$ & Ground & & $11 / 2$ & $11 / 2$ & 24310.43 & .15 \\
\hline $\mathrm{C}_{7}^{12} \mathrm{H}_{13} \mathrm{~N}^{14}$ & 4-1311 & $5, \leftarrow 4$, & Ground & & & & 24311.5 & \\
\hline $\mathrm{C}^{12} \mathrm{H}_{2}\left(\mathrm{C}^{12} \mathrm{~N}^{14}\right)_{2}$ & 4. 901 & Not Reported & Ground & & & & 24313.3 & .1 \\
\hline $\mathrm{C}^{13} \mathrm{H}_{3} \mathrm{C}^{12} \mathrm{H}_{2} \mathrm{C}^{12} \mathrm{H}_{3}$ & 3- 782 & $3,1,2 \leftarrow 3,0,3$ & Ground & & & & 24315.01 & .06 \\
\hline $\mathrm{C}^{12} \mathrm{HDCl}^{35} \mathrm{Si}^{28} \mathrm{H}_{3}$ & 3. 236 & $4,0,4 \leftarrow 3,0,3$ & Ground & & & & 24316.27 & .2 \\
\hline $\mathrm{O}^{16} \mathrm{C}^{12} \mathrm{~S}^{32}$ & 4. 521 & $2 \leftarrow 1$ & Excited & & & & 24316.76 & \\
\hline $\mathrm{C}^{12} \mathrm{H}_{3} \mathrm{O}^{16} \mathrm{H}$ & 3- 211 & Not Reported & Ground & & & & 24317 & 5. \\
\hline $\mathrm{C}_{6}^{12} \mathrm{H}_{5} \mathrm{Cl}^{37}$ & 4-1272 & $9,2,8 \leftarrow 8,2,7$ & Ground & & & & 24318 & 5.0 \\
\hline $\mathrm{C}^{13} \mathrm{H}_{3} \mathrm{~S}^{32} \mathrm{H}$ & 3- 222 & $1,0,1 \leftarrow 0,0,0$ & Ground & & & & 24318.5 & \\
\hline $\mathrm{S}^{32} \mathrm{O}_{2}^{16}$ & 4-1831 & Not Reported & & & & & 24319.67 & .1 \\
\hline $\mathrm{C}^{12} \mathrm{H}_{3} \mathrm{~N}^{14} \mathrm{O}_{2}^{16}$ & 3- 171 & Not Reported & Ground & & & & 24320 . & \\
\hline $\mathrm{C}^{12} \mathrm{H}_{3}{ }^{\mathrm{N}}{ }^{14} \mathrm{H}_{2}$ & 3. 261 & Not Reported & Ground & & & & 24320.57 & .1 \\
\hline $\mathrm{Cl}^{35} \mathrm{~F}_{3}^{19}$ & 4-1371 & $6,2,4 \leftarrow 6,1,5$ & Ground & & $7 / 2$ & $7 / 2$ & 24320.70 & .15 \\
\hline $\mathrm{Cl}^{35} \mathrm{~F}_{3}^{19}$ & $4-1371$ & $6,2,4 \leftarrow 6,1,5$ & Ground & & $15 / 2$ & $15 / 2$ & 24321.86 & .15 \\
\hline $\mathrm{C}^{12} \mathrm{H}_{3} \mathrm{~S}^{32} \mathrm{D}$ & 3- 223 & $1,0,1 \leftarrow 0,0,0$ & Ground & & & & 24. 322.2 & \\
\hline $\mathrm{C}^{12} \mathrm{H}_{3} \mathrm{C}^{12} \mathrm{~F}^{19}: \mathrm{C}^{12} \mathrm{H}_{2}$ & 3- 721 & $13,9,4 \leftarrow 13,9,5$ & Ground & & & & 24322.79 & .1 \\
\hline $\mathrm{H}_{2} \mathrm{C}^{12}: \mathrm{C}^{12} \mathrm{~F}_{2}^{19}$ & 4- 681 & Not Reported & & & & & 24. 323.2 & .3 \\
\hline
\end{tabular}




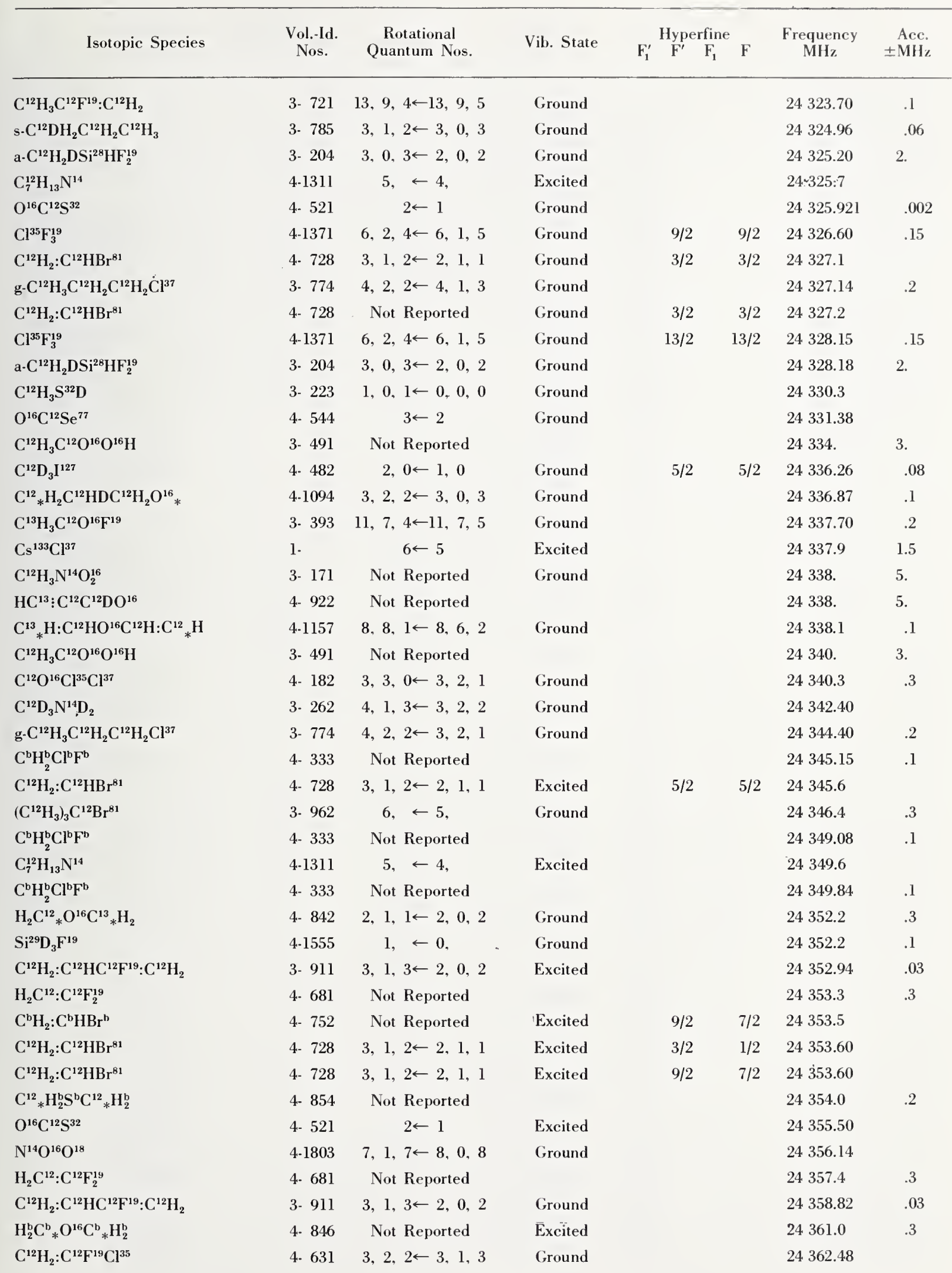


Vib. State

$\mathrm{F}_{1}^{\prime} \stackrel{\text { Hyperfine }}{\mathrm{F}^{\prime}} \mathrm{F}_{1} \mathrm{~F}$

Frequency $\mathrm{MHz}$

Acc. $\pm \mathrm{MHz}$

\begin{tabular}{|c|c|c|c|c|c|c|c|}
\hline $\mathrm{C}^{12} \mathrm{D}_{3} \mathrm{C}^{12} \mathrm{HDC}^{12} \mathrm{~N}^{14}$ & 3. 733 & $3,1,2 \leftarrow 2,1,1$ & Ground & & & 24.362 .51 & .1 \\
\hline $\mathrm{O}^{16} \mathrm{C}^{12} \mathrm{Se}^{77}$ & 4- 544 & $3 \leftarrow 2$ & Excited & & & 24. 363.97 & .03 \\
\hline $\mathrm{C}^{12} \mathrm{H}_{2}: \mathrm{C}^{12} \mathrm{HBr}^{81}$ & 4- 728 & $3,1,2 \leftarrow 2,1,1$ & Ground & $5 / 2$ & $5 / 2$ & 24365.0 & \\
\hline $\mathrm{C}^{\mathrm{b}} \mathrm{H}_{2}: \mathrm{C}^{\mathrm{b}} \mathrm{HBr}^{\mathrm{b}}$ & 4- 752 & Not Reported & Ground & $5 / 2$ & $5 / 2$ & 24365.1 & \\
\hline $\mathrm{C}^{12} \mathrm{H}_{3} \mathrm{C}^{12} \mathrm{H}_{2} \mathrm{C}^{12} \mathrm{H}_{3}$ & 3- 781 & $3,1,2 \leftarrow 3,0,3$ & Ground & & & 24.365 .47 & .03 \\
\hline $\mathrm{Mn}^{55} \mathrm{O}_{2}^{16} \mathrm{O}^{18} \mathrm{~F}^{19}$ & 4-1562 & $3,1,2 \leftarrow 2,1,1$ & Ground & $11 / 2$ & $9 / 2$ & 24.365 .64 & .030 \\
\hline $\mathrm{Mn}^{55} \mathrm{O}_{2}^{16} \mathrm{O}^{18} \mathrm{~F}^{19}$ & 4-1562 & $3,1,2 \leftarrow 2,1,1$ & Ground & $9 / 2$ & $7 / 2$ & 24366.331 & .060 \\
\hline $\mathrm{Mn}^{55} \mathrm{O}_{2}^{16} \mathrm{O}^{18} \mathrm{~F}^{19}$ & 4-1562 & $3,1,2 \leftarrow 2,1,1$ & Ground & $7 / 2$ & $7 / 2$ & 24.366 .331 & .060 \\
\hline $\mathrm{H}_{2} \mathrm{C}^{12}: \mathrm{C}^{12} \mathrm{Cl}_{2}^{\mathrm{h}}$ & 4- 663 & Not Reported & Ground & & & 24. 366.5 & 1. \\
\hline $\mathrm{Mn}^{55} \mathrm{O}_{2}^{16} \mathrm{O}^{18} \mathrm{~F}^{19}$ & 4-1562 & $3,1,2 \leftarrow 2,1,1$ & Ground & $5 / 2$ & $3 / 2$ & 24366.80 & .050 \\
\hline $\mathrm{Mn}^{55} \mathrm{O}_{2}^{16} \mathrm{O}^{18} \mathrm{~F}^{19}$ & 4-1562 & $3,1,2 \leftarrow 2,1,1$ & Ground & $7 / 2$ & $5 / 2$ & 24366.80 & .050 \\
\hline $\mathrm{Mn}^{55} \mathrm{O}_{2}^{16} \mathrm{O}^{18} \mathrm{~F}^{19}$ & 4-1562 & $3,1,2 \leftarrow 2,1,1$ & Ground & $9 / 2$ & $9 / 2$ & 24367.89 & .030 \\
\hline $\mathrm{t}-\mathrm{C}^{12} \mathrm{H}_{2} \mathrm{DC}^{12} \mathrm{H}_{2} \mathrm{Cl}^{35}$ & 3. 543 & $5,0,5 \leftarrow 4,1,4$ & Ground & & & 24.368 .57 & .05 \\
\hline $\mathrm{C}^{12} \mathrm{H}_{3} \mathrm{C}^{12} \mathrm{H}_{2} \mathrm{O}^{16} \mathrm{H}$ & 3- 581 & Not Reported & & & & 24369 . & \\
\hline $\mathrm{C}^{12} \mathrm{H}_{2}\left(\mathrm{C}^{12} \mathrm{~N}^{14}\right)_{2}$ & 4- 901 & Not Reported & Ground & & & 24. 369.4 & .1 \\
\hline $\mathrm{C}^{\mathrm{h}} \mathrm{H}_{3}^{\mathrm{b}} \mathrm{C}^{\mathrm{h}} \mathrm{H}_{2}^{\mathrm{b}} \mathrm{Cl}^{35}$ & 3- 548 & Not Reported & & & & 24369.61 & .05 \\
\hline $\mathrm{C}^{12} \mathrm{H}_{2}\left(\mathrm{C}^{12} \mathrm{~N}^{14}\right)_{2}$ & 4- 901 & Not Reported & Ground & & & 24371.6 & .1 \\
\hline $\mathrm{C}^{12} \mathrm{HCl}^{37} \mathrm{~F}_{2}^{19}$ & 4- 252 & $2,1,1 \leftarrow 1,0,1$ & Ground & $3 / 2$ & $1 / 2$ & 24372.39 & \\
\hline $\mathrm{C}^{12} \mathrm{H}_{2}: \mathrm{C}^{12} \mathrm{HBr}^{81}$ & 4- 728 & $3,1,2 \leftarrow 2,1,1$ & Ground & $9 / 2$ & $7 / 2$ & 24372.9 & \\
\hline $\mathrm{C}^{12} \mathrm{H}_{2}: \mathrm{C}^{12} \mathrm{HBr}^{81}$ & 4- 728 & $3,1,2 \leftarrow 2,1,1$ & Ground & $3 / 2$ & $1 / 2$ & 24372.9 & \\
\hline $\mathrm{C}^{\mathrm{b}} \mathrm{H}_{2}: \mathrm{C}^{\mathrm{b}} \mathrm{HBr}^{\mathrm{b}}$ & 4- 752 & Not Reported & Ground & $9 / 2$ & $7 / 2$ & 24373.0 & \\
\hline $\mathrm{C}^{12} \mathrm{D}_{3} \mathrm{I}^{127}$ & 4- 482 & $2,1 \leftarrow 1,1$ & Ground & $3 / 2$ & $3 / 2$ & 24373.36 & .08 \\
\hline $\mathrm{S}^{32} \mathrm{C}^{12} \mathrm{Se}^{78}$ & 4- 563 & $6 \leftarrow 5$ & Ground & & & 24376. & 4. \\
\hline $\mathrm{HC}^{13}: \mathrm{C}^{12} \mathrm{C}^{12} \mathrm{DO}^{16}$ & 4. 922 & Not Reported & & & & 24376.5 & \\
\hline $\mathrm{S}^{32}{ }_{*} \mathrm{HC}^{12}: \mathrm{C}^{12} \mathrm{HC}^{12} \mathrm{H}: \mathrm{C}^{12}{ }_{*} \mathrm{H}$ & $4-1161$ & $6,2,5 \leftarrow 6,2,4$ & Ground & & & 24377.0 & .1 \\
\hline $\mathrm{H}_{2} \mathrm{~N}^{14} \mathrm{~N}^{14} \mathrm{H}_{2}$ & 3- 51 & Not Reported & & & & 24377.18 & \\
\hline $\mathrm{C}^{12} \mathrm{HCl}^{37} \mathrm{~F}_{2}^{19}$ & 4. 252 & $2,1,1 \leftarrow 1,0,1$ & Ground & $5 / 2$ & $5 / 2$ & 24377.65 & \\
\hline $\mathrm{C}^{\mathrm{b}} \mathrm{H}_{2}: \mathrm{C}^{\mathrm{b}} \mathrm{HBr}^{\mathrm{b}}$ & 4. 752 & Not Reported & Excited & $7 / 2$ & $5 / 2$ & 24377.9 & \\
\hline $\mathrm{C}^{12} \mathrm{H}_{2}: \mathrm{C}^{12} \mathrm{HBr}^{81}$ & 4- 728 & $3,1,2 \leftarrow 2,1,1$ & Excited & $5 / 2$ & $3 / 2$ & 24378.0 & \\
\hline $\mathrm{C}^{12} \mathrm{H}_{2}: \mathrm{C}^{12} \mathrm{HBr}^{81}$ & 4- 728 & $3,1,2 \leftarrow 2,1,1$ & Excited & $7 / 2$ & $5 / 2$ & 24378.0 & \\
\hline $\mathrm{C}^{12} \mathrm{HCl}^{37} \mathrm{~F}_{2}^{19}$ & 4. 252 & $2,1,1 \leftarrow 1,0,1$ & Ground & $1 / 2$ & $1 / 2$ & 24379.38 & \\
\hline $\mathrm{C}^{12} \mathrm{H}_{3} \mathrm{C}^{12} \mathrm{H}: \mathrm{C}^{12}: \mathrm{C}^{12} \mathrm{H}_{2}$ & 3- 931 & $3,0,3 \leftarrow 2,0,2$ & Ground & & & 24380.36 & .03 \\
\hline $\mathrm{C}^{12} \mathrm{H}_{2} \mathrm{~N}^{14} \mathrm{O}^{16} \mathrm{D}$ & 3- 142 & $8,1,7 \leftarrow 7,2,6$ & Ground & 7 & 6 & 24380.58 & .10 \\
\hline $\mathrm{C}^{12} \mathrm{H}_{2} \mathrm{~N}^{14} \mathrm{O}^{16} \mathrm{D}$ & 3. 142 & $8,1,7 \leftarrow 7,2,6$ & Ground & 9 & 8 & 24380.58 & .10 \\
\hline $\mathrm{C}^{12} \mathrm{H}_{3} \mathrm{C}^{12} \mathrm{H}: \mathrm{C}^{12}: \mathrm{C}^{12} \mathrm{H}_{2}$ & 3- 931 & $3,0,3 \leftarrow 2,0,2$ & Ground & & & 24380.63 & .03 \\
\hline $\mathrm{O}^{16} \mathrm{C}^{12} \mathrm{~S}^{32}$ & 4- 521 & $2 \leftarrow 1$ & Excited & & & 24381.07 & \\
\hline $\mathrm{N}^{14} \mathrm{O}^{16} \mathrm{O}^{18}$ & 4-1803 & $7,1,7 \leftarrow 8,0,8$ & Ground & & & 24381.5 & \\
\hline $\mathrm{C}^{12} \mathrm{H}_{2} \mathrm{~N}^{14} \mathrm{O}^{16} \mathrm{D}$ & 3- 142 & $8,1,7 \leftarrow 7,2,6$ & Ground & 8 & 7 & 24381.78 & .10 \\
\hline $\mathrm{C}^{12} \mathrm{H}_{3} \mathrm{~N}^{14} \mathrm{H}_{2}$ & 3. 261 & Not Reported & Ground & & & 24382.16 & .1 \\
\hline $\mathrm{C}^{12} \mathrm{H}_{3} \mathrm{C}^{12} \mathrm{HF}_{2}^{19}$ & 3- 461 & $2,1,2 \leftarrow 1,1,1$ & Excited & & & 24382.5 & .1 \\
\hline $\mathrm{O}^{16} \mathrm{C}^{12} \mathrm{Se}^{77}$ & 4- 544 & $3 \leftarrow 2$ & Excited & & & 24383.21 & .03 \\
\hline $\mathrm{C}^{12} \mathrm{H}_{3} \mathrm{C}^{12} \mathrm{H}_{2} \mathrm{O}^{16} \mathrm{H}$ & 3. 581 & Not Reported & & & & 24383.24 & .01 \\
\hline $\mathrm{C}^{12} \mathrm{H}_{2}: \mathrm{C}^{12} \mathrm{HBr}^{81}$ & 4- 728 & $3,1,2 \leftarrow 2,1,1$ & Ground & & & 24383.26 & .05 \\
\hline $\mathrm{C}^{12} \mathrm{H}_{2} \mathrm{Cl}^{35} \mathrm{Si}^{28} \mathrm{H}_{3}$ & 3- 231 & $10,3,8 \leftarrow 11,2,9$ & Ground & & & 24383.97 & .2 \\
\hline $\mathrm{C}^{12} \mathrm{H}_{3} \mathrm{C}^{12} \mathrm{H}_{2} \mathrm{O}^{16} \mathrm{H}$ & 3. 581 & Not Reported & & & & 24384.04 & .01 \\
\hline
\end{tabular}




\begin{tabular}{|c|c|c|c|c|c|c|c|c|c|}
\hline \multirow{2}{*}{ Isotopic Species } & \multirow{2}{*}{$\begin{array}{l}\text { Vol.-Id. } \\
\text { Nos. }\end{array}$} & \multirow{2}{*}{$\begin{array}{c}\text { Rotational } \\
\text { Quantum Nos. }\end{array}$} & \multirow{2}{*}{ Vib. Statc } & \multicolumn{4}{|c|}{ Hyperfine } & \multirow{2}{*}{$\begin{array}{l}\text { Frequency } \\
\qquad \mathrm{MHz}^{2}\end{array}$} & \multirow{2}{*}{$\begin{aligned} & \text { Acc. } \\
\pm & \mathrm{MHz}\end{aligned}$} \\
\hline & & & & $\mathrm{F}_{1}^{\prime}$ & $\mathrm{F}^{\prime}$ & & $\mathrm{F}$ & & \\
\hline $\mathrm{C}^{12} \mathrm{HCl}^{37} \mathrm{~F}_{2}^{19}$ & 4. 252 & $2,1,1 \leftarrow 1,0,1$ & Ground & & $7 / 2$ & & $5 / 2$ & 24384.64 & \\
\hline $\mathrm{C}^{12} \mathrm{HCl}^{37} \mathrm{~F}_{2}^{19}$ & 4- 252 & $2,1,1 \leftarrow 1,0,1$ & Ground & & $7 / 2$ & & $5 / 2$ & 24384.7 & .05 \\
\hline $\mathrm{C}^{12} \mathrm{H}_{2}: \mathrm{C}^{12} \mathrm{HBr}^{\mathrm{b}}$ & 4- 751 & $3, \quad \leftarrow 2, \quad$, & Ground & & & & & 24384.9 & .1 \\
\hline $\mathrm{HDO}^{17}$ & $4-1714$ & $3, \quad \leftarrow 2$, & Ground & & & & & 24384.9 & .5 \\
\hline $\mathrm{C}^{12} \mathrm{H}_{2} \mathrm{Cl}^{35} \mathrm{Si}^{28} \mathrm{H}_{3}$ & $3 \cdot 231$ & $10,3,8 \leftarrow 11,2,9$ & Ground & & & & & 24384.93 & .2 \\
\hline $\mathrm{C}^{12} \mathrm{H}_{3} \mathrm{C}^{12} \mathrm{O}^{16} \mathrm{O}^{16} \mathrm{H}$ & 3- 491 & Not Reported & & & & & & 24385 . & 3. \\
\hline $\mathrm{C}^{12} \mathrm{H}_{3} \mathrm{C}^{12} \mathrm{H}_{2} \mathrm{O}^{16} \mathrm{H}$ & 3- 581 & Not Reported & & & & & & 24385 & \\
\hline $\mathrm{C}^{12} \mathrm{HCl}^{37} \mathrm{~F}_{2}^{19}$ & 4- 252 & $2,1,1 \leftarrow 1,0,1$ & Ground & & & & & 24385.21 & .03 \\
\hline $\mathrm{Ge}^{70} \mathrm{H}_{3} \mathrm{Br}^{79}$ & 4. 101 & $5, \leftarrow 4$, & Ground & & & & & 24385.54 & 1. \\
\hline $\mathrm{C}^{12} \mathrm{H}_{3} \mathrm{~S}^{32} \mathrm{D}$ & 3- 223 & $1,0,1 \leftarrow 0,0,0$ & Ground & & & & & 24385.9 & \\
\hline $\mathrm{C}^{12} \mathrm{H}_{3} \mathrm{~N}^{14} \mathrm{O}_{2}^{16}$ & 3- 171 & Not Reported & Ground & & & & & 24386. & 5. \\
\hline $\mathrm{S}^{32} \mathrm{C}^{12} \mathrm{Se}^{78}$ & 4- 563 & $6 \leftarrow 5$ & Excited & & & & & 24386 & 4. \\
\hline $\mathrm{D}_{3} \mathrm{C}^{12} \mathrm{C}^{12}: \mathrm{C}^{12} \mathrm{C}^{12}: \mathrm{C}^{12} \mathrm{D}$ & 4-1194 & $7,5 \leftarrow 6,5$ & Ground & & & & & 24386.10 & .1 \\
\hline $\mathrm{C}^{12}{ }_{*} \mathrm{H}_{2} \mathrm{C}^{12} \mathrm{H}_{2} \mathrm{C}^{12} \mathrm{H}_{2} \mathrm{C}^{12} \mathrm{H}_{2} \mathrm{C}^{12}{ }_{*} \mathrm{O}^{16}$ & 4-1241 & $4,2,2 \leftarrow 3,2,1$ & Ground & & & & & 24.387 .2 & \\
\hline $\mathrm{D}_{3} \mathrm{C}^{12} \mathrm{C}^{12}: \mathrm{C}^{12} \mathrm{C}^{12}: \mathrm{C}^{12} \mathrm{D}$ & $4-1194$ & $7,4 \leftarrow 6,4$ & Ground & & & & & 24387.83 & .1 \\
\hline $\mathrm{C}^{13} \mathrm{H}_{3} \mathrm{~S}^{32} \mathrm{H}$ & 3- 222 & $1,0,1 \leftarrow 0,0,0$ & Ground & & & & & 24388.0 & \\
\hline $\mathrm{C}^{12} \mathrm{H}_{3} \mathrm{~S}^{32} \mathrm{D}$ & 3- 223 & $1,0,1 \leftarrow 0,0,0$ & Ground & & & & & 24388.3 & \\
\hline $\mathrm{C}^{13} \mathrm{H}_{3} \mathrm{~S}^{32} \mathrm{H}$ & 3- 222 & $1,0,1 \leftarrow 0,0,0$ & Ground & & & & & 24389.1 & \\
\hline $\mathrm{D}_{3} \mathrm{C}^{12} \mathrm{C}^{12}: \mathrm{C}^{12} \mathrm{C}^{12}: \mathrm{C}^{12} \mathrm{D}$ & $4-1194$ & $7,3 \leftarrow 6,3$ & Ground & & & & & 24389.17 & .1 \\
\hline $\mathrm{C}^{12} \mathrm{H}_{3} \mathrm{C}^{12} \mathrm{H}: \mathrm{C}^{12}: \mathrm{C}^{12} \mathrm{H}_{2}$ & 3- 931 & $3,2,2 \leftarrow 2,2,1$ & Ground & & & & & 24389.35 & .03 \\
\hline $\mathrm{S}^{32} \mathrm{O}^{16} \mathrm{~F}_{2}^{19}$ & 4-1621 & Not Reported & & & & & & 24389.65 & .1 \\
\hline $\mathrm{D}_{3} \mathrm{C}^{12} \mathrm{C}^{12}: \mathrm{C}^{12} \mathrm{C}^{12}: \mathrm{C}^{12} \mathrm{D}$ & 4-1194 & $7,2 \leftarrow 6,2$ & Ground & & & & & 24. 390.12 & .1 \\
\hline $\mathrm{Ga}^{69} \mathrm{Br}^{81}$ & 1 - & $5 \leftarrow 4$ & Excited & $7 / 2$ & 2 & $5 / 2$ & 1 & 24390.37 & 0.20 \\
\hline $\mathrm{Ga}^{69} \mathrm{Br}^{81}$ & 1 - & $5 \leftarrow 4$ & Excited & $7 / 2$ & 4 & $5 / 2$ & 3 & 24.390 .37 & 0.20 \\
\hline $\mathrm{Ga}^{69} \mathrm{Br}^{81}$ & 1. & $5 \leftarrow 4$ & Excited & $13 / 2$ & 8 & $11 / 2$ & 7 & 24390.37 & 0.20 \\
\hline $\mathrm{Ga}^{69} \mathrm{Br}^{81}$ & $1-$ & $5 \leftarrow 4$ & Excited & $13 / 2$ & 7 & $11 / 2$ & 6 & 24390.37 & 0.20 \\
\hline $\mathrm{Ga}^{69} \mathrm{Br}^{81}$ & $1-$ & $5 \leftarrow 4$ & Excited & $13 / 2$ & 6 & $11 / 2$ & 5 & 24390.37 & 0.20 \\
\hline $\mathrm{Ga}^{69} \mathrm{Br}^{81}$ & 1 . & $5 \leftarrow 4$ & Excited & $13 / 2$ & 5 & $11 / 2$ & 4 & 24390.37 & 0.20 \\
\hline $\mathrm{Ga}^{69} \mathrm{Br}^{81}$ & 1. & $5 \leftarrow 4$ & Excited & $11 / 2$ & 7 & $9 / 2$ & 6 & 24390.37 & 0.20 \\
\hline $\mathrm{Ga}^{69} \mathrm{Br}^{81}$ & $1-$ & $5 \leftarrow 4$ & Excited & $11 / 2$ & 6 & $9 / 2$ & 5 & 24390.37 & 0.20 \\
\hline $\mathrm{Ga}^{69} \mathrm{Br}^{81}$ & $1-$ & $5 \leftarrow 4$ & Excited & $11 / 2$ & 5 & $9 / 2$ & 4 & 24390.37 & 0.20 \\
\hline $\mathrm{Ga}^{69} \mathrm{Br}^{81}$ & $1-$ & $5 \leftarrow 4$ & Excited & $11 / 2$ & 4 & $9 / 2$ & 3 & 24390.37 & 0.20 \\
\hline $\mathrm{Ga}^{69} \mathrm{Br}^{81}$ & $1-$ & $5 \leftarrow 4$ & Excited & $9 / 2$ & 6 & $7 / 2$ & 5 & 24390.37 & 0.20 \\
\hline $\mathrm{Ga}^{69} \mathrm{Br}^{81}$ & $1-$ & $5 \leftarrow 4$ & Excited & $9 / 2$ & 5 & $7 / 2$ & 4 & 24390.37 & 0.20 \\
\hline $\mathrm{Ga}^{69} \mathrm{Br}^{81}$ & $1-$ & $5 \leftarrow 4$ & Excited & $9 / 2$ & 4 & $7 / 2$ & 3 & 24390.37 & 0.20 \\
\hline $\mathrm{Ga}^{69} \mathrm{Br}^{81}$ & $1-$ & $5 \leftarrow 4$ & Excited & $9 / 2$ & 3 & $7 / 2$ & 2 & 24390.37 & 0.20 \\
\hline $\mathrm{Ga}^{69} \mathrm{Br}^{81}$ & $1-$ & $5 \leftarrow 4$ & Excited & $7 / 2$ & 3 & $5 / 2$ & 2 & 24390.37 & 0.20 \\
\hline $\mathrm{C}^{12} \mathrm{HCl}^{37} \mathrm{~F}_{2}^{19}$ & 4. 252 & $2,1,1 \leftarrow 1,0,1$ & Ground & & $5 / 2$ & & $3 / 2$ & 24390.43 & \\
\hline $\mathrm{D}_{3} \mathrm{C}^{12} \mathrm{C}^{12}: \mathrm{C}^{12} \mathrm{C}^{12}: \mathrm{C}^{12} \mathrm{D}$ & 4-1194 & $7,1 \leftarrow 6,1$ & Ground & & & & & 24390.68 & .1 \\
\hline $\mathrm{D}_{3} \mathrm{C}^{12} \mathrm{C}^{12}: \mathrm{C}^{12} \mathrm{C}^{12}: \mathrm{C}^{12} \mathrm{D}$ & $4-1194$ & $7,0 \leftarrow 6,0$ & Ground & & & & & 24390.85 & .1 \\
\hline $\mathrm{C}_{7}^{12} \mathrm{H}_{13} \mathrm{~N}^{14}$ & $4-1311$ & $5, \leftarrow 4$, & Excited & & & & & 24391.4 & \\
\hline $\mathrm{C}^{12} \mathrm{H}_{2}: \mathrm{C}^{12} \mathrm{HC}^{12} \mathrm{~F}^{19}: \mathrm{C}^{12} \mathrm{H}_{2}$ & 3. 911 & $9,3,6 \leftarrow 9,2,7$ & Excited & & & & & 24392.35 & .03 \\
\hline $\mathrm{C}^{12} \mathrm{H}_{3} \mathrm{C}^{12} \mathrm{H}: \mathrm{C}^{12}: \mathrm{C}^{12} \mathrm{H}_{2}$ & 3- 931 & $3,2,2 \leftarrow 2,2,1$ & Ground & & & & & 24392.8 & .03 \\
\hline $\mathrm{C}^{12} \mathrm{H}_{3} \mathrm{C}^{12} \mathrm{H}: \mathrm{C}^{12}: \mathrm{C}^{12} \mathrm{H}$ & 3- 931 & $3,2,1 \leftarrow 2,2,0$ & Ground & & & & & 24393.2 & .1 \\
\hline $\mathrm{C}^{12} \mathrm{H}_{2}: \mathrm{C}^{12} \mathrm{HC}^{12} \mathrm{~F}^{19}: \mathrm{C}^{12} \mathrm{H}_{2}$ & 3- 911 & $3,1,3 \leftarrow 2,0,2$ & Ground & & & & & 24393.53 & .03 \\
\hline
\end{tabular}




\begin{tabular}{|c|c|c|c|c|c|c|c|c|c|}
\hline \multirow{3}{*}{$\frac{\text { Isotopic Species }}{\mathrm{C}^{12} \mathrm{H}_{3} \mathrm{C}^{12} \mathrm{H}_{2} \mathrm{~F}^{19}}$} & \multirow{3}{*}{$\begin{array}{l}\text { Vol.-Id. } \\
\text { Nos. } \\
\text { 3- } 551\end{array}$} & \multirow{3}{*}{$\begin{array}{c}\begin{array}{c}\text { Rotational } \\
\text { Quantum Nos. }\end{array} \\
6,1,5 \leftarrow 6,1,6\end{array}$} & \multirow{3}{*}{$\begin{array}{c}\text { Vib. State } \\
\text { Ground }\end{array}$} & \multicolumn{4}{|c|}{ Hyperfine } & \multirow{2}{*}{$\begin{array}{c}\text { Frequency } \\
\mathrm{MHz}\end{array}$} & \multirow{2}{*}{$\begin{array}{r}\text { Acc. } \\
\pm \mathrm{MHz}\end{array}$} \\
\hline & & & & $F_{1}^{\prime}$ & & & $\mathbf{F}$ & & \\
\hline & & & & & & & & 24393.70 & .10 \\
\hline $\mathrm{C}^{12} \mathrm{H}_{2} \mathrm{DC}^{12} \mathrm{HDF}^{19}$ & 3- 557 & $6,1,6 \leftarrow 5,2,3$ & Ground & & & & & 24395 . & 1. \\
\hline $\mathrm{C}^{12} \mathrm{HCl}^{37} \mathrm{~F}_{2}^{19}$ & 4- 252 & $2,1,1 \leftarrow 1,0,1$ & Ground & & $3 / 2$ & & $3 / 2$ & 24395.56 & \\
\hline $\mathrm{H}_{2}^{\mathrm{b}} \mathrm{C}_{*}^{\mathrm{b}} \mathrm{O}^{16} \mathrm{C}_{*}^{\mathrm{b}} \mathrm{H}_{2}^{\mathrm{b}}$ & 4- 846 & Not Reported & Excited & & & & & 24395.8 & .3 \\
\hline $\mathrm{Si}^{28} \mathrm{H}_{3} \mathrm{~N}^{14} \mathrm{C}^{12} \mathrm{~S}^{32}$ & 4. 491 & $8,5 \leftarrow 7,5$ & Excited & & & & & 24396.19 & \\
\hline $\mathrm{C}^{12} \mathrm{H}_{3} \mathrm{C}^{12} \mathrm{H}: \mathrm{C}^{12}: \mathrm{C}^{12} \mathrm{H}_{2}$ & 3- 931 & $3,2,1 \leftarrow 2,2,0$ & Ground & & & & & 24396.90 & .03 \\
\hline $\mathrm{C}^{12} \mathrm{D}_{3} \mathrm{C}^{13}: \mathrm{C}^{12} \mathrm{C}^{12} \mathrm{~F}_{3}^{19}$ & 3- 895 & $10, \leftarrow 9$ & Ground & & & & & 24397.0 & .5 \\
\hline $\mathrm{C}^{12} \mathrm{H}_{2}: \mathrm{C}^{12} \mathrm{HBr}^{81}$ & 4. 728 & $3,1,2 \leftarrow 2,1,1$ & Ground & & $5 / 2$ & & $3 / 2$ & 24. 397.25 & \\
\hline $\mathrm{C}^{12} \mathrm{H}_{2}: \mathrm{C}^{12} \mathrm{HBr}^{81}$ & 4- 728 & $3,1,2 \leftarrow 2,1,1$ & Ground & & $7 / 2$ & & $5 / 2$ & 24397.25 & \\
\hline $\mathrm{C}^{\mathrm{b}} \mathrm{H}_{2}: \mathrm{C}^{\mathrm{b}} \mathrm{HBr}^{\mathrm{b}}$ & 4- 752 & Not Reported & Ground & & $7 / 2$ & & $5 / 2$ & 24397.3 & \\
\hline $\mathrm{Si}^{28} \mathrm{H}_{3} \mathrm{~N}^{14} \mathrm{C}^{12} \mathrm{~S}^{32}$ & 4- 491 & $8,1 \leftarrow 7,1$ & Excited & & & & & 24399.00 & \\
\hline $\mathrm{Ga}^{71} \mathrm{Br}^{79}$ & 1 - & $5 \leftarrow 4$ & Ground & $9 / 2$ & 4 & $7 / 2$ & 3 & 24399.00 & 0.20 \\
\hline $\mathrm{Ga}^{71} \mathrm{Br}^{79}$ & $1-$ & $5 \leftarrow 4$ & Ground & $11 / 2$ & 5 & $9 / 2$ & 4 & 24399.00 & 0.20 \\
\hline $\mathrm{Ga}^{71} \mathrm{Br}^{79}$ & $1-$ & $5 \leftarrow 4$ & Ground & $11 / 2$ & 7 & $9 / 2$ & 6 & 24399.00 & 0.20 \\
\hline $\mathrm{Ga}^{71} \mathrm{Br}^{79}$ & $1-$ & $5 \leftarrow 4$ & Ground & $7 / 2$ & 4 & $5 / 2$ & 3 & 24. 399.00 & 0.20 \\
\hline $\mathrm{Ga}^{71} \mathrm{Br}^{79}$ & $1-$ & $5 \leftarrow 4$ & Ground & $7 / 2$ & 2 & $5 / 2$ & 1 & 24399.00 & 0.20 \\
\hline $\mathrm{Ga}^{71} \mathrm{Br}^{79}$ & $1-$ & $5 \leftarrow 4$ & Ground & $9 / 2$ & 6 & $7 / 2$ & 5 & 24399.00 & 0.20 \\
\hline $\mathrm{Ga}^{71} \mathrm{Br}^{79}$ & $1-$ & $5 \leftarrow 4$ & Ground & $11 / 2$ & 6 & $9 / 2$ & 5 & 24399.00 & 0.20 \\
\hline $\mathrm{Ga}^{71} \mathrm{Br}^{79}$ & $1-$ & $5 \leftarrow 4$ & Ground & $13 / 2$ & 8 & $11 / 2$ & 7 & 24399.00 & 0.20 \\
\hline $\mathrm{Ga}^{71} \mathrm{Br}^{79}$ & $1-$ & $5 \leftarrow 4$ & Ground & $13 / 2$ & 7 & $11 / 2$ & 6 & 24399.00 & 0.20 \\
\hline $\mathrm{Ga}^{71} \mathrm{Br}^{79}$ & $1-$ & $5 \leftarrow 4$ & Ground & $13 / 2$ & 5 & $11 / 2$ & 4 & 24399.00 & 0.20 \\
\hline $\mathrm{Ga}^{71} \mathrm{Br}^{79}$ & $1-$ & $5 \leftarrow 4$ & Ground & $13 / 2$ & 6 & $11 / 2$ & 5 & 24399.00 & 0.20 \\
\hline $\mathrm{Ga}^{71} \mathrm{Br}^{79}$ & 1. & $5 \leftarrow 4$ & Ground & $11 / 2$ & 4 & $9 / 2$ & 3 & 24399.00 & 0.20 \\
\hline $\mathrm{Ga}^{71} \mathrm{Br}^{79}$ & 1 . & $5 \leftarrow 4$ & Ground & $7 / 2$ & 3 & $5 / 2$ & 2 & 24399.00 & 0.20 \\
\hline $\mathrm{Ga}^{71} \mathrm{Br}^{79}$ & 1. & $5 \leftarrow 4$ & Ground & $9 / 2$ & 5 & $7 / 2$ & 4 & 24.399 .00 & 0.20 \\
\hline $\mathrm{Ga}^{71} \mathrm{Br}^{79}$ & 1 - & $5 \leftarrow 4$ & Ground & $9 / 2$ & 3 & $7 / 2$ & 2 & 24.399 .00 & 0.20 \\
\hline $\mathrm{C}^{12}{ }_{*} \mathrm{H}: \mathrm{C}^{12} \mathrm{HO}^{16} \mathrm{C}^{12} \mathrm{H}: \mathrm{C}^{12}{ }_{*} \mathrm{H}$ & 4-1151 & $10,9,2 \leftarrow 10,7,3$ & Ground & & & & & 24. 399.77 & \\
\hline $\mathrm{C}_{*}^{\mathrm{b}} \mathrm{H}_{2}^{\mathrm{b}} \mathrm{N}^{\mathrm{b}} \mathrm{H}^{\mathrm{b}} \mathrm{C}^{\mathrm{b}}{ }_{*} \mathrm{H}_{2}^{\mathrm{b}}$ & 4- 863 & Not Reported & & & & & & 24.400 & 10. \\
\hline $\mathrm{O}^{16} \mathrm{C}^{12} \mathrm{~S}^{32}$ & 4- 521 & $2 \leftarrow 1$ & Excited & & & & & 24.401 .0 & \\
\hline $\mathrm{Si}^{28} \mathrm{H}_{3} \mathrm{~N}^{14} \mathrm{C}^{12} \mathrm{~S}^{32}$ & 4. 491 & $8,7 \leftarrow 7,7$ & Excited & & & & & 24.401 .33 & \\
\hline $\mathrm{C}^{12}{ }_{*} \mathrm{H}: \mathrm{C}^{12} \mathrm{HO}^{16} \mathrm{C}^{12} \mathrm{H}: \mathrm{C}^{12}{ }_{*} \mathrm{D}$ & 4-1155 & $5,5,1 \leftarrow 5,3,2$ & Ground & & & & & 24.401 .7 & \\
\hline $\mathrm{Tl}^{205} \mathrm{I}^{127}$ & $1-$ & $15 \leftarrow 14$ & Ground & & $29 / 2$ & & $27 / 2$ & 24.402 .36 & 0.10 \\
\hline $\mathrm{T} \mathrm{I}^{205} \mathrm{I}^{127}$ & 1. & $15 \leftarrow 14$ & Ground & & $25 / 2$ & & $23 / 2$ & 24.402 .36 & 0.10 \\
\hline $\mathrm{Tl}^{205} \mathrm{I}^{127}$ & 1 . & $15 \leftarrow 14$ & Ground & & $27 / 2$ & & $25 / 2$ & 24.402 .36 & 0.10 \\
\hline $\mathrm{T} l^{205} \mathrm{I}^{127}$ & 1. & $15 \leftarrow 14$ & Ground & & $31 / 2$ & & $29 / 2$ & 24.403 .14 & 0.10 \\
\hline$T l^{205} \mathrm{I}^{127}$ & $1-$ & $15 \leftarrow 14$ & Ground & & $35 / 2$ & & $33 / 2$ & 24.403 .14 & 0.10 \\
\hline $\mathrm{Tl}^{205} \mathrm{I}^{127}$ & 1. & $15 \leftarrow 14$ & Ground & & $33 / 2$ & & $31 / 2$ & 24.403 .14 & 0.10 \\
\hline $\mathrm{H}_{2} \mathrm{C}^{12}: \mathrm{C}^{12} \mathrm{Cl}_{2}^{\mathrm{b}}$ & 4. 663 & Not Reported & Ground & & & & & 24.403 .2 & 1. \\
\hline $\mathrm{Tl}^{205} \mathrm{I}^{127}$ & 1. & $15 \leftarrow 14$ & Ground & & $35 / 2$ & & $33 / 2$ & 24.403 .20 & 0.10 \\
\hline $\mathrm{Si}^{28} \mathrm{H}_{3} \mathrm{~N}^{14} \mathrm{C}^{12} \mathrm{~S}^{32}$ & 4- 491 & $8,4 \leftarrow 7,4$ & Excited & & & & & 24403.55 & \\
\hline $\left.\mathrm{C}^{12} \mathrm{DHCl}\right]^{35} \mathrm{Cl}^{37}$ & 4- 345 & $2,1,1 \leftarrow 2,0,2$ & Ground & & & & & 24405 & 5. \\
\hline $\mathrm{C}^{12} \mathrm{DH}_{2} \mathrm{C}^{12} \mathrm{HDF}^{19}$ & 3- 562 & $7,1,7 \leftarrow 6,2,4$ & Ground & & & & & 24405.0 & .1 \\
\hline $\mathrm{S}^{32} \mathrm{C}^{12} \mathrm{Se}^{78}$ & 4- 563 & $6 \leftarrow 5$ & Excited & & & & & 24406 & 4. \\
\hline $\mathrm{Si}^{28} \mathrm{H}_{3} \mathrm{~N}^{14} \mathrm{C}^{12} \mathrm{~S}^{32}$ & 4- 491 & $8,6 \leftarrow 7,6$ & Excited & & & & & 24406.83 & \\
\hline $\mathrm{C}^{12} \mathrm{H}_{3} \mathrm{C}^{12} \mathrm{HF}_{2}^{19}$ & 3- 461 & $8,7,2 \leftarrow 8,5,3$ & Ground & & & & & 24.408 .7 & \\
\hline
\end{tabular}




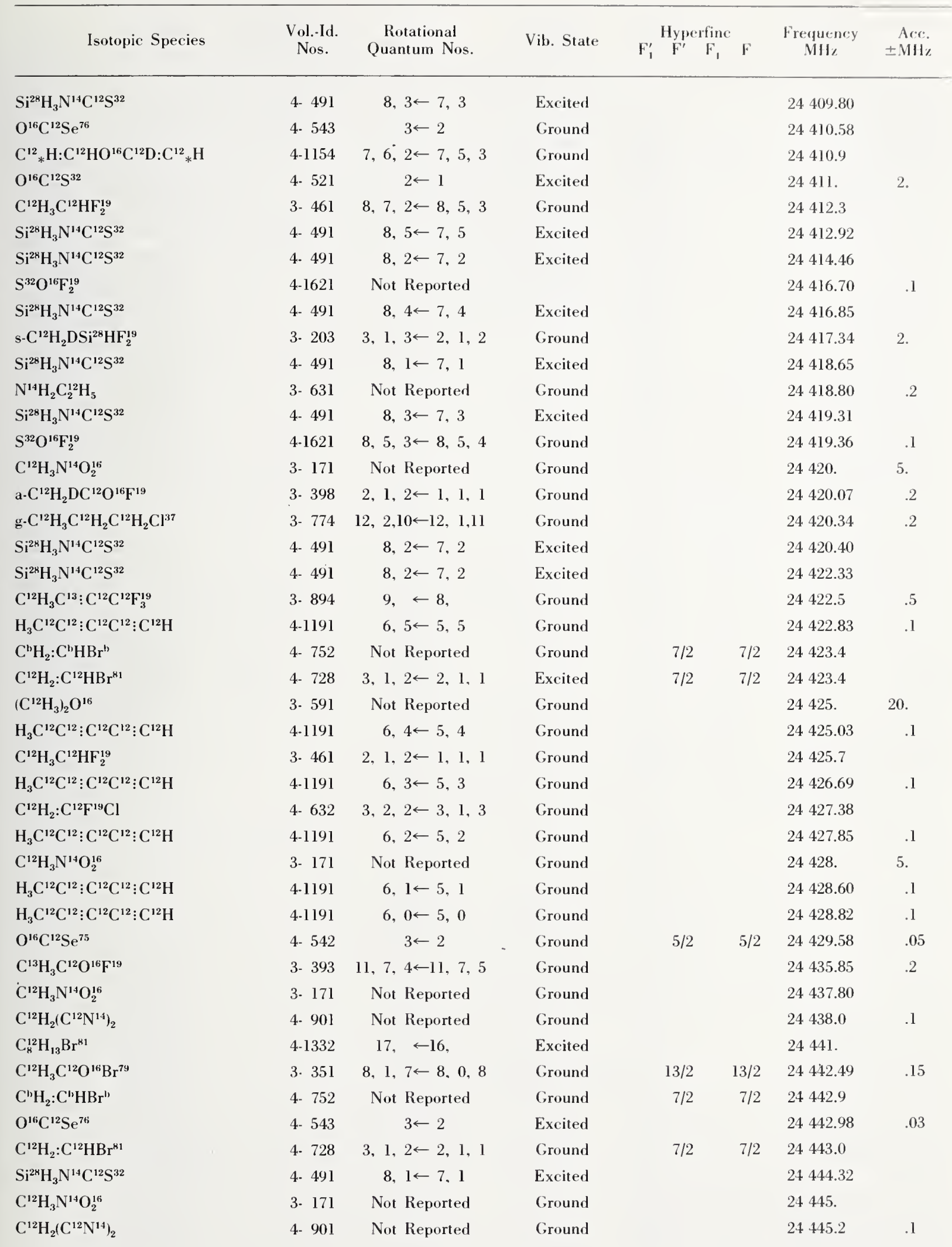




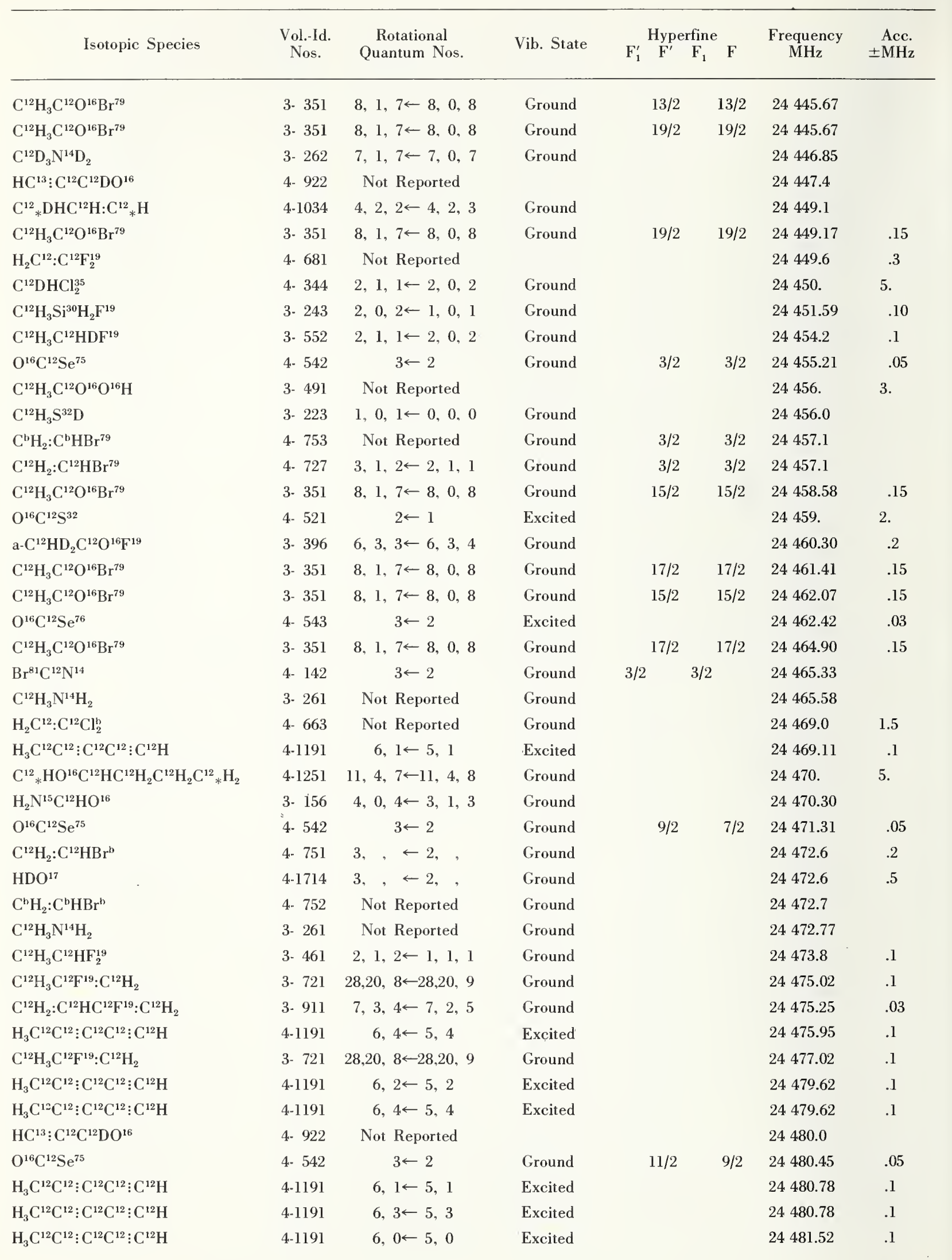




\begin{tabular}{|c|c|c|c|c|c|c|c|c|c|}
\hline \multirow{2}{*}{ Isotopic Species } & \multirow{2}{*}{$\begin{array}{l}\text { Vol.-Id. } \\
\text { Nos. }\end{array}$} & \multirow{2}{*}{$\begin{array}{c}\text { Rotational } \\
\text { Quantum Nos. }\end{array}$} & \multirow{2}{*}{ Vib. State } & \multicolumn{4}{|c|}{ Hyperfine } & \multirow{2}{*}{$\begin{array}{c}\text { Frequency } \\
\text { MHz }\end{array}$} & \multirow{2}{*}{$\begin{aligned} & \text { Are. } \\
& \pm \mathrm{MH} \%\end{aligned}$} \\
\hline & & & & $\mathrm{F}_{1}^{\prime}$ & & & $\mathrm{F}$ & & \\
\hline $\mathrm{H}_{3} \mathrm{C}^{12} \mathrm{C}^{12}: \mathrm{C}^{12} \mathrm{C}^{12}: \mathrm{C}^{12} \mathrm{H}$ & 4-1191 & $6,2 \leftarrow 5,2$ & Excited & & & & & 24.481 .52 & .1 \\
\hline $\mathrm{C}^{12} \mathrm{H}_{2}: \mathrm{C}^{12} \mathrm{HBr}^{79}$ & 4. 727 & $3,1,2 \leftarrow 2,1,1$ & Excited & & $5 / 2$ & & $5 / 2$ & 24483.0 & \\
\hline $\mathrm{Ga}^{69} \mathrm{Br}^{\mathrm{\gamma 1}}$ & $1-$ & $5 \leftarrow 4$ & Ground & $7 / 2$ & 5 & $5 / 2$ & 4 & 24. 483.58 & 0.20 \\
\hline $\mathrm{C}^{12}{ }_{*} \mathrm{H}_{2} \mathrm{C}^{12} \mathrm{H}_{2} \mathrm{C}^{12} \mathrm{H}_{2} \mathrm{C}^{12} \mathrm{H}_{2} \mathrm{C}^{12}{ }_{*} \mathrm{O}^{16}$ & 4-1241 & $55,18,37 \leftarrow 55,18,38$ & Ground & & & & & 24,484 & 5. \\
\hline $\mathrm{F}_{2}^{19} \mathrm{O}_{2}^{16}$ & 3- 11 & $1,1,1 \leftarrow 0,0,0$ & Excited & & & & & 24.484 .06 & .1 \\
\hline $\mathrm{C}^{12} \mathrm{H}_{3} \mathrm{Si}^{29} \mathrm{H}_{2} \mathrm{~F}^{19}$ & 3- 242 & $2,0,2 \leftarrow 1,0,1$ & Ground & & & & & 24.484 .70 & .10 \\
\hline $\mathrm{C}^{12} \mathrm{H}_{3} \mathrm{C}^{12}{ }_{*} \mathrm{HO}^{16} \mathrm{C}^{12}{ }_{*} \mathrm{H}_{2}$ & 3. 761 & $22,14, \leftarrow 23,13$, & Ground & & & & & 24.484 .77 & .1 \\
\hline $\mathrm{C}^{12} \mathrm{H}_{3} \mathrm{~S}^{32} \mathrm{H}$ & 3. 221 & Not Reported & Ground & & & & & 24.485 .0 & .1 \\
\hline $\mathrm{C}^{12} \mathrm{H}_{2} \mathrm{Cl}^{37} \mathrm{Si}^{28} \mathrm{H}_{3}$ & 3. 232 & $4,1,3 \leftarrow 3,1,2$ & Ground & & & & & 24485.10 & .2 \\
\hline $\mathrm{C}^{13} \mathrm{H}_{2} \mathrm{Cl}^{35} \mathrm{Si}^{2 \times} \mathrm{H}_{3}$ & 3. 233 & $4,0,4 \leftarrow 3,0,3$ & Ground & & & & & 24485.55 & .05 \\
\hline $\mathrm{C}^{12} \mathrm{H}_{3} \mathrm{C}^{12}{ }_{*} \mathrm{HO}^{16} \mathrm{C}^{12}{ }_{*} \mathrm{H}_{2}$ & 3. 761 & $22,14, \quad \leftarrow 23,13$ & Ground & & & & & 24485.56 & .1 \\
\hline $\mathrm{Ga}^{69} \mathrm{Br}^{\mathrm{N1}}$ & 1 & $5 \leftarrow 4$ & Ground & $9 / 2$ & 5 & $7 / 2$ & 4 & 24486.56 & 0.20 \\
\hline $\mathrm{Ga}^{69} \mathrm{Br}^{\mathrm{K1}}$ & 1 & $5 \leftarrow 4$ & Ground & $9 / 2$ & 4 & $7 / 2$ & 3 & 24486.56 & 0.20 \\
\hline $\mathrm{Ga}^{69} \mathrm{Br}^{81}$ & $1-$ & $5 \leftarrow 4$ & Ground & $9 / 2$ & 3 & $7 / 2$ & 2 & 24486.56 & 0.20 \\
\hline$G a^{69} \mathrm{Br}^{\mathrm{H1}}$ & 1 & $5 \leftarrow 4$ & Ground & $7 / 2$ & 4 & $5 / 2$ & 3 & 24486.56 & 0.20 \\
\hline $\mathrm{Ga}^{69} \mathrm{Br}^{\mathrm{K1}}$ & $1-$ & $5 \leftarrow 4$ & Ground & $7 / 2$ & 3 & $5 / 2$ & 2 & 24486.56 & 0.20 \\
\hline $\mathrm{Ga}^{69} \mathrm{Br}^{\mathrm{k1}}$ & 1 - & $5 \leftarrow 4$ & Ground & $7 / 2$ & 2 & $5 / 2$ & 1 & 24486.56 & 0.20 \\
\hline $\mathrm{Ga}^{69} \mathrm{Br}^{81}$ & $1-$ & $5 \leftarrow 4$ & Ground & $11 / 2$ & 4 & $9 / 2$ & 3 & 24486.56 & 0.20 \\
\hline $\mathrm{Ga}^{69} \mathrm{Br}^{81}$ & $1-$ & $5 \leftarrow 4$ & Ground & $9 / 2$ & 6 & $7 / 2$ & 5 & 24.486 .56 & 0.20 \\
\hline $\mathrm{Ga}^{69} \mathrm{Br}^{81}$ & 1 - & $5 \leftarrow 4$ & Ground & $13 / 2$ & 6 & $11 / 2$ & 5 & 24486.56 & 0.20 \\
\hline $\mathrm{Ga}^{69} \mathrm{Br}^{81}$ & 1 . & $5 \leftarrow 4$ & Ground & $13 / 2$ & 5 & $11 / 2$ & 4 & 24486.56 & 0.20 \\
\hline $\mathrm{Ga}^{69} \mathrm{Br}^{81}$ & 1 - & $5 \leftarrow 4$ & Ground & $11 / 2$ & 7 & $9 / 2$ & 6 & 24486.56 & 0.20 \\
\hline $\mathrm{Ga}^{69} \mathrm{Br}^{81}$ & $1-$ & $5 \leftarrow 4$ & Ground & $11 / 2$ & 6 & $9 / 2$ & 5 & 24486.56 & 0.20 \\
\hline $\mathrm{Ga}^{69} \mathrm{Br}^{81}$ & 1 . & $5 \leftarrow 4$ & Ground & $11 / 2$ & 5 & $9 / 2$ & 4 & 24486.56 & 0.20 \\
\hline $\mathrm{Ga}^{69} \mathrm{Br}^{81}$ & $1-$ & $5 \leftarrow 4$ & Ground & $13 / 2$ & 8 & $11 / 2$ & 7 & 24486.56 & 0.20 \\
\hline $\mathrm{Ga}^{69} \mathrm{Br}^{81}$ & $1-$ & $5 \leftarrow 4$ & Ground & $13 / 2$ & 7 & $11 / 2$ & 6 & 24486.56 & 0.20 \\
\hline $\mathrm{C}^{12} \mathrm{D}_{3} \mathrm{~N}^{14} \mathrm{D}_{2}$ & 3- 262 & $4,1,3 \leftarrow 3,2,2$ & Ground & & & & & 24489.58 & \\
\hline $\mathrm{s}-\mathrm{C}^{12} \mathrm{HD}_{2} \mathrm{C}^{12} \mathrm{O}^{16} \mathrm{~F}^{19}$ & 3- 395 & $9,5,4 \leftarrow 9,5,5$ & Ground & & & & & 24.490 .4 & .2 \\
\hline $\mathrm{C}^{12} \mathrm{H}_{2}\left(\mathrm{C}^{12} \mathrm{~N}^{14}\right)_{2}$ & 4- 901 & Not Reported & Ground & & & & & 24.490 .9 & .1 \\
\hline $\mathrm{H}_{2} \mathrm{C}^{12}: \mathrm{C}^{12} \mathrm{Cl}_{2}^{1,}$ & 4- 663 & Not Reported & Ground & & & & & 24.491 .2 & .5 \\
\hline $\mathrm{C}^{12} \mathrm{H}_{3} \mathrm{Si}^{28} \mathrm{H}_{2} \mathrm{~F}^{19}$ & 3- 241 & $2,0,2 \leftarrow 1,0,1$ & Ground & & & & & 24.492 .10 & .10 \\
\hline $\mathrm{C}^{h \prime} \mathrm{H}_{2}: \mathrm{C}^{\prime \prime} \mathrm{HBr}^{\mathrm{h}}$ & 4. 752 & Not Reported & Excited & & $9 / 2$ & & $7 / 2$ & 24.492 .4 & \\
\hline $\mathrm{C}^{12} \mathrm{H}_{2}: \mathrm{C}^{12} \mathrm{HBr}^{79}$ & 4. 727 & $3,1,2 \leftarrow 2,1,1$ & Excited & & $3 / 2$ & & $1 / 2$ & 24492.55 & \\
\hline $\mathrm{C}^{12} \mathrm{H}_{2}: \mathrm{C}^{12} \mathrm{HBr}^{79}$ & 4. 727 & $3,1,2 \leftarrow 2,1,1$ & Excited & & $9 / 2$ & & $7 / 2$ & 24492.55 & \\
\hline $\mathrm{C}^{12} \mathrm{D}_{3} \mathrm{I}^{127}$ & 4- 482 & $2,1 \leftarrow 1,1$ & Ground & & $1 / 2$ & & $3 / 2$ & 24493.36 & .08 \\
\hline $\mathrm{H}_{3} \mathrm{C}^{12} \mathrm{C}^{12}: \mathrm{C}^{12} \mathrm{C}^{12}: \mathrm{C}^{12} \mathrm{H}$ & 4-1191 & $6,1 \leftarrow 5,1$ & Excited & & & & & 24.494 .38 & .1 \\
\hline $\mathrm{C}^{12} \mathrm{D}_{2} \mathrm{Cl}^{35} \mathrm{Si}^{2 \mathrm{~K}} \mathrm{H}_{3}$ & 3- 235 & $10,1,9 \leftarrow 10,0,10$ & Ground & & & & & 24495.28 & .2 \\
\hline c. $\mathrm{C}^{12} \mathrm{H}_{3} \mathrm{C}^{12} \mathrm{H}: \mathrm{C}^{12} \mathrm{HF}^{19} \cdot \mathrm{E}$ & 3- 702 & $5,1,4 \leftarrow 5,0,5$ & & & & & & 24498.38 & .2 \\
\hline $\mathrm{C}^{\prime \prime} \mathrm{H}_{2}: \mathrm{C}^{\prime \prime} \mathrm{HBr}$ & 4- 752 & Not Reported & Ground & & & & & 24500.0 & .3 \\
\hline $\mathrm{C}^{12} \mathrm{H}_{3} \mathrm{Si}^{2 \times} \mathrm{H}_{2} \mathrm{~F}^{19}$ & 3- 241 & $2,0,2 \leftarrow 1,0,1$ & Ground & & & & & 24500.10 & .10 \\
\hline $\mathrm{C}^{13}{ }_{*} \mathrm{H}: \mathrm{C}^{12} \mathrm{HO}^{16} \mathrm{C}^{12} \mathrm{H}: \mathrm{C}^{12}{ }_{*} \mathrm{H}$ & 4.1157 & $8,7,2 \leftarrow 8,5,3$ & Ground & & & & & 24501.3 & .1 \\
\hline $\mathrm{C}^{12} \mathrm{H}_{2}: \mathrm{C}^{12} \mathrm{HBr}^{79}$ & 4- 727 & $3,1,2 \leftarrow 2,1,1$ & Ground & & $5 / 2$ & & $5 / 2$ & 24502.3 & \\
\hline $\mathrm{C}^{h)} \mathrm{H}_{2}: \mathrm{C}^{h} \mathrm{HBr}^{h}$ & 4- 752 & Not Reported & Ground & & $5 / 2$ & & $5 / 2$ & 24502.4 & \\
\hline $\mathrm{C}^{12} \mathrm{H}_{3} \mathrm{~N}^{14} \mathrm{O}_{2}^{16}$ & 3- 171 & Not Reported & Ground & & & & & 24506 & 5. \\
\hline $\mathrm{Br}^{81} \mathrm{C}^{12} \mathrm{~N}^{14}$ & 4. 142 & $3 \leftarrow 2$ & Excited & $9 / 2$ & & $7 / 2$ & & 24.506 .75 & \\
\hline
\end{tabular}




\begin{tabular}{|c|c|c|c|c|c|c|c|c|}
\hline Isotopic Species & $\begin{array}{l}\text { Vol.-Id. } \\
\text { Nos. }\end{array}$ & $\begin{array}{c}\text { Rotational" } \\
\text { Quantum Nos. }\end{array}$ & Vib. State & $\mathrm{F}_{1}^{\prime}$ & $\begin{array}{l}\text { Hyper } \\
\mathrm{F}^{\prime}\end{array}$ & $\mathrm{rfine}_{1} \mathrm{~F}$ & $\begin{array}{c}\text { Frequency } \\
\mathrm{MHz}\end{array}$ & $\begin{aligned} & \text { Acc. } \\
\pm & \mathrm{MHz}\end{aligned}$ \\
\hline $\mathrm{Br}^{81} \mathrm{C}^{12} \mathrm{~N}^{14}$ & 4- 142 & $3 \leftarrow 2$ & Excited & $7 / 2$ & & $5 / 2$ & 24506.75 & \\
\hline $\mathrm{Si}^{28} \mathrm{D}_{3} \mathrm{~F}^{19}$ & 4-1554 & $1, \leftarrow 0$ & Ground & & & & 24507.0 & .1 \\
\hline $\mathrm{C}^{12} \mathrm{H}_{2}\left(\mathrm{C}^{12} \mathrm{~N}^{14}\right)_{2}$ & 4. 901 & Not Reported & Ground & & & & 24.507 .3 & .1 \\
\hline $\mathrm{Br}^{81} \mathrm{C}^{12} \mathrm{~N}^{14}$ & 4- 142 & $3 \leftarrow 2$ & Ground & $5 / 2$ & & $5 / 2$ & 24.507 .38 & \\
\hline $\mathrm{C}^{12}{ }_{*} \mathrm{D}: \mathrm{C}^{12} \mathrm{DC}^{12} \mathrm{D}: \mathrm{C}^{12} \mathrm{DN}^{14}{ }_{*} \mathrm{H}$ & 4-1185 & $10,10,1 \leftarrow 10,9,2$ & Ground & & & & 24. 507.5 & \\
\hline $\mathrm{S}^{32} \mathrm{C}^{12} \mathrm{Se}^{77}$ & 4. 564 & $6 \leftarrow 5$ & Ground & & & & 24508. & 4. \\
\hline $\mathrm{C}^{12} \mathrm{H}_{2} \mathrm{Cl}^{37} \mathrm{C}^{12}: \mathrm{C}^{12} \mathrm{H}$ & 4- 992 & $6,1,5 \leftarrow 6,0,6$ & Ground & & & & 24508.91 & \\
\hline $\mathrm{C}_{6}^{12} \mathrm{H}_{5} \mathrm{C}^{12} \mathrm{~N}^{14}$ & 4-1291 & $9,2,8 \leftarrow 8,2,7$ & Ground & & & & 24.509 .3 & \\
\hline $\mathrm{Sb}^{123} \mathrm{Cl}_{3}^{35}$ & 4-1542 & $7, \leftarrow 6$, & Ground & & & & 24510 & 10.0 \\
\hline $\mathrm{C}^{12}{ }_{*} \mathrm{H}_{2} \mathrm{C}^{12} \mathrm{H}_{2} \mathrm{C}^{12} \mathrm{H}_{2} \mathrm{C}^{12} \mathrm{H}_{2} \mathrm{C}^{12} \mathrm{O}^{16}$ & 4-1241 & $4,1,3 \leftarrow 3,1.2$ & Ground & & & & 24510.9 & \\
\hline $\mathrm{C}^{12} \mathrm{H}_{2}: \mathrm{C}^{12} \mathrm{HBr}^{79}$ & 4. 727 & $3,1,2 \leftarrow 2,1,1$ & Ground & & $3 / 2$ & $1 /$ & 24511.95 & \\
\hline $\mathrm{C}^{12} \mathrm{H}_{2}: \mathrm{C}^{12} \mathrm{HBr}^{79}$ & 4- 727 & $3,1,2 \leftarrow 2,1,1$ & Ground & & $9 / 2$ & $7 /$ & 24511.95 & \\
\hline $\mathrm{C}^{\mathrm{b}} \mathrm{H}_{2}: \mathrm{C}^{\mathrm{b}} \mathrm{HBr}^{\mathrm{b}}$ & 4- 752 & Not Reported & Ground & & $9 / 2$ & $7 /$ & 24512.0 & \\
\hline$F_{2}^{19} N^{14} N^{14} F_{2}^{19}$ & 3. 21 & $15,5,10 \leftarrow 15,4,12$ & Ground & & & & 24512.5 & .3 \\
\hline $\mathrm{C}^{12} \mathrm{H}_{2}: \mathrm{C}^{12} \mathrm{HC}^{12} \mathrm{~F}^{19}: \mathrm{C}^{12} \mathrm{H}_{2}$ & 3- 911 & $9,3,6 \leftarrow 9,2,7$ & Ground & & & & 24512.80 & .03 \\
\hline $\mathrm{O}^{16} \mathrm{C}^{12} \mathrm{Se}^{74}$ & 4- 541 & $3 \leftarrow 2$ & Ground & & & & 24.514 .67 & .03 \\
\hline g- $\mathrm{C}^{12} \mathrm{H}_{3} \mathrm{C}^{12} \mathrm{H}_{2} \mathrm{C}^{12} \mathrm{H}_{2} \mathrm{Cl}^{35}$ & 3- 773 & $4,0,4 \leftarrow 3,0,3$ & Ground & & & & 24514.76 & .2 \\
\hline $\mathrm{c}-\mathrm{C}^{12} \mathrm{H}_{3} \mathrm{C}^{12} \mathrm{H}: \mathrm{C}^{12} \mathrm{HF}^{19} \cdot \mathrm{A}$ & 3. 701 & $5,1,4 \leftarrow 5,0,5$ & & & & & 24515.44 & .2 \\
\hline $\mathrm{O}^{16} \mathrm{C}^{12} \mathrm{Se}^{75}$ & 4- 542 & $3 \leftarrow 2$ & Ground & & $7 / 2$ & $5 /$ & 24517.93 & .05 \\
\hline $\mathrm{C}^{12} \mathrm{H}_{3} \mathrm{Si}^{28} \mathrm{H}_{2} \mathrm{~F}^{19}$ & 3- 241 & $2,0,2 \leftarrow 1,0,1$ & Ground & & & & 24519.10 & .10 \\
\hline $\mathrm{C}^{12} \mathrm{H}_{3} \mathrm{~N}^{11} \mathrm{H}_{2}$ & 3- 261 & Not Reported & Ground & & & & 24520.75 & .1 \\
\hline $\mathrm{S}^{32} \mathrm{C}^{12} \mathrm{Se}^{77}$ & 4- 564 & $6 \leftarrow 5$ & Excited & & & & 24521. & 4. \\
\hline $\mathrm{HC}^{12} \mathrm{O}^{16} \mathrm{O}^{16} \mathrm{C}^{12} \mathrm{D}_{3}-\mathrm{A}$ & 3- 507 & $5,1,4 \leftarrow 5,0,5$ & Ground & & & & 24521.48 & .2 \\
\hline $\mathrm{C}^{12} \mathrm{H}_{2}: \mathrm{C}^{12} \mathrm{HBr}^{79}$ & 4- 727 & $3,1,2 \leftarrow 2,1,1$ & Excited & & $7 / 2$ & $5 /$ & 24521.5 & \\
\hline $\mathrm{C}^{12} \mathrm{H}_{2}: \mathrm{C}^{12} \mathrm{HBr}^{79}$ & 4. 727 & $3,1,2 \leftarrow 2,1,1$ & Excited & & $5 / 2$ & $3 / 2$ & 24521.5 & \\
\hline $\mathrm{C}^{\mathrm{b}} \mathrm{H}_{2}: \mathrm{C}^{\mathrm{h}} \mathrm{HBr}^{\mathrm{b}}$ & 4- 752 & Not Reported & Excited & & $7 / 2$ & $5 /$ & 24521.6 & \\
\hline $\mathrm{C}^{12} \mathrm{H}_{2}: \mathrm{C}^{12} \mathrm{HBr}^{79}$ & 4. 727 & $3,1,2 \leftarrow 2,1,1$ & Ground & & & & 24524.28 & .05 \\
\hline $\mathrm{S}^{32} \mathrm{C}^{12} \mathrm{Se}^{77}$ & 4- 564 & $6 \leftarrow 5$ & Excited & & & & 24527 . & 4. \\
\hline $\mathrm{C}^{b} \mathrm{H}_{2}: \mathrm{C}^{\mathrm{l}} \mathrm{HBr}^{\mathrm{b}}$ & 4- 752 & Not Reported & Ground & & & & 24528.6 & \\
\hline $\mathrm{C}^{12} \mathrm{H}_{2}: \mathrm{C}^{12} \mathrm{HBr}^{\mathrm{b}}$ & 4- 751 & $3, \quad \leftarrow 2$, & Ground & & & & 24528.8 & .2 \\
\hline $\mathrm{HDO}^{17}$ & 4-1714 & $3, \quad \leftarrow 2$, & Ground & & & & 24528.8 & .5 \\
\hline $\mathrm{C}^{12} \mathrm{D}_{3} \mathrm{~N}^{14} \mathrm{D}_{2}$ & 3- 262 & $7,1,7 \leftarrow 7,0,7$ & Ground & & & & 24531.04 & \\
\hline $\mathrm{C}^{12}{ }_{*} \mathrm{D}_{2} \mathrm{C}^{12} \mathrm{H}_{2} \mathrm{C}^{12} \mathrm{D}_{2} \mathrm{O}^{16} *$ & 4-1092 & $5,4,2 \leftarrow 5,3,3$ & Excited & & & & 24531.6 & .1 \\
\hline $\mathrm{HC}^{13}: \mathrm{C}^{12} \mathrm{C}^{12} \mathrm{DO}^{16}$ & 4. 922 & Not Reported & & & & & 24532 . & 5. \\
\hline $\mathrm{N}^{14} \mathrm{H}_{3}$ & $4 \cdot 1771$ & $5,5 \leftarrow 5,5$ & Ground & & & & 24532.98 & .02 \\
\hline $\mathrm{C}^{\mathrm{b}} \mathrm{H}_{2}: \mathrm{C}^{\mathrm{s}} \mathrm{HBr}^{\mathrm{l}}$ & 4- 752 & Not Reported & Ground & & & & 24533.1 & \\
\hline $\mathrm{O}^{16} \mathrm{~F}_{2}^{19}$ & 4-1611 & $15,2,14 \leftarrow 14,3,11$ & Ground & & & & 24533.39 & .10 \\
\hline $\mathrm{C}^{12} \mathrm{H}_{3} \mathrm{O}^{16} \mathrm{H}$ & 3- 211 & Not Reported & Ground & & & & 24533.7 & .1 \\
\hline $4 \mathrm{~d} \cdot \mathrm{C}_{6}^{12} \mathrm{H}_{5} \mathrm{~F}^{19}$ & $4 \cdot 1283$ & $6,2,5 \leftarrow 5,2,4$ & Ground & & & & 24535.6 & .1 \\
\hline $\mathrm{As}^{75} \mathrm{Cl}_{3}^{37}$ & 4. 14 & $6, \leftarrow 5$, & Ground & & & & 24536. & 2. \\
\hline $\mathrm{C}^{12} \mathrm{H}_{3} \mathrm{C}^{12}{ }_{*} \mathrm{HO}^{16} \mathrm{C}^{12}{ }_{*} \mathrm{H}_{2}$ & 3- 761 & $2,1,2 \leftarrow 1,1,1$ & Ground & & & & 24536.55 & .1 \\
\hline$\left(\mathrm{C}^{12} \mathrm{H}_{3}\right)_{3} \mathrm{C}^{12} \mathrm{Br}^{79}$ & 3- 961 & $6, \leftarrow 5$ & Ground & & & & 24538.1 & .3 \\
\hline $\mathrm{DC}^{12} \mathrm{~N}^{14}$ & 4- 292 & $11 \leftarrow 11$ & Excited & & & & 24538.92 & .05 \\
\hline $\mathrm{C}^{12} \mathrm{D}_{3} \mathrm{C}^{12}: \mathrm{C}^{12} \mathrm{C}^{13} \mathrm{~F}_{3}^{19}$ & 3- 896 & $10, \leftarrow 9$ & Ground & & & & 24539.0 & .5 \\
\hline $\mathrm{C}^{12} \mathrm{H}_{2}\left(\mathrm{C}^{12} \mathrm{~N}^{14}\right)_{2}$ & 4- 901 & Not Reported & Ground & & & & 24539.2 & .1 \\
\hline
\end{tabular}


Vib. State

$F_{1}^{\prime} F^{\prime} F_{1}^{\prime}$

Frequency
MHz

\begin{tabular}{|c|c|c|c|c|c|c|c|c|c|}
\hline $\mathrm{C}^{12} \mathrm{H}_{2} \mathrm{Cl}^{35} \mathrm{Si}^{28} \mathrm{H}_{3}$ & 3- 231 & $4,0,4 \leftarrow 3,0,3$ & Ground & & & & & 24539.45 & .2 \\
\hline $\mathrm{C}^{\mathrm{b}} \mathrm{H}_{2}: \mathrm{C}^{\mathrm{b}} \mathrm{HBr}^{\mathrm{b}}$ & 4- 752 & Not Reported & Ground & & $7 / 2$ & & $5 / 2$ & 24541.1 & \\
\hline $\mathrm{C}^{12} \mathrm{H}_{2}: \mathrm{C}^{12} \mathrm{HBr}^{79}$ & 4. 727 & $3,1,2 \leftarrow 2,1,1$ & Ground & & $7 / 2$ & & $5 / 2$ & 24541.1 & \\
\hline $\mathrm{C}^{12} \mathrm{H}_{2}: \mathrm{C}^{12} \mathrm{HBr}^{79}$ & 4- 727 & $3,1,2 \leftarrow 2,1,1$ & Ground & & $5 / 2$ & & $3 / 2$ & 24541.1 & \\
\hline $\mathrm{Br}^{81} \mathrm{C}^{12} \mathrm{~N}^{14}$ & 4- 142 & $3 \leftarrow 2$ & Excited & $5 / 2$ & & $3 / 2$ & & 24541.18 & \\
\hline $\mathrm{Br}^{81} \mathrm{C}^{12} \mathrm{~N}^{14}$ & 4- 142 & $3 \leftarrow 2$ & Excited & $3 / 2$ & & $1 / 2$ & & 24541.18 & \\
\hline $\mathrm{Cs}^{133} \mathrm{Cl}^{37}$ & $1-$ & $6 \leftarrow 5$ & Excited & & & & & 24541.40 & .50 \\
\hline $\mathrm{H}_{2} \mathrm{C}^{12}: \mathrm{C}^{12} \mathrm{~F}_{2}^{19}$ & 4- 681 & Not Reported & & & & & & 24543.3 & .3 \\
\hline $\mathrm{D}_{2} \mathrm{O}_{2}^{16}$ & $3-\quad 42$ & Not Reported & & & & & & 24545. & 3. \\
\hline $\mathrm{C}^{12}{ }_{*} \mathrm{H}_{2} \mathrm{~N}^{14} \mathrm{DC}^{12}{ }_{*} \mathrm{H}_{2}$ & 4. 862 & $6,6,1 \leftarrow 6,4,2$ & Ground & & & & & 24553.2 & .5 \\
\hline $\mathrm{N}^{15} \mathrm{H}_{3}$ & 4-1772 & $7,7 \leftarrow 7,7$ & Ground & & & & & 24553.42 & .02 \\
\hline $\mathrm{S}^{32} \mathrm{O}^{16} \mathrm{~F}_{2}^{19}$ & $4-1621$ & $7,4,3 \leftarrow 7,4,4$ & Ground & & & & & 24553.93 & .1 \\
\hline $\mathrm{Sb}^{121} \mathrm{Cl}_{3}^{35}$ & $4-1541$ & $7, \leftarrow 6$, & Ground & & & & & 24554 & 10.0 \\
\hline $\mathrm{C}^{12}{ }_{*} \mathrm{H}_{2} \mathrm{~N}^{14} \mathrm{DC}^{12}{ }_{*} \mathrm{H}_{2}$ & 4- 862 & $6,6,1 \leftarrow 6,4,2$ & Ground & & & & & 24.554 .6 & .5 \\
\hline $\mathrm{H}_{2} \mathrm{C}^{12}: \mathrm{C}^{12} \mathrm{Cl}_{2}^{11}$ & 4- 663 & Not Reported & Ground & & & & & 24563.5 & .5 \\
\hline $\mathrm{O}^{16} \mathrm{C}^{12} \mathrm{Se}^{75}$ & 4. 542 & $3 \leftarrow 2$ & Ground & & $5 / 2$ & & $3 / 2$ & 24565.87 & .03 \\
\hline $\mathrm{HC}^{12} \mathrm{O}^{16} \mathrm{O}^{16} \mathrm{H}$ & $3-71$ & $5,1,4 \leftarrow 5,1,5$ & & & & & & 24568.99 & .03 \\
\hline $\mathrm{C}^{12} \mathrm{H}_{3} \mathrm{C}^{12}{ }_{*} \mathrm{HO}^{16} \mathrm{C}^{12}{ }_{*} \mathrm{H}_{2}$ & 3- 761 & $25,12, \quad \leftarrow 24,13$ & Ground & & & & & 24.570 .46 & .1 \\
\hline $\mathrm{C}^{12} \mathrm{H}_{3} \mathrm{C}^{12}{ }_{*} \mathrm{HO}^{16} \mathrm{C}^{12}{ }_{*} \mathrm{H}_{2}$ & 3- 761 & $25,12, \quad \leftarrow 24,13$, & Ground & & & & & 24.571 .27 & .1 \\
\hline $\mathrm{C}^{12} \mathrm{H}_{2}\left(\mathrm{C}^{12} \mathrm{~N}^{14}\right)_{2}$ & 4. 901 & Not Reported & Ground & & & & & 24571.3 & .1 \\
\hline $\mathrm{Br}^{81} \mathrm{C}^{12} \mathrm{~N}^{14}$ & 4- 142 & $3 \leftarrow 2$ & Ground & $7 / 2$ & & $5 / 2$ & & 24573.86 & \\
\hline $\mathrm{Br}^{81} \mathrm{C}^{12} \mathrm{~N}^{14}$ & 4- 142 & $3 \leftarrow 2$ & Ground & $9 / 2$ & & $7 / 2$ & & 24573.86 & \\
\hline $\mathrm{O}^{16} \mathrm{C}^{12} \mathrm{Se}^{74}$ & 4- 541 & $3 \leftarrow 2$ & Ground & & & & & 24574.86 & \\
\hline $\mathrm{Ga}^{69} \mathrm{Br}^{79}$ & 1 - & $5 \leftarrow 4$ & Excited & $7 / 2$ & 2 & $5 / 2$ & 1 & 24576.08 & 0.20 \\
\hline $\mathrm{Ga}^{69} \mathrm{Br}^{79}$ & $1-$ & $5 \leftarrow 4$ & Excited & $7 / 2$ & 3 & $5 / 2$ & 2 & 24576.08 & 0.20 \\
\hline $\mathrm{Ga}^{69} \mathrm{Br}^{79}$ & $1-$ & $5 \leftarrow 4$ & Excited & $7 / 2$ & 4 & $5 / 2$ & 3 & 24576.08 & 0.20 \\
\hline $\mathrm{Ga}^{69} \mathrm{Br}^{79}$ & $1-$ & $5 \leftarrow 4$ & Excited & $9 / 2$ & 3 & $7 / 2$ & 2 & 24576.08 & 0.20 \\
\hline $\mathrm{Ga}^{69} \mathrm{Br}^{79}$ & $1-$ & $5 \leftarrow 4$ & Excited & $9 / 2$ & 4 & $7 / 2$ & 3 & 24576.08 & 0.20 \\
\hline $\mathrm{Ga}^{69} \mathrm{Br}^{79}$ & $1-$ & $5 \leftarrow 4$ & Excited & $9 / 2$ & 5 & $7 / 2$ & 4 & 24576.08 & 0.20 \\
\hline $\mathrm{Ga}^{69} \mathrm{Br}^{79}$ & 1 - & $5 \leftarrow 4$ & Excited & $9 / 2$ & 6 & $7 / 2$ & 5 & 24576.08 & 0.20 \\
\hline $\mathrm{Ga}^{69} \mathrm{Br}^{79}$ & $1-$ & $5 \leftarrow 4$ & Excited & $11 / 2$ & 4 & $9 / 2$ & 3 & 24.576 .08 & 0.20 \\
\hline $\mathrm{Ga}^{69} \mathrm{Br}^{79}$ & 1 - & $5 \leftarrow 4$ & Excited & $11 / 2$ & 5 & $9 / 2$ & 4 & 24576.08 & 0.20 \\
\hline $\mathrm{Ga}^{69} \mathrm{Br}^{79}$ & $1-$ & $5 \leftarrow 4$ & Excited & $11 / 2$ & 6 & $9 / 2$ & 5 & 24576.08 & 0.20 \\
\hline $\mathrm{Ga}^{69} \mathrm{Br}^{79}$ & $1-$ & $5 \leftarrow 4$ & Excited & $11 / 2$ & 7 & $9 / 2$ & 6 & 24576.08 & 0.20 \\
\hline $\mathrm{Ga}^{69} \mathrm{Br}^{79}$ & $1-$ & $5 \leftarrow 4$ & Excited & $13 / 2$ & 5 & $11 / 2$ & 4 & 24576.08 & 0.20 \\
\hline $\mathrm{Ga}^{69} \mathrm{Br}^{79}$ & $1-$ & $5 \leftarrow 4$ & Excited & $13 / 2$ & 6 & $11 / 2$ & 5 & 24576.08 & 0.20 \\
\hline $\mathrm{Ga}^{69} \mathrm{Br}^{79}$ & 1 - & $5 \leftarrow 4$ & Excited & $13 / 2$ & 7 & $11 / 2$ & 6 & 24.576 .08 & 0.20 \\
\hline $\mathrm{Ga}^{69} \mathrm{Br}^{79}$ & $1-$ & $5 \leftarrow 4$ & Excited & $13 / 2$ & 8 & $11 / 2$ & 7 & 24576.08 & 0.20 \\
\hline $\mathrm{HC}^{13}: \mathrm{C}^{12} \mathrm{C}^{12} \mathrm{DO}^{16}$ & 4- 922 & Not Reported & & & & & & 24.578 .6 & \\
\hline $\mathrm{C}^{12} \mathrm{DH}_{2} \mathrm{C}^{12} \mathrm{HDF}^{19}$ & 3- 562 & $2,1,1 \leftarrow 2,0,2$ & Ground & & & & & 24.580 .2 & .1 \\
\hline $\mathrm{H}_{2} \mathrm{C}^{12}: \mathrm{C}^{12} \mathrm{~F}_{2}^{19}$ & 4- 681 & Not Reported & & & & & & 24.581 .4 & .3 \\
\hline $\mathrm{C}^{12} \mathrm{D}_{3} \mathrm{C}^{12}: \mathrm{C}^{12} \mathrm{C}^{12} \mathrm{~F}_{3}^{19}$ & 3- 892 & $10, \leftarrow 9$ & Ground & & & & & 24. 582.8 & .1 \\
\hline $\mathrm{Br}^{79} \mathrm{C}^{12} \mathrm{~N}^{14}$ & 4- 141 & $3 \leftarrow 2$ & Ground & $3 / 2$ & & $3 / 2$ & & 24. 583.00 & \\
\hline $\mathrm{C}^{12} \mathrm{H}_{2}: \mathrm{C}^{12} \mathrm{HC}^{12} \mathrm{~F}^{19}: \mathrm{C}^{12} \mathrm{H}_{2}$ & 3- 911 & $7,3,4 \leftarrow 7,2,5$ & Excited & & & & & 24. 583.80 & .03 \\
\hline $\mathrm{C}^{12} \mathrm{H}_{3} \mathrm{C}^{12} \mathrm{O}^{16} \mathrm{O}^{16} \mathrm{H}$ & 3- 491 & $8,6,2 \leftarrow 8,5,3$ & Ground & & & & & 24.587 .82 & \\
\hline
\end{tabular}




\begin{tabular}{|c|c|c|c|c|c|c|c|c|c|}
\hline \multirow{3}{*}{$\begin{array}{l}\text { Isotopic Species } \\
\mathrm{S}^{32} \mathrm{O}^{16} \mathrm{~F}_{2}^{19}\end{array}$} & \multirow{3}{*}{$\begin{array}{c}\text { Vol.-Id. } \\
\text { Nos. }\end{array}$} & \multirow{3}{*}{$\begin{array}{c}\begin{array}{c}\text { Rotational } \\
\text { Quantum Nos. }\end{array} \\
\text { Not Reported }\end{array}$} & \multirow{2}{*}{ Vib. State } & \multicolumn{4}{|c|}{ Hyperfine } & \multirow{2}{*}{$\begin{array}{c}\text { Frequency } \\
\mathrm{MHz}\end{array}$} & \multirow{2}{*}{$\begin{array}{r}\text { Acc. } \\
\pm \mathrm{MHz}\end{array}$} \\
\hline & & & & $\mathrm{F}_{1}^{\prime}$ & & & $\mathrm{F}$ & & \\
\hline & & & & & & & & 24591.78 & .1 \\
\hline $\mathrm{DC}^{12} \mathrm{O}^{16} \mathrm{O}^{16} \mathrm{C}^{12} \mathrm{H}_{3} \cdot \mathrm{E}$ & 3- 504 & $5,1,4 \leftarrow 5,1,5$ & Ground & & & & & 24591.85 & .35 \\
\hline $\mathrm{C}^{12}{ }_{*} \mathrm{H}_{2} \mathrm{C}^{12} \mathrm{H}_{2} \mathrm{C}^{12} \mathrm{H}_{2} \mathrm{O}^{16} *$ & 4-1091 & $7,5,2 \leftarrow 7,5,3$ & Ground & & & & & 24592. & \\
\hline $\mathrm{C}^{13} \mathrm{H}_{3} \mathrm{Si}^{28} \mathrm{HF}_{2}^{19}-\mathrm{A}$ & 3- 195 & $3,1,3 \leftarrow 2,1,2$ & Ground & & & & & 24592.56 & \\
\hline $\mathrm{C}^{12} \mathrm{H}_{3} \mathrm{~N}^{14} \mathrm{O}_{2}^{16}$ & 3- 171 & Not Reported & Ground & & & & & 24592.85 & \\
\hline $\mathrm{HC}^{12} \mathrm{O}^{16} \mathrm{O}^{16} \mathrm{H}$ & 3- 71 & Not Reported & & & & & & 24595. & 5. \\
\hline $\mathrm{HDC}^{12}: \mathrm{C}^{12} \mathrm{~F}_{2}^{19}$ & 4. 682 & $3,1,2 \leftarrow 3,1,3$ & Ground & & & & & 24595.1 & .3 \\
\hline $\mathrm{C}^{12} \mathrm{D}_{3} \mathrm{~N}^{14} \mathrm{D}_{2}$ & 3. 262 & $7,1,7 \leftarrow 7,0,7$ & Ground & & & & & 24595.38 & \\
\hline $\mathrm{C}^{\prime \prime} \mathrm{H}_{2}: \mathrm{C}^{\prime \prime} \mathrm{HBr}^{\prime \prime}$ & 4. 752 & Not Reported & Ground & & $7 / 2$ & & $7 / 2$ & 24595.7 & \\
\hline $\mathrm{C}^{12} \mathrm{H}_{2}: \mathrm{C}^{12} \mathrm{HBr}^{79}$ & 4- 727 & $3,1,2 \leftarrow 2,1,1$ & Ground & & $7 / 2$ & & $7 / 2$ & 24595.70 & \\
\hline $\mathrm{C}^{12} \mathrm{H}_{3} \mathrm{~N}^{14} \mathrm{O}_{2}^{16}$ & 3- 171 & Not Reported & Ground & & & & & 24599. & 5. \\
\hline $\mathrm{C}^{12} \mathrm{H}_{2}: \mathrm{C}^{12} \mathrm{~F}^{19} \mathrm{Cl}^{35}$ & 4- 631 & $5,1,4 \leftarrow 5,0,5$ & Ground & & & & & 24601.24 & \\
\hline $\mathrm{S}^{32} \mathrm{C}^{12} \mathrm{Se}^{76}$ & 4. 565 & $6 \leftarrow 5$ & Ground & & & & & 24602 & 4. \\
\hline $\mathrm{C}^{12}{ }_{*} \mathrm{HC}^{12} \mathrm{H}: \mathrm{C}^{12} \mathrm{HC}^{12} \mathrm{H}: \mathrm{C}^{12} \mathrm{HN}^{14} *$ & 4-1201 & $16,12,4 \leftarrow 16,12,5$ & Ground & & & & & 24602.0 & .1 \\
\hline $\mathrm{DC}^{12}: \mathrm{C}^{12} \mathrm{C}^{12} \mathrm{~N}^{15}$ & 4- 891 & $3 \leftarrow 2$ & Ground & & & & & 24602.45 & \\
\hline $\mathrm{C}_{6}^{12} \mathrm{H}_{5} \mathrm{O}^{16} \mathrm{H}$ & 3-1051 & $8,4,5 \leftarrow 8,3,6$ & Ground & & & & & 24604.4 & \\
\hline $\mathrm{C}^{12} \mathrm{H}_{3} \mathrm{~N}^{14} \mathrm{O}_{2}^{16}$ & 3- 171 & Not Reported & Ground & & & & & 24605 & \\
\hline $\mathrm{C}^{12} \mathrm{H}_{3} \mathrm{C}^{12} \mathrm{O}^{16} \mathrm{C}^{13} \mathrm{~N}^{14}$ & 3- 673 & $3,1,3 \leftarrow 2,0,2$ & Ground & & & & & 24605.75 & .2 \\
\hline $\mathrm{DC}^{12} \mathrm{O}^{16} \mathrm{O}^{16} \mathrm{C}^{12} \mathrm{H}_{3}-\mathrm{A}$ & 3- 503 & $5,1,4 \leftarrow 5,1,5$ & Ground & & & & & 24605.93 & .35 \\
\hline $\mathrm{H}_{2} \mathrm{C}^{12}: \mathrm{C}^{12} \mathrm{Cl}_{2}^{\mathrm{b}}$ & 4. 663 & Not Reported & Ground & & & & & 24607.2 & 1.5 \\
\hline $\mathrm{C}^{12} \mathrm{H}_{2}\left(\mathrm{C}^{12} \mathrm{~N}^{14}\right)_{2}$ & 4. 901 & Not Reported & Ground & & & & & 24607.5 & .1 \\
\hline $\mathrm{C}^{12} \mathrm{D}_{3} \mathrm{I}^{127}$ & 4- 482 & $2,0 \leftarrow 1,0$ & Ground & & $3 / 2$ & & $5 / 2$ & 24608.61 & .08 \\
\hline $\mathrm{Br}^{81} \mathrm{C}^{12} \mathrm{~N}^{14}$ & 4- 142 & $3 \leftarrow 2$ & Ground & $3 / 2$ & & $1 / 2$ & & 24.608 .92 & \\
\hline $\mathrm{Br}^{81} \mathrm{C}^{12} \mathrm{~N}^{14}$ & 4- 142 & $3 \leftarrow 2$ & Ground & $5 / 2$ & & $3 / 2$ & & 24608.92 & \\
\hline $\mathrm{C}^{12} \mathrm{H}_{3} \mathrm{~N}^{14} \mathrm{C}^{12} \mathrm{~S}^{34}$ & 3- 425 & $5, \quad \leftarrow 4, \quad$, & Ground & & & & & 24609 & \\
\hline a- $\mathrm{C}^{12} \mathrm{HD}_{2} \mathrm{C}^{12} \mathrm{O}^{16} \mathrm{~F}^{19}$ & 3- 396 & $2,0,2 \leftarrow 1,0,1$ & Ground & & & & & 24612.25 & .2 \\
\hline $\mathrm{S}^{32} \mathrm{C}^{12} \mathrm{Se}^{76}$ & 4- 565 & $6 \leftarrow 5$ & Excited & & & & & 24614 & 4. \\
\hline $\mathrm{s}-\mathrm{C}^{12} \mathrm{H}_{2} \mathrm{DSi}^{28} \mathrm{HF}_{2}^{19}$ & 3. 203 & $3,0,3 \leftarrow 2,0,2$ & Ground & & & & & 24620.48 & 2. \\
\hline $\mathrm{C}^{12} \mathrm{H}_{3} \mathrm{C}^{12} \mathrm{HF}_{2}^{19}$ & 3. 461 & $10,7,3 \leftarrow 10,7,4$ & Ground & & & & & 24621.7 & \\
\hline $\mathrm{Br}^{81} \mathrm{C}^{12} \mathrm{~N}^{14}$ & 4- 142 & $3 \leftarrow 2$ & Excited & $3 / 2$ & & $1 / 2$ & & 24622.93 & \\
\hline $\mathrm{Br}^{81} \mathrm{C}^{12} \mathrm{~N}^{14}$ & 4- 142 & $3 \leftarrow 2$ & Excited & $9 / 2$ & & $7 / 2$ & & 24622.93 & \\
\hline $\mathrm{HDO}_{2}^{16}$ & 3- 43 & $19, \quad \leftarrow 19$, & & & & & & 24624 & 3. \\
\hline $\mathrm{F}_{2}^{19} \mathrm{O}_{2}^{16}$ & 3. 11 & $1,1,1 \leftarrow 0,0,0$ & Ground & & & & & 24626.32 & .1 \\
\hline $\mathrm{S}^{32} \mathrm{C}^{12} \mathrm{Se}^{76}$ & 4- 565 & $6 \leftarrow 5$ & Excited & & & & & 24627 & 4. \\
\hline $\mathrm{C}^{12} \mathrm{D}_{2} \mathrm{Cl}^{35} \mathrm{Si}^{28} \mathrm{H}_{3}$ & 3- 235 & $4,1,3 \leftarrow 3,1,2$ & Ground & & & & & 24631.06 & .2 \\
\hline $\mathrm{C}^{12}{ }_{*} \mathrm{H}_{2}^{\mathrm{b}} \mathrm{S}^{\mathrm{b}} \mathrm{C}^{12}{ }_{*} \mathrm{H}_{2}^{\mathrm{b}}$ & 4- 854 & Not Reported & & & & & & 24632.7 & .2 \\
\hline $\mathrm{Br}^{79} \mathrm{C}^{12} \mathrm{~N}^{14}$ & 4- 141 & $3 \leftarrow 2$ & Ground & $5 / 2$ & & $5 / 2$ & & 24633.71 & \\
\hline $\mathrm{C}^{12} \mathrm{H}_{3} \mathrm{~N}^{14} \mathrm{H}_{2}$ & 3- 261 & $7,1, \leftarrow 7,1$, & Ground & & & & & 24634.04 & \\
\hline $\mathrm{C}^{12} \mathrm{H}_{2}\left(\mathrm{C}^{12} \mathrm{~N}^{14}\right)_{2}$ & 4. 901 & Not Reported & Ground & & & & & 24638.7 & .1 \\
\hline$\left(\mathrm{C}^{12} \mathrm{H}_{3}\right)_{2} \mathrm{C}^{12}: \mathrm{C}^{12} \mathrm{H}_{2}$ & 3. 941 & $9,6,3 \leftarrow 9,5,4$ & Ground & & & & & 24638.80 & .05 \\
\hline $\mathrm{H}_{2} \mathrm{C}^{12}: \mathrm{C}^{12} \mathrm{~F}_{2}^{19}$ & 4. 681 & Not Reported & & & & & & 24639.8 & .3 \\
\hline $\mathrm{s}-\left(\mathrm{C}^{12} \mathrm{H}_{2} \mathrm{D}\right)\left(\mathrm{C}^{12} \mathrm{H}_{3}\right) \mathrm{O}^{16}$ & 3- 596 & Not Reported & Ground & & & & & 24640 & 20. \\
\hline $\mathrm{HC}^{13}:^{12} \mathrm{C}^{12} \mathrm{DO}^{16}$ & 4- 922 & Not Reported & & & & & & 24640.1 & \\
\hline $\mathrm{C}^{12} \mathrm{H}_{2}\left(\mathrm{C}^{12} \mathrm{~N}^{14}\right)_{2}$ & 4- 901 & Not Reported & Ground & & & & & 24641.2 & .1 \\
\hline $\mathrm{C}^{12} \mathrm{H}_{2} \mathrm{DCl}^{35}$ & 4- 428 & $1,0,1 \leftarrow 0,0,0$ & Ground & & & & & 24641.70 & \\
\hline
\end{tabular}


Vib. State

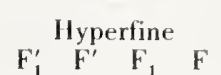

Frequency $\mathrm{MH}_{2}$
Acc. $\pm \mathrm{MH}$ \%

\begin{tabular}{|c|c|c|c|c|c|c|c|c|c|}
\hline $\mathrm{S}^{32} \mathrm{O}^{16} \mathrm{~F}_{2}^{19}$ & $4-1621$ & $6,3,3 \leftarrow 6,3,4$ & Ground & & & & & 24642.79 & .1 \\
\hline $\mathrm{DC}^{13}: \mathrm{C}^{12} \mathrm{C}^{12} \mathrm{~N}^{14}$ & 4- 887 & $3 \leftarrow 2$ & Ground & & & & & 24643.29 & \\
\hline $\mathrm{Br}^{81} \mathrm{C}^{12} \mathrm{~N}^{14}$ & 4- 142 & $3 \leftarrow 2$ & Excited & $9 / 2$ & & $7 / 2$ & & 24645.82 & \\
\hline $\mathrm{Br}^{81} \mathrm{C}^{12} \mathrm{~N}^{14}$ & 4- 142 & $3 \leftarrow 2$ & Excited & $3 / 2$ & & $1 / 2$ & & 24645.82 & \\
\hline$\left(\mathrm{C}^{12} \mathrm{H}_{3}\right)_{2} \mathrm{C}^{12} \mathrm{O}^{16}$ & 3- 751 & Not Reported & & & & & & 24646 & 5. \\
\hline $\mathrm{S}^{32} \mathrm{O}^{16} \mathrm{~F}_{2}^{19}$ & 4-1621 & Not Reported & & & & & & 24646.04 & .1 \\
\hline $\mathrm{C}^{12} \mathrm{H}_{3} \mathrm{~N}^{14} \mathrm{H}_{2}$ & 3- 261 & $7,1, \leftarrow 7,1$, & Ground & & & & & 24647.08 & \\
\hline $\mathrm{C}^{12} \mathrm{O}^{16} \mathrm{CI}^{35} \mathrm{Cl}^{37}$ & 4. 182 & $5,0,5 \leftarrow 4,1,4$ & Ground & & & & & 24653.6 & .3 \\
\hline $\mathrm{C}^{12} \mathrm{H}_{3} \mathrm{C}^{12}{ }_{*} \mathrm{HO}^{16} \mathrm{C}^{12}{ }_{*} \mathrm{H}_{2}$ & 3- 761 & $7,1,6 \leftarrow 7,0,7$ & Ground & & & & & 24653.60 & .1 \\
\hline $\mathrm{C}^{12} \mathrm{H}_{3} \mathrm{C}^{12}: \mathrm{C}^{12} \mathrm{C}^{12} \mathrm{~F}_{3}^{19}$ & 3. 891 & 9 & Ground & & & & & 24654.5 & .1 \\
\hline $\mathrm{Cs}^{133} \mathrm{Cl}^{37}$ & $1-$ & $6 \leftarrow 5$ & Excited & & & & & 24654.86 & .30 \\
\hline $\mathrm{s}-\mathrm{C}^{12} \mathrm{H}_{2} \mathrm{DC}^{12} \mathrm{O}^{16} \mathrm{C}^{12} \mathrm{~N}^{14}$ & 3- 677 & $9,3,6 \leftarrow 9,2,7$ & Ground & & & & & 24655.85 & .2 \\
\hline $\mathrm{C}^{12} \mathrm{H}_{2}\left(\mathrm{C}^{12} \mathrm{~N}^{14}\right)_{2}$ & 4- 901 & $8,1,7 \leftarrow 8,0,8$ & Ground & & & & & 24656.01 & \\
\hline $\mathrm{S}^{32} \mathrm{O}^{16} \mathrm{~F}_{2}^{19}$ & $4-1621$ & Not Reported & & & & & & 24656.31 & .1 \\
\hline $\mathrm{C}^{12} \mathrm{Cl}_{3}^{35} \mathrm{~F}^{19}$ & 4- 191 & $5, \leftarrow 4$ & Ground & & & & & 24657.26 & .03 \\
\hline $\mathrm{C}^{12}{ }_{*} \mathrm{DN}^{14} \mathrm{C}^{12} \mathrm{DC}^{12} \mathrm{H}: \mathrm{C}^{12} \mathrm{DN}^{14} *$ & $4-1142$ & $3, \mathbf{1}, 2 \leftarrow 2,2, \mathbf{l}$ & Ground & & & & & 24657.4 & \\
\hline $\mathrm{C}^{12} \mathrm{H}_{2}: \mathrm{C}^{12} \mathrm{HC}^{12} \mathrm{~F}^{19}: \mathrm{C}^{12} \mathrm{H}_{2}$ & 3. 911 & $9,3,6 \leftarrow 9,2,7$ & Excited & & & & & 24657.75 & .03 \\
\hline $\mathrm{C}^{12} \mathrm{H}_{3} \mathrm{~N}^{14} \mathrm{O}_{2}^{16}$ & $3 \cdot 171$ & Not Reported & Ground & & & & & 24658. & 5. \\
\hline $\mathrm{C}^{12} \mathrm{H}_{3} \mathrm{C}^{12} \mathrm{H}_{2} \mathrm{C}^{12} \mathrm{~N}^{14}$ & 3. 731 & $3,1,2 \leftarrow 3,0,3$ & Ground & & & & & 24658.69 & .1 \\
\hline $\mathrm{Br}^{81} \mathrm{C}^{12} \mathrm{~N}^{14}$ & 4- 142 & $3 \leftarrow 2$ & Excited & $5 / 2$ & & $3 / 2$ & & 24658.89 & \\
\hline $\mathrm{Br}^{81} \mathrm{C}^{12} \mathrm{~N}^{14}$ & 4- 142 & $3 \leftarrow 2$ & Excited & $7 / 2$ & & $5 / 2$ & & 24. 658.89 & \\
\hline $\mathrm{s}-\left(\mathrm{C}^{12} \mathrm{H}_{2} \mathrm{D}\right)\left(\mathrm{C}^{12} \mathrm{H}_{3}\right) \mathrm{O}^{16}$ & 3- 596 & Not Reported & Ground & & & & & 24660 & 20. \\
\hline $\mathrm{C}^{12} \mathrm{H}_{2} \mathrm{DCl}^{35}$ & 4. 428 & $1,0,1 \leftarrow 0,0,0$ & Ground & & & & & 24660.33 & \\
\hline $\mathrm{HC}^{12} \mathrm{~N}^{14}$ & 4. 291 & $10 \leftarrow 10$ & Excited & & & & & 24660.37 & .05 \\
\hline $\mathrm{H}_{2} \mathrm{C}^{12}: \mathrm{C}^{12} \mathrm{Cl}_{2}^{1 \mathrm{~b}}$ & 4- 663 & Not Reported & Ground & & & & & 24661.2 & 1. \\
\hline $\mathrm{C}^{12} \mathrm{H}_{3} \mathrm{C}^{12}{ }_{*} \mathrm{HO}^{16} \mathrm{C}^{12}{ }_{*} \mathrm{H}_{2}$ & 3- 761 & $7,1,6 \leftarrow 7,0,7$ & Ground & & & & & 24663.52 & .1 \\
\hline $\mathrm{H}_{2} \mathrm{C}^{12}{ }_{*} \mathrm{O}^{16} \mathrm{C}^{13}{ }_{*} \mathrm{H}_{2}$ & 4- 842 & $3,3,0 \leftarrow 3,2,1$ & Ground & & & & & 24667.9 & .3 \\
\hline $\mathrm{D}_{2} \mathrm{C}^{12}{ }^{16} \mathrm{O}^{16} \mathrm{C}^{12} * \mathrm{D}_{2}$ & 4. 843 & $5,3,2 \leftarrow 5,2,3$ & Ground & & & & & 24668. & \\
\hline $\mathrm{C}^{12} \mathrm{H}_{2} \mathrm{~N}^{14} \mathrm{O}^{16} \mathrm{D}$ & 3- 142 & $5,2,4 \leftarrow 6,1,5$ & Ground & & 5 & & 6 & 24669.18 & .10 \\
\hline $\mathrm{C}^{12} \mathrm{H}_{2}\left(\mathrm{C}^{12} \mathrm{~N}^{14}\right)_{2}$ & 4- 901 & Not Reported & Ground & & & & & 24670.0 & .1 \\
\hline $\mathrm{C}^{12} \mathrm{H}_{2} \mathrm{~N}^{14} \mathrm{O}^{16} \mathrm{D}$ & 3- 142 & $5,2,4 \leftarrow 6,1,5$ & Ground & & 4 & & 5 & 24670.63 & .10 \\
\hline $\mathrm{C}^{12} \mathrm{H}_{2} \mathrm{~N}^{14} \mathrm{O}^{16} \mathrm{D}$ & 3- 142 & $5,2,4 \leftarrow 6,1,5$ & Ground & & 6 & & 7 & 24670.63 & .10 \\
\hline $\mathrm{H}_{2} \mathrm{C}^{12}: \mathrm{C}^{12} \mathrm{Cl}^{35} \mathrm{Cl}^{37}$ & 4- 662 & $11,3,8 \leftarrow 11,2,9$ & Ground & & & & & 24672.6 & 1. \\
\hline $\mathrm{Ga}^{69} \mathrm{Br}^{79}$ & 1. & $5 \leftarrow 4$ & Excited & $13 / 2$ & 8 & $11 / 2$ & 7 & 24673.55 & 0.20 \\
\hline $\mathrm{Ga}^{69} \mathrm{Br}^{79}$ & 1 . & $5 \leftarrow 4$ & Excited & $13 / 2$ & 6 & $11 / 2$ & 5 & 24673.55 & 0.20 \\
\hline $\mathrm{Ga}^{69} \mathrm{Br}^{79}$ & $1-$ & $5 \leftarrow 4$ & Excited & $13 / 2$ & 5 & $11 / 2$ & 4 & 24673.55 & 0.20 \\
\hline $\mathrm{Ga}^{69} \mathrm{Br}^{79}$ & 1. & $5 \leftarrow 4$ & Excited & $11 / 2$ & 7 & $9 / 2$ & 6 & 24673.55 & 0.20 \\
\hline $\mathrm{Ca}^{69} \mathrm{Br}^{79}$ & 1 - & $5 \leftarrow 4$ & Excited & $13 / 2$ & 7 & $11 / 2$ & 6 & 24673.55 & 0.20 \\
\hline $\mathrm{Ga}^{69} \mathrm{Br}^{79}$ & 1 - & $5 \leftarrow 4$ & Excited & $11 / 2$ & 6 & $9 / 2$ & 5 & 24673.55 & 0.20 \\
\hline $\mathrm{Ga}^{69} \mathrm{Br}^{79}$ & 1 . & $5 \leftarrow 4$ & Excited & $11 / 2$ & 5 & $9 / 2$ & 4 & 24673.55 & 0.20 \\
\hline $\mathrm{Ga}^{69} \mathrm{Br}^{79}$ & $1-$ & $5 \leftarrow 4$ & Excited & $11 / 2$ & 4 & $9 / 2$ & 3 & 24673.55 & 0.20 \\
\hline $\mathrm{Ga}^{69} \mathrm{Br}^{79}$ & $1-$ & $5 \leftarrow 4$ & Excited & $9 / 2$ & 6 & $7 / 2$ & 5 & 24673.55 & 0.20 \\
\hline $\mathrm{Ga}^{69} \mathrm{Br}^{79}$ & $1-$ & $5 \leftarrow 4$ & Excited & $9 / 2$ & 4 & $7 / 2$ & 3 & 24673.55 & 0.20 \\
\hline $\mathrm{Ga}^{69} \mathrm{Br}^{79}$ & $1-$ & $5 \leftarrow 4$ & Excited & $7 / 2$ & 4 & $5 / 2$ & 3 & 24673.55 & 0.20 \\
\hline $\mathrm{Ga}^{69} \mathrm{Br}^{79}$ & 1. & $5 \leftarrow 4$ & Excited & $7 / 2$ & 2 & $5 / 2$ & 1 & 24673.55 & 0.20 \\
\hline
\end{tabular}




\begin{tabular}{|c|c|c|c|c|c|c|c|c|c|}
\hline \multirow{2}{*}{ Isotopic Species } & \multirow{2}{*}{$\begin{array}{l}\text { Vol.-Id. } \\
\text { Nos. }\end{array}$} & \multirow{2}{*}{$\begin{array}{c}\text { Rotational } \\
\text { Quantum Nos. }\end{array}$} & \multirow{2}{*}{ Vib. State } & \multicolumn{4}{|c|}{ Hyperfine } & \multirow{2}{*}{$\begin{array}{c}\text { Frequency } \\
\mathrm{MHz}\end{array}$} & \multirow{2}{*}{$\begin{array}{r}\text { Acc. } \\
\pm \mathrm{MHz}\end{array}$} \\
\hline & & & & $\mathrm{F}_{1}^{\prime}$ & $\mathrm{F}^{\prime}$ & $\mathrm{F}_{1}$ & $\mathrm{~F}$ & & \\
\hline $\mathrm{Ga}^{69} \mathrm{Br}^{79}$ & $1-$ & $5 \leftarrow 4$ & Excited & $9 / 2$ & 5 & $7 / 2$ & 4 & 24673.55 & 0.20 \\
\hline $\mathrm{Ga}^{69} \mathrm{Br}^{79}$ & 1 . & $5 \leftarrow 4$ & Excited & $9 / 2$ & 3 & $7 / 2$ & 2 & 24673.55 & 0.20 \\
\hline $\mathrm{Ga}^{69} \mathrm{Br}^{79}$ & 1 . & $5 \leftarrow 4$ & Excited & $7 / 2$ & 3 & $5 / 2$ & 2 & 24.673 .55 & 0.20 \\
\hline $\mathrm{C}_{6}^{12} \mathrm{H}_{5} \mathrm{C}^{12}: \mathrm{C}^{12} \mathrm{H}$ & $3 \cdot 1091$ & $9,8,1 \leftarrow 8,8,0$ & Ground & & & & & 24674.5 & .5 \\
\hline $\mathrm{C}_{6}^{12} \mathrm{H}_{5} \mathrm{C}^{12}: \mathrm{C}^{12} \mathrm{H}$ & 3-1091 & $9,8,2 \leftarrow 8,8,1$ & Ground & & & & & 24674.5 & .5 \\
\hline $\mathrm{C}^{12} \mathrm{H}_{2} \mathrm{DCl}^{35}$ & 4- 428 & $1,0,1 \leftarrow 0,0,0$ & Ground & & & & & 24675.25 & \\
\hline$\left(\mathrm{C}^{12} \mathrm{H}_{3}\right)_{3} \mathrm{C}^{12} \mathrm{C}^{12}: \mathrm{C}^{13} \mathrm{D}$ & $3-1075$ & $5, \leftarrow 4$, & Ground & & & & & 24675.4 & .1 \\
\hline $\mathrm{C}^{12} \mathrm{H}_{3} \mathrm{C}^{12}{ }_{*} \mathrm{HO}^{16} \mathrm{C}^{12}{ }_{*} \mathrm{H}_{2}$ & $3 \cdot 761$ & Not Reported & Ground & & & & & 24678.02 & .1 \\
\hline $\mathrm{N}^{14} \mathrm{H}_{3}$ & $4 \cdot 1771$ & $17,15 \leftarrow 17,15$ & Ground & & & & & 24680.1 & .1 \\
\hline $\mathrm{a}-\mathrm{C}^{12} \mathrm{H}_{2} \mathrm{DSi}^{28} \mathrm{H}_{2} \mathrm{~F}^{19}$ & 3- 248 & $2,1,1 \leftarrow 1,1,0$ & Ground & & & & & 24681.03 & .1 \\
\hline $\mathrm{Br}^{81} \mathrm{C}^{12} \mathrm{~N}^{14}$ & 4- 142 & $3 \leftarrow 2$ & Excited & $5 / 2$ & & $3 / 2$ & & 24682.13 & \\
\hline $\mathrm{Br}^{81} \mathrm{C}^{12} \mathrm{~N}^{14}$ & 4- 142 & $3 \leftarrow 2$ & Excited & $7 / 2$ & & $5 / 2$ & & 24682.13 & \\
\hline $\mathrm{S}^{32} \mathrm{O}^{16} \mathrm{~F}_{2}^{19}$ & 4-1621 & $5,2,3 \leftarrow 5,2,4$ & Ground & & & & & 24682.55 & .1 \\
\hline $\mathrm{C}^{12}{ }_{*} \mathrm{H}_{2} \mathrm{~N}^{14} \mathrm{HC}^{12}{ }_{*} \mathrm{H}_{2}$ & 4- 861 & $5,5,0 \leftarrow 5,4,1$ & Ground & & & & & 24682.8 & \\
\hline $\mathrm{H} . \mathrm{C}^{12}: \mathrm{C}^{12} \mathrm{HI}^{127}$ & 4- 801 & $4,1,4 \leftarrow 3.13$ & Ground & & $11 / 2$ & & $11 / 2$ & 24.683 .33 & .05 \\
\hline $\mathrm{s}-\left(\mathrm{C}^{12} \mathrm{H}_{2} \mathrm{D}\right)\left(\mathrm{C}^{12} \mathrm{H}_{3}\right) \mathrm{O}^{16}$ & 3. 596 & $3,0,3 \leftarrow 2,1,2$ & Ground & & & & & 24684.6 & .2 \\
\hline $\mathrm{C}_{6}^{12} \mathrm{H}_{5} \mathrm{C}^{12}: \mathrm{C}^{12} \mathrm{H}$ & $3-1091$ & $9,7,2 \leftarrow 8,7,1$ & Ground & & & & & 24685.6 & .5 \\
\hline $\mathrm{C}_{6}^{12} \mathrm{H}_{5} \mathrm{C}^{12}: \mathrm{C}^{12} \mathrm{H}$ & $3-1091$ & $9,7,3 \leftarrow 8,7,2$ & Ground & & & & & 24685.6 & .5 \\
\hline $\mathrm{C}^{12} \mathrm{D}_{2} \mathrm{Cl}^{35} \mathrm{Cl}^{37}$ & 4. 347 & $7,1,6 \leftarrow 7,0,7$ & Ground & & & & & 24687 & 5. \\
\hline $\mathrm{C}^{12} \mathrm{H}_{3} \mathrm{~N}^{14} \mathrm{O}_{2}^{16}$ & 3- 171 & Not Reported & Ground & & & & & 24687.00 & \\
\hline $\mathrm{Br}^{79} \mathrm{C}^{12} \mathrm{~N}^{14}$ & 4- 141 & $3 \leftarrow 2$ & Excited & $5 / 2$ & & $3 / 2$ & & 24687.11 & \\
\hline $\mathrm{Br}^{79} \mathrm{C}^{12} \mathrm{~N}^{14}$ & 4. 141 & $3 \leftarrow 2$ & Excited & $3 / 2$ & & $1 / 2$ & & 24687.11 & \\
\hline g- $\mathrm{C}^{12} \mathrm{H}_{3} \mathrm{C}^{12} \mathrm{H}_{2} \mathrm{C}^{12} \mathrm{H}_{2} \mathrm{Cl}^{35}$ & 3. 773 & $4,2,3 \leftarrow 3,2,2$ & Ground & & & & & 24687.66 & .2 \\
\hline $\mathrm{HC}^{12} \mathrm{~N}^{14}$ & 4- 291 & $10 \leftarrow 10$ & Excited & & & & & 24689.96 & .1 \\
\hline$\left(\mathrm{C}^{12} \mathrm{H}_{3}\right)_{2} \mathrm{C}^{12} \mathrm{O}^{16}$ & 3- 751 & Not Reported & & & & & & 24691. & 5. \\
\hline $\mathrm{C}_{8}^{12} \mathrm{H}_{13} \mathrm{Br}^{79}$ & 4-1331 & $17, \leftarrow 16$ & 'Excited & & & & & 24691 & \\
\hline $\mathrm{a}-\mathrm{C}^{12} \mathrm{H}_{2} \mathrm{DC}^{12} \mathrm{O}^{16} \mathrm{C}^{12} \mathrm{~N}^{14}$ & 3- 679 & $10,3,7 \leftarrow 10,2,8$ & Ground & & & & & 24691.50 & \\
\hline $\mathrm{C}^{12} \mathrm{HCl}^{35}: \mathrm{C}^{12} \mathrm{~F}_{2}^{19}$ & 4. 611 & $13,2,11 \leftarrow 13,1,12$ & Ground & & & & & 24691.6 & .1 \\
\hline $\mathrm{C}^{12} \mathrm{D}_{3} \mathrm{O}^{16} \mathrm{H}$ & 3- 214 & Not Reported & Ground & & & & & 24691.9 & .5 \\
\hline $\mathrm{a}-\mathrm{C}^{12} \mathrm{H}_{2} \mathrm{DC}^{12} \mathrm{O}^{16} \mathrm{C}^{12} \mathrm{~N}^{14}$ & 3- 679 & $10,3,7 \leftarrow 10,2,8$ & Ground & & & & & 24692.58 & \\
\hline $\mathrm{C}^{12} \mathrm{HCl}^{35}: \mathrm{C}^{12} \mathrm{~F}_{2}^{19}$ & 4- 611 & $13,2,11 \leftarrow 13,1,12$ & Ground & & & & & 24693.2 & .1 \\
\hline $\mathrm{S}^{32} \mathrm{O}^{16} \mathrm{~F}_{2}^{19}$ & $4 \cdot 1621$ & Not Reported & & & & & & 24694.31 & .1 \\
\hline $\mathrm{N}^{14} \mathrm{H}_{2} \mathrm{C}_{2}^{12} \mathrm{H}_{5}$ & 3- 631 & Not Reported & Ground & & & & & 24695.13 & .2 \\
\hline $\mathrm{s}-\left(\mathrm{C}^{12} \mathrm{H}_{2} \mathrm{D}\right)\left(\mathrm{C}^{12} \mathrm{H}_{3}\right) \mathrm{O}^{16}$ & 3. 596 & Not Reported & Ground & & & & & 24700 & 20. \\
\hline $\mathrm{C}_{6}^{12} \mathrm{H}_{5} \mathrm{C}^{12}: \mathrm{C}^{12} \mathrm{H}$ & $3 \cdot 1091$ & $9,6,4 \leftarrow 8,6,3$ & Ground & & & & & 24.702 .7 & .5 \\
\hline $\mathrm{C}_{6}^{12} \mathrm{H}_{5} \mathrm{C}^{12}: \mathrm{C}^{12} \mathrm{H}$ & $3 \cdot 1091$ & $9,6,3 \leftarrow 8,6,2$ & Ground & & & & & 24.702 .7 & .5 \\
\hline $\mathrm{S}^{32} \mathrm{O}^{16} \mathrm{~F}_{2}^{19}$ & $4-1621$ & $4,1,3 \leftarrow 4,1,4$ & Ground & & & & & 24. 703.35 & .1 \\
\hline $\mathrm{C}^{12} \mathrm{HCl}^{35}: \mathrm{C}^{12} \mathrm{~F}_{2}^{19}$ & 4. 611 & $3,2,1 \leftarrow 3,1,2$ & Ground & & $3 / 2$ & & $3 / 2$ & 24. 704.2 & .5 \\
\hline $\mathrm{C}^{12} \mathrm{H}_{3} \mathrm{C}^{12}{ }_{*} \mathrm{HO}^{16} \mathrm{C}^{12}{ }_{*} \mathrm{H}_{2}$ & 3- 761 & $1,1,0 \leftarrow 0,0,0$ & Ground & & & & & 24705.86 & .1 \\
\hline $\mathrm{C}^{12} \mathrm{D}_{3} \mathrm{C}^{12} \mathrm{H}_{2} \mathrm{Br}^{81}$ & 3- 525 & $7,1,6 \leftarrow 7,0,7$ & Ground & & $15 / 2$ & & $15 / 2$ & 24.706 .90 & .05 \\
\hline $\mathrm{HDO}_{2}^{16}$ & 3. 43 & $19,, \leftarrow 19$, & & & & & & 24707 & 3. \\
\hline $\mathrm{HC}^{13}: \mathrm{C}^{12} \mathrm{C}^{12} \mathrm{DO}^{16}$ & 4- 922 & Not Reported & & & & & & 24707. & 5. \\
\hline $\mathrm{C}^{12} \mathrm{HCl}^{35}: \mathrm{C}^{12} \mathrm{~F}_{2}^{19}$ & 4. 611 & $3,2,1 \leftarrow 3,1,2$ & Ground & & $9 / 2$ & & $9 / 2$ & 24708.2 & .3 \\
\hline
\end{tabular}




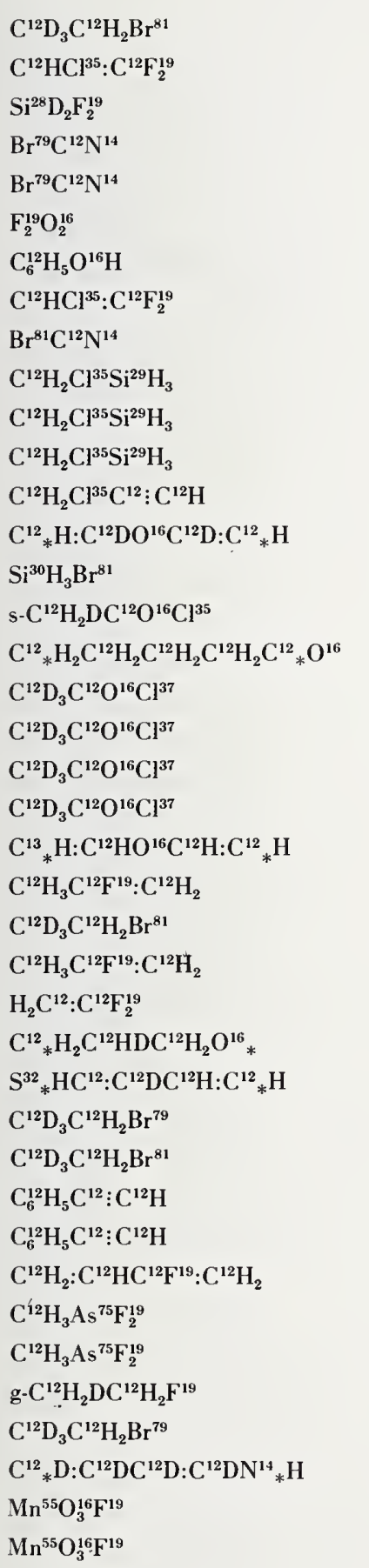

\begin{tabular}{|c|c|c|c|c|c|c|}
\hline 3. 525 & $7,1,6 \leftarrow 7,0,7$ & Ground & $13 / 2$ & $13 / 2$ & 24.711 .31 & .05 \\
\hline 4- 611 & $3,2,1 \leftarrow 3,1,2$ & Ground & $5 / 2$ & $5 / 2$ & 24.712 .3 & .5 \\
\hline 4-1603 & $5,1,4 \leftarrow 5,0,5$ & Ground & & & 24.712 .75 & .10 \\
\hline 4. 141 & $3 \leftarrow 2$ & Ground & $7 / 2$ & $5 / 2$ & 24.713 .05 & \\
\hline 4- 141 & $3 \leftarrow 2$ & Ground & $9 / 2$ & $7 / 2$ & 24.713 .05 & \\
\hline 3- $\quad 11$ & $1,1,1 \leftarrow 0,0,0$ & Ground & & & 24.715 .57 & .1 \\
\hline $3-1051$ & $8,4,5 \leftarrow 8,3,6$ & Ground & & & 24. 715.9 & \\
\hline 4. 611 & $3,2,1 \leftarrow 3,1,2$ & Ground & $7 / 2$ & $7 / 2$ & 24.716 .3 & .5 \\
\hline 4- 142 & $3 \leftarrow 2$ & Ground & $7 / 2$ & $7 / 2$ & 24.717 .19 & \\
\hline 3- 234 & $4,1,3 \leftarrow 3,1,2$ & Ground & $7 / 2 \quad 9 / 2$ & $5 / 2 \quad 7 / 2$ & .24 .718 .0 & .1 \\
\hline 3- 234 & $4,1,3 \leftarrow 3,1,2$ & Ground & $5 / 211 / 2$ & $3 / 2 \quad 9 / 2$ & 24718.0 & .1 \\
\hline 3- 234 & $4,1,3 \leftarrow 3,1,2$ & Ground & & & 24.718 .01 & .2 \\
\hline 4- 991 & $6,1,5 \leftarrow 6,0,6$ & Ground & & & 24.719 .31 & \\
\hline $4-1156$ & $9,6,3 \leftarrow 9,5,4$ & Ground & & & 24720.3 & \\
\hline 4. 116 & $3, \leftarrow 2$, & Ground & & & 24720.57 & .08 \\
\hline 3- 365 & $9,3,6 \leftarrow 9,2,7$ & Ground & & & 24.722 .25 & .2 \\
\hline $4-1241$ & $31,10,21 \leftarrow 31,10,22$ & Ground & & & 24.723 & 5. \\
\hline 3- 364 & $10,4,6 \leftarrow 10,3,7$ & Ground & $21 / 2$ & $21 / 2$ & 24725.0 & \\
\hline 3- 364 & $10,4,6 \leftarrow 10,3,7$ & Ground & $19 / 2$ & $19 / 2$ & 24725.0 & \\
\hline 3- 364 & $10,4,6 \leftarrow 10,3,7$ & Ground & $17 / 2$ & $17 / 2$ & 24725.0 & \\
\hline 3- 364 & $10,4,6 \leftarrow 10,3,7$ & Ground & $23 / 2$ & $23 / 2$ & 24. 725.0 & \\
\hline $4-1157$ & $9,8,2 \leftarrow 9,7,3$ & Ground & & & 24.726 .7 & .1 \\
\hline 3- 721 & $2,0,2 \leftarrow 1,0,1$ & Ground & & & 24727.07 & .1 \\
\hline 3. 525 & $7,1,6 \leftarrow 7,0,7$ & Ground & $17 / 2$ & $17 / 2$ & 24. 728.53 & .05 \\
\hline 3- 721 & $2,0,2 \leftarrow 1,0,1$ & Ground & & & 24.728 .61 & .1 \\
\hline 4- 681 & Not Reported & & & & 24. 729.2 & .3 \\
\hline 4-1094 & $4,3,2 \leftarrow 4,1,3$ & Excited & & & 24.730 .0 & .1 \\
\hline $4-1163$ & $3,2,2 \leftarrow 2,2,1$ & Ground & & & 24.730 .6 & .1 \\
\hline 3- 523 & $7,1,6 \leftarrow 7,0,7$ & Ground & $15 / 2$ & $15 / 2$ & 24.731 .52 & .05 \\
\hline 3- 525 & $7,1,6 \leftarrow 7,0,7$ & Ground & $11 / 2$ & $11 / 2$ & 24731.62 & .05 \\
\hline $3-1091$ & $9,5,5 \leftarrow 8,5,4$ & Ground & & & 24732.1 & .5 \\
\hline 3-1091 & $9,5,4 \leftarrow 8,5,3$ & Ground & & & 24732.1 & .5 \\
\hline 3- 911 & $7,3,4 \leftarrow 7,2,5$ & Ground & & & 24.732 .10 & .03 \\
\hline 3- 81 & $3,1,3 \leftarrow 2,1,2$ & Ground & $5 / 2$ & $5 / 2$ & 24733.01 & .2 \\
\hline 3- 81 & $3,0,3 \leftarrow 2,0,2$ & Ground & $5 / 2$ & $5 / 2$ & 24733.01 & .2 \\
\hline 3- 553 & $1,1,0 \leftarrow 1,0,1$ & Ground & & & 24735.6 & .1 \\
\hline 3- 523 & $7,1,6 \leftarrow 7,0,7$ & Ground & $13 / 2$ & $13 / 2$ & 24.736 .91 & .05 \\
\hline $4-1185$ & $11,10,2 \leftarrow 11,9,3$ & Ground & & & 24737.3 & \\
\hline $4-1561$ & $3,2 \leftarrow 2,2$ & Excited & $11 / 2$ & $9 / 2$ & 24738.20 & .05 \\
\hline $4-1561$ & $3,2 \leftarrow 2,2$ & Excited & $3 / 2$ & $3 / 2$ & 24. 738.20 & .05 \\
\hline
\end{tabular}




\begin{tabular}{|c|c|c|c|c|c|c|c|c|c|}
\hline \multirow{2}{*}{ Isotopic Species } & \multirow{2}{*}{$\begin{array}{l}\text { Vol.-Id. } \\
\text { Nos. }\end{array}$} & \multirow{2}{*}{$\begin{array}{c}\text { Rotational } \\
\text { Quantum Nos. }\end{array}$} & \multirow{2}{*}{ Vib. State } & \multicolumn{4}{|c|}{ Hyperfine } & \multirow{2}{*}{$\begin{array}{l}\text { Frequency } \\
\mathrm{MHz}\end{array}$} & \multirow{2}{*}{$\begin{aligned} \text { Acc. } \\
\pm \mathrm{MHz}\end{aligned}$} \\
\hline & & & & $\mathrm{F}_{1}^{\prime}$ & $\mathrm{F}^{\prime}$ & & $\mathrm{F}$ & & \\
\hline $\mathrm{Mn}^{55} \mathrm{O}_{3}^{16} \mathrm{~F}^{19}$ & 4-1561 & $3,2 \leftarrow 2,2$ & Excited & & $9 / 2$ & & $9 / 2$ & 24738.20 & .05 \\
\hline $\mathrm{Mn}^{55} \mathrm{O}_{3}^{16} \mathrm{~F}^{19}$ & 4-1561 & $3,2 \leftarrow 2,2$ & Excited & & $7 / 2$ & & $9 / 2$ & 24738.20 & .05 \\
\hline $\mathrm{Mn}^{55} \mathrm{O}_{3}^{16} \mathrm{~F}^{19}$ & $4 \cdot 1561$ & $3,2 \leftarrow 2,2$ & Excited & & $5 / 2$ & & $3 / 2$ & 24.738 .20 & .05 \\
\hline $\mathrm{Mn}^{55} \mathrm{O}_{3}^{16} \mathrm{~F}^{19}$ & 4-1561 & $3,2 \leftarrow 2,2$ & Excited & & $1 / 2$ & & $3 / 2$ & 24738.20 & .05 \\
\hline $\mathrm{H}_{2} \mathrm{C}^{12}: \mathrm{C}^{12} \mathrm{Cl}_{2}^{35}$ & 4- 661 & $5,0,5 \leftarrow 4,1,4$ & Ground & & & & & 24739.8 & 1. \\
\hline $\mathrm{Mn}^{55} \mathrm{O}_{3}^{16} \mathrm{~F}^{19}$ & 4-1561 & $3,2 \leftarrow 2,2$ & Excited & & $5 / 2$ & & $5 / 2$ & 24. 740.60 & .05 \\
\hline $\mathrm{Mn}^{55} \mathrm{O}_{3}^{16} \mathrm{~F}^{19}$ & 4-1561 & $3,2 \leftarrow 2,2$ & Excited & & $7 / 2$ & & $5 / 2$ & 24740.60 & .05 \\
\hline $\mathrm{Mn}^{55} \mathrm{O}_{3}^{16} \mathrm{~F}^{19}$ & 4-1561 & $3,2 \leftarrow 2,2$ & Excited & & $3 / 2$ & & $5 / 2$ & 24740.60 & .05 \\
\hline $\mathrm{Mn}^{55} \mathrm{O}_{3}^{16} \mathrm{~F}^{19}$ & 4-1561 & $3,2 \leftarrow 2,2$ & Excited & & $7 / 2$ & & $7 / 2$ & 24. 741.49 & .05 \\
\hline $\mathrm{Mn}^{55} \mathrm{O}_{3}^{16} \mathrm{~F}^{19}$ & 4-1561 & $3,2 \leftarrow 2,2$ & Excited & & $9 / 2$ & & $7 / 2$ & 24. 741.49 & .05 \\
\hline $\mathrm{Mn}^{55} \mathrm{O}_{3}^{16} \mathrm{~F}^{19}$ & 4-1561 & $3,2 \leftarrow 2,2$ & Excited & & $5 / 2$ & & $7 / 2$ & 24.741 .49 & .05 \\
\hline $\mathrm{C}^{13} \mathrm{HCl}^{35} \mathrm{~F}_{2}^{19}$ & 4. 253 & $2,1,1 \leftarrow 1,0,1$ & Ground & & & & & 24.742 .15 & .05 \\
\hline $\mathrm{HC}^{13}: \mathrm{C}^{12} \mathrm{C}^{12} \mathrm{DO}^{16}$ & 4. 922 & Not Reported & & & & & & 24746. & 5. \\
\hline $\mathrm{C}_{6}^{12} \mathrm{H}_{5} \mathrm{Cl}^{37}$ & 4-1272 & $9,6,4 \leftarrow 8,6,3$ & Ground & & & & & 24746 & 5.0 \\
\hline $\mathrm{C}_{6}^{12} \mathrm{H}_{5} \mathrm{Cl}^{37}$ & 4-1272 & $9,6,3 \leftarrow 8,6,2$ & Ground & & & & & 24746 & 5.0 \\
\hline g- $\mathrm{C}^{12} \mathrm{H}_{3} \mathrm{C}^{12} \mathrm{H}_{2} \mathrm{C}^{12} \mathrm{H}_{2} \mathrm{Cl}^{35}$ & 3- 773 & $12,2,10 \leftarrow 12,1,11$ & Ground & & & & & 24.74 .7 .74 & .2 \\
\hline $\mathrm{C}^{12} \mathrm{H}_{3} \mathrm{As}^{75} \mathrm{~F}_{2}^{19}$ & $3-81$ & $3,0,3 \leftarrow 2,0,2$ & Ground & & $9 / 2$ & & $7 / 2$ & 24. 748.55 & .2 \\
\hline $\mathrm{C}^{12} \mathrm{H}_{3} \mathrm{As}^{75} \mathrm{~F}_{2}^{19}$ & $3-81$ & $3,1,3 \leftarrow 2,1,2$ & Ground & & $9 / 2$ & & $7 / 2$ & 24. 748.55 & .2 \\
\hline $\mathrm{C}^{12} \mathrm{H}_{3} \mathrm{C}^{12} \mathrm{~F}^{19}: \mathrm{C}^{12} \mathrm{H}_{2}$ & 3- 721 & $2,0,2 \leftarrow 1,0,1$ & Ground & & & & & 24. 749.12 & .1 \\
\hline $\mathrm{C}^{12} \mathrm{H}_{3} \mathrm{C}^{12}{ }_{*} \mathrm{HO}^{16} \mathrm{C}^{12}{ }_{*} \mathrm{H}_{2}$ & 3- 761 & $7,1,6 \leftarrow 7,0,7$ & Ground & & & & & 24. 749.23 & .1 \\
\hline $\mathrm{s}-\left(\mathrm{C}^{12} \mathrm{H}_{2} \mathrm{D}\right)\left(\mathrm{C}^{12} \mathrm{H}_{3}\right) \mathrm{O}^{16}$ & 3- 596 & Not Reported & Ground & & & & & 24.750 & 20. \\
\hline $\mathrm{C}^{12} \mathrm{H}_{3} \mathrm{C}^{12}{ }_{*} \mathrm{HO}^{16} \mathrm{C}^{12}{ }_{*} \mathrm{H}_{2}$ & 3- 761 & $7,1,6 \leftarrow 7,0,7$ & Ground & & & & & 24. 750.32 & .1 \\
\hline $\mathrm{C}^{12} \mathrm{H}_{3} \mathrm{As}^{75} \mathrm{~F}_{2}^{19}$ & 3- 81 & $3,0,3 \leftarrow 2,0,2$ & Ground & & $9 / 2$ & & $7 / 2$ & 24750.91 & .2 \\
\hline $\mathrm{C}^{12} \mathrm{H}_{3} \mathrm{As}^{75} \mathrm{~F}_{2}^{19}$ & $3-81$ & $3,1,3 \leftarrow 2,1,2$ & Ground & & $9 / 2$ & & $7 / 2$ & 24. 750.91 & .2 \\
\hline $\mathrm{C}^{12}{ }_{*} \mathrm{HO}^{16} \mathrm{C}^{12} \mathrm{HC}^{12} \mathrm{H}_{2} \mathrm{C}^{12} \mathrm{H}_{2} \mathrm{C}^{12}{ }_{*} \mathrm{H}_{2}$ & 4-1251 & $3,1,2 \leftarrow 2,1,1$ & Ground & & & & & 24751 & 5. \\
\hline $\mathrm{C}^{12} \mathrm{H}_{3} \mathrm{As}^{75} \mathrm{~F}_{2}^{19}$ & 3. 81 & $3,0,3 \leftarrow 2,0,2$ & Ground & & $9 / 2$ & & $7 / 2$ & 24. 752.13 & .2 \\
\hline $\mathrm{C}^{12} \mathrm{H}_{3} \mathrm{As}^{75} \mathrm{~F}_{2}^{19}$ & $3 \cdot 81$ & $3,1,3 \leftarrow 2,1,2$ & Ground & & $9 / 2$ & & $7 / 2$ & 24. 752.13 & .2 \\
\hline $\mathrm{C}^{12} \mathrm{D}_{2} \mathrm{Cl}^{35} \mathrm{Si}^{28} \mathrm{H}_{3}$ & 3. 235 & $4,1,3 \leftarrow 3,1,2$ & Ground & & & & & 24. 752.39 & .2 \\
\hline $\mathrm{Br}^{79} \mathrm{C}^{12} \mathrm{~N}^{14}$ & 4- 141 & $3 \leftarrow 2$ & Ground & $3 / 2$ & & $1 / 2$ & & 24. 755.22 & \\
\hline $\mathrm{Br}^{79} \mathrm{C}^{12} \mathrm{~N}^{14}$ & 4- 141 & $3 \leftarrow 2$ & Ground & $5 / 2$ & & $3 / 2$ & & 24755.22 & \\
\hline $\mathrm{Mn}^{55} \mathrm{O}_{3}^{16} \mathrm{~F}^{19}$ & 4-1561 & $3,2 \leftarrow 2,2$ & Excited & & $1 / 2$ & & $1 / 2$ & 24. 755.95 & .15 \\
\hline $\mathrm{Mn}^{55} \mathrm{O}_{3}^{16} \mathrm{~F}^{19}$ & 4-1561 & $3,2 \leftarrow 2,2$ & Excited & & $3 / 2$ & & $1 / 2$ & 24. 755.95 & .15 \\
\hline $\mathrm{s}-\mathrm{C}^{12} \mathrm{HD}_{2} \mathrm{C}^{12} \mathrm{O}^{16} \mathrm{~F}^{19}$ & 3. 395 & $2,0,2 \leftarrow 1,0,1$ & Ground & & & & & 24.756 .10 & .2 \\
\hline $\mathrm{C}^{12}{ }_{*} \mathrm{H}: \mathrm{C}^{12} \mathrm{HO}^{16} \mathrm{C}^{12} \mathrm{H}: \mathrm{C}^{12}{ }_{*} \mathrm{D}$ & 4-1155 & $9,6,3 \leftarrow 9,6,4$ & Ground & & & & & 24757.1 & \\
\hline $\mathrm{C}^{12} \mathrm{D}_{3} \mathrm{C}^{12} \mathrm{H}_{2} \mathrm{Br}^{79}$ & 3. 523 & $7,1,6 \leftarrow 7,0,7$ & Ground & & $17 / 2$ & & $17 / 2$ & 24.757 .70 & .05 \\
\hline $\mathrm{C}^{12} \mathrm{H}_{3} \mathrm{As}^{75} \mathrm{~F}_{2}^{19}$ & 3. 81 & $3,1,3 \leftarrow 2,1,2$ & Ground & & $3 / 2$ & & $1 / 2$ & 24757.70 & .2 \\
\hline $\mathrm{C}^{12} \mathrm{H}_{3} \mathrm{As}^{75} \mathrm{~F}_{2}^{19}$ & 3. 81 & $3,0,3 \leftarrow 2,0,2$ & Ground & & $3 / 2$ & & $1 / 2$ & 24757.70 & .2 \\
\hline$\left(\mathrm{C}^{12} \mathrm{H}_{3}\right)_{2} \mathrm{C}^{12} \mathrm{O}^{16}$ & 3. 751 & Not Reported & & & & & & 24758 & 5. \\
\hline $\mathrm{C}^{12} \mathrm{H}_{2} \mathrm{~F}_{2}^{19}$ & 4- 351 & $15,3,13 \leftarrow 14,4,10$ & Ground & & & & & 24760.40 & .10 \\
\hline $\mathrm{Br}^{79} \mathrm{C}^{12} \mathrm{~N}^{14}$ & 4. 141 & $3 \leftarrow 2$ & Excited & $3 / 2$ & & $1 / 2$ & & 24.760 .76 & \\
\hline $\mathrm{Br}^{79} \mathrm{C}^{12} \mathrm{~N}^{14}$ & 4. 141 & $3 \leftarrow 2$ & Excited & $9 / 2$ & & $7 / 2$ & & 24.760 .76 & \\
\hline $\mathrm{C}^{12} \mathrm{H}_{3} \mathrm{As}^{75} \mathrm{~F}_{2}^{19}$ & 3- 81 & $3,0,3 \leftarrow 2,0,2$ & Ground & & $7 / 2$ & & $5 / 2$ & 24. 761.98 & .2 \\
\hline $\mathrm{C}^{12} \mathrm{H}_{3} \mathrm{As}^{75} \mathrm{~F}_{2}^{19}$ & $3-81$ & $3,1,3 \leftarrow 2,1,2$ & Ground & & $7 / 2$ & & $5 / 2$ & 24. 761.98 & .2 \\
\hline $\mathrm{C}^{12}{ }_{*} \mathrm{H}: \mathrm{C}^{12} \mathrm{DC}^{12} \mathrm{H}: \mathrm{C}^{12} \mathrm{HN}^{14}{ }_{*} \mathrm{H}$ & 4-1184 & $9,6,3 \leftarrow 9,6,4$ & Ground & & & & & 24762.6 & \\
\hline
\end{tabular}




\begin{tabular}{|c|c|c|c|c|c|c|c|c|c|}
\hline Isotopic Species & $\begin{array}{l}\text { Vol.-Id. } \\
\text { Nos. }\end{array}$ & $\begin{array}{l}\text { Rotational } \\
\text { Quantum Nos. }\end{array}$ & Vib. State & $\mathrm{F}_{1}^{\prime}$ & $\begin{array}{l}\text { Iype } \\
\mathrm{F}^{\prime}\end{array}$ & $\underset{F_{1}}{\text { erfine }}$ & $\mathrm{F}$ & $\begin{array}{c}\text { Frequency } \\
\mathrm{MHz}^{2}\end{array}$ & $\begin{array}{r}\text { Acc. } \\
\pm \text { MII\% }\end{array}$ \\
\hline $\mathrm{C}^{12} \mathrm{D}_{3} \mathrm{C}^{12} \mathrm{H}_{2} \mathrm{Br}^{79}$ & 3. 523 & $7,1,6 \leftarrow 7,0,7$ & Ground & & $11 / 2$ & & $11 / 2$ & $24 \cdot 762.80$ & .05 \\
\hline $\mathrm{C}^{12} \mathrm{H}_{2}\left(\mathrm{C}^{12} \mathrm{~N}^{14}\right)_{2}$ & 4- 901 & Not Reported & Ground & & & & & 24764.3 & .1 \\
\hline $\mathrm{C}^{12} \mathrm{H}_{3} A \mathrm{~s}^{75} \mathrm{~F}_{2}^{19}$ & 3- 81 & $3,1,3 \leftarrow 2,1,2$ & Ground & & $7 / 2$ & & $5 / 2$ & 24764.87 & .2 \\
\hline $\mathrm{C}^{12} \mathrm{H}_{3} \mathrm{As}^{75} \mathrm{~F}_{2}^{19}$ & $3-81$ & $3,0,3 \leftarrow 2,0,2$ & Ground & & $7 / 2$ & & $5 / 2$ & 24.764 .87 & .2 \\
\hline $\mathrm{C}^{12} \mathrm{H}_{3} \mathrm{As}^{75} \mathrm{~F}_{2}^{19}$ & 3. 81 & $3,0,3 \leftarrow 2,0,2$ & Ground & & $7 / 2$ & & $5 / 2$ & 24.766 .40 & .2 \\
\hline $\mathrm{C}^{12} \mathrm{H}_{3} \mathrm{As}^{75} \mathrm{~F}_{2}^{19}$ & 3. 81 & $3,1,3 \leftarrow 2,1,2$ & Ground & & $7 / 2$ & & $5 / 2$ & 24.766 .40 & .2 \\
\hline $\mathrm{C}^{12}{ }_{*} \mathrm{H}: \mathrm{C}^{12} \mathrm{HO}^{16} \mathrm{C}^{12} \mathrm{H}: \mathrm{C}^{12}{ }_{*} \mathrm{H}$ & 4.1151 & $11,11,1 \leftarrow 11,9,2$ & Ground & & & & & 24.767 .50 & \\
\hline $\mathrm{Cs}^{133} \mathrm{Cl}^{37}$ & $1-$ & $6 \leftarrow 5$ & Ground & & & & & 24767.86 & .10 \\
\hline $\mathrm{Mn}^{55} \mathrm{O}_{3}^{16} \mathrm{~F}^{19}$ & 4-1561 & 3. $1 \leftarrow 2,1$ & Excited & & $1 / 2$ & & $1 / 2$ & 24.768 .00 & .05 \\
\hline $\mathrm{Mn}^{55} \mathrm{O}_{3}^{16} \mathrm{~F}^{19}$ & $4-1561$ & $3,1 \leftarrow 2,1$ & Excited & & $3 / 2$ & & $3 / 2$ & 24. 768.00 & .05 \\
\hline$\left(\mathrm{a}^{69} \mathrm{Br}^{79}\right.$ & $1-$ & $5 \leftarrow 4$ & Ground & $7 / 2$ & 5 & $5 / 2$ & 4 & 24768.02 & 0.20 \\
\hline $\mathrm{Mn}^{55} \mathrm{O}_{3}^{16} \mathrm{~F}^{19}$ & 4-1561 & $3,1 \leftarrow 2,1$ & Excited & & $11 / 2$ & & $9 / 2$ & $24 \cdot 768.38$ & .05 \\
\hline $\mathrm{Mn}^{55} \mathrm{O}_{3}^{16} \mathrm{~F}^{19}$ & 4-1561 & $3,1 \leftarrow 2,1$ & Excited & & $9 / 2$ & & $7 / 2$ & 24769.14 & .05 \\
\hline $\mathrm{Mn}^{55} \mathrm{O}_{3}^{16} \mathrm{~F}^{19}$ & 4-1561 & $3,1 \leftarrow 2,1$ & Excited & & $3 / 2$ & & $1 / 2$ & 24.769 .14 & .05 \\
\hline $\mathrm{Mn}^{55} \mathrm{O}_{3}^{16} \mathrm{~F}^{19}$ & 4.1561 & $3,1 \leftarrow 2,1$ & Excited & & $7 / 2$ & & $7 / 2$ & 24.769 .14 & .05 \\
\hline $\mathrm{C}^{12} \mathrm{H}_{3} \mathrm{As}^{75} \mathrm{~F}_{2}^{19}$ & $3-81$ & $3,0,3 \leftarrow 2,0,2$ & Ground & & $5 / 2$ & & $3 / 2$ & 24769.26 & .2 \\
\hline $\mathrm{C}^{12} \mathrm{H}_{3} \mathrm{As}^{75} \mathrm{~F}_{2}^{19}$ & $3-81$ & $3,1,3 \leftarrow 2,1,2$ & Ground & & $5 / 2$ & & $3 / 2$ & 24.769 .26 & .2 \\
\hline $\mathrm{Mn}^{55} \mathrm{O}_{3}^{16} \mathrm{~F}^{19}$ & 4-1561 & $3,1 \leftarrow 2,1$ & Excited & & $7 / 2$ & & $5 / 2$ & 24.769 .55 & .05 \\
\hline $\mathrm{Mn}^{55} \mathrm{O}_{3}^{16} \mathrm{~F}^{19}$ & 4-1561 & $3,1 \leftarrow 2,1$ & Excited & & $5 / 2$ & & $3 / 2$ & 24.769 .55 & .05 \\
\hline $\mathrm{Mn}^{55} \mathrm{O}_{3}^{16} \mathrm{~F}^{19}$ & 4-1561 & $3,1 \leftarrow 2,1$ & Excited & & $9 / 2$ & & $9 / 2$ & 24.770 .68 & .05 \\
\hline $\mathrm{H}_{2} \mathrm{C}^{12}: \mathrm{C}^{12} \mathrm{~F}_{2}^{19}$ & 4. 681 & $6,4,2 \leftarrow 6,4,3$ & Ground & & & & & 24771.0 & .3 \\
\hline$\left(\mathrm{a}^{69} \mathrm{Br}^{79}\right.$ & $1-$ & $5 \leftarrow 4$ & Ground & $13 / 2$ & 6 & $11 / 2$ & 5 & 24.771 .22 & 0.20 \\
\hline${ }^{6 a^{69}} \mathrm{Br}^{79}$ & $1-$ & $5 \leftarrow 4$ & Ground & $13 / 2$ & 5 & $11 / 2$ & 4 & 24.771 .22 & 0.20 \\
\hline $\mathrm{Ga}^{69} \mathrm{Br}^{79}$ & $1-$ & $5 \leftarrow 4$ & Ground & $9 / 2$ & 5 & $7 / 2$ & 4 & $24,771.22$ & 0.20 \\
\hline $\mathrm{Ca}^{69} \mathrm{Br}^{79}$ & $1-$ & $5 \leftarrow 4$ & Ground & $13 / 2$ & 8 & $11 / 2$ & 7 & 24.771 .22 & 0.20 \\
\hline$\left(\mathrm{a}^{69} \mathrm{Br}^{79}\right.$ & $1-$ & $5 \leftarrow 4$ & Ground & $13 / 2$ & 7 & $11 / 2$ & 6 & 24771.22 & 0.20 \\
\hline${ }^{8 a^{69}} \mathrm{Br}^{79}$ & $1-$ & $5 \leftarrow 4$ & Ground & $11 / 2$ & 6 & $9 / 2$ & 5 & 24771.22 & 0.20 \\
\hline${ }^{9} a^{69} \mathrm{Br}^{79}$ & 1 & $5 \leftarrow 4$ & Ground & $9 / 2$ & 6 & $7 / 2$ & 5 & 24.771 .22 & 0.20 \\
\hline$\left(\mathrm{Ca}^{69} \mathrm{Br}^{79}\right.$ & 1 . & $5 \leftarrow 4$ & Ground & $11 / 2$ & 7 & $9 / 2$ & 6 & 24.771 .22 & 0.20 \\
\hline$\left(\mathrm{a}^{69} \mathrm{Br}^{79}\right.$ & $1-$ & $5 \leftarrow 4$ & Ground & $7 / 2$ & 2 & $5 / 2$ & 1 & 24.771 .22 & 0.20 \\
\hline$\left(\mathrm{a}^{69} \mathrm{Br}^{79}\right.$ & $1-$ & $5 \leftarrow 4$ & Ground & $11 / 2$ & 5 & $9 / 2$ & 4 & 24.771 .22 & 0.20 \\
\hline $\mathrm{Ca}^{69} \mathrm{Br}^{79}$ & $1-$ & $5 \leftarrow 4$ & Ground & $11 / 2$ & 4 & $9 / 2$ & 3 & 24.771 .22 & 0.20 \\
\hline $\mathrm{Ca}^{69} \mathrm{Br}^{79}$ & $1-$ & $5 \leftarrow 4$ & Ground & $9 / 2$ & 4 & $7 / 2$ & 3 & 24.771 .22 & 0.20 \\
\hline$\left(\mathrm{a}^{699} \mathrm{Br}^{79}\right.$ & $1-$ & $5 \leftarrow 4$ & Ground & $9 / 2$ & 3 & $7 / 2$ & 2 & 24.771 .22 & 0.20 \\
\hline$\left(\mathrm{Ga}^{69} \mathrm{Br}^{79}\right.$ & 1 . & $5 \leftarrow 4$ & Ground & $7 / 2$ & 4 & $5 / 2$ & 3 & 24771.22 & 0.20 \\
\hline $\mathrm{Ga}^{69} \mathrm{Br}^{79}$ & $1-$ & $5 \leftarrow 4$ & Ground & $7 / 2$ & 3 & $5 / 2$ & 2 & 24771.22 & 0.20 \\
\hline $\mathrm{Mn}^{55} \mathrm{O}_{3}^{16} \mathrm{~F}^{19}$ & 4-1561 & $3,0 \leftarrow 2,0$ & Ground & & $3 / 2$ & & $5 / 2$ & 24771.56 & .1 \\
\hline $\mathrm{C}^{12} \mathrm{H}_{3} \mathrm{As}^{75} \mathrm{~F}_{2}^{19}$ & $3-81$ & $3,0,3 \leftarrow 2,0,2$ & Ground & & $5 / 2$ & & $3 / 2$ & 24771.88 & .2 \\
\hline $\mathrm{C}^{12} \mathrm{H}_{3} \mathrm{As}^{75} \mathrm{~F}_{2}^{19}$ & $3-81$ & $3,1,3 \leftarrow 2,1,2$ & Ground & & $5 / 2$ & & $3 / 2$ & 24771.88 & .2 \\
\hline $\mathrm{HC}^{13}: \mathrm{C}^{12} \mathrm{C}^{12} \mathrm{DO}^{16}$ & 4. 922 & Not Reported & & & & & & 24772 & 5. \\
\hline $\mathrm{Mn}^{55} \mathrm{O}_{3}^{16} \mathrm{~F}^{19}$ & 4-1561 & $3,0 \leftarrow 2,0$ & Ground & & $1 / 2$ & & $3 / 2$ & 24772.39 & .1 \\
\hline $\mathrm{Mn}^{55} \mathrm{O}_{3}^{16} \mathrm{~F}^{19}$ & 4-1561 & $3,0 \leftarrow 2,0$ & Ground & & $5 / 2$ & & $5 / 2$ & 24773.505 & .05 \\
\hline $\mathrm{Mn}^{55} \mathrm{O}_{3}^{16} \mathrm{~F}^{19}$ & 4-1561 & $3,0 \leftarrow 2,0$ & Ground & & $5 / 2$ & & $3 / 2$ & 24773.85 & .15 \\
\hline $\mathrm{Mn}^{55} \mathrm{O}_{3}^{16} \mathrm{~F}^{19}$ & 4-1561 & $3,0 \leftarrow 2,0$ & Ground & & $9 / 2$ & & $7 / 2$ & 24.774 .250 & .05 \\
\hline
\end{tabular}




\begin{tabular}{|c|c|c|c|c|c|c|c|c|c|}
\hline \multirow{3}{*}{$\begin{aligned} \text { Isotopic Species } \\
\mathrm{Mn}^{55} \mathrm{O}_{3}^{16} \mathrm{~F}^{19}\end{aligned}$} & \multirow{3}{*}{$\begin{array}{c}\text { Vol.-Id. } \\
\text { Nos. } \\
4-1561\end{array}$} & \multirow{3}{*}{$\begin{array}{c}\begin{array}{c}\text { Rotational } \\
\text { Quantum Nos. }\end{array} \\
3,0 \leftarrow 2,0\end{array}$} & \multirow{3}{*}{$\begin{array}{c}\text { Vib. State } \\
\text { Ground }\end{array}$} & \multicolumn{4}{|c|}{ Hyperfine } & \multirow{2}{*}{$\begin{array}{l}\text { Frequency } \\
\mathrm{MHz}\end{array}$} & \multirow{2}{*}{$\begin{array}{r}\text { Acc. } \\
\pm \mathrm{MHz}\end{array}$} \\
\hline & & & & $F_{1}^{\prime}$ & $\mathrm{F}^{\prime}$ & $F_{1}$ & $\mathrm{~F}$ & & \\
\hline & & & & & $11 / 2$ & & $9 / 2$ & 24774.445 & .05 \\
\hline $\mathrm{Si}^{29} \mathrm{D}_{2} \mathrm{~F}_{2}^{19}$ & $4-1604$ & $5,1,4 \leftarrow 5,0,5$ & Ground & & & & & 24774.80 & .10 \\
\hline $\mathrm{Mn}^{55} \mathrm{O}_{3}^{16} \mathrm{~F}^{19}$ & $4-1561$ & $3,0 \leftarrow 2,0$ & Ground & & $7 / 2$ & & $5 / 2$ & 24775.125 & .05 \\
\hline $\mathrm{Mn}^{55} \mathrm{O}_{3}^{16} \mathrm{~F}^{19}$ & $4-1561$ & $3,0 \leftarrow 2,0$ & Ground & & $5 / 2$ & & $3 / 2$ & 24.775 .949 & .05 \\
\hline $\mathrm{C}_{6}^{12} \mathrm{H}_{5} \mathrm{Cl}^{37}$ & 4-1272 & $9,5,4 \leftarrow 8,5,3$ & Ground & & & & & 24776 & 5.0 \\
\hline $\mathrm{C}_{6}^{12} \mathrm{H}_{5} \mathrm{Cl}^{32}$ & 4-1272 & $9,5,5 \leftarrow 8,5,4$ & Ground & & & & & 24776 & 5.0 \\
\hline $\mathrm{S}^{32} \mathrm{O}^{16} \mathrm{~F}_{2}^{19}$ & 4-1621 & Not Reported & & & & & & 24776.46 & .1 \\
\hline $\mathrm{Mn}^{55} \mathrm{O}_{3}^{16} \mathrm{~F}^{19}$ & $4-1561$ & $3,0 \leftarrow 2,0$ & Ground & & $9 / 2$ & & $9 / 2$ & 24777.526 & .05 \\
\hline $\mathrm{D}_{2} \mathrm{O}_{2}^{16}$ & 3- 42 & Not Reported & & & & & & 24778 & 3. \\
\hline $\mathrm{D}_{2} \mathrm{C}^{12}: \mathrm{C}^{12} \mathrm{~F}_{2}^{19}$ & 4. 683 & $2,0,2 \leftarrow 1,0,1$ & Ground & & & & & 24778.2 & .3 \\
\hline $\mathrm{HC}^{13}: \mathrm{C}^{12} \mathrm{C}^{12} \mathrm{DO}^{16}$ & 4- 922 & Not Reported & & & & & & 24783 & 5. \\
\hline $\mathrm{Br}^{79} \mathrm{C}^{12} \mathrm{~N}^{14}$ & 4- 141 & $3 \leftarrow 2$ & Excited & $9 / 2$ & & $7 / 2$ & & 24784.02 & \\
\hline $\mathrm{Br}^{79} \mathrm{C}^{12} \mathrm{~N}^{14}$ & 4. 141 & $3 \leftarrow 2$ & Excited & $3 / 2$ & & $1 / 2$ & & 24784.02 & \\
\hline $\mathrm{H}_{3} \mathrm{C}^{12} \mathrm{C}^{12}: \mathrm{C}^{12} \mathrm{C}^{12} \mathrm{~N}^{14}$ & 4-1121 & $6,4 \leftarrow 5,4$ & Ground & & 6 & & 5 & 24.784 .37 & \\
\hline $\mathrm{s}-\left(\mathrm{C}^{12} \mathrm{H}_{2} \mathrm{D}\right)\left(\mathrm{C}^{12} \mathrm{H}_{3}\right) \mathrm{O}^{16}$ & 3- 596 & Not Reported & Ground & & & & & 24785 & 20. \\
\hline $\mathrm{H}_{3} \mathrm{C}^{12} \mathrm{C}^{12}: \mathrm{C}^{12} \mathrm{C}^{12} \mathrm{~N}^{14}$ & $4-1121$ & $6,4 \leftarrow 5,4$ & Ground & & 7 & & 6 & 24785.14 & \\
\hline $\mathrm{H}_{3} \mathrm{C}^{12} \mathrm{C}^{12}: \mathrm{C}^{12} \mathrm{C}^{12} \mathrm{~N}^{14}$ & $4-1121$ & $6,4 \leftarrow 5,4$ & Ground & & 5 & & 4 & 24.785 .14 & \\
\hline $\mathrm{C}^{12}{ }_{*} \mathrm{D}_{2} \mathrm{C}^{12} \mathrm{H}_{2} \mathrm{C}^{12} \mathrm{D}_{2} \mathrm{O}^{16} *$ & $4-1092$ & $8,6,2 \leftarrow 8,5,3$ & Ground & & & & & 24785.55 & .1 \\
\hline $\mathrm{H}_{3} \mathrm{C}^{12} \mathrm{C}^{12}: \mathrm{C}^{12} \mathrm{C}^{12} \mathrm{~N}^{14}$ & $4-1121$ & $6,3 \leftarrow 5,3$ & Ground & & 6 & & 5 & 24.786 .31 & \\
\hline $\mathrm{H}_{3} \mathrm{C}^{12} \mathrm{C}^{12}: \mathrm{C}^{12} \mathrm{C}^{12} \mathrm{~N}^{14}$ & 4-1121 & $6,3 \leftarrow 5,3$ & Ground & & 7 & & 6 & 24786.61 & \\
\hline $\mathrm{H}_{3} \mathrm{C}^{12} \mathrm{C}^{12}: \mathrm{C}^{12} \mathrm{C}^{12} \mathrm{~N}^{14}$ & $4-1121$ & $6,3 \leftarrow 5,3$ & Ground & & 5 & & 4 & 24786.61 & \\
\hline $\mathrm{Si}^{30} \mathrm{D}_{3} \mathrm{~N}^{14} \mathrm{C}^{12} \mathrm{~S}^{32}$ & 4. 493 & $9, \leftarrow 8$ & Ground & & & & & 24786.84 & \\
\hline $\mathrm{H}_{3} \mathrm{C}^{12} \mathrm{C}^{12}: \mathrm{C}^{12} \mathrm{C}^{12} \mathrm{~N}^{14}$ & 4-1121 & $6,2 \leftarrow 5,2$ & Ground & & & & & 24787.85 & \\
\hline $\mathrm{H}_{3} \mathrm{C}^{12} \mathrm{C}^{12}: \mathrm{C}^{12} \mathrm{C}^{12} \mathrm{~N}^{14}$ & $4-1121$ & $6,1 \leftarrow 5,1$ & Ground & & & & & 24788.51 & \\
\hline $\mathrm{H}_{3} \mathrm{C}^{12} \mathrm{C}^{12}: \mathrm{C}^{12} \mathrm{C}^{12} \mathrm{~N}^{14}$ & $4-1121$ & $6,0 \leftarrow 5,0$ & Ground & & & & & 24788.69 & \\
\hline $\mathrm{DC}^{13}: \mathrm{C}^{12} \mathrm{C}^{12} \mathrm{HO}^{16}$ & 4- 917 & $3,1,3 \leftarrow 2,1,2$ & Ground & & & & & 24790.45 & .02 \\
\hline $\mathrm{N}^{\mathrm{b}} \mathrm{O}_{2}^{\mathrm{b}} \mathrm{Cl}^{\mathrm{b}}$ & 4-1463 & Not Reported & & & & & & 24791 & \\
\hline $\mathrm{C}^{13} \mathrm{H}_{3} \mathrm{Si}^{28} \mathrm{HF}_{2}^{19}-\mathrm{E}$ & 3- 196 & $3,0,3 \leftarrow 2,0,2$ & Ground & & & & & $2+793.40$ & \\
\hline $\mathrm{C}^{13} \mathrm{H}_{3} \mathrm{Si}^{28} \mathrm{HF}_{2}^{19}-\mathrm{A}$ & 3- 195 & $3,0,3 \leftarrow 2,0,2$ & Ground & & & & & 24794.63 & \\
\hline $\mathrm{C}^{12} \mathrm{H}_{3} \mathrm{C}^{12} \mathrm{H}: \mathrm{C}^{12}: \mathrm{C}^{12} \mathrm{H}_{2}$ & 3- 931 & $3,1,2 \leftarrow 2,1,1$ & Ground & & & & & 24796.20 & .03 \\
\hline $\mathrm{C}_{6}^{12} \mathrm{H}_{5} \mathrm{C}^{12}: \mathrm{C}^{12} \mathrm{H}$ & 3-1091 & $9,4,5 \leftarrow 8,4,4$ & Ground & & & & & 24796.4 & .5 \\
\hline $\mathrm{Ga}^{69} \mathrm{Br}^{79}$ & $1-$ & $5 \leftarrow 4$ & Ground & $7 / 2$ & 5 & $7 / 2$ & 5 & 24796.70 & 0.30 \\
\hline $\mathrm{C}^{12} \mathrm{H}_{3} \mathrm{C}^{12} \mathrm{H}: \mathrm{C}^{12}: \mathrm{C}^{12} \mathrm{H}_{2}$ & 3-931 & $3,1,2 \leftarrow 2,1,1$ & Ground & & & & & 24. 797.09 & .03 \\
\hline $\mathrm{C}^{12}{ }_{*} \mathrm{DN}^{14} \mathrm{C}^{12} \mathrm{DC}^{12} \mathrm{H}: \mathrm{C}^{12} \mathrm{DN}^{14} *$ & $4 \cdot 1142$ & $12,8,4 \leftarrow 12,7,5$ & Ground & & & & & 24801.8 & \\
\hline $\mathrm{C}^{12}{ }_{*} \mathrm{DN}^{14} \mathrm{C}^{12} \mathrm{DC}^{12} \mathrm{H}: \mathrm{C}^{12} \mathrm{DN}^{14} *$ & $4-1142$ & $12,9,4 \leftarrow 12,8,5$ & Ground & & & & & 24801.8 & \\
\hline $\mathrm{C}^{12} \mathrm{HCl}^{35} \mathrm{~F}_{2}^{19}$ & 4- 251 & $2,1,1 \leftarrow 1,0,1$ & Ground & & $3 / 2$ & & $1 / 2$ & 24801.9 & .05 \\
\hline $\mathrm{C}^{12} \mathrm{HCl}^{35} \mathrm{~F}_{2}^{19}$ & 4- 251 & $2,1,1 \leftarrow 1,0,1$ & Ground & & $3 / 2$ & & $1 / 2$ & 24.802 .17 & \\
\hline $\mathrm{Ga}^{69} \mathrm{Br}^{79}$ & $1-$ & $5 \leftarrow 4$ & Ground & $7 / 2$ & 3 & $7 / 2$ & 3 & 24802.17 & 0.30 \\
\hline $\mathrm{Ga}^{69} \mathrm{Br}^{79}$ & $1-$ & $5 \leftarrow 4$ & Ground & $7 / 2$ & 2 & $7 / 2$ & 2 & 24802.17 & 0.30 \\
\hline $2,4,6 d_{3}-C_{6}^{12} H_{5} F^{19}$ & 4-1284 & $7,1,7 \leftarrow 6,1,6$ & Ground & & & & & 24.802 .5 & .1 \\
\hline${ }^{14} \mathrm{H}_{2} \mathrm{C}_{2}^{12} \mathrm{H}_{5}$ & 3- 631 & Not Reported & Ground & & & & & 24802.94 & .2 \\
\hline $\mathrm{S}^{32}{ }_{*} \mathrm{HC}^{13}: \mathrm{C}^{12} \mathrm{HC}^{12} \mathrm{H}: \mathrm{C}^{12}{ }_{*} \mathrm{H}$ & $4-1167$ & $6,2,4 \leftarrow 6,2,5$ & Ground & & & & & 24803.0 & .05 \\
\hline $\mathrm{Br}^{79} \mathrm{C}^{12} \mathrm{~N}^{14}$ & 4. 141 & $3 \leftarrow 2$ & Excited & $5 / 2$ & & $3 / 2$ & & 24803.00 & \\
\hline $\mathrm{Br}^{79} \mathrm{C}^{12} \mathrm{~N}^{14}$ & 4. 141 & $3 \leftarrow 2$ & Excited & $7 / 2$ & & $5 / 2$ & & 24.803 .00 & \\
\hline
\end{tabular}


Vib. State

$F^{\prime} F^{\prime} \quad F_{1}$

Frequency

Acc. $\mathrm{MH}_{2} \pm \mathrm{MHz}$

\begin{tabular}{|c|c|c|c|c|c|c|c|}
\hline $\mathrm{F}_{2}^{19} \mathrm{O}_{2}^{16}$ & $3-\quad 11$ & $1,1,1 \leftarrow 0,0,0$ & Ground & & & 24804.00 & .1 \\
\hline $\mathrm{HDC}^{12}: \mathrm{C}^{12} \mathrm{~F}_{2}^{19}$ & 4- 682 & $2,1,2 \leftarrow 1,1,1$ & Ground & & & 24805.5 & .3 \\
\hline $\mathrm{C}^{12} \mathrm{HCl}^{35} \mathrm{~F}_{2}^{19}$ & 4- 251 & $2,1,1 \leftarrow 1,0,1$ & Ground & $5 / 2$ & $5 / 2$ & 24808.7 & .05 \\
\hline $\mathrm{C}^{12} \mathrm{HCl}^{35} \mathrm{~F}_{2}^{19}$ & 4- 251 & $2,2,1 \leftarrow 1,0,1$ & Ground & $5 / 2$ & $5 / 2$ & 24808.76 & \\
\hline $\mathrm{H}_{2} \mathrm{C}^{12}: \mathrm{C}^{12} \mathrm{~F}_{2}^{19}$ & 4- 681 & Not Reported & & & & 24809.7 & .3 \\
\hline $\mathrm{C}^{12} \mathrm{HCl}^{35} \mathrm{~F}_{2}^{19}$ & 4- 251 & $2,1,1 \leftarrow 1,0,1$ & Ground & $1 / 2$ & $1 / 2$ & 24810.8 & .05 \\
\hline $\mathrm{C}^{12} \mathrm{HCl}^{35} \mathrm{~F}_{2}^{19}$ & 4. 251 & $2,1,1 \leftarrow 1,0,1$ & Ground & $1 / 2$ & $1 / 2$ & 24810.96 & \\
\hline $\mathrm{HC}^{13}: \mathrm{C}^{12} \mathrm{C}^{12} \mathrm{DO}^{16}$ & 4- 922 & Not Reported & & & & 24812 & 5. \\
\hline $\mathrm{C}^{12}{ }_{*} \mathrm{D}_{2} \mathrm{C}^{12} \mathrm{H}_{2} \mathrm{C}^{12} \mathrm{D}_{2} \mathrm{O}^{16}{ }_{*}$ & 4-1092 & $5,2,3 \leftarrow 5,1,4$ & Excited & & & 24812.0 & .1 \\
\hline $\mathrm{C}^{12} \mathrm{H}_{3} \mathrm{Si}^{28} \mathrm{D}_{2} \mathrm{~F}^{19}$ & 3- 245 & $2,1,1 \leftarrow 1,1,0$ & Ground & & & 24814.44 & .10 \\
\hline $\mathrm{C}^{12} \mathrm{HCl}^{35} \mathrm{~F}_{2}^{19}$ & 4- 251 & $2,1,1 \leftarrow 1,0,1$ & Ground & $7 / 2$ & $5 / 2$ & 24817.4 & .05 \\
\hline $\mathrm{C}^{12} \mathrm{HCl}^{35} \mathrm{~F}_{2}^{19}$ & 4- 251 & $2,1,1 \leftarrow 1,0,1$ & Ground & $7 / 2$ & $5 / 2$ & 24817.64 & \\
\hline $\mathrm{C}^{12} \mathrm{HCl}^{35} \mathrm{~F}_{2}^{19}$ & 4- 251 & $2,1,1 \leftarrow 1,0,1$ & Ground & & & 24818.34 & .03 \\
\hline $\mathrm{C}^{12} \mathrm{H}_{3} \mathrm{As}^{75} \mathrm{~F}_{2}^{19}$ & 3- 81 & $3,1,3 \leftarrow 2,1,2$ & Ground & $7 / 2$ & $7 / 2$ & 24819.80 & .2 \\
\hline $\mathrm{C}^{12} \mathrm{H}_{3} \mathrm{As}^{75} \mathrm{~F}_{2}^{19}$ & $3-81$ & $3,0,3 \leftarrow 2,0,2$ & Ground & $7 / 2$ & $7 / 2$ & 24819.80 & .2 \\
\hline $\mathrm{C}^{12} \mathrm{DHCl}^{35} \mathrm{Cl}^{37}$ & 4- 345 & $3,1,2 \leftarrow 3,0,3$ & Ground & & & 24820 . & 5. \\
\hline $\mathrm{C}^{13} \mathrm{H}_{3} \mathrm{C}^{12} \mathrm{O}^{16} \mathrm{Cl}^{37}$ & 3. 368 & $9,3,6 \leftarrow 9,2,7$ & Ground & $15 / 2$ & $15 / 2$ & 24.822 .00 & .2 \\
\hline $\mathrm{C}^{13} \mathrm{H}_{3} \mathrm{C}^{12} \mathrm{O}^{16} \mathrm{Cl}^{37}$ & 3. 368 & $9,3,6 \leftarrow 9,2,7$ & Ground & $17 / 2$ & $17 / 2$ & 24822.00 & .2 \\
\hline $\mathrm{C}^{13} \mathrm{H}_{3} \mathrm{C}^{12} \mathrm{O}^{16} \mathrm{Cl}^{37}$ & 3. 368 & $9,3,6 \leftarrow 9,2,7$ & Ground & $19 / 2$ & $19 / 2$ & 24822.00 & .2 \\
\hline $\mathrm{C}^{13} \mathrm{H}_{3} \mathrm{C}^{12} \mathrm{O}^{16} \mathrm{Cl}^{37}$ & 3- 368 & $9,3,6 \leftarrow 9,2,7$ & Ground & $21 / 2$ & $21 / 2$ & 24822.00 & .2 \\
\hline $\mathrm{C}^{\prime \prime} \mathrm{H}_{3}^{\mathrm{b}} \mathrm{N}^{\mathrm{h}} \mathrm{C}^{\mathrm{b}} \mathrm{S}^{\mathrm{b}}$ & 3- 426 & $5, \quad \leftarrow 4$, & & & & 24824 & \\
\hline $\mathrm{C}^{12} \mathrm{H}_{2}\left(\mathrm{C}^{12} \mathrm{~N}^{14}\right)_{2}$ & 4- 901 & Not Reported & Ground & & & 24824.0 & .1 \\
\hline $\mathrm{H}_{2} \mathrm{~N}^{14} \mathrm{~N}^{14} \mathrm{H}_{2}$ & 3. 51 & Not Reported & & & & 24824.59 & \\
\hline $\mathrm{C}^{12} \mathrm{HCl}^{35} \mathrm{~F}_{2}^{19}$ & 4. 251 & $2,1,1 \leftarrow 1,0,1$ & Ground & $5 / 2$ & $3 / 2$ & 24.824 .9 & .05 \\
\hline $\mathrm{C}^{12} \mathrm{HCl}^{35} \mathrm{~F}_{2}^{19}$ & 4. 251 & $2,1,1 \leftarrow 1,0,1$ & Ground & $5 / 2$ & $3 / 2$ & 24.825 .06 & \\
\hline $\mathrm{C}^{13} \mathrm{H}_{3} \mathrm{C}^{12} \mathrm{O}^{16} \mathrm{Cl}^{37}$ & 3- 368 & $9,3,6 \leftarrow 9,2,7$ & Ground & $17 / 2$ & $17 / 2$ & 24825.58 & .2 \\
\hline $\mathrm{C}^{13} \mathrm{H}_{3} \mathrm{C}^{12} \mathrm{O}^{16} \mathrm{Cl}^{37}$ & 3- 368 & $9,3,6 \leftarrow 9,2,7$ & Ground & $19 / 2$ & $19 / 2$ & 24.825 .58 & .2 \\
\hline $\mathrm{C}^{13} \mathrm{H}_{3} \mathrm{C}^{12} \mathrm{O}^{16} \mathrm{Cl}^{37}$ & 3. 368 & $9,3,6 \leftarrow 9,2,7$ & Ground & $15 / 2$ & $15 / 2$ & 24.825 .58 & .2 \\
\hline $\mathrm{C}^{13} \mathrm{H}_{3} \mathrm{C}^{12} \mathrm{O}^{16} \mathrm{Cl}^{37}$ & 3. 368 & $9,3,6 \leftarrow 9,2,7$ & Ground & $21 / 2$ & $21 / 2$ & 24825.58 & .2 \\
\hline $\mathrm{C}^{12} \mathrm{D}_{3} \mathrm{~N}^{14} \mathrm{D}_{2}$ & 3- 262 & $7,1,7 \leftarrow 7,0,7$ & Ground & & & 24. 826.54 & \\
\hline $\mathrm{Br}^{79} \mathrm{C}^{12} \mathrm{~N}^{14}$ & 4- 141 & $3 \leftarrow 2$ & Excited & $7 / 2$ & $5 / 2$ & 24826.70 & \\
\hline $\mathrm{Br}^{79} \mathrm{C}^{12} \mathrm{~N}^{14}$ & 4- 141 & $3 \leftarrow 2$ & Excited & $5 / 2$ & $3 / 2$ & 24. 826.70 & \\
\hline $\mathrm{C}_{6}^{12} \mathrm{H}_{5} \mathrm{Cl}^{37}$ & $4-1272$ & $9,3,7 \leftarrow 8,3,6$ & Ground & & & 24827. & 5.0 \\
\hline $\mathrm{C}_{6}^{12} \mathrm{H}_{5} \mathrm{Cl}^{37}$ & 4-1272 & $9,4,6 \leftarrow 8,4,5$ & Ground & & & 24827 & 5.0 \\
\hline $\mathrm{C}^{12}{ }_{*} \mathrm{HC}^{12} \mathrm{H}: \mathrm{C}^{12} \mathrm{DC}^{12} \mathrm{H} \mathrm{C}^{12} \mathrm{HN}^{14}{ }_{*}$ & 4-1204 & $3,2,2 \leftarrow 2,2,1$ & Ground & & & 24.827 .8 & .1 \\
\hline $\mathrm{C}^{12} \mathrm{H}_{2}\left(\mathrm{C}^{12} \mathrm{~N}^{14}\right)_{2}$ & 4- 901 & Not Reported & Ground & & & 24.830 .1 & .1 \\
\hline $\mathrm{C}^{12} \mathrm{HCl}^{35} \mathrm{~F}_{2}^{19}$ & 4- 251 & $2,1,1 \leftarrow 1,0,1$ & Ground & $3 / 2$ & $3 / 2$ & 24.831 .2 & .05 \\
\hline $\mathrm{C}^{12} \mathrm{HCl}^{35} \mathrm{~F}_{2}^{19}$ & 4- 251 & $2,1,1 \leftarrow 1,0,1$ & Ground & $3 / 2$ & $3 / 2$ & 24.831 .37 & \\
\hline $\mathrm{S}^{32} \mathrm{O}^{16} \mathrm{~F}_{2}^{19}$ & 4-1621 & Not Reported & & & & 24832.14 & .1 \\
\hline $\mathrm{C}_{6}^{12} \mathrm{H}_{5} \mathrm{Cl}^{37}$ & 4-1272 & $9,4,5 \leftarrow 8,4,4$ & Ground & & & 24.834 & 5.0 \\
\hline $\mathrm{H}_{2} \mathrm{C}^{12}{ }_{*} \mathrm{O}^{16} \mathrm{C}^{12}{ }_{*} \mathrm{H}_{2}$ & 4. 841 & $4,3,1 \leftarrow 4,2,2$ & Ground & & & 24834.26 & .03 \\
\hline g- $\mathrm{C}^{12} \mathrm{H}_{2} \mathrm{DC}^{12} \mathrm{H}_{2} \mathrm{Cl}^{35}$ & 3. 544 & $3,1,2 \leftarrow 3,0,3$ & Ground & $3 / 2$ & $3 / 2$ & 24835.97 & .05 \\
\hline $\mathrm{Si}^{30} \mathrm{D}_{2} \mathrm{~F}_{2}^{19}$ & 4-1605 & $5,1,4 \leftarrow 5,0,5$ & Ground & & & 24836.28 & .10 \\
\hline g- $\mathrm{C}^{12} \mathrm{H}_{2} \mathrm{DC}^{12} \mathrm{H}_{2} \mathrm{Cl}^{35}$ & 3. 544 & $3,1,2 \leftarrow 3,0,3$ & Ground & $9 / 2$ & $9 / 2$ & 24.838 .76 & .05 \\
\hline g- $\mathrm{C}^{12} \mathrm{H}_{2} \mathrm{DC}^{12} \mathrm{H}_{2} \mathrm{Cl}^{35}$ & 3. 544 & $3,1,2 \leftarrow 3,0,3$ & Ground & $5 / 2$ & $5 / 2$ & 24842.03 & .05 \\
\hline
\end{tabular}




\begin{tabular}{|c|c|c|c|c|c|c|c|c|c|}
\hline Isotopic Species & $\begin{array}{l}\text { Vol.-Id. } \\
\text { Nos. }\end{array}$ & $\begin{array}{c}\text { Rotational } \\
\text { Quantum Nos. }\end{array}$ & Vib. State & $F_{1}^{\prime}$ & $\begin{array}{l}\text { Hyper } \\
\mathrm{F}^{\prime}\end{array}$ & $\begin{array}{c}\text { rfine } \\
F_{1}\end{array}$ & $F$ & $\begin{array}{c}\text { Frequency } \\
\mathrm{MHz}\end{array}$ & $\begin{array}{r}\text { Acc. } \\
\pm \mathrm{MHz}\end{array}$ \\
\hline g. $\mathrm{C}^{12} \mathrm{H}_{2} \mathrm{DC}^{12} \mathrm{H}_{2} \mathrm{Cl}^{35}$ & 3. 544 & $3,1,2 \leftarrow 3,0,3$ & Ground & & $7 / 2$ & & $7 / 2$ & 24844.87 & .05 \\
\hline $\mathrm{HC}^{13}: \mathrm{C}^{12} \mathrm{C}^{12} \mathrm{DO}^{16}$ & 4. 922 & Not Reported & & & & & & 24847 . & 5. \\
\hline $\mathrm{C}^{12} \mathrm{H}_{2}\left(\mathrm{C}^{12} \mathrm{~N}^{14}\right)_{2}$ & 4- 901 & Not Reported & Ground & & & & & 24852.9 & .1 \\
\hline $\mathrm{Cl}^{37} \mathrm{O}_{2}^{16}$ & $4-1382$ & $7,1,6 \leftarrow 6,2,5$ & Ground & & & & & 24856.0 & .2 \\
\hline $\mathrm{C}^{12} \mathrm{H}_{2}: \mathrm{C}^{12} \mathrm{HC}^{12} \mathrm{~F}^{19}: \mathrm{C}^{12} \mathrm{H}_{2}$ & 3. 911 & $8,2,6 \leftarrow 8,1,7$ & Ground & & & & & 24858.1 & .2 \\
\hline $\mathrm{Br}^{79} \mathrm{C}^{12} \mathrm{~N}^{14}$ & 4- 141 & $3 \leftarrow 2$ & Excited & $5 / 2$ & & $3 / 2$ & & 24860.6 & \\
\hline $\mathrm{Br}^{79} \mathrm{C}^{12} \mathrm{~N}^{14}$ & 4. 141 & $3 \leftarrow 2$ & Excited & $3 / 2$ & & $3 / 2$ & & 24860.6 & \\
\hline $\mathrm{C}^{13} \mathrm{H}_{3} \mathrm{O}^{16} \mathrm{H}$ & 3. 213 & $28,2, \leftarrow 28,1$, & Ground & & & & & 24860.62 & .1 \\
\hline $3 \mathrm{~d}-\mathrm{C}_{6}^{12} \mathrm{H}_{5} \mathrm{~F}^{19}$ & $4-1282$ & $6,2,5 \leftarrow 5,2,4$ & Ground & & & & & 24.860 .7 & .1 \\
\hline $\mathrm{C}^{12} \mathrm{D}_{3} \mathrm{C}^{12} \mathrm{O}^{16} \mathrm{Cl}^{35}$ & 3. 363 & $9,4,5 \leftarrow 9,3,6$ & Ground & & $15 / 2$ & & $15 / 2$ & 24862.10 & \\
\hline $\mathrm{C}^{12} \mathrm{D}_{3} \mathrm{C}^{12} \mathrm{O}^{16} \mathrm{Cl}^{35}$ & 3- 363 & $9,4,5 \leftarrow 9,3,6$ & Ground & & $21 / 2$ & & $21 / 2$ & 24862.10 & \\
\hline $\mathrm{C}^{12}{ }_{*} \mathrm{DN}^{14} \mathrm{C}^{12} \mathrm{DC}^{12} \mathrm{H}: \mathrm{C}^{12} \mathrm{DN}^{14} *$ & 4.1142 & $11,8,4 \leftarrow 11,7,5$ & Ground & & & & & 24863.4 & \\
\hline $\mathrm{C}^{12} \mathrm{DN}^{14} \mathrm{C}^{12} \mathrm{DC}^{12} \mathrm{H}: \mathrm{C}^{12} \mathrm{DN}^{14} *$ & $4 \cdot 1142$ & $11,7,4 \leftarrow 11,6,5$ & Ground & & & & & 24863.4 & \\
\hline $\mathrm{C}^{12} \mathrm{D}_{3} \mathrm{C}^{12} \mathrm{O}^{16} \mathrm{Cl}^{35}$ & 3. 363 & $9,4,5 \leftarrow 9,3,6$ & Ground & & $17 / 2$ & & $17 / 2$ & 24865.15 & \\
\hline $\mathrm{C}^{12} \mathrm{D}_{3} \mathrm{C}^{12} \mathrm{O}^{16} \mathrm{Cl}^{35}$ & 3- 363 & $9,4,5 \leftarrow 9,3,6$ & Ground & & $19 / 2$ & & $19 / 2$ & 24865.15 & \\
\hline $\mathrm{C}^{12} \mathrm{H}_{3} \mathrm{C}^{12}{ }_{*} \mathrm{HO}^{16} \mathrm{C}^{12}{ }_{*} \mathrm{H}_{2}$ & 3. 761 & $7,1,6 \leftarrow 7,0,7$ & Ground & & & & & 24869.10 & .1 \\
\hline $\mathrm{H}_{2} \mathrm{C}^{12}: \mathrm{C}^{12} \mathrm{HI}^{127}$ & 4- 801 & $4,1,4 \leftarrow 3,1,3$ & Ground & & $7 / 2$ & & $5 / 2$ & 24869.49 & .05 \\
\hline $\mathrm{H}_{2}^{\mathrm{l}} \mathrm{C}^{\mathrm{b}} * \mathrm{O}^{16} \mathrm{C}^{\mathrm{l}}{ }_{*} \mathrm{H}_{2}^{\mathrm{\prime}}$ & 4. 846 & Not Reported & Excited & & & & & 24870 & 1. \\
\hline $\mathrm{C}^{12} \mathrm{D}_{3} \mathrm{C}^{12} \mathrm{O}^{16} \mathrm{O}^{16} \mathrm{H}$ & 3- 492 & $2,1,2 \leftarrow 1,0,1$ & & & & & & 24.871 .11 & .4 \\
\hline $\mathrm{C}^{12} \mathrm{H}_{2} \mathrm{C}^{12} \mathrm{HDC}^{12} \mathrm{H}_{2} \mathrm{O}^{16}{ }_{*}$ & $4-1094$ & $4,3,2 \leftarrow 4,1,3$ & Ground & & & & & 24.872 .5 & .1 \\
\hline g- $\mathrm{C}^{12} \mathrm{H}_{3} \mathrm{C}^{12} \mathrm{H}_{2} \mathrm{C}^{12} \mathrm{H}_{2} \mathrm{Cl}^{35}$ & 3- 773 & $4,2,2 \leftarrow 3,2,1$ & Ground & & & & & 24.874 .53 & .2 \\
\hline $\mathrm{s}-\left(\mathrm{C}^{12} \mathrm{H}_{2} \mathrm{D}\right)\left(\mathrm{C}^{12} \mathrm{H}_{3}\right) \mathrm{O}^{16}$ & 3. 596 & Not Reported & Ground & & & & & 24875 . & 20. \\
\hline $\mathrm{P}^{31} \mathrm{Cl}_{3}^{37}$ & $4-1524$ & $5, \leftarrow 4$ & Ground & & & & & 24875 . & 1. \\
\hline$\left(\mathrm{C}^{12} \mathrm{H}_{3}\right)_{2} \mathrm{C}^{12} \mathrm{O}^{16}$ & 3- 751 & $2,1,2 \leftarrow 1,0,1$ & Ground & & & & & 24876.48 & .04 \\
\hline $\mathrm{Cl}^{37} \mathrm{O}_{2}^{16}$ & 4-1382 & $7,1,6 \leftarrow 6,2,5$ & Ground & & & & & 24876.8 & .2 \\
\hline $\mathrm{C}^{12} \mathrm{H}_{3} \mathrm{C}^{12}: \mathrm{C}^{12} \mathrm{C}^{12} \mathrm{H}_{2} \mathrm{Cl}^{37}$ & 3- 902 & $9,1,9 \leftarrow 8,1,8$ & Ground & & & & & 24.877 .4 & .3 \\
\hline $\mathrm{H}_{2} \mathrm{C}^{12}: \mathrm{C}^{12} \mathrm{HI}^{127}$ & 4. 801 & $4,1,4 \leftarrow 3,1,3$ & Ground & & $5 / 2$ & & $3 / 2$ & 24877.60 & .05 \\
\hline $\mathrm{C}^{12} \mathrm{DHCl}_{2}^{355}$ & 4- 344 & $3,1,2 \leftarrow 3,0,3$ & Ground & & & & & 24878. & 5. \\
\hline $\mathrm{C}^{12} \mathrm{H}_{3} \mathrm{~S}^{34} \mathrm{H}$ & 3. 225 & $1,0,1 \leftarrow 0,0.0$ & Ground & & & & & 24878.9 & \\
\hline $\mathrm{Ge}^{76} \mathrm{H}_{3} \mathrm{Cl}^{37}$ & 4-1434 & $3, \leftarrow 2$, & Ground & & & & & 24879.0 & .5 \\
\hline $\mathrm{C}^{12} \mathrm{H}_{3} \mathrm{~N}^{14} \mathrm{O}_{2}^{16}$ & 3. 171 & Not Reported & Ground & & & & & 24879.62 & \\
\hline $\mathrm{C}^{12} \mathrm{H}_{3} \mathrm{C}^{12} \mathrm{O}^{18} \mathrm{~F}^{19}$ & 3- 394 & $2,1,2 \leftarrow 1,1,1$ & Ground & & & & & 24879.75 & .2 \\
\hline $\mathrm{C}^{12} \mathrm{H}_{3} \mathrm{~S}^{34} \mathrm{H}$ & 3- 225 & $1,0,1 \leftarrow 0,0,0$ & Ground & & & & & 24879.8 & \\
\hline $\mathrm{N}^{14} \mathrm{H}_{3}$ & $4-1771$ & $11,10 \leftarrow 11,10$ & Ground & & & & & 24881.90 & .02 \\
\hline $\mathrm{Br}^{79} \mathrm{C}^{12} \mathrm{~N}^{14}$ & 4- 141 & $3 \leftarrow 2$ & Ground & $7 / 2$ & & $7 / 2$ & & 24884.57 & \\
\hline $\mathrm{HDO}^{16}$ & $4-1712$ & $8,4,4 \leftarrow 8,4,5$ & Ground & & & & & 24884.77 & .05 \\
\hline $\mathrm{C}^{12} \mathrm{H}_{2}: \mathrm{C}^{12} \mathrm{HC}^{12} \mathrm{~F}^{19}: \mathrm{C}^{12} \mathrm{H}_{2}$ & 3- 911 & $7,3,4 \leftarrow 7,2,5$ & Excited & & & & & 24887.38 & .03 \\
\hline$\left(\mathrm{C}^{12} \mathrm{H}_{3}\right)_{2} \mathrm{C}^{12} \mathrm{O}^{16}$ & 3. 751 & $2,1,2 \leftarrow 1,0,1$ & Ground & & & & & 24888.30 & .04 \\
\hline $\mathrm{H}_{2} \mathrm{C}^{12}: \mathrm{C}^{12} \mathrm{HI}^{127}$ & 4- 801 & $4,1,4 \leftarrow 3,1,3$ & Ground & & $9 / 2$ & & $7 / 2$ & 24. 888.45 & .05 \\
\hline $\mathrm{C}^{12}{ }_{*} \mathrm{H}: \mathrm{C}^{12} \mathrm{HO}^{16} \mathrm{C}^{12} \mathrm{H}: \mathrm{C}^{12}{ }_{*} \mathrm{H}$ & 4-1151 & $11,10,2 \leftarrow 11,8,3$ & Ground & & & & & 24888.97 & \\
\hline $\mathrm{C}^{12} \mathrm{H}_{3} \mathrm{~N}^{14} \mathrm{H}_{2}$ & 3- 261 & Not Reported & Ground & & & & & 24.889 .42 & .04 \\
\hline $\mathrm{C}^{12} \mathrm{D}_{2} \mathrm{C}^{12} \mathrm{H}_{2} \mathrm{C}^{12} \mathrm{D}_{2} \mathrm{O}^{16} *$ & 4-1092 & $5,4,2 \leftarrow 5,3,3$ & Ground & & & & & 24889.50 & .1 \\
\hline $\mathrm{H}_{2} \mathrm{C}^{12}: \mathrm{C}^{12} \mathrm{HI}^{127}$ & 4- 801 & $4,1,4 \leftarrow 3,1,3$ & Ground & & $9 / 2$ & & $9 / 2$ & 24889.69 & .05 \\
\hline $\mathrm{C}^{12} \mathrm{H}_{3} \mathrm{~N}^{14} \mathrm{H}_{2}$ & 3- 261 & Not Reported & Ground & & & & & 24889.80 & .1 \\
\hline $\mathrm{Br}^{79} \mathrm{C}^{12} \mathrm{~N}^{14}$ & 4- 141 & $3 \leftarrow 2$ & Excited & $7 / 2$ & & $7 / 2$ & & 24890.0 & \\
\hline
\end{tabular}




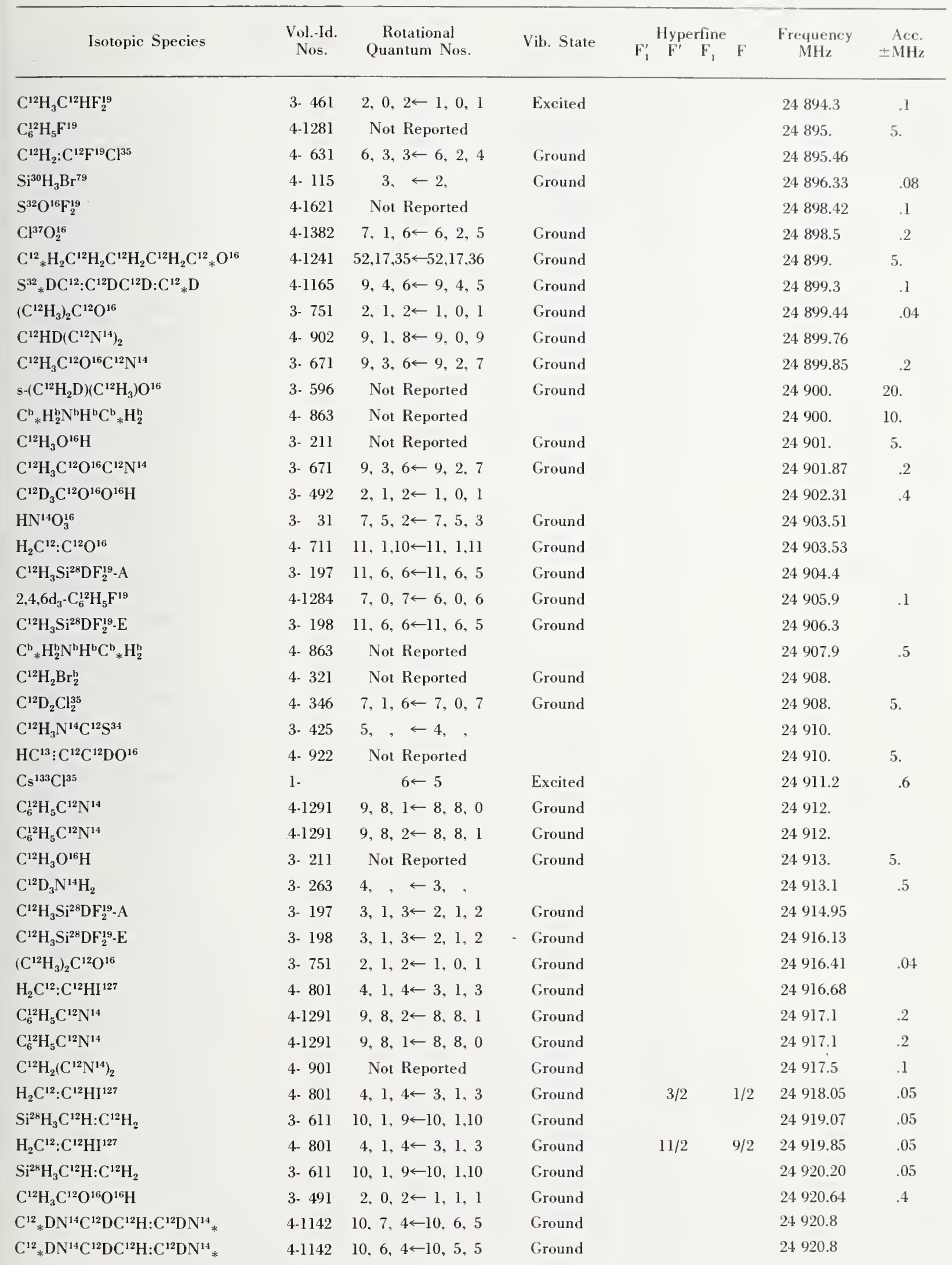




\begin{tabular}{|c|c|c|c|c|c|c|c|}
\hline \multirow{2}{*}{ Isotopic Species } & \multirow{2}{*}{$\begin{array}{l}\text { Vol.-Id. } \\
\text { Nos. }\end{array}$} & \multirow{2}{*}{$\begin{array}{c}\text { Rotational } \\
\text { Quantum Nos. }\end{array}$} & \multirow{2}{*}{ Vib. State } & \multicolumn{2}{|c|}{ Hyperfine } & \multirow{2}{*}{$\begin{array}{c}\text { Frequency } \\
\text { MHz }\end{array}$} & \multirow{2}{*}{$\begin{aligned} & \text { Acc. } \\
\pm & \mathrm{MHz}\end{aligned}$} \\
\hline & & & & $\begin{array}{lll}F_{1}^{\prime} & F^{\prime} & F_{1}\end{array}$ & $\mathrm{~F}$ & & \\
\hline $\mathrm{Si}^{28} \mathrm{D}_{2} \mathrm{~F}_{2}^{19}$ & 4-1603 & $5,1,4 \leftarrow 5,0,5$ & Excited & & & 24921.75 & .10 \\
\hline $\mathrm{H}_{2} \mathrm{~N}^{14} \mathrm{~N}^{14} \mathrm{H}_{2}$ & 3- 51 & Not Reported & & & & 24.923 .34 & \\
\hline $\mathrm{H}_{2} \mathrm{C}^{12}{ }_{*} \mathrm{O}^{16} \mathrm{C}^{12}{ }_{*} \mathrm{H}_{2}$ & 4- 841 & $2,1,1 \leftarrow 2,0,2$ & Ground & & & 24923.66 & .03 \\
\hline $\mathrm{C}^{12} \mathrm{H}_{3} \mathrm{C}^{12} \mathrm{~F}^{19}: \mathrm{C}^{12} \mathrm{H}_{2}$ & 3- 721 & $5,4,2 \leftarrow 5,3,3$ & Ground & & & 24924.15 & .1 \\
\hline $\mathrm{Cl}^{37} \mathrm{O}_{2}^{16}$ & 4-1382 & $7,1,6 \leftarrow 6,2,5$ & Ground & & & 24924.6 & .2 \\
\hline $\mathrm{HC}^{13}: \mathrm{C}^{12} \mathrm{C}^{12} \mathrm{DO}^{16}$ & 4- 922 & Not Reported & & & & 24926. & 5. \\
\hline $\mathrm{C}^{12} \mathrm{H}_{3} \mathrm{O}^{16} \mathrm{H}$ & 3- 211 & Not Reported & & & & 24926. & 5. \\
\hline $\mathrm{C}^{12} \mathrm{H}_{3} \mathrm{C}^{12} \mathrm{HF}_{2}^{19}$ & 3- 461 & $2,0,2 \leftarrow 1,0,1$ & Ground & & & 24926.6 & \\
\hline $\mathrm{C}^{\mathrm{b}} \mathrm{H}_{2}^{\mathrm{b}} \mathrm{Cl}^{\mathrm{b}} \mathrm{F}^{\mathrm{b}}$ & 4- 333 & Not Reported & & & & 24. 928.22 & .1 \\
\hline $\mathrm{C}_{6}^{12} \mathrm{H}_{5} \mathrm{Cl}^{35}$ & 4-1271 & $9,2,8 \leftarrow 8,2,7$ & Ground & & & 24928.7 & \\
\hline $\mathrm{C}^{12} \mathrm{H}_{3} \mathrm{O}^{16} \mathrm{H}$ & 3- 211 & $3,2, \leftarrow 3,1$ & Ground & & & 24928.70 & .1 \\
\hline $\mathrm{C}_{6}^{12} \mathrm{H}_{5} \mathrm{C}^{12} \mathrm{~N}^{14}$ & 4-1291 & $9,7,2 \leftarrow 8,7,1$ & Ground & & & 24929.0 & .2 \\
\hline $\mathrm{C}_{6}^{12} \mathrm{H}_{5} \mathrm{C}^{12} \mathrm{~N}^{14}$ & 4-1291 & $9,7,3 \leftarrow 8,7,2$ & Ground & & & 24929.0 & .2 \\
\hline $\mathrm{C}^{13} \mathrm{H}_{3} \mathrm{C}^{12} \mathrm{O}^{16} \mathrm{~F}^{19}$ & 3- 393 & $2,1,2 \leftarrow 1,1,1$ & Ground & & & 24929.38 & .2 \\
\hline $\mathrm{C}^{12} \mathrm{H}_{3} \mathrm{~N}^{14} \mathrm{C}^{12} \mathrm{~S}^{33}$ & 3- 424 & $5, \quad, \quad \leftarrow 4, \quad$, & Ground & & & 24.930 & \\
\hline $\mathrm{As}^{75} \mathrm{Cl}^{35} \mathrm{Cl}_{2}^{37}$ & 4- $\quad 13$ & $6, \quad, \leftarrow 5$, & Ground & & & 24932. & 10. \\
\hline $\mathrm{C}^{12} \mathrm{H}_{3} \mathrm{C}^{12} \mathrm{~F}^{19}: \mathrm{C}^{12} \mathrm{H}_{2}$ & 3- 721 & $2,1,2 \leftarrow 1,0,1$ & Ground & & & 24932.50 & .1 \\
\hline $\mathrm{O}^{\mathrm{l}} \mathrm{O}^{\mathrm{l}} \mathrm{O}^{\mathrm{b}}$ & $4-1847$ & Not Reported & & & & 24932.6 & \\
\hline $\mathrm{C}^{12} \mathrm{H}_{3} \mathrm{C}^{12} \mathrm{O}^{16} \mathrm{Br}^{81}$ & 3- 352 & $5,1,5 \leftarrow 4,1,4$ & Ground & $13 / 2$ & $11 / 2$ & 24932.92 & .15 \\
\hline $\mathrm{C}^{12} \mathrm{H}_{3} \mathrm{O}^{16} \mathrm{H}$ & 3- 211 & $4,2, \leftarrow 4,1$, & Ground & & & 24933.47 & .1 \\
\hline $\mathrm{C}^{12} \mathrm{H}_{3} \mathrm{O}^{16} \mathrm{H}$ & 3- 211 & $2,2, \leftarrow 2,1$, & Ground & & & 24934.38 & .1 \\
\hline $\mathrm{C}^{12} \mathrm{H}_{3} \mathrm{C}^{12} \mathrm{~F}^{19}: \mathrm{C}^{12} \mathrm{H}_{2}$ & 3- 721 & $5,4,2 \leftarrow 5,3,3$ & Ground & & & 24935.22 & .1 \\
\hline $\mathrm{C}^{12} \mathrm{H}_{3} \mathrm{C}^{12} \mathrm{~F}^{19}: \mathrm{C}^{12} \mathrm{H}_{2}$ & 3- 721 & $2,1,2 \leftarrow 1,0,1$ & Ground & & & 24935.22 & .1 \\
\hline $\mathrm{H}_{2} \mathrm{~N}^{14} \mathrm{~N}^{14} \mathrm{H}_{2}$ & $3-51$ & Not Reported & & & & 24935.41 & \\
\hline $\mathrm{C}^{12} \mathrm{~F}_{3}^{19} \mathrm{Br}^{81}$ & 4- 222 & $6,2 \leftarrow 5,2$ & Ground & $15 / 2$ & $13 / 2$ & 24935.7 & \\
\hline $\mathrm{C}^{12} \mathrm{~F}_{3}^{19} \mathrm{Br}^{81}$ & 4- 222 & $6,2 \leftarrow 5,2$ & Ground & $9 / 2$ & $7 / 2$ & 24935.7 & \\
\hline $\mathrm{C}^{12}{ }_{*} \mathrm{H}_{2} \mathrm{~N}^{14} \mathrm{DC}^{12}{ }_{*} \mathrm{H}_{2}$ & 4- 862 & $7,7,1 \leftarrow 7,5,2$ & Ground & & & 24936.3 & .5 \\
\hline $\mathrm{C}^{12} \mathrm{H}_{3} \mathrm{C}^{12} \mathrm{O}^{16} \mathrm{Br}^{81}$ & 3- 352 & $5,1,5 \leftarrow 4,1,4$ & Ground & $7 / 2$ & $5 / 2$ & 24936.55 & .15 \\
\hline $\mathrm{C}^{12} \mathrm{H}_{3} \mathrm{C}^{12} \mathrm{O}^{16} \mathrm{Br}^{81}$ & 3- 352 & $5,1,5 \leftarrow 4,1,4$ & Ground & $11 / 2$ & $9 / 2$ & 24937.28 & .15 \\
\hline $\mathrm{C}^{12}{ }_{*} \mathrm{H}_{2} \mathrm{~N}^{14} \mathrm{DC}^{12}{ }_{*} \mathrm{H}_{2}$ & 4- 862 & $7,7,1 \leftarrow 7,5,2$ & Ground & & & 24937.3 & .5 \\
\hline $\mathrm{C}_{6}^{12} \mathrm{H}_{5} \mathrm{C}^{12} \mathrm{~N}^{14}$ & 4-1291 & $9,6,4 \leftarrow 8,6,3$ & Ground & & & 24938 & \\
\hline $\mathrm{C}_{6}^{12} \mathrm{H}_{5} \mathrm{C}^{12} \mathrm{~N}^{14}$ & 4-1291 & $9,6,3 \leftarrow 8,6,2$ & Ground & & & 24938. & \\
\hline $\mathrm{C}^{12} \mathrm{~F}_{3}^{19} \mathrm{Br}^{81}$ & 4- 222 & $6,1 \leftarrow 5,1$ & Ground & $15 / 2$ & $13 / 2$ & 24939.6 & \\
\hline $\mathrm{C}^{12} \mathrm{H}_{3} \mathrm{C}^{12} \mathrm{O}^{16} \mathrm{Br}^{81}$ & 3- 352 & $5,1,5 \leftarrow 4,1,4$ & Ground & $9 / 2$ & $7 / 2$ & 24940.70 & .15 \\
\hline $\mathrm{C}^{12} \mathrm{~F}_{3}^{19} \mathrm{Br}^{81}$ & 4- 222 & $6,0 \leftarrow 5,0$ & Ground & $13 / 2$ & $11 / 2$ & 24941.2 & \\
\hline $\mathrm{C}^{12} \mathrm{~F}_{3}^{19} \mathrm{Br}^{81}$ & 4- 222 & $6,0 \leftarrow 5,0$ & Ground & $15 / 2$ & $13 / 2$ & 24941.2 & \\
\hline $\mathrm{H}_{2} \mathrm{C}^{12}: \mathrm{C}^{12} \mathrm{HI}^{127}$ & 4- 801 & $4,1,4 \leftarrow 3,1,3$ & Ground & $13 / 2$ & $11 / 2$ & 24942.47 & .05 \\
\hline $\mathrm{C}^{12} \mathrm{H}_{2} \mathrm{Br}_{2}^{13}$ & 4- 321 & Not Reported & Ground & & & 24.943. & \\
\hline $\mathrm{C}^{12} \mathrm{~F}_{3}^{19} \mathrm{Br}^{81}$ & 4- 222 & $6,1 \leftarrow 5,1$ & Ground & $13 / 2$ & $11 / 2$ & 24.943 .3 & \\
\hline $\mathrm{C}^{12} \mathrm{H}_{3} \mathrm{C}^{12} \mathrm{~F}^{19}: \mathrm{C}^{12} \mathrm{H}_{2}$ & 3- 721 & $5,4,2 \leftarrow 5,3,3$ & Ground & & & 24943.63 & .1 \\
\hline $\mathrm{C}^{12} \mathrm{H}_{2} \mathrm{Cl}^{35} \mathrm{Cl}^{37}$ & 4- 342 & $8,2,7 \leftarrow 9,1,8$ & Ground & & & 24947 & 5. \\
\hline $\mathrm{HC}^{12} \mathrm{O}^{18} \mathrm{O}^{16} \mathrm{C}^{12} \mathrm{H}_{3}-\mathrm{E}$ & 3- 514 & $2,1,1 \leftarrow 1,1,0$ & Ground & & & 24947.31 & .2 \\
\hline $\mathrm{C}_{6}^{12} \mathrm{H}_{5} \mathrm{C}^{12} \mathrm{~N}^{14}$ & 4-1291 & $9,6,4 \leftarrow 8,6,3$ & Ground & & & 24947.5 & .2 \\
\hline $\mathrm{C}_{6}^{12} \mathrm{H}_{5} \mathrm{C}^{1}{ }^{2} \mathrm{~N}^{14}$ & 4-1291 & $9,6,3 \leftarrow 8,6,2$ & Ground & & & 24947.5 & .2 \\
\hline $\mathrm{C}^{12} \mathrm{~F}_{3}^{19} \mathrm{Br}^{8 t}$ & 4- 222 & $6,1 \leftarrow 5,1$ & Ground & $11 / 2$ & $9 / 2$ & 24947.6 & \\
\hline
\end{tabular}




\begin{tabular}{|c|c|c|c|c|c|c|c|c|c|}
\hline Isotopic Species & $\begin{array}{l}\text { Vol.-Id. } \\
\text { Nos. }\end{array}$ & $\begin{array}{c}\text { Rotational } \\
\text { Quantum Nos. }\end{array}$ & Vib. State & $F_{1}^{\prime}$ & $\begin{array}{l}\text { Hypo } \\
\mathrm{F}^{\prime}\end{array}$ & $\begin{array}{c}\mathrm{F}_{1} \\
\mathrm{r} \text { fine }\end{array}$ & $\mathrm{F}$ & $\begin{array}{l}\text { Frequency } \\
\qquad \mathrm{MHz}^{2}\end{array}$ & $\begin{aligned} & \text { Acc. } \\
& \pm \mathrm{MHz}\end{aligned}$ \\
\hline $\mathrm{C}^{12} \mathrm{H}_{3} \mathrm{C}^{12} \mathrm{O}^{16} \mathrm{O}^{16} \mathrm{H}$ & 3- 491 & $9,6,3 \leftarrow 9,5,4$ & Ground & & & & & 24949.51 & .4 \\
\hline $\mathrm{C}^{12} \mathrm{~F}_{3}^{19} \mathrm{Br}^{81}$ & 4. 222 & $6,2 \leftarrow 5,2$ & Ground & & $13 / 2$ & & $11 / 2$ & 24950.4 & \\
\hline $\mathrm{HC}^{12} \mathrm{O}^{18} \mathrm{O}^{16} \mathrm{C}^{12} \mathrm{H}_{3} \cdot \mathrm{A}$ & 3- 513 & $2,1,1 \leftarrow 1,1,0$ & Ground & & & & & 24950.66 & .2 \\
\hline $\mathrm{D}_{2} \mathrm{C}^{12}: \mathrm{C}^{12} \mathrm{~F}_{2}^{19}$ & 4- 683 & $3,2,2 \leftarrow 3,0,3$ & Ground & & & & & 24950.7 & .3 \\
\hline $\mathrm{C}^{12} \mathrm{H}_{3} \mathrm{C}^{12} \mathrm{~F}^{19}: \mathrm{C}^{12} \mathrm{H}_{2}$ & 3- 721 & $2,1,2 \leftarrow 1,0,1$ & Ground & & & & & 24.950 .96 & .1 \\
\hline $\mathrm{C}^{12} \mathrm{H}_{3} \mathrm{C}^{12} \mathrm{HF}_{2}^{19}$ & 3. 461 & $2,0,2 \leftarrow 1,0,1$ & Ground & & & & & 24951.6 & .1 \\
\hline $\mathrm{C}^{12} \mathrm{H}_{3} \mathrm{O}^{16} \mathrm{H}$ & 3- 211 & Not Reported & Ground & & & & & 24954.6 & \\
\hline $\mathrm{t}-\mathrm{C}^{12} \mathrm{H}_{2} \mathrm{DC}^{12} \mathrm{H}_{2} \mathrm{~F}^{19}$ & 3- 554 & $6,1,5 \leftarrow 6,2,4$ & Ground & & & & & 24955.0 & .1 \\
\hline $\mathrm{C}^{12} \mathrm{~F}_{3}^{19} \mathrm{Br}^{81}$ & 4- 222 & $6,3 \leftarrow 5,3$ & Ground & & $11 / 2$ & & $9 / 2$ & 24955.4 & \\
\hline $\mathrm{C}^{12} \mathrm{H}_{2}\left(\mathrm{C}^{12} \mathrm{~N}^{14}\right)_{2}$ & 4. 901 & Not Reported & Ground & & & & & 24955.5 & .1 \\
\hline $\mathrm{C}^{12} \mathrm{H}_{3} \mathrm{~N}^{14} \mathrm{O}_{2}^{16}$ & 3- 171 & Not Reported & Ground & & & & & 24959. & 5. \\
\hline $\mathrm{S}^{32} \mathrm{O}^{16} \mathrm{~F}_{2}^{19}$ & 4-1621 & $15.15,1 \leftarrow 15,14,1$ & & & & & & 24. 959.04 & .1 \\
\hline $\mathrm{C}^{12} \mathrm{H}_{3} \mathrm{O}^{16} \mathrm{H}$ & 3- 211 & $5,2, \leftarrow 5,1$, & Ground & & & & & 24959.08 & .1 \\
\hline $\mathrm{C}^{12} \mathrm{H}_{3} \mathrm{C}^{12} \mathrm{~F}^{19}: \mathrm{C}^{12} \mathrm{H}_{2}$ & 3. 721 & $9,6,3 \leftarrow 9,5,4$ & Ground & & & & & 24959.57 & .1 \\
\hline $\mathrm{H}_{2} \mathrm{C}^{12}: \mathrm{C}^{12} \mathrm{Cl}_{2}^{35}$ & 4- 661 & $9,4,5 \leftarrow 9,3,6$ & Ground & & & & & 24960.08 & .5 \\
\hline $\mathrm{C}^{12}{ }_{*} \mathrm{D}_{2} \mathrm{C}^{12} \mathrm{H}_{2} \mathrm{C}^{12} \mathrm{D}_{2} \mathrm{O}^{16}{ }_{*}$ & 4-1092 & $5,2,3 \leftarrow 5,1,4$ & Ground & & & & & 24.960 .27 & .1 \\
\hline $\mathrm{H}_{2} \mathrm{C}^{12}: \mathrm{C}^{12} \mathrm{Cl}_{2}^{35}$ & 4- 661 & $9,4,5 \leftarrow 9,3.6$ & Ground & & & & & 24961.40 & .5 \\
\hline $\mathrm{C}^{12} \mathrm{O}^{16} \mathrm{Cl}_{2}^{35}$ & 4. 181 & $3,3,1 \leftarrow 3,2,2$ & Ground & $9 / 2$ & 3 & $9 / 2$ & 3 & 24961.48 & .1 \\
\hline $\mathrm{H}_{2} \mathrm{C}^{12}: \mathrm{C}^{12} \mathrm{Cl}_{2}^{35}$ & 4. 661 & $9,4,5 \leftarrow 9,3,6$ & Ground & & & & & 24962.72 & .5 \\
\hline $\mathrm{HC}^{13}: \mathrm{C}^{12} \mathrm{C}^{12} \mathrm{DO}^{16}$ & 4- 922 & Not Reported & & & & & & 24963. & 5. \\
\hline$\left(\mathrm{C}^{12} \mathrm{H}_{3}\right)_{3} \mathrm{C}^{12} \mathrm{C}^{12}: \mathrm{C}^{12} \mathrm{Cl}^{35}$ & $3-1061$ & $14, \leftarrow 13$ & Ground & & & & & 24967.1 & .5 \\
\hline $\mathrm{C}^{12} \mathrm{H}_{3} \mathrm{C}^{12} \mathrm{O}^{16} \mathrm{O}^{16} \mathrm{H}$ & 3- 491 & Not Reported & & & & & & 24968. & 3. \\
\hline $\mathrm{HC}^{13}: \mathrm{C}^{12} \mathrm{C}^{12} \mathrm{DO}^{16}$ & 4- 922 & Not Reported & & & & & & 24968. & 5. \\
\hline $\mathrm{C}^{12}{ }_{*} \mathrm{HO}^{16} \mathrm{C}^{12} \mathrm{HC}^{12} \mathrm{H}_{2} \mathrm{C}^{12} \mathrm{H}_{2} \mathrm{C}^{12}{ }_{*} \mathrm{H}_{2}$ & 4-1251 & $12,7,6 \leftarrow 12,5,7$ & Ground & & & & & 24968. & 5. \\
\hline $\mathrm{S}^{32} \mathrm{~F}_{5}^{19} \mathrm{Cl}$ & 4-1422 & $7, \leftarrow 6$ & Ground & & & & & 24969.50 & .5 \\
\hline $\mathrm{C}^{12}{ }_{*} \mathrm{DN}^{14} \mathrm{C}^{12} \mathrm{DC}^{12} \mathrm{H}: \mathrm{C}^{12} \mathrm{DN}^{14}{ }_{*}$ & 4-1142 & $9,6,4 \leftarrow 9,5,5$ & Ground & & & & & 24969.9 & \\
\hline $\mathrm{C}^{12}{ }_{*} \mathrm{DN}^{14} \mathrm{C}^{12} \mathrm{DC}^{12} \mathrm{H}: \mathrm{C}^{12} \mathrm{DN}^{14} *$ & 4-1142 & $9,5,4 \leftarrow 9,4,5$ & Ground & & & & & 24.969 .9 & \\
\hline $\mathrm{C}^{12} \mathrm{H}_{3} \mathrm{C}^{12} \mathrm{~F}^{19}: \mathrm{C}^{12} \mathrm{H}_{2}$ & 3. 721 & $9,6,3 \leftarrow 9,5,4$ & Ground & & & & & 24. 969.90 & .1 \\
\hline $\mathrm{C}^{\mathrm{b}} \mathrm{H}_{3}^{\mathrm{b}} \mathrm{N}^{\mathrm{b}} \mathrm{C}^{\mathrm{b}} \mathrm{S}^{\mathrm{b}}$ & 3. 426 & $5, \quad \leftarrow 44$, & & & & & & 24971 & \\
\hline $\mathrm{N}^{\mathrm{b}} \mathrm{O}_{2}^{\mathrm{b}} \mathrm{Cl}^{\mathrm{b}}$ & $4 \cdot 1463$ & Not Reported & & & & & & 24971. & \\
\hline $\mathrm{C}^{12} \mathrm{H}_{3} \mathrm{C}^{12} \mathrm{O}^{16} \mathrm{C}^{13} \mathrm{~N}^{14}$ & 3- 673 & $9,3,6 \leftarrow 9,2,7$ & Ground & & & & & 24971.91 & .2 \\
\hline $\mathrm{C}_{6}^{12} \mathrm{H}_{5} \mathrm{C}^{12} \mathrm{~N}^{14}$ & 4-1291 & $9,5,4 \leftarrow 8,5,3$ & Ground & & & & & 24972. & \\
\hline $\mathrm{C}_{6}^{12} \mathrm{H}_{5} \mathrm{C}^{12} \mathrm{~N}^{14}$ & 4.1291 & $9,5,5 \leftarrow 8,5,4$ & Ground & & & & & 24972. & \\
\hline $\mathrm{C}^{12} \mathrm{H}_{2} \mathrm{Br}_{2}^{\mathrm{b}}$ & 4. 321 & Not Reported & Ground & & & & & 24972. & \\
\hline $\mathrm{Cl}^{37} \mathrm{O}_{2}^{16}$ & 4-1382 & $7,1,6 \leftarrow 6,2,5$ & Ground & & & & & 24972.7 & \\
\hline $\mathrm{As}^{75} \mathrm{Cl}^{35} \mathrm{Cl}_{2}^{37}$ & 4- 13 & Not Reported & Ground & & & & & 24973 & 10. \\
\hline $\mathrm{C}^{12} \mathrm{O}^{16} \mathrm{Cl}_{2}^{35}$ & 4- 181 & $3,3,1 \leftarrow 3,2,2$ & Ground & $5 / 2$ & 1 & $5 / 2$ & 1 & 24973.78 & .1 \\
\hline $\mathrm{C}^{12} \mathrm{O}^{16} \mathrm{Cl}_{2}^{35}$ & 4- 181 & $3,3,1 \leftarrow 3,2,2$ & Ground & $9 / 2$ & 5 & $9 / 2$ & 5 & 24973.78 & .1 \\
\hline $\mathrm{C}^{12} \mathrm{O}^{16} \mathrm{Cl}_{2}^{35}$ & 4. 181 & $3,3,1 \leftarrow 3,2,2$ & Ground & $5 / 2$ & 2 & $5 / 2$ & 2 & 24973.78 & .1 \\
\hline $\mathrm{C}^{12} \mathrm{O}^{16} \mathrm{Cl}_{2}^{35}$ & 4. 181 & $3,3,1 \leftarrow 3,2,2$ & Ground & $5 / 2$ & 4 & $5 / 2$ & 4 & 24973.78 & .1 \\
\hline $\mathrm{C}^{12} \mathrm{H}_{3} \mathrm{C}^{12} \mathrm{O}^{16} \mathrm{C}^{13} \mathrm{~N}^{14}$ & 3- 673 & $9,3,6 \leftarrow 9,2,7$ & Ground & & & & & 24973.89 & .2 \\
\hline $\mathrm{H}_{2}^{\mathrm{h}} \mathrm{C}^{\mathrm{b}}: \mathrm{C}^{\mathrm{b}} \mathrm{H}^{\mathrm{h}} \mathrm{Cl}^{\mathrm{b}}$ & 4- 772 & Not Reported & Ground & & & & & 24975 . & \\
\hline $\mathrm{C}^{12} \mathrm{H}_{3} \mathrm{O}^{16} \mathrm{H}$ & 3- 211 & Not Reported & Ground & & & & & 24977 & 5. \\
\hline $\mathrm{C}_{6}^{12} \mathrm{H}_{5} \mathrm{C}^{12} \mathrm{~N}^{14}$ & $4-1291$ & 9. $5,4 \leftarrow 8,5,3$ & Ground & & & & & 24978.6 & \\
\hline $\mathrm{C}_{6}^{12} \mathrm{H}_{5} \mathrm{C}^{12} \mathrm{~N}^{14}$ & 4-1291 & $9,5,5 \leftarrow 8,5,4$ & Ground & & & & & 24978.6 & \\
\hline
\end{tabular}




\begin{tabular}{|c|c|c|c|c|c|c|c|c|c|}
\hline \multirow{2}{*}{ Isotopic Species } & \multirow{2}{*}{$\begin{array}{l}\text { Vol.-Id. } \\
\text { Nos. }\end{array}$} & \multirow{2}{*}{$\begin{array}{c}\text { Rotational } \\
\text { Quantum Nos. }\end{array}$} & \multirow{2}{*}{ Vib. State } & \multicolumn{4}{|c|}{ Hyperfine } & \multirow{2}{*}{$\begin{array}{l}\text { Frequency } \\
\mathrm{MHz}\end{array}$} & \multirow{2}{*}{$\begin{aligned} & \text { Acc. } \\
& \pm \mathrm{MHz}\end{aligned}$} \\
\hline & & & & $\mathrm{F}_{1}^{\prime}$ & & $\mathrm{F}_{1}$ & $\mathbf{F}$ & & \\
\hline $\mathrm{s}-\left(\mathrm{C}^{12} \mathrm{H}_{2} \mathrm{D}\right)\left(\mathrm{C}^{12} \mathrm{H}_{3}\right) \mathrm{O}^{16}$ & 3. 596 & Not Reported & Ground & & & & & 24.980. & 20. \\
\hline $\mathrm{Br}^{79} \mathrm{C}^{12} \mathrm{~N}^{14}$ & 4- 141 & $3 \leftarrow 2$ & Excited & $5 / 2$ & & $5 / 2$ & & 24981.5 & \\
\hline $\mathrm{Br}^{79} \mathrm{C}^{12} \mathrm{~N}^{14}$ & 4. 141 & $3 \leftarrow 2$ & Excited & $7 / 2$ & & $5 / 2$ & & 24981.5 & \\
\hline $\mathrm{Br}^{79} \mathrm{C}^{12} \mathrm{~N}^{14}$ & 4- 141 & $3 \leftarrow 2$ & Excited & $3 / 2$ & & $5 / 2$ & & 24981.5 & \\
\hline $\mathrm{C}^{12} \mathrm{H}_{2} \mathrm{Br}_{2}^{\mathrm{b}}$ & 4- 321 & Not Reported & Ground & & & & & 24982. & \\
\hline $\mathrm{HC}^{13} \vdots \mathrm{C}^{12} \mathrm{C}^{12} \mathrm{DO}^{16}$ & 4- 922 & Not Reported & & & & & & 24.983. & 5. \\
\hline $\mathrm{C}^{\mathrm{b}}{ }_{*} \mathrm{H}_{2}^{\mathrm{b}} \mathrm{N}^{\mathrm{b}} \mathrm{H}^{\mathrm{b}} \mathrm{C}^{\mathrm{b}}{ }_{*} \mathrm{H}_{2}^{\mathrm{b}}$ & 4- 863 & Not Reported & & & & & & 24985 . & 10. \\
\hline $\mathrm{C}^{12} \mathrm{O}^{16} \mathrm{Cl}_{2}^{35}$ & 4. 181 & $3,3,1 \leftarrow 3,2,2$ & Ground & $7 / 2$ & 3 & $7 / 2$ & 3 & 24985.83 & .1 \\
\hline $\mathrm{C}^{12} \mathrm{DN}^{14} \mathrm{C}^{12} \mathrm{DC}^{12} \mathrm{H}: \mathrm{C}^{12} \mathrm{DN}^{14}{ }_{*}$ & 4-1142 & $2,2,0 \leftarrow 1,1,1$ & Ground & & & & & 24.986 .1 & \\
\hline $2,4,6 \mathrm{~d}_{3^{-}} \mathrm{C}_{6}^{12} \mathrm{H}_{5} \mathrm{~F}^{19}$ & 4-1284 & $6,5,1 \leftarrow 5,5,0$ & Ground & & & & & 24987.5 & .1 \\
\hline $2,4,6 \mathrm{~d}_{3}-\mathrm{C}_{6}^{12} \mathrm{H}_{5} \mathrm{~F}^{19}$ & 4-1284 & $6,5,2 \leftarrow 5,5,1$ & Ground & & & & & 24. 987.5 & .1 \\
\hline $\mathrm{C}^{12} \mathrm{H}_{3} \mathrm{~S}^{32} \mathrm{H}$ & 3- 221 & Not Reported & Ground & & & & & 24. 988.5 & .1 \\
\hline $\mathrm{S}^{32} \mathrm{O}^{16} \mathrm{~F}_{2}^{19}$ & 4-1621 & Not Reported & & & & & & 24.990 .58 & .1 \\
\hline $\mathrm{c}-\mathrm{HDC}^{12}: \mathrm{C}^{12} \mathrm{HF}^{19}$ & 4. 787 & $5,1,4 \leftarrow 5,1,5$ & Ground & & & & & 24. 990.6 & .1 \\
\hline $\mathrm{H}_{2} \mathrm{C}^{12}: \mathrm{C}^{12} \mathrm{HI}^{127}$ & 4. 801 & $4,1,4 \leftarrow 3,1,3$ & Ground & & $7 / 2$ & & $7 / 2$ & 24991.87 & .05 \\
\hline $\mathrm{C}^{\mathrm{b}}{ }_{*} \mathrm{H}_{2}^{\mathrm{b}} \mathrm{N}^{\mathrm{b}} \mathrm{H}^{\mathrm{b}} \mathrm{C}^{\mathrm{b}}{ }_{*} \mathrm{H}_{2}^{\mathrm{b}}$ & 4- 863 & Not Reported & & & & & & 24991.9 & .5 \\
\hline $\mathrm{C}^{12}{ }_{*} \mathrm{H}: \mathrm{C}^{12} \mathrm{DO}^{16} \mathrm{C}^{12} \mathrm{D}: \mathrm{C}^{12}{ }_{*} \mathrm{H}$ & $4-1156$ & $12,10,2 \leftarrow 12,9,3$ & Ground & & & & & 24991.9 & \\
\hline $\mathrm{C}^{12} \mathrm{H}_{3} \mathrm{~N}^{14} \mathrm{H}_{2}$ & 3- 261 & Not Reported & Ground & & & & & 24.993 .76 & .1 \\
\hline $\mathrm{C}^{12} \mathrm{H}_{3} \mathrm{C}^{12}{ }_{*} \mathrm{H}_{2} \mathrm{O}^{16} \mathrm{C}^{12}{ }_{*} \mathrm{C}^{12} \mathrm{H}_{3}$ & 3- 951 & $7,3,5 \leftarrow 7,2,6$ & Ground & & & & & 24993.89 & .2 \\
\hline $\mathrm{C}^{12} \mathrm{H}_{3} \mathrm{C}^{12} \mathrm{D}_{3} \mathrm{Si}^{28} \mathrm{H}_{2}$ & 3- 642 & $6,2,4 \leftarrow 6,1,5$ & Ground & & & & & 24994.91 & \\
\hline s- $\left(\mathrm{C}^{12} \mathrm{H}_{2} \mathrm{D}\right)\left(\mathrm{C}^{12} \mathrm{H}_{3}\right) \mathrm{O}^{16}$ & 3- 596 & Not Reported & Ground & & & & & 24995 . & 20. \\
\hline $\mathrm{C}^{12} \mathrm{H}_{3} \mathrm{C}^{12} \mathrm{D}_{3} \mathrm{Si}^{28} \mathrm{H}_{2}$ & 3- 642 & $6,2,4 \leftarrow 6,1,5$ & Ground & & & & & 24996.80 & \\
\hline $\mathrm{C}^{12} \mathrm{H}_{3} \mathrm{O}^{16} \mathrm{H}$ & 3- 211 & Not Reported & Ground & & & & & 24997. & 5. \\
\hline $\mathrm{s} \cdot\left(\mathrm{C}^{12} \mathrm{H}_{2} \mathrm{D}\right)\left(\mathrm{C}^{12} \mathrm{H}_{3}\right) \mathrm{O}^{16}$ & 3. 596 & Not Reported & Ground & & & & & 25000 & 20. \\
\hline $\mathrm{C}^{12} \mathrm{H}_{3} \mathrm{~N}^{14} \mathrm{C}^{13} \mathrm{~S}^{32}$ & 3. 423 & $5, \quad \leftarrow 4, \quad$, & Ground & & & & & 25002 . & \\
\hline $\mathrm{C}^{12} \mathrm{H}_{2} \mathrm{Br}_{2}^{\mathrm{b}}$ & 4. 321 & Not Reported & Ground & & & & & 25002. & \\
\hline $\mathrm{H}_{2}^{\mathrm{b}} \mathrm{C}_{*}^{\mathrm{b}} \mathrm{O}^{16} \mathrm{C}^{\mathrm{b}}{ }_{*} \mathrm{H}_{2}^{\mathrm{b}}$ & 4. 846 & Not Reported & Excited & & & & & 25002.2 & .3 \\
\hline$\left(\mathrm{C}^{12} \mathrm{D}_{3}\right)_{3} \mathrm{C}^{12} \mathrm{Cl}^{37}$ & 3- 977 & $5, \leftarrow 4$, & Ground & & & & & 25002.5 & 3. \\
\hline $\mathrm{S}^{32} \mathrm{C}^{12} \mathrm{Te}^{130}$ & 4- 577 & $8 \leftarrow 7$ & Excited & & & & & 25005.326 & .010 \\
\hline $\mathrm{Br}^{79} \mathrm{C}^{12} \mathrm{~N}^{14}$ & 4- 141 & $3 \leftarrow 2$ & Excited & $7 / 2$ & & $7 / 2$ & & 25006.0 & \\
\hline $\mathrm{Cl}^{37} \mathrm{O}_{2}^{16}$ & 4-1382 & $7,1,6 \leftarrow 6,2,5$ & Ground & & & & & 25006.3 & .2 \\
\hline $\mathrm{C}^{12} \mathrm{H}_{2}\left(\mathrm{C}^{12} \mathrm{~N}^{14}\right)_{2}$ & 4- 901 & Not Reported & Ground & & & & & 25008.8 & .1 \\
\hline $\mathrm{C}^{12}{ }_{*} \mathrm{DN}^{14} \mathrm{C}^{12} \mathrm{DC}^{12} \mathrm{H}: \mathrm{C}^{12} \mathrm{DN}^{14}{ }_{*}$ & 4-1142 & $8,5,4 \leftarrow 8,4,5$ & Ground & & & & & 25009.0 & \\
\hline $\mathrm{C}^{12}{ }_{*} \mathrm{DN}^{14} \mathrm{C}^{12} \mathrm{DC}^{12} \mathrm{H}: \mathrm{C}^{12} \mathrm{DN}^{14}{ }_{*}$ & 4-1142 & $8,4,4 \leftarrow 8,3,5$ & Ground & & & & & 25009.0 & \\
\hline $\mathrm{C}^{12} \mathrm{H}_{3} \mathrm{~S}^{32} \mathrm{H}$ & 3. 221 & Not Reported & Ground & & & & & 25009.0 & .1 \\
\hline $\mathrm{C}^{13} \mathrm{H}_{3}\left(\mathrm{C}^{12} \mathrm{H}_{3}\right)_{2} \mathrm{C}^{12} \mathrm{C}^{12}: \mathrm{C}^{12} \mathrm{D}$ & $3 \cdot 1078$ & $5,1,5 \leftarrow 4,1,4$ & Ground & & & & & 25010.9 & .1 \\
\hline $\mathrm{Si}^{28} \mathrm{D}_{2} \mathrm{~F}_{2}^{19}$ & $4 \cdot 1603$ & $1,1,1 \leftarrow 0,0,0$ & Ground & & & & & 25011.17 & .10 \\
\hline $\mathrm{C}^{12} \mathrm{H}_{2} \mathrm{Br}_{2}^{\mathrm{b}}$ & 4. 321 & Not Reported & Ground & & & & & 25013. & \\
\hline $\mathrm{C}^{12} \mathrm{H}_{2}\left(\mathrm{C}^{12} \mathrm{~N}^{14}\right)_{2}$ & 4- 901 & Not Reported & Ground & & & & & 25013.1 & .1 \\
\hline $\mathrm{S}^{32} \mathrm{C}^{12} \mathrm{Te}^{130}$ & 4- 577 & $8 \leftarrow 7$ & Excited & & & & & 25015.884 & .010 \\
\hline $\mathrm{C}^{13} \mathrm{H}_{3} \mathrm{Si}^{28} \mathrm{H}_{2} \mathrm{~F}^{19}$ & 3- 249 & $2,1,1 \leftarrow 1,1,0$ & Ground & & & & & 25017.26 & .10 \\
\hline $\mathrm{C}^{12} \mathrm{H}_{3} \mathrm{O}^{16} \mathrm{H}$ & 3- 211 & Not Reported & Ground & & & & & 25017.8 & \\
\hline $\mathrm{C}^{12} \mathrm{H}_{3} \mathrm{O}^{16} \mathrm{H}$ & 3- 211 & $6,2, \leftarrow 6,1$, & Ground & & & & & 25018.14 & .1 \\
\hline $\mathrm{C}^{12} \mathrm{H}_{2}\left(\mathrm{C}^{12} \mathrm{~N}^{14}\right)_{2}$ & 4- 901 & Not Reported & Ground & & & & & 25018.4 & .1 \\
\hline $\mathrm{C}^{\mathrm{b}}{ }_{*} \mathrm{H}_{2}^{\mathrm{b}} \mathrm{N}^{\mathrm{b}} \mathrm{H}^{\mathrm{h}} \mathrm{C}^{\mathrm{h}}{ }_{*} \mathrm{H}_{2}^{\mathrm{b}}$ & 4- 863 & Not Reported & & & & & & 25020 . & 10. \\
\hline
\end{tabular}




\begin{tabular}{|c|c|c|c|c|c|c|c|c|}
\hline Isotopic Species & $\begin{array}{l}\text { Vol.-Id. } \\
\text { Nos. }\end{array}$ & $\begin{array}{c}\text { Rotational } \\
\text { Quantum Nos. }\end{array}$ & Vib. State & $F_{i}^{\prime}$ & $\begin{array}{c}\text { Hyperfine } \\
F^{\prime} \quad F_{1}\end{array}$ & $\mathrm{~F}$ & $\begin{array}{c}\text { Frequency } \\
\text { MHz }\end{array}$ & $\begin{aligned} & \text { Acc. } \\
\pm & \mathrm{MHz}\end{aligned}$ \\
\hline $\mathrm{s}-\left(\mathrm{C}^{12} \mathrm{H}_{2} \mathrm{D}\right)\left(\mathrm{C}^{12} \mathrm{H}_{3}\right) \mathrm{O}^{16}$ & 3- 596 & Not Reported & Ground & & & & 25020. & 20. \\
\hline $3 d-C_{6}^{12} H_{5} F^{19}$ & 4-1282 & $9,3,7 \leftarrow 9,1,8$ & Ground & & & & 25020.2 & .1 \\
\hline $\mathrm{N}^{14} \mathrm{H}_{2} \mathrm{D}$ & $4-1773$ & $4,1,4 \leftarrow 4,0,4$ & Ground & & & & 25023.88 & .05 \\
\hline $\mathrm{C}^{12} \mathrm{H}_{2}\left(\mathrm{C}^{12} \mathrm{~N}^{14}\right)_{2}$ & 4- 901 & Not Reported & Ground & & & & 25024.1 & .1 \\
\hline $\mathrm{HC}^{13}: \mathrm{C}^{12} \mathrm{C}^{12} \mathrm{DO}^{16}$ & 4- 922 & Not Reported & & & & & 25025 . & 5. \\
\hline $\mathrm{N}^{14} \mathrm{O}^{16} \mathrm{O}^{18}$ & 4-1803 & $25,1,24 \leftarrow 24,2,23$ & Ground & & & & 25025.0 & \\
\hline $\mathrm{C}^{12} \mathrm{H}_{3} \mathrm{C}^{13} \mathrm{H}_{2} \mathrm{~F}^{19}$ & 3. 555 & $5,3,3 \leftarrow 6,2,4$ & Ground & & & & 25025.1 & .1 \\
\hline $\mathrm{Cl}^{37} \mathrm{O}_{2}^{16}$ & 4-1382 & $7,1,6 \leftarrow 6,2,5$ & Ground & & & & 25026.1 & .2 \\
\hline $\mathrm{C}^{12} \mathrm{H}_{2}: \mathrm{C}^{12} \mathrm{HC}^{12} \mathrm{~F}^{19}: \mathrm{C}^{12} \mathrm{H}_{2}$ & 3- 911 & $8,2,6 \leftarrow 8,1,7$ & Ground & & & & 25027.10 & .03 \\
\hline $2,4,6 \mathrm{~d}_{3}-\mathrm{C}_{6}^{12} \mathrm{H}_{5} \mathrm{~F}^{19}$ & 4-1284 & $6,3,4 \leftarrow 5,3,3$ & Ground & & & & 25027.3 & .1 \\
\hline $\mathrm{H}_{2} \mathrm{C}^{12}: \mathrm{C}^{12} \mathrm{HI}^{127}$ & 4- 801 & $4,1,4 \leftarrow 3,1,3$ & Ground & & $5 / 2$ & $5 / 2$ & 25029.18 & .05 \\
\hline$R b^{87} I^{127}$ & $1-$ & $13 \hookleftarrow 12$ & Excited & & & & 25029.38 & 0.10 \\
\hline $\mathrm{s}-\left(\mathrm{C}^{12} \mathrm{H}_{2} \mathrm{D}\right)\left(\mathrm{C}^{12} \mathrm{H}_{3}\right) \mathrm{O}^{16}$ & 3- 596 & Not Reported & Ground & & & & 25030. & 20. \\
\hline $\mathrm{C}_{6}^{12} \mathrm{H}_{5} \mathrm{C}^{12} \mathrm{~N}^{14}$ & 4-1291 & $9,3,7 \leftarrow 8,3,6$ & Ground & & & & 25030. & \\
\hline $\mathrm{C}_{6}^{12} \mathrm{H}_{5} \mathrm{C}^{12} \mathrm{~N}^{14}$ & 4-1291 & $9,4,6 \leftarrow 8,4,5$ & Ground & & & & 25030. & \\
\hline $\mathrm{C}^{12} \mathrm{H}_{3} \mathrm{Si}^{26} \mathrm{DF}_{2}^{19} \cdot \mathrm{E}$ & 3- 198 & $3,0,3 \leftarrow 2,0,2$ & Ground & & & & 25030.55 & \\
\hline $\mathrm{Cs}^{133} \mathrm{Cl}^{35}$ & $1-$ & $6 \leftarrow 5$ & Excited & & & & 25031.0 & .6 \\
\hline $\mathrm{C}^{\mathrm{b}} \mathrm{H}_{2}^{\mathrm{b}} \mathrm{N}^{\mathrm{b}} \mathrm{H}^{\mathrm{b}} \mathrm{C}^{\mathrm{b}} \mathrm{H}_{2}^{\mathrm{b}}$ & 4- 863 & Not Reported & & & & & 25032.4 & .5 \\
\hline $\mathrm{C}^{12} \mathrm{H}_{3} \mathrm{Si}^{28} \mathrm{DF}_{2}^{19}-\mathrm{A}$ & 3- 197 & $3,0,3 \leftarrow 2,0,2$ & Ground & & & & 25032.63 & \\
\hline $\mathrm{C}_{6}^{12} \mathrm{H}_{5} \mathrm{C}^{12} \mathrm{~N}^{14}$ & 4-1291 & $9,4,6 \leftarrow 8,3,6$ & Ground & & & & 25032.7 & \\
\hline $\mathrm{N}^{14} \mathrm{O}^{16} \mathrm{O}^{18}$ & 4-1803 & $25,1,24 \leftarrow 24,2,23$ & Ground & & & & 25033.4 & \\
\hline $\mathrm{H}_{2} \mathrm{C}^{12}: \mathrm{C}^{12} \mathrm{HI}^{127}$ & 4- 801 & $4,1,4 \leftarrow 3,1,3$ & Ground & & $3 / 2$ & $3 / 2$ & 25034.06 & .05 \\
\hline $\mathrm{s}-\left(\mathrm{C}^{12} \mathrm{H}_{2} \mathrm{D}\right)\left(\mathrm{C}^{12} \mathrm{H}_{3}\right) \mathrm{O}^{16}$ & 3- 596 & Not Reported & Ground & & & & 25035. & 20. \\
\hline $\mathrm{N}^{14} \mathrm{O}^{16} \mathrm{O}^{18}$ & 4-1803 & $25,1,24 \leftarrow 24,2,23$ & Ground & & & & 25035.8 & \\
\hline $\mathrm{C}^{12}{ }^{2} \mathrm{DN}^{14} \mathrm{C}^{12} \mathrm{DC}^{12} \mathrm{H}: \mathrm{C}^{12} \mathrm{DN}^{14} *$ & 4-1142 & $7,4,4 \leftarrow 7,3,5$ & Ground & & & & 25038.4 & \\
\hline $\mathrm{C}^{12}{ }_{*} \mathrm{DN}^{14} \mathrm{C}^{12} \mathrm{DC}^{12} \mathrm{H}: \mathrm{C}^{12} \mathrm{DN}^{14} *$ & 4-1142 & $7,3,4 \longleftarrow 7,2,5$ & Ground & & & & 25038.4 & \\
\hline $\mathrm{Rb}^{85} \mathrm{I}^{127}$ & $1-$ & $13 \leftarrow 12$ & Excited & & & & 25038.99 & 0.10 \\
\hline $\mathrm{D}_{2} \mathrm{O}_{2}^{16}$ & $3-\quad 42$ & Not Reported & & & & & 25040. & 3. \\
\hline $\mathrm{C}^{12} \mathrm{H}_{3} \mathrm{~S}^{32} \mathrm{C}^{12} \mathrm{D}_{3}$ & 3- 606 & $5,1,4 \leftarrow 5,0,5$ & Ground & & & & 25040.66 & .05 \\
\hline $\mathrm{Cl}^{37} \mathrm{O}_{2}^{16}$ & $4-1382$ & $7,1,6 \leftarrow 6,2,5$ & Ground & & & & 25041.0 & .2 \\
\hline $\mathrm{C}^{12} \mathrm{H}_{2} \mathrm{Br}_{2}^{\mathrm{b}}$ & 4- 321 & Not Reported & Ground & & & & 25042. & \\
\hline $\mathrm{C}^{\mathrm{b}}{ }_{*} \mathrm{H}_{2}^{\mathrm{b}} \mathrm{N}^{\mathrm{b}} \mathrm{H}^{\mathrm{b}} \mathrm{C}^{\mathrm{b}}{ }_{*} \mathrm{H}_{2}^{\mathrm{b}}$ & 4- 863 & Not Reported & & & & & 25042.0 & .5 \\
\hline $\mathrm{C}_{6}^{12} \mathrm{H}_{5} \mathrm{C}^{12} \mathrm{~N}^{14}$ & $4-1291$ & $9,4,5 \leftarrow 8,4,4$ & Ground & & & & 25044 . & \\
\hline $\mathrm{C}^{12} \mathrm{H}_{3} \mathrm{O}^{16} \mathrm{~N}^{14} \mathrm{O}_{2}^{16}$ & 3- 181 & $3,2,1 \leftarrow 2,2,0$ & Ground & & & & 25044.80 & .1 \\
\hline $\mathrm{S}^{32} \mathrm{O}_{2}^{16}$ & 4-1831 & $35,6,30 \leftarrow 34,7,27$ & Ground & & & & 25049.13 & .1 \\
\hline $\mathrm{C}^{12} \mathrm{H}_{3} \mathrm{O}^{16} \mathrm{H}$ & 3- 211 & Not Reported & Ground & & & & 25050 . & 5. \\
\hline g- $\mathrm{C}^{12} \mathrm{H}_{3} \mathrm{C}^{12} \mathrm{H}_{2} \mathrm{C}^{12} \mathrm{H}_{2} \mathrm{Cl}^{37}$ & 3- 774 & $4,1,3 \leftarrow 3,1,2$ & Ground & & & & 25050.53 & .2 \\
\hline $\mathrm{Cl}^{37} \mathrm{O}_{2}^{16}$ & 4-1382 & $7,1,6 \leftarrow 6,2,5$ & Ground & & & & 25054.7 & .2 \\
\hline $\mathrm{C}^{12} \mathrm{H}_{2} \mathrm{Br}_{2}^{\mathrm{b}}$ & 4- 321 & Not Reported & Ground & & & & 25056. & 5. \\
\hline $\mathrm{N}^{14} \mathrm{H}_{3}$ & 4-1771 & $6,6 \leftarrow 6,6$ & Ground & & & & 25056.02 & .02 \\
\hline $\mathrm{C}^{12} \mathrm{H}_{3} \mathrm{O}^{16} \mathrm{H}$ & 3- 211 & Not Reported & Ground & & & & 25056.31 & .1 \\
\hline $\mathrm{N}^{14} \mathrm{O}^{16} \mathrm{O}^{18}$ & 4-1803 & $25,1,24 \leftarrow 24,2,23$ & Ground & & & & 25056.8 & \\
\hline 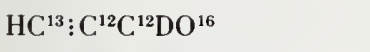 & 4- 922 & Not Reported & & & & & 25057. & 5. \\
\hline $\mathrm{C}^{12}{ }_{*} \mathrm{DN}^{14} \mathrm{C}^{12} \mathrm{DC}^{12} \mathrm{H}: \mathrm{C}^{12} \mathrm{DN}^{14} *$ & 4-1142 & $6,2,4 \leftarrow 6,1,5$ & Ground & & & & 25058.5 & \\
\hline $\mathrm{C}^{12}{ }_{*} \mathrm{DN}^{14} \mathrm{C}^{12} \mathrm{DC}^{12} \mathrm{H}: \mathrm{C}^{12} \mathrm{DN}^{14}{ }_{*}$ & 4-1142 & $6,3,4 \leftarrow 6,2,5$ & Ground & & & & 25058.5 & \\
\hline
\end{tabular}




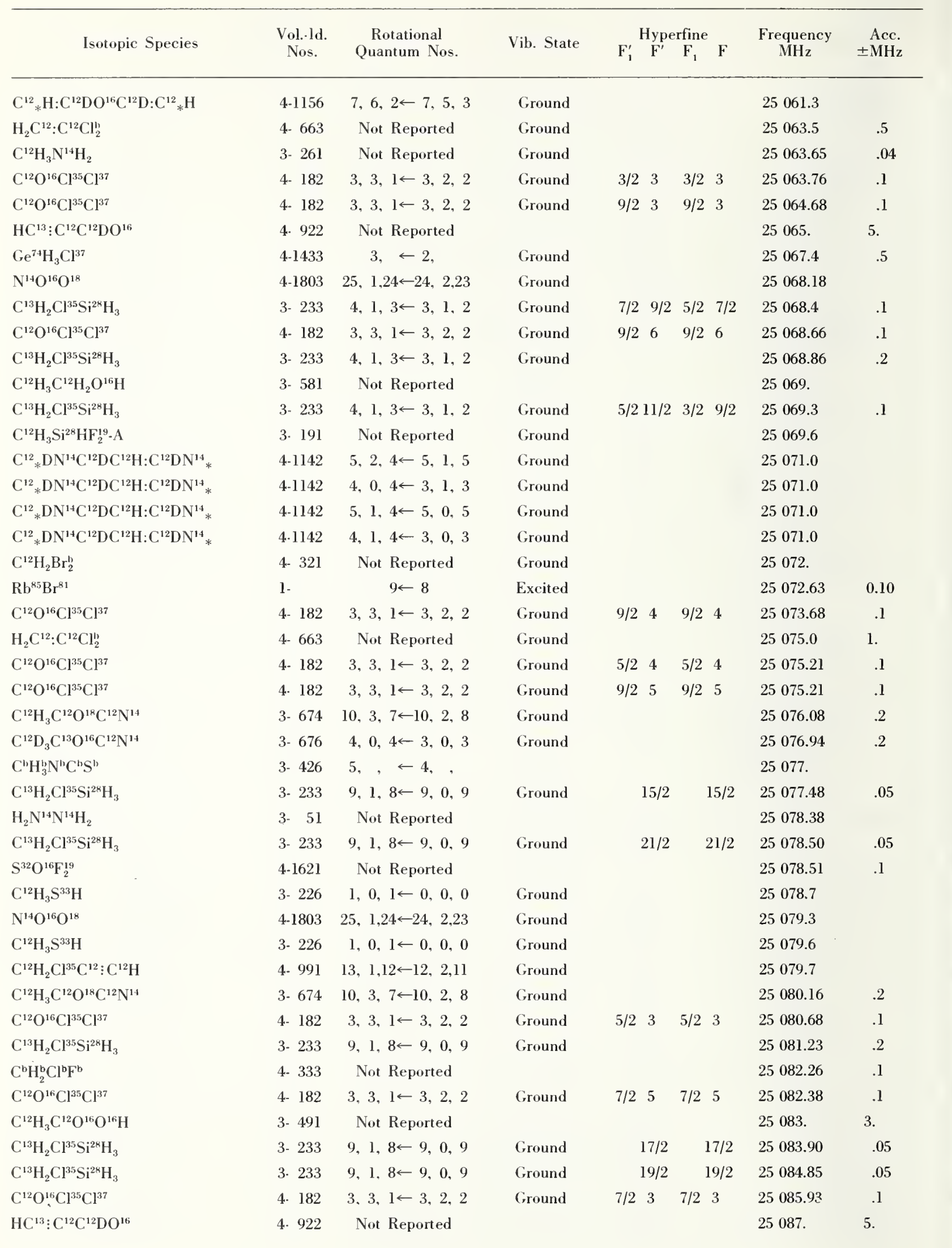




\begin{tabular}{|c|c|c|c|c|c|c|c|c|c|}
\hline \multirow{2}{*}{ Isotopic Species } & \multirow{2}{*}{$\begin{array}{l}\text { Vol.-Id. } \\
\text { Nos. }\end{array}$} & \multirow{2}{*}{$\begin{array}{c}\text { Rotational } \\
\text { Quantum Nos. }\end{array}$} & \multirow{2}{*}{ Vib. State } & \multicolumn{4}{|c|}{ Hyperfine } & \multirow{2}{*}{$\begin{array}{c}\text { Frequency } \\
\text { MHz }\end{array}$} & \multirow{2}{*}{$\begin{aligned} & \text { Acce. } \\
& \pm \text { MHz }\end{aligned}$} \\
\hline & & & & $F_{1}^{\prime}$ & $F^{\prime}$ & & $\mathrm{F}$ & & \\
\hline $\mathrm{C}^{12} \mathrm{O}^{16} \mathrm{Cl}^{35} \mathrm{Cl}^{37}$ & 4- 182 & $3,3,1 \leftarrow 3,2,2$ & Ground & $7 / 2$ & 4 & $7 / 2$ & 4 & 25088.13 & .1 \\
\hline $\mathrm{C}^{b} \mathrm{H}_{2}^{\mathrm{b}} \mathrm{Cl}^{\mathrm{b}} \mathrm{F}^{\mathrm{b}}$ & 4- 333 & Not Reported & & & & & & 25088.20 & .1 \\
\hline $\mathrm{C}^{12} \mathrm{H}_{2} \mathrm{Br}_{2}^{\mathrm{b}}$ & 4- 321 & Not Reported & Ground & & & & & 25090 & \\
\hline $\mathrm{C}^{12} \mathrm{H}_{3} \mathrm{C}^{12} \mathrm{O}^{16} \mathrm{O}^{16} \mathrm{H}$ & 3- 491 & $2,0,2 \leftarrow 1,0,1$ & Ground & & & & & 25091 . & 3. \\
\hline $\mathrm{C}^{13} \mathrm{H}_{3} \mathrm{Si}^{28} \mathrm{H}_{2} \mathrm{~F}^{19}$ & 3- 249 & $10,2,8 \leftarrow 10,2,9$ & Ground & & & & & 25091.04 & .10 \\
\hline $\mathrm{C}^{13} \mathrm{H}_{3} \mathrm{Si}^{28} \mathrm{H}_{2} \mathrm{~F}^{19}$ & 3- 249 & $10,2,8 \leftarrow 10,2,9$ & Ground & & & & & 25091.97 & .10 \\
\hline $\mathrm{C}^{12} \mathrm{H}_{2} \mathrm{Cl}^{35} \mathrm{Si}^{28} \mathrm{H}_{3}$ & 3- 231 & $4,1,3 \leftarrow 3,1,2$ & Ground & & & & & 25093.48 & .2 \\
\hline $\mathrm{H}_{2} \mathrm{C}^{12}: \mathrm{C}^{12} \mathrm{Cl}^{35} \mathrm{Cl}^{37}$ & 4- 662 & $13,4,9 \leftarrow 13,3,10$ & Ground & & & & & 25093.7 & .5 \\
\hline $\mathrm{N}^{\mathrm{b}} \mathrm{O}_{2}^{\mathrm{b}} \mathrm{Cl}{ }^{\mathrm{b}}$ & $4-1463$ & Not Reported. & & & & & & 25095. & \\
\hline $2,4,6 \mathrm{~d}_{3} \cdot \mathrm{C}_{6}^{12} \mathrm{H}_{5} \mathrm{~F}^{19}$ & 4-1284 & $6,4,3 \leftarrow 5,4,2$ & Ground & & & & & 25096.7 & .1 \\
\hline $\mathrm{C}^{12} \mathrm{H}_{2}\left(\mathrm{C}^{12} \mathrm{~N}^{14}\right)_{2}$ & 4. 901 & Not Reported & Ground & & & & & 25096.8 & .1 \\
\hline $\mathrm{S}^{32} \mathrm{C}^{12} \mathrm{~T} \mathrm{e}^{128}$ & 4- 576 & $8 \leftarrow 7$ & Excited & & & & & 25097.805 & .010 \\
\hline $\mathrm{C}^{12}{ }_{*} \mathrm{D}: \mathrm{C}^{12} \mathrm{HC}^{12} \mathrm{H}: \mathrm{C}^{12} \mathrm{HN}^{14}{ }_{*} \mathrm{H}$ & $4-1183$ & $8,7,2 \leftarrow 8,6,3$ & Ground & & & & & 25099.3 & \\
\hline $\mathrm{C}^{\mathrm{b}} \mathrm{H}_{3}^{\mathrm{b}} \mathrm{N}^{\mathrm{b}} \mathrm{C}^{\mathrm{b}} \mathrm{S}^{\mathrm{b}}$ & 3- 426 & $5, \quad \leftarrow 4, \quad$, & & & & & & 25100. & \\
\hline $\mathrm{HC}^{12}: \mathrm{C}^{12} \mathrm{C}^{12} \mathrm{HO}^{16}$ & 4- 911 & $3,1,3 \leftarrow 4,0,4$ & Ground & & & & & 25100.65 & .02 \\
\hline $\mathrm{HC}^{13}: \mathrm{C}^{12} \mathrm{C}^{12} \mathrm{DO}^{16}$ & 4. 922 & Not Reported & & & & & & 25103. & 5. \\
\hline $\mathrm{C}^{12} \mathrm{D}_{3} \mathrm{Si}^{30} \mathrm{DF}_{2}^{19}$ & 3. 202 & $3,2,2 \leftarrow 2,2,1$ & Ground & & & & & 25103.39 & .2 \\
\hline $\mathrm{C}^{12} \mathrm{H}_{2}\left(\mathrm{C}^{12} \mathrm{~N}^{14}\right)_{2}$ & 4- 901 & Not Reported & Ground & & & & & 25105.0 & .1 \\
\hline $\mathrm{C}^{12} \mathrm{H}_{3} \mathrm{C}^{12} \mathrm{O}^{16} \mathrm{Br}^{79}$ & 3- 351 & $5,1,5 \leftarrow 4,1,4$ & Ground & & $13 / 2$ & & $11 / 2$ & 25106.53 & .15 \\
\hline $\mathrm{C}^{12} \mathrm{D}_{3} \mathrm{C}^{12} \mathrm{O}^{16} \mathrm{C}^{12} \mathrm{~N}^{14}$ & 3. 675 & $4,0,4 \leftarrow 3,0,3$ & Ground & & & & & 25106.62 & .2 \\
\hline $\mathrm{C}^{12} \mathrm{H}_{3} \mathrm{~B}^{\mathrm{b}} \mathrm{F}_{2}^{19}$ & 3. 91 & $6, \quad \leftarrow 6$, & Ground & & & & & 25107.2 & .1 \\
\hline $\mathrm{S}^{32} \mathrm{C}^{12} \mathrm{~T} \mathrm{e}^{128}$ & 4- 576 & $8 \leftarrow 7$ & Excited & & & & & 25108.444 & .010 \\
\hline $\mathrm{C}^{12} \mathrm{H}_{3} \mathrm{Si}^{28} \mathrm{H}_{2} \mathrm{~F}^{19}$ & 3- 241 & $6,1,5 \leftarrow 6,1,6$ & Ground & & & & & 25110.42 & .10 \\
\hline $\mathrm{C}^{12} \mathrm{H}_{3} \mathrm{C}^{12} \mathrm{O}^{16} \mathrm{Br}^{79}$ & 3- 351 & $5,1,5 \leftarrow 4,1,4$ & Ground & & $7 / 2$ & & $5 / 2$ & 25110.84 & .15 \\
\hline $\mathrm{HC}^{13}: \mathrm{C}^{12} \mathrm{C}^{12} \mathrm{DO}^{16}$ & 4- 922 & Not Reported & & & & & & 25111. & 5. \\
\hline $\mathrm{C}^{12} \mathrm{H}_{3} \mathrm{C}^{12} \mathrm{O}^{16} \mathrm{Br}^{79}$ & 3- 351 & $5,1,5 \leftarrow 4,1,4$ & Ground & & $11 / 2$ & & $9 / 2$ & 25111.43 & .15 \\
\hline $\mathrm{Rb}^{87} \mathrm{I}^{127}$ & $1-$ & $13 \leftarrow 12$ & Excited & & & & & 25112.84 & 0.10 \\
\hline $\mathrm{C}^{12} \mathrm{H}_{3} \mathrm{Si}^{28} \mathrm{H}_{2} \mathrm{~F}^{19}$ & 3. 241 & $6,1,5 \leftarrow 6,1,6$ & Ground & & & & & 25113.08 & .10 \\
\hline c- $\mathrm{HDN}^{14} \mathrm{C}^{12} \mathrm{HO}^{16}$ & 3. 152 & $5,1,4 \leftarrow 5,1,5$ & Ground & & 5 & & 5 & 25113.15 & .1 \\
\hline $\mathrm{C}_{6}^{12} \mathrm{H}_{5} \mathrm{Cl}^{37}$ & 4-1272 & $9,3,6 \leftarrow 8,3,5$ & Ground & & & & & 25114. & 5.0 \\
\hline $\mathrm{c}-\mathrm{HDN}^{14} \mathrm{C}^{12} \mathrm{HO}^{16}$ & 3. 152 & 5. $1,4 \leftarrow 5,1,5$ & Ground & & 6 & & 6 & 25115.24 & .1 \\
\hline $\mathrm{c}-\mathrm{HDN}{ }^{14} \mathrm{C}^{12} \mathrm{HO}^{16}$ & 3. 152 & $5,1,4 \leftarrow 5,1,5$ & Ground & & 4 & & 4 & 25115.24 & .1 \\
\hline $\operatorname{Re}^{187} \mathrm{O}_{3}^{16} \mathrm{Cl}^{35}$ & 4-1473 & $6,3 \leftarrow 5,3$ & Ground & $17 / 2$ & 9 & $15 / 2$ & 8 & 25115.33 & .1 \\
\hline $\operatorname{Re}^{187} \mathrm{O}_{3}^{16} \mathrm{Cl}^{35}$ & 4-1473 & $6,3 \leftarrow 5,3$ & Ground & $17 / 2$ & 8 & $15 / 2$ & 7 & 25115.33 & .1 \\
\hline $\mathrm{C}^{12} \mathrm{H}_{3} \mathrm{C}^{12} \mathrm{O}^{16} \mathrm{Br}^{79}$ & 3. 351 & 5. $1,5 \leftarrow 4,1,4$ & Ground & & $9 / 2$ & & $7 / 2$ & 25115.74 & .15 \\
\hline $\mathrm{Rb}^{87} \mathrm{Br}^{79}$ & $1-$ & $9 \leftarrow 8$ & Excited & & & & & 25116.57 & 0.10 \\
\hline $\mathrm{C}^{12} \mathrm{H}_{3} \mathrm{C}^{12} \mathrm{~F}^{19}: \mathrm{C}^{12} \mathrm{H}_{2}$ & 3. 721 & $9,6,3 \leftarrow 9,5,4$ & Ground & & & & & 25116.76 & .1 \\
\hline $\operatorname{Re}^{187} \mathrm{O}_{3}^{16} \mathrm{Cl}^{35}$ & $4-1473$ & $6,3 \leftarrow 5,3$ & Ground & $17 / 2$ & 10 & $15 / 2$ & 9 & 251.17 .36 & .06 \\
\hline $\mathrm{Re}^{187} \mathrm{O}_{3}^{16} \mathrm{Cl}^{35}$ & 4-1473 & $6,3 \leftarrow 5,3$ & Ground & $17 / 2$ & 7 & $15 / 2$ & 6 & 25117.66 & .04 \\
\hline $\operatorname{Re}^{h} \mathrm{O}_{3}^{16} \mathrm{Cl}^{35}$ & 4-1475 & $6, \leftarrow 5$, & & & & & & 25120. & \\
\hline $\operatorname{Re}^{187} \mathrm{O}_{3}^{16} \mathrm{Cl}^{35}$ & $4-1473$ & $6,3 \leftarrow 5,3$ & Ground & $9 / 2$ & 5 & $7 / 2$ & 4 & 25120.10 & .1 \\
\hline $\mathrm{Re}^{187} \mathrm{O}_{3}^{16} \mathrm{Cl}^{35}$ & 4-1473 & $6,3 \leftarrow 5,3$ & Ground & $9 / 2$ & 4 & $7 / 2$ & 3 & 25120.10 & .1 \\
\hline $\mathrm{Na}^{23} \mathrm{Cl}^{37}$ & 1 - & $2 \leftarrow 1$ & Excited & & & & & 25120.3 & 0.75 \\
\hline $\mathrm{C}^{12} \mathrm{H}_{3} \mathrm{~S}^{32} \mathrm{H}$ & 3- 221 & Not Reported & Ground & & & & & 25121.4 & .1 \\
\hline $\mathrm{N}^{14} \mathrm{~N}^{15} \mathrm{O}^{16}$ & 4-1812 & $1 \leftarrow 0$ & Ground & & & & & 25121.55 & \\
\hline
\end{tabular}




\begin{tabular}{|c|c|c|c|c|c|c|c|c|c|}
\hline \multirow{3}{*}{$\frac{\text { Isotopic Species }}{\operatorname{Re}^{187} \mathrm{O}_{3}^{16} \mathrm{Cl}^{35}}$} & \multirow{3}{*}{$\begin{array}{l}\text { Vol.-Id. } \\
\text { Nos. } \\
\text { 4-1473 }\end{array}$} & \multirow{3}{*}{$\begin{array}{c}\text { Rotational } \\
\text { Quantum Nos. } \\
\text { 6. } 0 \leftarrow 5,0\end{array}$} & \multirow{3}{*}{$\frac{\text { Vib. State }}{\text { Ground }}$} & \multicolumn{4}{|c|}{ Hyperfine } & \multirow{2}{*}{$\begin{array}{c}\text { Frequency } \\
\mathrm{MHz}^{2}\end{array}$} & \multirow{2}{*}{$\begin{array}{r}\text { Acc. } \\
\pm \mathrm{MHz}\end{array}$} \\
\hline & & & & $F_{1}^{\prime}$ & & $\mathrm{F}_{1}$ & $\mathrm{~F}$ & & \\
\hline & & & & & $17 / 2$ & & $15 / 2$ & 25122.08 & .05 \\
\hline $\mathrm{C}^{12} \mathrm{D}_{3} \mathrm{Si}^{29} \mathrm{DF}_{2}^{19}$ & 3. 201 & $3,2,2 \leftarrow 2,2,1$ & Ground & & & & & 25122.39 & .2 \\
\hline $\mathrm{N}_{2}^{14} \mathrm{O}^{16}$ & 4-1811 & $1 \leftarrow 0$ & Ground & & & & & 25123.25 & \\
\hline $\operatorname{Re}^{187} \mathrm{O}_{3}^{16} \mathrm{Cl}^{35}$ & 4-1473 & $6,0 \leftarrow 5,0$ & Ground & $13 / 2$ & 5 & $11 / 2$ & 6 & 25123.45 & .20 \\
\hline $\operatorname{Re}^{187} \mathrm{O}_{3}^{16} \mathrm{Cl}^{35}$ & 4-1473 & $6,0 \leftarrow 5,0$ & Ground & $13 / 2$ & 8 & $11 / 2$ & 9 & 25123.45 & .20 \\
\hline $\operatorname{Rb}^{85} \mathbf{I}^{127}$ & $1-$ & $13 \leftarrow 12$ & Excited & & & & & 25123.45 & 0.10 \\
\hline $\operatorname{Re}^{185} \mathrm{O}_{3}^{16} \mathrm{Cl}^{35}$ & 4-1471 & $6,3 \leftarrow 5,3$ & Ground & $17 / 2$ & 10 & $15 / 2$ & 9 & 25124.35 & .06 \\
\hline $\operatorname{Re}^{185} \mathrm{O}_{3}^{16} \mathrm{Cl}^{35}$ & $4-1471$ & $6,3 \leftarrow 5,3$ & Ground & $17 / 2$ & 7 & $15 / 2$ & 6 & 25124.35 & .06 \\
\hline $\mathrm{C}^{12} \mathrm{H}_{3} \mathrm{O}^{16} \mathrm{H}$ & 3- 211 & $7,2, \leftarrow 7,1$, & Ground & & & & & 25124.88 & .1 \\
\hline $\operatorname{Re}^{187} \mathrm{O}_{3}^{16} \mathrm{Cl}^{35}$ & 4-1473 & $6,0 \leftarrow 5,0$ & Ground & $11 / 2$ & 5 & $9 / 2$ & 4 & 25125.00 & .1 \\
\hline $\operatorname{Re}^{187} \mathrm{O}_{3}^{16} \mathrm{Cl}^{35}$ & $4-1473$ & $6,0 \leftarrow 5,0$ & Ground & $11 / 2$ & 6 & $9 / 2$ & 5 & 25125.00 & .1 \\
\hline $\operatorname{Re}^{187} \mathrm{O}_{3}^{16} \mathrm{Cl}^{35}$ & 4-1473 & $6,0 \leftarrow 5,0$ & Ground & $11 / 2$ & 4 & $9 / 2$ & 3 & 25125.75 & .1 \\
\hline $\operatorname{Re}^{187} \mathrm{O}_{3}^{16} \mathrm{Cl}^{35}$ & 4-1473 & $6,0 \leftarrow 5,0$ & Ground & $9 / 2$ & 4 & $7 / 2$ & 3 & 25125.75 & .1 \\
\hline $\operatorname{Re}^{187} \mathrm{O}_{3}^{16} \mathrm{Cl}^{35}$ & 4-1473 & $6,0 \leftarrow 5,0$ & Ground & $11 / 2$ & 7 & $9 / 2$ & 6 & 25125.75 & .1 \\
\hline $\operatorname{Re}^{187} \mathrm{O}_{3}^{16} \mathrm{Cl}^{35}$ & 4-1473 & $6,0 \leftarrow 5,0$ & Ground & $7 / 2$ & 5 & $5 / 2$ & 4 & 25125.75 & .1 \\
\hline $\operatorname{Re}^{187} \mathrm{O}_{3}^{16} \mathrm{Cl}^{35}$ & 4-1473 & $6,0 \leftarrow 5,0$ & Ground & $9 / 2$ & 5 & $7 / 2$ & 4 & 25125.75 & .1 \\
\hline $\operatorname{Re}^{187} \mathrm{O}_{3}^{16} \mathrm{Cl}^{35}$ & 4-1473 & $6,3 \leftarrow 5,3$ & Ground & $15 / 2$ & 8 & $13 / 2$ & 7 & 25126.52 & .1 \\
\hline $\operatorname{Re}^{187} \mathrm{O}_{3}^{16} \mathrm{Cl}^{35}$ & 4-1473 & $6,3 \leftarrow 5,3$ & Ground & $15 / 2$ & 7 & $13 / 2$ & 6 & 25126.52 & .1 \\
\hline $\operatorname{Re}^{187} \mathrm{O}_{3}^{16} \mathrm{Cl}^{35}$ & 4-1473 & $6,3 \leftarrow 5,3$ & Ground & $11 / 2$ & 6 & $9 / 2$ & 5 & 25126.52 & .1 \\
\hline $\operatorname{Re}^{187} \mathrm{O}_{3}^{16} \mathrm{Cl}^{35}$ & 4-1473 & $6,3 \leftarrow 5,3$ & Ground & $11 / 2$ & 5 & $9 / 2$ & 4 & 25126.52 & .1 \\
\hline $\mathrm{Si}^{28} \mathrm{D}_{2} \mathrm{~F}_{2}^{19}$ & 4-1603 & $1,1,1 \leftarrow 0,0,0$ & Excited & & & & & 25126.60 & .10 \\
\hline $\mathrm{C}^{12} \mathrm{H}_{3} \mathrm{~S}^{32} \mathrm{H}$ & 3- 221 & $1,0,1 \leftarrow 0,0,0$ & Ground & & & & & 25126.9 & .1 \\
\hline $\operatorname{Re}^{187} \mathrm{O}_{3}^{16} \mathrm{Cl}^{35}$ & 4-1473 & $6,0 \leftarrow 5,0$ & Ground & $9 / 2$ & 3 & $7 / 2$ & 2 & 25127.03 & .06 \\
\hline $\operatorname{Re}^{187} \mathrm{O}_{3}^{16} \mathrm{Cl}^{35}$ & $4 \cdot 1473$ & $6,0 \leftarrow 5,0$ & Ground & $9 / 2$ & 6 & $7 / 2$ & 5 & 25127.03 & .06 \\
\hline $\mathrm{C}^{12} \mathrm{H}_{2} \mathrm{Br}_{2}^{\mathrm{b}}$ & 4- 321 & Not Reported & Ground & & & & & 25128. & \\
\hline $\operatorname{Re}^{187} \mathrm{O}_{3}^{16} \mathrm{Cl}^{35}$ & 4-1473 & $6,3 \leftarrow 5,3$ & Ground & $11 / 2$ & 6 & $9 / 2$ & 5 & 25128.15 & .05 \\
\hline $\operatorname{Re}^{187} \mathrm{O}_{3}^{16} \mathrm{Cl}^{35}$ & 4-1473 & $6,3 \leftarrow 5,3$ & Ground & $11 / 2$ & 7 & $9 / 2$ & 6 & 25128.15 & .05 \\
\hline $\operatorname{Re}^{187} \mathrm{O}_{3}^{16} \mathrm{Cl}^{35}$ & 4-1473 & $6,3 \leftarrow 5,3$ & Ground & $15 / 2$ & 6 & $13 / 2$ & 5 & 25128.15 & .05 \\
\hline $\operatorname{Re}^{187} \mathrm{O}_{3}^{16} \mathrm{Cl}^{35}$ & 4-1473 & $6,3 \leftarrow 5,3$ & Ground & $15 / 2$ & 9 & $13 / 2$ & 8 & 25128.15 & .05 \\
\hline $\mathrm{C}^{12} \mathrm{H}_{2}\left(\mathrm{C}^{12} \mathrm{~N}^{14}\right)_{2}$ & 4- 901 & Not Reported & Ground & & & & & 25128.4 & .1 \\
\hline $\operatorname{Re}^{185} \mathrm{O}_{3}^{16} \mathrm{Cl}^{35}$ & 4-1471 & $6,0 \leftarrow 5,0$ & Ground & & $17 / 2$ & & $15 / 2$ & 25129.42 & .08 \\
\hline $\operatorname{Re}^{187} \mathrm{O}_{3}^{16} \mathrm{Cl}^{35}$ & 4-1473 & $6,3 \leftarrow 5,3$ & Ground & 6 & $11 / 2$ & 5 & 12 & 25129.47 & .1 \\
\hline $\operatorname{Re}^{187} \mathrm{O}_{3}^{16} \mathrm{Cl}^{35}$ & 4-1473 & $6,3 \leftarrow 5,3$ & Ground & 7 & $11 / 2$ & 6 & $/ 2$ & 25129.47 & .1 \\
\hline $\operatorname{Re}^{185} \mathrm{O}_{3}^{16} \mathrm{Cl}^{35}$ & 4-1471 & $6,0 \leftarrow 5,0$ & Ground & $13 / 2$ & 5 & $11 / 2$ & 6 & 25130.80 & .2 \\
\hline $\operatorname{Re}^{185} \mathrm{O}_{3}^{16} \mathrm{Cl}^{35}$ & $4 \cdot 1471$ & $6,0 \leftarrow 5,0$ & Ground & $13 / 2$ & 8 & $11 / 2$ & 9 & 25130.80 & .2 \\
\hline $\operatorname{Re}^{187} \mathrm{O}_{3}^{16} \mathrm{Cl}^{35}$ & 4-1473 & $6,3 \leftarrow 5,3$ & Ground & $13 / 2$ & 8 & $11 / 2$ & 7 & 25130.93 & .06 \\
\hline $\operatorname{Re}^{187} \mathrm{O}_{3}^{16} \mathrm{Cl}^{35}$ & $4 \cdot 1473$ & $6,3 \leftarrow 5,3$ & Ground & $13 / 2$ & 5 & $11 / 2$ & 4 & 25130.93 & .06 \\
\hline $\mathrm{C}^{12} \mathrm{H}_{3} \mathrm{O}^{16} \mathrm{H}$ & 3- 211 & Not Reported & Ground & & & & & 25131. & 5. \\
\hline $\operatorname{Re}^{185} \mathrm{O}_{3}^{16} \mathrm{Cl}^{35}$ & $4-1471$ & $6,0 \leftarrow 5,0$ & Ground & $11 / 2$ & 6 & $9 / 2$ & 5 & 25132.56 & .1 \\
\hline $\operatorname{Re}^{185} \mathrm{O}_{3}^{16} \mathrm{Cl}^{35}$ & 4-1471 & $6,0 \leftarrow 5,0$ & Ground & $11 / 2$ & 5 & $9 / 2$ & 4 & 25132.56 & .1 \\
\hline $\mathrm{C}^{12}{ }_{*} \mathrm{HO}^{16} \mathrm{C}^{12} \mathrm{HC}^{12} \mathrm{H}_{2} \mathrm{C}^{12} \mathrm{H}_{2} \mathrm{C}^{12}{ }_{*} \mathrm{H}_{2}$ & 4-1251 & $12,6,7 \leftarrow 12,4,8$ & Ground & & & & & 25133. & 5. \\
\hline $\mathrm{C}^{12} \mathrm{D}_{3} \mathrm{O}^{16} \mathrm{H}$ & 3- 214 & Not Reported & Ground & & & & & 25133.2 & .5 \\
\hline $\operatorname{Re}^{185} \mathrm{O}_{3}^{16} \mathrm{Cl}^{35}$ & 4-1471 & $6,0 \leftarrow 5,0$ & Ground & $11 / 2$ & 4 & $9 / 2$ & 3 & 25133.38 & .1 \\
\hline $\operatorname{Re}^{185} \mathrm{O}_{3}^{16} \mathrm{Cl}^{35}$ & 4-1471 & $6,0 \leftarrow 5,0$ & Ground & $7 / 2$ & 5 & $5 / 2$ & 4 & 25133.38 & .1 \\
\hline $\operatorname{Re}^{185} \mathrm{O}_{3}^{16} \mathrm{Cl}^{35}$ & $4-1471$ & $6,0 \leftarrow 5,0$ & Ground & $9 / 2$ & 4 & $7 / 2$ & 3 & 25133.38 & .1 \\
\hline
\end{tabular}




\begin{tabular}{|c|c|c|c|c|c|c|c|c|c|}
\hline Isotopic Species & $\begin{array}{c}\text { Vol.-Id. } \\
\text { Nos. }\end{array}$ & $\begin{array}{c}\text { Rotational } \\
\text { Quantum Nos. }\end{array}$ & Vib. State & $F_{1}^{\prime}$ & $\begin{array}{l}\text { Hype } \\
\mathrm{F}^{\prime}\end{array}$ & $\begin{array}{c}\text { erfine } \\
\mathrm{F}_{1}\end{array}$ & $\mathrm{~F}$ & $\begin{array}{c}\text { Frequency } \\
\text { MHz }\end{array}$ & $\begin{aligned} & \text { Acc. } \\
\pm & \mathrm{MH} \%\end{aligned}$ \\
\hline $\operatorname{Re}^{185} \mathrm{O}_{3}^{16} \mathrm{Cl}^{35}$ & 4-1471 & $6,0 \leftarrow 5,0$ & Ground & $9 / 2$ & 5 & $7 / 2$ & 4 & 25133.38 & .1 \\
\hline $\operatorname{Re}^{185} \mathrm{O}_{3}^{16} \mathrm{Cl}^{35}$ & 4-1471 & $6,0 \leftarrow 5,0$ & Ground & $11 / 2$ & 7 & $9 / 2$ & 6 & 25133.38 & .1 \\
\hline $\operatorname{Re}^{185} \mathrm{O}_{3}^{16} \mathrm{Cl}^{35}$ & 4-1471 & $6,3 \leftarrow 5,3$ & Ground & $11 / 2$ & 6 & $9 / 2$ & 5 & 25134.24 & .1 \\
\hline $\operatorname{Re}^{185} \mathrm{O}_{3}^{16} \mathrm{Cl}^{35}$ & 4-1471 & $6,3 \leftarrow 5,3$ & Ground & $15 / 2$ & 8 & $13 / 2$ & 7 & 25134.24 & .1 \\
\hline $\operatorname{Re}^{185} \mathrm{O}_{3}^{16} \mathrm{Cl}^{35}$ & 4-1471 & $6,3 \leftarrow 5,3$ & Ground & $15 / 2$ & 7 & $13 / 2$ & 6 & 25134.24 & .1 \\
\hline $\operatorname{Re}^{185} \mathrm{O}_{3}^{16} \mathrm{Cl}^{35}$ & 4-1471 & $6,3 \leftarrow 5,3$ & Ground & $11 / 2$ & 5 & $9 / 2$ & 4 & 25134.24 & .1 \\
\hline $\operatorname{Re}^{185} \mathrm{O}_{3}^{16} \mathrm{Cl}^{35}$ & 4-1471 & $6,0 \leftarrow 5,0$ & Ground & $9 / 2$ & 6 & $7 / 2$ & 5 & 25134.59 & .07 \\
\hline $\operatorname{Re}^{185} \mathrm{O}_{3}^{16} \mathrm{Cl}^{35}$ & 4-1471 & $6,0 \leftarrow 5,0$ & Ground & $9 / 2$ & 3 & $7 / 2$ & 2 & 25134.59 & .07 \\
\hline $\mathrm{C}^{12}{ }_{*} \mathrm{D}: \mathrm{C}^{12} \mathrm{DC}^{12} \mathrm{D}: \mathrm{C}^{12} \mathrm{DN}^{14}{ }_{*} \mathrm{H}$ & 4-1185 & $9,6,3 \leftarrow 9,5,4$ & Ground & & & & & 25135.0 & \\
\hline $\operatorname{Re}^{185} \mathrm{O}_{3}^{16} \mathrm{Cl}^{35}$ & $4-1471$ & $6,3 \leftarrow 5,3$ & Ground & $15 / 2$ & 9 & $13 / 2$ & 8 & 25135.82 & .06 \\
\hline $\operatorname{Re}^{185} \mathrm{O}_{3}^{16} \mathrm{Cl}^{35}$ & 4-1471 & $6,3 \leftarrow 5,3$ & Ground & $11 / 2$ & 7 & $9 / 2$ & 6 & 25135.82 & .06 \\
\hline $\operatorname{Re}^{185} \mathrm{O}_{3}^{16} \mathrm{Cl}^{35}$ & $4-1471$ & $6,3 \leftarrow 5,3$ & Ground & $15 / 2$ & 6 & $13 / 2$ & 5 & 25135.82 & .06 \\
\hline $\operatorname{Re}^{185} \mathrm{O}_{3}^{16} \mathrm{Cl}^{35}$ & 4-1471 & $6,3 \leftarrow 5,3$ & Ground & $11 / 2$ & 6 & $9 / 2$ & 5 & 25135.82 & .06 \\
\hline $\operatorname{Re}^{185} \mathrm{O}_{3}^{16} \mathrm{Cl}^{35}$ & 4-1471 & $6,3 \leftarrow 5,3$ & Ground & $13 / 2$ & 7 & $11 / 2$ & 6 & 25137.40 & .1 \\
\hline $\operatorname{Re}^{185} \mathrm{O}_{3}^{16} \mathrm{Cl}^{35}$ & 4-1471 & $6,3 \leftarrow 5,3$ & Groünd & $13 / 2$ & 6 & $11 / 2$ & 5 & 25137.40 & .1 \\
\hline $\operatorname{Re}^{185} \mathrm{O}_{3}^{16} \mathrm{Cl}^{35}$ & 4-1471 & $6,3 \leftarrow 5,3$ & Ground & $13 / 2$ & 5 & $11 / 2$ & 4 & 25138.80 & .07 \\
\hline $\operatorname{Re}^{185} \mathrm{O}_{3}^{16} \mathrm{Cl}^{35}$ & $4 \cdot 1471$ & $6,3 \leftarrow 5,3$ & Ground & $13 / 2$ & 8 & $11 / 2$ & 7 & 25138.80 & .07 \\
\hline $\mathrm{C}^{12} \mathrm{D}_{3} \mathrm{Si}^{28} \mathrm{DF}_{2}^{19}$ & 3- 199 & $3,2,2 \leftarrow 2,2,1$ & Ground & & & & & 25140.47 & .1 \\
\hline $\mathrm{C}^{13} \mathrm{H}_{3}\left(\mathrm{C}^{12} \mathrm{H}_{3}\right)_{2} \mathrm{C}^{12} \mathrm{C}^{12}: \mathrm{C}^{12} \mathrm{D}$ & $3-1078$ & $5,1,4 \leftarrow 4,1,3$ & Ground & & & & & 25140.6 & .1 \\
\hline $\mathrm{C}^{12} \mathrm{H}_{3} \mathrm{C}^{12} \mathrm{O}^{16} \mathrm{C}^{12} \mathrm{~N}^{14}$ & 3- 671 & $8,3,5 \leftarrow 8,2,6$ & Ground & & & & & 25141.40 & .2 \\
\hline $\mathrm{C}^{12} \mathrm{H}_{3} \mathrm{~S}^{32} \mathrm{H}$ & 3. 221 & $1,0,1 \leftarrow 0,0,0$ & Ground & & & & & 25142.2 & .1 \\
\hline $\mathrm{C}^{12} \mathrm{H}_{3} \mathrm{C}^{12} \mathrm{O}^{16} \mathrm{C}^{12} \mathrm{~N}^{14}$ & 3- 671 & $8,3,5 \leftarrow 8,2,6$ & Ground & & & & & 25142.58 & .2 \\
\hline $\mathrm{C}^{12} \mathrm{H}_{3} \mathrm{~S}^{32} \mathrm{H}$ & 3- 221 & $1,0,1 \leftarrow 0,0,0$ & Ground & & & & & 25143.6 & .1 \\
\hline $\mathrm{C}^{13} \mathrm{H}_{3} \mathrm{C}^{12} \mathrm{H}_{3} \mathrm{Si}^{28} \mathrm{H}_{2}$ & 3- 646 & $6,1,5 \leftarrow 6,0,6$ & Ground & & & & & 25144.60 & .20 \\
\hline $\mathrm{C}^{12} \mathrm{H}_{3} \mathrm{C}^{12}{ }_{*} \mathrm{HO}^{16} \mathrm{C}^{12}{ }_{*} \mathrm{H}_{2}$ & 3. 761 & Not Reported & Ground & & & & & 25145.18 & .1 \\
\hline $\mathrm{C}^{12} \mathrm{H}_{3} \mathrm{Si}^{28} \mathrm{HF}_{2}^{19} \cdot \mathrm{A}$ & 3- 191 & Not Reported & Ground & & & & & 25145.6 & \\
\hline $\mathrm{C}^{13} \mathrm{H}_{3} \mathrm{C}^{12} \mathrm{H}_{3} \mathrm{Si}^{28} \mathrm{H}_{2}$ & 3- 646 & $6,1,5 \leftarrow 6,0,6$ & Ground & & & & & 25146.60 & .20 \\
\hline $\mathrm{C}^{12} \mathrm{H}_{2} \mathrm{Br}_{2}^{\mathrm{b}}$ & 4- 321 & Not Reported & Ground & & & & & 25147. & \\
\hline $\mathrm{C}^{12} \mathrm{H}_{3} \mathrm{C}^{12}{ }_{*} \mathrm{HO}^{16} \mathrm{C}^{12}{ }_{*} \mathrm{H}_{2}$ & 3. 761 & Not Reported & Ground & & & & & 25149.28 & .1 \\
\hline $\mathrm{Cs}^{133} \mathrm{Cl}^{35}$ & $1-$ & $6 \leftarrow 5$ & Excited & & & & & 25150.1 & .6 \\
\hline $\mathrm{C}^{12} \mathrm{H}_{3} \mathrm{C}^{12} \mathrm{O}^{16} \mathrm{Cl}^{35}$ & 3- 361 & $5,3,2 \leftarrow 5,2,3$ & Ground & & $7 / 2$ & & $7 / 2$ & 25150.65 & .2 \\
\hline $\mathrm{C}^{12} \mathrm{H}_{3} \mathrm{O}^{16} \mathrm{H}$ & 3- 211 & Not Reported & Ground & & & & & 25151. & 5. \\
\hline $\mathrm{C}^{12} \mathrm{H}_{2} \mathrm{Br}_{2}^{b}$ & 4. 321 & Not Reported & Ground & & & & & 25152. & \\
\hline $\mathrm{C}^{12} \mathrm{H}_{3} \mathrm{C}^{12} \mathrm{O}^{16} \mathrm{Cl}^{35}$ & 3. 361 & $5,3,2 \leftarrow 5,2,3$ & Ground & & $13 / 2$ & & $13 / 2$ & 25153.00 & .2 \\
\hline $\mathrm{C}^{12} \mathrm{H}_{3} \mathrm{~S}^{32} \mathrm{H}$ & 3. 221 & $1,0,1 \leftarrow 0,0,0$ & Ground & & & & & 25154.8 & .1 \\
\hline $\mathrm{O}^{16} \mathrm{~F}_{2}^{19}$ & 4-1611 & $14,4,11 \leftarrow 15,3,12$ & Ground & & & & & 25155.14 & .10 \\
\hline $\mathrm{C}^{12} \mathrm{H}_{3} \mathrm{C}^{12}{ }_{*} \mathrm{HO}^{16} \mathrm{C}^{12}{ }_{*} \mathrm{H}_{2}$ & 3- 761 & $2,0,2 \leftarrow 1,0,1$ & Ground & & & & & 25156.18 & .1 \\
\hline $\mathrm{C}^{12} \mathrm{H}_{3} \mathrm{C}^{12} \mathrm{O}^{16} \mathrm{O}^{16} \mathrm{H}$ & 3- 491 & $2,0,2 \leftarrow 1,1,1$ & Ground & & & & & 25156.42 & .4 \\
\hline $\mathrm{C}^{12} \mathrm{H}_{2}\left(\mathrm{C}^{12} \mathrm{~N}^{14}\right)_{2}$ & 4- 901 & Not Reported & Ground & & & & & 25156.6 & .1 \\
\hline$K^{39} I^{127}$ & $1-$ & $7 \leftarrow 6$ & Excited & & & & & 25157.04 & 0.30 \\
\hline $2,4,6 \mathrm{~d}_{3} \cdot \mathrm{C}_{6}^{12} \mathrm{H}_{5} \mathrm{~F}^{19}$ & 4-1284 & $6,4,2 \leftarrow 5,4,1$ & Ground & & & & & 25159.0 & .1 \\
\hline $\mathrm{C}^{12} \mathrm{H}_{3} \mathrm{C}^{12} \mathrm{O}^{16} \mathrm{Cl}^{35}$ & 3- 361 & $5,3,2 \leftarrow 5,2,3$ & Ground & & $9 / 2$ & & $9 / 2$ & 25159.20 & .2 \\
\hline $\mathrm{C}^{12} \mathrm{H}_{3} \mathrm{C}^{12}{ }_{*} \mathrm{HO}^{16} \mathrm{C}^{12}{ }_{*} \mathrm{H}_{2}$ & 3- 761 & Not Reported & Ground & & & & & 25159.28 & .1 \\
\hline $\mathrm{C}^{12} \mathrm{H}_{2} \mathrm{Br}_{2}^{\mathrm{b}}$ & 4- 321 & Not Reported & Ground & & & & & 25160. & \\
\hline $\mathrm{C}^{12} \mathrm{H}_{3} \mathrm{Si}^{30} \mathrm{HF}_{2}^{19}$ & 3- 194 & $3,1,3 \leftarrow 2,1,2$ & Ground & & & & & 25160.94 & \\
\hline
\end{tabular}




\begin{tabular}{|c|c|c|c|c|c|c|c|c|}
\hline \multirow{3}{*}{$\frac{\text { Isotopic Species }}{\mathrm{C}^{\mathrm{\prime}} \mathrm{H}_{3}^{\mathrm{l}} \mathrm{N}^{\mathrm{h}} \mathrm{C}^{\mathrm{l}} \mathrm{S}^{\mathrm{l}}}$} & \multirow{3}{*}{$\begin{array}{l}\text { Vol.-Id. } \\
\text { Nos. } \\
\text { 3. } 426\end{array}$} & \multirow{3}{*}{$\begin{array}{l}\text { Rotational } \\
\text { Quantum Nos. } \\
5, \quad \leftarrow 4,\end{array}$} & \multirow{2}{*}{ Vib. State } & \multicolumn{3}{|c|}{ Hyperfine } & \multirow{2}{*}{$\begin{array}{c}\text { Frequency } \\
\mathrm{MHz}\end{array}$} & \multirow{2}{*}{$\begin{aligned} & \text { Acc. } \\
\pm & \mathrm{MHz}\end{aligned}$} \\
\hline & & & & $\mathrm{F}_{1}^{\prime}$ & $\mathrm{F}^{\prime} \quad \mathrm{F}_{1}$ & $\mathrm{~F}$ & & \\
\hline & & & & & & & 25161. & \\
\hline $\mathrm{C}^{12} \mathrm{~F}_{3}^{19} \mathrm{Br}^{79}$ & 4. 221 & $6,3 \leftarrow 5,3$ & Ground & & $15 / 2$ & $13 / 2$ & 25161.3 & \\
\hline $\mathrm{C}^{12} \mathrm{H}_{33} \mathrm{C}^{12} \mathrm{O}^{16} \mathrm{Cl}^{35}$ & 3. 361 & $5,3,2 \leftarrow 5,2,3$ & Ground & & $11 / 2$ & $11 / 2$ & 25161.60 & .2 \\
\hline $\mathrm{C}^{12} \mathrm{H}_{2}\left(\mathrm{C}^{12} \mathrm{~N}^{14}\right)_{2}$ & 4- 901 & Not Reported & Ground & & & & 25162.1 & $.1 \mathrm{i}$ \\
\hline $\mathrm{C}^{12} \mathrm{H}_{3} \mathrm{C}^{12}{ }_{*} \mathrm{HO}^{16} \mathrm{C}^{12}{ }_{*} \mathrm{H}_{2}$ & 3- 761 . & $2,0,2 \leftarrow 1,0,1$ & Ground & & & & 25165.43 & .1 \\
\hline $\mathrm{C}^{13} \mathrm{H}_{3} \mathrm{Cl}^{37}$ & 4. 427 & $1, \leftarrow 0$, & Ground & & & & 25167.68 & .1 \\
\hline$\left(\mathrm{C}^{12} \mathrm{H}_{3}\right)_{3} \mathrm{C}^{12} \mathrm{C}^{13}: \mathrm{C}^{12} \mathrm{D}$ & $3-1076$ & $5, \leftarrow 4$, & Ground & & & & 25168.2 & .1 \\
\hline $\mathrm{C}^{12} \mathrm{H}_{2} \mathrm{Br}_{2}^{\mathrm{b}}$ & 4- 321 & Not Reported & Ground & & & & 25170 & \\
\hline $\mathrm{C}^{12} \mathrm{H}_{3} \mathrm{Si}^{29} \mathrm{HF}_{2}^{19}$ & 3. 193 & $3,1,3 \leftarrow 2,1,2$ & Ground & & & & 25170.35 & \\
\hline $\mathrm{Rb}^{\mathrm{RS}} \mathrm{Br}^{\mathrm{N1}}$ & $1-$ & $9 \leftarrow 8$ & Excited & & & & 25170.56 & 0.10 \\
\hline $\mathrm{S}^{32} \mathrm{O}_{2}^{16}$ & $4-1831$ & Not Reported & & & & & 25170.97 & .1 \\
\hline $\mathrm{C}^{12} \mathrm{H}_{3} \mathrm{C}^{12} \mathrm{O}^{16} \mathrm{O}^{16} \mathrm{H}$ & 3. 491 & $2,0,2 \leftarrow 1,0,1$ & Excited & & & & 25171. & 3. \\
\hline $\mathrm{C}^{12} \mathrm{H}_{3} \mathrm{Si}^{29} \mathrm{HF}_{2}^{19}$ & 3- 193 & $3,1,3 \leftarrow 2,1,2$ & Ground & & & & 25171.55 & \\
\hline $\mathrm{C}^{12}{ }_{*} \mathrm{H}_{2} \mathrm{C}^{12} \mathrm{H}_{2} \mathrm{C}^{12} \mathrm{H}_{2} \mathrm{C}^{12} \mathrm{H}_{2} \mathrm{C}^{12}{ }^{2} \mathrm{O}^{16}$ & $4-1241$ & $34,11,23 \leftarrow 34,11,24$ & Ground & & & & 25172 & 5. \\
\hline $\mathrm{O}^{16}{ }_{*} \mathrm{C}^{12} \mathrm{H}_{2} \mathrm{C}^{12} \mathrm{H}_{2} \mathrm{C}^{12}{ }_{*} \mathrm{O}^{16}$ & $4-1071$ & $3,1,3 \leftarrow 2,1,2$ & Ground & & & & 25172.11 & .1 \\
\hline $\mathrm{C}^{12} \mathrm{~F}_{3}^{19} \mathrm{Br}^{79}$ & 4- 221 & $6,1 \leftarrow 5,1$ & Ground & & $15 / 2$ & $13 / 2$ & 25173.3 & \\
\hline $\mathrm{C}^{12} \mathrm{H}_{3} \mathrm{Si}^{28} \mathrm{HF}_{2}^{19}-\mathrm{A}$ & 3- 191 & Not Reported & Ground & & & & 25173.4 & \\
\hline $\mathrm{C}^{12} \mathrm{~F}_{3}^{19} \mathrm{Br}^{79}$ & 4- 221 & $6,0 \leftarrow 5,0$ & Ground & & $13 / 2$ & $11 / 2$ & 25175.2 & \\
\hline$\left(\mathrm{C}^{12} \mathrm{H}_{3}\right)_{3} \mathrm{~N}^{14} \cdot \mathrm{B}^{11}\left(\mathrm{C}^{12} \mathrm{H}_{3}\right)_{3}$ & $3-1081$ & $8, \leftarrow 7$, & & & & & 25179. & 10. \\
\hline $\mathrm{C}^{12} \mathrm{H}_{3} \mathrm{Si}^{28} \mathrm{HF}_{2}^{19} \cdot \mathrm{A}$ & 3. 191 & $3,1,3 \leftarrow 2,1,2$ & Ground & & & & 25179.49 & \\
\hline $\mathrm{C}^{12} \mathrm{H}_{3} \mathrm{Si}^{28} \mathrm{HF}_{2}^{19} \cdot \mathrm{E}$ & 3. 192 & $3,1,3 \leftarrow 2,1,2$ & Ground & & & & 25.180 .66 & \\
\hline $\mathrm{C}^{12} \mathrm{H}_{2} \mathrm{Cl}^{35} \mathrm{Si}^{29} \mathrm{H}_{3}$ & 3- 234 & $9,1,8 \leftarrow 9,0,9$ & Ground & & $15 / 2$ & $15 / 2$ & 25180.8 & .1 \\
\hline $\mathrm{C}^{12} \mathrm{H}_{2} \mathrm{Cl}^{35} \mathrm{Si}^{29} \mathrm{H}_{3}$ & 3- 234 & $9,1.8 \leftarrow 9,0,9$ & Ground & & $21 / 2$ & $21 / 2$ & 25181.6 & .1 \\
\hline $\mathrm{C}^{13} \mathrm{H}_{3} \mathrm{Cl}^{37}$ & 4. 427 & $1, \leftarrow 0$, & Ground & & & & 25182.50 & .1 \\
\hline $\mathrm{C}^{12} \mathrm{H}_{2} \mathrm{Cl}^{35} \mathrm{Si}^{29} \mathrm{H}_{3}$ & 3- 234 & $9,1,8 \leftarrow 9,0,9$ & Ground & & & & 25184.38 & .2 \\
\hline $\mathrm{C}^{12} \mathrm{H}_{3} \mathrm{C}^{12} \mathrm{O}^{16} \mathrm{~F}^{19}$ & 3. 391 & Not Reported & Ground & & & & 25186.63 & .2 \\
\hline $\mathrm{C}^{12} \mathrm{~F}_{3}^{19} \mathrm{Br}^{79}$ & 4- 221 & $6,2 \leftarrow 5,2$ & Ground & & $13 / 2$ & $11 / 2$ & 25186.7 & \\
\hline $\mathrm{C}^{12} \mathrm{H}_{2}\left(\mathrm{C}^{12} \mathrm{~N}^{14}\right)_{2}$ & 4. 901 & Not Reported & Ground & & & & 25186.7 & .1 \\
\hline $\mathrm{C}^{12} \mathrm{H}_{2} \mathrm{Cl}^{35} \mathrm{Si}^{29} \mathrm{H}_{3}$ & 3- 234 & $9,1,8 \leftarrow 9.0,9$ & Ground & & $17 / 2$ & $17 / 2$ & 25187.0 & .1 \\
\hline $\mathrm{C}^{12} \mathrm{H}_{2} \mathrm{Cl}^{35} \mathrm{Si}^{29} \mathrm{H}_{3}$ & 3- 234 & $9,1,8 \leftarrow 9,0,9$ & Ground & & $19 / 2$ & $19 / 2$ & 25187.9 & .1 \\
\hline $\mathrm{C}^{12} \mathrm{~F}_{3}^{19} \mathrm{Br}^{79}$ & 4- 221 & $6,3 \leftarrow 5,3$ & Ground & & $11 / 2$ & $9 / 2$ & 25192.5 & \\
\hline $\mathrm{DC}^{13}: \mathrm{C}^{12} \mathrm{C}^{12} \mathrm{HO}^{16}$ & 4- 917 & $3,0,3 \leftarrow 2,0,2$ & Ground & & & & 25192.85 & .02 \\
\hline $\mathrm{S}^{32} \mathrm{C}^{12} \mathrm{~T} \mathrm{e}^{126}$ & 4- 575 & $8 \leftarrow 7$ & Excited & & & & 25193.132 & .010 \\
\hline $\mathrm{C}^{13} \mathrm{H}_{3} \mathrm{Cl}^{37}$ & 4. 427 & $1, \leftarrow 0$ & Ground & & & & 25194.20 & .1 \\
\hline $\mathrm{C}^{12} \mathrm{H}_{3} \mathrm{~N}^{14} \mathrm{C}^{12} \mathrm{~S}^{32}$ & 3- 421 & $5,1,5 \leftarrow 4,1,4$ & Ground & & & & 25195. & \\
\hline $\mathrm{O}^{16} \mathrm{O}^{18} \mathrm{O}^{18}$ & 4-1844 & $17,2,15 \leftarrow 18,1,18$ & Ground & & & & 25196. & \\
\hline $\mathrm{Rb}^{\mathrm{R} 7} \mathrm{I}^{127}$ & $1-$ & $13 \leftarrow 12$ & Ground & & & & 25196.01 & 0.10 \\
\hline $\mathrm{C}^{12} \mathrm{H}_{3} \mathrm{C}^{12}{ }_{*} \mathrm{HO}^{16} \mathrm{C}^{12}{ }_{*} \mathrm{H}_{2}$ & 3- 761 & $2,0,2 \leftarrow 1,0,1$ & Ground & & & & 25196.48 & .1 \\
\hline $\mathrm{C}^{12} \mathrm{H}_{2}\left(\mathrm{C}^{12} \mathrm{~N}^{14}\right)_{2}$ & 4. 901 & Not Reported & Ground & & & & 25197.3 & .1 \\
\hline $\mathrm{Rb}^{85} \mathrm{Br}^{79}$ & $1-$ & $9 \leftarrow 8$ & Excited & & & & 25197.32 & 0.10 \\
\hline $\mathrm{C}^{\mathrm{b}} \mathrm{H}_{2}^{\mathrm{b}} \mathrm{Cl}^{\mathrm{b}} \mathrm{F}^{\mathrm{b}}$ & 4. 333 & Not Reported & & & & & 25197.90 & .1 \\
\hline $\mathrm{C}^{12}{ }_{*} \mathrm{HC}{ }^{12} \mathrm{H}: \mathrm{C}^{12} \mathrm{HC}^{12} \mathrm{H}: \mathrm{C}^{12} \mathrm{HN}^{14}{ }_{*}$ & 4-1201 & $15,11,4 \leftarrow 15,11,5$ & Ground & & & & 25198.9 & .1 \\
\hline $\mathrm{DC}^{13}: \mathrm{C}^{12} \mathrm{C}^{12} \mathrm{HO}^{16}$ & 4- 917 & $3,2,2 \leftarrow 2,2,1$ & Ground & & & & 25199.51 & .02 \\
\hline $\mathrm{H}_{2} \mathrm{~N}^{14} \mathrm{~N}^{14} \mathrm{H}_{2}$ & $3-\quad 51$ & Not Reported & & & & & 25201.35 & \\
\hline $\mathrm{DC}^{13}: \mathrm{C}^{12} \mathrm{C}^{12} \mathrm{HO}^{16}$ & 4- 917 & $3,2,1 \leftarrow 2,2,0$ & Ground & & & & 25202.96 & .02 \\
\hline
\end{tabular}




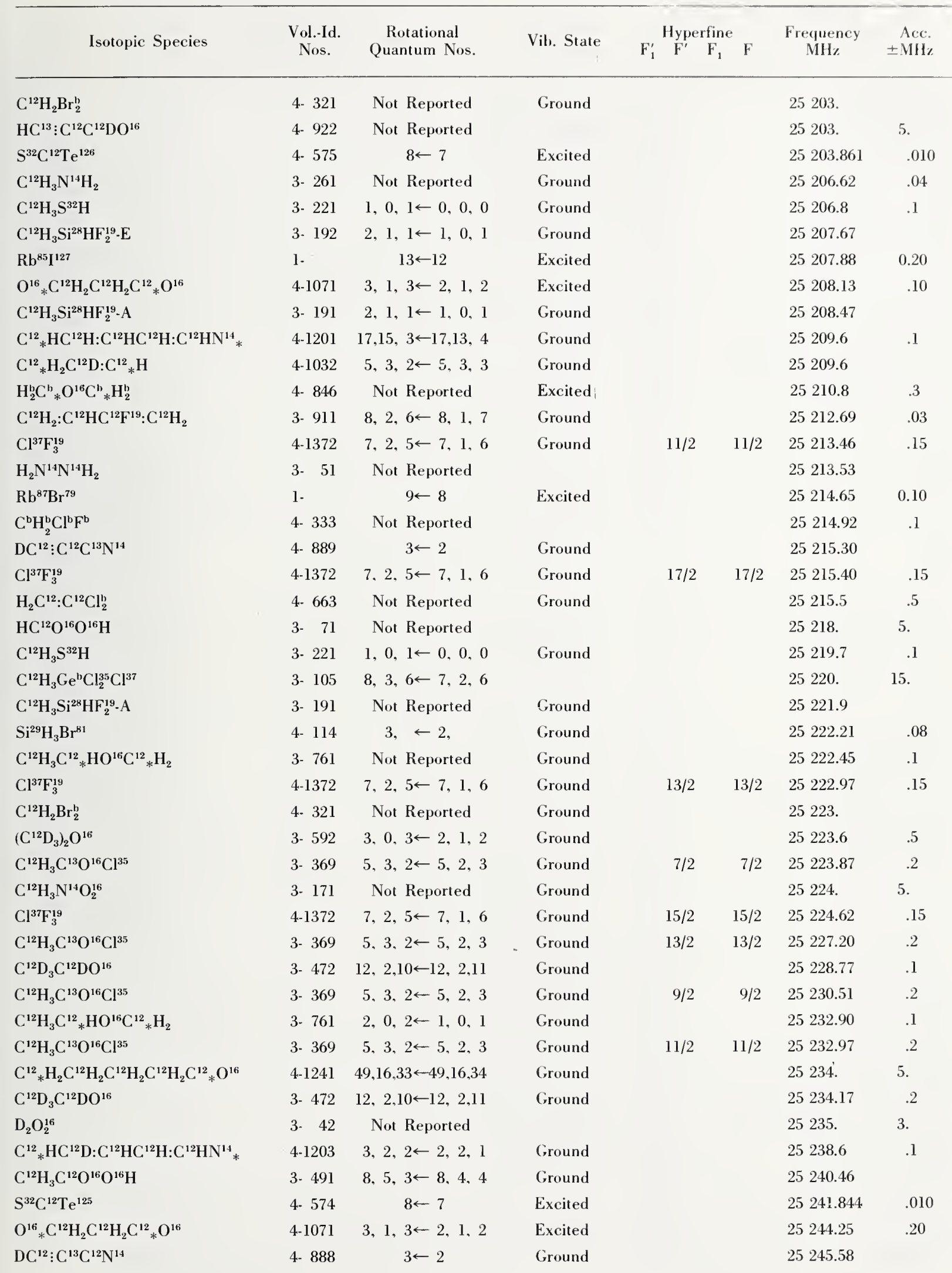




\begin{tabular}{|c|c|c|c|c|c|c|c|}
\hline \multirow{2}{*}{ Isotopic Species } & \multirow{2}{*}{$\begin{array}{l}\text { Vol.-Id. } \\
\text { Nos. }\end{array}$} & \multirow{2}{*}{$\begin{array}{c}\text { Rotational } \\
\text { Quantum Nos. }\end{array}$} & \multirow{2}{*}{ Vib. State } & \multicolumn{2}{|c|}{ Hyperfine } & \multirow{2}{*}{$\begin{array}{c}\text { Frequency } \\
\mathrm{MHz}\end{array}$} & \multirow{2}{*}{$\begin{aligned} & \text { Acc. } \\
\pm & \mathrm{MHz}\end{aligned}$} \\
\hline & & & & $F_{1}^{\prime} \quad F^{\prime} \quad I$ & $\mathrm{~F}$ & & \\
\hline $\mathrm{H}_{2} \mathrm{C}^{12}: \mathrm{C}^{12} \mathrm{~F}_{2}^{19}$ & 4. 681 & $6,4,1 \leftarrow 6,4,2$ & Ground & & & 25245.7 & .3 \\
\hline $\mathrm{H}_{2} \mathrm{C}^{12}{ }_{*} \mathrm{O}^{16} \mathrm{C}^{13}{ }_{*} \mathrm{H}_{2}$ & 4- 842 & $4,3,1 \leftarrow 4,2,2$ & Ground & & & 25246.8 & .3 \\
\hline $\mathrm{C}^{12}{ }_{*} \mathrm{H}_{2}^{\mathrm{b}} \mathrm{S}^{\mathrm{b}} \mathrm{C}^{12}{ }_{*} \mathrm{H}_{2}^{\mathrm{b}}$ & 4. 854 & Not Reported & & & & 25247.2 & .2 \\
\hline $\mathrm{C}^{12} \mathrm{H}_{3} \mathrm{~S}^{32} \mathrm{C}^{12} \mathrm{D}_{3}$ & 3- 606 & $5,1,4 \leftarrow 5,0,5$ & Ground & & & 25249.00 & .05 \\
\hline $\mathrm{C}^{12} \mathrm{HCl}^{35}: \mathrm{C}^{12} \mathrm{~F}_{2}^{19}$ & 4- 611 & $2,2,0 \leftarrow 2,1,1$ & Ground & $7 / 2$ & $7 / 2$ & 25249.3 & .3 \\
\hline $\mathrm{C}^{12} \mathrm{H}_{2}: \mathrm{C}^{12} \mathrm{HC}^{12} \mathrm{~F}^{19}: \mathrm{C}^{12} \mathrm{H}_{2}$ & 3- 911 & $5,1,4 \leftarrow 4,2,3$ & Ground & & & 25249.7 & .2 \\
\hline $\mathrm{S}^{32} \mathrm{C}^{12} \mathrm{~T} \mathrm{e}^{125}$ & 4. 574 & $8 \leftarrow 7$ & Excited & & & 25252.608 & .010 \\
\hline $\mathrm{C}^{12} \mathrm{HCl}^{35}: \mathrm{C}^{12} \mathrm{~F}_{2}^{19}$ & 4- 611 & $2,2,0 \leftarrow 2,1,1$ & Ground & $3 / 2$ & $3 / 2$ & 25254.3 & .5 \\
\hline $\mathrm{O}^{16} \mathrm{O}^{18} \mathrm{O}^{18}$ & $4-1844$ & $17,2,15 \leftarrow-16,3,14$ & Ground & & & 25257 & \\
\hline $\mathrm{C}^{12} \mathrm{HCl}^{35}: \mathrm{C}^{12} \mathrm{~F}_{2}^{19}$ & 4- 611 & $2,2,0 \leftarrow 2,1,1$ & Ground & $3 / 2$ & $5 / 2$ & 25257.2 & .5 \\
\hline $\mathrm{C}^{12}{ }_{*} \mathrm{DC}^{12} \mathrm{H}: \mathrm{C}^{12} \mathrm{HC}^{12} \mathrm{H}: \mathrm{C}^{12} \mathrm{HN}^{14}{ }_{*}$ & 4-1202 & $3,2,2 \leftarrow 2,2,1$ & Ground & & & 25260.5 & .1 \\
\hline $\mathrm{HC}^{13}: \mathrm{C}^{12} \mathrm{C}^{12} \mathrm{DO}^{16}$ & 4- 922 & Not Reported & & & & 25261. & 5. \\
\hline $\mathrm{Cl}^{35} \mathrm{O}_{2}^{16}$ & $4-1381$ & $4,2,3 \leftarrow 5,1,4$ & Ground & 3 & 4 & 25261.0 & .2 \\
\hline $\mathrm{C}^{12} \mathrm{HCl}^{35}: \mathrm{C}^{12} \mathrm{~F}_{2}^{19}$ & 4- 611 & $2,2,0 \leftarrow 2,1,1$ & Ground & $5 / 2$ & $3 / 2$ & 25263.7 & .5 \\
\hline $\mathrm{Cl}^{35} \mathrm{O}_{2}^{16}$ & 4-1381 & $4,2,3 \leftarrow 5,1,4$ & Ground & & & 25265.80 & .05 \\
\hline $\mathrm{C}^{12} \mathrm{HCl}^{35}: \mathrm{C}^{12} \mathrm{~F}_{2}^{19}$ & 4- 611 & $2,2,0 \leftarrow 2,1,1$ & Ground & $5 / 2$ & $5 / 2$ & 25266.9 & .5 \\
\hline $\mathrm{S}^{32} \mathrm{O}^{16} \mathrm{~F}_{2}^{19}$ & $4-1621$ & Not Reported & & & & 25268.61 & .1 \\
\hline $\mathrm{Rb}^{85} \mathrm{Br}^{81}$ & $1-$ & $9 \leftarrow 8$ & Ground & & & 25268.84 & 0.10 \\
\hline $\mathrm{K}^{39} \mathrm{I}^{127}$ & 1 - & $7 \leftarrow 6$ & Excited & & & 25268.95 & 0.15 \\
\hline $\mathrm{C}^{12} \mathrm{H}_{3} \mathrm{~N}^{14} \mathrm{C}^{12} \mathrm{~S}^{32}$ & 3- 421 & $5, \quad \leftarrow 4, \quad$, & Ground & & & 25269. & \\
\hline $\mathrm{C}_{*}^{\mathrm{b}} \mathrm{H}_{2}^{\mathrm{b}} \mathrm{N}^{\mathrm{b}} \mathrm{H}^{\mathrm{b}} \mathrm{C}^{\mathrm{b}}{ }_{*} \mathrm{H}_{2}^{\mathrm{b}}$ & 4. 863 & Not Reported & & & & 25270 . & 10. \\
\hline $\mathrm{Cs}^{133} \mathrm{Cl}^{35}$ & $1-$ & $6 \leftarrow 5$ & Excited & & & 25270.0 & .6 \\
\hline $\mathrm{HC}^{13}: \mathrm{C}^{12} \mathrm{C}^{12} \mathrm{DO}^{16}$ & 4. 922 & Not Reported & & & & 25273. & 5. \\
\hline $\mathrm{Cl}^{35} \mathrm{O}_{2}^{16}$ & 4-1381 & $4,2,3 \leftarrow 5,1,4$ & Ground & 4 & 5 & $252 \dot{7} 4.6$ & .2 \\
\hline $\mathrm{C}^{12}{ }_{*} \mathrm{H}_{2}^{\mathrm{b}} \mathrm{S}^{\mathrm{b}} \mathrm{C}^{12}{ }_{*} \mathrm{H}_{2}^{\mathrm{b}}$ & 4- 854 & Not Reported & & & & 25275.0 & 10. \\
\hline $\mathrm{C}^{13} \mathrm{H}_{3} \mathrm{C}^{12} \mathrm{O}^{16} \mathrm{C}^{12} \mathrm{~N}^{14}$ & 3- 672 & $7,3,4 \leftarrow 7,2,5$ & Ground & & & 25278.01 & .2 \\
\hline $\mathrm{C}^{12}{ }_{*} \mathrm{D}: \mathrm{C}^{12} \mathrm{DC}^{12} \mathrm{D}: \mathrm{C}^{12} \mathrm{DN}^{14}{ }_{*} \mathrm{H}$ & $4-1185$ & $11,11,0 \leftarrow 11,10,1$ & Ground & & & 25278.2 & \\
\hline $\mathrm{C}^{12} \mathrm{H}_{3} \mathrm{C}^{12} \mathrm{O}^{16} \mathrm{Cl}^{37}$ & 3- 362 & $9,3,6 \leftarrow 9,2,7$ & Ground & $15 / 2$ & $15 / 2$ & 25279.18 & .2 \\
\hline $\mathrm{C}^{12} \mathrm{H}_{3} \mathrm{C}^{12} \mathrm{O}^{16} \mathrm{Cl}^{37}$ & 3- 362 & $9,3,6 \leftarrow 9,2,7$ & Ground & $17 / 2$ & $17 / 2$ & 25279.18 & .2 \\
\hline $\mathrm{C}^{12} \mathrm{H}_{3} \mathrm{C}^{12} \mathrm{O}^{16} \mathrm{Cl}^{37}$ & 3- 362 & $9,3,6 \leftarrow 9,2,7$ & Ground & $21 / 2$ & $21 / 2$ & 25279.18 & .2 \\
\hline $\mathrm{C}^{12} \mathrm{H}_{3} \mathrm{C}^{12} \mathrm{O}^{16} \mathrm{Cl}^{37}$ & 3- 362 & $9,3,6 \leftarrow 9,2,7$ & Ground & $19 / 2$ & $19 / 2$ & 25279.18 & .2 \\
\hline $\mathrm{C}^{12} \mathrm{H}_{3} \mathrm{C}^{12} \mathrm{O}^{16} \mathrm{~F}^{19}$ & 3. 391 & Not Reported & Ground & & & 25279.90 & .2 \\
\hline $\mathrm{C}^{12} \mathrm{H}_{3} \mathrm{Si}^{30} \mathrm{HF}_{2}^{19}$ & 3- 194 & $3,0,3 \leftarrow 2,0,2$ & Ground & & & 25282.51 & \\
\hline $\mathrm{C}^{12} \mathrm{H}_{3} \mathrm{C}^{12} \mathrm{O}^{16} \mathrm{Cl}^{37}$ & 3- 362 & $9,3,6 \leftarrow 9,2,7$ & Ground & $15 / 2$ & $15 / 2$ & 25282.92 & .2 \\
\hline $\mathrm{C}^{12} \mathrm{H}_{3} \mathrm{C}^{12} \mathrm{O}^{16} \mathrm{Cl}^{37}$ & 3- 362 & $9,3,6 \leftarrow 9,2,7$ & Ground & $19 / 2$ & $19 / 2$ & 25282.92 & .2 \\
\hline $\mathrm{C}^{12} \mathrm{H}_{3} \mathrm{C}^{12} \mathrm{O}^{16} \mathrm{Cl}^{37}$ & 3- 362 & $9,3,6 \leftarrow 9,2,7$ & Ground & $17 / 2$ & $17 / 2$ & 25282.92 & .2 \\
\hline $\mathrm{C}^{12} \mathrm{H}_{3} \mathrm{C}^{12} \mathrm{O}^{16} \mathrm{Cl}^{37}$ & 3. 362 & $9,3,6 \leftarrow 9,2,7$ & Ground & $21 / 2$ & $21 / 2$ & 25282.92 & .2 \\
\hline $\mathrm{C}^{12} \mathrm{H}_{3} \mathrm{Si}^{30} \mathrm{HF}_{2}^{19}$ & 3. 194 & $3,0,3 \leftarrow 2,0,2$ & Ground & & & 25284.83 & \\
\hline $\mathrm{C}^{12}{ }_{*} \mathrm{HO}^{16} \mathrm{C}^{12} \mathrm{HC}^{12} \mathrm{H}_{2} \mathrm{C}^{12} \mathrm{H}_{2} \mathrm{C}^{12}{ }_{*} \mathrm{H}_{2}$ & 4-1251 & $3,2,1 \leftarrow 2,2,0$ & Ground & & & 25286. & 5. \\
\hline $\mathrm{C}^{12} \mathrm{H}_{3} \mathrm{O}^{16} \mathrm{H}$ & 3- 211 & Not Reported & Ground & & & 25289 . & 5. \\
\hline $\mathrm{Cl}^{35} \mathrm{O}_{2}^{16}$ & 4-1381 & $4,2,3 \leftarrow 5,1,4$ & Ground & 5 & 6 & 25290.1 & .2 \\
\hline $\mathrm{C}^{12} \mathrm{H}_{3} \mathrm{~S}^{32} \mathrm{H}$ & 3- 221 & $1,0,1 \leftarrow 0,0,0$ & Ground & & & 25290.8 & .1 \\
\hline $\mathrm{S}^{32} \mathrm{C}^{12} \mathrm{Te}^{124}$ & 4. 573 & $8 \leftarrow 7$ & Excited & & & 25291.465 & .010 \\
\hline $\mathrm{C}^{12} \mathrm{H}_{3} \mathrm{~S}^{32} \mathrm{H}$ & 3- 221 & $1,0,1 \leftarrow 0,0,0$ & Ground & & & 25291.8 & .1 \\
\hline $\mathrm{C}^{12} \mathrm{H}_{3} \mathrm{Si}^{29} \mathrm{HF}_{2}^{19}$ & 3- 193 & $3,0,3 \leftarrow 2,0,2$ & Ground & & & 25292.55 & \\
\hline
\end{tabular}


Vol.-Id. Rotational

Nos. Quantum Nos.
Vib. State $F^{\prime} F^{\prime} F_{1} F$
Frequency Ace. NH\% $\pm \mathrm{NH} \%$

\begin{tabular}{|c|c|c|c|}
\hline $\mathrm{Rb}^{85} \mathrm{I}^{127}$ & 1. & $13 \leftarrow 12$ & Excited \\
\hline $\mathrm{C}^{12} \mathrm{H}_{3} \mathrm{C}^{12}: \mathrm{C}^{12} \mathrm{C}^{12} \mathrm{H}_{2} \mathrm{Cl}^{37}$ & 3- 902 & $9,0,9 \leftarrow 8,0,8$ & Ground \\
\hline $\mathrm{C}^{12} \mathrm{H}_{3} \mathrm{O}^{16} \mathrm{H}$ & 3- 211 & $8,2, \leftarrow 8,1$ & Ground \\
\hline $\mathrm{C}^{12} \mathrm{H}_{3} \mathrm{Si}^{29} \mathrm{HF}_{2}^{19}$ & 3- 193 & $3,0,3 \leftarrow 2,0,2$ & Ground \\
\hline $\mathrm{H}_{2} \mathrm{C}^{12}: \mathrm{C}^{12} \mathrm{HI}^{127}$ & 4. 801 & $4,0,4 \leftarrow 3,0,3$ & Ground \\
\hline $\mathrm{Rb}^{85} \mathrm{Br}^{79}$ & $1-$ & $9 \leftarrow 8$ & Excited \\
\hline $\mathrm{C}^{12} \mathrm{O}^{16} \mathrm{Cl}^{35} \mathrm{Cl}^{37}$ & 4. 182 & $9,2,7 \leftarrow 9,1,8$ & Ground \\
\hline $\mathrm{S}^{32}{ }_{*} \mathrm{DC}^{12}: \mathrm{C}^{12} \mathrm{DC}^{12} \mathrm{D}: \mathrm{C}^{12}{ }_{*} \mathrm{D}$ & $4-1165$ & $3,1,2 \leftarrow 2,1,1$ & Ground \\
\hline $\mathrm{C}^{12} \mathrm{H}_{3} \mathrm{C}^{12} \mathrm{O}^{16} \mathrm{C}^{13} \mathrm{~N}^{14}$ & 3. 673 & $8,3,5 \leftarrow 8,2,6$ & Ground \\
\hline $\mathrm{O}_{3}^{16}$ & 4-1841 & $45,7,39 \leftarrow 46,6,40$ & Ground \\
\hline $\mathrm{C}^{12} \mathrm{H}_{3} \mathrm{O}^{16} \mathrm{H}$ & 3. 211 & Not Reported & Ground \\
\hline $\mathrm{C}^{12} \mathrm{H}_{3} \mathrm{C}^{12} \mathrm{O}^{16} \mathrm{C}^{13} \mathrm{~N}^{14}$ & $3-673$ & $8,3,5 \leftarrow 8,2,6$ & Ground \\
\hline $\mathrm{S}^{32} \mathrm{C}^{12} \mathrm{Te}^{124}$ & 4- 573 & $8 \leftarrow 7$ & Excited \\
\hline $\mathrm{C}^{12} \mathrm{H}_{3} \mathrm{Si}^{28} \mathrm{HF}_{2}^{19}-\mathrm{E}$ & 3- 992 & $3,0,3 \leftarrow 2,0,2$ & Ground \\
\hline $\mathrm{C}^{12} \mathrm{H}_{3} \mathrm{C}^{13} \mathrm{H}_{2} \mathrm{~F}^{19}$ & 3- 555 & $6,1,5 \leftarrow 6,1,6$ & Ground \\
\hline $\mathrm{C}^{12}{ }_{*} \mathrm{HO}^{16} \mathrm{C}^{12} \mathrm{HC}^{12} \mathrm{H}_{2} \mathrm{C}^{12} \mathrm{H}_{2} \mathrm{C}^{12}{ }_{*} \mathrm{H}_{2}$ & 4-1251 & $11,5,7 \leftarrow 11,3,8$ & Ground \\
\hline $\mathrm{C}^{12} \mathrm{H}_{3} \mathrm{Si}^{28} \mathrm{HF}_{2}^{19}-\mathrm{A}$ & 3- 191 & $3,0,3 \leftarrow 2,0,2$ & Ground \\
\hline $\mathrm{C}^{12} \mathrm{O}^{16} \mathrm{Cl}_{2}^{35}$ & 4- 181 & $5,0,5 \leftarrow 4,1,4$ & Ground \\
\hline $\mathrm{C}^{12} \mathrm{H}_{3} \mathrm{~N}^{14} \mathrm{C}^{12} \mathrm{~S}^{32}$ & 3. 421 & $5, \quad, \quad \leftarrow 4$. & Excited \\
\hline $\mathrm{P}^{31} \mathrm{Cl}^{35} \mathrm{Cl}_{2}^{37}$ & $4-1523$ & $5, \quad \leftarrow 4$, & Ground \\
\hline $\mathrm{CL}^{35} \mathrm{O}_{2}^{16}$ & 4-1381 & $4,2,3 \leftarrow 5,1,4$ & Ground \\
\hline $\mathrm{C}^{12} \mathrm{H}_{3} \mathrm{C}^{12} \mathrm{H}_{2} \mathrm{O}^{16} \mathrm{H}$ & 3- 581 & Not Reported & \\
\hline $\mathrm{C}^{12} \mathrm{H}_{3} \mathrm{C}^{12} \mathrm{H}_{2} \mathrm{O}^{16} \mathrm{H}$ & 3- 581 & $1,1,0 \leftarrow 1,0,1$ & Ground \\
\hline $\mathrm{Na}^{23} \mathrm{Cl}^{37}$ & $1-$ & $2 \leftarrow 1$ & Excited \\
\hline $\mathrm{As}^{75} \mathrm{Cl}_{2}^{35} \mathrm{Cl}^{37}$ & 4- $\quad 12$ & $6, \quad \leftarrow 5$, & Ground \\
\hline$\left(\mathrm{C}^{12} \mathrm{H}_{3}\right)_{3} \mathrm{C}^{12} \mathrm{C}^{12}: \mathrm{C}^{12} \mathrm{D}$ & $3-1072$ & $5, \leftarrow 4$, & Ground \\
\hline $\mathrm{C}^{12} \mathrm{H}_{3} \mathrm{O}^{16} \mathrm{H}$ & 3. 211 & Not Reported & Ground \\
\hline $\mathrm{Rb}^{87} \mathrm{Br}^{79}$ & $1-$ & $9 \leftarrow 8$ & Ground \\
\hline $\operatorname{Cs}^{133} I^{127}$ & $1-$ & $18 \leftarrow 17$ & Excited \\
\hline $\mathrm{C}_{6}^{12} \mathrm{H}_{5} \mathrm{~F}^{19}$ & $4-1281$ & $42,13,29 \longleftarrow 42,13,30$ & Ground \\
\hline $\mathrm{C}^{12} \mathrm{H}_{2}: \mathrm{C}^{12} \mathrm{HC}^{12} \mathrm{~F}^{19}: \mathrm{C}^{12} \mathrm{H}_{2}$ & 3- 911 & $6,1,5 \leftarrow 6,0,6$ & Ground \\
\hline $\mathrm{C}^{12} \mathrm{H}_{3} \mathrm{C}^{12} \mathrm{O}^{16} \mathrm{O}^{16} \mathrm{H}$ & 3. 491 & Not Reported & \\
\hline $\mathrm{C}^{13} \mathrm{H}_{3} \mathrm{C}^{12} \mathrm{H}_{2} \mathrm{~F}^{19}$ & 3. 556 & $3,0,3 \leftarrow 2,1,2$ & Ground \\
\hline $\mathrm{C}^{12} \mathrm{H}_{3} \mathrm{O}^{16} \mathrm{H}$ & 3- 211 & Not Reported & Ground \\
\hline $\mathrm{N}^{15} \mathrm{H}_{3}$ & 4-1772 & $8,8 \leftarrow 8,8$ & Ground \\
\hline $\mathrm{a}-\mathrm{C}^{12} \mathrm{H}_{2} \mathrm{DC}^{12} \mathrm{O}^{16} \mathrm{Cl}^{35}$ & 3- 366 & $9,3,6 \leftarrow 9,2,7$ & Ground \\
\hline $\mathrm{C}^{12} \mathrm{H}_{3} \mathrm{C}^{12} \mathrm{O}^{16} \mathrm{O}^{16} \mathrm{H}$ & $3-491$ & Not Reported & \\
\hline $\mathrm{N}^{\mathrm{b}} \mathrm{O}_{2}^{\mathrm{b}} \mathrm{Cl}^{\mathrm{b}}$ & $4-1463$ & Not Reported & \\
\hline $\mathrm{C}_{6}^{12} \mathrm{H}_{5} \mathrm{C}^{12} \mathrm{~N}^{14}$ & 4-1291 & $9,3,6 \leftarrow 8,3,5$ & Ground \\
\hline $\mathrm{H}_{2} \mathrm{C}^{12}: \mathrm{C}^{12} \mathrm{Cl}_{2}^{b}$ & 4- 663 & Not Reported & Ground \\
\hline $\mathrm{N}^{14} \mathrm{H}_{2} \mathrm{C}_{2}^{12} \mathrm{H}_{5}$ & $3 \cdot 631$ & Not Reported & Ground \\
\hline $\mathrm{DC}^{12}: \mathrm{C}^{12} \mathrm{C}^{12} \mathrm{~N}^{14}$ & 4. 886 & $3 \leftarrow 2$ & Ground \\
\hline $2,4,6 \mathrm{~d}_{3}-\mathrm{C}_{6}^{12} \mathrm{H}_{5} \mathrm{~F}^{19}$ & $4 \cdot 1284$ & $6,1,5 \leftarrow 5,1,4$ & Ground \\
\hline $\mathrm{C}^{12} \mathrm{H}_{3} \mathrm{O}^{16} \mathrm{H}$ & 3- 211 & Not Reported & Ground \\
\hline
\end{tabular}

$25292.65 \quad 0.10$

$25293.3 \quad .3$

$25294.41 \quad .1$

25294.58

25295.40

$25296.52 \quad 0.10$

$25297.0 \quad .3$

$25297.2 \quad .1$

$25299.99 \quad .2$

25300 .

25300.3

$25301.05 \quad .2$

$25302.268 \quad .010$

25302.51

$25303.5 \quad .1$

25304 . 5 .

25304.74

$\begin{array}{ll}25 & 304.87\end{array}$

25306.

25306.10.

$25306.7 \quad .2$

$25307.03 \quad .01$

$25307.25 \quad .01$

$25307.5 \quad 0.75$

$25308 . \quad 10$.

$25310.9 \quad .1$

$25312 . \quad 5$.

$25312.99 \quad 0.10$

$25313.66 \quad 0.10$

25315.0

$25316.9 \quad .2$

25320 . $\quad 3$.

25321.0 .1

25322.98 . 1

$25323.51 \quad .02$

$25324.9 \quad .2$

$25327 . \quad 3$.

25327.

25328.

$25328.2 \quad 1.5$

$25328.64 \quad .2$

25329.62

$25330.1 \quad .1$

$25332 . \quad 5$. 


\begin{tabular}{|c|c|c|c|c|c|c|c|}
\hline \multirow{2}{*}{ Isotopic Species } & \multirow{2}{*}{$\begin{array}{l}\text { Vol.-Id. } \\
\text { Nos. }\end{array}$} & \multirow{2}{*}{$\begin{array}{c}\text { Rotational } \\
\text { Quantum Nos. }\end{array}$} & \multirow{2}{*}{ Vib. State } & \multicolumn{2}{|c|}{ Hyperfine } & \multirow{2}{*}{$\begin{array}{l}\text { Frequency } \\
\mathrm{MHz}\end{array}$} & \multirow{2}{*}{$\begin{aligned} & \text { Acc. } \\
\pm & \mathrm{MHz}\end{aligned}$} \\
\hline & & & & $\begin{array}{lll}F_{1}^{\prime} & F^{\prime} & F_{1}\end{array}$ & $\mathbf{F}$ & & \\
\hline $\mathrm{C}^{12} \mathrm{H}_{3} \mathrm{~N}^{14} \mathrm{C}^{12} \mathrm{~S}^{32}$ & 3- 421 & $5,1,4 \leftarrow 4,1,3$ & Ground & & & 25333. & \\
\hline $\mathrm{C}^{12} \mathrm{H}_{3} \mathrm{Si}^{28} \mathrm{HDF}^{19}$ & 3- 252 & $2,1,1 \leftarrow 1,1,0$ & Ground & & & 25336.60 & .10 \\
\hline $\mathrm{N}^{14} \mathrm{O}_{2}^{16} \mathrm{Cl}^{37}$ & 4-1462 & $3,0,3 \leftarrow 2,0,2$ & Ground & $7 / 2$ & $7 / 2$ & 25338.08 & \\
\hline $4 d-\mathrm{C}_{6}^{12} \mathrm{H}_{5} \mathrm{~F}^{19}$ & $4-1283$ & $6,5,1 \leftarrow 5,5,0$ & Ground & & & 25338.6 & .1 \\
\hline $4 \mathrm{~d}-\mathrm{C}_{6}^{12} \mathrm{H}_{5} \mathrm{~F}^{19}$ & 4-1283 & $6,5,2 \leftarrow 5,5,1$ & Ground & & & 25338.6 & .1 \\
\hline $\mathrm{C}^{12} \mathrm{H}_{3} \mathrm{C}^{12} \mathrm{O}^{16} \mathrm{O}^{16} \mathrm{H}$ & 3. 491 & Not Reported & & & & 25339. & 3. \\
\hline $\mathrm{c}-\mathrm{HF}^{19} \mathrm{C}^{12}: \mathrm{C}^{13} \mathrm{HF}^{19}$ & 4- 692 & $1.1 .1 \leftarrow 0,0,0$ & Ground & & & 25339.02 & .05 \\
\hline $\mathrm{S}^{32} \mathrm{C}^{12} \mathrm{Te}^{123}$ & 4- 572 & $8 \leftarrow 7$ & Excited & & & 25341.714 & .010 \\
\hline $\mathrm{C}^{12} \mathrm{H}_{2}\left(\mathrm{C}^{12} \mathrm{~N}^{14}\right)_{2}$ & 4- 901 & Not Reported & Ground & & & 25347.8 & .1 \\
\hline $\mathrm{C}^{12} \mathrm{H}_{3} \mathrm{O}^{16} \mathrm{H}$ & 3- 211 & Not Reported & Ground & & & 25349 . & 5. \\
\hline $\mathrm{DC}^{12}: \mathrm{C}^{12} \mathrm{C}^{13} \mathrm{HO}^{16}$ & 4- 919 & $3,1,3 \leftarrow 2,1,2$ & Ground & & & 25350.41 & .02 \\
\hline $\mathrm{N}^{14} \mathrm{O}_{2}^{16} \mathrm{Cl}^{37}$ & 4-1462 & $3,0,3 \leftarrow 2,0,2$ & Ground & $3 / 2$ & $1 / 2$ & 25351.20 & \\
\hline $\mathrm{N}^{14} \mathrm{O}_{2}^{16} \mathrm{Cl}^{37}$ & 4- 1462 & $3,0,3 \leftarrow 2,0,2$ & Ground & $5 / 2$ & $3 / 2$ & 25351.64 & \\
\hline $\mathrm{H}_{2} \mathrm{C}^{12}: \mathrm{C}^{12} \mathrm{~F}_{2}^{19}$ & 4- 681 & Not Reported & & & & 25352.1 & .3 \\
\hline $\mathrm{S}^{32} \mathrm{C}^{12} \mathrm{Te}^{123}$ & 4- 572 & $8 \leftarrow 7$ & Excited & & & 25352.555 & .010 \\
\hline $\mathrm{As}^{75} \mathrm{Cl}_{2}^{35} \mathrm{Cl}^{37}$ & 4. 12 & Not Reported & Ground & & & 25354 . & 10. \\
\hline $\mathrm{C}^{12} \mathrm{H}_{3} \mathrm{C}^{12} \mathrm{O}^{16} \mathrm{~F}^{19}$ & 3- 391 & Not Reported & Ground & & & 25354.51 & .2 \\
\hline $\mathrm{a}-\mathrm{HC}^{12} \mathrm{O}^{16} \mathrm{O}^{16} \mathrm{C}^{12} \mathrm{H}_{2} \mathrm{D}$ & 3- 506 & $2,1,1 \leftarrow 1,1,0$ & Ground & & & 25354.60 & .2 \\
\hline $\mathrm{HC}^{12}{ }_{*}: \mathrm{C}^{12} \mathrm{HO}^{16} \mathrm{C}^{12} \mathrm{O}^{16} \mathrm{O}^{16}{ }_{*}$ & 4- 931 & $4,1,4 \leftarrow 3,1,3$ & Ground & & & 25355.29 & .10 \\
\hline $\mathrm{N}^{14} \mathrm{O}_{2}^{16} \mathrm{Cl}^{37}$ & 4-1462 & $3,0,3 \leftarrow 2,0,2$ & Ground & $9 / 2$ & $7 / 2$ & 25355.97 & \\
\hline $\mathrm{C}^{12} \mathrm{D}_{3} \mathrm{C}^{12} \mathrm{O}^{16} \mathrm{Cl}^{37}$ & 3- 364 & $11,4,7 \leftarrow 11,3,8$ & Ground & $25 / 2$ & $25 / 2$ & 25356.28 & \\
\hline $\mathrm{C}^{12} \mathrm{D}_{3} \mathrm{C}^{12} \mathrm{O}^{16} \mathrm{Cl}^{37}$ & 3- 364 & $11,4,7 \leftarrow 11,3,8$ & Ground & $19 / 2$ & $19 / 2$ & 25356.28 & \\
\hline $\mathrm{N}^{14} \mathrm{O}_{2}^{16} \mathrm{Cl}^{37}$ & $4-1462$ & $3,0,3 \leftarrow 2,0,2$ & Ground & $7 / 2$ & $5 / 2$ & 25356.38 & \\
\hline $\mathrm{C}^{12} \mathrm{D}_{3} \mathrm{C}^{12} \mathrm{O}^{16} \mathrm{Cl}^{37}$ & 3. 364 & $11,4,7 \leftarrow 11,3,8$ & Ground & $21 / 2$ & $21 / 2$ & 25357.04 & \\
\hline $\mathrm{C}^{12} \mathrm{D}_{3} \mathrm{C}^{12} \mathrm{O}^{16} \mathrm{Cl}^{37}$ & 3- 364 & $11,4,7 \leftarrow 11,3,8$ & Ground & $23 / 2$ & $23 / 2$ & 25357.04 & \\
\hline $\mathrm{C}_{6}^{12} \mathrm{H}_{5} \mathrm{Cl}^{35}$ & $4-1271$ & $9,8,2 \leftarrow 8,8,1$ & Ground & & & 25359. & 5.0 \\
\hline $\mathrm{C}_{6}^{12} \mathrm{H}_{5} \mathrm{Cl}^{35}$ & $4-1271$ & $9,8,1 \leftarrow 8,8,0$ & Ground & & & 25359. & 5.0 \\
\hline $\mathrm{C}^{12}{ }_{*} \mathrm{H}: \mathrm{C}^{12} \mathrm{HC}^{12} \mathrm{H}: \mathrm{C}^{12} \mathrm{HN}^{14}{ }_{*} \mathrm{D}$ & 4-1182 & $9,6,3 \leftarrow 9,6,4$ & Ground & & & 25360.5 & \\
\hline $\mathrm{C}^{12} \mathrm{H}_{3} \mathrm{C}^{12}: \mathrm{C}^{12} \mathrm{C}^{12} \mathrm{H}_{2} \mathrm{Cl}^{37}$ & 3. 902 & $9,3,6 \leftarrow 8,3,5$ & Ground & & & 25363.7 & .3 \\
\hline $\mathrm{C}^{12} \mathrm{H}_{3} \mathrm{C}^{12}: \mathrm{C}^{12} \mathrm{C}^{12} \mathrm{H}_{2} \mathrm{Cl}^{37}$ & 3- 902 & $9,4,6 \leftarrow 8,4,5$ & Ground & & & 25363.7 & .3 \\
\hline $\mathrm{C}^{12} \mathrm{H}_{3} \mathrm{C}^{12}: \mathrm{C}^{12} \mathrm{C}^{12} \mathrm{H}_{2} \mathrm{Cl}^{37}$ & 3- 902 & $9,4,5 \leftarrow 8,4,4$ & Ground & & & 25363.7 & .3 \\
\hline $\mathrm{C}^{12} \mathrm{H}_{3} \mathrm{C}^{12}: \mathrm{C}^{12} \mathrm{C}^{12} \mathrm{H}_{2} \mathrm{Cl}^{37}$ & 3- 902 & $9,3,7 \leftarrow 8,3,6$ & Ground & & & 25363.7 & .3 \\
\hline $\mathrm{C}^{12} \mathrm{H}_{2} \mathrm{Cl}^{35} \mathrm{Si}^{28} \mathrm{H}_{3}$ & 3- 231 & $9,1,8 \leftarrow 9,0,9$ & Ground & $15 / 2$ & $15 / 2$ & 25364.62 & .2 \\
\hline $\mathrm{N}^{14} \mathrm{O}_{2}^{16} \mathrm{Cl}^{37}$ & $4-1462$ & $3,0,3 \leftarrow 2,0,2$ & Ground & $5 / 2$ & $5 / 2$ & 25364.68 & \\
\hline $\mathrm{C}^{12} \mathrm{DHCl}^{35} \mathrm{Cl}^{37}$ & 4- 345 & $4,1,3 \leftarrow 4,0,4$ & Ground & & & 25365 . & 5. \\
\hline $\mathrm{C}^{12} \mathrm{H}_{2} \mathrm{Cl}^{35} \mathrm{Si}^{28} \mathrm{H}_{3}$ & 3- 231 & 9. $1,8 \leftarrow 9,0,9$ & Ground & $21 / 2$ & $21 / 2$ & 25365.55 & .2 \\
\hline $\mathrm{Cl}^{35} \mathrm{~F}_{3}^{19}$ & 4-1371 & $7,2,5 \leftarrow 7,1,6$ & Ground & $11 / 2$ & $11 / 2$ & 25365.84 & .15 \\
\hline $\mathrm{Cl}^{35} \mathrm{~F}_{3}^{19}$ & 4-1371 & $7,2,5 \leftarrow 7,1,6$ & Ground & $17 / 2$ & $17 / 2$ & 25368.11 & .15 \\
\hline $\mathrm{C}^{12} \mathrm{H}_{2} \mathrm{Cl}^{35} \mathrm{Si}^{28} \mathrm{H}_{3}$ & 3- 231 & $9,1,8 \leftarrow 9,0,9$ & Ground & & & 25368.30 & .2 \\
\hline $\mathrm{N}^{14} \mathrm{O}_{2}^{16} \mathrm{Cl}^{37}$ & 4-1462 & $3,0,3 \leftarrow 2,0,2$ & Ground & $3 / 2$ & $3 / 2$ & 25369.52 & \\
\hline $\mathrm{C}^{\prime \prime}{ }_{*} \mathrm{H}_{2}^{\prime \prime} \mathrm{N}^{1} \mathrm{H}^{\prime \prime} \mathrm{C}^{\prime \prime}{ }_{*} \mathrm{H}_{2}^{\prime \prime}$ & 4. 863 & Not Reported & & & & 25370 . & 10. \\
\hline $\mathrm{F}_{2}^{19} \mathrm{~N}^{14} \mathrm{~N}^{14} \mathrm{~F}_{2}^{19}$ & $3-\quad 21$ & $3,2,1 \leftarrow 2,1,1$ & Ground & & & 25370.14 & .05 \\
\hline $\mathrm{C}^{12} \mathrm{H}_{2} \mathrm{Cl}^{35} \mathrm{Si}^{2 \times} \mathrm{H}_{3}$ & 3- 231 & $9,1,8 \leftarrow 9,0,9$ & Ground & $17 / 2$ & $17 / 2$ & 25370.91 & .2 \\
\hline $\mathrm{C}^{12} \mathrm{H}_{2} \mathrm{Cl}^{35} \mathrm{Si}^{28} \mathrm{H}_{3}$ & 3- 231 & $9,1,8 \leftarrow 9,0,9$ & Ground & $19 / 2$ & $19 / 2$ & 25371.91 & .2 \\
\hline $\mathrm{C}^{12} \mathrm{H}_{3} \mathrm{~N}^{14} \mathrm{O}_{2}^{16}$ & 3- 171 & Not Reported & Ground & & & 25371.95 & \\
\hline
\end{tabular}




\begin{tabular}{|c|c|c|c|c|c|c|c|c|c|}
\hline \multirow{2}{*}{ Isotopic Species } & \multirow{2}{*}{$\begin{array}{l}\text { Vol.-Id. } \\
\text { Nos. }\end{array}$} & \multirow{2}{*}{$\begin{array}{c}\text { Rotational } \\
\text { Quantum Nos. }\end{array}$} & \multirow{2}{*}{ Vib. State } & \multicolumn{4}{|c|}{ Hyperfine } & \multirow{2}{*}{$\begin{array}{c}\text { Frequency } \\
\text { Mllz }\end{array}$} & \multirow{2}{*}{$\begin{aligned} & \text { Acc. } \\
\pm & \mathrm{MH} /\end{aligned}$} \\
\hline & & & & $F_{1}^{\prime}$ & $\mathrm{F}^{\prime}$ & $F_{1}$ & $\mathbf{F}$ & & \\
\hline $\mathrm{S}^{34}{ }_{*} \mathrm{HC}^{12}: \mathrm{C}^{12} \mathrm{HC}^{12} \mathrm{H}: \mathrm{C}^{12}{ }_{*} \mathrm{H}$ & $4-1166$ & $3,2,2 \leftarrow 2,2,1$ & Ground & & & & & 25373.4 & 3. \\
\hline $\mathrm{C}_{6}^{12} \mathrm{H}_{5} \mathrm{Cl}^{35}$ & 4-1271 & $9,7,2 \leftarrow 8,7,1$ & Ground & & & & & 25375. & 5.0 \\
\hline $\mathrm{C}_{6}^{12} \mathrm{H}_{5} \mathrm{Cl}^{35}$ & 4-1271 & $9,7,3 \leftarrow 8,7,2$ & Ground & & & & & 25375. & 5.0 \\
\hline $\mathrm{C}^{12} \mathrm{H}_{3} \mathrm{C}^{12} \mathrm{H}: \mathrm{C}^{12} \mathrm{O}^{16}$ & 3- 681 & $3,1,3 \leftarrow 2,1,2$ & Ground & & & & & 25375.6 & .1 \\
\hline $\mathrm{Cl}^{35} \mathrm{~F}_{3}^{19}$ & $4-1371$ & $7,2,5 \leftarrow 7,1,6$ & Ground & & $13 / 2$ & & $13 / 2$ & 25376.85 & .15 \\
\hline$R b^{85} I^{127}$ & $1-$ & $13 \leftarrow 12$ & Excited & & & & & 25377.33 & 0.10 \\
\hline $\mathrm{T}^{205} \mathrm{Br}^{81}$ & $1-$ & $10 \leftarrow 9$ & Ground & & & & & 25377.53 & 0.05 \\
\hline $\mathrm{C}^{12}{ }_{*} \mathrm{H}: \mathrm{C}^{12} \mathrm{HO}^{18} \mathrm{C}^{12} \mathrm{H}: \mathrm{C}^{12}{ }_{*} \mathrm{H}$ & 4-1152 & $7,6,2 \leftarrow 7,4,3$ & Ground & & & & & 25379.1 & .1 \\
\hline $\mathrm{Cl}^{35} \mathrm{~F}_{3}^{19}$ & 4-1371 & $7,2,5 \leftarrow 7,1,6$ & Ground & & $15 / 2$ & & $15 / 2$ & 25379.38 & .15 \\
\hline $\mathrm{C}^{12} \mathrm{H}_{3} \mathrm{C}^{12} \mathrm{O}^{16} \mathrm{Br}^{81}$ & 3. 352 & $11,2,9 \leftarrow 11,1,10$ & Ground & & $19 / 2$ & & $19 / 2$ & 25379.89 & .15 \\
\hline $\mathrm{K}^{39} \mathrm{I}^{127}$ & $1-$ & $7 \leftarrow 6$ & Excited & & & & & 25380.71 & 0.15 \\
\hline $\mathrm{C}^{12} \mathrm{H}_{3} \mathrm{C}^{12} \mathrm{O}^{16} \mathrm{Br}^{81}$ & 3- 352 & $11,2,9 \leftarrow 11,1,10$ & Ground & & $25 / 2$ & & $25 / 2$ & 25380.83 & .15 \\
\hline $\mathrm{As}^{75} \mathrm{Cl}_{2}^{35} \mathrm{Cl}^{37}$ & 4- 12 & Not Reported & Ground & & & & & 25381. & 10. \\
\hline $\mathrm{C}^{12} \mathrm{H}_{3} \mathrm{C}^{12} \mathrm{O}^{16} \mathrm{~F}^{19}$ & 3- 391 & Not Reported & Ground & & & & & 25382.23 & .2 \\
\hline $\mathrm{C}^{12} \mathrm{H}_{3} \mathrm{C}^{12} \mathrm{O}^{16} \mathrm{Br}^{81}$ & 3- 352 & $11,2,9 \leftarrow 11,1,10$ & Ground & & $19 / 2$ & & $19 / 2$ & 25383.41 & .15 \\
\hline $\mathrm{C}^{12} \mathrm{H}_{3} \mathrm{Si}^{28} \mathrm{HF}_{2}^{19} \cdot \mathrm{A}$ & 3- 191 & Not Reported & Ground & & & & & 25383.5 & \\
\hline $\mathrm{C}^{12} \mathrm{H}_{3} \mathrm{C}^{12} \mathrm{O}^{16} \mathrm{Br}^{81}$ & 3- 352 & $11,2,9 \leftarrow 11,1,10$ & Ground & & $25 / 2$ & & $25 / 2$ & 25384.32 & .15 \\
\hline $\mathrm{C}^{12} \mathrm{H}_{3} \mathrm{O}^{16} \mathrm{H}$ & 3- 211 & Not Reported & Ground & & & & & 25385. & 5. \\
\hline $\mathrm{C}^{12} \mathrm{H}_{3} \mathrm{C}^{12} \mathrm{O}^{16} \mathrm{Br}^{81}$ & 3- 352 & $11,2,9 \leftarrow 11,1,10$ & Ground & & $21 / 2$ & & $21 / 2$ & 25386.35 & .15 \\
\hline $\mathrm{C}^{12} \mathrm{H}_{3} \mathrm{C}^{12} \mathrm{H}: \mathrm{C}^{12} \mathrm{O}^{16}$ & 3- 681 & $3,1,3 \leftarrow 2,1,2$ & Ground & & & & & 25386.4 & .1 \\
\hline $\mathrm{Cs}^{133} \mathrm{I}^{127}$ & $1-$ & $18 \leftarrow 17$ & Excited & & & & & 25387.04 & 0.10 \\
\hline $\mathrm{C}^{12} \mathrm{H}_{3} \mathrm{C}^{12} \mathrm{O}^{16} \mathrm{Br}^{81}$ & 3- 352 & $11,2,9 \leftarrow 11,1,10$ & Ground & & $23 / 2$ & & $23 / 2$ & 25387.14 & .15 \\
\hline $\mathrm{C}^{12} \mathrm{H}_{3} \mathrm{C}^{12} \mathrm{O}^{16} \mathrm{Br}^{81}$ & 3. 352 & $11,2,9 \leftarrow 11,1,10$ & Ground & & $21 / 2$ & & $21 / 2$ & 25389.77 & .15 \\
\hline $\mathrm{C}^{\mathrm{b}} \mathrm{H}_{3}^{\mathrm{b}} \mathrm{N}^{\mathrm{b}} \mathrm{C}^{\mathrm{b}} \mathrm{S}^{\mathrm{b}}$ & 3- 426 & $5, \quad \leftarrow 4, \quad$ & & & & & & 25390. & \\
\hline $\mathrm{Cs}^{133} \mathrm{Cl}^{35}$ & $1-$ & $6 \leftarrow 5$ & Excited & & & & & 25390.36 & .40 \\
\hline $\mathrm{C}^{13} \mathrm{H}_{3} \mathrm{C}^{12}: \mathrm{C}^{12} \mathrm{Cl}^{37}$ & 4- 978 & $6,0 \leftarrow 5,0$ & Ground & & $15 / 2$ & & $13 / 2$ & 25390.51 & .04 \\
\hline $\mathrm{C}^{13} \mathrm{H}_{3} \mathrm{C}^{12}: \mathrm{C}^{12} \mathrm{Cl}^{37}$ & 4- 978 & $6,0 \leftarrow 5,0$ & Ground & & $13 / 2$ & & $11 / 2$ & 25390.51 & .04 \\
\hline $\mathrm{C}^{12} \mathrm{H}_{3} \mathrm{C}^{12} \mathrm{O}^{16} \mathrm{Br}^{81}$ & 3- 352 & $11,2,9 \leftarrow 11,1,10$ & Ground & & $23 / 2$ & & $23 / 2$ & 25390.60 & .15 \\
\hline $\mathrm{C}^{12} \mathrm{H}_{3} \mathrm{C}^{12}: \mathrm{C}^{12} \mathrm{C}^{12} \mathrm{H}_{2} \mathrm{Cl}^{35}$ & 3- 901 & $9,1,9 \leftarrow 8,1,8$ & Ground & & & & & 25390.67 & .05 \\
\hline $\mathrm{C}^{12} \mathrm{O}^{16} \mathrm{Cl}_{2}^{35}$ & 4- 181 & $4,3,2 \leftarrow 4,2,3$ & Ground & $5 / 2$ & 4 & $5 / 2$ & 4 & 25391.24 & .1 \\
\hline $\mathrm{S}^{32} \mathrm{O}_{2}^{16}$ & 4-1831 & $8,1,7 \leftarrow 7,2,6$ & Ground & & & & & 25392.797 & .014 \\
\hline $\mathrm{C}^{12} \mathrm{H}_{3} \mathrm{C}^{12} \mathrm{O}^{18} \mathrm{C}^{12} \mathrm{~N}^{14}$ & 3. 674 & $4,1,4 \leftarrow 3,1,3$ & Ground & & & & & 25392.84 & .2 \\
\hline $\mathrm{S}^{32} \mathrm{C}^{12} \mathrm{Te}^{122}$ & 4- 571 & $8 \leftarrow 7$ & Excited & & & & & 25392.929 & .010 \\
\hline $\mathrm{As}^{75} \mathrm{Cl}_{2}^{35} \mathrm{Cl}^{37}$ & 4. 12 & Not Reported & Ground & & & & & 25393. & 10. \\
\hline $\mathrm{C}^{12}{ }_{*} \mathrm{H}_{2} \mathrm{~N}^{14} \mathrm{DC}^{12}{ }_{*} \mathrm{H}_{2}$ & 4- 862 & $8,8,1 \leftarrow 8,6,2$ & Ground & & & & & 25393.3 & .5 \\
\hline $\mathrm{C}^{12} \mathrm{O}^{16} \mathrm{Cl}_{2}^{35}$ & 4- 181 & $4,3,2 \leftarrow 4,2,3$ & Ground & $11 / 2$ & 71 & $11 / 2$ & 7 & 25393.35 & .1 \\
\hline $\mathrm{I}^{127} \mathrm{C}^{12} \mathrm{~N}^{14}$ & 4- 511 & $4 \leftarrow 3$ & Ground & $11 / 2$ & $9 / 2$ & $11 / 2$ & $9 / 2$ & 25393.517 & \\
\hline${ }^{127} C^{12} N^{14}$ & 4. 511 & $4 \leftarrow 3$ & Ground & $11 / 2$ & $13 / 2$ & $11 / 21$ & $13 / 2$ & 25393.517 & \\
\hline$I^{127} \mathrm{C}^{12} \mathrm{~N}^{14}$ & 4- 511 & $4 \leftarrow 3$ & Ground & $11 / 2$ & $11 / 2$ & $11 / 21$ & $11 / 2$ & 25393.776 & \\
\hline $\mathrm{C}^{12} \mathrm{H}_{3} \mathrm{~N}^{14} \mathrm{O}_{2}^{16}$ & 3- 171 & Not Reported & Ground & & & & & 25394.28 & \\
\hline $\mathrm{C}^{13}{ }_{*} \mathrm{H}: \mathrm{C}^{12} \mathrm{HO}^{16} \mathrm{C}^{12} \mathrm{H}: \mathrm{C}^{12}{ }_{*} \mathrm{H}$ & 4-1157 & $9,8,2 \leftarrow 9,6,3$ & Ground & & & & & 25394.7 & .1 \\
\hline $\mathrm{C}_{6}^{12} \mathrm{H}_{5} \mathrm{Cl}^{35}$ & 4-1271 & $9,6,4 \leftarrow 8.6 .3$ & Ground & & & & & 25395 . & 5.0 \\
\hline $\mathrm{C}_{6}^{12} \mathrm{H}_{5} \mathrm{Cl}^{35}$ & 4-1271 & $9,6,3 \leftarrow 8,6,2$ & Ground & & & & & 25395. & 5.0 \\
\hline $\mathrm{Rb}^{85} \mathrm{Br}^{79}$ & $1-$ & $9 \leftarrow 8$ & Excited & & & & & 25396.14 & 0.10 \\
\hline $\mathrm{C}^{12} \mathrm{O}^{16} \mathrm{Cl}_{2}^{35}$ & 4- 181 & $4,3,2 \leftarrow 4,2,3$ & Ground & $5 / 2$ & 3 & $5 / 2$ & 3 & 25396.48 & .1 \\
\hline
\end{tabular}




\begin{tabular}{|c|c|c|c|c|c|c|c|c|c|}
\hline Isotopic Species & $\begin{array}{l}\text { Vol.-Id. } \\
\text { Nos. }\end{array}$ & $\begin{array}{c}\text { Rotational } \\
\text { Quantum Nos. }\end{array}$ & Vib. State & $\mathbf{F}_{1}^{\prime}$ & $\begin{array}{l}\text { Hype } \\
\mathbf{F}^{\prime}\end{array}$ & $\underset{F_{1}}{\text { erfine }}$ & $\mathrm{F}$ & $\begin{array}{c}\text { Frequency } \\
\mathrm{MHz}\end{array}$ & $\begin{aligned} & \text { Ace. } \\
\pm & \mathrm{MHz}\end{aligned}$ \\
\hline $\mathrm{Si}^{29} \mathrm{H}_{3} \mathrm{Br}^{79}$ & 4. 113 & $3, \leftarrow 2$, & Ground & & & & & 25397.80 & .08 \\
\hline $\mathrm{C}^{12} \mathrm{O}^{16} \mathrm{Cl}_{2}^{35}$ & 4- 181 & $4,3,2 \leftarrow 4,2,3$ & Ground & $11 / 2$ & 5 & $11 / 2$ & 5 & 25397.98 & .1 \\
\hline $\mathrm{DC}^{12}: \mathrm{C}^{13} \mathrm{C}^{12} \mathrm{HO}^{16}$ & 4- 918 & $3,1,3 \leftarrow 2,1,2$ & Ground & & & & & 25400.78 & .02 \\
\hline $\mathrm{C}^{12} \mathrm{H}_{3} \mathrm{~N}^{14} \mathrm{H}_{2}$ & 3- 261 & Not Reported & Ground & & & & & 25401.99 & .1 \\
\hline $\mathrm{HC}^{13}: \mathrm{C}^{12} \mathrm{C}^{12} \mathrm{DO}^{16}$ & 4. 922 & Not Reported & & & & & & 25402 . & 5. \\
\hline $\mathrm{C}^{12} \mathrm{O}^{16} \mathrm{Cl}_{2}^{35}$ & 4- 181 & $4,3,2 \leftarrow 4,2,3$ & Ground & $9 / 2$ & 6 & $9 / 2$ & 6 & 25402.67 & .1 \\
\hline $\mathrm{Cl}_{2}^{\mathrm{b}} \mathrm{O}^{16}$ & $4-1484$ & $24,3,21 \leftarrow 25,2,24$ & Ground & & & & & 25402.94 & \\
\hline $\mathrm{C}_{6}^{12} \mathrm{H}_{5} \mathrm{~F}^{19}$ & 4-1281 & Not Reported & & & & & & 25403. & 5. \\
\hline $\mathrm{Cl}^{35} \mathrm{O}_{2}^{16}$ & 4-1381 & $4,2,3 \leftarrow 5,1,4$ & Ground & & & & & 25403.65 & .05 \\
\hline $\mathrm{C}^{12} \mathrm{H}_{3} \mathrm{C}^{12} \mathrm{O}^{16} \mathrm{~F}^{19}$ & 3- 391 & Not Reported & Ground & & & & & 25403.68 & .2 \\
\hline $\mathrm{S}^{32} \mathrm{C}^{12} \mathrm{Te}^{122}$ & 4- 571 & $8 \leftarrow 7$ & Excited & & & & & 25403.788 & .010 \\
\hline $\mathrm{C}^{12} \mathrm{H}_{3} \mathrm{~N}^{14} \mathrm{O}_{2}^{16}$ & 3. 171 & Not Reported & Ground & & & & & 25403.82 & \\
\hline $\mathrm{C}^{12} \mathrm{O}^{16} \mathrm{Cl}_{2}^{35}$ & 4. 181 & $4,3,2 \leftarrow 4,2,3$ & Ground & $7 / 2$ & 4 & $7 / 2$ & 4 & 25403.90 & .1 \\
\hline $\mathrm{C}^{12} \mathrm{O}^{16} \mathrm{Cl}_{2}^{35}$ & 4. 181 & $4,3,2 \leftarrow 4,2,3$ & Ground & $9 / 2$ & 3 & $9 / 2$ & 3 & 25403.90 & .1 \\
\hline $\mathrm{C}^{12} \mathrm{H}_{2}: \mathrm{C}^{12} \mathrm{HC}^{12} \mathrm{~F}^{19}: \mathrm{C}^{12} \mathrm{H}_{2}$ & 3- 911 & $8,2,6 \leftarrow 8,1,7$ & Ground & & & & & 25406.25 & .03 \\
\hline $\mathrm{C}^{12} \mathrm{O}^{16} \mathrm{Cl}_{2}^{35}$ & 4- 181 & $4,3,2 \leftarrow 4,2,3$ & Ground & $9 / 2$ & 5 & $9 / 2$ & 5 & 25407.53 & .1 \\
\hline $\mathrm{C}^{12} \mathrm{H}_{3} \mathrm{C}^{12} \mathrm{O}^{16} \mathrm{~F}^{19}$ & 3- 391 & Not Reported & Ground & & & & & 25408.60 & .2 \\
\hline $\mathrm{C}^{\mathrm{b}} \mathrm{H}_{3}^{\mathrm{b}} \mathrm{N}^{\mathrm{b}} \mathrm{C}^{\mathrm{b}} \mathrm{S}^{\mathrm{b}}$ & 3. 426 & $5, \quad, \quad \leftarrow 4, \quad$, & & & & & & 25409. & \\
\hline $\mathrm{As}^{75} \mathrm{Cl}_{2}^{35} \mathrm{Cl}^{37}$ & 4- $\quad 12$ & Not Reported & Ground & & & & & 25411. & 10. \\
\hline $\mathrm{C}^{12} \mathrm{H}_{3} \mathrm{C}^{12} \mathrm{O}^{18} \mathrm{Cl}^{35}$ & 3- 372 & $9,3,6 \leftarrow 9,2,7$ & Ground & & $19 / 2$ & & $19 / 2$ & 25411.05 & .2 \\
\hline $\mathrm{C}^{12} \mathrm{H}_{3} \mathrm{~N}^{14} \mathrm{O}_{2}^{16}$ & 3- 171 & Not Reported & Ground & & & & & 25412. & 5. \\
\hline $\mathrm{C}^{12} \mathrm{H}_{3} \mathrm{C}^{12} \mathrm{O}^{16} \mathrm{~F}^{19}$ & 3. 391 & Not Reported & Ground & & & & & 25413.40 & .2 \\
\hline $\mathrm{DC}^{12} \mathrm{O}^{16} \mathrm{O}^{16} \mathrm{C}^{12} \mathrm{H}_{3} \cdot \mathrm{E}$ & 3- 504 & $2,1,1 \leftarrow 1,1,0$ & Ground & & & & & 25413.66 & .2 \\
\hline $\mathrm{HC}^{12} \mathrm{O}^{16} \mathrm{O}^{16} \mathrm{C}^{13} \mathrm{H}_{3}-\mathrm{E}$ & 3- 512 & $2,1,1 \leftarrow 1,1,0$ & Ground & & & & & 25414.42 & .2 \\
\hline $\mathrm{C}^{12} \mathrm{H}_{3} \mathrm{C}^{12} \mathrm{O}^{18} \mathrm{Cl}^{35}$ & 3- 372 & $9,3,6 \leftarrow 9,2,7$ & Ground & & $19 / 2$ & & $19 / 2$ & 25414.85 & .2 \\
\hline $\mathrm{C}^{12} \mathrm{H}_{3} \mathrm{C}^{12} \mathrm{O}^{18} \mathrm{Cl}^{35}$ & 3- 372 & $9,3,6 \leftarrow 9,2,7$ & Ground & & $15 / 2$ & & $15 / 2$ & 25414.85 & .2 \\
\hline $\mathrm{C}^{12} \mathrm{H}_{3} \mathrm{C}^{12} \mathrm{O}^{18} \mathrm{Cl}^{35}$ & 3- 372 & $9,3,6 \leftarrow 9,2,7$ & Ground & & $17 / 2$ & & $17 / 2$ & 25414.85 & .2 \\
\hline $\mathrm{C}^{12} \mathrm{H}_{3} \mathrm{C}^{12} \mathrm{O}^{18} \mathrm{Cl}^{35}$ & 3- 372 & $9,3,6 \leftarrow 9,2,7$ & Ground & & $21 / 2$ & & $21 / 2$ & 25414.85 & .2 \\
\hline $4 \mathrm{~d}-\mathrm{C}_{6}^{12} \mathrm{H}_{5} \mathrm{~F}^{19}$ & $4 \cdot 1283$ & $6,3,4 \leftarrow 5,3,3$ & Ground & & & & & 25416.4 & .1 \\
\hline $\mathrm{DC}^{12} \mathrm{O}^{16} \mathrm{O}^{16} \mathrm{C}^{12} \mathrm{H}_{3}-\mathrm{A}$ & 3- 503 & $2,1,1 \leftarrow 1,1,0$ & Ground & & & & & 25416.57 & .2 \\
\hline $\mathrm{HC}^{12} \mathrm{O}^{16} \mathrm{O}^{16} \mathrm{C}^{13} \mathrm{H}_{3}-\mathrm{A}$ & 3. 511 & $2,1,1 \leftarrow 1,1,0$ & Ground & & & & & 25417.99 & .2 \\
\hline $\mathrm{D}_{2} \mathrm{~N}^{15} \mathrm{C}^{12} \mathrm{HO}^{16}$ & 3. 161 & $6,1,5 \leftarrow 5,2,4$ & Ground & & & & & 25418.95 & \\
\hline $\mathrm{C}^{12} \mathrm{H}_{3} \mathrm{~N}^{14} \mathrm{O}_{2}^{16}$ & 3- 171 & Not Reported & Ground & & & & & 25420 . & \\
\hline $\mathrm{C}^{12} \mathrm{D}_{3} \mathrm{C}^{12} \mathrm{O}^{16} \mathrm{O}^{16} \mathrm{H}$ & 3- 492 & $9,5,4 \leftarrow 9,4,5$ & Ground & & & & & 25422.18 & \\
\hline $\mathrm{Si}^{28} \mathrm{D}_{3} \mathrm{~N}^{14} \mathrm{C}^{12} \mathrm{~S}^{32}$ & 4- 492 & $9, \leftarrow 8$ & Ground & & & & & 25423.26 & \\
\hline $\mathrm{Cl}^{35} \mathrm{O}_{2}^{16}$ & 4-1381 & $4,2,3 \leftarrow 5,1,4$ & Ground & & & & & 25424.78 & .05 \\
\hline $\mathrm{C}^{12} \mathrm{D}_{3} \mathrm{C}^{12} \mathrm{O}^{16} \mathrm{~F}^{19}$ & 3- 392 & $5,2,3 \leftarrow 5,2,4$ & Ground & & & & & 25426.89 & .2 \\
\hline $\mathrm{C}_{6}^{12} \mathrm{H}_{5} \mathrm{Cl}^{35}$ & 4-1271 & $9,5,5 \leftarrow 8,5,4$ & Ground & & & & & 25427. & 5.0 \\
\hline $\mathrm{C}_{6}^{12} \mathrm{H}_{5} \mathrm{Cl}^{35}$ & 4-1271 & $9,5,4 \leftarrow 8,5,3$ & Ground & & & & & 25427. & 5.0 \\
\hline $\mathrm{C}_{6}^{12} \mathrm{H}_{5} \mathrm{~F}^{19}$ & 4-1281 & $6,2,5 \leftarrow 5,2,4$ & Ground & & & & & 25427.3 & .1 \\
\hline
\end{tabular}




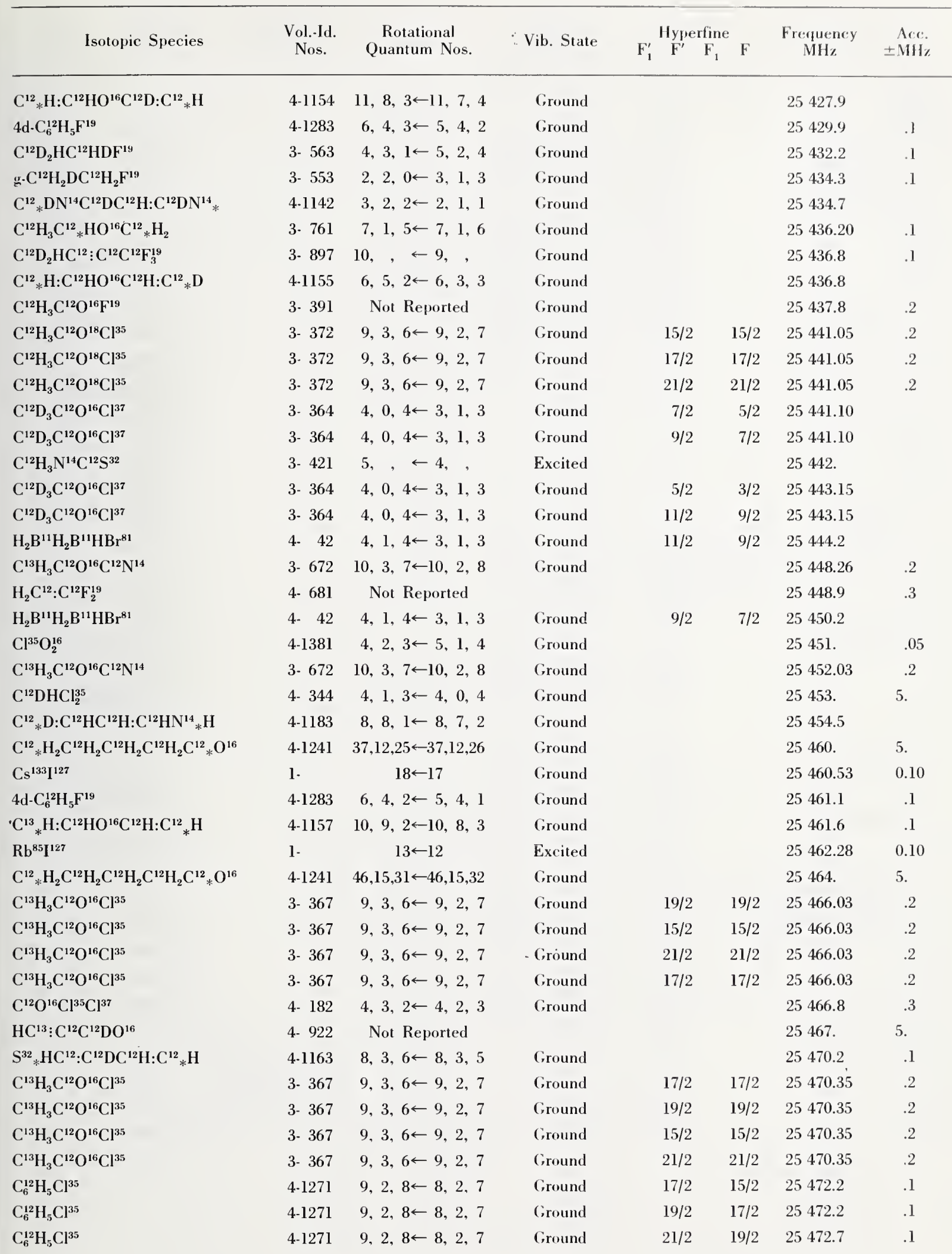




\begin{tabular}{|c|c|c|c|c|c|c|c|}
\hline \multirow{2}{*}{ Isotopic Species } & \multirow{2}{*}{$\begin{array}{l}\text { Vol.-Id. } \\
\text { Nos. }\end{array}$} & \multirow{2}{*}{$\begin{array}{c}\text { Rotational } \\
\text { Quantum Nos. }\end{array}$} & \multirow{2}{*}{ Vib. State } & \multicolumn{2}{|l|}{ Hyperfine } & \multirow{2}{*}{$\begin{array}{l}\text { Frequency } \\
\qquad \mathrm{MHz}\end{array}$} & \multirow{2}{*}{$\begin{aligned} & \text { Acc. } \\
\pm & \mathrm{MH} z\end{aligned}$} \\
\hline & & & & $\begin{array}{lll}F_{1}^{\prime} & F^{\prime} & F_{1}\end{array}$ & $\mathbf{F}$ & & \\
\hline $\mathrm{C}_{6}^{12} \mathrm{H}_{5} \mathrm{Cl}^{35}$ & $4-1271$ & $9,2,8 \leftarrow 8,2,7$ & Ground & $15 / 2$ & $13 / 2$ & 25472.7 & .1 \\
\hline $\mathrm{Na}^{23} \mathrm{Cl}^{35}$ & $1-$ & $2 \leftarrow 1$ & Excited & & & 25473.9 & 0.75 \\
\hline $\mathrm{HC}^{13}: \mathrm{C}^{12} \mathrm{C}^{12} \mathrm{DO}^{16}$ & 4- 922 & Not Reported & & & & 25475 . & 5. \\
\hline $\mathrm{C}^{12} \mathrm{H}_{3} \mathrm{C}^{12}{ }_{*} \mathrm{HO}^{16} \mathrm{C}^{12}{ }_{*} \mathrm{H}_{2}$ & 3- 761 & $9,7, \quad \leftarrow 10,6$ & Ground & & & 25479.05 & .1 \\
\hline $\mathrm{C}^{12} \mathrm{H}_{3} \mathrm{C}^{12}{ }_{*} \mathrm{HO}^{16} \mathrm{C}^{12}{ }_{*} \mathrm{H}_{2}$ & 3-.761 & $9,7, \leftarrow 10,6$ & Ground & & & 25480.04 & .1 \\
\hline $\mathrm{C}_{6}^{12} \mathrm{H}_{5} \mathrm{Cl}^{35}$ & 4-1271 & $9,4,6 \leftarrow 8,4,5$ & Ground & & & 25483.6 & \\
\hline $\mathrm{C}_{6}^{12} \mathrm{H}_{5} \mathrm{Cl}^{35}$ & $4-1271$ & $9,3,7 \leftarrow 8,3,6$ & Ground & & & 25483.6 & \\
\hline $\mathrm{C}_{6}^{12} \mathrm{H}_{5} \mathrm{Cl}^{35}$ & 4-1271 & $9,4,6 \leftarrow 8,4,5$ & Ground & & & 25485.9 & \\
\hline $\mathrm{HC}^{13}: \mathrm{C}^{12} \mathrm{C}^{12} \mathrm{DO}^{16}$ & 4. 922 & Not Reported & & & & 25487 . & 5. \\
\hline $\mathrm{C}_{6}^{12} \mathrm{H}_{5} \mathrm{O}^{16} \mathrm{H}$ & 3-1051 & $9,4,6 \leftarrow 9,3,7$ & Ground & & & 25489.4 & \\
\hline $\mathrm{C}^{12} \mathrm{H}_{2}: \mathrm{C}^{12} \mathrm{HC}^{12} \mathrm{~F}^{19}: \mathrm{C}^{12} \mathrm{H}_{2}$ & 3- 911 & $6,1,5 \leftarrow 6,0,6$ & Ground & & & 25492.18 & .03 \\
\hline $\mathrm{K}^{39} \mathrm{I}^{127}$ & 1. & $7 \leftarrow 6$ & Ground & & & 25492.81 & 0.15 \\
\hline $\mathrm{C}^{12} \mathrm{H}_{3} \mathrm{Si}^{28} \mathrm{H}_{2} \mathrm{~F}^{19}$ & 3. 241 & Not Reported & & & & 25492.96 & .1 \\
\hline $\mathrm{Na}^{23} \mathrm{Cl}^{37}$ & 1 - & $2 \leftarrow 1$ & Ground & & & 25493.9 & 0.75 \\
\hline $\mathrm{C}^{12} \mathrm{H}_{2} \mathrm{Cl}^{37} \mathrm{~F}^{19}$ & 4. 332 & $15,2,14 \leftarrow 14,3,11$ & Ground & & & 25494.60 & .1 \\
\hline $\mathrm{Rb}^{85} \mathrm{Br}^{79}$ & 1 - & $9 \leftarrow 8$ & Excited & & & 25495.98 & 0.10 \\
\hline $\mathrm{DC}^{12}: \mathrm{C}^{12} \mathrm{C}^{12} \mathrm{HO}^{16}$ & 4. 916 & $3,1,3 \leftarrow 2,1,2$ & Ground & & & 25496.13 & .02 \\
\hline $\mathrm{H}_{2} \mathrm{C}^{12}: \mathrm{C}^{12} \mathrm{Cl}^{35} \mathrm{Cl}^{37}$ & 4. 662 & $9,2,7 \leftarrow 9,1,8$ & Ground & & & 25497.8 & 1. \\
\hline $\mathrm{C}_{6}^{12} \mathrm{H}_{5} \mathrm{Cl}^{35}$ & $4-1271$ & $9,4,5 \leftarrow 8,4,4$ & Ground & & & 25502.0 & \\
\hline $\mathrm{C}_{6}^{12} \mathrm{H}_{5} \mathrm{Cl}^{35}$ & 4-1271 & $9,4,5 \leftarrow \overline{8}, 4,4$ & Ground & & & 25504.2 & \\
\hline $\mathrm{Cs}^{133} \mathrm{Br}^{81}$ & 1 . & $12 \leftarrow 11$ & Ground & & & 25504.69 & 0.10 \\
\hline $\mathrm{C}^{12} \mathrm{H}_{3} \mathrm{C}^{12} \mathrm{O}^{16} \mathrm{O}^{16} \mathrm{H}$ & $3 \cdot 491$ & Not Reported & & & & 25506. & 3. \\
\hline $\mathrm{C}^{12} \mathrm{H}_{3} \mathrm{~N}^{14} \mathrm{H}_{2}$ & 3- 261 & Not Reported & Ground & & & 25507.61 & .1 \\
\hline $\mathrm{O}_{3}^{16}$ & 4-1841 & $38,6,32 \leftarrow 39,5,35$ & Ground & & & 25511. & \\
\hline $\mathrm{Cs}^{133} \mathrm{Cl}^{35}$ & $1-$ & $6 \leftarrow 5$ & Excited & & & 25511.25 & .20 \\
\hline $\mathrm{H}_{2} \mathrm{C}^{12}: \mathrm{C}^{12} \mathrm{~F}_{2}^{19}$ & 4- 681 & Not Reported & & & & 25516.3 & .3 \\
\hline $\mathrm{C}^{12} \mathrm{H}_{2} \mathrm{Cl}^{35} \mathrm{~F}^{19}$ & 4- 331 & $7,1,6 \leftarrow 6,2,5$ & Ground & & & 25518.46 & .1 \\
\hline $\mathrm{Cl}^{35} \mathrm{O}_{2}^{16}$ & $4-1381$ & $4,2,3 \leftarrow 5,1,4$ & Ground & & & 25518.7 & \\
\hline $\mathrm{s} \cdot \mathrm{C}^{12} \mathrm{H}_{2} \mathrm{DC}^{12} \mathrm{O}^{16} \mathrm{~F}^{19}$ & 3- 397 & $10,6,4 \leftarrow 10,6,5$ & Ground & & & 25519.13 & .2 \\
\hline $\mathrm{O}^{16} \mathrm{~F}_{2}^{19}$ & $4 \cdot 1611$ & $12,2,10 \leftarrow 11,3,9$ & Ground & & & 25527.21 & .10 \\
\hline$\left(\mathrm{C}^{12} \mathrm{D}_{3}\right)_{3} \mathrm{C}^{12} \mathrm{Cl}^{35}$ & 3- 976 & $5, \leftarrow, 4$ & Ground & & & 25528.0 & 3. \\
\hline $\mathrm{S}^{32}{ }_{*} \mathrm{DC}^{12}: \mathrm{C}^{12} \mathrm{HC}^{12} \mathrm{H}: \mathrm{C}^{12}{ }_{*} \mathrm{H}$ & $4 \cdot 1162$ & $6,2,5 \leftarrow 6,2,4$ & Ground & & & 25528.1 & .1 \\
\hline $\mathrm{S}^{32}{ }_{*} \mathrm{C}^{12} \mathrm{H}: \mathrm{C}^{13} \mathrm{HC}^{12} \mathrm{H}: \mathrm{C}^{12}{ }_{*} \mathrm{H}$ & $4-1168$ & $3,2,2 \leftarrow 2,2,1$ & Ground & & & 25529.2 & 3. \\
\hline $\mathrm{C}^{12} \mathrm{H}_{2} \mathrm{Cl}_{2}^{35}$ & 4- 341 & $8,0,8 \leftarrow 7,1,7$ & Ground & & & 25533. & 5. \\
\hline $\mathrm{S}^{34} \mathrm{~F}_{5}^{19} \mathrm{Cl}^{35}$ & $4-1423$ & $7, \leftarrow 6$, & Ground & & & 25533.97 & .5 \\
\hline $\mathrm{C}^{12} \mathrm{H}_{3} \mathrm{O}^{16} \mathrm{H}$ & 3. 211 & $9,2, \leftarrow 9,1$ & Ground & & & 25541.43 & .1 \\
\hline $\mathrm{C}^{12}{ }_{*} \mathrm{H}: \mathrm{C}^{12} \mathrm{HO}^{16} \mathrm{C}^{12} \mathrm{H}: \mathrm{C}^{12}{ }_{*} \mathrm{H}$ & 4-1151 & $12,11,2 \leftarrow 12,9,3$ & Ground & & & 25541.64 & \\
\hline$I^{127} \mathrm{C}^{12} \mathrm{~N}^{14}$ & 4. 511 & $4 \leftarrow 3$ & Excited & $11 / 211 / 211 / 2$ & $11 / 2$ & 25542.856 & \\
\hline $\mathrm{I}^{127} \mathrm{C}^{12} \mathrm{~N}^{14}$ & 4- 511 & $4 \leftarrow 3$ & Excited & $11 / 213 / 211 / 2$ & $13 / 2$ & 25542.856 & \\
\hline $\mathrm{I}^{127} \mathrm{C}^{12} \mathrm{~N}^{14}$ & 4. 511 & $4 \leftarrow 3$ & Excited & $11 / 2 \quad 9 / 2 \quad 11 / 2$ & $9 / 2$ & 25542.856 & \\
\hline $\mathrm{S}^{32} \mathrm{~F}_{3}^{19} \mathrm{Cl}^{35}$ & $4-1421$ & $7, \leftarrow 6$ & Ground & & & 25543.85 & .5 \\
\hline
\end{tabular}




\begin{tabular}{|c|c|c|c|c|c|c|c|c|}
\hline \multirow{2}{*}{ Isotopic Species } & \multirow{2}{*}{$\begin{array}{l}\text { Vol.-Id. } \\
\text { Nos. }\end{array}$} & \multirow{2}{*}{$\begin{array}{c}\text { Rotational } \\
\text { Quantum Nos. }\end{array}$} & \multirow{2}{*}{ Vib. State } & \multicolumn{3}{|c|}{ Hyperfine } & \multirow{2}{*}{$\begin{array}{l}\text { Frequency } \\
\mathrm{MHz}\end{array}$} & \multirow{2}{*}{$\begin{aligned} & \text { Acc. } \\
& \pm \mathrm{MH}\end{aligned}$} \\
\hline & & & & $\mathrm{F}_{1}^{\prime}$ & $F^{\prime} \quad F_{1}$ & $\mathbf{F}$ & & \\
\hline $\mathrm{C}^{12} \mathrm{HCl}^{35} \mathrm{~F}_{2}^{19}$ & 4- 251 & $6,3,4 \leftarrow 6,2,4$ & Ground & & $15 / 2$ & $15 / 2$ & 25547.5 & .05 \\
\hline$R b^{85} I^{127}$ & 1 . & $13 \leftarrow 12$ & Ground & & & & 25547.52 & 0.10 \\
\hline $\mathrm{C}^{12}{ }_{*} \mathrm{H}_{2} \mathrm{C}^{12} \mathrm{D}: \mathrm{C}^{12}{ }_{*} \mathrm{D}$ & 4-1033 & $2,1,1 \leftarrow 2,1,2$ & Ground & & & & 25549.3 & \\
\hline $\mathrm{C}^{12} \mathrm{H}_{3} \mathrm{~N}^{14} \mathrm{C}^{12} \mathrm{~S}^{32}$ & $3-421$ & $5, \quad \leftarrow 4, \quad$, & & & & & 25550. & \\
\hline $\mathrm{C}^{12}{ }_{*} \mathrm{H}_{2}^{\mathrm{b}} \mathrm{S}^{\mathrm{b}} \mathrm{C}^{12}{ }_{*} \mathrm{H}_{2}^{\mathrm{b}}$ & 4- 854 & Not Reported & & & & & 25550.0 & 20. \\
\hline $\mathrm{Cs}^{133} \mathrm{Br}^{79}$ & 1. & $12 \leftarrow 11$ & Excited & & & & 25550.22 & 0.20 \\
\hline $\mathrm{C}^{\mathrm{b}}{ }_{*} \mathrm{H}_{2}^{\mathrm{b}} \mathrm{N}^{\mathrm{b}} \mathrm{H}^{\mathrm{b}} \mathrm{C}^{\mathrm{b}}{ }_{*} \mathrm{H}_{2}^{\mathrm{b}}$ & 4. 863 & Not Reported & & & & & 25550.8 & .5 \\
\hline $\mathrm{C}^{12} \mathrm{HDHC}^{12} \mathrm{HDF}^{19}$ & 3- 559 & $6,1,5 \leftarrow 6,1,6$ & Ground & & & & 25551.1 & .1 \\
\hline $\mathrm{P}^{31} \mathrm{Cl}_{2}^{35} \mathrm{Cl}^{37}$ & $4-1522$ & $5,4,1 \leftarrow 4,3,1$ & Ground & & & & 25552. & 1. \\
\hline $\mathrm{D}_{2} \mathrm{C}^{12}: \mathrm{C}^{12} \mathrm{O}^{16}$ & 4- 712 & $9,1,8 \leftarrow 9,1,9$ & Ground & & & & 25558.93 & \\
\hline $\mathrm{D}_{2} \mathrm{O}_{2}^{16}$ & 3- 42 & Not Reported & & & & & 25560 . & 3. \\
\hline $\mathrm{C}^{12} \mathrm{H}_{3} \mathrm{C}^{12}{ }_{*} \mathrm{HO}^{16} \mathrm{C}^{12}{ }_{*} \mathrm{H}_{2}$ & 3- 761 & $38,19, \leftarrow 37,20$ & Ground & & & & 25560.73 & .1 \\
\hline $\mathrm{C}^{12} \mathrm{H}_{3} \mathrm{C}^{12}{ }_{*} \mathrm{HO}^{16} \mathrm{C}^{12}{ }_{*} \mathrm{H}_{2}$ & 3- 761 & $38,19, \leftarrow 37,20$, & Ground & & & & 25561.43 & .1 \\
\hline $\mathrm{C}^{12} \mathrm{H}_{3} \mathrm{~S}^{32} \mathrm{H}$ & 3- 221 & Not Reported & Ground & & & & 25562.0 & .1 \\
\hline$c-\mathrm{C}^{12} \mathrm{HF}^{19}: \mathrm{C}^{12} \mathrm{HCl}^{35}$ & 4. 641 & $2,1,2 \leftarrow 1,0,1$ & Ground & & $5 / 2$ & $3 / 2$ & 25563.1 & \\
\hline $\mathrm{C}^{12} \mathrm{H}_{3} \mathrm{C}^{12} \mathrm{O}^{18} \mathrm{~F}^{19}$ & 3- 394 & $9,6,3 \leftarrow 9,6,4$ & Ground & & & & 25563.55 & .2 \\
\hline$c-\mathrm{C}^{12} \mathrm{HF}^{19}: \mathrm{C}^{12} \mathrm{HCl}^{35}$ & 4. 641 & $2,1,2 \leftarrow 1,0,1$ & Ground & & $7 / 2$ & $5 / 2$ & 25565.7 & \\
\hline $\mathrm{I}^{127} \mathrm{C}^{12} \mathrm{~N}^{14}$ & 4- 511 & $4 \leftarrow 3$ & Excited & $11 / 2$ & $9 / 211 / 2$ & $9 / 2$ & 25567.571 & \\
\hline $\mathrm{I}^{127} \mathrm{C}^{12} \mathrm{~N}^{14}$ & 4. 511 & $4 \leftarrow 3$ & Excited & $11 / 21$ & $11 / 211 / 2$ & $211 / 2$ & 25567.571 & \\
\hline $\mathrm{I}^{127} \mathrm{C}^{12} \mathrm{~N}^{14}$ & 4- 511 & $4 \leftarrow 3$ & Excited & $11 / 21$ & $13 / 211 / 2$ & $13 / 2$ & 25567.571 & \\
\hline $\mathrm{O}^{16} \mathrm{~F}_{2}^{19}$ & 4-1611 & $38,9,30 \leftarrow 39,8,31$ & Ground & & & & 25569.29 & .10 \\
\hline $\mathrm{C}^{12} \mathrm{D}_{3} \mathrm{~N}^{14} \mathrm{H}_{2}$ & 3- 263 & $3, \quad \leftarrow 2, \quad$, & & & & & 25570.4 & .5 \\
\hline $\mathrm{H}_{2} \mathrm{C}^{12}: \mathrm{C}^{12} \mathrm{Cl}^{35} \mathrm{Cl}^{37}$ & 4. 662 & $9,4,5 \leftarrow 9,3,6$ & Ground & & & & 25573.4 & 1. \\
\hline $\mathrm{s} \cdot \mathrm{C}^{12} \mathrm{H}_{2} \mathrm{DC}^{12} \mathrm{O}^{16} \mathrm{Cl}^{35}$ & 3- 365 & $7,2,5 \leftarrow 7,1,6$ & Ground & & & & 25573.58 & .2 \\
\hline $\mathrm{C}^{12}{ }_{*} \mathrm{H}: \mathrm{C}^{12} \mathrm{HO}^{16} \mathrm{C}^{12} \mathrm{D}: \mathrm{C}^{12}{ }_{*} \mathrm{H}$ & $4-1154$ & $8,7,2 \leftarrow 8,6,3$ & Ground & & & & 25575.1 & \\
\hline $\mathrm{s}-\mathrm{C}^{12} \mathrm{H}_{2} \mathrm{DC}^{12} \mathrm{O}^{16} \mathrm{~F}^{19}$ & 3. 397 & $2,0,2 \leftarrow 1,0,1$ & Ground & & & & 25576.50 & .2 \\
\hline $\mathrm{C}^{13} \mathrm{H}_{3} \mathrm{Cl}^{35}$ & 4- 426 & $1, \leftarrow 0$ & Ground & & & & 25577.40 & .1 \\
\hline $\mathrm{H}_{2} \mathrm{~B}^{11} \mathrm{H}_{2} \mathrm{~B}^{11} \mathrm{HBr}^{79}$ & 4- 41 & $4,1,4 \leftarrow 3,1,3$ & Ground & & $11 / 2$ & $9 / 2$ & 25581.2 & \\
\hline $\mathrm{C}_{8}^{12} \mathrm{H}_{13} \mathrm{Cl}^{37}$ & 4-1342 & $12, \leftarrow 11$, & Ground & & & & 25582.7 & \\
\hline $\mathrm{C}^{12}{ }_{*} \mathrm{H}: \mathrm{C}^{12} \mathrm{HO}^{16} \mathrm{C}^{12} \mathrm{D}: \mathrm{C}^{12}{ }_{*} \mathrm{H}^{\prime}$ & 4-1154 & $8,8,1 \leftarrow 8,7,2$ & Ground & & & & 25584.7 & \\
\hline $\mathrm{C}^{12} \mathrm{D}_{3} \mathrm{C}^{12} \mathrm{O}^{16} \mathrm{Cl}^{35}$ & 3- 363 & $11,4,7 \leftarrow 11,3,8$ & Ground & & $23 / 2$ & $23 / 2$ & 25585.28 & \\
\hline $\mathrm{C}^{12} \mathrm{D}_{3} \mathrm{C}^{12} \mathrm{O}^{16} \mathrm{Cl}^{35}$ & 3- 363 & $11,4,7 \leftarrow 11,3,8$ & Ground & & $21 / 2$ & $21 / 2$ & 25585.28 & \\
\hline $\mathrm{C}^{12} \mathrm{D}_{3} \mathrm{C}^{12} \mathrm{O}^{16} \mathrm{Cl}^{35}$ & 3. 363 & $11,4,7 \leftarrow 11,3,8$ & Ground & & $25 / 2$ & $25 / 2$ & 25585.28 & \\
\hline $\mathrm{C}^{12} \mathrm{D}_{3} \mathrm{C}^{12} \mathrm{O}^{16} \mathrm{Cl}^{35}$ & 3- 363 & $11,4,7 \leftarrow 11,3,8$ & - Ground & & $19 / 2$ & $19 / 2$ & 25585.28 & \\
\hline $\mathrm{C}^{12}{ }^{2} \mathrm{H}: \mathrm{C}^{12} \mathrm{HO}^{18} \mathrm{C}^{12} \mathrm{H}: \mathrm{C}^{12}{ }_{*} \mathrm{H}$ & $4-1152$ & $11,8,3 \leftarrow 11,8,4$ & Ground & & & & 25586.5 & .1 \\
\hline $\mathrm{H}_{2} \mathrm{~B}^{11} \mathrm{H}_{2} \mathrm{~B}^{11} \mathrm{HBr}^{79}$ & 4- $\quad 41$ & $4,1,4 \leftarrow 3,1,3$ & Ground & & $9 / 2$ & $7 / 2$ & 25587.5 & \\
\hline $\mathrm{C}^{12}{ }_{*} \mathrm{H}_{2} \mathrm{C}^{12} \mathrm{H}_{2} \mathrm{C}^{12} \mathrm{H}_{2} \mathrm{C}^{12} \mathrm{H}_{2} \mathrm{C}^{12}{ }_{*} \mathrm{O}^{16}$ & $4-1241$ & $43,14,29 \longleftarrow 43,14,30$ & Ground & & & & 25589. & 5. \\
\hline $\mathrm{C}^{12} \mathrm{H}_{3} \mathrm{Ge}^{\mathrm{b}} \mathrm{Cl}_{3}^{35}$ & 3- 107 & $8, \leftarrow 7$, & & & & & 25590. & 15. \\
\hline $\mathrm{C}^{12} \mathrm{H}_{3} \mathrm{C}^{12} \mathrm{D}_{3} \mathrm{Si}^{28} \mathrm{H}_{2}$ & 3- 642 & $5,2,3 \leftarrow 5,1,4$ & Ground & & & & 25590.10 & \\
\hline $\mathrm{C}^{12} \mathrm{H}_{3} \mathrm{C}^{12} \mathrm{D}_{3} \mathrm{Si}^{28} \mathrm{H}_{2}$ & 3- 642 & $5,2,3 \leftarrow 5,1,4$ & Ground & & & & 25592.00 & \\
\hline $\mathrm{C}^{12}{ }_{*} \mathrm{H}_{2} \mathrm{C}^{12} \mathrm{H}_{2} \mathrm{C}^{12} \mathrm{H}_{2} \mathrm{C}^{12} \mathrm{H}_{2} \mathrm{C}^{12}{ }_{*} \mathrm{O}^{16}$ & $4-1241$ & $40,13,27 \leftarrow 40,13,28$ & Ground & & & & 25594. & 5. \\
\hline $\mathrm{HC}^{13}: \mathrm{C}^{12} \mathrm{C}^{12} \mathrm{DO}^{16}$ & 4. 922 & Not Reported & & & & & 25595. & 5. \\
\hline $\mathrm{Rb}^{85} \mathrm{Br}^{79}$ & 1 - & $9 \leftarrow 8$ & Ground & & & & 25596.03 & 0.10 \\
\hline $\mathrm{C}^{13} \mathrm{H}_{3} \mathrm{Cl}^{35}$ & 4- 426 & $1, \leftarrow 0$ & Ground & & & & 25596.19 & .1 \\
\hline $\mathrm{C}_{6}^{12} \mathrm{H}_{5} \mathrm{~F}^{19}$ & $4-1281$ & $18,5,13 \leftarrow 18,5,14$ & Ground & & & & 25596.4 & \\
\hline
\end{tabular}




\begin{tabular}{|c|c|c|c|c|c|c|c|}
\hline \multirow{2}{*}{ Isotopic Species } & \multirow{2}{*}{$\begin{array}{l}\text { Vol.-Id. } \\
\text { Nos. }\end{array}$} & \multirow{2}{*}{$\begin{array}{c}\text { Rotational } \\
\text { Quantum Nos. }\end{array}$} & \multirow{2}{*}{ Vib. State } & \multicolumn{2}{|c|}{ Hyperfine } & \multirow{2}{*}{$\begin{array}{c}\text { Frequency } \\
\mathrm{MHz}\end{array}$} & \multirow{2}{*}{$\begin{aligned} & \text { Acc. } \\
\pm & \mathrm{MHz}\end{aligned}$} \\
\hline & & & & $\begin{array}{lll}F_{1}^{\prime} & F^{\prime} & F\end{array}$ & $\mathbf{F}$ & & \\
\hline $\mathrm{C}^{12} \mathrm{H}_{3} \mathrm{Si}^{28} \mathrm{HF}_{2}^{19}-\mathrm{A}$ & 3- 191 & Not Reported & Ground & & & 25598.7 & \\
\hline $\mathrm{C}_{6}^{12} \mathrm{H}_{5} \mathrm{O}^{16} \mathrm{H}$ & 3-1051 & $9,4,6 \leftarrow 9,3,7$ & Ground & & & 25601.4 & \\
\hline g- $\mathrm{C}^{12} \mathrm{H}_{3} \mathrm{C}^{12} \mathrm{H}_{2} \mathrm{C}^{12} \mathrm{H}_{2} \mathrm{Cl}^{35}$ & 3- 773 & $4,1,3 \leftarrow 3,1,2$ & Ground & & & 25601.63 & .2 \\
\hline $\mathrm{DC}^{13}: \mathrm{C}^{12} \mathrm{C}^{12} \mathrm{HO}^{16}$ & 4. 917 & $3,1,2 \leftarrow 2,1,1$ & Ground & & & 25602.50 & .02 \\
\hline $\mathrm{C}^{12} \mathrm{H}_{2}: \mathrm{C}^{12} \mathrm{HC}^{12} \mathrm{~F}^{19}: \mathrm{C}^{12} \mathrm{H}_{2}$ & 3- 911 & $8,2,6 \leftarrow 8,1,7$ & Ground & & & 25605.61 & .03 \\
\hline $\mathrm{Si}^{28} \mathrm{H}_{3} \mathrm{I}^{127}$ & 4-1761 & $4,3 \leftarrow 3,3$ & Ground & $11 / 2$ & $9 / 2$ & 25605.80 & .1 \\
\hline $\mathrm{C}^{13} \mathrm{H}_{3} \mathrm{Cl}^{35}$ & 4- 426 & $1, \leftarrow 0$, & Ground & & & 25611.09 & .1 \\
\hline $\mathrm{Si}^{28} \mathrm{H}_{3} \mathrm{I}^{127}$ & $4-1761$ & $4,3 \leftarrow 3,3$ & Ground & $9 / 2$ & $7 / 2$ & 25614.02 & .1 \\
\hline $\mathrm{C}^{12} \mathrm{H}_{3} \mathrm{C}^{12} \mathrm{O}^{16} \mathrm{~F}^{19}$ & 3- 391 & Not Reported & Ground & & & 25619.50 & .2 \\
\hline $\mathrm{C}^{\mathrm{b}} \mathrm{H}_{2}^{\mathrm{b}} \mathrm{Cl}^{\mathrm{b}} \mathrm{F}^{\mathrm{b}}$ & 4- 333 & Not Reported & & & & 25619.82 & .1 \\
\hline $\mathrm{C}^{12} \mathrm{H}_{3} \mathrm{C}^{12}{ }_{*} \mathrm{HO}^{16} \mathrm{C}^{12}{ }_{*} \mathrm{H}_{2}$ & 3- 761 & $14,6,9 \leftarrow 13,7,6$ & Ground & & & 25622.24 & .1 \\
\hline $\mathrm{s} \cdot \mathrm{C}^{12} \mathrm{H}_{2} \mathrm{DC}^{12} \mathrm{O}^{16} \mathrm{Cl}^{35}$ & 3- 365 & $3,1,3 \leftarrow 2,0,2$ & Ground & & & 25623.0 & .2 \\
\hline $\mathrm{C}^{12} \mathrm{H}_{3} \mathrm{C}^{12}{ }_{*} \mathrm{HO}^{16} \mathrm{C}^{12}{ }_{*} \mathrm{H}_{2}$ & 3- 761 & $14,6,8 \leftarrow 13,7,7$ & Ground & & & 25623.46 & .1 \\
\hline $\mathrm{C}^{12} \mathrm{H}_{3} \mathrm{C}^{12}{ }_{*} \mathrm{HO}^{16} \mathrm{C}^{12} * \mathrm{H}_{2}$ & 3- 761 & $14,6,9 \leftarrow 13,7,6$ & Ground & & & 25623.66 & .1 \\
\hline $\mathrm{C}_{6}^{12} \mathrm{H}_{5} \mathrm{C}^{12} \mathrm{~N}^{14}$ & $4-1291$ & $10,0,10 \leftarrow 9,0,9$ & Ground & & & 25625 . & \\
\hline $\mathrm{Si}^{29} \mathrm{H}_{2} \mathrm{~F}_{2}^{19}$ & $4 \cdot 1602$ & $4,1,3 \leftarrow 4,0,4$ & Ground & & & 25625.45 & .10 \\
\hline $\mathrm{C}^{12} \mathbf{H C l}^{35} \mathbf{F}_{2}^{19}$ & 4- 251 & $5,3,3 \leftarrow 5,2,3$ & Ground & $13 / 2$ & $13 / 2$ & 25625.6 & .05 \\
\hline $\mathrm{C}^{12} \mathrm{H}_{3} \mathrm{C}^{12} \mathrm{O}^{18} \mathrm{~F}^{19}$ & 3. 394 & $9,6,3 \leftarrow 9,6,4$ & Ground & & & 25626.39 & .2 \\
\hline $\mathrm{C}^{\mathrm{b}} \mathrm{H}_{2}^{\mathrm{b}} \mathrm{N}^{\mathrm{b}} \mathrm{H}^{\mathrm{b}} \mathrm{C}^{\mathrm{b}}{ }_{*} \mathrm{H}_{2}^{\mathrm{b}}$ & 4- 863 & Not Reported & & & & 25627. & 10. \\
\hline $\mathrm{C}_{6}^{12} \mathrm{H}_{5} \mathrm{C}^{12} \mathrm{~N}^{14}$ & $4-1291$ & $9,1,8 \leftarrow 8,1,7$ & Ground & & & 25628. & \\
\hline $\mathrm{C}^{12}{ }_{*} \mathrm{H}: \mathrm{C}^{12} \mathrm{HO}^{16} \mathrm{C}^{12} \mathrm{D}: \mathrm{C}^{12}{ }_{*} \mathrm{H}$ & 4-1154 & $9,9,0 \leftarrow 9,8,1$ & Ground & & & 25628.6 & \\
\hline $\mathrm{C}^{\mathrm{b}} \mathrm{H}_{2}^{\mathrm{b}} \mathrm{Cl}^{\mathrm{b}} F^{\mathrm{b}}$ & 4- 333 & Not Reported & & & & 25628.67 & .1 \\
\hline $\mathrm{C}^{12} \mathrm{HCl}^{35} \mathrm{~F}_{2}^{19}$ & 4- 251 & $5,3,3 \leftarrow 5,2,3$ & Ground & & & 25629.03 & .46 \\
\hline $\mathrm{C}^{12} \mathrm{H}_{3} \mathrm{Si}^{28} \mathrm{H}_{2} \mathrm{~F}^{19}$ & 3- 241 & $2,1,1 \leftarrow 1,1,0$ & Ground & & & 25630.50 & .10 \\
\hline $\mathrm{Cs}^{133} \mathrm{Cl}^{35}$ & 1 - & $6 \leftarrow 5$ & Excited & & & 25631.58 & .20 \\
\hline $\mathrm{C}^{12} \mathrm{HCl}^{35} \mathrm{~F}_{2}^{19}$ & 4- 251 & $5,3,3 \leftarrow 5,2,3$ & Ground & $9 / 2$ & $9 / 2$ & 25632.7 & .05 \\
\hline $\mathrm{C}^{12} \mathrm{HCl}^{35} \mathrm{~F}_{2}^{19}$ & 4. 251 & $5,3,3 \leftarrow 5,2,3$ & Ground & $11 / 2$ & $11 / 2$ & 25635.3 & .05 \\
\hline $\mathrm{C}^{12} \mathrm{H}_{3} \mathrm{~B}^{\mathrm{b}} \mathrm{F}_{2}^{19}$ & 3- 91 & $2, \quad \leftarrow 1$, & Ground & & & 25635.5 & .1 \\
\hline $\mathrm{S}^{32} \mathrm{DC}^{12}: \mathrm{C}^{12} \mathrm{HC}^{12} \mathrm{H}: \mathrm{C}^{12}{ }_{*} \mathrm{H}$ & 4-1162 & $3,2,2 \leftarrow 2,2,1$ & Ground & & & 25636.3 & .1 \\
\hline $\mathrm{C}^{12} \mathrm{H}_{3} \mathrm{C}^{12}{ }_{*} \mathrm{HO}^{16} \mathrm{C}^{12}{ }_{*} \mathrm{H}_{2}$ & 3- 761 & Not Reported & Ground & & & 25637.07 & .1 \\
\hline $\mathrm{C}^{12} \mathrm{H}_{3} \mathrm{C}^{12} \mathrm{O}^{16} \mathrm{Br}^{79}$ & 3- 351 & $11,2,9 \leftarrow 11.1,10$ & Ground & $19 / 2$ & $19 / 2$ & 25637.62 & .15 \\
\hline $\mathrm{C}^{12} \mathrm{H}_{3} \mathrm{C}^{12} \mathrm{O}^{16} \mathrm{Br}^{79}$ & 3- 351 & $11,2,9 \leftarrow 11,1,10$ & Ground & $25 / 2$ & $25 / 2$ & 25638.65 & .15 \\
\hline $\mathrm{N}^{\mathrm{b}} \mathrm{O}_{2}^{\mathrm{b}} \mathrm{Cl}$ & 4-1463 & Not Reported & & & & 25640 . & \\
\hline $\mathrm{C}^{12} \mathrm{HC}^{12} \mathrm{H}: \mathrm{C}^{12} \mathrm{HC}^{12} \mathrm{H}: \mathrm{C}^{12} \mathrm{HN}^{14}{ }_{*}$ & 4-1201 & $14.10 .4 \leftarrow 14,10,5$ & Ground & & & 25640.1 & .1 \\
\hline $\mathrm{C}^{12} \mathrm{H}_{3} \mathrm{C}^{12} \mathrm{O}^{16} \mathrm{Br}^{79}$ & 3- 351 & $11,2,9 \leftarrow 11,1,10$ & Ground & $19 / 2$ & $19 / 2$ & 25641.10 & .15 \\
\hline $\mathrm{H}_{2} \mathrm{C}^{12}: \mathrm{C}^{12} \mathrm{HI}^{127}$ & 4- 801 & $4,1,3 \leftarrow 3,1,2$ & Ground & $7 / 2$ & $5 / 2$ & 25641.14 & .05 \\
\hline $\mathrm{C}^{12} \mathrm{H}_{3} \mathrm{C}^{12} \mathrm{O}^{16} \mathrm{Br}^{79}$ & 3- 351 & $11,2,9 \leftarrow 11,1,10$ & Ground & $25 / 2$ & $25 / 2$ & 25642.22 & .15 \\
\hline $\mathrm{C}^{13} \mathrm{H}_{3} \mathrm{C}^{12} \mathrm{O}^{16} \mathrm{C}^{12} \mathrm{~N}^{14}$ & 3- 672 & $4,1,4 \leftarrow 3,1,3$ & Ground & & & 25644.76 & .2 \\
\hline $\mathrm{C}^{12} \mathrm{H}_{3} \mathrm{C}^{12} \mathrm{O}^{16} \mathrm{Br}^{79}$ & 3- 351 & $11,2,9 \leftarrow 11,1,10$ & Ground & $21 / 2$ & $21 / 2$ & 25645.62 & .15 \\
\hline $\mathrm{C}^{12} \mathrm{H}_{3} \mathrm{C}^{12} \mathrm{O}^{16} \mathrm{Br}^{79}$ & 3- 351 & $11,2,9 \leftarrow 11,1,10$ & Ground & $23 / 2$ & $23 / 2$ & 25646.50 & .15 \\
\hline $4 \mathrm{~d}-\mathrm{C}_{6}^{12} \mathrm{H}_{5} \mathrm{~F}^{19}$ & $4-1283$ & $7,1,7 \leftarrow 6,1,6$ & Ground & & & 25647.9 & .1 \\
\hline $\mathrm{Cs}^{133} \mathrm{Br}^{79}$ & $1-$ & $12 \leftarrow 11$ & Excited & & & 25648.95 & 0.20 \\
\hline $\mathrm{O}_{3}^{16}$ & 4-1841 & $16,2,14 \leftarrow 17,1,17$ & Ground & & & 25649 . & \\
\hline $\mathrm{P}^{31} \mathrm{Cl}_{2}^{35} \mathrm{Cl}^{37}$ & 4-1522 & $5,3,2 \leftarrow 4,2,2$ & Ground & & & 25649. & 10. \\
\hline $\mathrm{C}^{12} \mathrm{H}_{3} \mathrm{Si}^{2 x} \mathrm{HF}_{2}^{14}-\mathrm{A}$ & 3- 191 & Not Reported & Ground & & & 25649.2 & \\
\hline
\end{tabular}


Vib. State

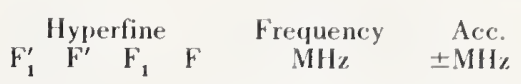

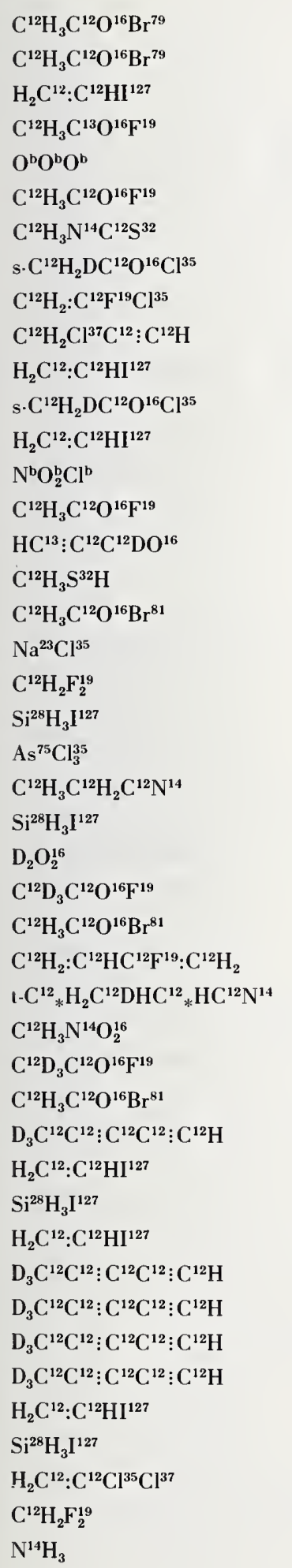

3. $351 \quad 11,2,9 \leftarrow 11,1,10$

3- $351 \quad 11,2,9 \leftarrow 11,1,10$

Ground

4- 801

3. 399

$4,1,3 \leftarrow 3,1,2$

Ground

$2,1,2 \leftarrow 1,1,1$

Ground

Ground

4-1847

3- 391

Not Reported

3. 421

$2,1,2 \leftarrow 1,1,1$

Ground

3- 365

4. 631

$5,1,4 \leftarrow 4,1,3$

4. 992

$5,3,2 \leftarrow 5,2,3$

Ground

$7,2,5 \leftarrow 7,1,6$

Ground

$7,1,6 \leftarrow 7,0,7$

4. 801

$4,1,3 \leftarrow 3,1,2$

Ground

3- 365

4- 801

4-1463

3. 391

4. 922

3- 221

3- 352

1 -

4. 351

4-1761

4. 11

3- 731

4-1761

3. 42

3. 392

3. 352

$5,3,2 \leftarrow 5,2,3$

Ground

$4,1,3 \leftarrow 3,1,2$

Ground

Not Reported

Not Reported

Ground

Not Reported

$9,2,8 \leftarrow 10,1,9$

Ground

$4,1,4 \leftarrow 3,0,3$

Ground

$$
2 \leftarrow 1
$$

Excited

Ground

$7,8,20 \leftarrow 28,7,21$

Ground

$4,2 \leftarrow 3,2$

$$
6, \leftarrow 5 \text {, }
$$

Excited

$4,1,3 \leftarrow 4,0,4$

Ground

$4,2 \leftarrow 3,2$

Not Reported

3- 911

$11,6,5 \leftarrow 11,6,6$

$4,1,4 \leftarrow 3,0,3$

Ground

Ground

$6,1,5 \leftarrow 6,0,6$

4-1173

$4,1,4 \leftarrow 3,1,3$

Ground

3- 171

3- 392

3. 352

4-1193

4. 801

4-1761

4. 801

4-1193

4-1193

4-1193

4-1193

4- 801

4-1761

Not Reported

Ground

$11,6,5 \leftarrow 11,6,6$

Ground

$4,1,4 \leftarrow 3,0,3$

Ground

$7,4 \leftarrow 6,4$

Ground

$4,1,3 \leftarrow 3,1,2 \quad$ - Ground

$$
4,0 \leftarrow 3,0
$$

$4,1,3 \leftarrow 3,1,2$

Ground

$$
7,3 \leftarrow 6,3
$$

Ground

$7,2 \leftarrow 6,2$

Ground

Ground

$$
7,1 \leftarrow 6,1
$$

Ground

$$
7,0 \leftarrow 6,0
$$

$4,1,3 \leftarrow 3,1,2$

$4,1 \leftarrow 3,1$

4. 662

$6,3,4 \leftarrow 6,2,5$

4. 351

$27,8,19 \leftarrow 28,7,22$

4-1771

$12,11 \leftarrow 12,11$

Ground

Ground

Ground

Ground

Ground
Ground

Ground

$\begin{array}{rrrr}21 / 2 & 21 / 2 & 25649.20 & .15 \\ 23 / 2 & 23 / 2 & 25650.34 & .15 \\ 5 / 2 & 3 / 2 & 25650.43 & .05 \\ & & 25650.62 & .2 \\ & & 25651 . & \end{array}$

$25651.87 \quad .2$

25653.

$25655.5 \quad .2$

25656.30

25656.94

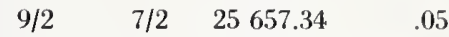

$25657.85 \quad .2$

$\begin{array}{llll}9 / 2 & 9 / 2 & 25657.89 & .05\end{array}$

25658.

$25658.53 \quad .2$

25659 . 5 .

$25659.7 \quad .1$

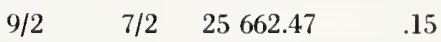

$25666.5 \quad 0.75$

$25669.29 \quad .10$

$\begin{array}{lllll}9 / 2 & 7 / 2 & 25670.18 & .1\end{array}$

25675 . 10 .

$25676.20 \quad .1$

$11 / 2 \quad 9 / 2 \quad 25679.38 \quad .1$

25680 . $\quad 3$.

$25680.09 \quad .2$

$\begin{array}{llll}7 / 2 & 5 / 2 & 25680.83 & .15\end{array}$

$25682.88 \quad .03$

$25683.31 \quad .1$

25684 . 5 .

$25684.02 \quad .2$

$11 / 2 \quad 9 / 2 \quad 25684.46 \quad .15$

$25684.57 \quad .1$

25684.77

$\begin{array}{llll}7 / 2 & 5 / 2 & 25685.10 & .1\end{array}$

$11 / 2 \quad 9 / 2 \quad 25685.91 \quad .05$

$25686.05 \quad .1$

$25687.03 \quad .1$

$25687.66 \quad .1$

$25687.84 \quad .1$ 5

.




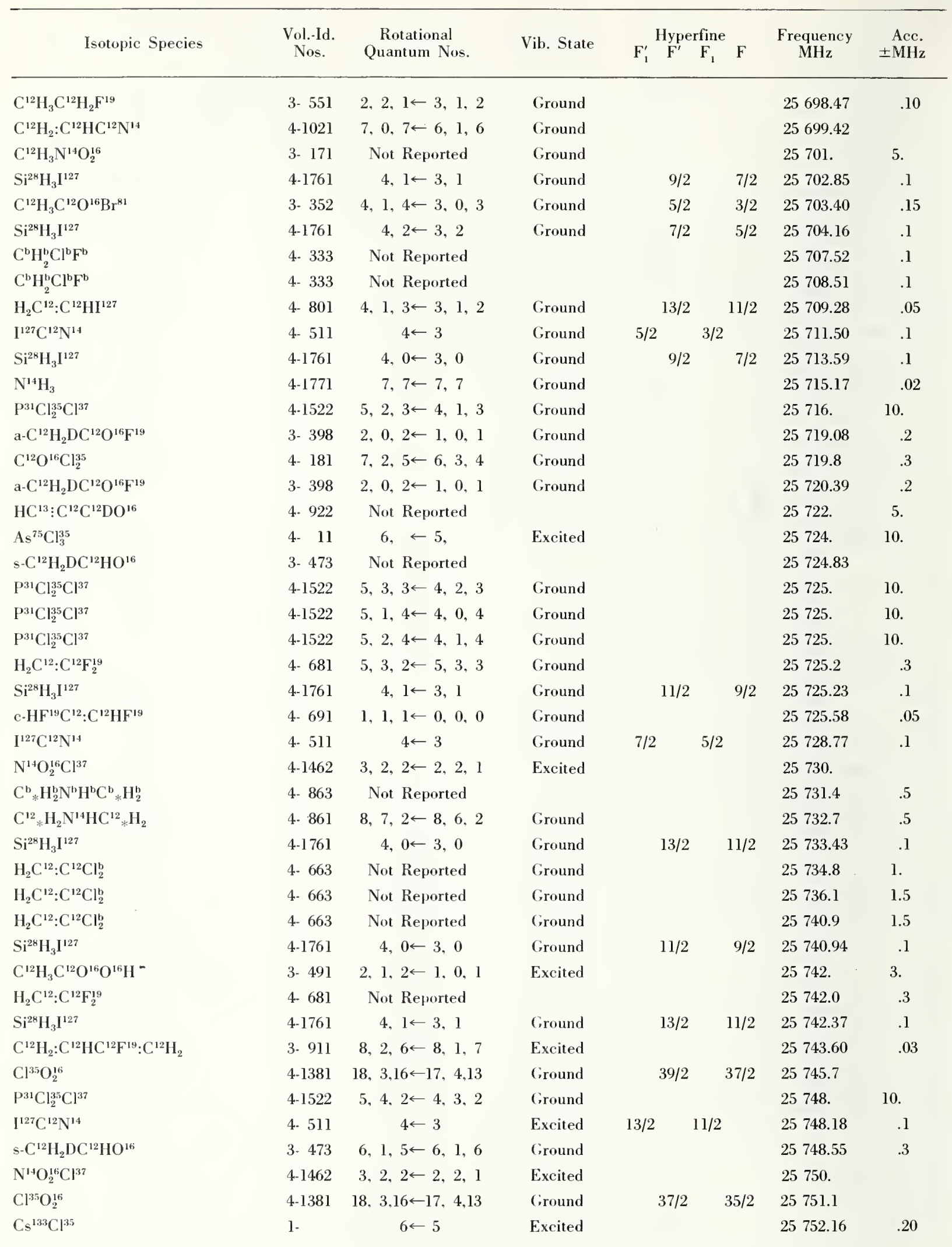




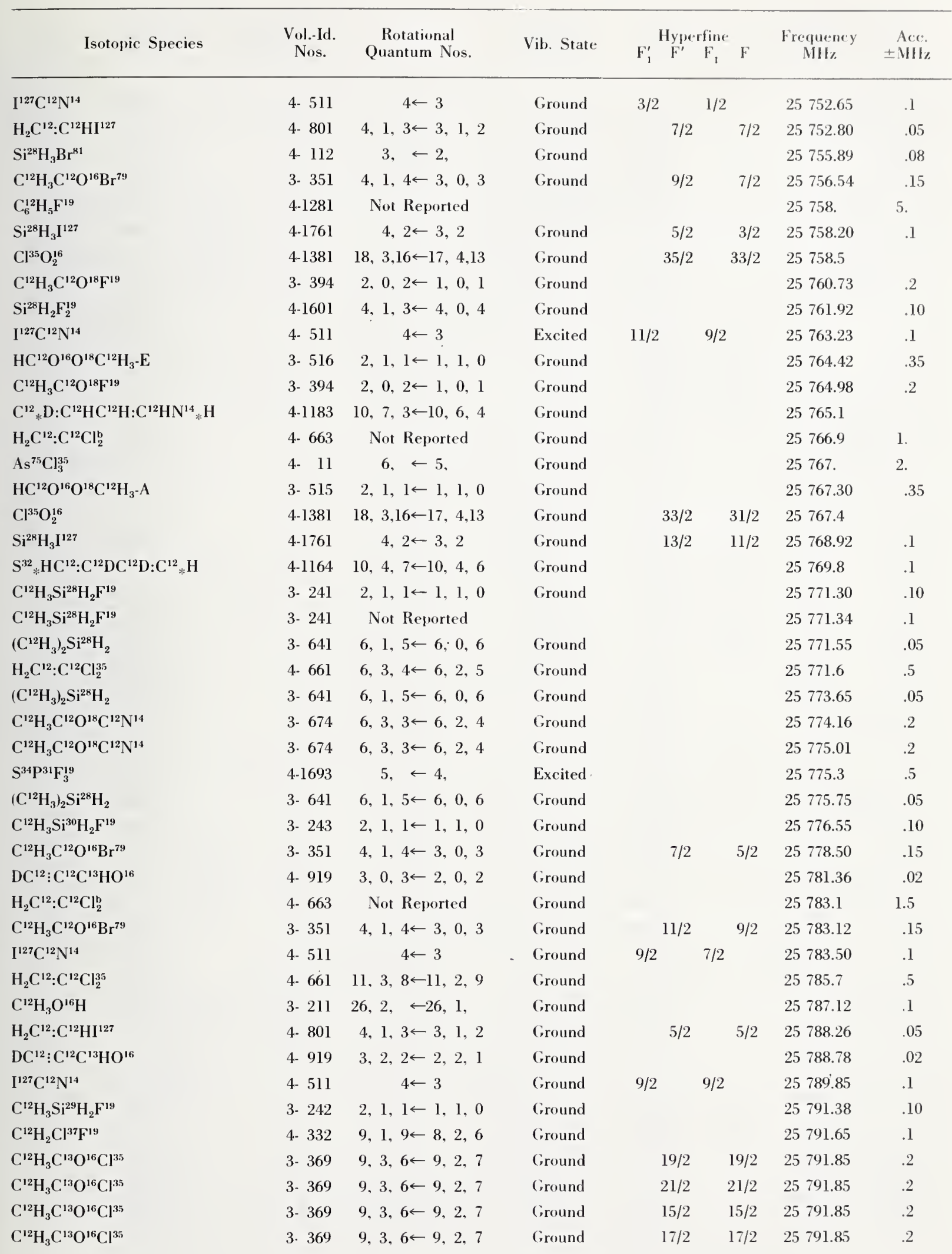




\begin{tabular}{|c|c|c|c|c|c|c|c|c|c|}
\hline Isotopic Species & $\begin{array}{l}\text { Vol.-Id. } \\
\text { Nos. }\end{array}$ & $\begin{array}{c}\text { Rotational } \\
\text { Quantum Nos. }\end{array}$ & Vib. State & $F_{1}^{\prime}$ & $\begin{array}{c}\text { Hyper } \\
\mathrm{F}^{\prime}\end{array}$ & $\begin{array}{l}\text { rfine } \\
F_{1}\end{array}$ & $\mathbf{F}$ & $\begin{array}{l}\text { Frequency } \\
\mathrm{MHz}\end{array}$ & $\begin{aligned} \text { Acc. } \\
\pm \mathrm{MHz}\end{aligned}$ \\
\hline $\mathrm{DC}^{12}: \mathrm{C}^{12} \mathrm{C}^{13} \mathrm{HO}^{16}$ & 4. 919 & $3,2,1 \leftarrow 2,2,0$ & Ground & & & & & 25792.59 & .02 \\
\hline $\mathrm{H}_{2} \mathrm{C}^{12}: \mathrm{C}^{12} \mathrm{HI}^{127}$ & 4. 801 & $4,1,3 \stackrel{\leftarrow}{\leftarrow} 3,1,2$ & Ground & & $3 / 2$ & & $3 / 2$ & 25793.83 & .05 \\
\hline $\mathrm{C}^{12} \mathrm{H}_{3} \mathrm{O}^{16} \mathrm{H}$ & 3. 211 & Not Reported & Ground & & & & & 25796. & 5. \\
\hline $\mathrm{C}^{12} \mathrm{H}_{2} \mathrm{Cl}^{37} \mathrm{~F}^{19}$ & 4. 332 & $9,1,9 \leftarrow 8,2,6$ & Ground & & & & & 25796.15 & .1 \\
\hline $\mathrm{C}^{12} \mathrm{H}_{3} \mathrm{C}^{13} \mathrm{O}^{16} \mathrm{Cl}^{35}$ & 3- 369 & $9,3,6 \leftarrow 9,2,7$ & Ground & & $15 / 2$ & & $15 / 2$ & 25796.17 & .2 \\
\hline $\mathrm{C}^{12} \mathrm{H}_{3} \mathrm{C}^{13} \mathrm{O}^{16} \mathrm{Cl}^{35}$ & 3- 369 & $9,3,6 \leftarrow 9,2,7$ & Ground & & $19 / 2$ & & $19 / 2$ & 25796.17 & .2 \\
\hline $\mathrm{C}^{12} \mathrm{H}_{3} \mathrm{C}^{13} \mathrm{O}^{16} \mathrm{Cl}^{35}$ & 3- 369 & $9,3,6 \leftarrow 9,2,7$ & Ground & & $21 / 2$ & & $21 / 2$ & 25796.17 & .2 \\
\hline $\mathrm{C}^{12} \mathrm{H}_{3} \mathrm{C}^{13} \mathrm{O}^{16} \mathrm{Cl}^{35}$ & 3. 369 & $9,3,6 \leftarrow 9,2,7$ & Ground & & $17 / 2$ & & $17 / 2$ & 25796.17 & .2 \\
\hline $\mathrm{O}^{16} \mathrm{~F}_{2}^{19}$ & $4-1611$ & $38,9,29 \longleftarrow 39,8,32$ & Ground & & & & & 25796.85 & .10 \\
\hline $\mathrm{S}^{34} \mathrm{P}^{31} \mathrm{~F}_{3}^{19}$ & $4-1693$ & $5, \leftarrow 4$, & Ground & & & & & 25797.87 & .03 \\
\hline $\mathrm{Cl}^{35} \mathrm{O}_{2}^{165}$ & 4-1381 & $4,2,3 \leftarrow 5,1,4$ & Ground & & 5 & & 6 & 25798.5 & .2 \\
\hline $\mathrm{I}^{127} \mathrm{C}^{12} \mathrm{~N}^{14}$ & 4. 511 & $4 \leftarrow 3$ & Excited & $7 / 2$ & & $5 / 2$ & & 25802.92 & .1 \\
\hline $\mathrm{C}^{12} \mathrm{H}_{3} \mathrm{C}^{12} \mathrm{O}^{16} \mathrm{Br}^{79}$ & 3. 351 & $4,1,4 \leftarrow 3,0,3$ & Ground & & $5 / 2$ & & $3 / 2$ & 25805.56 & .15 \\
\hline $\mathrm{C}^{12} \mathrm{H}_{3} \mathrm{Si}^{28} \mathrm{H}_{2} \mathrm{~F}^{19}$ & 3- 241 & $2,1,1 \leftarrow 1,1,0$ & Ground & & & & & 25806.77 & .10 \\
\hline $\mathrm{C}^{12} \mathrm{H}_{2}: \mathrm{C}^{12} \mathrm{HC}^{12} \mathrm{~F}^{19}: \mathrm{C}^{12} \mathrm{H}_{2}$ & 3- 911 & $4,2,3 \leftarrow 4,1,4$ & Ground & & & & & 25807.92 & .03 \\
\hline $\mathrm{C}^{12} \mathrm{H}_{3} \mathrm{~N}^{14} \mathrm{H}_{2}$ & 3- 261 & Not Reported & Ground & & & & & 25810.49 & .1 \\
\hline $\mathrm{C}_{6}^{12} \mathrm{H}_{5} \mathrm{Cl}^{35}$ & $4-1271$ & $9,3,6 \leftarrow 8,3,5$ & Ground & & & & & 25810.9 & \\
\hline $\mathrm{C}^{12} \mathrm{H}_{3} \mathrm{~N}^{14} \mathrm{H}_{2}$ & 3- 261 & Not Reported & Ground & & & & & 25810.96 & .1 \\
\hline $\mathrm{Si}^{28} \mathrm{H}_{3} \mathrm{I}^{127}$ & $4-1761$ & $4,3 \leftarrow 3,3$ & Ground & & $13 / 2$ & & $11 / 2$ & 25812.69 & .1 \\
\hline$I^{127} \mathrm{C}^{12} \mathrm{~N}^{14}$ & 4- 511 & $4 \leftarrow 3$ & Excited & $5 / 2$ & & $3 / 2$ & & 25815.34 & .1 \\
\hline $\mathrm{Cs}^{133} \mathrm{Br}^{79}$ & $1-$ & $12 \leftarrow 11$ & Excited & & & & & 25816.53 & 0.20 \\
\hline $\mathrm{C}^{12} \mathrm{H}_{3} \mathrm{~B}^{\mathrm{b}} \mathrm{F}_{2}^{19}$ & 3- 91 & $2, \quad \leftarrow 1$, & Ground & & & & & 25817.4 & .1 \\
\hline $\mathrm{C}^{12} \mathrm{H}_{3} \mathrm{C}^{12}: \mathrm{C}^{12} \mathrm{C}^{12} \mathrm{H}_{2} \mathrm{Cl}^{35}$ & 3. 901 & $9,0,9 \leftarrow 8,0,8$ & Ground & & & & & 25817.70 & .05 \\
\hline $\mathrm{S}^{34} \mathrm{P}^{31} \mathrm{~F}_{3}^{19}$ & 4-1693 & $5, \leftarrow 4$, & Excited & & & & & 25818.0 & 2. \\
\hline $\mathrm{C}^{12} \mathrm{Cl}_{3}^{37} \mathrm{C}^{12} \mathrm{~N}^{14}$ & 4- 584 & $8, \leftarrow 7$, & Ground & & & & & 25818.5 & 1.0 \\
\hline $\mathrm{DC}^{12}: \mathrm{C}^{13} \mathrm{C}^{12} \mathrm{HO}^{16}$ & 4- 918 & $3,0,3 \leftarrow 2,0,2$ & Ground & & & & & 25822.90 & .02 \\
\hline $\mathrm{I}^{127} \mathrm{C}^{12} \mathrm{~N}^{14}$ & 4- 511 & $4 \leftarrow 3$ & Ground & $13 / 2$ & & $11 / 2$ & & 25823.08 & .1 \\
\hline $\mathrm{C}^{12} \mathrm{DHDC}^{12} \mathrm{HDF}^{19}$ & 3. 561 & $4,3,1 \leftarrow 5,2,4$ & Ground & & & & & 25823.1 & .1 \\
\hline $4 \mathrm{~d}-\mathrm{C}_{6}^{12} \mathrm{H}_{5} \mathrm{~F}^{19}$ & 4-1283 & $7,0,7 \leftarrow 6,0,6$ & Ground & & & & & 25823.5 & .1 \\
\hline $\mathrm{C}^{12} \mathrm{HD}_{2} \mathrm{I}^{127}$ & 4. 484 & $2,1, \leftarrow 1,0$, & Ground & & $9 / 2$ & & $7 / 2$ & 25826.9 & \\
\hline $\mathrm{C}^{12} \mathrm{D}_{3} \mathrm{C}^{12} \mathrm{O}^{16} \mathrm{Cl}^{37}$ & 3- 364 & $9,4,5 \leftarrow 9,3,6$ & Ground & & $21 / 2$ & & $21 / 2$ & 25827.40 & \\
\hline $\mathrm{C}^{12} \mathrm{D}_{3} \mathrm{C}^{12} \mathrm{O}^{16} \mathrm{Cl}^{37}$ & 3- 364 & $9,4,5 \leftarrow 9,3,6$ & Ground & & $15 / 2$ & & $15 / 2$ & 25827.40 & \\
\hline $\mathrm{Cl}^{35} \mathrm{O}_{2}^{16}$ & 4-1381 & $4,2,3 \leftarrow 5,1,4$ & Ground & & 4 & & 5 & 25828.1 & .2 \\
\hline $\mathrm{C}^{12}{ }_{*} \mathrm{H}: \mathrm{C}^{12} \mathrm{DO}^{16} \mathrm{C}^{12} \mathrm{D}: \mathrm{C}^{12} * \mathrm{H}$ & $4-1156$ & $7,7,1 \leftarrow 7,6,2$ & Ground & & & & & 25828.6 & \\
\hline${ }^{127} \mathrm{C}^{12} \mathrm{~N}^{14}$ & 4- 511 & $4 \leftarrow 3$ & Excited & $9 / 2$ & & $7 / 2$ & & 25829.31 & .1 \\
\hline $\mathrm{C}^{12} \mathrm{D}_{3} \mathrm{C}^{12} \mathrm{O}^{16} \mathrm{Cl}^{37}$ & 3- 364 & $9,4,5 \leftarrow 9,3,6$ & Ground & & $19 / 2$ & & $19 / 2$ & 25829.70 & \\
\hline $\mathrm{C}^{12} \mathrm{D}_{3} \mathrm{C}^{12} \mathrm{O}^{16} \mathrm{Cl}^{37}$ & 3- 364 & $9,4,5 \leftarrow 9,3,6$ & Ground & & $17 / 2$ & & $17 / 2$ & 25829.70 & \\
\hline $\mathrm{C}^{13} \mathrm{H}_{2} \mathrm{~F}_{2}^{19}$ & 4- 352 & $4,2,2 \leftarrow 5,1,5$ & Ground & & & & & 25829.9 & .4 \\
\hline $\mathrm{DC}^{12}: \mathrm{C}^{13} \mathrm{C}^{12} \mathrm{HO}^{16}$ & 4. 918 & $3,2,2 \leftarrow 2,2,1$ & Ground & & & & & 25830.23 & .02 \\
\hline $\mathrm{HC}^{13}: \mathrm{C}^{12} \mathrm{C}^{12} \mathrm{DO}^{16}$ & 4- 922 & Not Reported & & & & & & 25833. & 5. \\
\hline $\mathrm{DC}^{12}: \mathrm{C}^{13} \mathrm{C}^{12} \mathrm{HO}^{16}$ & 4- 918 & $3,2,1 \leftarrow 2,2,0$ & Ground & & & & & 25833.92 & .02 \\
\hline $\mathrm{C}^{12} \mathrm{D}_{3} \mathrm{~N}^{14} \mathrm{H}_{2}$ & 3- 263 & Not Reported & & & & & & 25834.5 & .5 \\
\hline $\mathrm{C}^{12} \mathrm{H}_{3} \mathrm{C}^{12} \mathrm{H}: \mathrm{C}^{12} \mathrm{O}^{16}$ & 3- 681 & $3,2, \leftarrow 2,2$, & Ground & & & & & 25835.2 & .1 \\
\hline $\mathrm{I}^{127} \mathrm{C}^{12} \mathrm{~N}^{14}$ & 4- 511 & $4 \leftarrow 3$ & Ground & $11 / 2$ & & $9 / 2$ & & 25837.64 & .1 \\
\hline $\mathrm{C}^{12} \mathrm{H}_{3} \mathrm{~B}^{\mathrm{b}} \mathrm{F}_{2}^{19}$ & 3. 91 & $12, \quad \leftarrow 12$, & Ground & & & & & 25848.0 & .1 \\
\hline
\end{tabular}




\begin{tabular}{|c|c|c|c|c|c|c|c|}
\hline Isotopic Species & $\begin{array}{l}\text { Vol..Id. } \\
\text { Nos. }\end{array}$ & $\begin{array}{c}\text { Rotational } \\
\text { Quantum Nos. }\end{array}$ & Vib. State & $\mathrm{F}_{1}^{\prime} \stackrel{\text { Hypre }}{\mathrm{F}^{\prime}}$ & $\begin{array}{l}\text { rfine } \\
F\end{array}$ & $\begin{array}{c}\text { Frequency } \\
\text { MH\% }\end{array}$ & $\begin{aligned} & \text { Acc. } \\
\pm & \text { MIl } \%\end{aligned}$ \\
\hline $\mathrm{c}-\mathrm{HF}^{19} \mathrm{C}^{12}: \mathrm{C}^{12} \mathrm{HF}^{19}$ & 4. 691 & $1,1,1 \leftarrow 0,0,0$ & Excited & & & 25848.69 & .05 \\
\hline $\mathrm{I}^{127} \mathrm{C}^{12} \mathrm{~N}^{14}$ & 4. 511 & $4 \leftarrow 3$ & Excited & $9 / 2$ & $7 / 2$ & 25850.78 & .1 \\
\hline $\mathrm{Cl}^{35} \mathrm{O}_{2}^{16}$ & $4-1381$ & $4,2,3 \leftarrow 5,1,4$ & Ground & 3 & 4 & 25852.7 & .2 \\
\hline $\mathrm{C}^{12} \mathrm{H}_{3} \mathrm{C}^{12}{ }_{*} \mathrm{HO}^{16} \mathrm{C}^{12}{ }_{*} \mathrm{H}_{2}$ & 3. 761 & $8,1,7 \leftarrow 8,1,8$ & Ground & & & 25853.9 & .1 \\
\hline $\mathrm{HC}^{13} \mathrm{O}^{16} \mathrm{O}^{16} \mathrm{C}^{12} \mathrm{H}_{3}-\mathrm{E}$ & 3- 509 & $2,1,1 \leftarrow 1,1,0$ & Ground & & & 25854.88 & .2 \\
\hline $\mathrm{Na}^{23} \mathrm{Cl}^{35}$ & $1-$ & $2 \leftarrow 1$ & Excited & & & 25857.6 & 0.75 \\
\hline $\mathrm{HC}^{13} \mathrm{O}^{16} \mathrm{O}^{16} \mathrm{C}^{12} \mathrm{H}_{3}-\mathrm{A}$ & 3- 508 & $2,1,1 \leftarrow 1,1,0$ & Ground & & & 25858.48 & .2 \\
\hline $\mathrm{H}_{2} \mathrm{C}^{12}: \mathrm{C}^{12} \mathrm{Cl}_{2}^{35}$ & 4- 661 & $13,4,9 \leftarrow 13,3,10$ & Ground & & & 25859.5 & .5 \\
\hline $\alpha-\mathrm{C}^{12} \mathrm{H}_{2} \mathrm{DC}^{12} \mathrm{H}_{2} \mathrm{~F}^{19}$ & 3- 553 & $2,1,1 \leftarrow 2,0,2$ & Ground & & & 25860.0 & .1 \\
\hline $\mathrm{C}^{12} \mathrm{H}_{3} \mathrm{C}^{12} \mathrm{O}^{16} \mathrm{Cl}^{35}$ & 3. 361 & $9,3,6 \leftarrow 9,2,7$ & Ground & $19 / 2$ & $19 / 2$ & 25860.85 & .2 \\
\hline $\mathrm{C}^{12} \mathrm{H}_{3} \mathrm{C}^{12} \mathrm{O}^{16} \mathrm{Cl}^{35}$ & 3- 361 & $9,3,6 \leftarrow 9,2,7$ & Ground & $15 / 2$ & $15 / 2$ & 25860.85 & .2 \\
\hline $\mathrm{C}^{12} \mathrm{H}_{3} \mathrm{C}^{12} \mathrm{O}^{16} \mathrm{Cl}^{35}$ & 3- 361 & $9,3,6 \leftarrow 9,2,7$ & Ground & $17 / 2$ & $17 / 2$ & 25860.85 & .2 \\
\hline $\mathrm{C}^{\mathrm{i} 2} \mathrm{H}_{3} \mathrm{C}^{12} \mathrm{O}^{16} \mathrm{Cl}^{35}$ & 3- 361 & $9,3,6 \leftarrow 9,2,7$ & Ground & $21 / 2$ & $21 / 2$ & 25860.85 & .2 \\
\hline $\mathrm{C}^{12} \mathrm{H}_{3} \mathrm{~N}^{14} \mathrm{H}_{2}$ & 3- 261 & Not Reported & Ground & & & 25861.23 & .1 \\
\hline $\mathrm{H}_{2} \mathrm{C}^{12}: \mathrm{C}^{12} \mathrm{Cl}_{2}^{35}$ & 4. 661 & $13,4,9 \leftarrow 13,3,10$ & Ground & & & 25861.5 & .5 \\
\hline $\mathrm{H}_{2} \mathrm{C}^{12}: \mathrm{C}^{12} \mathrm{Cl}_{2}^{35}$ & 4- 661 & $13,4,9 \leftarrow 13,3,10$ & Ground & & & 25863.3 & .5 \\
\hline $\mathrm{HC}^{12} \mathrm{~N}^{14}$ & 4- 291 & $7 \leftarrow 7$ & Excited & & & 25863.35 & .1 \\
\hline $\mathrm{Si}^{28} \mathrm{H}_{3} \mathrm{I}^{127}$ & $4-1761$ & $4,3 \leftarrow 3,3$ & Ground & $5 / 2$ & $3 / 2$ & 25864.27 & .1 \\
\hline $\mathrm{C}^{12} \mathrm{H}_{3} \mathrm{C}^{12} \mathrm{O}^{16} \mathrm{Cl}^{35}$ & 3. 361 & $9,3,6 \leftarrow 9,2,7$ & Ground & $15 / 2$ & $15 / 2$ & 25865.30 & .2 \\
\hline $\mathrm{C}^{12} \mathrm{H}_{3} \mathrm{C}^{12} \mathrm{O}^{16} \mathrm{Cl}^{35}$ & 3- 361 & $9,3,6 \leftarrow 9,2,7$ & Ground & $19 / 2$ & $19 / 2$ & 25865.30 & .2 \\
\hline $\mathrm{C}^{12} \mathrm{H}_{3} \mathrm{C}^{12} \mathrm{O}^{16} \mathrm{Cl}^{35}$ & 3- 361 & $9,3,6 \leftarrow 9,2,7$ & Ground & $17 / 2$ & $17 / 2$ & 25865.30 & .2 \\
\hline $\mathrm{C}^{12} \mathrm{H}_{3} \mathrm{C}^{12} \mathrm{O}^{16} \mathrm{Cl}^{35}$ & 3- 361 & $9,3,6 \leftarrow 9,2,7$ & Ground & $21 / 2$ & $21 / 2$ & 25865.30 & .2 \\
\hline $\mathrm{HC}^{13}: \mathrm{C}^{12} \mathrm{C}^{12} \mathrm{DO}^{16}$ & 4. 922 & Not Reported & & & & 25868. & 5. \\
\hline $\mathrm{S}^{32}{ }_{*} \mathrm{HC}^{13}: \mathrm{C}^{12} \mathrm{HC}^{12} \mathrm{H} \mathrm{C}^{12}{ }_{*} \mathrm{H}$ & $4-1167$ & $3,2,2 \leftarrow 2,2,1$ & Ground & & & 25869.0 & 3. \\
\hline $\mathrm{C}^{12} \mathrm{O}^{18} \mathrm{~F}_{2}^{19}$ & 4- 213 & $5,3,2 \leftarrow 5,3,3$ & Ground & & & 25869.20 & .10 \\
\hline $2,4,6 \mathrm{~d}_{3}{ }^{-} \mathrm{C}_{6}^{12} \mathrm{H}_{5} \mathrm{~F}^{19}$ & $4-1284$ & $6,3,3 \leftarrow 5,3,2$ & Ground & & & 25869.5 & .1 \\
\hline $\mathrm{Cl}^{135} \mathrm{O}_{2}^{16}$ & $4-1381$ & $4,2,3 \leftarrow 5,1,4$ & Ground & 2 & 3 & 25870.1 & .2 \\
\hline $\mathrm{C}^{12} \mathrm{H}_{3} \mathrm{C}^{12}: \mathrm{C}^{12} \mathrm{C}^{12} \mathrm{H}_{2} \mathrm{Cl}^{35}$ & 3- 901 & $9,2,8 \leftarrow 8,2,7$ & Ground & & & 25872.05 & .05 \\
\hline $\mathrm{I}^{127} \mathrm{C}^{12} \mathrm{~N}^{14}$ & 4- 511 & $4 \leftarrow 3$ & Excited & $11 / 2$ & $9 / 2$ & 25872.24 & .1 \\
\hline $\mathrm{Cs}^{133} \mathrm{Cl}^{35}$ & 1 - & $6 \leftarrow 5$ & Ground & & & 25873.11 & .10 \\
\hline $\mathrm{C}^{12} \mathrm{H}_{3} \mathrm{~N}^{14} \mathrm{O}_{2}^{16}$ & 3- 171 & Not Reported & Ground & & & 25877.28 & \\
\hline $\mathrm{C}^{12} \mathrm{H}_{3} \mathrm{O}^{16} \mathrm{H}$ & 3- 211 & $10,2, \leftarrow 10,1$, & Ground & & & 25878.18 & .1 \\
\hline $\mathrm{C}_{*}^{\mathrm{b}} \mathrm{H}_{2}^{\mathrm{b}} \mathrm{N}^{\mathrm{b}} \mathrm{H}^{\mathrm{b}} \mathrm{C}^{\mathrm{b}} \mathrm{H}_{*} \mathrm{H}_{2}^{\mathrm{b}}$ & 4- 863 & Not Reported & & & & 25878.3 & .5 \\
\hline $\mathrm{C}^{12} \mathrm{H}_{2} \mathrm{Cl}^{37} \mathrm{~F}^{19}$ & 4- 332 & $18,2,16 \leftarrow 17,3,15$ & Ground & & & 25878.70 & .1 \\
\hline $\mathrm{C}_{8}^{12} \mathrm{H}_{13} \mathrm{Br}^{81}$ & 4-1332 & $18, \leftarrow 17$, & Excited & & & 25882. & \\
\hline $\mathrm{C}^{12} \mathrm{H}_{2}: \mathrm{C}^{12} \mathrm{HC}^{12} \mathrm{~F}^{19}: \mathrm{C}^{12} \mathrm{H}_{2}$ & 3. 911 & $6,1,5 \leftarrow 6,0,6$ & Ground & & & 25882.63 & .03 \\
\hline $3 \mathrm{~d}-\mathrm{C}_{6}^{12} \mathrm{H}_{5} \mathrm{~F}^{19}$ & $4 \cdot 1282$ & $6,5,2 \leftarrow 5,5,1$ & Ground & & & 25888.4 & .1 \\
\hline $3 d \cdot \mathrm{C}_{6}^{12} \mathrm{H}_{5} \mathrm{~F}^{19}$ & $4-1282$ & $6,5,1 \leftarrow 5,5,0$ & Ground & & & 25888.4 & .1 \\
\hline $\mathrm{C}^{12}{ }_{*} \mathrm{D}: \mathrm{C}^{12} \mathrm{HC}^{12} \mathrm{H}: \mathrm{C}^{12} \mathrm{HN}^{14}{ }_{*} \mathrm{H}$ & $4 \cdot 1183$ & $9,9,0 \leftarrow 9,8,1$ & Ground & & & 25888.6 & \\
\hline $\mathrm{H}_{2} \mathrm{~B}^{11} \mathrm{H}_{2} \mathrm{~B}^{11} \mathrm{HBr}^{\mathrm{B}}$ & 4- 42 & $4,0,4 \leftarrow 3,0,3$ & Ground & $9 / 2$ & $7 / 2$ & 25889.0 & \\
\hline $\mathrm{H}_{2} \mathrm{~B}^{11} \mathrm{H}_{2} \mathrm{~B}^{11} \mathrm{HBr}^{81}$ & 4- 42 & $4,0,4 \leftarrow 3,0,3$ & Ground & $11 / 2$ & $9 / 2$ & 25889.0 & \\
\hline $\mathrm{s}-\mathrm{C}^{12} \mathrm{H}_{2} \mathrm{DC}^{12} \mathrm{HO}^{16}$ & 3. 473 & $6,1,5 \leftarrow 6,1,6$ & Ground & & & 25889.3 & .5 \\
\hline $\mathrm{C}^{12} \mathrm{H}_{3} \mathrm{C}^{12}: \mathrm{C}^{12} \mathrm{C}^{12} \mathrm{H}_{2} \mathrm{C}^{35}$ & 3. 901 & $9,4,5 \leftarrow 8,4,4$ & Ground & & & 25892.2 & .15 \\
\hline $\mathrm{C}^{12} \mathrm{H}_{3} \mathrm{C}^{12}: \mathrm{C}^{12} \mathrm{C}^{12} \mathrm{H}_{2} \mathrm{C}^{35}$ & 3- 901 & $9,3,7 \leftarrow 8,3,6$ & Ground & & & 25892.2 & .15 \\
\hline $\mathrm{C}^{12} \mathrm{H}_{3} \mathrm{C}^{12}: \mathrm{C}^{12} \mathrm{C}^{12} \mathrm{H}_{2} \mathrm{Cl}^{35}$ & 3. 901 & $9,4,6 \leftarrow 8,4,5$ & Ground & & & 25892.2 & .15 \\
\hline
\end{tabular}




\begin{tabular}{|c|c|c|c|c|c|c|c|c|c|}
\hline \multirow{3}{*}{$\frac{\text { Isotopic Species }}{\mathrm{C}^{12} \mathrm{H}_{3} \mathrm{C}^{12}: \mathrm{C}^{12} \mathrm{C}^{12} \mathrm{H}_{2} \mathrm{Cl}^{35}}$} & \multirow{3}{*}{$\begin{array}{l}\text { Vol.-Id. } \\
\text { Nos. } \\
\text { 3- } 901\end{array}$} & \multirow{3}{*}{$\begin{array}{c}\begin{array}{c}\text { Rotational } \\
\text { Quantum Nos. }\end{array} \\
9,3,6 \leftarrow 8,3,5\end{array}$} & \multirow{2}{*}{ Vib. State } & \multicolumn{4}{|c|}{ Hyperfine } & \multirow{2}{*}{$\begin{array}{c}\text { Frequency } \\
\mathrm{MHz}\end{array}$} & \multirow{2}{*}{$\begin{array}{r}\text { Acc. } \\
\pm \mathrm{MHz}\end{array}$} \\
\hline & & & & $\mathrm{F}_{1}^{\prime}$ & & $F_{1}$ & $\mathrm{~F}$ & & \\
\hline & & & Ground & & & & & 25892.2 & .15 \\
\hline $\mathrm{I}^{127} \mathrm{C}^{12} \mathrm{~N}^{14}$ & 4- 511 & $4 \leftarrow 3$ & Excited & $11 / 2$ & & $9 / 2$ & & 25893.73 & .1 \\
\hline $\mathrm{S}^{32}{ }_{*} \mathrm{HC}^{13}: \mathrm{C}^{12} \mathrm{HC}^{12} \mathrm{H}: \mathrm{C}^{12}{ }_{*} \mathrm{H}$ & $4-1167$ & $11,5,6 \leftarrow 11,5,7$ & Ground & & & & & 25894.3 & .05 \\
\hline $\mathrm{C}^{12} \mathrm{H}_{2}\left(\mathrm{C}^{12} \mathrm{~N}^{14}\right)_{2}$ & 4- 901 & Not Reported & Ground & & & & & 25895.4 & .1 \\
\hline $\mathrm{H}_{2} \mathrm{~B}^{11} \mathrm{H}_{2} \mathrm{~B}^{11} \mathrm{HBr}^{81}$ & 4- 42 & $4,0,4 \leftarrow 3,0,3$ & Ground & & $7 / 2$ & & $5 / 2$ & 25895.5 & \\
\hline $\mathrm{H}_{2} \mathrm{~B}^{11} \mathrm{H}_{2} \mathrm{~B}^{11} \mathrm{HBr}^{81}$ & 4. 42 & $4,0,4 \leftarrow 3,0,3$ & Ground & & $5 / 2$ & & $3 / 2$ & 25895.5 & \\
\hline $\mathrm{C}^{12} \mathrm{H}_{3} \mathrm{O}^{16} \mathrm{H}$ & 3. 211 & Not Reported & Ground & & & & & 25898 & 5. \\
\hline $\mathrm{I}^{127} \mathrm{C}^{12} \mathrm{~N}^{14}$ & 4- 511 & $4 \leftarrow 3$ & Excited & $13 / 2$ & & $11 / 2$ & & 25906.28 & .1 \\
\hline $\mathrm{H}_{2} \mathrm{~B}^{11} \mathrm{H}_{2} \mathrm{~B}^{11} \mathrm{HBr}^{81}$ & 4- 42 & $4,2,2 \leftarrow 3,2,1$ & Ground & & $11 / 2$ & & $9 / 2$ & 25906.7 & \\
\hline $\mathrm{H}_{2} \mathrm{~B}^{11} \mathrm{H}_{2} \mathrm{~B}^{11} \mathrm{HBr}^{81}$ & 4- 42 & $4,2,3 \leftarrow 3,2,2$ & Ground & & $7 / 2$ & & $5 / 2$ & 25906.7 & \\
\hline $\mathrm{C}^{12} \mathrm{H}_{3} \mathrm{C}^{12} \mathrm{O}^{16} \mathrm{C}^{13} \mathrm{~N}^{14}$ & 3. 673 & $4,1,4 \leftarrow 3,1,3$ & Ground & & & & & 25907.24 & .2 \\
\hline $\mathrm{C}^{12} \mathrm{D}_{3} \mathrm{Si}^{28} \mathrm{H}_{2} \mathrm{~F}^{19}$ & 3- 244 & $7,1,6 \leftarrow 7,1,7$ & Ground & & & & & 25908.00 & .10 \\
\hline $\mathrm{C}^{12} \mathrm{H}_{2}: \mathrm{C}^{12} \mathrm{HC}^{12} \mathrm{~N}^{14}$ & 4-1021 & $1,1,1 \leftarrow 2,0,2$ & Ground & & 0 & & 1 & 25908.70 & \\
\hline $\mathrm{C}^{12} \mathrm{H}_{2}: \mathrm{C}^{12} \mathrm{HC}^{12} \mathrm{~F}^{19}: \mathrm{C}^{12} \mathrm{H}_{2}$ & 3. 911 & $10,3,7 \leftarrow 10,2,8$ & Ground & & & & & 25909.1 & .2 \\
\hline $\mathrm{C}^{12} \mathrm{H}_{2}: \mathrm{C}^{12} \mathrm{HC}^{12} \mathrm{~N}^{14}$ & $4-1021$ & $1,1,1 \leftarrow 2,0,2$ & Ground & & 2 & & 3 & 25910.08 & \\
\hline $\mathrm{C}^{12} \mathrm{H}_{2} \mathrm{Cl}^{35} \mathrm{C}^{12} \vdots \mathrm{C}^{12} \mathrm{H}$ & 4- 991 & $7,1,6 \leftarrow 7,0,7$ & Ground & & & & & 25911.16 & \\
\hline $\mathrm{C}^{12} \mathrm{H}_{2}: \mathrm{C}^{12} \mathrm{HC}^{12} \mathrm{~N}^{14}$ & $4-1021$ & $1,1,1 \leftarrow 2,0,2$ & Ground & & 2 & & 2 & 25911.28 & \\
\hline $\mathrm{C}^{12} \mathrm{H}_{2}: \mathrm{C}^{12} \mathrm{HC}^{12} \mathrm{~N}^{14}$ & $4-1021$ & $1,1,1 \leftarrow 2,0,2$ & Ground & & 1 & & 2 & 25911.78 & \\
\hline $\mathrm{a}-\mathrm{C}^{12} \mathrm{HD}_{2} \mathrm{C}^{12} \mathrm{O}^{16} \mathrm{~F}^{19}$ & 3- 396 & $12,7,6 \leftarrow 12,7,5$ & Ground & & & & & 25912.13 & .2 \\
\hline $\mathrm{C}^{12} \mathrm{H}_{3} \mathrm{~N}^{14} \mathrm{O}_{2}^{16}$ & 3- 171 & Not Reported & Ground & & & & & 25912.55 & \\
\hline $\mathrm{HDC}^{12}: \mathrm{C}^{12} \mathrm{~F}_{2}^{19}$ & 4- 682 & $2,0,2 \leftarrow 1,0,1$ & Ground & & & & & 25912.7 & .3 \\
\hline $\mathrm{s}-\mathrm{C}^{12} \mathrm{H}_{2} \mathrm{DC}^{12} \mathrm{HO}^{16}$ & 3. 473 & $6,1,5 \leftarrow 6,1,6$ & Ground & & & & & 25917.11 & .2 \\
\hline $\mathrm{C}^{12} \mathrm{H}_{3} \mathrm{~S}^{32} \mathrm{H}$ & 3- 221 & Not Reported & Ground & & & & & 25917.5 & .1 \\
\hline $\mathrm{a}-\mathrm{C}^{12} \mathrm{HD}_{2} \mathrm{C}^{12} \mathrm{O}^{16} \mathrm{~F}^{19}$ & 3- 396 & $12,7,6 \leftarrow-12,7,5$ & Ground & & & & & 25917.58 & .2 \\
\hline $\mathrm{H}_{2} \mathrm{C}^{12}: \mathrm{C}^{12} \mathrm{Cl}_{2}^{\mathrm{b}}$ & 4- 663 & Not Reported & Ground & & & & & 25918.4 & 1. \\
\hline $\mathrm{H}_{2} \mathrm{~B}^{11} \mathrm{H}_{2} \mathrm{~B}^{11} \mathrm{HBr}^{81}$ & 4- 42 & $4,2,3 \leftarrow 3,2,2$ & Ground & & $9 / 2$ & & $7 / 2$ & 25919.0 & \\
\hline $\mathrm{C}^{12} \mathrm{H}_{3} \mathrm{C}^{12} \mathrm{H}: \mathrm{C}^{12} \mathrm{O}^{16}$ & 3- 681 & $3,0,3 \leftarrow 2,0,2$ & Ground & & & & & 25919.8 & .1 \\
\hline $\mathrm{C}^{12}{ }_{*} \mathrm{H}_{2} \mathrm{~N}^{14} \mathrm{DC}^{12}{ }_{*} \mathrm{H}_{2}$ & 4- 862 & $9,9,1 \leftarrow 9,7,2$ & Ground & & & & & 25920. & 10. \\
\hline $\mathrm{DC}^{12}: \mathrm{C}^{12} \mathrm{C}^{12} \mathrm{HO}^{16}$ & 4. 916 & $3,0,3 \leftarrow 2,0,2$ & Ground & & & & & 25920.83 & .02 \\
\hline $\mathrm{C}^{12} \mathrm{H}_{3} \mathrm{C}^{12} \mathrm{H}: \mathrm{C}^{12} \mathrm{O}^{16}$ & 3- 681 & $3,0,3 \leftarrow 2,0,2$ & Ground & & & & & 25921.0 & .1 \\
\hline $\mathrm{H}_{2} \mathrm{~B}^{11} \mathrm{H}_{2} \mathrm{~B}^{11} \mathrm{HBr}^{81}$ & 4- $\quad 42$ & $4,2,2 \leftarrow 3,2,1$ & Ground & & $7 / 2$ & & $5 / 2$ & 25921.8 & \\
\hline $\mathrm{C}^{12} \mathrm{H}_{3} \mathrm{~N}^{\mathrm{i} 4} \mathrm{O}_{2}^{16}$ & 3- 171 & Not Reported & Ground & & & & & 25923.90 & \\
\hline $\mathrm{C}^{12} \mathrm{H}_{2}\left(\mathrm{C}^{12} \mathrm{~N}^{14}\right)_{2}$ & 4- 901 & Not Reported & Ground & & & & & 25926.1 & .1 \\
\hline $\mathrm{HC}^{13}: \mathrm{C}^{12} \mathrm{C}^{12} \mathrm{DO}^{16}$ & 4- 922 & Not Reported & & & & & & 25927. & 5. \\
\hline $\mathrm{I}^{127} \mathrm{C}^{12} \mathrm{~N}^{14}$ & 4- 511 & $4 \leftarrow 3$ & Excited & $13 / 2$ & & $11 / 2$ & & 25927.66 & .1 \\
\hline $\mathrm{C}^{12}{ }_{*} \mathrm{H}_{2} \mathrm{C}^{12} \mathrm{H}_{2} \mathrm{C}^{12} \mathrm{H}_{2} \mathrm{O}^{16} *$ & $4-1091$ & $6,5,2 \leftarrow 6,3,3$ & Excited & & & & & 25928. & \\
\hline $\mathrm{DC}^{12}: \mathrm{C}^{12} \mathrm{C}^{12} \mathrm{HO}^{16}$ & 4- 916 & $3,2,2 \leftarrow 2,2,1$ & Ground & & & & & 25928.19 & .02 \\
\hline $\mathrm{C}^{12} \mathrm{DHDC}^{12} \mathrm{HDF}^{19}$ & 3. 561 & $4,1,3 \leftarrow 4,0,4$ & Ground & & & & & 25928.2 & .1 \\
\hline $\mathrm{C}^{12} \mathrm{H}_{3} \mathrm{C}^{12} \mathrm{O}^{16} \mathrm{Br}^{81}$ & 3- 352 & $5,0,5 \leftarrow 4,0,4$ & Ground & & $11 / 2$ & & $9 / 2$ & 25930.24 & .15 \\
\hline $\mathrm{Si}^{28} \mathrm{H}_{3} \mathrm{Br}^{79}$ & 4- 111 & $3, \leftarrow 2$, & Ground & & & & & 25930.32 & .08 \\
\hline $\mathrm{Li}^{\top} \mathrm{I}^{127}$ & 1 . & $1 \leftarrow 0$ & Excited & & $5 / 2$ & & $5 / 2$ & 25931.21 & 0.20 \\
\hline $\mathrm{DC}^{12}: \mathrm{C}^{12} \mathrm{C}^{12} \mathrm{HO}^{16}$ & 4- 916 & $3,2,1 \leftarrow 2,2,0$ & Ground & & & & & 25931.96 & .02 \\
\hline $\mathrm{C}^{12} \mathrm{H}_{3} \mathrm{C}^{12} \mathrm{O}^{16} \mathrm{Br}^{81}$ & 3. 352 & $5,0,5 \leftarrow 4,0,4$ & Ground & & $13 / 2$ & & $11 / 2$ & 25932.46 & .15 \\
\hline $\mathrm{C}^{12} \mathrm{H}_{3} \mathrm{C}^{12}: \mathrm{C}^{12} \mathrm{C}^{12} \mathrm{H}_{2} \mathrm{Cl}^{35}$ & 3- 901 & $9,2,7 \leftarrow 8,2,6$ & Ground & & & & & 25933.76 & .05 \\
\hline $\mathrm{C}^{12} \mathrm{H}_{3} \mathrm{C}^{12} \mathrm{H}: \mathrm{C}^{12} \mathrm{O}^{16}$ & 3- 681 & $3,2,2 \leftarrow 2,2,1$ & Ground & & & & & 25934.9 & .1 \\
\hline
\end{tabular}


Vib. State

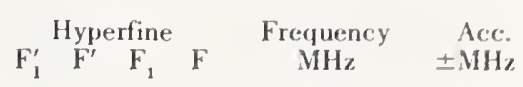

\begin{tabular}{|c|c|c|c|c|c|c|c|c|c|}
\hline $\mathrm{C}^{12} \mathrm{H}_{3} \mathrm{C}^{12} \mathrm{O}^{16} \mathrm{Br}^{81}$ & 3- 352 & $5,0,5 \leftarrow 4,0,4$ & Ground & & $9 / 2$ & & $7 / 2$ & 25936.96 & .15 \\
\hline $\mathrm{HDC}^{12}: \mathrm{C}^{12} \mathrm{~F}_{2}^{19}$ & 4. 682 & $3,2,2 \leftarrow 3,0,3$ & Ground & & & & & 25937.9 & .3 \\
\hline $3 \mathrm{~d} \cdot \mathrm{C}_{6}^{12} \mathrm{H}_{5} \mathrm{~F}^{19}$ & 4-1282 & $6,3,4 \leftarrow 5,3,3$ & Ground & & & & & 25938.4 & .1 \\
\hline $\mathrm{C}^{12} \mathrm{H}_{3} \mathrm{C}^{12} \mathrm{O}^{16} \mathrm{Br}^{81}$ & 3- 352 & $5,0,5 \leftarrow 4,0,4$ & Ground & & $7 / 2$ & & $5 / 2$ & 25938.87 & .15 \\
\hline $\mathrm{C}^{12} \mathrm{H}_{3} \mathrm{Cl}^{37}$ & 4- 423 & $1,0 \leftarrow 0,0$ & Excited & & $3 / 2$ & & $3 / 2$ & 25939.87 & .05 \\
\hline $\mathrm{HC}^{13}: \mathrm{C}^{12} \mathrm{C}^{12} \mathrm{DO}^{16}$ & 4. 922 & Not Reported & & & & & & 25940. & 5. \\
\hline $\mathrm{C}^{12} \mathrm{H}_{3} \mathrm{~N}^{14} \mathrm{O}_{2}^{16}$ & 3- 171 & Not Reported & Ground & & & & & 25942.44 & \\
\hline $\mathrm{Si}^{30} \mathrm{H}_{3} \mathrm{Cl}^{35}$ & 4-1442 & $2, \leftarrow 1$, & Ground & & & & & 25943.2 & .1 \\
\hline $\mathrm{C}^{12} \mathrm{H}_{3} \mathrm{C}^{12} \mathrm{H}: \mathrm{C}^{12} \mathrm{O}^{16}$ & 3. 681 & $3,2,1 \leftarrow 2,2,0$ & Ground & & & & & 25946.8 & .1 \\
\hline $\mathrm{C}^{12} \mathrm{H}_{2}\left(\mathrm{C}^{12} \mathrm{~N}^{14}\right)_{2}$ & 4. 901 & Not Reported & Ground & & & & & 25947.9 & .1 \\
\hline $\mathrm{C}^{12}{ }_{*} \mathrm{HC}^{12} \mathrm{D}: \mathrm{C}^{12} \mathrm{HC}^{12} \mathrm{H}: \mathrm{C}^{12} \mathrm{HN}^{14} *$ & 4-1203 & $2,2,0 \leftarrow 1,0,1$ & Ground & & & & & 25949.0 & .1 \\
\hline $\mathrm{t}-\mathrm{C}^{12} \mathrm{H}_{3} \mathrm{C}^{12} \mathrm{H}: \mathrm{C}^{12} \mathrm{HC}^{12} \mathrm{~N}^{14}$ & 3- 921 & $8,2, \leftarrow 7,2$, & Ground & & & & & 25954.3 & .5 \\
\hline $\mathrm{I}^{127} \mathrm{C}^{12} \mathrm{~N}^{14}$ & 4- 511 & $4 \leftarrow 3$ & Ground & $7 / 2$ & & $7 / 2$ & & 25954.36 & .1 \\
\hline $\mathrm{C}^{12} \mathrm{H}_{3} \mathrm{C}^{12} \mathrm{O}^{16} \mathrm{C}^{13} \mathrm{~N}^{14}$ & 3- 673 & $10,3,7 \leftarrow 10,2,8$ & Ground & & & & & 25954.59 & .2 \\
\hline $\mathrm{C}^{12} \mathrm{H}_{3} \mathrm{Cl}^{37}$ & 4- 423 & $1,0 \leftarrow 0,0$ & Excited & & $5 / 2$ & & $3 / 2$ & 25954.60 & .05 \\
\hline $\mathrm{C}^{12}{ }_{*} \mathrm{HC}^{12} \mathrm{H}: \mathrm{C}^{12} \mathrm{HC}^{12} \mathrm{H}: \mathrm{C}^{12} \mathrm{HN}^{14}{ }_{*}$ & 4-1201 & $13,9,4 \leftarrow 13,9,5$ & Ground & & & & & 25958.0 & .1 \\
\hline $\mathrm{C}^{12} \mathrm{H}_{3} \mathrm{C}^{12} \mathrm{O}^{16} \mathrm{C}^{13} \mathrm{~N}^{14}$ & 3. 673 & $10,3,7 \leftarrow 10,2,8$ & Ground & & & & & 25958.15 & .2 \\
\hline $\mathrm{S}^{32}{ }_{*} \mathrm{HC}^{12}: \mathrm{C}^{12} \mathrm{HC}^{12} \mathrm{H}: \mathrm{C}^{12}{ }_{*} \mathrm{H}$ & 4-1161 & $3,2,2 \leftarrow 2,2,1$ & Ground & & & & & 25961.8 & .1 \\
\hline $\mathrm{HC}^{13}: \mathrm{C}^{12} \mathrm{C}^{12} \mathrm{DO}^{16}$ & 4. 922 & Not Reported & & & & & & 25962. & 5. \\
\hline $\mathrm{C}^{12} \mathrm{O}^{16} \mathrm{Cl}^{35} \mathrm{Cl}^{37}$ & 4- 182 & $2,2,1 \leftarrow 1,1,0$ & Ground & $1 / 2$ & 1 & $5 / 2$ & 2 & 25962.1 & .3 \\
\hline $\mathrm{C}^{12} \mathrm{H}_{3} \mathrm{C}^{12} \mathrm{O}^{16} \mathrm{Cl}^{37}$ & 3. 362 & $5,3,2 \leftarrow 5,2,3$ & Ground & & $7 / 2$ & & $7 / 2$ & 25962.30 & .2 \\
\hline $\mathrm{C}^{12} \mathrm{O}^{16} \mathrm{Cl}^{35} \mathrm{Cl}^{37}$ & 4- 182 & $2,2,1 \leftarrow 1,1,0$ & Ground & $7 / 2$ & 5 & $5 / 2$ & 4 & 25962.5 & .3 \\
\hline $\mathrm{C}^{12} \mathrm{H}_{2}\left(\mathrm{C}^{12} \mathrm{~N}^{14}\right)_{2}$ & 4. 901 & Not Reported & Ground & & & & & 25962.7 & .1 \\
\hline $\mathrm{C}^{12} \mathrm{H}_{3} \mathrm{C}^{12} \mathrm{O}^{16} \mathrm{Cl}^{37}$ & 3- 362 & $5,3,2 \leftarrow 5,2,3$ & Ground & & $13 / 2$ & & $13 / 2$ & 25964.05 & .2 \\
\hline $\mathrm{C}^{12} \mathrm{O}^{16} \mathrm{Cl}^{35} \mathrm{Cl}^{37}$ & 4- 182 & $2,2,1 \leftarrow 1,1,0$ & Ground & $7 / 2$ & 4 & $5 / 2$ & 3 & 25964.6 & .3 \\
\hline $\mathrm{N}^{14} \mathrm{O}_{2}^{16} \mathrm{Cl}^{37}$ & 4-1462 & $3,2,2 \leftarrow 2,2,1$ & Ground & & $5 / 2$ & & $5 / 2$ & 25964.60 & \\
\hline $\mathrm{N}^{14} \mathrm{O}_{2}^{16} \mathrm{Cl}^{35}$ & 4-1461 & $3,0,3 \leftarrow 2,0,2$ & Ground & & $7 / 2$ & & $7 / 2$ & 25964.70 & \\
\hline $\mathrm{C}^{12} \mathrm{O}^{16} \mathrm{Cl}^{35} \mathrm{Cl}^{37}$ & 4. 182 & $2,2,1 \leftarrow 1,1,0$ & Ground & $3 / 2$ & 3 & $1 / 2$ & 2 & 25964.9 & .3 \\
\hline $\mathrm{C}^{12} \mathrm{O}^{16} \mathrm{Cl}^{35} \mathrm{Cl}^{37}$ & 4- 182 & $2,2,1 \leftarrow 1,1,0$ & Ground & $3 / 2$ & 3 & $5 / 2$ & 3 & 25964.9 & .3 \\
\hline $\mathrm{C}^{12} \mathrm{O}^{16} \mathrm{Cl}^{35} \mathrm{Cl}^{37}$ & 4. 182 & $2,2,1 \leftarrow 1,1,0$ & Ground & $5 / 2$ & 4 & $3 / 2$ & 3 & 25964.9 & .3 \\
\hline $\mathrm{C}^{12} \mathrm{O}^{16} \mathrm{Cl}^{35} \mathrm{Cl}^{37}$ & 4- 182 & $2,2,1 \leftarrow 1,1,0$ & Ground & $5 / 2$ & 2 & $3 / 2$ & 1 & 25966.0 & .3 \\
\hline $\mathrm{C}^{12} \mathrm{H}_{3} \mathrm{Cl}^{37}$ & 4. 423 & $1,0 \leftarrow 0,0$ & Excited & & $1 / 2$ & & $3 / 2$ & 25966.37 & .05 \\
\hline $\mathrm{C}^{12} \mathrm{O}^{16} \mathrm{Cl}^{35} \mathrm{Cl}^{37}$ & 4- 182 & $2,2,1 \leftarrow 1,1,0$ & Ground & $5 / 2$ & 3 & $3 / 2$ & 3 & 25967.0 & .3 \\
\hline $\mathrm{C}^{13} \mathrm{H}_{3} \mathrm{C}^{12}: \mathrm{C}^{12} \mathrm{Cl}^{35}$ & 4. 977 & $6,0 \leftarrow 5,0$ & Ground & & $11 / 2$ & & $9 / 2$ & 25967.36 & .04 \\
\hline $\mathrm{C}^{13} \mathrm{H}_{3} \mathrm{C}^{12}: \mathrm{C}^{12} \mathrm{Cl}^{35}$ & 4. 977 & $6,0 \leftarrow 5,0$ & Ground & & $9 / 2$ & & $7 / 2$ & 25967.36 & .04 \\
\hline $\mathrm{C}^{13} \mathrm{H}_{3} \mathrm{C}^{12} \vdots \mathrm{C}^{12} \mathrm{Cl}^{35}$ & 4- 977 & $6,0 \leftarrow 5,0$ & Ground & & $15 / 2$ & & $13 / 2$ & 25968.26 & .04 \\
\hline $\mathrm{C}^{13} \mathrm{H}_{3} \mathrm{C}^{12}: \mathrm{C}^{12} \mathrm{Cl}^{35}$ & 4. 977 & $6,0 \leftarrow 5,0$ & Ground & & $13 / 2$ & & $11 / 2$ & 25968.26 & .04 \\
\hline $\mathrm{HC}^{13}: \mathrm{C}^{12} \mathrm{C}^{12} \mathrm{DO}^{16}$ & 4. 922 & Not Reported & & & & & & 25969. & 5. \\
\hline $\mathrm{C}^{12} \mathrm{H}_{3} \mathrm{C}^{12} \mathrm{O}^{16} \mathrm{Cl}^{37}$ & 3- 362 & $5,3,2 \leftarrow 5,2,3$ & Ground & & $9 / 2$ & & $9 / 2$ & 25969.00 & .2 \\
\hline $\mathrm{Tl}^{205} \mathrm{Cl}^{37}$ & 1 . & $5 \leftarrow 4$ & Excited & & & & & 25969.04 & 0.20 \\
\hline $\mathrm{I}^{127} \mathrm{C}^{12} \mathrm{~N}^{14}$ & 4. 511 & $4 \leftarrow 3$ & Ground & $3 / 2$ & & $3 / 2$ & & 25969.58 & .1 \\
\hline $\mathrm{C}^{12} \mathrm{O}^{16} \mathrm{Cl}^{35} \mathrm{Cl}^{37}$ & 4- 182 & $2,2,1 \leftarrow 1,1,0$ & Ground & $5 / 2$ & 3 & $3 / 2$ & 2 & 25970.3 & .3 \\
\hline $\mathrm{C}^{12} \mathrm{H}_{3} \mathrm{C}^{12} \mathrm{O}^{16} \mathrm{Cl}^{37}$ & 3- 362 & $5,3,2 \leftarrow 5,2,3$ & Ground & & $11 / 2$ & & $11 / 2$ & 25970.85 & .2 \\
\hline $\mathrm{P}^{31} \mathrm{Cl}_{2}^{35} \mathrm{Cl}^{37}$ & 4-1522 & $5,5,1 \leftarrow 4,4,1$ & Ground & & & & & 25971. & 1. \\
\hline $\mathrm{C}^{12} \mathrm{H}_{3} \mathrm{~N}^{14} \mathrm{O}_{2}^{16}$ & 3- 171 & Not Reported & Ground & & & & & 25971.05 & \\
\hline
\end{tabular}




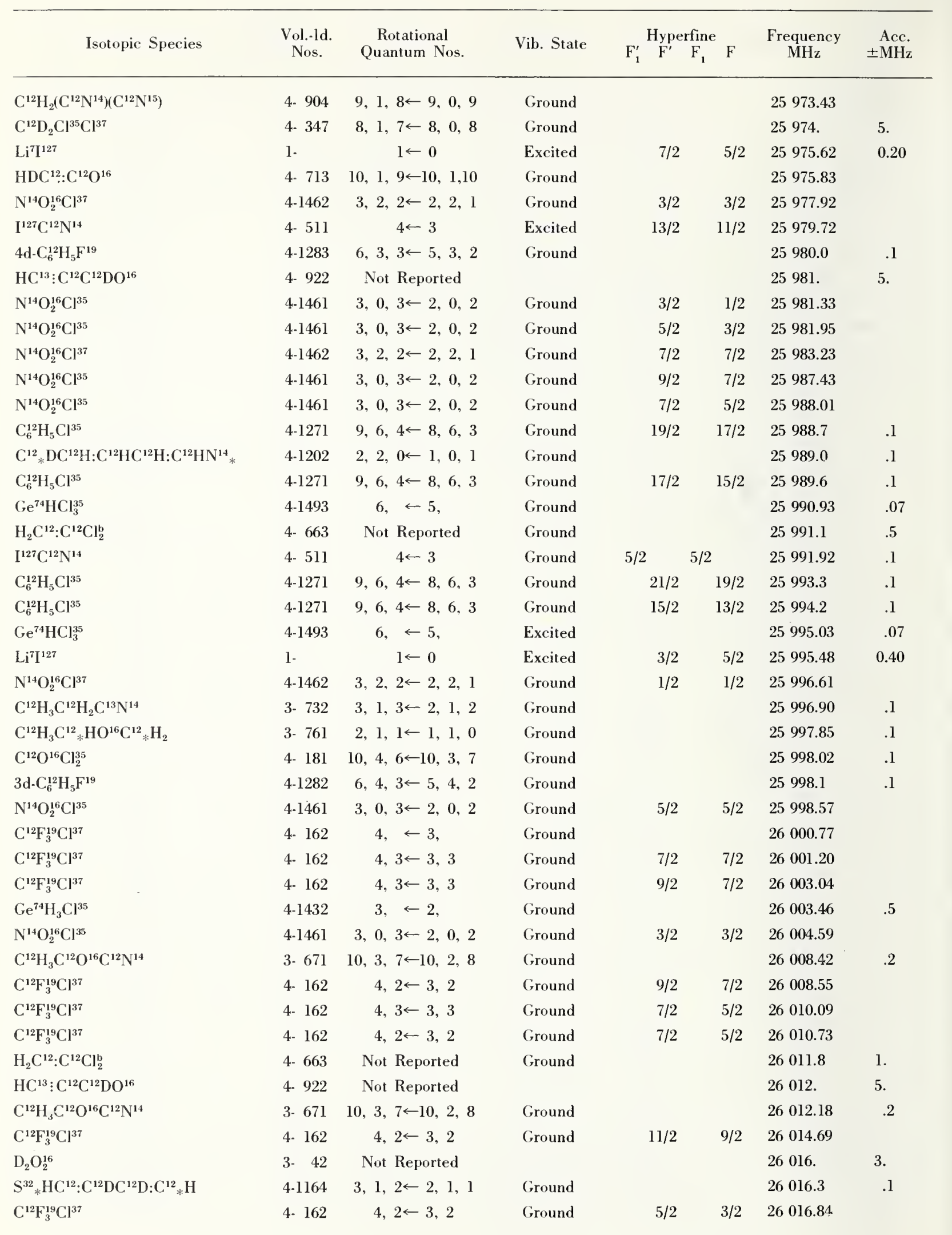


Vib. State

$F^{\prime} F^{\prime} F_{1} \quad$ Frequency Acc.

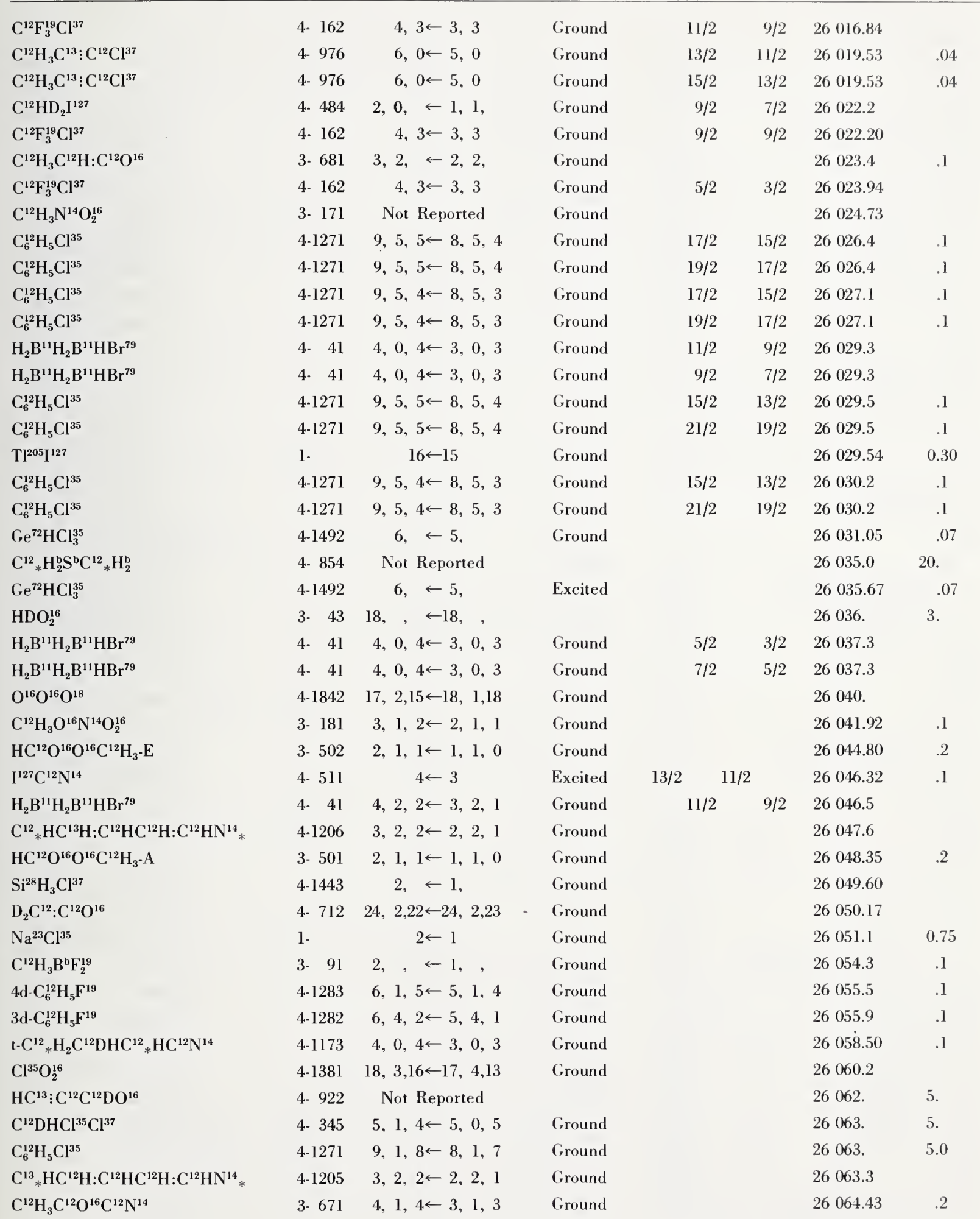




\begin{tabular}{|c|c|c|c|c|c|c|c|}
\hline Isotopic Species & $\begin{array}{l}\text { Vol.-Id. } \\
\text { Nos. }\end{array}$ & $\begin{array}{c}\text { Rotational } \\
\text { Quantum Nos. }\end{array}$ & Vib. State & 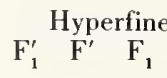 & $\mathrm{F}$ & $\begin{array}{l}\text { Frequency } \\
\qquad \mathrm{MHz}\end{array}$ & $\begin{aligned} & \text { Acc. } \\
\pm & \mathrm{MHz}\end{aligned}$ \\
\hline $\mathrm{H}_{2} \mathrm{~B}^{11} \mathrm{H}_{2} \mathrm{~B}^{11} \mathrm{HBr}^{79}$ & 4- 41 & $4,2,2 \leftarrow 3,2,1$ & Ground & $7 / 2$ & $5 / 2$ & 26065 & \\
\hline $\mathrm{Si}^{28} \mathrm{H}_{2} \mathrm{~F}_{2}^{19}$ & $4-1601$ & $4,1,3 \leftarrow 4,0,4$ & Excited & & & 26067.51 & .10 \\
\hline $\mathrm{C}^{12} \mathrm{H}_{3} \mathrm{Cl}^{37}$ & 4. 423 & $1,0 \leftarrow 0,0$ & Excited & $3 / 2$ & $3 / 2$ & 26068.83 & .10 \\
\hline $\mathrm{C}^{12} \mathrm{H}_{2}\left(\mathrm{C}^{12} \mathrm{~N}^{14}\right)_{2}$ & 4- 901 & Not Reported & Ground & & & 26069.9 & .1 \\
\hline $\mathrm{C}^{12} \mathrm{H}_{3} \mathrm{C}^{12}{ }_{*} \mathrm{H}_{2} \mathrm{O}^{16} \mathrm{C}^{12}{ }_{*} \mathrm{C}^{12} \mathrm{H}_{3}$ & 3- 951 & $16,6,11 \leftarrow 16,5,11$ & Ground & & & 26072.78 & .2 \\
\hline $\mathrm{Ge}^{70} \mathrm{HCl}_{3}^{35}$ & $4-1491$ & $6, \leftarrow 5$, & Ground & & & 26073.24 & .07 \\
\hline $\mathrm{HC}^{12}: \mathrm{C}^{12} \mathrm{C}^{12} \mathrm{HO}^{16}$ & 4- 911 & $9,0,9 \leftarrow 8,1,8$ & Ground & & & 26074.66 & .02 \\
\hline $\mathrm{C}^{12} \mathrm{H}_{2} \mathrm{Cl}^{35} \mathrm{Si}^{29} \mathrm{H}_{3}$ & 3- 234 & $7,0,7 \leftarrow 6,1,6$ & Ground & $11 / 2$ & $9 / 2$ & 26075.08 & .05 \\
\hline $\mathrm{C}^{12} \mathrm{H}_{2} \mathrm{Cl}^{35} \mathrm{Si}^{29} \mathrm{H}_{3}$ & 3- 234 & $7,0,7 \leftarrow 6,1,6$ & Ground & $17 / 2$ & $15 / 2$ & 26076.00 & .05 \\
\hline $\mathrm{C}^{12} \mathrm{H}_{3} \mathrm{Si}^{28} \mathrm{HF}_{2}^{19}-\mathrm{E}$ & 3- 192 & $2,2,0 \leftarrow 1,1,0$ & Ground & & & 26076.68 & \\
\hline $\mathrm{C}^{12} \mathrm{H}_{3} \mathrm{~S}^{32} \mathrm{H}$ & 3- 221 & Not Reported & Ground & & & 26077.4 & .1 \\
\hline $\mathrm{C}_{6}^{12} \mathrm{H}_{5} \mathrm{Cl}^{35}$ & $4-1271$ & $9,3,7 \leftarrow 8,3,6$ & Ground & $19 / 2$ & $17 / 2$ & 26078.0 & .1 \\
\hline $\mathrm{C}_{6}^{12} \mathrm{H}_{5} \mathrm{Cl}^{35}$ & $4-1271$ & $9,3,7 \leftarrow 8,3,6$ & Ground & $17 / 2$ & $15 / 2$ & 26078.0 & .1 \\
\hline $\mathrm{C}^{12} \mathrm{H}_{2} \mathrm{Cl}^{35} \mathrm{Si}^{29} \mathrm{H}_{3}$ & 3- 234 & $7,0,7 \leftarrow 6,1,6$ & Ground & $13 / 2$ & $11 / 2$ & 26078.28 & .05 \\
\hline $\mathrm{C}^{12} \mathrm{H}_{3} \mathrm{Si}^{28} \mathrm{HF}_{2}^{19}-\mathrm{A}$ & 3. 191 & $2,2,0 \leftarrow 1,1,0$ & Ground & & & 26078.78 & \\
\hline $\mathrm{C}_{6}^{12} \mathrm{H}_{5} \mathrm{Cl}^{35}$ & $4-1271$ & $9,3,7 \leftarrow 8,3,6$ & Ground & $21 / 2$ & $19 / 2$ & 26079.2 & .1 \\
\hline $\mathrm{C}_{6}^{12} \mathrm{H}_{5} \mathrm{Cl}^{35}$ & $4-1271$ & $9,3,7 \leftarrow 8,3,6$ & Ground & $15 / 2$ & $13 / 2$ & 26079.2 & .1 \\
\hline $\mathrm{C}^{12} \mathrm{H}_{2} \mathrm{Cl}^{35} \mathrm{Si}^{29} \mathrm{H}_{3}$ & 3- 234 & $7,0,7 \leftarrow 6,1,6$ & Ground & $15 / 2$ & $13 / 2$ & 26079.28 & .05 \\
\hline $\mathrm{C}^{12} \mathrm{H}_{2}: \mathrm{C}^{12} \mathrm{HC}^{12} \mathrm{HO}^{16}$ & 3- 691 & $3,1,3 \leftarrow 2,1,2$ & Ground & & & 26079.47 & \\
\hline $\mathrm{T}^{205} \mathrm{Cl}^{37}$ & $1-$ & $5 \leftarrow 4$ & Ground & & & 26079.87 & 0.10 \\
\hline $\mathrm{Ge}^{70} \mathrm{HCl}_{3}^{35}$ & $4-1491$ & $6, \leftarrow 5$, & Excited & & & 26080.10 & .07 \\
\hline $\mathrm{t}-\mathrm{C}^{12}{ }_{*} \mathrm{H}_{2} \mathrm{C}^{12} \mathrm{DHC}^{12}{ }_{*} \mathrm{HC}^{12} \mathrm{~N}^{14}$ & $4-1173$ & $4,2,3 \leftarrow 3,2,2$ & Ground & & & 26080.94 & .1 \\
\hline $\mathrm{C}^{12}{ }_{*} \mathrm{H}_{2} \mathrm{C}^{12} \mathrm{H}_{2} \mathrm{C}^{12} \mathrm{H}_{2} \mathrm{O}_{*}^{16_{1}}$ & $4-1091$ & $6,5,2 \leftarrow 6,3,3$ & Ground & & & 26081. & \\
\hline $\mathrm{C}^{12} \mathrm{H}_{3} \mathrm{Cl}^{37}$ & 4- 423 & $1,0 \leftarrow 0,0$ & Excited & $5 / 2$ & $3 / 2$ & 26082.83 & .10 \\
\hline $\mathrm{HDO}_{2}^{16}$ & 3- 43 & $18, \quad \leftarrow 18, \quad$, & & & & 26084 & 3. \\
\hline $\mathrm{C}_{6}^{12} \mathrm{H}_{5} \mathrm{Cl}^{35}$ & 4-1271 & $9,4,6 \leftarrow 8,4,5$ & Ground & $19 / 2$ & $17 / 2$ & 26086.9 & .1 \\
\hline $\mathrm{C}_{6}^{12} \mathrm{H}_{5} \mathrm{Cl}^{35}$ & $4-1271$ & $9,4,6 \leftarrow 8,4,5$ & Ground & $17 / 2$ & $15 / 2$ & 26086.9 & .1 \\
\hline $\mathrm{t}-\mathrm{C}^{12}{ }_{*} \mathrm{H}_{2} \mathrm{C}^{12} \mathrm{DHC}^{12}{ }_{*} \mathrm{HC}^{12} \mathrm{~N}^{14}$ & $4-1173$ & $4,3,2 \leftarrow 3,3,1$ & Ground & & & 26087.74 & .1 \\
\hline $\mathrm{t}-\mathrm{C}^{12}{ }_{*} \mathrm{H}_{2} \mathrm{C}^{12} \mathrm{DHC}^{12}{ }_{*} \mathrm{HC}^{12} \mathrm{~N}^{14}$ & $4-1173$ & $4,3,1 \leftarrow 3,3,0$ & Ground & & & 26087.74 & .1 \\
\hline $\mathrm{C}_{6}^{12} \mathrm{H}_{5} \mathrm{Cl}^{35}$ & $4-1271$ & $9,4,6 \leftarrow 8,4,5$ & Ground & $21 / 2$ & $19 / 2$ & 26088.9 & .1 \\
\hline $\mathrm{C}_{6}^{12} \mathrm{H}_{5} \mathrm{Cl}^{35}$ & $4-1271$ & $9,4,6 \leftarrow 8,4,5$ & Ground & $15 / 2$ & $13 / 2$ & 26088.9 & .1 \\
\hline $\mathrm{C}^{12} \mathrm{H}_{2}: \mathrm{C}^{12} \mathrm{HC}^{12} \mathrm{~F}^{19}: \mathrm{C}^{12} \mathrm{H}_{2}$ & 3- 911 & $6,1,5 \leftarrow 6,0,6$ & Ground & & & 26089.45 & .03 \\
\hline $\mathrm{C}^{12} \mathrm{H}_{2}: \mathrm{C}^{12} \mathrm{HC}^{12} \mathrm{~F}^{19}: \mathrm{C}^{12} \mathrm{H}_{2}$ & 3. 911 & $10,3,7 \leftarrow 10,2,8$ & Ground & & & 26091.38 & .03 \\
\hline$\left(\mathrm{C}^{12} \mathrm{H}_{3}\right)_{3} \mathrm{C}^{12} \mathrm{C}^{12}: \mathrm{C}^{13} \mathrm{H}$ & $3-1073$ & $5, \leftarrow 4$ & Ground & & & 26093.5 & .1 \\
\hline $\mathrm{C}^{12} \mathrm{H}_{3} \mathrm{C}^{37}$ & 4. 423 & $1,0 \leftarrow 0,0$ & Excited & $1 / 2$ & $3 / 2$ & 26094.56 & .10 \\
\hline $\mathrm{C}^{12}{ }_{*} \mathrm{HC}^{12} \mathrm{D}: \mathrm{C}^{12} \mathrm{HC}^{12} \mathrm{H}: \mathrm{C}^{12} \mathrm{HN}^{14}{ }_{*}$ & $4-1203$ & $3,1,2 \leftarrow 2,1,1$ & Ground & & & 26098.0 & .1 \\
\hline $\mathrm{HC}^{13}: \mathrm{C}^{12} \mathrm{C}^{12} \mathrm{DO}^{16}$ & 4. 922 & Not Reported & & & & 26099. & 5. \\
\hline $\mathrm{C}^{12} \mathrm{H}_{3} \mathrm{O}^{16} \mathrm{~N}^{14} \mathrm{O}_{2}^{16}$ & 3- 181 & $3,1,2 \leftarrow 2,1,1$ & Ground & & & 26101.23 & .1 \\
\hline $\mathrm{s}-\mathrm{C}^{12} \mathrm{H}_{2} \mathrm{DC}^{12} \mathrm{HO}^{16}$ & 3- 473 & Not Reported & & & & 26105.14 & \\
\hline $\mathrm{t} \cdot \mathrm{C}^{12}{ }_{*} \mathrm{H}_{2} \mathrm{C}^{12} \mathrm{DHC}^{12}{ }_{*} \mathrm{HC}^{12} \mathrm{~N}^{14}$ & $4-1173$ & $4,2,2 \leftarrow 3,2,1$ & Ground & & & 26105.89 & .1 \\
\hline $\mathrm{C}^{12} \mathrm{H}_{3} \mathrm{C}^{12} \mathrm{~F}^{19}: \mathrm{C}^{12} \mathrm{H}_{2}$ & 3. 721 & $8,5,3 \leftarrow 8,5,4$ & Ground & & & 26107.98 & .1 \\
\hline $\mathrm{C}^{12} \mathrm{H}_{3} \mathrm{C}^{12} \mathrm{O}^{16} \mathrm{Br}^{79}$ & 3- 351 & $5,0,5 \leftarrow 4,0,4$ & Ground & $11 / 2$ & $9 / 2$ & 26108.30 & .15 \\
\hline $\mathrm{C}_{6}^{12} \mathrm{H}_{5} \mathrm{Cl}^{35}$ & $4-1271$ & $9,4,5 \leftarrow 8,4,4$ & Ground & $19 / 2$ & $17 / 2$ & 26110.3 & .1 \\
\hline $\mathrm{C}_{6}^{12} \mathrm{H}_{5} \mathrm{Cl}^{35}$ & $4-1271$ & $9,4,5 \leftarrow 8,4,4$ & Ground & $17 / 2$ & $15 / 2$ & 26110.3 & .1 \\
\hline $\mathrm{S}^{32}{ }_{*} \mathrm{HC}^{12}: \mathrm{C}^{12} \mathrm{DC}^{12} \mathrm{D}: \mathrm{C}^{12}{ }_{*} \mathrm{H}$ & $4-1164$ & $3,2,1 \leftarrow 2,2,0$ & Ground & & & 26110.8 & .1 \\
\hline
\end{tabular}




\begin{tabular}{|c|c|c|c|c|c|c|c|c|c|}
\hline Isotopic Species & $\begin{array}{l}\text { Vol.-Id. } \\
\text { Nos. }\end{array}$ & $\begin{array}{c}\text { Rotational } \\
\text { Quantum Nos. }\end{array}$ & Vib. State & $F_{i}^{\prime}$ & $\begin{array}{l}\text { Нype } \\
\mathrm{F}^{\prime}\end{array}$ & $\begin{array}{l}\text { rfine } \\
\mathrm{F}_{1}\end{array}$ & F & $\begin{array}{l}\text { Frequency } \\
\mathrm{MHz}\end{array}$ & $\begin{aligned} & \text { Ace. } \\
\pm & \mathrm{MHz}\end{aligned}$ \\
\hline $\mathrm{C}^{12} \mathrm{H}_{3} \mathrm{C}^{12} \mathrm{O}^{16} \mathrm{Br}^{79}$ & 3- 351 & $5,0,5 \leftarrow 4,0,4$ & Ground & & $13 / 2$ & & $11 / 2$ & 26111.40 & .15 \\
\hline $\mathrm{C}_{6}^{12} \mathrm{H}_{5} \mathrm{Cl}^{35}$ & $4-1271$ & $9,4,5 \leftarrow 8,4,4$ & Ground & & $21 / 2$ & & $19 / 2$ & 26112.3 & .1 \\
\hline $\mathrm{C}_{6}^{12} \mathrm{H}_{5} \mathrm{Cl}^{35}$ & 4-1271 & $9,4,5 \leftarrow 8,4,4$ & Ground & & $15 / 2$ & & $13 / 2$ & 26112.3 & .1 \\
\hline g- $\mathrm{C}^{12} \mathrm{H}_{3} \mathrm{C}^{12} \mathrm{H}_{2} \mathrm{C}^{12} \mathrm{H}_{2} \mathrm{Cl}^{37}$ & 3- 774 & $10,1,9 \leftarrow 10,0,10$ & Ground & & & & & 26115.03 & .2 \\
\hline $\mathrm{C}^{12} \mathrm{Cl}^{35} \mathrm{Cl}_{2}^{37} \mathrm{C}^{12} \mathrm{~N}^{14}$ & 4- 583 & $8, \quad \leftarrow 7, \quad$, & Ground & & & & & 26115.9 & 1.0 \\
\hline $\mathrm{H}_{2} \mathrm{C}^{12}: \mathrm{C}^{12} \mathrm{~F}_{2}^{19}$ & 4- 681 & Not Reported & & & & & & 26116.4 & .3 \\
\hline $\mathrm{C}^{12} \mathrm{H}_{3} \mathrm{C}^{12} \mathrm{O}^{16} \mathrm{Br}^{79}$ & 3- 351 & $5,0,5 \leftarrow 4,0,4$ & Ground & & $9 / 2$ & & $7 / 2$ & 26116.67 & .15 \\
\hline $\mathrm{Tl}^{203} \mathrm{Cl}^{37}$ & 1 - & $5 \leftarrow 4$ & Ground & & & & & 26119.36 & 0.10 \\
\hline $\mathrm{C}^{12} \mathrm{H}_{3} \mathrm{C}^{12} \mathrm{O}^{16} \mathrm{Br}^{79}$ & 3- 351 & $5,0,5 \leftarrow 4,0,4$ & Ground & & $7 / 2$ & & $5 / 2$ & 26119.37 & .15 \\
\hline $\mathrm{HC}^{13}: \mathrm{C}^{12} \mathrm{C}^{12} \mathrm{DO}^{16}$ & 4- 922 & Not Reported & & & & & & 26120. & 5. \\
\hline $\mathrm{C}^{12} \mathrm{H}_{3} \mathrm{O}^{16} \mathrm{H}$ & 3- 211 & Not Reported & Ground & & & & & 26120.50 & .1 \\
\hline $\mathrm{C}^{12} \mathrm{H}_{3} \mathrm{C}^{12} \mathrm{H}_{2} \mathrm{C}^{12} \mathrm{~N}^{14}$ & 3- 731 & $3,1,3 \leftarrow 2,1,2$ & Ground & & & & & 26124.57 & .1 \\
\hline $\mathrm{C}^{12} \mathrm{H}_{3} \mathrm{C}^{12} \mathrm{~F}^{19}: \dot{\mathrm{C}}^{12} \mathrm{H}_{2}$ & 3- 721 & $8,5,3 \leftarrow 8,5,4$ & Ground & & & & & 26125.28 & .1 \\
\hline $\mathrm{C}^{12} \mathrm{D}_{3} \mathrm{C}^{12} \mathrm{O}^{16} \mathrm{Cl}^{35}$ & 3- 363 & $4,0,4 \leftarrow 3,1,3$ & Ground & & $7 / 2$ & & $5 / 2$ & 26125.90 & \\
\hline $\mathrm{C}^{12} \mathrm{D}_{3} \mathrm{C}^{12} \mathrm{O}^{16} \mathrm{Cl}^{35}$ & 3- 363 & $4,0,4 \leftarrow 3,1,3$ & Ground & & $9 / 2$ & & $7 / 2$ & 26125.90 & \\
\hline $\mathrm{C}^{12} \mathrm{D}_{3} \mathrm{C}^{12} \mathrm{O}^{16} \mathrm{Cl}^{35}$ & 3- 363 & $4,0,4 \leftarrow 3,1,3$ & Ground & & $5 / 2$ & & $3 / 2$ & 26128.35 & \\
\hline $\mathrm{C}^{12} \mathrm{D} \mathrm{C}^{12} \mathrm{O}^{16} \mathrm{Cl}^{35}$ & 3- 363 & $4,0,4 \leftarrow 3,1,3$ & Ground & & $11 / 2$ & & $9 / 2$ & 26128.35 & \\
\hline $\mathrm{HC}^{13}: \mathrm{C}^{12} \mathrm{C}^{12} \mathrm{DO}^{16}$ & 4- 922 & Not Reported & & & & & & 26133. & 5. \\
\hline $\mathrm{C}^{12} \mathrm{H}_{3} \mathrm{~N}^{14} \mathrm{H}_{2}$ & 3- 261 & Not Reported & Ground & & & & & 26134.72 & .1 \\
\hline $\mathrm{C}^{12}{ }_{*} \mathrm{DC}^{12} \mathrm{H}: \mathrm{C}^{12} \mathrm{HC}^{12} \mathrm{H}: \mathrm{C}^{12} \mathrm{HN}^{14} *$ & 4-1202 & $3,1,2 \leftarrow 2,1,1$ & Ground & & & & & 26135.7 & .1 \\
\hline $\mathrm{C}^{12} \mathrm{Cl}^{35} \mathrm{Cl}_{2}^{37} \mathrm{C}^{12} \mathrm{~N}^{14}$ & 4- 583 & $8, \quad \leftarrow 7, \quad$, & Excited & & & & & 26142.3 & 1.0 \\
\hline $\mathrm{C}^{12} \mathrm{H}_{3} \mathrm{C}^{12} \mathrm{H}_{2} \mathrm{C}^{12} \mathrm{~N}^{14}$ & 3- 731 & $3,1,3 \leftarrow 2,1,2$ & Excited & & & & & 26143.64 & .1 \\
\hline $\mathrm{C}^{12} \mathrm{H}_{3} \mathrm{C}^{12} \mathrm{H}_{2} \mathrm{C}^{12} \mathrm{~N}^{14}$ & 3- 731 & $3,1,3 \leftarrow 2,1,2$ & Ground & & & & & 26144.2 & .2 \\
\hline $\mathrm{C}^{12} \mathrm{H}_{3} \mathrm{C}^{12} \mathrm{O}^{16} \mathrm{~F}^{19}$ & 3- 391 & Not Reported & Ground & & & & & 26144.27 & .2 \\
\hline $\mathrm{C}^{12} \mathrm{H}_{3} \mathrm{~S}^{32} \mathrm{H}$ & $3 \cdot 221$ & Not Reported & Ground & & & & & 26144.7 & .1 \\
\hline $\mathrm{C}_{8}^{12} \mathrm{H}_{13} \mathrm{Br}^{79}$ & 4-1331 & $18, \leftarrow 17$ & Excited & & & & & 26146. & \\
\hline $\mathrm{C}^{12} \mathrm{O}^{16} \mathrm{Cl}^{35} \mathrm{Cl}^{37}$ & 4- 182 & $7,1,6 \leftarrow 7,0,7$ & Ground & & & & & 26146.5 & .3 \\
\hline $\mathrm{C}^{12} \mathrm{H}_{3} \mathrm{C}^{12} \mathrm{H}_{2} \mathrm{O}^{16} \mathrm{H}$ & 3- 581 & Not Reported & & & & & & 26148.24 & .01 \\
\hline $\mathrm{P}^{31} \mathrm{Cl}_{3}^{35}$ & 4-1521 & $5, \leftarrow 4$ & Excited & & & & & 26152. & 10. \\
\hline $\mathrm{C}^{12}{ }_{*} \mathrm{H}_{2} \mathrm{C}^{12} \mathrm{H}_{2} \mathrm{C}^{12} \mathrm{H}_{2} \mathrm{O}^{16} *$ & 4-1091 & $7,6,2 \leftarrow 7,4,3$ & Excited & & & & & 26152.0 & .1 \\
\hline $\mathrm{C}^{12} \mathrm{O}^{16} \mathrm{Cl}_{2}^{35}$ & 4- 181 & $2,2,1 \leftarrow 1,1,0$ & Ground & $7 / 2$ & 3 & $3 / 2$ & 3 & 26158.02 & .1 \\
\hline $\mathrm{C}^{12} \mathrm{O}^{16} \mathrm{Cl}_{2}^{35}$ & 4- 181 & $2,2,1 \leftarrow 1,1,0$ & Ground & $3 / 2$ & 2 & $3 / 2$ & 3 & 26160.72 & .1 \\
\hline $\mathrm{C}^{12} \mathrm{O}^{16} \mathrm{Cl}_{2}^{35}$ & 4- 181 & $2,2,1 \leftarrow 1,1,0$ & Ground & $7 / 2$ & 3 & $3 / 2$ & 2 & 26161.73 & .1 \\
\hline $\mathrm{H}_{2} \mathrm{~N}^{14} \mathrm{~N}^{14} \mathrm{H}_{2}$ & 3. 51 & Not Reported & & & & & & 26162.06 & \\
\hline $\mathrm{C}^{12} \mathrm{O}^{16} \mathrm{Cl}_{2}^{35}$ & 4- 181 & $2,2,1 \leftarrow 1,1,0$ & Ground & & 2 & & 1 & 26163.24 & .1 \\
\hline $\mathrm{C}^{12} \mathrm{O}^{16} \mathrm{Cl}_{2}^{35}$ & 4. 181 & $2,2,1 \leftarrow 1,1,0$ & Ground & $3 / 2$ & 2 & $3 / 2$ & 2 & 26164.10 & .1 \\
\hline $\mathrm{C}^{12} \mathrm{H}_{3} \mathrm{Cl}^{37}$ & 4- 423 & $1,0 \leftarrow 0,0$ & Ground & & $3 / 2$ & & $3 / 2$ & 26164.48 & .05 \\
\hline $\mathrm{C}^{12} \mathrm{H}_{3} \mathrm{C}^{12} \mathrm{O}^{16} \mathrm{Cl}^{37}$ & 3- 362 & $3,1,3 \leftarrow 2,0,2$ & Ground & & $3 / 2$ & & $1 / 2$ & 26165.30 & .2 \\
\hline $\mathrm{C}^{12} \mathrm{O}^{16} \mathrm{Cl}_{2}^{35}$ & 4. 181 & $2,2,1 \leftarrow 1,1,0$ & Ground & $5 / 2$ & 1 & $3 / 2$ & 0 & 26165.52 & .1 \\
\hline $\mathrm{C}^{12} \mathrm{O}^{16} \mathrm{Cl}_{2}^{35}$ & 4- 181 & $2,2,1 \leftarrow 1,1,0$ & Ground & $1 / 2$ & 1 & $5 / 2$ & 2 & 26165.52 & .1 \\
\hline $\mathrm{C}^{12} \mathrm{H}_{2}: \mathrm{C}^{12} \mathrm{HC}^{12} \mathrm{HO}^{16}$ & 3. 691 & $3,1,3 \leftarrow 2,1,2$ & Ground & & & & & 26165.87 & \\
\hline $\mathrm{C}^{12} \mathrm{O}^{16} \mathrm{Cl}_{2}^{35}$ & 4- 181 & $2,2,1 \leftarrow 1,1,0$ & Ground & $7 / 2$ & 5 & $5 / 2$ & 4 & 26165.95 & .1 \\
\hline $\mathrm{C}^{12} \mathrm{O}^{16} \mathrm{Cl}_{2}^{35}$ & 4- 181 & $2,2,1 \leftarrow 1,1,0$ & Ground & $1 / 2$ & 2 & $5 / 2$ & 2 & 26167.72 & .1 \\
\hline $\mathrm{C}^{12} \mathrm{O}^{16} \mathrm{Cl}_{2}^{35}$ & 4. 181 & $2,2,1 \leftarrow 1,1,0$ & Ground & $5 / 2$ & 4 & $3 / 2$ & 3 & 26168.50 & .1 \\
\hline $\mathrm{C}^{12} \mathrm{H}_{3} \mathrm{C}^{12} \mathrm{O}^{16} \mathrm{Cl}^{37}$ & 3. 362 & $3,1,3 \leftarrow 2,0,2$ & Ground & & $9 / 2$ & & $7 / 2$ & 26169.10 & .2 \\
\hline
\end{tabular}




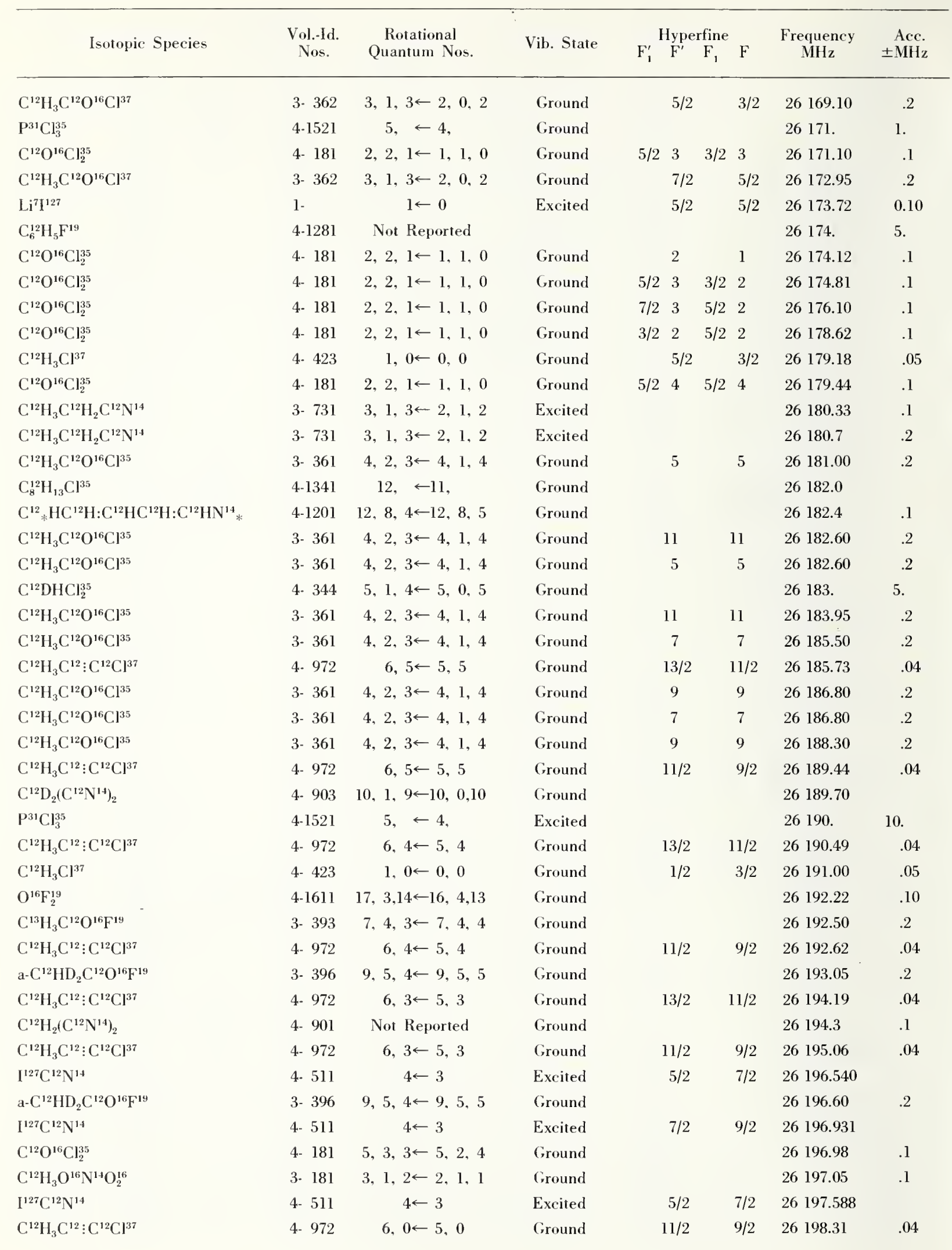




\begin{tabular}{|c|c|c|c|c|c|c|c|c|}
\hline \multirow{3}{*}{$\begin{array}{r}\text { Isotopic Species } \\
\mathrm{C}^{12} \mathrm{H}_{3} \mathrm{C}^{12}: \mathrm{C}^{12} \mathrm{Cl}^{37}\end{array}$} & \multirow{3}{*}{$\begin{array}{l}\text { Vol.-Id. } \\
\text { Nos. } \\
\text { 4- } 972\end{array}$} & \multirow{3}{*}{$\begin{array}{c}\text { Rotational } \\
\text { Quantum Nos. } \\
6,0 \leftarrow 5,0\end{array}$} & \multirow{3}{*}{$\begin{array}{c}\text { Vib. State } \\
\text { Ground }\end{array}$} & \multicolumn{3}{|c|}{ Ilyperfine } & \multirow{2}{*}{$\begin{array}{c}\text { Frequency } \\
\text { MHz }\end{array}$} & \multirow{2}{*}{$\begin{aligned} & \text { Acc. } \\
& \pm \mathrm{MHz}\end{aligned}$} \\
\hline & & & & $\mathrm{F}_{1}^{\prime} \quad \mathrm{F}^{\prime}$ & & $\mathrm{F}$ & & \\
\hline & & & & $9 / 2$ & & $7 / 2$ & 26198.31 & .04 \\
\hline $\mathrm{C}^{12} \mathrm{H}_{3} \mathrm{C}^{12}: \mathrm{C}^{12} \mathrm{Cl}^{37}$ & 4. 972 & $6,2 \leftarrow 5,2$ & Ground & $15 / 2$ & & $13 / 2$ & 26198.64 & .04 \\
\hline $\mathrm{C}^{12} \mathrm{H}_{3} \mathrm{C}^{12}: \mathrm{C}^{12} \mathrm{Cl}^{37}$ & 4- 972 & $6,2 \leftarrow 5,2$ & Ground & $13 / 2$ & & $11 / 2$ & 26198.64 & .04 \\
\hline $\mathrm{C}^{12} \mathrm{H}_{3} \mathrm{C}^{12} \vdots \mathrm{C}^{12} \mathrm{Cl}^{37}$ & 4. 972 & $6,0 \leftarrow 5,0$ & Ground & $15 / 2$ & & $13 / 2$ & 26199.01 & .04 \\
\hline $\mathrm{C}^{12} \mathrm{H}_{3} \mathrm{C}^{12}: \mathrm{C}^{12} \mathrm{Cl}^{37}$ & 4. 972 & $6,0 \leftarrow 5,0$ & Ground & $13 / 2$ & & $11 / 2$ & 26199.01 & .04 \\
\hline $\mathrm{C}^{12} \mathrm{H}_{3} \mathrm{C}^{12}: \mathrm{C}^{12} \mathrm{Cl}^{37}$ & 4. 972 & $6,3 \leftarrow 5,3$ & Ground & $9 / 2$ & & $7 / 2$ & 26199.09 & .04 \\
\hline $\mathrm{C}^{12}{ }_{*} \mathrm{HC}^{12} \mathrm{H}: \mathrm{C}^{12} \mathrm{DC}^{12} \mathrm{H}: \mathrm{C}^{12} \mathrm{HN}^{14}{ }_{*}$ & 4-1204 & $2,2,0 \leftarrow 1,0,1$ & Ground & & & & 26199.3 & .1 \\
\hline $\mathrm{C}^{12} \mathrm{H}_{3} \mathrm{C}^{12}: \mathrm{C}^{12} \mathrm{Cl}^{37}$ & 4. 972 & $6,4 \leftarrow 5,4$ & Ground & $9 / 2$ & & $7 / 2$ & 26199.74 & .04 \\
\hline $\mathrm{C}_{*}^{\mathrm{b}} \mathrm{H}_{2}^{\mathrm{b}} \mathrm{N}^{\mathrm{b}} \mathrm{H}^{\mathrm{b}} \mathrm{C}_{*}^{\mathrm{b}} \mathrm{H}_{2}^{\mathrm{b}}$ & 4. 863 & Not Reported & & & & & 26200 & 10. \\
\hline $\mathrm{C}^{12} \mathrm{H}_{3} \mathrm{C}^{12}: \mathrm{C}^{12} \mathrm{Cl}^{37}$ & 4. 972 & $6,5 \leftarrow 5,5$ & Ground & $9 / 2$ & & $7 / 2$ & 26200.63 & .04 \\
\hline $\mathrm{C}^{12} \mathrm{H}_{3} \mathrm{~B}^{\mathrm{b}} \mathrm{F}_{2}^{19}$ & 3. 91 & $2, \quad \leftarrow 1$, & Ground & & & & 26201.6 & .1 \\
\hline $\mathrm{C}^{12} \mathrm{O}^{16} \mathrm{Cl}^{35} \mathrm{Cl}^{37}$ & 4. 182 & $5,3,3 \leftarrow 5,2,4$ & Ground & & & & 26201.9 & .3 \\
\hline $\mathrm{D}_{2} \mathrm{C}^{12}: \mathrm{C}^{12} \mathrm{~F}_{2}^{19}$ & 4. 683 & $4,3,2 \leftarrow 4,2,4$ & Ground & & & & 26203.4 & .3 \\
\hline $\mathrm{C}^{12}{ }_{*} \mathrm{HC}^{12} \mathrm{H}: \mathrm{C}^{12} \mathrm{DC}^{12} \mathrm{H}: \mathrm{C}^{12} \mathrm{HN}^{14} *$ & 4-1 204 & $3,1,2 \leftarrow 2,1,1$ & Ground & & & & $26 \cdot 204.2$ & .1 \\
\hline $\mathrm{C}^{12} \mathrm{H}_{3} \mathrm{O}^{16} \mathrm{~N}^{14} \mathrm{O}_{2}^{16}$ & 3- 181 & $3,1,2 \leftarrow 2,1,1$ & Ground & & & & 26208.24 & .1 \\
\hline c- $\mathrm{C}^{12}{ }_{*} \mathrm{H}_{2} \mathrm{C}^{12} \mathrm{HDC}^{12}{ }_{*} \mathrm{HC}^{12} \mathrm{~N}^{14}$ & $4 \cdot 1172$ & $4,1,4 \leftarrow 3,1,3$ & Ground & & & & 26208.77 & .1 \\
\hline $\mathrm{P}^{31} \mathrm{Cl}_{3}^{35}$ & 4-1521 & $5, \leftarrow 4$ & Excited & & & & 26210 & 10. \\
\hline $\mathrm{C}^{13} \mathrm{H}_{3} \mathrm{C}^{12} \mathrm{O}^{16} \mathrm{~F}^{19}$ & 3- 393 & $2,0,2 \leftarrow 1,0,1$ & Ground & & & & 26214.86 & .2 \\
\hline $\mathrm{C}^{12}{ }_{*} \mathrm{H}_{2} \mathrm{C}^{12} \mathrm{H}_{2} \mathrm{C}^{12} \mathrm{H}_{2} \mathrm{O}^{16} *$ & 4-1091 & $7,6,2 \leftarrow 7,4,3$ & Excited & & & & 26215 . & \\
\hline $\mathrm{C}^{12} \mathrm{H}_{2} \mathrm{Cl}^{37} \mathrm{~F}^{19}$ & 4- 332 & $14,2,12 \longleftarrow 13,3,11$ & Ground & & & & 26215.43 & .1 \\
\hline $\mathrm{I}^{127} \mathrm{C}^{12} \mathrm{~N}^{14}$ & 4- 511 & $4 \leftarrow 3$ & Excited & $5 / 2$ & & $7 / 2$ & 26216.380 & \\
\hline$I^{127} \mathrm{C}^{12} \mathrm{~N}^{14}$ & 4- 511 & $4 \leftarrow 3$ & Excited & $7 / 2$ & & $9 / 2$ & 26216.771 & \\
\hline $\mathrm{C}^{12} \mathrm{H}_{2} \mathrm{Cl}^{37} \mathrm{~F}^{19}$ & 4- 332 & $14,2,12 \longleftarrow 13,3,11$ & Ground & & & & 26216.84 & .1 \\
\hline$I^{127} \mathrm{C}^{12} \mathrm{~N}^{14}$ & 4. 511 & $4 \leftarrow 3$ & Ground & $5 / 211 / 2$ & $7 / 21$ & $11 / 2$ & 26217.022 & \\
\hline $\mathrm{Li}^{7} \mathrm{I}^{127}$ & 1 - & $1 \leftarrow 0$ & Excited & $7 / 2$ & & $5 / 2$ & 26217.11 & 0.10 \\
\hline $\mathrm{I}^{127} \mathrm{C}^{12} \mathrm{~N}^{14}$ & 4. 511 & $4 \leftarrow 3$ & Excited & $5 / 2$ & & $7 / 2$ & 26217.428 & \\
\hline $\mathrm{C}^{13} \mathrm{H}_{3} \mathrm{C}^{12} \mathrm{O}^{16} \mathrm{~F}^{19}$ & 3- 393 & $2,0,2 \leftarrow 1,0,1$ & Ground & & & & 26218.70 & .2 \\
\hline $\mathrm{C}^{12} \mathrm{H}_{3} \mathrm{O}^{16} \mathrm{~N}^{14} \mathrm{O}_{2}^{16}$ & 3- 181 & $3,1,2 \leftarrow 2,1,1$ & Ground & & & & 26219.05 & .1 \\
\hline $\mathrm{DC}^{12}: \mathrm{C}^{12} \mathrm{C}^{13} \mathrm{HO}^{16}$ & 4- 919 & $3,1,2 \leftarrow 2,1,1$ & Ground & & & & 26221.04 & .02 \\
\hline $\mathrm{a}-\left(\mathrm{C}^{12} \mathrm{H}_{2} \mathrm{D}\right)\left(\mathrm{C}^{12} \mathrm{H}_{3}\right) \mathrm{O}^{16}$ & 3. 597 & $1,1,0 \leftarrow 1,0,1$ & Ground & & & & 26226.9 & .2 \\
\hline $\mathrm{C}^{13} \mathrm{H}_{3} \mathrm{C}^{12} \mathrm{O}^{16} \mathrm{~F}^{19}$ & 3- 393 & $7,4,3 \leftarrow 7,4,4$ & Ground & & & & 26228.50 & .2 \\
\hline $\mathrm{C}^{12} \mathrm{H}_{3} \mathrm{O}^{16} \mathrm{~N}^{14} \mathrm{O}_{2}^{16}$ & 3- 181 & $3,1,2 \leftarrow 2,1,1$ & Ground & & & & 26228.62 & .1 \\
\hline $\mathrm{C}^{12} \mathrm{H}_{2}: \mathrm{C}^{12} \mathrm{HC}^{12} \mathrm{~F}^{19}: \mathrm{C}^{12} \mathrm{H}_{2}$ & 3- 911 & $6,1,5 \leftarrow 6,0,6$ & Excited & & & & 26231.29 & .03 \\
\hline $\operatorname{Li}^{7} I^{127}$ & $1-$ & $1 \leftarrow 0$ & Excited & $3 / 2$ & & $5 / 2$ & 26235.65 & 0.10 \\
\hline $\mathrm{H}_{2} \mathrm{C}^{12}: \mathrm{C}^{12} \mathrm{Cl}_{2}^{\mathrm{b}}$ & 4- 663 & Not Reported & Ground & & & & 26236.0 & 1. \\
\hline $\mathrm{C}^{12} \mathrm{H}_{3} \mathrm{O}^{16} \mathrm{~N}^{14} \mathrm{O}_{2}^{16}$ & 3. 181 & $3,1,2 \leftarrow 2,1,1$ & Ground & & & & 26237.30 & .1 \\
\hline $\mathrm{Cl}^{35} \mathrm{O}_{2}^{16}$ & 4-1381 & $18,5,14 \leftarrow 19,4,15$ & Ground & $33 / 2$ & & $35 / 2$ & 26239.4 & \\
\hline $\mathrm{C}^{12} \mathrm{H}_{3} \mathrm{C}^{12} \mathrm{O}^{16} \mathrm{~F}^{19}$ & 3. 391 & Not Reported & Ground & & & & 26239.61 & .2 \\
\hline $\mathrm{Cl}^{35} \mathrm{O}_{2}^{16}$ & 4-1381 & $18,5,14 \leftarrow 19,4,15$ & Ground & $35 / 2$ & & $37 / 2$ & 26242.6 & \\
\hline $\mathrm{N}^{15} \mathrm{H}_{3}$ & 4-1772 & $9,9 \leftarrow 9,9$ & Ground & & & & 26243.0 & .5 \\
\hline $\mathrm{Cl}^{35} \mathrm{O}_{2}^{16}$ & 4-1381 & $18,5,14 \leftarrow 19,4,15$ & Ground & $37 / 2$ & & $39 / 2$ & 26246.1 & \\
\hline $\mathrm{I}^{127} \mathrm{C}^{12} \mathrm{~N}^{14}$ & 4. 511 & $4 \leftarrow 3$ & Excited & $3 / 2 \quad 5 / 2$ & $5 / 2$ & $5 / 2$ & 26247.900 & \\
\hline $\mathrm{I}^{127} \mathrm{C}^{12} \mathrm{~N}^{14}$ & 4- 511 & $4 \leftarrow 3$ & Excited & $3 / 2 \quad 5 / 2$ & $5 / 2$ & $7 / 2$ & 26247.900 & \\
\hline $\mathrm{I}^{127} \mathrm{C}^{12} \mathrm{~N}^{14}$ & 4. 511 & $4 \leftarrow 3$ & Excited & $3 / 2 \quad 3 / 2$ & $5 / 2$ & $5 / 2$ & 26248.238 & \\
\hline $\mathrm{I}^{127} \mathrm{C}^{12} \mathrm{~N}^{14}$ & 4- 511 & $4 \leftarrow 3$ & Excited & $3 / 2 \quad 3 / 2$ & $5 / 2$ & $3 / 2$ & 26248.238 & \\
\hline
\end{tabular}




\begin{tabular}{|c|c|c|c|c|c|c|c|c|c|}
\hline \multirow{2}{*}{ Isotopic Species } & \multirow{2}{*}{$\begin{array}{l}\text { Vol.-Id. } \\
\text { Nos. }\end{array}$} & \multirow{2}{*}{$\begin{array}{c}\text { Rotational } \\
\text { Quantum Nos. }\end{array}$} & \multirow{2}{*}{ Vib. State } & \multicolumn{4}{|c|}{ Hyperfine } & \multirow{2}{*}{$\begin{array}{l}\text { Frequency } \\
\mathrm{MHz}^{-}\end{array}$} & \multirow{2}{*}{$\begin{array}{r}\text { Acc. } \\
\pm \mathrm{MHz}\end{array}$} \\
\hline & & & & $\mathrm{F}_{1}^{\prime}$ & $F^{\prime}$ & $\mathrm{F}_{1}$ & $\mathrm{~F}$ & & \\
\hline $\mathrm{I}^{127} \mathrm{C}^{12} \mathrm{~N}^{14}$ & 4. 511 & $4 \leftarrow 3$ & Excited & $3 / 2$ & $1 / 2$ & $5 / 2$ & $3 / 2$ & 26248.300 & \\
\hline $\mathrm{I}^{127} \mathrm{C}^{12} \mathrm{~N}^{14}$ & 4- 511 & $4 \leftarrow 3$ & Ground & $3 / 2$ & $3 / 2$ & $5 / 2$ & $5 / 2$ & 26248.971 & \\
\hline $\mathrm{Cl}^{35} \mathrm{O}_{2}^{16}$ & 4-1381 & $18,5,14 \leftarrow 19,4,15$ & Ground & & $39 / 2$ & & $41 / 2$ & 26249.4 & \\
\hline $\mathrm{DC}^{12}: \mathrm{C}^{13} \mathrm{C}^{12} \mathrm{HO}^{16}$ & 4- 918 . & $3,1,2 \leftarrow 2,1,1$ & Ground & & & & & 26253.29 & .02 \\
\hline $\mathrm{C}^{\mathrm{b}}{ }_{*} \mathrm{H}_{2}^{\mathrm{b}} \mathrm{N}^{\mathrm{b}} \mathrm{H}^{\mathrm{b}} \mathrm{C}^{\mathrm{b}}{ }_{*} \mathrm{H}_{2}^{\mathrm{b}}$ & 4. 863 & Not Reported & & & & & & 26256 & 10. \\
\hline $\mathrm{C}^{12} \mathrm{HD}\left(\mathrm{C}^{12} \mathrm{~N}^{14}\right)_{2}$ & 4. 902 & $2,1,2 \leftarrow 1,0,1$ & Ground & & & & & 26256.39 & \\
\hline $\mathrm{C}^{12} \mathrm{D}_{3} \mathrm{Si}^{28} \mathrm{H}_{2} \mathrm{~F}^{19}$ & 3. 244 & $11,2,9 \leftarrow 11,2,10$ & Ground & & & & & 26256.50 & .10 \\
\hline $\mathrm{C}^{\mathrm{b}} \mathrm{H}_{2}^{\mathrm{b}} \mathrm{Cl}^{\mathrm{b}} \mathrm{F}^{\mathrm{b}}$ & 4- 333 & Not Reported & & & & & & 26257.63 & .1 \\
\hline $\mathrm{s}-\mathrm{C}^{12} \mathrm{DH}_{2} \mathrm{C}^{12} \mathrm{H}_{2} \mathrm{C}^{12} \mathrm{H}_{3}$ & 3. 785 & $4,1,3 \leftarrow 4,0,4$ & Ground & & & & & 26262.62 & .06 \\
\hline $\mathrm{I}^{127} \mathrm{C}^{12} \mathrm{~N}^{14}$ & 4- 511 & $4 \leftarrow 3$ & Excited & $3 / 2$ & $5 / 2$ & $5 / 2$ & $7 / 2$ & 26265.210 & \\
\hline$I^{127} \mathrm{C}^{12} \mathrm{~N}^{14}$ & 4. 511 & $4 \leftarrow 3$ & Excited & $3 / 2$ & $5 / 2$ & $5 / 2$ & $5 / 2$ & 26265.210 & \\
\hline $\mathrm{I}^{127} \mathrm{C}^{12} \mathrm{~N}^{14}$ & 4- 511 & $4 \leftarrow 3$ & Excited & $3 / 2$ & $3 / 2$ & $5 / 2$ & $3 / 2$ & 26265.548 & \\
\hline $\mathrm{I}^{127} \mathrm{C}^{12} \mathrm{~N}^{14}$ & 4- 511 & $4 \leftarrow 3$ & Excited & $3 / 2$ & $3 / 2$ & $5 / 2$ & $5 / 2$ & 26265.548 & \\
\hline$I^{127} \mathrm{C}^{12} \mathrm{~N}^{14}$ & 4- 511 & $4 \leftarrow 3$ & Excited & $3 / 2$ & $1 / 2$ & $5 / 2$ & $3 / 2$ & 26265.610 & \\
\hline $\mathrm{C}^{12} \mathrm{D}_{2} \mathrm{Cl}_{2}^{35}$ & 4- 346 & $8,1,7 \leftarrow 8,0,8$ & Ground & & & & & 26268. & 5. \\
\hline $\mathrm{C}^{12} \mathrm{H}_{3} \mathrm{~B}^{\mathrm{b}} \mathrm{F}_{2}^{19}$ & 3- 91 & $2, \quad \leftarrow 1$, & Ground & & & & & 26276.7 & .1 \\
\hline $\mathrm{HC}^{13} \vdots \mathrm{C}^{12} \mathrm{C}^{12} \mathrm{DO}^{16}$ & 4- 922 & Not Reported & & & & & & 26277. & 5. \\
\hline $\mathrm{C}_{6}^{12} \mathrm{H}_{5} \mathrm{~F}^{19}$ & 4-1281 & $39,12,27 \leftarrow 39,12,28$ & Ground & & & & & 26280 . & 5. \\
\hline $\mathrm{a}-\mathrm{C}^{12} \mathrm{H}_{2} \mathrm{DC}^{12} \mathrm{O}^{16} \mathrm{Cl}^{35}$ & $3 \cdot 366$ & $10,4,6 \leftarrow 10,3,7$ & Ground & & & & & 26281.5 & .2 \\
\hline a- $\mathrm{C}^{12} \mathrm{H}_{2} \mathrm{DC}^{12} \mathrm{O}^{16} \mathrm{Cl}^{35}$ & 3- 366 & $10,4,6 \leftarrow 10,3,7$ & Ground & & & & & 26282.0 & .2 \\
\hline $\mathrm{C}^{12} \mathrm{H}_{2} \mathrm{Cl}^{35} \mathrm{Si}^{28} \mathrm{H}_{3}$ & 3- 231 & $10,3,7 \leftarrow 11,2,10$ & Ground & & & & & 26282.6 & .2 \\
\hline $\mathrm{C}^{12} \mathrm{H}_{3} \mathrm{C}^{12} \mathrm{HDF}^{19}$ & 3. 552 & $6,1,5 \leftarrow 6,1,6$ & Ground & & & & & 26283.3 & .1 \\
\hline $\mathrm{C}^{12} \mathrm{H}_{2} \mathrm{Cl}^{35} \mathrm{Si}^{28} \mathrm{H}_{3}$ & 3. 231 & $10,3,7 \leftarrow 11,2,10$ & Ground & & & & & 26283.9 & .2 \\
\hline $\mathrm{C}^{12} \mathrm{H}_{2} \mathrm{Cl}^{35} \mathrm{Si}^{28} \mathrm{H}_{3}$ & 3. 231 & $10,3,7 \leftarrow 11,2,10$ & Ground & & & & & 26284.7 & .2 \\
\hline $\mathrm{H}_{2} \mathrm{~B}^{11} \mathrm{H}_{2} \mathrm{~B}^{10} \mathrm{HBr}^{79}$ & 4- 45 & $4,0,4 \leftarrow 3,0,3$ & Ground & & $9 / 2$ & & $7 / 2$ & 26284.7 & \\
\hline $\mathrm{H}_{2} \mathrm{~B}^{11} \mathrm{H}_{2} \mathrm{~B}^{10} \mathrm{HBr}^{79}$ & 4- 45 & $4,0,4 \leftarrow 3,0,3$ & Ground & & $11 / 2$ & & $9 / 2$ & 26284.7 & \\
\hline $\mathrm{C}^{12} \mathrm{H}_{2} \mathrm{Cl}^{35} \mathrm{Si}^{28} \mathrm{H}_{3}$ & 3- 231 & $10,3,7 \leftarrow 11,2,10$ & Ground & & & & & 26285.8 & .2 \\
\hline $\mathrm{H}_{2} \mathrm{C}^{12}: \mathrm{C}^{12} \mathrm{Cl}^{35} \mathrm{Cl}^{37}$ & 4- 662 & $5,1,5 \leftarrow 4,0,4$ & Ground & & & & & 26287.3 & .5 \\
\hline $\mathrm{HC}^{12}: \mathrm{C}^{12} \mathrm{C}^{12} \mathrm{HO}^{18}$ & 4. 915 & $3,1,3 \leftarrow 2,1,2$ & Ground & & & & & 26289.67 & .05 \\
\hline $\mathrm{S}^{32}{ }_{*} \mathrm{DC}^{12}: \mathrm{C}^{12} \mathrm{HC}^{12} \mathrm{H}: \mathrm{C}^{12}{ }_{*} \mathrm{H}$ & $4 \cdot 1162$ & $9,4,6 \leftarrow 9,4,5$ & Ground & & & & & 26289.8 & .1 \\
\hline $\mathrm{C}^{12}{ }_{*} \mathrm{HC}^{12} \mathrm{H}: \mathrm{C}^{12} \mathrm{HC}^{12} \mathrm{H}: \mathrm{C}^{12} \mathrm{HN}^{14}{ }_{*}$ & 4-1201 & $15,12,4 \leftarrow 15,10,5$ & Ground & & & & & 26290.2 & .1 \\
\hline $\mathrm{Tl}^{203} \mathrm{~F}^{19}$ & $1-$ & $2 \leftarrow 1$ & Ground & & & & & 26291.86 & 0.10 \\
\hline $\mathrm{C}^{12}{ }_{*} \mathrm{HC}^{12} \mathrm{H}: \mathrm{C}^{12} \mathrm{HC}^{12} \mathrm{H}: \mathrm{C}^{12} \mathrm{HN}^{14} *$ & $4 \cdot 1201$ & $14,11,4 \leftarrow 14,9,5$ & Ground & & & & & 26292.3 & .1 \\
\hline $\mathrm{H}_{2} \mathrm{~B}^{11} \mathrm{H}_{2} \mathrm{~B}^{10} \mathrm{HBr}^{79}$ & 4. 45 & $4,0,4 \leftarrow 3,0,3$ & Ground & & $7 / 2$ & & $5 / 2$ & 26292.4 & \\
\hline $\mathrm{H}_{2} \mathrm{~B}^{11} \mathrm{H}_{2} \mathrm{~B}^{10} \mathrm{HBr}^{79}$ & 4. 45 & $4,0,4 \leftarrow 3,0,3$ & Ground & & $5 / 2$ & & $3 / 2$ & 26292.4 & \\
\hline $\mathrm{C}^{12} * \mathrm{HC}^{12} \mathrm{H}: \mathrm{C}^{12} \mathrm{HC}^{12} \mathrm{H}: \mathrm{C}^{12} \mathrm{HN}^{14} *$ & $4 \cdot 1201$ & $3,2,2 \leftarrow 2,2,1$ & Ground & & & & & 26292.62 & .10 \\
\hline $\mathrm{C}^{12} \mathrm{H}_{2}: \mathrm{C}^{12} \mathrm{HC}^{12} \mathrm{~F}^{19}: \mathrm{C}^{12} \mathrm{H}_{2}$ & 3- 911 & $10,3,7 \leftarrow 10,2,8$ & Ground & & & & & 26293.23 & .03 \\
\hline $\mathrm{HC}^{13}: \mathrm{C}^{12} \mathrm{C}^{12} \mathrm{DO}^{16}$ & 4- 922 & Not Reported & & & & & & 26294. & 5. \\
\hline $\mathrm{F}_{2}^{19} \mathrm{~N}^{14} \mathrm{~N}^{14} \mathrm{~F}_{2}^{19}$ & 3. 21 & $3,2,2 \leftarrow 2,1,2$ & Ground & & & & & 26297. & 1. \\
\hline $\mathrm{C}^{12} \mathrm{H}_{3} \mathrm{C}^{12} \mathrm{HF}_{2}^{19}$ & 3. 461 & $9,8,2 \leftarrow 9,6,3$ & Ground & & & & & 26303.3 & \\
\hline $\mathrm{C}^{12} \mathrm{H}_{3} \mathrm{C}^{13} \mathrm{H}_{2} \mathrm{C}^{12} \mathrm{H}_{3}$ & 3- 783 & $4,1,3 \leftarrow 4,0,4$ & Ground & & & & & 26306.35 & .06 \\
\hline $\mathrm{C}^{12} \mathrm{H}_{3} \mathrm{O}^{16} \mathrm{H}$ & 3- 211 & $11,2, \leftarrow 11,1$, & Ground & & & & & 26313.11 & .1 \\
\hline $\mathrm{C}^{12}{ }_{*} \mathrm{H}_{2} \mathrm{~N}^{14} \mathrm{HC}^{12}{ }_{*} \mathrm{H}_{2}$ & 4. 861 & $7,6,1 \leftarrow 7,5,2$ & Ground & & & & & 26314.1 & \\
\hline $3 \mathrm{~d}-\mathrm{C}_{6}^{12} \mathrm{H}_{5} \mathrm{~F}^{19}$ & $4-1282$ & $6,1,5 \leftarrow 5,1,4$ & Ground & & & & & 26316.0 & .1 \\
\hline $\mathrm{C}^{12} \mathrm{H}_{3} \mathrm{Si}^{28} \mathrm{HF}_{2}^{19}-\mathrm{A}$ & 3- 191 & $12,7,6 \leftarrow 12,7,5$ & Ground & & & & & 26319.80 & \\
\hline
\end{tabular}


Vol.-Id. Rotational

Nos. Quantum Nos.
Frequency Acc. $\mathrm{MH}_{2} \pm \mathrm{MHz}$
$\mathrm{C}^{12} \mathrm{H}_{2}: \mathrm{C}^{12} \mathrm{HC}^{12} \mathrm{HO}^{16}$

$\mathrm{C}^{12} \mathrm{H}_{3} \mathrm{Si}^{28} \mathrm{HF}_{2}^{19}-\mathrm{E}$

$\mathrm{HDC}^{12}: \mathrm{C}^{12} \mathrm{~F}_{2}^{19}$

$\mathrm{C}^{12} \mathrm{O}^{16} \mathrm{Cl}^{35} \mathrm{Cl}^{37}$

$\mathrm{C}^{12}{ }_{*} \mathrm{HC}^{12} \mathrm{H}: \mathrm{C}^{12} \mathrm{HC}^{12} \mathrm{H}: \mathrm{C}^{12} \mathrm{HN}^{14}$ *

$\mathrm{H}_{2} \mathrm{C}^{12}: \mathrm{C}^{12} \mathrm{~F}_{2}^{19}$

$\mathrm{C}^{12}{ }_{*} \mathrm{H}_{2} \mathrm{~N}^{14} \mathrm{HC}^{12}{ }_{*} \mathrm{H}_{2}$

$\mathrm{C}^{12}{ }_{*} \mathrm{H}_{2} \mathrm{C}^{12} \mathrm{H}_{2} \mathrm{C}^{12} \mathrm{H}_{2} \mathrm{O}^{16}{ }_{*}$

$\mathrm{O}_{3}^{18}$

$\mathrm{O}^{16} \mathrm{O}^{18} \mathrm{O}^{16}$

$\mathrm{H}_{2} \mathrm{C}^{12}: \mathrm{C}^{12} \mathrm{~F}_{2}^{19}$

$\mathrm{C}^{12} \mathrm{D}_{2} \mathrm{HC}^{12} \mathrm{HDF}^{19}$

$\mathrm{Cl}^{35} \mathrm{O}_{2}^{16}$

$\mathrm{C}^{12}{ }_{*} \mathrm{HC}^{12} \mathrm{H}: \mathrm{C}^{12} \mathrm{HC}^{12} \mathrm{H}: \mathrm{C}^{12} \mathrm{HN}^{14}$ *

$\mathrm{C}^{12} \mathrm{H}_{3} \mathrm{C}^{12}: \mathrm{C}^{12} \mathrm{C}^{12} \mathrm{H}_{2} \mathrm{Cl}^{35}$

$\mathrm{C}^{12} \mathrm{H}_{3} \mathrm{~N}^{14} \mathrm{H}_{2}$

$\mathrm{C}^{12} \mathrm{H}_{3} \mathrm{Cl}^{35}$

$\mathrm{Cl}^{35} \mathrm{O}_{2}^{16}$

$\mathrm{HC}^{12} \mathrm{O}^{16} \mathrm{O}^{16} \mathrm{H}$

$\mathrm{C}^{12} \mathrm{D}_{3} \mathrm{O}^{16} \mathrm{H}$

$\mathrm{H}_{2} \mathrm{~N}^{14} \mathrm{~N}^{14} \mathrm{H}_{2}$

$\mathrm{C}^{12}{ }_{*} \mathrm{HC}^{12} \mathrm{H}: \mathrm{C}^{12} \mathrm{HC}^{12} \mathrm{H}: \mathrm{C}^{12} \mathrm{HN}^{14}$ * $\mathrm{C}^{12} \mathrm{DH}_{2} \mathrm{C}^{12} \mathrm{HDF}^{19}$

$\mathrm{Cl}^{35} \mathrm{O}_{2}^{16}$

$\mathrm{N}^{14} \mathrm{O}_{2}^{16} \mathrm{Cl}^{37}$

$\mathrm{H}_{2} \mathrm{~B}^{11} \mathrm{H}_{2} \mathrm{~B}^{11} \mathrm{HBr}^{81}$.

$\mathrm{DC}^{12}: \mathrm{C}^{12} \mathrm{C}^{12} \mathrm{HO}^{16}$

$\mathrm{Cl}^{35} \mathrm{O}_{2}^{16}$

$\mathrm{HC}^{13}: \mathrm{C}^{12} \mathrm{C}^{12} \mathrm{DO}^{16}$

$\mathrm{HC}^{12} \mathrm{HO}^{16}$

$\mathrm{C}^{12} \mathrm{H}_{3} \mathrm{Cl}^{35}$

$\mathrm{O}^{16} \mathrm{~F}_{2}^{19}$

$\mathrm{Si}^{28} \mathrm{H}_{2} \mathrm{~F}_{2}^{19}$

$\mathrm{C}^{12} \mathrm{H}_{3} \mathrm{Si}^{\mathrm{b}} \mathrm{H}_{2} \mathrm{D}$

$\mathrm{C}^{12} \mathrm{H}_{2}\left(\mathrm{C}^{12} \mathrm{~N}^{14}\right)\left(\mathrm{C}^{13} \mathrm{~N}^{14}\right)$

$\mathrm{C}^{\mathrm{b}} \mathrm{H}_{2}^{\mathrm{b}} \mathrm{Cl}^{\mathrm{b}} \mathrm{F}^{\mathrm{b}}$

$\mathrm{P}^{31} \mathrm{O}^{18} \mathrm{~F}_{3}^{19}$

$\mathrm{C}^{12} \mathrm{H}_{3} \mathrm{Cl}^{36}$

$\mathrm{S}^{32}{ }_{*} \mathrm{DC}^{12}: \mathrm{C}^{12} \mathrm{DC}^{12} \mathrm{D}: \mathrm{C}^{12}{ }_{*} \mathrm{D}$

$\mathrm{C}^{12} \mathrm{H}_{3} \mathrm{Cl}^{35}$

$\mathrm{N}^{14} \mathrm{O}_{2}^{16} \mathrm{Cl}^{37}$

$\mathrm{C}^{12} \mathrm{O}^{16} \mathrm{Cl}_{2}^{35}$

$\mathrm{C}^{12} \mathrm{H}_{3} \mathrm{Cl}^{36}$

$\mathrm{C}^{12} \mathrm{H}_{3} \mathrm{Cl}^{36}$

$\mathrm{C}^{13}{ }_{*} \mathrm{H}: \mathrm{C}^{12} \mathrm{HO}^{16} \mathrm{C}^{12} \mathrm{H}: \mathrm{C}^{12}{ }_{*} \mathrm{H}$
3. $6913,1,3 \leftarrow 2,1,2$

3- $19212,7,6 \leftarrow 12,7,5$

Ground

4- 682

$4,4,1 \leftarrow 4,2,2$

Ground

4. 182

$6,2,5 \leftarrow 6,1,6$

Ground

Ground

4-1201

$13,10,4 \leftarrow 13,8,5$

Ground

4- 681 Not Reported

4. 861

$7,6,1 \leftarrow 7,5,2$

Ground

4-1091

$7,6,2 \leftarrow 7,4,3$

Ground

4-1845

4-1843

4- 681

$15,3,13 \leftarrow 16,2,14$

Ground

Ground

3- 563

$23,3,21 \leftarrow 22,4,18$

4-1381

Reported

4.1381

4-1201

3- 901

3. 261

4- 421

4-1381

3. 71

3- 214

3- 51

4-1201

3- 562

4-1381

$4,1,3 \leftarrow 4,0,4$

Ground

$18,3,16 \leftarrow 17,4,13$

Ground

$11,7,4 \leftarrow 11,7,5$

Ground

$9,1,8 \leftarrow 8,1,7$

Ground

Not Reported

Ground

$1,0 \leftarrow 0,0$

$18,3,16 \leftarrow 17,4,13$

Excited

Ground

Not Reported

Not Reported

Ground

Not Reported

$16,13,4 \leftarrow 16,11,5$

Ground

$3,1,2 \leftarrow 3,0,3$

Ground

Ground

4-1462

$18,3,16 \leftarrow 17,4,13$

Excited

4- 42

$3,2,1 \leftarrow 2,2,0$

Ground

4. 916

$3,1,2 \leftarrow 2,1,1$

Ground

4. 1381

$18,3,16 \leftarrow 17,4,13$

Ground

4- 922

Not Reported

4- 381

$26,4,22 \leftarrow 26,4,23$

4. 421

$1,0 \leftarrow 0,0$

4-1611

$22,4,18 \leftarrow 21,5,17$

4-1601

3- 325

$3,0,3 \leftarrow 2,1,2$

$11,1,10 \leftarrow 11,1,11$

4. 905

$9,1,8 \leftarrow 9,0,9$

4- 333

4-1672

4. 422

4-1165

4. 421

4-1462

4. 181

4- 422

Not Reported

4. 422

$3, \leftarrow 2$,

$1,0 \leftarrow 0,0$

$3,2,1 \leftarrow 2,2,0$

$1,0 \leftarrow 0,0$

$3,2,1 \leftarrow 2,2,0$

$9,2,7 \leftarrow 9,1,8$

$1,0 \leftarrow 0,0$

4-1157

$1,0 \leftarrow 0,0$

$11,10,2 \leftarrow 11,9,3$

Ground

Excited

Ground

Excited

Ground

Ground

Ground

Ground

Excited

Excited

Ground

Ground

Ground

Ground
Vib. State
$F_{1}^{\prime} F^{\prime} F_{1} F$

26322.50

26326.02

26327.3

.3

26328.5

26328.9

26329.0

26329.2

26333.

26334.

26334.

26335.6

26335.9

$33 / 2$

$31 / 2$

26337.6

$26338.8 \quad$. 1

$26339.34 \quad .05$

26339.57 .1

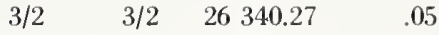

$35 / 2 \quad 33 / 2 \quad 26341.9$

26342 . 5 .

26344.7

26346.36

26347.5

26348.0

$37 / 2 \quad 35 / 2 \quad 26348.2$

26350 .

$9 / 2 \quad 7 / 2 \quad 26353.2$

26353.89

.02

$39 / 2 \quad 37 / 2 \quad 26356.8$

26357

5.

26358.82

$\begin{array}{llll}5 / 2 & 3 / 2 & 26359.01 & .05\end{array}$

$26359.08 \quad .10$

$26363.39 \quad .10$

26365.07

26367.03

$26368.30 \quad .1$

$26371.7 \quad .06$

$2 \quad 2$

.025

26373.5

$1 / 2$

$3 / 2$

26373.96

26375.

26375.1

26376.03

26377.96

26378.0

.1

.05

.3

.035

.025

.1 


\begin{tabular}{|c|c|c|c|c|c|c|c|}
\hline \multirow{2}{*}{ Isotopic Species } & \multirow{2}{*}{$\begin{array}{l}\text { Vol.-Id. } \\
\text { Nos. }\end{array}$} & \multirow{2}{*}{$\begin{array}{c}\text { Rotational } \\
\text { Quantum Nos. }\end{array}$} & \multirow{2}{*}{ Vib. State } & \multicolumn{2}{|c|}{ Hyperfine } & \multirow{2}{*}{$\begin{array}{c}\text { Frequency } \\
\mathrm{MHz}\end{array}$} & \multirow{2}{*}{$\begin{aligned} & \text { Acc. } \\
& \pm \mathrm{MHz}\end{aligned}$} \\
\hline & & & & $F_{1}^{\prime} \quad F^{\prime} \quad F_{1}$ & $\mathrm{~F}$ & & \\
\hline $\mathrm{C}_{6}^{12} \mathrm{H}_{5} \mathrm{~F}^{19}$ & $4-1281$ & $6,5,1 \leftarrow 5,5,0$ & Ground & & & 26378.8 & .1 \\
\hline $\mathrm{C}_{6}^{12} \mathrm{H}_{5} \mathrm{~F}^{19}$ & $4-1281$ & $6,5,2 \leftarrow 5,5,1$ & Ground & & & 26378.8 & .1 \\
\hline $\mathrm{C}^{12}{ }_{*} \mathrm{HC}^{12} \mathrm{H}: \mathrm{C}^{12} \mathrm{HC}^{12} \mathrm{H}: \mathrm{C}^{12} \mathrm{HN}^{14}{ }_{*}$ & 4-1201 & $12,9,4 \leftarrow 12,7,5$ & Ground & & & 26382.3 & .1 \\
\hline $\mathrm{C}^{12} \mathrm{H}_{2}: \mathrm{C}^{12} \mathrm{HC}^{12} \mathrm{~F}^{19}: \mathrm{C}^{12} \mathrm{H}_{2}$ & 3- 911 & $6,3,3 \leftarrow 6,2,4$ & Ground & & & 26386.24 & .03 \\
\hline $\mathrm{O}^{16} \mathrm{O}^{16} \mathrm{O}^{18}$ & $4-1842$ & $16,2,14 \leftarrow 17,1,17$ & Ground & & & 26388. & \\
\hline $\mathrm{C}^{12} \mathrm{H}_{3} \mathrm{~S}^{32} \mathrm{H}$ & 3- 221 & Not Reported & Ground & & & 26388.4 & .1 \\
\hline $\mathrm{C}^{12} \mathrm{H}_{3} \mathrm{C}^{12} \mathrm{O}^{16} \mathrm{C}^{12} \mathrm{~N}^{14}$ & 3- 671 & $7,3,4 \leftarrow 7,2,5$ & Ground & & & 26389.94 & .2 \\
\hline $\mathrm{P}^{31} \mathrm{O}^{18} \mathrm{~F}_{3}^{19}$ & 4-1672 & $3, \leftarrow 2$, & Ground & & & 26391.61 & .10 \\
\hline $\mathrm{C}^{12} \mathrm{Cl}_{2}^{35} \mathrm{Cl}^{37} \mathrm{C}^{12} \mathrm{~N}^{14}$ & 4. 582 & $8, \quad \leftarrow 7, \quad$, & Ground & & & 26394.8 & 1.0 \\
\hline $\mathrm{C}^{12} \mathrm{H}_{2}\left(\mathrm{C}^{12} \mathrm{~N}^{14}\right)_{2}$ & 4. 901 & Not Reported & Ground & & & 26398.4 & .1 \\
\hline $\mathrm{C}^{12} \mathrm{H}_{3} \mathrm{Si}^{28} \mathrm{H}_{2} \mathrm{~F}^{19}$ & 3- 241 & Not Reported & & & & 26402.76 & .1 \\
\hline $\mathrm{HC}^{13}: \mathrm{C}^{12} \mathrm{C}^{12} \mathrm{DO}^{16}$ & 4- 922 & Not Reported & & & & 26403. & 5. \\
\hline $\mathrm{C}^{12} \mathrm{H}_{3} \mathrm{Si}^{28} \mathrm{H}_{2} \mathrm{~F}^{19}$ & 3- 241 & Not Reported & & & & 26405.2 & .1 \\
\hline $2,4,6 \mathrm{~d}_{3}-\mathrm{C}_{6}^{12} \mathrm{H}_{5} \mathrm{~F}^{19}$ & 4-1284 & $10,3,8 \leftarrow 10,1,9$ & Ground & & & 26405.5 & .1 \\
\hline $\mathrm{Ge}^{70} \mathrm{H}_{3} \mathrm{Cl}^{35}$ & 4-1431 & $3, \leftarrow 2$, & Ground & & & 26410.26 & .5 \\
\hline $\mathrm{HC}^{13}: \mathrm{C}^{12} \mathrm{C}^{12} \mathrm{DO}^{16}$ & 4. 922 & Not Reported & & & & 26414. & 5. \\
\hline $\mathrm{C}^{12} \mathrm{HCl}_{3}^{35}$ & 4- 261 & $4, \leftarrow 3$, & Ground & & & 26417 . & \\
\hline $\mathrm{Li}^{7}{ }^{127}$ & $1-$ & $1 \leftarrow 0$ & Ground & $5 / 2$ & $5 / 2$ & 26418.44 & 0.10 \\
\hline $\mathrm{N}^{14} \mathrm{O}_{2}^{16} \mathrm{Cl}^{35}$ & 4-1461 & $3,2,2 \leftarrow 2,2,1$ & Excited & & & 26425 . & \\
\hline $\mathrm{C}^{12}{ }_{*} \mathrm{D}_{2} \mathrm{C}^{12} \mathrm{H}_{2} \mathrm{C}^{12} \mathrm{D}_{2} \mathrm{O}^{16} *$ & 4-1092 & $4,1,3 \leftarrow 4,0,4$ & Excited & & & 26426. & 2. \\
\hline $\mathrm{C}^{12} \mathrm{Cl}_{2}^{35} \mathrm{Cl}^{37} \mathrm{C}^{12} \mathrm{~N}^{14}$ & 4- 582 & $8, \quad \leftarrow 7$, & Excited & & & 26426.0 & 1.0 \\
\hline $\mathrm{C}^{12} \mathrm{D}_{3} \mathrm{C}^{13} \mathrm{O}^{16} \mathrm{C}^{12} \mathrm{~N}^{14}$ & 3- 676 & $4,2,3 \leftarrow 3,2,2$ & Ground & & & 26427.20 & .2 \\
\hline $\mathrm{C}^{b} \mathrm{H}_{2}^{\mathrm{b}} \mathrm{Cl}^{\mathrm{b}} \mathrm{F}^{\mathrm{b}}$ & 4- 333 & Not Reported & & & & 26429.08 & .1 \\
\hline $\mathrm{C}^{12} \mathrm{D}_{3} \mathrm{C}^{12} \mathrm{DO}^{16}$ & 3- 472 & Not Reported & & & & 26433.48 & \\
\hline $\mathrm{C}^{12} \mathrm{DH}_{2} \mathrm{C}^{12} \mathrm{HDF}^{19}$ & 3- 562 & $3,0,3 \leftarrow 2,1,2$ & Ground & & & 26433.5 & .1 \\
\hline $\mathrm{C}^{12} \mathrm{H}_{3} \mathrm{C}^{12} \mathrm{H}_{2} \mathrm{O}^{16} \mathrm{H}$ & 3- 581 & Not Reported & & & & 26436.88 & .01 \\
\hline $\mathrm{C}^{12} \mathrm{H}_{3} \mathrm{C}^{12} \mathrm{H}_{2} \mathrm{O}^{16} \mathrm{H}$ & 3- 581 & $2,1,1 \leftarrow 2,0,2$ & Ground & & & 26437.15 & .01 \\
\hline $\mathrm{C}^{12} \mathrm{H}_{3} \mathrm{C}^{12} \mathrm{H}_{2} \mathrm{I}^{127}$ & 3- 571 & $2,1,1 \leftarrow 2,0,2$ & Ground & $9 / 2$ & $9 / 2$ & 26438.02 & .05 \\
\hline $\mathrm{C}^{12} \mathrm{HCl}^{35} \mathrm{~F}_{2}^{19}$ & 4- 251 & $10,4,7 \leftarrow 10,3,7$ & Ground & $17 / 2$ & $17 / 2$ & 26439.4 & .05 \\
\hline $\mathrm{C}^{12}{ }_{*} \mathrm{HC}^{12} \mathrm{H}: \mathrm{C}^{12} \mathrm{HC}^{12} \mathrm{H}: \mathrm{C}^{12} \mathrm{HN}^{14}{ }_{*}$ & 4-1201 & $11,8,4 \leftarrow 11,6,5$ & Ground & & & 26439.9 & .1 \\
\hline $\mathrm{C}^{12} \mathrm{HCl}^{35} \mathrm{~F}_{2}^{19}$ & 4- 251 & $10,4,7 \leftarrow 10,3,7$ & Ground & $23 / 2$ & $23 / 2$ & 26440.0 & .05 \\
\hline $\mathrm{C}^{12} \mathrm{D}_{3} \mathrm{Si}^{28} \mathrm{~F}_{3}^{19}$ & 3- 132 & $4, \leftarrow 3$, & Excited & & & 26440.62 & \\
\hline $\mathrm{C}^{12} \mathrm{HCl}^{35} \mathrm{~F}_{2}^{19}$ & 4- 251 & $10,4,7 \leftarrow 10,3,7$ & Ground & $19 / 2$ & $19 / 2$ & 26443.8 & .05 \\
\hline $\mathrm{C}^{12} \mathrm{HCl}^{35} \mathrm{~F}_{2}^{19}$ & 4. 251 & $10,4,7 \leftarrow 10,3,7$ & Ground & $21 / 2$ & $21 / 2$ & 26444.4 & .05 \\
\hline $\mathrm{C}_{6}^{12} \mathrm{H}_{5} \mathrm{~F}^{19}$ & $4-1281$ & $6,3,4 \leftarrow 5,3,3$ & Ground & & & 26445.2 & .1 \\
\hline $\mathrm{Cl}^{35} \mathrm{O}_{2}^{16}$ & 4-1381 & $18,5,14 \leftarrow 19,4,15$ & Ground & & & 26445.5 & \\
\hline $\mathrm{C}^{12} \mathrm{D}_{3} \mathrm{C}^{12} \mathrm{DO}^{16}$ & 3- 472 & Not Reported & & & & 26445.68 & \\
\hline $\mathrm{C}^{12}{ }_{*} \mathrm{HC}^{12} \mathrm{H}: \mathrm{C}^{12} \mathrm{HC}^{12} \mathrm{H}: \mathrm{C}^{12} \mathrm{HN}^{14}{ }_{*}$ & 4-1201 & $10,6,4 \leftarrow 10,6,5$ & Ground & & & 26446.7 & .1 \\
\hline $\mathrm{C}^{12} \mathrm{H}_{3} \mathrm{~N}^{14} \mathrm{H}_{2}$ & 3- 261 & Not Reported & Ground & & & 26448.15 & .1 \\
\hline $\mathrm{N}^{14} \mathrm{O}_{2}^{16} \mathrm{Cl}^{35}$ & 4-1461 & $3,2,2 \leftarrow 2,2,1$ & Excited & & & 26450 & \\
\hline $\mathrm{HC}^{12}{ }_{*}: \mathrm{C}^{12} \mathrm{HO}^{16} \mathrm{C}^{12} \mathrm{O}^{16} \mathrm{O}^{16}{ }_{*}$ & 4- 931 & $4,0,4 \leftarrow 3,0,3$ & Ground & & & 26450.13 & .10 \\
\hline $\mathrm{HC}^{13}: \mathrm{C}^{12} \mathrm{C}^{12} \mathrm{~N}^{14}$ & 4- 882 & $3 \leftarrow 2$ & Ground & & & 26450.73 & \\
\hline $\mathrm{Na}^{23} \mathrm{Br}^{79}$ & $1-$ & $3 \leftarrow 2$ & Excited & $7 / 2$ & $5 / 2$ & 26455.8 & .8 \\
\hline $\mathrm{Na}^{23} \mathrm{Br}^{79}$ & 1 - & $3 \leftarrow 2$ & Excited & $9 / 2$ & $7 / 2$ & 26455.8 & .8 \\
\hline $\mathrm{C}^{13} \mathrm{H}_{3} \mathrm{C}^{12} \mathrm{H}_{2} \mathrm{C}^{12} \mathrm{H}_{3}$ & 3- 782 & $4,1,3 \leftarrow 4,0,4$ & Ground & & & 26456.74 & .06 \\
\hline
\end{tabular}




\begin{tabular}{|c|c|c|c|c|c|c|c|}
\hline $\mathrm{Li}^{7} \mathrm{I}^{127}$ & 1 - & $1 \leftarrow 0$ & Ground & $7 / 2$ & $5 / 2$ & 26460.14 & 0.10 \\
\hline $\mathrm{C}_{6}^{12} \mathrm{H}_{5} \mathrm{Cl}^{35}$ & $4-1271$ & $9,3,6 \leftarrow 8,3,5$ & Ground & $17 / 2$ & $15 / 2$ & 26460.2 & .1 \\
\hline $\mathrm{C}_{6}^{12} \mathrm{H}_{5} \mathrm{Cl}^{35}$ & $4-1271$ & $9,3,6 \leftarrow 8,3,5$ & Ground & $19 / 2$ & $17 / 2$ & 26460.2 & .1 \\
\hline $\mathrm{C}_{6}^{12} \mathrm{H}_{5} \mathrm{~F}^{19}$ & $4-1281$ & $7,1,7 \leftarrow 6,1,6$ & Ground & & & 26460.7 & .1 \\
\hline $\mathrm{C}_{6}^{12} \mathrm{H}_{5} \mathrm{Cl}^{35}$ & 4-1271 & $9,3,6 \leftarrow 8,3,5$ & Ground & $21 / 2$ & $19 / 2$ & 26461.4 & .1 \\
\hline $\mathrm{C}_{6}^{12} \mathrm{H}_{5} \mathrm{Cl}^{35}$ & $4-1271$ & $9,3,6 \leftarrow 8,3,5$ & Ground & $15 / 2$ & $13 / 2$ & 26461.4 & .1 \\
\hline $\mathrm{C}^{12} \mathrm{D}_{3} \mathrm{C}^{12} \mathrm{O}^{16} \mathrm{C}^{12} \mathrm{~N}^{14}$ & 3- 675 & $4,2,3 \leftarrow 3,2,2$ & Ground & & & 26461.42 & .2 \\
\hline $\mathrm{C}^{12} \mathrm{D}_{3} \mathrm{Si}^{28} \mathrm{~F}_{3}^{19}$ & 3- 132 & $4, \leftarrow 3$, & Excited & & & 26463.93 & \\
\hline $\mathrm{H}_{2} \mathrm{C}^{12}: \mathrm{C}^{12} \mathrm{~F}_{2}^{19}$ & 4- 681 & $2,1,2 \leftarrow 1,1,1$ & Ground & & & 26465.6 & .3 \\
\hline $\mathrm{C}^{12} \mathrm{H}_{2} \mathrm{DC}^{12} \mathrm{HDF}^{19}$ & 3- 557 & $4,1,3 \leftarrow 4,0,4$ & Ground & & & 26466.0 & .1 \\
\hline $\mathrm{C}^{12} \mathrm{H}_{3} \mathrm{C}^{12} \mathrm{O}^{16} \mathrm{Cl}^{35}$ & 3- 361 & $3,1,3 \leftarrow 2,0,2$ & Ground & $7 / 2$ & $7 / 2$ & 26467.75 & .2 \\
\hline $\mathrm{HC}^{13}: \mathrm{C}^{12} \mathrm{C}^{12} \mathrm{DO}^{16}$ & 4. 922 & Not Reported & & & & 26470 . & 5. \\
\hline $\mathrm{C}^{12} \mathrm{H}_{3} \mathrm{C}^{12} \mathrm{O}^{16} \mathrm{Cl}^{35}$ & 3- 361 & $3,1,3 \leftarrow 2,0,2$ & Ground & $3 / 2$ & $1 / 2$ & 26471.05 & .2 \\
\hline $\mathrm{C}^{12} \mathrm{H}_{3} \mathrm{Cl}^{35}$ & 4- 421 & $1,0 \leftarrow 0,0$ & Excited & $3 / 2$ & $3 / 2$ & 26472.68 & .10 \\
\hline $\mathrm{t}-\mathrm{C}^{12}{ }_{*} \mathrm{H}_{2} \mathrm{C}^{12} \mathrm{DHC}^{12}{ }_{*} \mathrm{HC}^{12} \mathrm{~N}^{14}$ & $4-1173$ & $4,1,3 \leftarrow 3,1,2$ & Ground & & & 26473.41 & .1 \\
\hline $\mathrm{C}^{12} \mathrm{H}_{3} \mathrm{C}^{12} \mathrm{H}: \mathrm{C}^{12} \mathrm{O}^{16}$ & 3- 681 & $3,1,2 \leftarrow 2,1,1$ & Ground & & & 26474.7 & .1 \\
\hline $\mathrm{Na}^{23} \mathrm{Br}^{81}$ & 1 - & $3 \leftarrow 2$ & Excited & $9 / 2$ & $7 / 2$ & 26475.0 & .8 \\
\hline $\mathrm{Na}^{23} \mathrm{Br}^{81}$ & $1-$ & $3 \leftarrow 2$ & Excited & $7 / 2$ & $5 / 2$ & 26475.0 & .8 \\
\hline $\mathrm{C}^{12} \mathrm{H}_{3} \mathrm{C}^{12} \mathrm{O}^{16} \mathrm{Cl}^{35}$ & 3- 361 & $3,1,3 \leftarrow 2,0,2$ & Ground & $9 / 2$ & $7 / 2$ & 26476.55 & .2 \\
\hline $\mathrm{C}^{12} \mathrm{H}_{3} \mathrm{C}^{12} \mathrm{O}^{16} \mathrm{Cl}^{35}$ & 3- 361 & $3,1,3 \leftarrow 2,0,2$ & Ground & $5 / 2$ & $3 / 2$ & 26476.55 & .2 \\
\hline $\mathrm{C}^{12}{ }_{*} \mathrm{H}_{2} \mathrm{~S}^{34} \mathrm{C}^{12}{ }_{*} \mathrm{H}_{2}$ & 4. 852 & $4,1,4 \leftarrow 4,1,3$ & Ground & & & 26477.7 & .2 \\
\hline $\mathrm{Li}^{7} \mathrm{I}^{127}$ & 1. & $1 \leftarrow 0$ & Ground & $3 / 2$ & $5 / 2$ & 26477.88 & 0.10 \\
\hline $\mathrm{C}^{12} \mathrm{D}_{3} \mathrm{C}^{12} \mathrm{DO}^{16}$ & 3. 472 & Not Reported & & & & 26481.08 & \\
\hline $\mathrm{C}^{12} \mathrm{H}_{3} \mathrm{C}^{12} \mathrm{O}^{16} \mathrm{Cl}^{35}$ & 3- 361 & $3,1,3 \leftarrow 2,0,2$ & Ground & $7 / 2$ & $5 / 2$ & 26481.53 & .2 \\
\hline $\mathrm{C}_{6}^{12} \mathrm{H}_{5} \mathrm{~F}^{19}$ & $4-1281$ & $6,4,3 \leftarrow 5,4,2$ & Ground & & & 26483.2 & .1 \\
\hline $\mathrm{N}^{14} \mathrm{O}_{2}^{16}$ & $4-1801$ & $24,1,23 \leftarrow 23,2,22$ & Ground & & & 26484. & \\
\hline $\mathrm{C}^{12} \mathrm{H}_{3} \mathrm{C}^{12} \mathrm{O}^{16} \mathrm{Cl}^{35}$ & 3. 361 & $3,1,3 \leftarrow 2,0,2$ & Ground & $3 / 2$ & $3 / 2$ & 26485.20 & .2 \\
\hline $\mathrm{C}^{12} \mathrm{H}_{3} \mathrm{C}^{12} \mathrm{O}^{16} \mathrm{Cl}^{35}$ & 3- 361 & $3,1,3 \leftarrow 2,0,2$ & Ground & $5 / 2$ & $5 / 2$ & 26485.20 & .2 \\
\hline $\mathrm{C}^{12} \mathrm{H}_{3} \mathrm{~N}^{14} \mathrm{H}_{2}$ & 3- 261 & Not Reported & Ground & & & 26487.00 & .1 \\
\hline $\mathrm{C}^{12} \mathrm{H}_{3} \mathrm{C}^{12} \mathrm{H}: \mathrm{C}^{12} \mathrm{O}^{16}$ & 3- 681 & $3,1,2 \leftarrow 2,1,1$ & Ground & & & 26487.7 & .1 \\
\hline $\mathrm{C}^{12} \mathrm{D}_{3} \mathrm{Si}^{28} \mathrm{~F}_{3}^{19}$ & 3. 132 & $4, \leftarrow 3$, & Excited & & & 26488.90 & \\
\hline $\mathrm{Tl}^{205} \mathrm{~F}^{19}$ & $1-$ & $2 \leftarrow 1$ & Excited & & & 26489.86 & .20 \\
\hline $\mathrm{C}^{12} \mathrm{H}_{3} \mathrm{CI}^{35}$ & 4. 421 & $1,0 \leftarrow 0,0$ & Excited & $5 / 2$ & $3 / 2$ & 26491.39 & .10 \\
\hline $\mathrm{C}^{12} \mathrm{H}_{3} \mathrm{~N}^{14} \mathrm{H}_{2}$ & 3. 261 & Not Reported & Ground & & & 26493.54 & .1 \\
\hline $\mathrm{C}^{12} \mathrm{H}_{3} \mathrm{~N}^{14} \mathrm{H}_{2}$ & 3. 261 & Not Reported & Ground & & & 26493.82 & .1 \\
\hline $\mathrm{HC}^{13}: \mathrm{C}^{12} \mathrm{C}^{12} \mathrm{DO}^{16}$ & 4. 922 & Not Reported & & & & 26494. & 5. \\
\hline $\mathrm{C}^{12}{ }_{*} \mathrm{HC}^{12} \mathrm{H}: \mathrm{C}^{12} \mathrm{HC}^{12} \mathrm{H}: \mathrm{C}^{12} \mathrm{HN}^{14}{ }_{*}$ & $4-1201$ & $10,7,4 \leftarrow 10,5,5$ & Ground & & & 26494.1 & .1 \\
\hline $\mathrm{C}^{12} \mathrm{D}_{3} \mathrm{C}^{12} \mathrm{DO}^{16}$ & 3- 472 & Not Reported & & & & 26494.55 & \\
\hline $\mathrm{C}^{12}{ }_{*} \mathrm{HC}^{12} \mathrm{H}: \mathrm{C}^{12} \mathrm{HC}^{12} \mathrm{H}: \mathrm{C}^{12} \mathrm{HN}^{14}{ }_{*}$ & 4-1201 & $17,14,4 \leftarrow 17,12,5$ & Ground & & & 26495.8 & .1 \\
\hline $\mathrm{C}^{12} \mathrm{H}_{2}\left(\mathrm{C}^{12} \mathrm{~N}^{14}\right)_{2}$ & 4. 901 & $9,1,8 \leftarrow 9,0,9$ & Ground & & & 26497.38 & \\
\hline $\mathrm{HC}^{12}: \mathrm{C}^{12} \mathrm{C}^{12} \mathrm{~N}^{15}$ & 4- 885 & $3 \leftarrow 2$ & Ground & & & 26501.46 & \\
\hline $\mathrm{C}^{12} \mathrm{D}_{2} \mathrm{Cl}^{35} \mathrm{Cl}^{37}$ & 4. 347 & $1,1,1 \leftarrow 0,0,0$ & Ground & & & 26501.5 & .2 \\
\hline $\mathrm{C}^{13} \mathrm{H}_{3}\left(\mathrm{C}^{12} \mathrm{H}_{3}\right)_{2} \mathrm{C}^{12} \mathrm{C}^{12}: \mathrm{C}^{12} \mathrm{H}$ & 3-1077 & $5,1,5 \leftarrow 4,1,4$ & Ground & & & 26504.7 & .1 \\
\hline $\mathrm{C}^{12} \mathrm{H}_{3} \mathrm{Cl}^{35}$. & 4- 421 & $1,0 \leftarrow 0,0$ & Excited & $1 / 2$ & $3 / 2$ & 26506.38 & .10 \\
\hline $\mathrm{C}^{12} \mathrm{D}_{3} \mathrm{C}^{13} \mathrm{O}^{16} \mathrm{C}^{12} \mathrm{~N}^{14}$ & 3. 676 & $11,3,8 \leftarrow 11,2,9$ & Ground & & & 26507.05 & .2 \\
\hline
\end{tabular}




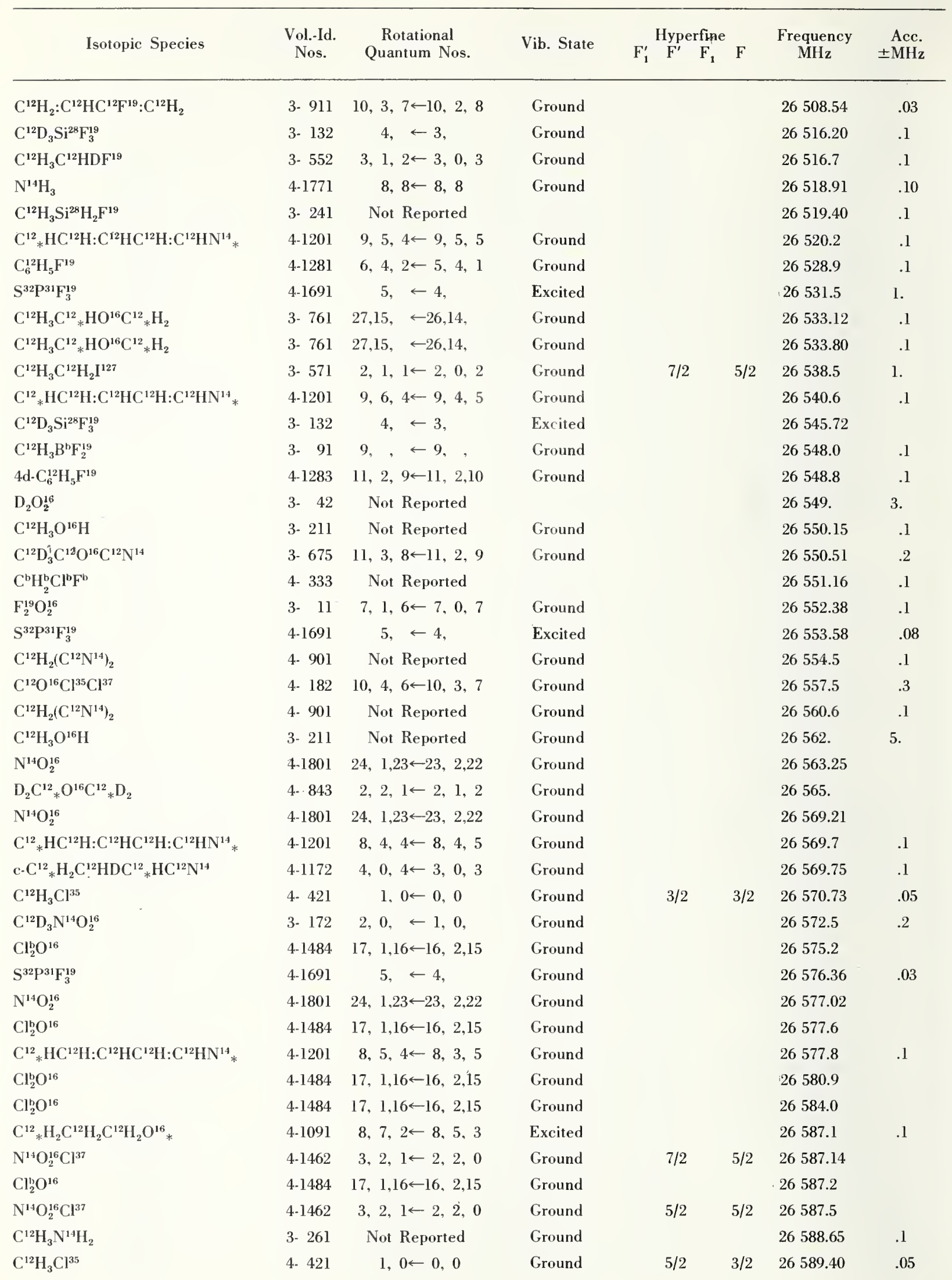


$\mathrm{Cl}_{2}^{\mathrm{b}} \mathrm{O}^{16}$

$\mathrm{C}^{12} \mathrm{H}_{3} \mathrm{Si}^{28} \mathrm{H}_{2} \mathrm{~F}^{19}$

$\mathrm{C}^{12} \mathrm{H}_{3} \mathrm{~B}^{\mathrm{b}} \mathrm{F}_{2}^{19}$

c- $\mathrm{C}^{12}{ }_{*} \mathrm{H}_{2} \mathrm{C}^{12} \mathrm{HDC}^{12}{ }_{*} \mathrm{HC}^{12} \mathrm{~N}^{14}$

$\mathrm{C}^{12} \mathrm{H}_{3} \mathrm{C}^{12} \mathrm{O}^{16} \mathrm{C}^{13} \mathrm{~N}^{14}$

$\mathrm{S}^{32} \mathrm{P}^{31} \mathrm{~F}_{3}^{19}$

$\mathrm{C}^{13} \mathrm{H}_{3} \mathrm{C}^{12}: \mathrm{C}^{12} \mathrm{C}^{12} \mathrm{~F}_{3}^{19}$

$\left(\mathrm{C}^{12} \mathrm{H}_{3}\right)_{2} \mathrm{O}^{16}$

c- $\mathrm{C}^{12}{ }_{*} \mathrm{H}_{2} \mathrm{C}^{12} \mathrm{HDC}^{12}{ }_{*} \mathrm{HC}^{12} \mathrm{~N}^{14}$

c- $\mathrm{C}^{12}{ }_{*} \mathrm{H}_{2} \mathrm{C}^{12} \mathrm{HDC}^{12}{ }_{*} \mathrm{HC}^{12} \mathrm{~N}^{14}$

$\mathrm{HC}^{12}: \mathrm{C}^{12} \mathrm{C}^{12} \mathrm{H}: \mathrm{C}^{12} \mathrm{H}_{2}$

$\mathrm{N}^{14} \mathrm{O}_{2}^{16} \mathrm{Cl}^{37}$

$\mathrm{N}^{14} \mathrm{O}_{2}^{16} \mathrm{Cl}^{37}$

$\mathrm{C}^{12}{ }_{*} \mathrm{HC}^{12} \mathrm{H}: \mathrm{C}^{12} \mathrm{HC}^{12} \mathrm{H}: \mathrm{C}^{12} \mathrm{HN}^{14}$ * $\mathrm{N}^{14} \mathrm{O}_{2}^{16}$

$\mathrm{C}^{12} \mathrm{H}_{3} \mathrm{Cl}^{35}$

$\mathrm{C}^{12}{ }_{*} \mathrm{HC}^{12} \mathrm{H}: \mathrm{C}^{12} \mathrm{HC}^{12} \mathrm{H}: \mathrm{C}^{12} \mathrm{HN}^{14}{ }^{4}$ $\mathrm{C}_{6}^{12} \mathrm{H}_{5} \mathrm{~F}^{19}$

$\mathrm{H}_{2} \mathrm{~N}^{14} \mathrm{~N}^{14} \mathrm{H}_{2}$

$\mathrm{N}^{14} \mathrm{O}_{2}^{16} \mathrm{Cl}^{37}$

$\mathrm{C}^{12} \mathrm{H}_{3} \mathrm{C}^{12} \mathrm{H}_{2} \mathrm{C}^{12} \mathrm{H}_{3}$

$\mathrm{C}^{12} \mathrm{H}_{3} \mathrm{C}^{13}: \mathrm{C}^{12} \mathrm{Cl}^{35}$

$\mathrm{C}^{12} \mathrm{H}_{3} \mathrm{C}^{13}: \mathrm{C}^{12} \mathrm{Cl}^{35}$

$\mathrm{C}^{12} \mathrm{H}_{3} \mathrm{C}^{13}: \mathrm{C}^{12} \mathrm{Cl}^{35}$

$\mathrm{C}^{12} \mathrm{H}_{3} \mathrm{C}^{13}: \mathrm{C}^{12} \mathrm{Cl}^{35}$

$\mathrm{C}^{12} \mathrm{H}_{3} \mathrm{C}^{12} \mathrm{O}^{16} \mathrm{~F}^{19}$

$\mathrm{C}_{6}^{12} \mathrm{H}_{5} \mathrm{Cl}^{35}$

c- $\mathrm{C}^{12}{ }_{*} \mathrm{H}_{2} \mathrm{C}^{12} \mathrm{HDC}^{12}{ }_{*} \mathrm{HC}^{12} \mathrm{~N}^{14}$

$\mathrm{C}^{\mathrm{b}} \mathrm{H}_{2}^{\mathrm{b}} \mathrm{Cl}^{\mathrm{b}} \mathrm{F}^{\mathrm{b}}$

$\mathrm{C}^{\mathrm{b}} \mathrm{H}_{2}^{\mathrm{b}} \mathrm{Cl}^{\mathrm{b}} \mathrm{F}^{\mathrm{b}}$

$\mathrm{N}^{14} \mathrm{O}_{2}^{16}$

$\mathrm{C}^{12} \mathrm{H}_{2}\left(\mathrm{C}^{12} \mathrm{~N}^{14}\right)_{2}$

$\mathrm{N}^{14} \mathrm{O}_{2}^{16} \mathrm{Cl}^{37}$

$\mathrm{C}^{12} \mathrm{H}_{3} \mathrm{C}^{12} \mathrm{H}_{2} \mathrm{I}^{127}$

$\mathrm{Na}^{23} \mathrm{Br}^{29}$

$\mathrm{Na}^{23} \mathrm{Br}^{29}$

$\mathrm{HC}^{13}: \mathrm{C}^{12} \mathrm{C}^{12} \mathrm{HO}^{16}$

$\mathrm{C}^{13}{ }_{*} \mathrm{HC}^{12} \mathrm{H}: \mathrm{C}^{12} \mathrm{HC}^{12} \mathrm{H}: \mathrm{C}^{12} \mathrm{HN}^{14}{ }_{*}$

$\mathrm{C}^{12}{ }_{*} \mathrm{D}_{2} \mathrm{C}^{12} \mathrm{H}_{2} \mathrm{C}^{12} \mathrm{D}_{2} \mathrm{O}^{16}{ }_{*}$

$\mathrm{C}_{6}^{12} \mathrm{H}_{5} \mathrm{O}^{16} \mathrm{H}$

$\mathrm{C}^{12}{ }_{*} \mathrm{HC}^{12} \mathrm{H}: \mathrm{C}^{12} \mathrm{HC}^{12} \mathrm{H}: \mathrm{C}^{12} \mathrm{HN}^{14}$ *

$\mathrm{C}^{12}{ }_{*} \mathrm{HC}^{12} \mathrm{H}: \mathrm{C}^{12} \mathrm{HC}^{12} \mathrm{H}: \mathrm{C}^{12} \mathrm{HN}^{14}$ *

$\mathrm{C}^{12} \mathrm{H}_{2}: \mathrm{C}^{12} \mathrm{HC}^{12} \mathrm{~F}^{19}: \mathrm{C}^{12} \mathrm{H}_{2}$

$\mathrm{H}_{2} \mathrm{C}^{12}: \mathrm{C}^{12} \mathrm{~F}_{2}^{19}$

$\mathrm{C}^{12}{ }_{*} \mathrm{H}_{2} \mathrm{C}^{12} \mathrm{H}_{2} \mathrm{C}^{12} \mathrm{H}_{2} \mathrm{O}^{16}{ }_{*}$
$4-1484 \quad 17,1,16 \leftarrow-16,2,15$

3- 241 Not Reported

3. 91

$2, \quad \leftarrow 1$, ,

4-1172

$4,2,3 \leftarrow 3,2,2$

Ground

3- 673

4-1691

$7,3,4 \leftarrow 7,2,5$

Ground

$$
5, \leftarrow 4 \text {, }
$$

Ground

3- 893

$10, \leftarrow 9$,

Excited

3- 591

$12,3,9 \leftarrow 11,4,8$

Ground

4-1172

$4,3,1 \leftarrow 3,3,0$

Ground

4-1172

$4,3,2 \leftarrow 3,3,1$

Ground

4-1131

$3,1,3 \leftarrow 2,1,2$

Ground

4-1462

$3,2,1 \leftarrow 2,2,0$

4-1462

$3,2,1 \leftarrow 2,2,0$

4-1201

$7,3,4 \leftarrow 7,3,5$

4-1801

4- 421

$24,1,23 \leftarrow-23,2,22$

4-1201

$1,0 \leftarrow 0,0$

4-1281

$7,4,4 \leftarrow 7,2,5$

$7,0,7 \leftarrow 6,0,6$

3- 51

Not Reported

4-1462

$3,2,1 \leftarrow 2,2,0$

3- 781

4- 975

$4,1,3 \leftarrow 4,0,4$

4. 975

$6,0 \leftarrow 5,0$

$6,0 \leftarrow 5,0$

4- 975

$6,0 \leftarrow 5,0$

4- 975

3- 391

$6,0 \leftarrow 5,0$

Not Reported

4-1271

$9,2,7 \leftarrow 8,2,6$

4-1172

4- 333

$4,2,2 \leftarrow 3,2,1$

Not Reported

4. 333

Not Reported

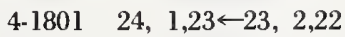

Ground

4. 901

Not Reported

4-1462

$3,2,1 \leftarrow 2,2,0$

3- 571

$2,1,1 \leftarrow 2,0,2$

l.

$$
3 \leftarrow 2
$$

1 -

4. 912

$3 \leftarrow 2$

4-1205

$3,1,3 \leftarrow 2,1,2$

Ground

Ground

Ground

Ground

Ground

Ground

Ground

Ground

Ground

Ground

Ground

Ground

Ground

Ground

Ground

Ground

Ground

4-1092

$3,1,2 \leftarrow 2,1,1$

$4,1,3 \leftarrow 4,0,4$

$7,0,7 \leftarrow 6,1,6$

4. 1201

$6,2,4 \leftarrow 6,2,5$

4-1201

$6,3,4 \leftarrow 6,1,5$

3- 911

$10,3,7 \leftarrow 10,2,8$

4- 681

$4,2,2 \leftarrow 4,2,3$

4-1091
$8,7,2 \leftarrow 8,5,3$
Ground

Ground

Ground

Excited

Excited

Ground

Ground

Excited

Ground

Ground

Ground

Excited

Ground

Excited
26589.5

26589.80

$26590.5 \quad$. 1

26591.95 . 1

$26593.24 \quad .2$

$26595.5 \quad .1$

$26596.5 \quad .5$

$26598.6 \quad .2$

$26598.95 \quad .1$

26598.95 . 1

$26600.00 \quad .05$

$5 / 2 \quad 3 / 2 \quad 26600.60$

$3 / 2 \quad 3 / 2 \quad 26601.4$

26602.6

26603.65

$1 / 2 \quad 3 / 2$

$26604.38 \quad .05$

$26605.2 \quad .1$

$26605.3 \quad .1$

26605.60

$9 / 2 \quad 7 / 2 \quad 26606.22$

$26609.24 \quad .03$

$\begin{array}{llll}9 / 2 & 7 / 2 & 26611.16 & .04\end{array}$

$11 / 2 \quad 9 / 2 \quad 26611.16 \quad .04$

$\begin{array}{llll}13 / 2 & 11 / 2 & 26612.05 & .04\end{array}$

$\begin{array}{llll}15 / 2 & 13 / 2 & 26612.05 & .04\end{array}$

$26612.3 \quad .2$

$26616 . \quad 5.0$

$26616.19 \quad .1$

$26616.38 \quad .1$

$26617.97 \quad . \quad 1$

26619.38

$26619.6 \quad$.1

$3 / 2 \quad 1 / 2 \quad 26619.69$

$7 / 2 \quad 7 / 2 \quad 26620.2$.

$\begin{array}{lllll}9 / 2 & 7 / 2 & 26 & 621.8 & .8\end{array}$

$\begin{array}{llll}7 / 2 & 5 / 2 & 26621.8 & .8\end{array}$

$26622.49 \quad .02$

26622.8

$26623.1 \quad .1$

26623.56

$26623.7 \quad .1$

$26624.4 \quad$.1

$26626.69 \quad .03$

$26627.6 \quad .3$

$26630.1 \quad .1$ 


\begin{tabular}{|c|c|c|c|c|c|c|c|}
\hline \multirow{3}{*}{$\underbrace{\text { Isotopic Species }}_{\mathrm{C}_{6}^{12} \mathrm{H}_{5} \mathrm{Cl}^{35}}$} & \multirow{3}{*}{$\begin{array}{l}\text { Vol.-Id. } \\
\text { Nos. } \\
\text { 4-1271 }\end{array}$} & \multirow{3}{*}{$\begin{array}{c}\text { Rotational } \\
\text { Quantum Nos. } \\
\text { Not Reported }\end{array}$} & \multirow{3}{*}{$\begin{array}{l}\text { Vib. State } \\
\text { Ground }\end{array}$} & \multicolumn{2}{|c|}{ Hyperfine } & \multirow{2}{*}{$\begin{array}{c}\text { Frequency } \\
\mathrm{MHz}\end{array}$} & \multirow{2}{*}{$\begin{array}{r}\text { Acc. } \\
\pm \mathrm{MHz}\end{array}$} \\
\hline & & & & $F_{1}^{\prime} \quad F^{\prime}$ & $\mathrm{F}_{1} \mathrm{~F}$ & & \\
\hline & & & & & & 26630.9 & .1 \\
\hline $\mathrm{C}_{6}^{12} \mathrm{H}_{5} \mathrm{Cl}^{35}$ & 4-1271 & $9,1,8 \leftarrow 8,1,7$ & Ground & $15 / 2$ & $13 / 2$ & 26631.1 & .1 \\
\hline $\mathrm{C}_{6}^{12} \mathrm{H}_{5} \mathrm{Cl}^{35}$ & 4-1271 & $9,1,8 \leftarrow 8,1,7$ & Ground & $17 / 2$ & $15 / 2$ & 26631.1 & .1 \\
\hline $\mathrm{C}_{6}^{12} \mathrm{H}_{5} \mathrm{Cl}^{35}$ & $4-1271$ & $9,1,8 \leftarrow 8,1,7$ & Ground & $21 / 2$ & $19 / 2$ & 26631.1 & .1 \\
\hline $\mathrm{C}_{6}^{12} \mathrm{H}_{5} \mathrm{Cl}^{35}$ & 4-1271 & $9,1,8 \leftarrow 8,1,7$ & Ground & $19 / 2$ & $17 / 2$ & 26631.1 & .1 \\
\hline $\mathrm{C}^{12} \mathrm{~F}_{3}^{19} \mathrm{Cl}^{35}$ & 4- 161 & $4,2 \leftarrow 3,2$ & Excited & $9 / 2$ & $7 / 2$ & 26631.58 & \\
\hline $\mathrm{N}^{14} \mathrm{O}_{2}^{16}$ & 4-1801 & $24,1,23 \leftarrow 23,2,22$ & Ground & & & 26633.83 & \\
\hline $\mathrm{C}^{12}{ }_{*} \mathrm{HC}^{12} \mathrm{H}: \mathrm{C}^{12} \mathrm{DC}^{12} \mathrm{H}: \mathrm{C}^{12} \mathrm{HN}^{14}{ }_{*}$ & 4-1204 & $11,9,3 \leftarrow 11,7,4$ & Ground & & & 26634.1 & .1 \\
\hline $\mathrm{C}^{12} \mathrm{~F}_{3}^{19} \mathrm{Cl}^{35}$ & 4. 161 & $4,2 \leftarrow 3,2$ & Excited & $7 / 2$ & $5 / 2$ & 26634.31 & \\
\hline $\mathrm{C}^{12}{ }_{*} \mathrm{HC}^{12} \mathrm{H}: \mathrm{C}^{12} \mathrm{HC}^{12} \mathrm{H}: \mathrm{C}^{12} \mathrm{HN}^{14}{ }_{*}$ & 4-1201 & $4,0,4 \leftarrow 3,0,3$ & Ground & & & 26634.8 & .1 \\
\hline $\mathrm{C}^{12}{ }_{*} \mathrm{HC}^{12} \mathrm{H}: \mathrm{C}^{12} \mathrm{HC}^{12} \mathrm{H}: \mathrm{C}^{12} \mathrm{HN}^{14}{ }_{*}$ & $4-1201$ & $4,1,4 \leftarrow 3,1,3$ & Ground & & & 26634.8 & .1 \\
\hline $\mathrm{C}^{12}{ }_{*} \mathrm{HC}^{12} \mathrm{H}: \mathrm{C}^{12} \mathrm{HC}^{12} \mathrm{H}: \mathrm{C}^{12} \mathrm{HN}^{14} *$ & 4.1201 & $5,2,4 \leftarrow 5,0,5$ & Ground & & & 26636.9 & .1 \\
\hline $\mathrm{C}^{12}{ }_{*} \mathrm{HC}^{12} \mathrm{H}: \mathrm{C}^{12} \mathrm{HC}^{12} \mathrm{H}: \mathrm{C}^{12} \mathrm{HN}^{14}{ }_{*}$ & 4-1201 & $5,1,4 \leftarrow 5,1,5$ & Ground & & & 26636.9 & .1 \\
\hline $\mathrm{C}^{12} \mathrm{~F}_{3}^{19} \mathrm{Cl}^{35}$ & 4- 161 & $4,2 \leftarrow 3,2$ & Excited & $11 / 2$ & $9 / 2$ & 26639.40 & \\
\hline $\mathrm{Na}^{23} \mathrm{Br}^{81}$ & 1 - & $3 \leftarrow 2$ & Excited & $7 / 2$ & $5 / 2$ & 26639.9 & .8 \\
\hline $\mathrm{Na}^{23} \mathrm{Br}^{81}$ & $1-$ & $3 \leftarrow 2$ & Excited & $9 / 2$ & $7 / 2$ & 26639.9 & .8 \\
\hline $\mathrm{O}^{16}{ }_{*}^{12} \mathrm{H}_{2} \mathrm{C}^{12} \mathrm{H}_{2} \mathrm{C}^{12}{ }_{*} \mathrm{O}^{16}$ & 4-1071 & $3,0,3 \leftarrow 2,0,2$ & Ground & & & 26641.64 & .1 \\
\hline $\mathrm{C}^{12} \mathrm{~F}_{3}^{19} \mathrm{Cl}^{35}$ & 4- 161 & $4,2 \leftarrow 3,2$ & Excited & $5 / 2$ & $3 / 2$ & 26642.22 & \\
\hline $\mathrm{Si}^{28} \mathrm{H}_{2} \mathrm{~F}_{2}^{19}$ & 4-1601 & $3,0,3 \leftarrow 2,1,2$ & Ground & & & 26642.93 & .10 \\
\hline $\mathrm{Na}^{23} \mathrm{Br}^{81}$ & 1 . & $3 \leftarrow 2$ & Excited & $5 / 2$ & $3 / 2$ & 26643.2 & .8 \\
\hline $\mathrm{Na}^{23} \mathrm{Br}^{81}$ & $1-$ & $3 \leftarrow 2$ & Excited & $3 / 2$ & $1 / 2$ & 26643.2 & .8 \\
\hline $\mathrm{C}^{12}{ }_{*} \mathrm{H}_{2} \mathrm{C}^{12} \mathrm{H}_{2} \mathrm{C}^{12}{ }_{*} \mathrm{HC}^{12} \mathrm{~N}^{14}$ & 4-1171 & $4,1,4 \leftarrow 3,1,3$ & Ground & & & 26643.54 & .05 \\
\hline $\mathrm{C}^{12} \mathrm{H}_{2} \mathrm{Cl}^{37} \mathrm{Si}^{28} \mathrm{H}_{3}$ & 3- 232 & $10,1,9 \leftarrow 10,0,10$ & Ground & & & 26645.25 & .2 \\
\hline $\mathrm{H}_{2} \mathrm{C}^{12}: \mathrm{C}^{12} \mathrm{~F}_{2}^{19}$ & 4- 681 & $3,1,2 \leftarrow 3,1,3$ & Ground & & & 26646.2 & .3 \\
\hline $\mathrm{t}-\mathrm{C}^{12} \mathrm{H}_{3} \mathrm{C}^{12} \mathrm{H}: \mathrm{C}^{12} \mathrm{HC}^{12} \mathrm{~N}^{14}$ & 3- 921 & $6,1, \leftarrow 5,1$ & Ground & & & 26646.22 & .5 \\
\hline $\mathrm{N}^{14} \mathrm{O}_{2}^{16}$ & 4-1801 & $24,1,23 \leftarrow 23,2,22$ & Ground & & & 26647.17 & \\
\hline $\mathrm{C}^{12} \mathrm{H}_{3} \mathrm{C}^{12} \mathrm{H}_{2} \mathrm{I}^{127}$ & 3- 571 & $2,1,1 \leftarrow 2,0,2$ & Ground & $5 / 2$ & $7 / 2$ & 26647.50 & .05 \\
\hline $\mathrm{HC}^{13}: \mathrm{C}^{12} \mathrm{C}^{12} \mathrm{DO}^{16}$ & 4- 922 & Not Reported & & & & 26650. & 5. \\
\hline $\mathrm{C}^{13} \mathrm{H}_{3}\left(\mathrm{C}^{12} \mathrm{H}_{3}\right)_{2} \mathrm{C}^{12} \mathrm{C}^{12}: \mathrm{C}^{12} \mathrm{H}$ & 3-1077 & $5,1,4 \leftarrow 4,1,3$ & Ground & & & 26650.1 & .1 \\
\hline $\mathrm{C}^{12} \mathrm{H}_{3} \mathrm{~N}^{14} \mathrm{H}_{2}$ & 3- 261 & Not Reported & Ground & & & 26654.86 & .1 \\
\hline $\mathrm{N}^{14} \mathrm{H}_{3}$ & 4-1771 & $13,12 \leftarrow 13,12$ & Ground & & & 26655.00 & .10 \\
\hline $\mathrm{Cl}^{35} \mathrm{O}_{2}^{16}$ & 4-1381 & $18,5,14 \leftarrow 19,4,15$ & Ground & $39 / 2$ & $41 / 2$ & 26657.1 & \\
\hline$\left(\mathrm{C}^{12} \mathrm{H}_{3}\right)_{3} \mathrm{C}^{12} \mathrm{C}^{13}: \mathrm{C}^{12} \mathrm{H}$ & $3-1074$ & $5, \leftarrow 4$ & Ground & & & 26659.1 & .1 \\
\hline $\mathrm{C}^{12} \mathrm{H}_{3} \mathrm{Si}^{28} \mathrm{HF}_{2}^{19}-\mathrm{E}$ & 3- 192 & $2,2,1 \leftarrow 1,1,1$ & Ground & & & 26659.23 & \\
\hline $\mathrm{C}^{35} \mathrm{O}_{2}^{16}$ & 4-1381 & $18,5,14 \leftarrow 19,4,15$ & Ground & $37 / 2$ & $39 / 2$ & 26661.3 & \\
\hline$\left(\mathrm{C}^{12} \mathrm{H}_{3}\right)_{2} \mathrm{C}^{12} \mathrm{O}^{16}$ & 3- 751 & Not Reported & & & & 26661.5 & \\
\hline $\mathrm{C}^{12} \mathrm{H}_{3} \mathrm{Si}^{28} \mathrm{HF}_{2}^{19}-\mathrm{A}$ & 3- 191 & $2,2,1 \leftarrow 1,1,1$ & Ground & & & 26662.15 & \\
\hline $\mathrm{C}^{12} \mathrm{H}_{2} \mathrm{~N}^{14} \mathrm{O}^{16} \mathrm{H}$ & 3- 141 & $5,1,4 \leftarrow 5,1,5$ & Ground & 6 & 6 & 26664.83 & .10 \\
\hline $\mathrm{C}^{12} \mathrm{H}_{2} \mathrm{~N}^{14} \mathrm{O}^{16} \mathrm{H}$ & 3- 141 & $5,1,4 \leftarrow 5,1,5$ & Ground & 4 & 4 & 26664.83 & .10 \\
\hline $\mathrm{C}^{12}{ }_{*} \mathrm{H}_{2} \mathrm{C}^{12} \mathrm{H}_{2} \mathrm{C}^{12} \mathrm{H}_{2} \mathrm{O}^{16}{ }_{*}$ & 4-1091 & $8,7,2 \leftarrow 8,5,3$ & Excited & & & 26665 . & \\
\hline $\mathrm{Cl}^{35} \mathrm{O}_{2}^{16}$ & 4-1381 & $18,5,14 \leftarrow 19,4,15$ & Ground & $35 / 2$ & $37 / 2$ & 26665.1 & \\
\hline $\mathrm{C}^{12} \mathrm{D}_{3} \mathrm{C}^{12} \mathrm{DO}^{16}$ & 3- 472 & Not Reported & & & & 26666.14 & \\
\hline $\mathrm{C}^{12} \mathrm{H}_{2} \mathrm{~N}^{14} \mathrm{O}^{16} \mathrm{H}$ & 3. 141 & $5,1,4 \leftarrow 5,1,5$ & Ground & 5 & 5 & 26667.27 & .10 \\
\hline $\mathrm{N}^{14} \mathrm{O}_{2}^{16} \mathrm{Cl}^{35}$ & $4-1461$ & $3,2,2 \leftarrow 2,2,1$ & Ground & $5 / 2$ & $5 / 2$ & 26667.77 & \\
\hline $\mathrm{Cl}^{35} \mathrm{O}_{2}^{16}$ & $4-1381$ & $18,5,14 \leftarrow 19,4,15$ & Ground & $33 / 2$ & $35 / 2$ & 26668.4 & \\
\hline
\end{tabular}




\begin{tabular}{|c|c|c|c|c|c|c|c|}
\hline \multirow{2}{*}{ Isotopic Species } & \multirow{2}{*}{$\begin{array}{l}\text { Vol.-Id. } \\
\text { Nos. }\end{array}$} & \multirow{2}{*}{$\begin{array}{c}\text { Rotational } \\
\text { Quantum Nos. }\end{array}$} & \multirow{2}{*}{ Vib. State } & \multicolumn{2}{|c|}{ Hyperfine } & \multirow{2}{*}{$\begin{array}{c}\text { Frequency } \\
\mathrm{MH}_{2}\end{array}$} & \multirow{2}{*}{$\begin{aligned} & \text { Acc. } \\
\pm & \mathrm{MHz}\end{aligned}$} \\
\hline & & & & $\begin{array}{lll}F_{1}^{\prime} & F^{\prime} & F_{1}\end{array}$ & $\mathbf{F}$ & & \\
\hline $\mathrm{C}^{12} \mathrm{H}_{3} \mathrm{C}^{12} \mathrm{O}^{16} \mathrm{~F}^{19}$ & 3- 391 & Not Reported & Ground & & & 26668.7 & .2 \\
\hline $\mathrm{Tl}^{205} \mathrm{~F}^{19}$ & 1 - & $2 \leftarrow 1$ & Ground & & & 26669.76 & 0.10 \\
\hline $\mathrm{C}^{12} \mathrm{~F}_{3}^{19} \mathrm{Cl}^{35}$ & 4- 161 & $4, \leftarrow 3$, & Ground & & & 26669.78 & \\
\hline $\mathrm{C}^{12} \mathrm{~F}_{3}^{19} \mathrm{Cl}^{35}$ & 4- 161 & $4,3 \leftarrow 3,3$ & Ground & $7 / 2$ & $7 / 2$ & 26670.19 & \\
\hline $\mathrm{C}^{12} \mathrm{D}_{2} \mathrm{Cl}_{2}^{35}$ & 4. 346 & $1,1,1 \leftarrow 0,0,0$ & Ground & & & 26670.2 & .2 \\
\hline $\mathrm{C}^{12} \mathrm{H}_{2} \mathrm{Cl}^{35} \mathrm{Si}^{28} \mathrm{H}_{3}$ & 3- 231 & $10,1,9 \leftarrow 10,0,10$ & Ground & & & 26672.38 & .2 \\
\hline $\mathrm{C}^{12} \mathrm{~F}_{3}^{19} \mathrm{Cl}^{35}$ & 4- 161 & $4,3 \leftarrow 3,3$ & Ground & $9 / 2$ & $7 / 2$ & 26672.59 & \\
\hline $\mathrm{C}^{12} \mathrm{~F}_{3}^{19} \mathrm{Cl}^{35}$ & 4. 161 & $4,3 \leftarrow 3,3$ & Ground & $5 / 2$ & $5 / 2$ & 26674.77 & \\
\hline $\mathrm{C}^{12} \mathrm{H}_{3} \mathrm{C}^{12} \mathrm{O}^{16} \mathrm{~F}^{19}$ & 3- 391 & $8,5,3 \leftarrow 8,5,4$ & Ground & & & 26679.20 & .2 \\
\hline $\mathrm{C}^{12} \mathrm{~F}_{3}^{19} \mathrm{Cl}^{35}$ & 4- 161 & $4,2 \leftarrow 3,2$ & Ground & $9 / 2$ & $7 / 2$ & 26679.62 & \\
\hline $\mathrm{N}^{14} \mathrm{O}_{2}^{16}$ & 4-1801 & $24,1,23 \leftarrow 23,2,22$ & Ground & & & 26681.4 & \\
\hline $\mathrm{C}^{12} \mathrm{~F}_{3}^{19} \mathrm{Cl}^{35}$ & 4- 161 & $4,3 \leftarrow 3,3$ & Ground & $7 / 2$ & $5 / 2$ & 26681.52 & \\
\hline $\mathrm{C}^{12} \mathrm{~F}_{3}^{19} \mathrm{Cl}^{35}$ & 4- 161 & $4,2 \leftarrow 3,2$ & Ground & $7 / 2$ & $5 / 2$ & 26682.30 & \\
\hline $\mathrm{C}^{12} \mathrm{~F}_{3}^{19} \mathrm{Cl}^{35}$ & 4- 161 & $4,1 \leftarrow 3,1$ & Ground & $7 / 2$ & $5 / 2$ & 26682.81 & \\
\hline $\mathrm{C}^{12} \mathrm{~F}_{3}^{19} \mathrm{Cl}^{35}$ & 4- 161 & $4,1 \leftarrow 3,1$ & Ground & $9 / 2$ & $7 / 2$ & 26683.78 & \\
\hline $\mathrm{C}^{12} \mathrm{H}_{3} \mathrm{C}^{12} \mathrm{H}_{2} \mathrm{C}^{13} \mathrm{~N}^{14}$ & 3- 732 & $3,0,3 \leftarrow 2,0,2$ & Ground & & & 26684.09 & .1 \\
\hline $\mathrm{N}^{14} \mathrm{O}_{2}^{16} \mathrm{Cl}^{35}$ & 4-1461 & $3,2,2 \leftarrow 2,2,1$ & Ground & $3 / 2$ & $3 / 2$ & 26684.68 & \\
\hline $\mathrm{C}^{12} \mathrm{~F}_{3}^{19} \mathrm{Cl}^{35}$ & 4- 161 & $4,1 \leftarrow 3,1$ & Ground & $5 / 2$ & $3 / 2$ & 26684.69 & \\
\hline $\mathrm{C}^{12} \mathrm{~F}_{3}^{19} \mathrm{Cl}^{35}$ & 4. 161 & $4,1 \leftarrow 3,1$ & Ground & $11 / 2$ & $9 / 2$ & 26685.73 & \\
\hline $\mathrm{C}^{12} \mathrm{~F}_{3}^{19} \mathrm{Cl}^{35}$ & 4- 161 & $4,2 \leftarrow 3,2$ & Ground & $11 / 2$ & $9 / 2$ & 26687.38 & \\
\hline $\mathrm{O}_{3}^{18}$ & 4-1845 & $14,2,12 \leftarrow 15,1,15$ & Ground & & & 26690 & \\
\hline $\mathrm{C}^{12} \mathrm{~F}_{3}^{19} \mathrm{Cl}^{35}$ & 4. 161 & $4,2 \leftarrow 3,2$ & Ground & $5 / 2$ & $3 / 2$ & 26690.14 & \\
\hline $\mathrm{C}^{12} \mathrm{~F}_{3}^{19} \mathrm{Cl}^{35}$ & 4. 161 & $4,3 \leftarrow 3,3$ & Ground & $11 / 2$ & $9 / 2$ & 26690.14 & \\
\hline $\mathrm{N}^{14} \mathrm{O}^{16} \mathrm{Cl}^{35}$ & 4-1461 & $3,2,2 \leftarrow 2,2,1$ & Ground & $7 / 2$ & $7 / 2$ & 26691.44 & \\
\hline $\mathrm{C}^{12} \mathrm{Cl}_{3}^{35} \mathrm{C}^{12} \mathrm{~N}^{14}$ & 4- 581 & $8, \leftarrow 7$ & Excited & & & 26691.9 & 1.0 \\
\hline $\mathrm{C}^{12} \mathrm{H}_{2}: \mathrm{C}^{12} \mathrm{HC}^{12} \mathrm{HO}^{16}$ & 3- 691 & $3,0,3 \leftarrow 2,0,2$ & Ground & & & 26694.37 & \\
\hline $\mathrm{N}^{14} \mathrm{O}_{2}^{16}$ & 4-1801 & $24,1,23 \leftarrow 23,2,22$ & Ground & & & 26695.08 & \\
\hline $\mathrm{Si}^{28} \mathrm{H}_{3} \mathrm{Cl}^{35}$ & 4-1441 & $2, \leftarrow 1$, & Ground & & & 26695.24 & \\
\hline $\mathrm{C}^{12} \mathrm{H}_{3} \mathrm{~N}^{14} \mathrm{H}_{2}$ & 3- 261 & Not Reported & Ground & & & 26695.43 & .1 \\
\hline $\mathrm{C}^{12} \mathrm{~F}_{3}^{19} \mathrm{Cl}^{35}$ & 4- 161 & $4,3 \leftarrow 3,3$ & Ground & $9 / 2$ & $9 / 2$ & 26697.04 & \\
\hline $\mathrm{C}^{12} \mathrm{H}_{2} \mathrm{~F}^{19} \mathrm{C}^{12} \mathrm{~N}^{14}$ & 4- 701 & $3,1,3 \leftarrow 2,1,2$ & Ground & & & 26697.8 & .2 \\
\hline $\mathrm{C}^{12} \mathrm{~F}_{3}^{19} \mathrm{Cl}^{35}$ & 4- 161 & $4,3 \leftarrow 3,3$ & Ground & $5 / 2$ & $3 / 2$ & 26699.14 & \\
\hline $\mathrm{C}^{12} \mathrm{Cl}_{3}^{35} \mathrm{C}^{12} \mathrm{~N}^{14}$ & 4. 581 & $8, \leftarrow 7$ & Excited & & & 26705.4 & 1.0 \\
\hline $\mathrm{N}^{14} \mathrm{O}_{2}^{16} \mathrm{Cl}^{35}$ & $4-1461$ & $3,2,2 \leftarrow 2,2,1$ & Ground & $1 / 2$ & $1 / 2$ & 26708.33 & \\
\hline $\mathrm{C}^{12} \mathrm{H}_{3} \mathrm{C}^{12} \mathrm{H}_{2} \mathrm{C}^{13} \mathrm{~N}^{14}$ & 3- 732 & $3,2,2 \leftarrow 2,2,1$ & Ground & & & 26713.9 & .5 \\
\hline $\mathrm{C}^{12} \mathrm{D}_{3} \mathrm{O}^{16} \mathrm{H}$ & 3- 214 & Not Reported & Ground & & & 26715.3 & .5 \\
\hline $\mathrm{C}^{12} \mathrm{H}_{3} \mathrm{~N}^{14} \mathrm{H}_{2}$ & 3- 261 & Not Reported & Ground & & & 26717.89 & .1 \\
\hline $\mathrm{C}^{12} \mathrm{H}_{3} \mathrm{C}^{12} \mathrm{O}^{16} \mathrm{~F}^{19}$ & 3- 391 & Not Reported & Ground & & & 26723.74 & .2 \\
\hline $\mathrm{C}^{12}{ }_{*} \mathrm{H}_{2} \mathrm{C}^{12} \mathrm{H}_{2} \mathrm{C}^{12} \mathrm{H}_{2} \mathrm{O}^{16}{ }_{*}$ & 4-1091 & $8,7,2 \leftarrow 8,5,3$ & Ground & & & 26725 . & \\
\hline $\mathrm{HC}^{13}: \mathrm{C}^{12} \mathrm{C}^{12} \mathrm{DO}^{16}$ & 4. 922 & Not Reported & & & & 26725 . & 5. \\
\hline $\mathrm{H}_{2} \mathrm{C}^{12}: \mathrm{C}^{12} \mathrm{~F}_{2}^{19}$ & 4- 681 & Not Reported & & & & 26726. & 1. \\
\hline g- ${ }^{12} \mathrm{H}_{3} \mathrm{C}^{12} \mathrm{H}_{2} \mathrm{C}^{12} \mathrm{H}_{2} \mathrm{Cl}^{35}$ & 3- 773 & $13,2,11 \leftarrow 13,1,12$ & Ground & & & 26726.06 & .2 \\
\hline $\mathrm{C}^{12} \mathrm{H}_{3} \mathrm{~N}^{14} \mathrm{H}_{2}$ & 3- 261 & Not Reported & Ground & & & 26728.77 & .1 \\
\hline $\mathrm{C}^{12} \mathrm{H}_{3} \mathrm{C}^{12} \mathrm{O}^{16} \mathrm{~F}^{19}$ & 3- 391 & $8,5,3 \leftarrow 8,5,4$ & Ground & & & 26732.94 & .2 \\
\hline $\mathrm{C}^{12} \mathrm{H}_{3} \mathrm{~N}^{14} \mathrm{H}_{2}$ & 3- 261 & Not Reported & Ground & & & 26733.54 & .1 \\
\hline
\end{tabular}




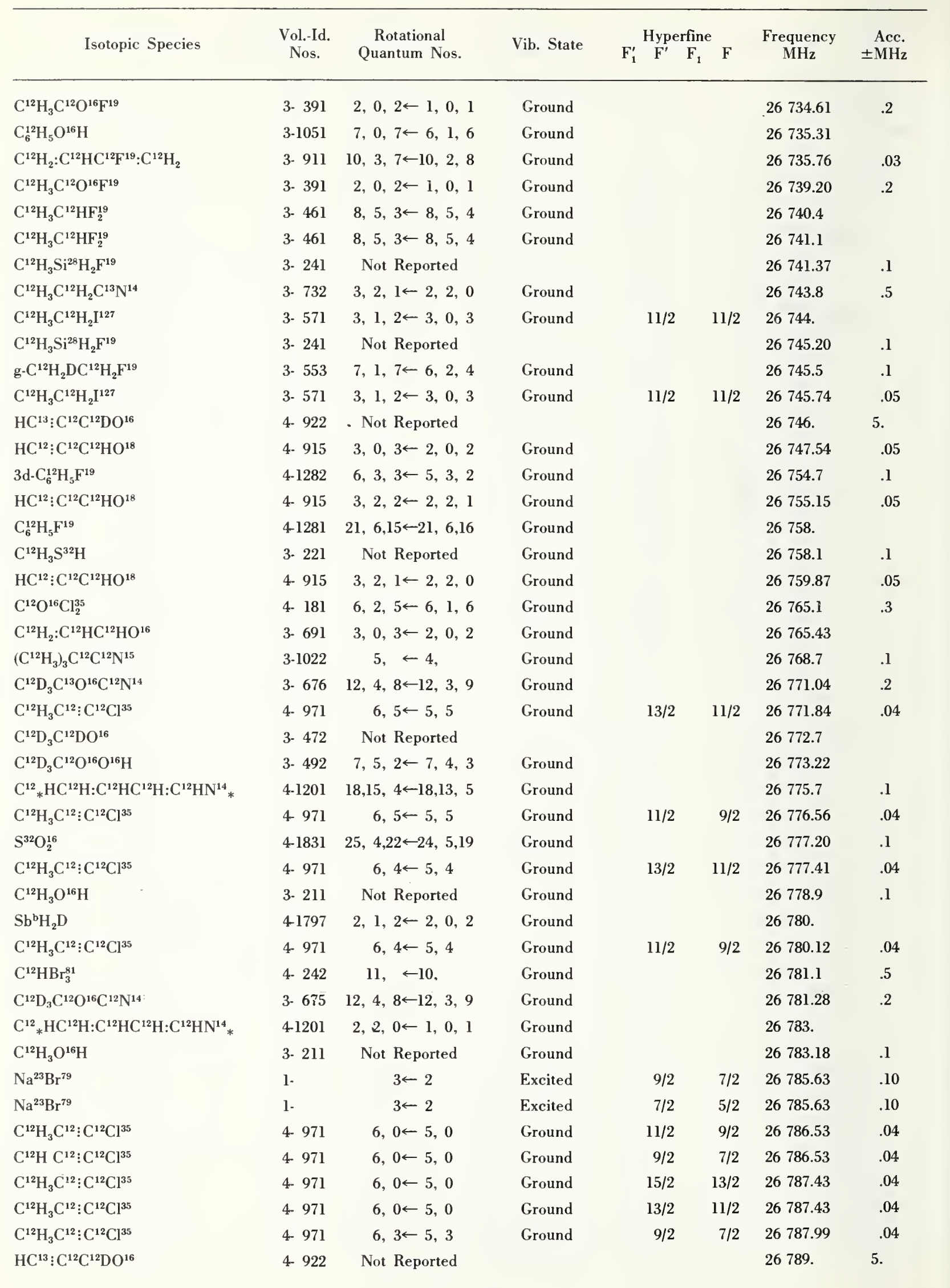




\begin{tabular}{|c|c|c|c|c|c|c|c|}
\hline Isotopic Species & $\begin{array}{l}\text { Vol.-Id. } \\
\text { Nos. }\end{array}$ & $\begin{array}{c}\text { Rotational } \\
\text { Quantum Nos. }\end{array}$ & Vib. State & $F_{1}^{2} \begin{array}{l}\text { Hyperfin } \\
F^{\prime} \quad F_{1}\end{array}$ & e $F$ & $\begin{array}{c}\text { Frequency } \\
\text { MHz. }\end{array}$ & $\begin{aligned} & \text { Acc. } \\
\pm & \mathrm{MH} /\end{aligned}$ \\
\hline $\mathrm{C}^{12} \mathrm{H}_{3} \mathrm{C}^{12}: \mathrm{C}^{12} \mathrm{Cl}^{35}$ & 4. 971 & $6,4 \leftarrow 5,4$ & Ground & $9 / 2$ & $7 / 2$ & 26789.21 & .04 \\
\hline $\mathrm{Na}^{23} \mathrm{Br}^{79}$ & $1-$ & $3 \leftarrow 2$ & Excited & $5 / 2$ & $3 / 2$ & 26789.51 & .30 \\
\hline $\mathrm{Na}^{23} \mathrm{Br}^{79}$ & $1-$ & $3 \leftarrow 2$ & Excited & $3 / 2$ & $1 / 2$ & 26789.51 & .30 \\
\hline $\mathrm{C}^{12} \mathrm{H}_{2} \mathrm{Cl}^{35} \mathrm{Si}^{29} \mathrm{H}_{3}$ & 3- 234 & $10,1,9 \leftarrow 10,0,10$ & Ground & $17 / 2$ & $17 / 2$ & 26790.7 & .1 \\
\hline $\mathrm{C}^{12} \mathrm{H}_{3} \mathrm{C}^{12}: \mathrm{C}^{12} \mathrm{Cl}^{35}$ & 4. 971 & $6,5 \leftarrow 5,5$ & Ground & $9 / 2$ & $7 / 2$ & 26790.76 & .04 \\
\hline $\mathrm{C}^{12} \mathrm{H}_{2} \mathrm{Cl}^{35} \mathrm{Si}^{29} \mathrm{H}_{3}$ & 3- 234 & $10,1,9 \leftarrow 10,0,10$ & Ground & $23 / 2$ & $23 / 2$ & 26791.7 & .1 \\
\hline $\mathrm{C}^{12} \mathrm{H}_{2} \mathrm{Cl}^{35} \mathrm{Si}^{29} \mathrm{H}_{3}$ & 3. 234 & $10,1,9 \leftarrow 10,0,10$ & Ground & & & 26794.74 & .2 \\
\hline $\mathrm{C}^{12} \mathrm{H}_{3} \mathrm{C}^{12} \mathrm{H}_{2} \mathrm{I}^{127}$ & 3- 571 & $3,1,2 \leftarrow 3,0,3$ & Ground & $5 / 2$ & $5 / 2$ & 26796. & \\
\hline $\mathrm{C}^{12} \mathrm{D}_{3} \mathrm{Si}^{28} \mathrm{DF}_{2}^{19}$ & 3- 199 & $3,1,2 \leftarrow 2,1,1$ & Ground & & & 26796.36 & .1 \\
\hline $\mathrm{C}^{12} \mathrm{H}_{3} \mathrm{Si}^{\mathrm{h}} \mathrm{HD}_{2}$ & 3. 326 & $11,1,10 \leftarrow 11,1,11$ & & & & 26797.15 & .2 \\
\hline $\mathrm{C}^{12} \mathrm{H}_{2} \mathrm{Cl}^{35} \mathrm{Si}^{29} \mathrm{H}_{3}$ & 3. 234 & $10,1,9 \leftarrow 10,0,10$ & Ground & $19 / 2$ & $19 / 2$ & 26797.7 & .1 \\
\hline $\mathrm{C}^{12} \mathrm{H}_{2} \mathrm{Cl}^{35} \mathrm{Si}^{29} \mathrm{H}_{3}$ & 3. 234 & $10,1,9 \leftarrow 10,0,10$ & Ground & $21 / 2$ & $21 / 2$ & 26798.7 & .1 \\
\hline $\mathrm{Na}^{23} \mathrm{Br}^{81}$ & $1-$ & $3 \leftarrow 2$ & Excited & $7 / 2$ & $5 / 2$ & 26803.55 & .10 \\
\hline $\mathrm{Na}^{23} \mathrm{Br}^{81}$ & 1 - & $3 \leftarrow 2$ & Excited & $9 / 2$ & $7 / 2$ & 26803.55 & .10 \\
\hline $\mathrm{Na}^{23} \mathrm{Br}^{81}$ & 1 - & $3 \leftarrow 2$ & Excited & $5 / 2$ & $3 / 2$ & 26806.32 & .40 \\
\hline $\mathrm{Na}^{23} \mathrm{Br}^{81}$ & $1-$ & $3 \leftarrow 2$ & Excited & $3 / 2$ & $1 / 2$ & 26806.32 & .40 \\
\hline$\left(\mathrm{C}^{12} \mathrm{H}_{3}\right)_{3} \mathrm{C}^{12} \mathrm{C}^{12} \vdots \mathrm{C}^{12} \mathrm{H}$ & $3-1071$ & $5,1 \leftarrow 4,1$ & Ground & & & 26807.3 & .1 \\
\hline $\mathrm{HDC}^{12}: \mathrm{C}^{12} \mathrm{~F}_{2}^{19}$ & 4- 682 & $4,3,2 \leftarrow 4,1,3$ & Ground & & & 26815.7 & .3 \\
\hline$\left(\mathrm{C}^{12} \mathrm{H}_{3}\right)_{3} \mathrm{C}^{12} \mathrm{C}^{12} \vdots \mathrm{C}^{12} \mathrm{H}$ & $3-1071$ & $5, \leftarrow 4$ & Ground & & & 26816.8 & .1 \\
\hline $\mathrm{C}^{13} \mathrm{H}_{3} \mathrm{C}^{12} \mathrm{O}^{16} \mathrm{C}^{12} \mathrm{~N}^{14}$ & 3- 672 & $4,0,4 \leftarrow 3,0,3$ & Ground & & & 26817.10 & .2 \\
\hline $\mathrm{C}^{12} \mathrm{H}_{3} \mathrm{C}^{12} \mathrm{H}_{2} \mathrm{C}^{12} \mathrm{~N}^{14}$ & 3- 731 & $3,0,3 \leftarrow 2,0,2$ & Ground & & & 26817.80 & .1 \\
\hline $4 d-C_{6}^{12} \mathrm{H}_{5} \mathrm{~F}^{19}$ & $4-1283$ & $9,1,8 \leftarrow 9,1,9$ & Ground & & & 26818.2 & .1 \\
\hline$\left(\mathrm{C}^{12} \mathrm{H}_{3}\right)_{3} \mathrm{C}^{12} \mathrm{C}^{12} \vdots \mathrm{C}^{12} \mathrm{H}$ & $3-1071$ & $5, \leftarrow 4$ & Ground & & & 26820.4 & .1 \\
\hline $\mathrm{D}_{2} \mathrm{O}_{2}^{16}$ & 3- 42 & Not Reported & & & & 26821. & 3. \\
\hline $\mathrm{s}-\mathrm{C}^{12} \mathrm{H}_{2} \mathrm{DC}^{12} \mathrm{O}^{16} \mathrm{Cl}^{35}$ & 3. 365 & $4,0,4 \leftarrow 3,1,3$ & Ground & & & 26821.50 & .1 \\
\hline $\mathrm{C}_{6}^{12} \mathrm{H}_{5} \mathrm{O}^{16} \mathrm{H}$ & 3-1051 & $10,4,7 \leftarrow 10,3,8$ & Ground & & & 26821.7 & \\
\hline $\mathrm{s}-\mathrm{C}^{12} \mathrm{H}_{2} \mathrm{DC}^{12} \mathrm{O}^{16} \mathrm{Cl}^{35}$ & 3- 365 & $4,0,4 \leftarrow 3,1,3$ & Ground & & & 26822.75 & .2 \\
\hline $\mathrm{s} \cdot \mathrm{C}^{12} \mathrm{H}_{2} \mathrm{DC}^{12} \mathrm{O}^{16} \mathrm{Cl}^{35}$ & 3- 365 & $4,0,4 \leftarrow 3,1,3$ & Ground & & & 26824.00 & .1 \\
\hline $\mathrm{C}^{12} \mathrm{H}_{2}: \mathrm{C}^{12} \mathrm{HC}^{12} \mathrm{HO}^{16}$ & 3. 691 & $3,0,3 \leftarrow 2,0,2$ & Ground & & & 26824.88 & \\
\hline $\mathrm{HC}^{13}: \mathrm{C}^{12} \mathrm{C}^{12} \mathrm{DO}^{16}$ & 4- 922 & Not Reported & & & & 26827. & 5. \\
\hline $\mathrm{C}^{12} \mathrm{H}_{3} \mathrm{C}^{12} \mathrm{H}_{2} \mathrm{C}^{12} \mathrm{~N}^{14}$ & 3- 731 & $3,0,3 \leftarrow 2,0,2$ & Ground & & & 26829.3 & .2 \\
\hline$\left(\mathrm{C}^{12} \mathrm{H}_{3}\right)_{3} \mathrm{C}^{12} \mathrm{C}^{12}: \mathrm{C}^{12} \mathrm{H}$ & 3-1071 & $5, \leftarrow 4$ & Ground & & & 26831.9 & .1 \\
\hline $\mathrm{H}_{2} \mathrm{C}^{12}: \mathrm{C}^{12} \mathrm{~F}_{2}^{19}$ & 4. 681 & Not Reported & 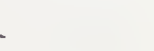 & & & 26832.0 & .3 \\
\hline $\mathrm{C}^{12} \mathrm{H}_{3} \mathrm{C}^{12} \mathrm{H}_{2} \mathrm{I}^{127}$ & 3- 571 & $3,1,2 \leftarrow 3,0,3$ & Ground & $7 / 2$ & $7 / 2$ & 26835.20 & .05 \\
\hline $\mathrm{C}^{12} \mathrm{D}_{3} \mathrm{C}^{13}: \mathrm{C}^{12} \mathrm{C}^{12} \mathrm{~F}_{3}^{19}$ & 3- 895 & $11, \leftarrow 10$ & Ground & & & 26836.0 & 2. \\
\hline $\mathrm{C}^{12} \mathrm{H}_{3} \mathrm{C}^{12} \mathrm{H}_{2} \mathrm{I}^{127}$ & 3- 571 & $3,1,2 \leftarrow 3,0.3$ & Ground & $9 / 2$ & $9 / 2$ & 26840.46 & .05 \\
\hline $\mathrm{C}^{12} \mathrm{H}_{3} \mathrm{C}^{12} \mathrm{H}_{2} \mathrm{I}^{127}$ & 3- 571 & $3,1,2 \leftarrow 3,0,3$ & Ground & $7 / 2$ & $9 / 2$ & 26843.04 & .05 \\
\hline $\mathrm{C}^{12} \mathrm{H}_{3} \mathrm{C}^{12} \mathrm{H}_{2} \mathrm{I}^{127}$ & 3. 571 & $3,1,2 \leftarrow 3,0,3$ & Ground & $9 / 2$ & $9 / 2$ & 26845 & \\
\hline $2,4,6 \mathrm{~d}_{3} \cdot \mathrm{C}_{6}^{12} \mathrm{H}_{5} \mathrm{~F}^{19}$ & $4-1284$ & $6,2,4 \leftarrow 5,2,3$ & Ground & & & 26847.2 & .1 \\
\hline $\mathrm{C}^{12} \mathrm{H}_{3} \mathrm{O}^{16} \mathrm{H}$ & 3. 211 & $12,2, \leftarrow 12,1$, & Ground & & & 26847.27 & .1 \\
\hline g- $\mathrm{C}^{12} \mathrm{H}_{3} \mathrm{C}^{12} \mathrm{H}_{2} \mathrm{C}^{12} \mathrm{H}_{2} \mathrm{Cl}^{35}$ & 3- 773 & $10,1,9 \leftarrow 10,0,10$ & Ground & & & 26847.33 & .2 \\
\hline $\mathrm{C}^{12} \mathrm{H}_{3} \mathrm{C}^{12} \mathrm{H}_{2} \mathrm{C}^{12} \mathrm{~N}^{14}$ & 3- 731 & $3,2,2 \leftarrow 2,2,1$ & Ground & 3 & 2 & 26847.89 & .1 \\
\hline $\mathrm{C}^{13} \mathrm{H}_{2} \mathrm{Cl}^{35} \mathrm{Si}^{28} \mathrm{H}_{3}$ & 3. 233 & $10,1,9 \leftarrow 10,0,10$ & Ground & $17 / 2$ & $17 / 2$ & 26848.5 & .1 \\
\hline $\mathrm{C}^{12} \mathrm{H}_{3} \mathrm{C}^{12} \mathrm{H}_{2} \mathrm{C}^{12} \mathrm{~N}^{14}$ & 3. 731 & $3,2,2 \leftarrow 2,2,1$ & Ground & & & 26848.70 & .1 \\
\hline $\mathrm{C}^{12} \mathrm{H}_{3} \mathrm{C}^{12} \mathrm{H}_{2} \mathrm{C}^{12} \mathrm{~N}^{14}$ & 3- 731 & $3,2,2 \leftarrow 2,2,1$ & Ground & 4 & 3 & 26848.95 & .1 \\
\hline
\end{tabular}




\begin{tabular}{|c|c|c|c|c|c|c|c|c|}
\hline \multirow{2}{*}{ Isotopic Species } & \multirow{2}{*}{$\begin{array}{l}\text { Vol.-Id. } \\
\text { Nos. }\end{array}$} & \multirow{2}{*}{$\begin{array}{c}\text { Rotational } \\
\text { Quantum Nos. }\end{array}$} & \multirow{2}{*}{ Vib. State } & \multicolumn{3}{|c|}{ Hyperfine } & \multirow{2}{*}{$\begin{array}{l}\text { Frequency } \\
\mathrm{MHz}\end{array}$} & \multirow{2}{*}{$\begin{aligned} & \text { Acc. } \\
\pm & \mathrm{MHz}\end{aligned}$} \\
\hline & & & & $F_{1}^{\prime}$ & & $\mathbf{F}$ & & \\
\hline $\mathrm{C}^{13} \mathrm{H}_{2} \mathrm{Cl}^{35} \mathrm{Si}^{28} \mathrm{H}_{3}$ & $3 \cdot 233$ & $10,1,9 \leftarrow 10,0,10$ & Ground & & $23 / 2$ & $23 / 2$ & 26849.4 & .1 \\
\hline $\mathrm{C}^{12} \mathrm{H}_{3} \mathrm{C}^{12} \mathrm{H}_{2} \mathrm{C}^{12} \mathrm{~N}^{14}$ & 3. 731 & $3,2,2 \leftarrow 2,2,1$ & Ground & & 2 & 1 & 26849.51 & .1 \\
\hline $\mathrm{C}^{13} \mathrm{H}_{2} \mathrm{Cl}^{35} \mathrm{Si}^{28} \mathrm{H}_{3}$ & 3- 233 & $10,1,9 \leftarrow 10,0,10$ & Ground & & & & 26852.29 & .2 \\
\hline $\mathrm{C}^{12} \mathrm{H}_{3} \mathrm{O}^{16} \mathrm{H}$ & 3. 211 & Not Reported & Ground & & & & 26854 & \\
\hline $\mathrm{C}^{13} \mathrm{H}_{3} \mathrm{O}^{16} \mathrm{H}$ & 3- 213 & $27,2, \leftarrow 27,1$, & Ground & & & & 26855.01 & .1 \\
\hline $\mathrm{C}^{13} \mathrm{H}_{2} \mathrm{Cl}^{35} \mathrm{Si}^{28} \mathrm{H}_{3}$ & 3- 233 & $10,1,9 \leftarrow 10,0,10$ & Ground & & $19 / 2$ & $19 / 2$ & 26855.1 & .1 \\
\hline $\mathrm{C}^{13} \mathrm{H}_{2} \mathrm{Cl}^{35} \mathrm{Si}^{28} \mathrm{H}_{3}$ & $3 \cdot 233$ & $10,1,9 \leftarrow 10,0,10$ & Ground & & $21 / 2$ & $21 / 2$ & 26856.0 & .1 \\
\hline$\left(\mathrm{C}^{12} \mathrm{H}_{3}\right)_{3} \mathrm{C}^{12} \mathrm{C}^{12}: \mathrm{C}^{12} \mathrm{H}$ & $3-1071$ & $5, \leftarrow 4$ & Excited & & & & 26857.7 & .1 \\
\hline $\mathrm{C}^{12} \mathrm{H}_{3} \mathrm{C}^{12} \mathrm{H}_{2} \mathrm{C}^{12} \mathrm{~N}^{14}$ & 3. 731 & $3,2,2 \leftarrow 2,2,1$ & Ground & & & & 26859.1 & .2 \\
\hline $\mathrm{C}^{12} \mathrm{H}_{3} \mathrm{C}^{12} \mathrm{H}_{2} \mathrm{C}^{12} \mathrm{~N}^{14}$ & 3- 731 & $3,0,3 \leftarrow 2,0,2$ & Excited & & & & 26860.5 & .2 \\
\hline $\mathrm{HC}^{12} \mathrm{O}^{16} \mathrm{O}^{16} \mathrm{D}$ & $3-\quad 72$ & $5,1,5 \leftarrow 5,1,4$ & Ground & & & & 26865.5 & .3 \\
\hline $\mathrm{HC}^{13}: \mathrm{C}^{12} \mathrm{C}^{12} \mathrm{DO}^{16}$ & 4- 922 & Not Reported & & & & & 26866. & 5. \\
\hline $\mathrm{C}^{12} \mathrm{H}_{3} \mathrm{C}^{12} \mathrm{H}_{2} \mathrm{C}^{12} \mathrm{~N}^{14}$ & 3- 731 & $3,2,2 \leftarrow 2,2,1$ & Ground & & & & 26866.1 & .2 \\
\hline $\mathrm{C}^{12} \mathrm{H}_{2} \mathrm{Cl}^{37} \mathrm{C}^{12}: \mathrm{C}^{12} \mathrm{H}$ & 4- 992 & $1,1,1 \leftarrow 0,0,0$ & Ground & & & & 26868.46 & \\
\hline $\mathrm{C}^{12} \mathrm{D}_{3} \mathrm{C}^{12} \mathrm{O}^{16} \mathrm{O}^{16} \mathrm{H}$ & 3. 492 & $8,4,4 \leftarrow 8,3,5$ & Ground & & & & 26870.71 & \\
\hline $\mathrm{H}_{2} \mathrm{~N}^{14} \mathrm{~N}^{14} \mathrm{H}_{2}$ & $3-\quad 51$ & Not Reported & & & & & 26872.2 & \\
\hline $\mathrm{H}_{2} \mathrm{~N}^{14} \mathrm{~N}^{14} \mathrm{H}_{2}$ & 3. 51 & Not Reported & & & & & 26874.2 & \\
\hline$\left(\mathrm{C}^{12} \mathrm{H}_{3}\right)_{3} \mathrm{C}^{12} \mathrm{C}^{12}: \mathrm{C}^{12} \mathrm{H}$ & $3-1071$ & $5,1 \leftarrow 4,1$ & Excited & & & & 26874.5 & .1 \\
\hline $\mathrm{C}^{12} \mathrm{D}_{3} \mathrm{C}^{13} \mathrm{O}^{16} \mathrm{C}^{12} \mathrm{~N}^{14}$ & 3- 676 & $4,1,4 \leftarrow 3,0,3$ & Ground & & & & 26877.25 & .2 \\
\hline $\mathrm{C}^{12} \mathrm{H}_{3} \mathrm{C}^{12} \mathrm{H}_{2} \mathrm{C}^{12} \mathrm{~N}^{14}$ & 3- 731 & $3,2,1 \leftarrow 2,2,0$ & Ground & & 3 & 2 & 26877.45 & .1 \\
\hline $\mathrm{C}^{12} \mathrm{H}_{3} \mathrm{C}^{12} \mathrm{H}_{2} \mathrm{C}^{12} \mathrm{~N}^{14}$ & 3. 731 & $3,2,1 \leftarrow 2,2,0$ & Ground & & & & 26878.27 & .1 \\
\hline $\mathrm{C}^{12} \mathrm{H}_{3} \mathrm{C}^{12} \mathrm{H}_{2} \mathrm{C}^{12} \mathrm{~N}^{14}$ & 3- 731 & $3,2,1 \leftarrow 2,2,0$ & Ground & & & & 26878.3 & .2 \\
\hline $\mathrm{C}^{12} \mathrm{H}_{3} \mathrm{C}^{12} \mathrm{H}_{2} \mathrm{C}^{12} \mathrm{~N}^{14}$ & 3- 731 & $3,2,1 \leftarrow 2,2,0$ & Ground & & 4 & 3 & 26878.54 & .1 \\
\hline $\mathrm{C}^{12} \mathrm{H}_{3} \mathrm{C}^{12} \mathrm{H}_{2} \mathrm{C}^{12} \mathrm{~N}^{14}$ & 3- 731 & $3,2,1 \leftarrow 2,2,0$ & Ground & & 2 & 1 & 26879.08 & .1 \\
\hline $\mathrm{HDO}^{16}$ & $4 \cdot 1712$ & $7,1,7 \leftarrow 6,2,4$ & Ground & & & & 26880.38 & .05 \\
\hline $\mathrm{H}_{2} \mathrm{C}^{12}: \mathrm{C}^{12} \mathrm{~F}_{2}^{19}$ & 4. 681 & $3,2,2 \leftarrow 3,0,3$ & Ground & & & & 26881.2 & .3 \\
\hline $\mathrm{H}_{2} \mathrm{~N}^{14} \mathrm{~N}^{14} \mathrm{H}_{2}$ & $3 \cdot \quad 51$ & $11,3 \leftarrow 12,2$ & Ground & & & & 26883.9 & \\
\hline $\mathrm{C}^{12}{ }_{*} \mathrm{D}_{2} \mathrm{C}^{12} \mathrm{H}_{2} \mathrm{C}^{12} \mathrm{D}_{2} \mathrm{O}^{16}{ }_{*}$ & 4-1092 & $10,7,3 \leftarrow 10,6,4$ & Excited & & & & 26885. & 5. \\
\hline $\mathrm{C}^{12} \mathrm{H}_{3} \mathrm{C}^{12} \mathrm{H}_{2} \mathrm{C}^{12} \mathrm{~N}^{14}$ & 3- 731 & $3,2,1 \leftarrow 2,2,0$ & Ground & & & & 26885.3 & .2 \\
\hline $\mathrm{C}^{12} \mathrm{H}_{2}: \mathrm{C}^{12} \mathrm{HC}^{12} \mathrm{~F}^{19}: \mathrm{C}^{12} \mathrm{H}_{2}$ & 3- 911 & $10,3,7 \leftarrow 10,2,8$ & Excited & & & & 26886.28 & .03 \\
\hline $\mathrm{C}^{12} \mathrm{H}_{3} \mathrm{C}^{12} \mathrm{H}_{2} \mathrm{C}^{12} \mathrm{~N}^{14}$ & 3- 731 & $3,2,2 \leftarrow 2,2,1$ & Excited & & & & 26889.6 & .2 \\
\hline $\mathrm{C}^{12} \mathrm{H}_{2}: \mathrm{C}^{12} \mathrm{HC}^{12} \mathrm{HO}^{16}$ & 3- 691 & $3,0,3 \leftarrow 2,0,2$ & Ground & & & & 26895.18 & \\
\hline $\mathrm{H}_{2} \mathrm{~N}^{14} \mathrm{~N}^{14} \mathrm{H}_{2}$ & 3- 51 & $11,3 \leftarrow 12,2$ & Ground & & & & 26895.4 & \\
\hline $\mathrm{C}^{12} \mathrm{H}_{3} \mathrm{C}^{12} \mathrm{H}_{2} \mathrm{I}^{127}$ & 3- 571 & $3,1,2 \leftarrow 3,0,3$ & Ground & & $5 / 2$ & $7 / 2$ & 26900 & 1. \\
\hline $\mathrm{C}^{12} \mathrm{D}_{3} \mathrm{C}^{12} \mathrm{O}^{16} \mathrm{C}^{12} \mathrm{~N}^{14}$ & 3- 675 & $4,1,4 \leftarrow 3,0,3$ & Ground & & & & 26903.58 & .2 \\
\hline $\mathrm{HC}^{13}: \mathrm{C}^{12} \mathrm{C}^{12} \mathrm{DO}^{16}$ & 4- 922 & Not Reported & & & & & 26905. & 5. \\
\hline $\mathrm{C}^{12} \mathrm{H}_{2}\left(\mathrm{C}^{12} \mathrm{~N}^{14}\right)_{2}$ & 4. 901 & Not Reported & Ground & & & & 26906.3 & .1 \\
\hline $\mathrm{a}-\mathrm{C}^{12} \mathrm{H}_{2} \mathrm{DC}^{12} \mathrm{O}^{16} \mathrm{Cl}^{35}$ & 3. 366 & $9,4,5 \leftarrow 9,3,6$ & Ground & & & & 26909.85 & .1 \\
\hline $\mathrm{C}^{\mathrm{b}} \mathrm{H}_{3}^{\mathrm{b}} \mathrm{C}^{\mathrm{b}} \mathrm{H}_{2}^{\mathrm{b}} \mathrm{Cl}^{35}$ & 3. 548 & Not Reported & & & & & 26911.26 & .05 \\
\hline $\mathrm{a}-\mathrm{C}^{12} \mathrm{H}_{2} \mathrm{DC}^{12} \mathrm{O}^{16} \mathrm{Cl}^{35}$ & 3- 366 & $9,4,5 \leftarrow 9,3,6$ & Ground & & & & 26911.43 & .2 \\
\hline $\mathrm{C}^{\mathrm{b}} \mathrm{H}_{3}^{\mathrm{b}} \mathrm{C}^{\prime \prime} \mathrm{H}_{2}^{\mathrm{b}} \mathrm{Cl}^{35}$ & 3- 548 & Not Reported & & & & & 26912.37 & .05 \\
\hline $\mathrm{a} \cdot \mathrm{C}^{12} \mathrm{H}_{2} \mathrm{DC}^{12} \mathrm{O}^{16} \mathrm{Cl}^{35}$ & 3. 366 & $9,4,5 \leftarrow 9,3,6$ & Ground & & & & 26913.00 & .1 \\
\hline $\mathrm{C}^{\mathrm{h}} \mathrm{H}_{3}^{\mathrm{l}} \mathrm{C}^{\mathrm{h}} \mathrm{H}_{2}^{\mathrm{l}} \mathrm{Cl}^{35}$ & 3. 548 & Not Reported & & & & & 26914.32 & .05 \\
\hline $\mathrm{C}^{12} \mathrm{H}_{3} \mathrm{C}^{12}{ }_{*} \mathrm{HO}^{16} \mathrm{C}^{12}{ }_{*} \mathrm{H}_{2}$ & 3- 761 & Not Reported & Ground & & & & 26916.24 & .1 \\
\hline $\mathrm{C}^{\mathrm{l}} \mathrm{H}_{3}^{\mathrm{b}} \mathrm{C}^{\mathrm{b}} \mathrm{H}_{2}^{\mathrm{b}} \mathrm{Cl}^{35}$ & 3- 548 & Not Reported & & & & & 26917.65 & .05 \\
\hline
\end{tabular}


Vib. State

\begin{tabular}{|c|c|c|c|c|c|c|c|}
\hline $\mathrm{C}^{12} \mathrm{H}_{3} \mathrm{C}^{12}{ }_{*} \mathrm{HO}^{16} \mathrm{C}^{12}{ }_{*} \mathrm{H}_{2}$ & 3. 761 & $3,0,3 \leftarrow 2,1,2$ & Ground & & & 26918.07 & .1 \\
\hline $\mathrm{C}^{12} \mathrm{DHCl}^{35} \mathrm{Cl}^{37}$ & 4- 345 & $6,1,5 \leftarrow 6,0,6$ & Ground & & & 26920. & 5. \\
\hline $\mathrm{C}^{\mathrm{b}} \mathrm{H}_{2}^{\mathrm{b}} \mathrm{Cl}^{\mathrm{b}} \mathrm{F}^{\mathrm{b}}$ & 4- 333 & Not Reported & & & & 26920.64 & .1 \\
\hline $\mathrm{C}^{\mathrm{b}} \mathrm{H}_{3}^{\mathrm{b}} \mathrm{C}^{\mathrm{b}} \mathrm{H}_{2}^{\mathrm{h}} \mathrm{Cl}^{35}$ & 3- 548 & Not Reported & & & & 26920.98 & .05 \\
\hline $\mathrm{C}^{12} \mathrm{H}_{3} \mathrm{C}^{12} \mathrm{H}_{2} \mathrm{C}^{12} \mathrm{~N}^{14}$ & 3- 731 & $3,2,1 \leftarrow 2,2,0$ & Excited & & & 26922.1 & .2 \\
\hline $\mathrm{C}^{\prime \prime} \mathrm{H}_{3}^{\prime \prime} \mathrm{C}^{\prime \prime} \mathrm{H}_{2}^{\prime \prime} \mathrm{Cl}^{35}$ & 3- 548 & Not Reported & & & & 26923.82 & .05 \\
\hline $\mathrm{HC}^{12} \mathrm{O}^{16} \mathrm{~N}^{14} \mathrm{H}_{2}$ & 3. 151 & $4,0,4 \leftarrow 3,1,3$ & Ground & 3 & 2 & 26924.05 & .1 \\
\hline $\mathrm{HC}^{12} \mathrm{O}^{16} \mathrm{~N}^{14} \mathrm{H}_{2}$ & 3. 151 & $4,0,4 \leftarrow 3,1,3$ & Ground & 4 & 3 & 26924.05 & .1 \\
\hline $\mathrm{HC}^{12} \mathrm{O}^{16} \mathrm{~N}^{14} \mathrm{H}_{2}$ & 3- 151 & $4,0,4 \leftarrow 3,1,3$ & Ground & 5 & 4 & 26924.05 & .1 \\
\hline $\mathrm{C}^{12}{ }_{*} \mathrm{HC}^{12} \mathrm{H}: \mathrm{C}^{12} \mathrm{HC}^{12} \mathrm{H}: \mathrm{C}^{12} \mathrm{HN}^{14}{ }_{*}$ & $4-1201$ & $3,1,2 \leftarrow 2,1,1$ & Ground & & & 26926.3 & .1 \\
\hline $\mathrm{C}^{12} \mathrm{H}_{3} \mathrm{C}^{12}{ }_{*} \mathrm{HO}^{16} \mathrm{C}^{12}{ }_{*} \mathrm{H}_{2}$ & 3- 761 & Not Reported & Ground & & & 26927.34 & .1 \\
\hline $\mathrm{C}^{12} \mathrm{H}_{3} \mathrm{C}^{12} \mathrm{H}_{2} \mathrm{I}^{127}$ & 3- 571 & $3,1,2 \leftarrow 3,0,3$ & Ground & $3 / 2$ & $5 / 2$ & 26928. & 1. \\
\hline $\mathrm{C}_{6}^{12} \mathrm{H}_{5} \mathrm{O}^{16} \mathrm{H}$ & $3-1051$ & $10,4,7 \leftarrow 10,3,8$ & Ground & & & 26932.8 & \\
\hline $\mathrm{H}_{2} \mathrm{~N}^{14} \mathrm{~N}^{14} \mathrm{H}_{2}$ & 3. 51 & $11,3 \leftarrow 12,2$ & Ground & & & 26934.0 & \\
\hline $\mathrm{C}^{12} \mathrm{DHDC}^{12} \mathrm{HDF}^{19}$ & 3- 561 & $3,0,3 \leftarrow 2,1,2$ & Ground & & & 26935.4 & .1 \\
\hline $\mathrm{C}^{12} \mathrm{H}_{3} \mathrm{C}^{12} \mathrm{H}_{2} \mathrm{~F}^{19}$ & 3- 551 & $3,0,3 \leftarrow 2,1,2$ & Ground & & & 26935.69 & \\
\hline $\mathrm{C}^{12} \mathrm{D}_{3} \mathrm{C}^{12}: \mathrm{C}^{12} \mathrm{D}$ & 4-1046 & $2,1 \leftarrow 1,1$ & Ground & & & 26936.87 & .10 \\
\hline $\mathrm{C}^{12} \mathrm{D}_{3} \mathrm{C}^{12}: \mathrm{C}^{12} \mathrm{D}$ & $4-1046$ & $2,0 \leftarrow 1,0$ & Ground & & & 26937.24 & .10 \\
\hline $\mathrm{H}_{2} \mathrm{~N}^{14} \mathrm{~N}^{14} \mathrm{H}_{2}$ & 3- 51 & Not Reported & & & & 26937.28 & \\
\hline $\mathrm{DN}^{14} \mathrm{O}_{3}^{16}$ & 3- 32 & $9,6,3 \leftarrow 9,6,2$ & Ground & & & 26938.68 & \\
\hline $\mathrm{C}^{12} \mathrm{H}_{3} \mathrm{C}^{12} \mathrm{H}_{2} \mathrm{~F}^{19}$ & 3. 551 & $3,0,3 \leftarrow 2,1,2$ & Ground & & & 26940.54 & \\
\hline t-DHC ${ }^{12}: \mathrm{C}^{12} \mathrm{HF}^{19}$ & 4- 788 & $6,1,5 \leftarrow 6,1,6$ & Ground & & & 26942.9 & .1 \\
\hline $\mathrm{H}_{2} \mathrm{~N}^{14} \mathrm{~N}^{14} \mathrm{H}_{2}$ & 3. 51 & $11,3 \leftarrow 12,2$ & Ground & & & 26945.4 & \\
\hline t. $\mathrm{C}^{12} \mathrm{H}_{3} \mathrm{C}^{12} \mathrm{H}: \mathrm{C}^{12} \mathrm{HC}^{12} \mathrm{~N}^{14}$ & 3- 921 & $6,0, \leftarrow 5,0$, & Ground & & & 26945.74 & .5 \\
\hline $\mathrm{C}^{12} \mathrm{H}_{3} \mathrm{~S}^{32} \mathrm{H}$ & 3- 221 & Not Reported & Ground & & & 26947.0 & l \\
\hline $\mathrm{H}_{2} \mathrm{~N}^{14} \mathrm{~N}^{14} \mathrm{H}_{2}$ & 3- 51 & Not Reported & & & & 26950.5 & \\
\hline $\mathrm{Na}^{23} \mathrm{Br}^{79}$ & $1-$ & $3 \leftarrow 2$ & Excited & $7 / 2$ & $5 / 2$ & 26952.98 & .10 \\
\hline $\mathrm{Na}^{23} \mathrm{Br}^{79}$ & 1 . & $3 \leftarrow 2$ & Excited & $9 / 2$ & $7 / 2$ & 26952.98 & .10 \\
\hline $\mathrm{t}-\mathrm{C}^{12} \mathrm{H}_{3} \mathrm{C}^{12} \mathrm{H}: \mathrm{C}^{12} \mathrm{HC}^{12} \mathrm{~N}^{14}$ & 3. 921 & $6,2, \leftarrow 5,2$, & Ground & & & 26953.3 & .5 \\
\hline $\mathrm{Na}^{23} \mathrm{Br}^{79}$ & 1 . & $3 \leftarrow 2$ & Excited & $5 / 2$ & $3 / 2$ & 26956.30 & .30 \\
\hline $\mathrm{Na}^{23} \mathrm{Br}^{79}$ & $1-$ & $3 \leftarrow 2$ & Excited & $3 / 2$ & $1 / 2$ & 26956.30 & .30 \\
\hline $\mathrm{t}-\mathrm{C}^{12} \mathrm{H}_{3} \mathrm{C}^{12} \mathrm{H}: \mathrm{C}^{12} \mathrm{HC}^{12} \mathrm{~N}^{14}$ & 3- 921 & $6,4, \leftarrow 5,4$, & Ground & & & 26956.48 & .5 \\
\hline $\mathrm{t} \cdot \mathrm{C}^{12} \mathrm{H}_{3} \mathrm{C}^{12} \mathrm{H}: \mathrm{C}^{12} \mathrm{HC}^{12} \mathrm{~N}^{14}$ & 3. 921 & $6,3, \leftarrow 5,3$ & Ground & & & 26956.48 & .5 \\
\hline t. $\mathrm{C}^{12} \mathrm{H}_{3} \mathrm{C}^{12} \mathrm{H}: \mathrm{C}^{12} \mathrm{HC}^{12} \mathrm{~N}^{14}$ & 3. 921 & $6,5, \leftarrow 5,5$ & Ground & & & 26957.60 & .5 \\
\hline $\mathrm{C}_{6}^{12} \mathrm{H}_{5} \mathrm{~F}^{19}$ & $4-1281$ & $6,1,5 \leftarrow 5,1,4$ & Ground & & & 26960.2 & .1 \\
\hline $\mathrm{t}-\mathrm{C}^{12} \mathrm{H}_{3} \mathrm{C}^{12} \mathrm{H}: \mathrm{C}^{12} \mathrm{HC}^{12} \mathrm{~N}^{14}$ & 3. 921 & $6,2 . \leftarrow 5,2$, & Ground & & & 26961.1 & .5 \\
\hline $\mathrm{C}^{12} \mathrm{H}_{2} \mathrm{~N}^{14} \mathrm{O}^{16} \mathrm{D}$ & 3. 142 & $8,2,6 \leftarrow 9,1,9$ & Ground & 9 & 10 & 26961.70 & .10 \\
\hline $\mathrm{C}^{12} \mathrm{H}_{2} \mathrm{~N}^{14} \mathrm{O}^{16} \mathrm{D}$ & 3. 142 & $8,2,6 \leftarrow 9,1,9$ & Ground & 7 & 8 & $26961: 70$ & .10 \\
\hline $\mathrm{C}^{12} \mathrm{H}_{2} \mathrm{~N}^{14} \mathrm{O}^{16} \mathrm{D}$ & 3- 142 & $8,2,6 \leftarrow 9,1,9$ & Ground & 8 & 9 & 26963.42 & .10 \\
\hline $\mathrm{C}^{12} \mathrm{H}_{3} \mathrm{C}^{12} \mathrm{H}_{2} \mathrm{~F}^{19}$ & 3- 551 & $3,0,3 \leftarrow 2,1,2$ & Ground & & & 26965.09 & \\
\hline c- $\mathrm{C}^{12}{ }_{*} \mathrm{H}_{2} \mathrm{C}^{12} \mathrm{HDC}^{12}{ }_{*} \mathrm{HC}^{12} \mathrm{~N}^{14}$ & $4 \cdot 1172$ & $4,1,3 \leftarrow 3,1,2$ & Ground & & & 26969.51 & .1 \\
\hline $\mathrm{C}^{12} \mathrm{H}_{2}: \mathrm{C}^{12} \mathrm{HC}^{12} \mathrm{~N}^{15}$ & 4.1025 & $3,1,3 \leftarrow 2,1,2$ & Ground & & & 26969.6 & .15 \\
\hline $\mathrm{C}^{12}{ }_{*} \mathrm{H}_{2} \mathrm{~S}^{32} \mathrm{C}^{12}{ }_{*} \mathrm{H}_{2}$ & 4- 851 & $9,3,7 \leftarrow 9,3,6$ & Ground & & & 26973.2 & .2 \\
\hline $\mathrm{t}-\mathrm{C}^{12} \mathrm{H}_{3} \mathrm{C}^{12} \mathrm{H}_{2} \mathrm{C}^{12} \mathrm{H}_{2} \mathrm{C}^{37}$ & 3. 772 & $6,1,6 \leftarrow 5,1,5$ & Ground & & & 26976.65 & .2 \\
\hline $\mathrm{C}^{12} \mathrm{H}_{3} \mathrm{C}^{12} \mathrm{HF}_{2}^{19}$ & 3. 461 & $9,8,2 \leftarrow 9,6,3$ & Ground & & & 26977.9 & \\
\hline
\end{tabular}




\begin{tabular}{|c|c|c|c|c|c|c|c|}
\hline \multirow{2}{*}{ Isotopic Species } & \multirow{2}{*}{$\begin{array}{l}\text { Vol.-Id. } \\
\text { Nos. }\end{array}$} & \multirow{2}{*}{$\begin{array}{c}\text { Rotational } \\
\text { Quantum Nos. }\end{array}$} & \multirow{2}{*}{ Vib. State } & \multicolumn{2}{|c|}{ Hyperfine } & \multirow{2}{*}{$\begin{array}{c}\text { Frequency } \\
\qquad \mathrm{MHz}\end{array}$} & \multirow{2}{*}{$\begin{aligned} & \text { Acc. } \\
& \pm \mathrm{MHz}\end{aligned}$} \\
\hline & & & & $\begin{array}{lll}F_{1}^{\prime} & F^{\prime} & F_{1}\end{array}$ & $\mathrm{~F}$ & & \\
\hline $\mathrm{C}^{12} \mathrm{D}_{3} \mathrm{C}^{12} \mathrm{O}^{16} \mathrm{~F}^{19}$ & 3- 392 & $8,4,4 \leftarrow 8,4,5$ & Ground & & & 26977.99 & .2 \\
\hline $\mathrm{C}^{13} \mathrm{H}_{3} \mathrm{O}^{16} \mathrm{H}$ & 3- 213 & $13, \quad \leftarrow 12$, & Ground & & & 26979.03 & .1 \\
\hline $\mathrm{C}^{12} \mathrm{D}_{3} \mathrm{C}^{12} \mathrm{O}^{16} \mathrm{~F}^{19}$ & 3- 392 & $8,4,4 \leftarrow 8,4,5$ & Ground & & & 26980.24 & .2 \\
\hline $\mathrm{C}^{13} \mathrm{H}_{3} \mathrm{O}^{16} \mathrm{H}$ & 3. 213 & $13, \quad \leftarrow 12$, & Ground & & & 26980.40 & .1 \\
\hline $\mathrm{C}^{12} \mathrm{H}_{3} \mathrm{C}^{12} \mathrm{HF}_{2}^{19}$ & 3. 461 & $9,8,2 \leftarrow 9,6,3$ & Ground & & & 26983.1 & \\
\hline $\mathrm{C}_{6}^{12} \mathrm{H}_{5} \mathrm{O}^{16} \mathrm{H}$ & $3-1051$ & $7,1,7 \leftarrow 6,1,6$ & Ground & & & 26985.21 & \\
\hline $\mathrm{C}^{12}{ }_{*} \mathrm{H}_{2} \mathrm{C}^{12} \mathrm{H}_{2} \mathrm{C}^{12}{ }_{*} \mathrm{HC}^{12} \mathrm{~N}^{14}$ & 4-1171 & $4,0,4 \leftarrow 3,0,3$ & Ground & & & 26985.78 & .05 \\
\hline $\mathrm{C}^{12} \mathrm{H}_{3} \mathrm{C}^{12} \mathrm{HF}_{2}^{19}$ & 3- 461 & $8,5,3 \leftarrow 8,5,4$ & Ground & & & 26985.8 & .1 \\
\hline $\mathrm{C}^{12} \mathrm{H}_{3} \mathrm{C}^{12} \mathrm{H}_{2} \mathrm{C}^{12} \mathrm{~N}^{14}$ & 3- 731 & $5,1,4 \leftarrow 5,0,5$ & Ground & & & 26988.70 & .1 \\
\hline $\mathrm{H}_{2} \mathrm{C}^{12}: \mathrm{C}^{12} \mathrm{~F}_{2}^{19}$ & 4. 681 & $2,0,2 \leftarrow 1,0,1$ & Ground & & & 26991.7 & .3 \\
\hline $\mathrm{C}^{12} \mathrm{D}_{3} \mathrm{C}^{12}: \mathrm{C}^{12} \mathrm{C}^{13} \mathrm{~F}_{3}^{19}$ & 3- 896 & $11, \leftarrow 10$ & Ground & & & 26992.0 & .5 \\
\hline $\mathrm{C}^{\mathrm{b}} \mathrm{H}_{3}^{\mathrm{b}} \mathrm{C}^{\mathrm{b}} \mathrm{H}_{2}^{\mathrm{b}} \mathrm{Cl}^{35}$ & 3- 548 & Not Reported & & & & 26992.78 & .05 \\
\hline $\mathrm{H}_{2} \mathrm{~N}^{14} \mathrm{~N}^{14} \mathrm{H}_{2}$ & 3- 51 & Not Reported & & & & 26992.83 & \\
\hline $\mathrm{C}^{12} \mathrm{H}_{3} \mathrm{Si}^{28} \mathrm{DF}_{2}^{19} \cdot \mathrm{E}$ & 3- $19 \overline{8}$ & $7,2,6 \leftarrow 7,2,5$ & Ground & & & 26993.5 & \\
\hline $\mathrm{C}^{12} \mathrm{H}_{3} \mathrm{~S}^{32} \mathrm{H}$ & 3. 221 & $5,0, \leftarrow 4,1$, & Ground & & & 26994.2 & .1 \\
\hline $\mathrm{H}_{2} \mathrm{~N}^{14} \mathrm{~N}^{14} \mathrm{H}_{2}$ & 3. 51 & Not Reported & & & & 26995.23 & \\
\hline $\mathrm{C}^{\mathrm{b}} \mathrm{H}_{3}^{\mathrm{b}} \mathrm{C}^{\mathrm{b}} \mathrm{H}_{2}^{\mathrm{b}} \mathrm{Cl}^{35}$ & 3- 548 & Not Reported & & & & 26995.60 & .05 \\
\hline $\mathrm{C}^{12} \mathrm{H}_{3} \mathrm{Si}^{28} \mathrm{DF}_{2}^{19}-\mathrm{A}$ & 3- 197 & $7,2,6 \leftarrow 7,2,5$ & Ground & & & 26996.8 & \\
\hline $\mathrm{C}^{12} \mathrm{H}_{2} \mathrm{~N}^{14} \mathrm{O}^{16} \mathrm{H}$ & 3- 141 & $11,2,9 \leftarrow 11,2,10$ & Ground & 12 & 12 & 26999.14 & .10 \\
\hline $\mathrm{C}^{12} \mathrm{H}_{2} \mathrm{~N}^{14} \mathrm{O}^{16} \mathrm{H}$ & 3- 141 & $11,2,9 \leftarrow 11,2,10$ & Ground & 10 & 10 & 26999.14 & .10 \\
\hline $\mathrm{C}^{12} \mathrm{H}_{2} \mathrm{~N}^{14} \mathrm{O}^{16} \mathrm{H}$ & 3. 141 & $11,2,9 \leftarrow 11,2,10$ & Ground & 11 & 11 & 27000.07 & .10 \\
\hline $\mathrm{C}^{12}{ }_{*} \mathrm{H}_{2} \mathrm{C}^{12} \mathrm{H}_{2} \mathrm{C}^{12}{ }_{*} \mathrm{HC}^{12} \mathrm{~N}^{14}$ & $4-1171$ & $4,2,3 \leftarrow 3,2,2$ & Ground & & & 27003.61 & .05 \\
\hline $\mathrm{D}_{2} \mathrm{O}_{2}^{16}$ & 3. 42 & Not Reported & & & & 27005. & \\
\hline $\mathrm{c}-\mathrm{HDC}^{12}{ }_{*} \mathrm{O}^{16} \mathrm{C}^{12}{ }_{*} \mathrm{DH}$ & 4- 845 & $3,3,0 \leftarrow 3,2,1$ & Ground & & & 27008.50 & .05 \\
\hline $\mathrm{C}^{12}{ }_{*} \mathrm{H}_{2} \mathrm{C}^{12} \mathrm{H}_{2} \mathrm{C}^{12}{ }_{*} \mathrm{HC}^{12} \mathrm{~N}^{14}$ & 4-1171 & $4,3,2 \leftarrow 3,3,1$ & Ground & & & 27008.78 & .05 \\
\hline $\mathrm{C}^{12}{ }_{*} \mathrm{H}_{2} \mathrm{C}^{12} \mathrm{H}_{2} \mathrm{C}^{12}{ }_{*} \mathrm{HC}^{12} \mathrm{~N}^{14}$ & $4 \cdot 1171$ & $4,3,1 \leftarrow 3,3,0$ & Ground & & & 27008.78 & .05 \\
\hline $\mathrm{C}^{12} \mathrm{D}_{3} \mathrm{C}^{12} \mathrm{O}^{16} \mathrm{Cl}^{35}$ & 3. 363 & $5,3,3 \leftarrow 5,2,4$ & Ground & $7 / 2$ & $7 / 2$ & 27010.3 & \\
\hline $\mathrm{C}^{12} \mathrm{H}_{2} \mathrm{Cl}^{37} \mathrm{C}^{12}: \mathrm{C}^{12} \mathrm{H}$ & 4- 992 & $8,1,7 \leftarrow 8,0,8$ & Ground & & & 27011.07 & \\
\hline $\mathrm{C}^{12} \mathrm{D}_{3} \mathrm{C}^{12} \mathrm{O}^{16} \mathrm{Cl}^{35}$ & 3. 363 & $5,3,3 \leftarrow 5,2,4$ & Ground & $13 / 2$ & $13 / 2$ & 27011.9 & \\
\hline $\mathrm{H}_{2} \mathrm{C}^{12}: \mathrm{C}^{12} \mathrm{~F}_{2}^{19}$ & 4. 681 & $4,3,2 \leftarrow 4,1,3$ & Ground & & & 27014.7 & .3 \\
\hline $\mathrm{C}^{12} \mathrm{D}_{3} \mathrm{C}^{12} \mathrm{O}^{16} \mathrm{Cl}^{35}$ & 3. 363 & $5,3,3 \leftarrow 5,2,4$ & Ground & $9 / 2$ & $9 / 2$ & 27016.2 & \\
\hline $\mathrm{C}^{12} \mathrm{D}_{3} \mathrm{C}^{12} \mathrm{O}^{16} \mathrm{Cl}^{35}$ & 3- 363 & $5,3,3 \leftarrow 5,2,4$ & Ground & $11 / 2$ & $11 / 2$ & 27017.7 & \\
\hline $\mathrm{C}^{12}{ }_{*} \mathrm{H}_{2} \mathrm{C}^{12} \mathrm{H}_{2} \mathrm{C}^{12}{ }_{*} \mathrm{HC}^{12} \mathrm{~N}^{14}$ & 4-1171 & $4,2,2 \leftarrow 3,2,1$ & Ground & & & 27022.79 & .05 \\
\hline $\mathrm{C}^{12} \mathrm{H}_{2} \mathrm{Cl}^{35} \mathrm{Si}^{28} \mathrm{H}_{3}$ & 3- 231 & $10,1,9 \leftarrow 10,0,10$ & Ground & $17 / 2$ & $17 / 2$ & 27027.28 & .2 \\
\hline $\mathrm{H}_{2} \mathrm{~N}^{14} \mathrm{~N}^{14} \mathrm{H}_{2}$ & 3- 51 & Not Reported & & & & 27027.4 & \\
\hline $\mathrm{C}^{12} \mathrm{H}_{2} \mathrm{Cl}^{35} \mathrm{Si}^{28} \mathrm{H}_{3}$ & 3- 231 & $10,1,9 \leftarrow 10,0,10$ & Ground & $23 / 2$ & $23 / 2$ & 27028.20 & .2 \\
\hline $\mathrm{C}^{12} \mathrm{H}_{2} \mathrm{Cl}^{35} \mathrm{Si}^{28} \mathrm{H}_{3}$ & 3- 231 & $10,1,9 \leftarrow 10,0,10$ & Ground & & & 27031.04 & .2 \\
\hline $\mathrm{C}^{12}{ }_{*} \mathrm{HC}^{12} \mathrm{H}: \mathrm{C}^{12} \mathrm{HC}^{12} \mathrm{H}: \mathrm{C}^{12} \mathrm{HN}^{14}{ }_{*}$ & $4-1201$ & $18,16,3 \leftarrow 18,14,4$ & Ground & & & 27033.0 & .1 \\
\hline $\mathrm{C}^{12} \mathrm{H}_{2} \mathrm{Cl}^{35} \mathrm{Si}^{28} \mathrm{H}_{3}$ & 3- 231 & $10,1,9 \leftarrow 10,0,10$ & Ground & $19 / 2$ & $19 / 2$ & 27033.77 & .2 \\
\hline $\mathrm{C}^{12} \mathrm{H}_{2} \mathrm{Cl}^{35} \mathrm{Si}^{28} \mathrm{H}_{3}$ & 3- 231 & $10,1,9 \leftarrow 10,0,10$ & Ground & $21 / 2$ & $21 / 2$ & 27034.75 & .2 \\
\hline $\mathrm{HC}^{13}: \mathrm{C}^{12} \mathrm{C}^{12} \mathrm{DO}^{16}$ & 4- 922 & Not Reported & & & & 27036. & 5. \\
\hline $\mathrm{DC}^{12}: \mathrm{C}^{12} \mathrm{C}^{12} \mathrm{HO}^{16}$ & 4. 916 & $3,1,3 \leftarrow 4,0,4$ & Ground & & & 27039.67 & .02 \\
\hline $\mathrm{C}^{12} \mathrm{D}_{3} \mathrm{C}^{12}: \mathrm{C}^{12} \mathrm{C}^{12} \mathrm{~F}_{3}^{19}$ & 3- 892 & $11, \leftarrow 10$ & Ground & & & 27041.8 & .1 \\
\hline $\mathrm{C}^{12} \mathrm{H}_{3} \mathrm{C}^{12} \mathrm{O}^{16} \mathrm{Br}^{81}$ & 3- 352 & $6,0,6 \leftarrow 5,1,5$ & Ground & $9 / 2$ & $7 / 2$ & 27041.92 & \\
\hline $\mathrm{C}^{12} \mathrm{H}_{3} \mathrm{C}^{12} \mathrm{O}^{16} \mathrm{Br}^{81}$ & 3- 352 & $6,0,6 \leftarrow 5,1,5$ & Ground & $15 / 2$ & $13 / 2$ & 27041.92 & \\
\hline
\end{tabular}




\begin{tabular}{|c|c|c|c|c|c|c|c|}
\hline Isotopic Species & $\begin{array}{l}\text { Vol.-Id. } \\
\text { Nos. }\end{array}$ & $\begin{array}{c}\text { Rotational } \\
\text { Quantum Nos. }\end{array}$ & Vib. State & $\mathrm{F}_{1}^{\prime} \mathrm{F}^{\prime} \mathrm{F}_{1}$ & $\mathrm{~F}$ & $\begin{array}{c}\text { Frequeney } \\
\mathrm{MH}_{z}\end{array}$ & $\begin{array}{r}\text { Acc. } \\
\pm \mathrm{MH} \%\end{array}$ \\
\hline $\mathrm{C}^{13} \mathrm{H}_{3} \mathrm{C}^{12} \mathrm{O}^{16} \mathrm{Cl}^{37}$ & 3. 368 & $4,0,4 \leftarrow 3,1,3$ & Ground & $7 / 2$ & $5 / 2$ & 27044.25 & .2 \\
\hline $\mathrm{C}^{13} \mathrm{H}_{3} \mathrm{C}^{12} \mathrm{O}^{16} \mathrm{Cl}^{37}$ & 3- 368 & $4,0,4 \leftarrow 3,1,3$ & Ground & $9 / 2$ & $7 / 2$ & 27044.25 & .2 \\
\hline $\mathrm{C}^{13} \mathrm{H}_{3} \mathrm{C}^{12} \mathrm{O}^{16} \mathrm{Cl}^{37}$ & 3- 368 & $4,0,4 \leftarrow 3,1,3$ & Ground & $7 / 2$ & $5 / 2$ & 27044.25 & .2 \\
\hline $\mathrm{C}^{13} \mathrm{H}_{3} \mathrm{C}^{12} \mathrm{O}^{16} \mathrm{Cl}^{37}$ & 3- 368 & $4,0,4 \leftarrow 3,1,3$ & Ground & $9 / 2$ & $7 / 2$ & 27044.25 & .2 \\
\hline $\mathrm{C}^{13} \mathrm{H}_{2}: \mathrm{C}^{12} \mathrm{HC}^{12} \mathrm{~N}^{14}$ & 4-1022 & $3,1,3 \leftarrow 2,1,2$ & Ground & & & 27046.5 & .15 \\
\hline $\mathrm{C}^{12} \mathrm{H}_{3} \mathrm{C}^{12} \mathrm{O}^{16} \mathrm{Cl}^{37}$ & 3- 362 & $4,0,4 \leftarrow 3,1,3$ & Ground & $5 / 2$ & $3 / 2$ & 27046.88 & .2 \\
\hline $\mathrm{C}^{12} \mathrm{H}_{3} \mathrm{C}^{12} \mathrm{O}^{16} \mathrm{Cl}^{37}$ & 3- 362 & $4,0,4 \leftarrow 3,1,3$ & Ground & $11 / 2$ & $9 / 2$ & 27046.88 & .2 \\
\hline $\mathrm{C}^{12} \mathrm{H}_{3} \mathrm{C}^{12} \mathrm{O}^{16} \mathrm{Cl}^{37}$ & 3- 362 & $4,0,4 \leftarrow 3,1,3$ & Ground & $5 / 2$ & $3 / 2$ & 27046.88 & .2 \\
\hline $\mathrm{C}^{12} \mathrm{H}_{3} \mathrm{C}^{12} \mathrm{O}^{16} \mathrm{Cl}^{37}$ & 3- 362 & $4,0,4 \leftarrow 3,1,3$ & Ground & $11 / 2$ & $9 / 2$ & 27046.88 & .2 \\
\hline $\mathrm{C}^{13} \mathrm{H}_{3} \mathrm{O}^{16} \mathrm{H}$ & 3- 213 & $3,2, \leftarrow 3,1$, & Ground & & & 27047.19 & .1 \\
\hline $\mathrm{H}_{2} \mathrm{~B}^{10} \mathrm{H}_{2} \mathrm{~B}^{11} \mathrm{HBr}^{81}$ & 4- 44 & $4,0,4 \leftarrow 3,0,3$ & Ground & $11 / 2$ & $9 / 2$ & 27049.0 & \\
\hline $\mathrm{H}_{2} \mathrm{~B}^{10} \mathrm{H}_{2} \mathrm{~B}^{11} \mathrm{HBr}^{81}$ & 4- 44 & $4,0,4 \leftarrow 3,0,3$ & Ground & $9 / 2$ & $7 / 2$ & 27049.0 & \\
\hline $\mathrm{C}^{13} \mathrm{H}_{3} \mathrm{O}^{16} \mathrm{H}$ & 3. 213 & $4,2, \leftarrow 4,1$, & Ground & & & 27050.45 & .1 \\
\hline $\mathrm{P}^{31} \mathrm{O}^{16} \mathrm{Cl}_{3}^{37}$ & $4-1512$ & $7, \leftarrow 6$, & Ground & & & 27052.0 & .5 \\
\hline $\mathrm{C}^{13} \mathrm{H}_{3} \mathrm{O}^{16} \mathrm{H}$ & 3. 213 & $2,2, \leftarrow 2,1$, & Ground & & & 27052.97 & .1 \\
\hline $\mathrm{C}^{12} \mathrm{H}_{3} \mathrm{C}^{12} \mathrm{O}^{16} \mathrm{Br}^{81}$ & 3- 352 & $6,0,6 \leftarrow 5,1,5$ & Ground & $13 / 2$ & $11 / 2$ & 27053.88 & \\
\hline $\mathrm{C}^{12} \mathrm{H}_{3} \mathrm{C}^{12} \mathrm{O}^{16} \mathrm{Br}^{81}$ & 3- 352 & $6,0,6 \leftarrow 5,1,5$ & Ground & $11 / 2$ & $9 / 2$ & 27053.88 & \\
\hline $\mathrm{C}^{12} \mathrm{H}_{3} \mathrm{C}^{12}{ }_{*} \mathrm{HO}^{16} \mathrm{C}^{12}{ }_{*} \mathrm{H}_{2}$ & 3- 761 & $3,0,3 \leftarrow 2,1,2$ & Ground & & & 27056.70 & .1 \\
\hline $\mathrm{C}^{12} \mathrm{H}_{3} \mathrm{Si}^{28} \mathrm{H}_{2} \mathrm{~F}^{19}$ & 3- 241 & $10,2,8 \leftarrow 10,2,9$ & Ground & & & 27060.92 & .10 \\
\hline $\mathrm{C}^{12} \mathrm{H}_{3} \mathrm{C}^{12}{ }_{*} \mathrm{HO}^{16} \mathrm{C}^{12}{ }_{*} \mathrm{H}_{2}$ & 3- 761 & $3,0,3 \leftarrow 2,1,2$ & Ground & & & 27061.01 & .1 \\
\hline $\mathrm{C}^{12} \mathrm{H}_{3} \mathrm{Si}^{28} \mathrm{H}_{2} \mathrm{~F}^{19}$ & 3- 241 & $10,2,8 \leftarrow 10,2,9$ & Ground & & & 27062.30 & .10 \\
\hline $\mathrm{HC}^{13} \vdots \mathrm{C}^{12} \mathrm{C}^{12} \mathrm{DO}^{16}$ & 4- 922 & Not Reported & & & & 27069 . & 5. \\
\hline $\mathrm{C}^{13} \mathrm{H}_{3} \mathrm{O}^{16} \mathrm{H}$ & 3- 213 & $5,2, \leftarrow 5,1$, & Ground & & & 27072.17 & .1 \\
\hline $\mathrm{C}^{12} \mathrm{H}_{2}\left(\mathrm{C}^{12} \mathrm{~N}^{14}\right)_{2}$ & 4- 901 & Not Reported & Ground & & & 27072.7 & .1 \\
\hline $\mathrm{C}^{12} \mathrm{H}_{2} \mathrm{Cl}^{35} \mathrm{C}^{12}: \mathrm{C}^{12} \mathrm{H}$ & 4- 991 & $1,1,1 \leftarrow 0,0,0$ & Ground & & & 27077.01 & \\
\hline $\mathrm{HC}^{12}: \mathrm{C}^{12} \mathrm{C}^{12} \mathrm{HO}^{16}$ & 4- 911 & $3,0,3 \leftarrow 2,0,2$ & Excited & & & 27077.49 & .15 \\
\hline $\mathrm{HC}^{13}: \mathrm{C}^{12} \mathrm{C}^{12} \mathrm{HO}^{16}$ & 4. 912 & $3,0,3 \leftarrow 2,0,2$ & Ground & & & 27078.64 & .02 \\
\hline $\mathrm{HC}^{13} \vdots \mathrm{C}^{12} \mathrm{C}^{12} \mathrm{DO}^{16}$ & 4. 922 & Not Reported & & & & 27083. & 5. \\
\hline $\mathrm{HC}^{13} \vdots \mathrm{C}^{12} \mathrm{C}^{12} \mathrm{HO}^{16}$ & 4. 912 & $3,2,2 \leftarrow 2,2,1$ & Ground & & & 27086.60 & .02 \\
\hline $4 d-\mathrm{C}_{6}^{12} \mathrm{H}_{5} \mathrm{~F}^{19}$ & $4-1283$ & $6,2,4 \leftarrow 5,2,3$ & Ground & & & 27088.5 & .1 \\
\hline $\mathrm{H}_{2} \mathrm{~N}^{14} \mathrm{~N}^{14} \mathrm{H}_{2}$ & 3- 51 & Not Reported & & & & 27088.7 & \\
\hline $\mathrm{C}^{12} \mathrm{DHCl}_{2}^{35}$ & 4. 344 & $6,1,5 \leftarrow 6,0,6$ & Ground & & & 27090 . & 5. \\
\hline $\mathrm{HC}^{13}: \mathrm{C}^{12} \mathrm{C}^{12} \mathrm{HO}^{16}$ & 4- 912 & $3,2,1 \leftarrow 2,2,0$ & Ground & & & 27090.94 & .02 \\
\hline $\mathrm{C}^{12} \mathrm{H}_{3} \mathrm{C}^{12} \mathrm{H}_{2} \mathrm{I}^{127}$ & 3- 571 & $4,1,3 \leftarrow 4,0,4$ & Ground & $3 / 2$ & $3 / 2$ & 27092.56 & .05 \\
\hline $\mathrm{C}^{12} \mathrm{H}_{3} \mathrm{C}^{13} \mathrm{H}_{2} \mathrm{~F}^{19}$ & 3- 555 & $1,1,0 \leftarrow 1,0,1$ & Ground & & & 27092.7 & .1 \\
\hline $\mathrm{C}^{12} \mathrm{H}_{3} \mathrm{C}^{12} \mathrm{H}_{2} \mathrm{I}^{127}$ & 3- 571 & $4,1,3 \leftarrow 4,0,4$ & Ground & $5 / 2$ & $5 / 2$ & 27096. & \\
\hline $\mathrm{C}_{6}^{12} \mathrm{H}_{5} \mathrm{O}^{16} \mathrm{H}$ & $3-1051$ & $7,1,7 \leftarrow 6,1,6$ & Ground & & & 27097.02 & \\
\hline $\mathrm{Tl}^{205} \mathrm{Cl}^{35}$ & 1 - & $5 \leftarrow 4$ & Excited & & & $27102: 42$ & 0.10 \\
\hline $\mathrm{C}^{13} \mathrm{H}_{3} \mathrm{O}^{16} \mathrm{H}$ & 3- 213 & $13, \quad \leftarrow 12$, & Ground & & & 27104.80 & .1 \\
\hline $\mathrm{C}^{13} \mathrm{H}_{3} \mathrm{O}^{16} \mathrm{H}$ & 3- 213 & $13, \quad \leftarrow 12$, & Ground & & & 27105.93 & .1 \\
\hline $\mathrm{N}^{14} \mathrm{O}_{2}^{16} \mathrm{Cl}^{35}$ & $4-1461$ & $3,2,1 \leftarrow 2,2,0$ & Excited: & & & 27110. & \\
\hline $\mathrm{C}^{12} \mathrm{H}_{3} \mathrm{C}^{12} \mathrm{H}_{2} \mathrm{I}^{127}$ & 3. 571 & $4,1,3 \leftarrow 4,0,4$ & Ground & $13 / 2$ & $13 / 2$ & 27110.00 & .05 \\
\hline $\mathrm{C}^{12} \mathrm{H}_{3} \mathrm{C}^{12} \mathrm{O}^{16} \mathrm{C}^{13} \mathrm{~N}^{14}$ & 3- 673 & $4,0,4 \leftarrow 3,0,3$ & Ground & & & 27110.93 & .2 \\
\hline $\mathrm{H}_{2} \mathrm{C}^{12}: \mathrm{C}^{12} \mathrm{~F}_{2}^{19}$ & 4. 681 & Not Reported & & & & 27112.0 & .3 \\
\hline $\mathrm{S}^{32}{ }_{*} \mathrm{C}^{12} \mathrm{H}: \mathrm{C}^{13} \mathrm{HC}^{12} \mathrm{H}: \mathrm{C}^{12}{ }_{*} \mathrm{H}$ & $4-1168$ & $5,1,4 \leftarrow 5,1,5$ & Ground & & & 27113.5 & .05 \\
\hline
\end{tabular}




\begin{tabular}{|c|c|c|c|c|c|c|c|c|c|}
\hline Isotopic Species & $\begin{array}{l}\text { Vol.-Id. } \\
\text { Nos. }\end{array}$ & $\begin{array}{c}\text { Rotational } \\
\text { Quantum Nos. }\end{array}$ & Vib. State & $\mathrm{F}_{1}^{\prime}$ & $\underset{\mathrm{F}^{\prime}}{\text { Hyper }}$ & $\begin{array}{l}\text { rfine } \\
F_{1}\end{array}$ & $F$ & $\begin{array}{c}\text { Frequency } \\
\mathrm{MHz}\end{array}$ & $\begin{aligned} & \text { Acc. } \\
& \pm \mathrm{MHz}\end{aligned}$ \\
\hline $\mathrm{C}^{12} \mathrm{D}_{2} \mathrm{HC}^{12} \mathrm{HDF}^{19}$ & 3- 563 & $3,0,3 \leftarrow 2,1,2$ & Ground & & & & & 27116.9 & .1 \\
\hline $\mathrm{C}^{12} \mathrm{H}_{3} \mathrm{C}^{12}{ }_{*} \mathrm{HO}^{16} \mathrm{C}^{12}{ }_{*} \mathrm{H}_{2}$ & 3. 761 & $3,0,3 \leftarrow 2,1,2$ & Ground & & & & & 27119.10 & .1 \\
\hline $\mathrm{N}^{15} \mathrm{~S}^{32} \mathrm{~F}_{3}^{19}$ & $4-1664$ & $3, \leftarrow 2$ & Ground & & & & & 27121.49 & \\
\hline $\mathrm{C}^{13} \mathrm{H}_{3} \mathrm{O}^{16} \mathrm{H}$ & 3. 213 & $6,2, \leftarrow 6,1$, & Ground & & & & & 27122.76 & .1 \\
\hline $\mathrm{C}^{12} \mathrm{H}_{3} \mathrm{C}^{12} \mathrm{H}_{2} \mathrm{I}^{127}$ & 3. 571 & $4,1,3 \leftarrow 4,0,4$ & Ground & & $5 / 2$ & & $5 / 2$ & 27126. & 1. \\
\hline $\mathrm{C}^{12} \mathrm{H}_{3} \mathrm{C}^{12}{ }_{*} \mathrm{HO}^{16} \mathrm{C}^{12}{ }_{*} \mathrm{H}_{2}$ & 3- 761 & Not Reported & Ground & & & & & 27127.45 & .1 \\
\hline $\mathrm{S}^{32}{ }_{*} \mathrm{C}^{12} \mathrm{H}: \mathrm{C}^{13} \mathrm{HC}^{12} \mathrm{H}: \mathrm{C}^{12}{ }_{*} \mathrm{H}$ & $4-1168$ & $8,3,5 \leftarrow 8,3,6$ & Ground & & & & & 27132.7 & .05 \\
\hline $\mathrm{C}^{12} \mathrm{H}_{3} \mathrm{C}^{13}: \mathrm{C}^{12} \mathrm{C}^{12} \mathrm{~F}_{3}^{19}$ & 3. 894 & $10, \leftarrow 9$ & Ground & & & & & 27135.0 & .5 \\
\hline $\mathrm{C}^{12} \mathrm{H}_{3} \mathrm{C}^{12}{ }_{*} \mathrm{HO}^{16} \mathrm{C}^{12}{ }_{*} \mathrm{H}_{2}$ & 3- 761 & Not Reported & Ground & & & & & 27138.22 & .1 \\
\hline $\mathrm{C}^{\mathrm{b}} \mathrm{H}_{2}^{\mathrm{b}} \mathrm{Cl}^{\mathrm{b}} \mathrm{F}^{\mathrm{b}}$ & 4- 333 & Not Reported & & & & & & 27138.5 & 1. \\
\hline $\mathrm{Tl}^{203} \mathrm{Cl}^{35}$ & $1-$ & $5 \leftarrow 4$ & Excited & & $11 / 2$ & & $9 / 2$ & 27140.35 & 0.10 \\
\hline $\mathrm{Tl}^{203} \mathrm{Cl}^{35}$ & 1 . & $5 \leftarrow 4$ & Excited & & $9 / 2$ & & $7 / 2$ & 27140.35 & 0.10 \\
\hline $\mathrm{Tl}^{203} \mathrm{Cl}^{35}$ & $1-$ & $5 \leftarrow 4$ & Excited & & $7 / 2$ & & $5 / 2$ & 27140.35 & 0.10 \\
\hline $\mathrm{Tl}^{203} \mathrm{Cl}^{35}$ & 1 . & $5 \leftarrow 4$ & Excited & & $13 / 2$ & & $11 / 2$ & 27140.35 & 0.10 \\
\hline $\mathrm{D}_{2} \mathrm{O}_{2}^{16}$ & 3- 42 & Not Reported & & & & & & 27141 & 3. \\
\hline a- $\mathrm{C}^{12} \mathrm{H}_{2} \mathrm{DC}^{12} \mathrm{H}_{2} \mathrm{C}^{12} \mathrm{H}_{3}$ & 3. 786 & $5,1,4 \leftarrow 5,0,5$ & Ground & & & & & 27141.90 & .06 \\
\hline $\mathrm{S}^{32}{ }_{*} \mathrm{HC}^{12}: \mathrm{C}^{12} \mathrm{DC}^{12} \mathrm{H}: \mathrm{C}^{12}{ }_{*} \mathrm{H}$ & 4-1163 & $3,1,2 \leftarrow 2,1,1$ & Ground & & & & & 27144.7 & .1 \\
\hline $\mathrm{N}^{14} \mathrm{O}_{2}^{16} \mathrm{Cl}^{35}$ & 4-1461 & $3,2,1 \leftarrow 2,2,0$ & Excited & & & & & 27145 & \\
\hline $\mathrm{C}^{12}{ }_{*} \mathrm{H}_{2}^{\mathrm{b}} \mathrm{S}^{\mathrm{b}} \mathrm{C}^{12}{ }_{*} \mathrm{H}_{2}^{\mathrm{b}}$ & 4- 854 & Not Reported & & & & & & 27150.0 & 20. \\
\hline $\mathrm{D}_{2} \mathrm{O}_{2}^{16}$ & 3- 42 & Not Reported & & & & & & 27152. & 3. \\
\hline $\mathrm{C}^{12} \mathrm{D}_{3} \mathrm{C}^{13} \mathrm{O}^{16} \mathrm{C}^{12} \mathrm{~N}^{14}$ & 3. 676 & $11,4,7 \leftarrow 11,3,8$ & Ground & & & & & 27152.82 & .2 \\
\hline$\left(\mathrm{C}^{13} \mathrm{H}_{3}\right)\left(\mathrm{C}^{12} \mathrm{H}_{3}\right)_{2} \mathrm{C}^{12} \mathrm{C}^{12} \mathrm{~N}^{14}$ & $3 \cdot 1023$ & $5,1,5 \leftarrow 4,1,4$ & Ground & & & & & 27153.6 & .1 \\
\hline $\mathrm{C}^{12} \mathrm{H}_{3} \mathrm{C}^{12}{ }_{*} \mathrm{HO}^{16} \mathrm{C}^{12}{ }_{*} \mathrm{H}_{2}$ & 3. 761 & Not Reported & Ground & & & & & 27159.69 & .1 \\
\hline $\mathrm{g}-\mathrm{C}^{12} \mathrm{H}_{2} \mathrm{Cl}^{35} \mathrm{C}^{12} \mathrm{H}_{2} \mathrm{Cl}^{35}$ & 3- 451 & $11,1,10 \leftarrow 11,0,11$ & & & & & & 27160. & \\
\hline $\mathrm{C}^{12} \mathrm{H}_{3} \mathrm{C}^{12} \mathrm{H}_{2} \mathrm{I}^{127}$ & 3- 571 & $4,1,3 \leftarrow 4,0,4$ & Ground & & $7 / 2$ & & $7 / 2$ & 27161 & 1. \\
\hline $\mathrm{C}_{6}^{12} \mathrm{H}_{5} \mathrm{~F}^{19}$ & $4-1281$ & $6,3,3 \leftarrow 5,3,2$ & Ground & & & & & 27163.3 & .1 \\
\hline $\mathrm{HC}^{13}: \mathrm{C}^{12} \mathrm{C}^{12} \mathrm{DO}^{16}$ & 4- 922 & Not Reported & & & & & & 27164 & 5. \\
\hline $\mathrm{C}^{12} \mathrm{H}_{3} \mathrm{C}^{12} \mathrm{H}_{2} \mathrm{I}^{127}$ & 3- 571 & $4,1,3 \leftarrow 4,0,4$ & Ground & & $7 / 2$ & & $7 / 2$ & 27166. & \\
\hline $\mathrm{HC}^{13}: \mathrm{C}^{12} \mathrm{C}^{12} \mathrm{DO}^{16}$ & 4- 922 & Not Reported & & & & & & 27175. & 5. \\
\hline $\mathrm{C}^{12} \mathrm{D}_{3} \mathrm{~N}^{14} \mathrm{O}_{2}^{16}$ & 3. 172 & $2,1, \leftarrow 1,1$, & Ground & & & & & 27176.6 & .2 \\
\hline $\mathrm{HC}^{12}: \mathrm{C}^{13} \mathrm{C}^{12} \mathrm{~N}^{14}$ & 4. 883 & $3 \leftarrow 2$ & Ground & & & & & 27179.10 & \\
\hline $\mathrm{HC}^{12}: \mathrm{C}^{12} \mathrm{C}^{13} \mathrm{~N}^{14}$ & 4. 884 & $3 \leftarrow 2$ & Ground & & & & & 27181.45 & \\
\hline $\mathrm{S}^{32}{ }_{*} \mathrm{HC}^{12}: \mathrm{C}^{12} \mathrm{DC}^{12} \mathrm{D}: \mathrm{C}^{12}{ }_{*} \mathrm{H}$ & $4-1164$ & $12,5,8 \leftarrow 12,5,7$ & Ground & & & & & 27185.0 & .1 \\
\hline $\mathrm{C}^{12} \mathrm{H}_{3} \mathrm{C}^{12}{ }_{*} \mathrm{HO}^{16} \mathrm{C}^{12}{ }_{*} \mathrm{H}_{2}$ & 3. 761 & Not Reported & Ground & & & & & 27186.05 & .1 \\
\hline $\mathrm{HC}^{13}: \mathrm{C}^{12} \mathrm{C}^{12} \mathrm{DO}^{16}$ & 4. 922 & Not Reported & & & & & & 27188. & 5. \\
\hline $\mathrm{H}_{2} \mathrm{~B}^{10} \mathrm{H}_{2} \mathrm{~B}^{11} \mathrm{HBr}^{79}$ & 4. $\quad 43$ & $4,0,4 \leftarrow 3,0,3$ & Ground & & $11 / 2$ & & $9 / 2$ & 27191.6 & \\
\hline $\mathrm{H}_{2} \mathrm{~B}^{10} \mathrm{H}_{2} \mathrm{~B}^{11} \mathrm{HBr}^{79}$ & 4. 43 & $4,0,4 \leftarrow 3,0,3$ & Ground & & $9 / 2$ & & $7 / 2$ & 27191.6 & \\
\hline $\mathrm{O}_{3}^{18}$ & $4-1845$ & $18,2,16 \leftarrow 19,1,19$ & Ground & & & & & 27192. & \\
\hline $\mathrm{C}^{12} \mathrm{H}_{3} \mathrm{C}^{12} \mathrm{H}_{2} \mathrm{I}^{127}$ & 3- 571 & $4,1,3 \leftarrow 4,0,4$ & Ground & & $9 / 2$ & & $9 / 2$ & 27194.28 & .05 \\
\hline$\left[^{127} \mathrm{Cl}^{35}\right.$ & $1-$ & $4 \leftarrow 3$ & Ground & $5 / 2$ & 3 & $3 / 2$ & 2 & 27194.75 & \\
\hline $\mathrm{C}^{12} \mathrm{H}_{3} \mathrm{C}^{12}{ }_{*} \mathrm{HO}^{16} \mathrm{C}^{12}{ }_{*} \mathrm{H}_{2}$ & 3- 761 & Not Reported & Ground & & & & & 27196.07 & .1 \\
\hline $\mathrm{C}^{12} \mathrm{H}_{3} \mathrm{C}^{12} \mathrm{H}_{2} \mathrm{I}^{127}$ & 3. 571 & $4,1,3 \leftarrow 4,0,4$ & Ground & & $11 / 2$ & & $11 / 2$ & 27196.26 & .05 \\
\hline $\mathrm{s}-\left(\mathrm{C}^{12} \mathrm{H}_{2} \mathrm{D}\right)\left(\mathrm{C}^{12} \mathrm{H}_{3}\right) \mathrm{O}^{16}$ & 3. 596 & Not Reported & Ground & & & & & 27200 & 20. \\
\hline$I^{127} \mathrm{Cl}^{35}$ & $1-$ & $4 \leftarrow 3$ & Ground & $5 / 2$ & 2 & $3 / 2$ & 1 & 27202.64 & \\
\hline $\mathrm{C}^{12} \mathrm{H}_{3} \mathrm{C}^{12} \mathrm{H}_{2} \mathrm{~F}^{19}$ & 3- 551 & Not Reported & & & & & & 27204.33 & \\
\hline
\end{tabular}




\begin{tabular}{|c|c|c|c|c|c|c|c|c|c|}
\hline \multirow{2}{*}{ Isotopic Species } & \multirow{2}{*}{$\begin{array}{l}\text { Vol.-ld. } \\
\text { Nos. }\end{array}$} & \multirow{2}{*}{$\begin{array}{c}\text { Rotational } \\
\text { Quantum Nos. }\end{array}$} & \multirow{2}{*}{ Vib. State } & \multicolumn{4}{|c|}{ Hyperfine } & \multirow{2}{*}{$\begin{array}{l}\text { Frequency } \\
\text { Mll } \%\end{array}$} & \multirow{2}{*}{$\begin{aligned} & \text { Ace. } \\
& \pm \text { MHI }\end{aligned}$} \\
\hline & & & & $\mathrm{F}_{1}^{\prime}$ & $\mathrm{F}^{\prime}$ & $F_{1}$ & $\mathrm{~F}$ & & \\
\hline $\mathrm{I}^{127} \mathrm{Cl}^{35}$ & 1 - & $4 \leftarrow 3$ & Ground & $5 / 2$ & 4 & $3 / 2$ & 3 & 27204.99 & \\
\hline $\mathrm{C}^{12} \mathrm{H}_{3} \mathrm{C}^{12} \mathrm{O}^{16} \mathrm{O}^{16} \mathrm{H}$ & 3- 491 & $2,1,2 \leftarrow 1,0,1$ & Ground & & & & & 27205.64 & .4 \\
\hline $\mathrm{C}^{12} \mathrm{H}_{3} \mathrm{C}^{12} \mathrm{HO}^{16}$ & 3- 471 & Not Reported & & & & & & 27206.96 & \\
\hline $\mathrm{C}^{12} \mathrm{O}^{18} \mathrm{~F}_{2}^{19}$ & 4. 213 & $4,2,2 \leftarrow 4,2,3$ & Ground & & & & & 27207.95 & .10 \\
\hline $\mathrm{I}^{127} \mathrm{Cl}^{35}$ & 1 . & $4 \leftarrow 3$ & Excited & $13 / 2$ & & $11 / 2$ & & 27208.54 & \\
\hline $\mathrm{HC}^{12}: \mathrm{C}^{12} \mathrm{C}^{12} \mathrm{H}: \mathrm{C}^{12} \mathrm{H}_{2}$ & 4-1131 & $3,0,3 \leftarrow 2,0,2$ & Ground & & & & & 27212.71 & .05 \\
\hline $\mathrm{HC}^{12}: \mathrm{C}^{12} \mathrm{C}^{12} \mathrm{HO}^{18}$ & 4- 915 & $3,1,2 \leftarrow 2,1,1$ & Ground & & & & & 27213.69 & .05 \\
\hline $\mathrm{C}^{12} \mathrm{H}_{3} \mathrm{C}^{12} \mathrm{HO}^{16}$ & 3- 471 & Not Reported & & & & & & 27214.44 & \\
\hline $\mathrm{C}^{13} \mathrm{H}_{3} \mathrm{O}^{16} \mathrm{H}$ & 3- 213 & $7,2, \leftarrow 7,1$, & Ground & & & & & 27215.60 & .1 \\
\hline $\mathrm{DN}^{14} \mathrm{O}_{3}^{16}$ & 3- 32 & $4,2,2 \leftarrow 4,2,3$ & Ground & & & & & 27215.84 & \\
\hline $\mathrm{I}^{127} \mathrm{Cl}^{35}$ & $1-$ & $4 \leftarrow 3$ & Ground & $7 / 2$ & 4 & $5 / 2$ & 3 & 27217.51 & \\
\hline $\mathrm{H}_{2} \mathrm{C}^{12}: \mathrm{C}^{12} \mathrm{~F}_{2}^{19}$ & 4- 681 & Not Reported & & & & & & 27218.6 & .3 \\
\hline $\mathbf{I}^{127} \mathrm{Cl}^{35}$ & $1-$ & $4 \leftarrow 3$ & Ground & $7 / 2$ & 3 & $5 / 2$ & 2 & 27221.02 & \\
\hline $\mathrm{Tl}^{205} \mathrm{Cl}^{35}$ & $1-$ & $5 \leftarrow 4$ & Excited & & & & & 27221.30 & 0.10 \\
\hline $\mathrm{C}^{12}{ }_{*} \mathrm{H}: \mathrm{C}^{12} \mathrm{HO}^{18} \mathrm{C}^{12} \mathrm{H}: \mathrm{C}^{12}{ }_{*} \mathrm{H}$ & $4-1152$ & $8,7,2 \leftarrow 8,5,3$ & Ground & & & & & 27222.6 & .1 \\
\hline$\left(\mathrm{C}^{13} \mathrm{H}_{3}\right)\left(\mathrm{C}^{12} \mathrm{H}_{3}\right)_{2} \mathrm{C}^{12} \mathrm{C}^{12} \mathrm{~N}^{14}$ & $3-1023$ & $5,0,5 \leftarrow 4,0,4$ & Ground & & & & & 27223.8 & .1 \\
\hline $\mathrm{I}^{127} \mathrm{Cl}^{35}$ & $1-$ & $4 \leftarrow 3$ & Ground & $7 / 2$ & 5 & $5 / 2$ & 4 & 27225.32 & \\
\hline $\mathrm{HC}^{12}: \mathrm{C}^{12} \mathrm{C}^{12} \mathrm{H}: \mathrm{C}^{12} \mathrm{H}_{2}$ & 4-1131 & $3,2,2 \leftarrow 2,2,1$ & Ground & & & & & 27226.03 & .05 \\
\hline $\mathrm{C}^{12} \mathrm{H}_{3} \mathrm{O}^{16} \mathrm{H}$ & 3- 211 & Not Reported & Ground & & & & & 27227.02 & .1 \\
\hline${ }^{127} \mathrm{Cl}^{35}$ & $1-$ & $4 \leftarrow 3$ & Ground & $7 / 2$ & 2 & $5 / 2$ & 1 & 27228.34 & \\
\hline $\mathrm{C}^{12} \mathrm{H}_{3} \mathrm{C}^{12} \mathrm{HO}^{16}$ & 3- 471 & Not Reported & & & & & & 27231.02 & \\
\hline $\mathrm{C}^{12} \mathrm{H}_{3} \mathrm{~S}^{32} \mathrm{H}$ & 3- 221 & Not Reported & Ground & & & & & 27235.8 & .1 \\
\hline $\mathrm{HC}^{12}: \mathrm{C}^{12} \mathrm{C}^{12} \mathrm{H}: \mathrm{C}^{12} \mathrm{H}_{2}$ & 4-1131 & $3,2,1 \leftarrow 2,2,0$ & Ground & & & & & 27237.09 & .05 \\
\hline$\left(\mathrm{C}^{13} \mathrm{H}_{3}\right)\left(\mathrm{C}^{12} \mathrm{H}_{3}\right)_{2} \mathrm{C}^{12} \mathrm{C}^{12} \mathrm{~N}^{14}$ & 3-1023 & $5,2,4 \leftarrow 4,2,3$ & Ground & & & & & 27238.6 & .1 \\
\hline $\mathrm{s}-\left(\mathrm{C}^{12} \mathrm{H}_{2} \mathrm{D}\right)\left(\mathrm{C}^{12} \mathrm{H}_{3}\right) \mathrm{O}^{16}$ & 3- 596 & Not Reported & Ground & & & & & 27240 . & 20. \\
\hline $\mathrm{C}^{12} \mathrm{H}_{3} \mathrm{C}^{12}{ }_{*} \mathrm{HO}^{16} \mathrm{C}^{12}{ }_{*} \mathrm{H}_{2}$ & 3- 761 & $3,0,3 \leftarrow 2,1,2$ & Ground & & & & & 27240.85 & .1 \\
\hline $\mathrm{C}^{12} \mathrm{H}_{3} \mathrm{C}^{12}{ }_{*} \mathrm{HO}^{16} \mathrm{C}^{12}{ }_{*} \mathrm{H}_{2}$ & 3- 761 & Not Reported & Ground & & & & & 27241.74 & .1 \\
\hline $\mathrm{I}^{127} \mathrm{Cl}^{35}$ & 1. & $4 \leftarrow 3$ & Ground & $3 / 2$ & 2 & $1 / 2$ & 1 & 27242.59 & \\
\hline $\mathrm{C}^{12} \mathrm{H}_{2}\left(\mathrm{C}^{12} \mathrm{~N}^{14}\right)_{2}$ & 4- 901 & Not Reported & Ground & & & & & 27244.4 & .1 \\
\hline $\mathrm{HC}^{13}: \mathrm{C}^{12} \mathrm{C}^{12} \mathrm{DO}^{16}$ & 4- 922 & Not Reported & & & & & & 27245 . & 5. \\
\hline $\mathrm{C}^{12} \mathrm{HD}_{2} \mathrm{C}^{12} \mathrm{HDF}^{19}$ & 3- 558 & $6,1,6 \leftarrow 5,2,3$ & Ground & & & & & 27245.5 & .1 \\
\hline $\mathrm{s}-\left(\mathrm{C}^{12} \mathrm{H}_{2} \mathrm{D}\right)\left(\mathrm{C}^{12} \mathrm{H}_{3}\right) \mathrm{O}^{16}$ & 3- 596 & Not Reported & Ground & & & & & 27250 & 20. \\
\hline $\mathrm{I}^{127} \mathrm{Cl}^{35}$ & $1-$ & $4 \leftarrow 3$ & Ground & $3 / 2$ & 3 & $1 / 2$ & 2 & 27254.90 & \\
\hline $\mathrm{t}-\mathrm{C}^{12} \mathrm{H}_{3} \mathrm{C}^{12} \mathrm{H}: \mathrm{C}^{12} \mathrm{HC}^{12} \mathrm{~N}^{14}$ & 3- 921 & $6,1, \leftarrow 5,1$, & Ground & & & & & 27257.39 & .5 \\
\hline $\mathrm{Tl}^{203} \mathrm{Cl}^{35}$ & $1-$ & $5 \leftarrow 4$ & Excited & & $7 / 2$ & & $5 / 2$ & 27260.18 & 0.10 \\
\hline $\mathrm{T}^{203} \mathrm{Cl}^{35}$ & 1 . & $5 \leftarrow 4$ & Excited & & $9 / 2$ & & $7 / 2$ & 27260.18 & 0.10 \\
\hline $\mathrm{Tl}^{203} \mathrm{Cl}^{35}$ & 1 - & $5 \leftarrow 4$ & Excited & & $13 / 2$ & & $11 / 2$ & 27260.18 & 0.10 \\
\hline $\mathrm{Tl}^{203} \mathrm{Cl}^{35}$ & 1. & $5 \leftarrow 4$ & Excited & & $11 / 2$ & & $9 / 2$ & 27260.18 & 0.10 \\
\hline $\mathrm{C}^{12} \mathrm{HD}\left(\mathrm{C}^{12} \mathrm{~N}^{14}\right)_{2}$ & 4- 902 & $10,1,9 \leftarrow 10,0,10$ & Ground & & & & & 27261.51 & \\
\hline $\mathrm{C}^{12} \mathrm{H}_{3} \mathrm{Si}^{28} \mathrm{DF}_{2}^{19}-\mathrm{A}$ & 3- 197 & Not Reported & Ground & & & & & 27262.5 & \\
\hline $\mathrm{C}^{12}{ }_{*} \mathrm{D}_{2} \mathrm{C}^{12} \mathrm{H}_{2} \mathrm{C}^{12} \mathrm{D}_{2} \mathrm{O}^{16} *$ & 4-1092 & $5,5,1 \leftarrow 5,4,2$ & Excited & & & & & 27263. & 2. \\
\hline $\mathrm{C}^{12} \mathrm{H}_{3} \mathrm{Si}^{28} \mathrm{DF}_{2}^{19} \cdot \mathrm{A}$ & 3- 197 & Not Reported & Ground & & & & & 27272.0 & \\
\hline $\mathrm{C}^{12} \mathrm{H}_{2}\left(\mathrm{C}^{12} \mathrm{~N}^{14}\right)_{2}$ & 4- 901 & Not Reported & Ground & & & & & 27281.0 & .1 \\
\hline $\mathrm{D}_{2} \mathrm{O}_{2}^{16}$ & 3- 42 & Not Reported & & & & & & 27282 & 3. \\
\hline $\mathrm{C}^{12} \mathrm{H}_{3} \mathrm{O}^{16} \mathrm{H}$ & 3- 211 & Not Reported & Ground & & & & & 27283.29 & .1 \\
\hline
\end{tabular}




\begin{tabular}{|c|c|c|c|c|c|c|c|c|c|}
\hline Isotopic Species & $\begin{array}{l}\text { Vol.-Id. } \\
\text { Nos. }\end{array}$ & $\begin{array}{c}\text { Rotational } \\
\text { Quantum Nos. }\end{array}$ & Vib. State & $\mathrm{F}_{1}^{\prime}$ & $\begin{array}{r}\text { Hyp } \\
\mathrm{F}^{\prime}\end{array}$ & $\underset{F_{1}}{\operatorname{erfine}}$ & $F$ & $\begin{array}{l}\text { Frequency } \\
\mathrm{MHz}\end{array}$ & $\begin{array}{r}\text { Acc. } \\
+\mathrm{MHz}\end{array}$ \\
\hline$I^{127} \mathrm{Cl}^{35}$ & 1 . & $4 \leftarrow 3$ & Ground & $9 / 2$ & & $9 / 2$ & & 27283.66 & \\
\hline $\mathrm{I}^{127} \mathrm{Cl}^{35}$ & 1. & $4 \leftarrow 3$ & Ground & $9 / 2$ & & $7 / 2$ & & 27283.66 & \\
\hline $\mathrm{C}^{12} \mathrm{O}^{16} \mathrm{Cl}^{35} \mathrm{Cl}^{37}$ & 4. 182 & $5,1,5 \leftarrow 4,0,4$ & Ground & & & & & 27285.5 & .3 \\
\hline $\mathrm{I}^{127} \mathrm{Cl}^{35}$ & $1-$ & $4 \leftarrow 3$ & Ground & $9 / 2$ & & $9 / 2$ & & 27286.25 & \\
\hline $\mathrm{I}^{127} \mathrm{Cl}^{35}$ & 1. & $4 \leftarrow 3$ & Ground & $9 / 2$ & & $7 / 2$ & & 27286.25 & \\
\hline$\left(\mathrm{C}^{12} \mathrm{H}_{3}\right)_{3} \mathrm{Si}^{28} \mathrm{~F}^{19}$ & 3- 831 & $4, \leftarrow 3$, & Ground & & & & & 27287.8 & .3 \\
\hline g. $\mathrm{C}^{12} \mathrm{H}_{2} \mathrm{Cl}^{35} \mathrm{C}^{12} \mathrm{H}_{2} \mathrm{Cl}^{35}$ & 3- 451 & $5,1,5 \leftarrow 4,0,4$ & & & & & & 27289. & \\
\hline $\mathrm{s}-\left(\mathrm{C}^{12} \mathrm{H}_{2} \mathrm{D}\right)\left(\mathrm{C}^{12} \mathrm{H}_{3}\right) \mathrm{O}^{16}$ & 3- 596 & Not Reported & Ground & & & & & 27290. & 20. \\
\hline $\mathrm{I}^{127} \mathrm{Cl}^{35}$ & $1 \cdot$ & $4 \leftarrow 3$ & Ground & $9 / 2$ & & $9 / 2$ & & 27292.63 & \\
\hline $\mathrm{I}^{127} \mathrm{Cl}^{35}$ & 1. & $4 \leftarrow 3$ & Ground & $9 / 2$ & & $7 / 2$ & & 27292.63 & \\
\hline $\mathrm{HC}^{12}: \mathrm{C}^{12} \mathrm{C}^{12} \mathrm{~N}^{14}$ & 4. 881 & $3 \leftarrow 2$ & Ground & & 3 & & 3 & 27293.09 & \\
\hline $\mathrm{C}^{12} * \mathrm{D}_{2} \mathrm{C}^{12} \mathrm{H}_{2} \mathrm{C}^{12} \mathrm{D}_{2} \mathrm{O}^{16} *$ & 4-1092 & $10,7,3 \leftarrow 10,6,4$ & Ground & & & & & 27293.4 & .1 \\
\hline $\mathrm{HC}^{12}: \mathrm{C}^{12} \mathrm{C}^{12} \mathrm{~N}^{14}$ & 4. 881 & $3 \leftarrow 2$ & Ground & & 4 & & 3 & 27294.47 & \\
\hline $\mathrm{I}^{127} \mathrm{Cl}^{35}$ & 1. & $4 \leftarrow 3$ & Ground & $9 / 2$ & & $7 / 2$ & & 27295.05 & \\
\hline $\mathrm{I}^{127} \mathrm{Cl}^{35}$ & $1-$ & $4 \leftarrow 3$ & Ground & $9 / 2$ & & $9 / 2$ & & 27295.05 & \\
\hline $\mathrm{HC}^{12}: \mathrm{C}^{12} \mathrm{C}^{12} \mathrm{~N}^{14}$ & 4. 881 & $3 \leftarrow 2$ & Ground & & 2 & & 2 & 27296.29 & \\
\hline $\mathrm{H}_{2} \mathrm{C}^{12}: \mathrm{C}^{12} \mathrm{~F}_{2}^{19}$ & 4. 681 & $5,4,2 \leftarrow 5,2,3$ & Ground & & & & & 27297.0 & .3 \\
\hline $\mathrm{C}^{12}{ }_{*} \mathrm{H}_{2} \mathrm{C}^{12} \mathrm{H}_{2} \mathrm{C}^{12} \mathrm{H}_{2} \mathrm{O}^{16}{ }_{*}$ & $4-1091$ & $9,8,2 \leftarrow 9,6,3$ & Ground & & & & & 27302.9 & .1 \\
\hline $\mathrm{HC}^{13}: \mathrm{C}^{12} \mathrm{C}^{12} \mathrm{DO}^{16}$ & 4. 922 & Not Reported & & & & & & 27305 . & 5. \\
\hline$\left(\mathrm{C}^{13} \mathrm{H}_{3}\right)\left(\mathrm{C}^{12} \mathrm{H}_{3}\right)_{2} \mathrm{C}^{12} \mathrm{C}^{12} \mathrm{~N}^{14}$ & $3-1023$ & $5,1,4 \leftarrow 4,1,3$ & Ground & & & & & 27306.5 & .1 \\
\hline $\mathrm{C}^{12} \mathrm{H}_{2}\left(\mathrm{C}^{12} \mathrm{~N}^{14}\right)_{2}$ & 4. 901 & Not Reported & Ground & & & & & 27309.6 & .1 \\
\hline $\mathrm{C}^{12} \mathrm{H}_{2} \mathrm{Cl}^{35} \mathrm{C}^{12}: \mathrm{C}^{12} \mathrm{H}$ & 4- 991 & $8,1,7 \leftarrow 8,0,8$ & Ground & & & & & 27319.22 & \\
\hline$\left(\mathrm{C}^{12} \mathrm{H}_{3}\right)_{3} \mathrm{C}^{12} \mathrm{C}^{13} \mathrm{~N}^{14}$ & $3 \cdot 1024$ & $5, \leftarrow 4$, & Ground & & & & & 27321.6 & .1 \\
\hline $\mathrm{C}^{12} \mathrm{H}_{3} \mathrm{~N}^{14} \mathrm{H}_{2}$ & 3- 261 & Not Reported & Ground & & & & & 27323.13 & .1 \\
\hline $\mathrm{C}^{12} \mathrm{H}_{2}: \mathrm{C}^{12} \mathrm{HC}^{12} \mathrm{~F}^{19}: \mathrm{C}^{12} \mathrm{H}_{2}$ & 3- 911 & $5,3,2 \leftarrow 5,2,3$ & Ground & & & & & 27324.1 & .2 \\
\hline $\mathrm{s}-\left(\mathrm{C}^{12} \mathrm{H}_{2} \mathrm{D}\right)\left(\mathrm{C}^{12} \mathrm{H}_{3}\right) \mathrm{O}^{16}$ & 3- 596 & Not Reported & Ground & & & & & 27325. & 20. \\
\hline $\mathrm{S}^{32}{ }_{*} \mathrm{HC}^{12}: \mathrm{C}^{12} \mathrm{DC}^{12} \mathrm{H}: \mathrm{C}^{12}{ }_{*} \mathrm{H}$ & 4-1163 & $3,2,1 \leftarrow 2,2,0$ & Ground & & & & & 27325.5 & .1 \\
\hline $\mathrm{C}^{12}{ }_{*} \mathrm{D}_{2} \mathrm{C}^{12} \mathrm{H}_{2} \mathrm{C}^{12} \mathrm{D}_{2} \mathrm{O}^{16}{ }_{*}$ & $4 \cdot 1092$ & $4,2,3 \leftarrow 4,1,4$ & Excited & & & & & 27327. & 2. \\
\hline $\mathrm{C}^{12} \mathrm{H}_{2}: \mathrm{C}^{12} \mathrm{HC}^{12} \mathrm{HO}^{16}$ & 3. 691 & $3,1,2 \leftarrow 2,1,1$ & Ground & & & & & 27329.62 & \\
\hline $\mathrm{C}^{12}{ }_{*} \mathrm{H}_{2} \mathrm{C}^{12} \mathrm{H}_{2} \mathrm{C}^{12} \mathrm{H}_{2} \mathrm{O}^{16}{ }_{*}$ & 4-1091 & $9,8,2 \leftarrow 9,6,3$ & Excited & & & & & 27332.3 & .1 \\
\hline $\mathrm{HC}^{13}: \mathrm{C}^{12} \mathrm{C}^{12} \mathrm{DO}^{16}$ & 4- 922 & Not Reported & & & & & & 27333. & 5. \\
\hline $\mathrm{I}^{127} \mathrm{Cl}^{35}$ & $1 \cdot$ & $4 \leftarrow 3$ & Ground & $11 / 2$ & 6 & $7 / 2$ & 5 & 27333.85 & \\
\hline $\mathrm{I}^{127} \mathrm{Cl}^{35}$ & $1-$ & $4 \leftarrow 3$ & Ground & $11 / 2$ & 6 & $9 / 2$ & 5 & 27333.85 & \\
\hline $\mathrm{C}^{12} \mathrm{H}_{3} \mathrm{~S}^{32} \mathrm{H}$ & 3. 221 & Not Reported & Ground & & & & & 27333.9 & .1 \\
\hline${ }^{127} \mathrm{Cl}^{35}$ & $1-$ & $4 \leftarrow 3$ & Ground & $13 / 2$ & 6 & $11 / 2$ & 5 & 27336.68 & \\
\hline $\mathrm{I}^{127} \mathrm{Cl}^{35}$ & $1-$ & $4 \leftarrow 3$ & Ground & $13 / 2$ & 7 & $11 / 2$ & 6 & 27336.68 & \\
\hline $\mathrm{C}^{12}{ }_{*} \mathrm{H}_{2} \mathrm{C}^{12} \mathrm{H}_{2} \mathrm{C}^{12} \mathrm{H}_{2} \mathrm{O}^{16} *$ & 4-1091 & $9,8,2 \leftarrow 9,6,3$ & Excited & & & & & 27337.0 & .1 \\
\hline$I^{127} \mathrm{Cl}^{35}$ & $1-$ & $4 \leftarrow 3$ & Ground & $13 / 2$ & 5 & $11 / 2$ & 4 & 27337.38 & \\
\hline $\mathrm{I}^{127} \mathrm{Cl}^{35}$ & $1 \cdot$ & $4 \leftarrow 3$ & Ground & $13 / 2$ & 8 & $11 / 2$ & 7 & 27337.38 & \\
\hline $\mathrm{HC}^{12}: \mathrm{C}^{12} \mathrm{C}^{13} \mathrm{HO}^{16}$ & 4. 914 & $3,1,3 \leftarrow 2,1,2$ & Ground & & & & & 27338.45 & .02 \\
\hline $\mathrm{Tl}^{205} \mathrm{Cl}^{35}$ & $1-$ & $5 \leftarrow 4$ & Ground & & & & & 27340.51 & 0.10 \\
\hline $\mathrm{O}^{16}{ }_{*} \mathrm{C}^{12} \mathrm{H}_{2} \mathrm{C}^{12} \mathrm{H}_{2} \mathrm{C}^{12}{ }_{*} \mathrm{O}^{16}$ & 4-1071 & $3,2,2 \leftarrow 2,2,1$ & Ground & & & & & 27340.69 & .1 \\
\hline $\mathrm{C}^{12}{ }_{*} \mathrm{H}_{2} \mathrm{C}^{12} \mathrm{H}_{2} \mathrm{C}^{12} \mathrm{H}_{2} \mathrm{O}^{16} *$ & 4-1091 & $9,8,2 \leftarrow 9,6,3$ & Excited & & & & & 27341.8 & .1 \\
\hline g- $\mathrm{C}^{12} \mathrm{H}_{2} \mathrm{DC}^{12} \mathrm{H}_{2} \mathrm{Cl}^{35}$ & 3. 544 & $5,1,4 \leftarrow 5,0,5$ & Ground & & $7 / 2$ & & $7 / 2$ & 27342.62 & .05 \\
\hline $\mathrm{g} \cdot \mathrm{C}^{12} \mathrm{H}_{2} \mathrm{DC}^{12} \mathrm{H}_{2} \mathrm{Cl}^{35}$ & 3- 544 & $5,1,4 \leftarrow 5,0,5$ & Ground & & $13 / 2$ & & $13 / 2$ & 27343.98 & .05 \\
\hline
\end{tabular}


Vol.-Id. Rotational Nos. Quantum Nos.
Vib. State
Frequency Acc. MHz $\pm \mathrm{MHz}$

\section{$\mathrm{C}^{12} \overline{\mathrm{H}}_{2} \mathrm{~F}^{19} \mathrm{C}^{12} \mathrm{~N}^{14}$}

$\mathrm{C}^{12}{ }_{*} \mathrm{H}_{2} \mathrm{C}^{12} \mathrm{H}_{2} \mathrm{C}^{12} \mathrm{H}_{2} \mathrm{O}^{16}{ }_{*}$

$\mathrm{HC}^{13}: \mathrm{C}^{12} \mathrm{C}^{12} \mathrm{DO}^{16}$

$\mathrm{I}^{127} \mathrm{Cl}^{35}$

$\mathrm{I}^{127} \mathrm{Cl}^{35}$

g- $\mathrm{C}^{12} \mathrm{H}_{2} \mathrm{DC}^{12} \mathrm{H}_{2} \mathrm{Cl}^{35}$

g. $\mathrm{C}^{12} \mathrm{H}_{2} \mathrm{DC}^{12} \mathrm{H}_{2} \mathrm{Cl}^{35}$

$\mathrm{HC}^{13}: \mathrm{C}^{12} \mathrm{C}^{12} \mathrm{DO}^{16}$

$\mathrm{I}^{127} \mathrm{Cl}^{35}$

$\mathrm{I}^{127} \mathrm{Cl}^{35}$

$\mathrm{I}^{127} \mathrm{Cl}^{35}$

$\mathrm{I}^{127} \mathrm{Cl}^{35}$

$\mathrm{I}^{127} \mathrm{Cl}^{35}$

$\mathrm{HC}^{12}: \mathrm{C}^{13} \mathrm{C}^{12} \mathrm{HO}^{16}$

$\mathrm{C}^{12}{ }_{*} \mathrm{H}_{2} \mathrm{C}^{12} \mathrm{H}_{2} \mathrm{C}^{12}{ }_{*} \mathrm{HC}^{12} \mathrm{~N}^{14}$

$\mathrm{C}^{13} \mathrm{H}_{3} \mathrm{O}^{16} \mathrm{H}$

$\mathrm{C}^{12} \mathrm{H}_{3} \mathrm{~S}^{32} \mathrm{H}$

$\mathrm{C}^{12} \mathrm{H}_{2} \mathrm{~F}^{19} \mathrm{C}^{12} \mathrm{~N}^{14}$

$\mathrm{N}^{14} \mathrm{O}_{2}^{16} \mathrm{Cl}^{35}$

$\mathrm{N}^{14} \mathrm{O}_{2}^{16} \mathrm{Cl}^{35}$

a- $\left(\mathrm{C}^{12} \mathrm{H}_{2} \mathrm{D}\right)\left(\mathrm{C}^{12} \mathrm{H}_{3}\right) \mathrm{O}^{16}$

$\mathrm{HN}^{14} \mathrm{O}_{3}^{16}$

$\mathrm{C}^{12} \mathrm{H}_{3} \mathrm{C}^{12} \mathrm{HDC}^{12} \mathrm{H}_{3}$

$\mathrm{O}^{16}{ }_{*} \mathrm{C}^{12} \mathrm{H}_{2} \mathrm{C}^{12} \mathrm{H}_{2} \mathrm{C}^{12} \mathrm{O}^{16}$

$\mathrm{HDO}_{2}^{16}$

$\mathrm{Tl}^{203} \mathrm{Cl}^{35}$

$\mathrm{Tl}^{203} \mathrm{Cl}^{35}$

$\mathrm{Tl}^{203} \mathrm{Cl}^{35}$

$\mathrm{Tl}^{203} \mathrm{Cl}^{35}$

$\mathrm{Tl}^{203} \mathrm{Cl}^{35}$

$\mathrm{C}^{12} \mathrm{H}_{2} \mathrm{~F}^{19} \mathrm{C}^{12} \mathrm{~N}^{14}$

$\mathrm{N}^{14} \mathrm{O}_{2}^{16} \mathrm{Cl}^{35}$

$\mathrm{C}^{12} \mathrm{H}_{3} \mathrm{C}^{12} \mathrm{H}_{2} \mathrm{Cl}^{37}$

$\mathrm{N}^{14} \mathrm{O}_{2}^{16} \mathrm{Cl}^{35}$

$\mathrm{C}^{12} \mathrm{O}^{16} \mathrm{Cl}^{35} \mathrm{Cl}^{37}$

$\mathrm{N}^{14} \mathrm{O}_{2}^{16} \mathrm{Cl}^{35}$

$\mathrm{N}^{14} \mathrm{O}_{2}^{16} \mathrm{Cl}^{35}$

$\mathrm{HDS}^{34}$

$\mathrm{C}^{12} \mathrm{H}_{3} \mathrm{C}^{12}: \mathrm{C}^{12} \mathrm{C}^{12} \mathrm{~F}_{3}^{19}$

$\mathrm{C}^{12} \mathrm{H}_{3} \mathrm{C}^{12} \mathrm{O}^{16} \mathrm{O}^{16} \mathrm{H}$

$\mathrm{O}^{16}{ }_{*} \mathrm{C}^{12} \mathrm{H}_{2} \mathrm{C}^{12} \mathrm{H}_{2} \mathrm{C}^{12}{ }_{*} \mathrm{O}^{16}$

$\mathrm{HC}^{13}: \mathrm{C}^{12} \mathrm{C}^{12} \mathrm{DO}^{16}$

$\mathrm{C}^{12} \mathrm{H}_{3} \mathrm{~S}^{32} \mathrm{H}$

$\mathrm{C}^{12}{ }_{*} \mathrm{HN}^{14} \mathrm{C}^{12} \mathrm{HC}^{12} \mathrm{H}: \mathrm{C}^{12} \mathrm{HN}^{14} *$

$\mathrm{HDO}_{2}^{16}$
4. $701 \quad 3,0,3 \leftarrow 2,0,2 \quad$ Ground

4-1091 9, 8, $2 \leftarrow 9,6,3 \quad$ Excited

4. 922 Not Reported

1 .

1 -

$4 \leftarrow 3$

$4 \leftarrow 3$

3- $544 \quad 5,1,4 \leftarrow 5,0,5$

3- 544

$5,1,4 \leftarrow 5,0,5$

4- 922

Not Reported

1 -

$4 \leftarrow 3$

1 .

$4 \leftarrow 3$

1 -

$4 \leftarrow 3$

$1-$

$4 \leftarrow 3$

1.

$4 \leftarrow 3$

4. $913 \quad 3,1,3 \leftarrow 2,1,2$

4.1171

$4,1,3 \leftarrow 3,1,2$

3. 213

$8,2, \leftarrow 8,1$,

3. 221

Not Reported

4. $701 \quad 3,2,2 \leftarrow 2,2,1$

4.1461

$3,2,1 \leftarrow 2,2,0$

4.1461

$3,2,1 \leftarrow 2,2,0$

3- 597

$2,1,1 \leftarrow 2,0,2$

3- 31

$6,4,2 \leftarrow 6,4,3$

3- 784

$5,1,4 \leftarrow 5,0,5$

4-1071

$3,2,2 \leftarrow 2,2,1$

3- $4317,, \leftarrow 17$, ,

1 -

1 .

$5 \leftarrow 4$

1.

$5 \leftarrow 4$

1.

$5 \leftarrow 4$

1. $5 \leftarrow 4$

1- $\quad 5 \leftarrow 4$

4. 701

$3,2,1 \leftarrow 2,2,0$

4-1461

$3,2,1 \leftarrow 2,2,0$

3- 542

$5,0,5 \leftarrow 4,1,4$

4-1461

$3,2,1 \leftarrow 2,2,0$

4- 182

$6,3,4 \leftarrow 6,2,5$

4-1461

$3,2,1 \leftarrow 2,2,0$

4-1461

$3,2,1 \leftarrow 2,2,0$

4-1729

$7,4,3 \leftarrow 7,4,4$

3- 891

$10, \leftarrow 9$,

3- 491

$2,1,2 \leftarrow 1,0,1$

4-1071

$3,2,2 \leftarrow 2,2,1$

4. 922

Not Reported

3. 221

Not Reported

4-1141

$3,1,2 \leftarrow 2,2,1$

3. $4317,, \leftarrow 17$, ,

Ground

Ground

Ground

Ground

Ground

Ground

Ground

Ground

Ground

Ground

Ground

Ground

Ground

Ground

Excited

Ground

Ground

Ground

Ground

Ground

Ground

Ground

Ground

Ground

Ground

Ground

Ground

Ground

Ground

Excited

Ground

Ground
27345.

1.0

27345.0

27346.

5.

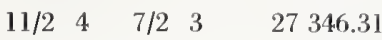

$11 / 2 \quad 4 \quad 9 / 2 \quad 3$

$9 / 2 \quad 9 / 2 \quad 27347.22$

$11 / 2 \quad 11 / 2 \quad 27348.50$

.05

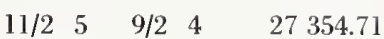

$11 / 2 \quad 5 \quad 7 / 2 \quad 4 \quad 27354.71$

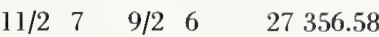

$\begin{array}{llll}11 / 2 & 6 & 7 / 2 & 5\end{array}$

27357.73

$11 / 2 \quad 6 \quad 9 / 2 \quad 5 \quad 27357.73$

27358.89

27358.91

27364.12

27364.5

27365.

$7 / 2$

$5 / 2$

27365.61

$5 / 2$

$5 / 2$

27366.1

27367.7

27369.67

27370.09

27370.21

27375.

Ground

$\begin{array}{llll}11 / 2 & 11 / 2 & 27376.62 & 0.10\end{array}$

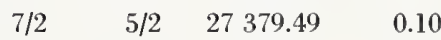

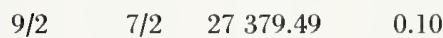

$\begin{array}{llll}13 / 2 & 11 / 2 & 27379.49 & 0.10\end{array}$

$\begin{array}{llll}11 / 2 & 9 / 2 & 27379.49 & 0.10\end{array}$

27382.

$5 / 2 \quad 3 / 2 \quad 27382.73$

27382.99

$3 / 2 \quad 3 / 2 \quad 27383.8$

27387.0

$7 / 2 \quad 7 / 2 \quad 27388.8$

$9 / 2 \quad 7 / 2 \quad 27389.88$

27392.00

27393.6

27394.12

27399.95

27401.

27402.2

27403.5

27406.
3.

1.0

.05

.05

5.

.02

.05

.1

1.0

.2

.06

.10

\section{0}

10

3. 


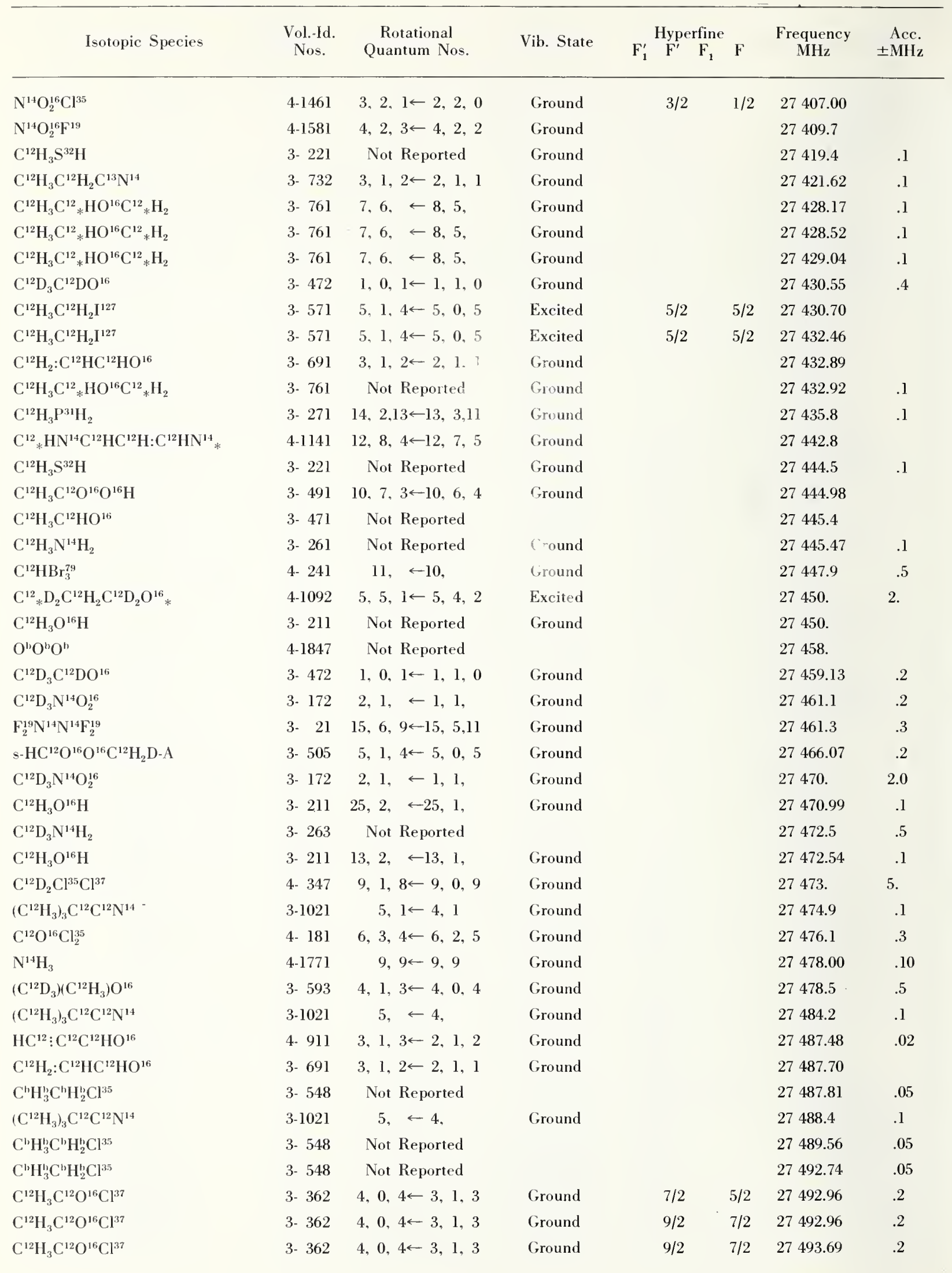


Vib. State

\begin{tabular}{cccc}
\multicolumn{2}{c}{ Hyperfine } & Frequency & Acr: \\
$\mathrm{F}_{1}^{\prime} \mathrm{F}^{\prime} \mathrm{F}_{1} \mathrm{~F}$ & MH\% & \pm Mll
\end{tabular}

$\mathrm{C}^{12} \mathrm{H}_{3} \mathrm{C}^{12} \mathrm{O}^{16} \mathrm{Cl}^{37}$

$\mathrm{C}^{\mathrm{b}} \mathrm{H}_{3}^{\mathrm{b}} \mathrm{C}^{\mathrm{b}} \mathrm{H}_{2}^{\mathrm{b}} \mathrm{Cl}^{35}$

$\mathrm{C}^{12} \mathrm{H}_{3} \mathrm{C}^{12} \mathrm{O}^{16} \mathrm{Cl}^{37}$

$\mathrm{C}^{12} \mathrm{H}_{3} \mathrm{C}^{12} \mathrm{O}^{16} \mathrm{Cl}^{37}$

$\mathrm{O}^{16} \mathrm{~F}_{2}^{19}$

$\mathrm{C}^{12} \mathrm{H}_{3} \mathrm{C}^{12} \mathrm{O}^{16} \mathrm{Cl}^{37}$

$\mathrm{C}^{12} \mathrm{H}_{3} \mathrm{C}^{12} \mathrm{O}^{16} \mathrm{Cl}^{37}$

$\mathrm{C}^{12} \mathrm{H}_{2} \mathrm{Cl}^{35} \mathrm{~F}^{19}$

$\left(\mathrm{C}^{12} \mathrm{H}_{3}\right)_{3} \mathrm{C}^{12} \mathrm{C}^{12} \mathrm{~N}^{14}$

$\mathrm{C}^{12} \mathrm{H}_{2} \mathrm{Cl}^{35} \mathrm{~F}^{19}$

$\mathrm{C}^{12} \mathrm{H}_{3} \mathrm{C}^{12} \mathrm{H}_{2} \mathrm{I}^{127}$

$\mathrm{F}_{2}^{19} \mathrm{~N}^{14} \mathrm{~N}^{14} \mathrm{~F}_{2}^{19}$

$\mathrm{C}^{12} \mathrm{H}_{3} \mathrm{C}^{12} \mathrm{H}_{2} \mathrm{I}^{127}$

$\mathrm{C}^{12} \mathrm{H}_{3} \mathrm{~N}^{14} \mathrm{H}_{2}$

$\mathrm{C}^{12} \mathrm{H}_{3} \mathrm{~N}^{14} \mathrm{H}_{2}$

$\mathrm{HC}^{13}: \mathrm{C}^{12} \mathrm{C}^{12} \mathrm{DO}^{16}$

$\mathrm{C}^{12} \mathrm{D}_{3} \mathrm{C}^{12} \mathrm{~F}_{3}^{19}$

$\mathrm{C}^{12} \mathrm{H}_{3} \mathrm{C}^{12} \mathrm{H}_{2} \mathrm{~F}^{19}$

$\mathrm{D}_{2} \mathrm{~N}^{15} \mathrm{C}^{12} \mathrm{HO}^{16}$

$\mathrm{C}^{12} \mathrm{H}_{2} \mathrm{~F}_{2}^{19}$

$\mathrm{C}^{12} \mathrm{H}_{3} \mathrm{Sn}^{120} \mathrm{H}_{3}$

$\mathrm{Tl}^{205} \mathrm{I}^{127}$

$\left(\mathrm{C}^{12} \mathrm{H}_{3}\right)_{3} \mathrm{C}^{12} \mathrm{C}^{12} \mathrm{~N}^{14}$

c. $-\mathrm{HF}^{19} \mathrm{C}^{12}: \mathrm{C}^{13} \mathrm{HF}^{19}$

$\mathrm{C}^{12} \mathrm{H}_{3} \mathrm{C}^{12} \mathrm{O}^{16} \mathrm{O}^{16} \mathrm{H}$

$\mathrm{C}^{12} \mathrm{H}_{3} \mathrm{C}^{12} \mathrm{HO}^{16}$

$\mathrm{F}_{2}^{19} \mathrm{~N}^{14} \mathrm{~N}^{14} \mathrm{~F}_{2}^{19}$

$\mathrm{C}^{12} \mathrm{H}_{3} \mathrm{C}^{12} \mathrm{H}_{2} \mathrm{I}^{127}$

$\mathrm{C}^{12} \mathrm{H}_{3} \mathrm{C}^{12}{ }_{*} \mathrm{HO}^{16} \mathrm{C}^{12}{ }_{*} \mathrm{H}_{2}$

$\mathrm{C}^{12} \mathrm{H}_{3} \mathrm{C}^{12}{ }_{*} \mathrm{HO}^{16} \mathrm{C}^{12}{ }_{*} \mathrm{H}_{2}$

$\mathrm{C}^{12} \mathrm{H}_{3} \mathrm{C}^{12}{ }_{*} \mathrm{HO}^{16} \mathrm{C}^{12}{ }_{*} \mathrm{H}_{2}$

$\mathrm{C}^{12} \mathrm{H}_{3} \mathrm{C}^{12} \mathrm{H}_{2} \mathrm{I}^{127}$

$\mathrm{HC}^{13}: \mathrm{C}^{12} \mathrm{C}^{12} \mathrm{DO}^{16}$

$\mathrm{C}^{12} \mathrm{H}_{2} \mathrm{Cl}^{35} \mathrm{Si}^{28} \mathrm{D}_{3}$

$\left(\mathrm{C}^{12} \mathrm{H}_{3}\right)_{3} \mathrm{C}^{12} \mathrm{C}^{12} \mathrm{~N}^{14}$

$\mathrm{P}^{31} \mathrm{O}^{16} \mathrm{~F}_{3}^{19}$

$\mathrm{HC}^{13}: \mathrm{C}^{12} \mathrm{C}^{12} \mathrm{HO}^{16}$

$\mathrm{C}^{12} \mathrm{H}_{3} \mathrm{C}^{12} \mathrm{HO}^{18}$

$\left(\mathrm{C}^{13} \mathrm{H}_{3}\right)\left(\mathrm{C}^{12} \mathrm{H}_{3}\right) \mathrm{O}^{16}$

$\mathrm{C}^{12}{ }_{*} \mathrm{HN}^{14} \mathrm{C}^{12} \mathrm{HC}^{12} \mathrm{H}: \mathrm{C}^{12} \mathrm{HN}^{14}{ }_{*}$

$\mathrm{C}^{12} \mathrm{H}_{3} \mathrm{~N}^{14} \mathrm{H}_{2}$

$\mathrm{HC}^{13}: \mathrm{C}^{12} \mathrm{C}^{12} \mathrm{DO}^{16}$

$\mathrm{HC}^{13} \mathrm{HO}^{16}$

$\mathrm{C}^{13} \mathrm{H}_{3} \mathrm{C}^{12} \mathrm{H}_{2} \mathrm{Cl}^{35}$

$\mathrm{C}^{12} \mathrm{H}_{3} \mathrm{Sn}^{118} \mathrm{H}_{3}$
3- 362

3. 548

3. 362

3- 362

4-1611

3. 362

3. 362

4. 331

3-1021

4- 331

3- 571

3- 21

3. 571

3- 261

3. 261

4- 922

3- 414

3. 551

3. 161

4- 351

3. 345

1 -

3-1021

4- 692

3. 491

3- 471

3. 21

3- 571

3- 761

3- 761

3- 761

3. 571

4- 922

3- 237

3-1021

4-1671

4- 912

3. 479

3- 594

4-1141

3- 261

4. 922

4- 382

3- 545

3- 341
$4,0,4 \leftarrow 3,1,3$

Not Reported

$4,0,4 \leftarrow 3,1,3$

$4,0,4 \leftarrow 3,1,3$

$9,3,7 \leftarrow 10,2,8$

$4,0,4 \leftarrow 3,1,3$

$4,0,4 \leftarrow 3,1,3$

$11,1,10 \leftarrow 10,2,9$

$5, \leftarrow 4$,

$11,1,10 \leftarrow 10,2,9$

$5,1,4 \leftarrow 5,0,5$

$16,6,10 \leftarrow 16,5,12$

$5,1,4 \leftarrow 5,0,5$

$15,5, \leftarrow 16,4$,

Not Reported

Not Reported

$$
2, \leftarrow 1,
$$

Not Reported

$4,0,4 \leftarrow 3,1,3$

$23,7,17 \leftarrow 24,6,18$

$$
2, \leftarrow 1,
$$$$
17 \leftarrow 16
$$

$$
5, \leftarrow 4,
$$

$5,1,4 \leftarrow 5,0,5$

$7,4,3 \leftarrow 7,3,4$

Not Reported

$14,6,8 \leftarrow 14,5,10$

$5,1,4 \leftarrow 5,0,5$

$40,20, \leftarrow 39,21$,

$40,20, \leftarrow 39,21$,

$40,20, \leftarrow 39,21$,

$5,1,4 \leftarrow 5,0,5$

Not Reported

$5,1,5 \leftarrow 4,1,4$

$5,1 \leftarrow 4,1$

$3, \leftarrow 2$,

$3,1,2 \leftarrow 2,1,1$

$7,1,6 \leftarrow 7,1,7$

$3,0,3 \leftarrow 2,1,2$

$11,7,4 \leftarrow 11,6,5$

Not Reported

Not Reported

$3,1,2 \leftarrow 3,1,3$

$3,1,2 \leftarrow 3,0,3$

$2, \leftarrow 1$,
Ground

Ground

Ground

Ground

Ground

Ground

Ground

Ground

Ground

Excited

Ground

Excited

Ground

Ground

Ground

Ground

Ground

Ground

Excited

Excited

Ground

Ground

Ground

Excited

Ground

Ground

Ground

Excited

Ground

Excited

Excited

Ground

Ground

Ground

Ground

Ground

Ground

Ground

Ground
$7 / 2 \quad 5 / 2 \quad 27493.69$

$27494.32 \quad .05$

$11 / 2 \quad 9 / 2 \quad 27495.40 \quad .2$

$\begin{array}{lllll}5 / 2 & 3 / 2 & 27 & 495.40 & .2\end{array}$

$27495.80 \quad .10$

$\begin{array}{llll}5 / 2 & 3 / 2 & 27 & 496.12\end{array}$

$\begin{array}{llll}11 / 2 & 9 / 2 & 27 & 496.12\end{array}$

$27498.50 \quad .1$

$27498.9 \quad .1$

$27500.30 \quad .1$

$13 / 2 \quad 13 / 2 \quad 27501$.

$27501.8 \quad .3$

$13 / 2 \quad 13 / 2 \quad 27502$.

27504

27504.75 .1

27510.

5.

27510.5

27515.68

27516.69

$27516.98 \quad .10$

$27517.58 \quad .10$

$27520.39 \quad 0.20$

$27521.5 \quad .1$

$27524.86 \quad .05$

27525.60

27526.04

27526.5

$11 / 2 \quad 11 / 2 \quad 27528.10$

$27528.39 \quad .1$

27528.84

$27529.07 \quad .1$

$11 / 2 \quad 11 / 2 \quad 27529.56$

27530.5 .

$27534.57 \quad .2$

$27539.1 \quad .1$

$27539.39 \quad .05$

$27543.73 \quad .02$

$27547.7 \quad .5$

$27548.3 \quad .5$

27549.4

27553.24

27555.

5.

27555.73

$\begin{array}{llll}3 / 2 & 3 / 2 & 27557.89 & .05\end{array}$

$27558.79 \quad .10$ 


\begin{tabular}{|c|c|c|c|c|c|c|c|}
\hline Isotopic Species & $\begin{array}{l}\text { Vol.-Id. } \\
\text { Nos. }\end{array}$ & $\begin{array}{c}\text { Rotational } \\
\text { Quantum Nos. }\end{array}$ & Vib. State & 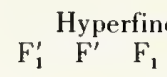 & $F$ & $\begin{array}{c}\text { Frequency } \\
\mathrm{MHz}\end{array}$ & $\begin{aligned} & \text { Acc. } \\
& \pm \mathrm{MHz}\end{aligned}$ \\
\hline $\mathrm{Si}^{2 k} \mathrm{~F}_{3}^{19} \mathrm{D}$ & $4-1642$ & $2, \leftarrow 1$, & Ground & & & 27560.17 & .1 \\
\hline $\mathrm{C}^{13} \mathrm{H}_{3} \mathrm{C}^{12} \mathrm{H}_{2} \mathrm{Cl}^{35}$ & 3- 545 & $3,1,2 \leftarrow 3,0,3$ & Ground & $9 / 2$ & $9 / 2$ & 27560.62 & .05 \\
\hline $\mathrm{C}^{12} \mathrm{H}_{3} \mathrm{Sn}^{120} \mathrm{H}_{3}$ & 3- 345 & $2, \leftarrow 1$ & Ground & & & 27560.69 & .10 \\
\hline $\mathrm{C}^{12} \mathrm{H}_{3} \mathrm{C}^{12} \mathrm{H}_{2} \mathrm{C}^{12} \mathrm{~N}^{14}$ & 3. 731 & $3,1,2 \leftarrow 2,1,1$ & Ground & & & 27561.71 & .1 \\
\hline $\mathrm{C}^{12} \mathrm{H}_{3} \mathrm{C}^{12} \mathrm{H}_{2} \mathrm{I}^{127}$ & $3-571$ & $5,1,4 \leftarrow 5,0,5$ & Ground & $5 / 2$ & $5 / 2$ & 27562.46 & \\
\hline $\mathrm{C}^{12} \mathrm{H}_{3} \mathrm{C}^{12} \mathrm{H}_{2} \mathrm{C}^{12} \mathrm{~N}^{14}$ & 3. 731 & $3,1,2 \leftarrow 2,1,1$ & Ground & & & 27562.9 & .2 \\
\hline $\mathrm{C}^{12} \mathrm{D}_{3} \mathrm{C}^{12} \mathrm{~F}_{3}^{19}$ & 3- 414 & $2, \leftarrow 1$ & Ground & & & 27563.0 & .2 \\
\hline $\mathrm{C}^{13} \mathrm{H}_{3} \mathrm{C}^{12} \mathrm{H}_{2} \mathrm{Cl}^{35}$ & 3. 545 & $3,1,2 \leftarrow 3,0,3$ & Ground & $5 / 2$ & $5 / 2$ & 27563.76 & .05 \\
\hline $\mathrm{C}^{12} \mathrm{H}_{3} \mathrm{C}^{12} \mathrm{H}_{2} \mathrm{I}^{127}$ & 3- 571 & $5,1,4 \leftarrow 5,0,5$ & Ground & $5 / 2$ & $5 / 2$ & 27565. & \\
\hline $\mathrm{P}^{31} \mathrm{O}^{16} \mathrm{~F}_{3}^{19}$ & 4-1671 & $3, \leftarrow 2$, & Ground & & & 27565.42 & .05 \\
\hline HDS $^{32}$ & 4-1727 & $7,4,3 \leftarrow 7,4,4$ & Ground & & & 27566.31 & .05 \\
\hline $\mathrm{C}^{13} \mathrm{H}_{3} \mathrm{C}^{12} \mathrm{H}_{2} \mathrm{Cl}^{35}$ & 3- 545 & $3,1,2 \leftarrow 3,0,3$ & Ground & $7 / 2$ & $7 / 2$ & 27566.63 & .05 \\
\hline $\mathrm{HC}^{12}: \mathrm{C}^{12} \mathrm{C}^{12} \mathrm{HO}^{16}$ & 4. 911 & $3,1,3 \leftarrow 2,1,2$ & Excited & & & 27570.57 & .15 \\
\hline $\mathrm{C}^{12} \mathrm{H}_{3} \mathrm{C}^{12}{ }_{*} \mathrm{HO}^{16} \mathrm{C}^{12}{ }_{*} \mathrm{H}_{2}$ & 3- 761 & $16,7, \leftarrow 15,8$ & Ground & & & 27575.98 & .1 \\
\hline $\mathrm{C}^{12} \mathrm{H}_{3} \mathrm{C}^{12} \mathrm{H}_{2} \mathrm{C}^{12} \mathrm{~N}^{14}$ & 3- 731 & $3,1,2 \leftarrow 2,1,1$ & Excited & & & 27576.62 & .1 \\
\hline $\mathrm{C}^{12} \mathrm{H}_{3} \mathrm{C}^{12}{ }_{*} \mathrm{HO}^{16} \mathrm{C}^{12}{ }_{*} \mathrm{H}_{2}$ & 3- 761 & $16,7, \quad \leftarrow 15,8$ & Ground & & & 27576.76 & .1 \\
\hline $\mathrm{HC}^{12}: \mathrm{C}^{12} \mathrm{C}^{12} \mathrm{HO}^{16}$ & 4. 911 & $3,1,3 \leftarrow 2,1,2$ & Excited & & & 27578.10 & .15 \\
\hline $\mathrm{C}^{12} \mathrm{H}_{3} \mathrm{Sn}^{119} \mathrm{H}_{3}$ & 3- 344 & $2, \leftarrow 1$, & Ground & & & 27580.52 & .10 \\
\hline $\mathrm{t}-\mathrm{C}^{12} \mathrm{H}_{3} \mathrm{C}^{12} \mathrm{H}_{2} \mathrm{C}^{12} \mathrm{H}_{2} \mathrm{Cl}^{35}$ & 3. 771 & $6,1,6 \leftarrow 5,1,5$ & Ground & & & 27580.96 & .2 \\
\hline $\mathrm{C}^{13} \mathrm{H}_{3} \mathrm{O}^{16} \mathrm{H}$ & 3. 213 & $9,2, \leftarrow 9,1$, & Ground & & & 27581.65 & .1 \\
\hline $\mathrm{C}^{12}{ }_{*} \mathrm{H}_{2} \mathrm{C}^{12} \mathrm{H}_{2} \mathrm{C}^{12} \mathrm{H}_{2} \mathrm{O}^{18}{ }_{*}$ & 4-1093 & $6,5,2 \leftarrow 6,3,3$ & Excited & & & 27582.45 & .1 \\
\hline $\mathrm{Tl}^{205} \mathrm{I}^{127}$ & $1-$ & $17 \leftarrow 16$ & Excited & & & 27588.22 & 0.20 \\
\hline $\mathrm{C}^{12} \mathrm{H}_{3} \mathrm{C}^{12} \mathrm{H}_{2} \mathrm{C}^{12} \mathrm{~N}^{14}$ & 3- 731 & $3,1,2 \leftarrow 2,1,1$ & Excited & & & 27592.2 & .2 \\
\hline $\mathrm{C}^{12} \mathrm{H}_{3} \mathrm{C}^{12} \mathrm{H}_{2} \mathrm{I}^{127}$ & 3- 571 & $5,1,4 \leftarrow 5,0,5$ & Ground & $9 / 2$ & $9 / 2$ & 27593.5 & \\
\hline $\mathrm{C}^{12} \mathrm{H}_{3} \mathrm{C}^{12} \mathrm{H}_{2} \mathrm{I}^{127}$ & 3- 571 & $5,1,4 \leftarrow 5,0,5$ & Ground & $15 / 2$ & $15 / 2$ & 27595. & \\
\hline $\mathrm{C}^{12} \mathrm{H}_{3} \mathrm{C}^{12} \mathrm{H}_{2} \mathrm{I}^{127}$ & 3. 571 & $5,1,4 \leftarrow 5,0,5$ & Ground & $7 / 2$ & $7 / 2$ & 27595. & \\
\hline $\mathrm{C}^{12} \mathrm{H}_{3} \mathrm{C}^{12} \mathrm{H}_{2} \mathrm{I}^{127}$ & 3- 571 & $5,1,4 \leftarrow 5,0,5$ & Ground & $7 / 2$ & $7 / 2$ & 27596.0 & 1. \\
\hline $\mathrm{t}-\mathrm{C}^{12} \mathrm{H}_{3} \mathrm{C}^{12} \mathrm{H}_{2} \mathrm{C}^{12} \mathrm{H}_{2} \mathrm{Cl}^{37}$ & 3- 772 & $6,1,5 \leftarrow 5,1,4$ & Ground & & & 27596.50 & .2 \\
\hline $\mathrm{C}^{12} \mathrm{H}_{3} \mathrm{C}^{12} \mathrm{H}_{2} \mathrm{I}^{127}$ & 3- 571 & $5,1,4 \leftarrow 5,0,5$ & Ground & $15 / 2$ & $15 / 2$ & 27597.48 & \\
\hline $\mathrm{C}^{12} \mathrm{H}_{3} \mathrm{C}^{12} \mathrm{H}_{2} \mathrm{I}^{127}$ & 3- 571 & $5,1,4 \leftarrow 5,0,5$ & Ground & $15 / 2$ & $15 / 2$ & 27597.48 & .05 \\
\hline $\mathrm{C}^{12} \mathrm{D}_{3} \mathrm{C}^{12} \mathrm{~F}_{3}^{19}$ & 3- 414 & $2, \leftarrow 1$, & Ground & & & 27597.5 & .2 \\
\hline $\mathrm{C}^{12}{ }_{*} \mathrm{H}_{2} \mathrm{C}^{12} \mathrm{H}: \mathrm{C}^{12}{ }_{*} \mathrm{H}$ & 4-1031 & $7,4,3 \leftarrow 7,4,4$ & Ground & & & 27599.8 & \\
\hline $\mathrm{C}^{12} \mathrm{H}_{3} \mathrm{Sn}^{118} \mathrm{H}_{3}$ & 3- 341 & $2, \leftarrow 1$, & Ground & & & 27600.80 & .10 \\
\hline $\mathrm{C}^{12}{ }_{*} \mathrm{HN}^{14} \mathrm{C}^{12} \mathrm{HCC}^{12} \mathrm{H} \mathrm{C}^{12} \mathrm{HN}^{14}{ }^{14}$ & 4-114.1 & $11,8,4 \leftarrow 11,7,5$ & Ground & & & 27603. & \\
\hline $\mathrm{C}^{12} \mathrm{H}_{2} \mathrm{~F}_{2}^{19}$ & 4- 351 & $23,7,16 \leftarrow 24,6,19$ & Ground & & & 27603.66 & .10 \\
\hline $\mathrm{C}^{12} \mathrm{H}_{2}: \mathrm{C}^{13} \mathrm{HC}^{12} \mathrm{~N}^{14}$ & 4-1023 & $3,1,3 \leftarrow 2,1,2$ & Ground & & & 27605.5 & .15 \\
\hline $\mathrm{C}^{12} \mathrm{H}_{2}: \mathrm{C}^{12} \mathrm{HC}^{12} \mathrm{~N}^{15}$ & 4-1025 & $3,0,3 \leftarrow 2,0,2$ & Ground & & & 27607.3 & .15 \\
\hline $\mathrm{O}^{16} \mathrm{O}^{16} \mathrm{O}^{18}$ & 4-1842 & $11,1,10 \leftarrow 10,2,9$ & Ground & & & 27608. & \\
\hline $\mathrm{Re}^{11} \mathrm{O}_{2}^{16} \mathrm{O}^{14} \mathrm{~F}^{19}$ & 4-1593 & $4,1,4 \leftarrow 3,1,3$ & Ground & & & 27608.25 & .20 \\
\hline $\mathrm{C}^{12} \mathrm{H}_{2} \mathrm{Cl}^{35} \mathrm{Si}^{28} \mathrm{D}_{3}$ & 3- 237 & $5,1,5 \leftarrow 4,1,4$ & Ground & & & 27609.21 & .2 \\
\hline $\mathrm{C}^{12}{ }_{*} \mathrm{D}_{2} \mathrm{C}^{12} \mathrm{H}_{2} \mathrm{C}^{12} \mathrm{D}_{2} \mathrm{O}^{16} *$ & 4-1092 & $5,3,3 \leftarrow 5,2,4$ & Excited & & & 27613 & 2. \\
\hline $\mathrm{g}-\mathrm{C}^{12} \mathrm{H}_{2} \mathrm{DC}^{12} \mathrm{H}_{2} \mathrm{~F}^{19}$ & 3- 553 & $3,1,2 \leftarrow 3,0,3$ & Ground & & & 27615.1 & .1 \\
\hline $\mathrm{C}^{12} \mathrm{H}_{3} \mathrm{C}^{12} \mathrm{HF}_{2}^{19}$ & 3- 461 & $7,4,3 \leftarrow 7,4,4$ & Ground & & & 27618.3 & .1 \\
\hline $\mathrm{C}^{12} \mathrm{H}_{3} \mathrm{Sn}^{117} \mathrm{H}_{3}$ & 3- 343 & $2, \leftarrow 1$, & Ground & & & 27621.20 & .10 \\
\hline $\mathrm{C}^{12} \mathrm{H}_{2}: \mathrm{C}^{12} \mathrm{HC}^{12} \mathrm{~N}^{15}$ & 4-1025 & $3,2,2 \leftarrow 2,2,1$ & Ground & & & 27622.4 & .15 \\
\hline
\end{tabular}




\begin{tabular}{|c|c|c|c|c|c|c|c|}
\hline Isotopic Species & $\begin{array}{l}\text { Vol.-Id. } \\
\text { Nos. }\end{array}$ & $\begin{array}{c}\text { Rotational } \\
\text { Quantum Nos. }\end{array}$ & Vib. State & \begin{tabular}{r}
\multicolumn{2}{r}{ Hyperfir } \\
$\mathrm{F}_{1}^{\prime} \quad \mathrm{F}^{\prime} \quad \mathrm{F}^{\prime}$
\end{tabular} & $F$ & $\begin{array}{l}\text { Frequency } \\
\text { Ml1: }\end{array}$ & $\begin{aligned} & \text { Acc. } \\
\pm & \mathrm{MH} \%\end{aligned}$ \\
\hline $\mathrm{Tl}^{203} \mathbf{I}^{127}$ & 1 - & $17 \leftarrow 16$ & Excited & & & 27624.02 & 0.20 \\
\hline $\mathrm{C}^{13} \mathrm{H}_{3} \mathrm{C}^{12} \mathrm{H}_{2} \mathrm{~F}^{19}$ & 3- 556 & $2,2,1 \leftarrow 3,1,2$ & Ground & & & 27624.6 & .1 \\
\hline $\mathrm{C}^{12}{ }_{*} \mathrm{HN}^{14} \mathrm{C}^{12} \mathrm{HC}^{12} \mathrm{H}: \mathrm{C}^{12} \mathrm{HN}^{14}{ }_{*}$ & $4-1141$ & $10,6,4 \leftarrow 10,5,5$ & Ground & & & 27625.2 & \\
\hline $\mathrm{C}^{12} \mathrm{H}_{3} \mathrm{~B}^{\prime \prime} \mathrm{F}_{2}^{19}$ & 3- 91 & $2, \quad, \leftarrow 1$, & Ground & & & 27625.8 & .1 \\
\hline $\mathrm{C}^{12} \mathrm{H}_{3} \mathrm{C}^{12} \mathrm{H}_{2} \mathrm{C}^{12} \mathrm{~N}^{14}$ & 3. 731 & Not Reported & Excited & & & 27626.49 & .1 \\
\hline$\left(\mathrm{C}^{12} \mathrm{H}_{3}\right)_{2} \mathrm{O}^{16}$ & 3. 591 & $3,1,2 \leftarrow 2,2,1$ & Ground & & & 27629.5 & .5 \\
\hline$\left(\mathrm{C}^{12} \mathrm{D}_{3}\right)\left(\mathrm{C}^{12} \mathrm{H}_{3}\right) \mathrm{O}^{16}$ & 3. 593 & $3,0,3 \leftarrow 2,1,2$ & Ground & & & 27630.0 & .1 \\
\hline $\mathrm{C}^{12}{ }_{*} \mathrm{DHC}^{12} \mathrm{H}: \mathrm{C}^{12}{ }_{*} \mathrm{H}$ & 4-1034 & $6,3,3 \leftarrow 6,3,4$ & Ground & & & 27632.7 & \\
\hline $\mathrm{C}^{12} \mathrm{H}_{2}: \mathrm{C}^{12} \mathrm{HC}^{12} \mathrm{~N}^{15}$ & $4-1025$ & $3,2,1 \leftarrow 2,2,0$ & Ground & & & 27634.4 & .15 \\
\hline $\mathrm{a}-\mathrm{C}^{12} \mathrm{HD}_{2} \mathrm{C}^{12} \mathrm{HO}^{16}$ & 3. 482 & $7,1,6 \leftarrow 7,1,7$ & Ground & & & 27634.90 & .5 \\
\hline $\mathrm{C}^{12} \mathrm{D}_{3} \mathrm{C}^{12} \mathrm{~F}_{3}^{19}$ & 3- 414 & $3, \leftarrow 2$ & Ground & & & 27635.9 & .2 \\
\hline $\mathrm{C}^{12} \mathrm{H}_{3} \mathrm{C}^{12}: \mathrm{C}^{12} \mathrm{C}^{12} \mathrm{H}_{2} \mathrm{Cl}^{37}$ & 3- 902 & $10,1,10 \leftarrow 9,1,9$ & Ground & & & 27637.7 & .3 \\
\hline $\mathrm{C}^{12} \mathrm{H}_{3} \mathrm{C}^{12} \mathrm{H}_{2} \mathrm{I}^{127}$ & 3- 571 & $5,1,4 \leftarrow 5,0,5$ & Ground & $13 / 2$ & $13 / 2$ & 27638. & \\
\hline $\mathrm{C}^{12} \mathrm{H}_{3} \mathrm{C}^{12} \mathrm{H}_{2} \mathrm{I}^{127}$ & 3. 571 & $5,1,4 \leftarrow 5,0,5$ & Ground & $13 / 2$ & $13 / 2$ & 27639.18 & \\
\hline $\mathrm{C}^{12} \mathrm{H}_{3} \mathrm{C}^{12} \mathrm{H}_{2} \mathrm{I}^{127}$ & 3- 571 & $5,1,4 \leftarrow 5,0,5$ & Ground & $13 / 2$ & $13 / 2$ & 27639.18 & .05 \\
\hline $\mathrm{H}_{2} \mathrm{O}_{2}^{16}$ & 3. 41 & Not Reported & & & & 27639.6 & .2 \\
\hline $\mathrm{C}^{12} \mathrm{H}_{3} \mathrm{Sn}^{116} \mathrm{H}_{3}$ & 3- 342 & $2, \leftarrow 1$, & Ground & & & 27641.99 & .10 \\
\hline $\mathrm{D}_{2} \mathrm{O}_{2}^{16}$ & 3- 42 & Not Reported & & & & 27645 & 3. \\
\hline $\mathrm{C}^{12} \mathrm{H}_{2}: \mathrm{C}^{12} \mathrm{HC}^{13} \mathrm{~N}^{14}$ & 4-1024 & $3,1,3 \leftarrow 2,1,2$ & Ground & & & 27646.6 & .15 \\
\hline $\mathrm{C}^{12}{ }_{*} \mathrm{H}_{2} \mathrm{~S}^{32} \mathrm{C}^{12}{ }_{*} \mathrm{H}_{2}$ & 4- 851 & $4,1,5 \leftarrow 4,1,4$ & Ground & & & 27648.4 & .2 \\
\hline $\mathrm{C}^{12}{ }_{*} \mathrm{H}_{2} \mathrm{C}^{12} \mathrm{D}: \mathrm{C}^{12}{ }_{*} \mathrm{H}$ & 4-1032 & $10,6,4 \leftarrow 10,6,5$ & Ground & & & 27649.2 & \\
\hline $\mathrm{C}^{12}{ }_{*} \mathrm{HN}^{14} \mathrm{C}^{12} \mathrm{HC}^{12} \mathrm{H}: \mathrm{C}^{12} \mathrm{HN}^{14}{ }_{*}$ & 4-1141 & $10,7,4 \leftarrow 10,6,5$ & Ground & & & 27651. & \\
\hline $\mathrm{C}^{12} \mathrm{D}_{3} \mathrm{Si}^{28} \mathrm{DF}_{2}^{19}$ & 3- 199 & $3,2,1 \leftarrow 2,2,0$ & Ground & & & 27653.13 & .1 \\
\hline a- $\mathrm{C}^{12} \mathrm{HD}_{2} \mathrm{C}^{12} \mathrm{HO}^{16}$ & 3. 482 & $7,1,6 \leftarrow 7,1,7$ & Ground & & & 27655.01 & .2 \\
\hline $\mathrm{T}^{205} \mathrm{I}^{127}$ & 1 - & $17 \leftarrow 16$ & Ground & & & 27655.37 & 0.10 \\
\hline $\mathrm{HC}^{13}: \mathrm{C}^{12} \mathrm{C}^{12} \mathrm{DO}^{16}$ & 4. 922 & Not Reported & & & & 27656. & 5. \\
\hline $\mathrm{C}^{12}{ }_{*} \mathrm{H}_{2} \mathrm{C}^{12} \mathrm{H}_{2} \mathrm{C}^{12} \mathrm{H}_{2} \mathrm{O}^{18}{ }_{*}$ & $4 \cdot 1093$ & $6,5,2 \leftarrow 6,3,3$ & Ground & & & 27656.0 & .1 \\
\hline $\mathrm{C}^{12} \mathrm{H}_{3} \mathrm{C}^{12} \mathrm{H}_{2} \mathbf{I}^{127}$ & 3- 571 & $5,1,4 \leftarrow 5,0,5$ & Ground & $11 / 2$ & $11 / 2$ & 27663. & \\
\hline $\mathrm{C}^{12}{ }_{*} \mathrm{H}: \mathrm{C}^{12} \mathrm{HO}^{18} \mathrm{C}^{12} \mathrm{H}: \mathrm{C}^{12}{ }_{*} \mathrm{H}$ & $4-1152$ & $10,7,3 \leftarrow 10,7,4$ & Ground & & & 27663.6 & .1 \\
\hline $\mathrm{C}^{12} \mathrm{H}_{3} \mathrm{C}^{12} \mathrm{H}_{2} \mathbf{I}^{127}$ & 3. 571 & $5,1,4 \leftarrow 5,0,5$ & Ground & $11 / 2$ & $11 / 2$ & 27664.54 & .05 \\
\hline $\mathrm{C}^{12} \mathrm{H}_{3} \mathrm{C}^{12} \mathrm{H}_{2} \mathbf{I}^{127}$ & 3. 571 & $5,1,4 \leftarrow 5,0,5$ & Ground & $11 / 2$ & $11 / 2$ & 27664.54 & \\
\hline $\mathrm{HC}^{13}: \mathrm{C}^{12} \mathrm{C}^{12} \mathrm{DO}^{16}$ & 4- 922 & Not Reported & & & & 27669. & 5. \\
\hline $\mathrm{H}_{2} \mathrm{~N}^{14} \mathrm{C}^{12} \mathrm{~N}^{14}$ & 4- 361 & $14,1,13 \leftarrow 14,1,14$ & Ground & & & 27676.0 & .5 \\
\hline $\mathrm{H}_{2} \mathrm{~N}^{14} \mathrm{C}^{12} \mathrm{~N}^{14}$ & 4- 361 & $14,1,13 \leftarrow 14,1,14$ & Ground & & & 27678.6 & .5 \\
\hline $\mathrm{C}^{12}{ }_{*} \mathrm{HN}^{14} \mathrm{C}^{12} \mathrm{HC}^{12} \mathrm{H} \mathrm{C}^{12} \mathrm{HN}^{14}{ }_{*}$ & $4-1141$ & $9,5,4 \leftarrow 9,4,5$ & Ground & & & 27680. & \\
\hline 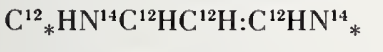 & $4-1141$ & $2,2,0 \leftarrow 1,1,1$ & Ground & & & 27680. & \\
\hline $\mathrm{H}_{2} \mathrm{C}^{12}: \mathrm{C}^{12} \mathrm{~F}_{2}^{19}$ & 4- 681 & Not Reported & & & & 27680.4 & .3 \\
\hline $\mathrm{D}_{2} \mathrm{O}_{2}^{16}$ & 3- 42 & Not Reported & & & & 27681 & 3. \\
\hline $\mathrm{C}^{12} \mathrm{H}_{3} \mathrm{C}^{13} \mathrm{H}_{2} \mathrm{~F}^{19}$ & 3- 555 & $3,0,3 \leftarrow 2,1,2$ & Ground & & & 27683.8 & .1 \\
\hline $\mathrm{C}^{12} \mathrm{H}_{3} \mathrm{Si}^{28} \mathrm{HF}_{2}^{19}-\mathrm{A}$ & 3- 191 & $11,6,6 \leftarrow 11,6,5$ & Ground & & & 27688.80 & \\
\hline $\mathrm{C}^{12} \mathrm{H}_{3} \mathrm{Si}^{28} \mathrm{HF}_{2}^{19}-\mathrm{A}$ & 3. 191 & Not Reported & Ground & & & 27688.9 & \\
\hline $\mathrm{C}^{12}{ }_{*} \mathrm{HN}^{14} \mathrm{C}^{12} \mathrm{HC}^{12} \mathrm{H}: \mathrm{C}^{12} \mathrm{HN}^{14}{ }_{*}$ & $4-1141$ & $9,6,4 \leftarrow 9,5,5$ & Ground & & & 27689.7 & \\
\hline $\mathrm{C}^{12} \mathrm{H}_{3} \mathrm{Si}^{28} \mathrm{HF}_{2}^{19} \cdot \mathrm{E}$ & 3. 192 & $11,6,6 \leftarrow 11,6,5$ & Ground & & & 27690.15 & \\
\hline $\mathrm{Tl}^{203 \mathrm{I}^{127}}$ & 1. & $17 \leftarrow 16$ & Excited & & & 27692.01 & 0.40 \\
\hline $\mathrm{C}^{13} \mathrm{H}_{2}: \mathrm{C}^{12} \mathrm{HC}^{12} \mathrm{~N}^{14}$ & $4-1022$ & $3,0,3 \leftarrow 2,0,2$ & Ground & & & 27693.9 & .15 \\
\hline
\end{tabular}




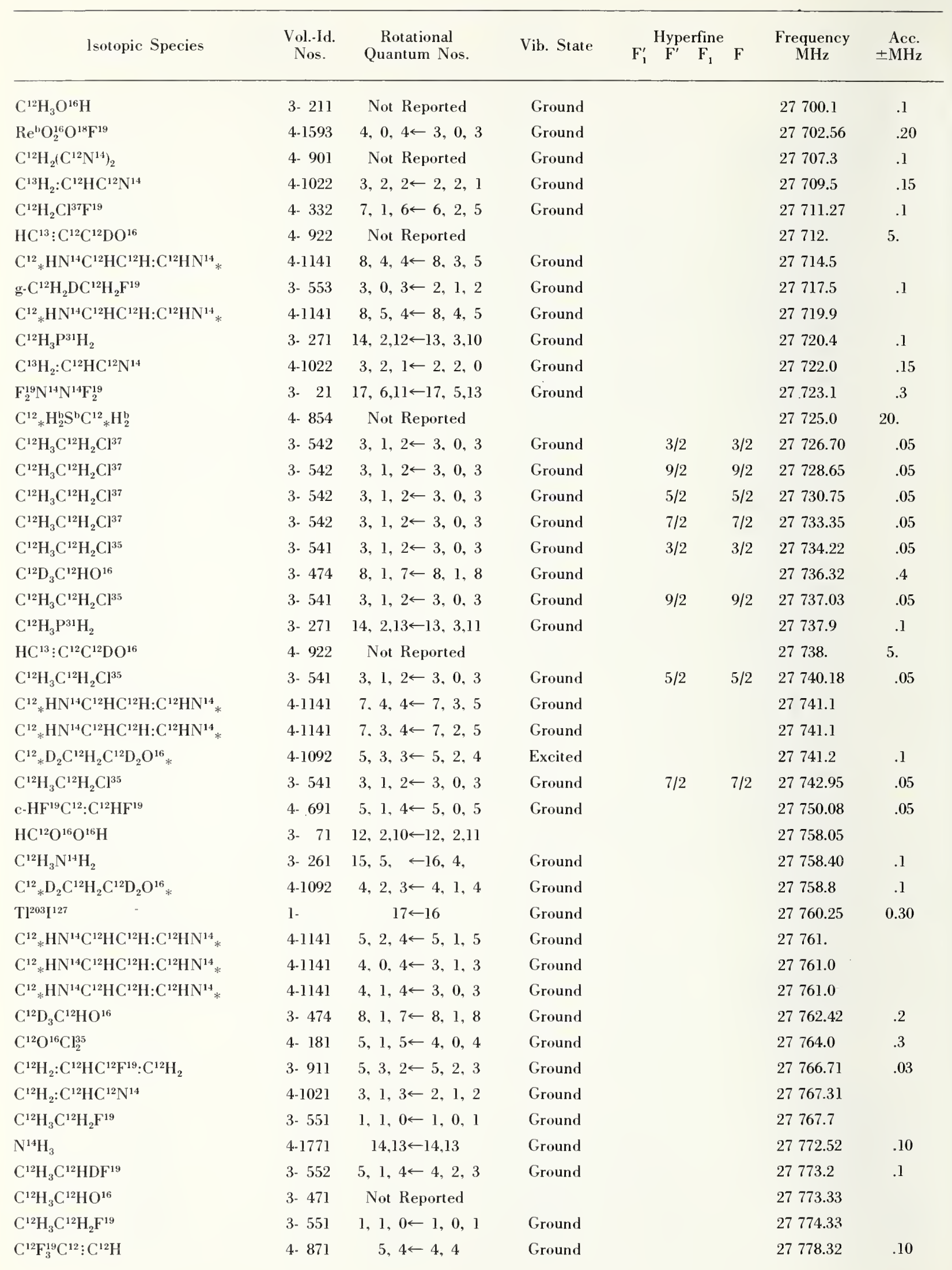




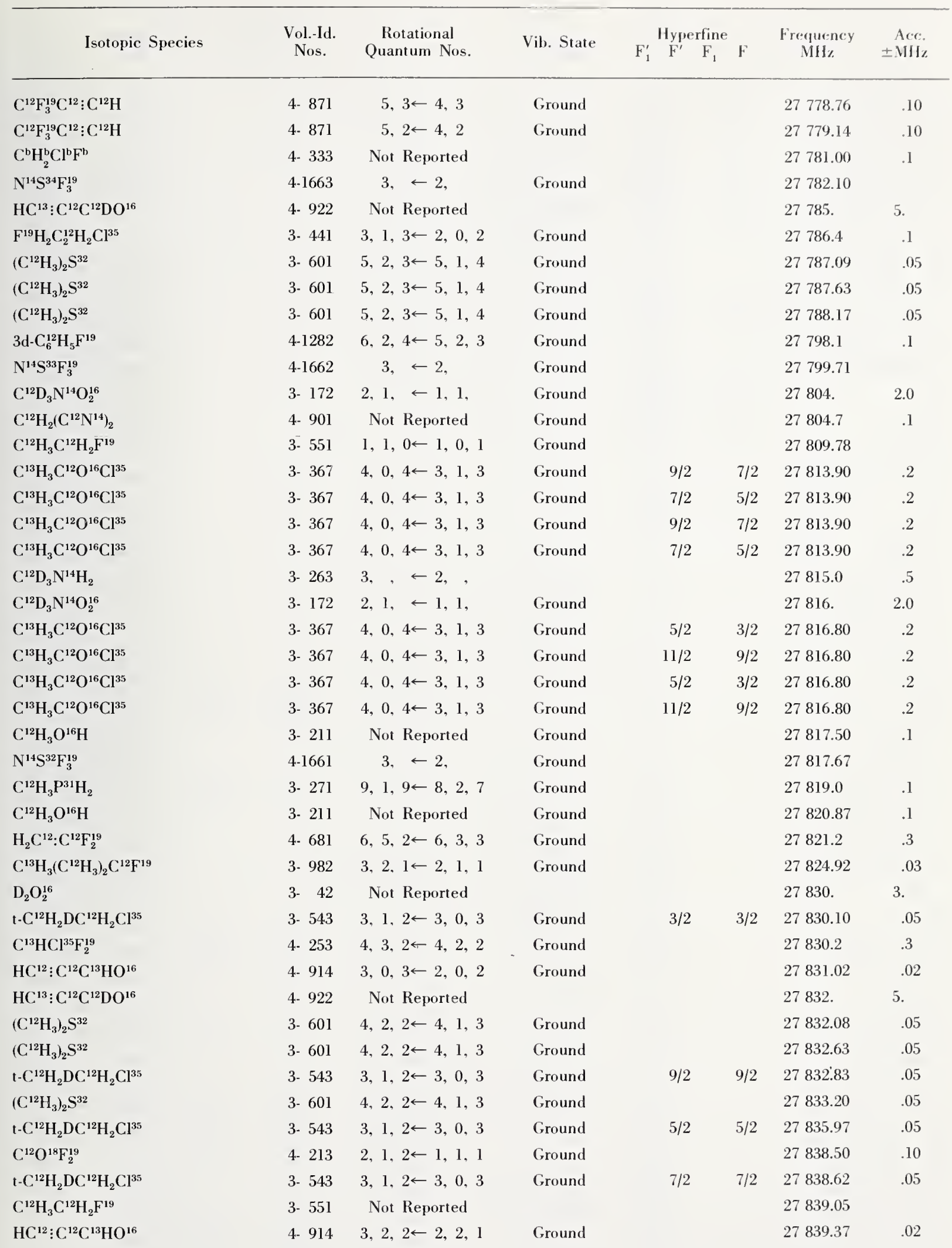




\begin{tabular}{|c|c|c|c|c|c|c|c|}
\hline \multirow{2}{*}{ Isotopic Species } & \multirow{2}{*}{$\begin{array}{l}\text { Vol.-Id. } \\
\text { Nos. }\end{array}$} & \multirow{2}{*}{$\begin{array}{c}\text { Rotational } \\
\text { Quantum Nos. }\end{array}$} & \multirow{2}{*}{ Vib. State } & \multicolumn{2}{|c|}{ Hyperfine } & \multirow{2}{*}{$\begin{array}{l}\text { Frequency } \\
\mathrm{MHz}\end{array}$} & \multirow{2}{*}{$\begin{aligned} & \text { Acc. } \\
\pm & \mathrm{MHz}\end{aligned}$} \\
\hline & & & & $\mathrm{F}_{1}^{\prime} \quad \mathrm{F}^{\prime}$ & $F_{1} \quad F$ & & \\
\hline $\mathrm{HC}^{12}: \mathrm{C}^{13} \mathrm{C}^{12} \mathrm{HO}^{16}$ & 4- 913 & $3,0,3 \leftarrow 2,0,2$ & Ground & & & 27839.50 & .02 \\
\hline $\mathrm{C}^{12} \mathrm{H}_{2}\left(\mathrm{C}^{12} \mathrm{~N}^{14}\right)_{2}$ & 4- 901 & Not Reported & Ground & & & 27842.7 & .1 \\
\hline $\mathrm{HC}^{12}: \mathrm{C}^{12} \mathrm{C}^{13} \mathrm{HO}^{16}$ & 4. 914 & $3,2,1 \leftarrow 2,2,0$ & Ground & & & 27844.65 & .02 \\
\hline $\mathrm{C}^{13} \mathrm{H}_{3}\left(\mathrm{C}^{12} \mathrm{H}_{3}\right)_{2} \mathrm{C}^{12} \mathrm{~F}^{19}$ & 3. 982 & $3,1,2 \leftarrow 2,0,2$ & Ground & & & 27844.69 & .03 \\
\hline $\mathrm{HC}^{12}: \mathrm{C}^{12} \mathrm{C}^{12} \mathrm{H}: \mathrm{C}^{12} \mathrm{H}_{2}$ & 4-1131 & $3,1,2 \leftarrow 2,1,1$ & Ground & & & 27845.35 & .05 \\
\hline $\mathrm{C}^{12}{ }_{*} \mathrm{D}_{2} \mathrm{C}^{12} \mathrm{H}_{2} \mathrm{C}^{12} \mathrm{D}_{2} \mathrm{O}^{16}{ }_{*}$ & 4-1092 & $5,3,3 \leftarrow 5,2,4$ & Excited & & & 27847.3 & .1 \\
\hline $\mathrm{HC}^{12}: \mathrm{C}^{13} \mathrm{C}^{12} \mathrm{HO}^{16}$ & 4- 913 & $3,2,2 \leftarrow 2,2,1$ & Ground & & & 27847.98 & .02 \\
\hline $\mathrm{C}^{12} \mathrm{D}_{2} \mathrm{Cl}_{2}^{35}$ & 4- 346 & $9,1,8 \leftarrow 9,0,9$ & Ground & & & 27850 & 5. \\
\hline $\mathrm{S}^{32}{ }_{*} \mathrm{HC}^{12}: \mathrm{C}^{12} \mathrm{DC}^{12} \mathrm{H}: \mathrm{C}^{12}{ }_{*} \mathrm{H}$ & $4-1163$ & $10,4,7 \leftarrow 10,4,6$ & Ground & & & 27851.2 & .1 \\
\hline $\mathrm{HC}^{12}: \mathrm{C}^{13} \mathrm{C}^{12} \mathrm{HO}^{16}$ & 4- 913 & $3,2,1 \leftarrow 2,2,0$ & Ground & & & 27852.84 & .02 \\
\hline $\operatorname{Re}^{b} \mathrm{O}_{2}^{16} \mathrm{O}^{18} \mathrm{~F}^{19}$ & 4-1593 & $4,2,3 \leftarrow 3,2,2$ & Ground & & & 27858.61 & .20 \\
\hline $\mathrm{O}_{3}^{16}$ & 4-1841 & $41,5,37 \leftarrow 40,6,34$ & Ground & & & 27862 & \\
\hline $\mathrm{O}^{16} \mathrm{O}^{16} \mathrm{O}^{18}$ & 4-1842 & $18,2,16 \leftarrow 19,1,19$ & Ground & & & 27862. & \\
\hline $\mathrm{D}_{2} \mathrm{O}_{2}^{16}$ & 3- 42 & Not Reported & & & & 27863. & 3. \\
\hline $\mathrm{a}-\mathrm{HC}^{12} \mathrm{O}^{16} \mathrm{O}^{16} \mathrm{C}^{12} \mathrm{H}_{2} \mathrm{D}$ & 3- 506 & $5,1,4 \leftarrow 5,0,5$ & Ground & & & 27864.67 & .2 \\
\hline $\mathrm{S}_{2}^{32} \mathrm{O}^{16}$ & 4-1821 & $3,1,3 \leftarrow 2,1,2$ & Ground & & & 27867.0 & \\
\hline $\mathrm{a}-\mathrm{HC}^{12} \mathrm{O}^{16} \mathrm{O}^{16} \mathrm{C}^{12} \mathrm{H}_{2} \mathrm{D}$ & 3- 506 & $5,1,4 \leftarrow 5,0,5$ & Ground & & & 27868.96 & .2 \\
\hline $\mathrm{C}^{\mathrm{b}} \mathrm{H}_{2}^{\mathrm{b}} \mathrm{Cl}^{\mathrm{b}} \mathrm{F}^{\mathrm{b}}$ & 4- 333 & Not Reported & & & & 27869.96 & .1 \\
\hline $\mathrm{C}^{12} \mathrm{H}_{3} \mathrm{C}^{12} \mathrm{H}_{2} \mathrm{~F}^{19}$ & 3- 551 & $1,1,0 \leftarrow 1,0,1$ & Ground & & & 27870.71 & \\
\hline $\mathrm{C}^{12} \mathrm{H}_{3} \mathrm{C}^{13} \mathrm{H}_{2} \mathrm{~F}^{19}$ & 3- 555 & $5,3,2 \leftarrow 6,2,5$ & Ground & & & 27874.3 & .1 \\
\hline $\mathrm{HC}^{13}: \mathrm{C}^{12} \mathrm{C}^{12} \mathrm{DO}^{16}$ & 4- 922 & Not Reported & & & & 27875 & 5. \\
\hline $\mathrm{C}^{13} \mathrm{H}_{3} \mathrm{O}^{16} \mathrm{H}$ & 3. 213 & $10,2, \leftarrow 10,1$ & Ground & & & 27880.04 & .1 \\
\hline $\mathrm{H}_{3} \mathrm{C}^{12} \mathrm{C}^{12}: \mathrm{C}^{12} \mathrm{Br}^{81}$ & 4. 942 & $9,5 \leftarrow 8,5$ & Ground & $21 / 2$ & $19 / 2$ & 27890.79 & \\
\hline $\mathrm{H}_{3} \mathrm{C}^{12} \mathrm{C}^{12}: \mathrm{C}^{12} \mathrm{Br}^{81}$ & 4. 942 & $9,4 \leftarrow 8,4$ & Ground & $15 / 2$ & $13 / 2$ & 27894.38 & \\
\hline $\mathrm{C}^{12} \mathrm{D}_{3} \mathrm{~N}^{14} \mathrm{O}_{2}^{16}$ & 3. 172 & $2,0, \leftarrow 1,0$, & Ground & & & 27894.8 & .2 \\
\hline $\mathrm{a} \cdot \mathrm{C}^{12} \mathrm{H}_{2} \mathrm{DC}^{12} \mathrm{O}^{16} \mathrm{Cl}^{35}$ & 3- 366 & $4,0,4 \leftarrow 3,1,3$ & Ground & & & 27896.28 & .1 \\
\hline $\mathrm{H}_{3} \mathrm{C}^{12} \mathrm{C}^{12}: \mathrm{C}^{12} \mathrm{Br}^{81}$ & 4- 942 & $9,4 \leftarrow 8,4$ & Ground & $21 / 2$ & $19 / 2$ & 27896.59 & \\
\hline $\mathrm{HC}^{13}: \mathrm{C}^{12} \mathrm{C}^{12} \mathrm{DO}^{16}$ & 4. 922 & Not Reported & & & & 27897. & 5. \\
\hline $\mathrm{a}-\mathrm{C}^{12} \mathrm{H}_{2} \mathrm{DC}^{12} \mathrm{O}^{16} \mathrm{Cl}^{35}$ & 3. 366 & $4,0,4 \leftarrow 3,1,3$ & Ground & & & 27897.37 & .2 \\
\hline $\mathrm{a}-\mathrm{C}^{12} \mathrm{H}_{2} \mathrm{DC}^{12} \mathrm{O}^{16} \mathrm{Cl}^{35}$ & 3- 366 & $4,0,4 \leftarrow 3,1,3$ & Ground & & & 27898.46 & .1 \\
\hline $\mathrm{D}_{2} \mathrm{O}_{2}^{16}$ & 3- $\quad 42$ & Not Reported & & & & 27899. & 3. \\
\hline $\mathrm{H}_{3} \mathrm{C}^{12} \mathrm{C}^{12}: \mathrm{C}^{12} \mathrm{Br}^{81}$ & 4- 942 & $9,3 \leftarrow 8,3$ & Ground & $15 / 2$ & $13 / 2$ & 27900.86 & \\
\hline $\mathrm{H}_{3} \mathrm{C}^{12} \mathrm{C}^{12}: \mathrm{C}^{12} \mathrm{Br}^{81}$ & 4- 942 & $9,3 \leftarrow 8,3$ & Ground & $21 / 2$ & $19 / 2$ & 27900.86 & \\
\hline $\mathrm{H}_{3} \mathrm{C}^{12} \mathrm{C}^{12}: \mathrm{C}^{12} \mathrm{Br}^{81}$ & 4- 942 & $9,2 \leftarrow 8,2$ & Ground & $21 / 2$ & $19 / 2$ & 27904.18 & \\
\hline $\mathrm{C}^{12} \mathrm{H}_{3} \mathrm{~B}^{\mathrm{b}} \mathrm{F}_{2}^{19}$ & 3- 91 & $2, \quad \leftarrow 1$, & Ground & & & 27904.3 & .1 \\
\hline $\mathrm{H}_{3} \mathrm{C}^{12} \mathrm{C}^{12}: \mathrm{C}^{12} \mathrm{Br}^{81}$ & 4- 942 & $9,2 \leftarrow 8,2$ & Ground & $15 / 2$ & $13 / 2$ & 27905.53 & \\
\hline $\mathrm{C}^{12} \mathrm{HCl}^{35} \mathrm{~F}_{2}^{19}$ & 4. 251 & $4,3,2 \leftarrow 4,2,2$ & Ground & & & 27906.05 & .05 \\
\hline $\mathrm{H}_{3} \mathrm{C}^{12} \mathrm{C}^{12}: \mathrm{C}^{12} \mathrm{Br}^{81}$ & 4- 942 & $9,1 \leftarrow 8,1$ & Ground & $21 / 2$ & $19 / 2$ & 27906.09 & \\
\hline $\mathrm{H}_{3} \mathrm{C}^{12} \mathrm{C}^{12}: \mathrm{C}^{12} \mathrm{Br}^{81}$ & 4. 942 & $9,0 \leftarrow 8,0$ & Ground & $21 / 2$ & $19 / 2$ & 27906.60 & \\
\hline $\mathrm{H}_{3} \mathrm{C}^{12} \mathrm{C}^{12}: \mathrm{C}^{12} \mathrm{Br}^{81}$ & 4- 942 & $9,0 \leftarrow 8,0$ & Ground & $19 / 2$ & $17 / 2$ & 27906.60 , & \\
\hline $\mathrm{H}_{3} \mathrm{C}^{12} \mathrm{C}^{12}: \mathrm{C}^{12} \mathrm{Br}^{81}$ & 4- 942 & $9,1 \leftarrow 8,1$ & Ground & $19 / 2$ & $17 / 2$ & 27907.14 & \\
\hline $\mathrm{c}-\mathrm{HF}^{19} \mathrm{C}^{12}: \mathrm{C}^{12} \mathrm{HF}^{19}$ & 4- 691 & $5,1,4 \leftarrow 5,0,5$ & Excited & & & 27908.28 & .05 \\
\hline $\mathrm{H}_{3} \mathrm{C}^{12} \mathrm{C}^{12}: \mathrm{C}^{12} \mathrm{Br}^{81}$ & 4- 942 & $9,2 \leftarrow 8,2$ & Ground & $19 / 2$ & $17 / 2$ & 27908.37 & \\
\hline $\mathrm{H}_{3} \mathrm{C}^{12} \mathrm{C}^{12}: \mathrm{C}^{12} \mathrm{Br}^{81}$ & 4- 942 & $9,1 \leftarrow 8,1$ & Ground & $15 / 2$ & $13 / 2$ & 27908.37 & \\
\hline $\mathrm{H}_{3} \mathrm{C}^{12} \mathrm{C}^{12}: \mathrm{C}^{12} \mathrm{Br}^{81}$ & 4. 942 & $9,0 \leftarrow 8,0$ & Ground & $17 / 2$ & $15 / 2$ & 27909.17 & \\
\hline
\end{tabular}


Vib. State

Frequency Acc.

\begin{tabular}{|c|c|c|c|c|c|c|c|}
\hline $\mathrm{H}_{3} \mathrm{C}^{12} \mathrm{C}^{12}: \mathrm{C}^{12} \mathrm{Br}^{81}$ & 4. 942 & $9,2 \leftarrow 8,2$ & Ground & $15 / 2$ & $13 / 2$ & 27909.17 & \\
\hline $\mathrm{H}_{3} \mathrm{C}^{12} \mathrm{C}^{12}: \mathrm{C}^{12} \mathrm{Br}^{81}$ & 4. 942 & $9,1 \leftarrow 8,1$ & Ground & $17 / 2$ & $15 / 2$ & 27909.17 & \\
\hline $\mathrm{H}_{3} \mathrm{C}^{12} \mathrm{C}^{12}: \mathrm{C}^{12} \mathrm{Br}^{81}$ & 4. 942 & $9,2 \leftarrow 8,2$ & Ground & $17 / 2$ & $15 / 2$ & 27910.00 & \\
\hline $\mathrm{H}_{3} \mathrm{C}^{12} \mathrm{C}^{12}: \mathrm{C}^{12} \mathrm{Br}^{81}$ & 4- 942 & $9,3 \leftarrow 8,3$ & Ground & $19 / 2$ & $17 / 2$ & 27910.92 & \\
\hline $\mathrm{H}_{3} \mathrm{C}^{12} \mathrm{C}^{12}: \mathrm{C}^{12} \mathrm{Br}^{81}$ & 4. 942 & $9,3 \leftarrow 8,3$ & Ground & $17 / 2$ & $15 / 2$ & 27910.92 & \\
\hline $\mathrm{C}^{12} \mathrm{H}_{2} \mathrm{~N}^{14} \mathrm{O}^{16} \mathrm{D}$ & 3. 142 & $5,2,4 \leftarrow 6,1,5$ & Ground & 5 & 6 & 27911.82 & .10 \\
\hline $\mathrm{C}^{12} \mathrm{H}_{3} \mathrm{~S}^{32} \mathrm{H}$ & 3. 221 & Not Reported & Ground & & & 27911.9 & .1 \\
\hline $\mathrm{O}^{\mathrm{b}} \mathrm{O}^{\mathrm{b}} \mathrm{O}^{\mathrm{b}}$ & $4-1847$ & Not Reported & & & & 27912. & \\
\hline $\mathrm{H}_{3} \mathrm{C}^{12} \mathrm{C}^{12}: \mathrm{C}^{12} \mathrm{Br}^{81}$ & 4. 942 & $9,4 \leftarrow 8,4$ & Ground & $17 / 2$ & $15 / 2$ & 27912.39 & \\
\hline $\mathrm{C}^{12} \mathrm{H}_{2} \mathrm{~N}^{14} \mathrm{O}^{16} \mathrm{D}$ & 3. 142 & $5,2,4 \leftarrow 6,1,5$ & Ground & 6 & 5 & 27913.06 & .10 \\
\hline $\mathrm{C}^{12} \mathrm{H}_{2} \mathrm{~N}^{14} \mathrm{O}^{16} \mathrm{D}$ & 3. 142 & $5,2,4 \leftarrow 6,1,5$ & Ground & 6 & 7 & 27913.06 & .10 \\
\hline $\mathrm{H}_{3} \mathrm{C}^{12} \mathrm{C}^{12}: \mathrm{C}^{12} \mathrm{Br}^{81}$ & 4- 942 & $9,5 \leftarrow 8,5$ & Ground & $17 / 2$ & $15 / 2$ & 27914.35 & \\
\hline $\mathrm{H}_{3} \mathrm{C}^{12} \mathrm{C}^{12}: \mathrm{C}^{12} \mathrm{Br}^{81}$ & 4- 942 & $9,4 \leftarrow 8,4$ & Ground & $19 / 2$ & $17 / 2$ & 27914.35 & \\
\hline $\mathrm{H}_{3} \mathrm{C}^{12} \mathrm{C}^{12}: \mathrm{C}^{12} \mathrm{Br}^{81}$ & 4- 942 & $9,6 \leftarrow 8,6$ & Ground & $17 / 2$ & $15 / 2$ & 27916.40 & \\
\hline $\mathrm{C}^{12} \mathrm{D}_{3} \mathrm{~N}^{14} \mathrm{O}_{2}^{16}$ & 3. 172 & $2,0, \leftarrow 1,0$, & Ground & & & 27916.7 & .2 \\
\hline $\mathrm{H}_{3} \mathrm{C}^{12} \mathrm{C}^{12}: \mathrm{C}^{12} \mathrm{Br}^{81}$ & 4- 942 & $9,5 \leftarrow 8,5$ & Ground & $19 / 2$ & $17 / 2$ & 27918.60 & \\
\hline $\mathrm{H}_{3} \mathrm{C}^{12} \mathrm{C}^{12}: \mathrm{C}^{12} \mathrm{Br}^{81}$ & 4- 942 & $9,7 \leftarrow 8,7$ & Ground & $17 / 2$ & $15 / 2$ & 27918.60 & \\
\hline $\mathrm{HC}^{13}: \mathrm{C}^{12} \mathrm{C}^{12} \mathrm{DO}^{16}$ & 4. 922 & Not Reported & & & & 27933. & 5. \\
\hline $\mathrm{C}^{13} \mathrm{H}_{3} \mathrm{C}^{12} \mathrm{H}_{2} \mathrm{~F}^{19}$ & 3- 556 & $1,1,0 \leftarrow 1,0,1$ & Ground & & & 27935.2 & .1 \\
\hline $\mathrm{C}^{12} \mathrm{H}_{2} \mathrm{Cl}^{37} \mathrm{C}^{12}: \mathrm{C}^{12} \mathrm{H}$ & 4. 992 & $5,1,5 \leftarrow 4,1,4$ & Ground & & & 27936.00 & \\
\hline $\mathrm{C}^{12} \mathrm{DHCl}^{35} \mathrm{Cl}^{37}$ & 4- 345 & $7,1,6 \leftarrow 7,0,7$ & Ground & & & 27943. & 5. \\
\hline $\mathrm{C}^{12} \mathrm{D}_{3} \mathrm{~N}^{14} \mathrm{O}_{2}^{16}$ & 3- 172 & $2,1, \leftarrow 1,1$, & Ground & & & 27944. & 2.0 \\
\hline $\mathrm{C}^{13} \mathrm{H}_{3}\left(\mathrm{C}^{12} \mathrm{H}_{3}\right)_{2} \mathrm{C}^{12} \mathrm{~F}^{19}$ & 3. 982 & $3,2,2 \leftarrow 2,1,2$ & Ground & & & 27944.38 & .03 \\
\hline $\mathrm{O}^{\mathrm{b}} \mathrm{O}^{\mathrm{b}} \mathrm{O}^{\mathrm{b}}$ & $4-1847$ & Not Reported & & & & 27949. & \\
\hline $\mathrm{Cl}^{35} \mathrm{~F}^{19} \mathrm{C}^{12} \mathrm{O}^{16}$ & 4- 151 & $7,3,4 \leftarrow 7,2,5$ & Ground & & & 27960.91 & .05 \\
\hline $\mathrm{HC}^{12}: \mathrm{C}^{12} \mathrm{C}^{12} \mathrm{HO}^{16}$ & 4. 911 & $3,0,3 \leftarrow 2,0,2$ & Ground & & & 27972.13 & .02 \\
\hline $\mathrm{C}^{12} \mathrm{O}^{16} \mathrm{Cl}_{2}^{35}$ & 4. 181 & $9,4,5 \leftarrow 9,3,6$ & Ground & & & 27977.6 & .3 \\
\hline $\mathrm{C}^{12} \mathrm{D}_{3} \mathrm{~N}^{14} \mathrm{O}_{2}^{16}$ & 3- 172 & $2,1, \leftarrow 1,1$, & Ground & & & 27978. & 2.0 \\
\hline $\mathrm{C}^{12} \mathrm{D}_{2} \mathrm{HC}^{12}: \mathrm{C}^{12} \mathrm{C}^{12} \mathrm{~F}_{3}^{19}$ & 3. 897 & $11, \quad \leftarrow 10$, & Ground & & & 27980.8 & .1 \\
\hline $\mathrm{HC}^{12}: \mathrm{C}^{12} \mathrm{C}^{12} \mathrm{HO}^{16}$ & 4. 911 & $3,2,2 \leftarrow 2,2,1$ & Ground & & & 27980.86 & .02 \\
\hline $\mathrm{C}^{12} \mathrm{D}_{3} \mathrm{O}^{16} \mathrm{H}$ & 3. 214 & Not Reported & Ground & & & 27982.7 & .5 \\
\hline $\mathrm{HC}^{12} \mathrm{:C}^{12} \mathrm{C}^{12} \mathrm{HO}^{16}$ & 4- 911 & $3,2,1 \leftarrow 2,2,0$ & Ground & & & 27985.53 & .02 \\
\hline $\mathrm{C}^{12} \mathrm{D}_{3} \mathrm{~N}^{14} \mathrm{O}_{2}^{16}$ & 3- 172 & $2,0, \leftarrow 1,0$ & Ground & & & 27987.7 & .2 \\
\hline $\mathrm{C}^{12} \mathrm{H}_{3} \mathrm{C}^{12} \mathrm{HF}_{2}^{19}$ & 3- 461 & $6,3,3 \leftarrow 6,3,4$ & Ground & & & 27991.3 & .1 \\
\hline $\mathrm{C}^{12}{ }_{*} \mathrm{D}_{2} \mathrm{C}^{12} \mathrm{H}_{2} \mathrm{C}^{12} \mathrm{D}_{2} \mathrm{O}^{16}{ }_{*}$ & $4-1092$ & $6,5,2 \leftarrow 6,4,3$ & Excited & & & 27993. & 2. \\
\hline $\mathrm{C}^{12} \mathrm{HD}: \mathrm{C}^{12} \mathrm{DBr}^{\mathrm{b}}$ & 4. 749 & Not Reported & Ground & & & 27998.4 & .1 \\
\hline $\mathrm{C}^{12} \mathrm{HD}: \mathrm{C}^{12} \mathrm{DBr}^{\mathrm{b}}$ & 4. 749 & Not Reported & Ground & & & 28000.5 & .1 \\
\hline $\mathrm{H}_{2} \mathrm{~N}^{14} \mathrm{~N}^{14} \mathrm{H}_{2}$ & 3- 51 & Not Reported & Ground & & & 28002.87 & \\
\hline $\mathrm{a}-\mathrm{C}^{12} \mathrm{H}_{2} \mathrm{DSi}^{28} \mathrm{HF}_{2}^{19}$ & 3- 204 & $3,2,2 \leftarrow 2,2,1$ & Ground & & & 28004.28 & 2. \\
\hline $\mathrm{C}^{\mathrm{b}} \mathrm{H}_{2}^{\mathrm{b}} \mathrm{Cl}^{\mathrm{b}} \mathrm{F}^{\mathrm{b}}$ & 4- 333 & Not Reported & & & & 28006.22 & .1 \\
\hline $\mathrm{C}^{\mathrm{b}} \mathrm{H}_{2}^{\mathrm{b}} \mathrm{Cl}^{\mathrm{b}} \mathrm{F}^{\mathrm{b}}$ & 4. 333 & Not Reported & & & & 28007.90 & .1 \\
\hline $\mathrm{C}^{12} \mathrm{H}_{2}\left(\mathrm{C}^{12} \mathrm{~N}^{14}\right)\left(\mathrm{C}^{12} \mathrm{~N}^{15}\right)$ & 4. 904 & $10,1,9 \leftarrow 10,0,10$ & Ground & & & 28008.57 & \\
\hline $\mathrm{B}_{5}^{11} \mathrm{H}_{9}$ & 4. 51 & $2, \leftarrow 1$, & Ground & & & 28011.4 & .1 \\
\hline $\mathrm{S}^{32}{ }_{*} \mathrm{C}^{12} \mathrm{H}: \mathrm{C}^{13} \mathrm{HC}^{12} \mathrm{H}: \mathrm{C}^{12}{ }_{*} \mathrm{H}$ & $4-1168$ & $3,1,2 \leftarrow 2,1,1$ & Ground & & & 28018.5 & .05 \\
\hline $\mathrm{C}^{12} \mathrm{H}_{2} \mathrm{~F}^{19} \mathrm{C}^{12} \mathrm{~N}^{14}$ & 4- 701 & $3,1,2 \leftarrow 2,1,1$ & Ground & & & 28022.6 & .2 \\
\hline
\end{tabular}




\begin{tabular}{|c|c|c|c|c|c|c|c|c|}
\hline \multirow{2}{*}{ Isotopic Species } & \multirow{2}{*}{$\begin{array}{l}\text { Vol.-Id. } \\
\text { Nos. }\end{array}$} & \multirow{2}{*}{$\begin{array}{c}\text { Rotational } \\
\text { Quantum Nos. }\end{array}$} & \multirow{2}{*}{ Vib. State } & \multicolumn{3}{|c|}{ Hyperfine } & \multirow{2}{*}{$\begin{array}{c}\text { Frequency } \\
\mathrm{MHz}\end{array}$} & \multirow{2}{*}{$\begin{array}{r}\text { Acc. } \\
\pm \mathrm{MHz}\end{array}$} \\
\hline & & & & $\mathbf{F}_{1}^{\prime}$ & $F^{\prime} \quad F_{1}$ & $\mathrm{~F}$ & & \\
\hline $\mathrm{H}_{2} \mathrm{~N}^{14} \mathrm{~N}^{14} \mathrm{H}_{2}$ & 3- 51 & Not Reported & Ground & & & & 28025.6 & \\
\hline $\mathrm{C}^{12} \mathrm{H}_{2} \mathrm{Cl}^{35} \mathrm{Si}^{28} \mathrm{D}_{3}$ & 3. 237 & $5,0,5 \leftarrow 4,0,4$ & Ground & & & & 28028.14 & .2 \\
\hline $\mathrm{a}-\mathrm{C}^{12} \mathrm{H}_{2} \mathrm{DC}^{12} \mathrm{O}^{16} \mathrm{~F}^{19}$ & 3- 398 & $6,3,3 \leftarrow 6,3,4$ & Ground & & & & 28029.77 & .2 \\
\hline $\operatorname{Re}^{b} \mathrm{O}_{2}^{16} \mathrm{O}^{18} \mathrm{~F}^{19}$ & 4-1593 & $4,2,2 \leftarrow 3,2,1$ & Ground & & & & 28030.30 & .20 \\
\hline $\mathrm{C}^{12} \mathrm{H}_{2}: \mathrm{C}^{12} \mathrm{HC}^{12} \mathrm{~F}^{19}: \mathrm{C}^{12} \mathrm{H}_{2}$ & 3- 911 & $5,3,2 \leftarrow 5,2,3$ & Ground & & & & 28031.28 & .03 \\
\hline $\mathrm{C}^{12} \mathrm{D}_{3} \mathrm{O}^{16} \mathrm{H}$ & 3- 214 & Not Reported & Ground & & & & 28032.7 & .5 \\
\hline $\mathrm{a}-\mathrm{C}^{12} \mathrm{H}_{2} \mathrm{DC}^{12} \mathrm{O}^{16} \mathrm{~F}^{19}$ & 3. 398 & $6,3,3 \leftarrow 6,3,4$ & Ground & & & & 28035.49 & .2 \\
\hline $\mathrm{C}^{12} \mathrm{HD}: \mathrm{C}^{12} \mathrm{DBr}^{\mathrm{b}}$ & 4- 749 & Not Reported & Ground & & & & 28037.5 & .2 \\
\hline $\mathrm{O}^{16}{ }_{*} \mathrm{C}^{12} \mathrm{H}_{2} \mathrm{C}^{12} \mathrm{H}_{2} \mathrm{C}^{12}{ }_{*} \mathrm{O}^{16}$ & 4-1071 & $3,2,1 \leftarrow 2,2,0$ & Ground & & & & 28039.96 & .1 \\
\hline $\mathrm{C}^{12} \mathrm{HD}_{2} \mathrm{C}^{12}: \mathrm{C}^{12} \mathrm{D}$ & 4-1051 & $2,1,2 \leftarrow 1,1,1$ & Ground & & & & 28042.28 & .1 \\
\hline 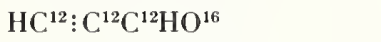 & 4. 911 & $3,0,3 \leftarrow 2,0,2$ & Excited & & & & 28044.06 & .15 \\
\hline $\mathrm{C}^{13} \mathrm{H}_{3}\left(\mathrm{C}^{12} \mathrm{H}_{3}\right)_{2} \mathrm{C}^{12} \mathrm{~F}^{19}$ & 3- 982 & $3,3,0 \leftarrow 2,2,0$ & Ground & & & & 28044.08 & .03 \\
\hline $\mathrm{C}^{12} \mathrm{D}_{3} \mathrm{Ge}^{76} \mathrm{H}_{3}$ & 3. 308 & $2,0 \leftarrow 1,0$ & Ground & & & & 28046.70 & .10 \\
\hline $\mathrm{S}^{32} \mathrm{P}^{31} \mathrm{Cl}_{3}^{35}$ & 4-1531 & $10, \leftarrow 9$ & Ground & & & & 28053.1 & .5 \\
\hline $\mathrm{S}^{34}{ }_{*} \mathrm{HC}^{12}: \mathrm{C}^{12} \mathrm{HC}^{12} \mathrm{H}: \mathrm{C}^{12}{ }_{*} \mathrm{H}$ & $4-1166$ & $3,2,1 \leftarrow 2,2,0$ & Ground & & & & 28054.2 & .05 \\
\hline $\mathrm{S}^{32}{ }_{*} \mathrm{DC}^{12}: \mathrm{C}^{12} \mathrm{HC}^{12} \mathrm{H}: \mathrm{C}^{12}{ }_{*} \mathrm{H}$ & 4-1162 & $3,1,2 \leftarrow 2,1,1$ & Ground & & & & 28056.1 & .1 \\
\hline $\mathrm{C}^{12}{ }_{*} \mathrm{H}_{2} \mathrm{~N}^{14} \mathrm{HC}^{12}{ }_{*} \mathrm{H}_{2}$ & 4- 861 & $2,2,1 \leftarrow 2,1,2$ & Ground & & & & 28058.34 & .1 \\
\hline $\operatorname{Re}^{\mathrm{b}} \mathrm{O}_{2}^{16} \mathrm{O}^{18} \mathrm{~F}^{19}$ & 4-1593 & $4,1,3 \leftarrow 3,1,2$ & Ground & & & & 28059.01 & .20 \\
\hline $\mathrm{C}^{12} \mathrm{HD}: \mathrm{C}^{12} \mathrm{DBr}^{\mathrm{b}}$ & 4. 749 & Not Reported & Ground & & & & 28064.0 & .1 \\
\hline $\mathrm{C}^{12}{ }_{*} \mathrm{D}_{2} \mathrm{C}^{12} \mathrm{H}_{2} \mathrm{C}^{12} \mathrm{D}_{2} \mathrm{O}^{16} *$ & 4-1092 & $5,3,3 \leftarrow 5,2,4$ & Ground & & & & 28065.3 & .1 \\
\hline $\mathrm{C}^{13} \mathrm{H}_{3} \mathrm{I}^{127}$ & 4- 483 & $2,0 \leftarrow 1,0$ & Ground & & $5 / 2$ & $3 / 2$ & 28069.99 & .08 \\
\hline $\mathrm{Cl}_{2}^{\mathrm{b}} \mathrm{O}^{16}$ & 4-1484 & $10,2,9 \leftarrow 11,1,10$ & Ground & & & & 28072.16 & \\
\hline $\mathrm{Cl}_{2}^{\mathrm{b}} \mathrm{O}^{16}$ & 4-1484 & $10,2,9 \leftarrow 11,1,10$ & Ground & & & & 28073.35 & \\
\hline $\mathrm{Cl}_{2}^{\mathrm{b}} \mathrm{O}^{16}$ & 4-1484 & $10,2,9 \leftarrow 11,1,10$ & Ground & & & & 28076.76 & \\
\hline $\mathrm{C}^{12} \mathrm{H}_{3} \mathrm{~S}^{32} \mathrm{H}$ & 3- 221 & Not Reported & Ground & & & & 28078.2 & .1 \\
\hline $\mathrm{Cl}_{2}^{\mathrm{b}} \mathrm{O}^{16}$ & 4-1484 & $10,2,9 \leftarrow 11,1,10$ & Ground & & & & 28078.35 & \\
\hline $\mathrm{Cl}_{2}^{\mathrm{b}} \mathrm{O}^{16}$ & $4-1484$ & $10,2,9 \leftarrow 11,1,10$ & Ground & & & & 28078.56 & \\
\hline $\mathrm{Cl}_{2}^{\mathrm{b}} \mathrm{O}^{16}$ & 4-1484 & $10,2,9 \leftarrow 11,1,10$ & Ground & & & & 28080.28 & \\
\hline $\mathrm{t}-\mathrm{C}^{12} \mathrm{H}_{2} \mathrm{DC}^{12} \mathrm{H}_{2} \mathrm{~F}^{19}$ & 3- 554 & $1,1,0 \leftarrow 1,0,1$ & Ground & & & & 28081.6 & .1 \\
\hline $\mathrm{C}^{12}{ }_{*} \mathrm{HN}^{14} \mathrm{C}^{12} \mathrm{HC}^{12} \mathrm{H}: \mathrm{C}^{12} \mathrm{HN}^{14}{ }_{*}$ & 4-1141 & $3,2,2 \leftarrow 2,1,1$ & Ground & & & & 28083.53 & \\
\hline $\mathrm{Cl}_{2}^{\mathrm{b}} \mathrm{O}^{16}$ & 4-1484 & $10,2,9 \leftarrow 11,1,10$ & Ground & & & & 28083.75 & \\
\hline $\mathrm{Cl}_{2}^{\mathrm{b}} \mathrm{O}^{16}$ & 4-1484 & $10,2,9 \leftarrow 11,1,10$ & Ground & & & & 28084.74 & \\
\hline$\left(\mathrm{C}^{12} \mathrm{H}_{3}\right)_{3} \mathrm{C}^{12} \mathrm{I}^{127}$ & 3- 991 & $9, \leftarrow 8$ & Ground & & & & 28085 . & 30. \\
\hline $\mathrm{HC}^{12} \mathrm{O}^{16} \mathrm{O}^{16} \mathrm{H}$ & $3-71$ & $4,0,4 \leftarrow 3,1,3$ & & & & & 28086.39 & \\
\hline $\mathrm{C}^{12} \mathrm{H}_{3} \mathrm{C}^{12}: \mathrm{C}^{12} \mathrm{C}^{12} \mathrm{H}_{2} \mathrm{Cl}^{37}$ & 3- 902 & $10,0,10 \leftarrow 9,0,9$ & Ground & & & & 28087.9 & .3 \\
\hline $\mathrm{c}-\mathrm{HDC}^{12}{ }_{*} \mathrm{O}^{16} \mathrm{C}^{12}{ }_{*} \mathrm{DH}$ & 4- 845 & $5,3,2 \leftarrow 5,2,3$ & Ground & & & & 28097.1 & .2 \\
\hline $\mathrm{H}_{3} \mathrm{C}^{12} \mathrm{C}^{12}: \mathrm{C}^{12} \mathrm{Br}^{79}$ & 4. 941 & $9, \leftarrow 8$ & Ground & & & & 28099.90 & .1 \\
\hline $\mathrm{C}^{13} \mathrm{H}_{3}\left(\mathrm{C}^{12} \mathrm{H}_{3}\right)_{2} \mathrm{C}^{12} \mathrm{~F}^{19}$ & 3- 982 & $3,3,1 \leftarrow 2,2,1$ & Ground & & & & 28100.92 & .03 \\
\hline $\mathrm{Sb}^{123} \mathrm{H}_{2} \mathrm{D}$ & $4-1796$ & $1,1,1 \leftarrow 1,0,1$ & Ground & & $7 / 2$ & $5 / 2$ & 28102.66 & \\
\hline $\mathrm{D}_{2} \mathrm{O}_{2}^{16}$ & 3- 42 & Not Reported & & & & & 28105. & 3. \\
\hline $\mathrm{Sb}^{121} \mathrm{H}_{2} \mathrm{D}$ & 4-1795 | & $1,1,1 \leftarrow 1,0,1$ & Ground & & $5 / 2$ & $3 / 2$ & 28105.28 & \\
\hline $\mathrm{Sb}^{123} \mathrm{H}_{2} \mathrm{D}$ & 4-1796 & $1,1,1 \leftarrow 1,0,1$ & Ground & & $7 / 2$ & $9 / 2$ & 28105.80 & \\
\hline $\mathrm{C}^{12} \mathrm{H}_{3} \mathrm{~N}^{14} \mathrm{H}_{2}$ & 3- 261 & Not Reported & Ground & & & & 28107.75 & .04 \\
\hline $\mathrm{Sb}^{121} \mathrm{H}_{2} \mathrm{D}$ & 4-1795 & $1,1,1 \leftarrow 1,0,1$ & Ground & & $5 / 2$ & $7 / 2$ & 28108.55 & \\
\hline $\mathrm{O}^{\mathrm{b}} \mathrm{O}^{\mathrm{b}} \mathrm{O}^{\mathrm{b}}$ & $4-1847$ & Not Reported & & & & & 28116. & \\
\hline
\end{tabular}




\begin{tabular}{|c|c|c|c|c|c|c|c|c|}
\hline \multirow{2}{*}{ Isotopic Species } & \multirow{2}{*}{$\begin{array}{l}\text { Vol.-Id. } \\
\text { Nos. }\end{array}$} & \multirow{2}{*}{$\begin{array}{c}\text { Rotational } \\
\text { Quantum Nos. }\end{array}$} & \multirow{2}{*}{ Vib. State } & \multicolumn{3}{|c|}{ Hyperfine } & \multirow{2}{*}{$\begin{array}{l}\text { Frequency } \\
\quad \text { MHz }\end{array}$} & \multirow{2}{*}{$\begin{aligned} & \text { Acc: } \\
& \pm .1 \mathrm{H} /\end{aligned}$} \\
\hline & & & & $\mathrm{F}_{1}^{\prime}$ & $F^{\prime} \quad F_{1}$ & $\mathbf{F}$ & & \\
\hline $\mathrm{C}^{12} \mathrm{H}_{2} \mathrm{Cl}^{35} \mathrm{Si}^{28} \mathrm{D}_{3}$ & 3. 237 & $5,0,5 \leftarrow 4,0,4$ & Ground & & & & 28116.99 & .2 \\
\hline $\mathrm{C}^{12} \mathrm{H}_{3} \mathrm{O}^{16} \mathrm{H}$ & 3. 211 & Not Reported & Ground & & & & 28119.5 & .1 \\
\hline $\mathrm{H}_{2}^{\mathrm{b}} \mathrm{C}^{\mathrm{b}}: \mathrm{C}^{\mathrm{b}} \mathrm{H}^{\mathrm{b}} \mathrm{Cl}^{\mathrm{b}}$ & 4. 772 & Not Reported & Ground & & & & 28120.18 & \\
\hline$\left(\mathrm{C}^{12} \mathrm{H}_{3}\right)_{2} \mathrm{C}^{12}: \mathrm{C}^{12} \mathrm{H}_{2}$ & 3- 941 & $6,3,3 \leftarrow 6,2,4$ & Ground & & & & 28121.48 & .05 \\
\hline $\mathrm{H}_{2}^{\mathrm{b}} \mathrm{C}^{\mathrm{b}}: \mathrm{C}^{\mathrm{b}} \mathrm{H}^{\mathrm{b}} \mathrm{Cl}^{\mathrm{b}}$ & 4- 772 & Not Reported & Ground & & & & 28122.02 & \\
\hline $\mathrm{C}^{12}{ }_{*} \mathrm{H}_{2} \mathrm{C}^{12} \mathrm{H}_{2} \mathrm{C}^{12} \mathrm{H}_{2} \mathrm{O}^{16}{ }_{*}$ & 4-1091 & $10,9,2 \leftarrow 10,7,3$ & Ground & & & & 28125.0 & .1 \\
\hline $\mathrm{C}^{12} \mathrm{D}_{3} \mathrm{C}^{12} \mathrm{O}^{16} \mathrm{Cl}^{37}$ & 3- 364 & $12,4,8 \leftarrow 12,3,9$ & Ground & & & & 28139.55 & .1 \\
\hline $\mathrm{C}^{12} \mathrm{D}_{3} \mathrm{C}^{12} \mathrm{O}^{16} \mathrm{Cl}^{37}$ & 3- 364 & $12,4,8 \leftarrow 12,3,9$ & Ground & & & & 28141.00 & .1 \\
\hline $\mathrm{C}^{12} \mathrm{H}_{3} \mathrm{~N}^{14} \mathrm{H}_{2}$ & 3- 261 & Not Reported & Ground & & & & 28142.85 & .04 \\
\hline $\mathrm{C}^{12} \mathrm{HD}: \mathrm{C}^{12} \mathrm{DBr}^{\mathrm{b}}$ & 4- 749 & Not Reported & Ground & & & & 28144.2 & .1 \\
\hline $\mathrm{C}^{13} \mathrm{H}_{3} \mathrm{I}^{127}$ & 4- 483 & $2,0 \leftarrow 1,0$ & Ground & & $7 / 2$ & $7 / 2$ & 28145.01 & .08 \\
\hline $\mathrm{Si}^{30} \mathrm{H}_{3} \mathrm{~F}^{19}$ & 4-1553 & $1, \leftarrow 0$ & Ground & & & & 28145.2 & .2 \\
\hline $\mathrm{HC}^{12}{ }_{*}: \mathrm{C}^{12} \mathrm{HO}^{16} \mathrm{C}^{12} \mathrm{O}^{16} \mathrm{O}^{16}{ }_{*}$ & 4- 931 & $4,2,3 \leftarrow 3,2,2$ & Ground & & & & 28151.36 & .10 \\
\hline $\mathrm{Si}^{28} \mathrm{HCl}_{3}^{37}$ & 4-1504 & $6, \leftarrow 5$, & Ground & & & & 28152.85 & .5 \\
\hline $\mathrm{HC}^{13}: \mathrm{C}^{12} \mathrm{C}^{12} \mathrm{DO}^{16}$ & 4- 922 & Not Reported & & & & & 28154. & 5. \\
\hline $\mathrm{C}^{12} \mathrm{H}_{3} \mathrm{C}^{12} \mathrm{H}_{2} \mathrm{I}^{127}$ & 3- 571 & $6,1,5 \leftarrow 6,0,6$ & Excited & & $7 / 2$ & $7 / 2$ & 28154.7 & .5 \\
\hline $\mathrm{C}^{12} \mathrm{HD}_{2} \mathrm{C}^{12}: \mathrm{C}^{12} \mathrm{D}$ & 4-1051 & $2,0,2 \leftarrow 1,0,1$ & Ground & & & & 28155.14 & .1 \\
\hline $\mathrm{C}^{12} \mathrm{D}_{3} \mathrm{Ge}^{74} \mathrm{H}_{3}$ & 3- 296 & $2,0 \leftarrow 1,0$ & Ground & & & & 28155.20 & .10 \\
\hline $\mathrm{C}^{12} \mathrm{H}_{2}: \mathrm{C}^{12} \mathrm{HC}^{12} \mathrm{~F}^{19}: \mathrm{C}^{12} \mathrm{H}_{2}$ & 3- 911 & $5,3,2 \leftarrow 5,2,3$ & Excited & & & & 28155.63 & .03 \\
\hline $\mathrm{Sb}^{121} \mathrm{H}_{2} \mathrm{D}$ & 4-1795 & $1,1,1 \leftarrow 1,0,1$ & Ground & & $7 / 2$ & $7 / 2$ & 28158.14 & \\
\hline $\mathrm{P}^{31} \mathrm{H}_{2} \mathrm{D}$ & 4-1782 & $3,1,3 \leftarrow 3,0,3$ & Ground & & & & 28158.53 & .05 \\
\hline $\mathrm{Sb}^{123} \mathrm{H}_{2} \mathrm{D}$ & $4-1796$ & $1,1,1 \leftarrow 1,0,1$ & Ground & & $9 / 2$ & $9 / 2$ & 28162.78 & \\
\hline $\mathrm{C}^{12} \mathrm{DHCl}_{2}^{35}$ & 4- 344 & $7,1,6 \leftarrow 7,0,7$ & Ground & & & & 28167. & 5. \\
\hline $\mathrm{Sb}^{121} \mathrm{H}_{2} \mathrm{D}$ & 4-1795 & $1,1,1 \leftarrow 1,0,1$ & Ground & & $7 / 2$ & $5 / 2$ & 28168.04 & \\
\hline $\mathrm{C}^{12} \mathrm{H}_{3} \mathrm{O}^{16} \mathrm{H}$ & 3- 211 & $14,2, \leftarrow 14,1$, & Ground & & & & 28169.31 & .1 \\
\hline $\mathrm{C}^{12} \mathrm{H}_{3} \mathrm{C}^{12} \mathrm{H}_{2} \mathrm{I}^{127}$ & 3- 571 & $6,1,5 \leftarrow 6,0,6$ & Excited & & $9 / 2$ & $9 / 2$ & 28171.66 & \\
\hline $\mathrm{C}^{12} \mathrm{H}_{3} \mathrm{C}^{12} \mathrm{H}_{2} \mathrm{I}^{127}$ & 3- 571 & $6,1,5 \leftarrow 6,0,6$ & Excited & & $9 / 2$ & $9 / 2$ & 28173.18 & \\
\hline $\mathrm{C}^{12} \mathrm{H}_{3} \mathrm{C}^{13} \mathrm{H}_{2} \mathrm{Cl}^{35}$ & 3- 546 & $4,1,3 \leftarrow 4,0,4$ & Ground & & $5 / 2$ & $5 / 2$ & 28173.62 & .05 \\
\hline $\mathrm{Sb}^{123} \mathrm{H}_{2} \mathrm{D}$ & 4-1796 & $1,1,1 \leftarrow 1,0,1$ & Ground & & $9 / 2$ & $7 / 2$ & 28174.48 & \\
\hline $\mathrm{Sb}^{123} \mathrm{H}_{2} \mathrm{D}$ & 4-1796 & $1,1,1 \leftarrow 1,0,1$ & Ground & & $5 / 2$ & $5 / 2$ & 28175.07 & \\
\hline $\mathrm{C}^{12} \mathrm{H}_{3} \mathrm{C}^{13} \mathrm{H}_{2} \mathrm{Cl}^{35}$ & 3- 546 & $4,1,3 \leftarrow 4,0,4$ & Ground & & $11 / 2$ & $11 / 2$ & 28175.25 & .05 \\
\hline $\mathrm{H}_{2} \mathrm{C}^{12}: \mathrm{C}^{12} \mathrm{~F}_{2}^{19}$ & 4- 681 & Not Reported & & & & & 28177.7 & .3 \\
\hline $\mathrm{C}^{12} \mathrm{H}_{3} \mathrm{C}^{13} \mathrm{H}_{2} \mathrm{Cl}^{35}$ & 3- 546 & $4,1,3 \leftarrow 4,0,4$ & - Ground & & $7 / 2$ & $7 / 2$ & 28178.26 & .05 \\
\hline $\mathrm{C}^{12} \mathrm{H}_{3} \mathrm{C}^{13} \mathrm{H}_{2} \mathrm{Cl}^{35}$ & 3- 546 & $4,1,3 \leftarrow 4,0,4$ & Ground & & $9 / 2$ & $9 / 2$ & 28179.95 & .05 \\
\hline $\mathrm{C}^{12} \mathrm{H}_{3} \mathrm{C}^{12} \mathrm{O}^{16} \mathrm{C}^{12} \mathrm{~N}^{14}$ & 3- 671 & $6,3,3 \leftarrow 6,2,4$ & Ground & & & & 28180.80 & .2 \\
\hline$c-\mathrm{C}^{12} \mathrm{HD}: \mathrm{C}^{12} \mathrm{DBr}^{81}$ & 4- 746 & $4,1,4 \leftarrow 3,1,3$ & Ground & & $5 / 2$ & $5 / 2$ & 28181.3 & \\
\hline $\mathrm{C}^{12} \mathrm{H}_{3} \mathrm{~N}^{14} \mathrm{H}_{2}$ & 3- 261 & Not Reported & Ground & & & & 28183,46 & .1 \\
\hline $\mathrm{C}^{12} \mathrm{H}_{3} \mathrm{C}^{12}: \mathrm{C}^{12} \mathrm{C}^{12} \mathrm{H}_{2} \mathrm{Cl}^{37}$ & 3- 902 & $10,5,6 \leftarrow 9,5,5$ & Ground & & & & 28183.7 & .3 \\
\hline $\mathrm{C}^{12} \mathrm{H}_{3} \mathrm{C}^{12}: \mathrm{C}^{12} \mathrm{C}^{12} \mathrm{H}_{2} \mathrm{Cl}^{37}$ & 3- 902 & $10,3,7 \leftarrow 9,3,6$ & Ground & & & & 28183.7 & .3 \\
\hline $\mathrm{C}^{12} \mathrm{H}_{3} \mathrm{C}^{12}: \mathrm{C}^{12} \mathrm{C}^{12} \mathrm{H}_{2} \mathrm{Cl}^{37}$ & 3- 902 & $10,5,5 \leftarrow 9,5,4$ & Ground & & & & 28183.7 & .3 \\
\hline $\mathrm{C}^{12} \mathrm{H}_{3} \mathrm{C}^{12}: \mathrm{C}^{12} \mathrm{C}^{12} \mathrm{H}_{2} \mathrm{Cl}^{37}$ & 3- 902 & $10,3,8 \leftarrow 9,3,7$ & Ground & & & & 28183.7 & .3 \\
\hline $\mathrm{HC}^{13}: \mathrm{C}^{12} \mathrm{C}^{12} \mathrm{DO}^{16}$ & 4- 922 & Not Reported & & & & & 28185. & 5. \\
\hline $\mathrm{C}^{12} \mathrm{H}_{3} \mathrm{~N}^{14} \mathrm{H}_{2}$ & 3- 261 & Not Reported & Ground & & & & 28186.02 & .1 \\
\hline $\mathrm{C}^{12} \mathrm{H}_{3} \mathrm{C}^{12} \mathrm{H}_{2} \mathrm{I}^{127}$ & 3. 571 & $6,1,5 \leftarrow 6,0,6$ & Excited & & $17 / 2$ & $17 / 2$ & 28186.94 & \\
\hline $\mathrm{B}^{11} \mathrm{~B}^{10} \mathrm{~B}_{3}^{11} \mathrm{H}_{9}$ & 4- 53 & $2,1,1 \leftarrow 1,0,1$ & Ground & & & & 28187.1 & .2 \\
\hline
\end{tabular}




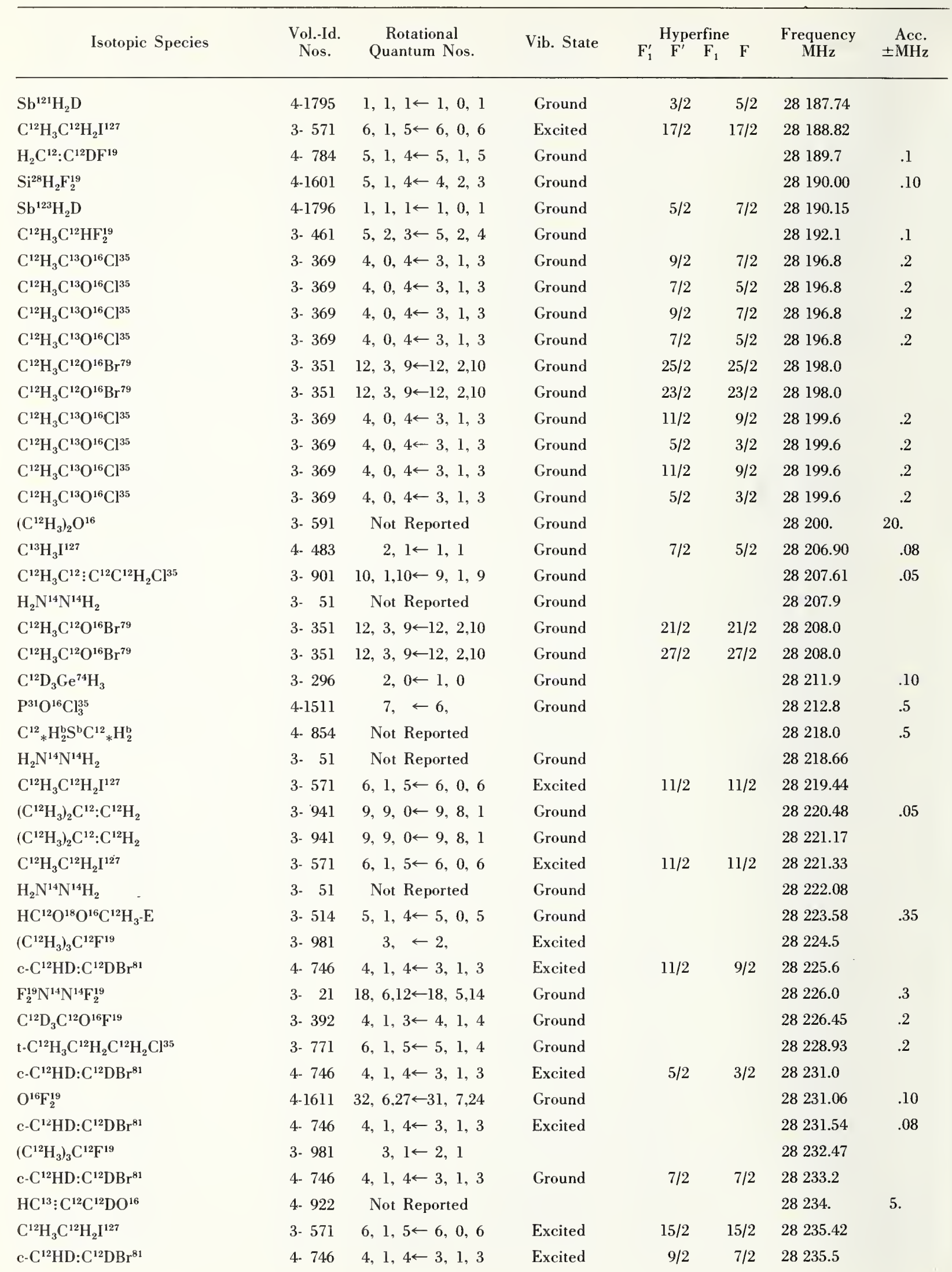




\begin{tabular}{|c|c|c|c|c|c|c|c|}
\hline Isotopic Species & $\begin{array}{l}\text { Vol.-Id. } \\
\text { Nos. }\end{array}$ & $\begin{array}{c}\text { Rotational } \\
\text { Quantum Nos. }\end{array}$ & Vib. State & \begin{tabular}{c}
\multicolumn{2}{c}{ Hyperfin } \\
$F_{1}^{\prime} \stackrel{F^{\prime}}{F_{1}}$
\end{tabular} & e $F$ & $\begin{array}{c}\text { Frequency } \\
\text { MHz }\end{array}$ & $\begin{aligned} \text { Acc. } \\
\pm \mathrm{MHz}\end{aligned}$ \\
\hline $\mathrm{C}^{12} \mathrm{H}_{3} \mathrm{C}^{12} \mathrm{H}_{2} \mathrm{I}^{127}$ & 3- 571 & $6,1,5 \leftarrow 6,0,6$ & Excited & $15 / 2$ & $15 / 2$ & 28237.20 & \\
\hline $\mathrm{HC}^{12} \mathrm{O}^{18} \mathrm{O}^{16} \mathrm{C}^{12} \mathrm{H}_{3}-\mathrm{A}$ & 3- 513 & $5,1,4 \leftarrow 5,0,5$ & Ground & & & 28238.31 & .2 \\
\hline $\mathrm{O}^{\mathrm{b}} \mathrm{O}^{\mathrm{n}} \mathrm{O}^{\mathrm{b}}$ & $4-1847$ & Not Reported & & & & 28239. & \\
\hline c. $\mathrm{C}^{12} \mathrm{HD}: \mathrm{C}^{12} \mathrm{DBr}^{81}$ & 4- 746 & $4,1,4 \leftarrow 3,1,3$ & Excited & $7 / 2$ & $5 / 2$ & 28241.2 & \\
\hline $\mathrm{HC}^{13}: \mathrm{C}^{12} \mathrm{C}^{12} \mathrm{DO}^{16}$ & 4. 922 & Not Reported & & & & 28246. & 5. \\
\hline $\mathrm{C}^{12} \mathrm{H}_{3} \mathrm{C}^{12} \mathrm{H}_{2} \mathrm{I}^{127}$ & 3- 571 & $6,1,5 \leftarrow 6,0,6$ & Excited & $13 / 2$ & $13 / 2$ & 28246.1 & .5 \\
\hline$\left(\mathrm{C}^{12} \mathrm{H}_{3}\right)_{3} \mathrm{C}^{12} \mathrm{~F}^{19}$ & 3- 981 & $3,0 \leftarrow 2,0$ & & & & 28250.32 & \\
\hline$\left(\mathrm{C}^{12} \mathrm{H}_{3}\right)_{3} \mathrm{C}^{12} \mathrm{~F}^{19}$ & 3- 981 & $3,1 \leftarrow 2,1$ & & & & 28251.82 & \\
\hline$\left(\mathrm{C}^{12} \mathrm{H}_{3}\right)_{3} \mathrm{C}^{12} \mathrm{~F}^{19}$ & 3- 981 & $3,2 \leftarrow 2,2$ & & & & 28252.49 & \\
\hline $\mathrm{C}^{13} \mathrm{H}_{3} \mathrm{I}^{127}$ & 4. 483 & $2,1 \leftarrow 1,1$ & Ground & $5 / 2$ & $5 / 2$ & 28253.84 & .08 \\
\hline c- $\mathrm{C}^{12} \mathrm{HD}: \mathrm{C}^{12} \mathrm{DBr}^{81}$ & 4. 746 & $4,1,4 \leftarrow 3,1,3$ & Ground & $11 / 2$ & $9 / 2$ & 28253.9 & \\
\hline$\left(\mathrm{C}^{12} \mathrm{H}_{3}\right)_{3} \mathrm{C}^{12} \mathrm{~F}^{19}$ & 3- 981 & $3, \leftarrow 2$ & Ground & & & 28254.05 & .03 \\
\hline$\left(\mathrm{C}^{12} \mathrm{H}_{3}\right)_{3} \mathrm{C}^{12} \mathrm{~F}^{19}$ & 3. 981 & $3,2 \leftarrow 2,2$ & & & & 28254.8 & \\
\hline $\mathrm{C}^{12} \mathrm{H}_{3} \mathrm{C}^{12} \mathrm{HF}_{2}^{19}$ & 3. 461 & $6,4,3 \leftarrow 6,2,4$ & Ground & & & 28254.8 & .1 \\
\hline $\mathrm{HC}^{13}: \mathrm{C}^{12} \mathrm{C}^{12} \mathrm{DO}^{16}$ & 4- 922 & Not Reported & & & & 28258. & 5. \\
\hline c- $\mathrm{C}^{12} \mathrm{HD}: \mathrm{C}^{12} \mathrm{DBr}^{81}$ & 4. 746 & $4,1,4 \leftarrow 3,1,3$ & Ground & $5 / 2$ & $3 / 2$ & 28259.3 & \\
\hline c- $\mathrm{C}^{12} \mathrm{H}_{3} \mathrm{C}^{12} \mathrm{H}: \mathrm{C}^{12} \mathrm{HF}^{19}-\mathrm{E}$ & 3- 702 & $3,1,3 \leftarrow 2,1,2$ & & & & 28259.80 & .2 \\
\hline c- $\mathrm{C}^{12} \mathrm{HD}: \mathrm{C}^{12} \mathrm{DBr}^{81}$ & 4- 746 & $4,1,4 \leftarrow 3,1,3$ & Ground & & & 28259.86 & .06 \\
\hline c- $\mathrm{C}^{12} \mathrm{H}_{3} \mathrm{C}^{12} \mathrm{H}: \mathrm{C}^{12} \mathrm{HF}^{19}-\mathrm{A}$ & 3- 701 & $3,1,3 \leftarrow 2,1,2$ & & & & 28261.19 & .2 \\
\hline c- $\mathrm{C}^{12} \mathrm{HD}: \mathrm{C}^{12} \mathrm{DBr}^{81}$ & 4- 746 & $4,1,4 \leftarrow 3,1,3$ & Ground & $9 / 2$ & $7 / 2$ & 28263.7 & \\
\hline $\mathrm{C}^{12} \mathrm{H}_{3} \mathrm{C}^{12} \mathrm{H}_{2} \mathrm{I}^{127}$ & 3- 571 & $6,1,5 \leftarrow 6,0,6$ & Ground & $7 / 2$ & $7 / 2$ & 28264.34 & \\
\hline $\mathrm{C}^{12} \mathrm{H}_{3} \mathrm{C}^{12} \mathrm{HF}_{2}^{19}$ & 3- 461 & $7,5,3 \leftarrow 7,3,4$ & Ground & & & 28265.6 & .1 \\
\hline $\mathrm{C}^{12} \mathrm{H}_{2}: \mathrm{C}^{12} \mathrm{HC}^{12} \mathrm{~N}^{15}$ & $4-1025$ & $3,1,2 \leftarrow 2,1,1$ & Ground & & & 28267.2 & .15 \\
\hline $\mathrm{C}^{12} \mathrm{HD}_{2} \mathrm{C}^{12}: \mathrm{C}^{12} \mathrm{D}$ & $4-1051$ & $2,1,1 \leftarrow 1,1,0$ & Ground & & & 28267.33 & .1 \\
\hline $\mathrm{C}^{13} \mathrm{H}_{3} \mathrm{O}^{16} \mathrm{H}$ & 3- 213 & $11,2, \leftarrow 11,1$ & Ground & & & 28267.71 & .1 \\
\hline $\mathrm{C}^{12} \mathrm{H}_{3} \mathrm{~N}^{14} \mathrm{O}_{2}^{16}$ & $3-\cdot 171$ & Not Reported & Ground & & & 28268.49 & \\
\hline $\mathrm{C}^{12} \mathrm{D}_{3} \mathrm{Ge}^{72} \mathrm{H}_{3}$ & 3- 295 & $2,0 \leftarrow 1,0$ & Ground & & & 28269.15 & .10 \\
\hline$c-\mathrm{C}^{12} \mathrm{HD}: \mathrm{C}^{12} \mathrm{DBr}^{81}$ & 4- 746 & $4,1,4 \leftarrow 3,1,3$ & Ground & $7 / 2$ & $5 / 2$ & 28269.4 & \\
\hline$\left(\mathrm{C}^{12} \mathrm{H}_{3}\right)_{3} \mathrm{C}^{12} \mathrm{~F}^{19}$ & 3- 981 & $3, \leftarrow 2$, & Ground & & & 28272.72 & .03 \\
\hline $\mathrm{C}^{12} \mathrm{H}_{3} \mathrm{~S}^{32} \mathrm{H}$ & 3- 221 & Not Reported & Ground & & & 28275.1 & .1 \\
\hline $\mathrm{C}^{12} \mathrm{H}_{3} \mathrm{C}^{12} \mathrm{H}_{2} \mathrm{I}^{127}$ & 3- 571 & $6,1,5 \leftarrow 6,0,6$ & Ground & $9 / 2$ & $9 / 2$ & 28275.88 & \\
\hline $\mathrm{C}^{12} \mathrm{H}_{3} \mathrm{C}^{12} \mathrm{O}^{16} \mathrm{Cl}^{35}$ & 3- 361 & $4,0,4 \leftarrow 3,1,3$ & Ground & $9 / 2$ & $7 / 2$ & 28278.10 & .2 \\
\hline $\mathrm{C}^{12} \mathrm{H}_{3} \mathrm{C}^{12} \mathrm{O}^{16} \mathrm{Cl}^{35}$ & 3. 361 & $4,0,4 \leftarrow 3,1,3$ & Ground & $7 / 2$ & $5 / 2$ & 28278.10 & .2 \\
\hline$\left(\mathrm{C}^{12} \mathrm{H}_{3}\right)_{2} \mathrm{~S}^{32}$ & 3. 601 & $13,2,12 \leftarrow 12,3,9$ & Ground & & & 28278.31 & .05 \\
\hline $\mathrm{C}^{12} \mathrm{H}_{3} \mathrm{C}^{12} \mathrm{O}^{16} \mathrm{Cl}^{35}$ & 3. 361 & $4,0,4 \leftarrow 3,1,3$ & Ground & $9 / 2$ & $7 / 2$ & 28278.78 & .2 \\
\hline $\mathrm{C}^{12} \mathrm{H}_{3} \mathrm{C}^{12} \mathrm{O}^{16} \mathrm{Cl}^{35}$ & 3- 361 & $4,0,4 \leftarrow 3,1,3$ & Ground & $7 / 2$ & $5 / 2$ & 28278.78 & .2 \\
\hline $\mathrm{C}^{12}{ }_{*} \mathrm{H}_{2} \mathrm{C}^{12} \mathrm{H}_{2} \mathrm{C}^{12} \mathrm{H}_{2} \mathrm{O}^{16}{ }_{*}$ & $4-1091$ & $10,9,2 \leftarrow 10,7,3$ & Excited & & & 28279.0 & .1 \\
\hline $\mathrm{C}^{12} \mathrm{HD}: \mathrm{C}^{12} \mathrm{DBr}^{\mathrm{b}}$ & 4- 749 & Not Reported & Ground & & & 28279.5 & .1 \\
\hline$\left(\mathrm{C}^{12} \mathrm{H}_{3}\right)_{2} \mathrm{~S}^{32}$ & 3- 601 & $13,2,12 \leftarrow 12,3,9$ & Ground & & & 28279.87 & .05 \\
\hline $\mathrm{C}^{12} \mathrm{H}_{3} \mathrm{C}^{12} \mathrm{HF}_{2}^{19}$ & 3- 461 & $5,3,3 \leftarrow 5,1,4$ & Ground & & & 28280.6 & .1 \\
\hline $\mathrm{C}^{12} \mathrm{H}_{3} \mathrm{C}^{12} \mathrm{O}^{16} \mathrm{Cl}^{35}$ & 3- 361 & $4,0,4 \leftarrow 3,1,3$ & Ground & $11 / 2$ & $9 / 2$ & 28281.08 & .2 \\
\hline $\mathrm{C}^{12} \mathrm{H}_{3} \mathrm{C}^{12} \mathrm{O}^{16} \mathrm{Cl}^{35}$ & 3- 361 & $4,0,4 \leftarrow 3,1,3$ & Ground & $5 / 2$ & $3 / 2$ & 28281.08 & .2 \\
\hline$\left(\mathrm{C}^{12} \mathrm{H}_{3}\right)_{2} \mathrm{~S}^{32}$ & 3- 601 & $13,2,12 \leftarrow 12,3,9$ & Ground & & & 28281.45 & .05 \\
\hline $\mathrm{C}^{12} \mathrm{H}_{3} \mathrm{C}^{12} \mathrm{O}^{16} \mathrm{Cl}^{35}$ & 3- 361 & $4,0,4 \leftarrow 3,1,3$ & Ground & $11 / 2$ & $9 / 2$ & 28281.76 & .2 \\
\hline $\mathrm{C}^{12} \mathrm{H}_{3} \mathrm{C}^{12} \mathrm{O}^{16} \mathrm{Cl}^{35}$ & 3- 361 & $4,0,4 \leftarrow 3,1,3$ & Ground & $5 / 2$ & $3 / 2$ & 28281.76 & .2 \\
\hline
\end{tabular}




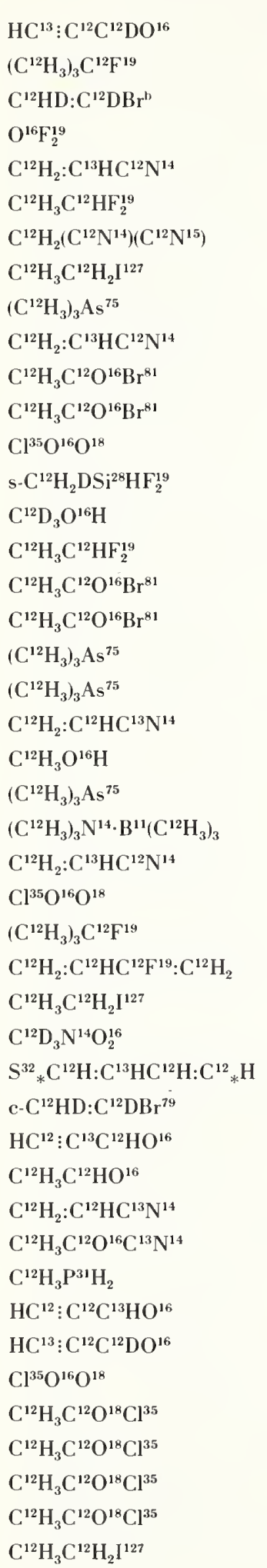

4. $922 \quad$ Not Reported

3. $981 \quad 3, \leftarrow 2$,

4. 749

Not Reported

4-1611 27, 5,22 -26, 6,21

Excited

4-1023

$3,0,3 \leftarrow 2,0,2$

3. 461

$4,1,3 \leftarrow 4,1,4$

4- 904

$2,1,2 \leftarrow 1,0,1$

3- 571

$6,1,5 \leftarrow 6,0,6$

3. 791

$$
3,0 \leftarrow 2,0
$$

4-1023

3- 352

$3,2,2 \leftarrow 2,2,1$

3. 352

$12,3,9 \leftarrow 12,2,10$

4-1383

$12,3,9 \leftarrow 12,2,10$

3. 203

$4,2,3 \leftarrow 5,1,4$

3- 214

$3,2,2 \leftarrow 2,2,1$

3. 461

Not Reported

3. 352

3- 352

3- 791

$4,2,3 \leftarrow 4,0,4$

$12,3,9 \leftarrow 12,2,10$

$12,3,9 \leftarrow 12,2,10$

3. 791

$3,2 \leftarrow 2,2$

$3,2 \leftarrow 2,2$

4-1024

3- 211

$3,0,3 \leftarrow 2,0,2$

3- 791

$4,0, \leftarrow 3,1$,

3-1081

4-1023

4-1383

3- 981

$3,1 \leftarrow 2,1$

$$
9, \leftarrow 8 \text {, }
$$

3. 911

$3,2,1 \leftarrow 2,2,0$

$4,2,3 \leftarrow 5,1,4$

$$
3, \leftarrow 2,
$$

3. 571

3- 172

$5,3,2 \leftarrow 5,2,3$

$6,1,5 \leftarrow 6,0,6$

4.1168

$2,1, \leftarrow 1,1$,

4. 744

$3,2,1 \leftarrow 2,2,0$

4. 913

$4,1,4 \leftarrow 3,1,3$

3- 471

$3,1,2 \leftarrow 2,1,1$

Not Reported

4-1024

$3,2,2 \leftarrow 2,2,1$

3- 673

3- 271

4. 914

$4,2,3 \leftarrow 3,2,2$

$14,2,12 \leftarrow 13,3,10$

4- 922

$3,1,2 \leftarrow 2,1,1$

Not Reported

4- 1383

3- 372

3- 372

3. 372

3. 372

$4,2,3 \leftarrow 5,1,4$

$11,4,7 \leftarrow 11,3,8$

$11,4,7 \leftarrow 11,3,8$

$11,4,7 \leftarrow 11,3,8$

3. 571
$11,4,7 \leftarrow 11,3,8$

$6,1,5 \leftarrow 6,0,6$
Ground

Ground

Ground

Ground

Ground

Ground

Ground

Ground

Ground

Ground

Ground

Ground

Ground

Ground

Ground

Ground

Ground

Ground

Ground

Ground

Ground

Ground

Ground

Excited

Ground

Ground

Ground

Ground

Ground

Ground

Ground

Ground

Ground

Ground

Ground

Ground

Ground

Ground

Ground

Ground
28282 .

5.

28282.19

28284.85

28286.80

28287.5

28290.1

28290.63

$17 / 2 \quad 17 / 2 \quad 28291.66$

$7 / 2 \quad 7 / 2 \quad 28302$.

28304.8

$25 / 2 \quad 25 / 2 \quad 28305.51$

$23 / 2 \quad 23 / 2 \quad 28305.51$

$\begin{array}{lll}3 & 4 & 28 \\ 3 & 308.2\end{array}$

$28311.60 \quad 2$.

28311.9

.5

28312.4

$21 / 2 \quad 21 / 2 \quad 28313.04$

$27 / 2 \quad 27 / 2 \quad 28313.04$

$5 / 2 \quad 5 / 2 \quad 28313.36$

.05

$7 / 2 \quad 5 / 2$

28313.36

28315.2

.05

28316.03

.15

$7 / 2$

$7 / 2$

28316.95

.05

28318.

10.

28319.0

.15

$\begin{array}{lll}4 & 5 & 28322.1\end{array}$

28323.09

28323.90

.03

$11 / 2 \quad 11 / 2 \quad 28324.08$

28327.9

28328.0

.2

.05

$5 / 2$

$5 / 2$

28329.3

28330.10

.02

28330.59

28331.6

.15

28332.05

28332.3

28334.12

28336.

5.

$\begin{array}{lll}5 & 6 & 28 \\ & 337.4\end{array}$

$25 / 2 \quad 25 / 2 \quad 28338.33$

$19 / 2 \quad 19 / 2 \quad 28338.33$

$23 / 2 \quad 23 / 2 \quad 28338.33$

$21 / 2 \quad 21 / 2 \quad 28338.33$

28339.12 


\begin{tabular}{|c|c|c|c|c|c|c|c|}
\hline \multirow{2}{*}{ Isotopic Species } & \multirow{2}{*}{$\begin{array}{l}\text { Vol.-Id. } \\
\text { Nos. }\end{array}$} & \multirow{2}{*}{$\begin{array}{c}\text { Rotational } \\
\text { Quantum Nos. }\end{array}$} & \multirow{2}{*}{ Vib. State } & \multicolumn{2}{|c|}{ Hyperfine } & \multirow{2}{*}{$\begin{array}{l}\text { Frequency } \\
\text { MHz }\end{array}$} & \multirow{2}{*}{$\begin{aligned} & \text { Ace. } \\
\pm & \mathrm{MH}\end{aligned}$} \\
\hline & & & & $\begin{array}{lll}\mathrm{F}_{1}^{\prime} & \mathrm{F}^{\prime} & \mathrm{F}_{1}\end{array}$ & $\mathrm{~F}$ & & \\
\hline$\left(\mathrm{C}^{12} \mathrm{H}_{3}\right)_{3} \mathrm{As}^{75}$ & 3- 791 & $3,0 \leftarrow 2,0$ & Ground & $3 / 2$ & $1 / 2$ & 28339.44 & .05 \\
\hline$\left(\mathrm{C}^{12} \mathrm{H}_{3}\right)_{3} \mathrm{As}^{75}$ & 3- 791 & $3,0 \leftarrow 2,0$ & Ground & $5 / 2$ & $3 / 2$ & 28339.44 & .05 \\
\hline$\left(\mathrm{C}^{12} \mathrm{H}_{3}\right)_{2} \mathrm{C}^{12} \mathrm{O}^{16}$ & 3- 751 & Not Reported & & & & 28340.0 & \\
\hline $\mathrm{C}^{12} \mathrm{H}_{3} \mathrm{C}^{12} \mathrm{O}^{18} \mathrm{Cl}^{35}$ & 3- 372 & $11,4,7 \leftarrow 11,3,8$ & Ground & $23 / 2$ & $23 / 2$ & 28341.10 & .2 \\
\hline $\mathrm{C}^{12} \mathrm{H}_{3} \mathrm{C}^{12} \mathrm{O}^{18} \mathrm{Cl}^{35}$ & 3- 372 & $11,4,7 \leftarrow 11,3,8$ & Ground & $25 / 2$ & $25 / 2$ & 28341.10 & .2 \\
\hline $\mathrm{C}^{12} \mathrm{H}_{3} \mathrm{C}^{12} \mathrm{O}^{18} \mathrm{Cl}^{35}$ & 3- 372 & $11,4,7 \leftarrow 11,3,8$ & Ground & $19 / 2$ & $19 / 2$ & 28341.10 & .2 \\
\hline $\mathrm{C}^{12} \mathrm{H}_{3} \mathrm{C}^{12} \mathrm{O}^{18} \mathrm{Cl}^{35}$ & 3- 372 & $11,4,7 \leftarrow 11,3,8$ & Ground & $21 / 2$ & $21 / 2$ & 28341.10 & .2 \\
\hline$\left(\mathrm{C}^{12} \mathrm{H}_{3}\right)_{3} \mathrm{As}^{75}$ & 3- 791 & $3,1 \leftarrow 2,1$ & Ground & $5 / 2$ & $3 / 2$ & 28342.11 & .05 \\
\hline$\left(\mathrm{C}^{12} \mathrm{H}_{3}\right)_{3} \mathrm{As}^{75}$ & 3- 791 & $3,1 \leftarrow 2,1$ & Ground & $7 / 2$ & $5 / 2$ & 28342.11 & .05 \\
\hline c. $\mathrm{C}^{12} \mathrm{HD}: \mathrm{C}^{12} \mathrm{DBr}^{81}$ & 4- 746 & $4,1,4 \leftarrow 3,1,3$ & Ground & $9 / 2$ & $9 / 2$ & 28342.3 & \\
\hline $\mathrm{C}^{12}{ }_{*} \mathrm{H}_{2} \mathrm{C}^{12} \mathrm{H}_{2} \mathrm{C}^{12} \mathrm{H}_{2} \mathrm{O}^{16} *$ & 4-1091 & $10,9,2 \leftarrow 10,7,3$ & Excited & & & 28342.4 & .1 \\
\hline $\mathrm{C}^{12} \mathrm{H}_{3} \mathrm{C}^{13} \mathrm{H}_{2} \mathrm{~F}^{19}$ & 3- 555 & $2,1,1 \leftarrow 2,0,2$ & Ground & & & 28343.1 & .1 \\
\hline $\mathrm{C}^{13} \mathrm{H}_{3} \mathrm{I}^{127}$ & 4- 483 & $2,0 \leftarrow 1,0$ & Ground & $3 / 2$ & $3 / 2$ & 28343.64 & .08 \\
\hline $\mathrm{C}^{12} \mathrm{D}_{3} \mathrm{~N}^{14} \mathrm{O}_{2}^{16}$ & 3- 172 & $2,1, \leftarrow 1,1$, & Ground & & & 28344. & 2.0 \\
\hline $\mathrm{C}^{12} \mathrm{H}_{2}: \mathrm{C}^{12} \mathrm{HC}^{13} \mathrm{~N}^{14}$ & 4-1024 & $3,2,1 \leftarrow 2,2,0$ & Ground & & & 28344.7 & .15 \\
\hline $\mathrm{C}^{12} \mathrm{H}_{3} \mathrm{C}^{12} \mathrm{H}_{2} \mathrm{I}^{127}$ & 3- 571 & $6,1,5 \leftarrow 6,0,6$ & Ground & $13 / 2$ & $13 / 2$ & 28347.34 & \\
\hline$\left(\mathrm{C}^{12} \mathrm{H}_{3}\right)_{3} \mathrm{As}^{75}$ & 3- 791 & $3,2 \leftarrow 2,2$ & Ground & $5 / 2$ & $3 / 2$ & 28349.62 & .05 \\
\hline$\left(\mathrm{C}^{12} \mathrm{H}_{3}\right)_{3} \mathrm{As}^{75}$ & 3- 791 & $3,2 \leftarrow 2,2$ & Ground & $3 / 2$ & $3 / 2$ & 28349.62 & .05 \\
\hline$\left(\mathrm{C}^{12} \mathrm{H}_{3}\right)_{3} \mathrm{As}^{75}$ & 3- 791 & $3,0 \leftarrow 2,0$ & Ground & $9 / 2$ & $7 / 2$ & 28351.95 & .05 \\
\hline$\left(\mathrm{C}^{12} \mathrm{H}_{3}\right)_{3} \mathrm{As}^{75}$ & 3- 791 & $3,0 \leftarrow 2,0$ & Ground & $7 / 2$ & $5 / 2$ & 28351.95 & .05 \\
\hline $\mathrm{Cl}^{35} \mathrm{O}^{16} \mathrm{O}^{18}$ & 4-1383 & $4,2,3 \leftarrow 5,1,4$ & Ground & 6 & 7 & 28354.2 & \\
\hline$\left(\mathrm{C}^{12} \mathrm{H}_{3}\right)_{3} \mathrm{As}^{75}$ & 3- 791 & $3,1 \leftarrow 2,1$ & Ground & $9 / 2$ & $7 / 2$ & 28354.93 & .05 \\
\hline$\left(\mathrm{C}^{12} \mathrm{H}_{3}\right)_{3} \mathrm{As}^{75}$ & 3- 791 & $3,1 \leftarrow 2,1$ & Ground & $3 / 2$ & $1 / 2$ & 28354.93 & .05 \\
\hline $\mathrm{B}^{11} \mathrm{~B}^{10} \mathrm{~B}_{3}^{11} \mathrm{H}_{9}$ & 4- 53 & $2,2,0 \leftarrow 1,1,0$ & Ground & & & 28359.7 & .2 \\
\hline $\mathrm{B}^{10} \mathrm{~B}_{4}^{11} \mathrm{H}_{9}$ & 4- 52 & $2, \leftarrow 1$, & Ground & & & 28359.7 & .2 \\
\hline$\left(\mathrm{C}^{12} \mathrm{H}_{3}\right)_{3} \mathrm{As}^{75}$ & 3- 791 & $3,1 \leftarrow 2,1$ & Ground & $5 / 2$ & $5 / 2$ & 28360.04 & .05 \\
\hline $\mathrm{HC}^{13}: \mathrm{C}^{12} \mathrm{C}^{12} \mathrm{DO}^{16}$ & 4- 922 & Not Reported & & & & 28361. & 5. \\
\hline$\left(\mathrm{C}^{12} \mathrm{H}_{3}\right)_{3} \mathrm{As}^{75}$ & 3. 791 & $3,2 \leftarrow 2,2$ & Ground & $9 / 2$ & $7 / 2$ & 28364.13 & .05 \\
\hline$\left(\mathrm{C}^{12} \mathrm{H}_{3}\right)_{3} \mathrm{As}^{75}$ & 3. 791 & $3,2 \leftarrow 2,2$ & Ground & $7 / 2$ & $7 / 2$ & 28364.13 & .05 \\
\hline $\mathrm{B}^{11} \mathrm{~B}^{10} \mathrm{~B}^{11} \mathrm{~B}^{10} \mathrm{~B}^{11} \mathrm{H}_{9}$ & 4- 55 & $2,1,1 \leftarrow 1,0,1$ & Ground & & & 28364.5 & .5 \\
\hline $\mathrm{C}^{13} \mathrm{H}_{2}: \mathrm{C}^{12} \mathrm{HC}^{12} \mathrm{~N}^{14}$ & $4-1022$ & $3,1,2 \leftarrow 2,1,1$ & Ground & & & 28364.5 & .15 \\
\hline $\mathrm{C}^{12} \mathrm{H}_{3} \mathrm{C}^{12} \mathrm{HF}_{2}^{19}$ & 3- 461 & $8,6,3 \leftarrow 8,4,4$ & Ground & & & 28364.6 & .1 \\
\hline $\mathrm{C}^{12} \mathrm{H}_{2}\left(\mathrm{C}^{12} \mathrm{~N}^{14}\right)_{2}$ & 4- 901 & Not Reported & Ground & & & 28368.5 & .1 \\
\hline $\mathrm{HC}^{13}: \mathrm{C}^{12} \mathrm{C}^{12} \mathrm{DO}^{16}$ & 4- 922 & Not Reported & & & & 28371. & 5. \\
\hline$\left(\mathrm{C}^{12} \mathrm{H}_{3}\right)_{2} \mathrm{O}^{18}$ & 3- 595 & $1,1,0 \leftarrow 1,0,1$ & Ground & & & 28372.7 & .2 \\
\hline $\mathrm{D}_{2} \mathrm{O}_{2}^{16}$ & $3-\quad 42$ & Not Reported & & & & 28373. & 3. \\
\hline $\mathrm{S}^{32}{ }_{*} \mathrm{HC}^{13}: \mathrm{C}^{12} \mathrm{HC}^{12} \mathrm{H}: \mathrm{C}^{12}{ }_{*} \mathrm{H}$ & 4-1167 & $3,1,2 \leftarrow 2,1,1$ & Ground & & & 28373.6 & .05 \\
\hline $\mathrm{C}^{13} \mathrm{H}_{3} \mathrm{C}^{12} \mathrm{O}^{16} \mathrm{C}^{12} \mathrm{~N}^{14}$ & 3. 672 & $11,3,8 \leftarrow 11,2,9$ & Ground & & & 28375.46 & .2 \\
\hline $\mathrm{C}^{12} \mathrm{H}_{3} \mathrm{~S}^{32} \mathrm{C}^{12} \mathrm{~N}^{14}$ & 3- 431 & $5, \quad \leftarrow 4$, & Excited & & & 28380. & 10. \\
\hline$\left(\mathrm{C}^{12} \mathrm{H}_{3}\right)_{3} \mathrm{As}^{75}$ & 3- 791 & $3,1 \leftarrow 2,1$ & Ground & $3 / 2$ & $3 / 2$ & 28380.00 & .05 \\
\hline $\mathrm{C}^{12} \mathrm{H}_{3} \mathrm{~N}^{14} \mathrm{H}_{2}$ & 3- 261 & Not Reported & Ground & & & 28380.93 & .1 \\
\hline $\mathrm{C}^{13} \mathrm{H}_{3} \mathrm{C}^{12} \mathrm{O}^{16} \mathrm{C}^{12} \mathrm{~N}^{14}$ & 3- 672 & $11,3,8 \leftarrow 11,2,9$ & Ground & & & 28381.10 & .2 \\
\hline $\mathrm{O}^{16} \mathrm{O}^{18} \mathrm{O}^{18}$ & $4-1844$ & $13,2,11 \leftarrow 14,1,14$ & Ground & & & 28384 . & \\
\hline $\mathrm{C}^{13}{ }_{*} \mathrm{H}: \mathrm{C}^{12} \mathrm{HO}^{16} \mathrm{C}^{12} \mathrm{H}: \mathrm{C}^{12}{ }_{*} \mathrm{H}$ & 4-1157 & $11,10,2 \leftarrow 11,8,3$ & Ground & & & 28384.5 & .1 \\
\hline $\mathrm{c}-\mathrm{C}^{12} \mathrm{HD}: \mathrm{C}^{12} \mathrm{DBr}^{79}$ & 4- 744 & $4,1,4 \leftarrow 3,1,3$ & Excited & $11 / 2$ & $9 / 2$ & 28387.4 & \\
\hline
\end{tabular}




\begin{tabular}{|c|c|c|c|c|c|c|c|}
\hline Isotopic Species & $\begin{array}{l}\text { Vol.-Id. } \\
\text { Nos. }\end{array}$ & $\begin{array}{c}\text { Rotational } \\
\text { Quantum Nos. }\end{array}$ & Vib. State - & $\mathrm{F}_{1}^{\prime} \stackrel{\text { Hyperfin }}{\mathrm{F}^{\prime}} \mathrm{F}_{1}$ & $\mathrm{~F}$ & $\begin{array}{l}\text { Frequency } \\
\quad \mathrm{MHz}\end{array}$ & $\begin{array}{r}\text { Acc. } \\
\pm \mathrm{MHz}\end{array}$ \\
\hline $\mathrm{C}^{12} \mathrm{D}_{3} \mathrm{Ce}^{70} \mathrm{H}_{3}$ & 3- 294 & $2,0 \leftarrow 1,0$ & Ground & & & 28389.10 & .10 \\
\hline $\mathrm{C}^{12} \mathrm{H}_{3} \mathrm{C}^{12} \mathrm{H}_{2} \mathbf{I}^{127}$ & 3. 571 & $5,1,5 \leftarrow 4,1,4$ & Ground & $7 / 2$ & $5 / 2$ & 28389.12 & \\
\hline $\mathrm{C}^{12} \mathrm{H}_{3} \mathrm{C}^{12} \mathrm{O}^{16} \mathrm{C}^{13} \mathrm{~N}^{14}$ & 3. 673 & $6,3,3 \leftarrow 6,2,4$ & Ground & & & 28389.86 & .2 \\
\hline$\left(\mathrm{C}^{12} \mathrm{H}_{3}\right)_{3} \mathrm{As}^{75}$ & 3. 791 & $3,0 \leftarrow 2,0$ & Ground & $3 / 2$ & $3 / 2$ & 28390.13 & .05 \\
\hline $\mathrm{C}^{12} \mathrm{H}_{3} \mathrm{C}^{12} \mathrm{H}_{2} \mathrm{I}^{127}$ & 3. 571 & $5,1,5 \leftarrow 4,1,4$ & Ground & $9 / 2$ & $7 / 2$ & 28390.42 & \\
\hline $\mathrm{c} \cdot \mathrm{C}^{12} \mathrm{HD}: \mathrm{C}^{12} \mathrm{DBr}^{79}$ & 4. 744 & $4,1,4 \leftarrow 3,1,3$ & Ground & $7 / 2$ & $7 / 2$ & 28391.3 & \\
\hline $\mathrm{B}_{5}^{\mathrm{b}} \mathrm{H}_{9}$ & 4. 65 & Not Reported & Ground & & & 28392. & .1 \\
\hline $\mathrm{Si}^{29} \mathrm{H}_{3} \mathrm{~F}^{19}$ & 4-1552 & $1, \leftarrow 0$ & Ground & & & 28393.4 & .2 \\
\hline $\mathrm{c}-\mathrm{C}^{12} \mathrm{HD}: \mathrm{C}^{12} \mathrm{DBr}^{79}$ & 4. 744 & $4,1,4 \leftarrow 3,1,3$ & Excited & $5 / 2$ & $3 / 2$ & 28394.1 & \\
\hline $\mathrm{c}-\mathrm{C}^{12} \mathrm{HD}: \mathrm{C}^{12} \mathrm{DBr}^{79}$ & 4- 744 & $4,1,4 \leftarrow 3,1,3$ & Excited & & & 28394.63 & .04 \\
\hline c- $\mathrm{C}^{12} \mathrm{HD}: \mathrm{C}^{12} \mathrm{DBr}^{79}$ & 4- 744 & $4,1,4 \leftarrow 3,1,3$ & Excited & $9 / 2$ & $7 / 2$ & 28399.45 & \\
\hline$\left(\mathrm{C}^{12} \mathrm{H}_{3}\right)_{3} \mathrm{As}^{75}$ & 3- 791 & $3,2 \leftarrow 2,2$ & Ground & $1 / 2$ & $1 / 2$ & 28400.43 & .05 \\
\hline$\left(\mathrm{C}^{12} \mathrm{H}_{3}\right)_{3} \mathrm{As}^{75}$ & 3- 791 & $3,2 \leftarrow 2,2$ & Ground & $3 / 2$ & $1 / 2$ & 28400.43 & .05 \\
\hline $\mathrm{C}^{12} \mathrm{H}_{3} \mathrm{C}^{12} \mathrm{H}_{2} \mathrm{I}^{127}$ & 3. 571 & $5,1,5 \leftarrow 4,1,4$ & Ground & $11 / 2$ & $9 / 2$ & 28405.78 & \\
\hline$\left(\mathrm{C}^{12} \mathrm{H}_{3}\right)_{3} \mathrm{C}^{12} \mathrm{Br}^{81}$ & 3. 962 & $7, \leftarrow 6$ & Ground & & & 28405.8 & .3 \\
\hline c-C $\mathrm{C}^{12} \mathrm{HD}: \mathrm{C}^{12} \mathrm{DBr}^{29}$ & 4. 744 & $4,1,4 \leftarrow 3,1,3$ & Excited & $7 / 2$ & $5 / 2$ & 28406.2 & \\
\hline $\mathrm{HC}^{13}: \mathrm{C}^{12} \mathrm{C}^{12} \mathrm{DO}^{16}$ & 4- 922 & Not Reported & & & & 28407. & 5. \\
\hline $\mathrm{C}^{12} \mathrm{H}_{2}\left(\mathrm{C}^{12} \mathrm{~N}^{14}\right)_{2}$ & 4. 901 & Not Reported & Ground & & & 28409.8 & .1 \\
\hline $\mathrm{C}^{12} \mathrm{D}_{3} \mathrm{C}^{12} \mathrm{O}^{16} \mathrm{C}^{12} \mathrm{~N}^{14}$ & 3- 675 & $4,1,3 \leftarrow 3,1,2$ & Ground & & & 28410.93 & .2 \\
\hline $\mathrm{C}^{13} \mathrm{H}_{3} \mathrm{I}^{127}$ & 4. 483 & $2,1 \leftarrow 1,1$ & Ground & $7 / 2$ & $7 / 2$ & 28411.19 & .08 \\
\hline $\mathrm{C}^{12} \mathrm{H}_{3} \mathrm{C}^{12} \mathrm{H}_{2} \mathbf{I}^{127}$ & 3- 571 & $5,1,5 \leftarrow 4,1,4$ & & $5 / 2$ & $3 / 2$ & 28413.20 & \\
\hline $\mathrm{H}_{2} \mathrm{C}^{12}: \mathrm{C}^{12} \mathrm{~F}_{2}^{19}$ & 4- 681 & Not Reported & & & & 28414.2 & .3 \\
\hline$c-\mathrm{C}^{12} \mathrm{HD}: \mathrm{C}^{12} \mathrm{DBr}^{79}$ & 4. 744 & $4,1,4 \leftarrow 3,1,3$ & Ground & $11 / 2$ & $9 / 2$ & 28416.1 & \\
\hline $\mathrm{HC}^{13}: \mathrm{C}^{12} \mathrm{C}^{12} \mathrm{DO}^{16}$ & 4. 922 & Not Reported & & & & 23420 . & 5. \\
\hline $\mathrm{C}^{12}{ }_{*} \mathrm{H}_{2} \mathrm{C}^{12} \mathrm{H}_{2} \mathrm{C}^{12} \mathrm{H}_{2} \mathrm{O}^{16}{ }_{*}$ & $4-1091$ & $10,9,2 \leftarrow 10,7,3$ & Excited & & & 28421.2 & .1 \\
\hline $\mathrm{C}^{12} \mathrm{H}_{3} \mathrm{C}^{12}{ }_{*} \mathrm{HO}^{16} \mathrm{C}^{12}{ }_{*} \mathrm{H}_{2}$ & 3. 761 & Not Reported & Ground & & & 28421.47 & .1 \\
\hline$c-\mathrm{C}^{12} \mathrm{HD}: \mathrm{C}^{12} \mathrm{DBr}^{79}$ & 4. 744 & $4,1,4 \leftarrow 3,1,3$ & Ground & $5 / 2$ & $3 / 2$ & 28422.4 & \\
\hline${ }^{c-C^{12}} \mathrm{HD}: \mathrm{C}^{12} \mathrm{DBr}^{79}$ & 4-. 744 & $4,1,4 \leftarrow 3,1,3$ & Ground & & & 28423.22 & .07 \\
\hline $\mathrm{C}^{12} \mathrm{H}_{3} \mathrm{C}^{12} \mathrm{H}_{2} \mathrm{I}^{127}$ & 3. 571 & $5,1,5 \leftarrow 4,1,4$ & Ground & $13 / 2$ & $11 / 2$ & 28425.40 & \\
\hline $\mathrm{c} \cdot \mathrm{C}^{12} \mathrm{HD}: \mathrm{C}^{12} \mathrm{DBr}^{79}$ & 4- 744 & $4,1,4 \leftarrow 3,1,3$ & Ground & $9 / 2$ & $7 / 2$ & 28427.9 & \\
\hline $\mathrm{C}^{12} \mathrm{H}_{3} \mathrm{C}^{12} \mathrm{H}_{2} \mathrm{I}^{127}$ & 3- 571 & $5,1,5 \leftarrow 4,1,4$ & Ground & $15 / 2$ & $13 / 2$ & 28433.50 & \\
\hline c. $\mathrm{C}^{12} \mathrm{HD}: \mathrm{C}^{12} \mathrm{DBr}^{79}$ & 4- 744 & $4,1,4 \leftarrow 3,1,3$ & Ground & $7 / 2$ & $5 / 2$ & 28434.6 & \\
\hline $\mathrm{C}^{12} \mathrm{H}_{3} \mathrm{C}^{12} \mathrm{H}_{2} \mathrm{Br}^{81}$ & 3- 522 & $5,1,4 \leftarrow 5,0,5$ & Ground & $11 / 2$ & $11 / 2$ & 28436.96 & .05 \\
\hline $\mathrm{HC}^{13}: \mathrm{C}^{12} \mathrm{C}^{12} \mathrm{DO}^{16}$ & 4- 922 & Not Reported & & & & 28438. & 5. \\
\hline $\mathrm{H}_{2} \mathrm{C}^{12}: \mathrm{C}^{12} \mathrm{~F}_{2}^{19}$ & 4- 681 & Not Reported & & & & 28438.1 & .3 \\
\hline $\mathrm{C}^{12} \mathrm{H}_{2}: \mathrm{C}^{12} \mathrm{HC}^{12} \mathrm{~N}^{14}$ & $4-1021$ & $3,0,3 \leftarrow 2,0,2$ & Ground & & & 28440.84 & \\
\hline $\mathrm{C}^{12} \mathrm{H}_{3} \mathrm{C}^{12} \mathrm{H}_{2} \mathrm{Br}^{81}$ & 3. 522 & $5,1,4 \leftarrow 5,0,5$ & Ground & $9 / 2$ & $9 / 2$ & 28443.22 & .05 \\
\hline $\mathrm{C}^{12} \mathrm{HD}: \mathrm{C}^{12} \mathrm{DBr}^{\mathrm{b}}$ & 4. 749 & Not Reported & Ground & & & 28443.7 & .1 \\
\hline $\mathrm{C}^{12} \mathrm{H}_{2} \mathrm{Cl}^{37} \mathrm{Si}^{28} \mathrm{H}_{3}$ & 3- 232 & $11,1,10 \leftarrow 11,0,11$ & Ground & & & 28445.64 & .2 \\
\hline $\mathrm{C}^{12} \mathrm{H}_{3} \mathrm{C}^{12} \mathrm{H}_{2} \mathrm{Br}^{79}$ & 3- 521 & $5,1,4 \leftarrow 5,0,5$ & Ground & $13 / 2$ & $11 / 2$ & 28445.75 & .05 \\
\hline $\mathrm{N}^{14} \mathrm{O}^{16} \mathrm{O}^{18}$ & $4-1803$ & $10,0,10 \leftarrow 9,1,9$ & Ground & & & 28446.98 & \\
\hline $\mathrm{C}^{12} \mathrm{H}_{3} \mathrm{C}^{12} \mathrm{D}_{2} \mathrm{Cl}^{35}$ & 3- 547 & $7,1,6 \leftarrow 7,0,7$ & Ground & $11 / 2$ & $11 / 2$ & 28448.6 & .05 \\
\hline $\mathrm{C}^{12} \mathrm{H}_{3} \mathrm{C}^{12} \mathrm{D}_{2} \mathrm{Cl}^{35}$ & 3. 547 & $7,1,6 \leftarrow 7,0,7$ & Ground & $17 / 2$ & $17 / 2$ & 28449.4 & .05 \\
\hline $\mathrm{C}^{12} \mathrm{HD}: \mathrm{C}^{12} \mathrm{DBr}^{\mathrm{b}}$ & 4. 749 & Not Reported & Ground & & & 28450.0 & .2 \\
\hline $\mathrm{C}^{12} \mathrm{H}_{3} \mathrm{C}^{12} \mathrm{D}_{2} \mathrm{Cl}^{35}$ & 3. 547 & $7,1,6 \leftarrow 7,0,7$ & Ground & & & 28451.00 & .05 \\
\hline
\end{tabular}




\section{Isotopic Species}

Vol.-Id. Rotational

Vib. State

$F^{\prime} F^{\prime} F$ Frequency Acc.

\begin{tabular}{|c|c|c|c|c|c|c|c|}
\hline $\mathrm{C}^{12} \mathrm{H}_{3} \mathrm{C}^{12} \mathrm{D}_{2} \mathrm{Cl}^{35}$ & 3- 547 & $7,1,6 \leftarrow 7,0,7$ & Ground & $13 / 2$ & $13 / 2$ & 284.52 .5 & .05 \\
\hline $\mathrm{C}^{12} \mathrm{H}_{3} \mathrm{C}^{12} \mathrm{D}_{2} \mathrm{CI}^{35}$ & 3- 547 & $7,1,6 \leftarrow 7,0,7$ & Ground & $15 / 2$ & $15 / 2$ & 2845.3 .3 & .0 .5 \\
\hline $\mathrm{C}^{12} \mathrm{H}_{3} \mathrm{C}^{12} \mathrm{H}_{2} \mathrm{Br}^{79}$ & 3- 521 & $5,1,4 \leftarrow 5,0,5$ & Ground & $11 / 2$ & $9 / 2$ & 284.53 .58 & .0 .5 \\
\hline $\mathrm{C}^{12} \mathrm{H}_{2}\left(\mathrm{C}^{12} \mathrm{~N}^{14}\right)_{2}$ & 4. 901 & Not Reported & Ground & & & 28453.7 & .1 \\
\hline $\mathrm{H}_{2} \mathrm{C}^{12}: \mathrm{C}^{12} \mathrm{~F}_{2}^{19}$ & 4. 681 & Not Reported & & & & 28455.1 & .3 \\
\hline $\mathrm{C}^{12} \mathrm{H}_{2}\left(\mathrm{C}^{12} \mathrm{~N}^{14}\right)\left(\mathrm{C}^{13} \mathrm{~N}^{14}\right)$ & 4. 905 & $10,1,9 \leftarrow 10,0,10$ & Ground & & & 28456.41 & \\
\hline $\mathrm{C}^{12} \mathrm{H}_{2}: \mathrm{C}^{12} \mathrm{HC}^{12} \mathrm{~N}^{14}$ & 4-1021 & $3,2,2 \leftarrow 2,2,1$ & Ground & & & 28457.34 & \\
\hline $\mathrm{C}^{12} \mathrm{H}_{3} \mathrm{C}^{12} \mathrm{H}_{2} \mathrm{Br}^{81}$ & 3. 522 & $5,1,4 \leftarrow 5,0,5$ & Ground & $13 / 2$ & $13 / 2$ & 28460.03 & .05 \\
\hline $\mathrm{C}^{\mathrm{b}} \mathrm{H}_{2}^{\mathrm{b}} \mathrm{Cl}^{\mathrm{b}} \mathrm{F}^{\mathrm{b}}$ & 4- 333 & Not Reported & & & & 28462.5 & 1. \\
\hline $\mathrm{C}^{12} \mathrm{H}_{3} \mathrm{C}^{12} \mathrm{H}_{2} \mathrm{Br}^{81}$ & 3- 522 & $5,1,4 \leftarrow 5,0,5$ & Ground & $7 / 2$ & $7 / 2$ & 28466.19 & .05 \\
\hline $\mathrm{HC}^{12}: \mathrm{C}^{12} \mathrm{C}^{12} \mathrm{HO}^{16}$ & 4- 911 & $3,1,2 \leftarrow 2,1,1$ & Ground & & & 28467.15 & .02 \\
\hline $\mathrm{C}^{12} \mathrm{H}_{3} \mathrm{C}^{12} \mathrm{O}^{16} \mathrm{C}^{13} \mathrm{~N}^{14}$ & 3- 673 & $11,3,8 \leftarrow 11,2,9$ & Ground & & & 28467.34 & .2 \\
\hline $\mathrm{HC}^{13}: \mathrm{C}^{12} \mathrm{C}^{12} \mathrm{DO}^{16}$ & 4- 922 & Not Reported & & & & 28468. & 5. \\
\hline $\mathrm{C}^{12} \mathrm{H}_{2}: \mathrm{C}^{12} \mathrm{HC}^{12} \mathrm{~N}^{14}$ & 4-1021 & $3,2,1 \leftarrow 2,2,0$ & Ground & & & 28470.75 & \\
\hline $\mathrm{C}^{12} \mathrm{H}_{3} \mathrm{C}^{12} \mathrm{O}^{16} \mathrm{C}^{13} \mathrm{~N}^{14}$ & 3. 673 & $11,3,8 \leftarrow 11,2,9$ & Ground & & & 28473.03 & .2 \\
\hline $\mathrm{C}^{12} \mathrm{H}_{3} \mathrm{C}^{12} \mathrm{H}_{2} \mathrm{Br}^{79}$ & 3. 521 & $5,1,4 \leftarrow 5,0,5$ & Ground & $15 / 2$ & $13 / 2$ & 28473.63 & .05 \\
\hline $\mathrm{C}^{12} \mathrm{H}_{2}\left(\mathrm{C}^{12} \mathrm{~N}^{14}\right)_{2}$ & 4. 901 & Not Reported & Ground & & & 28480.5 & .1 \\
\hline $\mathrm{C}^{12} \mathrm{H}_{3} \mathrm{C}^{12} \mathrm{H}_{2} \mathrm{Br}^{79}$ & 3- 521 & $5,1,4 \leftarrow 5,0,5$ & Ground & $9 / 2$ & $i / 2$ & 28480.95 & .05 \\
\hline $\mathrm{C}^{12}{ }_{*} \mathrm{H}_{2} \mathrm{C}^{12} \mathrm{H}_{2} \mathrm{C}^{12} \mathrm{H}_{2} \mathrm{O}^{16} *$ & 4-1091 & $10,9,2 \leftarrow 10,7,3$ & Excited & & & 28485.0 & .1 \\
\hline $\mathrm{S}^{32}{ }_{*} \mathrm{HC}^{12}: \mathrm{C}^{12} \mathrm{HC}^{12} \mathrm{H}: \mathrm{C}^{12}{ }_{*} \mathrm{H}$ & 4-1161 & $3,1,2 \leftarrow 2,1,1$ & Ground & & & 28488.6 & .1 \\
\hline $\mathrm{D}_{2} \mathrm{C}^{12}{ }_{*} \mathrm{O}^{16} \mathrm{C}^{12} * \mathrm{D}_{2}$ & 4- 843 & $6,3,3 \leftarrow 6,2,4$ & Ground & & & 28495 . & \\
\hline $\mathrm{C}^{12} \mathrm{H}_{3} \mathrm{C}^{12}{ }_{*} \mathrm{HO}^{16} \mathrm{C}^{12}{ }_{*} \mathrm{H}_{2}$ & 3. 761 & $29,14, \leftarrow 28,15$, & Ground & & & 28496.04 & .1 \\
\hline $\mathrm{C}^{12} \mathrm{H}_{3} \mathrm{C}^{12}{ }_{*} \mathrm{HO}^{16} \mathrm{C}^{12}{ }_{*} \mathrm{H}_{2}$ & 3- 761 & $29,14, \leftarrow 28,15$ & Ground & & & 28496.19 & .1 \\
\hline $\mathrm{C}^{12} \mathrm{H}_{3} \mathrm{C}^{12}{ }_{*} \mathrm{HO}^{16} \mathrm{C}^{12}{ }_{*} \mathrm{H}_{2}$ & $3-761$ & $29,14, \leftarrow 28,15$, & Ground & & & 28496.98 & .1 \\
\hline $\mathrm{C}^{12} \mathrm{H}_{3} \mathrm{O}^{16} \mathrm{H}$ & $3 \cdot 211$ & Not Reported & Ground & & & 28500 . & \\
\hline $\mathrm{C}^{12} \mathrm{H}_{2}: \mathrm{C}^{12} \mathrm{HC}^{12} \mathrm{~F}^{19}: \mathrm{C}^{12} \mathrm{H}_{2}$ & 3- 911 & $5,3,2 \leftarrow 5,2,3$ & Excited & & & 28501.20 & .03 \\
\hline $\mathrm{C}^{12} \mathrm{H}_{2} \mathrm{Cl}^{35} \mathrm{Si}^{28} \mathrm{H}_{3}$ & 3. 231 & $11,1,10 \leftarrow 11,0,11$ & Ground & & & 28501.29 & .2 \\
\hline $\mathrm{C}^{12} \mathrm{D}_{3} \mathrm{C}^{12} \mathrm{DO}^{16}$ & 3- 472 & $2,0,2 \leftarrow 2,1,1$ & Ground & & & 28506.78 & .4 \\
\hline $\mathrm{C}^{12} \mathrm{H}_{2}\left(\mathrm{C}^{12} \mathrm{~N}^{14}\right)_{2}$ & 4. 901 & Not Reported & Ground & & & 28509.6 & .1 \\
\hline $\mathrm{O}^{\mathrm{b}} \mathrm{O}^{\mathrm{b}} \mathrm{O}^{\mathrm{b}}$ & 4-1847 & Not Reported & & & & 28510. & \\
\hline $\mathrm{C}^{12} \mathrm{D}_{3} \mathrm{O}^{16} \mathrm{H}$ & 3- 214 & Not Reported & Ground & & & 28511.7 & .5 \\
\hline $\mathrm{B}^{11} \mathrm{~B}^{10} \mathrm{~B}_{3}^{11} \mathrm{H}_{9}$ & 4- 53 & $2,2,1 \leftarrow 1,1,1$ & Ground & & & 28513.8 & .2 \\
\hline $\mathrm{s}-\mathrm{C}^{12} \mathrm{H}_{2} \mathrm{DC}^{12} \mathrm{O}^{16} \mathrm{Cl}^{35}$ & 3- 365 & $8,2,6 \leftarrow 8,1,7$ & Ground & & & 28513.80 & .1 \\
\hline $\mathrm{C}^{12} \mathrm{H}_{3} \mathrm{C}^{12} \mathrm{O}^{16} \mathrm{C}^{13} \mathrm{~N}^{14}$ & 3. 673 & $9,2,7 \leftarrow 9,1,8$ & Ground & & & 28513.87 & .2 \\
\hline $\mathrm{s}-\mathrm{C}^{12} \mathrm{H}_{2} \mathrm{DC}^{12} \mathrm{O}^{16} \mathrm{Cl}^{35}$ & 3- 365 & $8,2,6 \leftarrow 8,1,7$ & Ground & & & 28514.05 & .2 \\
\hline $\mathrm{C}^{12} \mathrm{H}_{3} \mathrm{~N}^{14} \mathrm{H}_{2}$ & 3- 261 & $10,2, \leftarrow 9,3$, & Ground & & & 28515.45 & .1 \\
\hline $\mathrm{C}^{13} \mathrm{H}_{3} \mathbf{I}^{127}$ & 4. 483 & $2,0 \leftarrow 1,0$ & Ground & $9 / 2$ & $7 / 2$ & 28518.14 & .08 \\
\hline $\mathrm{C}^{12} \mathrm{H}_{2} \mathrm{Cl}^{35} \mathrm{C}^{12}: \mathrm{C}^{12} \mathrm{H}$ & 4. 991 & $5,1,5 \leftarrow 4,1,4$ & Ground & & & 28518.24 & \\
\hline $\mathrm{C}^{12} \mathrm{D}_{2} \mathrm{HC}^{12} \mathrm{~F}_{3}^{19}$ & $3-413$ & $2,1,1 \leftarrow 1,1,0$ & Ground & & & 28519.5 & .2 \\
\hline $\mathrm{c}-\mathrm{C}^{12} \mathrm{HD}: \mathrm{C}^{12} \mathrm{DBr}^{79}$ & 4. 744 & $4,1,4 \leftarrow 3,1,3$ & Ground & $9 / 2$ & $9 / 2$ & 28521.6 & \\
\hline $\mathrm{C}^{12} \mathrm{H}_{3} \mathrm{C}^{12} \mathrm{O}^{16} \mathrm{C}^{13} \mathrm{~N}^{14}$ & 3- 673 & $9,2,7 \leftarrow 9,1,8$ & Ground & & & 28521.60 & .2 \\
\hline $\mathrm{S}^{34} \mathrm{~F}_{5}^{19} \mathrm{Cl}^{37}$ & 4-1424 & $8, \leftarrow 7$, & Ground & & & 28522.04 & .5 \\
\hline $\mathrm{C}^{\mathrm{b}} \mathrm{H}_{2}^{\mathrm{b}} \mathrm{CI}^{\mathrm{b}} \mathrm{F}^{\mathrm{b}}$ & 4- 333 & Not Reported & & & & 28526.33 & .1 \\
\hline $\mathrm{HC}^{12}: \mathrm{C}^{12} \mathrm{C}^{12} \mathrm{HO}^{16}$ & 4. 911 & $3,1,2 \leftarrow 2,1,1$ & Excited & & & 28527.18 & .15 \\
\hline $\operatorname{Re}^{187} \mathrm{O}_{3}^{16} \mathrm{~F}^{19}$ & 4-1592 & $4,3 \leftarrow 3,3$ & Ground & & & 28529.35 & \\
\hline
\end{tabular}




\begin{tabular}{|c|c|c|c|c|c|c|c|}
\hline \multirow{2}{*}{ Isotopic Species } & \multirow{2}{*}{$\begin{array}{l}\text { Vol.-Id. } \\
\text { Nos. }\end{array}$} & \multirow{2}{*}{$\begin{array}{c}\text { Rotational } \\
\text { Quantum Nos. }\end{array}$} & \multirow{2}{*}{ Vib. State } & \multicolumn{2}{|c|}{ Hyperfine } & \multirow{2}{*}{$\begin{array}{c}\text { Frequency } \\
\text { MHz }\end{array}$} & \multirow{2}{*}{$\begin{aligned} & \text { Acc. } \\
& \pm \mathrm{MHz}\end{aligned}$} \\
\hline & & & & $F_{1}^{\prime} \quad F^{\prime} \quad F_{1}$ & $\mathbf{F}$ & & \\
\hline $\mathrm{HC}^{13}: \mathrm{C}^{12} \mathrm{C}^{12} \mathrm{DO}^{16}$ & 4- 922 & Not Reported & & & & 28530. & 5. \\
\hline $\mathrm{C}^{12} \mathrm{H}_{3} \mathrm{~S}^{32} \mathrm{H}$ & 3- 221 & Not Reported & Ground & & & 28530.1 & .1 \\
\hline $\mathrm{C}^{12} \mathrm{H}_{3} \mathrm{~N}^{14} \mathrm{H}_{2}$ & 3- 261 & $4,2, \leftarrow 5,1$, & Ground & & & 28533.92 & .1 \\
\hline $\mathrm{C}^{12} \mathrm{H}_{3} \mathrm{~N}^{14} \mathrm{H}_{2}$ & 3- 261 & $4,2, \leftarrow 5,1$, & Ground & & & 28534. & \\
\hline $\mathrm{C}^{12} \mathrm{D}_{3} \mathrm{C}^{12} \mathrm{DO}^{16}$ & 3- 472 & $2,0,2 \leftarrow 2,1,1$ & Ground & & & 28536.30 & .2 \\
\hline $\mathrm{S}^{32} \mathrm{~F}_{5}^{19} \mathrm{Cl}$ & $4-1422$ & $8, \leftarrow 7$, & Ground & & & 28536.32 & .5 \\
\hline $\operatorname{Re}^{185} \mathrm{O}_{3}^{16} \mathrm{~F}^{19}$ & $4-1591$ & $4,3 \leftarrow 3,3$ & Ground & & & 28537.27 & \\
\hline $\mathrm{B}_{2}^{10} \mathrm{~B}_{3}^{11} \mathrm{H}_{9}$ & 4. 54 & $2,1,1 \leftarrow 1,0,1$ & Ground & & & 28537.7 & .2 \\
\hline $\mathrm{C}^{12} \mathrm{H}_{3} \mathrm{Si}^{28} \mathrm{HF}_{2}^{19}-\mathrm{A}$ & 3- 191 & $10,5,6 \leftarrow 10,5,5$ & Ground & & & 28540.65 & \\
\hline $\mathrm{C}^{12} \mathrm{H}_{2}\left(\mathrm{C}^{12} \mathrm{~N}^{14}\right)_{2}$ & 4. 901 & Not Reported & Ground & & & 28541.7 & .1 \\
\hline $\mathrm{C}^{12} \mathrm{HD}: \mathrm{C}^{12} \mathrm{DBr}^{\mathrm{b}}$ & 4- 749 & Not Reported & Ground & & & 28542.2 & .1 \\
\hline $\mathrm{C}^{12} \mathrm{D}_{2} \mathrm{HC}^{12} \mathrm{~F}_{3}^{19}$ & 3. 413 & $3,1,3 \leftarrow 2,1,2$ & Ground & & & 28549.1 & .2 \\
\hline$F_{2}^{19} N^{14} N^{14} F_{2}^{19}$ & $3-\quad 21$ & $4,1,3 \leftarrow 3,0,3$ & Ground & & & 28549.9 & .3 \\
\hline $\mathrm{C}^{12} \mathrm{H}_{3} \mathrm{O}^{16} \mathrm{H}$ & 3- 211 & Not Reported & Ground & & & 28550 . & \\
\hline $\mathrm{C}^{13} \mathrm{H}_{3} \mathrm{I}^{127}$ & 4- 483 & $2,0 \leftarrow 1,0$ & Ground & $7 / 2$ & $5 / 2$ & 28550.86 & .08 \\
\hline $\mathrm{C}^{12} \mathrm{HD}: \mathrm{C}^{12} \mathrm{DBr}^{\mathrm{b}}$ & 4. 749 & Not Reported & Ground & & & 28556.9 & .1 \\
\hline$\left(\mathrm{C}^{12} \mathrm{H}_{3}\right)_{2} \mathrm{C}^{12}: \mathrm{C}^{12} \mathrm{H}_{2}$ & 3- 941 & $5,2,3 \leftarrow 5,1,4$ & Ground & & & 28557.28 & .05 \\
\hline $\mathrm{N}^{14} \mathrm{D}_{2} \mathrm{H}$ & $4-1774$ & $2,1,2 \leftarrow 2,0,2$ & Ground & & & 28560.90 & .05 \\
\hline $\mathrm{C}^{12} \mathrm{H}_{3} \mathrm{C}^{12} \mathrm{H}_{2} \mathrm{Cl}^{35}$ & 3- 541 & $5,0,5 \leftarrow 4,1,4$ & Ground & & & 28563.29 & .05 \\
\hline $\mathrm{C}^{12} \mathrm{H}_{3} \mathrm{C}^{12} \mathrm{H}_{2} \mathrm{Br}^{81}$ & 3- 522 & $4,1,4 \leftarrow 3,1,3$ & Ground & $11 / 2$ & $9 / 2$ & 28570.80 & \\
\hline $\mathrm{s}-\mathrm{C}^{12} \mathrm{H}_{2} \mathrm{DC}^{12} \mathrm{HO}^{16}$ & 3- 473 & Not Reported & & & & 28571.69 & \\
\hline $\mathrm{C}^{12}{ }_{*} \mathrm{D}_{2} \mathrm{C}^{12} \mathrm{H}_{2} \mathrm{C}^{12} \mathrm{D}_{2} \mathrm{O}^{16}{ }_{*}$ & 4-1092 & $6,4,3 \leftarrow 6,3,4$ & Excited & & & 28573. & 2. \\
\hline $\mathrm{C}^{12} \mathrm{H}_{3} \mathrm{C}^{12} \mathrm{H}_{2} \mathrm{Br}^{81}$ & $3 \cdot 522$ & $4,1,4 \leftarrow 3,1,3$ & Ground & & & 28576.3 & \\
\hline $\mathrm{C}^{12} \mathrm{H}_{3} \mathrm{C}^{12} \mathrm{H}_{2} \mathrm{Br}^{81}$ & 3- 522 & $4,1,4 \leftarrow 3,1,3$ & Ground & $5 / 2$ & $3 / 2$ & 28576.70 & \\
\hline $\mathrm{HC}^{13}: \mathrm{C}^{12} \mathrm{C}^{12} \mathrm{DO}^{16}$ & 4- 922 & Not Reported & & & & 28578. & 5. \\
\hline g- $\mathrm{C}^{12} \mathrm{H}_{3} \mathrm{C}^{12} \mathrm{H}_{2} \mathrm{C}^{12} \mathrm{H}_{2} \mathrm{Cl}^{37}$ & 3- 774 & $14,2,12 \leftarrow 14,1,13$ & Ground & & & 28578.27 & .2 \\
\hline $\mathrm{C}^{12} \mathrm{H}_{3} \mathrm{C}^{12} \mathrm{H}_{2} \mathrm{Br}^{81}$ & 3- 522 & $4,1,4 \leftarrow 3,1,3$ & Ground & $9 / 2$ & $7 / 2$ & 28579.50 & \\
\hline $\mathrm{HC}^{13} \mathrm{HO}^{16}$ & 4- 382 & $18,3,15 \leftarrow 18,3,16$ & Ground & & & 28582.40 & \\
\hline $\mathrm{C}^{12}{ }_{*} \mathrm{D}_{2} \mathrm{C}^{12} \mathrm{H}_{2} \mathrm{C}^{12} \mathrm{D}_{2} \mathrm{O}^{16}{ }_{*}$ & 4-1092 & $2,1,2 \leftarrow 1,0,1$ & Excited & & & 28582.65 & .1 \\
\hline $\mathrm{C}^{12} \mathrm{H}_{3} \mathrm{C}^{12} \mathrm{H}_{2} \mathrm{Br}^{81}$ & 3. 522 & $4,1,4 \leftarrow 3,1,3$ & Ground & $7 / 2$ & $5 / 2$ & 28585.70 & \\
\hline $\mathrm{s}-\mathrm{C}^{12} \mathrm{H}_{2} \mathrm{DC}^{12} \mathrm{HO}^{16}$ & 3- 473 & Not Reported & & & & 28586.2 & \\
\hline $\mathrm{HC}^{12}: \mathrm{C}^{12} \mathrm{C}^{12} \mathrm{HO}^{16}$ & 4- 911 & $3,1,2 \leftarrow 2,1,1$ & Excited & & & 28587.40 & .15 \\
\hline $\mathrm{C}^{12} \mathrm{H}_{2} \mathrm{Cl}^{37} \mathrm{C}^{12}: \mathrm{C}^{12} \mathrm{H}$ & 4- 992 & $9,1,8 \leftarrow 9,0,9$ & Ground & & & 28587.43 & \\
\hline $\mathrm{C}^{12} \mathrm{H}_{2} \mathrm{Cl}^{35} \mathrm{Si}^{28} \mathrm{D}_{3}$ & 3- 237 & $5,1,4 \leftarrow 4,1,3$ & Ground & & & 28592.69 & .2 \\
\hline $\mathrm{C}^{12} \mathrm{H}_{3} \mathrm{~S}^{32} \mathrm{H}$ & 3- 221 & Not Reported & Ground & & & 28593.5 & .1 \\
\hline $\mathrm{C}^{13} \mathrm{H}_{3} \mathrm{I}^{127}$ & 4- 483 & $2,1 \leftarrow 1,1$ & Ground & $9 / 2$ & $7 / 2$ & 28594.74 & .08 \\
\hline $\mathrm{t}-\mathrm{HDN}^{14} \mathrm{C}^{12} \mathrm{HO}^{16}$ & 3- 153 & $7,1,6 \leftarrow 6,2,5$ & Ground & & & 28596.20 & \\
\hline $\mathrm{C}^{12} \mathrm{D}_{3} \mathrm{~N}^{14} \mathrm{H}_{2}$ & 3- 263 & $2, \quad \leftarrow 2, \quad$ & & & & 28601.6 & .5 \\
\hline $\mathrm{HC}^{13}: \mathrm{C}^{12} \mathrm{C}^{12} \mathrm{DO}^{16}$ & 4. 922 & Not Reported & & & & 28602 & 5. \\
\hline $\mathrm{N}^{14} \mathrm{H}_{3}$ & $4-1771$ & $10,10 \leftarrow 10,10$ & Ground & & & 28604.73 & .10 \\
\hline $\mathrm{C}^{12} \mathrm{H}_{2}\left(\mathrm{C}^{12} \mathrm{~N}^{14}\right)_{2}$ & 4- 901 & Not Reported & Ground & & & 28605.5 & .1 \\
\hline $\mathrm{C}^{12} \mathrm{D}_{2} \mathrm{HC}^{12} \mathrm{~F}_{3}^{19}$ & 3- 413 & $3,1,3 \leftarrow 2,1,2$ & Ground & & & 28607.4 & .2 \\
\hline $\mathrm{t}-\mathrm{HDC}^{12}{ }_{*} \mathrm{O}^{16} \mathrm{C}^{12}{ }_{*} \mathrm{HD}$ & 4- 844 & $5,3,2 \leftarrow 5,2,3$ & Ground & & & 28611.8 & .2 \\
\hline $\mathrm{C}^{12} \mathrm{H}_{2}\left(\mathrm{C}^{12} \mathrm{~N}^{14}\right)_{2}$ & 4- 901 & Not Reported & Ground & & & 28612.1 & .1 \\
\hline $\mathrm{F}^{19} \mathrm{HC}^{12} \mathrm{O}^{16}$ & 4- 271 & $6,1,5 \leftarrow 6,1,6$ & & & & 28613.9 & .1 \\
\hline
\end{tabular}


Vol.-Id. Rotational

Nos. Quantum Nos.
Vib. State
Frequency

\begin{tabular}{|c|c|c|c|}
\hline $\mathrm{C}^{12}{ }_{*} \mathrm{D}_{2} \mathrm{C}^{12} \mathrm{H}_{2} \mathrm{C}^{12} \mathrm{D}_{2} \mathrm{O}^{16} *$ & 4-1092 & $2,1,2 \leftarrow 1,0,1$ & Excited \\
\hline $\mathrm{C}^{12} \mathrm{H}_{2} \mathrm{Cl}^{37} \mathrm{C}^{12}: \mathrm{C}^{12} \mathrm{H}$ & 4- 992 & $5,0,5 \leftarrow 4,0,4$ & Ground \\
\hline $\mathrm{C}^{13} \mathrm{H}_{3} \mathrm{O}^{16} \mathrm{H}$ & 3- 213 & $26,2, \leftarrow 26,1$, & Ground \\
\hline $\mathrm{C}^{12} \mathrm{D}_{3} \mathrm{~N}^{14} \mathrm{O}_{2}^{16}$ & 3- 172 & $2,1, \leftarrow 1,1$, & Ground \\
\hline$\left(\mathrm{C}^{12} \mathrm{H}_{3}\right)_{3} \mathrm{C}^{12} \mathrm{Br}^{79}$ & 3- 961 & $7, \leftarrow 6$, & Ground \\
\hline $\mathrm{C}^{12} \mathrm{H}_{3} \mathrm{C}^{12} \mathrm{H}_{2} \mathrm{C}^{12} \mathrm{~N}^{14}$ & 3- 731 & $6,1,5 \leftarrow 6,0,6$ & Ground \\
\hline$\left(\mathrm{C}^{12} \mathrm{H}_{3}\right)_{2} \mathrm{C}^{12} \mathrm{O}^{16}$ & 3. 751 & Not Reported & \\
\hline 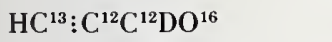 & 4. 922 & Not Reported & \\
\hline $\mathrm{C}^{12}{ }_{*} \mathrm{D}_{2} \mathrm{C}^{12} \mathrm{H}_{2} \mathrm{C}^{12} \mathrm{D}_{2} \mathrm{O}^{16}{ }_{*}$ & 4-1092 & $6,5,2 \leftarrow 6,4,3$ & Ground \\
\hline $\mathrm{C}^{12} \mathrm{D}_{2} \mathrm{HC}^{12} \mathrm{~F}_{3}^{19}$ & 3. 413 & $3,0,3 \leftarrow 2,0,2$ & Ground \\
\hline $\mathrm{N}^{14} \mathrm{O}^{16} \mathrm{O}^{18}$ & 4-1803 & $10,0,10 \leftarrow 9,1,9$ & Ground \\
\hline $\mathrm{C}^{12} \mathrm{H}_{2} \mathrm{Cl}^{35} \mathrm{Si}^{29} \mathrm{H}_{3}$ & 3. 234 & $11,1,10 \leftarrow 11,0,11$ & Ground \\
\hline $\mathrm{C}^{12} \mathrm{H}_{2}\left(\mathrm{C}^{12} \mathrm{~N}^{14}\right)_{2}$ & 4- 901 & $10,1,9 \leftarrow 10,0,10$ & Ground \\
\hline $\mathrm{C}^{12} \mathrm{HD}: \mathrm{C}^{12} \mathrm{HBr}^{\mathrm{b}}$ & 4- 748 & Not Reported & Ground \\
\hline $\mathrm{C}_{6}^{12} \mathrm{H}_{5} \mathrm{O}^{16} \mathrm{H}$ & $3-1051$ & $11,4,8 \leftarrow 11,3,9$ & Ground \\
\hline $\mathrm{C}^{12} \mathrm{H}_{3} \mathrm{C}^{12} \mathrm{HF}_{2}^{19}$ & 3- 461 & $9,7,3 \leftarrow 9,5,4$ & Ground \\
\hline $\mathrm{C}^{12} \mathrm{H}_{2} \mathrm{Cl}^{35} \mathrm{Si}^{29} \mathrm{H}_{3}$ & 3- 234 & $11,1,10 \leftarrow 11,0,11$ & Ground \\
\hline $\mathrm{HDO}_{2}^{16}$ & 3. 43 & $16, \quad \leftarrow 16, \quad$, & \\
\hline $\mathrm{C}^{13} \mathrm{H}_{3} \mathrm{C}^{12} \mathrm{H}_{2} \mathrm{Cl}^{35}$ & 3. 545 & $4,1,3 \leftarrow 4,0,4$ & Ground \\
\hline $\mathrm{C}^{12} \mathrm{H}_{2} \mathrm{Cl}^{35} \mathrm{Si}^{29} \mathrm{H}_{3}$ & 3- 234 & $11,1,10 \leftarrow 11,0,11$ & Ground \\
\hline $\mathrm{C}^{13} \mathrm{H}_{3} \mathrm{C}^{12} \mathrm{H}_{2} \mathrm{Cl}^{35}$ & 3- 545 & $4,1,3 \leftarrow 4,0,4$ & Ground \\
\hline $\mathrm{C}^{12} \mathrm{H}_{3} \mathrm{C}^{12}{ }_{*} \mathrm{H}_{2} \mathrm{O}^{16} \mathrm{C}^{12}{ }_{*} \mathrm{C}^{12} \mathrm{H}_{3}$ & 3- 951 & $2,2,1 \leftarrow 1,1,1$ & Ground \\
\hline $\mathrm{HC}^{12}: \mathrm{C}^{12} \mathrm{C}^{12} \mathrm{DO}^{16}$ & 4. 921 & $1,1,1 \leftarrow 2,0,2$ & Ground \\
\hline $\mathrm{C}^{13} \mathrm{H}_{3} \mathrm{C}^{12} \mathrm{H}_{2} \mathrm{Cl}^{35}$ & 3. 545 & $4,1,3 \leftarrow 4,0,4$ & Ground \\
\hline $\mathrm{N}^{14} \mathrm{O}^{16} \mathrm{O}^{18}$ & $4 \cdot 1803$ & $10,0,10 \leftarrow 9,1,9$ & Ground \\
\hline $\mathrm{C}^{13} \mathrm{H}_{3} \mathrm{C}^{12} \mathrm{H}_{2} \mathrm{Cl}^{35}$ & 3- 545 & $4,1,3 \leftarrow 4,0,4$ & Ground \\
\hline $\mathrm{C}^{12} \mathrm{HD}: \mathrm{C}^{12} \mathrm{DBr}^{\mathrm{b}}$ & 4- 749 & Not Reported & Ground \\
\hline $\mathrm{C}^{12} \mathrm{D}_{2} \mathrm{HC}^{12} \mathrm{~F}_{3}^{19}$ & 3- 413 & $3,2,2 \leftarrow 2,2,1$ & Ground \\
\hline $\mathrm{C}^{12} \mathrm{H}_{3} \mathrm{C}^{12} \mathrm{O}^{18} \mathrm{~F}^{19}$ & 3. 394 & $8,5,3 \leftarrow 8,5,4$ & Ground \\
\hline $\mathrm{C}^{12} \mathrm{HD}: \mathrm{C}^{12} \mathrm{DBr}^{b}$ & 4. 749 & Not Reported & Ground \\
\hline $\mathrm{C}^{12} \mathrm{H}_{2}\left(\mathrm{C}^{12} \mathrm{~N}^{14}\right)_{2}$ & 4. 901 & Not Reported & Ground \\
\hline $\mathrm{C}^{12} \mathrm{HD}: \mathrm{C}^{12} \mathrm{DBr}^{\mathrm{b}}$ & 4. 749 & Not Reported & Ground \\
\hline $\mathrm{C}^{13} \mathrm{H}_{3} \mathrm{I}^{127}$ & 4. 483 & $2,0 \leftarrow 1,0$ & Ground \\
\hline $\mathrm{HDO}_{2}^{16}$ & 3- 43 & $16, \quad \leftarrow 16$, & \\
\hline $\mathrm{C}^{12}{ }_{*} \mathrm{D}_{2} \mathrm{C}^{12} \mathrm{H}_{2} \mathrm{C}^{12} \mathrm{D}_{2} \mathrm{O}^{16}{ }_{*}$ & 4-1092 & $2,1,2 \leftarrow 1,0,1$ & Excited \\
\hline $\mathrm{Si}^{28} \mathrm{H}_{3} \mathrm{~F}^{19}$ & 4-1551 & $1, \leftarrow 0$, & Ground \\
\hline $\mathrm{C}^{12} \mathrm{O}^{18} \mathrm{~F}_{2}^{19}$ & 4. 213 & $2,0,2 \leftarrow 1,0,1$ & Ground \\
\hline $\mathrm{C}^{12} \mathrm{H}_{3} \mathrm{C}^{12}: \mathrm{C}^{12} \mathrm{C}^{12} \mathrm{H}_{2} \mathrm{Cl}^{37}$ & 3. 902 & $10,1,9 \leftarrow 9,1,8$ & Ground \\
\hline $\mathrm{C}^{12} \mathrm{D}_{2} \mathrm{HC}^{12} \mathrm{~F}_{3}^{19}$ & 3. 413 & $3,2,1 \leftarrow 2,2,0$ & Ground \\
\hline $\mathrm{C}^{12} \mathrm{D}_{3} \mathrm{C}^{12} \mathrm{O}^{16} \mathrm{Cl}^{37}$ & 3- 364 & $4,1,4 \leftarrow 3,0,3$ & Ground \\
\hline $\mathrm{C}^{12} \mathrm{D}_{3} \mathrm{C}^{12} \mathrm{O}^{16} \mathrm{Cl}^{37}$ & 3. 364 & $4,1,4 \leftarrow 3,0,3$ & Ground \\
\hline $\mathrm{C}^{12} \mathrm{D}_{3} \mathrm{C}^{12} \mathrm{O}^{16} \mathrm{Cl}^{37}$ & 3- 364 & $4,1,4 \leftarrow 3,0,3$ & Ground \\
\hline $\mathrm{C}^{12} \mathrm{D}_{3} \mathrm{C}^{12} \mathrm{O}^{16} \mathrm{Cl}^{37}$ & 3- 364 & $4,1,4 \leftarrow 3,0,3$ & Ground \\
\hline $\mathrm{C}^{12} \mathrm{D}_{3} \mathrm{C}^{12} \mathrm{O}^{16} \mathrm{Cl}^{37}$ & 3- 364 & $4,1,4 \leftarrow 3,0,3$ & Ground \\
\hline $\mathrm{C}^{12} \mathrm{H}_{3} \mathrm{C}^{12}: \mathrm{C}^{12} \mathrm{C}^{12} \mathrm{H}_{2} \mathrm{Cl}^{35}$ & 3- 901 & $10,0,10 \leftarrow 9,0,9$ & Ground \\
\hline
\end{tabular}

28614.75 . I

28617.83

$28621.04 \quad .1$

$28621.6 \quad .2$

$28622.2 \quad .3$

$28622.28 \quad .1$

28622.3

28624.55.

$28624.7 \quad .5$

$28625.8 \quad .2$

28626.13

$25 / 2 \quad 25 / 2 \quad 28626.79 \quad .05$

28626.87

$28628.4 \quad .2$

28629.7

$28630.2 \quad .1$

$28630.20 \quad .2$

28631.

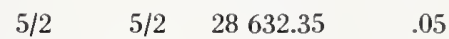

$23 / 2 \quad 23 / 2 \quad 28633.52 \quad .05$

$11 / 2 \quad 11 / 2 \quad 28634.10 \quad .05$

$28634.49 \quad .2$

$28635.67 \quad .02$

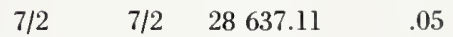

28638.28

$\begin{array}{llll}9 / 2 & 9 / 2 \quad 28 & 638.88 & .05\end{array}$

$28645.6 \quad .2$

$28645.7 \quad .2$

$28646.37 \quad .2$

$28647.0 \quad .2$

$28648.3 \quad .1$

$28648.8 \quad .2$

$\begin{array}{llll}5 / 2 & 5 / 2 \quad 28650.91 \quad .08\end{array}$

28651 . $\quad 3$.

$28654.5 \quad .5$

$28655.8 \quad .1$

$28658.85 \quad .10$

$28661.5 \quad .3$

$28661.7 \quad .2$

$28662.85 \quad .1$

$28664.17 \quad .1$

$11 / 2 \quad 9 / 2 \quad 28667.02$

$7 / 2 \quad 5 / 2 \quad 28667.02$

$9 / 2 \quad 7 / 2 \quad 28668.73$

28669.96
5

(1)

5

05

8

.05




\begin{tabular}{|c|c|c|c|c|c|c|c|}
\hline Isotopic Species & $\begin{array}{l}\text { Vol.-Id. } \\
\text { Nos. }\end{array}$ & $\begin{array}{c}\text { Rotational } \\
\text { Quantum Nos. }\end{array}$ & Vib. State & $\mathrm{F}_{1}^{\prime} \quad \begin{array}{c}\text { Hyperfine } \\
\mathrm{F}^{\prime}\end{array} \mathrm{F}_{1}$ & $\mathrm{~F}$ & $\begin{array}{l}\text { Frequency } \\
\quad \mathrm{MHz}\end{array}$ & $\begin{array}{r}\text { Acc. } \\
\pm \mathrm{MHz}\end{array}$ \\
\hline $\mathrm{C}^{12} \mathrm{H}_{2} \mathrm{C}^{37} \mathrm{C}^{12}: \mathrm{C}^{12} \mathrm{H}$ & 4- 992 & $5,2,4 \leftarrow 4,2,3$ & Ground & & & 28672.8 & \\
\hline $\mathrm{N}^{14} \mathrm{O}^{16} \mathrm{O}^{18}$ & $4-1803$ & $10,0,10 \leftarrow 9,1,9$ & Ground & & & 28674.0 & \\
\hline $\mathrm{S}_{2}^{32} \mathrm{O}^{16}$ & $4-1821$ & $3,0,3 \leftarrow 2,0,2$ & Ground & & & 28674.3 & \\
\hline $\mathrm{N}^{14} \dot{\mathrm{D}}_{2} \mathrm{H}$ & $4-1774$ & $5,2,4 \leftarrow 5,1,4$ & Ground & & & 28677.86 & .05 \\
\hline $\mathrm{C}^{12} \mathrm{H}_{3} \mathrm{C}^{12} \mathrm{O}^{16} \mathrm{C}^{12} \mathrm{~N}^{14}$ & 3. 671 & $11,3,8 \leftarrow 11,2,9$ & Ground & & & 28680.63 & .2 \\
\hline $\mathrm{C}^{12} \mathrm{HCl}^{37} \mathrm{~F}_{2}^{19}$ & 4- 252 & $4,3,2 \leftarrow 4,2,2$ & Ground & $5 / 2$ & $5 / 2$ & 28681.8 & .05 \\
\hline $\mathrm{C}^{12} \mathrm{H}_{3} \mathrm{C}^{12} \mathrm{O}^{18} \mathrm{~F}^{19}$ & 3- 394 & $8,5,3 \leftarrow 8,5,4$ & Ground & & & 28685.18 & .2 \\
\hline $\mathrm{C}^{12} \mathrm{HC}^{37} \mathrm{~F}_{2}^{19}$ & 4- 252 & $4,3,2 \leftarrow 4,2,2$ & Ground & $11 / 2$ & $11 / 2$ & 28685.5 & .05 \\
\hline $\mathrm{B}_{3}^{11} \mathrm{~B}_{2}^{10} \mathrm{H}_{9}$ & 4- 56 & $2,1,1 \leftarrow 1,0,1$ & Ground & & & 28686.5 & 1.0 \\
\hline $\mathrm{C}^{12} \mathrm{H}_{3} \mathrm{C}^{12} \mathrm{O}^{16} \mathrm{C}^{12} \mathrm{~N}^{14}$ & 3- 671 & $11,3,8 \leftarrow 11,2,9$ & Ground & & & 28686.62 & .2 \\
\hline $\mathrm{C}^{12} \mathrm{H}_{3} \mathrm{~S}^{32} \mathrm{H}$ & 3- 221 & Not Reported & Ground & & & 28686.8 & .1 \\
\hline $\mathrm{C}^{13} \mathrm{H}_{3}{ }^{127}$ & 4- 483 & $2,1 \leftarrow 1,1$ & Ground & $3 / 2$ & $3 / 2$ & 28687.21 & .08 \\
\hline $\mathrm{C}^{12} \mathrm{HC}^{37} \mathrm{~F}_{2}^{19}$ & 4- 252 & $4,3,2 \leftarrow 4,2,2$ & Ground & & & 28689.19 & .05 \\
\hline $\mathrm{B}_{3}^{11} \mathrm{~B}_{2}^{10} \mathrm{H}_{9}$ & 4- 56 & $2,2,0 \leftarrow 1,1,0$ & Ground & & & 28689.5 & .2 \\
\hline $\mathrm{C}^{12} \mathrm{HCl}^{37} \mathrm{~F}_{2}^{19}$ & 4- 252 & $4,3,2 \leftarrow 4,2,2$ & Ground & $7 / 2$ & $7 / 2$ & 28692.0 & .05 \\
\hline $\mathrm{D}_{2} \mathrm{O}_{2}^{16}$ & 3- 42 & Not Reported & & & & 28694. & 3. \\
\hline $\mathrm{B}_{3}^{11} \mathrm{~B}_{2}^{10} \mathrm{H}_{9}$ & 4- 56 & $2,2,1 \leftarrow 1,1,1$ & Ground & & & 28694.0 & .5 \\
\hline $\mathrm{C}^{12} \mathrm{H}_{2} \mathrm{C}^{13} \mathrm{C}^{12}: \mathrm{C}^{12} \mathrm{H}$ & 4- 992 & $5,3,2 \leftarrow 4,3,1$ & Ground & & & 28694.4 & \\
\hline $\mathrm{C}^{12} \mathrm{H}_{2} \mathrm{Cl}^{37} \mathrm{C}^{12}: \mathrm{C}^{12} \mathrm{H}$ & 4- 992 & $5,3,3 \leftarrow 4,3,2$ & Ground & & & 28694.4 & \\
\hline $\mathrm{C}^{12} \mathrm{H}_{3} \mathrm{Si}^{28} \mathrm{H}_{2} \mathrm{~F}^{19}$ & 3- 241 & Not Reported & & & & 28695.25 & .1 \\
\hline $\mathrm{C}^{12} \mathrm{HC}^{37} \mathrm{~F}_{2}^{19}$ & 4. 252 & $4,3,2 \leftarrow 4,2,2$ & Ground & $9 / 2$ & $9 / 2$ & 28695.6 & .05 \\
\hline $\mathrm{C}^{12} \mathrm{D}_{3} \mathrm{C}^{12} \mathrm{O}^{16} \mathrm{C}^{12} \mathrm{~N}^{14}$ & 3. 675 & $10,4,6 \leftarrow 10,3,7$ & Ground & & & 28695.97 & .2 \\
\hline $\mathrm{H}_{2} \mathrm{C}^{12}: \mathrm{C}^{12} \mathrm{~F}_{2}^{19}$ & 4- 681 & $7,6.2 \leftarrow 7,4,3$ & Ground & & & 28696. & 1. \\
\hline $\mathrm{C}^{12} \mathrm{HCl}^{37} \mathrm{~F}_{2}^{19}$ & 4. 252 & $10,4,7 \leftarrow 10,3,7$ & Ground & $17 / 2$ & $17 / 2$ & 28697.7 & .05 \\
\hline $\mathrm{C}^{12} \mathrm{H}_{2}\left(\mathrm{C}^{12} \mathrm{~N}^{14}\right)_{2}$ & 4. 901 & Not Reported & Ground & & & 28697.7 & .1 \\
\hline $\mathrm{C}^{12} \mathrm{HCl}^{37} \mathrm{~F}_{2}^{19}$ & 4- 252 & $10,4,7 \leftarrow 10,3,7$ & Ground & $23 / 2$ & $23 / 2$ & 28698.2 & .05 \\
\hline $\mathrm{S}_{2}^{32} \mathrm{O}^{16}$ & $4-1821$ & $3,2,2 \leftarrow 2,2,1$ & Ground & & & 28699.3 & \\
\hline $\mathrm{C}^{12} \mathrm{H}_{2} \mathrm{Cl}^{35} \mathrm{Si}^{28} \mathrm{D}_{3}$ & 3- 237 & $5,1,4 \leftarrow 4,1,3$ & Ground & & & 28700.44 & .2 \\
\hline $\mathrm{C}^{12} \mathrm{HC}^{37} \mathrm{~F}_{2}^{19}$ & 4- 252 & $10,4,7 \leftarrow 10,3,7$ & Ground & $19 / 2$ & $19 / 2$ & 28701.1 & .05 \\
\hline $\mathrm{C}^{12} \mathrm{HCl}^{37} \mathrm{~F}_{2}^{19}$ & 4- 252 & $10,4,7 \leftarrow 10,3,7$ & Ground & $21 / 2$ & $21 / 2$ & 28701.6 & .05 \\
\hline $\mathrm{HC}^{13}: \mathrm{C}^{12} \mathrm{C}^{12} \mathrm{DO}^{16}$ & 4- 922 & Not Reported & & & & 28702. & 5. \\
\hline $\mathrm{C}^{12} \mathrm{D}_{3} \mathrm{C}^{13} \mathrm{O}^{16} \mathrm{C}^{12} \mathrm{~N}^{14}$ & 3. 676 & $10,4,6 \leftarrow 10,3,7$ & Ground & & & 28705.21 & .2 \\
\hline $\mathrm{C}^{12} \mathrm{D}_{2} \mathrm{HC}^{12} \mathrm{~F}_{3}^{19}$ & 3- 413 & $3,2,1 \leftarrow 2,2,0$ & Ground & & & 28705.6 & .2 \\
\hline $\mathrm{C}^{13} \mathrm{H}_{3} \mathrm{Si}^{28} \mathrm{HF}_{2}^{19}-\mathrm{A}$ & 3. 195 & $3,2,2 \leftarrow 2,2,1$ & Ground & & & 28708.60 & \\
\hline $\mathrm{C}^{13} \mathrm{H}_{3} \mathrm{Si}^{28} \mathrm{HF}_{2}^{19}-\mathrm{E}$ & 3. 196 & $3,2,2 \leftarrow 2,2,1$ & Ground & & & 28708.60 & \\
\hline $\mathrm{C}^{12} \mathrm{H}_{3} \mathrm{C}^{12} \mathrm{O}^{16} \mathrm{Br}^{79}$ & 3- 351 & $11,3,8 \leftarrow 11,2,9$ & Ground & $23 / 2$ & $23 / 2$ & 28710.85 & .15 \\
\hline $\mathrm{C}^{12} \mathrm{H}_{3} \mathrm{C}^{12} \mathrm{O}^{16} \mathrm{Br}^{79}$ & 3- 351 & $11,3,8 \leftarrow 11,2,9$ & Ground & $21 / 2$ & $21 / 2$ & 28712.58 & .15 \\
\hline $\mathrm{B}_{2}^{10} \mathrm{~B}_{3}^{11} \mathrm{H}_{9}$ & 4- 54 & $2,2,0 \leftarrow 1,1,0$ & Ground & & & 28715. & 1.0 \\
\hline $\mathrm{B}^{10} \mathrm{~B}^{11} \mathrm{~B}^{10} \mathrm{~B}^{11} \mathrm{~B}^{10} \mathrm{H}_{9}$ & 4- 59 & $2,1,1 \leftarrow 1,0,1$ & Ground & & & 28715. & 1.0 \\
\hline $\mathrm{HC}^{13}: \mathrm{C}^{12} \mathrm{C}^{12} \mathrm{DO}^{16}$ & 4. 922 & Not Reported & & & & 28716. & 5. \\
\hline $\mathrm{C}^{12}{ }_{*} \mathrm{D}_{2} \mathrm{C}^{12} \mathrm{H}_{2} \dot{\mathrm{C}}^{12} \mathrm{D}_{2} \mathrm{O}^{16}{ }_{*}$ & $4-1092$ & $6,4,3 \leftarrow 6,3,4$ & Excited & & & 28716.5 & .5 \\
\hline $\mathrm{C}^{12} \mathrm{HD}: \mathrm{C}^{12} \mathrm{DBr}^{\mathrm{h}}$ & 4- 749 & Not Reported & Ground & & & 28718.4 & .1 \\
\hline $\mathrm{HC}^{12} \mathrm{O}^{16} \mathrm{O}^{16} \mathrm{C}^{13} \mathrm{H}_{3}-\mathrm{E}$ & 3- 512 & $5,1,4 \leftarrow 5,0,5$ & Ground & & & 28720.05 & .2 \\
\hline $\mathrm{C}^{12} \mathrm{D}_{3} \mathrm{C}^{12} \mathrm{O}^{16} \mathrm{~F}^{19}$ & 3- 392 & $2,1,1 \leftarrow 1,1,0$ & Ground & & & 28721.12 & .2 \\
\hline $\mathrm{S}_{2}^{32} \mathrm{O}^{16}$ & $4-1821$ & $3,2,1 \leftarrow 2,2,0$ & Ground & & & 28723.4 & \\
\hline
\end{tabular}


Vib. State

$F^{\prime} \stackrel{\text { Hyperfine }}{F^{\prime}} F_{1} \quad$ Frequency Acc.

\begin{tabular}{|c|c|c|c|c|c|c|c|}
\hline $\mathrm{C}^{12} \mathrm{H}_{3} \mathrm{C}^{12} \mathrm{O}^{16} \mathrm{Br}^{79}$ & 3- 351 & $11,3,8 \leftarrow 11,2,9$ & Ground & $25 / 2$ & $25 / 2$ & 28725.02 & .15 \\
\hline $\mathrm{C}^{12} \mathrm{HD}: \mathrm{C}^{12} \mathrm{DBr}^{\mathrm{h}}$ & 4- 749 & Not Reported & Ground & & & 28726.4 & .1 \\
\hline $\mathrm{C}^{12} \mathrm{H}_{3} \mathrm{C}^{12} \mathrm{O}^{16} \mathrm{Br}^{79}$ & 3- 351 & $11,3,8 \leftarrow 11,2,9$ & Ground & $19 / 2$ & $19 / 2$ & 28726.92 & .15 \\
\hline $\mathrm{HDC}^{12}: \mathrm{C}^{12} \mathrm{~F}_{2}^{19}$ & 4- 682 & $5,4,2 \leftarrow 5,2,3$ & Ground & & & 28728.4 & .3 \\
\hline $\mathrm{B}^{11} \mathrm{~B}^{10} \mathrm{~B}^{11} \mathrm{~B}^{10} \mathrm{~B}^{11} \mathrm{H}_{9}$ & 4- 55 & $2,2,0 \leftarrow 1,1,0$ & Ground & & & 28732. & 1.0 \\
\hline $\mathrm{C}^{12} \mathrm{H}_{2}\left(\mathrm{C}^{12} \mathrm{~N}^{14}\right)_{2}$ & 4- 901 & $2,1,2 \leftarrow 1,0,1$ & Ground & & & 28732.50 & \\
\hline $\mathrm{C}^{12} \mathrm{H}_{3} \mathrm{C}^{12} \mathrm{H}_{2} \mathrm{Br}^{79}$ & 3- 521 & $4,1,4 \leftarrow 3,1,3$ & Ground & $11 / 2$ & $9 / 2$ & 28733.50 & \\
\hline $\mathrm{C}^{12} \mathrm{HD}: \mathrm{C}^{12} \mathrm{DBr}^{\mathrm{b}}$ & 4- 749 & Not Reported & Ground & & & 28734.4 & .1 \\
\hline $\mathrm{C}^{12} \mathrm{D}_{2} \mathrm{HC}^{12} \mathrm{~F}_{3}^{19}$ & 3- 413 & $3,1,2 \leftarrow 2,1,1$ & Ground & & & 28734.7 & .2 \\
\hline $\mathrm{Si}^{30} \mathrm{~F}_{3}^{19} \mathrm{H}$ & $4-1645$ & $2, \leftarrow 1$, & Ground & & & 28734.80 & .1 \\
\hline $\mathrm{HC}^{12} \mathrm{O}^{16} \mathrm{O}^{16} \mathrm{C}^{13} \mathrm{H}_{3}-\mathrm{A}$ & 3- 511 & $5,1,4 \leftarrow 5,0,5$ & Ground & & & 28735.17 & .2 \\
\hline$\left(\mathrm{C}^{12} \mathrm{H}_{3}\right)_{2} \mathrm{~S}^{32}$ & $3 \cdot 601$ & $4,1,3 \leftarrow 3,2,2$ & Ground & & & 28738.25 & .05 \\
\hline$\left(\mathrm{C}^{12} \mathrm{H}_{3}\right)_{2} \mathrm{~S}^{32}$ & 3- 601 & $4,1,3 \leftarrow 3,2,2$ & Ground & & & 28738.69 & .05 \\
\hline$\left(\mathrm{C}^{12} \mathrm{H}_{3}\right)_{2} \mathrm{~S}^{32}$ & 3- 601 & $4,1,3 \leftarrow 3,2,2$ & Ground & & & 28739.14 & .05 \\
\hline $\mathrm{s}-\mathrm{C}^{12} \mathrm{H}_{2} \mathrm{DC}^{12} \mathrm{O}^{16} \mathrm{Cl}^{35}$ & 3- 365 & $10,3,7 \leftarrow 10,2,8$ & Ground & & & 28739.25 & .2 \\
\hline $\mathrm{C}^{12} \mathrm{H}_{3} \mathrm{C}^{12} \mathrm{H}_{2} \mathrm{Br}^{79}$ & 3- 521 & $4,1,4 \leftarrow 3,1.3$ & Ground & & & 28740.1 & \\
\hline $\mathrm{C}^{12} \mathrm{HD}: \mathrm{C}^{12} \mathrm{DBr}^{\mathrm{b}}$ & 4. 749 & Not Reported & Ground & & & 28740.5 & .2 \\
\hline $\mathrm{C}^{12} \mathrm{H}_{3} \mathrm{C}^{12} \mathrm{H}_{2} \mathrm{Br}^{79}$ & 3- 521 & $4,1,4 \leftarrow 3,1,3$ & Ground & $5 / 2$ & $3 / 2$ & 28740.80 & \\
\hline $\mathrm{C}_{6}^{12} \mathrm{H}_{5} \mathrm{O}^{16} \mathrm{H}$ & $3-1051$ & $11,4,8 \leftarrow 11,3,9$ & Ground & & & 28741.2 & \\
\hline $\mathrm{C}^{12} \mathrm{H}_{3} \mathrm{C}^{12}: \mathrm{C}^{12} \mathrm{C}^{12} \mathrm{H}_{2} \mathrm{Cl}^{35}$ & 3. 901 & $10,2,9 \leftarrow 9,2,8$ & Ground & & & 28743.74 & .05 \\
\hline $\mathrm{C}^{12} \mathrm{H}_{3} \mathrm{C}^{12} \mathrm{H}_{2} \mathrm{Br}^{79}$ & 3- 521 & $4,1,4 \leftarrow 3,1,3$ & Ground & $9 / 2$ & $7 / 2$ & 28743.80 & \\
\hline $\mathrm{C}^{\mathrm{b}} \mathrm{H}_{2}^{\mathrm{b}} \mathrm{Cl}^{\mathrm{b}} \mathrm{F}^{\mathrm{b}}$ & 4- 333 & Not Reported & & & & 28746.70 & .1 \\
\hline $\mathrm{C}^{13} \mathrm{H}_{3} \mathrm{O}^{16} \mathrm{H}$ & 3- 213 & $12,2, \leftarrow 12,1$, & Ground & & & 28747.67 & .1 \\
\hline $\mathrm{C}^{12} \mathrm{H}_{3} \mathrm{~S}^{32} \mathrm{H}$ & 3- 221 & $10,1,9 \leftarrow 10,1,10$ & Ground & & & 28747.9 & .1 \\
\hline $\mathrm{C}^{12} \mathrm{HD}: \mathrm{C}^{12} \mathrm{DBr}^{13}$ & 4- 749 & Not Reported & Ground & & & 28749.6 & .1 \\
\hline $\mathrm{H}_{2}^{\mathrm{b}} \mathrm{C}^{\mathrm{b}} \mathrm{O}^{16} \mathrm{C}^{\mathrm{b}}{ }_{*} \mathrm{H}_{2}^{\mathrm{b}}$ & 4. 846 & Not Reported & Excited & & & 28751.0 & .3 \\
\hline $\mathrm{C}^{12} \mathrm{H}_{3} \mathrm{C}^{12} \mathrm{H}_{2} \mathrm{Br}^{79}$ & 3- 521 & $4,1,4 \leftarrow 3,1,3$ & Ground & $7 / 2$ & $5 / 2$ & 28751.00 & \\
\hline $\mathrm{P}^{31} \mathrm{H}_{3}^{\mathrm{h}}$ & $4-1785$ & Not Reported & & & & 28759.35 & .05 \\
\hline $\mathrm{C}^{37} \mathrm{~F}^{19} \mathrm{C}^{12} \mathrm{O}^{16}$ & 4- 152 & $7,3,4 \leftarrow 7,2,5$ & Ground & & & 28761.07 & .05 \\
\hline $\mathrm{HC}^{13}: \mathrm{C}^{12} \mathrm{C}^{12} \mathrm{DO}^{16}$ & 4- 922 & Not Reported & & & & 28762. & 5. \\
\hline $\mathrm{c}-\mathrm{C}^{12} \mathrm{HD}: \mathrm{C}^{12} \mathrm{DBr}^{81}$ & 4- 746 & $4,0,4 \leftarrow 3,0,3$ & Ground & $5 / 2$ & $5 / 2$ & 28767.2 & \\
\hline $\mathrm{C}^{12} \mathrm{H}_{3} \mathrm{C}^{12}: \mathrm{C}^{12} \mathrm{C}^{12} \mathrm{H}_{2} \mathrm{Cl}^{35}$ & 3- 901 & $10,4,6 \leftarrow 9,4,5$ & Ground & & & 28770.2 & .15 \\
\hline $\mathrm{C}^{12} \mathrm{H}_{3} \mathrm{C}^{12}: \mathrm{C}^{12} \mathrm{C}^{12} \mathrm{H}_{2} \mathrm{Cl}^{35}$ & 3- 901 & $10,3.8 \leftarrow 9,3,7$ & Ground & & & 28770.2 & .15 \\
\hline $\mathrm{C}^{12} \mathrm{H}_{3} \mathrm{C}^{12}: \mathrm{C}^{12} \mathrm{C}^{12} \mathrm{H}_{2} \mathrm{Cl}^{35}$ & 3- 901 & $10,4,7 \leftarrow 9,4,6$ & Ground & & & 28770.2 & .15 \\
\hline$\left(\mathrm{C}^{12} \mathrm{H}_{3}\right)_{2} \mathrm{C}^{12}: \mathrm{C}^{12} \mathrm{H}_{2}$ & 3- 941 & $4,1,3 \leftarrow 4,0,4$ & Ground & & & 28771.06 & .05 \\
\hline $\mathrm{C}^{12} \mathrm{H}_{3} \mathrm{C}^{12}: \mathrm{C}^{12} \mathrm{C}^{12} \mathrm{H}_{2} \mathrm{Cl}^{35}$ & 3- 901 & $10,3,7 \leftarrow 9,3,6$ & Ground & & & 28772.3 & .15 \\
\hline$\left(\mathrm{C}^{12} \mathrm{H}_{3}\right)_{2} \mathrm{C}^{12}: \mathrm{C}^{12} \mathrm{H}_{2}$ & 3- 941 & $6,4,3 \leftarrow 6,3,4$ & Ground & & & 28775.67 & .05 \\
\hline $\mathrm{C}^{12}{ }_{*} \mathrm{D}_{2} \mathrm{C}^{12} \mathrm{H}_{2} \mathrm{C}^{12} \mathrm{D}_{2} \mathrm{O}^{16}{ }_{*}$ & $4-1092$ & $12,8.4 \leftarrow 12,7,5$ & Ground & & & 28778. & 2. \\
\hline $\mathrm{C}^{12} \mathrm{~F}_{3}^{19} \mathrm{C}^{12} \vdots \mathrm{C}^{12} \mathrm{H}$ & 4- 871 & $5,1 \leftarrow 4,1$ & Ground & & & 28779.31 & .10 \\
\hline $\mathrm{C}^{12} \mathrm{~F}_{3}^{19} \mathrm{C}^{12}: \mathrm{C}^{12} \mathrm{H}$ & 4. 871 & 5. $0 \leftarrow 4,0$ & Ground & & & 28779.31 & .10 \\
\hline $\mathrm{Si}^{29} \mathrm{~F}_{3}^{19} \mathrm{H}$ & 4-1643 & $2, \leftarrow 1$, & Ground & & & 28782.65 & .1 \\
\hline $\mathrm{C}^{12} \mathrm{H}_{3} \mathrm{~S}^{32} \mathrm{H}$ & 3- 221 & Not Reported & Ground & & & 28786.0 & .1 \\
\hline $\mathrm{C}^{12} \mathrm{H}_{3} \mathrm{C}^{12} \mathrm{HO}^{16}$ & 3- 471 & Not Reported & & & & 28788.00 & \\
\hline $\mathrm{C}^{12} \mathrm{H}_{3} \mathrm{C}^{12} \mathrm{HO}^{16}$ & 3- 471 & Not Reported & & & & 28789.01 & \\
\hline
\end{tabular}




\begin{tabular}{|c|c|c|c|c|c|c|c|}
\hline Isotopic Species & $\begin{array}{l}\text { Vol.-Id. } \\
\text { Nos. }\end{array}$ & $\begin{array}{c}\text { Rotational } \\
\text { Quantum Nos. }\end{array}$ & Vib. State & $\mathrm{F}_{1}^{\prime} \quad \stackrel{\text { Hyperfine }}{\mathrm{F}^{\prime} \quad \mathrm{F}_{1}}$ & e $F$ & $\begin{array}{l}\text { Frequency } \\
\qquad \mathrm{MHz}\end{array}$ & $\begin{aligned} & \text { Acc. } \\
& \pm \mathrm{MHz}\end{aligned}$ \\
\hline $\mathrm{C}^{13} \mathrm{H}_{3} \mathrm{C}^{12} \mathrm{O}^{16} \mathrm{C}^{12} \mathrm{~N}^{14}$ & 3- 672 & $9,2,7 \leftarrow 9,1,8$ & Ground & & & 28789.33 & .2 \\
\hline $\mathrm{C}^{12}{ }_{*} \mathrm{DHC}^{12} \mathrm{H}: \mathrm{C}^{12}{ }_{*} \mathrm{H}$ & 4-1034 & $12,6,6 \leftarrow 12,6,7$ & Ground & & & 28790.1 & \\
\hline $\mathrm{D}_{2} \mathrm{O}_{2}^{16}$ & 3- 42 & Not Reported & & & & 28793. & 3. \\
\hline $\mathrm{C}^{13} \mathrm{H}_{3} \mathrm{C}^{12} \mathrm{O}^{16} \mathrm{C}^{12} \mathrm{~N}^{14}$ & 3- 672 & $9,2,7 \leftarrow 9,1,8$ & Ground & & & 28796.36 & .2 \\
\hline $\mathrm{C}^{12} \mathrm{H}_{3} \mathrm{C}^{12} \mathrm{HO}^{16}$ & 3- 471 & $14,2,12 \leftarrow 14,2,13$ & Ground & & & 28797.83 & .2 \\
\hline $\mathrm{t}-\mathrm{C}^{12} \mathrm{H}_{2} \mathrm{DC}^{12} \mathrm{H}_{2} \mathrm{Cl}^{35}$ & 3- 543 & $4,1,3 \leftarrow 4,0,4$ & Ground & $5 / 2$ & $5 / 2$ & 28801.67 & .05 \\
\hline $\mathrm{D}_{2} \mathrm{O}_{2}^{16}$ & 3- 42 & Not Reported & & & & 28802. & 3. \\
\hline $\mathrm{t}-\mathrm{C}^{12} \mathrm{H}_{2} \mathrm{DC}^{12} \mathrm{H}_{2} \mathrm{Cl}^{35}$ & 3- 543 & $4,1,3 \leftarrow 4,0,4$ & Ground & $11 / 2$ & $11 / 2$ & 28803.29 & .05 \\
\hline t. $-\mathrm{C}^{12} \mathrm{H}_{2} \mathrm{DC}^{12} \mathrm{H}_{2} \mathrm{Cl}^{35}$ & 3- 543 & $4,1,3 \leftarrow 4,0,4$ & Ground & $7 / 2$ & $7 / 2$ & 28806.52 & .05 \\
\hline $\mathrm{C}^{12} \mathrm{HD}: \mathrm{C}^{12} \mathrm{DBr}^{\mathrm{b}}$ & 4- 749 & Not Reported & Ground & & & 28806.75 & .1 \\
\hline $\mathrm{C}^{12}{ }_{*} \mathrm{D}_{2} \mathrm{C}^{12} \mathrm{H}_{2} \mathrm{C}^{12} \mathrm{D}_{2} \mathrm{O}^{16}{ }_{*}$ & 4-1092 & $4,1,3 \leftarrow 4,0,4$ & Ground & & & 28806.9 & .1 \\
\hline $\mathrm{t}-\mathrm{C}^{12} \mathrm{H}_{2} \mathrm{DC}^{12} \mathrm{H}_{2} \mathrm{Cl}^{35}$ & 3- 543 & $4,1,3 \leftarrow 4,0,4$ & Ground & $9 / 2$ & $9 / 2$ & 28808.10 & .05 \\
\hline c- $\mathrm{C}^{12} \mathrm{HD}: \mathrm{C}^{12} \mathrm{DBr}^{81}$ & 4- 746 & $4,3,2 \leftarrow 3,3,1$ & Ground & $5 / 2$ & $3 / 2$ & 28808.8 & \\
\hline $\mathrm{C}^{12} \mathrm{HD}: \mathrm{C}^{12} \mathrm{DBr}^{\mathrm{b}}$ & 4- 749 & Not Reported & Ground & & & 28809.5 & .1 \\
\hline $\mathrm{C}^{12} \mathrm{H}_{3} \mathrm{C}^{12} \mathrm{H}_{2} \mathrm{Cl}^{37}$ & 3- 542 & $4,1,3 \leftarrow 4,0,4$ & Ground & $5 / 2$ & $5 / 2$ & 28810.74 & .05 \\
\hline $\mathrm{F}^{19} \mathrm{H}_{2} \mathrm{C}_{2}^{12} \mathrm{H}_{2} \mathrm{Cl}^{35}$ & 3- 441 & $6,0,6 \leftarrow 5,1,5$ & Ground & & & 28812. & .1 \\
\hline $\mathrm{C}^{12} \mathrm{H}_{3} \mathrm{C}^{12} \mathrm{H}_{2} \mathrm{Cl}^{37}$ & 3- 542 & $4,1,3 \leftarrow 4,0,4$ & Ground & $11 / 2$ & $11 / 2$ & 28812.06 & .05 \\
\hline $\mathrm{C}^{12} \mathrm{H}_{3} \mathrm{C}^{12} \mathrm{H}_{2} \mathrm{Cl}^{37}$ & 3- 542 & $4,1,3 \leftarrow 4,0,4$ & Ground & $7 / 2$ & $7 / 2$ & 28814.56 & .05 \\
\hline $\mathrm{C}^{12} \mathrm{H}_{3} \mathrm{C}^{12} \mathrm{H}_{2} \mathrm{Cl}^{37}$ & 3- 542 & $4,1,3 \leftarrow 4,0,4$ & Ground & $9 / 2$ & $9 / 2$ & 28815.92 & .05 \\
\hline $\mathrm{C}^{12} \mathrm{~F}_{3}^{19} \mathrm{C}^{12}: \mathrm{C}^{12} \mathrm{H}$ & 4- 871 & $5,1 \leftarrow 4,1$ & Excited & & & 28816.48 & .20 \\
\hline $\mathrm{C}^{12}{ }_{*} \mathrm{D}_{2} \mathrm{C}^{12} \mathrm{H}_{2} \mathrm{C}^{12} \mathrm{D}_{2} \mathrm{O}^{16}{ }_{*}$ & $4-1092$ & $8,4,4 \leftarrow 8,3,5$ & Ground & & & 28818.6 & .1 \\
\hline c- $\mathrm{C}^{12} \mathrm{HD}: \mathrm{C}^{12} \mathrm{DBr}^{81}$ & 4- 746 & $4,3,2 \leftarrow 3,3,1$ & Ground & $9 / 2$ & $9 / 2$ & 28819.8 & \\
\hline $\mathrm{N}^{14} \mathrm{O}^{16} \mathrm{Br}^{\mathrm{b}}$ & 4- 123 & $4, \quad \leftarrow 3, \quad$, & & & & 28820.1 & \\
\hline $\mathrm{C}^{12} \mathrm{H}_{3} \mathrm{P}^{31} \mathrm{H}_{2}$ & 3- 271 & $9,1,9 \leftarrow 8,2,7$ & Ground & & & 28820.8 & .1 \\
\hline $\mathrm{s}-\mathrm{C}^{12} \mathrm{DH}_{2} \mathrm{C}^{12} \mathrm{H}_{2} \mathrm{C}^{12} \mathrm{H}_{3}$ & 3- 785 & $5,1,4 \leftarrow 5,0,5$ & Ground & & & 28822.23 & .06 \\
\hline $\mathrm{c}-\mathrm{C}^{12} \mathrm{HD}: \mathrm{C}^{12} \mathrm{DBr}^{81}$ & 4- 746 & $4,0,4 \leftarrow 3,0,3$ & Ground & $7 / 2$ & $7 / 2$ & 28822.7 & \\
\hline $\mathrm{N}^{14} \mathrm{O}^{16} \mathrm{Br}^{\mathrm{b}}$ & 4. 123 & $4, \quad, \leftarrow 3$, & & & & 28823.9 & \\
\hline $\mathrm{HC}^{13}: \mathrm{C}^{12} \mathrm{C}^{12} \mathrm{DO}^{16}$ & 4- 922 & Not Reported & & & & 28825. & 5. \\
\hline $\mathrm{c}-\mathrm{C}^{12} \mathrm{HD}: \mathrm{C}^{12} \mathrm{DBr}^{81}$ & 4- 746 & $4,2,3 \leftarrow 3,2,2$ & Excited & $5 / 2$ & $3 / 2$ & 28825.5 & \\
\hline $\mathrm{N}^{14} \mathrm{O}^{16} \mathrm{Br}^{1}$ & 4- 123 & $4, \quad, \leftarrow 3,$, & & & & 28827.4 & \\
\hline $\mathrm{C}^{12} \mathrm{H}_{3} \mathrm{C}^{12}: \mathrm{C}^{12} \mathrm{C}^{12} \mathrm{H}_{2} \mathrm{Cl}^{35}$ & 3. 901 & $10,2,8 \leftarrow 9,2,7$ & Ground & & & 28828.23 & .05 \\
\hline $\mathrm{N}^{14} \mathrm{O}^{16} \mathrm{Br}^{\mathrm{b}}$ & 4- 123 & $4, \quad, \leftarrow 3$, & & & & 28829.4 & \\
\hline $\mathrm{C}^{12} \mathrm{HD}: \mathrm{C}^{12} \mathrm{DBr}^{\mathrm{b}}$ & 4- 749 & Not Reported & Ground & & & 28829.8 & .2 \\
\hline $\mathrm{HC}^{13}: \mathrm{C}^{12} \mathrm{C}^{12} \mathrm{DO}^{16}$ & 4- 922 & Not Reported & & & & 28830. & 5. \\
\hline $\mathrm{C}^{12} \mathrm{HD}: \mathrm{C}^{12} \mathrm{DBr}^{\mathrm{b}}$ & 4- 749 & Not Reported & Ground & & & 28830.3 & .1 \\
\hline $\mathrm{H}_{2} \mathrm{~N}^{14} \mathrm{~N}^{14} \mathrm{H}_{2}$ & 3. 51 & Not Reported & Ground & & & 28830.5 & \\
\hline$\left(\mathrm{C}^{12} \mathrm{H}_{3}\right)_{2} \mathrm{C}^{12}: \mathrm{C}^{12} \mathrm{H}_{2}$ & 3. 941 & $4,2,3 \leftarrow 4,1,4$ & Ground & & & 28830.61 & .05 \\
\hline $\mathrm{N}^{14} \mathrm{O}^{16} \mathrm{Br}^{\mathrm{b}}$ & 4- 123 & $4, \quad \leftarrow 3$, & & & & 28831.7 & \\
\hline $\mathrm{Si}^{28} \mathrm{~F}_{3}^{19} \mathrm{H}$ & $4-1641$ & $2, \leftarrow 1$, & Ground & & & 28831.90 & .1 \\
\hline $\mathrm{C}^{12} \mathrm{~F}_{3}^{19} \mathrm{C}^{12}: \mathrm{C}^{12} \mathrm{H}$ & 4- 871 & $5,4 \leftarrow 4,4$ & Excited & & & 28832. & 1. \\
\hline $\mathrm{HC}^{13}: \mathrm{C}^{12} \mathrm{C}^{12} \mathrm{DO}^{16}$ & 4- 922 & Not Reported & & & & 28833. & 5. \\
\hline $\mathrm{C}^{12} \mathrm{~F}_{3}^{19} \mathrm{C}^{12}: \mathrm{C}^{12} \mathrm{H}$ & 4- 871 & $5,3 \leftarrow 4,3$ & Excited & & & 28833.22 & .20 \\
\hline $\mathrm{C}^{12} \mathrm{~F}_{3}^{19} \mathrm{C}^{12}: \mathrm{C}^{12} \mathrm{H}$ & 4- 871 & $5,2 \leftarrow 4,2$ & Excited & & & 28833.81 & .20 \\
\hline $\mathrm{C}^{12} \mathrm{~F}_{3}^{19} \mathrm{C}^{12}: \mathrm{C}^{12} \mathrm{H}$ & 4- 871 & $5,3 \leftarrow 4,3$ & Excited & & & 28834.29 & .20 \\
\hline
\end{tabular}




\section{$\mathrm{C}^{12} \mathrm{~F}_{3}^{19} \mathrm{C}^{12}: \mathrm{C}^{12} \mathrm{H}$ \\ $\mathrm{C}^{12} \mathrm{~F}_{3}^{19} \mathrm{C}^{12}: \mathrm{C}^{12} \mathrm{H}$ \\ $\mathrm{C}^{12} \mathrm{~F}_{3}^{19} \mathrm{C}^{12}: \mathrm{C}^{12} \mathrm{H}$ \\ $\mathrm{C}^{12}{ }_{*} \mathrm{D}_{2} \mathrm{C}^{12} \mathrm{H}_{2} \mathrm{C}^{12} \mathrm{D}_{2} \mathrm{O}^{16}{ }_{*}$ c- $\mathrm{C}^{12} \mathrm{HD}: \mathrm{C}^{12} \mathrm{DBr}^{81}$}

HDS $^{32}$

$\mathrm{Cl}^{35} \mathrm{O}^{16} \mathrm{O}^{18}$

$\mathrm{H}_{2} \mathrm{~N}^{14} \mathrm{~N}^{14} \mathrm{H}_{2}$

$\mathrm{C}^{12} \mathrm{H}_{3} \mathrm{Si}^{28} \mathrm{DF}_{2}^{19}-\mathrm{A}$

c- $\mathrm{C}^{12} \mathrm{HD}: \mathrm{C}^{12} \mathrm{DBr}^{81}$

$\mathrm{C}^{12} \mathrm{H}_{2}\left(\mathrm{C}^{12} \mathrm{~N}^{14}\right)_{2}$

$\mathrm{HC}^{13}: \mathrm{C}^{12} \mathrm{C}^{12} \mathrm{DO}^{16}$

$\left(\mathrm{C}^{12} \mathrm{H}_{3}\right)_{2} \mathrm{C}^{12}: \mathrm{C}^{12} \mathrm{H}_{2}$

$\mathrm{C}^{12} \mathrm{~F}_{3}^{19} \mathrm{C}^{12}: \mathrm{C}^{12} \mathrm{H}$

$\mathrm{C}^{12} \mathrm{H}_{3} \mathrm{Si}^{28} \mathrm{DF}_{2}^{19}-\mathrm{A}$

c- $\mathrm{C}^{12} \mathrm{HD}: \mathrm{C}^{12} \mathrm{DBr}^{81}$

c- $\mathrm{C}^{12} \mathrm{HD}: \mathrm{C}^{12} \mathrm{DBr}^{81}$

$\mathrm{H}_{2} \mathrm{~N}^{14} \mathrm{~N}^{14} \mathrm{H}_{2}$

$\mathrm{H}_{2} \mathrm{~N}^{14} \mathrm{~N}^{14} \mathrm{H}_{2}$

$\mathrm{C}^{12}{ }_{*} \mathrm{H}_{2} \mathrm{C}^{12} \mathrm{H}_{2} \mathrm{C}^{12}{ }_{*} \mathrm{HC}^{37}$

$\mathrm{C}^{12} \mathrm{HD}: \mathrm{C}^{12} \mathrm{HBr}^{b}$

$\mathrm{C}^{12} \mathrm{HD}: \mathrm{C}^{12} \mathrm{DBr}^{\mathrm{b}}$

$\mathrm{S}^{32} \mathrm{O}_{2}^{16}$

$\mathrm{C}^{12} \mathrm{H}_{3} \mathrm{C}^{12} \mathrm{O}^{16} \mathrm{C}^{12} \mathrm{~N}^{14}$

c-C ${ }^{12} \mathrm{HD}: \mathrm{C}^{12} \mathrm{DBr}^{81}$

$\mathrm{C}^{12} \mathrm{H}_{3} \mathrm{C}^{12} \mathrm{H}_{2} \mathrm{Cl}^{35}$

$\mathrm{C}^{12} \mathrm{H}_{3} \mathrm{C}^{12}{ }_{*} \mathrm{HO}^{16} \mathrm{C}^{12}{ }_{*} \mathrm{H}_{2}$

c- $\mathrm{C}^{12} \mathrm{HD}: \mathrm{C}^{12} \mathrm{DBr}^{81}$

s- $\mathrm{C}^{12} \mathrm{H}_{2} \mathrm{DSi}^{28} \mathrm{H}_{2} \mathrm{~F}^{19}$

$\mathrm{C}^{12} \mathrm{H}_{3} \mathrm{C}^{12} \mathrm{H}_{2} \mathrm{Cl}^{35}$

c.- ${ }^{12} \mathrm{HD}: \mathrm{C}^{12} \mathrm{DBr}^{81}$

c-C ${ }^{12} \mathrm{HD}: \mathrm{C}^{12} \mathrm{DBr}^{81}$

$\mathrm{C}^{12} \mathrm{H}_{3} \mathrm{C}^{12} \mathrm{O}^{16} \mathrm{C}^{12} \mathrm{~N}^{14}$

$\mathrm{C}^{12} \mathrm{H}_{3} \mathrm{C}^{12} \mathrm{H}_{2} \mathrm{Cl}^{35}$

$\mathrm{C}^{13} \mathrm{H}_{3} \mathrm{O}^{16} \mathrm{H}$

$\mathrm{C}^{12} \mathrm{H}_{3} \mathrm{C}^{12} \mathrm{H}_{2} \mathrm{Cl}^{35}$

$\mathrm{B}_{3}^{10} \mathrm{~B}_{2}^{11} \mathrm{H}_{9}$

$\mathrm{C}^{13} \mathrm{H}_{2} \mathrm{Cl}^{35} \mathrm{Si}^{28} \mathrm{H}_{3}$

$\mathrm{C}^{13} \mathrm{H}_{2} \mathrm{Cl}^{35} \mathrm{Si}^{28} \mathrm{H}_{3}$

$\mathrm{C}^{12} \mathrm{H}_{3} \mathrm{Si}^{28} \mathrm{HF}_{2}^{19}-\mathrm{A}$

$\mathrm{B}_{2}^{10} \mathrm{~B}_{3}^{11} \mathrm{H}_{9}$

$\mathrm{C}^{12} \mathrm{HD}: \mathrm{C}^{12} \mathrm{HBr}^{\mathrm{b}}$

$\mathrm{C}^{12} \mathrm{HD}: \mathrm{C}^{12} \mathrm{DBr}^{\mathrm{b}}$

$\mathrm{C}^{12} \mathrm{H}_{3} \mathrm{Si}^{28} \mathrm{HF}_{2}^{19}-\mathrm{A}$

$\mathrm{Cl}^{35} \mathrm{O}^{16} \mathrm{O}^{18}$

\section{871}

$5,4 \leftarrow 4,4$

4. 871

$5,1 \leftarrow 4,1$

4- 871

$5,0 \leftarrow 4,0$

4-1092

$6,4,3 \leftarrow 6,3,4$

4. 746

$4,2,3 \leftarrow 3,2,2$

4-1727

4-1383

$12,6,6 \leftarrow 12,6,7$

$4,2,3 \leftarrow 5,1,4$

$6,2 \leftarrow 7,1$

3- 51

3- 197

4. 746

4- 901

Not Reported

$4,2,3 \leftarrow 3,2,2$

4- 922

3- 941

4. 871

3- 197

4. 746

4. 746

3- 51

3- 51

4-1082

4. 748

4. 749

Not Reported

Not Reported

$7,5,3 \leftarrow 7,4,4$

$5,1 \leftarrow 4,1$

Not Reported

$4,2,3 \leftarrow 3,2,2$

$4,3,2 \leftarrow 3,3,1$

$6,2 \leftarrow 7,1$

Not Reported

$4,1,4 \leftarrow 3,1,3$

4-1831

Not Reported

Not Reported

3- 671

$17,2,16 \leftarrow 16,3,13$

4. 746

$9,2,7 \leftarrow 9,1,8$

3- 541

$4,0,4 \leftarrow 3,0,3$

$4,1,3 \leftarrow 4,0,4$

3. 761

Not Reported

4- 746

3. 247

$4,2,3 \leftarrow 3,2,2$

3. 541

$11,2,9 \leftarrow 11,2,10$

$4,1,3 \leftarrow 4,0,4$

4. 746

4.- 746

$4,2,3 \leftarrow 3,2,2$

3. 671

$4,2,2 \leftarrow 3,2,1$

3- 541

$9,2,7 \leftarrow 9,1,8$

$4,1,3 \leftarrow 4,0,4$

3- 213

Not Reported

3. 541

$4,1,3 \leftarrow 4,0,4$

4.- 58

$2,1,1 \leftarrow 1,0,1$

3. 233

3- 233

$11,1,10 \leftarrow 11,0,11$

3. 191

$11,1,10 \leftarrow 11,0,11$

4. 54

Not Reported

4. 748

$2,2,1 \leftarrow 1,1,1$

Not Reported

4- 749

Not Reported

3- 191

Not Reported

4-1383
$4,2,3 \leftarrow 5,1,4$
Excited

Excited

Excited

Excited

Excited

Ground

Ground

Ground

Ground

Ground

Ground

Ground

Excited

Ground

Excited

Ground

Ground

Ground

Ground

Ground

Ground

Ground

Ground

Ground

Ground

Ground

Ground

Ground

Ground

Excited

Ground

Ground

Ground

Ground

Ground

Ground

Ground

Ground

Ground

Ground

Ground

Ground

Ground

Ground
$28834.20 \quad .20$

$28834.45 \quad .20$

$28835.26 \quad .20$

$28836.27 \quad .1$

$11 / 2 \quad 9 / 2 \quad 28839.8$

$28842.84 \quad .05$

$\begin{array}{lll}5 & 6 & 28843.6\end{array}$

28844.2

28849.1

$5 / 2 \quad 3 / 2 \quad 28849.5$

28850 . . . .

28850 . 5 .

$28851.31 \quad .05$

$28852.61 \quad .20$

28853.3

$28854.59 \quad .02$

$11 / 2 \quad 9 / 2 \quad 28854.8$

28855.4

28855.75

28856.2

$28857.8 \quad$. 1

$28857.8 \quad$.1

$28858.11 \quad .1$

$28859.57 \quad .2$

28862.34

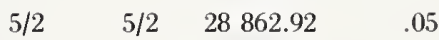

$28863.35 \quad$.

$11 / 2 \quad 9 / 2 \quad 28863.7$

$28864.70 \quad .10$

$11 / 2 \quad 11 / 2 \quad 28864.73 \quad .05$

$7 / 2 \quad 5 / 2 \quad 28866.2$

$5 / 2 \quad 3 / 2 \quad 28867.1$

$28867.37 \quad .2$

$\begin{array}{llll}7 / 2 & 7 / 2 & 28 & 867.92 \quad .05\end{array}$

$28869.59 \quad .1$

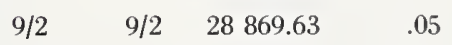

28870 . $\quad 1.0$

$19 / 2 \quad 19 / 2 \quad 28870.45 \quad .05$

$25 / 2 \quad 25 / 2 \quad 28871.18 \quad .05$

28871.5

28872.

1.0

28872.8

28873.2

28873.4

28873.7 


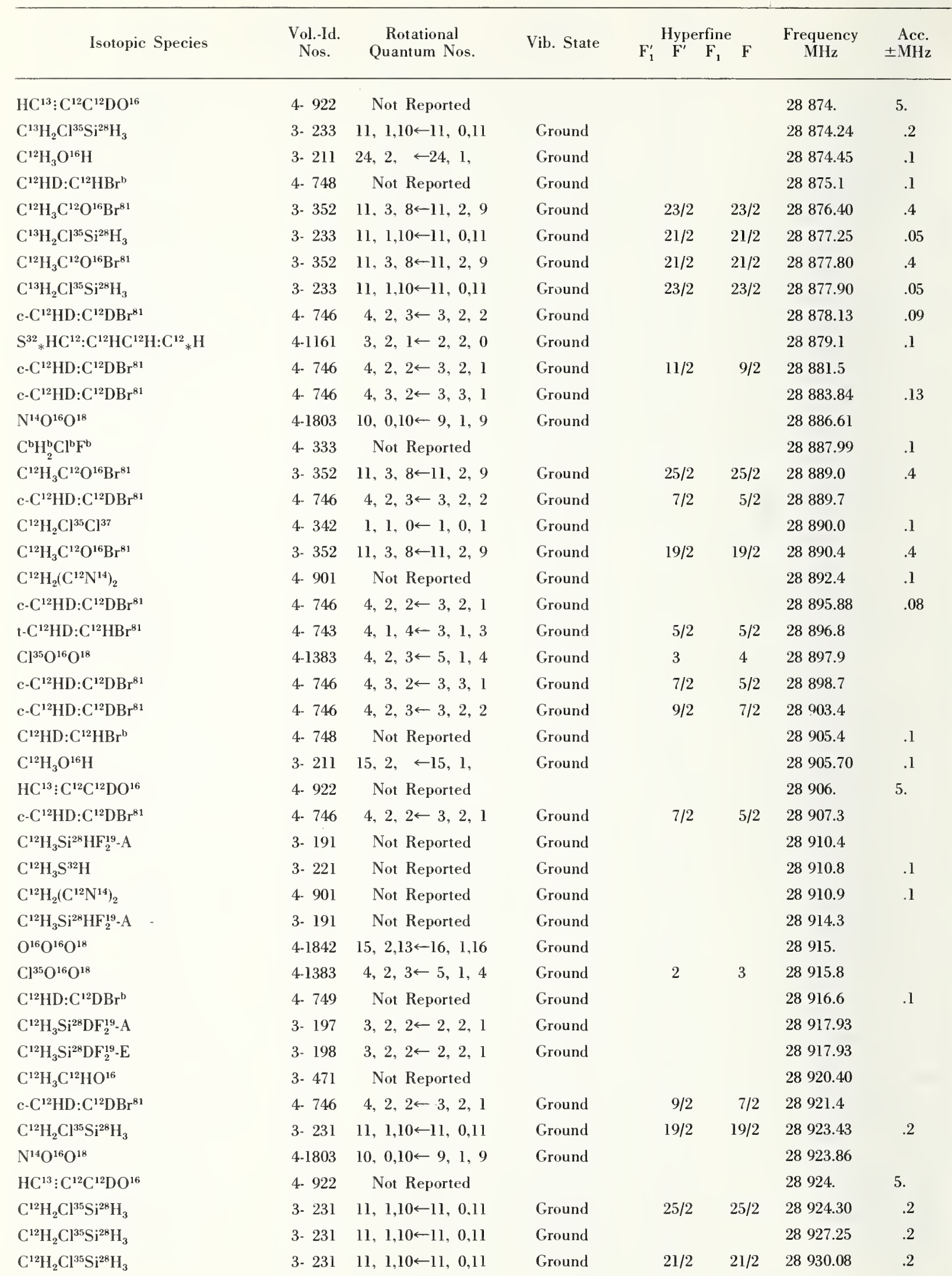


$\begin{array}{ccc}\text { Vol.-Id. } & \text { Rotational } & \text { Vib. State } \\ \text { Nos. } & \text { Quantum Nos. } & \end{array}$

$\begin{array}{cccc}\text { Hyperfine } & \text { Frequency } & \text { Arce } \\ \mathrm{F}_{1}^{\prime} \mathrm{F}^{\prime} \mathrm{F}_{1} \mathrm{~F} & \mathrm{Mll} \mathrm{H} & \pm \mathrm{ML}\end{array}$

\begin{tabular}{|c|c|c|c|c|c|c|c|}
\hline $\mathrm{C}^{12} \mathrm{HD}: \mathrm{C}^{12} \mathrm{DBr}^{\mathrm{b}}$ & 4- 749 & Not Reported & Ground & & & 28930.6 & .2 \\
\hline $\mathrm{HC}^{13}: \mathrm{C}^{12} \mathrm{C}^{12} \mathrm{DO}^{16}$ & 4. 922 & Not Reported & & & & 28930.7 & \\
\hline $\mathrm{C}^{12} \mathrm{H}_{2} \mathrm{Cl}^{35} \mathrm{Si}^{28} \mathrm{H}_{3}$ & 3- 231 & $11,1,10 \leftarrow 11,0,11$ & Ground & $23 / 2$ & $23 / 2$ & 28931.01 & .2 \\
\hline $\mathrm{S}^{32}{ }_{*} \mathrm{HC}^{13}: \mathrm{C}^{12} \mathrm{HC}^{12} \mathrm{H}: \mathrm{C}^{12}{ }_{*} \mathrm{H}$ & $4-1167$ & $8,3,5 \leftarrow 8,3,6$ & Ground & & & 28931.2 & .05 \\
\hline $\mathrm{H}_{2} \mathrm{~N}^{14} \mathrm{~N}^{14} \mathrm{H}_{2}$ & 3- 51 & Not Reported & Ground & & & 28933.1 & \\
\hline $\mathrm{D}_{2} \mathrm{C}^{12}: \mathrm{C}^{12} \mathrm{~F}_{2}^{19}$ & 4- 683 & $5,4,2 \leftarrow 5,2,3$ & Ground & & & 28933.9 & .3 \\
\hline$c-\mathrm{C}^{12} \mathrm{HD}: \mathrm{C}^{12} \mathrm{DBr}^{81}$ & 4. 746 & $4,3,2 \leftarrow 3,3,1$ & Ground & $5 / 2$ & $5 / 2$ & 28934.5 & \\
\hline $\mathrm{HC}^{12} \mathrm{O}^{16} \mathrm{O}^{16} \mathrm{H}$ & 3- 71 & $28,4,24 \leftarrow 28,4,25$ & & & & 28935. & \\
\hline $\mathrm{S}^{32}{ }_{*} \mathrm{HC}^{13}: \mathrm{C}^{12} \mathrm{HC}^{12} \mathrm{H}: \mathrm{C}^{12}{ }_{*} \mathrm{H}$ & $4-1167$ & $3,2,1 \leftarrow 2,2,0$ & Ground & & & 28935.8 & .05 \\
\hline $\mathrm{DC}^{12} \mathrm{O}^{16} \mathrm{O}^{16} \mathrm{C}^{12} \mathrm{H}_{3}-\mathrm{A}$ & 3- 503 & $5,1,4 \leftarrow 5,0,5$ & Ground & & & 28936.10 & .2 \\
\hline $\mathrm{C}^{12} \mathrm{H}_{2} \mathrm{Cl}_{2}^{35}$ & 4- 341 & $1,1,0 \leftarrow 1,0,1$ & Ground & & & 28936.6 & .1 \\
\hline $\mathrm{C}^{12} \mathrm{H}_{3} \mathrm{C}^{12}{ }_{*} \mathrm{HO}^{16} \mathrm{C}^{12}{ }_{*} \mathrm{H}_{2}$ & 3. 761 & $7,2,6 \leftarrow 6,3,3$ & Ground & & & 28938.18 & .1 \\
\hline $\mathrm{t}-\mathrm{C}^{12} \mathrm{HD}: \mathrm{C}^{12} \mathrm{HBr}^{81}$ & 4. 743 & $4,1,4 \leftarrow 3,1,3$ & Excited & $11 / 2$ & $9 / 2$ & 28940.9 & \\
\hline$c-\mathrm{C}^{12} \mathrm{HD}: \mathrm{C}^{12} \mathrm{DBr}^{81}$ & 4. 746 & $4,3,2 \leftarrow 3,3,1$ & Ground & $9 / 2$ & $7 / 2$ & 28944.7 & \\
\hline $\mathrm{H}_{2} \mathrm{C}^{12}: \mathrm{C}^{12} \mathrm{~F}_{2}^{19}$ & 4- 681 & Not Reported & & & & 28945.3 & .3 \\
\hline t. $\mathrm{C}^{12} \mathrm{HD}: \mathrm{C}^{12} \mathrm{HBr}^{81}$ & 4- 743 & $4,1,4 \leftarrow 3,1,3$ & Excited & & & 28947.00 & .33 \\
\hline $\mathrm{t}-\mathrm{HDC}^{12}{ }_{*} \mathrm{O}^{16} \mathrm{C}^{12}{ }_{*} \mathrm{HD}$ & 4. 844 & $3,3,0 \leftarrow 3,2,1$ & Ground & & & 28947.30 & .05 \\
\hline $\mathrm{HC}^{13}: \mathrm{C}^{12} \mathrm{C}^{12} \mathrm{DO}^{16}$ & 4- 922 & Not Reported & & & & 28950 . & 5. \\
\hline $\mathrm{t}-\mathrm{C}^{12} \mathrm{HD}: \mathrm{C}^{12} \mathrm{HBr}^{81}$ & 4- 743 & $4,1,4 \leftarrow 3,1,3$ & Excited & $9 / 2$ & $7 / 2$ & 28950.6 & \\
\hline $\mathrm{C}^{12} \mathrm{H}_{3} \mathrm{C}^{12} \mathrm{H}_{2} \mathrm{~F}^{19}$ & 3. 551 & $2,1,1 \leftarrow 2,0,2$ & Ground & & & 28954.4 & \\
\hline $\mathrm{N}^{14} \mathrm{O}^{16} \mathrm{O}^{18}$ & 4-1803 & $10,0.10 \leftarrow 9,1,9$ & Ground & & & 28954.85 & \\
\hline $\mathrm{C}^{12} \mathrm{H}_{3} \mathrm{C}^{12}{ }_{*} \mathrm{HO}^{16} \mathrm{C}^{12}{ }_{*} \mathrm{H}_{2}$ & 3. 761 & Not Reported & Ground & & & 28955.44 & .1 \\
\hline $\mathrm{C}^{12}{ }_{*} \mathrm{H}_{2} \mathrm{C}^{12} \mathrm{D}: \mathrm{C}^{12}{ }_{*} \mathrm{D}$ & $4-1033$ & $10,7,3 \leftarrow 10,7,4$ & Ground & & & 28955.5 & \\
\hline$c-\mathrm{C}^{12} \mathrm{HD}: \mathrm{C}^{12} \mathrm{DBr}^{81}$ & 4. 746 & $4,3,2 \leftarrow 3,3,1$ & Ground & $7 / 2$ & $7 / 2$ & 28956.4 & \\
\hline $\mathrm{t}-\mathrm{C}^{12} \mathrm{HD}: \mathrm{C}^{12} \mathrm{HBr}^{81}$ & 4- 743 & $4,1,4 \leftarrow 3,1,3$ & Excited & $7 / 2$ & $5 / 2$ & 28957.0 & \\
\hline $\mathrm{C}^{12} \mathrm{HD}: \mathrm{C}^{12} \mathrm{DBr}^{\mathrm{b}}$ & 4. 749 & Not Reported & Ground & & & 28957.8 & .1 \\
\hline $\mathrm{C}^{12} \mathrm{H}_{2} \mathrm{Cl}^{35} \mathrm{C}^{12}: \mathrm{C}^{12} \mathrm{H}$ & 4- 991 & $9,1,8 \leftarrow 9,0,9$ & Ground & & & 28958.40 & \\
\hline $\mathrm{O}_{3}^{16}$ & 4-1841 & $24,4,20 \longleftarrow 25,3,23$ & Ground & & & 28960. & \\
\hline $\mathrm{C}^{12} \mathrm{H}_{3} \mathrm{C}^{12} \mathrm{H}_{2} \mathrm{~F}^{19}$ & $3 \cdot 551$ & $2,1,1 \leftarrow 2,0,2$ & Ground & & & 28960.42 & \\
\hline $\mathrm{C}^{12} \mathrm{H}_{3} \mathrm{C}^{12} \mathrm{H}_{2} \mathrm{~F}^{19}$ & 3- 551 & Not Reported & & & & 28961.55 & \\
\hline $\mathrm{C}^{12} \mathrm{H}_{2}\left(\mathrm{C}^{12} \mathrm{~N}^{14}\right)_{2}$ & 4. 901 & Not Reported & Ground & & & 28961.9 & .1 \\
\hline$c-\mathrm{C}^{12} \mathrm{HD}: \mathrm{C}^{12} \mathrm{DBr}^{79}$ & 4. 744 & $4,3,2 \leftarrow 3,3,1$ & Ground & $5 / 2$ & $3 / 2$ & 28964.6 & \\
\hline $\mathrm{C}^{12} \mathrm{HD}: \mathrm{C}^{12} \mathrm{DBr}^{\mathrm{b}}$ & 4- 749 & Not Reported & Ground & & & 28965.5 & .1 \\
\hline $\mathrm{C}^{12} \mathrm{H}_{2}\left(\mathrm{C}^{12} \mathrm{~N}^{14}\right)_{2}$ & 4. 901 & Not Reported & Ground & & & 28967.2 & .1 \\
\hline $\mathrm{C}^{12} \mathrm{HD}: \mathrm{C}^{12} \mathrm{DBr}^{b}$ & 4- 749 & Not Reported & Ground & & & 28969.1 & .1 \\
\hline $\mathrm{t}-\mathrm{C}^{12} \mathrm{HD}: \mathrm{C}^{12} \mathrm{HBr}^{81}$ & 4- 743 & $4,1,4 \leftarrow 3,1,3$ & Ground & $11 / 2$ & $9 / 2$ & 28969.2 & \\
\hline $\mathrm{C}^{12} \mathrm{H}_{3} \mathrm{O}^{16} \mathrm{H}$ & 3- 211 & Not Reported & Ground & & & 28969.9 & .1 \\
\hline $\mathrm{C}^{12} \mathrm{HD}: \mathrm{C}^{12} \mathrm{DBr}^{\mathrm{b}}$ & 4- 749 & Not Reported & Ground & & & 28974.4 & .1 \\
\hline t- $\mathrm{C}^{12} \mathrm{HD}: \mathrm{C}^{12} \mathrm{HBr}^{81}$ & 4- 743 & $4,1,4 \leftarrow 3,1,3$ & Ground & $5 / 2$ & $3 / 2$ & 28974.5 & \\
\hline $\mathrm{HC}^{12} \mathrm{HO}^{16}$ & 4- 381 & $3,1,2 \leftarrow 3,1,3$ & Ground & & & 28974.85 & \\
\hline $\mathrm{C}^{12} \mathrm{H}_{3} \mathrm{C}^{12} \mathrm{HO}^{16}$ & 3. 471 & Not Reported & & & & 28974.95 & \\
\hline t. $\mathrm{C}^{12} \mathrm{HD}: \mathrm{C}^{12} \mathrm{HBr}^{81}$ & 4- 743 & $4,1,4 \leftarrow 3,1,3$ & Ground & & & 28975.00 & .06 \\
\hline $\mathrm{C}^{12} \mathrm{H}_{3} \mathrm{C}^{12}{ }_{*} \mathrm{HO}^{16} \mathrm{C}^{12}{ }_{*} \mathrm{H}_{2}$ & 3- 761 & Not Reported & Ground & & & 28975.36 & .1 \\
\hline $\mathrm{C}^{12} \mathrm{H}_{2}\left(\mathrm{C}^{12} \mathrm{~N}^{14}\right)_{2}$ & 4- 901 & Not Reported & Ground & & & 28976.1 & .1 \\
\hline$c-\mathrm{C}^{12} \mathrm{HD}: \mathrm{C}^{12} \mathrm{DBr}^{79}$ & 4- 744 & $4,3,2 \leftarrow 3,3,1$ & Ground & $9 / 2$ & $9 / 2$ & 28978.7 & \\
\hline
\end{tabular}




\begin{tabular}{|c|c|c|c|c|c|c|c|}
\hline \multirow{2}{*}{ Isotopic Species } & \multirow{2}{*}{$\begin{array}{l}\text { Vol.-Id. } \\
\text { Nos. }\end{array}$} & \multirow{2}{*}{$\begin{array}{c}\text { Rotational } \\
\text { Quantum Nos. }\end{array}$} & \multirow{2}{*}{ Vib. State } & \multicolumn{2}{|l|}{ Hyperfine } & \multirow{2}{*}{$\begin{array}{c}\text { Frequency } \\
\mathrm{MHz}\end{array}$} & \multirow{2}{*}{$\begin{aligned} & \text { Acc. } \\
\pm & \mathrm{MHz}\end{aligned}$} \\
\hline & & & & $F_{1}^{\prime} \quad F^{\prime} \quad F_{1}$ & $\mathrm{~F}$ & & \\
\hline $\mathrm{t}-\mathrm{C}^{12} \mathrm{HD}: \mathrm{C}^{12} \mathrm{HBr}^{81}$ & 4- 743 & $4,1,4 \leftarrow 3,1,3$ & Ground & $9 / 2$ & $7 / 2$ & 28978.9 & \\
\hline $\mathrm{C}^{12} \mathrm{H}_{3} \mathrm{C}^{12} \mathrm{O}^{16} \mathrm{C}^{12} \mathrm{~N}^{14}$ & $3 \cdot 671$ & $4,3,1 \leftarrow 3,3,0$ & Ground & & & 28981.60 & .2 \\
\hline$\left(\mathrm{C}^{12} \mathrm{H}_{3}\right)_{3} \mathrm{Si}^{28} \mathrm{Br}^{81}$ & 3. $812^{\circ}$ & $10, \leftarrow 9$, & Ground & & & 28982.5 & .3 \\
\hline c- $\mathrm{C}^{12} \mathrm{HD}: \mathrm{C}^{12} \mathrm{DBr}^{79}$ & 4- 744 & $4,0,4 \leftarrow 3,0,3$ & Ground & $7 / 2$ & $7 / 2$ & 28984.1 & \\
\hline $\mathrm{t}-\mathrm{C}^{12} \mathrm{HD}: \mathrm{C}^{12} \mathrm{HBr}^{81}$ & 4- 743 & $4,1,4 \leftarrow 3,1,3$ & Ground & $7 / 2$ & $5 / 2$ & 28984.4 & \\
\hline $\mathrm{C}^{12} \mathrm{H}_{3} \mathrm{C}^{12} \mathrm{H}_{2} \mathrm{~F}^{19}$ & 3- 551 & $2,1,1 \leftarrow 2,0,2$ & Ground & & & 28984.5 & \\
\hline $\mathrm{C}^{12} \mathrm{H}_{2}\left(\mathrm{C}^{12} \mathrm{~N}^{14}\right)_{2}$ & 4- 901 & Not Reported & Ground & & & 28986.9 & .1 \\
\hline $\mathrm{B}_{5}^{\mathrm{b}} \mathrm{H}_{9}$ & 4- 65 & Not Reported & Ground & & & 28989. & .1 \\
\hline $\mathrm{C}^{12} \mathrm{H}_{2}\left(\mathrm{C}^{12} \mathrm{~N}^{14}\right)_{2}$ & 4. 901 & Not Reported & Ground & & & 28989.2 & .1 \\
\hline $\mathrm{C}^{12} \mathrm{H}_{3} \mathrm{~S}^{32} \mathrm{H}$ & 3- 221 & Not Reported & Ground & & & 28990.3 & .1 \\
\hline $\mathrm{C}^{12} \mathrm{H}_{3} \mathrm{C}^{12} \mathrm{H}_{2} \mathrm{~F}^{19}$ & 3- 551 & $5,3,3 \leftarrow 6,2,4$ & Ground & & & 28990.30 & \\
\hline $\mathrm{C}^{12} \mathrm{HD}: \mathrm{C}^{12} \mathrm{HBr}^{b}$ & 4- 748 & Not Reported & Ground & & & 28990.6 & .3 \\
\hline $\mathrm{c}-\mathrm{C}^{12} \mathrm{HD}: \mathrm{C}^{12} \mathrm{DBr}^{79}$ & 4- 744 & $4,2,3 \leftarrow 3,2,2$ & Excited & $5 / 2$ & $3 / 2$ & 28990.7 & \\
\hline $\mathrm{DC}^{12} \mathrm{~N}^{14}$ & 4- 292 & $12 \leftarrow 12$ & Excited & & & 28992.55 & .20 \\
\hline $\mathrm{C}^{12} \mathrm{H}_{2}: \mathrm{C}^{13} \mathrm{HC}^{12} \mathrm{~N}^{14}$ & 4-1023 & $3,1,2 \leftarrow 2,1,1$ & Ground & & & 28995.49 & .15 \\
\hline $\mathrm{N}^{14} \mathrm{O}^{16} \mathrm{Br}^{\mathrm{b}}$ & 4- 123 & $4, \quad \leftarrow 3$, & & & & 29007.1 & \\
\hline $\mathrm{c}-\mathrm{C}^{12} \mathrm{HD}: \mathrm{C}^{12} \mathrm{DBr}^{79}$ & 4- 744 & $4,2,3 \leftarrow 3,2,2$ & Excited & $11 / 2$ & $9 / 2$ & 29007.4 & \\
\hline $\mathrm{C}^{12} \mathrm{H}_{2}: \mathrm{C}^{12} \mathrm{HC}^{13} \mathrm{~N}^{14}$ & $4-1024$ & $3,1,2 \leftarrow 2,1,1$ & Ground & & & 29008.07 & .15 \\
\hline $\mathrm{H}_{2} \mathrm{~N}^{14} \mathrm{~N}^{14} \mathrm{H}_{2}$ & 3. 51 & Not Reported & Ground & & & 29010.24 & \\
\hline $\mathrm{C}^{12} \mathrm{H}_{2}\left(\mathrm{C}^{12} \mathrm{~N}^{14}\right)_{2}$ & 4. 901 & Not Reported & Ground & & & 29011.0 & .1 \\
\hline $\mathrm{H}_{2} \mathrm{~N}^{14} \mathrm{~N}^{14} \mathrm{H}_{2}$ & $3-51$ & Not Reported & Ground & & & 29011.74 & \\
\hline $\mathrm{H}_{2} \mathrm{~N}^{14} \mathrm{~N}^{14} \mathrm{H}_{2}$ & 3- 51 & Not Reported & Ground & & & 29012.73 & \\
\hline $\mathrm{C}^{12} \mathrm{HD}: \mathrm{C}^{12} \mathrm{HBr}^{\mathrm{b}}$ & 4- 748 & Not Reported & Ground & & & 29012.9 & .1 \\
\hline $\mathrm{c} \cdot \mathrm{C}^{12} \mathrm{HD}: \mathrm{C}^{12} \mathrm{DBr}^{79}$ & 4- 744 & $4,2,3 \leftarrow 3,2,2$ & Ground & $5 / 2$ & $3 / 2$ & 29014.1 & \\
\hline $\mathrm{N}^{14} \mathrm{O}^{16} \mathrm{Br}^{\mathrm{h}}$ & 4. 123 & $4, \quad \leftarrow 3$, & & & & 29014.9 & \\
\hline $\mathrm{D}_{2} \mathrm{O}_{2}^{16}$ & $3-\quad 42$ & Not Reported & & & & 29017 & 3. \\
\hline $\mathrm{C}^{12} \mathrm{H}_{3} \mathrm{Si}^{28} \mathrm{HF}_{2}^{19}-\mathrm{A}$ & 3- 191 & Not Reported & Ground & & & 29018.2 & \\
\hline$c-\mathrm{HF}^{19} \mathrm{C}^{12}: \mathrm{C}^{12} \mathrm{HF}^{19}$ & 4- .691 & $4,0,4 \leftarrow 3,1,3$ & Excited & & & 29020.76 & .05 \\
\hline $\mathrm{HC}^{13}: \mathrm{C}^{12} \mathrm{C}^{12} \mathrm{DO}^{16}$ & 4- 922 & Not Reported & & & & 29021 & 5. \\
\hline $\mathrm{g}-\mathrm{C}^{12} \mathrm{H}_{3} \mathrm{C}^{12} \mathrm{H}_{2} \mathrm{C}^{12} \mathrm{H}_{2} \mathrm{Cl}^{37}$ & 3- 774 & $5,1,5 \leftarrow 4,1,4$ & Ground & & & 29022.88 & .2 \\
\hline $\mathrm{B}^{11} \mathrm{~B}^{10} \mathrm{~B}^{11} \mathrm{~B}^{10} \mathrm{~B}^{11} \mathrm{H}_{9}$ & 4- 55 & $2,2,1 \leftarrow 1,1,1$ & Ground & & & 29024 & 1.0 \\
\hline c- $\mathrm{C}^{12} \mathrm{HD}: \mathrm{C}^{12} \mathrm{DBr}^{79}$ & 4. 744 & $4,2,3 \leftarrow 3,2,2$ & Excited & & & 29024.96 & .18 \\
\hline c. $\mathrm{C}^{12} \mathrm{HD}: \mathrm{C}^{12} \mathrm{DBr}^{79}$ & 4- 744 & $4,0,4 \leftarrow 3,0,3$ & Ground & $11 / 2$ & $9 / 2$ & 29027.4 & \\
\hline $\mathrm{c} \cdot \mathrm{C}^{12} \mathrm{HD}: \mathrm{C}^{12} \mathrm{DBr}^{79}$ & 4- 744 & $4,0,4 \leftarrow 3,0,3$ & Ground & $9 / 2$ & $7 / 2$ & 29027.4 & \\
\hline $\mathrm{C}^{12} \mathrm{DBr}_{3}^{81}$ & 4- 244 & $12, \leftarrow 11$ & Ground & & & 29028.2 & .5 \\
\hline c. $\mathrm{C}^{12} \mathrm{HD}: \mathrm{C}^{12} \mathrm{DBr}^{79}$ & 4- 744 & $4,3,2 \leftarrow 3,3,1$ & Ground & $11 / 2$ & $9 / 2$ & 29029.4 & \\
\hline $\mathrm{t}-\mathrm{C}^{12} \mathrm{HD}: \mathrm{C}^{12} \mathrm{HBr}^{81}$ & 4- 743 & $4,1,4 \leftarrow 3,1,3$ & Excited & $9 / 2$ & $9 / 2$ & 29029.6 & \\
\hline $\mathrm{c}-\mathrm{C}^{12} \mathrm{HD}: \mathrm{C}^{12} \mathrm{DBr}^{79}$ & 4- 744 & $4,2,3 \leftarrow 3,2,2$ & Ground & $11 / 2$ & $9 / 2$ & 29031.1 & \\
\hline$c-\mathrm{C}^{12} \mathrm{HD}: \mathrm{C}^{12} \mathrm{DBr}^{79}$ & 4. 744 & $4,0,4 \leftarrow 3,0,3$ & Ground & & & 29031.45 & 1.53 \\
\hline $\mathrm{c}-\mathrm{C}^{12} \mathrm{HD}: \mathrm{C}^{12} \mathrm{DBr}^{79}$ & 4- 744 & $4,2,2 \leftarrow 3,2,1$ & Ground & $5 / 2$ & $3 / 2$ & 29032.5 & \\
\hline$c-\mathrm{C}^{12} \mathrm{HD}: \mathrm{C}^{12} \mathrm{DBr}^{79}$ & 4- 744 & $4,2,3 \leftarrow 3,2,2$ & Excited & $7 / 2$ & $5 / 2$ & 29038.6 & \\
\hline $\mathrm{C}^{12} \mathrm{H}_{2}\left(\mathrm{C}^{12} \mathrm{~N}^{14}\right)_{2}$ & 4- 901 & Not Reported & Ground & & & 29039.5 & .1 \\
\hline $\mathrm{C}^{12} \mathrm{HD}: \mathrm{C}^{12} \mathrm{DBr}^{1}$ & 4- 749 & Not Reported & Ground & & & 29041.4 & .1 \\
\hline $\mathrm{S}^{32} \mathrm{O}^{16} \mathrm{~F}_{2}^{19}$ & $4-1621$ & Not Reported & & & & 29042.10 & .1 \\
\hline
\end{tabular}




\section{c- $\mathrm{C}^{12} \mathrm{HD}: \mathrm{C}^{12} \mathrm{DBr}^{79}$}

c- $\mathrm{C}^{12} \mathrm{HD}: \mathrm{C}^{12} \mathrm{DBr}^{79}$

$\mathrm{S}^{32}{ }_{*} \mathrm{DC}^{12}: \mathrm{C}^{12} \mathrm{HC}^{12} \mathrm{H}: \mathrm{C}^{12}{ }_{*} \mathrm{H}$

$\mathrm{B}_{3}^{10} \mathrm{~B}_{2}^{11} \mathrm{H}_{9}$

$\mathrm{B}_{2}^{11} \mathrm{~B}_{3}^{10} \mathrm{H}_{9}$

t- $\mathrm{C}^{12} \mathrm{HD}: \mathrm{C}^{12} \mathrm{HBr}^{79}$

c- $\mathrm{C}^{12} \mathrm{HD}: \mathrm{C}^{12} \mathrm{DBr}^{79}$

c- $\mathrm{C}^{12} \mathrm{HD}: \mathrm{C}^{12} \mathrm{DBr}^{79}$

$\mathrm{C}^{12} \mathrm{Cl}_{3}^{37} \mathrm{C}^{12} \mathrm{~N}^{14}$

$\mathrm{B}_{2}^{11} \mathrm{~B}_{3}^{10} \mathrm{H}_{9}$

$\mathrm{C}^{12} \mathrm{H}_{3} \mathrm{Si}^{28} \mathrm{HF}_{2}^{19} \cdot \mathrm{A}$

$\mathrm{S}^{32} \mathrm{O}^{16} \mathrm{~F}_{2}^{19}$

$\mathrm{H}_{2} \mathrm{~N}^{14} \mathrm{~N}^{14} \mathrm{H}_{2}$

c- $\mathrm{C}^{12} \mathrm{HD}: \mathrm{C}^{12} \mathrm{DBr}^{79}$

$\mathrm{C}^{12} \mathrm{H}_{3} \mathrm{~N}^{14} \mathrm{H}_{2}$

c- $\mathrm{C}^{12} \mathrm{HD}: \mathrm{C}^{12} \mathrm{DBr}^{79}$

$\mathrm{t}-\mathrm{C}^{12} \mathrm{HD}: \mathrm{C}^{12} \mathrm{HBr}^{81}$

$\mathrm{B}_{2}^{11} \mathrm{~B}_{3}^{10} \mathrm{H}_{9}$

$\left(\mathrm{C}^{12} \mathrm{H}_{3}\right)_{2} \mathrm{~S}^{32}$

$\left(\mathrm{C}^{12} \mathrm{H}_{3}\right)_{2} \mathrm{~S}^{32}$

$\mathrm{N}^{14} \mathrm{H}_{3}$

$\left(\mathrm{C}^{12} \mathrm{H}_{3}\right)_{2} \mathrm{~S}^{32}$

c. $\mathrm{C}^{12} \mathrm{HD}: \mathrm{C}^{12} \mathrm{DBr}^{79}$

$\mathrm{B}_{5}^{\mathrm{b}} \mathrm{H}_{9}$

$\mathrm{C}^{12} \mathrm{D}_{3} \mathrm{C}^{12} \mathrm{O}^{16} \mathrm{Cl}^{35}$

c- ${ }^{12} \mathrm{HD}: \mathrm{C}^{12} \mathrm{DBr}^{79}$

$\mathrm{C}^{12} \mathrm{D}_{3} \mathrm{C}^{12} \mathrm{O}^{16} \mathrm{Cl}^{35}$

$\mathrm{C}^{12} \mathrm{D}_{3} \mathrm{C}^{12} \mathrm{O}^{16} \mathrm{Cl}^{35}$

$\mathrm{C}^{12} \mathrm{H}_{3} \mathrm{C}^{12}{ }_{*} \mathrm{HO}^{16} \mathrm{C}^{12}{ }_{*} \mathrm{H}_{2}$

$\mathrm{C}^{12} \mathrm{D}_{3} \mathrm{C}^{12} \mathrm{O}^{16} \mathrm{Cl}^{35}$

c- $\mathrm{C}^{12} \mathrm{HD}: \mathrm{C}^{12} \mathrm{DBr}^{79}$

$\mathrm{C}^{12} \mathrm{H}_{3} \mathrm{C}^{12} \mathrm{H}_{2} \mathrm{~F}^{19}$

$\mathrm{P}^{31} \mathrm{HD}_{2}$

$\mathrm{C}^{12} \mathrm{H}_{3} \mathrm{~S}^{32} \mathrm{H}$

$\mathrm{C}^{12} \mathrm{D}_{3} \mathrm{C}^{12} \mathrm{O}^{16} \mathrm{Cl}^{35}$

$\mathrm{C}^{12} \mathrm{H}_{3} \mathrm{~S}^{32} \mathrm{H}$

$\mathrm{C}^{12} \mathrm{H}_{3} \mathrm{C}^{12}{ }_{*} \mathrm{HO}^{16} \mathrm{C}^{12}{ }_{*} \mathrm{H}_{2}$

$\mathrm{C}^{12} \mathrm{H}_{3} \mathrm{C}^{12} \mathrm{HO}^{16}$

c. $\mathrm{C}^{12} \mathrm{HD}: \mathrm{C}^{12} \mathrm{DBr}^{79}$

$\mathrm{D}_{2} \mathrm{C}^{12} * \mathrm{O}^{16} \mathrm{C}^{12} * \mathrm{D}_{2}$

c- $\mathrm{C}^{12} \mathrm{HD}: \mathrm{C}^{12} \mathrm{DBr}^{79}$

$\mathrm{C}^{12}{ }_{*} \mathrm{D}_{2} \mathrm{C}^{12} \mathrm{H}_{2} \mathrm{C}^{12} \mathrm{D}_{2} \mathrm{O}^{16} *$

$\mathrm{C}^{12} \mathrm{H}_{3} \mathrm{C}^{12}{ }_{*} \mathrm{HO}^{16} \mathrm{C}^{12}{ }_{*} \mathrm{H}_{2}$

$\mathrm{S}^{32} \mathrm{O}^{16} \mathrm{~F}_{2}^{19}$

$\mathrm{C}^{12} \mathrm{H}_{3} \mathrm{Si}^{28} \mathrm{HF}_{2}^{19}-\mathrm{A}$
4. 74

$4,0,4 \leftarrow 3,0,3$

4- 744

$4,0,4 \leftarrow 3,0,3$

4-1162

$3,2,1 \leftarrow 2,2,0$

4- 58

$2,2,0 \leftarrow 1,1,0$

4- 57

$2,1,1 \leftarrow 1,0,1$

4. 741

4, $1,4 \leftarrow 3,1,3$

4. 744

$4,2,3 \leftarrow 3,2,2$

4. 744

$4,2,2 \leftarrow 3,2,1$

4. 584

$9, \leftarrow 8$,

4. 57

2. $2,0 \leftarrow 1,1,0$

3. 191

9. $4,6 \leftarrow 9,4.5$

4-1621

Not Reported

3. 51

$$
\text { 6. } 2 \leftarrow 7,1
$$

4. 744

$4,3,2 \leftarrow 3,3,1$

3- 261

Not Reported

4- 744

$4,2,3 \leftarrow 3,2,2$

4- 743

$4,1,4 \leftarrow 3,1,3$

4. 57

$2,2,1 \leftarrow 1,1,1$

3. 601

$3,2,1 \leftarrow 3,1,2$

3- 601

$3,2,1 \leftarrow 3,1,2$

4-1771

$15,14 \leftarrow 15.14$

3- 601

$3,2,1 \leftarrow 3,1,2$

4. 744

4, $2,3 \leftarrow 3,2,2$

4- 65

Not Reported

3- 363

$4,1,4 \leftarrow 3,0,3$

4. 744

$4,2,2 \leftarrow 3,2,1$

3. 363

$4,1,4 \leftarrow 3,0,3$

3- 363

$4,1,4 \leftarrow 3,0,3$

3- 761

Not Reported

3- 363

4. 1. $4 \leftarrow 3.0 .3$

4. 744

4, 3, $2 \leftarrow 3,3,1$

3- 551

$2,1,1 \leftarrow 2,0,2$

4-1783

1. $1,0 \leftarrow 1,0,1$

3- 221

Not Reported

3. 363

3. 221

4. 1. $4 \leftarrow 3,0,3$

3- 761

Not Reported

3- 471

8, 1. $7 \leftarrow 8,0,8$

4. 744

Not Reported

4- 843

4. $2,3 \leftarrow 3,2,2$

4- 744

3. $3,0 \leftarrow 3,2,1$

4. $2.2 \leftarrow 3,2$. 1

4-1092

$6,4,3 \leftarrow 6,3,4$

3- 761

8, 1. $7 \leftarrow 8,0,8$

4-1621

Not Reported

3- 191
Ground

Ground

Ground

Ground

Ground

Ground

Ground

Ground

Ground

Ground

Ground

Ground

Ground

Ground

Excited

Ground

Ground

Ground

Ground

Ground

Ground

Ground

Ground

Ground

Ground

Ground

Ground

Ground

Ground

Ground

Ground

Ground

Ground

Ground

Ground

Ground

Ground

Ground

Ground

Ground

Ground

Ground

\begin{tabular}{|c|c|c|c|}
\hline $7 / 2$ & $5 / 2$ & 29043.8 & \\
\hline \multirow[t]{4}{*}{$5 / 2$} & $3 / 2$ & 29043.8 & \\
\hline & & 29044.7 & .1 \\
\hline & & 29045 & 1.0 \\
\hline & & 29045 & 1.0 \\
\hline \multirow[t]{2}{*}{$5 / 2$} & $5 / 2$ & 29046.5 & \\
\hline & & 29048.49 & .07 \\
\hline \multirow[t]{8}{*}{$11 / 2$} & $9 / 2$ & 29049.7 & \\
\hline & & 29050.0 & 20. \\
\hline & & 29052 & 1.0 \\
\hline & & 29052.30 & \\
\hline & & 29052.39 & .1 \\
\hline & & 29053.6 & .05 \\
\hline & & 29054.80 & .28 \\
\hline & & 29055.20 & .1 \\
\hline $9 / 2$ & $7 / 2$ & 29056.5 & \\
\hline \multirow[t]{6}{*}{$9 / 2$} & $9 / 2$ & 29056.8 & \\
\hline & & 29057. & 1.0 \\
\hline & & 29060.28 & .05 \\
\hline & & 29060.86 & .05 \\
\hline & & 29061.14 & .10 \\
\hline & & 29061.45 & .05 \\
\hline \multirow[t]{2}{*}{$7 / 2$} & $5 / 2$ & 29062.1 & \\
\hline & & 29063 & .1 \\
\hline \multirow[t]{2}{*}{$5 / 2$} & $3 / 2$ & 29066.43 & \\
\hline & & 29066.90 & .11 \\
\hline
\end{tabular}

$11 / 2 \quad 9 / 2 \quad 29068.51$

$7 / 2 \quad 5 / 2 \quad 29068.51$

29069.38

$9 / 2 \quad 7 / 2 \quad 29070.50$

$7 / 2 \quad 5 / 2 \quad 29072.4$

$29072.68 \quad .10$

$29073.21 \quad .05$

29073.9

$7 / 2 \quad 7 / 2 \quad 29074.00$

29074.4

$29075.76 \quad$.1

29075.76

$9 / 2 \quad 7 / 2 \quad 29079.2$

29080.

$7 / 2 \quad 5 / 2 \quad 29080.4$

29080.7

29082.36

29087.73

29088.5 


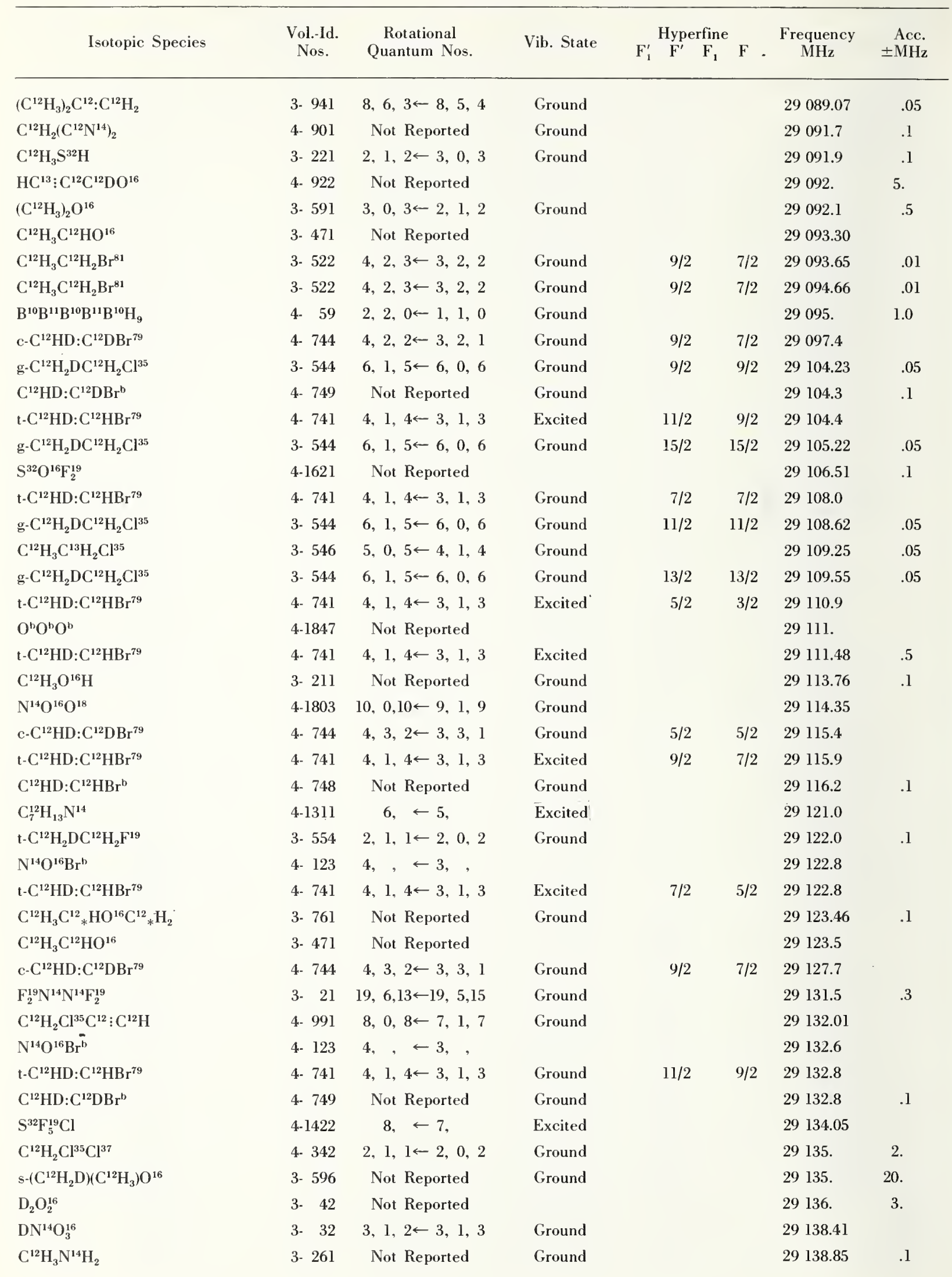


Vib. State

\begin{tabular}{|c|c|c|c|c|c|c|c|}
\hline $\mathrm{C}^{12} \mathrm{H}_{2}: \mathrm{C}^{12} \mathrm{HC}^{12} \mathrm{~N}^{14}$ & 4-1021 & $3,1,2 \leftarrow 2,1,1$ & Ground & & & 29139.01 & \\
\hline $\mathrm{t}-\mathrm{C}^{12} \mathrm{HD}: \mathrm{C}^{12} \mathrm{HBr}^{79}$ & 4- 741 & $4,1,4 \leftarrow 3,1,3$ & Ground & $5 / 2$ & $3 / 2$ & 29139.3 & \\
\hline $\mathrm{C}^{12} \mathrm{HD}: \mathrm{C}^{12} \mathrm{DBr}^{\mathrm{b}}$ & 4. 749 & Not Reported & Ground & & & 29139.3 & .1 \\
\hline $\mathrm{t}-\mathrm{C}^{12} \mathrm{HD}: \mathrm{C}^{12} \mathrm{HBr}^{79}$ & 4. 741 & $4,1,4 \leftarrow 3,1,3$ & Ground & & & 29139.88 & .04 \\
\hline $\mathrm{Si}^{28} \mathrm{HCl}_{2}^{35} \mathrm{Cl}^{37}$ & 4-1502 & $6, \quad \leftarrow 5$, & Ground & & & 29140. & 20. \\
\hline $\mathrm{s}-\left(\mathrm{C}^{12} \mathrm{H}_{2} \mathrm{D}\right)\left(\mathrm{C}^{12} \mathrm{H}_{3}\right) \mathrm{O}^{16}$ & 3. 596 & Not Reported & Ground & & & 29140. & 20. \\
\hline $\mathrm{C}^{12} \mathrm{D}_{2} \mathrm{Cl}^{35} \mathrm{Si}^{28} \mathrm{H}_{3}$ & 3- 235 & $12,1,11 \leftarrow 12,0,12$ & Ground & & & 29142.97 & .2 \\
\hline $\mathrm{C}^{12} \mathrm{DHCl}^{35} \mathrm{Cl}^{37}$ & 4- 345 & $8,1,7 \leftarrow 8,0,8$ & Ground & & & 29143. & 5. \\
\hline $\mathrm{c}-\mathrm{C}^{12} \mathrm{HD}: \mathrm{C}^{12} \mathrm{DBr}^{79}$ & 4- 744 & $4,3,2 \leftarrow-3,3,1$ & Ground & $7 / 2$ & $7 / 2$ & 29144.3 & \\
\hline $\mathrm{t}-\mathrm{C}^{12} \mathrm{HD}: \mathrm{C}^{12} \mathrm{HBr}^{79}$ & 4- 741 & $4,1,4 \leftarrow-3,1,3$ & Ground & $9 / 2$ & $7 / 2$ & 29144.6 & \\
\hline $\mathrm{a}-\left(\mathrm{C}^{12} \mathrm{H}_{2} \mathrm{D}\right)\left(\mathrm{C}^{12} \mathrm{H}_{3}\right) \mathrm{O}^{16}$ & 3- 597 & $3,1,2 \leftarrow 3,0,3$ & Ground & & & 29145.4 & .5 \\
\hline $\mathrm{C}^{12} \mathrm{HD}: \mathrm{C}^{12} \mathrm{DBr}^{\mathrm{b}}$ & 4. 749 & Not Reported & Ground & & & 29146.6 & .1 \\
\hline $\mathrm{C}^{12} \mathrm{H}_{3} \mathrm{~N}^{14} \mathrm{H}_{2}$ & 3- 261 & Not Reported & Ground & & & 29147.37 & .1 \\
\hline$c-\mathrm{C}^{12} \mathrm{HD}: \mathrm{C}^{12} \mathrm{DBr}^{79}$ & 4. 744 & $4,0,4 \leftarrow 3,0,3$ & Ground & $9 / 2$ & $9 / 2$ & 29148.0 & \\
\hline s. $\left(\mathrm{C}^{12} \mathrm{H}_{2} \mathrm{D}\right)\left(\mathrm{C}^{12} \mathrm{H}_{3}\right) \mathrm{O}^{16}$ & 3- 596 & Not Reported & Ground & & & 29150. & 20. \\
\hline $\mathrm{C}^{12} \mathrm{HD}: \mathrm{C}^{12} \mathrm{DBr}^{\mathrm{b}}$ & 4- 749 & Not Reported & Ground & & & 29150.7 & .1 \\
\hline $\mathrm{t}-\mathrm{C}^{12} \mathrm{HD}: \mathrm{C}^{12} \mathrm{HBr}^{79}$ & 4. 741 & $4,1,4 \leftarrow 3,1,3$ & Ground & $7 / 2$ & $5 / 2$ & 29151.1 & \\
\hline $\mathrm{N}^{14} \mathrm{O}^{16} \mathrm{Br}^{\mathrm{b}}$ & 4- 123 & $4, \quad \leftarrow 3$, & & & & 29154.0 & \\
\hline t- $\mathrm{C}^{12} \mathrm{HD}: \mathrm{C}^{12} \mathrm{DBr}^{81}$ & 4- 747 & $4,1,4 \leftarrow 3,1,3$ & Ground & $5 / 2$ & $5 / 2$ & 29154.2 & \\
\hline $\mathrm{C}^{12} \mathrm{H}_{2}\left(\mathrm{C}^{12} \mathrm{~N}^{14}\right)_{2}$ & 4- 901 & Not Reported & Ground & & & 29155.5 & .1 \\
\hline$c-\mathrm{HF}^{19} \mathrm{C}^{12}: \mathrm{C}^{12} \mathrm{HF}^{19}$ & 4. 691 & $4,0,4 \leftarrow 3,1,3$ & Ground & & & 29158.73 & .05 \\
\hline $\mathrm{C}_{7}^{12} \mathrm{H}_{13} \mathrm{~N}^{14}$ & 4-1311 & $6, \leftarrow 5$, & Excited & & & 29160.6 & \\
\hline $\mathrm{S}^{32} \mathrm{~F}_{5}^{19} \mathrm{Cl}^{35}$ & 4-1421 & $8, \leftarrow 7$, & Excited & & & 29163.27 & \\
\hline $\mathrm{C}^{12}{ }_{*} \mathrm{DHC}^{12} \mathrm{H}: \mathrm{C}^{12}{ }_{*} \mathrm{H}$ & 4-1034 & $8,4,4 \leftarrow 8,4,5$ & Ground & & & 29165.3 & \\
\hline $\mathrm{C}^{12} \mathrm{O}^{16} \mathrm{~F}_{2}^{19}$ & 4- 211 & $12,10,2 \leftarrow 12,10,3$ & Ground & & & 29166.78 & .10 \\
\hline $\mathrm{C}^{12} \mathrm{H}_{2}\left(\mathrm{C}^{12} \mathrm{~N}^{14}\right)_{2}$ & 4- 901 & Not Reported & Ground & & & 29167.6 & .1 \\
\hline $\mathrm{C}^{12} \mathrm{D}_{3} \mathrm{C}^{12} \mathrm{DO}^{16}$ & 3. 472 & $7,1,6 \leftarrow 7,1,7$ & Ground & & & 29170.90 & .4 \\
\hline $\mathrm{HC}^{12} \mathrm{O}^{16} \mathrm{O}^{18} \mathrm{C}^{12} \mathrm{H}_{3}-\mathrm{E}$ & $3 \cdot 516$ & $5,1,4 \leftarrow 5,0,5$ & Ground & & & 29171.96 & .2 \\
\hline $\mathrm{C}_{7}^{12} \mathrm{H}_{13} \mathrm{~N}^{14}$ & 4-1311 & $6, \leftarrow 5$ & Ground & & & 29173.5 & \\
\hline $\mathrm{HN}^{14} \mathrm{O}_{3}^{16}$ & $3-31$ & $5,3,2 \leftarrow 5,3,3$ & Ground & & & 29175.32 & \\
\hline $\mathrm{C}^{12} \mathrm{H}_{2}\left(\mathrm{C}^{12} \mathrm{~N}^{14}\right)_{2}$ & 4- 901 & Not Reported & Ground & & & 29179. & .1 \\
\hline $\mathrm{C}^{12} \mathrm{D}_{3} \mathrm{C}^{12} \mathrm{O}^{16} \mathrm{Cl}^{37}$ & $3-364$ & $6,3,4 \leftarrow 6,2,5$ & Ground & & & 29179.00 & .1 \\
\hline $\mathrm{C}^{12} \mathrm{D}_{3} \mathrm{C}^{12} \mathrm{DO}^{16}$ & 3- 472 & $7,1,6 \leftarrow 7,1,7$ & Ground & & & 29179.77 & .2 \\
\hline $\mathrm{S}^{34} \mathrm{~F}_{5}^{19} \mathrm{Cl}^{35}$ & 4-1423 & $8, \leftarrow 7$, & Ground & & & 29181.73 & .5 \\
\hline $\mathrm{S}^{32} \mathrm{~F}_{5}^{19} \mathrm{Cl}^{35}$ & $4-1421$ & $8,7 \leftarrow 7,7$ & Ground & $17 / 2$ & $15 / 2$ & 29184.14 & .5 \\
\hline $\mathrm{S}^{32} \mathbf{F}_{5}^{19} \mathrm{Cl}^{35}$ & 4-1421 & $8,7 \leftarrow 7,7$ & Ground & $15 / 2$ & $13 / 2$ & 29186.38 & .5 \\
\hline $\mathrm{S}^{32} \mathrm{~F}_{5}^{19} \mathrm{Cl}^{35}$ & $4-1421$ & $8,6 \leftarrow 7,6$ & Ground & $17 / 2$ & $15 / 2$ & 29186.38 & .5 \\
\hline $\mathrm{C}^{12} \mathrm{D}_{3} \mathrm{C}^{12} \mathrm{DO}^{16}$ & 3- 472 & Not Reported & & & & 29186.9 & \\
\hline $\mathrm{N}^{14} \mathrm{H}_{2} \mathrm{D}$ & 4-1773 & $7,2,6 \leftarrow 7,1,6$ & Ground & & & 29186.99 & .05 \\
\hline $\mathrm{HC}^{12} \mathrm{O}^{16} \mathrm{O}^{18} \mathrm{C}^{12} \mathrm{H}_{3}-\mathrm{A}$ & 3- 515 & $5,1,4 \leftarrow 5,0,5$ & Ground & & & 29187.25 & .2 \\
\hline $\mathrm{C}_{7}^{12} \mathrm{H}_{13} \mathrm{~N}^{14}$ & 4.1311 & $6, \leftarrow 5$, & Excited & & & 29187.6 & \\
\hline $\mathrm{C}^{12} \mathrm{H}_{2}\left(\mathrm{C}^{12} \mathrm{~N}^{14}\right)_{2}$ & 4. 901 & Not Reported & Ground & & & 29188. & .1 \\
\hline $\mathrm{S}^{32} \mathrm{~F}_{5}^{19} \mathrm{Cl}^{35}$ & 4-1421 & $8,5 \leftarrow 7,5$ & Ground & $17 / 2$ & $15 / 2$ & 29188.28 & .5 \\
\hline $\mathrm{S}^{32} \mathrm{~F}_{5}^{19} \mathrm{Cl}^{35}$ & $4-1421$ & $8,6 \leftarrow 7,6$ & Ground & $15 / 2$ & $13 / 2$ & 29188.28 & .5 \\
\hline $\mathrm{S}^{32} \mathrm{~F}_{5}^{19} \mathrm{Cl}^{35}$ & 4-1421 & $8,4 \leftarrow 7,4$ & Ground & $15 / 2$ & $13 / 2$ & 29189.65 & .5 \\
\hline
\end{tabular}




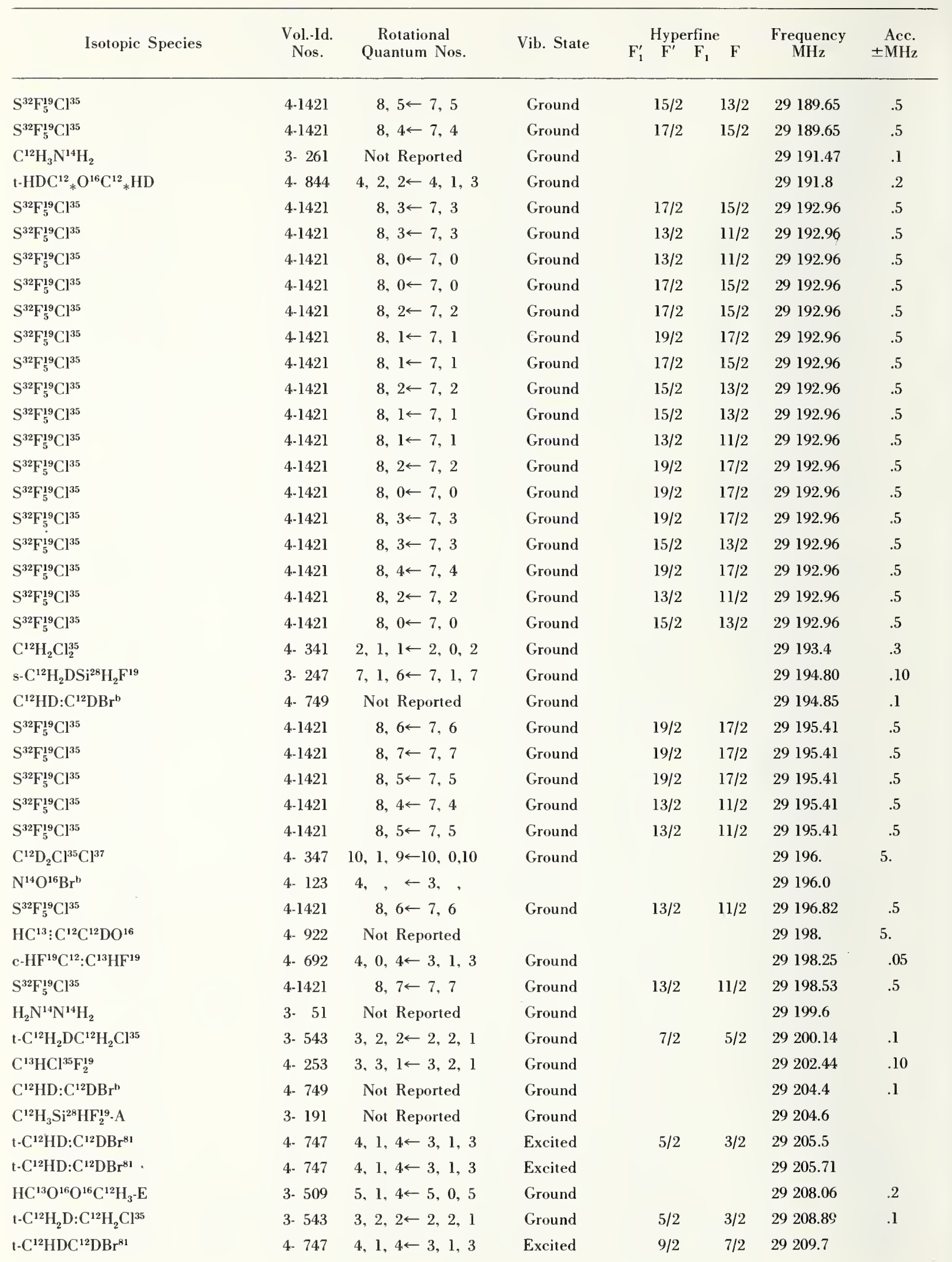


$\begin{array}{cc}\text { Vol.-Id. } & \text { Rotational } \\ \text { Nos. } & \text { Quantum Nos. }\end{array}$
Vib. Statc
Frequency Acc.

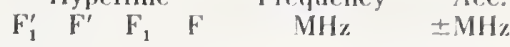

$\mathrm{C}_{7}^{12} \mathrm{H}_{13} \mathrm{~N}^{14}$

t- $\mathrm{C}^{12} \mathrm{H}_{2} \mathrm{DC}^{12} \mathrm{H}_{2} \mathrm{Cl}^{35}$

$\mathrm{C}^{12} \mathrm{H}_{3} \mathrm{C}^{12}{ }_{*} \mathrm{HO}^{16} \mathrm{C}^{12}{ }_{*} \mathrm{H}_{2}$

$\mathrm{C}^{12} \mathrm{HBr}_{3}^{81}$

t- $\dot{\mathrm{C}}^{12} \mathrm{H} \mathrm{D}: \mathrm{C}^{12} \mathrm{DBr}^{31}$

$\mathrm{C}^{12} \mathrm{H}_{3} \mathrm{C}^{12} \mathrm{H}_{2} \mathrm{Br}^{79}$

$\mathrm{C}^{12} \mathrm{H}_{2}\left(\mathrm{C}^{12} \mathrm{~N}^{14}\right)_{2}$

$\mathrm{N}^{14} \mathrm{O}^{16} \mathrm{O}^{18}$

$\mathrm{C}^{12} \mathrm{H}_{3} \mathrm{C}^{12} \mathrm{H}_{2} \mathrm{Br}^{79}$

$\mathrm{C}^{12} \mathrm{H}_{3} \mathrm{Si}^{28} \mathrm{HF}_{2}^{19}$-A

$\mathrm{C}^{12} \mathrm{H}_{3} \mathrm{C}^{12}{ }_{*} \mathrm{HO}^{16} \mathrm{C}^{12}{ }_{*} \mathrm{H}_{2}$

$\mathrm{C}^{12} \mathrm{D}_{3} \mathrm{C}^{12} \mathrm{DO}^{16}$

$\mathrm{C}^{12} \mathrm{H}_{2} \mathrm{Cl}^{35} \mathrm{C}^{12}: \mathrm{C}^{12} \mathrm{H}$

$\mathrm{HC}^{13} \mathrm{O}^{16} \mathrm{O}^{16} \mathrm{C}^{12} \mathrm{H}_{3}-\mathrm{A}$

t- $\mathrm{C}^{12} \mathrm{H}_{2} \mathrm{DC}^{12} \mathrm{H}_{2} \mathrm{Cl}^{35}$

t-C ${ }^{12} \mathrm{HD}: \mathrm{C}^{12} \mathrm{DBr}^{81}$.

$\mathrm{O}^{16} \mathrm{O}^{18} \mathrm{O}^{16}$

$\mathrm{C}^{13} \mathrm{H}_{3} \mathrm{C}^{12} \mathrm{O}^{16} \mathrm{C}^{12} \mathrm{~N}^{14}$

$\mathrm{t}-\mathrm{C}^{12} \mathrm{HD}: \mathrm{C}^{12} \mathrm{DBr}^{81}$

t-C ${ }^{12} \mathrm{HD}: \mathrm{C}^{12} \mathrm{DBr}^{81}$

t- $\mathrm{C}^{12} \mathrm{H}_{2} \mathrm{DC}^{12} \mathrm{H}_{2} \mathrm{Cl}^{35}$

t-C ${ }^{12} \mathrm{HD}: \mathrm{C}^{12} \mathrm{DBr}^{81}$

$\mathrm{D}_{2} \mathrm{C}^{12}: \mathrm{C}^{12} \mathrm{DCl}^{35}$

t. $\mathrm{C}^{12} \mathrm{H}_{2} \mathrm{DC}^{12} \mathrm{H}_{2} \mathrm{Cl}^{35}$

t-C ${ }^{12} \mathrm{HD}: \mathrm{C}^{12} \mathrm{HBr}^{79}$

$\mathrm{C}^{12} \mathrm{H}_{2}\left(\mathrm{C}^{12} \mathrm{~N}^{14}\right)_{2}$

$\left(\mathrm{C}^{12} \mathrm{H}_{3}\right)_{3} \mathrm{Si}^{28} \mathrm{Br}^{79}$

$\mathrm{D}_{2} \mathrm{C}^{12}: \mathrm{C}^{12} \mathrm{DCl}^{35}$

$\mathrm{C}^{12} \mathrm{HD}: \mathrm{C}^{12} \mathrm{DBr}^{\mathrm{b}}$

$\mathrm{H}_{2} \mathrm{~N}^{14} \mathrm{~N}^{14} \mathrm{H}_{2}$

$\mathrm{C}^{12} \mathrm{H}_{2}: \mathrm{C}^{12} \mathrm{HC}^{12} \mathrm{~F}^{19}: \mathrm{C}^{12} \mathrm{H}_{2}$ $\mathrm{t}-\mathrm{C}^{12} \mathrm{HD}: \mathrm{C}^{12} \mathrm{DBr}^{81}$

$\mathrm{C}^{12} \mathrm{H}_{3} \mathrm{~N}^{14} \mathrm{H}_{2}$

t- $\mathrm{C}^{12} \mathrm{H}_{2} \mathrm{DC}^{12} \mathrm{H}_{2} \mathrm{Cl}^{35}$

$\mathrm{C}_{7}^{12} \mathrm{H}_{13} \mathrm{~N}^{14}$

$\mathrm{H}_{2} \mathrm{~N}^{14} \mathrm{~N}^{14} \mathrm{H}_{2}$

$\mathrm{H}_{2} \mathrm{~N}^{14} \mathrm{~N}^{14} \mathrm{H}_{2}$

$\mathrm{H}_{2} \mathrm{~N}^{14} \mathrm{~N}^{14} \mathrm{H}_{2-}$

$\mathrm{C}^{\mathrm{b}} \mathrm{H}_{2}^{\mathrm{b}} \mathrm{Cl}^{\mathrm{b}} \mathrm{F}^{\mathrm{b}}$

$\mathrm{C}^{12}{ }_{*} \mathrm{H}_{2} \mathrm{C}^{12} \mathrm{H}_{2} \mathrm{C}^{12} \mathrm{H}_{2} \mathrm{O}^{16} *$

$\mathrm{C}^{12} \mathrm{HD}: \mathrm{C}^{12} \mathrm{DBr}^{\mathrm{b}}$

$\mathrm{C}^{12} \mathrm{HD}: \mathrm{C}^{12} \mathrm{HBr}^{\mathrm{b}}$

$\mathrm{C}^{12} \mathrm{H}_{2}\left(\mathrm{C}^{12} \mathrm{~N}^{14}\right)_{2}$

$\mathrm{C}^{12} \mathrm{H}_{3} \mathrm{C}^{12} \mathrm{H}_{2} \mathrm{Br}^{79}$

$\mathrm{C}^{12} \mathrm{H}_{3} \mathrm{C}^{12} \mathrm{H}_{2} \mathrm{Br}^{79}$
4-1311 6, $\leftarrow 5, \quad$ Excited

3- $543 \quad 3,2,2 \leftarrow 2,2,1 \quad$ Ground

3- $761 \quad$ Not Reported Ground

4- 242

$12, \leftarrow 11$,

4- 747

$4,1,4 \leftarrow 3,1,3$

Ground

3- 521

$4,2,3 \leftarrow 3,2,2$

4. 901

Not Reported

4-1803

$10,0,10 \leftarrow 9,1,9$

3- 521

$4,2,3 \leftarrow 3,2,2$

3. 191

Not Reported

3- 761

$8,1,7 \leftarrow 8,0,8$

Excited

Ground

Ground

Ground

Ground

Ground

3- 472

Not Reported

4. 991

$5,0,5 \leftarrow 4,0,4$

Ground

3. 508

$5,1,4 \leftarrow 5,0,5$

Ground

3. 543

$3,2,1 \leftarrow 2,2,0$

4- 747

$4,1,4 \leftarrow 3,1,3$

4. 1843

$7,2,6 \leftarrow 8,1,7$

3- 672

$4,1,4 \leftarrow 3,0,3$

4. 747

$4,1,4 \leftarrow 3,1,3$

4. 747

$4,1,4 \leftarrow 3,1,3$

3. 543

$3,2,1 \leftarrow 2,2,0$

4- 747

$4,1,4 \leftarrow 3,1,3$

4. 763

$3,1,3 \leftarrow 2,1,2$

3- 543

$3,2,1 \leftarrow 2,2,0$

4- 741

$4,1,4 \leftarrow 3,1,3$

4. 901

Not Reported

3. 811

4. 763

$10, \leftarrow 9$,

4. 749

$3,1,3 \leftarrow 2,1,2$

3- 51

Not Reported

3- 911

$6,2 \leftarrow 7,1$

4. 747

$5,2,4 \leftarrow 5,1,5$

$4,1,4 \leftarrow 3,1,3$

3- 261

Not Reported

3- 543

4-1311

$3,2,1 \leftarrow 2,2,0$

$6, \leftarrow 5$,

3. 51

Not Reported

3. 51

$6,2 \leftarrow 7,1$

3- 51

Not Reported

4. 333

Not Reported

4-1091

$11,10,2 \leftarrow 11,8,3$

4- 749

Not Reported

4. 748

Not Reported

4- 901

Not Reported

3- 521

$4,2,3 \leftarrow 3,2,2$

3- 521

Ground

Ground

Ground

Ground

Ground

Ground

Ground

Ground

Ground

Ground

Ground

Ground

Ground

Ground

Ground

Ground

Ground

Ground

Ground

Ground

Ground

Excited.

Ground

Ground

Ground

Ground

Ground

Ground

Ground

Ground

Ground

$\begin{array}{rr}7 / 2 & 5 / 2 \\ 11 / 2 & 9 / 2 \\ & \\ 11 / 2 & 9 / 2 \\ & \\ & \\ & \\ & \\ 7 / 2 & 5 / 2 \\ 11 / 2 & 9 / 2 \\ & \\ & \\ 5 / 2 & 3 / 2 \\ & \\ 5 / 2 & 3 / 2 \\ 9 / 2 & 7 / 2 \\ 9 / 2 & 7 / 2 \\ 9 / 2 & 9 / 2 \\ & \\ & \\ & \\ & \\ & \\ & \\ & \\ & \\ & \\ & \\ & \\ & \\ & \\ & \\ & \\ & \\ & \end{array}$

292 J1. 1

$\begin{array}{rrll}9 / 2 & 7 / 2 & 29212.44 & .1 \\ & & 29213.55 & .1 \\ & & 29215.4 & .5 \\ 7 / 2 & 5 / 2 & 29215.7 & \\ 11 / 2 & 9 / 2 & 29217.71 & .0 \\ & & 29218 . & .1 \\ & & 29218.7 & \end{array}$

29218.71

29219.2

29220.78

29221.05

29222.29

29223.59

$5 / 2 \quad 29224.23$

29226.5

29227.

29228.46

29231.7

$29232.17 \quad .06$

$29233.08 \quad .1$

29235.9

29235.95

$29236.53 \quad .1$

29237.6

$29238.6 \quad$.1

29238.7

29239.54

29239.7

29240.3

29240.6

$7 / 2 \quad 5 / 2 \quad 29241.9$

$29244.20 \quad$.1

$\begin{array}{llll}3 / 2 & 1 / 2 & 29 & 245.64\end{array}$

29251.2

29251.64

29251.8

29252.01

$29252.29 \quad .1$

$29252.6 \quad$.1

$29254.7 \quad .1$

$29255.9 \quad .1$

$29257.5 \quad$.1

$\begin{array}{llll}9 / 2 & 7 / 2 & 29259.34 & .01\end{array}$

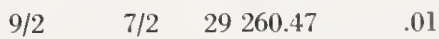




\begin{tabular}{|c|c|c|c|c|c|c|c|}
\hline Isotopic Species & $\begin{array}{l}\text { Vol.-Id. } \\
\text { Nos. }\end{array}$ & Rotational & Vib. State & $F_{F^{\prime}} \begin{array}{c}\text { Hyperfine } \\
F^{\prime}\end{array}$ & $F$ & Frequency & Acc. \\
\hline $\mathrm{C}^{12} \mathrm{O}^{16} \mathrm{~F}_{2}^{19}$ & 4- 211 & $11,9,2 \leftarrow 11,9,3$ & Ground & & & 29261.23 & .10 \\
\hline $\mathrm{C}^{12} \mathrm{H}_{3} \mathrm{C}^{12}: \mathrm{C}^{12} \mathrm{C}^{12} \mathrm{H}_{2} \mathrm{Cl}^{35}$ & 3- 901 & $10,1,9 \leftarrow 9,1,8$ & Ground & & & 29261.28 & .05 \\
\hline $\mathrm{C}^{12} \mathrm{HD}: \mathrm{C}^{12} \mathrm{DBr}^{\mathrm{b}}$ & 4. 749 & Not Reported & Ground & & & 29265.0 & .1 \\
\hline $\mathrm{C}^{12} \mathrm{H}_{3} \mathrm{C}^{12} \mathrm{H}_{2} \mathrm{Br}^{79}$ & 3- 521 & $4,2,2 \leftarrow 3,2,1$ & Ground & $7 / 2$ & $5 / 2$ & 29265.88 & .01 \\
\hline $\mathrm{N}^{14} \mathrm{O}^{16} \mathrm{Br}^{\mathrm{b}}$ & 4- 123 & $4, \quad \leftarrow 3, \quad$, & & & & 29266.4 & \\
\hline $\mathrm{C}^{12} \mathrm{H}_{3} \mathrm{C}^{12} \mathrm{H}_{2} \mathrm{Br}^{79}$ & 3- 521 & $4,2,2 \leftarrow 3,2,1$ & Ground & $7 / 2$ & $5 / 2$ & 29266.88 & .01 \\
\hline $\mathrm{C}^{12} \mathrm{HD}: \mathrm{C}^{12} \mathrm{HBr}^{\mathrm{b}}$ & 4- 748 & Not Reported & Ground & & & 29267.0 & .1 \\
\hline $\mathrm{C}^{12} \mathrm{H}_{2} \mathrm{~F}_{2}^{19}$ & 4- 351 & $4,2,2 \leftarrow 5,1,5$ & Ground & & & 29268.90 & .10 \\
\hline $\mathrm{C}^{12}{ }_{*} \mathrm{H}: \mathrm{C}^{12} \mathrm{HO}^{18} \mathrm{C}^{12} \mathrm{H}: \mathrm{C}^{12}{ }_{*} \mathrm{H}$ & $4-1152$ & $9,6,3 \leftarrow 9,6,4$ & Ground & & & 29270.9 & .1 \\
\hline g. $\mathrm{C}^{12} \mathrm{H}_{3} \mathrm{C}^{12} \mathrm{H}_{2} \mathrm{C}^{12} \mathrm{H}_{2} \mathrm{C}^{35}$ & 3- 773 & $14,2,12 \leftarrow 14,1,13$ & Ground & & & 29275.28 & .2 \\
\hline $\mathrm{C}^{12} \mathrm{H}_{2}\left(\mathrm{C}^{12} \mathrm{~N}^{14}\right)_{2}$ & 4. 901 & Not Reported & Ground & & & 29277.2 & .1 \\
\hline $\mathrm{C}^{12} \mathrm{D}_{2} \mathrm{Cl}^{35} \mathrm{Si}^{28} \mathrm{H}_{3}$ & 3- 235 & $5,1,5 \leftarrow 4,1,4$ & Ground & & & 29277.72 & .2 \\
\hline $\mathrm{C}^{12} \mathrm{HCl}^{35} \mathrm{~F}_{2}^{19}$ & 4- 251 & $3,3,1 \leftarrow 3,2,1$ & Ground & $3 / 2$ & $3 / 2$ & 29277.84 & \\
\hline $\mathrm{C}^{12} \mathrm{H}_{2} \mathrm{Cl}^{35} \mathrm{C}^{22}: \mathrm{C}^{12} \mathrm{H}$ & 4- 991 & $5,2,4 \leftarrow 4,2,3$ & Ground & & & 29281.78 & \\
\hline $\mathrm{C}^{12} \mathrm{HD}: \mathrm{C}^{12} \mathrm{DBr}^{\mathrm{b}}$ & 4- 749 & Not Reported & Ground & & & 29282.2 & .1 \\
\hline $\mathrm{O}^{16}{ }_{*} \mathrm{C}^{12} \mathrm{H}_{2} \mathrm{C}^{12} \mathrm{H}_{2} \mathrm{C}^{12}{ }_{*} \mathrm{O}^{16}$ & $4-1071$ & $3,1,2 \leftarrow 2,1,1$ & Ground & & & 29282.90 & .1 \\
\hline $\mathrm{C}^{12} \mathrm{HD}: \mathrm{C}^{12} \mathrm{DBr}^{\mathrm{b}}$ & 4- 749 & Not Reported & Ground & & & 29285.3 & .1 \\
\hline $\mathrm{C}^{12} \mathrm{HD}: \mathrm{C}^{12} \mathrm{DBr}^{\mathrm{b}}$ & 4- 749 & Not Reported & Ground & & & 29286.8 & .1 \\
\hline $\mathrm{C}^{12} \mathrm{HCl}^{35} \mathrm{~F}_{2}^{19}$ & 4. 251 & $3,3,1 \leftarrow 3,2,1$ & Ground & $9 / 2$ & $9 / 2$ & 29287.5 & .05 \\
\hline $\mathrm{C}^{12} \mathrm{H}_{3} \mathrm{C}^{12}{ }_{*} \mathrm{HO}^{16} \mathrm{C}^{12}{ }_{*} \mathrm{H}_{2}$ & 3- 761 & $8,2,6 \leftarrow 8,1,7$ & Ground & & & 29289.95 & .1 \\
\hline $\mathrm{C}^{12} \mathrm{H}_{2}\left(\mathrm{C}^{12} \mathrm{~N}^{14}\right)_{2}$ & 4- 901 & Not Reported & Ground & & & 29290. & .1 \\
\hline $\mathrm{HC}^{13}: \mathrm{C}^{12} \mathrm{C}^{12} \mathrm{DO}^{16}$ & 4. 922 & Not Reported & & & & 29293. & 5. \\
\hline $\mathrm{C}_{7}^{12} \mathrm{H}_{13} \mathrm{~N}^{14}$ & $4-1311$ & $6, \leftarrow 5$ & Excited & & & 29294.1 & \\
\hline $\mathrm{C}^{12} \mathrm{HCl}^{35} \mathrm{~F}_{2}^{19}$ & 4- 251 & $3,3,1 \leftarrow 3,2,1$ & Ground & & & 29294.80 & .03 \\
\hline $\mathrm{C}^{13} \mathrm{H}_{3} \mathrm{C}^{12} \mathrm{H}_{2} \mathrm{C}^{12} \mathrm{H}_{3}$ & 3- 782 & $5,1,4 \leftarrow 5,0,5$ & Ground & & & 29298.58 & .06 \\
\hline $\mathrm{C}^{12} \mathrm{HCl}^{35} \mathrm{~F}_{2}^{19}$ & 4- 251 & $3,3,1 \leftarrow 3,2,1$ & Ground & $5 / 2$ & $5 / 2$ & 29298.9 & .05 \\
\hline $\mathrm{C}^{12} \mathrm{H}_{3} \mathrm{C}^{12}{ }_{*} \mathrm{HO}^{16} \mathrm{C}^{12}{ }_{*} \mathrm{H}_{2}$ & 3- 761 & $8,2,6 \leftarrow 8,1,7$ & Ground & & & 29301.61 & .1 \\
\hline $\mathrm{C}^{12} \mathrm{H}_{3} \mathrm{C}^{12}{ }_{*} \mathrm{HO}^{16} \mathrm{C}^{12}{ }_{*} \mathrm{H}_{2}$ & 3- 761 & $8,2,6 \leftarrow 8,1,7$ & Ground & & & 29301.82 & .1 \\
\hline $\mathrm{C}^{12} \mathrm{H}_{2} \mathrm{Cl}^{35} \mathrm{C}^{12}: \mathrm{C}^{12} \mathrm{H}$ & 4. 991 & $5,3,3 \leftarrow 4,3,2$ & Ground & & & 29302.15 & \\
\hline $\mathrm{C}^{12} \mathrm{H}_{2} \mathrm{C}^{35} \mathrm{C}^{12}: \mathrm{C}^{12} \mathrm{H}$ & 4- 991 & $5,3,2 \leftarrow 4,3,1$ & Ground & & & 29302.15 & \\
\hline $\mathrm{C}^{12} \mathrm{H}_{3} \mathrm{C}^{12}{ }_{*} \mathrm{HO}^{16} \mathrm{C}^{12}{ }_{*} \mathrm{H}_{2}$ & 3- 761 & $8,2,6 \leftarrow 8,1,7$ & Ground & & & 29302.49 & .1 \\
\hline $\mathrm{O}^{16}{ }_{*} \mathrm{C}^{12} \mathrm{H}_{2} \mathrm{C}^{12} \mathrm{H}_{2} \mathrm{C}^{12}{ }_{*} \mathrm{O}^{16}$ & $4-1071$ & $3,1,2 \leftarrow 2,1,1$ & Excited & & & 29305.27 & .10 \\
\hline $\mathrm{t}-\mathrm{C}^{12} \mathrm{HD}: \mathrm{C}^{12} \mathrm{DBr}^{79}$ & 4. 745 & $4,1,4 \leftarrow 3,1,3$ & Ground & $5 / 2$ & $5 / 2$ & 29307.4 & \\
\hline $\mathrm{N}^{14} \mathrm{O}^{16} \mathrm{Br}^{\mathrm{b}}$ & 4- 123 & $4, \quad \leftarrow 3, \quad$, & & & & 29307.9 & \\
\hline $\mathrm{C}^{12} \mathrm{HCl}^{35} \mathrm{~F}_{2}^{19}$ & 4- 251 & $3,3,1 \leftarrow 3,2,1$ & Ground & $7 / 2$ & $7 / 2$ & 29308.7 & .05 \\
\hline $\mathrm{C}^{12} \mathrm{H}_{3} \mathrm{~N}^{14} \mathrm{H}_{2}$ & 3- 261 & $6,1, \leftarrow 5,2$, & Ground & & & 29312.4 & \\
\hline $\mathrm{C}^{12} \mathrm{H}_{2}\left(\mathrm{C}^{12} \mathrm{~N}^{14}\right)_{2}$ & 4. 901 & Not Reported & Ground & & & 29312.7 & .1 \\
\hline t- $\mathrm{C}^{12} \mathrm{HD}: \mathrm{C}^{12} \mathrm{DBr}^{81}$ & 4- 747 & $4,1,4 \leftarrow 3,1,3$ & Ground & $9 / 2$ & $9 / 2$ & 29313.75 & \\
\hline $\mathrm{C}^{13} \mathrm{H}_{3} \mathrm{O}^{16} \mathrm{H}$ & 3- 213 & $13,2, \leftarrow 13,1$ & Ground & & & 29315.20 & .1 \\
\hline $\mathrm{N}^{14} \mathrm{D}_{2} \mathrm{Hi}$ & $4-1774$ & $8,3,6 \leftarrow 8,2,6$ & Ground & & & 29319.47 & .05 \\
\hline $\mathrm{C}^{12} \mathrm{H}_{3} \mathrm{C}^{12} \mathrm{H}_{2} \mathrm{I}^{127}$ & 3- 571 & $5,1,4 \leftarrow 4,1,3$ & & $9 / 2$ & $7 / 2$ & 29319.70 & \\
\hline $\mathrm{N}^{14} \mathrm{O}^{16} \mathrm{Br}^{\mathrm{b}}$ & 4- 123 & $4, \quad \leftarrow 3, \quad$, & & & & 29320.0 & \\
\hline $\mathrm{C}^{12} \mathrm{H}_{3} \mathrm{C}^{12} \mathrm{H}_{2} \mathrm{I}^{127}$ & 3- 571 & $5,1,4 \leftarrow 4,1,3$ & & $7 / 2$ & $5 / 2$ & 29320.60 & \\
\hline $\mathrm{S}^{32} \mathrm{O}_{2}^{16}$ & $4-1831$ & $4,0,4 \leftarrow 3,1,3$ & Ground & & & 29321.22 & .03 \\
\hline $\mathrm{C}^{12} \mathrm{HD}: \mathrm{C}^{12} \mathrm{HBr}^{\mathrm{b}}$ & 4- 748 & Not Reported & Ground & & & 29321.3 & .1 \\
\hline
\end{tabular}




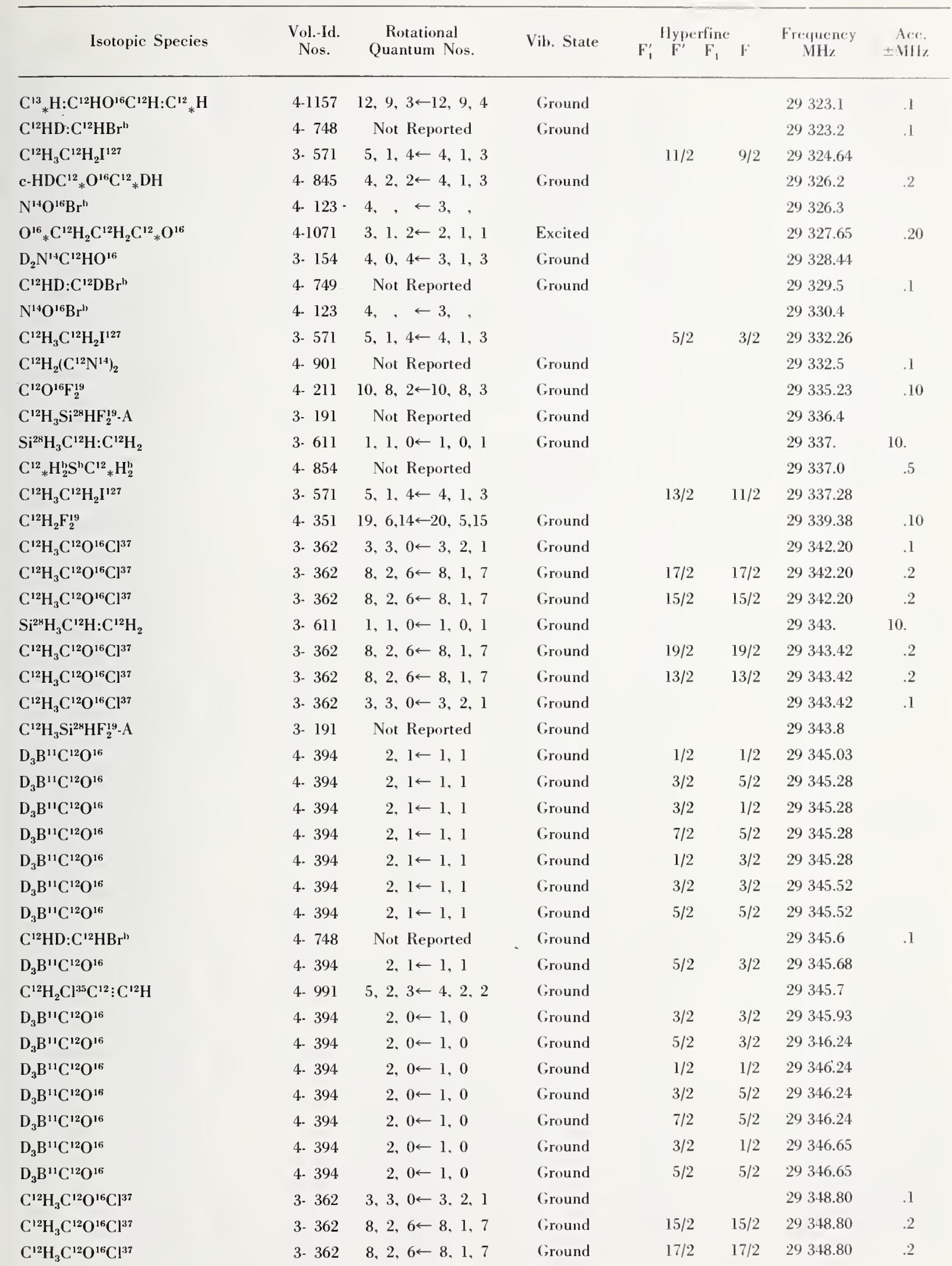




\begin{tabular}{|c|c|c|c|c|c|c|c|}
\hline \multirow{2}{*}{ Isotopic Species } & \multirow{2}{*}{$\begin{array}{l}\text { Vol.-Id. } \\
\text { Nos. }\end{array}$} & \multirow{2}{*}{$\begin{array}{c}\text { Rotational } \\
\text { Quantum Nos. }\end{array}$} & \multirow{2}{*}{ Vib. State } & \multicolumn{2}{|c|}{ Hyperfine } & \multirow{2}{*}{$\begin{array}{c}\text { Frequency } \\
\mathrm{MHz}\end{array}$} & \multirow{2}{*}{$\begin{aligned} & \text { Acc. } \\
\pm & \mathrm{MHz}\end{aligned}$} \\
\hline & & & & $\mathrm{F}_{1}^{\prime} \quad \mathrm{F}^{\prime}$ & $\mathrm{F}_{1} \quad \mathrm{~F}$ & & \\
\hline $\mathrm{C}^{12} \mathrm{H}_{3} \mathrm{C}^{12} \mathrm{O}^{16} \mathrm{Cl}^{37}$ & 3- 362 & $8,2,6 \leftarrow 8,1,7$ & Ground & $13 / 2$ & $13 / 2$ & 29350.15 & .2 \\
\hline $\mathrm{C}^{12} \mathrm{H}_{3} \mathrm{C}^{12} \mathrm{O}^{16} \mathrm{Cl}^{37}$ & 3- 362 & $8,2,6 \leftarrow 8,1,7$ & Ground & $19 / 2$ & $19 / 2$ & 29350.15 & .2 \\
\hline $\mathrm{C}^{12} \mathrm{H}_{3} \mathrm{C}^{12} \mathrm{O}^{16} \mathrm{Cl}^{37}$ & 3- 362 & $3,3,0 \leftarrow 3,2,1$ & Ground & & & 29350.15 & .1 \\
\hline $\mathrm{C}^{12} \mathrm{H}_{2}\left(\mathrm{C}^{12} \mathrm{~N}^{14}\right)_{2}$ & 4. 901 & Not Reported & Ground & & & 29351. & .1 \\
\hline $\mathrm{C}^{12} \mathrm{H}_{3} \mathrm{C}^{12} \mathrm{H}_{2} \mathrm{I}^{127}$ & 3- 571 & $5,1,4 \leftarrow 4,1,3$ & & $15 / 2$ & $13 / 2$ & 29357.16 & \\
\hline $\mathrm{C}^{\mathrm{b}} \mathrm{H}_{2}^{\mathrm{b}} \mathrm{Cl}^{\mathrm{b}} \mathrm{F}^{\mathrm{b}}$ & 4- 333 & Not Reported & & & & 29358.15 & .1 \\
\hline $\mathrm{C}^{12}{ }_{*} \mathrm{H}_{2} \mathrm{C}^{12} \mathrm{H}_{2} \mathrm{C}^{12}{ }_{*} \mathrm{HCl}^{37}$ & 4-1082 & $4,0,4 \leftarrow 3,0,3$ & Ground & & & 29358.4 & .3 \\
\hline $\mathrm{N}^{14} \mathrm{O}^{16} \mathrm{Br}^{\mathrm{b}}$ & 4. 123 & $4, \quad \leftarrow 3$, & & & & 29359.1 & \\
\hline $\mathrm{C}^{12} \mathrm{H}_{3} \mathrm{Si}^{28} \mathrm{HF}_{2}^{19}-\mathrm{A}$ & 3- 191 & $8,3,6 \leftarrow 8,3,5$ & Ground & & & 29360.07 & \\
\hline $\mathrm{t}-\mathrm{C}^{12} \mathrm{HD}: \mathrm{C}^{12} \mathrm{DBr}^{79}$ & 4- 745 & $4,1,4 \leftarrow 3,1,3$ & Excited & $11 / 2$ & $9 / 2$ & 29361.9 & \\
\hline $\mathrm{O}^{16} \mathrm{~F}_{2}^{19}$ & 4-1611 & $23,2,22 \longleftarrow 22,3,19$ & Ground & & & 29365.40 & .10 \\
\hline $\mathrm{t}-\mathrm{C}^{12} \mathrm{HD}: \mathrm{C}^{12} \mathrm{DBr}^{79}$ & 4- 745 & $4,1,4 \leftarrow 3,1,3$ & Excited & & & 29368.86 & \\
\hline $\mathrm{t}-\mathrm{C}^{12} \mathrm{HD}: \mathrm{C}^{12} \mathrm{DBr}^{79}$ & 4- 745 & $4,1,4 \leftarrow 3,1,3$ & Ground & $7 / 2$ & $7 / 2$ & 29369.0 & \\
\hline $\mathrm{C}^{12} \mathrm{H}_{3} \mathrm{C}^{12} * \mathrm{HO}^{16} \mathrm{C}^{12}{ }_{*} \mathrm{H}_{2}$ & 3- 761 & Not Reported & Ground & & & 29370.43 & .1 \\
\hline $\mathrm{C}^{12} \mathrm{H}_{3} \mathrm{C}^{12}{ }_{*} \mathrm{HO}^{16} \mathrm{C}^{12}{ }_{*} \mathrm{H}_{2}$ & 3- 761 & Not Reported & Ground & & & 29371.74 & .1 \\
\hline $\mathrm{C}^{12} \mathrm{H}_{3} \mathrm{C}^{12}{ }_{*} \mathrm{HO}^{16} \mathrm{C}^{12}{ }_{*} \mathrm{H}_{2}$ & $3-761$ & Not Reported & Ground & & & 29373.24 & .1 \\
\hline t. $\mathrm{C}^{12} \mathrm{HD}: \mathrm{C}^{12} \mathrm{DBr}^{79}$ & 4- 745 & $4,1,4 \leftarrow 3,1,3$ & Excited & $9 / 2$ & $7 / 2$ & 29373.3 & \\
\hline $\mathrm{C}^{12} \mathrm{H}_{2}\left(\mathrm{C}^{12} \mathrm{~N}^{14}\right)_{2}$ & 4. 901 & Not Reported & Ground & & & 29376.7 & .1 \\
\hline $\mathrm{t}-\mathrm{C}^{12} \mathrm{HD}: \mathrm{C}^{12} \mathrm{DBr}^{79}$ & 4- 745 & $4,1,4 \leftarrow 3,1,3$ & Excited & $7 / 2$ & $5 / 2$ & 29380.1 & \\
\hline $\mathrm{C}^{12} \mathrm{H}_{3} \mathrm{C}^{12}{ }_{*} \mathrm{HO}^{16} \mathrm{C}^{12}{ }_{*} \mathrm{H}_{2}$ & 3- 761 & $8,1,7 \leftarrow 8,0,8$ & Ground & & & 29380.35 & .1 \\
\hline $\mathrm{C}^{13} \mathrm{O}^{16} \mathrm{~F}_{2}^{19}$ & 4- 212 & $2,1,2 \leftarrow 1,1,1$ & Ground & & & 29386.69 & .10 \\
\hline $\mathrm{C}^{12} \mathrm{D}_{2} \mathrm{Cl}^{35} \mathrm{Si}^{28} \mathrm{H}_{3}$ & 3- 235 & $5,1,5 \leftarrow 4,1,4$ & Ground & & & 29389.83 & .2 \\
\hline $\mathrm{C}^{12} \mathrm{H}_{3} \mathrm{C}^{13} \mathrm{O}^{16} \mathrm{Cl}^{37}$ & 3- 371 & $10,3,7 \leftarrow 10,2,8$ & Ground & $21 / 2$ & $21 / 2$ & 29390.91 & .2 \\
\hline $\mathrm{C}^{12} \mathrm{H}_{3} \mathrm{C}^{13} \mathrm{O}^{16} \mathrm{Cl}^{37}$ & 3- 371 & $10,3,7 \leftarrow 10,2,8$ & Ground & $17 / 2$ & $17 / 2$ & 29390.91 & .2 \\
\hline $\mathrm{C}^{12} \mathrm{H}_{3} \mathrm{C}^{13} \mathrm{O}^{16} \mathrm{Cl}^{37}$ & 3- 371 & $10,3,7 \leftarrow 10,2,8$ & Ground & $23 / 2$ & $23 / 2$ & 29390.91 & .2 \\
\hline $\mathrm{C}^{12} \mathrm{H}_{3} \mathrm{C}^{13} \mathrm{O}^{16} \mathrm{Cl}^{37}$ & 3- 371 & $10,3,7 \leftarrow 10,2,8$ & Ground & $19 / 2$ & $19 / 2$ & 29390.91 & .2 \\
\hline $\mathrm{C}^{12} \mathrm{H}_{3} \mathrm{C}^{12} \mathrm{O}^{16} \mathrm{O}^{16} \mathrm{H}$ & 3- 491 & $5,4,2 \leftarrow 5,3,3$ & Ground & & & 29391.68 & \\
\hline $\mathrm{C}^{12} \mathrm{O}^{16} \mathrm{~F}_{2}^{19}$ & 4- 211 & $9,7,2 \leftarrow 9,7,3$ & Ground & & & 29391.88 & .10 \\
\hline $\mathrm{t}-\mathrm{C}^{12} \mathrm{HD}: \mathrm{C}^{12} \mathrm{DBr}^{79}$ & 4- 745 & $4,1,4 \leftarrow 3,1,3$ & Ground & $11 / 2$ & $9 / 2$ & 29393.9 & \\
\hline $\mathrm{C}^{12} \mathrm{H}_{2} \mathrm{Cl}^{37} \mathrm{C}^{12}: \mathrm{C}^{12} \mathrm{H}$ & 4- 992 & $5,1,4 \leftarrow 4,1,3$ & Ground & & & 29394. & \\
\hline $\mathrm{C}^{12} \mathrm{O}^{16} \mathrm{~F}_{2}^{19}$ & 4- 211 & $2,1,2 \leftarrow 1,1,1$ & Ground & & & 29395.71 & .10 \\
\hline $\mathrm{C}^{12} \mathrm{H}_{3} \mathrm{C}^{13} \mathrm{O}^{16} \mathrm{Cl}^{37}$ & 3- 371 & $10,3,7 \leftarrow 10,2,8$ & Ground & $21 / 2$ & $21 / 2$ & 29396.97 & .2 \\
\hline $\mathrm{C}^{12} \mathrm{H}_{3} \mathrm{C}^{13} \mathrm{O}^{16} \mathrm{Cl}^{37}$ & 3- 371 & $10,3,7 \leftarrow 10,2,8$ & Ground & $19 / 2$ & $19 / 2$ & 29396.97 & .2 \\
\hline $\mathrm{C}^{12} \mathrm{H}_{3} \mathrm{C}^{13} \mathrm{O}^{16} \mathrm{Cl}^{37}$ & 3- 371 & $10,3,7 \leftarrow 10,2,8$ & Ground & $17 / 2$ & $17 / 2$ & 29396.97 & .2 \\
\hline $\mathrm{C}^{12} \mathrm{H}_{3} \mathrm{C}^{13} \mathrm{O}^{16} \mathrm{Cl}^{37}$ & 3- 371 & $10,3,7 \leftarrow 10,2,8$ & Ground & $23 / 2$ & $23 / 2$ & 29396.97 & .2 \\
\hline $\mathrm{C}^{12} \mathrm{H}_{3} \mathrm{C}^{12} \mathrm{HO}^{16}$ & 3- 471 & Not Reported & & & & 29396.99 & \\
\hline $\mathrm{C}^{12} \mathrm{Cl}^{35} \mathrm{Cl}_{2}^{37} \mathrm{C}^{12} \mathrm{~N}^{14}$ & 4- 583 & $9, \quad, \quad \leftarrow 8$, & Ground & & & 29400.0 & 20. \\
\hline $\mathrm{t}-\mathrm{C}^{12} \mathrm{HD}: \mathrm{C}^{12} \mathrm{DBr}^{79}$ & 4- 745 & $4,1,4 \leftarrow 3,1,3$ & Ground & $5 / 2$ & $3 / 2$ & 29400.1 & \\
\hline $\mathrm{t}-\mathrm{C}^{12} \mathrm{HD}: \mathrm{C}^{12} \mathrm{DBr}^{79}$ & 4- 745 & $4,1,4 \leftarrow 3,1,3$ & Ground & & & 29400.73 & .09 \\
\hline $\mathrm{HC}^{12} \mathrm{O}^{16} \mathrm{O}^{16} \mathrm{C}^{12} \mathrm{H}_{3}-\mathrm{E}$ & 3- 502 & $5,1,4 \leftarrow 5,0,5$ & Ground & & & 29401.50 & .2 \\
\hline $\mathrm{C}^{12} \mathrm{H}_{2}\left(\mathrm{C}^{12} \mathrm{~N}^{14}\right)_{2}$ & 4- 901 & Not Reported & Ground & & & 29403.3 & .1 \\
\hline $\mathrm{C}^{12}{ }_{*} \mathrm{H}_{2} \mathrm{C}^{12} \mathrm{H}_{2} \mathrm{C}^{12}{ }_{*} \mathrm{HCl}^{37}$ & 4-1082 & $4,2,3 \leftarrow 3,2,2$ & Ground & & & 29403.8 & \\
\hline $\mathrm{t}-\mathrm{C}^{12} \mathrm{HD}: \mathrm{C}^{12} \mathrm{DBr}^{79}$ & 4- 745 & $4,1,4 \leftarrow 3,1,3$ & Ground & $9 / 2$ & $7 / 2$ & 29405.2 & \\
\hline $\mathrm{t}-\mathrm{C}^{12} \mathrm{HD}: \mathrm{C}^{12} \mathrm{DBr}^{79}$ & 4- 745 & $4,1,4 \leftarrow 3,1,3$ & Ground & $7 / 2$ & $5 / 2$ & 29411.9 & \\
\hline $\mathrm{t}-\mathrm{C}^{12} \mathrm{HD}: \mathrm{C}^{12} \mathrm{HBr}^{81}$ & 4- 743 & $4,3,2 \leftarrow 3,3,1$ & Ground & $5 / 2$ & $3 / 2$ & 29413.1 & \\
\hline
\end{tabular}


Vol.-Id. Rotational

Nos. Quantum Nos.
Vib. State

\begin{tabular}{|c|c|c|c|c|c|c|c|}
\hline$\left(\mathrm{C}^{12} \mathrm{D}_{3}\right)_{2} \mathrm{C}^{12} \mathrm{O}^{16}$ & 3- 752 & $2,2,1 \leftarrow 1,1,0$ & Ground & & & 29415.18 & .04 \\
\hline$\left(\mathrm{C}^{12} \mathrm{D}_{3}\right)_{2} \mathrm{C}^{12} \mathrm{O}^{16}$ & 3- 752 & $2,2,1 \leftarrow 1,1,0$ & Ground & & & 29416.28 & .04 \\
\hline $\mathrm{C}^{12} \mathrm{H}_{2}\left(\mathrm{C}^{12} \mathrm{~N}^{14}\right)_{2}$ & 4- 901 & Not Reported & Ground & & & 29416.5 & .1 \\
\hline $\mathrm{HC}^{12} \mathrm{O}^{16} \mathrm{O}^{16} \mathrm{C}^{12} \mathrm{H}_{3}-\mathrm{A}$ & 3- 501 & $5,1,4 \leftarrow 5,0,5$ & Ground & & & 29417.37 & .2 \\
\hline $\mathrm{DN}^{14} \mathrm{O}_{3}^{16}$ & 3- 32 & $2,1,2 \leftarrow 1,1,1$ & Ground & 1 & 0 & 29417.40 & \\
\hline $\mathrm{DN}^{14} \mathrm{O}_{3}^{16}$ & $3-\quad 32$ & $2,1,2 \leftarrow 1,1,1$ & Ground & 3 & 2 & 29417.40 & \\
\hline $\mathrm{DN}^{14} \mathrm{O}_{3}^{16}$ & $3-\quad 32$ & $2,1,2 \leftarrow 1,1,1$ & Ground & 2 & 1 & 29417.40 & \\
\hline $\mathrm{c}-\mathrm{C}^{12} \mathrm{HD}: \mathrm{C}^{12} \mathrm{DBr}^{81}$ & 4- 746 & $4,1,3 \leftarrow 3,1,2$ & Ground & $5 / 2$ & $5 / 2$ & 29417.5 & \\
\hline $\mathrm{HC}^{13}: \mathrm{C}^{12} \mathrm{C}^{12} \mathrm{DO}^{16}$ & 4- 922 & Not Reported & & & & 29418. & 5. \\
\hline$\left(\mathrm{C}^{12} \mathrm{D}_{3}\right)_{2} \mathrm{C}^{12} \mathrm{O}^{16}$ & 3- 752 & $2,2,1 \leftarrow 1,1,0$ & Ground & & & 29420.63 & .04 \\
\hline $\mathrm{C}^{12} \mathrm{D}_{3} \mathrm{C}^{12}: \mathrm{C}^{12} \mathrm{H}$ & 4- 1052 & $2,1 \leftarrow 1,1$ & Ground & & & 29422.50 & .1 \\
\hline $\mathrm{C}^{12} \mathrm{D}_{3} \mathrm{C}^{12}: \mathrm{C}^{12} \mathrm{H}$ & 4-1052 & $2,0 \leftarrow 1,0$ & Ground & & & 29422.89 & .1 \\
\hline $\mathrm{t}-\mathrm{C}^{12} \mathrm{HD}: \mathrm{C}^{12} \mathrm{HBr}^{81}$ & 4- 743 & $4,3,2 \leftarrow 3,3,1$ & Ground & $9 / 2$ & $9 / 2$ & 29424.3 & \\
\hline$\left(\mathrm{C}^{12} \mathrm{D}_{3}\right)_{2} \mathrm{C}^{12} \mathrm{O}^{16}$ & 3- 752 & $2,2,1 \leftarrow 1,1,0$ & Ground & & & 29425.84 & .04 \\
\hline$\left(\mathrm{C}^{12} \mathrm{H}_{3}\right)_{2} \mathrm{O}^{16}$ & 3- 591 & Not Reported & Ground & & & 29430 . & 20. \\
\hline $\mathrm{H}_{2} \mathrm{C}^{12}: \mathrm{C}^{12} \mathrm{O}^{16}$ & 4- 711 & $12,1,11 \leftarrow 12,1,12$ & Ground & & & 29430.02 & \\
\hline $\mathrm{t}-\mathrm{C}^{12} \mathrm{HD}: \mathrm{C}^{12} \mathrm{HBr}^{81}$ & 4- 743 & $4,2,3 \leftarrow 3,2,2$ & Excited & $5 / 2$ & $3 / 2$ & 29430.8 & \\
\hline $\mathrm{C}^{12} \mathrm{D}_{3} \mathrm{~N}^{14} \mathrm{D}_{2}$ & 3. 262 & $5,1,5 \leftarrow 5,0,5$ & Ground & & & 29431.36 & \\
\hline $\mathrm{C}^{12} \mathrm{H}_{3} \mathrm{C}^{13} \mathrm{H}_{2} \mathrm{C}^{12} \mathrm{H}_{3}$ & 3. 783 & $5,1,4 \leftarrow 5,0,5$ & Ground & & & 29432.48 & .06 \\
\hline $\mathrm{C}^{12} \mathrm{O}^{16} \mathrm{~F}_{2}^{19}$ & 4- 211 & $8,6,2 \leftarrow 8,6,3$ & Ground & & & 29433.64 & .10 \\
\hline g- $\mathrm{C}^{12} \mathrm{H}_{2} \mathrm{DC}^{12} \mathrm{H}_{2} \mathrm{Cl}^{35}$ & 3- 544 & $5,0,5 \leftarrow 4,1,4$ & Ground & & & 29433.82 & .05 \\
\hline $\mathrm{C}^{12} \mathrm{HD}: \mathrm{C}^{12} \mathrm{DBr}^{\mathrm{b}}$ & 4. 749 & Not Reported & Ground & & & 29433.9 & .2 \\
\hline $\mathrm{C}^{12} \mathrm{DHCl}_{2}^{35}$ & 4- 344 & $8,1,7 \leftarrow 8,0,8$ & Ground & & & 29434 & 5. \\
\hline $\mathrm{t}-\mathrm{C}^{12} \mathrm{HD}: \mathrm{C}^{12} \mathrm{HBr}^{81}$ & 4- 743 & $4,0,4 \leftarrow 3,0,3$ & Ground & $7 / 2$ & $7 / 2$ & 29434.5 & \\
\hline $\mathrm{C}^{12} \mathrm{H}_{3} \mathrm{C}^{12}{ }_{*} \mathrm{HO}^{16} \mathrm{C}^{12}{ }_{*} \mathrm{H}_{2}$ & 3- 761 & $7,2,5 \leftarrow 7,1,6$ & Ground & & & 29435.25 & .1 \\
\hline $\mathrm{C}^{12} \mathrm{H}_{3} \mathrm{C}^{12}{ }_{*} \mathrm{HO}^{16} \mathrm{C}^{12}{ }_{*} \mathrm{H}_{2}$ & 3- 761 & $7,2,5 \leftarrow 7,1,6$ & Ground & & & 29435.50 & .1 \\
\hline $\mathrm{C}^{12} \mathrm{H}_{2} \mathrm{DC}^{12}: \mathrm{C}^{12} \mathrm{D}$ & 4-1049 & $2,1,2 \leftarrow 1,1,1$ & Ground & & & 29436.09 & .1 \\
\hline $\mathrm{C}^{12} \mathrm{H}_{3} \mathrm{~S}^{32} \mathrm{H}$ & 3- 221 & Not Reported & Ground & & & 29436.3 & .1 \\
\hline $\mathrm{C}^{12} \mathrm{H}_{3} \mathrm{C}^{12}{ }_{*} \mathrm{HO}^{16} \mathrm{C}^{12}{ }_{*} \mathrm{H}_{2}$ & 3- 761 & $7,2,5 \leftarrow 7,1,6$ & Ground & & & 29438.42 & .1 \\
\hline $\mathrm{C}^{12}{ }_{*} \mathrm{H}_{2} \mathrm{C}^{12} \mathrm{H}_{2} \mathrm{C}^{12}{ }_{*} \mathrm{HCl}^{37}$ & 4:1082 & $4,2,2 \leftarrow 3,2,1$ & Ground & $9 / 2$ & $7 / 2$ & 29439.9 & .1 \\
\hline $\mathrm{C}^{12}{ }_{*} \mathrm{H}_{2} \mathrm{C}^{12} \mathrm{H}_{2} \mathrm{C}^{12}{ }_{*} \mathrm{HCl}^{37}$ & $4-1082$ & $4,2,2 \leftarrow 3,2,1$ & Ground & $7 / 2$ & $5 / 2$ & 29441.7 & .1 \\
\hline $\mathrm{C}^{12}{ }_{*} \mathrm{H}_{2} \mathrm{C}^{12} \mathrm{H}_{2} \mathrm{C}^{12}{ }_{*} \mathrm{HCl}^{37}$ & 4-1082 & $4,2,2 \leftarrow 3,2,1$ & Ground & $11 / 2$ & $9 / 2$ & 29444.6 & .1 \\
\hline $\mathrm{t}-\mathrm{C}^{12} \mathrm{HD}: \mathrm{C}^{12} \mathrm{HBr}^{81}$ & 4- 743 & $4,2,3 \leftarrow 3,2,2$ & Excited & $11 / 2$ & $9 / 2$ & 29445.3 & \\
\hline $\mathrm{C}^{12}{ }_{*} \mathrm{H}_{2} \mathrm{C}^{12} \mathrm{H}_{2} \mathrm{C}^{12}{ }_{*} \mathrm{HCl}^{37}$ & $4-1082$ & $4,2,2 \leftarrow 3,2,1$ & Ground & $5 / 2$ & $3 / 2$ & 29446.2 & .1 \\
\hline $\mathrm{C}^{12}{ }_{*} \mathrm{DHC}^{12} \mathrm{H}: \mathrm{C}^{12}{ }_{*} \mathrm{H}$ & $4-1034$ & $10,5,5 \leftarrow 10,5,6$ & Ground & & & 29446.2 & \\
\hline $\mathrm{HC}^{13}: \mathrm{C}^{12} \mathrm{C}^{12} \mathrm{DO}^{16}$ & 4- 922 & Not Reported & & & & 29451. & 5. \\
\hline $\mathrm{C}^{12} \mathrm{H}_{3} \mathrm{C}^{12}{ }_{*} \mathrm{HO}^{16} \mathrm{C}^{12}{ }_{*} \mathrm{H}_{2}$ & 3- 761 & $7,2,5 \leftarrow 7,1,6$ & Ground & & & 29452.50 & .1 \\
\hline$\left(\mathrm{C}^{12} \mathrm{H}_{3}\right)_{2} \mathrm{~S}^{32}$ & 3- 601 & $6,2,4 \leftarrow 6,1,5$ & Ground & & & 29452.88 & .05 \\
\hline $\mathrm{D}_{2} \mathrm{O}_{2}^{16}$ & 3- 42 & Not Reported & & & & 29453. & 3. \\
\hline$\left(\mathrm{C}^{12} \mathrm{H}_{3}\right)_{2} \mathrm{~S}^{32}$ & 3- 601 & $6,2,4 \leftarrow-6,1,5$ & Ground & & & 29453.41 & .05 \\
\hline $\mathrm{C}^{13} \mathrm{O}^{16} \mathrm{~F}_{2}^{19}$ & 4- 212 & $2,0,2 \leftarrow 1,0,1$ & Ground & & & 29453.50 & .10 \\
\hline$\left(\mathrm{C}^{12} \mathrm{H}_{3}\right)_{2} \mathrm{~S}^{32}$ & 3- 601 & $6,2,4 \leftarrow 6,1,5$ & Ground & & & 29453.93 & .05 \\
\hline $\mathrm{C}^{\mathrm{b}} \mathrm{H}_{3}^{\mathrm{b}} \mathrm{C}^{\mathrm{b}} \mathrm{H}_{2}^{\mathrm{b}} \mathrm{Cl}^{35}$ & 3- 548 & Not Reported & & & & 29454.08 & .05 \\
\hline $\mathrm{t}-\mathrm{C}^{12} \mathrm{HD}: \mathrm{C}^{12} \mathrm{HBr}^{81}$ & 4- 743 & $4,2,3 \leftarrow 3,2,2$ & Ground & $5 / 2$ & $3 / 2$ & 29455.0 & \\
\hline $\mathrm{C}^{12} \mathrm{O}^{16} \mathrm{~F}_{2}^{19}$ & 4- 211 & $2,0,2 \leftarrow 1,0,1$ & Ground & & & 29455.70 & .10 \\
\hline
\end{tabular}




\begin{tabular}{|c|c|c|c|c|c|c|c|}
\hline \multirow{2}{*}{ Isotopic Species } & \multirow{2}{*}{$\begin{array}{l}\text { Vol.-Id. } \\
\text { Nos. }\end{array}$} & \multirow{2}{*}{$\begin{array}{c}\text { Rotational } \\
\text { Quantum Nos. }\end{array}$} & \multirow{2}{*}{ Vib. State } & \multicolumn{2}{|c|}{ Hyperfine } & \multirow{2}{*}{$\begin{array}{c}\text { Frequency } \\
\mathrm{MHz}\end{array}$} & \multirow{2}{*}{$\begin{aligned} & \text { Acc. } \\
\pm & \mathrm{MH} 2\end{aligned}$} \\
\hline & & & & $\begin{array}{lll}F_{1}^{\prime} & F^{\prime} & F_{1}\end{array}$ & $\mathrm{~F}$ & & \\
\hline $\mathrm{t}-\mathrm{C}^{12} \mathrm{HD}: \mathrm{C}^{12} \mathrm{HBr}^{81}$ & 4- 743 & $4,3, .2 \leftarrow 3,3,1$ & Ground & $11 / 2$ & $9 / 2$ & 29458.2 & \\
\hline $\mathrm{C}^{12} \mathrm{HD}: \mathrm{C}^{12} \mathrm{DBr}^{\mathrm{b}}$ & 4- 749 & Not Reported & Ground & & & 29458.4 & .1 \\
\hline $\mathrm{t}-\mathrm{C}^{12} \mathrm{HD}: \mathrm{C}^{12} \mathrm{HBr}^{81}$ & 4- 743 & $4,2,3 \leftarrow 3,2,2$ & Excited & & & 29460.33 & \\
\hline $\mathrm{N}^{14} \mathrm{O}^{16} \mathrm{Br}^{\mathrm{b}}$ & 4- 123 & $4, \quad \leftarrow 3, \quad$, & & & & 29463.3 & \\
\hline $\mathrm{C}^{12} \mathrm{O}^{16} \mathrm{~F}_{2}^{19}$ & 4- 211 & $7,5,2 \leftarrow 7,5,3$ & Ground & & & 29463.51 & .10 \\
\hline $\mathrm{C}^{\mathrm{b}} \mathrm{H}_{2}^{\mathrm{b}} \mathrm{Cl}^{\mathrm{b}} \mathbf{F}^{\mathrm{b}}$ & 4- 333 & Not Reported & & & & 29463.66 & .1 \\
\hline $\mathrm{t}-\mathrm{C}^{12} \mathrm{HD}: \mathrm{C}^{12} \mathrm{HBr}^{81}$ & 4- 743 & $4,2,2 \leftarrow 3,2,1$ & Ground & $5 / 2$ & $3 / 2$ & 29464.2 & \\
\hline c- $\mathrm{C}^{12} \mathrm{HD}: \mathrm{C}^{12} \mathrm{DBr}^{81}$ & 4- 746 & $4,1,3 \leftarrow 3,1,2$ & Excited & $11 / 2$ & $9 / 2$ & 29466.7 & \\
\hline $\mathrm{s}-\mathrm{C}^{12} \mathrm{H}_{2} \mathrm{DC}^{12} \mathrm{HO}^{16}$ & 3. 473 & Not Reported & & & & 29467.7 & \\
\hline $\mathrm{N}^{14} \mathrm{O}^{16} \mathrm{Br}^{17}$ & 4- 123 & $4, \quad, \quad \leftarrow 3, \quad$, & & & & 29468.4 & \\
\hline $\mathrm{t}-\mathrm{C}^{12} \mathrm{HD}: \mathrm{C}^{12} \mathrm{HBr}^{81}$ & 4. 743 & $4,2,3 \leftarrow 3,2,2$ & Ground & $11 / 2$ & $9 / 2$ & 29469.1 & \\
\hline $\mathrm{c}-\mathrm{C}^{12} \mathrm{HD}: \mathrm{C}^{12} \mathrm{DBr}^{81}$ & 4. 746 & $4,1,3 \leftarrow 3,1,2$ & Excited & $5 / 2$ & $3 / 2$ & 29470.4 & \\
\hline $\mathrm{t}-\mathrm{C}^{12} \mathrm{HD}: \mathrm{C}^{12} \mathrm{HBr}^{81}$ & 4- 743 & $4,0,4 \leftarrow 3,0,3$ & Ground & $11 / 2$ & $9 / 2$ & 29470.5 & \\
\hline $\mathrm{t}-\mathrm{C}^{12} \mathrm{HD}: \mathrm{C}^{12} \mathrm{HBr}^{81}$ & 4- 743 & $4,0,4 \leftarrow 3,0,3$ & Ground & $9 / 2$ & $7 / 2$ & 29470.5 & \\
\hline $\mathrm{c}-\mathrm{C}^{12} \mathrm{HD}: \mathrm{C}^{12} \mathrm{DBr}^{81}$ & 4. 746 & $4,1,3 \leftarrow 3,1,2$ & Excited & & & 29472.0 & .38 \\
\hline $\mathrm{O}^{16} \mathrm{~F}_{2}^{19}$ & 4-1611 & $36,4,32 \leftarrow 37,3,35$ & Ground & & & 29473.73 & .10 \\
\hline $\mathrm{t}-\mathrm{C}^{12} \mathrm{HD}: \mathrm{C}^{12} \mathrm{HBr}^{81}$ & 4- 743 & $4,0,4 \leftarrow 3,0,3$ & Ground & & & 29473.75 & .30 \\
\hline $\mathrm{c}-\mathrm{C}^{12} \mathrm{HD}: \mathrm{C}^{12} \mathrm{DBr}^{81}$ & 4- 746 & $4,1,3 \leftarrow 3,1,2$ & Excited & $9 / 2$ & $7 / 2$ & 29475.9 & \\
\hline $\mathrm{C}^{12} \mathrm{H}_{3} \mathrm{C}^{12} \mathrm{O}^{16} \mathrm{C}^{13} \mathrm{~N}^{14}$ & 3- 673 & $4,1,4 \leftarrow 3,0,3$ & Ground & & & 29478.10 & .2 \\
\hline $\mathrm{t}-\mathrm{C}^{12} \mathrm{HD}: \mathrm{C}^{12} \mathrm{HBr}^{81}$ & 4- 743 & $4,2,2 \leftarrow 3,2,1$ & Ground & $11 / 2$ & $9 / 2$ & 29478.2 & \\
\hline $\mathrm{c}-\mathrm{C}^{12} \mathrm{HD}: \mathrm{C}^{12} \mathrm{DBr}^{81}$ & 4- 746 & $4,1,3 \leftarrow 3,1,2$ & Excited & $7 / 2$ & $5 / 2$ & 29481.0 & \\
\hline $\mathrm{t}-\mathrm{C}^{12} \mathrm{HD}: \mathrm{C}^{12} \mathrm{HBr}^{81}$ & 4- 743 & $4,0,4 \leftarrow 3,0,3$ & Ground & $5 / 2$ & $3 / 2$ & 29482.5 & \\
\hline $\mathrm{t}-\mathrm{C}^{12} \mathrm{HD}: \mathrm{C}^{12} \mathrm{HBr}^{81}$ & 4. 743 & $4,0,4 \leftarrow 3,0,3$ & Ground & $7 / 2$ & $5 / 2$ & 29482.5 & \\
\hline $\mathrm{Ge}^{74} \mathbf{F}_{3}^{19} \mathrm{Cl}^{37}$ & $4-1406$ & $7, \leftarrow 6$ & Ground & & & 29482.88 & .30 \\
\hline $\mathrm{t}-\mathrm{C}^{12} \mathrm{HD}: \mathrm{C}^{12} \mathrm{HBr}^{81}$ & 4- 743 & $4,2,3 \leftarrow 3,2,2$ & Ground & & & 29483.16 & .09 \\
\hline $\mathrm{C}^{12} \mathrm{O}^{16} \mathrm{~F}_{2}^{19}$ & 4- 211 & $6,4,2 \leftarrow 6,4,3$ & Ground & & & 29483.85 & .10 \\
\hline $\mathrm{C}^{12} \mathrm{HD}: \mathrm{C}^{12} \mathrm{HBr}^{\mathrm{b}}$ & 4- 748 & Not Reported & Ground & & & 29484.6 & .1 \\
\hline $\mathrm{C}^{12} \mathrm{H}_{2}\left(\mathrm{C}^{12} \mathrm{~N}^{14}\right)_{2}$ & 4- 901 & Not Reported & Ground & & & 29484.8 & .1 \\
\hline c-C ${ }^{12} \mathrm{HD}: \mathrm{C}^{12} \mathrm{DBr}^{81}$ & 4- 746 & $4,1,3 \leftarrow 3,1,2$ & Ground & $11 / 2$ & $9 / 2$ & 29485.4 & \\
\hline $\mathrm{t}-\mathrm{C}^{12} \mathrm{HD}: \mathrm{C}^{12} \mathrm{HBr}^{81}$ & 4- 743 & $4,3,2 \leftarrow 3,3,1$ & Ground & & & 29487.72 & .62 \\
\hline $\mathrm{HC}^{13}: \mathrm{C}^{12} \mathrm{C}^{12} \mathrm{DO}^{16}$ & 4- 922 & Not Reported & & & & 29488 & 5. \\
\hline $\mathrm{c}-\mathrm{C}^{12} \mathrm{HD}: \mathrm{C}^{12} \mathrm{DBr}^{81}$ & 4- 746 & $4,1,3 \leftarrow 3,1,2$ & Ground & $5 / 2$ & $3 / 2$ & 29489.3 & \\
\hline $\mathrm{c}-\mathrm{C}^{12} \mathrm{HD}: \mathrm{C}^{12} \mathrm{DBr}^{81}$ & 4- 746 & $4,1,3 \leftarrow 3,1,2$ & Ground & & & 29490.94 & .13 \\
\hline $\mathrm{H}_{2} \mathrm{~N}^{14} \mathrm{~N}^{14} \mathrm{H}_{2}$ & $3-\quad 51$ & Not Reported & Ground & & & 29491.6 & \\
\hline $\mathrm{t}-\mathrm{C}^{12} \mathrm{HD}: \mathrm{C}^{12} \mathrm{HBr}^{81}$ & 4. 743 & $4,2,2 \leftarrow 3,2,1$ & Ground & & & 29492.59 & .11 \\
\hline $\mathrm{C}^{12}{ }_{*} \mathrm{D}_{2} \mathrm{C}^{12} \mathrm{H}_{2} \mathrm{C}^{12} \mathrm{D}_{\overline{2}} \mathrm{O}^{16}{ }_{*}$ & 4-1092 & $2,1,2 \leftarrow 1,0,1$ & Ground & & & 29493.5 & .1 \\
\hline $\mathrm{t}-\mathrm{C}^{12} \mathrm{HD}: \mathrm{C}^{12} \mathrm{HBr}^{81}$ & 4- 743 & $4,2,3 \leftarrow 3,2,2$ & Ground & $7 / 2$ & $5 / 2$ & 29494.5 & \\
\hline c- $\mathrm{C}^{12} \mathrm{HD}: \mathrm{C}^{12} \mathrm{DBr}^{81}$ & 4- 746 & $4,1,3 \leftarrow 3,1,2$ & Ground & $9 / 2$ & $7 / 2$ & 29495.2 & \\
\hline $\mathrm{C}^{12} \mathrm{H}_{3} \mathrm{C}^{12} * \mathrm{HO}^{16} \mathrm{C}^{12}{ }_{*} \mathrm{H}_{2}$ & 3- 761 & $42,21, \leftarrow 41,22$, & Ground & & & 29496.35 & .1 \\
\hline $\mathrm{C}^{12} \mathrm{H}_{3} \mathrm{C}^{12}{ }_{*} \mathrm{HO}^{16} \mathrm{C}^{12}{ }_{*} \mathrm{H}_{2}$ & 3- 761 & $42,21, \quad \leftarrow 41,22$, & Ground & & & 29496.60 & .1 \\
\hline $\mathrm{C}^{12} \mathrm{O}^{16} \mathrm{~F}_{2}^{19}$ & 4. 211 & $5,3,2 \leftarrow 5,3,3$ & Ground & & & 29497.00 & .10 \\
\hline $\mathrm{C}^{12} \mathrm{H}_{3} \mathrm{C}^{12}{ }_{*} \mathrm{HO}^{16} \mathrm{C}^{12}{ }_{*} \mathrm{H}_{2}$ & 3- 761 & $42,21, \leftarrow 41,22$, & Ground & & & 29497.04 & .1 \\
\hline $\mathrm{Ge}^{72} \mathrm{~F}_{3}^{19} \mathrm{Cl}^{37}$ & $4-1404$ & $7, \leftarrow 6$, & Ground & & & 29497.57 & .30 \\
\hline$\left(\mathrm{C}^{12} \mathrm{H}_{3}\right)_{3} \mathrm{C}^{13} \mathrm{Cl}^{37}$ & 3- 974 & $5, \leftarrow 4$ & Ground & & & 29498.0 & \\
\hline $\mathrm{t}-\mathrm{C}^{12} \mathrm{HD}: \mathrm{C}^{12} \mathrm{DBr}^{79}$ & 4- 745 & 4. $1,4 \leftarrow 3,1,3$ & Ground & $9 / 2$ & $9 / 2$ & 29498.3 & \\
\hline
\end{tabular}


Vib. State

$\begin{array}{cccc}\text { Hyperfine } & \text { Frequency } & \text { Acc: } \\ \mathrm{F}_{1}^{\prime} \mathrm{F}^{\prime} \mathrm{F}_{1} \mathrm{~F} & \mathrm{MH} \% & \pm \mathrm{MH} \%\end{array}$

\begin{tabular}{|c|c|c|c|c|c|c|c|}
\hline $\mathrm{As}^{75} \mathrm{H}_{2} \mathrm{D}$ & 4- 32 & $3,1,3 \leftarrow 3,0,3$ & Ground & $3 / 2$ & $5 / 2$ & 29498.52 & \\
\hline $\mathrm{C}^{12} \mathrm{H}_{3} \mathrm{C}^{12}{ }_{*} \mathrm{HO}^{16} \mathrm{C}^{12}{ }_{*} \mathrm{H}_{2}$ & 3. 761 & Not Reported & Ground & & & 29499.04 & .1 \\
\hline$c-\mathrm{C}^{12} \mathrm{HD}: \mathrm{C}^{12} \mathrm{DBr}^{81}$ & 4. 746 & $4,1,3 \leftarrow 3,1,2$ & Ground & $7 / 2$ & $5 / 2$ & 29500.3 & \\
\hline $\mathrm{a}-\mathrm{C}^{12} \mathrm{H}_{2} \mathrm{DC}^{12} \mathrm{HO}^{16}$ & 3- 481 & $8,1,7 \leftarrow 8,1,8$ & Ground & & & 29500.67 & .2 \\
\hline $\mathrm{t}-\mathrm{C}^{12} \mathrm{HD}: \mathrm{C}^{12} \mathrm{HBr}^{81}$ & 4. 743 & $4,3,2 \leftarrow 3,3,1$ & Ground & $7 / 2$ & $5 / 2$ & 29503.0 & \\
\hline 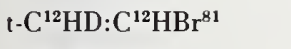 & 4- 743 & $4,2,2 \leftarrow 3,2,1$ & Ground & $7 / 2$ & $5 / 2$ & 29504.1 & \\
\hline $\mathrm{N}^{14} \mathrm{O}^{16} \mathrm{Br}^{b}$ & 4- 123 & $4, \quad \leftarrow 3$, & & & & 29504.3 & \\
\hline $\mathrm{C}^{12} \mathrm{O}^{16} \mathrm{~F}_{2}^{19}$ & 4- 211 & $4,2,2 \leftarrow 4,2,3$ & Ground & & & 29.504 .93 & .10 \\
\hline $\mathrm{C}^{12} \mathrm{D}_{3} \mathrm{~N}^{14} \mathrm{H}_{2}$ & 3- 263 & Not Reported & & & & 29507.2 & .5 \\
\hline $\mathrm{As}^{75} \mathrm{H}_{2} \mathrm{D}$ & 4- $\quad 32$ & $3,1,3 \leftarrow 3,0,3$ & Ground & $9 / 2$ & $7 / 2$ & 29507.91 & \\
\hline $\mathrm{As}^{75} \mathrm{H}_{2} \mathrm{D}$ & 4- 32 & $3,1,3 \leftarrow 3,0,3$ & Ground & $3 / 2$ & $3 / 2$ & 29507.91 & \\
\hline $\mathrm{t}-\mathrm{C}^{12} \mathrm{HD}: \mathrm{C}^{12} \mathrm{HBr}^{81}$ & 4- 743 & $4,2,3 \leftarrow 3,2,2$ & Ground & $9 / 2$ & $7 / 2$ & 29508.05 & \\
\hline $\mathrm{C}^{12} \mathrm{H}_{2} \mathrm{Cl}^{35} \mathrm{Cl}^{37}$ & 4- 342 & $3,1,2 \leftarrow 3,0,3$ & Ground & & & 29509. & 5. \\
\hline $\mathrm{C}^{12} \mathrm{O}^{16} \mathrm{~F}_{2}^{19}$ & 4- 211 & $3,1,2 \leftarrow 3,1,3$ & Ground & & & 29509.27 & .10 \\
\hline $\mathrm{C}^{12} \mathrm{H}_{2}\left(\mathrm{C}^{12} \mathrm{~N}^{14}\right)_{2}$ & 4. 901 & Not Reported & Ground & & & 29509.3 & .1 \\
\hline $\mathrm{C}^{12} \mathrm{O}^{16} \mathrm{~F}_{2}^{19}$ & 4- 211 & $3,2,2 \leftarrow 3,0,3$ & Ground & & & 29512.10 & .10 \\
\hline $\mathrm{Ge}^{70} \mathrm{~F}_{3}^{19} \mathrm{Cl}^{37}$ & 4-1402 & $7, \leftarrow 6$, & Ground & & & 29512.96 & .30 \\
\hline $\mathrm{C}^{12} \mathrm{O}^{16} \mathrm{~F}_{2}^{19}$ & 4- 211 & $4,3,2 \leftarrow 4,1,3$ & Ground & & & 29513.80 & .10 \\
\hline $\mathrm{As}^{75} \mathrm{H}_{2} \mathrm{D}$ & 4- $\quad 32$ & $3,1,3 \leftarrow 3,0,3$ & Ground & $9 / 2$ & $9 / 2$ & 29516.96 & \\
\hline $\mathrm{C}^{12} \mathrm{O}^{16} \mathrm{~F}_{2}^{19}$ & 4- 211 & $5,4,2 \leftarrow 5,2,3$ & Ground & & & 29517.37 & .10 \\
\hline t- $\mathrm{C}^{12} \mathrm{HD}: \mathrm{C}^{12} \mathrm{HBr}^{81}$ & 4- 743 & $4,2,2 \leftarrow 3,2,1$ & Ground & $9 / 2$ & $7 / 2$ & 29517.6 & \\
\hline $\mathrm{C}^{12} \mathrm{HD}: \mathrm{C}^{12} \mathrm{DBr}^{\mathrm{b}}$ & 4- 749 & Not Reported & Ground & & & 29517.7 & .1 \\
\hline $\mathrm{N}^{14} \mathrm{O}^{16} \mathrm{Br}^{b}$ & 4- 123 & $4, \quad, \quad \leftarrow 3, \quad$, & & & & 29517.8 & \\
\hline $\mathrm{C}^{13} \mathrm{H}_{3} \mathrm{C}^{12} \mathrm{O}^{16} \mathrm{C}^{12} \mathrm{~N}^{14}$ & 3- 672 & $4,2,2 \leftarrow 3,2,1$ & Ground & & & 29518.4 & .2 \\
\hline $\mathrm{s}-\left(\mathrm{C}^{12} \mathrm{H}_{2} \mathrm{D}\right)\left(\mathrm{C}^{12} \mathrm{H}_{3}\right) \mathrm{O}^{16}$ & 3. 596 & Not Reported & Ground & & & 29520 . & 20. \\
\hline $\mathrm{C}^{12} \mathrm{D}_{3} \mathrm{~N}^{14} \mathrm{D}_{2}$ & 3- 262 & $5,1,5 \leftarrow 5,0,5$ & Ground & & & 29520.90 & \\
\hline $\mathrm{C}^{12} \mathrm{H}_{3} \mathrm{C}^{12} \mathrm{O}^{16} \mathrm{Cl}^{37}$ & 3. 362 & $10,3,7 \leftarrow 10,2,8$ & Ground & $19 / 2$ & $19 / 2$ & 29521.30 & .2 \\
\hline $\mathrm{C}^{12} \mathrm{H}_{3} \mathrm{C}^{12} \mathrm{O}^{16} \mathrm{Cl}^{37}$ & 3- 362 & $10,3,7 \leftarrow 10,2,8$ & Ground & $21 / 2$ & $21 / 2$ & 29521.30 & .2 \\
\hline $\mathrm{C}^{12} \mathrm{H}_{3} \mathrm{C}^{12} \mathrm{O}^{16} \mathrm{Cl}^{37}$ & 3- 362 & $10,3,7 \leftarrow 10,2,8$ & Ground & $17 / 2$ & $17 / 2$ & 29522.04 & .2 \\
\hline $\mathrm{C}^{12} \mathrm{H}_{3} \mathrm{C}^{12} \mathrm{O}^{16} \mathrm{Cl}^{37}$ & 3. 362 & $10,3,7 \leftarrow 10,2,8$ & Ground & $23 / 2$ & $23 / 2$ & 29522.04 & .2 \\
\hline $\mathrm{C}^{12} \mathrm{H}_{3} \mathrm{C}^{12} \mathrm{O}^{16} \mathrm{O}^{16} \mathrm{H}$ & 3- 491 & $7,6,1 \leftarrow 7,5,2$ & Ground & & & 29522.57 & .4 \\
\hline $\mathrm{As}^{75} \mathrm{H}_{2} \mathrm{D}$ & 4- $\quad 32$ & $3,1,3 \leftarrow 3,0,3$ & Ground & $5 / 2$ & $7 / 2$ & $2952 \cdot 2.64$ & \\
\hline $\mathrm{S}_{2}^{32} \mathrm{O}^{16}$ & $4-1821$ & $3,1,2 \leftarrow 2,1,1$ & Ground & & & 29522.8 & \\
\hline $\mathrm{C}^{12} \mathrm{O}^{16} \mathrm{~F}_{2}^{19}$ & 4- 211 & $6,5,2 \leftarrow 6,3,3$ & Ground & & & 29523.74 & .10 \\
\hline $\mathrm{C}^{12} \mathrm{H}_{3} \mathrm{~S}^{32} \mathrm{H}$ & 3- 221 & Not Reported & Ground & & & 29526.2 & .1 \\
\hline $\mathrm{As}^{75} \mathrm{H}_{2} \mathrm{D}$ & 4- 32 & $3,1,3 \leftarrow 3,0,3$ & Ground & $5 / 2$ & $5 / 2$ & 29526.69 & \\
\hline $\mathrm{C}^{12}{ }_{*} \mathrm{H}_{2} \mathrm{C}^{12} \mathrm{H}_{2} \mathrm{C}^{12}{ }_{*} \mathrm{HCl}^{35}$ & 4-1081 & $4,1,4 \leftarrow 3,1,3$ & Ground & $9 / 2$ & $9 / 2$ & 29527.1 & .1 \\
\hline $\mathrm{C}^{12} \mathrm{H}_{3} \mathrm{C}^{12} \mathrm{O}^{16} \mathrm{Cl}^{37}$ & 3- 362 & $10,3,7 \leftarrow 10,2,8$ & Ground & $21 / 2$ & $21 / 2$ & $29527: 40$ & .2 \\
\hline $\mathrm{C}^{12} \mathrm{H}_{3} \mathrm{C}^{12} \mathrm{O}^{16} \mathrm{Cl}^{37}$ & 3- 362 & $10,3,7 \leftarrow 10,2,8$ & Ground & $19 / 2$ & $19 / 2$ & 29527.40 & .2 \\
\hline $\mathrm{C}^{12} \mathrm{H}_{3} \mathrm{C}^{12} \mathrm{H}: \mathrm{C}^{12} \mathrm{HF}^{19}$ & 3. 711 & $4,1,4 \leftarrow 3,1,3$ & Ground & & & 29527.6 & \\
\hline $\mathrm{C}^{12} \mathrm{H}_{3} \mathrm{C}^{12} \mathrm{O}^{16} \mathrm{Cl}^{37}$ & 3- 362 & $10,3,7 \leftarrow 10,2,8$ & Ground & $23 / 2$ & $23 / 2$ & 29528.13 & .2 \\
\hline $\mathrm{C}^{12} \mathrm{H}_{3} \mathrm{C}^{12} \mathrm{O}^{16} \mathrm{Cl}^{37}$ & 3- 362 & $10,3,7 \leftarrow 10,2,8$ & Ground & $17 / 2$ & $17 / 2$ & 29528.13 & .2 \\
\hline $\mathrm{C}^{12} \mathrm{H}_{3} \mathrm{C}^{12}{ }_{*} \mathrm{HO}^{16} \mathrm{C}^{12}{ }_{*} \mathrm{H}_{2}$ & 3- 761 & $18,8, \leftarrow 17,9$ & Ground & & & 29530.32 & .1 \\
\hline $\mathrm{C}^{12} \mathrm{H}_{3} \mathrm{Si}^{28} \mathrm{D}_{2} \mathrm{~F}^{19}$ & 3. 245 & $10,2,8 \leftarrow 10,2,9$ & Ground & & & 29530.95 & .10 \\
\hline $\mathrm{C}^{12} \mathrm{H}_{3} \mathrm{C}^{12}{ }_{*} \mathrm{HO}^{16} \mathrm{C}^{12}{ }_{*} \mathrm{H}_{2}$ & 3- 761 & $18,8, \leftarrow 17,9$ & Ground & & & 29531.24 & .1 \\
\hline
\end{tabular}




\begin{tabular}{|c|c|c|c|c|c|c|c|}
\hline \multirow{2}{*}{ Isotopic Species } & \multirow{2}{*}{$\begin{array}{l}\text { Vol.-Id. } \\
\text { Nos. }\end{array}$} & \multirow{2}{*}{$\begin{array}{c}\text { Rotational } \\
\text { Quantum Nos. }\end{array}$} & \multirow{2}{*}{ Vib. State } & \multicolumn{2}{|c|}{ Hyperfine } & \multirow{2}{*}{$\begin{array}{l}\text { Frequency } \\
\mathrm{MHz}\end{array}$} & \multirow{2}{*}{$\begin{aligned} & \text { Acc. } \\
\pm & \mathrm{MHz}\end{aligned}$} \\
\hline & & & & $\mathrm{F}_{1}^{\prime} \quad \mathrm{F}^{\prime} \quad \mathrm{F}_{1}$ & $\mathrm{~F}$ & & \\
\hline $\mathrm{C}^{12} \mathrm{H}_{3} \mathrm{Si}^{28} \mathrm{D}_{2} \mathrm{~F}^{19}$ & 3- 245 & $10,2,8 \leftarrow 10,2,9$ & Ground & & & 29532.75 & .10 \\
\hline $\mathrm{HC}^{13}: \mathrm{C}^{12} \mathrm{C}^{12} \mathrm{DO}^{16}$ & 4- 922 & Not Reported & & & & 29533. & 5. \\
\hline $\mathrm{O}^{16} \mathrm{~F}_{2}^{19}$ & 4-1611 & $19,5,14 \leftarrow 20,4,17$ & Ground & & & 29533.85 & .10 \\
\hline $\mathrm{C}^{12} \mathrm{O}^{16} \mathrm{~F}_{2}^{19}$ & 4- 211 & $7,6,2 \leftarrow 7,4,3$ & Ground & & & 29533.95 & .10 \\
\hline s- $\left(\mathrm{C}^{12} \mathrm{H}_{2} \mathrm{D}\right)\left(\mathrm{C}^{12} \mathrm{H}_{3}\right) \mathrm{O}^{16}$ & 3- 596 & Not Reported & Ground & & & 29535. & 20. \\
\hline $\mathrm{C}^{12}{ }_{*} \mathrm{H}_{2} \mathrm{C}^{12} \mathrm{H}_{2} \mathrm{C}^{12}{ }_{*} \mathrm{HCl}^{35}$ & 4-1081 & $4,1,4 \leftarrow 3,1,3$ & Ground & $7 / 2$ & $5 / 2$ & 29535.1 & .1 \\
\hline $\mathrm{As}^{75} \mathrm{H}_{2} \mathrm{D}$ & 4. 32 & $3,1,3 \leftarrow 3,0,3$ & Ground & $5 / 2$ & $3 / 2$ & 29535.30 & \\
\hline $\mathrm{As}^{75} \mathrm{H}_{2} \mathrm{D}$ & 4- 32 & $3,1,3 \leftarrow 3,0,3$ & Ground & $7 / 2$ & $7 / 2$ & 29535.30 & \\
\hline $\mathrm{C}^{12}{ }_{*} \mathrm{H}_{2} \mathrm{C}^{12} \mathrm{H}_{2} \mathrm{C}^{12}{ }_{*} \mathrm{HCl}^{35}$ & 4-1081 & $4,1,4 \leftarrow 3,1,3$ & Ground & $9 / 2$ & $7 / 2$ & 29535.6 & .1 \\
\hline$\left(\mathrm{C}^{12} \mathrm{H}_{3}\right)_{3} \mathrm{C}^{12} \mathrm{Cl}^{37}$ & 3- 972 & $5, \leftarrow 4$, & Ground & & & 29535.6 & .3 \\
\hline $\mathrm{t}-\mathrm{C}^{12} \mathrm{HD}: \mathrm{C}^{12} \mathrm{HBr}^{81}$ & 4- 743 & $4,3,2 \leftarrow 3,3,1$ & Ground & $5 / 2$ & $5 / 2$ & 29536.3 & \\
\hline $\mathrm{C}^{12}{ }_{*} \mathrm{H}_{2} \mathrm{C}^{12} \mathrm{H}_{2} \mathrm{C}^{12}{ }_{*} \mathrm{HCl}^{35}$ & 4-1081 & $4,1,4 \leftarrow 3,1,3$ & Ground & $5 / 2$ & $3 / 2$ & 29536.4 & .1 \\
\hline $\mathrm{C}^{12}{ }_{*} \mathrm{H}_{2} \mathrm{C}^{12} \mathrm{H}_{2} \mathrm{C}^{12}{ }_{*} \mathrm{HCl}^{35}$ & 4-1081 & $4,1,4 \leftarrow 3,1,3$ & Ground & $11 / 2$ & $9 / 2$ & 29536.9 & .1 \\
\hline $\mathrm{C}^{12}{ }_{*} \mathrm{H}_{2} \mathrm{C}^{12} \mathrm{H}_{2} \mathrm{C}^{12}{ }_{*} \mathrm{HCl}^{35}$ & 4-1081 & $4,1,4 \leftarrow 3,1,3$ & Ground & $7 / 2$ & $7 / 2$ & 29539.1 & .1 \\
\hline $\mathrm{As}^{75} \mathrm{H}_{2} \mathrm{D}$ & 4- 32 & $3,1,3 \leftarrow 3,0,3$ & Ground & $7 / 2$ & $5 / 2$ & 29539.38 & \\
\hline $\mathrm{C}^{12} \mathrm{H}_{3} \mathrm{~N}^{14} \mathrm{C}^{12} \mathrm{~S}^{34}$ & $3-425$ & $6, \quad \leftarrow 5$, & Ground & & & 29540 . & \\
\hline $\mathrm{s}-\left(\mathrm{C}^{12} \mathrm{H}_{2} \mathrm{D}\right)\left(\mathrm{C}^{12} \mathrm{H}_{3}\right) \mathrm{O}^{16}$ & 3. 596 & Not Reported & Ground & & & 29540 . & 20. \\
\hline $\mathrm{C}^{\mathrm{b}} \mathbf{H}_{3}^{\mathrm{b}} \mathrm{C}^{\mathrm{b}} \mathrm{H}_{2}^{\mathrm{b}} \mathrm{Cl}^{35}$ & 3- 548 & Not Reported & & & & 29544.1 & .05 \\
\hline $\mathrm{As}^{75} \mathrm{H}_{2} \mathrm{D}$ & 4. 32 & $3,1,3 \leftarrow 3,0,3$ & Ground & $7 / 2$ & $9 / 2$ & 29545.05 & \\
\hline $\mathrm{C}^{12} \mathrm{H}_{2} \mathrm{DC}^{12}: \mathrm{C}^{12} \mathrm{D}$ & 4-1049 & $2,0,2 \leftarrow 1,0,1$ & Ground & & & 29545.33 & .1 \\
\hline $\mathrm{C}^{12}{ }_{*} \mathrm{H}_{2} \mathrm{C}^{12} \mathrm{H}_{2} \mathrm{C}^{12}{ }_{*} \mathrm{HCl}^{35}$ & 4-1081 & $4,1,4 \leftarrow 3,1,3$ & Ground & $5 / 2$ & $5 / 2$ & 29545.4 & .1 \\
\hline $\mathrm{t}-\mathrm{C}^{12} \mathrm{HD}: \mathrm{C}^{12} \mathrm{HBr}^{81}$ & 4- 743 & $4,3,2 \leftarrow 3,3,1$ & Ground & $9 / 2$ & $7 / 2$ & 29547.2 & \\
\hline $\mathrm{a}-\mathrm{C}^{12} \mathrm{H}_{2} \mathrm{DC}{ }^{12} \mathrm{HO}^{16}$ & 3- 481 & $8,1,7 \leftarrow 8,1,8$ & Ground & & & 29548.31 & .2 \\
\hline $\mathrm{C}^{12} \mathrm{O}^{16} \mathrm{~F}_{2}^{19}$ & 4- 211 & $8,7,2 \leftarrow 8,5,3$ & Ground & & & 29549.17 & .10 \\
\hline $\mathrm{C}^{12} \mathrm{H}_{3} \mathrm{Si}^{28} \mathrm{HF}_{2}^{19}-\mathrm{E}$ & 3- 192 & $7,2,6 \leftarrow 7,2,5$ & Ground & & & 29549.49 & \\
\hline $\mathrm{C}^{12}{ }_{*} \mathrm{H}_{2} \mathrm{C}^{12} \mathrm{H}: \mathrm{C}^{12} \mathrm{HC}^{12} \mathrm{H}: \mathrm{C}^{12}{ }_{*} \mathrm{H}$ & 4-1231 & $2,2,1 \leftarrow 1,1,0$ & Ground & & & 29549.8 & .1 \\
\hline s. $\left(\mathrm{C}^{12} \mathrm{H}_{2} \mathrm{D}\right)\left(\mathrm{C}^{12} \mathrm{H}_{3}\right) \mathrm{O}^{16}$ & 3- 596 & Not Reported & Ground & & & 29550. & 20. \\
\hline $\mathrm{s}^{\mathrm{C}} \mathrm{C}^{12} \mathrm{H}_{2} \mathrm{DC}^{12} \mathrm{HO}^{16}$ & 3- 473 & Not Reported & & & & 29550.43 & \\
\hline $\mathrm{C}^{12} \mathrm{H}_{2}\left(\mathrm{C}^{12} \mathrm{~N}^{14}\right)_{2}$ & 4- 901 & Not Reported & Ground & & & 29550.6 & .1 \\
\hline $\mathrm{C}^{12} \mathrm{H}_{3} \mathrm{Si}^{28} \mathrm{HF}_{2}^{19}-\mathrm{A}$ & 3- 191 & $7,2,6 \leftarrow 7,2,5$ & Ground & & & 29552.40 & \\
\hline $\mathrm{C}^{12} \mathrm{HD}: \mathrm{C}^{12} \mathrm{DBr}^{\mathrm{b}}$ & 4- 749 & Not Reported & Ground & & & 29554.05 & .1 \\
\hline $\mathrm{s}-\left(\mathrm{C}^{12} \mathrm{H}_{2} \mathrm{D}\right)\left(\mathrm{C}^{12} \mathrm{H}_{3}\right) \mathrm{O}^{-16}$ & 3- 596 & Not Reported & Ground & & & 29555. & 20. \\
\hline $\mathrm{t}-\mathrm{C}^{12} \mathrm{HD}: \mathrm{C}^{12} \mathrm{HBr}^{81}$ & 4. 743 & $4,3,2 \leftarrow 3,3,1$ & Ground & $7 / 2$ & $7 / 2$ & 29558.3 & \\
\hline $\mathrm{s}-\left(\mathrm{C}^{12} \mathrm{H}_{2} \mathrm{D}\right)\left(\mathrm{C}^{12} \mathrm{H}_{3}\right) \mathrm{O}^{16}$ & 3- 596 & Not Reported & Ground & & & 29560 & 20. \\
\hline $\mathrm{a}-\left(\mathrm{C}^{12} \mathrm{H}_{2} \mathrm{D}\right)\left(\mathrm{C}^{12} \mathrm{H}_{3}\right)_{2} \mathrm{C}^{12} \mathrm{H}$ & $3-1006$ & $2,1,1 \leftarrow 1,0,1$ & & & & 29560.45 & .05 \\
\hline $\mathrm{c}-\mathrm{C}^{12} \mathrm{HD}: \mathrm{C}^{12} \mathrm{DBr}^{81}$ & 4- 746 & $4,1,3 \leftarrow 3,1,2$ & Ground & $9 / 2$ & $9 / 2$ & 29567.4 & \\
\hline $\mathrm{t}-\mathrm{C}^{12} \mathrm{HD}: \mathrm{C}^{12} \mathrm{HBr}^{81}$ & 4- 743 & $4,0,4 \leftarrow 3,0,3$ & Ground & $9 / 2$ & $9 / 2$ & 29569.0 & \\
\hline $\mathrm{t}-\mathrm{C}^{12} \mathrm{HD}: \mathrm{C}^{12} \mathrm{HBr}^{79}$ & 4- 741 & $4,3,2 \leftarrow 3,3,1$ & Ground & $5 / 2$ & $3 / 2$ & 29570.4 & \\
\hline $\mathrm{C}^{12} \mathrm{O}^{16} \mathrm{~F}_{2}^{19}$ & 4- 211 & $9,8,2 \leftarrow 9,6,3$ & Ground & & & 29570.75 & .10 \\
\hline $\mathrm{C}^{12} \mathrm{H}_{3} \mathrm{~N}^{14} \mathrm{O}_{2}^{16}$ & 3- 171 & Not Reported & Ground & & & 29572.23 & \\
\hline $\mathrm{C}^{12} \mathrm{H}_{3} \mathrm{Si}^{30} \mathrm{HF}_{2}^{19}$ & 3- 194 & $3,2,2 \leftarrow 2,2,1$ & Ground & & & 29573.50 & \\
\hline $\mathrm{C}^{12} \mathrm{H}_{3} \mathrm{~S}^{32} \mathrm{H}$ & 3- 221 & Not Reported & Ground & & & 29574.4 & .1 \\
\hline $\mathrm{C}^{12} \mathrm{H}_{3} \mathrm{C}^{12} \mathrm{H}: \mathrm{C}^{12} \mathrm{HF}^{19}$ & 3- 711 & $4,1,4 \leftarrow 3,1,3$ & Ground & & & 29576.65 & \\
\hline$c-\mathrm{C}^{12} \mathrm{HD}: \mathrm{C}^{12} \mathrm{DBr}^{79}$ & 4- 744 & $4,1,3 \leftarrow 3,1,2$ & Ground & $5 / 2$ & $5 / 2$ & 29580.5 & \\
\hline
\end{tabular}


Vib. State $F_{1}^{\prime} F^{\prime} F_{1}$

Frequency Are.

\begin{tabular}{|c|c|c|c|c|c|c|c|}
\hline $\mathrm{C}^{12} \mathrm{D}_{3} \mathrm{~N}^{14} \mathrm{D}_{2}$ & 3. 262 & $5,1,5 \leftarrow 5,0,5$ & Ground & & & 29581.31 & \\
\hline $\mathrm{t}-\mathrm{C}^{12} \mathrm{HD}: \mathrm{C}^{12} \mathrm{HBr}^{79}$ & 4- 741 & $4,3,2 \leftarrow 3,3,1$ & Ground & $9 / 2$ & $9 / 2$ & 29581.8 & \\
\hline $\mathrm{C}^{12} \mathrm{H}_{2} \mathrm{Cl}_{2}^{35}$ & 4- 341 & $3,1,2 \leftarrow 3,0,3$ & Ground & & & 29582.0 & .3 \\
\hline $\mathrm{C}^{12} \mathrm{H}_{2}\left(\mathrm{C}^{12} \mathrm{~N}^{14}\right)_{2}$ & 4- 901 & Not Reported & Ground & & & 29582.3 & .1 \\
\hline $\mathrm{HC}^{12} \mathrm{~N}^{14}$ & 4. 291 & $11 \leftarrow 11$ & Excited & & & 29585.12 & .20 \\
\hline $\mathrm{C}^{12} \mathrm{H}_{2}\left(\mathrm{C}^{12} \mathrm{~N}^{14}\right)_{2}$ & 4. 901 & Not Reported & Ground & & & 29.586 .0 & .1 \\
\hline $\mathrm{C}^{12} \mathrm{Cl}_{3}^{35} \mathrm{~F}^{19}$ & 4- 191 & $6, \leftarrow 5$, & Ground & & & 29588.95 & .01 \\
\hline $\mathrm{s}-\left(\mathrm{C}^{12} \mathrm{H}_{2} \mathrm{D}\right)\left(\mathrm{C}^{12} \mathrm{H}_{3}\right) \mathrm{O}^{16}$ & 3. 596 & Not Reported & Ground & & & 29590. & 20. \\
\hline $\mathrm{C}^{12} \mathrm{HD}: \mathrm{C}^{12} \mathrm{HBr}^{1}$ & 4- 748 & Not Reported & Ground & & & 29591.9 & .1 \\
\hline $\mathrm{C}^{12} \mathrm{H}_{3} \mathrm{C}^{12} \mathrm{H}_{2} \mathrm{C}^{12} \mathrm{H}_{3}$ & 3- 781 & $5,1,4 \leftarrow 5,0,5$ & Ground & & & 29592.51 & .03 \\
\hline $\mathrm{C}^{12} \mathrm{H}_{3} \mathrm{~S}^{32} \mathrm{H}$ & 3- 221 & Not Reported & Ground & & & 29593.1 & .1 \\
\hline $\mathrm{t}-\mathrm{C}^{12} \mathrm{HD}: \mathrm{C}^{12} \mathrm{HBr}^{79}$ & 4. 741 & $4,2,3 \leftarrow 3,2,2$ & Excited & $5 / 2$ & $3 / 2$ & 29596.0 & \\
\hline $\mathrm{C}^{12} \mathrm{H}_{3} \mathrm{I}^{127}$ & 4. 481 & $2,0 \leftarrow 1,0$ & Ground & $5 / 2$ & $3 / 2$ & 29598.95 & .08 \\
\hline $\mathrm{t}-\mathrm{C}^{12} \mathrm{HD}: \mathrm{C}^{12} \mathrm{HBr}^{79}$ & 4. 741 & $4,0,4 \leftarrow 3,0,3$ & Ground & $7 / 2$ & $7 / 2$ & 29599.2 & \\
\hline $\mathrm{C}^{12} \mathrm{H}_{2} \mathrm{Cl}^{35} \mathrm{Si}^{29} \mathrm{H}_{3}$ & 3- 234 & $5,1,5 \leftarrow 4,1,4$ & Ground & $7 / 2 \quad 9 / 2$ & $5 / 2 \quad 7 / 2$ & 29599.25 & .05 \\
\hline $\mathrm{C}^{12} \mathrm{H}_{2} \mathrm{Cl}^{35} \mathrm{Si}^{29} \mathrm{H}_{3}$ & 3- 234 & $5,1,5 \leftarrow 4,1,4$ & Ground & $11 / 213 / 2$ & $9 / 211 / 2$ & 29599.25 & .05 \\
\hline $\mathrm{C}^{12} \mathrm{H}_{2}\left(\mathrm{C}^{12} \mathrm{~N}^{14}\right)_{2}$ & 4. 901 & Not Reported & Ground & & & 29599.3 & .1 \\
\hline $\mathrm{C}^{12} \mathrm{H}_{2} \mathrm{Cl}^{35} \mathrm{Si}^{29} \mathrm{H}_{3}$ & 3. 234 & $5,1,5 \leftarrow 4,1,4$ & Ground & & & 29599.32 & .2 \\
\hline $\mathrm{s}-\left(\mathrm{C}^{12} \mathrm{H}_{2} \mathrm{D}\right)\left(\mathrm{C}^{12} \mathrm{H}_{3}\right) \mathrm{O}^{16}$ & 3. 596 & Not Reported & Ground & & & 29600. & 20. \\
\hline $\mathrm{C}^{12} \mathrm{O}^{16} \mathrm{~F}_{2}^{19}$ & 4. 211 & $10,9,2 \leftarrow 10,7,3$ & Ground & & & 29600.24 & .10 \\
\hline $\mathrm{C}^{12} \mathrm{H}_{3} \mathrm{Si}^{29} \mathrm{HF}_{2}^{19}$ & 3. 193 & $3,2,2 \leftarrow 2,2,1$ & Ground & & & 29600.40 & \\
\hline $\mathrm{C}^{12} \mathrm{D}_{3} \mathrm{Si}^{\mathrm{h}} \mathrm{HD}_{2}$ & 3- 331 & $14,1,13 \leftarrow 14,1,14$ & & & & 29600.50 & 1. \\
\hline $\mathrm{C}^{12} \mathrm{H}_{3} \mathrm{C}^{12}{ }_{*} \mathrm{HO}^{16} \mathrm{C}^{12}{ }_{*} \mathrm{H}_{2}$ & 3- 761 & Not Reported & Ground & & & 29604.65 & .1 \\
\hline $\mathrm{C}^{13}{ }_{*} \mathrm{H}: \mathrm{C}^{12} \mathrm{HO}^{16} \mathrm{C}^{12} \mathrm{H}: \mathrm{C}^{12}{ }_{*} \mathrm{H}$ & $4-1157$ & $12,9,3 \leftarrow 12,8,4$ & Ground & & & 29605.5 & .1 \\
\hline$\left(\mathrm{C}^{12} \mathrm{H}_{3}\right)_{3} \mathrm{C}^{12} \mathrm{C}^{12}: \mathrm{C}^{13} \mathrm{D}$ & $3-1075$ & $6, \leftarrow 5$ & Ground & & & 29610.2 & .1 \\
\hline $\mathrm{t}-\mathrm{C}^{12} \mathrm{HD}: \mathrm{C}^{12} \mathrm{HBr}^{79}$ & 4. 741 & $4,2,3 \leftarrow 3,2,2$ & Excited & $11 / 2$ & $9 / 2$ & 29612.6 & \\
\hline $\mathrm{C}^{12} \mathrm{D}_{2} \mathrm{Cl}^{35} \mathrm{Si}^{28} \mathrm{H}_{3}$ & 3- 235 & $12,1,11 \leftarrow 12,0,12$ & Ground & & & 29613.69 & .2 \\
\hline $\mathrm{C}^{12} \mathrm{HD}: \mathrm{C}^{12} \mathrm{HBr}^{b}$ & 4- 748 & Not Reported & Ground & & & 29616.0 & .1 \\
\hline $\mathrm{N}^{14} \mathrm{O}^{16} \mathrm{Br}^{b}$ & 4- 123 & $4, \quad \leftarrow 3, \quad$ & & & & 29618.2 & \\
\hline $\mathrm{t}-\mathrm{C}^{12} \mathrm{HD}: \mathrm{C}^{12} \mathrm{HBr}^{79}$ & 4- 741 & $4,2,3 \leftarrow 3,2,2$ & Ground & $5 / 2$ & $3 / 2$ & 29620.3 & \\
\hline $\mathrm{t}-\mathrm{C}^{12} \mathrm{HD}: \mathrm{C}^{12} \mathrm{HBr}^{79}$ & 4. 741 & $4,3,2 \leftarrow 3,3,1$ & Ground & $11 / 2$ & $9 / 2$ & 29622.9 & \\
\hline $\mathrm{C}^{12} \mathrm{HD}: \mathrm{C}^{12} \mathrm{DBr}^{\mathrm{b}}$ & 4- 749 & Not Reported & Ground & & & 29623.3 & .2 \\
\hline $\mathrm{C}^{12} \mathrm{H}_{2} \mathrm{~F}_{2}^{19}$ & 4- 351 & $19,4,16 \leftarrow 18,5,13$ & Ground & & & 29624.66 & .10 \\
\hline $\mathrm{C}^{12} \mathrm{H}_{3} \mathrm{Si}^{28} \mathrm{HF}_{2}^{19}-\mathrm{A}$ & 3- 191 & Not Reported & Ground & & & 29625.6 & \\
\hline g- $\mathrm{C}^{12} \mathrm{H}_{3} \mathrm{C}^{12} \mathrm{H}_{2} \mathrm{C}^{12} \mathrm{H}_{2} \mathrm{Cl}^{35}$ & 3. 773 & $5,1,5 \leftarrow 4,1,4$ & Ground & & & 29625.73 & .2 \\
\hline $\mathrm{C}^{12} \mathrm{HD}: \mathrm{C}^{12} \mathrm{HBr}^{\mathrm{h}}$ & 4- 748 & Not Reported & Ground & & & 29627.0 & .1 \\
\hline $\mathrm{C}^{12} \mathrm{H}_{3} \mathrm{Si}^{28} \mathrm{HF}_{2}^{19}-\mathrm{E}$ & 3- 192 & $3,2,2 \leftarrow 2,2,1$ & Ground & & & 29627.82 & \\
\hline $\mathrm{C}^{12} \mathrm{H}_{3} \mathrm{Si}^{28} \mathrm{HF}_{2}^{9} \cdot \mathrm{A}$ & 3- 191 & $3,2,2 \leftarrow 2,2,1$ & Ground & & & 29627.82 & \\
\hline $\mathrm{C}^{12} \mathrm{H}_{3} \mathrm{C}^{12} \mathrm{O}^{16} \mathrm{Br}^{81}$ & 3- 352 & $5,1,5 \leftarrow 4,0,4$ & Ground & $11 / 2$ & $9 / 2$ & 29628.40 & .15 \\
\hline $\mathrm{t}-\mathrm{C}^{12} \mathrm{HD}: \mathrm{C}^{12} \mathrm{HBr}^{79}$ & 4. 741 & $4,2,2 \leftarrow 3,2,1$ & Ground & $5 / 2$ & $3 / 2$ & 29629.2 & \\
\hline $\mathrm{t}-\mathrm{C}^{12} \mathrm{HD}: \mathrm{C}^{12} \mathrm{HBr}^{79}$ & 4. 74.1 & $4,2,3 \leftarrow 3,2,2$ & Excited & & & 29629.81 & .07 \\
\hline $\mathrm{s}-\mathrm{C}^{12} \mathrm{H}_{2} \mathrm{DO}^{16} \mathrm{~N}^{14} \mathrm{O}_{2}^{16}$ & 3- 183 & $4,0,4 \leftarrow 3,0,3$ & Ground & & & 29629.85 & .1 \\
\hline $\mathrm{s}-\left(\mathrm{C}^{12} \mathrm{H}_{2} \mathrm{D}\right)\left(\mathrm{C}^{12} \mathrm{H}_{3}\right) \mathrm{O}^{16}$ & 3. 596 & Not Reported & Ground & & & 29630 & 20. \\
\hline $\mathrm{C}^{12} \mathrm{HD}: \mathrm{C}^{12} \mathrm{HBr}^{1}$ & 4. 748 & Not Reported & Ground & & & 29630.1 & .1 \\
\hline
\end{tabular}




\begin{tabular}{|c|c|c|c|c|c|c|c|}
\hline \multirow{2}{*}{ Isotopic Species } & \multirow{2}{*}{$\begin{array}{l}\text { Vol.-Id. } \\
\text { Nos. }\end{array}$} & \multirow{2}{*}{$\begin{array}{c}\text { Rotational } \\
\text { Quantum Nos. }\end{array}$} & \multirow{2}{*}{ Vib. State } & \multicolumn{2}{|c|}{ Hyperfine } & \multirow{2}{*}{$\begin{array}{l}\text { Frequency } \\
\mathrm{MHz}^{2}\end{array}$} & \multirow{2}{*}{$\begin{aligned} & \text { Acc. } \\
& \pm \mathrm{MHz}\end{aligned}$} \\
\hline & & & & $F_{1}^{\prime} \quad F^{\prime} \quad F_{1}$ & $\mathrm{~F}$ & & \\
\hline $\mathrm{C}^{12} \mathrm{H}_{2} \mathrm{~F}_{2}^{19}$ & 4. 351 & $19,6,13 \longleftarrow 20,5,16$ & Ground & & & 29630.87 & .10 \\
\hline $\mathrm{C}^{12} \mathrm{H}_{3} \mathrm{O}^{16} \mathrm{~N}^{14} \mathrm{O}_{2}^{16}$ & 3- 181 & $4,1,4 \leftarrow 3,1,3$ & Ground & & & 29633.65 & .1 \\
\hline$\left(\mathrm{C}^{12} \mathrm{H}_{3}\right)_{2} \mathrm{O}^{18}$ & 3. 595 & $1,1,0 \leftarrow 1,0,1$ & Excited & & & 29635. & 20. \\
\hline $\mathrm{t}-\mathrm{C}^{12} \mathrm{HD}: \mathrm{C}^{12} \mathrm{HBr}^{79}$ & 4. 741 & $4,2,3 \leftarrow 3,2,2$ & Ground & $11 / 2$ & $9 / 2$ & 29636.9 & \\
\hline $\mathrm{C}^{12} \mathrm{H}_{3} \mathrm{O}^{16} \mathrm{H}$ & 3- 211 & $16,2, \leftarrow 16,1$, & Ground & & & 29636.91 & .1 \\
\hline $\mathrm{C}^{12} \mathrm{H}_{3} \mathrm{O}^{16} \mathrm{~N}^{14} \mathrm{O}_{2}^{16}$ & 3- 181 & $4,1,4 \leftarrow 3,1,3$ & Ground & & & 29637. & 2. \\
\hline $\mathrm{C}^{12} \mathrm{H}_{3} \mathrm{~B}^{\mathrm{b}} \mathbf{F}_{2}^{19}$ & 3. 91 & $2, \quad \leftarrow 1$, & Ground & & & 29637.6 & .1 \\
\hline $\mathrm{C}^{12} \mathrm{H}_{3} \mathrm{C}^{12} \mathrm{H}: \mathrm{C}^{12} \mathrm{HF}^{19}$ & 3- 711 & $4,1,4 \leftarrow 3,1,3$ & Ground & & & 29638.0 & \\
\hline $\mathrm{C}^{12} \mathrm{H}_{3} \mathrm{C}^{12} \mathrm{O}^{16} \mathrm{Br}^{81}$ & 3. 352 & $5,1,5 \leftarrow 4,0,4$ & Ground & $9 / 2$ & $7 / 2$ & 29638.95 & .15 \\
\hline $\mathrm{C}^{12} \mathrm{O}^{16} \mathrm{~F}_{2}^{19}$ & 4- 211 & $11,10,2 \leftarrow 11,8,3$ & Ground & & & 29639.29 & .10 \\
\hline c- $\mathrm{C}^{12} \mathrm{HD}: \mathrm{C}^{12} \mathrm{DBr}^{79}$ & 4. 744 & $4,1,3 \leftarrow 3,1,2$ & Ground & $7 / 2$ & $7 / 2$ & 29639.7 & \\
\hline $\mathrm{t}-\mathrm{C}^{12} \mathrm{HD}: \mathrm{C}^{12} \mathrm{HBr}^{79}$ & 4- 741 & $4,0,4 \leftarrow 3,0,3$ & Ground & $11 / 2$ & $9 / 2$ & 29640.5 & \\
\hline $\mathrm{t}-\mathrm{C}^{12} \mathrm{HD}: \mathrm{C}^{12} \mathrm{HBr}^{79}$ & 4- 741 & $4,0,4 \leftarrow 3,0,3$ & Ground & $9 / 2$ & $7 i_{2}$ & 29640.5 & \\
\hline c- $\mathrm{C}^{12} \mathrm{HD}: \mathrm{C}^{12} \mathrm{DBr}^{79}$ & 4- 744 & $4,1,3 \leftarrow 3,1,2$ & Excited & $11 / 2$ & $9 / 2$ & 29642.6 & \\
\hline $\mathrm{t}-\mathrm{C}^{12} \mathrm{HD}: \mathrm{C}^{12} \mathrm{HBr}^{79}$ & 4- 741 & $4,2,3 \leftarrow 3,2,2$ & Excited & $7 / 2$ & $5 / 2$ & 29643.5 & \\
\hline $\mathrm{t}-\mathrm{C}^{12} \mathrm{HD}: \mathrm{C}^{12} \mathrm{HBr}^{79}$ & 4- 741 & $4,0,4 \leftarrow 3,0,3$ & Ground & & & 29644.39 & .24 \\
\hline $\mathrm{C}^{12} \mathrm{H}_{3} \mathrm{C}^{12} \mathrm{O}^{16} \mathrm{Br}^{81}$ & 3- 352 & $5,1,5 \leftarrow 4,0,4$ & Ground & $13 / 2$ & $11 / 2$ & 29644.39 & .15 \\
\hline 1. $\mathrm{C}^{12} \mathrm{HD}: \mathrm{C}^{12} \mathrm{HBr}^{79}$ & 4- 741 & $4,2,2 \leftarrow 3,2,1$ & Ground & $11 / 2$ & $9 / 2$ & 29646.5 & \\
\hline c- $\mathrm{C}^{12} \mathrm{HD}: \mathrm{C}^{12} \mathrm{DBr}^{79}$ & 4. 744 & $4,1,3 \leftarrow 3,1,2$ & Excited & $5 / 2$ & $3 / 2$ & 29648.0 & \\
\hline c- $\mathrm{C}^{12} \mathrm{HD}: \mathrm{C}^{12} \mathrm{DBr}^{79}$ & 4- 744 & $4,1,3 \leftarrow 3,1,2$ & Excited & & & 29649.35 & .16 \\
\hline $\mathrm{HC}^{12} \mathrm{~N}^{14}$ & 4- 291 & $11 \leftarrow-11$ & Excited & & & 29650 . & 30. \\
\hline $\mathrm{DC}^{12}: \mathrm{C}^{12} \mathrm{C}^{12} \mathrm{DO}^{16}$ & 4- 926 & $1,1,1 \leftarrow 2,0,2$ & Ground & & & 29650.85 & .02 \\
\hline $\mathrm{C}^{12} \mathrm{H}_{2} \mathrm{DC}^{12}: \mathrm{C}^{12} \mathrm{D}$ & 4-1049 & $2,1,1 \leftarrow 1,1,0$ & Ground & & & 29653.70 & .1 \\
\hline t- $\mathrm{C}^{12} \mathrm{HD}: \mathrm{C}^{12} \mathrm{HBr}^{79}$ & 4- 741 & $4,2,3 \leftarrow 3,2,2$ & Ground & & & 29654.06 & .06 \\
\hline $\mathrm{c}-\mathrm{C}^{12} \mathrm{HD}: \mathrm{C}^{12} \mathrm{DBr}^{79}$ & 4- 744 & $4,1,3 \leftarrow 3,1,2$ & Excited & $9 / 2$ & $7 / 2$ & 29654.2 & \\
\hline $\mathrm{C}^{12}{ }_{*} \mathrm{D}_{2} \mathrm{~S}^{32} \mathrm{C}^{12} * \mathrm{D}_{2}$ & 4. 853 & $2,1,2 \leftarrow 1,1,1$ & Ground & & & 29654.6 & .2 \\
\hline 1. $\mathrm{C}^{12} \mathrm{HD}: \mathrm{C}^{12} \mathrm{HBr}^{79}$ & 4. 741 & $4,0,4 \leftarrow 3,0,3$ & Ground & $5 / 2$ & $3 / 2$ & 29654.8 & \\
\hline t. $\mathrm{C}^{12} \mathrm{HD}: \mathrm{C}^{12} \mathrm{HBr}^{79}$ & 4- 741 & $4,0,4 \leftarrow 3,0,3$ & Ground & $7 / 2$ & $5 / 2$ & 29654.8 & \\
\hline $\mathrm{C}^{12} \mathrm{HD}: \mathrm{C}^{12} \mathrm{HBr}^{\mathrm{b}}$ & 4- 748 & Not Reported & Ground & & & 29654.8 & .1 \\
\hline $\mathrm{C}^{12} \mathrm{H}_{3} \mathrm{C}^{12} \mathrm{O}^{16} \mathrm{Br}^{81}$ & 3- 352 & $5,1,5 \leftarrow 4,0,4$ & Ground & $7 / 2$ & $5 / 2$ & 29655.20 & .15 \\
\hline $\mathrm{C}^{12} \mathrm{H}_{3} \mathrm{Si}^{28} \mathrm{~F}_{3}^{19}$ & 3. 131 & $4, \leftarrow 3$ & Excited & & & 29656.06 & \\
\hline $\mathrm{t}-\mathrm{C}^{12} \mathrm{HD}: \mathrm{C}^{12} \mathrm{HBr}^{79}$ & 4- 741 & $4,3,2 \leftarrow 3,3,1$ & Ground & & & 29657.76 & .42 \\
\hline $\mathrm{N}^{14} \mathrm{O}^{16} \mathrm{Br}^{\mathrm{b}}$ & 4- 123 & $4, \quad \leftarrow 3$, & & & & 29657.8 & \\
\hline $\mathrm{C}^{\mathrm{b}} \mathrm{H}_{2}^{\mathrm{b}} \mathrm{Cl}^{\mathrm{b}} \mathrm{F}^{\mathrm{b}}$ & 4- 333 & Not Reported & & & & 29658.40 & .1 \\
\hline $\mathrm{C}^{12} \mathrm{H}_{3} \mathrm{Si}^{28} \mathrm{~F}_{3}^{19}$ & 3- 131 & $4, \leftarrow 3$ & Excited & & & 29659.06 & \\
\hline t- $\mathrm{C}^{12} \mathrm{HD}: \mathrm{C}^{12} \mathrm{HBr}^{79}$ & 4. 741 & $4,2,3 \leftarrow 3,2,2$ & Excited & $9 / 2$ & $7 / 2$ & 29659.8 & \\
\hline$\left(\mathrm{C}^{12} \mathrm{H}_{3}\right)_{2} \mathrm{O}^{18}$ & 3. 595 & $1,1,0 \leftarrow 1,0,1$ & Excited & & & 29660. & 20. \\
\hline $\mathrm{c}-\mathrm{C}^{12} \mathrm{HD}: \mathrm{C}^{12} \mathrm{DBr}^{79}$ & 4- 744 & $4,1,3 \leftarrow-3,1,2$ & Excited & $7 / 2$ & $5 / 2$ & 29660.2 & \\
\hline c-C ${ }^{12} \mathrm{HD}: \mathrm{C}^{12} \mathrm{DBr}^{79}$ & 4- 744 & $4,1,3 \leftarrow 3,1,2$ & Ground & $11 / 2$ & $9 / 2$ & 29662.0 & \\
\hline $\mathrm{C}^{12} \mathrm{HD}: \mathrm{C}^{12} \mathrm{HBr}^{\mathrm{b}}$ & 4- 748 & Not Reported & Ground & & & 29662.4 & .1 \\
\hline $\mathrm{C}^{12} \mathrm{H}_{3} \mathrm{Si}^{28} \mathrm{HF}_{2}^{19} \cdot \mathrm{E}$ & 3- 192 & $6,1,6 \leftarrow 6,1,5$ & Ground & & & 29662.8 & \\
\hline $\mathrm{Cl}^{35} \mathrm{~F}^{19} \mathrm{C}^{12} \mathrm{O}^{16}$ & 4- 151 & $6,3,3 \leftarrow 6,2,4$ & Ground & & & 29663.01 & .05 \\
\hline t $-\mathrm{C}^{12} \mathrm{HD}: \mathrm{C}^{12} \mathrm{HBr}^{79}$ & 4. 741 & $4,2,2 \leftarrow 3,2,1$ & Ground & & & 29663.22 & .19 \\
\hline $\mathrm{N}^{14} \mathrm{O}^{16} \mathrm{Br}^{\mathrm{h}}$ & 4- 123 & $4, \quad \leftarrow 3$, & & & & 29664.0 & \\
\hline c. $\mathrm{C}^{12} \mathrm{HD}: \mathrm{C}^{12} \mathrm{DBr}^{79}$ & 4- 744 & $4,1,3 \leftarrow 3,1,2$ & Ground & $5 / 2$ & $3 / 2$ & 29667.2 & \\
\hline
\end{tabular}




\begin{tabular}{|c|c|c|c|c|c|c|c|}
\hline \multirow{2}{*}{ Isotopic Species } & \multirow{2}{*}{$\begin{array}{l}\text { Vol.-Id. } \\
\text { Nos. }\end{array}$} & \multirow{2}{*}{$\begin{array}{c}\text { Rotational } \\
\text { Quantum Nos. }\end{array}$} & \multirow{2}{*}{ Vib. State } & \multicolumn{2}{|c|}{ Hyperfine } & \multirow{2}{*}{$\begin{array}{l}\text { Frequency } \\
\text { MHz }\end{array}$} & \multirow{2}{*}{$\begin{aligned} & \text { Acc. } \\
\pm & \mathrm{MHz}\end{aligned}$} \\
\hline & & & & $\begin{array}{lll}F_{1}^{\prime} & F^{\prime \prime} & F_{1}\end{array}$ & $\mathrm{~F}$ & & \\
\hline $\mathrm{t}-\mathrm{C}^{12} \mathrm{HD}: \mathrm{C}^{12} \mathrm{HBr}^{79}$ & 4- 741 & $4,2,3 \leftarrow 3,2,2$ & Ground & $7 / 2$ & $5 / 2$ & 29667.3 & \\
\hline $\mathrm{C}^{12} \mathrm{D}_{2} \mathrm{Cl}_{2}^{35}$ & 4- 346 & $10,1,9 \leftarrow 10,0,10$ & Ground & & & 29667.7 & .2 \\
\hline $\mathrm{C}^{12} \mathrm{H}_{3} \mathrm{Si}^{28} \mathrm{HF}_{2}^{19}-\mathrm{A}$ & 3- 191 & $6,1,6 \leftarrow 6,1,5$ & Ground & & & 29667.8 & \\
\hline$c-\mathrm{C}^{12} \mathrm{HD}: \mathrm{C}^{12} \mathrm{DBr}^{79}$ & 4- 744 & $4,1,3 \leftarrow 3,1,2$ & Ground & & & 29668.64 & .16 \\
\hline $\mathrm{Si}^{28} \mathrm{HCl}_{3}^{35}$ & 4-1501 & $6, \leftarrow 5$ & Ground & & & 29669.87 & .5 \\
\hline$c-C^{12} \mathrm{HD}: \mathrm{C}^{12} \mathrm{DBr}^{79}$ & 4- 744 & $4,1,3 \leftarrow 3,1,2$ & Ground & $9 / 2$ & $7 / 2$ & 29673.4 & \\
\hline $\mathrm{C}^{12} \mathrm{H}_{3} \mathrm{I}^{127}$ & 4- 481 & $2,0 \leftarrow 1,0$ & Ground & $7 / 2$ & $7 / 2$ & 29673.95 & .08 \\
\hline$\left(\mathrm{C}^{12} \mathrm{H}_{3}\right)_{2} \mathrm{O}^{18}$ & 3- 595 & $2,1,1 \leftarrow 2,0,2$ & Ground & & & 29674.3 & .2 \\
\hline $1-\mathrm{C}^{12} \mathrm{HD}: \mathrm{C}^{12} \mathrm{HBr}^{79}$ & 4- 741 & $4,3,2 \leftarrow 3,3,1$ & Ground & $7 / 2$ & $5 / 2$ & 29675.4 & \\
\hline $\mathrm{t}-\mathrm{C}^{12} \mathrm{HD}: \mathrm{C}^{12} \mathrm{HBr}^{79}$ & 4- 741 & $4,2,2 \leftarrow 3,2,1$ & Ground & $7 / 2$ & $5 / 2$ & 29676.6 & \\
\hline $\mathrm{C}^{12}{ }_{*} \mathrm{H}_{2} \mathrm{C}^{12} \mathrm{H}: \mathrm{C}^{12} \mathrm{HC}^{12} \mathrm{H}: \mathrm{C}^{12}{ }_{*} \mathrm{H}$ & $4-1231$ & $3,0,3 \leftarrow 2,1,2$ & Ground & & & 29678.4 & .1 \\
\hline$c-\mathrm{C}^{12} \mathrm{HD}: \mathrm{C}^{12} \mathrm{DBr}^{79}$ & 4- 744 & $4,1,3 \leftarrow 3,1,2$ & Ground & $7 / 2$ & $5 / 2$ & 29679.7 & \\
\hline $\mathrm{s}-\left(\mathrm{C}^{12} \mathrm{H}_{2} \mathrm{D}\right)\left(\mathrm{C}^{12} \mathrm{H}_{3}\right) \mathrm{O}^{16}$ & 3- 596 & Not Reported & Ground & & & 29680 . & 20. \\
\hline $\mathrm{C}^{12} \mathrm{H}_{3} \mathrm{C}^{13} \mathrm{H}_{2} \mathrm{Cl}^{35}$ & 3. 546 & $5,1,4 \leftarrow 5,0,5$ & Ground & $7 / 2$ & $7 / 2$ & 29682.75 & .05 \\
\hline $\mathrm{C}^{12} \mathrm{H}_{3} \mathrm{C}^{13} \mathrm{H}_{2} \mathrm{Cl}^{35}$ & 3. 546 & $5,1,4 \leftarrow 5,0,5$ & Ground & $13 / 2$ & $13 / 2$ & 29683.97 & .05 \\
\hline $\mathrm{t}-\mathrm{C}^{12} \mathrm{HD}: \mathrm{C}^{12} \mathrm{HBr}^{79}$ & 4- 741 & $4,2,3 \leftarrow 3,2,2$ & Ground & $9 / 2$ & $7 / 2$ & 29684.2 & \\
\hline $\mathrm{C}^{12} \mathrm{H}_{3} \mathrm{C}^{12}{ }_{*} \mathrm{HO}^{16} \mathrm{C}^{12}{ }_{*} \mathrm{H}_{2}$ & 3. 761 & Not Reported & Ground & & & 29684.32 & .1 \\
\hline $\mathrm{C}^{12}{ }_{*} \mathrm{H}_{2} \mathrm{C}^{12} \mathrm{H}: \mathrm{C}^{12} \mathrm{HC}^{12} \mathrm{H}: \mathrm{C}^{12}{ }_{*} \mathrm{H}$ & 4-1231 & $3,1,3 \leftarrow 2,0,2$ & Ground & & & 29686.2 & .1 \\
\hline $\mathrm{C}^{12} \mathrm{H}_{3} \mathrm{C}^{13} \mathrm{H}_{2} \mathrm{Cl}^{35}$ & 3- 546 & $5,1,4 \leftarrow 5,0,5$ & Ground & $9 / 2$ & $9 / 2$ & 29686.99 & .05 \\
\hline $\mathrm{H}_{2} \mathrm{C}^{12}{ }_{*} \mathrm{O}^{16} \mathrm{C}^{12}{ }_{*} \mathrm{H}_{2}$ & 4- 841 & $5,4,1 \leftarrow 5,3,2$ & Ground & & & 29688. & 1. \\
\hline $\mathrm{C}^{12} \mathrm{H}_{3} \mathrm{C}^{13} \mathrm{H}_{2} \mathrm{Cl}^{35}$ & 3- 546 & $5,1,4 \leftarrow 5,0,5$ & Ground & $11 / 2$ & $11 / 2$ & 29688.18 & .05 \\
\hline $\mathrm{C}^{12} \mathrm{H}_{3} \mathrm{Si}^{28} \mathrm{~F}_{3}^{19}$ & 3- 131 & $4, \leftarrow 3$, & Excited & & & 29689.70 & \\
\hline $\mathrm{C}^{12} \mathrm{O}^{16} \mathrm{~F}_{2}^{19}$ & 4. 211 & $12,11,2 \leftarrow 12,9,3$ & Ground & & & 29689.77 & .10 \\
\hline $\mathrm{C}^{12} \mathrm{H}_{3} \mathrm{Si}^{28} \mathrm{~F}_{3}^{19}$ & 3- 131 & $4, \leftarrow 3$, & Excited & & & 29690.07 & \\
\hline t- $\mathrm{C}^{12} \mathrm{HD}: \mathrm{C}^{12} \mathrm{HBr}^{79}$ & 4. 741 & $4,2,2 \leftarrow 3,2,1$ & Ground & $9 / 2$ & $7 / 2$ & 29693.25 & \\
\hline $\mathrm{C}^{12} \mathrm{HD}: \mathrm{C}^{12} \mathrm{DBr}^{\mathrm{b}}$ & 4- 749 & Not Reported & Ground & & & 29693.3 & .1 \\
\hline$\left(\mathrm{C}^{12} \mathrm{H}_{3}\right)_{2} \mathrm{O}^{18}$ & 3- 595 & $1,1,0 \leftarrow 1,0,1$ & Excited & & & 29695 & 20. \\
\hline $\mathrm{C}^{12} \mathrm{Cl}_{2}^{35} \mathrm{Cl}^{37} \mathrm{C}^{12} \mathrm{~N}^{14}$ & 4- 582 & $9, \quad \leftarrow 8, \quad$ & Ground & & & 29695.1 & 1.0 \\
\hline $\mathrm{C}^{12} \mathrm{H}_{2} \mathrm{DC}^{12} \mathrm{~F}_{3}^{19}$ & 3- 412 & Not Reported & Ground & & & 29695.6 & \\
\hline $\mathrm{C}^{12} \mathrm{HDCl}^{35} \mathrm{Si}^{28} \mathrm{H}_{3}$ & 3- 236 & $5,1,5 \leftarrow 4,1,4$ & Ground & & & 29696.89 & .2 \\
\hline $\mathrm{C}^{12} \mathrm{H}_{3} \mathrm{~N}^{14} \mathrm{C}^{12} \mathrm{~S}^{3 !}$ & 3. 425 & $6, \quad \leftarrow 5$, & Ground & & & 29700. & \\
\hline $\mathrm{C}^{12} \mathrm{H}_{3} \mathrm{Si}^{28} \mathrm{~F}_{3}^{19}$ & 3- 131 & $4, \leftarrow 3$ & Excited & & & 29704.12 & \\
\hline $\mathrm{C}^{12} \mathrm{H}_{3} \mathrm{Si}^{28} \mathrm{~F}_{3}^{19}$ & 3- 131 & $4, \leftarrow 3$, & Excited & & & 29704.70 & \\
\hline $\mathrm{C}^{12} \mathrm{H}_{2}\left(\mathrm{C}^{12} \mathrm{~N}^{14}\right)_{2}$ & 4- 901 & Not Reported & Ground & & & 29708.9 & .1 \\
\hline$\left(\mathrm{C}^{12} \mathrm{H}_{3}\right)_{2} \mathrm{O}^{18}$ & 3- 595 & $1,1,0 \leftarrow 1,0,1$ & Excited & & & 29710. & 20. \\
\hline $\mathrm{C}^{12}{ }_{*} \mathrm{H}_{2} \mathrm{C}^{12} \mathrm{H}_{2} \mathrm{C}^{12} \mathrm{H}_{2} \mathrm{O}^{16}{ }_{*}$ & 4-1091 & $11,10,2 \leftarrow 11,8,3$ & Excited & & & 29717.5 & .1 \\
\hline $\mathrm{C}^{12} \mathrm{H}_{3} \mathrm{C}^{12} \mathrm{HO}^{16}$ & 3- 471 & $7,1,6 \leftarrow 7,1,7$ & Ground & & & 29718.83 & .3 \\
\hline $\mathrm{C}^{12} \mathrm{H}_{2}\left(\mathrm{C}^{12} \mathrm{~N}^{14}\right)_{2}$ & 4- 901 & Not Reported & Ground & & & 29719. & .1 \\
\hline$\left(\mathrm{C}^{12} \mathrm{H}_{3}\right)_{2} \mathrm{O}^{18}$ & 3- 595 & $1,1,0 \leftarrow 1,0,1$ & Excited & & & 29720 & 20. \\
\hline $\mathrm{C}^{12} \mathrm{H}_{3} \mathrm{Si}^{28} \mathrm{~F}_{3}^{19}$ & 3- 131 & $4, \leftarrow 3$, & Excited & & & 29724.87 & \\
\hline $\mathrm{C}^{12} \mathrm{H}_{3} \mathrm{Si}^{28} \mathrm{~F}_{3}^{19}$ & 3- 131 & $4, \leftarrow 3$, & Ground & & & 29724.99 & .1 \\
\hline $\mathrm{C}^{12} \mathrm{H}_{2} \mathrm{DC}^{12} \mathrm{~F}_{3}^{19}$ & 3- 412 & $3,1,3 \leftarrow 2,1,2$ & Ground & & & 29727.20 & .2 \\
\hline $\mathrm{C}^{12} \mathrm{H}_{3} \mathrm{Si}^{28} \mathrm{~F}_{3}^{19}$ & 3- 131 & $4, \leftarrow 3$ & Excited & & & 29729.13 & \\
\hline $\mathrm{t}-\mathrm{C}^{12} \mathrm{HD}: \mathrm{C}^{12} \mathrm{HBr}^{79}$ & 4- 741 & $4,3,2 \leftarrow 3,3,1$ & Ground & $9 / 2$ & $7 / 2$ & 29729.8 & \\
\hline $\mathrm{s}-\left(\mathrm{C}^{12} \mathrm{H}_{2} \mathrm{D}\right)\left(\mathrm{C}^{12} \mathrm{H}_{3}\right) \mathrm{O}^{16}$ & 3- 596 & Not Reported & Ground & & & 29730 . & 20. \\
\hline
\end{tabular}




\begin{tabular}{|c|c|c|c|c|c|c|c|}
\hline Isotopic Species & $\begin{array}{l}\text { Vol.-Id. } \\
\text { Nos. }\end{array}$ & $\begin{array}{c}\text { Rotational } \\
\text { Quantum Nos. }\end{array}$ & Vib. State & 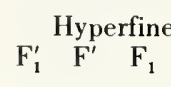 & $\mathrm{F}$ & $\begin{array}{l}\text { Frequency } \\
\quad \mathrm{MHz}\end{array}$ & $\begin{aligned} & \text { Acc. } \\
& \pm \mathrm{MHz}\end{aligned}$ \\
\hline $\mathrm{C}^{12} \mathrm{H}_{3} \mathrm{C}^{12}{ }_{*} \mathrm{HO}^{16} \mathrm{C}^{12}{ }_{*} \mathrm{H}_{2}$ & 3. 761 & $9,2,7 \leftarrow 9,1,8$ & Ground & & & 29730.32 & .1 \\
\hline $\mathrm{C}^{12} \mathrm{H}_{3} \mathrm{I}^{127}$ & 4- 481 & $2,1 \leftarrow 1,1$ & Ground & $7 / 2$ & $5 / 2$ & 29735.71 & .08 \\
\hline $\mathrm{C}^{12} \mathrm{H}_{3} \mathrm{C}^{12}{ }_{*} \mathrm{HO}^{16} \mathrm{C}^{12}{ }_{*} \mathrm{H}_{2}$ & 3- 761 & $9,2,7 \leftarrow 9,1,8$ & Ground & & & 29740.80 & .1 \\
\hline $\mathrm{t}-\mathrm{C}^{12} \mathrm{HD}: \mathrm{C}^{12} \mathrm{HBr}^{79}$ & 4. 741 & $4,3,2 \leftarrow 3,3,1$ & Ground & $7 / 2$ & $7 / 2$ & 29743.7 & \\
\hline $\mathrm{C}^{13} \mathrm{H}_{3}\left(\mathrm{C}^{12} \mathrm{H}_{3}\right)_{2} \mathrm{C}^{12} \mathrm{Cl}^{35}$ & 3. 975 & $5,1,5 \leftarrow 4,1,4$ & Ground & & & 29747.06 & .20 \\
\hline $\mathrm{C}^{12} \mathrm{DBr}_{3}^{79}$ & 4- 243 & $12, \leftarrow 11$, & Ground & & & 29747.2 & .5 \\
\hline $\mathrm{C}^{12}{ }_{*} \mathrm{H}_{2} \mathrm{C}^{12} \mathrm{H}_{2} \mathrm{C}^{12} \mathrm{H}_{2} \mathrm{O}^{18}{ }_{*}$ & 4-1093 & $7,6,2 \leftarrow 7,4,3$ & Ground & & & 29751. & 5. \\
\hline $\mathrm{D}_{2} \mathrm{O}_{2}^{16}$ & 3- 42 & Not Reported & & & & 29759. & 3. \\
\hline c- $\mathrm{C}^{12} \mathrm{HD}: \mathrm{C}^{12} \mathrm{DBr}^{79}$ & 4- 744 & $4,1,3 \leftarrow 3,1,2$ & Ground & $9 / 2$ & $9 / 2$ & 29760.1 & \\
\hline $\mathrm{C}^{12} \mathrm{H}_{3} \mathrm{Si}^{28} \mathrm{~F}_{3}^{19}$ & 3- 131 & $4, \leftarrow 3$, & Excited & & & 29764.24 & \\
\hline $\mathrm{C}^{12} \mathrm{H}_{3} \mathrm{C}^{12}{ }_{*} \mathrm{HO}^{16} \mathrm{C}^{12}{ }_{*} \mathrm{H}_{2}$ & 3. 761 & $9,2,7 \leftarrow 9,1,8$ & Ground & & & 29764.80 & .1 \\
\hline $\mathrm{C}^{12} \mathrm{H}_{3} \mathrm{C}^{12}{ }_{*} \mathrm{HO}^{16} \mathrm{C}^{12}{ }_{*} \mathrm{H}_{2}$ & 3. 761 & $9,2,7 \leftarrow 9,1,8$ & Ground & & & 29765.05 & .1 \\
\hline $\mathrm{s}-\left(\mathrm{C}^{12} \mathrm{H}_{2} \mathrm{D}\right)\left(\mathrm{C}^{12} \mathrm{H}_{3}\right)_{2} \mathrm{C}^{12} \mathrm{H}$ & $3-1005$ & $2,1,1 \leftarrow 1,0,1$ & & & & 29765.6 & 1. \\
\hline $\mathrm{C}^{12} \mathrm{H}_{3} \mathrm{O}^{16} \mathrm{~N}^{14} \mathrm{O}_{2}^{16}$ & 3- 181 & $4,1,4 \leftarrow 3,1,3$ & Ground & & & 29765.97 & .1 \\
\hline $\mathrm{C}^{12} \mathrm{H}_{2} \mathrm{DC}^{12} \mathrm{~F}_{3}^{19}$ & 3- 412 & $3,0,3 \leftarrow 2,0,2$ & Ground & & & 29766.45 & .2 \\
\hline $\mathrm{C}^{12} \mathrm{H}_{3} \mathrm{~N}^{14} \mathrm{H}_{2}$ & 3- 261 & Not Reported & Ground & & & 29770.2 & \\
\hline $\mathrm{C}^{12} \mathrm{H}_{3} \mathrm{~N}^{14} \mathrm{H}_{2}$ & 3- 261 & $6,1, \leftarrow 5,2$, & Ground & & & 29771.4 & \\
\hline $\mathrm{C}^{12} \mathrm{H}_{3} \mathrm{~N}^{14} \mathrm{H}_{2}$ & 3- 261 & Not Reported & Ground & & & 29771.40 & \\
\hline $\mathrm{C}^{12} \mathrm{H}_{2} \mathrm{DC}^{12} \mathrm{~F}_{3}^{19}$ & 3- 412 & $3,2,2 \leftarrow 2,2,1$ & Ground & & & 29771.66 & .2 \\
\hline $\mathrm{C}^{12} \mathrm{H}_{3} \mathrm{~S}^{32} \mathrm{H}$ & 3- 221 & Not Reported & Ground & & & 29772.81 & \\
\hline $\mathrm{C}^{12} \mathrm{H}_{3}{ }^{127}$ & 4. 481 & $2,0 \leftarrow 1,0$ & Ground & $5 / 2$ & $7 / 2$ & 29773.95 & .08 \\
\hline $\mathrm{C}^{12} \mathrm{H}_{3} \mathrm{C}^{12} \mathrm{HO}^{16}$ & 3- 471 & $7,1,6 \leftarrow 7,1,7$ & Ground & & & 29774.15 & .2 \\
\hline $\mathrm{C}^{12} \mathrm{H}_{2} \mathrm{DC}^{12} \mathrm{~F}_{3}^{19}$ & 3- 412 & $3,2,1 \leftarrow 2,2,0$ & Ground & & & 29776.39 & .2 \\
\hline $\mathrm{C}^{12} \mathrm{H}_{3} \mathrm{I}^{127}$ & 4- 481 & $2,1 \leftarrow 1,1$ & Ground & $5 / 2$ & $5 / 2$ & 29782.71 & .08 \\
\hline $\mathrm{C}^{12}{ }_{*} \mathrm{H}_{2} \mathrm{C}^{12} \mathrm{H}_{2} \mathrm{C}^{12} \mathrm{H}_{2} \mathrm{O}^{18}{ }_{*}$ & 4-1093 & $7,6,2 \leftarrow 7,4,3$ & Excited & & & 29783.0 & .1 \\
\hline $\mathrm{C}^{12} \mathrm{H}_{2}\left(\mathrm{C}^{12} \mathrm{~N}^{14}\right)_{2}$ & 4. 901 & Not Reported & Ground & & & 29783.9 & .1 \\
\hline $\mathrm{Si}^{28} \mathrm{H}_{3} \mathrm{C}^{12} \mathrm{H}: \mathrm{C}^{12} \mathrm{H}_{2}$ & 3- 611 & $2,1,1 \leftarrow 2,0,2$ & Ground & & & 29784. & 10. \\
\hline $\mathrm{HC}^{13}: \mathrm{C}^{12} \mathrm{C}^{12} \mathrm{DO}^{16}$ & 4- 922 & Not Reported & & & & 29785. & 5. \\
\hline $\mathrm{C}^{12} \mathrm{H}_{3} \mathrm{O}^{16} \mathrm{~N}^{14} \mathrm{O}_{2}^{16}$ & 3- 181 & $4,1,4 \leftarrow 3,1,3$ & Ground & & & 29785.75 & .1 \\
\hline $\mathrm{a}-\mathrm{C}^{12} \mathrm{H}_{2} \mathrm{DSi}^{28} \mathrm{HF}_{2}^{19}$ & 3. 204 & $3,1,2 \leftarrow 2,1,1$ & Ground & & & 29787.24 & 2. \\
\hline $\mathrm{Si}^{28} \mathrm{H}_{3} \mathrm{C}^{12} \mathrm{H}: \mathrm{C}^{12} \mathrm{H}_{2}$ & 3- 611 & $2,1,1 \leftarrow 2,0,2$ & Ground & & & 29789. & 10. \\
\hline $\mathrm{a}-\mathrm{C}^{12} \mathrm{H}_{2} \mathrm{DSi}^{28} \mathrm{HF}_{2}^{19}$ & ' 3- 204 & $3,1,2 \leftarrow 2,1,1$ & Ground & & & 29789.34 & 2. \\
\hline $\mathrm{C}^{12} \mathrm{H}_{3} \mathrm{~N}^{14} \mathrm{O}_{2}^{16}$ & 3- 171 & Not Reported & Ground & & & 29797.36 & \\
\hline $\mathrm{S}^{32} \mathrm{O}^{16} \mathrm{~F}_{2}^{19}$ & 4-1621 & Not Reported & & & & 29801.69 & .1 \\
\hline $\mathrm{C}^{12} \mathrm{HD}: \mathrm{C}^{12} \mathrm{HBr}^{\mathrm{b}}$ & 4- 748 & Not Reported & Ground & & & 29804.6 & .1 \\
\hline $\mathrm{S}^{32} \mathrm{O}^{16} \mathrm{~F}_{2}^{19}$ & $4-1621$ & Not Reported & & & & 29807.10 & .1 \\
\hline $\mathrm{C}^{12} \mathrm{H}_{2} \mathrm{DC}^{12} \mathrm{~F}_{3}^{19}$ & 3- 412 & $3,1,2 \leftarrow 2,1,1$ & Ground & & & 29814.08 & .2 \\
\hline $\mathrm{C}^{12} \mathrm{H}_{2}\left(\mathrm{C}^{12} \mathrm{~N}^{14}\right)_{2}$ & 4. 901 & Not Reported & Ground & & & 29815.1 & .1 \\
\hline $\mathrm{C}^{12} \mathrm{D}_{3} \mathrm{~N}^{14} \mathrm{D}_{2}$ & 3- 262 & $5,1,5 \leftarrow 5,0,5$ & Ground & & & 29817.76 & \\
\hline $\mathrm{C}^{12} \mathrm{H}_{3} \mathrm{C}^{12} \mathrm{O}^{16} \mathrm{Cl}^{35}$ & 3- 361 & $11,4,7 \leftarrow 11,3,8$ & Ground & $19 / 2$ & $19 / 2$ & 29817.85 & .2 \\
\hline $\mathrm{C}^{12} \mathrm{H}_{3} \mathrm{C}^{12} \mathrm{O}^{16} \mathrm{Cl}^{35}$ & 3- 361 & $11,4,7 \leftarrow 11,3,8$ & Ground & $25 / 2$ & $25 / 2$ & 29817.85 & .2 \\
\hline $\mathrm{HDO}_{2}^{16}$ & 3- 43 & $15, \quad \leftarrow 15$, & & & & 29818. & 3. \\
\hline $\mathrm{C}^{12} \mathrm{H}_{3} \mathrm{C}^{12} \mathrm{O}^{16} \mathrm{Cl}^{35}$ & 3. 361 & $11,4,7 \leftarrow 11,3,8$ & Ground & $21 / 2$ & $21 / 2$ & 29819.00 & .2 \\
\hline $\mathrm{C}^{12} \mathrm{H}_{3} \mathrm{C}^{12} \mathrm{O}^{16} \mathrm{Cl}^{35}$ & 3- 361 & $11,4,7 \leftarrow 11,3,8$ & Ground & $23 / 2$ & $23 / 2$ & 29819.00 & .2 \\
\hline $\mathrm{C}^{12} \mathrm{H}_{3} \mathrm{C}^{12} \mathrm{O}^{16} \mathrm{Cl}^{35}$ & 3- 361 & $11,4,7 \leftarrow 11,3,8$ & Ground & $19 / 2$ & $19 / 2$ & 29820.30 & .2 \\
\hline
\end{tabular}


Vib. State

$F_{1}^{\text {Hyperfine }} \mathrm{F}^{\prime} \mathrm{F}_{1} \quad$ Frequency Acc.

\begin{tabular}{|c|c|c|c|c|c|c|c|}
\hline $\mathrm{C}^{12} \mathrm{H}_{3} \mathrm{C}^{12} \mathrm{O}^{16} \mathrm{Cl}^{35}$ & 3- 361 & $11,4,7 \leftarrow 11,3,8$ & Ground & $25 / 2$ & $25 / 2$ & 29820.30 & .2 \\
\hline $\mathrm{C}^{12} \mathrm{H}_{3} \mathrm{C}^{12} \mathrm{O}^{16} \mathrm{Cl}^{35}$ & 3- 361 & $11,4,7 \leftarrow 11,3,8$ & Ground & $21 / 2$ & $21 / 2$ & 29821.40 & .2 \\
\hline $\mathrm{C}^{12} \mathrm{H}_{3} \mathrm{C}^{12} \mathrm{O}^{16} \mathrm{Cl}^{35}$ & 3- 361 & $11,4,7 \leftarrow 11,3,8$ & Ground & $23 / 2$ & $23 / 2$ & 29821.40 & .2 \\
\hline $\mathrm{C}^{12} \mathrm{H}_{3} \mathrm{C}^{12} \mathrm{O}^{16} \mathrm{Cl}^{37}$ & 3- 362 & $11,4,7 \leftarrow 11,3,8$ & Ground & $21 / 2$ & $21 / 2$ & 29821.40 & .2 \\
\hline $\mathrm{C}^{12} \mathrm{H}_{3} \mathrm{C}^{12} \mathrm{O}^{16} \mathrm{Cl}^{37}$ & 3- 362 & $11,4,7 \leftarrow 11,3,8$ & Ground & $23 / 2$ & $23 / 2$ & 29821.40 & .2 \\
\hline $\mathrm{S}^{32} \mathrm{P}^{31} \mathrm{Cl}_{3}^{37}$ & $4-1534$ & $11, \leftarrow 10$, & Ground & & & 29825.5 & 1.0 \\
\hline$c-\mathrm{C}^{12} \mathrm{H}_{3} \mathrm{C}^{12} \mathrm{H}: \mathrm{C}^{12} \mathrm{HF}^{19}-\mathrm{E}$ & 3. 702 & $3,0,3 \leftarrow 2,0,2$ & & & & 29826.39 & .2 \\
\hline $\mathrm{C}^{13} \mathrm{H}_{3}\left(\mathrm{C}^{12} \mathrm{H}_{3}\right)_{2} \mathrm{C}^{12} \mathrm{Cl}^{35}$ & 3- 975 & $5,0,5 \leftarrow 4,0,4$ & Ground & & & 29827.79 & .20 \\
\hline$c-\mathrm{C}^{12} \mathrm{H}_{3} \mathrm{C}^{12} \mathrm{H}: \mathrm{C}^{12} \mathrm{HF}^{19}-\mathrm{A}$ & 3- 701 & $3,0,3 \leftarrow 2,0,2$ & & & & 29829.55 & .2 \\
\hline $\mathrm{HDO}_{2}^{16}$ & 3. 43 & $15, \quad \leftarrow 15, \quad$, & & & & 29830. & 3. \\
\hline $\mathrm{C}^{\mathrm{b}}{ }_{*} \mathrm{H}_{2}^{\mathrm{b}} \mathrm{N}^{\mathrm{b}} \mathrm{H}^{\mathrm{b}} \mathrm{C}^{\mathrm{b}}{ }_{*} \mathrm{H}_{2}^{\mathrm{b}}$ & 4. 863 & Not Reported & & & & 29830. & 10. \\
\hline $\mathrm{C}^{12} \mathrm{H}_{3} \mathrm{C}^{12} \mathrm{HO}^{16}$ & 3. 471 & Not Reported & & & & 29832. & \\
\hline $\mathrm{P}^{31} \mathrm{H}_{3}^{\mathrm{b}}$ & $4-1785$ & Not Reported & & & & 29833.95 & .05 \\
\hline $\mathrm{s}-\left(\mathrm{C}^{12} \mathrm{H}_{2} \mathrm{D}\right)\left(\mathrm{C}^{12} \mathrm{H}_{3}\right) \mathrm{O}^{16}$ & 3- 596 & Not Reported & Ground & & & 29835. & 20. \\
\hline $\mathrm{HC}^{13}: \mathrm{C}^{12} \mathrm{C}^{12} \mathrm{DO}^{16}$ & 4. 922 & Not Reported & & & & 29841. & 5. \\
\hline$\left(\mathrm{C}^{12} \mathrm{H}_{3}\right)_{2} \mathrm{O}^{16}$ & 3. 591 & $1,1,0 \leftarrow 1,0,1$ & Excited & & & 29850. & 20. \\
\hline $\mathrm{C}^{12} \mathrm{H}_{2} \mathrm{~F}^{19} \mathrm{C}^{12} \mathrm{~N}^{14}$ & 4- 701 & $12,1,11 \leftarrow 11,2,10$ & Ground & & & 29854. & 1.0 \\
\hline $\mathrm{Si}^{29} \mathrm{D}_{2} \mathrm{~F}_{2}^{19}$ & $4-1604$ & $6,2,4 \leftarrow 6,1,5$ & Ground & & & 29859.10 & .10 \\
\hline $\mathrm{C}^{12} \mathrm{H}_{3} \mathrm{I}^{127}$ & 4. 481 & $2,0 \leftarrow 1,0$ & Ground & $3 / 2$ & $3 / 2$ & 29872.52 & .08 \\
\hline $\mathrm{S}^{32} \mathrm{O}^{16} \mathrm{~F}_{2}^{19}$ & $4-1621$ & Not Reported & & & & 29878.60 & .1 \\
\hline$\left(\mathrm{C}^{12} \mathrm{H}_{3}\right)_{2} \mathrm{O}^{16}$ & 3. 591 & $1,1,0 \leftarrow 1,0,1$ & Excited & & & 29880. & 20. \\
\hline $\mathrm{s}-\left(\mathrm{C}^{12} \mathrm{H}_{2} \mathrm{D}\right)\left(\mathrm{C}^{12} \mathrm{H}_{3}\right) \mathrm{O}^{16}$ & 3. 596 & Not Reported & Ground & & & 29880. & 20. \\
\hline g- $\mathrm{C}^{12} \mathrm{H}_{3} \mathrm{C}^{12} \mathrm{H}_{2} \mathrm{C}^{12} \mathrm{H}_{2} \mathrm{Cl}^{37}$ & 3- 774 & $5,0,5 \leftarrow 4,0,4$ & Ground & & & 29883.72 & .2 \\
\hline $\mathrm{O}^{16} \mathrm{O}^{18} \mathrm{O}^{16}$ & $4-1843$ & $17,2,16 \leftarrow 16,3,13$ & Ground & & & 29889. & \\
\hline $\mathrm{C}^{12} \mathrm{H}_{3} \mathrm{O}^{16} \mathrm{H}$ & 3. 211 & Not Reported & Ground & & & 29889.33 & .1 \\
\hline $\mathrm{C}^{12}{ }_{*} \mathrm{H}_{2}^{\mathrm{b}} \mathrm{S}^{\mathrm{b}} \mathrm{C}^{12}{ }_{*} \mathrm{H}_{2}^{\mathrm{b}}$ & 4. 854 & Not Reported & & & & 29890.0 & 25. \\
\hline $\mathrm{C}^{12}{ }_{*} \mathrm{H}_{2} \mathrm{C}^{12} \mathrm{H}_{2} \mathrm{C}^{12} \mathrm{H}_{2} \mathrm{O}^{16}{ }_{*}$ & $4-1091$ & $11,10,2 \leftarrow 11,8,3$ & Excited & & & 29893.2 & .1 \\
\hline $\mathrm{Si}^{28} \mathrm{D}_{2} \mathrm{~F}_{2}^{19}$ & $4-1603$ & $3,0,3 \leftarrow 2,1,2$ & Excited & & & 29894.05 & .10 \\
\hline $\mathrm{s}-\left(\mathrm{C}^{12} \mathrm{H}_{2} \mathrm{D}\right)\left(\mathrm{C}^{12} \mathrm{H}_{3}\right) \mathrm{O}^{16}$ & 3- 596 & Not Reported & Ground & & & 29895 . & 20. \\
\hline $\mathrm{C}^{12} \mathrm{D}_{3} \mathrm{C}^{12} \mathrm{O}^{16} \mathrm{C}^{12} \mathrm{~N}^{14}$ & 3- 675 & $5,1,5 \leftarrow 4,1,4$ & Ground & & & 29895.95 & .2 \\
\hline$\left(\mathrm{C}^{12} \mathrm{H}_{3}\right)_{2} \mathrm{O}^{16}$ & 3. 591 & $1,1,0 \leftarrow 1,0,1$ & Ground & & & 29901.4 & .2 \\
\hline $\mathrm{C}^{12} \mathrm{HD}: \mathrm{C}^{12} \mathrm{DBr}^{\mathrm{b}}$ & 4- 749 & Not Reported & Ground & & & 29904.9 & .2 \\
\hline $\mathrm{C}^{12} \mathrm{H}_{2} \mathrm{Cl}_{2}^{37}$ & 4. 343 & $4,1,3 \leftarrow 4,0,4$ & Ground & & & 29905. & 5. \\
\hline $\mathrm{C}^{12} \mathrm{HD}: \mathrm{C}^{12} \mathrm{DBr}^{\mathrm{b}}$ & 4. 749 & Not Reported & Ground & & & 29905.9 & .2 \\
\hline$\left(\mathrm{C}^{12} \mathrm{H}_{3}\right)_{2} \mathrm{C}^{12}: \mathrm{C}^{12} \mathrm{H}_{2}$ & 3. 941 & $14,12,2 \leftarrow 14,11,3$ & Ground & & & 29909.89 & .05 \\
\hline $\mathrm{C}^{12}{ }_{*} \mathrm{H}_{2} \mathrm{C}^{12} \mathrm{H}_{2} \mathrm{C}^{12} \mathrm{H}_{2} \mathrm{O}^{18}{ }_{*}$ & $4-1093$ & $9,6,3 \leftarrow 9,6,4$ & Excited & & & 29910.5 & .1 \\
\hline$\left(\mathrm{C}^{12} \mathrm{H}_{3}\right)_{2} \mathrm{C}^{12}: \mathrm{C}^{12} \mathrm{H}_{2}$ & 3. 941 & $14,12,2 \leftarrow 14,11,3$ & Ground & & & 29910.98 & \\
\hline$\left(\mathrm{C}^{12} \mathrm{H}_{3}\right)_{2} \mathrm{C}^{12}: \mathrm{C}^{12} \mathrm{H}_{2}$ & 3- 941 & $14,12,2 \leftarrow 14,11,3$ & Ground & & & 29911,02 & \\
\hline $\mathrm{C}^{12} \mathrm{H}_{3} \mathrm{Si}^{28} \mathrm{DF}_{2}^{19} \cdot \mathrm{A}$ & 3- 197 & Not Reported & Ground & & & 29911.8 & \\
\hline $\mathrm{C}^{12} \mathrm{D}_{3} \mathrm{~N}^{14} \mathrm{H}_{2}$ & 3. 263 & Not Reported & & & & 29913.2 & .5 \\
\hline $\mathrm{N}^{14} \mathrm{H}_{3}$ & $4-1771$ & $11,11 \leftarrow 11,11$ & Ground & & & 29914.66 & .10 \\
\hline $\mathrm{C}^{12} \mathrm{H}_{2} \mathrm{Cl}^{35} \mathrm{Si}^{28} \mathrm{H}_{3}$ & 3- 231 & $5,1,5 \leftarrow 4,1,4$ & Ground & & & 29915.57 & .2 \\
\hline $\mathrm{t}-\mathrm{C}^{12} \mathrm{HD}: \mathrm{C}^{12} \mathrm{HBr}^{81}$ & 4- 743 & $4,1,3 \leftarrow 3,1,2$ & Ground & $5 / 2$ & $5 / 2$ & 29916.2 & \\
\hline $\mathrm{HC}^{13} \vdots \mathrm{C}^{12} \mathrm{C}^{12} \mathrm{DO}^{16}$ & 4. 922 & Not Reported & & & & 29918. & 5. \\
\hline $\mathrm{DC}^{12} \mathrm{O}^{16} \mathrm{O}^{16} \mathrm{C}^{12} \mathrm{H}_{3}-\mathrm{E}$ & 3- 504 & $5,1,4 \leftarrow 5,0,5$ & Ground & & & 29921.44 & .2 \\
\hline
\end{tabular}




\begin{tabular}{|c|c|c|c|c|c|c|c|}
\hline \multirow{3}{*}{$\begin{array}{r}\text { Isotopic Species } \\
\text { c. } \mathrm{C}^{12} \mathrm{H}_{3} \mathrm{C}^{12} \mathrm{H}: \mathrm{C}^{12} \mathrm{HF}^{19} \cdot \mathrm{E}\end{array}$} & \multirow{3}{*}{$\begin{array}{c}\text { Vol.-Id. } \\
\text { Nos. } \\
\text { 3. } 702\end{array}$} & \multirow{3}{*}{$\begin{array}{c}\begin{array}{c}\text { Rotational } \\
\text { Quantum Nos. }\end{array} \\
3,0,3 \leftarrow 2,1,2\end{array}$} & \multirow{2}{*}{ Vib. State } & \multicolumn{2}{|c|}{ Hyperfine } & \multirow{2}{*}{$\begin{array}{c}\text { Frequency } \\
\mathrm{MHz}\end{array}$} & \multirow{2}{*}{$\begin{aligned} & \text { Acc } \\
& \pm \mathrm{MH}\end{aligned}$} \\
\hline & & & & $F_{1}^{\prime} \quad F^{\prime}$ & $F_{1} \quad F$ & & \\
\hline & & & & & & 29922.74 & .2 \\
\hline $\mathrm{HDO}_{2}^{16}$ & $3-\quad 43$ & $11,, \leftarrow 11$, & & & & 29923. & 3. \\
\hline $\mathrm{C}^{12} \mathrm{H}_{3} \mathrm{I}^{127}$ & 4- 481 & $2,1 \leftarrow 1,1$ & Ground & $3 / 2$ & $5 / 2$ & 29923.50 & .08 \\
\hline c. $\mathrm{C}^{12} \mathrm{H}_{3} \mathrm{C}^{12} \mathrm{H}: \mathrm{C}^{12} \mathrm{HF}^{19}-\mathrm{A}$ & 3- 701 & $4,0,4 \leftarrow 3,1,3$ & & & & 29923.74 & .2 \\
\hline $\mathrm{C}^{12} \mathrm{H}_{2} \mathrm{Cl}^{37} \mathrm{Si}^{28} \mathrm{H}_{3}$ & 3- 232 & $5,0,5 \leftarrow 4,0,4$ & Ground & & & 29923.80 & .2 \\
\hline $\mathrm{C}^{12}{ }_{*} \mathrm{H}_{2}^{\mathrm{b}} \mathrm{S}^{\mathrm{b}} \mathrm{C}^{12}{ }_{*} \mathrm{H}_{2}^{\mathrm{b}}$ & 4. 854 & Not Reported & & & & 29924.0 & .5 \\
\hline $\mathrm{C}^{12} \mathrm{HD}: \mathrm{C}^{12} \mathrm{DBr}^{\mathrm{b}}$ & 4- 749 & Not Reported & Ground & & & 29925.4 & .1 \\
\hline $\mathrm{C}^{\mathrm{b}} \mathrm{H}_{2}^{\mathrm{b}} \mathrm{Cl}^{\mathrm{b}} \mathrm{F}^{\mathrm{b}}$ & 4- 333 & Not Reported & & & & 29925.4 & 1. \\
\hline $\mathrm{C}^{\mathrm{b}} \mathrm{H}_{2}^{\mathrm{b}} \mathrm{Cl}^{\mathrm{b}} \mathrm{F}^{\mathrm{b}}$ & 4- 333 & Not Reported & & & & 29926. & 1. \\
\hline c. $\mathrm{C}^{12} \mathrm{HD}: \mathrm{C}^{12} \mathrm{HBr}^{81}$ & 4- 742 & $4,1,4 \leftarrow 3,1,3$ & Ground & $5 / 2$ & $5 / 2$ & 29926.4 & \\
\hline $\mathrm{C}^{13} \mathrm{H}_{3}\left(\mathrm{C}^{12} \mathrm{H}_{3}\right)_{2} \mathrm{C}^{12} \mathrm{Cl}^{35}$ & 3- 975 & $5,1,4 \leftarrow 4,1,3$ & Ground & & & 29929.33 & .20 \\
\hline$\left(\mathrm{C}^{12} \mathrm{H}_{3}\right)_{2} \mathrm{O}^{16}$ & 3. 591 & $1,1,0 \leftarrow 1,0,1$ & Excited & & & 29931. & 5. \\
\hline $\mathrm{C}^{12} \mathrm{HCl}^{32} \mathrm{~F}_{2}^{19}$ & 4. 252 & $3,3,1 \leftarrow 3,2,1$ & Ground & $3 / 2$ & $3 / 2$ & 29931.86 & \\
\hline $\mathrm{C}^{13} \mathrm{H}_{3} \mathrm{C}^{12} \mathrm{O}^{16} \mathrm{Cl}^{37}$ & 3- 368 & $10,3,7 \leftarrow 10,2,8$ & Ground & $19 / 2$ & $19 / 2$ & 29932.42 & .2 \\
\hline $\mathrm{C}^{13} \mathrm{H}_{3} \mathrm{C}^{12} \mathrm{O}^{16} \mathrm{Cl}^{37}$ & 3- 368 & $10,3,7 \leftarrow 10,2,8$ & Ground & $17 / 2$ & $17 / 2$ & 29932.42 & .2 \\
\hline $\mathrm{C}^{13} \mathrm{H}_{3} \mathrm{C}^{12} \mathrm{O}^{16} \mathrm{Cl}^{37}$ & 3- 368 & $10,3,7 \leftarrow 10,2,8$ & Ground & $23 / 2$ & $23 / 2$ & 29932.42 & .2 \\
\hline $\mathrm{C}^{13} \mathrm{H}_{3} \mathrm{C}^{12} \mathrm{O}^{16} \mathrm{Cl}^{37}$ & 3. 368 & $10,3,7 \leftarrow 10,2,8$ & Ground & $21 / 2$ & $21 / 2$ & 29932.42 & .2 \\
\hline $\mathrm{C}^{12}{ }_{*} \mathrm{H}_{2} \mathrm{C}^{12} \mathrm{H}_{2} \mathrm{C}^{12}{ }_{*} \mathrm{HCl}^{37}$ & 4- 1082 & $4,1,3 \leftarrow 3,1,2$ & Ground & & & 29935.1 & \\
\hline $\mathrm{C}^{13} \mathrm{H}_{2} \mathrm{Cl}^{35} \mathrm{Si}^{28} \mathrm{H}_{3}$ & 3. 233 & $5,1,5 \leftarrow 4,1,4$ & Ground & $7 / 2 \quad 9 / 2$ & $5 / 2 \quad 7 / 2$ & 29935.7 & .1 \\
\hline $\mathrm{C}^{13} \mathrm{H}_{2} \mathrm{Cl}^{35} \mathrm{Si}^{28} \mathrm{H}_{3}$ & 3. 233 & $5,1,5 \leftarrow 4,1,4$ & Ground & & & 29936.02 & .2 \\
\hline $\mathrm{C}^{13} \mathrm{H}_{2} \mathrm{Cl}^{35} \mathrm{Si}^{28} \mathrm{H}_{3}$ & 3- 233 & $5,1,5 \leftarrow 4,1,4$ & Ground & $11 / 213 / 2$ & $9 / 211 / 2$ & 29936.2 & .1 \\
\hline$\left(\mathrm{C}^{12} \mathrm{H}_{3}\right)_{2} \mathrm{O}^{16}$ & 3- 591 & $1,1,0 \leftarrow 1,0,1$ & Excited & & & 29937. & 5. \\
\hline $\mathrm{C}^{13} \mathrm{H}_{3} \mathrm{C}^{12} \mathrm{O}^{16} \mathrm{Cl}^{37}$ & 3- 368 & $10,3,7 \leftarrow 10,2,8$ & Ground & $17 / 2$ & $17 / 2$ & 29938.48 & .2 \\
\hline $\mathrm{C}^{13} \mathrm{H}_{3} \mathrm{C}^{12} \mathrm{O}^{16} \mathrm{Cl}^{37}$ & 3. 368 & $10,3,7 \leftarrow 10,2,8$ & Ground & $23 / 2$ & $23 / 2$ & 29938.48 & .2 \\
\hline $\mathrm{C}^{13} \mathrm{H}_{3} \mathrm{C}^{12} \mathrm{O}^{16} \mathrm{Cl}^{37}$ & 3. 368 & $10,3,7 \leftarrow 10,2,8$ & Ground & $19 / 2$ & $19 / 2$ & 29938.48 & .2 \\
\hline $\mathrm{C}^{13} \mathrm{H}_{3} \mathrm{C}^{12} \mathrm{O}^{16} \mathrm{Cl}^{37}$ & 3- 368 & $10,3,7 \leftarrow 10,2,8$ & Ground & $21 / 2$ & $21 / 2$ & 29938.48 & .2 \\
\hline $\mathrm{C}^{12} \mathrm{HCl}^{37} \mathrm{~F}_{2}^{19}$ & 4- 252 & $3,3,1 \leftarrow 3,2,1$ & Ground & $9 / 2$ & $9 / 2$ & 29939.30 & \\
\hline $\mathrm{C}^{12} \mathrm{H}_{3} \mathrm{I}^{127}$ & 4- 481 & $2,1 \leftarrow 1,1$ & Ground & $7 / 2$ & $7 / 2$ & 29939.87 & .08 \\
\hline$\left(\mathrm{C}^{13} \mathrm{H}_{3}\right)\left(\mathrm{C}^{12} \mathrm{H}_{3}\right) \mathrm{O}^{16}$ & 3. 594 & $1,1,0 \leftarrow 1,0,1$ & Ground & & & 29942.1 & .2 \\
\hline $\mathrm{C}^{12} \mathrm{HBr}_{3}^{79}$ & 4. 241 & $12, \leftarrow 11$, & Ground & & & 29942.7 & .5 \\
\hline $\mathrm{t}-\mathrm{C}^{12} \mathrm{HD}: \mathrm{C}^{12} \mathrm{HBr}^{81}$ & 4- 743 & $4,1,3 \leftarrow 3,1,2$ & Excited & $7 / 2$ & $7 / 2$ & 29944.4 & \\
\hline $\mathrm{C}^{12} \mathrm{HCl}^{37} \mathrm{~F}_{2}^{19}$ & 4- 252 & $3,3,1 \leftarrow 3,2,1$ & Ground & & & 29944.7 & .3 \\
\hline$\left(\mathrm{C}^{12} \mathrm{H}_{3}\right)_{2} \mathrm{O}^{16}$ & 3. 591 & $1,1,0 \leftarrow-1,0,1$ & Excited & & & 29946.2 & .2 \\
\hline $\mathrm{C}^{12} \mathrm{HCl}^{37} \mathrm{~F}_{2}^{19}$ & 4- 252 & $3,3,1 \leftarrow 3,2,1$ & Ground & $5 / 2$ & $5 / 2$ & 29948.23 & \\
\hline $\mathrm{C}^{12} \mathrm{H}_{3} \mathrm{O}^{16} \mathrm{H}$ & 3- 211 & Not Reported & Ground & & & 29950. & \\
\hline $\mathrm{C}^{12} \mathrm{HD}: \mathrm{C}^{12} \mathrm{DBr}^{\mathrm{b}}$ & 4- 749 & Not Reported & Ground & & & 29951.2 & .1 \\
\hline $\mathrm{t} \cdot \mathrm{C}^{12} \mathrm{HD}: \mathrm{C}^{12} \mathrm{DBr}^{81}$ & 4- 747 & $4,3,2 \leftarrow 3,3,1$ & Ground & $5 / 2$ & $3 / 2$ & 29952.5 & \\
\hline $\mathrm{C}^{12} \mathrm{D}_{2} \mathrm{Cl}^{35} \mathrm{Si}^{28} \mathrm{H}_{3}$ & 3. 235 & $5,0,5 \leftarrow 4,0,4$ & Ground & & & 29954.65 & .2 \\
\hline $\mathrm{C}^{13} \mathrm{H}_{3} \mathrm{O}^{16} \mathrm{H}$ & 3- 213 & $14,2, \leftarrow 14,1$ & Ground & & & 29955.72 & .1 \\
\hline $\mathrm{C}^{12} \mathrm{HCl}^{37} \mathrm{~F}_{2}^{19}$ & 4. 252 & $3,3,1 \leftarrow 3,2,1$ & Ground & $7 / 2$ & $7 / 2$ & 29955.81 & \\
\hline$\left(\mathrm{C}^{12} \mathrm{H}_{3}\right)_{2} \mathrm{O}^{16}$ & 3. 591 & $1,1,0 \leftarrow 1,0,1$ & Excited & & & 29957.6 & 1. \\
\hline $\mathrm{t} \cdot \mathrm{C}^{12} \mathrm{HD}: \mathrm{C}^{12} \mathrm{DBr}^{81}$ & 4- 747 & $4,2,3 \leftarrow 3,2,2$ & Excited & $5 / 2$ & $3 / 2$ & 29960.0 & \\
\hline $\mathrm{D}_{2} \mathrm{O}_{2}^{16}$ & 3- 42 & Not Reported & & & & 29962. & 3. \\
\hline $\mathrm{t}-\mathrm{C}^{12} \mathrm{HD}: \mathrm{C}^{12} \mathrm{HBr}^{81}$ & 4- 743 & $4,1,3 \leftarrow 3,1,2$ & Excited & $11 / 2$ & $9 / 2$ & 29962.3 & \\
\hline $\mathrm{t}-\mathrm{C}^{12} \mathrm{HD}: \mathrm{C}^{12} \mathrm{DBr}^{81}$ & 4. 747 & $4,3,2 \leftarrow 3,3,1$ & Ground & $9 / 2$ & $9 / 2$ & 29963.8 & \\
\hline
\end{tabular}


Vib. State

Hyperfine Frequency Acc.

t- $\mathrm{C}^{12} \mathrm{HD}: \mathrm{C}^{12} \mathrm{HBr}^{81}$

$\mathrm{C}^{13} \mathrm{H}_{3} \mathrm{C}^{12} \mathrm{O}^{16} \mathrm{~F}^{19}$

t-C $\mathrm{C}^{12} \mathrm{HD}: \mathrm{C}^{12} \mathrm{HBr}^{81}$

$\mathrm{s}-\mathrm{C}^{12} \mathrm{H}_{2} \mathrm{DSi}^{28} \mathrm{HF}_{2}^{19}$

t- $\mathrm{C}^{12} \mathrm{HD}: \mathrm{C}^{12} \mathrm{HBr}^{81}$

$\mathrm{C}^{12} \mathrm{HD}: \mathrm{C}^{12} \mathrm{DBr}^{\mathrm{b}}$

$\left(\mathrm{C}^{12} \mathrm{H}_{3}\right)_{2} \mathrm{O}^{16}$

i- $\mathrm{C}^{12} \mathrm{HD}: \mathrm{C}^{12} \mathrm{HBr}^{81}$

$\mathrm{C}^{12} \mathrm{H}_{3} \mathrm{O}^{16} \mathrm{H}$

t- $\mathrm{C}^{12} \mathrm{HD}: \mathrm{C}^{12} \mathrm{DBr}^{81}$

$\mathrm{F}^{19} \mathrm{Cl}^{37}$

c- $\mathrm{C}^{12} \mathrm{HD}: \mathrm{C}^{12} \mathrm{HBr}^{81}$

c- $\mathrm{C}^{12} \mathrm{HD}: \mathrm{C}^{12} \mathrm{HBr}^{81}$

c-C ${ }^{12} \mathrm{HD}: \mathrm{C}^{12} \mathrm{HBr}^{81}$

$\left(\mathrm{C}^{12} \mathrm{H}_{3}\right)_{2} \mathrm{O}^{16}$

$\mathrm{C}^{13} \mathrm{H}_{3} \mathrm{C}^{12} \mathrm{O}^{16} \mathrm{~F}^{19}$

c- $\mathrm{C}^{12} \mathrm{HD}: \mathrm{C}^{12} \mathrm{HBr}^{81}$

t. $\mathrm{C}^{12} \mathrm{HD}: \mathrm{C}^{12} \mathrm{DBr}^{81}$

t- $\mathrm{C}^{12} \mathrm{HD}: \mathrm{C}^{12} \mathrm{DBr}^{81}$

$\mathrm{Cl}_{2}^{\mathrm{p}} \mathrm{O}^{16}$

$\mathrm{Cl}_{2}^{13} \mathrm{O}^{16}$

1- ${ }^{12} \mathrm{HD}: \mathrm{C}^{12} \mathrm{HBr}^{81}$

$\mathrm{C}^{12} \mathrm{HD}: \mathrm{C}^{12} \mathrm{DBr}^{\mathrm{h}}$

t- $\mathrm{C}^{12} \mathrm{HD}: \mathrm{C}^{12} \mathrm{DBr}^{81}$

$\mathrm{Cl}_{2}^{1} \mathrm{O}^{16}$

$\mathrm{D}_{2} \mathrm{O}_{2}^{16}$

t-C ${ }^{12} \mathrm{HD}: \mathrm{C}^{12} \mathrm{HBr}^{81}$

1. $\mathrm{C}^{12} \mathrm{HD}: \mathrm{C}^{12} \mathrm{DBr}^{81}$

$\mathrm{C}^{12} \mathrm{H}_{3} \mathrm{I}^{127}$

$\mathrm{Cl}_{2} \mathrm{O}^{16}$

$\mathrm{Cl}_{2}^{1 \mathrm{O}^{16}}$

1-C ${ }^{12} \mathrm{HD}: \mathrm{C}^{12} \mathrm{DBr}^{81}$

t- $\mathrm{C}^{12} \mathrm{HD}: \mathrm{C}^{12} \mathrm{HBr}^{11}$

$\mathrm{Cl}_{2}^{14} \mathrm{O}^{16}$

$\mathrm{C}^{12} \mathrm{H}_{2}\left(\mathrm{C}^{12} \mathrm{~N}^{14}\right)_{2}$ t- $\mathrm{C}^{12} \mathrm{HD}: \mathrm{C}^{12} \mathrm{DBr}^{81}$ $2-\mathrm{C}^{12} \mathrm{HD}: \mathrm{C}^{12} \mathrm{DBr}^{81}$

$\left(\mathrm{C}^{12} \mathrm{H}_{3}\right)_{2} \mathrm{O}^{16}$

$\mathrm{Cl}_{2}^{\mathrm{l}} \mathrm{O}^{16}$

t- $\mathrm{C}^{12} \mathrm{HD}: \mathrm{C}^{12} \mathrm{HBr}^{81}$

$\mathrm{Cl}_{2}^{\mathrm{H}} \mathrm{O}^{16}$

t- $\mathrm{C}^{12} \mathrm{HD}: \mathrm{C}^{12} \mathrm{DBr}^{81}$

1-C ${ }^{12} \mathrm{HD}: \mathrm{C}^{12} \mathrm{HBr}^{81}$

$\mathrm{C}^{\mathrm{b}} \mathrm{H}_{2}^{\mathrm{b}} \mathrm{Cl}^{\mathrm{b}} \mathrm{F}^{\mathrm{b}}$

t. $\mathrm{C}^{12} \mathrm{HD}: \mathrm{C}^{12} \mathrm{DBr}^{81}$
4. 74

3- 393

4- -743

$4,1,3 \leftarrow 3,1,2$

$6,3,3 \leftarrow 6,3,4$

$4,1,3 \leftarrow 3,1,2$

3- 203

$3,1,2 \leftarrow 2,1,1$

4- 743

$4,1,3 \leftarrow 3,1,2$

4. 749

Not Reported

3. 591

$1,1,0 \leftarrow 1,0,1$

4- 743

$4,1,3 \leftarrow 3,1,2$

3- 211

$23,2, \leftarrow 23,1$,

4- 747

$4,2,3 \leftarrow 3,2,2$

1 -

$1 \leftarrow 0$

4. 742

$4,1,4 \leftarrow 3,1,3$

4- 742

$4,1,4 \leftarrow 3,1,3$

4. 742

$4,1,4 \leftarrow 3,1,3$

3. 591

$1,1,0 \leftarrow 1,0,1$

3- 393

$6,3,3 \leftarrow 6,3,4$

4. 742

$4,1,4 \leftarrow 3,1,3$

4. 747

$4,0,4 \leftarrow 3,0,3$

4. 747

$4,0,4 \leftarrow 3,0,3$

4-1484

4-1484

$9,0,9 \leftarrow 8,1,8$

4- 743

$9,0,9 \leftarrow 8,1,8$

4. 749

$4,1,3 \leftarrow 3,1,2$

4. 747

4- 1484

Not Reported

$4,0,4 \leftarrow 3,0,3$

$9,0,9 \leftarrow 8,1,8$

3- 42

Not Reported

4- 743

4. 747

4. 481

$4,1,3 \leftarrow 3,1,2$

$4,2,3 \leftarrow 3,2,2$

$2,1 \leftarrow 1,1$

4-1484

$9,0,9 \leftarrow 8,1,8$

4-1484

$9,0,9 \leftarrow 8,1,8$

4. 747

$4,2,3 \leftarrow 3,2,2$

4. 743

$4,1,3 \leftarrow 3,1,2$

4. 1484

$9,0,9 \leftarrow 8,1,8$

4- 901

Not Reported

4- 747

$4,0,4 \leftarrow 3,0,3$

4. 747

$4,0,4 \leftarrow 3,0,3$

3. 591

$1,1,0 \leftarrow 1,0,1$

4-1484

4. 743

$9,0,9 \leftarrow 8,1,8$

4-1484

$4,1,3 \leftarrow 3,1,2$

$9,0,9 \leftarrow 8,1,8$

4. 747

$4,3,2 \leftarrow 3,3,1$

4- 743

$4,1,3 \leftarrow 3,1,2$

4- 333

Not Reported

4. 747

$4,2,3 \leftarrow 3,2,2$
Ground

Ground

Excited

Ground

Excited

Ground

Excited

Excited

Ground

Excited

Excited

Excited

Excited

Ground

Excited

Ground

Excited

Ground

Ground

Ground

Ground

Ground

Ground

Ground

Ground

Ground

Ground

Ground

Ground

Ground

Excited

Ground

Ground

Ground

Ground

Ground

Excited

Ground

Ground

Ground

Ground

Ground

Excited
$7 / 2 \quad 7 / 2 \quad 29964.0$

$29965.25 \quad .2$

$5 / 2 \quad 3 / 2 \quad 29966.5$

$29966.89 \quad 2$.

$29967.75 \quad .12$

29970.1

.1

29971.1

$9 / 2 \quad 7 / 2 \quad 29971.9$

$29973.06 \quad$.1

$11 / 2 \quad 9 / 2 \quad 29974.3$

$\begin{array}{llll}3 / 2 & 3 / 2 & 29974.470 & 0.069\end{array}$

$5 / 2 \quad 3 / 2 \quad 29975.7$

29975.83

$\begin{array}{lll}7 / 2 & 7 / 2 & 29976.5\end{array}$

29976.5

29979.27

$9 / 2 \quad 7 / 2 \quad 29979.45$

$11 / 2 \quad 9 / 2 \quad 29979.6$

$9 / 2 \quad 7 / 2 \quad 29979.6$

29980.5

29982.10

$11 / 2 \quad 9 / 2 \quad 29982.2$

29982.2

29982.50

29983.12

29984.

3.

$5 / 2 \quad 3 / 2 \quad 29986.65$

$5 / 2 \quad 3 / 2 \quad 29986.7$

$5 / 2 \quad 7 / 2 \quad 29986.84$

.08

29987.0

29987.5

$29987.70 \quad .4$

$29987.78 \quad .05$

29989.38

29990.3

$7 / 2 \quad 5 / 2 \quad 29990.7$

$5 / 2 \quad 3 / 2$

29990.7

$29990: 8$

29991.62

$9 / 2 \quad 7 / 2 \quad 29991.85$

29992.70

$11 / 2 \quad 9 / 2 \quad 29995.9$

$7 / 2 \quad 5 / 2 \quad 29996.6$

$29997.2 \quad 1$.

$7 / 2 \quad 5 / 2 \quad 29997.9$ 
Vib. State

$\mathrm{F}_{1}^{\prime} \stackrel{\text { Hyperfine }}{\mathrm{F}^{\prime}} \mathrm{F}_{1} \mathrm{~F}$

Frequency $\mathrm{MHz}$

Acc. $\pm \mathrm{MHz}$

\begin{tabular}{|c|c|c|c|c|c|c|c|}
\hline c- $\mathrm{C}^{12} \mathrm{HD}: \mathrm{C}^{12} \mathrm{HBr}^{81}$ & 4. 742 & $4,1,4 \leftarrow 3,1,3$ & Ground & $11 / 2$ & $9 / 2$ & 29998.0 & \\
\hline $\mathrm{t}-\mathrm{C}^{12} \mathrm{HD}: \mathrm{C}^{12} \mathrm{DBr}^{81}$ & 4. 747 & $4,2,3 \leftarrow 3,2,2$ & Ground & $11 / 2$ & $9 / 2$ & 30000.7 & \\
\hline $\mathrm{F}^{19} \mathrm{Cl}^{37}$ & 1. & $1 \leftarrow 0$ & Excited & $5 / 2$ & $3 / 2$ & 30003.218 & 0.069 \\
\hline c- $\mathrm{C}^{12} \mathrm{HD}: \mathrm{C}^{12} \mathrm{HBr}^{81}$ & 4- 742 & $4,1,4 \leftarrow 3.1,3$ & Ground & $5 / 2$ & $3 / 2$ & 30003.3 & \\
\hline c. $\mathrm{C}^{12} \mathrm{HD}: \mathrm{C}^{12} \mathrm{HBr}^{81}$ & 4- 742 & $4,1,4 \leftarrow 3,1,3$ & Ground & & & 30003.58 & .09 \\
\hline $\mathrm{s}-\left(\mathrm{C}^{12} \mathrm{H}_{2} \mathrm{D}\right)\left(\mathrm{C}^{12} \mathrm{H}_{3}\right) \mathrm{O}^{16}$ & 3. 596 & $1,1,0 \leftarrow 1,0,1$ & Ground & & & 30003.6 & .2 \\
\hline $\mathrm{C}^{12} \mathrm{H}_{2} \mathrm{Cl}^{35} \mathrm{Cl}^{37}$ & 4- 342 & $4,1,3 \leftarrow 4,0,4$ & Ground & & & 30005. & 5. \\
\hline c. $\mathrm{C}^{12} \mathrm{HD}: \mathrm{C}^{12} \mathrm{HBr}^{81}$ & 4- 742 & $4,1,4 \leftarrow 3,1,3$ & Ground & $9 / 2$ & $7 / 2$ & 30007.4 & \\
\hline $\mathrm{C}^{12} \mathrm{D}_{3} \mathrm{C}^{12} \mathrm{O}^{16} \mathrm{O}^{16} \mathrm{H}$ & 3- 492 & $11,6,5 \leftarrow 11,5,6$ & Ground & & & 30008.04 & \\
\hline $\mathrm{C}^{12} \mathrm{HD}: \mathrm{C}^{12} \mathrm{DBr}^{\mathrm{b}}$ & 4- 749 & Not Reported & Ground & & & 30009.0 & .1 \\
\hline $\mathrm{C}^{12} \mathrm{Cl}_{3}^{35} \mathrm{C}^{12} \mathrm{~N}^{14}$ & 4- 581 & $9, \leftarrow 8$ & Ground & & & 30009.2 & 1.0 \\
\hline $\mathrm{C}^{12} \mathrm{D}_{3} \mathrm{~N}^{14} \mathrm{H}_{2}$ & 3- 263 & Not Reported & & & & 30010.5 & .5 \\
\hline $\mathrm{C}^{13} \mathrm{H}_{3}\left(\mathrm{C}^{12} \mathrm{H}_{3}\right)_{2} \mathrm{C}^{12} \mathrm{C}^{12}: \mathrm{C}^{12} \mathrm{D}$ & $3-1078$ & $6,1,6 \leftarrow 5,1,5$ & Ground & & & 30012.2 & .1 \\
\hline c- $\mathrm{C}^{12} \mathrm{HD}: \mathrm{C}^{12} \mathrm{HBr}^{81}$ & 4- 742 & $4,1,4 \leftarrow 3,1,3$ & Ground & $7 / 2$ & $5 / 2$ & 30013.0 & \\
\hline $\mathrm{t}-\mathrm{C}^{12} \mathrm{HD}: \mathrm{C}^{12} \mathrm{DBr}^{81}$ & 4- 747 & $4,2,3 \leftarrow 3,2,2$ & Excited & $9 / 2$ & $7 / 2$ & 30013.1 & \\
\hline $\mathrm{t} \cdot \mathrm{C}^{12} \mathrm{HD}: \mathrm{C}^{12} \mathrm{DBr}^{81}$ & 4. 747 & $4,2,3 \leftarrow 3,2,2$ & Ground & & & 30014.77 & .07 \\
\hline $\mathrm{C}^{13} \mathrm{H}_{3} \mathrm{C}^{12} \mathrm{H}_{2} \mathrm{Cl}^{35}$ & 3. 545 & $5,1,4 \leftarrow 5,0,5$ & Ground & $7 / 2$ & $7 / 2$ & 30015.11 & .05 \\
\hline $\mathrm{C}^{13} \mathrm{H}_{3} \mathrm{C}^{12} \mathrm{H}_{2} \mathrm{Cl}^{35}$ & 3- 545 & $5,1,4 \leftarrow 5,0,5$ & Ground & $13 / 2$ & $13 / 2$ & 30016.32 & .05 \\
\hline $\mathrm{HC}^{12}{ }_{*}: \mathrm{C}^{12} \mathrm{HO}^{16} \mathrm{C}^{12} \mathrm{O}^{16} \mathrm{O}^{16}{ }_{*}$ & 4. 931 & $4,2,2 \leftarrow 3,2,1$ & Ground & & & 30019.22 & .10 \\
\hline $\mathrm{C}^{13} \mathrm{H}_{3} \mathrm{C}^{12} \mathrm{H}_{2} \mathrm{Cl}^{35}$ & 3. 545 & $5,1,4 \leftarrow 5,0,5$ & Ground & $9 / 2$ & $9 / 2$ & 30019.42 & .05 \\
\hline $\mathrm{C}^{13} \mathrm{H}_{3} \mathrm{C}^{12} \mathrm{H}_{2} \mathrm{Cl}^{35}$ & 3- 545 & $5,1,4 \leftarrow 5,0,5$ & Ground & $11 / 2$ & $11 / 2$ & 30020.68 & .05 \\
\hline $\mathrm{t}-\mathrm{C}^{12} \mathrm{HD}: \mathrm{C}^{12} \mathrm{DBr}^{81}$ & 4. 747 & $4,2,2 \leftarrow 3,2,1$ & Ground & $5 / 2$ & $3 / 2$ & 30021.1 & \\
\hline $\mathrm{S}^{32} \mathrm{O}^{16} \mathrm{~F}_{2}^{19}$ & $4 \cdot 1621$ & $2,1,1 \leftarrow 1,1,0$ & Ground & & & 30023.90 & .1 \\
\hline $\mathrm{t}-\mathrm{C}^{12} \mathrm{HD}: \mathrm{C}^{12} \mathrm{DBr}^{81}$ & 4. 747 & $4,3,2 \leftarrow 3,3,1$ & Ground & & & 30025.14 & .23 \\
\hline $\mathrm{C}^{12} \mathrm{H}_{3} \mathrm{~N}^{14} \mathrm{H}_{2}$ & 3. 261 & Not Reported & Ground & & & 30025.9 & \\
\hline $\mathrm{t}-\mathrm{C}^{12} \mathrm{HD}: \mathrm{C}^{12} \mathrm{DBr}^{81}$ & 4. 747 & $4,2,3 \leftarrow 3,2,2$ & Ground & $7 / 2$ & $5 / 2$ & 30026.0 & \\
\hline $\mathrm{F}^{19} \mathrm{Cl}^{37}$ & 1 . & $1 \leftarrow 0$ & Excited & $1 / 2$ & $3 / 2$ & 30026.195 & 0.069 \\
\hline $\mathrm{C}^{12} \mathrm{Cl}_{3}^{35} \mathrm{C}^{12} \mathrm{~N}^{14}$ & 4. 581 & $9, \leftarrow 8$ & Excited & & & 30027.4 & 1.0 \\
\hline $\mathrm{s}-\left(\mathrm{C}^{12} \mathrm{H}_{2} \mathrm{D}\right)\left(\mathrm{C}^{12} \mathrm{H}_{3}\right)_{2} \mathrm{C}^{12} \mathrm{H}$ & $3-1005$ & $2,2,0 \leftarrow 1,1,0$ & & & & 30031.28 & .10 \\
\hline $\mathrm{C}^{12} \mathrm{H}_{2} \mathrm{Cl}^{35} \mathrm{Si}^{28} \mathrm{H}_{3}$ & 3- 231 & $5,1,5 \leftarrow 4,1,4$ & Ground & & & 30032.34 & .2 \\
\hline $\mathrm{C}^{12} \mathrm{C}_{3}^{35} \mathrm{C}^{12} \mathrm{~N}^{14}$ & 4. 581 & $9, \leftarrow 8$, & Excited & & & 30035.0 & 1.0 \\
\hline t- $\mathrm{C}^{12} \mathrm{HD}: \mathrm{C}^{12} \mathrm{DBr}^{81}$ & 4- 747 & $4,2,2 \leftarrow 3,2,1$ & Ground & $11 / 2$ & $9 / 2$ & 30035.1 & \\
\hline $\mathrm{C}^{12} \mathrm{HD}: \mathrm{C}^{12} \mathrm{HBr}^{1}$ & 4. 748 & Not Reported & Ground & & & 30035.65 & .1 \\
\hline $\mathrm{C}^{12} \mathrm{H}_{3} \mathrm{~N}^{14} \mathrm{O}_{2}^{16}$ & 3- 171 & $2,0, \leftarrow 1,0$, & Ground & & & 30037.2 & .2 \\
\hline $\mathrm{C}^{12} \mathrm{H}_{3} \mathrm{C}^{12}{ }_{*} \mathrm{HO}^{16} \mathrm{C}^{12}{ }_{*} \mathrm{H}_{2}$ & 3. 761 & $6,2,4 \leftarrow 6,1,5$ & Ground & & & 30038.11 & .1 \\
\hline $\mathrm{C}^{12} \mathrm{H}_{3} \mathrm{C}^{12}{ }_{*} \mathrm{HO}^{16} \mathrm{C}^{12}{ }_{*} \mathrm{H}_{2}$ & 3- 761 & $6,2,4 \leftarrow 6,1,5$ & Ground & & & 30038.37 & .1 \\
\hline $\mathrm{t} \cdot \mathrm{C}^{12} \mathrm{HD}: \mathrm{C}^{12} \mathrm{DBB}^{81}$ & 4. 747 & $4,2,3 \leftarrow 3,2,2$ & Ground & $9 / 2$ & $7 / 2$ & 30039.6 & \\
\hline $\mathrm{C}^{12}{ }_{*} \mathrm{H}_{2} \mathrm{C}^{12} \mathrm{H}_{2} \mathrm{C}^{12} \mathrm{H}_{2} \mathrm{O}^{16}{ }_{*}$ & $4-1091$ & $11,10,2 \leftarrow 11,8,3$ & Excited & & & 30040.8 & .1 \\
\hline $\mathrm{C}^{12} \mathrm{DHCl}^{35} \mathrm{Cl}^{37}$ & 4. 345 & $1,1,1 \leftarrow 0,0,0$ & Ground & & & 30042.2 & .2 \\
\hline $\mathrm{C}^{12} \mathrm{HD}: \mathrm{C}^{12} \mathrm{HBr}^{1}$ & 4. 748 & Not Reported & Ground & & & 30044.7 & .1 \\
\hline $\mathrm{C}^{12} \mathrm{H}_{3}{ }^{127}$ & 4. 481 & $2,0 \leftarrow 1,0$ & Ground & $9 / 2$ & $7 / 2$ & 30046.99 & .08 \\
\hline $\mathrm{t} \cdot \mathrm{C}^{12} \mathrm{H}_{2} \mathrm{DC}^{12} \mathrm{H}_{2} \mathrm{Cl}^{35}$ & 3. 543 & $5,1,4 \leftarrow 5,0,5$ & Ground & $7 / 2$ & $7 / 2$ & 30048.54 & .05 \\
\hline $\mathrm{C}^{12} \mathrm{H}_{3} \mathrm{C}^{12}{ }_{*} \mathrm{HO}^{16} \mathrm{C}^{12}{ }_{*} \mathrm{H}_{2}$ & 3. 761 & $6,2,4 \leftarrow 6,1,5$ & Ground & & & 30048.77 & .1 \\
\hline $\mathrm{Si}^{29} \mathrm{D}_{2} \mathrm{~F}_{2}^{19}$ & $4-1604$ & $5,2,3 \leftarrow 5,1,4$ & Ground & & & 30049.00 & .10 \\
\hline t-C $\mathrm{C}^{12} \mathrm{HD}: \mathrm{C}^{12} \mathrm{DBr}^{81}$ & 4. 747 & $4,2,2 \leftarrow 3,2,1$ & Ground & & & 30049.17 & .07 \\
\hline
\end{tabular}


Vib. State

Hyperfine $\mathrm{F}_{1}^{\prime} \mathrm{F}^{\prime} \mathrm{F}_{1} \quad \mathrm{~F}$
Frequency $\mathrm{MH}_{2}+\mathrm{HII}$ t- $\mathrm{C}^{12} \mathrm{H}_{2} \mathrm{DC}^{12} \mathrm{H}_{2} \mathrm{Cl}^{35}$

t- $\mathrm{C}^{12} \mathrm{HD}: \mathrm{C}^{12} \mathrm{DBr}^{79}$

$\mathrm{O}_{3}^{16}$

t- $\mathrm{C}^{12} \mathrm{H}_{2} \mathrm{DC}^{12} \mathrm{H}_{2} \mathrm{Cl}^{35}$

t- $\mathrm{C}^{12} \mathrm{H}_{2} \mathrm{DC}^{12} \mathrm{H}_{2} \mathrm{Cl}^{35}$

$\mathrm{C}^{12} \mathrm{H}_{3} \mathrm{C}^{12} \mathrm{H}: \mathrm{C}^{12} \mathrm{HF}^{19}$

$\mathrm{C}^{12} \mathrm{D}_{3} \mathrm{~N}^{14} \mathrm{H}_{2}$

$\mathrm{t}-\mathrm{C}^{12} \mathrm{HD}: \mathrm{C}^{12} \mathrm{DBr}^{81}$

$\mathrm{C}^{12} \mathrm{H}_{3} \mathrm{C}^{12} \mathrm{H}: \mathrm{C}^{12} \mathrm{HF}^{19}$

t- $\mathrm{C}^{12} \mathrm{HD}: \mathrm{C}^{12} \mathrm{HBr}^{81}$

$\mathrm{C}^{12} \mathrm{H}_{3} \mathrm{C}^{12} \mathrm{H}: \mathrm{C}^{12} \mathrm{HF}^{19}$

$\mathrm{C}^{12} \mathrm{H}_{3} \mathrm{C}^{12} \mathrm{H}: \mathrm{C}^{12} \mathrm{HF}^{19}$

$\mathrm{C}^{12} \mathrm{H}_{3} \mathrm{C}^{12}{ }_{*} \mathrm{HO}^{16} \mathrm{C}^{12}{ }_{*} \mathrm{H}_{2}$

$\mathrm{C}^{12} \mathrm{H}_{3} \mathrm{C}^{12} \mathrm{O}^{16} \mathrm{Cl}^{37}$

$\mathrm{C}^{12} \mathrm{H}_{3} \mathrm{C}^{12} \mathrm{O}^{16} \mathrm{Cl}^{37}$

$\mathrm{C}^{12} \mathrm{H}_{3} \mathrm{C}^{12} \mathrm{O}^{16} \mathrm{Cl}^{37}$

$\mathrm{C}^{12} \mathrm{H}_{3} \mathrm{C}^{12} \mathrm{O}^{16} \mathrm{Cl}^{37}$

$\mathrm{Si}^{28} \mathrm{D}_{2} \mathrm{~F}_{2}^{19}$

$\left(\mathrm{C}^{12} \mathrm{H}_{3}\right)_{2} \mathrm{C}^{12} \mathrm{O}^{16}$

$\mathrm{C}^{12} \mathrm{H}_{3} \mathrm{C}^{12} \mathrm{H}: \mathrm{C}^{12} \mathrm{HF}^{19}$

t-C ${ }^{12} \mathrm{HD}: \mathrm{C}^{12} \mathrm{DBr}^{81}$

$\mathrm{HC}^{13}: \mathrm{C}^{12} \mathrm{C}^{12} \mathrm{DO}^{16}$

$\mathrm{C}^{12} \mathrm{H}_{3} \mathrm{I}^{127}$

$\mathrm{C}^{12} \mathrm{H}_{3} \mathrm{C}^{12} \mathrm{H}: \mathrm{C}^{12} \mathrm{HF}^{19}$

t- $\mathrm{C}^{12} \mathrm{HD}: \mathrm{C}^{12} \mathrm{HBr}^{79}$

$\mathrm{C}^{12} \mathrm{H}_{3} \mathrm{I}^{127}$

$\mathrm{C}^{12} \mathrm{H}_{3} \mathrm{C}^{12} \mathrm{H}: \mathrm{C}^{12} \mathrm{HF}^{19}$

c- $\mathrm{C}^{12} \mathrm{HD}: \mathrm{C}^{12} \mathrm{HBr}^{79}$

$\mathrm{C}^{12} \mathrm{H}_{3} \mathrm{~S}^{32} \mathrm{H}$

c- $\mathrm{C}^{12} \mathrm{HD}: \mathrm{C}^{12} \mathrm{HBr}^{81}$

1. $\mathrm{C}^{12} \mathrm{HD}: \mathrm{C}^{12} \mathrm{DBr}^{81}$

$\mathrm{C}^{12} \mathrm{H}_{3} \mathrm{~N}^{14} \mathrm{H}_{2}$

$\mathrm{t}-\mathrm{C}^{12} \mathrm{HD}: \mathrm{C}^{12} \mathrm{DBr}^{81}$

g- $\mathrm{C}^{12} \mathrm{H}_{3} \mathrm{C}^{12} \mathrm{H}_{2} \mathrm{C}^{12} \mathrm{H}_{2} \mathrm{Cl}^{37}$

$\mathrm{C}^{\mathrm{b}} \mathrm{H}_{2}^{\mathrm{b}} \mathrm{Cl}^{\mathrm{b}} \mathrm{F}^{\mathrm{b}}$

$\mathrm{C}^{12}{ }_{*} \mathrm{H}_{2} \mathrm{C}^{12} \mathrm{H}_{2} \mathrm{C}^{12}{ }_{*} \mathrm{HCl}^{35}$

$\mathrm{C}^{12} \mathrm{H}_{2} \mathrm{Cl}_{2}^{35}$

$\mathrm{HC}^{13}: \mathrm{C}^{12} \mathrm{C}^{12} \mathrm{DO}^{16}$

$\mathrm{C}^{12} \mathrm{HD}: \mathrm{C}^{12} \mathrm{DBr}^{\mathrm{b}}$

$\mathrm{C}^{12}{ }_{*} \mathrm{H}_{2} \mathrm{C}^{12} \mathrm{H}_{2} \mathrm{C}^{12}{ }_{*} \mathrm{HCl}^{35}$

$\mathrm{C}^{12}{ }_{*} \mathrm{H}_{2} \mathrm{C}^{12} \mathrm{H}_{2} \mathrm{C}^{12}{ }_{*} \mathrm{HCl}^{35}$

$\mathrm{C}^{12}{ }_{*} \mathrm{H}_{2} \mathrm{C}^{12} \mathrm{H}_{2} \mathrm{C}^{12}{ }_{*} \mathrm{HCl}^{35}$

$\mathrm{C}^{12}{ }_{*} \mathrm{H}_{2} \mathrm{C}^{12} \mathrm{H}_{2} \mathrm{C}^{12}{ }_{*} \mathrm{HCl}^{35}$

$\mathrm{C}^{12}{ }_{*} \mathrm{H}_{2} \mathrm{C}^{12} \mathrm{H}_{2} \mathrm{C}^{12}{ }_{*} \mathrm{HCl}^{35}$

$\mathrm{C}^{12}{ }_{*} \mathrm{H}_{2} \mathrm{C}^{12} \mathrm{H}_{2} \mathrm{C}^{12}{ }_{*} \mathrm{HCl}^{35}$
3. 543

$5,1,4 \leftarrow 5,0,5$

4- 745

$4,0,4 \leftarrow 3,0,3$

Ground

4-1841

$15,3,13 \leftarrow 16,2,14$

Ground

3. 543

$5,1,4 \leftarrow 5,0,5$

Ground

3. 543

$5,1,4 \leftarrow 5,0,5$

Ground

3. 711

$4,2,3 \leftarrow 3,2,2$

Ground

Ground

3. 263

Not Reported

4. 747

$4,2,2 \leftarrow 3,2,1$

Ground

3. 711

$4,2,3 \leftarrow 3,2,2$

4. 743

$4,1,3 \leftarrow 3,1,2$

Ground

3- 711

$4,3,1 \leftarrow 3,3,0$

Ground

3. 711

$4,3,2 \leftarrow 3,3,1$

Ground

3- 761

$6,2,4 \leftarrow 6,1,5$

Ground

3- 362

3. 362

$11,4,7 \leftarrow 11,3,8$

Ground

Ground

$11,4,7 \leftarrow 11,3,8$

Ground

3. 362

$11,4,7 \leftarrow 11,3,8$

Ground

3- 362

$11,4,7 \leftarrow 11,3,8$

Ground

4-1603

$3,0,3 \leftarrow 2,1,2$

Ground

3. 751

Not Reported

3. 711

4- 747

$4,2,2 \leftarrow 3,2,1$

Ground

4. 922

$4,2,2 \leftarrow 3,2,1$

Ground

4- 481

3- 711

4- 741

4- 481

3- 711

4. 739

3- 221

4- 742

Not Reported

$2,1 \leftarrow 1,1$

Ground

$4,2,2 \leftarrow 3,2,1$

$4,1,3 \leftarrow 3,1,2$

$2,0 \leftarrow 1,0$

$4,0,4 \leftarrow 3,0,3$

$4,1,4 \leftarrow 3,1,3$

Not Reported

4. 747

3- 261

$4,1,4 \leftarrow 3,1,3$

$4,3,2 \leftarrow 3,3,1$

Not Reported

4- 747

$4,3,2 \leftarrow 3,3,1$

3. 774

$11,1.10 \leftarrow 11,0,11$

4- 333

4-1081

4- 341

4- 922

Not Reported

$4,2,3 \leftarrow 3,2,2$

Ground

$4,1,3 \leftarrow 4,0,4$

Ground

4- 749

Not Reported

4-1081

Not Reported

4-1081

$4,2,3 \leftarrow 3,2,2$

Ground

Ground

Ground

4-1081

$4,2,3 \leftarrow 3,2,2$

Ground

4-1081

4-1081

$4,3,2 \leftarrow 3,3,1$

Ground

Ground

4-1081
$4,2,3 \leftarrow 3,2,2$

$4,3,1 \leftarrow 3,3,0$

$4,3,2 \leftarrow 3,3,1$
Ground
$13 / 2$

$5 / 2$

$13 / 2$

30049.65

.0 .5

$$
5 / 2
$$

30050.8

30052.

$\begin{array}{rr}9 / 2 & 9 / 2 \\ 11 / 2 & 11 / 2\end{array}$

30052.73

30053.86

30056.33

30057.2

$7 / 2 \quad 5 / 2 \quad 30060.4$

30060.63

$9 / 2 \quad 9 / 2 \quad 30062.2$

30063.60

30063.60

30064.48

$21 / 2$

$21 / 2 \quad 30068.48$

$23 / 2 \quad 23 / 2 \quad 30068.48$

$19 / 2 \quad 19 / 2 \quad 30069.05$

$25 / 2 \quad 25 / 2$

30069.05

30069.60

30070.

30071.05

$9 / 2 \quad 7 / 2 \quad 30074.0$

30075 .

$5 / 2 \quad 3 / 2 \quad 30075.08$

5.

30075.50

$5 / 2 \quad 5 / 2 \quad 30078.9$

$7 / 2 \quad 5 / 2 \quad 30079.72$

30081.20

$5 / 2 \quad 5 / 2 \quad 30081.8$

30083.34

$9 / 2 \quad 9 / 2 \quad 30084.65$

$9 / 2 \quad 7 / 2 \quad 30084.8$

30088.5

$7 / 2$

$7 / 2 \quad 30096.9$

$30098.56 \quad .2$

30100.

$9 / 2$

$7 / 2$

30104.3

1.

30105.

30105.

30105.4

$7 / 2$

$5 / 2$

30106.2

$11 / 2$

$9 / 2$

30109.8

$7 / 2$

$7 / 2$

30112.0

$5 / 2$

$3 / 2$

30112.0

$7 / 2$

$7 / 2$

30112.0

$9 / 2$

$7 / 2$

30113.5
.08

.08

.1
5.

5.

.2

.1

.1

.1

.1

.1

.1 


\begin{tabular}{|c|c|c|c|c|c|c|c|}
\hline \multirow{2}{*}{ Isotopic Species } & \multirow{2}{*}{$\begin{array}{l}\text { Vol.-Id. } \\
\text { Nos. }\end{array}$} & \multirow{2}{*}{$\begin{array}{c}\text { Rotational } \\
\text { Quantum Nos. }\end{array}$} & \multirow{2}{*}{ Vib. State } & \multicolumn{2}{|c|}{$F^{\prime}$ Hyperfine } & \multirow{2}{*}{$\begin{array}{l}\text { Frequency } \\
\mathrm{MHz}\end{array}$} & \multirow{2}{*}{$\begin{aligned} & \text { Acc. } \\
& \pm \mathrm{MHz}\end{aligned}$} \\
\hline & & & & $F_{1}^{\prime} \quad F^{\prime} \quad F_{1}$ & $\mathrm{~F}$ & & \\
\hline $\mathrm{C}^{12}{ }_{*} \mathrm{H}_{2} \mathrm{C}^{12} \mathrm{H}_{2} \mathrm{C}^{12}{ }_{*} \mathrm{HCl}^{35}$ & 4-1081 & $4,3,1 \leftarrow 3,3,0$ & Ground & $5 / 2$ & $5 / 2$ & 30113.5 & .1 \\
\hline $\mathrm{C}^{12}{ }_{*} \mathrm{H}_{2} \mathrm{C}^{12} \mathrm{H}_{2} \mathrm{C}^{12}{ }_{*} \mathrm{HCl}^{35}$ & 4-1081 & $4,3,1 \leftarrow 3,3,0$ & Ground & $9 / 2$ & $7 / 2$ & 30113.5 & .1 \\
\hline $\mathrm{C}^{12}{ }_{*} \mathrm{H}_{2} \mathrm{C}^{12} \mathrm{H}_{2} \mathrm{C}^{12}{ }_{*} \mathrm{HCl}^{35}$ & 4-1081 & $4,3,2 \leftarrow 3,3,1$ & Ground & $5 / 2$ & $5 / 2$ & 30113.5 & .1 \\
\hline $\mathrm{t} \cdot \mathrm{C}^{12} \mathrm{HD}: \mathrm{C}^{12} \mathrm{DBr}^{79}$ & 4. 745 & $4,0,4 \leftarrow 3,0,3$ & Ground & $7 / 2$ & $7 / 2$ & 30115.2 & \\
\hline $\mathrm{C}^{12} \mathrm{HD}: \mathrm{C}^{12} \mathrm{HBr}^{\mathrm{b}}$ & 4- 748 & Not Reported & Ground & & & 30116.9 & .1 \\
\hline $\mathrm{C}^{12}{ }_{*} \mathrm{H}_{2} \mathrm{C}^{12} \mathrm{H}_{2} \mathrm{C}^{12}{ }_{*} \mathrm{HCl}^{35}$ & 4-1081 & $4,3,2 \leftarrow 3,3,1$ & Ground & $7 / 2$ & $5 / 2$ & 30118.8 & .1 \\
\hline $\mathrm{C}^{12}{ }_{*} \mathrm{H}_{2} \mathrm{C}^{12} \mathrm{H}_{2} \mathrm{C}^{12}{ }_{*} \mathrm{HCl}^{35}$ & 4-1081 & $4,3,1 \leftarrow 3,3,0$ & Ground & $7 / 2$ & $5 / 2$ & 30118.8 & .1 \\
\hline $\mathrm{D}_{3} \mathrm{~B}^{10} \mathrm{C}^{12} \mathrm{O}^{16}$ & 4- 393 & $2,1 \leftarrow 1,1$ & Ground & 1 & 2 & 30119.91 & \\
\hline $\mathrm{D}_{3} \mathrm{~B}^{10} \mathrm{C}^{12} \mathrm{O}^{16}$ & 4- 393 & $2,1 \leftarrow 1,1$ & Ground & 5 & 4 & 30120.21 & \\
\hline $\mathrm{D}_{3} \mathrm{~B}^{10} \mathrm{C}^{12} \mathrm{O}^{16}$ & 4- 393 & $2,1 \leftarrow 1,1$ & Ground & 2 & 2 & 30120.21 & \\
\hline $\mathrm{D}_{3} \mathrm{~B}^{10} \mathrm{C}^{12} \mathrm{O}^{16}$ & 4. 393 & $2,1 \leftarrow 1,1$ & Ground & 3 & 4 & 30120.56 & \\
\hline $\mathrm{D}_{3} \mathrm{~B}^{10} \mathrm{C}^{12} \mathrm{O}^{16}$ & 4- 393 & $2,1 \leftarrow 1,1$ & Ground & 2 & 3 & 30120.56 & \\
\hline $\mathrm{D}_{3} \mathrm{~B}^{10} \mathrm{C}^{12} \mathrm{O}^{16}$ & 4- 393 & $2,1 \leftarrow 1,1$ & Ground & 4 & 4 & 30120.56 & \\
\hline $\mathrm{D}_{3} \mathrm{~B}^{10} \mathrm{C}^{12} \mathrm{O}^{16}$ & 4- 393 & $2,1 \leftarrow 1,1$ & Ground & 4 & 3 & 30120.86 & \\
\hline $\mathrm{D}_{3} \mathrm{~B}^{10} \mathrm{C}^{12} \mathrm{O}^{16}$ & 4- 393 & $2,1 \leftarrow 1,1$ & Ground & 3 & 3 & 30120.86 & \\
\hline $\mathrm{D}_{3} \mathrm{~B}^{10} \mathrm{C}^{12} \mathrm{O}^{16}$ & 4- 393 & $2,0 \leftarrow 1,0$ & Ground & 2 & 3 & 30120.86 & \\
\hline $\mathrm{D}_{3} \mathrm{~B}^{10} \mathrm{C}^{12} \mathrm{O}^{16}$ & 4- 393 & $2,0 \leftarrow 1,0$ & Ground & 5 & 4 & 30121.21 & \\
\hline $\mathrm{D}_{3} \mathrm{~B}^{10} \mathrm{C}^{12} \mathrm{O}^{16}$ & 4- 393 & $2,0 \leftarrow 1,0$ & Ground & 4 & 3 & 30121.21 & \\
\hline $\mathrm{D}_{3} \mathrm{~B}^{10} \mathrm{C}^{12} \mathrm{O}^{16}$ & 4- 393 & $2,0 \leftarrow 1,0$ & Ground & 3 & 3 & 30121.21 & \\
\hline $\mathrm{D}_{3} \mathrm{~B}^{10} \mathrm{C}^{12} \mathrm{O}^{16}$ & 4- 393 & $2,0 \leftarrow 1,0$ & Ground & 1 & 2 & 30121.21 & \\
\hline $\mathrm{C}^{12} \mathrm{H}_{3}{ }^{127}$ & 4- 481 & $2,0 \leftarrow 1,0$ & Ground & $1 / 2$ & $3 / 2$ & 30121.32 & .08 \\
\hline $\mathrm{D}_{3} \mathrm{~B}^{10} \mathrm{C}^{12} \mathrm{O}^{16}$ & 4- 393 & $2,0 \leftarrow 1,0$ & Ground & 2 & 2 & 30121.56 & \\
\hline $\mathrm{C}^{12} \mathrm{HD}: \mathrm{C}^{12} \mathrm{DBr}^{\mathrm{b}}$ & 4. 749 & Not Reported & Ground & & & 30121.6 & .1 \\
\hline $\mathrm{D}_{3} \mathrm{~B}^{10} \mathrm{C}^{12} \mathrm{O}^{16}$ & 4- 393 & $2,0 \leftarrow 1,0$ & Ground & 4 & 4 & 30121.86 & \\
\hline $\mathrm{D}_{3} \mathrm{~B}^{10} \mathrm{C}^{12} \mathrm{O}^{16}$ & 4- 393 & $2,0 \leftarrow 1,0$ & Ground & 3 & 4 & 30121.86 & \\
\hline $\mathrm{D}_{3} \mathrm{~B}^{10} \mathrm{C}^{12} \mathrm{O}^{16}$ & 4- 393 & $2,0 \leftarrow 1,0$ & Ground & 3 & 2 & 30121.86 & \\
\hline $\mathrm{C}^{12} \mathrm{H}_{3} \mathrm{I}^{127}$ & 4- 481 & $2,1 \leftarrow 1,1$ & Ground & $9 / 2$ & $7 / 2$ & 30123.64 & .08 \\
\hline $\mathrm{C}^{12}{ }_{*} \mathrm{H}_{2} \mathrm{C}^{12} \mathrm{H}_{2} \mathrm{C}^{12}{ }_{*} \mathrm{HCl}^{35}$ & $4-1081$ & $4,3,2 \leftarrow 3,3,1$ & Ground & $11 / 2$ & $9 / 2$ & 30124.9 & .1 \\
\hline $\mathrm{C}^{12}{ }_{*} \mathrm{H}_{2} \mathrm{C}^{12} \mathrm{H}_{2} \mathrm{C}^{12}{ }_{*} \mathrm{HCl}^{35}$ & 4-1081 & $4,3,1 \leftarrow 3,3,0$ & Ground & $11 / 2$ & $9 / 2$ & 30124.9 & .1 \\
\hline $\mathrm{C}^{13} \mathrm{H}_{3} \mathrm{O}^{16} \mathrm{H}$ & 3- 213 & $25,2, \leftarrow 25,1$, & Ground & & & 30127.80 & .1 \\
\hline $\mathrm{t}-\mathrm{C}^{12} \mathrm{HD}: \mathrm{C}^{12} \mathrm{DBr}^{79}$ & 4- 745 & $4,3,2 \leftarrow 3,3,1$ & Ground & $9 / 2$ & $9 / 2$ & 30128.7 & \\
\hline $\mathrm{t}-\mathrm{C}^{12} \mathrm{HD}: \mathrm{C}^{12} \mathrm{HBr}^{79}$ & 4- 741 & $4,1,3 \leftarrow 3,1,2$ & Excited & $11 / 2$ & $9 / 2$ & 30129.6 & \\
\hline $\mathrm{C}^{12}{ }_{*} \mathrm{H}_{2} \mathrm{C}^{12} \mathrm{H}_{2} \mathrm{C}^{12}{ }_{*} \mathrm{HCl}^{35}$ & $4-1081$ & $4,3,1 \leftarrow 3,3,0$ & Ground & $9 / 2$ & $9 / 2$ & 30131.6 & .1 \\
\hline $\mathrm{C}^{12}{ }_{*} \mathrm{H}_{2} \mathrm{C}^{12} \mathrm{H}_{2} \mathrm{C}^{12}{ }_{*} \mathrm{HCl}^{35}$ & $4-1081$ & $4,3,2 \leftarrow 3,3,1$ & Ground & $9 / 2$ & $9 / 2$ & 30131.6 & .1 \\
\hline $\mathrm{C}^{12}{ }_{*} \mathrm{H}_{2} \mathrm{C}^{12} \mathrm{H}_{2} \mathrm{C}^{12}{ }_{*} \mathrm{HCl}^{35}$ & 4-1081 & $4,3,2 \leftarrow 3,3,1$ & Ground & $5 / 2$ & $3 / 2$ & 30131.6 & .1 \\
\hline $\mathrm{C}^{12}{ }_{*} \mathrm{H}_{2} \mathrm{C}^{12} \mathrm{H}_{2} \mathrm{C}^{12}{ }_{*} \mathrm{HCl}^{35}$ & 4-1081 & $4,3,1 \leftarrow 3,3,0$ & Ground & $5 / 2$ & $3 / 2$ & 30131.6 & .1 \\
\hline $\mathrm{t}-\mathrm{C}^{12} \mathrm{HD}: \mathrm{C}^{12} \mathrm{DBr}^{79}$ & 4- 745 & $4,2,3 \leftarrow 3,2,2$ & Excited & $5 / 2$ & $3 / 2$ & 30132.0 & \\
\hline $\mathrm{D}_{2} \mathrm{O}_{2}^{16}$ & 3. 42 & Not Reported & & & & 30134. & 3. \\
\hline $\mathrm{t}-\mathrm{C}^{12} \mathrm{HD}: \mathrm{C}^{12} \mathrm{HBr}^{79}$ & 4. 741 & $4,1,3 \leftarrow 3,1,2$ & Excited & $5 / 2$ & $3 / 2$ & 30135.5 & \\
\hline t- $\mathrm{C}^{12} \mathrm{HD}: \mathrm{C}^{12} \mathrm{HBr}^{79}$ & 4- 741 & $4,1,3 \leftarrow 3,1,2$ & Ground & $7 / 2$ & $7 / 2$ & 30135.5 & \\
\hline $\mathrm{t}-\mathrm{C}^{12} \mathrm{HD}: \mathrm{C}^{12} \mathrm{HBr}^{79}$ & 4- 741 & $4,1,3 \leftarrow 3,1,2$ & Excited & & & 30137.14 & .42 \\
\hline $\mathrm{C}^{12} \mathrm{HD}: \mathrm{C}^{12} \mathrm{DBr}{ }^{1}$ & 4- 749 & Not Reported & Ground & & & 30137.3 & .1 \\
\hline$c-\mathrm{C}^{12} \mathrm{HD}: \mathrm{C}^{12} \mathrm{HBr}^{79}$ & 4- 739 & $4,1,4 \leftarrow 3,1,3$ & Excited & $11 / 2$ & $9 / 2$ & 30137.4 & \\
\hline $\mathrm{C}^{12} \mathrm{HD}: \mathrm{C}^{12} \mathrm{DBr}^{\mathrm{b}}$ & 4- 749 & Not Reported & Ground & & & $\begin{array}{lll}30 & 139.4\end{array}$ & .2 \\
\hline $\mathrm{C}^{12} \mathrm{HD}: \mathrm{C}^{12} \mathrm{DBr}^{\mathrm{b}}$ & 4- 749 & Not Reported & Ground & & & 30142.1 & .1 \\
\hline
\end{tabular}


$F_{1}^{\prime} F^{\prime} F_{1} F$

Frequency

MHz Ares

\begin{tabular}{|c|c|c|c|c|c|c|c|}
\hline$\left(\mathrm{C}^{12} \mathrm{H}_{3}\right)_{3} \mathrm{C}^{\mathrm{r}} \mathrm{Cl}^{35}$ & 3- 973 & $5, \leftarrow 4$, & Ground & & & 30142.5 & \\
\hline$c-\mathrm{C}^{12} \mathrm{HD}: \mathrm{C}^{12} \mathrm{HBr}^{79}$ & 4- 739 & $4,1,4 \leftarrow 3,1,3$ & Excited & $5 / 2$ & $3 / 2$ & 30142.6 & \\
\hline $\mathrm{t}-\mathrm{C}^{12} \mathrm{HD}: \mathrm{C}^{12} \mathrm{HBr}^{79}$ & 4- 741 & $4,1,3 \leftarrow 3,1,2$ & Excited & $9 / 2$ & $7 / 2$ & 30142.6 & \\
\hline c. $\mathrm{C}^{12} \mathrm{HD}: \mathrm{C}^{12} \mathrm{HBr}^{79}$ & 4- 739 & $4,1,4 \leftarrow 3,1,3$ & Ground & $7 / 2$ & $7 / 2$ & 30142.65 & \\
\hline $\mathrm{S}^{34} \mathrm{P}^{31} \mathrm{Cl}_{3}^{35}$ & 4-1535 & $11, \leftarrow 10$ & Ground & & & $30 \quad 143.2$ & 1.0 \\
\hline $\mathrm{c} \cdot \mathrm{C}^{12} \mathrm{HD}: \mathrm{C}^{12} \mathrm{HBr}^{79}$ & 4- 739 & $4,1,4 \leftarrow 3,1,3$ & Excited & & & 30144.14 & .47 \\
\hline t. $\mathrm{C}^{12} \mathrm{HD}: \mathrm{C}^{12} \mathrm{HBr}^{79}$ & 4. 741 & $4,1,3 \leftarrow 3,1,2$ & Excited & $7 / 2$ & $5 / 2$ & 30147.0 & \\
\hline $\mathrm{C}^{12} \mathrm{HD}: \mathrm{C}^{12} \mathrm{HBr}^{b}$ & 4. 748 & Not Reported & Ground & & & 30147.0 & .1 \\
\hline $\mathrm{C}^{12} \mathrm{HD}: \mathrm{C}^{12} \mathrm{DBr}^{b}$ & 4. 749 & Not Reported & Ground & & & 30147.1 & .1 \\
\hline a- $\left(\mathrm{C}^{12} \mathrm{H}_{2} \mathrm{D}\right)\left(\mathrm{C}^{12} \mathrm{H}_{3}\right)_{2} \mathrm{C}^{12} \mathrm{H}$ & $3-1006$ & $2,2,0 \leftarrow 1,1,0$ & & & & 30147.92 & .05 \\
\hline $\mathrm{t}-\mathrm{C}^{12} \mathrm{HD}: \mathrm{C}^{12} \mathrm{DBr}^{79}$ & 4- 745 & $4,2,3 \leftarrow 3,2,2$ & Excited & $11 / 2$ & $9 / 2$ & 30148.9 & \\
\hline$c-C^{12} \mathrm{HD}: \mathrm{C}^{12} \mathrm{HBr}^{79}$ & 4- 739 & $4,1,4 \leftarrow 3,1,3$ & Excited & $9 / 2$ & $7 / 2$ & 30149.1 & \\
\hline $\mathrm{c} \cdot \mathrm{HDC}^{12}{ }_{*} \mathrm{O}^{16} \mathrm{C}^{12}{ }_{*} \mathrm{DH}$ & 4- 845 & $2,2,1 \leftarrow 2,1,2$ & Ground & & & 30150.10 & .05 \\
\hline $\mathrm{C}^{12}{ }_{*} \mathrm{H}_{2} \mathrm{C}^{12} \mathrm{H}_{2} \mathrm{C}^{12}{ }_{*} \mathrm{HCl}^{35}$ & 4-1081 & $4,2,2 \leftarrow 3,2,1$ & Ground & $9 / 2$ & $7 / 2$ & 30151.0 & .1 \\
\hline $\mathrm{C}^{12}{ }_{*} \mathrm{H}_{2} \mathrm{C}^{12} \mathrm{H}_{2} \mathrm{C}^{12}{ }_{*} \mathrm{HCl}^{35}$ & 4-1081 & $4,2,2 \leftarrow 3,2,1$ & Ground & $7 / 2$ & $5 / 2$ & 30153.1 & .1 \\
\hline $\mathrm{C}^{12} \mathrm{HD}: \mathrm{C}^{12} \mathrm{HBr}^{12}$ & 4. 748 & Not Reported & Ground & & & 30153.4 & .1 \\
\hline$c-\mathrm{C}^{12} \mathrm{HD}: \mathrm{C}^{12} \mathrm{HBr}^{79}$ & 4. 739 & $4,1,4 \leftarrow 3,1,3$ & Excited & $7 / 2$ & $5 / 2$ & 30154.6 & \\
\hline $\mathrm{t}-\mathrm{C}^{12} \mathrm{HD}: \mathrm{C}^{12} \mathrm{DBr}^{79}$ & 4- 745 & $4,0,4 \leftarrow 3,0,3$ & Ground & $9 / 2$ & $7 / 2$ & 30155.6 & \\
\hline $\mathrm{t}-\mathrm{C}^{12} \mathrm{HD}: \mathrm{C}^{12} \mathrm{DBr}^{79}$ & 4- 745 & $4,0,4 \leftarrow 3,0,3$ & Ground & $11 / 2$ & $9 / 2$ & 30155.6 & \\
\hline $\mathrm{C}^{12}{ }_{*} \mathrm{H}_{2} \mathrm{C}^{12} \mathrm{H}_{2} \mathrm{C}^{12}{ }_{*} \mathrm{HCl}^{35}$ & 4-1081 & $4,2,2 \leftarrow 3,2,1$ & Ground & $11 / 2$ & $9 / 2$ & 30156.9 & .1 \\
\hline $\mathrm{t}-\mathrm{C}^{12} \mathrm{HD}: \mathrm{C}^{12} \mathrm{HBr}^{79}$ & 4- 741 & $4,1,3 \leftarrow 3,1,2$ & Ground & $11 / 2$ & $9 / 2$ & 30157.35 & \\
\hline $\mathrm{C}^{12} \mathrm{HD}: \mathrm{C}^{12} \mathrm{DBr}^{\mathrm{b}}$ & 4. 749 & Not Reported & Ground & & & 30157.5 & .1 \\
\hline $\mathrm{C}^{12}{ }_{*} \mathrm{H}_{2} \mathrm{C}^{12} \mathrm{H}_{2} \mathrm{C}^{12}{ }_{*} \mathrm{HCl}^{35}$ & $4-1081$ & $4,2,2 \leftarrow 3,2,1$ & Ground & $5 / 2$ & $3 / 2$ & 30158.3 & .1 \\
\hline t. $\mathrm{C}^{12} \mathrm{HD}: \mathrm{C}^{12} \mathrm{DBr}^{79}$ & 4. 745 & $4,0,4 \leftarrow 3,0,3$ & Ground & & & 30158.51 & .91 \\
\hline $\mathrm{t}-\mathrm{C}^{12} \mathrm{HD}: \mathrm{C}^{12} \mathrm{DBr}^{79}$ & 4- 745 & $4,2,3 \leftarrow 3,2,2$ & Ground & $5 / 2$ & $3 / 2$ & 30158.8 & \\
\hline $\mathrm{HC}^{13}: \mathrm{C}^{12} \mathrm{C}^{12} \mathrm{DO}^{16}$ & 4- 922 & Not Reported & & & & 30160. & 5. \\
\hline $\mathrm{t}-\mathrm{C}^{12} \mathrm{HD}: \mathrm{C}^{12} \mathrm{HBr}^{79}$ & 4- 741 & $4,1,3 \leftarrow 3,1,2$ & Ground & $5 / 2$ & $3 / 2$ & 30162.7 & \\
\hline$\left(\mathrm{C}^{12} \mathrm{H}_{3}\right)_{3} \mathrm{C}^{12} \mathrm{D}$ & 3-1003 & $2, \leftarrow 1$, & & & & 30162.95 & .05 \\
\hline$c-\mathrm{C}^{18} \mathrm{H}_{3} \mathrm{C}^{12} \mathrm{H}: \mathrm{C}^{12} \mathrm{HF}^{19}-\mathrm{E}$ & 3- 702 & $6,1,5 \leftarrow 6,0,6$ & & & & 30163.59 & .2 \\
\hline $\mathrm{t}-\mathrm{C}^{12} \mathrm{HD}: \mathrm{C}^{12} \mathrm{HBr}^{79}$ & 4- 741 & $4,1,3 \leftarrow 3,1,2$ & Ground & & & 30164.08 & .048 \\
\hline $\mathrm{t}-\mathrm{C}^{12} \mathrm{HD}: \mathrm{C}^{12} \mathrm{DBr}^{79}$ & 4- 745 & $4,2,3 \leftarrow 3,2,2$ & Excited & & & 30165.20 & \\
\hline $\mathrm{t}-\mathrm{C}^{12} \mathrm{HD}: \mathrm{C}^{12} \mathrm{DBr}^{79}$ & 4- 745 & $4,0,4 \leftarrow 3,0,3$ & Ground & $7 / 2$ & $5 / 2$ & 30167.3 & \\
\hline $\mathrm{t}-\mathrm{C}^{12} \mathrm{HD}: \mathrm{C}^{12} \mathrm{DBr}^{79}$ & 4- 745 & $4,0,4 \leftarrow 3,0,3$ & Ground & $5 / 2$ & $3 / 2$ & 30167.3 & \\
\hline$c-\mathrm{C}^{12} \mathrm{HD}: \mathrm{C}^{12} \mathrm{HBr}^{79}$ & 4- 739 & $4,1,4 \leftarrow 3,1,3$ & Ground & $11 / 2$ & $9 / 2$ & 30167.4 & \\
\hline $\mathrm{C}^{13} \mathrm{H}_{3}\left(\mathrm{C}^{12} \mathrm{H}_{3}\right)_{2} \mathrm{C}^{12} \mathrm{C}^{12}: \mathrm{C}^{12} \mathrm{D}$ & $3-1078$ & $6,1,5 \leftarrow 5,1,4$ & Ground & & & 30167.8 & .1 \\
\hline $\mathrm{t}-\mathrm{C}^{12} \mathrm{HD}: \mathrm{C}^{12} \mathrm{DBr}^{79}$ & 4- 745 & $4,3,2 \leftarrow 3,3,1$ & Ground & $11 / 2$ & $9 / 2$ & 30169.0 & \\
\hline $\mathrm{t}-\mathrm{C}^{12} \mathrm{HD}: \mathrm{C}^{12} \mathrm{HBr}^{79}$ & 4- 741 & $4,1,3 \leftarrow 3,1,2$ & Ground & $9 / 2$ & $7 / 2$ & 30169.2 & \\
\hline c- $\mathrm{C}^{12} \mathrm{HD}: \mathrm{C}^{12} \mathrm{HBr}^{79}$ & 4- 739 & $4,1,4 \leftarrow 3,1,3$ & Ground & $5 / 2$ & $3 / 2$ & $30 \quad 173.8$ & \\
\hline c- $\mathrm{C}^{12} \mathrm{HD}: \mathrm{C}^{12} \mathrm{HBr}^{79}$ & 4- 739 & $4,1,4 \leftarrow 3,1,3$ & Ground & & & 30174.38 & .13 \\
\hline${ }^{t}-\mathrm{C}^{12} \mathrm{HD}: \mathrm{C}^{12} \mathrm{HBr}^{79}$ & 4- 741 & $4,1,3 \leftarrow 3,1,2$ & Ground & $7 / 2$ & $5 / 2$ & 30174.8 & \\
\hline t. $\mathrm{C}^{12} \mathrm{HD}: \mathrm{C}^{12} \mathrm{DBr}^{79}$ & 4- 745 & $4,2,3 \leftarrow 3,2,2$ & Ground & $11 / 2$ & $9 / 2$ & 30175.6 & \\
\hline$\left(\mathrm{C}^{12} \mathrm{H}_{3}\right)_{3} \mathrm{C}^{12} \mathrm{Cl}^{35}$ & 3. 971 & $5, \leftarrow 4$ & Ground & & & 30176.8 & .10 \\
\hline $\mathrm{t}-\mathrm{C}^{12} \mathrm{HD}: \mathrm{C}^{12} \mathrm{DBr}^{79}$ & 4. 745 & $4,2,3 \leftarrow 3,2,2$ & Excited & $7 / 2$ & $5 / 2$ & 30178.7 & \\
\hline c. $\mathrm{C}^{12} \mathrm{HD}: \mathrm{C}^{12} \mathrm{HBr}^{79}$ & 4- 739 & $4,1,4 \leftarrow 3,1,3$ & Ground & $9 / 2$ & $7 / 2$ & 30179.7 & \\
\hline $\mathrm{C}^{12} \mathrm{H}_{3} \mathrm{I}^{127}$ & 4- 481 & $2,0 \leftarrow 1,0$ & Ground & $5 / 2$ & $5 / 2$ & 30179.71 & .08 \\
\hline
\end{tabular}


$\mathrm{O}_{3}^{16}$

$\mathrm{C}^{12}{ }_{*} \mathrm{H}_{2} \mathrm{C}^{12} \mathrm{HDC}^{12} \mathrm{H}_{2} \mathrm{O}^{16} *$

$\mathrm{C}^{12} \mathrm{HD}: \mathrm{C}^{12} \mathrm{DBr}^{13}$

c- $\mathrm{C}^{12} \mathrm{HD}: \mathrm{C}^{12} \mathrm{HBr}^{79}$

$\mathrm{Si}^{28} \mathrm{D}_{2} \mathrm{~F}_{2}^{19}$

$\mathrm{C}^{12} \mathrm{H}_{3} \mathrm{C}^{12} \mathrm{O}^{18} \mathrm{C}^{12} \mathrm{~N}^{14}$

c- $\mathrm{C}^{12} \mathrm{H}_{3} \mathrm{C}^{12} \mathrm{H}: \mathrm{C}^{12} \mathrm{HF}^{19}-\mathrm{A}$

g- $\mathrm{C}^{12} \mathrm{H}_{3} \mathrm{C}^{12} \mathrm{H}_{2} \mathrm{C}^{12} \mathrm{H}_{2} \mathrm{Cl}^{37}$

$\mathrm{C}^{12} \mathrm{HD}: \mathrm{C}^{12} \mathrm{DBr}^{\mathrm{b}}$

g. $\mathrm{C}^{12} \mathrm{H}_{2} \mathrm{Cl}^{35} \mathrm{C}^{12} \mathrm{H}_{2} \mathrm{Cl}^{35}$

$\mathrm{HC}^{13}: \mathrm{C}^{12} \mathrm{C}^{12} \mathrm{DO}^{16}$

$\mathrm{S}^{33} \mathrm{O}_{2}^{16}$

t-C ${ }^{12} \mathrm{HD}: \mathrm{C}^{12} \mathrm{DBr}^{79}$

$\mathrm{S}^{33} \mathrm{O}_{2}^{16}$

t-C ${ }^{12} \mathrm{HD}: \mathrm{C}^{12} \mathrm{DBr}^{79}$

$\mathrm{S}^{33} \mathrm{O}_{2}^{16}$

$\mathrm{S}^{33} \mathrm{O}_{2}^{16}$

$\left(\mathrm{C}^{12} \mathrm{H}_{3}\right)_{3} \mathrm{C}^{12} \mathrm{C}^{13}: \mathrm{C}^{12} \mathrm{D}$

t $-\mathrm{C}^{12} \mathrm{HD}: \mathrm{C}^{12} \mathrm{DBr}^{79}$

$\mathrm{C}^{12} \mathrm{H}_{2} \mathrm{Cl}^{35} \mathrm{Si}^{29} \mathrm{H}_{3}$

$\mathrm{C}^{12} \mathrm{H}_{2} \mathrm{Cl}^{35} \mathrm{Si}^{29} \mathrm{H}_{3}$

t- $\mathrm{C}^{12} \mathrm{HD}: \mathrm{C}^{12} \mathrm{DBr}^{79}$

$\mathrm{C}^{12} \mathrm{H}_{3} \mathrm{C}^{12} \mathrm{H}_{2} \mathrm{Cl}^{37}$

$\mathrm{C}^{12} \mathrm{H}_{3} \mathrm{C}^{12} \mathrm{H}_{2} \mathrm{Cl}^{37}$

$\mathrm{C}^{12} \mathrm{H}_{3} \mathrm{C}^{12} \mathrm{H}_{2} \mathrm{Cl}^{37}$

t-C ${ }^{12} \mathrm{HD}: \mathrm{C}^{12} \mathrm{DBr}^{79}$

$\mathrm{C}^{12} \mathrm{H}_{3} \mathrm{C}^{12} \mathrm{H}_{2} \mathrm{Cl}^{37}$

$\mathrm{D}_{2} \mathrm{C}^{12}: \mathrm{C}^{12} \mathrm{DCl}^{35}$

$\mathrm{D}_{2} \mathrm{C}^{12}: \mathrm{C}^{12} \mathrm{DCl}^{35}$

$\mathrm{C}^{\mathrm{b}}{ }_{*} \mathrm{H}_{2}^{\mathrm{h}} \mathrm{N}^{\mathrm{b}} \mathrm{H}^{\mathrm{s}} \mathrm{C}^{\mathrm{b}}{ }_{*} \mathrm{H}_{2}^{\mathrm{b}}$

$\mathrm{C}^{12} \mathrm{H}_{3} \mathrm{~J}^{127}$

$\mathrm{C}^{13} \mathrm{H}_{3} \mathrm{C}^{12} \mathrm{HO}$

a- $\mathrm{C}^{12} \mathrm{H}_{2} \mathrm{DO}^{16} \mathrm{~N}^{14} \mathrm{O}_{2}^{16}$

$\mathrm{C}^{\mathrm{b}} \mathrm{H}_{2}^{\mathrm{b}} \mathrm{Cl}^{\mathrm{b}} \mathrm{F}^{\mathrm{b}}$

t-C ${ }^{12} \mathrm{HD}: \mathrm{C}^{12} \mathrm{DBr}^{79}$

$\mathrm{C}^{\mathrm{b}} \mathrm{H}_{2}^{\mathrm{b}} \mathrm{Cl}^{\mathrm{b}} \mathrm{F}^{\mathrm{b}}$

t-C ${ }^{12} \mathrm{HD}: \mathrm{C}^{12} \mathrm{DBr}^{79}$

$\mathrm{C}^{12} \mathrm{DHCl}_{2}^{35}$

$\mathrm{C}^{12} \mathrm{H}_{3} \mathrm{~N}^{14} \mathrm{H}_{2}$

t-C ${ }^{12} \mathrm{HD}: \mathrm{C}^{12} \mathrm{DBr}^{79}$

$\mathrm{HC}^{13}: \mathrm{C}^{12} \mathrm{C}^{12} \mathrm{DO}^{15}$

$\mathrm{F}^{19} \mathrm{Cl}^{37}$

s- $\mathrm{C}^{12} \mathrm{HD}_{2} \mathrm{C}^{12} \mathrm{O}^{16} \mathrm{~F}^{19}$

$\mathrm{C}^{12} \mathrm{H}_{3} \mathrm{~N}^{14} \mathrm{H}_{2}$

g- $\mathrm{C}^{12} \mathrm{H}_{2} \mathrm{DC}^{12} \mathrm{H}_{2} \mathrm{Cl}^{35}$
4-1841 14, 2,12 -15, 1,15

4. 1094

2, $1,2 \leftarrow 1,1,1$

Ground

4- 749

Not Reported

Ground

4. 739

$4,1,4 \leftarrow 3,1,3$

Ground

4- 1603

$6,2,4 \leftarrow 6,1,5$

Ground

3- 674

$5,0,5 \leftarrow 4,1,4$

Ground

Ground

3- 701

$6,1,5 \leftarrow 6,0,6$

3- 774

$5,2,4 \leftarrow 4,2,3$

Ground

4- 749

Not Reported

3- 451

$2,2,1 \leftarrow 1,1,0$

4- 922

Not Reported

4- 1832

4- 745

$4,0,4 \leftarrow 3,1,3$

Ground

$4,2,3 \leftarrow 3,2,2$

Ground

4-1832

$4,0,4 \leftarrow 3,1,3$

Ground

4- 745

4-1832

4. 1832

$4,2,2 \leftarrow 3,2,1$

Ground

Ground

$4,0,4 \leftarrow 3,1,3$

$4,0,4 \leftarrow 3,1,3$

Ground

$3 \cdot 1076$

$6, \leftarrow 5$,

4- 745

3. 234

$4,3,2 \leftarrow 3,3,1$

Ground

Ground

Ground

Ground

3. 234

$5,0,5 \leftarrow 4,0,4$

Ground

3- 542

3. 542

$4,2,3 \leftarrow 3,2,2$

Ground

Ground

Ground

3- 542

$5,1,4 \leftarrow 5,0,5$

$5,1,4 \leftarrow 5,0,5$

Ground

4. 745

$4,2,2 \leftarrow 3,2,1$

$5,1,4 \leftarrow 5,0,5$

Ground

Ground

4- 763

$3,0,3 \leftarrow 2,0,2$

$3,0,3 \leftarrow 2,0,2$

Ground

4. 863

4. 481

3- 476

3- 184

4- 333

4- 745

4- 333

4- 745

4- 344

3- 261

4- 745

4- 922

Not Reported

$$
2,1 \leftarrow 1,1
$$

$4,0,4 \leftarrow 3,1,3$

Ground

$4,0,4 \leftarrow 3,0,3$

Ground

Ground

Not Reported

$4,3,2 \leftarrow 3,3,1$

Not Reported

$4,2,3 \leftarrow 3,2,2$

Ground

Ground

$1,1,1 \leftarrow 0,0,0$

Ground

Not Reported

$4,2,2 \leftarrow 3,2,1$

Ground

Ground

1 -

3. 395

3. 261

Not Reported

$$
1 \leftarrow 0
$$

Ground

$2,1,1 \leftarrow 1,1,0$

Ground

Ground

3- 544
Not Reported

$3,2,2 \leftarrow 2,2,1$
Ground
30181.

30181.8

30184.5

$7 / 2$

30185.3

$30186.00 \quad .10$

$30186.53 \quad .2$

$30187.73 \quad .2$

$30187.94 \quad .2$

$30189.8 \quad .2$

30190.

30190.

5.

$9 / 2 \quad 7 / 2 \quad 30190.37$

30192.38

.11

$7 / 2 \quad 5 / 2 \quad 30193.01$

$5 / 2 \quad 3 / 2 \quad 30194.05$

$11 / 2 \quad 9 / 2 \quad 30195.91$

$5 / 2 \quad 3 / 2 \quad 30198.56$

30201.9

30202.98

30203.92

30203.97

21

.05

.2

$7 / 2 \quad 5 / 2$

30205.85

$7 / 2 \quad 7 / 2 \quad 30206.62$

.05

$13 / 2 \quad 13 / 2$

30207.53

.05

$9 / 2 \quad 9 / 2 \quad 30209.95$

.05

$11 / 2 \quad 9 / 2 \quad 30210.8$

$11 / 2 \quad 11 / 2 \quad 30210.87$

30211.10

30214.65

30215.

10.

$3 / 2 \quad 3 / 2$

30215.95

.08

30216.05

.2

30217.30

.1

30219.4

1.

$7 / 2 \quad 5 / 2 \quad 30220.5$

30220.7

$9 / 2 \quad 7 / 2 \quad 30222.0$

30224.7

30226.8

30227.62

30228.

$3 / 2$

$3 / 2$

30228.344

0.004

30233.13

30236.7

$7 / 2 \quad 5 / 2 \quad 30238.96$
.15

5.

.2

1.

.2

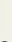

.1 


\begin{tabular}{|c|c|c|c|c|c|c|c|}
\hline Isotopic Species & $\begin{array}{l}\text { Vol.-Id. } \\
\text { Nos. }\end{array}$ & $\begin{array}{c}\text { Rotational } \\
\text { Quantum Nos. }\end{array}$ & Vil. State & $\mathrm{F}_{1}^{\prime} \mathrm{F}^{\prime} \mathrm{F}_{1}$ & $\mathrm{~F}$ & $\begin{array}{l}\text { Frequency } \\
\text { NII\% }\end{array}$ & $\begin{array}{l}\text { Arre } \\
\pm \text { WII }\end{array}$ \\
\hline c- $\mathrm{C}^{12} \mathrm{HD}: \mathrm{C}^{12} \mathrm{HBr}^{79}$ & 4- 739 & $4,1,4 \leftarrow 3,1,3$ & Excited & $9 / 2$ & $9 / 2$ & 30239.6 & \\
\hline $\mathrm{t}-\mathrm{C}^{12} \mathrm{HD}: \mathrm{C}^{12} \mathrm{DBr}^{79}$ & 4. 745 & $4,2,2 \leftarrow 3,2,1$ & Ground & $7 / 2$ & $5 / 2$ & 30242.1 & \\
\hline g- $\mathrm{C}^{12} \mathrm{H}_{2} \mathrm{DC}^{12} \mathrm{H}_{2} \mathrm{Cl}^{35}$ & 3. 544 & $3,2,2 \leftarrow 2,2,1$ & Ground & $5 / 2$ & $3 / 2$ & 30247.36 & .1 \\
\hline g- $\left.\mathrm{C}^{12} \mathrm{H}_{2} \mathrm{DC}^{12} \mathrm{H}_{2} \mathrm{Cl}\right]^{35}$ & 3. 544 & $3,2,2 \leftarrow 2,2,1$ & Ground & $9 / 2$ & $7 / 2$ & 30250.87 & .1 \\
\hline $\mathrm{t}-\mathrm{C}^{12} \mathrm{HD}: \mathrm{C}^{12} \mathrm{HBr}^{79}$ & 4. 741 & $4,1,3 \leftarrow 3,1,2$ & Ground & $9 / 2$ & $9 / 2$ & 30252.8 & \\
\hline $\mathrm{t} \cdot \mathrm{C}^{12} \mathrm{HD}: \mathrm{C}^{12} \mathrm{DBr}^{79}$ & 4- 745 & $4,2,2 \leftarrow 3,2,1$ & Ground & $9 / 2$ & $7 / 2$ & 30256.9 & \\
\hline $\mathrm{F}^{19} \mathrm{Cl}^{37}$ & $1-$ & $1 \leftarrow 0$ & Ground & $5 / 2$ & $3 / 2$ & 30257.135 & 0.003 \\
\hline $\mathrm{F}_{2}^{19} \mathrm{O}_{2}^{16}$ & 3- 11 & $8,1,7 \leftarrow 8,0,8$ & Ground & & & 30258.95 & .1 \\
\hline g- $\mathrm{C}^{12} \mathrm{H}_{2} \mathrm{DC}^{12} \mathrm{H}_{2} \mathrm{Cl}^{35}$ & 3- 544 & $3,2,2 \leftarrow 2,2,1$ & Ground & $3 / 2$ & $1 / 2$ & 30259.08 & .1 \\
\hline $\mathrm{D}_{2} \mathrm{C}^{12}: \mathrm{C}^{12} \mathrm{DCl}^{35}$ & 4- 763 & $3,2,2 \leftarrow 2,2,1$ & Ground & & & 30260.80 & \\
\hline $\mathrm{HC}^{13}: \mathrm{C}^{12} \mathrm{C}^{12} \mathrm{DO}^{16}$ & 4- 922 & Not Reported & & & & 30263. & 5. \\
\hline $\mathrm{s}-\left(\mathrm{C}^{12} \mathrm{H}_{2} \mathrm{D}\right)\left(\mathrm{C}^{12} \mathrm{H}_{3}\right)_{2} \mathrm{C}^{12} \mathrm{H}$ & $3 \cdot 1005$ & $2,2,1 \leftarrow 1,1,1$ & & & & 30266.06 & .20 \\
\hline$c-\mathrm{C}^{12} \mathrm{HD}: \mathrm{C}^{12} \mathrm{HBr}^{79}$ & 4. 739 & $4,1,4 \leftarrow 3,1,3$ & Ground & $9 / 2$ & $9 / 2$ & 30271.1 & \\
\hline $\mathrm{g}-\mathrm{C}^{12} \mathrm{H}_{2} \mathrm{DC}^{12} \mathrm{H}_{2} \mathrm{Cl}^{35}$ & 3. 544 & $3,2,1 \leftarrow 2,2,0$ & Ground & $7 / 2$ & $5 / 2$ & 30272.84 & .1 \\
\hline $\mathrm{t} \cdot \mathrm{C}^{12} \mathrm{HD}: \mathrm{C}^{12} \mathrm{DBr}^{79}$ & 4- 745 & $4,3,2 \leftarrow 3,3,1$ & Ground & $9 / 2$ & $7 / 2$ & 30273.8 & \\
\hline $\mathrm{F}^{19} \mathrm{Cl}^{37}$ & 1 - & $1 \leftarrow 0$ & Ground & $1 / 2$ & $3 / 2$ & 30280.056 & 0.003 \\
\hline $\mathrm{g}-\mathrm{C}^{12} \mathrm{H}_{2} \mathrm{DC}^{12} \mathrm{H}_{2} \mathrm{Cl}^{35}$ & 3. 544 & $3,2,1 \leftarrow 2,2,0$ & Ground & $5 / 2$ & $3 / 2$ & 30281.45 & .1 \\
\hline $\mathrm{g}-\mathrm{C}^{12} \mathrm{H}_{2} \mathrm{DC}^{12} \mathrm{H}_{2} \mathrm{Cl}^{35}$ & 3- 544 & $3,2,1 \leftarrow 2,2,0$ & Ground & $9 / 2$ & $7 / 2$ & 30284.50 & .1 \\
\hline $\mathrm{C}^{12} \mathrm{H}_{3} \mathrm{Si}^{28} \mathrm{DF}_{2}^{19}-\mathrm{E}$ & 3. 198 & $3,1,2 \leftarrow 2,1,1$ & Ground & & & 30287.49 & \\
\hline $\mathrm{C}^{12} \mathrm{H}_{3} \mathrm{Si}^{28} \mathrm{DF}_{2}^{19}-\mathrm{A}$ & 3. 197 & $3,1,2 \leftarrow 2,1,1$ & Ground & & & 30288.46 & \\
\hline$t \cdot \mathrm{C}^{12} \mathrm{HD}: \mathrm{C}^{12} \mathrm{DBr}^{79}$ & 4- 745 & $4,3,2 \leftarrow 3,3,1$ & Ground & $7 / 2$ & $7 / 2$ & 30289.1 & \\
\hline $\mathrm{C}^{12}{ }_{*} \mathrm{H}_{2} \mathrm{C}^{12} \mathrm{HDC}^{12} \mathrm{H}_{2} \mathrm{O}^{16}{ }_{*}$ & 4-1094 & $2,1,2 \leftarrow 1,1,1$ & Excited & & & 30290.5 & .1 \\
\hline $\mathrm{C}^{\mathrm{b}} \mathrm{H}_{2}^{\mathrm{b}} \mathrm{Cl}^{\mathrm{b}} \mathrm{F}^{\mathrm{b}}$ & 4- 333 & Not Reported & & & & 30290.67 & .1 \\
\hline $\mathrm{C}^{\mathrm{b}} \mathrm{H}_{2}^{\mathrm{b}} \mathrm{Cl}^{\mathrm{b}} \mathrm{F}^{\mathrm{b}}$ & 4- 333 & Not Reported & & & & 30292. & 1. \\
\hline g- $\mathrm{C}^{12} \mathrm{H}_{2} \mathrm{DC}^{12} \mathrm{H}_{2} \mathrm{Cl}^{35}$ & 3- 544 & $3,2,1 \leftarrow 2,2,0$ & Ground & $3 / 2$ & $1 / 2$ & 30293.03 & .1 \\
\hline $\mathrm{D}_{2} \mathrm{C}^{12}: \mathrm{C}^{12} \mathrm{DCl}^{35}$ & 4- 763 & $3,2,1 \leftarrow 2,2,0$ & Ground & & & 30296. & \\
\hline $\mathrm{C}^{13} \mathrm{HCl}^{35} \mathrm{~F}_{2}^{19}$ & 4- 253 & $3,3,0 \leftarrow 3,2,2$ & Ground & & & 30299.2 & .2 \\
\hline $\mathrm{C}^{12} \mathrm{HD}: \mathrm{C}^{12} \mathrm{HBr}^{\mathrm{b}}$ & 4- 748 & Not Reported & Ground & & & 30299.6 & .2 \\
\hline $\mathrm{C}^{12} \mathrm{H}_{3} \mathrm{O}^{16} \mathrm{H}$ & 3- 211 & $17,2, \leftarrow 17,1$, & Ground & & & 30308.00 & .1 \\
\hline $\mathrm{a}-\mathrm{C}^{12} \mathrm{HD}_{2} \mathrm{C}^{12} \mathrm{O}^{16} \mathrm{~F}^{19}$ & 3- 396 & $2,1,1 \leftarrow 1,1,0$ & Ground & & & 30312.30 & .2 \\
\hline $\mathrm{Li}^{6} I^{127}$ & $1-$ & $1 \leftarrow 0$ & Excited & $7 / 2$ & $5 / 2$ & 30317.79 & 0.20 \\
\hline $\mathrm{Si}^{28} \mathrm{H}_{3} \mathrm{~N}^{14} \mathrm{C}^{12} \mathrm{~S}^{32}$ & 4- 491 & $10, \leftarrow 9$ & Ground & & & 30320.35 & \\
\hline $\mathrm{Ge}^{74} \mathrm{HCl}_{3}^{35}$ & 4-1493 & $7, \leftarrow 6$, & Ground & & & 30321.85 & .07 \\
\hline $\mathrm{Ge}^{74} \mathrm{HCl}_{3}^{35}$ & 4-1493 & $7, \leftarrow 6$, & Excited & & & 30327.36 & .07 \\
\hline $\mathrm{S}^{32} \mathrm{O}_{2}^{16} \mathrm{~F}_{2}^{19}$ & 4-1631 & $3,2,1 \leftarrow 2,1,1$ & Excited & & & 30328.21 & .10 \\
\hline $\mathrm{C}^{12} \mathrm{D}_{3} \mathrm{Si}^{30} \mathrm{H}_{2} \mathrm{~F}^{19}$ & 3- 246 & $3,1,3 \leftarrow 2,1,2$ & Ground & & & 30328.58 & .10 \\
\hline $\mathrm{Ge}^{74} \mathrm{HCl}_{3}^{35}$ & 4-1493 & $7, \leftarrow 6$, & Excited & & & 30332.33 & .07 \\
\hline $\mathrm{Ge}^{74} \mathrm{~F}_{3}^{19} \mathrm{Cl}^{35}$ & $4 \cdot 1405$ & $7, \leftarrow 6$ & Ground & & & 30332.58 & 1.00 \\
\hline $\mathrm{Li}^{6} \mathrm{I}^{127}$ & $1-$ & $1 \leftarrow 0$ & Excited & $3 / 2$ & $5 / 2$ & 30336.40 & 0.40 \\
\hline $\mathrm{c}-\mathrm{DHC}^{12}: \mathrm{C}^{12} \mathrm{DCl}^{35}$ & 4. 762 & $3,1,3 \leftarrow 2,1,2$ & Ground & & & 30336.75 & \\
\hline $\mathrm{S}^{32} \mathrm{O}_{2}^{16} \mathrm{~F}_{2}^{19}$ & 4-1631 & $3,1,3 \leftarrow 2,1,2$ & Excited & & & 30337.21 & .10 \\
\hline $\mathrm{S}^{32} \mathrm{O}_{2}^{16} \mathrm{~F}_{2}^{19}$ & $4 \cdot 1631$ & $3,0,3 \leftarrow 2,0,2$ & Excited & & & 30339.09 & .10 \\
\hline $\mathrm{C}^{12} \mathrm{HD}: \mathrm{C}^{12} \mathrm{HBr}^{\mathrm{h}}$ & 4- 748 & Not Reported & Ground & & & 30340.15 & .1 \\
\hline $\mathrm{c} \cdot \mathrm{DHC}^{12}: \mathrm{C}^{12} \mathrm{DCl}^{35}$ & 4. 762 & $3,1,3 \leftarrow 2,1,2$ & Ground & & & 30340.50 & \\
\hline $\mathrm{S}^{32} \mathrm{O}_{2}^{16} \mathrm{~F}_{2}^{19}$ & 4-1631 & $3,1,2 \leftarrow 2,1,1$ & Excited & & & 30341.39 & .10 \\
\hline
\end{tabular}




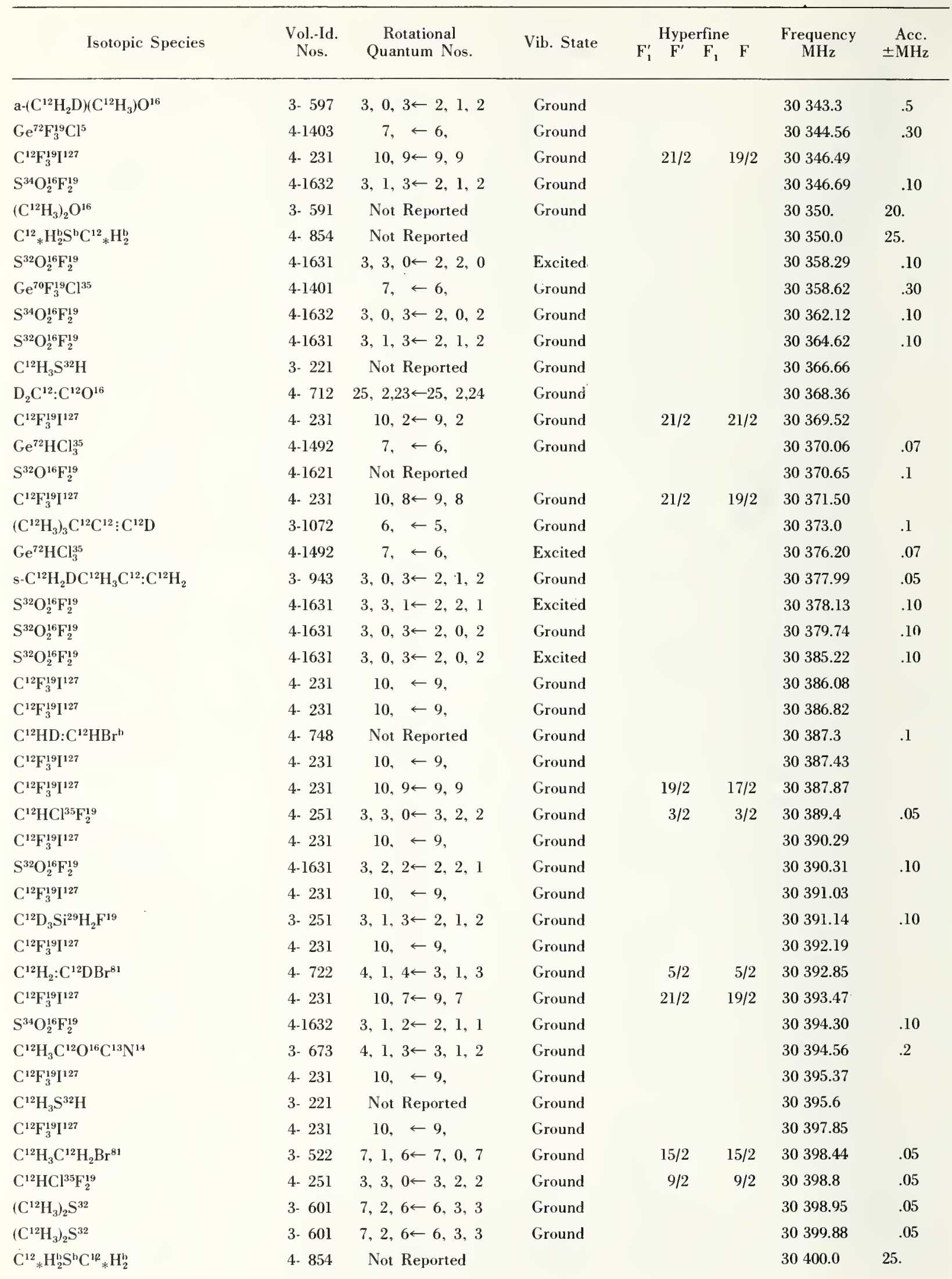




\begin{tabular}{|c|c|c|c|c|c|c|c|}
\hline \multirow{2}{*}{ Isotopic Species } & \multirow{2}{*}{$\begin{array}{l}\text { Vol.-Id. } \\
\text { Nos. }\end{array}$} & \multirow{2}{*}{$\begin{array}{c}\text { Rotational } \\
\text { Quantum Nos. }\end{array}$} & \multirow{2}{*}{ Vib. State } & \multicolumn{2}{|c|}{ Hyperfine } & \multirow{2}{*}{$\begin{array}{c}\text { Frequency } \\
\mathrm{MH} z\end{array}$} & \multirow{2}{*}{$\begin{aligned} & \text { Acc. } \\
& \pm \mathrm{MH} \%\end{aligned}$} \\
\hline & & & & $F_{1}^{\prime} \quad F^{\prime}$ & $F_{1} \quad F$ & & \\
\hline $\mathrm{S}^{32} \mathrm{O}_{2}^{16} \mathrm{~F}_{2}^{19}$ & 4-1631 & $3,2,1 \leftarrow 2,2,0$ & Ground & & & 30400.64 & .10 \\
\hline$\left(\mathrm{C}^{12} \mathrm{H}_{3}\right)_{2} \mathrm{~S}^{32}$ & 3- 601 & $7,2,6 \leftarrow 6,3,3$ & Ground & & & 30400.80 & .05 \\
\hline $\mathrm{C}^{12} \mathrm{~F}_{3}^{19} \mathrm{I}^{127}$ & 4- 231 & $10,8 \leftarrow 9,8$ & Ground & $23 / 2$ & $21 / 2$ & 30400.97 & \\
\hline $\mathrm{C}^{12} \mathrm{H}_{3} \mathrm{C}^{12} \mathrm{H}_{2} \mathrm{Br}^{81}$ & 3- 522 & $7,1,6 \leftarrow 7,0,7$ & Ground & $13 / 2$ & $13 / 2$ & 30402.48 & .05 \\
\hline $\mathrm{C}^{12} \mathrm{~F}_{3}^{19} \mathrm{I}^{127}$ & 4- 231 & $10,8 \leftarrow 9,8$ & Ground & $19 / 2$ & $17 / 2$ & 30402.76 & \\
\hline $\mathrm{C}^{12} \mathrm{HCl}^{35} \mathrm{~F}_{2}^{19}$ & 4. 251 & $3,3,0 \leftarrow 3,2,2$ & Ground & & & 30405.68 & .10 \\
\hline $\mathrm{C}^{12} \mathrm{H}_{2}: \mathrm{C}^{12} \mathrm{DBr}^{81}$ & 4- 722 & $4,1,4 \leftarrow 3,1,3$ & Excited & $7 / 2$ & $7 / 2$ & 30408.3 & \\
\hline $\mathrm{HC}^{12}{ }_{*}: \mathrm{C}^{12} \mathrm{HO}^{16} \mathrm{C}^{12} \mathrm{O}^{16} \mathrm{O}^{16}{ }_{*}$ & 4. 931 & $4,1,3 \leftarrow 3,1,2$ & Ground & & & 30409.18 & .10 \\
\hline $\mathrm{C}^{12} \mathrm{HCl}^{35} \mathrm{~F}_{2}^{19}$ & 4. 251 & $3,3,0 \leftarrow 3,2,2$ & Ground & $5 / 2$ & $5 / 2$ & 30409.4 & .05 \\
\hline $\mathrm{C}^{12} \mathrm{~F}_{3}^{19} \mathrm{I}^{127}$ & 4. 231 & $10,5 \leftarrow 9,5$ & Ground & $21 / 2$ & $21 / 2$ & 30412.09 & \\
\hline $\mathrm{S}^{32} \mathrm{O}_{2}^{16} \mathrm{~F}_{2}^{19}$ & 4-1631 & $3,1,2 \leftarrow 2,1,1$ & Ground & & & 30412.33 & .10 \\
\hline $\mathrm{C}^{12} \mathrm{~F}_{3}^{19} \mathrm{I}^{127}$ & 4- 231 & $10,6 \leftarrow 9,6$ & Ground & $21 / 2$ & $19 / 2$ & 30412.64 & \\
\hline $\mathrm{C}^{12} \mathrm{~F}_{3}^{19} \mathrm{I}^{127}$ & 4- 231 & $10,6 \leftarrow 9,6$ & Ground & $19 / 2$ & $19 / 2$ & 30413.84 & \\
\hline $\mathrm{C}^{12} \mathrm{~F}_{3}^{19} \mathrm{I}^{127}$ & 4- 231 & $10, \leftarrow 9$, & Ground & & & 30414.44 & \\
\hline $\mathrm{C}^{12} \mathrm{~F}_{3}^{19} \mathrm{I}^{127}$ & 4- 231 & $10,7 \leftarrow 9,7$ & Ground & $19 / 2$ & $17 / 2$ & 30416.42 & \\
\hline $\mathrm{C}^{12} \mathrm{H}_{3} \mathrm{C}^{12} \mathrm{H}_{2} \mathrm{Br}^{81}$ & 3- 522 & $7,1,6 \leftarrow 7,0,7$ & Ground & $17 / 2$ & $17 / 2$ & 30418.10 & .05 \\
\hline $\mathrm{Ge}^{70} \mathrm{HCl}_{3}^{35}$ & $4-1491$ & $7, \leftarrow 6$ & Ground & & & 30418.73 & .07 \\
\hline $\mathrm{C}^{12} \mathrm{HCl}^{35} \mathrm{~F}_{2}^{19}$ & 4- 251 & $3,3,0 \leftarrow 3,2,2$ & Ground & $7 / 2$ & $7 / 2$ & 30418.9 & .05 \\
\hline $\mathrm{C}^{13} \mathrm{H}_{3} \mathrm{Si}^{28} \mathrm{HF}_{2}^{19} \cdot \mathrm{E}$ & 3- 196 & $3,1,2 \leftarrow 2,1,1$ & Ground & & & 30419.40 & \\
\hline $\mathrm{C}^{13} \mathrm{H}_{3} \mathrm{Si}^{28} \mathrm{HF}_{2}^{19} \cdot \mathrm{A}$ & 3- 195 & $3,1,2 \leftarrow 2,1,1$ & Ground & & & 30420.24 & \\
\hline $\mathrm{C}^{12} \mathrm{~F}_{3}^{19} \mathrm{I}^{127}$ & 4- 231 & $10,7 \leftarrow 9,7$ & Ground & $23 / 2$ & $21 / 2$ & 30420.49 & \\
\hline $\mathrm{C}^{12} \mathrm{~F}_{3}^{19} \mathrm{I}^{127}$ & 4- 231 & $10, \leftarrow 9$, & Ground & & & 30421.04 & \\
\hline $\mathrm{C}^{12} \mathrm{HD}: \mathrm{C}^{12} \mathrm{HBr}^{b}$ & 4- 748 & Not Reported & Ground & & & 30421.6 & .1 \\
\hline $\mathrm{C}^{12} \mathrm{H}_{3} \mathrm{C}^{12} \mathrm{H}_{2} \mathrm{Br}^{81}$ & 3- 522 & $7,1,6 \leftarrow 7,0,7$ & Ground & $11 / 2$ & $11 / 2$ & 30422.02 & .05 \\
\hline $\mathrm{C}^{12} \mathrm{~F}_{3}^{19} \mathrm{I}^{127}$ & 4- 231 & $10, \leftarrow 9$, & Ground & & & 30425.23 & \\
\hline$\left(\mathrm{C}^{13} \mathrm{H}_{3}\right)\left(\mathrm{C}^{12} \mathrm{H}_{3}\right)_{2} \mathrm{C}^{12} \mathrm{H}$ & 3-1004 & $2,1,1 \leftarrow 1,0,1$ & & & & 30426.24 & .10 \\
\hline $\mathrm{C}^{12} \mathrm{~F}_{3}^{19} \mathrm{I}^{127}$ & 4- 231 & $10, \leftarrow 9$ & Ground & & & 30426.25 & \\
\hline $\mathrm{Ge}^{70} \mathrm{HCl}_{3}^{35}$ & 4-1491 & $7, \leftarrow 6$, & Excited & & & 30426.84 & .07 \\
\hline $\mathrm{C}^{12} \mathrm{~F}_{3}^{19} \mathrm{I}^{127}$ & 4- 231 & $10,6 \leftarrow 9,6$ & Ground & $19 / 2$ & $17 / 2$ & 30427.99 & \\
\hline $\mathrm{C}^{12} \mathrm{~F}_{3}^{19} \mathrm{I}^{127}$ & 4- 231 & $10,5 \leftarrow 9,5$ & Ground & $21 / 2$ & $19 / 2$ & 30428.97 & \\
\hline $\mathrm{C}^{12} \mathrm{H}_{2}: \mathrm{C}^{12} \mathrm{DBr}^{81}$ & 4. 722 & $4,1,4 \leftarrow 3,1,3$ & Excited & $11 / 2$ & $9 / 2$ & 30429.5 & \\
\hline $\mathrm{C}^{12} \mathrm{H}_{3} \mathrm{C}^{12} \mathrm{H}_{2} \mathrm{Br}^{79}$ & 3. 521 & $7,1,6 \leftarrow 7,0,7$ & Ground & $17 / 2$ & $15 / 2$ & 30431.79 & .05 \\
\hline $\mathrm{C}^{12} \mathrm{~F}_{3}^{19} \mathrm{I}^{127}$ & 4. 231 & $10,6 \leftarrow 9,6$ & Ground & $21 / 2$ & $21 / 2$ & 30432.06 & \\
\hline $\mathrm{C}^{12} \mathrm{~F}_{3}^{19} \mathrm{I}^{127}$ & 4- 231 & $10,6 \leftarrow 9,6$ & Ground & $17 / 2$ & $17 / 2$ & 30432.06 & \\
\hline $\mathrm{C}^{12} \mathrm{~F}_{3}^{19} \mathrm{I}^{127}$ & 4- 231 & $10, \leftarrow 9$ & Ground & & & 30434.89 & \\
\hline $\mathrm{C}^{12} \mathrm{H}_{2}: \mathrm{C}^{12} \mathrm{DBr}^{81}$ & 4- 722 & $4,1,4 \leftarrow 3,1,3$ & Excited & $5 / 2$ & $3 / 2$ & 30434.9 & \\
\hline $\mathrm{C}^{12} \mathrm{H}_{3} \mathrm{C}^{12}{ }_{*} \mathrm{HO}^{16} \mathrm{C}^{12}{ }_{*} \mathrm{H}_{2}$ & 3. 761 & Not Reported & Ground & & & 30434.95 & .1 \\
\hline $\mathrm{C}^{12} \mathrm{~F}_{3}^{19} \mathrm{I}^{127}$ & 4- 231 & $10,5 \leftarrow 9,5$ & Ground & $23 / 2$ & $21 / 2$ & 30436.24 & \\
\hline $\mathrm{C}^{12} \mathrm{H}_{3} \mathrm{C}^{12} \mathrm{H}_{2} \mathrm{Br}^{79}$ & 3- 521 & $7,1,6 \leftarrow 7,0,7$ & Ground & $15 / 2$ & $13 / 2$ & 30436.59 & .05 \\
\hline $\mathrm{C}^{12} \mathrm{~F}_{3}^{19} \mathrm{I}^{127}$ & 4- 231 & $10, \leftarrow 9$ & Ground & & & 30436.74 & \\
\hline $\mathrm{C}^{12} \mathrm{~F}_{3}^{19} \mathrm{I}^{127}$ & 4- 231 & $10,5 \leftarrow 9,5$ & Ground & $19 / 2$ & $17 / 2$ & 30437.54 & \\
\hline $\mathrm{C}^{12} \mathrm{H}_{3} \mathrm{C}^{12}{ }_{*} \mathrm{HO}^{16} \mathrm{C}^{12}{ }_{*} \mathrm{H}_{2}$ & 3- 761 & Not Reported & Ground & & & 30438.57 & .1 \\
\hline $\mathrm{C}^{12}{ }_{*} \mathrm{H}_{2}^{\mathrm{b}} \mathrm{S}^{\mathrm{b}} \mathrm{C}^{12}{ }_{*} \mathrm{H}_{2}^{\mathrm{b}}$ & 4- 854 & Not Reported & & & & 30439.7 & .2 \\
\hline $\mathrm{Si}^{28} \mathrm{D}_{2} \mathrm{~F}_{2}^{19}$ & $4-1603$ & $5,2,3 \leftarrow 5,1,4$ & Ground & & & 30441.65 & .10 \\
\hline $\mathrm{C}^{12} \mathrm{H}_{2}: \mathrm{C}^{12} \mathrm{DBr}^{81}$ & 4- 722 & $4,1,4 \leftarrow 3,1,3$ & Excited & $9 / 2$ & $7 / 2$ & 30441.8 & \\
\hline
\end{tabular}




\begin{tabular}{|c|c|c|c|c|c|c|c|c|}
\hline \multirow{2}{*}{ Isotopic Species } & \multirow{2}{*}{$\begin{array}{l}\text { Vol.-Id. } \\
\text { Nos. }\end{array}$} & \multirow{2}{*}{$\begin{array}{c}\text { Rotational } \\
\text { Quantum Nos. }\end{array}$} & \multirow{2}{*}{ Vib. State } & \multicolumn{3}{|c|}{ Hyperfine } & \multirow{2}{*}{$\begin{array}{c}\text { Frequency } \\
\mathrm{MHz}\end{array}$} & \multirow{2}{*}{$\begin{aligned} & \text { Acc. } \\
& \pm \mathrm{MHz}\end{aligned}$} \\
\hline & & & & $F_{1}^{\prime}$ & $F^{\prime} \quad F_{1}$ & $\mathbf{F}$ & & \\
\hline $\mathrm{C}^{12} \mathrm{~F}_{3}^{19} \mathrm{I}^{127}$ & 4- 231 & $10,4 \leftarrow 9,4$ & Ground & & $21 / 2$ & $19 / 2$ & 30442.17 & \\
\hline $\mathrm{C}^{12} \mathrm{H}_{2}: \mathrm{C}^{12} \mathrm{DBr}^{81}$ & 4- 722 & $4,1,4 \leftarrow 3,1,3$ & Ground & & $7 / 2$ & $7 / 2$ & 30444.8 & \\
\hline $\mathrm{C}^{12} \mathrm{~F}_{3}^{19} \mathrm{I}^{127}$ & 4- 231 & $10,4 \leftarrow 9,4$ & Ground & & $19 / 2$ & $17 / 2$ & 30445.32 & \\
\hline $\mathrm{C}^{12} \mathrm{H}_{3} \mathrm{~S}^{32} \mathrm{H}$ & 3- 221 & Not Reported & Ground & & & & 30446.3 & \\
\hline $\mathrm{C}^{12} \mathrm{~F}_{3}^{19} \mathrm{I}^{127}$ & 4- 231 & $10, \leftarrow 9$, & Ground & & & & 30446.96 & \\
\hline $\mathrm{C}^{12} \mathrm{~F}_{3}^{19} \mathrm{I}^{127}$ & 4- 231 & $10,5 \leftarrow 9,5$ & Ground & & $23 / 2$ & $21 / 2$ & 30449.49 & \\
\hline $\mathrm{C}^{12} \mathrm{~F}_{3}^{19} \mathrm{I}^{127}$ & 4- 231 & $10,3 \leftarrow 9,3$ & Ground & & $19 / 2$ & $17 / 2$ & 30451.31 & \\
\hline $\mathrm{C}^{12} \mathrm{~F}_{3}^{19} \mathrm{I}^{127}$ & 4- 231 & $10,3 \leftarrow 9,3$ & Ground & & $21 / 2$ & $19 / 2$ & 30452.49 & \\
\hline $\mathrm{C}^{12} \mathrm{H}_{3} \mathrm{I}^{127}$ & 4- 481 & $2,0 \leftarrow 1,0$ & Ground & & $3 / 2$ & $5 / 2$ & 30453.46 & .08 \\
\hline $\mathrm{C}^{12} \mathrm{H}_{3} \mathrm{C}^{12} \mathrm{H}_{2} \mathrm{Br}^{79}$ & 3. 521 & $7,1,6 \leftarrow 7,0,7$ & Ground & & $19 / 2$ & $17 / 2$ & 30455.39 & .05 \\
\hline $\mathrm{C}^{12} \mathrm{~F}_{3}^{19} \mathrm{I}^{127}$ & 4- 231 & $10,2 \leftarrow 9,2$ & Ground & & $19 / 2$ & $17 / 2$ & 30455.46 & \\
\hline $\mathrm{C}^{12} \mathrm{~F}_{3}^{19} \mathrm{I}^{127}$ & 4. 231 & $10,0 \leftarrow 9,0$ & Ground & & $17 / 2$ & $15 / 2$ & 30455.63 & \\
\hline $\mathrm{C}^{12} \mathrm{~F}_{3}^{19} \mathrm{I}^{127}$ & 4. 231 & $10,1 \leftarrow 9,1$ & Ground & & $17 / 2$ & $15 / 2$ & 30456.13 & \\
\hline $\mathrm{C}^{12} \mathrm{~F}_{3}^{19} \mathrm{I}^{127}$ & 4- 231 & $10,2 \leftarrow 9,2$ & Ground & & $17 / 2$ & $15 / 2$ & 30457.42 & \\
\hline $\mathrm{C}^{12} \mathrm{~F}_{3}^{19} \mathrm{I}^{127}$ & 4- 231 & $10,1 \leftarrow 9,1$ & Ground & & $19 / 2$ & $17 / 2$ & 30458.15 & \\
\hline $\mathrm{C}^{12} \mathrm{~F}_{3}^{19} \mathrm{I}^{127}$ & 4. 231 & $10,0 \leftarrow 9,0$ & Ground & & $19 / 2$ & $17 / 2$ & 30459.00 & \\
\hline $\mathrm{C}^{12} \mathrm{~F}_{3}^{19} \mathrm{I}^{127}$ & 4- 231 & $10,7 \leftarrow 9,7$ & Ground & & $21 / 2$ & $21 / 2$ & 30459.00 & \\
\hline $\mathrm{C}^{12} \mathrm{H}_{3} \mathrm{C}^{12}{ }_{*} \mathrm{HO}^{16} \mathrm{C}^{12}{ }_{*} \mathrm{H}_{2}$ & 3- 761 & $31,15, \quad \leftarrow 30,16$ & Ground & & & & 30459.2 & .1 \\
\hline $\mathrm{C}^{12} \mathrm{~F}_{3}^{19} \mathrm{I}^{127}$ & 4- 231 & $10,3 \leftarrow 9,3$ & Ground & & $17 / 2$ & $15 / 2$ & 30459.51 & \\
\hline $\mathrm{C}^{12} \mathrm{~F}_{3}^{19} \mathrm{I}^{127}$ & 4- 231 & $10,0 \leftarrow 9,0$ & Ground & & $15 / 2$ & $13 / 2$ & 30459.51 & \\
\hline $\mathrm{C}^{12} \mathrm{~F}_{3}^{19} \mathrm{I}^{127}$ & 4- 231 & $10,2 \leftarrow 9,2$ & Ground & & $21 / 2$ & $19 / 2$ & 30459.83 & \\
\hline $\mathrm{C}^{12} \mathrm{H}_{3} \mathrm{C}^{12} \mathrm{H}_{2} \mathrm{Br}^{79}$ & 3- 521 & $7,1,6 \leftarrow 7,0,7$ & Ground & & $13 / 2$ & $11 / 2$ & 30460.07 & .05 \\
\hline $\mathrm{C}^{12} \mathrm{~F}_{3}^{19} \mathrm{I}^{127}$ & 4. 231 & $10,4 \leftarrow 9,4$ & Ground & & $23 / 2$ & $21 / 2$ & 30461.76 & \\
\hline $\mathrm{C}^{12} \mathrm{~F}_{3}^{19} \mathrm{I}^{127}$ & 4- 231 & $10,1 \leftarrow 9,1$ & Ground & & $15 / 2$ & $13 / 2$ & 30462.16 & \\
\hline $\mathrm{C}^{12} \mathrm{~F}_{3}^{19} \mathrm{I}^{127}$ & 4- 231 & $10,4 \leftarrow 9,4$ & Ground & & $17 / 2$ & $15 / 2$ & 30462.46 & \\
\hline $\mathrm{C}^{12} \mathrm{~F}_{3}^{19} \mathrm{I}^{127}$ & 4- 231 & $10,1 \leftarrow 9,1$ & Ground & & $21 / 2$ & $19 / 2$ & 30464.26 & \\
\hline $\mathrm{C}^{12} \mathrm{H}_{2}: \mathrm{C}^{12} \mathrm{DBr}^{81}$ & 4- 722 & $4,1,4 \leftarrow 3,1,3$ & Ground & & $11 / 2$ & $9 / 2$ & 30465.6 & \\
\hline $\mathrm{C}^{12} \mathrm{HD}: \mathrm{C}^{12} \mathrm{DBr}^{\mathrm{b}}$ & 4. .749 & Not Reported & Ground & & & & 30465.7 & .1 \\
\hline $\mathrm{C}^{12} \mathrm{~F}_{3}^{19} \mathrm{I}^{127}$ & 4- 231 & $10,0 \leftarrow 9,0$ & Ground & & $21 / 2$ & $19 / 2$ & 30465.76 & \\
\hline $\left.\mathrm{C}^{12} \mathrm{~F}_{3}^{19}\right\rfloor^{127}$ & 4- 231 & $10,5 \leftarrow 9,5$ & Ground & & $17 / 2$ & $15 / 2$ & 30466.29 & \\
\hline $\mathrm{C}^{12} \mathrm{~F}_{3}^{19} \mathrm{I}^{127}$ & 4- 231 & $10, \leftarrow 9$ & Ground & & & & 30467.09 & \\
\hline $\mathrm{C}^{12} \mathrm{~F}_{3}^{19} \mathrm{I}^{127}$ & 4- 231 & $10,2 \leftarrow 9,2$ & Ground & & $15 / 2$ & $13 / 2$ & 30467.72 & \\
\hline $\mathrm{C}^{12} \mathrm{~F}_{3}^{19} \mathrm{I}^{127}$ & 4- 231 & $10,0 \leftarrow 9,0$ & Ground & & $25 / 2$ & $23 / 2$ & 30468.32 & \\
\hline $\mathrm{HC}^{13}: \mathrm{C}^{12} \mathrm{C}^{12} \mathrm{DO}^{16}$ & 4- 922 & Not Reported & & & & & 30469. & 5. \\
\hline $\mathrm{C}^{12} \mathrm{~F}_{3}^{19} \mathrm{I}^{127}$ & 4- 231 & $10,3 \leftarrow 9,3$ & Ground & & $23 / 2$ & $21 / 2$ & 30469.63 & \\
\hline $\mathrm{C}^{12} \mathrm{~F}_{3}^{19} \mathbf{I}^{127}$ & 4. 231 & $10,7 \leftarrow 9,7$ & Ground & & $25 / 2$ & $23 / 2$ & 30470.02 & \\
\hline $\mathrm{C}^{12} \mathrm{H}_{2}: \mathrm{C}^{12} \mathrm{DBr}^{81}$ & 4- 722 & $4,1,4 \leftarrow 3,1,3$ & Ground & & $5 / 2$ & $3 / 2$ & 30470.9 & \\
\hline $\mathrm{C}^{12} \mathrm{~F}_{3}^{19} \mathrm{I}^{127}$ & 4. 231 & $10,6 \leftarrow 9,6$ & Ground & & $17 / 2$ & $15 / 2$ & 30470.95 & \\
\hline $\mathrm{C}^{12} \mathrm{H}_{2}: \mathrm{C}^{12} \mathrm{DBr}^{81}$ & 4. 722 & $4,1,4 \leftarrow 3,1,3$ & Ground & & & & 30471.54 & \\
\hline $\mathrm{C}^{12} \mathrm{~F}_{3}^{19} \mathrm{I}^{127}$ & 4- 231 & $10,2 \leftarrow 9,2$ & Ground & & $25 / 2$ & $23 / 2$ & 30473.55 & \\
\hline $\mathrm{C}^{12} \mathrm{HD}: \mathrm{C}^{12} \mathrm{DBr}^{\mathrm{b}}$ & 4- 749 & Not Reported & Ground & & & & 30475.5 & .1 \\
\hline $\mathrm{C}^{12} \mathrm{H}_{2}: \mathrm{C}^{12} \mathrm{DBr}^{81}$ & 4- 722 & $4,1,4 \leftarrow 3,1,3$ & Ground & & $9 / 2$ & $7 / 2$ & 30475.6 & \\
\hline$\left(\mathrm{C}^{12} \mathrm{H}_{3}\right)_{2} \mathrm{C}^{12}: \mathrm{C}^{12} \mathrm{HD}$ & 3- 944 & $3,0,3 \leftarrow 2,1,2$ & Ground & & & & 30475.68 & \\
\hline $\mathrm{C}^{12} \mathrm{~F}_{3}^{19} \mathrm{I}^{127}$ & 4- 231 & $10,2 \leftarrow 9,2$ & Ground & & $23 / 2$ & $21 / 2$ & 30476.54 & \\
\hline $\mathrm{C}^{12} \mathrm{~F}_{3}^{19} \mathrm{I}^{127}$ & 4- 231 & $10,4 \leftarrow 9,4$ & Ground & & $19 / 2$ & $19 / 2$ & 30476.54 & \\
\hline
\end{tabular}




\begin{tabular}{|c|c|c|c|c|c|c|c|c|}
\hline \multirow{2}{*}{ Isotopic Species } & \multirow{2}{*}{$\begin{array}{l}\text { Vol.-Id. } \\
\text { Nos. }\end{array}$} & \multirow{2}{*}{$\begin{array}{c}\text { Rotational } \\
\text { Quantum Nos. }\end{array}$} & \multirow{2}{*}{ Vib. State } & \multicolumn{3}{|c|}{ Hyperfine } & \multirow{2}{*}{$\begin{array}{l}\text { Frequency } \\
\text { MHz }\end{array}$} & \multirow{2}{*}{$\begin{aligned} & \text { Acc. } \\
\pm & \mathrm{MH}\end{aligned}$} \\
\hline & & & & $F_{1}^{\prime}$ & $F^{\prime} \quad F_{1}$ & $\mathrm{~F}$ & & \\
\hline $\mathrm{C}^{12} \mathrm{~F}_{3}^{19} \mathrm{I}^{127}$ & 4. 231 & $10,6 \leftarrow 9,6$ & Ground & & $15 / 2$ & $15 / 2$ & 30476.54 & \\
\hline $\mathrm{C}^{12} \mathrm{D}_{3} \mathrm{C}^{12} \mathrm{~N}^{15}$ & 4- 821 & $2, \leftarrow 1$, & Ground & & & & 30477.54 & \\
\hline $\mathrm{C}^{12} \mathrm{~F}_{3}^{19} \mathrm{I}^{127}$ & 4- 231 & $10,3 \leftarrow 9,3$ & Ground & & $15 / 2$ & $13 / 2$ & 30477.65 & \\
\hline$C^{12} F_{3}^{19} I^{127}$ & 4- 231 & $10,7 \leftarrow 9,7$ & Ground & & $17 / 2$ & $15 / 2$ & 30477.65 & \\
\hline $\mathrm{C}^{12} \mathrm{~F}_{3}^{19} \mathrm{I}^{127}$ & 4- 231 & $10,0 \leftarrow 9,0$ & Ground & & $23 / 2$ & $21 / 2$ & 30480.14 & \\
\hline $\mathrm{C}^{12} \mathrm{~F}_{3}^{19} \mathbf{I}^{127}$ & 4. 231 & $10,1 \leftarrow 9,1$ & Ground & & $23 / 2$ & $21 / 2$ & 30480.14 & \\
\hline $\mathrm{C}^{12} \mathrm{~F}_{3}^{19} \mathrm{I}^{127}$ & 4- 231 & $10,3 \leftarrow 9,3$ & Ground & & $25 / 2$ & $23 / 2$ & 30480.14 & \\
\hline $\mathrm{C}^{12} \mathrm{HD}: \mathrm{C}^{12} \mathrm{DBr}^{\mathrm{b}}$ & 4. 749 & Not Reported & Ground & & & & 30480.9 & .1 \\
\hline $\mathrm{C}^{12} \mathrm{H}_{2}: \mathrm{C}^{12} \mathrm{DBr}^{81}$ & 4- 722 & $4,1,4 \leftarrow 3,1,3$ & Ground & & $7 / 2$ & $5 / 2$ & 30481.0 & \\
\hline $\mathrm{C}^{12} \mathrm{H}_{3} \mathrm{C}^{12} \mathrm{H}: \mathrm{C}^{12} \mathrm{HF}^{19}$ & 3- 711 & $4,1,3 \leftarrow 3,1,2$ & Ground & & & & 30486.4 & \\
\hline $\mathrm{C}^{12} \mathrm{H}_{3} \mathrm{~S}^{32} \mathrm{H}$ & 3- 221 & Not Reported & Ground & & & & 30487.4 & \\
\hline $\mathrm{C}^{12} \mathrm{~F}_{3}^{19} \mathrm{I}^{127}$ & 4- 231 & $10,9 \leftarrow 9,9$ & Ground & & $17 / 2$ & $15 / 2$ & 30489.17 & \\
\hline $\mathrm{C}^{12} \mathrm{~F}_{3}^{19} \mathrm{I}^{127}$ & 4- 231 & $10,4 \leftarrow 9,4$ & Ground & & $25 / 2$ & $23 / 2$ & 30489.17 & \\
\hline $\mathrm{C}^{12} \mathrm{~F}_{3}^{19} \mathrm{I}^{127}$ & 4- 231 & $10,8 \leftarrow 9,8$ & Ground & & $21 / 2$ & $21 / 2$ & 30489.17 & \\
\hline $\mathrm{HC}^{13}: \mathrm{C}^{12} \mathrm{C}^{12} \mathrm{DO}^{16}$ & 4- 922 & Not Reported & & & & & 30491. & 5. \\
\hline $\mathrm{C}^{12} \mathrm{~F}_{3}^{19} \mathrm{I}^{127}$ & 4- 231 & $10,4 \leftarrow 9,4$ & Ground & & $15 / 2$ & $13 / 2$ & 30491.56 & \\
\hline $\mathrm{C}^{12}{ } \mathrm{H}_{2} \mathrm{~N}^{14} \mathrm{HC}^{12}{ }_{*} \mathrm{H}_{2}$ & 4- 861 & $3,3,1 \leftarrow 3,2,2$ & Ground & & & & 30494.62 & .1 \\
\hline $\mathrm{C}^{12} \mathrm{~F}_{3}^{19} \mathrm{I}^{127}$ & 4. 231 & $10,5 \leftarrow 9,5$ & Ground & & $17 / 2$ & $17 / 2$ & 30500.73 & \\
\hline $\mathrm{C}^{12} \mathrm{~F}_{3}^{19} \mathrm{I}^{127}$ & 4- 231 & $10,3 \leftarrow 9,3$ & Ground & & $19 / 2$ & $19 / 2$ & 30500.73 & \\
\hline $\mathrm{C}^{12} \mathrm{~F}_{3}^{19} \mathrm{I}^{127}$ & 4- 231 & $10,5 \leftarrow 9,5$ & Ground & & $25 / 2$ & $23 / 2$ & 30500.73 & \\
\hline $\mathrm{C}^{13} \mathrm{H}_{3} \mathrm{C}^{12} \mathrm{O}^{16} \mathrm{~F}^{19}$ & 3- 393 & $10,6,4 \leftarrow 10,6,5$ & Ground & & & & 30501.80 & .2 \\
\hline $\mathrm{C}^{12} \mathrm{H}_{2} \mathrm{Cl}_{2}^{37}$ & 4- 343 & $5,1,4 \leftarrow 5,0,5$ & Ground & & & & 30502. & 5. \\
\hline$\left(\mathrm{C}^{12} \mathrm{H}_{3}\right)_{2} \mathrm{O}^{18}$ & 3- 595 & $3,0,3 \leftarrow 2,1,2$ & Ground & & & & 30503.0 & .5 \\
\hline$\left(\mathrm{C}^{12} \mathrm{H}_{3}\right)_{2} \mathrm{C}^{12}: \mathrm{C}^{12} \mathrm{HD}$ & 3. .944 & $2,2,1 \leftarrow 1,1,0$ & Ground & & & & 30503.15 & \\
\hline $\mathrm{C}^{12} \mathrm{D}_{3} \mathrm{O}^{16} \mathrm{D}$ & 3- 216 & Not Reported & & & & & 30505. & \\
\hline g- $\mathrm{C}^{12} \mathrm{H}_{3} \mathrm{C}^{12} \mathrm{H}_{2} \mathrm{C}^{12} \mathrm{H}_{2} \mathrm{Cl}^{35}$ & 3- 773 & $5,0,5 \leftarrow 4,0,4$ & Ground & & & & 30507.94 & .2 \\
\hline $\mathrm{C}^{12} \mathrm{H}_{3} \mathrm{~S}^{32} \mathrm{H}$ & 3- 221 & $14,1,14 \leftarrow 13,2,11$ & Ground & & & & 30508.6 & \\
\hline $\mathrm{Si}^{29} \mathrm{H}_{2} \mathrm{~F}_{2}^{19}$ & 4- 1602 & $5,1,4 \leftarrow 5,0,5$ & Ground & & & & 30509.25 & .10 \\
\hline $\mathrm{C}^{12} \mathrm{~F}_{3}^{19} \mathrm{I}^{127}$ & 4- 231 & $10,6 \leftarrow 9,6$ & Ground & & $23 / 2$ & $23 / 2$ & 30509.58 & \\
\hline $\mathrm{C}^{12} \mathrm{~F}_{3}^{19} \mathrm{I}^{127}$ & 4- 231 & $10,5 \leftarrow 9,5$ & Ground & & $15 / 2$ & $13 / 2$ & 30509.58 & \\
\hline $\mathrm{D}_{2} \mathrm{O}_{2}^{16}$ & 3- 42 & Not Reported & & & & & 30511. & 3. \\
\hline $\mathrm{C}^{12} \mathrm{~F}_{3}^{19} \mathrm{I}^{127}$ & 4- 231 & $10,6 \leftarrow 9,6$ & Ground & & $25 / 2$ & $23 / 2$ & 30514.83 & \\
\hline $\mathrm{C}^{12} \mathrm{~F}_{3}^{19} \mathrm{I}^{127}$ & 4- 231 & $10,2 \leftarrow 9,2$ & Ground & & $19 / 2$ & $19 / 2$ & 30514.83 & \\
\hline $\mathrm{C}^{12} \mathrm{H}_{2}: \mathrm{C}^{12} \mathrm{DBr}^{79}$ & 4. 721 & $4,1,4 \leftarrow 3,1,3$ & Excited & & $5 / 2$ & $5 / 2$ & 30515.7 & \\
\hline $\mathrm{C}^{12} \mathrm{H}_{2} \mathrm{Cl}^{35} \mathrm{Si}^{28} \mathrm{H}_{3}$ & 3- 231 & $5,0,5 \leftarrow 4,0,4$ & Ground & & & & 30517.53 & .2 \\
\hline $\mathrm{C}^{12} \mathrm{H}_{2}: \mathrm{C}^{12} \mathrm{DBr}^{81}$ & 4- 722 & $4,1,4 \leftarrow 3,1,3$ & Excited & & $9 / 2$ & $9 / 2$ & 30517.9 & \\
\hline $\mathrm{C}^{12} \mathrm{H}_{3} \mathrm{C}^{12} \mathrm{O}^{16} \mathrm{O}^{16} \mathrm{H}$ & 3- 491 & $6,3,3 \leftarrow 6,2,4$ & Ground & & & & 30521.46 & \\
\hline $\mathrm{C}^{12} \mathrm{HD}: \mathrm{C}^{12} \mathrm{HBr}^{\mathrm{b}}$ & 4- 748 & Not Reported & Ground & & & & $305 \dot{1} 1.8$ & .1 \\
\hline $\mathrm{HC}^{12} \mathrm{O}^{16} \mathrm{O}^{16} \mathrm{H}$ & 3- 71 & $20,3,17 \leftarrow 20,3,18$ & & & & & 30523.12 & \\
\hline $\mathrm{C}^{12} \mathrm{H}_{3} \mathrm{C}^{12} \mathrm{O}^{16} \mathrm{C}^{13} \mathrm{~N}^{14}$ & 3- 673 & $5,0,5 \leftarrow 4,1,4$ & Ground & & & & 30524.12 & .2 \\
\hline $\mathrm{C}^{12} \mathrm{HD}: \mathrm{C}^{12} \mathrm{HBr}^{\mathrm{b}}$ & 4- 748 & Not Reported & Ground & & & & 30524.5 & .1 \\
\hline $\mathrm{Si}^{28} \mathrm{D}_{2} \mathrm{~F}_{2}^{19}$ & $4-1603$ & $6,2,4 \leftarrow 6,1,5$ & Excited & & & & 30524.85 & .10 \\
\hline $\mathrm{O}_{3}^{16}$ & 4-1841 & $18,2,16 \leftarrow 19,1,19$ & Ground & & & & 30525. & \\
\hline $\mathrm{HC}^{13}: \mathrm{C}^{12} \mathrm{C}^{12} \mathrm{DO}^{16}$ & 4- 922 & Not Reported & & & & & 30525 . & 5. \\
\hline $\mathrm{C}^{12} \mathrm{H}_{3} \mathrm{~N}^{14} \mathrm{O}_{2}^{16}$ & 3- 171 & Not Reported & Ground & & & & 30526.20 & \\
\hline
\end{tabular}




\begin{tabular}{|c|c|c|c|c|c|c|c|}
\hline Isotopic Species & $\begin{array}{l}\text { Vol.-Id. } \\
\text { Nos. }\end{array}$ & $\begin{array}{c}\text { Rotational } \\
\text { Quantum Nos. }\end{array}$ & Vib. State & 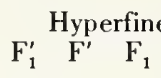 & e $\mathrm{F}$ & $\begin{array}{l}\text { Frequency } \\
\mathrm{MHz}\end{array}$ & $\begin{aligned} & \text { Acc. } \\
\pm & \mathrm{MHz}\end{aligned}$ \\
\hline g. $\mathrm{C}^{12} \mathrm{H}_{3} \mathrm{C}^{12} \mathrm{H}_{2} \mathrm{C}^{12} \mathrm{H}_{2} \mathrm{Cl}^{37}$ & 3. 774 & $5,2,3 \leftarrow 4,2,2$ & Ground & & & 30530.25 & .2 \\
\hline $\mathrm{C}^{12} \mathbf{F}_{3}^{19}{ }^{127}$ & 4. 231 & $10,7 \leftarrow 9,7$ & Ground & $25 / 2$ & $23 / 2$ & 30531.33 & \\
\hline $\mathrm{P}^{31} \mathrm{H}_{3}^{\mathrm{b}}$ & $4-1785$ & Not Reported & & & & 30531.33 & .05 \\
\hline $\mathrm{C}^{12} \mathrm{H}_{3} \mathrm{C}^{12} \mathrm{O}^{18} \mathrm{C}^{12} \mathrm{~N}^{14}$ & 3- 674 & $12,4,8 \leftarrow 12,3,9$ & Ground & & & 30531.92 & .2 \\
\hline $\mathrm{C}^{12} \mathbf{F}_{3}^{19} \mathbf{1}^{127}$ & 4- 231 & $10,6 \leftarrow 9,6$ & Ground & $15 / 2$ & $13 / 2$ & 30532.05 & \\
\hline $\mathrm{C}^{12} \mathrm{DHCl}^{35} \mathrm{Cl}^{37}$ & 4. 345 & $9,1,8 \leftarrow 9,0,9$ & Ground & & & 30535. & 5. \\
\hline $\mathrm{C}^{12} \mathrm{H}_{3} \mathrm{C}^{12} \mathrm{O}^{16} \mathrm{C}^{12} \mathrm{~N}^{14}$ & 3. 671 & $7,1,6 \leftarrow 7,0,7$ & Ground & & & 30537.91 & .2 \\
\hline $\mathrm{C}^{12} \mathrm{H}_{3} \mathrm{C}^{12} \mathrm{H}: \mathrm{C}^{12} \mathrm{HF}^{19}$ & 3- 711 & $4,1,3 \leftarrow 3,1,2$ & Ground & & & 30542.05 & \\
\hline$\left(\mathrm{C}^{12} \mathrm{H}_{3}\right)_{2} \mathrm{~S}^{32}$ & 3- 601 & $3,0,3 \leftarrow 2,1,2$ & Ground & & & 30542.49 & .05 \\
\hline$\left(\mathrm{C}^{12} \mathrm{H}_{3}\right)_{2} \mathrm{~S}^{32}$ & 3- 601 & $3,0,3 \leftarrow 2,1,2$ & Ground & & & 30542.60 & .05 \\
\hline$\left(\mathrm{C}^{12} \mathrm{H}_{3}\right)_{2} \mathrm{~S}^{32}$ & 3- 601 & $3,0,3 \leftarrow 2,1,2$ & Ground & & & 30542.70 & .05 \\
\hline$\left(\mathrm{C}^{12} \mathrm{H}_{3}\right)_{2} \mathrm{C}^{12}: \mathrm{C}^{12} \mathrm{HD}$ & 3. 944 & $3,1,3 \leftarrow 2,0,2$ & Ground & & & 30542.80 & \\
\hline $\mathrm{C}^{12} \mathrm{H}_{3} \mathrm{C}^{12} \mathrm{O}^{16} \mathrm{C}^{12} \mathrm{~N}^{14}$ & 3- 671 & $7,1,6 \leftarrow 7,0,7$ & Ground & & & 30545.52 & .2 \\
\hline $\mathrm{F}^{19} \mathrm{Cl}^{35}$ & $1-$ & $1 \leftarrow 0$ & Excited & $3 / 2$ & $3 / 2$ & 30545.994 & 0.069 \\
\hline $\mathrm{Si}^{28} \mathrm{H}_{2} \mathrm{~F}_{2}^{19}$ & $4-1601$ & $5,1,4 \leftarrow 5,0,5$ & Ground & & & 30548.92 & .10 \\
\hline $\mathrm{s} \cdot \mathrm{C}^{12} \mathrm{HD}_{2} \mathrm{C}^{12} \mathrm{O}^{16} \mathrm{~F}^{19}$ & 3- 395 & $8,4,4 \leftarrow 8,4,5$ & Ground & & & 30549.9 & .2 \\
\hline $\mathrm{C}^{12} \mathrm{H}_{2}: \mathrm{C}^{12} \mathrm{DBr}^{79}$ & 4- 721 & $4,1,4 \leftarrow 3,1,3$ & Ground & $5 / 2$ & $5 / 2$ & 30550.2 & \\
\hline $\mathrm{C}^{12} \mathrm{H}_{2}: \mathrm{C}^{12} \mathrm{DBr}^{81}$ & 4- 722 & $4,1,4 \leftarrow 3,1,3$ & Ground & $9 / 2$ & $9 / 2$ & 30553.8 & \\
\hline c- $\mathrm{C}^{12} \mathrm{H}_{3} \mathrm{C}^{12} \mathrm{H}: \mathrm{C}^{12} \mathrm{HF}^{19}-\mathrm{A}$ & 3. 701 & $3,2,1 \leftarrow 2,2,0$ & & & & 30555.37 & .2 \\
\hline $\mathrm{C}^{12}{ }_{*} \mathrm{H}_{2}^{\prime \prime} \mathrm{S}^{11} \mathrm{C}^{12}{ }_{*} \mathrm{H}_{2}^{\prime \prime}$ & 4- 854 & Not Reported & & & & 30560.3 & .3 \\
\hline $\mathrm{C}^{12} \mathrm{D}_{3} \mathrm{C}^{12} \mathrm{~N}^{15}$ & 4. 821 & $2, \leftarrow 1$ & Excited & & & 30563.8 & \\
\hline $\mathrm{C}^{12} \mathrm{H}_{3} \mathrm{~N}^{14} \mathrm{H}_{2}$ & 3- 261 & Not Reported & Ground & & & 30564.89 & \\
\hline $\mathrm{C}^{12} \mathrm{H}_{3} \mathrm{~N}^{14} \mathrm{H}_{2}$ & 3- 261 & $21,5, \leftarrow 20,6$, & Ground & & & 30565. & \\
\hline $\mathrm{C}^{12} \mathrm{H}_{3} \mathrm{~N}^{14} \mathrm{H}_{2}$ & 3. 261 & $4,2, \leftarrow 5,1$, & Ground & & & 30565.9 & \\
\hline $\mathrm{C}^{12} \mathrm{H}_{3} \mathrm{~N}^{14} \mathrm{H}_{2}$ & 3- 261 & $21,5, \leftarrow 20,6$, & Ground & & & 30566. & \\
\hline $\mathrm{C}^{12} \mathrm{H}_{3} \mathrm{~N}^{14} \mathrm{H}_{2}$ & 3- 261 & Not Reported & Ground & & & 30566.42 & \\
\hline $\mathrm{C}^{12} \mathrm{H}_{3} \mathrm{Si}^{28} \mathrm{Cl}_{3}^{37}$ & 3- 112 & $9, \leftarrow 8$ & Excited & & & 30569.09 & .5 \\
\hline $\mathrm{F}_{2}^{19} \mathrm{~N}^{14} \mathrm{~N}^{14} \mathrm{~F}_{2}^{19}$ & 3- 21 & $20,6,14 \leftarrow 20,5,16$ & Ground & & & 30572.0 & .3 \\
\hline $\mathrm{C}^{12} \mathrm{H}_{2}: \mathrm{C}^{12} \mathrm{DBr}^{79}$ & 4- 721 & $4,1,4 \leftarrow 3,1,3$ & Excited & $7 / 2$ & $7 / 2$ & 30576.1 & \\
\hline $\mathrm{C}^{13} \mathrm{H}_{3} \mathrm{C}^{12} \mathrm{O}^{16} \mathrm{~F}^{19}$ & 3- 393 & $10,6,4 \leftarrow 10,6,5$ & Ground & & & 30577.20 & .2 \\
\hline $\mathrm{Li}^{6} \mathrm{I}^{127}$ & 1 - & $1 \leftarrow 0$ & Ground & $5 / 2$ & $5 / 2$ & 30578.28 & 0.10 \\
\hline $\mathrm{C}^{\mathrm{b}} \mathrm{H}_{2}^{\mathrm{b}} \mathrm{Cl}^{\mathrm{b}} \mathrm{F}^{\mathrm{b}}$ & 4- 333 & Not Reported & & & & 30580.73 & .1 \\
\hline $\mathrm{C}^{13} \mathrm{H}_{2} \mathrm{Cl}^{35} \mathrm{Si}^{28} \mathrm{H}_{3}$ & 3- 233 & $5,0,5 \leftarrow 4,0,4$ & Ground & & & 30582.3 & .1 \\
\hline $\mathrm{C}^{13} \mathrm{H}_{2} \mathrm{Cl}^{35} \mathrm{Si}^{28} \mathrm{H}_{3}$ & 3. 233 & $5,0,5 \leftarrow 4,0,4$ & Ground & & & 30582.35 & .2 \\
\hline $\mathrm{F}^{19} \mathrm{Cl}^{35}$ & $1-$ & $1 \leftarrow 0$ & Excited & $5 / 2$ & $3 / 2$ & 30582.614 & 0.069 \\
\hline $\mathrm{D}_{2} \mathrm{C}^{12}: \mathrm{C}^{12} \mathrm{DCl}^{37}$ & 4- 765 & $3,1,2 \leftarrow 2,1,1$ & Ground & & & 30593.66 & \\
\hline $\mathrm{C}^{12} \mathrm{H}_{3} \mathrm{C}^{12} \mathrm{H}: \mathrm{C}^{12} \mathrm{HF}^{19}$ & 3. 711 & $4,1,3 \leftarrow 3,1,2$ & Ground & & & 30596.0 & \\
\hline $\mathrm{D}_{2} \mathrm{C}^{12}: \mathrm{C}^{12} \mathrm{DCl}^{37}$ & 4. 765 & $3,1,2 \leftarrow 2,1,1$ & Ground & & & 30596.50 & \\
\hline c- $\mathrm{C}^{12} \mathrm{HD}: \mathrm{C}^{12} \mathrm{HBr}^{\mathrm{k}}$ & 4- 742 & $4,3,2 \leftarrow 3,3,1$ & Ground & $5 / 2$ & $3 / 2$ & 30598.9 & \\
\hline $\mathrm{H}_{2}^{\prime \prime} \mathrm{C}^{\prime \prime}: \mathrm{C}^{\prime \prime} \mathrm{H}^{\prime \prime} \mathrm{Cl}^{\prime \prime}$ & 4. 772 & Not Reported & Ground & & & 30599.32 & \\
\hline $\mathrm{C}^{12} \mathrm{D}_{3} \mathrm{O}^{16} \mathrm{D}$ & 3. 216 & Not Reported & & & & 30600. & \\
\hline $\mathrm{C}^{12} \mathrm{H}_{2}: \mathrm{C}^{12} \mathrm{DBr}^{79}$ & 4- 721 & $4,1,4 \leftarrow 3,1,3$ & Excited & $11 / 2$ & $9 / 2$ & 30600.9 & \\
\hline $\mathrm{C}^{12} \mathrm{H}_{2} \mathrm{Cl}^{37} \mathrm{Si}^{28} \mathrm{H}_{3}$ & 3- 232 & $5,1,4 \leftarrow 4,1,3$ & Ground & & & 30601.08 & .2 \\
\hline $\mathrm{a}-\left(\mathrm{C}^{12} \mathrm{H}_{2} \mathrm{D}\right)\left(\mathrm{C}^{12} \mathrm{H}_{3}\right)_{2} \mathrm{C}^{12} \mathrm{H}$ & $3 \cdot 1006$ & $2,2,1 \leftarrow 1,1,1$ & & & & 30607.11 & .05 \\
\hline $\mathrm{C}^{12} \mathrm{H}_{3} \mathrm{C}^{12} \mathrm{O}^{16} \mathrm{C}^{12} \mathrm{~N}^{14}$ & 3. 671 & $4,1,3 \leftarrow 3,1,2$ & Ground & & & 30608.53 & .2 \\
\hline
\end{tabular}




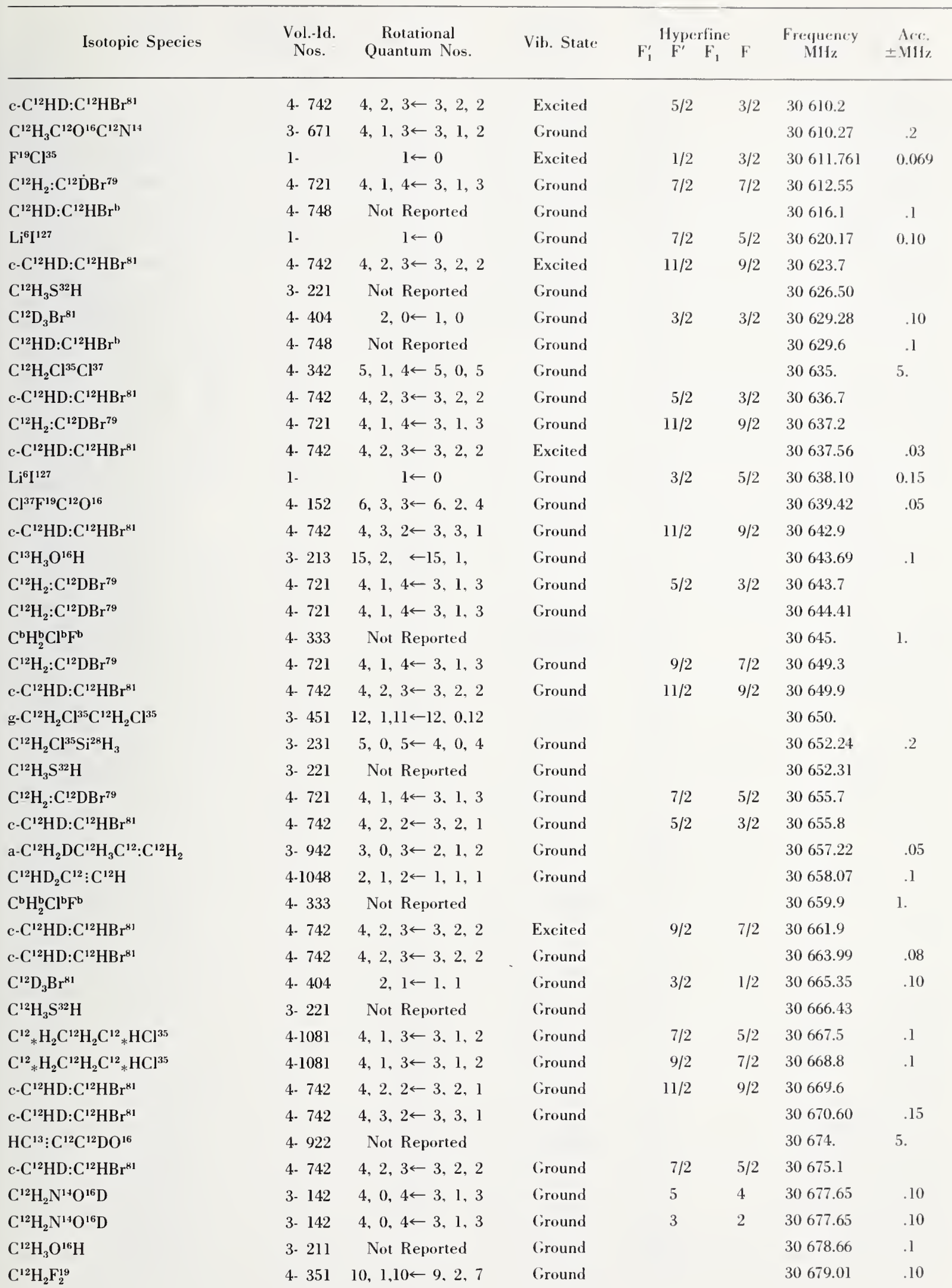




\begin{tabular}{|c|c|c|c|c|c|c|c|}
\hline Isotopic Species & $\begin{array}{l}\text { Vol.-Id. } \\
\text { Nos. }\end{array}$ & $\begin{array}{c}\text { Rotational } \\
\text { Quantum Nos. }\end{array}$ & Vib. State & $\mathrm{F}_{1} \begin{array}{r}\text { Hyperfin } \\
\mathrm{F}^{\prime}\end{array}$ & $F$ & $\begin{array}{c}\text { Frequency } \\
\mathrm{MHz}\end{array}$ & $\begin{aligned} & \text { Acc. } \\
& \pm \mathrm{MHz}\end{aligned}$ \\
\hline $\mathrm{C}^{12} \mathrm{H}_{2} \mathrm{~N}^{14} \mathrm{O}^{16} \mathrm{D}$ & 3. 142 & $4,0,4 \leftarrow 3,1,3$ & Ground & 4 & 3 & 30679.05 & .10 \\
\hline$\left(\mathrm{C}^{13} \mathrm{H}_{3}\right)\left(\mathrm{C}^{12} \mathrm{H}_{3}\right)_{2} \mathrm{C}^{12} \mathrm{H}$ & $3-1004$ & $2,2,0 \leftarrow 1,1,0$ & & & & 30682.00 & .10 \\
\hline c- $\mathrm{C}^{12} \mathrm{HD}: \mathrm{C}^{12} \mathrm{HBr}^{81}$ & 4. 742 & $4,2,2 \leftarrow 3,2,1$ & Ground & & & 30683.39 & .06 \\
\hline c- $\mathrm{C}^{12} \mathrm{HD}: \mathrm{C}^{12} \mathrm{HBr}^{81}$ & 4- 742 & $4,3,2 \leftarrow 3,3,1$ & Ground & $7 / 2$ & $5 / 2$ & 30684.6 & \\
\hline $\mathrm{C}^{12} \mathrm{HD}: \mathrm{C}^{12} \mathrm{DBr}{ }^{b}$ & 4- 749 & Not Reported & Ground & & & 30684.9 & .1 \\
\hline c- $\mathrm{C}^{12} \mathrm{HD}: \mathrm{C}^{12} \mathrm{HBr}^{81}$ & 4. 742 & $4,2,3 \leftarrow 3,2,2$ & Ground & $9 / 2$ & $7 / 2$ & 30688.3 & \\
\hline $\mathrm{C}^{12} \mathrm{HD}: \mathrm{C}^{12} \mathrm{DBr}^{b}$ & 4. 749 & Not Reported & Ground & & & 30688.4 & .1 \\
\hline $\mathrm{C}^{12} \mathrm{H}_{3} \mathrm{O}^{16} \mathrm{H}$ & 3- 211 & Not Reported & Ground & & & 30693.42 & .1 \\
\hline $\mathrm{C}^{12} \mathrm{HD}: \mathrm{C}^{12} \mathrm{DBr} \mathrm{r}^{1}$ & 4- 749 & Not Reported & Ground & & & 30694.5 & .1 \\
\hline c- $\mathrm{C}^{12} \mathrm{HD}: \mathrm{C}^{12} \mathrm{HBr}^{81}$ & 4- 742 & $4,2,2 \leftarrow 3,2,1$ & Ground & $7 / 2$ & $5 / 2$ & 30694.5 & \\
\hline $\mathrm{C}^{12} \mathrm{D}_{3} \mathrm{Br}^{81}$ & 4. 404 & $2,1 \leftarrow 1,1$ & Ground & $7 / 2$ & $5 / 2$ & 30695.83 & .10 \\
\hline $\mathrm{C}^{12} \mathrm{H}_{3} \mathrm{C}^{13} \mathrm{O}^{16} \mathrm{Cl}^{35}$ & 3- 369 & $10,3,7 \leftarrow 10,2,8$ & Ground & $19 / 2$ & $19 / 2$ & 30696.01 & .2 \\
\hline $\mathrm{C}^{12} \mathrm{H}_{3} \mathrm{C}^{13} \mathrm{O}^{16} \mathrm{Cl}^{35}$ & 3- 369 & $10,3,7 \leftarrow 10,2,8$ & Ground & $21 / 2$ & $21 / 2$ & 30696.01 & .2 \\
\hline $\mathrm{C}^{12} \mathrm{H}_{3} \mathrm{C}^{13} \mathrm{O}^{16} \mathrm{Cl}^{35}$ & 3. 369 & $10,3,7 \leftarrow 10,2,8$ & Ground & $23 / 2$ & $23 / 2$ & 30697.15 & .2 \\
\hline $\mathrm{C}^{12} \mathrm{H} \mathrm{C}^{13} \mathrm{O}^{16} \mathrm{Cl}^{35}$ & 3- 369 & $10,3,7 \leftarrow 10,2,8$ & Ground & $17 / 2$ & $17 / 2$ & 30697.15 & .2 \\
\hline $\mathrm{HC}^{13}: \mathrm{C}^{12} \mathrm{C}^{12} \mathrm{DO}^{16}$ & 4- 922 & Not Reported & & & & 30699 . & 5. \\
\hline $\mathrm{C}^{12} \mathrm{HD}: \mathrm{C}^{12} \mathrm{HBr}^{13}$ & 4- 748 & Not Reported & Ground & & & 30702.05 & .05 \\
\hline $\mathrm{C}^{12} \mathrm{H}_{3} \mathrm{C}^{13} \mathrm{O}^{16} \mathrm{Cl}^{35}$ & 3. 369 & $10,3,7 \leftarrow 10,2,8$ & Ground & $21 / 2$ & $21 / 2$ & 30702.86 & .2 \\
\hline $\mathrm{C}^{12} \mathrm{H}_{3} \mathrm{C}^{13} \mathrm{O}^{16} \mathrm{Cl}^{35}$ & 3. 369 & $10,3,7 \leftarrow 10,2,8$ & Ground & $19 / 2$ & $19 / 2$ & 30702.86 & .2 \\
\hline $\mathrm{C}^{12} \mathrm{H}_{3} \mathrm{C}^{13} \mathrm{O}^{16} \mathrm{Cl}^{35}$ & 3. 369 & $10,3,7 \leftarrow 10,2,8$ & Ground & $23 / 2$ & $23 / 2$ & 30703.99 & .2 \\
\hline $\mathrm{C}^{12} \mathrm{H}_{3} \mathrm{C}^{13} \mathrm{O}^{16} \mathrm{Cl}^{35}$ & 3. 369 & $10,3,7 \leftarrow 10,2,8$ & Ground & $17 / 2$ & $17 / 2$ & 30703.99 & .2 \\
\hline $\mathrm{HC}^{13}: \mathrm{C}^{12} \mathrm{C}^{12} \mathrm{DO}^{16}$ & 4- 922 & Not Reported & & & & 30705 . & 5. \\
\hline c. $\mathrm{C}^{12} \mathrm{HD}: \mathrm{C}^{12} \mathrm{HBr}^{\mathrm{\gamma}}$ & 4. 742 & $4,2,2 \leftarrow 3,2,1$ & Ground & $9 / 2$ & $7 / 2$ & 30707.9 & \\
\hline $\mathrm{C}^{12} \mathrm{D}_{3} \mathrm{Br}^{81}$ & 4- 404 & $2,0 \leftarrow 1,0$ & Ground & $5 / 2$ & $3 / 2$ & 30714.74 & .10 \\
\hline $\mathrm{C}^{12} \mathrm{D}_{3} \mathrm{Br}^{81}$ & 4. 404 & $2,0 \leftarrow 1,0$ & Ground & $7 / 2$ & $5 / 2$ & 30714.74 & .10 \\
\hline t-C $\mathrm{C}^{12} \mathrm{HD}: \mathrm{C}^{12} \mathrm{DBr}^{81}$ & 4- 747 & $4,1,3 \leftarrow 3,1,2$ & Ground & $5 / 2$ & $5 / 2$ & 30717.2 & \\
\hline e- $\mathrm{C}^{12} \mathrm{HD}: \mathrm{C}^{12} \mathrm{HBr}^{81}$ & 4- 742 & $4,3,2 \leftarrow 3,3,1$ & Ground & $5 / 2$ & $5 / 2$ & 30718.9 & \\
\hline $\mathrm{C}^{12} \mathrm{H}_{3} \mathrm{~N}^{14} \mathrm{H}_{2}$ & 3- 261 & Not Reported & Ground & & & 30721.3 & \\
\hline $\mathrm{C}^{12} \mathrm{D}_{3} \mathrm{Br}^{81}$ & 4- 404 & $2,0 \leftarrow 1,0$ & Ground & $1 / 2$ & $1 / 2$ & 30724.89 & .10 \\
\hline$c-\mathrm{C}^{12} \mathrm{HD}: \mathrm{C}^{12} \mathrm{HBr}^{\mathrm{r}}$ & 4- 742 & $4,3,2 \leftarrow 3,3,1$ & Ground & $9 / 2$ & $7 / 2$ & 30728.9 & \\
\hline $\mathrm{D}_{2} \mathrm{O}_{2}^{16 i}$ & $3-\quad 42$ & Not Reported & & & & 30739 . & 3. \\
\hline $\mathrm{C}^{12} \mathrm{H}_{3} \mathrm{~S}^{32} \mathrm{H}$ & 3. 221 & $12,1,11 \leftarrow 11,2,10$ & Ground & & & 30741.8 & \\
\hline $\mathrm{C}^{12} \mathrm{H}_{2}: \mathrm{C}^{12} \mathrm{DBr}^{79}$ & 4- 721 & $4,1,4 \leftarrow 3,1,3$ & Ground & $9 / 2$ & $9 / 2$ & 30742.8 & \\
\hline $\mathrm{C}^{12} \mathrm{D}_{3} \mathrm{Br}^{79}$ & 4- 403 & $2,0 \leftarrow 1,0$ & Ground & $3 / 2$ & $3 / 2$ & 30743.99 & .10 \\
\hline $\mathrm{C}^{12} \mathrm{H}_{3} \mathrm{O}^{16} \mathrm{H}$ & 3- 211 & $22,2, \leftarrow 22,1$, & Ground & & & 30752.26 & .1 \\
\hline $\mathrm{C}^{12} \mathrm{H}_{2}: \mathrm{C}^{12} \mathrm{HC}^{12} \mathrm{~F}^{19}: \mathrm{C}^{12} \mathrm{H}_{2}$ & 3. 911 & $11,3,8 \leftarrow 11,2,9$ & Ground & & & 30754.10 & .03 \\
\hline $\mathrm{C}^{12} \mathrm{H}_{33} \mathrm{~N}^{14} \mathrm{O}_{2}^{16}$ & 3. 171 & Not Reported & Ground & & & 30754.75 & \\
\hline $\mathrm{C}^{12} \mathrm{D}_{3} \mathrm{Br}^{41}$ & 4. 404 & $2,1 \leftarrow 1,1$ & Ground & $5 / 2$ & $5 / 2$ & 30756.12 & .10 \\
\hline $\mathrm{a}-\mathrm{C}^{12} \mathrm{H}_{2} \mathrm{DC}^{12} \mathrm{O}^{16} \mathrm{~F}^{19}$ & 3. 398 & $5,2,3 \leftarrow 5,2,4$ & Ground & & & 30757.31 & .2 \\
\hline $\mathrm{a}-\mathrm{C}^{12} \mathrm{H}_{2} \mathrm{DC}^{12} \mathrm{O}^{16} \mathrm{~F}^{19}$ & 3- 398 & $5,2,3 \leftarrow 5,2,4$ & Ground & & & 30758.58 & .2 \\
\hline $\mathrm{C}^{12} \mathrm{H}_{3} \mathrm{C}^{12} \mathrm{O}^{16} \mathrm{C}^{12} \mathrm{~N}^{14}$ & 3- 671 & $5,0,5 \leftarrow 4,1,4$ & Ground & & & 30759.12 & .2 \\
\hline $\mathrm{s}-\mathrm{C}^{12} \mathrm{H}_{2} \mathrm{DC}^{12} \mathrm{H}_{3} \mathrm{C}^{12}: \mathrm{C}^{12} \mathrm{H}_{2}$ & 3- 943 & $3,1,3 \leftarrow 2,0,2$ & Ground & & & 30759.55 & .05 \\
\hline $\mathrm{t}-\mathrm{C}^{12} \mathrm{HD}: \mathrm{C}^{12} \mathrm{DBr} \mathrm{r}^{81}$ & 4. 747 & $4,1,3 \leftarrow 3,1,2$ & Excited & $11 / 2$ & $9 / 2$ & 30759.9 & \\
\hline $\mathrm{C}^{12}{ }_{*} \mathrm{H}_{2}^{\mathrm{l}} \mathrm{S}^{\mathrm{l}} \mathrm{C}^{12}{ }_{*} \mathrm{H}_{2}^{\mathrm{b}}$ & 4. 854 & Not Reported & & & & 30762.0 & 1. \\
\hline c. $\mathrm{C}^{12} \mathrm{HD}: \mathrm{C}^{12} \mathrm{HBr}^{74}$ & 4- 739 & $4,3,2 \leftarrow 3,3,1$ & Ground & $5 / 2$ & $3 / 2$ & 30762.6 & \\
\hline
\end{tabular}




\begin{tabular}{|c|c|c|c|c|c|c|c|}
\hline$\left(\mathrm{C}^{12} \mathrm{H}_{3}\right)_{3} \mathrm{Si}^{28} \mathrm{Cl}^{35}$ & 3. 821 & $7, \leftarrow 6$, & Ground & & & 30762.89 & .2 \\
\hline $\mathrm{t}-\mathrm{C}^{12} \mathrm{HD}: \mathrm{C}^{12} \mathrm{DBr}^{81}$ & 4. 747 & $4,1,3 \leftarrow 3,1,2$ & Ground & $7 / 2$ & $7 / 2$ & 30763.4 & \\
\hline $\mathrm{C}^{\prime \prime}{ }_{*} \mathrm{H}_{2}^{\mathrm{l}} \mathrm{N}^{\prime \prime} \mathrm{H}^{\prime \prime} \mathrm{C}^{\prime \prime}{ }_{*} \mathrm{H}_{2}^{b}$ & 4- 863 & Not Reported & & & & 3076.5 & 10. \\
\hline $\mathrm{t}-\mathrm{C}^{12} \mathrm{HD}: \mathrm{C}^{12} \mathrm{DBr}^{81}$ & 4. 747 & $4,1,3 \leftarrow 3,1,2$ & Excited & $5 / 2$ & $3 / 2$ & 30765.4 & \\
\hline $\mathrm{t}-\mathrm{C}^{12} \mathrm{HD}: \mathrm{C}^{12} \mathrm{DBr}^{81}$ & 4. 747 & $4,1,3 \leftarrow 3,1,2$ & Excited & & & 30765.91 & .63 \\
\hline $\mathrm{C}^{12} \mathrm{H}_{3} \mathrm{~N}^{14} \mathrm{O}_{2}^{16}$ & 3. 171 & Not Reported & Ground & & & 30768.28 & \\
\hline $\mathrm{C}^{12} \mathrm{H}_{2} \mathrm{Cl}_{2}^{35}$ & 4. 341 & $5,1,4 \leftarrow 5,0,5$ & Ground & & & 30769. & 5. \\
\hline $\mathrm{t}-\mathrm{C}^{12} \mathrm{HD}: \mathrm{C}^{12} \mathrm{DBr}^{81}$ & 4. 747 & $4,1,3 \leftarrow 3,1,2$ & Excited & $9 / 2$ & $7 / 2$ & 30770.5 & \\
\hline $\mathrm{H}_{2}^{\mathrm{b}} \mathrm{C}^{\mathrm{h}}: \mathrm{C}^{\mathrm{h}} \mathrm{H}^{\mathrm{h}} \mathrm{Cl}^{\mathrm{h}}$ & 4. 772 & Not Reported & Ground & & & 30770.90 & \\
\hline $\mathrm{C}^{12} \mathrm{HD}: \mathrm{C}^{12} \mathrm{HBr}^{11}$ & 4- 748 & Not Reported & Ground & & & 30771.9 & .1 \\
\hline $\mathrm{C}^{12} \mathrm{D}_{3} \mathrm{Br}^{81}$ & 4- 404 & $2,1 \leftarrow 1,1$ & Ground & $3 / 2$ & $3 / 2$ & 30773.17 & .10 \\
\hline $\mathrm{H}_{2}^{\mathrm{b}} \mathrm{C}^{\mathrm{l}}: \mathrm{C}^{\mathrm{l}} \mathrm{H}^{\mathrm{l}} \mathrm{Cl}^{\mathrm{l}}$ & 4. 772 & Not Reported & Ground & & & 30773.62 & \\
\hline $\mathrm{t}-\mathrm{C}^{12} \mathrm{HD}: \mathrm{C}^{12} \mathrm{DBr}^{81}$ & 4. 747 & $4,1,3 \leftarrow 3,1,2$ & Excited & $7 / 2$ & $5 / 2$ & 30773.7 & \\
\hline $\mathrm{C}^{12} \mathrm{D}_{2} \mathrm{Cl}^{35} \mathrm{Si}^{28} \mathrm{H}_{3}$ & 3- 235 & $5,1,4 \leftarrow 4,1,3$ & Ground & & & 30779.07 & .2 \\
\hline $\mathrm{C}^{13} \mathrm{D}_{3} \mathrm{C}^{12} \mathrm{~N}^{14}$ & 4. 819 & $2, \leftarrow 1$ & Ground & & & 30780.90 & \\
\hline $\mathrm{t} \cdot \mathrm{C}^{12} \mathrm{HD}: \mathrm{C}^{12} \mathrm{DBr}^{81}$ & 4- 747 & $4,1,3 \leftarrow 3,1,2$ & Ground & $11 / 2$ & $9 / 2$ & 30781.4 & \\
\hline $\mathrm{c} \cdot \mathrm{C}^{12} \mathrm{HD}: \mathrm{C}^{12} \mathrm{HBr}^{79}$ & 4- 739 & $4,2,3 \leftarrow 3,2,2$ & Excited & $5 / 2$ & $3 / 2$ & 30782.6 & \\
\hline $\mathrm{C}^{12} \mathrm{H}_{3} \mathrm{~N}^{14} \mathrm{O}_{2}^{16}$ & 3- 171 & Not Reported & Ground & & & 30784.13 & \\
\hline $\mathrm{t}-\mathrm{C}^{12} \mathrm{HD}: \mathrm{C}^{12} \mathrm{DBr}^{81}$ & 4- 747 & $4,1,3 \leftarrow 3,1,2$ & Ground & $5 / 2$ & $3 / 2$ & 30786.9 & \\
\hline $\mathrm{t}-\mathrm{C}^{12} \mathrm{HD}: \mathrm{C}^{12} \mathrm{DBr}^{81}$ & 4- 747 & $4,1,3 \leftarrow 3,1,2$ & Ground & & & 30787.25 & .24 \\
\hline $\mathrm{C}^{12} \mathrm{HD}: \mathrm{C}^{12} \mathrm{HBr}^{\mathrm{h}}$ & 4- 748 & Not Reported & Ground & & & 30788.6 & .1 \\
\hline $\mathrm{D}_{2} \mathrm{O}_{2}^{16}$ & 3- 42 & Not Reported & & & & 30791. & 3. \\
\hline $\mathrm{t}-\mathrm{C}^{12} \mathrm{HD} ; \mathrm{C}^{12} \mathrm{DBr}^{81}$ & 4. 747 & $4,1,3 \leftarrow 3,1,2$ & Ground & $9 / 2$ & $7 / 2$ & 30791.9 & \\
\hline $\mathrm{C}^{12} \mathrm{HD}_{2} \mathrm{C}^{12}: \mathrm{C}^{12} \mathrm{H}$ & 4-1048 & $2,0,2 \leftarrow 1,0,1$ & Ground & & & 30793.13 & .1 \\
\hline t- $\mathrm{C}^{12} \mathrm{HD}: \mathrm{C}^{12} \mathrm{DBr}^{81}$ & 4- 747 & $4,1,3 \leftarrow 3,1,2$ & Ground & $7 / 2$ & $5 / 2$ & 30795.05 & \\
\hline $\mathrm{C}^{12} \mathrm{H}_{3} \mathrm{~N}^{14} \mathrm{O}_{2}^{16}$ & 3- 171 & Not Reported & Ground & & & 30795.32 & \\
\hline $\mathrm{Si}^{2 \times} \mathrm{D}_{2} \mathrm{~F}_{2}^{19}$ & $4-1603$ & $5,2,3 \leftarrow 5,1,4$ & Excited & & & 30796.10 & .10 \\
\hline$c-\mathrm{C}^{12} \mathrm{HD}: \mathrm{C}^{12} \mathrm{HBr}^{79}$ & 4- 739 & $4,2,3 \leftarrow 3,2,2$ & Excited & $11 / 2$ & $9 / 2$ & 30798.75 & \\
\hline $\mathrm{HC}^{\mathrm{i3}}: \mathrm{C}^{12} \mathrm{C}^{12} \mathrm{DO}^{16}$ & 4. 922 & Not Reported & & & & 30800 & 5. \\
\hline $\mathrm{C}^{12} \mathrm{D}_{3} \mathrm{C}^{12} \mathrm{O}^{16} \mathrm{O}^{16} \mathrm{H}$ & 3- 492 & $7,3,4 \leftarrow 7,2,5$ & Ground & & & 30800.79 & \\
\hline $\mathrm{C}^{12} \mathrm{H}_{3} \mathrm{C}^{12} \mathrm{H}_{2} \mathrm{~F}^{19}$ & 3- 551 & $3,1,2 \leftarrow 3,0,3$ & Ground & & & 30802.1 & \\
\hline $\mathrm{a}-\mathrm{C}^{12} \mathrm{H}_{2} \mathrm{DC}^{12} \mathrm{H}_{3} \mathrm{C}^{12}: \mathrm{C}^{12} \mathrm{H}_{2}$ & 3- 942 & $3,1,3 \leftarrow 2,0,2$ & Ground & & & 30803.61 & .05 \\
\hline $\mathrm{HDC}^{12}: \mathrm{C}^{12} \mathrm{~F}_{2}^{19}$ & 4. 682 & $7,4,3 \leftarrow 7,4,4$ & Ground & & & 30804.8 & .3 \\
\hline$\left(\mathrm{C}^{12} \mathrm{H}_{3}\right)_{2} \mathrm{~S}^{32}$ & 3- 601 & $2,2,0 \leftarrow 2,1,1$ & Ground & & & 30806.69 & .05 \\
\hline$\left(\mathrm{C}^{12} \mathrm{H}_{3}\right)_{2} \mathrm{~S}^{32}$ & 3- 601 & $2,2,0 \leftarrow 2,1,1$ & Ground & & & 30806.83 & .05 \\
\hline$\left(\mathrm{C}^{12} \mathrm{H}_{3}\right)_{2} \mathrm{~S}^{32}$ & 3- 601 & $2,2,0 \leftarrow 2,1,1$ & Ground & & & 30807.35 & .05 \\
\hline $\mathrm{F}^{19} \mathrm{Cl}^{35}$ & 1 - & $1 \leftarrow 0$ & Ground & $3 / 2$ & $3 / 2$ & 30807.366 & 0.003 \\
\hline$\left(\mathrm{C}^{12} \mathrm{H}_{3}\right)_{2} \mathrm{~S}^{32}$ & 3- 601 & $2,2,0 \leftarrow 2,1,1$ & Ground & & & 30807.95 & .05 \\
\hline $\mathrm{C}^{12} \mathrm{H}_{3} \mathrm{C}^{12} \mathrm{H}_{2} \mathrm{~F}^{19}$ & 3- 551 & $3,1,2 \leftarrow 3,0,3$ & Ground & & & 30808.22 & \\
\hline $\mathrm{O}^{16} \mathrm{~F}_{2}^{19}$ & $4-1611$ & $33,8,26 \leftarrow 34,7,27$ & Ground & & & 30808.75 & .10 \\
\hline $\mathrm{c}-\mathrm{C}^{12} \mathrm{HD}: \mathrm{C}^{12} \mathrm{HBr}^{79}$ & 4. 739 & $4,2,3 \leftarrow 3,2,2$ & Ground & $5 / 2$ & $3 / 2$ & 30809.2 & \\
\hline $\mathrm{a}-\mathrm{C}^{12} \mathrm{H}_{2} \mathrm{DC}^{12} \mathrm{H}_{22} \mathrm{C}^{12} \mathrm{H}_{33}$ & 3. 786 & $6,1,5 \leftarrow 6,0.6$ & Ground & & & 30811.32 & .06 \\
\hline $\mathrm{C}^{12} \mathrm{H}_{2} \mathrm{Cl}_{2}^{355}$ & 4- 341 & $7,2,6 \leftarrow 8,1,7$ & Ground & & & 30812. & 5. \\
\hline $\mathrm{c}-\mathrm{C}^{12} \mathrm{HD}: \mathrm{C}^{12} \mathrm{HBr}^{79}$ & 4- 739 & $4,3,2 \leftarrow 3,3,1$ & Ground & $11 / 2$ & $9 / 2$ & 30814.9 & \\
\hline $\mathrm{C}^{12} \mathrm{HD}: \mathrm{C}^{12} \mathrm{DBr}^{1}$ & 4- 749 & Not Reported & Ground & & & 30815.2 & .1 \\
\hline
\end{tabular}




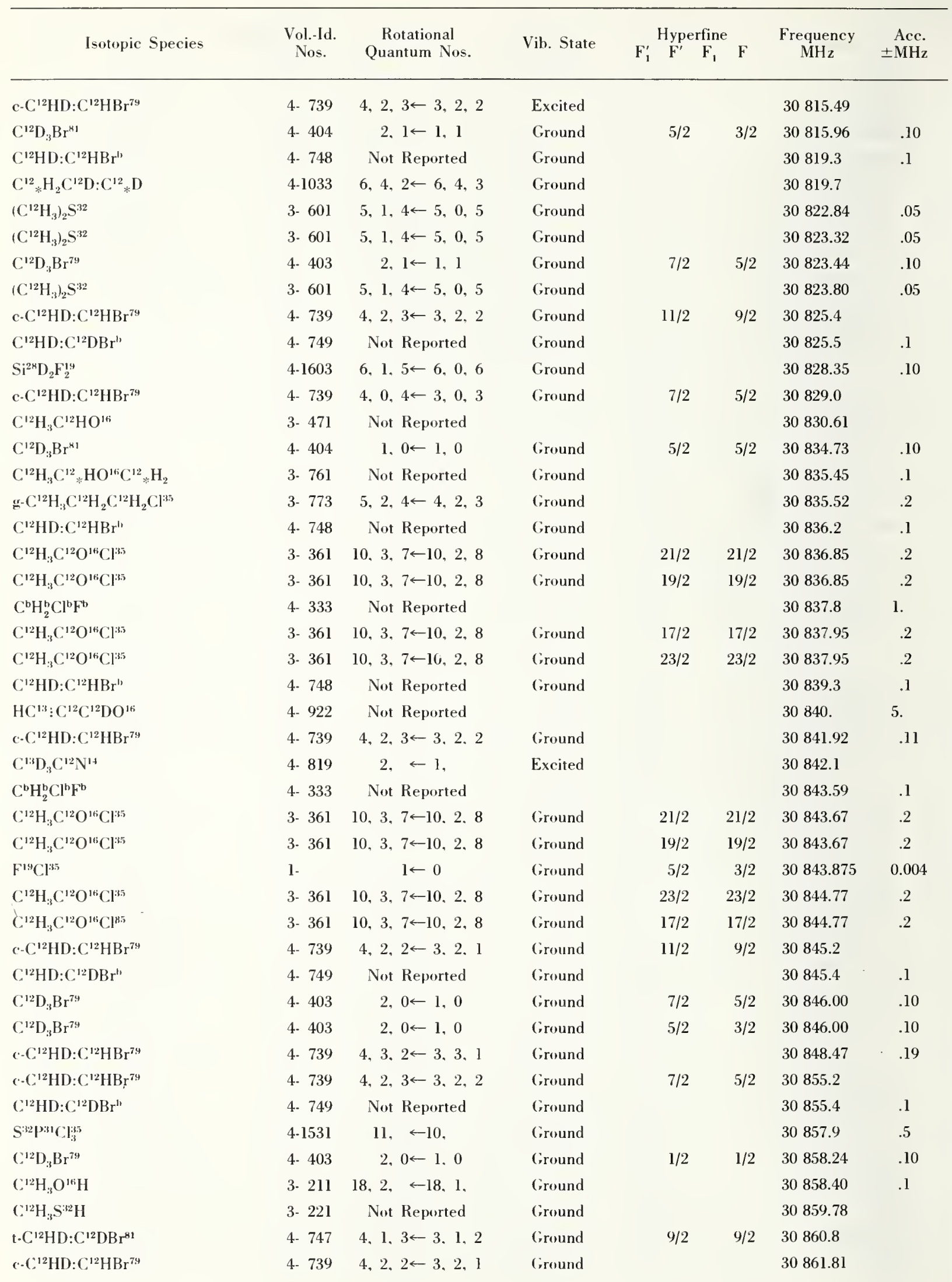




\begin{tabular}{|c|c|c|c|c|c|c|c|}
\hline \multirow{2}{*}{ Isotopic Species } & \multirow{2}{*}{$\begin{array}{l}\text { Vol.-Id. } \\
\text { Nos. }\end{array}$} & \multirow{2}{*}{$\begin{array}{c}\text { Rotational } \\
\text { Quantum Nos. }\end{array}$} & \multirow{2}{*}{ Vib. State } & \multicolumn{2}{|c|}{ Iyperfine } & \multirow{2}{*}{$\begin{array}{l}\text { Frequency } \\
\mathrm{MHz}\end{array}$} & \multirow{2}{*}{$\begin{aligned} & \text { Acc. } \\
\pm & \mathrm{MH} /\end{aligned}$} \\
\hline & & & & $F_{1}^{\prime} \quad F^{\prime}$ & $F_{1} \quad F$ & & \\
\hline $\mathrm{HC}^{13} \vdots_{\mathrm{C}^{12}} \mathrm{C}^{12} \mathrm{DO}^{16}$ & 4- 922 & Not Reported & & & & 30863. & 5. \\
\hline $\mathrm{C}^{12} \mathrm{H}_{3} \mathrm{C}^{12}{ }_{*} \mathrm{HO}^{16} \mathrm{C}^{12}{ }_{*} \mathrm{H}_{2}$ & 3. 761 & $10,2,8 \leftarrow 10,1,9$ & Ground & & & 30864.26 & .1 \\
\hline $\mathrm{C}^{12} \mathrm{HD}: \mathrm{C}^{12} \mathrm{DBr}^{\prime \prime}$ & 4- 749 & Not Reported & Ground & & & 30865.0 & .2 \\
\hline$c-\mathrm{C}^{12} \mathrm{HD}: \mathrm{C}^{12} \mathrm{HBr}^{79}$ & 4- 739 & $4,3,2 \leftarrow 3,3,1$ & Ground & $7 / 2$ & $5 / 2$ & 30865.3 & \\
\hline $\mathrm{C}^{13} \mathrm{D}_{3} \mathrm{C}^{12} \mathrm{~N}^{14}$ & 4. 819 & $2, \leftarrow 1$, & Excited & & & 30867.1 & \\
\hline$F_{2}^{19} N^{14} N^{14} F_{2}^{19}$ & 3. 21 & $3,3,0 \leftarrow 2,2,0$ & Ground & & & 30868.47 & .05 \\
\hline c- $\mathrm{C}^{12} \mathrm{HD}: \mathrm{C}^{12} \mathrm{HBr}^{79}$ & 4- 739 & $4,2,3 \leftarrow 3,2,2$ & Ground & $9 / 2$ & $7 / 2$ & 30870.8 & \\
\hline $\mathrm{C}^{12} \mathrm{HD}: \mathrm{C}^{12} \mathrm{DBr}{ }^{1}$ & 4. 749 & Not Reported & Ground & & & 30870.8 & .1 \\
\hline $\mathrm{C}^{12}{ }_{*} \mathrm{H}_{2} \mathrm{C}^{12} \mathrm{H}_{2} \mathrm{C}^{12} \mathrm{H}_{2} \mathrm{O}^{18}{ }_{*}$ & 4-1093 & $2,1,2 \leftarrow 1,1,1$ & Ground & & & 30871.35 & .1 \\
\hline $\mathrm{C}^{12} \mathrm{H}_{3} \mathrm{C}^{12}{ }_{*} \mathrm{HO}^{16} \mathrm{C}^{12}{ }_{*} \mathrm{H}_{2}$ & 3. 761 & $10,2,8 \leftarrow 10,1,9$ & Ground & & & 30872.70 & .1 \\
\hline $\mathrm{F}^{19} \mathrm{Cl}^{35}$ & 1 . & $1 \leftarrow 0$ & Ground & $1 / 2$ & $3 / 2$ & 30872.963 & 0.004 \\
\hline $\mathrm{C}^{12} \mathrm{HD}: \mathrm{C}^{12} \mathrm{DBr}^{\prime \prime}$ & 4- 749 & Not Reported & Ground & & & 30874.8 & .1 \\
\hline $\mathrm{C}^{12} \mathrm{H}_{3} \mathrm{~S}^{32} \mathrm{H}$ & 3- 221 & Not Reported & Ground & & & 30874.84 & \\
\hline$c-\mathrm{C}^{12} \mathrm{HD}: \mathrm{C}^{12} \mathrm{HBr}^{79}$ & 4- 739 & $4,2,2 \leftarrow 3,2,1$ & Ground & $7 / 2$ & $5 / 2$ & 30874.9 & \\
\hline$\left(\mathrm{C}^{12} \mathrm{H}_{3}\right)_{3} \mathrm{Si}^{30} \mathrm{D}$ & 3. 876 & $3, \leftarrow 2$ & Ground & & & 30875.6 & .2 \\
\hline $\mathrm{O}^{16} \mathrm{O}^{18} \mathrm{O}^{16}$ & 4-1843 & $12,2,10 \leftarrow 13,1,13$ & Ground & & & 30877. & \\
\hline $\mathrm{HN}^{15} \mathrm{O}_{3}^{16}$ & 3. 33 & $2,1,2 \leftarrow 1,1,1$ & Ground & & & 30877.22 & \\
\hline $\mathrm{C}^{12} \mathrm{H}_{3} \mathrm{C}^{12}: \mathrm{C}^{12} \mathrm{C}^{12} \mathrm{H}_{2} \mathrm{Cl}^{37}$ & 3. 902 & $11,0,11 \leftarrow 10,0,10$ & Ground & & & 30877.9 & .3 \\
\hline $\mathrm{D}_{2} \mathrm{O}_{2}^{16}$ & 3. 42 & Not Reported & & & & 30878. & 3. \\
\hline $\mathrm{HN}^{14} \mathrm{O}_{3}^{16}$ & $3-\quad 31$ & $2,1,2 \leftarrow 1,1,1$ & Ground & 1 & 0 & 30881.24 & \\
\hline $\mathrm{HN}^{14} \mathrm{O}_{3}^{16}$ & $3-\quad 31$ & $2,1,2 \leftarrow 1,1,1$ & Ground & 3 & 2 & 30881.69 & \\
\hline $\mathrm{C}^{12} \mathrm{H}_{3} \mathrm{C}^{12} \mathrm{H}_{2} \mathrm{~F}^{19}$ & 3. 551 & Not Reported & & & & 30881.71 & \\
\hline $\mathrm{HN}^{14} \mathrm{O}_{3}^{16}$ & $3-31$ & $2,1,2 \leftarrow 1,1,1$ & Ground & 2 & 1 & 30881.92 & \\
\hline $\mathrm{Si}^{28} \mathrm{H}_{2} \mathrm{~F}_{2}^{19}$ & 4-1601 & $5,1,4 \leftarrow 5,0,5$ & Excited & & & 30884.00 & .10 \\
\hline $\mathrm{C}^{12} \mathrm{HD}: \mathrm{C}^{12} \mathrm{HBr}^{\prime \prime}$ & 4. 748 & Not Reported & Ground & & & 30884.5 & .1 \\
\hline $\mathrm{t}-\mathrm{C}^{12} \mathrm{HD}: \mathrm{C}^{12} \mathrm{DBr}^{79}$ & 4- 745 & $4,1,3 \leftarrow 3,1,2$ & Ground & $5 / 2$ & $5 / 2$ & 30889.6 & \\
\hline $\mathrm{C}^{12} \mathrm{D}_{3} \mathrm{C}^{12} \mathrm{O}^{16} \mathrm{C}^{12} \mathrm{~N}^{14}$ & 3- 675 & $9,4,5 \leftarrow 9,3,6$ & Ground & & & 30889.66 & .2 \\
\hline $\mathrm{C}^{12} \mathrm{HD}: \mathrm{C}^{12} \mathrm{DBr}^{6}$ & 4- 749 & Not Reported & Ground & & & 30890.8 & .1 \\
\hline $\mathrm{C}^{12} \mathrm{H}_{2} \mathrm{Cl}^{35} \mathrm{Si}^{29} \mathrm{H}_{3}$ & 3. 234 & $5,1,4 \leftarrow 4,1,3$ & Ground & $9 / 211 / 2$ & $7 / 2 \quad 9 / 2$ & 30892.78 & .05 \\
\hline $\mathrm{C}^{12} \mathrm{H}_{2} \mathrm{Cl}^{35} \mathrm{Si}^{29} \mathrm{H}_{3}$ & 3- 234 & $5,1,4 \leftarrow 4,1,3$ & Ground & $7 / 213 / 2$ & $5 / 211 / 2$ & 30892.78 & .05 \\
\hline $\mathrm{C}^{12} \mathrm{H}_{2} \mathrm{Cl}^{35} \mathrm{Si}^{29} \mathrm{H}_{3}$ & 3- 234 & $5,1,4 \leftarrow 4,1,3$ & Ground & & & 30892.79 & .2 \\
\hline $\mathrm{C}^{13} \mathrm{D}_{3} \mathrm{C}^{12} \mathrm{~N}^{14}$ & 4- 819 & $2, \leftarrow 1$, & Excited & & & 30895.5 & \\
\hline $\mathrm{C}^{12} \mathrm{D}_{3} \mathrm{Br}^{79}$ & 4. 403 & $2,1 \leftarrow 1,1$ & Ground & $5 / 2$ & $5 / 2$ & 30895.58 & .10 \\
\hline $\mathrm{C}^{12} \mathrm{D}_{3} \mathrm{Br}^{79}$ & 4- 403 & $2,0 \leftarrow 1,0$ & Ground & $5 / 2$ & $5 / 2$ & 30898.82 & .10 \\
\hline $\mathrm{C}^{12} \mathrm{DHCl}_{2}^{35}$ & 4- 344 & $9,1,8 \leftarrow 9,0,9$ & Ground & & & 30900. & 5. \\
\hline $\mathrm{HC}^{13}: \mathrm{C}^{12} \mathrm{C}^{12} \mathrm{DO}^{16}$ & 4- 922 & Not Reported & & & & 30903. & 5. \\
\hline$F_{2}^{19} N^{14} N^{14} F_{2}^{19}$ & 3- 21 & $3,3,1 \leftarrow 2,2,1$ & Ground & & & 30906.52 & .05 \\
\hline$c \cdot \mathrm{C}^{12} \mathrm{HD}: \mathrm{C}^{12} \mathrm{HBr}^{79}$ & 4. 739 & $4,3,2 \leftarrow 3,3,1$ & Ground & $5 / 2$ & $5 / 2$ & 30906.6 & \\
\hline$\left(\mathrm{C}^{13} \mathrm{H}_{3}\right)\left(\mathrm{C}^{12} \mathrm{H}_{3}\right)_{2} \mathrm{C}^{12} \mathrm{H}$ & 3-1004 & $2,2,1 \leftarrow 1,1,1$ & & & & 30910.58 & .10 \\
\hline $\mathrm{O}^{16} \mathrm{O}^{18} \mathrm{O}^{16}$ & 4-1843 & $12,2,10 \leftarrow 13,1.13$ & Ground & & & 30914. & \\
\hline $\mathrm{C}^{12} \mathrm{H}_{2} \mathrm{Cl}^{35} \mathrm{Si}^{28} \mathrm{H}_{3}$ & 3- 231 & $9,3,7 \leftarrow 10,2,8$ & Ground & & & 30914.77 & .2 \\
\hline $\mathrm{C}^{12} \mathrm{H}_{2} \mathrm{Cl}^{35} \mathrm{Si}^{28} \mathrm{H}_{3}$ & 3. 231 & $9,3,7 \leftarrow 10,2,8$ & Ground & & & 30915.52 & .2 \\
\hline $\mathrm{C}^{12} \mathrm{D}_{3} \mathrm{Br}^{79}$ & 4- 403 & $2,1 \leftarrow 1,1$ & Ground & $3 / 2$ & $3 / 2$ & 30916.21 & .10 \\
\hline$\left(\mathrm{C}^{12} \mathrm{H}_{3}\right)_{3} \mathrm{Si}^{29} \mathrm{D}$ & 3- 874 & $3, \leftarrow 2$, & Ground & & & 30916.4 & .1 \\
\hline $\mathrm{P}^{31} \mathrm{O}^{16} \mathrm{Cl}_{3}^{37}$ & 4-1512 & $8, \leftarrow 7$, & Ground & & & 30918.4 & .5 \\
\hline
\end{tabular}




\begin{tabular}{|c|c|c|c|c|c|c|c|}
\hline Isotopic Species & $\begin{array}{l}\text { Vol.-Id. } \\
\text { Nos. }\end{array}$ & $\begin{array}{c}\text { Rotational } \\
\text { Quantum Nos. }\end{array}$ & Vib. State & $\begin{array}{c}\mathrm{F}_{1}^{\prime} \quad \mathrm{F}^{\prime} \quad \mathrm{F}_{1} \\
\text { Hyperfine }\end{array}$ & $F$ & $\begin{array}{l}\text { Frequency } \\
\qquad \mathrm{MHz}\end{array}$ & $\begin{aligned} & \text { Acc. } \\
& \pm \mathrm{MHz}\end{aligned}$ \\
\hline c- $\mathrm{C}^{12} \mathrm{HD}: \mathrm{C}^{12} \mathrm{HBr}^{79}$ & 4. 739 & $4,3,2 \leftarrow 3,3,1$ & Ground & $9 / 2$ & $7 / 2$ & 30918.5 & \\
\hline $\mathrm{HDO}_{2}^{16}$ & 3- 43 & $14, \quad \leftarrow 14$, & & & & 30921. & 3. \\
\hline $\mathrm{C}^{12} \mathrm{HD}_{2} \mathrm{C}^{12}: \mathrm{C}^{12} \mathrm{H}$ & $4-1048$ & $2,1,1 \leftarrow 1,1,0$ & Ground & & & 30927.55 & .1 \\
\hline $\mathrm{a}-\mathrm{C}^{12} \mathrm{H}_{2} \mathrm{DC}^{12} \mathrm{H}_{3} \mathrm{C}^{12}: \mathrm{C}^{12} \mathrm{H}_{2}$ & 3. 942 & $2,2,1 \leftarrow 1,1,0$ & Ground & & & 30927.96 & .05 \\
\hline $\mathrm{HDO}_{2}^{16}$ & 3- 43 & $14, \quad \leftarrow 14$, & & & & 30928. & 3. \\
\hline$\left(\mathrm{C}^{12} \mathrm{H}_{3}\right)_{3} \mathrm{Si}^{28} \mathrm{D}$ & 3- 872 & $3, \leftarrow 2$ & Excited & & & 30928.5 & .1 \\
\hline $\mathrm{C}^{12} \mathrm{D}_{2} \mathrm{Cl}^{35} \mathrm{Si}^{28} \mathrm{H}_{3}$ & 3. 235 & $5,1,4 \leftarrow 4,1,3$ & Ground & & & 30930.22 & .2 \\
\hline $\mathrm{C}^{12} \mathrm{H}_{3} \mathrm{C}^{12}{ }_{*} \mathrm{HO}^{16} \mathrm{C}^{12}{ }_{*} \mathrm{H}_{2}$ & 3- 761 & $10,2,8 \leftarrow 10,1,9$ & Ground & & & 30930.46 & .1 \\
\hline$c-C^{12} \mathrm{HD}: \mathrm{C}^{12} \mathrm{HBr}^{79}$ & 4. 739 & $4,3,2 \leftarrow 3,3,1$ & Ground & $7 / 2$ & $7 / 2$ & 30932.0 & \\
\hline $\mathrm{C}^{12} \mathrm{HCl}^{37} \mathrm{~F}_{2}^{19}$ & 4. 252 & $3,3,0 \leftarrow 3,2.2$ & Ground & & & 30932.07 & .10 \\
\hline$\left(\mathrm{C}^{12} \mathrm{H}_{3}\right)_{3} \mathrm{Si}^{28} \mathrm{D}$ & 3- 872 & $3, \leftarrow 2$, & Excited & & & 30933.4 & .2 \\
\hline $\mathrm{C}^{12} \mathrm{H}_{3} \mathrm{C}^{12} \mathrm{H}_{2} \mathrm{~F}^{19}$ & 3- 551 & $3,1,2 \leftarrow 3,0,3$ & Ground & & & 30945.15 & \\
\hline $\mathrm{t} \cdot \mathrm{C}^{12} \mathrm{HD}: \mathrm{C}^{12} \mathrm{DBr}^{79}$ & 4- 745 & $4,1,3 \leftarrow 3,1,2$ & Ground & $7 / 2$ & $7 / 2$ & 30945.2 & \\
\hline $\mathrm{F}^{19} \mathrm{HC}^{13} \mathrm{O}^{16}$ & 4. 273 & $7,2,6 \leftarrow 8,1,7$ & & & & 30947.4 & .2 \\
\hline $\mathrm{t}-\mathrm{C}^{12} \mathrm{HD}: \mathrm{C}^{12} \mathrm{DBr}^{79}$ & 4. 745 & $4,1,3 \leftarrow 3,1,2$ & Excited & $5 / 2$ & $3 / 2$ & 30951.2 & \\
\hline $\mathrm{C}^{13} \mathrm{D}_{3} \mathrm{C}^{12} \mathrm{~N}^{14}$ & 4. 819 & $2, \leftarrow 1$ & Excited & & & 30951.3 & \\
\hline $\mathrm{t}-\mathrm{C}^{12} \mathrm{HD}: \mathrm{C}^{12} \mathrm{DBr}^{79}$ & 4. 745 & $4,1,3 \leftarrow 3,1,2$ & Excited & & & 30953.09 & \\
\hline $\mathrm{t} \cdot \mathrm{C}^{12} \mathrm{HD}: \mathrm{C}^{12} \mathrm{DBr}^{79}$ & 4- 745 & $4,1,3 \leftarrow 3,1,2$ & Excited & $9 / 2$ & $7 / 2$ & 30957.6 & \\
\hline$\left(\mathrm{C}^{12} \mathrm{H}_{3}\right)_{3} \mathrm{Si}^{28} \mathrm{D}$ & 3. 872 & $3, \leftarrow 2$ & Ground & & & 30957.8 & .1 \\
\hline $\mathrm{HC}^{13}: \mathrm{C}^{12} \mathrm{C}^{12} \mathrm{DO}^{16}$ & 4. 922 & Not Reported & & & & 30958. & 5. \\
\hline $\mathrm{C}^{12} \mathrm{H}_{3} \mathrm{C}^{12}{ }_{*} \mathrm{HO}^{16} \mathrm{C}^{12}{ }_{*} \mathrm{H}_{2}$ & 3. 761 & $5,2,3 \leftarrow 5,1,4$ & Ground & & & 30961.14 & .1 \\
\hline $\mathrm{t}-\mathrm{C}^{12} \mathrm{HD}: \mathrm{C}^{12} \mathrm{DBr}^{79}$ & 4- 745 & $4,1,3 \leftarrow 3,1,2$ & Excited & $7 / 2$ & $5 / 2$ & 30961.2 & \\
\hline $\mathrm{C}^{12} \mathrm{H}_{3} \mathrm{C}^{12}{ }_{*} \mathrm{HO}^{16} \mathrm{C}^{12}{ }_{*} \mathrm{H}_{2}$ & 3- 761 & $5,2,3 \leftarrow 5,1,4$ & Ground & & & 30961.40 & .1 \\
\hline$\left(\mathrm{C}^{12} \mathrm{H}_{3}\right)_{2} \mathrm{C}^{12}: \mathrm{C}^{13} \mathrm{H}_{2}$ & 3- 946 & $2,2,1 \leftarrow 1,1,0$ & Ground & & & 30962.08 & \\
\hline $\mathrm{C}^{12} \mathrm{H}_{2} \mathrm{~F}_{2}^{19}$ & 4. 351 & $15,5,11 \leftarrow 16,4,12$ & Ground & & & 30962.08 & .10 \\
\hline $\mathrm{t}-\mathrm{C}^{12} \mathrm{HD}: \mathrm{C}^{12} \mathrm{DBr}^{79}$ & 4- 745 & $4,1,3 \leftarrow 3,1,2$ & Ground & $11 / 2$ & $9 / 2$ & 30966.4 & \\
\hline $\mathrm{C}^{12} \mathrm{D}_{3} \mathrm{Br}^{79}$ & 4- 403 & $2,1 \leftarrow 1,1$ & Ground & $5 / 2$ & $3 / 2$ & 30967.53 & .10 \\
\hline $\mathrm{C}^{12} \mathrm{H}_{3} \mathrm{~S}^{32} \mathrm{H}$ & 3- 221 & Not Reported & Ground & & & 30972.32 & \\
\hline 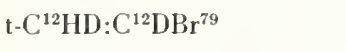 & 4- 745 & $4,1,3 \leftarrow 3,1,2$ & Ground & $5 / 2$ & $3 / 2$ & 30973.1 & \\
\hline $\mathrm{C}^{12} \mathrm{H}_{3} \mathrm{C}^{12}{ }_{*} \mathrm{HO}^{16} \mathrm{C}^{12}{ }_{*} \mathrm{H}_{2}$ & 3- 761 & $5,2,3 \leftarrow 5,1,4$ & Ground & & & 30973.40 & .1 \\
\hline $\mathrm{t}-\mathrm{C}^{12} \mathrm{HD}: \mathrm{C}^{12} \mathrm{DBr}^{79}$ & 4. 745 & $4,1,3 \leftarrow 3,1,2$ & Ground & & & 30973.48 & .45 \\
\hline $\mathrm{S}^{34} \mathrm{O}_{2}^{16}$ & 4-1833 & $8,1,7 \leftarrow 7,2,6$ & Ground & & & 30975.39 & .02 \\
\hline g- $\mathrm{C}^{12} \mathrm{H}_{3} \mathrm{C}^{12} \mathrm{H}_{2} \mathrm{C}^{12} \mathrm{H}_{2} \mathrm{Cl}^{35}$ & 3- 773 & $11,1,10 \leftarrow 11,0,11$ & Ground & & & 30975.79 & .2 \\
\hline $\mathrm{C}^{12} \mathrm{H}_{3} \mathrm{C}^{12} \mathrm{~F}_{3}^{19}$ & 3- 411 & $2, \leftarrow 1$, & Excited & & & 30978.5 & \\
\hline $\mathrm{t}-\mathrm{C}^{12} \mathrm{HD}: \mathrm{C}^{12} \mathrm{DBr}^{79}$ & 4- 745 & $4,1,3 \leftarrow 3,1,2$ & Ground & $9 / 2$ & $7 / 2$ & 30979.2 & \\
\hline $\mathrm{HC}^{13}: \mathrm{C}^{12} \mathrm{C}^{12} \mathrm{DO}^{16}$ & 4- 922 & Not Reported & & & & 30980. & 5. \\
\hline $\mathrm{C}^{12} \mathrm{H}_{3} \mathrm{Si}^{28} \mathrm{Cl}^{35} \mathrm{Cl}_{2}^{37}$ & 3. 114 & $9, \ldots \leftarrow 8$, & Ground & & & 30980. & 20. \\
\hline$\left(\mathrm{C}^{12} \mathrm{H}_{3}\right)_{3} \mathrm{Si}^{28} \mathrm{D}$ & 3. 872 & $3 . \leftarrow 2$ & Excited & & & 30982.0 & .2 \\
\hline $\mathrm{t}-\mathrm{C}^{12} \mathrm{HD}: \mathrm{C}^{12} \mathrm{DBr}^{79}$ & 4. 745 & $4,1,3 \leftarrow 3,1,2$ & Ground & $7 / 2$ & $5 / 2$ & 30982.7 & \\
\hline $\mathrm{C}^{12} \mathrm{H}_{2} \mathrm{C}^{137} \mathrm{~F}^{19}$ & 4. 332 & $6,0,6 \leftarrow 5,1,5$ & Ground & & & 30984.37 & .1 \\
\hline $\mathrm{C}^{12}{ }_{*} \mathrm{H}_{2} \mathrm{C}^{12} \mathrm{H}_{2} \mathrm{C}^{12} \mathrm{H}_{2} \mathrm{O}^{18} *$ & $4-1093$ & $2,1,2 \leftarrow 1,1,1$ & Excited & & & 30985.7 & .1 \\
\hline $\mathrm{C}^{12} \mathrm{H}_{3} \mathrm{C}^{12} \mathrm{O}^{18} \mathrm{Cl}^{35}$ & 3- 372 & $10,3,7 \leftarrow 10,2,8$ & Ground & $23 / 2$ & $23 / 2$ & 30988.90 & .2 \\
\hline $\mathrm{C}^{12} \mathrm{H}_{3} \mathrm{C}^{12} \mathrm{O}^{18} \mathrm{Cl}^{35}$ & 3- 372 & $10,3,7 \leftarrow 10,2,8$ & Ground & $17 / 2$ & $17 / 2$ & 30988.90 & .2 \\
\hline $\mathrm{C}^{12} \mathrm{H}_{3} \mathrm{C}^{12} \mathrm{O}^{18} \mathrm{Cl}^{35}$ & 3- 372 & $10,3,7 \leftarrow 10,2,8$ & Ground & $21 / 2$ & $21 / 2$ & 30988.90 & .2 \\
\hline $\mathrm{C}^{12} \mathrm{H}_{3} \mathrm{C}^{12} \mathrm{O}^{18} \mathrm{Cl}^{35}$ & 3- 372 & $10,3,7 \leftarrow 10,2,8$ & Ground & $19 / 2$ & $19 / 2$ & 30988.90 & .2 \\
\hline
\end{tabular}


Vol.Id. Rotational

Nos. Quantum Nos.
Vib. State
$\mathrm{C}^{12} \mathrm{H}_{3} \mathrm{C}^{12}{ }_{*} \mathrm{HO}^{16} \mathrm{C}^{12}{ }_{*} \mathrm{H}_{2}$ g- $\mathrm{C}^{12} \mathrm{H}_{2} \mathrm{Cl}^{35} \mathrm{C}^{12} \mathrm{H}_{2} \mathrm{Cl}^{35}$ $\mathrm{C}^{\mathrm{b}} \mathrm{H}_{2}^{\mathrm{b}} \mathrm{Cl}^{\mathrm{b}} \mathrm{F}^{\mathrm{b}}$

$\mathrm{C}^{12} \mathrm{H}_{3} \mathrm{C}^{12} \mathrm{O}^{18} \mathrm{Cl}^{35}$

$\mathrm{C}^{12} \mathrm{H}_{3} \mathrm{C}^{12} \mathrm{O}^{18} \mathrm{Cl}^{35}$

$\mathrm{C}^{12} \mathrm{H}_{3} \mathrm{C}^{12} \mathrm{O}^{18} \mathrm{Cl}^{35}$

$\mathrm{C}^{12} \mathrm{H}_{3} \mathrm{C}^{12} \mathrm{O}^{18} \mathrm{Cl}^{35}$

$\mathrm{C}^{12} \mathrm{H}_{3} \mathrm{C}^{12} \mathrm{~F}_{3}^{19}$

$\mathrm{C}^{12} \mathrm{H}_{3} \mathrm{O}^{16} \mathrm{~N}^{14} \mathrm{O}_{2}^{16}$

$\mathrm{C}^{12} \mathrm{HD}: \mathrm{C}^{12} \mathrm{DBr}^{\mathrm{b}}$

s. $\left(\mathrm{C}^{12} \mathrm{H}_{2} \mathrm{D}\right)\left(\mathrm{C}^{12} \mathrm{H}_{3}\right) \mathrm{O}^{16}$

$\mathrm{C}^{12} \mathrm{D}_{3} \mathrm{Br}^{79}$

$\mathrm{HC}^{12} \mathrm{O}^{16} \mathrm{O}^{18} \mathrm{H}$

$\mathrm{S}^{34} \mathrm{O}_{2}^{16}$

$\mathrm{C}^{12} \mathrm{H}_{3} \mathrm{C}^{12} \mathrm{~F}_{3}^{19}$

$\mathrm{HC}^{13}: \mathrm{C}^{12} \mathrm{C}^{12} \mathrm{DO}^{16}$

$\mathrm{C}^{12} \mathrm{H}_{3} \mathrm{O}^{16} \mathrm{~N}^{14} \mathrm{O}_{2}^{16}$

$\mathrm{C}^{12} \mathrm{H}_{3} \mathrm{C}^{12} \mathrm{~F}_{3}^{19}$

$\mathrm{C}^{\mathrm{b}} \mathrm{H}_{2}^{\mathrm{b}} \mathrm{Cl}^{\mathrm{b}} \mathrm{F}^{\mathrm{b}}$

$\mathrm{Si}^{28} \mathrm{D}_{2} \mathrm{~F}_{2}^{19}$

$\mathrm{C}^{12} \mathrm{H}_{3} \mathrm{~N}^{14} \mathrm{O}_{2}^{16}$

$\mathrm{C}^{12} \mathrm{H}_{3} \mathrm{C}^{12}{ }_{*} \mathrm{HO}^{16} \mathrm{C}^{12}{ }_{*} \mathrm{H}_{2}$ $\mathrm{C}^{12} \mathrm{H}_{3} \mathrm{C}^{12}{ }_{*} \mathrm{HO}^{16} \mathrm{C}^{12}{ }_{*} \mathrm{H}_{2}$ $\mathrm{C}^{12} \mathrm{H}_{3} \mathrm{C}^{12}{ }_{*} \mathrm{HO}^{16} \mathrm{C}^{12}{ }_{*} \mathrm{H}_{2}$ $\mathrm{C}^{12} \mathrm{H}_{3} \mathrm{C}^{12}{ }_{*} \mathrm{HO}^{16} \mathrm{C}^{12}{ }_{*} \mathrm{H}_{2}$ $\mathrm{C}^{12} \mathrm{H}_{3} \mathrm{C}^{12} \mathrm{~F}_{3}^{19}$ c- $\mathrm{C}^{12} \mathrm{H}_{3} \mathrm{C}^{12} \mathrm{H}: \mathrm{C}^{12} \mathrm{HF}^{19}-\mathrm{E}$ $\left(\mathrm{C}^{12} \mathrm{H}_{3}\right)_{3} \mathrm{Si}^{28} \mathrm{D}$

$\mathrm{HC}^{13}: \mathrm{C}^{12} \mathrm{C}^{12} \mathrm{DO}^{16}$

c- $\mathrm{C}^{12} \mathrm{H}_{3} \mathrm{C}^{12} \mathrm{H}: \mathrm{C}^{12} \mathrm{HF}^{19}-\mathrm{A}$

$\mathrm{C}^{12} \mathrm{H}_{3} \mathrm{~S}^{32} \mathrm{H}$

$\mathrm{C}^{12} \mathrm{H}_{3} \mathrm{~N}^{14} \mathrm{O}_{2}^{16}$

$\mathrm{Si}^{29} \mathrm{D}_{2} \mathrm{~F}_{2}^{19}$

$\mathrm{C}^{12}{ }_{*} \mathrm{H}_{2} \mathrm{~N}^{14} \mathrm{HC}^{12}{ }_{*} \mathrm{H}_{2}$

$\left(\mathrm{C}^{12} \mathrm{H}_{3}\right)_{2} \mathrm{O}^{16}$

s- $\left(\mathrm{C}^{12} \mathrm{H}_{2} \mathrm{D}\right)\left(\mathrm{C}^{12} \mathrm{H}_{3}\right) \mathrm{O}^{16}$

$\mathrm{C}^{12} \mathrm{H}_{3} \mathrm{C}^{12} \mathrm{~F}_{3}^{19}$

$\mathrm{C}^{12} \mathrm{H}_{3} \mathrm{C}^{12} \mathrm{~F}_{3}^{19}$

$\mathrm{H}_{2} \mathrm{~N}^{14} \mathrm{~N}^{14} \mathrm{H}_{2}$

a- $\mathrm{C}^{12} \mathrm{H}_{2} \mathrm{DC}^{12} \mathrm{O}^{16} \mathrm{Cl}^{35}$

$\mathrm{C}^{12} \mathrm{H}_{3} \mathrm{C}^{12} \mathrm{~F}_{3}^{19}$

$\left(\mathrm{C}^{12} \mathrm{H}_{3}\right)_{2} \mathrm{O}^{16}$

a- $\mathrm{C}^{12} \mathrm{H}_{2} \mathrm{DC}^{12} \mathrm{O}^{16} \mathrm{Cl}^{35}$

$\mathrm{C}^{12} \mathrm{H}_{2} \mathrm{Cl}^{35} \mathrm{Si}^{28} \mathrm{H}_{3}$

a- $\mathrm{C}^{12} \mathrm{H}_{2} \mathrm{DC}^{12} \mathrm{O}^{16} \mathrm{Cl}^{35}$
3- $761 \quad 5,2,3 \leftarrow 5,1,4$

Ground

3- $451 \quad 6,1,6 \leftarrow 5,0,5$

4- 333 Not Reported

3- $372 \quad 10,3,7 \leftarrow 10,2,8 \quad$ Ground

3- $372 \quad 10,3,7 \leftarrow 10,2,8 \quad$ Ground

3- $37210,3,7 \leftarrow 10,2,8 \quad$ Ground

3- $37210,3,7 \leftarrow 10,2,8 \quad$ Ground

3- 411

$3, \leftarrow 2$.

Ground

3- 181

$4,0,4 \leftarrow 3,0,3$

Ground

4. 749

Not Reported

Ground

3- 596

Not Reported

Ground

4. 403

$2,0 \leftarrow 1,0$

3- 77

$6,1,6 \leftarrow 6,1,5$

Ground

4-1833

3. 411

4. 922

$4,0,4 \leftarrow 3,1,3$

Ground

$$
3, \leftarrow 2,
$$

Ground

Not Reported

3- 181

$4,0,4 \leftarrow 3,0,3$

Ground

3- 411

4- 333

$3, \leftarrow 2$,

Excited

4- 1603

Not Reported

3. 171

$7,2,5 \leftarrow 7,1,6$

Ground

3- 761

Not Reported

Ground

3- 761

Not Reported

Ground

Ground

3- 761

Not Reported

3. 761

Not Reported

Ground

Ground

3- 411

Not Reported

Excited

3- 702

3. 872

$3, \leftarrow 2$,

$2,1,2 \leftarrow 1,0,1$

4- 922

$$
3, \leftarrow 2,
$$

Excited

3- 701

Not Reported

3- 221

$2,1,2 \leftarrow 1,0,1$

3- 171

Not Reported

Ground

4-1604

Not Reported

Ground

4- 861

$4,2,3 \leftarrow 4,1,4$

Ground

Ground

3- 591

$6,6,1 \leftarrow 6,5,1$

Excited

3- 596

$2, \overline{1}, 1 \leftarrow 2,0,2$

Ground

3. 411

$2,1,1 \leftarrow 2,0,2$

Excited

3- 411

$$
3, \leftarrow 2,
$$

$3, \leftarrow 2$,

3- 51

$1,1 \leftarrow 2,0$

Excited

3- 366

$4,1,4 \leftarrow 3,0,3$

Ground

3. 411

$$
3, \leftarrow 2,
$$

Ground

3. 591

$2,1,1 \leftarrow 2,0,2$

Excited

3. 366

$4,1,4 \leftarrow 3,0,3$

Excited

Ground

3- 231

$12,1,11 \leftarrow 12,0,12$

3. 366

$4,1,4 \leftarrow 3,0,3$

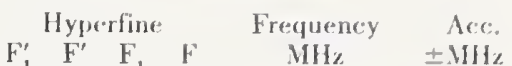




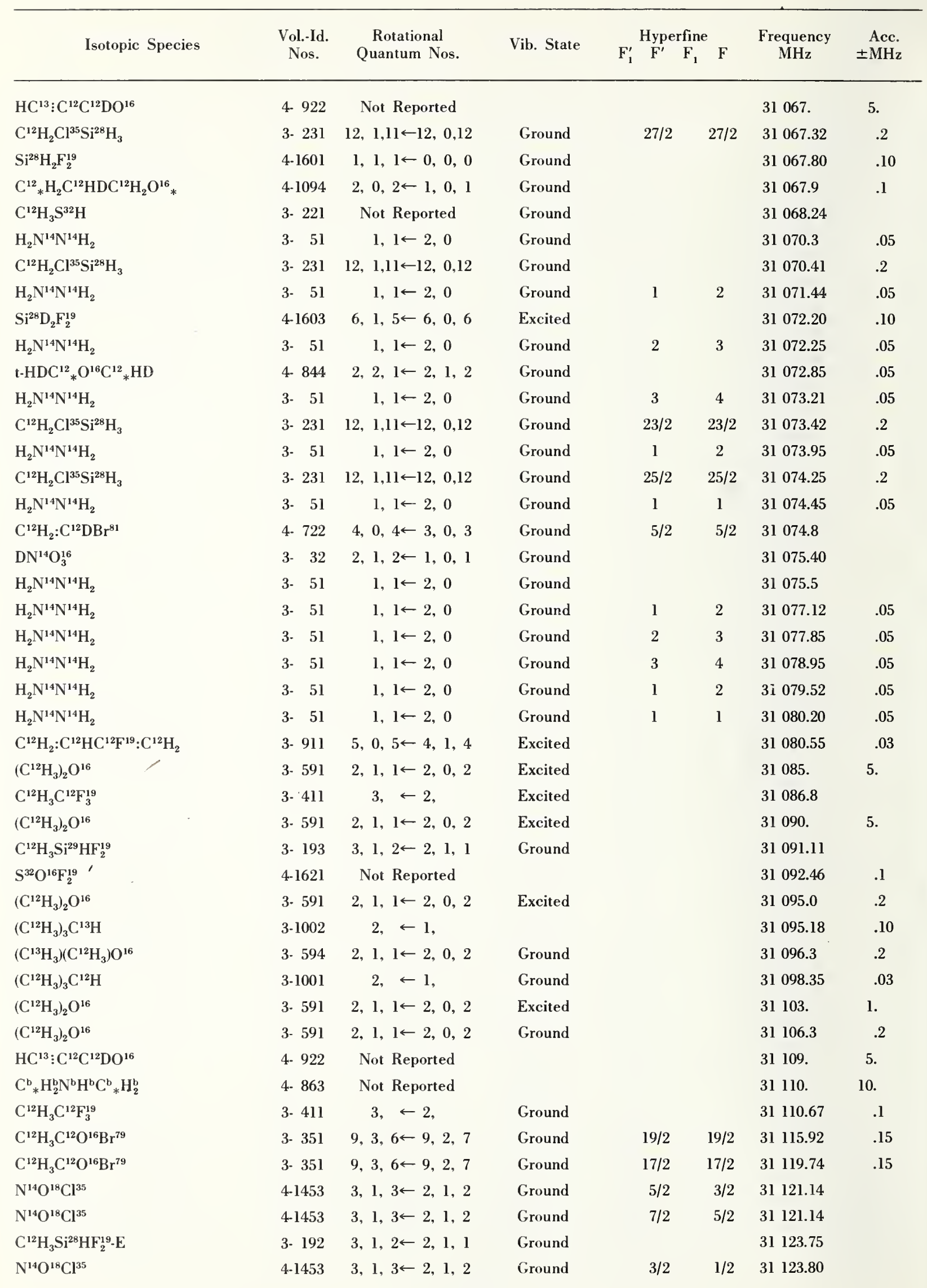




\begin{tabular}{|c|c|c|c|c|c|c|c|c|}
\hline \multirow{2}{*}{ Isotopic Species } & \multirow{2}{*}{$\begin{array}{l}\text { Yol.-Id. } \\
\text { Nos. }\end{array}$} & \multirow{2}{*}{$\begin{array}{c}\text { Rotational } \\
\text { Quantum Nos. }\end{array}$} & \multirow{2}{*}{ Vib. State } & \multicolumn{3}{|c|}{ Hyperfine } & \multirow{2}{*}{$\begin{array}{c}\text { Frequency } \\
\mathrm{MHz}^{-}\end{array}$} & \multirow{2}{*}{$\begin{aligned} & \text { Acc. } \\
\pm & \mathrm{Mllz}\end{aligned}$} \\
\hline & & & & $F_{1}^{\prime}$ & $F^{\prime} \quad F_{1}$ & $\mathrm{~F}$ & & \\
\hline $\mathrm{N}^{14} \mathrm{O}^{18} \mathrm{Cl}^{35}$ & 4-1453 & $3,1,3 \leftarrow 2,1,2$ & Ground & & $9 / 2$ & $7 / 2$ & 31123.80 & \\
\hline $\mathrm{N}^{14} \mathrm{O}^{18} \mathrm{Cl}^{35}$ & $4-1453$ & $3,1,3 \leftarrow 2,1,2$ & Ground & & $5 / 2$ & $5 / 2$ & 31123.80 & \\
\hline $\mathrm{C}^{12} \mathrm{H}_{3} \mathrm{Si}^{28} \mathrm{HF}_{2}^{19}-\mathrm{A}$ & 3- 191 & $3,1,2 \leftarrow 2,1,1$ & Ground & & & & 31124.90 & \\
\hline$\left(\mathrm{C}^{12} \mathrm{H}_{3}\right)_{2} \mathrm{O}^{16}$ & 3- 591 & $2,1,1 \leftarrow 2,0,2$ & Excited & & & & 31125. & 20. \\
\hline $\mathrm{P}^{31} \mathrm{~F}_{3}^{19}$ & 4-1681 & Not Reported & Excited & & & & 31130. & .10 \\
\hline $\mathrm{C}^{12} \mathrm{H}_{3} \mathrm{Si}^{\mathrm{b}} \mathrm{H}_{2} \mathrm{D}$ & 3- 325 & $12,1,11 \leftarrow 12,1,12$ & & & & & 31130.43 & \\
\hline$\left(\mathrm{C}^{12} \mathrm{H}_{3}\right)_{3} \mathrm{C}^{12} \mathrm{H}$ & $3-1001$ & $2, \leftarrow 1$, & Ground & & & & 31130.99 & .03 \\
\hline $\mathrm{C}^{12} \mathrm{H}_{2}: \mathrm{C}^{12} \mathrm{HC}^{12} \mathrm{~F}^{19}: \mathrm{C}^{12} \mathrm{H}_{2}$ & 3. 911 & $5,0,5 \leftarrow 4,1,4$ & Excited & & & & 31134.21 & .03 \\
\hline$\left(\mathrm{C}^{12} \mathrm{H}_{3}\right)_{2} \mathrm{O}^{16}$ & 3. 591 & $2,1,1 \leftarrow 2,0,2$ & Excited & & & & 31135. & 20. \\
\hline $\mathrm{C}^{12} \mathrm{H}_{3} \mathrm{C}^{12} \mathrm{~F}_{3}^{19}$ & 3- 411 & $3, \leftarrow 2$, & Excited & & & & 31136.0 & \\
\hline $\mathrm{C}_{*}^{12} \mathrm{H}_{2}^{\mathrm{b}} \mathrm{S}^{\mathrm{b}} \mathrm{C}^{12}{ }_{*} \mathrm{H}_{2}^{\mathrm{b}}$ & 4- 854 & Not Reported & & & & & 31139.9 & .5 \\
\hline $\mathrm{C}^{12} \mathrm{H}_{2} \mathrm{Cl}^{35} \mathrm{Cl}^{37}$ & 4- 342 & $9,0,9 \leftarrow 8,1,8$ & Ground & & & & 31140. & 5. \\
\hline $\mathrm{C}^{12} \mathrm{D}_{3} \mathrm{O}^{16} \mathrm{D}$ & 3. 216 & Not Reported & & & & & 31140. & \\
\hline $\mathrm{C}^{12} \mathrm{H}_{3} \mathrm{~N}^{14} \mathrm{H}_{2}$ & 3. 261 & Not Reported & Ground & & & & 31140.5 & \\
\hline $\mathrm{C}^{12} \mathrm{H}_{2}: \mathrm{C}^{12} \mathrm{HC}^{12} \mathrm{~F}^{19}: \mathrm{C}^{12} \mathrm{H}_{2}$ & 3- 911 & $5,0,5 \leftarrow 4,1,4$ & Ground & & & & 31140.55 & .03 \\
\hline $\mathrm{C}^{12} \mathrm{H}_{3} \mathrm{C}^{12} \mathrm{O}^{16} \mathrm{Br}^{79}$ & 3- 351 & $9,3,6 \leftarrow 9,2,7$ & Ground & & $21 / 2$ & $21 / 2$ & 31141.07 & .15 \\
\hline$\left(\mathrm{C}^{12} \mathrm{H}_{3}\right)_{2} \mathrm{O}^{16}$ & 3. 591 & $2,1,1 \leftarrow 2,0,2$ & Excited & & & & 31145. & 20. \\
\hline $\mathrm{C}^{12} \mathrm{H}_{3} \mathrm{C}^{12} \mathrm{O}^{16} \mathrm{Br}^{79}$ & 3- 351 & $9,3,6 \leftarrow 9,2,7$ & Ground & & $15 / 2$ & $15 / 2$ & 31145.05 & .15 \\
\hline $\mathrm{C}^{12} \mathrm{H}_{3} \mathrm{O}^{16} \mathrm{~N}^{14} \mathrm{O}_{2}^{16}$ & 3. 181 & $4,0,4 \leftarrow 3,0,3$ & Ground & & & & 31149.42 & .1 \\
\hline $\mathrm{C}^{12} \mathrm{H}_{3} \mathrm{C}^{12} \vdots \mathrm{C}^{12} \mathrm{D}$ & $4 \cdot 1045$ & $2,1 \leftarrow 1,1$ & Ground & & & & 31152.00 & .10 \\
\hline $\mathrm{C}^{12} \mathrm{H}_{3} \mathrm{C}^{12}: \mathrm{C}^{12} \mathrm{D}$ & 4-1045 & $2,0 \leftarrow 1,0$ & Ground & & & & 31152.56 & .10 \\
\hline $\mathrm{C}^{13} \mathrm{H}_{3} \mathrm{C}^{12} \mathrm{H}_{3} \mathrm{C}^{12}: \mathrm{C}^{12} \mathrm{H}_{2}$ & 3. 945 & $3,0,3 \leftarrow 2,1,2$ & Ground & & & & 31153.16 & \\
\hline $\mathrm{C}^{12} \mathrm{HDCl}^{35} \mathrm{Si}^{28} \mathrm{H}_{3}$ & 3- 236 & $5,1,4 \leftarrow 4,1,3$ & Ground & & & & 31156.99 & .2 \\
\hline$\left(\mathrm{C}^{12} \mathrm{H}_{3}\right)_{3} \mathrm{C}^{12} \mathrm{H}$ & $3-1001$ & $2, \leftarrow 1$ & Ground & & & & 31157.46 & .03 \\
\hline $\mathrm{C}^{12} \mathrm{H}_{3} \mathrm{O}^{16} \mathrm{~N}^{14} \mathrm{O}_{2}^{16}$ & 3. 181 & $4,0,4 \leftarrow 3,0,3$ & Ground & & & & 31157.90 & .1 \\
\hline$\left(\mathrm{C}^{12} \mathrm{H}_{3}\right)_{3} \mathrm{C}^{12} \mathrm{H}$ & $3 \cdot 1001$ & $2, \leftarrow 1$, & Excited & & & & 31161. & \\
\hline $\mathrm{D}_{2} \mathrm{O}_{2}^{16}$ & 3. 42 & Not Reported & & & & & 31162. & 3. \\
\hline $\mathrm{C}^{12} \mathrm{H}_{3} \mathrm{O}^{16} \mathrm{~N}^{14} \mathrm{O}_{2}^{16}$ & 3- 181 & $4,0,4 \leftarrow 3,0,3$ & Ground & & & & 31165.00 & .1 \\
\hline $\mathrm{C}^{12} \mathrm{H}_{3} \mathrm{C}^{12}{ }_{*} \mathrm{HO}^{16} \mathrm{C}^{12}{ }_{*} \mathrm{H}_{2}$ & 3. 761 & Not Reported & Ground & & & & 31167.79 & .1 \\
\hline $\mathrm{HC}^{13}: \mathrm{C}^{12} \mathrm{C}^{12} \mathrm{DO}^{16}$ & 4. 922 & Not Reported & & & & & 31168. & 5. \\
\hline $\mathrm{C}^{12} \mathrm{H}_{3} \mathrm{C}^{12}{ }_{*} \mathrm{HO}^{16} \mathrm{C}^{12}{ }_{*} \mathrm{H}_{2}$ & 3. 761 & Not Reported & Ground & & & & 31168.63 & .1 \\
\hline $\mathrm{C}^{12} \mathrm{D}_{3} \mathrm{C}^{12} \mathrm{DO}^{16}$ & 3. 472 & $2,1,2 \leftarrow 1,1,1$ & Ground & & & & 31171.36 & .2 \\
\hline $\mathrm{t}-\mathrm{C}^{12} \mathrm{H}_{3} \mathrm{C}^{12} \mathrm{H}: \mathrm{C}^{12} \mathrm{HD}$ & 3. 746 & $2,1,2 \leftarrow 1,1,1$ & Ground & & & & 31174.64 & .05 \\
\hline $\mathrm{t}-\mathrm{C}^{12} \mathrm{H}_{3} \mathrm{C}^{12} \mathrm{H}: \mathrm{C}^{12} \mathrm{HD}$ & 3- 746 & $2,1,2 \leftarrow 1,1,1$ & Ground & & & & 31175.18 & .05 \\
\hline$\left(\mathrm{C}^{12} \mathrm{H}_{3}\right)_{3} \mathrm{C}^{12} \mathrm{H}$ & $3-1001$ & $2, \leftarrow 1$, & Excited & & & & 31180. & \\
\hline$\left(\mathrm{C}^{12} \mathrm{H}_{3}\right)_{2} \mathrm{O}^{16}$ & 3. 591 & $2,1,1 \leftarrow 2,0,2$ & Excited & & & & 31180 & 20. \\
\hline $\mathrm{D}_{2} \mathrm{O}_{2}^{16}$ & 3- 42 & Not Reported & & & & & 31181. & 3. \\
\hline $\mathrm{S}^{32} \mathrm{O}^{16} \mathrm{~F}_{2}^{19}$ & 4-1621 & Not Reported & & & & & 31182.88 & .1 \\
\hline$\left(\mathrm{C}^{12} \mathrm{H}_{3}\right)_{3} \mathrm{C}^{12} \mathbf{I}^{127}$ & 3. 991 & $10, \leftarrow 9$ & Ground & & & & 31185. & 30. \\
\hline $\mathrm{t}-\mathrm{C}^{12} \mathrm{H}_{3} \mathrm{C}^{12} \mathrm{H}: \mathrm{C}^{12} \mathrm{HD}$ & 3. 746 & $2,1,1 \leftarrow 1,1,0$ & Ground & & & & 31185.46 & .05 \\
\hline $\mathrm{C}^{12} \mathrm{H}_{2}: \mathrm{C}^{12} \mathrm{HC}^{12} \mathrm{~F}^{19}: \mathrm{C}^{12} \mathrm{H}_{2}$ & 3. 911 & $5,0,5 \leftarrow 4,1,4$ & Ground & & & & 31185.84 & .03 \\
\hline $\mathrm{C}^{12}{ }_{*} \mathrm{H}_{2} \mathrm{C}^{12} \mathrm{HDC}^{12} \mathrm{H}_{2} \mathrm{O}^{16}{ }_{*}$ & 4-1094 & $2,0,2 \leftarrow 1,0,1$ & Excited & & & & 31187.2 & .1 \\
\hline$F_{2}^{19} N^{14} N^{14} F_{2}^{19}$ & 3. 21 & $4,2,2 \leftarrow 3,1,2$ & Ground & & & & 31187.4 & .1 \\
\hline $\mathrm{HC}^{13}: \mathrm{C}^{12} \mathrm{C}^{12} \mathrm{DO}^{16}$ & 4- 922 & Not Reported & & & & & 31192. & 5. \\
\hline $\mathrm{N}^{14} \mathrm{O}_{2}^{16} \mathrm{~F}^{19}$ & 4-1581 & $2,0,2 \leftarrow 1,0,1$ & Ground & & & & 31192.3 & \\
\hline
\end{tabular}




\begin{tabular}{|c|c|c|c|c|c|c|c|c|}
\hline \multirow{2}{*}{ Isotopic Species } & \multirow{2}{*}{$\begin{array}{l}\text { Vol.-Id. } \\
\text { Nos. }\end{array}$} & \multirow{2}{*}{$\begin{array}{c}\text { Rotational } \\
\text { Quantum Nos. }\end{array}$} & \multirow{2}{*}{ Vib. State } & \multicolumn{3}{|c|}{ Hyperfine } & \multirow{2}{*}{$\begin{array}{l}\text { Frequency } \\
\qquad \mathrm{MHz}\end{array}$} & \multirow{2}{*}{$\begin{aligned} \text { Acc. } \\
\pm \mathrm{MHz}\end{aligned}$} \\
\hline & & & & $\mathrm{F}_{1}^{\prime}$ & $F^{\prime} \quad F_{1}$ & $\mathbf{F}$ & & \\
\hline $\mathrm{a}-\mathrm{C}^{12} \mathrm{H}_{2} \mathrm{DC}^{12} \mathrm{O}^{16} \mathrm{Cl}^{35}$ & 3. 366 & $10,3,7 \leftarrow 10,2,8$ & Ground & & & & 31193.77 & .1 \\
\hline $\mathrm{P}^{31} \mathrm{~F}_{3}^{19}$ & 4-1681 & Not Reported & Excited & & & & 31194. & 5.0 \\
\hline $\mathrm{C}^{12} \mathrm{HCl}^{35} \mathrm{~F}_{2}^{19}$ & 4. 251 & $9,4,6 \leftarrow 9,3,6$ & Ground & & $15 / 2$ & $15 / 2$ & 31194.9 & .05 \\
\hline $\mathrm{a}-\mathrm{C}^{12} \mathrm{H}_{2} \mathrm{DC}^{12} \mathrm{O}^{16} \mathrm{Cl}^{35}$ & 3- 366 & $10,3,7 \leftarrow 10,2,8$ & Ground & & & & 31195.35 & .1 \\
\hline $\mathrm{C}^{12} \mathrm{HCl}^{35} \mathrm{~F}_{2}^{19}$ & 4- 251 & $9,4,6 \leftarrow 9,3,6$ & Ground & & $21 / 2$ & $21 / 2$ & 31195.8 & .05 \\
\hline $\mathrm{a}-\mathrm{C}^{12} \mathrm{H}_{2} \mathrm{DC}^{12} \mathrm{O}^{16} \mathrm{Cl}^{35}$ & 3- 366 & $10,3,7 \leftarrow 10,2,8$ & Ground & & & & 31196.34 & .1 \\
\hline $\mathrm{a}-\mathrm{C}^{12} \mathrm{H}_{2} \mathrm{DC}^{12} \mathrm{O}^{16} \mathrm{Cl}^{35}$ & 3- 366 & $10,3,7 \leftarrow 10,2,8$ & Ground & & & & 31197.88 & .1 \\
\hline $\mathrm{C}^{12} \mathrm{H}_{2}: \mathrm{C}^{12} \mathrm{DBr}^{81}$ & 4. 722 & $4,3,2 \leftarrow 3,3,1$ & Ground & & & & 31199.71 & \\
\hline $\mathrm{s}-\left(\mathrm{C}^{12} \mathrm{H}_{2} \mathrm{D}\right)\left(\mathrm{C}^{12} \mathrm{H}_{3}\right) \mathrm{O}^{16}$ & 3- 596 & Not Reported & Ground & & & & 31200. & 20. \\
\hline $\mathrm{C}^{12} \mathrm{HCl}^{35} \mathrm{~F}_{2}^{19}$ & 4- 251 & $9,4,6 \leftarrow 9,3,6$ & Ground & & $17 / 2$ & $17 / 2$ & 31200.1 & .05 \\
\hline $\mathrm{a}-\mathrm{C}^{12} \mathrm{H}_{2} \mathrm{DSi}^{28} \mathrm{H}_{2} \mathrm{~F}^{19}$ & 3- 248 & $7,1,6 \leftarrow 7,1,7$ & Ground & & & & 31201. & 1. \\
\hline $\mathrm{C}^{12} \mathrm{HCl}^{35} \mathrm{~F}_{2}^{19}$ & 4. 251 & $9,4,6 \leftarrow 9,3,6$ & Ground & & $19 / 2$ & $19 / 2$ & 31201.0 & .05 \\
\hline $\mathrm{C}^{12} \mathrm{H}_{2} \mathrm{Cl}^{35} \mathrm{Si}^{28} \mathrm{H}_{3}$ & 3. 231 & $5,1,4 \leftarrow 4,1,3$ & Ground & & & & 31203.74 & .2 \\
\hline $\mathrm{g}^{\mathrm{g}} \mathrm{C}^{12} \mathrm{H}_{3} \mathrm{C}^{12} \mathrm{H}_{2} \mathrm{C}^{12} \mathrm{H}_{2} \mathrm{Cl}^{35}$ & 3- 773 & $5,2,3 \leftarrow 4,2,2$ & Ground & & & & 31204.35 & .2 \\
\hline $\mathrm{C}^{12} \mathrm{H}_{3} \mathrm{O}^{16} \mathrm{H}$ & 3- 211 & $21,2, \leftarrow 21,1$, & Ground & & & & 31209.75 & .1 \\
\hline $\mathrm{C}^{12} \mathrm{H}_{2}: \mathrm{C}^{12} \mathrm{DBr}^{81}$ & 4. 722 & $4,2,2 \leftarrow 3,2,1$ & Ground & & & & 31218.09 & \\
\hline $\mathrm{C}^{12} \mathrm{H}_{3} \mathrm{~N}^{14} \mathrm{H}_{2}$ & 3- 261 & Not Reported & Ground & & & & 31220.80 & \\
\hline $\mathrm{C}^{12} \mathrm{H}_{3} \mathrm{~N}^{14} \mathrm{H}_{2}$ & 3- 261 & Not Reported & Ground & & & & 31221.20 & \\
\hline $\mathrm{P}^{31} \mathrm{~F}_{3}^{19}$ & 4.168I & Not Reported & Excited & & & & 31224 . & 3.0 \\
\hline $\mathrm{C}^{12} \mathrm{H}_{2} \mathrm{Cl}_{2}^{37}$ & 4. 343 & $6,1,5 \leftarrow 6,0,6$ & Ground & & & & 31225 . & 5. \\
\hline $\mathrm{C}^{12} \mathrm{H}_{3} \mathrm{O}^{16} \mathrm{H}$ & 3. 211 & $19,2, \leftarrow 19,1$, & Ground & & & & 31226.70 & .1 \\
\hline $\mathrm{C}^{12} \mathrm{H}_{2}: \mathrm{C}^{12} \mathrm{HC}^{12} \mathrm{~F}^{19}: \mathrm{C}^{12} \mathrm{H}_{2}$ & 3. 911 & $5,0,5 \leftarrow 4,1,4$ & Ground & & & & 31227.04 & .03 \\
\hline $\mathrm{C}^{12} \mathrm{H}_{2}: \mathrm{C}^{12} \mathrm{DBr}^{81}$ & 4- 722 & $4,2,2 \leftarrow 3,2,1$ & Ground & & $7 / 2$ & $7 / 2$ & 31229.5 & \\
\hline $\mathrm{C}^{12} \mathrm{H}_{2}: \mathrm{C}^{12} \mathrm{DBr}^{81}$ & 4. 722 & $4,2,2 \leftarrow 3,2,1$ & Ground & & $7 / 2$ & $5 / 2$ & 31229.5 & \\
\hline $\mathrm{C}^{13} \mathrm{H}_{3} \mathrm{C}^{13} \mathrm{HO}^{16}$ & 3- 478 & $4,0,4 \leftarrow 3,1,3$ & Ground & & & & 31229.94 & .2 \\
\hline$\left(\mathrm{C}^{12} \mathrm{H}_{3}\right)_{2} \mathrm{C}^{12}: \mathrm{C}^{13} \mathrm{H}_{2}$ & 3- 946 & $3,0,3 \leftarrow 2,1,2$ & Ground & & & & 31233.01 & \\
\hline $\mathrm{D}_{2} \mathrm{C}^{12}: \mathrm{C}^{12} \mathrm{O}^{16}$ & 4- 712 & $10,1,9 \leftarrow 10,1,10$ & Ground & & & & 31235.60 & \\
\hline $\mathrm{P}^{31} \mathrm{~F}_{3}^{19}$ & 4-1681 & Not Reported & Excited & & & & 31237. & 3.0 \\
\hline $\mathrm{C}^{12} \mathrm{D}_{3} \mathrm{C}^{12} \mathrm{~N}^{14}$ & 4- 816 & $2, \leftarrow 1$, & Excited & & & & 31242.98 & \\
\hline $\mathrm{C}^{12} \mathrm{H}_{2}: \mathrm{C}^{12} \mathrm{DBr}^{81}$ & 4- 722 & $4,2,2 \leftarrow 3,2,1$ & Ground & & $9 / 2$ & $9 / 2$ & 31243.5 & \\
\hline $\mathrm{C}^{12} \mathrm{H}_{2}: \mathrm{C}^{12} \mathrm{DBr}^{81}$ & 4. 722 & $4,2,2 \leftarrow 3,2,1$ & Ground & & $9 / 2$ & $7 / 2$ & 31243.5 & \\
\hline $\mathrm{C}^{12} \mathrm{H}_{2}: \mathrm{C}^{12} \mathrm{HBr}^{81}$ & 4. 728 & $4,1,4 \leftarrow 3,1,3$ & Ground & & $5 / 2$ & $5 / 2$ & 31244.2 & \\
\hline $\mathrm{C}^{12} \mathrm{H}_{2}: \mathrm{C}^{12} \mathrm{DBr}^{81}$ & 4. 722 & $4,3,2 \leftarrow 3,3,1$ & Excited & & $7 / 2$ & $7 / 2$ & 31252.3 & \\
\hline $\mathrm{C}^{12} \mathrm{H}_{3} \mathrm{~S}^{32} \mathrm{H}$ & 3- 221 & Not Reported & Ground & & & & 31252.87 & \\
\hline $\mathrm{C}^{12} \mathrm{H}_{2}: \mathrm{C}^{12} \mathrm{HBr}^{81}$ & 4- 728 & $4,1,4 \leftarrow 3,1,3$ & Excited & & $7 / 2$ & $7 / 2$ & 31259.6 & \\
\hline $\mathrm{C}^{12} \mathrm{H}_{2}: \mathrm{C}^{12} \mathrm{DBr}^{81}$ & 4- 722 & $4,3,2 \leftarrow 3,3,1$ & Ground & & $9 / 2$ & $7 / 2$ & 31262.4 & \\
\hline $\mathrm{C}^{12} \mathrm{H}_{2}: \mathrm{C}^{12} \mathrm{HC}^{12} \mathrm{~F}^{19}: \mathrm{C}^{12} \mathrm{H}_{2}$ & 3- 911 & $5,0,5 \leftarrow 4,1,4$ & Ground & & & & 31263.84 & .03 \\
\hline $\mathrm{F}^{19} \mathrm{HC}^{12} \mathrm{O}^{18}$ & 4. 274 & $5,0,5 \leftarrow 4,1,4$ & Ground & & & & 31267.2 & .2 \\
\hline$\left(\mathrm{C}^{12} \mathrm{H}_{3}\right)_{2} \mathrm{C}^{12}: \mathrm{C}^{13} \mathrm{H}_{2}$ & 3- 946 & $3,1,3 \leftarrow 2,0,2$ & Ground & & & & 31268.52 & \\
\hline $\mathrm{C}^{12} \mathrm{D}_{3} \mathrm{C}^{12} \mathrm{~N}^{14}$ & 4- 816 & $2, \leftarrow 1$, & Excited & & & & 31271.22 & \\
\hline c. $\mathrm{C}^{12} \mathrm{HD}: \mathrm{C}^{12} \mathrm{HBr}^{81}$ & 4- 742 & $4,1,3 \leftarrow 3,1,2$ & Excited & & $7 / 2$ & $7 / 2$ & 31274.8 & \\
\hline $\mathrm{C}^{12} \mathrm{H}_{2}: \mathrm{C}^{12} \mathrm{DBr}^{81}$ & 4- 722 & $4,3,2 \leftarrow 3,3,1$ & Ground & & $7 / 2$ & $7 / 2$ & 31275.0 & \\
\hline $\mathrm{g} \cdot \mathrm{C}^{12} \mathrm{H}_{3} \mathrm{C}^{12} \mathrm{H}_{2} \mathrm{C}^{12} \mathrm{H}_{2} \mathrm{Cl}^{37}$ & 3- 774 & $5,1,4 \leftarrow 4,1,3$ & Ground & & & & 31275.86 & .2 \\
\hline $\mathrm{P}^{31} \mathrm{~F}_{3}^{19}$ & 4. 1681 & $2, \leftarrow 1$ & Ground & & & & 31279.60 & .10 \\
\hline $\mathrm{D}_{2} \mathrm{C}^{12}{ }_{*} \mathrm{O}^{16} \mathrm{C}^{12}{ }_{*} \mathrm{D}_{2}$ & 4. 843 & $5,2,3 \leftarrow 5,1,4$ & Ground & & & & 31280 . & \\
\hline
\end{tabular}




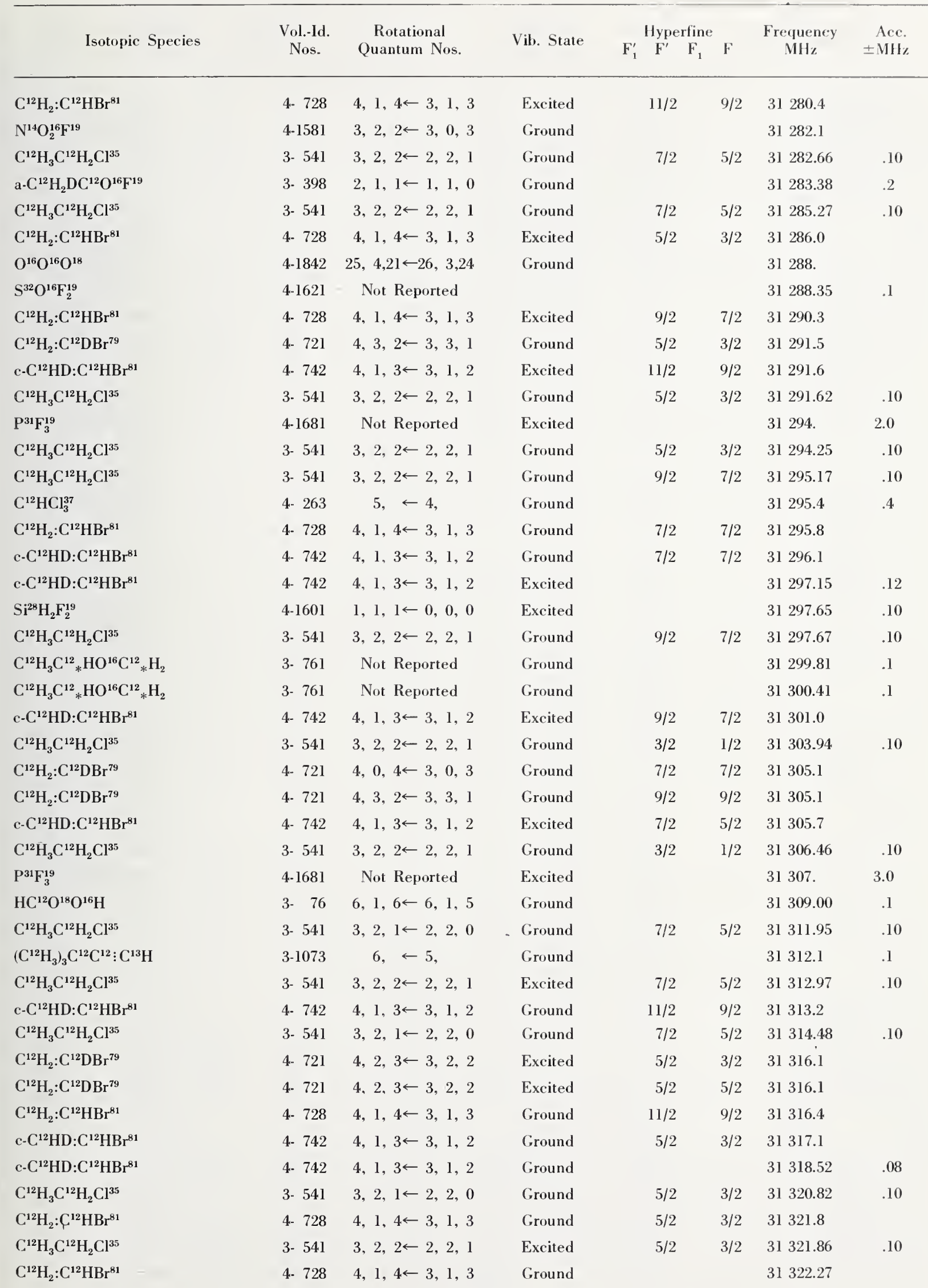




\begin{tabular}{|c|c|c|c|c|c|c|c|}
\hline \multirow{2}{*}{ Isotopic Species } & \multirow{2}{*}{$\begin{array}{l}\text { Vol.-Id. } \\
\text { Nos. }\end{array}$} & \multirow{2}{*}{$\begin{array}{c}\text { Rotational } \\
\text { Quantum Nos. }\end{array}$} & \multirow{2}{*}{ Vib. State } & \multicolumn{2}{|c|}{ Hyperfine } & \multirow{2}{*}{$\begin{array}{c}\text { Frequency } \\
\mathrm{MHz}\end{array}$} & \multirow{2}{*}{$\begin{aligned} & \text { Acc. } \\
\pm & \mathrm{MHz}\end{aligned}$} \\
\hline & & & & $\mathbf{F}_{1}^{\prime} \quad F^{\prime}$ & $F_{1} \quad F$ & & \\
\hline $\mathrm{c}-\mathrm{C}^{12} \mathrm{HD}: \mathrm{C}^{12} \mathrm{HBr}^{81}$ & 4- 742 & $4,1,3 \leftarrow 3,1,2$ & Ground & $9 / 2$ & $7 / 2$ & 31322.5 & \\
\hline $\mathrm{C}^{12} \mathrm{H}_{3} \mathrm{C}^{12} \mathrm{H}_{2} \mathrm{Cl}^{35}$ & 3- 541 & $3,2,1 \leftarrow 2,2,0$ & Ground & $5 / 2$ & $3 / 2$ & 31323.36 & .10 \\
\hline $\mathrm{C}^{12} \mathrm{H}_{3} \mathrm{C}^{12} \mathrm{H}_{2} \mathrm{Cl}^{35}$ & 3- 541 & $3,2,1 \leftarrow 2,2,0$ & Ground & $9 / 2$ & $7 / 2$ & 31324.37 & .10 \\
\hline $\mathrm{C}^{12} \mathrm{H}_{3} \mathrm{C}^{12} \mathrm{H}_{2} \mathrm{Cl}^{35}$ & 3- 541 & $3,2,2 \leftarrow 2,2,1$ & Excited & $9 / 2$ & $7 / 2$ & 31325.49 & .10 \\
\hline $\mathrm{C}^{13} \mathrm{H}_{3} \mathrm{C}^{12} \mathrm{H}_{3} \mathrm{C}^{12}: \mathrm{C}^{12} \mathrm{H}_{2}$ & 3- 945 & $3,1,3 \leftarrow 2,0,2$ & Ground & & & 31325.69 & \\
\hline $\mathrm{O}^{16} \mathrm{~F}_{2}^{19}$ & 4-1611 & $33,8,25 \leftarrow 34,7,28$ & Ground & & & 31325.95 & .10 \\
\hline $\mathrm{C}^{12} \mathrm{H}_{2}: \mathrm{C}^{12} \mathrm{DBr}^{79}$ & 4. 721 & $4,3,2 \leftarrow 3,3,1$ & Excited & $11 / 2$ & $9 / 2$ & 31326.2 & \\
\hline $\mathrm{C}^{12} \mathrm{H}_{2}: \mathrm{C}^{12} \mathrm{HBr}^{81}$ & 4.- 728 & $4,1,4 \leftarrow 3,1,3$ & Ground & $9 / 2$ & $7 / 2$ & 31326.2 & \\
\hline $\mathrm{C}^{12} \mathrm{H}_{3} \mathrm{C}^{12} \mathrm{H}_{2} \mathrm{Cl}^{35}$ & 3- 541 & $3,2,1 \leftarrow 2,2,0$ & Ground & $9 / 2$ & $7 / 2$ & 31326.78 & .10 \\
\hline $\mathrm{C}^{12} \mathrm{H}_{3} \mathrm{C}^{12} \mathrm{O}^{16} \mathrm{Br}^{81}$ & 3- 352 & $9,3,6 \leftarrow 9,2,7$ & Ground & $19 / 2$ & $19 / 2$ & 31326.92 & .15 \\
\hline$c-C^{12} \mathrm{HD}: \mathrm{C}^{12} \mathrm{HBr}^{81}$ & 4.- 742 & $4,1,3 \leftarrow 3,1,2$ & Ground & $7 / 2$ & $5 / 2$ & 31327.1 & \\
\hline $\mathrm{C}^{12} \mathrm{H}_{2}: \mathrm{C}^{12} \mathrm{DBr}^{79}$ & 4. 721 & $4,0,4 \leftarrow 3,0,3$ & Excited & $11 / 2$ & $9 / 2$ & 31327.65 & \\
\hline $\mathrm{C}^{12} \mathrm{H}_{2}: \mathrm{C}^{12} \mathrm{DBr}^{79}$ & 4.- 721 & $4,0,4 \leftarrow 3,0,3$ & Excited & $9 / 2$ & $7 / 2$ & 31327.65 & \\
\hline $\mathrm{C}^{12} \mathrm{H}_{3} \mathrm{~N}^{14} \mathrm{H}_{2}$ & 3- 261 & Not Reported & Ground & & & 31328.0 & \\
\hline $\mathrm{C}^{13} \mathrm{H}_{2} \mathrm{Cl}^{35} \mathrm{Si}^{28} \mathrm{H}_{3}$ & 3- 233 & $5,1,4 \leftarrow 4,1,3$ & Ground & $9 / 211 / 2$ & $7 / 2 \quad 9 / 2$ & 31329.88 & .05 \\
\hline $\mathrm{C}^{12} \mathrm{H}_{3} \mathrm{C}^{12} \mathrm{O}^{16} \mathrm{Br}^{81}$ & 3- 352 & $9,3,6 \leftarrow 9,2,7$ & Ground & $17 / 2$ & $17 / 2$ & 31330.21 & .15 \\
\hline $\mathrm{C}^{13} \mathrm{H}_{2} \mathrm{Cl}^{35} \mathrm{Si}^{28} \mathrm{H}_{3}$ & 3- 233 & $5,1,4 \leftarrow 4,1,3$ & Ground & & & 31330.29 & .2 \\
\hline $\mathrm{C}^{13} \mathrm{H}_{2} \mathrm{Cl}^{35} \mathrm{Si}^{28} \mathrm{H}_{3}$ & 3- 233 & $5,1,4 \leftarrow 4,1,3$ & Ground & $7 / 213 / 2$ & $5 / 211 / 2$ & 31330.68 & .05 \\
\hline $\mathrm{C}^{12} \mathrm{HD}: \mathrm{C}^{12} \mathrm{HBr}^{\mathrm{b}}$ & 4. 748 & Not Reported & Ground & & & 31331.7 & .1 \\
\hline $\mathrm{C}^{12} \mathrm{H}_{2}: \mathrm{C}^{12} \mathrm{HBr}^{81}$ & 4- 728 & $4,1,4 \leftarrow 3,1,3$ & Ground & $7 / 2$ & $5 / 2$ & 31331.8 & \\
\hline $\mathrm{C}^{12} \mathrm{H}_{3} \mathrm{C}^{12} \mathrm{H}_{2} \mathrm{Cl}^{35}$ & 3. 541 & $3,2,1 \leftarrow 2,2,0$ & Ground & $3 / 2$ & $1 / 2$ & 31333.03 & .10 \\
\hline $\mathrm{C}^{12} \mathrm{H}_{3} \mathrm{C}^{12} \mathrm{H}_{2} \mathrm{Cl}^{35}$ & 3- 541 & $3,2,2 \leftarrow 2,2,1$ & Excited & $3 / 2$ & $1 / 2$ & 31333.95 & .10 \\
\hline $\mathrm{C}^{12} \mathrm{H}_{2}: \mathrm{C}^{12} \mathrm{DBr}^{79}$ & 4- 721 & $4,2,3 \leftarrow 3,2,2$ & Excited & $11 / 2$ & $9 / 2$ & 31334.6 & \\
\hline $\mathrm{P}^{31} \mathrm{~F}_{3}^{19}$ & $4-1681$ & Not Reported & Excited & & & 31335. & 3.0 \\
\hline $\mathrm{C}^{12} \mathrm{H}_{3} \mathrm{C}^{12} \mathrm{H}_{2} \mathrm{Cl}^{35}$ & 3- 541 & $3,2,1 \leftarrow 2,2,0$ & Ground & $3 / 2$ & $1 / 2$ & 31335.62 & .10 \\
\hline $\mathrm{C}^{12} \mathrm{H}_{2}: \mathrm{C}^{12} \mathrm{DBr}^{79}$ & 4- 721 & $4,2,3 \leftarrow 3,2,2$ & Ground & $5 / 2$ & $5 / 2$ & 31339.9 & \\
\hline $\mathrm{C}^{12} \mathrm{H}_{2}: \mathrm{C}^{12} \mathrm{DBr}^{79}$ & 4. 721 & $4,2,3 \leftarrow 3,2,2$ & Ground & $5 / 2$ & $3 / 2$ & 31339.9 & \\
\hline $\mathrm{C}^{13} \mathrm{H}_{3} \mathrm{O}^{16} \mathrm{H}$ & 3- 213 & $16,2, \leftarrow 16,1$, & Ground & & & 31342.31 & .1 \\
\hline $\mathrm{C}^{12} \mathrm{H}_{3} \mathrm{C}^{12} \mathrm{H}_{2} \mathrm{Cl}^{35}$ & 3- 541 & $3,2,1 \leftarrow 2,2,0$ & Excited & $7 / 2$ & $5 / 2$ & 31345.78 & .10 \\
\hline $\mathrm{C}^{12} \mathrm{H}_{2}: \mathrm{C}^{12} \mathrm{DBr}^{79}$ & 4- 721 & $4,3,2 \leftarrow 3,3,1$ & Ground & $11 / 2$ & $9 / 2$ & 31346.6 & \\
\hline $\mathrm{C}^{12} \mathrm{H}_{2}: \mathrm{C}^{12} \mathrm{DBr}^{79}$ & 4- 721 & $4,0,4 \leftarrow 3,0,3$ & Ground & $11 / 2$ & $9 / 2$ & 31347.4 & \\
\hline $\mathrm{C}^{12} \mathrm{H}_{2}: \mathrm{C}^{12} \mathrm{DBr}^{79}$ & 4- 721 & $4,0,4 \leftarrow 3,0,3$ & Ground & $9 / 2$ & $7 / 2$ & 31347.4 & \\
\hline $\mathrm{C}^{12} \mathrm{H}_{3} \mathrm{C}^{12} \mathrm{O}^{16} \mathrm{Br}^{81}$ & 3- 352 & $9,3,6 \leftarrow 9,2,7$ & Ground & $21 / 2$ & $21 / 2$ & 31348.15 & .15 \\
\hline $\mathrm{C}^{13} \mathrm{H}_{3} \mathrm{O}^{16} \mathrm{H}$ & 3- 213 & $24,2, \leftarrow 24,1$, & Ground & & & 31350.19 & .1 \\
\hline $\mathrm{C}^{12} \mathrm{H}_{2}: \mathrm{C}^{12} \mathrm{DBr}^{79}$ & 4- 721 & $4,0,4 \leftarrow 3,0,3$ & Ground & & & 31351.06 & \\
\hline $\mathrm{C}^{12} \mathrm{H}_{3} \mathrm{C}^{12} \mathrm{O}^{16} \mathrm{Br}^{81}$ & 3- 352 & $9,3,6 \leftarrow 9,2,7$ & Ground & $15 / 2$ & $15 / 2$ & 31351.55 & .15 \\
\hline $\mathrm{C}^{12} \mathrm{H}_{3} \mathrm{C}^{12} \mathrm{H}_{2} \mathrm{Cl}^{35}$ & 3- 541 & $3,2,1 \leftarrow 2,2,0$ & Excited & $5 / 2$ & $3 / 2$ & 31354.66 & .10 \\
\hline $\mathrm{C}^{12} \mathrm{H}_{2}: \mathrm{C}^{12} \mathrm{DBr}^{79}$ & 4. 721 & $4,2,3 \leftarrow 3,2,2$ & Ground & $11 / 2$ & $9 / 2$ & 31357.0 & \\
\hline $\mathrm{C}^{12} \mathrm{H}_{3} \mathrm{O}^{16} \mathrm{H}$ & 3- 211 & $20,2, \leftarrow 20,1$, & Ground & & & 31358.31 & .1 \\
\hline $\mathrm{P}^{31} \mathrm{~F}_{3}^{19}$ & 4-1681 & Not Reported & Excited & & & 31359. & 3.0 \\
\hline $\mathrm{C}^{12} \mathrm{H}_{3} \mathrm{C}^{12} \mathrm{H}_{2} \mathrm{Cl}^{35}$ & 3- 541 & $3,2,2 \leftarrow 2,2,1$ & Ground & $7 / 2$ & $5 / 2$ & 31359.15 & .1 \\
\hline $\mathrm{C}^{12} \mathrm{H}_{2} \mathrm{Cl}^{35} \mathrm{Si}^{28} \mathrm{H}_{3}$ & 3- 231 & $5,1,4 \leftarrow 4,1,3$ & Ground & & & 31360.87 & .2 \\
\hline $\mathrm{C}^{12} \mathrm{H}_{2}: \mathrm{C}^{12} \mathrm{DBr}^{79}$ & 4- 721 & $4,2,2 \leftarrow 3,2,1$ & Ground & $5 / 2$ & $5 / 2$ & 31365.1 & \\
\hline $\mathrm{C}^{12} \mathrm{H}_{2}: \mathrm{C}^{12} \mathrm{DBr}^{79}$ & 4. 721 & $4,2,2 \leftarrow 3,2,1$ & Ground & $5 / 2$ & $3 / 2$ & 31365.1 & \\
\hline $\mathrm{c}-\mathrm{C}^{12} \mathrm{HD}: \mathrm{C}^{12} \mathrm{HBr}^{81}$ & 4- 742 & $4,1,3 \leftarrow 3,1,2$ & Excited & $9 / 2$ & $9 / 2$ & 31367.3 & \\
\hline
\end{tabular}


$\mathrm{C}^{12} \mathrm{H}_{3} \mathrm{C}^{12} \mathrm{H}_{2} \mathrm{Cl}^{35}$

$\mathrm{C}^{12} \mathrm{H}_{3} \mathrm{C}^{12} \mathrm{H}_{2} \mathrm{Cl}^{35}$

$\mathrm{C}^{12} \mathrm{H}_{2}: \mathrm{C}^{12} \mathrm{DBr}^{79}$

$\mathrm{C}^{12} \mathrm{H}_{2}: \mathrm{C}^{12} \mathrm{DBr}^{79}$

a- $\mathrm{C}^{12} \mathrm{H}_{2} \mathrm{DSi}^{28} \mathrm{HF}_{2}^{19}$

$\mathrm{C}^{12} \mathrm{H}_{3} \mathrm{C}^{12} \mathrm{H}_{2} \mathrm{Cl}^{35}$

$\mathrm{C}^{12} \mathrm{H}_{2}: \mathrm{C}^{12} \mathrm{DBr}^{79}$

$\mathrm{C}^{12} \mathrm{H}_{2}: \mathrm{C}^{12} \mathrm{DBr}^{79}$

$\mathrm{C}^{12} \mathrm{H}_{3} \mathrm{~S}^{32} \mathrm{H}$

$\mathrm{C}^{12} \mathrm{H}_{3} \mathrm{C}^{12} \mathrm{H}_{2} \mathrm{Cl}^{35}$

$\mathrm{C}^{12} \mathrm{H}_{2}: \mathrm{C}^{12} \mathrm{DBr}^{79}$

$\mathrm{C}^{12} \mathrm{H}_{2}: \mathrm{C}^{12} \mathrm{DBr}^{79}$

$\mathrm{C}^{12} \mathrm{H}_{2}: \mathrm{C}^{12} \mathrm{DBr}^{79}$

$\mathrm{C}^{12} \mathrm{H}_{2}: \mathrm{C}^{12} \mathrm{DBr}^{79}$

c-C ${ }^{12} \mathrm{HD}: \mathrm{C}^{12} \mathrm{HBr}^{81}$

$\mathrm{C}^{12} \mathrm{H}_{3} \mathrm{C}^{12} \mathrm{H}_{2} \mathrm{Cl}^{35}$

$\mathrm{C}^{12} \mathrm{H}_{2}: \mathrm{C}^{12} \mathrm{DBr}^{79}$

$\mathrm{C}^{12} \mathrm{H}_{2}: \mathrm{C}^{12} \mathrm{DBr}^{79}$

$\mathrm{C}^{12} \mathrm{H}_{3} \mathrm{C}^{12} \mathrm{H}_{2} \mathrm{Cl}^{35}$

$\mathrm{C}^{12} \mathrm{H}_{3} \mathrm{C}^{12} \mathrm{H}_{2} \mathrm{Cl}^{35}$

$\mathrm{C}^{12} \mathrm{HD}: \mathrm{C}^{12} \mathrm{HBr}^{\mathrm{b}}$

$\mathrm{C}^{12} \mathrm{H}_{2}: \mathrm{C}^{12} \mathrm{HBr}^{81}$

$\mathrm{C}^{12} \mathrm{H}_{2}: \mathrm{C}^{12} \mathrm{HBr}^{79}$

$\mathrm{C}^{12} \mathrm{H}_{3} \mathrm{C}^{12} \mathrm{H}_{2} \mathrm{Cl}^{35}$

$\mathrm{C}^{12} \mathrm{H}_{2}: \mathrm{C}^{12} \mathrm{DBr}^{79}$

$\mathrm{C}^{12} \mathrm{H}_{2}: \mathrm{C}^{12} \mathrm{DBr}^{79}$

$\mathrm{C}^{12} \mathrm{H}_{2} \mathrm{Cl}^{35} \mathrm{Cl}^{37}$

$\mathrm{HC}^{13}: \mathrm{C}^{12} \mathrm{C}^{12} \mathrm{DO}^{16}$

$\mathrm{C}^{12} \mathrm{D}_{3} \mathrm{C}^{12} \mathrm{~N}^{14}$

$\mathrm{C}^{12} \mathrm{H}_{3} \mathrm{Si}^{28} \mathrm{Cl}_{2}^{35} \mathrm{Cl}^{37}$

$\mathrm{C}^{12} \mathrm{H}_{3} \mathrm{C}^{12} \mathrm{H}_{2} \mathrm{Cl}^{35}$

$\mathrm{S}^{33} \mathrm{P}^{31} \mathrm{~F}_{3}^{19}$

$\mathrm{C}^{12} \mathrm{H}_{2}: \mathrm{C}^{12} \mathrm{DBr}^{79}$

$\mathrm{C}^{12} \mathrm{H}_{2}: \mathrm{C}^{12} \mathrm{DBr}^{79}$

$\mathrm{C}^{12} \mathrm{H}_{3} \mathrm{~S}^{32} \mathrm{H}$

$\mathrm{S}^{32} \mathrm{O}^{16} \mathrm{~F}_{2}^{19}$

$\mathrm{HC}^{12}{ }_{*}: \mathrm{C}^{12} \mathrm{HO}^{16} \mathrm{C}^{12} \mathrm{O}^{16} \mathrm{O}^{16}{ }_{*}$

c- $\mathrm{C}^{12} \mathrm{HD}: \mathrm{C}^{12} \mathrm{HBr}^{79}$

$\mathrm{C}^{12} \mathrm{D}_{3} \mathrm{~N}^{14} \mathrm{H}_{2}$

$\mathrm{N}^{14} \mathrm{H}_{3}$

$\mathrm{C}^{12} \mathrm{H}_{2}: \mathrm{C}^{12} \mathrm{HBr}^{79}$

$\mathrm{C}^{12} \mathrm{H}_{2}: \mathrm{C}^{12} \mathrm{DBr}^{79}$

$\mathrm{C}^{12} \mathrm{H}_{2}: \mathrm{C}^{12} \mathrm{DBr}^{79}$

$\mathrm{C}^{12} \mathrm{D}_{3} \mathrm{C}^{12} \mathrm{~N}^{14}$

$\mathrm{HC}^{13}: \mathrm{C}^{12} \mathrm{C}^{12} \mathrm{DO}^{16}$
3. $541 \quad 3,2,2 \leftarrow 2,2,1$

Ground

3. 541

$3,2,2 \leftarrow 2,2,1$

Ground

4- 721

$4,2,3 \leftarrow 3,2,2$

4- 721

$4,2,3 \leftarrow 3,2,2$

3- 204

$4,1,4 \leftarrow 3,1,3$

3. 541

$3,2,2 \leftarrow 2,2,1$

4- 721

$4,3,2 \leftarrow 3,3,1$

4. 721

$4,2,3 \leftarrow 3,2,2$

3. 221

Not Reported

3- 541

$3,2,2 \leftarrow 2,2,1$

4- 721

$4,3,2 \leftarrow 3,3,1$

4. 721

$4,2,2 \leftarrow 3,2,1$

4- 721

$4,2,3 \leftarrow 3,2,2$

4- 721

$4,2,3 \leftarrow 3,2,2$

4. 742

$4,1,3 \leftarrow 3,1,2$

3- 541

$3,2,1 \leftarrow 2,2,0$

4- 721

$4,2,2 \leftarrow 3,2,1$

4. 721

$4,3,2 \leftarrow 3,3,1$

3. 541

$3,2,1 \leftarrow 2,2,0$

3- 541

$3,2,1 \leftarrow 2,2,0$

4. 748

4. 728

4. 727

Not Reported

3- 541

$4,1,4 \leftarrow 3,1,3$

4- 721

$4,1,4 \leftarrow 3,1,3$

4. 721

$3,2,1 \leftarrow 2,2,0$

4. 342

4. 922

$4,2,3 \leftarrow 3,2,2$

$4,2,3 \leftarrow 3,2,2$

$6,1,5 \leftarrow 6,0,6$

4. 816

3- 113

3- 541

4-1692

4- 721

4. 721

Not Reported

$$
2,1 \leftarrow 1,1
$$

$9, \quad \leftarrow 8, \quad$

3- 221

$3,2,1 \leftarrow 2,2,0$

$6, \leftarrow 5$,

$4,2,2 \leftarrow 3,2,1$

$4,2,2 \leftarrow 3,2,1$

4-1621

Not Reported

4- 931

Not Reported

4. 739

$5,1,5 \leftarrow 4,1,4$

$4,1,3 \leftarrow 3,1,2$

3. 263

Not Reported

4-1771

$12,12 \leftarrow 12,12$

4. 727

$4,1,4 \leftarrow 3,1,3$

4. 721

$4,2,2 \leftarrow 3,2,1$

4. 721

$4,2,2 \leftarrow 3,2,1$

$$
2, \leftarrow 1,
$$

4- 922

Excited

Excited

Ground

Ground

Excited

Ground

Ground

Ground

Ground

Ground

Ground

Ground

Ground

Ground

Ground

Ground

Ground

Ground

Ground

Ground

Ground

Ground

Ground

Ground

Excited

Ground

Ground

Ground

Ground

Ground

Ground

Ground

Ground

Excited

Ground

Ground

Ground
Ground

$\begin{array}{llll}5 / 2 & 3 / 2 & 31367.95 & .1 \\ & & 31368.07 & .1 \\ 7 / 2 & 5 / 2 & 31368.7 & \end{array}$

$\begin{array}{llll}7 / 2 & 7 / 2 & 31368.7\end{array}$

$31370.12 \quad 2$.

$\begin{array}{lllll}9 / 2 & 7 / 2 & 31 & 371.65 & .1\end{array}$

$7 / 2 \quad 5 / 2 \quad 31374.2$

31374.41

31378.7

$3 / 2 \quad 1 / 2 \quad 31380.55$

31381.76

$11 / 2 \quad 9 / 2 \quad 31382.2$

$7 / 2 \quad 7 / 2 \quad 31388.4$

$7 / 2 \quad 5 / 2 \quad 31388.4$

$9 / 2 \quad 9 / 2 \quad 31388.9$

$7 / 2 \quad 5 / 2 \quad 31391.53$

31399.58

$7 / 2 \quad 5 / 2 \quad 31399.7$

$31400.29 \quad .1$

$\begin{array}{lllll}5 / 2 & 3 / 2 & 31 & 400.44 & .1\end{array}$

$31400.6 \quad .1$

$9 / 2 \quad 9 / 2 \quad 31403.6$

$5 / 2 \quad 5 / 2 \quad 31403.6$

$9 / 2 \quad 7 / 2 \quad 31403.78$

$9 / 2 \quad 7 / 2 \quad 31404.85$

$9 / 2 \quad 9 / 2 \quad 31404.85$

31405.

5.

31407.

5.

31409.64

31410.

10.

$3 / 2$

$1 / 2$

31412.5

.1

31412.7

$7 / 2 \quad 5 / 2 \quad 31413.4$

$7 / 2 \quad 7 / 2 \quad 31413.4$

31414.80

31418.02

31420.68

.1

$5 / 2$

$5 / 2$

31422.4

31422.9

31424.97

$7 / 2 \quad 7 / 2 \quad 31428.7$

$9 / 2 \quad 7 / 2 \quad 31430.1$

$9 / 2 \quad 9 / 2 \quad 31430.1$

31431.50

31440.

.1

1

1

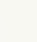

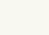




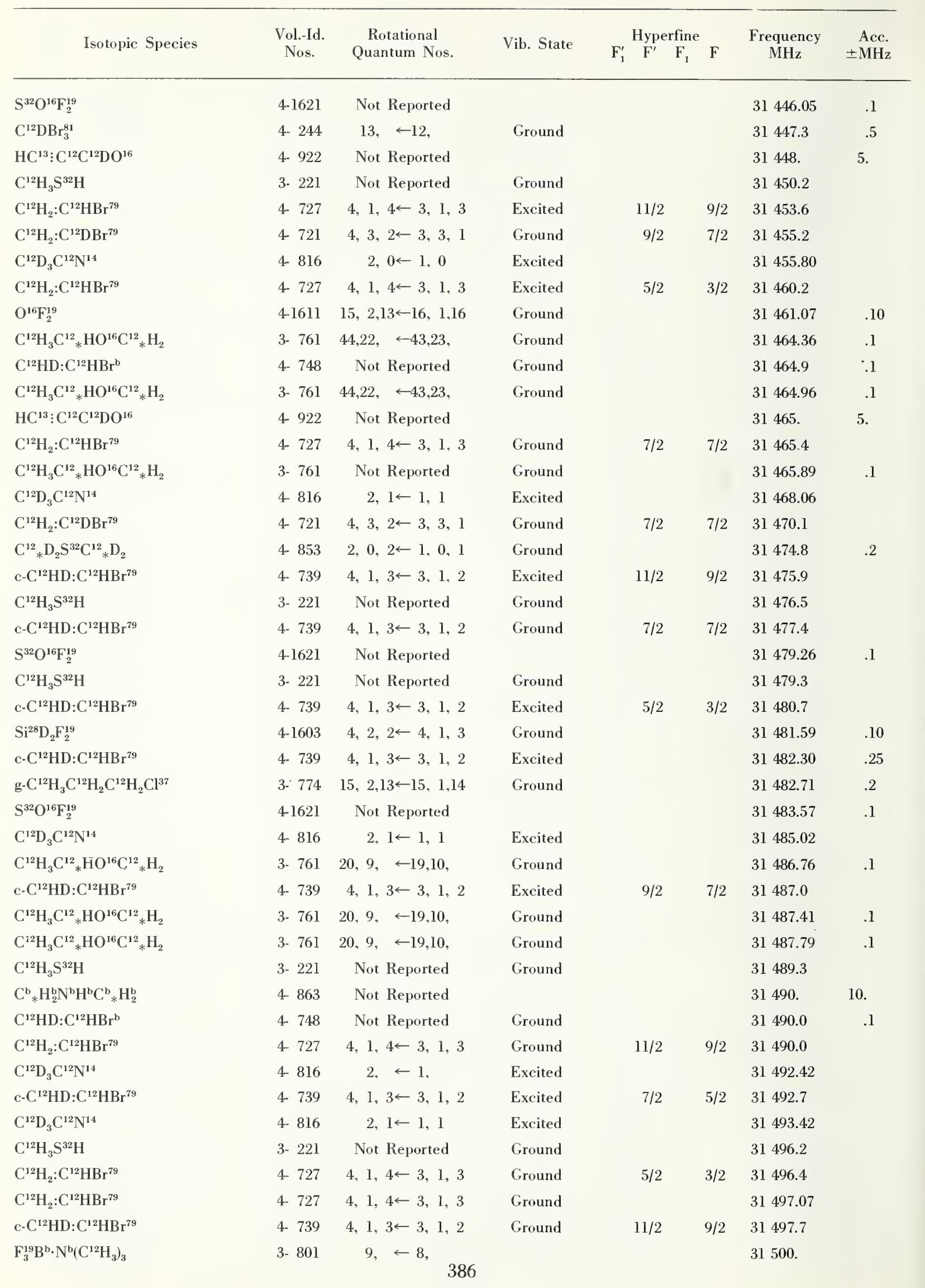




\begin{tabular}{|c|c|c|c|c|c|c|c|c|}
\hline \multirow{2}{*}{ Isotopic Species } & \multirow{2}{*}{$\begin{array}{l}\text { Vol.-Id. } \\
\text { Nos. }\end{array}$} & \multirow{2}{*}{$\begin{array}{c}\text { Rotational } \\
\text { Quantum Nos. }\end{array}$} & \multirow{2}{*}{ Vib. State } & \multicolumn{3}{|c|}{ Hyperfine } & \multirow{2}{*}{$\begin{array}{l}\text { Frequency } \\
\qquad \mathrm{MHz}\end{array}$} & \multirow{2}{*}{$\begin{aligned} & \text { Acc. } \\
\pm & \mathrm{MHz}_{2}\end{aligned}$} \\
\hline & & & & $F_{1}^{\prime}$ & $F^{\prime} \quad F_{1}$ & $\mathrm{~F}$ & & \\
\hline $\mathrm{C}^{12} \mathrm{H}_{3} \mathrm{~S}^{32} \mathrm{H}$ & 3- 221 & Not Reported & Ground & & & & 31500.8 & \\
\hline $\mathrm{C}^{12} \mathrm{H}_{2}: \mathrm{C}^{12} \mathrm{HBr}^{79}$ & 4- 727 & $4,1,4 \leftarrow 3,1,3$ & Ground & & $9 / 2$ & $7 / 2$ & 31501.7 & \\
\hline$c-\mathrm{C}^{12} \mathrm{HD}: \mathrm{C}^{12} \mathrm{HBr}^{79}$ & 4- 739 & $4,1,3 \leftarrow 3,1,2$ & Ground & & $5 / 2$ & $3 / 2$ & 31502.2 & \\
\hline$c-\mathrm{C}^{12} \mathrm{HD}: \mathrm{C}^{12} \mathrm{HBr}^{79}$ & 4- 739 & $4,1,3 \leftarrow 3,1,2$ & Ground & & & & 31503.89 & .17 \\
\hline $\mathrm{C}^{12} \mathrm{H}_{2}: \mathrm{C}^{12} \mathrm{HBr}^{79}$ & 4- 727 & $4,1,4 \leftarrow 3,1,3$ & Ground & & $7 / 2$ & $5 / 2$ & 31508.25 & \\
\hline$c-\mathrm{C}^{12} \mathrm{HD}: \mathrm{C}^{12} \mathrm{HBr}^{79}$ & 4- 739 & $4,1,3 \leftarrow 3,1,2$ & Ground & & $9 / 2$ & $7 / 2$ & 31508.6 & \\
\hline $\mathrm{C}^{\mathrm{b}} \mathrm{H}_{2}^{\mathrm{b}} \mathrm{Cl}^{\mathrm{b}} \mathrm{F}^{\mathrm{b}}$ & 4- 333 & Not Reported & & & & & 31509.67 & .1 \\
\hline$c-\mathrm{C}^{12} \mathrm{HD}: \mathrm{C}^{12} \mathrm{HBr}^{79}$ & 4. 739 & $4,1,3 \leftarrow 3,1,2$ & Ground & & $7 / 2$ & $5 / 2$ & 31514.3 & \\
\hline $\mathrm{C}^{12} \mathrm{H}_{3} \mathrm{C}^{12} \mathrm{O}^{18} \mathrm{C}^{12} \mathrm{~N}^{14}$ & 3- 674 & $5,1,5 \leftarrow 4,1,4$ & Ground & & & & 31519.18 & .2 \\
\hline $\mathrm{C}^{12} \mathrm{D}_{3} \mathrm{C}^{12} \mathrm{~N}^{14}$ & 4- 816 & $2, \leftarrow 1$, & Excited & & & & 31520.26 & \\
\hline $\mathrm{C}^{12} \mathrm{D}_{3} \mathrm{C}^{12} \mathrm{~N}^{14}$ & 4- 816 & $2,1 \leftarrow 1,1$ & Excited & & & & 31520.92 & \\
\hline $\mathrm{C}^{12} \mathrm{H}_{3} \mathrm{~S}^{32} \mathrm{H}$ & 3- 221 & Not Reported & Ground & & & & 31522.7 & \\
\hline $\mathrm{C}^{12} \mathrm{H}_{3} \mathrm{~S}^{32} \mathrm{H}$ & 3- 221 & Not Reported & Ground & & & & 31527.2 & \\
\hline $\mathrm{C}^{12} \mathrm{H}_{3} \mathrm{~S}^{32} \mathrm{H}$ & 3- 221 & Not Reported & Ground & & & & 31529.9 & \\
\hline $\mathrm{C}^{\mathrm{b}} \mathrm{H}_{2}^{\mathrm{b}} \mathrm{Cl}^{\mathrm{b}} \mathrm{F}^{\mathrm{b}}$ & 4- 333 & Not Reported & & & & & 31535.33 & .1 \\
\hline $\mathrm{C}^{12}{ }_{*} \mathrm{H}_{2} \mathrm{~N}^{14} \mathrm{HC}^{12}{ }_{*} \mathrm{H}_{2}$ & 4- 861 & $8,7,1 \leftarrow 8,6,2$ & Ground & & & & 31540. & 10. \\
\hline $\mathrm{C}^{12} \mathrm{H}_{3} \mathrm{~S}^{32} \mathrm{H}$ & 3- 221 & Not Reported & Ground & & & & 31540.4 & \\
\hline $\mathrm{C}^{12} \mathrm{H}_{3} \mathrm{C}^{12} \mathrm{O}^{18} \mathrm{C}^{12} \mathrm{~N}^{14}$ & 3- 674 & $11,4,7 \leftarrow 11,3,8$ & Ground & & & & 31542.42 & .2 \\
\hline $\mathrm{C}^{12} \mathrm{H}_{2} \mathrm{~F}_{2}^{19}$ & 4- 351 & $3,2,2 \leftarrow 4,1,3$ & Ground & & & & 31543.75 & .10 \\
\hline $\mathrm{C}^{12} \mathrm{D}_{3} \mathrm{C}^{12} \mathrm{~N}^{14}$ & 4- 816 & $2,1 \leftarrow 1,1$ & Excited & & & & 31549.10 & \\
\hline $\mathrm{C}^{12} \mathrm{H}_{3} \mathrm{~S}^{32} \mathrm{H}$ & 3- 221 & Not Reported & Ground & & & & 31555.09 & \\
\hline $\mathrm{C}^{13} \mathrm{D}_{3} \mathrm{Si}^{28} \mathrm{D}_{3}$ & 3- 322 & $2, \leftarrow 1$, & & & & & 31558.70 & .3 \\
\hline $\mathrm{C}^{12} \mathrm{H}_{3} \mathrm{~S}^{32} \mathrm{H}$ & 3- 221 & Not Reported & Ground & & & & 31563.8 & \\
\hline $\mathrm{C}^{12} \mathrm{H}_{3} \mathrm{C}^{12} \mathrm{H}_{2} \mathrm{~F}^{19}$ & 3- 551 & $5,3,2 \leftarrow 6,2,5$ & Ground & & & & 31564.84 & .10 \\
\hline $\mathrm{C}^{12} \mathrm{D}_{3} \mathrm{C}^{12} \mathrm{~N}^{14}$ & 4- 816 & $2, \leftarrow 1$, & Excited & & & & 31565.0 & \\
\hline $\mathrm{C}^{12} \mathrm{D}_{3} \mathrm{~N}^{14} \mathrm{D}_{2}$ & 3- 262 & $4,1,4 \leftarrow 4,0,4$ & Ground & & & & 31565.45 & \\
\hline $\mathrm{C}^{12} \mathrm{H}_{3} \mathrm{~S}^{32} \mathrm{H}$ & 3- 221 & Not Reported & Ground & & & & 31567.9 & \\
\hline $\mathrm{C}_{*}^{\mathrm{b}} \mathrm{H}_{2}^{\mathrm{b}} \mathrm{N}^{\mathrm{b}} \mathrm{H}^{\mathrm{b}} \mathrm{C}_{*}^{\mathrm{b}} \mathrm{H}_{2}^{\mathrm{b}}$ & 4- 863 & Not Reported & & & & & 31570. & 10. \\
\hline $\mathrm{C}^{12} \mathrm{H}_{3} \mathrm{~S}^{32} \mathrm{H}$ & 3- 221 & Not Reported & Ground & & & & 31571.8 & \\
\hline $\mathrm{C}^{12} \mathrm{H}_{3} \mathrm{~B}^{\mathrm{b}} \mathrm{F}_{2}^{19}$ & 3- 91 & $4, \quad \leftarrow 4, \quad$, & Ground & & & & 31575.1 & .1 \\
\hline $\mathrm{C}^{12} \mathrm{H}_{3} \mathrm{~S}^{32} \mathrm{H}$ & 3- 221 & Not Reported & Ground & & & & 31575.4 & \\
\hline $\mathrm{C}^{12} \mathrm{H}_{2} \mathrm{Cl}_{2}^{35}$ & 4- 341 & $6,1,5 \leftarrow 6,0,6$ & - Ground & & & & 31577. & 5. \\
\hline $\mathrm{C}^{12} \mathrm{D}_{3} \mathrm{Si}^{30} \mathrm{H}_{2} \mathrm{~F}^{19}$ & 3- 246 & $3,0,3 \leftarrow 2,0,2$ & Ground & & & & 31577.4 & 1. \\
\hline $\mathrm{C}^{12} \mathrm{H}_{3} \mathrm{~N}^{14} \mathrm{H}_{2}$ & 3- 261 & Not Reported & Ground & & & & 31583.41 & \\
\hline $\mathrm{C}^{12} \mathrm{H}_{3} \mathrm{~N}^{14} \mathrm{H}_{2}$ & 3- 261 & Not Reported & Ground & & & & 31583.87 & \\
\hline$c-\mathrm{C}^{12} \mathrm{HD}: \mathrm{C}^{12} \mathrm{HBr}^{79}$ & 4- 739 & $4,1,3 \leftarrow 3,1,2$ & Ground & & $9 / 2$ & $9 / 2$ & $31588: 2$ & \\
\hline $\mathrm{C}^{12} \mathrm{D}_{3} \mathrm{C}^{12} \mathrm{~N}^{14}$ & 4. 816 & $2, \leftarrow 1$, & Excited & & & & 31588.6 & \\
\hline $\mathrm{HC}^{13}: \mathrm{C}^{12} \mathrm{C}^{12} \mathrm{DO}^{16}$ & 4- 922 & Not Reported & & & & & 31590. & 5. \\
\hline $\mathrm{C}^{12} \mathrm{H}_{2}: \mathrm{C}^{12} \mathrm{HBr}^{79}$ & 4- 727 & $4,1,4 \leftarrow 3,1,3$ & Ground & & $9 / 2$ & $9 / 2$ & 31594.8 & \\
\hline $\mathrm{C}^{12} \mathrm{D}_{3} \mathrm{C}^{12} \mathrm{~N}^{14}$ & 4- 816 & $2,1 \leftarrow 1,1$ & Excited & & & & 31605.10 & \\
\hline $\mathrm{C}^{12}{ }_{*} \mathrm{H}_{2} \mathrm{C}^{12} \mathrm{H}_{2} \mathrm{C}^{12} \mathrm{H}_{2} \mathrm{O}^{18}{ }_{*}$ & 4-1093 & $2,0,2 \leftarrow 1,0,1$ & Ground & & & & 31605.4 & .1 \\
\hline $\mathrm{C}^{12} \mathrm{D}_{3} \mathrm{C}^{12} \mathrm{~N}^{14}$ & 4- 816 & $2,1 \leftarrow 1,1$ & Excited & & & & 31609.10 & \\
\hline $\mathrm{C}^{12} \mathrm{D}_{3} \mathrm{C}^{12} \mathrm{~N}^{14}$ & 4- 816 & $2,1 \leftarrow 1,1$ & Excited & & & & 31609.10 & \\
\hline $\mathrm{N}^{14} \mathrm{O}^{18} \mathrm{Cl}^{35}$ & $4-1453$ & $3,0,3 \leftarrow 2,0,2$ & Ground & & $7 / 2$ & $7 / 2$ & 31611.34 & \\
\hline $\mathrm{HC}^{13}: \mathrm{C}^{12} \mathrm{C}^{12} \mathrm{DO}^{16}$ & 4- 922 & Not Reported & & & & & 31615. & 5. \\
\hline
\end{tabular}




\begin{tabular}{|c|c|c|c|c|c|c|c|}
\hline \multirow{2}{*}{ Isotopic Species } & \multirow{2}{*}{$\begin{array}{l}\text { Vol.-Id. } \\
\text { Nos. }\end{array}$} & \multirow{2}{*}{$\begin{array}{c}\text { Rotational } \\
\text { Quantum Nos. }\end{array}$} & \multirow{2}{*}{ Vib. State } & \multicolumn{2}{|c|}{ Hyperfine } & \multirow{2}{*}{$\begin{array}{l}\text { Frequency } \\
\qquad \mathrm{MHz}\end{array}$} & \multirow{2}{*}{$\begin{aligned} & \text { Acc. } \\
& \pm \mathrm{MHz}\end{aligned}$} \\
\hline & & & & $\begin{array}{lll}\mathrm{F}_{1}^{\prime} & \mathrm{F}^{\prime} & \mathrm{F}_{1}\end{array}$ & $\mathbf{F}$ & & \\
\hline $\mathrm{N}^{14} \mathrm{O}^{18} \mathrm{Cl}^{35}$ & 4-1453 & $3,0,3 \leftarrow 2,0,2$ & Ground & $3 / 2$ & $1 / 2$ & 31620.48 & \\
\hline $\mathrm{N}^{14} \mathrm{O}^{18} \mathrm{Cl}^{35}$ & 4- 1453 & $3,0,3 \leftarrow 2,0,2$ & Ground & $3 / 2$ & $5 / 2$ & 31620.48 & \\
\hline $\mathrm{N}^{14} \mathrm{O}^{18} \mathrm{Cl}^{35}$ & $4-1453$ & $3,0,3 \leftarrow 2,0,2$ & Ground & $7 / 2$ & $5 / 2$ & 31623.50 & \\
\hline $\mathrm{N}^{14} \mathrm{O}^{18} \mathrm{Cl}^{35}$ & $4-1453$ & $3,0,3 \leftarrow 2,0,2$ & Ground & $9 / 2$ & $7 / 2$ & 31623.50 & \\
\hline $\mathrm{N}^{14} \mathrm{O}^{18} \mathrm{Cl}^{35}$ & 4-1453 & $2,2,0 \leftarrow 3,2,1$ & Ground & $5 / 2$ & $5 / 2$ & 31623.50 & \\
\hline $\mathrm{N}^{14} \mathrm{O}^{18} \mathrm{Cl}^{35}$ & 4-1453 & $2,2,0 \leftarrow 3,2,1$ & Ground & $3 / 2$ & $5 / 2$ & 31623.50 & \\
\hline $\mathrm{H}_{2} \mathrm{~N}^{14} \mathrm{C}^{12} \mathrm{~N}^{14}$ & 4- 361 & $15,1,14 \leftarrow 15,1,15$ & Ground & & & 31627.4 & .5 \\
\hline $\mathrm{C}^{12} \mathrm{H}_{3} \mathrm{Si}^{\mathrm{b}} \mathrm{HD}_{2}$ & 3- 326 & $12,1,11 \leftarrow 12,1,12$ & & & & 31627.61 & .2 \\
\hline $\mathrm{C}^{12} \mathrm{D}_{3} \mathrm{Si}^{29} \mathrm{H}_{2} \mathrm{~F}^{19}$ & 3- 251 & $3,0,3 \leftarrow 2,0,2$ & Ground & & & 31628.73 & .10 \\
\hline $\mathrm{N}^{14} \mathrm{O}^{18} \mathrm{Cl}^{35}$ & 4-1453 & $3,0,3 \leftarrow 2,0,2$ & Ground & $5 / 2$ & $5 / 2$ & 31628.97 & \\
\hline $\mathrm{H}_{2} \mathrm{~N}^{14} \mathrm{C}^{12} \mathrm{~N}^{14}$ & 4- 361 & $15,1,14 \leftarrow 15,1,15$ & Ground & & & 31630.6 & .5 \\
\hline $\mathrm{N}^{14} \mathrm{O}^{18} \mathrm{Cl}^{35}$ & $4-1453$ & $2,2,0 \leftarrow 3,2,1$ & Ground & $3 / 2$ & $3 / 2$ & 31632.28 & \\
\hline $\mathrm{N}^{14} \mathrm{O}^{18} \mathrm{Cl}^{35}$ & $4-1453$ & $2,2,0 \leftarrow 3,2,1$ & Ground & $7 / 2$ & $5 / 2$ & 31632.28 & \\
\hline $\mathrm{N}^{14} \mathrm{O}^{18} \mathrm{Cl}^{35}$ & $4-1453$ & $2,2,0 \leftarrow 3,2,1$ & Ground & $5 / 2$ & $3 / 2$ & 31632.28 & \\
\hline $\mathrm{N}^{14} \mathrm{O}^{18} \mathrm{Cl}^{35}$ & 4-1453 & $3,0,3 \leftarrow 2,0,2$ & Ground & $3 / 2$ & $3 / 2$ & 31632.28 & \\
\hline $\mathrm{C}^{12} \mathrm{H}_{2} \mathrm{~N}^{14} \mathrm{O}^{16} \mathrm{H}$ & 3- 141 & $11,3,8 \leftarrow 12,2,11$ & Ground & 10 & 11 & 31633.09 & .10 \\
\hline $\mathrm{C}^{12} \mathrm{H}_{2} \mathrm{~N}^{14} \mathrm{O}^{16} \mathrm{H}$ & 3- 141 & $11,3,8 \leftarrow 12,2,11$ & Ground & 12 & 13 & 31633.09 & .10 \\
\hline $\mathrm{C}^{12} \mathrm{H}_{2} \mathrm{~N}^{14} \mathrm{O}^{16} \mathrm{H}$ & 3- 141 & $11,3,8 \leftarrow 12,2,11$ & Ground & 11 & 12 & 31633.42 & .10 \\
\hline $\mathrm{C}^{12} \mathrm{D}_{3} \mathrm{C}^{12} \mathrm{~N}^{14}$ & 4- 816 & $2,1 \leftarrow 1,1$ & Excited & & & 31635. & \\
\hline $\mathrm{C}^{12} \mathrm{HBr}_{3}^{81}$ & 4- 242 & $13, \leftarrow 12$, & Ground & & & 31649.9 & .5 \\
\hline $\mathrm{HC}^{13} \vdots \mathrm{C}^{12} \mathrm{C}^{12} \mathrm{DO}^{16}$ & 4. 922 & Not Reported & & & & 31650. & 5. \\
\hline $\mathrm{C}^{12} \mathrm{H}_{3} \mathrm{O}^{16} \mathrm{~N}^{14} \mathrm{O}_{2}^{16}$ & 3- 181 & $3,2,2 \leftarrow 3,0,3$ & Ground & & & 31652.05 & .1 \\
\hline $\mathrm{C}^{12} \mathrm{D}_{3} \mathrm{~N}^{14} \mathrm{H}_{2}$ & 3- 263 & $4, \quad \leftarrow 3$, & & & & 31656.2 & .5 \\
\hline $\mathrm{C}^{12} \mathrm{D}_{3} \mathrm{~N}^{14} \mathrm{D}_{2}$ & 3- 262 & $4,1,4 \leftarrow 4,0,4$ & Ground & & & 31656.92 & \\
\hline $\mathrm{HC}^{13}: \mathrm{C}^{12} \mathrm{C}^{12} \mathrm{DO}^{16}$ & 4- 922 & Not Reported & & & & 31658. & 5. \\
\hline $\mathrm{C}^{12} \mathrm{H}_{3} \mathrm{O}^{16} \mathrm{H}$ & 3- 211 & Not Reported & Ground & & & 31673.05 & .1 \\
\hline $\mathrm{C}^{12} \mathrm{H}_{3} \mathrm{~S}^{32} \mathrm{H}$ & 3- 221 & Not Reported & Ground & & & 31675.02 & \\
\hline $\mathrm{C}^{12} \mathrm{H}_{3} \mathrm{~N}^{14} \mathrm{O}_{2}^{16}$ & 3- 171 & $2,1, \leftarrow 1,1$, & Ground & & & 31677.3 & .2 \\
\hline a. $\mathrm{C}^{12} \mathrm{H}_{2} \mathrm{DSi}^{28} \mathrm{HF}_{2}^{19}$ & 3- 204 & $3,2,1 \leftarrow 2,2,0$ & Ground & & & 31678.18 & 2. \\
\hline $\mathrm{C}^{12} \mathrm{D}_{3} \mathrm{Si}^{28} \mathrm{H}_{2} \mathrm{~F}^{19}$ & 3- 244 & $3,0,3 \leftarrow 2,0,2$ & Ground & & & 31681.20 & .10 \\
\hline $\mathrm{C}^{12}{ }_{*} \mathrm{H}_{2} \mathrm{C}^{12} \mathrm{D}: \mathrm{C}^{12}{ }_{*} \mathrm{D}$ & 4-1033 & $1,0,1 \leftarrow 0,0,0$ & Ground & & & 31687.4 & \\
\hline $\mathrm{C}^{12} \mathrm{D}_{3} \mathrm{C}^{12} \mathrm{~N}^{14}$ & 4- 816 & $2,1 \leftarrow 1,1$ & Excited & & & 31688.5 & \\
\hline $\mathrm{C}^{12} \mathrm{D}_{3} \mathrm{C}^{12} \mathrm{O}^{16} \mathrm{C}^{12} \mathrm{~N}^{14}$ & 3- 675 & $5,1,5 \leftarrow 4,0,4$ & Ground & & & 31690.10 & .2 \\
\hline $\mathrm{C}^{12} \mathrm{D}_{3} \mathrm{C}^{12} \mathrm{~N}^{14}$ & 4- 816 & $2,1 \leftarrow 1,1$ & Excited & & & 31694.5 & \\
\hline $\mathrm{C}^{12} \mathrm{D}_{3} \mathrm{C}^{12} \mathrm{~N}^{14}$ & 4- 816 & $2,1 \leftarrow 1,1$ & Excited & & & 31694.5 & \\
\hline $\mathrm{F}_{2}^{19} \mathrm{O}_{2}^{18}$ & 3- $\quad 13$ & $2,1,2 \leftarrow 1,0,1$ & Ground & & & 31697.0 & .5 \\
\hline $\mathrm{HC}^{13}: \mathrm{C}^{12} \mathrm{C}^{12} \mathrm{DO}^{16}$ & 4- 922 & Not Reported & & & & 31703. & 5. \\
\hline$\left(\mathrm{C}^{12} \mathrm{H}_{3}\right)_{2} \mathrm{O}^{18}$ & 3- 595 & $3,1,2 \leftarrow 3,0,3$ & Ground & & & 31706.2 & .5 \\
\hline $\mathrm{C}^{12} \mathrm{D}_{3} \mathrm{~N}^{14} \mathrm{D}_{2}$ & 3- 262 & $4,1,4 \leftarrow 4,0,4$ & Ground & & & 31716.25 & \\
\hline $\mathrm{HC}^{13}: \mathrm{C}^{12} \mathrm{C}^{12} \mathrm{DO}^{16}$ & 4- 922 & Not Reported & & & & 31717. & 5. \\
\hline $\mathrm{I}^{127} \mathrm{C}^{13} \mathrm{~N}^{14}$ & 4- 512 & $5 \leftarrow 4$ & Ground & $7 / 2$ & $5 / 2$ & 31718.28 & \\
\hline $\mathrm{C}^{12} \mathrm{H}_{3} \mathrm{Ge}^{76} \mathrm{D}_{3}$ & 3- 307 & $2,0 \leftarrow 1,0$ & Ground & & & 31720.45 & .10 \\
\hline $\mathrm{C}^{12} \mathrm{H}_{3} \mathrm{Ge}^{74} \mathrm{D}_{3}$ & 3- 293 & $2,0 \leftarrow 1,0$ & Ground & & & 31729.5 & .10 \\
\hline $\mathrm{C}^{12}{ }_{*} \mathrm{H}_{2} \mathrm{C}^{12} \mathrm{H}_{2} \mathrm{C}^{12} \mathrm{H}_{2} \mathrm{O}^{18}{ }_{*}$ & 4-1093 & $2,0,2 \leftarrow 1,0,1$ & Excited & & & 31730. & 3. \\
\hline $\mathrm{I}^{127} \mathrm{C}^{13} \mathrm{~N}^{14}$ & 4. 512 & $5 \leftarrow 4$ & Ground & $9 / 2$ & $7 / 2$ & 31730.50 & \\
\hline
\end{tabular}




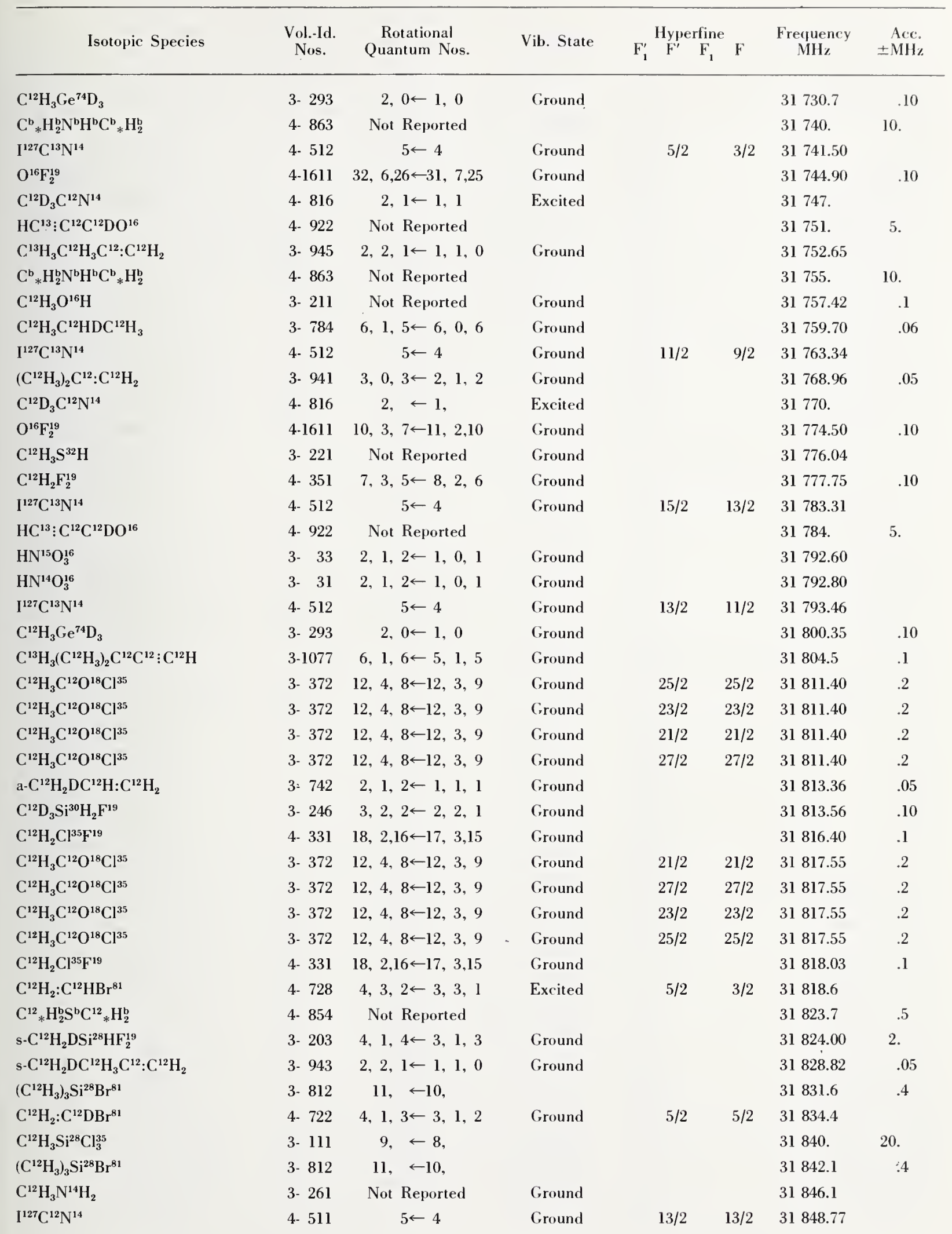




\begin{tabular}{|c|c|c|c|c|c|c|c|}
\hline Isotopic Species & $\begin{array}{l}\text { Vol.-ld. } \\
\text { Nos. }\end{array}$ & $\begin{array}{c}\text { Rotational } \\
\text { Quantum Nos. }\end{array}$ & Vib. State & $F_{1}^{\prime} F^{\prime} F_{1}$ & $\mathrm{~F}$ & $\begin{array}{c}\text { Frequency } \\
\mathrm{MH}_{2}\end{array}$ & $\begin{array}{r}\text { Acc. } \\
+\mathrm{MH}_{2}\end{array}$ \\
\hline $\mathrm{C}^{12} \mathrm{H}_{2}: \mathrm{C}^{12} \mathrm{HBr}^{81}$ & 4- 728 & $4,3,2 \leftarrow 3,3,1$ & Ground & $5 / 2$ & $3 / 2$ & 31849.5 & \\
\hline $\mathrm{C}^{12} \mathrm{D}_{3} \mathrm{C}^{12} \mathrm{~N}^{14}$ & 4- 816 & $2, \leftarrow 1$ & Excited & & & 31852. & \\
\hline $\mathrm{Si}^{28} \mathrm{D}_{2} \mathrm{~F}_{2}^{19}$ & 4-1603 & $4,2,2 \leftarrow 4,1,3$ & Excited & & & 31852.40 & .10 \\
\hline $\mathrm{C}^{12} \mathrm{D}_{3} \mathrm{Si}^{29} \mathrm{H}_{2} \mathrm{~F}^{19}$ & 3- 251 & $3,2,2 \leftarrow 2,2,1$ & Ground & & & 31854.5 & .10 \\
\hline$\left(\mathrm{C}^{12} \mathrm{H}_{3}\right)_{3} \mathrm{Si}^{28} \mathrm{Br}^{81}$ & 3. 812 & $11, \leftarrow 10$ & & & & 31856.2 & .4 \\
\hline $\mathrm{C}^{12} \mathrm{H}_{2}: \mathrm{C}^{12} \mathrm{HBr}^{81}$ & 4- 728 & $4,2,3 \leftarrow 3,2,2$ & Excited & $5 / 2$ & $3 / 2$ & 31859.0 & \\
\hline $\mathrm{C}^{12} \mathrm{H}_{2}: \mathrm{C}^{12} \mathrm{HBr}^{81}$ & 4- 728 & $4,2,3 \leftarrow 3,2,2$ & Excited & $5 / 2$ & $5 / 2$ & 31859.0 & \\
\hline $\mathrm{C}^{12} \mathrm{H}_{2}: \mathrm{C}^{12} \mathrm{DBr}^{81}$ & 4. 722 & $4,1,3 \leftarrow 3,1,2$ & Excited & $7 / 2$ & $7 / 2$ & 31859.3 & \\
\hline $\mathrm{C}^{12} \mathrm{H}_{3} \mathrm{~S}^{32} \mathrm{H}$ & 3. 221 & Not Reported & Ground & & & 31859.54 & \\
\hline $\mathrm{C}^{12} \mathrm{H}_{2}: \mathrm{C}^{12} \mathrm{HBr}^{81}$ & 4- 728 & $4,3,2 \leftarrow 3,3,1$ & Ground & $9 / 2$ & $9 / 2$ & 31860.3 & \\
\hline $\mathrm{C}^{12}{ }_{*} \mathrm{HC}^{12} \mathrm{H}: \mathrm{C}^{12} \mathrm{HC}^{12} \mathrm{H}: \mathrm{C}^{12} \mathrm{HN}^{14}{ }_{*}$ & $4-1201$ & $3,2,1 \leftarrow 2,2,0$ & Ground & & & 31862.31 & \\
\hline $\mathrm{C}^{12} \mathrm{H}_{2}: \mathrm{C}^{12} \mathrm{HBr}^{81}$ & 4. 728 & $4,3,2 \leftarrow 3,3,1$ & Excited & $11 / 2$ & $9 / 2$ & 31863.7 & \\
\hline $\mathrm{C}^{12} \mathrm{H}_{2}: \mathrm{C}^{12} \mathrm{HBr}^{81}$ & 4. 728 & $4,2,3 \leftarrow 3,2,2$ & Excited & $11 / 2$ & $9 / 2$ & 31872.85 & \\
\hline $\mathrm{C}^{12} \mathrm{H}_{2}: \mathrm{C}^{12} \mathrm{DBr}^{81}$ & 4. 722 & $4,1,3 \leftarrow 3,1,2$ & Excited & $11 / 2$ & $9 / 2$ & 31878.0 & \\
\hline$\left(\mathrm{C}^{12} \mathrm{H}_{3}\right)_{2} \mathrm{C}^{12}: \mathrm{C}^{12} \mathrm{H}_{2}$ & 3- 941 & $3,1,3 \leftarrow 2,0,2$ & Ground & & & 31879.31 & .05 \\
\hline $\mathrm{C}^{12} \mathrm{H}_{3} \mathrm{~S}^{32} \mathrm{H}$ & 3. 221 & Not Reported & Ground & & & 31880.2 & \\
\hline$\left(\mathrm{C}^{12} \mathrm{H}_{3}\right)_{3} \mathrm{Si}^{28} \mathrm{Br}^{81}$ & 3- 812 & $11, \quad \leftarrow 10$ & Ground & & & 31880.5 & .3 \\
\hline $\mathrm{C}^{12} \mathrm{H}_{2}: \mathrm{C}^{12} \mathrm{DBr}^{81}$ & 4- 722 & $4,1,3 \leftarrow 3,1,2$ & Excited & $5 / 2$ & $3 / 2$ & 31882.0 & \\
\hline $\mathrm{C}^{12} \mathrm{H}_{3} \mathrm{Ge}^{72} \mathrm{D}_{3}$ & 3- 292 & $2,0 \leftarrow 1,0$ & Ground & & & 31884.25 & .10 \\
\hline $\mathrm{C}^{12} \mathrm{H}_{2}: \mathrm{C}^{12} \mathrm{DBr}^{81}$ & 4. 722 & $4,1,3 \leftarrow 3,1,2$ & Ground & $7 / 2$ & $7 / 2$ & 31884.5 & \\
\hline $\mathrm{C}^{12} \mathrm{H}_{2}: \mathrm{C}^{12} \mathrm{HBr}^{81}$ & 4. 728 & $4,2,2 \leftarrow 3,2,1$ & Excited & $11 / 2$ & $9 / 2$ & 31886.1 & \\
\hline $\mathrm{C}^{12} \mathrm{H}_{2}: \mathrm{C}^{12} \mathrm{DBr}^{81}$ & 4. 722 & $4,1,3 \leftarrow 3,1,2$ & Excited & $9 / 2$ & $7 / 2$ & 31887.3 & \\
\hline $\mathrm{C}^{\mathrm{b}} \mathrm{H}_{2}^{\mathrm{b}} \mathrm{Cl}^{\mathrm{b}} \mathrm{F}^{\mathrm{b}}$ & 4- 333 & Not Reported & & & & 31887.8 & 1. \\
\hline $\mathrm{C}^{12} \mathrm{H}_{2}: \mathrm{C}^{12} \mathrm{HBr}^{81}$ & 4- 728 & $4,2,3 \leftarrow 3,2,2$ & Ground & $5 / 2$ & $3 / 2$ & 31889.95 & \\
\hline $\mathrm{C}^{12} \mathrm{H}_{2}: \mathrm{C}^{12} \mathrm{HBr}^{81}$ & 4- 728 & $4,2,3 \leftarrow 3,2,2$ & Ground & $5 / 2$ & $5 / 2$ & 31889.95 & \\
\hline $\mathrm{S}^{32} \mathrm{P}^{31} \mathrm{~F}_{3}^{19}$ & 4-1691 & $6,5 \leftarrow 5,5$ & Ground & & & 31891.13 & .05 \\
\hline $\mathrm{S}^{32} \mathrm{P}^{31} \mathrm{~F}_{3}^{19}$ & 4-1691 & $6,4 \leftarrow 5,4$ & Ground & & & 31891.27 & .05 \\
\hline $\mathrm{S}^{32} \mathrm{P}^{31} \mathrm{~F}_{3}^{19}$ & 4-1691 & $6,3 \leftarrow 5,3$ & Ground & & & 31891.45 & .05 \\
\hline $\mathrm{S}^{32} \mathrm{P}^{31} \mathrm{~F}_{3}^{19}$ & 4-1691 & $6,2 \leftarrow 5,2$ & Ground & & & 31891.62 & .05 \\
\hline $\mathrm{S}^{32} \mathrm{P}^{31} \mathrm{~F}_{3}^{19}$ & 4-1691 & $6,1 \leftarrow 5,1$ & Ground & & & 31891.62 & .05 \\
\hline $\mathrm{S}^{32} \mathrm{P}^{31} \mathrm{~F}_{3}^{19}$ & 4.1691 & $6,0 \leftarrow 5,0$ & Ground & & & 31891.62 & .05 \\
\hline $\mathrm{C}^{12} \mathrm{H}_{2}: \mathrm{C}^{12} \mathrm{DBr}^{81}$ & 4. 722 & $4,1,3 \leftarrow 3,1,2$ & Excited & $7 / 2$ & $5 / 2$ & 31892.8 & \\
\hline $\mathrm{C}^{12} \mathrm{H}_{2}: \mathrm{C}^{12} \mathrm{HBr}^{81}$ & 4- 728 & $4,3,2 \leftarrow 3,3,1$ & Ground & $11 / 2$ & $9 / 2$ & 31894.55 & \\
\hline $\mathrm{C}^{12} \mathrm{H}_{2}: \mathrm{C}^{12} \mathrm{HBr}^{81}$ & 4. 728 & $4,2,3 \leftarrow 3,2,2$ & Excited & $7 / 2$ & $7 / 2$ & 31898.8 & \\
\hline $\mathrm{C}^{12} \mathrm{H}_{2}: \mathrm{C}^{12} \mathrm{HBr}^{81}$ & 4- 728 & $4,2,3 \leftarrow 3,2,2$ & Excited & $7 / 2$ & $5 / 2$ & 31898.8 & \\
\hline $\mathrm{C}^{12} \mathrm{H}_{2}: \mathrm{C}^{12} \mathrm{DBr}^{81}$ & 4- 722 & $4,1,3 \leftarrow 3,1,2$ & Ground & $11 / 2$ & $9 / 2$ & 31903.1 & \\
\hline $\mathrm{C}^{12} \mathrm{H}_{2}: \mathrm{C}^{12} \mathrm{HBr}^{81}$ & 4. 728 & $4,2,3 \leftarrow 3,2,2$ & Ground & $11 / 2$ & $9 / 2$ & 31903.95 & \\
\hline $\mathrm{C}^{12} \mathrm{H}_{2}: \mathrm{C}^{12} \mathrm{DBr}^{81}$ & 4- 722 & $4,1,3 \leftarrow 3,1,2$ & Ground & $5 / 2$ & $3 / 2$ & 31907.05 & \\
\hline $\mathrm{C}^{12} \mathrm{H}_{2}: \mathrm{C}^{12} \mathrm{HBr}^{81}$ & 4- 728 & $4,3,2 \leftarrow 3,3,1$ & Excited & $7 / 2$ & $5 / 2$ & 31907.2 & \\
\hline $\mathrm{C}^{12} \mathrm{H}_{2}: \mathrm{C}^{\mathrm{i} 2} \mathrm{DBr}^{81}$ & 4. 722 & $4,1,3 \leftarrow 3,1,2$ & Ground & & & 31908.00 & \\
\hline $\mathrm{HC}^{13}: \mathrm{C}^{12} \mathrm{C}^{12} \mathrm{DO}^{16}$ & 4- 922 & Not Reported & & & & 31910. & 5. \\
\hline $\mathrm{C}^{12} \mathrm{H}_{2}: \mathrm{C}^{12} \mathrm{HBr}^{81}$ & 4- 728 & $4,2,2 \leftarrow 3,2,1$ & Excited & $7 / 2$ & $5 / 2$ & 31912.05 & \\
\hline $\mathrm{C}^{12} \mathrm{H}_{2}: \mathrm{C}^{12} \mathrm{HBr}^{81}$ & 4- 728 & $4,2,2 \leftarrow 3,2,1$ & Excited & $7 / 2$ & $7 / 2$ & 31912.05 & \\
\hline $\mathrm{C}^{12} \mathrm{H}_{2}: \mathrm{C}^{12} \mathrm{DBr}^{81}$ & 4- 722 & $4,1,3 \leftarrow 3,1,2$ & Ground & $9 / 2$ & $7 / 2$ & 31912.35 & \\
\hline$\left(\mathrm{C}^{12} \mathrm{H}_{3}\right)_{3} \mathrm{Si}^{28} \mathrm{Br}^{81}$ & 3- 812 & $11, \leftarrow 10$ & & & & 31913.2 & .4 \\
\hline
\end{tabular}


Vib. State

$\mathrm{F}_{1}^{\prime} \mathrm{F}^{\prime} \mathrm{F}_{1} \quad \mathrm{~F}$

Frequency

\begin{tabular}{|c|c|c|c|c|c|c|c|}
\hline $\mathrm{C}^{12} \mathrm{H}_{2}: \mathrm{C}^{12} \mathrm{HBr}^{81}$ & 4- 728 & $4,2,2 \leftarrow 3,2,1$ & Ground & $11 / 2$ & $9 / 2$ & 31917.0 & \\
\hline $\mathrm{C}^{12} \mathrm{H}_{2}: \mathrm{C}^{12} \mathrm{HBr}^{81}$ & 1. 728 & $4,2,3 \leftarrow 3,2,2$ & Ground & & & 31918.09 & \\
\hline $\mathrm{C}^{12} \mathrm{H}_{2}: \mathrm{C}^{12} \mathrm{DBr}^{81}$ & 4- 722 & $4,1,3 \leftarrow 3,1,2$ & Ground & $7 / 2$ & $5 / 2$ & 31918.1 & \\
\hline$\left(\mathrm{C}^{12} \mathrm{H}_{3}\right)_{3} \mathrm{Si}^{28} \mathrm{Br}^{81}$ & 3- 812 & $11, \leftarrow 10$, & & & & 31920.2 & .4 \\
\hline $\mathrm{HC}^{13}: \mathrm{C}^{12} \mathrm{C}^{12} \mathrm{DO}^{16}$ & 4. 922 & Not Reported & & & & 31921 & 5. \\
\hline $\mathrm{C}^{\mathrm{b}} \mathrm{H}_{2}^{\mathrm{b}} \mathrm{Cl}^{\mathrm{b}} \mathrm{F}^{\mathrm{b}}$ & 4- 333 & Not Reported & & & & 31922.92 & .1 \\
\hline $\mathrm{C}^{12} \mathrm{H}_{2}: \mathrm{C}^{12} \mathrm{HBr}^{81}$ & 4- 728 & $4,3,2 \leftarrow 3,3,1$ & Ground & & & 31923.19 & \\
\hline $\mathrm{C}^{\mathrm{b}} \mathrm{H}_{2}^{\mathrm{b}} \mathrm{Cl}^{\mathrm{b}} \mathrm{F}^{\mathrm{b}}$ & 4- 333 & Not Reported & & & & 31924.32 & .1 \\
\hline $\mathrm{C}^{12} \mathrm{D}_{3} \mathrm{Si}^{30} \mathrm{D}_{3}$ & $3-321$ & $2, \leftarrow 1$. & & & & 31924.49 & .15 \\
\hline $\mathrm{C}^{12} \mathrm{H}_{2}: \mathrm{C}^{12} \mathrm{HBr}^{81}$ & 4- 728 & $4,2,2 \leftarrow 3,2,1$ & Excited & $9 / 2$ & $7 / 2$ & 31925.65 & \\
\hline $\mathrm{C}^{12} \mathrm{H}_{2}: \mathrm{C}^{12} \mathrm{HBr}^{81}$ & 4- 728 & $4,2,2 \leftarrow 3,2,1$ & Excited & $9 / 2$ & $9 / 2$ & 31925.65 & \\
\hline $\mathrm{C}^{12}{ }_{*} \mathrm{H}_{2} \mathrm{C}^{12} \mathrm{H}_{2} \mathrm{C}^{12} \mathrm{H}_{2} \mathrm{O}^{16} *$ & 4-1091 & $2,1,2 \leftarrow 1,1,1$ & Ground & & & 31926.0 & .1 \\
\hline $\mathrm{C}^{12} \mathrm{H}_{3} \mathrm{~S}^{32} \mathrm{H}$ & 3- 221 & Not Reported & Ground & & & 31927.27 & \\
\hline c- $\mathrm{C}^{12} \mathrm{H}_{3} \mathrm{C}^{12} \mathrm{H}: \mathrm{C}^{12} \mathrm{HF}^{19}-\mathrm{E}$ & 3- 702 & $6,2,4 \leftarrow 6,1,5$ & & & & 31927.71 & .2 \\
\hline $\mathrm{C}^{12} \mathrm{H}_{2}: \mathrm{C}^{12} \mathrm{HBr}^{81}$ & 4- 728 & $4,2,3 \leftarrow 3,2.2$ & Ground & $7 / 2$ & $7 / 2$ & 31929.55 & \\
\hline $\mathrm{C}^{12} \mathrm{H}_{2}: \mathrm{C}^{12} \mathrm{HBr}^{81}$ & 4- 728 & $4,2,3 \leftarrow 3,2,2$ & Ground & $7 / 2$ & $5 / 2$ & 31929.55 & \\
\hline $\mathrm{C}^{12} \mathrm{H}_{2}: \mathrm{C}^{12} \mathrm{HBr}^{81}$ & 4- 728 & $4,2,2 \leftarrow 3,2,1$ & Ground & & & 31931.36 & \\
\hline $\mathrm{C}^{12} \mathrm{D}_{3} \mathrm{~N}^{14} \mathrm{H}_{2}$ & 3- 263 & Not Reported & & & & 31933.7 & .5 \\
\hline $\mathrm{C}^{12} \mathrm{H}_{2}: \mathrm{C}^{12} \mathrm{HBr}^{81}$ & 4- 728 & $4,3,2 \leftarrow 3,3,1$ & Ground & $7 / 2$ & $5 / 2$ & 31937.95 & \\
\hline c- $\mathrm{C}^{12} \mathrm{H}_{3} \mathrm{C}^{12} \mathrm{H}: \mathrm{C}^{12} \mathrm{HF}^{19}-\mathrm{A}$ & 3- 701 & $6,2,4 \leftarrow 6,1,5$ & & & & 31938.43 & .2 \\
\hline $\mathrm{D}_{2} \mathrm{O}_{2}^{16}$ & 3- 42 & Not Reported & & & & 31940. & 3. \\
\hline $\mathrm{HC}^{13}: \mathrm{C}^{12} \mathrm{C}^{12} \mathrm{DO}^{16}$ & 4- 922 & Not Reported & & & & 31940. & 5. \\
\hline $\mathrm{C}^{12} \mathrm{H}_{2}: \mathrm{C}^{12} \mathrm{HBr}^{81}$ & 4- 728 & $4,2,2 \leftarrow 3,2,1$ & Ground & $7 / 2$ & $7 / 2$ & 31942.8 & \\
\hline $\mathrm{C}^{12} \mathrm{H}_{2}: \mathrm{C}^{12} \mathrm{HBr}^{81}$ & 4- 728 & $4,2,3 \leftarrow 3,2,2$ & Ground & $9 / 2$ & $7 / 2$ & 31942.8 & \\
\hline $\mathrm{C}^{12} \mathrm{H}_{2}: \mathrm{C}^{12} \mathrm{HBr}^{81}$ & 4- 728 & $4,2,3 \leftarrow 3,2,2$ & Ground & $9 / 2$ & $9 / 2$ & 31942.8 & \\
\hline $\mathrm{C}^{12} \mathrm{H}_{2}: \mathrm{C}^{12} \mathrm{HBr}^{81}$ & 4- 728 & $4,2,2 \leftarrow 3,2,1$ & Cround & $7 / 2$ & $5 / 2$ & 31942.8 & \\
\hline $\mathrm{D}_{2} \mathrm{C}^{12}{ }_{*} \mathrm{O}^{16} \mathrm{C}^{12} * \mathrm{D}_{2}$ & 4- 843 & 1. $1,1 \leftarrow 0,0,0$ & Ground & & & 31913. & \\
\hline $\mathrm{HDO}_{2}^{16}$ & $3-43$ & 13. . -13. & & & & 31952. & 3. \\
\hline $\mathrm{C}^{12} \mathrm{H}_{2}: \mathrm{C}^{12} \mathrm{HBr}^{41}$ & 4- 728 & $4,3,2 \leftarrow 3,3,1$ & Excited & $9 / 2$ & $7 / 2$ & 31952.4 & \\
\hline $\mathrm{C}^{12} \mathrm{D}_{3} \mathrm{~N}^{14} \mathrm{D}_{2}$ & 3- 262 & $4,1,4 \leftarrow 4,0,4$ & Ground & & & 31954.11 & \\
\hline $\mathrm{HDO}_{2}^{16}$ & $3-43$ & $13, \quad \leftarrow 13$, & & & & 31956. & 3. \\
\hline $\mathrm{C}^{12} \mathrm{H}_{2}: \mathrm{C}^{12} \mathrm{HBr}^{61}$ & 4- 728 & 4. $2.2 \leftarrow 3,2.1$ & Ground & $9 / 2$ & $9 / 2$ & 31956.2 & \\
\hline $\mathrm{C}^{12} \mathrm{H}_{2}: \mathrm{C}^{12} \mathrm{HBr}^{81}$ & 4- 728 & $4,2,2 \leftarrow 3,2,1$ & Ground & $9 / 2$ & $7 / 2$ & 31956.2 & \\
\hline $\mathrm{C}^{12} \mathrm{H}_{2}: \mathrm{C}^{12} \mathrm{DBr}^{81}$ & 4- 722 & $4,1,3 \leftarrow 3,1,2$ & Excited & $9 / 2$ & $9 / 2$ & 31962.6 & \\
\hline [- $-\mathrm{C}^{12} \mathrm{H}_{3} \mathrm{C}^{12} \mathrm{H}_{2} \mathrm{C}^{12} \mathrm{H}_{2} \mathrm{Cl}^{35}$ & 3- 773 & $5.1,4 \leftarrow 4,1,3$ & Ground & & & 31962.82 & .2 \\
\hline $\mathrm{C}^{12} \mathrm{H}_{2} \mathrm{DC}, \mathrm{e}^{74} \mathrm{H}_{3}$ & 3- 306 & $2,1,2 \leftarrow 1,1,1$ & Ground & & & 31965.84 & .10 \\
\hline $\mathrm{C}^{12} \mathrm{H}_{3} \mathrm{C}^{12} \mathrm{HF}_{2}^{19}$ & 3- 461 & $2,1,1 \leftarrow 1,0,1$ & Ground & & & 31966.3 & \\
\hline $\mathrm{C}^{12} \mathrm{H}_{3} \mathrm{C}^{12} \mathrm{H}: \mathrm{C}^{12}: \mathrm{C}^{12} \mathrm{H}_{2}$ & 3- 931 & $4,1,4 \leftarrow 3,1,3$ & Ground & & & 31967.61 & .03 \\
\hline $\mathrm{C}^{12} \mathrm{H}_{3} \mathrm{C}^{12} \mathrm{H}: \mathrm{C}^{12}: \mathrm{C}^{12} \mathrm{H}_{2}$ & 3- 931 & $4,1,4 \leftarrow 3,1,3$ & Ground & & & 31967.67 & .03 \\
\hline $\mathrm{C}^{\mathrm{b}} \mathrm{H}_{2}^{\mathrm{l}} \mathrm{N}^{\prime \prime} \mathrm{H}^{\mathrm{l}} \mathrm{C}^{\mathrm{l}} \mathrm{H}_{2}^{\mathrm{l}}$ & 4- 863 & Not Reported & & & & 31970. & 10. \\
\hline 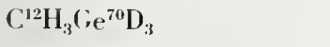 & 3- 291 & $2,0 \leftarrow 1,0$ & Ground & & & 31972.02 & .10 \\
\hline $\mathrm{C}^{12} \mathrm{H}_{2}: \mathrm{C}^{12} \mathrm{HBr}^{61}$ & 4- 728 & $4,3,2 \leftarrow 3,3,1$ & Ground & $5 / 2$ & $5 / 2$ & 31972.8 & \\
\hline $\mathrm{C}^{12} \mathrm{H}_{3} \mathrm{O}^{16} \mathrm{H}$ & 3- 211 & Not Reported & (iround & & & 31977.82 & .1 \\
\hline $\mathrm{C}^{13} \mathrm{H}_{3}\left(\mathrm{C}^{12} \mathrm{H}_{3}\right)_{2} \mathrm{C}^{\mathrm{I} 2} \mathrm{C}^{\mathrm{I} 2}: \mathrm{C}^{12} \mathrm{H}$ & 3-1077 & $6,1,5 \leftarrow 5,1,4$ & Ground & & & 31979.1 & .1 \\
\hline$\left(\mathrm{C}^{12} \mathrm{H}_{3}\right)_{2} \mathrm{O}^{16}$ & 3- 591 & $9,2,7 \leftarrow 8,3,6$ & Ground & & & 31980. & 20. \\
\hline
\end{tabular}




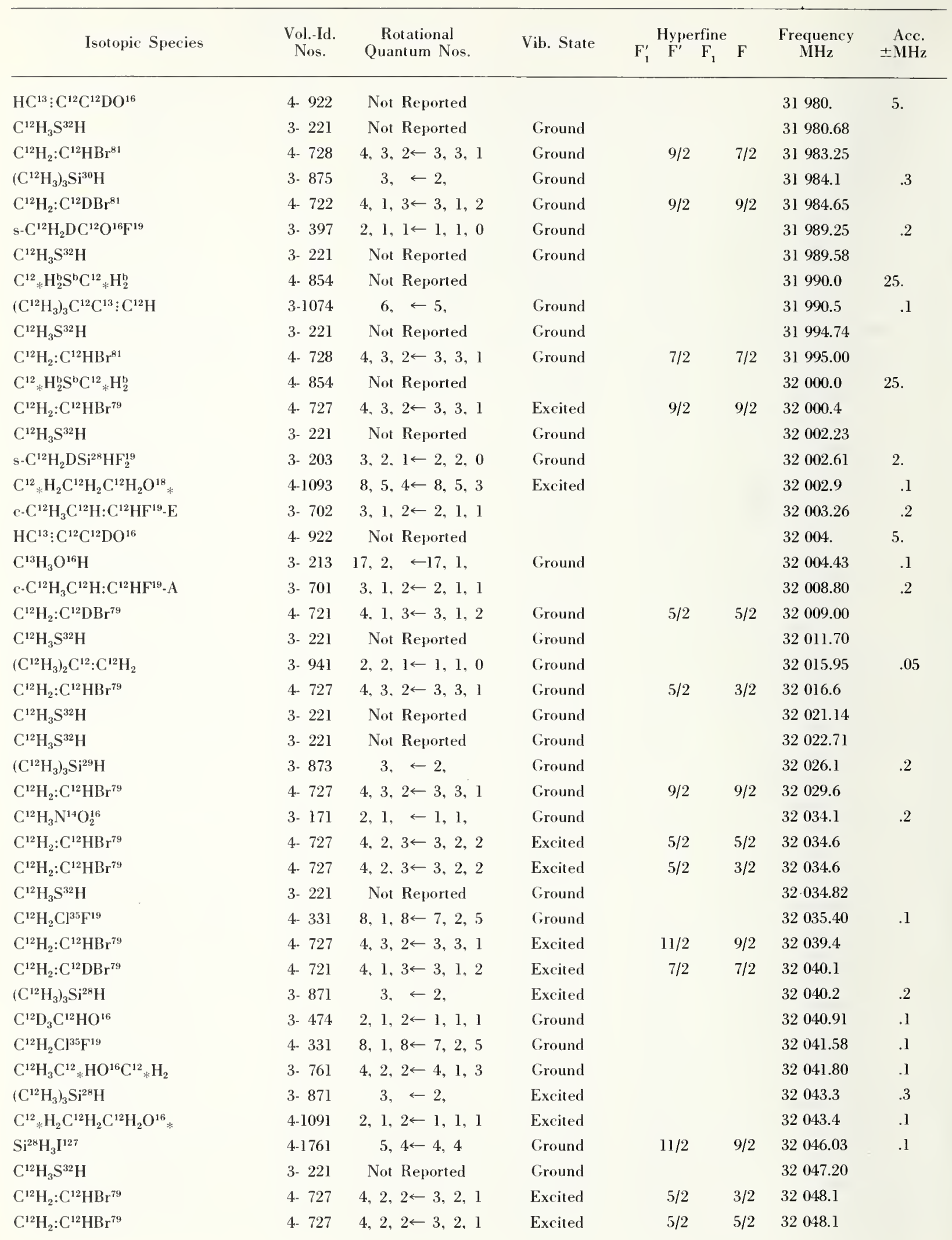




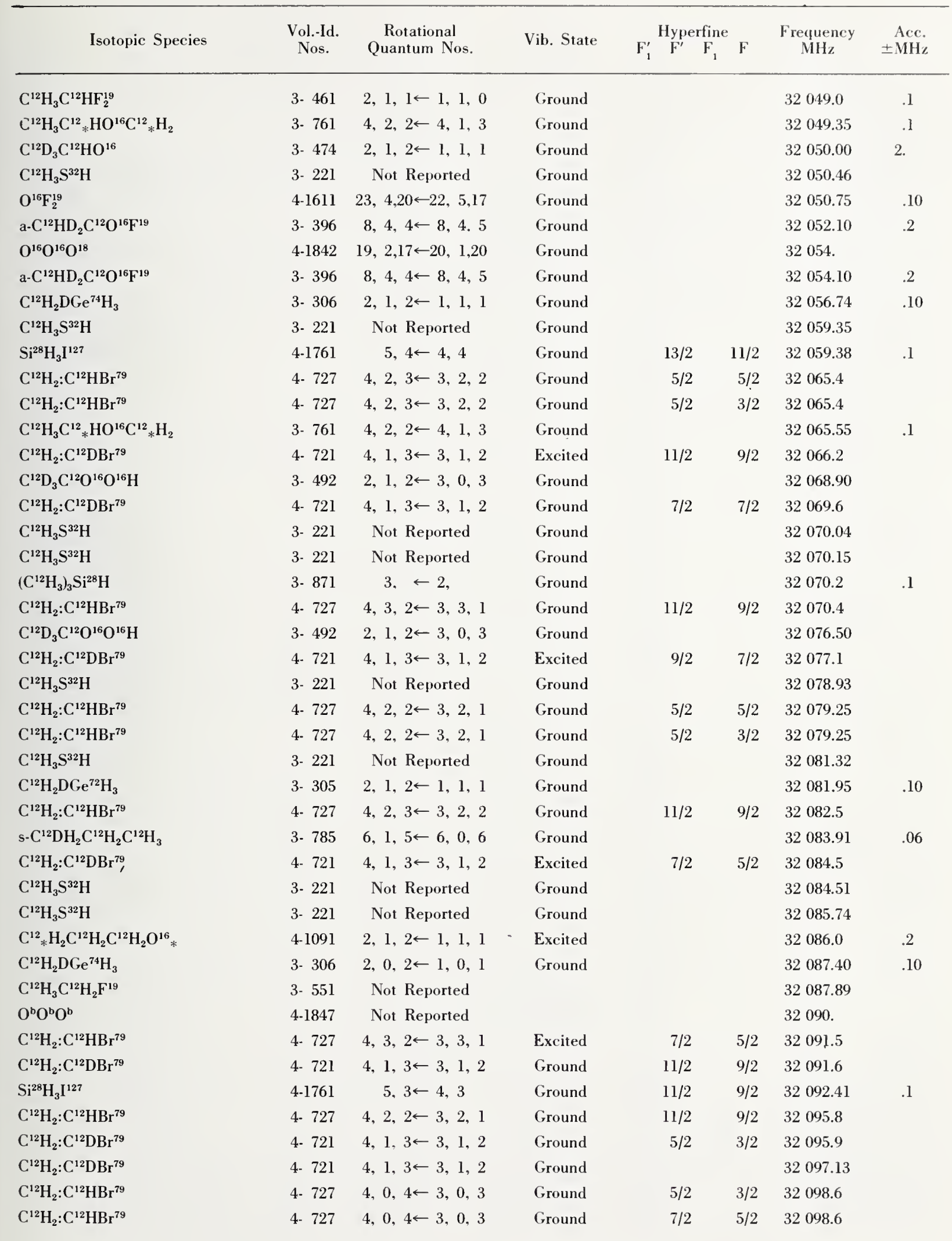




\begin{tabular}{|c|c|c|c|c|c|c|c|}
\hline Isotopic Species & $\begin{array}{l}\text { Vol.-Id. } \\
\text { Nos. }\end{array}$ & $\begin{array}{c}\text { Rotational } \\
\text { Quantum Nos. }\end{array}$ & Vib. State & $\mathrm{F}_{1}^{\prime} \stackrel{\text { Hyprerfine }}{\mathrm{F}^{\prime}} \mathrm{F}_{1}$ & $\mathrm{~F}$ & $\begin{array}{c}\text { Frequency } \\
\mathrm{MHz}\end{array}$ & $\begin{aligned} & \text { Acc. } \\
& \pm \mathrm{MHz}\end{aligned}$ \\
\hline $\mathrm{C}^{12} \mathrm{H}_{2}: \mathrm{C}^{12} \mathrm{HBr}^{79}$ & 4. 727 & $4,2,3 \leftarrow 3,2,2$ & Ground & & & 32099.42 & \\
\hline $\mathrm{C}^{12} \mathrm{H}_{2} \mathrm{Cl}_{2}^{37}$ & 4. 343 & $7,1,6 \leftarrow 7,0,7$ & Ground & & & 32100. & 5. \\
\hline$\left(\mathrm{C}^{12} \mathrm{H}_{3}\right)_{3} \mathrm{Si}^{28} \mathrm{H}$ & 3- 871 & $3, \leftarrow 2$ & Excited & & & 32101.2 & .1 \\
\hline $\mathrm{C}^{12} \mathrm{H}_{2}: \mathrm{C}^{12} \mathrm{DBr}^{79}$ & 4- 721 & $4,1,3 \leftarrow 3,1,2$ & Ground & $9 / 2$ & $7 / 2$ & 32102.4 & \\
\hline $\mathrm{C}^{12} \mathrm{H}_{3} \mathrm{~N}^{14} \mathrm{H}_{2}$ & 3- 261 & $11,4, \leftarrow 12,3$, & Ground & & & 32104. & \\
\hline $\mathrm{C}^{12} \mathrm{H}_{3} \mathrm{~N}^{14} \mathrm{H}_{2}$ & 3. 261 & Not Reported & Ground & & & 32104.0 & \\
\hline $\mathrm{C}^{12} \mathrm{H}_{2}: \mathrm{C}^{12} \mathrm{HBr}^{79}$ & 4- 727 & $4,3,2 \leftarrow 3,3,1$ & Ground & & & 32104.75 & \\
\hline $\mathrm{Si}^{28} \mathrm{H}_{3} \mathrm{I}^{127}$ & 4-1761 & $5,3 \leftarrow 4,3$ & Ground & $13 / 2$ & $11 / 2$ & 32105.13 & .1 \\
\hline $\mathrm{C}^{12} \mathrm{H}_{2}: \mathrm{C}^{12} \mathrm{DBr}^{79}$ & 4- 721 & $4,1,3 \leftarrow 3,1,2$ & Ground & $7 / 2$ & $5 / 2$ & 32109.55 & \\
\hline$\left(\mathrm{C}^{12} \mathrm{H}_{3}\right)_{3} \mathrm{Si}^{28} \mathrm{Br}^{79}$ & 3- 811 & $11, \leftarrow 10$ & & & & 32112.2 & .4 \\
\hline $\mathrm{S}^{32} \mathrm{O}^{18} \mathrm{~F}_{2}^{19}$ & 4-1622 & $2,1,1 \leftarrow 1,0,1$ & Ground & & & 32112.44 & .1 \\
\hline $\mathrm{C}^{12} \mathrm{H}_{3} \mathrm{~N}^{14} \mathrm{H}_{2}$ & 3- 261 & Not Reported & Ground & & & 32112.7 & \\
\hline $\mathrm{C}^{12} \mathrm{H}_{2}: \mathrm{C}^{12} \mathrm{HBr}^{79}$ & 4. 727 & $4,2,2 \leftarrow 3,2,1$ & Ground & & & 32112.88 & \\
\hline $\mathrm{C}^{12} \mathrm{H}_{2}: \mathrm{C}^{12} \mathrm{HBr}^{79}$ & 4- 727 & $4,2,3 \leftarrow 3,2,2$ & Ground & $7 / 2$ & $5 / 2$ & 32113.0 & \\
\hline $\mathrm{C}^{12} \mathrm{H}_{2}: \mathrm{C}^{12} \mathrm{HBr}^{79}$ & 4. 727 & $4,2,3 \leftarrow 3,2,2$ & Ground & $7 / 2$ & $7 / 2$ & 32113.0 & \\
\hline $\mathrm{C}^{12} \mathrm{D}_{3} \mathrm{Si}^{29} \mathrm{D}_{3}$ & 3. 319 & $2, \leftarrow 1$ & & & & 32115.25 & .15 \\
\hline $\mathrm{c}-\mathrm{HDC}^{12}{ }_{*} \mathrm{O}^{16} \mathrm{C}^{12}{ }_{*} \mathrm{DH}$ & 4- 845 & $6,4,2 \leftarrow 6,3,3$ & Ground & & & 32116.2 & .2 \\
\hline $\mathrm{C}^{12} \mathrm{D}_{3} \mathrm{Si}^{28} \mathrm{H}_{2} \mathrm{~F}^{19}$ & 3- 244 & $3,2,1 \leftarrow 2,2,0$ & Ground & & & 32117.38 & .10 \\
\hline $\mathrm{C}^{12} \mathrm{H}_{2} \mathrm{DGe}^{74} \mathrm{H}_{3}$ & 3- 306 & $2,1,1 \leftarrow 1,1,0$ & Ground & & & 32118.06 & .10 \\
\hline $\mathrm{C}^{12} \mathrm{D}_{3} \mathrm{~N}^{14} \mathrm{D}_{2}$ & 3- 262 & $1,0,1 \leftarrow 0,0,0$ & Ground & & & 32121.23 & \\
\hline $\mathrm{C}^{12} \mathrm{H}_{2}: \mathrm{C}^{12} \mathrm{HBr}^{79}$ & 4. 727 & $4,3,2 \leftarrow 3,3,1$ & Ground & $7 / 2$ & $5 / 2$ & 32122.2 & \\
\hline$\left(\mathrm{C}^{12} \mathrm{H}_{3}\right)_{3} \mathrm{Si}^{28} \mathrm{Br}^{79}$ & 3- 811 & $11, \leftarrow 10$ & & & & 32124.6 & .4 \\
\hline $\mathrm{Si}^{28} \mathrm{H}_{3} \mathrm{I}^{127}$ & 4-1761 & $5,2 \leftarrow 4,2$ & Ground & $11 / 2$ & $9 / 2$ & 32125.17 & .1 \\
\hline $\mathrm{C}^{12} \mathrm{H}_{2}: \mathrm{C}^{12} \mathrm{HBr}^{79}$ & 4- 727 & $4,2,2 \leftarrow 3,2,1$ & Ground & $7 / 2$ & $5 / 2$ & 32126.35 & \\
\hline $\mathrm{C}^{12} \mathrm{H}_{2}: \mathrm{C}^{12} \mathrm{HBr}^{79}$ & 4- 727 & $4,2,2 \leftarrow 3,2,1$ & Ground & $7 / 2$ & $7 / 2$ & 32126.35 & \\
\hline $\mathrm{C}^{12} \mathrm{DHCl}^{35} \mathrm{Cl}^{37}$ & 4- 345 & $10,1,9 \leftarrow 10,0,10$ & Ground & & & 32127. & 5. \\
\hline $\mathrm{Si}^{28} \mathrm{H}_{3} \mathrm{I}^{127}$ & $4 \cdot 1761$ & $5,0 \leftarrow 4,0$ & Ground & $7 / 2$ & $5 / 2$ & 32127.83 & .1 \\
\hline $\mathrm{N}^{14} \mathrm{O}^{18} \mathrm{Cl}^{35}$ & $4 \cdot 1453$ & $3,1,2 \leftarrow 2,1,1$ & Ground & $7 / 2$ & $5 / 2$ & 32129.17 & \\
\hline $\mathrm{N}^{14} \mathrm{O}^{18} \mathrm{Cl}^{35}$ & 4-1453 & $3,1,2 \leftarrow 2,1,1$ & Cround & $5 / 2$ & $3 / 2$ & 32129.17 & \\
\hline $\mathrm{C}^{12} \mathrm{H}_{2}: \mathrm{C}^{12} \mathrm{HBr}^{79}$ & 4. 727 & $4,2,3 \leftarrow 3,2,2$ & Ground & $9 / 2$ & $9 / 2$ & 32129.4 & \\
\hline $\mathrm{C}^{12} \mathrm{H}_{2}: \mathrm{C}^{12} \mathrm{HBr}^{79}$ & 4- 727 & $4,2,3 \leftarrow 3,2,2$ & Ground & $9 / 2$ & $7 / 2$ & 32129.4 & \\
\hline $\mathrm{Si}^{28} \mathrm{H}_{3} \mathrm{I}^{127}$ & 4-1761 & $5,3 \leftarrow 4,3$ & Ground & $9 / 2$ & $7 / 2$ & 32129.89 & .1 \\
\hline $\mathrm{Si}^{28} \mathrm{H}_{3} \mathrm{I}^{127}$ & 4-1761 & $5,2 \leftarrow 4,2$ & Ground & $9 / 2$ & $7 / 2$ & 32132.25 & .1 \\
\hline $\mathrm{N}^{14} \mathrm{O}^{18} \mathrm{Cl}^{35}$ & 4-1453 & $3,1,2 \leftarrow 2,1,1$ & Ground & $9 / 2$ & $7 / 2$ & 32132.36 & \\
\hline $\mathrm{Si}^{28} \mathrm{H}_{3} \mathrm{I}^{127}$ & $4-1761$ & $5,1 \leftarrow 4,1$ & Ground & $7 / 2$ & $5 / 2$ & 32134.64 & .1 \\
\hline $\mathrm{Si}^{28} \mathrm{H}_{3} \mathrm{I}^{127}$ & 4-1761 & $5,0 \leftarrow 4,0$ & Ground & $9 / 2$ & $7 / 2$ & 32134.64 & .1 \\
\hline $\mathrm{O}_{3}^{18}$ & 4-1845 & $23,2,22 \longleftarrow 22,3,19$ & Ground & & & 32137. & \\
\hline $\mathrm{DN}^{14} \mathrm{O}_{3}^{16}$ & $3-\quad 32$ & $8,5,3 \leftarrow 8,5,4$ & Ground & & & 32137.90 & \\
\hline $\mathrm{Si}^{28} \mathrm{H}_{3} \mathrm{I}^{127}$ & $4-1761$ & $5,2 \leftarrow 4,2$ & Ground & $13 / 2$ & $11 / 2$ & 32138.83 & .1 \\
\hline $\mathrm{C}^{12}{ }_{*} \mathrm{H}_{2} \mathrm{C}^{12} \mathrm{H}_{2} \mathrm{C}^{12} \mathrm{H}_{2} \mathrm{O}^{16} *$ & 4-1091 & $2,1,2 \leftarrow 1,1,1$ & Excited & & & 32138.9 & .1 \\
\hline$\left(\mathrm{C}^{12} \mathrm{H}_{3}\right)_{3} \mathrm{Si}^{28} \mathrm{Br}^{79}$ & 3- 811 & $11, \leftarrow 10$ & & & & 32139.0 & .4 \\
\hline $\mathrm{C}_{*}^{\mathrm{b}} \mathrm{H}_{2}^{\mathrm{b}} \mathrm{N}^{\mathrm{b}} \mathrm{H}^{\mathrm{b}} \mathrm{C}_{*}^{\mathrm{b}} \mathrm{H}_{2}^{\mathrm{b}}$ & 4. 863 & Not Reported & & & & 32142. & 10. \\
\hline $\mathrm{C}^{12} \mathrm{H}_{2}: \mathrm{C}^{12} \mathrm{HBr}^{79}$ & 4- 727 & $4,2,2 \leftarrow 3,2,1$ & Ground & $9 / 2$ & $7 / 2$ & 32142.8 & \\
\hline $\mathrm{C}^{12} \mathrm{H}_{2}: \mathrm{C}^{12} \mathrm{HBr}^{79}$ & 4- 727 & $4,2,2 \leftarrow 3,2,1$ & Ground & $9 / 2$ & $9 / 2$ & 32142.8 & \\
\hline $\mathrm{Si}^{28} \mathrm{H}_{3} \mathbf{I}^{127}$ & 4-1761 & $5,1 \leftarrow 4,1$ & Ground & $11 / 2$ & $9 / 2$ & 32144.78 & .1 \\
\hline
\end{tabular}




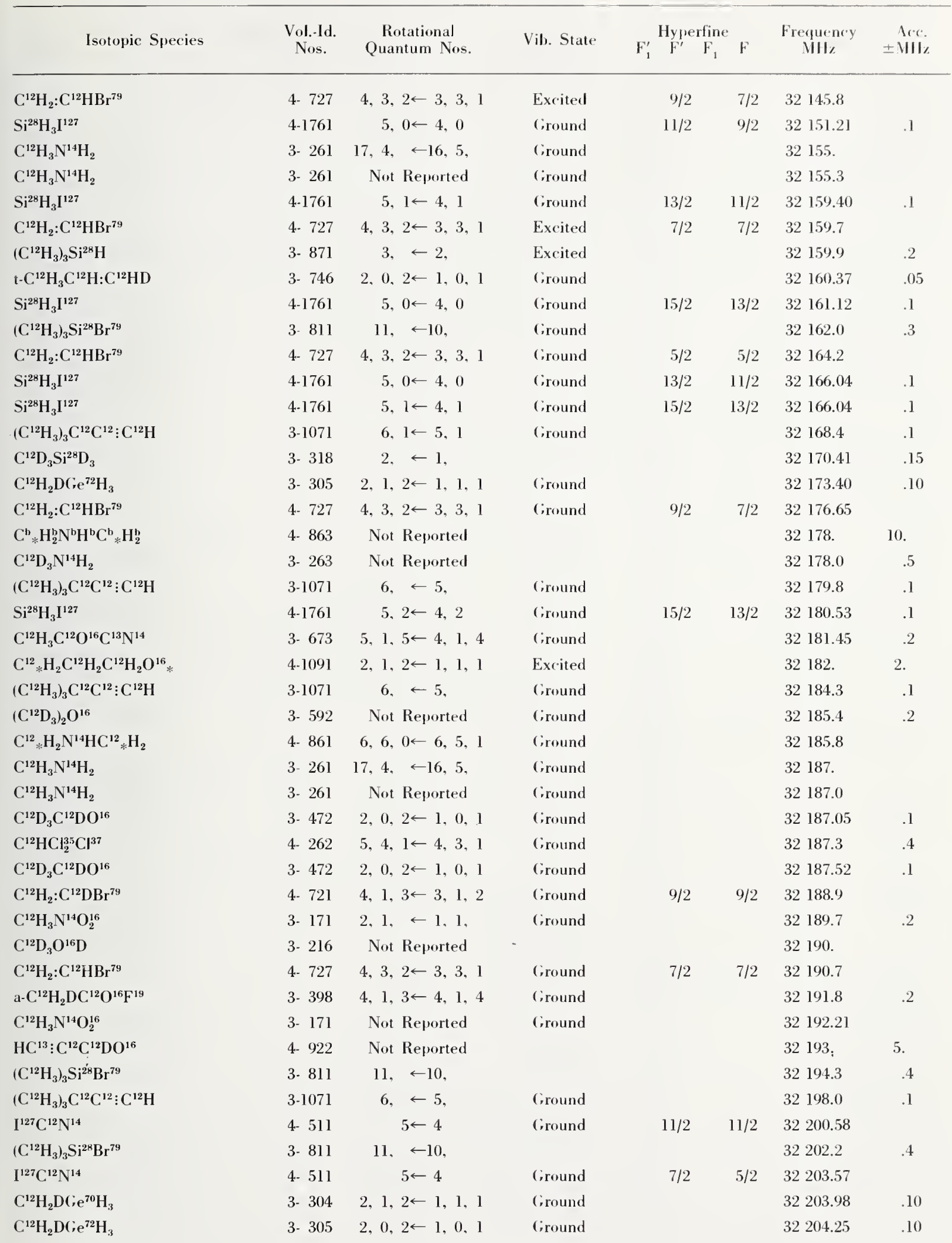




\begin{tabular}{|c|c|c|c|c|c|c|c|c|}
\hline Isotopic Species & $\begin{array}{l}\text { Vol.-Id. } \\
\text { Nos. }\end{array}$ & $\begin{array}{c}\text { Rotational } \\
\text { Quantum Nos. }\end{array}$ & Vib. State & $\mathrm{F}_{1}^{\prime}$ & $\begin{array}{c}\text { Hyperfin } \\
\mathbf{F}^{\prime} \quad \mathbf{F}_{1}\end{array}$ & $\mathrm{~F}$ & $\begin{array}{c}\text { Frequency } \\
\mathrm{MHz}\end{array}$ & $\begin{aligned} & \text { Acc. } \\
\pm & \mathrm{MHz}\end{aligned}$ \\
\hline $\mathrm{Si}^{28} \mathrm{H}_{3} \mathrm{I}^{127}$ & 4-1761 & $5,3 \leftarrow 4,3$ & Ground & & $15 / 2$ & $13 / 2$ & 32204.60 & .1 \\
\hline $\mathrm{C}^{12} \mathrm{H}_{2} \mathrm{DGe}^{74} \mathrm{H}_{3}$ & 3- 306 & $2,1,1 \leftarrow 1,1,0$ & Ground & & & & 32209.10 & .10 \\
\hline $\mathrm{I}^{127} \mathrm{C}^{12} \mathrm{~N}^{14}$ & 4- 511 & $5 \leftarrow 4$ & Ground & & $9 / 2$ & $7 / 2$ & 32215.56 & \\
\hline $\mathrm{C}^{\mathrm{b}}{ }_{*} \mathrm{H}_{2}^{\mathrm{b}} \mathrm{N}^{\mathrm{b}} \mathrm{H}^{\mathrm{b}} \mathrm{C}^{\mathrm{b}}{ }_{*} \mathrm{H}_{2}^{\mathrm{b}}$ & 4. 863 & Not Reported & & & & & 32220 . & 10. \\
\hline $\mathrm{C}^{12}{ }_{*} \mathrm{H}_{2} \mathrm{C}^{12} \mathrm{H}_{2} \mathrm{C}^{12} \mathrm{H}_{2} \mathrm{O}^{16} *$ & 4-1091 & $2,0,2 \leftarrow 1,0,1$ & Ground & & & & 32223.3 & .1 \\
\hline $\mathrm{C}^{12} \mathrm{DBr}_{3}^{79}$ & 4- 243 & $13, \leftarrow 12$ & Ground & & & & 32225.6 & .5 \\
\hline $\mathrm{I}^{127} \mathrm{C}^{12} \mathrm{~N}^{14}$ & 4- 511 & $5 \leftarrow 4$ & Ground & & $5 / 2$ & $3 / 2$ & 32226.85 & \\
\hline $\mathrm{C}^{12} \mathrm{H}_{2} \mathrm{Cl}^{35} \mathrm{Cl}^{37}$ & 4- 342 & $7,2,6 \leftarrow 8,1,7$ & Ground & & & & 32229 . & 5. \\
\hline$\left(\mathrm{C}^{12} \mathrm{H}_{3}\right)_{3} \mathrm{C}^{12} \mathrm{C}^{12}: \mathrm{C}^{12} \mathrm{H}$ & $3-1071$ & $6, \leftarrow 5$ & Excited & & & & 32229.0 & .1 \\
\hline$c-\mathrm{C}^{12} \mathrm{H}_{3} \mathrm{C}^{12} \mathrm{H}: \mathrm{C}^{12} \mathrm{HD}$ & 3. 745 & $2,1,2 \leftarrow 1,1,1$ & Ground & & & & 32229.17 & .05 \\
\hline $\mathrm{C}^{12} \mathrm{H}_{2} \mathrm{DC}^{12}: \mathrm{C}^{12} \mathrm{H}$ & $4-1047$ & $2,1,2 \leftarrow 1,1,1$ & Ground & & & & 32231.44 & .1 \\
\hline $\mathrm{C}^{12} \mathrm{H}_{2} \mathrm{Cl}^{35} \mathrm{Si}^{28} \mathrm{H}_{3}$ & 3. 231 & $9,3,6 \leftarrow 10,2,9$ & Ground & & & & 32233.43 & .2 \\
\hline $\mathrm{D}_{2} \mathrm{O}_{2}^{16}$ & $3-\quad 42$ & Not Reported & & & & & 32234 . & 3. \\
\hline $\mathrm{C}^{12} \mathrm{H}_{2} \mathrm{Cl}^{35} \mathrm{Si}^{28} \mathrm{H}_{3}$ & 3. 231 & $9,3,6 \leftarrow 10,2,9$ & Ground & & & & 32234.65 & .2 \\
\hline $\mathrm{C}^{12} \mathrm{H}_{2} \mathrm{DGe}^{72} \mathrm{H}_{3}$ & 3- 305 & $2,1,1 \leftarrow 1,1,0$ & Ground & & & & 32235.50 & .10 \\
\hline $\mathrm{C}^{12} \mathrm{H}_{2} \mathrm{Cl}^{35} \mathrm{Si}^{28} \mathrm{H}_{3}$ & 3- 231 & $9,3,6 \leftarrow 10,2,9$ & Ground & & & & 32235.62 & .2 \\
\hline $\mathrm{C}^{12} \mathrm{H}_{2} \mathrm{Cl}^{35} \mathrm{Si}^{28} \mathrm{H}_{3}$ & 3- 231 & $9,3,6 \leftarrow 10,2,9$ & Ground & & & & 32236.82 & .2 \\
\hline $\mathrm{Si}^{28} \mathrm{H}_{3} \mathrm{I}^{127}$ & $4-1761$ & $5,4 \leftarrow 4,4$ & Ground & & $15 / 2$ & $13 / 2$ & 32237.95 & .1 \\
\hline $\mathrm{C}^{12} \mathrm{D}_{3} \mathrm{Si}^{28} \mathrm{D}_{3}$ & 3- 318 & $2, \leftarrow 1$, & & & & & 32239.63 & .15 \\
\hline $\mathrm{P}^{31} \mathrm{O}^{16} \mathrm{Cl}_{3}^{35}$ & 4-1511 & $8, \leftarrow 7$, & Ground & & & & 32242.9 & .5 \\
\hline$\left(\mathrm{C}^{12} \mathrm{H}_{3}\right)_{3} \mathrm{Si}^{28} \mathrm{H}$ & 3. 871 & $3, \leftarrow 2$, & Excited & & & & 32248.4 & .2 \\
\hline $\mathrm{I}^{127} \mathrm{C}^{12} \mathrm{~N}^{14}$ & 4. 511 & $5-4$ & Ground & & $11 / 2$ & $9 / 2$ & 32248.52 & \\
\hline$\left(\mathrm{C}^{12} \mathrm{H}_{3}\right)_{3} \mathrm{C}^{12} \mathrm{C}^{12} \vdots \mathrm{C}^{12} \mathrm{H}$ & $3 \cdot 1071$ & $6,1 \leftarrow 5,1$ & Excited & & & & 32249.5 & .1 \\
\hline $\mathrm{O}^{\mathrm{b}} \mathrm{O}^{\mathrm{b}} \mathrm{O}^{\mathrm{b}}$ & $4-1847$ & Not Reported & & & & & 32254 & \\
\hline $\mathrm{HDC}^{12}: \mathrm{C}^{12} \mathrm{~F}_{2}^{19}$ & 4- 682 & $6,5,2 \leftarrow 6,3,3$ & Ground & & & & 32264.5 & .3 \\
\hline $\mathrm{C}^{12} \mathrm{D}_{3} \mathrm{~N}^{14} \mathrm{H}_{2}$ & 3- 263 & Not Reported & & & & & 32267.4 & .5 \\
\hline $\mathrm{I}^{127} \mathrm{C}^{12} \mathrm{~N}^{14}$ & 4- 511 & $5 \leftarrow 4$ & Ground & & $15 / 2$ & $13 / 2$ & 32268.33 & \\
\hline $\mathrm{C}^{13} \mathrm{H}_{3} \mathrm{O}^{16} \mathrm{H}$ & 3. 213 & $23,2, \leftarrow 23,1$, & Ground & & & & 32271.10 & .1 \\
\hline $\mathrm{C}^{12} \mathrm{H}_{3} \mathrm{~S}^{32} \mathrm{H}$ & 3- 221 & Not Reported & Ground & & & & 32278.04 & \\
\hline $\mathrm{I}^{127} \mathrm{C}^{12} \mathrm{~N}^{14}$ & 4- 511 & $5 \leftarrow 4$ & Ground & & $13 / 2$ & $11 / 2$ & 32278.55 & \\
\hline $\mathrm{C}^{12} \mathrm{Cl}_{3}^{37} \mathrm{C}^{12} \mathrm{~N}^{14}$ & 4- 584 & $10, \leftarrow 9$ & Ground & & & & 32279.5 & 1.0 \\
\hline $\mathrm{C}^{12} \mathrm{H}_{3} \mathrm{~N}^{14} \mathrm{H}_{2}$ & 3. 261 & Not Reported & Ground & & & & 32279.9 & \\
\hline $\mathrm{D}_{2} \mathrm{O}_{2}^{16}$ & $3-\quad 42$ & Not Reported & & & & & 32280 . & 3. \\
\hline $\mathrm{C}^{12} \mathrm{H}_{3} \mathrm{~N}^{14} \mathrm{H}_{2}$ & 3. 261 & $11,4, \leftarrow 12,3$, & Ground & & & & 32283. & \\
\hline $\mathrm{C}^{12} \mathrm{H}_{3} \mathrm{~N}^{14} \mathrm{H}_{2}$ & 3- 261 & Not Reported & Ground & & & & 32283.3 & \\
\hline $\mathrm{C}^{12} \mathrm{H}_{3} \mathrm{~N}^{14} \mathrm{H}_{2}$ & 3- 261 & Not Reported & Ground & & & & 32287.7 & \\
\hline $\mathrm{c}-\mathrm{HDN}{ }^{15} \mathrm{C}^{12} \mathrm{HO}^{16}$ & 3- 158 & $4,0,4 \leftarrow 3,1,3$ & Ground & & & & 32289.71 & \\
\hline $\mathrm{C}^{12} \mathrm{H}_{3} \mathrm{~B}^{\mathrm{b}} \mathrm{F}_{2}^{19}$ & 3- 91 & $3, \quad \leftarrow 2$, & Ground & & & & 32291.8 & .1 \\
\hline $\mathrm{C}^{12} \mathrm{H}_{2} \mathrm{DGe}^{70} \mathrm{H}_{3}$ & 3- 304 & $2,1,2 \leftarrow 1,1,1$ & Ground & & & & 32295.85 & .10 \\
\hline $\mathrm{D}_{2} \mathrm{C}^{12}{ }_{*} \mathrm{O}^{16} \mathrm{C}^{12}{ }_{*} \mathrm{D}_{2}$ & 4- 843 & $7,4,3 \leftarrow 7,3,4$ & Ground & & & & 32296. & \\
\hline $\mathrm{HC}^{12} \mathrm{O}^{16} \mathrm{~N}^{14} \mathrm{H}_{2}$ & 3- 151 & $6,1,5 \leftarrow 6,1,6$ & Ground & & 6 & 6 & 32296.18 & .1 \\
\hline $\mathrm{C}^{12} \mathrm{D}_{3} \mathrm{~N}^{14} \mathrm{H}_{2}$ & 3- 263 & Not Reported & & & & & 32298.0 & .5 \\
\hline $\mathrm{HC}^{12} \mathrm{O}^{16} \mathrm{~N}^{14} \mathrm{H}_{2}$ & 3- 151 & $6,1,5 \leftarrow 6,1,6$ & Ground & & 5 & 5 & 32298.19 & .1 \\
\hline $\mathrm{HC}^{12} \mathrm{O}^{16} \mathrm{~N}^{14} \mathrm{H}_{2}$ & 3- 151 & $6,1,5 \leftarrow 6,1,6$ & Ground & & 7 & 7 & 32298.19 & .1 \\
\hline $\mathrm{HC}^{13}:^{12} \mathrm{C}^{12} \mathrm{DO}^{16}$ & 4- 922 & Not Reported & & & & & 32301. & 5. \\
\hline
\end{tabular}




\begin{tabular}{|c|c|c|c|c|c|c|c|c|c|}
\hline Isotopic Species & $\begin{array}{l}\text { Vol.-Id. } \\
\text { Nos. }\end{array}$ & $\begin{array}{c}\text { Rotational } \\
\text { Quantum Nos. }\end{array}$ & Vib. State & $\mathbf{F}_{1}^{\prime}$ & Hype & $\stackrel{\text { rfine }}{F_{1}}$ & $\mathrm{~F}$ & $\begin{array}{c}\text { Frequency } \\
\mathrm{MHz}\end{array}$ & $\begin{aligned} & \text { Acc. } \\
\pm & \mathrm{MHz}\end{aligned}$ \\
\hline $\mathrm{C}^{12} \mathrm{D}_{3} \mathrm{Si}^{28} \mathrm{D}_{3}$ & 3- 318 & $2, \leftarrow 1$, & & & & & & 32316.07 & .15 \\
\hline $\mathrm{C}^{12} \mathrm{D}_{3} \mathrm{O}^{16} \mathrm{D}$ & 3- 216 & Not Reported & & & & & & 32325. & \\
\hline $\mathrm{C}^{12} \mathrm{H}_{2} \mathrm{Cl}^{35} \mathrm{Cl}^{37}$ & 4- 342 & $7,1,6 \leftarrow 7,0,7$ & Ground & & & & & 32325. & 5. \\
\hline c. $\mathrm{C}^{12} \mathrm{H}_{3} \mathrm{C}^{12} \mathrm{H}: \mathrm{C}^{12} \mathrm{HF}^{19}-\mathrm{E}$ & 3. 702 & $7,2,5 \leftarrow 7,1,6$ & & & & & & 32325.08 & .2 \\
\hline $\mathrm{C}^{12} \mathrm{H}_{2} \mathrm{DGe}^{72} \mathrm{H}_{3}$ & 3. 305 & $2,1,1 \leftarrow 1,1,0$ & Ground & & & & & 32326.96 & .10 \\
\hline $\mathrm{C}^{12} \mathrm{H}_{2} \mathrm{DGe}^{70} \mathrm{H}_{3}$ & 3- 304 & $2,0,2 \leftarrow 1,0,1$ & Ground & & & & & 32327.55 & .10 \\
\hline $\mathrm{C}^{12} \mathrm{H}_{3} \mathrm{C}^{12}{ }_{*} \mathrm{HO}^{16} \mathrm{C}^{12}{ }_{*} \mathrm{H}_{2}$ & 3. 761 & Not Reported & Ground & & & & & 32332.64 & .1 \\
\hline c- $\mathrm{C}^{12} \mathrm{H}_{3} \mathrm{C}^{12} \mathrm{H} \mathrm{C}^{12} \mathrm{HF}^{19}{ }_{-\mathrm{A}}$ & 3. 701 & $7,2,5 \leftarrow 7,1,6$ & & & & & & 32338.71 & .2 \\
\hline $\mathrm{C}^{12} \mathrm{D}_{3} \mathrm{C}^{12} \mathrm{O}^{16} \mathrm{Cl}^{37}$ & 3- 364 & $5,0,5 \leftarrow 4,1,4$ & Ground & & & & & 32346.0 & .2 \\
\hline $\mathrm{C}^{12} \mathrm{H}_{3} \mathrm{C}^{12}{ }_{*} \mathrm{HO}^{16} \mathrm{C}^{12}{ }_{*} \mathrm{H}_{2}$ & 3- 761 & $9,3,7 \leftarrow 8,4,4$ & Ground & & & & & 32347.36 & .1 \\
\hline $\mathrm{C}^{12} \mathrm{H}_{3} \mathrm{C}^{12}{ }_{*} \mathrm{HO}^{16} \mathrm{C}^{12}{ }_{*} \mathrm{H}_{2}$ & 3. 761 & $9,3,7 \leftarrow 8,4,4$ & Ground & & & & & 32347.71 & .1 \\
\hline $\mathrm{C}^{\mathrm{b}}{ }_{*} \mathrm{H}_{2}^{\mathrm{b}} \mathrm{N}^{\mathrm{b}} \mathrm{H}^{\mathrm{b}} \mathrm{C}^{\mathrm{b}}{ }_{*} \mathrm{H}_{2}^{\mathrm{b}}$ & 4- 863 & Not Reported & & & & & & 32350. & 10. \\
\hline $\mathrm{C}^{12} \mathrm{~F}_{3}^{19} \mathrm{C}^{12}: \mathrm{C}^{12} \mathrm{D}$ & 4- 874 & $6,5 \leftarrow 5,5$ & Ground & & & & & 32350.82 & .10 \\
\hline $\mathrm{C}^{12} \mathrm{~F}_{3}^{19} \mathrm{C}^{12}: \mathrm{C}^{12} \mathrm{D}$ & 4- 874 & $6,4 \leftarrow 5,4$ & Ground & & & & & 32351.47 & .10 \\
\hline $\mathrm{C}^{12} \mathrm{~F}_{3}^{19} \mathrm{C}^{12}: \mathrm{C}^{12} \mathrm{D}$ & 4. 874 & $6,3 \leftarrow 5,3$ & Ground & & & & & 32352.01 & .10 \\
\hline $\mathrm{C}^{12} \mathrm{~F}_{3}^{19} \mathrm{C}^{12}: \mathrm{C}^{12} \mathrm{D}$ & 4- 874 & $6,2 \leftarrow 5,2$ & Ground & & & & & 32352.36 & .10 \\
\hline $\mathrm{C}^{12} \mathrm{~F}_{3}^{19} \mathrm{C}^{12}: \mathrm{C}^{12} \mathrm{D}$ & 4- 874 & $6,1 \leftarrow 5,1$ & Ground & & & & & 32352.62 & .10 \\
\hline $\mathrm{C}^{12} \mathrm{~F}_{3}^{19} \mathrm{C}^{12}: \mathrm{C}^{12} \mathrm{D}$ & 4. 874 & $6,0 \leftarrow 5,0$ & Ground & & & & & 32352.62 & .10 \\
\hline $\mathrm{C}^{12}{ }_{*} \mathrm{H}_{2} \mathrm{C}^{12} \mathrm{H}_{2} \mathrm{C}^{12} \mathrm{H}_{2} \mathrm{O}^{16}{ }_{*}$ & $4-1091$ & $2,0,2 \leftarrow 1,0,1$ & Excited & & & & & 32358.6 & .1 \\
\hline $\mathrm{C}^{12} \mathrm{H}_{2} \mathrm{DGe}^{70} \mathrm{H}_{3}$ & 3- 304 & $2,1,1 \leftarrow 1,1,0$ & Ground & & & & & 32359.02 & .10 \\
\hline $\mathrm{C}^{12} \mathrm{H}_{2} \mathrm{DC}^{12}: \mathrm{C}^{12} \mathrm{H}$ & $4-1047$ & $2,0,2 \leftarrow 1,0,1$ & Ground & & & & & 32362.08 & .1 \\
\hline s- $\mathrm{C}^{12} \mathrm{H}_{2} \mathrm{DC}{ }^{12} \mathrm{H}: \mathrm{C}^{12} \mathrm{H}_{2}$ & 3. 743 & $2,1,2 \leftarrow 1,1,1$ & Ground & & & & & 32364.93 & .05 \\
\hline $\mathrm{C}^{12}{ }_{*} \mathrm{DHC}^{12} \mathrm{H}: \mathrm{C}^{12}{ }_{*} \mathrm{H}$ & 4-1034 & $1,0,1 \leftarrow 0,0,0$ & Ground & & & & & 32368.0 & \\
\hline $\mathrm{C}^{12} \mathrm{H}_{3} \mathrm{O}^{16} \mathrm{H}$ & 3- 211 & Not Reported & Ground & & & & & 32379.37 & .1 \\
\hline $\mathrm{I}^{127} \mathrm{C}^{12} \mathrm{~N}^{14}$ & 4- 511 & $5 \leftarrow 4$ & Ground & & $9 / 2$ & & $9 / 2$ & 32386.29 & \\
\hline $\mathrm{Br}^{81} \mathrm{C}^{13} \mathrm{~N}^{14}$ & 4. 144 & $4 \leftarrow 3$ & Ground & $9 / 2$ & & $7 / 2$ & & 32392.59 & \\
\hline $\mathrm{Br}^{81} \mathrm{C}^{13} \mathrm{~N}^{14}$ & 4. 144 & $4 \leftarrow 3$ & Ground & $11 / 2$ & & $9 / 2$ & & 32392.59 & \\
\hline g. $-\mathrm{C}^{12} \mathrm{H}_{3} \mathrm{C}^{12} \mathrm{H}_{2} \mathrm{C}^{12} \mathrm{H}_{2} \mathrm{Cl}^{35}$ & 3- 773 & $15,2,13 \leftarrow 15,1,14$ & Ground & & & & & 32394.45 & .2 \\
\hline $\mathrm{Li}^{7} \mathrm{Br}^{81}$ & $1-$ & $1 \leftarrow 0$ & Excited & & $5 / 2$ & & $3 / 2$ & 32397.13 & 0.10 \\
\hline $\mathrm{C}^{12} \mathrm{H}_{3} \mathrm{O}^{16} \mathrm{H}$ & 3- 211 & Not Reported & Ground & & & & & 32398.44 & .1 \\
\hline $\mathrm{C}^{12} \mathrm{H}_{2}: \mathrm{C}^{12} \mathrm{HBr}^{81}$ & 4- 728 & $4,1,3 \leftarrow 3,1,2$ & Excited & & $5 / 2$ & & $5 / 2$ & 32399.0 & \\
\hline $\mathrm{C}^{12} \mathrm{H}_{3} \mathrm{Ge}^{74} \mathrm{HD}_{2}$ & 3- 303 & $2,1,2 \leftarrow 1,1,1$ & Ground & & & & & 32400.66 & .10 \\
\hline $\mathrm{C}^{12}{ }_{*} \mathrm{H}_{2} \mathrm{C}^{12} \mathrm{H}_{2} \mathrm{C}^{12} \mathrm{H}_{2} \mathrm{O}^{16}{ }_{*}$ & $4-1091$ & $2,0,2 \leftarrow 1,0,1$ & Excited & & & & & 32405. & 2. \\
\hline $\mathrm{C}^{12}{ }_{*} \mathrm{H}_{2} \mathrm{~N}^{14} \mathrm{HC}^{12}{ }_{*} \mathrm{H}_{2}$ & 4- 861 & $9,7,2 \leftarrow 9,6,3$ & Ground & & & & & 32406.3 & \\
\hline $\mathrm{Br}^{81} \mathrm{C}^{13} \mathrm{~N}^{14}$ & 4- 144 & $4 \leftarrow 3$ & Ground & $5 / 2$ & & $3 / 2$ & & 32409.06 & \\
\hline $\mathrm{Br}^{81} \mathrm{C}^{13} \mathrm{~N}^{14}$ & 4- 144 & $4 \leftarrow 3$ & Ground & $7 / 2$ & & $5 / 2$ & & 32409.06 & \\
\hline $\mathrm{C}^{12} \mathrm{H}_{3} \mathrm{C}^{12}{ }_{*} \mathrm{HO}^{16} \mathrm{C}^{12}{ }_{*} \mathrm{H}_{2}$ & 3- 761 & $33,16, \quad \leftarrow 32,17$ & Ground & & & & & 32422.30 & .1 \\
\hline $\mathrm{C}^{12} \mathrm{H}_{3} \mathrm{C}^{12}{ }_{*} \mathrm{HO}^{16} \mathrm{C}^{12}{ }_{*} \mathrm{H}_{2}$ & 3. 761 & $33,16, \leftarrow 32,17$, & Ground & & & & & 32422.83 & .1 \\
\hline $\mathrm{C}^{12} \mathrm{H}_{3} \mathrm{C}^{12}{ }_{*} \mathrm{HO}^{16} \mathrm{C}^{12}{ }_{*} \mathrm{H}_{2}$ & 3- 761 & $33,16, \leftarrow 32,17$, & Ground & & & & & 32423.09 & .1 \\
\hline$\left(\mathrm{C}^{12} \mathrm{H}_{3}\right)_{2} \mathrm{O}^{16}$ & 3. 591 & Not Reported & Ground & & & & & 32425. & 20. \\
\hline $\mathrm{C}^{12} \mathrm{H}_{2}: \mathrm{C}^{12} \mathrm{HBr}^{81}$ & 4- 728 & $4,1,3 \leftarrow 3,1,2$ & Ground & & $5 / 2$ & & $5 / 2$ & 32438.2 & \\
\hline $\mathrm{C}^{12} \mathrm{HBr}_{3}^{79}$ & 4. 241 & $13, \leftarrow 12$ & Ground & & & & & 32438.2 & .5 \\
\hline $\mathrm{C}^{12}{ }_{*} \mathrm{H}_{2} \mathrm{C}^{12} \mathrm{H}_{2} \mathrm{C}^{12} \mathrm{H}_{2} \mathrm{O}^{18}{ }_{*}$ & $4-1093$ & $8,5,4 \leftarrow 8,5,3$ & Ground & & & & & 32440.75 & .1 \\
\hline $\mathrm{C}^{12} \mathrm{H}_{3} \mathrm{~N}^{14} \mathrm{O}_{2}^{16}$ & 3- 171 & Not Reported & Ground & & & & & 32446.09 & \\
\hline $\mathrm{C}^{12} \mathrm{H}_{3} \mathrm{C}^{12} \mathrm{H}_{2} \mathrm{~F}_{1}^{19}$ & 3- 551 & $7,1,6 \leftarrow 7,1,7$ & Ground & & & & & 32449.89 & .10 \\
\hline
\end{tabular}




\begin{tabular}{|c|c|c|c|c|c|c|c|}
\hline Isotopic Species & $\begin{array}{l}\text { Vol.-Id. } \\
\text { Nos. }\end{array}$ & $\begin{array}{c}\text { Rotational } \\
\text { Quantum Nos. }\end{array}$ & Vib. State & 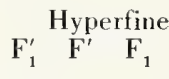 & $\mathbf{F}$ & $\begin{array}{c}\text { Frequency } \\
\mathrm{MHz}\end{array}$ & $\begin{aligned} & \text { Acc. } \\
\pm & \mathrm{MHz}\end{aligned}$ \\
\hline $\mathrm{C}_{*}^{\mathrm{b}} \mathrm{H}_{2}^{\mathrm{b}} \mathrm{N}^{\mathrm{b}} \mathrm{H}^{\mathrm{b}} \mathrm{C}_{*}^{\mathrm{b}}{ }_{*} \mathrm{H}_{2}^{\mathrm{b}}$ & 4- 863 & Not Reported & & & & 32450 . & 10. \\
\hline $\mathrm{C}^{12} \mathrm{H}_{2} \mathrm{DGe}^{70} \mathrm{H}_{3}$ & 3- 304 & $2,1,1 \leftarrow 1,1,0$ & Ground & & & 32451.02 & .10 \\
\hline $\mathrm{C}^{12} \mathrm{H}_{3} \mathrm{O}^{16} \mathrm{~N}^{14} \mathrm{O}_{2}^{16}$ & 3- 181 & $4,2,3 \leftarrow 3,2,2$ & Ground & & & 32461.38 & .1 \\
\hline $\mathrm{Li}^{7} \mathrm{Br}^{79}$ & $1-$ & $1 \leftarrow 0$ & Excited & $5 / 2$ & $3 / 2$ & 32461.52 & 0.10 \\
\hline$\left(\mathrm{C}^{12} \mathrm{H}_{3}\right)_{3} \mathrm{C}^{12} \mathrm{Br}^{81}$ & 3- 962 & $8, \leftarrow 7$, & Ground & & & 32464.8 & .3 \\
\hline $\mathrm{C}^{12} \mathrm{H}_{2}: \mathrm{C}^{12} \mathrm{HBr}^{81}$ & 4- 728 & $4,1,3 \leftarrow 3,1,2$ & Excited & $11 / 2$ & $9 / 2$ & 32470.1 & \\
\hline $\mathrm{C}^{12}{ }_{*} \mathrm{H}_{2} \mathrm{C}^{12} \mathrm{H}_{2} \mathrm{C}^{12} \mathrm{H}_{2} \mathrm{O}^{16} *$ & 4-1091 & $2,0,2 \leftarrow 1,0,1$ & Excited & & & 32471.3 & .1 \\
\hline$c-\mathrm{C}^{12} \mathrm{H}_{3} \mathrm{C}^{12} \mathrm{H}: \mathrm{C}^{12} \mathrm{HF}^{19}-\mathrm{E}$ & 3- 702 & $5,2,3 \leftarrow 5,1,4$ & & & & 32471.40 & .2 \\
\hline $\mathrm{C}^{12} \mathrm{H}_{2}: \mathrm{C}^{12} \mathrm{HBr}^{81}$ & 4- 728 & $4,1,3 \leftarrow 3,1,2$ & Excited & $5 / 2$ & $3 / 2$ & 32478.1 & \\
\hline $\mathrm{C}^{\mathrm{b}} \mathrm{H}_{2}^{\mathrm{b}} \mathrm{Cl}^{\mathrm{b}} \mathrm{F}^{\mathrm{b}}$ & 4- 333 & Not Reported & & & & 32479.50 & .1 \\
\hline$c-\mathrm{C}^{12} \mathrm{H}_{3} \mathrm{C}^{12} \mathrm{H}: \mathrm{C}^{12} \mathrm{HF}^{19}-\mathrm{A}$ & 3- 701 & $5,2,3 \leftarrow 5,1,4$ & & & & 32480.24 & .2 \\
\hline $\mathrm{C}^{12} \mathrm{H}_{3} \mathrm{Ge}^{74} \mathrm{HD}_{2}$ & 3- 303 & $2,1,2 \leftarrow 1, \mathrm{I}, 1$ & Ground & & & 32485.06 & .10 \\
\hline $\mathrm{C}^{12} \mathrm{H}_{2}: \mathrm{C}^{12} \mathrm{HBr}^{81}$ & 4- 728 & $4,1,3 \leftarrow 3,1,2$ & Ground & $7 / 2$ & $7 / 2$ & 32485.7 & \\
\hline $\mathrm{C}^{12} \mathrm{H}_{2}: \mathrm{C}^{12} \mathrm{HBr}^{81}$ & 4- 728 & $4,1,3 \leftarrow 3,1,2$ & Excited & $7 / 2$ & $5 / 2$ & 32488.0 & \\
\hline $\mathrm{F}_{2}^{19} \mathrm{O}^{16} \mathrm{O}^{18}$ & $3-\quad 12$ & $2,1,2 \leftarrow 1,0,1$ & Ground & & & 32488.1 & .5 \\
\hline $\mathrm{C}^{12} \mathrm{H}_{2} \mathrm{DC}^{12}: \mathrm{C}^{12} \mathrm{H}$ & $4-1047$ & $2,1,1 \leftarrow 1,1,0$ & Cround & & & 32491.86 & .1 \\
\hline $\mathrm{HC}^{13} \vdots \mathrm{C}^{12} \mathrm{C}^{12} \mathrm{DO}^{16}$ & 4- 922 & Not Reported & & & & 32492. & 5. \\
\hline $\mathrm{C}^{12} \mathrm{H}_{3} \mathrm{Ge}^{72} \mathrm{HD}_{2}$ & 3- 302 & $2,1,2 \leftarrow 1,1,1$ & Ground & & & 32492.95 & .10 \\
\hline$\left(\mathrm{C}^{12} \mathrm{D}_{3}\right)_{2} \mathrm{O}^{16}$ & 3- 592 & $1,1,1 \leftarrow 0,0,0$ & Ground & & & 32494.5 & .2 \\
\hline $\mathrm{C}^{12} \mathrm{H}_{3} \mathrm{As}^{75} \mathrm{~F}_{2}^{19}$ & 3- 81 & $4,0,4 \leftarrow 3,0,3$ & Ground & $11 / 2$ & $9 / 2$ & 32494.96 & .2 \\
\hline $\mathrm{C}^{12} \mathrm{H}_{3} \mathrm{As}^{75} \mathrm{~F}_{2}^{19}$ & 3- 81 & $4,1,4 \leftarrow 3,1,3$ & Ground & $11 / 2$ & $9 / 2$ & 32494.96 & .2 \\
\hline $\mathrm{C}^{12} \mathrm{H}_{3} \mathrm{As}^{75} \mathrm{~F}_{2}^{19}$ & 3- 81 & $4,0,4 \leftarrow 3,0,3$ & Ground & $11 / 2$ & $9 / 2$ & 32497.75 & .2 \\
\hline $\mathrm{C}^{12} \mathrm{H}_{3} \mathrm{As}^{75} \mathrm{~F}_{2}^{19}$ & 3- 81 & $4,1,4 \leftarrow 3,1,3$ & Ground & $11 / 2$ & $9 / 2$ & 32497.75 & .2 \\
\hline $\mathrm{C}^{12} \mathrm{H}_{3} \mathrm{C}^{12} \mathrm{H}: \mathrm{C}^{12}: \mathrm{C}^{12} \mathrm{H}_{2}$ & 3- 931 & $4,0,4 \leftarrow 3,0,3$ & Ground & & & 32498.28 & .03 \\
\hline $\mathrm{C}^{12} \mathrm{H}_{3} \mathrm{C}^{12} \mathrm{H}: \mathrm{C}^{12}: \mathrm{C}^{12} \mathrm{H}_{2}$ & 3- 931 & $4,0,4 \leftarrow 3,0,3$ & Ground & & & 32498.63 & .03 \\
\hline $\mathrm{C}^{12} \mathrm{DCl}_{3}^{35}$ & 4- 264 & $5, \leftarrow 4$ & Ground & & & 32502.1 & .4 \\
\hline $\mathrm{C}^{12} \mathrm{H}_{3} \mathrm{As}^{75} \mathbf{F}_{2}^{19}$ & 3- 81 & $4,0,4 \leftarrow 3,0,3$ & Ground & $5 / 2$ & $3 / 2$ & 32502.80 & .2 \\
\hline $\mathrm{C}^{12} \mathrm{H}_{3} \mathrm{As}^{75} \mathrm{~F}_{2}^{19}$ & 3- 81 & $4,1,4 \leftarrow 3,1,3$ & Ground & $5 / 2$ & $3 / 2$ & 32502.80 & .2 \\
\hline $\mathrm{C}^{12} \mathrm{H}_{2}: \mathrm{C}^{12} \mathrm{HBr}^{81}$ & 4- 728 & $4,1,3 \leftarrow 3,1,2$ & Ground & $11 / 2$ & $9 / 2$ & 32503.8 & \\
\hline $\mathrm{C}^{12} \mathrm{H}_{3} \mathrm{As}^{75} \mathrm{~F}_{2}^{19}$ & 3- 81 & $4,0,4 \leftarrow 3,0,3$ & Ground & $9 / 2$ & $7 / 2$ & 32506.10 & .2 \\
\hline $\mathrm{C}^{12} \mathrm{H}_{3} \mathrm{As}^{75} \mathrm{~F}_{2}^{19}$ & 3. 81 & $4,1,4 \leftarrow 3,1,3$ & Ground & $9 / 2$ & $7 / 2$ & 32506.10 & .2 \\
\hline $\mathrm{C}^{12} \mathrm{H}_{2}: \mathrm{C}^{12} \mathrm{HBr}^{81}$ & 4- 728 & $4,1,3 \leftarrow 3,1,2$ & Ground & $5 / 2$ & $3 / 2$ & 32508.5 & \\
\hline $\mathrm{C}^{12} \mathrm{H}_{2}: \mathrm{C}^{12} \mathrm{HBr}^{81}$ & 4- 728 & $4,1,3 \leftarrow 3,1,2$ & Ground & & & 32509.46 & \\
\hline $\mathrm{C}^{12} \mathrm{H}_{2}: \mathrm{C}^{12} \mathrm{HBr}^{81}$ & 4- 728 & 4. $1,3 \leftarrow 3,1,2$ & Ground & $9 / 2$ & $7 / 2$ & 32513.7 & \\
\hline $\mathrm{F}^{19} \mathrm{HC}^{13} \mathrm{O}^{16}$ & 4- 273 & $1,1,1 \leftarrow 2,0,2$ & & & & 32514.1 & .1 \\
\hline $\mathrm{C}^{12} \mathrm{H}_{3} \mathrm{C}^{12} \mathrm{H}: \mathrm{C}^{12}: \mathrm{C}^{12} \mathrm{H}_{2}$ & 3- 931 & $4,2,3 \leftarrow 3,2,2$ & Ground & & & 32517.58 & .03 \\
\hline $\mathrm{C}^{12} \mathrm{H}_{2}: \mathrm{C}^{12} \mathrm{HBr}^{81}$ & 4. 728 & $4,1,3 \leftarrow 3,1,2$ & Cround & $7 / 2$ & $5 / 2$ & 32518.3 & \\
\hline $\mathrm{C}^{12}{ }_{*} \mathrm{H}_{2} \mathrm{C}^{12} \mathrm{H}_{2} \mathrm{C}^{12} \mathrm{H}_{2} \mathrm{O}^{16} *$ & 4-1091 & $2,0,2 \leftarrow 1,0,1$ & Excited & & & 32521.6 & .1 \\
\hline $\mathrm{C}^{12} \mathrm{H}_{3} \mathrm{C}^{12} \mathrm{H}: \mathrm{C}^{12}: \mathrm{C}^{12} \mathrm{H}_{2}$ & 3- 931 & $4,3,1 \leftarrow 3,3,0$ & Ground & & & 32525.0 & .1 \\
\hline $\mathrm{C}^{12} \mathrm{H}_{3} \mathrm{C}^{12} \mathrm{H}: \mathrm{C}^{12}: \mathrm{C}^{12} \mathrm{H}_{2}$ & 3- 931 & $4,2,3 \leftarrow 3,2,2$ & Ground & & & 32525.0 & .1 \\
\hline $\mathrm{C}^{12} \mathrm{H}_{3} \mathrm{C}^{12} \mathrm{H}: \mathrm{C}^{12}: \mathrm{C}^{12} \mathrm{H}_{2}$ & 3- 931 & $4,3,2 \leftarrow 3,3,1$ & Cround & & & 32525.0 & .1 \\
\hline $\mathrm{C}^{12}{ }_{*} \mathrm{H}_{2} \mathrm{~N}^{14} \mathrm{HC}^{12}{ }_{*} \mathrm{H}_{2}$ & 4- 861 & $8,6,2 \leftarrow 8,5,3$ & Ground & & & 32526.3 & t) \\
\hline $\mathrm{C}^{12} \mathrm{H}_{3} \mathrm{C}^{12} \mathrm{H}: \mathrm{C}^{12}: \mathrm{C}^{12} \mathrm{H}_{2}$ & 3- 931 & $4,2,2 \leftarrow 3,2,1$ & Ground & & & 32528.1 & .1 \\
\hline
\end{tabular}




\begin{tabular}{|c|c|c|c|c|c|c|c|}
\hline \multirow{3}{*}{$\frac{\text { Isotopic Species }}{\mathrm{C}^{12} \mathrm{HC}^{12} \mathrm{H}: \mathrm{C}^{12} \mathrm{HC}^{12} \mathrm{H}: \mathrm{C}^{12} \mathrm{HN}^{14}{ }_{*}}$} & \multirow{3}{*}{$\begin{array}{l}\text { Vol.-Id. } \\
\text { Nos. } \\
\text { 4-1201 }\end{array}$} & \multirow{2}{*}{$\begin{array}{c}\text { Rotational } \\
\text { Quantum Nos. }\end{array}$} & \multirow{2}{*}{ Vil. State } & \multicolumn{2}{|c|}{ Hyperfine } & \multirow{2}{*}{$\begin{array}{l}\text { Freoguency } \\
\text { MHz }\end{array}$} & \multirow{2}{*}{$\begin{aligned} & \text { Ace } \\
\pm & \mathrm{MIl}\end{aligned}$} \\
\hline & & & & $\mathrm{F}_{1}^{\prime} \quad \mathrm{F}^{\prime}$ & $F_{1} \quad F$ & & \\
\hline & & $4,2,3 \leftarrow 3,2,2$ & Ground & & & $3253 \mathrm{~J}$ & \\
\hline $\mathrm{C}^{12} \mathrm{H}_{3} \mathrm{C}^{12} \mathrm{H}: \mathrm{C}^{12}: \mathrm{C}^{12} \mathrm{H}_{2}$ & 3-931 & $4,2,2 \leftarrow 3,2,1$ & Ground & & & 32536.26 & .03 \\
\hline $\mathrm{S}^{32} \mathrm{P}^{31} \mathrm{Cl}_{3}^{37}$ & 4-1534 & $12, \leftarrow 11$, & Ground & & & 32537.4 & 1.0 \\
\hline $\mathrm{F}^{19} \mathrm{HC}^{13} \mathrm{O}^{16}$ & 4- 273 & $1,1,1 \leftarrow 2,0,2$ & & & & 32544.1 & .2 \\
\hline $\mathrm{C}^{12} \mathrm{H}_{2} \mathrm{Cl}_{2}^{35}$ & 4. 341 & $7,1,6 \leftarrow 7,0,7$ & Ground & & & 32546. & 2. \\
\hline $\mathrm{C}^{12} \mathrm{HCl}_{2}^{35} \mathrm{Cl}^{37}$ & 4- 262 & $5,5,0 \leftarrow 4,4,0$ & Ground & & & 32565.3 & .4 \\
\hline $\mathrm{D}_{2} \mathrm{C}^{12}: \mathrm{C}^{12} \mathrm{~F}_{2}^{19}$ & 4. 683 & $5,2,3 \leftarrow 5,2,4$ & Ground & & & 32567.8 & .3 \\
\hline $\mathrm{HC}^{13}: \mathrm{C}^{12} \mathrm{C}^{12} \mathrm{DO}^{16}$ & 4. 922 & Not Reported & & & & 32575. & 5. \\
\hline $\mathrm{C}^{13} \mathrm{H}_{3} \mathrm{O}^{16} \mathrm{H}$ & 3- 213 & $18,2, \leftarrow 18,1$ & Ground & & & 32575.53 & .1 \\
\hline $\mathrm{C}^{12} \mathrm{H}_{3} \mathrm{Ge}^{72} \mathrm{HD}_{2}$ & 3. 302 & $2,1,2 \leftarrow 1,1,1$ & Ground & & & 32577.29 & .10 \\
\hline $\mathrm{Br}^{79} \mathrm{C}^{13} \mathrm{~N}^{14}$ & 4- 143 & $4 \leftarrow 3$ & Ground & $9 / 2$ & $7 / 2$ & 32581.73 & \\
\hline $\mathrm{Br}^{79} \mathrm{C}^{13} \mathrm{~N}^{14}$ & 4- 143 & $4 \leftarrow 3$ & Ground & $11 / 2$ & $9 / 2$ & 32581.73 & \\
\hline $\mathrm{C}^{12} \mathrm{DHCl}_{2}^{35}$ & 4- 344 & $10,1,9 \leftarrow 10,0,10$ & Ground & & & 32583. & 2. \\
\hline $\mathrm{C}^{12} \mathrm{H}_{2}: \mathrm{C}^{12} \mathrm{HBr}^{81}$ & 4- 728 & $4,1,3 \leftarrow 3,1,2$ & Ground & $9 / 2$ & $9 / 2$ & 32583.5 & \\
\hline $\mathrm{C}^{12} \mathrm{H}_{3} \mathrm{C}^{12} \mathrm{O}^{16} \mathrm{C}^{13} \mathrm{~N}^{14}$ & 3- 673 & $12,3,9 \leftarrow 12,2,10$ & Ground & & & 32586.38 & .2 \\
\hline $\mathrm{C}^{12} \mathrm{H}_{3} \mathrm{Ge}^{70} \mathrm{HD}_{2}$ & 3- 301 & $2,1,2 \leftarrow 1,1,1$ & Ground & & & 32589.79 & .10 \\
\hline $\mathrm{HC}^{13}: \mathrm{C}^{12} \mathrm{C}^{12} \mathrm{DO}^{16}$ & 4- 922 & Not Reported & & & & 32592. & 5. \\
\hline $\mathrm{C}^{12}{ }_{*} \mathrm{HC}^{12} \mathrm{H}: \mathrm{C}^{12} \mathrm{HC}^{12} \mathrm{H}: \mathrm{C}^{12} \mathrm{HN}^{14}{ }_{*}$ & 4-1201 & $4,1,3 \leftarrow 3,1,2$ & Ground & & & 32594. & \\
\hline $\mathrm{C}^{12} \mathrm{H}_{3} \mathrm{C}^{12} \mathrm{O}^{16} \mathrm{C}^{13} \mathrm{~N}^{14}$ & 3- 673 & $12,3,9 \leftarrow 12,2,10$ & Ground & & & 32594.33 & .2 \\
\hline $\mathrm{C}^{12} \mathrm{H}_{3} \mathrm{~N}^{14} \mathrm{O}_{2}^{16}$ & 3- 171 & Not Reported & Ground & & & 32595.16 & \\
\hline $\mathrm{H}_{2} \mathrm{~N}^{15} \mathrm{C}^{12} \mathrm{DO}^{16}$ & 3- 157 & $7,1,6 \leftarrow 6,2,5$ & Ground & & & 32595.74 & \\
\hline $\mathrm{Br}^{79} \mathrm{C}^{13} \mathrm{~N}^{14}$ & 4- 143 & $4 \leftarrow 3$ & Ground & $5 / 2$ & $3 / 2$ & 32601.46 & \\
\hline $\mathrm{Br}^{79} \mathrm{C}^{13} \mathrm{~N}^{14}$ & 4- 143 & $4 \leftarrow 3$ & Ground & $7 / 2$ & $5 / 2$ & 32601.46 & \\
\hline $\mathrm{C}^{12} \mathrm{H}_{3} \mathrm{C}^{12} \mathrm{O}^{16} \mathrm{Br}^{79}$ & 3- 351 & $8,3,5 \leftarrow 8,2,6$ & Ground & $17 / 2$ & $17 / 2$ & 32602.01 & .15 \\
\hline $\mathrm{C}^{12} \mathrm{H}_{3} \mathrm{C}^{12} \mathrm{O}^{16} \mathrm{Br}^{79}$ & $3-351$ & $8,3,5 \leftarrow 8,2,6$ & Ground & $15 / 2$ & $15 / 2$ & 32607.52 & .15 \\
\hline $\mathrm{C}^{12} \mathrm{HD}_{2} \mathrm{Br}^{81}$ & 4- 408 & $2,1,2 \leftarrow 1,1,1$ & Ground & $7 / 2$ & $5 / 2$ & 32610.6 & \\
\hline $\mathrm{C}^{12} \mathrm{H}_{2}: \mathrm{C}^{12} \mathrm{HBr}^{79}$ & 4- 727 & $4,1,3 \leftarrow 3,1,2$ & Ground & $5 / 2$ & $5 / 2$ & 32612.0 & \\
\hline $\mathrm{C}^{13} \mathrm{H}_{3} \mathrm{Si}^{28} \mathrm{HF}_{2}^{19}-\mathrm{E}$ & 3- 196 & $3,2,1 \leftarrow 2,2,0$ & Ground & & & 32622.61 & \\
\hline $\mathrm{C}^{13} \mathrm{H}_{3} \mathrm{Si}^{28} \mathrm{HF}_{2}^{19}-\mathrm{A}$ & 3- 195 & $3,2,1 \leftarrow 2,2,0$ & Ground & & & 32622.61 & \\
\hline $\mathrm{C}^{12} \mathrm{HCl}^{35} \mathrm{~F}_{2}^{19}$ & 4- 251 & $5,3,2 \leftarrow 5,2,4$ & Ground & $7 / 2$ & $7 / 2$ & 32630.4 & .05 \\
\hline $\mathrm{C}^{12} \mathrm{HCl}^{35} \mathrm{~F}_{2}^{19}$ & 4- 251 & $5,3,2 \leftarrow 5,2,4$ & Ground & $13 / 2$ & $13 / 2$ & 32632.4 & .05 \\
\hline $\mathrm{HC}^{13}: \mathrm{C}^{12} \mathrm{C}^{12} \mathrm{DO}^{16}$ & 4- 922 & Not Reported & & & & 32633. & 5. \\
\hline $\mathrm{C}^{12} \mathrm{H}_{3} \mathrm{C}^{12} \mathrm{O}^{16} \mathrm{Br}^{79}$ & 3- 351 & $8,3,5 \leftarrow 8,2,6$ & Ground & $19 / 2$ & $19 / 2$ & 32633.34 & .15 \\
\hline $\mathrm{C}^{12} \mathrm{H}_{3} \mathrm{~N}^{14} \mathrm{H}_{2}$ & $3-261$ & Not Reported & Ground & & & 32634.2 & \\
\hline $\mathrm{C}^{12} \mathrm{HCl}^{35} \mathrm{~F}_{2}^{19}$ & 4. 251 & $5,3,2 \leftarrow 5,2,4$ & Ground & $9 / 2$ & $9 / 2$ & 32637.6 & .05 \\
\hline $\mathrm{C}^{12} \mathrm{H}_{3} \mathrm{C}^{12} \mathrm{O}^{16} \mathrm{Br}^{79}$ & 3- 351 & $8,3,5 \leftarrow 8,2,6$ & Cround & $13 / 2$ & $13 / 2$ & 32638.93 & .15 \\
\hline $\mathrm{C}^{12} \mathrm{HCl}^{35} \mathrm{~F}_{2}^{19}$ & 4- 251 & $5,3,2 \leftarrow 5,2,4$ & Ground & $11 / 2$ & $11 / 2$ & 32639.6 & .05 \\
\hline $\mathrm{Br}^{81} \mathrm{C}^{12} \mathrm{~N}^{14}$ & 4- 142 & $4 \leftarrow 3$ & Ground & $5 / 2$ & $5 / 2$ & 32643,13 & \\
\hline $\mathrm{C}^{12} \mathrm{Cl}^{35} \mathrm{Cl}_{2}^{37} \mathrm{C}^{12} \mathrm{~N}^{14}$ & 4. 583 & $10, \quad \leftarrow 9$, & Cround & & & 32650.0 & 20. \\
\hline $\mathrm{C}^{12} \mathrm{D}_{2} \mathrm{Cl}_{2}^{35}$ & 4- 346 & $2,1,2 \leftarrow 1,0,1$ & Ground & & & 32656. & 2. \\
\hline $\mathrm{C}^{12} \mathrm{H}_{2} \mathrm{Cl}^{35} \mathrm{~F}^{19}$ & 4. 331 & $6,0,6 \leftarrow 5,1,5$ & Cround & & & 32659.51 & 1.0 \\
\hline $\mathrm{C}^{12} \mathrm{H}_{3} \mathrm{~N}^{14} \mathrm{O}_{2}^{16}$ & 3- 171 & $2,1, \leftarrow 1,1$, & Cround & & & 32660 & 2. \\
\hline $\mathrm{C}^{12} \mathrm{H}_{2} \mathrm{Cl}^{35} \mathrm{~F}^{19}$ & 4. 331 & $6,0,6 \leftarrow 5,1,5$ & Ground & & & 32660.83 & .1 \\
\hline $\mathrm{C}^{12} \mathrm{H}_{2} \mathrm{Cl}^{35} \mathrm{~F}^{19}$ & 4- 331 & $6,0,6 \leftarrow 5,1,5$ & Ground & & & 32662.11 & .1 \\
\hline $\mathrm{C}^{12} \mathrm{H}_{2}: \mathrm{C}^{12} \mathrm{HBr}^{79}$ & 4- 727 & $4,1,3 \leftarrow 3,1,2$ & Excited & $11 / 2$ & $9 / 2$ & 32664.9 & \\
\hline
\end{tabular}




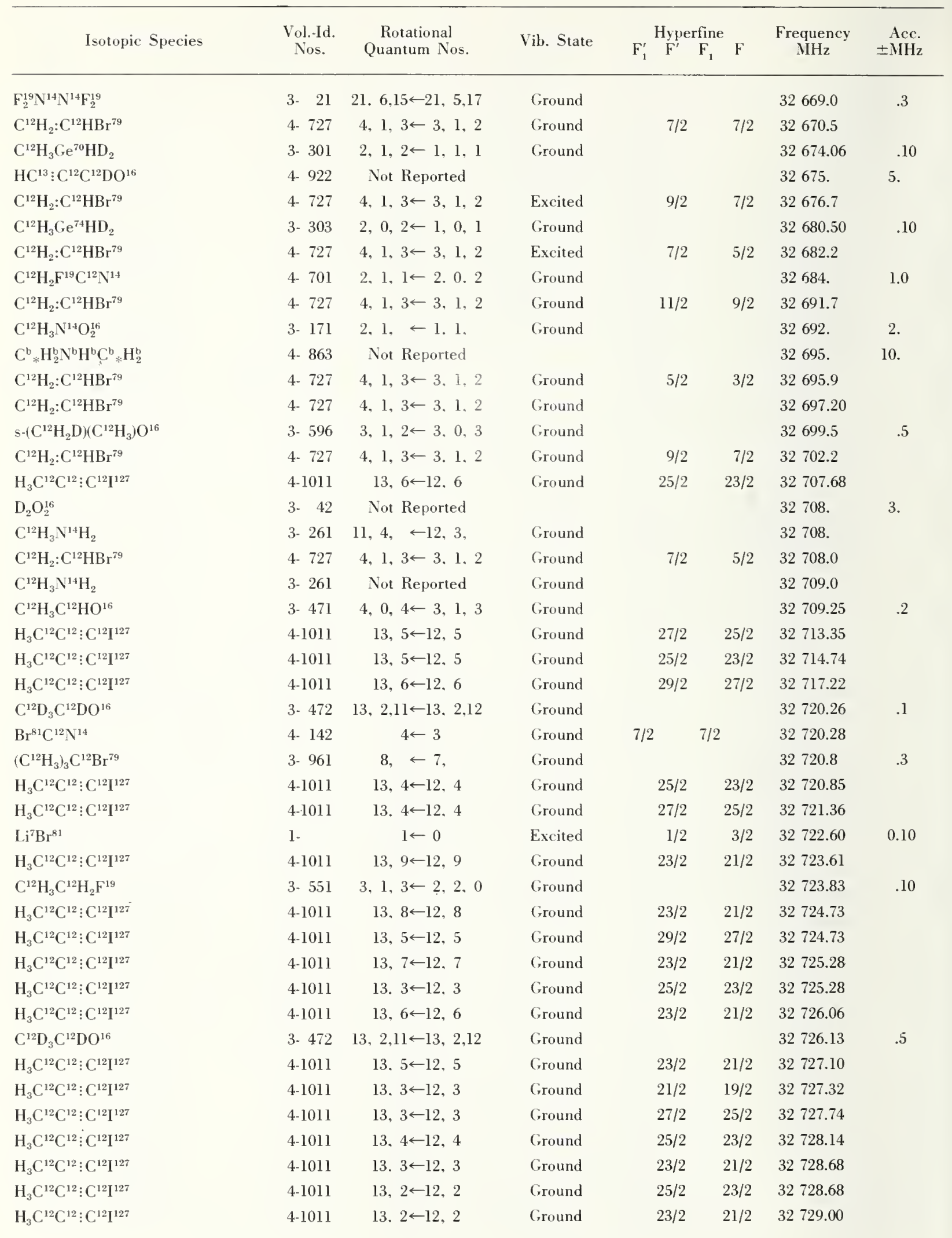


Rotational

Nos. Quantum Nos.
Vib. State
Frequency $\mathrm{MHz}$
Acc. $\pm \mathrm{MHz}$
$\mathrm{H}_{3} \mathrm{C}^{12} \mathrm{C}^{12}: \mathrm{C}^{12} \mathrm{I}^{127}$

$\mathrm{H}_{3} \mathrm{C}^{12} \mathrm{C}^{12}: \mathrm{C}^{12} \mathrm{I}^{127}$

$\mathrm{Li}^{7} \mathrm{Br}^{81}$

$\mathrm{H}_{3} \mathrm{C}^{12} \mathrm{C}^{12}: \mathrm{C}^{12} \mathrm{I}^{127}$

$\mathrm{H}_{3} \mathrm{C}^{12} \mathrm{C}^{12}: \mathrm{C}^{12} \mathrm{I}^{127}$

$\mathrm{H}_{3} \mathrm{C}^{12} \mathrm{C}^{12}: \mathrm{C}^{12} \mathrm{I}^{127}$

$\mathrm{H}_{3} \mathrm{C}^{12} \mathrm{C}^{12}: \mathrm{C}^{12} \mathrm{I}^{127}$

$\mathrm{H}_{3} \mathrm{C}^{12} \mathrm{C}^{12}: \mathrm{C}^{12} \mathrm{I}^{127}$

$\mathrm{H}_{3} \mathrm{C}^{12} \mathrm{C}^{12}: \mathrm{C}^{12} \mathrm{I}^{127}$

$\mathrm{H}_{3} \mathrm{C}^{12} \mathrm{C}^{12}: \mathrm{C}^{12} \mathrm{I}^{127}$

$\mathrm{H}_{3} \mathrm{C}^{12} \mathrm{C}^{12}: \mathrm{C}^{12} \mathrm{I}^{127}$

$\mathrm{H}_{3} \mathrm{C}^{12} \mathrm{C}^{12}: \mathrm{C}^{12} \mathrm{I}^{127}$

a- $\mathrm{C}^{12} \mathrm{H}_{2} \mathrm{DC}^{12} \mathrm{H}: \mathrm{C}^{12} \mathrm{H}_{2}$

$\mathrm{H}_{3} \mathrm{C}^{12} \mathrm{C}^{12}: \mathrm{C}^{12} \mathrm{I}^{127}$

$\mathrm{H}_{3} \mathrm{C}^{12} \mathrm{C}^{12}: \mathrm{C}^{12} \mathrm{I}^{127}$

$\mathrm{H}_{3} \mathrm{C}^{12} \mathrm{C}^{12}: \mathrm{C}^{12} \mathrm{I}^{127}$

$\mathrm{H}_{3} \mathrm{C}^{12} \mathrm{C}^{12}: \mathrm{C}^{12} \mathrm{I}^{127}$

$\mathrm{Li}^{7} \mathrm{Br}^{\mathrm{x}}$

$\mathrm{H}_{3} \mathrm{C}^{12} \mathrm{C}^{12}: \mathrm{C}^{12} \mathrm{I}^{127}$

$\mathrm{H}_{3} \mathrm{C}^{12} \mathrm{C}^{12}: \mathrm{C}^{12} \mathrm{I}^{127}$

$\mathrm{H}_{3} \mathrm{C}^{12} \mathrm{C}^{12}: \mathrm{C}^{12} \mathrm{I}^{127}$

$\mathrm{C}^{12} \mathrm{HD}_{2} \mathrm{Br}^{79}$

$\mathrm{H}_{3} \mathrm{C}^{12} \mathrm{C}^{12}: \mathrm{C}^{12} \mathrm{I}^{127}$

$\mathrm{O}^{\mathrm{b}} \mathrm{O}^{\mathrm{b}} \mathrm{O}^{\mathrm{b}}$

$\mathrm{O}^{16} \mathrm{O}^{16} \mathrm{O}^{18}$

$\mathrm{H}_{3} \mathrm{C}^{12} \mathrm{C}^{12}: \mathrm{C}^{12} \mathrm{I}^{127}$

$\mathrm{H}_{3} \mathrm{C}^{12} \mathrm{C}^{12}: \mathrm{C}^{12} \mathrm{I}^{127}$

$\mathrm{C}^{\mathrm{b}}{ }_{*} \mathrm{H}_{2}^{\mathrm{b}} \mathrm{N}^{\mathrm{b}} \mathrm{H}^{\mathrm{b}} \mathrm{C}^{\mathrm{b}}{ }_{*} \mathrm{H}_{2}^{\mathrm{b}}$

$\mathrm{H}_{3} \mathrm{C}^{12} \mathrm{C}^{12}$ : $\mathrm{C}^{12} \mathrm{I}^{127}$

$\left(\mathrm{C}^{12} \mathrm{H}_{3}\right)_{2} \mathrm{O}^{16}$

$\mathrm{H}_{3} \mathrm{C}^{12} \mathrm{C}^{12}: \mathrm{C}^{12} \mathrm{I}^{127}$

$\mathrm{H}_{3} \mathrm{C}^{12} \mathrm{C}^{12}: \mathrm{C}^{12} \mathrm{I}^{127}$

$\mathrm{C}^{12} \mathrm{HCl}_{2}^{35} \mathrm{Cl}^{37}$

$\mathrm{C}^{12}{ }_{*} \mathrm{H}_{2}^{\mathrm{b}} \mathrm{S}^{\mathrm{b}} \mathrm{C}^{12}{ }_{*} \mathrm{H}_{2}^{\mathrm{b}}$

$\mathrm{C}^{12} \mathrm{H}_{2} \mathrm{Cl}_{2}^{35}$

$\mathrm{Br}^{81} \mathrm{C}^{12} \mathrm{~N}^{14}$

$\mathrm{Br}^{81} \mathrm{C}^{12} \mathrm{~N}^{14}$

$\mathrm{C}^{13} \mathrm{H}_{3} \mathrm{C}^{12} \mathrm{O}^{16} \mathrm{C}^{12} \mathrm{~N}^{14}$

$\mathrm{C}^{12} \mathrm{H}_{3} \mathrm{Ge}^{72} \mathrm{HD}_{2}$

$\mathrm{C}^{\mathrm{b}}{ }_{*} \mathrm{H}_{2}^{\mathrm{b}} \mathrm{N}^{\mathrm{b}} \mathrm{H}^{\mathrm{b}} \mathrm{C}^{\mathrm{b}}{ }_{*} \mathrm{H}_{2}^{\mathrm{b}}$

$\mathrm{C}^{12} \mathrm{H}_{3} \mathrm{C}^{12}{ }_{*} \mathrm{HO}^{16} \mathrm{C}^{12}{ }_{*} \mathrm{H}_{2}$

$\mathrm{C}^{12} \mathrm{H}_{3} \mathrm{C}^{12}{ }_{*} \mathrm{HO}^{16} \mathrm{C}^{12}{ }_{*} \mathrm{H}_{2}$

$\mathrm{C}^{12} \mathrm{H}_{2}: \mathrm{C}^{12} \mathrm{HBr}^{79}$

$\mathrm{Br}^{81} \mathrm{C}^{12} \mathrm{~N}^{14}$

$\mathrm{Br}^{81} \mathrm{C}^{12} \mathrm{~N}^{14}$
4-1011

4. 1011

1 .

$13,1 \leftarrow 12,1$

$13,0 \leftarrow 12,0$

1. 1011

$$
1 \leftarrow 0
$$

4-1011

$13,4 \leftarrow 12,4$

4-1011

$13,1 \leftarrow 12,1$

4-1011

$13,0 \leftarrow 12,0$

4-1011

$13,0 \leftarrow 12,0$

4. 1011

$13,2 \leftarrow 12,2$

4-1011

$13,1 \leftarrow 12,1$

4. 1011

$13,3 \leftarrow 12,3$

4-1011

$13,2 \leftarrow 12,2$

4-1011

3- 742

$13,1 \leftarrow 12,1$

4-1011

$2,0,2 \leftarrow 1,0.1$

4. 1011

$13,0 \leftarrow 12,0$

4-1011

4-1011

1 -

4-1011

4.1011

4-1011

4. 407

4-1011

4-1847

4-1842

4-1011

4-1011

4. 863

4-1011

3- 591

4.1011

4-1011

4- 262

4. 854

$13,2 \leftarrow 12,2$

$13,0 \leftarrow 12,0$

$13,1 \leftarrow 12,1$

$$
1 \leftarrow 0
$$

$13,1 \leftarrow 12,1$

$13,0 \leftarrow 12,0$

$13,2 \leftarrow 12,2$

$2,1,2 \leftarrow 1,1,1$

$13,3 \leftarrow 12,3$

Not Reported

$5,0,5 \leftarrow 4.1,4$

$13,4 \leftarrow 12,4$

$13,4 \leftarrow 12,4$

Not Reported

$13,5 \leftarrow 12,5$

$3,1,2 \leftarrow 3,0,3$

$13,5 \leftarrow 12,5$

$13,6 \leftarrow 12,6$

$5,5,1 \leftarrow 4,4,1$

4. 341

4. 142

4- 142

3. 672

3. 302

4. 863

3- 761

3- 761

4- 727

4- 142

4. 142
Not Reported

$9,0,9 \leftarrow 8,1.8$

$4 \leftarrow 3$

$4 \leftarrow 3$

$5,0,5 \leftarrow 4,0,4$

2, $0,2 \leftarrow 1,0.1$

Not Reported

$11,2,9 \leftarrow 11,1,10$

$11,2,9 \leftarrow 11,1,10$

$4,1,3 \leftarrow 3,1,2$

$4 \leftarrow 3$

$4 \leftarrow 3$
Ground

Ground

Excited

Ground

Ground

Ground

Ground

Ground

Ground

Ground

Ground

Ground

Ground

Ground

Ground

Ground

Ground

Excited

Ground

Ground

Ground

Ground

Ground

Ground

Ground

Ground

Ground

Excited

Ground

Ground

Ground

Ground

Ground

Ground

Ground

Ground

Ground

Ground

Ground

Ground

Ground
$23 / 2$

$23 / 2$

$5 / 2$

$29 / 2$

$25 / 2$

$25 / 2$

$21 / 2$

$27 / 2$

$21 / 2$

$29 / 2$

$21 / 2$

$27 / 2$

21/2

32729.00

$21 / 2 \quad 32729.00$

$3 / 2 \quad 32729.14$

$27 / 2 \quad 32729.7$

$23 / 2 \quad 32730.52$

23/2 32731.19

$19 / 2 \quad 32731.52$

$25 / 2 \quad 32731.83$

$19 / 2 \quad 32732.18$

$27 / 2 \quad 32733.05$

$19 / 2 \quad 32734.26$

$25 / 2 \quad 32734.45$

32735.34

$27 / 2 \quad 25 / 2 \quad 32735.35$

$29 / 2 \quad 27 / 2 \quad 32736.05$

$31 / 2 \quad 29 / 2 \quad 32736.69$

$31 / 2 \quad 29 / 2 \quad 32737.22$

$3 / 2$

$3 / 2$

32737.53

$29 / 2 \quad 27 / 2 \quad 32737.72$

$29 / 2 \quad 27 / 2 \quad 32738.45$

$31 / 2 \quad 29 / 2 \quad 32738.45$

$7 / 2 \quad 5 / 2 \quad 32739.4$

$31 / 2 \quad 29 / 2 \quad 32740.77$

32741 .

32743.

$31 / 2 \quad 29 / 2 \quad 32743.89$

$21 / 2 \quad 19 / 2 \quad 32743.89$

32745 .

$31 / 2 \quad 29 / 2 \quad 32747.90$

32748.4

$21 / 2 \quad 19 / 2 \quad 32748.69$

$31 / 2 \quad 29 / 2 \quad 32752.83$

32756.4

32760.0

32769 .

$11 / 2 \quad 9 / 2$

32770.13

32770.13

32773.38

32774.60

32775 .

32777.28

32782.77

10.

.2

0.10

.05

.4

20.

5.

.2

.10

10.

32785.9

32786.65

32786.65 


\begin{tabular}{|c|c|c|c|c|c|c|c|}
\hline Isotopic Species & $\begin{array}{l}\text { Vol.-Id. } \\
\text { Nos. }\end{array}$ & $\begin{array}{c}\text { Rotational } \\
\text { Quantum Nos. }\end{array}$ & Vib. State & $\mathrm{F}_{1}^{\prime} \stackrel{\text { Hyper }}{\mathrm{F}^{\prime}}$ & $\begin{array}{l}\mathrm{rfine}_{1} \\
\mathrm{~F}_{1}\end{array}$ & $\begin{array}{c}\text { Frequency } \\
\mathrm{MHz}\end{array}$ & $\begin{aligned} & \text { Acc. } \\
\pm & \mathrm{MHz}\end{aligned}$ \\
\hline $\mathrm{C}^{12} \mathrm{D}_{3} \mathrm{O}^{16} \mathrm{D}$ & 3- 216 & Not Reported & & & & 32790. & \\
\hline $\mathrm{C}^{12} \mathrm{D}_{3} \mathrm{C}^{12} \mathrm{HO}^{16}$ & 3- 474 & $2,0,2 \leftarrow 1,0,1$ & Ground & & & 32799.89 & .4 \\
\hline $\mathrm{O}^{\mathrm{b}} \mathrm{O}^{\mathrm{b}} \mathrm{O}^{\mathrm{b}}$ & 4-1847 & Not Reported & & & & 32800 . & \\
\hline $\mathrm{C}^{12} \mathrm{D}_{3} \mathrm{C}^{12} \mathrm{HO}^{16}$ & 3- 474 & $2,0,2 \leftarrow 1,0,1$ & Ground & & & 32801.27 & .2 \\
\hline $\mathrm{C}^{12} \mathrm{H}_{3} \mathrm{Si}^{28} \mathrm{DF}_{2}^{19} \cdot \mathrm{E}$ & 3- 198 & $3,2,1 \leftarrow 2,2,0$ & Ground & & & 32803.71 & \\
\hline $\mathrm{C}^{12} \mathrm{H}_{3} \mathrm{Si}^{28} \mathrm{DF}_{2}^{19} \cdot \mathrm{A}$ & 3- 197 & $3,2,1 \leftarrow 2,2,0$ & Ground & & & 32803.71 & \\
\hline $\mathrm{Br}^{79} \mathrm{C}^{12} \mathrm{~N}^{14}$ & 4- 141 & $4 \leftarrow 3$ & Ground & $5 / 2$ & $5 / 2$ & 32804.56 & \\
\hline $\mathrm{C}^{12} \mathrm{H}_{3} \mathrm{C}^{12} \mathrm{O}^{16} \mathrm{Br}^{81}$ & 3- 352 & $8,3,5 \leftarrow 8,2,6$ & Ground & $17 / 2$ & $17 / 2$ & 32804.90 & .15 \\
\hline $\mathrm{C}^{12} \mathrm{H}_{3} \mathrm{C}^{12} \mathrm{O}^{16} \mathrm{Br}^{81}$ & 3- 352 & $8,3,5 \leftarrow 8,2,6$ & Ground & $15 / 2$ & $15 / 2$ & 32809.49 & .15 \\
\hline $\mathrm{C}^{12} \mathrm{HD}_{2} \mathrm{C}^{12} \mathrm{~N}^{14}$ & 4- 813 & $2,1,2 \leftarrow 1,1,1$ & Ground & 2 & 1 & 32811.64 & .1 \\
\hline $\mathrm{C}^{12} \mathrm{HD}_{2} \mathrm{C}^{12} \mathrm{~N}^{14}$ & 4- 813 & $2,1,2 \leftarrow 1,1,1$ & Ground & 3 & 2 & 32812.95 & .1 \\
\hline $\mathrm{C}^{12} \mathrm{H}_{3} \mathrm{C}^{12} \mathrm{D}: \mathrm{C}^{12} \mathrm{H}_{2}$ & 3- 747 & $2,1,2 \leftarrow 1,1,1$ & Ground & & & 32813.39 & .05 \\
\hline $\mathrm{C}^{12} \mathrm{HD}_{2} \mathrm{C}^{12} \mathrm{~N}^{14}$ & 4- 813 & $2,1,2 \leftarrow 1,1,1$ & Ground & 1 & 0 & 32814.30 & .1 \\
\hline $\mathrm{HC}^{13}: \mathrm{C}^{12} \mathrm{C}^{12} \mathrm{DO}^{16}$ & 4- 922 & Not Reported & & & & 32818. & 5. \\
\hline $\mathrm{C}^{12} \mathrm{H}_{3} \mathrm{~S}^{32} \mathrm{H}$ & 3- 221 & Not Reported & Ground & & & 32819.24 & \\
\hline $\mathrm{C}^{12} \mathrm{H}_{3} \mathrm{~S}^{32} \mathrm{H}$ & 3. 221 & Not Reported & Ground & & & 32820.71 & \\
\hline $\mathrm{C}^{12} \mathrm{H}_{3} \mathrm{~N}^{14} \mathrm{O}_{2}^{16}$ & 3- 171 & $2,0, \leftarrow 1,0$ & Ground & & & 32826. & 2. \\
\hline $\mathrm{C}^{12} \mathrm{D}_{3} \mathrm{C}^{13} \mathrm{O}^{16} \mathrm{C}^{12} \mathrm{~N}^{14}$ & 3- 676 & $5,2,4 \leftarrow 4,2,3$ & Ground & & & 32826.45 & .2 \\
\hline $\mathrm{s} \cdot \mathrm{C}^{12} \mathrm{H}_{2} \mathrm{DSi}^{28} \mathrm{H}_{2} \mathrm{~F}^{19}$ & 3. 247 & $3,1,3 \leftarrow 2,1,2$ & Ground & & & 32827.38 & .10 \\
\hline $\mathrm{C}^{12} \mathrm{H}_{3} \mathrm{~N}^{14} \mathrm{O}_{2}^{16}$ & 3- 171 & Not Reported & Ground & & & 32827.63 & \\
\hline $\mathrm{C}^{12} \mathrm{H}_{3} \mathrm{~S}^{32} \mathrm{H}$ & 3- 221 & Not Reported & Ground & & & 32827.91 & \\
\hline $\mathrm{C}^{12} \mathrm{H}_{3} \mathrm{C}^{12} \mathrm{O}^{16} \mathrm{Br}^{81}$ & 3- 352 & $8,3,5 \leftarrow 8,2,6$ & Ground & $19 / 2$ & $19 / 2$ & 32830.87 & .15 \\
\hline$\left(\mathrm{C}^{12} \mathrm{H}_{3}\right)_{3} \mathrm{Si}^{28} \mathrm{I}^{127}$ & 3- 841 & $15, \leftarrow 14$ & Excited & & & 32834.2 & .4 \\
\hline $\mathrm{C}^{12} \mathrm{H}_{3} \mathrm{C}^{12} \mathrm{O}^{16} \mathrm{Br}^{81}$ & 3. 352 & $8,3,5 \leftarrow 8,2,6$ & Ground & $13 / 2$ & $13 / 2$ & 32835.67 & .15 \\
\hline $\mathrm{O}^{\mathrm{b}} \mathrm{O}^{\mathrm{b}} \mathrm{O}^{\mathrm{b}}$ & $4-1847$ & Not Reported & & & & 32841. & \\
\hline $\mathrm{C}^{12} \mathrm{H}_{3} \mathrm{C}^{12} \mathrm{H}: \mathrm{C}^{13} \mathrm{H}_{2}$ & 3- 749 & $2,1,2 \leftarrow 1,1,1$ & Ground & & & 32841.16 & .10 \\
\hline $\mathrm{C}^{12} \mathrm{H}_{3} \mathrm{~S}^{32} \mathrm{H}$ & 3- 221 & Not Reported & Ground & & & 32844.33 & \\
\hline $\mathrm{Si}^{28} \mathrm{HCl}_{3}^{37}$ & 4-1504 & $7, \leftarrow 6$, & Ground & & & 32845.02 & .5 \\
\hline $\mathrm{C}^{13} \mathrm{H}_{3} \mathrm{C}^{12} \mathrm{H}: \mathrm{C}^{12} \mathrm{H}_{2}$ & 3- 748 & $2,1,2 \leftarrow 1,1,1$ & Ground & & & 32847.20 & .10 \\
\hline $\mathrm{C}^{12} \mathrm{H}_{3} \mathrm{C}^{12}{ }_{*} \mathrm{HO}^{16} \mathrm{C}^{12}{ }_{*} \mathrm{H}_{2}$ & 3- 761 & Not Reported & Ground & & & 32847.29 & .1 \\
\hline$\left(\mathrm{C}^{12} \mathrm{H}_{3}\right)_{3} \mathrm{Si}^{28} \mathrm{I}^{127}$ & 3- 841 & $15, \leftarrow 14$ & Excited & & & 32847.4 & .4 \\
\hline $\mathrm{C}^{12} \mathrm{H}_{3} \mathrm{C}^{12}{ }_{*} \mathrm{HO}^{16} \mathrm{C}^{12}{ }_{*} \mathrm{H}_{2}$ & 3- 761 & Not Reported & Ground & & & 32848.94 & .1 \\
\hline $\mathrm{C}^{\mathrm{b}}{ }_{*} \mathrm{H}_{2}^{\mathrm{b}} \mathrm{N}^{\mathrm{b}} \mathrm{H}^{\mathrm{b}} \mathrm{C}^{\mathrm{b}}{ }_{*} \mathrm{H}_{2}^{\mathrm{b}}$ & 4. 863 & Not Reported & & & & 32850 . & 10. \\
\hline $\mathrm{C}^{12} * \mathrm{H}_{2}^{\mathrm{b}} \mathrm{S}^{\mathrm{b}} \mathrm{C}^{12} * \mathrm{H}_{2}^{\mathrm{b}}$ & 4- 854 & Not Reported & & & & 32850.0 & 20. \\
\hline $\mathrm{C}^{12} \mathrm{H}_{3} \mathrm{~N}^{14} \mathrm{O}_{2}^{16}$ & 3- 171 & Not Reported & Ground & & & 32851.00 & \\
\hline$\left(\mathrm{C}^{12} \mathrm{H}_{3}\right)_{3} \mathrm{Si}^{28} \mathrm{I}^{127}$ & 3- 841 & $15, \leftarrow 14$ & Excited & & & 32854.4 & .4 \\
\hline $\mathrm{C}^{12} \mathrm{D}_{3} \mathrm{C}^{12} \mathrm{HO}^{16}$ & 3- 474 & $2,0,2 \leftarrow 1,0,1$ & Ground & & & 32854.7 & \\
\hline $\mathrm{F}_{2}^{19} \mathrm{~N}^{14} \mathrm{~N}^{14} \mathrm{~F}_{2}^{19}$ & $3-21$ & $4,2,3 \leftarrow 3,1,3$ & Ground & & & 32856. & 1. \\
\hline $\mathrm{C}^{12} \mathrm{H}_{3} \mathrm{~N}^{14} \mathrm{O}_{2}^{16}$ & 3- 171 & Not Reported & Ground & & & 32858.99 & \\
\hline $\mathrm{C}^{12} \mathrm{H}_{3} \mathrm{~N}^{14} \mathrm{O}_{2}^{16}$ & 3- 171 & $2,0, \leftarrow 1,0$, & Ground & & & 32859.5 & .2 \\
\hline $\mathrm{C}^{12} \mathrm{H}_{3} \mathrm{P}^{31} \mathrm{H}_{2}$ & 3. 271 & $9,1,8 \leftarrow 8,2,6$ & Ground & & & 32864.5 & .1 \\
\hline $\mathrm{C}^{12} \mathrm{D}_{3} \mathrm{C}^{12} \mathrm{O}^{16} \mathrm{C}^{12} \mathrm{~N}^{14}$ & 3- 675 & $5,2,4 \leftarrow 4,2,3$ & Ground & & & 32867.29 & .2 \\
\hline$\left(\mathrm{C}^{12} \mathrm{H}_{3}\right)_{2} \mathrm{O}^{16}$ & 3- 591 & $3,1,2 \leftarrow 3,0,3$ & Excited & & & 32872.9 & .2 \\
\hline $\mathrm{C}^{12} \mathrm{H}_{3} \mathrm{Ce}^{70} \mathrm{HD}_{2}$ & 3- 301 & $2,0,2 \leftarrow 1,0,1$ & Ground & & & 32873.10 & .10 \\
\hline$\left(\mathrm{C}^{12} \mathrm{H}_{3}\right)_{3} \mathrm{Si}^{28} \mathrm{I}^{127}$ & 3- 841 & $15, \leftarrow 14$ & Excited & & & 32874.3 & .4 \\
\hline
\end{tabular}




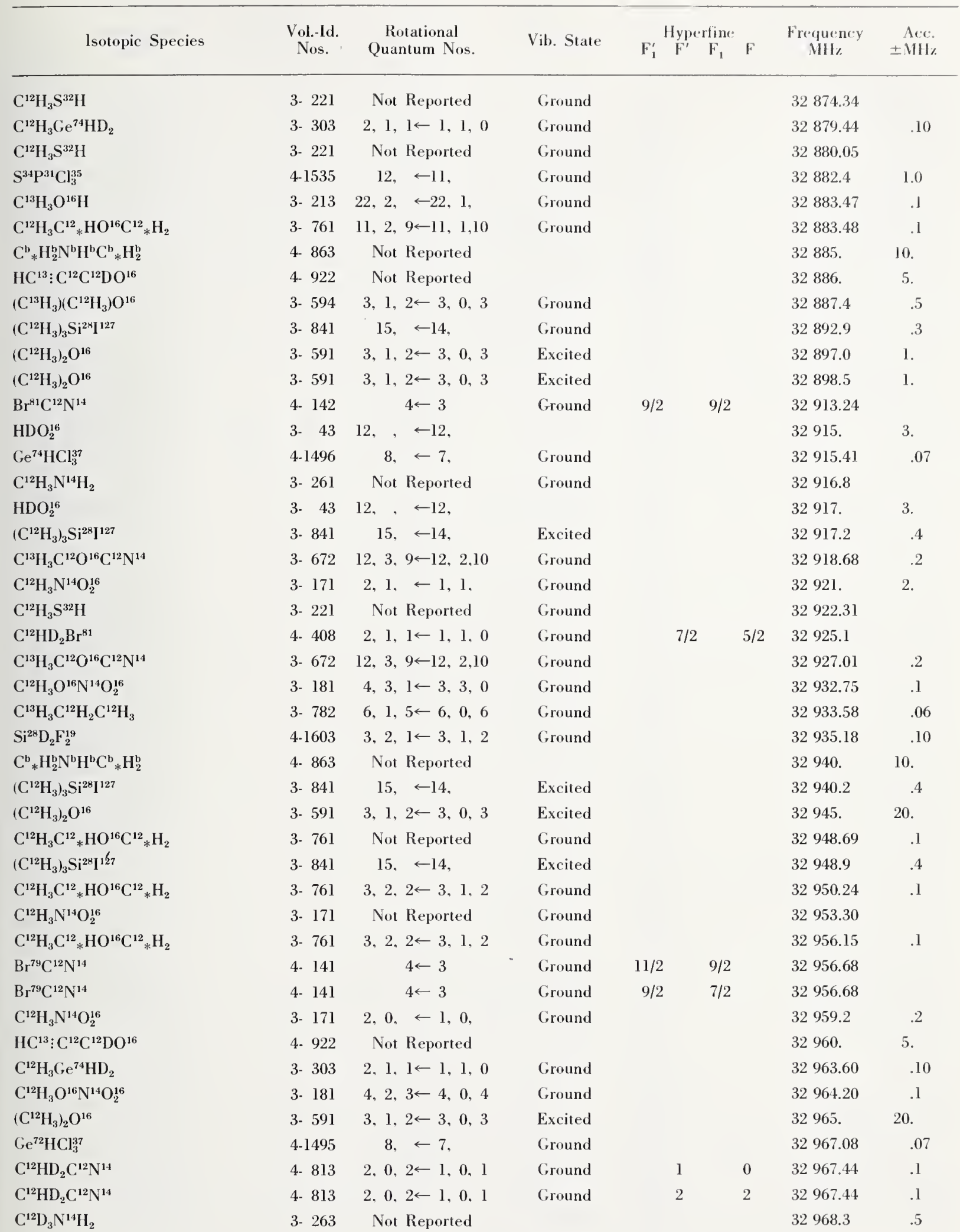




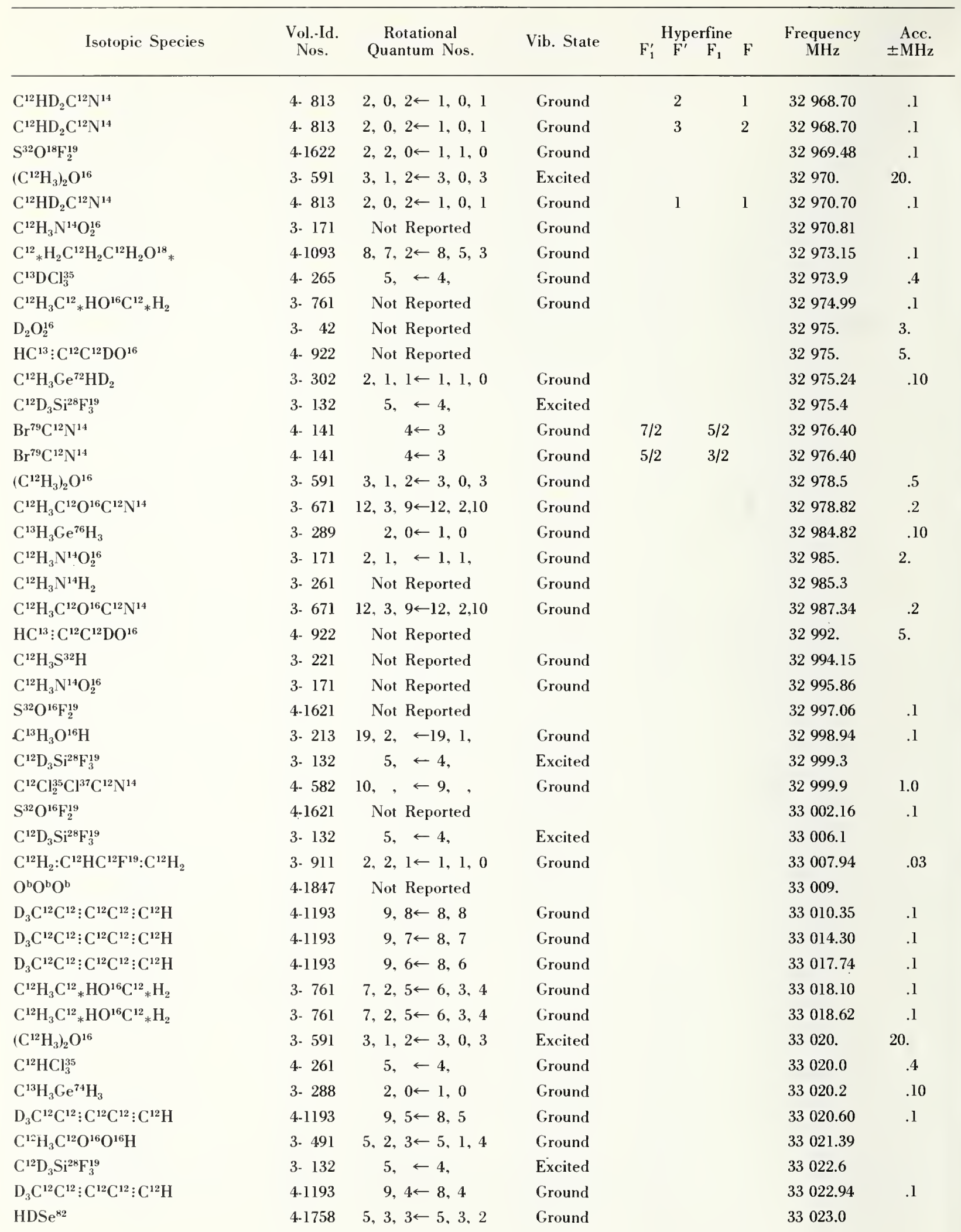




\begin{tabular}{|c|c|c|c|c|c|c|c|}
\hline Isotopic Species & $\begin{array}{l}\text { Vol.-Id. } \\
\text { Nos. }\end{array}$ & $\begin{array}{c}\text { Rotational } \\
\text { Quantum Nos. }\end{array}$ & Vib. State & $\mathrm{F}_{1}^{\prime} \quad \stackrel{\text { Hyperfine }}{\mathrm{F}^{\prime}} \quad \mathrm{F}_{1}$ & $\mathrm{~F}$ & $\begin{array}{c}\text { Frequency } \\
\text { MHz }\end{array}$ & $\begin{aligned} \text { Acc. } \\
\pm \mathrm{MHz}\end{aligned}$ \\
\hline $\mathrm{C}^{13} \mathrm{H}_{3} \mathrm{Ge}^{74} \mathrm{H}_{3}$ & 3. 288 & $2,0 \leftarrow 1,0$ & Ground & & & 33023.0 & .10 \\
\hline $\mathrm{D}_{3} \mathrm{C}^{12} \mathrm{C}^{12}: \mathrm{C}^{12} \mathrm{C}^{12}: \mathrm{C}^{12} \mathrm{H}$ & $4-1193$ & $9,3 \leftarrow 8,3$ & Ground & & & 33024.77 & .1 \\
\hline $\mathrm{D}_{3} \mathrm{C}^{12} \mathrm{C}^{12}: \mathrm{C}^{12} \mathrm{C}^{12}: \mathrm{C}^{12} \mathrm{H}$ & 4.1193 & $9,2 \leftarrow 8,2$ & Ground & & & 33026.08 & .1 \\
\hline $\mathrm{C}^{12} \mathrm{D}_{3} \mathrm{Si}^{28} \mathrm{~F}_{3}^{19}$ & 3. 132 & $5, \leftarrow 4$, & Excited & & & 33026.2 & \\
\hline $\mathrm{D}_{3} \mathrm{C}^{12} \mathrm{C}^{12}: \mathrm{C}^{12} \mathrm{C}^{12}: \mathrm{C}^{12} \mathrm{H}$ & $4-1193$ & $9,1 \leftarrow 8,1$ & Ground & & & 33026.86 & .1 \\
\hline $\mathrm{D}_{3} \mathrm{C}^{12} \mathrm{C}^{12}: \mathrm{C}^{12} \mathrm{C}^{12}: \mathrm{C}^{12} \mathrm{H}$ & $4-1193$ & $9,0 \leftarrow 8,0$ & Ground & & & 33027.09 & .1 \\
\hline $\mathrm{C}^{12}{ }_{*} \mathrm{H}_{2}^{\mathrm{h}} \mathrm{S}^{\mathrm{h}} \mathrm{C}^{12}{ }_{*} \mathrm{H}_{2}^{\mathrm{h}}$ & 4- 854 & Not Reported & & & & 33027.5 & .2 \\
\hline $\mathrm{C}^{12} \mathrm{H}_{2} \mathrm{~N}^{14} \mathrm{O}^{16} \mathrm{H}$ & 3- 141 & $7,2,5 \leftarrow 8,1,8$ & Ground & 8 & 9 & 33029.62 & .10 \\
\hline $\mathrm{C}^{12} \mathrm{H}_{2} \mathrm{~N}^{14} \mathrm{O}^{16} \mathrm{H}$ & 3. 141 & $7,2,5 \leftarrow 8,1,8$ & Ground & 6 & 7 & 33029.62 & .10 \\
\hline$\left(\mathrm{C}^{12} \mathrm{H}_{3}\right)_{2} \mathrm{O}^{16}$ & 3. 591 & $3,1,2 \leftarrow 3,0,3$ & Excited & & & 33030. & 20. \\
\hline $\mathrm{C}^{12} \mathrm{H}_{2} \mathrm{~N}^{14} \mathrm{O}^{16} \mathrm{H}$ & 3- 141 & $7,2,5 \leftarrow 8,1,8$ & Ground & 7 & 8 & 33031.20 & .10 \\
\hline $\mathrm{C}^{12} \mathrm{D}_{3} \mathrm{Si}^{28} \mathrm{~F}_{3}^{19}$ & 3. 132 & $5, \leftarrow 4$, & Excited & & & 33032.3 & \\
\hline $\mathrm{H}_{2} \mathrm{~N}^{14} \mathrm{~N}^{14} \mathrm{H}_{2}$ & 3- 51 & $3,0 \leftarrow 2,1$ & Ground & & & 33033.0 & .05 \\
\hline$\left(\mathrm{C}^{12} \mathrm{D}_{3}\right)_{2} \mathrm{C}^{12} \mathrm{O}^{16}$ & 3- 752 & 2. $2,0 \leftarrow 1,1,1$ & Ground & & & 33046.62 & .04 \\
\hline$\left(\mathrm{C}^{12} \mathrm{D}_{3}\right)_{2} \mathrm{C}^{12} \mathrm{O}^{16}$ & 3- 752 & $2,2,0 \leftarrow 1,1,1$ & Ground & & & 33047.70 & .04 \\
\hline $\mathrm{O}^{\mathrm{h}} \mathrm{O}^{\mathrm{h}} \mathrm{O}^{\mathrm{h}}$ & $4-1847$ & Not Reported & & & & 33050. & \\
\hline $\mathrm{C}^{12} \mathrm{D}_{3} \mathrm{Si}^{28} \mathrm{~F}_{3}^{19}$ & 3. 132 & $5, \leftarrow 4$, & Excited & & & 33050.53 & \\
\hline$\left(\mathrm{C}^{12} \mathrm{D}_{3}\right)_{2} \mathrm{C}^{12} \mathrm{O}^{16}$ & 3- 752 & $2,2,0 \leftarrow 1,1,1$ & Ground & & & 33051.65 & .04 \\
\hline $\mathrm{C}^{\mathrm{b}} \mathrm{H}_{2}^{\mathrm{b}} \mathrm{Cl}^{\mathrm{b}} \mathrm{F}^{\mathrm{b}}$ & 4- 333 & Not Reported & & & & 33051.68 & .1 \\
\hline $\mathrm{C}^{12} \mathrm{D}_{3} \mathrm{Si}^{28} \mathrm{~F}_{3}^{19}$ & 3. 132 & $5, \leftarrow 4$, & Excited & & & 33052.04 & \\
\hline $\mathrm{H}_{2} \mathrm{~N}^{14} \mathrm{~N}^{14} \mathrm{H}_{2}$ & 3. 51 & $3,0 \leftarrow 2,1$ & Ground & & & 33054.2 & \\
\hline$\left(\mathrm{C}^{12} \mathrm{D}_{3}\right)_{2} \mathrm{C}^{12} \mathrm{O}^{16}$ & 3- 752 & $2,2,0 \leftarrow 1,1,1$ & Ground & & & 33056.22 & .04 \\
\hline $\mathrm{C}^{12} \mathrm{HD}_{2} \mathrm{Br}^{79}$ & 4. 407 & $2,1,1 \leftarrow 1,1,0$ & Ground & $7 / 2$ & $5 / 2$ & 33057.1 & \\
\hline $\mathrm{Li}^{7} \mathrm{Br}^{81}$ & 1 . & $1 \leftarrow 0$ & Ground & $1 / 2$ & $3 / 2$ & 33057.54 & 0.25 \\
\hline $\mathrm{C}^{\mathrm{b}} \mathrm{H}_{2}^{\mathrm{b}} \mathrm{Cl}^{\mathrm{b}} \mathrm{F}^{\mathrm{b}}$ & 4- 333 & Not Reported & & & & 33057.8 & 1. \\
\hline $\mathrm{C}^{12} \mathrm{H}_{3} \mathrm{Ge}^{72} \mathrm{HD}_{2}$ & 3- 302 & $2,1,1 \leftarrow 1,1,0$ & Ground & & & 33059.35 & .10 \\
\hline $\mathrm{C}^{12} \mathrm{H}_{3} \mathrm{C}^{12} \mathrm{H}: \mathrm{C}^{12}: \mathrm{C}^{12} \mathrm{H}_{2}$ & 3- 931 & $4,1,3 \leftarrow 3,1,2$ & Ground & & & 33059.64 & .03 \\
\hline$\left(\mathrm{C}^{12} \mathrm{H}_{3}\right)_{2} \mathrm{O}^{16}$ & 3- 591 & $3,1,2 \leftarrow 3,0,3$ & Excited & & & 33060. & 20. \\
\hline $\mathrm{C}^{12} \mathrm{H}_{3} \mathrm{C}^{12} \mathrm{H}: \mathrm{C}^{12}: \mathrm{C}^{12} \mathrm{H}_{2}$ & 3- 931 & $4,1,3 \leftarrow 3,1,2$ & Ground & & & 33060.34 & .03 \\
\hline $\mathrm{HC}^{13}: \mathrm{C}^{12} \mathrm{C}^{12} \mathrm{DO}^{16}$ & 4. 922 & Not Reported & & & & 33062 & 5. \\
\hline $\mathrm{C}^{12} \mathrm{D}_{3} \mathrm{Si}^{28} \mathrm{~F}_{3}^{19}$ & 3. 132 . & $5, \leftarrow 4$, & Excited & & & 33063.5 & \\
\hline $\mathrm{Li}^{7} \mathrm{Br}^{41}$ & $1-$ & $1 \leftarrow 0$ & Ground & $5 / 2$ & $3 / 2$ & 33063.96 & 0.10 \\
\hline $\mathrm{H}_{2} \mathrm{~N}^{14} \mathrm{~N}^{14} \mathrm{H}_{2}$ & 3- 51 & $3,0 \leftarrow 2,1$ & Ground & & & 33065.4 & \\
\hline $\mathrm{C}^{\mathrm{h}}{ }_{*} \mathrm{H}_{2}^{\mathrm{h}} \mathrm{N}^{\mathrm{h}} \mathrm{H}^{\mathrm{h}} \mathrm{C}^{\mathrm{h}}{ }_{*} \mathrm{H}_{2}^{\mathrm{h}}$ & 4- 863 & Not Reported & & & & 33070. & 10. \\
\hline $\mathrm{Li}^{7} \mathrm{Br}^{81}$ & $1-$ & $1 \leftarrow 0$ & Ground & $3 / 2$ & $3 / 2$ & 33071.53 & 0.10 \\
\hline $\mathrm{HDSe}^{\mathrm{80}}$ & $4-1757$ & $5,3,3 \leftarrow 5,3,2$ & Ground & & & 33 075.4 & \\
\hline $\mathrm{C}^{12} \mathrm{H}_{3} \mathrm{Ci}^{70} \mathrm{HD}_{2}$ & 3- 301 & $2,1,1 \leftarrow 1,1,0$ & Ground & & & 33075.77 & .10 \\
\hline $\mathrm{HC}^{13}: \mathrm{C}^{12} \mathrm{C}^{12} \mathrm{DO}^{16}$ & 4. 922 & Not Reported & & & & 33076. & 5. \\
\hline $\mathrm{C}^{12} \mathrm{H}_{3} \mathrm{~S}^{32} \mathrm{H}$ & 3. 221 & $10,2,8 \leftarrow 11,1,11$ & Ground & & & 33077.9 & \\
\hline $\mathrm{H}_{2} \mathrm{~N}^{14} \mathrm{~N}^{14} \mathrm{H}_{2}$ & 3. 51 & $3,0 \leftarrow 2,1$ & Ground & 4 & 4 & 33077.98 & .05 \\
\hline $\mathrm{S}^{32} \mathrm{O}^{16} \mathrm{~F}_{2}^{19}$ & $4-1621$ & Not Reported & & & & 33078.20 & .1 \\
\hline $\mathrm{H}_{2} \mathrm{~N}^{14} \mathrm{~N}^{14} \mathrm{H}_{2}$ & 3. 51 & $3,0 \leftarrow 2,1$ & Ground & 4 & 3 & 33078.78 & .05 \\
\hline $\mathrm{H}_{2} \mathrm{~N}^{14} \mathrm{~N}^{14} \mathrm{H}_{2}$ & 3- 51 & $3,0 \leftarrow 2,1$ & Ground & 5 & 4 & 33079.36 & .05 \\
\hline $\mathrm{C}^{12} \mathrm{D}_{3} \mathrm{Si}^{28} \mathrm{~F}_{3}^{19}$ & 3- 132 & $5, \leftarrow 4$, & Excited & & & 33079.78 & \\
\hline $\mathrm{H}_{2} \mathrm{~N}^{14} \mathrm{~N}^{14} \mathrm{H}_{2}$ & 3. 51 & $3,0 \leftarrow 2,1$ & Ground & 3 & 2 & 33079.80 & .05 \\
\hline
\end{tabular}




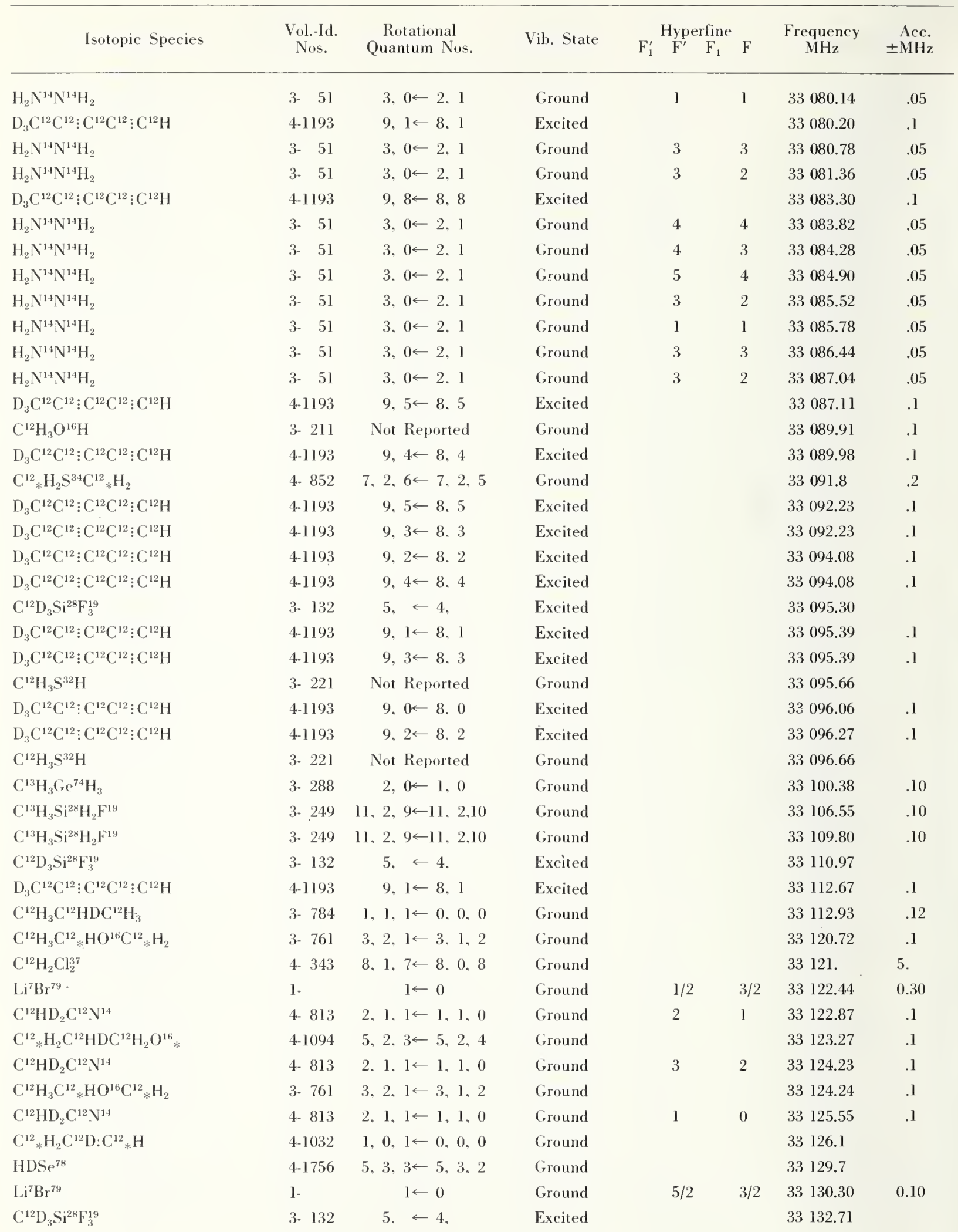




\begin{tabular}{|c|c|c|c|c|c|c|c|c|}
\hline Isotopic Species & $\begin{array}{l}\text { Vol.-Id. } \\
\text { Nos. }\end{array}$ & $\begin{array}{c}\text { Rotational } \\
\text { Quantum Nos. }\end{array}$ & Vit. State & $F_{1}^{\prime}$ & $\begin{array}{l}\text { Hyperfine } \\
\mathrm{F}^{\prime} \quad \mathrm{F}_{1}\end{array}$ & $\mathrm{~F}$ & $\begin{array}{l}\text { Frequency } \\
\text { lite }\end{array}$ & $\begin{aligned} & \text { Arce } \\
\pm & \text { MII\% }\end{aligned}$ \\
\hline $\mathrm{C}^{13} \mathrm{H}_{3} \mathrm{C}^{12} \mathrm{O}^{16} \mathrm{~F}^{14}$ & 3- 393 & $2,1,1 \leftarrow 1,1,0$ & Ground & & & & 33135.80 & .2 \\
\hline $\mathrm{C}^{12} \mathrm{H}_{3} \mathrm{~N}^{14} \mathrm{H}_{2}$ & 3- 261 & Not Reported & Ground & & & & 33136.5 & \\
\hline $\mathrm{Li}^{7} \mathrm{Br}^{74}$ & $1-$ & $1 \leftarrow 0$ & Ground & & $3 / 2$ & $3 / 2$ & 33139.50 & 0.10 \\
\hline $\mathrm{C}^{12} \mathrm{H}_{3} \mathrm{C}^{12}{ }_{*} \mathrm{HO}^{16} \mathrm{C}^{12}{ }_{*} \mathrm{H}_{2}$ & 3- 761 & Not Reported & Ground & & & & 33141.61 & .1 \\
\hline $\mathrm{S}^{32} \mathrm{O}^{16} \mathrm{~F}_{2}^{19}$ & 4-1621 & Not Reported & & & & & 33144.27 & .1 \\
\hline $\mathrm{HC}^{13}: \mathrm{C}^{12} \mathrm{C}^{12} \mathrm{DO}^{16}$ & 4- 922 & Not Reported & & & & & 33145. & 5. \\
\hline $\mathrm{C}^{12} \mathrm{D}_{3} \mathrm{Si}^{2 \times} \mathrm{F}_{3}^{19}$ & 3- 132 & $5, \leftarrow 4$ & Ground & & & & 33145.02 & .1 \\
\hline $\mathrm{C}^{12} \mathrm{D}_{3} \mathrm{Si}^{24} \mathrm{~F}_{3}^{19}$ & 3. 132 & $5, \leftarrow 4$ & Excited & & & & 33148.51 & \\
\hline $\mathrm{C}^{12} \mathrm{H}_{3} \mathrm{~N}^{14} \mathrm{H}_{2}$ & 3- 261 & $17,4, \quad \leftarrow 16,5$. & Ground & & & & 33152. & \\
\hline $\mathrm{C}^{12} \mathrm{H}_{3} \mathrm{~N}^{1-1} \mathrm{H}_{2}$ & 3. 261 & Not Reported & Ground & & & & 33152.3 & \\
\hline $\mathrm{S}^{32} \mathrm{O}^{16} \mathrm{~F}_{2}^{19}$ & 4-1621 & Not Reported & & & & & 33153.04 & .1 \\
\hline $\mathrm{C}^{12} \mathrm{H}_{3} \mathrm{C}^{12}{ }_{*} \mathrm{HO}^{16} \mathrm{C}^{12}{ }_{*} \mathrm{H}_{2}$ & 3- 761 & $3,2,1 \leftarrow 3,1,2$ & Ground & & & & 33155.45 & .1 \\
\hline $\mathrm{N}^{14} \mathrm{H}_{3}$ & 4-1771 & $13,13 \leftarrow 13,13$ & Ground & & & & 33156.95 & .10 \\
\hline $\mathrm{N}^{14} \mathrm{O}_{2}^{16} \mathrm{Cl}^{37}$ & 4-1462 & $4,0,4 \leftarrow 3,0,3$ & Ground & & $5 / 2$ & $3 / 2$ & 33156.97 & \\
\hline $\mathrm{HDSe}^{77}$ & 4-1755 & $5,3,3 \leftarrow 5,3,2$ & Ground & & & & 33157.4 & \\
\hline $\mathrm{N}^{14} \mathrm{O}_{2}^{16} \mathrm{Cl}^{37}$ & 4-1462 & $4,0,4 \leftarrow 3,0,3$ & Ground & & $7 / 2$ & $5 / 2$ & 33157.49 & \\
\hline $\mathrm{C}^{12} \mathrm{H}_{33} \mathrm{P}^{31} \mathrm{H}_{2}$ & 3- 271 & $9,1,8 \leftarrow 8,2,6$ & Ground & & & & 33158.1 & .1 \\
\hline $\mathrm{S}^{32} \mathrm{O}^{16} \mathrm{~F}_{2}^{19}$ & 4-1621 & Not Reported & & & & & 33158.40 & .1 \\
\hline $\mathrm{N}^{14} \mathrm{O}_{2}^{16} \mathrm{Cl}^{37}$ & $4 \cdot 1462$ & $4,0,4 \leftarrow 3,0,3$ & Ground & & $11 / 2$ & $9 / 2$ & 33159.29 & \\
\hline $\mathrm{N}^{14} \mathrm{O}_{2}^{16} \mathrm{Cl}^{37}$ & 4-1462 & $4,0,4 \leftarrow 3,0,3$ & Ground & & $9 / 2$ & $7 / 2$ & 33159.75 & \\
\hline $\mathrm{C}^{12} \mathrm{H}_{33}, \mathrm{e}^{70} \mathrm{HD}_{2}$ & 3- 301 & $2,1,1 \leftarrow 1,1,0$ & Ground & & & & 33159.90 & .10 \\
\hline $\mathrm{C}^{12} \mathrm{H}_{33} \mathrm{C}^{12}: \mathrm{C}^{13} \mathrm{H}$ & $4 \cdot 1044$ & $2,1 \leftarrow 1,1$ & Ground & & & & 33160.35 & .10 \\
\hline $\mathrm{C}^{12} \mathrm{D}_{3} \mathrm{~N}^{14} \mathrm{H}_{2}$ & 3- 263 & Not Reported & & & & & 33160.4 & .5 \\
\hline $\mathrm{C}^{12} \mathrm{H}_{3} \mathrm{C}^{12}: \mathrm{C}^{13} \mathrm{H}$ & 4-1044 & $2,0 \leftarrow 1,0$ & Ground & & & & 33160.94 & .10 \\
\hline $\mathrm{C}^{12} \mathrm{H}_{3} \mathrm{C}^{12} \mathrm{O}^{16} \mathrm{C}^{13} \mathrm{~N}^{14}$ & 3- 673 & $5,0,5 \leftarrow 4,0,4$ & Ground & & & & 33161.23 & .2 \\
\hline $\mathrm{C}^{\mathrm{b}} \mathrm{H}_{2}^{\mathrm{b}} \mathrm{Cl}^{\mathrm{b}} \mathrm{F}^{\mathrm{b}}$ & 4- 333 & Not Reported & & & & & 33162.40 & 1 \\
\hline $\mathrm{C}^{12} \mathrm{HCl}^{37} \mathrm{~F}_{2}^{19}$ & 4- 252 & $9,4,6 \leftarrow 9,3,6$ & Ground & & $15 / 2$ & $15 / 2$ & 33167.4 & .05 \\
\hline $\mathrm{C}^{12} \mathrm{HCl}^{37} \mathrm{~F}_{2}^{19}$ & 4- 252 & $9,4,6 \leftarrow 9,3,6$ & Ground & & $21 / 2$ & $21 / 2$ & 33168.1 & .05 \\
\hline $\mathrm{C}^{12} \mathrm{H}_{3} \mathrm{C}^{12} \mathrm{O}^{16} \mathrm{C}^{12} \mathrm{~N}^{14}$ & 3- 671 & $12,4,8 \leftarrow 12,3,9$ & Ground & & & & 33169.95 & .2 \\
\hline $\mathrm{HC}^{13}: \mathrm{C}^{12} \mathrm{C}^{12} \mathrm{DO}^{16}$ & 4. 922 & Not Reported & & & & & 33170. & 5. \\
\hline $\mathrm{C}^{12} \mathrm{HCl}^{37} \mathrm{~F}_{2}^{19}$ & 4- 252 & $9,4,6 \leftarrow 9,3,6$ & Ground & & $17 / 2$ & $17 / 2$ & 33171.4 & .05 \\
\hline $\mathrm{C}^{12} \mathrm{HCl}^{37} \mathrm{~F}_{2}^{19}$ & 4- 252 & $9.4 .6 \leftarrow 9,3.6$ & Ground & & $19 / 2$ & $19 / 2$ & 33172.1 & .05 \\
\hline $\mathrm{C}^{12} \mathrm{H}_{3} \mathrm{Si}^{2 \times} \mathrm{H}_{2} \mathrm{~F}^{19}$ & 3- 241 & $7,1,6 \leftarrow 7,1,7$ & Ground & & & & 33175.33 & .10 \\
\hline $\mathrm{C}^{12} \mathrm{H}_{3} \mathrm{Si}^{28} \mathrm{H}_{2} \mathrm{~F}^{19}$ & 3- 241 & $7,1,6 \leftarrow 7,1,7$ & Ground & & & & 33178.93 & .10 \\
\hline $\mathrm{C}^{12} \mathrm{D}_{3} \mathrm{Si}^{28} \mathrm{~F}_{3}^{19}$ & 3- 132 & $5, \leftarrow 4$ & Excited & & & & 33181.81 & \\
\hline $\mathrm{C}^{13} \mathrm{H}_{3} \mathrm{C}^{12} \mathrm{O}^{16} \mathrm{C}^{12} \mathrm{~N}^{14}$ & 3- 672 & $11,4,7 \leftarrow 11,3,8$ & Ground & & & & 33182.59 & .2 \\
\hline $\mathrm{HC}^{13} ! \mathrm{C}^{12} \mathrm{C}^{12} \mathrm{DO}^{16}$ & 4. 922 & Not Reported & & & & & 33183. & 5. \\
\hline $\mathrm{t}-\mathrm{C}^{12} \mathrm{H}_{3} \mathrm{C}^{12} \mathrm{H}: \mathrm{C}^{12} \mathrm{HD}$ & 3. 746 & $2,1,1 \leftarrow 1,1,0$ & Ground & & & & 33186.35 & .05 \\
\hline $\mathrm{HDSe}^{76}$ & $4-1759$ & $5,3,3 \leftarrow 5,3,2$ & Ground & & & & $33188: 2$ & \\
\hline $\mathrm{O}^{16} \mathrm{O}^{16} \mathrm{O}^{18}$ & 4-1842 & $14,2,12 \leftarrow 15,1,15$ & Ground & & & & 33191. & \\
\hline $\mathrm{C}^{13} \mathrm{H}_{3} \mathrm{O}^{16} \mathrm{H}$ & 3- 213 & $21,2, \leftarrow 21,1$ & Ground & & & & 33192.97 & .1 \\
\hline $\mathrm{Si}^{28} \mathrm{D}_{2} \mathrm{~F}_{2}^{19}$ & 4-1603 & $8,2,6 \leftarrow 8,1,7$ & Ground & & & & 33195.45 & .10 \\
\hline $\mathrm{t}-\mathrm{HDC}^{12}{ }_{*} \mathrm{O}^{16} \mathrm{C}^{12}{ }_{*} \mathrm{HD}$ & 4- 844 & $3,1,2 \leftarrow 3,0.3$ & Ground & & & & 33196.80 & .05 \\
\hline $\mathrm{C}^{12} \mathrm{H}_{3} \mathrm{P}^{31} \mathrm{H}_{2}$ & 3- 271 & $4,0,4 \leftarrow 3,1,2$ & Ground & & & & 33202.0 & .1 \\
\hline $\mathrm{HC}^{13} \vdots \mathrm{C}^{12} \mathrm{C}^{12} \mathrm{DO}^{16}$ & 4- 922 & Not Reported & & & & & 33205. & 5. \\
\hline
\end{tabular}




\begin{tabular}{|c|c|c|c|c|c|c|}
\hline Isotopic Species & $\begin{array}{l}\text { Vol.-Id. } \\
\text { Nos. }\end{array}$ & $\begin{array}{c}\text { Rotational } \\
\text { Quantum Nos. }\end{array}$ & Vib. State & $\mathrm{F}_{1}^{\prime} \stackrel{\text { Hyperfine }}{\mathrm{F}^{\prime}} \mathrm{F}_{1} \mathrm{~F}$ & $\begin{array}{c}\text { Frequency } \\
\mathrm{MHz}^{2}\end{array}$ & $\begin{aligned} & \text { Acc. } \\
\pm & \mathrm{MHz}\end{aligned}$ \\
\hline$\left(\mathrm{C}^{12} \mathrm{H}_{3}\right)_{2} \mathrm{~S}^{32}$ & 3- 601 & $7,2,5 \leftarrow 7,1,6$ & Ground & & 33210.66 & .05 \\
\hline$\left(\mathrm{C}^{12} \mathrm{H}_{3}\right)_{2} \mathrm{~S}^{32}$ & 3. 601 & $7,2,5 \leftarrow 7,1,6$ & Ground & & 33211.20 & .05 \\
\hline$\left(\mathrm{C}^{12} \mathrm{H}_{3}\right)_{2} \mathrm{~S}^{32}$ & 3- 601 & $7,2,5 \leftarrow 7,1,6$ & Ground & & 33211.73 & .05 \\
\hline $\mathrm{C}^{12} \mathrm{D}_{3} \mathrm{Si}^{\mathrm{b}} \mathrm{HD}_{2}$ & 3- 331 & $2,1,2 \leftarrow 1,1,1$ & & & 33213.00 & .2 \\
\hline $\mathrm{C}^{12} \mathrm{H}_{3} \mathrm{C}^{12} * \mathrm{HO}^{16} \mathrm{C}^{12} * \mathrm{H}_{2}$ & 3- 761 & Not Reported & Ground & & 33216.01 & .1 \\
\hline $\mathrm{C}^{13} \mathrm{H}_{3} \mathrm{O}^{16} \mathrm{H}$ & 3- 213 & $20,2, \leftarrow 20,1$, & Ground & & 33220.05 & .1 \\
\hline $\mathrm{C}^{13} \mathrm{H}_{3} \mathrm{Ge}^{72} \mathrm{H}_{3}$ & 3. 287 & $2,0 \leftarrow 1,0$ & Ground & & 33221.62 & .10 \\
\hline $\mathrm{S}^{32} \mathrm{O}^{16} \mathrm{~F}_{2}^{19}$ & $4-1621$ & Not Reported & & & 33222.20 & .1 \\
\hline $\mathrm{C}^{\mathrm{b}} \mathrm{H}_{2}^{\mathrm{b}} \mathrm{Cl}^{\mathrm{b}} \mathrm{F}^{\mathrm{b}}$ & 4- 333 & Not Reported & & & 33224.05 & .1 \\
\hline $\mathrm{C}^{12} \mathrm{D}_{3} \mathrm{Si}^{30} \mathrm{H}_{2} \mathrm{~F}^{19}$ & 3- 246 & $3,1,2 \leftarrow 2,1,1$ & Ground & & 33224.40 & .10 \\
\hline $\mathrm{C}^{12} \mathrm{H}_{3} \mathrm{~S}^{32} \mathrm{H}$ & 3- 221 & Not Reported & Ground & & 33233.51 & \\
\hline $\mathrm{HC}^{13}: \mathrm{C}^{12} \mathrm{C}^{12} \mathrm{DO}^{16}$ & 4- 922 & Not Reported & & & 33239 . & 5. \\
\hline $\mathrm{S}^{32} \mathrm{O}^{16} \mathrm{~F}_{2}^{19}$ & 4-1621 & $3,1,3 \leftarrow 2,1,2$ & Ground & & 33242.36 & .1 \\
\hline $\mathrm{C}^{12} \mathrm{H}_{3} \mathrm{C}^{12}{ }_{*} \mathrm{HO}^{16} \mathrm{C}^{12}{ }_{*} \mathrm{H}_{2}$ & 3- 761 & $9,3,6 \leftarrow 8,4,5$ & Ground & & 33247.86 & .1 \\
\hline $\mathrm{O}^{\prime \prime} \mathrm{O}^{\mathrm{h}} \mathrm{O}^{\mathrm{b}}$ & 4-1847 & Not Reported & & & 33248. & \\
\hline $\mathrm{C}^{12} \mathrm{H}_{3} \mathrm{C}^{12} * \mathrm{HO}^{16} \mathrm{C}^{12} * \mathrm{H}_{2}$ & 3. 761 & $9,3,6 \leftarrow 8,4,5$ & Ground & & 33248.84 & .1 \\
\hline $\mathrm{O}^{16} \mathrm{~F}_{2}^{19}$ & $4-1611$ & $4,2,3 \leftarrow 5,1,4$ & Ground & & 33251.80 & .10 \\
\hline $\mathrm{C}^{13} \mathrm{H}_{3} \mathrm{C}^{12}: \mathrm{C}^{12} \mathrm{H}$ & 4-1043 & $2,1 \leftarrow 1,1$ & Ground & & 33252.22 & .10 \\
\hline $\mathrm{C}^{13} \mathrm{H}_{3} \mathrm{C}^{12}: \mathrm{C}^{12} \mathrm{H}$ & 4-1043 & $2,0 \leftarrow 1,0$ & Ground & & 33252.88 & .10 \\
\hline $\mathrm{HC}^{13}: \mathrm{C}^{12} \mathrm{C}^{12} \mathrm{DO}^{16}$ & 4. 922 & Not Reported & & & 33254. & 5. \\
\hline $\mathrm{S}^{32} \mathrm{O}^{16} \mathrm{~F}_{2}^{19}$ & $4-1621$ & $3,0,3 \leftarrow 2,0,2$ & Ground & & 33255.43 & .1 \\
\hline $\mathrm{C}^{12} \mathrm{D}_{3} \mathrm{C}^{12} \mathrm{DO}^{16}$ & 3- 472 & $2,1,1 \leftarrow 1,1,0$ & Ground & & 33262.94 & .1 \\
\hline $\mathrm{C}^{12} \mathrm{D}_{3} \mathrm{~N}^{14} \mathrm{O}_{2}^{16}$ & 3- 172 & $2,3, \leftarrow 2,1$, & Ground & & 33264. & 1.0 \\
\hline $\mathrm{C}^{12} \mathrm{D}_{3} \mathrm{C}^{12} \mathrm{DO}^{16}$ & 3. 472 & $2,1,1 \leftarrow 1,1,0$ & Ground & & 33264.34 & .1 \\
\hline $\mathrm{C}^{12}{ }_{*} \mathrm{H}_{2} \mathrm{C}^{12} \mathrm{HDC}^{12} \mathrm{H}_{2} \mathrm{O}^{16} *$ & 4-1094 & $4,1,3 \leftarrow 4,1,4$ & Excited & & 33267.02 & .1 \\
\hline $\mathrm{C}^{12} \mathrm{D}_{3} \mathrm{Si}^{28} \mathrm{H}_{2} \mathrm{~F}^{19}$ & 3- 244 & $3,1,2 \leftarrow 2,1,1$ & Ground & & 33274.15 & .10 \\
\hline $\mathrm{C}^{12} \mathrm{H}_{3} \mathrm{~S}^{32} \mathrm{H}$ & 3- 221 & Not Reported & Ground & & 33277.30 & \\
\hline $\mathrm{C}^{12} \mathrm{D}_{3} \mathrm{Si}^{\mathrm{b}} \mathrm{HD}_{2}$ & 3- 331 & $2,1,2 \leftarrow 1,1,1$ & & & 33283.75 & .2 \\
\hline $\mathrm{D}_{2} \mathrm{C}^{12}{ }_{*} \mathrm{O}^{16} \mathrm{C}^{12}{ }_{*} \mathrm{D}_{2}$ & 4- 843 & $3,2,2 \leftarrow 3,1,3$ & Ground & & 33285. & \\
\hline $\mathrm{c}-\mathrm{HDC}^{12}{ }_{*} \mathrm{O}^{16} \mathrm{C}^{12}{ }_{*} \mathrm{DH}$ & 4- 845 & $3,1,2 \leftarrow 3,0,3$ & Ground & & 33290.16 & .05 \\
\hline $\mathrm{C}^{12} \mathrm{H}_{3} \mathrm{~N}^{14} \mathrm{O}_{2}^{16}$ & 3. 171 & Not Reported & Ground & & 33292.34 & \\
\hline $\mathrm{HC}^{13} \vdots \mathrm{C}^{12} \mathrm{C}^{12} \mathrm{DO}^{16}$ & 4- 922 & Not Reported & & & 33301 & 5. \\
\hline $\mathrm{C}^{12} \mathrm{H}_{3} \mathrm{~N}^{14} \mathrm{H}_{2}$ & 3- 261 & Not Reported & Ground & & 33302.0 & \\
\hline $\mathrm{s}-\mathrm{C}^{12} \mathrm{HD}_{2} \mathrm{C}^{12} \mathrm{HO}^{16}$ & 3- 475 & $2,1,2 \leftarrow 1,1,1$ & Ground & & 33302.30 & .3 \\
\hline $\mathrm{c}-\mathrm{HF}^{19} \mathrm{C}^{12}: \mathrm{C}^{13} \mathrm{HF}^{19}$ & 4- 692 & $6.1,5 \leftarrow 6,0,6$ & Ground & & 33305.61 & .05 \\
\hline $\mathrm{C}^{12} \mathrm{H}_{3} \mathrm{C}^{12} \mathrm{HO}^{16}$ & 3- 471 & Not Reported & & & 33312.64 & \\
\hline $\mathrm{Si}^{28} \mathrm{D}_{2} \mathrm{~F}_{2}^{19}$ & 4-1603 & $3,2,1 \leftarrow 3,1,2$ & Excited & & 33320.42 & .10 \\
\hline $\mathrm{C}^{12} \mathrm{D}_{3} \mathrm{Si}^{\mathrm{b}} \mathrm{HD}_{2}$ & 3. 331 & $2,0,2 \leftarrow 1,0,1$ & & & 33323. & \\
\hline $\mathrm{C}^{12} \mathrm{H}_{3} \mathrm{Ge}^{74} \mathrm{H}_{2} \mathrm{D}$ & 3. 299 & $2,1,2 \leftarrow 1,1,1$ & Ground & & 33328.63 & .10 \\
\hline $\mathrm{S}^{32} \mathrm{O}^{16} \mathrm{~F}_{2}^{19}$ & 4-1621 & Not Reported & & & 33336.80 & .1 \\
\hline $\mathrm{C}^{12} \mathrm{D}_{3} \mathrm{O}^{16} \mathrm{D}$ & 3. 216 & Not Reported & & & 3334.0 . & \\
\hline $\mathrm{S}^{32} \mathrm{O}^{16} \mathrm{~F}_{2}^{19}$ & $4-1621$ & Not Reported & & & 33341.66 & .1 \\
\hline $\mathrm{HC}^{13} \vdots \mathrm{C}^{12} \mathrm{C}^{12} \mathrm{DO}^{16}$ & 4- 922 & Not Reported & & & 33342. & 5. \\
\hline $\mathrm{C}^{12} \mathrm{H}_{3} \mathrm{C}^{12} \mathrm{O}^{16} \mathrm{C}^{12} \mathrm{~N}^{14}$ & 3- 671 & $5,0,5 \leftarrow 4,0,4$ & Ground & & 33344.70 & .2 \\
\hline $\mathrm{C}^{12} \mathrm{H}_{3} \mathrm{~N}^{14} \mathrm{O}_{2}^{16}$ & 3- 171 & Not Reported & Ground & & 33345.34 & \\
\hline
\end{tabular}




\begin{tabular}{|c|c|c|c|c|c|c|}
\hline Isotopic Species & $\begin{array}{l}\text { Vol.-Id. } \\
\text { Nos. }\end{array}$ & $\begin{array}{c}\text { Rotational } \\
\text { Quantum Nos. }\end{array}$ & Vib. State & $\mathrm{F}_{1}^{\prime} \quad \mathbf{F}^{\prime} \quad \mathbf{F}_{1} \quad \mathrm{~F}$ & $\begin{array}{c}\text { Frequency } \\
\mathrm{MH}_{\ell}\end{array}$ & $\begin{aligned} & \text { Acc. } \\
\pm & \mathrm{MHz}\end{aligned}$ \\
\hline $\mathrm{C}^{12} \mathrm{Cl}_{3}^{35} \mathrm{C}^{12} \mathrm{~N}^{14}$ & 4- 581 & $10, \leftarrow 9$ & Ground & & 33346.5 & 1.0 \\
\hline $\mathrm{F}_{2}^{19} \mathrm{O}_{2}^{16}$ & 3- 11 & $2,1,2 \leftarrow 1,0,1$ & Ground & & 33346.88 & .1 \\
\hline $\mathrm{C}^{13} \mathrm{H}_{3} \mathrm{C}^{70} \mathrm{H}_{3}$ & 3- 286 & $2,0 \leftarrow 1,0$ & Ground & & 33349.30 & .10 \\
\hline $\mathrm{HC}^{13}: \mathrm{C}^{12} \mathrm{C}^{12} \mathrm{DO}^{16}$ & 4. 922 & Not Reported & & & 33350. & 5. \\
\hline $\mathrm{C}^{12}{ }_{*} \mathrm{H}_{2} \mathrm{C}^{12} \mathrm{H}: \mathrm{C}^{12}{ }_{*} \mathrm{H}$ & 4-1031 & $9,5,4 \leftarrow 9,5,5$ & Ground & & 33353.4 & \\
\hline $\mathrm{C}^{12} \mathrm{D}_{3} \mathrm{~N}^{14} \mathrm{D}_{2}$ & 3- 262 & $3,1,3 \leftarrow 3,0,3$ & Ground & & 33360.49 & \\
\hline $\mathrm{C}^{12} \mathrm{H}_{2} \mathrm{~F}^{19} \mathrm{C}^{12} \mathrm{~N}^{14}$ & 4. 701 & $3,1,2 \leftarrow 3,0,3$ & Ground & & 33363.2 & .2 \\
\hline $\mathrm{C}^{12} \mathrm{Cl}_{3}^{35} \mathrm{C}^{12} \mathrm{~N}^{14}$ & 4- 581 & $10, \leftarrow 9$ & Excited & & 33363.7 & 1.0 \\
\hline $\mathrm{C}^{12}{ }_{*} \mathrm{H}_{2} \mathrm{C}^{12} \mathrm{HDC}^{12} \mathrm{H}_{2} \mathrm{O}^{16} *$ & 4-1094 & $5,3,3 \leftarrow 5,1,4$ & Excited & & 33367.40 & .1 \\
\hline $\mathrm{C}^{12} \mathrm{H}_{3} \mathrm{~N}^{14} \mathrm{O}_{2}^{16}$ & 3. 171 & Not Reported & Ground & & 33376.80 & \\
\hline $\mathrm{O}^{16}{ }_{*} \mathrm{C}^{12} \mathrm{H}_{2} \mathrm{C}^{12} \mathrm{H}_{2} \mathrm{C}^{12} * \mathrm{O}^{16}$ & $4-1071$ & $4,1,4 \leftarrow 3,1,3$ & Ground & & 33384.4 & .2 \\
\hline $\mathrm{C}^{12} \mathrm{H}_{3} \mathrm{~N}^{14} \mathrm{H}_{2}$ & 3- 261 & Not Reported & Ground & & 33386.4 & \\
\hline $\mathrm{C}^{12} \mathrm{H}_{3} \mathrm{~N}^{14} \mathrm{H}_{2}$ & 3- 261 & Not Reported & Ground & & 33388.2 & \\
\hline $\mathrm{C}^{12} \mathrm{H}_{2} \mathrm{Cl}^{35} \mathrm{Cl}^{37}$ & 4- 342 & $8,1,7 \leftarrow 8,0,8$ & Ground & & 33393. & 2. \\
\hline $\mathrm{C}^{12} \mathrm{H}_{3} \mathrm{~N}^{14} \mathrm{O}_{2}^{16}$ & 3. 171 & Not Reported & Ground & & 33396.58 & \\
\hline $\mathrm{C}^{12}{ }_{*} \mathrm{H}_{2} \mathrm{C}^{12} \mathrm{HDC}^{12} \mathrm{H}_{2} \mathrm{O}^{16} *$ & 4-1094 & $4,2,3 \leftarrow 4,0,4$ & Excited & & 33398.61 & .1 \\
\hline $\mathrm{C}^{\mathrm{b}} \mathrm{H}_{2}^{\mathrm{b}} \mathrm{Cl}^{\mathrm{b}} \mathbf{F}^{\mathrm{b}}$ & 4. 333 & Not Reported & & & 33404.40 & .1 \\
\hline $\mathrm{C}^{\mathrm{b}} \mathrm{H}_{2}^{\mathrm{b}} \mathrm{Cl}^{\mathrm{b}} \mathrm{F}^{\mathrm{b}}$ & 4. 333 & Not Reported & & & 33406.00 & .1 \\
\hline $\mathrm{C}^{12} \mathrm{D}_{3} \mathrm{Si}^{\mathrm{b}} \mathrm{HD}_{2}$ & 3- 331 & $2,0,2 \leftarrow 1,0,1$ & & & 33409.81 & .2 \\
\hline $\mathrm{C}^{\mathrm{b}}{ }_{*} \mathrm{H}_{2}^{\mathrm{l}} \mathrm{N}^{\mathrm{b}} \mathrm{H}^{\mathrm{h}} \mathrm{C}^{\mathrm{h}}{ }_{*} \mathrm{H}_{2}^{\mathrm{b}}$ & 4. 863 & Not Reported & & & 33410. & 10. \\
\hline $\mathrm{C}^{12} \mathrm{H}_{3} \mathrm{O}^{16} \mathrm{H}$ & 3- 211 & Not Reported & Ground & & 33414.1 & .1 \\
\hline $\mathrm{C}^{12} \mathrm{H}_{3} \mathrm{C}^{12} \mathrm{H}_{2} \mathrm{C}^{12} \mathrm{H}_{3}$ & 3- 781 & $6,1,5 \leftarrow 6,0,6$ & Ground & & 33414.72 & .03 \\
\hline $\mathrm{C}^{12} \mathrm{H}_{3} \mathrm{~S}^{32} \mathrm{H}$ & 3- 221 & Not Reported & Ground & & 33414.78 & \\
\hline $\mathrm{F}_{2}^{19} \mathrm{O}_{2}^{16}$ & 3- 11 & $2,1,2 \leftarrow 1,0,1$ & Ground & & 33414.80 & .1 \\
\hline $\mathrm{C}^{12} \mathrm{H}_{3} \mathrm{C}^{12} \mathrm{O}^{16} \mathrm{C}^{13} \mathrm{~N}^{14}$ & 3- 673 & $12,4,8 \leftarrow 12,3,9$ & Ground & & 33415.93 & .2 \\
\hline $\mathrm{C}^{12} \mathrm{H}_{3} \mathrm{~S}^{32} \mathrm{H}$ & 3. 221 & Not Reported & Ground & & 33416.85 & \\
\hline $\mathrm{C}^{12}{ }_{*} \mathrm{H}_{2} \mathrm{~N}^{14} \mathrm{DC}^{12}{ }_{*} \mathrm{H}_{2}$ & 4- 862 & $1,0,1 \leftarrow 0,0,0$ & Ground & & 33420. & 20. \\
\hline $\mathrm{C}^{12} \mathrm{H}_{3} \mathrm{~N}^{14} \mathrm{H}_{2}$ & 3- 261 & Not Reported & Ground & & 33422.3 & \\
\hline $\mathrm{S}^{32} \mathrm{O}^{16} \mathrm{~F}_{2}^{19}$ & $4-1621$ & Not Reported & & & 33430.28 & .1 \\
\hline $\mathrm{C}^{12} \mathrm{H}_{3} \mathrm{Ge}^{72} \mathrm{H}_{2} \mathrm{D}$ & 3- 298 & $2,1,2 \leftarrow 1,1,1$ & Ground & & 33432.60 & .10 \\
\hline $\mathrm{C}^{12} \mathrm{H}_{3} \mathrm{C}^{12}{ }_{*} \mathrm{HO}^{16} \mathrm{C}^{12}{ }_{*} \mathrm{H}_{2}$ & 3- 761 & $46,23, \leftarrow 45,24$, & Ground & & 33432.64 & .1 \\
\hline $\mathrm{C}^{12} \mathrm{H}_{3} \mathrm{C}^{12}{ }_{*} \mathrm{HO}^{16} \mathrm{C}^{12}{ }_{*} \mathrm{H}_{2}$ & 3- 761 & $46,23, \leftarrow 45,24$, & Ground & & 33433.28 & .1 \\
\hline $\mathrm{HC}^{13}: \mathrm{C}^{12} \mathrm{C}^{12} \mathrm{DO}^{16}$ & 4- 922 & Not Reported & & & 33435 . & 5. \\
\hline $\mathrm{C}^{12} \mathrm{H}_{3} \mathrm{C}^{12}{ }_{*} \mathrm{HO}^{16} \mathrm{C}^{12}{ }_{*} \mathrm{H}_{2}$ & 3. 761 & $22,10, \leftarrow 21,11$ & Ground & & 33444.73 & .1 \\
\hline $\mathrm{C}^{12} \mathrm{H}_{3} \mathrm{C}^{12}{ }_{*} \mathrm{HO}^{16} \mathrm{C}^{12}{ }_{*} \mathrm{H}_{2}$ & 3- 761 & $22,10, \leftarrow 21,11$, & - Ground & & 33445.03 & .1 \\
\hline $\mathrm{C}^{12} \mathrm{H}_{3} \mathrm{C}^{12}{ }_{*} \mathrm{HO}^{16} \mathrm{C}^{12}{ }_{*} \mathrm{H}_{2}$ & 3- 761 & $22,10, \leftarrow 21,11$, & Ground & & 33445.65 & .1 \\
\hline $\mathrm{C}^{12} \mathrm{H}_{3} \mathrm{C}^{13} \mathrm{H}_{2} \mathrm{C}^{12} \mathrm{H}_{3}$ & 3- 783 & $6,1,5 \leftarrow 6,0,6$ & Ground & & 33446.47 & .06 \\
\hline $\mathrm{C}^{12} \mathrm{D}_{3} \mathrm{~N}^{14} \mathrm{D}_{2}$ & 3. 262 & $3,1,3 \leftarrow 3,0,3$ & Ground & & 33454.41 & \\
\hline $\mathrm{HC}^{13}: \mathrm{C}^{12} \mathrm{C}^{12} \mathrm{DO}^{16}$ & 4- 922 & Not Reported & & & 33461 & 5. \\
\hline $\mathrm{C}^{12}{ }_{*} \mathrm{H}_{2} \mathrm{C}^{12} \mathrm{HDC}^{12} \mathrm{H}_{2} \mathrm{O}^{16} *$ & 4-1094 & $6,4,3 \leftarrow 6,2,4$ & Excited & & 33462.65 & .1 \\
\hline $\mathrm{C}^{\mathrm{h}}{ }_{*} \mathrm{H}_{2}^{\mathrm{l}} \mathrm{N}^{\mathrm{l}} \mathrm{H}^{\mathrm{l}} \mathrm{C}^{\mathrm{b}}{ }_{*} \mathrm{H}_{2}^{\mathrm{b}}$ & 4- 863 & Not Reported & & & 33470. & 10. \\
\hline $\mathrm{S}^{32} \mathrm{O}^{16} \mathrm{~F}_{2}^{19}$ & $4-1621$ & Not Reported & & & 33470.86 & .1 \\
\hline $\mathrm{C}^{12} \mathrm{H}_{3} \mathrm{~N}^{14} \mathrm{O}_{2}^{16}$ & 3- 171 & $2,1, \leftarrow 1,1$, & Ground & & 33476.5 & .2 \\
\hline $\mathrm{C}^{12} \mathrm{H}_{3} \mathrm{~N}^{14} \mathrm{O}_{2}^{16}$ & 3- 171 & Not Reported & Ground & & 33477.35 & \\
\hline$c-H F^{19} \mathrm{C}^{12}: \mathrm{C}^{12} \mathrm{HF}^{19}$ & 4- 691 & $6,1,5 \leftarrow 6,0,6$ & Ground & & 33478.20 & .05 \\
\hline
\end{tabular}




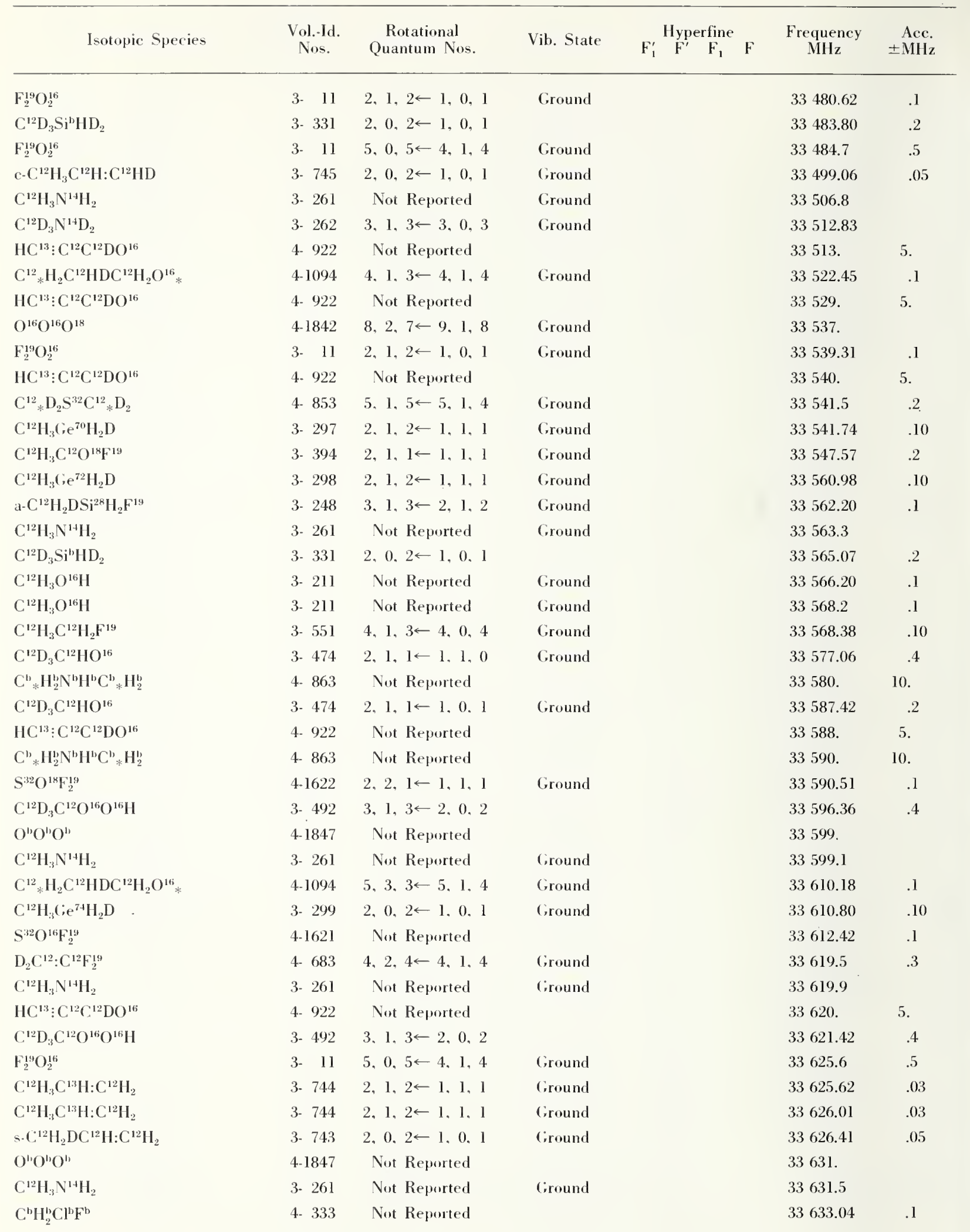




\begin{tabular}{|c|c|c|c|c|c|c|}
\hline Isotopic Species & $\begin{array}{l}\text { Vol.-Id. } \\
\text { Nos. }\end{array}$ & $\begin{array}{c}\text { Rotational } \\
\text { Quantum Nos. }\end{array}$ & Vib. State & $F_{1}^{3} F^{\prime} F_{1} \quad F$ & $\begin{array}{c}\text { Frequency } \\
\mathrm{MHz}\end{array}$ & $\begin{aligned} & \text { Acc. } \\
& \pm \text { MHz }\end{aligned}$ \\
\hline 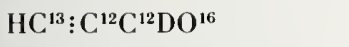 & 4. 922 & Not Reported & & & 33635 & 5. \\
\hline $\mathrm{C}^{12} \mathrm{H}_{3} \mathrm{~N}^{14} \mathrm{H}_{2}$ & 3. 261 & Not Reported & Ground & & 33636.8 & \\
\hline $\mathrm{C}^{12} \mathrm{H}_{3} \mathrm{~N}^{14} \mathrm{H}_{2}$ & 3. 261 & Not Reported & Ground & & 33639.5 & \\
\hline $\mathrm{C}^{13} \mathrm{D}_{3} \mathrm{~N}^{14} \mathrm{C}^{12}$ & 4- 835 & $2,0 \leftarrow 1,0$ & Cround & & 33640.6 & .3 \\
\hline $\mathrm{C}^{12} \mathrm{H}_{3} \mathrm{~N}^{14} \mathrm{O}_{2}^{16}$ & 3- 171 & $2,1, \leftarrow 1,1$, & Ground & & 33643.5 & .2 \\
\hline $\mathrm{C}^{12}{ }_{*} \mathrm{H}_{2} \mathrm{C}^{12} \mathrm{HDC}^{12} \mathrm{H}_{2} \mathrm{O}^{16}{ }_{*}$ & 4.1094 & $4,2,3 \leftarrow 4,0,4$ & Ground & & 33646.22 & .1 \\
\hline $\mathrm{C}^{12} \mathrm{H}_{3} \mathrm{~S}^{32} \mathrm{H}$ & 3. 221 & Not Reported & Ground & & 33647.20 & \\
\hline $\mathrm{C}^{12} \mathrm{H}_{3} \mathrm{~N}^{14} \mathrm{H}_{2}$ & 3. 261 & Not Reported & Cround & & 33654.3 & \\
\hline $\mathrm{C}^{12} \mathrm{H}_{3} \mathrm{~S}^{32} \mathrm{H}$ & 3- 221 & Not Reported & Cround & & 33658.81 & \\
\hline c. $\mathrm{C}^{12} \mathrm{H}_{3} \mathrm{C}^{12} \mathrm{H}: \mathrm{C}^{12} \mathrm{HF}^{19}-\mathrm{E}$ & 3- 702 & $4,2,2 \leftarrow 4,1,3$ & & & 33661.10 & .2 \\
\hline $\mathrm{S}^{32} \mathrm{P}^{31} \mathrm{Cl}_{3}^{35}$ & 4-1531 & $12, \leftarrow 11$, & Ground & & 33662.9 & .5 \\
\hline $\mathrm{C}^{12} \mathrm{D}_{3} \mathrm{~N}^{14} \mathrm{H}_{2}$ & 3. 263 & Not Reported & & & 33664.2 & .5 \\
\hline c- $\mathrm{C}^{12} \mathrm{H}_{3} \mathrm{C}^{12} \mathrm{H}: \mathrm{C}^{12} \mathrm{HF}^{19}-\mathrm{A}$ & 3- 701 & $4,2,2 \leftarrow 4,1,3$ & & & 33666.44 & .2 \\
\hline $\mathrm{C}^{12} \mathrm{H}_{3} \mathrm{Ce}^{70} \mathrm{H}_{2} \mathrm{D}$ & 3- 297 & $2,1,2 \leftarrow 1,1,1$ & Ground & & 33670.44 & .10 \\
\hline $\mathrm{C}^{12} \mathrm{H}_{2} \mathrm{Cl}_{2}^{35}$ & 4- 341 & $8,1,7 \leftarrow 8,0,8$ & Ground & & 33672 . & 2. \\
\hline $\mathrm{S}^{32} \mathrm{O}^{16} \mathrm{~F}_{2}^{19}$ & 4-1621 & Not Reported & & & 33673.74 & .1 \\
\hline $\mathrm{C}^{\mathrm{b}} \mathrm{H}_{2}^{\mathrm{b}} \mathrm{Cl}^{\mathrm{b}} \mathrm{F}^{\mathrm{b}}$ & 4- 333 & Not Reported & & & 33677.98 & .1 \\
\hline $\mathrm{C}^{\mathrm{b}}{ }_{*} \mathrm{H}_{2}^{\mathrm{b}} \mathrm{N}^{\mathrm{b}} \mathrm{H}^{\mathrm{b}} \mathrm{C}^{\mathrm{b}}{ }_{*} \mathrm{H}_{2}^{\mathrm{b}}$ & 4- 863 & Not Reported & & & 33680. & 10. \\
\hline $\mathrm{S}^{32} \mathrm{O}^{16} \mathrm{~F}_{2}^{19}$ & 4-1621 & $2,1,1 \leftarrow 1,0,1$ & Ground & & 33685.69 & .1 \\
\hline $\mathrm{O}^{b} \mathrm{O}^{b} \mathrm{O}^{b}$ & 4-1847 & Not Reported & & & 33691. & \\
\hline $\mathrm{C}^{12} \mathrm{H}_{3} \mathrm{O}^{16} \mathrm{H}$ & 3- 211 & Not Reported & Ground & & 33691.63 & .1 \\
\hline $\mathrm{C}^{12} \mathrm{D}_{3} \mathrm{~N}^{14} \mathrm{H}_{2}$ & 3. 263 & Not Reported & & & 33692.1 & .5 \\
\hline $\mathrm{C}^{12} \mathrm{H}_{3} \mathrm{O}^{16} \mathrm{H}$ & 3- 211 & Not Reported & Ground & & 33693.74 & .1 \\
\hline$\left(i \mathrm{e}^{74} \mathrm{~F}_{3}^{19} \mathrm{Cl}^{37}\right.$ & 4-1406 & $8, \leftarrow 7$, & Ground & & 33694.43 & .30 \\
\hline $\mathrm{C}^{12}{ }_{*} \mathrm{H}_{2} \mathrm{C}^{12} \mathrm{HDC}^{12} \mathrm{H}_{2} \mathrm{O}^{16} *$ & $4 \cdot 1094$ & $6,4,3 \leftarrow 6,2,4$ & Ground & & 33695.12 & .1 \\
\hline a- $\mathrm{C}^{12} \mathrm{H}_{2} \mathrm{DC}^{12} \mathrm{H}: \mathrm{C}^{12} \mathrm{H}_{2}$ & 3- 742 & $2,1,1 \leftarrow 1,1,0$ & Ground & & 33695.17 & .05 \\
\hline $\mathrm{F}_{2}^{19} \mathrm{O}_{2}^{16}$ & 3- 11 & $5,0,5 \leftarrow 4,1,4$ & Excited & & 33700.7 & .5 \\
\hline $\mathrm{C}^{12} \mathrm{H}_{2} \mathrm{Cl}^{37} \mathrm{~F}^{19}$ & 4- 332 & $8,1,8 \leftarrow 7,2,5$ & Ground & & 33703.27 & .1 \\
\hline $\mathrm{C}^{12} \mathrm{H}_{3} \mathrm{C}^{12} \mathrm{H}: \mathrm{C}^{12} \mathrm{H}_{2}$ & 3- 741 & $2,1,2 \leftarrow 1,1,1$ & Ground & & 33707.81 & .03 \\
\hline $\mathrm{C}^{12} \mathrm{H}_{2} \mathrm{Cl}^{37} \mathrm{~F}^{19}$ & 4- 332 & $8,1,8 \leftarrow 7,2,5$ & Ground & & 33708.06 & .1 \\
\hline $\mathrm{C}^{12} \mathrm{H}_{33} \mathrm{C}^{12} \mathrm{H}: \mathrm{C}^{12} \mathrm{H}_{2}$ & 3- 741 & $2,1,2 \leftarrow 1,1,1$ & Ground & & 33708.26 & .03 \\
\hline $\mathrm{Ce}^{72} \mathrm{~F}_{3}^{19} \mathrm{Cl}^{37}$ & $4-1404$ & $8, \leftarrow 7$ & Ground & & 33711.21 & .30 \\
\hline $\mathrm{C}^{12} \mathrm{H}_{3}\left(; \mathrm{e}^{72} \mathrm{H}_{2} \mathrm{D}\right.$ & 3- 298 & $2,0,2 \leftarrow 1,0,1$ & Ground & & 33716.38 & .10 \\
\hline $\mathrm{HDC}^{12}: \mathrm{C}^{12} \mathrm{~F}_{2}^{19}$ & 4. 682 & $2,1,1 \leftarrow 1,1,0$ & Ground & & 33723.1 & .3 \\
\hline $\mathrm{C}^{12} \mathrm{H}_{3} \mathrm{C}^{13} \mathrm{HO}^{16}$ & 3- 477 & $4,0,4 \leftarrow 3,1,3$ & Ground & & 33725 . & 1. \\
\hline $\mathrm{S}^{32} \mathrm{O}^{16} \mathrm{~F}_{2}^{19}$ & $4-1621$ & Not Reported & & & 33726.11 & .1 \\
\hline $\mathrm{C}^{\mathrm{e}} \mathrm{7}^{71} \mathrm{~F}_{3}^{19} \mathrm{Cl}^{37}$ & $4-1402$ & $8, \leftarrow 7$, & Ground & & 33728.15 & .80 \\
\hline $\mathrm{t}-\mathrm{HDC}^{12}: \mathrm{C}^{12} \mathrm{DCl}^{35}$ & 4- 761 & $3,1,2 \leftarrow 2,1,1$ & Ground & & 33729.57 & \\
\hline t.HDC ${ }^{12}: \mathrm{C}^{12} \mathrm{DCl}^{35}$ & 4- 761 & $3,1,2 \leftarrow 2,1,1$ & Ground & & 33733.08 & \\
\hline $\mathrm{C}^{\mathrm{b}} \mathrm{H}_{2}^{\mathrm{b}} \mathrm{Cl}^{\mathrm{b}} \mathrm{F}^{\mathrm{b}}$ & 4- 333 & Not Reported & & & 33733.21 & .1 \\
\hline $\mathrm{S}^{32} \mathrm{O}^{16} \mathrm{~F}_{2}^{19}$ & 4-1621 & Not Reported & & & 33737.34 & .1 \\
\hline $\mathrm{C}^{12} \mathrm{H}_{33} \mathrm{~S}^{32} \mathrm{H}$ & 3- 221 & Not Reported & Ground & & 33738.45 & \\
\hline $\mathrm{C}^{\mathrm{h}}{ }_{*} \mathrm{H}_{2}^{\mathrm{b}} \mathrm{N}^{\mathrm{\prime}} \mathrm{H}^{\mathrm{l}} \mathrm{C}^{\mathrm{b}}{ }_{*} \mathrm{H}_{2}^{\mathrm{b}}$ & 4- 863 & Not Reported & & & 33740. & 10. \\
\hline $\mathrm{S}^{32} \mathrm{O}^{16} \mathrm{~F}_{2}^{19}$ & 4-1621 & Not Reported & & & 33740.12 & .1 \\
\hline${ }^{a}-C^{12} \mathrm{HD}_{2} \mathrm{C}^{12} \mathrm{HO}^{16}$ & 3- 482 & $2,1,2 \leftarrow 1,1,1$ & Ground & & 33741.3 & .5 \\
\hline
\end{tabular}




\begin{tabular}{|c|c|c|c|c|c|c|}
\hline Isotopic Species & $\begin{array}{l}\text { Vol.-Id. } \\
\text { Nos. }\end{array}$ & $\begin{array}{c}\text { Rotational } \\
\text { Quantum Nos. }\end{array}$ & Vib. State & $F_{1}^{\prime} F^{\text {Hyperfine }} F_{1} F$ & $\begin{array}{c}\text { Frequency } \\
\mathrm{MHz}\end{array}$ & $\begin{aligned} & \text { Acc. } \\
\pm & \mathrm{MHz}\end{aligned}$ \\
\hline $\mathrm{C}^{12} \mathrm{D}_{33} \mathrm{~N}^{14} \mathrm{D}_{2}$ & 3. 262 & $3,1,3 \leftarrow 3,0,3$ & Ground & & 33751.65 & \\
\hline $\mathrm{C}^{12} \mathrm{D}_{33} \mathrm{Si}^{\mathrm{l}} \mathrm{HD}_{2}$ & 3- 331 & $15,1,14 \leftarrow 15,1,15$ & & & 33759.17 & .4 \\
\hline $\mathrm{S}^{32} \mathrm{O}^{16} \mathrm{~F}_{2}^{19}$ & $4-1621$ & Not Reported & & & 33760.50 & .1 \\
\hline $\mathrm{F}_{2}^{19} \mathrm{O}_{2}^{16}$ & $3-\quad 11$ & $5,0,5 \leftarrow 4,1,4$ & Ground & & 33765.25 & .1 \\
\hline $\mathrm{C}^{12} \mathrm{H}_{33}\left(\mathrm{Ce}^{74} \mathrm{H}_{2} \mathrm{D}\right.$ & 3- 299 & $2,1,1 \leftarrow 1,1,0$ & Ground & & 33767.66 & .10 \\
\hline $\mathrm{C}^{12} \mathrm{H}_{33} \mathrm{Ge}^{74} \mathrm{H}_{2} \mathrm{D}$ & 3- 299 & $2,1,2 \leftarrow 1,1,1$ & Ground & & 33767.80 & .10 \\
\hline $\mathrm{C}^{\mathrm{b}} \mathrm{H}_{2}^{\mathrm{b}} \mathrm{Cl}^{\mathrm{b}} \mathrm{F}^{\mathrm{b}}$ & 4- 333 & Not Reported & & & 33769.71 & 1 \\
\hline $\mathrm{S}^{32} \mathrm{O}^{16} \mathrm{~F}_{2}^{1.9}$ & $4-1621$ & Not Reported & & & 33779.84 & .1 \\
\hline $\mathrm{O}^{12} \mathrm{O}^{12} \mathrm{O}^{12}$ & $4-1847$ & Not Reported & & & 33781. & \\
\hline $\mathrm{C}^{12}{ }_{*} \mathrm{H}_{2} \mathrm{~N}^{14} \mathrm{HC}^{12}{ }_{*} \mathrm{H}_{2}$ & 4- 861 & $4,4,1 \leftarrow 4,3,2$ & Ground & & 33784.2 & \\
\hline $\mathrm{C}^{\mathrm{b}} \mathrm{H}_{2}^{\mathrm{b}} \mathrm{Cl}^{\mathrm{b}} \mathrm{F}^{\mathrm{th}}$ & 4- 333 & Not Reported & & & 33787.00 & .1 \\
\hline $\mathrm{HC}^{13}: \mathrm{C}^{12} \mathrm{C}^{12} \mathrm{DO}^{16}$ & 4- 922 & Not Reported & & & 33790. & 5. \\
\hline $\mathrm{HDO}_{2}^{16}$ & $3-43$ & $11, \quad \leftarrow 11$, & & & 33790. & 3. \\
\hline $\mathrm{HDO}_{2}^{1 \mathrm{i}}$ & $3-43$ & $11,, \leftarrow 11$, & & & 33791. & 3. \\
\hline $\mathrm{HDC}^{12}: \mathrm{C}^{12} \mathrm{~F}_{2}^{19}$ & 4- 682 & $5,5,1 \leftarrow 5,3,2$ & Ground & & 33792.5 & .3 \\
\hline $\mathrm{S}^{12} \mathrm{O}^{16} \mathrm{~F}_{2}^{19}$ & 4-1621 & Not Reported & & & 33804.39 & .1 \\
\hline $\mathrm{HC}^{13}: \mathrm{C}^{12} \mathrm{C}^{12} \mathrm{DO}^{16}$ & 4. 922 & Not Reported & & & 33808. & 5. \\
\hline $\mathrm{HC}^{13}: \mathrm{C}^{12} \mathrm{C}^{12} \mathrm{DO}^{16}$ & 4. 922 & Not Reported & & & 33822 . & 5. \\
\hline $\mathrm{C}^{12} \mathrm{H}_{3}\left(; \mathrm{e}^{70} \mathrm{H}_{2} \mathrm{D}\right.$ & 3- 297 & $2,0,2 \leftarrow 1,0,1$ & Ground & & 33827.32 & .10 \\
\hline $\mathrm{C}^{12} \mathrm{H}_{3} \mathrm{~S}^{32} \mathrm{H}$ & 3- 221 & Not Reported & Ground & & 33838.93 & \\
\hline $\mathrm{C}^{12} \mathrm{D}_{3} \mathrm{Si}^{11} \mathrm{HD}_{2}$ & 3- 331 & Not Reported & & & 33839.0 & .4 \\
\hline $\mathrm{HC}^{13}: \mathrm{C}^{12} \mathrm{C}^{12} \mathrm{DO}^{16}$ & 4- 922 & Not Reported & & & 33848. & 5. \\
\hline $\mathrm{C}^{12} \mathrm{D}_{3} \mathrm{Si}^{\mathrm{k}} \mathrm{HD}_{2}$ & 3- 331 & $2,1,1 \leftarrow 1,1,0$ & & & 33851.17 & .2 \\
\hline $\mathrm{D}_{2} \mathrm{C}^{12}: \mathrm{C}^{12} \mathrm{~F}_{2}^{19}$ & 4- 683 & $3,1,3 \leftarrow 2,1,2$ & Ground & & 33857.0 & .3 \\
\hline $\mathrm{C}^{12} \mathrm{H}_{3} \mathrm{~S}^{32} \mathrm{H}$ & 3- 221 & Not Reported & Ground & & 33858.74 & \\
\hline $\mathrm{C}^{12} \mathrm{D}_{3} \mathrm{~N}^{14} \mathrm{H}_{2}$ & 3- 263 & Not Reported & & & 33860. & \\
\hline $\mathrm{C}^{12} \mathrm{H}_{3} \mathrm{~N}^{14} \mathrm{H}_{2}$ & $3-261$ & Not Reported & Ground & & 33862.2 & \\
\hline $\mathrm{C}^{12} \mathrm{DBr}_{3}^{\mathrm{K} 1}$ & 4- 244 & $14, \leftarrow 13$ & (;round & & 33866.2 & .5 \\
\hline $\mathrm{F}_{2}^{19} \mathrm{O}_{2}^{16}$ & 3. 11 & $5,0,5 \leftarrow 4,1,4$ & (;round & & 33871.6 & .5 \\
\hline $\mathrm{C}^{12} \mathrm{H}_{33}\left(; \mathrm{e}^{72} \mathrm{H}_{2} \mathrm{D}\right.$ & 3- 298 & $2,1,1 \leftarrow 1,1,0$ & Ground & & 33874.76 & .10 \\
\hline $\mathrm{C}^{\mathrm{h}}{ }_{*} \mathrm{H}_{2}^{\mathrm{b}} \mathrm{N}^{\prime \prime} \mathrm{H}^{\prime \prime} \mathrm{C}^{\prime \prime}{ }_{*} \mathrm{H}_{2}^{\prime \prime}$ & 4- 863 & Not Reported & & & 33880. & 10. \\
\hline $\mathrm{C}^{12}{ }_{*} \mathrm{H}_{2} \mathrm{C}^{12} \mathrm{HDC}^{12} \mathrm{H}_{2} \mathrm{O}^{16}{ }_{*}$ & 4-1094 & $7,5,3 \leftarrow 7,3,4$ & Excited & & 33884.65 & .1 \\
\hline $\mathrm{S}^{32} \mathrm{O}^{16} \mathrm{~F}_{2}^{19}$ & 4-1621 & Not Reported & & & 33890.15 & .1 \\
\hline $\mathrm{C}^{12} \mathrm{H}_{3} \mathrm{O}^{16} \mathrm{~N}^{14} \mathrm{O}_{2}^{16}$ & 3- 181 & $4,2,2 \leftarrow 3,2,1$ & Ground & & 33893. & 5. \\
\hline $\mathrm{C}^{12} \mathrm{H}_{3} \mathrm{C}, \mathrm{e}^{74} \mathrm{H}_{2} \mathrm{D}$ & 3- 299 & $2,1,1 \leftarrow 1,1,0$ & Ground & & 33895.92 & .10 \\
\hline $\mathrm{S}^{32} \mathrm{O}^{16} \mathrm{~F}_{2}^{19}$ & $4-1621$ & Not Reported & & & 33896.54 & .1 \\
\hline $\mathrm{C}^{12} \mathrm{H}_{3} \mathrm{~N}^{14} \mathrm{O}_{2}^{16}$ & 3- 171 & Not Reported & (iround & & 33896.63 & \\
\hline $\mathrm{c}-\mathrm{HDC}^{12}: \mathrm{C}^{12} \mathrm{DF}^{19}$ & 4- 789 & $2,1,2 \leftarrow 1,1,1$ & Ground & & 33898.3 & .3 \\
\hline $\mathrm{C}^{\mathrm{h}}{ }_{*} \mathrm{H}_{2}^{\mathrm{l}} \mathrm{N}^{\mathrm{h}} \mathrm{H}^{\mathrm{h}} \mathrm{C}^{\mathrm{\prime}}{ }_{*} \mathrm{H}_{2}^{\mathrm{l}}$ & 4- 863 & Not Reported & & & 33900. & 10. \\
\hline $\mathrm{C}^{12} \mathrm{D}_{33} \mathrm{~N}^{1+4} \mathrm{H}_{2}$ & 3- 263 & Not Reported & & & 33900. & \\
\hline${ }^{2}-\mathrm{C}^{12} \mathrm{H}_{3} \mathrm{C}^{12} \mathrm{H}: \mathrm{C}^{12} \mathrm{HF}^{19}-\mathrm{E}$ & 3- 702 & $8,2,6 \leftarrow 8,1,7$ & & & 33900.78 & .2 \\
\hline $\mathrm{C}^{12} \mathrm{H}_{3} \mathrm{~N}^{14} \mathrm{O}_{2}^{16}$ & 3- 171 & Not Reported & (;round & & 33904.84 & \\
\hline $\mathrm{C}^{12} \mathrm{H}_{33} \mathrm{~N}^{14} \mathrm{O}_{2}^{16}$ & 3. 171 & Not Reported & (iround & & 33908.06 & \\
\hline $\mathrm{N}^{14} \mathrm{H}_{2} \mathrm{D}$ & $4-1773$ & $9.3,7 \leftarrow 9.2,7$ & Ciround & & 33909.34 & .05 \\
\hline $\mathrm{HC}^{13}: \mathrm{C}^{12} \mathrm{C}^{12} \mathrm{DO}^{16}$ & 4- 922 & Not Reported & & & 33910. & 5. \\
\hline
\end{tabular}




\begin{tabular}{|c|c|c|c|c|c|c|c|c|}
\hline Isotopic Species & $\begin{array}{l}\text { Vol.-Id. } \\
\text { Nos. }\end{array}$ & $\begin{array}{c}\text { Rotational } \\
\text { Quantum Nos. }\end{array}$ & Vib. State & $\mathrm{F}_{1}^{\prime}$ & $\begin{array}{c}\text { Hyperfine } \\
\mathrm{F}^{\prime} \quad \mathrm{F}_{1}\end{array}$ & $\mathrm{~F}$ & $\begin{array}{c}\text { Frequency } \\
\mathrm{MH}_{z}\end{array}$ & $\begin{aligned} & \text { Acc. } \\
& \pm \mathrm{MH}\end{aligned}$ \\
\hline $\mathrm{N}^{14} \mathrm{O}_{2}^{16} \mathrm{Cl}^{35}$ & $4-1461$ & $4,0,4 \leftarrow 3,0,3$ & Ground & & $9 / 2$ & $9 / 2$ & 33911.19 & \\
\hline $\mathrm{C}^{12} \mathrm{H}_{3} \mathrm{~N}^{14} \mathrm{H}_{2}$ & 3. 261 & Not Reported & Ground & & & & 3.3917 .5 & \\
\hline c- $\mathrm{C}^{12} \mathrm{H}_{3} \mathrm{C}^{12} \mathrm{H}: \mathrm{C}^{12} \mathrm{HF}^{19} \cdot \mathrm{A}$ & 3- 701 & $8,2,6 \leftarrow 8,1,7$ & & & & & 33917.68 & .2 \\
\hline $\mathrm{C}^{12} \mathrm{H}_{3} \mathrm{O}^{18} \mathrm{H}$ & 3- 217 & $2,2, \leftarrow 2,1$, & Ground & & & & 33918.97 & .1 \\
\hline $\mathrm{HC}^{13}: \mathrm{C}^{12} \mathrm{C}^{12} \mathrm{DO}^{16}$ & 4. 922 & Not Reported & & & & & 33924. & 5. \\
\hline $\mathrm{C}^{12} \mathrm{H}_{3} \mathrm{O}^{18} \mathrm{H}$ & 3- 217 & $3,2, \leftarrow 3,1$, & Ground & & & & 33925.49 & .1 \\
\hline $\mathrm{C}^{12} \mathrm{H}_{3} \mathrm{~N}^{14} \mathrm{O}_{2}^{16}$ & 3- 171 & Not Reported & Ground & & & & 33929.63 & \\
\hline $\mathrm{N}^{14} \mathrm{O}_{2}^{16} \mathrm{Cl}^{35}$ & $4-1461$ & $4,0,4 \leftarrow 3,0,3$ & Ground & & $5 / 2$ & $3 / 2$ & 33930.27 & \\
\hline $\mathrm{N}^{14} \mathrm{O}_{2}^{16} \mathrm{Cl}^{35}$ & $4-1461$ & $4,0,4 \leftarrow 3,0,3$ & Ground & & $7 / 2$ & $5 / 2$ & 33930.97 & \\
\hline $\mathrm{O}^{\mathrm{b}} \mathrm{O}^{\mathrm{b}} \mathrm{O}^{\mathrm{b}}$ & 4- 1847 & Not Reported & & & & & 33931. & \\
\hline $\mathrm{N}^{14} \mathrm{O}_{2}^{16} \mathrm{Cl}^{35}$ & $4-1461$ & $4,0,4 \leftarrow 3,0,3$ & Ground & & $11 / 2$ & $9 / 2$ & 33933.17 & \\
\hline $\mathrm{C}^{12} \mathrm{H}_{3} \mathrm{C}^{12} \mathrm{H}: \mathrm{C}^{13} \mathrm{H}_{2}$ & 3- 749 & $2,0,2 \leftarrow 1,0,1$ & Ground & & & & 33933.42 & .10 \\
\hline $\mathrm{N}^{14} \mathrm{O}_{2}^{16} \mathrm{Cl}^{35}$ & 4-1461 & $4,0,4 \leftarrow 3,0,3$ & Ground & & $9 / 2$ & $7 / 2$ & 33933.83 & \\
\hline $\mathrm{S}^{32} \mathrm{O}^{16} \mathrm{~F}_{2}^{19}$ & $4-1621$ & Not Reported & & & & & 33936.10 & .1 \\
\hline $\mathrm{C}^{13} \mathrm{H}_{3} \mathrm{C}^{12} \mathrm{H}: \mathrm{C}^{12} \mathrm{H}_{2}$ & 3- 748 & $2,0,2 \leftarrow 1,0,1$ & Ground & & & & 33937.14 & .10 \\
\hline $\mathrm{C}^{12} \mathrm{H}_{3} \mathrm{~S}^{32} \mathrm{H}$ & 3- 221 & Not Reported & Ground & & & & 33938.69 & \\
\hline $\mathrm{C}^{12}{ }_{*} \mathrm{H}_{2}^{\mathrm{b}} \mathrm{S}^{\mathrm{b}} \mathrm{C}^{12}{ }_{*} \mathrm{H}_{2}^{\mathrm{b}}$ & 4- 854 & Not Reported & & & & & 33940.0 & 15. \\
\hline $\mathrm{N}^{14} \mathrm{O}_{2}^{16} \mathrm{Cl}^{35}$ & $4-1461$ & $4,0,4 \leftarrow 3,0,3$ & Ground & & $7 / 2$ & $7 / 2$ & 33941.4 & \\
\hline $\mathrm{C}^{12}{ }_{*} \mathrm{D}_{2} \mathrm{~S}^{32} \mathrm{C}^{12}{ }_{*} \mathrm{D}_{2}$ & 4- 853 & $7,2,6 \leftarrow 7,2,5$ & Ground & & & & 33942.5 & .2 \\
\hline $\mathrm{C}^{12} \mathrm{H}_{3} \mathrm{O}^{18} \mathrm{H}$ & 3. 217 & $4,2, \leftarrow 4,1$, & Ground & & & & 33943.63 & .1 \\
\hline $\mathrm{HC}^{13}: \mathrm{C}^{12} \mathrm{C}^{12} \mathrm{DO}^{16}$ & 4. 922 & Not Reported & & & & & 33944. & 5. \\
\hline $\mathrm{C}^{12} \mathrm{H}_{3} \mathrm{Si}^{28} \mathrm{HF}_{2}^{19}-\mathrm{A}$ & 3- 191 & $3,2,1 \leftarrow 2,2,0$ & Ground & & & & 33951.02 & \\
\hline $\mathrm{C}^{12} \mathrm{H}_{3} \mathrm{Si}^{28} \mathrm{HF}_{2}^{19}-\mathrm{E}$ & 3- 192 & $3,2,1 \leftarrow 2,2,0$ & Ground & & & & 33951.02 & \\
\hline $\mathrm{N}^{14} \mathrm{O}_{2}^{16} \mathrm{Cl}^{35}$ & $4-1461$ & $4,0,4 \leftarrow 3,0,3$ & Ground & & $5 / 2$ & $5 / 2$ & 33953.0 & \\
\hline $\mathrm{S}^{32} \mathrm{O}^{16} \mathrm{~F}_{2}^{19}$ & 4-1621 & $2,2,0 \leftarrow 1,1,0$ & Ground & & & & 33957.43 & .1 \\
\hline $\mathrm{C}^{12}{ }_{*} \mathrm{H}_{2}^{\mathrm{b}} \mathrm{S}^{\mathrm{b}} \mathrm{C}^{12}{ }_{*} \mathrm{H}_{2}^{\mathrm{b}}$ & 4- 854 & Not Reported & & & & & 33960.0 & 15. \\
\hline $\mathrm{C}^{12} \mathrm{H}_{3} \mathrm{C}^{12} \mathrm{H}_{2} \mathrm{~F}^{19}$ & 3- 551 & $2,1,1 \leftarrow 1,1,0$ & Ground & & & & 33963.77 & .10 \\
\hline $\mathrm{C}^{12} \mathrm{D}_{3} \mathrm{O}^{16} \mathrm{D}$ & 3- 216 & Not Reported & & & & & 33965. & \\
\hline $\mathrm{S}^{32} \mathrm{O}^{16} \mathrm{~F}_{2}^{19}$ & $4-1621$ & Not Reported & & & & & 33974.94 & .1 \\
\hline $\mathrm{C}^{12} \mathrm{H}_{3} \mathrm{O}^{18} \mathrm{H}$ & 3- 217 & $5,2, \leftarrow 5,1$. & Ground & & & & 33981.35 & .1 \\
\hline $\mathrm{C}^{12} \mathrm{H}_{3} \mathrm{~N}^{14} \mathrm{O}_{2}^{16}$ & 3- 171 & Not Reported & Ground & & & & 33984.11 & \\
\hline $\mathrm{C}^{12} \mathrm{H}_{3} \mathrm{Cie}^{70} \mathrm{H}_{2} \mathrm{D}$ & 3- 297 & $2,1,1 \leftarrow 1,1,0$ & Ground & & & & 33987.35 & .10 \\
\hline $\mathrm{C}^{12} \mathrm{H}_{3} \mathrm{~N}^{14} \mathrm{O}_{2}^{16}$ & 3- 171 & $2,1, \leftarrow 1,1$, & Ground & & & & 33988.5 & .2 \\
\hline $\mathrm{C}_{*}^{\mathrm{b}}{ }_{*} \mathrm{H}_{2}^{\mathrm{b}} \mathrm{N}^{\mathrm{h}} \mathrm{H}^{\mathrm{b}} \mathrm{C}^{\mathrm{b}}{ }_{*} \mathrm{H}_{2}^{\mathrm{b}}$ & 4- 863 & Not Reported & & & & & 33990. & 10. \\
\hline $\mathrm{C}^{12} \mathrm{H}_{3} \mathrm{~N}^{14} \mathrm{H}_{2}$ & 3- 261 & Not Reported & Ground & & & & 33990.5 & \\
\hline $\mathrm{C}^{12} \mathrm{H}_{3} \mathrm{~N}^{14} \mathrm{O}_{2}^{16}$ & 3. 171 & Not Reported & Ground & & & & 33995.68 & \\
\hline $\mathrm{C}^{12} \mathrm{H}_{3} \mathrm{Si}^{28} \mathrm{Cl}_{3}^{37}$ & 3- 112 & $10, \leftarrow 9$ & Excited & & & & 33995.81 & .5 \\
\hline $\mathrm{C}^{12} \mathrm{H}_{3} \mathrm{C}^{12}{ }_{*} \mathrm{HO}^{16} \mathrm{C}^{12}{ }_{*} \mathrm{H}_{2}$ & 3- 761 & $2,2,1 \leftarrow 2,1,1$ & Ground & & & & 33997.63 & .1 \\
\hline $\mathrm{HC}^{13}: \mathrm{C}^{12} \mathrm{C}^{12} \mathrm{DO}^{16}$ & 4- 922 & Not Reported & & & & & 33998 & 5. \\
\hline $\mathrm{Si}^{28} \mathrm{HCl}_{2}^{35} \mathrm{Cl}^{37}$ & 4. 1502 & $7, \quad \leftarrow 6$, & Ground & & & & 34000 & 20. \\
\hline $\mathrm{C}^{12} \mathrm{H}_{3} \mathrm{O}^{16} \mathrm{H}$ & 3- 211 & Not Reported & Ground & & & & 34001.35 & .1 \\
\hline $\mathrm{C}^{12} \mathrm{H}_{3} \mathrm{Ge}^{72} \mathrm{H}_{2} \mathrm{D}$ & 3- 298 & $2,1,1 \leftarrow 1,1,0$ & Ground & & & & 34003.14 & .10 \\
\hline $\mathrm{C}^{12} \mathrm{H}_{3} \mathrm{O}^{16} \mathrm{H}$ & 3- 211 & Not Reported & Ground & & & & 34.003 .69 & .1 \\
\hline $\mathrm{S}^{32} \mathrm{O}^{16} \mathrm{~F}_{2}^{19}$ & 4-1621 & Not Reported & & & & & 34013.42 & .1 \\
\hline $\mathrm{C}^{12} \mathrm{H}_{3} \mathrm{~S}^{32} \mathrm{H}$ & 3- 221 & Not Reported & Ground & & & & 34013.70 & \\
\hline
\end{tabular}




\begin{tabular}{|c|c|c|c|c|c|c|}
\hline Isotopic Species & $\begin{array}{l}\text { Vol.-Id. } \\
\text { Nos. }\end{array}$ & $\begin{array}{c}\text { Rotational } \\
\text { Quantum Nos. }\end{array}$ & Vib. State & $\mathrm{F}_{1}^{\prime} \stackrel{\text { Hyperfine }}{\mathrm{F}^{\prime}} \mathrm{F}_{1} \mathrm{~F}$ & $\begin{array}{c}\text { Frequency } \\
\mathrm{MHz}\end{array}$ & $\begin{aligned} & \text { Acc. } \\
\pm & \mathrm{MHz}\end{aligned}$ \\
\hline a- $C^{12} \mathrm{H}_{2} \mathrm{DC}^{12} \mathrm{H}_{2} \mathrm{C}^{12} \mathrm{H}_{3}$ & 3. 786 & $1,1,1 \leftarrow 0,0,0$ & Ground & & 34014.10 & .12 \\
\hline $\mathrm{S}^{32} \mathrm{O}^{16} \mathrm{~F}_{2}^{19}$ & 4- 1621 & Not Reported & & & 34017.44 & .1 \\
\hline $\mathrm{t}-\mathrm{HDC}^{12}{ }_{*} \mathrm{O}^{16} \mathrm{C}^{12}{ }_{*} \mathrm{HD}$ & 4. 844 & $6,4,2 \leftarrow 6,3,3$ & Ground & & 34017.5 & .2 \\
\hline $\mathrm{C}_{7}^{12} \mathrm{H}_{13} \mathrm{~N}^{14}$ & 4- 1311 & $7, \leftarrow 6$, & Excited & & 34019.9 & \\
\hline $\mathrm{C}^{12} \mathrm{H}_{3} \mathrm{C}^{12}{ }_{*} \mathrm{HO}^{16} \mathrm{C}^{12}{ }_{*} \mathrm{H}_{2}$ & 3- 761 & $2,2,1 \leftarrow 2,1,1$ & Ground & & 34.022 .78 & .1 \\
\hline $\mathrm{C}^{12} \mathrm{H}_{3} \mathrm{C}^{12}{ }_{*} \mathrm{HO}^{16} \mathrm{C}^{12}{ }_{*} \mathrm{H}_{2}$ & 3- 761 & $2,2,1 \leftarrow 2,1,1$ & Ground & & 34024.55 & .1 \\
\hline $\mathrm{HC}^{13}: \mathrm{C}^{12} \mathrm{C}^{12} \mathrm{DO}^{16}$ & 4- 922 & Not Reported & & & 34025 . & 5. \\
\hline $\mathrm{C}^{12} \mathrm{H}_{3} \mathrm{~N}^{14} \mathrm{O}_{2}^{16}$ & 3- 171 & Not Reported & Ground & & 34032.79 & \\
\hline $\mathrm{C}_{7}^{12} \mathrm{H}_{13} \mathrm{~N}^{14}$ & 4-1311 & $7, \leftarrow 6$, & Ground & & 34033.7 & \\
\hline $\mathrm{C}^{12} \mathrm{H}_{3} \mathrm{~N}^{14} \mathrm{O}_{2}^{16}$ & 3. 171 & Not Reported & Ground & & 34040.42 & \\
\hline $\mathrm{O}^{16} \mathrm{~F}_{2}^{19}$ & 4-1611 & $6,2,4 \leftarrow 7,1,7$ & Ground & & 34. 044.45 & .10 \\
\hline $\mathrm{C}_{7}^{12} \mathrm{H}_{13} \mathrm{~N}^{14}$ & 4-1311 & $7, \leftarrow 6$ & Excited & & 34.048 .2 & \\
\hline $\mathrm{C}^{12} \mathrm{H}_{3} \mathrm{O}^{18} \mathrm{H}$ & 3- 217 & $6,2, \leftarrow 6,1$, & Ground & & 34.048 .42 & .1 \\
\hline $\mathrm{C}^{12}{ }_{*} \mathrm{H}_{2} \mathrm{~N}^{14} \mathrm{HC}^{12}{ }_{*} \mathrm{H}_{2}$ & 4- 861 & $7,5,2 \leftarrow 7,4,3$ & Ground & & 34053.3 & \\
\hline $\mathrm{C}^{12} \mathrm{H}_{3} \mathrm{C}^{12}{ }_{*} \mathrm{HO}^{16} \mathrm{C}^{12}{ }_{*} \mathrm{H}_{2}$ & 3. 761 & $2,2,0 \leftarrow 2,1,1$ & Ground & & 34. 055.65 & .1 \\
\hline$\left(\mathrm{C}^{12} \mathrm{H}_{3}\right)_{2} \mathrm{C}^{13} \mathrm{H}_{3} \mathrm{~N}^{14}$ & 3- 852 & $2,1,1 \leftarrow 1,0,1$ & Ground & & 34055.7 & .5 \\
\hline $\mathrm{C}^{12} \mathrm{H}_{3} \mathrm{C}^{12}{ }_{*} \mathrm{HO}^{16} \mathrm{C}^{12}{ }_{*} \mathrm{H}_{2}$ & 3- 761 & $2,2,0 \leftarrow 2,1,1$ & Ground & & 34058.49 & .1 \\
\hline $\mathrm{C}^{12} \mathrm{H}_{3} \mathrm{C}^{12}{ }_{*} \mathrm{HO}^{16} \mathrm{C}^{12}{ }_{*} \mathrm{H}_{2}$ & 3. 761 & Not Reported & Ground & & 34.070 .35 & .1 \\
\hline $\mathrm{C}_{7}^{12} \mathrm{H}_{13} \mathrm{~N}^{14}$ & $4-1311$ & $7, \leftarrow 6$, & Excited & & 34.072 .4 & \\
\hline $\mathrm{C}^{12}{ }_{*} \mathrm{H}_{2} \mathrm{C}^{12} \mathrm{HDC}^{12} \mathrm{H}_{2} \mathrm{O}^{16} *$ & 4-1094 & $7,5,3 \leftarrow 7,3,4$ & Ground & & 34082.82 & .1 \\
\hline $\mathrm{C}^{12} \mathrm{HBr}_{3}^{81}$ & 4- 242 & $14, \leftarrow 13$ & Ground & & 34084.1 & .5 \\
\hline$\left(\mathrm{C}^{12} \mathrm{H}_{3}\right)_{3} \mathrm{Si}^{28} \mathrm{~F}^{19}$ & 3- 831 & $5, \leftarrow 4$, & Excited & & 34088.6 & .5 \\
\hline$\left(\mathrm{C}^{12} \mathrm{H}_{3}\right)_{3} \mathrm{Si}^{28} \mathrm{~F}^{19}$ & 3- 831 & $5, \leftarrow 4$, & Excited & & 34094.9 & .5 \\
\hline $\mathrm{S}^{32} \mathrm{O}^{16} \mathrm{~F}_{2}^{19}$ & 4-1621 & Not Reported & & & 34097.96 & .1 \\
\hline $\mathrm{O}_{3}^{18}$ & 4- 1845 & $18,2,16 \leftarrow 17,3,15$ & Ground & & 34102. & \\
\hline $\mathrm{C}^{13} \mathrm{H}_{3}\left(\mathrm{C}^{12} \mathrm{H}_{3}\right)_{2} \mathrm{P}^{31}$ & 3- 862 & $3,2,1 \leftarrow 2,1,1$ & Ground & & 34103.5 & \\
\hline$\left(\mathrm{C}^{12} \mathrm{H}_{3}\right)_{3} \mathrm{Si}^{28} \mathrm{~F}^{19}$ & 3- 831 & $5, \leftarrow 4$ & Ground & & $34 \quad 109.8$ & .3 \\
\hline $\mathrm{C}^{12} \mathrm{H}_{3} \mathrm{C}^{12}{ }_{*} \mathrm{HO}^{16} \mathrm{C}^{12}{ }_{*} \mathrm{H}_{2}$ & 3- 761 & $2,2,0 \leftarrow 2,1,1$ & Ground & & 34111.51 & .1 \\
\hline $\mathrm{C}_{7}^{12} \mathrm{H}_{13} \mathrm{~N}^{14}$ & $4-1311$ & $7, \leftarrow 6$, & Excited & & 34113.0 & \\
\hline $\mathrm{C}^{12} \mathrm{H}_{3} \mathrm{Ge}^{70} \mathrm{H}_{2} \mathrm{D}$ & 3- 297 & $2,1,1 \leftarrow 1,1,0$ & Ground & & 34.115 .77 & .10 \\
\hline $\mathrm{S}^{32} \mathrm{O}^{16} \mathrm{~F}_{2}^{19}$ & 4-1621 & Not Reported & & & 34117.04 & .1 \\
\hline $\mathrm{C}^{\mathrm{b}}{ }_{*} \mathrm{H}_{2}^{\mathrm{b}} \mathrm{N}^{\mathrm{b}} \mathrm{H}^{\mathrm{b}} \mathrm{C}^{\mathrm{b}}{ }_{*} \mathrm{H}_{2}^{\mathrm{b}}$ & 4- 863 & Not Reported & & & 34120 . & 10. \\
\hline$\left(\mathrm{C}^{12} \mathrm{H}_{3}\right)_{3} \mathrm{Si}^{28} \mathrm{~F}^{19}$ & 3- 831 & $5, \leftarrow 4$, & Excited & & $34 \quad 133.4$ & .3 \\
\hline $\mathrm{HC}^{13}: \mathrm{C}^{12} \mathrm{C}^{12} \mathrm{DO}^{16}$ & 4- 922 & Not Reported & & & 341355. & 5. \\
\hline $\mathrm{S}^{32} \mathrm{O}^{16} \mathrm{~F}_{2}^{19}$ & 4-1621 & Not Reported & & & 34136.22 & .1 \\
\hline$\left(\mathrm{C}^{12} \mathrm{H}_{3}\right)_{3} \mathrm{Si}^{28} \mathrm{~F}^{19}$ & 3- 831 & $5, \leftarrow 4$, & Excited & & 34148. & \\
\hline $\mathrm{H}_{2} \mathrm{C}^{12} * \mathrm{O}^{16} \mathrm{C}^{12} * \mathrm{H}_{2}$ & 4- 841 & $4,4,0 \leftarrow 4,3,1$ & Ground & & 34148.3 & .5 \\
\hline $\mathrm{C}^{12} \mathrm{H}_{3} \mathrm{O}^{18} \mathrm{H}$ & 3- 217 & $7,2, \leftarrow 7,1$, & Ground & & 34.155 .63 & .1 \\
\hline $\mathrm{H}_{2} \mathrm{C}^{12} * \mathrm{O}^{16} \mathrm{C}^{12}{ }_{*} \mathrm{H}_{2}$ & 4- 841 & $2,2,1 \leftarrow 2,1,2$ & Ground & & 34157.1 & .5 \\
\hline $\mathrm{HC}^{13}: \mathrm{C}^{12} \mathrm{C}^{12} \mathrm{DO}^{16}$ & 4. 922 & Not Reported & & & 34158. & 5. \\
\hline $\mathrm{C}^{12}{ }_{*} \mathrm{H}_{2} \mathrm{~N}^{14} \mathrm{HC}^{12}{ }_{*} \mathrm{H}_{2}$ & 4- 861 & $10,8,2 \leftarrow 10,7,3$ & Ground & & 34165.1 & \\
\hline $\mathrm{C}^{12} \mathrm{H}_{3} \mathrm{C}^{13}: \mathrm{C}^{12} \mathrm{H}$ & 4-1042 & $2,1 \leftarrow 1,1$ & Ground & & 34168.47 & .14 \\
\hline $\mathrm{C}^{12} \mathrm{H}_{3} \mathrm{C}^{13} \vdots \mathrm{C}^{12} \mathrm{H}$ & $4-1042$ & $2,0 \leftarrow 1,0$ & Ground & & 34169.13 & .14 \\
\hline$\left(\mathrm{C}^{12} \mathrm{H}_{3}\right)_{3} \mathrm{Si}^{28} \mathrm{~F}^{19}$ & 3- 831 & $5, \leftarrow 4$, & Excited & & 34171 & \\
\hline $\mathrm{F}_{2}^{19} \mathrm{O}^{16} \mathrm{O}^{18}$ & 3- 12 & $5,0,5 \leftarrow 4,1,4$ & Ground & & 34171.9 & .5 \\
\hline
\end{tabular}




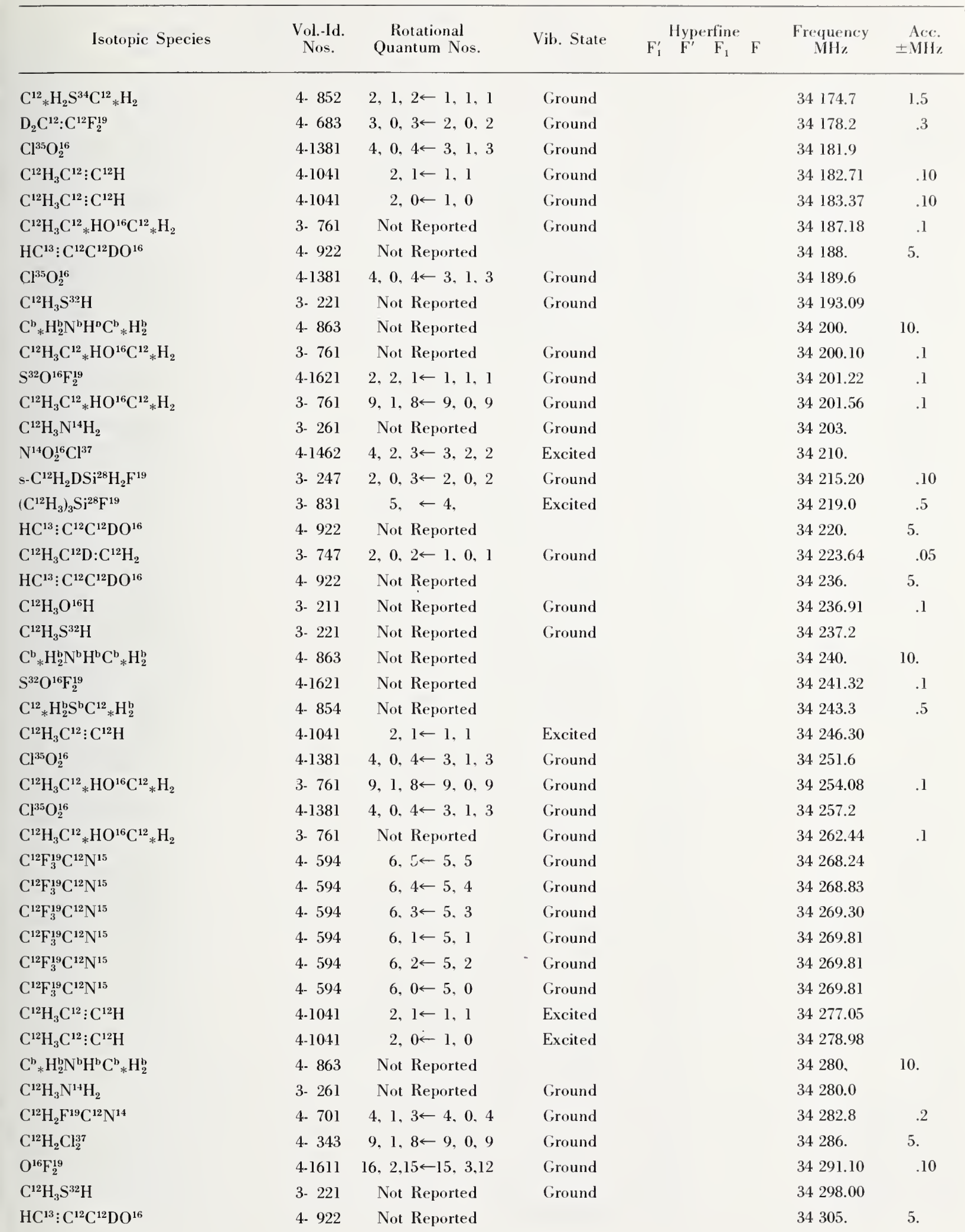




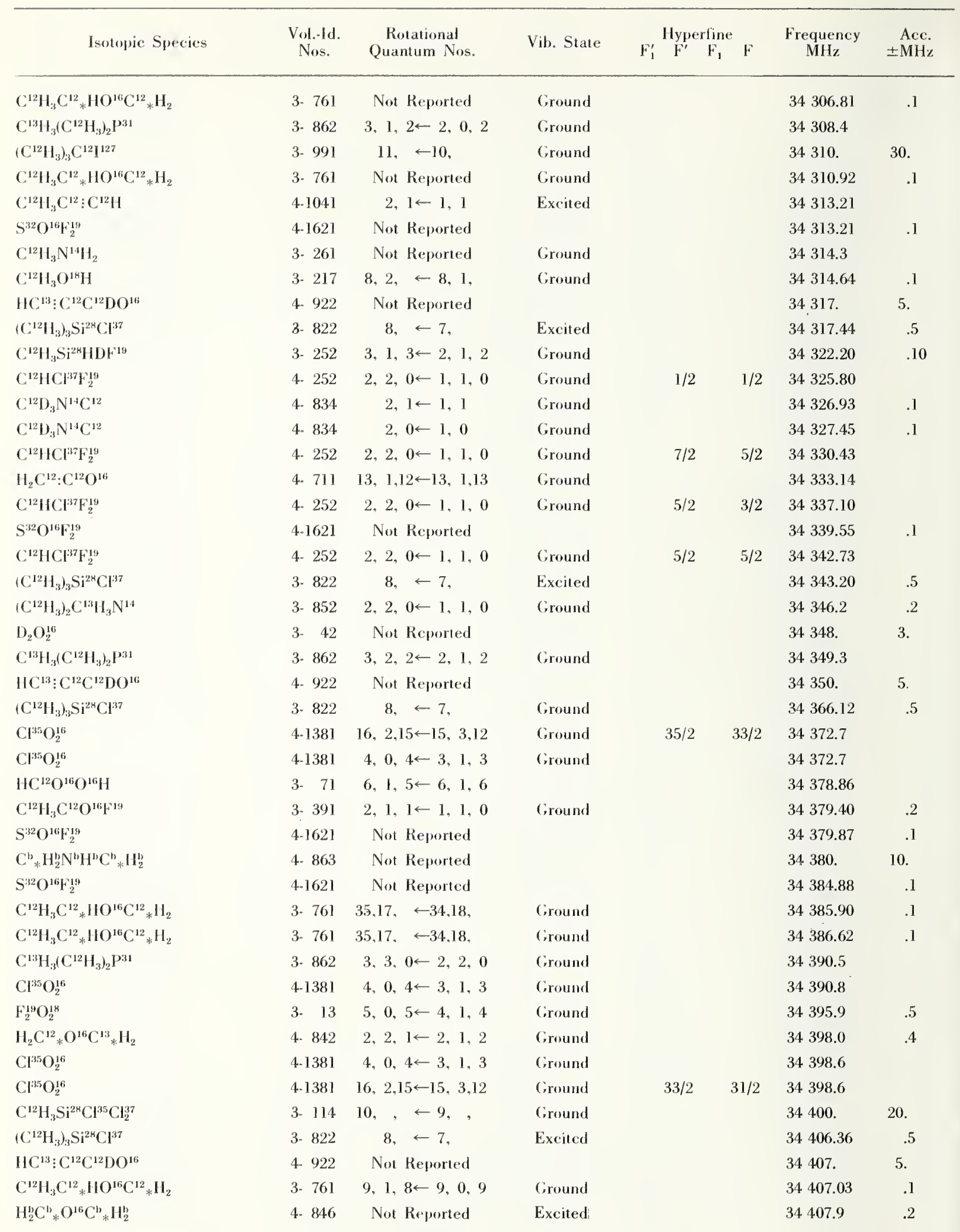




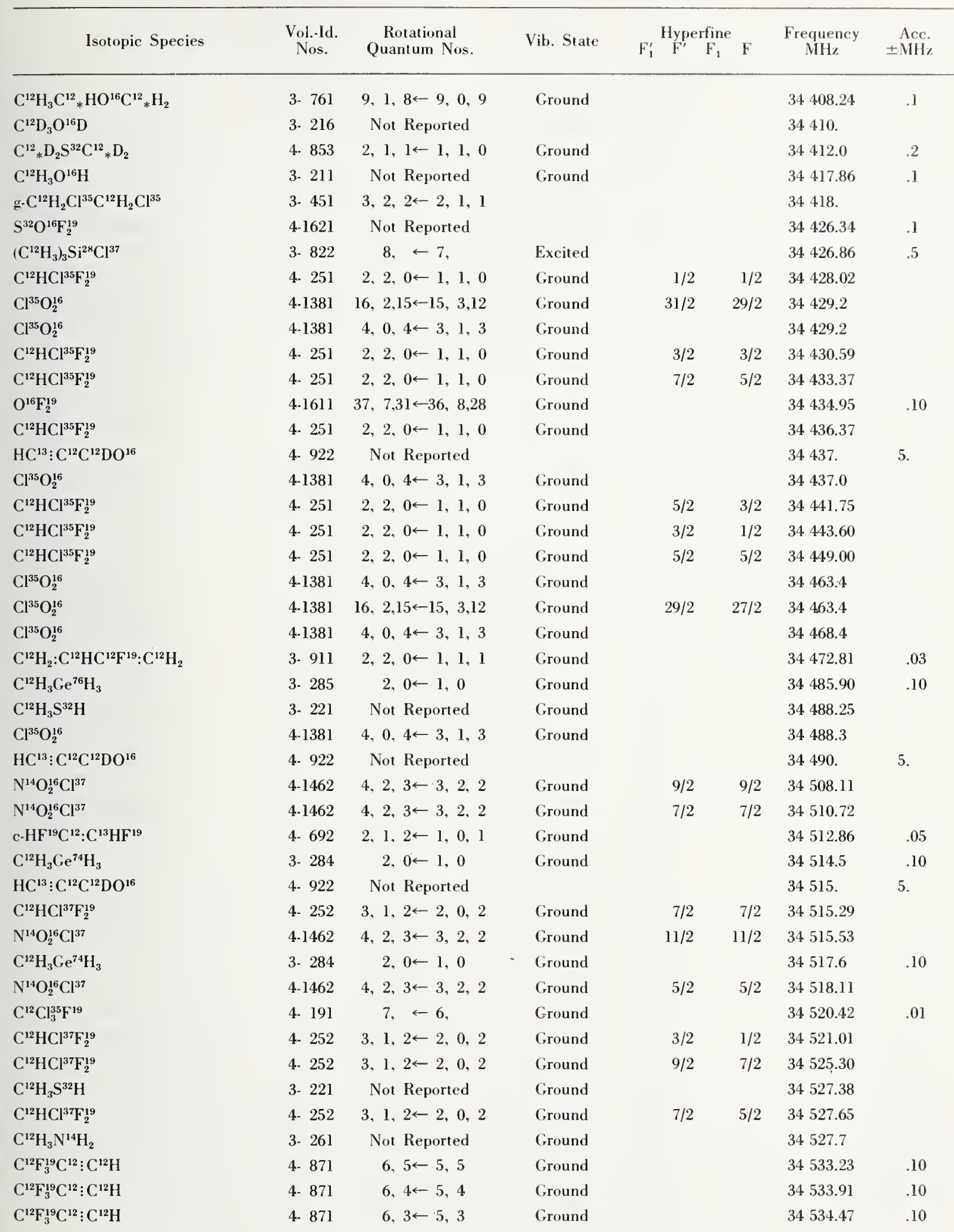




\begin{tabular}{|c|c|c|c|c|c|c|c|}
\hline \multirow{2}{*}{ Isotopic Species } & \multirow{2}{*}{$\begin{array}{l}\text { Vol.-Id. } \\
\text { Nos. }\end{array}$} & \multirow{2}{*}{$\begin{array}{c}\text { Rotational } \\
\text { Quantum Nos. }\end{array}$} & \multirow{2}{*}{ Vib. State } & \multicolumn{2}{|c|}{ Hyperfine } & \multirow{2}{*}{$\begin{array}{l}\text { Frequency } \\
\qquad \mathrm{MHz}\end{array}$} & \multirow{2}{*}{$\begin{aligned} & \text { Acc. } \\
\pm & \mathrm{MHz}\end{aligned}$} \\
\hline & & & & $\begin{array}{lll}\mathbf{F}_{1}^{\prime} & \mathbf{F}^{\prime} & \mathbf{F}_{1}\end{array}$ & $\mathbf{F}$ & & \\
\hline $\mathrm{C}^{12} \mathrm{~F}_{3}^{19} \mathrm{C}^{12}: \mathrm{C}^{12} \mathrm{H}$ & 4. 871 & $6,2 \leftarrow 5,2$ & Ground & & & 34.534 .86 & .10 \\
\hline $\mathrm{C}^{12} \mathrm{~F}_{3}^{19} \mathrm{C}^{12} \vdots \mathrm{C}^{12} \mathrm{H}$ & 4. 871 & $6,0 \leftarrow 5,0$ & Ground & & & 34535.09 & .10 \\
\hline $\mathrm{C}^{12} \mathrm{~F}_{3}^{19} \mathrm{C}^{12}: \mathrm{C}^{12} \mathrm{H}$ & 4. 871 & $6,1 \leftarrow 5,1$ & Ground & & & 34. 535.09 & .10 \\
\hline $\mathrm{C}^{12} \mathrm{H}_{3} \mathrm{O}^{18} \mathrm{H}$ & 3. 217 & $9,2, \leftarrow 9,1$, & Ground & & & 34536.74 & .1 \\
\hline $\mathrm{D}_{2} \mathrm{O}_{2}^{16}$ & 3. 42 & Not Reported & & & & 34540 . & 3. \\
\hline $\mathrm{C}^{12}{ }_{*} \mathrm{H}_{2} \mathrm{~N}^{14} \mathrm{HC}^{12}{ }_{*} \mathrm{H}_{2}$ & 4- 861 & $2,2,0 \leftarrow 2,1,2$ & Ground & & & 34540 . & 10. \\
\hline $\mathrm{C}^{12} \mathrm{H}_{3} \mathrm{O}^{16} \mathrm{~N}^{14} \mathrm{O}_{2}^{16}$ & 3. 181 & $4,1,3 \leftarrow 3,1,2$ & Ground & & & 34546.63 & .1 \\
\hline $\mathrm{HC}^{13}: \mathrm{C}^{12} \mathrm{C}^{12} \mathrm{DO}^{16}$ & 4- 922 & Not Reported & & & & 34557. & 5. \\
\hline $\mathrm{C}^{12} \mathrm{H}_{3} \mathrm{C}^{12}{ }_{*} \mathrm{HO}^{16} \mathrm{C}^{12}{ }_{*} \mathrm{H}_{2}$ & 3- 761 & $11,4,8 \leftarrow 10,5,5$ & Ground & & & 34570.45 & .1 \\
\hline $\mathrm{C}^{12} \mathrm{H}_{3} \mathrm{C}^{12}{ }_{*} \mathrm{HO}^{16} \mathrm{C}^{12}{ }_{*} \mathrm{H}_{2}$ & 3. 761 & $11,4,8 \leftarrow 10,5,5$ & Ground & & & 34571.04 & .1 \\
\hline $\mathrm{C}^{12} \mathrm{H}_{3} \mathrm{C}^{12} * \mathrm{HO}^{16} \mathrm{C}^{12}{ }_{*} \mathrm{H}_{2}$ & 3- 761 & Not Reported & Ground & & & 34572.69 & .1 \\
\hline $\mathrm{C}^{12} \mathrm{H}_{3} \mathrm{C}^{12}{ }_{*} \mathrm{HO}^{16} \mathrm{C}^{12}{ }_{*} \mathrm{H}_{2}$ & 3- 761 & $11,4,8 \leftarrow 10,5,5$ & Ground & & & 34574.92 & .1 \\
\hline $\mathrm{HC}^{13}: \mathrm{C}^{12} \mathrm{C}^{12} \mathrm{DO}^{16}$ & 4- 922 & Not Reported & & & & 34580. & 5. \\
\hline $\mathrm{D}_{2} \mathrm{O}_{2}^{16}$ & $3-\quad 42$ & Not Reported & & & & 34583. & 3. \\
\hline $\mathrm{C}^{12} \mathrm{H}_{2} \mathrm{DC}^{12} \mathrm{~N}^{14}$ & 4. 812 & $2,1,2 \leftarrow 1,1,1$ & Ground & 2 & 1 & 34583.03 & .1 \\
\hline $\mathrm{C}^{12} \mathrm{H}_{2} \mathrm{DC}^{12} \mathrm{~N}^{14}$ & 4- 812 & $2,1,2 \leftarrow 1,1,1$ & Ground & 3 & 2 & 34584.33 & .1 \\
\hline $\mathrm{C}^{12} \mathrm{H}_{2} \mathrm{DC}^{12} \mathrm{~N}^{14}$ & 4. 812 & $2,1,2 \leftarrow 1,1,1$ & Ground & 1 & 0 & 34585.59 & .1 \\
\hline $\mathrm{C}^{12} \mathrm{H}_{2}: \mathrm{C}^{12} \mathrm{HC}^{12} \mathrm{~F}^{19}: \mathrm{C}^{12} \mathrm{H}_{2}$ & 3- 911 & $5,1,5 \leftarrow 4,0,4$ & Ground & & & 34586.04 & .03 \\
\hline $\mathrm{HDO}_{2}^{16}$ & $3-\quad 43$ & $10, \quad, \quad \leftarrow 10$, & & & & 34598. & 3. \\
\hline $\mathrm{S}^{32} \mathrm{O}^{16} \mathrm{~F}_{2}^{19}$ & $4 \cdot 1621$ & Not Reported & & & & 34598.00 & .1 \\
\hline $\mathrm{C}^{12} \mathrm{H}_{3} \mathrm{Ge}^{74} \mathrm{H}_{3}$ & 3- 284 & $2,0 \leftarrow 1,0$ & Ground & & & 34598.62 & .10 \\
\hline$\left(\mathrm{C}^{12} \mathrm{H}_{3}\right)_{2} \mathrm{C}^{13} \mathrm{H}_{3} \mathrm{~N}^{14}$ & 3- 852 & $2,2,1 \leftarrow 1,1,1$ & Ground & & & 34603.5 & .5 \\
\hline $\mathrm{C}^{13} \mathrm{H}_{3}\left(\mathrm{C}^{12} \mathrm{H}_{3}\right)_{2} \mathrm{P}^{31}$ & 3- 862 & $3,3,1 \leftarrow 2,2,1$ & Ground & & & 34608.1 & \\
\hline $\mathrm{C}^{12} \mathrm{H}_{3} \mathrm{C}^{12}{ }_{*} \mathrm{HO}^{16} \mathrm{C}^{12}{ }_{*} \mathrm{H}_{2}$ & 3. 761 & $9,1,8 \leftarrow 9,0,9$ & Ground & & & 34611.20 & .1 \\
\hline $\mathrm{Si}^{28} \mathrm{HCl}_{3}^{35}$ & 4.1501 & $7, \leftarrow 6$ & Ground & & & 34614.34 & .5 \\
\hline $\mathrm{C}^{12} \mathrm{H}_{3} \mathrm{~S}^{32} \mathrm{H}$ & 3- 221 & Not Reported & Ground & & & 34616.85 & \\
\hline $\mathrm{O}^{\mathrm{b}} \mathrm{O}^{\mathrm{b}} \mathrm{O}^{\mathrm{b}}$ & $4-1847$ & Not Reported & & & & 34622 . & \\
\hline $\mathrm{C}^{12} \mathrm{H}_{2} \mathrm{Cl}^{35} \mathrm{Cl}^{37}$ & 4- 342 & $9,1,8 \leftarrow 9,0,9$ & Ground & & & 34623 . & 5. \\
\hline $\mathrm{C}^{12} \mathrm{H}_{3} \mathrm{~N}^{14} \mathrm{H}_{2}$ & 3- 261 & Not Reported & Ground & & & 34623.8 & \\
\hline $\mathrm{C}^{12}{ }_{*} \mathrm{H}_{2} \mathrm{C}^{12} \mathrm{H}_{2} \mathrm{C}^{12} \mathrm{H}_{2} \mathrm{O}^{18} *$ & $4-1093$ & $6,3,3 \leftarrow 6,3,4$ & Ground & & & 34624.3 & .1 \\
\hline $\mathrm{C}^{12} \mathrm{D}_{3} \mathrm{~N}^{14} \mathrm{H}_{2}$ & 3- 263 & Not Reported & & & & 34625 . & \\
\hline $\mathrm{H}_{3} \mathrm{~B}^{11} \mathrm{C}^{12} \mathrm{O}^{16}$ & 4- 392 & $2,1 \leftarrow 1,1$ & Ground & $1 / 2$ & $1 / 2$ & 34627.16 & \\
\hline $\mathrm{H}_{3} \mathrm{~B}^{11} \mathrm{C}^{12} \mathrm{O}^{16}$ & 4- 392 & $2,1 \leftarrow 1,1$ & Ground & $3 / 2$ & $5 / 2$ & 34627.42 & \\
\hline $\mathrm{H}_{3} \mathrm{~B}^{11} \mathrm{C}^{12} \mathrm{O}^{16}$ & 4- 392 & $2,1 \leftarrow 1,1$ & Ground & $1 / 2$ & $3 / 2$ & 34627.42 & \\
\hline $\mathrm{H}_{3} \mathrm{~B}^{11} \mathrm{C}^{12} \mathrm{O}^{16}$ & 4- 392 & $2,1 \leftarrow 1,1$ & Ground & $7 / 2$ & $5 / 2$ & 34627.42 & \\
\hline $\mathrm{H}_{3} \mathrm{~B}^{11} \mathrm{C}^{12} \mathrm{O}^{16}$ & 4. 392 & $2,1 \leftarrow 1,1$ & Ground & $3 / 2$ & $1 / 2$ & 34627.42 & \\
\hline $\mathrm{H}_{3} \mathrm{~B}^{11} \mathrm{C}^{12} \mathrm{O}^{16}$ & 4- 392 & $2,1 \leftarrow 1,1$ & Ground & $5 / 2$ & $5 / 2$ & 34.627 .64 & \\
\hline $\mathrm{H}_{3} \mathrm{~B}^{11} \mathrm{C}^{12} \mathrm{O}^{16}$ & 4- 392 & $2,1 \leftarrow 1,1$ & Ground & $3 / 2$ & $3 / 2$ & 34627.64 & \\
\hline $\mathrm{H}_{3} \mathrm{~B}^{11} \mathrm{C}^{12} \mathrm{O}^{16}$ & 4- 392 & $2,1 \leftarrow 1,1$ & Ground & $5 / 2$ & $3 / 2$ & 34627.81 & \\
\hline $\mathrm{H}_{3} \mathrm{~B}^{11} \mathrm{C}^{12} \mathrm{O}^{16}$ & 4- 392 & $2,0 \leftarrow 1,0$ & Ground & $1 / 2$ & $3 / 2$ & 34628.16 & \\
\hline $\mathrm{H}_{3} \mathrm{~B}^{11} \mathrm{C}^{12} \mathrm{O}^{16}$ & 4- 392 & $2,0 \leftarrow 1,0$ & Ground & $3 / 2$ & $3 / 2$ & 34628.58 & \\
\hline $\mathrm{H}_{3} \mathrm{~B}^{11} \mathrm{C}^{12} \mathrm{O}^{16}$ & 4- 392 & $2,0 \leftarrow 1,0$ & Ground & $3 / 2$ & $5 / 2$ & 34628.85 & \\
\hline $\mathrm{H}_{3} \mathrm{~B}^{11} \mathrm{C}^{12} \mathrm{O}^{16}$ & 4- 392 & $2,0 \leftarrow 1,0$ & Ground & $5 / 2$ & $3 / 2$ & 34628.85 & \\
\hline $\mathrm{H}_{3} \mathrm{~B}^{11} \mathrm{C}^{12} \mathrm{O}^{16}$ & 4- 392 & $2,0 \leftarrow 1,0$ & Ground & $1 / 2$ & $1 / 2$ & 34628.85 & \\
\hline $\mathrm{H}_{3} \mathrm{~B}^{11} \mathrm{C}^{12} \mathrm{O}^{16}$ & 4- 392 & $2,0 \leftarrow 1,0$ & Ground & $7 / 2$ & $5 / 2$ & 34628.85 & \\
\hline
\end{tabular}




\begin{tabular}{|c|c|c|c|c|c|c|c|c|}
\hline Isotopic Species & $\begin{array}{l}\text { Vol.-Id. } \\
\text { Nos. }\end{array}$ & $\begin{array}{c}\text { Rotational } \\
\text { Quantum Nos. }\end{array}$ & Vib. State & $\mathrm{F}_{1}^{\prime}$ & $\begin{array}{l}\text { Hyperfine } \\
\mathrm{F}^{\prime} \quad \mathrm{F}_{1}\end{array}$ & $\mathrm{~F}$ & $\begin{array}{c}\text { Frequency } \\
\text { MHz }\end{array}$ & $\begin{aligned} & \text { Acce. } \\
& \pm \text { Mlli }\end{aligned}$ \\
\hline $\mathrm{H}_{3} \mathrm{~B}^{11} \mathrm{C}^{12} \mathrm{O}^{16}$ & 4. 392 & $2,0 \leftarrow 1,0$ & Ground & & $5 / 2$ & $5 / 2$ & 34629.27 & \\
\hline $\mathrm{H}_{3} \mathrm{~B}^{11} \mathrm{C}^{12} \mathrm{O}^{16}$ & 4- 392 & $2,0 \leftarrow 1,0$ & Ground & & $3 / 2$ & $1 / 2$ & 34629.27 & \\
\hline $\mathrm{C}_{*}^{b} \mathrm{H}_{2}^{\mathrm{b}} \mathrm{N}^{\mathrm{b}} \mathrm{H}^{\mathrm{b}} \mathrm{C}^{\mathrm{h}}{ }_{*} \mathrm{H}_{2}^{\mathrm{b}}$ & 4- 863 & Not Reported & & & & & 34630 & 10. \\
\hline $\mathrm{F}_{2}^{19} \mathrm{O}_{2}^{16}$ & 3- 11 & $9,1,8 \leftarrow 9,0,9$ & Ground & & & & 34636.60 & .1 \\
\hline $\mathrm{S}^{32} \mathrm{O}^{16} \mathrm{~F}_{2}^{19}$ & 4-1621 & Not Reported & & & & & 34637.09 & .1 \\
\hline $\mathrm{c}-\mathrm{HDN}^{14} \mathrm{C}^{12} \mathrm{HO}^{16}$ & 3. 152 & $4,0,4 \leftarrow 3,1,3$ & Ground & & & & 34639.00 & \\
\hline$\left(\mathrm{C}^{12} \mathrm{H}_{3}\right)_{2} \mathrm{~S}^{32}$ & 3- 601 & $6,2,4 \leftarrow 5,3,3$ & Ground & & & & 34652.35 & .05 \\
\hline $\mathrm{Ge}^{74} \mathrm{HCl}_{3}^{35}$ & 4-1493 & $8, \leftarrow 7$, & Ground & & & & 34652.66 & .07 \\
\hline$\left(\mathrm{C}^{12} \mathrm{H}_{3}\right)_{2} \mathrm{~S}^{32}$ & 3- 601 & $6,2,4 \leftarrow 5,3,3$ & Ground & & & & 34653.19 & .05 \\
\hline$\left(\mathrm{C}^{12} \mathrm{H}_{3}\right)_{2} \mathrm{~S}^{32}$ & 3- 601 & $6,2,4 \leftarrow 5,3,3$ & Ground & & & & 34653.95 & .05 \\
\hline$\left(\mathrm{C}^{12} \mathrm{H}_{3}\right)_{2} \mathrm{~S}^{32}$ & 3- 601 & $6,2,4 \leftarrow 5,3,3$ & Ground & & & & 34654.08 & .05 \\
\hline $\mathrm{C}^{12} \mathrm{H}_{3} \mathrm{Ce}^{73} \mathrm{H}_{3}$ & 3- 283 & $2,1 \leftarrow 1,1$ & Ground & & $13 / 2$ & $11 / 2$ & 34656.75 & .10 \\
\hline $\mathrm{C}^{12} \mathrm{H}_{3} \mathrm{Ge}^{73} \mathrm{H}_{3}$ & 3- 283 & $2,1 \leftarrow 1,1$ & Ground & & $11 / 2$ & $9 / 2$ & 34657.23 & .10 \\
\hline $\mathrm{C}^{12} \mathrm{H}_{3} \mathrm{Ce}^{73} \mathrm{H}_{3}$ & 3. 283 & $2,1 \leftarrow 1,1$ & Ground & & $9 / 2$ & $9 / 2$ & 34657.23 & .10 \\
\hline $\mathrm{Ge}^{74} \mathrm{HCl}_{3}^{35}$ & 4-1493 & $8, \leftarrow 7$, & Excited & & & & 34659.03 & .07 \\
\hline $\mathrm{O}^{16} \mathrm{O}^{18} \mathrm{O}^{16}$ & $4 \cdot 1843$ & $18,2,16 \leftarrow 19,1,9$ & Ground & & & & 34662 . & \\
\hline $\mathrm{Ge}^{74} \mathrm{~F}_{3}^{19} \mathrm{Cl}^{35}$ & 4-1405 & $8, \leftarrow 7$, & Ground & & & & 34.664 .55 & .30 \\
\hline $\mathrm{Ge}^{74} \mathrm{HCl}_{3}^{35}$ & 4-1493 & $8, \leftarrow 7$, & Excited & & & & 34664.83 & .07 \\
\hline $\mathrm{C}^{12} \mathrm{H}_{2} \mathrm{Cl}_{2}^{37}$ & 4- 343 & $1,1,1 \leftarrow 0,0,0$ & Ground & & & & 34665.3 & .2 \\
\hline $\mathrm{C}^{12} \mathrm{D}_{3} \mathrm{Si}^{\mathrm{b}} \mathrm{H}_{2} \mathrm{D}$ & 3. 329 & $2,1,2 \leftarrow 1,1,1$ & & & & & 34667.79 & .2 \\
\hline $\mathrm{C}^{12} \mathrm{D}_{3} \mathrm{~N}^{14} \mathrm{H}_{2}$ & 3- 263 & $7, \quad \leftarrow 6, \quad$ & & & & & 34670. & \\
\hline $\mathrm{Ge}^{72} \mathrm{~F}_{3}^{19} \mathrm{Cl}^{5}$ & 4-1403 & $8, \leftarrow 7$ & Ground & & & & 34679.32 & .30 \\
\hline $\mathrm{D}_{2} \mathrm{C}^{12}{ }_{*} \mathrm{O}^{16} \mathrm{C}^{12}{ }_{*} \mathrm{D}_{2}$ & 4- 843 & $6,4,2 \leftarrow 6,3,3$ & Ground & & & & 34680 . & \\
\hline $\mathrm{C}^{\mathrm{b}}{ }_{*} \mathrm{H}_{2}^{\mathrm{b}} \mathrm{N}^{\mathrm{b}} \mathrm{H}^{\mathrm{b}} \mathrm{C}_{*}^{\mathrm{b}}{ }_{*} \mathrm{H}_{2}^{\mathrm{b}}$ & 4- 863 & Not Reported & & & & & 34680. & 10. \\
\hline$\left(\mathrm{C}^{12} \mathrm{H}_{3}\right)_{2} \mathrm{O}^{16}$ & 3- 591 & $3,1,3 \leftarrow 2,2,0$ & Ground & & & & 34.682 .5 & .5 \\
\hline $\mathrm{Ge}^{70} \mathrm{~F}_{3}^{19} \mathrm{Cl}^{35}$ & 4-1401 & $8, \leftarrow 7$ & Ground & & & & 34694.71 & .40 \\
\hline $\mathrm{HDC}^{12}: \mathrm{C}^{12} \mathrm{~F}_{2}^{19}$ & 4. 682 & $5,2,3 \leftarrow 5,2,4$ & Ground & & & & 34704.2 & .3 \\
\hline $\mathrm{C}^{12} \mathrm{DBr}_{3}^{79}$ & 4- 243 & $14, \leftarrow 13$ & Ground & & & & 34.704 .6 & .5 \\
\hline $\mathrm{a}-\mathrm{C}^{12} \mathrm{HD}_{2} \mathrm{C}^{12} \mathrm{HO}^{16}$ & 3- 482 & $2,0,2 \leftarrow 1,0,1$ & Ground & & & & 34706.02 & .2 \\
\hline $\mathrm{a} \cdot \mathrm{C}^{12} \mathrm{HD}_{2} \mathrm{C}^{12} \mathrm{HO}^{16}$ & 3- 482 & $2,0,2 \leftarrow 1,0,1$ & Ground & & & & 34707.32 & .2 \\
\hline $\mathrm{Ge}^{72} \mathrm{HCl}_{3}^{35}$ & 4-1492 & $8, \leftarrow 7$, & Ground & & & & 34707.67 & .07 \\
\hline $\mathrm{D}_{2} \mathrm{O}_{2}^{16}$ & $3-42$ & Not Reported & & & & & 34. 709 . & 3. \\
\hline $\mathrm{C}^{12} \mathrm{H}_{3} \mathrm{C}^{12} \mathrm{HO}^{16}$ & 3. 471 & Not Reported & & & & & 34711.88 & \\
\hline $\mathrm{Ge}^{72} \mathrm{HCl}_{3}^{35}$ & 4.1492 & $8, \leftarrow 7$ & Excited & & & & 34715.29 & .07 \\
\hline $\mathrm{C}^{12} \mathrm{H}_{3} \mathrm{Ge}^{72} \mathrm{H}_{3}$ & 3- 282 & $2,0 \leftarrow 1,0$ & Ground & & & & 34717.54 & .10 \\
\hline $\mathrm{Ge}^{72} \mathrm{HCl}_{3}^{35}$ & 4-1492 & $8, \leftarrow 7$, & Excited & & & & 34719.42 & .07 \\
\hline $\mathrm{C}^{12} \mathrm{H}_{3} \mathrm{C}^{12}{ }_{*} \mathrm{HO}^{16} \mathrm{C}^{12}{ }_{*} \mathrm{H}_{2}$ & 3- 761 & $11,4,7 \leftarrow 10,5,6$ & Ground & & & & 34722.35 & .1 \\
\hline $\mathrm{C}^{12} \mathrm{H}_{3} \mathrm{C}^{12}{ }_{*} \mathrm{HO}^{16} \mathrm{C}^{12}{ }_{*} \mathrm{H}_{2}$ & 3- 761 & Not Reported & Ground & & & & 34722.92 & .1 \\
\hline $\mathrm{C}^{12} \mathrm{H}_{3} \mathrm{C}^{12}{ }_{*} \mathrm{HO}^{16} \mathrm{C}^{12}{ }_{*} \mathrm{H}_{2}$ & 3- 761 & $11,4,7 \leftarrow 10,5,6$ & Ground & & & & 34724,83 & .1 \\
\hline$\left(\mathrm{C}^{12} \mathrm{H}_{3}\right)_{3} \mathrm{Si}^{28} \mathrm{Br}^{81}$ & 3- 812 & $12, \leftarrow 11$ & & & & & 34725.2 & .4 \\
\hline $\mathrm{O}^{16} \mathrm{O}^{18} \mathrm{O}^{18}$ & 4-1844 & $12,2,10 \leftarrow 13,1,13$ & Ground & & & & 34726. & \\
\hline $\mathrm{C}^{12}{ }_{*} \mathrm{H}_{2} \mathrm{C}^{12} \mathrm{D}: \mathrm{C}^{12}{ }_{*} \mathrm{H}$ & 4-1032 & $7,4,3 \leftarrow 7,4,4$ & Ground & & & & 34726.6 & \\
\hline $\mathrm{C}^{12} \mathrm{H}_{3} \mathrm{C}^{12}{ }_{*} \mathrm{HO}^{16} \mathrm{C}^{12}{ }_{*} \mathrm{H}_{2}$ & 3. 761 & $11,4,7 \leftarrow 10,5.6$ & Ground & & & & 34726.82 & .1 \\
\hline $\mathrm{C}^{12} \mathrm{H}_{3} \mathrm{~S}^{32} \mathrm{H}$ & 3- 221 & Not Reported & Ground & & & & 34. 733.89 & \\
\hline $\mathrm{C}^{12} \mathrm{H}_{2} \mathrm{DC}^{12} \mathrm{~N}^{14}$ & 4- 812 & $2,0,2 \leftarrow 1,0,1$ & Ground & & 2 & 2 & 34734.07 & .1 \\
\hline
\end{tabular}




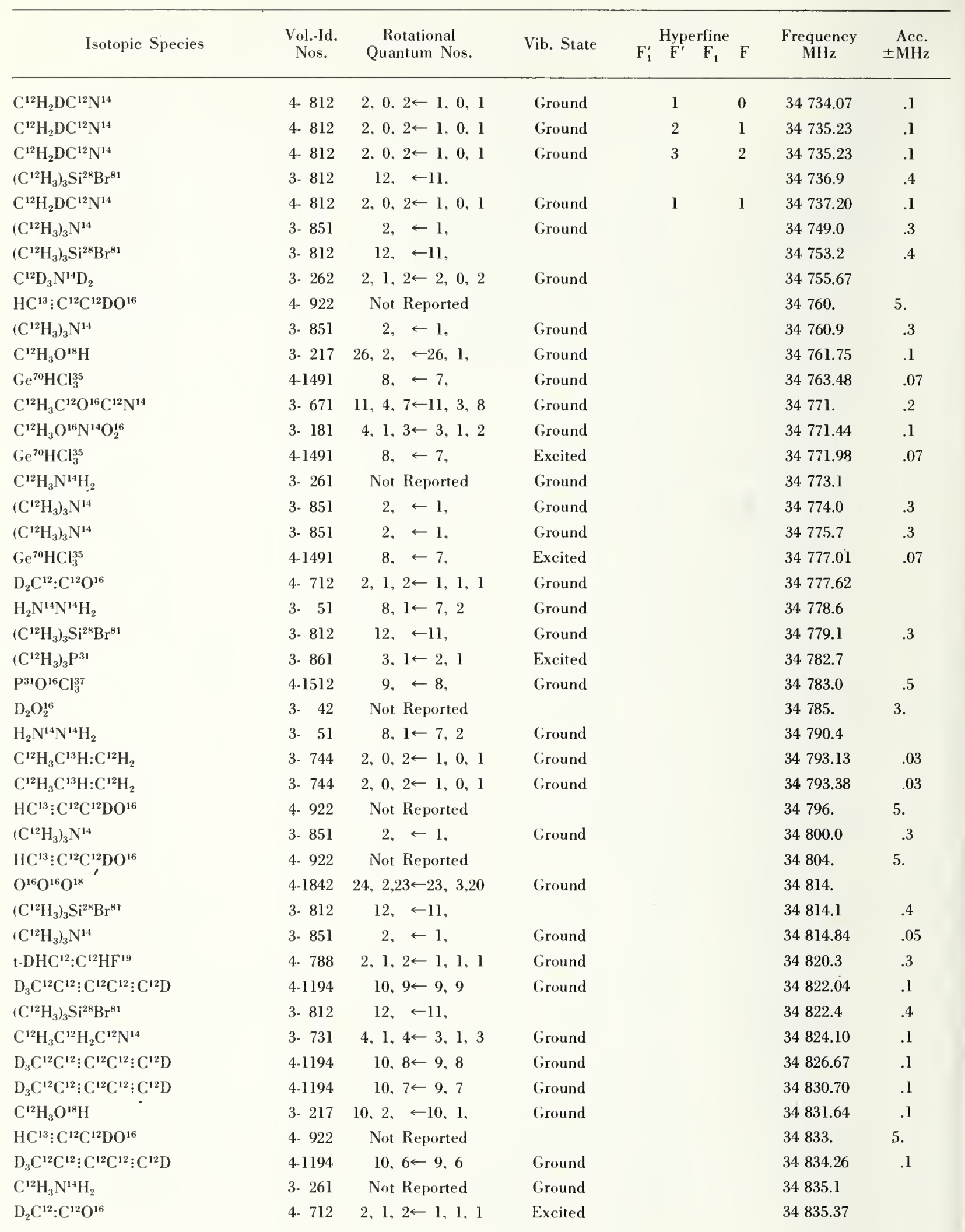




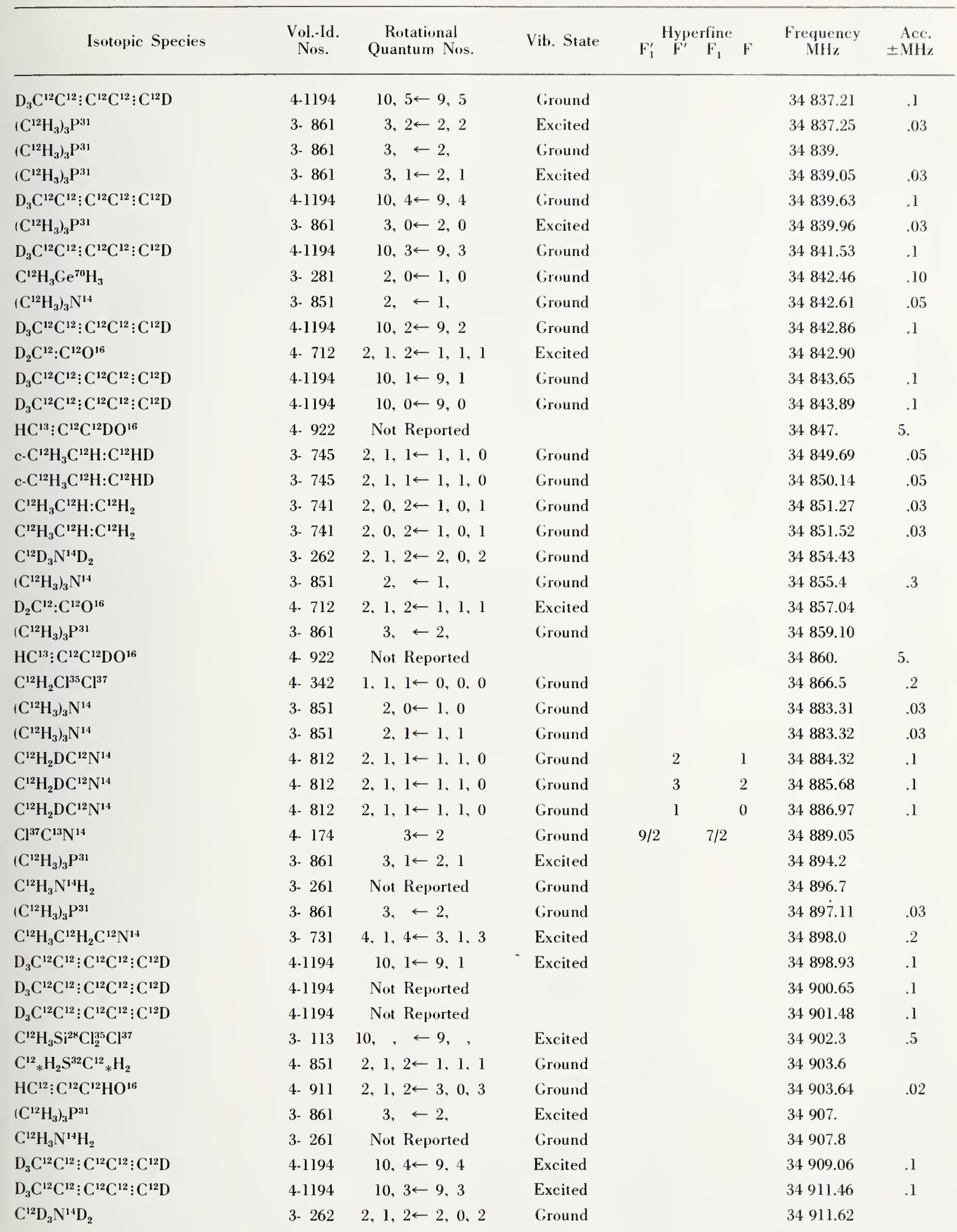




\begin{tabular}{|c|c|c|c|c|c|c|}
\hline Isotopic Species & $\begin{array}{l}\text { Vol.-Id. } \\
\text { Nos. }\end{array}$ & $\begin{array}{c}\text { Rotational } \\
\text { Quantum Nos. }\end{array}$ & Vib. State & 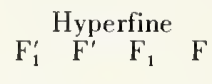 & $\begin{array}{c}\text { Frequency } \\
\mathrm{MHz}\end{array}$ & $\begin{aligned} & \text { Acc. } \\
\pm & \mathrm{MHz}\end{aligned}$ \\
\hline $\mathrm{D}_{3} \mathrm{C}^{12} \mathrm{C}^{12}: \mathrm{C}^{12} \mathrm{C}^{12}: \mathrm{C}^{12} \mathrm{D}$ & 4.1194 & $10,2 \leftarrow 9,2$ & Excited & & 34913.28 & .1 \\
\hline $\mathrm{D}_{3} \mathrm{C}^{12} \mathrm{C}^{12}: \mathrm{C}^{12} \mathrm{C}^{12}: \mathrm{C}^{12} \mathrm{D}$ & 4.1194 & $10,4 \leftarrow 9,4$ & Excited & & 34913.28 & .1 \\
\hline $\mathrm{D}_{3} \mathrm{C}^{12} \mathrm{C}^{12}: \mathrm{C}^{12} \mathrm{C}^{12}: \mathrm{C}^{12} \mathrm{D}$ & 4-1194 & $10,3 \leftarrow 9,3$ & Excited & & 34914.63 & .1 \\
\hline $\mathrm{D}_{3} \mathrm{C}^{12} \mathrm{C}^{12}: \mathrm{C}^{12} \mathrm{C}^{12}: \mathrm{C}^{12} \mathrm{D}$ & 4-1194 & $10,1 \leftarrow 9,1$ & Excited & & 34914.63 & .1 \\
\hline $\mathrm{D}_{3} \mathrm{C}^{12} \mathrm{C}^{12}: \mathrm{C}^{12} \mathrm{C}^{12}: \mathrm{C}^{12} \mathrm{D}$ & 4-1194 & $10,0 \leftarrow 9,0$ & Excited & & 34915.35 & .1 \\
\hline $\mathrm{D}_{3} \mathrm{C}^{12} \mathrm{C}^{12}: \mathrm{C}^{12} \mathrm{C}^{12}: \mathrm{C}^{12} \mathrm{D}$ & 4-1194 & $10,2 \leftarrow 9,2$ & Excited & & 34915.70 & .1 \\
\hline $\mathrm{O}^{\mathrm{b}} \mathrm{O}^{\mathrm{b}} \mathrm{O}^{\mathrm{b}}$ & 4-1847 & Not Reported & & & 34919. & \\
\hline $\mathrm{HC}^{13}: \mathrm{C}^{12} \mathrm{C}^{12} \mathrm{DO}^{16}$ & 4. 922 & Not Reported & & & 34920 . & 5. \\
\hline $\mathrm{C}^{12}{ }_{*} \mathrm{H}_{2} \mathrm{C}^{12} \mathrm{HDC}^{12} \mathrm{H}_{2} \mathrm{O}^{16} *$ & 4-1094 & $8,6,3 \leftarrow 8,4,4$ & Excited & & 34926.2 & .1 \\
\hline $\mathrm{D}_{3} \mathrm{C}^{12} \mathrm{C}^{12}: \mathrm{C}^{12} \mathrm{C}^{12}: \mathrm{C}^{12} \mathrm{D}$ & 4-1194 & $10,1 \leftarrow 9,1$ & Excited & & 34932.59 & .1 \\
\hline $\mathrm{C}^{12}{ }_{*} \mathrm{H}_{2} \mathrm{C}^{12} \mathrm{H}: \mathrm{C}^{12}{ }_{*} \mathrm{H}$ & 4-1031 & $4,2,2 \leftarrow 4,2,3$ & Ground & & 34935.4 & \\
\hline $\mathrm{HC}^{13}: \mathrm{C}^{12} \mathrm{C}^{12} \mathrm{DO}^{16}$ & 4- 922 & Not Reported & & & 34.939 . & 5. \\
\hline $\mathrm{Cl}^{35} \mathrm{O}_{2}^{16}$ & 4-1381 & $16,2,15 \leftarrow 15,3,12$ & Cround & & 34941.3 & \\
\hline $\mathrm{C}^{12} \mathrm{H}_{3} \mathrm{~S}^{32} \mathrm{H}$ & 3. 221 & Not Reported & Ground & & 34942.56 & \\
\hline $\mathrm{C}^{12} \mathrm{D}_{3} \mathrm{Si}^{\mathrm{b}} \mathrm{H}_{2} \mathrm{D}$ & 3. 329 & $2,0,2 \leftarrow 1,0,1$ & & & 34.942 .63 & .2 \\
\hline$\left(\mathrm{C}^{12} \mathrm{H}_{3}\right)_{3} \mathrm{P}^{31}$ & 3. 861 & $3, \leftarrow 2$, & Exrited & & 34943.46 & \\
\hline $\mathrm{HC}^{13}: \mathrm{C}^{12} \mathrm{C}^{12} \mathrm{DO}^{16}$ & 4- 922 & Not Reported & & & 34949 . & 5. \\
\hline $\mathrm{HC}^{12} \mathrm{~N}^{14}$ & 4- 291 & $12 \leftarrow 12$ & Excited & & 34.953 .5 & \\
\hline$\left(\mathrm{C}^{12} \mathrm{H}_{3}\right)_{3} \mathrm{~N}^{14}$ & 3. 851 & $2, \leftarrow 1$, & Excited & & 34955.6 & .3 \\
\hline $\mathrm{C}^{12} \mathrm{D}_{3} \mathrm{~N}^{14} \mathrm{H}_{2}$ & 3- 263 & Not Reported & & & 34962.4 & .5 \\
\hline$\left(\mathrm{C}^{12} \mathrm{H}_{3}\right)_{2} \mathrm{~S}^{32}$ & 3- 601 & 2. $1,2 \leftarrow 1,0,1$ & Ground & & 34.962 .82 & .05 \\
\hline$\left(\mathrm{C}^{12} \mathrm{H}_{3}\right)_{2} \mathrm{~S}^{32}$ & 3- 601 & $2,1,2 \leftarrow 1,0,1$ & Ground & & 34963.06 & .05 \\
\hline$\left(\mathrm{C}^{12} \mathrm{H}_{3}\right)_{2} \mathrm{~S}^{32}$ & 3- 601 & $2,1,2 \leftarrow 1,0,1$ & Cround & & 34.963 .29 & .05 \\
\hline $\mathrm{s}-\mathrm{C}^{12} \mathrm{H}_{2} \mathrm{DC}^{12} \mathrm{H}: \mathrm{C}^{12} \mathrm{H}_{2}$ & 3- 743 & $2,1,1 \leftarrow 1,1,0$ & Ground & & 34.966 .94 & .05 \\
\hline $\mathrm{O}^{\mathrm{b}} \mathrm{O}^{\mathrm{b}} \mathrm{O}^{\mathrm{b}}$ & 4-1847 & Not Reported & & & 34967. & \\
\hline $\mathrm{C}^{12} \mathrm{H}_{2} \mathrm{Cl}_{2}^{35}$ & 4. 341 & $9,1,8 \leftarrow 9,0,9$ & Ground & & 34970 . & 5. \\
\hline$c-\mathrm{HF}^{19} \mathrm{C}^{12}: \mathrm{C}^{12} \mathrm{HF}^{19}$ & 4. 691 & $2,1,2 \leftarrow 1,0,1$ & Ground & & 34970.12 & .05 \\
\hline $\mathrm{C}^{12} \mathrm{D}_{3} \mathrm{~N}^{14} \mathrm{H}_{2}$ & 3- 263 & Not Reported & & & 34995.0 & .5 \\
\hline $\mathrm{F}_{3}^{19} \mathrm{~B}^{\mathrm{b}} \cdot \mathrm{N}^{\mathrm{h}}\left(\mathrm{C}^{12} \mathrm{H}_{3}\right)_{3}$ & $3-801$ & $10, \leftarrow 9$ & & & 35000. & \\
\hline $\mathrm{O}^{16} \mathrm{O}^{18} \mathrm{O}^{16}$ & 4-1843 & $10,1,9 \leftarrow 9,2,8$ & Ground & & 35004 & \\
\hline $\mathrm{H}_{2} \mathrm{~N}^{14} \mathrm{~N}^{14} \mathrm{H}_{2}$ & 3- 51 & $8,1 \leftarrow 7,2$ & Ground & & 35004.7 & .05 \\
\hline $\mathrm{a}-\mathrm{C}^{12} \mathrm{H}_{2} \mathrm{DS} \mathbf{i}^{28} \mathrm{H}_{2} \mathrm{~F}^{19}$ & 3- 248 & $2,0,3 \leftarrow 2,0,2$ & Ground & & 35013.50 & .1 \\
\hline $\mathrm{C}^{12} \mathrm{H}_{3} \mathrm{C}^{12} \mathrm{H}_{2} \mathrm{~F}^{19}$ & 3- 551 & $2,0,2 \leftarrow 1,0,1$ & Ground & & 35024.2 & \\
\hline $\mathrm{D}_{2} \mathrm{O}_{2}^{16}$ & $3-\quad 42$ & Not Reported & & & 35028. & 3. \\
\hline$\left(\mathrm{C}^{12} \mathrm{H}_{3}\right)_{2} \mathrm{O}^{16}$ & 3- 591 & Not Reported & Ground & & 35030. & 20. \\
\hline $\mathrm{HC}^{13}: \mathrm{C}^{12} \mathrm{C}^{12} \mathrm{DO}^{16}$ & 4- 922 & Not Reported & & & 35032. & 5. \\
\hline$\left(\mathrm{C}^{12} \mathrm{H}_{3}\right)_{3} \mathrm{Si}^{28} \mathrm{Br}^{79}$ & 3. 811 & $12, \leftarrow 11$, & & & 35032.9 & .4 \\
\hline$\left(\mathrm{C}^{12} \mathrm{H}_{3}\right)_{3} \mathrm{Si}^{28} \mathrm{I}^{127}$ & 3. 841 & $16 . \leftarrow 15$ & Excited & & 35038.3 & .4 \\
\hline $\mathrm{c}-\mathrm{HDC}^{12}{ }_{*} \mathrm{O}^{16} \mathrm{C}^{12}{ }_{*} \mathrm{DH}$ & 4- 845 & $5,4,1 \leftarrow 5,3,2$ & Ground & & 35040.3 & .2 \\
\hline $\mathrm{HC}^{12} \mathrm{~N}^{14}$ & 4- 291 & $12 \leftarrow 12$ & Excited & & 35043.24 & .1 \\
\hline$\left(\mathrm{C}^{12} \mathrm{H}_{3}\right)_{3} \mathrm{Si}^{28} \mathrm{I}^{127}$ & 3- 841 & $16, \leftarrow 15$ & Excited & & 35044.9 & .4 \\
\hline$\left(\mathrm{C}^{12} \mathrm{H}_{3}\right)_{3} \mathrm{Si}^{28} \mathrm{Br}^{79}$ & 3- 811 & $12, \leftarrow 11$ & & & 35045.8 & .4 \\
\hline $\mathrm{C}^{12} \mathrm{H}_{3} \mathrm{C}^{12} \mathrm{HF}_{2}^{19}$ & 3- 461 & $3,1,3 \leftarrow 2,1,2$ & Ground & & 35049.0 & .1 \\
\hline $\mathrm{C}^{12}{ }_{*} \mathrm{H}_{2} \mathrm{C}^{12} \mathrm{HDC}^{12} \mathrm{H}_{2} \mathrm{O}^{16} *$ & $4-1094$ & $8,6,3 \leftarrow 8,4,4$ & Ground & & 35051.33 & .1 \\
\hline $\mathrm{HC}^{13}: \mathrm{C}^{12} \mathrm{C}^{12} \mathrm{DO}^{16}$ & 4- 922 & Not Reported & & & 35057. & 5. \\
\hline
\end{tabular}




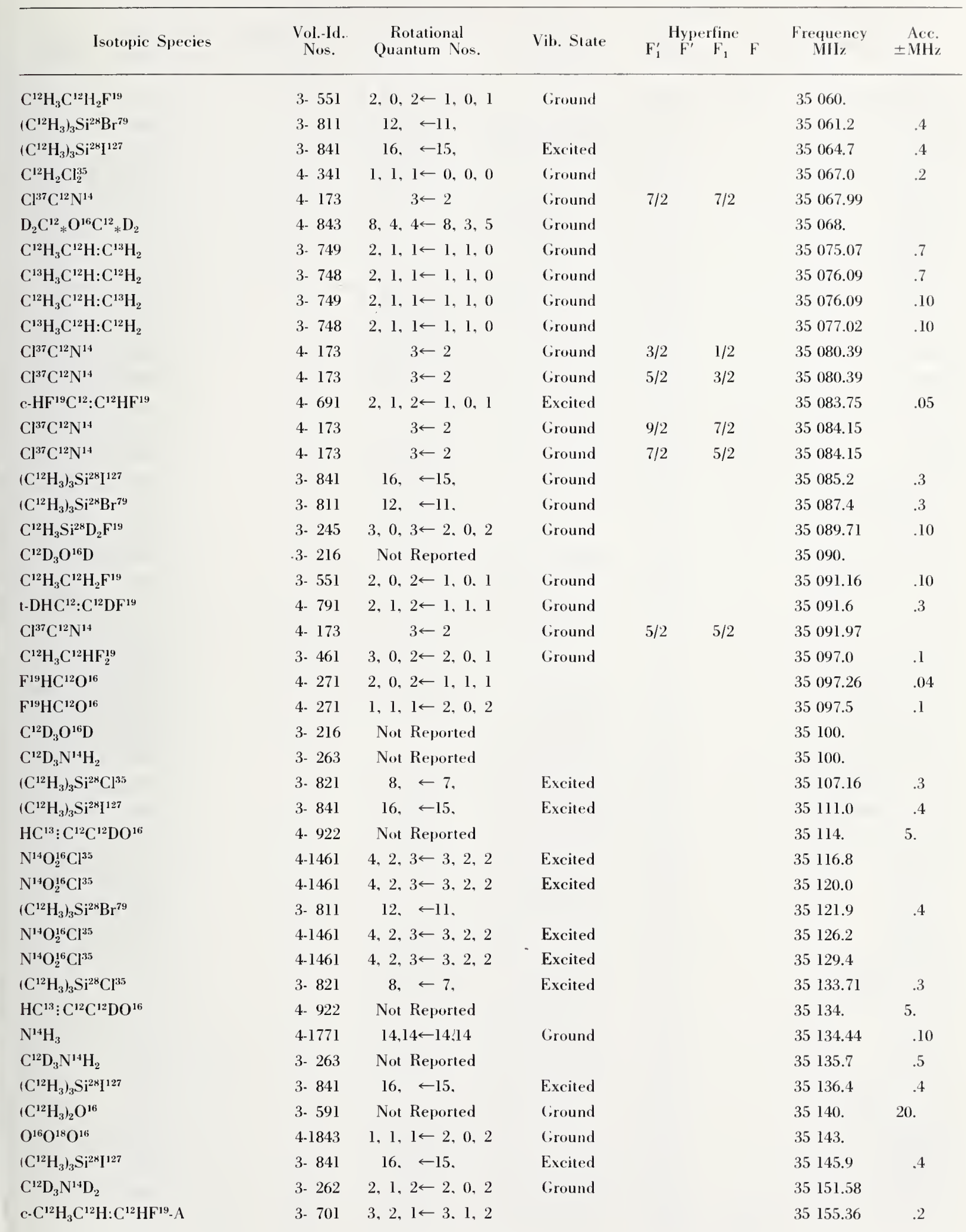




\begin{tabular}{|c|c|c|c|c|c|c|c|}
\hline Isotopic Species & $\begin{array}{l}\text { Vol.-ld. } \\
\text { Nos. }\end{array}$ & $\begin{array}{c}\text { Rotational } \\
\text { Quantum Nos. }\end{array}$ & Vib. State & $\mathrm{F}_{1}^{\prime} \stackrel{\text { Hyperfine }}{\mathrm{F}^{\prime} \quad \mathrm{F}_{1}}$ & $F$ & $\begin{array}{c}\text { Frequency } \\
\mathrm{MHz}_{\mathrm{z}}\end{array}$ & $\begin{aligned} & \text { Acc. } \\
\pm & \mathrm{MHz}\end{aligned}$ \\
\hline$\left(\mathrm{C}^{12} \mathrm{H}_{3}\right)_{3} \mathrm{Si}^{28} \mathrm{Cl}^{35}$ & 3- 821 & $8, \leftarrow 7$, & Ground & & & 35157.01 & .3 \\
\hline $\mathrm{D}_{2} \mathrm{C}^{12}: \mathrm{C}^{12} \mathrm{O}^{16}$ & 4- 712 & $26,2,24 \leftarrow 26,2,25$ & Ground & & & 35159.06 & \\
\hline $\mathrm{C}^{12} \mathrm{H}_{3} \mathrm{O}^{16} \mathrm{H}$ & 3- 211 & Not Reported & Ground & & & 35161.6 & .1 \\
\hline $\mathrm{P}^{31} \mathrm{O}^{18} \mathrm{~F}_{3}^{19}$ & $4-1672$ & $4, \leftarrow 3$, & Ground & & & 35162.0 & .5 \\
\hline $\mathrm{C}^{12} \mathrm{D}_{3} \mathrm{O}^{16} \mathrm{D}$ & 3. 216 & Not Reported & & & & 35165. & \\
\hline $\mathrm{S}^{32} \mathrm{O}^{16} \mathrm{~F}_{2}^{19}$ & $4-1621$ & Not Reported & & & & 35169.52 & .1 \\
\hline $\mathrm{C}^{12} \mathrm{D}_{3} \mathrm{~N}^{14} \mathrm{H}_{2}$ & 3- 263 & $6, \quad \leftarrow 6$, & & & & 35171.4 & .5 \\
\hline $\mathrm{C}^{13} \mathrm{HCl}^{35} \mathrm{~F}_{2}^{19}$ & 4. 253 & $3,1,2 \leftarrow 2,0,2$ & Ground & & & 35175.15 & .05 \\
\hline $\mathrm{C}^{12} \mathrm{H}_{3} \mathrm{~N}^{14} \mathrm{H}_{2}$ & 3. 261 & Not Reported & Ground & & & 35185. & \\
\hline $\mathrm{Cl}_{2}^{\mathrm{h}} \mathrm{O}^{16}$ & $4-1484$ & $13,2,11 \leftarrow 14,1,14$ & Ground & & & 35190.95 & \\
\hline$\left(\mathrm{C}^{12} \mathrm{H}_{3}\right)_{3} \mathrm{Si}^{28} \mathrm{Cl}^{35}$ & 3- 821 & $8, \leftarrow 7$, & Excited & & & 35198.47 & .3 \\
\hline $\mathrm{Cl}_{2}^{\mathrm{h}} \mathrm{O}^{16}$ & $4-1484$ & $13,2,11 \leftarrow 14,1,14$ & Ground & & & 35200.66 & \\
\hline $\mathrm{C}^{12} \mathrm{D}_{3} \mathrm{~N}^{14} \mathrm{H}_{2}$ & 3- 263 & Not Reported & & & & 35202.1 & .5 \\
\hline $\mathrm{Cl}_{2}^{\mathrm{b}} \mathrm{O}^{16}$ & $4-1484$ & $13,2,11 \leftarrow 14,1,14$ & Ground & & & 35202.77 & \\
\hline $\mathrm{Cl}_{2}^{\mathrm{b}} \mathrm{O}^{16}$ & $4-1484$ & $13,2,11 \leftarrow 14,1,14$ & Ground & & & 35204.82 & \\
\hline $\mathrm{C}^{12} \mathrm{H}_{3} \mathrm{O}^{18} \mathrm{H}$ & 3. 217 & $11,2, \leftarrow 11,1$ & Ground & & & 35206.11 & .1 \\
\hline $\mathrm{a}-\mathrm{C}^{12} \mathrm{H}_{2} \mathrm{DC}^{12} \mathrm{HO}^{16}$ & 3- 481 & $2,1,2 \leftarrow 1,1,1$ & Ground & & & 35206.37 & .5 \\
\hline $\mathrm{H}_{2} \mathrm{~N}^{14} \mathrm{~N}^{14} \mathrm{H}_{2}$ & 3. 51 & $8,1 \leftarrow 7,2$ & Ground & & & 35207.8 & \\
\hline $\mathrm{C}^{12} \mathrm{HCl}^{35} \mathrm{~F}_{2}^{19}$ & 4- 251 & $8,4,5 \leftarrow 8,3,5$ & Ground & & & 35209.96 & .04 \\
\hline $\mathrm{HC}^{13} \vdots \mathrm{C}^{12} \mathrm{C}^{12} \mathrm{DO}^{16}$ & 4- 922 & Not Reported & & & & 35210. & 5. \\
\hline $\mathrm{Cl}_{2}^{\mathrm{h}} \mathrm{O}^{16}$ & $4-1484$ & $13,2,11 \leftarrow 14,1,14$ & Ground & & & 35212.77 & \\
\hline $\mathrm{C}^{12} \mathrm{D}_{3} \mathrm{O}^{16} \mathrm{D}$ & 3- 216 & Not Reported & & & & 35215. & \\
\hline $\mathrm{H}_{2} \mathrm{~N}^{14} \mathrm{~N}^{14} \mathrm{H}_{2}$ & 3. 51 & $8,1 \leftarrow 7,2$ & Ground & & & 35219.0 & \\
\hline$\left(\mathrm{C}^{12} \mathrm{H}_{3}\right)_{3} \mathrm{Si}^{28} \mathrm{Cl}^{35}$ & 3. 821 & $8, \leftarrow 7$, & Excited & & & 35219.92 & .3 \\
\hline$\left(\mathrm{C}^{12} \mathrm{H}_{3}\right)_{2} \mathrm{C}^{12} \mathrm{O}^{16}$ & 3- 751 & $2,2,1 \leftarrow 1,1,0$ & Ground & & & 35220.0 & .04 \\
\hline $\mathrm{C}^{12} \mathrm{D}_{3} \mathrm{Si}^{\mathrm{b}} \mathrm{H}_{2} \mathrm{D}$ & 3. 329 & $2,1,1 \leftarrow 1,1,0$ & & & & 35221.73 & .2 \\
\hline $\mathrm{HC}^{13}: \mathrm{C}^{12} \mathrm{C}^{12} \mathrm{DO}^{16}$ & 4- 922 & Not Reported & & & & 35228. & 5. \\
\hline $\mathrm{C}^{12} \mathrm{H}_{3} \mathrm{C}^{12}{ }_{*} \mathrm{HO}^{16} \mathrm{C}^{12}{ }_{*} \mathrm{H}_{2}$ & 3. 761 & $23,15, \leftarrow 24,14$, & Ground & & & 35237.97 & .1 \\
\hline $\mathrm{C}^{12} \mathrm{H}_{3} \mathrm{C}^{12}{ }_{*} \mathrm{HO}^{16} \mathrm{C}^{12}{ }_{*} \mathrm{H}_{2}$ & 3- 761 & $23,15, \leftarrow 24,14$ & Ground & & & 35238.67 & .1 \\
\hline $\mathrm{C}^{12} \mathrm{H}_{3} \mathrm{C}^{12}{ }_{*} \mathrm{HO}^{16} \mathrm{C}^{12}{ }_{*} \mathrm{H}_{2}$ & 3- 761 & $23,15, \leftarrow 24,14$, & Ground & & & 35238.97 & .1 \\
\hline $\mathrm{C}^{12} \mathrm{H}_{3} \mathrm{~N}^{14} \mathrm{H}_{2}$ & 3- 261 & Not Reported & Ground & & & 35241 & \\
\hline $\mathrm{S}^{32} \mathrm{O}^{16} \mathrm{~F}_{2}^{19}$ & 4-1621 & Not Reported & & & & 35242.02 & .1 \\
\hline $\mathrm{C}^{12} \mathrm{H}_{3} \mathrm{~S}^{32} \mathrm{H}$ & 3- 221 & Not Reported & Ground & & & 35255.73 & \\
\hline $\mathrm{C}^{12} \mathrm{H}_{2} \mathrm{Cl}_{2}^{35}$ & 4- 341 & $1,1,1 \leftarrow 0,0,0$ & Excited & & & 35258. & 2. \\
\hline $\mathrm{C}^{12} \mathrm{H}_{3} \mathrm{C}^{12} \mathrm{H}_{2} \mathrm{~F}^{19}$ & 3. 551 & $6,1,5 \leftarrow 5,2,4$ & Ground & & & 35263.45 & .10 \\
\hline $\mathrm{HC}^{13}: \mathrm{C}^{12} \mathrm{C}^{12} \mathrm{DO}^{16}$ & 4- 922 & Not Reported & & & & 35267. & 5. \\
\hline $\mathrm{C}^{12} \mathrm{HCl}^{35} \mathrm{~F}_{2}^{19}$ & 4- 251 & $3,1,2 \leftarrow 2,0,2$ & Ground & $7 / 2$ & $7 / 2$ & 35275.12 & \\
\hline $\mathrm{O}^{16} \mathrm{O}^{18} \mathrm{O}^{16}$ & 4-1843 & $10,1,9 \leftarrow 9,2,8$ & Ground & & & 35280 . & \\
\hline $\mathrm{C}^{12} \mathrm{HCl}^{35} \mathrm{~F}_{2}^{19}$ & 4- 251 & $3,1,2 \leftarrow 2,0,2$ & Ground & $3 / 2$ & $1 / 2$ & 35282.61 & \\
\hline $\mathrm{C}^{12} \mathrm{HCl}^{35} \mathrm{~F}_{2}^{19}$ & 4- 251 & $3,1,2 \leftarrow 2,0,2$ & Ground & $5 / 2$ & $3 / 2$ & 35285.66 & \\
\hline $\mathrm{HC}^{13}: \mathrm{C}^{12} \mathrm{C}^{12} \mathrm{DO}^{16}$ & 4- 922 & Not Reported & & & & 35288. & 5. \\
\hline $\mathrm{C}^{12} \mathrm{HCl}^{35} \mathrm{~F}_{2}^{19}$ & 4- 251 & $3,1,2 \leftarrow 2,0,2$ & Ground & $9 / 2$ & $7 / 2$ & 35288.02 & \\
\hline $\mathrm{C}^{12} \mathrm{HCl}^{35} \mathrm{~F}_{2}^{19}$ & 4- 251 & $3,1,2 \leftarrow 2,0,2$ & Ground & & & 35288.25 & .05 \\
\hline $\mathrm{C}^{12} \mathrm{HCl}^{35} \mathrm{~F}_{2}^{19}$ & 4- 251 & $3,1,2 \leftarrow 2,0,2$ & Ground & $7 / 2$ & $5 / 2$ & 35290.94 & \\
\hline $\mathrm{C}^{12} \mathrm{HCl}^{35} \mathrm{~F}_{2}^{19}$ & 4. 251 & $3,1,2 \leftarrow 2,0,2$ & Ground & $5 / 2$ & $5 / 2$ & 35296.90 & \\
\hline
\end{tabular}




\begin{tabular}{|c|c|c|c|c|c|c|c|}
\hline Isotopic Species & $\begin{array}{l}\text { Vol.-Id. } \\
\text { Nos. }\end{array}$ & $\begin{array}{c}\text { Rotational } \\
\text { Quantum Nos. }\end{array}$ & Vib. State & $F_{1}^{\prime} F^{\prime} \quad F_{1}$ & $\mathrm{~F}$ & $\begin{array}{c}\text { Frequency } \\
\qquad \mathrm{MHz}\end{array}$ & $\begin{aligned} & \text { Acc. } \\
\pm & \mathrm{MHz}\end{aligned}$ \\
\hline $\mathrm{C}^{12} \mathrm{HCl}^{35} \mathrm{~F}_{2}^{19}$ & 4- 251 & $3,1,2 \leftarrow 2,0,2$ & Ground & $3 / 2$ & $3 / 2$ & 35298.48 & \\
\hline $\mathrm{C}^{12}{ }_{*} \mathrm{H}_{2} \mathrm{C}^{12} \mathrm{D}: \mathrm{C}^{12}{ }_{*} \mathrm{H}$ & 4-1032 & $12,7,5 \leftarrow 12,7,6$ & Ground & & & 35306.1 & \\
\hline a- $\mathrm{C}^{12} \mathrm{H}_{2} \mathrm{DSi}^{28} \mathrm{H}_{2} \mathrm{~F}^{19}$ & 3- 248 & $3,2,2 \leftarrow 2,2,1$ & Ground & & & 35315.64 & .1 \\
\hline $\mathrm{C}^{12} \mathrm{H}_{3} \mathrm{C}^{12} \mathrm{HO}^{16}$ & 3. 471 & Not Reported & & & & 35320.94 & \\
\hline $\mathrm{a} \cdot \mathrm{C}^{12} \mathrm{H}_{2} \mathrm{DC}^{12} \mathrm{HO}^{16}$ & 3- 481 & $2,1,2 \leftarrow 1,1,1$ & Ground & & & 35321.1 & .5 \\
\hline $\mathrm{C}^{12} \mathrm{D}_{3} \mathrm{~N}^{14} \mathrm{H}_{2}$ & 3- 263 & Not Reported & & & & 35324.7 & .5 \\
\hline$\left(\mathrm{C}^{12} \mathrm{H}_{3}\right)_{2} \mathrm{O}^{16}$ & 3- 591 & $4,1,3 \leftarrow 4,0,4$ & Excited & & & 35325. & 20. \\
\hline $\mathrm{HDO}_{2}^{16}$ & 3. 43 & $9, \quad \leftarrow 9, \quad$, & & & & 35332 . & 3. \\
\hline $\mathrm{C}^{12}{ }_{*} \mathrm{H}_{2} \mathrm{~N}^{14} \mathrm{HC}^{12}{ }_{*} \mathrm{H}_{2}$ & 4. 861 & $3,3,0 \leftarrow 3,2,2$ & Ground & & & 35334.4 & .5 \\
\hline$\left(\mathrm{C}^{12} \mathrm{H}_{3}\right)_{2} \mathrm{O}^{16}$ & 3- 591 & $4,1,3 \leftarrow 4,0,4$ & Excited & & & 35335. & 20. \\
\hline $\mathrm{C}^{12} \mathrm{D}_{3} \mathrm{O}^{16} \mathrm{D}$ & 3. 216 & Not Reported & & & & 35335. & \\
\hline $\mathrm{D}_{2} \mathrm{C}^{12} * \mathrm{O}^{16} \mathrm{C}^{12} * \mathrm{D}_{2}$ & 4. 843 & $3,3,1 \leftarrow 3,2,2$ & Ground & & & 35341. & \\
\hline $\mathrm{C}^{12} \mathrm{~F}_{3}^{19} \mathrm{C}^{12} \mathrm{~N}^{14}$ & 4- 591 & $6,5 \leftarrow 5,5$ & Ground & 6 & 5 & 35343.50 & \\
\hline $\mathrm{C}^{12} \mathrm{~F}_{3}^{19} \mathrm{C}^{12} \mathrm{~N}^{14}$ & 4- 591 & $6,4 \leftarrow 5,4$ & Ground & 6 & 5 & 35344.44 & \\
\hline $\mathrm{C}^{12} \mathrm{~F}_{3}^{19} \mathrm{C}^{12} \mathrm{~N}^{14}$ & 4- 591 & $6,5 \leftarrow 5,5$ & Ground & 7 & 6 & 35344.65 & \\
\hline $\mathrm{C}^{12} \mathrm{~F}_{3}^{19} \mathrm{C}^{12} \mathrm{~N}^{14}$ & 4. 591 & $6,5 \leftarrow 5,5$ & Ground & 5 & 4 & 35344.91 & \\
\hline $\mathrm{C}^{12} \mathrm{~F}_{3}^{19} \mathrm{C}^{12} \mathrm{~N}^{14}$ & 4. 591 & $6,4 \leftarrow 5,4$ & Ground & 7 & 6 & 35345.15 & \\
\hline $\mathrm{C}^{12} \mathrm{~F}_{3}^{19} \mathrm{C}^{12} \mathrm{~N}^{14}$ & 4. 591 & $6,4 \leftarrow 5,4$ & Ground & 5 & 4 & 35345.15 & \\
\hline $\mathrm{C}^{12} \mathrm{~F}_{3}^{19} \mathrm{C}^{12} \mathrm{~N}^{14}$ & 4- 591 & $6,3 \leftarrow 5,3$ & Ground & 6 & 5 & 35345.15 & \\
\hline $\mathrm{D}_{2} \mathrm{C}^{12}: \mathrm{C}^{12} \mathrm{O}^{16}$ & 4- 712 & $2,0,2 \leftarrow 1,0,1$ & Ground & & & 35345.20 & \\
\hline $\mathrm{C}^{12} \mathrm{~F}_{3}^{19} \mathrm{C}^{12} \mathrm{~N}^{14}$ & 4. 591 & $6,2 \leftarrow 5,2$ & Ground & 6 & 5 & 35345.60 & \\
\hline $\mathrm{C}^{12} \mathrm{~F}_{3}^{19} \mathrm{C}^{12} \mathrm{~N}^{14}$ & 4- 591 & $6,3 \leftarrow 5,3$ & Ground & 6 & 5 & 35345.60 & \\
\hline $\mathrm{C}^{12} \mathrm{~F}_{3}^{19} \mathrm{C}^{12} \mathrm{~N}^{14}$ & 4- 591 & $6,3 \leftarrow 5,3$ & Ground & 7 & 6 & 35345.60 & \\
\hline $\mathrm{C}^{12} \mathrm{~F}_{3}^{19} \mathrm{C}^{12} \mathrm{~N}^{14}$ & 4- 591 & $6,2 \leftarrow 5,2$ & Ground & 5 & 4 & 35345.90 & \\
\hline $\mathrm{C}^{12} \mathrm{~F}_{3}^{19} \mathrm{C}^{12} \mathrm{~N}^{14}$ & 4- 591 & $6,2 \leftarrow 5,2$ & Ground & 6 & 5 & 35345.90 & \\
\hline $\mathrm{C}^{12} \mathrm{~F}_{3}^{19} \mathrm{C}^{12} \mathrm{~N}^{14}$ & 4. 591 & $6,0 \leftarrow 5,0$ & Ground & 6 & 5 & 35346.03 & \\
\hline $\mathrm{C}^{12} \mathrm{~F}_{3}^{19} \mathrm{C}^{12} \mathrm{~N}^{14}$ & 4- 591 & $6,1 \leftarrow 5,1$ & Ground & 7 & 6 & 35346.03 & \\
\hline $\mathrm{C}^{12} \mathrm{~F}_{3}^{19} \mathrm{C}^{12} \mathrm{~N}^{14}$ & 4. 591 & $6,0 \leftarrow 5,0$ & Ground & 5 & 4 & 35346.03 & \\
\hline $\mathrm{C}^{12} \mathrm{~F}_{3}^{19} \mathrm{C}^{12} \mathrm{~N}^{14}$ & 4. 591 & $6,1 \leftarrow 5,1$ & Ground & 6 & 5 & 35346.03 & \\
\hline $\mathrm{C}^{12} \mathrm{~F}_{3}^{19} \mathrm{C}^{12} \mathrm{~N}^{14}$ & 4. 591 & $6,0 \leftarrow 5,0$ & Ground & 7 & 6 & 35346.03 & \\
\hline $\mathrm{C}^{12} \mathrm{~F}_{3}^{19} \mathrm{C}^{12} \mathrm{~N}^{14}$ & 4. 591 & $6,1 \leftarrow 5,1$ & Ground & 5 & 4 & 35346.03 & \\
\hline $\mathrm{HC}^{13}: \mathrm{C}^{12} \mathrm{C}^{12} \mathrm{DO}^{16}$ & 4- 922 & Not Reported & & & & 35350. & 5. \\
\hline $\mathrm{c}-\mathrm{HDC}^{12}{ }_{*} \mathrm{O}^{16} \mathrm{C}^{12} * \mathrm{DH}$ & 4- 845 & $1,1,1 \leftarrow 0,0,0$ & Ground & & & 35350.54 & .05 \\
\hline $\mathrm{HC}^{13}: \mathrm{C}^{12} \mathrm{C}^{12} \mathrm{DO}^{16}$ & 4- 922 & Not Reported & & & & 35355. & 5. \\
\hline$\left(\mathrm{C}^{12} \mathrm{H}_{3}\right)_{2} \mathrm{C}^{12} \mathrm{O}^{16}$ & 3- 751 & $2,2,1 \leftarrow 1,1,0$ & Ground & & & 35371.46 & .04 \\
\hline $\mathrm{C}^{12} \mathrm{H}_{3} \mathrm{~S}^{32} \mathrm{H}$ & 3. 221 & Not Reported & G'round & & & 35373.8 & \\
\hline$\left(\mathrm{C}^{12} \mathrm{H}_{3}\right)_{2} \mathrm{C}^{12} \mathrm{O}^{16}$ & 3- 751 & $2,2,1 \leftarrow 1,1,0$ & Ground & & & 35381.40 & .04 \\
\hline $\mathrm{D}_{2} \mathrm{C}^{12}: \mathrm{C}^{12} \mathrm{O}^{16}$ & 4- 712 & $1,0,1 \leftarrow 0,0,0$ & Excited & & & 35383.36 & \\
\hline $\mathrm{D}_{2} \mathrm{~N}^{14} \mathrm{C}^{12} \mathrm{~N}^{14}$ & 4- 363 & $2,1,2 \leftarrow 1,1,1$ & Ground & & & 35385.5 & .5 \\
\hline $\mathrm{D}_{2} \mathrm{C}^{12}: \mathrm{C}^{12} \mathrm{O}^{16}$ & 4- 712 & $2,0,2 \leftarrow 1,0,1$ & Excited & & & 35388.20 & \\
\hline$\left(\mathrm{C}^{12} \mathrm{H}_{3}\right)_{2} \mathrm{O}^{16}$ & 3- 591 & $4,1,3 \leftarrow 4,0,4$ & Excited & & & 35390. & 20. \\
\hline $\mathrm{HC}^{13}: \mathrm{C}^{12} \mathrm{C}^{12} \mathrm{DO}^{16}$ & 4- 922 & Not Reported & & & & 35392. & 5. \\
\hline $\mathrm{C}^{12} \mathrm{H}_{3} \mathrm{Si}^{24} \mathrm{Cl}_{3}^{35}$ & 3- 111 & $10 . \leftarrow 9$, & Excited & & & 35396.71 & .5 \\
\hline$\left(\mathrm{C}^{12} \mathrm{H}_{3}\right)_{3} \mathrm{C}^{13} \mathrm{Cl}^{37}$ & 3- 974 & $6, \leftarrow 5$ & Ground & & & 35397.3 & \\
\hline $\mathrm{Cl}^{35} \mathrm{O}_{2}^{16}$ & $4-1381$ & $16,2,15 \leftarrow 15,3.12$ & Ground & $29 / 2$ & $27 / 2$ & 35399.6 & \\
\hline
\end{tabular}




\begin{tabular}{|c|c|c|c|c|c|c|c|}
\hline Isotopic Species & $\begin{array}{l}\text { Vol.-Id. } \\
\text { Nos. }\end{array}$ & $\begin{array}{c}\text { Rotational } \\
\text { Quantum Nos. }\end{array}$ & Vib. State & $\mathrm{F}_{1}^{\prime} \quad \mathrm{F}^{\prime} \quad \mathrm{F}_{1}$ & $\mathrm{~F}$ & $\begin{array}{c}\text { Frequency } \\
\mathrm{MHz}\end{array}$ & $\begin{aligned} & \text { Acc. } \\
\pm & \mathrm{MHz}\end{aligned}$ \\
\hline $\mathrm{Cl}^{35} \mathrm{O}_{2}^{16}$ & $4-1381$ & $9,3,6 \leftarrow 10,2,9$ & Ground & & & 35399.6 & .05 \\
\hline $\mathrm{Cl}^{37} \mathrm{O}_{2}^{16}$ & 4-1382 & $4,0,4 \leftarrow 3,1,3$ & Ground & & & 35399.6 & \\
\hline $\mathrm{C}^{12} \mathrm{H}_{3} \mathrm{C}^{12}{ }_{*} \mathrm{HO}^{16} \mathrm{C}^{12}{ }_{*} \mathrm{H}_{2}$ & 3- 761 & $48,24, \quad \leftarrow 47,25$, & Ground & & & 35400.94 & .1 \\
\hline $\mathrm{C}^{12} \mathrm{H}_{3} \mathrm{C}^{12}{ }_{*} \mathrm{HO}^{16} \mathrm{C}^{12}{ }_{*} \mathrm{H}_{2}$ & 3- 761 & $48,24, \quad \leftarrow 47,25$, & Ground & & & 35401.45 & .1 \\
\hline $\mathrm{C}^{12} \mathrm{H}_{3} \mathrm{C}^{12}{ }_{*} \mathrm{HO}^{16} \mathrm{C}^{12}{ }_{*} \mathrm{H}_{2}$ & 3. 761 & $24,11, \leftarrow 23,12$, & Ground & & & 35402.99 & .1 \\
\hline $\mathrm{C}^{12} \mathrm{H}_{3} \mathrm{C}^{12} * \mathrm{HO}^{16} \mathrm{C}^{12} * \mathrm{H}_{2}$ & 3. 761 & $24,11, \leftarrow 23,12$, & Ground & & & 35403.15 & .1 \\
\hline $\mathrm{C}^{12} \mathrm{H}_{3} \mathrm{C}^{12}{ }_{*} \mathrm{HO}^{16} \mathrm{C}^{12}{ }_{*} \mathrm{H}_{2}$ & 3. 761 & $24,11, \leftarrow 23,12$, & Ground & & & 35403.83 & .1 \\
\hline $\mathrm{C}^{12} \mathrm{HCl}^{37} \mathrm{~F}_{2}^{19}$ & 4- 252 & $2,2,1 \leftarrow 1,1,1$ & Ground & $3 / 2$ & $3 / 2$ & 35412.78 & \\
\hline $\mathrm{As}^{75} \mathrm{H}_{2} \mathrm{D}$ & 4- 32 & $1,1,1 \leftarrow 1,0,1$ & Ground & $1 / 2$ & $3 / 2$ & 35413.79 & \\
\hline $\mathrm{C}^{12} \mathrm{HCl}^{37} \mathrm{~F}_{2}^{19}$ & 4- 252 & $2,2,1 \leftarrow 1,1,1$ & Ground & $7 / 2$ & $5 / 2$ & 35416.22 & \\
\hline $\mathrm{Cl}^{35} \mathrm{O}_{2}^{16}$ & 4-1381 & $9,3,6 \leftarrow 10,2,9$ & Ground & & & 35418.5 & .05 \\
\hline $\mathrm{C}^{12} \mathrm{HCl}^{37} \mathrm{~F}_{2}^{19}$ & 4- 252 & $2,2,1 \leftarrow 1,1,1$ & Ground & & & 35418.51 & .10 \\
\hline $\mathrm{Cl}^{35} \mathrm{O}_{2}^{16}$ & 4-1381 & $9,3,6 \leftarrow 10,2,9$ & Ground & & & 35418.7 & .05 \\
\hline $\mathrm{Cl}^{35} \mathrm{O}_{2}^{16}$ & 4. 1381 & $16,2,15 \leftarrow 15,3,12$ & Ground & $31 / 2$ & $29 / 2$ & 35418.8 & \\
\hline $\mathrm{Cl}^{37} \mathrm{O}_{2}^{16}$ & 4. 1382 & $4,0,4 \leftarrow 3,1,3$ & Ground & & & 35418.8 & \\
\hline $\mathrm{HC}^{13}: \mathrm{C}^{12} \mathrm{C}^{12} \mathrm{DO}^{16}$ & 4- 922 & Not Reported & & & & 35420 . & 5. \\
\hline $\mathrm{D}_{2} \mathrm{~N}^{14} \mathrm{C}^{12} \mathrm{~N}^{14}$ & 4. 363 & $2,1,2 \leftarrow 1,1,1$ & Excited & & & 35422.0 & .5 \\
\hline $\mathrm{C}^{12} \mathrm{HCl}^{37} \mathrm{~F}_{2}^{19}$ & 4- 252 & $2,2,1 \leftarrow 1,1,1$ & Ground & $5 / 2$ & $3 / 2$ & 35422.15 & \\
\hline $\mathrm{C}^{12} \mathrm{HCl}^{37} \mathrm{~F}_{2}^{19}$ & 4. 252 & $2,2,1 \leftarrow 1,1,1$ & Ground & $3 / 2$ & $1 / 2$ & 35425.55 & \\
\hline $\mathrm{D}_{2} \mathrm{~N}^{14} \mathrm{C}^{12} \mathrm{~N}^{14}$ & 4. 363 & $2,1,2 \leftarrow 1,1,1$ & Excited & & & 35425.8 & .2 \\
\hline $\mathrm{C}^{12} \mathrm{HCl}^{37} \mathrm{~F}_{2}^{19}$ & 4. 252 & $2,2,1 \leftarrow 1,1,1$ & Ground & $5 / 2$ & $5 / 2$ & 35429.16 & \\
\hline $\mathrm{As}^{75} \mathrm{H}_{2} \mathrm{D}$ & 4- 32 & $1,1,1 \leftarrow 1,0,1$ & Ground & $5 / 2$ & $3 / 2$ & 35430.10 & \\
\hline $\mathrm{N}^{14} \mathrm{O}_{2}^{16} \mathrm{Cl}^{35}$ & $4-1461$ & $4,2,3 \leftarrow 3,2,2$ & Ground & $9 / 2$ & $9 / 2$ & 35433.63 & \\
\hline $\mathrm{HC}^{13}: \mathrm{C}^{12} \mathrm{C}^{12} \mathrm{DO}^{16}$ & 4- 922 & Not Reported & & & & 35 435: & 5. \\
\hline $\mathrm{As}^{75} \mathrm{H}_{2} \mathrm{D}$ & 4. 32 & $1,1,1 \leftarrow 1,0,1$ & Ground & $5 / 2$ & $5 / 2$ & 35435.19 & \\
\hline $\mathrm{N}^{14} \mathrm{O}_{2}^{16} \mathrm{Cl}^{35}$ & 4-1461 & $4,2,3 \leftarrow 3,2,2$ & Ground & $7 / 2$ & $7 / 2$ & 35436.91 & \\
\hline $\mathrm{C}^{12} \mathrm{D}_{3} \mathrm{O}^{16} \mathrm{D}$ & 3- 216 & Not Reported & & & & 35440 . & \\
\hline c-HDC ${ }^{12}: \mathrm{C}^{12} \mathrm{DF}^{19}$ & 4. 789 & $2,0,2 \leftarrow 1,0,1$ & Ground & & & 35441.4 & .3 \\
\hline$\left(\mathrm{C}^{12} \mathrm{H}_{3}\right)_{3} \mathrm{C}^{12} \mathrm{Cl}^{37}$ & $3 \cdot 972$ & $6, \leftarrow 5$, & Ground & & & 35442.3 & .3 \\
\hline $\mathrm{N}^{14} \mathrm{O}_{2}^{16} \mathrm{Cl}^{35}$ & 4-1461 & $4,2,3 \leftarrow 3,2,2$ & Ground & $11 / 2$ & $11 / 2$ & 35443.08 & \\
\hline $\mathrm{Cl}^{35} \mathrm{O}_{2}^{16}$ & $4-1381$ & $16,2,15 \leftarrow 15,3,12$ & Ground & $33 / 2$ & $31 / 2$ & 35444.0 & \\
\hline $\mathrm{Cl}^{37} \mathrm{O}_{2}^{16}$ & 4-1382 & $4,0,4 \leftarrow 3,1,3$ & Ground & & & 35444.0 & \\
\hline $\mathrm{N}^{14} \mathrm{O}_{2}^{16} \mathrm{Cl}^{35}$ & $4-1461$ & $4,2,3 \leftarrow 3,2,2$ & Ground & $5 / 2$ & $5 / 2$ & 35446.36 & \\
\hline $\mathrm{Cl}^{35} \mathrm{O}_{2}^{16}$ & $4 \cdot 1381$ & $9,3,6 \leftarrow 10,2,9$ & Ground & & & 35447.1 & .05 \\
\hline$A s^{75} \mathrm{H}_{2} \mathrm{D}$ & 4. 32 & $1,1,1 \leftarrow 1,0,1$ & Ground & $3 / 2$ & $3 / 2$ & 35450.51 & \\
\hline $\mathrm{C}^{12} \mathrm{H}_{2} \mathrm{Cl}_{2}^{35}$ & 4- 341 & $1,1,1 \leftarrow 0,0,0$ & Excited & & & 35451. & 5. \\
\hline $\mathrm{D}_{2} \mathrm{C}^{12}: \mathrm{C}^{12} \mathrm{O}^{16}$ & 4. 712 & $2,0,2 \leftarrow 1,0,1$ & Excited & & & 35451.85 & \\
\hline $\mathrm{O}^{16} \mathrm{~F}_{2}^{19}$ & 4-1611 & $19,3,17 \leftarrow 18,4,14$ & Ground & & & 35455.35 & .10 \\
\hline $\mathrm{As}^{75} \mathrm{H}_{2} \mathrm{D}$ & 4- $\quad 32$ & $1,1,1 \leftarrow 1,0,1$ & Ground & $3 / 2$ & $5 / 2$ & 35455.64 & \\
\hline $\mathrm{Cl}^{35} \mathrm{O}_{2}^{16}$ & 4-1381 & $9,3,6 \leftarrow 10,2,9$ & Ground & & & 35456.1 & .05 \\
\hline $\mathrm{C}^{12} \mathrm{H}_{2} \mathrm{~F}^{19} \mathrm{C}^{12} \mathrm{~N}^{14}$ & 4- 701 & $5,1,4 \leftarrow 5,0,5$ & Ground & & & 35457.5 & .2 \\
\hline $\mathrm{Cl}^{35} \mathrm{O}_{2}^{16}$ & 4-1381 & $9,3,6 \leftarrow 10,2,9$ & Ground & & & 35457.9 & .05 \\
\hline $\mathrm{Cl}^{35} \mathrm{O}_{2}^{16}$ & 4-1381 & $9,3,6 \leftarrow 10,2,9$ & Ground & & & 35459.6 & .05 \\
\hline $\mathrm{As}^{75} \mathrm{H}_{2} \mathrm{D}$ & 4. 32 & $1,1,1 \leftarrow 1,0,1$ & Ground & $3 / 2$ & $1 / 2$ & 35460.08 & \\
\hline $\mathrm{HC}^{12}: \mathrm{C}^{12} \mathrm{C}^{12} \mathrm{H}: \mathrm{C}^{12} \mathrm{H}_{2}$ & 4-1131 & $4,1,4 \leftarrow 3,1,3$ & Ground & & & 35463.23 & \\
\hline
\end{tabular}




\begin{tabular}{|c|c|c|c|c|c|c|c|c|}
\hline Isotopic Species & $\begin{array}{l}\text { Vol.-Id. } \\
\text { Nos. }\end{array}$ & $\begin{array}{c}\text { Rotational } \\
\text { Quantum Nos. }\end{array}$ & Vib. State & $\mathrm{F}_{1}^{\prime}$ & $\begin{array}{c}\text { Hyperfine } \\
\mathrm{F}^{\prime} \quad \mathrm{F}_{\mathrm{i}}\end{array}$ & $\mathrm{F}$ & $\begin{array}{c}\text { Frequency } \\
\text { MH } \%\end{array}$ & $\begin{aligned} & \text { Acc. } \\
& \pm \mathrm{MHz}\end{aligned}$ \\
\hline $\mathrm{D}_{2} \mathrm{O}_{2}^{16}$ & 3. 42 & Not Reported & & & & & 35466 . & 3. \\
\hline$\left(\mathrm{C}^{12} \mathrm{H}_{3}\right)_{2} \mathrm{C}^{12} \mathrm{O}^{16}$ & 3- 751 & $2,2,1 \leftarrow 1,1,0$ & Ground & & & & 35468.06 & .04 \\
\hline $\mathrm{Cl}^{35} \mathrm{O}_{2}^{16}$ & 4-1381 & $9,3,6 \leftarrow 10,2,9$ & Ground & & & & 35475.3 & .05 \\
\hline $\mathrm{Cl}^{35} \mathrm{O}_{2}^{16}$ & $4-1381$ & $16,2,15 \leftarrow 15,3,12$ & Ground & & $35 / 2$ & $33 / 2$ & 35477.4 & \\
\hline $\mathrm{Cl}^{37} \mathrm{O}_{2}^{16}$ & 4-1382 & $4,0,4 \leftarrow 3,1,3$ & Ground & & & & 35477.4 & \\
\hline $\mathrm{C}^{12} \mathrm{H}_{3} \mathrm{O}^{16} \mathrm{H}$ & 3- 211 & Not Reported & Ground & & & & 35478.55 & .1 \\
\hline $\mathrm{C}^{\mathrm{b}}{ }_{*} \mathrm{H}_{2}^{\mathrm{b}} \mathrm{N}^{\mathrm{b}} \mathrm{H}^{\mathrm{b}} \mathrm{C}^{\mathrm{b}}{ }_{*} \mathrm{H}_{2}^{\mathrm{b}}$ & 4. 863 & Not Reported & & & & & 35480. & 10. \\
\hline $\mathrm{C}^{12} \mathrm{H}_{3} \mathrm{Si}^{28} \mathrm{D}_{2} \mathrm{~F}^{19}$ & 3. 245 & $3,2,2 \leftarrow 2,2,1$ & Ground & & & & 35485.60 & .10 \\
\hline $\mathrm{HC}^{13} \vdots \mathrm{C}^{12} \mathrm{C}^{12} \mathrm{DO}^{16}$ & 4. 922 & Not Reported & & & & & 35486 . & 5. \\
\hline $\mathrm{HC}^{13}: \mathrm{C}^{12} \mathrm{C}^{12} \mathrm{DO}^{16}$ & 4- 922 & Not Reported & & & & & 35493. & 5. \\
\hline $\mathrm{Cl}^{35} \mathrm{O}_{2}^{16}$ & 4-1381 & $9,3,6 \leftarrow 10,2,9$ & Ground & & & & 35495.7 & .05 \\
\hline $\mathrm{Cl}^{37} \mathrm{O}_{2}^{16}$ & 4.1382 & $4,0,4 \leftarrow 3,1,3$ & Ground & & & & 35496.4 & \\
\hline $\mathrm{C}^{12} \mathrm{Cl}_{3}^{37} \mathrm{C}^{12} \mathrm{~N}^{14}$ & 4. 584 & $11, \leftarrow 10$ & Ground & & & & 35499.4 & 1.0 \\
\hline $\mathrm{C}^{12} \mathrm{H}_{3} \mathrm{~N}^{14} \mathrm{O}_{2}^{16}$ & 3- 171 & Not Reported & Ground & & & & 35511.81 & \\
\hline $\mathrm{HDC}^{12}: \mathrm{C}^{12} \mathrm{~F}_{2}^{19}$ & 4- 682 & $3,1,3 \leftarrow 2,1,2$ & Ground & & & & 35512.2 & .3 \\
\hline $\mathrm{C}^{13} \mathrm{H}_{3} \mathrm{Si}^{28} \mathrm{H}_{2} \mathrm{~F}^{19}$ & 3- 249 & $3,0,3 \leftarrow 2,0,2$ & Ground & & & & 35514.66 & .10 \\
\hline $\mathrm{D}_{2} \mathrm{O}_{2}^{16}$ & 3- 42 & Not Reported & & & & & 35515. & 3. \\
\hline $\mathrm{C}^{12}{ }_{*} \mathrm{H}_{2} \mathrm{~S}^{32} \mathrm{C}^{12}{ }_{*} \mathrm{H}_{2}$ & 4- 851 & $7,2,6 \leftarrow 7,2,5$ & Ground & & & & 35515.3 & \\
\hline $\mathrm{HC}^{13}: \mathrm{C}^{12} \mathrm{C}^{12} \mathrm{DO}^{16}$ & 4. 922 & Not Reported & & & & & 35518. & 5. \\
\hline $\mathrm{C}^{12} \mathrm{H}_{3} \mathrm{~S}^{32} \mathrm{H}$ & 3. 221 & Not Reported & Ground & & & & 35521.54 & \\
\hline $\mathrm{C}^{12} \mathrm{H}_{3} \mathrm{~N}^{14} \mathrm{O}_{2}^{16}$ & 3. 171 & Not Reported & Ground & & & & 35521.62 & \\
\hline$\left(\mathrm{C}^{12} \mathrm{H}_{3}\right)_{2} \mathrm{O}^{16}$ & 3- 591 & $4,1,3 \leftarrow 4,0,4$ & Excited & & & & 35525 . & 20. \\
\hline I. $\mathrm{C}^{12} \mathrm{H}_{3} \mathrm{C}^{12} \mathrm{H}: \mathrm{C}^{12} \mathrm{HC}^{12} \mathrm{~N}^{14}$ & 3- 921 & $8,1, \leftarrow 7,1$, & Ground & & & & 35526.03 & .5 \\
\hline $\mathrm{t}-\mathrm{HDC}^{12}{ }_{*} \mathrm{O}^{16} \mathrm{C}^{12}{ }_{*} \mathrm{HD}$ & 4- 844 & $1,1,1 \leftarrow 0,0,0$ & Ground & & & & 35528.56 & .05 \\
\hline $\mathrm{C}^{12} \mathrm{H}_{3} \mathrm{C}^{12}{ }_{*} \mathrm{HO}^{16} \mathrm{C}^{12}{ }_{*} \mathrm{H}_{2}$ & 3. 761 & $12,2,10 \leftarrow 12,1,11$ & Ground & & & & 35537.88 & .1 \\
\hline $\mathrm{C}^{12}{ }_{*} \mathrm{H}_{2}^{\mathrm{b}} \mathrm{S}^{\mathrm{b}} \mathrm{C}^{12}{ }_{*} \mathrm{H}_{2}^{\mathrm{b}}$ & 4- 854 & Not Reported & & & & & 35538.0 & .5 \\
\hline $\mathrm{C}^{12} \mathrm{HCl}^{35} \mathrm{~F}_{2}^{19}$ & 4- 251 & $2,2,1 \leftarrow 1,1,1$ & Ground & & $1 / 2$ & $3 / 2$ & 35541.81 & \\
\hline $\mathrm{C}^{12} \mathrm{H}_{3} \mathrm{~S}^{32} \mathrm{H}$ & 3- 221 & Not Reported & Ground & & & & 35543.34 & \\
\hline $\mathrm{Cl}^{37} \mathrm{O}_{2}^{16}$ & 4.1382 & $4,0,4 \leftarrow 3,1,3$ & Ground & & & & 35545.2 & \\
\hline $\mathrm{Cl}^{35} \mathrm{O}_{2}^{16}$ & $4-1381$ & $9,3,6 \leftarrow 10,2,9$ & Ground & & & & 35545.3 & .05 \\
\hline $\mathrm{C}^{12} \mathrm{H}_{3} \mathrm{~S}^{32} \mathrm{H}$ & 3- 221 & Not Reported & Ground & & & & 35547.33 & \\
\hline$\left(\mathrm{C}^{12} \mathrm{H}_{3}\right)_{2} \mathrm{O}^{16}$ & 3- 591 & $4,1,3 \leftarrow 4,0,4$ & Excited & & & & 35550. & 20. \\
\hline $\mathrm{C}^{12} \mathrm{H}_{3} \mathrm{~S}^{32} \mathrm{H}$ & 3- 221 & Not Reported & Ground & & & & 35552.2 & \\
\hline $\mathrm{C}^{12} \mathrm{HCl}^{35} \mathrm{~F}_{2}^{19}$ & 4- 251 & $2,2,1 \leftarrow 1,1,1$ & Ground & & $3 / 2$ & $3 / 2$ & 35557.98 & \\
\hline $\mathrm{D}_{2} \mathrm{O}_{2}^{16}$ & $3-\quad 42$ & Not Reported & & & & & 35560. & 3. \\
\hline $\mathrm{C}^{12} \mathrm{HCl}^{35} \mathrm{~F}_{2}^{19}$ & 4. 251 & $2,2,1 \leftarrow 1,1,1$ & Ground & & $7 / 2$ & $5 / 2$ & 35562.30 & \\
\hline $\mathrm{C}^{12} \mathrm{HCl}^{35} \mathrm{~F}_{2}^{19}$ & 4. 251 & $2,2,1 \leftarrow 1,1,1$ & Ground & & & & 35565.3 & .2 \\
\hline $\mathrm{C}^{12} \mathrm{H}_{3} \mathrm{C}^{12}{ }_{*} \mathrm{HO}^{16} \mathrm{C}^{12}{ }_{*} \mathrm{H}_{2}$ & 3- 761 & $2,1,2 \leftarrow 1,0,1$ & Ground & & & & 35566.15 & .1 \\
\hline $\mathrm{C}^{12} \mathrm{H}_{3} \mathrm{C}^{12}{ }_{*} \mathrm{HO}^{16} \mathrm{C}^{12}{ }_{*} \mathrm{H}_{2}$ & 3- 761 & Not Reported & Ground & & & & 35571.32 & .1 \\
\hline $\mathrm{S}^{32} \mathrm{O}^{16} \mathrm{~F}_{2}^{19}$ & 4-1621 & Not Reported & & & & & 35574.23 & .1 \\
\hline$\left(\mathrm{C}^{12} \mathrm{H}_{3}\right)_{2} \mathrm{O}^{16}$ & 3- 591 & $4,1,3 \leftarrow 4,0,4$ & Excited & & & & 35575. & 20. \\
\hline $\mathrm{C}^{12} \mathrm{H}_{2}: \mathrm{C}^{12} \mathrm{HC}^{12} \mathrm{HO}^{16}$ & 3. 691 & $4,0,4 \leftarrow 3,0,3$ & Ground & & & & 35577.96 & \\
\hline $\mathrm{HC}^{13}: \mathrm{C}^{12} \mathrm{C}^{12} \mathrm{DO}^{16}$ & 4. 922 & Not Reported & & & & & 35578. & 5. \\
\hline $\mathrm{C}^{12} \mathrm{HCl}^{35} \mathrm{~F}_{2}^{19}$ & 4- 251 & $2,2,1 \leftarrow 1,1,1$ & Ground & & $5 / 2$ & $5 / 2$ & 35578.59 & \\
\hline $\mathrm{D}_{2} \mathrm{~N}^{15} \mathrm{C}^{12} \mathrm{HO}^{16}$ & 3- 161 & $2,1,2 \leftarrow 1,1,1$ & Ground & & & & 35586.15 & \\
\hline
\end{tabular}




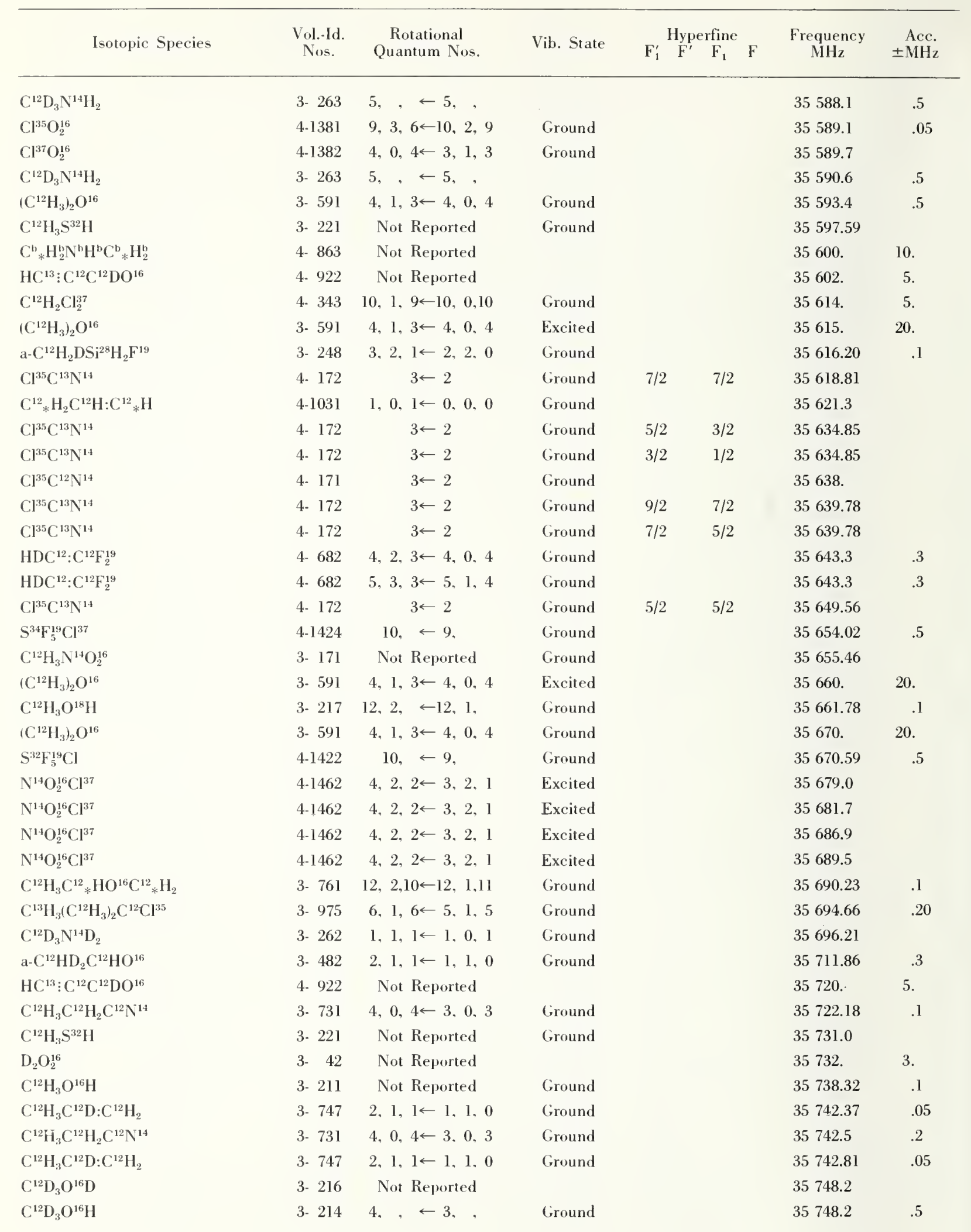




\begin{tabular}{|c|c|c|c|c|c|c|c|c|c|}
\hline Isotopic Species & $\begin{array}{l}\text { Vol.-Id. } \\
\text { Nos. }\end{array}$ & $\begin{array}{c}\text { Rotational } \\
\text { Quantum Nos. }\end{array}$ & Vib. State & $F_{1}^{\prime}$ & $\begin{array}{c}\text { Hyp } \\
F^{\prime}\end{array}$ & rfine & $\mathbf{F}$ & $\begin{array}{l}\text { Frequency } \\
: \mathrm{MH} \%\end{array}$ & $\begin{aligned} & \text { Acc. } \\
\pm & \mathrm{MH} z\end{aligned}$ \\
\hline $\mathrm{C}^{\mathrm{b}}{ }_{*} \mathrm{H}_{2}^{\mathrm{b}} \mathrm{N}^{\mathrm{b}} \mathrm{H}^{\mathrm{h}} \mathrm{C}^{\mathrm{b}}{ }_{*} \mathrm{H}_{2}^{\mathrm{b}}$ & 4- 863 & Not Reported & & & & & & 35750 . & 10. \\
\hline $\mathrm{HDC}^{12}: \mathrm{C}^{12} \mathrm{~F}_{2}^{19}$ & 4- 682 & $3,0,3 \leftarrow 2,0,2$ & Ground & & & & & 35751.8 & .3 \\
\hline $\mathrm{C}^{12} \mathrm{H}_{2}: \mathrm{C}^{12} \mathrm{HC}^{12} \mathrm{HO}^{16}$ & 3- 691 & $4,0,4 \leftarrow 3,0,3$ & Cround & & & & & 35752.72 & \\
\hline $\mathrm{C}^{12} \mathrm{H}_{3} \mathrm{~S}^{32} \mathrm{H}$ & 3- 221 & Not Reported & Ground & & & & & 35754.19 & \\
\hline $\mathrm{s}-\mathrm{C}^{12} \mathrm{H}_{2} \mathrm{DC}^{12} \mathrm{HO}^{16}$ & 3. 473 & $2,1,2 \leftarrow 1,1,1$ & Ground & & & & & 35775.8 & .3 \\
\hline $\mathrm{C}^{12} \mathrm{H}_{3} \mathrm{C}^{12} \mathrm{H}_{2} \mathrm{C}^{12} \mathrm{~N}^{14}$ & 3- 731 & $4,0,4 \leftarrow 3,0,3$ & Excited & & & & & 35776.5 & .2 \\
\hline $\mathrm{C}^{12} \mathrm{H}_{3} \mathrm{C}^{12}{ }_{*} \mathrm{HO}^{16} \mathrm{C}^{12}{ }_{*} \mathrm{H}_{2}$ & 3- 761 & Not Reported & Ground & & & & & 35776.82 & .1 \\
\hline $\mathrm{C}^{12} \mathrm{H}_{2} \mathrm{~N}^{14} \mathrm{O}^{16} \mathrm{H}$ & 3- 141 & $4,0,4 \leftarrow 3,1,3$ & Ground & & 3 & & 2 & 35782.59 & .10 \\
\hline $\mathrm{C}^{12} \mathrm{H}_{2} \mathrm{~N}^{14} \mathrm{O}^{16} \mathrm{H}$ & 3- 141 & $4,0,4 \leftarrow 3,1,3$ & Ground & & 5 & & 4 & 35782.59 & .10 \\
\hline $\mathrm{C}^{12} \mathrm{H}_{2} \mathrm{~N}^{14} \mathrm{O}^{16} \mathrm{H}$ & 3- 141 & $4,0,4 \leftarrow 3,1,3$ & Ground & & 4 & & 3 & 35783.93 & .10 \\
\hline $\mathrm{C}^{12}{ }_{*} \mathrm{H}_{2}^{\mathrm{b}} \mathrm{S}^{\mathrm{b}} \mathrm{C}^{12}{ }_{*} \mathrm{H}_{2}^{\mathrm{b}}$ & 4- 854 & Not Reported & & & & & & 35785.0 & 1. \\
\hline $\mathrm{C}^{13} \mathrm{H}_{3}\left(\mathrm{C}^{12} \mathrm{H}_{3}\right)_{2} \mathrm{C}^{12} \mathrm{Cl}^{35}$ & 3. 975 & $6,0,6 \leftarrow 5,0,5$ & Ground & & & & & 35785.80 & .20 \\
\hline $\mathrm{H}_{2} \mathrm{C}^{12}{ }_{*} \mathrm{O}^{16} \mathrm{C}^{12}{ }_{*} \mathrm{H}_{2}$ & 4- 841 & $6.4,2 \leftarrow 6,3,3$ & Ground & & & & & 35791. & 1. \\
\hline $\mathrm{C}^{12} \mathrm{H}_{3} \mathrm{~S}^{32} \mathrm{H}$ & 3. 221 & Not Reported & Ground & & & & & 35791.03 & \\
\hline $\mathrm{C}^{12} \mathrm{H}_{3} \mathrm{C}^{12} \mathrm{H}_{2} \mathrm{C}^{12} \mathrm{~N}^{14}$ & 3- 731 & $4,2,3 \leftarrow 3,2,2$ & Ground & & 4 & & 3 & 35791.80 & .1 \\
\hline $\mathrm{C}^{12} \mathrm{H}_{3} \mathrm{C}^{12} \mathrm{H}_{2} \mathrm{C}^{12} \mathrm{~N}^{14}$ & 3. 731 & $4,2,3 \leftarrow 3,2,2$ & Ground & & & & & 35792.1 & .2 \\
\hline $\mathrm{C}^{12} \mathrm{H}_{3} \mathrm{~S}^{32} \mathrm{H}$ & 3- 221 & Not Reported & Ground & & & & & 35792.1 & \\
\hline $\mathrm{C}^{12} \mathrm{H}_{3} \mathrm{C}^{12} \mathrm{H}_{2} \mathrm{C}^{12} \mathrm{~N}^{14}$ & 3- 731 & $4,2,3 \leftarrow 3,2,2$ & Ground & & 5 & & 4 & 35792.29 & .1 \\
\hline $\mathrm{C}^{12} \mathrm{H}_{3} \mathrm{C}^{12} \mathrm{H}_{2} \mathrm{C}^{12} \mathrm{~N}^{14}$ & 3. 731 & $4,2,3 \leftarrow 3,2,2$ & Ground & & 3 & & 2 & 35792.29 & .1 \\
\hline $\mathrm{D}_{2} \mathrm{~N}^{14} \mathrm{C}^{12} \mathrm{~N}^{14}$ & 4- 363 & $2,0,2 \leftarrow 1,0,1$ & Ground & & & & & 35797.8 & .5 \\
\hline $\mathrm{C}^{13} \mathrm{H}_{3} \mathrm{Si}^{28} \mathrm{H}_{2} \mathrm{~F}^{19}$ & 3. 249 & $3,2,2 \leftarrow 2,2,1$ & Ground & & & & & 35799.60 & .10 \\
\hline $\mathrm{Cl}^{35} \mathrm{C}^{12} \mathrm{~N}^{14}$ & 4. 171 & $3 \leftarrow 2$ & Ground & $7 / 2$ & & $7 / 2$ & & 35805.09 & \\
\hline $\mathrm{C}^{12} \mathrm{D}_{3} \mathrm{O}^{16} \mathrm{H}$ & 3. 214 & Not Reported & Ground & & & & & 35805.7 & .5 \\
\hline $\mathrm{C}^{12} \mathrm{D}_{3} \mathrm{O}^{16} \mathrm{D}$ & 3- 216 & Not Reported & & & & & & 35805.7 & \\
\hline $\mathrm{C}^{12} \mathrm{H}_{3} \mathrm{C}^{12} \mathrm{H}_{2} \mathrm{C}^{12} \mathrm{~N}^{14}$ & 3. 731 & $4,2,3 \leftarrow 3,2,2$ & Ground & & & & & 35806.3 & .2 \\
\hline $\mathrm{D}_{2} \mathrm{~N}^{14} \mathrm{C}^{12} \mathrm{~N}^{14}$ & 4. 363 & $2,0,2 \leftarrow 1,0,1$ & Excited & & & & & 35809.7 & .5 \\
\hline $\mathrm{C}^{12} \mathrm{H}_{3} \mathrm{C}^{12} \mathrm{H}_{2} \mathrm{C}^{12} \mathrm{~N}^{14}$ & 3- 731 & $4,2,3 \leftarrow 3,2,2$ & Ground & & & & & 35810.8 & .2 \\
\hline $\mathrm{C}^{12} \mathrm{D}_{3} \mathrm{O}^{16} \mathrm{H}$ & 3. 214 & Not Reported & Ground & & & & & 35810.8 & .5 \\
\hline $\mathrm{C}^{12} \mathrm{D}_{3} \mathrm{O}^{16} \mathrm{D}$ & 3- 216 & Not Reported & & & & & & 35810.8 & \\
\hline $\mathrm{C}^{12} \mathrm{D}_{3} \mathrm{~N}^{14} \mathrm{D}_{2}$ & 3- 262 & $1,1,1 \leftarrow 1,0,1$ & Ground & & & & & 35812.36 & \\
\hline $\mathrm{C}^{12} \mathrm{H}_{3} \mathrm{C}^{12} \mathrm{H}_{2} \mathrm{C}^{12} \mathrm{~N}^{14}$ & 3. 731 & $4,3,1 \leftarrow 3,3,0$ & Ground & & 4 & & 3 & 35813.85 & .1 \\
\hline $\mathrm{C}^{12} \mathrm{H}_{3} \mathrm{C}^{12} \mathrm{H}_{2} \mathrm{C}^{12} \mathrm{~N}^{14}$ & 3- 731 & $4,3,2 \leftarrow 3,3,1$ & Ground & & 4 & & 3 & 35813.85 & .1 \\
\hline $\mathrm{C}^{12} \mathrm{H}_{3} \mathrm{C}^{12} \mathrm{H}_{2} \mathrm{C}^{12} \mathrm{~N}^{14}$ & 3- 731 & $4,3,1 \leftarrow 3,3,0$ & Ground & & & & & 35814.6 & .2 \\
\hline $\mathrm{C}^{12} \mathrm{H}_{3} \mathrm{C}^{12} \mathrm{H}_{2} \mathrm{C}^{12} \mathrm{~N}^{14}$ & 3- 731 & $4,3,2 \leftarrow 3,3,1$ & Ground & & & & & 35814.6 & .2 \\
\hline $\mathrm{C}^{12} \mathrm{H}_{3} \mathrm{C}^{12} \mathrm{H}_{2} \mathrm{C}^{12} \mathrm{~N}^{14}$ & 3. 731 & $4,3,1 \leftarrow 3,3,0$ & Ground & & 3 & & 2 & 35814.96 & .1 \\
\hline $\mathrm{C}^{12} \mathrm{H}_{3} \mathrm{C}^{12} \mathrm{H}_{2} \mathrm{C}^{12} \mathrm{~N}^{14}$ & 3. 731 & $4,3,2 \leftarrow 3,3,1$ & Ground & & 3 & & 2 & 35814.96 & .1 \\
\hline $\mathrm{C}^{12} \mathrm{H}_{3} \mathrm{C}^{12} \mathrm{H}_{2} \mathrm{C}^{12} \mathrm{~N}^{14}$ & 3- 731 & $4,3,1 \leftarrow 3,3,0$ & Ground & & 5 & & 4 & 35814.96 & .1 \\
\hline $\mathrm{C}^{12} \mathrm{H}_{3} \mathrm{C}^{12} \mathrm{H}_{2} \mathrm{C}^{12} \mathrm{~N}^{14}$ & 3. 731 & $4,3,2 \leftarrow 3,3,1$ & Ground & & 5 & & 4 & 35814.96 & .1 \\
\hline $\mathrm{Cl}^{35} \mathrm{C}^{12} \mathrm{~N}^{14}$ & 4- 171 & $3 \leftarrow 2$ & Ground & $5 / 2$ & & $3 / 2$ & & 35820,65 & \\
\hline $\mathrm{Cl}^{35} \mathrm{C}^{12} \mathrm{~N}^{14}$ & 4. 171 & $3 \leftarrow 2$ & Ground & $3 / 2$ & & $1 / 2$ & & 35820.65 & \\
\hline $\mathrm{Cl}^{35} \mathrm{C}^{13} \mathrm{~N}^{14}$ & 4- 172 & $3 \leftarrow 2$ & Ground & & & & & 35824. & \\
\hline $\mathrm{C}^{12} \mathrm{H}_{3} \mathrm{Si}^{28} \mathrm{HDF}^{19}$ & 3- 252 & $3,0,3 \leftarrow 2,0,2$ & Ground & & & & & 35825.50 & .10 \\
\hline $\mathrm{Cl}^{35} \mathrm{C}^{12} \mathrm{~N}^{14}$ & 4- 171 & $3 \leftarrow 2$ & Ground & $9 / 2$ & & $7 / 2$ & & 35825.95 & \\
\hline $\mathrm{C}^{35} \mathrm{C}^{12} \mathrm{~N}^{14}$ & 4- 171 & $3 \leftarrow 2$ & Ground & $7 / 2$ & & $5 / 2$ & & 35825.95 & \\
\hline $\mathrm{C}^{12} \mathrm{HD}_{2} \mathrm{~N}^{14} \mathrm{C}^{12}$ & 4- 839 & $2,1,2 \leftarrow 1,1,1$ & Ground & & & & & 35827.44 & .1 \\
\hline
\end{tabular}




\begin{tabular}{|c|c|c|c|c|c|c|c|}
\hline Isotopic Species & $\begin{array}{l}\text { Vol.-Id. } \\
\text { Nos. }\end{array}$ & $\begin{array}{c}\text { Rotational } \\
\text { Quantum Nos. }\end{array}$ & Vib. State & $\mathrm{F}_{1}^{\prime} \mathrm{F}^{\prime}$ Hyper & $\underset{F_{1}}{\text { rfine }} \mathrm{F}$ & $\begin{array}{c}\text { Frequency } \\
\mathrm{MHz}\end{array}$ & $\begin{aligned} & \text { Acc. } \\
\pm & \mathrm{MHz}\end{aligned}$ \\
\hline $\mathrm{HC}^{13}: \mathrm{C}^{12} \mathrm{C}^{12} \mathrm{DO}^{16}$ & 4- 922 & Not Reported & & & & 35830. & 5. \\
\hline $\mathrm{C}^{12} \mathrm{H}_{3} \mathrm{C}^{12} \mathrm{H}_{2} \mathrm{C}^{12} \mathrm{~N}^{14}$ & 3- 731 & $4,3,2 \leftarrow 3,3,1$ & Ground & & & 35830.4 & .2 \\
\hline $\mathrm{C}^{12} \mathrm{H}_{3} \mathrm{C}^{12} \mathrm{H}_{2} \mathrm{C}^{12} \mathrm{~N}^{1 / 4}$ & 3- 731 & $4,3,1 \leftarrow 3,3,0$ & Ground & & & 35830.4 & .2 \\
\hline $\mathrm{Cl}^{35} \mathrm{C}^{12} \mathrm{~N}^{14}$ & 4. 171 & $3 \leftarrow 2$ & Ground & $5 / 2$ & $5 / 2$ & 35835.74 & \\
\hline $\mathrm{C}^{12} \mathrm{H}_{3} \mathrm{C}^{12}{ }_{*} \mathrm{HO}^{16} \mathrm{C}^{12}{ }_{*} \mathrm{H}_{2}$ & 3- 761 & Not Reported & Ground & & & 35840.37 & .1 \\
\hline $\mathrm{HC}^{13}: \mathrm{C}^{12} \mathrm{C}^{12} \mathrm{DO}^{16}$ & 4. 922 & Not Reported & & & & 35841. & 5. \\
\hline $\mathrm{H}_{2} \mathrm{~N}^{14} \mathrm{C}^{12} \mathrm{~N}^{14}$ & 4. 361 & $16,1,15 \leftarrow 16,1,16$ & Ground & & & 35841.7 & .5 \\
\hline $\mathrm{H}_{2} \mathrm{~N}^{14} \mathrm{C}^{12} \mathrm{~N}^{14}$ & 4- 361 & $16,1,15 \leftarrow-16,1,16$ & Ground & & & 35844.4 & .5 \\
\hline $\mathrm{C}^{12} \mathrm{H}_{3} \mathrm{C}^{12} \mathrm{H}_{2} \mathrm{C}^{12} \mathrm{~N}^{14}$ & 3. 731 & $4,2,3 \leftarrow 3,2,2$ & Excited & & & 35844.6 & .2 \\
\hline $\mathrm{C}^{12} \mathrm{H}_{3} \mathrm{C}^{12}{ }_{*} \mathrm{HO}^{16} \mathrm{C}^{12}{ }_{*} \mathrm{H}_{2}$ & 3. 761 & $2,1,2 \leftarrow 1,0,1$ & Ground & & & 35845.46 & .1 \\
\hline $\mathrm{C}^{12} \mathrm{H}_{3} \mathrm{~S}^{32} \mathrm{H}$ & 3. 221 & Not Reported & Ground & & & 35846.05 & \\
\hline $\mathrm{C}^{12} \mathrm{H}_{2}: \mathrm{C}^{12} \mathrm{HC}^{12} \mathrm{HO}^{16}$ & 3. 691 & $4,0,4 \leftarrow 3,0,3$ & Ground & & & 35846.64 & \\
\hline $\mathrm{C}^{12} \mathrm{H}_{3} \mathrm{C}^{12}{ }_{*} \mathrm{HO}^{16} \mathrm{C}^{12}{ }_{*} \mathrm{H}_{2}$ & 3- 761 & $2,1,2 \leftarrow 1,0,1$ & Ground & & & 35850.67 & .1 \\
\hline $\mathrm{C}^{12} \mathrm{H}_{3} \mathrm{C}^{12} \mathrm{H}_{2} \mathrm{C}^{12} \mathrm{~N}^{14}$ & 3. 731 & $4,1,4 \leftarrow 3,1,3$ & Ground & & & 35855.2 & .2 \\
\hline $\mathrm{C}^{12} \mathrm{H}_{3} \mathrm{~S}^{32} \mathrm{H}$ & 3- 221 & $4,0, \leftarrow 3,1$. & Ground & & & 35857.4 & \\
\hline $\mathrm{C}^{12} \mathrm{H}_{3} \mathrm{C}^{12} \mathrm{H}_{2} \mathrm{C}^{12} \mathrm{~N}^{14}$ & 3. 731 & $4,3,2 \leftarrow 3.3,1$ & Excited & & & 35861.4 & .2 \\
\hline $\mathrm{C}^{12} \mathrm{H}_{3} \mathrm{C}^{12} \mathrm{H}_{2} \mathrm{C}^{12} \mathrm{~N}^{14}$ & 3. 731 & $4,3,1 \leftarrow 3,3,0$ & Excited & & & 35861.4 & .2 \\
\hline $\mathrm{C}^{12} \mathrm{H}_{3} \mathrm{C}^{12} \mathrm{H}_{2} \mathrm{C}^{12} \mathrm{~N}^{14}$ & 3. 731 & $4,2,2 \leftarrow 3,2,1$ & Ground & & & 35866.1 & .2 \\
\hline $\mathrm{C}^{12} \mathrm{D}_{3} \mathrm{~N}^{14} \mathrm{D}_{2}$ & 3- 262 & $1,1,1 \leftarrow 1,0,1$ & Ground & & & 35866.30 & \\
\hline $\mathrm{C}^{12} \mathrm{H}_{3} \mathrm{C}^{12} \mathrm{H}_{2} \mathrm{C}^{12} \mathrm{~N}^{14}$ & 3- 731 & $4,2,2 \leftarrow 3,2,1$ & Ground & & & 35867.6 & .2 \\
\hline $\mathrm{N}^{14} \mathrm{O}^{16} \mathrm{Br}^{\mathrm{b}}$ & 4- 123 & $5, \quad \leftarrow 4$, & & & & 35870. & \\
\hline $\mathrm{C}^{12} \mathrm{H}_{3} \mathrm{C}^{12} \mathrm{H}_{2} \mathrm{C}^{12} \mathrm{~N}^{14}$ & 3. 731 & $4,2,2 \leftarrow 3,2,1$ & Ground & & & 35871.8 & .2 \\
\hline $\mathrm{HC}^{13}: \mathrm{C}^{12} \mathrm{C}^{12} \mathrm{DO}^{16}$ & 4- 922 & Not Reported & & & & 35872. & 5. \\
\hline $\mathrm{P}^{31} \mathrm{O}^{16} \mathrm{~F}_{2}^{19} \mathrm{Cl}^{35}$ & 4.1391 & $20,10,10 \leftarrow 20,9,11$ & Ground & $43 / 2$ & $43 / 2$ & 35872.46 & \\
\hline $\mathrm{P}^{31} \mathrm{O}^{16} \mathrm{~F}_{2}^{1.9} \mathrm{Cl}^{35}$ & 4.1391 & $20,10,10 \leftarrow 20,9,11$ & Ground & $37 / 2$ & $37 / 2$ & 35872.46 & \\
\hline $\mathrm{C}^{12} \mathrm{H}_{2} \mathrm{DSi}^{1 /} \mathrm{D}_{3}$ & 3- 328 & $2,1,2 \leftarrow 1,1,1$ & & & & 35873.39 & .3 \\
\hline $\mathrm{C}^{12} \mathrm{H}_{3} \mathrm{~S}^{32} \mathrm{H}$ & 3- 221 & Not Reported & Ground & & & 35873.42 & \\
\hline $\mathrm{P}^{31} \mathrm{O}^{16} \mathrm{~F}_{2}^{19} \mathrm{Cl}^{35}$ & 4-1391 & $20.10,10 \leftarrow 20.9 .11$ & Ground & $41 / 2$ & $41 / 2$ & 35874.50 & \\
\hline $\mathrm{P}^{331} \mathrm{O}^{16} \mathrm{~F}_{2}^{19} \mathrm{Cl}^{35}$ & 4-1391 & $20,10,10 \leftarrow 20,9,11$ & Ground & $39 / 2$ & $39 / 2$ & 35874.50 & \\
\hline $\mathrm{C}^{12} \mathrm{H}_{2} \mathrm{~N}^{14} \mathrm{O}^{16} \mathrm{H}$ & $3-141$ & $8,1,7 \leftarrow 7,2,6$ & Ground & 7 & 6 & 35878.00 & .10 \\
\hline $\mathrm{C}^{12} \mathrm{H}_{2} \mathrm{~N}^{14} \mathrm{O}^{16} \mathrm{H}$ & 3. 141 & $8,1,7 \leftarrow 7,2,6$ & Ground & 9 & 8 & 35878.00 & .10 \\
\hline $\mathrm{C}^{12} \mathrm{H}_{3} \mathrm{C}^{12}{ }_{*} \mathrm{HO}^{16} \mathrm{C}^{12}{ }_{*} \mathrm{H}_{2}$ & 3- 761 & $2,1,2 \leftarrow 1,0,1$ & Cround & & & 35878.14 & .1 \\
\hline $\mathrm{C}^{12} \mathrm{H}_{2} \mathrm{~N}^{14} \mathrm{O}^{16} \mathrm{H}$ & 3- 141 & $8,1,7 \leftarrow 7,2,6$ & Ground & 8 & 7 & 35879.33 & .10 \\
\hline $\mathrm{P}^{31} \mathrm{O}^{16} \mathrm{~F}_{2}^{19} \mathrm{Cl}^{35}$ & 4-1391 & $19.10,9 \leftarrow 19,9.10$ & Ground & $35 / 2$ & $35 / 2$ & 35880.25 & \\
\hline $\mathrm{P}^{31} \mathrm{O}^{16} \mathrm{~F}_{2}^{19} \mathrm{Cl}^{35}$ & 4-1391 & $19,10,9 \leftarrow 19,9,10$ & Ground & $41 / 2$ & $41 / 2$ & 35880.25 & \\
\hline $\mathrm{P}^{31} \mathrm{O}^{16} \mathrm{~F}_{2}^{19} \mathrm{Cl}^{35}$ & 4-1391 & $19.10,9 \leftarrow 19,9,10$ & Ground & $37 / 2$ & $37 / 2$ & 35882.35 & \\
\hline $\mathrm{P}^{31} \mathrm{O}^{16} \mathrm{~F}_{2}^{19} \mathrm{Cl}^{35}$ & $4-1391$ & $19,10,9 \leftarrow 19,9,10$ & Ground & $39 / 2$ & $39 / 2$ & 35882.35 & \\
\hline $\mathrm{P}^{31} \mathrm{O}^{16} \mathrm{~F}_{2}^{19} \mathrm{Cl}^{35}$ & 4-1391 & $18,10,8 \leftarrow 18,9,9$ & Ground & $39 / 2$ & $39 / 2$ & 35886.40 & \\
\hline $\mathrm{P}^{31} \mathrm{O}^{16} \mathrm{~F}_{2}^{19} \mathrm{Cl}^{35}$ & 4-1391 & $18,10,8 \leftarrow 18,9,9$ & Ground & $33 / 2$ & $33 / 2$ & 35886.40 & \\
\hline $\mathrm{P}^{31} \mathrm{O}^{16} \mathrm{~F}_{2}^{19} \mathrm{Cl}^{35}$ & 4-1391 & $18.10,8 \leftarrow 18,9,9$ & Ground & $37 / 2$ & $37 / 2$ & 35888.78 & \\
\hline $\mathrm{P}^{31} \mathrm{O}^{16} \mathrm{~F}_{2}^{19} \mathrm{Cl}^{35}$ & 4-1391 & $18,10,8 \leftarrow 18,9,9$ & Ground & $35 / 2$ & $35 / 2$ & 35888.78 & \\
\hline $\mathrm{HC}^{13}: \mathrm{C}^{12} \mathrm{C}^{12} \mathrm{DO}^{16}$ & 4- 922 & Not Reported & & & & 35890. & 5. \\
\hline $\mathrm{P}^{31} \mathrm{O}^{16} \mathrm{~F}_{2}^{19} \mathrm{Cl}^{35}$ & 4.1391 & $17,10,7 \leftarrow 17,9,8$ & Ground & $31 / 2$ & $31 / 2$ & 35891.94 & \\
\hline $\mathrm{P}^{331} \mathrm{O}^{16} \mathrm{~F}_{2}^{19} \mathrm{Cl}^{35}$ & 4-1391 & $17,10,7 \leftarrow 17,9,8$ & Ground & $37 / 2$ & $37 / 2$ & 35892.06 & \\
\hline $\mathrm{P}^{331} \mathrm{O}^{16} \mathrm{~F}_{2}^{19} \mathrm{Cl}^{35}$ & 4-1391 & $17,10,7 \leftarrow 17,9,8$ & Ground & $33 / 2$ & $33 / 2$ & 35894.58 & \\
\hline
\end{tabular}


Vol.-ld. Rotational Nos. Quantum Nos.
Vib. State
Frequency $\mathrm{MH} \%$
Acc. $\pm \mathrm{MH} \%$

\section{$\mathrm{P}^{31} \mathrm{O}^{16} \mathrm{~F}_{2}^{19} \mathrm{Cl}^{35}$}

$\mathrm{P}^{31} \mathrm{O}^{16} \mathrm{~F}_{2}^{19} \mathrm{Cl}^{35}$

${ }^{331} \mathrm{O}^{16} \mathrm{~F}_{2}^{19} \mathrm{Cl}^{35}$

$\mathrm{P}^{31} \mathrm{O}^{16} \mathrm{~F}_{2}^{19} \mathrm{Cl}^{35}$

$\mathrm{C}^{\mathrm{b}}{ }_{*} \mathrm{H}_{2}^{\mathrm{ln}} \mathrm{N}^{\prime \prime} \mathrm{H}^{\mathrm{n}} \mathrm{C}^{\mathrm{l}}{ }_{*} \mathrm{H}_{2}^{\mathrm{b}}$

$\mathrm{C}^{12} \mathrm{Cl}^{35} \mathrm{Cl}_{2}^{37} \mathrm{C}^{12} \mathrm{~N}^{14}$

$\mathrm{P}^{31} \mathrm{O}^{16} \mathrm{~F}_{2}^{19} \mathrm{Cl}^{35}$

$\mathrm{P}^{31} \mathrm{O}^{16} \mathrm{~F}_{2}^{19} \mathrm{Cl}^{35}$

$\mathrm{P}^{31} \mathrm{O}^{16} \mathrm{~F}_{2}^{19} \mathrm{Cl}^{35}$

$\mathrm{P}^{31} \mathrm{O}^{16} \mathrm{~F}_{2}^{19} \mathrm{Cl}^{35}$

$\mathrm{P}^{31} \mathrm{O}^{16} \mathrm{~F}_{2}^{19} \mathrm{Cl}^{35}$

$\mathrm{P}^{31} \mathrm{O}^{16} \mathrm{~F}_{2}^{14} \mathrm{Cl}^{35}$

$\mathrm{P}^{31} \mathrm{O}^{16} \mathrm{~F}_{2}^{19} \mathrm{Cl}^{35}$

$\mathrm{P}^{31} \mathrm{O}^{16} \mathrm{~F}_{2}^{19} \mathrm{Cl}^{35}$

$\mathrm{P}^{31} \mathrm{O}^{16} \mathrm{~F}_{2}^{19} \mathrm{Cl}^{35}$

$\mathrm{P}^{31} \mathrm{O}^{16} \mathrm{~F}_{2}^{19} \mathrm{Cl}^{35}$

$\mathrm{P}^{31} \mathrm{O}^{16} \mathrm{~F}_{2}^{19} \mathrm{Cl}^{35}$

$\mathrm{P}^{31} \mathrm{O}^{16} \mathrm{~F}_{2}^{19} \mathrm{Cl}^{35}$

$\mathrm{P}^{31} \mathrm{O}^{16} \mathrm{~F}_{2}^{19} \mathrm{Cl}^{35}$

$\mathrm{P}^{31} \mathrm{O}^{16} \mathrm{~F}_{2}^{19} \mathrm{Cl}^{35}$

$\mathrm{P}^{31} \mathrm{O}^{16} \mathrm{~F}_{2}^{19} \mathrm{Cl}^{35}$

$\mathrm{C}^{12} \mathrm{H}_{3} \mathrm{Hg}^{202} \mathrm{Br}^{81}$

$\mathrm{C}^{12} \mathrm{H}_{3} \mathrm{C}^{12}{ }_{*} \mathrm{HO}^{16} \mathrm{C}^{12}{ }_{*} \mathrm{H}_{2}$

$\mathrm{C}^{13} \mathrm{H}_{3}\left(\mathrm{C}^{12} \mathrm{H}_{3}\right)_{2} \mathrm{C}^{12} \mathrm{Cl}^{35}$

$\mathrm{C}^{12} \mathrm{H}_{3} \mathrm{~S}^{32} \mathrm{H}$

$\mathrm{D}_{2} \mathrm{C}^{12}: \mathrm{C}^{12} \mathrm{O}^{16}$

$\mathrm{P}^{31} \mathrm{O}^{16} \mathrm{~F}_{2}^{19} \mathrm{Cl}^{35}$

$\mathrm{P}^{31} \mathrm{O}^{16} \mathrm{~F}_{2}^{19} \mathrm{Cl}^{35}$

$\mathrm{H}_{2} \mathrm{O}_{2}^{16}$

$\mathrm{P}^{31} \mathrm{O}^{16} \mathrm{~F}_{2}^{19} \mathrm{Cl}^{35}$

$\mathrm{H}_{3} \mathrm{~B}^{111} \mathrm{C}^{12} \mathrm{O}^{16}$

$\mathrm{P}^{31} \mathrm{O}^{16} \mathrm{~F}_{2}^{19} \mathrm{Cl}^{35}$

$\mathrm{H}_{3} \mathrm{~B}^{10} \mathrm{C}^{12} \mathrm{O}^{16}$

$\mathrm{H}_{3} \mathrm{~B}^{10} \mathrm{C}^{12} \mathrm{O}^{16}$

$\mathrm{H}_{3} \mathrm{~B}^{10} \mathrm{C}^{12} \mathrm{O}^{16}$

$\mathrm{H}_{3} \mathrm{~B}^{10} \mathrm{C}^{12} \mathrm{O}^{16}$

$\mathrm{H}_{3} \mathrm{~B}^{10} \mathrm{C}^{12} \mathrm{O}^{16}$

$\mathrm{H}_{3} \mathrm{~B}^{10} \mathrm{C}^{12} \mathrm{O}^{16}$

$\mathrm{H}_{3} \mathrm{~B}^{10} \mathrm{C}^{12} \mathrm{O}^{16}$

$\mathrm{H}_{3} \mathrm{~B}^{10} \mathrm{C}^{12} \mathrm{O}^{16}$

t. $\mathrm{C}^{12} \mathrm{H}_{3} \mathrm{C}^{12} \mathrm{H}: \mathrm{C}^{12} \mathrm{HC}^{12} \mathrm{~N}^{14}$

$\mathrm{H}_{3} \mathrm{~B}^{10} \mathrm{C}^{12} \mathrm{O}^{16}$

$\mathrm{H}_{3} \mathrm{~B}^{10} \mathrm{C}^{12} \mathrm{O}^{16}$

$\mathrm{H}_{3} \mathrm{~B}^{10} \mathrm{C}^{12} \mathrm{O}^{16}$

$\mathrm{H}_{3} \mathrm{~B}^{116} \mathrm{C}^{12} \mathrm{O}^{16}$

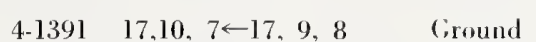

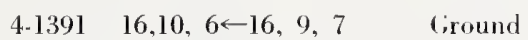

4-1391 16.10, 6־16, 9, $7 \quad$ Ground

4-1391

4- 863

$16,10,6 \leftarrow 16,9,7$

(;round

4- 583

Not Reported

4-1391

$11, \quad \leftarrow 10$,

Ground

Ground

$4-1391 \quad 15,10,5 \leftarrow 15,9,6$

Cround

4-1391

$15,10,5 \leftarrow 15,9,6$

Cround

4-1391

$15,10,5 \leftarrow 15,9,6$

Ground

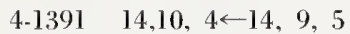

Ground

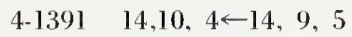

Cround

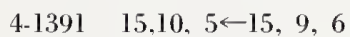

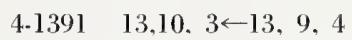

4-1391 13.10, $3 \leftarrow 13,9,4$

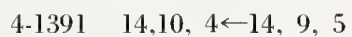

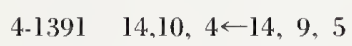

4-1391 12,10, $2 \leftarrow 12,9,3$

4-1391 12,10, $2 \leftarrow 12,9,3$

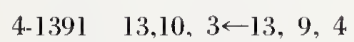

4-1391

4- 418

$13,10,3 \leftarrow 13,9,4$

3. 761

$16, \leftarrow 15$,

3- 975

$2,1,2 \leftarrow 1,0,1$

$6,1,5 \leftarrow 5,1,4$

3. 221

11. $1 . \leftarrow 10,2$,

4- 712

$2,1,1 \leftarrow 1,0,1$

4-1391

4-1391

12.10. $2 \leftarrow 12,9,3$

3- 41

$12,10,2 \leftarrow 12,9,3$

Not Reported

4-1391

$11,10,1 \leftarrow 11,9,2$

4- 391

$2,1 \leftarrow 1,1$

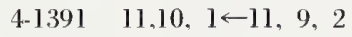

4- 391

$2,1 \leftarrow 1,1$

4- 391

4- 391

4- 391

$2,1 \leftarrow 1,1$

$2,1 \leftarrow 1,1$

$2,1 \leftarrow 1,1$

4- 391

$2,1 \leftarrow 1,1$

4- 391

$2,1 \leftarrow 1,1$

4- 391

2. $1 \leftarrow 1,1$

4- 391

$2,0 \leftarrow 1,0$

3- 921

$8,0, \leftarrow 7,0$,

$2,0 \leftarrow 1,0$

$2,0 \leftarrow 1,0$

4- 391

$2,0 \leftarrow 1,0$

4. 391

2, $0 \leftarrow 1,0$

Ground

Ground

Ground

Ground

Ground

(iround

Ground

Ground

Ground

Ground

Ground

Ground

Ground

Ground

Ground
$35 / 2$

$29 / 2 \quad 29 / 2 \quad 35896.84$

$35 / 2 \quad 35 / 2 \quad 35896.98$

$31 / 2 \quad 31 / 2 \quad 35899.73$

35900 .

35900.0

$33 / 2 \quad 33 / 2 \quad 35900.04$

$27 / 2 \quad 27 / 2 \quad 35900.79$

$33 / 2 \quad 33 / 2 \quad 35901.03$

$29 / 2 \quad 29 / 2 \quad 35904.14$

$25 / 2 \quad 25 / 2 \quad 35904.14$

$31 / 2 \quad 31 / 2 \quad 35904.84$

$31 / 2 \quad 31 / 2 \quad 35904.84$

$23 / 2 \quad 23 / 2 \quad 35906.92$

$29 / 2 \quad 29 / 2 \quad 35907.40$

$27 / 2 \quad 27 / 2 \quad 35908.02$

$29 / 2 \quad 29 / 2 \quad 35908.44$

$27 / 2 \quad 27 / 2 \quad 35909.08$

$21 / 2 \quad 21 / 2 \quad 35909.76$

$25 / 2 \quad 25 / 2 \quad 35911.44$

$27 / 2 \quad 27 / 2 \quad 35911.93$

35912.50

35913.04

35913.15

35913.5

35913.83

$23 / 2 \quad 23 / 2 \quad 35914.45$

$25 / 2 \quad 25 / 2 \quad 35914.97$

35916.

2.

$21 / 2 \quad 21 / 2 \quad 35917.00$
35917.66

35917.82

35917.96

35917.96

35918.29

35918.29

35918.29

35 918:55

35918.55

35919.08

35919.24

35919.60

35919.60

35919.60

35919.60
10.

20. 


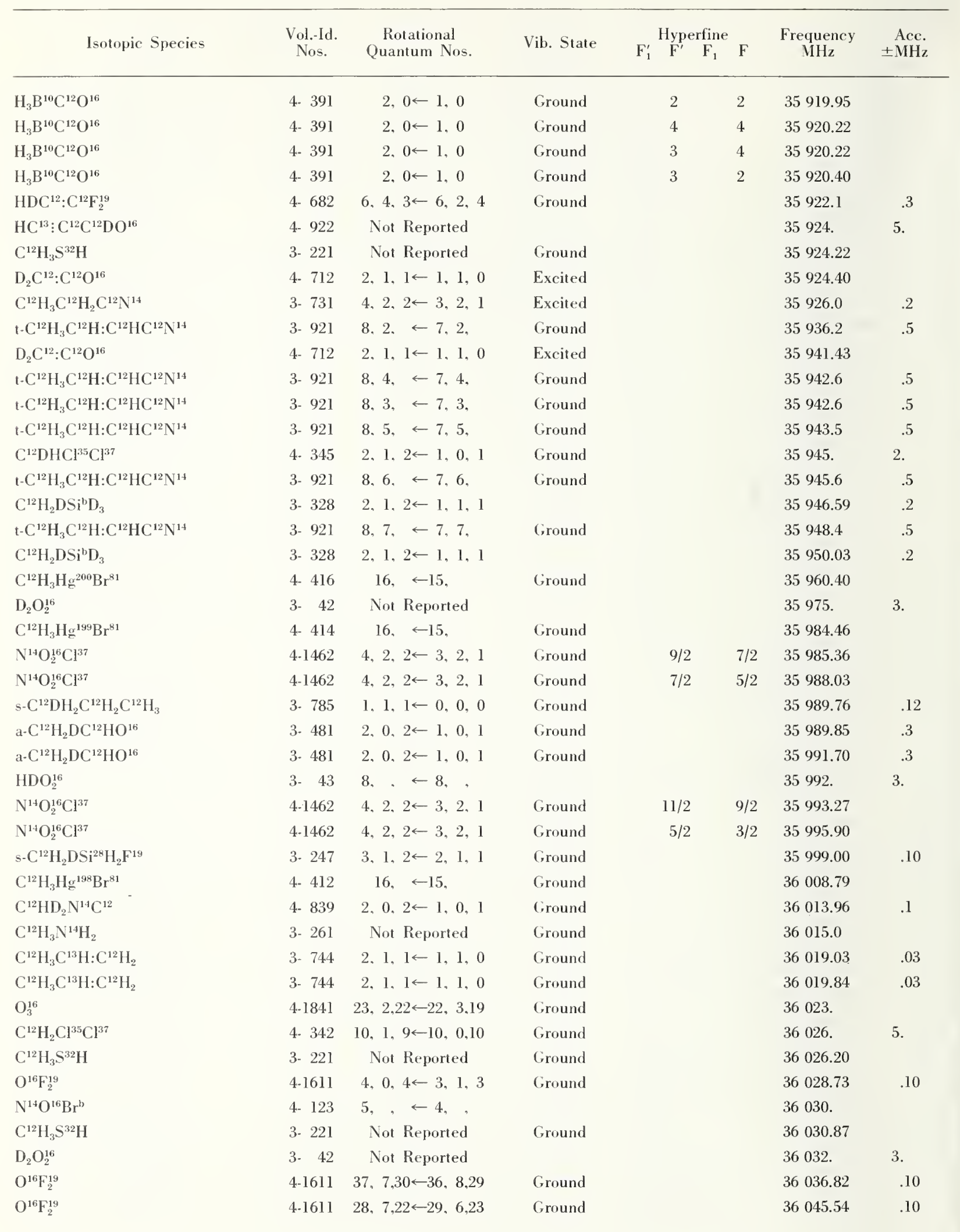




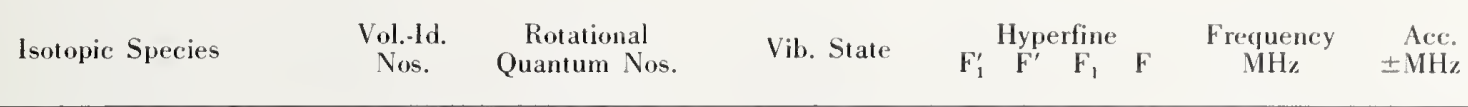

\begin{tabular}{|c|c|c|c|c|c|c|c|}
\hline $\mathrm{D}_{2} \mathrm{C}^{12}: \mathrm{C}^{12} \mathrm{O}^{16}$ & 4- 712 & $2,1,1 \leftarrow 1,0,1$ & Excited & & & 36048.80 & \\
\hline $\mathrm{C}^{12} \mathrm{H}_{3} \mathrm{C}^{12} \mathrm{H}: \mathrm{C}^{12} \mathrm{H}_{2}$ & 3- 741 & $2,1,1 \leftarrow 1,1,0$ & Ground & & & 36049.29 & .03 \\
\hline $\mathrm{C}^{12} \mathrm{H}_{3} \mathrm{C}^{12} \mathrm{H}: \mathrm{C}^{12} \mathrm{H}_{2}$ & 3- 741 & $2,1,1 \leftarrow 1,1,0$ & Ground & & & 360.50 .21 & .03 \\
\hline $\mathrm{C}^{12} \mathrm{H}_{3} \mathrm{Hg}^{204} \mathrm{Cl}^{37}$ & 4. 451 & $9 . \leftarrow 8$ & Ground & & & 36073.62 & \\
\hline $\mathrm{C}^{12} \mathrm{D}_{3} \mathrm{O}^{16} \mathrm{D}$ & 3. 216 & Not Reported & & & & 36080.0 & \\
\hline $\mathrm{t}-\mathrm{DHC} \mathrm{C}^{12}: \mathrm{C}^{12} \mathrm{HF}^{19}$ & 4- 788 & $2,0,2 \leftarrow 1,0,1$ & Ground & & & 36081.3 & .3 \\
\hline $\mathrm{C}^{13} \mathrm{H}_{3} \mathrm{Si}^{28} \mathrm{H}_{2} \mathrm{~F}^{19}$ & 3. 249 & $3,2,1 \leftarrow 2,2,0$ & Ground & & & 36083.60 & .10 \\
\hline $\mathrm{C}^{12} \mathrm{H}_{3} \mathrm{C}^{13} \mathrm{H}_{2} \mathrm{C}^{12} \mathrm{H}_{3}$ & 3- 783 & $1,1,1 \leftarrow 0,0,0$ & Ground & & & 36083.69 & .12 \\
\hline $\mathrm{C}^{12} \mathrm{H}_{3} \mathrm{Hg}^{202} \mathrm{Cl}^{37}$ & 4. 448 & $9 . \leftarrow 8$ & Ground & & & 36085.75 & \\
\hline $\mathrm{C}^{12} \mathrm{H}_{2} \mathrm{DSi}^{\prime \prime} \mathrm{D}_{3}$ & 3- 328 & $2,0,2 \leftarrow 1,0,1$ & & & & 36097.35 & .2 \\
\hline $\mathrm{C}^{12} \mathrm{H}_{33} \mathrm{Hg}^{200} \mathrm{Cl}^{37}$ & 4- 446 & $9, \leftarrow 8$ & Ground & & & 36098.07 & \\
\hline $\mathrm{DC}^{12}: \mathrm{C}^{12} \mathrm{C}^{12} \mathrm{HO}^{16}$ & 4- 916 & $2,1,2 \leftarrow 3,0,3$ & Ground & & & 36099.79 & .02 \\
\hline $\mathrm{CI}_{2}^{\mathrm{H}} \mathrm{O}^{16}$ & $4-1484$ & $18,1.17 \leftarrow-17,2,16$ & Ground & & & 36100.46 & \\
\hline $\mathrm{C}^{12} \mathrm{H}_{3} \mathrm{Hg}^{199} \mathrm{Cl}^{37}$ & 4- 444 & $9 . \leftarrow 8$, & Ground & & & 36104.30 & \\
\hline $\mathrm{D}_{2} \mathrm{O}_{2}^{16}$ & 3- 42 & Not Reported & & & & 36105. & 3. \\
\hline$c-\mathrm{HDC}^{12}: \mathrm{C}^{12} \mathrm{HF}^{19}$ & 4- 787 & $2,1,2 \leftarrow 1,1,1$ & Ground & & & 36109.5 & .3 \\
\hline $\mathrm{C}^{12} \mathrm{D}_{3} \mathrm{~N}^{14} \mathrm{D}_{2}$ & 3- 262 & $1,1,1 \leftarrow 1,0,1$ & Ground & & & 36109.50 & \\
\hline $\mathrm{C}^{12} \mathrm{H}_{3} \mathrm{Hg}^{198} \mathrm{Cl}^{37}$ & 4- 442 & $9, \leftarrow 8$, & Ground & & & 36110.53 & \\
\hline $\mathrm{S}^{34} \mathrm{P}^{31} \mathrm{~F}_{3}^{19}$ & 4-1693 & $7,6 \leftarrow 6,6$ & Ground & & & 36115.78 & .05 \\
\hline$S^{34} P^{31} F_{3}^{19}$ & 4-1693 & $7,3 \leftarrow 6,3$ & Ground & & & 36116.47 & .05 \\
\hline $\mathrm{S}^{34} \mathrm{P}^{31} \mathrm{~F}_{3}^{19}$ & 4-1693 & $7,0 \leftarrow 6,0$ & Ground & & & 36116.72 & .05 \\
\hline $\mathrm{S}^{34} \mathrm{P}^{31} \mathrm{~F}_{3}^{19}$ & 4-1693 & $7,1 \leftarrow 6,1$ & Ground & & & 36116.72 & .05 \\
\hline $\mathrm{S}^{34} \mathrm{P}^{31} \mathrm{~F}_{3}^{19}$ & 4-1693 & $7,2 \leftarrow 6,2$ & Ground & & & 36116.72 & .05 \\
\hline $\mathrm{C}^{12}{ }_{*} \mathrm{H}_{2} \mathrm{~N}^{14} \mathrm{HC}^{12}{ }_{*} \mathrm{H}_{2}$ & 4- 861 & 1. $1,1 \leftarrow 0,0,0$ & Ground & & & 36119.4 & \\
\hline $\mathrm{D}_{2} \mathrm{O}_{2}^{16}$ & 3- 42 & Not Reported & & & & 36162. & 3. \\
\hline $\mathrm{C}^{12} \mathrm{H}_{3} \mathrm{O}^{16} \mathrm{H}$ & 3. 211 & $4,1, \leftarrow 3,0$, & Ground & & & 36169.24 & .1 \\
\hline$\left(\mathrm{C}^{12} \mathrm{H}_{3}\right)_{3} \mathrm{C}^{13} \mathrm{Cl}^{35}$ & 3- 973 & $6 . \leftarrow 5$ & Ground & & & 36171.1 & \\
\hline $\mathrm{C}^{12} \mathrm{H}_{3} \mathrm{~S}^{32} \mathrm{H}$ & 3- 221 & Not Reported & Ground & & & 36172.20 & \\
\hline $\mathrm{C}^{12} \mathrm{H}_{3} \mathrm{C}^{12}{ }_{*} \mathrm{HO}^{16} \mathrm{C}^{12}{ }_{*} \mathrm{H}_{2}$ & 3- 761 & $2,2,1 \leftarrow 2,1,2$ & Ground & & & 36173.03 & .1 \\
\hline $\mathrm{t}-\mathrm{C}^{12} \mathrm{HD}: \mathrm{C}^{12} \mathrm{HBr}^{81}$ & 4- 743 & $5,1,5 \leftarrow 4,1,4$ & Excited & $13 / 2$ & $11 / 2$ & 36177.6 & \\
\hline $\mathrm{C}^{\mathrm{h}}{ }_{*} \mathrm{H}_{2}^{\mathrm{b}} \mathrm{N}^{\mathrm{b}} \mathrm{H}^{\mathrm{b}} \mathrm{C}^{\mathrm{b}}{ }_{*} \mathrm{H}_{2}^{\mathrm{b}}$ & 4- 863 & Not Reported & & & & 36180. & 10. \\
\hline $\mathrm{t} \cdot \mathrm{C}^{12} \mathrm{HD}: \mathrm{C}^{12} \mathrm{HBr}^{81}$ & 4- 743 & $5,1,5 \leftarrow 4,1,4$ & Excited & $7 / 2$ & $5 / 2$ & 36182.1 & \\
\hline t- $\mathrm{C}^{12} \mathrm{HD}: \mathrm{C}^{12} \mathrm{HBr}^{81}$ & 4- 743 & $5,1,5 \leftarrow 4,1,4$ & Excited & $11 / 2$ & $9 / 2$ & 36184.2 & \\
\hline $\mathrm{C}^{12} \mathrm{HD}: \mathrm{C}^{12} \mathrm{HBr}^{\mathrm{b}}$ & 4- 748 & Not Reported & Ground & & & 36192.0 & .2 \\
\hline $\mathrm{C}^{12} \mathrm{H}_{3} \mathrm{Si}^{28} \mathrm{HDF}^{19}$ & 3. 252 & $3,2,1 \leftarrow 2,2,0$ & Ground & & & 36192.50 & .10 \\
\hline $\mathrm{C}^{12} \mathrm{H}_{3} \mathrm{O}^{18} \mathrm{H}$ & 3- 217 & $13,2, \leftarrow 13,1$, & Ground & & & 36193.55 & .1 \\
\hline $\mathrm{C}^{12} \mathrm{H}_{3} \mathrm{C}^{12}{ }_{*} \mathrm{HO}^{16} \mathrm{C}^{12}{ }_{*} \mathrm{H}_{2}$ & 3- 761 & $2,2,1 \leftarrow 2,1,2$ & Ground & & & 36198.17 & .1 \\
\hline $\mathrm{C}^{12} \mathrm{HD}_{2} \mathrm{~N}^{14} \mathrm{C}^{12}$ & 4. 839 & $2,1,1 \leftarrow 1,1,0$ & Ground & & & 36199.82 & .1 \\
\hline $\mathrm{D}_{2} \mathrm{~N}^{14} \mathrm{C}^{12} \mathrm{~N}^{14}$ & 4- 363 & $2,1,1 \leftarrow 1,1,0$ & Ground & & & 36209.0 & .5 \\
\hline $\mathrm{C}^{12} \mathrm{H}_{3} \mathrm{C}^{12}{ }_{*} \mathrm{HO}^{16} \mathrm{C}^{12}{ }_{*} \mathrm{H}_{2}$ & 3- 761 & Not Reported & Ground & & & 36211.58 & .1 \\
\hline$\left(\mathrm{C}^{12} \mathrm{H}_{3}\right)_{3} \mathrm{C}^{12} \mathrm{Cl}^{35}$ & 3. 971 & $6, \leftarrow 5$, & Ground & & & 36212.3 & .10 \\
\hline $\mathrm{t}-\mathrm{C}^{12} \mathrm{HD}: \mathrm{C}^{12} \mathrm{HBr}^{81}$ & 4- 743 & $5,1,5 \leftarrow 4,1,4$ & Ground & $13 / 2$ & $11 / 2$ & 36212.5 & \\
\hline $\mathrm{C}^{12} \mathrm{H}_{3} \mathrm{C}^{12}{ }_{*} \mathrm{HO}^{16} \mathrm{C}^{12}{ }_{*} \mathrm{H}_{2}$ & 3- 761 & $2,2,1 \leftarrow 2,1,2$ & Ground & & & 36216.40 & .1 \\
\hline $\mathrm{C}^{12} \mathrm{H}_{3} \mathrm{~S}^{32} \mathrm{H}$ & 3. 221 & Not Reported & Ground & & & 36216.46 & \\
\hline $\mathrm{t}-\mathrm{C}^{12} \mathrm{HD}: \mathrm{C}^{12} \mathrm{HBr}^{81}$ & 4- 743 & $5,1,5 \leftarrow 4,1,4$ & Ground & $7 / 2$ & $5 / 2$ & 36217.2 & \\
\hline
\end{tabular}




\begin{tabular}{|c|c|c|c|c|c|c|}
\hline Isotopic Species & $\begin{array}{l}\text { Vol.-Id. } \\
\text { Nos. }\end{array}$ & $\begin{array}{c}\text { Rotational } \\
\text { Quantum Nos. }\end{array}$ & Vib. State & $\mathrm{F}_{1}^{\prime} \stackrel{\text { Hyperfine }}{\mathrm{F}^{\prime}} \mathrm{F}_{1} \quad \mathrm{~F}$ & $\begin{array}{c}\text { Frequency } \\
\mathrm{MHz}^{2}\end{array}$ & $\begin{aligned} & \text { Ace. } \\
\pm & \mathrm{MHz}\end{aligned}$ \\
\hline $\mathrm{C}^{12} \mathrm{HD}: \mathrm{C}^{12} \mathrm{HBr}^{\mathrm{b}}$ & 4- 748 & Not Reported & Ground & & 36222.1 & .1 \\
\hline $\mathrm{D}_{2} \mathrm{~N}^{14} \mathrm{C}^{12} \mathrm{~N}^{14}$ & 4- 363 & $2,1,1 \leftarrow 1,1,0$ & Excited & & 36223.6 & .5 \\
\hline $\mathrm{D}_{2} \mathrm{~N}^{14} \mathrm{C}^{12} \mathrm{~N}^{14}$ & 4- 363 & $2,1,1 \leftarrow 1,1,0$ & Excited & & 36229.0 & .5 \\
\hline $\mathrm{C}^{12} \mathrm{H}_{3} \mathrm{O}^{16} \mathrm{H}$ & 3- 211 & Not Reported & & & 36240 . & \\
\hline $\mathrm{C}^{12} \mathrm{H}_{2} \mathrm{DSi}^{\mathrm{b}} \mathrm{D}_{3}$ & 3- 328 & $2,1,1 \leftarrow 1,1,0$ & & & 36246.17 & .3 \\
\hline $\mathrm{C}^{12} \mathrm{H}_{3} \mathrm{O}^{16} \mathrm{H}$ & $3-211$ & Not Reported & Ground & & 36248.14 & .1 \\
\hline $\mathrm{C}^{12} \mathrm{H}_{2} \mathrm{DSi}^{\mathrm{h}} \mathrm{D}_{3}$ & 3- 328 & $2,1,1 \leftarrow 1,1,0$ & & & 36249.26 & .3 \\
\hline $\mathrm{C}^{12}{ }_{*} \mathrm{H}_{2} \mathrm{~N}^{14} \mathrm{HC}^{12}{ }_{*} \mathrm{H}_{2}$ & 4- 861 & $12,10,3 \leftarrow 12.9,3$ & Ground & & 36250 . & 10. \\
\hline$\left(\mathrm{C}^{12} \mathrm{H}_{3}\right)_{2} \mathrm{~S}^{32}$ & 3- 601 & $12,2,11 \leftarrow 11,3,8$ & Ground & & 36258.98 & .05 \\
\hline$\left(\mathrm{C}^{12} \mathrm{H}_{3}\right)_{2} \mathrm{~S}^{32}$ & 3. 601 & $12,2,11 \leftarrow 11,3,8$ & Ground & & 36260.33 & .05 \\
\hline$\left(\mathrm{C}^{12} \mathrm{H}_{3}\right)_{2} \mathrm{~S}^{32}$ & 3- 601 & $12,2,11 \leftarrow 11,3,8$ & Ground & & 36261.67 & .05 \\
\hline $\mathrm{C}^{12} \mathrm{H}_{3} \mathrm{C}^{12} \mathrm{HF}_{2}^{19}$ & 3- 461 & $7,3,4 \leftarrow 7,3,5$ & Ground & & 36263.9 & .1 \\
\hline $\mathrm{D}_{2} \mathrm{O}_{2}^{16}$ & 3- 42 & Not Reported & & & 36268. & 3. \\
\hline $\mathrm{HC}^{12}: \mathrm{C}^{12} \mathrm{C}^{12} \mathrm{H}: \mathrm{C}^{12} \mathrm{H}_{2}$ & 4-1131 & $4,0,4 \leftarrow 3,0,3$ & Ground & & 36270.16 & \\
\hline $\mathrm{P}^{31} \mathrm{O}^{16} \mathrm{Cl}_{3}^{35}$ & 4-1511 & $9, \leftarrow 8$ & Ground & & 36273.5 & .5 \\
\hline$\left(\mathrm{C}^{12} \mathrm{H}_{3}\right)_{2} \mathrm{~S}^{32}$ & 3- 601 & $2,2,1 \leftarrow 2,1,2$ & Ground & & 36273.68 & .05 \\
\hline$\left(\mathrm{C}^{12} \mathrm{H}_{3}\right)_{2} \mathrm{~S}^{32}$ & 3- 601 & $2,2,1 \leftarrow 2,1,2$ & Ground & & 36273.81 & .05 \\
\hline$\left(\mathrm{C}^{12} \mathrm{H}_{3}\right)_{2} \mathrm{~S}^{32}$ & 3. 601 & $2,2,1 \leftarrow 2,1,2$ & Ground & & 36274.50 & .05 \\
\hline$\left(\mathrm{C}^{12} \mathrm{H}_{3}\right)_{2} \mathrm{~S}^{32}$ & 3. 601 & $2,2,1 \leftarrow 2,1,2$ & Ground & & 36275.25 & .05 \\
\hline $\mathrm{N}^{14} \mathrm{O}^{16} \mathrm{Br}^{6}$ & 4- 123 & $5, \quad \leftarrow 4, \quad$ & & & 36280 . & \\
\hline $\mathrm{C}^{12} \mathrm{H}_{3} \mathrm{~S}^{32} \mathrm{H}$ & 3- 221 & Not Reported & Ground & & 36281.75 & \\
\hline $\mathrm{C}^{12} \mathrm{DHCl}_{2}^{35}$ & 4. 344 & $2,1,2 \leftarrow 1,0,1$ & Ground & & 36283 . & 2. \\
\hline $\mathrm{C}^{12} \mathrm{H}_{3} \mathrm{C}^{12} \mathrm{HF}_{2}^{19}$ & 3- 461 & $7,4,4 \leftarrow 7,2,5$ & Ground & & 36291.4 & .1 \\
\hline $\mathrm{C}^{12} \mathrm{H}_{3} \mathrm{C}^{12} \mathrm{H}_{2} \mathrm{~F}^{19}$ & 3- 551 & $2,1,2 \leftarrow 1,1,1$ & Ground & & 36293.37 & .10 \\
\hline $\mathrm{HC}^{12}: \mathrm{C}^{12} \mathrm{C}^{12} \mathrm{H}: \mathrm{C}^{12} \mathrm{H}_{2}$ & 4.1131 & $4,2,3 \leftarrow 3,2,2$ & Ground & & 35298.87 & \\
\hline $\mathrm{C}^{12} \mathrm{Cl}_{2}^{35} \mathrm{Cl}^{37} \mathrm{C}^{12} \mathrm{~N}^{14}$ & 4. 582 & $11, \quad \leftarrow 10$, & Ground & & 36301.8 & 1.0 \\
\hline $\mathrm{C}^{13} \mathrm{H}_{3} \mathrm{C}^{13} \mathrm{HO}^{16}$ & 3- 478 & $2,1,2 \leftarrow 1,1,1$ & Ground & & 36309.26 & .3 \\
\hline $\mathrm{HC}^{12}: \mathrm{C}^{12} \mathrm{C}^{12} \mathrm{H}: \mathrm{C}^{12} \mathrm{H}_{2}$ & 4. 1131 & $4,3,1 \leftarrow 3,3,0$ & Ground & & 36310.02 & \\
\hline $\mathrm{HC}^{12}: \mathrm{C}^{12} \mathrm{C}^{12} \mathrm{H}: \mathrm{C}^{12} \mathrm{H}_{2}$ & 4-1131 & $4,3,2 \leftarrow 3,3,1$ & Ground & & 36310.02 & \\
\hline $\mathrm{C}^{12} \mathrm{H}_{3} \mathrm{O}^{18} \mathrm{H}$ & 3- 217 & $25,2, \leftarrow 25,1$, & Ground & & 36312.57 & .1 \\
\hline $\mathrm{D}_{2} \mathrm{~N}^{14} \mathrm{C}^{12} \mathrm{HO}^{16}$ & 3. 154 & $2,1,2 \leftarrow 1,1,1$ & Ground & & 36325.76 & .2 \\
\hline $\mathrm{HC}^{12}: \mathrm{C}^{12} \mathrm{C}^{12} \mathrm{H}: \mathrm{C}^{12} \mathrm{H}_{2}$ & 4-1131 & 4. $2,2 \leftarrow 3,2,1$ & Ground & & 36327.98 & \\
\hline $\mathrm{C}^{13} \mathrm{H}_{3} \mathrm{Br}^{81}$ & 4- 406 & $2, \leftarrow 1$ & Ground & & 36331.10 & .09 \\
\hline $\mathrm{C}^{12} \mathrm{D}_{3} \mathrm{O}^{16} \mathrm{D}$ & 3- 216 & Not Reported & & & 36332.7 & \\
\hline $\mathrm{C}^{12} \mathrm{D}_{3} \mathrm{O}^{16} \mathrm{H}$ & 3. 214 & Not Reported & Ground & & 36332.7 & .5 \\
\hline $\mathrm{C}^{12} \mathrm{Cl}_{2}^{35} \mathrm{Cl}^{37} \mathrm{C}^{12} \mathrm{~N}^{14}$ & 4- 582 & $11, \quad \leftarrow 10$, & Excited & & 36335.2 & 1.0 \\
\hline $\mathrm{t}-\mathrm{C}^{12} \mathrm{H}_{3} \mathrm{C}^{12} \mathrm{H}: \mathrm{C}^{12} \mathrm{HC}^{12} \mathrm{~N}^{14}$ & 3. 921 & $8,1, \leftarrow 7,1$ & Ground & & 36340.65 & .5 \\
\hline $\mathrm{C}^{12} \mathrm{H}_{3} \mathrm{C}^{12}{ }_{*} \mathrm{HO}^{16} \mathrm{C}^{12} * \mathrm{H}_{2}$ & 3- 761 & $37,18, \leftarrow 36,19$, & Ground & & 36348.78 & .1 \\
\hline $\mathrm{C}^{12} \mathrm{H}_{3} \mathrm{C}^{12}{ }_{*} \mathrm{HO}^{16} \mathrm{C}^{12}{ }_{*} \mathrm{H}_{2}$ & 3- 761 & $37,18, \quad \leftarrow 36,19$, & Ground & & 36349.51 & .1 \\
\hline $\mathrm{C}^{\mathrm{b}}{ }_{*} \mathrm{H}_{2}^{\mathrm{b}} \mathrm{N}^{\mathrm{b}} \mathrm{H}^{\mathrm{b}} \mathrm{C}^{\mathrm{b}}{ }_{*} \mathrm{H}_{2}^{\mathrm{b}}$ & 4- 863 & Not Reported & & & 36350. & 10. \\
\hline $\mathrm{C}^{12} \mathrm{H}_{3} \mathrm{C}^{12} \mathrm{HF}_{2}^{19}$ & 3- 461 & $6,2,4 \leftarrow 6,2,5$ & Ground & & 36351.2 & .1 \\
\hline $\mathrm{C}^{12} \mathrm{H}_{3} \mathrm{~S}^{32} \mathrm{H}$ & 3- 221 & Not Reported & Ground & & 36354.69 & \\
\hline $\mathrm{C}^{12} \mathrm{H}_{3} \mathrm{C}^{12} \mathrm{HF}_{2}^{19}$ & 3- 461 & $6,3,4 \leftarrow 6,1,5$ & Ground & & 36358.5 & .1 \\
\hline $\mathrm{C}^{13} \mathrm{H}_{3} \mathrm{C}^{12} \mathrm{H}_{2} \mathrm{C}^{12} \mathrm{H}_{3}$ & 3- 782 & $1,1,1 \leftarrow 0,0,0$ & Ground & & 36373.78 & .12 \\
\hline $\mathrm{C}^{12}{ }_{*} \mathrm{H}_{2} \mathrm{~N}^{14} \mathrm{HC}^{12}{ }_{*} \mathrm{H}_{2}$ & 4- 861 & $6,4,2 \leftarrow 6,3,3$ & Ground & & 36374.0 & .5 \\
\hline
\end{tabular}




\begin{tabular}{|c|c|c|c|c|c|c|c|c|}
\hline Isotopic Species & $\begin{array}{l}\text { Vol.-Id. } \\
\text { Nos. }\end{array}$ & $\begin{array}{c}\text { Rotational } \\
\text { Quantum Nos. }\end{array}$ & Vib. State & $\mathrm{F}_{1}^{\prime}$ & $\begin{array}{l}\text { Hyperfine } \\
\mathrm{F}^{\prime} \mathrm{F}_{1}\end{array}$ & $\mathrm{~F}$ & $\begin{array}{c}\text { Frequency } \\
\mathrm{MH}_{z}\end{array}$ & $\begin{aligned} & \text { Acc. } \\
\pm & \mathrm{MHz}\end{aligned}$ \\
\hline $\mathrm{C}^{12} \mathrm{H}_{3} \mathrm{C}^{12} \mathrm{HF}_{2}^{19}$ & 3- 461 & $2,1,1 \leftarrow 1,0,1$ & Ground & & & & 36379.9 & .1 \\
\hline t-C $\mathrm{C}^{12} \mathrm{HD}: \mathrm{C}^{12} \mathrm{HBr}^{79}$ & 4- 741 & $5,1,5 \leftarrow 4,1,4$ & Excited & & $13 / 2$ & $11 / 2$ & 36382.6 & \\
\hline t. $\mathrm{C}^{12} \mathrm{HD}: \mathrm{C}^{12} \mathrm{HBr}^{79}$ & 4- 74] & $5,1,5 \leftarrow 4,1,4$ & Excited & & $11 / 2$ & $9 / 2$ & 36388.5 & \\
\hline t. $\mathrm{C}^{12} \mathrm{HD}: \mathrm{C}^{12} \mathrm{HBr}^{79}$ & 4- 741 & 5. $1,5 \leftarrow 4,1,4$ & Excited & & $9 / 2$ & $7 / 2$ & 36393.5 & \\
\hline $\mathrm{C}^{13} \mathrm{H}_{3} \mathrm{C}^{12} \mathrm{HO}$ & 3. 476 & $2,1,2 \leftarrow 1,1,1$ & Ground & & & & 36402.86 & .3 \\
\hline $\mathrm{C}^{12} \mathrm{H}_{3} \mathrm{C}^{12} \mathrm{HF}_{2}^{19}$ & 3. 461 & $5,1,4 \leftarrow 5,1,5$ & Ground & & & & 36403.3 & .1 \\
\hline $\mathrm{C}^{12} \mathrm{H}_{3} \mathrm{C}^{12} \mathrm{HF}_{2}^{19}$ & 3- 461 & $5,2,4 \leftarrow 5,0,5$ & Ground & & & & 36403.3 & .1 \\
\hline $\mathrm{t}-\mathrm{C}^{12} \mathrm{HD}: \mathrm{C}^{12} \mathrm{HBr}^{79}$ & 4- 741 & $5,1,5 \leftarrow 4,1,4$ & Ground & & $13 / 2$ & $11 / 2$ & 36418.4 & \\
\hline $\mathrm{N}^{14} \mathrm{O}^{16} \mathrm{Br}^{\mathrm{b}}$ & 4- 123 & $5, \quad \leftarrow 4, \quad$ & & & & & 36420 . & \\
\hline $\mathrm{C}^{12} \mathrm{D}_{3} \mathrm{O}^{16} \mathrm{H}$ & 3- 214 & Not Reported & Ground & & & & 36422.9 & .5 \\
\hline $\mathrm{C}^{12} \mathrm{D}_{3} \mathrm{O}^{16} \mathrm{D}$ & 3- 216 & Not Reported & & & & & 36422.9 & \\
\hline t- $\mathrm{C}^{12} \mathrm{HD}: \mathrm{C}^{12} \mathrm{HBr}^{79}$ & 4- 741 & $5,1,5 \leftarrow 4,1,4$ & Ground & & $11 / 2$ & $9 / 2$ & 36423.9 & \\
\hline $\mathrm{C}^{12} \mathrm{H}_{2}: \mathrm{C}^{12} \mathrm{HC}^{12} \mathrm{HO}^{16}$ & 3- 691 & $4,1,3 \leftarrow 3,1,2$ & Ground & & & & 36436.03 & \\
\hline $\mathrm{C}^{12} \mathrm{D}_{3} \mathrm{~N}^{14} \mathrm{H}_{2}$ & 3- 263 & $1,0,1 \leftarrow 0,0,0$ & & & & & 36436.2 & .5 \\
\hline $\mathrm{C}^{12} \mathrm{D}_{3} \mathrm{~N}^{14} \mathrm{H}_{2}$ & 3- 263 & $1,0,1 \leftarrow 0,0,0$ & & & & & 36436.8 & .5 \\
\hline$\left(\mathrm{C}^{12} \mathrm{H}_{3}\right)_{2} \mathrm{O}^{16}$ & 3- 591 & Not Reported & Ground & & & & 36440 . & 20. \\
\hline$\left(\mathrm{C}^{12} \mathrm{H}_{3}\right)_{2} \mathrm{O}^{16}$ & 3. 591 & Not Reported & Ground & & & & 36450 . & 20. \\
\hline $\mathrm{C}^{12} \mathrm{D}_{3} \mathrm{~N}^{14} \mathrm{H}_{2}$ & 3- 263 & $4, \quad \leftarrow 4$, & & & & & 36451.1 & .5 \\
\hline $\mathrm{C}^{12} \mathrm{H}_{2} \mathrm{Cl}_{2}^{35}$ & 4- 341 & $10,1,9 \leftarrow 10,0,10$ & Ground & & & & 36451.3 & .3 \\
\hline $\mathrm{C}^{12} \mathrm{H}_{3} \mathrm{~N}^{14} \mathrm{H}_{2}$ & 3- 261 & $4,2, \leftarrow 5,1$, & Ground & & & & 36452.1 & \\
\hline $\mathrm{C}^{12} \mathrm{H}_{3} \mathrm{~N}^{1 \cdot 4} \mathrm{H}_{2}$ & 3. 261 & Not Reported & Ground & & & & 36452.1 & \\
\hline $\mathrm{C}^{12} \mathrm{H}_{3} \mathrm{Hg}^{202} \mathrm{Br}^{79}$ & 4- 417 & $16, \leftarrow 15$, & Ground & & & & 36476.28 & \\
\hline $\mathrm{C}^{13} \mathrm{H}_{3} \mathrm{Br}^{79}$ & 4- 405 & $2, \leftarrow 1$, & Ground & & & & 36477.67 & .09 \\
\hline $\mathrm{N}^{14} \mathrm{O}^{16} \mathrm{Br}^{b}$ & 4- 123 & $5, \quad \leftarrow 4, \quad$, & & & & & 36480. & \\
\hline $\mathrm{D}_{2} \mathrm{O}_{2}^{16}$ & 3- 42 & Not Reported & & & & & 36482 . & 3. \\
\hline $\mathrm{C}^{12} \mathrm{D}_{3} \mathrm{O}^{16} \mathrm{D}$ & 3- 216 & Not Reported & & & & & 36483.9 & \\
\hline $\mathrm{C}^{12} \mathrm{D}_{3} \mathrm{O}^{16} \mathrm{H}$ & 3- 214 & Not Reported & Ground & & & & 36483.9 & .5 \\
\hline $\mathrm{O}^{16} \mathrm{C}^{12} \mathrm{~S}^{32}$ & 4- 521 & $3 \leftarrow 2$ & Ground & & & & 36488.82 & .03 \\
\hline $\mathrm{C}^{12} \mathrm{H}_{3} \mathrm{C}^{12} \mathrm{HO}^{16}$ & 3. 471 & Not Reported & & & & & 36489.52 & \\
\hline $\mathrm{S}^{32} \mathrm{~F}_{5}^{19} \mathrm{Cl}^{35}$ & 4-1421 & $10, \leftarrow 9$ & Ground & & & & 36490.59 & .5 \\
\hline $\mathrm{C}^{12}{ }_{*} \mathrm{H}_{2} \mathrm{C}^{12} \mathrm{D}: \mathrm{C}^{12}{ }_{*} \mathrm{H}$ & 4-1032 & $4,2,2 \leftarrow 4,2,3$ & Ground & & & & 36498.7 & \\
\hline $\mathrm{C}^{13} \mathrm{H}_{3} \mathrm{C}^{13} \mathrm{HO}^{16}$ & 3- 478 & $2,1,2 \leftarrow 1,1,1$ & Ground & & & & 36515.58 & .2 \\
\hline$\left(\mathrm{C}^{12} \mathrm{H}_{3}\right)_{3} \mathrm{C}^{12} \mathrm{Br}^{81}$ & 3- 962 & $9, \leftarrow 8$, & Ground & & & & 36521.8 & .3 \\
\hline $\mathrm{C}^{12} \mathrm{H}_{3} \mathrm{Hg}^{200} \mathrm{Br}^{79}$ & 4- 415 & $16, \leftarrow 15$ & Ground & & & & 36523.48 & \\
\hline $\mathrm{O}^{16} \mathrm{C}^{12} \mathrm{~S}^{32}$ & 4- 521 & $3 \leftarrow 2$ & Excited & & & & 36532.47 & \\
\hline $\mathrm{C}^{12} \mathrm{H}_{3} \mathrm{C}^{12}{ }_{*} \mathrm{HO}^{16} \mathrm{C}^{12}{ }_{*} \mathrm{H}_{2}$ & 3- 761 & $13,5,9 \leftarrow 12,6,6$ & Ground & & & & 36540.92 & .1 \\
\hline $\mathrm{C}^{12} \mathrm{H}_{3} \mathrm{C}^{12}{ }_{*} \mathrm{HO}^{16} \mathrm{C}^{12}{ }_{*} \mathrm{H}_{2}$ & 3- 761 & $13,5,9 \longleftarrow 12,6,6$ & Ground & & & & 36542.27 & .1 \\
\hline $\mathrm{C}^{12} \mathrm{H}_{3} \mathrm{C}^{12}{ }_{*} \mathrm{HO}^{16} \mathrm{C}^{12}{ }_{*} \mathrm{H}_{2}$ & 3- 761 & $13,5,9 \longleftarrow 12,6,6$ & Ground & & & & 36545.43 & .1 \\
\hline $\mathrm{C}^{12} \mathrm{H}_{3} \mathrm{Hg}^{199} \mathrm{Br}^{79}$ & 4- 413 & $16, \leftarrow 15$, & Ground & & & & 36547.33 & \\
\hline $\mathrm{C}^{12} \mathrm{H}_{3} \mathrm{C}^{12}{ }_{*} \mathrm{HO}^{16} \mathrm{C}^{12}{ }_{*} \mathrm{H}_{2}$ & 3- 761 & $13,5,8 \leftarrow 12,6,7$ & Ground & & & & 36563.90 & .1 \\
\hline $\mathrm{C}^{12} \mathrm{H}_{3} \mathrm{C}^{12}{ }_{*} \mathrm{HO}^{16} \mathrm{C}^{12}{ }_{*} \mathrm{H}_{2}$ & 3- 761 & $13,5,8 \leftarrow 12,6,7$ & Ground & & & & 36565.29 & .1 \\
\hline $\mathrm{C}^{12} \mathrm{H}_{3} \mathrm{C}^{12}{ }_{*} \mathrm{HO}^{16} \mathrm{C}^{12}{ }_{*} \mathrm{H}_{2}$ & 3. 761 & $13,5,8 \leftarrow 12,6,7$ & Ground & & & & 36568.41 & .1 \\
\hline $\mathrm{O}^{16} \mathrm{C}^{12} \mathrm{~S}^{32}$ & 4- 521 & $3 \leftarrow 2$ & Excited & & & & 36570.83 & \\
\hline $\mathrm{C}^{12} \mathrm{H}_{3} \mathrm{Hg}^{198} \mathrm{Br}^{79}$ & 4- 411 & $16 . \leftarrow 15$ & Ground & & & & 36571.55 & \\
\hline $\mathrm{C}^{\mathrm{b}}{ }_{*} \mathrm{H}_{2}^{\mathrm{b}} \mathrm{N}^{\mathrm{b}} \mathrm{H}^{\mathrm{b}} \mathrm{C}^{1 \mathrm{~b}}{ }_{*} \mathrm{H}_{2}^{\mathrm{b}}$ & 4- 863 & Not Reported & & & & & 36575 . & 10. \\
\hline
\end{tabular}




\begin{tabular}{|c|c|c|c|c|c|c|}
\hline Isotopic Species & $\begin{array}{l}\text { Vol.-Id. } \\
\text { Nos. }\end{array}$ & $\begin{array}{c}\text { Rotational } \\
\text { Quantum Nos. }\end{array}$ & Vib. State & $\mathrm{F}_{1}^{\prime} \stackrel{\text { Hyperfine }}{\mathrm{F}^{\prime}} \mathrm{F}_{1} \mathrm{~F}$ & $\begin{array}{c}\text { Frequency } \\
\mathrm{MHz}\end{array}$ & $\begin{aligned} & \text { Acc. } \\
& \pm \mathrm{MHz}\end{aligned}$ \\
\hline $\mathrm{HDO}_{2}^{16}$ & 3- 43 & $7, \quad \leftarrow 7$, & & & 36575 . & 3. \\
\hline $\mathrm{C}^{\mathrm{b}} \mathrm{H}_{2}^{\mathrm{b}} \mathrm{Cl}^{\mathrm{b}} \mathrm{F}^{\mathrm{b}}$ & 4- 333 & Not Reported & & & 36583.05 & 1. \\
\hline $\mathrm{C}^{12} \mathrm{H}_{3} \mathrm{Si}^{28} \mathrm{H}_{2} \mathrm{~F}^{19}$ & 3. 241 & $3,0,3 \leftarrow 2,0,2$ & Ground & & 36583.44 & .10 \\
\hline $\mathrm{C}^{12} \mathrm{H}_{3} \mathrm{~S}^{32} \mathrm{H}$ & 3- 221 & Not Reported & Ground & & 36585.17 & \\
\hline $\mathrm{C}^{\mathrm{b}} \mathrm{H}_{2}^{\mathrm{b}} \mathrm{Cl}^{\mathrm{b}} \mathrm{F}^{\mathrm{b}}$ & 4- 333 & Not Reported & & & 36585.2 & 1. \\
\hline $\mathrm{C}^{\mathrm{b}} \mathrm{H}_{2}^{\mathrm{b}} \mathrm{Cl}^{\mathrm{b}} \mathrm{F}^{\mathrm{b}}$ & 4- 333 & Not Reported & & & 36587.57 & 1. \\
\hline $\mathrm{C}^{12} \mathrm{H}_{2} \mathrm{Cl}^{35} \mathrm{~F}^{19}$ & 4- 331 & $1,1,0 \leftarrow 1,0,1$ & Ground & & 36592.71 & 1.0 \\
\hline $\mathrm{C}^{12} \mathrm{H}_{3} \mathrm{~S}^{32} \mathrm{H}$ & 3- 221 & Not Reported & Ground & & 36597.09 & \\
\hline $\mathrm{O}^{16} \mathrm{C}^{12} \mathrm{~S}^{32}$ & 4- 521 & $3 \leftarrow 2$ & Excited & & 36600.81 & \\
\hline $\mathrm{C}^{12} \mathrm{H}_{3} \mathrm{C}^{12} \mathrm{HO}^{16}$ & 3. 471 & Not Reported & & & 36602.12 & \\
\hline $\mathrm{C}^{12} \mathrm{H}_{2} \mathrm{Cl}^{35} \mathrm{~F}^{19}$ & 4- 331 & $1,1,0 \leftarrow 1,0,1$ & Ground & & 36611.22 & .1 \\
\hline $\mathrm{C}^{12} \mathrm{H}_{3} \mathrm{C}^{12} \mathrm{HO}^{16}$ & 3. 471 & Not Reported & & & 36613.28 & \\
\hline $\mathrm{O}^{16} \mathrm{C}^{12} \mathrm{~S}^{32}$ & 4- 521 & $3 \leftarrow 2$ & Excited & & 36615.3 & \\
\hline $\mathrm{C}^{12} \mathrm{H}_{2} \mathrm{Cl}^{35} \mathrm{~F}^{19}$ & 4. 331 & $1,1,0 \leftarrow 1,0,1$ & Ground & & 36616.50 & .1 \\
\hline $\mathrm{C}^{12} \mathrm{H}_{2} \mathrm{Cl}^{35} \mathrm{~F}^{19}$ & 4- 331 & $1,1,0 \leftarrow 1.0,1$ & Ground & & 36620.92 & .1 \\
\hline $\mathrm{C}^{12} \mathrm{H}_{2} \mathrm{Cl}^{35} \mathrm{~F}^{19}$ & 4. 331 & $1,1,0 \leftarrow 1,0.1$ & Ground & & 36624.40 & .1 \\
\hline $\mathrm{C}^{13} \mathrm{H}_{3} \mathrm{C}^{12} \mathrm{HO}$ & 3- 476 & $2,1,2 \leftarrow 1,1,1$ & Ground & & 36628.12 & .5 \\
\hline $\mathrm{N}^{14} \mathrm{O}^{16} \mathrm{Br}^{1)}$ & 4- 123 & $5, \quad, \leftarrow 4$, & & & 36630 . & \\
\hline $\mathrm{H}_{3} \mathrm{C}^{12} \mathrm{C}^{12}: \mathrm{C}^{12} \mathrm{C}^{12}: \mathrm{C}^{12} \mathrm{H}$ & 4-1191 & $9,6 \leftarrow 8,6$ & Ground & & 36630.24 & .1 \\
\hline $\mathrm{C}^{\mathrm{b}} \mathrm{H}_{2}^{\mathrm{b}} \mathrm{Cl}^{\mathrm{b}} \mathrm{F}^{\mathrm{b}}$ & 4. 333 & Not Reported & & & 36631. & 1. \\
\hline $\mathrm{H}_{2} \mathrm{C}^{12}: \mathrm{C}^{12} \mathrm{~F}_{2}^{19}$ & 4. 681 & $2,1,1 \leftarrow 1,1,0$ & Ground & & 36633. & 1. \\
\hline $\mathrm{H}_{3} \mathrm{C}^{12} \mathrm{C}^{12}: \mathrm{C}^{12} \mathrm{C}^{12}: \mathrm{C}^{12} \mathrm{H}$ & $4-1191$ & $9,5 \leftarrow 8,5$ & Ground & & 36634.20 & .1 \\
\hline $\mathrm{H}_{3} \mathrm{C}^{12} \mathrm{C}^{12}: \mathrm{C}^{12} \mathrm{C}^{12}: \mathrm{C}^{12} \mathrm{H}$ & 4-1191 & $9,4 \leftarrow 8,4$ & Ground & & 36637.49 & .1 \\
\hline $\mathrm{H}_{3} \mathrm{C}^{12} \mathrm{C}^{12}: \mathrm{C}^{12} \mathrm{C}^{12}: \mathrm{C}^{12} \mathrm{H}$ & 4-1191 & $9,3 \leftarrow 8,3$ & Ground & & 36639.90 & .1 \\
\hline $\mathrm{H}_{3} \mathrm{C}^{12} \mathrm{C}^{12}: \mathrm{C}^{12} \mathrm{C}^{12}: \mathrm{C}^{12} \mathrm{H}$ & 4. 1191 & $9,2 \leftarrow 8,2$ & Ground & & 36641.70 & .1 \\
\hline $\mathrm{H}_{3} \mathrm{C}^{12} \mathrm{C}^{12}: \mathrm{C}^{12} \mathrm{C}^{12}: \mathrm{C}^{12} \mathrm{H}$ & 4-1191 & $9,1 \leftarrow 8,1$ & Ground & & 36642.77 & .1 \\
\hline $\mathrm{H}_{3} \mathrm{C}^{12} \mathrm{C}^{12}: \mathrm{C}^{12} \mathrm{C}^{12}: \mathrm{C}^{12} \mathrm{H}$ & 4-1191 & $9,0 \leftarrow 8,0$ & Ground & & 36643.08 & .1 \\
\hline $\mathrm{H}_{2} \mathrm{~N}^{14} \mathrm{~N}^{14} \mathrm{H}_{2}$ & 3. 51 & $13,2 \leftarrow-12,3$ & Ground & & 36647.1 & \\
\hline $\mathrm{C}^{12} \mathrm{H}_{2} \mathrm{Cl}^{37} \mathrm{~F}^{19}$ & 4- 332 & $1,1,0 \leftarrow 1.0,1$ & Ground & & 36652.77 & 1.0 \\
\hline $\mathrm{C}^{12} \mathrm{D}_{3} \mathrm{O}^{16} \mathrm{D}$ & 3. 216 & Not Reported & & & 36655. & \\
\hline $\mathrm{C}^{12} \mathrm{H}_{2} \mathrm{Cl}^{37} \mathrm{~F}^{19}$ & 4- 332 & $1,1,0 \leftarrow 1,0,1$ & Ground & & 36657.47 & 1.0 \\
\hline $\mathrm{H}_{2} \mathrm{~N}^{14} \mathrm{~N}^{14} \mathrm{H}_{2}$ & 3. 51 & $13,2 \leftarrow 12,3$ & Ground & & 36658.7 & \\
\hline $\mathrm{C}^{12} \mathrm{H}_{2} \mathrm{Cl}^{37} \mathrm{~F}^{19}$ & 4- 332 & $1,1,0 \leftarrow 1,0,1$ & Ground & & 36660.75 & 1.0 \\
\hline $\mathrm{C}^{12} \mathrm{D}_{3} \mathrm{O}^{16} \mathrm{H}$ & 3- 214 & Not Reported & Ground & & 36663.0 & .5 \\
\hline $\mathrm{C}^{12} \mathrm{H}_{2} \mathrm{Cl}^{37} \mathrm{~F}^{19}$ & 4. 332 & $1,1,0 \leftarrow 1,0,1$ & Ground & & 36663.42 & 1.0 \\
\hline $\mathrm{C}^{12} \mathrm{H}_{3} \mathrm{C}^{12} \mathrm{H}_{2} \mathrm{C}^{12} \mathrm{H}_{3}$ & 3- 781 & $1,1,1 \leftarrow 0,0,0$ & Ground & & 36666.33 & .06 \\
\hline $\mathrm{C}^{12} \mathrm{D}_{3} \mathrm{O}^{16} \mathrm{D}$ & 3- 216 & $1,0,1 \leftarrow 0,0,0$ & Ground & & 36673.93 & .5 \\
\hline $\mathrm{C}^{12} \mathrm{Cl}_{3}^{35} \mathrm{C}^{12} \mathrm{~N}^{14}$ & 4- 581 & 11. $\leftarrow 10$ & Ground & & 36681.9 & 1.0 \\
\hline $\mathrm{O}^{16} \mathrm{O}^{18} \mathrm{O}^{18}$ & 4-1844 & $1,1,1 \leftarrow 2,0.2$ & Ground & & 36688. & \\
\hline $\mathrm{C}^{12} \mathrm{H}_{3} \mathrm{C}^{12}{ }_{*} \mathrm{HO}^{16} \mathrm{C}^{12}{ }_{*} \mathrm{H}_{2}$ & 3- 761 & $3,1,3 \leftarrow 2,1,2$ & Ground & & 36700.24 & .1 \\
\hline $\mathrm{C}^{12} \mathrm{Cl}_{3}^{35} \mathrm{C}^{12} \mathrm{~N}^{14}$ & 4. 581 & $11, \leftarrow 10$ & Excited & & 36701.7 & 1.0 \\
\hline $\mathrm{H}_{3} \mathrm{C}^{12} \mathrm{C}^{12}: \mathrm{C}^{12} \mathrm{C}^{12}: \mathrm{C}^{12} \mathrm{H}$ & 4-1191 & $9,1 \leftarrow 8.1$ & Excited & & 36703.62 & .1 \\
\hline $\mathrm{H}_{3} \mathrm{C}^{12} \mathrm{C}^{12}: \mathrm{C}^{12} \mathrm{C}^{12}: \mathrm{C}^{12} \mathrm{H}$ & 4-1191 & Not Reported & & & 36707.00 & .1 \\
\hline $\mathrm{N}^{14} \mathrm{O}^{16} \mathrm{Br}^{11}$ & 4- 123 & $5, \quad, \leftarrow 4,$, & & & 36710. & \\
\hline $\mathrm{H}_{3} \mathrm{C}^{12} \mathrm{C}^{12}: \mathrm{C}^{12} \mathrm{C}^{12}: \mathrm{C}^{12} \mathrm{H}$ & 4-1191 & $9,5 \leftarrow 8,4$ & Excited & & 36710.05 & .1 \\
\hline
\end{tabular}


Vol.-ld. Rotational Nos. Quantum Nos.
Vib. State
Frequency
Allt
Allll
$\mathrm{H}_{3} \mathrm{C}^{12} \mathrm{C}^{12}: \mathrm{C}^{12} \mathrm{C}^{12}: \mathrm{C}^{12} \mathrm{H}$

$\mathrm{H}_{3} \mathrm{C}^{12} \mathrm{C}^{12}: \mathrm{C}^{12} \mathrm{C}^{12}: \mathrm{C}^{12} \mathrm{H}$

$\mathrm{H}_{3} \mathrm{C}^{12} \mathrm{C}^{12}: \mathrm{C}^{12} \mathrm{C}^{12}: \mathrm{C}^{12} \mathrm{H}$

$\mathrm{H}_{2} \mathrm{~N}^{14} \mathrm{~N}^{14} \mathrm{H}_{2}$

$\mathrm{H}_{3} \mathrm{C}^{12} \mathrm{C}^{12}: \mathrm{C}^{12} \mathrm{C}^{12}: \mathrm{C}^{12} \mathrm{H}$

$\mathrm{H}_{3} \mathrm{C}^{12} \mathrm{C}^{12}: \mathrm{C}^{12} \mathrm{C}^{12}: \mathrm{C}^{12} \mathrm{H}$

$\mathrm{C}^{12} \mathrm{H}_{3} \mathrm{C}^{12} \mathrm{HO}^{18}$

$\mathrm{H}_{3} \mathrm{C}^{12} \mathrm{C}^{12}: \mathrm{C}^{12} \mathrm{C}^{12}: \mathrm{C}^{12} \mathrm{H}$

$\mathrm{H}_{3} \mathrm{C}^{12} \mathrm{C}^{12}: \mathrm{C}^{12} \mathrm{C}^{12}: \mathrm{C}^{12} \mathrm{H}$

$\mathrm{H}_{3} \mathrm{C}^{12} \mathrm{C}^{12}: \mathrm{C}^{12} \mathrm{C}^{12}: \mathrm{C}^{12} \mathrm{H}$

$\mathrm{H}_{3} \mathrm{C}^{12} \mathrm{C}^{12}: \mathrm{C}^{12} \mathrm{C}^{12}: \mathrm{C}^{12} \mathrm{H}$

$\mathrm{C}^{12} \mathrm{H}_{3} \mathrm{C}^{12} \mathrm{HO}^{18}$

$\mathrm{H}_{2} \mathrm{~N}^{14} \mathrm{~N}^{14} \mathrm{H}_{2}$

$\mathrm{C}^{12} \mathrm{D}_{3} \mathrm{O}^{16} \mathrm{D}$

$\mathrm{C}^{12} \mathrm{H}_{3} \mathrm{C}^{12}{ }_{*} \mathrm{HO}^{16} \mathrm{C}^{12}{ }_{*} \mathrm{H}_{2}$

$\mathrm{C}^{12} \mathrm{H}_{3} \mathrm{C}^{12}{ }_{*} \mathrm{HO}^{16} \mathrm{C}^{12}{ }_{*} \mathrm{H}_{2}$

$\mathrm{Cl}_{2}^{\mathrm{b}} \mathrm{O}^{16}$

$\mathrm{N}^{14} \mathrm{O}_{2}^{16} \mathrm{Cl}^{35}$

$\mathrm{H}_{3} \mathrm{C}^{12} \mathrm{C}^{12}: \mathrm{C}^{12} \mathrm{C}^{12}: \mathrm{C}^{12} \mathrm{H}$

$\mathrm{Cl}_{2}^{\mathrm{b}} \mathrm{O}^{16}$

$\mathrm{F}^{19} \mathrm{HC}^{12} \mathrm{O}^{18}$

$\mathrm{C}^{12} \mathrm{H}_{2} \mathrm{~F}^{19} \mathrm{C}^{12} \mathrm{~N}^{14}$

$\mathrm{C}^{12} \mathrm{D}_{3} \mathrm{~N}^{14} \mathrm{H}_{2}$

$\mathrm{P}^{31} \mathrm{O}^{16} \mathrm{~F}_{3}^{19}$

$\mathrm{C}^{12} \mathrm{H}_{3} \mathrm{C}^{12}{ }_{*} \mathrm{HO}^{16} \mathrm{C}^{12}{ }_{*} \mathrm{H}_{2}$

$\mathrm{C}^{12} \mathrm{H}_{3} \mathrm{C}^{13} \mathrm{~N}^{14}$

$\mathrm{C}^{12} \mathrm{H}_{3} \mathrm{C}^{13} \mathrm{~N}^{14}$

$\mathrm{C}^{12} \mathrm{H}_{3} \mathrm{C}^{12}{ }_{*} \mathrm{HO}^{16} \mathrm{C}^{12}{ }_{*} \mathrm{H}_{2}$

$\mathrm{C}^{12} \mathrm{H}_{3} \mathrm{O}^{18} \mathrm{H}$

$\mathrm{C}^{12} \mathrm{H}_{3} \mathrm{C}^{12} \mathrm{~N}^{14}$

$\mathrm{C}^{12} \mathrm{H}_{3} \mathrm{C}^{12} \mathrm{~N}^{14}$

$\mathrm{C}^{12} \mathrm{H}_{3} \mathrm{C}^{12} \mathrm{~N}^{14}$

$\mathrm{C}^{12} \mathrm{H}_{3} \mathrm{C}^{12} \mathrm{~N}^{14}$

$\mathrm{C}^{12} \mathrm{H}_{3} \mathrm{C}^{12} \mathrm{~N}^{14}$

$\mathrm{C}^{12} \mathrm{H}_{3} \mathrm{C}^{12} \mathrm{~N}^{14}$

$\mathrm{C}^{12} \mathrm{H}_{3} \mathrm{C}^{12} \mathrm{~N}^{14}$

$\mathrm{C}^{12} \mathrm{H}_{3} \mathrm{C}^{12} \mathrm{~N}^{14}$

a- $\mathrm{C}^{12} \mathrm{H}_{2} \mathrm{DC}^{12} \mathrm{HO}^{16}$

$\mathrm{C}^{12} \mathrm{D}_{3} \mathrm{O}^{16} \mathrm{D}$

$\left(\mathrm{C}^{12} \mathrm{H}_{3}\right)_{3} \mathrm{C}^{12} \mathrm{Br}^{79}$

$\mathrm{N}^{14} \mathrm{O}^{16} \mathrm{Br}^{\mathrm{b}}$

$\mathrm{C}^{12} \mathrm{H}_{3} \mathrm{~N}^{14} \mathrm{O}_{2}^{16}$

$\mathrm{C}^{12} \mathrm{D}_{3} \mathrm{~N}^{14} \mathrm{H}_{2}$

$\mathrm{C}^{12} \mathrm{H}_{3} \mathrm{~S}^{32} \mathrm{H}$

$\mathrm{C}^{12} \mathrm{H}_{3} \mathrm{~S}^{32} \mathrm{H}$

\begin{tabular}{|c|c|c|}
\hline $4-1191$ & $9,4 \leftarrow 8,4$ & Excited \\
\hline $4-1191$ & $9,5 \leftarrow 8,5$ & Excited \\
\hline $4-1191$ & $9,3 \leftarrow 8,3$ & Excited \\
\hline 3. 51 & $13,2 \leftarrow 12,3$ & Ground \\
\hline $4-1191$ & $9.4 \leftarrow 8,4$ & Excited \\
\hline 4-1191 & 9. $2 \leftarrow 8,2$ & Excited \\
\hline 3. 479 & $2,0,2 \leftarrow 1,0,1$ & Ground \\
\hline $4-1191$ & $9,1 \leftarrow 8,1$ & Excited \\
\hline 4-1191 & $9,3 \leftarrow 8,3$ & Excited \\
\hline $4-1191$ & $9,2 \leftarrow 8,2$ & Excited \\
\hline 4-1191 & 9. $0 \leftarrow 8,0$ & Excited \\
\hline 3. 479 & $2,0,2 \leftarrow 1,0,1$ & Ground \\
\hline 3- 51 & $13,2 \leftarrow 12,3$ & Ground \\
\hline 3. 216 & $1,0,1 \leftarrow 0,0,0$ & Ground \\
\hline 3. 761 & $3,1,3 \leftarrow 2,1,2$ & Ground \\
\hline 3- 761 & $3,1,3 \leftarrow 2,1,2$ & Ground \\
\hline $4-1484$ & $9,2,8 \leftarrow 10,1,9$ & Ground \\
\hline $4-1461$ & $4,2,2 \leftarrow 3,2,1$ & Excited \\
\hline $4-1191$ & $9,1 \leftarrow 8,1$ & Excited \\
\hline 4-1484 & $22,3,19 \leftarrow 23,2,22$ & Ground \\
\hline 4- 274 & $1,1,1 \leftarrow 2,0,2$ & Ground \\
\hline 4- 701 & $6,1,5 \leftarrow 5,2,4$ & Ground \\
\hline 3. 263 & Not Reported & \\
\hline
\end{tabular}

4-1671

3- 761

4- 815

4. $\leftarrow 3$,

Ground

$3,1,3 \leftarrow 2,1,2 \quad$ Ground

4- 815

$2,0 \leftarrow 1,0$

3- 761

$2,0 \leftarrow 1,0$

Ground

$3,1,3 \leftarrow 2,1,2$

Ground

3- 217

$14,2, \leftarrow 14,1$,

Ground

4. 811

$2,1 \leftarrow 1,1$

4- 811

$$
2,1 \leftarrow 1,1
$$

4- 811

$2,0 \leftarrow 1,0$

4. 811

$2,1 \leftarrow 1,1$

4- 811

4. 811

$2,0 \leftarrow 1,0$

$2,0 \leftarrow 1,0$

$2,1 \leftarrow 1,1$

$2,0 \leftarrow 1,0$

4- 811

3- 481

$2,1,1 \leftarrow 1,1,0$

Ground

Ground

Ground

Ground

Ground

Ground

Ground

Ground

Ground

3- 216

3- 961

$1,0,1 \leftarrow 0,0,0$

Ground

Ground

$9, \leftarrow 8$,

Ground

4. 123

$5, \quad \leftarrow 4$, ,

3- 171

Not Reported

Ground

3- 263

Not Reported

3- 221

Not Reported

Ground

3- 221

Not Reported

Ground

\begin{tabular}{|c|c|}
\hline 36713.83 & .1 \\
\hline 36716.90 & .1 \\
\hline 36716.90 & .1 \\
\hline 36717.4 & \\
\hline 36719.38 & .1 \\
\hline 36719.38 & .1 \\
\hline 36719.90 & .4 \\
\hline 36721.20 & .1 \\
\hline 36721.20 & 1 \\
\hline 36722.30 & .1 \\
\hline 36722.30 & .1 \\
\hline 36725.26 & .4 \\
\hline 36729.0 & \\
\hline 36730.94 & .5 \\
\hline 36736.13 & .1 \\
\hline 36737.03 & .1 \\
\hline 36739.68 & \\
\hline 36740 . & \\
\hline 36741.46 & .1 \\
\hline 36746.02 & \\
\hline 36748.3 & .2 \\
\hline 36752.8 & .2 \\
\hline 36753.7 & .5 \\
\hline 36753.83 & .05 \\
\hline 36774.08 & .1 \\
\hline 36777.18 & \\
\hline 36777.18 & \\
\hline 36783.14 & .1 \\
\hline 36787.33 & .1 \\
\hline 36793.64 & \\
\hline 36794.26 & \\
\hline 36794.26 & \\
\hline 36794.88 & \\
\hline 36795.38 & \\
\hline 36795.38 & \\
\hline 36796.27 & \\
\hline 36797.52 & \\
\hline 36799. & 3. \\
\hline 36799.01 & .5 \\
\hline 36809.8 & .3 \\
\hline 36810. & \\
\hline 36815.0 & \\
\hline 36816.6 & .5 \\
\hline 36822.40 & \\
\hline 36824.83 & \\
\hline
\end{tabular}


Vol.-ld. Nos.
Rotational Quantum Nos.
Vib. State

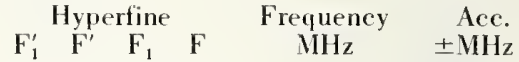

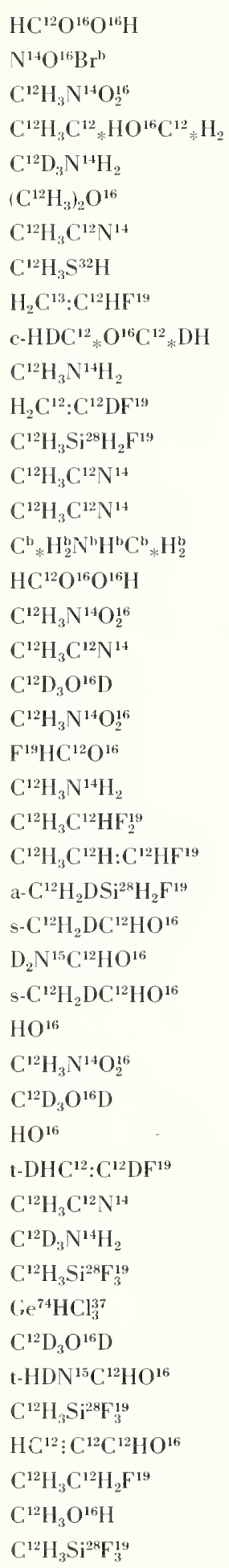

3. $71 \quad 13,2,11 \leftarrow 13,2,12$

4- 1235 , , $\leftarrow 4$, ,

3- $171 \quad$ Not Reported

3- 761

3. 263

3- 591

4- 811

3- 221

4. 782

4- 845

3- 261

4- 784

3. 241

4- 811

4. 811

4- 863

3- 71

3- 171

4. 811

3- 216

3- 171

4- 271

3- 261

3- 461

3- 711

3- 248

3. 473

3. 161

3- 473

1-

3- 171

3- 216

1 -

4- 791

4- 811

3- 263

3- 131

4. 1496

3. 216

3- 159

3- 131

4- 911

3- 551

3. 211

3- 131
Not Reported

Not Reported

Not Reported

$$
2,1 \leftarrow 1,1
$$

Not Reported

$2,1,2 \leftarrow 1,1,1$

$7,4,3 \leftarrow 7,3,4$

Not Reported

2, $1,2 \leftarrow 1,1.1$

$3,2,2 \leftarrow 2,2,1$

$$
2,1 \leftarrow 1,1
$$

$2,0 \leftarrow 1,0$

Not Reported

29, $4,25 \leftarrow 29,4,26$

Not Reported

$$
2,1 \leftarrow 1,1
$$

\section{Not Reported}

Not Reported

$5,0,5 \leftarrow 4.1,4$

Not Reported

$2,2,0 \leftarrow 1,1,0$

$5,1,5 \leftarrow 4,1,4$

$3,1,2 \leftarrow 2,1,1$

$2,0,2 \leftarrow 1,0,1$

$2,0,2 \leftarrow 1,0,1$

$2,0,2 \leftarrow 1,0,1$

$11 / 2,5 \leftarrow 11 / 2,5$

Not Reported

Not Reported

$11 / 2,5 \leftarrow 11 / 2,5$

$2,0,2 \leftarrow 1,0,1$

$$
2, \leftarrow 1,
$$

$3, \quad \leftarrow 3$,

$$
5, \leftarrow 4,
$$$$
9, \leftarrow 8,
$$

Not Reported

$2,1,2 \leftarrow 1,1,1$

$$
5, \leftarrow 4,
$$

$4,1,3 \leftarrow 3,1,2$

$5,1,4 \leftarrow 5,0,5$

Not Reported

$5, \leftarrow 4$,
Ground

ciround

Ground

Excited

Ground

ciround

ciround

Ground

Ground

Ground

Excited

Excited

Ground

Excited

Ground

Ground

Ground

Ground

Ground

Ground

Ground

Ground

Ground

Ground

Ground

Ground

Excited

Excited

Ground

Ground

Excited

Excited

Ground

Ground

Excited
36830.

36830 .

36830.0

36831.82

36856.9

36870 .

36870.94

36871.10

36872.34

36874.3

36885.4

36895.8

36897.80

36903.40

36903.40

36910.

10.

36 91.

36941.21

36942.15

36946.4

36954.07

36956.0

36957.5

36959.4

36968.20

36972.82

36975.

36980.00

36981.7

20.

.05

.2

.3

.10

36983.47

36984.23

36987.

36994.43

.15

37003.9

.3

37013.2

37015.4

.5

37025.7

37029.43

.07

37030.

37031.65

37034.4

37034.77

.15

37042.99

.10

37044.68

.1 


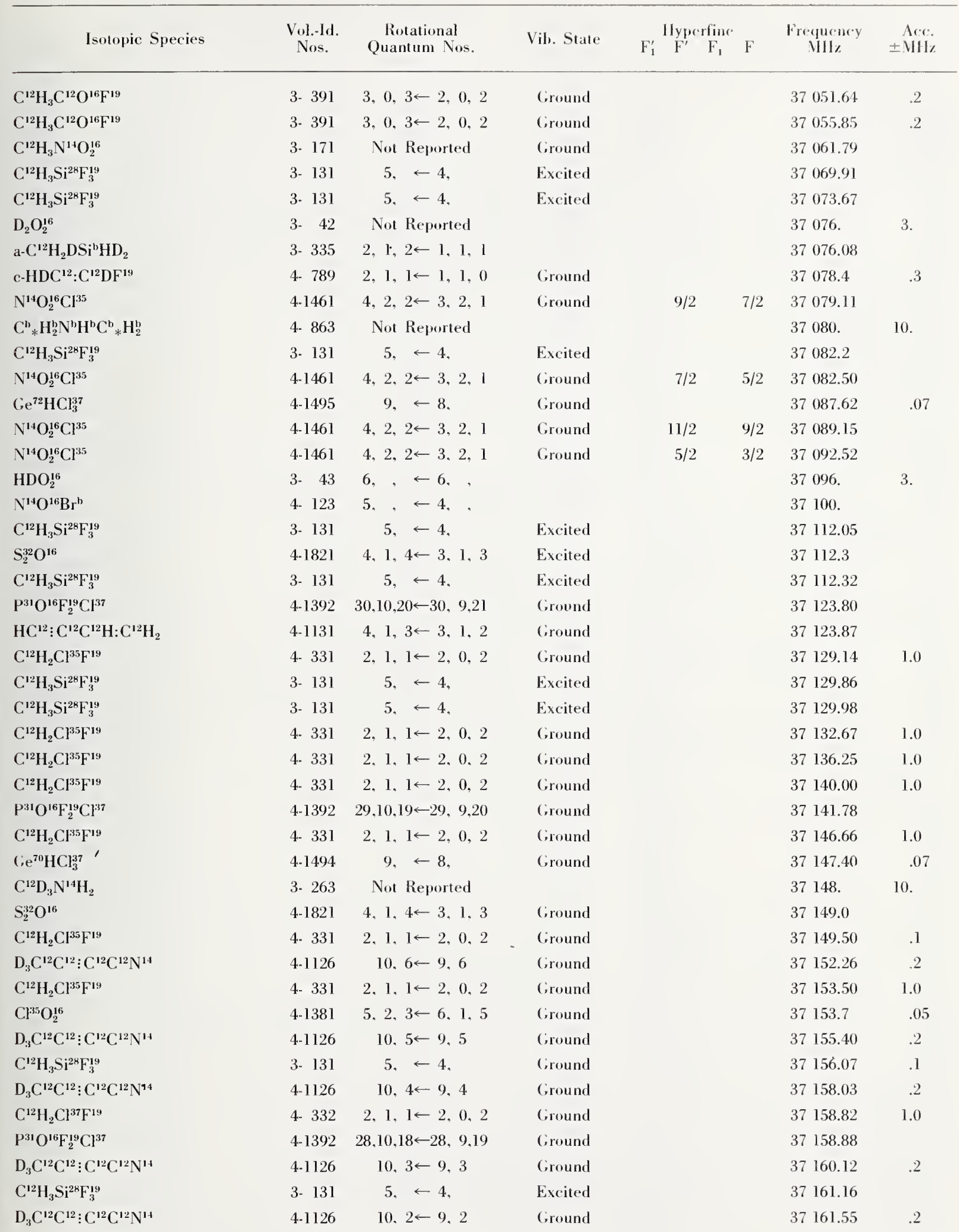




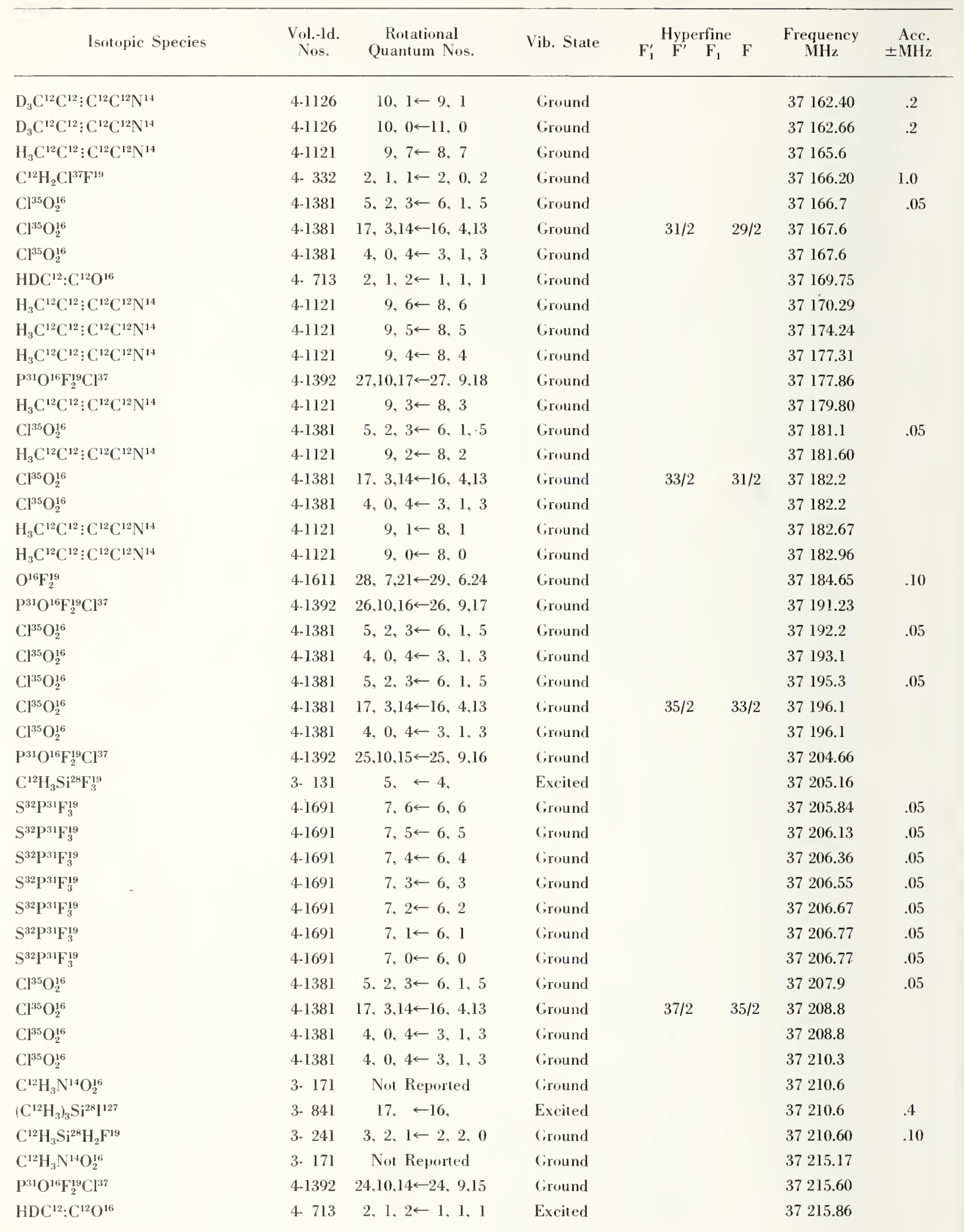




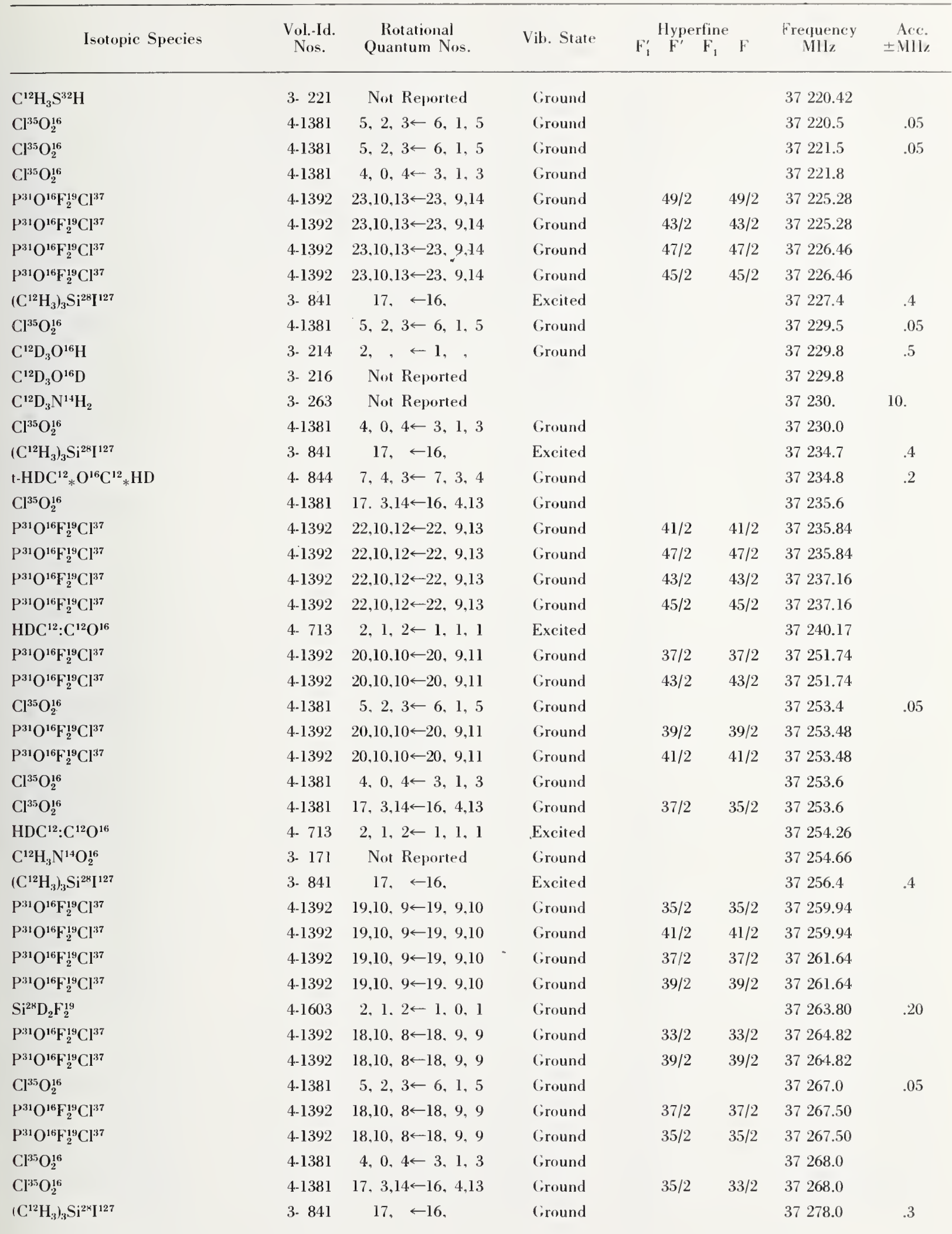




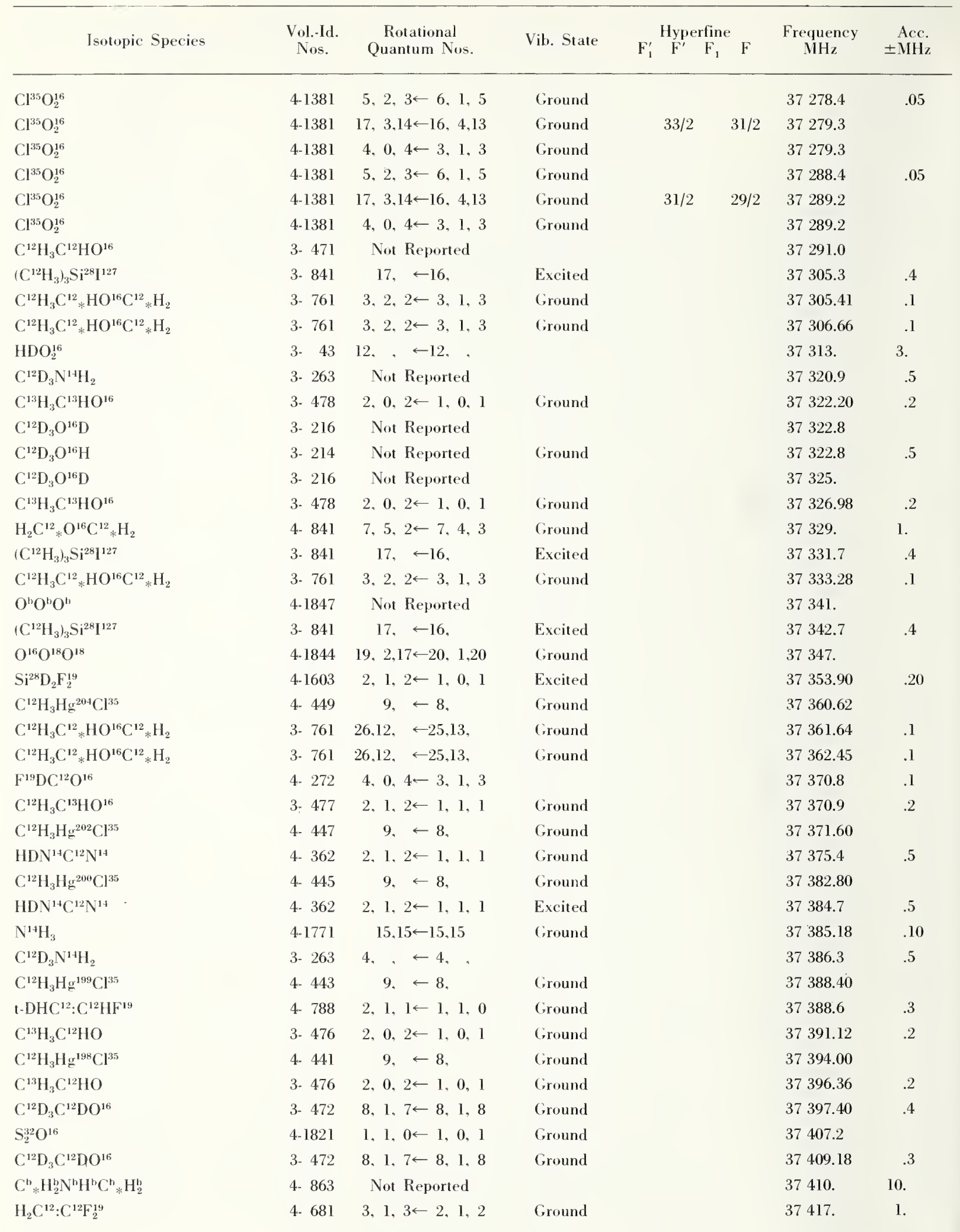


Vib. State $\mathrm{F}_{1}^{\prime} \stackrel{\text { Hyperfine }}{\mathrm{F}^{\prime}} \mathrm{F}_{1}$

Frequeney Ace. NIIt \pm MH\%

$\mathrm{C}^{12} \mathrm{H}_{3} \mathrm{O}^{18} \mathrm{H}$

$\mathrm{C}^{12} \mathrm{D}_{3} \mathrm{O}^{16} \mathrm{D}$

$\mathrm{C}^{12} \mathrm{D}_{3} \mathrm{~N}^{14} \mathrm{H}_{2}$

$\mathrm{C}^{12} \mathrm{HBr}_{3}^{79}$

$\mathrm{C}^{12} \mathrm{H}_{3} \mathrm{~S}^{32} \mathrm{H}$

$\mathrm{C}^{12} \mathrm{H}_{3} \mathrm{C}^{12} \mathrm{HF}_{2}^{19}$

$\left(\mathrm{C}^{12} \mathrm{D}_{3}\right)_{2} \mathrm{C}^{12} \mathrm{O}^{16}$

s- $\mathrm{C}^{12} \mathrm{H}_{2} \mathrm{DSi}^{1} \mathrm{HD}_{2}$

$\left(\mathrm{C}^{12} \mathrm{D}_{3}\right)_{2} \mathrm{C}^{12} \mathrm{O}^{16}$

$\left(\mathrm{C}^{12} \mathrm{D}_{3}\right)_{2} \mathrm{C}^{12} \mathrm{O}^{16}$

$\mathrm{H}_{2} \mathrm{C}^{12}: \mathrm{C}^{12} \mathrm{~F}_{2}^{19}$

$\mathrm{C}^{12} \mathrm{D}_{3} \mathrm{O}^{16} \mathrm{H}$

$\mathrm{C}^{12} \mathrm{D}_{3} \mathrm{O}^{16} \mathrm{D}$

$\mathrm{C}^{12} \mathrm{H}_{3} \mathrm{C}^{12} \mathrm{HO}^{16}$

$\mathrm{C}^{12} \mathrm{D}_{3} \mathrm{~N}^{14} \mathrm{O}_{2}^{16}$

$\mathrm{C}^{13} \mathrm{H}_{3} \mathrm{Si}^{28} \mathrm{H}_{2} \mathrm{~F}^{19}$

$\left(\mathrm{C}^{12} \mathrm{H}_{3}\right)_{3} \mathrm{C}^{12}$ $^{127}$

$\mathrm{C}^{12}{ }_{*} \mathrm{DHC}^{12} \mathrm{H}: \mathrm{C}^{12}{ }_{*} \mathrm{H}$

$\mathrm{C}^{12} \mathrm{H}_{3} \mathrm{C}^{12} \mathrm{HO}^{16}$

$\mathrm{H}_{2} \mathrm{O}_{2}^{16}$

$\mathrm{HDO}_{2}^{16}$

$\mathrm{C}^{12} \mathrm{D}_{3} \mathrm{C}^{12} \mathrm{HO}^{16}$

a- $\mathrm{C}^{12} \mathrm{H}_{2} \mathrm{DS}^{\mathrm{l}} \mathrm{HD}_{2}$

$\mathrm{C}^{12} \mathrm{HCl}_{3}^{37}$

$\mathrm{C}^{12} \mathrm{H}_{3} \mathrm{C}^{12} \mathrm{H}_{2} \mathrm{C}^{12} \mathrm{HF}^{19}$

$\mathrm{C}^{12} \mathrm{H}_{3} \mathrm{~N}^{14} \mathrm{H}_{2}$

$\mathrm{C}^{12} \mathrm{H}_{3} \mathrm{C}^{13} \mathrm{HO}^{16}$

$\mathrm{C}^{12} \mathrm{H}_{3} \mathrm{O}^{18} \mathrm{H}$

$\mathrm{C}^{12} \mathrm{H}_{3} \mathrm{C}^{12} \mathrm{H}: \mathrm{C}^{12} \mathrm{HF}^{19}$

$\mathrm{C}^{12} \mathrm{H}_{3} \mathrm{C}^{12} \mathrm{H}: \mathrm{C}^{12} \mathrm{HF}^{19}$

$\mathrm{D}_{2} \mathrm{O}_{2}^{16}$

$\mathrm{C}^{12} \mathrm{H}_{3} \mathrm{C}^{12} \mathrm{H}: \mathrm{C}^{12} \mathrm{HF}^{19}$

$\mathrm{C}^{12} \mathrm{H}_{3} \mathrm{C}^{12} \mathrm{H}: \mathrm{C}^{12} \mathrm{HF}^{19}$

$\mathrm{O}^{\mathrm{N}} \mathrm{O}^{\mathrm{N}} \mathrm{O}$

$\mathrm{C}^{12} \mathrm{H}_{3} \mathrm{C}^{12}{ }_{*} \mathrm{HO}^{16} \mathrm{C}^{12}{ }_{*} \mathrm{H}_{2}$

$\mathrm{C}^{12} \mathrm{H}_{3} \mathrm{C}^{12}{ }_{*} \mathrm{HO}^{16} \mathrm{C}^{12}{ }_{*} \mathrm{H}_{2}$

s- $\mathrm{C}^{12} \mathrm{H}_{2} \mathrm{DSi}^{\mathrm{h}} \mathrm{HD}_{2}$

$\mathrm{C}^{12} \mathrm{H}_{3} \mathrm{~N}^{14} \mathrm{O}_{2}^{16}$

$\mathrm{C}^{12} \mathrm{D}_{3} \mathrm{C}^{12} \mathrm{HO}^{16}$

$\mathrm{HDC}^{12}: \mathrm{C}^{12} \mathrm{O}^{16}$

$\mathrm{Cl}^{35} \mathrm{~F}^{19} \mathrm{C}^{12} \mathrm{O}^{16}$

$\mathrm{C}^{12} \mathrm{H}_{3} \mathrm{C}^{12} * \mathrm{HO}^{16} \mathrm{C}^{12}{ }_{*} \mathrm{H}_{2}$

c- $\mathrm{HDC}^{12}{ }_{*} \mathrm{O}^{16} \mathrm{C}^{12}{ }_{*} \mathrm{DH}$

$\mathrm{C}^{12} \mathrm{H}_{3} \mathrm{C}^{12}{ }_{*} \mathrm{HO}^{16} \mathrm{C}^{12}{ }_{*} \mathrm{H}_{2}$ $\mathrm{C}^{12} \mathrm{H}_{3} \mathrm{~N}^{14} \mathrm{O}_{2}^{16}$
3. $217 \quad 15,2, \leftarrow 15,1$.

3- $216 \quad$ Not Reported

3. $2636, \quad \leftarrow 6$, ,

4- 241

$15, \leftarrow 14$,

3- 221

Not Reported

3- 461

$2,2,1 \leftarrow 1,1,1$

$3,2,2 \leftarrow 2,1,1$

2. $1,2 \leftarrow 1,1,1$

3- 334

3. $2,2 \leftarrow 2,1,1$

3- 752

3- 752

4- 681

$3,2,2 \leftarrow 2,2,1$

$3,0,3 \leftarrow 2,0,2$

3- 214

3. 216

3- 471

3- 172

3- 249

3. 991

4-1034

3- 471

3- 41

3. 43

3- 474

3- 335

4- 263

3- 711

3. 261

3- 477

3- 217

3. 711

3. 711

3. 42

3- 711

3. 711

4-1847

3. 761

3. 761

3. 334

3- 171

3. 474

4- 713

4- 151

3. 761

4. 845

3. 761

3- 171

Not Reported

Not Reported

$3,0, \leftarrow 2,0$,

$3,1,2 \leftarrow 2,1,1$

$12, \leftarrow 11$,

3, $1,2 \leftarrow 3,1,3$

2. $1.2 \leftarrow 1,1,1$

Not Reported

$5, \quad \leftarrow 5$, ,

4. $1.3 \leftarrow 4,0,4$

$2,0,2 \leftarrow 1,0,1$

$6, \leftarrow 5$,

$5,0,5 \leftarrow 4,0,4$

Not Reported

$2,1,2 \leftarrow 1,1,1$

$24,2, \leftarrow 24,1$,

5. $3,2 \leftarrow 4,3,1$

$5,3,3 \leftarrow 4,3,2$

Not Reported

$5,2,3 \leftarrow 4,2,2$

$5,2,3 \leftarrow 4,2,2$

Not Reported

Not Reported

Not Reported

$2,0,2 \leftarrow 1,0,1$

Not Reported

$4,1,3 \leftarrow 4,0,4$

$2,0,2 \leftarrow 1,0,1$

$4,3,2 \leftarrow 4,2,3$

$3,0,3 \leftarrow 2,0,2$

$3,3,1 \leftarrow 3,2,2$

Not Reported

Not Reported
$2,1,2 \leftarrow 1,1,1 \quad$ Ground

Ground

Ground

Ground

Ground

Ground

Ground

firound

Ciround

Ground

Ground

Ground

Ground

Ground
Ground

37418.97

37425.

$37427.1 \quad .5$

37427.8

37437.33

37438.4

$37438.80 \quad .04$

37439.40

$37443.15 \quad .04$

$37447.95 \quad .04$

$37461 . \quad 1$.

$37462.6 \quad .5$

37462.6

$37464.58 \quad .3$

$37465.3 \quad .2$

$37479.80 \quad .10$

37490.

30.

37508.9

$37515.24 \quad .3$

37517.6

37526.

3.

37527.60

37533.0

37554.11

.40

37554.80

37564 .

37574.6

1.

37579.85

37580.50

37580.50

37582.

3.

37590.00

37595.6

37608 .

37610.25

37617.40

37618.28

37622.16

37626.28

37642.41

37647.41

37651.04

37657.0

37658.65

37659.84 


\begin{tabular}{|c|c|c|c|c|c|c|}
\hline Isotopic Species & $\begin{array}{l}\text { Vol.-Id. } \\
\text { Nos. }\end{array}$ & $\begin{array}{c}\text { Rotational } \\
\text { Quantum Nos. }\end{array}$ & Vib. State & $\mathrm{F}_{1}^{\prime} \stackrel{\text { Hyperfine }}{\mathrm{F}^{\prime}} \mathrm{F}_{1} \quad \mathrm{~F}$ & $\begin{array}{c}\text { Frequency } \\
\mathrm{MHz}\end{array}$ & $\begin{aligned} & \text { Acc. } \\
\pm & \mathrm{MHz}\end{aligned}$ \\
\hline $\mathrm{C}^{12} \mathrm{H}_{3} \mathrm{C}^{12}{ }_{*} \mathrm{HO}^{16} \mathrm{C}^{12}{ }_{*} \mathrm{H}_{2}$ & $3-761$ & Not Reported & Ground & & 37660.53 & .1 \\
\hline $\mathrm{HDC}^{12}: \mathrm{C}^{12} \mathrm{O}^{16}$ & 4- 713 & $2,0,2 \leftarrow 1,0,1$ & Excited & & 37664.81 & \\
\hline $\mathrm{C}^{12} \mathrm{H}_{3} \mathrm{C}^{12} * \mathrm{HO}^{16} \mathrm{C}^{12} * \mathrm{H}_{2}$ & 3- 761 & $3,0,3 \leftarrow 2,0,2$ & Ground & & 37666.36 & .1 \\
\hline$\left(\mathrm{C}^{12} \mathrm{H}_{3}\right)_{3} \mathrm{Si}^{28} \mathrm{Br}^{81}$ & 3- 812 & 13. $\leftarrow 12$ & Ground & ' & 37675.3 & .4 \\
\hline $\mathrm{C}^{12} \mathrm{H}_{3} \mathrm{C}^{12} \mathrm{HO}^{16}$ & 3. 471 & $2,1,2 \leftarrow 1,1,1$ & Ground & & 37687.18 & .4 \\
\hline $\mathrm{C}^{12} \mathrm{H}_{3} \mathrm{O}^{16} \mathrm{H}$ & 3. 211 & Not Reported & & & 37690. & \\
\hline $\mathrm{HDC}^{12}: \mathrm{C}^{12} \mathrm{O}^{16}$ & 4. 713 & $2,0,2 \leftarrow 1,0,1$ & Excited & & 37693.05 & \\
\hline $\mathrm{C}^{12} \mathrm{H}_{3} \mathrm{C}^{12} * \mathrm{HO}^{16} \mathrm{C}^{12}{ }_{*} \mathrm{H}_{2}$ & 3. 761 & Not Reported & Ground & & 37698.01 & .1 \\
\hline $\mathrm{C}^{12} \mathrm{H}_{3} \mathrm{O}^{16} \mathrm{H}$ & 3- 211 & $8,2, \leftarrow 7,1$, & Ground & & 37703.72 & .1 \\
\hline $\mathrm{C}^{12} \mathrm{H}_{3} \mathrm{C}^{12} \mathrm{HO}^{16}$ & 3. 471 & Not Reported & Ground & & 37708.80 & .3 \\
\hline $\mathrm{C}^{12} \mathrm{H}_{3} \mathrm{C}^{12}{ }_{*} \mathrm{HO}^{16} \mathrm{C}^{12}{ }_{*} \mathrm{H}_{2}$ & 3- 761 & $3,0,3 \leftarrow 2,0,2$ & Ground & & 37710.31 & .1 \\
\hline $\mathrm{HDN}^{14} \mathrm{C}^{12} \mathrm{~N}^{14}$ & 4. 362 & $2,0,2 \leftarrow 1,0,1$ & Ground & & 37723.8 & .5 \\
\hline $\mathrm{HDN}^{14} \mathrm{C}^{12} \mathrm{~N}^{14}$ & 4. 362 & $2,0,2 \leftarrow 1,0,1$ & Excited & & 37723.8 & .5 \\
\hline $\mathrm{C}^{12} \mathrm{H}_{3} \mathrm{C}^{12} \mathrm{HO}^{18}$ & 3. 479 & $2,1,1 \leftarrow 1,1,0$ & Ground & & 37724.4 & 1. \\
\hline $\mathrm{c}-\mathrm{HDC}^{12}: \mathrm{C}^{12} \mathrm{HF}^{19}$ & 4. 787 & $2,0,2 \leftarrow 1,0,1$ & Ground & & 37729.8 & .3 \\
\hline $\mathrm{HDC}^{12}: \mathrm{C}^{12} \mathrm{O}^{16}$ & 4. 713 & $2,0,2 \leftarrow 1,0,1$ & Excited & & 37754.59 & \\
\hline $\mathrm{C}^{12} \mathrm{H}_{3} \mathrm{C}^{12}{ }_{*} \mathrm{HO}^{16} \mathrm{C}^{12}{ }_{*} \mathrm{H}_{2}$ & 3- 761 & $3,0,3 \leftarrow 2,0,2$ & Ground & & 37764.55 & .1 \\
\hline $\mathrm{H}_{2} \mathrm{~N}^{14} \mathrm{C}^{12} \mathrm{DO}^{16}$ & 3- 155 & $7,1,6 \leftarrow 6,2,5$ & Ground & & 37765.17 & \\
\hline $\mathrm{O}^{\mathrm{h}} \mathrm{O}^{\mathrm{h}} \mathrm{O}^{\mathrm{h}}$ & 4.1847 & Not Reported & & & 37768. & \\
\hline $\mathrm{C}^{12} \mathrm{H}_{3} \mathrm{C}^{12} * \mathrm{HO}^{16} \mathrm{C}^{12} * \mathrm{H}_{2}$ & 3- 761 & Not Reported & Ground & & 37769.29 & .1 \\
\hline $\mathrm{C}^{12} \mathrm{H}_{2} \mathrm{DN}^{14} \mathrm{C}^{12}$ & 4. 838 & $2,1,2 \leftarrow 1,1,1$ & Ground & & 37770.79 & .1 \\
\hline $\mathrm{D}_{2} \mathrm{~N}^{14} \mathrm{C}^{12} \mathrm{HO}^{16}$ & 3. 154 & $2,0,2 \leftarrow 1,0,1$ & Ground & & 37775.20 & .2 \\
\hline $\mathrm{H}_{2} \mathrm{C}^{12}{ }_{*} \mathrm{O}^{16} \mathrm{C}^{12} * \mathrm{H}_{2}$ & 4- 841 & $5,3,2 \leftarrow 5,2,3$ & Ground & & 37781. & 1. \\
\hline $\mathrm{C}^{12} \mathrm{H}_{3} \mathrm{C}^{12}{ }_{*} \mathrm{HO}^{16} \mathrm{C}^{12}{ }_{*} \mathrm{H}_{2}$ & 3- 761 & Not Reported & Ground & & 37782.96 & .1 \\
\hline $\mathrm{C}^{12}{ }_{*} \mathrm{HC}^{12} \mathrm{H}: \mathrm{C}^{12} \mathrm{HC}^{12} \mathrm{H}: \mathrm{C}^{12} \mathrm{HN}^{14} *$ & 4.1201 & $4,3,2 \leftarrow 3,3,1$ & Ground & & 37788.10 & \\
\hline $\mathrm{C}^{12} \mathrm{H}_{3} \mathrm{C}^{12}{ }_{*} \mathrm{HO}^{16} \mathrm{C}^{12}{ }_{*} \mathrm{H}_{2}$ & 3. 761 & Not Reported & Ground & & 37791.71 & .1 \\
\hline $\mathrm{C}^{12} \mathrm{H}_{33} \mathrm{C}^{12}{ }_{*} \mathrm{HO}^{16} \mathrm{C}^{12} * \mathrm{H}_{2}$ & 3- 761 & $3,2,2 \leftarrow 2,2,1$ & Ground & & 37796.16 & .1 \\
\hline $\mathrm{s}-\mathrm{C}^{12} \mathrm{H}_{2} \mathrm{DS}^{\mathrm{b}} \cdot \mathrm{HD}_{2}$ & 3. 334 & $2,1,1 \leftarrow 1,1,0$ & & & 37798.60 & \\
\hline $\mathrm{C}^{12} \mathrm{H}_{3} \mathrm{C}^{12}{ }_{*} \mathrm{HO}^{16} \mathrm{C}^{12}{ }_{*} \mathrm{H}_{2}$ & 3- 761 & Not Reported & Ground & & 37799.76 & .1 \\
\hline$\left(\mathrm{C}^{12} \mathrm{H}_{3}\right)_{2} \mathrm{~S}^{32}$ & 3- 601 & $8,2,7 \leftarrow 7,3,4$ & Ground & & 37805.82 & .05 \\
\hline$\left(\mathrm{C}^{12} \mathrm{H}_{3}\right)_{2} \mathrm{~S}^{32}$ & 3. 601 & $8,2,7 \leftarrow 7,3,4$ & Ground & & 37807.71 & .05 \\
\hline $\mathrm{C}^{12} \mathrm{D}_{3} \mathrm{~N}^{1+4} \mathrm{H}_{2}$ & 3- 263 & Not Reported & & & 37807.9 & .5 \\
\hline $\mathrm{C}^{12} \mathrm{D}_{3} \mathrm{~N}^{1+} \mathrm{H}_{2}$ & 3- 263 & Not Reported & & & 37812.2 & .5 \\
\hline $\mathrm{O}_{3}^{16}$ & 4. 1841 & $18,2,16 \leftarrow 17,3.15$ & Ground & & 37832. & \\
\hline $\mathrm{C}^{12} \mathrm{D}_{33} \mathrm{~N}^{1+} \mathrm{H}_{2}$ & $3-263$ & Not Reported & & & 37840.5 & .5 \\
\hline $\mathrm{C}^{12} \mathrm{H}_{3} \mathrm{C}^{12}{ }_{*} \mathrm{HO}^{16} \mathrm{C}^{12} * \mathrm{H}_{2}$ & 3. 761 & Not Reported & Ground & & 37841.92 & .1 \\
\hline $\mathrm{C}^{12} \mathrm{H}_{3} \mathrm{C}^{12}{ }_{*} \mathrm{HO}^{16} \mathrm{C}^{12}{ }_{*} \mathrm{H}_{2}$ & 3- 761 & $3,2,2 \leftarrow 2,2,1$ & Ground & & 37844.07 & .1 \\
\hline$\left(\mathrm{C}^{12} \mathrm{H}_{3}\right)_{2} \mathrm{~S}^{32}$ & 3- 601 & $8,2,7 \leftarrow 7,3,4$ & Ground & & 37846.77 & .05 \\
\hline $\mathrm{C}^{12} \mathrm{H}_{3} \mathrm{C}^{12} * \mathrm{HO}^{16} \mathrm{C}^{12} * \mathrm{H}_{2}$ & 3- 761 & $3,2,2 \leftarrow 2,2,1$ & Ground & & 37853.03 & .1 \\
\hline $\mathrm{C}^{12} \mathrm{H}_{3} \mathrm{~N}^{14} \mathrm{H}_{2}$ & 3- 261 & Noi Reported & Ground & & 37854. & \\
\hline $\mathrm{C}^{12} \mathrm{H}_{3} \mathrm{C}^{12} * \mathrm{HO}^{16} \mathrm{C}^{12}{ }_{*} \mathrm{H}_{2}$ & 3- 761 & $3,2,1 \leftarrow 2,2,0$ & Ground & & 37855.93 & .1 \\
\hline $\mathrm{C}^{12} \mathrm{H}_{3} \mathrm{C}^{12}{ }_{*} \mathrm{HO}^{16} \mathrm{C}^{12}{ }_{*} \mathrm{H}_{2}$ & 3- 761 & $3,2,2 \leftarrow 2,2,1$ & Ground & & 37869.28 & .1 \\
\hline t. $\mathrm{HDN}^{14} \mathrm{C}^{12} \mathrm{HO}^{16}$ & 3- 153 & $2,1,2 \leftarrow 1,1,1$ & Ground & & 37870.72 & .2 \\
\hline $\mathrm{C}^{12} \mathrm{H}_{3} \mathrm{C}^{12}{ }_{*} \mathrm{HO}^{16} \mathrm{C}^{12}{ }_{*} \mathrm{H}_{2}$ & 3. 761 & Not Reported & Ground & & 37870.87 & .1 \\
\hline $\mathrm{C}^{12} \mathrm{H}_{33} \mathrm{C}^{12}{ }_{*} \mathrm{HO}^{16} \mathrm{C}^{12}{ }_{*} \mathrm{H}_{2}$ & 3- 761 & Not Reported & Ground & & 37879.45 & .1 \\
\hline
\end{tabular}




\begin{tabular}{|c|c|c|c|c|c|c|c|c|}
\hline \multirow{2}{*}{ lsotopic Species } & \multirow{2}{*}{$\begin{array}{l}\text { Vol.-Id. } \\
\text { Nos. }\end{array}$} & \multirow{2}{*}{$\begin{array}{l}\text { Rotational } \\
\text { Quantum Nos. }\end{array}$} & \multirow{2}{*}{ Vib. State } & \multicolumn{3}{|c|}{ Hyperline } & \multirow{2}{*}{$\begin{array}{l}\text { Frequency } \\
\text { lillz }\end{array}$} & \multirow{2}{*}{$\begin{aligned} & \text { Acce } \\
\pm & \text { Mll }\end{aligned}$} \\
\hline & & & & $F_{i}^{\prime}$ & $F^{\prime} \quad F_{1}$ & $\mathrm{~F}$ & & \\
\hline $\mathrm{t}-\mathrm{HDC}^{12} * \mathrm{O}^{16} \mathrm{C}^{12}{ }_{*} \mathrm{HD}$ & 4. 844 & $5,4,1 \leftarrow 5,3,2$ & Ground & & & & 37879.9 & .2 \\
\hline $\mathrm{H}_{2} \mathrm{C}^{12}: \mathrm{C}^{13} \mathrm{HF}^{19}$ & 4- 783 & $2,1,2 \leftarrow 1,1,1$ & Ciround & & & & 37883.28 & .05 \\
\hline$\left(\mathrm{C}^{12} \mathrm{H}_{3}\right)_{2} \mathrm{O}^{16}$ & 3- 591 & Not Reported & Ciround & & & & 37890. & 20. \\
\hline $\mathrm{C}^{12} * \mathrm{H}_{2} \mathrm{C}^{12} \mathrm{D}: \mathrm{C}^{12}{ }_{*} \mathrm{D}$ & 4- 1033 & $5,3,2 \leftarrow 5,3,3$ & Ground & & & & 37894.2 & \\
\hline $\mathrm{C}^{12} \mathrm{D}_{3} \mathrm{O}^{16} \mathrm{D}$ & 3. 216 & Not Reported & & & & & 37900. & \\
\hline $\mathrm{C}^{12} \mathrm{H}_{3} \mathrm{Si}^{28} \mathrm{Cl}^{35} \mathrm{Cl}_{2}^{37}$ & 3. 114 & $11, \quad \leftarrow 10$, & Ground & & & & 37900. & 20. \\
\hline $\mathrm{C}^{12} \mathrm{D}_{33} \mathrm{O}^{16} \mathrm{H}$ & 3- 214 & Not Reported & Ground & & & & 37900.0 & .5 \\
\hline $\mathrm{C}^{12} \mathrm{H}_{3} \mathrm{C}^{12}{ }_{*} \mathrm{HO}^{16} \mathrm{C}^{12}{ }_{*} \mathrm{H}_{2}$ & 3- 761 & $3,2,2 \leftarrow 2,2,1$ & Ground & & & & 37900.09 & .1 \\
\hline$\left(; e^{74} \mathrm{~F}_{: !}^{19} \mathrm{Cl}^{37}\right.$ & $4 \cdot 1406$ & $9, \leftarrow 8$, & Ground & & & & 37905.91 & .30 \\
\hline $\mathrm{C}^{\mathrm{b}} \mathrm{H}_{2}^{\mathrm{b}} \mathrm{Cl}^{\mathrm{b}} \mathrm{F}^{\mathrm{b}}$ & 4- 333 & Not Rejorted & & & & & 37914. & .1 \\
\hline $\mathrm{C}^{12} \mathrm{H}_{2} \mathrm{Cl}^{37} \mathrm{~F}^{19}$ & 4- 332 & $3,1,2 \leftarrow 3,0,3$ & Ground & & & & 37924.77 & 1.0 \\
\hline$\left(. \mathrm{e}^{72} \mathrm{~F}_{3}^{19} \mathrm{Cl}^{37}\right.$ & 4-1404 & $9, \leftarrow 8$ & Giround & & & & 37925.87 & .90 \\
\hline $\mathrm{C}^{12} \mathrm{H}_{33} \mathrm{C}^{12}{ }_{*} \mathrm{HO}^{16} \mathrm{C}^{12}{ }_{*} \mathrm{H}_{2}$ & 3- 761 & $3,2,1 \leftarrow 2,2,0$ & Ground & & & & 37926.73 & .1 \\
\hline $\mathrm{C}^{12}{ }_{*} \mathrm{H}_{2} \mathrm{~N}^{14} \mathrm{HC}^{12}{ }_{*} \mathrm{H}_{2}$ & 4- 861 & $5.5,1 \leftarrow 5.4 .2$ & Ground & & & & 37930. & 10 \\
\hline $\mathrm{C}^{\mathrm{b}} \mathrm{H}_{2}^{\mathrm{b}} \mathrm{Cl}^{\mathrm{b}} \mathrm{F}^{\mathrm{b}}$ & 4- 333 & Not Reported & & & & & 37930.0 & 1. \\
\hline $\mathrm{C}^{\mathrm{b}} \mathrm{H}_{2}^{\mathrm{b}} \mathrm{Cl}^{\mathrm{b}} \mathrm{F}^{\mathrm{b}}$ & 4- 333 & Not Reported & & & & & 37938. & 1. \\
\hline$\left({ }^{12} \mathrm{H}_{2} \mathrm{Cl}^{35} \mathrm{~F}^{19}\right.$ & 4- 331 & $3,1,2 \leftarrow 3,0.3$ & Ground & & & & 37940.52 & 1.0 \\
\hline $\mathrm{C}^{12} \mathrm{H}_{33} \mathrm{Si}^{2 \times} \mathrm{HDF}^{19}$ & 3- 252 & $3,1,2 \leftarrow 2,1,1$ & (iround & & & & 37943.80 & .10 \\
\hline (, $e^{70} \mathrm{~F}_{3}^{199} \mathrm{Cl}^{37}$ & $4-1402$ & $9 . \leftarrow 8$ & (iround & & & & 37945.47 & .90 \\
\hline $\mathrm{C}^{\mathrm{b}} \mathrm{H}_{2}^{\mathrm{b}} \mathrm{Cl}^{\mathrm{b}} \mathrm{F}^{\mathrm{b}}$ & 4- 333 & Not Reported & & & & & 37950. & 1. \\
\hline $\mathrm{C}^{12} \mathrm{D}_{3} \mathrm{~N}^{14} \mathrm{H}_{2}$ & 3- 263 & $3 . . \leftarrow 3$. & & & & & 37951.4 & .5 \\
\hline $\mathrm{C}^{12} \mathrm{H}_{2} \mathrm{DN}^{14} \mathrm{C}^{12}$ & 4- 838 & $2,0,2 \leftarrow 1,0,1$ & (iround & & & & 37951.67 & .1 \\
\hline $\mathrm{C}^{\mathrm{b}} \mathrm{H}_{2}^{\mathrm{b}} \mathrm{Cl}^{\mathrm{b}} \mathrm{F}^{\mathrm{b}}$ & 4- 333 & Not Reported & & & & & 37952. & 1. \\
\hline $\mathrm{H}_{2} \mathrm{C}^{12}: \mathrm{C}^{12} \mathrm{HF}^{19}$ & 4- 781 & $2,1,2 \leftarrow 1,1,1$ & Excited & & & & 37952.07 & .05 \\
\hline $\mathrm{C}^{12} \mathrm{H}_{3} \mathrm{C}^{12}{ }_{*} \mathrm{HO}^{16} \mathrm{C}^{12}{ }_{*} \mathrm{H}_{2}$ & 3- 761 & Not Reported & (iround & & & & 37953.44 & .1 \\
\hline $\mathrm{C}^{12} \mathrm{H}_{33} \mathrm{C}^{12}{ }_{*} \mathrm{HO}^{16} \mathrm{C}^{12}{ }_{*} \mathrm{H}_{2}$ & 3- 761 & $3,2,1 \leftarrow 2,2,0$ & Ground & & & & 37954.79 & .1 \\
\hline $\mathrm{HC}^{12}: \mathrm{C}^{12} \mathrm{C}^{12} \mathrm{HO}^{16}$ & 4- 911 & $4,1,3 \leftarrow 3,1,2$ & Ground & & & & 37954.95 & .10 \\
\hline $\mathrm{C}^{12} \mathrm{H}_{33} \mathrm{C}^{12} \mathrm{Cl}_{33}^{35}$ & 3- 381 & $8, \leftarrow 7$ & (iround & & & & 37955.88 & .40 \\
\hline $\mathrm{C}^{\mathrm{b}} \mathrm{H}_{2}^{\mathrm{b}} \mathrm{Cl}^{\mathrm{b}} \mathrm{F}^{\mathrm{b}}$ & 4- 333 & Not Reported & & & & & 37957. & 1. \\
\hline $\mathrm{C}^{\mathrm{b}} \mathrm{H}_{2}^{\mathrm{b}} \mathrm{Cl}^{\mathrm{b}} \mathrm{F}^{\mathrm{b}}$ & 4- 333 & Not Reported & & & & & 37962.76 & 1. \\
\hline $\mathrm{S}_{2}^{32} \mathrm{O}^{16}$ & $4-1821$ & $2,1,1 \leftarrow 2,0,2$ & (iround & & & & 37965.3 & \\
\hline $\mathrm{O}^{\prime \prime} \mathrm{O}^{1 /} \mathrm{O}^{\prime \prime}$ & $4-1847$ & Not Reported & & & & & 37970. & \\
\hline $\mathrm{O}^{16} \mathrm{O}^{16} \mathrm{O}^{18}$ & 4-1842 & $20,2.18 \leftarrow 21.1 .20$ & Ground & & & & 37979. & \\
\hline $\mathrm{C}^{12} \mathrm{H}_{3} \mathrm{C}^{12}{ }_{*} \mathrm{HO}^{16} \mathrm{C}^{12}{ }_{*} \mathrm{H}_{2}$ & 3- 761 & $3,2.1 \leftarrow 2,2,0$ & (iround & & & & 37979.00 & .1 \\
\hline $\mathrm{C}^{12} \mathrm{H}_{33} \mathrm{C}^{12}{ }_{*} \mathrm{HO}^{16} \mathrm{C}^{12}{ }_{* 3} \mathrm{H}_{2}$ & 3- 761 & Not Reported & (iround & & & & 37985.33 & .1 \\
\hline $\mathrm{H}_{2} \mathrm{C}^{12}: \mathrm{C}^{12} \mathrm{HF}^{19}$ & 4- 781 & $2,1,2 \leftarrow 1,1,1$ & Ground & & & & 37991.28 & .05 \\
\hline$\left({ }^{12}{ }_{*} \mathrm{H}_{2} \mathrm{~V}^{14} \mathrm{HC}^{12}{ }_{*} \mathrm{H}_{2}\right.$ & 4- 861 & 11. $9.2 \leftarrow 11.8 .3$ & firound & & & & 38000 & 10 \\
\hline a- $\left({ }^{12} \mathrm{H}_{2} \mathrm{DSi}^{11} \mathrm{HD}_{2}\right.$ & 3- 335 & $2,1,1 \leftarrow 1,1,0$ & & & & & 38001.08 & \\
\hline $\mathrm{C}^{12} \mathrm{H}_{33} \mathrm{~N}^{14} \mathrm{H}_{22}$ & 3- 261 & Not Reported & Ground & & & & $38003 . \dot{6}$ & \\
\hline $\mathrm{C}^{12} \mathrm{H}_{3} \mathrm{Br}^{\mathrm{x1}}$ & 4- 402 & $2.1 \leftarrow 1.1$ & (iround & & $1 / 2$ & $1 / 2$ & 38006.47 & .08 \\
\hline$\left(\mathrm{C}^{12} \mathrm{H}_{3}\right)_{3} \mathrm{Si}^{2 \times} \mathrm{Br}^{73}$ & 3- 811 & $13 . \leftarrow 12$ & (iround & & & & 38010.8 & .3 \\
\hline $\mathrm{C}^{12} \mathrm{H}_{3} \mathrm{C}^{12}{ }_{*} \mathrm{HO}^{16} \mathrm{C}^{12}{ }_{*} \mathrm{H}_{2}$ & 3- 761 & $2,1,1 \leftarrow 1.0 .1$ & Ground & & & & 38021.11 & .1 \\
\hline $\mathrm{C}^{12} \mathrm{D}_{3} \mathrm{~N}^{14} \mathrm{H}_{2}$ & 3- 263 & Not Reported & & & & & 38023.7 & .5 \\
\hline $\mathrm{C}^{12} \mathrm{H}_{3} \mathrm{C}^{12}{ }_{*} \mathrm{HO}^{16} \mathrm{C}^{12}{ }_{*} \mathrm{H}_{2}$ & 3- 761 & $2.1 .1 \leftarrow 1.0 .1$ & (iround & & & & 38026.70 & .1 \\
\hline${ }^{12} \mathrm{H}_{33} \mathrm{Br}^{41}$ & 4- 402 & $2.0 \leftarrow 1.0$ & Ciround & & $3 / 2$ & $3 / 2$ & 38030.77 & .08 \\
\hline
\end{tabular}




\begin{tabular}{|c|c|c|c|c|c|c|c|}
\hline Isotopic Species & $\begin{array}{l}\text { Vol.-Id. } \\
\text { Nos. }\end{array}$ & $\begin{array}{l}\text { Rotational } \\
\text { Quantum Nos. }\end{array}$ & Vib. State & $\mathrm{F}_{1}^{\prime} \stackrel{\text { Hyperfine }}{\mathrm{F}^{\prime}} \quad \mathrm{F}_{1}$ & $F$ & $\begin{array}{c}\text { Frequency } \\
\mathrm{MIHz}\end{array}$ & $\begin{aligned} & \text { Acc. } \\
\pm & 11 \mathrm{~Hz}\end{aligned}$ \\
\hline $\mathrm{C}^{12} \mathrm{H}_{3} \mathrm{C}^{12} * \mathrm{HO}^{16} \mathrm{C}^{12}{ }_{*} \mathrm{H}_{2}$ & 3- 761 & $3,2,1 \leftarrow 2,2,0$ & Ground & & & 38036.22 & .1 \\
\hline $\mathrm{C}^{12} \mathrm{D}_{2} \mathrm{Cl}^{35} \mathrm{Cl}^{37}$ & 4. 347 & $3.1,3 \leftarrow 2,0.2$ & Ground & & & 38043 & 2. \\
\hline $\mathrm{C}^{12} \mathrm{D}_{33} \mathrm{O}^{16} \mathrm{H}$ & $3-214$ & Not Reported & Ground & & & 38052.6 & .5 \\
\hline $\mathrm{C}^{12} \mathrm{D}_{3} \mathrm{O}^{16} \mathrm{D}$ & $3-216$ & Not Reported & & & & 38052.6 & \\
\hline $\mathrm{C}^{12} \mathrm{H}_{3} \mathrm{O}^{18} \mathrm{H}$ & 3- 217 & $16,2, \leftarrow 16,1$ & Ground & & & 38053.87 & .1 \\
\hline $\mathrm{O}_{3}^{1 \times}$ & 4-1845 & $1.1,1 \leftarrow 2,0,2$ & Ground & & & 38054. & \\
\hline $\mathrm{HD} N{ }^{14} \mathrm{C}^{12} \mathrm{~N}^{14}$ & 4- 362 & $2,1,1 \leftarrow 1,1,0$ & Excited & & & 38056.8 & .5 \\
\hline $\mathrm{C}^{12} \mathrm{H}_{33} \mathrm{Br}^{31}$ & 4- 402 & $2,1 \leftarrow 1,1$ & Ciround & $3 / 2$ & $1 / 2$ & 38066.72 & .08 \\
\hline $\mathrm{HDN} \mathrm{N}^{14} \mathrm{C}^{12} \mathrm{~N}^{14}$ & 4- 362 & $2,1,1 \leftarrow 1,1,0$ & (;round & & & 38069.1 & .5 \\
\hline $\mathrm{C}^{12} \mathrm{H}_{3} \mathrm{C}^{12} \mathrm{HO}^{16} \mathrm{C}^{12} \approx \mathrm{H}_{2}$ & 3- 761 & $2,1,1 \leftarrow 1,0,1$ & Ground & & & 38070.06 & .1 \\
\hline $\mathrm{O}^{\mathrm{h}} \mathrm{O}^{\mathrm{h}} \mathrm{O}^{\mathrm{h}}$ & 4-1847 & Not Reported & & & & 38086. & \\
\hline c- $-11 D N^{1.5} \mathrm{C}^{12} \mathrm{HO}^{16}$ & 3. 158 & $2,1,2 \leftarrow 1,1,1$ & Ground & & & 38096.52 & \\
\hline $\mathrm{C}^{12} \mathrm{H}_{33} \mathrm{Br}^{81}$ & 4- 402 & $2,1 \leftarrow 1,1$ & Ground & $7 / 2$ & $5 / 2$ & 38097.45 & .08 \\
\hline $1 . i^{6} \mathrm{Br}^{81}$ & $1-$ & $1 \leftarrow 0$ & Ground & $5 / 2$ & $3 / 2$ & 38112.72 & 0.10 \\
\hline $\mathrm{HDC}::^{12}: \mathrm{C}^{12} \mathrm{O}^{16}$ & 4. 713 & $2,1,1 \leftarrow 1,1,0$ & Excited & & & 38113.22 & \\
\hline $\mathrm{HDC}^{12}: \mathrm{C}^{12} \mathrm{O}^{16}$ & 4- 713 & $2,1,1 \leftarrow 1,1,0$ & Ground & & & 38114.40 & \\
\hline $\mathrm{C}^{12} \mathrm{H}_{33} \mathrm{Br}^{81}$ & 4. 402 & $2,0 \leftarrow 1.0$ & Ground & $7 / 2$ & $5 / 2$ & 38116.65 & .08 \\
\hline $\mathrm{C}^{12} \mathrm{H}_{33} \mathrm{Br}^{.81}$ & t- 402 & $2,0 \leftarrow 1,0$ & Ground & $5 / 2$ & $3 / 2$ & 38116.65 & .08 \\
\hline $\mathrm{C}^{12} \mathrm{H}_{33} \mathrm{Br}^{31}$ & 4. 402 & $2,0 \leftarrow 1,0$ & Ground & $1 / 2$ & $1 / 2$ & 38126.97 & .08 \\
\hline $\mathrm{C}^{12} \mathrm{H}_{33} \mathrm{Br}^{73}$ & 4. 401 & $2,1 \leftarrow 1,1$ & Ground & $1 / 2$ & $1 / 2$ & 38128.40 & .08 \\
\hline $\mathrm{C}^{12} \mathrm{H}_{2} \mathrm{DN}^{14} \mathrm{C}^{12}$ & 4- 838 & $2.1,1 \leftarrow 1,1,0$ & Ground & & & 38131.57 & .1 \\
\hline $\mathrm{D}_{2} \mathrm{O}_{2}^{16}$ & 3- 42 & Not Reported & & & & 38132. & 3. \\
\hline $\mathrm{C}^{12} \mathrm{D}_{33} \mathrm{O}^{16} \mathrm{D}$ & 3. 216 & Not Reported & & & & 38132.8 & \\
\hline $\mathrm{C}^{12} \mathrm{D}_{33} \mathrm{O}^{16} \mathrm{HI}$ & 3- 214 & Not Reported & Ground & & & 38132.8 & .5 \\
\hline $\mathrm{HC}^{12}: \mathrm{C}^{12} \mathrm{C}^{12} \mathrm{HO}^{16}$ & 4. 91$]$ & $4,1,3 \leftarrow 3,1,2$ & Excited & & & 38144.42 & .15 \\
\hline $\mathrm{HDC}{ }^{12}: \mathrm{C}^{12} \mathrm{O}^{16}$ & 4- 713 & $2,1,1 \leftarrow 1,1,0$ & Excited & & & 38144.71 & \\
\hline $\mathrm{C}^{12} \mathrm{H}_{3} \mathrm{C}^{12} \mathrm{H} \mathrm{H}^{16 i}$ & 3- 471 & $8,1,7 \leftarrow 8,1,8$ & Ground & & & 38151.3 & .4 \\
\hline$C^{12} \mathrm{H}_{33} \mathrm{Br}^{79}$ & 4. 401 & $2.0 \leftarrow 1.0$ & firound & $3 / 2$ & $3 / 2$ & 38157.30 & .08 \\
\hline $\mathrm{C}^{12} \mathrm{H}_{33} \mathrm{Br}^{81}$ & 4. 402 & $2,1 \leftarrow 1,1$ & Ground & $5 / 2$ & $5 / 2$ & 38157.70 & .08 \\
\hline $\mathrm{C}^{13} \mathrm{H}_{33} \mathrm{C}^{13} \mathrm{HO}^{16}$ & 3- 478 & $2,1,1 \leftarrow 1,1,0$ & Ground & & & 38164.5 & .4 \\
\hline C.1:2016 & $4-1484$ & $10.0 .10 \leftarrow 9.1 .9$ & firound & & & 38165.30 & \\
\hline $\mathrm{C}^{12} \mathrm{H}_{33} \mathrm{Br}^{41}$ & 4- 402 & Vot Reported & Cround & $3 / 2$ & $3 / 2$ & 38175.08 & .08 \\
\hline $\mathrm{Si}^{2 \times} \mathrm{HCl}^{35 \mathrm{Cl}_{2}^{37}}$ & 4- 1503 & $8, \quad \leftarrow 7$, & Giround & & & 38180. & 10. \\
\hline$S_{2}^{32}()^{16}$ & $4-1821$ & $4,0.4 \leftarrow 3,0.3$ & Excited & & & 38180.0 & \\
\hline $\mathrm{C}^{13} \mathrm{H}_{3} \mathrm{C}^{12} \mathrm{HO}$ & 3- 476 & $2,1,1 \leftarrow 1,1,0$ & Ground & & & 38186.94 & .3 \\
\hline$=\left(C^{12} \mathrm{H}_{2} \mathrm{DC} C^{12} \mathrm{HO}^{16}\right.$ & 3- 473 & 2. $1.1 \leftarrow 1.1 .0$ & Ground & & & 38187.2 & .5 \\
\hline $\mathrm{C}^{\mathrm{b}} \mathrm{H}_{2}^{\mathrm{b}} \mathrm{Cl}^{\mathrm{p}} \mathrm{F}^{\mathrm{b}}$ & 4- 333 & Vut Repurted & & & & 38198. & 1. \\
\hline $\mathrm{C}^{\mathrm{h}} \mathrm{H}_{2}^{\mathrm{b}} \mathrm{Cl}^{\mathrm{b}} \mathrm{F}^{\mathrm{b}}$ & 4- 333 & Vot Repurted & & & & 38199.27 & 1. \\
\hline $\mathrm{C}^{12} \mathrm{H}_{33} \mathrm{Br}^{74}$ & 4- 401 & $2.1 \leftarrow 1.1$ & Ciround & $3 / 2$ & $1 / 2$ & 38200.52 & .08 \\
\hline $\mathrm{S}_{2}^{32} \mathrm{O}^{16}$ & 4-1821 & $4.0 .4 \leftarrow 3.0 .3$ & Ground & & & 38203.0 & \\
\hline $\mathrm{C}^{12} \mathrm{H}_{33} \mathrm{Br}^{41}$ & 4- 402 & Vot Reperted & ciround & $5 / 2$ & $3 / 2$ & 38218.21 & .08 \\
\hline $\mathrm{s}-\mathrm{C}^{12} \mathrm{H}_{2} \mathrm{DC} \mathrm{C}^{12}=11 \mathrm{O}^{1 \mathrm{ii}}$ & 3- 473 & $2,1,1 \leftarrow 1.1 .0$ & Ciround & & & 38231.25 & .5 \\
\hline (:12 $\mathrm{H}_{33} \mathrm{Br}^{79}$ & 4- 401 & $2,1 \leftarrow 1.1$ & (iround & $7 / 2$ & $5 / 2$ & 38237.14 & .08 \\
\hline$\left({ }^{\prime 2} \mathrm{H}_{33} \mathrm{Br}^{\times 1}\right.$ & 4- 402 & $2.0 \leftarrow 1.0$ & Ciround & $5 / 2$ & $5 / 2$ & 38237.14 & .08 \\
\hline$\left(\mathrm{I}^{12} \mathrm{H}_{3} \mathrm{C}^{12} \mathrm{HO} \mathrm{O}^{163}\right.$ & 3- 471 & 8. 1. $7 \leftarrow 8.1 .8$ & (;round & & & 38241.2 & .3 \\
\hline
\end{tabular}




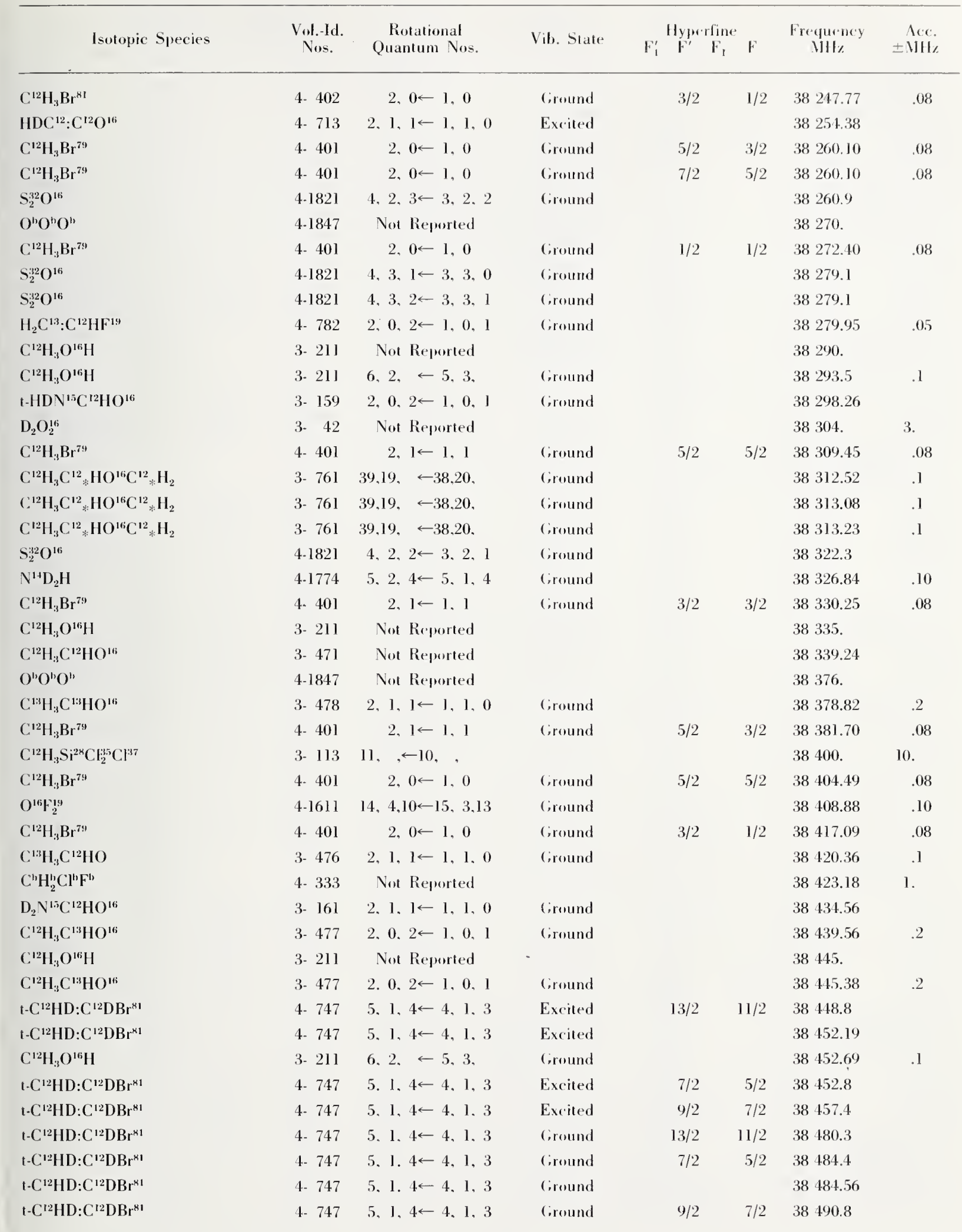




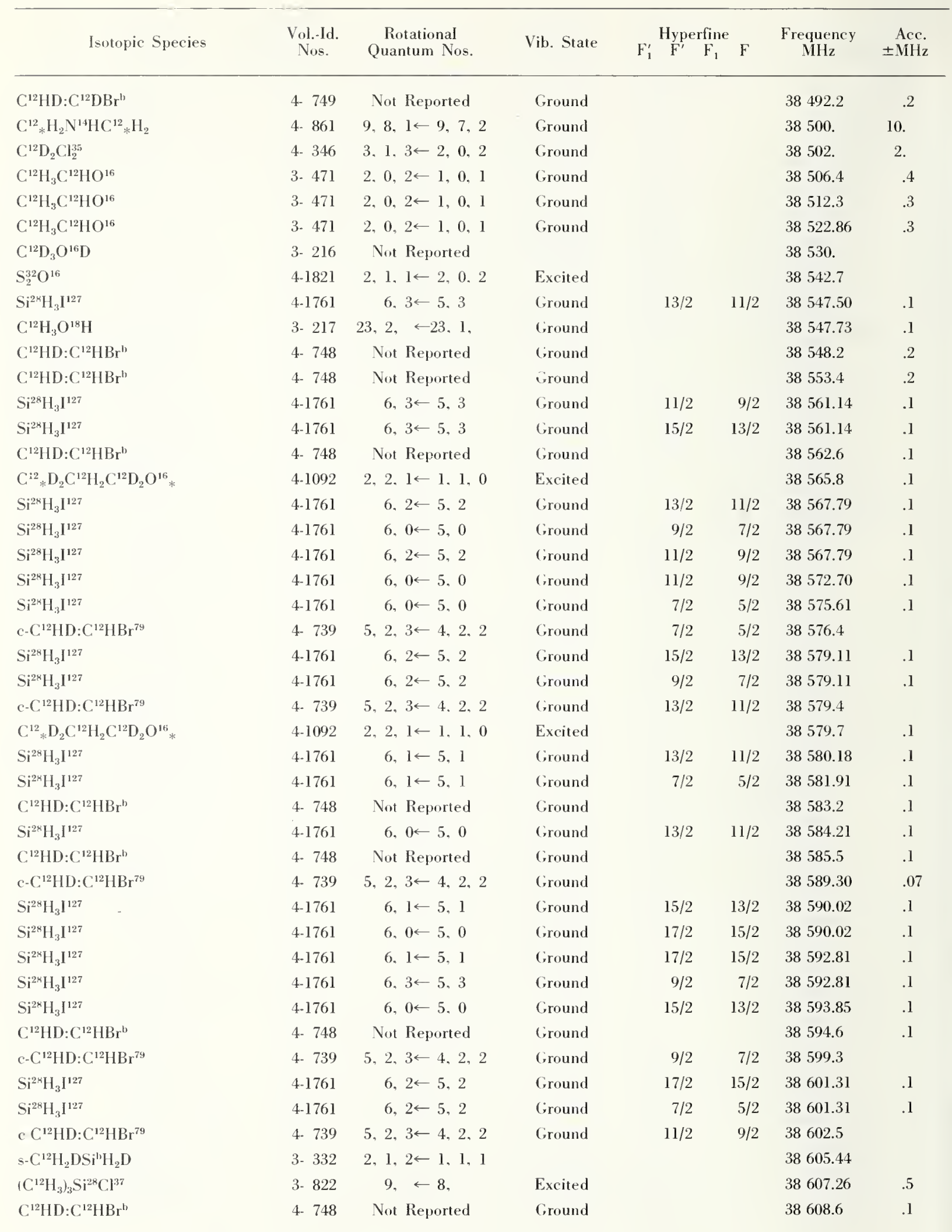




\begin{tabular}{|c|c|c|c|c|c|c|c|c|c|}
\hline \multirow{3}{*}{$\begin{aligned} \text { Isotopic Species } \\
\mathrm{Si}^{28} \mathrm{~F}_{3}^{19} \mathrm{Cl}^{37}\end{aligned}$} & \multirow{3}{*}{$\begin{array}{l}\text { Vol.-Id. } \\
\text { Nos. } \\
\text { 4-1412 }\end{array}$} & \multirow{2}{*}{$\begin{array}{c}\text { Rotational } \\
\text { Quantum Nos. }\end{array}$} & \multirow{2}{*}{ Vib. State } & \multicolumn{4}{|c|}{ Hyperfine } & \multirow{2}{*}{$\begin{array}{l}\text { Frequency } \\
\qquad \mathrm{HHz}_{\mathrm{z}}\end{array}$} & \multirow{2}{*}{$\begin{aligned} & \text { Acce. } \\
\pm & \mathrm{MH} \%\end{aligned}$} \\
\hline & & & & $\Gamma_{1}$ & & & $\mathrm{r}$ & & \\
\hline & & $8, \leftarrow 7$ & Ground & & & & & 38608.96 & .1 \\
\hline $\mathrm{Si}^{28} \mathrm{H}_{3} \mathrm{I}^{127}$ & 4-1761 & $6,3 \leftarrow 5,3$ & Ground & & $17 / 2$ & & $15 / 2$ & 38615.65 & .1 \\
\hline $\mathrm{C}^{12} \mathrm{HD}: \mathrm{C}^{12} \mathrm{HBr}^{\mathrm{b}}$ & 4- 748 & Not Reported & Ground & & & & & 38620.3 & .1 \\
\hline $\mathrm{HDSe}^{80}$ & $4-1757$ & $10,5,6 \leftarrow 10,5,5$ & Ground & & & & & 38629.0 & \\
\hline $\mathrm{H}_{2} \mathrm{~N}^{15} \mathrm{C}^{12} \mathrm{DO}^{16}$ & 3- 157 & $2,1,2 \leftarrow 1,1,1$ & Ground & & & & & 38632.02 & \\
\hline $\mathrm{Cl}_{2}^{\mathrm{l}} \mathrm{O}^{16}$ & 4-1484 & $1,1,0 \leftarrow 1,0,1$ & Ground & & & & & 38635.78 & \\
\hline$\left(\mathrm{C}^{12} \mathrm{H}_{3}\right)_{3} \mathrm{Si}^{28} \mathrm{Cl}^{37}$ & 3- 822 & $9, \leftarrow 8$, & Excited & & & & & 38636.09 & .5 \\
\hline$\left(\mathrm{C}^{12} \mathrm{D}_{3}\right)\left(\mathrm{C}^{12} \mathrm{H}_{3}\right) \mathrm{O}^{16}$ & 3- 593 & Not Reported & (;round & & & & & 38638. & .5 \\
\hline $\mathrm{C}^{12} \mathrm{HD}: \mathrm{C}^{12} \mathrm{HBr}^{b}$ & 4- 748 & Not Reported & Ground & & & & & 38640.0 & .1 \\
\hline $\mathrm{C}^{12} \mathrm{H}_{3} \mathrm{O}^{18} \mathrm{H}$ & 3- 217 & $17,2, \leftarrow 17,1$, & Ground & & & & & 38647.87 & .1 \\
\hline $\mathrm{P}^{31} \mathrm{O}^{16} \mathrm{Cl}_{3}^{37}$ & 4-1512 & $10 . \leftarrow 9$, & Ground & & & & & 38648.6 & .5 \\
\hline $\mathrm{Cl}_{2}^{3} \mathrm{O}^{16}$ & 4-1484 & 1. $1,0 \leftarrow 1,0,1$ & Ground & $5 / 2$ & 4 & $5 / 2$ & 4 & 38649.45 & \\
\hline$\left(\mathrm{C}^{12} \mathrm{D}_{3}\right)\left(\mathrm{C}^{12} \mathrm{H}_{3}\right) \mathrm{O}^{16}$ & 3- 593 & Not Reported & Ground & & & & & 38649.5 & .5 \\
\hline $\mathrm{C}^{12} \mathrm{HD}: \mathrm{C}^{12} \mathrm{HBr}^{12}$ & 4- 748 & Not Reported & Ground & & & & & 38652.7 & .2 \\
\hline $\mathrm{Cl}_{2}^{\mathrm{b}} \mathrm{O}^{16}$ & 4-1484 & $1,1,0 \leftarrow 1,0,1$ & Ground & $3 / 2$ & 3 & $5 / 2$ & 2 & 38656.30 & \\
\hline $\mathrm{C}^{12} \mathrm{H}_{3} \mathrm{Si}^{28} \mathrm{H}_{2} \mathrm{~F}^{19}$ & 3. 241 & $3,1,2 \leftarrow 2,1,1$ & Ground & & & & & 38658.40 & .10 \\
\hline $\mathrm{C}^{12} \mathrm{H}_{3} \mathrm{Si}^{28} \mathrm{H}_{2} \mathrm{~F}^{19}$ & 3- 241 & $3,1,2 \leftarrow 2,1,1$ & Ground & & & & & 38658.92 & .10 \\
\hline$\left(\mathrm{C}^{12} \mathrm{D}_{3}\right)\left(\mathrm{C}^{12} \mathrm{H}_{3}\right) \mathrm{O}^{16}$ & 3- 593 & 1. $1,1 \leftarrow 0,0,0$ & Ground & & & & & 38659. & 1.0 \\
\hline $\mathrm{Cl}_{2}^{\mathrm{h}} \mathrm{O}^{16}$ & 4-1484 & $1,1,0 \leftarrow 1,0,1$ & Ground & & & & & 38659.44 & \\
\hline$\left(\mathrm{C}^{12} \mathrm{H}_{3}\right)_{2} \mathrm{O}^{16}$ & 3. 591 & Not Reported & Ground & & & & & 38660. & 20. \\
\hline $\mathrm{Cl}_{2}^{\mathrm{b}} \mathrm{O}^{16}$ & $4-1484$ & $1,1,0 \leftarrow 1,0,1$ & Ground & & 1 & & 2 & 38661.00 & \\
\hline $\mathrm{Cl}_{2}^{\mathrm{b}} \mathrm{O}^{16}$ & $4-1484$ & 1. $1,0 \leftarrow 1,0.1$ & Ground & $5 / 2$ & 2 & $3 / 2$ & 3 & 38661.00 & \\
\hline$\left(\mathrm{C}^{12} \mathrm{H}_{3}\right)_{3} \mathrm{Si}^{28} \mathrm{Cl}^{37}$ & 3- 822 & $9 . \leftarrow 8$ & Excited & & & & & 38662.28 & .5 \\
\hline $\mathrm{Cl}_{2}^{\mathrm{b}} \mathrm{O}^{16}$ & 4-1484 & 1. $1,0 \leftarrow 1,0,1$ & Ground & $5 / 2$ & 2 & $5 / 2$ & 2 & 38663.02 & \\
\hline $\mathrm{Cl}_{2}^{\mathrm{h}} \mathrm{O}^{16}$ & 4-1484 & $1,1,0 \leftarrow 1,0,1$ & Ground & & 1 & & 2 & 38663.02 & \\
\hline$\left(\mathrm{C}^{12} \mathrm{H}_{3}\right)_{2} \mathrm{O}^{16}$ & 3- 591 & Not Reported & Ground & & & & & 38675 & 20. \\
\hline $\mathrm{Cl}_{2}^{\mathrm{h}} \mathrm{O}^{16}$ & 4-1484 & $1,1,0 \leftarrow 1,0,1$ & Ground & & 0 & & 1 & 38675.09 & \\
\hline $\mathrm{Cl}_{2}^{\mathrm{h}} \mathrm{O}^{16}$ & 4.1484 & $1,1,0 \leftarrow 1,0,1$ & Ground & $3 / 2$ & 3 & $5 / 2$ & 4 & 38675.09 & \\
\hline $\mathrm{Cl}_{2}^{\mathrm{b}} \mathrm{O}^{16}$ & $4-1484$ & $1,1,0 \leftarrow 1,0,1$ & Ground & $5 / 2$ & 2 & $3 / 2$ & 2 & 38675.09 & \\
\hline $\mathrm{O}^{16} \mathrm{~F}_{2}^{19}$ & 4-1611 & $22,2,21 \leftarrow 21,3,18$ & Ground & & & & & 38675.10 & .10 \\
\hline $\mathrm{Cl}_{2}^{\mathrm{ln}} \mathrm{O}^{16}$ & 4-1484 & $1,1,0 \leftarrow 1,0,1$ & Ground & $5 / 2$ & 4 & $3 / 2$ & 3 & 38678.09 & \\
\hline $\mathrm{Cl}_{2}^{11} \mathrm{O}^{16}$ & $4-1484$ & 1. $1,0 \leftarrow 1,0,1$ & Ground & $3 / 2$ & 2 & $5 / 2$ & 2 & 38678.09 & \\
\hline $\mathrm{Cl}_{2}^{\mathrm{b}} \mathrm{O}^{16}$ & $4-1484$ & 1. 1. $0 \leftarrow 1,0,1$ & Ground & & 1 & & 0 & 38678.09 & \\
\hline $\mathrm{C}^{12} \mathrm{H}_{3} \mathrm{~N}^{14} \mathrm{O}_{2}^{16}$ & 3- 171 & Not Reported & Ground & & & & & 38680.78 & \\
\hline $\mathrm{t}-\mathrm{C}^{12} \mathrm{HD}: \mathrm{C}^{12} \mathrm{DBr}^{79}$ & 4- 745 & 5. $1,4 \leftarrow 4,1,3$ & Excited & & $13 / 2$ & & $11 / 2$ & 38681.3 & \\
\hline t- $\mathrm{C}^{12} \mathrm{HD}: \mathrm{C}^{12} \mathrm{DBr}^{79}$ & 4- 745 & $5,1,4 \leftarrow 4,1,3$ & Excited & & $7 / 2$ & & $5 / 2$ & 38684.5 & \\
\hline I- $\mathrm{C}^{12} \mathrm{HD}: \mathrm{C}^{12} \mathrm{DBr}^{79}$ & 4- 745 & $5,1,4 \leftarrow 4,1,3$ & Excited & & & & & 38684.81 & .6 \\
\hline $\mathrm{S}^{34} \mathrm{~S}^{32} \mathrm{O}^{16}$ & 4-1822 & $3,1,2 \leftarrow 3,0.3$ & Ground & & & & & 38685.0 & \\
\hline 1- $\mathrm{C}^{12} \mathrm{HD}: \mathrm{C}^{12} \mathrm{DBr}^{79}$ & 4- 745 & $5,1,4 \leftarrow 4,1,3$ & Excited & & $11 / 2$ & & $9 / 2$ & 38686.0 & \\
\hline $\mathrm{Cl}_{2}^{\mathrm{b}} \mathrm{O}^{16}$ & 4-1484 & $1,1,0 \leftarrow 1,0,1$ & Ground & $3 / 2$ & 2 & $3 / 2$ & 2 & 38686.52 & \\
\hline$\left(\mathrm{C}^{12} \mathrm{H}_{3}\right)_{2} \mathrm{O}^{16}$ & 3- 591 & Not Reported & Ground & & & & & 38690. & 20. \\
\hline t. $\mathrm{C}^{12} \mathrm{HD}: \mathrm{C}^{12} \mathrm{DBr}^{79}$ & 4- 745 & $5,1,4 \leftarrow 4,1,3$ & Excited & & $9 / 2$ & & $7 / 2$ & 38691.5 & \\
\hline $\mathrm{Cl}_{2}^{\mathrm{b}} \mathrm{O}^{16}$ & 4-1484 & $1,1,0 \leftarrow 1,0,1$ & Ground & $3 / 2$ & 2 & $3 / 2$ & 3 & 38694.43 & \\
\hline $\mathrm{Cl}_{2}^{\mathrm{l}} \mathrm{O}^{16}$ & $4-1484$ & b $1,0 \leftarrow 1,0,1$ & Ground & $3 / 2$ & 3 & $3 / 2$ & 3 & 38694.43 & \\
\hline
\end{tabular}


Vib. State

$\mathrm{F}_{1}^{\prime} \stackrel{\text { Hyperfine }}{\mathrm{F}^{\prime}} \mathrm{F}_{1} \mathrm{~F}$

Frequency
$\mathrm{MHz}$

Acc. $\pm \mathrm{MHz}$

\begin{tabular}{|c|c|c|c|c|c|c|c|c|c|}
\hline $\mathrm{Cl}_{2}^{\mathrm{b}} \mathrm{O}^{16}$ & $4-1484$ & $1,1,0 \leftarrow 1,0,1$ & Ground & $3 / 2$ & 3 & $3 / 2$ & 2 & 38694.43 & \\
\hline $\mathrm{H}_{2} \mathrm{C}^{12}{ }_{*} \mathrm{O}^{16} \mathrm{C}^{12}{ }_{*} \mathrm{H}_{2}$ & 4- 841 & $6,5,1 \leftarrow 6,4,2$ & Ground & & & & & 38702 . & 1. \\
\hline$\left(\mathrm{C}^{12} \mathrm{H}_{3}\right)_{3} \mathrm{Si}^{28} \mathrm{Cl}^{37}$ & 3- 822 & $9, \leftarrow 8$ & Excited & & & & & 38707.44 & .5 \\
\hline $\mathrm{t}-\mathrm{C}^{12} \mathrm{HD}: \mathrm{C}^{12} \mathrm{DBr}^{79}$ & 4. 745 & $5,1,4 \leftarrow 4,1,3$ & Ground & & $13 / 2$ & & $11 / 2$ & 38707.5 & \\
\hline $\mathrm{H}_{2} \mathrm{C}^{12}: \mathrm{C}^{12} \mathrm{DF}^{19}$ & 4. 784 & $2,0,2 \leftarrow 1,0,1$ & Ground & & & & & 38710.6 & .3 \\
\hline $\mathrm{t}-\mathrm{C}^{12} \mathrm{HD}: \mathrm{C}^{12} \mathrm{DBr}^{79}$ & 4- 745 & $5,1,4 \leftarrow 4,1,3$ & Ground & & $7 / 2$ & & $5 / 2$ & 38711.6 & \\
\hline $\mathrm{t}-\mathrm{C}^{12} \mathrm{HD}: \mathrm{C}^{12} \mathrm{DBr}^{79}$ & 4. 745 & $5,1,4 \leftarrow 4,1,3$ & Ground & & & & & 38711.82 & .29 \\
\hline $\mathrm{t} \cdot \mathrm{C}^{12} \mathrm{HD}: \mathrm{C}^{12} \mathrm{DBr}^{79}$ & 4. 745 & $5,1,4 \leftarrow 4,1,3$ & Ground & & $11 / 2$ & & $9 / 2$ & 38713.4 & \\
\hline $\mathrm{t}-\mathrm{C}^{12} \mathrm{HD}: \mathrm{C}^{12} \mathrm{DBr}^{79}$ & 4- 745 & $5,1,4 \leftarrow 4,1,3$ & Ground & & $9 / 2$ & & $7 / 2$ & 38718.8 & \\
\hline $\mathrm{HDSe}^{78}$ & $4-1756$ & $10,5,6 \leftarrow 10,5,5$ & Ground & & & & & 38724.0 & \\
\hline$\left(\mathrm{C}^{12} \mathrm{H}_{3}\right)_{3} \mathrm{Si}^{28} \mathrm{Cl}^{37}$ & 3- 822 & $9, \leftarrow 8$ & Excited & & & & & 38731.09 & .5 \\
\hline $\mathrm{C}^{12} \mathrm{D}_{2} \mathrm{C}^{12} \mathrm{H}_{2} \mathrm{C}^{12} \mathrm{D}_{2} \mathrm{O}^{16} *$ & 4-1092 & $3,0,3 \leftarrow 2,1,2$ & Ground & & & & & 38735.5 & .1 \\
\hline $\mathrm{N}^{14} \mathrm{D}_{2} \mathrm{H}$ & 4-1774 & $2,1,2 \leftarrow 2,0,2$ & Ground & & & & & 38739.13 & .10 \\
\hline $\mathrm{D}_{2} \mathrm{O}_{2}^{16}$ & 3- 42 & Not Reported & & & & & & 38752. & 3. \\
\hline $\mathrm{C}^{12} \mathrm{H}_{3} \mathrm{C}^{12}{ }_{*} \mathrm{HO}^{16} \mathrm{C}^{12}{ }_{*} \mathrm{H}_{2}$ & 3- 761 & $3,1,2 \leftarrow 2,1,1$ & Ground & & & & & 38757.75 & .1 \\
\hline $\mathrm{C}^{12} \mathrm{H}_{3} \mathrm{C}^{12}{ }_{*} \mathrm{HO}^{16} \mathrm{C}^{12}{ }_{*} \mathrm{H}_{2}$ & 3- 761 & Not Reported & Ground & & & & & 38762.75 & .1 \\
\hline $\mathrm{C}^{12} \mathrm{H}_{3} \mathrm{~N}^{14} \mathrm{C}^{13}$ & 4- 833 & $2,1 \leftarrow 1,1$ & Ground & & & & & 38782.21 & \\
\hline $\mathrm{C}^{12} \mathrm{H}_{3} \mathrm{~N}^{14} \mathrm{C}^{13}$ & 4. 833 & $2,0 \leftarrow 1,0$ & Ground & & & & & 38783.21 & \\
\hline $\mathrm{D}_{2} \mathrm{O}_{2}^{16}$ & 3. 42 & Not Reported & & & & & & 38799. & 3. \\
\hline $\mathrm{C}^{12}{ }_{*} \mathrm{H}_{2} \mathrm{C}^{12} \mathrm{HDC}^{12} \mathrm{H}_{2} \mathrm{O}^{16} *$ & 4-1094 & $2,1,1 \leftarrow 1,1,0$ & Ground & & & & & 38811.4 & .1 \\
\hline $\mathrm{S}_{2}^{32} \mathrm{O}^{16}$ & $4-1821$ & $3,1,2 \leftarrow 3,0,3$ & Ground & & & & & 38814.0 & \\
\hline $\mathrm{C}^{\mathrm{b}} * \mathrm{H}_{2}^{\mathrm{b}} \mathrm{N}^{\mathrm{b}} \mathrm{H}^{\mathrm{b}} \mathrm{C}^{\mathrm{b}} * \mathrm{H}_{2}^{\mathrm{b}}$ & 4. 863 & Not Reported & & & & & & 38825. & 10. \\
\hline $\mathrm{C}^{12} \mathrm{H}_{3} \mathrm{C}^{12} \mathrm{HO}^{16}$ & 3- 471 & Not Reported & & & & & & 38833.0 & \\
\hline $\mathrm{Si}^{28} \mathrm{HCl}_{2}^{35} \mathrm{Cl}^{37}$ & $4 \cdot 1502$ & $8, \quad \leftarrow 7$, & Ground & & & & & 38834. & 1. \\
\hline $\mathrm{C}^{12} \mathrm{H}_{3} \mathrm{C}^{12} * \mathrm{HO}^{16} \mathrm{C}^{12} * \mathrm{H}_{2}$ & 3- 761 & $4,2,3 \leftarrow 4,1,4$ & Ground & & & & & 38834.10 & .1 \\
\hline $\mathrm{C}^{12}{ }_{*} \mathrm{H}_{2} \mathrm{C}^{12} \mathrm{HDC}^{12} \mathrm{H}_{2} \mathrm{O}^{16} *$ & 4-1094 & $2,1,1 \leftarrow 1,1,0$ & Excited & & & & & 38834.73 & .1 \\
\hline $\mathrm{C}^{12} \mathrm{H}_{3} \mathrm{C}^{12} * \mathrm{HO}^{16} \mathrm{C}^{12}{ }_{*} \mathrm{H}_{2}$ & 3- 761 & Not Reported & Ground & & & & & 38836.98 & .1 \\
\hline $\mathrm{C}^{12} \mathrm{H}_{3} \mathrm{C}^{12}{ }_{*} \mathrm{HO}^{16} \mathrm{C}^{12}{ }_{*} \mathrm{H}_{2}$ & 3- 761 & $3,1,2 \leftarrow 2,1,1$ & Ground & & & & & 38852.54 & .1 \\
\hline $\mathrm{O}^{16} \mathrm{O}^{18} \mathrm{O}^{18}$ & $4-1844$ & $7,2,6 \leftarrow 8,1,7$ & Ground & & & & & 38859. & \\
\hline $\mathrm{C}^{12} \mathrm{H}_{3} \mathrm{C}^{12}{ }_{*} \mathrm{HO}^{16} \mathrm{C}^{12}{ }_{*} \mathrm{H}_{2}$ & 3. 761 & Not Reported & Ground & & & & & 38861.90 & .1 \\
\hline $\mathrm{a}-\mathrm{C}^{12} \mathrm{H}_{2} \mathrm{DSi}^{\mathrm{b}} \mathrm{H}_{2} \mathrm{D}$ & 3. 333 & $2,1,2 \leftarrow 1,1,1$ & & & & & & 38899.06 & \\
\hline $\mathrm{C}^{12} \mathrm{H}_{3} \mathrm{C}^{12}{ }_{*} \mathrm{HO}^{16} \mathrm{C}^{12}{ }_{*} \mathrm{H}_{2}$ & 3- 761 & $3,1,2 \leftarrow 2,1,1$ & Ground & & & & & 38910.96 & .1 \\
\hline $\mathrm{C}^{12}{ }_{*} \mathrm{D}_{2} \mathrm{C}^{12} \mathrm{H}_{2} \mathrm{C}^{12} \mathrm{D}_{2} \mathrm{O}^{16} *$ & 4-1092 & $3,0,3 \leftarrow 2,1,2$ & Excited & & & & & 38915.7 & .3 \\
\hline $\mathrm{C}^{12}{ }_{*} \mathrm{HC}^{12} \mathrm{H}: \mathrm{C}^{12} \mathrm{HC}^{12} \mathrm{H}: \mathrm{C}^{12} \mathrm{HN}^{14} *$ & $4-1201$ & $3,3,0 \leftarrow 2,1,1$ & Ground & & & & & 38917.12 & \\
\hline $\mathrm{Cl}^{35} \mathrm{~F}^{19} \mathrm{C}^{12} \mathrm{O}^{16}$ & 4- 151 & $5,3,3 \leftarrow 5,2,4$ & Ground & & & & & 38919.47 & .05 \\
\hline $\mathrm{C}^{12} \mathrm{D}_{3} \mathrm{O}^{16} \mathrm{H}$ & 3- 214 & $1,0,1 \leftarrow 0,0,0$ & Ground & & & & & 38923.97 & .5 \\
\hline $\mathrm{C}^{\mathrm{b}} \mathrm{H}_{2}^{\mathrm{b}} \mathrm{Cl}^{\mathrm{b}} \mathrm{F}^{\mathrm{b}}$ & 4- 333 & Not Reported & & & & & & 38928.22 & 1. \\
\hline $\mathrm{C}^{12} \mathrm{D}_{3} \mathrm{O}^{16} \mathrm{H}$ & $3 \cdot 214$ & $1,0,1 \leftarrow 0,0,0$ & Ground & & & & & 38928.89 & .5 \\
\hline $\mathrm{C}_{*}^{\mathrm{b}}{ }_{*} \mathrm{H}_{2}^{\mathrm{b}} \mathrm{N}^{\mathrm{b}} \mathrm{H}^{\mathrm{b}} \mathrm{C}^{\mathrm{b}}{ }_{*} \mathrm{H}_{2}^{\mathrm{b}}$ & 4- 863 & Not Reported & & & & & & 38930. & 10. \\
\hline $\mathrm{Cl}_{2}^{\mathrm{b}} \mathrm{O}^{16}$ & $4-1484$ & $2,1,1 \leftarrow 2,0,2$ & Ground & $3 / 2$ & 3 & $7 / 2$ & 2 & 38947.12 & \\
\hline $\mathrm{Cl}_{2}^{\mathrm{b}} \mathrm{O}^{16}$ & 4-1484 & $2,1,1 \leftarrow 2,0,2$ & Ground & $3 / 2$ & 1 & $7 / 2$ & 2 & 38947.12 & \\
\hline $\mathrm{Cl}_{2}^{\mathrm{b}} \mathrm{O}^{16}$ & 4-1484 & $2,1,1 \leftarrow 2,0,2$ & Ground & $7 / 2$ & 2 & $7 / 2$ & 2 & 38948.98 & \\
\hline $\mathrm{C}^{12} \mathrm{H}_{3} \mathrm{Si}^{28} \mathrm{Cl}_{3}^{35}$ & 3- 111 & $11, \leftarrow 10$ & & & & & & 38950. & 20. \\
\hline $\mathrm{Cl}_{2}^{\mathrm{b}} \mathrm{O}^{16}$ & 4-1484 & $2,1,1 \leftarrow 2,0,2$ & Ground & $5 / 2$ & 2 & $3 / 2$ & 1 & 38964.53 & \\
\hline $\mathrm{Cl}_{2}^{\mathrm{b}} \mathrm{O}^{16}$ & 4-1484 & $2,1,1 \leftarrow 2,0,2$ & Ground & $5 / 2$ & 2 & $3 / 2$ & 3 & 38964.53 & \\
\hline
\end{tabular}

$\mathrm{Cl}_{2}^{\mathrm{b}} \mathrm{O}^{16}$

$\mathrm{H}_{2} \mathrm{C}^{12} * \mathrm{O}^{16} \mathrm{C}^{12}{ }_{*} \mathrm{H}$

$\left(\mathrm{C}^{12} \mathrm{H}_{3}\right)_{3} \mathrm{Si}^{28} \mathrm{Cl}^{37}$

$\mathrm{t}-\mathrm{C}^{12} \mathrm{HD}: \mathrm{C}^{12} \mathrm{DBr}^{79}$

$\mathrm{H}_{2} \mathrm{C}^{12}: \mathrm{C}^{12} \mathrm{DF}^{19}$

t- $\mathrm{C}^{12} \mathrm{HD}: \mathrm{C}^{12} \mathrm{DBr}^{79}$

$\mathrm{t}-\mathrm{C}^{12} \mathrm{HD}: \mathrm{C}^{12} \mathrm{DBr}^{79}$

$\mathrm{HDSe}^{78}$

$\left(\mathrm{C}^{12} \mathrm{H}_{3}\right)_{3} \mathrm{Si}^{28} \mathrm{Cl}^{37}$

$\mathrm{C}^{12} * \mathrm{D}_{2} \mathrm{C}^{12} \mathrm{H}_{2} \mathrm{C}^{12} \mathrm{D}_{2} \mathrm{O}^{16} *$

$\mathrm{D}_{2} \mathrm{O}_{2}^{16}$

$\mathrm{C}^{12} \mathrm{H}_{3} \mathrm{C}^{12}{ }_{*} \mathrm{HO}^{16} \mathrm{C}^{12} * \mathrm{H}_{2}$

$\mathrm{C}^{12} \mathrm{H}_{3} \mathrm{C}^{12}{ }_{*} \mathrm{HO}^{16} \mathrm{C}^{12}{ }_{*} \mathrm{H}_{2}$

$\mathrm{D}_{2} \mathrm{O}_{2}^{16}$

$\mathrm{C}^{12}{ }_{*} \mathrm{H}_{2} \mathrm{C}^{12} \mathrm{HDC}^{12} \mathrm{H}_{2} \mathrm{O}^{16} *$ $\mathrm{S}_{2}^{32} \mathrm{O}^{16}$
3. 42

4-1094

4-1821

4. 863

4-1094

3. 333

3. 761

1092

4- 151

3- 214

4- 333

3. 214
$2,1,1 \leftarrow 1,1,0$

$4,2,3 \leftarrow 4,1,4$

Not Reported

$3,3,0 \leftarrow 2,1$,

$, 0,1 \leftarrow 0,0,0$

Not Reported

$1 \leftarrow 0,0$,
10

3.

1.

.

.1

1

.05

.5

38964.53 


\begin{tabular}{|c|c|c|c|c|c|c|c|c|}
\hline \multirow{2}{*}{ Isotopic Species } & \multirow{2}{*}{$\begin{array}{l}\text { Vol.-Id. } \\
\text { Nos. }\end{array}$} & \multirow{2}{*}{$\begin{array}{c}\text { Rotational } \\
\text { Quantum Nos. }\end{array}$} & \multirow{2}{*}{ Vib. State } & \multicolumn{3}{|c|}{ Hyperfine } & \multirow{2}{*}{$\begin{array}{l}\text { Frequency } \\
\mathrm{MH}_{z}\end{array}$} & \multirow{2}{*}{$\begin{array}{r}\text { Acc. } \\
\pm \mathrm{MHz}\end{array}$} \\
\hline & & & & $F_{1}^{\prime}$ & & $\mathrm{F}_{1} \quad \mathrm{~F}$ & & \\
\hline $\mathrm{Cl}_{2}^{\mathrm{b}} \mathrm{O}^{16}$ & $4-1484$ & $2,1,1 \leftarrow 2,0,2$ & Ground & $7 / 2$ & 4 & $7 / 2 \quad 4$ & 38966.29 & \\
\hline $\mathrm{Cl}_{2}^{\mathrm{b}} \mathrm{O}^{16}$ & $4-1484$ & $2,1,1 \leftarrow 2,0,2$ & Ground & $3 / 2$ & 1 & $3 / 20$ & 38966.29 & \\
\hline $\mathrm{Cl}_{2}^{\mathrm{b}} \mathrm{O}^{16}$ & $4-1484$ & $2,1,1 \leftarrow 2,0,2$ & Ground & $3 / 2$ & 3 & $7 / 2 \quad 4$ & 38966.29 & \\
\hline $\mathrm{Cl}_{2}^{\mathrm{b}} \mathrm{O}^{16}$ & $4-1484$ & $2,1,1 \leftarrow 2,0,2$ & Ground & $3 / 2$ & 0 & $3 / 20$ & 38966.29 & \\
\hline $\mathrm{Cl}_{2}^{\mathrm{b}} \mathrm{O}^{16}$ & $4-1484$ & $2,1,1 \leftarrow 2,0,2$ & Ground & $7 / 2$ & 4 & $3 / 23$ & 38966.29 & \\
\hline $\mathrm{Cl}_{2}^{\mathrm{b}} \mathrm{O}^{16}$ & $4-1484$ & $2,1,1 \leftarrow 2,0,2$ & Ground & $3 / 2$ & 3 & $3 / 2 \quad 3$ & 38966.29 & \\
\hline $\mathrm{Cl}_{2}^{\mathrm{b}} \mathrm{O}^{16}$ & $4-1484$ & $2,1,1 \leftarrow 2,0,2$ & Ground & $3 / 2$ & 1 & $3 / 21$ & 38966.29 & \\
\hline $\mathrm{Cl}_{2}^{\mathrm{b}} \mathrm{O}^{16}$ & $4-1484$ & $2,1,1 \leftarrow 2,0,2$ & Ground & $3 / 2$ & 0 & $3 / 2 \quad 1$ & 38966.29 & \\
\hline $\mathrm{Cl}_{2}^{\mathrm{b}} \mathrm{O}^{16}$ & $4-1484$ & $2,1,1 \leftarrow 2,0,2$ & Ground & $7 / 2$ & 2 & $3 / 21$ & 38966.31 & \\
\hline $\mathrm{Cl}_{2}^{\mathrm{b}} \mathrm{O}^{16}$ & $4-1484$ & $2,1,1 \leftarrow 2,0,2$ & Ground & $7 / 2$ & 2 & $3 / 23$ & 38966.31 & \\
\hline $\mathrm{C}^{12} \mathrm{D}_{3} \mathrm{O}^{16} \mathrm{D}$ & 3- 216 & Not Reported & & & & & 38967.0 & \\
\hline $\mathrm{C}^{12} \mathrm{D}_{3} \mathrm{O}^{16} \mathrm{H}$ & 3- 214 & Not Reported & Ground & & & & 38967.6 & .5 \\
\hline $\mathrm{C}^{\mathrm{b}}{ }_{*} \mathrm{H}_{2}^{\mathrm{b}} \mathrm{N}^{\mathrm{b}} \mathrm{H}^{\mathrm{b}} \mathrm{C}^{\mathrm{b}}{ }_{*} \mathrm{H}_{2}^{\mathrm{b}}$ & 4- 863 & Not Reported & & & & & 38970. & 10. \\
\hline $\mathrm{C}^{12} \mathrm{I}_{3} \mathrm{O}^{16} \mathrm{H}$ & $3 \cdot 214$ & $1,0,1 \leftarrow 0,0,0$ & Ground & & & & 38972.05 & .5 \\
\hline $\mathrm{C}^{12} \mathrm{H}_{3} \mathrm{C}^{12}{ }_{*} \mathrm{HO}^{16} \mathrm{C}^{12}{ }_{*} \mathrm{H}_{2}$ & 3- 761 & $3,1,2 \leftarrow 2,1,1$ & Ground & & & & 38974.35 & .1 \\
\hline $\mathrm{C}^{12} \mathrm{D}_{3} \mathrm{O}^{16} \mathrm{H}$ & 3- 214 & $1,0,1 \leftarrow 0,0,0$ & Ground & & & & 38982.88 & .5 \\
\hline $\mathrm{Cl}_{2}^{\mathrm{h}} \mathrm{O}^{16}$ & $4-1484$ & $2,1,1 \leftarrow 2,0,2$ & Ground & $5 / 2$ & 2 & $5 / 2 \quad 2$ & 38983.65 & \\
\hline $\mathrm{Ge}^{74} \mathrm{HCl}_{3}^{35}$ & $4-1493$ & $9, \leftarrow 8$, & Ground & & & & 38984.86 & .07 \\
\hline $\mathrm{Cl}_{2}^{\mathrm{b}} \mathrm{O}^{16}$ & $4-1484$ & $2,1,1 \leftarrow 2,0,2$ & Ground & $3 / 2$ & 3 & $5 / 22$ & 38985.48 & \\
\hline $\mathrm{Cl}_{2}^{\mathrm{b}} \mathrm{O}^{16}$ & $4-1484$ & $2,1,1 \leftarrow 2,0,2$ & Ground & $3 / 2$ & 1 & $5 / 22$ & 38985.48 & \\
\hline $\mathrm{C}^{12}{ }_{*} \mathrm{HC}^{12} \mathrm{H}: \mathrm{C}^{12} \mathrm{HC}^{12} \mathrm{H} \mathrm{C}^{12} \mathrm{HN}^{14} *$ & $4-1201$ & $4,2,2 \leftarrow 3,2,1$ & Ground & & & & 38988.91 & \\
\hline $\mathrm{C}^{12} \mathrm{H}_{3} \mathrm{C}^{12}{ }_{*} \mathrm{HO}^{16} \mathrm{C}^{12}{ }_{*} \mathrm{H}_{2}$ & 3- 761 & Not Reported & Ground & & & & 38989.23 & .1 \\
\hline $\mathrm{Ge}^{74} \mathrm{HCl}_{3}^{35}$ & $4-1493$ & $9, \leftarrow 8$, & Excited & & & & 38992.19 & .07 \\
\hline $\mathrm{Ge}^{74} \mathrm{~F}_{3}^{19} \mathrm{Cl}^{35}$ & $4-1405$ & $9, \leftarrow 8$ & Ground & & & & 38996.78 & .20 \\
\hline $\mathrm{C}^{\mathrm{b}} \mathrm{H}_{2}^{\mathrm{b}} \mathrm{N}^{\mathrm{b}} \mathrm{H}^{\mathrm{b}} \mathrm{C}^{\mathrm{b}}{ }_{*} \mathrm{H}_{2}^{\mathrm{b}}$ & 4. 863 & Not Reported & & & & & 39000. & 10. \\
\hline $\mathrm{C}^{12} \mathrm{H}_{3} \mathrm{C}^{12}{ }_{*} \mathrm{HO}^{16} \mathrm{C}^{12}{ }_{*} \mathrm{H}_{2}$ & 3. 761 & Not Reported & Ground & & & & 39000.03 & .1 \\
\hline $\mathrm{C}^{12} \mathrm{H}_{3} \mathrm{C}^{12}{ }_{*} \mathrm{HO}^{16} \mathrm{C}^{12}{ }_{*} \mathrm{H}_{2}$ & 3. 761 & Not Reported & Ground & & & & 39003.23 & .1 \\
\hline $\mathrm{c}-\mathrm{HDN}^{14} \mathrm{C}^{12} \mathrm{HO}^{16}$ & 3- 152 & $2,1,2 \leftarrow 1,1,1$ & Ground & & & & 39013.50 & .2 \\
\hline $\mathrm{Ge}^{72} \mathrm{~F}_{3}^{19} \mathrm{Cl}^{5}$ & $4-1403$ & $9, \leftarrow 8$ & Ground & & & & 39013.81 & .20 \\
\hline $\mathrm{C}^{\mathrm{b}} \mathrm{H}_{2}^{\mathrm{b}} \mathrm{Cl}^{\mathrm{b}} \mathrm{F}^{\mathrm{b}}$ & 4- 333 & Not Reported & & & & & 39021.44 & 1. \\
\hline $\mathrm{C}^{\mathrm{b}} \mathrm{H}_{2}^{\mathrm{b}} \mathrm{Cl}^{\mathrm{b}} \mathrm{F}^{\mathrm{b}}$ & 4. 333 & Not Reported & & & & & 39028.46 & 1. \\
\hline $\mathrm{Ge}^{70} \mathrm{~F}_{3}^{19} \mathrm{Cl}^{35}$ & $4-1401$ & $9, \leftarrow 8$ & Ground & & & & 39031.91 & .30 \\
\hline $\mathrm{H}_{2} \mathrm{O}_{2}^{16}$ & 3- 41 & Not Reported & & & & & 39033. & 2. \\
\hline $\mathrm{C}^{12}{ }_{*} \mathrm{H}_{2} \mathrm{~S}^{34} \mathrm{C}^{12}{ }_{*} \mathrm{H}_{2}$ & 4. 852 & $5,1,5 \leftarrow 5,1,4$ & Ground & & & & 39034.6 & .2 \\
\hline $\mathrm{F}^{19} \mathrm{HC}^{12} \mathrm{O}^{16}$ & 4. 271 & $8,1,7 \leftarrow 7,2,6$ & & & & & 39039.23 & .04 \\
\hline $\mathrm{C}^{\mathrm{b}}{ }_{*} \mathrm{H}_{2}^{\mathrm{b}} \mathrm{N}^{\mathrm{b}} \mathrm{H}^{\mathrm{b}} \mathrm{C}^{\mathrm{b}}{ }_{*} \mathrm{H}_{2}^{\mathrm{b}}$ & 4. 863 & Not Reported & & & & & 39040. & 10. \\
\hline $\mathrm{F}^{19} \mathrm{HC}^{12} \mathrm{O}^{16}$ & 4- 271 & $7,2,6 \leftarrow 8,1,7$ & & & & & 39044.3 & .1 \\
\hline $\mathrm{Ce}^{72} \mathrm{HCl}_{3}^{35}$ & $4-1492$ & $9, \leftarrow 8$ & Ground & & & & 39047.07 & .07 \\
\hline$\left(\mathrm{C}^{12} \mathrm{H}_{3}\right)_{2} \mathrm{O}^{16}$ & 3. 591 & $5,1,4 \leftarrow 5,0,5$ & Ground & & & & 39047.1 & .5 \\
\hline $\mathrm{C}^{12} \mathrm{D}_{3} \mathrm{O}^{16} \mathrm{D}$ & 3- 216 & Not Reported & & & & & 39048. & \\
\hline $\mathrm{Ge}^{72} \mathrm{HCl}_{3}^{35}$ & $4-1492$ & $9, \leftarrow 8$ & Excited & & & & 39055.31 & .07 \\
\hline $\mathrm{C}^{12} \mathrm{D}_{3} \mathrm{O}^{16} \mathrm{D}$ & 3- 216 & Not Reported & & & & & 39065. & \\
\hline $\mathrm{C}^{12} \mathrm{D}_{3} \mathrm{O}^{16} \mathrm{H}$ & 3. 214 & $1,0,1 \leftarrow 0,0,0$ & Ground & & & & 39066.21 & .5 \\
\hline $\mathrm{N}^{14} \mathrm{O}_{2}^{16}$ & $4-1801$ & $21,2,20 \leftarrow 22,1,21$ & Ground & & & & 39066.70 & \\
\hline $\mathrm{C}^{12} \mathrm{D}_{3} \mathrm{O}^{16} \mathrm{H}$ & 3- 214 & $1,0,1 \leftarrow 0,0,0$ & Ground & & & & 39069.25 & .5 \\
\hline
\end{tabular}




\begin{tabular}{|c|c|c|c|c|c|c|c|c|c|}
\hline Isotopic Species & $\begin{array}{l}\text { Vol.-Id. } \\
\text { Nos. }\end{array}$ & $\begin{array}{l}\text { Rotational } \\
\text { Quantum Nos. }\end{array}$ & Vib. State & $\mathrm{F}_{1}^{\prime}$ & $\begin{array}{l}\text { Ayper } \\
\mathrm{F}^{\prime}\end{array}$ & $\begin{array}{l}\text { fine } \\
F_{1}\end{array}$ & $\mathbf{F}$ & $\begin{array}{l}\text { Frequency } \\
\text { MHz } \\
:\end{array}$ & $\begin{aligned} & \text { Acc. } \\
& \pm \mathrm{MHz}\end{aligned}$ \\
\hline $\mathrm{t}-\mathrm{DHC}^{12}: \mathrm{C}^{12} \mathrm{DF}^{19}$ & 4. 791 & $2,1,1 \leftarrow 1,1,0$ & Ground & & & & & 39096.0 & .3 \\
\hline $\mathrm{N}^{14} \mathrm{O}_{2}^{16}$ & $4-1801$ & $21,2,20 \longleftarrow 22,1,21$ & Ground & & & & & 39097.80 & \\
\hline $\mathrm{C}^{\mathrm{b}}{ }_{*} \mathrm{H}_{2}^{\mathrm{b}} \mathrm{N}^{\mathrm{b}} \mathrm{H}^{\mathrm{b}} \mathrm{C}^{\mathrm{b}}{ }_{*} \mathrm{H}_{2}^{\mathrm{b}}$ & 4- 863 & Not Reported & & & & & & 39100. & 10. \\
\hline $\mathrm{Ge}^{70} \mathrm{HCl}_{3}^{35}$ & 4-1491 & $9, \leftarrow 8$ & Ground & & & & & 39109.31 & .07 \\
\hline $\mathrm{s}-\mathrm{C}^{12} \mathrm{H}_{2} \mathrm{DSi} \mathrm{i}^{\mathrm{b}} \mathrm{H}_{2} \mathrm{D}$ & 3- 332 & $2,0,2 \leftarrow 1,0,1$ & & & & & & 39111.84 & \\
\hline $\mathrm{H}_{2} \mathrm{C}^{12} * \mathrm{O}^{16} \mathrm{C}^{13}{ }_{*} \mathrm{H}_{2}$ & 4- 842 & $1,1,1 \leftarrow 0,0,0$ & Ground & & & & & 39116.4 & .5 \\
\hline $\mathrm{Ge}^{70} \mathrm{HCl}_{3}^{35}$ & 4-1491 & $9, \leftarrow 8$ & Excited & & & & & 39118.91 & .07 \\
\hline $\mathrm{Cl}^{35} \mathrm{~F}^{19} \mathrm{C}^{12} \mathrm{O}^{16}$ & 4- 151 & $2,2,1 \leftarrow 1,1.0$ & Ground & & $7 / 2$ & & $5 / 2$ & 39135.12 & .05 \\
\hline $\mathrm{N}^{14} \mathrm{O}_{2}^{16}$ & 4-1801 & $21,2,20 \leftarrow 22,1,21$ & Ground & & & & & 39142.46 & \\
\hline $\mathrm{C}^{12} \mathrm{H}_{3} \mathrm{O}^{18} \mathrm{H}$ & 3- 217 & $18,2, \leftarrow 18,1$, & Ground & & & & & 39149.41 & .1 \\
\hline $\mathrm{C}^{12} \mathrm{Cl}^{35} \mathrm{Cl}_{2}^{37} \mathrm{C}^{12} \mathrm{~N}^{14}$ & 4- 583 & $12, \quad \leftarrow 11$, & Ground & & & & & 39150.0 & 20. \\
\hline $\mathrm{C}^{\mathrm{b}}{ }_{*} \mathrm{H}_{2}^{\mathrm{b}} \mathrm{N}^{\mathrm{b}} \mathrm{H}^{\mathrm{b}} \mathrm{C}^{\mathrm{b}}{ }_{*} \mathrm{H}_{2}^{\mathrm{b}}$ & 4- 863 & Not Reported & & & & & & 39170. & 10. \\
\hline $\mathrm{t}-\mathrm{HDN}^{14} \mathrm{C}^{12} \mathrm{HO}^{16}$ & 3- 153 & $2,0,2 \leftarrow 1,0,1$ & Ground & & & & & 39190.40 & .2 \\
\hline $\mathrm{N}^{14} \mathrm{O}_{2}^{16}$ & 4-1801 & $21,2,20 \longleftarrow 22,1,21$ & Ground & & & & & 39192.94 & \\
\hline $\mathrm{C}^{12} \mathrm{H}_{3} \mathrm{O}^{18} \mathrm{H}$ & 3- 217 & $22,2, \leftarrow 22,1$, & Ground & & & & & 39210.48 & .1 \\
\hline $\mathrm{a}-\mathrm{C}^{12} \mathrm{H}_{2} \mathrm{DS} \mathrm{i}^{\mathrm{b}} \mathrm{H}_{2} \mathrm{D}$ & 3- 333 & $2,0,2 \leftarrow 1,0,1$ & & & & & & 39213.18 & \\
\hline $\mathrm{N}^{14} \mathrm{O}_{2}^{16}$ & 4-1801 & $21,2,20 \longleftarrow 22,1,21$ & Ground & & & & & 39235.98 & \\
\hline $\mathrm{N}^{14} \mathrm{O}_{2}^{16}$ & 4-1801 & $21,2,20 \leftarrow 22,1,21$ & Ground & & & & & 3924.7 .28 & \\
\hline $\mathrm{t}-\mathrm{HDC}^{12}{ }_{*} \mathrm{O}^{16} \mathrm{C}^{12}{ }_{*} \mathrm{HD}$ & 4. 844 & $3,3,1 \leftarrow 3,2,2$ & Ground & & & & & 39254.37 & .05 \\
\hline$\left(\mathrm{C}^{12} \mathrm{H}_{3}\right)_{2} \mathrm{~S}^{32}$ & 3. 601 & $3,2,2 \leftarrow 3,1,3$ & Ground & & & & & 39272.12 & .05 \\
\hline$\left(\mathrm{C}^{12} \mathrm{H}_{3}\right)_{2} \mathrm{~S}^{32}$ & 3- 601 & $3,2,2 \leftarrow 3,1,3$ & Ground & & & & & 39272.87 & .05 \\
\hline$\left(\mathrm{C}^{12} \mathrm{H}_{3}\right)_{2} \mathrm{~S}^{32}$ & 3- 601 & $3,2,2 \leftarrow 3,1,3$ & Ground & & & & & 39273.64 & .05 \\
\hline $\mathrm{t}-\mathrm{HDC}^{12}{ }_{*} \mathrm{O}^{16} \mathrm{C}^{12}{ }_{*} \mathrm{HD}$ & 4. 844 & $6,3,3 \leftarrow 6,2,4$ & Ground & & & & & 39273.7 & .2 \\
\hline$\left(\mathrm{C}^{12} \mathrm{H}_{3}\right)_{2} \mathrm{~S}^{32}$ & 3- 601 & $8,2,6 \leftarrow 8,1,7$ & Ground & & & & & 39285.65 & .05 \\
\hline$\left(\mathrm{C}^{12} \mathrm{H}_{3}\right)_{2} \mathrm{~S}^{32}$ & 3- 601 & $8,2,6 \leftarrow 8,1,7$ & Ground & & & & & 39286.23 & .05 \\
\hline$\left(\mathrm{C}^{12} \mathrm{H}_{3}\right)_{2} \mathrm{~S}^{32}$ & 3- 601 & $8,2,6 \leftarrow 8,1,7$ & Ground & & & & & 39286.80 & .05 \\
\hline $\mathrm{D}_{2} \mathrm{~N}^{14} \mathrm{C}^{12} \mathrm{HO}^{16}$ & 3. 154 & $2,1,1 \leftarrow 1,1,0$ & Ground & & & & & 39290.66 & .2 \\
\hline $\mathrm{C}^{\mathrm{b}}{ }_{*} \mathrm{H}_{2}^{\mathrm{b}} \mathrm{N}^{\mathrm{b}} \mathrm{H}^{\mathrm{b}} \mathrm{C}^{\mathrm{b}}{ }_{*} \mathrm{H}_{2}^{\mathrm{b}}$ & 4. 863 & Not Reported & & & & & & 39300. & 10. \\
\hline $\mathrm{C}^{12} \mathrm{H}_{3} \mathrm{C}^{12}{ }_{*} \mathrm{HO}^{16} \mathrm{C}^{12}{ }_{*} \mathrm{H}_{2}$ & 3- 761 & $28,13, \leftarrow 27,14$ & Ground & & & & & 39320.40 & .1 \\
\hline $\mathrm{C}^{12} \mathrm{H}_{3} \mathrm{C}^{12}{ }_{*} \mathrm{HO}^{16} \mathrm{C}^{12}{ }_{*} \mathrm{H}_{2}$ & 3- 761 & $28,13, \leftarrow 27,14$, & Ground & & & & & 39321.14 & .1 \\
\hline $\mathrm{C}^{\mathrm{b}}{ }_{*} \mathrm{H}_{2}^{\mathrm{b}} \mathrm{N}^{\mathrm{b}} \mathrm{H}^{\mathrm{b}} \mathrm{C}^{\mathrm{b}}{ }_{*} \mathrm{H}_{2}^{\mathrm{b}}$ & 4- 863 & Not Reported & & & & & & 39325. & 10. \\
\hline $\mathrm{C}^{12} \mathrm{H}_{3} \mathrm{C}^{13} \mathrm{HO}^{16}$ & 3- 477 & $2,1,1 \leftarrow 1,1,0$ & Ground & & & & & 39343.4 & .5 \\
\hline $\mathrm{S}_{2}^{32} \mathrm{O}^{16}$ & 4-1821 & $4,1,3 \leftarrow 3,1,2$ & Excited & & & & & 39347.6 & \\
\hline $\mathrm{S}_{2}^{32} \mathrm{O}^{16}$ & 4-1821 & $4,1,3 \leftarrow 3,1,2$ & Ground & & & & & 39356.2 & \\
\hline $\mathrm{C}^{12} \mathrm{H}_{3} \mathrm{C}^{12} \mathrm{HO}^{16}$ & 3- 471 & $2,1,1 \leftarrow 1,1,0$ & Ground & & & & & 39362.46 & .4 \\
\hline $\mathrm{C}^{12} \mathrm{H}_{3} \mathrm{C}^{12}{ }_{*} \mathrm{HO}^{16} \mathrm{C}^{12}{ }_{*} \mathrm{H}_{2}$ & 3- 761 & $13,2,11 \leftarrow 13,1,12$ & Ground & & & & & 39388.43 & .1 \\
\hline $\mathrm{H}_{2} \mathrm{C}^{12}: \mathrm{C}^{13} \mathrm{HF}^{19}$ & 4- 783 & $2,0,2 \leftarrow 1,0,1$ & Ground & & & & & 39401.13 & .05 \\
\hline $\mathrm{S}_{2}^{32} \mathrm{O}^{16}$ & 4-1821 & $3,1,2 \leftarrow 3,0,3$ & Excited & & & & & 39402.2 & \\
\hline $\mathrm{Cl}_{2}^{\mathrm{b}} \mathrm{O}^{16}$ & 4-1484 & $3,1,2 \leftarrow 3,0,3$ & Ground & $9 / 2$ & 4 & $3 / 2$ & 3 & 39406.50 & \\
\hline $\mathrm{Cl}_{2}^{\mathrm{b}} \mathrm{O}^{16}$ & 4- 1484 & $3,1,2 \leftarrow 3,0,3$ & Ground & $3 / 2$ & 2 & $3 / 2$ & 1 & 39406.50 & \\
\hline $\mathrm{Cl}_{2}^{\mathrm{b}} \mathrm{O}^{16}$ & 4-1484 & $3,1,2 \leftarrow 3,0,3$ & Ground & $7 / 2$ & 5 & $9 / 2$ & 6 & 39408.03 & \\
\hline $\mathrm{Cl}_{2}^{\mathrm{h}} \mathrm{O}^{16}$ & 4-1484 & $3,1,2 \leftarrow 3,0,3$ & Ground & $3 / 2$ & 2 & $3 / 2$ & 3 & 39409.46 & \\
\hline $\mathrm{Cl}_{2}^{\mathrm{b}} \mathrm{O}^{16}$ & 4-1484 & $3,1,2 \leftarrow 3,0,3$ & Ground & $3 / 2$ & 3 & $3 / 2$ & 3 & 39412.14 & \\
\hline $\mathrm{Cl}_{2}^{\mathrm{b}} \mathrm{O}^{16}$ & $4-1484$ & $3,1,2 \leftarrow 3,0,3$ & Ground & $3 / 2$ & 0 & $3 / 2$ & 1 & 39412.14 & \\
\hline $\mathrm{Cl}_{2}^{\mathrm{b}} \mathrm{O}^{16}$ & 4-1484 & $3,1,2 \leftarrow 3,0,3$ & Ground & $9 / 2$ & 6 & $9 / 2$ & 6 & 39416.36 & \\
\hline
\end{tabular}




\begin{tabular}{|c|c|c|c|c|c|c|c|c|c|}
\hline Isotopic Species & $\begin{array}{l}\text { Vol.-1d. } \\
\text { Nos. }\end{array}$ & $\begin{array}{c}\text { Rotational } \\
\text { Quantum Nos. }\end{array}$ & Vib. State & $F_{1}^{\prime}$ & $\begin{array}{l}\text { Typ } \\
F^{\prime}\end{array}$ & $\begin{array}{l}\text { rfine } \\
F_{1}\end{array}$ & $\mathrm{~F}$ & $\begin{array}{l}\text { Frequency } \\
\mathrm{MH}_{z}\end{array}$ & $\begin{array}{r}\text { Acc. } \\
\pm \mathrm{MHz}\end{array}$ \\
\hline $\mathrm{Cl}_{2}^{\mathrm{b}} \mathrm{O}^{16}$ & 4.1484 & $3,1,2 \leftarrow 3,0,3$ & Ground & $5 / 2$ & 3 & $9 / 2$ & 4 & 39418.40 & \\
\hline $\mathrm{Cl}_{2}^{\mathrm{h}} \mathrm{O}^{16}$ & 4-1484 & $3,1,2 \leftarrow 3,0,3$ & Ground & $7 / 2$ & 5 & $9 / 2$ & 4 & 39418.40 & \\
\hline $\mathrm{Cl}_{2}^{\mathrm{b}} \mathrm{O}^{16}$ & 4-1484 & $3,1,2 \leftarrow 3,0,3$ & Ground & $9 / 2$ & 4 & $9 / 2$ & 4 & 39422.61 & \\
\hline $\mathrm{Cl}_{2}^{\mathrm{b}} \mathrm{O}^{16}$ & 4-1484 & $3,1,2 \leftarrow 3,0,3$ & Ground & $5 / 2$ & 3 & $3 / 2$ & 2 & 39424.22 & \\
\hline $\mathrm{Cl}_{2}^{\mathrm{b}} \mathrm{O}^{16}$ & $4-1484$ & $3,1,2 \leftarrow 3,0,3$ & Ground & $3 / 2$ & 2 & $3 / 2$ & 2 & 39424.22 & \\
\hline $\mathrm{Cl}_{2}^{\mathrm{b}} \mathrm{O}^{16}$ & $4-1484$ & $3,1,2 \leftarrow 3,0,3$ & Ground & $3 / 2$ & 3 & $3 / 2$ & 2 & 39425.92 & \\
\hline $\mathrm{Cl}_{2}^{\mathrm{b}} \mathrm{O}^{16}$ & 4-1484 & $3,1,2 \leftarrow 3,0,3$ & Ground & $7 / 2$ & 4 & $5 / 2$ & 3 & 39425.92 & \\
\hline $\mathrm{Cl}_{2}^{\mathrm{b}} \mathrm{O}^{16}$ & 4-1484. & $3,1,2 \leftarrow 3,0,3$ & Ground & $3 / 2$ & 1 & $3 / 2$ & 2 & 39425.92 & \\
\hline $\mathrm{Cl}_{2}^{b} \mathrm{O}^{16}$ & 4. 1484 & $3,1,2 \leftarrow 3,0,3$ & Ground & $7 / 2$ & 4 & $7 / 2$ & 5 & 39428.66 & \\
\hline $\mathrm{Cl}_{2}^{\mathrm{b}} \mathrm{O}^{16}$ & $4-1484$ & $3,1,2 \leftarrow 3,0,3$ & Ground & $3 / 2$ & 3 & $9 / 2$ & 4 & 39428.66 & \\
\hline $\mathrm{C}^{\mathrm{b}}{ }_{*} \mathrm{H}_{2}^{\mathrm{b}} \mathrm{N}^{\mathrm{b}} \mathrm{H}^{\mathrm{b}} \mathrm{C}^{\mathrm{b}}{ }_{*} \mathrm{H}_{2}^{\mathrm{b}}$ & 4. 863 & Not Reported & & & & & & 39430 . & 10. \\
\hline $\mathrm{Cl}_{2}^{13} \mathrm{O}^{16}$ & 4-1484 & $3,1,2 \leftarrow 3,0,3$ & Ground & $5 / 2$ & 3 & $5 / 2$ & 3 & 39430.00 & \\
\hline $\mathrm{Cl}_{2}^{\mathrm{b}} \mathrm{O}^{16}$ & 4-1484 & $3,1,2 \leftarrow 3,0,3$ & Ground & $7 / 2$ & 5 & $7 / 2$ & 5 & 39432.12 & \\
\hline $\mathrm{Cl}_{2}^{\mathrm{b}} \mathrm{O}^{16}$ & 4-1484 & $3,1,2 \leftarrow 3,0,3$ & Ground & $7 / 2$ & 2 & $7 / 2$ & 2 & 39432.78 & \\
\hline $\mathrm{Cl}_{2}^{\mathrm{b}} \mathrm{O}^{16}$ & $4-1484$ & $3,1,2 \leftarrow 3,0,3$ & Ground & $9 / 2$ & 4 & $7 / 2$ & 5 & 39437.30 & \\
\hline $\mathrm{Cl}_{2}^{\mathrm{b}} \mathrm{O}^{16}$ & $4-1484$ & $3,1,2 \leftarrow 3,0,3$ & Ground & $3 / 2$ & 2 & $5 / 2$ & 3 & 39437.30 & \\
\hline $\mathrm{Cl}_{2}^{\mathrm{b}} \mathrm{O}^{16}$ & 4.1484 & $3,1,2 \leftarrow 3,0,3$ & Ground & $7 / 2$ & 4 & $7 / 2$ & 4 & 39438.70 & \\
\hline $\mathrm{O}_{3}^{18}$ & 4-1845 & $12,2,10 \longleftarrow 13,1,13$ & Ground & & & & & 39439. & \\
\hline $\mathrm{Cl}_{2}^{\mathrm{b}} \mathrm{O}^{16}$ & 4-1484 & $3,1,2 \leftarrow 3,0,3$ & Ground & $7 / 2$ & 5 & $7 / 2$ & 4 & 39440.42 & \\
\hline $\mathrm{Cl}_{2}^{\mathrm{b}} \mathrm{O}^{16}$ & 4-1484 & $3,1,2 \leftarrow 3,0,3$ & Ground & $9 / 2$ & 6 & $7 / 2$ & 5 & 39440.42 & \\
\hline $\mathrm{CI}_{2}^{\mathrm{b}} \mathrm{O}^{16}$ & 4-1484 & $3,1,2 \leftarrow 3,0,3$ & Ground & $5 / 2$ & 3 & $7 / 2$ & 4 & 39443.04 & \\
\hline $\mathrm{c}-\mathrm{HDC}^{12}: \mathrm{C}^{12} \mathrm{HF}^{19}$ & 4- 787 & $2,1,1 \leftarrow 1,1,0$ & Ground & & & & & 39445.0 & .3 \\
\hline $\mathrm{H}_{2} \mathrm{C}^{12}: \mathrm{C}^{12} \mathrm{HF}^{19}$ & 4. 781 & $2,0,2 \leftarrow 1,0,1$ & Excited & & & & & 39445.40 & .05 \\
\hline $\mathrm{Cl}_{2}^{\mathrm{b}} \mathrm{O}^{16}$ & $4-1484$ & $12,2,10 \leftarrow 13,1,13$ & Ground & & & & & 39446.28 & \\
\hline $\mathrm{C}^{12} \mathrm{H}_{3} \mathrm{C}^{12} \mathrm{HO}^{16}$ & 3- 471 & $2,1,1 \leftarrow 1,1,0$ & Ground & & & & & 39454.94 & .3 \\
\hline $\mathrm{H}_{2}^{\mathrm{b}} \mathrm{C}_{*}^{\mathrm{b}} \mathrm{O}^{16} \mathrm{C}_{*}^{\mathrm{b}} \mathrm{H}_{2}^{\mathrm{b}}$ & 4- 846 & Not Reported & Excited & & & & & 39462 . & 3. \\
\hline $\mathrm{C}^{12} \mathrm{DF}_{3}^{19}$ & 4- 283 & $2, \leftarrow 1$ & Excited & & & & & 39462.03 & .10 \\
\hline $\mathrm{c}-\mathrm{HDC}^{12}{ }_{*} \mathrm{O}^{16} \mathrm{C}^{12} * \mathrm{DH}$ & 4. 845 & $8,5,3 \leftarrow 8,4,4$ & Ground & & & & & 39467.2 & .2 \\
\hline $\mathrm{H}_{2} \mathrm{C}^{12}: \mathrm{C}^{12} \mathrm{HF}^{19}$ & 4. 781 & $2,0,2 \leftarrow 1,0,1$ & Ground & & & & & 39477.97 & .05 \\
\hline$c-\mathrm{HDN}^{14} \mathrm{C}^{12} \mathrm{HO}^{16}$ & 3- 152 & $4,2,3 \leftarrow 5,1,4$ & Ground & & & & & 39492.18 & \\
\hline $\mathrm{H}_{2} \mathrm{O}_{2}^{16}$ & $3-41$ & Not Reported & & & & & & 39495 . & 2. \\
\hline $\mathrm{C}_{*}^{\mathrm{b}} \mathrm{H}_{2}^{\mathrm{b}} \mathrm{N}^{\mathrm{b}} \mathrm{H}^{\mathrm{b}} \mathrm{C}^{\mathrm{b}}{ }_{*} \mathrm{H}_{2}^{\mathrm{b}}$ & 4. 863 & Not Reported & & & & & & 39500 . & 10. \\
\hline $\mathrm{C}^{12} \mathrm{H}_{3} \mathrm{O}^{18} \mathrm{H}$ & 3- 217 & $19,2,1 \leftarrow 19,1$, & Ground & & & & & 39505.01 & .1 \\
\hline$\left(\mathrm{C}^{12} \mathrm{H}_{3}\right)_{3} \mathrm{Si}^{28} \mathrm{Cl}^{35}$ & 3- 821 & $9, \leftarrow 8$ & Excited & & & & & 39524.50 & .3 \\
\hline $\mathrm{C}^{12} * \mathrm{H}_{2} \mathrm{~S}^{34} \mathrm{C}^{12}{ }_{*} \mathrm{H}_{2}$ & 4. 852 & $2,1,1 \leftarrow 1,1,0$ & Ground & & & & & 39527.9 & \\
\hline $\mathrm{C}^{12} \mathrm{H}_{3} \mathrm{~N}^{14} \mathrm{O}_{2}^{16}$ & 3- 171 & Not Reported & Ground & & & & & 39531.29 & \\
\hline $\mathrm{a}-\mathrm{C}^{12} \mathrm{H}_{2} \mathrm{DSi}^{\mathrm{b}} \mathrm{H}_{2} \mathrm{D}$ & 3- 333 & $2,1,1 \leftarrow 1,1,0$ & & & & & & 39531.54 & \\
\hline $\mathrm{C}^{12} \mathrm{H}_{2} \mathrm{~N}^{14} \mathrm{O}^{16} \mathrm{D}$ & 3- 142 & $2,1,2 \leftarrow 1,1,1$ & & & 1 & & 0 & 39533.53 & .10 \\
\hline $\mathrm{C}^{12} \mathrm{H}_{2} \mathrm{~N}^{14} \mathrm{O}^{16} \mathrm{D}$ & 3- 142 & $2,1,2 \leftarrow 1,1,1$ & & & 3 & & 2 & 39535.25 & .10 \\
\hline $\mathrm{C}^{12} \mathrm{H}_{2} \mathrm{~N}^{14} \mathrm{O}^{16} \mathrm{D}$ & 3. 142 & $2,1,2 \leftarrow 1,1,1$ & & & 2 & & 1 & 39536.16 & .10 \\
\hline $\mathrm{C}^{12} \mathrm{H}_{2} \mathrm{~N}^{14} \mathrm{O}^{16} \mathrm{D}$ & 3. 142 & $2,1,2 \leftarrow 1,1,1$ & & & 1 & & 1 & 39536.88 & .10 \\
\hline$\left(\mathrm{C}^{12} \mathrm{H}_{3}\right)_{3} \mathrm{Si}^{28} \mathrm{Cl}^{35}$ & 3- 821 & $9, \leftarrow 8$, & Excited & & & & & 39550.89 & .3 \\
\hline $\mathrm{C}^{12} \mathrm{H}_{3} \mathrm{C}^{13} \mathrm{HO}^{16}$ & 3- 477 & $2,1,1 \leftarrow 1,1,0$ & Ground & & & & & 39557.00 & .3 \\
\hline $\mathrm{Si}^{28} \mathrm{HCl}_{3}^{35}$ & 4-1501 & $8, \leftarrow 7$ & Ground & & & & & 39560 . & 10. \\
\hline $\mathrm{C}^{12} \mathrm{H}_{2} \mathrm{~N}^{14} \mathrm{O}^{16} \mathrm{D}$ & 3- 142 & $2,1,2 \leftarrow 1,1,1$ & Ground & & 1 & & 0 & 39568.84 & .10 \\
\hline
\end{tabular}




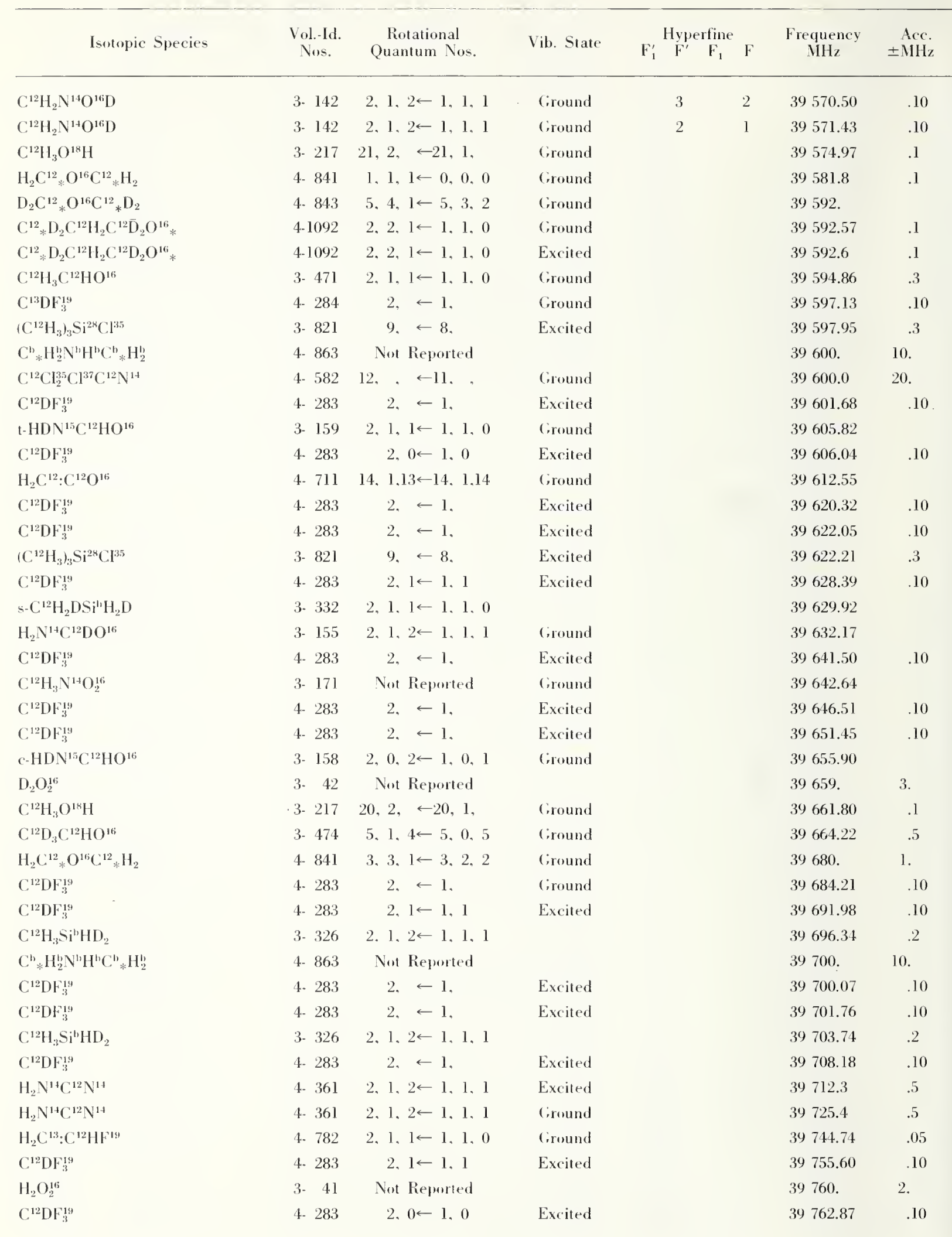




\begin{tabular}{|c|c|c|c|c|c|c|c|c|c|}
\hline Isotopic Species & $\begin{array}{l}\text { Vol.-Id. } \\
\text { Nos. }\end{array}$ & $\begin{array}{l}\text { Rotational } \\
\text { Quantum Nos. }\end{array}$ & Vil. State & $\mathrm{F}_{1}^{\prime}$ & Fyp & $\begin{array}{c}\mathrm{F}_{1} \\
\text { erfine }\end{array}$ & $\mathrm{F}$ & $\begin{array}{c}\text { Frequency } \\
\text { MIlz }\end{array}$ & $\begin{aligned} & \text { Acc. } \\
& \pm \text { Mlli }\end{aligned}$ \\
\hline $\mathrm{C}^{12} \mathrm{D}_{3} \mathrm{C}^{12} \mathrm{HO}^{16}$ & 3- 474 & $5,1,4 \leftarrow 5,0,5$ & Ground & & & & & 39763.40 & .3 \\
\hline $\mathrm{S}^{34} \mathrm{~S}^{32} \mathrm{O}^{16}$ & 4.1822 & $4,1,3 \leftarrow 4,0,4$ & Ground & & & & & 39772.9 & \\
\hline$\left(\mathrm{C}^{12} \mathrm{H}_{3}\right)_{2} \mathrm{O}^{16}$ & 3- 591 & Not Reported & Ground & & & & & 39800. & 20. \\
\hline $\mathrm{C}^{12} \mathrm{H}_{3} \mathrm{~N}^{14} \mathrm{O}_{2}^{16}$ & 3- 171 & Not Reported & Ground & & & & & 39804.42 & \\
\hline $\mathrm{C}^{12} \mathrm{H}_{3} \mathrm{~N}^{15} \mathrm{O}_{2}^{16}$ & 3- 171 & Not Reported & Ground & & & & & 39809.83 & \\
\hline $\mathrm{H}_{2} \mathrm{~N}^{14} \mathrm{C}^{12} \mathrm{~N}^{14}$ & 4- 361 & $2,1,2 \leftarrow 1,1,1$ & Excited & & & & & 39820. & \\
\hline $\mathrm{H}_{2} \mathrm{~N}^{15} \mathrm{C}^{12} \mathrm{HO}^{16}$ & 3- 156 & $2,1,2 \leftarrow 1,1,1$ & Ground & & & & & 39824.19 & \\
\hline $\mathrm{c}-\mathrm{HDC}^{12}{ }_{*} \mathrm{O}^{16} \mathrm{C}^{12}{ }_{*} \mathrm{DH}$ & 4- 845 & $6,3,3 \leftarrow 6,2,4$ & Ground & & & & & 39828.8 & .2 \\
\hline $\mathrm{H}_{2} \mathrm{~N}^{14} \mathrm{C}^{12} \mathrm{~N}^{14}$ & 4- 361 & $2,1,2 \leftarrow 1,1,1$ & Excited & & & & & 39845.8 & .5 \\
\hline $\mathrm{C}^{12}{ }_{*} \mathrm{H}_{2}^{\mathrm{b}} \mathrm{S}^{\mathrm{b}} \mathrm{C}^{12}{ }_{*} \mathrm{H}_{2}^{\mathrm{b}}$ & 4- 854 & Not Reported & & & & & & 39900.0 & 25. \\
\hline $\mathrm{C}^{12} \mathrm{H}_{3} \mathrm{~N}^{14} \mathrm{O}_{2}^{16}$ & 3- 171 & Not Reported & Ground & & & & & 39917.60 & \\
\hline $\mathrm{C}^{12}{ }_{*} \mathrm{H}_{2}^{\mathrm{b}} \mathrm{S}^{\mathrm{l}} \mathrm{C}^{12}{ }_{*} \mathrm{H}_{2}^{\mathrm{b}}$ & 4- 854 & Not Reported & & & & & & 39920.0 & 25. \\
\hline $\mathrm{N}^{14} \mathrm{H}_{3}$ & 4-1771 & $16,16 \leftarrow 16,16$ & Ground & & & & & 39941.54 & .30 \\
\hline $\mathrm{C}^{12} \mathrm{H}_{3} \mathrm{~N}^{14} \mathrm{O}_{2}^{16}$ & 3- 171 & Not Reported & Ground & & & & & 39942.66 & \\
\hline $\mathrm{H}_{2} \mathrm{~N}^{14} \mathrm{C}^{12} \mathrm{~N}^{14}$ & 4- 361 & $2,0,2 \leftarrow 1,0,1$ & Excited & & & & & 39958.2 & .5 \\
\hline $\mathrm{S}_{2}^{32} \mathrm{O}^{16}$ & 4-1821 & $4,1,3 \leftarrow 4,0,4$ & Ground & & & & & 39966.8 & \\
\hline $\mathrm{H}_{2} \mathrm{~N}^{14} \mathrm{C}^{12} \mathrm{~N}^{14}$ & 4- 361 & $2,0,2 \leftarrow 1,0,1$ & Ground & & & & & 39991.0 & .5 \\
\hline $\mathrm{C}^{\mathrm{b}}{ }_{*} \mathrm{H}_{2}^{\mathrm{b}} \mathrm{N}^{\mathrm{b}} \mathrm{H}^{\mathrm{b}} \mathrm{C}^{\mathrm{b}}{ }_{*} \mathrm{H}_{2}^{\mathrm{b}}$ & 4- 863 & Not Reported & & & & & & 40000 & 10. \\
\hline $\mathrm{Cl}_{2}^{\mathrm{h}} \mathrm{O}^{16}$ & 4-1484 & $4,1,3 \leftarrow 4,0,4$ & Ground & $7 / 2$ & 5 & $11 / 2$ & 4 & 40022.64 & \\
\hline $\mathrm{Cl}_{2}^{\mathrm{b}} \mathrm{O}^{16}$ & 4-1484 & $4,1,3 \leftarrow 4,0,4$ & Ground & $7 / 2$ & 3 & $11 / 2$ & 4 & 40022.64 & \\
\hline $\mathrm{Cl}_{2}^{\mathrm{b}} \mathrm{O}^{16}$ & $4-1484$ & $4,1,3 \leftarrow 4,0,4$ & Ground & $11 / 2$ & 4 & $11 / 2$ & 4 & 40030.56 & \\
\hline $\mathrm{Cl}_{2}^{\mathrm{b}} \mathrm{O}^{16}$ & 4-1484 & $4,1,3 \leftarrow 4,0,4$ & Ground & $9 / 2$ & 4 & $7 / 2$ & 5 & 40032.76 & \\
\hline $\mathrm{Cl}_{2}^{\mathrm{b}} \mathrm{O}^{16}$ & 4.1484 & $4,1,3 \leftarrow 4,0,4$ & Ground & $9 / 2$ & 4 & $7 / 2$ & 3 & 40032.76 & \\
\hline $\mathrm{C}^{12} \mathrm{H}_{3} \mathrm{~N}^{14} \mathrm{O}_{2}^{16}$ & 3. 171 & Not Reported & Ground & & & & & 40035.48 & \\
\hline $\mathrm{H}_{2} \mathrm{C}^{12}: \mathrm{C}^{12} \mathrm{O}^{16}$ & 4- 711 & $2,1,2 \leftarrow 1,1,1$ & Ground & & & & & 40038.80 & \\
\hline $\mathrm{Cl}_{2}^{\mathrm{h}} \mathrm{O}^{16}$ & 4-1484 & $4,1,3 \leftarrow 4,0,4$ & Ground & $7 / 2$ & 5 & $7 / 2$ & 5 & 40040.96 & \\
\hline $\mathrm{Cl}_{2}^{\mathrm{b}} \mathrm{O}^{16}$ & 4-1484 & $4,1,3 \leftarrow 4,0,4$ & Ground & $7 / 2$ & 2 & $7 / 2$ & 2 & 40040.96 & \\
\hline $\mathrm{Cl}_{2}^{\mathrm{h}} \mathrm{O}^{16}$ & 4. 1484 & $4,1,3 \leftarrow 4,0,4$ & Ground & $11 / 2$ & 6 & $11 / 2$ & 6 & 40040.96 & \\
\hline $\mathrm{Cl}_{2}^{\mathrm{h}} \mathrm{O}^{16}$ & 4-1484 & $4,1,3 \leftarrow 4,0,4$ & Ground & $7 / 2$ & 2 & $7 / 2$ & 3 & 40040.96 & \\
\hline $\mathrm{Cl}_{2}^{\mathrm{b}} \mathrm{O}^{16}$ & $4-1484$ & $4,1,3 \leftarrow 4,0,4$ & Ground & $7 / 2$ & 3 & $7 / 2$ & 2 & 40040.96 & \\
\hline $\mathrm{Cl}_{2}^{\mathrm{b}} \mathrm{O}^{16}$ & $4-1484$ & $4,1,3 \leftarrow 4,0,4$ & Ground & $7 / 2$ & 5 & $11 / 2$ & 6 & 40040.96 & \\
\hline $\mathrm{Cl}_{2}^{\natural} \mathrm{O}^{16}$ & 4-1484 & $4,1,3 \leftarrow 4,0,4$ & Ground & $11 / 2$ & 6 & $7 / 2$ & 5 & 40040.96 & \\
\hline $\mathrm{Cl}_{2}^{\mathrm{h}} \mathrm{O}^{16}$ & 4-1484 & $4,1,3 \leftarrow 4,0,4$ & Ground & $7 / 2$ & 3 & $7 / 2$ & 3 & 40040.98 & \\
\hline $\mathrm{Cl}_{2}^{\mathrm{h}} \mathrm{O}^{16}$ & 4.1484 & $4,1,3 \leftarrow 4,0,4$ & Ground & $11 / 2$ & 4 & $7 / 2$ & 5 & 40049.20 & \\
\hline $\mathrm{Cl}_{2}^{\mathrm{h}} \mathrm{O}^{16}$ & 4-1484 & $4,1,3 \leftarrow 4,0,4$ & Ground & $11 / 2$ & 4 & $7 / 2$ & 3 & 40049.20 & \\
\hline $\mathrm{C}^{12} \mathrm{Cl}_{3}^{35} \mathrm{C}^{12} \mathrm{~N}^{14}$ & 4- 581 & $12, \leftarrow 11$ & Ground & & & & & 40050.0 & 20. \\
\hline $\mathrm{Cl}_{2}^{\mathrm{b}} \mathrm{O}^{16}$ & 4-1484 & $4,1,3 \leftarrow 4,0,4$ & Ground & $9 / 2$ & 4 & $9 / 2$ & 4 & 40051.18 & \\
\hline $\mathrm{Cl}_{2}^{\mathrm{b}} \mathrm{O}^{16}$ & 4-1484 & $4,1,3 \leftarrow 4,0,4$ & Ground & $7 / 2$ & 5 & $9 / 2$ & 4 & 40059.51 & \\
\hline $\mathrm{Cl}_{2}^{\mathrm{h}} \mathrm{O}^{16}$ & 4-1484 & $4,1,3 \leftarrow 4,0,4$ & Ground & $7 / 2$ & 3 & $9 / 2$ & 4 & 40059.51 & \\
\hline $\mathrm{H}_{2} \mathrm{~N}^{14} \mathrm{C}^{12} \mathrm{~N}^{14}$ & 4- 361 & $2,0,2 \leftarrow 1,0,1$ & Excited & & & & & 40068.0 & .5 \\
\hline$\left(\mathrm{C}^{12} \mathrm{H}_{3}\right)_{2} \mathrm{~S}^{32}$ & 3- 601 & $6,1,5 \leftarrow 6,0,6$ & Ground & & & & & 40068.47 & .05 \\
\hline$\left(\mathrm{C}^{12} \mathrm{H}_{3}\right)_{2} \mathrm{~S}^{32}$ & 3- 601 & $6,1,5 \leftarrow 6,0,6$ & Ground & & & & & 40069.09 & .05 \\
\hline$\left(\mathrm{C}^{12} \mathrm{H}_{3}\right)_{2} \mathrm{~S}^{32}$ & 3- 601 & $6,1,5 \leftarrow 6,0,6$ & Ground & & & & & 40069.70 & .05 \\
\hline $\mathrm{C}^{12} \mathrm{H}_{3} \mathrm{~N}^{14} \mathrm{O}_{2}^{16}$ & 3- 171 & Not Reported & Ground & & & & & 40070.6 & \\
\hline $\mathrm{O}^{\mathrm{h}} \mathrm{O}^{\mathrm{b}} \mathrm{O}^{\mathrm{b}}$ & $4-1847$ & Not Reported & & & & & & 40080. & \\
\hline
\end{tabular}




\begin{tabular}{|c|c|c|c|c|c|c|}
\hline Isotopic Species & $\begin{array}{l}\text { Vol.-Id. } \\
\text { Nos. }\end{array}$ & $\begin{array}{c}\text { Rotational } \\
\text { Quantum Nos. }\end{array}$ & Vib. State & 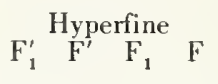 & $\begin{array}{c}\text { Frequency } \\
\mathrm{MHz}^{-}\end{array}$ & $\begin{aligned} & \text { Acc. } \\
& \pm \mathrm{MHz}\end{aligned}$ \\
\hline $\mathrm{C}^{12} \mathrm{D}_{3} \mathrm{O}^{16} \mathrm{D}$ & 3- 216 & Not Reported & & & 40083 & \\
\hline $\mathrm{H}_{2} \mathrm{C}^{12}: \mathrm{C}^{12} \mathrm{O}^{16}$ & 4. 711 & $2,1,2 \leftarrow 1,1,1$ & Excited & & 40087.77 & \\
\hline $\mathrm{C}^{12} \mathrm{H}_{3} \mathrm{Si}^{\mathrm{b}} \mathrm{HD}_{2}$ & 3. 326 & $2,0,2 \leftarrow 1,0,1$ & & & 40100.00 & .4 \\
\hline $\mathrm{C}^{12} \mathrm{H}_{3} \mathrm{~N}^{14} \mathrm{O}_{2}^{16}$ & 3. 171 & Not Reported & Ground & & 40106.6 & \\
\hline $\mathrm{H}_{2} \mathrm{C}^{12}: \mathrm{C}^{12} \mathrm{O}^{16}$ & 4. 711 & $2,1,2 \leftarrow 1,1,1$ & Excited & & 40110.92 & \\
\hline $\mathrm{H}_{2} \mathrm{~N}^{14} \mathrm{C}^{12} \mathrm{~N}^{14}$ & 4. 361 & $2,0,2 \leftarrow 1,0,1$ & Excited & & 40120.0 & .5 \\
\hline $\mathrm{H}_{2} \mathrm{C}^{12}: \mathrm{C}^{12} \mathrm{O}^{16}$ & 4. 711 & $2,1,2 \leftarrow 1,1,1$ & Excited & & 40135.35 & \\
\hline$\left(\mathrm{C}^{12} \mathrm{D}_{3}\right)_{2} \mathrm{O}^{16}$ & 3. 592 & Not Reported & Ground & & 40185.4 & 20. \\
\hline $\mathrm{H}_{2} \mathrm{~N}^{14} \mathrm{C}^{12} \mathrm{~N}^{14}$ & 4- 361 & $2,1,1 \leftarrow 1,1,0$ & Excited & & 40203.0 & .5 \\
\hline $\mathrm{C}^{12} \mathrm{H}_{3} \mathrm{~N}^{14} \mathrm{C}^{12}$ & 4- 831 & $2,1 \leftarrow 1,1$ & Ground & & 40210.46 & .1 \\
\hline $\mathrm{C}^{12} \mathrm{H}_{3} \mathrm{~N}^{1+4} \mathrm{C}^{12}$ & 4. 831 & $2,0 \leftarrow 1,0$ & Ground & & 40211.36 & .1 \\
\hline $\mathrm{C}^{13} \mathrm{D}_{3} \mathrm{~F}^{19}$ & 4. 464 & $1,0 \leftarrow 0,0$ & Ground & & 40223.64 & \\
\hline $\mathrm{C}^{12} \mathrm{H}_{3} \mathrm{~N}^{14} \mathrm{O}_{2}^{16}$ & 3- 171 & Not Reported & Ground & & 40229.30 & \\
\hline $\mathrm{C}^{12} \mathrm{D}_{3} \mathrm{O}^{16} \mathrm{H}$ & 3- 214 & Not Reported & Ground & & 40229.8 & .5 \\
\hline c- $-\mathrm{HDC}^{12}{ }_{*} \mathrm{O}^{16} \mathrm{C}^{12}{ }_{*} \mathrm{DH}$ & 4- 845 & $3,2,2 \leftarrow 3,1,3$ & Ground & & 40231.5 & .2 \\
\hline $\mathrm{C}^{12} \mathrm{D}_{3} \mathrm{O}^{16} \mathrm{D}$ & 3- 216 & Not Reported & & & 40240 & \\
\hline $\mathrm{H}_{2} \mathrm{~N}^{14} \mathrm{C}^{12} \mathrm{~N}^{14}$ & 4- 361 & $2,1,1 \leftarrow 1,1,0$ & Cround & & 40252.2 & .5 \\
\hline $\mathrm{C}^{12} \mathrm{H}_{3} \mathrm{C}^{12}{ }_{*} \mathrm{HO}^{16} \mathrm{C}^{12}{ }_{*} \mathrm{H}_{2}$ & 3. 761 & $41,20, \quad \leftarrow 40,21$, & Ground & & 40275.31 & .1 \\
\hline $\mathrm{C}^{12} \mathrm{H}_{3} \mathrm{C}^{12} * \mathrm{HO}^{16} \mathrm{C}^{12} * \mathrm{H}_{2}$ & 3. 761 & $41,20, \leftarrow 40,21$, & Ground & & 40276.05 & .1 \\
\hline $\mathrm{C}^{12} \mathrm{H}_{3} \mathrm{~N}^{14} \mathrm{O}_{2}^{16}$ & 3. 171 & Not Reported & Ground & & 40285.16 & \\
\hline $\mathrm{C}^{12} \mathrm{H}_{3} \mathrm{~N}^{14} \mathrm{C}^{12}$ & 4- 831 & $2,1 \leftarrow 1,1$ & Excited & & 40313.37 & \\
\hline $\mathrm{H}_{2} \mathrm{~N}^{14} \mathrm{C}^{12} \mathrm{~N}^{14}$ & 4- 361 & $2,1,1 \leftarrow 1,1,0$ & Excited & & 40315.9 & .5 \\
\hline t-HDN ${ }^{15} \mathrm{C}^{12} \mathrm{HO}^{16}$ & 3. 159 & $5,0,5 \leftarrow 4,1,4$ & Ground & & 40332.08 & \\
\hline $\mathrm{C}^{12} \mathrm{H}_{3} \mathrm{~N}^{14} \mathrm{O}_{2}^{16}$ & 3- 171 & Not Reported & Ground & & 40338.98 & \\
\hline $\mathrm{N}^{14} \mathrm{O}_{2}^{16}$ & 4-1801 & $10,0,10 \leftarrow 9,1,9$ & Ground & & 40357.96 & \\
\hline $\mathrm{C}^{12} \mathrm{H}_{3} \mathrm{~N}^{14} \mathrm{C}^{12}$ & 4- 831 & $2,1 \leftarrow 2,1$ & Excited & & 40364.07 & \\
\hline $\mathrm{C}^{12} \mathrm{H}_{3} \mathrm{~N}^{14} \mathrm{C}^{12}$ & 4. 831 & $2,0 \leftarrow 1,0$ & Excited & & 40366.55 & \\
\hline $\mathrm{C}^{12} \mathrm{H}_{3} \mathrm{~N}^{14} \mathrm{O}_{2}^{16}$ & 3- 171 & Not Reported & Ground & & 40386.20 & \\
\hline $\mathrm{H}_{2} \mathrm{~N}^{14} \mathrm{C}^{12} \mathrm{~N}^{14}$ & 4- 361 & $2,1,1 \leftarrow 1,1,0$ & Excited & & 40394.2 & .5 \\
\hline $\mathrm{C}^{12} \mathrm{D}_{3} \mathrm{C}^{12}: \mathrm{C}^{12} \mathrm{D}$ & 4-1046 & $3,2 \leftarrow 2,2$ & Ground & & 40403.60 & .1 \\
\hline $\mathrm{C}^{12} \mathrm{D}_{3} \mathrm{C}^{12}: \mathrm{C}^{12} \mathrm{D}$ & 4-1046 & $3,1 \leftarrow 2,1$ & Ground & & 40405.21 & .1 \\
\hline $\mathrm{C}^{12} \mathrm{D}_{3} \mathrm{C}^{12}: \mathrm{C}^{12} \mathrm{D}$ & 4-1046 & $3,0 \leftarrow 2,0$ & Ground & & 40405.75 & .1 \\
\hline $\mathrm{C}^{12} \mathrm{H}_{3} \mathrm{~N}^{14} \mathrm{O}_{2}^{16}$ & 3- 171 & Not Reported & Ground & & 40411.32 & \\
\hline $\mathrm{H}_{2} \mathrm{C}^{12}: \mathrm{C}^{12} \mathrm{O}^{16}$ & 4- 711 & $2,0,2 \leftarrow 1,0,1$ & Ground & & 40417.90 & \\
\hline $\mathrm{C}^{12} \mathrm{H}_{3} \mathrm{~N}^{14} \mathrm{C}^{12}$ & 4. 831 & $2,1 \leftarrow 1,1$ & Excited & & 40424.49 & \\
\hline $\mathrm{H}_{2} \mathrm{~N}^{15} \mathrm{C}^{12} \mathrm{DO}^{16}$ & 3- 157 & $2,0,2 \leftarrow 1,0,1$ & Ground & & 40433.42 & \\
\hline $\mathrm{H}_{2} \mathrm{C}^{12}: \mathrm{C}^{12} \mathrm{O}^{16}$ & 4- 711 & $2,0,2 \leftarrow 1,0,1$ & Excited & & 40440.17 & \\
\hline $\mathrm{H}_{2} \mathrm{C}^{12}: \mathrm{C}^{12} \mathrm{O}^{16}$ & 4. 711 & $2,0,2 \leftarrow 1,0,1$ & Excited & & 40462.26 & \\
\hline $\mathrm{N}^{14} \mathrm{O}_{2}^{16}$ & $4-1801$ & $10,0,10 \leftarrow 9,1,9$ & Ground & & 40467.44 & \\
\hline $\mathrm{C}^{12} \mathrm{H}_{3} \mathrm{C}^{12}{ }_{*} \mathrm{HO}^{16} \mathrm{C}^{12} * \mathrm{H}_{2}$ & 3- 761 & $10,1,9 \leftarrow 10,0,10$ & Ground & & 40469.72 & .1 \\
\hline $\mathrm{O}^{16} \mathrm{O}^{18} \mathrm{O}^{18}$ & 4-1844 & $5,0,5 \leftarrow 4,1,4$ & Ground & & 40476 & \\
\hline $\mathrm{C}^{12}{ }_{*} \mathrm{H}_{2} \mathrm{~S}^{32} \mathrm{C}^{12}{ }_{*} \mathrm{H}_{2}$ & 4. 851 & $2,1,1 \leftarrow 1,1,0$ & Ground & & 40500.5 & \\
\hline $\mathrm{C}^{12} \mathrm{H}_{3} \mathrm{Si}^{\mathrm{b}} \mathrm{HD}_{2}$ & 3- 326 & $2,1,1 \leftarrow 1,1,0$ & & & 40503.64 & .4 \\
\hline $\mathrm{C}^{12} \mathrm{H}_{3} \mathrm{Si}^{\mathrm{b}} \mathrm{HD}_{2}$ & 3. 326 & $2,1,1 \leftarrow 1,1,0$ & & & 40510.98 & .4 \\
\hline $\mathrm{H}_{2} \mathrm{C}^{12}: \mathrm{C}^{12} \mathrm{O}^{16}$ & 4- 711 & $2,0,2 \leftarrow 1,0,1$ & Excited & & 40532.78 & \\
\hline
\end{tabular}




\begin{tabular}{|c|c|c|c|c|c|c|c|c|}
\hline \multirow{3}{*}{$\frac{\text { Isotopic Species }}{\mathrm{t} \cdot \mathrm{HDN}^{14} \mathrm{C}^{12} \mathrm{HO}^{16}}$} & \multirow{3}{*}{$\begin{array}{l}\begin{array}{c}\text { Vol.-Id. } \\
\text { Nos. }\end{array} \\
\text { 3. } 153\end{array}$} & \multirow{3}{*}{$\begin{array}{c}\begin{array}{c}\text { Rotational } \\
\text { Quantum Nos. }\end{array} \\
2,1,1 \leftarrow 1,1,0\end{array}$} & \multirow{3}{*}{$\begin{array}{l}\text { Vib. State } \\
\text { Ground }\end{array}$} & \multicolumn{3}{|c|}{ Hyperfine } & \multirow{2}{*}{$\begin{array}{c}\text { Frequency } \\
\text { Milz }\end{array}$} & \multirow{2}{*}{$\begin{aligned} & \text { Acc. } \\
\pm & \mathrm{MHz}\end{aligned}$} \\
\hline & & & & $\mathbf{F}_{1}^{\prime}$ & $\begin{array}{ll}F^{\prime} & F_{1}\end{array}$ & $\mathbf{F}$ & & \\
\hline & & & & & & & 40551.94 & .2 \\
\hline$\left(\mathrm{C}^{12} \mathrm{H}_{3}\right)_{3} \mathrm{C}^{12} \mathrm{Br}^{81}$ & 3. 962 & $10, \leftarrow 9$ & Ground & & & & 40565.0 & .3 \\
\hline$\left(\mathrm{C}^{12} \mathrm{H}_{3}\right)_{3} \mathrm{C}^{12} \mathrm{I}^{127}$ & 3. 991 & $13, \leftarrow 12$ & Ground & & & & 40570 . & 30. \\
\hline$\left(\mathrm{C}^{12} \mathrm{H}_{3}\right)_{3} \mathrm{Si}^{28} \mathrm{Br}^{81}$ & 3. 812 & $14, \leftarrow 13$ & Ground & & & & 40575.5 & .3 \\
\hline $\mathrm{C}^{12} \mathrm{H}_{3} \mathrm{~N}^{14} \mathrm{O}_{2}^{16}$ & 3- 171 & Not Reported & Ground & & & & 40582.20 & \\
\hline $\mathrm{C}^{12}{ }_{*} \mathrm{H}_{2} \mathrm{~N}^{14} \mathrm{HC}^{12}{ }_{*} \mathrm{H}_{2}$ & 4. 861 & $7,7,0 \leftarrow 7,6,1$ & Ground & & & & 40588.6 & \\
\hline $\mathrm{N}^{14} \mathrm{O}_{2}^{16} \mathrm{Cl}^{37}$ & $4-1462$ & $5,0,5 \leftarrow 4,0,4$ & Ground & & $7 / 2$ & $5 / 2$ & 40599.43 & \\
\hline $\mathrm{N}^{14} \mathrm{O}_{2}^{16} \mathrm{Cl}^{37}$ & 4-1462 & $5,0,5 \leftarrow 4,0,4$ & Ground & & $9 / 2$ & $7 / 2$ & 40599.89 & \\
\hline $\mathrm{N}^{14} \mathrm{O}_{2}^{16} \mathrm{Cl}^{37}$ & 4.1462 & $5,0,5 \leftarrow 4,0,4$ & Ground & & $13 / 2$ & $11 / 2$ & 40600.75 & \\
\hline $\mathrm{N}^{14} \mathrm{O}_{2}^{16} \mathrm{Cl}^{37}$ & 4-1462 & $5,0,5 \leftarrow 4,0,4$ & Ground & & $11 / 2$ & $9 / 2$ & 40601.22 & \\
\hline $\mathrm{C}^{12} \mathrm{H}_{3} \mathrm{~N}^{14} \mathrm{O}_{2}^{16}$ & 3. 171 & Not Reported & Ground & & & & 40606.69 & \\
\hline $\mathrm{C}^{12} \mathrm{D}_{3} \mathrm{O}^{16} \mathrm{D}$ & 3. 216 & Not Reported & & & & & 40640 . & \\
\hline $\mathrm{c} \cdot \mathrm{HDN}^{14} \mathrm{C}^{12} \mathrm{HO}^{16}$ & 3. 152 & $2,0,2 \leftarrow 1,0,1$ & Ground & & & & 40647.52 & .2 \\
\hline $\mathrm{C}^{12} \mathrm{D}_{3} \mathrm{O}^{16} \mathrm{H}$ & 3- 214 & $2, \quad \leftarrow 1$, & Ground & & & & 40649.5 & .5 \\
\hline $\mathrm{H}_{2} \mathrm{C}^{12}: \mathrm{C}^{12} \mathrm{DF}^{19}$ & 4- 784 & $2,1,1 \leftarrow 1,1,0$ & Ground & & & & 40660.7 & .3 \\
\hline $\mathrm{N}^{14} \mathrm{O}_{2}^{16}$ & $4-1801$ & $10,0,10 \leftarrow 9,1,9$ & Ground & & & & 40661.38 & \\
\hline $\mathrm{N}^{14} \mathrm{O}_{2}^{16}$ & 4-1801 & $10,0,10 \leftarrow 9,1,9$ & Ground & & & & 40671.06 & \\
\hline $\mathrm{C}^{12}{ }_{*} \mathrm{H}_{2} \mathrm{~S}^{32} \mathrm{C}^{12}{ }_{*} \mathrm{H}_{2}$ & 4. 851 & $5,1,5 \leftarrow 5,1,4$ & Ground & & & & 40672.5 & .2 \\
\hline $\mathrm{C}^{12} \mathrm{H}_{3} \mathrm{~N}^{14} \mathrm{O}_{2}^{16}$ & 3- 171 & Not Reported & Ground & & & & 40682.11 & \\
\hline $\mathrm{F}^{19} \mathrm{HC}^{12} \mathrm{O}^{18}$ & 4. 274 & $2,1,2 \leftarrow 1,1,1$ & Ground & & & & 40692.6 & .4 \\
\hline $\mathrm{H}_{3} \mathrm{C}^{12} \mathrm{C}^{12}: \mathrm{C}^{12} \mathrm{C}^{12}: \mathrm{C}^{12} \mathrm{H}$ & $4-1191$ & $10,7 \leftarrow 9,7$ & Ground & & & & 40695.10 & .1 \\
\hline $\mathrm{H}_{3} \mathrm{C}^{12} \mathrm{C}^{12}: \mathrm{C}^{12} \mathrm{C}^{12}: \mathrm{C}^{12} \mathrm{H}$ & 4-1191 & $10,6 \leftarrow 9,6$ & Ground & & & & 40700.28 & .1 \\
\hline $\mathrm{N}^{14} \mathrm{O}_{2}^{16}$ & 4-1801 & $10,0,10 \leftarrow 9,1,9$ & Ground & & & & 40703.20 & \\
\hline $\mathrm{H}_{3} \mathrm{C}^{12} \mathrm{C}^{12}: \mathrm{C}^{12} \mathrm{C}^{12}: \mathrm{C}^{12} \mathrm{H}$ & $4-1191$ & $10,5 \leftarrow 9,5$ & Ground & & & & 40704.62 & .1 \\
\hline $\mathrm{H}_{3} \mathrm{C}^{12} \mathrm{C}^{12}: \mathrm{C}^{12} \mathrm{C}^{12}: \mathrm{C}^{12} \mathrm{H}$ & 4-1191 & $10,4 \leftarrow 9,4$ & Ground & & & & 40708.20 & .1 \\
\hline $\mathrm{H}_{3} \mathrm{C}^{12} \mathrm{C}^{12}: \mathrm{C}^{12} \mathrm{C}^{12}: \mathrm{C}^{12} \mathrm{H}$ & 4-1191 & $10,3 \leftarrow 9,3$ & Ground & & & & 40710.96 & .1 \\
\hline $\mathrm{H}_{3} \mathrm{C}^{12} \mathrm{C}^{12}: \mathrm{C}^{12} \mathrm{C}^{12}: \mathrm{C}^{12} \mathrm{H}$ & $4 \cdot 1191$ & $10,2 \leftarrow 9,2$ & Ground & & & & 40712.96 & .1 \\
\hline $\mathrm{H}_{3} \mathrm{C}^{12} \mathrm{C}^{12}: \mathrm{C}^{12} \mathrm{C}^{12}: \mathrm{C}^{12} \mathrm{H}$ & 4.1191 & $10,1 \leftarrow 9,1$ & Ground & & & & 40714.14 & .1 \\
\hline $\mathrm{H}_{3} \mathrm{C}^{12} \mathrm{C}^{12}: \mathrm{C}^{12} \mathrm{C}^{12}: \mathrm{C}^{12} \mathrm{H}$ & 4-1191 & $10,0 \leftarrow 9,0$ & Ground & & & & 40714.56 & .1 \\
\hline $\mathrm{C}^{12}{ }_{*} \mathrm{H}_{2} \mathrm{~N}^{14} \mathrm{HC}^{12}{ }_{*} \mathrm{H}_{2}$ & 4- 861 & $4,2,2 \leftarrow 4,1,3$ & Ground & & & & 40785.8 & \\
\hline $\mathrm{C}^{12} \mathrm{H}_{2} \mathrm{DSi}^{\mathrm{b}} \mathrm{H}_{3}$ & 3- 327 & $2,1,2 \leftarrow 1,1,1$ & & & & & 40791.24 & .2 \\
\hline $\mathrm{H}_{2} \mathrm{C}^{12}: \mathrm{C}^{12} \mathrm{O}^{16}$ & 4- 711 & $2,1,1 \leftarrow 1,1,0$ & Ground & & & & 40793.62 & \\
\hline $\mathrm{C}^{12} \mathrm{H}_{3} \mathrm{~N}^{14} \mathrm{O}_{2}^{16}$ & 3- 171 & Not Reported & Ground & & & & 40799.31 & \\
\hline $\mathrm{H}_{2} \mathrm{C}^{12}: \mathrm{C}^{12} \mathrm{O}^{16}$ & 4. 711 & $2,1,1 \leftarrow 1,1,0$ & Excited & & & & 40809.98 & \\
\hline $\mathrm{C}^{12} \mathrm{H}_{2} \mathrm{DSi}^{\mathrm{b}} \mathrm{H}_{3}$ & 3- 327 & $2,1,2 \leftarrow 1,1,1$ & - & & & & 40823.44 & .2 \\
\hline$\left(\mathrm{C}^{12} \mathrm{H}_{3}\right)_{3} \mathrm{C}^{12} \mathrm{Br}^{79}$ & 3- 961 & $10, \leftarrow 9$ & Ground & & & & 40831.8 & .3 \\
\hline $\mathrm{C}^{12} \mathrm{H}_{2} \mathrm{Cl}^{35} \mathrm{Cl}^{37}$ & 4- 342 & $2,1,2 \leftarrow 1,0,1$ & Ground & & & & 40842 & 1. \\
\hline $\mathrm{F}^{19} \mathrm{DC}^{12} \mathrm{O}^{16}$ & 4- 272 & $4,2,3 \leftarrow 5,1,4$ & & & & & 40852.1 & .1 \\
\hline $\mathrm{C}^{12}{ }_{*} \mathrm{H}_{2} \mathrm{~S}^{32} \mathrm{C}^{12}{ }_{*} \mathrm{H}_{2}$ & 4- 851 & $10,3,8 \leftarrow 10,3,7$ & Ground & & & & 40865.1 & .2 \\
\hline $\mathrm{HC}^{12} \mathrm{O}^{16} \mathrm{~N}^{14} \mathrm{H}_{2}$ & 3- 151 & $2,1,2 \leftarrow 1,1,1$ & Ground & & & & 40874.91 & \\
\hline $\mathrm{H}_{2} \mathrm{~N}^{14} \mathrm{C}^{12} \mathrm{DO}^{16}$ & 3. 155 & $3,2,2 \leftarrow 4,1,3$ & Ground & & & & 40883.81 & \\
\hline $\mathrm{C}^{12} \mathrm{H}_{3} \mathrm{~N}^{14} \mathrm{O}_{2}^{16}$ & 3- 171 & Not Reported & Ground & & & & 40898.49 & \\
\hline$\left(\mathrm{C}^{12} \mathrm{H}_{3}\right)_{3} \mathrm{Si}^{28} \mathrm{~F}^{19}$ & 3- 831 & $6, \leftarrow 5$ & Excited & & & & 40906.3 & .3 \\
\hline$\left(\mathrm{C}^{12} \mathrm{H}_{3}\right)_{3} \mathrm{Si}^{28} \mathrm{~F}^{19}$ & 3. 831 & $6, \leftarrow 5$ & Excited & & & & 40913.0 & .5 \\
\hline $\mathrm{C}^{12} \mathrm{D}_{3} \mathrm{~N}^{14} \mathrm{O}_{2}^{16}$ & 3. 172 & $3,1, \leftarrow 2,1$, & Ground & & & & 40922.9 & .2 \\
\hline
\end{tabular}




\begin{tabular}{|c|c|c|c|c|c|c|c|}
\hline Isotopic Species & $\begin{array}{l}\text { Vol.-td. } \\
\text { Nos. }\end{array}$ & $\begin{array}{c}\text { Rotational } \\
\text { Quantum Nos. }\end{array}$ & Vib. State & $\mathrm{F}_{1}^{\prime} \mathrm{F}^{\prime} \mathrm{F}_{1}$ & $F$ & $\begin{array}{c}\text { Frequency } \\
\mathrm{MHz}^{2}\end{array}$ & $\begin{array}{r}\text { Acc. } \\
\pm \mathrm{MHz}\end{array}$ \\
\hline $\mathrm{H}_{2} \mathrm{C}^{12}: \mathrm{C}^{12} \mathrm{O}^{16}$ & 4- 711 & $2,1,1 \leftarrow 1,1,0$ & Excited & & & 40926.95 & \\
\hline $\operatorname{HDS}^{32}$ & $4-1727$ & $5,3,2 \leftarrow 5,3,3$ & Ground & & & 40929.20 & .05 \\
\hline $\mathrm{N}^{14} \mathrm{O}_{2}^{16}$ & $4-1801$ & $10,0,10 \leftarrow 9,1.9$ & Ground & & & 40931.18 & \\
\hline$\left(\mathrm{C}^{12} \mathrm{H}_{33}\right)_{3} \mathrm{Si}^{28} \mathrm{~F}^{19}$ & 3- 831 & $6, \leftarrow 5$. & Ground & & & 40931.6 & .3 \\
\hline $\mathrm{C}^{12} \mathrm{D}_{3} \mathrm{O}^{16} \mathrm{D}$ & 3- 216 & Not Reported & & & & 40940. & \\
\hline$\left(\mathrm{C}^{12} \mathrm{H}_{3}\right)_{3} \mathrm{Si}^{28} \mathrm{~F}^{19}$ & 3- 831 & $6, \leftarrow 5$. & Excited & & & 40959.4 & .5 \\
\hline $\mathrm{N}^{14} \mathrm{O}_{2}^{16}$ & 4-1801 & $10,0,10 \leftarrow 9,1,9$ & Ground & & & 40964.38 & \\
\hline$\left(\mathrm{C}^{12} \mathrm{H}_{3}\right)_{3} \mathrm{Si}^{28} \mathrm{~F}^{19}$ & 3- 831 & $6, \leftarrow 5$ & Excited & & & 40977. & \\
\hline $\mathrm{C}^{12} \mathrm{D}_{3} \mathrm{~N}^{14} \mathrm{O}_{2}^{16}$ & 3- 172 & $3,2, \leftarrow 2,2$, & Ground & & & 40983.2 & .2 \\
\hline $\mathrm{H}_{2} \mathrm{C}^{12}: \mathrm{C}^{13} \mathrm{HF}^{19}$ & 4- 783 & $2,1,1 \leftarrow 1,1,0$ & Ground & & & 40987.77 & .05 \\
\hline $\mathrm{C}^{12} \mathrm{H}_{2} \mathrm{DSi}^{\mathrm{b}} \mathrm{H}_{3}$ & 3. 327 & $2,0,2 \leftarrow 1,0,1$ & & & & 40988.76 & .4 \\
\hline $\mathrm{t}-\mathrm{HDC}^{12}{ }_{*} \mathrm{O}^{16} \mathrm{C}^{12}{ }_{*} \mathrm{HD}$ & 4. 844 & $3,2,2 \leftarrow 3,1,3$ & Ground & & & 40992 . & \\
\hline $\mathrm{N}^{14} \mathrm{O}_{2}^{16}$ & 4-1801 & $10,0,10 \leftarrow 9,1,9$ & Ground & & & 40993.38 & \\
\hline $\mathrm{H}_{2} \mathrm{C}^{12}: \mathrm{C}^{12} \mathrm{HF}^{14}$ & 4- 781 & $2,1,1 \leftarrow 1,1,0$ & Excited & & & 41003.04 & .05 \\
\hline$\left(\mathrm{C}^{12} \mathrm{H}_{33}\right)_{3} \mathrm{Si}^{28} \mathrm{~F}^{19}$ & 3- 831 & $6, \leftarrow 5$ & Excited & & & 41008 & \\
\hline $\mathrm{H}_{2} \mathrm{C}^{12}: \mathrm{C}^{12} \mathrm{HF}^{19}$ & 4- 781 & $2,1,1 \leftarrow 1,1,0$ & Ground & & & 41028.57 & .05 \\
\hline $\mathrm{C}^{12} \mathrm{H}_{3} \mathrm{~N}^{14} \mathrm{O}_{2}^{16}$ & 3- 171 & Not Reported & Ground & & & 41040.98 & \\
\hline$\left(\mathrm{C}^{12} \mathrm{H}_{3}\right)_{3} \mathrm{Si}^{26} \mathrm{~F}^{19}$ & 3- 831 & $6, \leftarrow 5$ & Excited & & & 41062.5 & .5 \\
\hline $\mathrm{O}^{\mathrm{h}} \mathrm{O}^{\mathrm{h}} \mathrm{O}^{\mathrm{n}}$ & $4-1847$ & Not Reported & & & & 41063 & \\
\hline $\mathrm{C}^{12} \mathrm{H}_{2} \mathrm{~N}^{14} \mathrm{O}^{16} \mathrm{D}$ & 3- 142 & $2,0,2 \leftarrow 1,0,1$ & Ground & 2 & 1 & 41095.53 & .10 \\
\hline $\mathrm{C}^{12} \mathrm{H}_{2} \mathrm{~N}^{14} \mathrm{O}^{16} \mathrm{D}$ & 3- 142 & $2,0,2 \leftarrow 1,0,1$ & Ground & 3 & 2 & 41095.53 & .10 \\
\hline $\mathrm{C}^{12} \mathrm{H}_{2} \mathrm{~N}^{14} \mathrm{O}^{16} \mathrm{D}$ & 3- 142 & $2,0,2 \leftarrow 1,0,1$ & & 1 & 1 & 41096.43 & .10 \\
\hline $\mathrm{C}^{12} \mathrm{H}_{2} \mathrm{~N}^{14} \mathrm{O}^{16} \mathrm{D}$ & 3- 142 & $2,0,2 \leftarrow 1,0,1$ & & 3 & 2 & 41097.95 & .10 \\
\hline $\mathrm{C}^{12} \mathrm{H}_{2} \mathrm{~N}^{14} \mathrm{O}^{16} \mathrm{D}$ & 3- 142 & $2,0,2 \leftarrow 1,0,1$ & & 2 & 1 & 41097.95 & .10 \\
\hline $\mathrm{C}^{12} \mathrm{H}_{2} \mathrm{~N}^{14} \mathrm{O}^{16} \mathrm{D}$ & 3- 142 & $2,0,2 \leftarrow 1,0,1$ & & 2 & 2 & 41098.76 & .10 \\
\hline $\mathrm{C}^{12} \mathrm{H}_{2} \mathrm{~N}^{14} \mathrm{O}^{16} \mathrm{D}$ & 3- 142 & $2,0,2 \leftarrow 1,0,1$ & & 1 & 0 & 41098.76 & .10 \\
\hline $\mathrm{H}_{2} \mathrm{~N}^{15} \mathrm{C}^{12} \mathrm{DO}^{16}$ & 3- 157 & $4,0,4 \leftarrow 3,1,3$ & Ground & & & 41117.81 & \\
\hline$\left(; \mathrm{e}^{74} \mathrm{HCl}_{3}^{37}\right.$ & 4-1496 & $10 . \leftarrow 9$ & Ground & & & 41144.02 & .07 \\
\hline $\mathrm{C}^{12} \mathrm{H}_{2} \mathrm{DSi}^{\mathrm{h}} \mathrm{H}_{3}$ & -3- 327 & $2,1,1 \leftarrow 1,1,0$ & & & & 41155.38 & .2 \\
\hline $\mathrm{N}^{1+} \mathrm{O}_{2}^{16}$ & 4-1801 & $10,0,10 \leftarrow 9,1,9$ & Ground & & & 41167.52 & \\
\hline $\mathrm{C}^{12} \mathrm{H}_{2} \mathrm{DSi}^{\mathrm{l}} \mathrm{H}_{3}$ & $3-327$ & $2,1,1 \leftarrow 1,1,0$ & & & & 41187.62 & .2 \\
\hline $\mathrm{C}^{12} \mathrm{H}_{2} \mathrm{Cl}_{2}^{35}$ & 4- 341 & $2,1,2 \leftarrow 1,0,1$ & Ground & & & 41197.8 & .2 \\
\hline$\left(\mathrm{e}^{72} \mathrm{HCl}_{33}^{37}\right.$ & 4-1495 & $10 . \leftarrow 9$ & Ground & & & 41208.73 & .07 \\
\hline $\mathrm{Si}^{30} \mathrm{~F}_{3}^{199} \mathrm{D}$ & $4 \cdot 1646$ & $3 . \leftarrow 2$ & Cround & & & 41222.73 & .2 \\
\hline $\mathrm{C}^{12} \mathrm{D}_{3} \mathrm{O}^{16} \mathrm{D}$ & 3- 216 & Not Reported & & & & 41230. & \\
\hline $\mathrm{C}^{\mathrm{h}} \mathrm{HF}_{3}^{\prime \prime}$ & 4- 285 & $2, \leftarrow 1$. & & & & 41241.52 & .10 \\
\hline $\mathrm{C}^{12} \mathrm{D}_{33} \mathrm{~N}^{14} \mathrm{O}_{2}^{16}$ & 3- 172 & $3,1, \leftarrow 2,1$. & Ground & & & 41253.7 & .2 \\
\hline $\mathrm{H}_{2} \mathrm{~N}^{15} \mathrm{C}^{12} \mathrm{HO}^{16}$ & 3- 156 & $2,0,2 \leftarrow 1,0,1$ & Ground & & & 41262.58 & \\
\hline $\mathrm{N}^{14} \mathrm{O}_{2}^{16}$ & $4-1801$ & $10,0,10 \leftarrow 9,1,9$ & Ground & & & 41277.92 & \\
\hline $\mathrm{C}^{12} \mathrm{H}_{3} \mathrm{C}^{12}{ }_{*} \mathrm{HO}^{16} \mathrm{C}^{12}{ }_{*} \mathrm{H}_{2}$ & $3-761$ & $30,14, \quad \longleftarrow 29,15$, & Ground & & & 41279.30 & .1 \\
\hline $\mathrm{C}^{12} \mathrm{H}_{3} \mathrm{C}^{12} * \mathrm{HO}^{16} \mathrm{C}^{12} * \mathrm{H}_{2}$ & 3. 761 & $30,14, \leftarrow 29,15$ & Ground & & & 41279.97 & .1 \\
\hline $\mathrm{Si}^{29} \mathrm{~F}_{3^{19}}^{19} \mathrm{D}$ & $4-1644$ & $3, \leftarrow 2$, & Ground & & & 41280.46 & .1 \\
\hline $\mathrm{C}^{1,} \mathrm{HF}_{33}^{\prime, 3}$ & 4- 285 & $2, \leftarrow 1$, & & & & 41287.45 & .10 \\
\hline $\mathrm{c}-\mathrm{HDN}{ }^{15} \mathrm{C}^{12} \mathrm{HO}^{16}$ & 3- 158 & $2,1,1 \leftarrow 1,1,0$ & Ground & & & 41290.30 & \\
\hline $\mathrm{C}^{12} \mathrm{H}_{33} \mathrm{Si}^{24} \mathrm{Cl}^{35} \mathrm{Cl}_{2}^{37}$ & 3- 114 & $12, \quad \leftarrow 11$, & Ciround & & & 41310. & 20. \\
\hline
\end{tabular}




\begin{tabular}{|c|c|c|c|c|c|c|}
\hline Isotopic Species & $\begin{array}{l}\text { Vol.-Id. } \\
\text { Nos. }\end{array}$ & $\begin{array}{c}\text { Rotational } \\
\text { Quantum Nos. }\end{array}$ & Vib. State & $\mathrm{F}_{1}^{\prime} \quad \mathrm{F}^{\prime} \mathrm{F}_{1} \quad \mathrm{~F}$ & $\begin{array}{c}\text { Frequency } \\
\mathrm{MHz}^{2}\end{array}$ & $\begin{aligned} & \text { Acc. } \\
\pm & \mathrm{MH}_{2}\end{aligned}$ \\
\hline $\mathrm{C}^{12} \mathrm{HF}_{3}^{19}$ & 4. 281 & $2, \leftarrow 1$, & Excited & & 41316.72 & .10 \\
\hline$\left(\mathrm{C}^{12} \mathrm{H}_{3}\right)_{3} \mathrm{C}^{12} \mathrm{Cl}^{37}$ & 3- 972 & $7, \leftarrow 6$, & Ground & & 41330. & 30. \\
\hline $\mathrm{C}^{12} \mathrm{HF}_{3}^{19}$ & 4- 281 & $2,1 \leftarrow 1,1$ & Excited & & 41334.0 & .10 \\
\hline $\mathrm{C}^{12} \mathrm{HF}_{3}^{19}$ & 4- 281 & $2,1 \leftarrow 1,1$ & Excited & & 41338.99 & .10 \\
\hline $\mathrm{Si}^{28} \mathrm{~F}_{3}^{19} \mathrm{D}$ & $4-1642$ & $3, \leftarrow 2$, & Ground & & 41340.00 & .1 \\
\hline $\mathrm{C}^{\mathrm{b}} \mathrm{HF}_{3}^{\mathrm{b}}$ & 4. 285 & $2, \leftarrow 1$, & & & 41345.49 & .10 \\
\hline $\mathrm{C}^{\mathrm{b}} \mathrm{HF}_{3}^{\mathrm{b}}$ & 4- 285 & $2, \leftarrow 1$, & & & 41350.02 & .10 \\
\hline $\mathrm{C}^{12} \mathrm{H}_{3} \mathrm{C}^{12} \mathrm{~F}_{3}^{19}$ & 3- 411 & $4, \leftarrow 3$, & Excited & & 41356.06 & \\
\hline $\mathrm{C}^{12} \mathrm{HF}_{3}^{19}$ & 4. 281 & $2, \leftarrow 1$, & Ground & & 41394.95 & .18 \\
\hline $\mathrm{C}^{12} \mathrm{HF}_{3}^{19}$ & 4- 281 & $2,1 \leftarrow 1,1$ & Excited & & 41411.52 & .10 \\
\hline $\mathrm{C}^{12} \mathrm{H}_{3} \mathrm{C}^{12} \mathrm{~F}_{3}^{19}$ & 3. 411 & $4, \leftarrow 3$ & Excited & & 41415.94 & \\
\hline $\mathrm{C}^{12} \mathrm{H}_{3} \mathrm{C}^{12} \mathrm{~F}_{3}^{19}$ & 3. 411 & $4, \leftarrow 3$, & Excited & & 41418.30 & \\
\hline $\mathrm{C}^{12} \mathrm{H}_{3} \mathrm{C}^{12} \mathrm{~F}_{3}^{19}$ & 3. 411 & $4, \leftarrow 3$, & Excited & & 41419.48 & \\
\hline $\mathrm{C}^{12} \mathrm{HF}_{3}^{19}$ & 4- 281 & $2,0 \leftarrow 1,0$ & Excited & & 41426.22 & .10 \\
\hline $\mathrm{C}^{12} \mathrm{HF}_{3}^{19}$ & 4. 281 & $2, \leftarrow 1$ & Excited & & 41441.00 & .10 \\
\hline $\mathrm{S}_{2}^{32} \mathrm{O}^{16}$ & 4-1821 & $5,1,4 \leftarrow 5,0,5$ & Ground & & 41442.2 & \\
\hline $\mathrm{C}^{12} \mathrm{D}_{3} \mathrm{~N}^{14} \mathrm{O}_{2}^{16}$ & 3- 172 & $3,2, \leftarrow 2,2$, & Ground & & 41467.2 & 2 \\
\hline $\mathrm{HDSe}^{82}$ & 4.1 758 & $1,1,1 \leftarrow 1,1,0$ & Ground & & 41476.1 & \\
\hline $\mathrm{C}^{12} \mathrm{H}_{3} \mathrm{C}^{12} \mathrm{~F}_{3}^{19}$ & 3. 411 & $4, \leftarrow 3$, & Ground & & 41480.72 & .1 \\
\hline $\mathrm{C}^{12} \mathrm{H}_{3} \mathrm{Si}^{\mathrm{b}} \mathrm{H}_{2} \mathrm{D}$ & $3 \cdot 325$ & $2,1,2 \leftarrow 1,1,1$ & & & 41482.84 & 2 \\
\hline $\mathrm{C}^{12} \mathrm{HF}_{3}^{19}$ & 4. 281 & $2,1 \leftarrow 1,1$ & Excited & & 41483.60 & .10 \\
\hline $\mathrm{C}^{12} \mathrm{H}_{3} \mathrm{Si}^{\mathrm{b}} \mathrm{H}_{2} \mathrm{D}$ & 3- 325 & $2,1,2 \leftarrow 1,1,1$ & & & 41502.14 & .4 \\
\hline $\mathrm{HDSe}^{80}$ & 4-1757 & $1,1,1 \leftarrow 1,1,0$ & Ground & & 41504.5 & \\
\hline $\mathrm{H}_{2} \mathrm{~N}^{14} \mathrm{C}^{12} \mathrm{DO}^{16}$ & 3- 155 & $2,0,2 \leftarrow 1,0,1$ & Ground & & 41521.85 & \\
\hline$\left(\mathrm{C}^{12} \mathrm{H}_{3}\right)_{2} \mathrm{~S}^{32}$ & 3- 601 & $11,2,10 \leftarrow 10,3,7$ & Ground & & 4l 529.13 & .05 \\
\hline$\left(\mathrm{C}^{12} \mathrm{H}_{3}\right)_{2} \mathrm{~S}^{32}$ & 3. 601 & $11,2,10 \leftarrow 10,3,7$ & Ground & & 41530.31 & .05 \\
\hline$\left(\mathrm{C}^{12} \mathrm{H}_{3}\right)_{2} \mathrm{~S}^{32}$ & 3- 601 & $11,2,10 \leftarrow 10,3,7$ & Ground & & 41531.49 & .05 \\
\hline $\mathrm{HDSe}^{78}$ & 4-1756 & $1,1,1 \leftarrow 1,1,0$ & Ground & & 41534.1 & \\
\hline $\mathrm{C}^{12} \mathrm{H}_{3} \mathrm{~N}^{14} \mathrm{O}_{2}^{16}$ & 3- 171 & $3,0, \leftarrow 2,0$, & Ground & & 41534.9 & 2 \\
\hline $\mathrm{C}^{12} \mathrm{D}_{3} \mathrm{O}^{16} \mathrm{D}$ & 3- 216 & Not Reported & & & 41540. & \\
\hline $\mathrm{HDSe}^{77}$ & $4-1755$ & $1,1,1 \leftarrow 1,1,0$ & Ground & & 41549.0 & \\
\hline $\mathrm{HDSe}^{76}$ & 4.1759 & $1,1,1 \leftarrow 1,1,0$ & Ground & & 41565.4 & \\
\hline $\mathrm{H}_{2} \mathrm{C}^{12}{ }_{*} \mathrm{O}^{16} \mathrm{C}^{12}{ }_{*} \mathrm{H}_{2}$ & 4. 841 & $4,2,2 \leftarrow 4,1,3$ & Ground & & 41581. & 1. \\
\hline $\mathrm{F}^{19} \mathrm{DC}^{12} \mathrm{O}^{16}$ & 4- 272 & $2,1,2 \leftarrow 1,1,1$ & & & 41586.8 & .1 \\
\hline $\mathrm{C}^{12} \mathrm{D}_{3} \mathrm{~N}^{14} \mathrm{O}_{2}^{16}$ & 3. 172 & $3,2, \leftarrow 2,2$, & - Ground & & 41592.7 & 2 \\
\hline $\mathrm{C}^{12} \mathrm{H}_{3} \mathrm{~N}^{14} \mathrm{H}_{2}$ & 3. 261 & Not Reported & Ground & & 41615.12 & \\
\hline $\mathrm{C}^{12} \mathrm{H}_{3} \mathrm{~N}^{14} \mathrm{H}_{2}$ & 3. 261 & Not Reported & Ground & & 41615.76 & \\
\hline $\mathrm{C}^{12} \mathrm{D}_{3} \mathrm{~N}^{14} \mathrm{O}_{2}^{16}$ & 3- 172 & $3,2, \leftarrow 2,2$, & Ground & & 41638 & 2.0 \\
\hline $\mathrm{C}^{12} \mathrm{H}_{3} \mathrm{~N}^{14} \mathrm{H}_{2}$ & 3. 261 & Not Reported & Ground & & 41658.42 & \\
\hline $\mathrm{C}^{12} \mathrm{H}_{3} \mathrm{~N}^{14} \mathrm{H}_{2}$ & 3- 261 & $10,2, \leftarrow 9,3$, & Ground & & 41658.42 & \\
\hline $\mathrm{HC}^{12} \mathrm{O}^{16} \mathrm{O}^{16} \mathrm{D}$ & 3. 72 & $2,1,2 \leftarrow 1,1,1$ & Ground & & 41672.98 & 20 \\
\hline $\mathrm{C}^{12} \mathrm{D}_{3} \mathrm{O}^{16} \mathrm{H}$ & 3. 214 & Not Reported & Ground & & 41684.6 & .5 \\
\hline $\mathrm{C}^{12} \mathrm{D}_{3} \mathrm{O}^{16} \mathrm{D}$ & 3. 216 & Not Reported & & & 41688. & \\
\hline $\mathrm{C}^{12} \mathrm{D}_{3} \mathrm{~N}^{14} \mathrm{O}_{2}^{16}$ & 3- 172 & $3,1, \leftarrow 2,1$, & Ground & & 41736.0 & 2 \\
\hline $\mathrm{C}^{12} \mathrm{D}_{3} \mathrm{~N}^{14} \mathrm{O}_{2}^{16}$ & 3- 172 & $3,1, \leftarrow 2,1$, & Ground & & 41745.6 & .2 \\
\hline
\end{tabular}




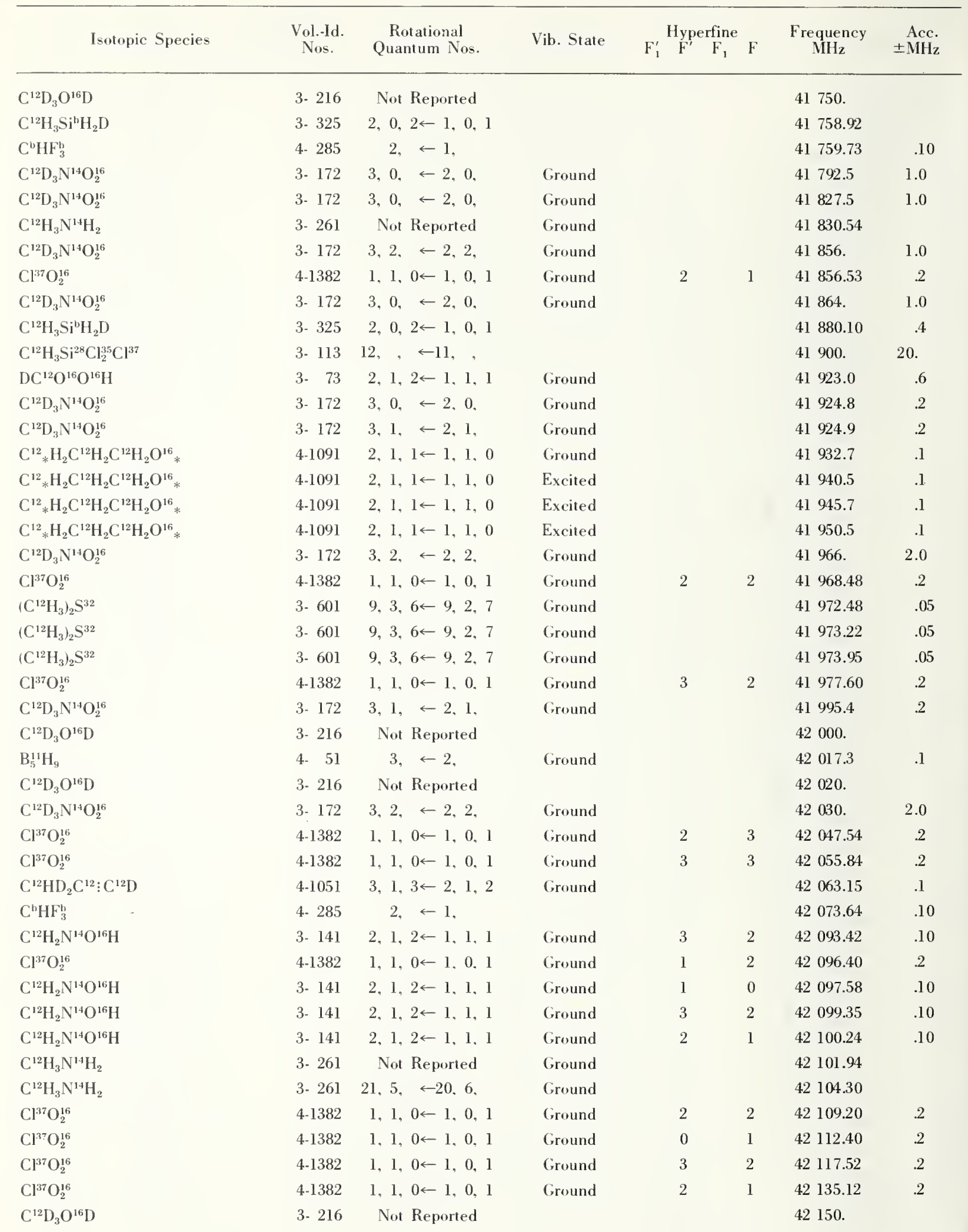




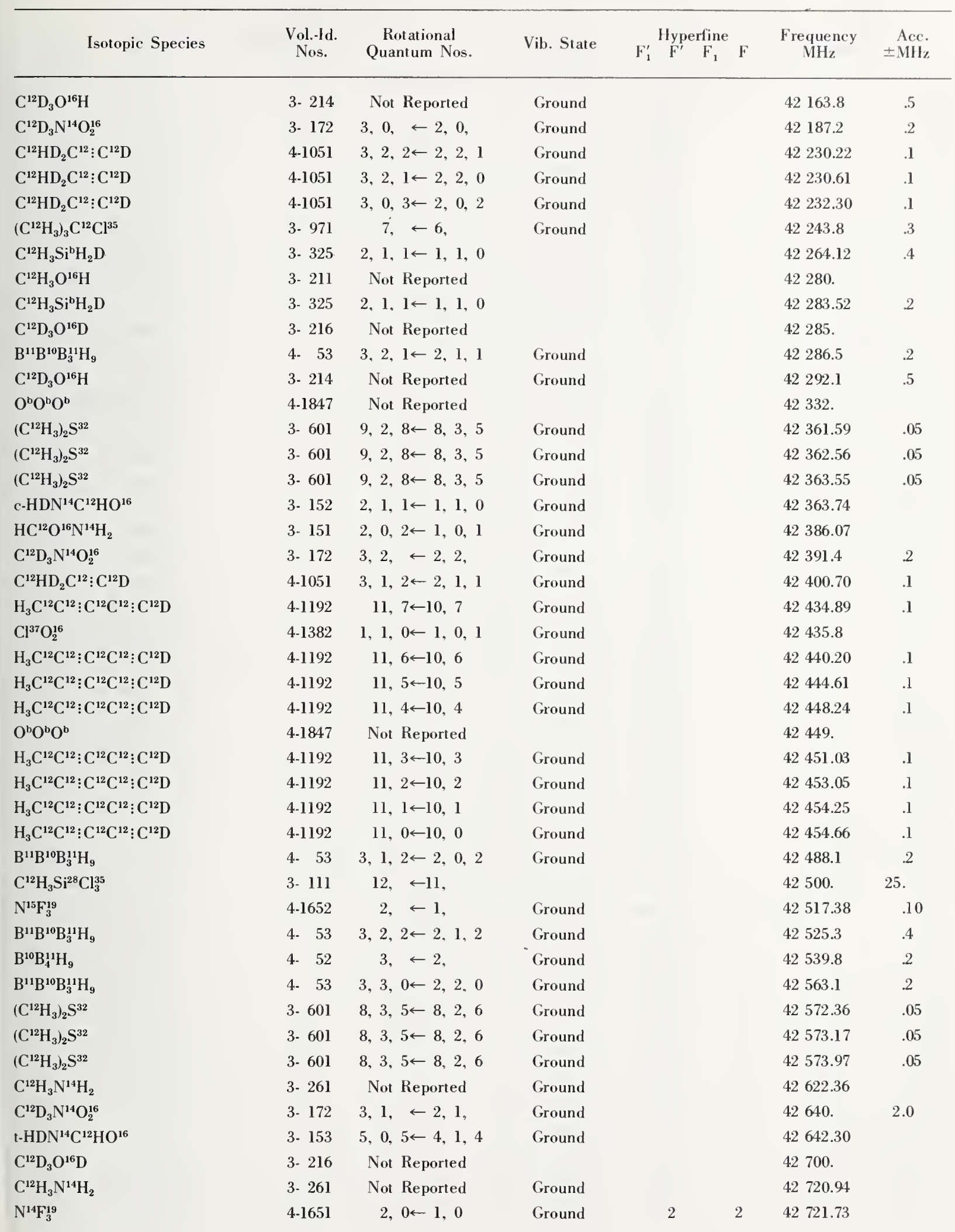




\begin{tabular}{|c|c|c|c|c|c|c|c|}
\hline Isotopic Species & $\begin{array}{l}\text { Vol.-Id. } \\
\text { Nos. }\end{array}$ & $\begin{array}{c}\text { Rotational } \\
\text { Quantum Nos. }\end{array}$ & Vib. State & $\mathrm{F}_{1}^{\prime} \stackrel{\mathrm{F}^{\prime}}{\text { Hyperfine }} \mathrm{F}_{1}$ & $\mathbf{F}$ & $\begin{array}{c}\text { Frequency } \\
\mathrm{MHz}\end{array}$ & $\begin{aligned} & \text { Acc. } \\
\pm & \mathrm{MHz}\end{aligned}$ \\
\hline $\mathrm{N}^{14} \mathrm{~F}_{3}^{19}$ & 4-1651 & $2,1 \leftarrow 1,1$ & Ground & 2 & 1 & 42722.16 & \\
\hline $\mathrm{N}^{14} \mathrm{~F}_{3}^{19}$ & 4-1651 & $2,0 \leftarrow 1,0$ & Ground & 1 & 0 & 42722.16 & \\
\hline $\mathrm{N}^{14} \mathrm{~F}_{3}^{19}$ & 4-1651 & $2,1 \leftarrow 1,1$ & Ground & 2 & 2 & 42723.28 & \\
\hline $\mathrm{N}^{14} \mathrm{~F}_{3}^{19}$ & 4-1651 & $2, \leftarrow 1$, & Ground & & & 42723.84 & .10 \\
\hline $\mathrm{N}^{14} \mathrm{~F}_{3}^{19}$ & 4-1651 & $2,0 \leftarrow 1,0$ & Ground & 2 & 1 & 42723.94 & \\
\hline $\mathrm{N}^{14} \mathrm{~F}_{3}^{19}$ & 4-1651 & $2,0 \leftarrow 1,0$ & Ground & 3 & 2 & 42723.94 & \\
\hline $\mathrm{N}^{14} \mathrm{~F}_{3}^{19}$ & 4-1651 & $2,1 \leftarrow 1,1$ & Ground & 3 & 2 & 42724.36 & \\
\hline $\mathrm{N}^{14} \mathrm{~F}_{3}^{19}$ & $4-1651$ & $2,1 \leftarrow 1,1$ & Ground & 1 & 0 & 42726.60 & \\
\hline $\mathrm{N}^{14} \mathrm{~F}_{3}^{19}$ & 4-1651 & $2,0 \leftarrow 1,0$ & Ground & 1 & 1 & 42727.39 & \\
\hline $\mathrm{C}^{12} \mathrm{H}_{2} \mathrm{~N}^{14} \mathrm{O}^{16} \mathrm{D}$ & 3- 142 & $2,1,1 \leftarrow 1,1,0$ & & 3 & 2 & 42728.98 & .10 \\
\hline $\mathrm{C}^{12} \mathrm{H}_{2} \mathrm{~N}^{14} \mathrm{O}^{16} \mathrm{D}$ & 3- 142 & $2,1,1 \leftarrow 1,1,0$ & & 1 & 0 & 42728.98 & .10 \\
\hline $\mathrm{B}^{11} \mathrm{~B}^{10} \mathrm{~B}_{3}^{11} \mathrm{H}_{9}$ & 4- 53 & $3,3,1 \leftarrow 2,2,1$ & Ground & & & 42776.1 & .2 \\
\hline $\mathrm{C}^{12} \mathrm{H}_{3} \mathrm{~N}^{14} \mathrm{H}_{2}$ & 3. 261 & $21,5, \quad \leftarrow 20,6$, & Ground & & & 42804.58 & \\
\hline $\mathrm{O}_{3}^{16}$ & $4 \cdot 1841$ & $1,1,1 \leftarrow 2,0,2$ & Ground & & & 42832.62 & .07 \\
\hline $\mathrm{C}^{12} \mathrm{D}_{3} \mathrm{~N}^{14} \mathrm{O}_{2}^{16}$ & 3- 172 & $3,1, \leftarrow 2,1$, & Ground & & & 42906.8 & .2 \\
\hline $\mathrm{Cl}^{37} \mathrm{O}_{2}^{16}$ & $4 \cdot 1382$ & $1,1,0 \leftarrow 1,0,1$ & Ground & 1 & 1 & 42948.50 & .2 \\
\hline $\mathrm{F}^{19} \mathrm{HC}^{12} \mathrm{O}^{16}$ & 4- 271 & $2,1,2 \leftarrow 1,1,1$ & & & & 42950.7 & .1 \\
\hline $\mathrm{C}^{12} \mathrm{D}_{3} \mathrm{~N}^{14} \mathrm{O}_{2}^{16}$ & 3- 172 & $3,1, \leftarrow 2,1$, & Ground & & & 42980.2 & .2 \\
\hline $\mathrm{C}^{12} \mathrm{H}_{3} \mathrm{~N}^{14} \mathrm{H}_{2}$ & 3. 261 & Not Reported & Ground & & & 43040.72 & \\
\hline $\mathrm{C}^{12} \mathrm{H}_{3} \mathrm{~N}^{14} \mathrm{H}_{2}$ & 3- 261 & $11,4, \leftarrow 12,3$, & Ground & & & 43040.72 & \\
\hline $\mathrm{N}^{14} \mathrm{H}_{2} \mathrm{D}$ & 4.1773 & $3,1,3 \leftarrow 3,0,3$ & Ground & & & 43042.48 & .10 \\
\hline $\mathrm{HDSe}^{82}$ & 4. 1758 & $3,2,2 \leftarrow 3,2,1$ & Ground & & & 43058.4 & \\
\hline $\mathrm{Cl}^{37} \mathrm{O}_{2}^{16}$ & 4-1382 & $1,1,0 \leftarrow 1,0,1$ & Ground & 1 & 2 & 43060.24 & .2 \\
\hline $\mathrm{Cl}^{37} \mathrm{O}_{2}^{16}$ & $4 \cdot 1382$ & $1,1,0 \leftarrow 1,0,1$ & Ground & 2 & 1 & 43104.18 & .2 \\
\hline $\operatorname{HDSe}^{80}$ & $4-1757$ & $3,2,2 \leftarrow 3,2,1$ & Ground & & & 43106.6 & \\
\hline $\mathrm{Cl}^{35} \mathrm{O}_{2}^{16}$ & $4-1381$ & $1,1,0 \leftarrow 1,0,1$ & Ground & 0 & 1 & 43112.78 & .2 \\
\hline $\mathrm{Cl}^{35} \mathrm{O}_{2}^{16}$ & $4 \cdot 1381$ & $1,1,0 \leftarrow 1,0,1$ & Ground & 1 & 1 & 43124.95 & 2 \\
\hline $\mathrm{Cl}^{35} \mathrm{O}_{2}^{16}$ & 4-1381 & $1,1,0 \leftarrow 1,0,1$ & Ground & 2 & 1 & 43140.30 & .2 \\
\hline $\mathrm{HDSe}^{78}$ & $4-1756$ & $3,2,2 \leftarrow 3,2,1$ & Ground & & & 43156.8 & \\
\hline $\mathrm{F}^{19} \mathrm{HC}^{12} \mathrm{O}^{18}$ & 4. 274 & $2,1,1 \leftarrow 1,0,1$ & Ground & & & 43172.2 & .4 \\
\hline $\mathrm{HDSe}^{77}$ & 4-1755 & $3,2,2 \leftarrow 3,2,1$ & Ground & & & $43 \quad 183.1$ & \\
\hline $\mathrm{HC}^{13} \mathrm{O}^{16} \mathrm{O}^{16} \mathrm{H}$ & 3. 75 & $2,1,2 \leftarrow 1,1,1$ & Ground & & & 43190.4 & .6 \\
\hline $\mathrm{Cl}^{37} \mathrm{O}_{2}^{16}$ & $4-1382$ & $1,1,0 \leftarrow 1,0,1$ & Ground & 1 & 2 & 43201.54 & 2 \\
\hline $\mathrm{HDSe}^{76}$ & $4-1759$ & $3,2,2 \leftarrow 3,2,1$ & Ground & & & 43209.8 & \\
\hline $\mathrm{Cl}^{37} \mathrm{O}_{2}^{16}$ & 4-1382 & $1,1,0 \leftarrow 1,0,1$ & Ground & 2 & 2 & 43215.84 & .2 \\
\hline $\mathrm{C}^{12} \mathrm{H}_{3} \mathrm{~N}^{14} \mathrm{H}_{2}$ & 3- 261 & Not Reported & Ground & & & 43220.12 & \\
\hline $\mathrm{Cl}^{37} \mathrm{O}_{2}^{16}$ & $4-1382$ & $1,1,0 \leftarrow 1,0,1$ & Ground & 1 & 1 & 43227.26 & .2 \\
\hline $\mathrm{Si}^{28} \mathrm{~F}_{3}^{19} \mathrm{H}$ & $4-1641$ & $3, \leftarrow 2$ & Ground & & & 43247.49 & .1 \\
\hline $\mathrm{Cl}^{35} \mathrm{O}_{2}^{16}$ & $4-1381$ & $1,1,0 \leftarrow 1,0,1$ & Ground & 2 & 2 & 43274.56 & .2 \\
\hline $\mathrm{Cl}^{35} \mathrm{O}_{2}^{16}$ & $4-1381$ & $1,1,0 \leftarrow 1,0,1$ & Ground & 3 & 2 & 43285.5 & .2 \\
\hline $\mathrm{Cl}^{37} \mathrm{O}_{2}^{16}$ & 4-1382 & $1,1,0 \leftarrow 1,0,1$ & Ground & 2 & 3 & 43294.8 & 2 \\
\hline $\mathrm{HC}^{12} \mathrm{O}^{16} \mathrm{O}^{16} \mathrm{H}$ & 3. 71 & $2,1,2 \leftarrow 1,1,1$ & & & & 43303.62 & .27 \\
\hline$\left(\mathrm{C}^{12} \mathrm{H}_{3}\right)_{2} \mathrm{~S}^{32}$ & 3- 601 & $4,2,3 \leftarrow 4,1,4$ & Ground & & & 43321.37 & .05 \\
\hline$\left(\mathrm{C}^{12} \mathrm{H}_{3}\right)_{2} \mathrm{~S}^{32}$ & 3. 601 & $4,2,3 \leftarrow 4,1,4$ & Ground & & & 43322.18 & .05 \\
\hline$\left(\mathrm{C}^{12} \mathrm{H}_{3}\right)_{2} \mathrm{~S}^{32}$ & $3 \cdot 601$ & $4,2,3 \leftarrow 4,1,4$ & Ground & & & 43322.98 & .05 \\
\hline
\end{tabular}




\begin{tabular}{|c|c|c|c|c|c|c|c|c|}
\hline Isotopic Species & $\begin{array}{l}\text { Vol.-Id. } \\
\text { Nos. }\end{array}$ & $\begin{array}{c}\text { Rotational } \\
\text { Quantum Nos. }\end{array}$ & Vib. State & $\mathrm{F}_{1}^{\prime}$ & $\begin{array}{c}\text { Hyperfine } \\
\mathbf{F}^{\prime} \quad F_{1}\end{array}$ & $\mathrm{~F}$ & $\begin{array}{c}\text { Frequeney } \\
\mathrm{MlH}_{2}\end{array}$ & $\begin{aligned} & \text { Acc. } \\
& \pm \mathrm{Mlll} / \mathrm{z}\end{aligned}$ \\
\hline $\mathrm{C}^{12} \mathrm{D}_{3} \mathrm{O}^{16} \mathrm{H}$ & 3- 214 & Not Reported & Ground & & & & 43325.0 & .5 \\
\hline $\mathrm{Cl}^{35} \mathrm{O}_{2}^{16}$ & 4-1381 & $1,1,0 \leftarrow 1,0,1$ & Ground & & 2 & 3 & 43338.16 & .2 \\
\hline $\mathrm{C}^{12} \mathrm{D}_{3} \mathrm{O}^{16} \mathrm{D}$ & 3- 216 & Not Reported & & & & & 43345 . & \\
\hline $\mathrm{C}^{12} \mathrm{H}_{3} \mathrm{~N}^{14} \mathrm{H}_{2}$ & 3. 261 & $21,5, \leftarrow 20,6$, & Ground & & & & 43346.58 & \\
\hline $\mathrm{Cl}^{35} \mathrm{O}_{2}^{16}$ & 4-1381 & $1,1,0 \leftarrow 1,0,1$ & Ground & & 3 & 3 & 43348.60 & .2 \\
\hline $\mathrm{F}^{19} \mathrm{DC}^{12} \mathrm{O}^{16}$ & 4- 272 & $2,0,2 \leftarrow 1,0,1$ & & & & & 43361.9 & .1 \\
\hline $\mathrm{H}_{2} \mathrm{C}^{12}{ }_{*} \mathrm{O}^{16} \mathrm{C}^{12}{ }_{*} \mathrm{H}_{2}$ & 4- 841 & $8,6,2 \leftarrow 8,5,3$ & Ground & & & & 43398. & 1. \\
\hline $\mathrm{Cl}^{35} \mathrm{O}_{2}^{16}$ & 4-1381 & $1,1,0 \leftarrow 1,0,1$ & Ground & & 1 & 2 & 43398.08 & .2 \\
\hline $\mathrm{C}^{12} \mathrm{H}_{3} \mathrm{~N}^{14} \mathrm{H}_{2}$ & 3- 261 & $11,4, \quad \leftarrow 12,3$, & Ground & & & & 43404.8 & \\
\hline $\mathrm{Cl}^{35} \mathrm{O}_{2}^{16}$ & 4-1381 & $1,1,0 \leftarrow 1,0,1$ & Ground & & 2 & 2 & 43413.60 & .2 \\
\hline $\mathrm{D}_{2} \mathrm{O}^{16}$ & 4-1713 & $4,2,3 \leftarrow 3,3,0$ & Ground & & & & 43414.57 & \\
\hline $\mathrm{Cl}^{35} \mathrm{O}_{2}^{16}$ & 4-1381 & $1,1,0 \leftarrow 1,0,1$ & Ground & & 0 & 1 & 43416.10 & .2 \\
\hline $\mathrm{HC}^{12} \mathrm{O}^{16} \mathrm{O}^{16} \mathrm{D}$ & 3- 72 & $2,0,2 \leftarrow 1,0,1$ & Ground & & & & 43421.36 & .20 \\
\hline $\mathrm{Cl}^{35} \mathrm{O}_{2}^{16}$ & 4-1381 & $1,1,0 \leftarrow 1,0,1$ & Ground & & 3 & 2 & 43423.60 & .2 \\
\hline $\mathrm{Cl}^{35} \mathrm{O}_{2}^{16}$ & 4-1381 & $1,1,0 \leftarrow 1,0,1$ & Ground & & 1 & 1 & 43428.72 & .2 \\
\hline $\mathrm{Cl}^{35} \mathrm{O}_{2}^{16}$ & 4-1381 & $1,1,0 \leftarrow 1,0,1$ & Ground & & 2 & 1 & 43444.10 & .2 \\
\hline$\left(\mathrm{C}^{12} \mathrm{H}_{3}\right)_{2} \mathrm{O}^{16}$ & 3- 591 & $6,1,5 \leftarrow 6,0,5$ & Ground & & & & 43450 . & 20. \\
\hline $\mathrm{C}^{12} \mathrm{D}_{3} \mathrm{O}^{16} \mathrm{H}$ & 3- 214 & $2, \quad \leftarrow 1$, & Ground & & & & 43453.7 & .5 \\
\hline $\mathrm{C}^{12} \mathrm{H}_{3} \mathrm{~N}^{14} \mathrm{H}_{2}$ & 3- 261 & $10,2, \leftarrow 9,3$, & Ground & & & & 43498.32 & \\
\hline $\mathrm{C}^{12} \mathrm{D}_{3} \mathrm{O}^{16} \mathrm{H}$ & 3- 214 & $5, \quad \leftarrow 4$, & Ground & & & & 43501.5 & .5 \\
\hline $\mathrm{C}^{12} \mathrm{D}_{3} \mathrm{O}^{16} \mathrm{D}$ & 3. 216 & Not Reported & & & & & 43525 . & \\
\hline$\left(\mathrm{C}^{12} \mathrm{H}_{3}\right)_{2} \mathrm{~S}^{32}$ & 3. 601 & $10,3,7 \leftarrow 10,2,8$ & Ground & & & & 43543.45 & .05 \\
\hline$\left(\mathrm{C}^{12} \mathrm{H}_{3}\right)_{2} \mathrm{~S}^{32}$ & 3- 601 & $10,3,7 \leftarrow 10,2,8$ & Ground & & & & 43544.14 & .05 \\
\hline$\left(\mathrm{C}^{12} \mathrm{H}_{3}\right)_{2} \mathrm{~S}^{32}$ & 3- 601 & $10,3,7 \leftarrow 10,2,8$ & Ground & & & & 43544.84 & .05 \\
\hline $\mathrm{C}^{12} \mathrm{D}_{3} \mathrm{O}^{16} \mathrm{D}$ & 3- 216 & Not Reported & & & & & 43545 . & \\
\hline $\mathrm{C}^{12} \mathrm{D}_{3} \mathrm{O}^{16} \mathrm{D}$ & 3. 216 & Not Reported & & & & & 43630 & \\
\hline$\left(\mathrm{C}^{12} \mathrm{H}_{3}\right)_{2} \mathrm{~S}^{32}$ & 3. 601 & $10,2,9 \leftarrow 9,3,6$ & Ground & & & & 43636.47 & .05 \\
\hline$\left(\mathrm{C}^{12} \mathrm{H}_{3}\right)_{2} \mathrm{~S}^{32}$ & 3- 601 & $10,2,9 \leftarrow 9,3,6$ & Ground & & & & 43637.52 & .05 \\
\hline$\left(\mathrm{C}^{12} \mathrm{H}_{3}\right)_{2} \mathrm{~S}^{32}$ & 3- 601 & $10,2,9 \leftarrow 9,3,6$ & Ground & & & & 43638.57 & .05 \\
\hline $\mathrm{O}_{3}^{16}$ & $4-1841$ & $12,2,10 \leftarrow 13,1,13$ & Ground & & & & 43654 . & \\
\hline $\mathrm{C}^{12} \mathrm{HD}_{2} \mathrm{~F}^{19}$ & 4. 466 & $1,0,1 \leftarrow 0,0,0$ & Ground & & & & 43689.82 & .1 \\
\hline $\mathrm{Si}^{28} \mathrm{HCl}_{2}^{35} \mathrm{Cl}^{37}$ & 4-1502 & $9, \quad \leftarrow 8$, & Ground & & & & 43690 & 10. \\
\hline $\mathrm{C}^{12} \mathrm{H}_{3} \mathrm{~N}^{14} \mathrm{H}_{2}$ & 3. 261 & Not Reported & Ground & & & & 43711.80 & \\
\hline $\mathrm{C}^{12} \mathrm{H}_{3} \mathrm{~N}^{14} \mathrm{H}_{2}$ & 3- 261 & Not Reported & Ground & & & & 43728.61 & \\
\hline $\mathrm{Cl}^{35} \mathrm{O}_{2}^{16}$ & 4-1381 & $1,1,0 \leftarrow 1,0,1$ & Ground & & & & 43745.0 & \\
\hline $\mathrm{C}^{12} \mathrm{H}_{2} \mathrm{~N}^{14} \mathrm{O}^{16} \mathrm{H}$ & 3. 141 & $2,0,2 \leftarrow 1,0,1$ & Ground & & 3 & 2 & 43794.02 & .10 \\
\hline $\mathrm{C}^{12} \mathrm{H}_{2} \mathrm{~N}^{14} \mathrm{O}^{16} \mathrm{H}$ & 3- 141 & $2,0,2 \leftarrow 1,0,1$ & Ground & & 2 & 1 & 43794.02 & .10 \\
\hline $\mathrm{C}^{12} \mathrm{H}_{2} \mathrm{~N}^{14} \mathrm{O}^{16} \mathrm{H}$ & 3- 141 & $2,0,2 \leftarrow 1,0,1$ & Ground & & 3 & 2 & 43836.50 & .10 \\
\hline $\mathrm{C}^{12} \mathrm{H}_{2} \mathrm{~N}^{14} \mathrm{O}^{16} \mathrm{H}$ & 3- 141 & $2,0,2 \leftarrow 1,0,1$ & Ground & & 2 & 1 & $43836: 50$ & .10 \\
\hline $\mathrm{C}^{12} \mathrm{H}_{2} \mathrm{~N}^{14} \mathrm{O}^{16} \mathrm{H}$ & 3- 141 & $2,0,2 \leftarrow 1,0,1$ & Ground & & 1 & 0 & 43837.38 & .10 \\
\hline $\mathrm{C}^{12} \mathrm{H}_{2} \mathrm{~N}^{14} \mathrm{O}^{16} \mathrm{H}$ & 3. 141 & $2,0,2 \leftarrow 1,0,1$ & Ground & & 2 & 2 & 43837.38 & .10 \\
\hline $\mathrm{Cl}^{35} \mathrm{~F}^{19} \mathrm{C}^{12} \mathrm{O}^{16}$ & 4- 151 & $7,3,5 \leftarrow 7,2,6$ & Ground & & & & 43850.54 & .05 \\
\hline $\mathrm{C}^{12} \mathrm{D}_{3} \mathrm{O}^{16} \mathrm{D}$ & 3- 216 & Not Reported & & & & & 43995. & \\
\hline $\mathrm{D}_{3} \mathrm{C}^{12} \mathrm{C}^{12}: \mathrm{C}^{12} \mathrm{C}^{12}: \mathrm{C}^{12} \mathrm{H}$ & 4-1193 & $12,6 \leftarrow 11,6$ & Ground & & & & 44023.24 & .1 \\
\hline $\mathrm{D}_{3} \mathrm{C}^{12} \mathrm{C}^{12}: \mathrm{C}^{12} \mathrm{C}^{12}: \mathrm{C}^{12} \mathrm{H}$ & 4-1193 & $12,5 \leftarrow 11,5$ & Ground & & & & 44027.08 & .1 \\
\hline
\end{tabular}




\begin{tabular}{|c|c|c|c|c|c|c|c|}
\hline Isotopic Species & $\begin{array}{l}\text { Vol.-Id. } \\
\text { Nos. }\end{array}$ & $\begin{array}{l}\text { Rotational } \\
\text { Quantum Nos. }\end{array}$ & Vib. State & $\mathrm{F}_{1}^{\prime} \stackrel{\text { Hyperfine }}{\mathrm{F}^{\prime}} \quad \mathrm{F}_{1}$ & $\mathrm{~F}$ & $\begin{array}{c}\text { Frequency } \\
\mathrm{MHz}^{2}\end{array}$ & $\begin{aligned} & \text { Aec. } \\
\pm & \mathrm{MHz}\end{aligned}$ \\
\hline $\mathrm{D}_{3} \mathrm{C}^{12} \mathrm{C}^{12}: \mathrm{C}^{12} \mathrm{C}^{12}: \mathrm{C}^{12} \mathrm{H}$ & 4-1193 & $12,4 \leftarrow 11,4$ & Ground & & & 44030.18 & .1 \\
\hline $\mathrm{D}_{3} \mathrm{C}^{12} \mathrm{C}^{12}: \mathrm{C}^{12} \mathrm{C}^{12}: \mathrm{C}^{12} \mathrm{H}$ & 4-1193 & $12,3 \leftarrow 11,3$ & Ground & & & 44032.64 & .1 \\
\hline $\mathrm{D}_{3} \mathrm{C}^{12} \mathrm{C}^{12}: \mathrm{C}^{12} \mathrm{C}^{12}: \mathrm{C}^{12} \mathrm{H}$ & 4-1193 & $12,2 \leftarrow 11,2$ & Ground & & & 44. 034.42 & .1 \\
\hline $\mathrm{D}_{3} \mathrm{C}^{12} \mathrm{C}^{12}: \mathrm{C}^{12} \mathrm{C}^{12}: \mathrm{C}^{12} \mathrm{H}$ & 4-1193 & $12,1 \leftarrow 11,1$ & Ground & & & 44035.48 & .1 \\
\hline $\mathrm{D}_{3} \mathrm{C}^{12} \mathrm{C}^{12}: \mathrm{C}^{12} \mathrm{C}^{12}: \mathrm{C}^{12} \mathrm{H}$ & $4-1193$ & $12,0 \leftarrow 11,0$ & Ground & & & 44.035 .80 & .1 \\
\hline $\mathrm{HC}^{12} \mathrm{O}^{16} \mathrm{O}^{18} \mathrm{H}$ & 3- 77 & $2,1,1 \leftarrow 1,1,0$ & Ground & & & 44056.8 & .2 \\
\hline $\mathrm{C}^{13} \mathrm{H}_{3} \mathrm{O}^{16} \mathrm{D}$ & 3- 215 & $1,0,1 \leftarrow 0,0,0$ & Ground & & & 44076.55 & .5 \\
\hline $\mathrm{C}^{13} \mathrm{H}_{3} \mathrm{O}^{16} \mathrm{D}$ & 3. 215 & $1,0,1 \leftarrow 0,0,0$ & Ground & & & 44. 079.30 & .5 \\
\hline $\mathrm{HC}^{12} \mathrm{O}^{18} \mathrm{O}^{16} \mathrm{H}$ & 3- 76 & $2,1,1 \leftarrow 1,1,0$ & Ground & & & 44095.5 & .2 \\
\hline $\mathrm{C}^{12} \mathrm{H}_{3} \mathrm{O}^{16} \mathrm{H}$ & 3- 211 & Not Reported & & & & 44100 & \\
\hline $\mathrm{C}^{12} \mathrm{D}_{3} \mathrm{C}^{12}: \mathrm{C}^{12} \mathrm{H}$ & 4-1052 & $3,2 \leftarrow 2,2$ & Ground & & & 44131.76 & .1 \\
\hline $\mathrm{C}^{12} \mathrm{D}_{3} \mathrm{C}^{12}: \mathrm{C}^{12} \mathrm{H}$ & 4-1052 & $3,1 \leftarrow 2,1$ & Ground & & & 44. 133.62 & .1 \\
\hline $\mathrm{C}^{12} \mathrm{D}_{3} \mathrm{C}^{12} \vdots \mathrm{C}^{12} \mathrm{H}$ & 4-1052 & $3,0 \leftarrow 2,0$ & Ground & & & $44 \quad 134.19$ & .1 \\
\hline $\mathrm{C}^{13} \mathrm{H}_{3} \mathrm{O}^{16} \mathrm{D}$ & 3- 215 & $1,0,1 \leftarrow 0,0,0$ & Ground & & & 44144.06 & .5 \\
\hline $\mathrm{C}^{13} \mathrm{H}_{3} \mathrm{O}^{16} \mathrm{D}$ & 3- 215 & $1,0,1 \leftarrow 0,0,0$ & Ground & & & 44151.09 & .5 \\
\hline $\mathrm{C}^{12} \mathrm{H}_{2} \mathrm{DC}^{12}: \mathrm{C}^{12} \mathrm{D}$ & $4-1049$ & $3,1,3 \leftarrow 2,1,2$ & Ground & & & 44154.10 & .1 \\
\hline $\mathrm{C}^{12} \mathrm{H}_{3} \mathrm{~N}^{1+} \mathrm{H}_{2}$ & 3- 261 & Not Reported & Ground & & & 44188.60 & \\
\hline $\mathrm{C}^{12} \mathrm{H}_{3} \mathrm{~N}^{14} \mathrm{H}_{2}$ & $3-261$ & Not Reported & & & & 44205. & \\
\hline $\mathrm{C}^{12} \mathrm{H}_{3} \mathrm{~N}^{14} \mathrm{H}_{2}$ & $3-261$ & Not Reported & & & & 44214 & \\
\hline $\mathrm{C}^{13} \mathrm{H}_{3} \mathrm{O}^{16} \mathrm{D}$ & 3- 215 & $1,0,1 \leftarrow 0,0,0$ & Ground & & & 44228.26 & .5 \\
\hline $\mathrm{C}^{13} \mathrm{H}_{3} \mathrm{O}^{16} \mathrm{D}$ & 3- 215 & $1,0,1 \leftarrow 0,0,0$ & Ground & & & 44241.43 & .5 \\
\hline $\mathrm{Cl}^{35} \mathrm{O}_{2}^{16}$ & 4-1381 & $1,1,0 \leftarrow 1,0,1$ & Ground & 1 & 1 & 44242.08 & .2 \\
\hline $\mathrm{C}^{12} \mathrm{H}_{3} \mathrm{~N}^{14} \mathrm{H}_{2}$ & $3 \cdot 261$ & Not Reported & Ground & & & 44286.76 & \\
\hline $\mathrm{F}^{19} \mathrm{HC}^{12} \mathrm{O}^{16}$ & 4- 271 & $2,0,2 \leftarrow 1,0,1$ & & & & 44296.0 & .1 \\
\hline $\mathrm{C}^{12} \mathrm{H}_{2} \mathrm{DC}^{12}: \mathrm{C}^{12} \mathrm{D}$ & 4-1049 & $3,2,2 \leftarrow 2,2,1$ & Ground & & & 44315.24 & .1 \\
\hline $\mathrm{C}^{12} \mathrm{H}_{2} \mathrm{DC}^{12}: \mathrm{C}^{12} \mathrm{D}$ & 4-1049 & $3,2,1 \leftarrow 2,2,0$ & Ground & & & 44315.50 & .1 \\
\hline $\mathrm{C}^{12} \mathrm{H}_{2} \mathrm{DC}^{12}: \mathrm{C}^{12} \mathrm{D}$ & 4-1049 & $3,0,3 \leftarrow 2,0,2$ & Ground & & & 44317.72 & .1 \\
\hline $\mathrm{Cl}^{35} \mathrm{O}_{2}^{16}$ & 4-1381 & $1,1,0 \leftarrow 1,0,1$ & Ground & 1 & 2 & 4. 376.00 & 2 \\
\hline $\mathrm{Cl}^{35} \mathrm{O}_{2}^{16}$ & 4-1381 & $1,1,0 \leftarrow 1,0,1$ & Ground & 2 & 1 & 44.429 .74 & .2 \\
\hline $\mathrm{C}^{12} \mathrm{H}_{3} \mathrm{~N}^{14} \mathrm{H}_{2}$ & 3- 261 & Not Reported & Ground & & & 44.462 .1 & \\
\hline $\mathrm{C}^{12} \mathrm{H}_{2} \mathrm{DC}^{12}: \mathrm{C}^{12} \mathrm{D}$ & 4-1049 & $3,1,2 \leftarrow 2,1,1$ & Ground & & & 44.480 .44 & .1 \\
\hline $\mathrm{Si}^{28} \mathrm{HCl}_{3}^{35}$ & 4-1501 & $9, \leftarrow 8$ & Ground & & & 44500 & 10. \\
\hline $\mathrm{Cl}^{35} \mathrm{O}_{2}^{16}$ & 4-1381 & $1,1,0 \leftarrow 1,0,1$ & Ground & 1 & 2 & 44515.28 & 2 \\
\hline $\mathrm{Cl}^{35} \mathrm{O}_{2}^{16}$ & $4-1381$ & $1,1,0 \leftarrow 1,0,1$ & Ground & 1 & 1 & 44545.80 & .2 \\
\hline $\mathrm{Cl}^{35} \mathrm{O}_{2}^{16}$ & 4-1381 & $1,1,0 \leftarrow 1,0,1$ & Ground & 2 & 2 & 44564.10 & 2 \\
\hline $\mathrm{C}^{12} \mathrm{H}_{3} \mathrm{~N}^{14} \mathrm{H}_{2}$ & $3 \cdot 261$ & Not Reported & Ground & & & 44573.06 & \\
\hline $\mathrm{O}^{\mathrm{b}} \mathrm{O}^{\mathrm{b}} \mathrm{O}^{\mathrm{b}}$ & $4-1847$ & Not Reported & & & & 44.575 & \\
\hline $\mathrm{Cl}^{35} \mathrm{O}_{2}^{16}$ & 4-1381 & $1,1,0 \leftarrow 1,0,1$ & Ground & 2 & 3 & 44627.20 & .2 \\
\hline $\mathrm{Cl}^{35} \mathrm{O}_{2}^{16}$ & 4-1381 & $1,1,0 \leftarrow 1,0,1$ & Ground & 2 & 2 & 44. 703.00 & 2 \\
\hline $\mathrm{H}_{3} \mathrm{C}^{12} \mathrm{C}^{12}: \mathrm{C}^{12} \mathrm{C}^{12}: \mathrm{C}^{12} \mathrm{H}$ & 4-1191 & $11,9 \leftarrow 10,9$ & Ground & & & 44750.52 & .1 \\
\hline$\left(\mathrm{C}^{12} \mathrm{H}_{3}\right)_{2} \mathrm{~S}^{32}$ & 3- 601 & $7,3,4 \leftarrow 7,2,5$ & Ground & & & 44762.10 & .05 \\
\hline$\left(\mathrm{C}^{12} \mathrm{H}_{3}\right)_{2} \mathrm{~S}^{32}$ & $3 \cdot 601$ & $7,3,4 \leftarrow 7,2,5$ & Ground & & & 44762.99 & .05 \\
\hline$\left(\mathrm{C}^{12} \mathrm{H}_{3}\right)_{2} \mathrm{~S}^{32}$ & 3. 601 & $7,3,4 \leftarrow 7,2,5$ & Ground & & & 44763.86 & .05 \\
\hline $\mathrm{H}_{3} \mathrm{C}^{12} \mathrm{C}^{12}: \mathrm{C}^{12} \mathrm{C}^{12}: \mathrm{C}^{12} \mathrm{H}$ & 4-1191 & $11,7 \leftarrow 10,7$ & Ground & & & 44764.52 & .1 \\
\hline $\mathrm{H}_{3} \mathrm{C}^{12} \mathrm{C}^{12}: \mathrm{C}^{12} \mathrm{C}^{12}: \mathrm{C}^{12} \mathrm{H}$ & 4-1191 & $11,6 \leftarrow 10,6$ & Ground & & & 44770.20 & .1 \\
\hline
\end{tabular}


Vol.-Id. Rotational Nos. Quantum Nos.
Vib. State
Frequency Acc. $\mathrm{MHz} \quad \pm \mathrm{MHz}$

\begin{tabular}{|c|c|c|c|c|c|c|c|}
\hline $\mathrm{H}_{3} \mathrm{C}^{12} \mathrm{C}^{12}: \mathrm{C}^{12} \mathrm{C}^{12}: \mathrm{C}^{12} \mathrm{H}$ & 4.1191 & $11,5 \leftarrow 10,5$ & Ground & & & 44. 775.04 & .1 \\
\hline $\mathrm{H}_{3} \mathrm{C}^{12} \mathrm{C}^{12}: \mathrm{C}^{12} \mathrm{C}^{12}: \mathrm{C}^{12} \mathrm{H}$ & 4-1191 & $11,4 \leftarrow 10,4$ & Ground & & & 44. 778.98 & .1 \\
\hline $\mathrm{H}_{3} \mathrm{C}^{12} \mathrm{C}^{12}: \mathrm{C}^{12} \mathrm{C}^{12}: \mathrm{C}^{12} \mathrm{H}$ & 4-1191 & $11,3 \leftarrow 10,3$ & Ground & & & 44. 782.02 & .1 \\
\hline $\mathrm{H}_{3} \mathrm{C}^{12} \mathrm{C}^{12}: \mathrm{C}^{12} \mathrm{C}^{12}: \mathrm{C}^{12} \mathrm{H}$ & 4-1191 & $11,2 \leftarrow 10,2$ & Ground & & & 44. 784.16 & .1 \\
\hline $\mathrm{H}_{3} \mathrm{C}^{12} \mathrm{C}^{12}: \mathrm{C}^{12} \mathrm{C}^{12}: \mathrm{C}^{12} \mathrm{H}$ & $4-1191$ & $11,1 \leftarrow 10,1$ & Ground & & & 4478.4 .48 & .1 \\
\hline $\mathrm{H}_{3} \mathrm{C}^{12} \mathrm{C}^{12}: \mathrm{C}^{12} \mathrm{C}^{12}: \mathrm{C}^{12} \mathrm{H}$ & 4.1191 & $11,0 \leftarrow 10,0$ & Ground & & & 44785.92 & .1 \\
\hline $\mathrm{DC}^{12} \mathrm{O}^{16} \mathrm{O}^{16} \mathrm{D}$ & $3-74$ & $2,1,1 \leftarrow 1,1,0$ & Ground & & & 44813.4 & .6 \\
\hline $\mathrm{C}^{12} \mathrm{H}_{3} \mathrm{~N}^{14} \mathrm{H}_{2}$ & 3. 261 & Not Reported & Ground & & & 44. 826.66 & \\
\hline $\mathrm{F}^{19} \mathrm{HC}^{13} \mathrm{O}^{16}$ & 4- 273 & $2,1,2 \leftarrow 1,1,1$ & & & & 44. 827.2 & .1 \\
\hline $\mathrm{HC}^{12} \mathrm{O}^{16} \mathrm{O}^{16} \mathrm{H}$ & 3. 71 & $2,0,2 \leftarrow 1,0,1$ & & & & 44. 911.68 & .28 \\
\hline $\mathrm{C}^{12} \mathrm{H}_{3} \mathrm{~N}^{14} \mathrm{H}_{2}$ & 3. 261 & Not Reported & Ground & & & 44967.40 & \\
\hline $\mathrm{HC}^{12} \mathrm{HO}^{16}$ & 4- 381 & $19,3,16 \leftarrow 19,3,17$ & Ground & & & 45063.10 & .1 \\
\hline $\mathrm{C}^{12} \mathrm{D}_{3} \mathrm{C}^{12} \mathrm{~N}^{14}$ & 4. 816 & $3,2 \leftarrow 2,2$ & Ground & 3 & 3 & 45145.20 & \\
\hline $\mathrm{C}^{12} \mathrm{D}_{3} \mathrm{C}^{12} \mathrm{~N}^{14}$ & 4. 816 & $3,2 \leftarrow 2,2$ & Ground & 4 & 3 & 45145.20 & \\
\hline $\mathrm{C}^{12} \mathrm{D}_{3} \mathrm{C}^{12} \mathrm{~N}^{14}$ & 4. 816 & $3,2 \leftarrow 2,2$ & Ground & 2 & 3 & 45145.20 & \\
\hline $\mathrm{C}^{12} \mathrm{H}_{3} \mathrm{O}^{16} \mathrm{D}$ & 3. 212 & $1,0,1 \leftarrow 0,0,0$ & Ground & & & 45189.46 & 1.0 \\
\hline $\mathrm{C}^{12} \mathrm{H}_{3} \mathrm{O}^{16} \mathrm{D}$ & 3- 212 & $1,0,1 \leftarrow 0,0,0$ & Ground & & & 45193.36 & 1.0 \\
\hline $\mathrm{F}^{19} \mathrm{DC}^{12} \mathrm{O}^{16}$ & 4- 272 & $2,1,1 \leftarrow 1,1,0$ & & & & 45226.9 & .1 \\
\hline $\mathrm{C}^{12} \mathrm{H}_{3} \mathrm{~N}^{14} \mathrm{H}_{2}$ & 3. 261 & Not Reported & Ground & & & 45256.68 & \\
\hline $\mathrm{HC}^{12} \mathrm{O}^{16} \mathrm{O}^{16} \mathrm{D}$ & 3. 72 & $2,1,1 \leftarrow 1,1,0$ & Ground & & & 45257.40 & .20 \\
\hline $\mathrm{C}^{12} \mathrm{H}_{3} \mathrm{O}^{16} \mathrm{D}$ & 3- 212 & $1,0,1 \leftarrow 0,0,0$ & Ground & & & 45259.44 & 1. \\
\hline $\mathrm{C}^{12} \mathrm{H}_{3} \mathrm{O}^{16} \mathrm{D}$ & 3- 212 & $1,0,1 \leftarrow 0,0,0$ & Ground & & & 45265.78 & 1. \\
\hline $\mathrm{D}_{3} \mathrm{C}^{12} \mathrm{C}^{12}: \mathrm{C}^{12} \mathrm{C}^{12}: \mathrm{C}^{12} \mathrm{D}$ & $4 \cdot 1194$ & $13,6 \leftarrow 12,6$ & Ground & & & 45284.10 & .1 \\
\hline $\mathrm{D}_{3} \mathrm{C}^{12} \mathrm{C}^{12}: \mathrm{C}^{12} \mathrm{C}^{12}: \mathrm{C}^{12} \mathrm{D}$ & 4-1194 & $13,5 \leftarrow 12,5$ & Ground & & & 45287.88 & .1 \\
\hline $\mathrm{D}_{3} \mathrm{C}^{12} \mathrm{C}^{12}: \mathrm{C}^{12} \mathrm{C}^{12}: \mathrm{C}^{12} \mathrm{D}$ & $4-1194$ & $13,4 \leftarrow 12,4$ & Ground & & & 45291.10 & .1 \\
\hline $\mathrm{D}_{3} \mathrm{C}^{12} \mathrm{C}^{12}: \mathrm{C}^{12} \mathrm{C}^{12}: \mathrm{C}^{12} \mathrm{D}$ & 4-1194 & $13,3 \leftarrow 12,3$ & Ground & & & 45293.56 & .1 \\
\hline $\mathrm{D}_{3} \mathrm{C}^{12} \mathrm{C}^{12}: \mathrm{C}^{12} \mathrm{C}^{12}: \mathrm{C}^{12} \mathrm{D}$ & 4.1194 & $13,2 \leftarrow 12,2$ & Ground & & & 45295.30 & .1 \\
\hline $\mathrm{D}_{3} \mathrm{C}^{12} \mathrm{C}^{12}: \mathrm{C}^{12} \mathrm{C}^{12}: \mathrm{C}^{12} \mathrm{D}$ & 4.1194 & $13,1 \leftarrow 12,1$ & Ground & & & 45296.40 & .1 \\
\hline $\mathrm{D}_{3} \mathrm{C}^{12} \mathrm{C}^{12}: \mathrm{C}^{12} \mathrm{C}^{12}: \mathrm{C}^{12} \mathrm{D}$ & 4-1194 & $13,0 \leftarrow 12,0$ & Ground & & & 45296.66 & .1 \\
\hline $\mathrm{C}^{12} \mathrm{H}_{3} \mathrm{~N}^{14} \mathrm{H}_{2}$ & 3- 261 & Not Reported & Ground & & & 45324.22 & \\
\hline $\mathrm{C}^{12} \mathrm{H}_{3} \mathrm{~N}^{14} \mathrm{H}_{2}$ & 3- 261 & Not Reported & Ground & & & 45325.04 & \\
\hline $\mathrm{C}^{12} \mathrm{H}_{3} \mathrm{~N}^{14} \mathrm{H}_{2}$ & 3. 261 & Not Reported & Ground & & & 45336.60 & \\
\hline $\mathrm{C}^{12} \mathrm{H}_{3} \mathrm{O}^{16} \mathrm{D}$ & 3- 212 & $1,0,1 \leftarrow 0,0,0$ & Ground & & & 45344.30 & 1. \\
\hline $\mathrm{C}^{12} \mathrm{H}_{3} \mathrm{O}^{16} \mathrm{D}$ & 3. 212 & $1,0,1 \leftarrow 0,0,0$ & Ground & & & 45359.43 & 1. \\
\hline $\mathrm{H}_{3} \mathrm{C}^{12} \mathrm{C}^{12} \vdots \mathrm{C}^{12} \mathrm{C}^{12} \mathrm{~N}^{14}$ & 4-1121 & $11,9 \leftarrow 10,9$ & Ground & & & 45410.2 & \\
\hline $\mathrm{H}_{3} \mathrm{C}^{12} \mathrm{C}^{12}: \mathrm{C}^{12} \mathrm{C}^{12} \mathrm{~N}^{14}$ & 4.1121 & $11,8 \leftarrow 10,8$ & Ground & & & 45417.5 & \\
\hline $\mathrm{H}_{3} \mathrm{C}^{12} \mathrm{C}^{12}: \mathrm{C}^{12} \mathrm{C}^{12} \mathrm{~N}^{14}$ & 4-1121 & $11,7 \leftarrow 10,7$ & Ground & & & 45424.2 & \\
\hline $\mathrm{H}_{3} \mathrm{C}^{12} \mathrm{C}^{12}: \mathrm{C}^{12} \mathrm{C}^{12} \mathrm{~N}^{14}$ & 4-1121 & $11,6 \leftarrow 10,6$ & Ground & & & 45429,98 & \\
\hline $\mathrm{H}_{3} \mathrm{C}^{12} \mathrm{C}^{12}: \mathrm{C}^{12} \mathrm{C}^{12} \mathrm{~N}^{14}$ & $4-1121$ & $11,5 \leftarrow 10,5$ & Ground & & & 45434.72 & \\
\hline $\mathrm{H}_{3} \mathrm{C}^{12} \mathrm{C}^{12}: \mathrm{C}^{12} \mathrm{C}^{12} \mathrm{~N}^{14}$ & $4-1121$ & $11,4 \leftarrow 10,4$ & Ground & & & 45438.66 & \\
\hline $\mathrm{H}_{3} \mathrm{C}^{12} \mathrm{C}^{12}: \mathrm{C}^{12} \mathrm{C}^{12} \mathrm{~N}^{14}$ & $4-1121$ & $11,3 \leftarrow 10,3$ & Ground & & & 45441.70 & \\
\hline $\mathrm{H}_{3} \mathrm{C}^{12} \mathrm{C}^{12}: \mathrm{C}^{12} \mathrm{C}^{12} \mathrm{~N}^{14}$ & $4-1121$ & $11,2 \leftarrow 10,2$ & Ground & & & 45443.90 & \\
\hline $\mathrm{H}_{3} \mathrm{C}^{12} \mathrm{C}^{12}: \mathrm{C}^{12} \mathrm{C}^{12} \mathrm{~N}^{14}$ & $4-1121$ & $11,1 \leftarrow 10,1$ & Ground & & & 45445.20 & \\
\hline $\mathrm{H}_{3} \mathrm{C}^{12} \mathrm{C}^{12}: \mathrm{C}^{12} \mathrm{C}^{12} \mathrm{~N}^{14}$ & 4-1121 & $11,0 \leftarrow 10,0$ & Ground & & & 45445.60 & \\
\hline $\mathrm{C}^{12} \mathrm{H}_{3} \mathrm{~N}^{14} \mathrm{H}_{2}$ & 3- 261 & Not Reported & Ground & & & 45458.06 & \\
\hline
\end{tabular}




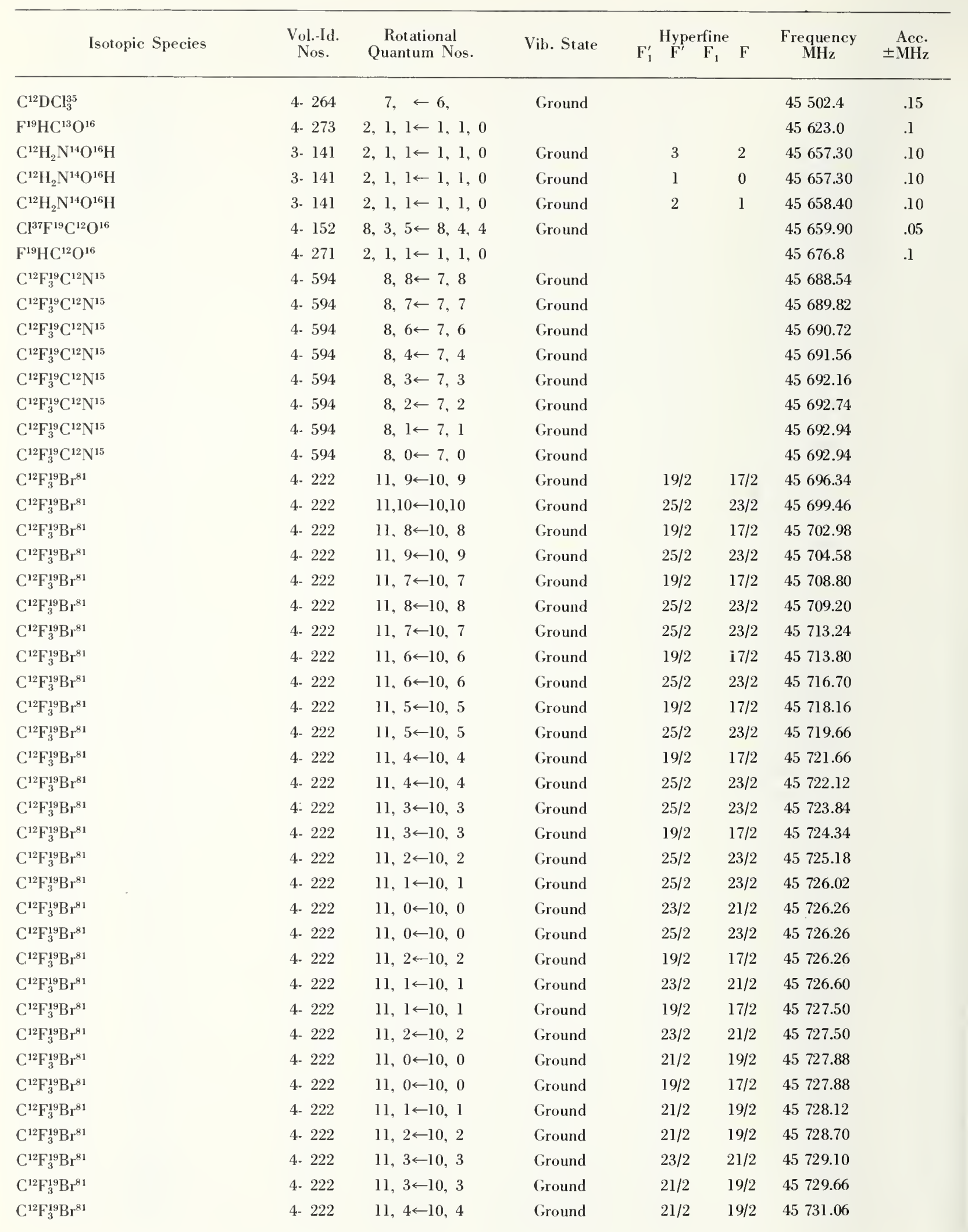




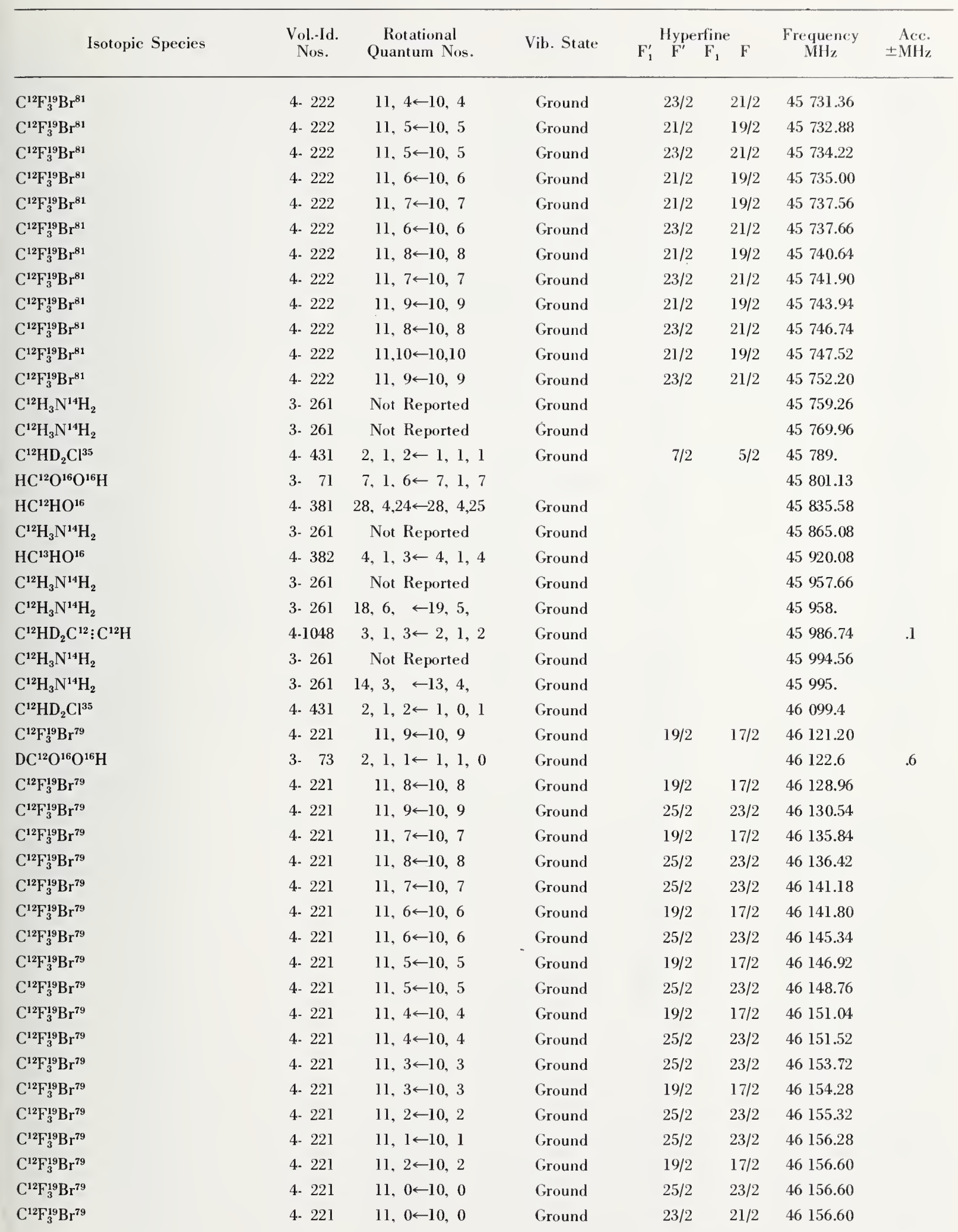




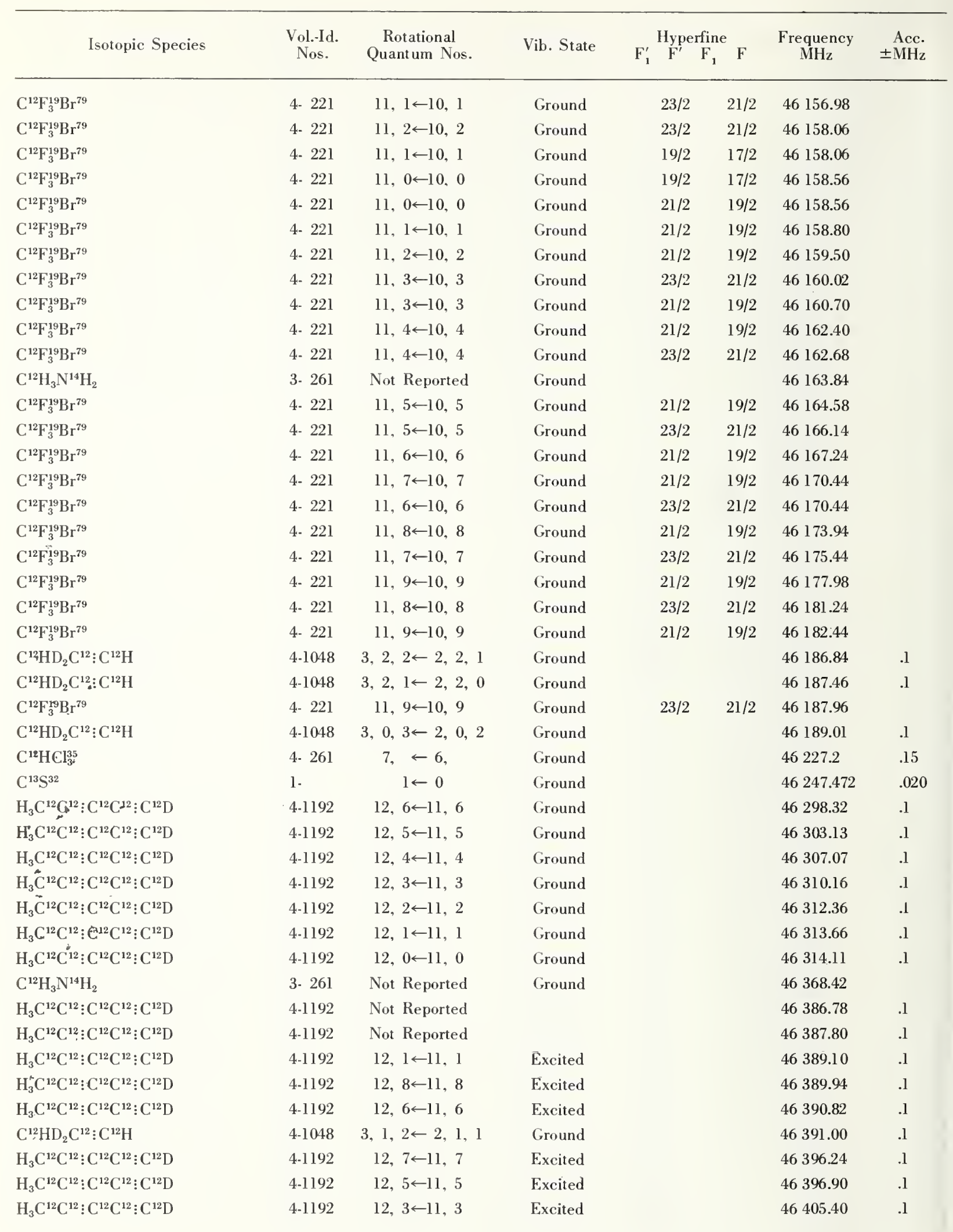




\begin{tabular}{|c|c|c|c|c|c|c|c|c|}
\hline Isotopic Species & $\begin{array}{l}\text { Vol.-Id. } \\
\text { Nos. }\end{array}$ & $\begin{array}{c}\text { Rotational } \\
\text { Quantum Nos. }\end{array}$ & Vib. State & $\mathrm{F}_{1}^{\prime}$ & $\begin{array}{c}\text { Hyperfine } \\
\mathrm{F}^{\prime} \quad \mathrm{F}_{1}\end{array}$ & $\mathrm{~F}$ & $\begin{array}{c}\text { Frequency } \\
\mathrm{MHz}^{-}\end{array}$ & $\begin{aligned} & \text { Acc. } \\
\pm & \mathrm{MHz}_{2}\end{aligned}$ \\
\hline $\mathrm{H}_{3} \mathrm{C}^{12} \mathrm{C}^{12}: \mathrm{C}^{12} \mathrm{C}^{12}: \mathrm{C}^{12} \mathrm{D}$ & $4 \cdot 1192$ & $12,5 \leftarrow 11,5$ & Excited & & & & 46405.40 & .1 \\
\hline $\mathrm{C}^{12} \mathrm{HD}_{2} \mathrm{Cl}^{35}$ & 4- 431 & $2,1,1 \leftarrow 1,1,0$ & Ground & & $7 / 2$ & $5 / 2$ & 46407 & \\
\hline $\mathrm{H}_{3} \mathrm{C}^{12} \mathrm{C}^{12}: \mathrm{C}^{12} \mathrm{C}^{12} \vdots \mathrm{C}^{12} \mathrm{D}$ & $4-1192$ & $12,2 \leftarrow 11,2$ & Excited & & & & 46408.54 & .1 \\
\hline $\mathrm{H}_{3} \mathrm{C}^{12} \mathrm{C}^{12}: \mathrm{C}^{12} \mathrm{C}^{12}: \mathrm{C}^{12} \mathrm{D}$ & 4-1192 & $12,4 \leftarrow 11,4$ & Excited & & & & 46408.54 & .1 \\
\hline $\mathrm{H}_{3} \mathrm{C}^{12} \mathrm{C}^{12}: \mathrm{C}^{12} \mathrm{C}^{12}: \mathrm{C}^{12} \mathrm{D}$ & 4-1192 & $12,3 \leftarrow 11,3$ & Excited & & & & 46410.76 & .1 \\
\hline $\mathrm{H}_{3} \mathrm{C}^{12} \mathrm{C}^{12}: \mathrm{C}^{12} \mathrm{C}^{12}: \mathrm{C}^{12} \mathrm{D}$ & 4-1192 & $12,1 \leftarrow 11,1$ & Excited & & & & 46410.76 & .1 \\
\hline $\mathrm{H}_{3} \mathrm{C}^{12} \mathrm{C}^{12}: \mathrm{C}^{12} \mathrm{C}^{12}: \mathrm{C}^{12} \mathrm{D}$ & 4-1192 & $12,0 \leftarrow 11,0$ & Excited & & & & 46411.82 & .1 \\
\hline $\mathrm{H}_{3} \mathrm{C}^{12} \mathrm{C}^{12}: \mathrm{C}^{12} \mathrm{C}^{12}: \mathrm{C}^{12} \mathrm{D}$ & 4-1192 & $12,2 \leftarrow 11,2$ & Excited & & & & 46412.42 & .1 \\
\hline $\mathrm{S}_{2}^{32} \mathrm{O}^{16}$ & 4-1821 & $1,1,1 \leftarrow 0,0,0$ & Ground & & & & 46421.6 & \\
\hline $\mathrm{H}_{3} \mathrm{C}^{12} \mathrm{C}^{12}: \mathrm{C}^{12} \mathrm{C}^{12}: \mathrm{C}^{12} \mathrm{D}$ & 4-1192 & $12,1 \leftarrow 11,1$ & Excited & & & & 46436.04 & .1 \\
\hline $\mathrm{Cl}^{37} \mathrm{O}_{2}^{16}$ & 4-1382 & $3,1,2 \leftarrow 3,0,3$ & Ground & & 5 & 5 & 46503.6 & .2 \\
\hline $\mathrm{Cl}^{37} \mathrm{O}_{2}^{16}$ & 4-1382 & $3,1,2 \leftarrow 3,0,3$ & Ground & & 4 & 4 & 46539.0 & 2 \\
\hline $\mathrm{C}^{12} \mathrm{H}_{3} \mathrm{~N}^{14} \mathrm{H}_{2}$ & 3- 261 & Not Reported & Ground & & & & 46544.84 & \\
\hline $\mathrm{C}^{12} \mathrm{H}_{3} \mathrm{~N}^{14} \mathrm{H}_{2}$ & 3. 261 & $7,3, \leftarrow 8,2$, & Ground & & & & 46545 . & \\
\hline $\mathrm{Cl}^{37} \mathrm{O}_{2}^{16}$ & 4-1382 & $3,1,2 \leftarrow 3,0,3$ & Ground & & 3 & 3 & 46560.0 & .2 \\
\hline $\mathrm{Cl}^{37} \mathrm{O}_{2}^{16}$ & 4-1382 & $3,1,2 \leftarrow 3,0,3$ & Ground & & 2 & 2 & 46571.0 & .2 \\
\hline $\mathrm{C}^{12} \mathrm{H}_{3} \mathrm{~N}^{14} \mathrm{H}_{2}$ & 3- 261 & Not Reported & Ground & & & & 46575.18 & \\
\hline $\mathrm{HC}^{12} \mathrm{O}^{16} \mathrm{O}^{16} \mathrm{H}$ & 3. 71 & $2,1,1 \leftarrow 1,1,0$ & & & & & 46581.22 & .29 \\
\hline $\mathrm{C}^{12} \mathrm{H}_{3} \mathrm{O}^{16} \mathrm{H}$ & 3- 211 & Not Reported & & & & & 46610 & \\
\hline $\mathrm{C}^{12} \mathrm{H}_{3} \mathrm{P}^{31} \mathrm{H}_{2}$ & 3- 271 & $2,1,2 \leftarrow 1,1,0$ & Ground & & & & 46685.8 & .1 \\
\hline $\mathrm{C}^{12} \mathrm{H}_{3} \mathrm{C}^{12}: \mathrm{C}^{12} \mathrm{D}$ & 4-1045 & $3,2 \leftarrow 2,2$ & Ground & & & & 46725.32 & .1 \\
\hline $\mathrm{C}^{12} \mathrm{H}_{3} \mathrm{C}^{12}: \mathrm{C}^{12} \mathrm{D}$ & $4-1045$ & $3,1 \leftarrow 2,1$ & Ground & & & & 46727.86 & .1 \\
\hline $\mathrm{C}^{12} \mathrm{H}_{3} \mathrm{C}^{12}: \mathrm{C}^{12} \mathrm{D}$ & $4-1045$ & $3,0 \leftarrow 2,0$ & Ground & & & & 46728.72 & .1 \\
\hline $\mathrm{C}^{12} \mathrm{H}_{3} \mathrm{~N}^{14} \mathrm{H}_{2}$ & 3- 261 & Not Reported & Ground & & & & 46771.70 & \\
\hline $\mathrm{Cl}^{37} \mathrm{O}_{2}^{16}$ & 4-1382 & $3,1,2 \leftarrow 3,0,3$ & Ground & & & & 46786.6 & \\
\hline $\mathrm{C}^{12} \mathrm{H}_{3} \mathrm{P}^{31} \mathrm{H}_{2}$ & 3- 271 & $2,1,2 \leftarrow 1,1,1$ & Ground & & & & 46787.4 & .1 \\
\hline $\mathrm{C}^{12} \mathrm{H}_{3} \mathrm{P}^{31} \mathrm{H}_{2}$ & 3- 271 & $2,0,2 \leftarrow 1,0,1$ & Ground & & & & 46789.2 & .1 \\
\hline $\mathrm{C}^{12} \mathrm{H}_{3} \mathrm{P}^{31} \mathrm{H}_{2}$ & 3- 271 & $2,0,2 \leftarrow 1,0,1$ & Ground & & & & 46791.4 & .1 \\
\hline $\mathrm{C}^{12} \mathrm{H}_{3} \mathrm{P}^{31} \mathrm{H}_{2}$ & 3- 271 & $2,1,1 \leftarrow 1,1,0$ & Ground & & & & 46791.5 & .1 \\
\hline $\mathrm{C}^{12} \mathrm{H}_{3} \mathrm{P}^{31} \mathrm{H}_{2}$ & 3- 271 & $2,1,2 \leftarrow 1,1,1$ & Ground & & & & 46827.3 & .1 \\
\hline $\mathrm{C}^{12} \mathrm{H}_{3} \mathrm{~N}^{14} \mathrm{H}_{2}$ & 3. 261 & Not Reported & Ground & & & & 46855.6 & \\
\hline $\mathrm{C}^{12} \mathrm{H}_{3} \mathrm{P}^{31} \mathrm{H}_{2}$ & 3. 271 & $2,1,1 \leftarrow 1,1,0$ & Ground & & & & 46895.1 & .5 \\
\hline $\mathrm{C}^{12} \mathrm{H}_{3} \mathrm{P}^{31} \mathrm{H}_{2}$ & 3- 271 & $2,1,2 \leftarrow 1,1,1$ & Ground & & & & 46904.6 & .1 \\
\hline $\mathrm{P}^{31} \mathrm{~F}_{3}^{19}$ & 4-1681 & $3,1 \leftarrow 2,1$ & Ground & & & & 46918.82 & .18 \\
\hline $\mathrm{P}^{31} \mathrm{~F}_{3}^{19}$ & $4 \cdot 1681$ & $3,0 \leftarrow 2,0$ & Ground & & & & 46918.82 & .18 \\
\hline $\mathrm{P}^{31} \mathrm{~F}_{3}^{19}$ & 4-1681 & $3,2 \leftarrow 2,2$ & Ground & & & & 46919.02 & .18 \\
\hline $\mathrm{P}^{31} \mathrm{~F}_{3}^{19}$ & 4-1681 & $3, \leftarrow 2$, & Excited & & & & 46940. & 10. \\
\hline $\mathrm{C}^{12} \mathrm{H}_{3} \mathrm{P}^{31} \mathrm{H}_{2}$ & 3- 271 & $2,0,2 \leftarrow 1,0,1$ & Ground & & & & 46940.1 & .1 \\
\hline $\mathrm{C}^{12} \mathrm{H}_{3} \mathrm{P}^{31} \mathrm{H}_{2}$ & 3- 271 & $2,1,1 \leftarrow 1,1,0$ & Ground & & & & $46975.7^{\prime}$ & .1 \\
\hline $\mathrm{C}^{12} \mathrm{H}_{2} \mathrm{DF}^{19}$ & 4. 465 & $1,0,1 \leftarrow 0,0,0$ & Ground & & & & 47002.52 & .1 \\
\hline $\mathrm{P}^{31} \mathrm{~F}_{3}^{19}$ & $4-1681$ & $3, \leftarrow 2$, & Excited & & & & 47010 & 10 \\
\hline $\mathrm{C}^{13} \mathrm{H}_{3} \mathrm{O}^{16} \mathrm{H}$ & $3 \cdot 213$ & $1,0,1 \leftarrow 0,0,0$ & Ground & & & & 47019.5 & 1.0 \\
\hline $\mathrm{C}^{13} \mathrm{H}_{3} \mathrm{O}^{16} \mathrm{H}$ & 3. 213 & $1,0,1 \leftarrow 0,0,0$ & Ground & & & & 47030.16 & .5 \\
\hline $\mathrm{C}^{12} \mathrm{H}_{3} \mathrm{~N}^{14} \mathrm{H}_{2}$ & 3- 261 & Not Reported & Ground & & & & 47032.08 & \\
\hline $\mathrm{P}^{31} \mathrm{~F}_{3}^{19}$ & 4-1681 & $3, \leftarrow 2$ & Excited & & & & 47033 & 10. \\
\hline
\end{tabular}




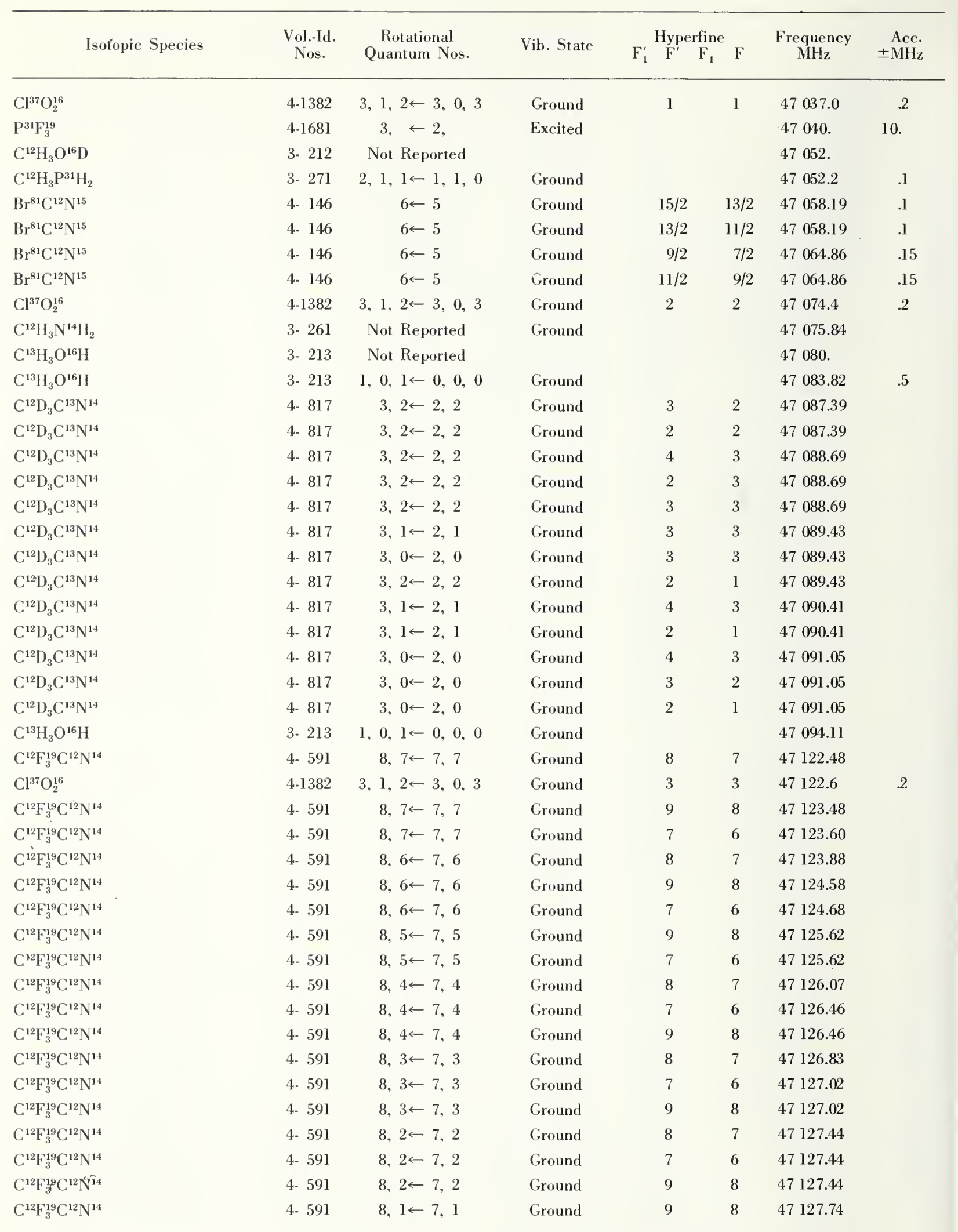




\begin{tabular}{|c|c|c|c|c|c|c|c|}
\hline Isotopic Species & $\begin{array}{l}\text { Vol.-Id. } \\
\text { Nos. }\end{array}$ & $\begin{array}{c}\text { Rotational } \\
\text { Quantum Nos. }\end{array}$ & Vib. State & $\mathrm{F}_{1}^{\prime} \mathrm{F}^{\prime} \mathrm{Fyperfi}$ & i $F$ & $\begin{array}{c}\text { Frequency } \\
\mathrm{MH}_{t}\end{array}$ & $\begin{aligned} & \text { Acc. } \\
\pm & \mathrm{MH} \%\end{aligned}$ \\
\hline $\mathrm{C}^{12} \mathrm{~F}_{3}^{19} \mathrm{C}^{12} \mathrm{~N}^{14}$ & 4. 591 & $8,0 \leftarrow 7,0$ & Ground & 8 & 7 & 47127.74 & \\
\hline $\mathrm{C}^{12} \mathrm{~F}_{3}^{19} \mathrm{C}^{12} \mathrm{~N}^{14}$ & 4- 591 & $8,0 \leftarrow 7,0$ & Ground & 7 & 6 & 47127.74 & \\
\hline $\mathrm{C}^{12} \mathrm{~F}_{3}^{19} \mathrm{C}^{12} \mathrm{~N}^{14}$ & 4- 591 & $8,0 \leftarrow 7,0$ & Ground & 9 & 8 & 47127.74 & \\
\hline $\mathrm{C}^{12} \mathrm{~F}_{3}^{19} \mathrm{C}^{12} \mathrm{~N}^{14}$ & 4- 591 & $8,1 \leftarrow 7,1$ & Ground & 7 & 6 & 47127.74 & \\
\hline $\mathrm{C}^{12} \mathrm{~F}_{3}^{19} \mathrm{C}^{12} \mathrm{~N}^{14}$ & 4. 591 & $8,1 \leftarrow 7,1$ & Ground & 8 & 7 & 47127.74 & \\
\hline $\mathrm{C}^{12} \mathrm{D}_{3} \mathrm{C}^{12} \mathrm{~N}^{14}$ & 4- 816 & $3,2 \leftarrow 2,2$ & Ground & 3 & 2 & 47143.85 & \\
\hline $\mathrm{C}^{12} \mathrm{D}_{3} \mathrm{C}^{12} \mathrm{~N}^{14}$ & 4- 816 & $3,2 \leftarrow 2,2$ & Ground & 2 & 2 & 47143.85 & \\
\hline $\mathrm{C}^{12} \mathrm{D}_{3} \mathrm{C}^{12} \mathrm{~N}^{14}$ & 4- 816 & $3,1 \leftarrow 2,1$ & Ground & 3 & 3 & 47146.00 & \\
\hline $\mathrm{C}^{12} \mathrm{D}_{3} \mathrm{C}^{12} \mathrm{~N}^{14}$ & 4. 816 & $3,2 \leftarrow 2,2$ & Ground & 2 & 1 & 47146.00 & \\
\hline $\mathrm{C}^{12} \mathrm{D}_{3} \mathrm{C}^{12} \mathrm{~N}^{14}$ & 4- 816 & $3,0 \leftarrow 2,0$ & Ground & 3 & 3 & 47146.00 & \\
\hline $\mathrm{C}^{12} \mathrm{D}_{3} \mathrm{C}^{12} \mathrm{~N}^{14}$ & 4- 816 & $3,1 \leftarrow 2,1$ & Ground & 3 & 2 & 47146.68 & \\
\hline $\mathrm{C}^{12} \mathrm{D}_{3} \mathrm{C}^{12} \mathrm{~N}^{14}$ & 4. 816 & $3,1 \leftarrow 2,1$ & Ground & 4 & 3 & 47147.00 & \\
\hline $\mathrm{C}^{12} \mathrm{D}_{3} \mathrm{C}^{12} \mathrm{~N}^{14}$ & 4- 816 & $3,1 \leftarrow 2,1$ & Ground & 2 & 1 & 47147.00 & \\
\hline $\mathrm{C}^{12} \mathrm{D}_{3} \mathrm{C}^{12} \mathrm{~N}^{14}$ & 4- 816 & $3,0 \leftarrow 2,0$ & Ground & 2 & 1 & 47147.60 & \\
\hline $\mathrm{C}^{12} \mathrm{D}_{3} \mathrm{C}^{12} \mathrm{~N}^{14}$ & 4- 816 & $3,0 \leftarrow 2,0$ & Ground & 4 & 3 & 47147.60 & \\
\hline $\mathrm{C}^{12} \mathrm{D}_{3} \mathrm{C}^{12} \mathrm{~N}^{14}$ & 4- 816 & $3,0 \leftarrow 2,0$ & Ground & 3 & 2 & 47147.60 & \\
\hline $\mathrm{Cl}^{37} \mathrm{O}_{2}^{16}$ & 4-1382 & $3,1,2 \leftarrow 3,0,3$ & Ground & 4 & 4 & 47175.7 & .2 \\
\hline $\mathrm{C}^{13} \mathrm{H}_{3} \mathrm{O}^{16} \mathrm{H}$ & 3- 213 & $1,0,1 \leftarrow 0,0,0$ & Ground & & & 47205.20 & .5 \\
\hline $\mathrm{C}^{13} \mathrm{H}_{3} \mathrm{O}^{16} \mathrm{H}$ & 3. 213 & $1,0,1 \leftarrow 0,0,0$ & Ground & & & 47209.63 & .5 \\
\hline $\mathrm{C}^{12} \mathrm{H}_{3} \mathrm{~N}^{14} \mathrm{H}_{2}$ & 3- 261 & Not Reported & Ground & & & 47239.84 & \\
\hline $\mathrm{C}^{12} \mathrm{H}_{3} \mathrm{O}^{16} \mathrm{D}$ & 3- 212 & Not Reported & & & & 47266 & \\
\hline $\mathrm{C}^{12} \mathrm{H}_{3} \mathrm{~N}^{14} \mathrm{H}_{2}$ & 3- 261 & Not Reported & Ground & & & 47334.60 & \\
\hline $\mathrm{Br}^{79} \mathrm{C}^{12} \mathrm{~N}^{15}$ & 4. 145 & $6 \leftarrow 5$ & Ground & $13 / 2$ & $11 / 2$ & 47334.84 & .10 \\
\hline $\mathrm{Br}^{79} \mathrm{C}^{12} \mathrm{~N}^{15}$ & 4- 145 & $6 \leftarrow 5$ & Ground & $15 / 2$ & $13 / 2$ & 47334.84 & .10 \\
\hline $\mathrm{C}^{12} \mathrm{H}_{3} \mathrm{~N}^{14} \mathrm{H}_{2}$ & 3- 261 & $18,6, \leftarrow 19,5$, & Ground & & & 47335. & \\
\hline $\mathrm{Br}^{79} \mathrm{C}^{12} \mathrm{~N}^{15}$ & 4- 145 & $6 \leftarrow 5$ & Ground & $9 / 2$ & $7 / 2$ & 47342.44 & .10 \\
\hline $\mathrm{Br}^{79} \mathrm{C}^{12} \mathrm{~N}^{15}$ & 4- 145 & $6 \leftarrow 5$ & Ground & $11 / 2$ & $9 / 2$ & 47342.44 & .10 \\
\hline $\mathrm{C}^{12} \mathrm{H}_{3} \mathrm{O}^{16} \mathrm{D}$ & 3- 212 & Not Reported & & & & 47346 & \\
\hline $\mathrm{C}^{12} \mathrm{H}_{3} \mathrm{O}^{16} \mathrm{D}$ & 3- 212 & $1,0,1 \leftarrow 0,0,0$ & & & & 47359.7 & \\
\hline $\mathrm{O}^{16} \mathrm{C}^{12} \mathrm{~S}^{34}$ & 4- 523 & $4 \leftarrow 3$ & Ground & & & 47462.40 & .05 \\
\hline $\mathrm{C}^{12} \mathrm{H}_{3} \mathrm{~N}^{14} \mathrm{H}_{2}$ & 3- 261 & Not Reported & Ground & & & 47608.08 & \\
\hline$\left(\mathrm{C}^{12} \mathrm{H}_{3}\right)_{2} \mathrm{~S}^{32}$ & 3. 601 & $9,2,7 \leftarrow 9,1,8$ & Ground & & & 47641.04 & .05 \\
\hline$\left(\mathrm{C}^{12} \mathrm{H}_{3}\right)_{2} \mathrm{~S}^{32}$ & 3- 601 & $9,2,7 \leftarrow 9,1,8$ & Ground & & & 47641.70 & .05 \\
\hline$\left(\mathrm{C}^{12} \mathrm{H}_{3}\right)_{2} \mathrm{~S}^{32}$ & 3- 601 & $9,2,7 \leftarrow 9,1,8$ & Ground & & & 47642.37 & .05 \\
\hline$\left(\mathrm{C}^{12} \mathrm{H}_{3}\right)_{2} \mathrm{~S}^{32}$ & 3- 601 & $11,3,8 \leftarrow 11,2,9$ & Ground & & & 47653.80 & .05 \\
\hline$\left(\mathrm{C}^{12} \mathrm{H}_{3}\right)_{2} \mathrm{~S}^{32}$ & 3- 601 & $11,3,8 \leftarrow 11,2,9$ & Ground & & & 47654.47 & .05 \\
\hline$\left(\mathrm{C}^{12} \mathrm{H}_{3}\right)_{2} \mathrm{~S}^{32}$ & 3- 601 & $11,3,8 \leftarrow 11,2,9$ & Ground & & & 47655.14 & .05 \\
\hline$\left(\mathrm{C}^{12} \mathrm{H}_{3}\right)_{2} \mathrm{O}^{16}$ & 3- 591 & $1,1,1 \leftarrow 0,0,0$ & Ground & & & 47675.4 & .2 \\
\hline $\mathrm{Cl}^{35} \mathrm{O}_{2}^{16}$ & 4-1381 & $3,1,2 \leftarrow 3,0,3$ & Ground & 5 & 5 & 47697,2 & .2 \\
\hline $\mathrm{C}^{12} \mathrm{H}_{3} \mathrm{~N}^{14} \mathrm{H}_{2}$ & 3- 261 & Not Reported & Ground & & & 47732.44 & \\
\hline $\mathrm{Cl}^{35} \mathrm{O}_{2}^{16}$ & 4-1381 & $3,1,2 \leftarrow 3,0,3$ & Ground & 4 & 4 & 47739.8 & .2 \\
\hline $\mathrm{C}^{13} \mathrm{H}_{3} \mathrm{O}^{16} \mathrm{H}$ & 3- 213 & Not Reported & & & & 47760. & \\
\hline $\mathrm{Cl}^{35} \mathrm{O}_{2}^{16}$ & 4-1381 & $3,1,2 \leftarrow 3,0,3$ & Ground & 3 & 3 & 47764.6 & .2 \\
\hline$\left(\mathrm{C}^{12} \mathrm{H}_{3}\right)_{2} \mathrm{~S}^{32}$ & 3- 601 & $6,3,3 \leftarrow 6,2,4$ & Ground & & & 47775.11 & .05 \\
\hline$\left(\mathrm{C}^{12} \mathrm{H}_{3}\right)_{2} \mathrm{~S}^{32}$ & 3- 601 & $6,3,3 \leftarrow 6,2,4$ & Ground & & & 47776.06 & .05 \\
\hline
\end{tabular}




\begin{tabular}{|c|c|c|c|c|c|c|c|}
\hline Isotopic Species & $\begin{array}{l}\text { Vol.-Id. } \\
\text { Nos. }\end{array}$ & $\begin{array}{l}\text { Rotational } \\
\text { Quant um Nos. }\end{array}$ & Vib. State & $\mathrm{F}_{1}^{\prime} \stackrel{\text { Hyperfine }}{\mathrm{F}^{\prime}} \quad \mathrm{F}_{1}$ & $\mathbf{F}$ & $\begin{array}{c}\text { Frequency } \\
\mathrm{MHz}\end{array}$ & $\begin{aligned} \text { Acc. } \\
\pm \mathrm{MHz}\end{aligned}$ \\
\hline$\left(\mathrm{C}^{12} \mathrm{H}_{3}\right)_{2} \mathrm{~S}^{32}$ & 3- 601 & $6,3,3 \leftarrow 6,2,4$ & Ground & & & 47777.01 & .05 \\
\hline $\mathrm{Cl}^{35} \mathrm{O}_{2}^{16}$ & 4-1381 & $3,1,2 \leftarrow 3,0,3$ & Ground & 2 & 2 & 47778.2 & .2 \\
\hline $\mathrm{C}^{12} \mathrm{H}_{3} \mathrm{O}^{16} \mathrm{H}$ & 3. 211 & Not Reported & & & & 47870 . & \\
\hline $\mathrm{C}^{13} \mathrm{H}_{3} \mathrm{O}^{16} \mathrm{H}$ & 3- 213 & Not Reported & & & & 47899.3 & \\
\hline $\mathrm{HDS}^{32}$ & 4-1727 & $10,5,5 \leftarrow 10,5,6$ & Ground & & & 47905.36 & .05 \\
\hline $\mathrm{C}^{13} \mathrm{H}_{3} \mathrm{O}^{16} \mathrm{H}$ & 3. 213 & Not Reported & & & & 47950.1 & \\
\hline $\mathrm{Cl}^{35} \mathrm{O}_{2}^{16}$ & 4.1381 & $3,1,2 \leftarrow 3,0,3$ & Ground & & & 47992.2 & \\
\hline $\mathrm{C}^{12} \mathrm{H}_{3} \mathrm{O}^{16} \mathrm{H}$ & 3. 211 & Not Reported & & & & 48010. & \\
\hline $\mathrm{O}^{16} \mathrm{C}^{12} \mathrm{~S}^{33}$ & 4. 522 & $4 \leftarrow 3$ & Ground & $7 / 2$ & $5 / 2$ & 48038.19 & .10 \\
\hline $\mathrm{O}^{16} \mathrm{C}^{12} \mathrm{~S}^{33}$ & 4- 522 & $2 \leftarrow 1$ & Ground & $5 / 2$ & $3 / 2$ & 48038.19 & .10 \\
\hline $\mathrm{O}^{16} \mathrm{C}^{12} \mathrm{~S}^{33}$ & 4- 522 & $4 \leftarrow 3$ & Ground & $11 / 2$ & $9 / 2$ & 48039.13 & 10 \\
\hline $\mathrm{O}^{16} \mathrm{C}^{12} \mathrm{~S}^{33}$ & 4. 522 & $4 \leftarrow 3$ & Ground & $9 / 2$ & $7 / 2$ & 48039.13 & .10 \\
\hline $\mathrm{C}^{12} \mathrm{H}_{3} \mathrm{~N}^{14} \mathrm{H}_{2}$ & $3-261$ & $7,3, \leftarrow 8,2$, & Ground & & & 48082 & \\
\hline $\mathrm{C}^{12} \mathrm{H}_{3} \mathrm{O}^{16} \mathrm{H}$ & 3- 211 & $1,0,1 \leftarrow 0,0,0$ & Ground & & & 48178.0 & 1. \\
\hline $\mathrm{C}^{12} \mathrm{H}_{3} \mathrm{~N}^{14} \mathrm{H}_{2}$ & 3- 261 & Not Reported & Ground & & & 48180.38 & \\
\hline $\mathrm{C}^{12} \mathrm{H}_{3} \mathrm{O}^{16} \mathrm{H}$ & 3- 211 & $1,0,1 \leftarrow 0,0,0$ & Ground & & & 48192.12 & .5 \\
\hline $\mathrm{C}^{12} \mathrm{~S}^{34}$ & 1 . & $1 \leftarrow 0$ & Ground & & & $48 \div 0 \mathrm{c} .948$ & .006 \\
\hline $\mathrm{O}^{16} \mathrm{C}^{12} \mathrm{Se}^{80}$ & 4- 547 & $6 \leftarrow 5$ & Ground & & & 48211.46 & .03 \\
\hline $\mathrm{Cl}^{35} \mathrm{O}_{2}^{16}$ & 4-1381 & $3,1,2 \leftarrow 3,0,3$ & Ground & 1 & 1 & 48232.10 & .2 \\
\hline $\mathrm{C}^{12} \mathrm{H}_{3} \mathrm{~N}^{14} \mathrm{H}_{2}$ & 3- 261 & Not Reported & Ground & & & 48243.46 & \\
\hline $\mathrm{C}^{12} \mathrm{H}_{3} \mathrm{O}^{16} \mathrm{H}$ & 3- 211 & $1,0,1 \leftarrow 0,0,0$ & Ground & & & 48247.89 & .5 \\
\hline $\mathrm{C}^{12} \mathrm{H}_{3} \mathrm{O}^{16} \mathrm{H}$ & 3. 211 & $1,0,1 \leftarrow 0,0,0$ & Ground & & & 48257.49 & .5 \\
\hline $\mathrm{C}^{12} \mathrm{H}_{3} \mathrm{O}^{16} \mathrm{H}$ & 3. 211 & Not Reported & & & & 48260. & \\
\hline $\mathrm{Cl}^{35} \mathrm{O}_{2}^{16}$ & 4-1381 & $3,1,2 \leftarrow 3,0,3$ & Ground & 2 & 2 & 48276.60 & .2 \\
\hline $\mathrm{HC}^{12} \mathrm{HO}^{16}$ & 4- 381 & $4,1,3 \leftarrow 4,1,4$ & Ground & & & 48284.60 & 5 \\
\hline $\mathrm{Cl}^{35} \mathrm{O}_{2}^{16}$ & 4-1381 & $3,1,2 \leftarrow 3,0,3$ & Ground & 3 & 3 & 48336.0 & .2 \\
\hline $\mathrm{Cl}^{17} \mathrm{~F}^{19} \mathrm{C}^{12} \mathrm{O}^{16}$ & 4. 152 & $7,3,4 \leftarrow 7,4,3$ & Ground & & & 48346.65 & .05 \\
\hline $\mathrm{C}^{12} \mathrm{H}_{2} \mathrm{DC}^{12}: \mathrm{C}^{12} \mathrm{H}$ & $4-1047$ & $3,1,3 \leftarrow 2,1,2$ & Ground & & & 48346.90 & .1 \\
\hline $\mathrm{C}^{12} \mathrm{H}_{3} \mathrm{O}^{16} \mathrm{H}$ & 3- 211 & $1,0,1 \leftarrow 0,0,0$ & Ground & & & 48372.60 & .5 \\
\hline $\mathrm{C}^{12} \mathrm{H}_{3} \mathrm{O}^{16} \mathrm{H}$ & 3. 211 & $1,0,1 \leftarrow 0,0,0$ & Ground & & & 48377.09 & .5 \\
\hline $\mathrm{C}^{12} \mathrm{H}_{3} \mathrm{~N}^{14} \mathrm{H}_{2}$ & $3 \cdot 261$ & Not Reported & & & & 48385. & \\
\hline $\mathrm{C}^{12} \mathrm{H}_{3} \mathrm{~N}^{14} \mathrm{H}_{2}$ & $3-261$ & Not Reported & Ground & & & 48386.64 & \\
\hline $\mathrm{C}^{12} \mathrm{H}_{3} \mathrm{~N}^{14} \mathrm{H}_{2}$ & $3-261$ & $7,3, \leftarrow 8,2$, & Ground & & & 48387. & \\
\hline $\mathrm{C}^{12} \mathrm{H}_{3} \mathrm{~N}^{14} \mathrm{H}_{2}$ & $3-261$ & $10.1, \leftarrow 10,1$ & Ground & & & 48392.46 & \\
\hline $\mathrm{Cl}^{35} \mathrm{O}_{2}^{16}$ & 4-1381 & $3,1,2 \leftarrow 3,0,3$ & Ground & 4 & 4 & 48398.20 & .2 \\
\hline $\mathrm{C}^{12} \mathrm{H}_{3} \mathrm{~N}^{14} \mathrm{H}_{2}$ & $3-261$ & $10,1, \leftarrow 10,1$, & Ground & & & 48400.26 & \\
\hline $\mathrm{C}^{12} \mathrm{H}_{3} \mathrm{~N}^{14} \mathrm{H}_{2}$ & 3- 261 & Not Reported & Ground & & & 48404.06 & \\
\hline $\mathrm{C}^{12} \mathrm{H}_{3} \mathrm{O}^{16} \mathrm{H}$ & 3. 211 & Not Reported & & & & 48406. & \\
\hline $\mathrm{C}^{12} \mathrm{H}_{3} \mathrm{~N}^{14} \mathrm{H}_{2}$ & $3 \cdot 261$ & Not Reported & Ground & & & 48414.83 & \\
\hline $\mathrm{C}^{12} \mathrm{H}_{3} \mathrm{~N}^{14} \mathrm{H}_{2}$ & 3- 261 & $18,6, \leftarrow 19,5$, & Ground & & & 48415. & \\
\hline$\left(\mathrm{C}^{12} \mathrm{H}_{3}\right)_{2} \mathrm{~S}^{32}$ & $3-601$ & $5,2,4 \leftarrow 5,1,5$ & Ground & & & 48418.84 & .05 \\
\hline$\left(\mathrm{C}^{12} \mathrm{H}_{3}\right)_{2} \mathrm{~S}^{32}$ & $3-601$ & $5,2,4 \leftarrow 5,1,5$ & Ground & & & 48419.72 & .05 \\
\hline$\left(\mathrm{C}^{12} \mathrm{H}_{3}\right)_{2} \mathrm{~S}^{32}$ & 3- 601 & $5,2,4 \leftarrow 5,1,5$ & Ground & & & 48420.60 & .05 \\
\hline $\mathrm{O}^{16} \mathrm{C}^{13} \mathrm{~S}^{32}$ & 4. 526 & $4 \leftarrow 3$ & Ground & & & 48494.76 & .10 \\
\hline $\mathrm{O}^{16} \mathrm{C}^{12} \mathrm{~S}^{32}$ & 4. 521 & $4 \leftarrow 3$ & Excited & & & 48506.24 & .10 \\
\hline
\end{tabular}




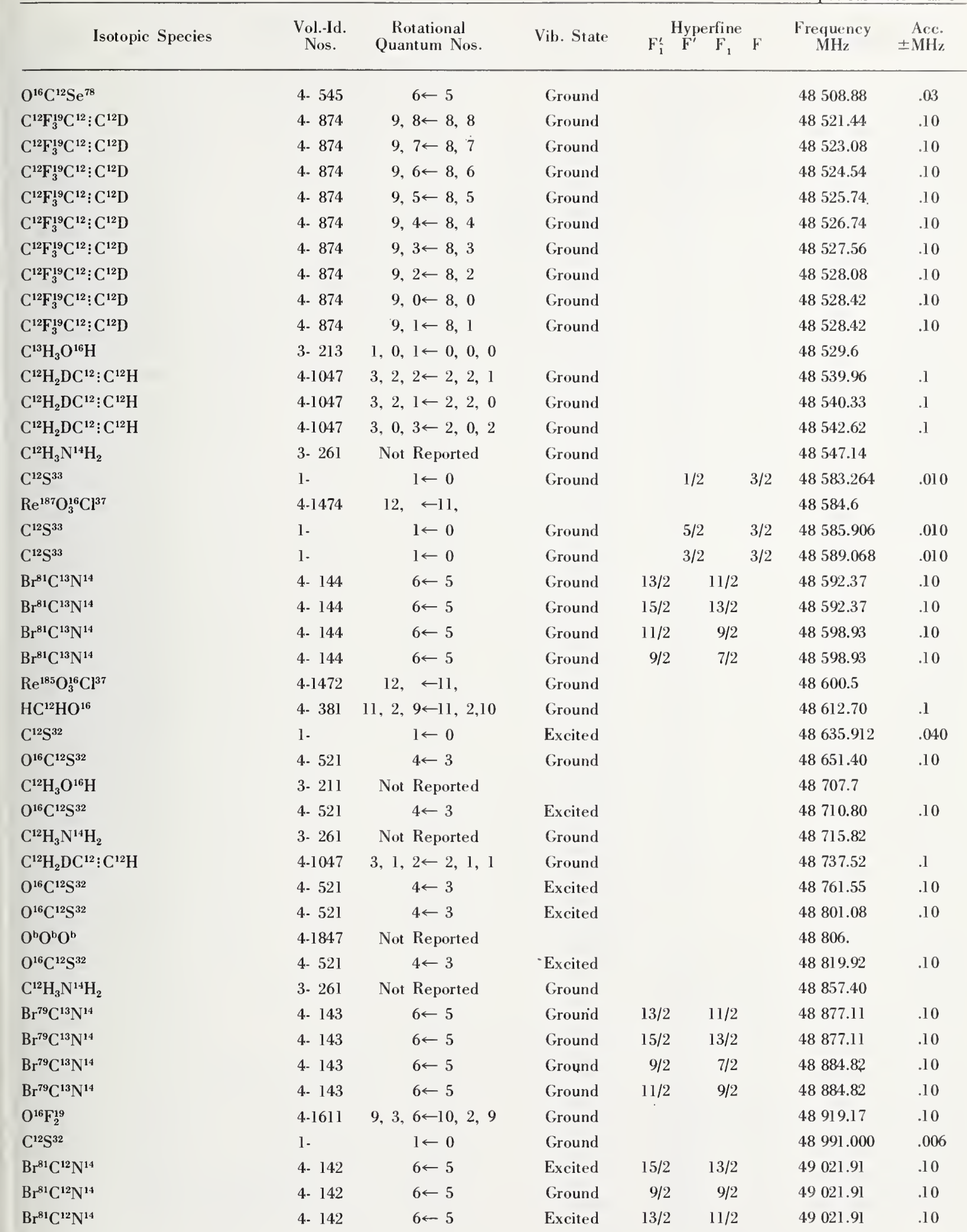




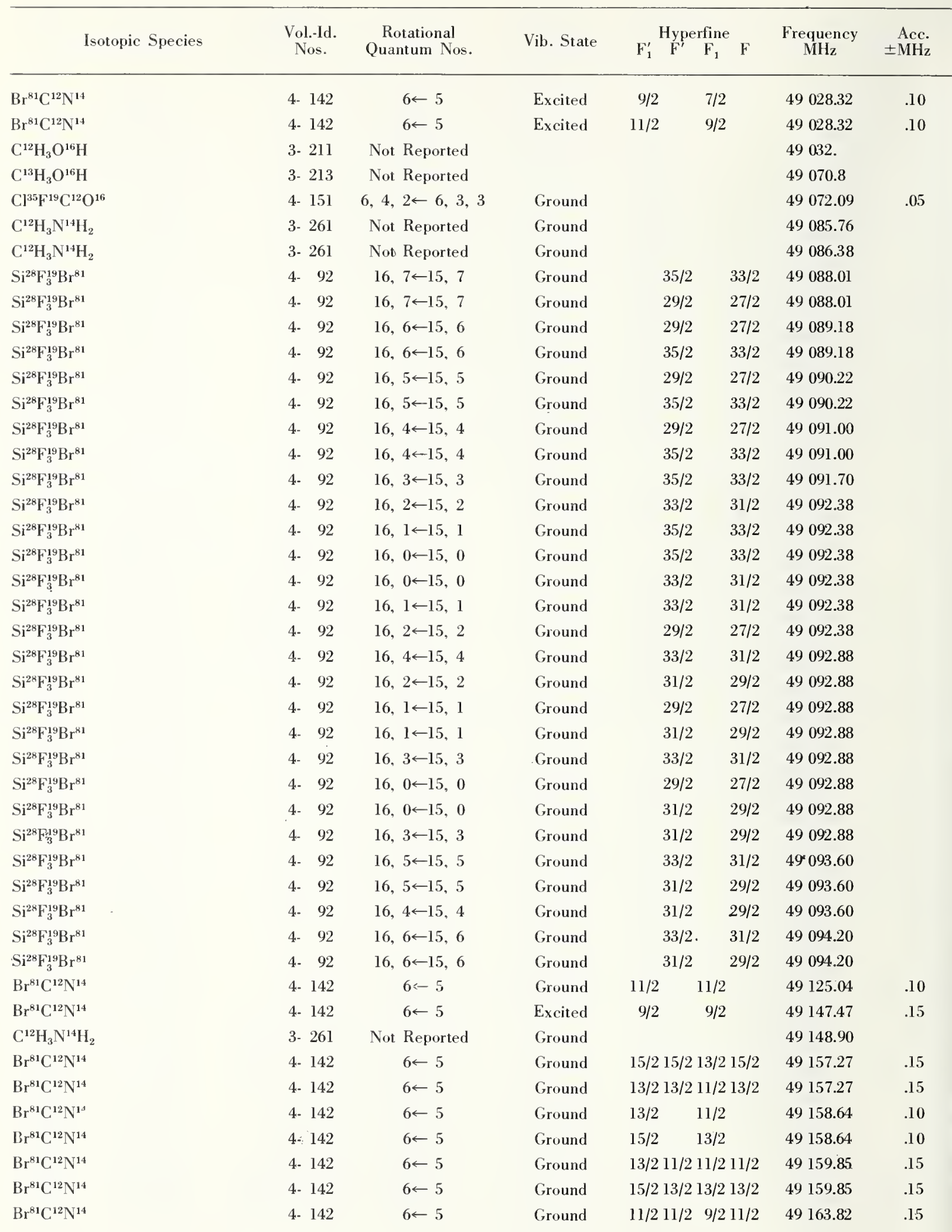


Isotopic Species $\begin{array}{ccc}\text { Vol.-Id. } & \text { Rotational } & \text { Vib. State } \\ \text { Nos. } & \text { Quantum Nos. } & \end{array}$ \begin{tabular}{ccccc}
\multicolumn{3}{c}{ Hyperfine } & Frequency & Acc. \\
$\mathrm{F}_{1}^{\prime}$ & $\mathrm{F}^{\prime} \mathrm{F}_{1}$ & $\mathrm{~F}$ & $\mathrm{MHz}$ & $\mathrm{MH} \mathrm{H}$
\end{tabular}

\begin{tabular}{|c|c|c|c|c|c|c|c|}
\hline $\mathrm{Br}^{81} \mathrm{C}^{12} \mathrm{~N}^{14}$ & 4. 142 & $6 \leftarrow 5$ & Ground & $9 / 2 \quad 9 / 2$ & $7 / 2 \quad 9 / 2$ & 49163.82 & .15 \\
\hline $\mathrm{Br}^{81} \mathrm{C}^{12} \mathrm{~N}^{14}$ & 4- 142 & $6 \leftarrow 5$ & Ground & $11 / 2$ & $9 / 2$ & 49165.10 & .10 \\
\hline $\mathrm{Br}^{81} \mathrm{C}^{12} \mathrm{~N}^{14}$ & 4- 142 & $6 \leftarrow 5$ & Ground & $9 / 2$ & $7 / 2$ & 49165.10 & .10 \\
\hline $\mathrm{Br}^{81} \mathrm{C}^{12} \mathrm{~N}^{14}$ & 4. 142 & $6 \leftarrow 5$ & Ground & $11 / 2 \quad 9 / 2$ & $9 / 2 \quad 9 / 2$ & 49166.56 & .15 \\
\hline $\mathrm{Br}^{81} \mathrm{C}^{12} \mathrm{~N}^{14}$ & 4. 142 & $6 \leftarrow 5$ & Ground & $9 / 2 \quad 7 / 2$ & $7 / 2 \quad 7 / 2$ & 49166.56 & .15 \\
\hline $\mathrm{O}^{16} \mathrm{~F}_{2}^{19}$ & 4-1611 & $13,4,10 \leftarrow 14,3,11$ & Ground & & & 49186.21 & .10 \\
\hline $\mathrm{Br}^{81} \mathrm{C}^{12} \mathrm{~N}^{14}$ & 4- 142 & $6 \leftarrow 5$ & Excited & $9 / 2$ & $9 / 2$ & 49195.39 & .15 \\
\hline $\mathrm{C}^{12} \mathrm{H}_{3} \mathrm{~N}^{14} \mathrm{H}_{2}$ & 3- 261 & $10,2, \leftarrow 9,3$, & Ground & & & 49229.64 & \\
\hline $\mathrm{Br}^{81} \mathrm{C}^{12} \mathrm{~N}^{14}$ & 4- 142 & $6 \leftarrow 5$ & Excited & $11 / 2$ & $11 / 2$ & 49244.47 & .15 \\
\hline $\mathrm{Br}^{81} \mathrm{C}^{12} \mathrm{~N}^{14}$ & 4- 142 & $6 \leftarrow 5$ & Excited & $15 / 2$ & $13 / 2$ & 49271.73 & .10 \\
\hline $\mathrm{Br}^{79} \mathrm{C}^{12} \mathrm{~N}^{14}$ & 4. 141 & $6 \leftarrow 5$ & Ground & $9 / 2$ & $9 / 2$ & 49274.99 & .10 \\
\hline $\mathrm{Br}^{81} \mathrm{C}^{12} \mathrm{~N}^{14}$ & 4- 142 & $6 \leftarrow 5$ & Excited & $13 / 2$ & $11 / 2$ & 49275.67 & .10 \\
\hline $\mathrm{Br}^{81} \mathrm{C}^{12} \mathrm{~N}^{14}$ & 4. 142 & $6 \leftarrow 5$ & Excited & $9 / 2$ & $7 / 2$ & 49276.54 & .10 \\
\hline $\mathrm{Br}^{81} \mathrm{C}^{12} \mathrm{~N}^{14}$ & 4. 142 & $6 \leftarrow-5$ & Excited & $11 / 2$ & $9 / 2$ & 49280.69 & .10 \\
\hline $\mathrm{Br}^{81} \mathrm{C}^{12} \mathrm{~N}^{14}$ & 4. 142 & $6 \leftarrow 5$ & Excited & $11 / 2$ & $11 / 2$ & 49291.25 & .15 \\
\hline $\mathrm{Br}^{81} \mathrm{C}^{12} \mathrm{~N}^{14}$ & 4- 142 & $6 \leftarrow 5$ & Ground & $13 / 2$ & $13 / 2$ & 49301.67 & .10 \\
\hline $\mathrm{Br}^{79} \mathrm{C}^{12} \mathrm{~N}^{14}$ & 4- 141 & $6 \leftarrow 5$ & Excited & $15 / 2$ & $13 / 2$ & 49302.27 & .10 \\
\hline $\mathrm{Br}^{79} \mathrm{C}^{12} \mathrm{~N}^{14}$ & 4. 141 & $6 \leftarrow 5$ & Excited & $13 / 2$ & $11 / 2$ & 49302.27 & .10 \\
\hline $\mathrm{Br}^{79} \mathrm{C}^{12} \mathrm{~N}^{14}$ & 4. 141 & $6 \leftarrow 5$ & Excited & $9 / 2$ & $7 / 2$ & 49310.06 & .10 \\
\hline $\mathrm{Br}^{79} \mathrm{C}^{12} \mathrm{~N}^{14}$ & 4. 141 & $6 \leftarrow 5$ & Excited & $11 / 2$ & $9 / 2$ & 49310.06 & .10 \\
\hline $\mathrm{Br}^{81} \mathrm{C}^{12} \mathrm{~N}^{14}$ & 4. 142 & $6 \leftarrow 5$ & Excited & $15 / 2$ & $13 / 2$ & 49318.15 & .10 \\
\hline $\mathrm{Br}^{81} \mathrm{C}^{12} \mathrm{~N}^{14}$ & 4. 142 & $6 \leftarrow 5$ & Excited & $13 / 2$ & $11 / 2$ & 49322.08 & .10 \\
\hline $\mathrm{Br}^{81} \mathrm{C}^{12} \mathrm{~N}^{14}$ & 4- 142 & $6 \leftarrow 5$ & Excited & $9 / 2$ & $7 / 2$ & 49323.03 & .10 \\
\hline $\mathrm{Br}^{81} \mathrm{C}^{12} \mathrm{~N}^{14}$ & 4. 142 & $6 \leftarrow 5$ & Excited & $11 / 2$ & $9 / 2$ & 49327.08 & .10 \\
\hline $\mathrm{Br}^{81} \mathrm{C}^{12} \mathrm{~N}^{14}$ & 4. 142 & $6 \leftarrow \cdot 5$ & Excited & $13 / 2$ & $11 / 2$ & 49385.48 & .10 \\
\hline $\mathrm{Br}^{81} \mathrm{C}^{12} \mathrm{~N}^{14}$ & 4- 142 & $6 \leftarrow 5$ & Excited & $15 / 2$ & $13 / 2$ & 49385.48 & .10 \\
\hline $\mathrm{Br}^{81} \mathrm{C}^{12} \mathrm{~N}^{14}$ & 4. 142 & $6 \leftarrow 5$ & Excited & $9 / 2$ & $7 / 2$ & 49391.95 & .10 \\
\hline $\mathrm{Br}^{81} \mathrm{C}^{12} \mathrm{~N}^{14}$ & 4- 142 & $6 \leftarrow 5$ & Excited & $11 / 2$ & $9 / 2$ & 49391.95 & .10 \\
\hline $\mathrm{Br}^{79} \mathrm{C}^{12} \mathrm{~N}^{14}$ & 4- 141 & $6 \leftarrow 5$ & Ground & $11 / 2$ & $11 / 2$ & 49398.90 & .10 \\
\hline $\mathrm{Br}^{79} \mathrm{C}^{12} \mathrm{~N}^{14}$ & 4- -141 & $6 \leftarrow 5$ & Excited & $9 / 2$ & $9 / 2$ & 49403.74 & .15 \\
\hline $\mathrm{Br}^{81} \mathrm{C}^{12} \mathrm{~N}^{14}$ & 4- 142 & $6 \leftarrow 5$ & Excited & $13 / 2$ & $13 / 2$ & 49404.69 & .15 \\
\hline $\mathrm{C}^{12} \mathrm{H}_{3} \mathrm{~N}^{14} \mathrm{H}_{2}$ & 3. 261 & $18,6, \leftarrow-19,5$, & Ground & & & 49426 & \\
\hline $\mathrm{C}^{12} \mathrm{H}_{3} \mathrm{~N}^{14} \mathrm{H}_{2}$ & 3- 261 & Not Reported & Ground & & & 49426.06 & \\
\hline $\mathrm{Br}^{81} \mathrm{C}^{12} \mathrm{~N}^{14}$ & 4- 142 & $6 \leftarrow 5$ & Excited & $9 / 2$ & $7 / 2$ & 49427.87 & .10 \\
\hline $\mathrm{Br}^{81} \mathrm{C}^{12} \mathrm{~N}^{14}$ & 4. 142 & $6 \leftarrow 5$ & Excited & $15 / 2$ & $13 / 2$ & 49427.87 & .10 \\
\hline $\mathrm{Br}^{79} \mathrm{C}^{12} \mathrm{~N}^{14}$ & 4- 141 & $6 \leftarrow 5$ & Ground & $13 / 213 / 2$ & $11 / 213 / 2$ & 49438.01 & .15 \\
\hline $\mathrm{Br}^{79} \mathrm{C}^{12} \mathrm{~N}^{14}$ & 4- 141 & $6 \leftarrow 5$ & Ground & $15 / 215 / 2$ & $13 / 215 / 2$ & 49438.01 & .15 \\
\hline $\mathrm{Br}^{79} \mathrm{C}^{12} \mathrm{~N}^{14}$ & 4. 141 & $6 \leftarrow 5$ & Ground & $15 / 2$ & $13 / 2$ & 49.439 .12 & .10 \\
\hline $\mathrm{Br}^{79} \mathrm{C}^{12} \mathrm{~N}^{14}$ & 4- 141 & $6 \leftarrow 5$ & Ground & $13 / 2$ & $11 / 2$ & 49439.12 & .10 \\
\hline $\mathrm{Br}^{79} \mathrm{C}^{12} \mathrm{~N}^{14}$ & 4. 141 & $6 \leftarrow 5$ & Ground & $13 / 211 / 2$ & $11 / 211 / 2$ & 49440.40 & .15 \\
\hline $\mathrm{Br}^{79} \mathrm{C}^{12} \mathrm{~N}^{14}$ & 4. 141 & $6 \leftarrow 5$ & Ground & $15 / 213 / 2$ & $13+213 / 2$ & 49440.40 & .15 \\
\hline $\mathrm{Br}^{79} \mathrm{C}^{12} \mathrm{~N}^{14}$ & 4. 141 & $6 \leftarrow 5$ & Excited & $15 / 2$ & $13 / 2$ & 49443.83 & .20 \\
\hline $\mathrm{Br}^{81} \mathrm{C}^{12} \mathrm{~N}^{14}$ & 4. 142 & $6 \leftarrow 5$ & Excited & $11 / 2$ & $9 / 2$ & 49444.30 & .10 \\
\hline $\mathrm{Br}^{81} \mathrm{C}^{12} \mathrm{~N}^{14}$ & 4- 142 & $6 \leftarrow 5$ & Excited & $13 / 2$ & $11 / 2$ & 49444.30 & .10 \\
\hline $\mathrm{Br}^{79} \mathrm{C}^{12} \mathrm{~N}^{14}$ & 4- 141 & $6 \leftarrow 5$ & Ground & $9 / 2 \quad 9 / 2$ & $7 / 2 \quad 9 / 2$ & 49445.65 & .15 \\
\hline
\end{tabular}




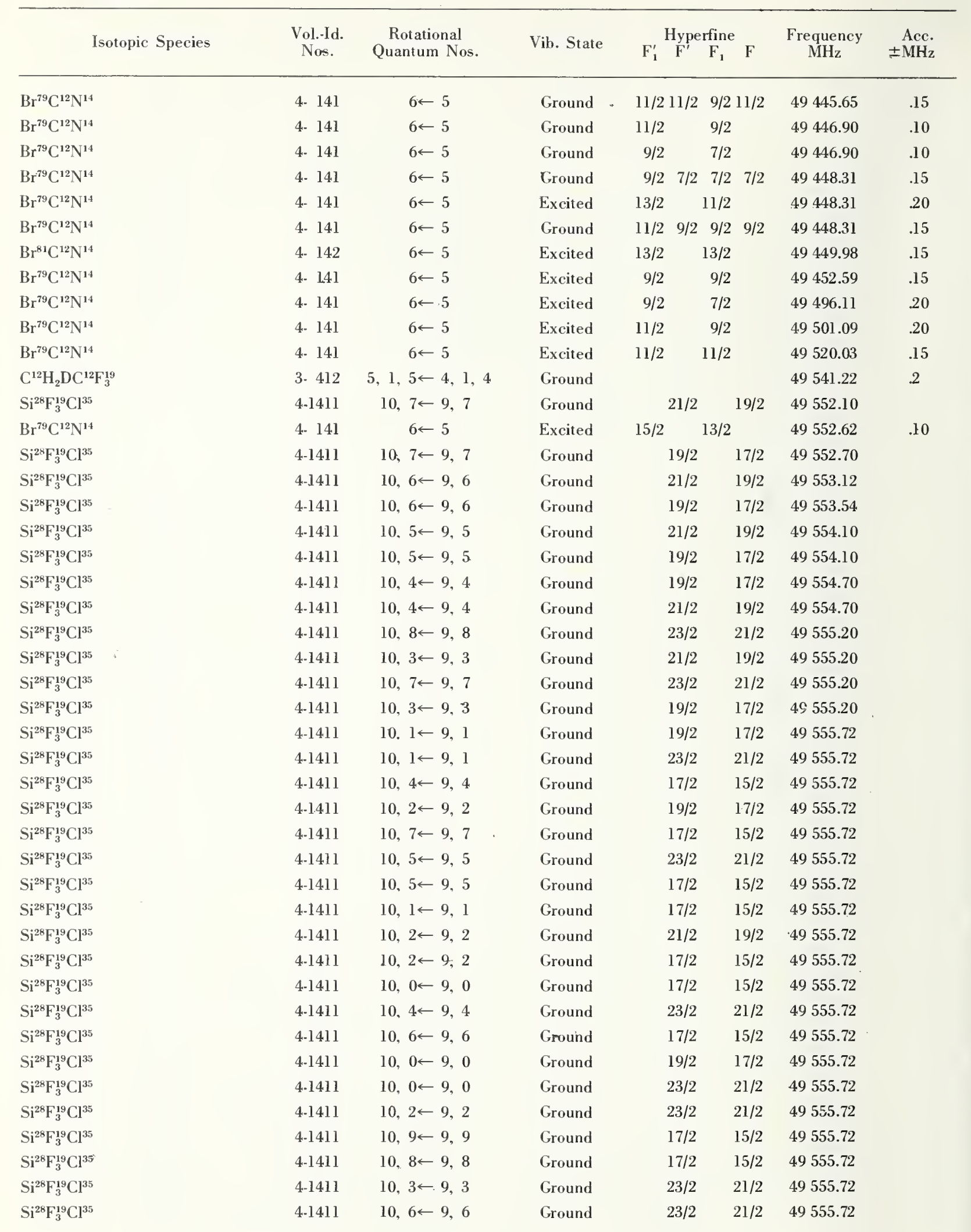




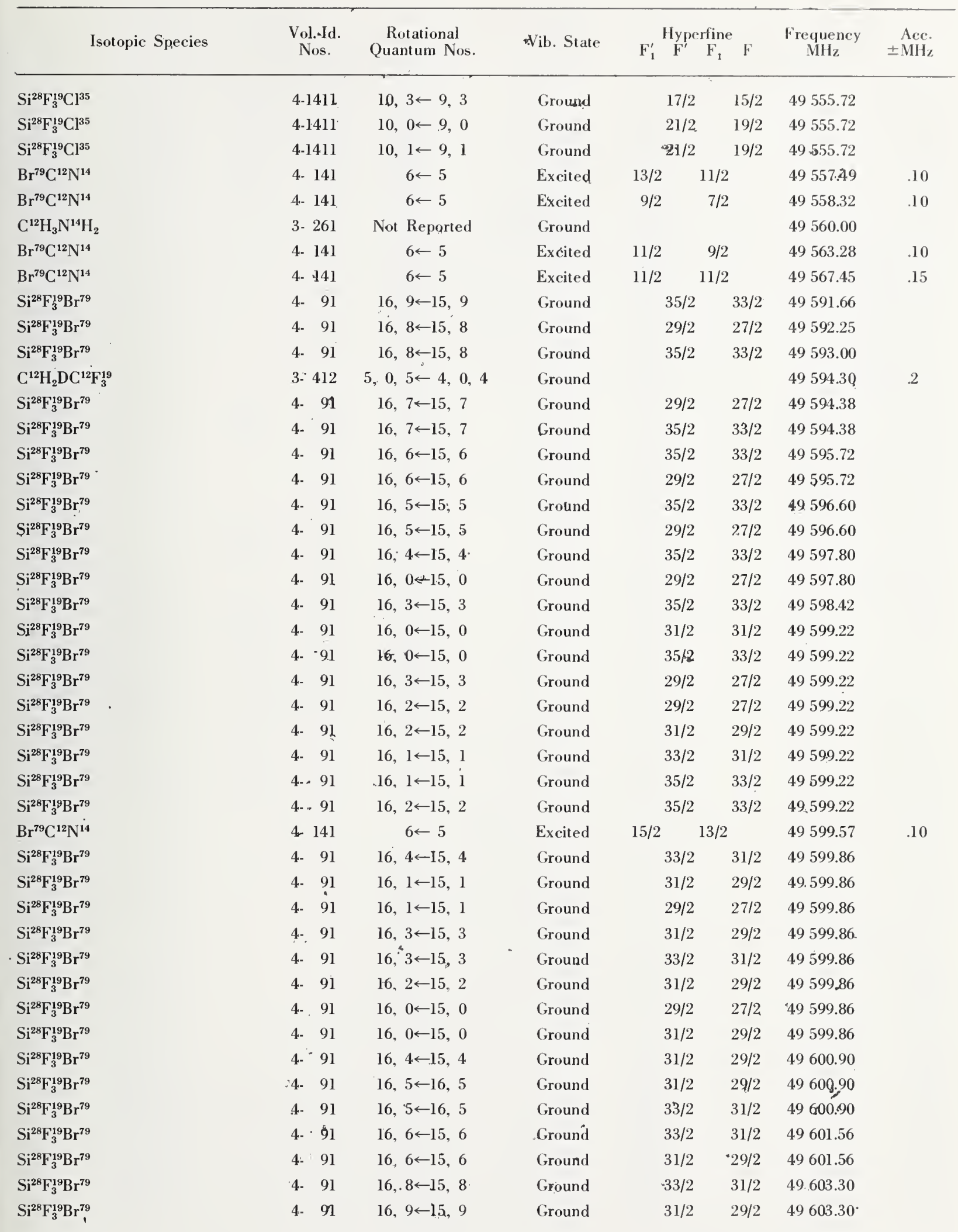




\begin{tabular}{|c|c|c|c|c|c|c|c|c|c|}
\hline Isotopic Species & $\begin{array}{l}\text { Vol.-Id. } \\
\text { Nos. }\end{array}$ & $\begin{array}{c}\text { Rotational } \\
\text { Quantum Nos. }\end{array}$ & Vib. State & $\mathrm{F}_{1}^{\prime}$ & $\mathrm{F}^{\prime}$ & $\begin{array}{c}\text { erfine } \\
F_{1}\end{array}$ & $\mathbf{F}$ & $\begin{array}{c}\text { Frequency } \\
\mathrm{MH}_{z}\end{array}$ & $\begin{aligned} & \text { Acc. } \\
\pm & \mathrm{MH}_{\mathrm{z}}\end{aligned}$ \\
\hline $\mathrm{Br}^{79} \mathrm{C}^{12} \mathrm{~N}^{14}$ & 4- 141 & $6 \leftarrow 5$ & Excited & $13 / 2$ & & $11 / 2$ & & 49604.35 & .10 \\
\hline $\mathrm{Br}^{79} \mathrm{C}^{12} \mathrm{~N}^{14}$ & 4- 141 & $6 \leftarrow 5$ & Excited & $9 / 2$ & & $7 / 2$ & & 49605.29 & .10 \\
\hline $\mathrm{Br}^{79} \mathrm{C}^{12} \mathrm{~N}^{14}$ & 4- 141 & $6 \leftarrow 5$ & Ground & $13 / 2$ & & $13 / 2$ & & 49610.43 & .15 \\
\hline $\mathrm{Br}^{79} \mathrm{C}^{12} \mathrm{~N}^{14}$ & 4- 141 & $6 \leftarrow 5$ & Excited & $11 / 2$ & & $9 / 2$ & & 49610.43 & .15 \\
\hline $\mathrm{O}^{16} \mathrm{~F}_{2}^{19}$ & $4-1611$ & $1,1,0 \leftarrow 1,0,1$ & Ground & & & & & 49613.55 & .10 \\
\hline $\mathrm{C}^{12} \mathrm{H}_{3} \mathrm{~N}^{14} \mathrm{H}_{2}$ & 3. 261 & Not Reported & Ground & & & & & 49614.02 & \\
\hline $\mathrm{C}^{12} \mathrm{H}_{2} \mathrm{DC}^{12} \mathrm{~F}_{3}^{19}$ & 3- 412 & $5,2,4 \leftarrow 4,2,3$ & Ground & & & & & 49616.02 & .2 \\
\hline $\mathrm{C}^{12} \mathrm{H}_{2} \mathrm{DC}^{12} \mathrm{~F}_{3}^{19}$ & 3- 412 & $5,4,2 \leftarrow 4,4,1$ & Ground & & & & & 49621.46 & .2 \\
\hline $\mathrm{C}^{12} \mathrm{H}_{2} \mathrm{DC}^{12} \mathrm{~F}_{3}^{19}$ & 3. 412 & $5,4,1 \leftarrow 4,4,0$ & Ground & & & & & 49621.46 & .2 \\
\hline $\mathrm{C}^{12} \mathrm{H}_{2} \mathrm{DC}^{12} \mathrm{~F}_{3}^{19}$ & 3- 412 & $5,3,3 \leftarrow 4,3,2$ & Ground & & & & & 49623.16 & .2 \\
\hline $\mathrm{C}^{12} \mathrm{H}_{2} \mathrm{DC}^{12} \mathrm{~F}_{3}^{19}$ & 3- 412 & $5,3,2 \leftarrow 4,3,1$ & Ground & & & & & 49623.16 & .2 \\
\hline $\mathrm{C}^{12} \mathrm{H}_{2} \mathrm{DC}^{12} \mathrm{~F}_{3}^{19}$ & 3- 412 & $5,2,3 \leftarrow-4,2,2$ & Ground & & & & & 49640.22 & .2 \\
\hline $\mathrm{Br}^{79} \mathrm{C}^{12} \mathrm{~N}^{14}$ & 4- 141 & $6 \leftarrow 5$ & Excited & $13 / 2$ & & $11 / 2$ & & 49666.19 & .10 \\
\hline $\mathrm{Br}^{79} \mathrm{C}^{12} \mathrm{~N}^{14}$ & 4. 141 & $6 \leftarrow 5$ & Excited & $15 / 2$ & & $13 / 2$ & & 49666.19 & .10 \\
\hline $\mathrm{C}^{12} \mathrm{D}_{3} \mathrm{~N}^{14} \mathrm{C}^{13}$ & 4- 836 & $3,2 \leftarrow 2,2$ & Ground & & & & & 49668.07 & \\
\hline $\mathrm{C}^{12} \mathrm{D}_{3} \mathrm{~N}^{14} \mathrm{C}^{13}$ & 4. 836 & $3,1 \leftarrow 2,1$ & Ground & & & & & 49670.43 & \\
\hline $\mathrm{C}^{12} \mathrm{D}_{3} \mathrm{~N}^{14} \mathrm{C}^{13}$ & 4- 836 & $3,0 \leftarrow 2,0$ & Ground & & & & & 49671.19 & \\
\hline $\mathrm{Br}^{79} \mathrm{C}^{12} \mathrm{~N}^{14}$ & 4- 141 & $6 \leftarrow 5$ & Excited & $9 / 2$ & & $7 / 2$ & & 49673.93 & .10 \\
\hline $\mathrm{Br}^{79} \mathrm{C}^{12} \mathrm{~N}^{14}$ & 4- 141 & $6 \leftarrow 5$ & Excited & $11 / 2$ & & $9 / 2$ & & 49673.93 & .10 \\
\hline $\mathrm{C}^{12} \mathrm{H}_{2} \mathrm{DC}^{12} \mathrm{~F}_{3}^{19}$ & 3. 412 & $5,1,4 \leftarrow 4,1,3$ & Ground & & & & & 49685.20 & .2 \\
\hline $\mathrm{Br}^{79} \mathrm{C}^{12} \mathrm{~N}^{14}$ & 4- 141 & $6 \leftarrow 5$ & Excited & $9 / 2$ & & $7 / 2$ & & 49709.00 & .10 \\
\hline $\mathrm{Br}^{79} \mathrm{C}^{12} \mathrm{~N}^{14}$ & 4- 141 & $6 \leftarrow 5$ & Excited & $15 / 2$ & & $13 / 2$ & & 49709.00 & .10 \\
\hline $\mathrm{Br}^{79} \mathrm{C}^{12} \mathrm{~N}^{14}$ & 4- 141 & $6 \leftarrow 5$ & Excited & $13 / 2$ & & $13 / 2$ & & 49712.00 & .15 \\
\hline $\mathrm{C}^{13} \mathrm{H}_{3} \mathrm{~F}^{19}$ & 4- 463 & $1,0 \leftarrow 0,0$ & Ground & & & & & 49724.73 & .18 \\
\hline $\mathrm{Br}^{79} \mathrm{C}^{12} \mathrm{~N}^{14}$ & 4- 141 & $6 \leftarrow 5$ & Excited & $11 / 2$ & & $9 / 2$ & & 49728.46 & .10 \\
\hline $\mathrm{Br}^{79} \mathrm{C}^{12} \mathrm{~N}^{14}$ & 4- 141 & $6 \leftarrow 5$ & Excited & $13 / 2$ & & $11 / 2$ & & 49728.46 & .10 \\
\hline $\mathrm{C}^{12} \mathrm{H}_{3} \mathrm{O}^{16} \mathrm{H}$ & 3- 211 & Not Reported & & & & & & 49750 . & \\
\hline $\mathrm{Br}^{79} \mathrm{C}^{12} \mathrm{~N}^{14}$ & 4- 141 & $6 \leftarrow 5$ & Excited & $13 / 2$ & & $13 / 2$ & & 49757.39 & .15 \\
\hline $\mathrm{F}_{2}^{19} \mathrm{O}_{2}^{16}$ & 3- 11 & $4,1,4 \leftarrow 3,0,3$ & Ground & & & & & 49860.8 & .5 \\
\hline $\mathrm{C}^{12} \mathrm{H}_{3} \mathrm{O}^{16} \mathrm{H}$ & 3- 211 & $1,0,1 \leftarrow 0,0,0$ & & & & & & 49867.2 & \\
\hline $\mathrm{F}_{2}^{19} \mathrm{O}_{2}^{16}$ & 3- 11 & $4,1,4 \leftarrow 3,0,3$ & Ground & & & & & 49870.9 & .5 \\
\hline $\mathrm{C}^{12} \mathrm{H}_{3} \mathrm{~N}^{14} \mathrm{H}_{2}$ & 3. 261 & Not Reported & Ground & & & & & 49874.58 & \\
\hline $\mathrm{F}_{2}^{19} \mathrm{O}_{2}^{16}$ & 3- 11 & $4,1,4 \leftarrow 3,0,3$ & Ground & & & & & 49880.2 & .5 \\
\hline $\mathrm{C}^{12} \mathrm{H}_{3} \mathrm{~N}^{14} \mathrm{H}_{2}$ & 3- -261 & $7,3 . \leftarrow 8,2$, & Ground & & & & & 49915. & \\
\hline $\mathrm{C}^{12} \mathrm{H}_{3} \mathrm{~N}^{14} \mathrm{H}_{2}$ & 3. 261 & Not Reported & Ground & & & & & 49952.46 & \\
\hline $\mathrm{N}^{1 \cdot} \mathrm{H}_{2} \mathrm{D}$ & 4-1773 & $2,1,2 \leftarrow 2,0,2$ & Ground & & & & & 49962.85 & .10 \\
\hline $\mathrm{O}^{16} \mathrm{~F}_{2}^{19}$ & 4-1611 & $33,6,28 \leftarrow 32,7,25$ & Ground & & & & & 50198.50 & .10 \\
\hline $\mathrm{Cl}^{37} \mathrm{~F}^{19} \mathrm{C}^{12} \mathrm{O}^{16}$ & 4. 152 & $6,3,3 \leftarrow 6,4,2$ & Ground & & & & & 50212.06 & .05 \\
\hline $\mathrm{HDO}^{16}$ & 4-1712 & $3,2,1 \leftarrow 3,2,2$ & Ground & & & & & 50236.30 & \\
\hline $\mathrm{N}_{2}^{14} \mathrm{O}^{16}$ & 4-1811 & $2 \leftarrow 1$ & Ground & 1 & 2 & 0 & 1 & 50245.63 & .15 \\
\hline $\mathrm{N}_{2}^{14} \mathrm{O}^{16}$ & 4-1811 & $2 \leftarrow 1$ & Ground & 2 & 2 & 2 & 3 & 50245.63 & .15 \\
\hline $\mathrm{N}_{2}^{14} \mathrm{O}^{16}$ & $4 \cdot 1811$ & $2 \leftarrow 1$ & Ground & 2 & 3 & 2 & 2 & 50245.63 & .15 \\
\hline $\mathrm{N}_{2}^{14} \mathrm{O}^{16}$ & $4-1811$ & $2 \leftarrow 1$ & Ground & 2 & 3 & 2 & 3 & 50245.63 & .15 \\
\hline $\mathrm{N}_{2}^{1.4} \mathrm{O}^{16}$ & 4-1811 & $2 \leftarrow 1$ & Ground & 2 & 2 & 2 & 1 & 50245.63 & .15 \\
\hline $\mathrm{N}_{2}^{14} \mathrm{O}^{16}$ & 4-1811 & $2 \leftarrow 1$ & Ground & 2 & 2 & 2 & 2 & 50245.63 & .15 \\
\hline
\end{tabular}


Vib. State

$\mathrm{F}_{1}^{\prime} \mathrm{F}^{\prime} \underset{F_{1}}{\text { Hyperfine }}$

Frequency Aces
VIl'

\begin{tabular}{|c|c|c|c|c|c|c|c|c|c|}
\hline $\mathrm{N}_{2}^{14} \mathrm{O}^{16}$ & 4-1811 & $2 \leftarrow 1$ & Cround & 1 & 0 & 0 & 1 & 50245.63 & .15 \\
\hline $\mathrm{N}_{2}^{14} \mathrm{O}^{16}$ & 4-1811 & $2 \leftarrow 1$ & Cround & 2 & 1 & 2 & 2 & 50245.63 & .15 \\
\hline $\mathrm{N}_{2}^{14} \mathrm{O}^{16}$ & 4-1811 & $2 \leftarrow 1$ & Ground & 1 & 1 & 0 & 1 & 50245.63 & .15 \\
\hline $\mathrm{N}_{2}^{14} \mathrm{O}^{16}$ & 4-1811 & $2 \leftarrow 1$ & Ground & 2 & I & 2 & 1 & 50245.63 & .15 \\
\hline $\mathrm{N}_{2}^{14} \mathrm{O}^{16}$ & 4-1811 & $2 \leftarrow 1$ & Ground & 1 & 1 & 2 & 1 & 50246.03 & .10 \\
\hline $\mathrm{N}_{2}^{14} \mathrm{O}^{16}$ & $4-1811$ & $2 \leftarrow 1$ & Ground & I & 0 & 2 & 1 & 50246.03 & .10 \\
\hline $\mathrm{N}_{2}^{14} \mathrm{O}^{16}$ & 4-1811 & $2 \leftarrow 1$ & Ground & 1 & 1 & 2 & 2 & 50246.03 & .10 \\
\hline $\mathrm{N}_{2}^{14} \mathrm{O}^{16}$ & 4-1811 & $2 \leftarrow 1$ & Ground & 2 & 2 & 1 & 1 & 50246.03 & .10 \\
\hline $\mathrm{N}_{2}^{14} \mathrm{O}^{16}$ & 4-1811 & $2 \leftarrow 1$ & Ground & 2 & 3 & 1 & 2 & 50246.03 & .10 \\
\hline $\mathrm{N}_{2}^{14} \mathrm{O}^{16}$ & 4-1811 & $2 \leftarrow 1$ & Ground & 3 & 3 & 2 & 3 & 50246.03 & .10 \\
\hline $\mathrm{N}_{2}^{14} \mathrm{O}^{16}$ & 4.1811 & $2 \leftarrow 1$ & Ground & 1 & 2 & 2 & 2 & 50246.03 & .10 \\
\hline $\mathrm{N}_{2}^{14} \mathrm{O}^{16}$ & 4-1811 & $2 \leftarrow 1$ & Ground & 3 & 2 & 2 & 3 & 50246.03 & .10 \\
\hline $\mathrm{N}_{2}^{14} \mathrm{O}^{16}$ & 4-1811 & $2 \leftarrow 1$ & Ground & 2 & 2 & 1 & 2 & 50246.03 & .10 \\
\hline $\mathrm{N}_{2}^{14} \mathrm{O}^{16}$ & 4-1811 & $2 \leftarrow 1$ & Ground & 1 & 2 & 2 & 1 & 50246.03 & .10 \\
\hline $\mathrm{N}_{2}^{14} \mathrm{O}^{16}$ & 4-1811 & $2 \leftarrow 1$ & Ground & 3 & 2 & 2 & 1 & 50246.03 & .10 \\
\hline $\mathrm{N}_{2}^{14} \mathrm{O}^{16}$ & 4-1811 & $2 \leftarrow 1$ & Ground & 1 & 2 & 2 & 3 & 50246.03 & .10 \\
\hline $\mathrm{N}_{2}^{14} \mathrm{O}^{16}$ & 4-1811 & $2 \leftarrow 1$ & Ground & 3 & 3 & 2 & 2 & 50246.03 & .10 \\
\hline $\mathrm{N}_{2}^{14} \mathrm{O}^{16}$ & 4-1811 & $2 \longleftarrow 1$ & Ground & 2 & 1 & 1 & 1 & 50246.03 & .10 \\
\hline $\mathrm{N}_{2}^{14} \mathrm{O}^{16}$ & 4-1811 & $2 \leftarrow 1$ & Ground & 3 & 2 & 2 & 2 & 50246.03 & .10 \\
\hline $\mathrm{N}_{2}^{14} \mathrm{O}^{16}$ & 4-1811 & $2 \leftarrow 1$ & Ground & 3 & 4 & 2 & 3 & 50246.03 & .10 \\
\hline $\mathrm{N}_{2}^{14} \mathrm{O}^{16}$ & 4-1811 & $2 \leftarrow 1$ & Ground & 2 & 1 & 1 & 2 & 50246.03 & .10 \\
\hline $\mathrm{N}_{2}^{14} \mathrm{O}^{16}$ & 4-1811 & $2 \leftarrow 1$ & Ground & 2 & I & 1 & 0 & 50246.03 & .10 \\
\hline $\mathrm{Re}^{187} \mathrm{O}_{3}^{16} \mathrm{Cl}^{3.5}$ & $4-1473$ & $12, \leftarrow 11$, & & & & & & 50246.1 & \\
\hline $\mathrm{N}_{2}^{14} \mathrm{O}^{16}$ & 4-1811 & $2 \leftarrow 1$ & Ground & 1 & 1 & 1 & 0 & 50246.53 & .15 \\
\hline $\mathrm{N}_{2}^{14} \mathrm{O}^{16}$ & 4-1811 & $2 \leftarrow 1$ & Ground & 1 & 1 & 1 & 1 & 50246.53 & .15 \\
\hline $\mathrm{N}_{2}^{14} \mathrm{O}^{16}$ & 4-1811 & $2 \leftarrow 1$ & Ground & 1 & 2 & 1 & 1 & 50246.53 & .15 \\
\hline $\mathrm{N}_{2}^{14} \mathrm{O}^{16}$ & 4-1811 & $2 \leftarrow 1$ & Ground & 1 & 2 & 1 & 2 & 50246.53 & .15 \\
\hline $\mathrm{N}_{2}^{14} \mathrm{O}^{16}$ & 4-1811 & $2 \leftarrow 1$ & Ground & 1 & 1 & 1 & 2 & 50246.53 & .15 \\
\hline $\mathrm{N}_{2}^{14} \mathrm{O}^{16}$ & 4-1811 & $2 \leftarrow 1$ & Ground & 1 & 0 & 1 & 1 & 50246.53 & .15 \\
\hline $\operatorname{Re}^{185} \mathrm{O}_{3}^{16} \mathrm{Cl}^{35}$ & $4-1471$ & $12, \leftarrow 11$, & & & & & & 50261.4 & \\
\hline $\mathrm{O}^{16} \mathrm{~F}_{2}^{19}$ & $4-1611$ & $18,5,13 \leftarrow 19,4,16$ & Ground & & & & & 50393.23 & .10 \\
\hline $\mathrm{C}^{12} \mathrm{H}_{3} \mathrm{~N}^{14} \mathrm{H}_{2}$ & 3- 261 & Not Reported & Ground & & & & & 50399.24 & \\
\hline $\mathrm{C}^{12} \mathrm{H}_{3} \mathrm{~N}^{14} \mathrm{H}_{2}$ & 3. 261 & Not Reported & Ground & & & & & 50423.40 & \\
\hline$\left(\mathrm{C}^{12} \mathrm{H}_{3}\right)_{2} \mathrm{~S}^{32}$ & 3- 601 & 7. $1,6 \leftarrow 7,0,7$ & Ground & & & & & 50547.58 & .05 \\
\hline$\left(\mathrm{C}^{12} \mathrm{H}_{3}\right)_{2} \mathrm{~S}^{32}$ & 3- 601 & $7,1,6 \leftarrow 7,0,7$ & Ground & & & & & 50548.33 & .05 \\
\hline$\left(\mathrm{C}^{12} \mathrm{H}_{3}\right)_{2} \mathrm{~S}^{32}$ & 3- 601 & $7,1,6 \leftarrow 7,0,7$ & Ground & & & & & 50549.11 & .05 \\
\hline $\mathrm{C}^{12} \mathrm{H}_{3} \mathrm{~N}^{14} \mathrm{H}_{2}$ & 3. 261 & Not Reported & Ground & & & & & 50558.60 & \\
\hline $\mathrm{C}^{12} \mathrm{H}_{3} \mathrm{~N}^{14} \mathrm{H}_{2}$ & $3-261$ & Not Reported & Ground & & & & & 50658,48 & \\
\hline$\left(\mathrm{C}^{12} \mathrm{H}_{3}\right)_{2} \mathrm{~S}^{32}$ & 3- 601 & $5,3,2 \leftarrow 5,2,3$ & Ground & & & & & 50797.50 & .05 \\
\hline$\left(\mathrm{C}^{12} \mathrm{H}_{3}\right)_{2} \mathrm{~S}^{32}$ & 3- 601 & $5,3,2 \leftarrow 5,2,3$ & Ground & & & & & 50798.49 & .05 \\
\hline$\left(\mathrm{C}^{12} \mathrm{H}_{3}\right)_{2} \mathrm{~S}^{32}$ & $3-601$ & $5,3,2 \leftarrow 5,2,3$ & Ground & & & & & 50799.48 & .05 \\
\hline $\mathrm{C}^{12} \mathrm{H}_{3} \mathrm{~N}^{14} \mathrm{H}_{2}$ & 3. 261 & Not Reported & Ground & & & & & 50875.60 & \\
\hline $\mathrm{HDS}^{34}$ & 4-1729 & $1,1,0 \leftarrow 1,1,1$ & Ground & & & & & 50912.27 & \\
\hline $\mathrm{C}^{12} \mathrm{H}_{3} \mathrm{~N}^{14} \mathrm{H}_{2}$ & 3- 261 & Not Reported & Ground & & & & & 50934.64 & \\
\hline $\mathrm{C}^{12} \mathrm{H}_{3} \mathrm{~N}^{14} \mathrm{H}_{2}$ & $3-261$ & Not Reported & Ground & & & & & 51048.46 & \\
\hline
\end{tabular}




\begin{tabular}{|c|c|c|c|c|c|c|}
\hline Isotopic Species & $\begin{array}{l}\text { Vol.-Id. } \\
\text { Nos. }\end{array}$ & $\begin{array}{c}\text { Rotational } \\
\text { Quantum Nos. }\end{array}$ & Vib. State & $\mathrm{F}_{1}^{\prime} \stackrel{\mathrm{F}^{\prime}}{\mathrm{F}_{1}} \mathrm{Fyperfine}$ & $\begin{array}{l}\text { Frequency } \\
\mathrm{MHz}\end{array}$ & $\begin{aligned} & \text { Acc. } \\
\pm & \mathrm{MHz}\end{aligned}$ \\
\hline $\mathrm{C}^{12} \mathrm{H}_{3} \mathrm{~F}^{19}$ & 4. 461 & $1,0 \leftarrow 0,0$ & Ground & & 51071.98 & \\
\hline $\mathrm{HDS}^{32}$ & $4-1727$ & $1,1,0 \leftarrow 1 ;<1,1$ & Ground & & 51073.27 & .05 \\
\hline $\mathrm{Cl}^{35} \mathrm{~F}^{19} \mathrm{C}^{12} \mathrm{O}^{16}$ & 4. 151 & $6,4,3 \leftarrow 6,3,4$ & Ground & & 51109.94 & .05 \\
\hline $\mathrm{C}^{12} \mathrm{H}_{3} \mathrm{C}^{12}: \mathrm{C}^{12} \mathrm{H}$ & $4-1041^{\circ}$ & $3 \leftarrow 2 \leftarrow 2,2$ & Ground & & 51270.86 & .10 \\
\hline $\mathrm{C}^{12} \mathrm{H}_{3} \mathrm{C}^{12}: \mathrm{C}^{12} \mathrm{H}$ & $4-1041$ & $3,1 \leftarrow 2,1$ & Ground & & 51273.76 & .10 \\
\hline $\mathrm{C}^{12} \mathrm{H}_{3} \mathrm{C}^{12}: \mathrm{C}^{12} \mathrm{H}$ & 4-1041 & $3,0 \leftarrow 2,0$ & Ground & & 51274.75 & .10 \\
\hline $\mathrm{C}^{12} \mathrm{H}_{3} \mathrm{C}^{12}: \mathrm{C}^{12} \mathrm{H}$ & $4.1041^{-}$ & $3,1 \leftarrow 2,1$ & Excited & & 51280.45 & \\
\hline $\mathrm{C}^{12} \mathrm{H}_{3} \mathrm{C}^{12}: \mathrm{C}^{12} \mathrm{H}$ & $4-1041$ & $3,2 \leftarrow 2,2$ & Excited & & 51296.33 & \\
\hline $\mathrm{C}^{12} \mathrm{H}_{3} \mathrm{C}^{12}: \mathrm{C}^{12} \mathrm{H}$ & 4.1041 & $3,1 \leftarrow 2,1$. & Excited & & 51304.05 & \\
\hline $\mathrm{C}^{12} \mathrm{H}_{3} \mathrm{C}^{12}: \mathrm{C}^{12} \mathrm{H}$ & $4-1041$ & $3,2 \leftarrow 2,2$. & Excited & & 51305.93 & \\
\hline $\mathrm{C}^{12} \mathrm{H}_{3} \mathrm{G}^{12}: \mathrm{C}^{12} \mathrm{H}$ & 4-1041 & $3,0 \leftarrow 2,0$ & Excited & & 51307.53 & \\
\hline $\mathrm{C}^{12} \mathrm{H}_{3} \mathrm{C}^{12}: \mathrm{C}^{12} \mathrm{H}$ & $4-1041$ & $3,1 \leftarrow 2,1$ & Excited & & 51334.81 & \\
\hline $\mathrm{C}^{12} \mathrm{H}_{3} \mathrm{C}^{12}: \mathrm{C}^{12} \mathrm{H}$ & $4-1041$ & $3,1 \leftarrow 2,1$ & Excited & & 51369.12 & \\
\hline $\mathrm{O}^{16} \mathrm{~F}_{2}^{19}$ & 4-1611 & $2,1,1 \leftarrow 2,0,2$ & Ground & & 51388.95 & .10 \\
\hline $\mathrm{C}^{12} \mathrm{H}_{3} \mathrm{C}^{12}: \mathrm{C}^{12} \mathrm{H}$ & 4.-1041 & $3,2 \leftarrow 2,2$ & Excited & & 51410.51 & \\
\hline $\mathrm{C}^{12} \mathrm{H}_{3} \mathrm{C}^{12}: \mathrm{C}^{12} \mathrm{H}$. & $4-1041$ & $3,1 \leftarrow 2,1$ & Excited & & 51415.35 & \\
\hline $\mathrm{C}^{12} \mathrm{H}_{3} \mathrm{C}^{12}: \mathrm{C}^{12} \mathrm{H}$ & $4-1041$ & $3,2 \leftarrow 2,2$ & Excited & & 51418.23 & \\
\hline $\mathrm{C}^{12} \mathrm{H}_{3} \mathrm{C}^{12}: \mathrm{C}^{12} \mathrm{H}$ & $4-1041$ & $.3,0 \leftarrow 2,0$ & Excited & & 51418.75 & \\
\hline $\mathrm{C}^{12} \mathrm{H}_{3} \mathrm{C}^{12}: \mathrm{C}^{12} \mathrm{H}$ & 4.1041 & $3,1 \leftarrow 2 \leftarrow 1$ & Excited & & 51469.85 & \\
\hline $\mathrm{C}^{12} \mathrm{D}_{3} \mathrm{~N}^{14} \mathrm{C}^{12}$ & 4. 834 & $3,2 \leftarrow 2,2$ & Ground & & 51487.84 & .15 \\
\hline $\mathrm{C}^{12} \mathrm{D}_{3} \mathrm{~N}^{14} \mathrm{C}^{12}$ & 4- 834 & $3,1 \leftarrow 2,1$ & Ground & & 51490.24 & .15 \\
\hline $\mathrm{C}^{12} \mathrm{D}_{3} \mathrm{~N}^{14} \mathrm{C}^{12}$ & 4- 834 & $3,0 \leftarrow 2,0$ & Ground & & 51491.04 & .15 \\
\hline $\mathrm{O}^{16} \mathrm{~F}_{2}^{19}$ & $4-1611$ & $20,3,18 \leftarrow 19,4,15$ & Ground & & 51747.90 & .10 \\
\hline $\mathrm{C}^{1{ }^{1 /}} \mathrm{H}_{3}^{19}{ }^{19} \mathrm{C}^{12} \vdots \mathrm{C}^{12} \mathrm{H}$ & 4- 871 & $9,8 \leftarrow 8,8$ & Ground & & 51795.10 & .10 \\
\hline $\mathrm{C}^{12} \mathrm{~F}_{3}^{19} \mathrm{C}^{12}: \mathrm{C}^{12} \mathrm{H}$ & 4- 871 & $9,7 \leftarrow 8,7$ & Ground & & 51796.78 & .10 \\
\hline $\mathrm{C}^{12} \mathrm{~F}_{3}^{19} \mathrm{C}^{12}: \mathrm{C}^{12} \mathrm{H}$ & 4- 871 & $9,6 \leftarrow 8,6$ & Ground & & 51798.26 & .10 \\
\hline $\mathrm{C}^{12} \mathrm{~F}_{3}^{19} \mathrm{C}^{12}: \mathrm{C}^{12} \mathrm{H}$ & 4- 871 & $9,5 \leftarrow 8,5$ & Ground & & 51799.56 & .10 \\
\hline $\mathrm{C}^{12} \mathrm{~F}_{3}^{19} \mathrm{C}^{12}: \mathrm{C}^{12} \mathrm{H}$ & .4- 871 & $9,4 \leftarrow 8,4$ & Ground & & 51800.54 & .10 \\
\hline $\mathrm{C}^{12} \mathrm{~F}_{3}^{19} \mathrm{C}^{12}: \mathrm{C}^{12} \mathrm{H}$ & 4.: 871 & $9,3 \leftarrow 8,3$ & Ground & & 51801.32 & .10 \\
\hline $\mathrm{C}^{12} \mathrm{~F}_{3}^{19} \mathrm{C}^{12}: \mathrm{C}^{12} \mathrm{H}$ & 4. 871 & $9,2 \leftarrow 8,2$ & Ground & & $51 \cdot 801.90$ & .10 \\
\hline $\mathrm{C}^{12} \mathrm{~F}_{3}^{19} \mathrm{C}^{12}: \mathrm{C}^{12} \mathrm{H}$ & 4- 871 & $9,0 \leftarrow^{\circ} 8,0$ & Ground & & 51802.26 & .10 \\
\hline $\mathrm{C}^{12} \mathrm{~F}_{3}^{19} \mathrm{C}^{12}: \mathrm{C}^{12} \mathrm{H}$ & 4- 871 & $9,1 \leftarrow 8,1$ & Ground & & 51.4802 .26 & .10 \\
\hline $\mathrm{C}^{12} \mathrm{~F}_{3}^{19} \mathrm{C}^{12}: \mathrm{C}^{12} \mathrm{H}^{-}$ & 4. 871 & $9,1 \leftarrow 8,1$ & Excited & & $51,869.14$ & .20 \\
\hline $\mathrm{C}^{12} \mathrm{~F}_{3}^{19} \mathrm{C}^{12}: \mathrm{C}^{12} \mathrm{H}$ & 4. $87 \mathrm{r}$ & $9,8 \leftarrow 8,8$ & Excited & & 51890.62 & .20 \\
\hline $\mathrm{C}^{12} \mathrm{~F}_{3}^{19} \mathrm{C}^{12}: \mathrm{C}^{12} \mathrm{H}$ & 4- 871 & $9,7 \leftarrow 8,7$ & Excited & & 51892.88 & .20 \\
\hline $\mathrm{C}^{12} \mathrm{~F}_{3}^{19} \mathrm{C}^{12}: \mathrm{C}^{12} \mathrm{H}$ & 4. 871 & $9,6 \leftarrow 8,6$ & Excited & & 5.1894 .95 & .20 \\
\hline $\mathrm{C}^{12} \mathrm{~F}_{3}^{19} \mathrm{C}^{12}: \mathrm{C}^{12} \mathrm{H}$ & 4. 871 & $9,2 \leftarrow 8,2$ & Excited & & 51896.86 & .20 \\
\hline $\mathrm{C}^{12} \mathrm{~F}_{3}^{19} \mathrm{C}^{12}: \mathrm{C}^{12} \mathrm{H}$ & 4- 871 & $9,7 \leftarrow 8,7$, & Excited & & 51897.63 & .20 \\
\hline $\mathrm{C}^{12} \mathrm{~F}_{3}^{19} \mathrm{C}^{12}: \mathrm{C}^{12} \mathrm{H}$ & -4. 871 & $9,4 \leftarrow 8,4$ & Excited & & 51898.61 & .20 \\
\hline $\mathrm{C}^{12} \mathrm{~F}_{3}^{19} \mathrm{C}^{12}: \mathrm{C}^{12} \mathrm{H}$ & 4- 871 & $9,6 \leftarrow<8,6$ & Excited & & 51898.61 & .20 \\
\hline $\mathrm{C}^{12} \mathrm{~F}_{3}^{19} \mathrm{C}^{12}: \mathrm{C}^{12} \mathrm{H}$ & 4. 871. & $9,3 \leftarrow 8,3$ & Excited & & 51899.44 & .20 \\
\hline $\mathrm{C}^{12} \mathrm{~F}_{3}^{19} \mathrm{C}^{12}: \mathrm{C}^{12} \mathrm{H}$ & 4. 871 & $9,5 \leftarrow 8,5$ & Excited & & 51.899 .44 & .20 \\
\hline $\mathrm{C}^{12} \mathrm{~F}_{3}^{19} \mathrm{C}^{12}: \mathrm{C}^{12} \mathrm{H}$ & $4 \cdots 871$ & $9,4 \leftarrow 8,4$ & Excited & & 51899.99 & .20 \\
\hline $\mathrm{C}^{12} \mathrm{~F}_{3}^{19} \mathrm{C}^{12}: \mathrm{C}^{12} \mathrm{H}$ & 4- 871 & $9,3 \leftarrow 8,3$ & Excited & & .51899 .99 & .20 \\
\hline $\mathrm{C}^{12} \mathrm{~F}_{3}^{19} \mathrm{C}^{12}: \mathrm{C}^{12} \cdot \mathrm{H}$ & 4. 871 & $9,2 \leftarrow 8,2$ & Excited & & 51901.68 & 20 . \\
\hline
\end{tabular}




\begin{tabular}{|c|c|c|c|c|c|c|}
\hline Isotopic Species & $\begin{array}{l}\text { Vol.-Id. } \\
\text { Nos. }\end{array}$ & $\begin{array}{c}\text { Rotational } \\
\text { Quantum Nos. }\end{array}$ & Vib. State & $\mathrm{F}_{1}^{\prime} \stackrel{\text { Hyperfine }}{\mathrm{F}^{\prime}} \mathrm{F}_{1} \mathrm{~F}$ & $\begin{array}{c}\text { Frequency } \\
\text { MH' }_{z}^{\prime}\end{array}$ & $\begin{aligned} & \text { Acc. } \\
\pm & \mathrm{MH}_{2}\end{aligned}$ \\
\hline $\mathrm{C}^{12} \mathrm{~F}_{3}^{19} \mathrm{C}^{12}: \mathrm{C}^{12} \mathrm{H}$ & 4- 871 & $9, \mathrm{l}_{i} \leftarrow 8,1$ & Excited & & 51903.42 & .20 \\
\hline $\mathrm{C}^{12} \mathrm{~F}_{3}^{19} \mathrm{C}^{12}: \mathrm{C}^{12} \mathrm{H}$ & 4. 871 & $9,0 \leftarrow 8,0$ & Excited & & 51906.64 & .20 \\
\hline $\mathrm{O}^{16} \mathrm{~F}_{2}^{19}$ & 4.1611 & $24,4,21 \leftarrow 23,5,18$ & Ground & & 51911.88 & .10 \\
\hline $\mathrm{C}^{12} \mathrm{~F}_{3}^{19} \mathrm{C}^{12}: \mathrm{C}^{12} \mathrm{H}$ & 4. 871 & $9,1 \leftarrow 8,1$ & Excited & & 51934.48 & .20 \\
\hline $\mathrm{N}^{15} \mathrm{O}_{2}^{16}$ & 4-1802 & $10,0,10 \leftarrow 9,1,9$ & Ground & & 52109.4 & \\
\hline $\mathrm{N}^{15} \mathrm{O}_{2}^{16}$ & 4-1802 & $10,0,10 \leftarrow 9,1,9$ & Ground & & 52110.4 & \\
\hline $\mathrm{N}^{15} \mathrm{O}_{2}^{16}$ & 4. 1802 & $10,0,10 \leftarrow 9,1,9$ & Ground & & 52149.8 & \\
\hline $\mathrm{Cl}^{37} \mathrm{~F}^{19} \mathrm{C}^{12} \mathrm{O}^{16}$ & 4: 152 & $7,3,5 \leftarrow 7,4,4$ & Ground & & 52207.15 & .05 \\
\hline $\mathrm{O}^{16} \mathrm{~F}_{2}^{19}$ & $4 \cdot 1611$ & $23,4,19 \leftarrow 22,5,18$ & Ground & & 52223.40 & .10 \\
\hline $\mathrm{O}^{16} \mathrm{~F}_{2}^{19}$ & $4 \cdot 161.1$ & $8,3,6 \leftarrow 9,2,7$ & Grøund & & 52302.40 & .10 \\
\hline $\mathrm{Cl}^{35} \mathrm{~F}^{19} \mathrm{C}^{12} \mathrm{O}^{16}$ & 4. 151 & $8,4,5 \leftarrow 8,3 ; 6$ & Ground & & $52 ; 320.30$ & .05 \\
\hline $\mathrm{N}^{15} \mathrm{O}_{2}^{16}$ & 4-1802 & $10,0,10 \leftarrow 9,1,9$ & Ground & & 52398.4 & \\
\hline $\mathrm{N}^{15} \mathrm{O}_{2}^{16}$ & 4-1802 & $10,0,10 \leftarrow 9,1,9$ & Ground & & 52419.2 & \\
\hline $\mathrm{O}^{16} \mathrm{~F}_{2}^{19}$ & 4-1611 & $32,8,25 \leftarrow 33,7,26$ & Ground & & 52643.25 & .10 \\
\hline $\mathrm{O}^{16} \mathrm{~F}_{2}^{19}$ & 4-1611 & $28,5,23 \longleftarrow 27,6,22$ & Ground & & 52676.00 & .10 \\
\hline $\mathrm{HDS}^{34}$ & 4-1729 & $3,2,1 \leftarrow 3,2,2$ & Ground & & 52979.67 & \\
\hline $\mathrm{O}^{16} \mathrm{~F}_{2}^{19}$ & $4-1611$ & $32,8,24 \leftarrow 33,7,27$ & Ground & & 52988.75 & .10 \\
\hline $\mathrm{D}_{2} \mathrm{~N}^{14} \mathrm{C}^{12} \mathrm{~N}^{14}$ & 4. 363 & $3,1,3 \leftarrow 2,1,2$ & Ground & & 53077.6 & .3 \\
\hline $\mathrm{D}_{2} \mathrm{~N}^{14} \mathrm{C}^{12} \mathrm{~N}^{14}$ & 4. 363 & $3,1,3 \leftarrow 2,1,2$ & Excited & & 53132.4 & .3 \\
\hline$\left(\mathrm{C}^{12} \mathrm{H}_{3}\right)_{2} \mathrm{~S}^{32}$ & 3- 601 & $4,3,1 \leftarrow 4,2,2$ & Ground & & 53188.71 & .05 \\
\hline$\left(\mathrm{C}^{12} \mathrm{H}_{3}\right)_{2} \mathrm{~S}^{32}$ & 3- 601 & $4,3,1 \leftarrow 4,2,2$ & Ground & & 53189.22 & .05 \\
\hline$\left(\mathrm{C}^{12} \mathrm{H}_{3}\right)_{2} \mathrm{~S}^{32}$ & 3- 601 & $4,3,1 \leftarrow 4,2,2$ & Ground & & 53189.91 & .05 \\
\hline$\left(\mathrm{C}^{12} \mathrm{H}_{3}\right)_{2} \mathrm{~S}^{32}$ & 3. 601 & $4,3,1 \leftarrow 4,2,2$ & Ground & & 53190.85 & .05 \\
\hline $\mathrm{HDS}^{32}$ & $4-1727$ & $3,2,1 \leftarrow 3,2,2$ & Ground & & 53200.93 & .05 \\
\hline $\mathrm{S}^{32} \mathrm{O}_{2}^{16}$ & 4-1831 & $2,1,1 \leftarrow 2,0,2$ & Ground & & 53529.16 & .16 \\
\hline $\mathrm{O}_{2}^{16}$ & $1 \cdot$ & $25,25 \leftarrow 24,25$ & Ground & & 53599.4 & .8 \\
\hline $\mathrm{D}_{2} \mathrm{~N}^{14} \mathrm{C}^{12} \mathrm{~N}^{14}$ & 4. 363 & $3,2,1 \leftarrow 2,2,0$ & Excited & & 53652.0 & .3 \\
\hline $\mathrm{D}_{2} \mathrm{~N}^{14} \mathrm{C}^{12} \mathrm{~N}^{14}$ & 4- 363 & $3,2,2 \leftarrow 2,2.1$ & Ground, & & 53672.8 & .3 \\
\hline $\mathrm{D}_{2} \mathrm{~N}^{14} \mathrm{C}^{12} \mathrm{~N}^{14}$ & 4- 363 & $3,2,1 \leftarrow 2,2,0$ & Ground & & 53672.8 & .3 \\
\hline $\mathrm{D}_{2} \mathrm{~N}^{14} \mathrm{C}^{12} \mathrm{~N}^{14}$ & 4- 363 & $3,0,3 \leftarrow 2,0,2$ & Ground & & 53694.8 & .3 \\
\hline $\mathrm{D}_{2} \mathrm{~N}^{14} \mathrm{C}^{12} \mathrm{~N}^{14}$ & 4- 363 & $3,2,2 \leftarrow 2,2,1$ & Excited & & 53702.1 & .1 \\
\hline $\mathrm{O}^{16} \mathrm{~F}_{2}^{19}$ & $4-1611$ & $13,2,11 \leftarrow 12,3,10$ & Ground & & 53708.85 & .10 \\
\hline $\mathrm{D}_{2} \mathrm{~N}^{14} \mathrm{C}^{12} \mathrm{~N}^{14}$ & 4- 363 & $3,0,3 \leftarrow 2,0,2$ & Excited & & 53712.2 & .3 \\
\hline $\mathrm{O}^{16} \mathrm{~F}_{2}^{19}$ & 4-1611 & $18,3,15 \leftarrow 17,4,14$ & Ground & & 53739.10 & .10 \\
\hline $\mathrm{O}_{2}^{16}$ & 1. & $23,23 \leftarrow 22,23$ & Ground & & 54.129 .4 & 4 \\
\hline $\mathrm{O}^{16} \mathrm{~F}_{2}^{19}$ & $4-16 \mathrm{Pl}$ & $3,1.2 \leftarrow 3,0,3$ & Ground & & 54137.05 & .10 \\
\hline$N^{15} S^{32} F_{3}^{19}$ & 4-1664 & $6, \leftarrow 5$ & Ground & & 54.241 .76 & \\
\hline $\mathrm{D}_{2} \mathrm{~N}^{14} \mathrm{C}^{12} \mathrm{~N}^{14}$ & 4- 363 & $3,1,2 \leftarrow-2,1,1$ & Ground & & 54.313 .6 & .3 \\
\hline $\mathrm{D}_{2} \mathrm{~N}^{14} \mathrm{C}^{12} \mathrm{~N}^{14}$ & 4. 363 & $3,1,2 \leftarrow 2,1,1$ & Excited & & 54.334 .4 & .3 \\
\hline$\left(\mathrm{C}^{12} \mathrm{H}_{3}\right)_{2} \mathrm{~S}^{32}$ & 3. 601 & $12,3,9 \leftarrow 12,2,10$ & Ground & & 54.439 .22 & .05 \\
\hline$\left(\mathrm{C}^{12} \mathrm{H}_{3}\right)_{2} \mathrm{~S}^{32}$ & 3- 601 & $12,3,9 \longleftarrow 12,2,10$ & Ground & & 54439.92 & .05 \\
\hline$\left(\mathrm{C}^{12} \mathrm{H}_{3}\right)_{2} \mathrm{~S}^{32}$ & 3- 601 & $12,3,9 \longleftarrow 12,2,10$ & Ground & & 54. 440.61 & .05 \\
\hline$\left(\mathrm{C}^{12} \mathrm{H}_{3}\right)_{2} \mathrm{~S}^{32}$ & $3-.601$ & $6,2,5 \leftarrow 6,1,6$ & Ground & & 54518.60 & .05 \\
\hline$\left(\mathrm{C}^{12} \mathrm{H}_{3}\right)_{2} \mathrm{~S}^{32}$ & $3-601$ & $6 ; 2,5 \leftarrow 6,1,6$ & Ground & & 54519.54 & .05 \\
\hline$\left(\mathrm{C}^{12} \mathrm{H}_{3}\right)_{2} \mathrm{~S}^{32}$ & 3. 601 & $6,2,5 \leftarrow 6,1,6$ & Ground & & 54.520 .48 & .05 \\
\hline
\end{tabular}




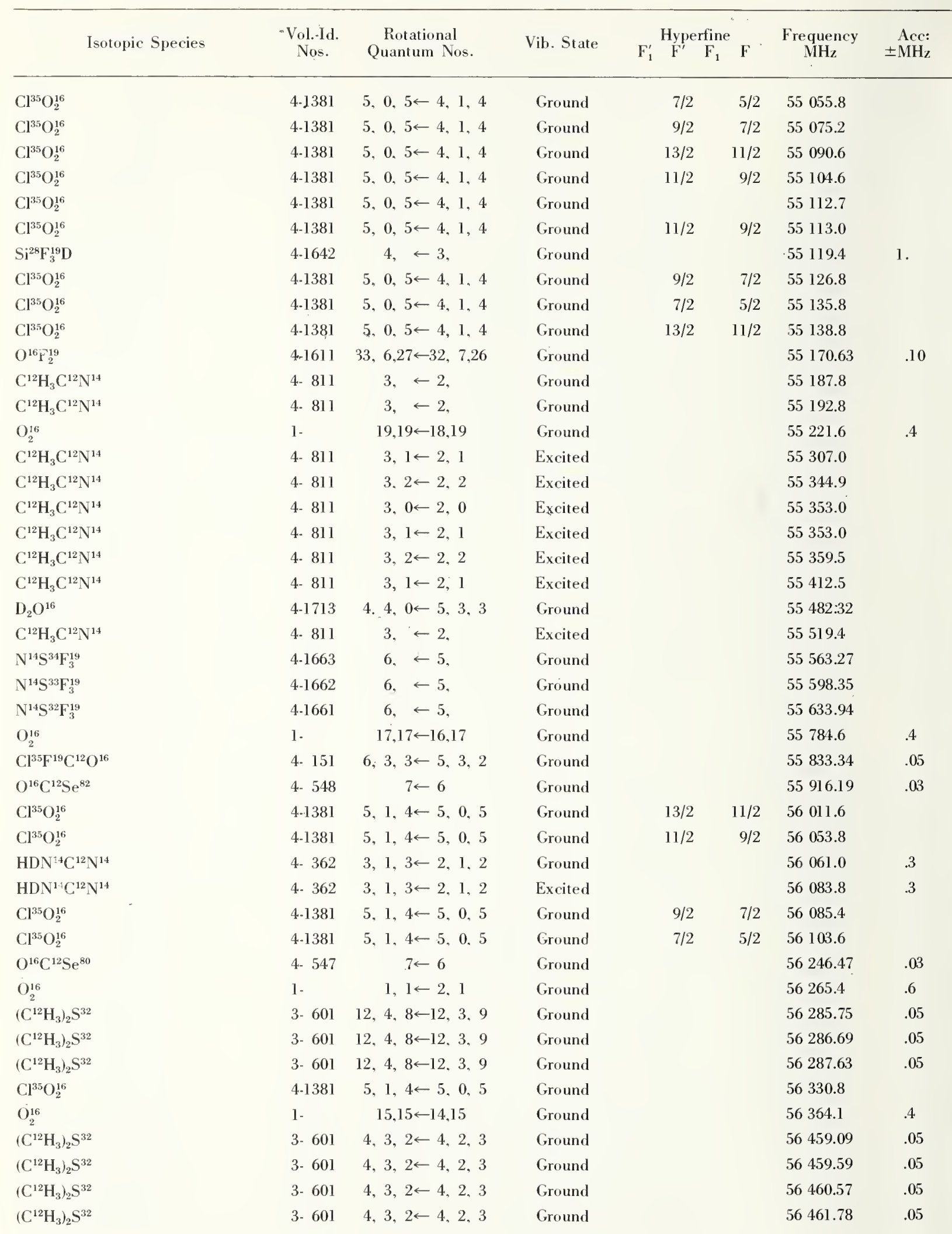




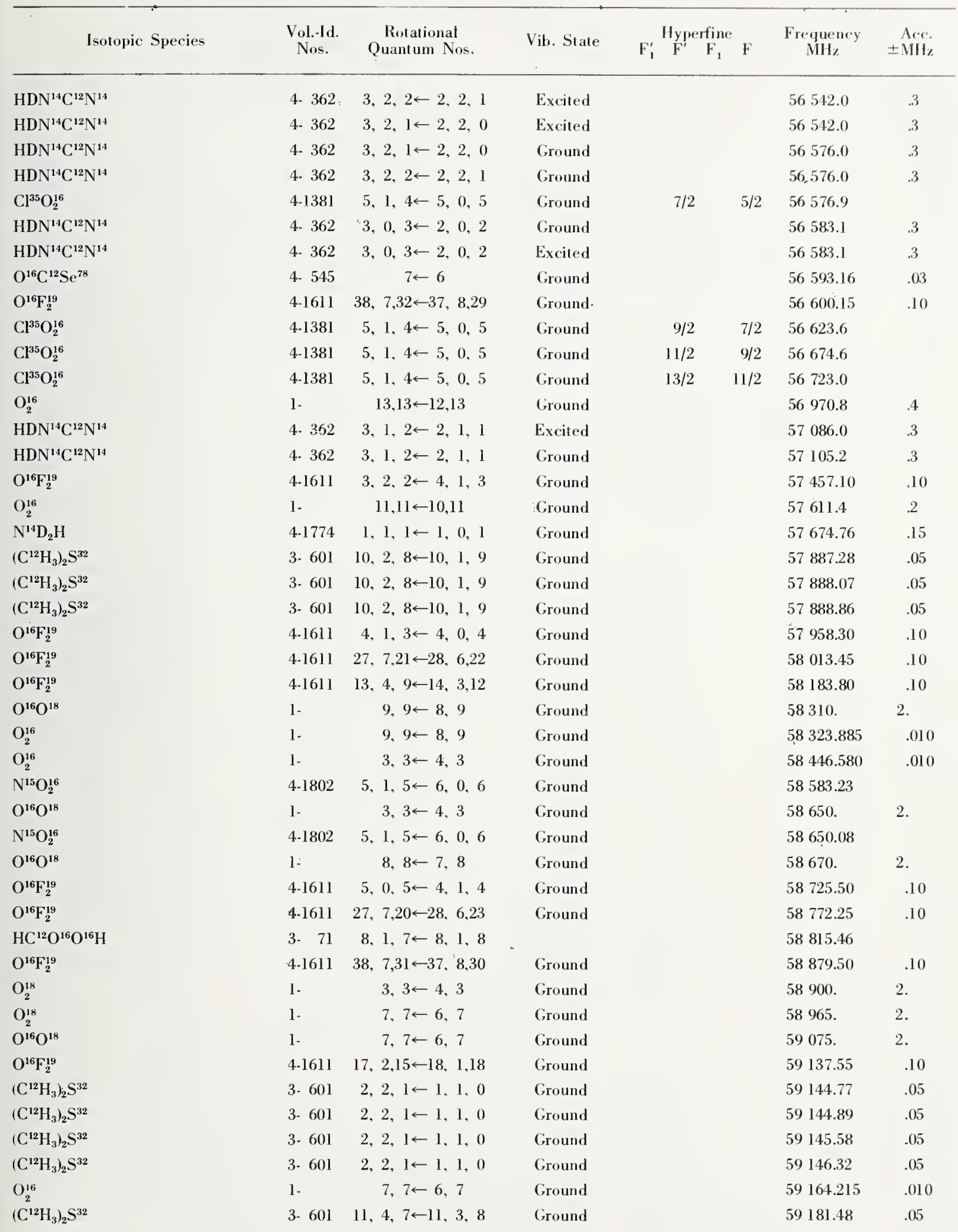




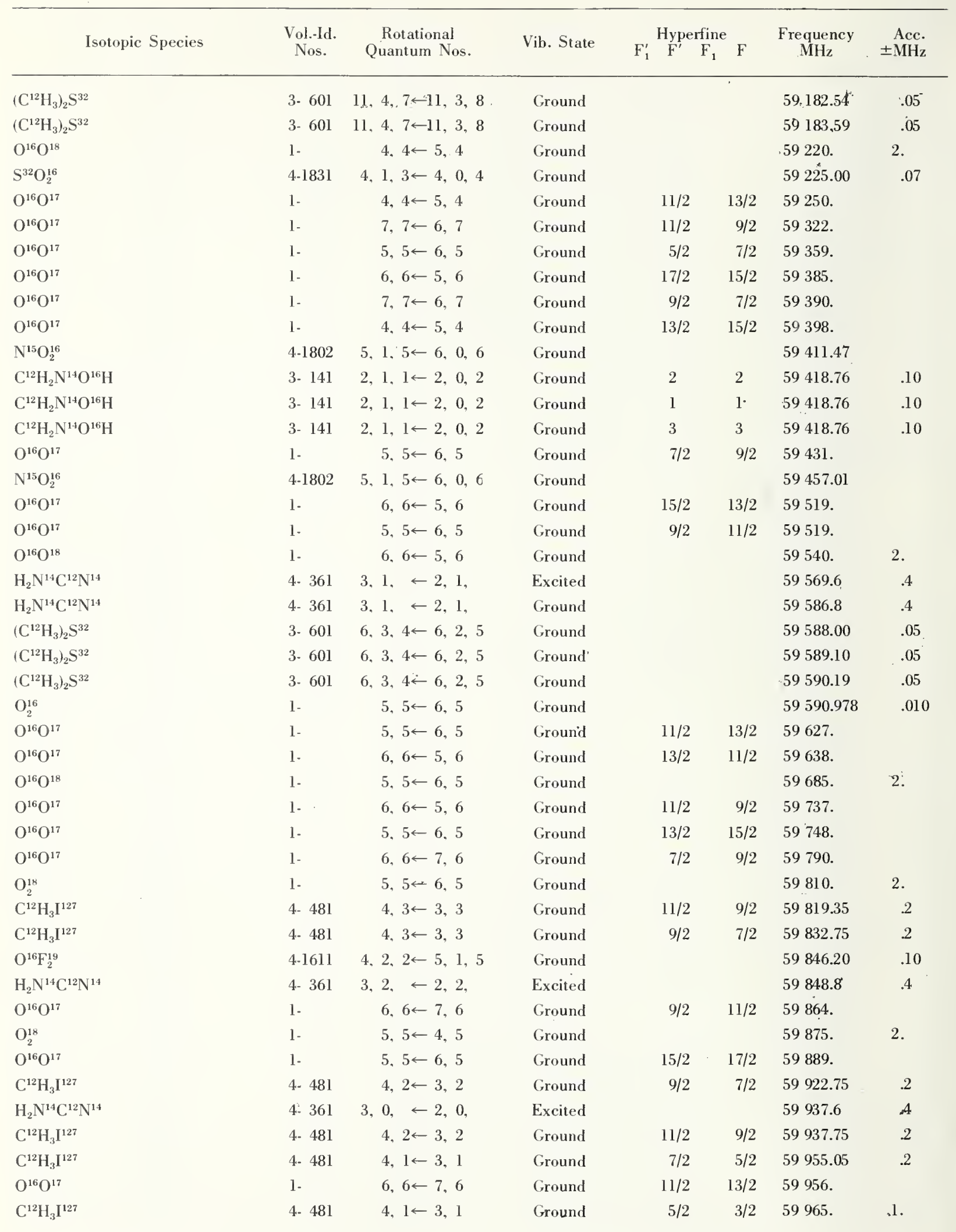




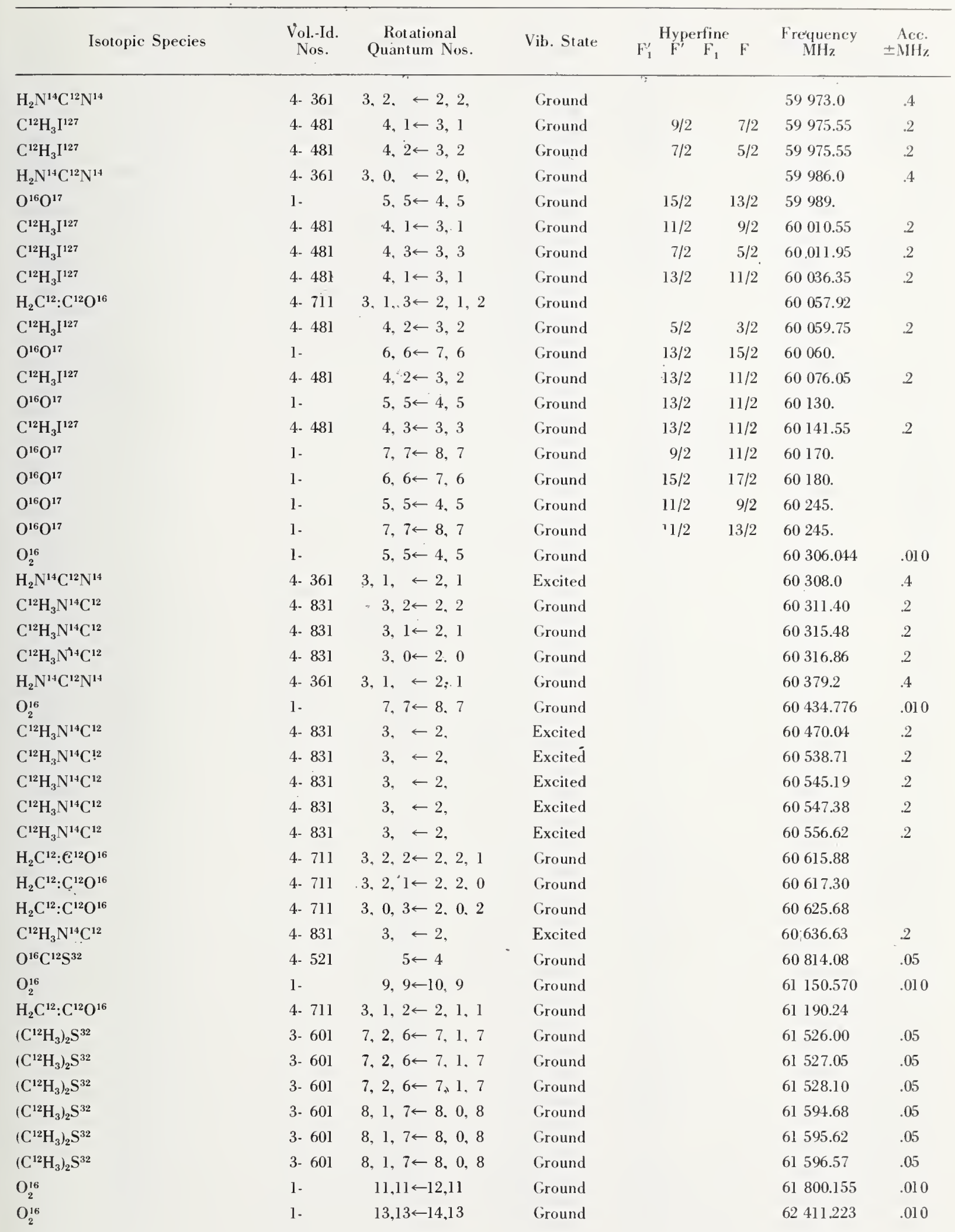




\begin{tabular}{|c|c|c|c|c|c|c|c|c|}
\hline Isotopic Species & $\begin{array}{l}\text { Vol.-Id. } \\
\text { Nos. }\end{array}$ & $\begin{array}{c}\text { Rotational } \\
\text { Quantum Nos. }\end{array}$ & Vib. State & $\mathrm{F}_{1}^{\prime}$ & $\begin{array}{c}\text { Hyperfine } \\
F^{\prime} F_{1}\end{array}$ & $\mathrm{~F}$ & $\underset{\mathrm{MHz}_{\mathbf{z}}}{\text { Frequency }}$ & $\begin{aligned} & \text { Acc. } \\
\pm & \mathrm{MHz}\end{aligned}$ \\
\hline$\left(\mathrm{C}^{12} \mathrm{H}_{3}\right)_{2} \mathrm{~S}^{32}$ & 3. 601 & $7,3,5 \leftarrow 7,2,6$ & Ground & & & & 62433.00 & .05 \\
\hline$\left(\mathrm{C}^{12} \mathrm{H}_{3}\right)_{2} \mathrm{~S}^{32}$ & 3. 601 & $7,3,5 \leftarrow 7,2,6$ & Ground & & & & 62434.12 & .05 \\
\hline$\left(\mathrm{C}^{12} \mathrm{H}_{3}\right)_{2} \mathrm{~S}^{32}$ & 3- 601 & $7,3,5 \leftarrow 7,2,6$ & Ground & & & & 62435.22 & .05 \\
\hline $\mathrm{O}_{2}^{16}$ & $1-$ & $3,3 \leftarrow 2,3$ & Ground & & & & $62486 \% 255$ & .010 \\
\hline $\mathrm{O}_{2}^{16}$ & $1-$ & $15,15 \leftarrow 16,15$ & Ground & & & & 62996.6 & .2 \\
\hline$\left(\mathrm{C}^{12} \mathrm{H}_{3}\right)_{2} \mathrm{~S}^{32}$ & 3- 601 & $10,4,6 \leftarrow 10,3,7$ & Ground & & & & 63236.56 & .05 \\
\hline$\left(\mathrm{C}^{12} \mathrm{H}_{3}\right)_{2} \mathrm{~S}^{32}$ & 3- 601 & $10,4,6 \leftarrow 10,3,7$ & Ground & & & & 63237.73 & .05 \\
\hline$\left(\mathrm{C}^{12} \mathrm{H}_{3}\right)_{2} \mathrm{~S}^{32}$ & 3- 601 & $10,4,6 \leftarrow 10,3,7$ & Ground & & & & 63238.90 & .05 \\
\hline $\mathrm{O}_{2}^{16}$ & $1-$ & $11,17 \leftarrow 18,17$ & Ground & & & & 63568.520 & .010 \\
\hline $\mathrm{O}_{2}^{16}$ & $1-$ & $19,19 \longleftarrow 20,19$ & Ground & & & & 64128.0 & .8 \\
\hline $\mathrm{O}_{2}^{16}$ & 1 - & $21,21 \leftarrow 22,21$ & Ground & & & & 646.78 .2 & .2 \\
\hline $\mathrm{HC}^{12} \mathrm{O}^{16} \mathrm{O}^{16} \mathrm{H}$ & 3. 71 & $3,1,3 \leftarrow 2,1,2$ & & & & & 64936.26 & .40 \\
\hline $\mathrm{O}_{2}^{16}$ & $1-$ & $23,23 \leftarrow 24,23$ & Ground & & & & 65224.120 & .2 \\
\hline $\mathrm{D}_{2} \mathrm{Se}^{82}$ & 4-1751 & $1,1,0 \leftarrow 1,0,1$ & Ground & & & & 65971.71 & \\
\hline $\mathrm{D}_{2} \mathrm{Se}^{80}$ & 4.1749 & $1,1,0 \leftarrow 1,0,1$ & Ground & & & & 66085.41 & \\
\hline $\mathrm{D}_{2} \mathrm{Se}^{78}$ & 4-1748 & $1,1,0 \leftarrow 1,0,1$ & Ground & & & & 66204.87 & \\
\hline $\mathrm{D}_{2} \mathrm{Se}^{77}$ & 4-1747 & $1,1,0 \leftarrow 1,0,1$ & Ground & & & & 66266.82 & \\
\hline $\mathrm{D}_{2} \mathrm{Se}^{76}$ & $4-1746$ & $1,1,0 \leftarrow 1,0,1$ & Ground & & & & 66330.78 & \\
\hline $\mathrm{HN}_{3}^{1+4}$ & $4-1701$ & $3,1,3 \leftarrow 2,1,2$ & Ground & & & & 66366.68 & .25 \\
\hline $\mathrm{H}_{2} \mathrm{~N}^{14} \mathrm{~N}^{14} \mathrm{H}_{2}$ & 3. 51 & 9. $1 \leftarrow 8,2$ & Ground & & & & 66902.0 & .05 \\
\hline $\mathrm{HN}_{3}^{14}$ & $4-1701$ & $3,2,2 \leftarrow 2,2,1$ & Ground & & 4 & 3 & 66935.94 & .25 \\
\hline $\mathrm{HN}_{3}^{14}$ & 4-1701 & $3,2,1 \leftarrow 2,2,0$ & Ground & & 2 & 1 & 66935.94 & .25 \\
\hline $\mathrm{HN}_{3}^{14}$ & 4-1701 & $3,2,2 \leftarrow 2,2,1$ & Ground & & 3 & 2 & 66937.27 & .25 \\
\hline $\mathrm{HN}_{3}^{1+}$ & $4-1701$ & $3,2,1 \leftarrow 2,2,0$ & Ground & & 4 & 3 & 66937.27 & .25 \\
\hline $\mathrm{HN}_{3}^{14}$ & $4-1701$ & $3,2,1 \leftarrow 2,2,0$ & Ground & & 3 & 2 & 66938.71 & .25 \\
\hline $\mathrm{HN}_{3}^{14}$ & 4-1701 & $3,0,3 \leftarrow 2,0,2$ & Ground & & & & 66945.50 & .25 \\
\hline $\mathrm{HC}^{12} \mathrm{O}^{16} \mathrm{O}^{16} \mathrm{H}$ & 3- 71 & $3,0,3 \leftarrow 2,0,2$ & & & & & 67291.05 & .41 \\
\hline $\mathrm{HC}^{12} \mathrm{O}^{16} \mathrm{O}^{16} \mathrm{H}$ & 3- 71 & $3,2,2 \leftarrow 2,2,1$ & & & & & 67414.80 & .41 \\
\hline $\mathrm{HN}_{3}^{14}$ & $4-1701$ & $3,1,-2 \leftarrow 2,1,1$ & Ground & & & & 67520.75 & .25 \\
\hline $\mathrm{HC}^{12} \mathrm{O}^{16} \mathrm{O}^{16} \mathrm{H}$ & 3- 71 & $3,2,1 \leftarrow 2,2,0$ & & & & & 67536.09 & .41 \\
\hline $\mathrm{H}_{2} \mathrm{~N}^{14} \mathrm{~N}^{14} \mathrm{H}_{2}$ & $3-51$ & $9,1 \leftarrow 8,2$ & Ground & & & & 67540.1 & .05 \\
\hline $\mathrm{N}^{14} \mathrm{D}_{2} \mathrm{H}$ & $4-1774$ & $1,1,1 \leftarrow 1,0,1$ & Grourd & & & & 67841.52 & .15 \\
\hline $\mathrm{Cl}^{35} \mathrm{~F}^{19} \mathrm{C}^{12} \mathrm{O}^{16}$ & 4- 151 & $8,2,7 \leftarrow 7,2,6$ & Ground & & & & 68433.00 & .05 \\
\hline $\mathrm{S}^{32} \mathrm{O}_{2}^{16}$ & 4-1831 & $6,1,5 \leftarrow 6,0,6$ & Ground & & & & 68972.10 & \\
\hline $\mathrm{S}^{32} \mathrm{O}_{2}^{16}$ & $4-1831^{\bar{r}}$ & $1,1,{ }^{n} 1 \leftarrow 0,0,0$ & Ground & & & & 69576.06 & .18 \\
\hline $\mathrm{HC}^{12} \mathrm{O}^{16} \mathrm{O}^{16} \mathrm{H}$ & $3-71$ & $3,1,2 \leftarrow 2,1,1$ & & & & & 69852.03 & .42 \\
\hline $\mathrm{C}^{12} \mathrm{H}_{3} \mathrm{Hg}^{202} \mathrm{Cl}^{35}$ & 4- 447 & $17,4 \leftarrow 16,4$ & Ground & & & & 70575.74 & \\
\hline $\mathrm{C}^{12} \mathrm{H}_{3} \mathrm{Hg}^{202} \mathrm{Cl}^{35}$ & 4- 447 & $17,3 \leftarrow 16,3$ & Ground & & & & 70580.86 & \\
\hline $\mathrm{C}^{12} \mathrm{H}_{3} \mathrm{Hg}^{202} \mathrm{Cl}^{35}$ & $4: 447$ & $17,2 \leftarrow 16,2$ & Ground & & & & 70584.44 & \\
\hline $\mathrm{C}^{12} \mathrm{H}_{3} \mathrm{Hg}^{202} \mathrm{Cd}^{35}$ & 4- 447 & $17,1 \leftarrow 16,1$ & Ground & & & & 70586.55 & \\
\hline $\mathrm{C}^{12} \mathrm{H}_{3} \mathrm{Hg}^{202} \mathrm{Cl}^{35}$ & 4- 447 & $17,0 \leftarrow 16,0$ & Ground & & & & 70587.33 & \\
\hline $\mathrm{C}^{12} \mathrm{H}_{3} \mathrm{Hg}^{200} \mathrm{Cl}^{35}$ & 4- 445 & $17,5 \leftarrow 16,5$ & Ground & & & & 70590.40 & \\
\hline $\mathrm{C}^{12} \mathrm{H}_{3} \mathrm{Hg}^{200} \mathrm{Cl}^{35}$ & 4- 445 & $17,4 \leftarrow 16,4$ & Ground & & & & 70596.92 & \\
\hline $\mathrm{C}^{12} \mathrm{H}_{3} \mathrm{Hg}^{200} \mathrm{Cl}^{35}$ & 4- 445 & $17,3 \leftarrow 16,3$ & Ground & & & & 70601.86 & \\
\hline $\mathrm{C}^{12} \mathrm{H}_{3} \mathrm{Hg}^{200} \mathrm{Cl}^{35}$ & 4- 445 & $17,2 \leftarrow 16,2$ & Ground & & & & 70605.45 & \\
\hline
\end{tabular}




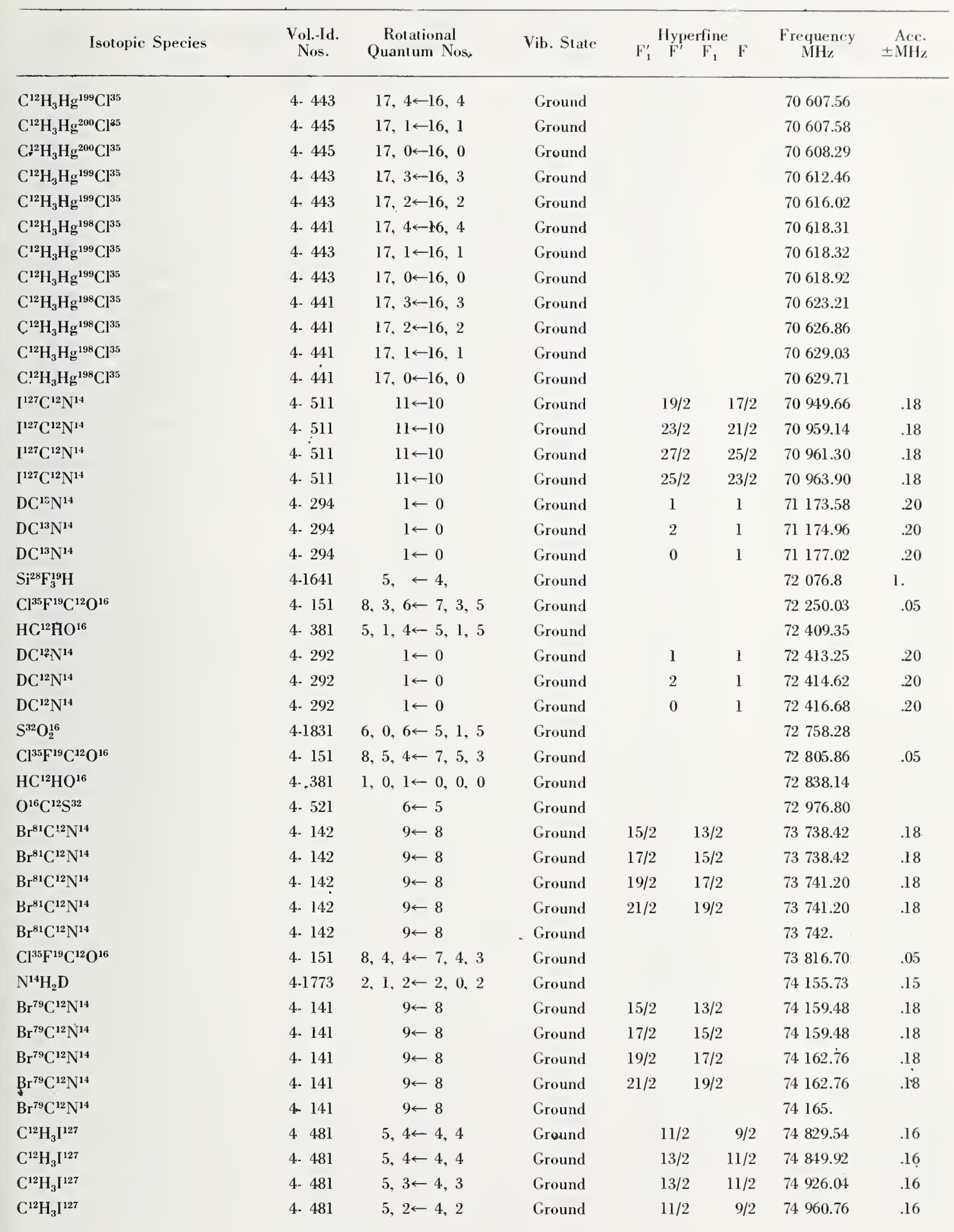




\begin{tabular}{|c|c|c|c|c|c|c|c|}
\hline \multirow{2}{*}{ Isotopic Species } & \multirow{2}{*}{$\begin{array}{l}\text { Vol.-Id. } \\
\text { Nos. }\end{array}$} & \multirow{2}{*}{$\begin{array}{c}\text { Rotational } \\
\text { Ouantum Nos. }\end{array}$} & \multirow{2}{*}{ Vib. State } & \multicolumn{2}{|c|}{ Hyperfine } & \multirow{2}{*}{$\begin{array}{l}\text { Frequency } \\
\qquad \mathrm{MHz}\end{array}$} & \multirow{2}{*}{$\begin{array}{r}\text { Acc. } \\
\pm \mathrm{MHz}\end{array}$} \\
\hline & & & & $F_{1} \quad F^{2} \quad F_{1}$ & $\mathrm{~F}$ & & \\
\hline $\mathrm{C}^{12} \mathrm{H}_{3} \mathrm{I}^{127}$ & 4- 481 & $5,3 \leftarrow 4,3$ & Ground & $9 / 2$ & $7 / 2$ & 74964.36 & 16 \\
\hline $\mathrm{C}^{12} \mathrm{H}_{3} \mathrm{I}^{127}$ & 4. 481 & $5,0 \leftarrow 4,0$ & Ground & $7 / 2$ & $5 / 2$ & 74967.66 & .16 \\
\hline $\mathrm{C}^{12} \mathrm{H}_{3}{ }^{127}$ & 4. 481 & $5,2 \leftarrow 4,2$ & Ground & $9 / 2$ & $7 / 2$ & 74971.76 & .16 \\
\hline $\mathrm{C}^{12} \mathrm{H}_{3} \mathrm{I}^{127}$ & 4. 481 & $5, \mathfrak{j} \leftarrow 4,1$ & Ground & $9 / 2$ & $7 / 2$ & 74976.22 & .16 \\
\hline $\mathrm{C}^{12} \mathrm{H}_{3} \mathbf{I}^{127}$ & 4. 481 & $5 ; 1 \leftarrow 4,1$ & Ground & $7 / 2$ & $5 / 2$ & 74977.62 & .16 \\
\hline $\mathrm{C}^{12} \mathrm{H}_{3} \mathrm{I}^{12 z}$ & 4. 481 & $5,0 \leftarrow 4,0$ & Ground & $9 / 2$ & $7 / 2$ & 74977.62 & .16 \\
\hline $\mathrm{C}^{12} \mathrm{H}_{3} \mathrm{I}^{127}$ & 4. 481 & $5,2 \leftarrow 4,2$ & Ground & $13 / 2$ & $11 / 2$ & 74982.18 & .16 \\
\hline $\mathrm{C}^{12} \mathrm{H}_{3} \mathrm{I}^{127}$ & 4- 481 & $5,0 \leftarrow 4,0$ & Ground & $5 / 2$ & $3 / 2$ & 74986.14 & .16 \\
\hline $\mathrm{C}^{12} \mathrm{H}_{3} \mathrm{I}^{127}$ & 4- 481 & $5,1 \leftarrow 4,1$ & Ground & $11 / 2$ & $9 / 2$ & 74993.28 & .16 \\
\hline $\mathrm{C}^{12} \mathrm{H}_{3} \mathrm{I}^{127}$ & 4. 481 & $5,0 \leftarrow 4,0$ & Ground & $11 / 2$ & $9 / 2$ & $7500 \$ .28$ & .16 \\
\hline $\mathrm{C}^{12} \mathrm{H}_{3} \mathrm{I}^{127}$ & 4- 481 & $5,2 \leftarrow 4,2$ & Ground & $7 / 2$ & $5 / 2$ & 75007.62 & .16 \\
\hline $\mathrm{C}^{12} \mathrm{H}_{3} \mathrm{I}^{127}$ & 4. 481 & $5,1 \leftarrow 4,1$ & Ground & $13 / 2$ & $11 / 2$ & $75016: 20$ & .16 \\
\hline $\mathrm{C}^{12} \mathrm{H}_{3} \mathrm{I}^{127}$ & 4- 481 & $5,0 \leftarrow 4,0$ & Ground & $15 / 2$ & $13 / 2$ & 75019.28 & .16 \\
\hline $\mathrm{C}^{12} \mathrm{H}_{3} \mathrm{I}^{127}$ & $4 \quad 481$ & $5,1 \leftarrow 4,1$ & Ground & $15 / 2$ & $13 / 2$ & 75026.20 & .16 \\
\hline $\mathrm{C}^{12} \mathrm{H}_{3} \mathrm{I}^{127}$ & 4. 481 & $5,0 \leftarrow 4,0$ & Ground & $13 / 2$ & $11 / 2$ & 75027.58 & .16 \\
\hline $\mathrm{C}^{12} \mathrm{H}_{3} \underline{I}^{127}$ & 4- 481 & $5,2 \leftarrow 4,2$ & Ground & $15 / 2$ & $13 / 2$ & 75046.48 & .16 \\
\hline $\mathrm{C}^{12} \mathrm{H}_{3} \mathbf{I}^{127}$ & 4. 481 & $5,3 \leftarrow 4,3$ & Ground & $15 / 2$ & $13 / 2$ & 75081.02 & .16 \\
\hline $\mathrm{HDS}^{32}$ & $4-1727$ & $8,4,4 \leftarrow 8,4,5$ & Ground & & & 75551.73 & .05 \\
\hline $\mathrm{C}^{12} \mathrm{H}_{3} \mathrm{Br}^{81}$ & 4- 402 & $4,3 \leftarrow 3,3$ & Ground & $5 / 2$ & $3 / 2$ & 76152.28 & .18 \\
\hline $\mathrm{C}^{12} \mathrm{H}_{3} \mathrm{Br}^{81}$ & 4- 402 & $4,3 \leftarrow 33$ & Ground & $11 / 2$ & $9 / 2$ & 76207.66 & .18 \\
\hline $\mathrm{C}^{12} \mathrm{H}_{3} \mathrm{Br}^{81}$ & 4- 402 & $4,2 \leftarrow 3,2$ & Ground & $5 / 2$ & $3 / 2$ & 76213.16 & .18 \\
\hline $\mathrm{C}^{12} \mathrm{H}_{3} \mathrm{Br}^{81}$ & 4. 402 & $4,2 \leftarrow 3,2$ & Ground & $11 / 2$ & $9 / 2$ & 76230.18 & .18 \\
\hline $\mathrm{C}^{12} \mathrm{H}_{3} \mathrm{Br}^{81}$ & 4. 402 & $4,1 \leftarrow 3,1$ & Ground & $11 / 2$ & $9 / 2$ & 76243.66 & .18 \\
\hline $\mathrm{C}^{12} \mathrm{H}_{3} \mathrm{Br}^{81}$ & 4- 402 & $4,0 \leftarrow 3,0$ & Ground & $11 / 2$ & $9 / 2$ & 76248,32 & .18 \\
\hline $\mathrm{C}^{12} \mathrm{H}_{3} \mathrm{Br}^{81}$ & 4. 402 & $4,0 \leftarrow 3,0$ & Ground & $9 / 2$ & $7 / 2$ & 76248.32 & .18 \\
\hline $\mathrm{C}^{12} \mathrm{H}_{3} \mathrm{Br}^{81}$ & 4. 402 & $4,1 \leftarrow 3,1$ & Ground & $5 / 2$ & $3 / 2$ & 76249.94 & .18 \\
\hline $\mathrm{C}^{12} \mathrm{H}_{3} \mathrm{Br}^{81}$ & 4. 402 & $4,1 \leftarrow 3,1$ & Ground & $9 / 2$ & $7 / 2$ & 76255.68 & !18 \\
\hline $\mathrm{C}^{12} \mathrm{H}_{3} \mathrm{Br}^{81}$ & 4- 402 & $4,2 \leftarrow 3,2$ & Ground & $7 / 2$ & $5 / 2$ & 76261.96 & .18 \\
\hline $\mathrm{C}^{12} \mathrm{H}_{3} \mathrm{Br}^{81}$ & 4. 402 & $4,1 \leftarrow 3,1$ & Ground & $7 / 2$ & $5 / 2$ & 76261.96 & .18 \\
\hline $\mathrm{C}^{12} \mathrm{H}_{3} \mathrm{Br}^{81}$ & 4. 402 & $4,0 \leftarrow 3,0$ & Ground & $5 / 2$ & $3 / 2$ & 76261.95 & .18 \\
\hline $\mathrm{C}^{12} \mathrm{H}_{3} \mathrm{Br}^{81}$ & 4- 402 & $4,0 \leftarrow 3,0$ & Ground & $7 / 2$ & $5 / 2$ & 76261.96 & .18 \\
\hline $\mathrm{C}^{12} \mathrm{H}_{3} \mathrm{Br}^{81}$ & 4. 402 & $4,2 \leftarrow 3,2$ & Excited & $9 / 2$ & $7 / 2$ & 76278.16 & .18 \\
\hline $\mathrm{C}^{12} \mathrm{H}_{3} \mathrm{Br}^{79}$ & 4. 401 & $4,3 \leftarrow 3,3$ & Ground & $5 / 2$ & $3 / 2$ & 76425.18 & .18 \\
\hline $\mathrm{C}^{12} \mathrm{H}_{3} \mathrm{Br}^{79}$ & 4. 401 & $4,3 \leftarrow 3,3$ & Ground & $11 / 2$ & $9 / 2$ & 76491.36 & .18 \\
\hline $\mathrm{C}^{12} \mathrm{H}_{3} \mathrm{Br}^{79}$ & 4- 401 & $4,2 \leftarrow 3,2$ & Ground & $5 / 2$ & $3 / 2$ & 76496.60 & .18 \\
\hline $\mathrm{C}^{12} \mathrm{H}_{3} \mathrm{Br}^{79}$ & 4. 401 & $4,2 \leftarrow 3,2$ & Ground & $11 / 2$ & $9 / 2$ & 76517.36 & .18 \\
\hline $\mathrm{C}^{12} \mathrm{H}_{3} \mathrm{Br}^{79}$ & 4. 401 & $4,1 \leftarrow 3,1$ & Ground & $11 / 2$ & $9 / 2$ & 76532.88 & .18 \\
\hline $\mathrm{C}^{12} \mathrm{H}_{3} \mathrm{Br}^{79}$ & 4. 401 & $4,0 \leftarrow 3,0$ & Ground & $9 / 2$ & $7 / 2$ & 76538.02 & .18 \\
\hline $\mathrm{C}^{12} \mathrm{H}_{3} \mathrm{Br}^{79}$ & 4- 401 & $4,0 \leftarrow 3,0$ & Ground & $11 / 2$ & $9 / 2$ & 76538.02 & .18 \\
\hline $\mathrm{C}^{12} \mathrm{H}_{3} \mathrm{Br}^{79}$ & 4401 & $4,1 \leftarrow 3,1$ & Ground & $5 / 2$ & $3 / 2$ & 76540.20 & .18 \\
\hline $\mathrm{C}^{12} \mathrm{H}_{3} \mathrm{Br}^{79}$ & 4- 401 & $4,1 \leftarrow 3,1$ & Ground & $9 / 2$ & $7 / 2$ & 76547.24 & .18 \\
\hline $\mathrm{C}^{12} \mathrm{H}_{3} \mathrm{Br}^{79}$ & 4. 401 & $4,2 \leftarrow 3,2$ & Ground & $7 / 2$ & $5 / 2$ & 76554.82 & .18 \\
\hline $\mathrm{C}^{12} \mathrm{H}_{3} \mathrm{Br}^{79}$ & 4. $40 \mathrm{I}$ & $4,1 \leftarrow 3,1$ & Ground & $7 / 2$ & $5 / 2$ & 76554.82 & .18 \\
\hline $\mathrm{C}^{12} \mathrm{H}_{3} \mathrm{Br}^{79}$ & $\cdot 4.401$ & $4,0 \leftarrow 3,0$ & Ground & $7 / 2$ & $5 / 2$ & 76554.82 & 18 \\
\hline $\mathrm{C}^{12} \mathrm{H}_{3} \mathrm{Br}^{79}$ & 4. .401 & $4,3 \leftarrow 3,3$ & Ground & $7 / 2$ & $5 / 2$ & 76554.82 & .18 \\
\hline
\end{tabular}




\begin{tabular}{|c|c|c|c|c|c|c|c|}
\hline $\mathrm{C}^{12} \mathrm{H}_{3} \mathrm{Br}^{79}$ & 4. 401 & $4,0 \leftarrow 3,0$ & Ground & $5 / 2$ & $3 / 2$ & 76554.82 & .18 \\
\hline $\mathrm{C}^{12} \mathrm{H}_{3} \mathrm{Br}^{79}$ & 4. 401 & $4,2 \leftarrow 3,2$ & Ground & $9 / 2$ & $7 / 2$ & 76575.22 & .18 \\
\hline $\mathrm{D}_{2} \mathrm{Se}^{82}$ & $4 \cdot 1751$ & $2,2,0 \leftarrow 2,1,1$ & Ground & & & 76612.14 & \\
\hline $\mathrm{C}^{12} \mathrm{H}_{3} \mathrm{Br}^{79}$ & 4. 401 & $4,3 \leftarrow 3,3$ & Ground & $9 / 2$ & $7 / 2$ & 76621.78 & .18 \\
\hline $\mathrm{Cl}^{35} \mathrm{~F}^{19} \mathrm{C}^{12} \mathrm{O}^{16}$ & 4. 151 & $8,3,5 \leftarrow 7,3,4$ & Ground & & & 76741.27 & .05 \\
\hline$\left(\mathrm{C}^{12} \mathrm{H}_{3}\right)_{2} \mathrm{~S}^{32}$ & 3. 601 & $7,3,5 \leftarrow 6,4,2$ & Ground & & & 76891.91 & .05 \\
\hline $\mathrm{D}_{2} \mathrm{Se}^{80}$ & $4-1749$ & $2,2,0 \leftarrow 2,1,1$ & Ground & & & 76907.04 & \\
\hline $\mathrm{D}_{2} \mathrm{Se}^{78}$ & 4-1748 & $2,2,0 \leftarrow 2,1,1$ & Ground & & & 77216.40 & \\
\hline $\mathrm{D}_{2} \mathrm{Se}^{77}$ & $4-1747$ & $2,2,0 \leftarrow 2,1,1$ & Ground & & & 77377.10 & \\
\hline$I^{127} \mathrm{C}^{12} \mathrm{~N}^{14}$ & 4. 511 & $12 \leftarrow 11$ & Ground & & & 77413 & \\
\hline $\mathrm{D}_{2} \mathrm{Se}^{76}$ & 4-1746 & $2,2,0 \leftarrow 2,1,1$ & Ground & & & 77542.71 & \\
\hline $\mathrm{C}^{12} \mathrm{H}_{3} \mathrm{Cl}^{37}$ & 4. 423 & $3,2 \leftarrow 2,2$ & Ground & $7 / 2$ & $5 / 2$ & 78511.68 & .16 \\
\hline $\mathrm{C}^{12} \mathrm{H}_{3} \mathrm{Cl}^{37}$ & 4. 423 & $3,2 \leftarrow 2,2$ & Ground & $5 / 2$ & $5 / 2$ & 78511.68 & .16 \\
\hline $\mathrm{C}^{12} \mathrm{H}_{3} \mathrm{Cl}^{37}$ & 4- 423 & $3,0 \leftarrow 2,0$ & Ground & $7 / 2$ & $7 / 2$ & 78512.80 & .16 \\
\hline $\mathrm{C}^{12} \mathrm{H}_{3} \mathrm{Cl}^{37}$ & 4. 423 & $3,2 \leftarrow 2,2$ & Ground & $5 / 2$ & $3 / 2$ & 78522.00 & .16 \\
\hline $\mathrm{C}^{12} \mathrm{H}_{3} \mathrm{Cl}^{37}$ & 4. 423 & $3,2 \leftarrow 2,2$ & Ground & $3 / 2$ & $3 / 2$ & 78522.00 & .16 \\
\hline $\mathrm{C}^{12} \mathrm{H}_{3} \mathrm{Cl}^{37}$ & 4- 423 & $3,1 \leftarrow 2,1$ & Ground & $7 / 2$ & $5 / 2$ & 78523.32 & .16 \\
\hline $\mathrm{C}^{12} \mathrm{H}_{3} \mathrm{Cl}^{37}$ & 4- 423 & $3,1 \leftarrow 2,1$ & Ground & $5 / 2$ & $3 / 2$ & 78523.32 & .16 \\
\hline $\mathrm{C}^{12} \mathrm{H}_{3} \mathrm{Cl}^{37}$ & 4. 423 & $3,0 \leftarrow 2,0$ & Ground & $3 / 2$ & $1 / 2$ & 78523.32 & .16 \\
\hline $\mathrm{C}^{12} \mathrm{H}_{3} \mathrm{Cl}^{37}$ & 4. 423 & $3,0 \leftarrow 2,0$ & Ground & $5 / 2$ & $3 / 2$ & 78523.32 & .16 \\
\hline $\mathrm{C}^{12} \mathrm{H}_{3} \mathrm{Cl}^{37}$ & 4. 423 & $3,2 \leftarrow 2,2$ & Ground & $7 / 2$ & $7 / 2$ & 78526.14 & .16 \\
\hline $\mathrm{C}^{12} \mathrm{H}_{3} \mathrm{Cl}^{37}$ & 4- 423 & $3,2 \leftarrow 2,2$ & Ground & $9 / 2$ & $7 / 2$ & 78526.14 & .16 \\
\hline $\mathrm{C}^{12} \mathrm{H}_{3} \mathrm{Cl}^{37}$ & 4- 423 & $3,0 \leftarrow 2,0$ & Ground & $9 / 2$ & $7 / 2$ & 78527.10 & .16 \\
\hline $\mathrm{C}^{12} \mathrm{H}_{3} \mathrm{Cl}^{37}$ & 4. 423 & $3,1 \leftarrow 2,1$ & Ground & $3 / 2$ & $1 / 2$ & 78527.10 & .16 \\
\hline $\mathrm{C}^{12} \mathrm{H}_{3} \mathrm{Cl}^{37}$ & 4- 423 & $3,0 \leftarrow 2,0$ & Ground & $7 / 2$ & $5 / 2$ & 78527.10 & .16 \\
\hline $\mathrm{C}^{12} \mathrm{H}_{3} \mathrm{Cl}^{37}$ & 4- 423 & $3,1 \leftarrow 2,1$ & Ground & $9 / 2$ & $7 / 2$ & 78527.10 & .16 \\
\hline $\mathrm{C}^{12} \mathrm{H}_{3} \mathrm{Cl}^{35}$ & 4. 421 & $3,2 \leftarrow 2,2$ & Ground & $5 / 2$ & $5 / 2$ & 79736.96 & .16 \\
\hline $\mathrm{C}^{12} \mathrm{H}_{3} \mathrm{Cl}^{35}$ & 4. 421 & $3,0 \leftarrow 2,0$ & Ground & $7 / 2$ & $7 / 2$ & 79736.96 & .16 \\
\hline $\mathrm{C}^{12} \mathrm{H}_{3} \mathrm{Cl}^{35}$ & 4. 421 & $3,2 \leftarrow 2,2$ & Ground & $7 / 2$ & $5 / 2$ & 79736.96 & .16 \\
\hline $\mathrm{C}^{12} \mathrm{H}_{3} \mathrm{Cl}^{35}$ & 4. 421 & $3,0 \leftarrow 2,0$ & Ground & $3 / 2$ & $1 / 2$ & 79751.44 & \\
\hline $\mathrm{C}^{12} \mathrm{H}_{3} \mathrm{Cl}^{35}$ & 4. 421 & $3,1 \leftarrow 2,1$ & Ground & $7 / 2$ & $5 / 2$ & 79751.44 & \\
\hline $\mathrm{C}^{12} \mathrm{H}_{3} \mathrm{Cl}^{35}$ & 4. 421 & $3,0 \leftarrow 2,0$ & Ground & $5 / 2$ & $3 / 2$ & 79751.44 & \\
\hline $\mathrm{C}^{12} \mathrm{H}_{3} \mathrm{Cl}^{35}$ & 4- 421 & $3,0 \leftarrow 2,0$ & Ground & $9 / 2$ & $7 / 2$ & 79756.00 & \\
\hline $\mathrm{C}^{12} \mathrm{H}_{3} \mathrm{Cl}^{35}$ & 4- 421 & $3,2 \leftarrow 2,2$ & Ground & $5 / 2$ & $7 / 2$ & 79756.00 & \\
\hline $\mathrm{C}^{12} \mathrm{H}_{3} \mathrm{Cl}^{35}$ & 4- 421 & $3,2 \leftarrow 2,2$ & Ground & $9 / 2$ & $7 / 2$ & 79756.00 & \\
\hline $\mathrm{C}^{12} \mathrm{H}_{3} \mathrm{Cl}^{35}$ & 4. 421 & $3,1 \leftarrow 2,1$ & Ground & $3 / 2$ & $1 / 2$ & 79756.00 & \\
\hline $\mathrm{C}^{12} \mathrm{H}_{3} \mathrm{Cl}^{35}$ & 4- 421 & $3,1 \leftarrow 2,1$ & Ground & $9 / 2$ & $7 / 2$ & 79756.00 & \\
\hline $\mathrm{C}^{12} \mathrm{H}_{3} \mathrm{Cl}^{35}$ & 4- 421 & $3,0 \leftarrow 2,0$ & Ground & $7 / 2$ & $5 / 2$ & 79756.00 & \\
\hline $\mathrm{C}^{12} \mathrm{H}_{3} \mathrm{Cl}^{35}$ & 4- 421 & $3,2 \leftarrow 2,2$ & Ground & $7 / 2$ & $7 / 2$ & 79756.00 & \\
\hline $\mathrm{C}^{12} \mathrm{H}_{3} \mathrm{Cl}^{35}$ & 4- 421 & $3,0 \leftarrow 2,0$ & Ground & $5 / 2$ & $5 / 2$ & 79764.56 & .16 \\
\hline $\mathrm{C}^{12} \mathrm{H}_{3} \mathrm{Cl}^{35}$ & 4- 421 & $3,2 \leftarrow 2,2$ & Ground & $3 / 2$ & $1 / 2$ & 79768.98 & .16 \\
\hline $\mathrm{C}^{12} \mathrm{H}_{3} \mathrm{Cl}^{35}$ & 4- 421 & $3,0 \leftarrow 2,0$ & Ground & $3 / 2$ & $3 / 2$ & 79769.94 & .16 \\
\hline $\mathrm{HDO}^{16}$ & 4-1712 & $1,1,0 \leftarrow 1,1,1$ & Ground & & & 80578.15 & \\
\hline $\mathrm{DN}^{14} \mathrm{C}^{12} \mathrm{O}^{16}$ & 4. 303 & $4,1,4 \leftarrow 3,1,3$ & Ground & & & 81106.32 & .5 \\
\hline $\mathrm{DN}^{14} \mathrm{C}^{12} \mathrm{O}^{16}$ & 4- 303 & $4,0,4 \leftarrow 3,0,3$ & Ground & & & 81571.53 & .5 \\
\hline
\end{tabular}




\begin{tabular}{|c|c|c|c|c|c|c|c|}
\hline \multirow{2}{*}{ Isotopic Species } & \multirow{2}{*}{$\begin{array}{l}\text { Vol.-Id. } \\
\text { Nos. }\end{array}$} & \multirow{2}{*}{$\begin{array}{c}\text { Rotational } \\
\text { Quantum Nos. }\end{array}$} & \multirow{2}{*}{ Vib. State } & \multicolumn{2}{|l|}{ Hyperfine } & \multirow{2}{*}{$\begin{array}{c}\text { Frequency } \\
\mathrm{MHz}\end{array}$} & \multirow{2}{*}{$\begin{aligned} & \text { Acc. } \\
\pm & \mathrm{MHz}\end{aligned}$} \\
\hline & & & & $\begin{array}{lll}\mathrm{F}_{1}^{\prime} & \mathrm{F}^{\prime} & \mathrm{F}_{1}\end{array}$ & $\mathrm{~F}$ & & \\
\hline $\mathrm{DN}^{14} \mathrm{C}^{12} \mathrm{O}^{16}$ & 4. 303 & $4,2,3 \leftarrow 3,2,2$ & Ground & & & 81578.97 & .5 \\
\hline $\mathrm{DN}^{14} \mathrm{C}^{12} \mathrm{O}^{16}$ & 4- 303 & $4,2,2 \leftarrow 3,2,1$ & Ground & & & 81579.61 & .5 \\
\hline $\mathrm{DN}^{14} \mathrm{C}^{12} \mathrm{O}^{16}$ & 4- 303 & $4,3,2 \leftarrow 3,3,1$ & Ground & & & 81586.95 & 1.0 \\
\hline $\mathrm{DN}^{14} \mathrm{C}^{12} \mathrm{O}^{16}$ & 4- 303 & $4,3,1 \leftarrow 3,3,0$ & Ground & & & 81586.95 & 1.0 \\
\hline $\mathrm{Br}^{81} \mathrm{C}^{12} \mathrm{~N}^{14}$ & 4- 142 & $10 \leftarrow 9$ & Ground & & & 81936. & \\
\hline $\mathrm{DN}^{14} \mathrm{C}^{12} \mathrm{O}^{16}$ & 4- 303 & $4,1,3 \leftarrow 3,1,2$ & Ground & & & 82042.23 & .5 \\
\hline $\mathrm{Br}^{79} \mathrm{C}^{12} \mathrm{~N}^{14}$ & 4- 141 & $10 \leftarrow 9$ & Ground & & & 82405 & \\
\hline $\mathrm{C}^{12} \mathrm{HF}_{3}^{19}$ & 4- 281 & $4,1 \leftarrow 3,1$ & Ground & & & 82788.00 & .20 \\
\hline $\mathrm{C}^{12} \mathrm{HF}_{3}^{19}$ & 4- 281 & $4,0 \leftarrow 3,0$ & Ground & & & 82788.00 & .20 \\
\hline $\mathrm{C}^{12} \mathrm{HF}_{3}^{19}$ & 4- 281 & $4,2 \leftarrow 3,2$ & Ground & & & 82788.59 & .20 \\
\hline $\mathrm{C}^{12} \mathrm{HF}_{3}^{19}$ & 4- 281 & 4. $3 \leftarrow 3,3$ & Ground & & & 82789.28 & .20 \\
\hline $\mathrm{S}^{32} \mathrm{O}_{2}^{16}$ & 4-1831 & $8,1,7 \leftarrow 8,0,8$ & Ground & & & 83687.88 & \\
\hline $\mathrm{I}^{127} \mathrm{C}^{12} \mathrm{~N}^{14}$ & 4- 511 & $13 \leftarrow 12$ & Ground & & & 83864 . & \\
\hline $\mathrm{C}^{12} \mathrm{H}_{3} \mathrm{C}^{12}: \mathrm{C}^{12} \mathrm{H}$ & 4-1041 & $5,4 \leftarrow 4,4$ & & & & 85431.34 & .20 \\
\hline $\mathrm{C}^{12} \mathrm{H}_{3} \mathrm{C}^{12}: \mathrm{C}^{12} \mathrm{H}$ & 4-1041 & $5,3 \leftarrow 4,3$ & & & & 85442.61 & .20 \\
\hline $\mathrm{C}^{12} \mathrm{H}_{3} \mathrm{C}^{12} \vdots \mathrm{C}^{12} \mathrm{H}$ & 4-1041 & $5,2 \leftarrow 4,2$ & & & & 85450.78 & .20 \\
\hline $\mathrm{C}^{12} \mathrm{H}_{3} \mathrm{C}^{12} \vdots \mathrm{C}^{12} \mathrm{H}$ & 4-1041 & $5,1 \leftarrow 4,1$ & & & & 85455.67 & .20 \\
\hline $\mathrm{C}^{12} \mathrm{H}_{3} \mathrm{C}^{12}: \mathrm{C}^{12} \mathrm{H}$ & 4-1041 & $5,0 \leftarrow 4,0$ & & & & 85457.29 & .20 \\
\hline $\mathrm{HC}^{13} \mathrm{~N}^{14}$ & 4- 293 & $1 \leftarrow 0$ & Ground & 1 & 1 & 86338.12 & .30 \\
\hline $\mathrm{HC}^{13} \mathrm{~N}^{14}$ & 4- 293 & $1 \leftarrow 0$ & Ground & 2 & 1 & 86339.49 & .30 \\
\hline $\mathrm{HC}^{13} \mathrm{~N}^{14}$ & 4- 293 & $1 \leftarrow 0$ & Ground & 0 & 1 & 86341.54 & .30 \\
\hline $\mathrm{Si}^{28} \mathrm{~F}_{3}^{19} \mathrm{H}$ & 4-1641 & $6,0 \leftarrow 5,0$ & Ground & & & 86490.06 & .20 \\
\hline $\mathrm{Si}^{28} \mathrm{~F}_{3}^{19} \mathrm{H}$ & 4-1641 & $6,1 \leftarrow 5,1$ & Ground & & & 86490.06 & .20 \\
\hline $\mathrm{Si}^{28} \mathrm{~F}_{3}^{19} \mathrm{H}$ & 4-1641 & $6,2 \leftarrow 5,2$ & Ground & & & 86490.67 & .20 \\
\hline $\mathrm{Si}^{28} \mathrm{~F}_{3}^{19} \mathrm{H}$ & 4-1641 & $6,3 \leftarrow 5,3$ & Ground & & & 86491.38 & .20 \\
\hline $\mathrm{Si}^{28} \mathrm{~F}_{3}^{19} \mathrm{H}$ & 4-1641 & $6,4 \leftarrow 5,4$ & Ground & & & 86492.42 & .20 \\
\hline $\mathrm{Si}^{28} \mathrm{~F}_{3}^{19} \mathrm{H}$ & 4-1641 & $6.5 \leftarrow 5.5$ & Ground & & & 86493.80 & .20 \\
\hline $\mathrm{HC}^{12} \mathrm{O}^{16} \mathrm{O}^{16} \mathrm{H}$ & $3-\cdot 71$ & $4,1,4 \leftarrow 3,1,3$ & & & & 86545.92 & .52 \\
\hline $\mathrm{DN}^{14} \mathrm{C}^{12} \mathrm{~S}^{32}$ & 4- 312 & $8,1,8 \leftarrow 7,1,7$ & Ground & & & 87361.71 & .5 \\
\hline $\mathrm{DN}^{14} \mathrm{C}^{12} \mathrm{~S}^{32}$ & 4- 312 & $8, \quad \leftarrow 7$, & Excited & & & 87531.0 & 1.0 \\
\hline $\mathrm{DN}^{14} \mathrm{C}^{12} \mathrm{~S}^{32}$ & 4- 312 & $8, \cdot \leftarrow 7$, & Excited & & & 87555.0 & 1.0 \\
\hline $\mathrm{DN}^{14} \mathrm{C}^{12} \mathrm{~S}^{32}$ & 4- 312 & $8,0,8 \leftarrow 7,0,7$ & Ground & & & 87563.05 & .5 \\
\hline $\mathrm{HN}^{14} \mathrm{C}^{12} \mathrm{O}^{16}$ & 4- 301 & $4,1,4 \leftarrow 3,1,3$ & Ground & & & 87597.03 & .5 \\
\hline $\mathrm{DN}^{14} \mathrm{C}^{12} \mathrm{~S}^{32}$ & 4- 312 & $8,2,6 \leftarrow 7,2,5$ & Ground & & & 87626.37 & .5 \\
\hline $\mathrm{DN}^{14} \mathrm{C}^{12} \mathrm{~S}^{32}$ & 4- 312 & $8,2,7 \leftarrow 7,2,6$ & Ground & & & 87626.37 & .5 \\
\hline $\mathrm{DN}^{14} \mathrm{C}^{12} \mathrm{~S}^{32}$ & 4- 312 & $8, \quad \leftarrow 7$, & Excited & & & 87631.1 & 1.0 \\
\hline $\mathrm{DN}^{14} \mathrm{C}^{12} \mathrm{~S}^{32}$ & 4- 312 & $8, \quad, \leftarrow 7, \quad$, & Excited & & & 87671.8 & 1.0 \\
\hline $\mathrm{DN}^{14} \mathrm{C}^{12} \mathrm{~S}^{32}$ & 4- 312 & $8,3,5 \leftarrow 7,3,4$ & Ground & & & 87679.66 & 1.0 \\
\hline $\mathrm{DN}^{14} \mathrm{C}^{12} \mathrm{~S}^{32}$ & 4- 312 & $8,3,6 \leftarrow 7,3,5$ & Ground & & & 87679.66 & 1.0 \\
\hline $\mathrm{DN}^{14} \mathrm{C}^{12} \mathrm{~S}^{32}$ & 4- 312 & $8, \quad, \quad \leftarrow 7$, & Excited & & & 87730.7 & 1.0 \\
\hline $\mathrm{DN}^{14} \mathrm{C}^{12} \mathrm{~S}^{32}$ & 4- 312 & $8, \quad \leftarrow 7$, & Excited & & & 87734.2 & 1.0 \\
\hline $\mathrm{DN}^{14} \mathrm{C}^{12} \mathrm{~S}^{32}$ & 4- 312 & $8, \quad \leftarrow 7$, & Excited & & & 87742.8 & 1.0 \\
\hline $\mathrm{DN}^{14} \mathrm{C}^{12} \mathrm{~S}^{32}$ & 4- 312 & $8, \quad \leftarrow 7$, & Excited & & & 87777.1 & 1.0 \\
\hline $\mathrm{DN}^{14} \mathrm{C}^{12} \mathrm{~S}^{32}$ & 4- 312 & $8, \quad \leftarrow \quad \leftarrow$, & Excited & & & 87799.3 & 1.0 \\
\hline $\mathrm{DN}^{14} \mathrm{C}^{12} \mathrm{~S}^{32}$ & 4- 312 & $8,1,7 \leftarrow 7,1,6$ & Ground & & & 87803.28 & .5 \\
\hline
\end{tabular}


Vib. State

\begin{tabular}{|c|c|c|c|c|c|c|c|}
\hline $\mathrm{HN}^{14} \mathrm{C}^{12} \mathrm{O}^{16}$ & 4- 301 & $4,3,2 \leftarrow 3,3,1$ & Ground & 5 & 4 & 87866.82 & 1.0 \\
\hline $\mathrm{HN}^{14} \mathrm{C}^{12} \mathrm{O}^{16}$ & 4. 301 & $4,3,2 \leftarrow 3,3,1$ & Ground & 3 & 2 & 87866.82 & 1.0 \\
\hline $\mathrm{HN}^{14} \mathrm{C}^{12} \mathrm{O}^{16}$ & 4- 301 & $4,3,1 \leftarrow 3,3,0$ & Ground & 5 & 4 & 87866.82 & 1.0 \\
\hline $\mathrm{HN}^{14} \mathrm{C}^{12} \mathrm{O}^{16}$ & 4- 301 & $4,3,1 \leftarrow 3,3,0$ & Ground & 3 & 2 & 87866.82 & 1.0 \\
\hline $\mathrm{HN}^{14} \mathrm{C}^{12} \mathrm{O}^{16}$ & 4- 301 & $4,3,1 \leftarrow 3,3,0$ & Ground & 4 & 3 & 87867.60 & 1.0 \\
\hline $\mathrm{HN}^{14} \mathrm{C}^{12} \mathrm{O}^{16}$ & 4- 301 & $4,3,2 \leftarrow 3,3,1$ & Ground & 4 & 3 & 87867.60 & 1.0 \\
\hline $\mathrm{DN}^{14} \mathrm{C}^{12} \mathrm{~S}^{32}$ & 4. 312 & $8, \quad \leftarrow 7, \quad$, & Excited! & & & 87870.4 & 1.0 \\
\hline $\mathrm{HN}^{14} \mathrm{C}^{12} \mathrm{O}^{16}$ & 4. 301 & $4,2,3 \leftarrow 3,2,2$ & Ground & & & 87898.53 & .5 \\
\hline $\mathrm{HN}^{14} \mathrm{C}^{12} \mathrm{O}^{16}$ & 4- 301 & $4,2,2 \leftarrow 3,2,1$ & Ground & & & 87898.53 & .5 \\
\hline $\mathrm{HN}^{14} \mathrm{C}^{12} \mathrm{O}^{16}$ & 4- 301 & $4, \quad, \quad \leftarrow 3$, & Excited & & & 87913.08 & 1.0 \\
\hline $\mathrm{HN}^{14} \mathrm{C}^{12} \mathrm{O}^{16}$ & 4- 301 & $4,0,4 \leftarrow 3,0,3$ & Ground & & & 87925.45 & .5 \\
\hline $\mathrm{HN}^{14} \mathrm{C}^{12} \mathrm{O}^{16}$ & 4- 301 & $4, \quad \leftarrow 3, \quad$, & Excited & & & 87969.72 & 1.0 \\
\hline $\mathrm{HN}^{14} \mathrm{C}^{12} \mathrm{O}^{16}$ & 4- 301 & $4,0, \leftarrow 3,0$ & Excited & & & 88067.49 & 1.0 \\
\hline $\mathrm{HN}^{14} \mathrm{C}^{12} \mathrm{O}^{16}$ & 4- 301 & $4,2, \leftarrow 3,2$, & Excited & & & 88069.80 & 1.0 \\
\hline $\mathrm{HN}^{14} \mathrm{C}^{12} \mathrm{O}^{16}$ & 4- 301 & $4,0, \leftarrow 3,0$, & Excited & & & 88083.84 & 1.0 \\
\hline $\mathrm{HN}^{14} \mathrm{C}^{12} \mathrm{O}^{16}$ & 4- 301 & $4,1, \leftarrow 3,1$, & Excited & & & 88131.78 & 1.0 \\
\hline $\mathrm{HN}^{14} \mathrm{C}^{12} \mathrm{O}^{16}$ & 4- 301 & $4,1,3 \leftarrow 3,1,2$ & Ground & & & 88239.03 & .5 \\
\hline $\mathrm{HN}^{14} \mathrm{C}^{12} \mathrm{O}^{16}$ & 4- 301 & $4,1, \leftarrow 3,1$ & Excited & & & 88334.64 & 1.0 \\
\hline $\mathrm{HN}_{3}^{14}$ & $4-1701$ & $4,1,4 \leftarrow 3,1,3$ & Ground & & & 88488.03 & .25 \\
\hline $\mathrm{HN}^{14} \mathrm{C}^{12} \mathrm{O}^{16}$ & 4- 301 & $4, \quad \leftarrow 3$, & Excited: & & & 88623.90 & 1.0 \\
\hline $\mathrm{HC}^{12} \mathrm{~N}^{14}$ & 4- 291 & $1 \leftarrow 0$ & Ground & 1 & 1 & 88630.431 & .005 \\
\hline $\mathrm{HC}^{12} \mathrm{~N}^{14}$ & 4- 291 & $1 \leftarrow 0$ & Ground & 2 & 1 & 88631.871 & .005 \\
\hline $\mathrm{HC}^{12} \mathrm{~N}^{14}$ & 4- 291 & $1 \leftarrow 0$ & Ground & 0 & 1 & 88633.954 & .005 \\
\hline $\mathrm{HC}^{12} \mathrm{~N}^{14}$ & 4- 291 & $1 \leftarrow 0$ & Ground & & & 88671. & \\
\hline $\mathrm{HN}_{3}^{14}$ & $4-1701$ & $4,3,1 \leftarrow 3,3.0$ & Ground & 5 & 4 & 89229.74 & .25 \\
\hline $\mathrm{HN}_{3}^{14}$ & 4-1701 & $4,3,2 \leftarrow 3,3,1$ & Ground & 3 & 2 & 89229.74 & .25 \\
\hline $\mathrm{HN}_{3}^{1+4}$ & $4-1701$ & $4,3,1 \leftarrow 3,3.0$ & Ground & 4 & 3 & 89231.45 & .25 \\
\hline $\mathrm{HN}_{3}^{1+4}$ & 4-1701 & $4,2,3 \leftarrow 3,2,2$ & Ground & 5 & 4 & 89247.11 & .25 \\
\hline $\mathrm{HN}_{3}^{14}$ & $4-1701$ & $4,2,3 \leftarrow 3,2,2$ & Ground & 3 & 2 & 89247.11 & .25 \\
\hline $\mathrm{HN}_{3}^{14}$ & 4-1701 & $4,2,3 \leftarrow 3,2,2$ & Ground & 4 & 3 & 89247.84 & .25 \\
\hline $\mathrm{HN}_{3}^{14}$ & 4-1701 & $4,2,2 \leftarrow 3,2,1$ & Ground & 3 & 2 & 89250.42 & .25 \\
\hline $\mathrm{HN}_{3}^{14}$ & $4-1701$ & $4,2,2 \leftarrow 3,2,1$ & Ground & 5 & 4 & $89250 . \dot{4} 2$ & .25 \\
\hline $\mathrm{HN}_{3}^{14}$ & 4-1701 & $4,2,2 \leftarrow 3,2,1$ & Ground & 4 & 3 & 89251.21 & .25 \\
\hline $\mathrm{HN}_{3}^{14}$ & 4-1701 & $4,0,4 \leftarrow 3,0,3$ & Ground & & & 89258.55 & .25 \\
\hline $\mathrm{Sb}^{123} \mathrm{D}_{3}$ & $4-1794$ & $1, \leftarrow 0$ & Ground & $5 / 2$ & $7 / 2$ & 89291.93 & .3 \\
\hline $\mathrm{Sb}^{121} \mathrm{D}_{3}$ & 4-1793 & $1, \leftarrow 0$ & Ground & $3 / 2$ & $5 / 2$ & 89322.65 & .3 \\
\hline $\mathrm{Sb}^{123} \mathrm{D}_{3}$ & 4-1794 & $1, \leftarrow 0$, & Ground & $9 / 2$ & $7 / 2$ & 89326.39 & .3 \\
\hline $\mathrm{Sb}^{121} \mathrm{D}_{3}$ & $4-1793$ & $1 . \leftarrow 0$, & Ground & $7 / 2$ & $5 / 2$ & 89365.05 & .3 \\
\hline $\mathrm{Sb}^{123} \mathrm{D}_{3}$ & 4-1794 & $1, \leftarrow 0$, & Ground & $7 / 2$ & $7 / 2$ & 89440.38 & .3 \\
\hline $\mathrm{Sb}^{121} \mathrm{D}_{3}$ & $4-1793$ & $1, \leftarrow 0$, & Ground & $5 / 2$ & $5 / 2$ & 89462.46 & .3 \\
\hline $\mathrm{HC}^{12} \mathrm{O}^{16} \mathrm{O}^{16} \mathrm{H}$ & $3-71$ & $4,0,4 \leftarrow 3,0,3$ & & & & 89579.18 & .53 \\
\hline $\mathrm{HC}^{12} \mathrm{O}^{16} \mathrm{O}^{16} \mathrm{H}$ & $3-71$ & $4,2,3 \leftarrow 3,2,2$ & & & & 89861.52 & .54 \\
\hline $\mathrm{HC}^{12} \mathrm{O}^{16} \mathrm{O}^{16} \mathrm{H}$ & 3- 71 & $4,3,2 \leftarrow 3,3,1$ & & & & 89948.32 & .54 \\
\hline $\mathrm{HC}^{12} \mathrm{O}^{16} \mathrm{O}^{16} \mathrm{H}$ & 3- 71 & $4,3,1 \leftarrow 3,3,0$ & & & & 89950.34 & .54 \\
\hline $\mathrm{HN}_{3}^{14}$ & 4-1701 & $4,1,3 \leftarrow 3,1,2$ & Ground & & & 90026.99 & .25 \\
\hline
\end{tabular}


$\mathrm{HC}^{12} \mathrm{O}^{16} \mathrm{O}^{16} \mathrm{H}$

$\mathrm{F}^{19} \mathrm{HC}^{12} \mathrm{O}^{16}$

$\mathrm{D}_{2} \mathrm{O}^{16}$

$\mathrm{Na}^{23} \mathrm{Cl}^{35}$

$\mathrm{HN}^{14} \mathrm{C}^{12} \mathrm{~S}^{34}$

$\mathrm{HN}^{14} \mathrm{C}^{12} \mathrm{~S}^{34}$

$\mathrm{HN}^{14} \mathrm{C}^{12} \mathrm{~S}^{34}$

$\mathrm{HN}^{14} \mathrm{C}^{12} \mathrm{~S}^{34}$

$\mathrm{HN}^{14} \mathrm{C}^{12} \mathrm{~S}^{34}$

$\mathrm{HN}^{14} \mathrm{C}^{12} \mathrm{~S}^{34}$

$\mathrm{HN}_{2}^{14} \mathrm{~N}^{15}$

$\mathrm{HN}^{14} \mathrm{C}^{12} \mathrm{~S}^{34}$

$\mathrm{P}^{31} \mathrm{O}^{16} \mathrm{~F}_{3}^{19}$

$\mathrm{P}^{31} \mathrm{O}^{16} \mathrm{~F}_{3}^{19}$

$\mathrm{P}^{31} \mathrm{O}^{16} \mathrm{~F}_{3}^{19}$

$\mathrm{P}^{31} \mathrm{O}^{16} \mathrm{~F}_{3}^{19}$

$\mathrm{P}^{31} \mathrm{O}^{16} \mathrm{~F}_{3}^{19}$

$\mathrm{P}^{31} \mathrm{O}^{16} \mathrm{~F}_{3}^{19}$

$\mathrm{P}^{31} \mathrm{O}^{16} \mathrm{~F}_{3}^{19}$

$\mathrm{P}^{31} \mathrm{O}^{16} \mathrm{~F}_{3}^{19}$

$\mathrm{P}^{31} \mathrm{O}^{16} \mathrm{~F}_{3}^{19}$

$\mathrm{P}^{31} \mathrm{O}^{16} \mathrm{~F}_{3}^{19}$

$\mathrm{HN}^{15} \mathrm{~N}_{2}^{14}$

$\mathrm{C}^{12} \mathrm{H}_{3} \mathrm{C}^{12} \mathrm{~N}^{14}$

$\mathrm{C}^{12} \mathrm{H}_{3} \mathrm{C}^{12} \mathrm{~N}^{14}$

$\mathrm{C}^{12} \mathrm{H}_{3} \mathrm{C}^{12} \mathrm{~N}^{14}$

$\mathrm{C}^{12} \mathrm{H}_{3} \mathrm{C}^{12} \mathrm{~N}^{14}$

$\mathrm{C}^{12} \mathrm{H}_{3} \mathrm{C}^{12} \mathrm{~N}^{14}$

$\mathrm{C}^{12} \mathrm{H}_{3} \mathrm{C}^{12} \mathrm{~N}^{14}$

$\mathrm{C}^{12} \mathrm{H}_{3} \mathrm{C}^{12} \mathrm{~N}^{14}$

$\mathrm{HN}_{2}^{14} \mathrm{~N}^{15}$

$\mathrm{HN}_{2}^{14} \mathrm{~N}^{15}$

$\mathrm{HN}_{2}^{14} \mathrm{~N}^{15}$

$\mathrm{HN}_{2}^{14} \mathrm{~N}^{15}$

$\mathrm{HN}_{2}^{14} \mathrm{~N}^{15}$

$\mathrm{HN}_{2}^{14} \mathrm{~N}^{15}$

$\mathrm{HN}_{2}^{14} \mathrm{~N}^{15}$

$\mathrm{HN}_{2}^{14} \mathrm{~N}^{15}$

$\mathrm{HN}_{2}^{14} \mathrm{~N}^{15}$

$\mathrm{HN}_{2}^{14} \mathrm{~N}^{15}$

$\mathrm{HN}_{2}^{14} \mathrm{~N}^{15}$

$\mathrm{HN}_{2}^{14} \mathrm{~N}^{15}$

$\mathrm{C}^{12} \mathrm{H}_{3} \mathrm{C}^{12} \mathrm{~N}^{14}$

$\mathrm{F}^{19} \mathrm{DC}^{12} \mathrm{O}^{16}$

$\mathrm{HN}_{2}^{14} \mathrm{~N}^{15}$
3- $\quad 714,2,2 \leftarrow 3,2,1$

4. $2715,1,4 \leftarrow 5,0,5$

4-1713 $6,1,6 \leftarrow 5,2,3$

Ground

1 .

$$
7 \leftarrow 6
$$

Ground

4- 316

$8,1,8 \leftarrow 7,1,7$

Ground

4. 316

$8,0,8 \leftarrow 7,0,7$

Ground

4. 316

$8,2,6 \leftarrow 7,2,5$

Ground

4. 316

$8,2,7 \leftarrow 7,2,6$

Ground

4- 316

$8,3,6 \leftarrow 7,3,5$

Ground

4. 316

$8,3,5 \leftarrow 7,3,4$

Ground

4-1703

$4,1,4 \leftarrow 3,1,3$

Ground

4. 316

$8,1,7 \leftarrow 7,1,6$

Ground

4-1671

$10,9 \leftarrow 9,9$

4-1671

$10,8 \leftarrow 9,8$

Ground

4-1671

$10,7 \leftarrow 9,7$

4-1671

$10,6 \leftarrow 9,6$

4-1671

$10,5 \leftarrow 9,5$

4-1671

$10,4 \leftarrow 9,4$

4-1671

$10,3 \leftarrow 9,3$

4-1671

$10,2 \leftarrow 9,2$

4-1671

$10,0 \leftarrow 9,0$

4-1671

4. 1704

$10,1 \leftarrow 9,1$

4. 811

$4,1,4 \leftarrow 3,1,3$

$5,4 \leftarrow 4,4$

4. 811

$5,4 \leftarrow 4,4$

4. 811

$5,3 \leftarrow 4,3$

4- 811

$5,3 \leftarrow 4,3$

4. 811

$5,2 \leftarrow 4,2$

4. 811

$5,1 \leftarrow 4,1$

4- 811

$5,0 \leftarrow 4,0$

4- 1703

$4,3,2 \leftarrow 3,3,1$

4- 1703

4-1703

$4,3,1 \leftarrow 3,3,0$

$4,3,1 \leftarrow 3,3,0$

4-1703

$4,3,1 \leftarrow 3,3,0$

4-1703

$4,2,3 \leftarrow 3,2,2$

4-1703

$4,2,3 \leftarrow 3,2,2$

4-1703

$4,2,2 \leftarrow 3,2,1$

4-1703

$4,2,2 \leftarrow 3,2,1$

4-1703

$4,2,3 \leftarrow 3,2,2$

4-1703

$4,2,2 \leftarrow 3,2,1$

4-1703

4, $2,2 \leftarrow 3,2,1$

4-1703

$4,2,2 \leftarrow 3,2,1$

4- 811

$5,1 \leftarrow 4,1$

4- 272

$2,2,1 \leftarrow 3,1,2$

4-1703
$4,0,4 \leftarrow 3,0,3$
Ground

Ground

Ground

Ground

Ground

Ground

Ground

Ground

Ground

Ground

Ground

Ground

Ground

Ground

Ground

Ground

Ground

Ground

Ground

Ground

Ground

Ground

Ground

Ground

Ground

Ground

Ground

Ground

Ground

Excited

Ground
90164.52

.54

90786.64

.05

90916.8

91170.45

0.04

91495.6

.5

91635.9

91658.7

.5

91658.7

$91671.7 \quad 1.0$

$91671.7 \quad 1.0$

$91706.67 \quad .15$

$91784.3 \quad .5$

$91879.08 \quad .20$

$91879.53 \quad .20$

$91879.92 \quad$.20

$91880.27 \quad 20$

$91880.56 \quad .20$

$91880.83 \quad .20$

$91881.00 \quad .20$

$91881.16 \quad .20$

$91881.16 \quad .20$

$91881.16 \quad .20$

$91894.81 \quad .15$

$91957.94 \quad$.25

$91959.20 \quad$.25

$91970.62 \quad$.25

$91971.35 \quad$.25

$91980.00 \quad$.25

$91985.35 \quad$.25

$91987.07 \quad$.25

$92131.38 \quad .15$

$92 \quad 131.38 \quad .15$

$92133.13 \quad .15$

$92133.13 \quad .15$

$92161.78 \quad .15$

$92161.78 \quad .15$

$92162.50 \quad .15$

$92162.50 \quad .15$

$92162.50 \quad .15$

$92162.50 \quad .15$

$92162.50 \quad .15$

$92 \quad 163.45 \quad .15$

$92175.46 \quad .25$

$92176.92 \quad .04$

92185.47 


\begin{tabular}{|c|c|c|c|c|c|c|}
\hline \multirow{2}{*}{ Isotopic Species } & \multirow{2}{*}{$\begin{array}{l}\text { Vol.-Id. } \\
\text { Nos. }\end{array}$} & \multirow{2}{*}{$\begin{array}{c}\text { Rotational } \\
\text { Quantum Nos. }\end{array}$} & \multirow{2}{*}{ Vib. State } & Hyperfine & \multirow{2}{*}{$\begin{array}{l}\text { Frequency } \\
\text { MHz }\end{array}$} & \multirow{2}{*}{$\begin{aligned} & \text { Acc. } \\
\pm & \mathrm{MH}_{2}\end{aligned}$} \\
\hline & & & & $\begin{array}{llll}F_{1}^{\prime} & F^{\prime} & F_{1} & F\end{array}$ & & \\
\hline $\mathrm{C}^{12} \mathrm{H}_{3} \mathrm{C}^{12} \mathrm{~N}^{14}$ & 4- 811 & $5,4 \leftarrow 4,4$ & Excited & & 92218.88 & .25 \\
\hline $\mathrm{C}^{12} \mathrm{H}_{3} \mathrm{C}^{12} \mathrm{~N}^{14}$ & 4- 811 & $5,3 \leftarrow 4,3$ & Excited & & 92234.88 & .25 \\
\hline $\mathrm{C}^{12} \mathrm{H}_{3} \mathrm{C}^{12} \mathrm{~N}^{14}$ & 4- 811 & $5,2 \leftarrow 4,2$ & Excited & & 92247.42 & .25 \\
\hline $\mathrm{C}^{12} \mathrm{H}_{3} \mathrm{C}^{12} \mathrm{~N}^{14}$ & 4- 811 & $5,4 \leftarrow 4,4$ & Excited & & 92250.14 & .25 \\
\hline $\mathrm{C}^{12} \mathrm{H}_{3} \mathrm{C}^{12} \mathrm{~N}^{14}$ & 4- 811 & $5,1 \leftarrow 4,1$ & Excited & & 92256.53 & .25 \\
\hline $\mathrm{C}^{12} \mathrm{H}_{3} \mathrm{C}^{12} \mathrm{~N}^{14}$ & 4- 811 & $5,3 \leftarrow 4,3$ & Excited & & 92258.59 & .25 \\
\hline $\mathrm{C}^{12} \mathrm{H}_{3} \mathrm{C}^{12} \mathrm{~N}^{14}$ & 4. 811 & $5,0 \leftarrow 4,0$ & Excited & & 92261.53 & .25 \\
\hline $\mathrm{C}^{12} \mathrm{H}_{3} \mathrm{C}^{12} \mathrm{~N}^{14}$ & 4- 811 & $5,2 \leftarrow 4,2$ & Excited & & 92264.23 & .25 \\
\hline $\mathrm{HN}^{15} \mathrm{~N}_{2}^{14}$ & $4-1704$ & $4,3,2 \leftarrow 3,3,1$ & Ground & & 92325.35 & .15 \\
\hline $\mathrm{HN}^{15} \mathrm{~N}_{2}^{14}$ & 4-1704 & $4,3,1 \leftarrow 3,3,0$ & Ground & & 92325.35 & .15 \\
\hline $\mathrm{C}^{12} \mathrm{H}_{3} \mathrm{C}^{12} \mathrm{~N}^{14}$ & 4- 811 & $5,1 \leftarrow 4,1$ & Excited & & 92353.67 & .25 \\
\hline $\mathrm{HN}^{15} \mathrm{~N}_{2}^{14}$ & 4-1704 & $4,2,3 \leftarrow 3,2,2$ & Ground & & 92355.67 & .15 \\
\hline $\mathrm{HN}^{15} \mathrm{~N}_{2}^{14}$ & 4-1704 & $4,2,2 \leftarrow 3,2,1$ & Ground & & 92356.46 & .15 \\
\hline $\mathrm{HN}^{15} \mathrm{~N}_{2}^{14}$ & 4-1704 & $4,0,4 \leftarrow 3,0,3$ & Ground & & 92379.68 & .15 \\
\hline $\mathrm{C}^{12} \mathrm{H}_{3} \mathrm{C}^{12} \mathrm{~N}^{14}$ & 4- 811 & $5, \leftarrow 4$, & Excited & & 92510.7 & .25 \\
\hline $\mathrm{C}^{12} \mathrm{H}_{3} \mathrm{C}^{12} \mathrm{~N}^{14}$ & 4- 811 & $5, \leftarrow 4$, & Excited & & 92519.6 & .25 \\
\hline $\mathrm{C}^{12} \mathrm{H}_{3} \mathrm{C}^{12} \mathrm{~N}^{14}$ & 4- 811 & $5, \leftarrow 4$, & Excited & & 92524.2 & .25 \\
\hline $\mathrm{C}^{12} \mathrm{H}_{3} \mathrm{C}^{12} \mathrm{~N}^{14}$ & 4- 811 & $5, \leftarrow 4$, & Excited & & 92525.1 & .25 \\
\hline $\mathrm{C}^{12} \mathrm{H}_{3} \mathrm{C}^{12} \mathrm{~N}^{14}$ & 4- 811 & $5,3 \leftarrow 4,3$ & Excited & - & 92526.9 & .25 \\
\hline $\mathrm{C}^{12} \mathrm{H}_{3} \mathrm{C}^{12} \mathrm{~N}^{14}$ & 4- 811 & $5,2 \leftarrow 4,2$ & Excited & & 92533.0 & .25 \\
\hline $\mathrm{C}^{12} \mathrm{H}_{3} \mathrm{C}^{12} \mathrm{~N}^{14}$ & 4- 811 & $5,1 \leftarrow 4,1$ & Excited & & 92538.7 & .25 \\
\hline $\mathrm{HN}_{2}^{14} \mathrm{~N}^{15}$ & 4-1703 & $4,1,3 \leftarrow 3,1,2$ & Ground & & 92653.45 & .15 \\
\hline $\mathrm{HN}^{15} \mathrm{~N}_{2}^{14}$ & 4-1704 & $4,1,3 \leftarrow 3,1,2$ & Ground & & 92853.53 & .15 \\
\hline $\mathrm{C}^{12} \mathrm{H}_{2} \mathrm{DF}^{19}$ & 4- 465 & $2,1,2 \leftarrow 1,1,1$ & Ground & & 92918.7 & 1. \\
\hline $\mathrm{HC}^{12} \mathrm{O}^{16} \mathrm{O}^{16} \mathrm{H}$ & 3- 71 & $4,1,3 \leftarrow 3,1,2$ & & & 93098.46 & .56 \\
\hline $\mathrm{F}^{19} \mathrm{HC}^{12} \mathrm{O}^{16}$ & 4- 271 & $5,2,4 \leftarrow 6,1,5$ & & & 93164.04 & .05 \\
\hline $\mathrm{Cl}^{37} \mathrm{C}^{12} \mathrm{~N}^{14}$ & 4- 173 & $8 \leftarrow 7$ & Ground & & 93552.59 & .20 \\
\hline $\mathrm{HN}^{14} \mathrm{C}^{12} \mathrm{~S}^{32}$ & 4- 311 & $8,1,8 \leftarrow 7,1,7$ & Ground & & 93692.76 & .5 \\
\hline $\mathrm{HN}^{14} \mathrm{C}^{12} \mathrm{~S}^{32}$ & 4- 311 & $8, \quad \leftarrow 7$, & Excited & & 93695.0 & 1.0 \\
\hline $\mathrm{Cl}^{37} \mathrm{C}^{12} \mathrm{~N}^{14}$ & 4- 173 & $8 \leftarrow 7$ & Excited & & 93751.28 & \\
\hline $\mathrm{HN}^{14} \mathrm{C}^{12} \mathrm{~S}_{j}^{32}$ & 4. 311 & $8,0,8 \leftarrow 7,0,7$ & Ground & & 93829.91 & .5 \\
\hline $\mathrm{HN}^{14} \mathrm{C}^{12} \mathrm{~S}^{32}$ & 4- 311 & $8, \quad \leftarrow 7$, & Excited & & 93851.2 & 1.0 \\
\hline $\mathrm{HN}^{14} \mathrm{C}^{12} \mathrm{~S}^{32}$ & 4. 311 & $8,2,7 \leftarrow 7,2,6$ & Ground & & 93863.28 & .5 \\
\hline $\mathrm{HN}^{14} \mathrm{C}^{12} \mathrm{~S}^{32}$ & 4- 311 & $8,2,6 \leftarrow 7,2,5$ & Ground & & 93863.28 & .5 \\
\hline $\mathrm{Cl}^{37} \mathrm{C}^{12} \mathrm{~N}^{14}$ & 4- 173 & $8 \leftarrow 7$ & Excited & & 93865.98 & \\
\hline $\mathrm{HN}^{14} \mathrm{C}^{12} \mathrm{~S}^{32}$ & 4- 311 & $8,3,6 \leftarrow 7,3,5$ & Ground & & 93875.28 & 1.0 \\
\hline $\mathrm{HN}^{14} \mathrm{C}^{12} \mathrm{~S}^{32}$ & 4- 311 & $8,3,5 \leftarrow 7,3,4$ & Ground & & 93875.28 & 1.0 \\
\hline $\mathrm{F}^{19} \mathrm{DC}^{12} \mathrm{O}^{16}$ & 4- 272 & $8,1,7 \leftarrow 8,0,8$ & & & 93881.72 & .04 \\
\hline $\mathrm{HN}^{14} \mathrm{C}^{12} \mathrm{~S}^{32}$ & 4- 311 & $8, \quad \leftarrow 7$, & Excited & & 93895.6 & 1.0 \\
\hline $\mathrm{HN}^{14} \mathrm{C}^{12} \mathrm{~S}^{32}$ & 4- 311 & $8, \quad \leftarrow 7$, & Excited & & 93899.3 & 1.0 \\
\hline $\mathrm{HN}^{14} \mathrm{C}^{12} \mathrm{~S}^{32}$ & 4- 311 & $8, \quad \leftarrow 7$, & Excited & & 93902.9 & 1.0 \\
\hline $\mathrm{HN}^{14} \mathrm{C}^{12} \mathrm{~S}^{32}$ & 4- 311 & $8, \quad \leftarrow 7$, & Excited & & 93953.3 & 1.0 \\
\hline $\mathrm{HN}^{14} \mathrm{C}^{12} \mathrm{~S}^{32}$ & 4- 311 & $8, \quad \leftarrow 7$, & Excited & & 93983.7 & 1.0 \\
\hline $\mathrm{C}^{12} \mathrm{H}_{2} \mathrm{DF}^{19}$ & 4- 465 & $2,0,2 \leftarrow 1,0,1$ & Ground & & 93994.7 & 1. \\
\hline $\mathrm{HN}^{14} \mathrm{C}^{12} \mathrm{~S}^{32}$ & 4. 311 & $8,1,7 \leftarrow 7,1,6$ & Ground & & 93994.96 & .5 \\
\hline
\end{tabular}




\begin{tabular}{|c|c|c|c|c|c|c|c|}
\hline \multirow{2}{*}{ Isotopic Species } & \multirow{2}{*}{$\begin{array}{l}\text { Vol.-Id. } \\
\text { Nos. }\end{array}$} & \multirow{2}{*}{$\begin{array}{c}\text { Rotational } \\
\text { Quantum Nos. }\end{array}$} & \multirow{2}{*}{ Vib. State } & \multicolumn{2}{|c|}{ Hyperfine } & \multirow{2}{*}{$\begin{array}{l}\text { Frequency } \\
\mathrm{MHz}\end{array}$} & \multirow{2}{*}{$\begin{array}{r}\text { Acc. } \\
\pm \mathrm{MHz}\end{array}$} \\
\hline & & & & $\begin{array}{lll}F_{1}^{\prime} & F^{\prime} & F_{1}\end{array}$ & $F$ & & \\
\hline $\mathrm{HN}^{14} \mathrm{C}^{12} \mathrm{~S}^{32}$ & 4- 311 & $8,0, \leftarrow 7,0$ & Excited & & & 94.003 .9 & 1.0 \\
\hline $\mathrm{HN}^{14} \mathrm{C}^{12} \mathrm{~S}^{32}$ & 4. 311 & $8,0, \leftarrow 7,0$ & Excited & & & 94012.2 & 1.0 \\
\hline $\mathrm{HN}^{14} \mathrm{C}^{12} \mathrm{~S}^{32}$ & 4- 311 & $8, \quad \leftarrow 7$, & Excited & & & 94053.4 & 1.0 \\
\hline $\mathrm{HN}^{14} \mathrm{C}^{12} \mathrm{~S}^{32}$ & 4- 311 & $8, \quad \leftarrow 7, \quad$, & Excited & & & 94073.3 & 1.0 \\
\hline $\mathrm{HN}^{14} \mathrm{C}^{12} \mathrm{~S}^{32}$ & 4- 311 & $8, \quad \leftarrow 7, \quad$, & Excited & & & 94086.9 & 1.0 \\
\hline $\mathrm{C}^{12} \mathrm{~F}_{3}^{19} \mathrm{C}^{12} \mathrm{~N}^{14}$ & 4- 591 & $16,12 \leftarrow 16,12$ & Ground & & & 94225.12 & .20 \\
\hline $\mathrm{C}^{12} \mathrm{~F}_{3}^{19} \mathrm{C}^{12} \mathrm{~N}^{14}$ & 4- 591 & $16,11 \leftarrow 16,11$ & Ground & & & 94229.43 & .20 \\
\hline $\mathrm{C}^{12} \mathrm{~F}_{3}^{19} \mathrm{C}^{12} \mathrm{~N}^{14}$ & 4- 591 & $16,10 \leftarrow 16,10$ & Ground & & & 94.233 .31 & .20 \\
\hline $\mathrm{C}^{12} \mathrm{~F}_{3}^{19} \mathrm{C}^{12} \mathrm{~N}^{14}$ & 4- 591 & $16,9 \leftarrow 15,9$ & Ground & & & 94236.82 & .20 \\
\hline $\mathrm{C}^{12} \mathrm{~F}_{3}^{19} \mathrm{C}^{12} \mathrm{~N}^{14}$ & 4. 591 & $16,8 \leftarrow 15,8$ & Ground & & & 94239.97 & .20 \\
\hline $\mathrm{C}^{12} \mathrm{~F}_{3}^{19} \mathrm{C}^{12} \mathrm{~N}^{14}$ & 4- 591 & $16,7 \leftarrow 15,7$ & Ground & & & 94.24 .2 .76 & .20 \\
\hline $\mathrm{C}^{12} \mathrm{~F}_{3}^{19} \mathrm{C}^{12} \mathrm{~N}^{14}$ & 4. 591 & $16,6 \leftarrow 15,6$ & Ground & & & 94.245 .17 & .20 \\
\hline $\mathrm{C}^{12} \mathrm{~F}_{3}^{19} \mathrm{C}^{12} \mathrm{~N}^{14}$ & 4- 591 & $16,5 \leftarrow 15,5$ & Ground & & & 94247.19 & .20 \\
\hline $\mathrm{C}^{12} \mathrm{~F}_{3}^{19} \mathrm{C}^{12} \mathrm{~N}^{14}$ & 4- 591 & $16,4 \leftarrow 15,4$ & Ground & & & 94. 248.88 & .20 \\
\hline $\mathrm{C}^{12} \mathrm{~F}_{3}^{19} \mathrm{C}^{12} \mathrm{~N}^{14}$ & 4- 591 & $16,3 \leftarrow 15,3$ & Ground & & & 94.250 .24 & .20 \\
\hline $\mathrm{C}^{12} \mathrm{~F}_{3}^{19} \mathrm{C}^{12} \mathrm{~N}^{14}$ & 4- 591 & $16,2 \leftarrow 15,2$ & Ground & & & 94.251 .20 & .20 \\
\hline $\mathrm{C}^{12} \mathrm{~F}_{3}^{19} \mathrm{C}^{12} \mathrm{~N}^{14}$ & 4- 591 & $16,1 \leftarrow 15,1$ & Ground & & & 94.251 .78 & .20 \\
\hline $\mathrm{C}^{12} \mathrm{~F}_{3}^{19} \mathrm{C}^{12} \mathrm{~N}^{14}$ & 4- 591 & $16,0 \leftarrow 15,0$ & Ground & & & 94251.93 & .20 \\
\hline $\mathrm{D}_{2} \mathrm{Se}^{82}$ & $4-1751$ & $3,3,0 \leftarrow 3,2,1$ & Ground & & & 94.462 .12 & \\
\hline $\mathrm{HN}_{3}^{14}$ & 4-1701 & $4,1,4 \leftarrow 3,1,3$ & Ground & & & 94.749 .42 & .25 \\
\hline $\mathrm{F}^{19} \mathrm{DC}^{12} \mathrm{O}^{16}$ & 4- 272 & $2,1,2 \leftarrow 1,0,1$ & & & & 94920.60 & .04 \\
\hline $\mathrm{D}_{2} \mathrm{Se}^{80}$ & $4-1749$ & $3,3,0 \leftarrow 3,2,1$ & Ground & & & 95082.56 & \\
\hline $\mathrm{C}^{12} \mathrm{H}_{2} \mathrm{DF}^{19}$ & 4- 465 & $2,1,1 \leftarrow 1,1,0$ & Ground & & & 95086.0 & 1. \\
\hline $\mathrm{HN}_{3}^{14}$ & 4-1701 & $4,3,2 \leftarrow 3,3,1$ & Ground & 5 & 4 & 95203.10 & .25 \\
\hline $\mathrm{HN}_{3}^{14}$ & 4-1701 & $4,3,2 \leftarrow 3,3,1$ & Ground & 3 & 2 & 95203.10 & .25 \\
\hline $\mathrm{HN}_{3}^{14}$ & $4-1701$ & $4,4,1 \leftarrow 3,3,0$ & Ground & 4 & 3 & 95205.12 & .25 \\
\hline $\mathrm{HN}_{3}^{14}$ & $4-1701$ & $4,2,3 \leftarrow 3,2,2$ & Ground & 5 & 4 & 95235.45 & .25 \\
\hline $\mathrm{HN}_{3}^{14}$ & $4-1701$ & $4,2,3 \leftarrow 3,2,2$ & Ground & 3 & 2 & 95235.45 & .25 \\
\hline $\mathrm{HN}_{3}^{14}$ & 4-1701 & $4,2,2 \leftarrow 3,2,1$ & Ground & 5 & 4 & 95236.17 & .25 \\
\hline $\mathrm{HN}_{3}^{14}$ & 4-1701 & $4,2,2 \leftarrow 3,2,1$ & Ground & 3 & 2 & 95236.17 & .25 \\
\hline $\mathrm{HN}_{3}^{14}$ & 4-1701 & $4,2,3 \leftarrow 3,2,2$ & Ground & 4 & 3 & 95236.17 & .25 \\
\hline $\mathrm{HN}_{3}^{14}$ & 4-1701 & $4,2,2 \leftarrow 3,2,1$ & Ground & 4 & 3 & 95237.03 & .25 \\
\hline $\mathrm{C}^{12} \mathrm{H}_{3} \mathrm{Br}^{81}$ & 4- 402 & $5,2 \leftarrow 4,2$ & Ground & $7 / 2$ & $5 / 2$ & 95253.89 & .27 \\
\hline $\mathrm{C}^{12} \mathrm{H}_{3} \mathrm{Br}^{81}$ & 4- 402 & $5,4 \leftarrow 4,4$ & Ground & $13 / 2$ & $11 / 2$ & 95259.24 & .27 \\
\hline $\mathrm{HN}_{3}^{14}$ & 4-1701 & $4,0,4 \leftarrow 3,0,3$ & Ground & & & 95260.50 & .25 \\
\hline $\mathrm{C}^{12} \mathrm{H}_{3} \mathrm{Br}^{81}$ & 4- 402 & $5,3 \leftarrow 4,3$ & Ground & $7 / 2$ & $5 / 2$ & 95263.47 & .27 \\
\hline $\mathrm{C}^{12} \mathrm{H}_{3} \mathrm{Br}^{81}$ & 4. 402 & $5,3 \leftarrow 4,3$ & Ground & $13 / 2$ & $11 / 2$ & 95281.53 & .27 \\
\hline $\mathrm{C}^{12} \mathrm{H}_{3} \mathrm{Br}^{81}$ & 4- 402 & $5,2 \leftarrow 4,2$ & Ground & $13 / 2$ & $11 / 2$ & 95297.55 & .27 \\
\hline $\mathrm{C}^{12} \mathrm{H}_{3} \mathrm{Br}^{81}$ & 4- 402 & $5,1 \leftarrow 4,1$ & Ground & $13 / 2$ & $11 / 2$ & 95307.48 & .27 \\
\hline $\mathrm{C}^{12} \mathrm{H}_{3} \mathrm{Br}^{81}$ & 4- 402 & $5,0 \leftarrow 4,0$ & Ground & $11 / 2$ & $9 / 2$ & 95310.78 & .27 \\
\hline $\mathrm{C}^{12} \mathrm{H}_{3} \mathrm{Br}^{81}$ & 4- 402 & $5,0 \leftarrow 4,0$ & Ground & $13 / 2$ & $11 / 2$ & 95310.78 & .27 \\
\hline $\mathrm{C}^{12} \mathrm{H}_{3} \mathrm{Br}^{81}$ & 4- 402 & $5,0 \leftarrow 4,0$ & Ground & $9 / 2$ & $7 / 2$ & 95319.12 & .27 \\
\hline $\mathrm{C}^{12} \mathrm{H}_{3} \mathrm{Br}^{81}$ & 4- 402 & $5,1 \leftarrow 4,1$ & Ground & $9 / 2$ & $7 / 2$ & 95319.12 & .27 \\
\hline $\mathrm{C}^{12} \mathrm{H}_{3} \mathrm{Br}^{81}$ & 4- 402 & $5,0 \leftarrow 4,0$ & Ground & $7 / 2$ & $5 / 2$ & 95319.12 & .27 \\
\hline $\mathrm{C}^{12} \mathrm{H}_{3} \mathrm{Br}^{81}$ & 4- 402 & $5,2 \leftarrow 4,2$ & Ground & $11 / 2$ & $9 / 2$ & 95322.15 & .27 \\
\hline
\end{tabular}


Vib. State

$\mathrm{F}^{\prime} \stackrel{\text { Hyperfine }}{\mathrm{F}^{\prime}} \mathrm{F}, \mathrm{F}$

Frequency

Ace. $\mathrm{MHz} \pm \mathrm{MHz}$

\begin{tabular}{|c|c|c|c|c|c|c|c|}
\hline $\mathrm{C}^{12} \mathrm{H}_{3} \mathrm{Br}^{81}$ & 4. 402 & $5,3 \leftarrow 4,3$ & Ground & $11 / 2$ & $9 / 2$ & 95336.01 & .27 \\
\hline $\mathrm{F}^{19} \mathrm{HC}^{12} \mathrm{O}^{16}$ & 4- 271 & $6,1,5 \leftarrow 6,0,6$ & & & & 95339.16 & .05 \\
\hline $\mathrm{Cl}^{35} \mathrm{C}^{12} \mathrm{~N}^{14}$ & 4. 171 & $8 \leftarrow 7$ & Ground & & & 95529.86 & .20 \\
\hline $\mathrm{C}^{12} \mathrm{H}_{3} \mathrm{Br}^{79}$ & 4. 401 & $5,4 \leftarrow 4,4$ & Ground & $13 / 2$ & $11 / 2$ & 95615.73 & .27 \\
\hline $\mathrm{C}^{12} \mathrm{H}_{3} \mathrm{Br}^{79}$ & 4. 401 & $5,3 \leftarrow 4,3$ & Ground & $7 / 2$ & $5 / 2$ & 95619.24 & .27 \\
\hline $\mathrm{C}^{12} \mathrm{H}_{3} \mathrm{Br}^{79}$ & $4-401$ & $5,3 \leftarrow 4,3$ & Ground & $13 / 2$ & $11 / 2$ & 95640.87 & .27 \\
\hline $\mathrm{C}^{12} \mathrm{H}_{3} \mathrm{Br}^{79}$ & 4- 401 & $5,2 \leftarrow 4,2$ & Ground & $7 / 2$ & $5 / 2$ & 95654.73 & .27 \\
\hline $\mathrm{C}^{12} \mathrm{H}_{3} \mathrm{Br}^{79}$ & 4- 401 & $5,2 \leftarrow 4,2$ & Ground & $13 / 2$ & $11 / 2$ & 95659.20 & .27 \\
\hline $\mathrm{C}^{12} \mathrm{H}_{3} \mathrm{Br}^{79}$ & 4- 401 & $5,1 \leftarrow 4,1$ & Ground & $13 / 2$ & $11 / 2$ & 95669.97 & .27 \\
\hline $\mathrm{C}^{12} \mathrm{H}_{3} \mathrm{Br}^{79}$ & 4- 401 & $5,0 \leftarrow 4,0$ & Ground & $13 / 2$ & $11 / 2$ & 95673.51 & .27 \\
\hline $\mathrm{C}^{12} \mathrm{H}_{3} \mathrm{Br}^{79}$ & 4- 401 & $5,0 \leftarrow 4,0$ & Ground & $11 / 2$ & $9 / 2$ & 95673.51 & .27 \\
\hline $\mathrm{C}^{12} \mathrm{H}_{3} \mathrm{Br}^{79}$ & 4- 401 & $5,1 \leftarrow 4,1$ & Ground & $7 / 2$ & $5 / 2$ & 95676.39 & .27 \\
\hline $\mathrm{C}^{12} \mathrm{H}_{3} \mathrm{Br}^{79}$ & 4. 401 & $5,1 \leftarrow 4,1$ & Ground & $11 / 2$ & $9 / 2$ & 95677.20 & .27 \\
\hline $\mathrm{C}^{12} \mathrm{H}_{3} \mathrm{Br}^{79}$ & 4. 401 & $5,0 \leftarrow 4,0$ & Ground & $7 / 2$ & $5 / 2$ & 95683.62 & .27 \\
\hline $\mathrm{C}^{12} \mathrm{H}_{3} \mathrm{Br}^{79}$ & 4- 401 & $5,0 \leftarrow 4,0$ & Ground & $9 / 2$ & $7 / 2$ & 95683.62 & .27 \\
\hline $\mathrm{C}^{12} \mathrm{H}_{3} \mathrm{Br}^{79}$ & 4- 401 & $5,1 \leftarrow 4,1$ & Ground & $9 / 2$ & $7 / 2$ & 95683.62 & .27 \\
\hline $\mathrm{C}^{12} \mathrm{H}_{3} \mathrm{Br}^{79}$ & 4. 401 & $5,3 \leftarrow 4,3$ & Ground & $9 / 2$ & $7 / 2$ & 95683.62 & .27 \\
\hline $\mathrm{C}^{12} \mathrm{H}_{3} \mathrm{Br}^{79}$ & 4- 401 & $5,2 \leftarrow 4,2$ & Ground & $9 / 2$ & $7 / 2$ & 95683.62 & .27 \\
\hline $\mathrm{C}^{12} \mathrm{H}_{3} \mathrm{Br}^{79}$ & 4- 401 & $5,2 \leftarrow 4,2$ & Ground & $11 / 2$ & $9 / 2$ & 95688.27 & .27 \\
\hline $\mathrm{C}^{12} \mathrm{H}_{3} \mathrm{Br}^{79}$ & 4- 401 & $5,3 \leftarrow 4,3$ & Ground & $11 / 2$ & $9 / 2$ & 95706.12 & .27 \\
\hline $\mathrm{Cl}^{35} \mathrm{C}^{12} \mathrm{~N}^{14}$ & 4. 171 & $8 \leftarrow 7$ & Exeited & & & 95731.52 & \\
\hline $\mathrm{D}_{2} \mathrm{Se}^{78}$ & $4-1748$ & $3,3,0 \leftarrow 3,2,1$ & Ground & & & 95733.92 & \\
\hline $\mathrm{HN}_{3}^{14}$ & 4-1701 & $4,1,3 \leftarrow 3,1,2$ & Ground & & & 95760.15 & .25 \\
\hline $\mathrm{Cl}^{35} \mathrm{C}^{12} \mathrm{~N}^{14}$ & 4. 171 & $8 \leftarrow 7$ & Excited & & & 95850.88 & \\
\hline $\mathrm{O}^{16} \mathrm{C}^{12} \mathrm{Se}^{82}$ & 4- 548 & $12 \leftarrow 11$ & Ground & & & 95852.94 & .20 \\
\hline $\mathrm{D}_{2} \mathrm{Se}^{77}$ & 4-1747 & $3,3,0 \leftarrow 3,2,1$ & Ground & & & 96073.00 & \\
\hline $\mathrm{O}_{3}^{16}$ & 4-1841 & $2,1,1 \leftarrow 2,0,2$ & Ground & & & 96228.84 & .18 \\
\hline $\mathrm{O}^{16} \mathrm{C}^{12} \mathrm{Se}^{80}$ & 4. 547 & $12 \leftarrow 11$ & Ground & & & 96418.95 & .20 \\
\hline $\mathrm{D}_{2} \mathrm{Se}^{76}$ & $4-1746$ & $3,3,0 \leftarrow 3,2,1$ & Ground & & & 96423.40 & \\
\hline $\mathrm{O}^{16} \mathrm{C}^{12} \mathrm{Se}^{80}$ & 4. 547 & $12 \leftarrow 11$ & Excited & & & 96546.60 & \\
\hline $\mathrm{O}^{16} \mathrm{C}^{12} \mathrm{Se}^{80}$ & 4- 547 & $12 \leftarrow 11$ & Exeited & & & 96622.76 & \\
\hline $\mathrm{O}^{16} \mathrm{C}^{12} \mathrm{Se}^{78}$ & 4- 545 & $12 \leftarrow 11$ & Ground & & & 97013.24 & .20 \\
\hline $\mathrm{O}^{16} \mathrm{C}^{12} \mathrm{~S}^{32}$ & 4. 521 & $8 \leftarrow 7$ & Ground & & & 97301.19 & .20 \\
\hline $\mathrm{O}^{16} \mathrm{C}^{12} \mathrm{~S}^{34}$ & 4- 523 & $8 \leftarrow 7$ & Ground & & & 97301.31 & .20 \\
\hline $\mathrm{O}^{16} \mathrm{C}^{12} \mathrm{Se}^{77}$ & 4. 544 & $12 \leftarrow 11$ & Ground & & & 97321.07 & .20 \\
\hline $\mathrm{O}^{16} \mathrm{C}^{12} \mathrm{Se}^{76}$ & 4- 543 & $12 \leftarrow 11$ & Ground & & & 97637.78 & .20 \\
\hline $\mathrm{DN}^{14} \mathrm{C}^{12} \mathrm{~S}^{32}$ & 4- 312 & $9,1,9 \leftarrow 8,1,8$ & Ground & & & 98281.15 & .5 \\
\hline $\mathrm{Br}^{81} \mathrm{C}^{12} \mathrm{~N}^{14}$ & 4- 142 & $12 \leftarrow 11$ & Ground & & & 98317.37 & .20 \\
\hline $\mathrm{DN}^{14} \mathrm{C}^{12} \mathrm{~S}^{32}$ & 4- 312 & $9, \quad \leftarrow 8, \quad$, & Excited & & & 98440.8 & 1.0 \\
\hline $\mathrm{DN}^{14} \mathrm{C}^{12} \mathrm{~S}^{32}$ & 4. 312 & $9, \quad \leftarrow \quad \leftarrow 8, \quad$, & Exeited & & & 98472.6 & 1.0 \\
\hline $\mathrm{DN}^{14} \mathrm{C}^{12} \mathrm{~S}^{32}$ & 4- 312 & $9, \quad \leftarrow \quad \leftarrow 8, \quad$, & Excited & & & 98504.1 & 1.0 \\
\hline $\mathrm{DN}^{14} \mathrm{C}^{12} \mathrm{~S}^{32}$ & 4. 312 & $9,0,9 \leftarrow 8,0,8$ & Ground & & & 98507.94 & .5 \\
\hline $\mathrm{Br}^{81} \mathrm{C}^{12} \mathrm{~N}^{14}$ & 4- 142 & $12 \leftarrow 11$ & Exeited & & & 98545.65 & \\
\hline $\mathrm{Br}^{81} \mathrm{C}^{12} \mathrm{~N}^{14}$ & 4- 142 & $12 \leftarrow 11$ & Exeited & & & 98546.18 & \\
\hline $\mathrm{Br}^{81} \mathrm{C}^{12} \mathrm{~N}^{14}$ & 4. 142 & $12 \leftarrow 11$ & Exeited & & & 98547.08 & \\
\hline
\end{tabular}




\begin{tabular}{|c|c|c|c|c|c|c|}
\hline \multirow{2}{*}{ Isotopic Species } & \multirow{2}{*}{$\begin{array}{l}\text { Vol.-Id. } \\
\text { Nos. }\end{array}$} & \multirow{2}{*}{$\begin{array}{c}\text { Rotational } \\
\text { Quantum Nos. }\end{array}$} & \multirow{2}{*}{ Vib. State } & Hyperfine & \multirow{2}{*}{$\begin{array}{c}\text { Frequency } \\
\mathrm{MHz}\end{array}$} & \multirow{2}{*}{$\begin{aligned} & \text { Acc. } \\
\pm & \mathrm{MHz}\end{aligned}$} \\
\hline & & & & $\begin{array}{lll}F_{1}^{\prime} & F^{\prime} & F_{1}\end{array}$ & & \\
\hline $\mathrm{Br}^{81} \mathrm{C}^{12} \mathrm{~N}^{14}$ & 4- 142 & $12 \leftarrow 11$ & Excited & & 98547.63 & \\
\hline $\mathrm{DN}^{14} \mathrm{C}^{12} \mathrm{~S}^{32}$ & 4- 312 & $9,2,8 \leftarrow 8,2,7$ & Ground & & 98578.99 & .5 \\
\hline $\mathrm{DN}^{14} \mathrm{C}^{12} \mathrm{~S}^{32}$ & 4- 312 & $9,2,7 \leftarrow 8,2,6$ & Ground & & 98579.41 & .5 \\
\hline $\mathrm{DN}^{14} \mathrm{C}^{12} \mathrm{~S}^{32}$ & 4- 312 & $9, \quad \leftarrow 8$, & Excited & & 98584.5 & 1.0 \\
\hline $\mathrm{DN}^{14} \mathrm{C}^{12} \mathrm{~S}^{32}$ & 4. 312 & $9, \quad \leftarrow 8, \quad$ & Excited & & 98628.9 & 1.0 \\
\hline $\mathrm{Br}^{81} \mathrm{C}^{12} \mathrm{~N}^{14}$ & 4- 142 & $12 \leftarrow 11$ & Excited & & 98638.49 & \\
\hline $\mathrm{DN}^{14} \mathrm{C}^{12} \mathrm{~S}^{32}$ & 4- 312 & $9,3,7 \leftarrow 8,3,6$ & Ground & & 98638.64 & 1.0 \\
\hline $\mathrm{DN}^{14} \mathrm{C}^{12} \mathrm{~S}^{32}$ & 4- 312 & $9,3,6 \leftarrow 8,3,5$ & Ground & & 98638.64 & 1.0 \\
\hline $\mathrm{Br}^{81} \mathrm{C}^{12} \mathrm{~N}^{14}$ & 4- 142 & $12 \leftarrow 11$ & Excited & & 98639.01 & \\
\hline $\mathrm{Br}^{81} \mathrm{C}^{12} \mathrm{~N}^{14}$ & 4- 142 & $12 \leftarrow 11$ & Excited & & 98639.95 & \\
\hline $\mathrm{Br}^{81} \mathrm{C}^{12} \mathrm{~N}^{14}$ & 4- 142 & $12 \leftarrow 11$ & Excited & & 98640.42 & \\
\hline $\mathrm{DN}^{14} \mathrm{C}^{12} \mathrm{~S}^{32}$ & 4- 312 & $9, \quad \leftarrow \quad \leftarrow 8, \quad$, & Excited & & 98691.0 & 1.0 \\
\hline $\mathrm{DN}^{14} \mathrm{C}^{12} \mathrm{~S}^{32}$ & 4. 312 & $9, \quad \leftarrow 8$, & Excited & & 98697.6 & 1.0 \\
\hline $\mathrm{DN}^{14} \mathrm{C}^{12} \mathrm{~S}^{32}$ & 4- 312 & $9, \quad \leftarrow 8$, & Excited & & 98701.6 & 1.0 \\
\hline $\mathrm{DN}^{14} \mathrm{C}^{12} \mathrm{~S}^{32}$ & 4- 312 & $9, \quad \leftarrow 8$, & Excited & & 98710.2 & 1.0 \\
\hline $\mathrm{DN}^{14} \mathrm{C}^{12} \mathrm{~S}^{32}$ & 4- 312 & $9, \quad \leftarrow 8$, & Excited & & 98773.9 & 1.0 \\
\hline $\mathrm{DN}^{14} \mathrm{C}^{12} \mathrm{~S}^{32}$ & 4- 312 & $9,1,8 \leftarrow 8,1,7$ & Ground & & 98778.22 & .5 \\
\hline $\mathrm{DN}^{14} \mathrm{C}^{12} \mathrm{~S}^{32}$ & 4- 312 & $9, \quad \leftarrow 8$, & Excited & & 98854.3 & 1.0 \\
\hline $\mathrm{Br}^{79} \mathrm{C}^{12} \mathrm{~N}^{14}$ & 4- 141 & $12 \leftarrow 11$ & Ground & & 98879.19 & .20 \\
\hline $\mathrm{Br}^{79} \mathrm{C}^{12} \mathrm{~N}^{14}$ & $4-141$ & $12 \leftarrow 11$ & Excited & & 99108.45 & \\
\hline $\mathrm{Br}^{79} \mathrm{C}^{12} \mathrm{~N}^{14}$ & 4. 141 & $12 \leftarrow 11$ & Excited & & 99109.06 & \\
\hline $\mathrm{Br}^{79} \mathrm{C}^{12} \mathrm{~N}^{14}$ & 4- 141 & $12 \leftarrow 11$ & Excited & & 99110.12 & \\
\hline $\mathrm{Br}^{79} \mathrm{C}^{12} \mathrm{~N}^{14}$ & 4- 141 & $12 \leftarrow 11$ & Excited & & 99110.75 & \\
\hline $\mathrm{Br}^{79} \mathrm{C}^{12} \mathrm{~N}^{14}$ & 4- 141 & $12 \leftarrow 11$ & Excited & & 99203.06 & \\
\hline $\mathrm{Br}^{79} \mathrm{C}^{12} \mathrm{~N}^{14}$ & 4- 141 & $12 \leftarrow 11$ & Excited & & 99204.09 & \\
\hline $\mathrm{Br}^{79} \mathrm{C}^{12} \mathrm{~N}^{14}$ & 4- 141 & $12 \leftarrow 11$ & Excited & & 99204.70 & \\
\hline $\mathrm{K}^{39} \mathrm{Cl}^{35}$ & $1-$ & $13 \leftarrow 12$ & Excited & & 99316.456 & .016 \\
\hline $\mathrm{K}^{39} \mathrm{Cl}^{35}$ & $1-$ & $13 \leftarrow 12$ & Ground & & 99929.450 & .016 \\
\hline $\mathrm{N}_{2}^{14} \mathrm{O}^{16}$ & 4-1811 & $4 \leftarrow 3$ & Ground & & 100491.74 & .20 \\
\hline $\mathrm{N}_{2}^{14} \mathrm{O}^{16}$ & 4-1811 & $4 \leftarrow 3$ & Excited & & 100531.65 & \\
\hline $\mathrm{N}_{2}^{14} \mathrm{O}^{16}$ & 4-1811 & $4 \leftarrow 3$ & Excited & & 100721.58 & \\
\hline $\mathrm{F}^{19} \mathrm{HC}^{12} \mathrm{O}^{16}$ & $4-271$ & $7,1,6 \leftarrow 7,0,7$ & & & 100838.05 & .05 \\
\hline $\mathrm{P}^{31} \mathrm{O}^{16} \mathrm{~F}_{3}^{19}$ & 4-1671 & $11,9 \leftarrow 10,9$ & Ground & & 101066.06 & .20 \\
\hline $\mathrm{P}^{31} \mathrm{O}^{16} \mathrm{~F}_{3}^{19}$ & 4- 1671 & $11,8 \leftarrow 10,8$ & Ground & & 101066.52 & .20 \\
\hline $\mathrm{P}^{31} \mathrm{O}^{16} \mathrm{~F}_{3}^{19}$ & 4-1671 & $11,7 \leftarrow 10,7$ & Ground & & 101066.91 & .20 \\
\hline $\mathrm{P}^{31} \mathrm{O}^{16} \mathrm{~F}_{3}^{19}$ & 4-1671 & $11,6 \leftarrow 10,6$ & Ground & & 101067.33 & .20 \\
\hline $\mathrm{P}^{31} \mathrm{O}^{16} \mathrm{~F}_{3}^{19}$ & 4-1671 & $11,5 \leftarrow 10,5$ & Ground & & 101067.62 & .40 \\
\hline $\mathrm{P}^{31} \mathrm{O}^{16} \mathrm{~F}_{3}^{19}$ & 4-1671 & $11,3 \leftarrow 10,3$ & Ground & & 101068.04 & .20 \\
\hline $\mathrm{P}^{31} \mathrm{O}^{16} \mathrm{~F}_{3}^{19}$ & 4-1671 & $11,0 \leftarrow 10,0$ & Ground & & 101068.35 & .20 \\
\hline $\mathrm{DN}^{14} \mathrm{C}^{12} \mathrm{O}^{16}$ & 4- 303 & $5,1,5 \leftarrow 4,1,4$ & Ground & & 101382.24 & .5 \\
\hline $\mathrm{F}^{19} \mathrm{HC}^{12} \mathrm{O}^{16}$ & 4. 271 & $1,1,1 \leftarrow 0,0,0$ & & & 101550.36 & .05 \\
\hline $\mathrm{O}_{3}^{16}$ & 4- 1841 & $4,1,3 \leftarrow 4,0,4$ & Ground & & 101736.83 & .14 \\
\hline $\mathrm{DN}^{14} \mathrm{C}^{12} \mathrm{O}^{16}$ & 4- 303 & $5,0,5 \leftarrow 4,0,4$ & Ground & & 101963.49 & .5 \\
\hline $\mathrm{DN}^{14} \mathrm{C}^{12} \mathrm{O}^{16}$ & 4- 303 & $5,2,4 \leftarrow 4,2,3$ & Ground & & 101973.63 & .5 \\
\hline $\mathrm{DN}^{14} \mathrm{C}^{12} \mathrm{O}^{16}$ & 4- 303 & $5,2,3 \leftarrow 4,2,2$ & Ground & & 101975.19 & .5 \\
\hline
\end{tabular}




\begin{tabular}{|c|c|c|c|c|c|c|c|}
\hline \multirow{2}{*}{ Isotopic Species } & \multirow{2}{*}{$\begin{array}{l}\text { Vol.-Id. } \\
\text { Nos. }\end{array}$} & \multirow{2}{*}{$\begin{array}{c}\text { Rotational } \\
\text { Quantum Nos. }\end{array}$} & \multirow{2}{*}{ Vib. State } & \multicolumn{2}{|c|}{ Hyperfine } & \multirow{2}{*}{$\begin{array}{c}\text { Frequency } \\
\mathrm{MH}_{z}\end{array}$} & \multirow{2}{*}{$\begin{aligned} & \text { Acc. } \\
& \pm \mathrm{MHz}\end{aligned}$} \\
\hline & & & & $\begin{array}{lll}F_{1}^{\prime} & F^{\prime} & F_{1}\end{array}$ & $F$ & & \\
\hline $\mathrm{DN}^{14} \mathrm{C}^{12} \mathrm{O}^{16}$ & 4- 303 & $5,3,3 \leftarrow 4,3,2$ & Ground & & & 101981.97 & 1.0 \\
\hline $\mathrm{DN}^{14} \mathrm{C}^{12} \mathrm{O}^{16}$ & 4- 303 & $5,3,2 \leftarrow 4,3,1$ & Ground & & & 101981.97 & 1.0 \\
\hline $\mathrm{DN}^{14} \mathrm{C}^{12} \mathrm{O}^{16}$ & 4- 303 & $5,4,2 \leftarrow 4,4,1$ & Ground & & & 101988.27 & 1.0 \\
\hline $\mathrm{DN}^{14} \mathrm{C}^{12} \mathrm{O}^{16}$ & 4- 303 & $5,4,1 \leftarrow 4,4,0$ & Ground & & & 101988.27 & 1.0 \\
\hline $\mathrm{C}^{12} \mathrm{H}_{3} \mathrm{~F}^{19}$ & 4- 461 & $2,1 \leftarrow 1,1$ & Ground & & & 102140.86 & .20 \\
\hline $\mathrm{C}^{12} \mathrm{H}_{3} \mathrm{~F}^{19}$ & 4. 461 & $2,0 \leftarrow 1,0$ & Ground & & & 102142.56 & .20 \\
\hline $\mathrm{DN}^{14} \mathrm{C}^{12} \mathrm{O}^{16}$ & 4- 303 & $5,1,4 \leftarrow 4,1,3$ & Ground & & & 102551.73 & .5 \\
\hline $\mathrm{S}^{32} \mathrm{O}_{2}^{16}$ & 4-1831 & $10,1,9 \leftarrow 10,0,10$ & Ground & & & 104029.43 & \\
\hline $\mathrm{S}^{32} \mathrm{O}_{2}^{16}$ & 4-1831 & $3,1,3 \leftarrow 2,0,2$ & Ground & & & 104.033 .53 & \\
\hline $\mathrm{C}^{13} \mathrm{O}^{18}$ & $1-$ & $1 \leftarrow 0$ & Ground & & & 104.711 .416 & .008 \\
\hline $\mathrm{HN}^{14} \mathrm{C}^{12} \mathrm{~S}^{32}$ & 4- 311 & $9,1,9 \leftarrow 8,1,8$ & Ground & & & 105403.63 & .5 \\
\hline $\mathrm{HN}^{14} \mathrm{C}^{12} \mathrm{~S}^{32}$ & 4- 311 & $9, \quad \leftarrow 8$, & Excited & & & 105406.7 & 1.0 \\
\hline $\mathrm{HN}^{14} \mathrm{C}^{12} \mathrm{~S}^{32}$ & 4. $3 ! 1$ & $9,0,9 \leftarrow 8,0,8$ & Ground & & & 105558.08 & .5 \\
\hline $\mathrm{F}^{19} \mathrm{DC}^{12} \mathrm{O}^{16}$ & 4- 272 & $9,1,8 \leftarrow 9,0,9$ & & & & 105584.79 & .04 \\
\hline $\mathrm{HN}^{14} \mathrm{C}^{12} \mathrm{~S}^{32}$ & 4. 311 & $9, \quad \leftarrow 8, \quad$ & Excited & & & 105585.4 & 1.0 \\
\hline $\mathrm{HN}^{14} \mathrm{C}^{12} \mathrm{~S}^{32}$ & 4- 311 & $9,2,7 \leftarrow 8,2,6$ & Ground & & & 105595.61 & .5 \\
\hline $\mathrm{HN}^{14} \mathrm{C}^{12} \mathrm{~S}^{32}$ & 4. 311 & $9,2,8 \leftarrow 8,2,7$ & Ground & & & 105595.61 & .5 \\
\hline $\mathrm{HN}^{14} \mathrm{C}^{12} \mathrm{~S}^{32}$ & 4- 311 & $9,3,6 \leftarrow 8,3,5$ & Ground & & & 105609.18 & 1.0 \\
\hline $\mathrm{HN}^{14} \mathrm{C}^{12} \mathrm{~S}^{32}$ & 4. 311 & $9,3,7 \leftarrow 8,3,6$ & Ground & & & 105609.18 & 1.0 \\
\hline $\mathrm{HN}^{14} \mathrm{C}^{12} \mathrm{~S}^{32}$ & 4- 311 & $9, \quad \leftarrow 8$, & Ground & & & 105631.7 & 1.0 \\
\hline $\mathrm{HN}^{14} \mathrm{C}^{12} \mathrm{~S}^{32}$ & 4- 311 & $9, \quad \leftarrow 8, \quad$ & Excited & & & 105640.1 & 1.0 \\
\hline $\mathrm{HN}^{14} \mathrm{C}^{12} \mathrm{~S}^{32}$ & 4- 311 & $9, \quad \leftarrow \quad \leftarrow 8$, & Excited & & & 105672.8 & 1.0 \\
\hline $\mathrm{HN}^{14} \mathrm{C}^{12} \mathrm{~S}^{32}$ & 4- 311 & $9, \quad \leftarrow 8, \quad$ & Excited & & & 105698.6 & 1.0 \\
\hline $\mathrm{HN}^{14} \mathrm{C}^{12} \mathrm{~S}^{32}$ & 4- 311 & $9, \quad \leftarrow \quad \leftarrow 8$, & Excited & & & 105730.5 & 1.0 \\
\hline $\mathrm{HN}^{14} \mathrm{C}^{12} \mathrm{~S}^{32}$ & 4- 311 & $9,1,8 \leftarrow 8,1,7$ & Ground & & & 105743.77 & .5 \\
\hline $\mathrm{HN}^{14} \mathrm{C}^{12} \mathrm{~S}^{32}$ & 4- 311 & $9,3, \leftarrow 8,3$, & Excited & & & 105748.3 & 1.0 \\
\hline $\mathrm{HN}^{14} \mathrm{C}^{12} \mathrm{~S}^{32}$ & 4- 311 & $9,2, \leftarrow 8,2$, & Excited & & & 105749.3 & 1.0 \\
\hline $\mathrm{HN}^{14} \mathrm{C}^{12} \mathrm{~S}^{32}$ & 4- 311 & $9,0, \leftarrow 8,0$, & Excited & & & 105756.8 & 1.0 \\
\hline $\mathrm{HN}^{14} \mathrm{C}^{12} \mathrm{~S}^{32}$ & 4- 311 & $9,2, \leftarrow 8,2$, & Excited & & & 105764.9 & 1.0 \\
\hline $\mathrm{HN}^{14} \mathrm{C}^{12} \mathrm{~S}^{32}$ & 4- 311 & $9,0, \leftarrow 8,0$, & Excited & & & 105765.8 & 1.0 \\
\hline $\mathrm{HN}^{14} \mathrm{C}^{12} \mathrm{~S}^{32}$ & 4- 311 & $9, \quad \leftarrow \quad \leftarrow 8$, & Excited & & & 105802.2 & 1.0 \\
\hline $\mathrm{HN}^{14} \mathrm{C}^{12} \mathrm{~S}^{32}$ & 4- 311 & $9, \quad \leftarrow 8$, & Excited & & & 105810.0 & 1.0 \\
\hline $\mathrm{HN}^{14} \mathrm{C}^{12} \mathrm{~S}^{32}$ & 4. 311 & $9, \quad \leftarrow 8$, & Excited & & & 105831.6 & 1.0 \\
\hline $\mathrm{HN}^{14} \mathrm{C}^{12} \mathrm{~S}^{32}$ & 4- 311 & $9, \quad \leftarrow 8$, & Excited & & & 105847.5 & 1.0 \\
\hline $\mathrm{C}^{14} \mathrm{O}^{16}$ & $1-$ & $1 \leftarrow 0$ & Ground & & & 105871.110 & .004 \\
\hline $\mathrm{C}^{12} \mathrm{H}_{3} \mathrm{Cl}^{35}$ & 4- 421 & $4,3 \leftarrow 3,3$ & Ground & $7 / 2$ & $7 / 2$ & 106310.31 & \\
\hline $\mathrm{C}^{12} \mathrm{H}_{3} \mathrm{Cl}^{35}$ & 4- 421 & $6,1 \leftarrow 5,1$ & Ground & $7 / 2$ & $7 / 2$ & 106310.31 & \\
\hline $\mathrm{C}^{12} \mathrm{H}_{3} \mathrm{Cl}^{35}$ & 4- 421 & $4,3 \leftarrow 3,3$ & Ground & $9 / 2$ & $7 / 2$ & 106312.37 & \\
\hline $\mathrm{C}^{12} \mathrm{H}_{3} \mathrm{Cl}^{35}$ & 4- 421 & $4,3 \leftarrow 3,3$ & Ground & $5 / 2$ & $5 / 2$ & 106314.52 & \\
\hline $\mathrm{C}^{12} \mathrm{H}_{3} \mathrm{Cl}^{35}$ & 4- 421 & $4,0 \leftarrow 3,0$ & Ground & $9 / 2$ & $9 / 2$ & 106320.08 & \\
\hline $\mathrm{C}^{12} \mathrm{H}_{3} \mathrm{Cl}^{35}$ & 4- 421 & $4,3 \leftarrow 3,3$ & Ground & $7 / 2$ & $5 / 2$ & 106321.24 & \\
\hline $\mathrm{C}^{12} \mathrm{H}_{3} \mathrm{Cl}^{35}$ & 4- 421 & $4,2 \leftarrow 3,2$ & Ground & $9 / 2$ & $9 / 2$ & 106327.02 & \\
\hline $\mathrm{C}^{12} \mathrm{H}_{3} \mathrm{Cl}^{35}$ & 4- 421 & $4,2 \leftarrow 3,2$ & Ground & $9 / 2$ & $7 / 2$ & 106327.02 & \\
\hline $\mathrm{C}^{12} \mathrm{H}_{3} \mathrm{Cl}^{35}$ & 4. 421 & $4,2 \leftarrow 3,2$ & Ground & $11 / 2$ & $9 / 2$ & 106334.53 & \\
\hline $\mathrm{C}^{12} \mathrm{H}_{3} \mathrm{Cl}^{35}$ & 4- 421 & $4,3 \leftarrow 3,3$ & Ground & $9 / 2$ & $9 / 2$ & 106335.79 & \\
\hline
\end{tabular}




\begin{tabular}{|c|c|c|c|c|c|c|c|}
\hline \multirow{2}{*}{ Isotopic Species } & \multirow{2}{*}{$\begin{array}{l}\text { Vol.-Id. } \\
\text { Nos. }\end{array}$} & \multirow{2}{*}{$\begin{array}{c}\text { Rotational } \\
\text { Quantum Nos. }\end{array}$} & \multirow{2}{*}{ Vib. State } & \multicolumn{2}{|c|}{ Hyperfine } & \multirow{2}{*}{$\begin{array}{c}\text { Frequency } \\
\mathrm{MHz}\end{array}$} & \multirow{2}{*}{$\begin{array}{r}\text { Acc. } \\
\pm \mathrm{MHz}\end{array}$} \\
\hline & & & & $\begin{array}{lll}F_{1}^{\prime} & F^{\prime} & F_{1}\end{array}$ & $\mathrm{~F}$ & & \\
\hline $\mathrm{C}^{12} \mathrm{H}_{3} \mathrm{Cl}^{35}$ & 4.- 421 & $4,1 \leftarrow 3,1$ & Ground & $9 / 2$ & $7 / 2$ & 106335.79 & \\
\hline $\mathrm{C}^{12} \mathrm{H}_{3} \mathrm{Cl}^{35}$ & 4- 421 & $4,1 \leftarrow 3,1$ & Ground & $5 / 2$ & $3 / 2$ & 106336.59 & \\
\hline $\mathrm{C}^{12} \mathrm{H}_{3} \mathrm{Cl}^{35}$ & 4. 421 & $4,0 \leftarrow 3,0$ & Ground & $5 / 2$ & $3 / 2$ & 106336.59 & \\
\hline $\mathrm{C}^{12} \mathrm{H}_{3} \mathrm{Cl}^{35}$ & 4- 421 & $4,0 \leftarrow 3,0$ & Ground & $7 / 2$ & $5 / 2$ & 106336.59 & \\
\hline $\mathrm{C}^{12} \mathrm{H}_{3} \mathrm{Cl}^{35}$ & 4. 421 & $4,1 \leftarrow 3,1$ & Ground & $11 / 2$ & $9 / 2$ & 106337.70 & \\
\hline $\mathrm{C}^{12} \mathrm{H}_{3} \mathrm{Cl}^{35}$ & 4- 421 & $4,0 \leftarrow 3,0$ & Ground & $9 / 2$ & $7 / 2$ & 106338.75 & \\
\hline $\mathrm{C}^{12} \mathrm{H}_{3} \mathrm{Cl}^{35}$ & 4. 421 & $4,0 \leftarrow 3,0$ & Ground & $11 / 2$ & $9 / 2$ & 106338.75 & \\
\hline $\mathrm{C}^{12} \mathrm{H}_{3} \mathrm{Cl}^{35}$ & 4. 421 & $4,1 \leftarrow 3,1$ & Ground & $7 / 2$ & $7 / 2$ & 106341.52 & \\
\hline $\mathrm{C}^{12} \mathrm{H}_{3} \mathrm{Cl}^{35}$ & 4- 421 & $4,0 \leftarrow 3,0$ & Ground & $7 / 2$ & $7 / 2$ & 106345.33 & \\
\hline $\mathrm{C}^{12} \mathrm{H}_{3} \mathrm{Cl}^{35}$ & 4- 421 & $4,1 \leftarrow 3,1$ & Ground & $5 / 2$ & $5 / 2$ & 106350.77 & \\
\hline $\mathrm{C}^{12} \mathrm{H}_{3} \mathrm{Cl}^{35}$ & 4- 421 & $4,0 \leftarrow 3,0$ & Ground & $5 / 2$ & $5 / 2$ & 106355.35 & \\
\hline $\mathrm{C}^{12} \mathrm{H}_{3} \mathrm{Cl}^{35}$ & 4- 421 & $4,3 \leftarrow 3,3$ & Ground & $11 / 2$ & $9 / 2$ & 106392.24 & \\
\hline $\mathrm{N}^{14} \mathrm{~F}_{3}^{19}$ & 4-1651 & $5,3 \leftarrow 4,3$ & Ground & & & 106803.62 & .20 \\
\hline $\mathrm{N}^{14} \mathrm{~F}_{3}^{19}$ & 4-1651 & $5,2 \leftarrow 4,2$ & Ground & & & 106804.54 & .50 \\
\hline $\mathrm{N}^{14} \mathrm{~F}_{3}^{19}$ & 4-1651 & $5,0 \leftarrow 4,0$ & Ground & & & 106805.93 & .20 \\
\hline $\mathrm{F}^{19} \mathrm{HC}^{12} \mathrm{O}^{16}$ & 4. 271 & $8,1,7 \leftarrow 8,0,8$ & & & & 107362.11 & .05 \\
\hline $\mathrm{HC}^{12} \mathrm{O}^{16} \mathrm{O}^{16} \mathrm{H}$ & 3- 71 & $5,1,5 \leftarrow 4,1,4$ & & & & 108127.00 & .65 \\
\hline $\mathrm{DN}^{14} \mathrm{C}^{12} \mathrm{~S}^{32}$ & 4. 312 & $10,1,10 \leftarrow 9,1,9$ & Ground & & & 109200.75 & .5 \\
\hline$D N^{14} C^{12} S^{32}$ & 4- 312 & $10, \quad \leftarrow 9$, & Excited & & & 109239.9 & 1.0 \\
\hline $\mathrm{DN}^{14} \mathrm{C}^{12} \mathrm{~S}^{32}$ & 4. 312 & $10, \quad \leftarrow 9$, & Excited & & & 109413.3 & 1.0 \\
\hline $\mathrm{DN}^{14} \mathrm{C}^{12} \mathrm{~S}^{32}$ & 4- 312 & $10, \quad \leftarrow 9$, & Excited & & & 109445.9 & 1.0 \\
\hline $\mathrm{DN}^{14} \mathrm{C}^{12} \mathrm{~S}^{32}$ & 4- 312 & $10,1,10 \leftarrow 9,0,9$ & Ground & & & 109452.06 & .5 \\
\hline $\mathrm{HN}^{14} \mathrm{C}^{12} \mathrm{O}^{16}$ & 4- 301 & $5,1,5 \leftarrow 4,1,4$ & Ground & & & 109495.71 & .5 \\
\hline $\mathrm{DN}^{14} \mathrm{C}^{12} \mathrm{~S}^{32}$ & 4- 312 & $10,2,9 \leftarrow 9,2,8$ & Ground & & & 109531.83 & .5 \\
\hline $\mathrm{DN}^{14} \mathrm{C}^{12} \mathrm{~S}^{32}$ & 4- 312 & $10,2,8 \leftarrow 9,2,7$ & Ground & & & 109532.36 & .5 \\
\hline $\mathrm{DN}^{14} \mathrm{C}^{12} \mathrm{~S}^{32}$ & 4- 312 & $10,0, \leftarrow 9,0$ & Excited & & & 109537.4 & .5 \\
\hline $\mathrm{N}^{15} \mathrm{O}_{2}^{16}$ & 4-1802 & $12,0,12 \leftarrow 11,1,11$ & Ground & & & 109559.23 & \\
\hline $\mathrm{N}^{15} \mathrm{O}_{2}^{16}$ & 4-1802 & $12,0,12 \leftarrow 11,1,11$ & Ground & & & 109576.98 & \\
\hline $\mathrm{DN}^{14} \mathrm{C}^{12} \mathrm{~S}^{32}$ & 4. 312 & $10, \quad, \quad \leftarrow 9$, & Excited & & & 109588.8 & 1.0 \\
\hline $\mathrm{DN}^{14} \mathrm{C}^{12} \mathrm{~S}^{32}$ & 4- 312 & $10,3,7 \leftarrow 9,3,6$ & Ground & & & 109597.60 & 1.0 \\
\hline $\mathrm{DN}^{14} \mathrm{C}^{12} \mathrm{~S}^{32}$ & 4. 312 & $10,3,8 \leftarrow 9,3,7$ & Ground & & & 109597.60 & 1.0 \\
\hline $\mathrm{DN}^{14} \mathrm{C}^{12} \mathrm{~S}^{32}$ & 4. 312 & $10, \quad \leftarrow 9$, & Excited & & & 109656.9 & 1.0 \\
\hline $\mathrm{DN}^{14} \mathrm{C}^{12} \mathrm{~S}^{32}$ & 4- 312 & $10, \quad \leftarrow 9, \quad$ & Excited & & & 109663.2 & 1.0 \\
\hline $\mathrm{DN}^{14} \mathrm{C}^{12} \mathrm{~S}^{32}$ & 4- 312 & $10, \quad \leftarrow 9$, & Excited & & & 109664.5 & 1.0 \\
\hline $\mathrm{DN}^{14} \mathrm{C}^{12} \mathrm{~S}^{32}$ & 4. 312 & $10, \quad \leftarrow 9$, & Excited & & & 109667.4 & 1.0 \\
\hline $\mathrm{DN}^{14} \mathrm{C}^{12} \mathrm{~S}^{32}$ & 4- 312 & $10, \quad \leftarrow 9$, & Excited & & & 109679.3 & 1.0 \\
\hline $\mathrm{DN}^{14} \mathrm{C}^{12} \mathrm{~S}^{32}$ & 4- 312 & $10, \quad \leftarrow 9$, & Excited & & & 109710.6 & 1.0 \\
\hline $\mathrm{DN}^{14} \mathrm{C}^{12} \mathrm{~S}^{32}$ & 4- 312 & $10, \quad \leftarrow 9$, & Excited & & & 109721.4 & 1.0 \\
\hline $\mathrm{N}^{15} \mathrm{O}_{2}^{16}$ & 4-1802 & $12,0,12 \leftarrow 11,1,11$ & Ground & & & 109743.01 & \\
\hline $\mathrm{N}^{15} \mathrm{O}_{2}^{16}$ & 4-1802 & $12,0,12 \leftarrow 11,1,11$ & Ground & & & 109743.83 & \\
\hline $\mathrm{DN}^{14} \mathrm{C}^{12} \mathrm{~S}^{32}$ & 4- 312 & $10, \quad, \quad \leftarrow 9$, & Excited & & & 109748.5 & 1.0 \\
\hline $\mathrm{DN}^{14} \mathrm{C}^{12} \mathrm{~S}^{32}$ & 4- 312 & $10,1,9 \leftarrow 9,1,8$ & Ground & & & 109752.49 & .5 \\
\hline $\mathrm{HN}^{14} \mathrm{C}^{12} \mathrm{O}^{16}$ & 4- 301 & $5,1, \leftarrow 4,1$, & Excited & & & 109776.42 & 1.0 \\
\hline $\mathrm{HN}^{14} \mathrm{C}^{12} \mathrm{O}^{16}$ & 4- 301 & $5,4,2 \leftarrow 4,4,1$ & Ground & 4 & 3 & 109778.37 & 1.0 \\
\hline $\mathrm{HN}^{14} \mathrm{C}^{12} \mathrm{O}^{16}$ & 4- 301 & $5,4,2 \leftarrow 4,4,1$ & Ground & 6 & 5 & 109778.37 & 1.0 \\
\hline
\end{tabular}




\begin{tabular}{|c|c|c|c|c|c|c|c|c|c|}
\hline \multirow{2}{*}{\multicolumn{2}{|c|}{ Isotopic Species }} & \multirow{2}{*}{$\begin{array}{l}\text { Vol.-Id. } \\
\text { Nos. }\end{array}$} & \multirow{2}{*}{$\begin{array}{c}\text { Rotational } \\
\text { Quantum Nos. }\end{array}$} & \multirow{2}{*}{ Vib. State } & \multicolumn{3}{|c|}{ Hyperfine } & \multirow{2}{*}{$\begin{array}{l}\text { Frequency } \\
\qquad \mathrm{MHz}\end{array}$} & \multirow{2}{*}{$\begin{aligned} & \text { Acc. } \\
& \pm \mathrm{MHz}_{2}\end{aligned}$} \\
\hline & & & & & $F_{1}^{\prime}$ & $F^{\prime} \quad F_{1}$ & $\mathrm{~F}$ & & \\
\hline $\mathrm{HN}^{14} \mathrm{C}^{12} \mathrm{O}^{16}$ & & 4- 301 & $5,4,1 \leftarrow 4,4,0$ & Ground & & 6 & 5 & 109778.37 & 1.0 \\
\hline $\mathrm{HN}^{14} \mathrm{C}^{12} \mathrm{O}^{16}$ & & 4- 301 & $5,4,1 \leftarrow 4,4,0$ & Ground & & 4 & 3 & 109778.37 & 1.0 \\
\hline $\mathrm{HN}^{14} \mathrm{C}^{12} \mathrm{O}^{16}$ & & 4- 301 & $5,4,1 \leftarrow 4,4,0$ & Ground & & 5 & 4 & 109778.94 & 1.0 \\
\hline $\mathrm{HN}^{14} \mathrm{C}^{12} \mathrm{O}^{16}$ & & 4- 301 & $5,4,2 \leftarrow 4,4,1$ & Ground & & 5 & 4 & 109778.94 & 1.0 \\
\hline $\mathrm{C}^{12} \mathrm{O}^{18}$ & & $1-$ & $1 \leftarrow 0$ & Ground & & & & 109782.182 & .008 \\
\hline $\mathrm{HN}^{14} \mathrm{C}^{12} \mathrm{O}^{16}$ & & 4- 301 & $5,3,3 \leftarrow 4,3,2$ & Ground & & 4 & 3 & 109833.45 & 1.0 \\
\hline $\mathrm{HN}^{14} \mathrm{C}^{12} \mathrm{O}^{16}$ & & 4- 301 & $5,3,3 \leftarrow 4,3,2$ & Ground & & 6 & 5 & 109833.45 & 1.0 \\
\hline $\mathrm{HN}^{14} \mathrm{C}^{12} \mathrm{O}^{16}$ & & 4- 301 & $5,3,2 \leftarrow 4,3,1$ & Ground & & 6 & 5 & 109833.45 & 1.0 \\
\hline $\mathrm{HN}^{14} \mathrm{C}^{12} \mathrm{O}^{16}$ & & 4- 301 & $5,3,2 \leftarrow 4,3,1$ & Ground & & 4 & 3 & 109833.45 & 1.0 \\
\hline $\mathrm{HN}^{14} \mathrm{C}^{12} \mathrm{O}^{16}$ & & 4- 301 & $5,3,3 \leftarrow 4,3,2$ & Ground & & 5 & 4 & 109833.84 & 1.0 \\
\hline $\mathrm{HN}^{14} \mathrm{C}^{12} \mathrm{O}^{16}$ & & 4- 301 & $5,3,2 \leftarrow 4,3,1$ & Ground & & 5 & 4 & 109833.84 & 1.0 \\
\hline $\mathrm{DN}^{14} \mathrm{C}^{12} \mathrm{~S}^{32}$ & & 4. 312 & $10, \quad \leftarrow 9$, & Excited & & & & 109837.2 & 1.0 \\
\hline $\mathrm{HN}^{14} \mathrm{C}^{12} \mathrm{O}^{16}$ & & 4- 301 & $5,2,4 \leftarrow 4,2,3$ & Ground & & & & 109872.60 & .5 \\
\hline $\mathrm{HN}^{14} \mathrm{C}^{12} \mathrm{O}^{16}$ & & 4- 301 & $5,2,3 \leftarrow 4,2,2$ & Ground & & & & 109872.99 & .5 \\
\hline $\mathrm{HN}^{14} \mathrm{C}^{12} \mathrm{O}^{16}$ & & 4- 301 & $5, \quad \leftarrow 4, \quad$, & Excited & & & & 109890.69 & 1.0 \\
\hline $\mathrm{HN}^{14} \mathrm{C}^{12} \mathrm{O}^{16}$ & & 4- 301 & $5,0,5 \leftarrow 4,0,4$ & Ground & & & & 109905.90 & .5 \\
\hline $\mathrm{HN}^{14} \mathrm{C}^{12} \mathrm{O}^{16}$ & & 4- 301 & $5, \quad \leftarrow 4$, & Excited & & & & 109958.67 & 1.0 \\
\hline $\mathrm{HN}^{14} \mathrm{C}^{12} \mathrm{O}^{16}$ & & 4- 301 & $5,0, \leftarrow 4,0$ & Excited & & & & 110083.80 & 1.0 \\
\hline $\mathrm{HN}^{14} \mathrm{C}^{12} \mathrm{O}^{16}$ & & 4- 301 & $5,2, \leftarrow 4,2$, & Excited & & & & 110086.08 & 1.0 \\
\hline $\mathrm{HN}^{14} \mathrm{C}^{12} \mathrm{O}^{16}$ & & 4- 301 & $5,3, \leftarrow 4,3$, & Excited & & & & 110089.41 & 1.0 \\
\hline $\mathrm{HN}^{14} \mathrm{C}^{12} \mathrm{O}^{16}$ & & 4- 301 & $5,0, \leftarrow 4,0$, & Excited & & & & 110104.11 & 1.0 \\
\hline $\mathrm{HN}^{14} \mathrm{C}^{12} \mathrm{O}^{16}$ & & 4- 301 & $5,2, \leftarrow 4,2$, & Excited & & & & 110105.52 & 1.0 \\
\hline $\mathrm{HN}^{14} \mathrm{C}^{12} \mathrm{O}^{16}$ & & 4- 301 & $5,1, \leftarrow 4,1$, & Excited & & & & 110164.08 & 1.0 \\
\hline $\mathrm{C}^{13} \mathrm{O}^{16}$ & & $1-$ & $1 \leftarrow 0$ & Ground & & & & 110201.370 & .002 \\
\hline $\mathrm{HN}^{14} \mathrm{C}^{12} \mathrm{O}^{16}$ & & 4- 301 & $5,1,4 \leftarrow 4,1,3$ & Ground & & & & 110297.82 & .5 \\
\hline $\mathrm{C}^{12} \mathrm{H}_{3} \mathrm{C}^{12} \mathrm{~N}^{14}$ & & 4. 811 & $6,5 \leftarrow 5,5$ & Ground & & & & 110329.70 & .25 \\
\hline $\mathrm{C}^{12} \mathrm{H}_{3} \mathrm{C}^{12} \mathrm{~N}^{14}$ & & 4- 811 & $6,5 \leftarrow 5,5$ & Ground & & & & 110330.79 & .25 \\
\hline $\mathrm{C}^{12} \mathrm{H}_{3} \mathrm{C}^{12} \mathrm{~N}^{14}$ & & 4- 811 & $6,4 \leftarrow 5,4$ & Ground & & & & 110349.00 & .25 \\
\hline $\mathrm{C}^{12} \mathrm{H}_{3} \mathrm{C}^{12} \mathrm{~N}^{14}$ & & 4- 811 & $6,4 \leftarrow 5,4$ & Ground & & & & 110349.68 & .25 \\
\hline $\mathrm{C}^{12} \mathrm{H}_{3} \mathrm{C}^{12} \mathrm{~N}^{14}$ & & 4- 811 & $6,3 \leftarrow 5,3$ & Ground & & & & 110364.02 & .25 \\
\hline $\mathrm{C}^{12} \mathrm{H}_{3} \mathrm{C}^{12} \mathrm{~N}^{14}$ & & 4. 811 & $6,3 \leftarrow 5,3$ & Ground & & & & 110364.52 & .25 \\
\hline $\mathrm{C}^{12} \mathrm{H}_{3} \mathrm{C}^{12} \mathrm{~N}^{14}$ & & 4- 811 & $6,2 \leftarrow 5,2$ & Ground & & & & 110375.01 & .25 \\
\hline $\mathrm{C}^{12} \mathrm{H}_{3} \mathrm{C}^{12} \mathrm{~N}^{14}$ & & 4- 811 & $6,1 \leftarrow 5,1$ & Ground & & & & 110381.39 & .25 \\
\hline $\mathrm{C}^{12} \mathrm{H}_{3} \mathrm{C}^{12} \mathrm{~N}^{14}$ & & 4- 811 & $6,0 \leftarrow 5,0$ & Ground & & & & 110383.47 & .25 \\
\hline $\mathrm{HN}^{14} \mathrm{C}^{12} \mathrm{O}^{16}$ & & 4- 301 & $5,1, \leftarrow 4,1$, & Excited & & & & 110419.08 & 1.0 \\
\hline $\mathrm{HN}_{3}^{14}$ & & 4-1701 & $5,1,5 \leftarrow 4,1,4$ & Ground & & & & 110608.76 & .25 \\
\hline $\mathrm{C}^{12} \mathrm{H}_{3} \mathrm{C}^{12} \mathrm{~N}^{14}$ & & 4- 811 & $6,1 \leftarrow 5,1$ & Excited & & & & 110609.77 & .25 \\
\hline $\mathrm{C}^{12} \mathrm{H}_{3} \mathrm{C}^{12} \mathrm{~N}^{14}$ & & 4- 811 & $6,5 \leftarrow 5,5$ & Excited & & & & 110637.22 & .25 \\
\hline $\mathrm{C}^{12} \mathrm{H}_{3} \mathrm{C}^{12} \mathrm{~N}^{14}$ & & 4- 811 & $6,4 \leftarrow 5,4$ & Excited & & & & 110660.88 & .25 \\
\hline $\mathrm{C}^{12} \mathrm{H}_{3} \mathrm{C}^{12} \mathrm{~N}^{14}$ & & 4- 811 & $6,3 \leftarrow 5,3$ & Excited & & & & 110680.36 & .25 \\
\hline $\mathrm{C}^{12} \mathrm{H}_{3} \mathrm{C}^{12} \mathrm{~N}^{14}$ & & 4- 811 & $6,5 \leftarrow 5,5$ & Excited & & & & 110684.52 & .25 \\
\hline $\mathrm{C}^{12} \mathrm{H}_{3} \mathrm{C}^{12} \mathrm{~N}^{14}$ & & 4- 811 & $6,2 \leftarrow 5,2$ & Excited & & & & 110697.07 & .25 \\
\hline $\mathrm{C}^{12} \mathrm{H}_{3} \mathrm{C}^{12} \mathrm{~N}^{14}$ & & 4- 811 & $6,4 \leftarrow 5,4$ & Excited & & & & 110698.62 & .25 \\
\hline $\mathrm{C}^{12} \mathrm{H}_{3} \mathrm{C}^{12} \mathrm{~N}^{14}$ & & 4- 811 & $6,1 \leftarrow 5,1$ & Excited & & & & 110706.25 & .25 \\
\hline $\mathrm{C}^{12} \mathrm{H}_{3} \mathrm{C}^{12} \mathrm{~N}^{14}$ & - & 4- 811 & $6,3 \leftarrow 5,3$ & Excited & & & & 110709.40 & .25 \\
\hline
\end{tabular}




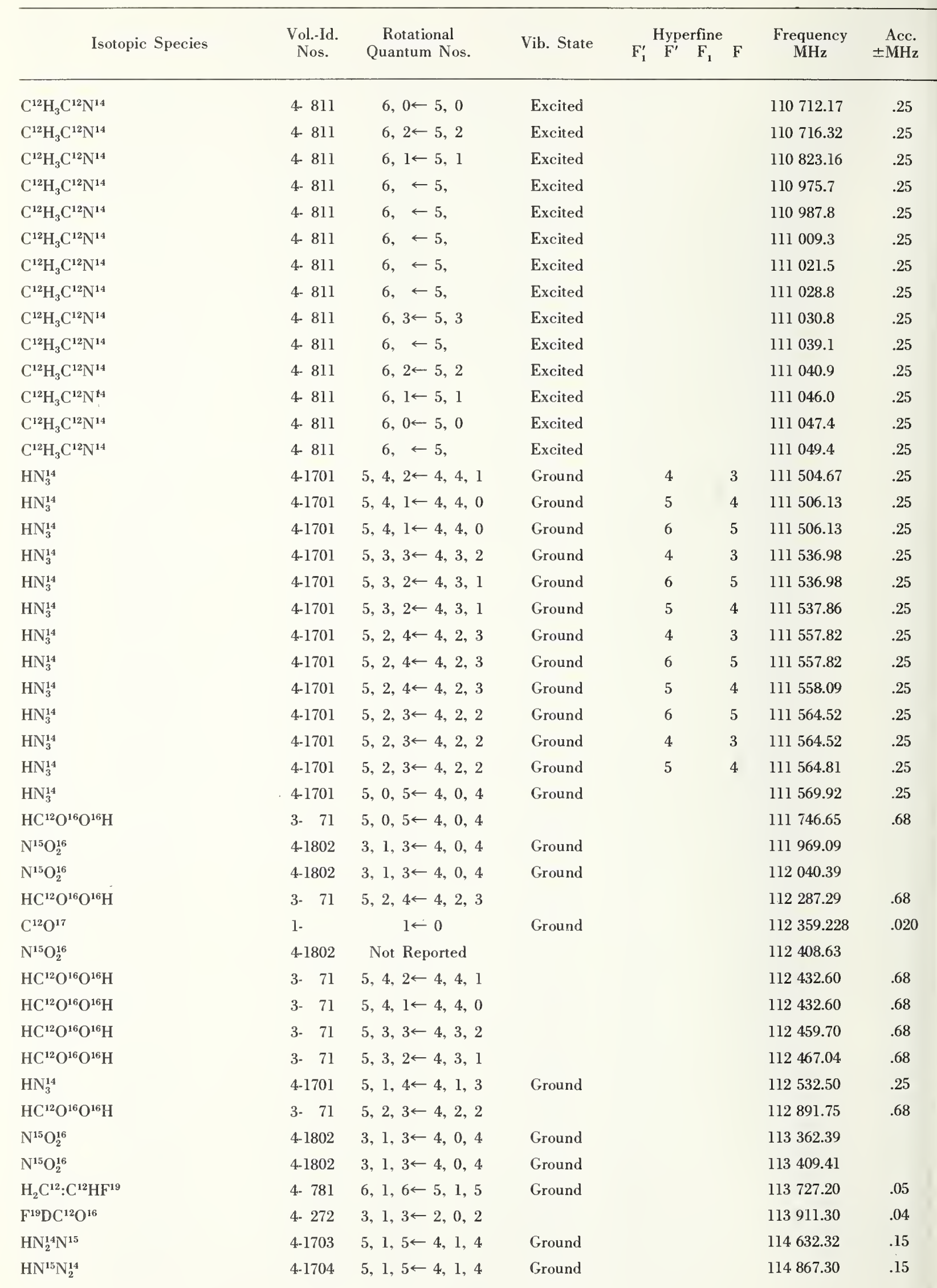


Vib. State

$\mathrm{F}_{1}^{\prime} \stackrel{\text { Hyperfine }}{\mathrm{F}^{\prime}} \mathrm{F}$

Frequency

\begin{tabular}{|c|c|c|c|c|c|c|c|}
\hline $\mathrm{As}^{75} \mathrm{D}_{3}$ & 4- 33 & $1,0 \leftarrow 0,0$ & Ground & $3 / 2$ & $3 / 2$ & 114918.94 & .3 \\
\hline $\mathrm{As}^{75} \mathrm{D}_{3}$ & 4- 33 & $1,0 \leftarrow 0,0$ & Ground & $5 / 2$ & $3 / 2$ & 114960.57 & .3 \\
\hline $\mathrm{As}^{75} \mathrm{D}_{3}$ & 4- 33 & $1,0 \leftarrow 0,0$ & Ground & $1 / 2$ & $3 / 2$ & 114993.50 & .3 \\
\hline $\mathrm{F}^{19} \mathrm{HC}^{12} \mathrm{O}^{16}$ & 4. 271 & $9,1,8 \leftarrow 9,0,9$ & & & & 114993.80 & .05 \\
\hline $\mathrm{HN}_{2}^{14} \mathrm{~N}^{15}$ & $4-1703$ & $5,3,3 \leftarrow 4,3,2$ & Ground & 4 & 3 & 115164.13 & .15 \\
\hline $\mathrm{HN}_{2}^{14} \mathrm{~N}^{15}$ & $4-1703$ & $5,3,3 \leftarrow 4,3,2$ & Ground & 6 & 5 & 115164.13 & .15 \\
\hline $\mathrm{HN}_{2}^{14} \mathrm{~N}^{15}$ & $4-1703$ & $5,3,2 \leftarrow 4,3,1$ & Ground & 5 & 4 & 115164.96 & .15 \\
\hline $\mathrm{HN}_{2}^{14} \mathrm{~N}^{15}$ & $4-1703$ & $5,2,4 \leftarrow 4,2,3$ & Ground & 6 & 5 & 115201.66 & .15 \\
\hline $\mathrm{HN}_{2}^{14} \mathrm{~N}^{15}$ & $4-1703$ & $5,2,4 \leftarrow 4,2,3$ & Ground & 4 & 3 & 115201.66 & .15 \\
\hline $\mathrm{HN}_{2}^{14} \mathrm{~N}^{15}$ & $4-1703$ & $5,2,4 \leftarrow 4,2,3$ & Ground & 5 & 4 & 115202.04 & .15 \\
\hline $\mathrm{HN}_{2}^{14} \mathrm{~N}^{15}$ & $4-1703$ & $5,2,3 \leftarrow 4,2,2$ & Ground & 6 & 5 & 115203.02 & .15 \\
\hline $\mathrm{HN}_{2}^{14} \mathrm{~N}^{15}$ & $4-1703$ & $5,2,3 \leftarrow 4,2,2$ & Ground & 4 & 3 & 115203.02 & .15 \\
\hline $\mathrm{HN}_{2}^{14} \mathrm{~N}^{15}$ & 4-1703 & $5,2,3 \leftarrow 4,2,2$ & Ground & 5 & 4 & 115203.44 & .15 \\
\hline $\mathrm{HN}_{2}^{14} \mathrm{~N}^{15}$ & 4-1703 & $5,0,5 \leftarrow 4,0,4$ & Ground & & & 115230.58 & .15 \\
\hline $\mathrm{C}^{12} \mathrm{O}^{16}$ & 1 - & $1 \leftarrow 0$ & Grouñd & & & 115271.201 & \\
\hline $\mathrm{HN}^{15} \mathrm{~N}_{2}^{14}$ & 4-1704 & $5,3,2 \leftarrow 4,3,1$ & Ground & & & 115405.63 & .15 \\
\hline $\mathrm{HN}^{15} \mathrm{~N}_{2}^{14}$ & 4-1704 & $5,3,3 \leftarrow 4,3,2$ & Ground & & & 115405.63 & .15 \\
\hline $\mathrm{HN}^{15} \mathrm{~N}_{2}^{14}$ & 4-1704 & $5,2,4 \leftarrow 4,2,3$ & Ground & & & 115443.81 & .15 \\
\hline $\mathrm{HN}^{15} \mathrm{~N}_{2}^{14}$ & $4-1704$ & $5,2,3 \leftarrow 4,2,2$ & Ground & & & 115445.25 & .15 \\
\hline $\mathrm{HN}^{15} \mathrm{~N}_{2}^{14}$ & 4-1704 & $5,0,5 \leftarrow 4,0,4$ & Ground & & & 115473.18 & .15 \\
\hline $\mathrm{HN}_{2}^{14} \mathrm{~N}^{15}$ & 4-1703 & $5,1,4 \leftarrow 4,1,3$ & Ground & & & 115815.77 & .15 \\
\hline $\mathrm{HN}^{15} \mathrm{~N}_{2}^{14}$ & $4-1704$ & $5,1,4 \leftarrow 4,1,3$ & Ground & & & 116065.79 & .15 \\
\hline $\mathrm{HC}^{12} \mathrm{O}^{16} \mathrm{O}^{16} \mathrm{H}$ & 3. 71 & $5,1,4 \leftarrow 4,1,3$ & & & & 116311.35 & .70 \\
\hline $\mathrm{Cl}^{37} \mathrm{C}^{12} \mathrm{~N}^{14}$ & 4. 173 & $10 \leftarrow 9$ & Ground & & & 116938.45 & .25 \\
\hline $\mathrm{S}^{32} \mathrm{O}_{2}^{16}$ & 4-1831 & $8,0,8 \leftarrow 7,1,7$ & Ground & & & 116980.60 & \\
\hline $\mathrm{N}^{14} \mathrm{D}_{3}$ & 4-1775 & Not Reported & Excited & & & 117000. & \\
\hline $\mathrm{HN}^{14} \mathrm{C}^{12} \mathrm{~S}^{32}$ & 4. 311 & $10,1,10 \leftarrow 9,1,9$ & Ground & & & 117114.04 & .5 \\
\hline $\mathrm{DN}^{14} \mathrm{C}^{12} \mathrm{~S}^{32}$ & 4- 312 & $10,1,10 \leftarrow 9,1,9$ & Excited & & & 117117.5 & .5 \\
\hline $\mathrm{HN}^{14} \mathrm{C}^{12} \mathrm{~S}^{32}$ & 4- 311 & $10,1,10 \leftarrow 9,1,9$ & Excited & & & 117117.5 & 1.0 \\
\hline $\mathrm{Cl}^{37} \mathrm{C}^{12} \mathrm{~N}^{14}$ & 4- 173 & $10 \leftarrow 9$ & Excited & & & 117186.54 & \\
\hline $\mathrm{HN}^{14} \mathrm{C}^{12} \mathrm{~S}^{32}$ & 4- 311 & $10,0,10 \leftarrow 9,0,9$ & Ground & & & 117285.45 & .5 \\
\hline $\mathrm{HN}^{14} \mathrm{C}^{12} \mathrm{~S}^{32}$ & 4. 311 & $10, \quad \leftarrow 9, \quad$ & Excited & & & 117315.4 & 1.0 \\
\hline $\mathrm{HN}^{14} \mathrm{C}^{12} \mathrm{~S}^{32}$ & 4- 311 & $10,2,8 \leftarrow 9,2,7$ & Ground & & & 117327.47 & .5 \\
\hline $\mathrm{HN}^{14} \mathrm{C}^{12} \mathrm{~S}^{32}$ & 4- 311 & $10,2,9 \leftarrow 9,2,8$ & Ground & & & 117327.47 & .5 \\
\hline $\mathrm{Cl}^{37} \mathrm{C}^{12} \mathrm{~N}^{14}$ & 4. 173 & $10 \leftarrow 9$ & Excited & & & 117329.90 & \\
\hline $\mathrm{HN}^{14} \mathrm{C}^{12} \mathrm{~S}^{32}$ & 4- 311 & $10,3,8 \leftarrow 9,3,7$ & Ground & & & 117342.63 & 1.0 \\
\hline $\mathrm{HN}^{14} \mathrm{C}^{12} \mathrm{~S}^{32}$ & 4- 311 & $10,3,7 \leftarrow 9,3,6$ & Ground & & & 117342.63 & 1.0 \\
\hline $\mathrm{HN}^{14} \mathrm{C}^{12} \mathrm{~S}^{32}$ & 4- 311 & $10,4, \leftarrow 9,4$, & Ground & & & 117367.94 & 1.0 \\
\hline $\mathrm{HN}^{14} \mathrm{C}^{12} \mathrm{~S}^{32}$ & 4. 311 & $10, \quad \leftarrow 9, \quad$, & Excited & & & 117371.3 & 1.0 \\
\hline $\mathrm{HN}^{14} \mathrm{C}^{12} \mathrm{~S}^{32}$ & 4- 311 & $10,0, \leftarrow 9,0$ & Excited & & & 117377.2 & 1.0 \\
\hline $\mathrm{HN}^{14} \mathrm{C}^{12} \mathrm{~S}^{32}$ & 4- 311 & $10, \quad \leftarrow 9$, & Excited & & & 117413.8 & 1.0 \\
\hline $\mathrm{H}_{2} \mathrm{C}^{12}: \mathrm{C}^{12} \mathrm{HF}^{19}$ & 4- 781 & $6,6,6 \leftarrow 5,6,5$ & Ground & & & 117431.32 & .05 \\
\hline $\mathrm{HN}^{14} \mathrm{C}^{12} \mathrm{~S}^{32}$ & 4- 311 & $10, \quad \leftarrow 9, \quad$, & Excited & & & 117444.9 & 1.0 \\
\hline $\mathrm{HN}^{14} \mathrm{C}^{12} \mathrm{~S}^{32}$ & 4- 311 & $10, \quad \leftarrow 9, \quad$, & Excited & & & 117479.9 & 1.0 \\
\hline $\mathrm{HN}^{14} \mathrm{C}^{12} \mathrm{~S}^{32}$ & 4. 311 & $10,1,9 \leftarrow 9,1,8$ & Ground & & & 117491.95 & .5 \\
\hline
\end{tabular}




\begin{tabular}{|c|c|c|c|c|c|c|c|}
\hline \multirow{2}{*}{ Isntopir Species } & \multirow{2}{*}{$\begin{array}{l}\text { Vol.-Id. } \\
\text { Nos. }\end{array}$} & \multirow{2}{*}{$\begin{array}{c}\text { Rotational } \\
\text { Quantum Nos. }\end{array}$} & \multirow{2}{*}{ Vib. State } & \multicolumn{2}{|c|}{ Hyperfine } & \multirow{2}{*}{$\begin{array}{c}\text { Frequency } \\
\text { MHz }\end{array}$} & \multirow{2}{*}{$\begin{aligned} & \text { Acc. } \\
\pm & \mathrm{MHz}\end{aligned}$} \\
\hline & & & & $\begin{array}{lll}F_{1}^{\prime} & F^{\prime} & F_{1}\end{array}$ & $F$ & & \\
\hline $\mathrm{HN}^{14} \mathrm{C}^{12} \mathrm{~S}^{32}$ & 4- 311 & $10,0, \leftarrow 9,0$ & Excited & & & 117506.6 & 1.0 \\
\hline $\mathrm{HN}^{14} \mathrm{C}^{12} \mathrm{~S}^{32}$ & 4. 311 & $10,0, \leftarrow 9,0$, & Excited & & & 117516.8 & 1.0 \\
\hline $\mathrm{HN}^{14} \mathrm{C}^{12} \mathrm{~S}^{32}$ & 4- 311 & $10,0, \leftarrow 9,0$, & Excited & & & 117523.4 & 1.0 \\
\hline $\mathrm{HN}^{14} \mathrm{C}^{12} \mathrm{~S}^{32}$ & 4- 311 & $10, \quad \leftarrow 9$, & Excited & & & 117562.5 & 1.0 \\
\hline $1 \mathrm{IN}^{14} \mathrm{C}^{12} \mathrm{~S}^{32}$ & 4- 311 & $10, \quad \leftarrow 9$, & Excited & & & 117589.8 & 1.0 \\
\hline $11 N^{14} C^{12} S^{32}$ & 4. 311 & $10, \quad \leftarrow 9$, & Excited & & & 117606.8 & 1.0 \\
\hline $\mathrm{HN}^{14} \mathrm{C}^{12} \mathrm{~S}^{32}$ & 4. 311 & $10, \quad \leftarrow 9$, & Excited & & & 117615.4 & 1.0 \\
\hline $\mathrm{O}_{3}^{16}$ & 4-1841 & $1,1,1 \leftarrow 0,0,0$ & Ground & & & 118364.3 & .5 \\
\hline $\mathrm{H}_{2} \mathrm{C}^{12}: \mathrm{C}^{12} \mathrm{HF}^{19}$ & 4- 781 & $6,2,5 \leftarrow 5,2,4$ & Ground & & & 118383.85 & .05 \\
\hline $\mathrm{HN}_{3}^{14}$ & 4-1701 & $5,1,5 \leftarrow 4,1,4$ & Ground & & & 118435.82 & .25 \\
\hline $\mathrm{H}_{2} \mathrm{C}^{12}: \mathrm{C}^{12} \mathrm{HF}^{19}$ & 4- 781 & $6,5, \leftarrow 5,5$, & Ground & & & 118623.85 & .05 \\
\hline $\mathrm{H}_{2} \mathrm{C}^{12}: \mathrm{C}^{12} \mathrm{HF}^{19}$ & 4- 781 & $6,4,2 \leftarrow 5,4,1$ & Ground & & & 118644.25 & .05 \\
\hline $\mathrm{H}_{2} \mathrm{C}^{12}: \mathrm{C}^{12} \mathrm{HF}^{19}$ & 4- 781 & $6,4,3 \leftarrow 5,4,2$ & Ground & & & 118644.35 & .05 \\
\hline $\mathrm{H}_{2} \mathrm{C}^{12}: \mathrm{C}^{12} \mathrm{HF}^{19}$ & 4- 781 & $6,3,4 \leftarrow 5,3,3$ & Ground & & & 118693.10 & .05 \\
\hline $\mathrm{H}_{2} \mathrm{C}^{12}: \mathrm{C}^{12} \mathrm{HF}^{19}$ & 4- 781 & $6,3,3 \leftarrow 5,3,2$ & Ground & & & 118715.90 & .05 \\
\hline $\mathrm{O}_{2}^{16}$ & $1-$ & $1,1 \leftarrow 0,1$ & Ground & & & 118750.5 & .5 \\
\hline $\mathrm{HN} \mathrm{N}_{3}^{14}$ & 4-1701 & $5,4,2 \leftarrow 4,4,1$ & Ground & & & 118946.42 & .25 \\
\hline $\mathrm{HN}_{: 3}^{1.4}$ & 4-1701 & $5,4,1 \leftarrow 4,4,0$ & Ground & & & 118946.42 & .25 \\
\hline $\mathrm{HN}_{3}^{14}$ & 4. 1701 & $5,3,3 \leftarrow 4,3,2$ & Ground & 4 & 3 & 119003.46 & .25 \\
\hline $\mathrm{HN}_{: !}^{1.4}$ & 4-1701 & $5,3,2 \leftarrow 4,3,1$ & Ground & 6 & 5 & 119003.46 & .25 \\
\hline $\mathrm{HN}_{3}^{14}$ & 4-1701 & $5,3,2 \leftarrow 4,3,1$ & Ground & 5 & 4 & 119004.33 & .25 \\
\hline $\mathrm{HN}_{: 3}^{14}$ & 4-1701 & $5,2,4 \leftarrow 4,2,3$ & Ground & & & 119043.41 & .25 \\
\hline $\mathrm{HN}_{3}^{14}$ & 4-1701 & $5,2,3 \leftarrow 4,2,2$ & Ground & & & 119044.95 & .25 \\
\hline $\mathrm{HN}_{3}^{1.4}$ & $4-1701$ & $5,0,5 \leftarrow 4,0,4$ & Ground & & & 119074.12 & .25 \\
\hline $\mathrm{F}^{16} \mathrm{DC} \mathrm{C}^{12} \mathrm{O}^{16}$ & 4- 272 & $10,1,9 \leftarrow 10,0,10$ & & & & 119163.65 & .04 \\
\hline $\mathrm{F}^{19} \mathrm{HC}^{12} \mathrm{O}^{16}$ & 4- 271 & $4,2,3 \leftarrow 5,1,4$ & & & & 119298.55 & .05 \\
\hline $\mathrm{Cl}^{135} \mathrm{C}^{12} \mathrm{~N}^{14}$ & 4- 171 & $10 \leftarrow 9$ & Ground & & & 119409.82 & .25 \\
\hline $\mathrm{P}^{3.31} \mathrm{O}^{16} \mathrm{~F}_{3}^{134}$ & 4-1671 & $13, \leftarrow 12$, & Ground & & & 119441.32 & .45 \\
\hline $\mathrm{H}_{2} \mathrm{C}^{12}: \mathrm{C}^{12} \mathrm{HF}^{19}$ & 4- 781 & $6,2,4 \leftarrow 5,2,3$ & Ground & & & 119474.65 & .05 \\
\hline $\mathrm{C}^{12} \mathrm{H}_{3} \mathrm{C}^{12}: \mathrm{C}^{12} \mathrm{H}$ & 4-1041 & $7,6 \leftarrow 6,6$ & & & & 119556.00 & .25 \\
\hline $\mathrm{C}^{12} \mathrm{H}_{33} \mathrm{C}^{12}: \mathrm{C}^{12} \mathrm{H}$ & 4-1041 & $7,5 \leftarrow 6,5$ & & & & 119581.12 & .25 \\
\hline $\mathrm{C}^{12} \mathrm{I}_{3} \mathrm{C}^{12}: \mathrm{C}^{12} \mathrm{H}$ & 4-104.1 & $7,4 \leftarrow 6,4$ & & & & 119601.62 & .25 \\
\hline $\mathrm{C}^{12} \mathrm{H}_{3} \mathrm{C}^{12}: \mathrm{C}^{12} \mathrm{H}$ & 4-104] & $7,3 \leftarrow 6,3$ & & & & 119617.67 & .25 \\
\hline $\mathrm{C}^{12} \mathrm{H}_{3} \mathrm{C}^{12}: \mathrm{C}^{12} \mathrm{H}$ & 4-104.1 & $7,2 \leftarrow 6,2$ & & & & 119629.13 & .25 \\
\hline $\mathrm{C}^{12} \mathrm{H}_{3} \mathrm{C}^{12}: \mathrm{C}^{12} \mathrm{H}$ & 4-104.1 & $7,1 \leftarrow 6,1$ & & & & 119635.97 & .25 \\
\hline $\mathrm{C}^{12} \mathrm{H}_{3} \mathrm{C}^{12}: \mathrm{C}^{12} \mathrm{H}$ & 4-1041 & $7,0 \leftarrow 6,0$ & & & & 119638.22 & .25 \\
\hline $\mathrm{C}^{135} \mathrm{C}^{12} \mathrm{~N}^{14}$ & 4. 171 & $10 \leftarrow 9$ & Excited & & & 119662.15 & \\
\hline $\mathrm{HN}_{3}^{1.4}$ & 4-1701 & $5,1,4 \leftarrow 4,1,3$ & Ground & & & 119698.95 & .25 \\
\hline $\mathrm{C}^{35} \mathrm{C}^{12} \mathrm{~N}^{14}$ & 4. 171 & $10 \leftarrow 9$ & Excited & & & 119811.35 & \\
\hline $\mathrm{O}^{16} \mathrm{C}^{12} \mathrm{Se}^{\mathrm{K} 2}$ & 4. 548 & $15 \leftarrow 14$ & Ground & & & 119812.89 & .25 \\
\hline $\mathrm{C}^{12} \mathrm{H}_{3} \mathrm{I}^{127}$ & 4- 481 & $8,6 \leftarrow 7,6$ & Ground & $17 / 2$ & $15 / 2$ & 119858.79 & \\
\hline $\mathrm{C}^{12} \mathrm{H}_{3} \mathrm{I}^{127}$ & 4- 481 & $8,6 \leftarrow 7,6$ & Ground & $19 / 2$ & $17 / 2$ & 119893.31 & \\
\hline $\mathrm{C}^{12} \mathrm{H}_{3} \Gamma^{127}$ & 4- 481 & $8,6 \leftarrow 7,6$ & Ground & $15 / 2$ & $13 / 2$ & 119897.38 & \\
\hline $\mathrm{C}^{12} \mathrm{H}_{3} \mathrm{I}^{127}$ & 4- 481 & $8,5 \leftarrow 7,5$ & Ground & $17 / 2$ & $15 / 2$ & 119904.58 & \\
\hline $\mathrm{C}^{12} \mathrm{H}_{3} \mathrm{I}^{127}$ & 4- 481 & $8,0 \leftarrow 7,0$ & Ground & $17 / 2$ & $17 / 2$ & 119919.48 & \\
\hline
\end{tabular}


Vib. State

Hyperfine $\mathrm{F}_{1}^{\prime} \mathrm{F}^{\prime} \mathrm{F}_{1} \quad \mathrm{H}$
Frequency $\mathrm{MI1z}+\mathrm{MH}$

\begin{tabular}{|c|c|c|c|c|c|c|}
\hline $\mathrm{C}^{12} \mathrm{H}_{3} \mathbf{I}^{127}$ & 4- 481 & $8,1 \leftarrow 7,1$ & Ground & $17 / 2$ & $17 / 2$ & 119920.02 \\
\hline $\mathrm{C}^{12} \mathrm{H}_{3} \mathrm{I}^{127}$ & 4- 481 & $8,2 \leftarrow 7,2$ & Ground & $17 / 2$ & $17 / 2$ & 119921.72 \\
\hline $\mathrm{C}^{12} \mathrm{H} \mathrm{I}^{127}$ & 4. 481 & $8,5 \leftarrow 7,5$ & Ground & $15 / 2$ & $13 / 2$ & 119928.43 \\
\hline $\mathrm{C}^{12} \mathrm{H}_{3} \mathrm{I}^{127}$ & 4. 481 & $8,5 \leftarrow 7,5$ & Ground & $19 / 2$ & $17 / 2$ & 119930.63 \\
\hline $\mathrm{C}^{12} \mathrm{H}_{3} \mathrm{I}^{127}$ & 4. 481 & $8,6 \leftarrow 7,6$ & Ground & $17 / 2$ & $17 / 2$ & 119941.94 \\
\hline $\mathrm{C}^{12} \mathrm{H}_{3} \mathrm{I}^{127}$ & 4- 481 & $8,4 \leftarrow 7,4$ & Ground & $17 / 2$ & $15 / 2$ & 119941.94 \\
\hline $\mathrm{C}^{12} \mathrm{H}_{3} \mathrm{I}^{127}$ & 4- 481 & $8,4 \leftarrow 7,4$ & Ground & $15 / 2$ & $13 / 2$ & 119953.94 \\
\hline $\mathrm{C}^{12} \mathrm{H}_{3} \mathrm{I}^{127}$ & 4- 481 & $8,4 \leftarrow 7,4$ & Ground & $19 / 2$ & $17 / 2$ & 119961.23 \\
\hline $\mathrm{C}^{12} \mathrm{H}_{3} \mathrm{I}^{127}$ & 4- 481 & $8,3 \leftarrow 7,3$ & Ground & $17 / 2$ & $15 / 2$ & 119971.10 \\
\hline $\mathrm{C}^{12} \mathrm{H}_{3} \mathrm{I}^{127}$ & 4. 481 & $8,3 \leftarrow 7,3$ & Ground & $15 / 2$ & $13 / 2$ & 119973.48 \\
\hline $\mathrm{C}^{12} \mathrm{H}_{3} \mathrm{I}^{127}$ & 4- 481 & $8,6 \leftarrow 7,6$ & Ground & $13 / 2$ & $11 / 2$ & 119980.18 \\
\hline $\mathrm{C}^{12} \mathrm{H}_{3} \mathrm{I}^{127}$ & 4- 481 & $8,5 \leftarrow 7,5$ & Ground & $13 / 2$ & $11 / 2$ & 119984.47 \\
\hline $\mathrm{C}^{12} \mathrm{H}_{3} \mathrm{I}^{127}$ & 4- 481 & $8,3 \leftarrow 7,3$ & Ground & $19 / 2$ & $17 / 2$ & 119985.10 \\
\hline $\mathrm{C}^{12} \mathrm{H}_{3} \mathrm{I}^{127}$ & 4- 481 & $8,2 \leftarrow 7,2$ & Ground & $15 / 2$ & $13 / 2$ & 119987.78 \\
\hline $\mathrm{C}^{12} \mathrm{H}_{3} \mathrm{I}^{127}$ & 4- 481 & $8,4 \leftarrow 7,4$ & Ground & $13 / 2$ & $11 / 2$ & 119987.78 \\
\hline $\mathrm{C}^{12} \mathrm{H}_{3} \mathrm{I}^{127}$ & 4- 481 & $8,3 \leftarrow 7,3$ & Ground & $13 / 2$ & $11 / 2$ & 119990.79 \\
\hline $\mathrm{C}^{12} \mathrm{H}_{3} \mathrm{I}^{127}$ & 4- 481 & $8,2 \leftarrow 7,2$ & Ground & $17 / 2$ & $15 / 2$ & 119991.88 \\
\hline $\mathrm{C}^{12} \mathrm{H}_{3} \mathrm{I}^{127}$ & 4- 481 & $8,2 \leftarrow 7,2$ & Ground & $13 / 2$ & $11 / 2$ & 119992.78 \\
\hline $\mathrm{C}^{12} \mathrm{H}_{3} \mathrm{I}^{127}$ & 4- 481 & $8,1 \leftarrow 7,1$ & Ground & $13 / 2$ & $11 / 2$ & 119993.97 \\
\hline $\mathrm{C}^{12} \mathrm{H}_{3} \mathrm{I}^{127}$ & 4- 481 & $8,0 \leftarrow 7,0$ & Ground & $13 / 2$ & $11 / 2$ & 119994.36 \\
\hline $\mathrm{C}^{12} \mathrm{H}_{3} \mathrm{I}^{127}$ & 4- 481 & $8,1 \leftarrow 7,1$ & Ground & $15 / 2$ & $13 / 2$ & 119996.05 \\
\hline $\mathrm{C}^{12} \mathrm{H}_{3} \mathrm{I}^{127}$ & 4- 481 & $8,0 \leftarrow 7,0$ & Ground & $15 / 2$ & $13 / 2$ & 119998.90 \\
\hline $\mathrm{C}^{12} \mathrm{H}_{3} \mathrm{I}^{127}$ & 4- 481 & $8,0 \leftarrow 7,0$ & Ground & $11 / 2$ & $9 / 2$ & 120000.34 \\
\hline $\mathrm{C}^{12} \mathrm{H}_{3} \mathrm{I}^{127}$ & 4- 481 & $8,2 \leftarrow 7,2$ & Ground & $19 / 2$ & $17 / 2$ & 120002.44 \\
\hline $\mathrm{C}^{12} \mathrm{H}_{3} \mathrm{I}^{127}$ & 4- 481 & $8,1 \leftarrow 7,1$ & Ground & $11 / 2$ & $9 / 2$ & 120002.44 \\
\hline $\mathrm{C}^{12} \mathrm{H}_{3} \mathrm{I}^{127}$ & 4- 481 & $8,1 \leftarrow 7,1$ & Ground & $17 / 2$ & $15 / 2$ & 120004.25 \\
\hline $\mathrm{C}^{12} \mathrm{H}_{3} \mathrm{I}^{127}$ & 4- 481 & $8,0 \leftarrow 7,0$ & Ground & $17 / 2$ & $15 / 2$ & 120008.43 \\
\hline $\mathrm{C}^{12} \mathrm{H}_{3} \mathrm{I}^{127}$ & 4- 481 & $8,2 \leftarrow 7,2$ & Ground & $11 / 2$ & $9 / 2$ & 120009.33 \\
\hline $\mathrm{C}^{12} \mathrm{H}_{3} \mathrm{I}^{127}$ & 4- 481 & $8,0 \leftarrow 7,0$ & Ground & $21 / 2$ & $19 / 2$ & 120012.42 \\
\hline $\mathrm{C}^{12} \mathrm{H}_{3} \mathrm{I}^{127}$ & 4- 481 & $8,1 \leftarrow 7,1$ & Ground & $19 / 2$ & $17 / 2$ & 120012.42 \\
\hline $\mathrm{C}^{12} \mathrm{H}_{3} \mathrm{I}^{127}$ & 4- 481 & $8,1 \leftarrow 7,1$ & Ground & $21 / 2$ & $19 / 2$ & 120012.99 \\
\hline $\mathrm{C}^{12} \mathrm{H}_{3} \mathrm{I}^{127}$ & 4. 481 & $8,4 \leftarrow 7,4$ & Ground & $13 / 2$ & $13 / 2$ & 120014.89 \\
\hline $\mathrm{C}^{12} \mathrm{H}_{3} \mathrm{I}^{127}$ & 4- 481 & $8,2 \leftarrow 7,2$ & Ground & $21 / 2$ & $19 / 2$ & 120014.89 \\
\hline $\mathrm{C}^{12} \mathrm{H}_{3} \mathrm{I}^{127}$ & 4- 481 & $8,0 \leftarrow 7,0$ & Ground & $19 / 2$ & $17 / 2$ & 120015.95 \\
\hline $\mathrm{C}^{12} \mathrm{H}_{3} \mathrm{I}^{127}$ & 4- 481 & $8,3 \leftarrow 7,3$ & Ground & $21 / 2$ & $19 / 2$ & 120017.88 \\
\hline $\mathrm{C}^{12} \mathrm{H}_{3} \mathrm{I}^{127}$ & 4- 481 & $8,3 \leftarrow 7,3$ & Ground & $11 / 2$ & $9 / 2$ & 120020.67 \\
\hline $\mathrm{C}^{12} \mathrm{H}_{3} \mathrm{I}^{127}$ & 4. 481 & $8,4 \leftarrow 7,4$ & Ground & $21 / 2$ & $19 / 2$ & 120022.18 \\
\hline $\mathrm{C}^{12} \mathrm{H}_{3} \mathrm{I}^{127}$ & 4- 481 & $8,5 \leftarrow 7,5$ & Ground & $21 / 2$ & $19 / 2$ & 120027.60 \\
\hline $\mathrm{C}^{12} \mathrm{H}_{3} \mathrm{I}^{127}$ & 4. 481 & $8,6 \leftarrow 7,6$ & Ground & $21 / 2$ & $19 / 2$ & 120034.26 \\
\hline $\mathrm{C}^{12} \mathrm{H}_{3} \mathrm{I}^{127}$ & 4- 481 & $8,4 \leftarrow 7,4$ & Ground & $11 / 2$ & $9 / 2$ & 120036.54 \\
\hline $\mathrm{C}^{12} \mathrm{H}_{3} \mathrm{I}^{127}$ & 4- 481 & $8,5 \leftarrow 7,5$ & Ground & $11 / 2$ & $9 / 2$ & 120057.13 \\
\hline $\mathrm{C}^{\mathrm{I} 2} \mathrm{H}_{3} \mathrm{I}^{127}$ & 4- 481 & $8,1 \leftarrow 7,1$ & Ground & $15 / 2$ & $15 / 2$ & 120070.89 \\
\hline $\mathrm{C}^{12} \mathrm{H}_{3} \mathrm{I}^{127}$ & 4- 481 & $8,6 \leftarrow 7,6$ & Ground & $11 / 2$ & $9 / 2$ & 120082.48 \\
\hline $\mathrm{DC}^{12} \mathrm{O}^{16} \mathrm{O}^{16} \mathrm{D}$ & 3- 74 & $6,1,6 \leftarrow 5,1,5$ & Ground & & & 120407.60 \\
\hline $\mathrm{O}^{16} \mathrm{C}^{12} \mathrm{Se}^{80}$ & 4- 547 & $15 \leftarrow 14$ & Ground & & & 120520.40 \\
\hline
\end{tabular}




\begin{tabular}{|c|c|c|c|c|c|c|}
\hline \multirow{2}{*}{ Isotopic Species } & \multirow{2}{*}{$\begin{array}{l}\text { Vol.-Id. } \\
\text { Nos. }\end{array}$} & \multirow{2}{*}{$\begin{array}{c}\text { Rotational } \\
\text { Quantum Nos. }\end{array}$} & \multirow{2}{*}{ Vib. State } & $\mathrm{F}^{\prime} \stackrel{\text { Hyperfine }}{\mathrm{F}^{\prime}} \stackrel{\mathrm{F}}{\mathrm{F}}$ & \multirow{2}{*}{$\begin{array}{l}\text { Frequency } \\
\mathrm{MHz}\end{array}$} & \multirow{2}{*}{$\begin{aligned} & \text { Acc. } \\
\pm & \mathrm{MHz}\end{aligned}$} \\
\hline & & & & $\begin{array}{lll}\mathrm{F}_{1}^{\prime} & \mathrm{F}^{\prime} \quad \mathrm{F}_{1}\end{array}$ & & \\
\hline $\mathrm{O}^{16} \mathrm{C}^{12} \mathrm{Se}^{80}$ & 4. 547 & $15 \leftarrow 14$ & Excited & & 120679.98 & \\
\hline $\mathrm{O}^{16} \mathrm{C}^{12} \mathrm{Se}^{80}$ & 4- 547 & $15 \leftarrow 14$ & Excited & & 120775.11 & \\
\hline $\mathrm{HDO}^{16}$ & $4-1712$ & $5,1,5 \leftarrow 4,2,2$ & Ground & & 120778.2 & \\
\hline $\mathrm{O}^{16} \mathrm{C}^{12} \mathrm{Se}^{78}$ & 4- 545 & $15 \leftarrow 14$ & Ground & & 121263.28 & .25 \\
\hline $\mathrm{O}^{16} \mathrm{C}^{12} \mathrm{~S}^{32}$ & 4. 521 & $10 \leftarrow 9$ & Ground & & 121624.63 & .25 \\
\hline $\mathrm{O}^{16} \mathrm{C}^{12} \mathrm{~S}^{34}$ & 4- 523 & $10 \leftarrow 9$ & Ground & & 121624.79 & .25 \\
\hline $\mathrm{O}^{16} \mathrm{C}^{12} \mathrm{Se}^{77}$ & 4. 544 & $15 \leftarrow 14$ & Ground & & 121647.98 & .25 \\
\hline $\mathrm{O}^{16} \mathrm{C}^{12} \mathrm{Se}^{76}$ & 4- 543 & $15 \leftarrow 14$ & Ground & & 122043.90 & .25 \\
\hline $\mathrm{S}^{32} \mathrm{P}^{31} \mathrm{~F}_{3}^{19}$ & 4-1691 & $23,15 \leftarrow 22,15$ & & & 122219.00 & .30 \\
\hline $\mathrm{S}^{32} \mathrm{P}^{31} \mathrm{~F}_{3}^{19}$ & 4-1691 & $23,12 \longleftarrow 22,12$ & & & 122225.50 & .30 \\
\hline $\mathrm{S}^{32} \mathrm{P}^{31} \mathrm{~F}_{3}^{19}$ & $4-1691$ & $23,9 \leftarrow 22,9$ & & & 122231.30 & .30 \\
\hline $\mathrm{S}^{32} \mathrm{P}^{31} \mathrm{~F}_{3}^{19}$ & $4-1691$ & $23,5 \leftarrow 22,5$ & & & 122235.80 & .30 \\
\hline $\mathrm{S}^{32} \mathrm{P}^{31} \mathrm{~F}_{3}^{19}$ & 4-1691 & $23,6 \leftarrow 22,6$ & & & 122235.80 & .30 \\
\hline $\mathrm{S}^{32} \mathrm{P}^{31} \mathrm{~F}_{3}^{19}$ & $4-1691$ & $23,0 \leftarrow 22,0$ & & & 122237.90 & .30 \\
\hline $\mathrm{F}^{19} \mathrm{HC}^{12} \mathrm{O}^{16}$ & 4- 271 & $2,1,2 \leftarrow 1,0,1$ & & & 122343.95 & .05 \\
\hline $\mathrm{C}^{12} \mathrm{D}_{3} \mathrm{~F}^{19}$ & 4. 462 & $3,2 \leftarrow 2,2$ & Ground & & 122690.02 & .30 \\
\hline $\mathrm{C}^{12} \mathrm{D}_{3} \mathrm{~F}^{19}$ & 4- 462 & $3,1 \leftarrow 2,1$ & Ground & & 122694.20 & .30 \\
\hline $\mathrm{C}^{12} \mathrm{D}_{3} \mathrm{~F}^{19}$ & 4- 462 & $3,0 \leftarrow 2,0$ & Ground & & 122695.50 & .30 \\
\hline $\mathrm{H}_{2} \mathrm{C}^{12}: \mathrm{C}^{12} \mathrm{HF}^{19}$ & 4- 781 & $6,1,5 \leftarrow 5,1,4$ & Ground & & 122813.35 & .05 \\
\hline $\mathrm{Br}^{81} \mathrm{C}^{12} \mathrm{~N}^{14}$ & 4- 142 & $15 \leftarrow 14$ & Ground & & 122892.50 & .25 \\
\hline $\mathrm{Br}^{81} \mathrm{C}^{12} \mathrm{~N}^{14}$ & 4- 142 & $15 \leftarrow 14$ & Excited & & 123178.33 & \\
\hline $\mathrm{Br}^{81} \mathrm{C}^{12} \mathrm{~N}^{14}$ & 4- 142 & $15 \leftarrow 14$ & Excited & & 123179.40 & \\
\hline $\mathrm{Br}^{81} \mathrm{C}^{12} \mathrm{~N}^{14}$ & 4- 142 & $15 \leftarrow 14$ & Excited & & 123294.38 & \\
\hline $\mathrm{Br}^{81} \mathrm{C}^{12} \mathrm{~N}^{14}$ & 4- 142 & $15 \leftarrow 14$ & Excited & & 123295.31 & \\
\hline $\mathrm{Br}^{79} \mathrm{C}^{12} \mathrm{~N}^{14}$ & 4- 141 & $15 \leftarrow 14$ & Ground & & 123594.73 & .25 \\
\hline $\mathrm{F}^{19} \mathrm{HC}^{12} \mathrm{O}^{16}$ & 4. 271 & $10,1,9 \leftarrow 10,0,10$ & & & 123812.35 & .05 \\
\hline $\mathrm{Br}^{79} \mathrm{C}^{12} \mathrm{~N}^{14}$ & 4- 141 & $15 \leftarrow 14$ & Excited & & 123881.78 & \\
\hline $\mathrm{Br}^{79} \mathrm{C}^{12} \mathrm{~N}^{14}$ & 4- 141 & $15 \leftarrow 14$ & Excited & & 123882.90 & \\
\hline $\mathrm{Br}^{79} \mathrm{C}^{12} \mathrm{~N}^{14}$ & 4- 141 & $15 \leftarrow 14$ & Excited & & 123999.22 & \\
\hline $\mathrm{Br}^{79} \mathrm{C}^{12} \mathrm{~N}^{14}$ & 4- 141 & $15 \leftarrow 14$ & Excited & & 124.000 .30 & \\
\hline $\mathrm{DC}^{12} \mathrm{O}^{16} \mathrm{O}^{16} \mathrm{D}$ & 3- 74 & $6,0,6 \leftarrow 5,0,5$ & Ground & & 124685.34 & .2 \\
\hline $\mathrm{P}^{31} \mathrm{~F}_{3}^{19}$ & 4-1681 & $8,0 \leftarrow 7,0$ & Ground & & 125103.89 & .20 \\
\hline $\mathrm{P}^{31} \mathrm{~F}_{3}^{19}$ & $4-1681$ & $8,3 \leftarrow 7,3$ & Ground & & 125105.60 & .20 \\
\hline $\mathrm{P}^{31} \mathrm{~F}_{3}^{19}$ & 4-1681 & $8,4 \leftarrow 7,4$ & Ground & & 125106.85 & .25 \\
\hline $\mathrm{P}^{31} \mathrm{~F}_{3}^{19}$ & 4-1681 & $8,5 \leftarrow 7,5$ & Ground & & 125108.60 & .20 \\
\hline $\mathrm{P}^{31} \mathrm{~F}_{3}^{19}$ & 4-1681 & $8,6 \leftarrow 7,6$ & Ground & & 125110.64 & .30 \\
\hline $\mathrm{N}_{2}^{14} \mathrm{O}^{16}$ & 4-1811 & $5 \leftarrow 4$ & Ground & & 125613.73 & .25 \\
\hline $\mathrm{N}_{2}^{14} \mathrm{O}^{16}$ & 4-1811 & $5 \leftarrow 4$ & Excited & & 125663.69 & \\
\hline $\mathrm{N}_{2}^{14} \mathrm{O}^{16}$ & 4-1811 & $5 \leftarrow 4$ & Excited & & 125900.99 & \\
\hline $\mathrm{DC}^{12} \mathrm{O}^{16} \mathrm{O}^{16} \mathrm{D}$ & 3- 74 & $6,2,5 \leftarrow 5,2,4$ & Ground & & 127342.80 & .2 \\
\hline $\mathrm{H}_{2} \mathrm{Se}^{82}$ & $4-1745$ & $1,1,0 \leftarrow 1,0,1$ & Ground & & 127860.35 & \\
\hline $\mathrm{H}_{2} \mathrm{Se}^{80}$ & 4-1744 & $1,1,0 \leftarrow 1,0,1$ & Ground & & 127973.40 & \\
\hline $\mathrm{DC}^{12} \mathrm{O}^{16} \mathrm{O}^{16} \mathrm{D}$ & 3. 74 & $6,5, \leftarrow 5,5$, & Ground & & 127996.80 & .2 \\
\hline $\mathrm{DC}^{12} \mathrm{O}^{16} \mathrm{O}^{16} \mathrm{D}$ & 3- 74 & $6,4,3 \leftarrow 5,4,2$ & Ground & & 128075.90 & .2 \\
\hline $\mathrm{DC}^{12} \mathrm{O}^{16} \mathrm{O}^{16} \mathrm{D}$ & 3. 74 & $6,4,2 \leftarrow 5,4,1$ & Ground & & 128077.64 & .2 \\
\hline
\end{tabular}




\begin{tabular}{|c|c|c|c|c|c|c|c|c|}
\hline \multirow{2}{*}{ Isotopic Species } & \multirow{2}{*}{$\begin{array}{l}\text { Vol.-Id. } \\
\text { Nos. }\end{array}$} & \multirow{2}{*}{$\begin{array}{c}\text { Rotational } \\
\text { Quantum Nos. }\end{array}$} & \multirow{2}{*}{ Vib. State } & \multicolumn{3}{|c|}{ Hyperfine } & \multirow{2}{*}{$\begin{array}{c}\text { Frequency } \\
\mathrm{MHz}\end{array}$} & \multirow{2}{*}{$\begin{aligned} & \text { Acc. } \\
& \pm \mathrm{MHz}\end{aligned}$} \\
\hline & & & & $F_{1}^{\prime}$ & $F^{\prime}$ & $F_{1} \quad F$ & & \\
\hline $\mathrm{H}_{2} \mathrm{Se}^{78}$ & 4-1743 & $1,1,0 \leftarrow 1,0,1$ & Ground & & & & 128098.70 & \\
\hline $\mathrm{H}_{2} \mathrm{Se}^{77}$ & $4-1742$ & $1, i, 0 \leftarrow 1,0,1$ & Ground & & & & 128155.40 & \\
\hline $\mathrm{DC}^{12} \mathrm{O}^{16} \mathrm{O}^{16} \mathrm{D}$ & 3. 74 & $6,3,4 \leftarrow 5,3,3$ & Ground & & & & 128203.04 & .2 \\
\hline $\mathrm{H}_{2} \mathrm{Se}^{76}$ & 4-1741 & $1,1,0 \leftarrow 1,0,1$ & Ground & & & & 128219.10 & \\
\hline $\mathrm{DC}^{12} \mathrm{O}^{16} \mathrm{O}^{16} \mathrm{D}$ & 3. 74 & $6,3,3 \leftarrow 5,3,2$ & Ground & & & & 128336.34 & .2 \\
\hline $\mathrm{S}^{32} \mathrm{O}_{2}^{16}$ & 4-1831 & $12,2,10 \leftarrow 12,1,11$ & Ground & & & & 128605.18 & \\
\hline $\mathrm{P}^{31} \mathrm{O}^{16} \mathrm{~F}_{3}^{19}$ & 4-1671 & $14, \leftarrow 13$ & Ground & & & & 128626.60 & .20 \\
\hline $\mathrm{C}^{12} \mathrm{H}_{3} \mathrm{C}^{12} \mathrm{~N}^{14}$ & 4. 811 & $7,6 \leftarrow 6,6$ & Ground & & & & 128689.48 & .25 \\
\hline $\mathrm{C}^{12} \mathrm{H}_{3} \mathrm{C}^{12} \mathrm{~N}^{14}$ & 4. 811 & $7,6 \leftarrow 6,6$ & Ground & & & & 128690.57 & .25 \\
\hline $\mathrm{C}^{12} \mathrm{H}_{3} \mathrm{C}^{12} \mathrm{~N}^{14}$ & 4- 811 & $7,5 \leftarrow 6,5$ & Ground & & & & 128717.18 & .25 \\
\hline $\mathrm{C}^{12} \mathrm{H}_{3} \mathrm{C}^{12} \mathrm{~N}^{14}$ & 4- 811 & $7,5 \leftarrow 6,5$ & Ground & & & & 128717.69 & .25 \\
\hline $\mathrm{C}^{12} \mathrm{H}_{3} \mathrm{C}^{12} \mathrm{~N}^{14}$ & 4- 811 & $7,4 \leftarrow 6,4$ & Ground & & & & 128739.39 & .25 \\
\hline $\mathrm{C}^{12} \mathrm{H}_{3} \mathrm{C}^{12} \mathrm{~N}^{14}$ & 4- 811 & $7,4 \leftarrow 6,4$ & Ground & & & & 128739.91 & .25 \\
\hline $\mathrm{C}^{12} \mathrm{H}_{3} \mathrm{C}^{12} \mathrm{~N}^{14}$ & 4. 811 & $7,3 \leftarrow 6,3$ & Ground & & & & 128757.03 & .25 \\
\hline $\mathrm{C}^{12} \mathrm{H}_{3} \mathrm{C}^{12} \mathrm{~N}^{14}$ & 4- 811 & $7,2 \leftarrow 6,2$ & Ground & & & & 128769.52 & .25 \\
\hline $\mathrm{C}^{12} \mathrm{H}_{3} \mathrm{C}^{12} \mathrm{~N}^{14}$ & 4- 811 & $7,1 \leftarrow 6,1$ & Ground & & & & 128777.02 & .25 \\
\hline $\mathrm{C}^{12} \mathrm{H}_{3} \mathrm{C}^{12} \mathrm{~N}^{14}$ & 4. 811 & $7,0 \leftarrow 6,0$ & Ground & & & & 128779.43 & .25 \\
\hline $\mathrm{I}^{127} \mathrm{C}^{12} \mathrm{~N}^{14}$ & 4. 511 & $20 \leftarrow 19$ & Ground & & & & 129000. & \\
\hline $\mathrm{S}^{32} \mathrm{O}_{2}^{16}$ & 4-1831 & $10,2,8 \leftarrow 10,1,9$ & Ground & & & & 129514.86 & \\
\hline $\mathrm{HC}^{12} \mathrm{O}^{16} \mathrm{O}^{16} \mathrm{H}$ & 3- 71 & $6,1,6 \leftarrow 5,1,5$ & & & & & 129671.70 & .78 \\
\hline $\mathrm{DC}^{12} \mathrm{O}^{16} \mathrm{O}^{16} \mathrm{D}$ & 3. 74 & $6,2,4 \leftarrow 5,2,3$ & Ground & & & & 130411.85 & .2 \\
\hline $\mathrm{S}^{32} \mathrm{O}_{2}^{16}$ & 4-1831 & $12,1,11 \leftarrow 12,0,12$ & Ground & & & & 131014.86 & \\
\hline $\mathrm{TI}^{127}$ & $1-$ & $1 \leftarrow 0$ & Ground & & $5 / 2$ & $5 / 2$ & 131210.20 & .25 \\
\hline $\mathrm{HN}^{14} \mathrm{C}^{12} \mathrm{O}^{16}$ & 4- 301 & $6,1,6 \leftarrow 5,1,5$ & Ground & & & & 131394.40 & .5 \\
\hline $\mathrm{TI}^{127}$ & 1. & $1 \leftarrow 0$ & Ground & & $7 / 2$ & $5 / 2$ & 131592.95 & .25 \\
\hline $\mathrm{HN}^{14} \mathrm{C}^{12} \mathrm{O}^{16}$ & 4- 301 & $6,5,1 \leftarrow 5,5,0$ & Ground & & & & 131640.60 & 1.0 \\
\hline $\mathrm{HN}^{14} \mathrm{C}^{12} \mathrm{O}^{16}$ & 4- 301 & $6,5,2 \leftarrow 5,5,1$ & Ground & & & & 131640.60 & 1.0 \\
\hline $\mathrm{HN}^{14} \mathrm{C}^{12} \mathrm{O}^{16}$ & 4- 301 & $6,1, \leftarrow 5,1$ & Excited & & & & 131730.84 & 1.0 \\
\hline $\mathrm{HN}^{14} \mathrm{C}^{12} \mathrm{O}^{16}$ & 4- 301 & $6,4,3 \leftarrow 5,4,2$ & Ground & & 5 & 4 & 131733.64 & 1.0 \\
\hline $\mathrm{HN}^{14} \mathrm{C}^{12} \mathrm{O}^{16}$ & 4- 301 & $6,4,3 \leftarrow 5,4,2$ & Ground & & 7 & 6 & 131733.64 & 1.0 \\
\hline $\mathrm{HN}^{14} \mathrm{C}^{12} \mathrm{O}^{16}$ & 4- 301 & $6,4,2 \leftarrow 5,4,1$ & Ground & & 5 & 4 & 131733.64 & 1.0 \\
\hline $\mathrm{HN}^{14} \mathrm{C}^{12} \mathrm{O}^{16}$ & 4- 301 & $6,4,2 \leftarrow 5,4,1$ & Ground & & 7 & 6 & 131733.64 & 1.0 \\
\hline $\mathrm{HN}^{14} \mathrm{C}^{12} \mathrm{O}^{16}$ & 4- 301 & $6,4,2 \leftarrow 5,4,1$ & Ground & & 6 & 5 & 131734.00 & 1.0 \\
\hline $\mathrm{HN}^{14} \mathrm{C}^{12} \mathrm{O}^{16}$ & 4- 301 & $6,4,3 \leftarrow 5,4,2$ & Ground & & 6 & 5 & 131734.00 & 1.0 \\
\hline $\mathrm{HN}^{14} \mathrm{C}^{12} \mathrm{O}^{16}$ & 4- 301 & $6,3,3 \leftarrow 5,3,2$ & Ground & & & & 131799.12 & 1.0 \\
\hline $\mathrm{HN}^{14} \mathrm{C}^{12} \mathrm{O}^{16}$ & 4- 301 & $6,3,4 \leftarrow 5,3,3$ & Ground & & & & 131799.12 & 1.0 \\
\hline $\mathrm{HN}^{14} \mathrm{C}^{12} \mathrm{O}^{16}$ & 4- 301 & $6,2,5 \leftarrow 5,2,4$ & Ground & & & & 131845.56 & .5 \\
\hline $\mathrm{HN}^{14} \mathrm{C}^{12} \mathrm{O}^{16}$ & 4- 301 & $6,2,4 \leftarrow 5,2,3$ & Ground & & & & 131846.28 & .5 \\
\hline $\mathrm{HN}^{14} \mathrm{C}^{12} \mathrm{O}^{16}$ & 4- 301 & $6, \quad \leftarrow 5$, & Excited & & & & 131863.33 & 1.0 \\
\hline $\mathrm{HN}^{14} \mathrm{C}^{12} \mathrm{O}^{16}$ & 4- 301 & $6,0,6 \leftarrow 5,0,5$ & Ground & & & & 131885.52 & .5 \\
\hline $\mathrm{HN}^{14} \mathrm{C}^{12} \mathrm{O}^{16}$ & 4- 301 & $6, \quad \leftarrow 5$, & Excited & & & & 131952.11 & 1.0 \\
\hline $\mathrm{F}^{19} \mathrm{DC}^{12} \mathrm{O}^{16}$ & 4. 272 & $4,1,4 \leftarrow 3,0,3$ & & & & & 132067.57 & .04 \\
\hline $\mathrm{HN}^{14} \mathrm{C}^{12} \mathrm{O}^{16}$ & 4- 301 & $6,0, \leftarrow 5,0$ & Excited & & & & 132099.82 & 1.0 \\
\hline $\mathrm{HN}^{14} \mathrm{C}^{12} \mathrm{O}^{16}$ & 4- 301 & $6,2, \leftarrow 5,2$ & Excited & & & & 132102.88 & 1.0 \\
\hline $\mathrm{HN}^{14} \mathrm{C}^{12} \mathrm{O}^{16}$ & 4- 301 & $6,3, \leftarrow 5,3$, & Excited & & & & 132106.60 & 1.0 \\
\hline
\end{tabular}




\begin{tabular}{|c|c|c|c|c|c|c|}
\hline \multirow{2}{*}{ Isotopic Species } & \multirow{2}{*}{$\begin{array}{l}\text { Vol.-Id. } \\
\text { Nos. }\end{array}$} & \multirow{2}{*}{$\begin{array}{c}\text { Rotational } \\
\text { Quantum Nos. }\end{array}$} & \multirow{2}{*}{ Vib. State } & Hyperfine & \multirow{2}{*}{$\begin{array}{l}\text { Frequency } \\
\mathrm{MHz}\end{array}$} & \multirow{2}{*}{$\begin{aligned} & \text { Acc. } \\
& \pm \mathrm{MHz}\end{aligned}$} \\
\hline & & & & $\mathrm{F}_{1}^{\prime} \quad \mathrm{F}^{\prime} \quad \mathrm{F}_{1}$ & & \\
\hline $\mathrm{HN}^{14} \mathrm{C}^{12} \mathrm{O}^{16}$ & 4- 301 & $6,0, \leftarrow 5,0$, & Excited & & 132115.04 & 1.0 \\
\hline $\mathrm{HN}^{14} \mathrm{C}^{12} \mathrm{O}^{16}$ & 4- 301 & $6,2, \leftarrow 5,2$, & Excited & & 132125.44 & 1.0 \\
\hline $\mathrm{HN}^{14} \mathrm{C}^{12} \mathrm{O}^{16}$ & 4- 301 & $6,1, \leftarrow 5,1$, & Excited & & 132195.68 & 1.0 \\
\hline $\mathrm{HN}^{14} \mathrm{C}^{12} \mathrm{O}^{16}$ & 4- 301 & $6,1,5 \leftarrow 5,1,4$ & Ground & & 132356.76 & .5 \\
\hline $\mathrm{HN}^{14} \mathrm{C}^{12} \mathrm{O}^{16}$ & 4- 301 & $6,1, \leftarrow 5,1$, & Excited & & 132500.92 & 1.0 \\
\hline $\mathrm{HN}_{3}^{14}$ & 4-1701 & $6,1,6 \leftarrow 5,1,5$ & Ground & & 132728.67 & .25 \\
\hline $\mathrm{DC}^{12} \mathrm{O}^{16} \mathrm{O}^{16} \mathrm{D}$ & 3- 74 & $6,1,5 \leftarrow 5,1,4$ & Ground & & 133623.69 & .2 \\
\hline $\mathrm{HN}_{3}^{14}$ & 4-1701 & $6,5,1 \leftarrow 5,5,0$ & Ground & & 133756.98 & .25 \\
\hline $\mathrm{HN}_{3}^{14}$ & 4-1701 & $6,5,2 \leftarrow 5,5,1$ & Ground & & 133756.98 & .25 \\
\hline $\mathrm{HC}^{12} \mathrm{O}^{16} \mathrm{O}^{16} \mathrm{H}$ & 3- 71 & $6,0,6 \leftarrow 5,0,5$ & & & 133767.06 & .81 \\
\hline $\mathrm{HN}_{3}^{14}$ & 4-1701 & $6,4,3 \leftarrow 5,4,2$ & Ground & & 133805.16 & .25 \\
\hline $\mathrm{HN}_{3}^{14}$ & 4-1701 & $6,4,2 \leftarrow 5,4,1$ & Ground & & 133805.16 & .25 \\
\hline $\mathrm{HN}_{3}^{14}$ & 4-1701 & $6,3,4 \leftarrow 5,3,3$ & Ground & & 133844.21 & .25 \\
\hline $\mathrm{HN}_{3}^{14}$ & 4-1701 & $6,3,3 \leftarrow 5,3,2$ & Ground & & 133844.21 & .25 \\
\hline $\mathrm{HN}_{3}^{14}$ & 4-1701 & $6,2,5 \leftarrow 5,2,4$ & Ground & & 133867.80 & .25 \\
\hline $\mathrm{HN}_{3}^{14}$ & 4-1701 & $6,2,4 \leftarrow 5,2,3$ & Ground & & 133879.14 & .25 \\
\hline $\mathrm{HN}_{3}^{14}$ & 4-1701 & $6,0,6 \leftarrow 5,0,5$ & Ground & & 133879.14 & .25 \\
\hline $\mathrm{F}^{19} \mathrm{DC}^{12} \mathrm{O}^{16}$ & 4- 272 & $11,1,10 \leftarrow 11,0,11$ & & & 134614.08 & .04 \\
\hline $\mathrm{HC}^{12} \mathrm{O}^{16} \mathrm{O}^{16} \mathrm{H}$ & 3- 71 & $6,2,5 \leftarrow 5,2,4$ & & & 134686.20 & .82 \\
\hline $\mathrm{HC}^{12} \mathrm{O}^{16} \mathrm{O}^{16} \mathrm{H}$ & 3- 71 & $6,5,2 \leftarrow 5,5,1$ & & & 134920.32 & .82 \\
\hline $\mathrm{HC}^{12} \mathrm{O}^{16} \mathrm{O}^{16} \mathrm{H}$ & 3- 71 & $6,5,1 \leftarrow 5,5,0$ & & & 134920.32 & .82 \\
\hline $\mathrm{HC}^{12} \mathrm{O}^{16} \mathrm{O}^{16} \mathrm{H}$ & 3- 71 & $6,4,2 \leftarrow 5,4,1$ & & & 134938.26 & .82 \\
\hline $\mathrm{HC}^{12} \mathrm{O}^{16} \mathrm{O}^{16} \mathrm{H}$ & 3. 71 & $6,4,3 \leftarrow 5,4,2$ & & & 134938.26 & .82 \\
\hline $\mathrm{HC}^{12} \mathrm{O}^{16} \mathrm{O}^{16} \mathrm{H}$ & 3- 71 & $6,3,4 \leftarrow 5,3,3$ & & & 134985.36 & .82 \\
\hline $\mathrm{HC}^{12} \mathrm{O}^{16} \mathrm{O}^{16} \mathrm{H}$ & 3- 71 & $6,3,3 \leftarrow 5,3,2$ & & & 135004.74 & .82 \\
\hline $\mathrm{HN}_{3}^{14}$ & 4.1701 & $6,1,5 \leftarrow 5,1,4$ & Ground & & 135036.98 & .25 \\
\hline $\mathrm{HC}^{12} \mathrm{O}^{16} \mathrm{O}^{16} \mathrm{H}$ & $3-71$ & $6,2,4 \leftarrow 5,2,3$ & & & 135737.70 & .82 \\
\hline $\mathrm{C}^{12} \mathrm{H}_{3} \mathrm{C}^{12}: \mathrm{C}^{12} \mathrm{H}$ & 4-1041 & $8,7 \leftarrow 7,7$ & & & 136600.15 & .30 \\
\hline $\mathrm{C}^{12} \mathrm{H}_{3} \mathrm{C}^{12}: \mathrm{C}^{12} \mathrm{H}$ & 4-1041 & $8,6 \leftarrow 7,6$ & & & 136634.03 & .30 \\
\hline $\mathrm{C}^{12} \mathrm{H}_{3} \mathrm{C}^{12}: \mathrm{C}^{12} \mathrm{H}$ & 4-1041 & $8,5 \leftarrow 7,5$ & & & 136662.74 & .30 \\
\hline $\mathrm{C}^{12} \mathrm{H}_{3} \mathrm{C}^{12}: \mathrm{C}^{12} \mathrm{H}$ & 4-1041 & $8,4 \leftarrow 7,4$ & & & 136686.19 & .30 \\
\hline $\mathrm{C}^{12} \mathrm{H}_{3} \mathrm{C}^{12}: \mathrm{C}^{12} \mathrm{H}$ & 4-1041 & $8,3 \leftarrow 7,3$ & & & 136704.48 & .30 \\
\hline $\mathrm{C}^{12} \mathrm{H}_{3} \mathrm{C}^{12}: \mathrm{C}^{12} \mathrm{H}$ & 4-1041 & $8,2 \leftarrow 7,2$ & & & 136717.60 & .30 \\
\hline $\mathrm{C}^{12} \mathrm{H}_{3} \mathrm{C}^{12}: \mathrm{C}^{12} \mathrm{H}$ & 4-1041 & $8,1 \leftarrow 7,1$ & & & 136725.36 & .30 \\
\hline $\mathrm{C}^{12} \mathrm{H}_{3} \mathrm{C}^{12}: \mathrm{C}^{12} \mathrm{H}$ & 4-1041 & $8,0 \leftarrow 7,0$ & & & 136727.93 & .30 \\
\hline $\mathrm{HN}_{2}^{14} \mathrm{~N}^{15}$ & 4-1703 & $6,1,6 \leftarrow 5,1,5$ & Ground & & 137557.30 & .15 \\
\hline $\mathrm{HN}^{15} \mathrm{~N}_{2}^{14}$ & 4-1704 & $6,1,6 \leftarrow 5,1,5$ & Ground & & 137839.42 & .15 \\
\hline $\mathrm{HN}_{2}^{14} \mathrm{~N}^{15}$ & 4-1703 & $6,3,4 \leftarrow 5,3,3$ & Ground & & 138195.85 & .15 \\
\hline $\mathrm{HN}_{2}^{14} \mathrm{~N}^{15}$ & 4-1703 & $6,3,3 \leftarrow 5,3,2$ & Ground & & 138195.85 & .15 \\
\hline $\mathrm{HN}_{2}^{14} \mathrm{~N}^{15}$ & 4-1703 & $6,2,5 \leftarrow 5,2,4$ & Ground & & 138240.77 & .15 \\
\hline $\mathrm{HN}_{2}^{14} \mathrm{~N}^{15}$ & 4-1703 & $6,2,4 \leftarrow 5,2,3$ & Ground & & 138243.25 & .15 \\
\hline $\mathrm{HN}_{2}^{14} \mathrm{~N}^{15}$ & 4-1703 & $6,0,6 \leftarrow 5,0,5$ & Ground & & 138274.77 & .15 \\
\hline $\mathrm{HN}^{15} \mathrm{~N}_{2}^{14}$ & 4-1704 & $6,4,3 \leftarrow 5,4,2$ & Ground & & 138420.28 & .15 \\
\hline $\mathrm{HN}^{15} \mathrm{~N}_{2}^{14}$ & 4-1704 & $6,4,2 \leftarrow 5,4,1$ & Ground & & 138420.28 & .15 \\
\hline $\mathrm{HN}^{15} \mathrm{~N}_{2}^{14}$ & 4-1704 & $6,3,4 \leftarrow 5,3,3$ & Ground & & 138485.62 & .15 \\
\hline
\end{tabular}




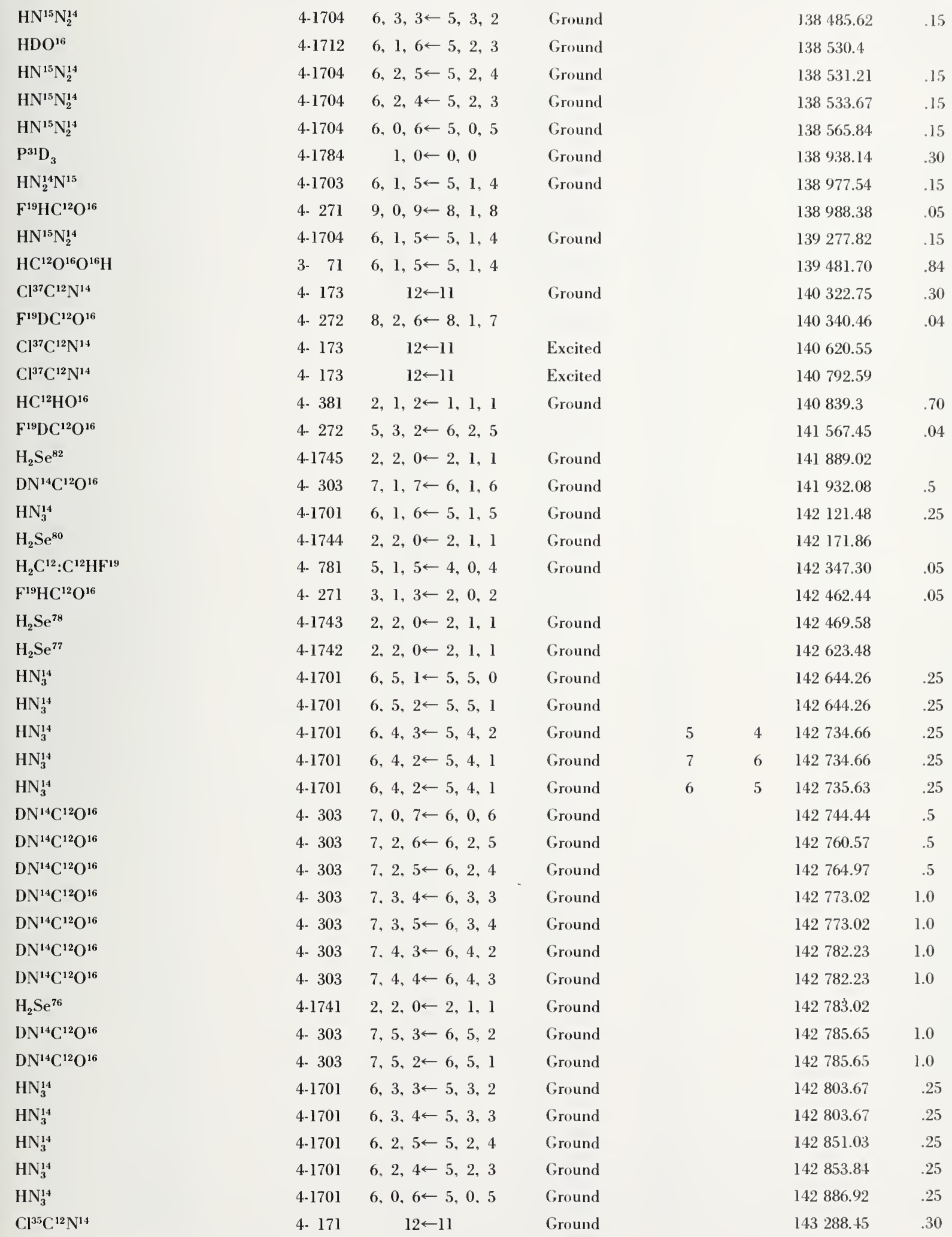




\begin{tabular}{|c|c|c|c|c|c|c|c|c|}
\hline \multirow{2}{*}{ Isotopic Species } & \multirow{2}{*}{$\begin{array}{l}\text { Vol.-Id. } \\
\text { Nos. }\end{array}$} & \multirow{2}{*}{$\begin{array}{c}\text { Rotational } \\
\text { Quantum Nos. }\end{array}$} & \multirow{2}{*}{ Vib. State } & \multicolumn{3}{|c|}{ Hyperfine } & \multirow{2}{*}{$\begin{array}{l}\text { Frequency } \\
\mathrm{MHz}\end{array}$} & \multirow{2}{*}{$\begin{aligned} & \text { Acc. } \\
& \pm \mathrm{MHz}\end{aligned}$} \\
\hline & & & & $F_{1}^{\prime}$ & $F^{\prime} \quad F_{1}$ & $\mathrm{~F}$ & & \\
\hline $\mathrm{F}^{19} \mathrm{DC}^{12} \mathrm{O}^{16}$ & 4- 272 & $7,2,5 \leftarrow 7,1,6$ & & & & & 143547.24 & .04 \\
\hline $\mathrm{DN}^{14} \mathrm{C}^{12} \mathrm{O}^{16}$ & 4- 303 & $7,1,6 \leftarrow 6,1,5$ & Ground & & & & 143569.77 & .5 \\
\hline $\mathrm{Cl}^{35} \mathrm{C}^{12} \mathrm{~N}^{14}$ & 4- 171 & $12 \leftarrow 11$ & Excited & & & & 143591.01 & \\
\hline $\mathrm{HN}_{3}^{14}$ & 4-1701 & $6,1,5 \leftarrow 5,1,4$ & Ground & & & & 143637.49 & .25 \\
\hline $\mathrm{HDO}^{16}$ & 4-1712 & $4,2,2 \leftarrow 4,2,3$ & Ground & & & & 143727.2 & \\
\hline $\mathrm{Cl}^{35} \mathrm{C}^{12} \mathrm{~N}^{14}$ & 4- 171 & $12 \leftarrow 11$ & Excited & & & & 143770.23 & \\
\hline $\mathrm{O}^{16} \mathrm{C}^{12} \mathrm{Se}^{82}$ & 4- 548 & $18 \leftarrow 17$ & Ground & & & & 143770.82 & .30 \\
\hline $\mathrm{Si}^{28} \mathrm{~F}_{3}^{19} \mathrm{H}$ & 4-1641 & $10,0 \leftarrow 9,0$ & Ground & & & & 144130.75 & .30 \\
\hline $\mathrm{Si}^{28} \mathrm{~F}_{3}^{19} \mathrm{H}$ & 4-1641 & $10,1 \leftarrow 9,1$ & Ground & & & & 144131.02 & .30 \\
\hline $\mathrm{Si}^{28} \mathrm{~F}_{3}^{19} \mathrm{H}$ & 4-164.1 & $10,2 \leftarrow 9,2$ & Ground & & & & 144131.75 & .30 \\
\hline $\mathrm{Si}^{28} \mathrm{~F}_{3}^{19} \mathrm{H}$ & 4-1641 & $10,3 \leftarrow 9,3$ & Ground & & & & 144132.99 & .30 \\
\hline $\mathrm{Si}^{28} \mathrm{~F}_{3}^{19} \mathrm{H}$ & 4-1641 & $10,4 \leftarrow 9,4$ & Ground & & & & 144134.75 & .30 \\
\hline $\mathrm{Si}^{28} \mathrm{~F}_{3}^{19} \mathrm{H}$ & 4-1641 & $10,5 \leftarrow 9,5$ & Ground & & & & 144137.00 & .30 \\
\hline $\mathrm{Si}^{28} \mathrm{~F}_{3}^{19} \mathrm{H}$ & 4-1641 & $10,6 \leftarrow 9,6$ & Ground & & & & 144139.76 & .30 \\
\hline $\mathrm{Si}^{28} \mathrm{~F}_{3}^{19} \mathrm{H}$ & 4-1641 & $10,7 \leftarrow 9,7$ & Ground & & & & 144143.00 & .30 \\
\hline $\mathrm{Si}^{28} \mathrm{~F}_{3}^{19} \mathrm{H}$ & 4-1641 & $10,8 \leftarrow 9,8$ & Ground & & & & 144146.72 & .30 \\
\hline $\mathrm{Si}^{28} \mathrm{~F}_{3}^{19} \mathrm{H}$ & 4-1641 & $10,9 \leftarrow 9,9$ & Ground & & & & 144151.04 & .30 \\
\hline $\mathrm{O}^{16} \mathrm{C}^{12} \mathrm{Se}^{80}$ & 4- 547 & $18 \leftarrow 17$ & Ground & & & & 144619.81 & .30 \\
\hline $\mathrm{O}^{16} \mathrm{C}^{12} \mathrm{Se}^{80}$ & 4- 547 & $18 \leftarrow 17$ & Excited & & & & 144811.06 & \\
\hline $\mathrm{DC}^{12} \mathrm{~N}^{14}$ & 4- 292 & $2 \leftarrow 1$ & Ground & & & & 144.827 .86 & .30 \\
\hline $\mathrm{C}^{12} \mathrm{HF}_{3}^{19}$ & 4- 281 & $7,0 \leftarrow 6,0$ & Ground & & & & 144868.57 & .30 \\
\hline $\mathrm{C}^{12} \mathrm{HF}_{3}^{19}$ & 4- 281 & $7,1 \leftarrow 6,1$ & Ground & & & & 144868.82 & .30 \\
\hline $\mathrm{C}^{12} \mathrm{HF}_{3}^{19}$ & 4- 281 & $7,2 \leftarrow 6,2$ & Ground & & & & 144869.58 & .30 \\
\hline $\mathrm{C}^{12} \mathrm{HF}_{3}^{19}$ & 4- 281 & $7,3 \leftarrow 6,3$ & Ground & & & & 144870.83 & .30 \\
\hline $\mathrm{C}^{12} \mathrm{HF}_{3}^{19}$ & 4- 281 & $7,4 \leftarrow 6,4$ & Ground & & & & 144872.60 & .30 \\
\hline $\mathrm{C}^{12} \mathrm{HF}_{3}^{19}$ & 4- 281 & $7,5 \leftarrow 6,5$ & Ground & & & & 144874.89 & .30 \\
\hline $\mathrm{C}^{12} \mathrm{HF}_{3}^{19}$ & 4- 281 & $7,6 \leftarrow-6,6$ & Ground & & & & 144877.70 & .30 \\
\hline $\mathrm{O}^{16} \mathrm{C}^{12} \mathrm{Se}^{80}$ & 4- 547 & $18 \leftarrow 17$ & Excited & & & & 144925.26 & \\
\hline $\mathrm{N}^{15} \mathrm{O}^{16}$ & $1-$ & $3 / 2 \leftarrow 1 / 2$ & Ground & & 1 & 1 & 144. 927.81 & 0.25 \\
\hline $\mathrm{N}^{15} \mathrm{O}^{16}$ & $1-$ & $3 / 2 \leftarrow 1 / 2$ & Ground & & 1 & 0 & 144.946 .34 & 0.25 \\
\hline $\mathrm{N}^{15} \mathrm{O}^{16}$ & $1-$ & $3 / 2 \leftarrow 1 / 2$ & Ground & & 2 & 1 & 144.976 .00 & 0.25 \\
\hline $\mathrm{F}^{19} \mathrm{DC}^{12} \mathrm{O}^{16}$ & 4- 272 & $7,1,7 \leftarrow 6,1,6$ & & & & & 144988.68 & .04 \\
\hline $\mathrm{N}^{15} \mathrm{O}^{16}$ & $1-$ & $3 / 2 \leftarrow 1 / 2$ & Ground & & 1 & 0 & 145236.09 & 0.25 \\
\hline $\mathrm{N}^{15} \mathrm{O}^{16}$ & $1-$ & $3 / 2 \leftarrow 1 / 2$ & Ground & & 2 & 1 & 145307.81 & 0.25 \\
\hline $\mathrm{HC}^{12} \mathrm{O}^{16} \mathrm{O}^{16} \mathrm{D}$ & 3- 72 & $7,1,7 \leftarrow 6,1,6$ & Ground & & & & 145312.14 & .2 \\
\hline $\mathrm{N}^{15} \mathrm{O}^{16}$ & $1-$ & $3 / 2 \leftarrow 1 / 2$ & Ground & & 1 & 1 & 145428.07 & 0.25 \\
\hline $\mathrm{O}^{16} \mathrm{C}^{12} \mathrm{Se}^{78}$ & 4- 545 & $18 \leftarrow 17$ & Ground & & & & 145511.08 & .30 \\
\hline $\mathrm{HC}^{12} \mathrm{HO}^{16}$ & 4- 381 & $2,0,2 \leftarrow 1,0,1$ & Ground & & & & 145603.1 & .73 \\
\hline $\mathrm{DC}^{12} \mathrm{O}^{16} \mathrm{O}^{16} \mathrm{H}$ & 3- 73 & $7,1,7 \leftarrow 6,1,6$ & Ground & & & & 145882.95 & .2 \\
\hline $\mathrm{O}^{16} \mathrm{C}^{12} \mathrm{~S}^{32}$ & 4- 521 & $12 \leftarrow 11$ & Ground & & & & 145946.79 & .30 \\
\hline $\mathrm{O}^{16} \mathrm{C}^{12} \mathrm{Se}^{77}$ & 4- 544 & $18 \leftarrow 17$ & Ground & & & & 145972.74 & .30 \\
\hline $\mathrm{O}^{16} \mathrm{C}^{12} \mathrm{Se}^{76}$ & 4- 543 & $18 \leftarrow 17$ & Ground & & & & 146447.90 & .30 \\
\hline $\mathrm{P}^{31} \mathrm{O}^{16} \mathrm{~F}_{3}^{19}$ & 4-1671 & $16,15 \leftarrow 15,15$ & Ground & & & & 146990.43 & .30 \\
\hline $\mathrm{P}^{31} \mathrm{O}^{16} \mathrm{~F}_{3}^{19}$ & 4-1671 & $16,14 \leftarrow 15,14$ & Ground & & & & 146991.67 & .30 \\
\hline $\mathrm{P}^{31} \mathrm{O}^{16} \mathrm{~F}_{3}^{19}$ & 4-1671 & $16,13 \leftarrow 15,13$ & Ground & & & & 146992.79 & .30 \\
\hline
\end{tabular}


Vib. State

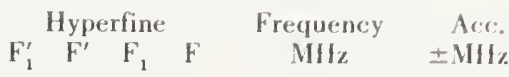

\section{$\mathrm{P}^{31} \mathrm{O}^{16} \mathrm{~F}_{3}^{19}$}

$\mathrm{P}^{31} \mathrm{O}^{16} \mathrm{~F}_{3}^{19}$

$\mathrm{P}^{31} \mathrm{O}^{16} \mathrm{~F}_{3}^{19}$

$\mathrm{P}^{31} \mathrm{O}^{16} \mathrm{~F}_{3}^{19}$

$\mathrm{P}^{31} \mathrm{O}^{16} \mathrm{~F}_{3}^{19}$

$\mathrm{P}^{31} \mathrm{O}^{16} \mathrm{~F}_{3}^{19}$

$\mathrm{P}^{31} \mathrm{O}^{16} \mathrm{~F}_{3}^{19}$

$\mathrm{P}^{31} \mathrm{O}^{16} \mathrm{~F}_{3}^{19}$

$\mathrm{P}^{31} \mathrm{O}^{16} \mathrm{~F}_{3}^{19}$

$\mathrm{P}^{31} \mathrm{O}^{16} \mathrm{~F}_{3}^{19}$

$\mathrm{P}^{31} \mathrm{O}^{16} \mathrm{~F}_{3}^{19}$

$\mathrm{P}^{31} \mathrm{O}^{16} \mathrm{~F}_{3}^{19}$

$\mathrm{P}^{31} \mathrm{O}^{16} \mathrm{~F}_{3}^{19}$

$\mathrm{C}^{12} \mathrm{H}_{3} \mathrm{C}^{12} \mathrm{~N}^{14}$

$\mathrm{C}^{12} \mathrm{H}_{3} \mathrm{C}^{12} \mathrm{~N}^{14}$

$\mathrm{C}^{12} \mathrm{H}_{3} \mathrm{C}^{12} \mathrm{~N}^{14}$

$\mathrm{C}^{12} \mathrm{~F}_{3}^{19} \mathrm{C}^{12} \mathrm{~N}^{14}$

$\mathrm{C}^{12} \mathrm{~F}_{3}^{19} \mathrm{C}^{12} \mathrm{~N}^{14}$

$\mathrm{C}^{12} \mathrm{H}_{3} \mathrm{C}^{12} \mathrm{~N}^{14}$

$\mathrm{C}^{12} \mathrm{~F}_{3}^{19} \mathrm{C}^{12} \mathrm{~N}^{14}$

$\mathrm{C}^{12} \mathrm{~F}_{3}^{19} \mathrm{C}^{12} \mathrm{~N}^{14}$

$\mathrm{C}^{12} \mathrm{H}_{3} \mathrm{C}^{12} \mathrm{~N}^{14}$

$\mathrm{C}^{12} \mathrm{~F}_{3}^{19} \mathrm{C}^{12} \mathrm{~N}^{14}$

$\mathrm{C}^{12} \mathrm{H}_{3} \mathrm{C}^{12} \mathrm{~N}^{14}$

$\mathrm{F}^{19} \mathrm{DC}^{12} \mathrm{O}^{16}$

$\mathrm{C}^{12} \mathrm{~F}_{3}^{19} \mathrm{C}^{12} \mathrm{~N}^{14}$

$\mathrm{C}^{12} \mathrm{~F}_{3}^{19} \mathrm{C}^{12} \mathrm{~N}^{14}$

$\mathrm{C}^{12} \mathrm{H}_{3} \mathrm{C}^{12} \mathrm{~N}^{14}$

$\mathrm{C}^{12} \mathrm{H}_{3} \mathrm{C}^{12} \mathrm{~N}^{14}$

$\mathrm{C}^{12} \mathrm{~F}_{3}^{19} \mathrm{C}^{12} \mathrm{~N}^{14}$

$\mathrm{C}^{12} \mathrm{H}_{3} \mathrm{C}^{12} \mathrm{~N}^{14}$

$\mathrm{C}^{12} \mathrm{~F}_{3}^{19} \mathrm{C}^{12} \mathrm{~N}^{14}$

$\mathrm{C}^{12} \mathrm{~F}_{3}^{19} \mathrm{C}^{12} \mathrm{~N}^{14}$

$\mathrm{C}^{12} \mathrm{~F}_{3}^{19} \mathrm{C}^{12} \mathrm{~N}^{14}$

$\mathrm{C}^{12} \mathrm{~F}_{3}^{19} \mathrm{C}^{12} \mathrm{~N}^{14}$

$\mathrm{C}^{12} \mathrm{~F}_{3}^{19} \mathrm{C}^{12} \mathrm{~N}^{14}$

$\mathrm{C}^{12} \mathrm{~F}_{3}^{19} \mathrm{C}^{12} \mathrm{~N}^{14}$

$\mathrm{C}^{12} \mathrm{~F}_{3}^{19} \mathrm{C}^{12} \mathrm{~N}^{14}$

$\mathrm{C}^{12} \mathrm{~F}_{3}^{19} \mathrm{C}^{12} \mathrm{~N}^{14}$

$\mathrm{C}^{12} \mathrm{~F}_{3}^{19} \mathrm{C}^{12} \mathrm{~N}^{14}$

$\mathrm{C}^{12} \mathrm{~F}_{3}^{19} \mathrm{C}^{12} \mathrm{~N}^{14}$

$\mathrm{C}^{12} \mathrm{~F}_{3}^{19} \mathrm{C}^{12} \mathrm{~N}^{14}$

$\mathrm{C}^{12} \mathrm{~F}_{3}^{19} \mathrm{C}^{12} \mathrm{~N}^{14}$

$\mathrm{C}^{12} \mathrm{~F}_{3}^{19} \mathrm{C}^{12} \mathrm{~N}^{14}$

$\mathrm{C}^{12} \mathrm{~F}_{3}^{19} \mathrm{C}^{12} \mathrm{~N}^{14}$

\begin{tabular}{|c|c|c|}
\hline $4-1671$ & $16,12 \leftarrow 15,12$ & Ground \\
\hline$-4-1671$ & $16,11 \leftarrow 15,11$ & Ground \\
\hline 4-1671 & $16,10 \leftarrow 15,10$ & Ground \\
\hline 4-1671 & $16,9 \leftarrow 15,9$ & Ground \\
\hline 4-1671 & $16,8 \leftarrow 15,8$ & Ground \\
\hline $4-1671$ & $16,7 \leftarrow 15,7$ & Ground \\
\hline 4-1671 & $16,6 \leftarrow 15,6$ & Ground \\
\hline 4-1671 & $16,5 \leftarrow 15,5$ & Ground \\
\hline 4-1671 & $16,4 \leftarrow 15,4$ & Ground \\
\hline 4-1671 & $16,3 \leftarrow 15,3$ & Ground \\
\hline $4-1671$ & $16,1 \leftarrow 15,1$ & Ground \\
\hline 4-1671 & $16,2 \leftarrow 15,2$ & Ground \\
\hline $4-1671$ & $16,0 \leftarrow 15,0$ & Ground \\
\hline 4. 811 & $8,7 \leftarrow 7,7$ & Ground \\
\hline 4- 811 & $8,6 \leftarrow 7,6$ & Ground \\
\hline 4. 811 & $8,6 \leftarrow 7,6$ & Ground \\
\hline 4. 591 & $25,24 \leftarrow 24,24$ & Ground \\
\hline 4. 591 & $25,23 \leftarrow 24,23$ & Ground \\
\hline 4- 811 & $8,5 \leftarrow 7,5$ & Ground \\
\hline 4- 591 & $25,22 \leftarrow 24,22$ & Ground \\
\hline 4. 591 & $25,21 \leftarrow 24,21$ & Ground \\
\hline 4- 811 & $8,4 \leftarrow 7,4$ & Ground \\
\hline 4- 591 & $25,20 \leftarrow 24,20$ & Ground \\
\hline 4. 811 & $8,3 \leftarrow 7,3$ & Ground \\
\hline 4- 272 & $6,2,4 \leftarrow 6,1,5$ & \\
\hline 4. 591 & $25,19 \leftarrow 24,19$ & Ground \\
\hline 4- 591 & $25,18 \leftarrow 24,18$ & Ground \\
\hline 4. 811 & $8,2 \leftarrow 7,2$ & Ground \\
\hline 4. 811 & $8,1 \leftarrow 7,1$ & Ground \\
\hline 4. 591 & $25,17 \leftarrow 24,17$ & Ground \\
\hline 4. 811 & $8,0 \leftarrow 7,0$ & Ground \\
\hline 4- 591 & $25,15 \leftarrow 24,15$ & Ground \\
\hline 4- 591 & $25,14 \leftarrow 24,14$ & Ground \\
\hline 4- 591 & $25,13 \leftarrow 24,13$ & Ground \\
\hline 4. 591 & $25,12 \leftarrow 24,12$ & Ground \\
\hline 4- 591 & $25,11 \leftarrow 24,11$ & Ground \\
\hline 4- 591 & $25,10 \leftarrow 24,10$ & Ground \\
\hline 4. 591 & $25,9 \leftarrow 24,9$ & Ground \\
\hline 4- 591 & $25,8 \leftarrow 24,8$ & Ground \\
\hline 4- 591 & $25,6 \leftarrow 24,6$ & Ground \\
\hline 4- 591 & $25,5 \leftarrow 24,5$ & Ground \\
\hline 4- 591 & $25,4 \leftarrow 24,4$ & Ground \\
\hline 4- 591 & $25,3 \leftarrow 24,3$ & Ground \\
\hline 4- 591 & $25,2 \leftarrow 24,2$ & Ground \\
\hline 4- 591 & $25,1 \leftarrow 24,1$ & Ground \\
\hline
\end{tabular}

$146993.83 \quad 30$

$146994.77 \quad .30$

$146995.62 \quad .30$

$146996.38 \quad .30$

$146997.06 \quad .30$

$146997.65 \quad .30$

$146998.02 \quad .30$

$146998.68 \quad .30$

$146999.07 \quad .30$

$146999.36 \quad .30$

$146999.65 \quad .30$

$146999.65 \quad .30$

$146999.65 \quad .30$

$147035.89 \quad .25$

$147072.27 \quad .25$

$147073.04 \quad .25$

$147089.91 \quad .30$

$147103.56 \quad .30$

$147104.07 \quad .25$

$147116.55 \quad .30$

$147129.08 \quad .30$

$147129.41 \quad .25$

$147140.97 \quad .30$

$147149.28 \quad .25$

$147150.05 \quad .04$

$147152.20 \quad .30$

$147163.10 \quad .30$

$147163.46 \quad .25$

$147171.95 \quad .25$

$147173.28 \quad .30$

$147174.72 \quad .25$

$147191.93 \quad .30$

$147200.36 \quad .30$

$147208.22 \quad .30$

$147215.48 \quad .30$

$147222.19 \quad .30$

$147228.26 \quad .30$

$147233.76 \quad .30$

$147238.71 \quad .30$

$147246.77 \quad .30$

$147249.92 \quad .30$

$147252.50 \quad .30$

$147254.55 \quad .30$

$147256.03 \quad .30$

$147257.03 \quad .30$ 


\begin{tabular}{|c|c|c|c|c|c|c|}
\hline \multirow{2}{*}{ Isotopic Species } & \multirow{2}{*}{$\begin{array}{l}\text { Vol.-Id. } \\
\text { Nos. }\end{array}$} & \multirow{2}{*}{$\begin{array}{c}\text { Rotational } \\
\text { Quantum Nos. }\end{array}$} & \multirow{2}{*}{ Vib. State } & Hyperfine & \multirow{2}{*}{$\begin{array}{c}\text { Frequency } \\
\mathrm{MHz}\end{array}$} & \multirow{2}{*}{$\begin{aligned} & \text { Acc. } \\
& \pm \mathrm{MHz}\end{aligned}$} \\
\hline & & & & $\begin{array}{llll}\mathrm{F}_{1}^{\prime} & \mathrm{F}^{\prime} & \mathrm{F}_{1} & \mathrm{~F}\end{array}$ & & \\
\hline $\mathrm{C}^{12} \mathrm{~F}_{3}^{19} \mathrm{C}^{12} \mathrm{~N}^{14}$ & 4. 591 & $25,0 \leftarrow 24,0$ & Ground & & 147257.28 & .30 \\
\hline $\mathrm{Br}^{81} \mathrm{C}^{12} \mathrm{~N}^{14}$ & 4- 142 & $18 \leftarrow 17$ & Ground & & 147464.71 & .30 \\
\hline $\mathrm{C}^{12} \mathrm{H}_{3} \mathrm{C}^{12} \mathrm{~N}^{14}$ & 4- 811 & $8,1 \leftarrow 7,1$ & Excited & & 147476.07 & .25 \\
\hline $\mathrm{C}^{12} \mathrm{H}_{3} \mathrm{C}^{12} \mathrm{~N}^{14}$ & 4- 811 & $8,5 \leftarrow 7,5$ & Excited & & 147512.50 & .25 \\
\hline $\mathrm{C}^{12} \mathrm{H}_{3} \mathrm{C}^{12} \mathrm{~N}^{14}$ & 4- 811 & $8,7 \leftarrow 7,7$ & Excited & & 147519.34 & .25 \\
\hline $\mathrm{C}^{12} \mathrm{H}_{3} \mathrm{C}^{12} \mathrm{~N}^{14}$ & 4- 811 & $8,4 \leftarrow 7,4$ & Excited & & 147543.84 & .25 \\
\hline $\mathrm{C}^{12} \mathrm{H}_{3} \mathrm{C}^{12} \mathrm{~N}^{14}$ & 4- 811 & $8,6 \leftarrow 7,6$ & Excited & & 147550.12 & .25 \\
\hline $\mathrm{C}^{12} \mathrm{H}_{3} \mathrm{C}^{12} \mathrm{~N}^{14}$ & 4- 811 & $8,3 \leftarrow 7,3$ & Excited & & 147569.86 & .25 \\
\hline $\mathrm{C}^{12} \mathrm{H}_{3} \mathrm{C}^{12} \mathrm{~N}^{14}$ & 4- 811 & $8,5 \leftarrow 7,5$ & Excited & & 147575.44 & .25 \\
\hline $\mathrm{C}^{12} \mathrm{H}_{3} \mathrm{C}^{12} \mathrm{~N}^{14}$ & 4- 811 & $8,2 \leftarrow 7,2$ & Excited & & 147589.93 & .25 \\
\hline $\mathrm{C}^{12} \mathrm{H}_{3} \mathrm{C}^{12} \mathrm{~N}^{14}$ & 4- 811 & $8,4 \leftarrow 7,4$ & Excited & & 147595.40 & .25 \\
\hline $\mathrm{C}^{12} \mathrm{H}_{3} \mathrm{C}^{12} \mathrm{~N}^{14}$ & 4- 811 & $8,1 \leftarrow 7,1$ & Excited & & 147603.96 & .25 \\
\hline $\mathrm{C}^{12} \mathrm{H}_{3} \mathrm{C}^{12} \mathrm{~N}^{14}$ & 4- 811 & $8,3 \leftarrow 7,3$ & Excited & & 147609.76 & .25 \\
\hline $\mathrm{C}^{12} \mathrm{H}_{3} \mathrm{C}^{12} \mathrm{~N}^{14}$ & 4- 811 & $8,0 \leftarrow 7,0$ & Excited & & 147611.01 & .25 \\
\hline $\mathrm{C}^{12} \mathrm{H}_{3} \mathrm{C}^{12} \mathrm{~N}^{14}$ & 4. 811 & $8,2 \leftarrow 7,2$ & Excited & & 147620.13 & .25 \\
\hline $\mathrm{C}^{12} \mathrm{H}_{3} \mathrm{C}^{12} \mathrm{~N}^{14}$ & 4- 811 & $8,1 \leftarrow 7,1$ & Excited & & 147760.38 & .25 \\
\hline $\mathrm{Br}^{81} \mathrm{C}^{12} \mathrm{~N}^{14}$ & 4. 142 & $18 \leftarrow 17$ & Excited & & 147807.77 & \\
\hline $\mathrm{Br}^{81} \mathrm{C}^{12} \mathrm{~N}^{14}$ & 4. 142 & $18 \leftarrow 17$ & Excited & & 147808.49 & \\
\hline $\mathrm{C}^{12} \mathrm{H}_{3} \mathrm{C}^{12} \mathrm{~N}^{14}$ & 4- 811 & $8, \leftarrow 7$, & Excited & & 147910.6 & .25 \\
\hline $\mathrm{C}^{12} \mathrm{H}_{3} \mathrm{C}^{12} \mathrm{~N}^{14}$ & 4- 811 & $8, \leftarrow 7$, & Excited & & 147921.1 & .25 \\
\hline $\mathrm{C}^{12} \mathrm{H}_{3} \mathrm{C}^{12} \mathrm{~N}^{14}$ & 4. 811 & $8, \leftarrow 7$, & Excited & & 147939.1 & .25 \\
\hline $\mathrm{Br}^{81} \mathrm{C}^{12} \mathrm{~N}^{14}$ & 4- 142 & $18 \leftarrow 17$ & Excited & & 147947.11 & \\
\hline $\mathrm{Br}^{81} \mathrm{C}^{12} \mathrm{~N}^{14}$ & 4- 142 & $18 \leftarrow 17$ & Excited & & 147947.85 & \\
\hline $\mathrm{C}^{12} \mathrm{H}_{3} \mathrm{C}^{12} \mathrm{~N}^{14}$ & 4. 811 & $8,7 \leftarrow 7,7$ & Excited & & 147947.9 & .25 \\
\hline $\mathrm{C}^{12} \mathrm{H}_{3} \mathrm{C}^{12} \mathrm{~N}^{14}$ & 4. 811 & $8, \leftarrow 7$, & Excited & & 147973.5 & .25 \\
\hline $\mathrm{C}^{12} \mathrm{H}_{3} \mathrm{C}^{12} \mathrm{~N}^{14}$ & 4- 811 & $8,6 \leftarrow 7,6$ & Excited & & 147977.5 & .25 \\
\hline $\mathrm{C}^{12} \mathrm{H}_{3} \mathrm{C}^{12} \mathrm{~N}^{14}$ & 4- 811 & $8,5 \leftarrow 7,5$ & Excited & & 148004.9 & .25 \\
\hline $\mathrm{C}^{12} \mathrm{H}_{3} \mathrm{C}^{12} \mathrm{~N}^{14}$ & 4- 811 & $8, \leftarrow 7$, & Excited & & 148019.2 & .25 \\
\hline $\mathrm{C}^{12} \mathrm{H}_{3} \mathrm{C}^{12} \mathrm{~N}^{14}$ & 4- 811 & $8,4 \leftarrow 7,4$ & Excited & & 148022.7 & .25 \\
\hline $\mathrm{C}^{12} \mathrm{H}_{3} \mathrm{C}^{12} \mathrm{~N}^{14}$ & 4- 811 & $8, \leftarrow 7$, & Excited & & 148032.5 & .25 \\
\hline $\mathrm{C}^{12} \mathrm{H}_{3} \mathrm{C}^{12} \mathrm{~N}^{14}$ & 4- 811 & $8, \leftarrow 7$, & Excited & & 148035.3 & .25 \\
\hline $\mathrm{C}^{12} \mathrm{H}_{3} \mathrm{C}^{12} \mathrm{~N}^{14}$ & 4- 811 & $8,3 \leftarrow 7,3$ & Excited & & 148038.6 & .25 \\
\hline $\mathrm{C}^{12} \mathrm{H}_{3} \mathrm{C}^{12} \mathrm{~N}^{14}$ & 4. 811 & $8,2 \leftarrow 7,2$ & Excited & & 148050.4 & .25 \\
\hline $\mathrm{C}^{12} \mathrm{H}_{3} \mathrm{C}^{12} \mathrm{~N}^{14}$ & 4- 811 & $8, \leftarrow 7$, & Excited & & 148052.0 & .25 \\
\hline $\mathrm{C}^{12} \mathrm{H}_{3} \mathrm{C}^{12} \mathrm{~N}^{14}$ & 4- 811 & $8,1 \leftarrow 7,1$ & Excited & & 148058.7 & .25 \\
\hline $\mathrm{C}^{12} \mathrm{H}_{3} \mathrm{C}^{12} \mathrm{~N}^{14}$ & 4- 811 & $8,0 \leftarrow 7,0$ & Excited & & 148060.0 & .25 \\
\hline $\mathrm{C}^{12} \mathrm{H}_{3} \mathrm{C}^{12} \mathrm{~N}^{14}$ & 4- 811 & $8, \leftarrow 7$, & Excited & & 148064.0 & .25 \\
\hline $\mathrm{C}^{12} \mathrm{H}_{3} \mathrm{C}^{12} \mathrm{~N}^{14}$ & 4. 811 & $8, \leftarrow 7$, & Excited & & 148082.0 & .25 \\
\hline $\mathrm{Br}^{79} \mathrm{C}^{12} \mathrm{~N}^{14}$ & 4- 141 & $18 \leftarrow 17$ & Ground & & 148307.36 & .30 \\
\hline $\mathrm{Br}^{79} \mathrm{C}^{12} \mathrm{~N}^{14}$ & 4- 141 & $18 \leftarrow 17$ & Excited & & 148652.01 & \\
\hline $\mathrm{Br}^{79} \mathrm{C}^{12} \mathrm{~N}^{14}$ & 4- 141 & $18 \leftarrow 17$ & Excited & & 148652.83 & \\
\hline $\mathrm{Br}^{79} \mathrm{C}^{12} \mathrm{~N}^{14}$ & 4- 141 & $18 \leftarrow 17$ & Excited & & 148792.99 & \\
\hline $\mathrm{Br}^{79} \mathrm{C}^{12} \mathrm{~N}^{14}$ & 4- 141 & $18 \leftarrow 17$ & Excited & & 148793.79 & \\
\hline $\mathrm{F}^{19} \mathrm{DC}^{12} \mathrm{O}^{16}$ & 4- 272 & $7,0,7 \leftarrow 6,0,6$ & & & 149439.56 & .04 \\
\hline $\mathrm{F}^{19} \mathrm{DC}^{12} \mathrm{O}^{16}$ & 4. 272 & $5,1,5 \leftarrow 4,0,4$ & & & 149483.49 & .04 \\
\hline
\end{tabular}




\begin{tabular}{|c|c|c|c|c|c|c|c|}
\hline \multirow{2}{*}{ Isotopic Species } & \multirow{2}{*}{$\begin{array}{l}\text { Vol.-Id. } \\
\text { Nos. }\end{array}$} & \multirow{2}{*}{$\begin{array}{c}\text { Rotational } \\
\text { Quantum Nos. }\end{array}$} & \multirow{2}{*}{ Vib. State } & \multicolumn{2}{|c|}{ Hyperfine } & \multirow{2}{*}{$\begin{array}{c}\text { Frequency } \\
\mathrm{MHz}\end{array}$} & \multirow{2}{*}{$\begin{aligned} & \text { Acc. } \\
& \pm \text { MHz }\end{aligned}$} \\
\hline & & & & $F_{1}^{\prime} \quad F^{\prime} \quad F_{1}$ & $\mathbf{F}$ & & \\
\hline $\mathrm{HC}^{12} \mathrm{O}^{16} \mathrm{O}^{16} \mathrm{D}$ & 3. 72 & $7,0,7 \leftarrow 6,0,6$ & Ground & & & 149753.66 & .2 \\
\hline $\mathrm{F}^{19} \mathrm{HC}^{12} \mathrm{O}^{16}$ & 4- 271 & $7,1,7 \leftarrow 6,1,6$ & & & & 150098.73 & .05 \\
\hline $\mathrm{N}^{14} \mathrm{O}^{16}$ & $1-$ & $3 / 2 \leftarrow 1 / 2$ & Ground & $5 / 2$ & $3 / 2$ & 150176.30 & 0.25 \\
\hline $\mathrm{N}^{14} \mathrm{O}^{16}$ & $1-$ & $3 / 2 \leftarrow 1 / 2$ & Ground & $3 / 2$ & $1 / 2$ & 150198.52 & 0.25 \\
\hline $\mathrm{N}^{14} \mathrm{O}^{16}$ & $1-$ & $3 / 2 \leftarrow 1 / 2$ & Ground & $3 / 2$ & $3 / 2$ & 150218.57 & 0.25 \\
\hline $\mathrm{N}^{14} \mathrm{O}^{16}$ & $1-$ & $3 / 2 \leftarrow 1 / 2$ & Ground & $1 / 2$ & $1 / 2$ & 150225.47 & 0.25 \\
\hline $\mathrm{N}^{14} \mathrm{O}^{16}$ & 1 . & $3 / 2 \leftarrow 1 / 2$ & Ground & $1 / 2$ & $3 / 2$ & 150245.38 & 0.25 \\
\hline $\mathrm{DC}^{12} \mathrm{O}^{16} \mathrm{O}^{16} \mathrm{H}$ & 3. 73 & $7,0,7 \leftarrow 6,0,6$ & Ground & & & 150345.06 & .2 \\
\hline $\mathrm{N}^{14} \mathrm{O}^{16}$ & $1-$ & $3 / 2 \leftarrow 1 / 2$ & Ground & $1 / 2$ & $3 / 2$ & 150375.02 & 0.25 \\
\hline $\mathrm{N}^{14} \mathrm{O}^{16}$ & 1 . & $3 / 2 \leftarrow 1 / 2$ & Ground & $3 / 2$ & $3 / 2$ & 150438.72 & 0.25 \\
\hline $\mathrm{HC}^{12} \mathrm{HO}^{16}$ & 4- 381 & $2,1,1 \leftarrow 1,1,0$ & Ground & & & 150498.2 & .75 \\
\hline $\mathrm{N}^{14} \mathrm{O}^{16}$ & $1-$ & $3 / 2 \leftarrow 1 / 2$ & Ground & $5 / 2$ & $3 / 2$ & 150546.25 & 0.25 \\
\hline $\mathrm{N}^{14} \mathrm{O}^{16}$ & $1-$ & $3 / 2 \leftarrow 1 / 2$ & Ground & $1 / 2$ & $1 / 2$ & 150580.38 & 0.25 \\
\hline $\mathrm{N}^{14} \mathrm{O}^{16}$ & $1-$ & $3 / 2 \leftarrow 1 / 2$ & Ground & $3 / 2$ & $1 / 2$ & 150644.11 & 0.25 \\
\hline $\mathrm{N}_{2}^{14} \mathrm{O}^{16}$ & $4-1811$ & $6 \leftarrow 5$ & Ground & & & 150735.13 & .30 \\
\hline $\mathrm{N}_{2}^{14} \mathrm{O}^{16}$ & 4-1811 & $6 \leftarrow 5$ & Excited & & & 150794.98 & \\
\hline $\mathrm{F}^{19} \mathrm{DC}^{12} \mathrm{O}^{16}$ & 4- 272 & $5,2,3 \leftarrow 5,1,4$ & & & & 150856.20 & .04 \\
\hline $\mathrm{N}_{2}^{14} \mathrm{O}^{16}$ & 4-1811 & $6 \leftarrow 5$ & Excited & & & 151079.83 & \\
\hline $\mathrm{HC}^{12} \mathrm{O}^{16} \mathrm{O}^{16} \mathrm{H}$ & $3-71$ & $7,1,7 \leftarrow 6,1,6$ & & & & 151176.1 & .1 \\
\hline $\mathrm{H}_{2} \mathrm{C}^{12}: \mathrm{C}^{12} \mathrm{HF}^{19}$ & 4- 781 & $8,1,8 \leftarrow 7,1,7$ & Ground & & & 151370.98 & .05 \\
\hline $\mathrm{F}^{19} \mathrm{DC}^{12} \mathrm{O}^{16}$ & 4- 272 & $7,2,6 \leftarrow 6,2,5$ & & & & 151558.74 & .04 \\
\hline $\mathrm{HC}^{12} \mathrm{O}^{16} \mathrm{O}^{16} \mathrm{D}$ & $3-72$ & $7,2,6 \leftarrow 6,2,5$ & Ground & & & 151778.74 & .2 \\
\hline $\mathrm{F}^{19} \mathrm{DC}^{12} \mathrm{O}^{16}$ & 4- 272 & $12,1,11 \leftarrow 12,0,12$ & & & & 151855.87 & .04 \\
\hline $\mathrm{F}^{19} \mathrm{DC}^{12} \mathrm{O}^{16}$ & 4- 272 & $7,6, \leftarrow 6,6$, & & & & 152059.08 & .04 \\
\hline $\mathrm{F}^{19} \mathrm{DC}^{12} \mathrm{O}^{16}$ & 4- 272 & $7,5, \leftarrow 6,5$, & & & & 152088.00 & .04 \\
\hline $\mathrm{F}^{19} \mathrm{DC}^{12} \mathrm{O}^{16}$ & 4- 272 & $7,4,3 \leftarrow 6,4,2$ & & & & 152147.81 & .04 \\
\hline $\mathrm{F}^{19} \mathrm{DC}^{12} \mathrm{O}^{16}$ & 4- 272 & $7,4,4 \leftarrow 6,4,3$ & & & & 152147.81 & .04 \\
\hline $\mathrm{F}^{19} \mathrm{DC}^{12} \mathrm{O}^{16}$ & 4- 272 & $7,3,5 \leftarrow 6,3,4$ & & & & 152253.06 & .04 \\
\hline $\mathrm{HC}^{12} \mathrm{O}^{16} \mathrm{O}^{16} \mathrm{D}$ & $3-72$ & $7,6, \leftarrow 6,6$, & Ground & & & 152264.95 & .2 \\
\hline $\mathrm{HC}^{12} \mathrm{O}^{16} \mathrm{O}^{16} \mathrm{D}$ & $3-\quad 72$ & $7,5, \leftarrow 6,5$, & Ground & & & 152288.87 & .2 \\
\hline $\mathrm{F}^{19} \mathrm{DC}^{12} \mathrm{O}^{16}$ & 4- 272 & $7,3,4 \leftarrow 6,3,3$ & & & & 152343.06 & .04 \\
\hline $\mathrm{HC}^{12} \mathrm{O}^{16} \mathrm{O}^{16} \mathrm{D}$ & 3- 72 & $7,4,4 \leftarrow 6,4,3$ & Ground & & & 152343.36 & .2 \\
\hline $\mathrm{HC}^{12} \mathrm{O}^{16} \mathrm{O}^{16} \mathrm{D}$ & 3- 72 & $7,4,3 \leftarrow 6,4,2$ & Ground & & & 152344.38 & .2 \\
\hline $\mathrm{HC}^{12} \mathrm{O}^{16} \mathrm{O}^{16} \mathrm{D}$ & $3-72$ & $7,3,5 \leftarrow 6,3,4$ & Ground & & & 152442.80 & .2 \\
\hline $\mathrm{C}^{12} \mathrm{H}_{3} \mathrm{Br}^{81}$ & 4- 402 & $8,4 \leftarrow 7,4$ & Ground & $13 / 2$ & $11 / 2$ & 152443.13 & \\
\hline $\mathrm{C}^{12} \mathrm{H}_{3} \mathrm{Br}^{81}$ & 4. 402 & $8,6 \leftarrow 7,6$ & Ground & $17 / 2$ & $15 / 2$ & 152446.88 & \\
\hline $\mathrm{C}^{12} \mathrm{H}_{3} \mathrm{Br}^{81}$ & 4- 402 & $8,4 \leftarrow 7,4$ & Ground & $19 / 2$ & $17 / 2$ & 152446.88 & \\
\hline $\mathrm{C}^{12} \mathrm{H}_{3} \mathrm{Br}^{81}$ & 4- 402 & $8,5 \leftarrow 7,5$ & Ground & $15 / 2$ & $13 / 2$ & 152452.02 & \\
\hline $\mathrm{C}^{12} \mathrm{H}_{3} \mathrm{Br}^{81}$ & 4- 402 & $8,5 \leftarrow 7,5$ & Ground & $17 / 2$ & $15 / 2$ & 152459.44 & \\
\hline $\mathrm{C}^{12} \mathrm{H}_{3} \mathrm{Br}^{81}$ & 4- 402 & $8,3 \leftarrow 7,3$ & Ground & $19 / 2$ & $17 / 2$ & 152464.97 & \\
\hline $\mathrm{C}^{12} \mathrm{H}_{3} \mathrm{Br}^{81}$ & 4- 402 & $8,4 \leftarrow 7,4$ & Ground & $15 / 2$ & $13 / 2$ & 152466.19 & \\
\hline $\mathrm{C}^{12} \mathrm{H}_{3} \mathrm{Br}^{81}$ & 4- 402 & $8,1 \leftarrow 7,1$ & Ground & $15 / 2$ & $15 / 2$ & 152466.19 & \\
\hline $\mathrm{C}^{12} \mathrm{H}_{3} \mathrm{Br}^{81}$ & 4- 402 & $8,4 \leftarrow 7,4$ & Ground & $17 / 2$ & $15 / 2$ & 152469.84 & \\
\hline $\mathrm{C}^{12} \mathrm{H}_{3} \mathrm{Br}^{81}$ & 4. 402 & $8,3 \leftarrow 7.3$ & Ground & $15 / 2$ & $13 / 2$ & 152477.06 & \\
\hline $\mathrm{C}^{12} \mathrm{H}_{3} \mathrm{Br}^{81}$ & 4. 402 & $8,3 \leftarrow 7,3$ & Ground & $17 / 2$ & $15 / 2$ & 152477.87 & \\
\hline
\end{tabular}


Vol.-Id. Rotational Nos. Quantum Nos.
Vib. State

\section{Hyperfine} $\begin{array}{llll}F_{1}^{\prime} & F^{\prime} & F_{1} & F\end{array}$
Frequency $\mathrm{MHz}$
Acc. $\pm \mathrm{MHz}$

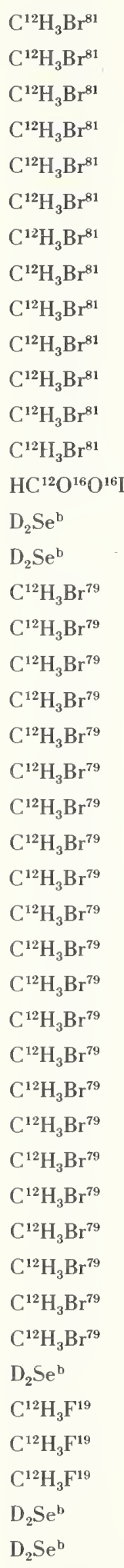

$\mathrm{DC}^{12} \mathrm{O}^{16} \mathrm{O}^{16} \mathrm{H}$

$\begin{array}{llll}\text { 4- } 402 & 8,2 \leftarrow 7,2 & \text { Ground } & 19 / 2 \\ \text { 4- } 402 & 8,2 \leftarrow 7,2 & \text { Ground } & 13 / 2 \\ \text { 4- } 402 & 8,2 \leftarrow 7,2 & \text { Ground } & 17 / 2 \\ \text { 4- } 402 & 8,2 \leftarrow 7,2 & \text { Ground } & 15 / 2 \\ \text { 4- } 402 & 8,1 \leftarrow 7,1 & \text { Ground } & 19 / 2 \\ \text { 4- } 402 & 8,1 \leftarrow 7,1 & \text { Ground } & 17 / 2 \\ \text { 4- } 402 & 8,4 \leftarrow 7,4 & \text { Ground } & 17 \\ \text { 4- } 402 & 8,1 \leftarrow 7,1 & \text { Ground } & 13 / 2 \\ \text { 4- } 402 & 8,0 \leftarrow 7,0 & \text { Ground } & 17 / 2 \\ \text { 4- } 402 & 8,0 \leftarrow 7,0 & \text { Ground } & 19 / 2 \\ \text { 4- } 402 & 8,1 \leftarrow 7,1 & \text { Ground } & 15 / 2 \\ \text { 4- } 402 & 8,0 \leftarrow 7,0 & \text { Ground } & 13 / 2 \\ \text { 4- } 402 & 8,0 \leftarrow 7,0 & \text { Ground } & 15 / 2 \\ \text { 3- } 72 & 7,3,4 \leftarrow 6,3,3 & \text { Ground } & \\ \text { 4-1754 } & \text { Not Reported } & \text { Ground } & \\ \text { 4-1754 } & \text { Not Reported } & \text { Ground }\end{array}$

$19 / 2 \quad 17 / 2 \quad 152477.87$

$13 / 2 \quad 11 / 2 \quad 152479.20$

$17 / 2 \quad 15 / 2 \quad 152483.60$

$15 / 2 \quad 13 / 2 \quad 152484.89$

$19 / 2 \quad 17 / 2 \quad 152485.61$

$17 / 2 \quad 15 / 2 \quad 152487.03$

$17 / 2 \quad 17 / 2 \quad 152487.03$

$13 / 2 \quad 11 / 2 \quad 152488.14$

$17 / 2 \quad 15 / 2 \quad 152488.14$

$19 / 2 \quad 17 / 2 \quad 152488.14$

$15 / 2 \quad 13 / 2 \quad 152489.56$

$13 / 2 \quad 11 / 2 \quad 152491.10$

$15 / 2 \quad 13 / 2 \quad 152491.10$

4- $401 \quad 8,5 \leftarrow 7,5 \quad$ Ground

4- $401 \quad 8,5 \leftarrow 7,5 \quad$ Ground

153126.12

.30
152526.01

152808.24

152955.12

$13 / 2 \quad 11 / 2 \quad 152992.98$

$19 / 2 \quad 17 / 2 \quad 153001.93$

$15 / 2 \quad 13 / 2 \quad 153019.63$

$13 / 2 \quad 11 / 2 \quad 153021.82$

$19 / 2 \quad 17 / 2 \quad 153026.32$

$17 / 2 \quad 15 / 2 \quad 153034.03$

$15 / 2 \quad 13 / 2 \quad 153035.98$

$13 / 2 \quad 11 / 2 \quad 153044.21$

$19 / 2 \quad 17 / 2 \quad 153045.22$

$15 / 2 \quad 13 / 2 \quad 153049.30$

$17 / 2 \quad 15 / 2 \quad 153053.70$

$19 / 2 \quad 17 / 2 \quad 153058.75$

$15 / 2 \quad 13 / 2 \quad 153059.73$

$17 / 2 \quad 15 / 2 \quad 153060.67$

$17 / 2 \quad 15 / 2 \quad 153065.61$

$19 / 2 \quad 17 / 2 \quad 153066.92$

$17 / 2 \quad 15 / 2 \quad 153068.60$

$19 / 2 \quad 17 / 2 \quad 153069.61$

$17 / 2 \quad 15 / 2 \quad 153069.61$

$15 / 2 \quad 13 / 2 \quad 153071.60$

$13 / 2 \quad 11 / 2 \quad 153073.09$

$15 / 2 \quad 13 / 2 \quad 153073.09$

153199.58

.30

153207.65

153210.44

.30

153214.14

153312.56

153521.68

.2

Ground

Ground

Ground
4-1754 Not Reported

$4-175$

$7,2,6 \leftarrow 6,2,5$ 


\begin{tabular}{|c|c|c|c|c|c|c|}
\hline Isotopic Species & $\begin{array}{l}\text { Vol.-Id. } \\
\text { Nos. }\end{array}$ & $\begin{array}{c}\text { Rotational } \\
\text { Quantum Nos. }\end{array}$ & Vib. State & 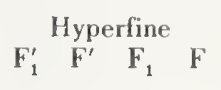 & $\begin{array}{l}\text { Frequency } \\
\text { MHz }\end{array}$ & $\begin{aligned} & \text { Acc. } \\
& \pm \text { MHz }\end{aligned}$ \\
\hline $\mathrm{C}^{12} \mathrm{H}_{3} \mathrm{C}^{12}: \mathrm{C}^{12} \mathrm{H}$ & $4-1041$ & $9,6 \leftarrow 8,6$ & & & 153711.55 & .30 \\
\hline $\mathrm{C}^{12} \mathrm{H}_{3} \mathrm{C}^{12}: \mathrm{C}^{12} \mathrm{H}$ & $4 \cdot 104.1$ & $9,5 \leftarrow 8,5$ & & & 153743.72 & .30 \\
\hline $\mathrm{C}^{12} \mathrm{H}_{3} \mathrm{C}^{12}: \mathrm{C}^{12} \mathrm{H}$ & $4-1041$ & $9,4 \leftarrow 8,4$ & & & 153770.15 & .30 \\
\hline $\mathrm{C}^{12} \mathrm{H}_{3} \mathrm{C}^{12}: \mathrm{C}^{12} \mathrm{H}$ & $4-1041$ & $9,3 \leftarrow 8,3$ & & & 153790.66 & .30 \\
\hline $\mathrm{C}^{12} \mathrm{H}_{3} \mathrm{C}^{12}: \mathrm{C}^{12} \mathrm{H}$ & $4-1041$ & $9,2 \leftarrow 8,2$ & & & 153805.37 & .30 \\
\hline $\mathrm{C}^{12} \mathrm{H}_{3} \mathrm{C}^{12}: \mathrm{C}^{12} \mathrm{H}$ & $4-1041$ & $9,1 \leftarrow 8,1$ & & & 153814.27 & .30 \\
\hline $\mathrm{C}^{12} \mathrm{H}_{3} \mathrm{C}^{12}: \mathrm{C}^{12} \mathrm{H}$ & 4-1041 & $9,0 \leftarrow 8,0$ & & & 153817.16 & .30 \\
\hline $\mathrm{D}_{2} \mathrm{Se}^{\mathrm{b}}$ & 4-1754 & Not Reported & Ground & & 153842.64 & \\
\hline $\mathrm{D}_{2} \mathrm{Se}^{\mathrm{b}}$ & $4-1754$ & Not Reported & Ground & & 153877.80 & \\
\hline $\mathrm{D}_{2} \mathrm{Se}^{\mathrm{b}}$ & 4-1754 & Not Reported & Ground & & 153920.46 & \\
\hline $\mathrm{D}_{2} \mathrm{Se}^{\mathrm{b}}$ & $4-1754$ & Not Reported & Ground & & 154001.70 & \\
\hline $\mathrm{F}^{19} \mathrm{DC}^{12} \mathrm{O}^{16}$ & 4- 272 & $7,2,5 \leftarrow 6,2,4$ & & & 154029.84 & .04 \\
\hline $\mathrm{D}_{2} \mathrm{Se}^{\mathrm{b}}$ & $4-1754$ & Not Reported & Ground & & 154080.18 & \\
\hline $\mathrm{F}^{19} \mathrm{HC}^{12} \mathrm{O}^{16}$ & 4. 271 & $7,0,7 \leftarrow 6,0,6$ & & & 154120.02 & .05 \\
\hline $\mathrm{HC}^{12} \mathrm{O}^{16} \mathrm{O}^{16} \mathrm{D}$ & 3. 72 & $7,2,5 \leftarrow 6,2,4$ & Ground & & 154137.58 & .2 \\
\hline $\mathrm{DC}^{12} \mathrm{O}^{16} \mathrm{O}^{16} \mathrm{H}$ & 3- 73 & $7,6, \leftarrow 6,6$, & Ground & & 154285.66 & .2 \\
\hline $\mathrm{DC}^{12} \mathrm{O}^{16} \mathrm{O}^{16} \mathrm{H}$ & 3- 73 & $7,5, \leftarrow 6,5$, & Ground & & 154332.94 & .2 \\
\hline $\mathrm{F}^{19} \mathrm{DC}^{12} \mathrm{O}^{16}$ & 4- 272 & $4,2,2 \leftarrow 4,1,3$ & & & 154391.16 & .04 \\
\hline $\mathrm{DC}^{12} \mathrm{O}^{16} \mathrm{O}^{16} \mathrm{H}$ & 3. 73 & $7,4,4 \leftarrow 6,4,3$ & Ground & & 154427.84 & .2 \\
\hline $\mathrm{DC}^{12} \mathrm{O}^{16} \mathrm{O}^{16} \mathrm{H}$ & 3. 73 & $7,4,2 \leftarrow 6,4,2$ & Ground & & 154431.13 & .2 \\
\hline $\mathrm{DC}^{12} \mathrm{O}^{16} \mathrm{O}^{16} \mathrm{H}$ & 3. 73 & $7,3,5 \leftarrow 6,3,4$ & Ground & & 154571.17 & .2 \\
\hline $\mathrm{DC}^{12} \mathrm{O}^{16} \mathrm{O}^{16} \mathrm{H}$ & 3. 73 & $7,3,4 \leftarrow 6,3,3$ & Ground & & 154757.18 & .2 \\
\hline $\mathrm{F}^{19} \mathrm{HC}^{12} \mathrm{O}^{16}$ & 4- 271 & $7,2,6 \leftarrow 6,2,5$ & & & 154955.55 & .04 \\
\hline $\mathrm{F}^{19} \mathrm{HC}^{12} \mathrm{O}^{16}$ & 4- 271 & $7,5, \leftarrow 6,5$, & & & 155183.56 & .04 \\
\hline $\mathrm{F}^{19} \mathrm{HC}^{12} \mathrm{O}^{16}$ & 4. 271 & $7,6, \leftarrow 6,6$, & & & 155186.37 & .04 \\
\hline $\mathrm{F}^{19} \mathrm{HC}^{12} \mathrm{O}^{16}$ & 4. 271 & $7,4, \leftarrow 6,4$, & & & 155195.15 & .04 \\
\hline $\mathrm{F}^{19} \mathrm{HC}^{12} \mathrm{O}^{16}$ & 4- 271 & $7,3,5 \leftarrow 6,3,4$ & & & 155234.17 & .04 \\
\hline $\mathrm{F}^{19} \mathrm{HC}^{12} \mathrm{O}^{16}$ & 4. 271 & $7,3,4 \leftarrow 6,3,3$ & & & 155251.93 & .04 \\
\hline $\mathrm{H}_{2} \mathrm{C}^{12}: \mathrm{C}^{12} \mathrm{HF}^{19}$ & 4- 781 & $8,0,8 \leftarrow 7,0,7$ & Ground & & 155476.98 & .05 \\
\hline $\mathrm{HC}^{12} \mathrm{O}^{16} \mathrm{O}^{16} \mathrm{H}$ & 3. 71 & $7,0,7 \leftarrow 6,0,6$ & & & 155617.9 & .1 \\
\hline $\mathrm{F}^{19} \mathrm{HC}^{12} \mathrm{O}^{16}$ & 4. 271 & $7,2,5 \leftarrow 6,2,4$ & & & 155923.97 & .04 \\
\hline $\mathrm{HC}^{12} \mathrm{O}^{16} \mathrm{O}^{16} \mathrm{H}$ & 3- 71 & $7,2,6 \leftarrow 6,2,5$ & & & 157054.0 & .1 \\
\hline $\mathrm{DC}^{12} \mathrm{O}^{16} \mathrm{O}^{16} \mathrm{H}$ & 3. 73 & $7,2,5 \leftarrow 6,2,4$ & Ground & & 157241.48 & .2 \\
\hline $\mathrm{HC}^{12} \mathrm{O}^{16} \mathrm{O}^{16} \mathrm{H}$ & 3- 71 & $7,6, \leftarrow 6,6$, & & & 157412.9 & .1 \\
\hline $\mathrm{HC}^{12} \mathrm{O}^{16} \mathrm{O}^{16} \mathrm{H}$ & 3- 71 & $7,5, \leftarrow 6,5$, & & & 157422.7 & .1 \\
\hline $\mathrm{HC}^{12} \mathrm{O}^{16} \mathrm{O}^{16} \mathrm{H}$ & 3- 71 & $7,4,3 \leftarrow 6,4,2$ & & & 157455.2 & .1 \\
\hline $\mathrm{HC}^{12} \mathrm{O}^{16} \mathrm{O}^{16} \mathrm{H}$ & 3. 71 & $7,4,4 \leftarrow 6,4,3$ & & & 157455.2 & .1 \\
\hline $\mathrm{F}^{19} \mathrm{DC}^{12} \mathrm{O}^{16}$ & 4. 272 & $3,2,1 \leftarrow 3,1,2$ & & & 157515.96 & .04 \\
\hline $\mathrm{HC}^{12} \mathrm{O}^{16} \mathrm{O}^{16} \mathrm{H}$ & 3- 71 & $7,3,5 \leftarrow 6,3,4$ & & & 157526.1 & .1 \\
\hline $\mathrm{HC}^{12} \mathrm{O}^{16} \mathrm{O}^{16} \mathrm{H}$ & 3. 71 & $7,3,4 \leftarrow 6,3,3$ & & & 157570.6 & .1 \\
\hline $\mathrm{F}^{19} \mathrm{DC}^{12} \mathrm{O}^{16}$ & 4. 272 & $7 ; 1,6 \leftarrow 6,1,5$ & & & 157633.14 & .04 \\
\hline $\mathrm{H}_{2} \mathrm{C}^{12}: \mathrm{C}^{12} \mathrm{HF}^{19}$ & 4- 781 & $8,2,7 \leftarrow 7,2,6$ & Ground & & 157641.90 & .05 \\
\hline $\mathrm{HC}^{12} \mathrm{O}^{16} \mathrm{O}^{16} \mathrm{D}$ & 3. 72 & $7,1,6 \leftarrow 6,1,5$ & Ground & & 157770.81 & .2 \\
\hline $\mathrm{H}_{2} \mathrm{C}^{12}: \mathrm{C}^{12} \mathrm{HF}^{19}$ & 4- 781 & $6,1,6 \leftarrow 5,0,5$ & Ground & & 157931.82 & .05 \\
\hline $\mathrm{H}_{2} \mathrm{C}^{12}: \mathrm{C}^{12} \mathrm{HF}^{19}$ & 4. 781 & $8,7, \leftarrow 7,7$, & Ground & & 158179.25 & .05 \\
\hline
\end{tabular}




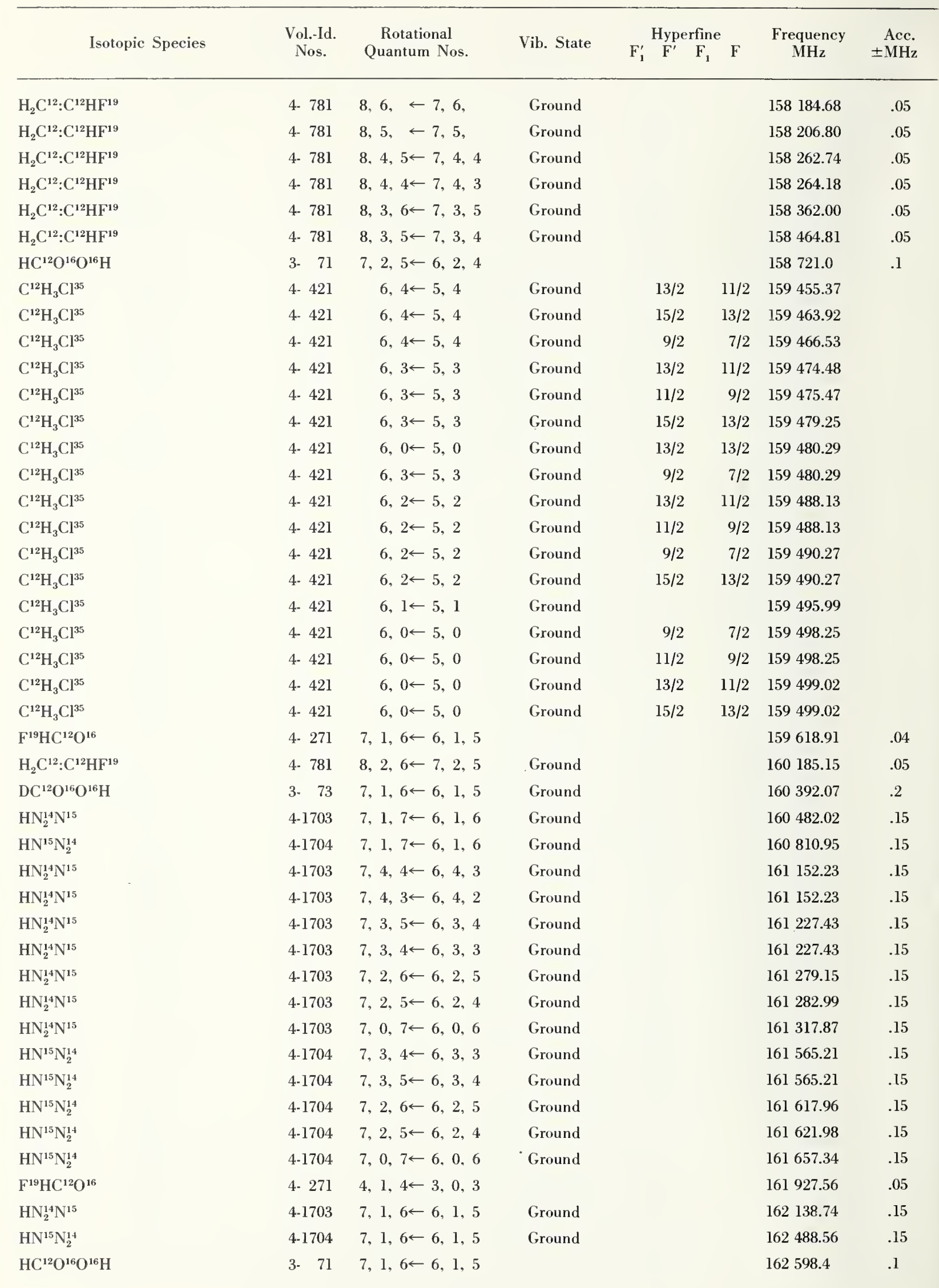




\begin{tabular}{|c|c|c|c|c|c|}
\hline $\mathrm{H}_{2} \mathrm{C}^{12}: \mathrm{C}^{12} \mathrm{HF}^{19}$ & 4- 781 & $8,1,7 \leftarrow 7,1,6$ & Ground & 163410.32 & .05 \\
\hline $\mathrm{Cl}^{37} \mathrm{C}^{12} \mathrm{~N}^{14}$ & 4- 173 & $14 \leftarrow 13$ & Ground & 163705.31 & .35 \\
\hline $\mathrm{Cl}^{37} \mathrm{C}^{12} \mathrm{~N}^{14}$ & 4- 173 & $14 \leftarrow 13$ & Excited & 164.052 .55 & \\
\hline $\mathrm{Cl}^{37} \mathrm{C}^{12} \mathrm{~N}^{14}$ & 4- 173 & $14 \leftarrow 13$ & Excited & 164253.26 & \\
\hline $\mathrm{H}_{2} \mathrm{Se}^{82}$ & 4-1745 & $3,3,0 \leftarrow 3,2,1$ & Ground & 164663.10 & \\
\hline $\mathrm{H}_{2} \mathrm{Se}^{80}$ & 4-1744 & $3,3,0 \leftarrow 3,2,1$ & Ground & 165240.46 & \\
\hline $\mathrm{C}^{12} \mathrm{H}_{3} \mathrm{C}^{12} \mathrm{~N}^{14}$ & 4- 811 & $9,8 \leftarrow 8,8$ & Ground & 165365.43 & .5 \\
\hline $\mathrm{C}^{12} \mathrm{H}_{3} \mathrm{C}^{12} \mathrm{~N}^{14}$ & 4- 811 & $9,7 \leftarrow 8,7$ & Ground & 165412.93 & .5 \\
\hline $\mathrm{F}^{19} \mathrm{DC}^{12} \mathrm{O}^{16}$ & 4- 272 & $2,2,1 \leftarrow 2,1,2$ & & 165448.32 & .04 \\
\hline $\mathrm{C}^{12} \mathrm{H}_{3} \mathrm{C}^{12} \mathrm{~N}^{14}$ & 4- 811 & $9,6 \leftarrow 8,6$ & Ground & 165454.09 & .5 \\
\hline $\mathrm{C}^{12} \mathrm{H}_{3} \mathrm{C}^{12} \mathrm{~N}^{14}$ & 4- 811 & $9,6 \leftarrow 8,6$ & Ground & 165454.34 & .5 \\
\hline $\mathrm{C}^{12} \mathrm{H}_{3} \mathrm{C}^{12} \mathrm{~N}^{14}$ & 4- 811 & $9,5 \leftarrow 8,5$ & Ground & 165489.39 & .5 \\
\hline $\mathrm{C}^{12} \mathrm{H}_{3} \mathrm{C}^{12} \mathrm{~N}^{14}$ & 4. 811 & $9,4 \leftarrow 8,4$ & Ground & 165517.93 & .5 \\
\hline $\mathrm{C}^{12} \mathrm{H}_{3} \mathrm{C}^{12} \mathrm{~N}^{14}$ & 4. 811 & $9,3 \leftarrow 8,3$ & Ground & 165540.31 & .5 \\
\hline $\mathrm{C}^{12} \mathrm{H}_{3} \mathrm{C}^{12} \mathrm{~N}^{14}$ & 4- 811 & $9,2 \leftarrow 8,2$ & Ground & 165556.18 & .5 \\
\hline $\mathrm{C}^{12} \mathrm{H}_{3} \mathrm{C}^{12} \mathrm{~N}^{14}$ & 4- 811 & $9,1 \leftarrow 8,1$ & Ground & 165565.71 & .5 \\
\hline $\mathrm{C}^{12} \mathrm{H}_{3} \mathrm{C}^{12} \mathrm{~N}^{14}$ & 4- 811 & $9,0 \leftarrow 8,0$ & Ground & 165568.95 & .5 \\
\hline $\mathrm{HN}_{3}^{14}$ & $4-1701$ & $7,1,7 \leftarrow 6,1,6$ & Ground & 165806.33 & .25 \\
\hline $\mathrm{H}_{2} \mathrm{Se}^{78}$ & 4-1743 & $3,3,0 \leftarrow 3,2,1$ & Ground & 165847.57 & \\
\hline $\mathrm{C}^{12} \mathrm{H}_{3} \mathrm{C}^{12} \mathrm{~N}^{14}$ & 4. 811 & $9,1 \leftarrow 8,1$ & Excited & 165908.28 & .5 \\
\hline $\mathrm{C}^{12} \mathrm{H}_{3} \mathrm{C}^{12} \mathrm{~N}^{14}$ & 4- 811 & $9,5 \leftarrow 8,5$ & Excited & 165948.85 & .5 \\
\hline $\mathrm{C}^{12} \mathrm{H}_{3} \mathrm{C}^{12} \mathrm{~N}^{14}$ & 4- 811 & $9,7 \leftarrow 8,7$ & Excited & 165957.03 & .5 \\
\hline $\mathrm{C}^{12} \mathrm{H}_{3} \mathrm{C}^{12} \mathrm{~N}^{14}$ & 4- 811 & $9,4 \leftarrow 8,4$ & Excited & 165983.98 & .5 \\
\hline $\mathrm{C}^{12} \mathrm{H}_{3} \mathrm{C}^{12} \mathrm{~N}^{14}$ & 4- 811 & $9,6 \leftarrow 8,6$ & Excited & 165992.06 & .5 \\
\hline $\mathrm{C}^{12} \mathrm{H}_{3} \mathrm{C}^{12} \mathrm{~N}^{14}$ & 4. 811 & $9,3 \leftarrow 8,3$ & Excited & 166013.38 & .5 \\
\hline $\mathrm{C}^{12} \mathrm{H}_{3} \mathrm{C}^{12} \mathrm{~N}^{14}$ & 4. 811 & $9,5 \leftarrow 8,5$ & Excited & 166020.50 & .5 \\
\hline $\mathrm{C}^{12} \mathrm{H}_{3} \mathrm{C}^{12} \mathrm{~N}^{14}$ & 4. 811 & $9,2 \leftarrow 8,2$ & Excited & 166036.03 & .5 \\
\hline $\mathrm{C}^{12} \mathrm{H}_{3} \mathrm{C}^{12} \mathrm{~N}^{14}$ & 4- 811 & $9,4 \leftarrow 8,4$ & Excited & 166042.93 & .5 \\
\hline $\mathrm{C}^{12} \mathrm{H}_{3} \mathrm{C}^{12} \mathrm{~N}^{14}$ & 4. 811 & $9,1 \leftarrow 8,1$ & Excited & 166051.73 & .5 \\
\hline $\mathrm{C}^{12} \mathrm{H}_{3} \mathrm{C}^{12} \mathrm{~N}^{14}$ & 4. 811 & $9,0 \leftarrow 8,0$ & Excited & 166059.13 & .5 \\
\hline $\mathrm{C}^{12} \mathrm{H}_{3} \mathrm{C}^{12} \mathrm{~N}^{14}$ & 4. 811 & $9,3 \leftarrow 8,3$ & Excited & 166059.13 & .5 \\
\hline $\mathrm{C}^{12} \mathrm{H}_{3} \mathrm{C}^{12} \mathrm{~N}^{14}$ & 4. 811 & $9,2 \leftarrow 8,2$ & Excited & 166071.30 & .5 \\
\hline $\mathrm{H}_{2} \mathrm{Se}^{77}$ & $4-1742$ & $3,3,0 \leftarrow 3,2,1$ & Ground & 166163.20 & \\
\hline $\mathrm{C}^{12} \mathrm{H}_{3} \mathrm{C}^{12} \mathrm{~N}^{14}$ & 4. 811 & $9,1 \leftarrow 8,1$ & Excited & 166228.53 & .5 \\
\hline $\mathrm{HN}_{3}^{14}$ & $4-1701$ & $7,5,3 \leftarrow 6,5,2$ & Ground & 166416.76 & .25 \\
\hline $\mathrm{HN}_{3}^{14}$ & $4-1701$ & $7,5,2 \leftarrow 6,5,1$ & Ground & 166416.76 & .25 \\
\hline $\mathrm{H}_{2} \mathrm{Se}^{76}$ & $4-174.1$ & $3,3,0 \leftarrow 3,2,1$ & Ground & 166488.14 & \\
\hline $\mathrm{HN}_{3}^{14}$ & $4-1701$ & $7,4,3 \leftarrow 6,4,2$ & Ground & 166522.79 & .25 \\
\hline $\mathrm{HN}_{3}^{14}$ & 4-1701 & $7,4,4 \leftarrow 6,4,3$ & Ground & $166522: 79$ & .25 \\
\hline $\mathrm{HN}_{3}^{14}$ & $4-1701$ & $7,3,5 \leftarrow 6,3,4$ & Ground & 166602.85 & .25 \\
\hline $\mathrm{HN}_{3}^{14}$ & $4-1701$ & $7,3,4 \leftarrow 6,3,3$ & Ground & 166602.85 & .25 \\
\hline $\mathrm{HN}_{3}^{14}$ & 4-1701 & $7,2,6 \leftarrow 6,2,5$ & Ground & 166657.66 & .25 \\
\hline $\mathrm{HN}_{3}^{14}$ & $4-1701$ & $7,2,5 \leftarrow 6,2,4$ & Ground & 166662.05 & .25 \\
\hline $\mathrm{HN}_{3}^{14}$ & $4-1701$ & $7,0,7 \leftarrow 6,0,6$ & Ground & 166698.40 & .25 \\
\hline $\mathrm{Cl}^{35} \mathrm{C}^{12} \mathrm{~N}^{14}$ & 4- 171 & $14 \leftarrow 13$ & Ground & 167165.15 & .35 \\
\hline
\end{tabular}




\begin{tabular}{|c|c|c|c|c|c|c|c|}
\hline Isotopic Species & $\begin{array}{l}\text { Vol.-Id. } \\
\text { Nos. }\end{array}$ & $\begin{array}{c}\text { Rotational } \\
\text { Quantum Nos. }\end{array}$ & Vib. State & 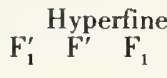 & $\mathrm{F}$ & $\begin{array}{l}\text { Frequency } \\
\mathrm{MHz}\end{array}$ & $\begin{aligned} & \text { Acc. } \\
\pm & \mathrm{MHz}\end{aligned}$ \\
\hline $\mathrm{Cl}^{35} \mathrm{C}^{12} \mathrm{~N}^{14}$ & 4- 171 & $14 \leftarrow-13$ & Excited & & & 167517.88 & \\
\hline $\mathrm{HN}_{3}^{14}$ & $4-1701$ & $7,1,6 \leftarrow 6,1,5$ & Ground & & & 167575.07 & .25 \\
\hline $\mathrm{O}^{16} \mathrm{C}^{12} \mathrm{Se}^{82}$ & 4- 548 & $21 \leftarrow 20$ & Ground & & & 167726.08 & .35 \\
\hline $\mathrm{Cl}^{35} \mathrm{C}^{12} \mathrm{~N}^{14}$ & 4- 171 & $14 \leftarrow 13$ & Excited & & & 167726.78 & \\
\hline $\mathrm{H}_{2} \mathrm{~S}^{34}$ & $4-1726$ & $1,1,0 \leftarrow 1,0,1$ & Ground & & & 167910.57 & .35 \\
\hline $\mathrm{F}^{19} \mathrm{DC}^{12} \mathrm{O}^{16}$ & 4- 272 & $3,2,2 \leftarrow 3,1,3$ & & & & 168210.00 & .04 \\
\hline $\mathrm{H}_{2} \mathrm{~S}^{33}$ & $4-1725$ & $1,1,0 \leftarrow 1,0,1$ & Ground & & & 168322.63 & .35 \\
\hline $\mathrm{O}^{16} \mathrm{C}^{12} \mathrm{Se}^{80}$ & 4- 547 & $21 \leftarrow 20$ & Ground & & & 168716.41 & .35 \\
\hline $\mathrm{H}_{2} \mathrm{~S}^{32}$ & $4-1724$ & $1,1,0 \leftarrow 1,0,1$ & Ground & & & 168762.51 & .35 \\
\hline $\mathrm{O}^{16} \mathrm{C}^{12} \mathrm{Se}^{80}$ & 4- 547 & $21 \leftarrow 20$ & Excited & & & 168939.60 & \\
\hline $\mathrm{O}^{16} \mathrm{C}^{12} \mathrm{Se}^{80}$ & 4- 547 & $21 \leftarrow 20$ & Excited & & & 169072.81 & \\
\hline $\mathrm{O}^{16} \mathrm{C}^{12} \mathrm{Se}^{78}$ & 4. 545 & $21 \leftarrow 20$ & Ground & & & 169756.27 & .35 \\
\hline $\mathrm{D}_{2} \mathrm{Se}^{76}$ & $4-1746$ & $2,1,1 \leftarrow 2,0,2$ & Ground & & & 170071.51 & \\
\hline $\mathrm{D}_{2} \mathrm{Se}^{77}$ & $4-1747$ & $2,1,1 \leftarrow 2,0,2$ & Ground & & & 170107.35 & \\
\hline $\mathrm{D}_{2} \mathrm{Se}^{78}$ & $4-1748$ & $2,1,1 \leftarrow 2,0,2$ & Ground & & & 170142.70 & \\
\hline $\mathrm{D}_{2} \mathrm{Se}^{80}$ & $4-1749$ & $2,1,1 \leftarrow 2,0,2$ & Ground & & & 170211.30 & \\
\hline $\mathrm{O}^{16} \mathrm{C}^{12} \mathrm{~S}^{32}$ & 4- 521 & $14 \leftarrow 13$ & Ground & & & 170267.49 & .35 \\
\hline $\mathrm{D}_{2} \mathrm{Se}^{82}$ & $4-1751$ & $2,1,1 \leftarrow 2,0,2$ & Ground & & & 170277.03 & \\
\hline $\mathrm{O}^{16} \mathrm{C}^{12} \mathrm{Se}^{77}$ & 4- 544 & $21 \leftarrow 20$ & Ground & & & 170294.80 & .35 \\
\hline $\mathrm{C}^{12} \mathrm{H}_{3} \mathrm{C}^{12}: \mathrm{C}^{12} \mathrm{H}$ & $4-1041$ & $10,7 \leftarrow 9,7$ & & & & 170746.05 & .35 \\
\hline $\mathrm{C}^{12} \mathrm{H}_{3} \mathrm{C}^{12}: \mathrm{C}^{12} \mathrm{H}$ & $4-1041$ & $10,6 \leftarrow 9,6$ & & & & 170788.29 & .35 \\
\hline $\mathrm{C}^{12} \mathrm{H}_{3} \mathrm{C}^{12}: \mathrm{C}^{12} \mathrm{H}$ & $4-1041$ & $10,5 \leftarrow 9,5$ & & & & 170824.13 & .35 \\
\hline $\mathrm{O}^{16} \mathrm{C}^{12} \mathrm{Se}^{76}$ & 4- 543 & $21 \leftarrow 20$ & Ground & & & 170849.06 & .35 \\
\hline $\mathrm{C}^{12} \mathrm{H}_{3} \mathrm{C}^{12}: \mathrm{C}^{12} \mathrm{H}$ & $4-1041$ & $10,4 \leftarrow 9,4$ & & & & 170853.50 & .35 \\
\hline $\mathrm{C}^{12} \mathrm{H}_{3} \mathrm{C}^{12}: \mathrm{C}^{12} \mathrm{H}$ & 4-1041 & $10,3 \leftarrow 9,3$ & & & & 170876.27 & .35 \\
\hline $\mathrm{C}^{12} \mathrm{H}_{3} \mathrm{C}^{12}: \mathrm{C}^{12} \mathrm{H}$ & $4-1041$ & $10,2 \leftarrow 9,2$ & & & & 170892.59 & .35 \\
\hline $\mathrm{C}^{12} \mathrm{H}_{3} \mathrm{C}^{12}: \mathrm{C}^{12} \mathrm{H}$ & $4-1041$ & $10,1 \leftarrow 9,1$ & & & & 170902.37 & .35 \\
\hline $\mathrm{C}^{12} \mathrm{H}_{3} \mathrm{C}^{12}: \mathrm{C}^{12} \mathrm{H}$ & $4-1041$ & $10,0 \leftarrow 9,0$ & & & & 170905.66 & .35 \\
\hline $\mathrm{Br}^{81} \mathrm{C}^{12} \mathrm{~N}^{14}$ & 4- 142 & $21 \leftarrow 20$ & Ground & & & 172033.53 & .35 \\
\hline $\mathrm{TBr}^{81}$ & $1-$ & $1 \leftarrow 0$ & Ground & $5 / 2$ & $3 / 2$ & 172320.96 & .40 \\
\hline $\mathrm{TBr}^{81}$ & 1 - & $1 \leftarrow 0$ & Ground & $3 / 2$ & $3 / 2$ & 172431.49 & .40 \\
\hline $\mathrm{Br}^{81} \mathrm{C}^{12} \mathrm{~N}^{14}$ & 4- 142 & $21 \leftarrow 20$ & Excited & & & 172434.07 & \\
\hline $\mathrm{TBr}^{79}$ & 1 . & $1 \leftarrow 0$ & Ground & $5 / 2$ & $3 / 2$ & 172472.72 & .40 \\
\hline $\mathrm{Br}^{81} \mathrm{C}^{12} \mathrm{~N}^{14}$ & 4- 142 & $21 \leftarrow 20$ & Excited & & & 172596.70 & \\
\hline $\mathrm{TBr}^{79}$ & 1. & $1 \leftarrow 0$ & Ground & $3 / 2$ & $3 / 2$ & 172604.60 & .40 \\
\hline $\mathrm{HC}^{12} \mathrm{O}^{16} \mathrm{O}^{16} \mathrm{H}$ & 3- 71 & $8,1,8 \leftarrow 7,1,7$ & & & & 172636.7 & .1 \\
\hline $\mathrm{Br}^{79} \mathrm{C}^{12} \mathrm{~N}^{14}$ & 4. 141 & $21 \leftarrow 20$ & Ground & & & 173016.45 & .35 \\
\hline $\mathrm{Br}^{79} \mathrm{C}^{12} \mathrm{~N}^{14}$ & 4- 141 & $21 \leftarrow 20$ & Excited & & & 173418.77 & \\
\hline $\mathrm{Br}^{79} \mathrm{C}^{12} \mathrm{~N}^{14}$ & 4- 141 & $21 \leftarrow 20$ & Excited & & & 173583.26 & \\
\hline $\mathrm{N}_{2}^{14} \mathrm{O}^{16}$ & 4-1811 & $7 \leftarrow 6$ & Ground & & & 175855.72 & .35 \\
\hline $\mathrm{Sb}^{123} \mathrm{H}_{3}$ & 4-1792 & $1, \leftarrow 0$ & Ground & $5 / 2$ & $7 / 2$ & 175973.49 & .5 \\
\hline $\mathrm{Sb}^{121} \mathrm{H}_{3}$ & $4-1791$ & $1, \leftarrow 0$ & Ground & $3 / 2$ & $5 / 2$ & 176004.64 & .5 \\
\hline $\mathrm{Sb}^{123} \mathrm{H}_{3}$ & $4-1792$ & $1, \leftarrow 0$ & Ground & $9 / 2$ & $7 / 2$ & 176008.39 & .5 \\
\hline $\mathrm{Sb}^{121} \mathrm{H}_{3}$ & $4-1791$ & $1, \leftarrow 0$ & Ground & $7 / 2$ & $5 / 2$ & 176047.74 & .5 \\
\hline $\mathrm{Sb}^{123} \mathrm{H}_{3}$ & 4-1792 & $1, \leftarrow 0$ & Ground & $7 / 2$ & $7 / 2$ & 176120.60 & .5 \\
\hline
\end{tabular}




\begin{tabular}{|c|c|c|c|c|c|c|c|}
\hline Isotopic Species & $\begin{array}{l}\text { Vol.-Id. } \\
\text { Nos. }\end{array}$ & $\begin{array}{c}\text { Rotational } \\
\text { Quantum Nos. }\end{array}$ & Vib. State & $F_{1}^{\prime} \stackrel{F^{\prime}}{\text { Hyperfine }} \quad F_{1}$ & $\mathrm{~F}$ & $\begin{array}{c}\text { Frequency } \\
\text { MII }\end{array}$ & $\begin{array}{r}\text { Acc. } \\
\pm \text { HIlz }\end{array}$ \\
\hline $\mathrm{Sb}^{121} \mathrm{H}_{3}$ & 4-1791 & $1, \leftarrow 0$ & Ground & $5 / 2$ & $5 / 2$ & 176142.92 & .5 \\
\hline $\mathrm{HN}_{3}^{14}$ & $4-1701$ & $8,1,8 \leftarrow 7,1,7$ & Ground & & & 176964.18 & .25 \\
\hline $\mathrm{HC}^{12} \mathrm{~N}^{14}$ & 4- 291 & $2 \leftarrow 1$ & Ground & & & 177260.99 & .40 \\
\hline $\mathrm{HC}^{12} \mathrm{O}^{16} \mathrm{O}^{16} \mathrm{H}$ & $3-71$ & $8,0,8 \leftarrow 7,0,7$ & & & & 177283.0 & .1 \\
\hline $\mathrm{HN}_{3}^{14}$ & 4-1701 & $8,5,3 \leftarrow 7,5,2$ & Ground & & & 178337.49 & .25 \\
\hline $\mathrm{HN}_{3}^{14}$ & 4-1701 & $8,5,4 \leftarrow 7,5,3$ & Ground & & & 178337.49 & .25 \\
\hline $\mathrm{HN}_{3}^{14}$ & $4-1701$ & $8,4,4 \leftarrow 7,4,3$ & Ground & & & 178404.21 & .25 \\
\hline $\mathrm{HN}_{3}^{14}$ & 4-1701 & $8,4,5 \leftarrow 7,4,4$ & Ground & & & 178404.21 & .25 \\
\hline $\mathrm{HN}_{3}^{14}$ & 4-1701 & $8,3,6 \leftarrow 7,3,5$ & Ground & & & 178456.64 & .25 \\
\hline $\mathrm{HN}_{3}^{14}$ & 4-1701 & $8,3,5 \leftarrow 7,3,4$ & Ground & & & 178456.64 & .25 \\
\hline $\mathrm{HN}_{3}^{14}$ & 4-1701 & $8,2,7 \leftarrow 7,2,6$ & Ground & & & 178484.73 & .25 \\
\hline $\mathrm{HN}_{3}^{14}$ & $4-1701$ & $8,0,8 \leftarrow 7,0,7$ & Ground & & & 178489.31 & .25 \\
\hline $\mathrm{HN}_{3}^{14}$ & $4-1701$ & $8,2,6 \leftarrow 7,2,5$ & Ground & & & 178512.13 & .25 \\
\hline $\mathrm{HC}^{12} \mathrm{O}^{16} \mathrm{O}^{16} \mathrm{H}$ & 3- 71 & $8,2,7 \leftarrow 7,2,6$ & & & & 179384.6 & .1 \\
\hline $\mathrm{HC}^{12} \mathrm{O}^{16} \mathrm{O}^{16} \mathrm{H}$ & 3. 71 & $8,5, \leftarrow 7,5$, & & & & 179932.2 & .1 \\
\hline $\mathrm{HC}^{12} \mathrm{O}^{16} \mathrm{O}^{16} \mathrm{H}$ & 3. 71 & $8,4,5 \leftarrow 7,4,4$ & & & & 179984.1 & .1 \\
\hline $\mathrm{HC}^{12} \mathrm{O}^{16} \mathrm{O}^{16} \mathrm{H}$ & $3-71$ & $8,4,4 \leftarrow 7,4,3$ & & & & 179985.3 & .1 \\
\hline $\mathrm{HN}_{3}^{14}$ & 4-1701 & $8,1,7 \leftarrow 7,1,6$ & Ground & & & 180042.27 & .25 \\
\hline $\mathrm{HC}^{12} \mathrm{O}^{16} \mathrm{O}^{16} \mathrm{H}$ & $3-71$ & $8,3,6 \leftarrow 7,3,5$ & & & & 180083.0 & .1 \\
\hline $\mathrm{HC}^{12} \mathrm{O}^{16} \mathrm{O}^{16} \mathrm{H}$ & 3- 71 & $8,3,5 \leftarrow 7,3,4$ & & & & 180171.4 & .1 \\
\hline $\mathrm{D}_{2} \mathrm{Se}^{\mathrm{b}}$ & $4-1754$ & Not Reported & Ground & & & 181658.80 & \\
\hline $\mathrm{HC}^{12} \mathrm{O}^{16} \mathrm{O}^{16} \mathrm{H}$ & 3. 71 & $8,2,6 \leftarrow 7,2,5$ & & & & 181850.2 & .1 \\
\hline $\mathrm{D}_{2} \mathrm{Se}^{\mathrm{b}}$ & 4-1754 & Not Reported & Ground & & & 182226.76 & \\
\hline $\mathrm{D}_{2} \mathrm{Se}^{\mathrm{b}}$ & $4-1754$ & Not Reported & Ground & & & 182279.28 & \\
\hline $\mathrm{H}_{2} \mathrm{O}^{16}$ & 4-1711 & $3,1,3 \leftarrow 2,2,0$ & Ground & & & 183311.30 & .30 \\
\hline $\mathrm{HN}_{2}^{14} \mathrm{~N}^{15}$ & 4-1703 & $8,1,8 \leftarrow 7,1,7$ & Ground & & & 183405.55 & .15 \\
\hline $\mathrm{C}^{12} \mathrm{H}_{3} \mathrm{C}^{12} \mathrm{~N}^{14}$ & 4- 811 & $10,8 \leftarrow 9,8$ & Ground & & & 183736.28 & .5 \\
\hline $\mathrm{HN}^{15} \mathrm{~N}_{2}^{14}$ & $4-1704$ & $8,1,8 \leftarrow 7,1,7$ & Ground & & & 183781.39 & .15 \\
\hline $\mathrm{C}^{12} \mathrm{H}_{3} \mathrm{C}^{12} \mathrm{~N}^{14}$ & 4- 811 & $10,7 \leftarrow 9,7$ & Ground & & & 183789.31 & .5 \\
\hline $\mathrm{C}^{12} \mathrm{H}_{3} \mathrm{C}^{12} \mathrm{~N}^{14}$ & 4- 811 & $10,6 \leftarrow 9,6$ & Ground & & & 183835.34 & .5 \\
\hline $\mathrm{C}^{12} \mathrm{H}_{3} \mathrm{C}^{12} \mathrm{~N}^{14}$ & 4- 811 & $10,5 \leftarrow 9,5$ & Ground & & & 183874.21 & .5 \\
\hline $\mathrm{C}^{12} \mathrm{H}_{3} \mathrm{C}^{12} \mathrm{~N}^{14}$ & 4. 811 & $10,4 \leftarrow 9,4$ & Ground & & & 183906.05 & .5 \\
\hline $\mathrm{C}^{12} \mathrm{H}_{3} \mathrm{C}^{12} \mathrm{~N}^{14}$ & 4- 811 & $10,3 \leftarrow 9,3$ & Ground & & & 183930.79 & .5 \\
\hline $\mathrm{C}^{12} \mathrm{H}_{3} \mathrm{C}^{12} \mathrm{~N}^{14}$ & 4- 811 & $10,2 \leftarrow 9,2$ & Ground & & & 183948.49 & .5 \\
\hline $\mathrm{C}^{12} \mathrm{H}_{3} \mathrm{C}^{12} \mathrm{~N}^{14}$ & 4- 811 & $10,1 \leftarrow 9,1$ & Ground & & & 183959.08 & .5 \\
\hline $\mathrm{C}^{12} \mathrm{H}_{3} \mathrm{C}^{12} \mathrm{~N}^{14}$ & 4- 811 & $10,0 \leftarrow 9,0$ & Ground & & & 183962.62 & .5 \\
\hline $\mathrm{HN}_{2}^{14} \mathrm{~N}^{15}$ & 4-1703 & $8,4,5 \leftarrow 7,4,4$ & Ground & & & 184171.91 & .15 \\
\hline $\mathrm{HN}_{2}^{14} \mathrm{~N}^{15}$ & 4-1703 & $8,4,4 \leftarrow 7,4,3$ & Ground & & & 184171.91 & .15 \\
\hline $\mathrm{HN}_{2}^{14} \mathrm{~N}^{15}$ & 4.1703 & $8,3,6 \leftarrow 7,3,5$ & Ground & & & 184257.81 & .15 \\
\hline $\mathrm{HN}_{2}^{14} \mathrm{~N}^{15}$ & 4-1703 & $8,3,6 \leftarrow 7,3,5$ & Ground & & & 184257.81 & .15 \\
\hline $\mathrm{D}_{2} \mathrm{Se}^{\mathrm{b}}$ & 4-1754 & Not Reported & Ground & & & 184.266 .88 & \\
\hline $\mathrm{HN}_{2}^{14} \mathrm{~N}^{15}$ & 4-1703 & $8,2,7 \leftarrow 7,2,6$ & Ground & & & 184316.65 & .15 \\
\hline $\mathrm{HN}_{2}^{14} \mathrm{~N}^{15}$ & 4-1703 & $8,2, \sigma \leftarrow 7,2,5$ & Ground & & & 184322.43 & .15 \\
\hline $\mathrm{C}^{12} \mathrm{H}_{3} \mathrm{C}^{12} \mathrm{~N}^{14}$ & 4- 811 & $10,1 \leftarrow 9,1$ & Excited & & & 184339.70 & .5 \\
\hline $\mathrm{HN}_{2}^{14} \mathrm{~N}^{15}$ & 4-1703 & $8,0,8 \leftarrow 7,0,7$ & Ground & & & 184359.48 & .15 \\
\hline
\end{tabular}




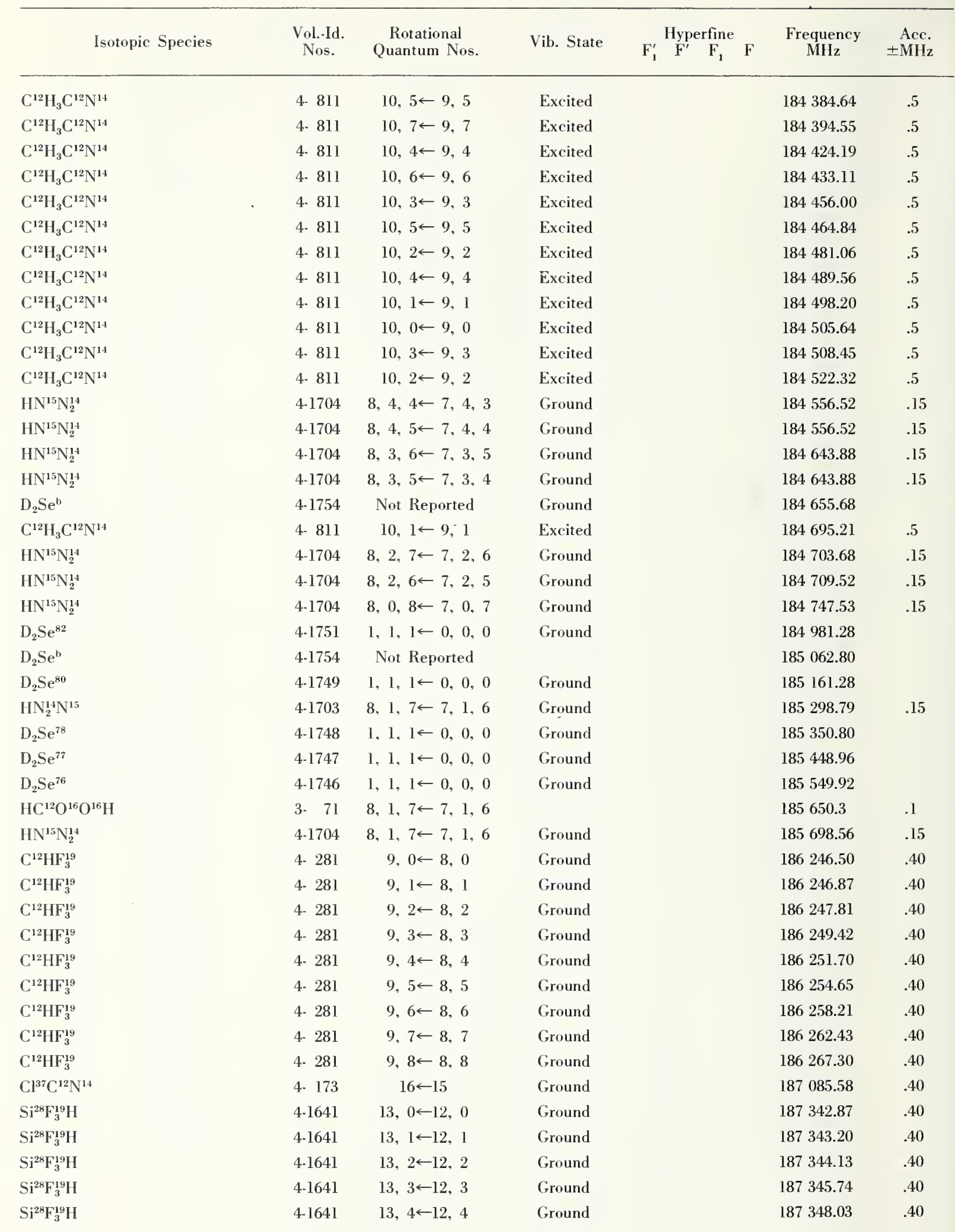




\begin{tabular}{|c|c|c|c|c|c|c|}
\hline \multirow{2}{*}{ Isotopic Species } & \multirow{2}{*}{$\begin{array}{l}\text { Vol.-Id. } \\
\text { Nos. }\end{array}$} & \multirow{2}{*}{$\begin{array}{c}\text { Rotational } \\
\text { Quantum Nos. }\end{array}$} & \multirow{2}{*}{ Vib. State } & Hyperfine & \multirow{2}{*}{$\begin{array}{l}\text { Frequency } \\
\text { MH\% }\end{array}$} & \multirow{2}{*}{$\begin{aligned} & \text { Acc. } \\
& \pm \text { Mlls }\end{aligned}$} \\
\hline & & & & $\begin{array}{llll}\mathrm{F}_{1} & \mathrm{~F}^{2} & \mathrm{~F}_{1} & \mathrm{~F}\end{array}$ & & \\
\hline $\mathrm{Si}^{28} \mathrm{~F}_{3}^{19} \mathrm{H}$ & $4-1641$ & $13,5 \leftarrow 12,5$ & Ground & & 187.350 .98 & .40 \\
\hline $\mathrm{Si}^{28} \mathrm{~F}_{3}^{19} \mathrm{H}$ & $4-1641$ & $13,6 \leftarrow 12,6$ & Ground & & 187354.52 & .40 \\
\hline $\mathrm{Si}^{28} \mathrm{~F}_{3}^{19} \mathrm{H}$ & 4-1641 & $13,7 \leftarrow 12,7$ & Ground & & 187358.70 & .40 \\
\hline $\mathrm{Si}^{28} \mathrm{~F}_{3}^{19} \mathrm{H}$ & $4-1641$ & $13,8 \leftarrow 12,8$ & Ground & & 187363.55 & .40 \\
\hline $\mathrm{Si}^{28} \mathrm{~F}_{3}^{19} \mathrm{H}$ & 4-1641 & $13,9 \leftarrow 12,9$ & Ground & & 187369.10 & .40 \\
\hline $\mathrm{HN}^{14} \mathrm{C}^{12} \mathrm{~S}^{32}$ & 4- 311 & $16,1,16 \leftarrow 15,1,15$ & Ground & & 187370.57 & .5 \\
\hline $\mathrm{Si}^{28} \mathrm{~F}_{3}^{19} \mathrm{H}$ & $4-1641$ & $13,10 \leftarrow 12,10$ & Ground & & 187375.26 & .40 \\
\hline $\mathrm{Si}^{28} \mathrm{~F}_{3}^{19} \mathrm{H}$ & 4-1641 & $13,11 \leftarrow 12,11$ & Ground & & 187382.00 & .40 \\
\hline $\mathrm{Si}^{28} \mathrm{~F}_{3}^{19} \mathrm{H}$ & $4-1641$ & $13,12 \leftarrow 12,12$ & Ground & & 187389.49 & .40 \\
\hline $\mathrm{Cl}^{37} \mathrm{C}^{12} \mathrm{~N}^{14}$ & 4- 173 & $16 \leftarrow 15$ & Excited & & 187482.50 & \\
\hline $\mathrm{HN}^{14} \mathrm{C}^{12} \mathrm{~S}^{32}$ & 4- 311 & $16,0,16 \leftarrow 15,0,15$ & Ground & & 187645.15 & .5 \\
\hline $\mathrm{Cl}^{37} \mathrm{C}^{12} \mathrm{~N}^{14}$ & 4- 173 & $16 \leftarrow 15$ & Excited & & 187711.52 & \\
\hline $\mathrm{HN}^{14} \mathrm{C}^{12} \mathrm{~S}^{32}$ & 4- 311 & $16,2,15 \leftarrow 15,2,14$ & Ground & & 187711.730 & .5 \\
\hline $\mathrm{HN}^{14} \mathrm{C}^{12} \mathrm{~S}^{32}$ & 4. 311 & $16,2,14 \leftarrow 15,2,13$ & Ground & & 187712.225 & .5 \\
\hline $\mathrm{HN}^{14} \mathrm{C}^{12} \mathrm{~S}^{32}$ & 4- 311 & $16,3,14 \leftarrow 15,3,13$ & Ground & & 187736.68 & 1.0 \\
\hline $\mathrm{HN}^{14} \mathrm{C}^{12} \mathrm{~S}^{32}$ & 4- 311 & $16,3,13 \leftarrow 15,3,12$ & Ground & & 187736.68 & 1.0 \\
\hline $\mathrm{C}^{12} \mathrm{H}_{3} \mathrm{C}^{12}: \mathrm{C}^{12} \mathrm{H}$ & $4-1041$ & $11,8 \leftarrow 10,8$ & & & 187763.96 & .40 \\
\hline $\mathrm{C}^{12} \mathrm{H}_{3} \mathrm{C}^{12}: \mathrm{C}^{12} \mathrm{H}$ & $4-1041$ & $11,7 \leftarrow 10,7$ & & & 187817.95 & .40 \\
\hline $\mathrm{C}^{12} \mathrm{H}_{3} \mathrm{C}^{12} \vdots \mathrm{C}^{12} \mathrm{H}$ & 4-1041 & $11,6 \leftarrow 10,6$ & & & 187864.42 & .40 \\
\hline $\mathrm{C}^{12} \mathrm{H}_{3} \mathrm{C}^{12}: \mathrm{C}^{12} \mathrm{H}$ & 4-1041 & $11,5 \leftarrow 10,5$ & & & 187903.96 & .40 \\
\hline $\mathrm{C}^{12} \mathrm{H}_{3} \mathrm{C}^{12}: \mathrm{C}^{12} \mathrm{H}$ & 4-1041 & $11,4 \leftarrow 10,4$ & & & 187936.34 & .40 \\
\hline $\mathrm{C}^{12} \mathrm{H}_{3} \mathrm{C}^{12}: \mathrm{C}^{12} \mathrm{H}$ & 4-1041 & $11,3 \leftarrow 10,3$ & & & 187961.41 & .40 \\
\hline $\mathrm{HN}^{14} \mathrm{C}^{12} \mathrm{~S}^{32}$ & 4- 311 & $16,1,15 \leftarrow 15,1,14$ & Ground & & 187976.13 & .5 \\
\hline $\mathrm{C}^{12} \mathrm{H}_{3} \mathrm{C}^{12}: \mathrm{C}^{12} \mathrm{H}$ & $4-1041$ & $11,2 \leftarrow 10,2$ & & & 187979.34 & .40 \\
\hline $\mathrm{C}^{12} \mathrm{H}_{3} \mathrm{C}^{12}: \mathrm{C}^{12} \mathrm{H}$ & 4-1041 & $11,1 \leftarrow 10,1$ & & & 187990.02 & .40 \\
\hline $\mathrm{C}^{12} \mathrm{H}_{3} \mathrm{C}^{12}: \mathrm{C}^{12} \mathrm{H}$ & 4-1041 & $11,0 \leftarrow 10,0$ & & & 187993.69 & .40 \\
\hline $\mathrm{HN}^{14} \mathrm{C}^{12} \mathrm{~S}^{32}$ & 4- 311 & $16,0, \leftarrow 15,0$ & Excited & & 188001.0 & 1.0 \\
\hline $\mathrm{HN}^{14} \mathrm{C}^{12} \mathrm{~S}^{32}$ & 4. 311 & $16,2, \quad \leftarrow 15,2$, & Excited & & 188010.9 & 1.0 \\
\hline $\mathrm{HN}^{14} \mathrm{C}^{12} \mathrm{~S}^{32}$ & 4- 311 & $16,0, \leftarrow 15,0$ & Excited & & 188015.4 & 1.0 \\
\hline$H N^{14} C^{12} S^{32}$ & 4- 311 & $16, \quad \leftarrow 15$, & Excited & & 188131.7 & 1.0 \\
\hline $\mathrm{HN}^{14} \mathrm{C}^{12} \mathrm{~S}^{32}$ & 4. 311 & $16, \quad \leftarrow 15$, & Excited & & 188181.5 & 1.0 \\
\hline $\mathrm{Cl}^{35} \mathrm{C}^{12} \mathrm{~N}^{14}$ & 4- 171 & $16 \leftarrow 15$ & Ground & & 191039.44 & .40 \\
\hline $\mathrm{Cl}^{35} \mathrm{C}^{12} \mathrm{~N}^{14}$ & 4- 171 & $16 \leftarrow 15$ & Excited & & 191442.66 & \\
\hline $\mathrm{O}^{16} \mathrm{C}^{12} \mathrm{Se}^{82}$ & 4- 548 & $24 \leftarrow 23$ & Ground & & 191678.34 & .40 \\
\hline $\mathrm{Cl}^{35} \mathrm{C}^{12} \mathrm{~N}^{14}$ & 4- 171 & $16 \leftarrow 15$ & Excited & & 191681.13 & \\
\hline $\mathrm{O}^{16} \mathrm{C}^{12} \mathrm{Se}^{80}$ & 4. 547 & $24 \leftarrow 23$ & Ground & & 192810.17 & .40 \\
\hline $\mathrm{P}^{31} \mathrm{O}^{16} \mathrm{~F}_{3}^{19}$ & $4-1671$ & $21,20 \leftarrow 20,20$ & Ground & & 192899.61 & .40 \\
\hline $\mathrm{P}^{31} \mathrm{O}^{16} \mathrm{~F}_{3}^{19}$ & 4-1671 & $21,19 \leftarrow 20,19$ & Ground & & 192901.76 & .40 \\
\hline $\mathrm{P}^{31} \mathrm{O}^{16} \mathrm{~F}_{3}^{19}$ & $4-1671$ & $21,18 \leftarrow 20,18$ & Ground & & $192903: 75$ & .40 \\
\hline $\mathrm{P}^{31} \mathrm{O}^{16} \mathrm{~F}_{3}^{19}$ & 4-1671 & $21,17 \leftarrow 20,17$ & Ground & & 192905.66 & .40 \\
\hline $\mathrm{P}^{31} \mathrm{O}^{16} \mathrm{~F}_{3}^{19}$ & $4-1671$ & $21,16 \leftarrow 20,16$ & Ground & & 192907.43 & .40 \\
\hline $\mathrm{P}^{31} \mathrm{O}^{16} \mathrm{~F}_{3}^{19}$ & 4-1671 & $21,15 \leftarrow 20,15$ & Ground & & 192909.10 & .40 \\
\hline $\mathrm{P}^{31} \mathrm{O}^{16} \mathrm{~F}_{3}^{19}$ & 4-1671 & $21,14 \leftarrow 20,14$ & Ground & & 192910.67 & .40 \\
\hline $\mathrm{P}^{31} \mathrm{O}^{16} \mathrm{~F}_{3}^{19}$ & 4-1671 & $21,13 \leftarrow-20,13$ & Ground & & 192912.14 & .40 \\
\hline $\mathrm{P}^{31} \mathrm{O}^{16} \mathrm{~F}_{3}^{19}$ & 4-1671 & $21,12 \leftarrow-20,12$ & Ground & & 192913.48 & .40 \\
\hline
\end{tabular}




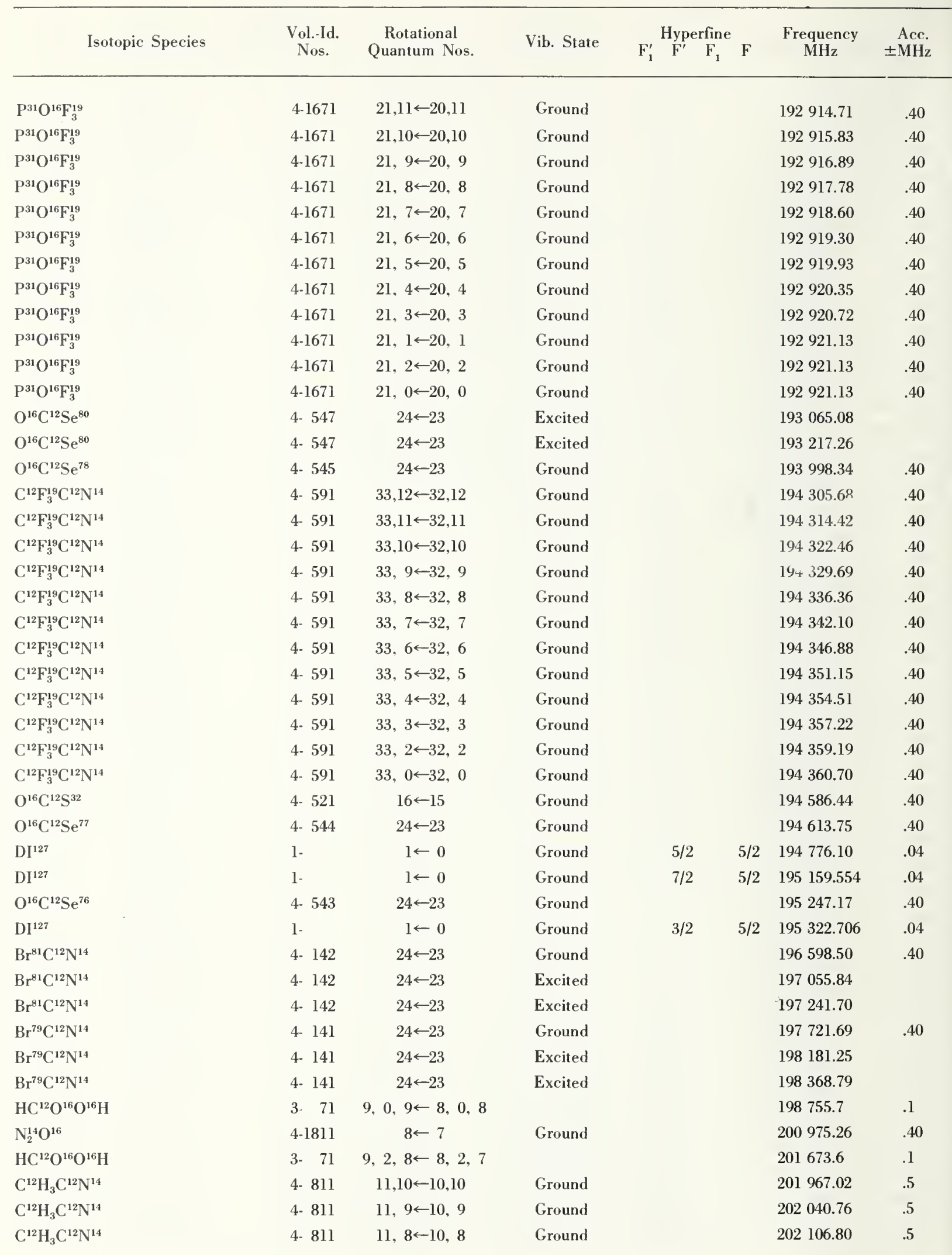




\begin{tabular}{|c|c|c|c|c|c|c|}
\hline \multirow{2}{*}{ Isotopic Species } & \multirow{2}{*}{$\begin{array}{l}\text { Vol.-Id. } \\
\text { Nos. }\end{array}$} & \multirow{2}{*}{$\begin{array}{c}\text { Rotational } \\
\text { Quantum Nos. }\end{array}$} & \multirow{2}{*}{ Vib. State } & Hyperfine & \multirow{2}{*}{$\begin{array}{c}\text { Frequency } \\
\text { MHz }\end{array}$} & \multirow{2}{*}{$\begin{aligned} & \text { Acc. } \\
\pm & \mathrm{MH} \%\end{aligned}$} \\
\hline & & & & $\begin{array}{llll}\mathrm{F}_{1}^{\prime} & \mathrm{F}^{\prime} & \mathrm{F}_{1} & \mathrm{~F}\end{array}$ & & \\
\hline $\mathrm{C}^{12} \mathrm{H}_{3} \mathrm{C}^{12} \mathrm{~N}^{14}$ & 4- 811 & $11,7 \leftarrow 10,7$ & Ground & & 202164.93 & .5 \\
\hline $\mathrm{C}^{12} \mathrm{H}_{3} \mathrm{C}^{12} \mathrm{~N}^{14}$ & 4- 811 & $11,6 \leftarrow 10,6$ & Ground & & 202215.87 & .5 \\
\hline $\mathrm{C}^{12} \mathrm{H}_{3} \mathrm{C}^{12} \mathrm{~N}^{14}$ & 4- 811 & $11,5 \leftarrow 10,5$ & Ground & & 202257.87 & .5 \\
\hline $\mathrm{C}^{12} \mathrm{H}_{3} \mathrm{C}^{12} \mathrm{~N}^{14}$ & 4- 811 & $11,4 \leftarrow 10,4$ & Ground & & 202293.78 & .5 \\
\hline $\mathrm{C}^{12} \mathrm{H}_{3} \mathrm{C}^{12} \mathrm{~N}^{14}$ & 4. 811 & $11,3 \leftarrow 10,3$ & Ground & & 202321.54 & .5 \\
\hline $\mathrm{C}^{12} \mathrm{H}_{3} \mathrm{C}^{12} \mathrm{~N}^{14}$ & 4- 811 & $11,2 \leftarrow 10,2$ & Ground & & 202340.10 & .5 \\
\hline $\mathrm{C}^{12} \mathrm{H}_{3} \mathrm{C}^{12} \mathrm{~N}^{14}$ & 4. 811 & $11,1 \leftarrow 10,1$ & Ground & & 202351.45 & .5 \\
\hline $\mathrm{C}^{12} \mathrm{H}_{3} \mathrm{C}^{12} \mathrm{~N}^{14}$ & 4- 811 & $11,0 \leftarrow 10,0$ & Ground & & 202355.61 & .5 \\
\hline $\mathrm{HC}^{12} \mathrm{O}^{16} \mathrm{O}^{16} \mathrm{H}$ & 3- 71 & $9,7, \leftarrow 8,7$, & & & 202409.6 & .1 \\
\hline $\mathrm{HC}^{12} \mathrm{O}^{16} \mathrm{O}^{16} \mathrm{H}$ & $3-71$ & $9,8, \leftarrow 8,8$, & & & 202413.8 & .1 \\
\hline $\mathrm{HC}^{12} \mathrm{O}^{16} \mathrm{O}^{16} \mathrm{H}$ & 3. 71 & $9,6, \leftarrow 8,6$, & & & 202418.2 & .1 \\
\hline $\mathrm{HC}^{12} \mathrm{O}^{16} \mathrm{O}^{16} \mathrm{H}$ & 3. 71 & $9,5,4 \leftarrow 8,5,3$ & & & 202449.9 & .1 \\
\hline $\mathrm{HC}^{12} \mathrm{O}^{16} \mathrm{O}^{16} \mathrm{H}$ & 3- 71 & $9,5,5 \leftarrow 8,5,4$ & & & 202449.9 & .1 \\
\hline $\mathrm{HC}^{12} \mathrm{O}^{16} \mathrm{O}^{16} \mathrm{H}$. & 3. 71 & $9,4,6 \leftarrow 8,4,5$ & & & 202527.3 & .1 \\
\hline $\mathrm{HC}^{12} \mathrm{O}^{16} \mathrm{O}^{16} \mathrm{H}$ & 3- 71 & $9,4,5 \leftarrow 8,4,4$ & & & 202530.0 & .1 \\
\hline $\mathrm{C}^{12} \mathrm{H}_{3} \mathrm{C}^{12} \mathrm{~N}^{14}$ & 4. 811 & $11,8 \leftarrow 10,8$ & Excited & & 202642.27 & .5 \\
\hline $\mathrm{HC}^{12} \mathrm{O}^{16} \mathrm{O}^{16} \mathrm{H}$ & $3-71$ & $9,3,7 \leftarrow 8,3,6$ & & & 202654.0 & .1 \\
\hline $\mathrm{C}^{12} \mathrm{H}_{3} \mathrm{C}^{12} \mathrm{~N}^{14}$ & 4- 811 & $11,10 \leftarrow 10,10$ & Excited & & 202655.71 & .5 \\
\hline $\mathrm{C}^{12} \mathrm{H}_{3} \mathrm{C}^{12} \mathrm{~N}^{14}$ & 4- 811 & $11,7 \leftarrow 10,7$ & Excited & & 202709.07 & .5 \\
\hline $\mathrm{C}^{12} \mathrm{H}_{3} \mathrm{C}^{12} \mathrm{~N}^{14}$ & 4- 811 & $11,9 \leftarrow 10,9$ & Excited & & 202721.62 & .5 \\
\hline $\mathrm{C}^{12} \mathrm{H}_{3} \mathrm{C}^{12} \mathrm{~N}^{14}$ & 4- 811 & $11,6 \leftarrow 10,6$ & Excited & & 202768.06 & .5 \\
\hline $\mathrm{C}^{12} \mathrm{H}_{3} \mathrm{C}^{12} \mathrm{~N}^{14}$ & 4- 811 & $11,1 \leftarrow 10,1$ & Excited & & 202769.94 & .5 \\
\hline $\mathrm{C}^{12} \mathrm{H}_{3} \mathrm{C}^{12} \mathrm{~N}^{14}$ & 4- 811 & $11,8 \leftarrow 10,8$ & Excited & & 202779.70 & .5 \\
\hline $\mathrm{HC}^{12} \mathrm{O}^{16} \mathrm{O}^{16} \mathrm{H}$ & $3-71$ & $9,3,6 \leftarrow 8,3,5$ & & & 202815.4 & .1 \\
\hline $\mathrm{C}^{12} \mathrm{H}_{3} \mathrm{C}^{12} \mathrm{~N}^{14}$ & 4- 811 & $11,5 \leftarrow 10,5$ & Excited & & 202819.06 & .5 \\
\hline $\mathrm{C}^{12} \mathrm{H}_{3} \mathrm{C}^{12} \mathrm{~N}^{14}$ & 4- 811 & $11,7 \leftarrow 10,7$ & Excited & & 202830.05 & .5 \\
\hline $\mathrm{C}^{12} \mathrm{H}_{3} \mathrm{C}^{12} \mathrm{~N}^{14}$ & 4. 811 & $11,4 \leftarrow 10,4$ & Excited & & 202862.38 & .5 \\
\hline $\mathrm{C}^{12} \mathrm{H}_{3} \mathrm{C}^{12} \mathrm{~N}^{14}$ & 4- 811 & $11,6 \leftarrow 10,6$ & Excited & & 202872.91 & .5 \\
\hline $\mathrm{C}^{12} \mathrm{H}_{3} \mathrm{C}^{12} \mathrm{~N}^{14}$ & 4- 811 & $11,3 \leftarrow 10,3$ & Excited & & 202897.68 & .5 \\
\hline $\mathrm{C}^{12} \mathrm{H}_{3} \mathrm{C}^{12} \mathrm{~N}^{14}$ & 4- 811 & $11,5 \leftarrow 10,5$ & Excited & & 202907.98 & .5 \\
\hline $\mathrm{C}^{12} \mathrm{H}_{3} \mathrm{C}^{12} \mathrm{~N}^{14}$ & 4- 811 & $11,2 \leftarrow 10,2$ & Excited & & 202924.94 & .5 \\
\hline $\mathrm{C}^{12} \mathrm{H}_{3} \mathrm{C}^{12} \mathrm{~N}^{14}$ & 4. 811 & $11,4 \leftarrow 10,4$ & Excited & & 202935.67 & .5 \\
\hline $\mathrm{C}^{12} \mathrm{H}_{3} \mathrm{C}^{12} \mathrm{~N}^{14}$ & 4- 811 & $11,1 \leftarrow 10,1$ & Excited & & 202943.39 & .5 \\
\hline $\mathrm{C}^{12} \mathrm{H}_{3} \mathrm{C}^{12} \mathrm{~N}^{14}$ & 4. 811 & $11,0 \leftarrow 10,0$ & Excited & & 202950.97 & .5 \\
\hline $\mathrm{C}^{12} \mathrm{H}_{3} \mathrm{C}^{12} \mathrm{~N}^{14}$ & 4- 811 & $11,3 \leftarrow 10,3$ & Excited & & 202956.31 & .5 \\
\hline $\mathrm{C}^{12} \mathrm{H}_{3} \mathrm{C}^{12} \mathrm{~N}^{14}$ & 4. 811 & $11,2 \leftarrow 10,2$ & Excited & & 202972.63 & .5 \\
\hline $\mathrm{C}^{12} \mathrm{H}_{3} \mathrm{C}^{12} \mathrm{~N}^{14}$ & 4- 811 & $11,1 \leftarrow 10,1$ & Excited & & 203161.23 & .5 \\
\hline $\mathrm{C}^{12} \mathrm{H}_{3} \mathrm{C}^{12} \mathrm{~N}^{14}$ & 4. 811 & $11, \leftarrow 10$ & Excited & & 203300. & .5 \\
\hline $\mathrm{C}^{12} \mathrm{H}_{3} \mathrm{C}^{12} \mathrm{~N}^{14}$ & 4- 811 & $11, \leftarrow 10$ & Excited & & 203 303.5' & .5 \\
\hline $\mathrm{C}^{12} \mathrm{H}_{3} \mathrm{C}^{12} \mathrm{~N}^{14}$ & 4- 811 & $11, \leftarrow 10$ & Excited & & 203409.5 & .5 \\
\hline $\mathrm{C}^{12} \mathrm{H}_{3} \mathrm{C}^{12} \mathrm{~N}^{14}$ & 4- 811 & $11, \leftarrow 10$ & Excited & & 203413.7 & .5 \\
\hline $\mathrm{C}^{12} \mathrm{H}_{3} \mathrm{C}^{12} \mathrm{~N}^{14}$ & 4- 811 & $11, \leftarrow 10$ & Excited & & 203441.2 & .5 \\
\hline $\mathrm{C}^{12} \mathrm{H}_{3} \mathrm{C}^{12} \mathrm{~N}^{14}$ & 4- 811 & $11, \leftarrow 10$ & Excited & & 203449.5 & .5 \\
\hline $\mathrm{C}^{12} \mathrm{H}_{3} \mathrm{C}^{12} \mathrm{~N}^{14}$ & 4. 811 & $11, \leftarrow 10$ & Excited & & 203485.0 & .5 \\
\hline $\mathrm{C}^{12} \mathrm{H}_{3} \mathrm{C}^{12} \mathrm{~N}^{14}$ & 4. 811 & $11, \leftarrow 10$ & Excited & & 203514.6 & .5 \\
\hline
\end{tabular}




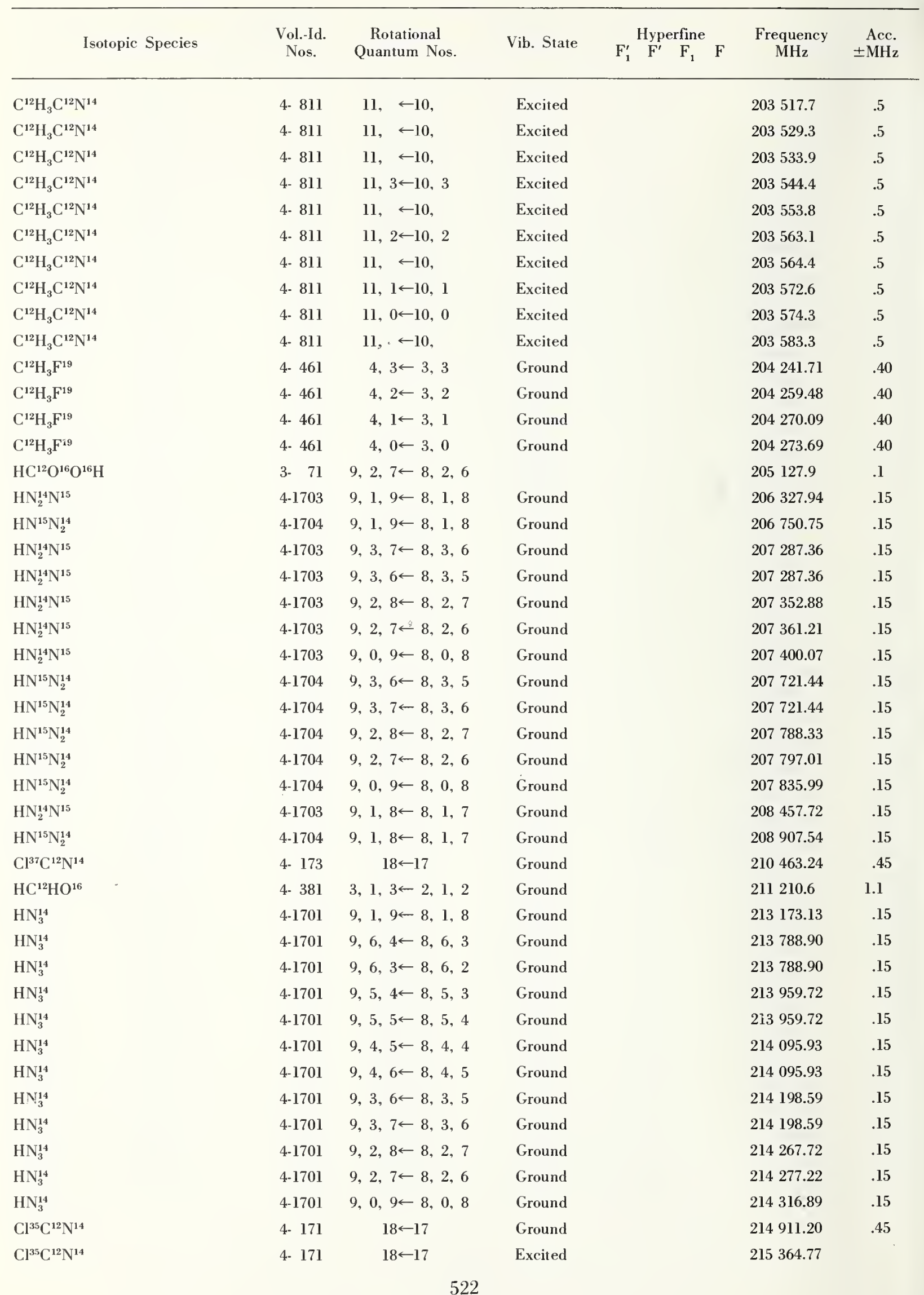


Vol.-Id. Rotational

Nos. Quantum Nos.
Vib. State $\mathrm{F}^{\prime} \stackrel{\text { Hyperfine }}{\mathrm{F}} \mathrm{F}$ Frequency Ace.

\section{$\mathrm{HN}_{3}^{14}$}

$\mathrm{O}^{16} \mathrm{C}^{12} \mathrm{Se}^{82}$

$\mathrm{Cl}^{35} \mathrm{C}^{12} \mathrm{~N}^{14}$

$\mathrm{Cl}^{37} \mathrm{C}^{12} \mathrm{~N}^{14}$

$\mathrm{Cl}^{37} \mathrm{C}^{12} \mathrm{~N}^{14}$

$\mathrm{H}_{2} \mathrm{~S}^{32}$

$\mathrm{O}^{16} \mathrm{C}^{12} \mathrm{Se}^{80}$

$\mathrm{O}^{16} \mathrm{C}^{12} \mathrm{Se}^{80}$

$\mathrm{DC}^{12} \mathrm{~N}^{14}$

$\mathrm{O}^{16} \mathrm{C}^{12} \mathrm{Se}^{80}$

$\mathrm{HC}^{12} \mathrm{HO}^{16}$

$\mathrm{O}^{16} \mathrm{C}^{12} \mathrm{Se}^{78}$

$\mathrm{HC}^{12} \mathrm{HO}^{16}$

$\mathrm{HC}^{12} \mathrm{HO}^{16}$

$\mathrm{O}^{16} \mathrm{C}^{12} \mathrm{~S}^{32}$

$\mathrm{O}^{16} \mathrm{C}^{12} \mathrm{Se}^{77}$

$\mathrm{O}^{16} \mathrm{C}^{12} \mathrm{Se}^{76}$

$\mathrm{C}^{12} \mathrm{H}_{3} \mathrm{C}^{12} \mathrm{~N}^{14}$

$\mathrm{C}^{12} \mathrm{H}_{3} \mathrm{C}^{12} \mathrm{~N}^{14}$

$\mathrm{C}^{12} \mathrm{H}_{3} \mathrm{C}^{12} \mathrm{~N}^{14}$

$\mathrm{C}^{12} \mathrm{H} \mathrm{C}^{12} \mathrm{~N}^{14}$

$\mathrm{C}^{12} \mathrm{H}_{3} \mathrm{C}^{12} \mathrm{~N}^{14}$

$\mathrm{C}^{12} \mathrm{H}_{3} \mathrm{C}^{12} \mathrm{~N}^{14}$

$\mathrm{C}^{12} \mathrm{H}_{3} \mathrm{C}^{12} \mathrm{~N}^{14}$

$\mathrm{C}^{12} \mathrm{H}_{3} \mathrm{C}^{12} \mathrm{~N}^{14}$

$\mathrm{C}^{12} \mathrm{H}_{3} \mathrm{C}^{12} \mathrm{~N}^{14}$

$\mathrm{C}^{12} \mathrm{H}_{3} \mathrm{C}^{12} \mathrm{~N}^{14}$

$\mathrm{Br}^{81} \mathrm{C}^{12} \mathrm{~N}^{14}$

$\mathrm{TCl}^{37}$

$\mathrm{TCl}^{37}$

$\mathrm{C}^{12} \mathrm{H}_{3} \mathrm{C}^{12} \mathrm{~N}^{14}$

$\mathrm{TCl}^{37}$

$\mathrm{C}^{12} \mathrm{H}_{3} \mathrm{C}^{12} \mathrm{~N}^{14}$

$\mathrm{C}^{12} \mathrm{H}_{3} \mathrm{C}^{12} \mathrm{~N}^{14}$

$\mathrm{C}^{12} \mathrm{H}_{3} \mathrm{C}^{12} \mathrm{~N}^{14}$

$\mathrm{C}^{12} \mathrm{H}_{3} \mathrm{C}^{12} \mathrm{~N}^{14}$

$\mathrm{C}^{12} \mathrm{H}_{3} \mathrm{C}^{12} \mathrm{~N}^{14}$

$\mathrm{C}^{12} \mathrm{H}_{3} \mathrm{C}^{12} \mathrm{~N}^{14}$

$\mathrm{C}^{12} \mathrm{H}_{3} \mathrm{C}^{12} \mathrm{~N}^{14}$

$\mathrm{C}^{12} \mathrm{H}_{3} \mathrm{C}^{12} \mathrm{~N}^{14}$

$\mathrm{C}^{12} \mathrm{H}_{3} \mathrm{C}^{12} \mathrm{~N}^{14}$

$\mathrm{C}^{12} \mathrm{H}_{3} \mathrm{C}^{12} \mathrm{~N}^{14}$

$\mathrm{C}^{12} \mathrm{H}_{3} \mathrm{C}^{12} \mathrm{~N}^{14}$

$\mathrm{C}^{12} \mathrm{H}_{3} \mathrm{C}^{12} \mathrm{~N}^{14}$

$\mathrm{C}^{12} \mathrm{H}_{3} \mathrm{C}^{12} \mathrm{~N}^{14}$
4-1701

4- 548

$9,1,8 \leftarrow 8,1,7$

Ground

$27 \leftarrow 26$

Ground

4- 171

$18 \leftarrow 17$

4- 173

$18 \leftarrow 17$

$18 \leftarrow 17$

Excited

4. 173

4-1724

4- 547

$2,2,0 \leftarrow 2,1,1$

Excited

Excited

4- 547

$27 \leftarrow 26$

Ground

4. 292

$27 \leftarrow 26$

Ground

Excited

4. 547

$3 \leftarrow 2$

Ground

Excited

4. 381

4- 545

4- 381

4- 381

4. 521

4- 544

4- 543

4- 811

4. 811

$27 \leftarrow 26$

Ground

$3,0,3 \leftarrow 2,0,2$

$27 \leftarrow 26$

Ground

$3,2,2 \leftarrow 2,2,1$

Ground

$3,2,0 \leftarrow 2,2,0$

Ground

$18 \leftarrow 17$

$27 \leftarrow 26$

$27 \leftarrow 26$

$12,9 \leftarrow 11,9$

$12,8 \leftarrow 11,8$

$12,7 \leftarrow 11,7$

$12,6 \leftarrow 11,6$

4- 811

4. 811

$12,5 \leftarrow 11,5$

4- 811

$12,4 \leftarrow 11,4$

4- 811

$12,3 \leftarrow 11,3$

4- 811

$12,2 \leftarrow 11,2$

4. 811

$12,1 \leftarrow 11,1$

4- 811

4. 142

$12,0 \leftarrow 11,0$

1 -

1 -

4- 811

1 -

4- 811

4- 811

4. 811

$27 \leftarrow 26$

$1 \leftarrow 0$

$1 \leftarrow 0$

4. 811

4- 811

4- 81$]$

4- 811

4. 811

4. 811

4- 811

4- 811

4- 811

4- 811
$12,1 \leftarrow 11,1$

$1 \leftarrow 0$

$12,5 \leftarrow 11,5$

$12,7 \leftarrow 11,7$

$12,4 \leftarrow 11,4$

$12,6 \leftarrow 11,6$

$12,3 \leftarrow 11,3$

$12,5 \leftarrow 11,5$

$12,2 \leftarrow 11,2$

$12,4 \leftarrow 11,4$

$12,1 \leftarrow 11,1$

$12,0 \leftarrow 11,0$

$12,3 \leftarrow 11,3$

$12,2 \leftarrow 11,2$

$12,1 \leftarrow 11,1$
Ground

Ground

Ground

Ground

Ground

Ground

Ground

Ground

Ground

Ground

Ground

Ground

Ground

Ground

Ground

Ground

Excited

Ground

Excited

Excited

Excited

Excited

Excited

Excited

Excited

Excited

Excitcd

Excited

Excited

Excited

Excited
215446.80

.15

215627.18

.45

215633.04

215769.51

216027.44

216710.42

216900.38

.45

217186.90

217238.40

.45

217358.18

218221.6

1.1

218236.97

.45

218475.1

1.1

218759.4

$218903.27 \quad .45$

$218929.21 \quad .45$

$219641.79 \quad .45$

$220403.96 \quad .5$

$220476.04 \quad .5$

$220539.30 \quad .5$

$220594.50 \quad .5$

$220641.12 \quad .5$

$220679.32 \quad .5$

$220709.08 \quad .5$

$220730.27 \quad .5$

$220742.99 \quad .5$

$220747.24 \quad .5$

$\begin{array}{lll}221 & 158.86 \quad .45\end{array}$

$3 / 2$

$221 \quad 184.82 \quad .4$

$5 / 2 \quad 3 / 2 \quad 221198.00 \quad$.4

$221200.23 \quad .5$

$1 / 2$

$3 / 2$

$221208.69 \quad 4$

$221252.93 \quad .5$

$221265.54 \quad .5$

$221299.88 \quad .5$

$221311.95 \quad .5$

$221338.22 \quad .5$

$221350.37 \quad .5$

$221367.67 \quad .5$

$221380.74 \quad .5$

$221387.30 \quad .5$

$221394.15 \quad .5$

$221403.82 \quad .5$

$221422.37 \quad .5$

$221625.91 \quad .5$ 


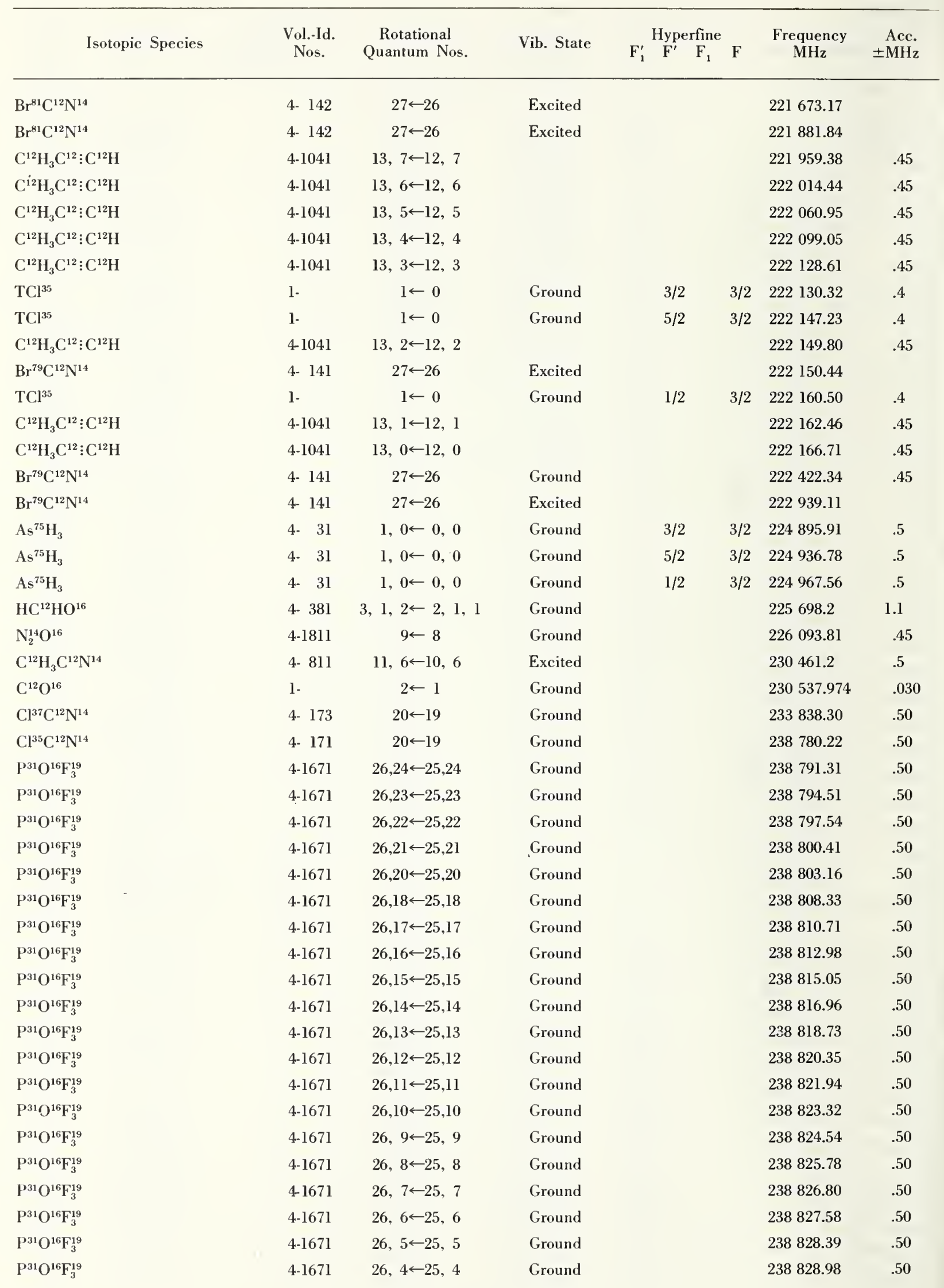


Vol.-Id. Rotational

Nos. Quantum Nos.
Vib. State $F_{1}^{\prime} F^{\prime} F_{1} \quad F$
Frequeney $\mathrm{MH}_{2} \pm \mathrm{MH}$ \%

\section{$\mathrm{P}^{31} \mathrm{O}^{16} \mathrm{~F}_{3}^{19}$ \\ $\mathrm{P}^{31} \mathrm{O}^{16} \mathrm{~F}_{3}^{19}$ \\ $\mathrm{P}^{31} \mathrm{O}^{16} \mathrm{~F}_{3}^{19}$ \\ $\mathrm{P}^{31} \mathrm{O}^{16} \mathrm{~F}_{3}^{19}$ \\ $\mathrm{C}^{12} \mathrm{H}_{3} \mathrm{C}^{12}: \mathrm{C}^{12} \mathrm{H}$ \\ $\mathrm{C}^{12} \mathrm{H}_{3} \mathrm{C}^{12}: \mathrm{C}^{12} \mathrm{H}$ \\ $\mathrm{C}^{12} \mathrm{H}_{3} \mathrm{C}^{12}: \mathrm{C}^{12} \mathrm{H}$ \\ $\mathrm{C}^{12} \mathrm{H}_{3} \mathrm{C}^{12}: \mathrm{C}^{12} \mathrm{H}$ \\ $\mathrm{C}^{12} \mathrm{H}_{3} \mathrm{C}^{12}: \mathrm{C}^{12} \mathrm{H}$ \\ $\mathrm{C}^{12} \mathrm{H}_{3} \mathrm{C}^{12}: \mathrm{C}^{12} \mathrm{H}$ \\ $\mathrm{C}^{12} \mathrm{H}_{3} \mathrm{C}^{12}: \mathrm{C}^{12} \mathrm{H}$ \\ $\mathrm{Cl}^{35} \mathrm{C}^{12} \mathrm{~N}^{14}$}

$\mathrm{O}^{16} \mathrm{C}^{12} \mathrm{Se}^{82}$

$\mathrm{Cl}^{35} \mathrm{C}^{12} \mathrm{~N}^{14}$

$\mathrm{O}^{16} \mathrm{C}^{12} \mathrm{Se}^{80}$

$\mathrm{HDO}^{16}$

$\mathrm{N}^{15} \mathrm{O}^{16}$

$\mathrm{N}^{15} \mathrm{O}^{16}$

$\mathrm{N}^{15} \mathrm{O}^{16}$

$\mathrm{N}^{15} \mathrm{O}^{16}$

$\mathrm{O}^{16} \mathrm{C}^{12} \mathrm{Se}^{78}$

$\mathrm{O}^{16} \mathrm{C}^{12} \mathrm{~S}^{32}$

$\mathrm{O}^{16} \mathrm{C}^{12} \mathrm{Se}^{76}$

$\mathrm{Br}^{81} \mathrm{C}^{12} \mathrm{~N}^{14}$

$\mathrm{Br}^{79} \mathrm{C}^{12} \mathrm{~N}^{14}$

$\mathrm{Br}^{79} \mathrm{C}^{12} \mathrm{~N}^{14}$

$\mathrm{Br}^{79} \mathrm{C}^{12} \mathrm{~N}^{14}$

$\mathrm{N}^{14} \mathrm{O}^{16}$

$\mathrm{N}^{14} \mathrm{O}^{16}$

$\mathrm{N}^{14} \mathrm{O}^{16}$

$\mathrm{N}^{14} \mathrm{O}^{16}$

$\mathrm{N}^{14} \mathrm{O}^{16}$

$\mathrm{N}^{14} \mathrm{O}^{16}$

$\mathrm{N}^{14} \mathrm{O}^{16}$

$\mathrm{N}^{14} \mathrm{O}^{16}$

$\mathrm{N}^{14} \mathrm{O}^{16}$

$\mathrm{N}^{14} \mathrm{O}^{16}$

$\mathrm{N}_{2}^{14} \mathrm{O}^{16}$

$\mathrm{DBr}^{81}$

$\mathrm{DBr}^{81}$

$\mathrm{DBr}^{79}$

$\mathrm{DBr}^{81}$

$\mathrm{DBr}^{79}$

$\mathrm{DBr}^{79}$

$\mathrm{Cl}^{37} \mathrm{C}^{12} \mathrm{~N}^{14}$

$\begin{array}{lll}\text { 4-1671 } & 26,3 \leftarrow 25,3 & \text { Ground } \\ 4-1671 & 26,2 \leftarrow 25,2 & \text { Ground } \\ 4-1671 & 26,1 \leftarrow 25,1 & \text { Ground } \\ 4-1671 & 26,0 \leftarrow 25,0 & \text { Ground } \\ 4-1041 & 14,6 \leftarrow 13,6 & \\ 4-1041 & 14,5 \leftarrow-13,5 & \\ 4-1041 & 14,4 \leftarrow 13,4 & \\ 4-1041 & 14,3 \leftarrow 13,3 & \\ 4-1041 & 14,2 \leftarrow 13,2 & \\ 4-1041 & 14,1 \leftarrow-13,1 & \\ 4-1041 & 14,0 \leftarrow 13,0 & \end{array}$

4. 171

4. 548

$20 \leftarrow 19$

4- 171

$30 \leftarrow 29$

Excited

4. 547

4-1712

1 -

$1-$

$1-$

1.

4. 545

$20 \leftarrow 19$

Ground

Excited

Ground

$2,1,1 \leftarrow 2,1,2$

Ground

Ground

Ground

Ground

Ground

Ground

4- 521

4- 543

4- 142

4- 141

4. 141

4. 141

1 -

1 .

1 -

$1-$

1 -

1 -

1.

1 -

1 .

1 -

4-1811

1 -

1 .

1 .

1 -

1-

1 -

4- 173

$$
5 / 2 \leftarrow 3 / 2
$$

$5 / 2 \leftarrow 3 / 2$

$5 / 2 \leftarrow 3 / 2$

$$
30 \leftarrow 29
$$

$20 \leftarrow 19$

$30 \leftarrow 29$

$30 \leftarrow 29$

$30 \leftarrow 29$

$30 \leftarrow 29$

$30 \leftarrow 29$

$5 / 2 \leftarrow 3 / 2$

$5 / 2 \leftarrow 3 / 2$

$5 / 2 \leftarrow 3 / 2$

$5 / 2 \leftarrow 3 / 2$

$5 / 2 \leftarrow 3 / 2$

$5 / 2 \leftarrow 3 / 2$

$5 / 2 \leftarrow 3 / 2$

$5 / 2 \leftarrow 3 / 2$

$5 / 2 \leftarrow 3 / 2$

$5 / 2 \leftarrow 3 / 2$

$10 \leftarrow 9$

$1 \leftarrow 0$

$1 \leftarrow 0$

$1 \leftarrow 0$

$1 \leftarrow 0$

$1 \leftarrow 0$

$1 \leftarrow 0$

$22 \leftarrow 21$
Excited

Ground

Ground

Ground

Ground

Ground

Ground

Ground

Ground

Ground

Ground

Ground

Ground

Ground

Ground

Ground

Ground

Ground

Ground
$238829.43 \quad .50$

$238829.94 \quad .50$

$238829.94 \quad .50$

$238829.94 \quad .50$

$239087.81 \quad .50$

$239138.04 \quad .50$

$239178.97 \quad .50$

$239210.93 \quad .50$

$239233.92 \quad .50$

$239247.62 \quad .50$

$239252.14 \quad .50$

239283.85

$239572.08 \quad .50$

239582.25

$240986.62 \quad .50$

241561.3

$241715.40 \quad 0.50$

$241723.79 \quad 0.50$

$242046.03 \quad 0.50$

$242060.35 \quad 0.50$

$242471.47 \quad .50$

$243218.09 \quad .50$

$244032.33 \quad .50$

$245714.32 \quad .50$

$247117.75 \quad .50$

247691.48

247925.95

50
50
50
50
50
50
50
50
50
50
50
50
50
50
50
50
50




\begin{tabular}{|c|c|c|c|c|c|c|c|}
\hline Isotopic Species & $\begin{array}{l}\text { Vol.-Id. } \\
\text { Nos. }\end{array}$ & $\begin{array}{c}\text { Rotational } \\
\text { Quantum Nos. }\end{array}$ & Vib. State & 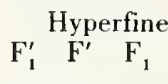 & $F$ & $\begin{array}{l}\text { Frequency } \\
\quad \mathrm{MHz}\end{array}$ & $\begin{aligned} & \text { Acc. } \\
\pm & \mathrm{MHz}\end{aligned}$ \\
\hline $\mathrm{N}^{14} \mathrm{O}^{16}$ & 1. & $5 / 2 \leftarrow 3 / 2$ & Ground & $7 / 2$ & $5 / 2$ & 257822.06 & 0.3 \\
\hline $\mathrm{N}^{14} \mathrm{O}^{16}$ & 1 - & $5 / 2 \leftarrow 3 / 2$ & Ground & $7 / 2$ & $5 / 2$ & 257825.02 & 0.3 \\
\hline $\mathrm{N}^{14} \mathrm{O}^{16}$ & $1-$ & $5 / 2 \leftarrow 3 / 2$ & Ground & $5 / 2$ & $3 / 2$ & 257852.87 & 0.3 \\
\hline $\mathrm{N}^{14} \mathrm{O}^{16}$ & $1-$ & $5 / 2 \leftarrow 3 / 2$ & Ground & $5 / 2$ & $3 / 2$ & 257855.36 & 0.3 \\
\hline $\mathrm{N}^{14} \mathrm{O}^{16}$ & 1 . & $5 / 2 \leftarrow 3 / 2$ & Ground & $3 / 2$ & $1 / 2$ & 257867.67 & 0.3 \\
\hline $\mathrm{N}^{14} \mathrm{O}^{16}$ & 1 . & $5 / 2 \leftarrow 3 / 2$ & Ground & $3 / 2$ & $1 / 2$ & 257870.35 & 0.3 \\
\hline $\mathrm{Cl}^{35} \mathrm{C}^{12} \mathrm{~N}^{14}$ & 4- 171 & $22 \leftarrow 21$ & Ground & & & 262645.82 & .55 \\
\hline $\mathrm{O}^{16} \mathrm{C}^{12} \mathrm{Se}^{82}$ & 4. 548 & $33 \leftarrow 32$ & Ground & & & 263512.90 & .55 \\
\hline $\mathrm{O}^{16} \mathrm{C}^{12} \mathrm{Se}^{80}$ & 4- 547 & $33 \leftarrow 32$ & Ground & & & 265068.60 & .55 \\
\hline $\mathrm{HC}^{12} \mathrm{~N}^{14}$ & 4- 291 & $3 \leftarrow 2$ & Ground & & & 265886.18 & .55 \\
\hline $\mathrm{O}^{16} \mathrm{C}^{12} \mathrm{Se}^{78}$ & 4. 545 & $33 \leftarrow 32$ & Ground & & & 266701.93 & .55 \\
\hline $\mathrm{P}^{31} \mathrm{H}_{3}$ & $4-1781$ & $1,0 \leftarrow 0,0$ & Ground & & & 266944.69 & .55 \\
\hline $0^{16} \mathrm{C}^{12} \mathrm{~S}^{32}$ & 4- 521 & $22 \leftarrow 21$ & Ground & & & 267529.56 & .55 \\
\hline $\mathrm{Br}^{81} \mathrm{C}^{12} \mathrm{~N}^{14}$ & 4- 142 & $33 \leftarrow 32$ & Ground & & & 270263.95 & .55 \\
\hline $\mathrm{Br}^{79} \mathrm{C}^{12} \mathrm{~N}^{14}$ & 4- 14.1 & $33 \leftarrow 32$ & Ground & & & 271807.59 & .55 \\
\hline $\mathrm{N}_{2}^{14} \mathrm{O}^{16}$ & 4-1811 & $11 \leftarrow 10$ & Ground & & & 276327.50 & .55 \\
\hline $\mathrm{P}^{31} \mathrm{D}_{3}$ & $4-1784$ & $2,0 \leftarrow 1,0$ & Ground & & & 277857.08 & .60 \\
\hline $\mathrm{Cl}^{37} \mathrm{C}^{12} \mathrm{~N}^{14}$ & 4. 173 & $24 \leftarrow 23$ & Ground & & & 280578.92 & .60 \\
\hline $\mathrm{Cl}^{35} \mathrm{C}^{12} \mathrm{~N}^{14}$ & 4- 171 & $24 \leftarrow 23$ & Ground & & & 286507.95 & .60 \\
\hline $\mathrm{DC}^{12} \mathrm{~N}^{14}$ & 4- 292 & $4 \leftarrow 3$ & Ground & & & 286644.67 & .60 \\
\hline $\mathrm{O}^{16} \mathrm{C}^{12} \mathrm{Se}^{80}$ & 4- 547 & $36 \leftarrow 35$ & Ground & & & 289145.50 & .60 \\
\hline $\mathrm{O}^{16} \mathrm{C}^{12} \mathrm{~S}^{32}$ & 4- 521 & $24 \leftarrow 23$ & Ground & & & 291839.22 & .60 \\
\hline $\mathrm{Br}^{81} \mathrm{C}^{12} \mathrm{~N}^{14}$ & 4- 142 & $36 \leftarrow 35$ & Ground & & & 294807.52 & .60 \\
\hline $\mathrm{Br}^{79} \mathrm{C}^{12} \mathrm{~N}^{14}$ & 4- 141 & $36 \leftarrow 35$ & Ground & & & 296490.86 & .60 \\
\hline $\mathrm{Cl}_{2}^{\mathrm{b}} \mathrm{O}^{16}$ & $4-1484$ & $9,0,9 \leftarrow 8,1,8$ & Ground & & & 299984.05 & \\
\hline $\mathrm{N}_{2}^{14} \mathrm{O}^{16}$ & $4-1811$ & $12 \leftarrow 11$ & Ground & & & 301442.38 & .60 \\
\hline $\mathrm{Cl}^{37} \mathrm{C}^{12} \mathrm{~N}^{14}$ & 4- 173 & $26 \leftarrow 25$ & Ground & & & 303943.87 & .65 \\
\hline $\mathrm{N}^{14} \mathrm{D}_{3}$ & $4-1775$ & $1,0 \leftarrow 0,0$ & Ground & 1 & 1 & 306735.0 & \\
\hline $\mathrm{N}^{14} \mathrm{D}_{3}$ & $4-1775$ & $1,0 \leftarrow 0,0$ & Ground & 2 & 1 & 306735.0 & \\
\hline $\mathrm{N}^{14} \mathrm{D}_{3}$ & $4-1775$ & $1,0 \leftarrow 0,0$ & Ground & 0 & 1 & 306735.0 & \\
\hline $\mathrm{N}^{14} \mathrm{D}_{3}$ & $4-1775$ & $1,0 \leftarrow 0,0$ & Ground & 1 & 1 & 309908.24 & \\
\hline $\mathrm{N}^{14} \mathrm{D}_{3}$ & $4-1775$ & $1,0 \leftarrow 0,0$ & Ground & 2 & 1 & 309909.54 & \\
\hline $\mathrm{N}^{14} \mathrm{D}_{3}$ & $4-1775$ & $1,0 \leftarrow 0,0$ & Ground & 0 & 1 & 309911.41 & \\
\hline $\mathrm{Cl}^{35} \mathrm{C}^{12} \mathrm{~N}^{14}$ & 4- 171 & $26 \leftarrow 25$ & Ground & & & 310365.90 & .65 \\
\hline $\mathrm{O}^{16} \mathrm{C}^{12} \mathrm{Se}^{80}$ & 4- 547 & $39 \leftarrow 38$ & Ground & & & 313217.57 & .65 \\
\hline $\mathrm{O}^{16} \mathrm{C}^{12} \mathrm{~S}^{32}$ & 4. 521 & $26 \leftarrow 25$ & Ground & & & 316144.7 & 1.0 \\
\hline $\mathrm{Br}^{81} \mathrm{C}^{12} \mathrm{~N}^{14}$ & 4- 142 & $39 \leftarrow 38$ & Ground & & & 319345.52 & 1.0 \\
\hline $\mathrm{Br}^{79} \mathrm{C}^{12} \mathrm{~N}^{14}$ & 4. 141 & $39 \longleftarrow 38$ & Ground & & & 321167.1 & .65 \\
\hline $\mathrm{DCl}^{37}$ & $1-$ & $1 \leftarrow 0$ & Ground & $3 / 2$ & $3 / 2$ & 322339.09 & .13 \\
\hline $\mathrm{DCl}^{37}$ & 1 - & $1 \leftarrow 0$ & Ground & $5 / 2$ & $3 / 2$ & 322352.33 & .13 \\
\hline $\mathrm{DCl}^{37}$ & 1 . & $1 \leftarrow 0$ & Ground & $1 / 2$ & $3 / 2$ & 322362.94 & .13 \\
\hline $\mathrm{DCl}^{35}$ & 1 . & $1 \leftarrow 0$ & Ground & $3 / 2$ & $3 / 2$ & 323282.28 & .13 \\
\hline $\mathrm{DCl}^{35}$ & $1-$ & $1 \leftarrow 0$ & Ground & $5 / 2$ & $3 / 2$ & 323299.17 & .13 \\
\hline $\mathrm{DCl}^{35}$ & $1-$ & $1 \leftarrow 0$ & Ground & $1 / 2$ & $3 / 2$ & 323312.52 & .13 \\
\hline $\mathrm{Cl}^{35} \mathrm{C}^{12} \mathrm{~N}^{14}$ & 4- 171 & $28 \leftarrow 27$ & Ground & & & 334219.5 & 1.5 \\
\hline
\end{tabular}


Vol.-Id. Rotational

Nos. Quantum Nos.
Vib. State

Hyperfine $\begin{array}{llll}F_{1}^{\prime} & F^{\prime} & F_{1} & F\end{array}$
Frequency

$\mathrm{MHz} \pm \mathrm{MHz}$

\begin{tabular}{|c|c|c|c|c|c|c|c|}
\hline $\mathrm{O}^{16} \mathrm{C}^{12} \mathrm{~S}^{32}$ & 4. 521 & $28 \leftarrow 27$ & Ground & & & $340 \quad 449.2$ & 1.0 \\
\hline $\mathrm{Br}^{81} \mathrm{C}^{12} \mathrm{~N}^{14}$ & 4- 142 & $42 \leftarrow 41$ & Ground & & & 343873.0 & 1.5 \\
\hline $\mathrm{C}^{12} \mathrm{O}^{16}$ & $1-$ & $3 \leftarrow 2$ & Ground & & & 345795.900 & .090 \\
\hline $\mathrm{Br}^{79} \mathrm{C}^{12} \mathrm{~N}^{14}$ & 4. 141 & $42 \leftarrow 41$ & Ground & & & 345837.0 & 1.0 \\
\hline $\mathrm{O}^{16} \mathrm{C}^{12} \mathrm{~S}^{32}$ & 4- 521 & $30 \leftarrow 29$ & Ground & & & 364747.5 & 1.5 \\
\hline $\mathrm{HI}^{127}$ & $1-$ & $1 \leftarrow 0$ & Ground & $5 / 2$ & $5 / 2$ & 385000.11 & .7 \\
\hline $\mathrm{HI}^{127}$ & $1-$ & $1 \leftarrow 0$ & Ground & $7 / 2$ & $5 / 2$ & 385385.52 & .7 \\
\hline $\mathrm{HI}^{127}$ & 1. & $1 \leftarrow 0$ & Ground & $3 / 2$ & $5 / 2$ & 385548.80 & .7 \\
\hline $\mathrm{O}^{16} \mathrm{C}^{12} \mathrm{~S}^{32}$ & 4- 521 & $32 \leftarrow 31$ & Ground & & & 389041. & 2.0 \\
\hline $\mathrm{Br}^{81} \mathrm{C}^{12} \mathrm{~N}^{14}$ & 4- 142 & $48 \leftarrow 47$ & Ground & & & 392907.0 & .9 \\
\hline $\mathrm{Br}^{81} \mathrm{C}^{12} \mathrm{~N}^{14}$ & 4- 142 & $52 \longleftarrow 51$ & Ground & & & 425575.9 & .9 \\
\hline $\mathrm{Br}^{81} \mathrm{C}^{12} \mathrm{~N}^{14}$ & 4- 142 & $56 \longleftarrow 55$ & Ground & & & 458226.2 & .9 \\
\hline $\mathrm{O}^{16} \mathrm{C}^{12} \mathrm{~S}^{32}$ & 4- 521 & $36 \leftarrow 35$ & Ground & & & $486 \quad 184.2$ & \\
\hline $\mathrm{O}^{16} \mathrm{C}^{12} \mathrm{~S}^{32}$ & 4. 521 & $42 \longleftarrow 41$ & Ground & & & 5104.57 .3 & \\
\hline
\end{tabular}




\section{Index}

Vol.-Id. No. Formula Name

1

BrCl

$\mathrm{BrF}$

CS

$\mathrm{CO}$

$\mathrm{CsBr}$

$\mathrm{CsCl}$

$\mathrm{CsF}$

CsI

FCl

$\mathrm{GaBr}$

GaCl

GaI

$\mathrm{HBr}$

$\mathrm{HCl}$

HI

$\mathrm{HO}$

$\mathrm{InBr}$

InCl

InI

ICl

$\mathrm{LiBr}$

LiI

$\mathrm{NO}$

$\mathrm{O}_{2}$

$\mathrm{KBr}$

$\mathrm{KCl}$

KI

$\mathrm{RbBr}$

RbCl

RbI

$\mathrm{NaBr}$

$\mathrm{NaCl}$

$\mathrm{NaI}$

TIBr

TICl

TIF

TII
$\mathrm{F}_{2} \mathrm{O}_{2}$

$\mathrm{F}_{2} \mathrm{NNF}_{2}$

$\mathrm{HNO}_{3}$

$\mathrm{HOOH}$

$\mathrm{H}_{2} \mathrm{NNH}_{2}$

$\mathrm{CF}_{3} \mathrm{SF}_{5}$

$\mathrm{HCOOH}$

$\mathrm{CH}_{3} \mathrm{AsF}_{2}$

$\mathrm{CH}_{3} \mathrm{BF}_{2}$

$\mathrm{CH}_{3} \mathrm{GeCl}_{3}$

$\mathrm{CH}_{3} \mathrm{SiCl}_{3}$

$\mathrm{CH}_{3} \mathrm{GeF}_{3}$
Bromine monochloride Bromine monofluoride Carbon monosulfide Carbon monoxide Cesium bromide Cesium chloride Cesium fluoride Cesium iodide Fluorine chloride Gallium monobromide Gallium monochloride Gallium monoiodide Hydrogen bromide Hydrogen chloride Hydrogen iodide Hydroxyl radical Indium bromide Indium chloride Indium iodide Iodine monochloride Lithium bromide Lithium iodide Nitric oxide

Oxygen

Potassium bromide

Potassium chloride

Potassium iodide

Rubidium bromide

Rubidium chloride

Rubidium iodide

Sodium bromide

Sodium chloride

Sodium iodide

Thallium bromide

Thallium chloride

Thallium fluoride

Thallium iodide

Dioxygen difluoride

Tetrafluorohydrazine

Nitric acid

Hydrogen peroxide

Hydrazine

Trifluoromethyl sulfur pentafluoride

Formic acid

Methyldifluoroarsine

Methyldifluoroborane

Methyltrichlorogermane

Methyltrichlorosilane

Methyltrifluorogermane 


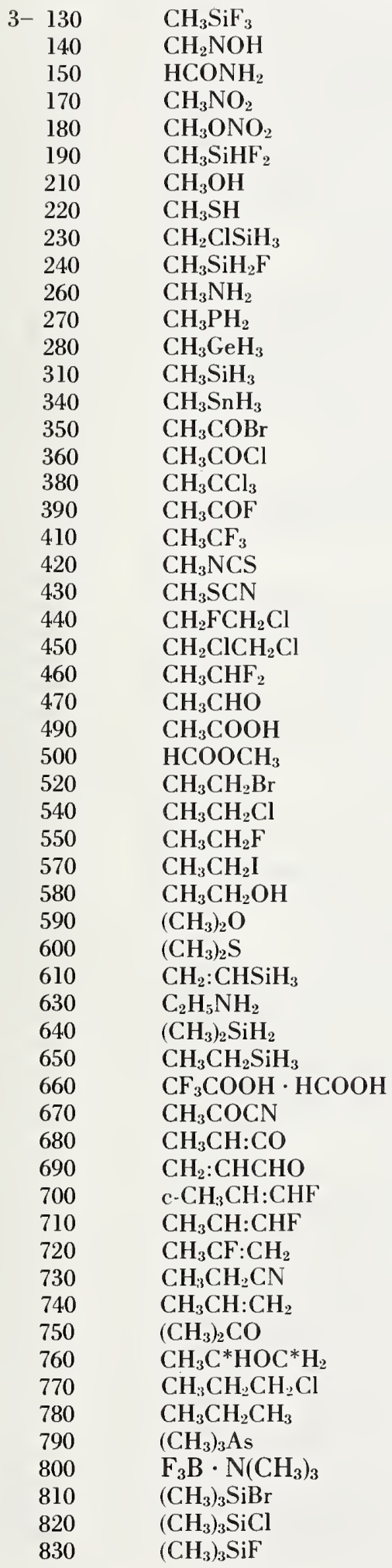

Methyltrifluorosilane

Formaldoxime

Formamide

Nitromethane

Methyl nitrate

Methyldifluorosilane

Methanol

Methanethiol

Chloromethylsilane

Methylmonofluorosilane

Methylamine

Methylphosphine

Methyl germane

Methylsilane

Methyltin

Acetyl bromide

Acetyl chloride

1,1,1-trichloroethane

Acetyl fluoride

1,1,1-trifluoroethane

Methyl isothiocyanate

Methyl thiocyanate

1-chloro-2-fluoroethane

1,2-dichloroethane

1,1-difluoroethane

Acetaldehyde

Acetic acid

Methyl formate

Bromoethane

Chloroethane

Fluoroethane

Iodoethane

Ethanol

Methoxymethane

Dimethyl sulfide

Vinyl silane

Ethylamine

Dimethylsilane

Ethylsilane

Trifluoroacetic acid · formic acid complex

Pyruvonitrile

Methyl ketene

$s$-trans-acrolein

cis-1-fluoropropene

trans-fluoropropene

2-fluoropropene

Propionitrile

Propene

Acetone

1,2-epoxypropane

1-chloropropane

Propane

Trimethylarsine

Trifluoroborane trimethylamine

Trimethylbromosilane

Trimethylchlorosilane

Trimethylfluorosilane 


\begin{tabular}{|c|c|}
\hline $3-840$ & $\left(\mathrm{CH}_{3}\right)_{3} \mathrm{SiI}$ \\
\hline 850 & $\left(\mathrm{CH}_{3}\right)_{3} \mathrm{~N}$ \\
\hline 860 & $\left(\mathrm{CH}_{3}\right)_{3} \mathrm{P}$ \\
\hline 870 & $\left(\mathrm{CH}_{3}\right)_{3} \mathrm{SiH}$ \\
\hline 890 & $\mathrm{CH}_{3} \mathrm{C}: \mathrm{CCF}_{3}$ \\
\hline 900 & $\mathrm{CH}_{3} \mathrm{C}: \mathrm{CCH}_{2} \mathrm{Cl}$ \\
\hline 910 & $\mathrm{CH}_{2}: \mathrm{CHCF}: \mathrm{CH}_{2}$ \\
\hline 920 & $t-\mathrm{CH}_{3} \mathrm{CH}: \mathrm{CHCN}$ \\
\hline 930 & $\mathrm{CH}_{3} \mathrm{CH}: \mathrm{C}: \mathrm{CH}_{2}$ \\
\hline 940 & $\left(\mathrm{CH}_{3}\right)_{2} \mathrm{C}: \mathrm{CH}_{2}$ \\
\hline 950 & $\mathrm{CH}_{3} \mathrm{C}^{*} \mathrm{HOC}^{*} \mathrm{HCH}$ \\
\hline 960 & $\left(\mathrm{CH}_{3}\right)_{3} \mathrm{CBr}$ \\
\hline 970 & $\left(\mathrm{CH}_{3}\right)_{3} \mathrm{CCl}$ \\
\hline 980 & $\left(\mathrm{CH}_{3}\right)_{3} \mathrm{CF}$ \\
\hline 990 & $\left(\mathrm{CH}_{3}\right)_{3} \mathrm{CI}$ \\
\hline 1000 & $\left(\mathrm{CH}_{3}\right)_{3} \mathrm{CH}$ \\
\hline 1010 & $\mathrm{C}_{2} \mathrm{H}_{5} \mathrm{OC}_{2} \mathrm{H}_{5}$ \\
\hline 1020 & $\left(\mathrm{CH}_{3}\right)_{3} \mathrm{CCN}$ \\
\hline 1030 & $\left(\mathrm{CH}_{3}\right)_{3} \mathrm{CNC}$ \\
\hline 1040 & $\mathrm{C}_{6} \mathrm{H}_{5} \mathrm{NO}_{2}$ \\
\hline 1050 & $\mathrm{C}_{6} \mathrm{H}_{5} \mathrm{OH}$ \\
\hline 1060 & $\left(\mathrm{CH}_{3}\right)_{3} \mathrm{CC}: \mathrm{CCl}$ \\
\hline 1070 & $\left(\mathrm{CH}_{3}\right)_{3} \mathrm{CC}: \mathrm{CH}$ \\
\hline 1080 & $\left(\mathrm{CH}_{3}\right)_{3} \mathrm{~N} \cdot \mathrm{B}\left(\mathrm{CH}_{3}\right)_{3}$ \\
\hline 1090 & $\mathrm{C}_{6} \mathrm{H}_{5} \mathrm{C}: \mathrm{CH}$ \\
\hline $4-\quad 10$ & $\mathrm{AsCl}_{3}$ \\
\hline 20 & $\mathrm{AsF}_{3}$ \\
\hline 30 & $\mathrm{AsH}_{3}$ \\
\hline 40 & $\mathrm{H}_{2} \mathrm{BH}_{2} \mathrm{BHBr}$ \\
\hline 50 & $\mathrm{~B}_{5} \mathrm{H}_{9}$ \\
\hline 70 & $\mathrm{BiCl}_{3}$ \\
\hline 80 & $\mathrm{BrF}_{3}$ \\
\hline 90 & $\mathrm{SiF}_{3} \mathrm{Br}$ \\
\hline 100 & $\mathrm{GeH}_{3} \mathrm{Br}$ \\
\hline 110 & $\mathrm{SiH}_{3} \mathrm{Br}$ \\
\hline 120 & NOBr \\
\hline 130 & $\mathrm{PBr}_{3}$ \\
\hline 140 & $\mathrm{BrCN}$ \\
\hline 150 & CIFCO \\
\hline 160 & $\mathrm{CF}_{3} \mathrm{Cl}$ \\
\hline 170 & $\mathrm{ClCN}$ \\
\hline 180 & $\mathrm{COCl}_{2}$ \\
\hline 190 & $\mathrm{CCl}_{3} \mathrm{~F}$ \\
\hline 200 & FCN \\
\hline 210 & $\mathrm{COF}_{2}$ \\
\hline 220 & $\mathrm{CF}_{3} \mathrm{Br}$ \\
\hline 230 & $\mathrm{CF}_{3} \mathrm{I}$ \\
\hline 240 & $\mathrm{CHBr}_{3}$ \\
\hline 250 & $\mathrm{CHClF}_{2}$ \\
\hline 260 & $\mathrm{CHCl}_{3}$ \\
\hline 270 & FCHO \\
\hline 280 & $\mathrm{CHF}_{3}$ \\
\hline 290 & HCN \\
\hline 300 & HNCO \\
\hline 310 & HNCS \\
\hline 320 & $\mathrm{CH}_{2} \mathrm{Br}_{2}$ \\
\hline 330 & $\mathrm{CH}_{2} \mathrm{ClF}$ \\
\hline
\end{tabular}

Trimethyliodosilane

Trimethylamine

Trimethylphosphine

Trimethylsilane

1,1,1-trifluoro-2-butyne

1-chloro-2-butyne

2-fluoro-1,3-butadiene

trans-crotononitrile

1,2-butadiene

2-meîhylpropene

cis-2,3-epoxybutane

2-bromo-2-methylpropane

2-chloro-2-methylpropane

2-fluoro-2-methylpropane

2-iodo-2-methylpropane

2-methylpropane

Ethoxyethane

2,2-dimethylpropanenitrile

tert-butyl isocyanide

Nitrobenzene

Phenol

1-chloro-3,3-dimethyl-1-butyne

3,3-dimethyl-1-butyne

Trimethylamine $\cdot$ trimethylborane

Ethynylbenzene

Arsenic trichloride

Arsenic trifluoride

Arsine

Bromodiborane

Pentaborane

Bismuth trichloride

Bromine trifluoride

Bromotrifluorosilane

Bromogermane

Bromosilane

Nitrosyl bromide

Phosphorus tribromide

Cyanogen bromide

Chlorofluorocarbonyl

Chlorotrifluoromethane

Cyanogen chloride

Phosgene

Trichlorofluoromethane

Cyanogen fluoride

Carbonyl fluoride

Bromotrifluoromethane

Trifluoroiodomethane

Tribromomethane

Chlorodifluoromethane

Trichloromethane

Formyl fluoride

Trifluoromethane

Hydrocyanic acid

Isocyanic acid

Isothiocyanic acid

Dibromomethane

Chlorofluoromethane 


\begin{tabular}{|c|c|c|}
\hline $4-340$ & $\mathrm{CH}_{2} \mathrm{Cl}_{2}$ & Dichloromethane \\
\hline 350 & $\mathrm{CH}_{2} \mathrm{~F}_{2}$ & Difluoromethane \\
\hline 360 & $\mathrm{H}_{2} \mathrm{NCN}$ & Cyanamide \\
\hline 370 & $\mathrm{H}_{2} \mathrm{CNN}$ & Diazomethane \\
\hline 380 & HCHO & Formaldehyde \\
\hline 390 & $\mathrm{H}_{3} \mathrm{BCO}$ & Carbonyl borane \\
\hline 400 & $\mathrm{CH}_{3} \mathrm{Br}$ & Bromomethane \\
\hline 410 & $\mathrm{CH}_{3} \mathrm{HgBr}$ & Methyl mercuric bromide \\
\hline 420 & $\mathrm{CH}_{3} \mathrm{Cl}$ & Chloromethane \\
\hline 440 & $\mathrm{CH}_{3} \mathrm{HgCl}$ & Methyl mercuric chloride \\
\hline 460 & $\mathrm{CH}_{3} \mathrm{~F}$ & Fluoromethane \\
\hline 470 & $\mathrm{CH}_{3} \mathrm{HgI}$ & Methyl mercuric iodide \\
\hline 480 & $\mathrm{CH}_{3} \mathrm{I}$ & Iodomethane \\
\hline 490 & $\mathrm{SiH}_{3} \mathrm{NCS}$ & Silyl isothiocyanate \\
\hline 500 & $\mathrm{H}_{3} \mathrm{SiCN}$ & Silyl cyanide \\
\hline 510 & $\mathrm{ICN}$ & Cyanogen iodide \\
\hline 520 & OCS & Carbonyl sulfide \\
\hline 540 & OCSe & Carbonyl selenide \\
\hline 560 & SCSe & Thiocarbonyl selenide \\
\hline 570 & SCTe & Thiocarbonyl telluride \\
\hline 580 & $\mathrm{CCl}_{3} \mathrm{CN}$ & Trichloroacetonitrile \\
\hline 590 & $\mathrm{CF}_{3} \mathrm{CN}$ & Trifluoroacetonitrile \\
\hline 600 & $\mathrm{HC}: \mathrm{CCl}$ & Chloroacetylene \\
\hline 610 & $\mathrm{CHCl}: \mathrm{CF}_{2}$ & 1,1-difluoro-2-chloroethene \\
\hline 620 & $\mathrm{HC}: \mathrm{CF}$ & Fluoroacetylene \\
\hline 630 & $\mathrm{CH}_{2} \mathrm{CFCl}$ & 1,1-chlorofluoroethene \\
\hline 640 & $\mathrm{CHF}: \mathrm{CHCl}$ & cis-1-chloro-2-fluoroethene \\
\hline 650 & $\mathrm{CH}_{2} \mathrm{ClCN}$ & Monochloroacetonitrile \\
\hline 660 & $\mathrm{H}_{2} \mathrm{C}: \mathrm{CCl}_{2}$ & 1,1-dichloroethene \\
\hline 670 & $\mathrm{HClC}: \mathrm{CHCl}$ & cis-1,2-dichloroethene \\
\hline 680 & $\mathrm{H}_{2} \mathrm{C}: \mathrm{CF}_{2}$ & 1,1-difluoroethene \\
\hline 690 & $\mathrm{HFC}: \mathrm{CHF}$ & cis-1,2-difluoroethene \\
\hline 700 & $\mathrm{CH}_{2} \mathrm{FCN}$ & Monofluoroacetonitrile \\
\hline 710 & $\mathrm{H}_{2} \mathrm{C}: \mathrm{CO}$ & Ketene \\
\hline 720 & $\mathrm{CH}_{2}: \mathrm{CHBr}$ & Bromoethene \\
\hline 760 & $\mathrm{H}_{2} \mathrm{C}: \mathrm{CHCl}$ & Chloroethene \\
\hline 780 & $\mathrm{H}_{2} \mathrm{C}: \mathrm{CHF}$ & Fluoroethene \\
\hline 800 & $\mathrm{H}_{2} \mathrm{C}: \mathrm{CHI}$ & Iodoethene \\
\hline 810 & $\mathrm{CH}_{3} \mathrm{CN}$ & Acetonitrile \\
\hline 830 & $\mathrm{CH}_{3} \mathrm{NC}$ & Methyl isocyanide \\
\hline 840 & $\mathrm{H}_{2} \mathrm{C}^{*} \mathrm{OC} * \mathrm{H}_{2}$ & Ethylene oxide \\
\hline 850 & $\mathrm{C}^{*} \mathrm{H}_{2} \mathrm{SC}^{*} \mathrm{H}_{2}$ & Ethylene sulfide \\
\hline 860 & $\mathrm{C}^{*} \mathrm{H}_{2} \mathrm{NHC}^{*} \mathrm{H}_{2}$ & Ethylenimine \\
\hline 870 & $\mathrm{CF}_{3} \mathrm{C}: \mathrm{CH}$ & 3,3,3-trifluoro-1-propyne \\
\hline 880 & $\mathrm{HC}: \mathrm{CCN}$ & Propiolonitrile \\
\hline 900 & $\mathrm{CH}_{2}(\mathrm{CN})_{2}$ & Malononitrile \\
\hline 910 & $\mathrm{HC}: \mathrm{CCHO}$ & Propiolaldehyde \\
\hline 930 & $\mathrm{HC}^{*}: \mathrm{CHOCOO}^{*}$ & Vinylene carbonate \\
\hline 940 & $\mathrm{H}_{3} \mathrm{CC}: \mathrm{CBr}$ & 1-bromopropyne \\
\hline 950 & $\mathrm{H}_{2} \mathrm{BrCC}: \mathrm{CH}$ & 3-bromopropyne \\
\hline 960 & $\mathrm{H}_{2} \mathrm{C}: \mathrm{C}: \mathrm{CHCl}$ & Chloroallene \\
\hline 970 & $\mathrm{CH}_{3} \mathrm{C}: \mathrm{CCl}$ & 1-chloropropyne \\
\hline 990 & $\mathrm{CH}_{2} \mathrm{ClC}: \mathrm{CH}$ & 3-chloropropyne \\
\hline 1000 & $\mathrm{H}_{2} \mathrm{FCC}: \mathrm{CH}$ & 3-fluoropropyne \\
\hline 1010 & $\mathrm{H}_{3} \mathrm{CC}: \mathrm{CI}$ & 1-iodopropyne \\
\hline 1020 & $\mathrm{CH}_{2}: \mathrm{CHCN}$ & Acrylonitrile \\
\hline
\end{tabular}




\begin{tabular}{|c|c|c|}
\hline $4-1030$ & $\mathrm{C}^{*} \mathrm{H}_{2} \mathrm{CH}: \mathrm{C}^{*} \mathrm{H}$ & Cyclopropene \\
\hline 1040 & $\mathrm{CH}_{3} \mathrm{C}: \mathrm{CH}$ & Propyne \\
\hline 1060 & $\mathrm{C}^{*} \mathrm{H}_{2} \mathrm{CH}_{2} \mathrm{C}^{*} \mathrm{Cl}_{2}$ & 1,1-dichlorocyclopropane \\
\hline 1070 & $\mathrm{O}^{*} \mathrm{CH}_{2} \mathrm{CH}_{2} \mathrm{C}^{*} \mathrm{O}$ & $\beta$-propiolactone \\
\hline 1080 & $\mathrm{C}^{*} \mathrm{H}_{2} \mathrm{CH}_{2} \mathrm{C}^{*} \mathrm{HCl}$ & 1-chlorocyclopropane \\
\hline 1090 & $\mathrm{C}^{*} \mathrm{H}_{2} \mathrm{CH}_{2} \mathrm{CH}_{2} \mathrm{O}^{*}$ & Trimethylene oxide \\
\hline 1100 & $\mathrm{O}^{*} \mathrm{CH}_{2} \mathrm{OCH}_{2} \mathrm{OC}^{*} \mathrm{H}_{2}$ & 1,3,5-trioxane \\
\hline 1110 & $\mathrm{P}(\mathrm{CN})_{3}$ & Phosphorus tricyanide \\
\hline 1120 & $\mathrm{H}_{3} \mathrm{CC}: \mathrm{CCN}$ & 2-butynenitrile \\
\hline 1130 & $\mathrm{HC}: \mathrm{CCH}: \mathrm{CH}_{2}$ & 1-buten-3-yne \\
\hline 1140 & C:HNCHCH:CHN* & Pyrimidine \\
\hline 1150 & $\mathrm{C}^{*} \mathrm{H}: \overline{\mathrm{CHOCH}} \mathrm{C}^{*} \mathrm{H}$ & Furan \\
\hline 1160 & $\mathrm{~S}^{*} \mathrm{HC}: \mathrm{CHCH}: \mathrm{C}^{*} \mathrm{H}$ & Thiophene \\
\hline 1170 & $\mathrm{C}^{*} \mathrm{H}_{2} \mathrm{CH}_{2} \mathrm{C}^{*} \mathrm{HCN}$ & Cyclopropanecarbonitrile \\
\hline 1180 & $\mathrm{C}_{4} \mathrm{H}_{5} \mathrm{~N}$ & Pyrrole \\
\hline 1190 & $\mathrm{H}_{3} \mathrm{CC}: \mathrm{CC}: \mathrm{CH}$ & Penta-1,3-diyne \\
\hline 1200 & $\mathrm{C}^{*} \mathrm{H}: \mathrm{CHCH}: \mathrm{CHN}{ }^{*} \overline{\mathrm{H}}$ & Pyridine \\
\hline 1210 & $\mathrm{C}_{5} \mathrm{H}_{5} \mathrm{NNiO}$ & Nickel cyclopentadienyl nitrosyl \\
\hline 1220 & $\mathrm{C}_{5} \mathrm{H}_{5} \mathrm{Tl}$ & Cyclopentadienyl thallium \\
\hline 1230 & $\mathrm{C}^{*} \mathrm{H}_{2} \mathrm{CH}: \mathrm{CHCH}: \mathrm{C}^{*} \mathrm{H}$ & 1,3-cyclopentadiene \\
\hline 1240 & $\mathrm{C}^{*} \mathrm{H}_{2} \mathrm{CH}_{2} \mathrm{CH}_{2} \mathrm{CH}_{2} \mathrm{C}^{*} \mathrm{O}$ & Cyclopentanone \\
\hline 1250 & $\mathrm{C}^{*} \mathrm{HOCHCH}_{2} \mathrm{CH}_{2} \mathrm{C}^{*} \mathrm{H}_{2}$ & Cyclopentene oxide \\
\hline 1260 & $\mathrm{C}_{6} \mathrm{H}_{5} \mathrm{Br}$ & Bromobenzene \\
\hline 1270 & $\mathrm{C}_{6} \mathrm{H}_{5} \mathrm{Cl}$ & Chlorobenzene \\
\hline 1280 & $\mathrm{C}_{6} \mathrm{H}_{5} \mathrm{~F}$ & Fluorobenzene \\
\hline 1290 & $\mathrm{C}_{6} \mathrm{H}_{5} \mathrm{CN}$ & Benzonitrile \\
\hline 1310 & $\mathrm{C}_{7} \mathrm{H}_{13} \mathrm{~N}$ & Quinuclidine \\
\hline 1320 & $\mathrm{C}_{5} \mathrm{H}_{5} \mathrm{Mn}(\mathrm{CO})_{3}$ & Cyclopentadienyl manganese tricarbonyl \\
\hline 1330 & $\mathrm{C}_{8} \mathrm{H}_{13} \mathrm{Br}$ & 1-bromo-bicyclo(2,2,2)-octane \\
\hline 1340 & $\mathrm{C}_{8} \mathrm{H}_{13} \mathrm{Cl}$ & 1-chloro-bicyclo $(2,2,2)$-octane \\
\hline 1350 & $\mathrm{C}_{6} \mathrm{H}_{6} \mathrm{Cr}(\mathrm{CO})_{3}$ & Benzene chromium tricarbonyl \\
\hline 1360 & $\mathrm{ClO}_{3} \mathrm{~F}$ & Perchloryl fluoride \\
\hline 1370 & $\mathrm{CIF}_{3}$ & Chlorine trifluoride \\
\hline 1380 & $\mathrm{ClO}_{2}$ & Chlorine dioxide \\
\hline 1390 & $\mathrm{POF}_{2} \mathrm{Cl}$ & Phosphoryl difluorochloride \\
\hline 1400 & $\mathrm{GeF}_{3} \mathrm{Cl}$ & Chlorotrifluorogermane \\
\hline 1410 & $\mathrm{SiF}_{3} \mathrm{Cl}$ & Chlorotrifluorosilane \\
\hline 1420 & $\mathrm{SF}_{5} \mathrm{Cl}$ & Sulfur chloride pentafluoride \\
\hline 1430 & $\mathrm{GeH}_{3} \mathrm{Cl}$ & Chlorogermane \\
\hline 1440 & $\mathrm{SiH}_{3} \mathrm{Cl}$ & Chlorosilane \\
\hline 1450 & NOCl & Nitrosyl chloride \\
\hline 1460 & $\mathrm{NO}_{2} \mathrm{Cl}$ & Nitryl chloride \\
\hline 1470 & $\mathrm{ReO}_{3} \mathrm{Cl}$ & Rhenium trioxychloride \\
\hline 1480 & $\mathrm{Cl}_{2} \mathrm{O}$ & Chlorine monoxide \\
\hline 1490 & $\mathrm{GeHCl}_{3}$ & Trichlorogermane \\
\hline 1500 & $\mathrm{SiHCl}_{3}$ & Trichlorosilane \\
\hline 1510 & $\mathrm{POCl}_{3}$ & Phosphoryl chloride \\
\hline 1520 & $\mathrm{PCl}_{3}$ & Phosphorus trichloride \\
\hline 1530 & $\mathrm{SPCl}_{3}$ & Thiophosphoryl chloride \\
\hline 1540 & $\mathrm{SbCl}_{3}$ & Antimony trichloride \\
\hline 1550 & $\mathrm{SiH}_{3} \mathrm{~F}$ & Fluorosilane \\
\hline 1560 & $\mathrm{MnO}_{3} \mathrm{~F}$ & Manganese trioxyfluoride \\
\hline 1570 & NOF & Nitrosyl fluoride \\
\hline 1580 & $\mathrm{NO}_{2} \mathrm{~F}$ & Nitryl fluoride \\
\hline 1590 & $\mathrm{ReO}_{3} \mathrm{~F}$ & Rhenium trioxyfluoride \\
\hline 1600 & $\mathrm{SiH}_{2} \mathrm{~F}_{2}$ & Difluorosilane \\
\hline
\end{tabular}




\begin{tabular}{|c|c|c|}
\hline Vol.-Id & Formula & Name \\
\hline $4-1610$ & $\mathrm{OF}_{2}$ & Oxygen difluoride \\
\hline 1620 & $\mathrm{SOF}_{2}$ & Thionyl fluoride \\
\hline 1630 & $\mathrm{SO}_{2} \mathrm{~F}_{2}$ & Sulfuryl fluoride \\
\hline 1640 & $\mathrm{SiF}_{3} \mathrm{H}$ & Trifluorosilane \\
\hline 1650 & $\mathrm{NF}_{3}$ & Nitrogen trifluoride \\
\hline 1660 & $\mathrm{NSF}_{3}$ & Trifluorosulfur nitride \\
\hline 1670 & $\mathrm{POF}_{3}$ & Phosphoryl fluoride \\
\hline 1680 & $\mathrm{PF}_{3}$ & Phosphorus trifluoride \\
\hline 1690 & $\mathrm{SPF}_{3}$ & Thiophosphoryl fluoride \\
\hline 1700 & $\mathrm{HN}_{3}$ & Hydrazoic acid \\
\hline 1710 & $\mathrm{H}_{2} \mathrm{O}$ & Water \\
\hline 1720 & $\mathrm{H}_{2} \mathrm{~S}$ & Hydrogen sulfide \\
\hline 1740 & $\mathrm{H}_{2} \mathrm{Se}$ & Hydrogen selenide \\
\hline 1760 & $\mathrm{SiH}_{3} \mathrm{I}$ & Iodosilane \\
\hline 1770 & $\mathrm{NH}_{3}$ & Ammonia \\
\hline 1780 & $\mathrm{PH}_{3}$ & Phosphine \\
\hline 1790 & $\mathrm{SbH}_{3}$ & Stibine \\
\hline 1800 & $\mathrm{NO}_{2}$ & Nitrogen dioxide \\
\hline 1810 & $\mathrm{~N}_{2} \mathrm{O}$ & Nitrous oxide \\
\hline 1820 & $\mathrm{~S}_{2} \mathrm{O}$ & Disulfur monoxide \\
\hline 1830 & $\mathrm{SO}_{2}$ & Sulfur dioxide \\
\hline 1840 & $\mathrm{O}_{3}$ & Ozone \\
\hline
\end{tabular}





\section{THE NATIONAL BUREAU OF STANDARDS}

The National Bureau of Standards ${ }^{1}$ provides measurement and technical information services essential to the efficiency and effectiveness of the work of the Nation's scientists and engineers. The Bureau serves also as a focal point in the Federal Government for assuring maximum application of the physical and engineering sciences to the advancement of technology in industry and commerce. To accomplish this mission, the Bureau is organized into three institutes covering broad program areas of research and services:

THE INSTITUTE FOR BASIC STANDARDS . . . provides the central basis within the United States for a complete and consistent system of physical measurements, coordinates that system with the measurement systems of other nations, and furnishes essential services leading to accurate and uniform physical measurements throughout the Nation's scientific community, industry, and commerce. This Institute comprises a series of divisions, each serving a classical subject matter area:

-Applied Mathematics-Electricity-Metrology-Mechanics-Heat-Atomic Physics-Physical Chemistry-Radiation Physics-Laboratory Astrophysics - Radio Standards Laboratory, ${ }^{2}$ which includes Radio Standards Physics and Radio Standards Engineering-Office of Standard Reference Data.

THE INSTITUTE FOR MATERIALS RESEARCH . . . conducts materials research and provides associated materials services including mainly reference materials and data on the properties of materials. Beyond its direct interest to the Nation's scientists and engineers, this Institute yields services which are essential to the advancement of technology in industry and commerce. This Institute is organized primarily by technical fields:

-Analytical Chemistry-Metallurgy-Reactor Radiations-Polymers-Inorganic Materials-Cryogenics $^{2}$-Office of Standard Reference Materials.

THE INSTITUTE FOR APPLIED TECHNOLOGY . . . provides technical services to promote the use of available technology and to facilitate technological innovation in industry and government. The principal elements of this Institute are:

-Building Research-Electronic Instrumentation-Technical Analysis-Center for Computer Sciences and Technology-Textile and Apparel Technology Center-Office of Weights and Measures -Office of Engineering Standards Services-Office of Invention and Innovation-Office of Vehicle Systems Research-Clearinghouse for Federal Scientific and Technical Information ${ }^{3}$-Materials Evaluation Laboratory-NBS/GSA Testing Laboratory.

${ }^{1}$ Headquarters and Laboratories at Gaithersburg, Maryland, unless otherwise noted; mailing address Washington, D. C., 20234.

2 Located at Boulder, Colorado, 80302.

${ }^{3}$ Located at 5285 Port Royal Road, Springfield, Virginia 22151. 


\section{NBS TECHNICAL PUBLICATIONS}

\section{PERIODICALS}

JOURNAL OF RESEARCH reports National Bureau of Standards research and development in physics, mathematics, chemistry, and engineering. Comprehensive scientific papers give complete details of the work, including laboratory data, experimental procedures, and theoretical and mathematical analyses. Illustrated with photographs, drawings, and charts.

\section{Published in three sections, available separately:}

\section{- Physics and Chemistry}

Papers of interest primarily to scientists working in these fields. This section covers a broad range of physical and chemical research, with major emphasis on standards of physical measurement, fundamental constants, and properties of matter. Issued six times a year. Annual subscription: Domestic, $\$ 5.00$; foreign, $\$ 6.00^{*}$.

\section{Mathematical Sciences}

Studies and compilations designed mainly for the mathematician and theoretical physicist. Topics in mathematical statistics, theory of experiment design, numerical analysis, theoretical physics and chemistry, logical design and programming of computers and computer systems. Short numerical tables. Issued quarterly. Annual subscription: Domestic, $\$ 2.25$; foreign, $\$ 2.75^{*}$.

\section{- Engineering and Instrumentation}

Reporting results of interest chiefly to the engineer and the applied scientist. This section includes many of the new developments in instrumentation resulting from the Bureau's work in physical measurement, data processing, and development of test methods. It will also cover some of the work in acoustics, applied mechanics, building research, and cryogenic engineering. Issued quarterly. Annual subscription: Domestic, $\$ 2.75$; foreign, $\$ 3.50^{*}$.

\section{TECHNICAL NEWS BULLETIN}

The best single source of information concerning the Bureau's research, developmental, cooperative and publication activities, this monthly publication is designed for the industry-oriented individual whose daily work involves intimate contact with science and technology-for engineers, chemists, physicists, research managers, product-development managers, and company executives. Annual subscription: Domestic, $\$ 1.50$; foreign, $\$ 2.25 *$.

*Difference in price is due to extra cost of foreign mailing.
NONPERIODICALS

Applied Mathematics Series. tables, manuals, and studies.

Mathematical

Building Science Series. Research results, test methods, and performance criteria of building materials, components, systems, and structures.

Handbooks. Recommended codes of engineering and industrial practice (including safety codes) developed in cooperation with interested industries, professional organizations, and regulatory bodies.

Special Publications. Proceedings of NBS conferences, bibliographies, annual reports, wall charts, pamphlets, etc.

Monographs. Major contributions to the technical literature on various subjects related to the Bureau's scientific and technical activities.

National Standard Reference Data Series. NSRDS provides quantitative data on the physical and chemical properties of materials, compiled from the world's literature and critically evaluated.

Product Standards. Provide requirements for sizes, types, quality and methods for testing various industrial products. These standards are developed cooperatively with interested Government and industry groups and provide the basis for common understanding of product characteristics for both buyers and sellers. Their use is voluntary.

Technical Notes. This series consists of communications and reports (covering both other agency and NBS-sponsored work) of limited or transitory interest.

\section{CLEARINGHOUSE}

The Clearinghouse for Federal Scientific and Technical Information, operated by NBS, supplies unclassified information related to Governmentgenerated science and technology in defense, space, atomic energy, and other national programs. For further information on Clearinghouse services, write:

Clearinghouse U.S. Department of Commerce Springfield, Virginia 22151

Order NBS publications from: Superintendent of Documents Government Printing Office Washington, D.C. 20402 





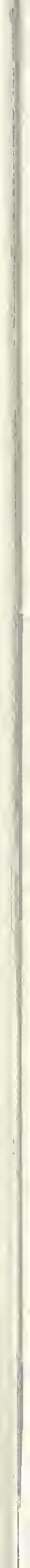


